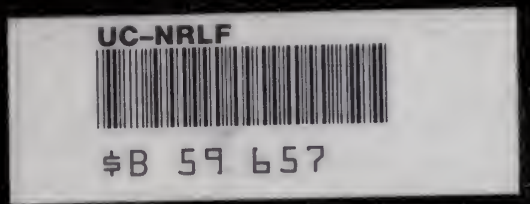



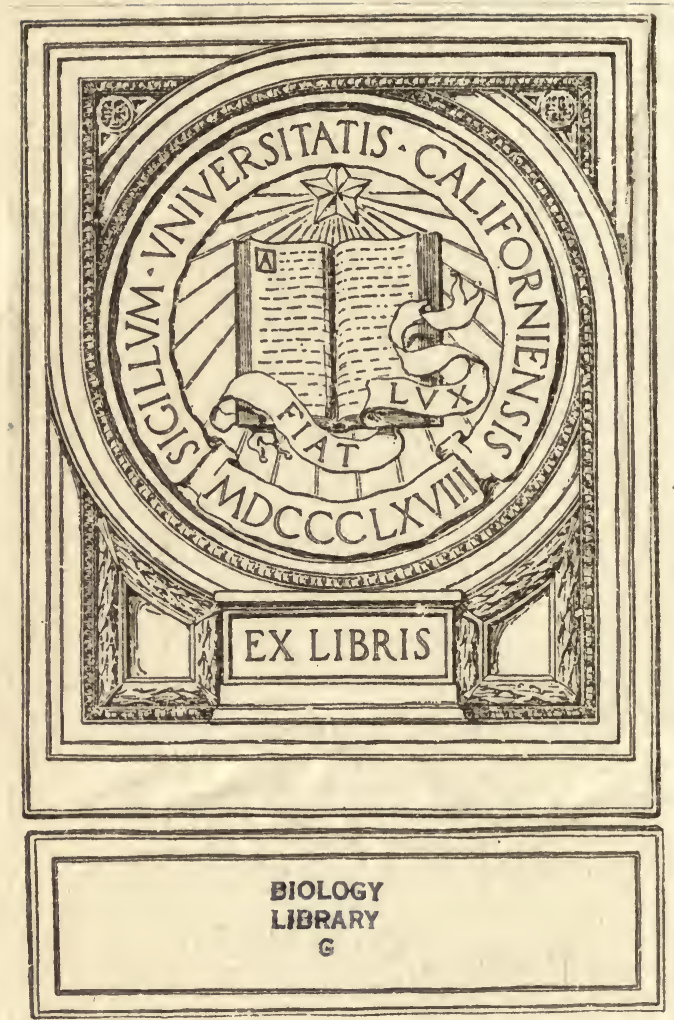






\title{
CLASS-BO0K OF BOTANY:
}

RERNG OUTLINES OF THE

\section{STRUCTURE, PHYSIOLOGY, AND CLASSIFICATION}

\author{
or \\ P LA N T S ; \\ WITE
}

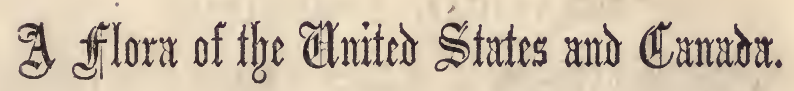

BY

ALPHONSO WOOD, A.M.

1

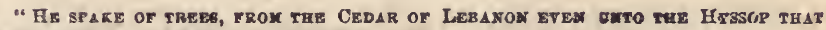
SPRIXGETH OUT OF Tun wALL."-1 Kinge, iv. 33.

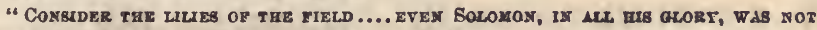

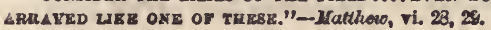

\section{NEW YORK:}

A. S. BARNES \& CO., 111 \& 113 WILLIAM STREET. TROY : MOORE \& NIMS 


\section{BIOLOGY \\ LIBRARY \\ G \\ PREFACE TO THE EDITIONS OF 1869.}

Is the present edition the Flora has been extensively revised, and numerous changes have been made, in accordance with recent discoveries and the general progress of the science of Phytology. These changes consist especially of the addition of species hitherto unknown to our Flora, of new and corrected names for the old species, of new localities of species and corrected dates of flowering. In these improvements we have received valuable aid from Mr. E. L. Hankenson, of Newark, Wayne Co., N. Y.; Messrs. W. R. Gerard, and G. M. Wilbur, of Poughkeepsie, N. Y., Mr J. Wolf, Canton, Fulton Co., Ill., and others whose names appear in the proper place.

\section{BOTANICAL APPARATUS.}

The publishers (Messrs. A. S. Barnes \& Co.) have recently provided and have on sale, suitable apparatus for the use of the student in Botany, made according to directions in this work (page 15). It consists of a knife-trowel for digging and cutting specimens; a microscope and tweezers for the examination of them; a tin-box for collecting and preserving them fresh, and a press for drying them. The set is securely packed and sent by express to order, at a moderate price.

\section{In Press,}

and will be published during the ensuing summer, The Botanical Index, a text-book for schools altogether new and peculiar, in which the study of the plants of the whole country is reduced to the last degree of precision and dispatch. Its use will lighten the labors of the teacher and add still new pleasures to botanical studies.

In the Clerk's Office of the District Court for the Southorn District of New York.

Electrotyped by

SMITII $\mathrm{MODOUGAI}$, 82 \& 84 Beekman St.
Printed by

G $\mathrm{E}$ O R G E W. W OOD, 2 Dntch St., N. Y. 


\section{P R E F A C E.}

Tre Class-Book of Botany was first offered to the student in 1845 . It was originally prepared with immediate reference to the wants of the author's own pupils, with scarcely a hope of approval from the community beyond. The event, however, proved that the wants of his own pupils were precisely the same as those of myriads of others; and the use of the book, notwithstanding its numerous imperfections, soon became general.

The lapse of fifteen years has done much to develop not only the knowledge of our native Flora, but of the science of Botany in general; and materials for the revision of our whole work have indefinitely accumulated. In this revision, which seems to be demanded not less by the growing appreciation of scientific studies as a means of intellectual and moral discipline, than by the progress of the science itself, we have still confined ourselves to the limits of a single volume, and sternly resolved against any essential enlargement, except such as the increased territory of our Flora requires. This we have done with direct reference to the convenience and the means of the thousands of youths who will still enter upon this delightful pursuit, and make their text-book their vade-mecum. The labor expended in this condensation will be appreciated by few, and those few, while they justify the motives, will regret the necessity.

The limit of our Flora in this new series has been much extended. It now embraces the territory lying East of the Mississippi River with the exception of the Southern Peninsula of Florida, and South of the Great Lakes and the River St. Lawrence. The States bordering upon the western shores of the Mississippi, although not strictly included, are essentially so, as well as those provinces of Camada upon the northern shore of the St. Lawrence. This Class-Book is, therefore, now professedly adapted to the student's use from Quebec to New Orleans and from St. Paul to St. Augustine.

The southern peninsula of Florida is neglected in consequence of the author's inability to visit that region hitherto. During his extended tour southward in 1857 , the Seminole war rendered the route to the 
Everglades unsafe, or at least undesirable. The species omitted are generally unknown northward of Key West. Students at Micanopy, Ocala, to St. Augustine, will scarcely miss them; but should they do so, they will confer a grateful favor by contributing specimens of such to the author.

That every species of native plant in this extensive region is accurately defined, or even noticed, we cannot presume; yet this has been onr aim; and as in the former series, so here, we have distrusted every source of information except that of our own personal inspection. Therefore, into nearly every section of this territory, from the St. Lawrence and the Lakes to the Gulf, and from the Sea-Coast to the Great River, the author has made repeated excursions in delighted converse with the regetable world.

Together with the plants of spontaneous growth which constitute our proper Flora, we have included in our sketches also our exotic Flora; that is, all those plants which seem to us to have attained a general cultivation in this country, either as nseful, curious, or nrnamental. By this accession, learners in the city, as well as in the country, may be supplied with subjects for illustration and for practice in botanical analysis; and all with the means of acquainting themselves with the beautiful tenants of their own fields, gardens, and conservatories.

From the multiplication of species and genera we have studiously refrained, believing that our books already contain more than Nature will warrant. In the case of any doubtful specimen, which might have served as the basis of a new species, or possibly genus, (had this been our aim), we have always inclined rather to the extension of the limits of some kindred group for its reception, having less apprehension of error in this direction than in the opposite, with all due regard for the permanence of true species. The same principle has compelled us to disallow the claims of many reputed species of the best authors.

In the sequence of the Natural Orders, we have, in common with all recent American authors, mainly adopted the arrangement of De Candolle, - an arrangement seen, in part, in the 'Flora of the State of New York,' by Dr. Torrey. It commences with those Orders supposed to be of the higher rank in organization, and proceeds gradually to the lower, regarding the completeness of the flower and the distinctness of its parts as the general criterion of rank.

Tables of analysis by the dichotomal method were first in the ClassBook applied to the genera of plants, and introduced into general use. They are now regarded as indispensable, and have been adopted into their Floras by nearly every subsequent author. In the present new 
series, wc have greatly modified, extended, and improved this system, adapting it to the analysis of Species as well as of Orders and Genera. By means of this addition, our Flora is now adapted to class exercises in analysis throughout, from the Grand division to the Species-an imimprovement which will be duly appreciated by the practical teacher.

An analytical Key to the Orders, mainly artificial, more simple than. any hitherto constructed by us, founded, as in the previous edition, almost solely upon characters taken from the flowers and leaves (not fruit), will readily conduct the student to that Order where any given flowering specimen may belong. Next, under the Order, a table of the utmost simplicity, analyzes the Genera, mostly in such a way as to do but little violence to their natural affinities. Lastly, under the Genus (when large enough to require it) another table conducts to the species in groups of twos or threes, which groups are instantly resolved by a brief diagnosis in italics catching the eye in some part of the description which follows.

The limited space allowed us in the Flora compels us to uso very sparingly illustrative engravings in this part of our work, which occasions us less regret considering the copiousness of illustration in the scientific treatise in the former part. Those engravings are designed partly with reference to the Flora, where frequent references will bo found. Tho few which we have adopted in the Flora, are prepared with reference to the deficiencies of the former part. In other words those which have no illustrative figure in the former treatise are generally furnished with one or more in the Flora. Throughout the work, these are mostly from original sketches and drawings on wood by the anthor's own hand. Others aro copied from Lindley, Henfrey, Payer, \&c.

In addition to those colaborers in Botany, whose invaluable aid is acknowledged in former editions, namely Dr. Edward E. Phelps, Da James W. Robbins, Dr. Joseph Barratt, Dr. Albert G. Skinner, Mr. I. A. Lapham, Dr. Truman Ricard, Dr. H. P. Sartwell, Dr. John Plummer, Dr. S. B. Mead, Mr. S. S. Olney, \&c., we have now to mention with grateful acknowledgments other names of equal merit.

Dr. Josiah Hale of Alexandria, La., has sent us a suit of specimens, well nigh representing the entire Flora of that State.

Dr. A. W. Chapman of Apalachicola, Fla., presented us with many of the more rare plants of Florida, on the occasion of our recent visit to his own familiar walks.

Dr. H. A. Mettauer of Macon, Ga., has made contributions of great value from that district, and from the vicinity of Tallahassee and St. Marks, Fla., with many critical notices and observations on the Flora of those States. 
Prof. William T. Feay, M.D., and Prof. Thomas G. Pond, both of Savannah, Ga., have sent almost the entire Flora of that State, with copious original notes and observations, such as result only from the most extensive and accurate investigation.

Miss Sarah Keen of Bainbridge, Ga. (now of Mariana, Fla.), has also sent an herbarium of beautiful specimens prepared by her own and her sister's hands. To her, as well as to the gentlemen last mentioned, the author is also indebted for every kind hospitality and encouragement during a protracted herborizing tour along our southern coasts.

Mr. William Wright of Bainbridge, and Prof. N. H. Stuart of Quincy, Florida (since deceased), also contributed to the consummation of onr work by many facilities afforded us in our laborious researches in their respective precincts, and by the shelter of their hospitable mansions.

To Rev. Dr. Curtis of Hillsborough, N. C., and to Rer. Dr. Bachman of Charleston, S. C., we are indebted for the free use of their very complete herbaria, during our sojourn in their respective cities; and Mr. S. B. Buckley, recently of Yellow Springs, Ohio, has afforded us similar facilities through his rich collection.

Dr. Cousens generously supplied us with the plants of the State of Iowa. His name often appears in our pages.

Dr. George Engelmann, of St. Louis, has also favored us with the free use of his admirable monograph of the genus Cuscuta, and with many important notes in MS. on other difficult genera in our Flora, especially on the Euphorbiaccæ. Our entire collection of specimens belonging to this Order was, by his kind permission, submitted to his inspection and determination.

The Rev. Chester Dewey, D.D., of Rochester, N. Y., the venerable pioneer in American Caricography, has placed us and our readers under renewed obligations by additional contributions to the genus Carex, rendering it complete for the extended territory of our present Flora.

Communications containing specimens, critical notices or corrections, or soliciting information, will always, as heretofore, be acceptable.

WEST FARMS, N. Y. 


\section{O N T E N T S}

Preface....................................... ${ }^{\text {PaG }}$

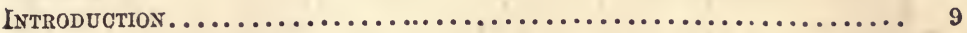

Chapter I.-The Leading Principles of Science;-Mental and Moral Discipline its Ardr and End........................ 9

Ch.1pter II. - The Departments of Botany . . . . . . . . . . . . 12

Chapter III.-Apparatus.-Methods of Study.............. 15

Part First.-Structural Botaxy, or Organograpiy............ 17

Chapter I.-Primary Divisions of the Vegetable Kingdom........ 17

Chapter II. - The Tery of Plant life..................... 19

Chapter III. -The Phexogamia ;-How Developed............. 22

Chapter IV. - The Root, or Descending Axis................ 24

Chapter V.-The Stem, or Ascending Axis ................ 30

Chapter Vi. - The Leaf-Bud.-Vernation................. 41

Chapter Vil. - The Leaf........................... 46

$\S$ Phyllotaxy, or Leaf-Arrangentemt................. 46

$\S$ Morphology of tңE Leaf.......................... 50

$\S$ Of the Stipules.............................. 51

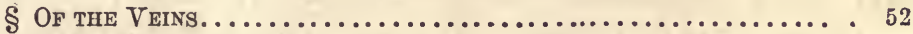

$\S$ Form of the Le.AF, or Figure. ..................... 54

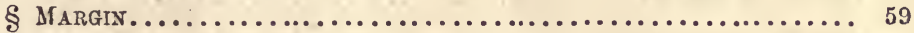

$\S$ APEx....................................... 59

$\S$ Coupound Leaves. ............................ 60

Chapter VIII.-Transformations of the Leaf............... 63

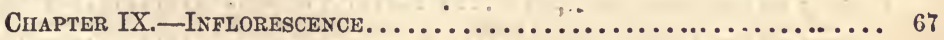

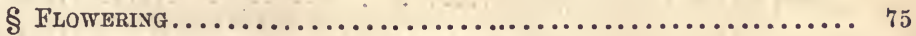

Chapter X.-Morphology of the Flower................

$\S$ Astivation................................. 59

$\S$ The Floral Organs. ............................ 81

$\S$ The Plan of the Flower.......................... 83

Chapter XI. -The Floral Envelopes.-Perianth............... 91

Chapter XiI. -The Essential Organs.................... 99

$\S$ The Stamens, or Andrcerum....................... 99

$\S$ The Pistils, or Grncecium........................... 104

$\S$ The Ovules ..................................... 108 
PAGR

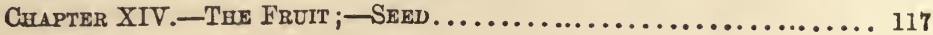

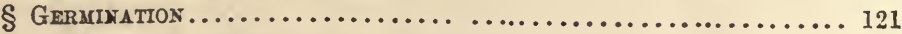

Chapter XV.-The Crtptogamia.-Organs................. 124

Part Second.-Physiological Botant.................... 130

Chapter I.-The Vegetable Cell. . . . . . . . . . . . . . . . . 130

Chapter II. -The Tissues............................. 134

Chapter III. -Thz Epidermal Sygtem. . . . . . . . . . . . . . 137

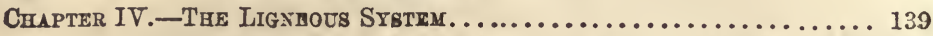

$\S$ Structure of Leaves........................... 145

Chapter V.-Of Vegutatiox, or the Physiology of Plant Life...... 146

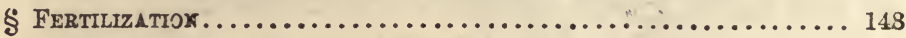

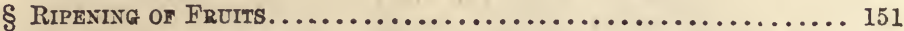

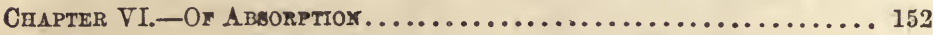

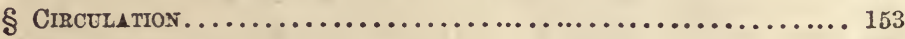

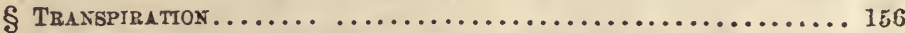

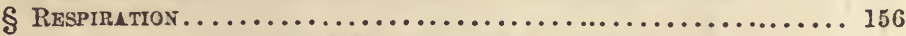

Chapter VII.-Review of the Prixciplins of Netrition.......... 158

Part ThrRd.-Systevatic Botany...................... 164

Chapter I.-Of tum Clasisification of Plants................ 164

Cirapter II.OF th

Chapter III. Of the Natural Systex. . . . . . . . . . . . . 169

Cinapter IV.-Nomerchature. - Axalysis................ 174

$\S$ Index AND Glosintr. ............................. 180

§ Key Analttical to the Natural Orders................ 191

Part Fourth.-Descriptive Botany; -The Flora................ 199

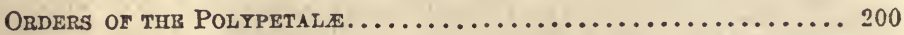

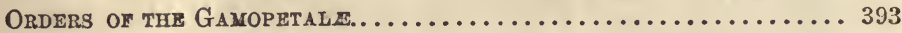

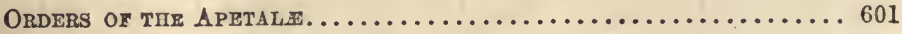

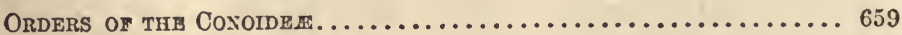

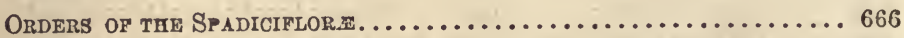

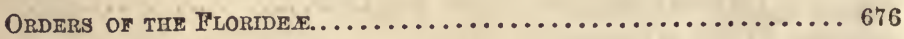

Orders of the Graminoides. ...................... 731

Orders of the Cryptoganda .......................... 810 


\title{
I N T R O D U C T I O N.
}

\author{
CH A P T E I.
}

\section{LEADING PRINCIPLES OF SCIENCE:-MENTAL AND MORAL DISCIPLINE ITS AIM AND END.}

1. Plants as Retated to Max. The vegetable kingdom maintains towarda man several important relations. Besides its obvious utility as the source of his food, shelter, clothing and medicine, it furnishes an exhaustless field for interesting and disciplinary study.

2. Proof that Nature is RELATED to MrND. This remark is commonplace. But the fact stated is neither a necessity nor accident. Since the plienomena of Nature are ordained subject to the coguizance of the human understanding while yet their depths are unfathomablo by it, it is evident that God made them for each other. It is certainly conceivable that Ho might have ordained otherwise.

3. ILLUSTration. The phenomena of vegetation, or of nature in general, might have been all simple and uniform, thus awakening no curiosity, presenting no motive for study. Or on the other hand, they might have involved plans so intricate as to defy all efforts of the mind in their investigation. In this case, as in the former, the mind and nature would have remained for ever estranged.

4. The STUdy of NATURE successful. But an intermediate conrse hath seemed good to an All-wise and Beneficent Creator. The works of His Hand are commensurate with the powers of the understanding. We study them not in vain. Step by step His plans are unfolded; and research, although never reaching the goal, yet never wearies, nor fails of its appropriate reward.

5.-Pleascrable. Hence the study of nature, through this beautifully adjusted relation, becomes a source of the purest pleasure, being ever accompanied by fresh discoveries of truth in the plans and operations of a sublime Intelligence.

6.-DisciplinaRY. But a higher purpose than present pleasure is accomplished by this means, namely, discipline. Entering lifo as a mere germ, the soul expands into intelligence and virtue through the teachings of surrounding objects and influences. In this good work the beauty, purity and wisdom displayed in the regetablo world bear a full share. These invite to investigation; and their tendency is to impress upon their votaries the characteristics of their own sincerity and loveliness.

7. Creative Wispom never works in vain, nor merely in sport. Even the flying cloud which now passes over the sun has its mission; the forms which it assumes, and the colors, were each necessary and divinely appointed for that special purpose. The hills and valleys, which seem scattered in accidental confusion, have received each their contour and position by desigu, according to the ends foreseen. Consequently, each stone or mineral composing those hills wras also the work of special design, as to its magnitude, form and place. 
8. No ACCLDENT OR CAPrice IN NATURE. Much more in the living kingdoms of nature may we look for an adequate purpose and end accomplished by every movement and in every creature of the Divine hand. Each species is created and sustained to answer some worthy end in the vast plan; and hence no individual, animal or plant is to be regarded in science as insignificant, inasmuch as the individual constitutes the species. Nor is accident or caprice to be found in the form of the leaf or the color of the flower. There is for each a special reason or adaptation worthy of unerring wisdom.

9. OBject of natural Science. In the study of uature we are therefore concerned in reasons and ends as well as in forms and appearances. That investigation which ceases contented with the latter only is puerile. It may amuse, but can scarcely instruct, and can never conduct to that purest source of the student's enjoyment, namely, the recognition of Intelligence by intelligence.

10. Design, a settled principle in Science. The end or purpose, it is true, is not always as easily discerned as the form and fashion are. In a thousand instances the end is yet inscrutable. Nevertheless it is now a settled principle of science that there is an end-a purpose-a reason, for every form which we contemplate; and the adaptation to that end is as beautiful as the form itself. That the tendril of the vine and the runner of the strawberry were happily adapted to a special purpose is readily admitted; for that purpose is immediate and obvious to all. Let us not then say that the spine, the stipule, or the varying tints of the rose, were made merely in caprice, their uses being less obvious in the present state of our knowledge.

11. Design, as distingurshed From "Trpical Folms." In addition to this sequence of cause and effect in nature, disclosing the Infinite Designer in all things, as early taught by Paley in his "Natural Theology," another class of principles more recently developed are shown by the author of "Typical Forms" (MCCOSH), to indicate with a still clearer light the thoughts of the Omniscient Mind in the operations of nature. A single observation often suffices for the discovery of design, as in the down of the thistle, by means of which the seed is wafted on the wiuds to flourish in distant lands. But a typical form or plan requires a long series of observations for its discernment.

12. Typical Forms inlustrated. The scientific world wero slow to learn that the numerous organs of plants so diversified in form and use are all modeled from a single type, one radical form, and that form, the leaf!

13. Results. This interesting doctrine, now universally admitted, sheds a new light upon nature, making it all luminous with the Divine Presence. It brings the operations of the Great Architect almost within the grasp of human intelligence, revealing the conceptions which occupied His mind before they were embodied in actual existence by His word.

14. Graduated Forms. Again, by continued observation, the principle of graduated forms, allied to the last, appeared as another grand characteristic of nature. This principle implies that while natural objects vary to wide and seemingly irreconcilable extremes, their differences are never abrupt, but they pass by insensible gradations and shades from species to species in a continuous series.

15. Illustration. Thus in magnitude, although the tiny moss is far removed from the gigantic oak, yet a series connects them representing every imaginable intermediate grade in size. So in number, from the one-stamened saltwort to the hundred-stamened rose, there is a connecting series, representing every intervening number. Moreover, in form and figure, we pass from the thread-leafed pine to the broad-leafed poplar throngh a series of every intcrmediate degree of leaf-expansion; 
and from the regular-flowered crowfoot to the distorted monks-hopd by a series graduated in like manner.

16. NATURA NON SALTUS FACTT, said Linnæus, in evident allusion to this beantiful principle, which will constitute one of the most interesting themes of botanical study.

17. Accomodated Forss or organs is a phraso applied to another principlo in the Divine plan, the reverse of the first. This principle appears in the adaptation of different organs in different species to one common use; of which there are many familiar

18. ExaMrples. Thus, the slender vine requires support. Now it throws out a tendril for this very purpose, grasping whatever object it may reach, as in the grape. Again, the prolonged leaf-stalk answers the same end, as in Clematis. Again, the supple stem itself, by its own coils supports itself, as in the hop; and, lastly, adventitious rootlets in the ivy.

19. Another illustration. Reproduction is the general office of the seed; but this end is also accomplished, in different species, by nearly every other organ, by buds, bulblets, bulbs, tubers, cuttings, scions, and even leaves.

20. ANother. This principle is also traced in the nutritious deposits of plants, which are generally mado in the fruit; but often the root serves as the reservoir instead, or eren the stem. And in case of the fruit, the rich deposit is now found in the pericarp of the peach, the calyx of the apple, the receptacle of the strawberry, the cotyledons of the almond, the bracts, flower-stalks, \&c., of the pine-apple. Thus God's boundless resources of skill can accomplish either one purpose in a thousand different ways, or a thousand different purposes by a single organ.

21. ARPESTED ForMs. This principle, demanding a wider range of generalization than either of the foregoing, we state rather as a hypothesis, that the student may hereafter test its probability by his own observations. The flowering plants which clothe the earth in such numbers, constituting the apparent vegetable world, are in truth but a minor part of it in respect to numbers. Numerous tribes, of lower rank, embracing thousands of species, reach far down the scale, beyond the utmost limits of the microscope. Now a principle of analogy seems to pervade these ranks, called the principle of arrested forms, binding all together in one consistent whole, proving that for the vast realm of vegetation there was but one plan and one origin.

22. The HYPotiesis stated. The successive tribes of regetation, beginning with the lowest, have each their type or analogue in the successive stages of embryonic growth in the highest tribe.

23. MORE EXPLICITLY: the flowering plant, in the course of its growth from the pollen grain to the completed embryo, passes necessarily through a series of transient forms. Now, suppose the development of the plant arrested at each of these stages; so that these transient forms become permanent, we should have a series of organisms analogous to the various tribes of Flowerless Plants; the Protococcus, e. g., an arrested pollen grain; the Oscillaria, an arrested pollen tube; and so on up to the Marsillea, whose organization answers to that of the full-formed embryo of the Howering plant. Thus we might truly say of the lower plants that they are the arrested forms of the higher.

24. INDIviddality OF THE PlaNt. The plant is both material and immaterial. Its form and substance is the material, its life the inmaterial. The material commences existence as a single cell, and is ever changing. The immaterial gives to that cell its individuality, and fixes inevitably its law of development, so that it must grow up to become such a plant as it is, and by no possibility any other.

25. Iluustration. The embryonic cell of a rose may not differ materially, in the 
least, from that of the grape: but the individuality of each is widely different. This principle in the one will make it a rose; in the other, a grape. Individuality can not be predicated of a stone.

26. LIFE AND DEATH ARE EQUALLY PREDICATED OF THE PLANT. The latter follows close upon the former, with unequal, inevitable step, and soon disputes possession in the same living fabric. The plant both lives and dies at once. Life passes on from cell to cell, and in the parts which it has abandoned dissolution and decay are soon manifest. Thus the whole existence of the individual is a contest. Life advances, death pursues, and ultimately triumphs. But not so in the species. Securely transferred to the seed, the living immaterial plant mocks the destroyer, and begins its career anew, multiplied a hundred fold.

27. THE SEED OF THE PLANT IS ITS REDEMPTION. Through this appointment, the conquest of death is apparent, while the triumph of life is real. In the "grain of mustard" there is literally a faith-an energy which will raise it from the dust, "a tree." Yet, as in the wheat and all other seed, "it shall not be quickened except it die." Hence,

28. Plants saAy teach US Lessons in sacred things. While wo study the facts and the forms of the vegetable world, we should also aim to learn the purposes accomplished, and the great principles adopted in its creation. We should also learn to rocognize here the tokens (too long overlooked) which declare that nature sympathizes with humanity in the circumstances of the Fall, the Redemption, and the Life. Such study alone is adapted to acquaint us with the thoughts of the intelligent Creator, and to discipline aright the mind which was created in His image.

29. BotaNy CONBINES PLeASURE WITH IMPROVEMENT. It conducts the student into the fields and forests amidst the verdure of spring and the bloom of summer; to the charming retreats of Nature in her wild luxuriance, or where she patiently smiles under the improving hand of cultivation. It furnishes him with vigorous exercise, both of body and mind, which is no less salutary than agreeable, and its subjects of investigation are all such as are adapted to please the eye, refine the taste, and improve the heart.

\section{II A P TER II.}

\section{THE DEPARTMENTS OF THE STUDY.}

30. Thinee great departments in nature are universally recognized, commonly called the mineral, vegetable, and animal kingdoms. The first constitutes the Inorganic, the other two the Organic World.

31. A mineral is an inorganic mass of matter, that is, without distinction of parts or organs. A stone, for example, may be broken into any number of fragments, each of which will retain all the essential characteristics of the original body, so that each fragment will still be a stone.

32. A PLANT is an organized body, endowed with vitality but not with sensation, composed of distinct parts, each of which is essential to 
the completeness of its being. A tulip is composed of organs which may be separated and subdivided indefinitely, but no one of the fragments, alone will be a complete plant.

33. Animals, like plants, are organized bodies endowed with ritality, and composed of distinct parts, no one of which is complete in itself, but they are elevated above either plants or minerals by their power of perception.

34. THESE DISTINCTIONS, long since suggested by Linnæus, the founder of botanical science, are perfectly obvious and definite in the higher grades of the animal and vegetable kingdoms. But in descending the scale, we recagnize a gradual approach, in both, to inorganic matter, and consequently to each other, so that in the lowest forms of life all traces of organization are lost to our perception, and the throe kingdoms of nature, like converging radii, apparently meet and blend in a common centre.

35. THE POSTTION OF THE PLANT-WORLD IN RANK and office is intermediate. While inferior to the animal in respect to perception and instinct, it is superior to tho mineral in its vitality. In office it constitutes the food and nourishment of the animal, the vesture and ornament of the mineral world, whence alone itself is fed. In other words, plants feed on minerals, animals feed on plants.

36. Physics is the

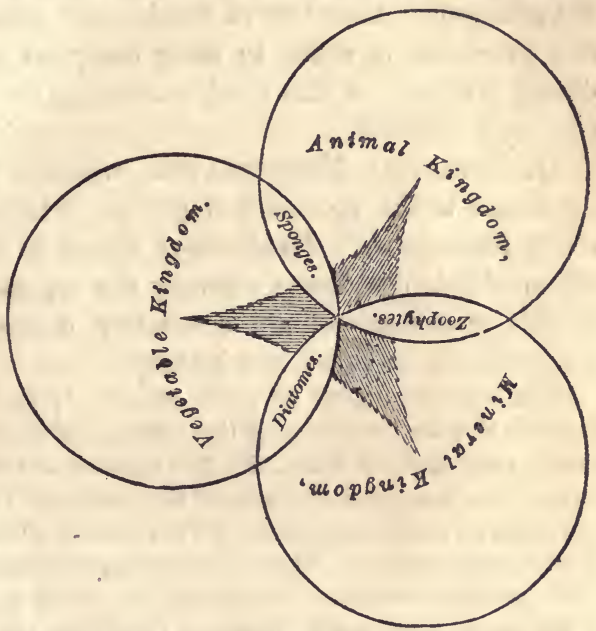

Froure 1. A diagram minstrating these views of the three kingdoms of nature-how related to each other. general name of the science which treats of the mineral or inorganic world.

37. Zoologr relates to the animal kingdom.

38. Вотамт is the science of the vegetable kingdom. It inclades the knowledge of the forms, organs, structure, growth, and uses of plants, together with their history and classification. Its several departments correspond to the various subjects to which they relate. Thus

39. Structural botaxy, or Organography, treats of the special organs of plants as compared with each other, answering to Comparative Anatomy in the science of Zoology. Morphology is a term often .used in a similar sense; but it especially relates to the mutual or typical transformations which the organs undergo in the course of development.

40. Elementary botany treats of the elementary tissues-the organic elements out of which the vegetable fabric is constructed. 
41. Physiological botany is that department which relates to the vital action of the several organs and tissues, including both the vital and chemical phenomena in the germination, growth, and reproduction of plants. It has, therefore, a direct and practical bearing upon the labors of husbandry in the propagation and culture of plants, both in the garden and in the field.

42. Systematic botany arises from the consideration of plants in relation to each other. It aims to arrange and classify plants into groups and families, according to their mutual affinities and relative rank, so as to constitute of them all one unbroken series or system.

43. Descriptive botany, or Phytology, is the art of expressing the distinctive characters of species and groups of plants with accuracy and precision, in order to their complete recognition. A flora is a descriptive work of this kind, embracing the plants of some particular country or district.

44. Botanical Nomenclature, which is the art of properly applying names to the species and groups, is intimately associated with the above department. Terminology relates to the explanation and application of botanical terms whereby the organs of plants, with their numerous modifications, are accurately designated. This is, therefore, inseparable from Structural Botany.

45. Ultimate aim of botany. Finally, in its extended sense, Botany comprehends also the knowledge of the relations of plants to the other departments of nature, particularly to mankind. The ultimate aim of its researches is the development of the boundless resources of the vegetable kingdom for our sustenance and protection as well as education; for the healing of our diseases and the alleviation of our wants and woes. This branch of botanical science is called

46. Applied Botany. It includes also several departments, as Medical Botany, or Pharmacy, Agricultural Botany, or Chemistry, Pomology, \&c.

47. Plan of the work. In the following pages, designed as a complete although compendious treatise for the special convenience of the learner, we shall commence with Structural Botany, whose subjects (the constituent organs of plants) are conspicuous and most readily comprehended.

48. Seconduy, the cell and the elementary tissues will claim our attention. Thirdur, we shall inquire into the vital activities of all these organs, and endeavor to explain the phenomena of vegetable life. Fourthly, the principles of vegetable nutrition which constitute the foundation of agricultural science.

49. IN THE FIFTH PLACE we shall treat of Systematic Botany, the principles of arrangement adopted in the Natural System, and the methods of Botanical Analysis.

50. Lastur, the Natural Orders will be defined, and illustrated by our flora, both native and cultivated. 
51. Notwithstanding the extreme brevity of this work, the author believes that no principle of the science essential to a liberal course in Botany is omitted. The brevity is attained by a studied conciseness of expression, and by the omission of all needless illustrations, theoretical views and wordy discussions. In the flora those multitudinous repetitions which are liable to encumber the descriptions of allied groups are avoided, without the sacrifice of minuteness by means of copious tables of analysis.

\section{CHA P TER III.}

\section{A P P RATUS-METHODSOF STUDY.}

52. THE PROPER SEASON FOR THE COMMENCEMENT OF THE STUDY of Botany in schools is in late winter, at the opening of the first session or term after New-Years. The class will thus be prepared before hand by a degree of acquaintance with first principles, for the analysis of the earliest spring flowers-the sweet Epigæa, Anemone, Erigenia or spring beauty, of the North, the yellow jessamine, Chaptalia, or Crysogonum of the South, the blood-root and violet every where.

53. SPECIMENS of leaves, stems, roots, fruit, flowers, \&c., in unlimited supply are roquisite during the whole course. In the absence of the living, let the dried specimens of the herbarium be consulted. Crayon sketches upon the black-board, if truthful, are always good for displaying minute or obscure forms. In the city, classes in Botany may employ, at small expense, a collector to supply them daily with fresh specimens from the country. Moreover, the gardens and conservatories will furnish to such an abundant supply of cultivated species for study and analysis, with almost equal advantage; since the present work embraces, togetler with the native flora, all exotics which are in any degree common in cultivation.

54. AN HERBARIUM (h. s., hortus siccus, dry garden), is a collection of botanic specimens, artificially dried, protected in papers and systematically arranged. Herbaria are useful in many ways ; (a.) for preserving the knowledge of rare, or inacces. sible, or lost species; $(b$.) for exchanges, enabling one to possess the flora of other countries; (c.) for refreshing one's memory of early scenes and studies; (d.) for aiding in more exact researches at leisure; (e.) for the comparison of species with species, genus with genus, \&c. $\cdot$ ?

55. For collecting Botanic SPECimexs, a strong knife for digging and cutting is needed, and a close tin box eighteen inches in length, of a portable form. Enclosed in such a box, with a little moisture, specimens will remain fresh for a week.

56. SPECIMENS FOR THE HERBARIUM should represent the leaves, flowers and fruit, and, if herbaceous, the root also. Much care is requisite in so drying them as to preserve the natural appearance, form and color. The true secret of this art consists in extracting the moisture from them by pressure in an abundance of dry, bibulous paper, before decomposition can take place.

57. THE DRYING PRESS, to be most efficient and convenient, should consist of a dozen quires of ordinary blotting paper, at least $11 \times 14$ inches, two sheets of wiro gauze, (same size) as covers, stiffened by folded edges, and three or four leather straps a yard in length, with buckles. When in use suspend it in the wind and sunshine. In such a press, the specimens dry well in fair weather without once changing. If boards be used for covers instead of wire-gauze, the papers must be changed and dried daily. 
58. Succulent plants may bo immersod in boiling water before pressing, to haston their desiccation.

59. The Less, either single, double, or triple, is almost indispensable in the ordinary pursuits of Morphology or Phytography. In viewing minute flowers or parts of flowers the use of the lens can not be too highly appreciated. For dissection with the lens, a needle inserted in a handle, a penknifo and tweezers are required. The dried flowers of the herbarium need to be thrown into boiling water before dissection.

60. THE COMPOUND MICROSCOPE is undoubtedly a higher aid in scientific investigation than any other instrument of human invention. It is like the bestowment of a new sense, or the opening of a now world. Through this, almost solely, all our knowledge of the cells, the tissues, growth, fertilization, \&c., is derived. The skillful use of this noble instrument is.itself an art which it is no part of our plan to explain. For such information the student is referred to the works of Carpenter and Quekett.

61. ON THE PREPARATION OF BOTANICAL SUBJECTS for examination we remark briefly. The field of view is necessarily small, and only minute portions of objects can be seen at once. The parts of it are to be brought under inspection successively by the movements of the stage.

62. THE TISSUES of LEAVES, \&c., are best soen by transmitted light. They are to be divided by the razor or scalpel into extremely thin parings or cuttiugs. Such cuttings may be made by holding the leaf between the two halves of a split cork. They are then made wet and viewed upon glass. The stomata are best seen in the epidermis stripped off; but in the sorrel leaf (Oxalis Violacea) they appear beautifully distinct ( $\$ 678$, Fig. 585, ) upon the entiro leaf.

63. WOODY TISSUES, \&c., may be viewed either as opaque or transparent. Sections and cuttings should be made in all directions, and attached to the glass by water, white of egg, Canada balsam. To obtain the elementary cells separately for inspection, the fragment of wood may be macerated in a few drops of nitric acid added to a grain of chlorate of potassa Softer structures may be macerated sim. ply in boiling water.

64. Certain reagents are applied to the sofer and more recent tissues to effect such changes in the cell contents, of either color or form, as shall render them visible. Thus sulphuric acid coagulates the primordial utricle $(\S 645)$; a solution of iodine turns it blue; ougar and nitrie acid change it to red. 


\title{
Q UESTIONS.
}

\section{INTRODUOTION.}

\author{
CHAPTER I.
}

What is the subject treated of in this chapter?

What is the "end and aim" of all seience?

frors.-The class may use this chapter as a Lesson in Reading, or for Rocitation, as preferred, but should by no means opait it.)

\section{CH APTER II.}

30. Name the three kingdoms of Nature.

31. What is a mineral? A stone?

32. What is a plant? A tulip?

33. What is an animal?

34. Are the three kingdoms perfectly distinct?

Explain the diagram.

35. How is the Vegetable kingdom related to the Animal?

How is it related to the Mineral kingdom?

36. Define the science of Physics.

37. Define the science of Zoology.

38. Repeat the full definition of the science of Botany.

39. Of what does Structural Botany treat?

40. Of what does Ellementary Botany treat?

41. Of what does Physiologioal Botany treat?

42. What is the aim of Systematic Botany?

43. What of the art Phytology? What is a Flora?

45. Some of the uses of Botany.

\section{CHAPTER III.}

What is the subject of this chapter?

52. Why should the study of Botany be commenced early in Spring?

53. What specimens are wanted? Use of the black-board.

How may classes in cities be supplied with specimens?

54. What is an herbarium? Mention some of its uses?

55. What apparatus is required for collecting specimens?

56. What sort of specimens are wanted for the herbarium?

What is the true secret of the art of preparing the specimens?

57. Describe the drying press. How often should the specimens be turned?

59. What apparatus needed in examining flowers?

(The remsinder of this chapter may be read aloud or recited by the pupils as the tesober may prefer.) 


\title{
PART FIRST.
}

\author{
CHAPTER I.
}

State the title of this chapter.

65. Name the two Natural Grand Divisions of the Vegetable kingdom.

66. What of the Organs, or Organic System of the Phrnogamia? How do the Cryptogamia differ from this?

67. How does the Fern differ from the Rose? How does the Lichen differ from a Violet?

68. Name the two subdivisions of the Phænogamia.

59. What plants are comprehended among the Exogens? Explain the meaning of the word.

70. What plants are comprehended among the Endogens? Explain the import of the word.

71. Why are the Exogens called also Dicotyledons? Why are the Endogens called also Monocotyledons?

72. How may these two subdivisions be known by their leaves? How may they be distinguished by their flowers?

73. What is said about the two-fold name of a plant? Which name is provincial, and which universal?

75. Show by example how the Latin name is double.

76. Recite verbatim the definition of a species.

77. Notice an example of a species.

78. How may we define a variety? Give an example.

80. Recite verbatim the definition of a genus.

81. Please illustrate by two good examples:-Clover; Pine.

\section{CHA PTER II.}

REPEAT the title of this chapter.

83. Wherein does animal life differ from plant life?

84. Name the several stages of plant life.

85. Notice the five picture sketches of its biography.

86. How much does the "term of plant life" vary?

Strange exception of the castor-oil bean.

87. What of flowering and fruiting? When do they prove fatal? How does the florist's "tree mignonette" bear on this question?

89. State the definition of "Annual herb," "Biennial herb."

91. Also define "Monocarpic herb," "Perennial plant."

93. What is the lierbaceous perennial? The woody perennial?

What three distinctions among woody perennials?

94. What the stature of a bush? Of an undershrub?

96. What is the form and stature of a tree? Of a shrub?

97. What is remarked of the age of trees?

98. How may the age of a tree be estimated?

99. Can you instance some trees remarkable for age?

101. Please instance some trees remarkable for grandeur.

102. Now give the distinotion of trees relative to their verdure. 


\section{CHAPTER III.}

103. WHAт is the earliest stage of the plant?

104. In growing, whither does the radicle direct itself?

What is the tendency of the plumule?

105. Explain the structure of the bud. How does it grow?

Why is the original bud called also terminal ?

106. What sort of axis does the terminal bud alone develop?

107. What other buds are also found? Whence arise the branches?

110. Whence does the flower originate?

111. What then is the nature of the flower?

112. From what organ does the fruit originate?

113. Explain these views by the figure of the pæony and its parts.

\section{CHA PTER IV.}

Or what does this chapter treat?

114. Define the root. How distinguish root from stem?

116. Please state the two-fold office of the root.

117. What is the leading propensity of the root?

What are the only proper appendages of the root?

What end or purpose is answered by the multiplication of these ex* tremities?

118. What is the part designated by the term collum?

What are the spongioles, or spongelets?

119. What are the fibrillæ? Their office and use?

120. Why should a tree or shrub be transplanted in Spring?

121. Name the two definite modes of root-development.

122. Define accurately the axial mode. The inaxial.

Give instances of them both.

124. Name the four varieties of the axial, or tap-root.

125. Define the ramous tap-root. The tuberous.

127. Define the fusiform tap-root. The conical. Napiform.

How are all these thickened roots reservoirs?

130. Name the six forms of inaxial roots.

131. Describe, with examples, the fibrous root.

132. Describe the fibro-tuberous root. Moniliform. Tubercular.

133. What is the thickening matter in all these cases?

134. What roots are said to be adventitious?

135. What roots are said to be cirrhous?

136. What curious style of root has the screw-pine?

137. Describe the adrentitious roots of the banyan.

138. Describe the curious habit of the mangrove tree.

139. How may the growth of adventitious roots be favored?

140. Mention a method of raising dwarf trees.

141. Axial and inaxial-which requires deep tillage?

If two crops are sown together-what should they be?

143. What is the nature of those plants called Epiphytes?

144. What are Parasites? Give examples of these classes.

145. Read the paragraph on subterranean stems. 


\section{CHAPTER V.}

Wнат is the title of this chapter? Define this phrase.

147. What is the general idea of the term "axis?"

148. Does the ascending axis always continue to grow erect?

What is the idea of the procumbent stem? Of the decumbent?

What the idea of the ascending stem? Of the subterranean?

149. How may this last be distinguished from roots?

150. Explain the development of the simple stem.

Where may the original plumule bud be always found?

151. Explain the development of a branching stem.

If the axillary buds grow, what do they then become?

153. Is there any apparent plan in the arrangement of the branches?

Please define the alternate arrangement. The opposite.

Define the rerticillate. Give examples of each mode.

154. What varieties in the "angle of divergence" in branches?

What is noticeable in the beech? The oak? elm?

155. What are some of the distinctions made by nurserymen?

156. What is a Sucker? A Stolon, or Layer? A Cion?

158. How are the grape-vine and hop propagated ?

159. Define an Offset. Define the Runner.

161. What is a Node? An Internode?

162. Why does the stem diminish upwards?

163. Can you describe the process of the growth of the stem?

164. State briefly, one great exception to this rule.

166. Give the precise definition to the "leaf-stem."

167. Give the precise definition of the "scale-stem."

166. Name the five principal forms of the leaf-stems.

167. Name the six principal forms of the scale-stems.

168. Distinguish between the herbaceous and woody leaf-stems.

169. What is the caulis? Define caulescent. Acaulescent.

170. What is the culm? What stems are called trunks?

172. What forms of trunk have you noticed?

173. Distinguish the "excurrent" from the "solvent" axis. Instance some examples of each.

176. What term is applicable to the stem of the palm tree?

177. Deseribe the singular stock of the Cactus tribe.

178. Describe the vine and its two varieties.

Which is furnished with tendrils, the climbers or twiners?

179. What is the law in regard to the course of the twiners?

181. How is the creeper defined? Its two classes please mention. How is the witch grass best cultivated?

1S2. What can be said of the utility of such repent stems?

What prevents our sandy or clayey hills from washing?

183. What is the proper description of the root-stock?

184. Show, by figure 52, the manner of its growth.

185. Describe the premorse root-stock.

186. The stem of clover, asparagus, etc., in winter, is what?

187. What is a tuber? Show by fig. 54, etc., how it grows.

189. What is a corm? Show how it grows.

191. Describe the bulb. Show, by fig. 60 , how it multiplies.

193. Varieties in bulbs-describe some.

Finally, notice the gradation in tuber, corm, and bulb. 


\section{CHAPTER VI.}

What is the topic of this chapter?

195. What two kinds of buds are mentioned?

196. Repeat the definition of the leaf-bud.

197. What is the nature of the scales? Show this by figs. 67,68 .

198. Where are bud-scales needed and found?

199. How are the buds protected in rain or cold?

200 . Which is the parent bud? "What the axillary bud?

202. Distinguish the two kinds of axillary buds.

203. When may the axillary become terminal?

204. What if a part of them be suppressed? What if all?

205. When is the axis said to be brachiate? How in the pink? (Fig. 70.)

207. What are adventitious buds? How are they caused?

209. Vernation is what? Best method of displaying it?

213. Considering each leaf alone, when is it said to be reclined?

When conduplicate? Plaited? Circinate?

When is it convolute? Involute? Revolute?

Which variety is seen in oak (fig. 71,)? In the tulip-tree? Fern?

Birch? Cherry? Dock? Balm-of-Gilead? Sycamore?

214. Considering the leaves in respect to each other, when are they obvolute? When triquetrous? Equitant?

215. State the principle of "budding." What are bulblets?

\section{CHAPTER VII.}

WHAT is the subject of this chapter?

217. How does the leaf figure in landscape scenery?

218. What is the general characteristic of the leaf?

219. What variations in the color of the leaf?

220. What is the etymology of the word Phyllotaxy?

221. Explain "leaves radical." Leaves cauline. Leaves ramial.

222. What is the alternate arrangement of leaves? Scattered? Rosulate? Fasciculate? Opposite? Verticillate?

223. If you reduce all these to two types, what are the two ?

224. What experiment reveals the true nature of the alternate type?

226. Can you show that the opposite leaved type may be spiral?

227. Decussate leaves-what are they ?

228. State an established law in plant-development

229. Will you carefully define the elm cycle?

230. Calling this the $\frac{1}{2}$ cycle, what does the numerator denote? What the denominator?

231. How is the alder cycle?

Calling this the $\frac{1}{3}$ cycle, what does the 1 denote? The 3 ?

232. Describe the cherry cycle.

Why call this the $\frac{2}{5}$ cycle?

233. Describe the Osage orange cycle.

Why denominate this the $\frac{3}{8}$ cycle?

234. Show how these cycles are related to each other.

If the third is $\frac{2}{3}$ and the fourth $\frac{3}{8}$, what will the fifth be ?

235. In what plants is this (the $\frac{5}{1 \frac{5}{3}}$ ) cycle realized ?

236. What cycle is next in order? What its numerical sign?

237. You may read the remarks on the higher cycles. 
239. What is the blade? What is the petiole? Explain the meaning of the word sessile. Petiolate.

240. What are stipules? How many to each leaf, if any? Explain the meaning of the word exstipulate. Stipulate.

241. Name the three distinct parts of a complete leaf.

242. To what transformations are they liable?

\section{OF THE PETIOLE.}

243. What is the more common form of the petiole? What is peculiar in the petiole of the aspen?

244. What is there peculiar in the petioles of the Asters, etc.? What peculiarity in the leaves of the mullein?

245. How is the amplexicaul petiole, or leaf, described? What constitutes a sheath? (See figs. 102, 104.)

246. In what sort of leaves do we find compound petioles?

\section{OF THE STIPULES.}

247. What is the location of the stipules? Appearance? What is remarked of their presence or absence?

248. What of the stipules of rose (fig. 100)? Of pansy (fig. 102)?

249. What plants exhibit ochrece? What their nature?

250. When the leaves are opposite, what are their stipules called?

251. The ligule of grasses; what is it? What are stipels? Explain fig. 102. 103. 104. 105.

\section{OF THE VEINS.}

253. How do you distinguish a simple leaf? A compound? 254. Of what is the frame-work of the leaf composed?

255 . Why are they called veins rather than ribs? What is denoted by the term venation? Name the four organs of venation.

256. Please describe the mid-vein. What leaf has such? If there be several such, as in maple, what are they called?

257. What branches shall we call the veinlets? The veinulets?

258. The venation of the Exogens-name and describe it. The venation of the Endogens-name and describe. The venation of the Cryptogamia-name and describe. Name the three forms of the reticulate venation.

Now please describe them - the feather-veined.

260. The palmi-veined. The tripli-veined.

262. What varieties in the parallel venation? What venation in fig. 106? 107? 108? 109? 110?

\section{FORM, OR FIGURE.}

263. Can you show the connection between the figure of the leaf and its venation?

264. On what principle shall we arrange or classify leaf-forms?

265. The first class, or feather-veined leaf-forms, define it. Name and describe the three forms belonging to it.

$a$. Define the second class of feather-veined leaf-forms.

Name and describe the four forms belonging to this class. 
266. In the third class, where are the longest veinlets?

Name and describe the four forms of this class.

267. In the fourth class, how are the lowest veinlets?

Note the form of the cordate leaf. The auriculate. The sagittate. The hastate.

Observe fig. 110-what is its form? Also of 111? 112? 113? 114? 115? 116? 117?

Observe fig. 130-what is its form? What of 131? 136? 137?

268. On what do the pinnatifid forms depend?

The term pinnated contrasts with what other term?

269. Describe the pinnatifid leaf. The runcinate. Lyrate.

270. What is pinately parted? Sinuate?

271. What figures on page 56 have palmate venation?

Which two are reniform? Which is peltate? Which trilobate?

272. Observe the figures on page 58 , - which is palmately cleft?

Which palmately parted? Which merely lobed?

273. What form is pedute? Find an example.

274. What is remarked of the parallel-veined leaves?

275. What is the linear leaf? Give examples.

Define the ensiform leaf. What good example is here?

276. By what term is the palm leaf denoted?

277. What two forms of leaf are peculiar to the fir tribe ?

\section{MARGIN.}

278. Speaking of merely the margin, when is it entire?

279. When is the margin dentate? When serrate? Crenate?

What if the teeth are very fine? What is doubly dentate?

280. Define an undulate margin.

281. What terms apply to irregularly divided margins?

282. What does the term crisped denote?

APEX.

283. Name and define an acuminate apex. An acute. An obtuse. Other terms.

284. The truncate leaf. The emarginate, etc.

\section{OF THE COMPOUND LEAF.}

285. Were a simple leaf to become compound, how might it become so?

Please illustrate this by cutting a simple leaf.

286. What are the leaflets? The petiolules? The rachis?

287. Can you describe a pinnate leaf?

What modification of pinnate is fig. 161? 160? 159 ?

288. As to the number of leaflets in the pinnate leaf-how many?

How many in the trifoliate? Binate?

What reason to say that the lemon leaf (167) is compound?

289. How may a pinnate leaf become bipinnate? Tripinnate?

What is a decompound leaf?

290. What are transition leaves? Describe fig. 165.

291. Define a biternate leaf. A triternate.

292. Please distinguish the palmately and pinnately ternate. 
Fig. 162 represents what kind of leaf? 163 ? 164 ?

Describe fig. $168 . \quad 166.169$.

293. How are amplexicaul leaves inserted? Describe 170.

294. Define perfoliate leaves. Connate. Point out the figures.

\section{TEXTURE AND SURFACE.}

295. Name five varieties in the texture of leaves.

296. As to the surface, what is glabrous? Scabrous?

297. Define carefully a pubescent surface. A villous. Sericeous. Lana. ginous. Tomentous. Floccose.

298. Define, also, hirsute. Pilous. Hispid.

299. Also setous. Spinous. Stinging.

300 . What covers the pruinous surface, as of grapes?

301. Explain, finally, such terms as ovatc-lanceolate.

302. Can you show the use of the preposition sub?

\section{CHA PTER VIII.}

Wrat is the title of this chapter?

303. What is one of the first aims of the botanist?

304. How does it appear that scales are transformed leaves?

305 . What is the nature of the brown scales of buds?

306. What is the nature of the cotyledons? Proof?

What is the cause of their deformity?

307. Can you tell what phyllodia are? Examples?

308. Explain how ascidia may be transformed leaves.

309. Mention three eurious examples.

311. What are air-bladders? What their uses?

312. How is the leaf of "Venus' fly-trap" constructed?

313. What is the use of the tendril?

Is it a new organ?

How does the tendril of the pea originate?

What its origin in Gloriosa superba? In Lathyrus?

314. In Clematis, what organs serve as tendrils?

In green-briar, what organs become tendrils ?

315 . Whence come the tendrils of the grape-vine?

316. How are some plants armed?

From what organs do the spines of Berberis originate?

Whence the spines of goat's-thorn? Of locust?

317. How do thorns differ from spines?

What the origin of the thorns in Osage orange?

Whence the tharns of honey-locust?

318. What are prickles? Examples?

319. What are bracts? What is their nature?

\section{CHAPTER IX.}

321. What is the title of this chapter? Define the term.

333. Whence do the flower-buds originate?

323. What proof of this theory is given?

324. As to arrangement-what two varieties of flower-buds?

325. What may a single bud develop?

326. What is said of the axis of the flower-bud?

327. What is a peduncle? May it bear leaves? 
328. What are pedicels? When is a flower sessile?

329. How does a scape differ from a peduncle?

330. What is the rachis of an inflorescence?

331. What is the torus?

332. Mention some odd varieties of the peduncle.

Deseribe fig. 115. 116. 117. 118.

333. What are bracteoles?

334. How are the bracts in Aster? How in the Crucifers?

335. What is said of the color of bracts?

336. What is a spathe? Examples in figures 189, 190, 191

337. How may an involucre be formed?

338. Describe a compound flower of the Compositæ.

What is the chaff on the torus? Describe fig. 193.

339. In the grasses, what are the glumes? The pales? (Fig. 195.)

340. In the oak, etc, what is the nature of the cup ?* (Fig. 194.)

342. Why is axillary inflorescence called indefinite?

Why is it called centripetal?

Where is the centre of a lengthened inflorescence?

343. Why is terminal inflorescence definite? Centrifugal?

344. Are both terminal and axillary inflorescence ever combined?

345. Name the nine varieties of axillary inflorescence.

346. How is the inflorescence of the mullein, and how named?

In Timothy grass, what are the spikes and spikelets?

347. What is a spadix? Give examples.

What inflorescence in figs. 200? 201? 202 ?

348. What is a catkin? Examples?

349. How does the raceme differ from the spike?

350. How does the corymb differ from the raceme?

351. How does the umbel differ from the corymb?

What the compound umbel? The rays? The umbellets?

352. What is a panicle? Give common examples.

353. What is a thyrse? What is a head?

355. In a head, or compound flower of Compositæ, what answers to calyx? What to corolla? What are the florets of the ray? What the florets of the disk?

Describe each of the following figures, viz.: 203, 204, 205, 206, 207, 208, $209,210,211,212,213,214,215$.

356. Name three varieties of terminal inflorescence.

357. What is a cyme? What is a scorpoid cyme?

359. Show the evolıtion of a cymc in chickweed (fig. 219).

360 . Show the evolution of a scorpoid cyme by figs. $220,221$.

361. What is a fascicle? A glomerule?

What does fig. 216 represent? Fig. 217? Fig. 218? Fig. 221 ?

363. How may a spike become a raceme (fig. 222)?

How a raceme a corymb (223)? An umbel (224)? A head (227)? What is fig. 225 ? 226 ? 228 ?

Into what is the entire inflorescence transformed in grapes?

\section{FLOWERING.}

364. What is the meaning of the word ?

365. What is said of the date of flowering for each species?

366. How would you make a floral calendar?

How is this related to the climate? 
367. Example as to the red maple in different elimes. Example as to different plants in New England.

368. How would you construct a floral clock?

What plant opens its flowers at 2 o'clock, A. M. ?

What plant at $12, \mathrm{M}_{0}$ ? At $4, \mathrm{P}_{\text {. M., }}$ etc.?

369. As to the colors of flowers-are they subject to art at all ?

Why not depend on the color of the flower in descriptions?

370. Describe the Xanthic series of colors. The Cyanic series.

\section{CHAPTER X.}

Wнат is the title of this chapter? Meaning of morphology?

372. Flowers have what relation to man?

373. How do flowers improve in the light of science?

374. How is the flower related to a leafy branch?

375. Is the flower a new organ? Whence is it?

378. What evidence of the transformation of leaves into flowers is seen in the Calycanthus? In the water lily? (Fig. 240, etc.)

379. What is remarked of the early bud of irregular flowers ?

380. What evidence of this doctrine in teratology? Illustrate this by the double rose. Flowering almond, etc.. Illustrate by figs. $241,242,243$.

383. What fact renders astivation important? Define the term.

386. Name the four general modes of æstivation?

387. Describe the valvate. Describe its two varieties.

389. Describe the contorted. Describe the imbricate.

391. What two varieties of the imbricate are mentioned?

Define carefully the quincuntial. The triquetrous. The convolute.

The vexillary. The plicate. The supervolute.

397. What is the torus?

399. What are, the floral envelopes?

Which of them is the calyx? Which the corolla?

Do both calyx and corolla always exist?

If but one be present, which is it?

400. Define carefully the calyx. What are the sepals?

401. Carefully define the corolla. What do we call its leares?

402. What is the use of the word perianth?

403. The essential organs-what two kinds?

404. Define the stamens. What of their number?

Collectively, what are they called?

405. Define the pistils. By what other names called.

406. Now recapitulate these four sets of organs in order.

407. What is said of appendages?

408. The pupil may read or rehearse Sec. 408.

410. In respect to symmetry-what of the number in each set?

411. In relative position-liow are the petals with sepals, etc.?

412. Define, then, the typical flower.

Why is it perfect? Complete? Regular? Symmetrical?

413. Is this type often realized?

Whence the endless variety in the floral world?

414. What flower in our flora approaches nearest the type?

415. Mention a perfect example.

416. How do the flowers of Sedum deviate from it?

417. Can you mention some of the modes of deviation?

418. What do you understand by the radical number?

419. What is the most common radical of the Exogens?

What most common in the Endogens?

What is the radical number of the flower in your hand?

420. What do incomplete flowers lack?

What is an apetalous flower? What example?

What is an achlamydeous flower? Examples. (Figs. 264, 265.) 
421. What do imperfect flowers lack? Deseribe a sterile flower.

Describe a fertile flower. Give the emblem of each. ( $\delta, \&$.

Use of the word diclinous? Explain tigures 266, 267, 268, 269, 270.

422. What is a neutral flower? (Fig. 271.)

423. What constitutes an uresymmetrical flower? Examples.

424. Describe the flower of mustard.

425. Describe the flowers of the Mint family, as Monarda, etc.

426. In what respect are the flowers of poppy unsymmetrical? Of lark-spur? Of Monk's-hood? Describe figs. 280, 281, 282, 283, 284, 285.

427. What is meant by "organs opposite?"

428. How is this anomaly explained? Explain figs. 272, 273, 274, 275.

429. By what law do "organs increase in number?"

430. Illustrate this in the lilies. The roseworts. Blood-root.

432. Illustrate the law of chorisis by figs. $276,277,278$.

433. Mention some appendicular organs.

434. What are spurs in various examples?

435. What are scales in the various examples cited?

What is the corona in Narcissus? In catchfly?

436. Describe the "glandular bodies" in grass-Parnassus.

437. What is said of the frequency of "union of organs?"

How may this union be detected?

438. Fxplain the difference between cohesion and adhesion.

440. Explain the proper use of the words free and distinct.

441. What is said of regularity in the early buds of flowers?

Mention certain modes of irregularity in flowers.

443. Describe a lengthened receptacle. How is this in figs. 288, 287, $286 ?$

444. Describe the excavated receptacle, as in rose, (fig. 289.)

446. What is the disk? Describe it in figs. 291, 292, 293.

447. What is said of "combined deviations?"

44S. Give an example, in any flower at hand.

\section{CHA PTER XI.}

449. Can you define, once more, the true idea of the typical flower?

450. What is the only true distinction between calyx and corolla?

451. How are sepals and petals as to number?

451. How do sepals resemble leaves? How do petals?

453. What corresponds to blade? What to petiole?

454. In the sepals, what appears to be the analogy? (See fig. 11, a. b. c.)

455. In outline, what are the forms of petals? Are they always entire?

State the peculiarity in the petal form of the Umbilifers (297). In the petal of chickweed (299). Of campion (296). Of Monk'shood. Mitrewort (298).

456. What of the nectary?

457. Are the floral organs more likely to be distinct, or united?

458. What do we call a calyx with united sepals?

What do we call a corolla with united petals?

What terms are opposed to these two?

459. What do we understand by the limb? The tube?

460. What varieties in the degree of cohesion (figs. $300,301,302,303$ )?

461. What sort of cohesion in caly $\mathrm{x}$ of Eschscholtzia, or grape?

463. Why are the outer organs of butter-cup hypogynous?

464. In the flower of cherry, why are the stamens perigynous?

Explain the term epigynous? What two phrases are of the same import?

166. Please mention two other phrases of the same meaning.

Describe figs. $304,305,306,307,308$, especially as to the ovary.

Also describe figs. $309,310,311$, as to ovary, etc. 
467. In the rose, (289) are the ovaries in a hollow receptacle, or in a tubular calyx? How is this in cherry and pear $(308,307)$ ?

468. What two phrases are synonymous with "calyx hypogynous?" How is the calyx in saxifrage (fig. 310 ) and in mock-orange?

469. Of regular polypetalous flowers, what four forms are named?

Of irregular polypetalous, what two forms?

Of regular monopetalous flowers, what seven forms?

Of irregular monopetalous, what two forms?

470-484. Describe each and all these forms in order.

To which of these classes belongs the tulip? The rose? The mustard? Pea? Elder? Kalmia? Harebell ? Whortleberry? Morn. ing-glory? Petunia? Honey-suckle? The florets of dandelion? The sage? Cypripedium?

485. What is pappus? Its etymology ? Give examples.

Describe figs. $323,329,330,331,332,333$.

487. In the flower of bog-rush, what represents the calyx (fig. 334)?

488. In Carex, what represents the perianth (fig. 335)?

489. In the grasses, what organs replace the perianth ?

In fig. 195, show the spikelet? The glumes? The pales?

490. Define the term caducous. Deciduous. Marescent. Persistent.

\section{CHAPTER XII.}

491. In what position are the essential organs found?

How may they be known from the envelopes?

492. Mention and describe each of the three parts of the stamen.

Which of these parts is not essential ?

What is the collective name of the stamens? (Fig. 336.)

In fig. 336, which is the androcium? Which the gynœeium?

In fig. 338, which is filament? Anther? Pollen? Connectile?

493. Describe the filament.

494. Please describe the anther. Connectile. Dehiscence.

495. When is the anther versatile? Adnate? Innate?

496. When is the dehiscence valvular? Porous? Opercular?

497. When is the anther introrse? Extrorse?

Describe figs. $339,340,341,342,343,344$.

498. At what points may the anther be appendaged? Describe figs. $349,350$.

499. When is the anther dimidiate? Describe figs. 354, 351.

Point out the stamens and pistils in figs. $355,356,357,358,359$

Describe figs. 360,361 .

502. What are staminodia? Where do we find them?

Describe fig. 372 , and show the staminodia.

503. As to number-what is definite? Indefinite? Monandrous? Diandrous? Triandrous? Pentandrous, etc.?

504 As to position-what is hypogynous? Perigynous, etc.

505. As to comparative length, what is didynamous? Tetradynamous?

506. As to the union of stamens, what is monadelphous? Diadelphous?

Polyadelphous? Syngenesious?

507. As to absence, how is a plant rendered monceious? Diœcious?

How are the flowers in a polygamous species? ( $\$ 421$.

508. What is the pollen? Its microscopic appearance?

Describe figs. $362,363,364,365,366$.

509. Describe particularly a grain of pollen.

510. How does pollinia differ from pollen?

511. Position of the gynœcium?

How is the gynœecium regularly constituted? 
512. Are its pistils always distinct as in columbine?

Is the gynocium always free and superior as in columbine?

513. What is said of the number of the pistils?

What is the meaning of the terms monogynous? Trigynous?

514. How may a simple pistil be known?

515. Name the three parts of the pistil? Which is non-essential ?

516. How is this carpellary leaf folded in becoming a pistil?

What forms the two sutures?

517. Explain figs. 378 bis, 379 bis, and illustrate this view.

Also compare these with figs. $380,381$.

519. What is therefore the full expression of the doctrine?

520. What are the placenta? When is it double?

521. Illustrate a simple carpel by a pea-pod.

$52 \%$. What is the stigma?

523. Of what does a compound pistil consist?

Describe the various degrees of cohesion, as in different plants.

Describe figs. 387, 388, 389, 390, 391, 392.

- Also here describe figs. $384,385,386$ and 371 to 379.

524. Mention carefully the five methods of determining the number of carpels.

525. In the first mode of cohesion, how are the carpels conditioned?

1. In this case, how many cells will there be?

2. How will the dissepiments be conditioned?

3. Why is the partition in the flax cell called spurious?

4. Where will the placentæ be located?

526. In the second mode of cohesion, how are the carpels?

1. In this case, how many cells will there be?

2. How will the placentio be located?

527. Can you mention any intermediate conditions?

528. Can you describe the free axile placentæ?

How many methods of explaining this singularity?

In which figures is such a placenta seen? (394, 398.)

Describe figs. 399, 400, 401, 402, 403, 404, 405.

529. Here notice forms of style and stigma in fig. 385 , and in 371 to 379 .

532. What is the nature of the ovule?

What evidence of this theory can you mention?

533. As to number, what is definite? Indefinite?

534. As to position, what is erect? Ascending, etc.?

Illustrate by figs. $414,415,416,417$.

535. As to its parts, what is the funiculus? Chalaza? Tegmen? Testa? Micropyle?

536. As to turns, what does orthotropous mean? Anatropous?

Describe fig. 406 . Describe figs. $413,407,408,409$.

In fig. 409 , point out the funiculus, chalaza, tegmen, testa, micropyle, and nucleus.

Describe figs. 410,411 , the same six parts, and the raphe and hilum.

539. What of the embryo sac?

\section{CHAPTER XIII.}

541. What short definition of fruit is given?

542. What becomes of the corolla and stamens after flowering?

What of the calyx? What of the style?

543. What is remarked of consolidated fruit?

544. Why is an early examination of the ovary safer than a late? 
545. Mlustrate this by the acorn. By the fruit of birch.

546. What other change occurs? Illustrate by thorn-apple. What is shown in figs. $418,419,420$ ?

547. Name the two parts of the fruit, and describe. Name the various textures of the pericarp.

548. Can you name instances of open periearps? Describe figs. 491, 492. How are the seeds of fleshy fruits liberated?

How are those of the dry fruits usually liberated?

550. Can you name the modes of dehiscence?

1. What is sutural dehiscence? In what fruits seen?

2. What kind of dehiscence is seen in diagram 429? 430 ? 431 ?

551. What kind of dehiscence in poppy? In henbane, etc.? (Fig. 444.)

553. What singular organ is seen in caraway? (Fig. 433.)

555. Explain the synopsis of the fruits, how fruits may be defined by it.

556. What is an achenium? A cremocarp? A cypsela?

558. How distinguished from seeds? Show figures of each kind.

559. What is a utricle? Show us one, or the figure.

560. A caryopsis? The figure. A samara? The figure.

561-581. (The same questions on each kind. showing the figure, or if pose sible, the very fruit.)

\section{CHAPTER XIV.}

582. Define the seed. What does it consist of?

583. What is the name of the outer covering? Of the inner?

584. What are the various textures of the testa? Of its surface?

585. How distinguish the coma from the pappus?

Which of these, properly, is cotton? Explain fig. 465.

586. What occasional covering is named? Examples.

Show it in nutmeg (fig. 461). In staff-tree (fig. 460).

What is the aril called in the seed of Polygala? (Fig. 641.)

588. What is the eye of the seed properly called?

589. When is the seed said to be albuminous? When exalbuminous?

590. Describe the albumen. Its quantity compared with the embryo. What its varieties of texture? Show examples.

591. What three parts of the embryo are mentioned?

592. Define the radicle. The plumule. The cotyledons.

594. How do these alternate with the albumen?

596. How are the monocotyledons characterized? The dicotyledons? How are these great classes distinguished by their leaves?

598. Have any plants more than two cotyledons?

What of fig. 466? Of fig. 467? 468? 469?

599. What varieties in position are mentioned?

601. When does the seed sleep?

What is then its condition, or state?

602. Give examples of the great longevity of the sced.

603. How may seeds longest retain their vitality?

604. How are thistle seeds dispersed?

605. How are tick-seeds, ctc., dispersed? The touch-me-not?

606. How the seeds of the squirting-cucumber?

607. What the agency of rivers? Squirrels? Birds

608. What is germination? Where may we observe the process?

610. How and why is the seed to be planted?

611. What changes take place in the material of the seed? 
Show the coiled embryo in fig. 475 .

Show the bursting embryo in fig. 476.

Show the liberated embryo in figs. $477,478,479,480$.

612. What becomes of the radicle? - Of the cotyledons?

How does the plumule develop? Show by the figures.

613. In what plants do the cotyledons remain below ?

- 614. Show by figs. 481, 482, how the monocotyledon germinates.

615. What the three conditions requisite for germination?

616. Why is moisture requisite?

617. Why air? Whence comes the sugar?

618. What degrees of warmth? Give some strange exceptions.

620. What good explanation of the downward tendency of the root can you give?

\section{CH A P T E R V .}

621. In the lowest Cryptogams, are the parts distinct?

In the higher, how is it?

622. How are they distinguished from the Phænogams ?

623. What is said of the root, stem, and leaves in Fungi, etc.?

(Noxk. -This chapter may be as well reviewed by the topics as by questions.)

\section{PART SECOND.}

\section{CHAPTER I.}

638. Of what is all vegetable structure composed ?

639. How is the cell defined? What is the primary form of the cell?

641. Mention three general types.

642. Whence do the casual forms result? Name some of them.

643. What is the size of vegetable cells?

G41. Of what length are some wood-cells and bark-cells?

645. Describe the two layers of the cell-wall.

646. How may we bring the primordial utricle to view as in fig. 568 ?

647. How does it appear that the cell-wall is porous?

648. What appearance does a third layer make?

649. What fills up the wood-cells? Show them by fig. 560 .

650. What the appearance of pitted cells?

Illustrate these cells in figs. 569 and 570.

651. What is the wonderful structure of spiral cells? Show them in figs. $571,572,573,577$, and in petioles.

652. Show an annular cell in fig. 574 , and where else?

- 653. Show a scalariform cell in fig. 575 , and where else?

654. What is the material of the outer cell-wall ?

What are its chemical elements? What are the chemical elements of the inner cell-wall?

655. What do the cells contain? What is cytoblast? Protoplasm?

656. What is the condition of the coloring matter?

657. What is the structure and color of chlorophylle? Describe fig. 567.

658. What is the composition of the starch granules? (Figs. 579, 580.)

660. What are raphides? Show figs. 582, 583.

661. Show how the cells are multiplied. 


\section{CHA PTER II.}

662. What is the simplest possible form of vegetation?

663. What constitutes a tissue? Name the four tissues.

664. What the form of the cells of Parenchyma? Classify them.

606. What the form of the cells of Pleurenchyma? Two varieties.

667. In what trees do we find the pitted cells? What is fig. 579 ?

Explain this beautiful appearance by fig. 579 bis.

668. What is trachenchyma? How are these tubes made?

Show the structure of dotted-ducts in figs. $566,576$. .

671. Office of cienchyma? What their nature?

673. What is said of the intercellular passages?

674. Give, finally, the import of the cell.

675. How is elevation of rank in plants indicated?

\section{CHAPTER III.}

Wrist does the "epidermal system" include?

676. What is the office of the epidermis? What its cells?

678. What are the stomata? When are they open, and when closed?

679. How many are found in the space of one square inch?

Point out the stomata in the figs. 582-586.

681. What is said of the structure of hairs?

682. What is the office of glands? What varieties are there?

683. Describe the mechanism of the sting, in fig. 591.

684. How do prick'es differ from spines? Describe the figures.

\section{CHA P TER IV.}

685. What does the "ligneous system" include?

686. Of what kind of tissue does the young rootlet consist?

687. What is the early tissue of all new growths?

638. What changes occur in the rootlet?

689. How is the increasing demand for moisture met?

690. Name the four grand divisions of plants.

691. Describe a cross-section of the stem of an Exogen.

692. Describe the pith; its composition, contents, etc.

693. Where do we find the medullary sheath? What are its vessels? Its connections? Its office?

691. Of what does the wood consist? How much grew the first year? How much each successive year?

695. Whence is the distinction between the annual wood-circles?

697. The alburnum and duramen-how üistinguished?

698. Which is the living wood? How does it become duramen?

Which is valuable as timber?

699. What has perished in a hollow tree?

700. Name the three layers of the bark.

701. The liber-of what tissues? Whence is its toughness?

702. What is the green bark?. What its structure?

703. The brown bark-what are its varying colors? What is its tissue ? How is it in the cork oak?

705. Define the medullary rays. What is their structure?

707. Why are they called the silver grain? Show it in figs. 597, 598.

708. What good purpose do they serve? 
709. Where is the cambium layer found? What is it?

710. Why is it called the generative layer?

711. Why is the growth of Exogens unlimited?

712. Why is the bark most sought in medicine, etc.?

713. What of a cross-section of an endogenous stem ?

714. Explain particularly its structure.

715. As to these bundles-of what does each consist?

717. Has the Endogen a true bark? Why does it split with difficulty ?

718. Why are these plants called inside-growers, or Endogens?

719. Why is the caudex of the palmetto, etc., often smaller at base?

720. In what plants is the acrogenous structure found? Why are they so called, $i$. e., point growers?

721. How does a cross-section of one of them appear? (Fig. 600.)

Here describe the figures 595 and 596.

722. What is the rank of the mass-growers? What is their only tissue? What semblance of stems have they?

724. What can you say of the fibrillæ of the root? (See the fig.)

725. What may be said of the pileorhiza? Show it in the figures.

726. How does the root grow, and penetrate the soil?

729. What is the substance of the veins?

730. How many layers of the parenchyma are there? When are the two alike, and when unlike?

732. What is the normal place of the stomata? How in floating leaves?

733. What is the condition of the chlorophylle?

734. The vessels of cienchyma-where, and of what use?

Explain fig. 604, and show the parts, as the epidermis, the two layers, chlorophylle, spiral vessels, stomata, etc.

\section{CHAPTER V.}

736. What inquiries are we now to start?

738. What problem remains unsolved? What phenomena do we refor to the vitality of the plant?

739. What is the lowest form of life? Whence does it spring?

740. How prove that the vegetable kingdom is subordinate?

742. In what steps does the process of vegetation consist?

What are the vital phenomena included in vegetation?

744. What two kinds of organic matter make up the cell?

Write out the symbols of these two. Which resembles animal matter?

745. What does the cell imbibe? From what fluid?

746. What chemical decomposition ensues? What becomes of the water formed? What of the cellulose?

747. How is chlorophylle formed? What becomes of the excess of the cellulose? What globule within a globule?

749. What becomes of the excess of protoplasm?

750. What per cent. of gluten and starch in wheat? Why is extra flour deficient in gluten?

751. Can a plant consist of a single cell? Give an example.

752. Describe the two modes of cell growth.

753. How is growth distinguished from reproduction?

754. What is the embryonic vesicle? Its origin? Its destination?

755. How does it receive its impulse in this direction?

756. Trace the growth of the pollen grain after it falls on the stigma.

757. Trace the course of the pollen tube, and in fig. 607 .

758. Show the process of growth in the fertilized cell, and in fig. 608 .

759. How does Schleiden's view differ from the above? Explain fig. 609. 
760. In the Coniferæ, where does the pollen fall?

761. What is the state of the embryo in the mature seed? What store is laid up for it?

762. What chemical changes ensue? What is diastase? Dextrine?

Whence is the yeast? The heat? The sugar?

766. In the process of ripening fruits, what material is formed?

767. Whence is the honey in the flower? What the use of the sugar?

768. Of what use is the honey to the plant?

\section{CHA PTER VI.}

770. WH八т the subject? What is the most important office of the root?

771. Illustration, by a plant of spearmint, hydrangea, etc.

772. What organs absorb the water in these cases?

773. Illustrate this by a radish plant.

774. In transplanting trees, what special care must be used ?

775. What of the force of this absorption? How may it be shown?

777. Name the two causes of the ascent of the sap.

778. Illustrate capillary attraction by glass tubes. By a napkin.

780. Illustrate endosmose by dried prunes.

781. Illustrate by a bladder and long glass tube.

784. Of what use to the vegetable is absorption? Have the roots the power of choice? Give examples.

785. What other organs absorb? What illustrations are given?

787. In what direction is the flowing of the sap?

788. How does it advance in the tissue of a Cryptogam ?

789. In higher plants, what is noticed in the different tissues?

790. What vessels and passages convey air only?

791. What seems to be the moving force which raises the sap ?

792. Through what tissne does the sap chiefly ascend?

793. Through which layers, and why?

794. What is the composition of the crude sap?

795. How do you account for the issue of sap from the sugar maple in early Spring? What eauses the flow to eease?

796. How does the crude sap become the true sap?

797. Trace the distribution of this fluid as it returns from the leaves.

798. Specify the places where this sap makes deposits.

799. In what direction is the growth, from above or from below?

800. Illustrate this by the girdling process. Why does the tree die?

801. Illustrate by a ligature. Illustrate by a wound in the trunk.

803. What the effect of eutting a branch just below a node?

801. What of girdling a potato plant? Fruit tree? Why?

806 . Where does the flow called rotation occur? Describe it.

808. What is the process called transpiration? It occurs where and when?

809. What other process depends upon it? Does it convey away puro water only?

810. How much water did a sunflower transpire per day? A cabbage?

811. Describe an arrangement for showing the quantity of transpiration.

812. What do we understand by respiration in plants?

813. What experiment with an air-pump shows its importance?

814. Why does the tree suffer when its roots hare been buried too deep?

815. Define respiration in plants. Where does it occur?

816. What does the vast extent of the respiratory apparatus show?

817. State in order the six facts given in relation to respiration.

818. State carefully the two opposite phases of respiration. 
819. When does the former phase become visible? When the latter?

820. Explain the phenomena of blanched plants.

821. Describe the interesting experiment of Saussure.

822 . Why is no oxygen obtained when boiled or distilled water is used?

824. What are the results of transpiration and respiration on the sap?

825. What proportion of carbonic acid in the air? Whence is it derived? How much is added to the atmosphere annually?

826. Why does the carbonic acid not accumulate in the air?

827. How might the air become poisonous for animals?

828. Now show how the animal and vegetable kingdoms mutually aid each other.

\section{CHAPTER VII.}

829. Name the four organogens, $i$. e., organic elements.

830. In what proportion does each exist? In what proportion all?

What the per cent. of carbon? What gives solidity and strength?

831. What do the oxygen and hydrogen form in plants?

Give some examples of its quantity from the table.

832. Name some earthy elements found in plants.

833. Give from the table some examples of the proportion of ashes and other elements in vegetables.

834. What is the object of inquiry in Agricultural Chemistry?

834. What is the food of plants? Whence comes their nourishment? Whence their carbon? Their oxygen? Hydrogen? Nitrogen?

835. What the whole quantity of carbon in the air?

837. Of what does soil consist? Its organic materials.

838. Of what is water composed? Whence the ammonia in rain?

839. What is the composition of ammonia?

840. What source of nitric acid in the air?

841. What are air-plants? Give some examples.

842. Name three requisite conditions of healthy vegetation.

843. What of the supply of the first? Of the second?

844. What is the object of tillage? What of sub-soiling?

845. What the object of manuring? What the use of amendments?

816. What is the good of bone-manure? What of guano?

848. What is fallow ground? What its benefit?

849. What gives efficiency to all these materials ?

850. Can you here state the outlines of digestion?

851. What are the constituents of the proper juice?

852. From this vital fluid what is first formed ? Next? Thirdly?

853. Where are gum, stareh, and sugar deposited?

854. How does sugar differ in composition from starch?

855. How may starch become cellulose? How become sugar?

856. Can you distinguish the vegetable products into two classes ?

857. On what principle is the table constructed? Illustrate.

\section{P A R T THIR D.}

CH A P T R I.

858. What is the object and aim of Systematic Botany ?

860. What is the higher purpose accomplished by it? 
861. How does it appear that the subject is rast?

862. Mention a wrong way to study.

863. What causes the limits of species? How may the student become acquainted with all the individuals of a species?

864. Glve an example of this mode of study.

865. Define a genus. Give an example of a genus.

868. How are the Genera associated into Orders?

869. For example, how is the Order Crucifere made up? The Coniferæe

870. Into what groups are the Orders themselves associated?

\section{CHA P TER II.}

873. Subject of this chapter? Illustrate an artificial classification.

874. Who was Carl von Linné ? What system did he invent?

875. What are its defects as a system?

876. Are these defects objections to it as a key? Is it now in use?

877. How many classes in the Linnæan system?

(Further examination at the teacher's option.)

\section{CH A P TER III.}

886. Trre subject? What is the aim of this system?

887. How does it differ from the Artificial System?

888. What the principle of the species and genera?

889. What rule is given as to the relative value of characters?

891. As to history, who may be regarded as the founder? What did he? What did Linnæus? Jussieu? Robert Brown? De Candolle?

892. What uncertainty in the system yet remains?

893. Whence is the difficulty in settling these divisions?

894. Is there more than one true Natural System?

895. What is the first and highest division of the Natural System?

Define the Phænogamia. The Cryptogamia.

896. What of the indefiniteness of natural groups?

897. Into what two provinces are the Phænogamia next resolved?

State the diagnosis of the Exogens. Of the Endogens.

898. What divisions next follow? Define the Angiospermæ.

Define the Gymnospermx. Name the two classes formed by the Endogens Describe each.

899. Into what two provinces is the sub-kingdom Cryptogamia divided?

Define the Acrogens. Define the Thallogens.

900. What two classes correspond with these two provinces? Define the Angiosporæ. Define the Gymnosporæ.

901. What name is given to the fourth set of groups? Are the cohorts quite natural groups? Why not?

903. Whose plan is generally adopted in this country ?

Into what three cohorts are the Angiospermæ divided?

Define the Dialypetalæ. The Gamopetalæ. The Apetalæ.

904. How is the class Petaliferæ divided? Define the Spadicifloræ. Define the Florideæ.

905. The class Glumiferæ is equivalent to what cohort?

906. Name the three cohorts of the class Angiosporæ.

907. Name the three cohorts of the class Gymnosporæ.

908. Write on the black-board the synopsis of the Natural System. 


\section{PART FIR ST.}

STRUCTURAL BOTANY;OR, ORGANOGRAPHY.

\section{CHA P T E I.}

PRIMARY DIVISIONS OF THE VEGETABLE KINGDOM.

65. Two natural Grand Divisions of the Vegetable Kingdom have long been recognized by botanists, viz., the Phrnogamia or Flowering Plants; the Cryptogamia, or Flowerless Plants. Besides the obvious distinction made by the presence and absence of the flower,

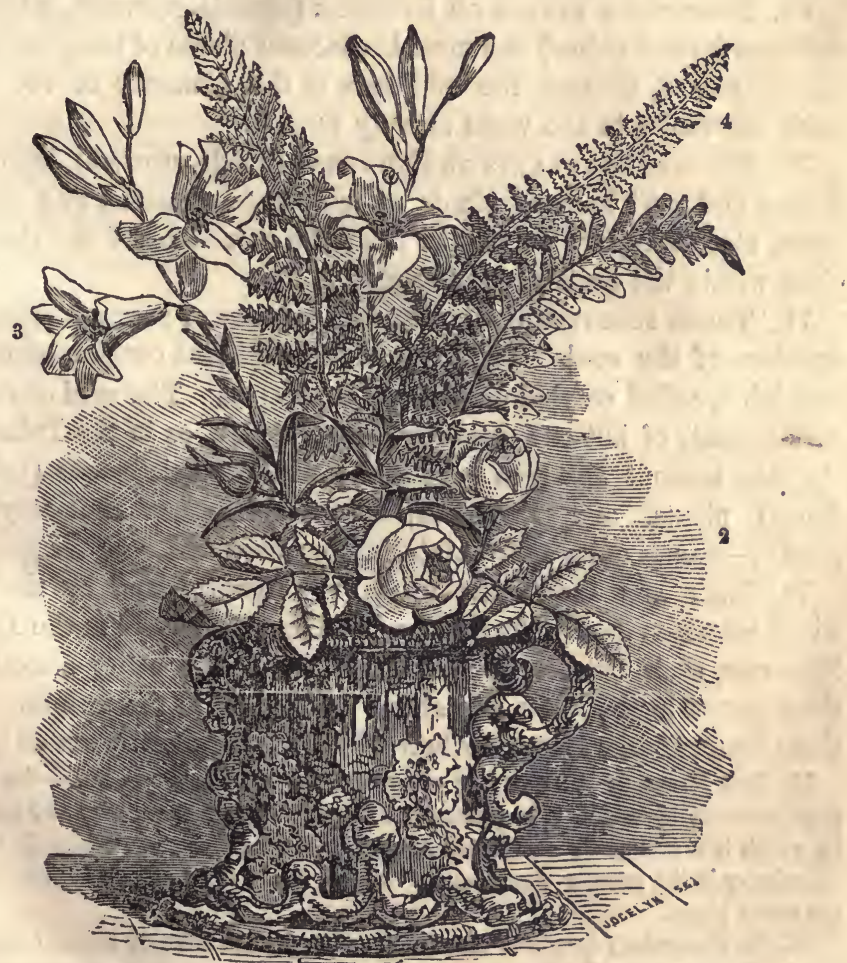

2. Rose (flowers double)-an Exogen. 3, Lily-an Endogen. 4, Fern-an acrogenou Cryptogam. 5, Lichen-a thallogenous Cryptogam. 
66. These Grand Drvisions are further distinguished by their organic structure and general aspects. In the Phænogamia we find a system of compound organs, such as root, stem, leaf, bud, flower, successively developed on a determinate plan; while in the Cryptogamia, a gradual departure from this plan commences, and they become, at length, in their lowest forms, simple expansions of a uniform tissue, without symmetry or proportion. This distinction is rendered perfectly clear by a reference to

67. Examples. Compare a rose with a fern. In the former a regular axis bears buds which are unfolded, some into leaves, others into flowers succeeded by fruit. In the fern no buds nor flowers appear, and the fruit dots sprinkle over the back of the leaf. Again, contrast the violet with a lichen, where neither stem, root, nor leaf appears, much less flowers, but disc-like expansions with fruit-dust (spores) produced indifferently in any part of them.

68. Subdivisions of the Phanogamia. This grand division is itself very naturally resolved into two subdivisions, named by $D e$ Candolle Exogens and Endogens.

69. Exogenous Plants or Exogens (outside-growers), including all the trees (except palms) and most herbaceous plants of temperate regions, are so named, because the additions to the diameter of the stem are made externally to the wood already formed.

70. Endogenous plants or Endogran (inside-growers), including the grasses and most bulbous plants of temperate climates, and the palms, canes, etc., south, are so named from the accretions of the stem taking place within the parts already formed.

71. These subdivisions are more accurately distinguished by the structure of the seed. The seeds of the Exogens consists of two equal seed-lobes, called cotyledons, as scen in the pea. The seed of the Endogens consists of but one seed-lobe or cotyledon, as in the Indian Corn. On this account Exogens were first called Dicotyledonous (two-cotyledoned) plants, and Endogens, Monocotyledonous (one-cotyledoned) plants;-names quite appropriate, but too hard and long for general use.

72. They are also very readily distinguished by their leaves, which are net-veined in the Exogens, and parallel-veined in the Endogens. Moreover, their flowers are remarkably different, being almost always three-parted in the latter and about five-parted in the former. But all these distinctions, with some others, will be more definitely stated hereafter.

73. The NaMe OF A PLANT or other natural object is twofold, - the trivial or popular name, by which it is generally known in the country; and the Latin name, by which it is accurately designated in science throughout the world. For example, strawberry is the popular name, and Fragaria vesca the Latin or scientific name of the same plant.

74. In elementary treatises, like the present, for the sake of being readily understood, plants are usually called by their popular names. Yet we earnestly recommend to the learner to accustom himself early to the use of the more accurate names employed in science. 
75. The Latin name is always double; - generic and specific. Thus Fragaria is generic, or the name of the genus of the plant, vesca is specific, or the name of the species.

76. A Specres embraces all such individuals as may have originated from a common stock. Such individuals bear an essential resemblance to each other as well as to their common parent, in all their parts.

77. For EXAMpLe, the white clover (Trifolium repens) is a species embracing thousands of cotemporary individuals scattered over our hills and plains, all of common descent, and producing other individuals of their own kind from their seed.

78. Varieties. To this law of resemblance in plants of one common origin there are some apparent exceptions. Individuals descended from the same parent often bear flowers differing in color, or fruit differing in flavor, or leaves differing in form, etc. Such plants are called varieties. They are never permanent, but exhibit a constant tendency to revert to their original type.

79. Examples. Varieties occur chiefly in species maintained by cultivation, as the apple, potato, rose, Dahlia. They also occur more or less in native plants (as Hepatica triloba), often rendering the limits of the spacies extremely doubtful. They are due to tho different circumstances of climate, soil, and culture to which they are snbjected, and continue distinct only until left again to multiply spontaneously from seed in their own proper soil, or some other change of circumstances.

80. A Genus is an assemblage of species closely related to each other in the structure of their flowers and fruit, and having more points of resemblance than of difference throughout.

81. Illustration. The genus clover (Trifolium) includes many species, as the white clover (T. repens), the red clover (T. pratense), the buffalo clover (T. reflexum), etc., agreeing in floral structure and general aspect so obviously that the most hasty observer would notice their relationship. So in the genus Pinus; no one would hesitate to include the white pine, the pitch pine, the long-leafed pine (P. strobus, rigida, and palustris), any more than we would fail to observe their differences.

82. Thus individuals are grouped into species, and species are associated into genera. These groups constitute the bases of all the systems of classification in use, whether by artificial or natural methods.

\section{CHAPTER II.}

\section{TER M OF PLA N T LIFE.}

83. Plant Life defined. The vital principle in the plant or its life is known only by its effects. In the animal these effects are, in kind, twofold, indicating two kinds of life, the organic and the nervous life. In the plant the latter kind is wanting, and the sum of its vital phenomena is popularly expressed in the one word, vegetation. 
84. Stages of plant life. The successive phenomena of regetation are germination, growth, flowering, fruit-bearing, sleeping, dying; and we may add along with these, absorption, digestion, secretion. The development of every plant, herb or tree, commences with the minute embryo, advances through a continual series of transformations, with a gradual increase of stature, to its appointed limit.

85. THE LIFE OF THE PLANT IS A BIOGRAPHY. Its form is never permanent, but changing like a series of dissolving views. The picture which it presents to the eye to-day differs, perhaps imperceptibly, from that of yesterday. But let the views be successively sketched when it sprouts from the seed in spring, when clothed in its leafy robes, when crowned with flowers, when laden with ripe fruit, and when dead or dormant in winter-and the pictures differ as widely as those of species the most opposite.

86. The term or Period of PLANT LIFE varies between wide extremes, from the ephemeral mushroom to the church-yard yew, whose years are reckoned by thousands. The term of life for each species is, of course, mainly dependent on its own laws of growth, yet is often modified by the climate and seasons. Thus the castor oil bean (Ricinus) is an annual herb in the Northern States, a shrub in the Southern, and a tree forty feet in height in its native India.

87. Flowering and frutt-bearing is an exhausting process. If it occur within the first or second year of the life of the plant it generally proves the fatal event. In all other cases it is either preceded or followed by a state of needful repose. Now if flowering be prevented by nipping the buds, the tender annual may become perennial, as in the florist's tree-mignionette.

88. We distinguish plants, $\Lambda$ S to their term of LIFe, into the annual (1), the biennial (2), and the perennial (४).

89. An andual herb is a plant whose entire life is limited to a single season. It germinates from the seed in spring, attains its growth, blossoms, bears fruit, and dies in autumn, as the flax, corn, morning-glory.

90. A BIENNIAL HERB is a plant which germinates and vegetates, bearing leaves only the first season, blossoms, bears fruit, and dies the second, as the beet and turnip. Wheat, rye, \&c., are annual plants, but when sown in autumn they have the habit of biennials, in consequence of the prevention of flowering by the sudden cold.

91. MoNocarpic HeRbS. The century plant (Agave), the talipot palm, \&c., are so called. They vegetate, bearing leaves only, for many years, accumulating materials and strength for one mighty effort in fructification, which being accomplished, they die. But although the vital principle is extinguished in the parent, it survives multiplied a thousand fold in the seed.

92. Perennial plants are such as have an indefinite duration of life, usually of many years. They may be either herbaceous or woody. 93. Herbaceous perennials, or perennial herbs, are plants whose 
parts are annual above ground and perennial below. In other words, their roots or subterranean stems live from year to year, sending up annually in spring flowering shoots, which perish after they have ripened their fruit in autumn; as the lily, dandelion, hop.

94. Woody Perennials usually vegetate several years, and attain well nigh their ordinary stature before flowering; thenceforward they fructify annually, resting or sleeping in winter. They are known as trees, shrubs, bushes and undershrubs-distinctions founded on size alone.

95. A shrub is a diminutive tree, limited to eighteen or twenty feet in stature, and generally dividing into branches at or near the surface of the ground (alder, quince). If the woody plant be limited to a still lower growth, say about the human stature, it is called a bush, (snow-ball, Andromeda.) If still smaller, it is an undershrub (whortleberry).

96. A TREE is understood to attain to a height many times greater than the human stature, with a permanent woody stem, whose lower part, the trunk, is unbranched.

97. Longevity of trees. Some trees live only a few years, rapidly attaining their growth and rapidly deeaying, as the peach; others have a longevity exceeding the age of man, and some species outlive many generations.

98. The age of a tree may be estimated by the number of woodcircles or rings seen in a cross section of the trunk ( $\$ 667)$, each ring being (very generally) an annual growth.

99. EXAMPLES. The known age of an elm, as stated by De Candolle, was 335 years; of a larch, 576 ; a chestnut, 600 ; an orange, 630 ; oaks, from 810 to 1500 ; yews, 1214 to 2820 .

100. Adarson estimated the age of the baobabs of Africa at 5000 years. Livingston reduces it to 1800. The yew trees of Britain, as described by Balfour, are of wonderful longevity. One in Bradburn church-yard, Kent, is 3000 years old, and the great yew at Hedsor, Bucks, twenty-seven feet in diameter, has vegetated 3200 years.

101. Magnitude. At the first establishment of Dartmouth College, a pine tree was felled upon the college plain which measured 210 feet in height. In the Ohio Valley the red maple attains a girth of 20 feet, the tulip-tree of 30 , and the sycamore of more than 60. But the monarch tree of the world is the Sequoya gigantea -the California pine. One which had fallen measured 31 feet in diameter, and 363 feet in length. Among those yet standing are some of still greater dimensions, as beautiful in form as they are sublime in height, the growth (as estimated by the wood-circles) of more than 3000 years.

102. Trees are again distinguished as decidous and evergreen-the former losing their foliage in autumn and remaining naked until the following spring; the latter retaining their leaves and verdure throughout all seasons. The fir tribe (Coniferae) includes nearly all the evergreens of the North; those of the South are far more numerous in kind, e. g., the magnolias, the live-oaks, holly, cherry, palmetto, \&c. 


\section{CHAPTER III.}

THE PHENOGÁMIA-HOW DEVELOPED.

103. The embryo. The plant in its earliest stage of life is an $\mathrm{em}$. bryo, contained in a seed. It then consists essentially of two parts, the radicle and the plumule. We may discern both in many seeds, as the pea, bean, acorn.

104. Growth of the embryo. After the seed begins to grow or germinate, the embryo extends itself in two directions, to form the axis of the plant. The radicle or root-end grows downward, penetrating the dark damp earth as if to avoid the light, and forms the root or descending axis. The plumule, taking the opposite direction, ascends, seeking the light, and expanding itself as much as possible to the influence of the atmosphere. This constitutes the stem or ascending axis, bearing the leaves.

105. Growti of the terminal Bud. At first the ascending axis is merely a bud, that is, a growing point, clothed and protected by little scales, the rudimentary leaves. As the growing point advances, and its lower scales gradually expand into leaves, new scales successively appear above. Thus the axis is always terminated by a bud.

106. Axillary Buds. By the growth of the terminal bud the axis is simply lengthened in one direction, an undivided stem. But besides this, buds also exist, ready formed, in the axils of the leaves, one in each.

\section{How BRANCHES} ARE FORMED. These axil-
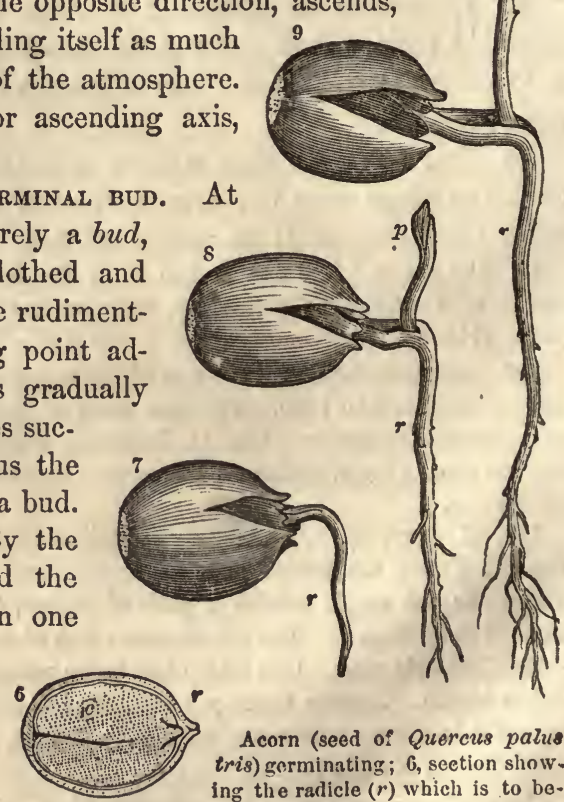

Acorn (seed of Quercus palus tris) germinating; 6 , seetion show. ing the radicle $(r)$ which is to become the root, and the two cotyledons $(c)$ which are to nourish it; 7 , the radicle $r$, descending; 8 and 9 , the radicle, $r$, descending, and the plumule $(p)$ ascending.

lary buds, a part or all of them, may grow and develop like the terminal bud, or they may always sleep, as in the simple-stemmed mullein or palm. But in growing they become branches, and these branches 
may, in turn, generate buds and branchlets in the axils of their own - leaves in like manner.

109. BY THE CONTINUAL REPETITION OF THIS STMPLE PROCESS the vegetablo fabric arises, ever advancing in the direction of all its growing points, clothing itself with leaves as it advances, and enlarging the diameter of its axis, until it reaches the limit of existence assigned by its Creator.

109. The organs of nutrition. Reared by this process alone the plant consists of such organs ouly as were designed for its own individual nourishment-roots to absorb its food, stem and branches to transmit it, and leaves to digest it. These are called organs of nutrition. But the divine command which caused the tribes of vegetation in their diversified beauty to spring from the earth, required that each plant should have its "seed within itself" for the perpetuation of its kind.

110. How the Flower originates. In the third stage of vegetation, therefore, a change occurs in the development of some of the buds. The growing point ceases to advance as hitherto, expands its leaves in crowded whorls, each successive whorl undergoing a gradual transformation departing from the original type,-the leaf. Thus, instead of a leafy branch, the ordinary progeny of the bud, a flower is the result.

111. Nature of the flower. A flower may be considered as a transformed branch, having the leaves crowded together by the nondevelopment of the axis, moulded into more delicate structures, and tinged with more brilliant liues, not only to adorn the face of nature, but to fulfill the important office of reproduction.
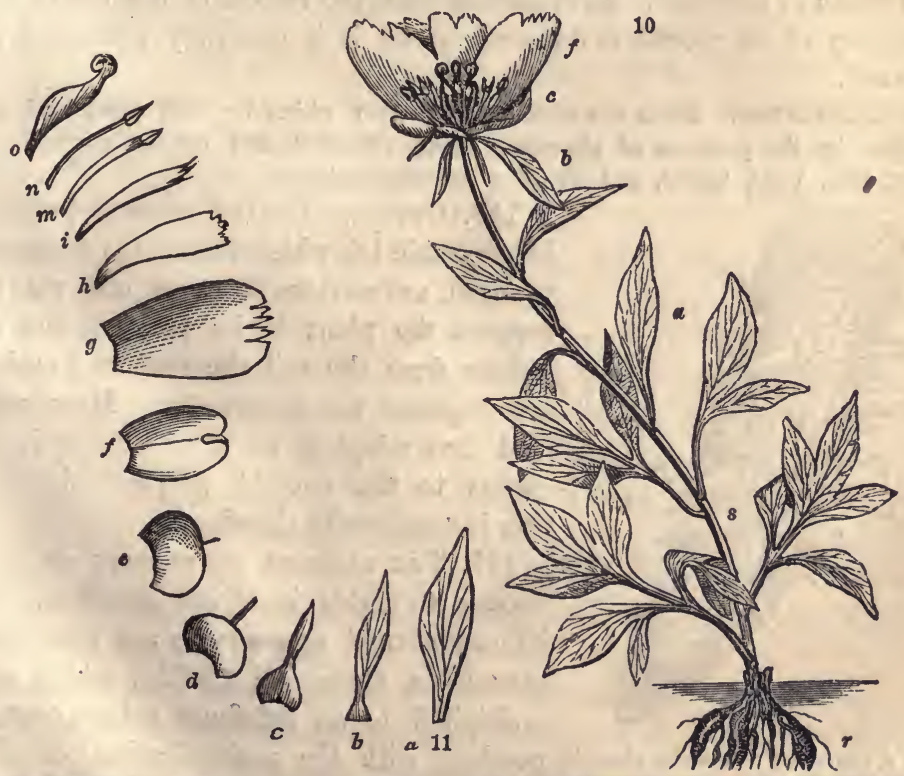

10. Pæony, with some of its petals removed to show the stamens and pistils. 11 to 22 , the organs, graduated from the leaf to the pistil. 
112. The Fruit. After the flower has fulfilled its office, the deciduous parts fall away, and the remaining energies of the plant are directed to the development of the pistils into the perfect fruit. Let us illustrate this doctrine by tracing out

113. A VIEW OF THE ORGANS OF THE PEONY, for example. $(r)$ The root with its numerous fibers and fibrilloe (some fibers tuberous) continues the axis downward, and $(s)$ the stem upward. The leaves (a) approaching the summit, gradually loso their characteristic divisions, and at length become simple bracts, $(b)$ still undoubted leaves. Next by an easy gradation they appear as sepals $(c, d, e$,$) in the calyx, the$ outer envelope of the flower, with stalk expanded and blade contracted. Then by a somewhat abrupt transition they pass into the delicate and highly colored petals of the corclla $(f, g$,$) , still retaining the essential marks of the leaf. To the corolla$ next succeed those slender organs called stamens $(m, n)$, known to be altered leaves from the fact of their being often converted into petals $(i, h)$. Lastly the pistils $(0$,$) destined to bear the seeds, two or more central organs green in color, are$ each the result of the infolding of a leaf, the mid-vein and united edges being yet discernible.

\section{CHAPTER IV.}

THE ROOT OR DESCENDING AXIS.

114. Definrrion. The root is the basis of the plant and the principal organ of nutrition. It originates with the radicle of the seed; the tendency of its growth is downward, and it is generally immersed in the soil.

115. Diagnosis. Roots are distinguished from stems by their downward direction, by the presence of absorbing fibers, (fibrillæ), and by the absence of color, pith, buds, leaves, and all other stem-appendages.

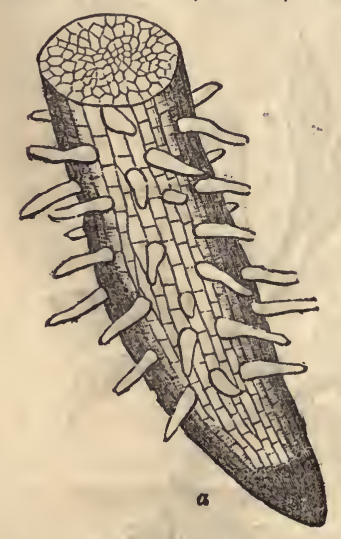

22, a. Extremity of a rootlet of maple with its fibrille and spongiole (magnined 50 diameters.)

116. Office. The two important offices in vegetable life which the root is designed to fulfill, are obvious to every one, viz., to support the plant in its position, and to imbibe from the soil the food and moisture requisite for its growth. How well God has adapted its structure and instincts to this twofold purpose observation is continually showing.

117. The Leading Propensity of the RоOт is, to divide itself into branches, and its only normal appendages are branches, branchlets, fibers and fibrillæ, which are multiplied to an indefinite extent corresponding with the multiplication of the leaves, twigs, \&c., above. This at once 
insures a firm hold upon the earth, and brings a large absorbing surface in contact with the moist soil.

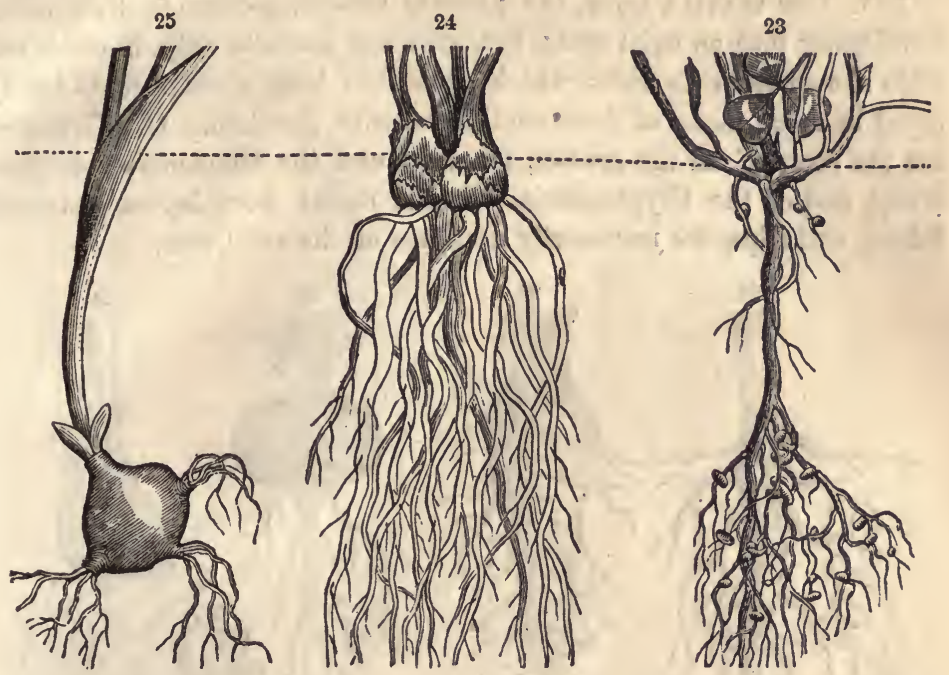

23. White clover-an sxial root (with minute tubers). 24, Buttercups-fibrous roots, inaxial. 25, Erigenia-root tuberous.

118. The summit of the root, or that place where the root meets the stem, is called the collum: the remote, opposite extremities, the ends of the fibers, being chiefly active in absorption, are the spongioles. Neither of these terms denote distinct organs, but places only, and are often convenient.

119. Fibrille, a Latin term, refers to those minute hairs, (seen only with a lens), which clothe the younger fibers. They arise from the tender epidermis or skin, and perish when that thickens into bark. These cooperate with the fibers in the absorption of fluids. :These two organs are the only efficient absorbers of liquid nourishment.

120. Transplanting trees. The fibrillæ are developed and perish annually with the leaves, whose servants they are. Few of them remain after the fall of the leaf. This fact plainly indicates that the proper time for transplanting trees or shrubs is the late autumn, winter, or early spring, when there are but few tender fibrillæ to be injured.

121. Two MODES OF ROOT-DEVELOPMENT are definitely distinguished, -the axial and the inaxial.

122. The AXIAL MODE is that where the primary, simple radicle, in growing extends itself downwards in a main body more or less branched, continuous with the stem, and forms the permanent root of the plant. 
Such is the case with the mustard, beet, maple, and most of the Dicotyledonous plants. In

123. The INAXIAL MODE, the primary radicle, proves abortive, never developing into an axial root; but, growing laterally only, it sends out little shoots from its sides, which grow into long, slender roots nearly equal in value, none of them" continuous with the stem. Of this nature are the roots of all the grasses, the lilies and the Monocotyledons generally, and of the Cryptogamia. Plants raised from layers, cuttings, tubers, and slips, are necessarily destitute of the axial root.
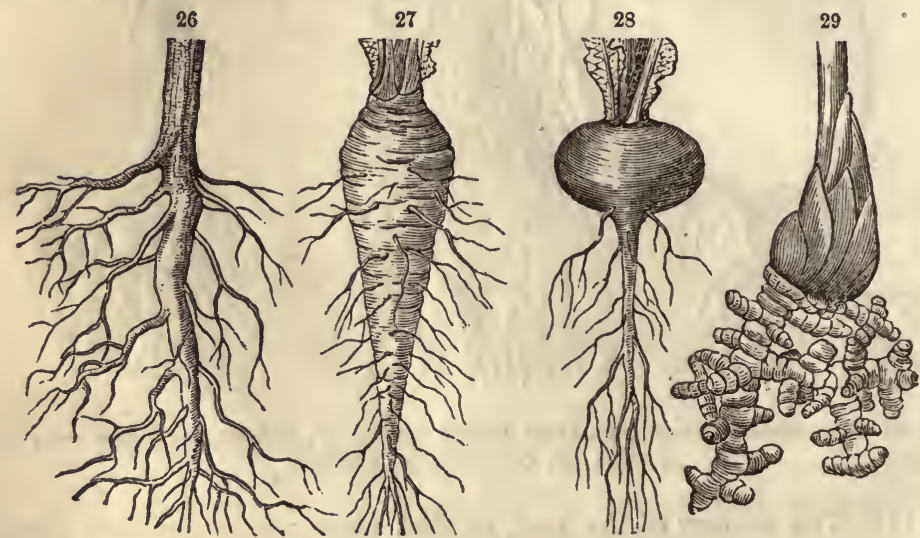

Frgs, 26, Maple-an axial, ramose root. 27, Parsnip-a fusiform root. 28, Turnip-a napiform root. 29, Corallorhiza-a coralline root.

124. The various forms of the root are naturally and conveniently referred to these two modes of development. The principal axial forms are the ramose, fusiform, napiform, conical. To all these forms the general name, tap-root, is applied.

125. The RAMOSE is the woody tap-root of most trees and shrubs, where the main root branches extensively, and is finally dissolved and lost in multiplied ramifications.

126. TUBERous tAP-Roots. In herbaceous plants the tap-root often becomes thick and fleshy, with comparatively few branches. This tendency is peculiarly marked in biennials $(\S 90)$, where the root serves as a reservoir of the superabundant food which the plant accumulates during its first year's growth, and keeps in store against the exhausting process of fruit-bearing in its second year. Such is

127. The Fusiform (spindle-shaped) root, thick, succulent, tapering downwards, and also for a short space upwards. The beet, radish, ginseng are examples. 
128. The conicax root tapers its whole length, from the collum downwards (carrot).

129. The NAPIFORM ROOT, (turnip,) swells out in its upper part so hat its diameter equals or exceeds its length, as in Erigenia bulbosa

i), Turnips (28).

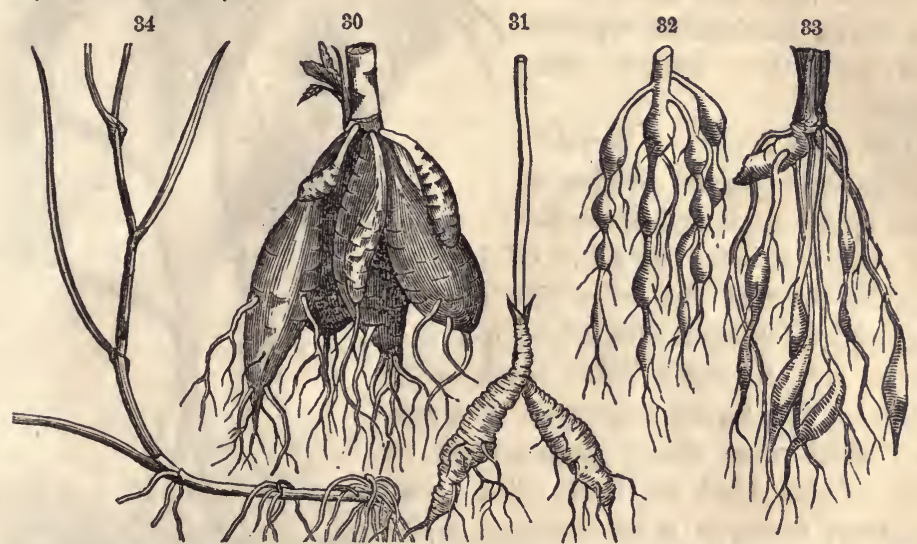

Figs. 30, Pxony-fibro-tuberous roots. 31, Ginseng-fusiform root. 32, Pelargonium tristemoniliform root. 33 , Spirea fllipendula - nodulose root. 34 , A croeping stem, with adventitious roots.

130. The forms of inaxial noots, are fibrous, fibro-tubcrous, tubercular, coraline, nodulous, moniliform.

131. The fibrous root consists of numerous thread-like divisions sent off directly from the base of the stem, with no main or tap-root. Such are the roots of most grasses, which multiply their fibres excessively in light sandy soils.

132. Fibro-tuberous roots (or fasciculate). Inaxial roots are so called when some of the fibres are thick and fleshy, as in the asphodel, crow-foot, pæony, Orchis, Dahlia. When the fibre is enlarged in certain parts only, it is vobulous, and when the enlargements occur at regular intervals, it is моNILIForm (necklace-like). When it bears little tubers here and there, as in squirrel-corn (Dicentra Canadensis), it is TUBERCULAR.

133. Deposits of STARCH, or farinaceous matter, in all these cases, constitute the thickening substance of the root, stored up for the future use of the plant.

134. Adventitious roots are such as originate in some part of the ascending axis,-stem or branches, whether above or below the ground. They are so called because their origin is indeterminate, both in place and time. Examples are seen in the ground-ivy, twin-flower, and other creeping plants. Several special forms should be noticed; as, 
135. THE CIRRHOUS ROOTS of certain climbing vines (European ivy, poison ivy, trumpetcreeper) put forth in great numbers from the stem, serving for its mechanical support and no other known use. Again,

136. The Fulcra of certain endogenous plants originate high up the stem, and descending obliquely, enter the soil. Of this kind are the roots of the screw-pine (Pandanus) of the conservatories, which are often several fect in length before reaching the ground. The figure represents a screwpine which was wholly propped up by roots of this kind as if on stilts. Similar roots occur, in a smaller way, at the lower joints of the Indian corn.

137. The Banyan Tree (Ficus Indica) develops adventitious roots on a grand scale. When the branches have stretched out so far as to need ad-

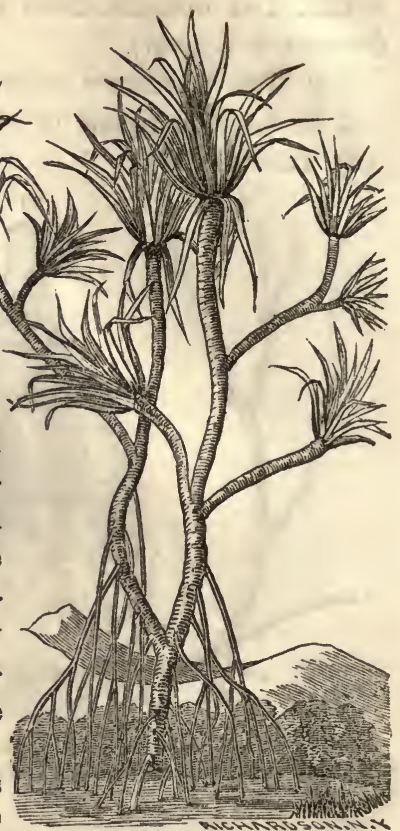

35. Screw-pine (Pandanus). ditional support, they send forth adventitious roots, descending to the earth. Haring penetrated the soil, these roots become supporting columns. The branches

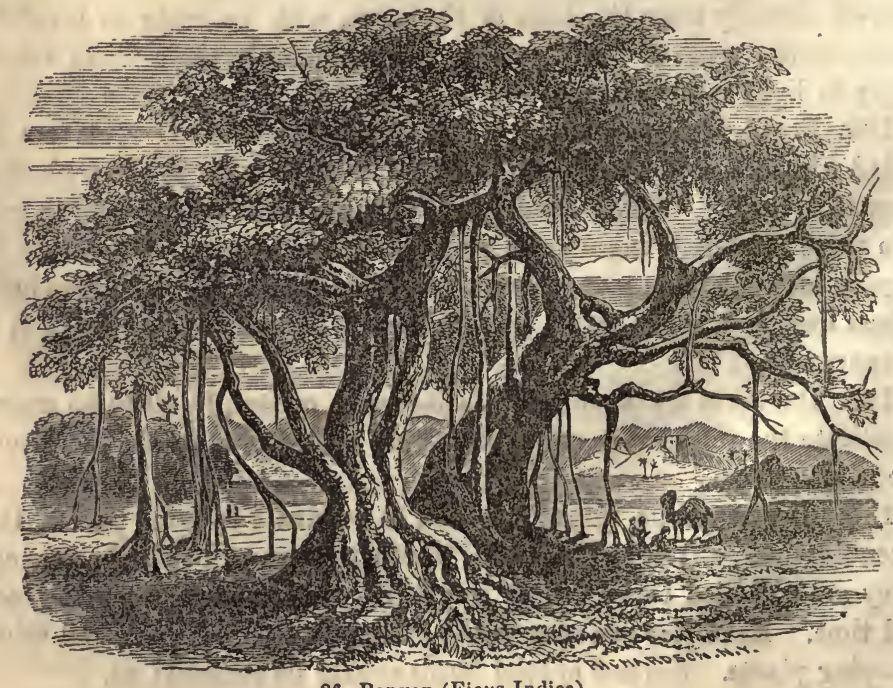


continuing to advance, send down other roots, which in turn become columns similar to trunks, until a single tree becomes a grove capable of sheltering an army of men.

138. The Mangrove (Rhizopora), of the West Indies, sends down axial roots from its branches. The seed germinates before detached, sending down its long radical until it reaches the mud in which these trees grow. Thus the young plants gain a firm standing before quitting their hold of the parent tree.

139. TO FAVOR THE DEVELOPMENT OF ADVENTITIOCS ROOTS on any particular part, keep that part in contact with moist soil. We often observe such roots to arise naturally, in prostrate branches or stems, at those points which touch the ground. In slips, cuttings, \&c., the same thing occurs artificially. Hence to increase the roots of the potato vine, or corn, heap the earth against the stems. The madder plant, which is cultivated solely for the rich coloring matter in its roots, is successfully treated in no other way. Its adventitious roots are excessively multiplied by deep spading and high " hilling."

140. TO PRODUCE DWARF TREES it is only necessary, by any contrivance, to retain a quantity of moist earth against the base of the selected branch until it strikes root. Afterwards it may be severed from the tree and transferred to the soil. (Fig. 40, $d$ ).

141. Axial and inaxial roots in agriculture. This distinction must never be lost sight of. The former strike deep, anchor firmly, and draw their nourishment from the lower strata of the soil. The latter abide near the surface, and feed upon the upper soil. Hence let us learn

a. Which class of crops requires deep and which shallow tillage:

b. Which should succeed each other in the rotation of crops;

c. Which may be sown together in the mixture of crops.

142. TO TRANSFORM A TAP-ROOT TO A FIBROUS. At a certain distance below the collum sever the tap-root without otherwise disturbing the plant. The consequence will be an increased growth of the lateral or fibrous roots nearer the surface of the ground.

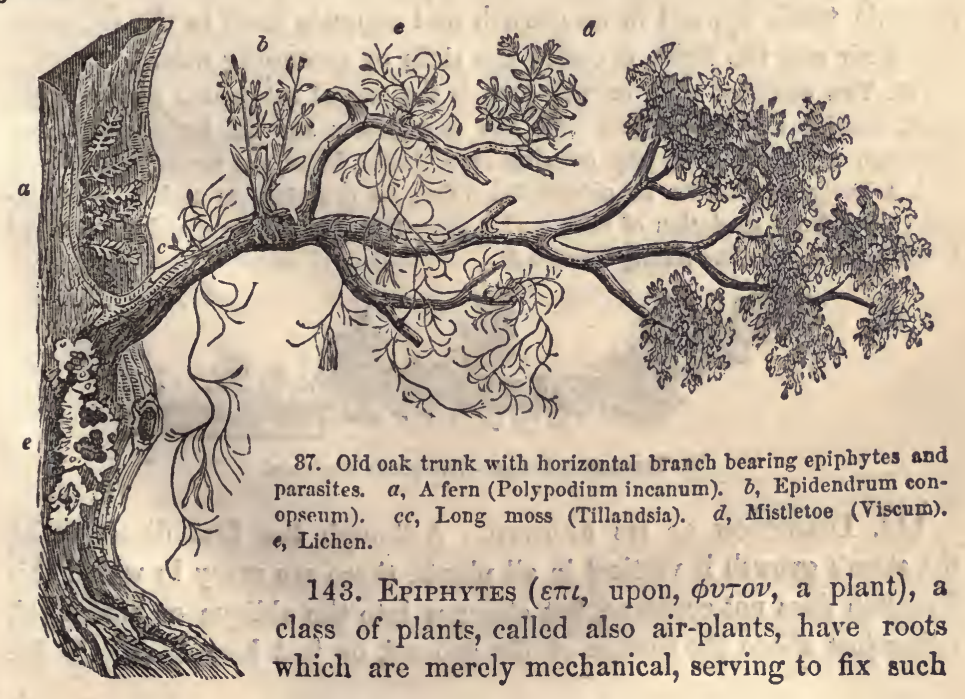


plants firmly upon other plants or trees, while they derive their nourishment wholly from the air. The long-moss (Tillandsia) and Conopseum are examples.

144. Parasites-three classes. Very different in nature are the roots of those plants called parasites, which feed upon the juices of other plants or trees. Such roots penetrate the bark of the nurse-plant to the cambium layer beneath, and appropriate the stolen juices to their own growth, as the dodder and mistletoe. Other parasites, although standing in the soil, are fixed upon foreign roots, and thence derive either their entire sustenance, as the beech-drops and other leafless, colorless plants; or a part of their sustenance, as the cow-wheat (Melampyrum), Gerardia.

145. SUBTERRANEAN STEMS. As there are ærial roots, so there are subterranean stems. These are frequently mistaken for roots, but may be known by their habitually and regularly producing buds. Of this nature are the tubers of the Irish potato, the root-stock of the sweet flag, the bulb of the tulip. But even the truo root may sometimes develop buds-accidentally as it were, in consequence of some injury to the upper axis, or some other unnatural condition.

\section{CHA P T E R . \\ THE STEM, OR A S CENDING AXIS.}

146. Definimion. That part of the plant which originates with the plumule, tends upward in its growth and expands itself to the influence of the air and the light, is called the stem or ascending axis.

147. THE GENERAL IDEA OF THE AXIS is the central substantial portion of the plant, bearing the appendages, viz, the root below and the leaf-organs above. Although not marked by gay coloring or fantastic forms, yet we regard the stem with a lively interest for its substantial value, its gracefulness and lofty proportions, its infinite gradation of form and texture from the tender speedwell crushed benealh the foot to the strong forest oak.

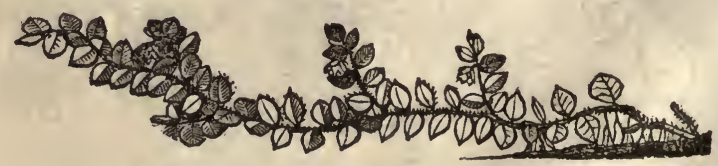

35. Procumbent stem-Chiogenes hispidula.

148. Direction of ITs growru. Although the first direction of the stem's growth is vertical in all plants, there are many in which this direction does not continue, but changes into the oblique or horizontal, either just above the surface of the ground, or just beneath it. If the 
stem continues to arise in the original direction, as it most commonly does, it is said to be erect. If it grow along the ground without rooting it is said to be procumbent, prostrate, trailing. If it recline upon the ground after having at the base arisen somewhat above it, it is decumbent. If it arise obliquely from a prostrate base, it is said to be ascending, and if it continue buried beneath the soil, it is subterranean.

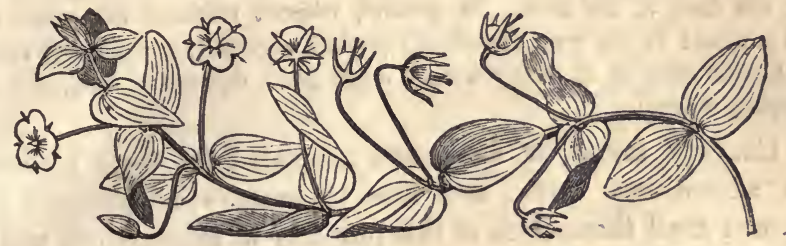

39. Decumbent stem-Anagallis arrensis.

149. Subterranean stems may be readily distinguished from the roots by the natural and habitual presence of buds in the former, regularly arranged, while no buds (unless rarely adventitious) exist in the latter.

150. Stems are either simple or branched. The simple stem is produced by the unfolding of the primary bud (the plumule) in the direction of its point alone. As this bud is developed below into the lengthening stem, it is continually reproduced at its summlt, and so is always borne at the termination of the stem. Hence the axis is always terminated by a bud.

151. The Branched Stem, which is by far the most common, is produced by the development of both terminal and axillary buds. The axis produces a bud in the axil of its every leaf, that is at a point just above the origin of the leaf-stalk. These buds remain inactive in the case of the simple stem, as the mullein, but more generally are developed into leafy subdivisions of the axis, and the stem thus becomes branched.

152. A Branch is, therefore, a division of the axis produced by the development of an axillary bud. This bud, also, ever renewed, is borne at the termination of the branch, so that axillary buds each in turn become terminal.

153. The Arrangement of the. Branches upon the stem depends therefore upon the arrangement of the leaves, which will be more particularly noticed hereafter. This arrangement is beautifully regular, according to established laws. In this place we briefly notice three general modes:

The alternate, where but one branch arises from the node on different sides of the stem, as in the elm. 
The opposite, where two branches stand on opposite sides of the same node, as in the maple.

Verticillate, where three or more branches, equidistant, encircle the stem at each node, as in the pine.

154. THE ANGLE of DIVERGENCE in branches is also subject to definite rules more obvious in the earlier stages of growth. While the divergence is uniform in the same species, it varies to every degree of the circle in different species, greatly affecting the form of the tree. In general, without marking the exact degree, branches are said to be erect (Lombardy poplar), spreading or obliquely ascending (common), divaricate or at nearly a right angle (oak), deflexed (beech), and pendulous (weeping willow).

155. Certain kinds of Branches are noted for thejr tendency to produce adventitious roots, and thus to become independent plants. Nurserymen avail themselves of this property in propagation, and name such branches cions, stolons, offsets, slips, layers, cuttings, and runners.

156. The Sucker is a branch issuing from some underground portion of the plant, leaf-bearing above and sending out roots from its own base, becoming finally a separate, independent plant. The rose and raspberry are thus multiplied.

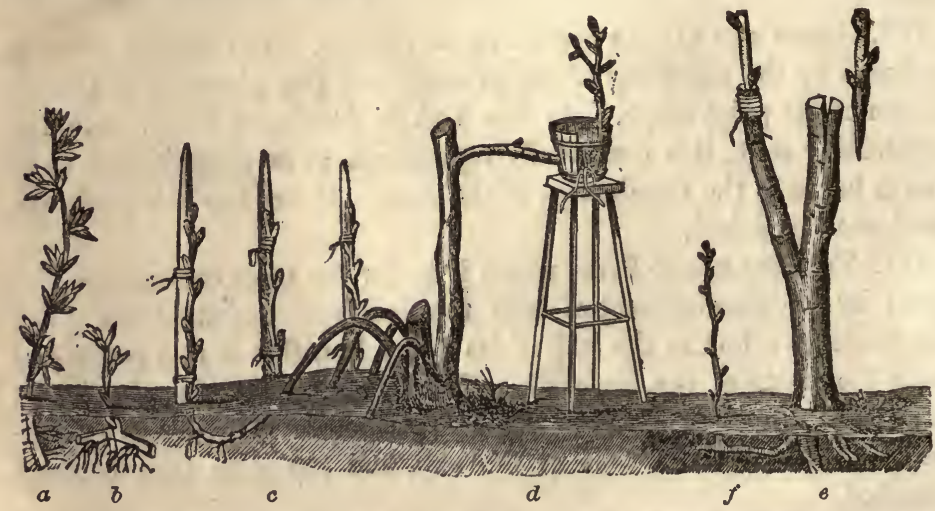

40. $a$, Slip (gooseberry) taking root. $\delta$, Cutting (grape) taking root. $c$, Stolons or layers artificially arranged for propagation. $d, \Delta$ mode of dwarfing (\$140). e, Cions-process of grafting. $f, \mathrm{~A}$ sncker.

157. The Stolon or Layer is a branch issuing from some aboveground portion of the stem, and afterward declining to the ground takes root at or near its extremity, sends up new shoots, and becomes a new plant. The hobble-bush and black raspberry do this naturally, and gardeners imitate the process in many plants.

158. The Crov is any healthy twig or branchlet bearing one or more buds, used by the gardeners in the common process of grafting. Slips and cuttings are fragments of ordinary branches or stems con- 
sisting of young wood bearing one or more buds. These "strike" root when planted in the earth. So the grape-vine and hop.

159. THE OFTSET is a term applied to short side-branches ending in a tuft (rosette) of leaves, and capable of taking root when separated from the parent plant, as in houseleek.

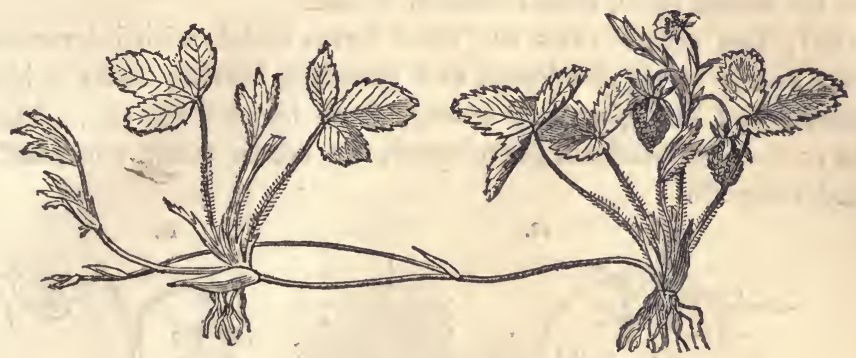

41, A strawberry plant (Fragaria vesca) sending out a runner.

160. The Runner is a prostrate, filiform branch issuing from certain short-stemmed herbs, extending itself along the surface of the ground, striking root at its end without being buried. Thence leaves arise and a new plant, which in turn sends out new runners; as in the strawberry.

161. THE NODE or joint of the stem marks a definite point of a peculiar organization where the leaf with its axillary bud arises. The nodes occur at regular intervals, and the spaces between them are termed internodes. This provides for the symmetrical arrangement of the leaves and branches of the stem. In the root no such provision is made, and the branches have no manner of arrangement.

162. Why the STEM GRAdUALLY DIMINISHES UPWARDS. In the internodes the fibres composing the stem are parallel, but at the nodes this order is interrupted in consequence of some of the inner fibres from below turning outwards into the leafstalk, causing more or less a jointed appearance. Hence each internode contains fewer fibres than those below it.

163. How THE STEM GROws. The growth of the stem consists in the development of the internodes. In the bud the nodes are closely crowded together, with no perceptible internodes, thus bringing the rudimentary leaves in close contact with each other. But in the stem, which is afterwards evolved from that bud, we see full grown leaves separated by considerable spaces. That is,' while leaves are developed from the rudiments, internodes are evolved from the growing point.

164. BUT THERE ARE EXCEPTIONS here as to all other rules in science, adding another element of diversity to the endless gradation of form in Nature's works. In 
many plants the axis of the prinary bud does not develop into internodes at all, or but partially in various degrees, as in the Trillium, Crocus, blood-root. Such stems seldom appear above ground, and are said to be subterranean.

165. This fact makes a wide difference in the forms of stems, and naturally con-F stitutes them into two great divisions, viz., the leaf-stem and the scale-stem.

166. The Leaf-Stems are those forms which, with internodes fully developed, arise into the air crowned with leaves. The principal forms are the caulis, culm, trunk, caudex, vine.

167. The SCAlE-STems are those forms which, with internodes partially or not at all developed, and generally bearing scales, which are undeveloped leaves, scarcely emerge from beneath the soil. They are the creeper and rhizoma (developed), the crown, tuber, corm and bulb (undeveloped).

42.

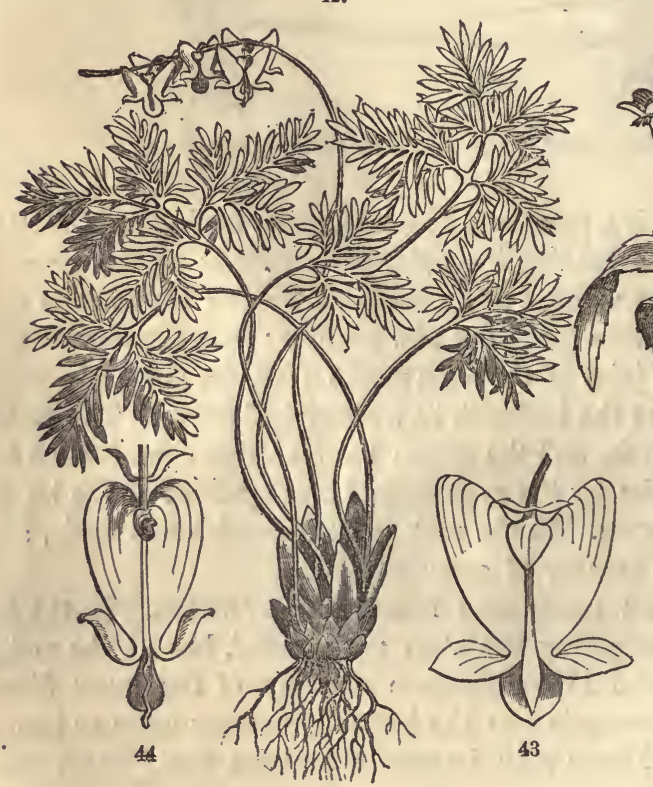

45.
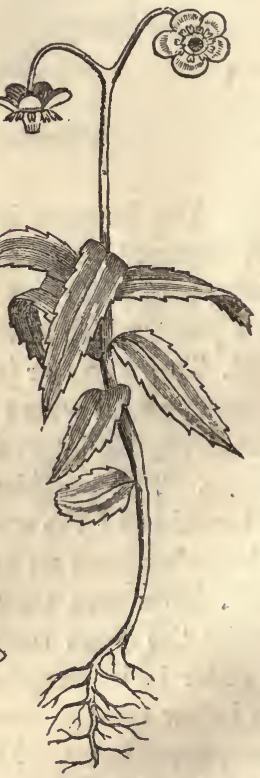

42. Scale-stem, (Dicentra cucnllaria). 43, A flower of the same. 44, A flower of D. Canadensis. 45, Leaf-stem (Chimaphila macuiata).

168. The Leaf-stems are either herbaceous or woodr. The herbaceous, whether arising from annual, biennial or perennial roots, bear fruit but one season and then perish at least down to the root, scarcely becoming woody; as the (1) mustard, (2) radish, and the 4 grasses. The woody leaf-stems survive the winter, and become firm and solid in texture in after years.

169. CAULIS is a term generally applied to the annual leaf-stems of 
herbaceous plants. "Halm" is a term used in England with the same signification. Caulescent and acaulescent are convenient terms denoting, the former the presence, and the latter the absence of the caulis or acrial stem.

170. The Culm is the stem of the grasses and the sedges, generally jointed, often hollow, rarely becoming woody, as in cane and bamboo.

171. The TRUNK is the name of the peculiar stems of arborescent plants. It is the central column or axis which supports their branching tops and withstands the assaults of the wind by means of the great firmness and strength of the woody or ligneous tissue with which it abounds.

172. VARIous Forms. The trunk is usually seen simple and columnar below, for a certain space, then variously dividing itself into branches. Here it is cylindrical, straight and erect, as in the forest pine; prismatic often, as in the gum-tree; gnarled and curved, as in the oak; or inclined far over its base, as in the sycamore.

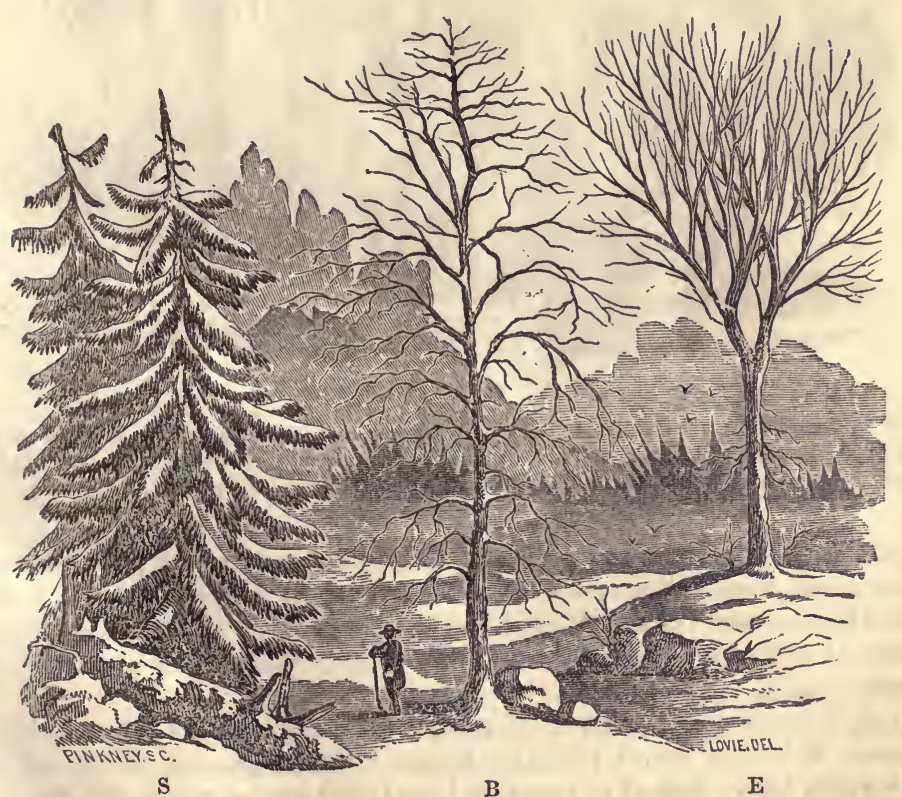

46. S, Spruce. B, Beech. E, Elm; to illustrate excurrent and solvent axis,

173. IN DIVIDING ITSELF INTO BRANCnES we observe two general modes, with their numerous variations, strikingly characterizing the true forms. In the one, named by Lindley the EXCURRENT, the trunk, from the superior vigor of its terminal bud, takes precedence of the branches, and runs through to the summit, as in the 
beech, birch, oak, and especially in the spruco-trees with oval or pyramidal crowns.

174. BUT IN THE OTHER, the sOLVENT axis, as seen in the elm, the apple-tree, the trunk suddenly divides into several subequal branches, which thence depart with different degrees of divergency, giving the urn form to the elm, the rounded form to the apple-tree, the depressed form to the sloe-tree (Viburnum) and dogwood.

175. THE FORM OF THE TRUNK sometimes changes with age, especially in tropical regions, some distorted by huge local excrescences, others swelling out in the midsts to "aldermanic" proportions.

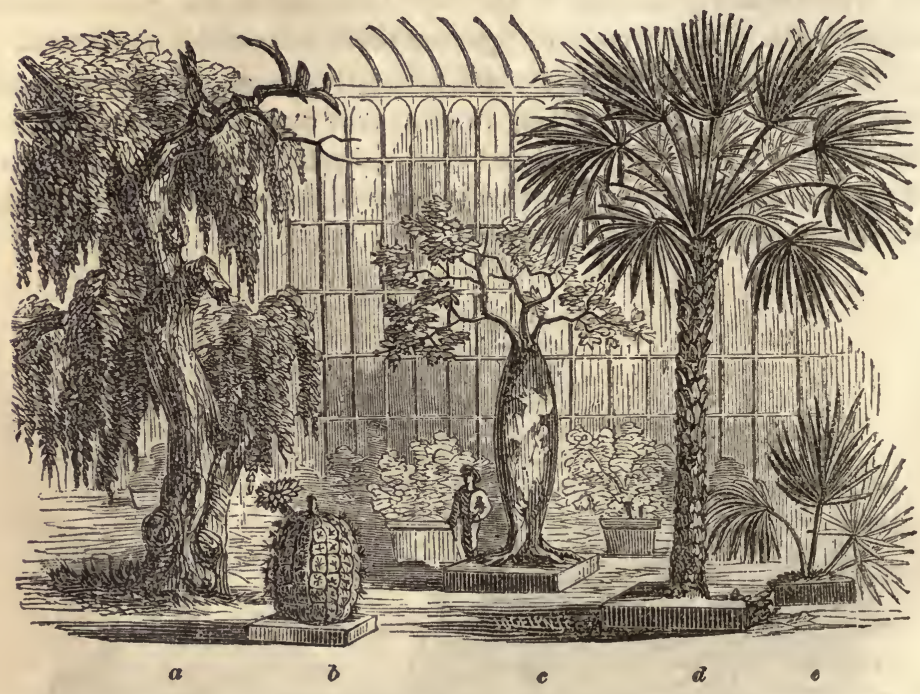

47. $a$, An old willow (Salix Babylonica) with gnarled and misshapen trank. $b$, Caudex of a cactus (Echinocactus Ottonis). c, Bombax, of Brazilian forests, with distended trunk. $d, \mathbf{P a l}-$ metto (Sabal, Adns), the caudex rough with the persistent bases of the petioles.

176. CAUDEX is a term now applied to the peculiar trunk of the palms and treeferns, simple, branchless columns; or rarely dividing in advanced age. It is produced by the growth of the terminal bud alone, and its sides are marked by the scars of the fallen leaf-stalks of former years, or are yet covered by their persistent bases.

177. THE STOCK or CAEDEX of the cactus tribe is extraordinary in form and substance. It is often jointed, prismatic, branched, always greenish, fleshy, and full of a watery juice. Instead of leaves, its lateral buds develop spines only, the stem itself performing the functions of leaves. These plants abound in the warm regions of tropical America, and afford a cooling, acid beverage to the thirsty traveler when springs dry up under the torrid sun.

178. The vrNe is either herbaccous or woody. It is a stem tooslender and weak to stand erect, but trails along the ground or any convenient support. Sometimes, by means of special organs for this purpose, 
ealled tendrils, it ascends trees and other objects to a great height, as the grape, gourd, and other climbing vines.
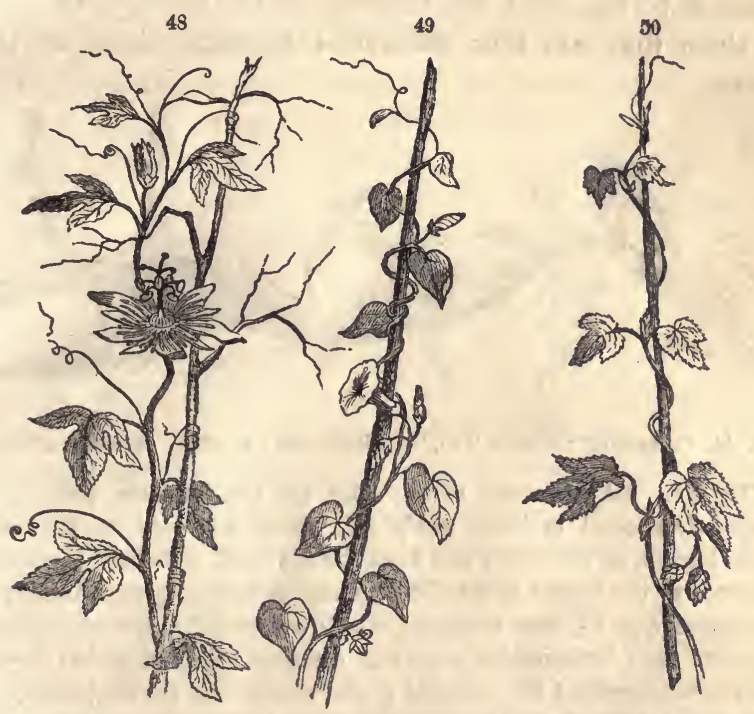

Vines. 49, Passion-flower (Passiflors lutea) climbing by tendrils. 49, Morning-glory, twining from right to left. 50 , Hop, twining from left to right.

179. THE TwINING VINE, having also a length greatly disproportioned to its diameter, supports itself on other plants or objects by entwining itself around them, being destitute of tendrils. Thus the hop ascends into the air by foreign aid, and it is a curious fact that the direction of its winding is always the same, viz, with the sun, from left to right; nor can any artificial training induce it to reverse its course. This is a general law among twining stems. Every individual plant of the same species revolves in the same direction, although opposite directions may characterize different species. Thus the morning glory revolves always against the sun

180. The forms of scale-stems are singular, often distorted in consequence of their underground growth and the unequal development of the internodes. They commonly belong to perennial herbs, and the principal forms are described as follows; but intermediate connecting forms are very numerous and often perplexing.

181. The Creeper is either subaerial or subterranean. In the former case it is prostrate, running and rooting at every joint, and hardly distinguishable otherwise from leaf-stems, as the twin-flower (Linnæa), the partridge-berry (Mitchella). In the latter case it is more commonly clothed with scales, often branching cxtensively, rooting at the nodes, exceedingly tenacious of life, extending horizontally in all directions beneath the soil, annually sending up from its terminal buds erect stems 
into the air. The witch-grass (Triticum repens) is an example. Such plants are a sore evil to the garden. They can have no better cultivation than to be torn and cut to pieces by the spade of the angry gardener, since they are thus multiplied as many times as there are fragments.

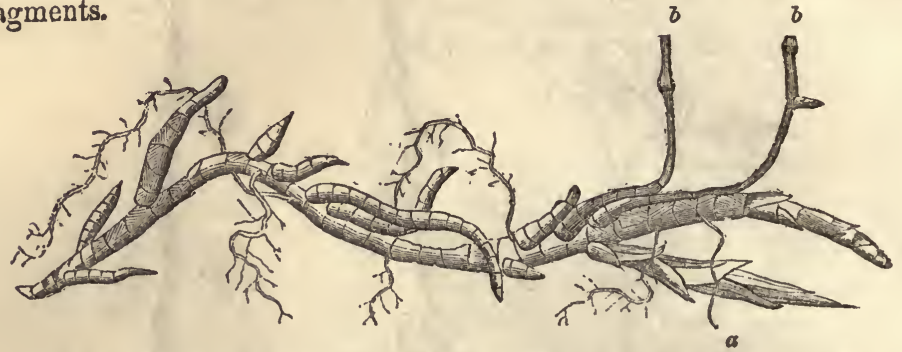

Fig. 51. Creeper of "Nimble Will," or witeh-grass; $a$, Bud; $b b$, Bases of culms.

182. UтіLіту. Repent stems of this kind are not, however, without their use. They frequently abound in loose, sandy soil, which they serve to bind and secure against the inroads of the water and even the sea itself. Holland is said to owe its very existence to the repent stems of such plants as the mat-grass (Arumdo arenaria), Carex arenarius and Elymus arenarius, which overrun the artificial dykes upon its shores, and by their innumerable roots and creepers apparently bind the loose sand into a firm barrier against the washing of the waves. So the turf, chiefly composed of repent grass-stems, forms the only security of our own sandy or clayey hills against the washing rains.

183. The RHIzOME or RoOT-STOCK differs from the creeper only in being shorter and thicker, having its internodes but partially developed. It is a prostrate, fleshy, rooting stem, either wholly or partially subterranean, often sealy with the bases of undeveloped leaves, or marked with the scars of former leaves, and yearly producing new shootis and roots. Such is the fleshy, horizontal portion of the blood-root, sweetflag, water-lily, bramble (the latter hardly different from the creeper).

184. THE GROWTH OF THE RHIZOSE is instructive, marking its peculiar character. Each joint marks the growth of a year. In spring the terminal bud unfolds into

53

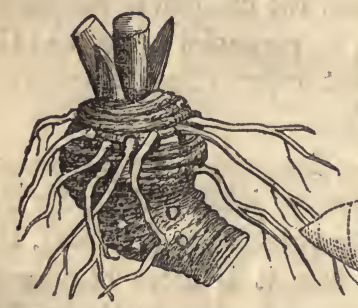

52

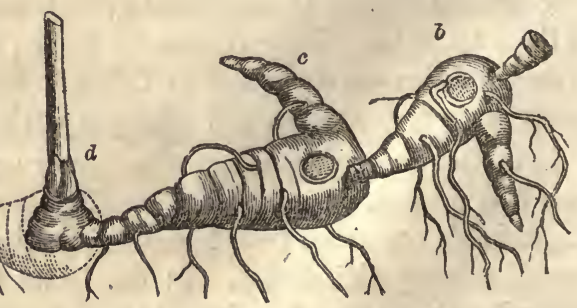

Fig. 52. Rhizoma of Solomon's-seal (Polygonatum multiflora) $a$, Fragment of the first year's growth ; $b$, the second year's growth; $c$, growth of the third year; $d$, growth of the present (fourth) year, bearing the stem which, on decnying, will leave a scar (seal) like the rest. 53. Premorse stem of Trillium. 
leaves and flowers to perish in autumn - a new bud to open the following springand a new internode with its roots to abide several years. The number of joints indicates, not the age of the plant, but the destined age of each internode. Thus if there are three joints, we infer that they are triennial, perishing after the third season, while the plant still grows on.

185. The premorse ROOT-STOck, formerly described as a root, is a short, erect rhizome, ending abruptly below as if bitten square off (præmorsus). This is owing to the death of the earlier and lower internodes in succession, as in the horizontal rhizome. Scabious, Viola pedata, benjamin-root (Trillium) are examples.

186. Crown of tue root designates' a short stem with condensed internodes, remaining upon some perennial roots, at or beneath the surface soil after the leaves and annual stems have perished.

187. Thz tuber is an annual thickened portion of a subterranean stem or branch, provided with latent buds called eyes, from which new plants ensue the succeeding year. It is the fact of its origin with the ascending axis, and the production of buds that places the tuber among stems instead of roots. The potato and artichoke are examples.

56

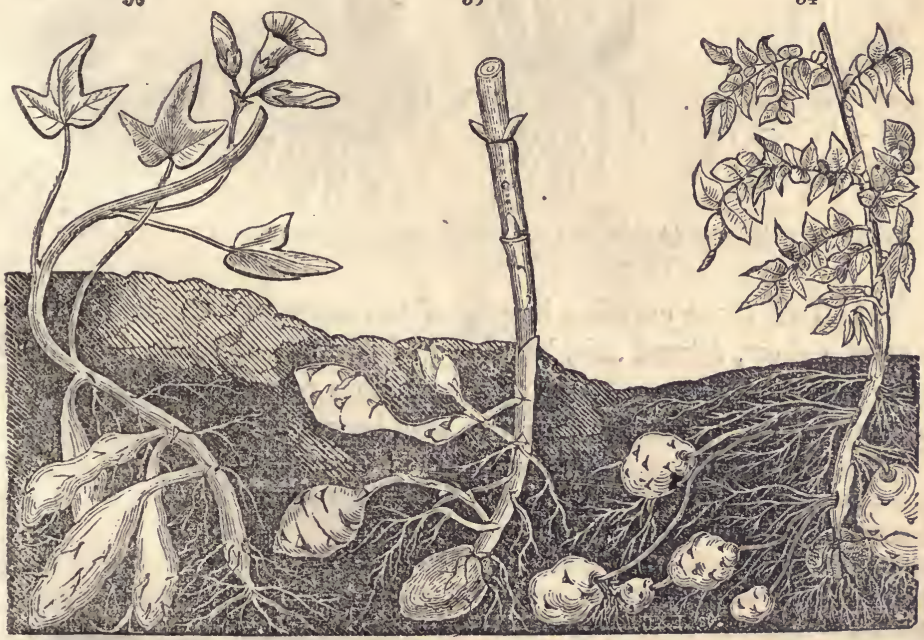

Tubers as they grow. 54, Tho common potato (Solanum). 55, Artichoke (Ilelianthus) 56 , Sweet potato (Convolvulus).

188. How THE POTATO Grows. The stem of the potato plant sends out roots from its base, and branches above like other plants; but we observe that its branches have two distinct modes of development. Those branches which arise into the air, whether issuing from the above-ground or the under-ground portion of the stern, expand regularly into leaves, \&c, while those lower branches which continuo to grope in tho dark, damp ground, cease at length to elongate, swell up at the ends into tubers with developed buds and abundance of nutritious matter in reserve for renewed growth the following year. 
189. The corm is an under-ground, solid, fleshy stem, with condensed internodes, never extending, but remaining of a rounded form covered with thin scales. It is distinguished from roots by its leaf-bud, which is either borne at the summit, as in the crocus, or at the side, as in the colchicum and putty-root (Aplectrum). Ajill?

190. HOW THE CORM GROWS. The corm usually accomplishes its part in vegetation in one or two seasons, and then gradually yields up its substance and life for the nourishment of the new progeny formed from the axils of its upper scales in case of the Crocus and Gladiolus, or the single new corm from the axil of a lateral scale, as in Colchicum.
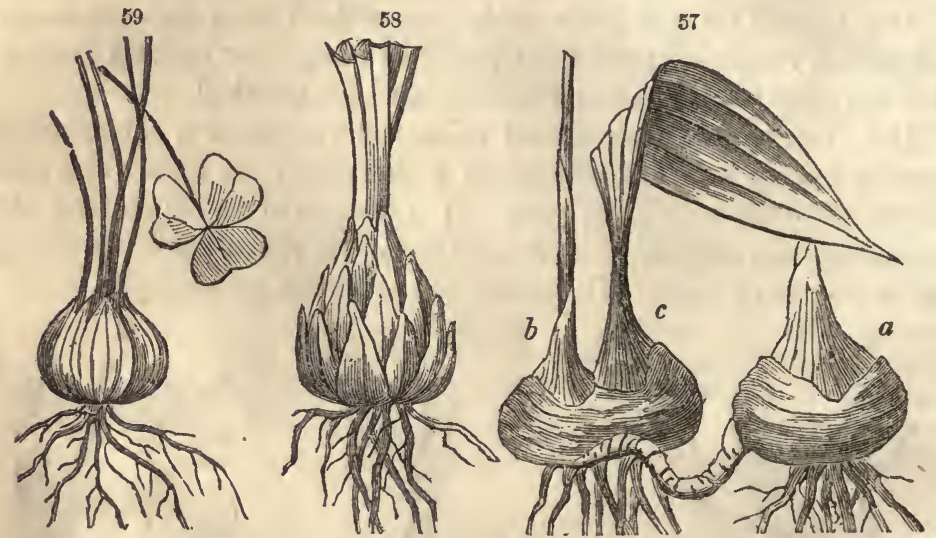

57 . Corms of putty-root (A plectrum); $a$, of last year, $b$, of the present year. $5 \varepsilon$, Scale bulb of white lily. 59, Scale bulb of Oxalis violacea.

191. Thr Bulb partakes largely of the nature of the bud. It consists of a short, dilated axis, bearing an oval mass of thick, fleshy scales closely packed above, a circle of adventitious roots around its base, and a flowering stem from the terminal, or a lateral bud.

192. How MOLTTPLike. Bulbs are renewed or multiplied annually at the approach of winter by the development of bulbs from the axils of the scales, which increase at the expense of the old, and ultimately become detached. Bulbs which flower from the terminal bud are necessarily either annual or biennial: those flowering from an axillary bud may be perennial, as the terminal bud may in this case continue to develop now scales indefinitely.

193. Bulbs are said to be tunicated when they consist of concentric layers, each entire and enclosing all within it, as in the onion. But the more com. of a rhizome; $a$, full-grown bulb sending mon variety is the scaly bulb - consist- the bulbs of next year. ing of fleshy, concave scales arranged spirally upon the axis, as in the lily.

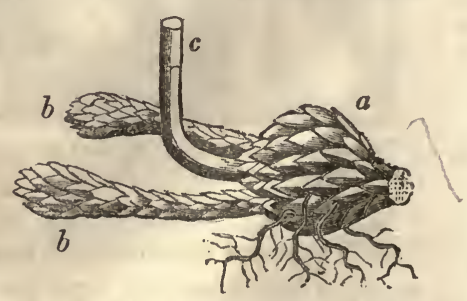

60. Bulb of Lilium superbum, with habit 


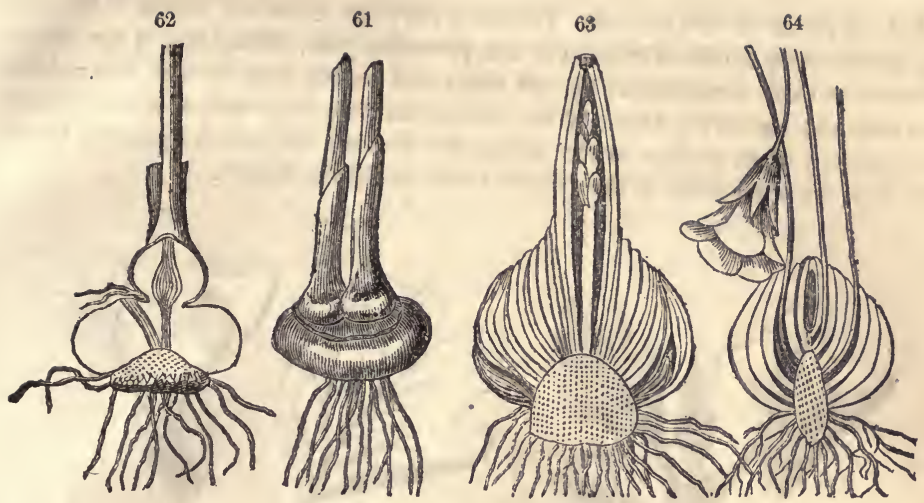

01, Corm of Crocus, with new ones forming above; 62 , Vertical section of the same; 63 , Scetion of bulb of Hyacinth with terminal seape and axillary bulblet; 64, Section of bulb of Oxalis violacea, with axillary scapes.

194. ThE TUBER, CORM AND BULB ARE ANALOGOUS FORMS approaching by degrees to the character of the bud, which consists of a little axis bearing a covering of scales. In the tuber the axis is excessively developed while the scales are reduced to mere linear points. In the corm the analogy is far more evident, for the axis is less excessive and the scales more manifest, and lastly in the bulb the analogy is complete, or overdone, the scales often becoming excessive.

\section{CHAPTER VI.}

\section{THE LEAF-BUD.}

195. It is but a step from the study of the bulb to that of the leaf-bud. Buds are of two kinds in respect to their contents; the leaf-bud containing the rudiments of a leafy stem or branch, the flowerbud containing the same elements transformed into the nascent organs of a flower for the purpose of reproduction.

196. The LeAF-Bud consists of a brief, concshaped axis with a tender growing point, bearing a protecting covering of imbricated scales and incipient leaves.

65. Branch of pear tree. The terminal bad $a$, having been de. stroyed, an axillary bud supplied its place, and formed the axis $b$. $c$, Thickened branch with flower-buds, $d$, branch with leaf-buds. 66. $t$, section of terminal bud; $l$, of axillary bud.

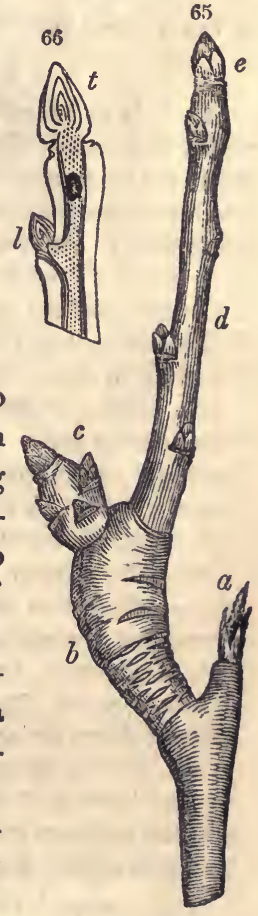


197. NATURE OF THE SCALES. The scaly envelops of the bud appear to be either the rudimentary leaves or stipules of the preceding year, formed late in the season, arrested in their development by the frosts and scanty nourishment, and reduced to a sear and hardened state. If the bud of the rose, tulip-tree, or horse-chestnut be examined when swollen in the spring, the student will notice a gradual transition from the outer scales to the evident leaves or stipules within.

67

68

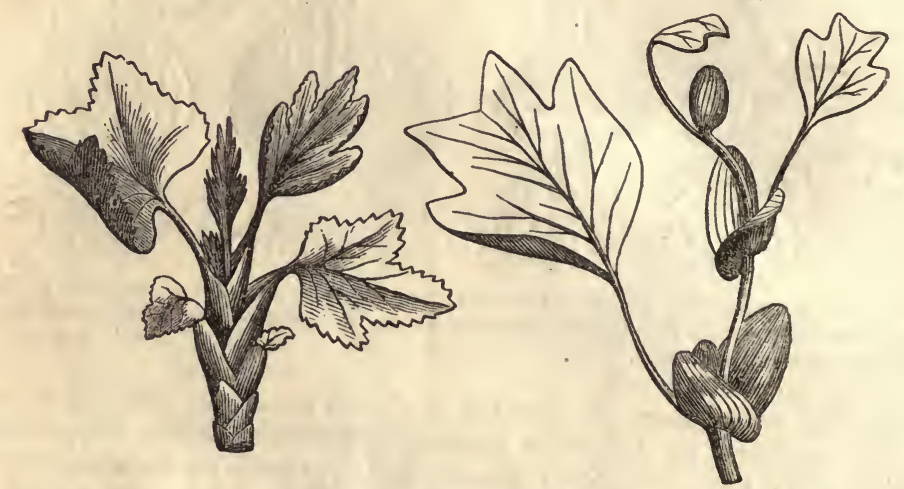

67, Bud of currant unfolding,-the scales gradually becoming leaves. 69 , Bud of tulip-tree,-the scales unfolding into stipules.

198. It is an interesting ILLUSTRATION OF DESIGNING Wispom that buds are furnished with scales only in wintry climates. In the Torrid Zone, or in conservatories, where the temperature is equalized through the year, plants develop their foliage into buds immediately after formation, without clothing them in scales. In annual plants also, the buds are destitute of scales, not being destined to survive the winter. Hence it is evident that the transformation of autumnal leaves into scales, is a means ordained by the great Author of Nature to protect the young shoots in their incipient stages from sudden cold and moisture, - an office which they effectually fulfil by their numerous downy folds and their insoluble coat of resin.

199. HOW BUDS ARE PROTECTED. In many trees the bud-scales are clothed with dense, downy hairs. In others, as in the horse-chestnut, balm of Gilead, and other species of poplar, the buds are covered with a viscid, aromatic resin, resembling a coat of varnish. A considerable quantity may be separated from a handful of such buds in boiling water.

200. The PARENT BUD. In regard to position, buds are either terminal or axillary-a distinction already noticed. The plumule of the embryo is the original parent bud, containing within its minute organization the manifold parts of the future plant-stem, leaves,-flower, fruit-all to be successively unfolded in future montbs or years. The unfolding of this first terminal bad in the one direction of its point produces the simple stem.

201. ORIGIN OF BRANCHES. But in every plant a special provision is made for the development of branches. It is a general law that every expanding leaf shall subtend an infant bud in its axil, that is, in the upper angle of the insertion of the leaf-stalk; hence the plaut may always have as many axillary buds as it has leaves.

202. AxILLARY BUDS are especially noted as being either ACTIVE or 
LATENT. In the former case they are unfolded into branches at once, or in the spring following their formation. But latent buds suspend their activities from year to year, or perhaps are never quickened into growth.

203. Axillary buds become terminal so soon as their development fairly commences, therefore each branch also has a terminal bud, and, like the main axis, is capable of extending its growth as long as that bud remains unharmed. If it be destroyed by violence or frost, or should it be transformed into a flower-bud, the growth in that direction forever ceases.

204. The suppression of axillary buds tends, of course, to simplify the form of the plant. Their total suppression during the first year's growth of the terminal bud is common, as in the annual stem of mullein and in most perennial stems. When axillary buds remain permanently latent, and only the terminal bud unfolds year after year, a simple, branchless trunk, crowned with a solitary tuft of leaves, is the result, as in the palmetto of our southern borders.

205. A PARTIAL SUPPRESSTON OF BuDS occurs in almost all species, and generally in some definite order. In plants with opposito leaves, sometimes one bud of the pair at each node is developed and the other is suppressed, as in the pink tribe (Caryophyllaceæ). When both buds are developed, the branches, appearing in pairs like arms, are said to be brachiate, as in the Labiatæ. In many trees the terminal buds are arrested by inflorescence each season, and the growth is continued by axillary buds alone, as in the Catalpa and horse-chestnut. In all trees, indeed, buds are suppressed more or less, from various causes, disguising at length the intended symmetry of the branches, to the utter confusion of twigs and spray.

206. $\Lambda$ CCESSORY BUDS, one or more, are sometimes found just above the true axillary bud, or clustered with it, and only distinguished from it by their smaller size : as in the cherry and honeysuckle.

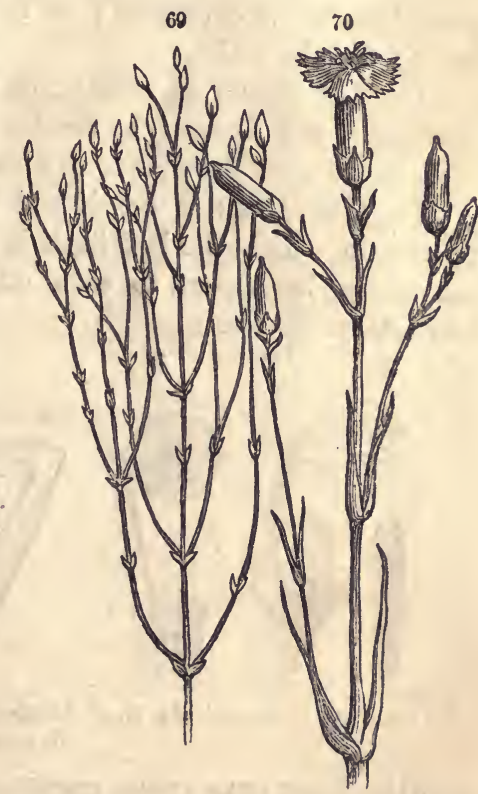

69, Iypericum Sarothra, with brachinte branches. 70, Pink (Dianthus)-axillary buds alternately suppreased.

207. Adventitious or ACCIDENTAl BUds are such as are neither terminal nor axillary. They occasionally appear on any part of the 
plant in the internodes of the stem or branches, on the root, or even leaves.

208. Causes and examples. Such buds generally result from some abnormal condition of the plant, from pruning or other destruction of branches or stem above, while the roots remain in full vigor; thus destroying the equilibrium of vital force between the upper and lower axis. The leaf of the walking-fern emits rootlets and buds at its apex; the leaf of Bryophyllum from its margin, each bud here also preceded by a rootlet. Some plants are thus artificially propagated in conservatories from the influence of heat and moisture on a leaf or the fragment of a leaf.

209. Vernation or prefoliation are terms denoting the mode of arrangement and folding of the leaf-organs composing the bud. This arrangement is definitely varied in different orders of plants, furnishing useful distinctions in systematic botany.

210. The vernation OF THE BUD IS EXHIBITED in an interesting manner by making with a keen instrument a cross-section of it in its swollen state, just before expansion; or it may be well observed by removing one by one the scales.

211. The forms of vernation are entirely analogous to those of æstivation, and denoted by similar terms. We shall here notice only such as are more peculiar to the leaf-buds.

212. Vernation is considered in two different aspects, first, the manner in which the leaf itself is folded; second, the arrangement of the leaves in respect to each other. This depends much upon the phyllotaxy. (\$220.)

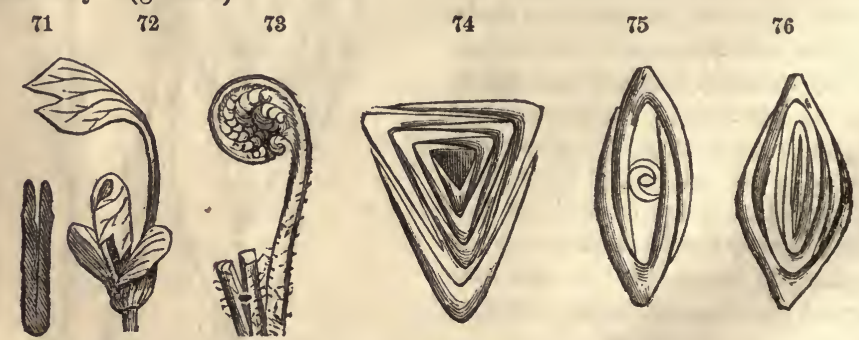

Vernation, 71, of oak leaf; 72, of Liriodendron (tulip tree); 73, of fern; 74, of carex; 75 , sage; 76 , iris.

213. EACH LeAf alone considered is either flat and open, as in the mistletoe, or it is folded or rolled, as follows:

Reclined, when folded crosswise with apex bent over forward towards the base as in the tulip-tree.

Conduplicate, when folded perpendicularly, with the lateral halves brought together, face to face, as in the oak. 
Plaited or plicate, each leaf folded like a fan; vine, birch.

Circinate, when each leaf is rolled or coiled downwards from the apex, as in the sun-dew and ferns.

Convolute, the leaf wholly rolled up from one of its sides, as in the cherry. Involute, having both edges rolled inwards as in apple, violet Revolute, with both margins rolled outwards ard backwards, as in the dock, willow, rosemary.
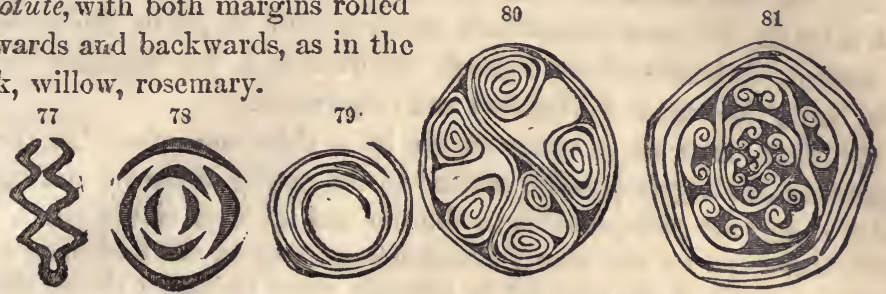

Vermation. 77 , of birch leaf; 79 , of lilac, (imbricate); 79, cherry leaves, (convolute); 80 , dock bud, (revolute); 81 , balm of Gilead, (involute).

214. The generil vernation is loosely distinguished in descriptive botany as valvate (edges meeting), and imbricate (edges overlapping), terms to be noticed hereafter. The valvate more often occurs in plants with opposite leaves. Imbricated vernation is

Equitant (riding astraddle), when conduplicate leaves alternately embrace-the outer one the next inner, by its unfolded margins, as in the privet and iris.

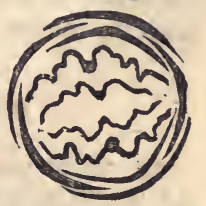

82. Vernation of Sy. camore bud.
83

Onvolute, or half-equitant, when the outer leaf embraces only one of the margins of the inner, as in the sage.

Triquetrous, where the bud is triangular in section, and the leaves equitant at each angle, as in the Carices.

215. The principle of budding. Each leaf-bud may be regarded as a distinct individual, capable of vegetating either in its native position, or when removed to another, as is extensively practiced in the important operation of budding.

216. Bulblets. In the tiger-lily, Cicuta bulbifera, and Aspidium bulbiferum, the axillary buds spon-

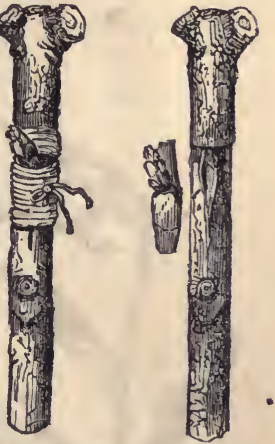
83,84 , Showing the process of "budding." taneously detach themselves, fall to the ground, and become new plants. These remarkable little bodies are called bulblets. 


\section{CHAPTER VII.}

\section{THE L E A .}

217. Its mportance. The leaf constitutes the verdure of plants, and is by far the most conspicuous and beautiful object in the scenery of nature. It is also of the highest importance in the vegetable economy, being the organ of digestion and respiration.

218. The Leaf is characterized by a thin and expanded form, presenting the largest possible surface to the action of the air and light, which agents are indispensable to the life and increase of the plant.

219. THE COLOR OF THE LEAF is almost universally green, which of all colors is the most agreeable to the eye; but its intensity varies by infinite shades, and is often finely contrasted with the more delicate tints of the flower. Towards maturity its verdure is changed, often to the most brilliant hues, as red, crimson, orange, yellow, giving our autumnal forest scenery a gaiety, variety, and splendor of coloring which the wildest fancy could scarcely surpass.

\section{PHYLLOTAXY, OR LEAF-ARRANGEMEN'.}

220. As the position of the leaf upon the stem marks the position or tinc exiliary bud, it follows that the order of the leaf-arrangement will be the order of the branches also. The careful investigation of this subject has developed a scienco of

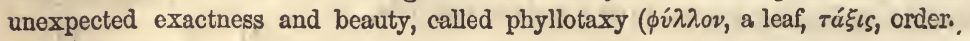

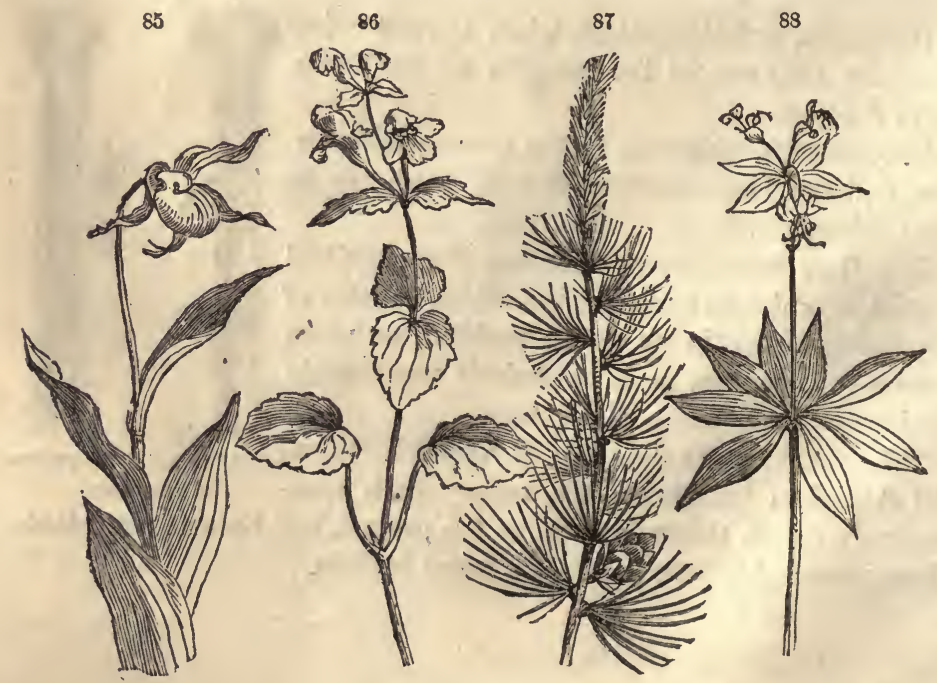

85, Ladies'-slipper (leaves alternate); 86. Synandra grandiflora (lenves opposite); 88, Nedeola Virginica (leaves verticillate); 87, Larix Americana (leaves fascloulate). 
221. Position upon the stem. Leaves are radical when they grow out of the stem at or beneath the surface of the ground, so as to appear to grow from the roots ; cauline when they grow from the stem, and ramial (ramus, a branch), when from the branches.

222. InsERTION UPON THE AXIS. The arrangement of the scales and young leaves in the bud appears to be in close, contiguous circles. By the development of the axis the leaves are separated, and their order variously modified, according to the following general modes :-

Alternate, one above another on opposite sides, as in the elm.

Scattered, irregularly spiral, as in the potato vine.

Rosulate, clustered regularly, like the petals of a rose, as in the plantain and shepherd's-purse.

Fasciculate, tufted, clustered many together in the axil, as seen in the pine, larch, berberry.

Opposite, two, against each other, at the same node. Ex. maple.

Verticillate, or whorled, more than two in a circle at each node, as in the meadow-lily, trumpet-weed. We may reduce all these modes to

223. Two general types, - the alternate, including all cases with one leaf at each node,-the opposite, including cases with two or more leaves at each node.

224. The true character of the alternate type may be learned by an experiment. Take a straight leafy shoot or stem of the elm or flax, or any other plant with seemingly scattered leaves, and beginning with the lowest leaf, pass a thread to the next above, thence to the next in the same direction, and so on by all the leaves to the top; the thread will form a regular spiral.

225. Fasciculate leaves are the members of an undeveloped branch, and in

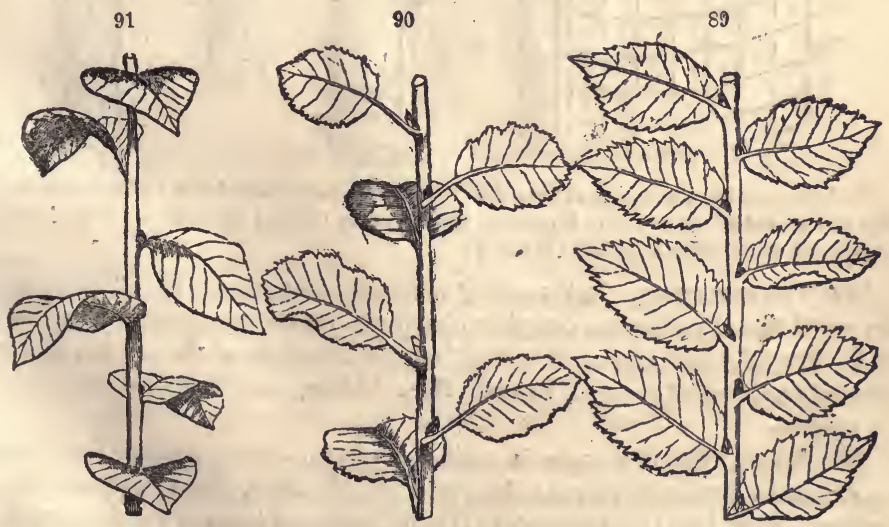

Phyllotaxy. 89, leafy branch of elm,-cycle $\frac{1}{2}$. 90, lenfy branch of alder,-cycle $\frac{1}{3} ; 91$, leafy branch of cherry,-cycle $\frac{2}{5}$. 
case of the subsequent development of the branch, as often ocours in the Berberis and larch, their spiral arrangement becomes manifest. In the pines the fascicles have fewer leaves, their number being definite and characteristic of the species. Thus P. strobus, the white pine, has 5 leares in each fascicle, P. palustris, the longleaved pine, has 3 , P. inops, 2.

226. THE OPPOSITE LEAVED TYPE is also spiral. The leaves in each cirele, whether two or more, are equidistant, dividing the circumference of the stem into equal ares. The members of the second circle are not placed directly above those of the first, but are turned, as it were, to the right or left, so as to stand over the intervening spaces. Hence there may be traced as many spirals as there are leaves in each whorl.

227. Decussate leaves result from this law, as in the motherwort and all the mint tribe, where each pair of opposite leaves crosses in direction the next pair, forming four vertical rows of leaves. Therefore, it is

228. An ESTABLIShed LAW that the course of development in the growing plant is universally spiral. But this, the formative cycle as it is called, has several variations.

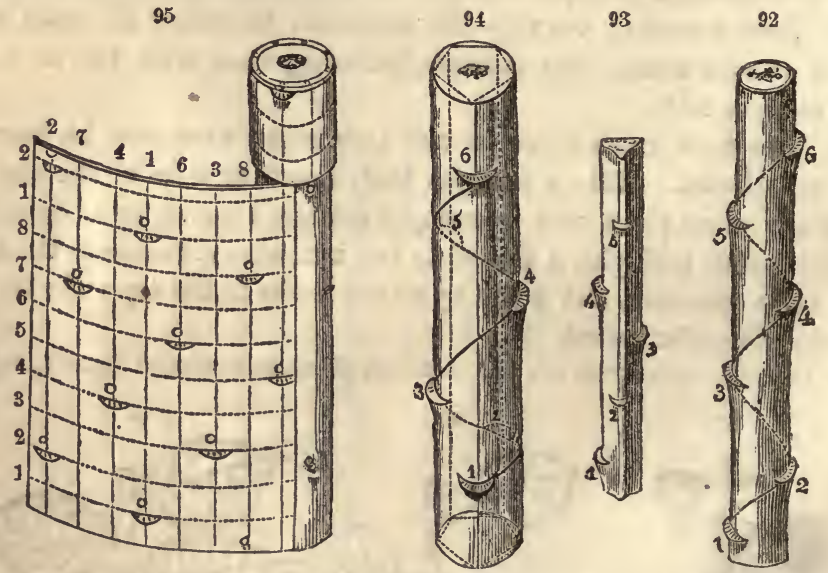

92, 93, 94, showing the course of the spiral thread and the order of the leaf-succession in the axes of elm, alder, and cherry. 95, axis of Osage-orange with a section of the bark peeled, disjlaying the order of the leaf-scars (cycle $\frac{3}{2}$ ).

229. THE ELM CYCLE. In the strictly alternate arrangement (elm, linden, grasses) the spiral thread makes one complete circuit and commences a new one at thè third leaf. The third leaf stands over the first, the fourth over the second, and so on, forming two veritical rows of leaves. Here (calling each complete cireuit a cycle) we observe

230. Frrst, That this cycle is composed of two leaves; second, that the angular distance between its leaves is $\frac{1}{2}$ a cycle $\left(180^{\circ}\right)$; third, if we express this cycle mathematically by $\frac{1}{2}$, the numerator (1) will denote the turns or revolutions, the denominator (2) its leaves, and the fraction itself the angular distance between the leaves $\left(\frac{1}{2}\right.$ of $\left.360^{\circ}\right)$. 
231. THE ALDER CYCLE. In the alder, birch, sedges, \&c., the cjele is not complete until the fourth leaf is reached. The fourth leaf stands over the first, the fifth over the second, \&c., forming three vertical rows. Here call the cycle $\frac{1}{8} ; 1$ denotes the turns, 3 the leaves, and this fraction itself the angular distance $\left(\frac{1}{8}\right.$ of $\left.360^{\circ}\right)$.

232. The cherry cycle. In the cherry, apple, peach, oak, willow, etc., neither the third nor the fourth leaf, but the sixth, stands over the first; and in order to reach it the thread makes two turns around the stem. The sixth leaf is over the first, the seventh over the second, \&c., forming five vertical rows. Call this the $\frac{2}{5}$ cycle; 2 denotes the turns, 5 the leaves in the cycle, and the fraction itself the angular distance $\left(\frac{2}{5}\right.$ of $\left.360^{\circ}\right)$.

233. The OSAGE-ORANGe CYCLE. In the common hedge plant, Osage-orange, the bolly, evening primrose, flax, etc., we find no leaf exactly over the first until wo come to the 9 th, and in reaching it the spiral makes three turns. Here the leaves form eight vertical rows. It is a $\frac{8}{8}$ cycle; 3 the number of turns, 8 the number of leaves, and the fraction the angular distance between the leaves $\left(\frac{8}{8}\right.$ of $\left.360^{\circ}\right)$.

234. The CYCLES COMPARED. These several fractions which represent the above cycles form a series as follows : $\frac{1}{2}, \frac{1}{8}, \frac{2}{5}, \frac{8}{8}$, in which each term is the sum of the two preceding. The fifth terms in order will, therefore, be $\frac{5}{13}$; and this arrangement is actually realized in

96

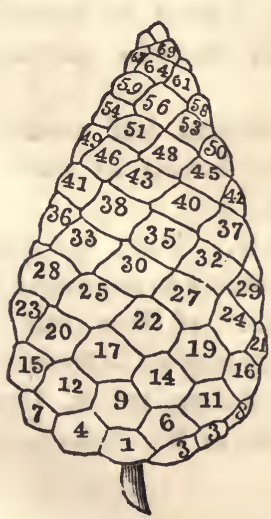

97

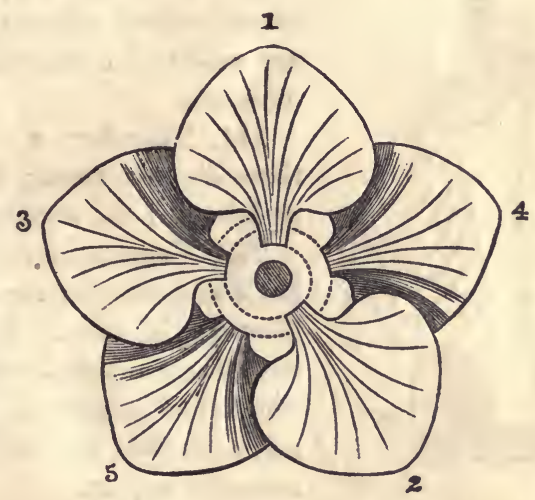

96, Phyllotaxy of the cone (cycle $\frac{8}{21}$ ) of Pinus serotina. 97, cherry cycle $\left(\frac{2}{5}\right)$, as seen from above, forming necessarily that kind of æestivation called quincuntial.

235. THE WHITE PINE crcle. In the young shoots of the white pine, in cones of most pines, in flea-bane (Erigeron Canadense), etc., the fourteenth leaf stands over the first, the fifteenth over the second, etc. The spiral thread makes five revolutions to complete the cycle, which is, therefore, truly expressed by $\frac{5}{1 \frac{3}{3}}$.

236. The HouseleEk crche is next in order, expressed by the fraction $\left(\frac{3+5}{8+13}\right)$ $\frac{8}{2 T}$ having eight turns and twenty-one leaves. Examples are found in the Scotch pine, houseleek, \&c.

237. How to DETERMINE THE HIGHER Cyches. To trace the course of the formative spiral in these higher cycles becomes difficult on account of the close proximity of the leaves. In the pine cone (Fig. 96, Pinus serotina) several sets of secondary spirals are seen ; one set of five parallel spirals turning right $(1-6-11-16$, 
etc., the common difference being also five); two sets (one of three, the other of eight) turning left; and still another set, of thirteen, steepest of all, turning right (1-14-27, etc.). Now the sum of the spirals contained in the two steepest sets gives the denominator of the fraction expressing the true formative spiral sought. Thus, $8+13=21$. The numerator corresponding is already known, and the fraction is $\frac{8}{21}$. See also the white pine cone, whose cycle is $\frac{5}{13}$.

238. Diagram 97 represents the leaves of a cherry cycle as seen from above, and verifeed in the æstivation of the flowers in the rose-family.

\section{MORPHOLOGY OF THE LEAF.}

239. General character. The leaf may be regarded as an expansion of the substance of the bark, extended into a broad thin plate by means of a woody frame work or skeleton, issuing from the inner part of the stem. The expanded portion is called the lamina or blade of the leaf, and it is either sessile, that is, attached to the stem by its base, or it is petiolate, attached to the stem by a footstalk ealled the petiole.

240. Strpules. But the regular petiole very often bears at its base

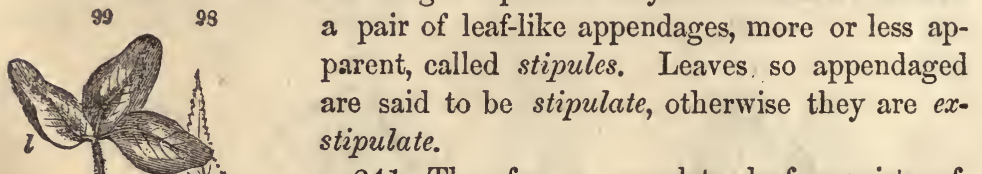

241. Therefore a complete leaf consists of three distinct parts; the lamina or blade, the petiole, and the stipules.

242. Transformations. Both the petiole, blade and stipules are subject to numerous modifications of form. Either of them may exist without the others, or they may all be transformed into other organs, as pitchers, spines, tendrils, and even into the organs of the flower, as will hereafter appear.

\section{OF THE PETIOLE.}

243. The Form of the Distinct Petiole is rarely cylindrical, but more generally flattened or channeled on the upper side. When it is flattened in a vertical direction, it is said to be compressed, as in the aspen or poplar. In this case the blade is very unstable, and agitated by

98. Leaf of willow (Salix lucida); 8 , the stipules. The midvein is 3 -lined; veinlets 2-lined; veinulets single-lined. 99, clover leaves; 8 , stipules, $p$, petiole, $l$, leaflets. the least breath of wind.

244. The winged petrole is flattened or expanded into a margin, but laterally instead of vertically, as in the asters. Sometimes the 
margins outrun the petioles, and extend down the stem, making that winged or alate also. Such leaves are said to be decurrent (decurro, run down). Ex. Mullein.

245. The amplexicaul or stem-clasping Petiole is dilated at the base into a margin which surrounds or clasps the stem, as in the umbilifers. Frequently we find the stem-clasping margins largely developed, constituting a sheath-with free edges in the grasses, or closed into a tube in the sedges.

246. The petiole is simple in the simple leaf, but compound or branched in the compound leaf, with as many branches (petiolules) as there are divisions of the lamina.

\section{OF THE STIPULES.}

247. Strpules are certain leaf-like expansions, always in pairs, situated one on each side of the petiole near the base. They do not oceur in every plant, but are pretty uniformly present in each species of the same natural order. In substance and color they usually resemble the leaf, sometimes they are colored like the stem, often they are membranous and colorless. In the palmetto its substance is a coarse net-work resembling canvass.

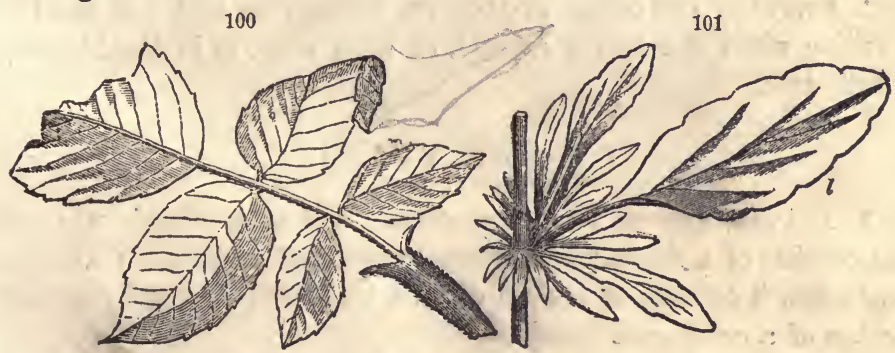

100, Rose leaf, odd-pinnate, with adnate stipules. 101, Violet, (V. tricolor), with simple leaf $(l)$, and freo compound stipules.

248. Stipules are often adnate or adherent to the petiole, as in the rose ; more generally they are free, as in the pea and pansy. In these cases and others they act the part of leaves; again they are very small and inconspicuous.

249. An ochrea is a membranous sheath inclesing the stem from the node upwards, as in the knot-grass family (Polygonaceæ). It is formed of the two stipules cohering by their two margins. In ease the two stipules cohere by their outer margin only, a double stipule is formed opposite to the leaf, as in the button-wood. If they cohere by their inner margin, the double stipule appears in the leaf axil, as in the pond-weed (Potamogeton). 
250. INTER-PETIOLAR STIPULES occur in a few opposite leaved tribes, as the Galium tribe. Here we find them as mere bristles in Diodia while in Galium they look like the leaves, forming whorls. Such whorls, if complete, will be apparently 6-leaved, consisting of two true leaves and four stipules. But the adjacent stipules are often united, and the whorl becomes 4-leaved.

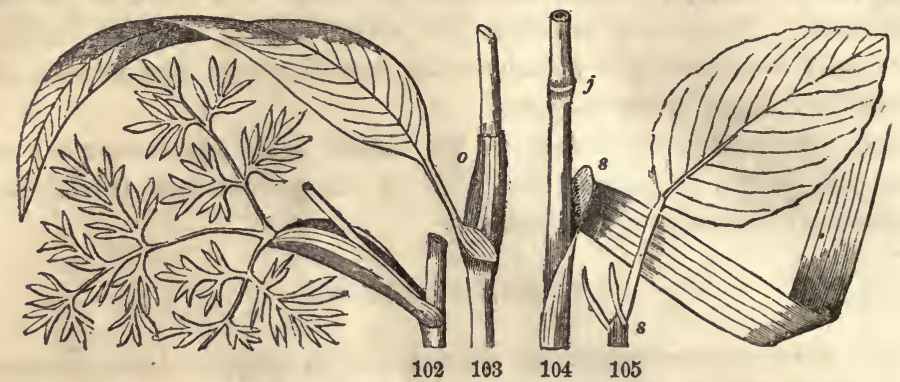

102, Leaf of Conioselinum, tripinnate, with sheathing petiole. 103, Leaf of Polygonum Pennsylvanicum, with its $(o)$ ochrea. 104, Culm of grass, with joint $(j)$, leaf $($.$) ligule (8)$. 105, Leaf of pear-tree, with slender stipules.

251. The Ligule of grasses is generally regarded as a double axillary stipule. The leaflets of compound leaves are sometimes furnished with little stipules, called stipels.

252. Stipules are often fugacious, existing as scales in the bud, and falling when the leaves expand, or soon after, as in the Magnolia and tulip-tree.

\section{O F THE $\mathrm{T}$ EINS.}

253. Leaves, simple and compound. A leaf is simple when its blade consists of a single piece, however cut, cleft or divided; and compound when it consists of several distinct blades, supported by as many branches of a compound petiole.

254. Nature of veins. The blade of the leaf consists of, (1) the frame-work, and (2) the tissue commonly called the parenchyma. The frame-work is made up of the branching vessels of the foot-stalk, which are woody tubes pervading the parenchyma, and conveying nourishment to every part. Collectively, these vessels are called veins, from the analogy of their functions.

255. Venation is a term denoting the manner in which the veins are divided and distributed. The several organs of venation, differing from each other only in size and position, may be termed the midvein, veins, veinlets and veinulets. (The old terms, midrib and nerves, being anatomically absurd, are here discarded).

256. The midvein is the principal axis of the venation, or prolongation of the petiole, running directly through the lamina, from base to 
apex, as seen in the leaf of the oak or birch. If there be several similar divisions of the petiole, radiating from the base of the leaf, they are appropriately termed veins; and the leaf is said to be three-veined, five-veined, etc. Ex. maple.

257. The primary branches sent off from the midvein, or the reins we may term the veINLETs, and the secondary branches, or those sent off from the veinlets, are the veinulets. These also branch and subdivide until they become too small for vision.

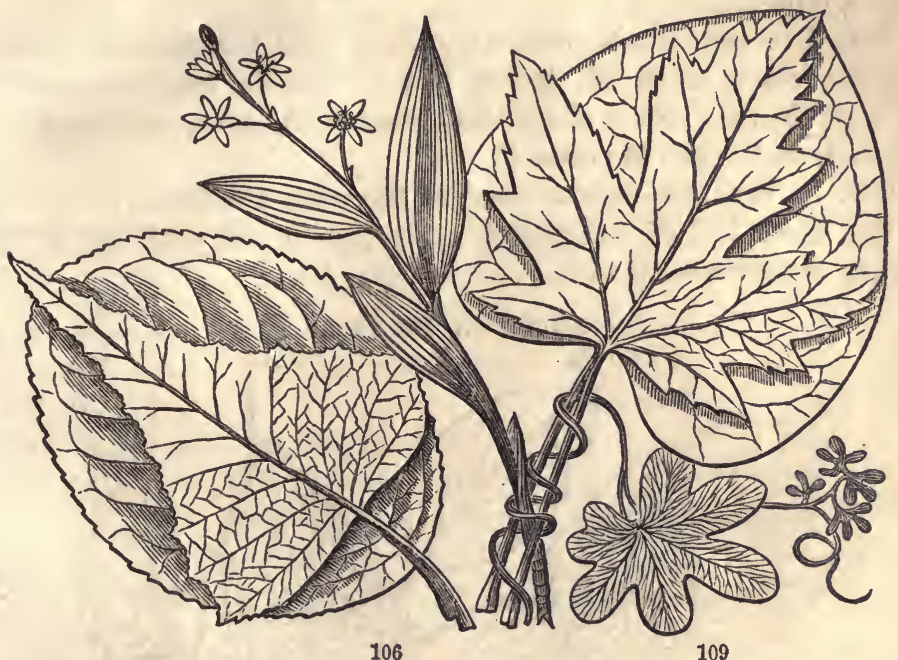

Varieties of veuation. 106, feather-veined,-leaf of Betula populifolia (white birch), lying upon a leaf of plum-tree; same venation with different outlines. 107, Palmate-veined,-leaf of white maple, contrasted with leaf of Cercis Canadensis. 108, Parallel venation,-plant of "three-leaved Solomon's-seal," (Asteranthemum trifoliatum Kunth.) 109, Forked venation,-climbing fern (Lygodium).

258. Modes of venation. Botanists distinguish three principa. modes of venation, which are in general characteristic of the three grand divisions of the regetable kingdom already noticed.

Reticulate, or Net-veined, as in the Exogens: this kind of venation is characterized by the frequent reunion or inosculation of its numerously branching veins, so as to form a kind of irregular net-work.

Parallel-veined, as in the Endogens. The veins, whether straight or curved, run parallel, or side by side, to the apex of the leaf, or to the margin, and are always connected by simple transverse veinlets.

Fork-verned, as in the ferns (and other Cryptogamia, where veins are present at all). Here the veins divide and subdivide in a furcate manner, and do not re-unite. 
259. Of the reticulate venation, the student should carefully note three leading forms, the feather-veined, the palmate-veined, and the tripli-veined.

The FEather-veined (pinni-veined) leaf is that in which the venation consists of a midvein giving off at intervals lateral veinlets and branching veinulets. Ex. beech, chestnut.

260. IN THE RADIATE-VEINED (palmi-veined) leaf the venation consists of several veins of nearly equal size, radiating from the base towards the circumference, each with its own system of veinlets. Ex. maple, crow-foot.

261. The tripli-veined seems to be a form intermediate between the two others when the lowest pair of veinlets are conspicuously stronger than the others above them towards the apex, extending with the midvein towards the summit.

262. IN PARALLEL-VEINED venation the veins are either straight, as in the linear leaf of the grasses, curved, as in the oval leaf of the orchis, or transverse as in the Canna, Calla, \&c.

\section{FORM OR FIGURE.}

\section{4}

118

112

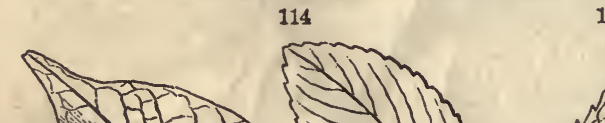

115

116 
of individual forms of outline we shall select only the most remarkable, leaving others for explanation in the glossary.

264. THE MOST OBVIOUS ARRANGEMENT is that which is founded upon the modes of veining; but it should be premised that different forms of venation often give rise to the same outline. Were we required to characterize our idea of the abstract, typical leaf-form, we should sketch an oval outline of surface, with equal sides and unequal ends. The nearest approach to this we find among the

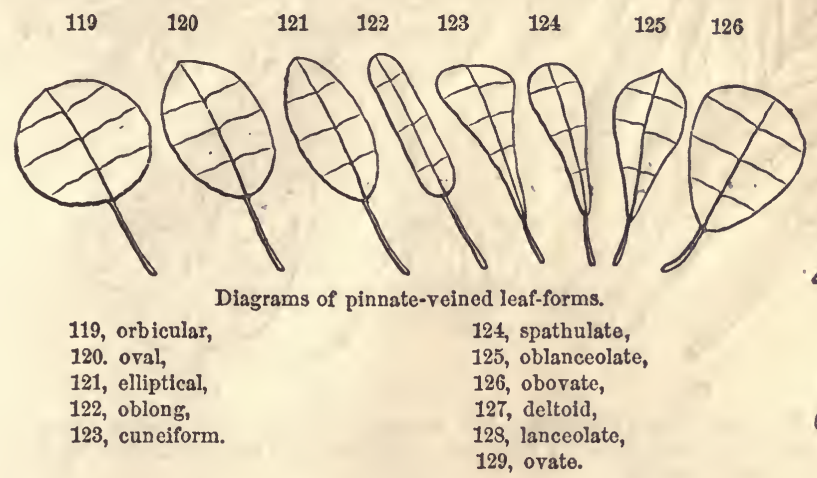

265. Feather-veined leaves. Of these, the following forms depend upon the length of the veinlets in relation

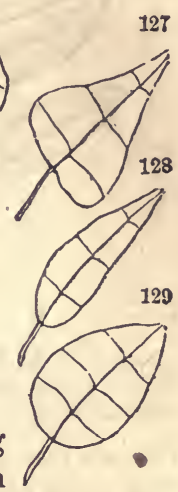
to each other and to the midvein. When the lower veinlets are longer than the others, the form of the blade will be (1) ovate, with the outline of an egg, the broad end at the base; (2) lanceolate, or lanceshaped, narrower than ovate, tapering gradually upwards; (3) deltoid or triangular-shaped, like the Greek letter $\Delta$.

a. If THE MIDDLE VEINLETS EXCEED the others in length, the leaf will be (4) orbicular, roundish or quite circular; (5) elliptical, with the outline of an ellipse, nearly twice longer than broad; (6) oval, broadly elliptical ; (7) oblong, narrowly elliptical.

266. WheN the VEINLETS ARE MORE LARGELY DEVELOPED IN THE UPPER REGION OF THE LEAF its form becomes (8) obovate, inversely ovate, the narrow end at base; (9).oblanceolate, that is, lanceolate with the narrow end at base; (10) spatulate, like a spatula, with a narrow base and a broader, rounded apex; (11) cuneate or cuneiform, shaped like a wedge with the point backwards.

267. Again, If the Lowest pair of veinlets ARE LeNGthened aNd MORE OR LESS RECURVED, the leaf will be variously modified in respect to its base, becoming (12) cordate, or heart-shaped, an ovate outline with a sinus or reëntering angle at base; (13) auriculate, with earshaped lobes at base; (14) sagittate, arrow-shaped, with the lobes pointed, and directed backwards; (15) hastate, halbert-shaped, the lobes directed outwards. 
268. Pinnatifid forms. The following pinnate-veined forms, approaching the compound leaf, depend less upon the proportion of the

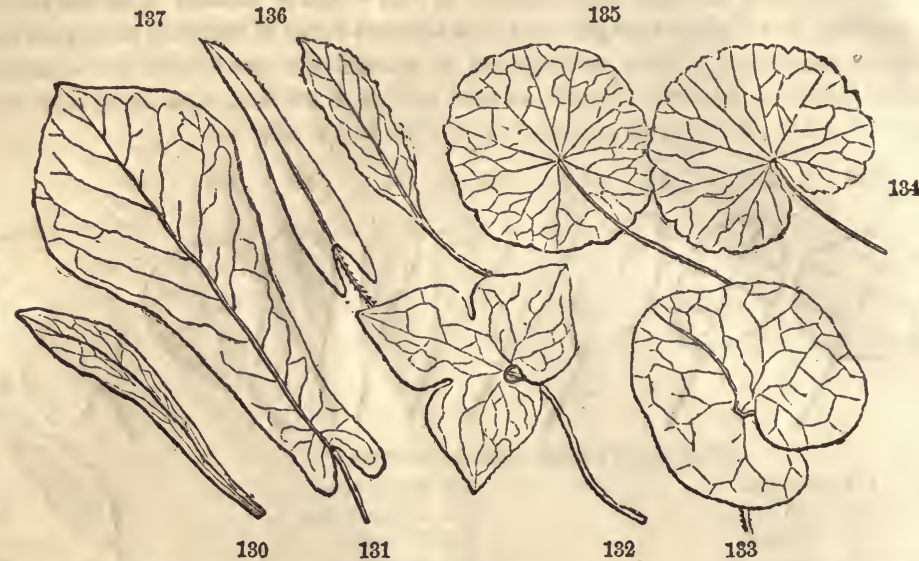

Forms of leaves. 130, Silene Virginica. 131, Magnolia Fraseri. 136, Arabis dentata. 187, Polygonum arifolium. 132, Hepatica acutiloba. 133, Asarum Virginicum. 134, Hydrocotyle Americana. 185, II. umbellata.

veimlets than upon the relative development of the intervening tissue. The prefix pinnated is obviously used in contrast with palmated among palmate-veined forms.

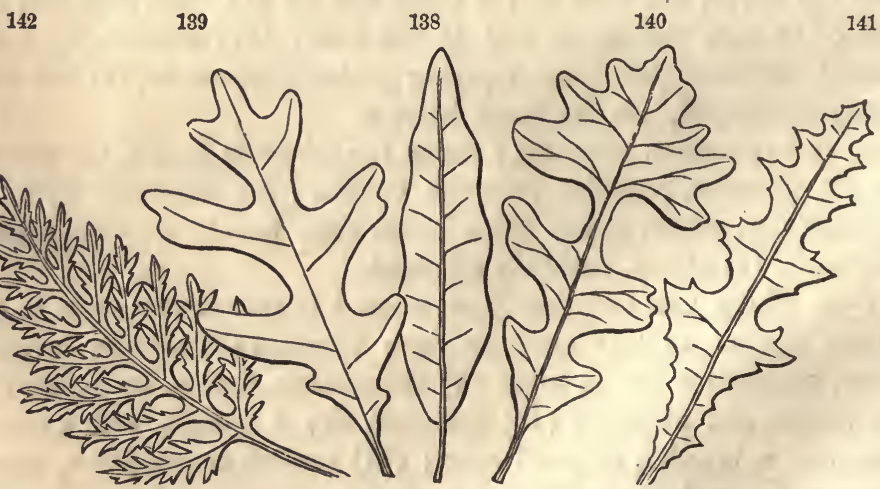

Feather-veined leaves, approaching the compound. 138, Quercas imbricaria-undulate. 139, Q. alba (white oak)-lobate-sinuate. 140, Q. macrocarpa-lyrate. 141, Mulgedium (millwced). 142, Bipinnatifid leaf of Ambrosia artemisifolia (hog-weed).

269. Pinnatifid (pinna, feather, findo, to cleave) Featmer-clewt, the tissue somewhat sharply cleft between the veinlets about half way to the midvein, forming oblong segments. When the segments of a pinnatifid leaf are pointed and curved backward it becomes runcinate, i. e., re-uncinate. When the terminal segment of a pinnatifid leaf is 
orbicular in figure and larger than any other, presenting the form of the ancient lyre, the form is termed lyrate.

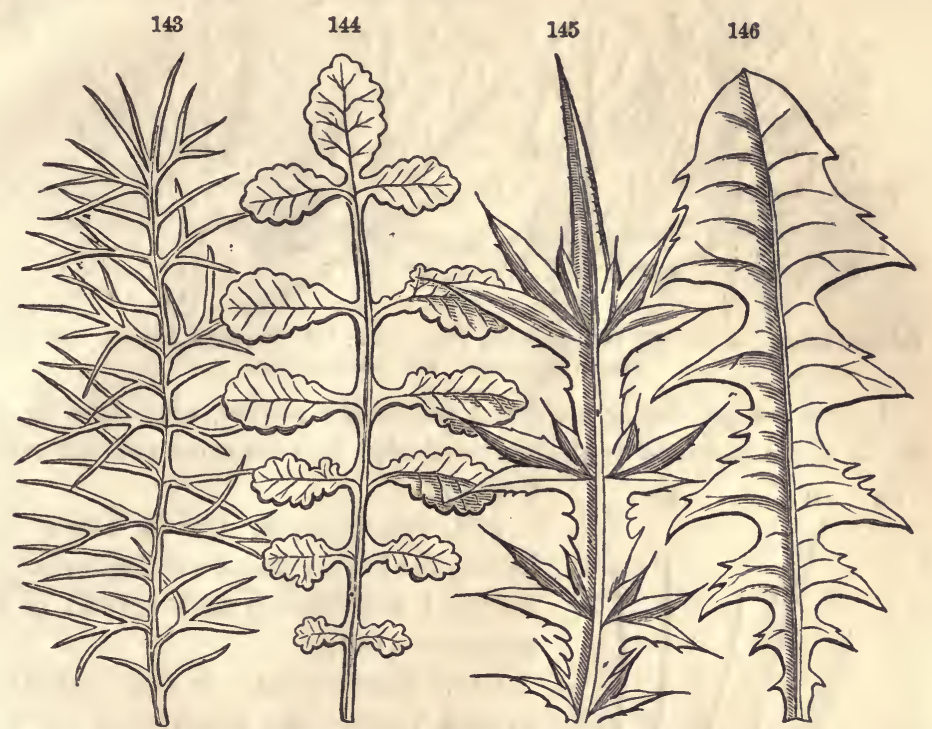

Feather-veined leaves almost compound. 143, Nigella (pinnatisect). 144, Chelidonium majus. 145, Thistlo (Cirsium lanceolatum). 146, Dandelion (runcinate-lyrate).

270. Pinnately parted implies that the incisions are deeper than pinnatifid, nearly reaching the midvein. In either case the leaf is said to be sinuate when the incisions (sinuses) as well as the segments are rounded and flowing in outline. Such segments are lobes, and the leaves lobate or lobed, a very generic term.

271. The palmate venation presents us with a set of forms which are, in general, broader in proportion than the pinnate, having the breadth about equaling the length. Such a leaf may be rarely broadly ovate or broadly cordate, terms which require no further explanation. Or it may be

Reniform, kidney-shaped, having a flowing outline broader than long, concave at base; or

Peltate, shield-form, the petiole not inserted at the margin but in the midst of the lower surface of the blade. This singular form evidently results from the blending of the base lobes of a deeply cordate leaf, as seen in hydrocotyle. It may be orbicular, oval, etc.

272. Palmate forms. The following result from deficiency of tissue, causing deep divisions between the veins. Leares thus dissected are said to be palmately-lobed when either the segments or the sinuses are somewhat rounded and continuous. The number of lobes is denoted by such terms as bilobate, trilobate, five-lobed, etc. 


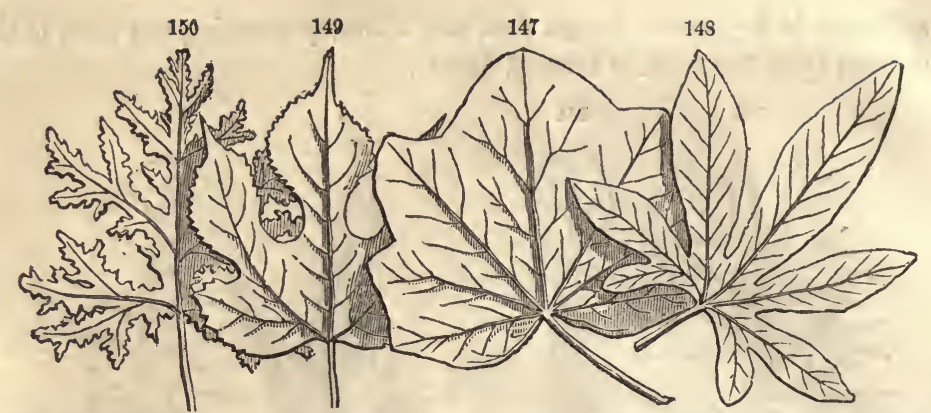

Palmate-reined leaves. 147, Menispermum Canadense. 148, Passiflora cerules. 149, Broussonetia papyrifera. 150, Oak geranium.

Leaves are palmately cleft and palmately parted, according to the depth of the incisions as above described. But the most peculiar modi-

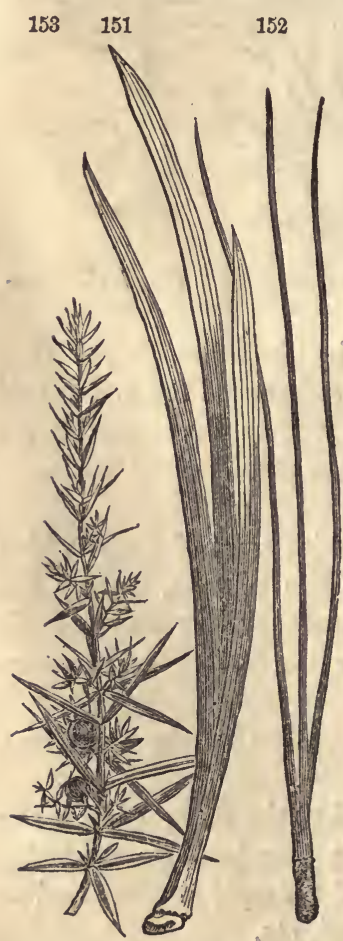

151, Ensiform leaves of iris. 152, Accrose leaves of Pinus. 153, Subulate leaves of Juniperus communis. fication is

273. The pedate, like a bird's foot, having the lowest pair of veinlets enlarged, recurved, and bearing each several of the segments (148).

274. The Forms of the ParalleL VEINED LEAVES are remarkable for their even, flowing outlines, diversified solely by the direction and curvature of the veins. When the veins are straight the most common form is

275. The Linear, long and narrow, with parallel margins, like the leaves of the grasses-a form which may also occur in the pinnate-veined leaf, when the veinlets are all equally shortened. The ensiform, or sword-shaped, is also linear, but has its edges vertical, that is, directed upward and downward.

276. If the veINS CuRve, we may have the lanceolate, elliptical, or even orbicular forms; and if the lower curve downward, the cordate, sagittate, etc., all of which are shown in the cuts.

The palmate or radiate form is finely illustrated in the palmetto and other palms, whose large, fan-shaped leaves are appropriately termed flabelliform (fan-shaped).

277. The Leaves of tire pine and the Fir tribe (Coniferæ) generally are parallel-veined also, and remarkable for their contracted 
forms, in which there is no distinction of petiole or blade. Such are the acerose (needle-shaped) leaves of the pine, the subulate (awl-shaped) and scale-form leaves of the cedars, etc.

\section{MARGIN.}

The following terms apply to the various modifications of the margin, as such, not affecting the general outline of the leaf.

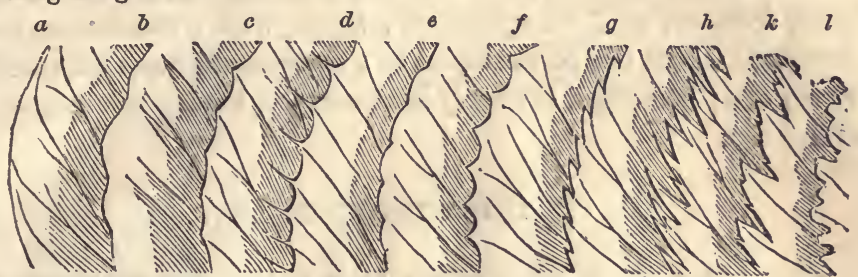

154. Diagram of leaf-margins. $a$, entire; $b$, undulate; $c$, repand; $d$, spinous; $e$, crenate ; $f$, dentate $g$, serrate; $h$, laciniate ; $k$, incised $l$, , erose.

278. Entire, even edged, having the tissue completely filled out. Sometimes a vein runs along the margin, which might otherwise be easily torn, as in the Caladium. But when the marginal tissue is deficient, the leaf becomes

279. Dentate, having sharp teeth pointing outward from the centre; serrate, with sharp teeth pointing forwards, like the teeth of a saw; renate, with rounded or blunt teeth. The terms denticulate, serrulate, crenulate, denote finer indentations of the several kinds; doubly dentate, \&c., denote that the teeth are themselves toothed.

280. The undulate, or wavy edge is somewhat different from the repand, which bends like the margin of an umbrella. If the reins project, and are tipped with spines, the leaf becomes spinous.

281. Irregularly divided margins are said to be erose or jagged, laciniate or torn, incised or cut.

282. Crisped. Often, instead of a deficiency there is a superabundance of marginal tissue, denoted by the term crispate or crisped.

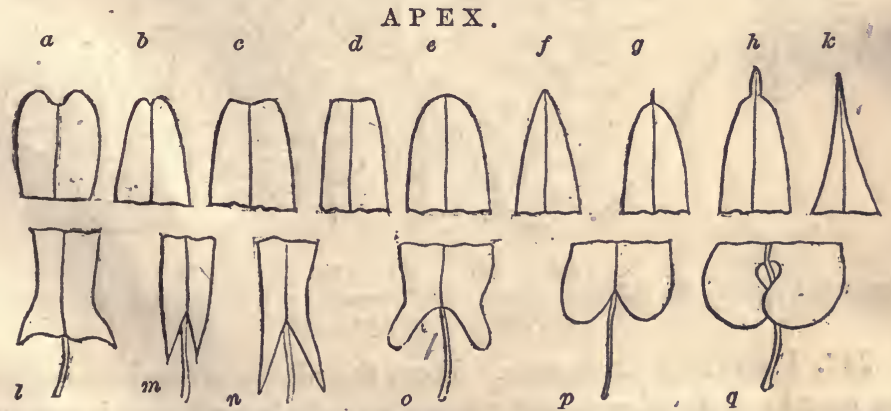

155 , A pex of leaves. $a$, obcordate ; $b$, emarginate ; $c$, retuse ; $d$, truncate ; e, obtnse $f$, acute ; $g$, mucronate; $h$, cuspidate; $k$, acuminate.

156. Bases of leaves. $l$, hastate; $m, n$, sagittate; 0 , auriculate; $p$, cordate; $q$, reniform. 
283. Pointed leaves. In regard to the termination of a leaf at its apex, it may be acuminate, ending with a long, tapering point ; cuspidate, abruptly contracted to a sharp, slender point; mucronate, tipped with a spiny point; acute, simply ending with an angle; obtuse, rounded at the point.

284. Pointless leaves. Or the leaf may end without a point, bcing truncate, as if cut square off ; retuse, with a rounded end slightly depressed where the point should be; emarginate, having a small notch at the end; obcordate, inversely heart-shaped, having a deep indentation at the end.

\section{OF THE COMPOUND LEAF.}

285. Theory. If we conceive of a simple leaf becoming a compound one, on the principle of "deficiency of tissue between the veims," it will be evident that the same forms of venation are represented by the branching petioles of the latter as by the veins of the former. The number and arrangement of the parts will therefore in like manner correspond with the mode of venation.

286. Leaflets. The divisions of a compound leaf are called leaflets, and the same distinction of outline, margin, \&c., occur in them as in simple leaves. The petiolules of the leaflets may or may not be articulated to the main petiole, or rachis, as it is called.

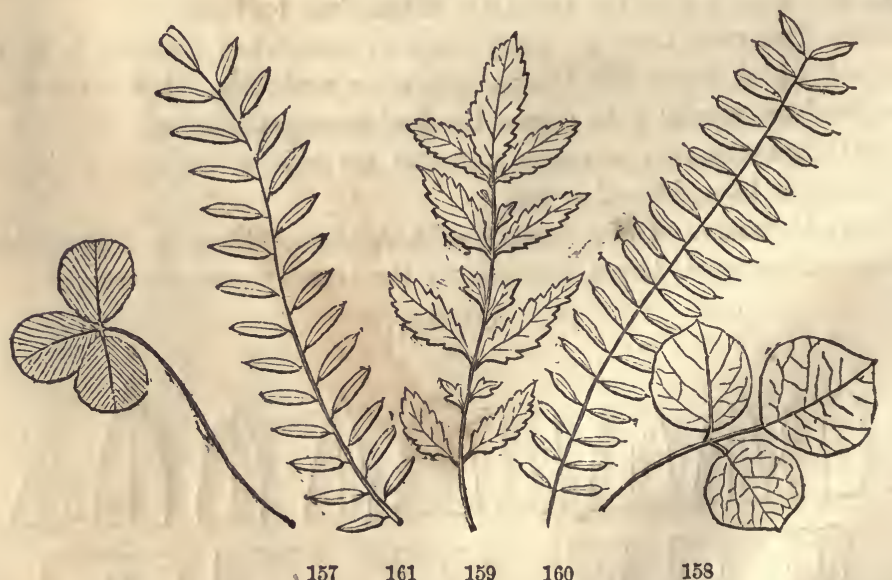

Compound leares. 157, Trifolium repens. 158, Desmodium rotundifolium. 160, Glotidium. 161, Cassia. 150, Agrimonia.

287. Pinnately compound. From the pinnate-veined arrangemert we may have the pinnate leaf, where the petiole (midvein) bears a row of leaflets on each side, either sessile or petiolulate, generally equal in 
number and opposite. It is unequally pinnate when the rachis bears an odd terminal leaflet, and equally pinnate when there is no terminal leaflet, and interruptedly pinnate when the leaflets are alternately large and small (159, etc).

288. The nUMber of Leaflets in the Pinnate Leaf varies from thirty pairs and upwards (as in some acacias), down to three, when the leaf is said to be ternate or trifoliate; or two, becoming binate, or finally even to one leaflet in the lemon. Such a leaf is theoretically compound, on account of the leaflet (blade) being articulated to the petiole.

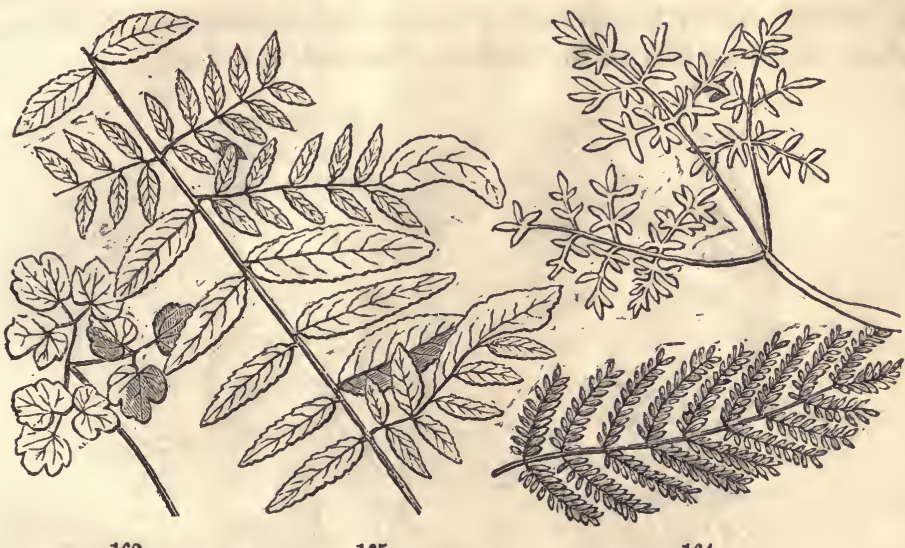

162

165

164

Componnd leaves. 162, Clematis. 163, Erigenia bulbosa. 164, Acacia. 165, Honey-locast.

289. A bipinnate leaf (twice pinnate) is formed when the rachis bears pinnoe or secondary pinnate leaves, instead of leaflets, and tripinnate (thrice pinnate), when pinnæ take the places of the leaflets of a bipinnate leaf. When the division is still more complicated the leaf is decompound.

290. Transition Leaves. Different degrees of division often exist in different parts of the same leaf, illustrating the gradual transition of leaves from simple to 169

166

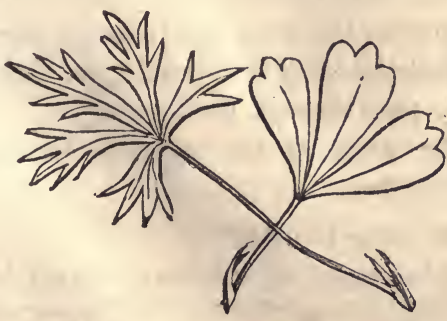

168

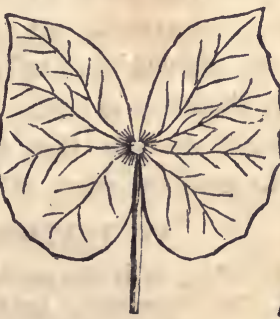

167

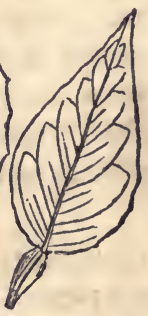

167, Lemon, 168, Jeffersonia. 169, Potentilla anserina, 166, P. tridentata. 
compound in all stages. The leaves of the honey-locust and coffee tree (Gymnocladus) often afford curious and instructive examples.

291. A biternate LEAF is formed when the leaflets of a ternate leaf give place themselves to ternate leaves, and triternate when the leaflets of a biternate leaf again give place to ternate leaves.

292. Palmately compound. A Distinction. The palmate venation has also its peculiar forms of compound leaves, as ternate, quinate, septinate, etc., according to the number of leaflets which arise together from the summit of the petiole. Ternate leaves of this venation are to be carefully distinguished from those of the pinnate plan. The palmately ternate leaf consists of three leaflets, which are either all sessile or stalked alike; the pinnately ternate has the terminal leaflet raised above the other two on the prolonged rachis $(157,158)$.

172

171

170

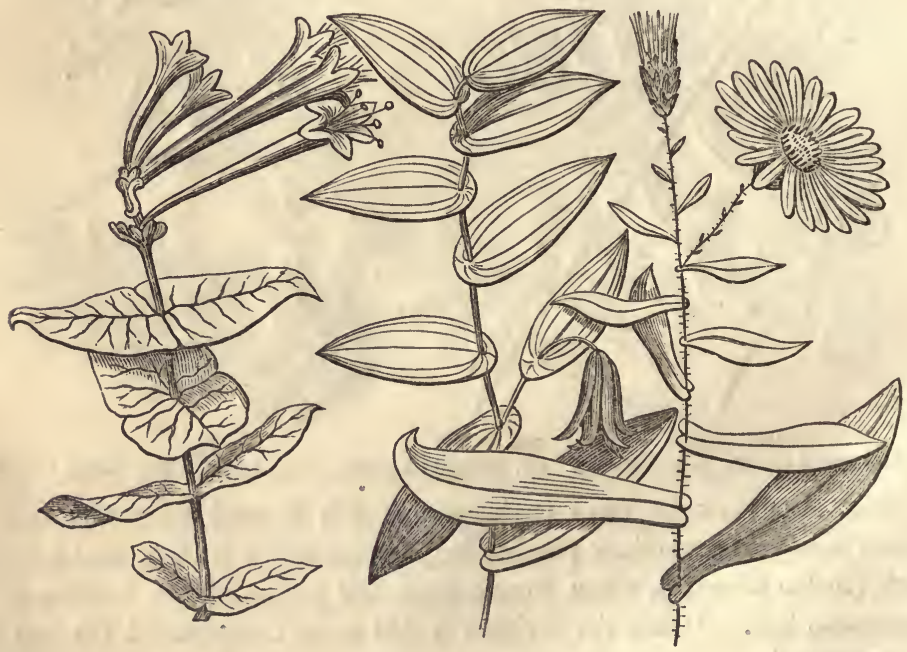

Insertion of leaves. 170, Aster oblongifolius? (amplexicaul). 171, Uvularia perfoliata 172, Lonicera sempervirens, (connate).

With regard to the insertion the leaf is said to be

293. Amplexicaul, when its base lobes adhere to and clasp the stem. Should these lobes extend quite around the stem and become blended together, on the other side a perfoliate leaf will be formed (per, through, folium, leaf), the stem seeming to pass through the leaves.

294. Connate denotes that the bases of two opposite leaves are united so as to form one piece of the two.

\section{OF TEXTURE AND SURFACE.}

IN descriptive botany it is also needful to regard the variations of leaves in the above respects. The terms which we briefly notice below are equally applicable to any other organs. 
295. IN TEXTURE leaves may be membranous, or coriaceous (leathery), or succulent (fleshy), or searious (dry), rugous (wrinkled), \&c., which terms need only to be mentioned.

296. IN THE QUALITY OF SURFACE, the leaf may be glabrous (smooth), destitute of all hairs, bristles, \&c., or scabrous (rough), with minute, hard points, hardly visible.

297. A DENSE COAT OF HAIRS will render the leaf pubescent when the hairs are soft and short; villous when they are rather long and weak ; sericeous, or silky, when close and satin-like; such a coat may also be lanuginous, woolly ; tomentous, matted like felt; or floccose, in soft, fleecy tufts.

298. Thinly SCATtered mains render the surface hirsute when they are long; pilous when short and soft; hispid when short and stiff. The surface will be

299. Setous, when beset with bristly hairs called setae; and spinous when beset with spines, as in the thistle and horse-nettle. Leaves may also be armed with stinging hairs which are sharp and tubular, containing a poisonous fluid, as in nettles and Jatropha stimulans.

300. A proinous surface is covered with a bluish-white waxy powder, called bloom, as in the eabbage, and a punctate leaf is dotted with colored points or pellueid glands.

301. DOUble tersis. The modifications of leaves are almost endless. Many other terms are defined in the glossary, yet it will be found often necessary in the exact description of a plant to combine two or more of the terms defined in order to express some intermediate figure or quality; thus ovate-lanceolate, signifying a form between ovate and lanceolate, etc.

302. SUB. The Latin preposition $s u b$ (undẹr) prefixed to a descriptive term denotes the quality which the term expresses, in a lower degree, as subsessile, nearly sessile, subserrate, somewhat serrate.

\section{CHAPTER VIII.}

\section{TRANSFORMATIONS OF THE LEAF。}

Hitherto wo have considered the leaf as foliage merely--constituted the fit organ of aëration by its large expansion of surface. This is indeed the chief, but not the only aspect in which it is to be viewed.

303. The LeAf is A tYPICAL FORM, that is, the type or idea from which the Divine Architect derived the form of every other appendage of the plant. To trace out this idea in all the disguises under which it lurks is one of the first aims of the botanist. Several of these forms of disguise have already been noticod, e. $g$. 
304. The SCALES which clothe the various forms of scale-stems are leaves, or more usually petioles, reduced and distorted, perhaps by the straitened circumstances of their underground growth. The scales of corms and rhizomas are mostly mere membranes, while those of the bulb are fleshy, serving as depositories of food for the future use of the plant. That these scales are leaves is evident, 1 st, from their position at the nodes of the stem, $2 \mathrm{~d}$, from their occasional development into true leaves.

305. Bud scales. The brown scales which cover winter buds are of the same nature and origin.

306. The COTYLEDONS of seeds or seed-lobes are readily recognized as leaves, especially when they arise above ground in germination, and form the first pair upon the young plant, as in the beech-nut and squash sced. Their deformity is due to the starchy deposits with which they are crammed for the nourishment of the embryo when germinating, and also to the way in which they are packed in the seed.

307. Phyllodra are certain leaf-forms, consisting of petioles excessively compressed, or expanded vertically into margins, while the true lamina is partly or entirely suppressed. Fine examples are seen in our greenhouse acacias from Australia. Their vertical or edgervise position readily distinguishes them from true leaves.

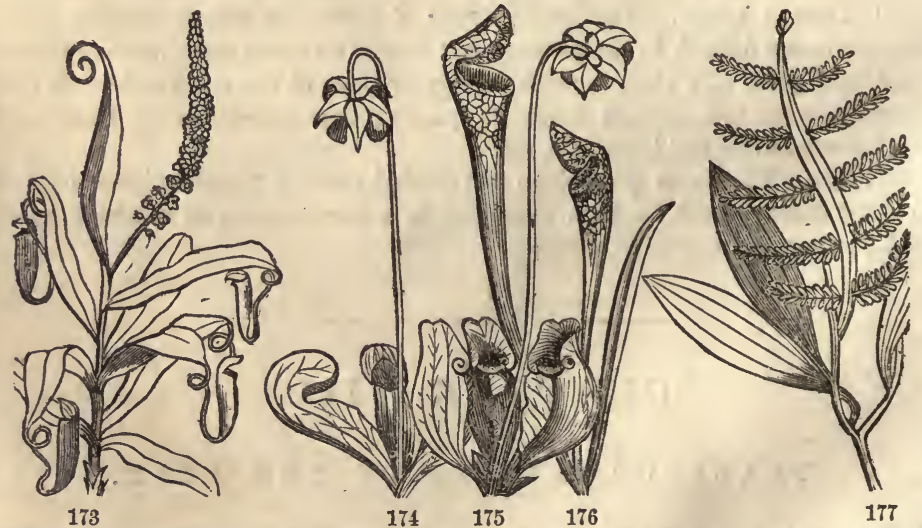

Ascidia. 173, Nepenthes. 174, Sarracenia psittacina. 175, S. purpurea. 176, S. Gronovii, $\beta$. Drummondil. 177, Acacia heterophylla, its phyllodia.

308. AscidiA or pitchers, are surprising forms of leaves, expressly contrived, as if by art, for holding water. The pitchers of Sarracenia, whose several species are common in bogs North and South, are evidently formed by the blending of the involute margins of the broadly winged petioles, so as to form a complete vase. The broad expansion which appears at the top may be regarded as the lamina. These pitchers contain water, in which insects are drowned, being prevented from escaping by the deflexed hairs at the mouth. 
309. NePENTHES. The greenhouse pitcher-plant is a native of the East Indies. Its proper leaves are sessile and lanceolate. The midvein extends beyond the apex like a tendril, to the length of six or eight inches. The extremity of this tendril is inflated into a hollow vessel, similar to a pitcher, and usually contains about half a pint of pure water. It is furnished with a leafy lid connected to it by a ligament which expands or contracts according to the state of the atmosphere, so that the cap is open in damp weather and closed in dry.

310. Dischidia. Another wonderful provision of this kind is observed in a plant growing in the forests of India, called Dischidia. It is a twining plant, ascending the tall trees to the distance of a hundred feet from its roots, and destitute of leaves except near its top. The pitchers seem formed of a leaf with its edges rolled inward and adherent, and its upper end or mouth is open to receive whatever moisture may descend into it. But the greatest marvel in its structure is that several bundles of absorbent fibres, resembling roots, are sent out from the nearest parts of the stem, enter the pitchers, and spread themselves through the cavity.

311. Air Bladders. Many weak-stemmed water plants are furnished with little sacks filled with air to buoy them up near to the surface. Such are the bladders of the common bladderwort, formed from the leaf lobes. In the horned-bladderwort the floats are made of the six upper inflated petioles lying upon the surface of the water like a wheelshaped raft, and sustaining the flower upon its own elevated stalk.

312. THE LEAF OF VENUS' FLY-TRAP (Dionæa), native of Carolina, is also of curious design. At the end of the leaf are two lobes bordered with spines. In the cavity between the lobes are several sharp points projecting upwards, and a gland which secretes a liquor attractive to insects. But when an unlucky fly, in search of food, alights upon it, the irritable lobes instantly close and impale him in their fatal embrace.

313. The Tendarl is a threadlike coiling appendage furnished to certain weak-stemmed plants as their means of support in place.

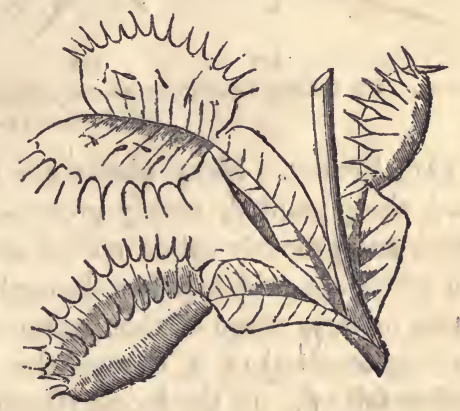

178, Leaves of Venus' fly-trap (Dionæa). Its first growth is straight, and it remains so until it reaches some object, when it immediately coils itself about it, and thus acquires a firm, though elastic hold. This beautiful appendage is finely exemplified in the Cucurbitaceæ and grape, above cited; also in many species of the pea tribe (Leguminosæ), when it is appended to the leaves. It is not a new organ, but some old one transformed and adapted to a new purpose. In Gloriosa superba the midvein of the leaf is prolonged beyond the blade into a coiling tendril. In the pea, vetch, etc., the tendrils represent the attenuated leaf blades themselves. Again, the entire leaf sometimes becomes a tendril in Lathyrus, while the stipules act as leaves. 
314. The petiole of the leaf of Clematis, otherwise unchanged, coils like a tendril for the support of the vine. In the greenbriar, the stipules are changed to tendrils, which thus arise in pairs from the base of the petioles. So probably in the gourd tribe.

315. BUT THE TENDRILS OF THE GRAPE-VINE are of a different nature. From their position opposite the leaves, and the tubercles occasionally seen upon them, representing flower buds, they are inferred to be abortive, or transformed flowerstalks.

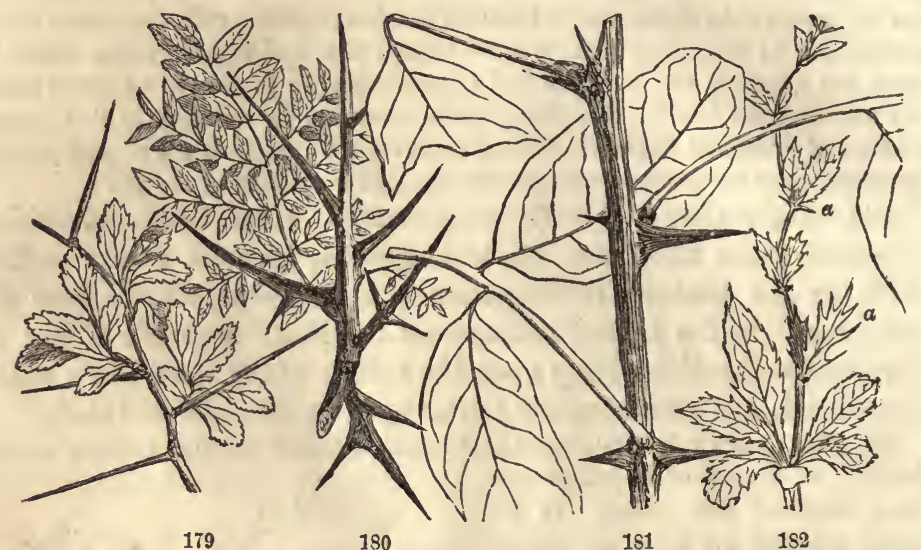

Thorns. 179, Cratægus parrifolia (thorns axillary.) 180, Honey-locust. 151, Common locust. 1S2. Berberis, $a, a$, its thorns.

316. Spines. Many plants are armed, as if for self-defense, with hard, sharp-pointed, woody processes, called spines or thorns. Those which are properly called spines originate from leaves. In Berberis the spines are evidently transformed leaves, as the same plant exhibits leaves in every stage of the metamorphosis. In goat's-thorn (Astragalus tragacanthus) of S. Europe, the petioles change to spines after the leaflets fall off. In the locust (Robinia), there is a pair of spines at the base of the petiole, in place of stipules.

317. THORss originate from axillary buds, and are abortive branches. This is evident from their position in the hawthorn and Osage orange. The alple and pear tree in their wild state produce thorns, but by cultivation become thornless, that is, the axillary buds, through better tillage, develop branehes instead of thorns. The terrible branching thorns of the honey-locust originate just above the axil, from accessory buds.

318. PRICKLES differ from either spines or thorns, growing from the epidermis upon stems or leaves, at no determinate point, and consisting of hardened cellular tissue, as in the rose, bramble.

319. Bracts. By a more gentle transformation, leaves pass into bracts, which are those smaller, reduced lcaf-forms situated near and among the flowers. So gradual is the transition from leaves to bracts 
in the peony, e.g., that no absolute limits can be assigned. Equally gradual is the transition from bracts to sepals of the flower-affording a beautiful illustration of the doctrine of metamorphosis. (374.)

Bracts will be further considered under the head of Inflorescence.

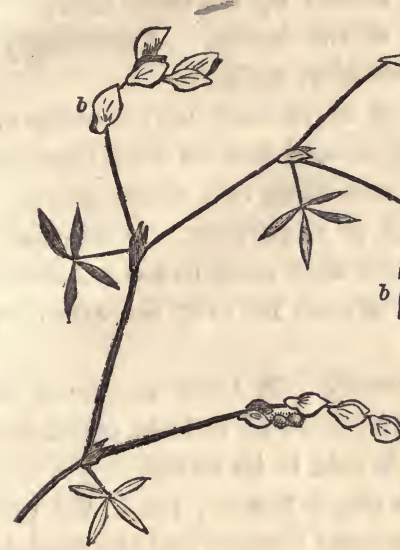

154

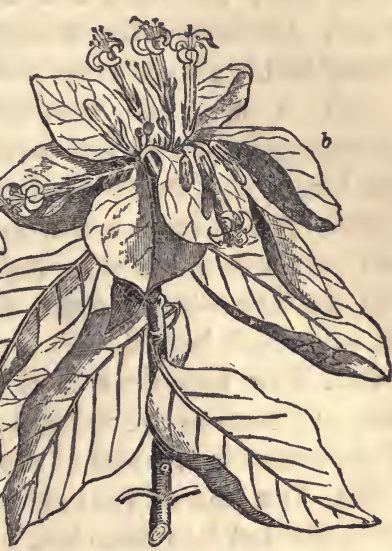

183

Bracts, 183, Pinckneya pubens; $b$, colored bracts (radiate sepals). 184, Zornia tetraphylla ; $b$, bracts (enlarged stipules).

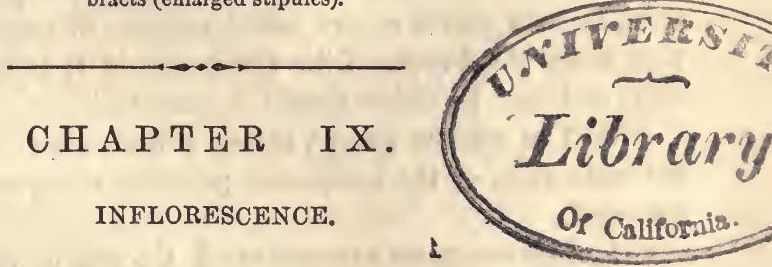

320. THE FUNCTIONS OF PLANT-LIFE ARE TWO-FOLD, namely, vegetation and roproduction: the former looking to the preservation of the individual plant itself, the latter to the species. Corresponding with this view, there are also two classes of organs. Having considered the former class, that is, the organs of vegetation, we come now to the organs of reproduction, including the flower, the fruit, and the seed.

321. Inflorescence is a term denoting the arrangement of the flowers, and their position upon the plant.

322. ORIGIN OF FLOWER BUDS. All the buds of a plant are supposed to be originally of one and the same nature, looking to the production of vegetative organs only. But at a certain period, a portion of the buds of the living plant, by an unerring instinct little understood, are converted from their ordinary intention into flower buds.

323. Proof of this theory. That this is the origin of the flower bud is evident from the known effects of cultivation, causing it to revert partly or wholly to its former intention, as in the green rose, when the petals, \&c., all return to leares; in 
the proliferous rose when the axis grows on through the flower bearing leaves above it. In some instances the skillful gardener learns how to effect this interchange of nature in the buds at pleasure.

324. Hence in position and arrangement flower buds can not differ from leaf buds, and both are settled by the same unerring law which determines the arrangement of the leaves. Accordingly the flower bud is always found either terminal or axillary.

325. A single bud, whether terminal or axillary, may develop either a compound inflorescence, consisting of several flowers with their stalks and bracts, or a solitary inflorescence, consisting of a single flower.

326. The flower-bud is incapable of extension. While the leafbud may unfold leaf after leaf and node after node to an indefinite extent, the flower-bud blooms, dies, and arrests for ever the extension of the axil which bore it.

327. The Peduncle is the flower-stalk. It bears no leaves, or at least only such as are reduced in size and changed in form, called bracts. If the peduncle is wanting the flower is said to be sessile.

328. The simple peduncle bears a single flower; but if the peduncle be divided into branches, it bears several flowers, and the final divisions bearing each a single flower, are called pedicels.

329. THE sCAPE is a flower-stalk which springs from a subterranean stem, in such plants as are called stemless or acaulescent, as the primrose, tulip, blood-root. Like the peduncle it is leafless or with bracts only, and may be either simple or branched.

330. The Rachis ( $\rho$ a $i \varsigma$, spine) is the axis of the inflorescence, or the main stem of the compound peduncle along which the pedicels are arranged.

331. The torus or RECEPTACLE is the end or summit of the flowerstalk.

187

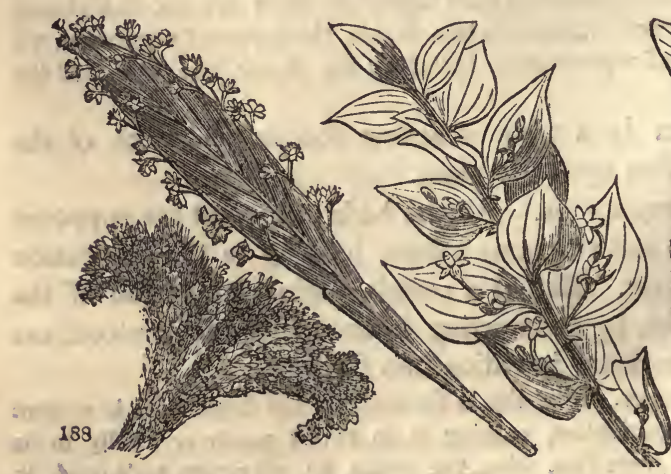

185

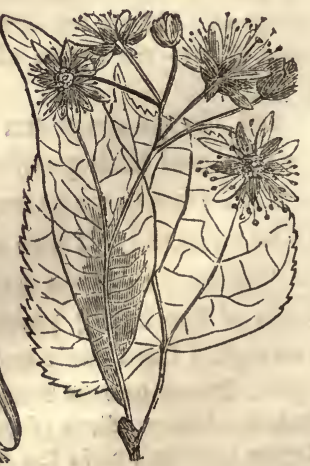

Anomalous peduncles. 185, Linden-tree. 156, Butcher's-broom. 187, Xylophylla. 188,Cockscomb. 
332. THE peduncle is subject to endless modifications. We find it sometimes excessively lengthened, again very short or wholly wanting; very slender or very thick. In cockscomb its branches are blended into a thick, fan-shaped mass; in butcher's-broom it expands into the form of a green leaf, and in the linden-tree into a seal-like bract. In Xylophylla it is foliaceous, bearing flowers along its margins.

333. Bracts. The branches of the inflorescence arise from the axils of reduced leaves, called bracts. These lcaves, still smaller, growing upon the pedicels, are called bracteoles.

334. The bracts are usually simple in outline and smaller than the leaf, often gradually diminishing to mere points, as in Aster, or even totally suppressed, as in the Cruciferæ.

335. In colon they are usually green, often colored, sometimes bril. liantly, as in painted-cup. Sometimes they are scale-like, and again they are evanescent membranes.

336. The spathe is a large bract formed in some of the monocotyledons, enveloping the inflorescence, and often colored as in the Arum, Calla, or membranous as in the onion and daffodil. Bracts also constitute an

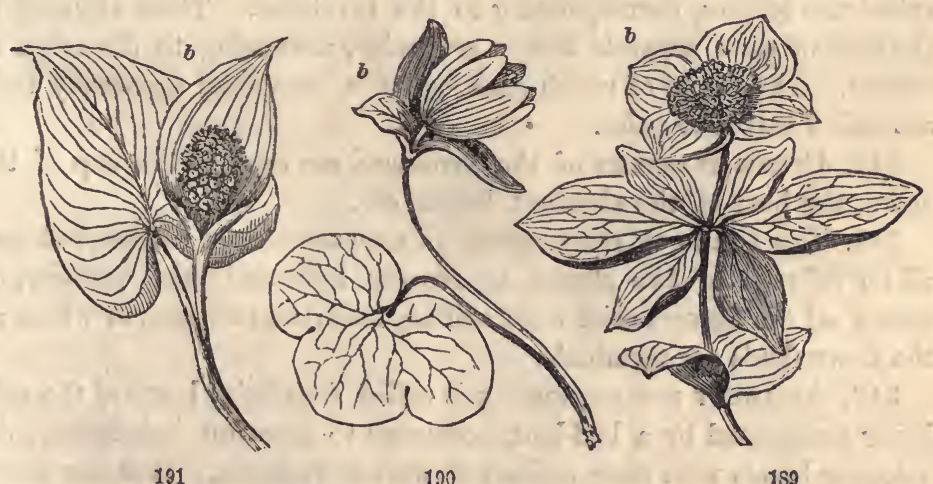

Bracts $(\zeta, \tau, \zeta)$,.159 , Cornus Canadensis, with an involucre of 4 colored bracts. 190 , Hepatica triloba, with an involucre of 3 green bracts. 191, Calla palustris, with a colored spathe of one bract.

337. Irvoldere when they are collected into a whorl or spiral group. In the Phlox, Dodecatheon, and generally, the involucre is green, but sometimes colored and petaloid, as in dogwood and Euphorbia. Situated at the base of a compound umbel, it is called a general involucre, at the base of a partial umbel it is a partial involucre or involucel, both of which are seen in the umbelliferæ.

338. IN THE CoMposite, where the flowers are crowded upon a common torus, forming what is called a compound flower, an involucre composed of many imbricated scales (bracts) surrounds them as a calyx surrounds a simple flower. The chaff also upon the torus are bract's to which each floret is axillary. 


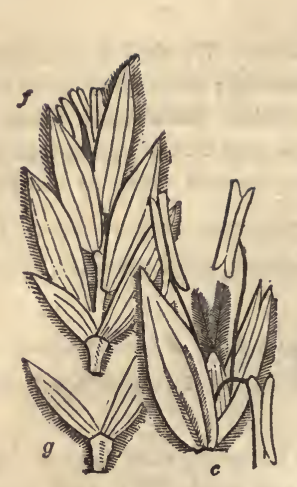

195 193

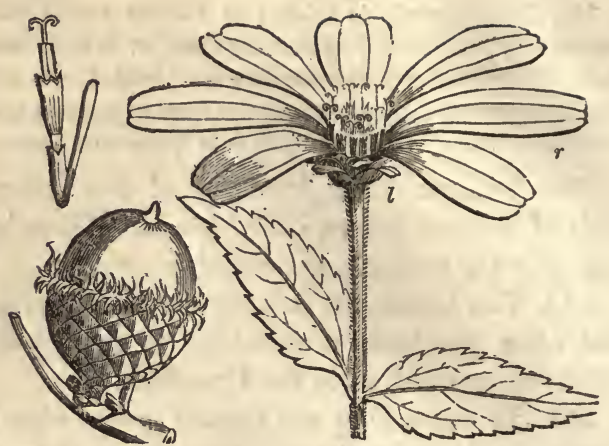

194

192

192, Helianthus grosse-serratus. $l$, involucre; $r$, rays, or ligulate flowers; 193 , one of the disk flowers with its chaff-scale (bract). 194, Acorn of moss-cup oak (Q. macrophylla). 195, Poa pratensis ; $f$, spikelet entire, $g$, glumes, separated; $c$, a flower separated, displaying the two paleæ, 8 stamens, and 2 styles.

339. IN THE GRASSES the bracts subsist under the general name of chaff. The bracts situated at the base of a spikelet of flowers, are called the glumes, corresponding to the involucre. Those situated at the base of each separate flower are paleo, answering to the calyx or corolla. The picces of which each calyx is composed (generally two) are called valves or pales.

340. Other examples of the involucre are seen in the cup of the acorn, the burr of the chestnut, beech, etc.

341. The Forms of INFLORESCENCE are exceedingly various, but may all be referred to two classes, as already indicated; the axillary, in which all the flowers arise from axillary buds, the terminal, in which all the flower-buds are terminal.

342. Axillary inflorescence is called indefinite, because the axis, being terminated by a leaf-bud, continues to grow on indefinitely, developing bracts with their axillary flowers as it grows. It is also called centripetal, because in the order of time the blossoming commences with the circumference, and proceeds towards the centre in case of a level topped cluster, as the hawthorn, or with the base, and proceeds towards the summit in case of the lengthened cluster, as the mustard.

The student will readily perceive that the circumference of a depressed (flattened) inflorescence corresponds to the base of a lengthened one; and also that the centre of the former answers to the summit of the latter. For when the axis or rachis is lengthened, it is the centre which bears it along with it at its apex, leaving the circumference at the base.

343. Terminal inflorescence, on the other hand, is definite, implying that the growth of the axis as well as of each branch is definitely arrested and cut short by a flower. It is also centrifugal, because the 
blossoming commences with the central flower and proceeds in order to the circumference, as in the sweet-william, elder, hydrangea.

In this kind of inflorescence all the flowers are considered terminal because they do in fact (except the first which terminates the axis) terminate lateral branches successively produced on a definite plan at the node next below the primary flower.

344. BOTH KINDS OF INFLORESCENCE ARE OCCASIONALLY COMBINED in the same plant, where the general system máy be distinguished from the partial clusters which compose it. Thus in the Compositæ, while the florets of each head open centripetally, the general inflorescence is centrifugal, that is, the terminal head is developed before the lateral ones. But in the Labiatæ the partial clusters (verticilasters) open centrifugally while the general inflorescence is indefinite, proceeding from the base upwards.

345. OF CENTRIPETAL OR AXILLARY INFLORESCENCE THE PRINCIPAL VARIETIES ARE the spike, spadix, catkin, raceme, corymb, umbel, panicle, thyrse, head.

346. TuE spIKe is a long rachis with sessile flowers either scattered, clustered, or crowded upon it, as plantain, mullein, vervain. The socalled spikes of the grasses, as wheat, timothy, are in fact compound spikes, bearing little spikes or spikelets in place of single flowers.

347. The SPadix is a thick, fleshy rachis with flowers closely sessile or imbedded on it, and usually with a spathe, as in the Afum, or without it, as in the Typha.

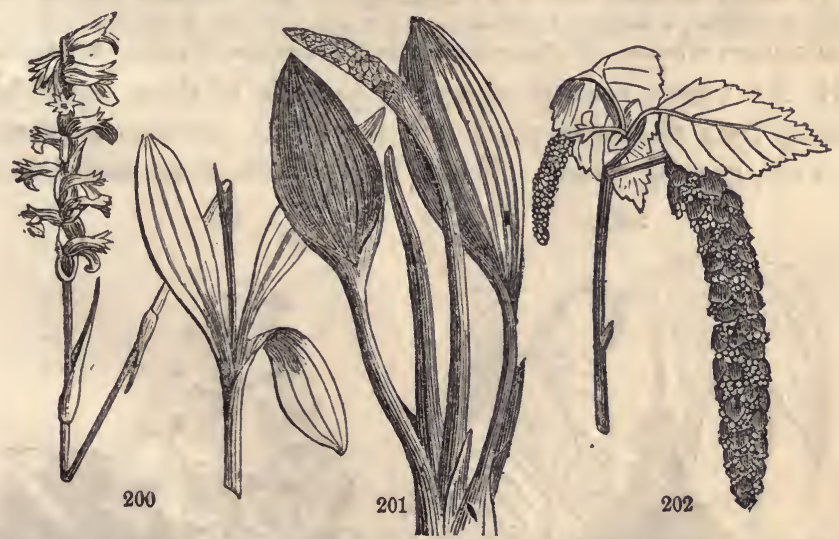

200 , Spiranthes cernua; flowers in a twisted spike. 201, Ornntium aquaticum; flowers on a naked spadix. 202, Betula lenta; flowers in aments.

348. The catkin or amentum is a slender, pendant rachis with scaly bracts subtending the naked, sessile flowers, and usually caducous, as in birch, beech, oak, willow.

349. ThE RACEME is a rachis bearing its flowers on distinct, simple pedicels. It may be erect, as in hyacinth, Pyrola, or pendulous, as in currant, blackberry. 
350. The corymb differs from the raceme in having the lower pedicels lengthened so as to elevate all the flowers to about the same level, as in the wild thorn.

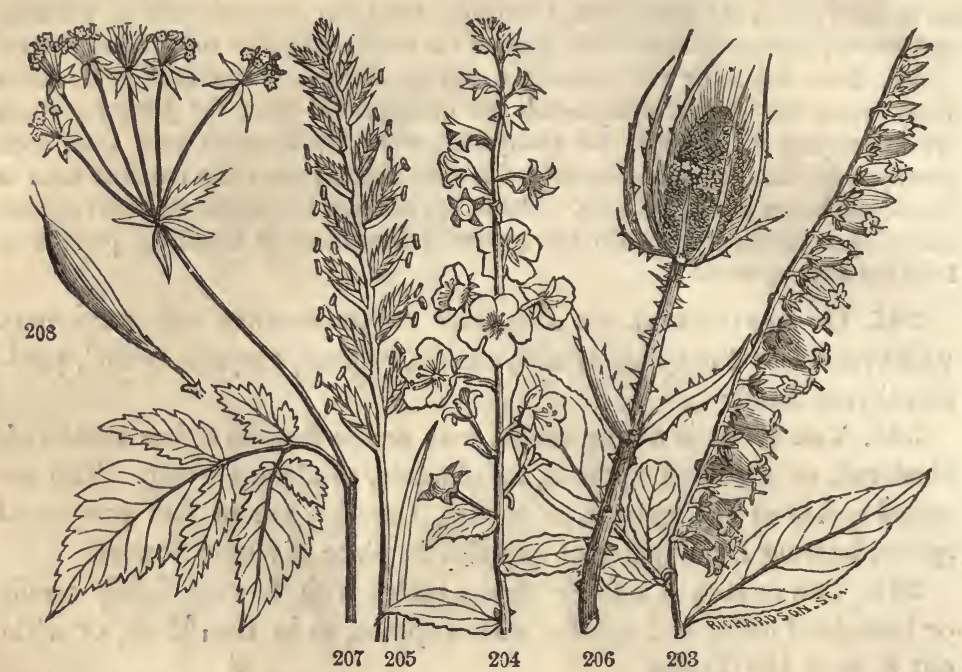

203, Andromeda racemosa ; flowers in a secund raceme. 204, Verbascum Blattaria; raceme. 205, Lolium perenne; a compound spike or a spike of spikelets. 206, Dipsacus sylvestris; head with an involucre of leaves. 207, Osmorhiza longistylis; a compound umbel. 20S, Its fruit.

351. AN UMBEL consists of several pedicels of about equal length radiating from the same point, the top of the common peduncle, as milk-weed, ginseng, onion. When the pedicels of an unbel become
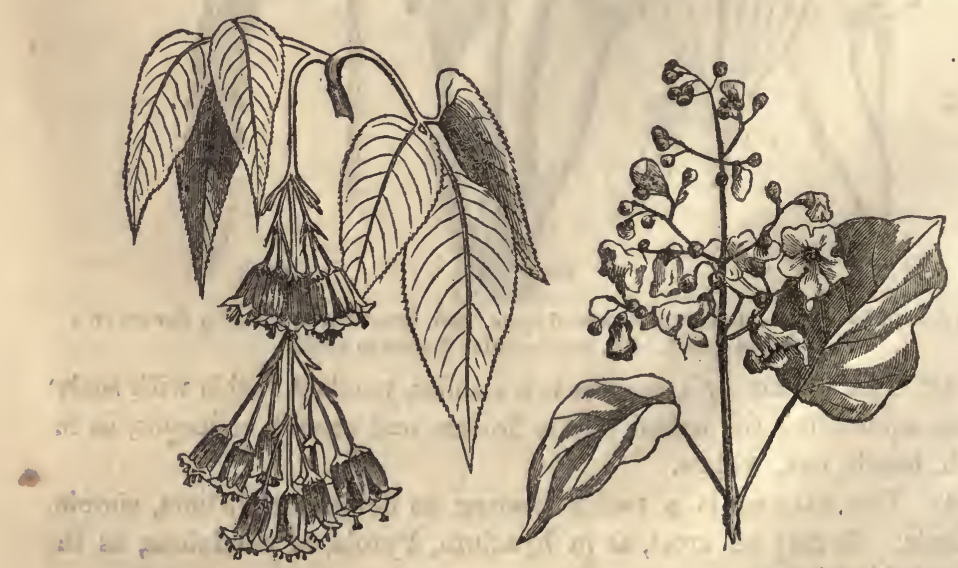

209, Staphylea trifolis; a pendulous, paniculate cyme. 210, Catalps; a paniale. 
themselves umbels, as in caraway and most of the Umbeliferæ, a compound umbel is produced. Such secondary umbels are called umbellets and the primary pedicels, rays.

352. The PANICLE is a compound inflorescence formed by the irregular branching of the pedicels of the raceme, as in oats, spear-grass, Catalpa.

353. A tHrase is a sort of compact, oblong, or pyramidal panicle, as in lilac, grape.

354. A HEAD OR CAPITULUM is a sort of reduced umbel, having the flowers all sessile upon the top of the peduncle, as in the button snakeroot, button-bush, clover.

But the more common examples of the capitulum are seen in the Compositæ, where the summit of the peduncle, that is, the receptacle, is dilated, bearing the sessile flowers above, and scalelike bracts around, as an involucre.

355. The capitulum of the Composite is often called a compound flower from its resemblance, the involucre answering to a calyx, the rays to the corolla. The flowers are called florets, those of the outer circle, florets of the ray, generally differing in form from those of the central portions, the florets of the disk.

356. Of terminal INFLORESCENCE THE FOLLOWING VARIETIES are described: cyme, fascicle (verticilaster), glomerule.

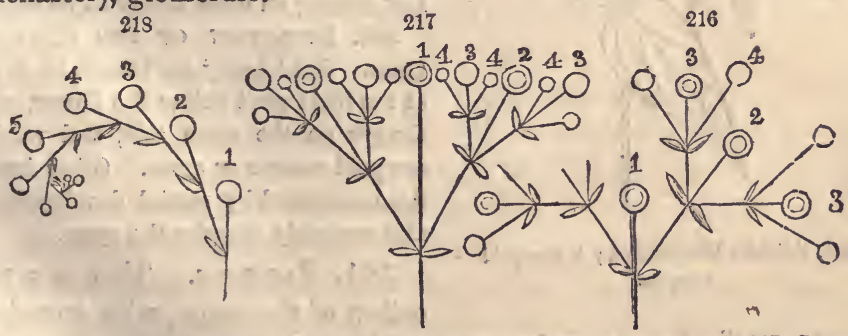

Diagrans ; 216 of a cyme; flowers numbered in the order of their development. 217, Cyme fastigiate. 215, Cyme half developed-a scorpoid raceme.

357. CrMe is a general term denoting any inflorescence with centri- 
fugal evolutions, but is properly applied to that level-topped or fastigiate form which resembles the corymb, as in the elder. If it is loosely spreading, not fastigiate, it is called a cymose panicle, as in the chickweed, spergula, etc. If it be rounded, as in the snowball, it is a globous cyme.

220

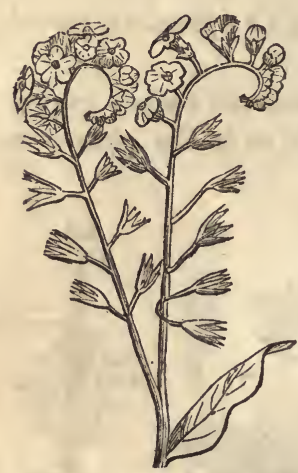

219

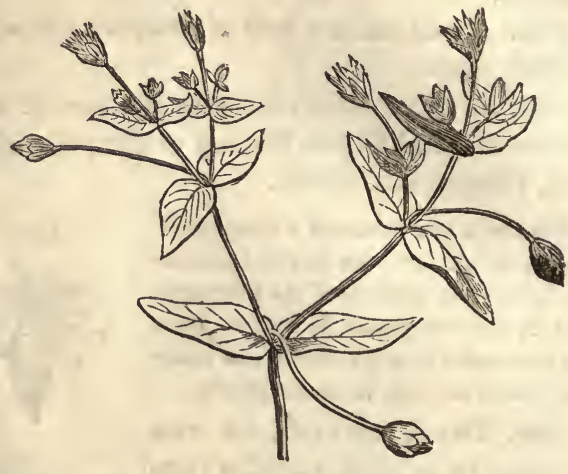

220, Myosotis palustris; scorpoid racemes. 219, Stellaria media ; a regular cyme.

358. A sCORPoId CYME, as seen in the sundew, Sedum, and borrage family, is a kind of coiled raceme, unrolling as it blossoms. It is understood to be a half-developed cyme, as illustrated in the cut.

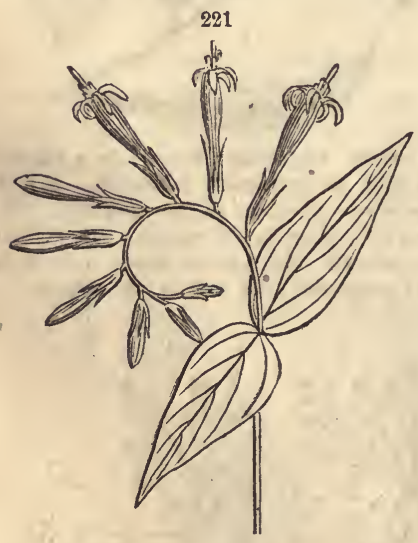

221. Spigelia Marilandica; a scorpoid raceme.

359. THE PECULIAR EVOLUTION OF THE CYME is well illustrated in the chick-weed (Alsine media). The first opening flower terminates the axis and stops its growth. Then from the pair of axils next below issue two opposite branches, each bearing a pair of leaves and a terminal flower. Next, the same process is repeated with each of these two branches, and so on indefinitely. Thus the stem becomes repeatedly forked, .each fork having an older flower in its angle.

360. EvOlution OF THE SCORPOID RACEME. But let only one branch be developed at the node next below the flower, and that always on the same side, and we have a scorpoid raceme or cyme. Other irregularities occasioned by partial development may also variously disguise the cyme.

361. Fascicle. This is a modification of the cyme, with crowded and nearly sessile flowers, as in sweet-william (Dianthus).

362. Glomerule, an axillary tufted cluster, with a centrifugal evolution, frequent in the Labiatx, etc. When they occur in the axils of 
opposite leaves and meet around the stem, each pair constitutes a verticilaster or verticil, as in catmint, hoarhound.

363. HOW THESE MODES ARE MUTUALLY RELATED. All the farms of inflorescence above described may, after all, be shown to be but modifications of a single type, as follows :

Let us commence with the spike, a slender rachis with sessile flowers. Conceive that pedicels be developed for the flowers, $=$ a raceme; let the pedicels branch, $=$

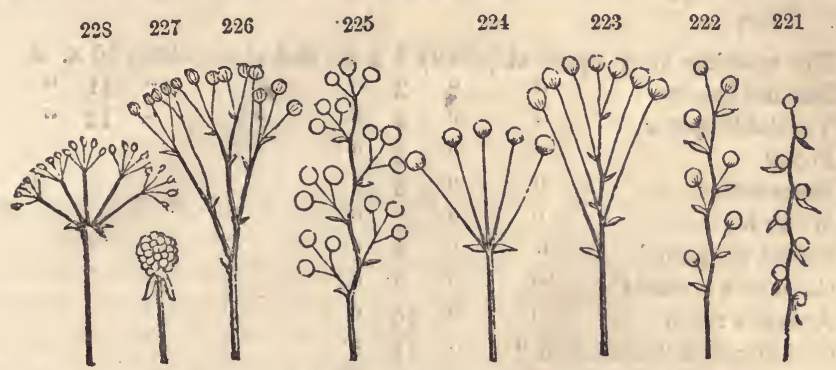

Diagrams illustrating the forms of inflorescence; graduated from the spike to the compound umbel, showing how related to each other.

a panicle; or let them all be lengthened to the height of the rachis, - a corymb. Now suppress the rachis to a point, making all the pedicels equal, - an umbel. Once more, suppress all the pedicels, $-a$ head. Now, if in each case we suppose the evolutions of the flowers to be reversed, we have a cymose inflorescence. Finally, by a metamorphosis still more remarkable,

The entire inflorescence is sometimes transformed into attenuated tendrils, as in the grape.

FLOWERING.

364. Definition. In the bud the floral leaves (sepals and petals) infold the floral organs (stamens and pistils) and conceal them from view. Flowering consists of the opening or expansion of these envelops, displaying every organ now perfected in growth and beauty, and ready for the exercise of its function.

365. Period of Flowering. Each species of plant has its own special season for flowering, uniform in the same climate, but varying in different climates according to the general temperature. Hence each month and each day of the month mark the date of flowering for somo one or more species, and these facts, when duly observed and recorded in their proper order, constitute the floral calender for that locality.

366. The floral CALENDAR is an index of climate, and may vary to a considerable degree in different years for the same locality or for different localities in the same year. Such a calendar is prepared by the botanical student when he carefully journalizes his discoveries from day to day throughout the season. 
367. Examples. At Savannah the red maple, shad-bush; blood-root, flower in Fobruary; in the District of Columbia in March; at Concord, N. H., in April. In New Fngland the witch-hazel flowers in February; Hepatica in April; dogwood in May; elder in June; lilies in July; boneset in August; asters and Solidagas in Sieptember and October; and chrysanthemum in November.

368. THE FLORAL CLOCK. Each plant has also its definite hours in the day for opening its flowers and for closing them-for waking and sleeping; and a careful record of these facts (as once made by Linnæus) may seem to indicate the hour of tho day. Thus,

The morning glory opens at (about) 2 A. M., and closes about 10 A. M.

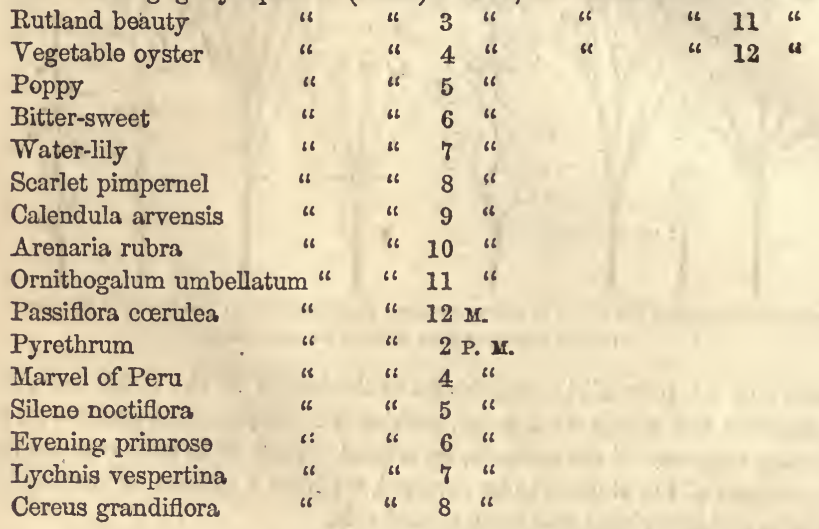

369. THE cOLORS OF FLOWERS constitute one of their chief attractions, and are of special interest to the florist. By various modes of culture he may often change at will those colors, thus producing numerous varieties, as in the tulip and dahlia. But in scientific descriptions the colors are seldom employed as characteristics on account of their variableness.

370. Classtfication of colors. De Candolle divides the colors of flowers into two series; 1 , those having yellow for their type and capable of varying to red and white, but never to blue; 2 , those having blue for their type, and capable of varying to red and white, but not to yellow. The first series is called Xanthic, the second, the Cyanic. Both series commence with green (which is composed of blue and yellow) and end in red, thus :

\begin{tabular}{l|l} 
Blue-green. & Gellow-green. \\
Blue. & Yellow. \\
Blue-violet. & Yellow-orange. \\
Violet. & Orange. \\
Violet-red. & Orange-red. \\
& RED.
\end{tabular}


371. Examples. The tulip was originally yellow. All its numerous varieties are of the xanthic series. So also the rose and Dahlia. Florists have never yet obtained a blue tulip, rose, or dahlia. The geranium varies throughout the cyanic series, and a yellow geranium is unknown. Different species of the same genus may belong to different series, so also different parts of the same flower.

\section{CHAPTER X.}

\section{MORPHOLOGY OF THE FLOWER.}

372. The Flower as the STANDARD OF BEAUTY. So it has ever been regarded. Through this attribute, so evidently divine in its origin, it breathes on the heart an influence which is essentially spiritual, always pleasing, elevating, and pure. The benevolent Thought which first conceived of this crowning glory of the vegetable world had evidently in view the education of man's moral nature as well as the reproduction and permanence of vegetable nature.

373. THE FLOWER IN THE LIGHT OF SCIENCE. The pleasuro of the florist in contemplating the flower as merely an object of taste is not diminished when he comes to view it in the light of science. Parts which ho before regarded as embellishments only, now assume new value as indispensable agents in fulfilling a great design; every organ takes form according to the sphere of its office, and the beauful flower no longer appears as the possible accident of a chance-world.

374. ITs NATURE AND ORIGIN. We have before observed that the flower-bud is, in nature and origin, one and the same with the leaf-bud. Now a leaf-bud is regularly unfolded into a leafy branch. A flowerbud is unfolded into a flower. Hence the flower, in its nature and origin, is one and the same with a leafy branch.

375. Theoretical VIEW. When, therefore, this now necessity arises in the life of a plant, viz., the perpetuation of its species, no new principle or organ is evoked, but the leaf, that same protean form which we have already detected in shapes so numerous and diverse, THE LEAF, is yet once more in nature's hand molded into a series of forms of superior elegance, touched with colors more brilliant, and adapted to a higher sphere as the organs of reproduction.

376. THE EVIDENCE ON WHICH THIS THEORY RESTS may bo referred to two sources; namely, natural and artificial development. We mention a few instances of each kind, earnestly recommending the student to study for himself the many facts which will fall under his own observation bearing upon this deeply interesting theory.

377. Case of tire poppr. 'The ordinary complete flower, e. g., the poppy, consists of four kinds or sets of organs, viz., the sepals (outside), petals next, stamens and pistils, and each kind is quite different and distinct from tho others. The metamorphosis of the leaf, first into the sepal then the petal, etc., is so abrupt that it neems to lose its identity at once. But there are some

378. Cases in the Natural Developarent of plants where the transition of the leaf is gradual, changing insensibly, first to bracts then to sepals, thus apparently making the metamorphosis in question visible beforo our eyes. Such cases 
240

$\begin{array}{llllllll}239 & 238 & 237 & 236 & 235 & 231 & 233 & 232\end{array}$
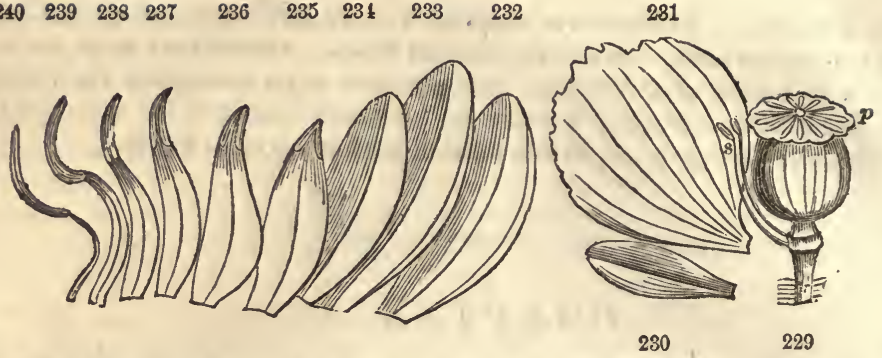

230

229, Papaver (poppy); 8, stamens; $p$, stigmas. 230, Sepal. 231, Petal-all very different. 232

Petals of the water-lily (Nymphæa) gradually passing into (240) stamens.

are exactly in point. The leaves of the pæony, large and much divided below, become smaller and more simple above, gradually passing into bracts and thence into sepals. In Calycanthus the sepal passes into the petal by gradations so gentle that we can not mark the limit between them. In the lilies these two organs are almost identical. In the water-lily, where the sepal, petal, and stamen are all thus graduated, the transition from petal to stamen is particularly instructive. These two forms meet half way by a perfect series. of gradations, when a narrowed petal is capped slightly with the semblance of an anther. And finally, cases of a close resemblance between stamen and pistil, so unlike in the poppy, are not wanting, as in the tulip-tree.

379. Flowers alWAYS REgUlar in the EARLY BUD. An early examination of flower-buds often exhibits the several kinds of organs much less diverse than they subsequently become. See the early bud of columbine. Those flowers which aro
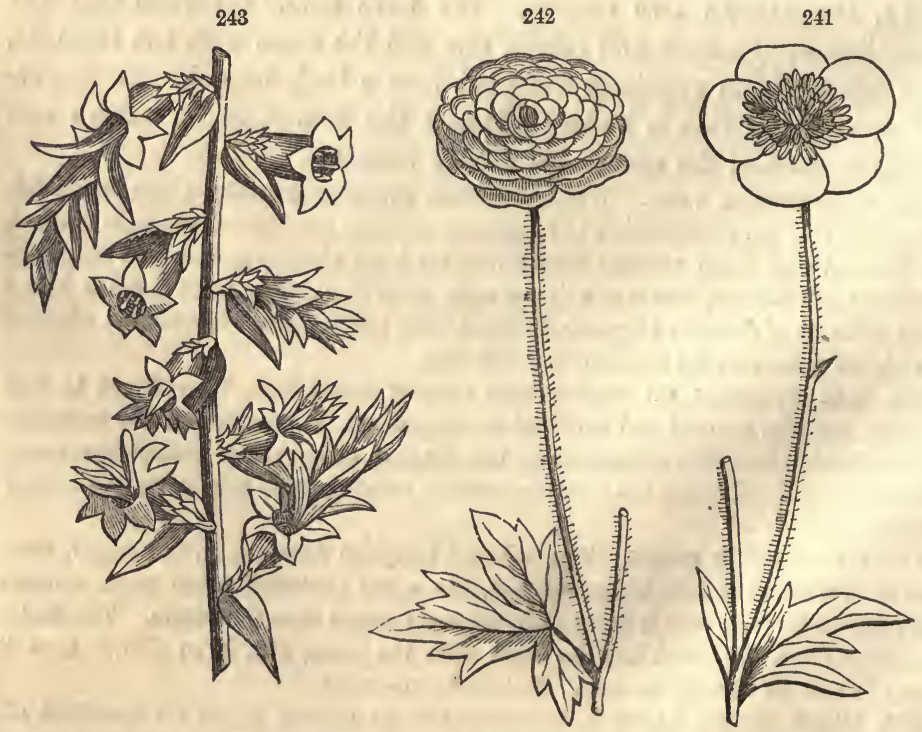

211, Ranunculus acris; a singlo flower. 242, R. acris, $\beta$. plena, a doublo llower. 243, Epacris impressa; the flowers changing to leafy branches (Lindley). 
called irregular, as the pea, eatmint, violet, are regular, like other flowers, in the carly bud; that is, the several petals are at first seen to be precisely similar, becom. ing dissimilar and distorted in their after growth; so in the stamens and other or. gans.

380. CaSES IN ARTIFICIAL DEVELOPMENT or TERATOLOGY (Tépa, a monstrosity, $\lambda \sigma \gamma_{0}$ ), where organs of one kind are converted into those of another kind by cultivation, afford undeniable evidence of the doctrine in question-the homology of all the floral organs with the leaf. Such cases are frequent in the garden, and however much admired, they are monstrous, because unnatural. In all double flowers, as rose, pæony, Camillia, the stamens have been reconverted into petals, either wholly or partially, some yet remaining in every conceivable stage of the transition. In the double butter-cup (242) the pistils as well as stamens revert to petals, and in the garden cherry, flowering almond, a pair of green leaves occupy the place of the pistils. By still further changes all parts of tho flower manifest their foliage affinities, and the entire flower-bud, after having given clear indications of its floral character, is at last developed into a leafy branch. (Fig. 243.)

381. In Clarkia, Celastrus, damask rose, and other garden plants, cases have been noted wherein the petal asserts its foliar nature by producing a secondary flower-bud in its axil! Thus in a thousand instances of abnormal growth, we find evidence proving the leaf to be the type whence all other forms of appendages are derived, and whither all tend to return.

382. Further evidence of this view, equally conclusive, is found in the essential agreement of the æstivation of the flower-bud with the phyllotaxy of the branch.

\section{ESTIVATION.}

383. Definition-importance. This term (from cestivus, of summer) refers to the arrangement of the floral envelops while yet in the bud. - It is an important subject, since in general the same mode of restivation regularly characterizes whole tribes or orders. It is to the flower-bud what vernation (vernus, spring) is to the leaf-bud.

384. THE VARIOUS MODES OF ESTIVATION ARE BEST OBSERVED in sections of tho bud made by cutting it through horizontally when just ready to open. From such sections our diagrams are copied.

385. Separately considered, we find each organ here folded in ways similar to those of the leaf-bud; that is, the sepal or the petal may be convolute, involute, revolute, etc, terms already defined.

386. Collectively CONSIDERed, the æestivation of the flower occurs in four general modes with their variations; the valvate, the contorted, imbricate, and plicate.

387. In VAlvate estivation the pieces meet by their margins without any overlapping; as in the sepals of the mallow, petals of Hydrangea, valves of a capsule. The following varieties of the valvate occur:

388. Induplicate, where each piece is involute; $i$. e., has its two margins bent or rolled inwards, as in Clematis; or reduplicate, when each piece is revolute-having its margins bent or rolled outwards, as in the sepals of Althea rosea. (Figs. 245, 246.) 


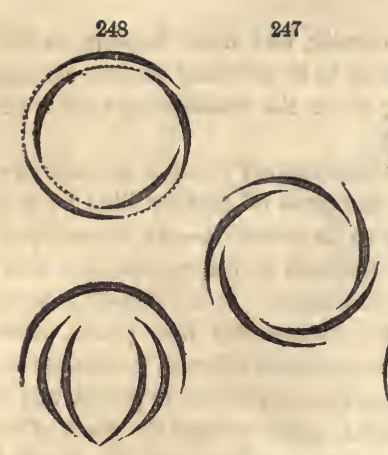

251

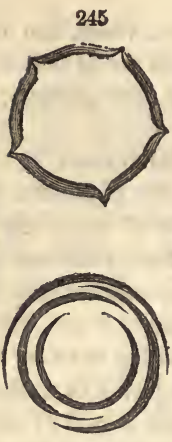

250

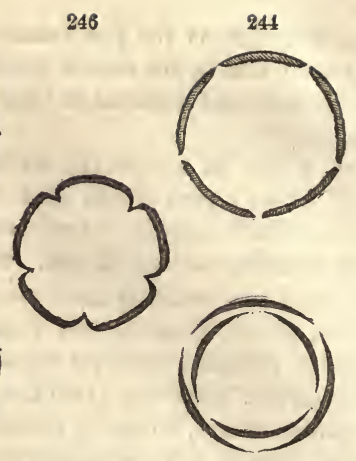

249

241-251, Modes of rstivation. 250, Petals of the wall-flower.

389. Contorted estivation, where each piece overlaps its neighbor, all in the same direction, appearing as if twisted together, as in Phlox, flax, oleander. $\quad(247,252$.

390. Imbricated estivation (imbrex, a tile) is a term restricted to those modes in which one or more of the petals or sepals is wholly outside, overlapping two others by both its margins. This kind of æstivation naturally results from the spiral arrangements so common in phyllotaxy, while the valvate, and contorted seem identified with the

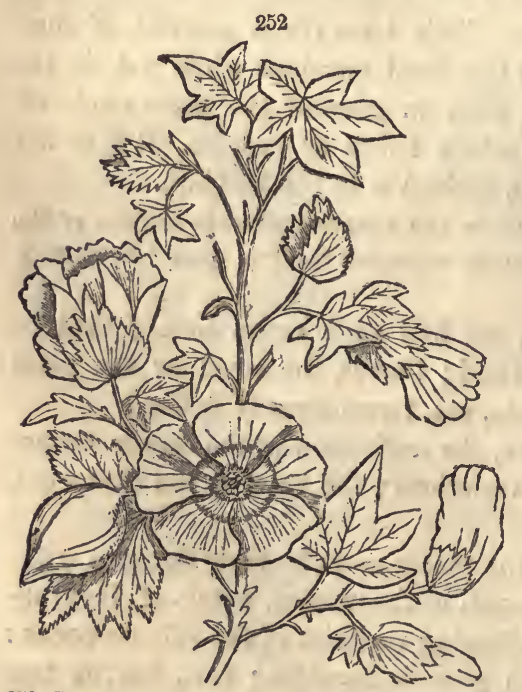

252, Gossypium herbaceum, the cotton plant. Petals contorted. opposite or whorled arrangement. The principal varieties are

391. The Quincuncial, consisting of five leaves, two of which are wholly without, two wholly within, and one partly both, or one margin out, the other in, as in the rose family (248). This accompanies the two-fifths plan in phyllotaxy; and corresponds precisely with it, each quincunx being in fact a cycle with its internodes suppressed. (§ 232.)

392. The triquetrous, consisting of three leaves in each set, one of which is outside, one inside, and the third partly both, as in tulip, Erythronium, according to the one-third plan in phyllotaxy. 
393. Convolute, when each leaf wholly involves all that are within it, as do the petals of Magnolia; and vexillary, when one piece larger than the rest is folded over them, as in the pea (251).

394. Plicate or folded xestivation occurs in tubular or monopetalous flowers, and has many varieties, of which the most remarkable is the supervolute, where the projecting folds all turn obliquely in the same direction, as in morning-glory, thorn-apple (Datura).

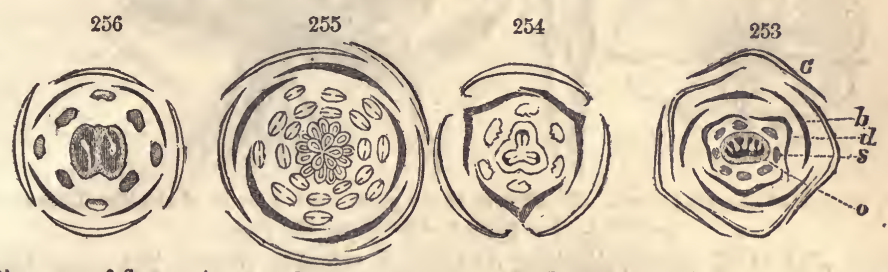

Diagrams of flowers (as seen by cross-sections). 253, Jeffersonia diphylla : $o$, ovary; s, stamens; $d$, inner row of petals, æstivation triquetrous; $b$, outer row of petals, æstivation contorted; c, sepals, æstivation quincuncial. 254, Lily. 255, Strawberry. 256, Mustard. The pupil will designate the modes of rstivation.

The rstivation of the sepals often differs from that of the petals in the same flower. Thus, in the pink the sepals are imbricated and the petals contorted.

395. TUE POSITION ON THE PARTS OF THE FLOWER, with respect to the main axis and the bract whence it arises, is often important in description. That part which is adjacent to the axis is the posterior or upper, while that which looks toward the bract is the anterior or lower part.

\section{THE FLORAL ORGANS.}

396. Technical definition of the flower. The flower is an assemblage of leaves more delicately and variously formed, borne at the upper nodes of the axis where the internodes are undeveloped. This portion of the axis is called

397. The ReCeptacle or torus. It is the axis of the flower situated at the summit of the flower-stalk. Its form above is commonly that of a flattened or somewhat conical disk, the center of which corresponds with the apex of the axis.

398. The Flower May consist of the following members: 1 , the floral envelops ; 2 , the essential floral organs.

399. The FLORAL. ENVELOPS consist of one or more circles or whorls of leaves surrounding the essential organs. The outer of these whorls is called the calyx and the other, if there be any, the corolla. The calyx may, therefore, exist without the corolla, but the corolla can not exist without

400. The calyx. This is a Greek word signifying a cup. It is applied to the external envelop of the flower, consisting of a whorl of 


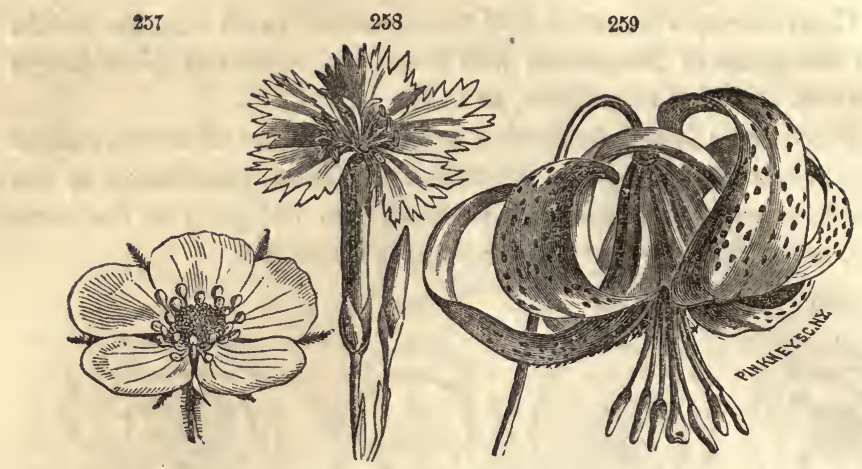

257, Flower of the strawberry. 253, Flower of the pink. 259, Flower of the lily (Lilium superbuin). The pupil will point out the parts.

leaves with their edges distinct or united, usually green, but sometimes highly colored. The calyx leaves are called sepals.

401. Conolla is a Latin word signifying a little crown, applied to the interior envelop of the flower. It consists of one or more circles of leaves, either distinct or united by their edges, usually of some other color than green, and of a more delicate texture than the calyx. Its leaves are called petals.

402. Perianth ( $\pi \varepsilon \rho i$, around, $\alpha \nu 0 o s$, flower) is a word in common use to designate the floral envelops, as a whole, without distinction of calyx and corolla. It is used in description, especially when these two envelops are so similar as not to be readily distinguished, as in the tulip, lily, and the endogens generally; also where only one envelop exists, as in Phytolacea, elm, etc. (259, per.)

403. The essential floral organs stand within the circles of the perianth, and are so called because they are the immediate instruments in perfecting the seed and thus accomplishing the final purposes of the flower. These organs are of two kinds, perfectly distinct in position and office; viz., the stamens and the pistils.

404. The stamens are those thread-like organs situated just within the perianth and around the pistils. Their number varies from one to a hundred or more; but the most common number is five. Collec-

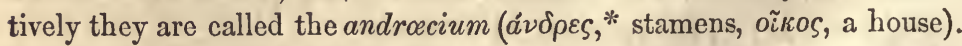
405. The pistils (called also carpels) oecupy the center of the flower at the absolute terminus of the flowering axis. They are sometimes numerous, often apparently but one, always destined to bear the

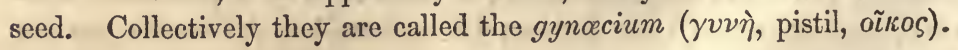

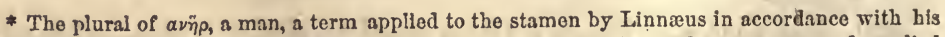
favorite theory of the sexes of plants. The term $\gamma v v \eta$, woman, is, on the same ground, applied to the pistil. 
406. Recapitulation. Thus we have noticed the members of the flower in the order of their succession from the outer to the inner circle. Now, in regard to the receptacle on which they stand in concentric whorls, we find (reversing the order) the gynœeium in the midst, the center of the flower, the androcium encircling it, the corolla next without, and the calyx embracing the whole.

407. Appendages. These are the four proper members or sets of organs composing the flower. Occasionally we meet with a fifth between the corolla and stamens, not easily referrible to either, like the scales in the throat of the Borrageworts, or the crown of the Narcissus and jonquils. Such are regarded as appendages, not necessary to the completeness of the flower.

\section{THE PLAN OF THE FLOWER.}

408. ESSENTIAL UNITY COMBINED TIITH ENDLESS DIVERSITY is every where a characteristic of nature. Herein consists the perpetual charm of her presence and the perpetual reward of her diligent study. There is no better example of this happy combination than is found in the structure of the flower. Unity or uniformity, when often repeated, becomes monotony. Diversity without unity is confusion. Hence, in our study of the thousand forms in which God has attired the flower we shall arrive at no satisfactory result until we come to discern that unity of plan, that simple idea of the flower in which all its diversities harmonize. There is such an idea. It originated in the Infinite Mind. Let us search for it.

409. The FLORAL ORGaNs. We have already seen that the flower may consist of four sets of organs-calyx, corolla, andrœcium, gynœcium ; or of four kinds of organs-sepals, petals, stamens, pistils, each arranged circularly around a common center.

410. Symmetry of the Flower. Now as the leaves of a branch are definitely apportioned into equal cycles, we naturally look for a corresponding symmetry in the flower. Each set of organs should consist of at least one cycle. And as the cycle itself may vary numerically, being 2-leaved, 3-leaved, 5-leaved, etc., in different species, so in the flower each cycle or set may bo 2-parted, 3-parted, 5-parted, etc. That is, the sepals, petals, stamens, pistils, may each bo two in number, or three, or four, or five in number, etc.

411. AGAin, IN RELATIVE position the organs of each set, as a rule, alternate with the organs of each adjacent set; the petals alternate with the sepals and stamens, the stamens with the petals and pistils. This alternation accords with the opposite and verticillate arrangement of leaves, where $(\S 226)$ the leaves of any given circle do not stand exactly over the leaves of the next circle below, but over the intervals between them. In a word,

412. The typical Flower, one that exemplifies the full idea of the floral structure, consists of four different circles of organs, each circle having the same number of separate, alternating parts. Such a flower is not only

Perfect, having both the essential organs, but also

Complete, having the four kinds of organs. 
Regular, the organs of the same kind similar, and

Symmetrical, the same number of organs in each whorl.

413. SELDOM REALIzED. Happily, this our conception of the typical flower is not often realized in nature, although the tendency toward it is universal. Deviations occur in every imaginable mode and degree, causing that endless variety in the floral world which we never cease to admire.

414. Examples. In our cut (Pink, 258) illustrating the organization of the flower the tendency in this direction is evident, but the stamens are too many and the pistils seem too few. Among the Flaxworts and the Houseleek tribe, however, are some good examples. The flower of the flax combines very nearly all the conditions above specified. It is complete, regular, symmetrical. Its organs are alternate and all separate, and (disregarding the slight cohesion of the pistils at their base) this flower well realizes our type. But

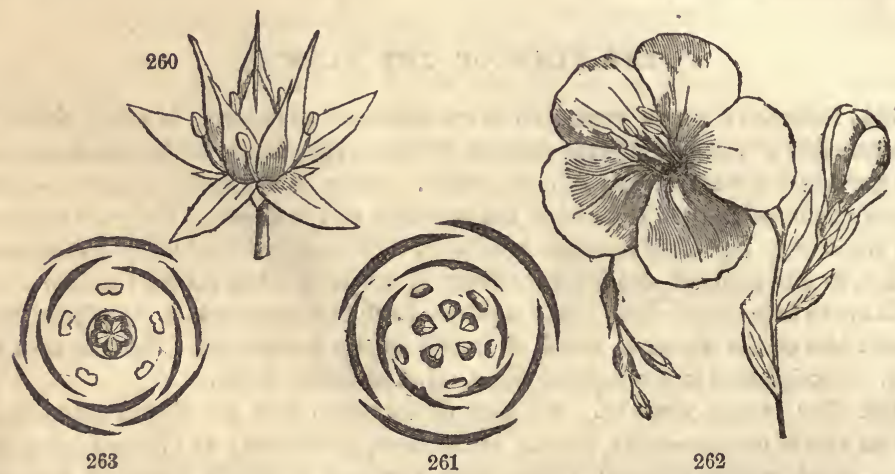

260, bis, Flower of Crassula lactea, regular, symmetrical, organs distinct. 261, Diagram showing its plan. 262, Flower of the Scarlet Flax. 263, Diagram of its plan.

415. The Flowers of Crassela, an African genus sometimes cultivated, afford unexceptionable cxamples, the sepals, petals, stamens, and pistils each being fivo in number, regularly alternating and perfectly separate.

416. FLOWERS OF SEDUM. Admitting two whorls of stamens instead of one, wo have a good example of our type in stone-crop (Sedum ternatum), a little fleshy herb of our woods. Its flowers are both 4-parted and 5-parted in the same plant. See also the 12-parted flowers of the common houseleek.

417. HOW TO STUDY THE FLOWER. If, with this type as our adopted standard of the floral structure, we compare any of the myriads of different forms which occur, we shall be able to trace out the features of the general plan even among the widest deviations. The more important of them are included in the following synopsis :-

1. Variations in the radical number of the flower.

2. Deficiencies rendering the flower

$a$, Incomplete,

$b$, Imperfect,

$c$, Unsymmetrical, $d$, Organs opposite. 
3. Redundancies,

$a$, In the multiplication of organs,

$b$, In appendicular organs.

4. Union of parts.

$a$, By cohesions,

$b$, By adhesions.

5. Irregularities of development,

$a$, In homogeneous parts,

$b$, In the receptacle.

6. Combined deviations.

We shall consider these several topics in their order.

418. THE RADICAL NUMBER OF THE FLOWER is that which enumerates the parts composing each whorl. It varies from one to twenty, and is expressed thus: $V, \sqrt[3]{ }, \sqrt[4]{ }, \sqrt[5]{ }$, etc, which mathematical expressions are to be read by the words, dimerous ( $\delta \iota s$, two, $\mu$ śpos, part), or 2-parted; trimerous, or 3-parted; 4-merous, or 4-parted; pentamerous, or 5-parted; 6-merous, or 6-parted, etc.

419. Exogens AND ENDOGENS distinguished. Pentamerous $(\sqrt[5]{ })$ flowers, like the rose, flax, when each whorl is (naturally) 5-parted, are more generally characteristic of the exogenous plants, $\sqrt[3]{ }$ flowers of the endogens, as the lily, Trillium. The flowers of Fuchsia are $\sqrt[4]{ }$, of Circæa $V$, and of Hippuris $1 V$.

420. Deficiencies. Incomplete flowers often occur. They lack some one or more entire sets of organs. When only one of the floral envelops, the calyx, ex-

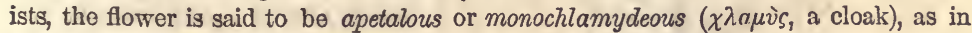
elm, Phytolacca. These terms are also loosely applied to such plants as rhubarb, Anemone, liverwort, where the pieces of the perianth are all similar, although in two or three whorls. When the perianth is wholly wanting, the flower is said to be achlamydeous or naked, as in lizard-tail. (264.)

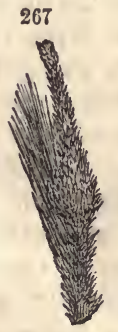

266

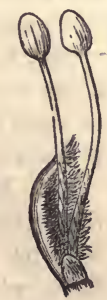

265

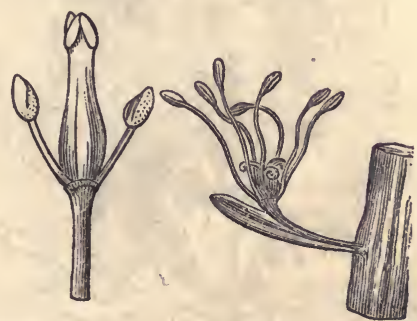

264, Flower of Saururus (lizard-tail) ; achla mydeous. 265, Flower of Fraxinus (ash). 266, Flower of Salix (willow), staminate. 267, pistillate.

421. IMPERFECT FLOWERS are also of frequent occurrence. They are deficient in respect to the essential organs. A sterile or staminate flower (denoted thus $\hat{\delta}$ ) has stamens without pistils. A fertile or pistillate flower ( $q$ ) has pistils without stamens. Such flowers being counterparts of each other, and both necessary to the perfection of the seed, must exist either together upon the same plant or upon separate plants of the same species. In the former case the species is monœcious (8) as in oak; in the latter case diœcious ( $(\delta)$ ) as in willow. The term diclinous, de. noting either 8 or $\hat{\delta}$ \& without distinction, is in common use. 


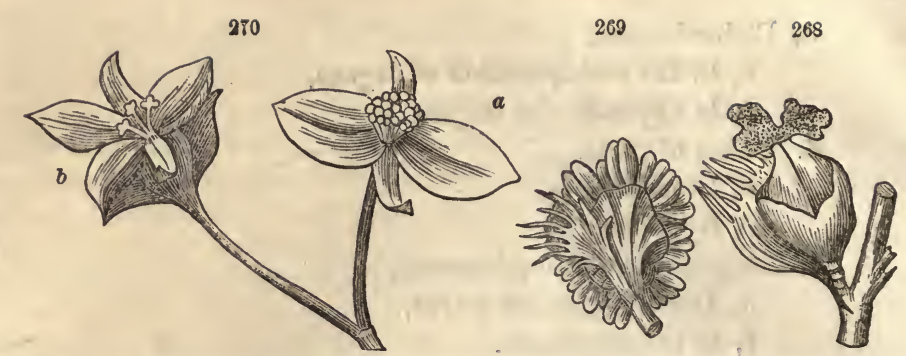

268, Pistillate flower of Balm-of-Gilead. 269, Staminate. 270, Diploclinium Evansianum. $a$, staminate; $b$, pistillate.

422. A NEUTRAL FLOWER is a perianth or calyx only, having neither stamens nor pistils. Such are the ray-flowers of many of the Compositx, and of the cymes of Hydrangea, high cranberry, etc., which in cultivation may all become neutral, as in the snow-ball.

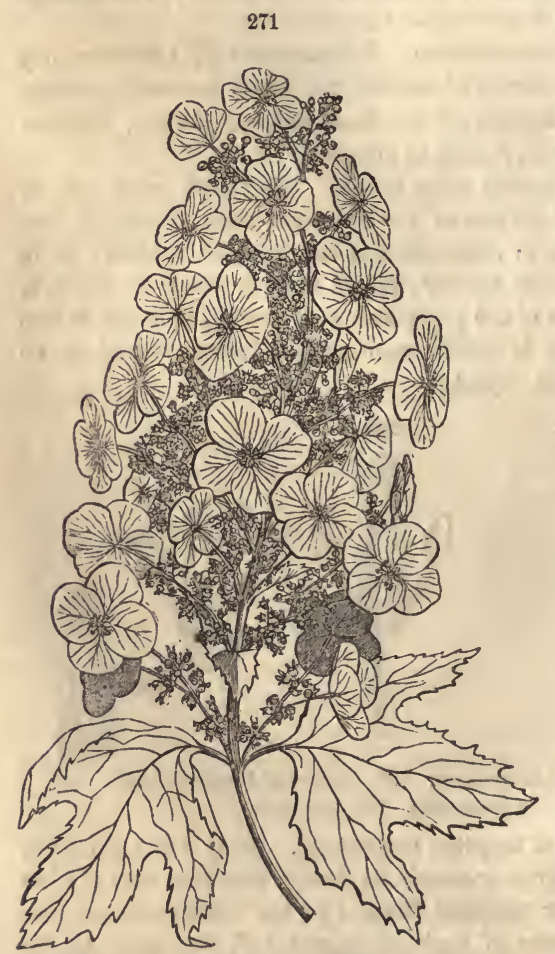

271, "Radiant" panicle of Hydrangea quercifolium; the larger flowers neutral.
423. UNSYMMETRICAL FLOWERS. The term symmetry, as used in botany, refers to number only. A flower becomes unsymmetrical by the partial development of any set or circle in respect to the num. ber of its organs. The mustard family affords a good example.

424. Flowers OF THE CRUCIFERS. The flowers of mustard, cress, etc, are understood to bo 4-merous $(\sqrt[4]{ })$. The sepals aro four, petals four, but the stamens are six and the styles but two. The stamens are arranged in two circles, having two of those in tho outer circle suppressed or reduced to mere glands. Two of the carpels are also suppressed. (256.)

425. IN THE MINT FAMILY and the figworts one or three of the stamens is generally abortive. Here, while the flowers are $\sqrt[5]{ }$, the stamens are four in some species and only two in others. Tho missing stamens, however, often appear in the guise of slender processes-the rudiments of stamens-proving in an interesting manner the natural tendency to symmetry.

426. OTHER EXAMpLes. In the $\sqrt[4]{ }$ flowers of poppy, the sepais are but two; in $\sqrt[5]{ }$ spring-beauty ihey are but two; in both cases too few for syminetry. In lark- 
spur the $\sqrt[5]{ }$ flowers have but four petals, and in monk's-hood, also $\sqrt[5]{ }$, the petals are apparently but two strangely deformed bodies. A careful inspection, however, generally reveals the other three, very minute, in their proper places, as displayed in the cut. (283.)

427. "ORGANS opposite" is a condition much less frequent than "organs alternate," but is highly interesting, as being sometimes characteristic of whole families. Thus in the primrose, thrift, and buckthorn families, the stamens always stand opposite to the petals!

428. How HAPPENS THIS? Among tho primworts this question is solved in tho flowers of Lysimachia and Samolus, where we find a circle of five teeth (abortive filaments) between the petals and stamens, alternating with both sets, thus restoring the lost symmetry. Hence we infer that in such cases generally a circle of alternating organs has been either partially or wholly suppressed. In the buckthorn, however, a different explanation has been given.

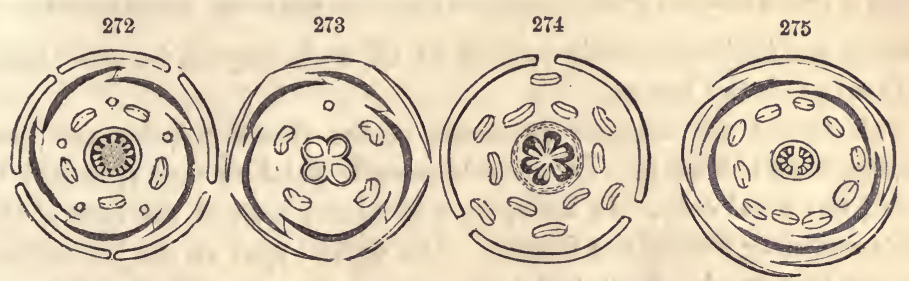

Diagrams. 272, Flower of Samolus, showing the rudimentary stamens alternating with the perfect. 273, Flower of a Labiate plant, showing the place of the deficient stamen. 274, Flower of Asarum; three sepals, twelve stamens, etc. 275, Flower of Saxifrage; two pistils, ten stamens, etc.

429. The MUtTIPLICATION OF oRgans is exceedingly common, and usually according to a definite plan. The increase takes place, as a rule, by circles, and consequently by multiples. That is, e. g., tho stamens of a $\sqrt[3]{ }$ flower, if increased, will be so by $3 \mathrm{~s}$; of $\mathrm{a} \sqrt[5]{ }$ flower by $5 \mathrm{~s}$, etc., sometimes to the extent of twenty such circles.

430. Crowfoots AND ROSEwORTS. In the crowfoot family the stamens are almost always multiplied. The carpels are also generally multiplied, yet often, on the contrary, diminished, as in the pæony. In Rosaceæ, also, the stamens are generally multiplied, whilo the carpels exist in all conditions as to number. Thus in strawberry they are multiplied, in the apple they are regularly five, in agrimony reduced to two, and in the cherry to one.

431. OTHER CASES. In Magnolia the $\sqrt[3]{ }$ flowers have three sepals in one circle, six or nine petals in two or three circles, numerous stamens and carpels in many circles of each. In the $\sqrt[4]{ }$ flowers or blood-root there are two sepals, eight petals, twenty-four stamens, and two carpels.

432. INCREMENT BY CLUSTERS (CHORISIS). In other cases the organs seem to be increased in number by clusters rather than by circles, as when in the same circlo several stamens stand in the place of one, e. g., in squirrel-corn, st. johnswort, linden. Such cases afford wide scope for conjecture. Perhaps each cluster originates by division, as the compound from the simple leaf; or as a tuft of axillary leaves ; or thirdly, by a partial union of organs.

433. Appendicular organs $(\$ 407)$ consist of spurs, scales, crown, glands, etc., and often afford excellent distinctive marks. The old term 


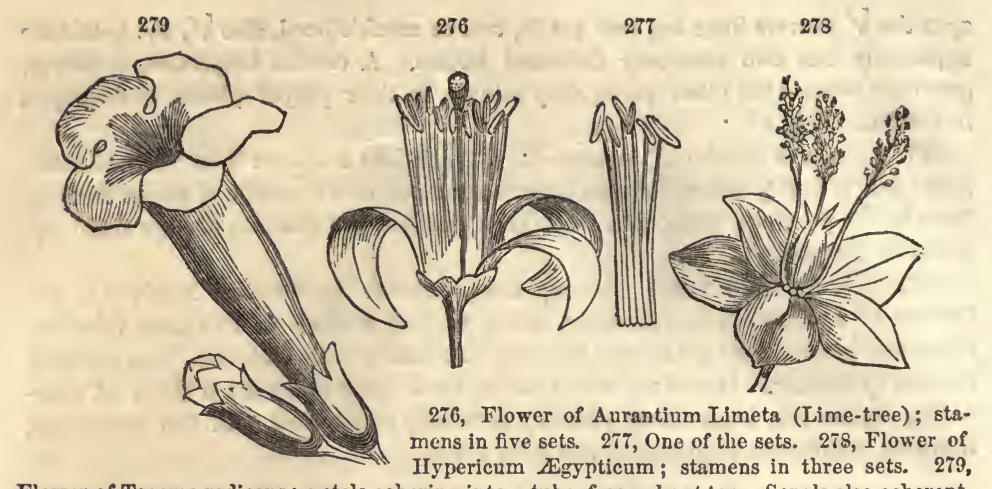

Flower of Tecoma radicans; petals cohering into a tube, free only at top. Sepals also coherent.

nectary was indiscriminately applied to all such organs, because some of them produced honey.

434. Spurs are singular processes of the flower, tubular and projecting from behind it. In columbine each petal is thus spurred; in violet, one petal only. In larkspur, a petal and a sepal, the spur of the latter inclosing that of the former. The curved spur of the jewel-weed belongs to a sepal. $(280,281$.)

435. Scales are attached to the inner side of the corolla, usually upon the claw of the petals, as in butter-cups, or within the throat of the corolla tube, as in the Borrageworts. Similar appendages, when enlarged and conspicuous, constitute a crown in catchfly, corn-cockle The flowers of Narcissus are distinguished by an excessively large crown or corona, with its parts all blended into a tube or rim.

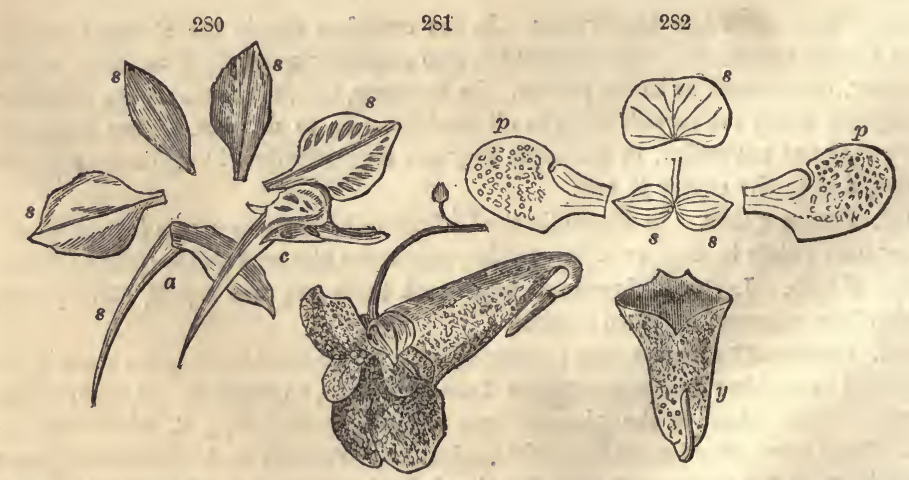

Flotrer of Delphinium Consolida (common larkspur), displaying, $8,8,8,8,8$, the five sepals, $n$, the upper one spurred; $c$, the corolla of four petals here united into one and produced into $a$ spnr. 281, Flower of Impatiens fulva (touch-me-not). 2S2, Displaying, $S, 8,8, y$, the four sepals, $S$, the anterior one, being probably double, and $y$, saccate and spurred; $p, p$, the two petals, both double. 
436. Glandular bodies are often found upon the receptable in the places of missing stamens or carpels, or as abortive organs of some kind. Examples are seen in the Crucifers and grape. In grass-Parnassus they are stalked and resemble stamens.

437. UNION OF ORGANS. This condition in some way occurs in almost every flower, and more perhaps than any other cause tends to disguise its plan and origin. The separate pieces which stood each as the representative of a leaf, now, by a gradual fusion, lose themselves in the common mass. Nevertheless, marks of this process are always discernible either in parts yet remaining free, or in the seams where the edges were conjoined. The floral organs may unite by cohesion or adhesion.

438. Cohesion, when the parts of the same whorl are joined together, as the sepals of the pink, the petals of morning-glory, the stamens of mallows, the carpels of poppy.

439. AdHesion, when the parts of different whorls are conjoined, as the stamens with the corolla in phlox, with the pistils in milkweed, ladies' slipper; or calyx with ovary in apple or wintergreen (Gaultheria).

440. The ADJECTIVE FREe is used in a sense opposite to adhesion, implying that the organ is inserted on (or grows out of) the receptacle, and otherwise separated from any other kind of organ. The adjective distinct is opposed to colresion, implying that like organs are separate from each other.

This subject and also the next will be more particularly noticed in another chapter.

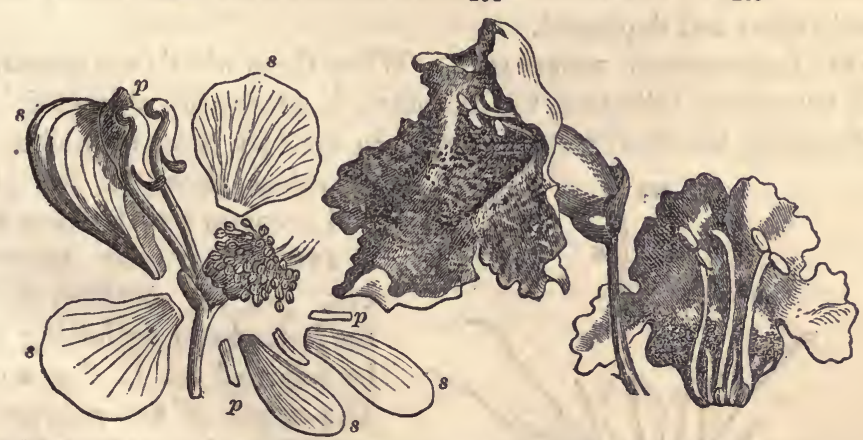

2S3, Flower of A conitum Napellus displayed; $s, s, s, s, s$, the five sepals, the upper one hooded ; $p, p, p$, the five petals, of which the two upper are nectaries covered by the hood, and the three lower very minute. 284, Flower of Catalpa, 2-lipped, 5-lobed. 235, Corolla laid open, showing the two perfect stamens and the three rudimentary.

441. Irregular development. Our typical flower, it will be remembered, is regular; and observation proves that all flowers are actually alike regular in the early bud. . These inequalities or "onesided" forms, therefore, which characterize certain flowers are occasioned by subsequent irregular growth from a regular type. The irregularity of flowers may consist 
1. In the unequal size of like organs (petals of mullein).

2. In their dissimilar forms or positions (petals of the pea).

3. In the unequal cohesion of like parts (petals of Lobelia).

4. In unequal suppressions (stamens of the Labiate flowers, where, indeed, as in many other flowers, all these phases of irregularity are combined).
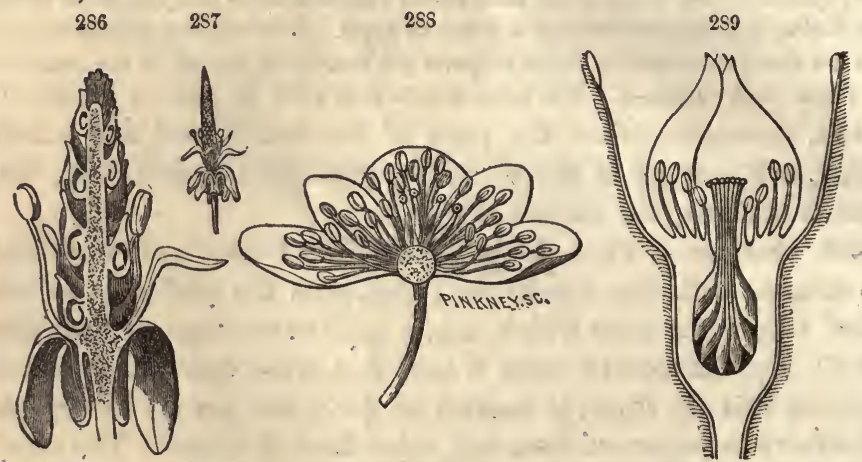

256, Flower (magnified) of Myosurus; a vertical section showing its elongated receptacle, etc. 287, The same, natural size. 288, Flower of Isopyrum biternatum; vertical section, showing the convex or globular receptacle, etc. $2 S 9$, Flower of rose, showing its excavated torus.

442. The regular receptacle has no internodes. It bears the several whorls of the flower in close contact with each other, and is usually short and depressed.

443. Lengthened RECEPTACLE. When these whorls are numerous, as in buttercups, tulip-tree, the receptacle is necessarily elongated. So in Myosurus, blackberry, strawberry. In the two latter it imbibes the

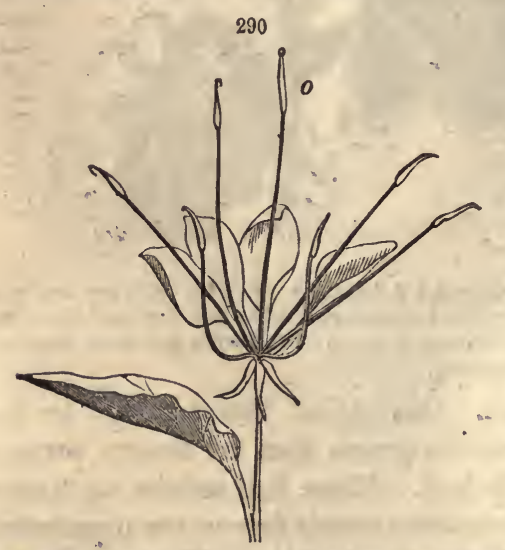

290, Flower of Cleome pungens, showing its ovary, 0 , mounted on a long stype. nutritious juices of the plant and becomes a part of the fruit.

444. Excavated RECEPTACLE. On the contrary, the torus instead of lengthening may be hollowed out in the eenter. The carpels of the rose are situated in such a cavity, while the other organs are borne upou its elevated rim. In Nelumbium the carpels are immersed in as many separate excavations in a large, fleshy receptacle:

445. BUT THE INTERNONES OF THE TORUS ARE SOMETIMES DEVELOPED, e. $g_{\text {. }}$ in noble liverwort a short internodo between the corolla and calyx 
has changed the latter (technically) to an involucre. In the pink a similar internode renders the ovary stipitate. In the Caper family the torus is developed into long internodes, sometimes raising the ovary upon a long stipe, sometimes the stamens and ovary.

446. THE DISK is a portion of the receptacle raised into a rim somewhere in the midst of the whorls. It is found between the ovary and stamens in pæony and buckthorn. It bears the stamens in maple, mignionette, and crowns the ovary in the Umbelliferr. Finally
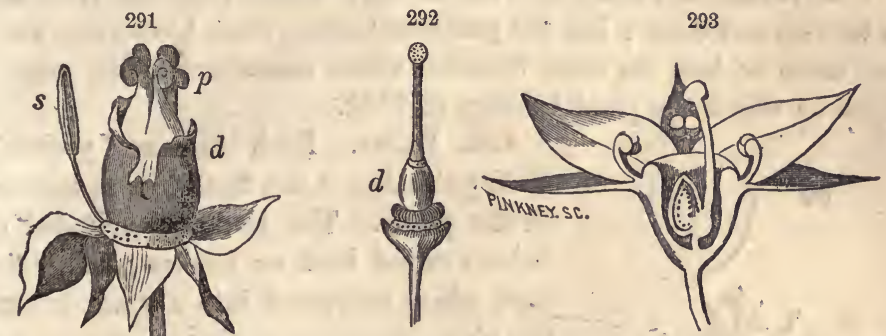

291, Pæonia Moutan, showing its very large disk $(d)$ sheathing the ovaries $(p)$. 292, Pistil of the lemon, with its base surrounded by the disk, $d$. 293, Section of flower of Alchemilla, show. ing its single simple pistil, large disk; etc.

447. Combined deviations are quite-frequent, and sometimes obscure the typical character of the flower to such a degree as to require close observation in tracing it out. The study of such cases is full of both amusement and improvement.

448. For EXAMPLE, the $\sqrt[4]{ }$ poppy has suppression in the calyx, multiplication in the stamens and carpels, and in the latter cohesion also. The $V^{5}$ sage has cohesion and irregularity in the calyx, every kind of irregularity in the corolla, suppression and irregularity in the stamens, suppression and cohesion in the pistils. The $\sqrt{\mathrm{V}}$ Cypripedium is perfectly symmetrical, yet has irregular cohesion in the calyx, great inequality in the petals, cohesion, adhesion, and metamorphosis in the stamens, and cohesion in the carpels.

(In this way let the pupil analyze the deviations in the flower of Geranium, hollyhock,-moth mullein, larkspur, sweetbriar, touch-me-not, Petunia, snapdragon, violet, Polygala, squirrel-corn, Orchiș, henbit, monk's-hood, Calceolaria, etc.)

\section{CHA P TER XI.}

\section{THE FLORAI ENVELOPS, OR PERIANTH.}

449. IDEA OF THE TYPICAL FLOWER. In our idea of the typical flower, the perianth consists of two whorls of expanded floral leaves encircling and protecting the more delicate essential organs in their midst. The outer circle, calyx, is ordinarily green and far less conspicuous than the inner circle of highly colored leares-the corolla. 
450. ExCEPTions. But to this, as to all other general rules, there are many exceptions. Strictly speaking, the calyx and corolla are in no way distinguishable except by position. The outer circle is the calyx, whatever be its form or color, and the inner, if there be more than one, is the corolla.

451. RuLes. The sepals of the calyx and petals of the corolla are, according to rule, equal in number and severally disconnected save by the torus on which they stand.

452. Resemblances. The sepals more nearly resemble true leaves in texture and color; but the petals in form. Both have veins and retain more or less the same venation which characterizes the grand division to which the plant belongs ( $§ 258$ ).

453. Parts. Both blade and petiole are

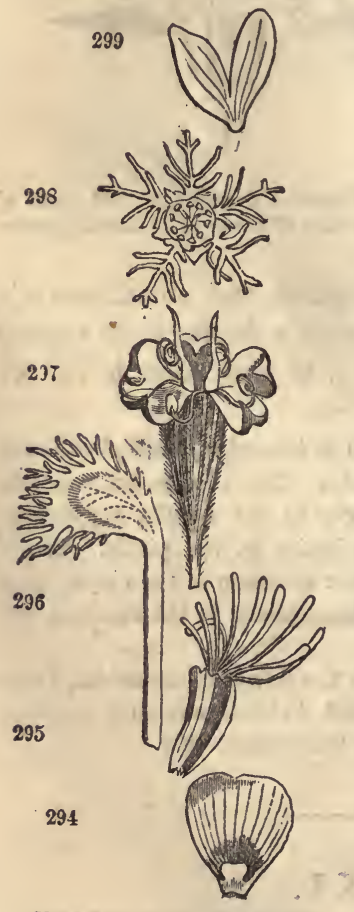

Forms of petals. 294, Buttercup, showing the scale at base. 295. Mignonette, fringed at top. 296 , Silene stellata, fringed and ungulenlate. 297, Flower of Osmorhiza longistylis, petals inllected. 29S, Flower of Mitella diphylla, petals pectinate-pinnatifid. 299, Petal of Cerastium nutans, 2-cleft. distinguishable in the floral leaves, especially in the petals. The blade or expanded part is here called limb or lamina: the petiolar part, when narrowed into a stalk, is called the claw.

454. Nature of the sepals. The sepals are more generally sessile, like bud-scales, and appear to represent the leaf-stalk only, with margins dilated like a sheathing petiole. In confirmation of this view, we find in some flowers, as the prony and rose, the lamina also developed, but smaller than the petiolar part.

455. Forms of petals. In form or outline there is a general resemblance between the limb and the leaf. It is ovate, oval, lanceolate, obcordate, orbicular, etc. In margin it is generally entire. Some peculiar forms, however, should be noticed, as the bilobate petal of the chickweed, the pinnatifid petal of mitrewort, the infiected petal of the Umbeliferæ, the fan-shaped petal of pink, the fringed (fimbriate) petal of campion (silene stellata), the hooded sepal of Napellus, the saccate petal of Calceolaria, Cypripedium.

456. Nectary. The limb is, moreover, often distorted into a true nectary, spurred, as already shown ( $\S 434)$, or otherwise de. formed, as in Napellus, Coptis, etc. 
457. Unron. We have seen that the floral organs are often in various ways united. Considering their erowded state in the flower, we rather wonder that they do not always coalesce in their growth.

458. The calyx with united sepals was called by the early botanists monosepalous; the corolla with united petals was called monopetalous ( $\mu$ óvos, one-from the false idea that such an organ consisted of a single piece or leaf !). Opposed to these terms were polypetalous ( $\pi 0 \lambda \dot{v} s$, many), petals distinct, and polysepalous, sepals distinct.

459. The monosepalous calyx, or monopetalous corolla, although thus compounded of several pieces, is usually described as a simple organ, wheel-shaped, cup-shaped, tubular, according to the degree of cohesion. The lower part of it, formed by the united claws, whether long or short, is the tube; the upper part, composed of the confluent laminæ, is the border or limb; the opening of the tube above is the throat.

460. The BORDER is either lobed, toothed, crenate, etc., by the distinct ends of the pieces composing it, as in the calyx of pink, the calyx and corolla of Primula, Phlox, and bellwort, or it may become by a complete lateral cohesion, entire, as in morning-glory. Here the com pound nature of the organ is shown by the seams alone.

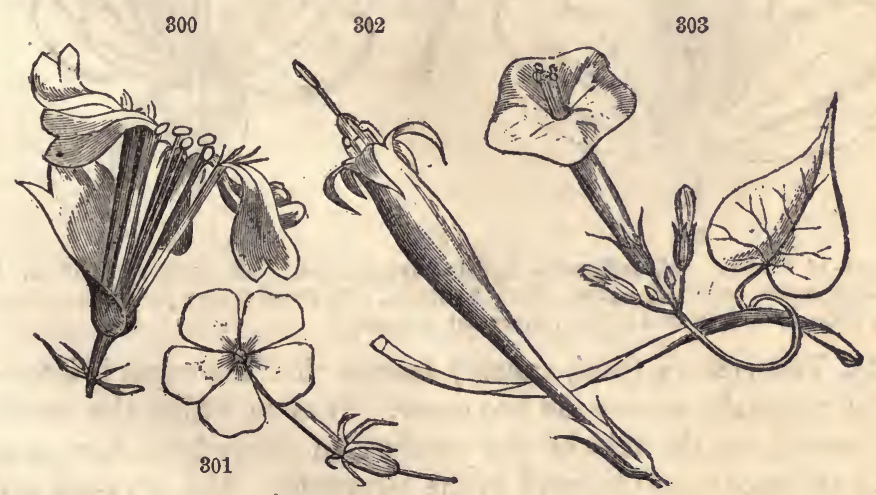

300, Flower of Saponaria (bouncing bet); petals and claws quite distinct. 301, Phlox; clawt united, with lamina distinct. 302, Spigella (pink-root), petals still further united. 303, Quamoclit coccinea, petals united throughout.

461. A terminal cohesion, where summit as well as sides are joined forming a cap rather than cup, rarely occurs, as in the calyx of the garden Escholtzia and the corolla of the grape.

462. THE modes of ADHESION are various and important, furmishing some of the most valuable distinctive characters. An organ is said to be adherent when it is conjoined with some dissimilar organ, as stamen with pistil. All the organs of our typical flower are described as free. 
463. HyPogyrous ( $v \pi \omega ́$, under, $\gamma v v \eta$, pistil) is an adjective term in frequent use, denoting that the organs are inserted into the receptacle under or at the base of the free pistil or ovary. It is, therefore, not applicable to the pistil itself. Thus the outer organs of buttercups are hypogynous.

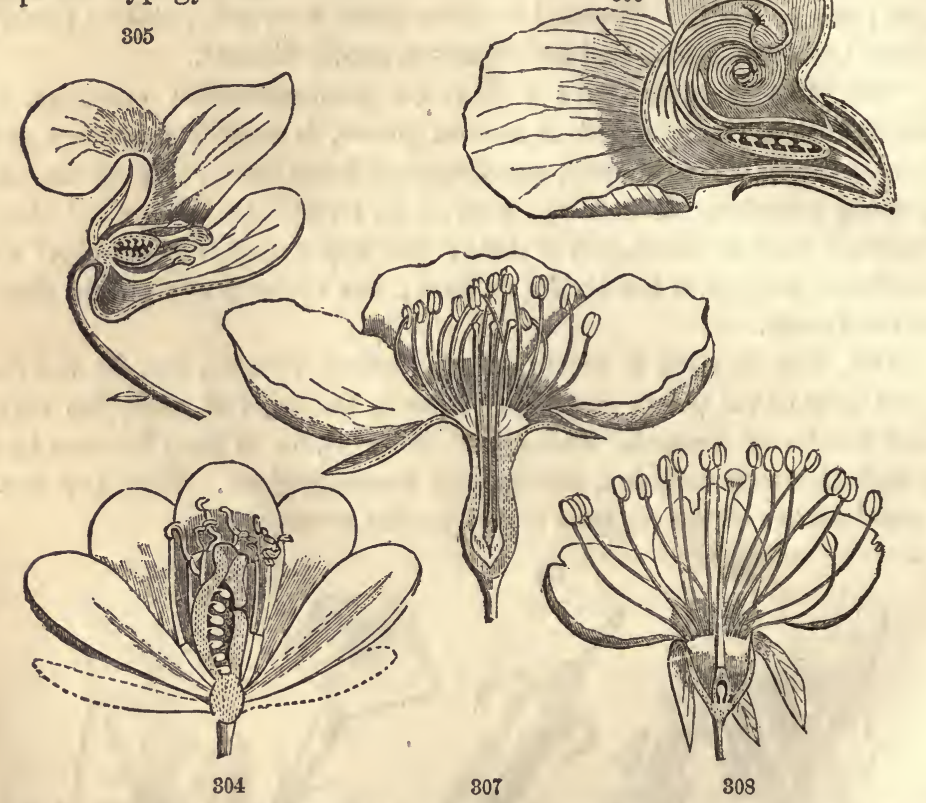

Section of flowers. 304, Jeffersonia diphylla, hypogynous. 305, Viola rotundifolia. 800 Phaseolus multiflorus (hean, organs spirally twisted). 307, Pyrus (Pear), perigynous; ovaries nearly inclosed. 308, Prunus (plum); ovary not inclosed.

464. Perigynous ( $\pi \varepsilon \rho i$, around) denotes that the organ is inserted on the calyx-tube around the free ovary. Thus in Phlox the stamens are inserted on the tube of the corolla. In cherry both stamens and petals are (apparently) inserted on the calyx-tube. The calyx can never be perigynous.

465. Epigynous ( $\varepsilon \pi i$, upon) denotes that all the organs are apparently inserted upon the ovary, as seen in the apple, caraway, sunflower. The common phrases "calyx superior," " ovary inferior," have the same signification as calyx epigynous, all implying the apparent insertion of the organs upon or above the ovary.

466. THere is also ANOTHER SET OF TERMS in use, of the samo application, founded upon a more modern view of the floral structure, viz., "calyx adherent," "ovary adherent." Which is the better form of expression will depend upon our location of the receptacle. 


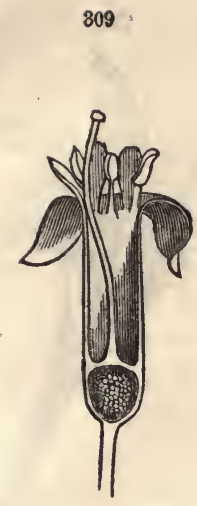

810

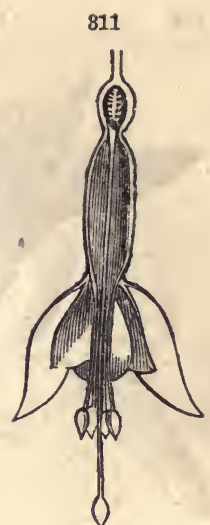

309, Ribes anreum (Missouri Currant); stamens and petals perig. ; ovary inferior. 810, Saxifraga Virginiensis; half superior. 311, Fuchsia gracilis (Ear-drop); inferior; stamens epipetalous.

467. In the cases above cited, it is commonly taught that the receptacle is located at the base of the ovary, and that all the organs thence arising are adherent to its sides. Another doctrine is also taught, viz., that the receptacle itself may. be elevated and become perigynous or epigynous, or, in other words, the ovary may be imbedded in the foot-stalk. That it is so in the rose (289) we can hardly doubt. The so-called calyx-tube of the cherry, peach, is certainly an analogous structure, more expanded, and so is the more contracted "calyx tube" of the apple, pomegranate. The analogy extends throughout the Roseworts, and perhaps still further.

468. Calyx half-superior. Calyx superior or free, ovary inferior or free, are all phrases of the same import as calyx hypogynous. Between the two conditions, calyx superior and calyx inferior, there are numerous gradations, of which one only is defined, to wit, calyx halfsuperior, as exemplified in the mock orange (and 310.)

469. SPECIAL FORMS OF THE PERIANTH, whether calyx, corolla, or both, have been named and described. We may arrange them thus :-

Polypetalous, regular-Cruciform, rosaceous, caryophyllaceous, liliaceous. Irregular-papilionaceous, orchidaceous.

Monopetalous, regular mostly-rotate, cup-shaped, campanulate, urceolate, funnel-form, salver-form, tubular. Irregular-ligulate, labiate.

470. Cruciform (crux, a cross) or cross-shaped, implies that four long clawed, spreading petals stand at right angles to each other, as in the flowers of the mustard family (Cruciferæ) in general.

471. Rosaceous, rose-like; a flower with five short-clawed, spreading petals.

472. CARY Ophyllaceous, pink-like ; a five-petaled corolla, with long, erect claws and spreading laminæ.

473. Liniaceous, like the lily; a flower with a six-leaved perianth, each leaf gradually spreading so as to resemble, as a whole, the funnel. form. 
815

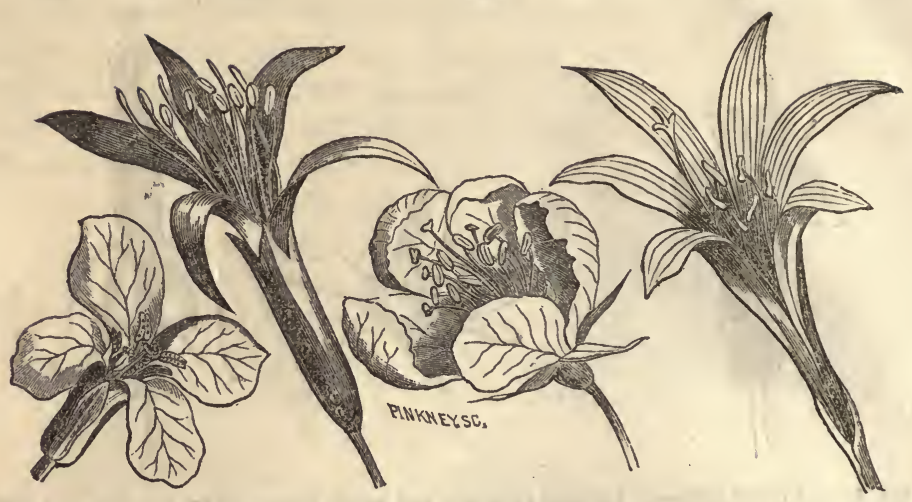

Forms of corollas. 312, Cheiranthus (stock). 313, Sileno regia (scarlet eatchfly). 814, Pyrus coronaria. 315, Amaryllis (Atamasco lily).

474. Papilionaceous, butterfly-shaped; a corolla consisting of five dissimilar petals, designated thus : the upper, largest, and exterior petal is the banner (vexillum); the two lateral, half-exterior; are the wings $(a l \infty)$; the two lower, interior petals, often united at their lower margin, are the keel (carina). The flowers of the pea, locust, clover, and of the great family of the Leguminosæ in general are examples.
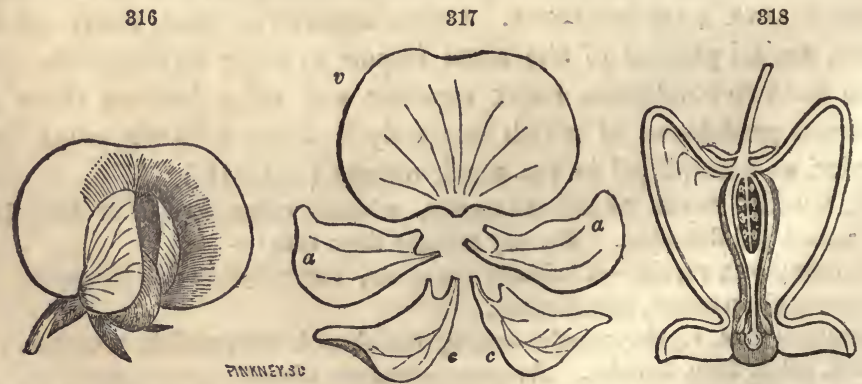

31G, Papilionaceous flower of the Pea 317, Displayed; $v$, the vexillum; $a, a$, the alro; $c, c$, the carinæ. 318, Section of flower of Dicentra Cucullaria.

475. Rотате, wheel-shaped or star-shaped, is a monpetalous form, with tube very short, if any, and a flat, spreading border, as the calyx of chickweed, corolla of Trientalis, elder. It is sometimes a little irregular, as in mullein.

476. CuP-SHAPED, with pieces cohering into a concave border, as in the calyx of mallows, corolla of Kalmia, etc.

477. Campanulate or bell-shaped; when the tube widens abruptly. at base and gradually in the border, as in the harebell, Canterbury bell. 
478. UrCeorate, urn-shaped; an oblong or globular corolla with a narrow opening, as the whortleberry, heath.

479. FunNeL-Form (infundibuliform), narrow tubular below, gradually enlarging to the border, as morning-glory.

480. SALVER-Form (hypocrateriform), the tube ending abruptly in a horizontal border, as in Phlox, Petunia, both of which are slightly irregular.

481. Tubular, a cylindraceous form spreading little or none at the border, as the calyx of the pink, corolla of the honeysuckle. It is often a little curved. Tubular flowers are common in the Compositæ, as the thistle, sunflower, when they are often associated with

482. Ligulate (ligula, a little tongue), apparently formed by the splitting of the tubular on one side. The notches at the end plainly indicate the number of united petals composing it, as also do the parallel, longitudinal seams.

483. Labiate, bilabiate, lip-shaped, resembling the mouth of an animal. This very common form results from the unequal union of the parts, accompanied with other irregularities. In the labiate corolla three petals unite more or less to form the lower lip, and two to form the upper. In the calyx, when bilabiate, this rule is reversed, accord-

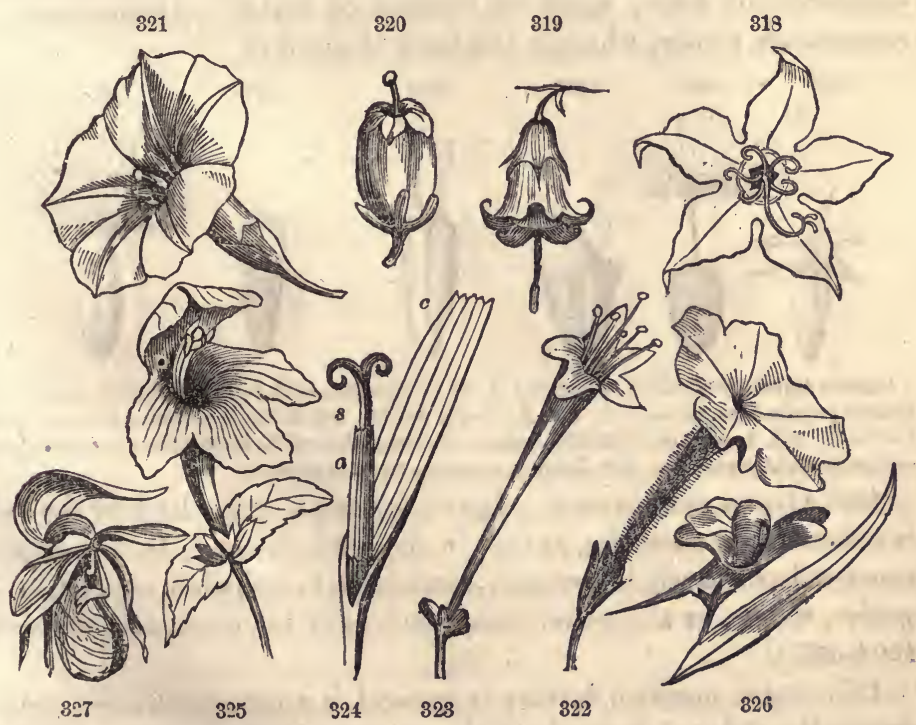

Forms of corollas. 315, Campanula Americana ; rotate. 319 , Campanula diraricata. 320 Andromeda, nrceolate. 321, Convolvulus (morning-glory). 322. Petunia. 323, Lonicera sempervirens (lioneysuckle). 324, Dandelion; ligulate corolla (c), 5 -toothed; $a$, five anthers united into a tube around $s$, the style. 325, Synandra grandiflora, ringent, upper lip 2-lobed, lower 3-lobed. 326, Linaria (yellow snapdragon), personate. 327, Cypripedium acaule, orchidaceous. 
ing to the law of alternation of organs; two sepals are united in tho lower lip and three in the upper, as seen in the sage and the Labiate Order generally. Labiate flowers are said to be galeate or helmeted when the upper lip is concave, as in catmint; ringent or gaping when the throat or mouth is wide open; personate or masked when the throat is closed as with a palate, like the snapdragon.

484. Orchidaceous, a form of the perianth peculiar to the Orchis with that large and singular tribe in general. It is a 6-parted double perianth, very irregular, characterized chiefly by its lip (labellum), which is the upper petal (lower by the twisting of the ovary) enlarged and variously deformed.

Certain reduced forms of the perianth require notice here :

485. Pappos ( $\pi a$ a $\pi \pi$ os, grandfather, alluding to his gray hairs) is a term applied to the hair-like calyx of the florets of the Composito and other kindred orders. The florets of this order are collected into heads so compactly that the calyxes have not room for expansion in th 3 ordinary way. The pappus is commonly persistent and often increases as the fruit matures, forming a feathery sail to waft away the seed through the air, as in the dandelion and thistle. It varies greatly in form and size, as seen in the cuts, sometimes consisting of scales, sometimes of hairs, again of feathers or bristles. Sometimes it is mounted on a stipe, which is the beak of the fruit.

331

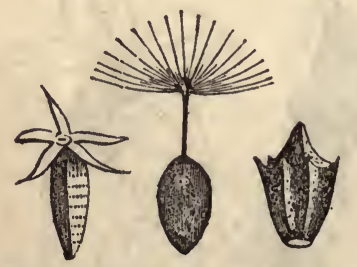

330

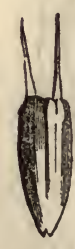

328

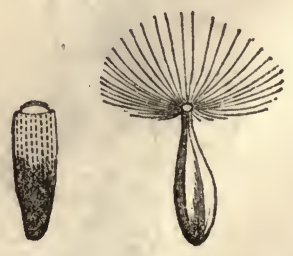

Cypsela (Incorrectly called achenium) of the Compositæ, with various forms of pappus. 328, Eclipta procumbens, no pappus. 329, Ambrosia trifida. 330, Helianthus grosse-serratus, pappus 2-awned. 831, Ageratum conizoides, pappus of five scales. 332, Mulgedium, capillary pappus -ypsela slightly rostrate. 333 , Lactuca clongati, rostrate cypsela.

486. Other reductions. Again, the calyx or the limb of the calyx is reduced to a mere rim, as seen in the Umbelliferæ. In the amentaceous orders the whole perianth diminishes to a shallow cup, as in the poplar, willow, or altogether disappears, as in the birch, ash, lizard-tail. (264-267).

487. SeT E, meaning bristles in general, is a term specifically used to denote the reduced perianth of the sedges. In the bog-rush (Scirpus) there is, outside the stamens, a circle of six setr, which doubtless represent a 6-leaved perianth. In the cotton-grass (Eriphorum) the setx are multiplied and persistent on the fruit, becoming long and cotton-like. 
488. Perigynium is the name given to the urceolate perianth of Carex, investing the ovary but allowing the style to issue at its summit. It is evidently composed of two united sepals.

489. Glumes aNd pales represent the floral envelops, or rather the involucre of the Grasses. Their alternating arrangement clearly distinguishes them from a perianth. They occur in pairs, the smaller usually above. The glumes cnvelop the spikelet, the pales the single flower, and often within the pales are two or three scales representing the perianth, surrounding the stamens and ovary, all which are illustrated in the wheat. (195.)

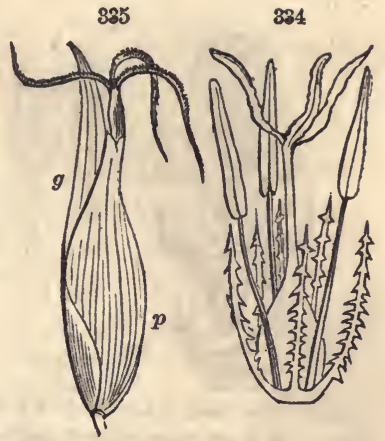

834, Flower of Sclrpus lacustris, mag. nifled; consisting of six setæ, three stamens, three pistils united, except the stigmas. 335, Flower of Carex rivularis $q$, with $g$, its giume, $p$, its bottle-shaped perigynium, 2-toothed at top, enveloping the tripie ovary; stigmas, three.

490. The duration of the calyx and corolla varies widely, and is marked by certain general terms. It is caducous when it falls off immediately, as the calyx of poppy, corolla of grape; deciduous when it falls with the stamens, as in most plants; and persistent if it remain until the fruit ripens, as the calyx of apple. If it continue to grow after flowering, it is accrescent, and if it wither without falling off it is marescent.

\section{CHA P TER XII.}

\section{OF THE ESENTIAL ORGANS.}

\section{§ THE STAMENS, OR ANDRGCIUM.}

491. Positron. Within the safe inclosure of the floral envelops stand the essential organs-the stamens and pistils, clearly distinguishable from the perianth by their more slight and delicate forms, and from each other by various marks. In the complete flower the androcium next succeeds the corolla in the order of position, being the third set, counting from the calyx.

492. A PERFECT STAMEN consists of two parts-the filament, corresponding with the petiole of the typical leaf, and the anther, answering to the blade. Within the cells of the anther the pollen is produced, a substance essential to the fertility of the flower. Hence the anther alone is the essential part of the stamen. 


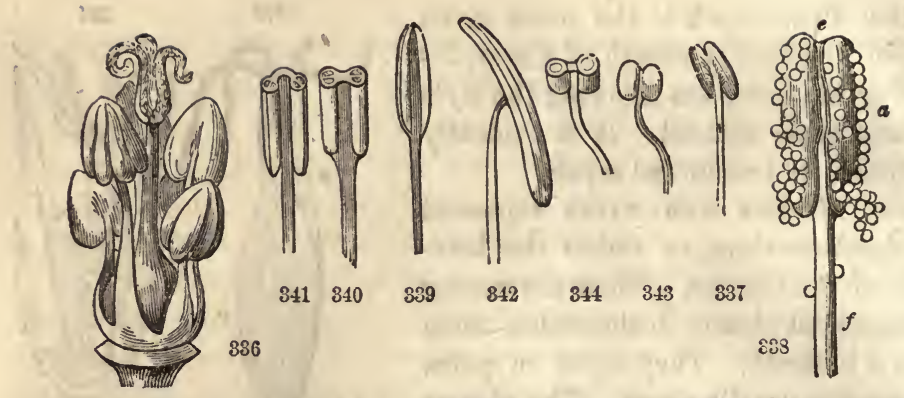

Andrœcium (and gynœcium) of Frankenia (after Peyer). 337, Stamen (adnate) of morningglory. 338 , Same enlarged, with pollen grains discharged; $f$, filament; $a, a$, anther, 2-lobed; $c$, top of the connectile. 339 , Ranunculus. 340 , Same, cut transversely. 341 , Iris cut transversely (extrorse). 842, Amaryllis, versatile. 343, Larkspur, innate. 344, Same, cut.

493. The Filament (filum, a thread) is the stalk supporting the anther at or near its top. It is ordinarily slender and filiform, yet firmly sustaining itself with the anther in position. Sometimes it is capillary and pendulous with its weight, as in the Grasses.

494. The ANTHER is regularly an oblong body at the summit of the filament, composed of two hollow parallel lobes joined to each other and to the filament by the connectile. In front of the connectile, louking toward the pistil, there is usually a furrow ; on its back a ridge, and on the face of each lobe a seam, the usual place of dehiscence or opening, all running parallel with the filament and connectile.

The stamen, as thus described, may be considered regular or typical in form, and is well exemplified in that of the buttercup (Fig. 339). But the variations of structure are as remarkable here as in other organs, depending on circumstances like tho following-

495. Attachurent of Filament to ANTHER. This may occur in three ways. The anther is said to be innats when it stands centrally erect on the top of the filament, adnate when it seems attached to one side of the filament, versatile when connected by a single point in the back to the top of the filament.

496. Demiscence, or the modes of opening, are also three, viz., valvular, where the seam opens vertically its whole length, which is the usual way; porous where the cells open by a chink or pore usually at the top, as in Rhododendron and potato; opercular when by a lid opening upward, as in sassafras, berberis. (346.)

497. TIIE FACING OF THE ANTIIER is also an important character. It is introrse when the lines of dehiscence look toward the pistil, as in violet; extrorse when they look outward toward the corolla, as in Iris.

498. THE CONNECTILE is usually a mero prolongation of the filament, terminating, not at the base, but at the top of the anther. If it fall short, the anther will be emarginate. Sometimes it outruns the anther and tips it with a terminal appendage of some sort, as in violet, oleander, Paris. Again, its base may be dilated into epurs, as in two of the stamens of violet.

499. Dimmiate ANtuer. If the connectile be laterally dilated, as we see gra. dually done in the various species of the Labiate Order, the lobes of the anther will be separated, forming two dimidiate anthers (halved anthers) on ono filament, as in sage, Prunella. Such are, of course, 1-celled. (351.) 


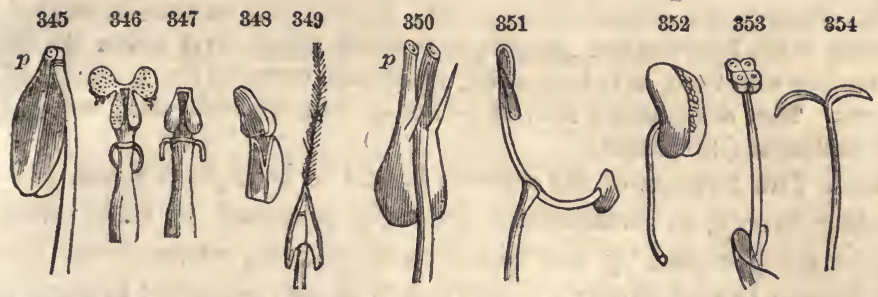

Peculiar forms of stamens. 345, Pyrola rotundifolia; $p$, dehiscence by pores at top. 850 Vaccinium uliginosum; $p$, dehiscence. 347 , Berberis aquifolium, anthers opening (346) by valves upward. 348, Anther of Violet, introrse, with an appendage at top. 349 , Oleander, sagittate, appendaged. 354, Catalpa, lobes of anther separated. 351, Sage, lobes of anther widely separated, on stipes; $b$, barren lobe without pollen. 352 , Malva, anther 1-celled. 353, Ephedra (after Peyer), anther 4-celled.

500. The cells of the anthers are at first commonly four, all parallel, becoming two only at maturity. In some plants the four are retained, as in the anthers of Ephedra. (353.) In others, as mallows, all the cells coalesce into one. (352.)

501. APPENDAGES of many kinds distinguish the stamens of different species. In the Ericaceæ there are horns, spurs, tails, queues, etc. In onions and garlic tho filament is $\mathbf{2}$ or 3 -forked, bearing the anther on one of the tips. Sometimes a pair of appendages appear at base, as if stipulate. It is often conspicuously clothed with hairs, as in Tradescantia.

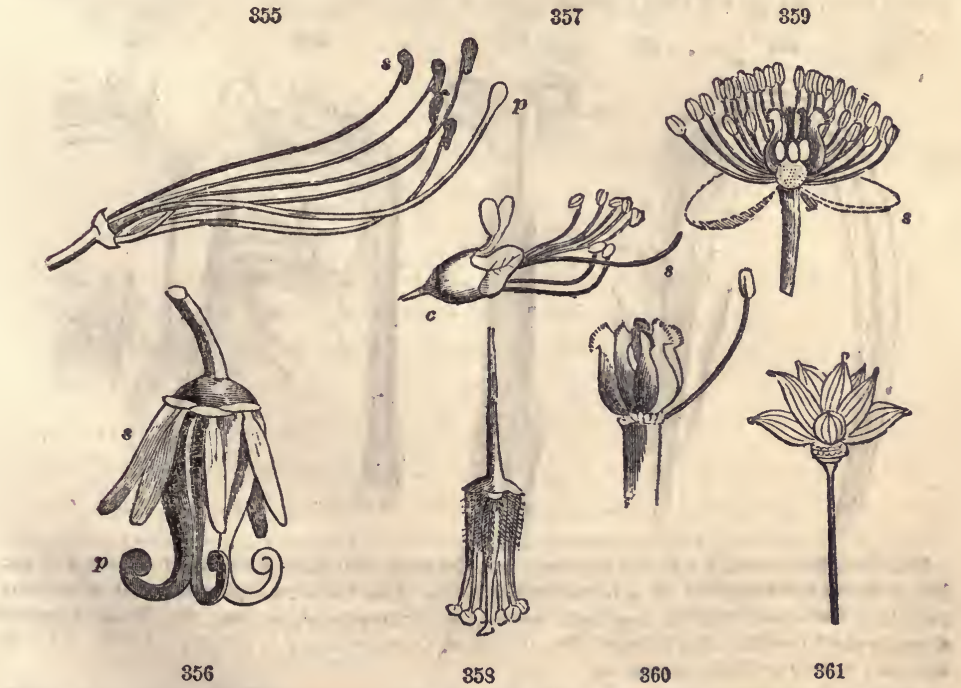

Esseritial orrans. 355 , Rhododendron, five stamens $(s)$, one pistil $(p)$, oblique or slightly irregular. 357, Flower of Aisculus (Buckeye), regular, 5-toothed calyx (c), very irregular 4-petaled corollah, seven stamens unequal, one style $(8)$. 359, Flower of Hydrastis; \&, sepals deciduous. 860, Same, showing the distinct pistils and one stamen remaining. 361, Anemone thalictroides, the gynœcium of distinct, ribbed achenia. 856 , Trillium, six stamens (8), threo plstif (v). 358, Staphylea trifolia. 
502. STAMINODIA, or sterile filaments with abortive anthers or none, occur singly in many of the Figworts and Labiates, or in entire whorls next within the petals, alternating with them, as in loose-strife; in all cases restoring the symmetry of the flowers. They are generally reduced in size, as in Scrophularia, rarely enlarged, as in beardtongue (Pentstemon).

503. The NUMBER of the stamens is said to be definite when not exceeding twenty, as is sometimes definitely expressed by such terms as follow, compounded by the Greek numerals, viz., monandrous, having one stamen to each flower; diandrous, with two stamens ; pentandrous, with five stamens. If the number exceeds twenty, it is said to be indefinite (denoted thus, $\infty$ ) or polyandrous.

504. The position or insertion of the stamens ( $\$ 463)$ may be more definitely stated here, as hypogynous, on the receptacle below the ovaries; perigynous, on the calyx around the ovary ; epipetalous, on the corolla, as in Phlox; epigynous, on the ovary at its summit, and gynandrous

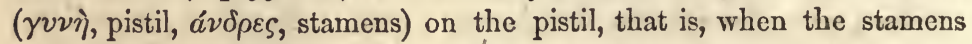
are adherent to the style, as in Orchis.

505. INEQUALITY IN LENGTH is definitely marked in two cases, as

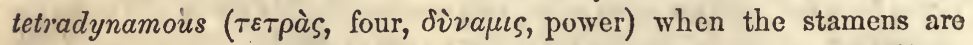
six, whereof four are longer than the other two, as in all the Crucifers; didynamous, where the stamens are four, two of them longer than the otker two, as in all the Labiates, etc.
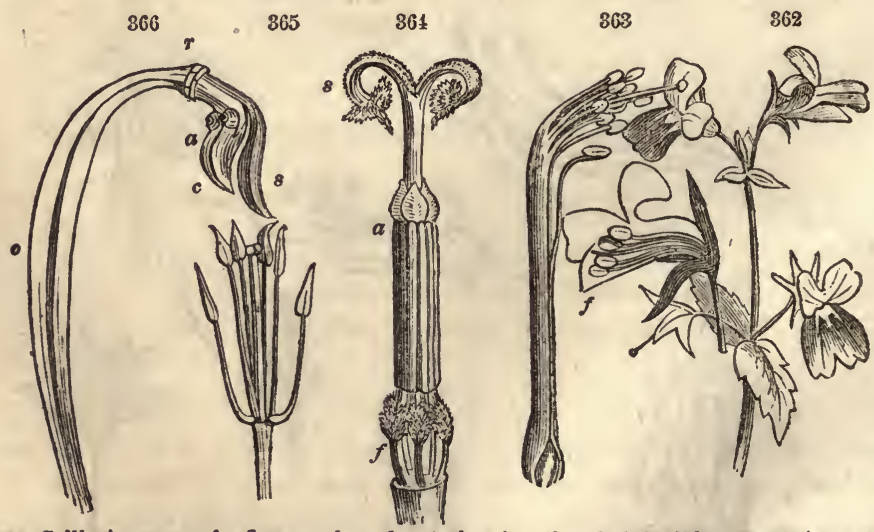

362, Collinsia verna: $f$, a flower enlarged, cut, showing the slightly didynamous stamens, etc. 363 , Stamens (diadelphous) of a Leguminous plant. 364, Stamens (syngenesious) of a Composite ; $f$, filaments distinct; $a$, anthers united ; $s$, stigmas revolute, etc. 365 , Tetradynamous stamens of a Crucifer. 366, Gynandrous column of Cypripedium; 0 , ovary; $r$, torus; 8 , sterilo otamen; $a$, two pellinia ; $c$, stigma.

506. Comesron is as frequent with stamens as with petals. They

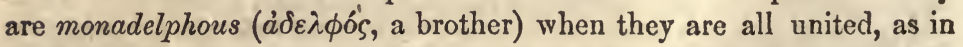
mallow, into one set or brotherhood by the filaments; diadelphous in two sets, whether equal or unequal, as in pea, squirrel-corn; polyadel- 
phous, many sets, as in St. John'swort; and syngenesious, when they are united by their anthers, as in the Composite. Finally,

507. The absence of the stamens altogether, whether by abortion, as in the $q$ flowers of Veratrum, or by suppression, as in oak, occurs in various modes, rendering the plant monœcious ( 8 ), diœcious ( $\hat{o} q$ ), or polygamous ( $\hat{\delta} \not{\succ}$ 우), as already explained ( $\$ 421$ ).

508. The pollen is in appearance a small, yellow dust, contained in the cells of the anther. When viewed with the microscope it appears as grains of various forms, usually spheroidal, or oval, sometimes triangular or polyhedral, but always of the same form and appearance in the same species. Externally they are curiously, and often elegantly figured with stripes, bands, dots, checks, etc.

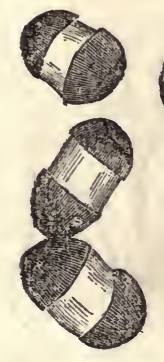

367

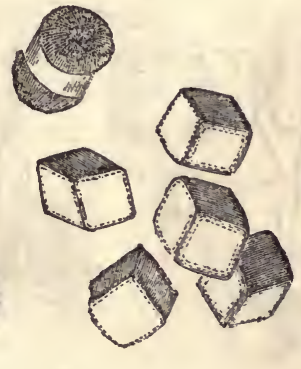

863

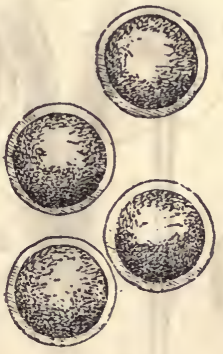

369
871

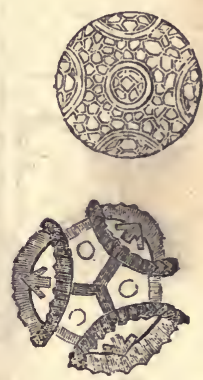

870

Pollen grains. 367, Pinus larico. 369, Basella rubra. 369, Ranunculus repens. 370, Scolymus grandiflorus. 3i1, Passifiora incarnata.

509. EACH grain OF POLLEN is a membranous cell or sack containing a fluid. Its coat is double, the outer is more thick and firm, exhibiting one or more breaks where the inner coat, which is very thin and expansible, is uncovered. In the fluid are suspended molecules of inconceivable minuteness, said to possess a tremulous motion. When the membrane is exposed to moisture it swells and bursts, discharging its contents.

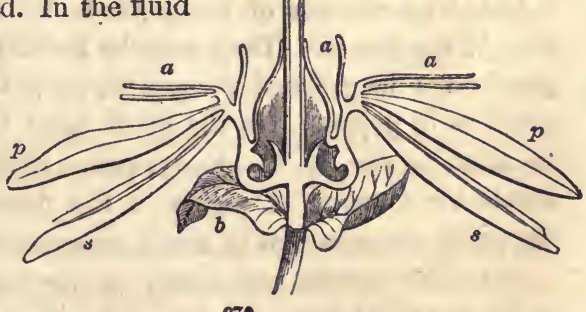

372, Section of the Passion-flower (Passiflora cœrulea);

510. Pollinia. In $b$, bracts of the involncre; $s$, sepals; $p$, petals; $a, a$, stami

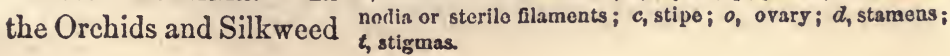


tribe, the pollen grains do not separate as into a dust or powder, but all cohere into masses called pollinia, accompanied by a viscid fluid.

\section{THE PISTILS, OR GYN@CIUM.}

511. Posrtion. The Gynœcium occupies the center of the llower at the termination of the axis. It consists regularly of a circle of distinct pistils, ( $\S 405)$, symmetrical in number with the other circles. It is subject to great variation. The pistil may be distinct and simple, as in columbine, or coherent in various degrees into a compound body, as in St. John's wort.

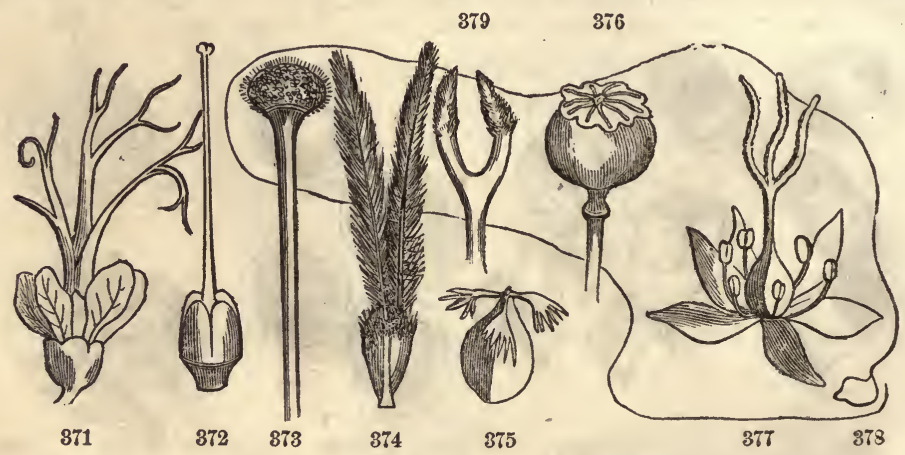

Pistils. 372, Symphytum, basilar style, ovary 4-parted. 371, \& Fl. of Emblica (Enphorbiacea), branching styles. 373, Mirabilis Jalapa, globular stig. 377 , Fl. of Luzula, stigmas linear. 374, Fenthery stigmas of a grass. 379, Stigmas of $\Delta$ ster. 375, Rumex. 376, Poppy. 378, Filiform stigma of Zea Mays, (Corn).

512. Exception. Also instead of being free and superior, as it regularly should be, it may adhere to the other circles, as already explained ( $\$ 462)$, and become inferior, that is, apparently placed below the flower, as in the currant.

513. The number of the pistils is by no means confined to the radical of the flower. They may be increased by multiples, becoming a spiral on a lengthened receptacle, as in tulip-tree, or still remaining a circle, as in poppy. On the other hand they may be reduced in number often to one, as in cherry, pea. Certain terms are employed to denote the number of pistils in the flower, such as monogynous, with one pistil, trigynous, with three, polygynous, with many, etc.

514. The simple PISTil may usually be known from the compound, by its one-sided forms-having two sides similar and two dissimilar. If the pistils appear distinct, they are all simple, never being united into more than one set, as the stamens often are. 
515. The parts of a simple pistil are three, the ovary at base, the stigma at the summit, and the style, intervening. Like the filament the style is not essential, and when it is wanting, the stigma is sessile upon the ovary, as in crowfoot. In order to understand the relation of these parts we must needs first study

516. The MorpHology of tile pistil. $\Lambda$ s before stated, $(\S 380)$, the

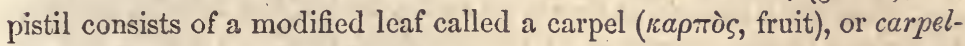
lary leaf. This leaf is folded together (induplicate) toward the axis, so that the upper surface becomes the inner, while the lower becomes the outer surface of the ovary. By this arrangement two sutures or seams will be formed, the dorsal, at the back by the midvein, the ventral, in front by the joined margins of the leaf.

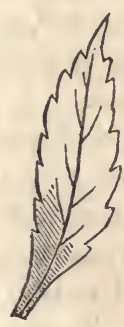

875 bis

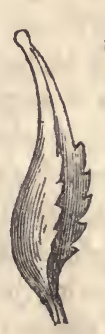

379 bis

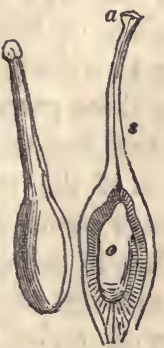

ss1

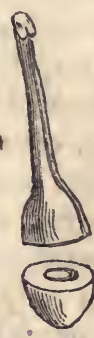

392

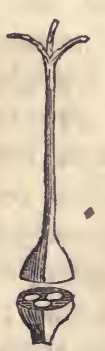

ss3

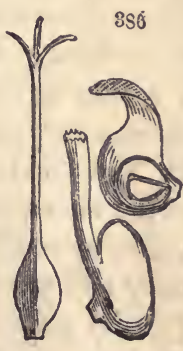

isj

3S5, Simple pistil of Strawberry, the stylo lateral. 356, Simple pistil of Crowfoot, cut to show the ovule. $3 S 0$, Simple pistil of the Cherry. 3S1, Vertical section showing the orule (o), style $(s)$, stigma $(a)$. 332 , Cross-section of the same. 334, Compound pistil of Spring-beauty. $3 S 3$, Cross-section of the same showing the 3 cells of the ovary. 3i8, Expanded carpellary Ieas of the double cherry. 379 , The same partly folded as if to form a pistil.

517. Illustration. This view of the pistil is remarkably confirmed and illustrated by the flowers of the double cherry, where the pistil may be seen in every degree of transition, revefting toward the form of a leaf. This carpellary leaf stands in the place of the pistil, having the edges infoldod toward each other, the midvein prolonged and dilated at the apex.

518. If this bo compared with the pistil of the cherry seen in the figure (378, 379), no doubt can bo entertained that the two sides of the leaf correspond to the walls of the ovary, the margins to the ventral suture, the midvein to the dorsal suture, and the lengthened apex to the style and stigma. Sometimes the flower contains two such leaves, which always present their faces toward each other. This corresponds to the position of the truo carpels, in which the ventral sutures of both are contiguous.

519. The Doctrise Deduced. Many other plants, as the rose, Anemone, Ranunculus, flowering almond, exhibit similar transformations of the pistil, making it probable that it is formed upon the same plan in all plants. Thэ ovary, therefore, is the blade of a leaf, folded into a sack: the style is the length ned apex folded into a tube; the stigma, a thickened and denuded portion of the upper margin of the leaf. 
520. The PLACENT a are usually prominent lines or ridges extending along the ventral suture within the cell of the ovary, and bearing the ovules. They are developed at each of the two edges of the carpellary leaf, and are consequently closely parallel when those edges are united, forming one double placenta in the cell of each ovary.

521. THE SIMPLE CARPEL, with all its parts, is completely exemplified in the peapod.- When this is laid open at the ventral suture, the leaf form becomes manifest, with the peas (ovules) arranged in an alternate order along each margin, so as to form but one row when the pod is closed. In the pod of columbine the ovules form - two distinct rows; in the simple plum carpel each margin bears a single ovule, and in the one-ovuled cherry only one of the margins is fruitful.

522. The stigma is the glandular arifice of the ovary, communicating with it either directly or through the tubiform style. It is usually globular and terminal, often linear and lateral, but subject to great variations in form. It is sometimes double or halved, or 2-lobed, even when belonging to a single carpel or to a simple style, as in Linden, where these carpels are surmounted by three pairs of stigmas.

523. The compound PIstil consists of the united circle of pistils, just as the monopetalous corolla consists of the united circle of petals. The union occurs in every degree, always commencing at the base of the ovary and proceeding upward. Thus in columbine we see the carpels (pistils) quite distinet; in early saxifrage cohering just at base; in pink as far as the top of the ovaries, with styles distinct; in evening primrose to the top of the styles, with stigmas distinct; and in Rhododendron the union is complete throughout.

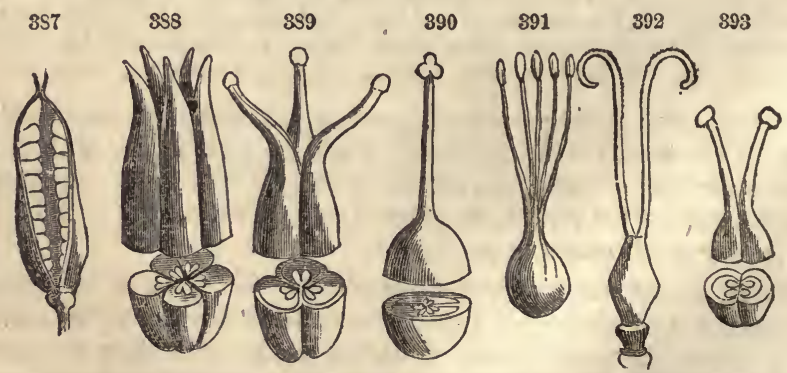

3S7, Ovary (follicle) of Larkspur, composed of single carpellary leaf. 38s, Ovaries of the Columbine, five, contiguous but distinct 3S9, Compound ovary of Hypericum, of carpels united below with distinct styles. 390, Ovary of another Hypericum of three carpels completely united. 391, Ovary of Flax; carpels fire, united below, distinct abovo. 392, Dianthus (Pink). 393, Sasifraga.

524. To DETERMINE THE NUMBER OF CARPELS in a compound ovary is an important matter. It may be known, 1, by the number of styles; 2 , by the number of free stigmas (remembering that these organs are liable to be halved, $\S 522$ ); 3 , by the lobes, angles, or seams of the ovary ; 4 , by the cells; 5 , by the placenta. 
525, Two modes of conesion in the carpellary circle greatly affect the structure of the ovary and fruit. First and regularly, the carpels may be closed as when simple, and conjoined by their sides and fronts, as in lily and marsh mallow. In this case,

1, The compound ovary will have as many cells as carpels.

2, The partitions between the cells, i. c., the dissepiments (dissepio, to separate) will each be double, will meet in the center, will be vertical and alternate with the stigmas.

3 , The single carpel can have no true dissepiment. If any ever occur it is regarded as spurious, being a membranous expansion of the dorsal suture or the placentæ, as in flax.

4, The placentæ as well as the ventral suture will be axial, and the dorsal suture on the outer wall, opposite the stigmas.

526. Agars, the carpels may each be open and conjoined by their edges, as the petals in a monopetalous corolla. So it is in the compound ovary of the violet, rock-rose. In this case,

1, There will be no dissepiment (unless spurious, as in the Cruciferæ), and but one cell.

2, The placentæe of each carpel will be separated and carried back to the wall of the ovary, i. e., they will become parietal (paries, a wall.)

527. Intermediate conditions. Between the two conditions of axile (or central) and parietal placentæe we find all degrees of transition, as illustrated in the different species of St. John'swort, and in poppy, where the inflected margins of

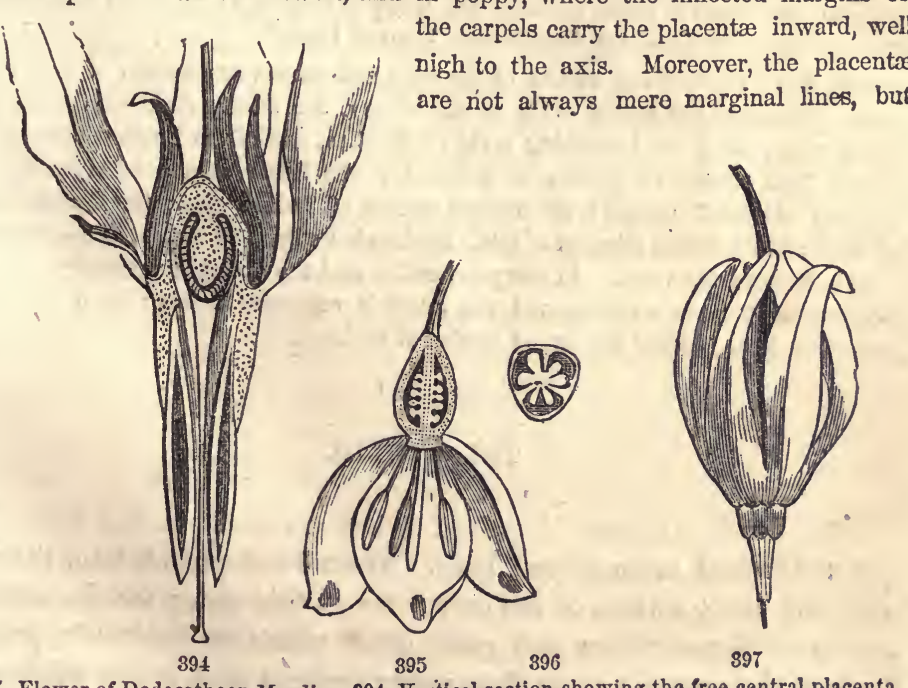

397, Flower of Dodecatheon Meadia. 394, Vertical section showing the free central placenta. 395, Vertical section of Lucojun (Snow-flake). 396, Cross section of ovary. 
often wide spaces covering large portions of the walls of the cell, as in poppy, water-lily, and in other cases, as Datura, they become large and fleshy, nearly filling the cell.

528. A FREe AXIle PLACENTA, without dissepiments, occurs in some compound, one-celled ovaries, as in the pink and primrose orders. This anomaly is explained in two ways : first, by the obliteration of the carly formed dissepiments, as is actually seen to occur in the pinks; secondly, by supposing the placenta to be, at least in some cases, an axial rather than a marginal growth; that is, to grow from the point- of the axis rather than from the margin of the carpellary leaf, for in primrose no dissepiments ever appear.

404

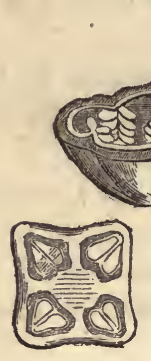

403

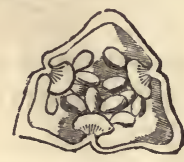

402
395

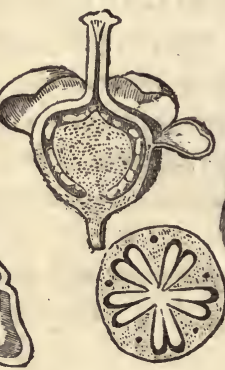

401
405

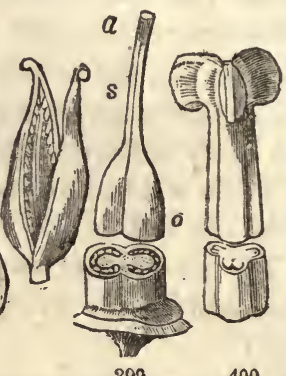

39S. Samolus Valerandi, section of flower showing the free axile placenta. 399, Orary of Scrophularlacer. 400, Ovary of Tulip. 401, Cross-section of ovary of Flax, 5-celled, falsely 10-celled. 402, Ovary of Violet, 1-celled. 403, Ovary of Fuchsia, 4-celled. 404, Ovary of rockrose, 1-celled, 5-carpelled. 405. Gentianaceæ, 2-valved, 1-celled.

529. A FEW PECULIAR FORMS of the style and stigma are worthy of note in our narrow limits, as the lateral style of strawberry, the basilar style of the Labiatæ and Borrageworts, the branching style of Emblica, one of the Euphorbiacer; also,

530. The GLOBdLAR STigma of Mirabilis; the linear stigma of Gyromia; the feathery stigma of grasses; the filiform stigma of Indian corn; the lateral stigma of Aster; the petaloid stigmas of Iris ; the hooded stigma of violet (371-379).

531. Stigira wanting. In the pine, cedar, and the Coniferæ generally, both the style and stigma are wanting, and the ovary is represented only by a flat, open, carpellary scale bearing the naked ovules at its base.

\section{THE OVULES.}

532. Their nature. Destined to become seeds in the fruit ovules are understood to be altered buds. Their development from the margins and inner surface of the carpel favors this view; for the ordinary leaves of Bryophyllum and some other plants do habitually produce buds at their margin or on their upper surface; and in the mignonette ovules themselves have been seen transformed into leaves. 


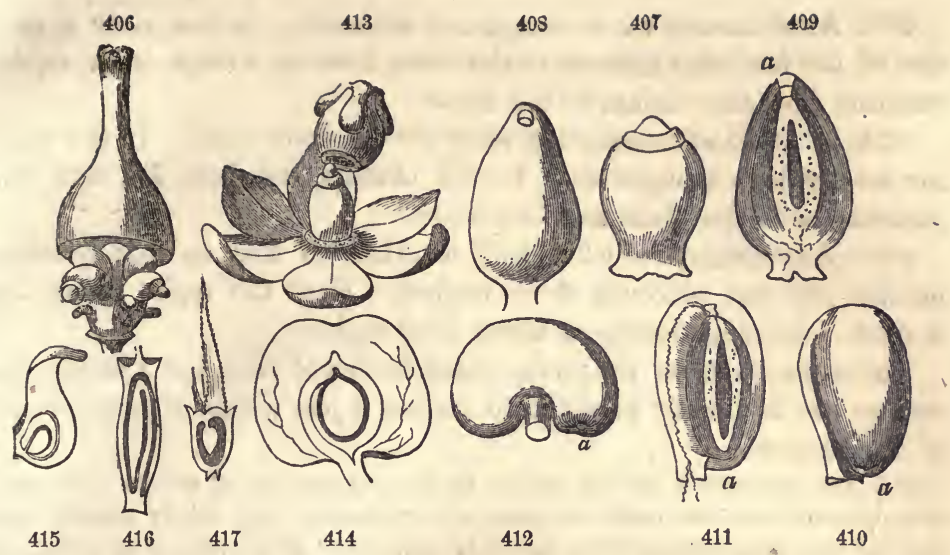

406, Pistil of Celosia, the pericarp detached showing the young ovules. 413, Flower of Rhubarb; pericarp removed showing the young ovule. $407, \mathrm{~A}$ similar ovule (orthotropous) of Polygonum. 40S, The same, full grown; foramen at top. 409, Section showing its two coats, nucleus and sac. 410, Anatropous ovule, as of columbine; $a$, foramen. 411, Section of same. 412, Campylotropous ovule, as of Bean; $a$, foramen. 414, Section of a cherry, ovulo anatropous, suspended. 415, Section of carpel of Ranunculus; ovule ascending. 416, Senccio; ovule erect. 417, Hippuris; ovule pendulous.

533. The number of ovules in the ovary varies from one to hundreds. Thus in buttercups, Compositæ and grasses the ovule is solitary; in Umbeliferæ it is also solitary in each of the two carpels; in the Pea Order they are definite, being but few ; in Mullein, Poppy, indefinite $(\infty)$, too many to be readily counted.

534. The position of the ovule in the cell is defined by certain terms as follows; erect, when it grows upwards from the base of the cell, as in Compositæ ; ascending, when it turns upwards from its point of lateral attachment; horizontal, when neither turning upwards nor downwards ; pendulous, when turned downwards, and suspended, when growing directly downwards from the top of the cell, as in birch. (415, $416,417,419)$.

535. The ovule at the time of flowering is soft and pulpy, consisting of a nucleus within two coats, supported on a stalk. The stalk is called funiculus; the point of its juncture with the base of the nucleus is the chalaza. The nucleus was first formed, then the tegmen or inner coat grew up from the chalaza and covered it, and lastly the outer coat, the testa, invested the whole. Both coats remain open at the top by a small passage, the micropyle.

536. Change of position. In most cases the ovule, in the course of its growth, changes position, curving over in various degrees upon its lengthening funiculus or upon itsclf. When no such curvature exists, and it stands straight, as in the buckwheat order, it is orthotropous. It is 
537. Anatropous when completely inverted. In this state a portion of the funiculus adheres to the testa, forming a ridge called raphe, reaching from the chalaza to the hilum.

538. IT IS CAMPYLOTROPOUS when curved upon itself. In this state the micropyle is brought near to the chalaza, and both are next the placenta, as in the pinks and Cruciferæ.

539. Амphitropous when half inverted, so that its axis becomes parallel with the placenta, as in mallow. Here the raphe exists, but is short. In campylotropous there is no raphe.

The ovule contains no young plant (embryo) yet; but a cavity, the embryo sac, is already provided to receive it just within the upper end of the nucleus.

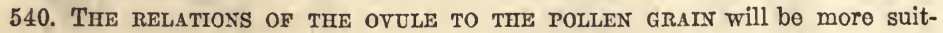
ably discussed hereafter under the head of fertilization. We briefly remark here that the immediate contact of the two is brought about at the time of flowering by special arrangements; and that, as the undoubted result of their combined action, the embryo soon after originates in the embryo sac.

\section{CH A P TR XIII.}

\section{THE FRUIT.}

541. Its origin. After having imbibed the pollen which the anthers have discharged, the pistil or its ovary continues its growth and enlargement, and is finally matured in the form of the peculiar fruit of the plant. The fruit is, therefore, properly speaking, the ovary brought to perfection.

542. State OF the other PARTS IN FRUtT. The other organs of the flower, having accomplished their work, the fertilization of the ovary, soon wither and fall away. Some of them, however, often persist, to protect or become blended with the ripening fruit. Thus the tube of the superior calyx ( $(446)$ always blends with the ovary in fruit, as in currant, cucumber, apple, etc. In Compositæ the persistent limb enlarges into the pappus of the fruit. In buttercups the fruit is beaked with the short, persistent style. In Clematis, Geum, it is caudate (tailed) with the long, growing style. In the Potato tribe, Labiatæ, and many others, the inferior calyx continues to vegetate like leaves until the fruit ripens.

543. Consolidated FrUit. In some cases the fruit, so-called, consists of the receptacle and ovaries blended, as in blackberry, strawberry. Again, in mulberry, fig, pine-apple, the whole inflorescence is consolidated into the matured fruit.

544. A rule and exception. As a rule, the structure of the fruit agrees essentially with that of the ovary. In many cases, however, the fruit undergoes such changes in the course of its growth from the ovary as to disguise its real structure. An early examination, therefore, is always more reliable in its results than a late one. 
545. For EXAMPLE, the oak-acorn is a fruit with but one cell and one seed, altlough its ovary had three cells and six ovules! This singular change is due to the non-development of five of its ovules, while the sixth grew the more rapidly, obliterated the dissepiments by pressing them to the wall, and filled the whole space itself. Similar changes characterize the chestnut, hazelnut, and that whole order. The ovary of

422

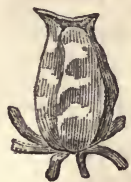

418

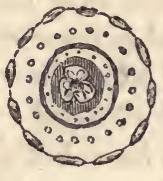

419

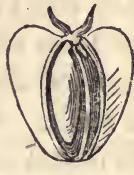

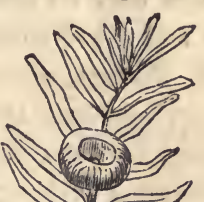

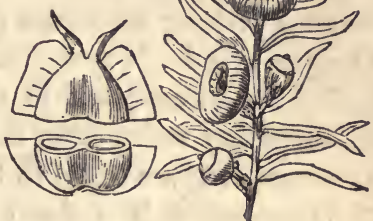

418, Section of the ovary of an acorn, 3-celled, 6-ovnled. 420, Section of ovary of Birch, 2-ce!led, 2-ovuled. 419, Vertical section of the same in fruit. 422. Perlearp of Mignionette open soon after flowering. 421 , Naked seed of Taxus Canadensis, surrounded, not covered by the fleshy pericarp.

the birch is 2-celled, 2-ovuled; but by the suppression of one cell with its orule, the fruit becomes 1-celled and 1-seeded.

546. ON THE OTHER HAND the cells are sometimes multiplied in the fruit by the formation of false partitions. Thus the pod of thorn-apple (Datura) becomes 4-celled from a 2-celled ovary, and the longer pods of some leguminous plants have crosspartitions formed between the seeds.

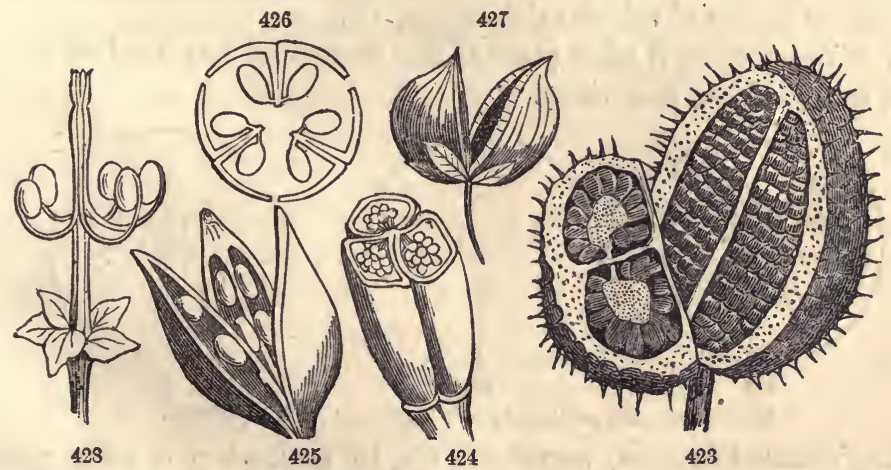

Capsule, 427, ne Scrophularia, 2-celled ; 423, of Datura Stramonium ; 425, of Iris ; 426, showing its mode of dehiscenco (loculicidal); 421, of Colchicum, 3-celled. 429, Regma, ripo fruit of Geranium, the carpels (cocci) separating from the axis and bending upwards on the elastic styles.

\section{PERICARP.}

The fruit consists of the pericarp and the seed.

547. The pericarp ( $\pi \varepsilon \rho i$, around) is the envelope of the seeds, consisting of the earpels and whatever other parts they may be combined with. It varies greatly in texture and substance when mature, being 
then either dry, as the pea-pod, or succulent, as the currant. Dry pericarps are memibranous, or coriaceous (leathery), or woody. Succulent pericarps may be either wholly so, as the grape, or partly so, as the peach and other stone fruit.

548. Pericarp closed or open. With very few exceptions the pericarp encloses the seed while maturing. In mignonette (322), however, it opens, exposing the seed, immediately after flowering. The membranous pericarp of cohosh (Leontice) falls away early leaving the seed to ripen naked. In yew (Taxus) the seed is never enclosed wholly by its fleshy pericarp; but in most of the other Coniferæ, the closepressed, carpellary scales cover the seeds. One-seeded fruits, like thos of butter-cups, etc., are liable to be mistaken for naked seeds.

549. Dehiscence. The fleshy pericarp is always indehiscent. Its seeds are liberated only by its decay, or bursting in germination. So also in many cases the dry pericarp, as the acorn. But more commonly the dry fruit, when arrived at maturity, opens in some way, discharging its seeds. Such fruits are dehiscent.

550. Modes. Dehiscence is either valvular, porous, or circumscissile; valvular, when the pericarp opens vertically along the sutures, forming regular parts called valves. These valves may separate quite to the base, or only at the top, forming teeth, as in chickweed. We notice four modes of valvular dehiscence, viz. :

1, Sutural, when it takes place at the sutures of any 1-celled pericarp, as columbine, pea, violet.
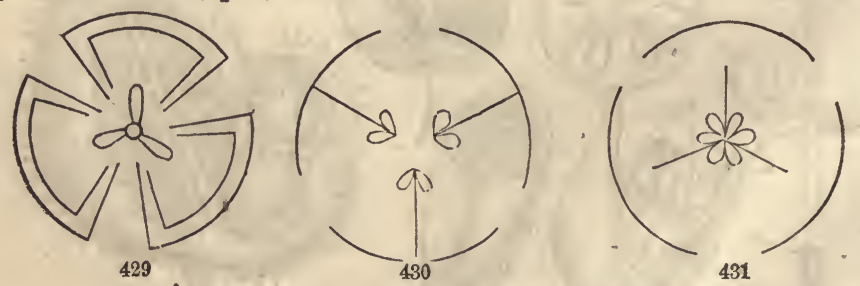

Dehiscence; 429, septicidal ; 430, loculicidal; 431, septifragal.

2, Septícidal (septum, partition, cocdo, to cut), when it takes place through the dissepiments (which are double, $\S 525$ ). The carpels thus separated may open severally by sutures, (Mallows), or remain indehiscent, as in Vervain.

3, Loculicidal (loculus, a cell, cado, to cut), when each carpel opens at its dorsal suture directly into the cell (evening-primrose, lily). Here the dissepiments come away attached to the middle of the valves.

4, 'Septifragal (septum, and frango, to break), when the valves separate from the dissepiments which renain still united in the axis (Convolvulus). 
551. Porous dehiscence is exemplified in the poppy, where the seeds escape by orifices near the top of the fruit. It is not common.

552. Circumscissile (circumscindo, to cut around), when the top of the ovary opens or falls off like a lid, as in Jeffersonia, henbane, plantain.

553. Carpophone. Some fruits, as the Gerania and Umbeliferæ, are furnished with a carpophore, that is, a slender column from the receptacle, prolonged through the axis of the fruit, supporting the carpels.

554. THE MORPHOLOGY of the pericarp is exceedingly diversified, but it will suffice the learner at first to acquaint himself with the leading forms only, such as are indicated in the following synopsis and more definitely described afterward.

555. The following is a synopsis of the principal forms of Pericarps.

§ 1. FREE FRUITS (FORMED BY A SINGLE FLOWER).

* Pericarps indeitiscent,

$\dagger$ With usually but one seed, and

$\ddagger$ Uniform, or l-coated.

1. Separated from the seed.

2. Inflated, often breaking away.

3. Inseparable from the seed.

4. Invested with a cupule (involucre).

5. Having winged appendages.

Double or triple-coated, fleshy or fibrous.

6. Three-coated. Stone cell entire.

7. Two-coated. Stone cell 2-parted.

8. Drupes aggregated.

$\uparrow$ With two or more seeds,

$\ddagger$ Immersed in a fleshy or pulpy mass.

9. Rind membranous.

10. Rind leathery, separable.

11. Rind hard, crustaceous.

$\ddagger$ Inclosed in distinct cells.

Achenium (buttercups).

Utricle (pigweed).

Caryopsis (grasses).

Glans (oak).

Samara (ash).

Drupe (cherry).

Tryma (walnut).

Etærio (raspberry).

Berry (gooseberry).

Hesperidium(orange)

Pepo (squash)

Pome (apple).

- Pericarps dehiscent.

12. Dehiscence circumscissile. seeds $\infty$. Pyxis (henbane).

+ Dehiscence valvular or porous;

$\ddagger$ Simple or 1-carpeled,

13. Opening by the ventral suture.

14. Opening by both sutures.

15. Jugume jointed.

$\ddagger$ Compound pericarps;

16. Placentæ parietal with two cells.

Silique short.

17. Placentæ parietal only when 1-celled.

Follicle (columbine).

Legume (pea).

Loment (Desmodiura).

18. Capsule with carpophore and elastic styles. Regma (Geranium).

§ 2. CONFLUENT FRUITS (FORMED OF AN INFLORESCENCE).

* With open carpels aggregated into a cone.

Strobile (pine).

* With closed carpels aggregated into a mass, as in the fig, mulberry, Osage-orange,

pine-apple, etc. 
556. The ACHeniom is a small, dry, indehiscent pericarp, free from the one seed which it contains, and tipped with the remains of the style (buttercups, Lithospermum).

557. The double achenium of the Umbeliferæ, supported on a carpophore is called cremocarp. The 2-carpeled achenium of the Compositæ, usually crowned with a pappus, is called cypsela.

558. The ACHenia ARE OFTEN MISTAKen for seeds. In the Labiatæe and Borrageworts they are associated in fours (372). In Geum, Anemone, etc., they are collected in heads. The rich pulp of the strawberry consists wholly of the overgrown receptacle, which bears the dry achenia on its surfacs. (440).

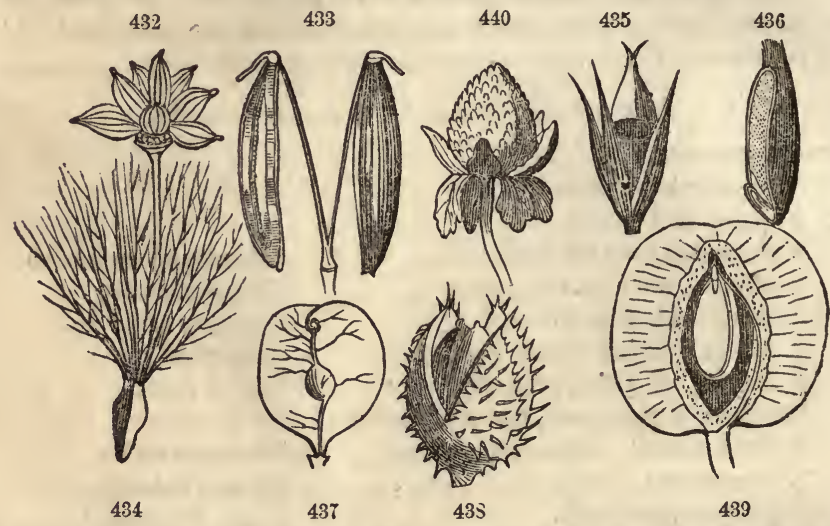

432, Achenia of Anemone thalictroides. 433, Cremocarp of Archangelica officinalis, its halves (merocarps) separated anil suspended on tho carpophore. 43t, Cypsela of Thistle with its plumous pappus. 435, Utricle of Chenopodium (pigweed). 436, Caryopsis of Wheat. 437. Samara of Eim. 438, Glans of Beoch. 439, Drupo of Prunus. 440, Fruit of Fragaria Indica, a fleshy torus liko the strawberry.

559. The UTRICle is a small, thin, pericarp fitting loosely upon its one seed, and often opening transversely to discharge it (pigweed, prince's feather).

560. Caryopsis, the grain or fruit of the grasses, is a thin, dry, 1seeded pericarp, inseparable from the seed.

561. Samara; dry, 1-seeded, indehiscent, furnished with a membranous wing or wings (ash, elm, maple).

562. Glans or NUT; hard, dry, indehiscent, commonly 1-seeded by suppression $(\S 545)$, and invested with a persistent involucre called a cupule, either solitary (acorn, hazelnut) or several together (chestnut, beechnut).

563. DruPE, stone-fruit; a 3-coated, 1-celled, indehiscent pericarp, exemplified in the cherry, peach. The outer coat (epidermis) is called the epicarp, the inner is the nucleus or endocarp, hard and stony ; the intervening pulp or fleshy coat is the $\operatorname{sarcocarp}(\sigma a ̀ \rho \xi$, flesh). These coats are not distinguishable in the ovary. 
564. TRYMA, a kind of dryish drupe, 2-coated, the epicarp fibrofleshy (butternut) or woody (hickory), the nucleus bony with its cell often deeply 2-parted (cocoa-nut).

565. ET ÆRIO, an aggregate fruit consisting of numerous little drupes united to each other (raspberry) or to the fleshy receptacle (blackberry).

- 566. Berry, a succulent, thin-skinned pericarp holding the seeds loosely imbedded in the pulp (currant, grape).

567. Hesperidium a succulent, many-carpeled fruit, the rind thick, leathery, scparable from the pulpy mass within (orange, lemon).

1 568. PEPO, an indehiscent, compound, fleshy fruit, with a hardened rind and parietal placentx (melon).

659. The pome is a fleshy, indehiscent pericarp formed of the permanent calyx, containing several cartilaginous (apple) or bony (haw) cells.

$\times$ 570. The PyXIs is a many-seeded, dry fruit, opening like a lid by a circumscissile dehiseence (plantain, henbane, Jeffersonia).

571. The Follicle is a single carpel, 1-celled, many-seeded, opening at the ventral suture (columbine, larkspur, silk-grass).

572. The LEgume or pod is a single carpel, 1-celled, usually splitting into two valves, but bearing its $1-\infty$ seeds along the ventral suture only, in one row, as in the bean and all the Leguminosæ. It is sometimes curved or coiled like a snail-shell (Medicago).

573. The loment is a jointed pod, separating across into 1-seeded portions (Desmodium).

574. Silique. This is also a pod, linear, 2-carpeled, 2-valved, 2celled by a false dissepiment extended between the two parietal placentæ. To this false dissepiment on both sides of both edges the seeds are attached (mustard).

575. Siricle. This is a short silique, nearly as wide as long (shepherd's purse). The silique and silicle are the peculiar fruit of all the Cruciferæ.

- 576. Capsule (easket). This term includes all other forms of dry, dehiscent fruits, compound, opening by as many valves as there are carpels (Iris), or by twice as many (chickweed), or by pores (poppy).

577. The regma is a kind of capsule like that of the Geranium, whose dehiscent carpels separate elastically but still remain attached to the carpophore.

578. Strobile or coNe; an aggregate fruit consisting of a conical or oval mass of imbricated scales, each an open carpel ( $q$ flower), bearing seeds on its inner side at base, i.e., axillary seeds (pine and the Gymnosperms generally).

1 579. The cone (syncarpium, $\sigma v v$, together) of the Magnolia tribe 


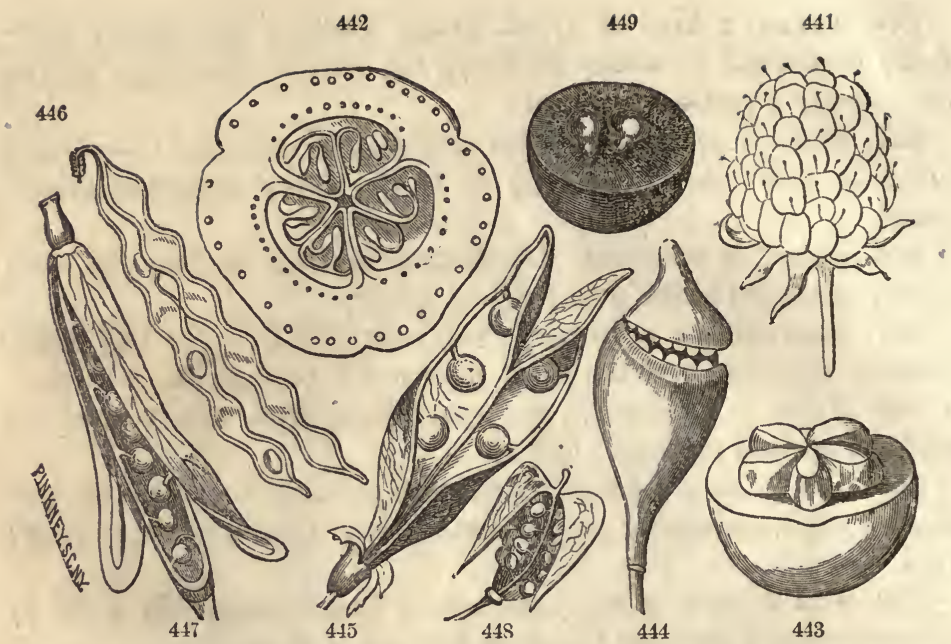

Fruits. 441, Etario of Rubus strigosus (Blackberry). 442, Pepo; section of cucumber. 449, Berry, Grape. 443, Pome, Cratægus (IIaw). 444, Pyxis of .Teffersonia. 445, Legume of Pea. 446, Loment of Desmodium: 447, Silique of Sinapis. 44S, Siliele of Capsella.

is a mass of confluent, closed pericarps on a lengthened torus (cucumber tree).

580. The FIG (syconus) is an aggregate fruit, consisting of numerous seed-like pericarps inclosed within a hollow, fleshy receptacle where the flowers were attached.

581. Other confluent fruits (sorosis) consist of the entire inflorescence developed into a mass of united pericarps, as in the mulberry, osage-orange, pine-apple.

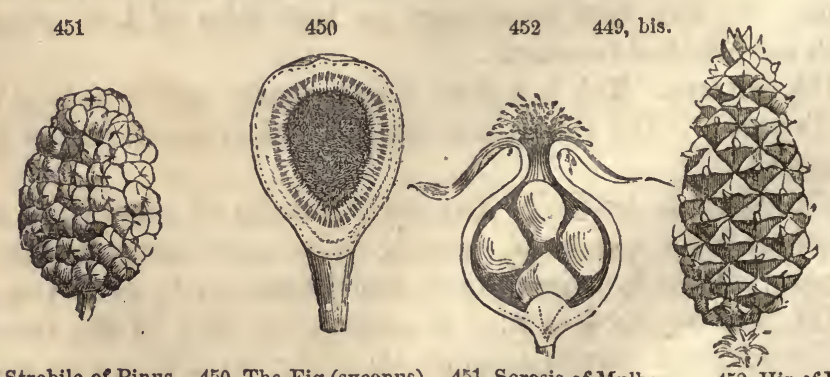

449, bis, Strobile of Pinus. 450, The Fig (syconus). 451, Sorosis of Mulberry. 452, Hip of Rosa, achenia nearly inclosed in the leathery calyx tube: 


\section{CHAPTER XIV.}

\section{THE SEED.}

582. THE SEED is the perfected ovule, having an embryo formed with in, which is the rudiment of a new plant similar in all respects to the original. The seed consists of a nucleus or kernel invested with

583. The integuments or coverings. The outer covering is the testa, the inner the tegmen, as in the ovule. The latter is thin and delicate, often indistinguishable from the testa.

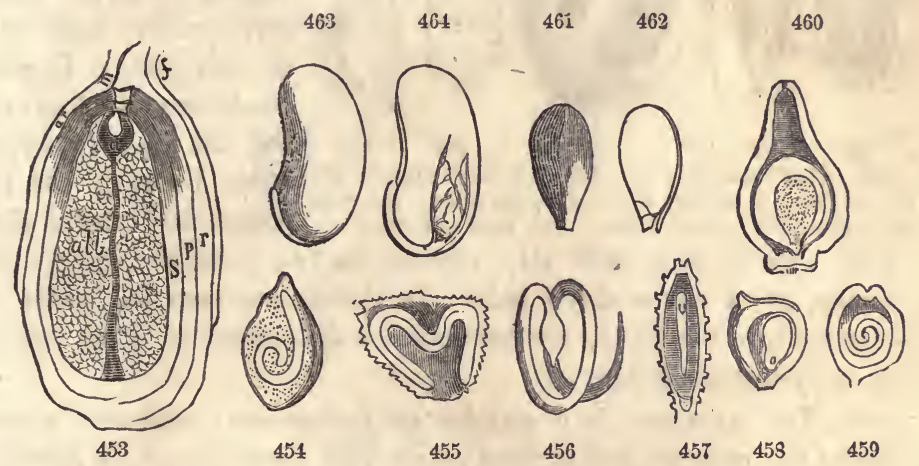

Seed of Water-Lily (Nymphra), enlarged section; $a l b .$, albumen; $a$, the embryo contain'ed In the embryo-sac; $s$, secundine or tegmen; $p$, primine or testa ; $r$, raphe, ar, aril; $m, \mathrm{mi}$ cropyle ; $f$. funiculus. 463, Seed of Bean. 464, Same, one cotyledon with the leafy embryo. 461, Seed of Apple. 462, One cotyledon showing the raphe and embryo. 460, Fruit of Mirabilis; embryo coiled into a ring. 454, Onion; embryo coiled. 455, Convolvulus; leafy embryo folded. 456, Embryo of Cuscuta. 457, Typha. 458, Ranunculus. 459, Hop.

584. The testa is either membranous (papery), coriaceous (leathery), crustaceous (horny), bony, woody, or fleshy. Its surface is generally smooth, etc. $(118, a)$.

585. THE COMA MUST NOT BE CONFOUNDED WITH the pappus, which is a modification of the calyx, appended to the pericarp, and not to the seed, as in the achenia of the thistle, dandelion, and other Compositæ. Its intention in the economy of the plant cannot be mistaken, serving like the pappus to secure the dispersion of the seed, while incidently as it were, in the case of the cotton-seed, it furnishes clothing and employment to a large portion of the human race.

586. The ARIL is an'occasional appendage, partially or wholly investing the seed. It originates after fertilization, at or near the hilum, where the seed is attached to its stalk (funiculus). Fine examples are seen in the gashed covering of the nutmeg, called mace, and in the scarlet coat of the seed of staff-trec. In the seed of Polygala, ete., it is but a small seale, entire or 2-cleft, called caruncle. 


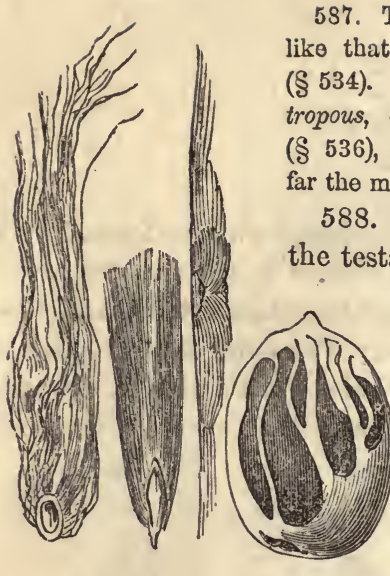

$465 \quad 464 \quad 463$

461

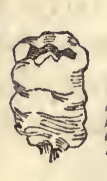

460

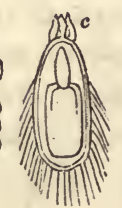

462 Seed of Polygala, embryo, caruncle, $c_{q}$ (too small.) 463 , Seed of Catalpa. 464, Seed of Willow. 465, Seed of Cotton.

589. The SEed kernel MaY consist of two parts, the embryo and albumen, or of the emibryo only. In the former case the seeds are albuminous, in the latter, exalbuminous, a distinction of great importance in systematic botany.

590. The albumen is a starchy or farinaceous substance accom. panying the embryo and serving as its first nourishment in germination. Its qualities are wholesome and nutritious, even in poisonous plants. Its quantity when compared with the embryo varies in every possible degree; being excessive (Ranunculaceæ), or about equal (Violaceæ), or scanty (Convolvulaceæ), or none at all (Leguminosæ). In texture it is mealy in wheat, mucilaginous in mallows, oily in Ricinus, lorny in coffee, ruminated in nutmeg and pawpaw, ivory-like in the ivory-palm (Phytolephas), fibrous in cocoa-nut, where it is also hollow, enclosing the milk.

591. Trie embryo is an organized body, the rudiment of the future plant, consisting of root (radicle), stem-bud (plumule), and leaves (cotyledons). But these parts are sometimes quite undistinguishable until germination, as in the Orchis tribe.

592. THE RADICLE is the descending part of the embryo, almost always directed towards the micropyle, the true axis of the seed.

593. The plumule is the rudimentary ascending axis, the terminal bud, located at the base of, or between

594. The сотyledons. These, the seed-lobes, are the bulky, farinaceous part of the embryo, destined to form the first or seminal leaves 
of the young plant. The nutritive matter deposited in the seed for the early sustenance of the germinating embryo is found more abundant in the cotyledons in proportion as there is less of it in the albumen,often wholly in the albumen (wheat), again all absorbed in the bulky cotyledons (squash).

595. The number of the cotyledons is variable, and upon this circumstance is founded the most important subdivision of the Phænogamia, or Flowering-plants.

596. The moxocotyledons are plants bearing seeds with one cotyledon, or if two are present, one is minute or abortive. Such plants are also called Endogens, because their stems grow by internal accretions ( $\S 716)$. Such are the grasses, the palms, Liliaceæ, whose leaves are mostly constructed with parallel veins.

597. The dicotrledons are plants bearing seeds with two cotyledons. These are also called Exogens, because their stems grow by external accretions, including the Bean tribe, Melon tribe, all our forest trees, etc. These are also distinguished at a glance by the structure of their leaves, which are net-veined ( $\S 258)$.

598. More than two cotyledons. The Pine and Fir have seeds with several cotyledons, while the dodder is almost the only known example of an embryo with no cotyledon.

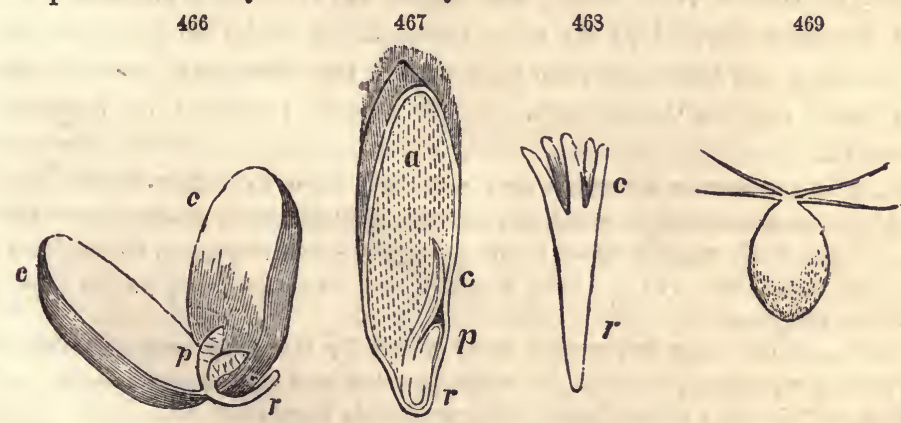

466, Dicotyledonous (Bean). 467, Monocotyledonous (Wheat). 469, Polycotyledonous (Pine). 469 , Acotyledonous (zóospore of one of the Confervæ). ( $r, r, r$, radicle; $p, p, p$, plumule; $c ; c, c$, cotyledon ; $a$, albumen).

599. The Position of THE Embryo, whether with or without albumen, is singularly varied and interesting to study. It may be straight, as in cat-tail, violet, or curved in various degrees (moon-seed, pink), or coiled (hop), or rolled (spice-bush), or bent angularly (buckwheat), or folded (Cruciferæ). In the last case two modes are to be specially noticed. 1, Incumbent, when the cotyledons fold over so as to bring the back of one against the radicle (shepherd's purse); 2, accumbent, when the edges touch the radicle (Arabis). 
600. The Leafy Nature of the cotyledons is often distinctly manifest in their form and structure, as in Convolvulus (455).

A few plants, as the onion, orange, Coniferæ, occasionally have two or even several embryos in a seed, while all the Cryptogamia or flowerless plants have no embryo at all, nor even seeds, but are reproduced from spores, bodies analogous to" the pollen grains of flowering plants (469).

\section{OFFICE OF THE SEED.}

601. Its NATURE AND USE. After the embryo has reached its wonted growth in the ripened seed, it becomes suddenly inactive and torpid, yet still alive. In this condition it is, in fact, a living plant, safely packed and sealed up for transportation. This is the distinctive and wonderful nature of the seed.

602. LoNGEVITY OF THE SEED. This suspended vitality of the seed may endure for years, or even, in some species, for ages. The seeds of maize and rye have been known to grow when 30 to 40 years old; kidney-beans when 100 ; the raspberry after 1700 years (Lindley), and kernels of wheat found in a mummy-case, and therefore 3000 years old, were a few years ago successfully cultivated in Germany and England (Schleiden). Seeds of Mountain Potentilla (P. tridentata) were known to us to germinate at Meriden, N. II., after a slumber of 60 years. On the other hand the sceds of some species are short-lived, retaining vitality hardly a year (Coffee, Magnolia).

603. In ORDER THAT SEEDS MAY LONG RETAIN TIIEIR VITALITy they must be kept dry. But an even temperature is by no means necessary, as they are generally able to resist all the changes of our climate from many degrees below zero to $110^{\circ}$ above, provided no moisture is present.

604. THE DISPERsion of sEeDs over wide, and often to distant regions is offected by special agencies, in which the highest intelligence and wisdom are clearly seen. Some seeds made buoyant by means of the coma, or pappus, already mentioned, are wafted afar by the winds, beyond rivers, lakes and seas; as the thistle, dandelion, silkgrass.

605. SeEds ARE ALSO FURNished Witil wings for the same purpose. Others are provided with hooks or barbs, by which they lay hold of men and animals, and are thus, by unwilling agents, scattered far and wide (burr-seed, tick-seed).

606. OTHER SEEDS, destitute of all such appendages, are thrown to a distance by the sudden coiling of the elastic carpels (touch-me-not). The squirting cucumber becomes distended with water by absorption, and at length, when ripe, bursts an aperture at base and projects the mingled seeds and water with amazing force.

607. Transportation. Rivers, streams, and ocean currents are all means of transporting seeds from country to country. Thus the cocoa and the casliew-nut and the seeds of mahogany have been known to perform long voyages without in. jury to their vitality. Squirrels laying up their winter stores in the earth, birds migrating from clime to clime, and from island to island, in like manner conspire to effect the same important end. 


\section{GERMINATION.}

608. Definition. The recommencement of growth in the seed is called germination. It is the awakening of the embryo from its torpor, and the beginning of development in its parts already formed, so as to become a plant like its parent.

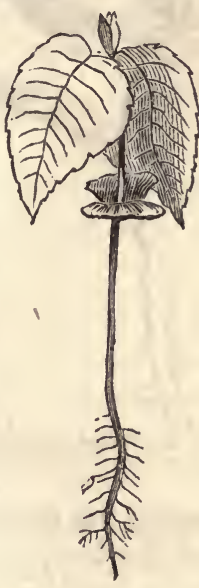

474

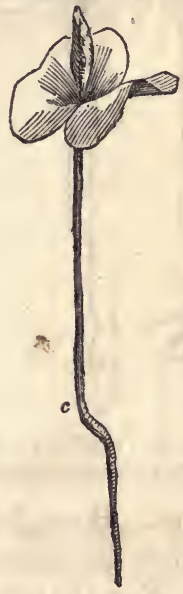

473

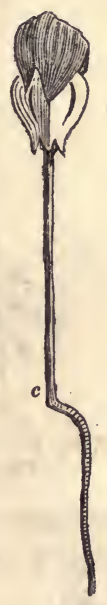

472

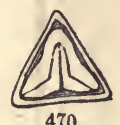

470

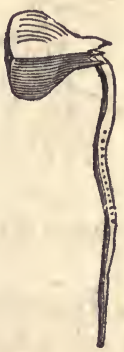

471

Germination of the Beach-nut. 470, Cross-section, showing the folded cotyledons. 471, The radicle only. 472, The ascending axis, above $c$, appears. 473 , The cotyledons expand into the primordial leaves. 474 , The first true leaves.

609. Experiment. All the stages of this interesting process may be conveniently observed, at any season, by an experiment. Let a few seeds, as of flax, cotton, wheat, pea, be enveloped in a lock of cotton resting upon water in a bulbglass, and kept coustantly at a proper temperature. Or, in spring, the garden soil will give us examples of all kinds everywhere.

610. That the seed May Begin to GRow, or germinate, it is first planted, or, at least, placed in contact with warm, moist soil. Concerning the proper depth of the planted seed agriculturalists are not agreed; but nature seems to indicate that no covering is needed beyond what will secure the requisite moisture and shade.

611. The process COMmenced. Thus situated the integuments gradually absorb water, soften and expand. The insoluble, starchy matter deposited in the cotyledons, or in the albumen, or in both, undergoes a certain chemical change, becoming sweet and soluble, capable of affording nourishment to the embryo now beginning to dilate and develop its parts. First (in the winged seed of the maple, scattered everywhere) the radicle is seen protruding from the micropyle, or the 
bursting integument. A section of this seed would now show the folded embryo impatient of confinement.

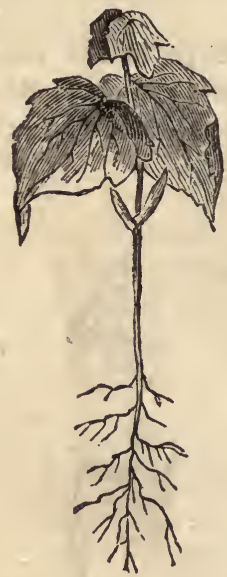

480

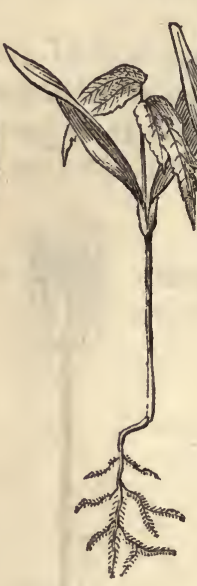

479

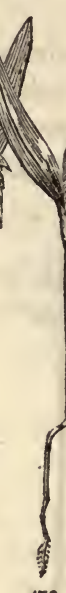

478

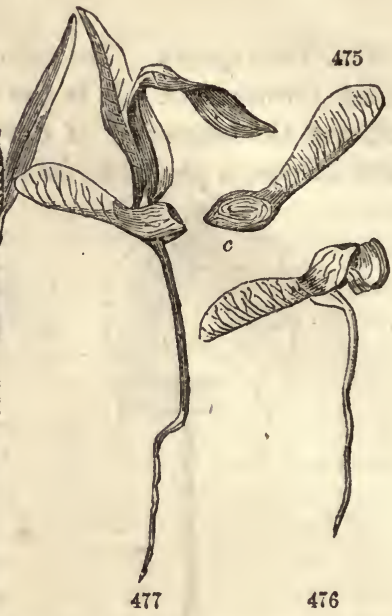

476

Germination of the Maple. 475, Samara; section showing the folded cotyledons at $c$. 476-430, Progressive stages.

612. The Process concluded. Soon the radicle has extended, and, pale in color, has hidden itself in the bosom of the dark, damp earth.

481

\section{2}

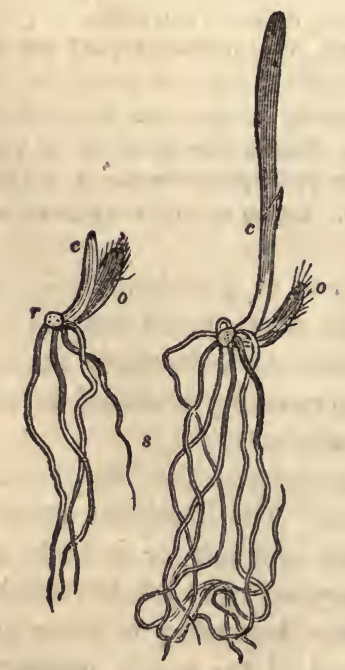

Now the cotyledons, unfolding and gradually freed from the seed coats, display themselves at length as a pair of green leaves. Lastly the plumule appears in open air, a green bud, already showing a lengthening base, its first internode, and soon a pair of regular leaves, lobed as all maple leaves. The embryo is now an embryo no longer, but a growing plant descending by its lower axis, ascending and expanding by its upper.

613. What BeCOMES OF tHe COTYLEDONS. The germination of the tulip-tree, oak, pea, squash, and other Dicotyledons may be watched with equal advantage, and the chief difference observed among them will be in the disposal of the cotyledons. In general, these arise with the ascending axis, as in the maple and bean, and act as the first pair of leaves; but sometimes, when they are very thick, as in the pea, buck-eye, oak $(6-9)$, they remain as first

Germination of Wheat; $o$, the grain containing the cotyledon; $c$, plumule; $r$, radicle; rootlets (adventitious). placed with the collum ( $\$ 118)$, neither ascending nor descending. 
614. The germination of monocotyledons, as seen in Indian corn, wheat, tulip, is in this wise. The cotyledon is not disengaged from the seed, but remains stationary with it. The radicle $(r)$ protrudes slightly and one or more rootlets (s) break out from it and descend. The plumule $(c)$ shoots, at first parallel with the cotyledon along the face of the seed, but soon ascends, pushing out leaf from within leaf.

615. The CONDITIONS REQUISITE for germination are moisture, air, and warmth.

616. Moisture is necessary for softening the integuments, dissolving the nutritive matter, and facilitating its cireulation. This is supplied in the rain and dew.

617. Arr, or rather its oxygen, is required for the conversion of the starch into sugar-a process always depending upon oxydation.

$4 \$ 3$

484
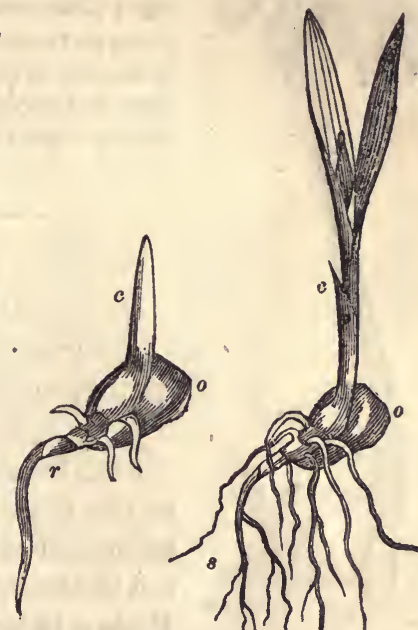

The oxygen absorbed unites with a portion of the carbon of the starch, producing heat, evolving carbonic acid, and thus converting the remainder into grape sugar, soluble and nutritive.

618. W the sprouting of a seed as in the hatching of an egg. The proper de. gree of temperature for our own climate may be stated at $60^{\circ}$ to $80^{\circ}$. Extremes of heat and of cold are not, however, fatal to all germination. In one of the Geysers of Iceland, which was hot enough to boil an egg in four minutes, a species of Chara was found in a growing and fruitful state. A hot spring in the island of Luzon, which raises the thermometer to $187^{\circ}$, has plants growing in it and on its borders. Many specics of plants also seem well adapted to growth in the Arctic regions.

619. DARKNess is farorable to germination, as proved by experiment, but not an indispensable condition. Hence, while the seed should be covered for the sake of the moisture and shade, the covering should be very thin and light, for the sake of a free access to air. 
485

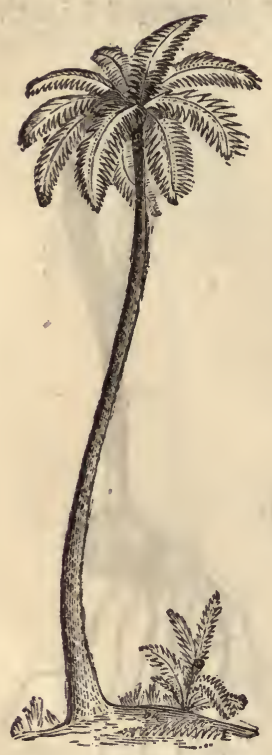

620. THE CAUSE OF THE DOWNWARD TENDENCY OF THE ROOT is a theme of much discussion. Some have referred it to the principle of gravitation; others to its supposed aversion to light. But it is a simple and satisfactory explanation that its growth or cell-development takes place most readily on the moist side of its growing point, and consequently in a downward direction, so long as the soil in contact with its lower surface is more moist than that above. Hence also the well-known tendency of roots toward springs and water-courses.

\section{H A P T R X V.}

\section{THE CRYPTOGAMIA OR FLOWERLESS PLANTS.}

621. Distinction of Parts. In the lowest of the Cryptogamic tribes the organs of vegetation and of reproduction are the same. Each cell in the structure grows, nourishes, multiplies. Higher in the scale we find a gradual specializa4S5, A Tree Fern (of the Island tion of organs, and in the higher tribes, as in
of Java), 40 feet in height.

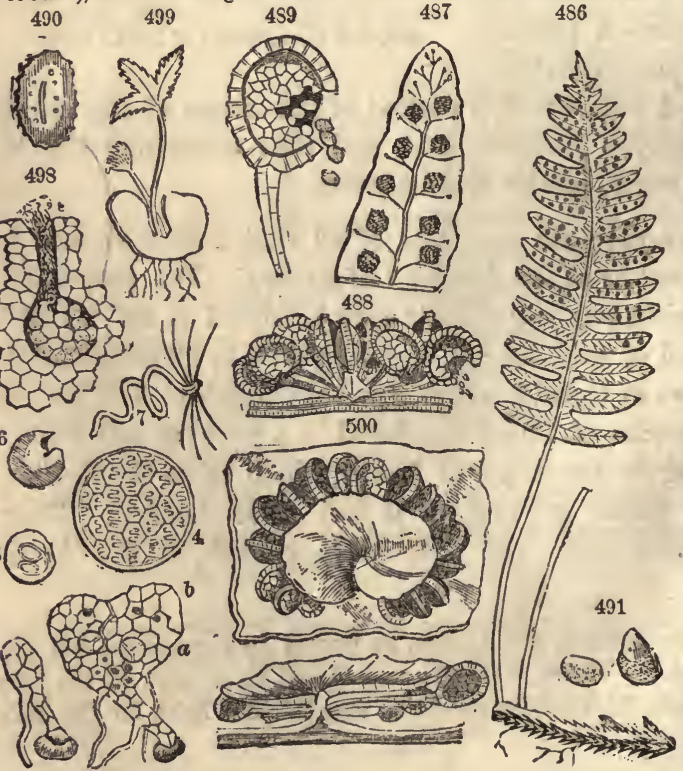

$\$ 92$
493
A Fern, Polypodium vulgare. 4S6, Its frond. 4S7, Lobe of the frond en. larged, showing the sori, $4 S S$, One of the sori (magnified) consisting of many sporangi. 4S9, One sporange (further inagnified) bursting and discharging the spores. 490, A spore. 491 , Spores beginning to germinate; and 492,493 , producing the prothallus with rootlets. At $a$ appear the antheridia and at $b$ the archegones on the surface of the prothallus. 494, Antheridium. 495, One of its cells. 496, The saine burst; and 497 , the spermatozold escaped. These float about, and some of them at length enter, 498 , the archegone, fertilizing, and nt length producing, 499, the young Fern. 500, Sorus of Aspidium marginale, covered with the indusium. 501, Same, side view. 
the Phænogamia, one portion is devoted to the preservation of the individual, the other to the preservation of the species; in other words, the organs of vegetation and of reproduction become separate and distinct.

622. Distinguished from Phenogamia. But the reproductive organs, although distinct from the nutritive, are never seen combined into flowers, nor producing seeds marked by the presence of an embryo. Hence in the scale of rank the cryptogams are inferior to the flowering plants and easily distinguished from them.

623. Vegetative organs. Again in the lower tribes, viz., the seaweeds, Fungi and Lichens, there is no distinction of root, stem and leaves; but the entire plant grows into an expansion of substance more or less uniform and indefinite, called a thallus. But the higher Hepaticæ, mosses, club-mosses,Equisetaceæ, ferns and marsileads, possess stems, roots and leaves like the Phænogamia.

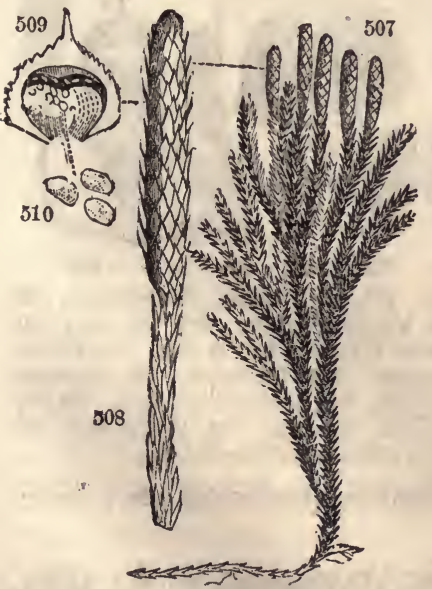

507, Lycopodium dendroideum. 509, A single spike. 509, a scale with its sporango bursting. 510, Spores.

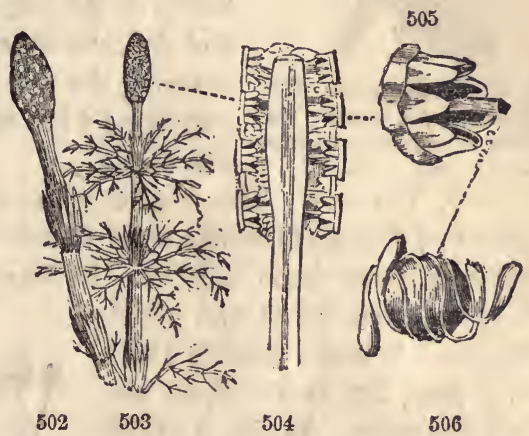

502, Equisetum arvense. 503, E. sylvaticum. 504. Section of the spike. 505, A sporange. 506, A spore with its elators coiled.

624. Classes. The tribe last mentioned are embraced in the class Acrogens, so named by Lindley from their manner of growth (ákpóv, point orsummit), lengthening into an axis. The remaining three tribes first named above constitute the lowest class of the vegetable kingdom, called Thallogens, and named from their manner of growth.

625. The stems of the MARSILEADS and ferns are mostly rbizomes, but in tropical countries some species of the latter arise on firm ærial trunks like palms. The club.mosses have slender, woody stems much inclined to bifurcate. Those of the Equisetacex, Characeæ are jointed, 


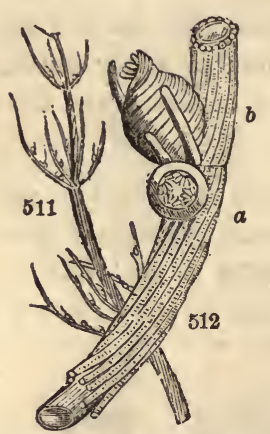

511, Chara foetida. 512, Portion of a branch; the two reproductive organs. $a$, Globule; $b$, nucule.

bearing slender, whorled, leafless branches. The mosses and Hepaticæ have filiform stems and branches, erect and creeping. Fern leaves and mushrooms arise on stipes.

626. Leaves. The ferns are characterized by their great development of leaves called fronds. They are rarely simple, often pinnatifid, or pinnate, simply, doubly or triply. Their venation is fork-veined and their vernation circinate. The leaves of the mosses and Hepaticn are veinless and delicate, mostly ovate and entire, numerously covering the axis. Those of the latter are often garnished with stipule-like processes called amphigastria.

627. Trallus. The vegetative system of the Thallogens consists either of delicate filaments or of flattened membranes, varying in color through every shade and hue. In Marchantia, lichens, and seaweeds it is green, olive or red, and called thallus. It may resemble a leaf or a stem, but its functions are still the same. In size it varies from the microscopic Conferva to the gigantic seawrack, a furlong in length. Its structure is purely cellular and uniform, or, as in Marchantia, in layers.

628. Mycelium or spawn is the vegetative system of the Fungi, distinguished from thalli by its want of coloring matter in its cells. It consists of meshes of white or colorless filaments, branching and anastamosing to form entangled masses pervading the substance in which the Fungus grows. It

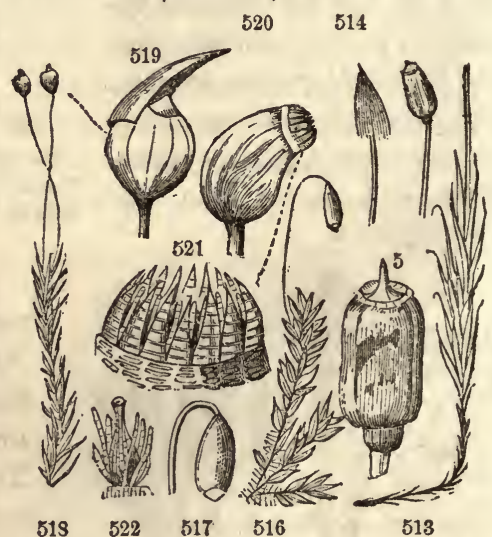

Mosses. 513, Polytrichlum. 514, Sporange with calyptra, without calyptra. 515, Sporango (enlarged) with the operculum at top. 516, Mnlum, 517, Sporange. 518, Bartramia. 519, Sporange with calyptra. 520, Same mature, open. 521, Peristeme. with its teetl. 522, Antheridium and paraphyses (a flower) of P'olytrichium.

is far less conspicuous than the fructification (toad-stool, etc.) which ultimately arises from it.

629. The reproductive organs of the Cryptogamia are the antheridia and archegonia; and by their reaction spores in various sporevessels are produced. They have been detected in nearly all the cryptogamic tribes, and are supposed to represent the stamens and pistils 

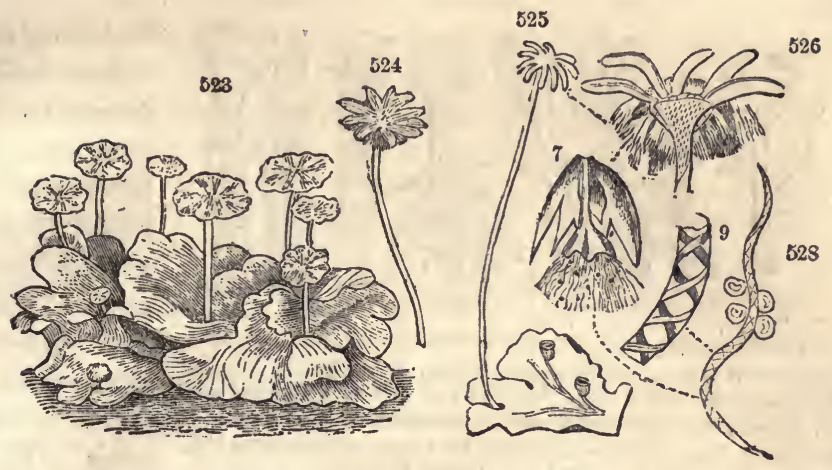

Hepaticæ. 523, Marchantia, sterile plant. 524-5, Fertile plant. 526, Vertical section of the fertil-receptacle; 527 , of a perianth, showing the sporange bursting. 528, One of the elators with four spores. 529, Portion of it highly magxified.

of the flowering plants. In the mosses, liverworts, etc., they appear only on the full-grown plant; in the ferns, Equisetacex, etc., they appear only on the prothallus, the earliest growth of the spore, and here the archegone gives birth to an embryo, whence at length the true fern arises, while the prothallus dies away.

630. Spores. These are the true reproductive germinating bodies of the Cryptogams. They consist each of a single cell, often exceedingly minute, and produced in immense numbers. The cell.wall of the spore may be simple (Botrytis) or double, as if a cell within a cell (ferns). But the spores 545 544 are often apparently tearingi. 537, Agaricus (Mushroom) in various stages: \& double or 2-celled (lich- $(e) ; c$, pileus; $a$, mycelium. 538, Portion of the gills. 539, (the same (mann. 490 diam.). 540, ens), or 4-celled, or 6, 8, Cyathus; 541, Section. 542, One of the conceptacles. 543, or many-celled. These Penicillum (mildew). 544, Mucor; $a$, mycellum.

compound spores are in fact spore-vessels inclosing several spores yet immature, and called sporidia or theca-spores. The spores or sporidia are often inclosed in still larger cells called the sac.

631. Endospores and exospores. Spores are developed either in the interior of the parent cell or on the outside of it, and hence the di- 


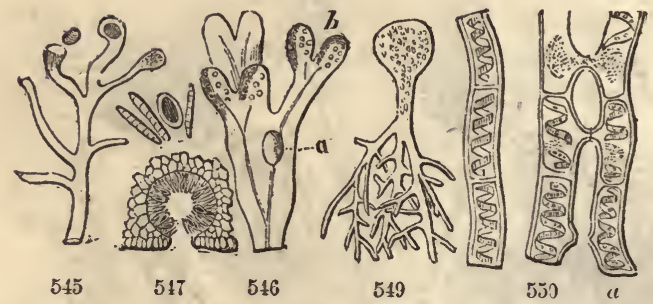

- Seaweeds (Algac). 545, Vaucheria forming and discharging its spores $(a)$ at the extremities. 516, Fucus; $a$, air-vessel; $b$, fruit, a mass of conceptacles. 547, Transverse section of a conceptacle. 543, A spore with paraphyses, 549, Ifydrogastrum, consisting of a single cell. 550, Spirogyrae (Frogspittle) one of the Confervæ; $a$, two threads (thalli) conjurgated, $i$. e., united by tubes. such sporiferous tissues existing in spots of definite form, constitute the apothecia when flat, receptacles when concave, and conceptacles when hol-. low.

632. The thec or SPorangia of ferns and mosses consist of tissues rather than of single cells, and contain division of the Cryptogams into the Endospores and the Exospores. In the latter case the parent-cells are called basidia, and many such united, as in the lichens and mushrooms, form a tissue ealled hymenium. In lichens

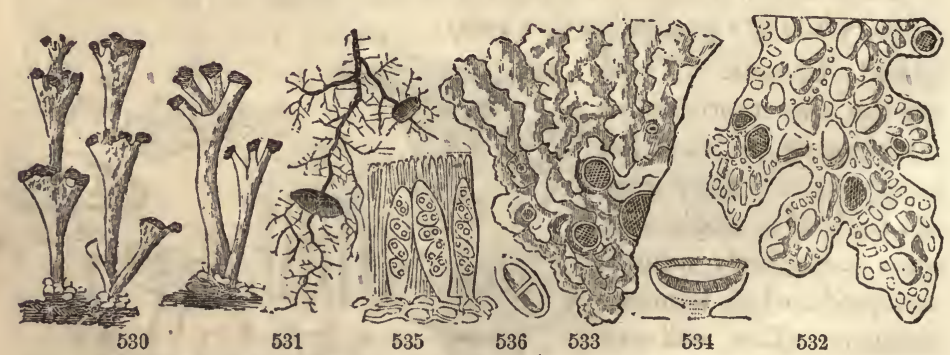

Lichens, 530, Cladonia; the minute thallns at the base of the podetia, cup-like above, bearing scarlet conceptacles. 531, Usnea. 532, Sticta. 533, Parmelia. 534, Receptacle, vertical section. $53 \overline{5}, \mathbf{A}$ portion (highly magnified) with theco and paraphases. $536, \mathbf{A}$ spore (double).

numerous spores. In ferns they grow on the back of the fronds in little elusters called sori. When mature, the sporange is torn open by the contraction of an elastic ring which surrounds it. In the mosses the sporange is stalked, solitary, terminal, and opens by a definite number of teeth called the peristome.

633. ZoosPores AND SPERMATOZOIDS are minute bodies endowed with spontaneous locomotion in water by means of vibratile ciliæ. Zoōspores of ovate form proceed from the vegetative cells of the Algæ, swim about for a time, then settle down and grow into new plants. Spermatozoids are mostly filiform bodies with several cilia, discharged from the 
antheridia (as pollen?) and actively floating until they reach the archegones, or perish.

634. A.LTERNATE GENERATION is a phenomenon distinctly traced in many of the cryptogams. Thus the mosses, in germinating, first produce long, greenish filaments quite analogous to the Confervæ (frog's-spawn). From these, at length, buds arise and grow into a true moss. Ferns, also, and Equisetacex, first from the spore exist in the form of a liverwort-a small green thallus, creeping and rooting along the ground. Secondly, upon this prothallus reproductive organs are developed and an embryo, whence a true fern arises. Thus the plant is transiently, as it were, a liverwort, permanently, a fern. (\$21-23.)

635. OTHER MODES OF PROPAGATION occur in these plants, as, for example, by innovations, sporules, gonidia. These bodies are analogous to bulbs and bulblets in the flowering plants, originating from the nutritive organs, and capable of separating from the parent and growing up independent plants.

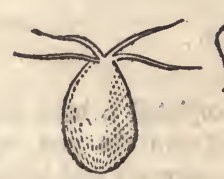

352

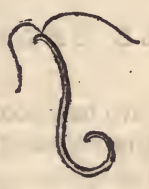

553

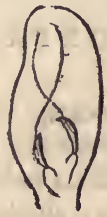

554

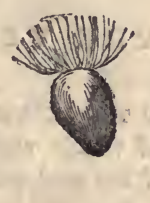

555

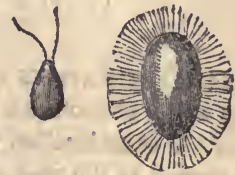

557

552, Zoöspore of one of the Conferva (Chsetophora). 553, Phytozoön of Chara. 554; Antheridium of Fucus containing two phytozoa. 555, Zoöspore of Conferva with a taft of cilix. 556, Another species with but two cilia. 557 Zoöspore of Vaucheria with cilio all around.

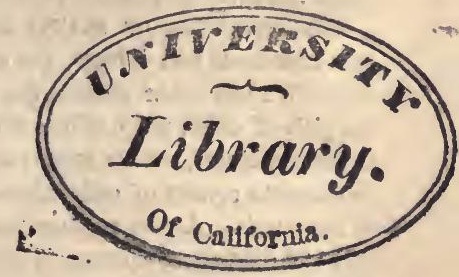




\section{P A R T SEC OND.

\author{
PHYSIOLOGICAL BOTANY.
}

\section{H A P T E I.}

\section{OF THE VEGETABLE CELL。}

636. ReVElations of THE MICROSCOPE. We have now completed a brief survey of the phenomena of visible vegetation. We commenced with the root and now the consideration of the seed with its embryo completes the circle and brings us around to the root again. We have studied bitherto superficially, as best we were able by the unassisted eye. But the microscope opens to us a new world in botany, more wonderful and fair, if possible, than that which we have already surveyed. No just appreciation of microscopic botany can be obtained from drawings or descriptions. Here the microscope itself is the only adequate teacher.

637. Next INQuiries. We have seen and studied the general organs of regetation and their metamorphoses; but of what are these organs made? What their structure within? What their office and use in the life and growth of the plant? These inquiries must next be answered.

638. Structure of PLANTS CELlular. All forms of vegetable structure, however numerous and diverse, are alike composed of little bladders, called vescicles or cells. We can often discern the cells in some structures with the naked eye, as in the pith of elder, pulp of snowberry, and especially plain in the pulp of orange. Other structures, which appear as a solid mass to the eye, are seen at once, under the lens, to consist of cells also-even the most solid wood or the stony substance of the peach. A thin cutting (shaving) from the rhizome of the blood-root, magnified 100 diameters, appears in outline (to say nothing of its brilliant coloring) as here sketched (557). Thereforo

639. THE CELL is the elementary organism which by its repetitions makes up the mass of all vegetation. It is defined as a closed sac composed of membrane containing a fluid.

640. The primary form of the Cell is spheroidal. In some cases it retains this form during its existence, but generally, in growing, it takes new and various forms, which, on account of the two causes which control them, may be classed as inherent and casual.

641. The inherent forms of the celi, or those which depend upon its own laws of growth, may be referred to three general types; 
(1) spheroidal, like pollen grains, the red snow-plant, the cells of leaftissue, etc, varying to oblong, or lobed, or stellate ; (2) cylindrical, or tube-form, as most wood-cells are; (3) tabular or flattened, as the cells of the epidermis.

\section{The casual Forms} result from external pressure, as of cells crowding against cells, in stems or pith. In this way spheroidal cells may become cubical, 8-sided, 12-sided, etc ; tubiform cells prismatic, and tabular cells 4angled, hexagonal, etc., in outline according to the original pattern.

643. IN MAGNITJDE the plant cell varies from $\frac{1}{10} \overline{0}$ to $\frac{1}{30} \overline{0}$ of an ixch in diameter; the more common size is about $\frac{1}{30} \overline{0}$ inch. The cells of elder pith measure

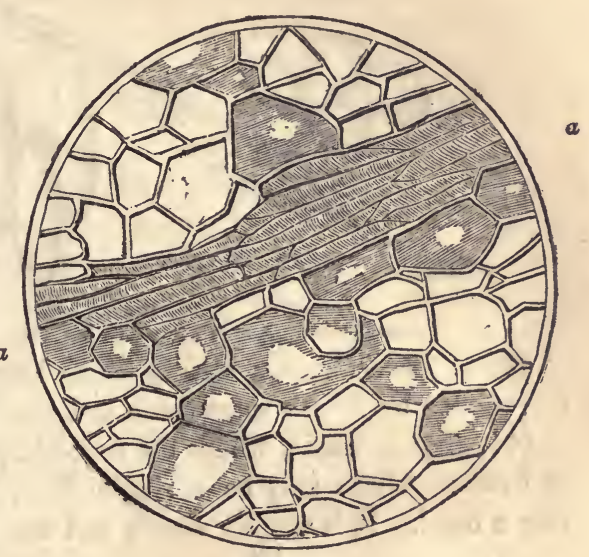

557 , Section of the rhizome of Blood-root. $a, a$. A bundie of wood-cells. The shaded cells contain the color. about $\frac{1}{200}$ inch; those of parenchyma (leaf-tissue) about $\frac{1}{4 \frac{1}{5}}$; . consequently, $64,000,000$ of them would occupy only one cubic inch. The cells of cork are computed to be To $_{0}$ o inch in diameter1000 millions to a cubic inch.

644. BUT THE LENGTH of some cells is much more considerable. Wood-cells measure $\frac{1}{50}$ inch ; bark cells, as flax, hemp, nearly $\frac{1}{2}$ inch; the cells of some planthairs an inch or more.

645. The wall of the new cell consists of two layers; the outer one a firm, colorless membrane, made of cellulose, the inner a plastic, gelatinous layer applied to the outer, and chiefly concerned in cell-life and multiplication. This is called the primordial utricle.

646. IT IS BEST SEEN WHEN treated with a weak solution of nitric acid, iodine, or alcohol. It thus becomes colored, contracts, and lies loose in the cell.

647. The cell wall is easily permeated by fluids flowing in and out. It must, therefore, be regarded as porous; although it appears perfectly entire even under the highest magnifier.

648. A SECONDARY LAYER is subsequently added to the outer layer, between it and the primordial utricle, as if to strengthen it. This new layer is seldom entire, but perforated and cleft in a great variety of patterns, leaving certain points or parts of the cell-wall still bare and discernible by their transparency. Hence the following varieties of cells :- 
649. Woon celLs, which are finally filled up by the repetitions of the secondary layers, leaving only minute points of the original cell-wall bare and transparent.

558
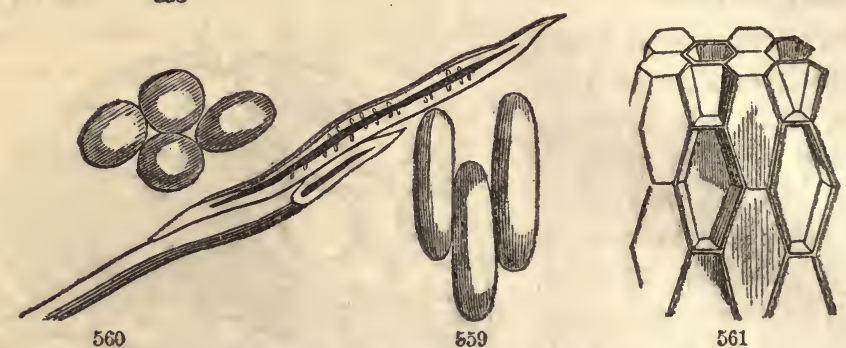

Forms of cells. 560, Wood-cells. 561, Cellular tissue of a rootlet, etc.

650. Pitted Celds, a variety where larger transparent points appear, surrounded by 2 or 3 rings (pine and the Coniferæ in general).

651. Spiral celis, where the secondary layer consists of spiral fibers or bands. There may be a single fiber, or several ( 2 to 20 ) united into a band. It is usually elastic and may be drawn out and uncoiled.

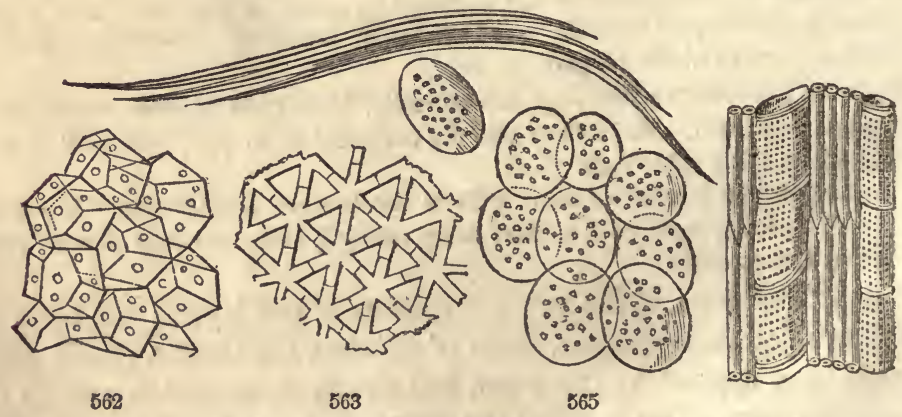

562 , Polyhedral cells of parenchyma in pith of Elder. 563, Stellate cells in pith of Rush. 565 , Spherical cells in Houseloek. 566, Wood-cells and ducts of Oak. 564, Wood-cells of the Flax-fiber.

These beautiful cells may be well seen in a shoot of elder, in the petiole of rhubarb, Geranium, strawberry. In the two latter, if gently pulled asunder, the coiled fibers appear to the naked eye.

652. Annular cells, when there are numerous rings within, instead of a spiral coil, as in the stems of balsam and some Cryptogamia.

653. Scalariform cells, when the rings seem conjoined by bars crossing between them, giving an appearance compared to a ladder (scala), as in the vine and ferns. Porous cells with the secondary layers full of perforations, reticulated cells, as if a net-work; and many other forms. 
654. Cellolose, the material of which the outer cell-walls and other secondary layers are made, is proved by a chemical analysis to consist of three simple elements, carbon, hydrogen, oxygen, in the proportions of $\mathrm{C}_{24} \quad \mathrm{H}_{20} \mathrm{O}_{20}$ - carbon and the exact elements of water. In the material of the primordial utricle nitrogen is added. Out of these four simple elements ( $\mathrm{CHON}$ ) with slight additions of lime, silex, and a few other earthy matters, God is able to produce all the countless varieties of plants which clothe and beautify the earth.

655. Contents of the cell. Some cells contain air only. Others are filled with solid matter; but the greater part contain both fluids and solids. There is the cytoblast, a globular atom, earnest of new cells; and protoplasm, the nourishing semi-fluid, both of the same material as the primordial utricle, and with it, and the fluid cell-sap, ever flowing, acting, combining, transforming, and producing either new cells or products like the following.

656. The colorive MaTTER, which gives to fruits and flowers their bright and varying tints of yellow, red, and blue, is generally dissolved in the cell-sap which is otherwise colorless; but

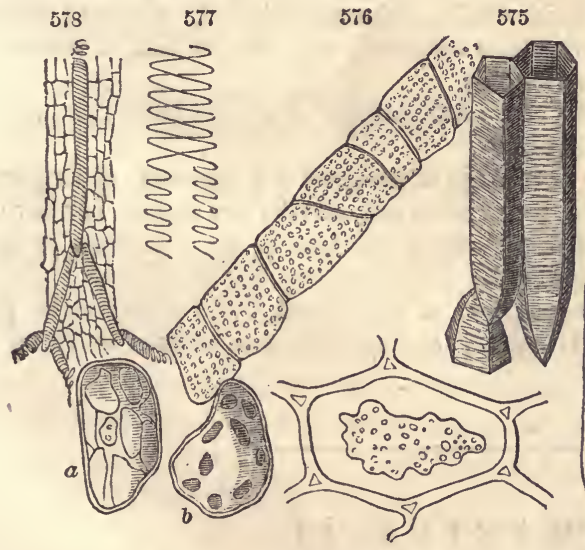

567
568

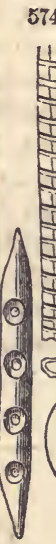

569

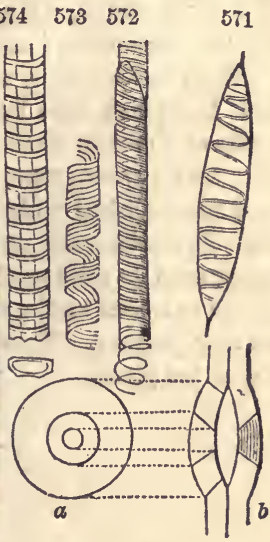

570

567 , Cells, $a$, of the pulp of Snow-berry, showing tho nucleus; $b$, of the parenchyma of the leaf of Pink, showing the granules of chlorophylle. 568, Cell of a Cactus, soaked in Alcohol, the primordial ntricle separated and contracted. 569, Cell of pleurenchyma of Pine, dotted. 570, Sketch to illustrato the nature of those dots; $\alpha$, dot seen in front; $b$, a side view of the same. 571, Trachenchyma, a spiral cell from the sporange of Equisetum. 572, Spiral vessel of the Melon, single thread; 578 , of the Elder, 4 threads. 574, Annular duct, distenderl by rings instead of a coil. 575, Scalariform vessels, from Osmunda (Fern). 576, A dotted duct from Gymnocladus (Coffee-tree). 578. Spiral vessels apparently branched. 577, Branching spirals in the Gourd.

657. Chlorophyle, the green coloring matter of leaves, consists of green corpuscles floating in the colorless sap or attached to the colorless wall. In the indigo plant these corpuscles are blue and constitute that poisonous drug. 
658. The STARCH of the plant also originates here, in the form of little striated granules of the same composition as cellulose $\left(\mathrm{C}_{24} \mathrm{H}_{20}\right.$ $\mathrm{O}_{20}$ ). Some 20 such granules appear in the same cell, either loosely or compactly filling it. Starch is nutritive matter, sealed up for preservation and future use.

579

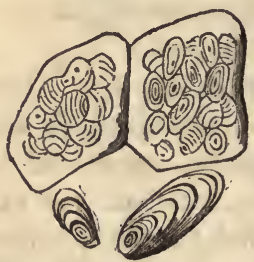

580
$5 \$ 3$

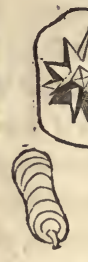

$5 S 1$
584

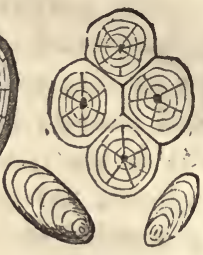

586
592

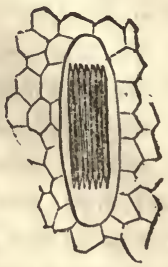

Contents of cells. 579, Cells of Potato containing starch grains. 580, Starch grains from the potato; 5S1, from the E. Indian Atrow-root. 582, Raphides, acicular crystals, in a cell of Polyanthes tuberosa. 583, Crystals in a cell of Cactus. 584, Cells from the pulp of Pear, coated internally; a longitudinal section; 585 , Transverse section. 586 , Starch granules from W. Indian Arrow-root.

659. GUY, SUGAR, SALTS, acids, alkalies, poisons, medicines, whatever is peculiar in the properties of each regetable substance, may also be held in solution in the cell-sap and invisible, unless forming

660. RAPHIDES, little bundles of crystals, acicular or of some other form, seen in the cells of rhubarb, Cactus, Hyacinth.

661. THE DEVELOPMENT OF NEW CELLS in the plant is the process of its growth. This is accomplished within the pre-existing cells and by the agency of their contents. The primordial utricle divides itself into two or more utricles, by septa growing from its sides until they meet. These then acquire the cellulose layer outside, the cytoblast inside, at the expense of the old cell, which shortly gives place to its new progeny. Thus cells multiply, and by millions on millions build up the fabric of the plant.

\section{CH A P T E II.}

\section{THE TISSUES.}

662. One-Cenled Plants. The cell, as heretofore described, is endowed with a life within itself. It can imbibe fluids, nourish itself, and reproduce others like itself. It may, therefore, and actually does in some cases, exist alone as a plant! Many species of the Conferroids and Diatomes are plants consisting of a single cell-the simplest possible form of vegetation.

663. Plants many-celled. With a few such exceptions, vegetation consists of a combination of cells united in a definite manner and form. 
Such combinations are called tissues, which we may describe under four general names or types :

\section{Cellular tissue (Parenchyma) : \\ II. Fibrous tissue (Pleurenchyma) : \\ III. Vascular tissue (Trachenchyma) : \\ IV. Laticiferous tissue (Cienchyma).}

664. Parenchyma, composed of spheroidal cells, is the most com. mon form of tissue, no plant being without it, and many, especially of the lower orders, being entirely composed of it. Numerous varieties occur according to the forms of the cells and their closeness of contact, intermediate between the following extremes, 1 , when there are copious intercellular spaces, the cells slightly touching, and being $(a)$ rounded, or $(b)$ lobed, or $(c)$ stellate; 2 , when the cells are crowded, leaving no intercellular space and being $(d)$ prismatic, or $(e)$ polyhedral, or $(f)$ irregular.

665. EXAMPLES of these tissues are found $(a)$ in the pulp of fruits, in newly-formed pith, and in all young growths; $(b)$ in the lower stratum of leaf-tissue; $(c)$ in the pith of rushes and other aquatic plants; $(d)$ in the herbaceous stems of Monocotyledons; $(e)$ everywhere, but well observed in full-formed pith; $(f)$ abundant in all the soft, fleshy parts of plants.

666. Pleurenchyma is composed of elongated cells cohering by their sides in such a way that end overreaches end, forming a continuous fibre. Two varieties are noticed $(a)$ woodfibre, with cells of moderate length, remarkable for its firmness, the main constituent of the stems and trunks of the higher plants; $(b)$ liber, with very long attenuated cells, the substance of the inner layers of bark, remarkable for its tenacity, especially in flax, l.cmp, linden.

667. The pitted cells $(\S 650)$ constitute a singular variety of wood-fiber, common in pines, firs, etc. That mysterious double ring which encircles each pit, is projected, the inner by the pit itself,

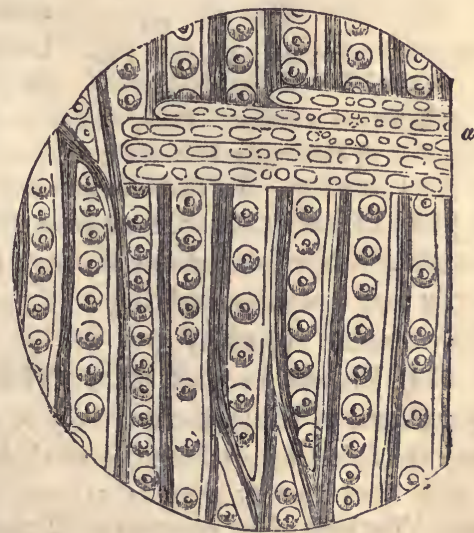

579 , Longitudinal section of Thuja (Rod Codar). $a$, Medullary rays. which is an aperture in the secondary layer, the outer by a lens-shaped intercellular cavity right opposite outside. (570).

668. Tracienchyma is a tissue of vessels or tubes rather than cells. The vessels are extended lengthwise, and composed each of a row of cells joined end to end, and fused into one by the absorption of the 
contiguous walls. This tissue varies according to the character of the constituent cells, which are $(a)$ spiral, or $(b)$ annular, or $(c)$ sclariform, or $(d)$ reticulated.

669. Such cells, with their tapering ends, form vessels with oblique joints. When porous cells (653) with their truncated ends unite they form right-jointed vessels resembling strings of beads, called dotted or vascular ducts. These are usually quite large, and characteristic of the woody layers of all exogenous plants. (470.)

670. THE DIFFERENT VARIETIES OF TRACHENCHYMA are assigned to different regions and offices, $(a)$ to the earliest formed part of the wood, the petioles and veins of leaves, petals of flowers, etc. ; $(b)$ to similar parts, but later formed, most abundant

Es0

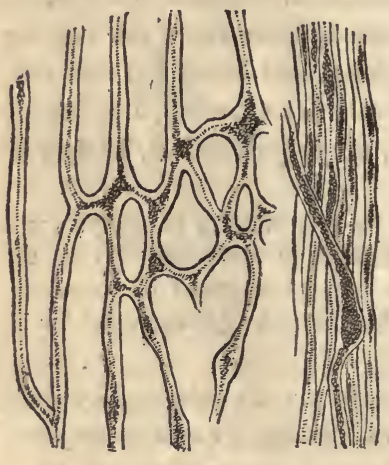

581

Vessels of Cienchyma ; 580, from Dandelion; 581, from the Celandine. in ferns and Equisetacex; (c) in the woody bundles of the Endogens and in the succulent parts of plants in general; (d) most abundant in ferns, club-mosses.

671. Cienchyma is a system of milk-vessels - vessels secreting the latex or peculiar juice of the plant, white, yellow, red, turbid, containing opium, gamboge, caoutchouc, resin, etc. It occurs in the petioles and veins; in the parenchyma of roots, in the liber especially; sometimes simple, generally branched and netted in a complicated manner, as well seen in the poppy, celandine, blood-root, gum-elastic tree, ctc.

672. THEIR NATURE. These vessels are probably mere open spaces between the cells at first, subsequently acquiring a lining membrane which never exhibits pores or spiral markings. But there are also true

673. Intercellular Passages filled with air and admitting its free circulation in all directions through the parenchyma. These are necessarily very irregular, and they communicate with the external air through the stomata. ( $\$ 678$.

674. IMPORT OF THE CELL. Thus the cell appears to be the type of every form of tissue, the material of which the vegetable fabric is built, and the laboratory where the work is performed.

675. Elevation IN RANK IS MARKED BY the increasing complication of the tissues. The basis of the structure of all plants is parenchyma. In the lowest tribes no other tissue is ever added, this alone performing all the functions. Higher in the scale, as in mosses, a few central bundles of wood tissue are added, as if to strengthen the stem. Still higher, as in ferns, etc., we begin to find ressels (trachenchyma) of the simpler sort, for the freer circulation of the fluids, together with the strengthening pleurenchyma. Lastly, in the highest plants, Phænogamia, the true spiral vessels appear, filled with air, cienchyma with secretions, and all the tissues in their appropriate functions. 


\section{CHAPTER III.}

\section{THE EPIDERMAL SYSTEM}

Ircuudes the external covering of all herbaceous growths, viz., the epidermis, stomata, hairs, glands, cuticle, etc., organs which in older stems give place to bark.

676. The EPIDERMIS (skin) consists of a layer of united, empty cells, mostly tabular, forming a superficial membrane. It invests all plants higher than mosses, and all parts save the extremities, the stigma and rootlets. Its office is to check evaporation.

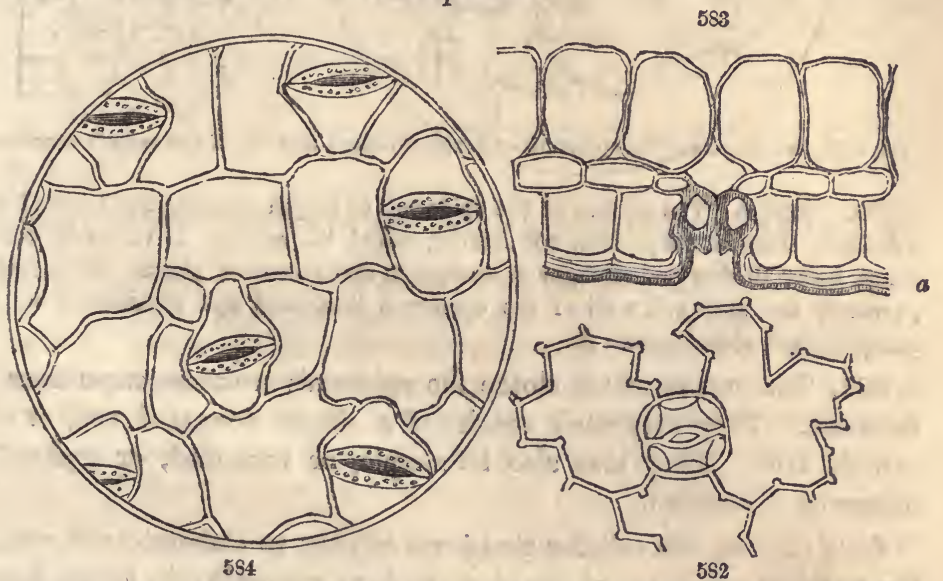

552, Cells of epidermis with a stoma from leaf of Helleborus foetidus. 5\$3, Vertical section of a stoma of Narcissus; a, cuticle. 5S4, Epidermis cells with stomata of Tradescantia Virginica.

677. EXAMPLE. That delicate membrano which may be easily stripped off from the leaf of the houseleek or the garden iris is the epidermis. It is transparent, colorless, and under the microscope reveals its cellular structure.

678. Stomata. The epidermis does not entirely exclude the tissues beneath it from the external air, but is cleft here and there by little chinks called stomata (mouths). Each stoma is guarded by a pair of reniform cells, of such mechanism (not well understood) as to open in a moist atmosphere and close in a diry.

679. Position of Stomata. The stomata are always placed over and communiعate with the intercellular passages. They are found only on the green surfaces of parts exposed to the air, most abundant on the under surface of the leaves. Their numbers are immense. On the leaf of garden rhubarb 5,000 were counted in the space of a square inch; in the garden iris, 12,000 ; in the pink, 36,000 ; in Hydrangea, 160,000 . 

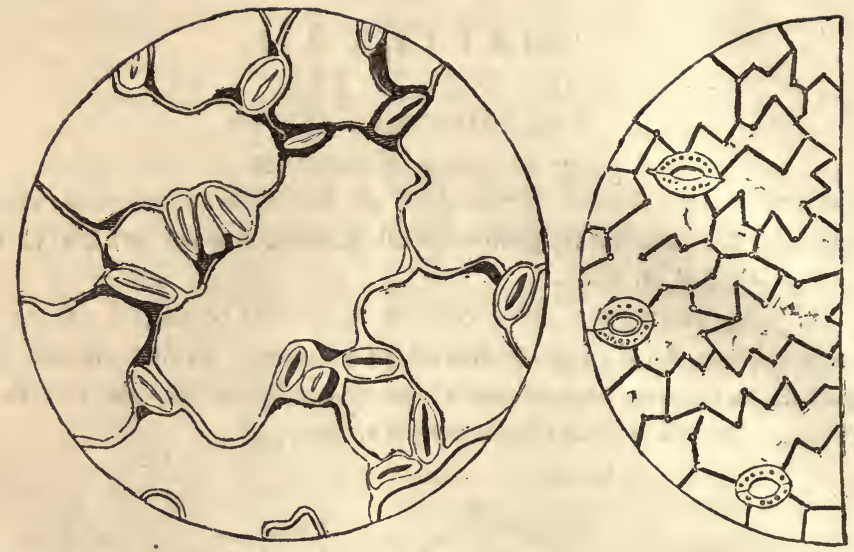

5S5, Cells and stomata of the epidermis of Oxalis violaces; and 586, of Convallaria racemosa.

680. Cuticle. The surface of the epidermis at length becomes itself coated with a delicate, transparent pellicle, not cellular, called the cuticle. It varies in consistency, being thicker and stronger in evergreen and succulent plants. It seems to be merely the outer cell wall of the epidermis thickened and separated from the newly-formed wall beneath it.

681. The haIrs which clothe the epidermis are mere expansions of its tissue. They may each consist of a single elongated cell, or of a row of cells. They may also be simple, or branched, or stellate, or otherwise diversified.

682. GLANDs are cellular structures serving to elaborate and contain the peculiar secretions of the plant, such as aromatic oils, resins, honey, poisons, etc. A gland may be merely an expanded cell at the summit of a hair, or at its base, and hence called a glandular hair (Labiatæ). Or it may be a peculiar cell under the epidermis, giving to the organ a punctate appearance, as in the leaf of lemon. Other glands are compound and either external (sundew), or internal reservoirs of secretion (rind of orange).

683. Strngs are stiff-pointed, 1-celled hairs expanded at base into a gland containing poisonous secretion. An elastic ring of epidermal cells presses upon the gland so as to inject the poison into the wound made by its broken point (nettle).

684. Prickles are hardened hairs connected with the epidermis alone, thus differing from spines, which have a deeper origin. Examples in the rose. 

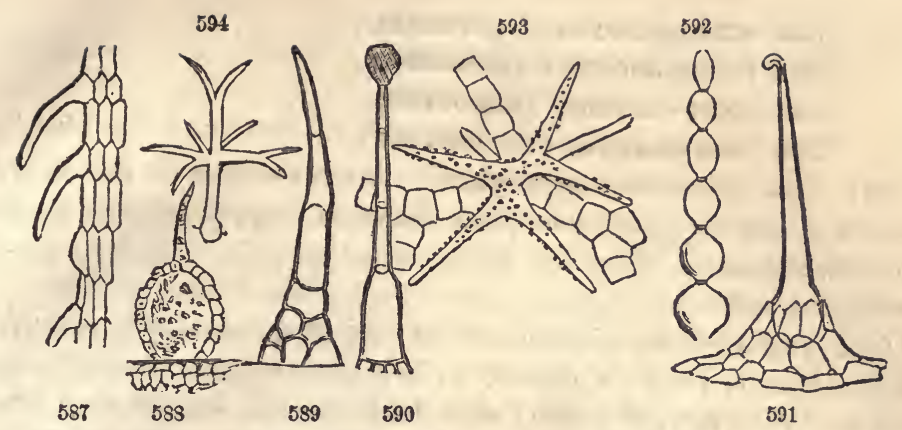

5S7, Rootlet of Madder, showing cells expanded into fibrillæ. 588, Gilandular hair of Fraxinella, section. 589, Hair of Bryonia, of several cells. 590, Hair of several cells, surmounted by a gland, of Antirrhinum majus. 591, Sting of Urtica dioica. 592, Jointed hair of the stamens of Tradescantia. 595, Stellate hair from the petiole of Nuphar advena (magnified 200 diameters, Henfrey). 594, Branched hair, one cell, of Arabis.

\section{CHA P T ER I V.}

\section{THE LIGNEOUS SYSTEM}

685. INCLUDES the firm structures of roots, stems, and their appendages, summarily called the wood.

686. STRUCTURE. The growing rootlet of the germinating plant exhibits under a microscope a nearly uniform mass of cellular tissue. The cells composing it are soft and delicate, with thin, porous walls adapted to absorb moisture, which it has already begun to do. It grows by the accession of cell to cell through their division and enlargement at its point, or rather just behind the advance layer which constitutes its cap (pileorhiza $\S 725$.

687. The EARLIEST TISSUE. The same structure also appears in the expanding cotyledons and the opening bud of the plumule. At this early stage, therefore, all plants alike in all their parts are composed of simple parenchyma. Subsequent changes in structure occur, giving to each tribe its several peculiarities. Still the growing points of the axis, both ascending and descending, advance by the forma- tion of the same tissue, and the vessels, if formed at all, follow a little later.

688. The changes. The rootlet soon becomes a root, assumes a corky layer instead of the tender, spongiform epidermis, and ceases to absorb. But new rootlets spring from the radicle, or branch from the axis, which in their turn absorb, harden, divide and subdivide; and so on indefinitely.

689. The INCREASING DEMAND FOR MOISTURE IS THUS MET by the multiplication of these root ends, which have been called the spongelets. The absorbing surface is also greatly increased by the hair-like processes of the epidermis;-the fibrillæ ( $(724)$ which multiply generally in proportion to the dryness of the soil.

690. There ARE FOUR GENERAL MODES OF GRowtr and structure, whereby the vegetable kingdom is distinguished into as many great classes, viz.: 


\section{The OUTSIDE-Growers (Exogens), \\ THE INSIDE-GROWERS (ENDOGENS), \\ The POINT-Growers (Acrogens), \\ The mass-growers (Thallogens).}

691. The exogenous structure. A cross section of the stem or branch of any dicotyledonous plant (mustard, maple), exhibits zones of different structures, which are distinguished as pith, medullary sheath, wood, and bark.

692. The PITH occupies the central part of the stem. It consists of parenchyma, is chiefly abundant in herbaceous plants and all young stems. When new, it is filled with fluids for the nourishment of the buds until they can make food for themselves. As the plant advances in age, the pith loses its vitality, is filled with air only, is often torn into irregular cavities, or disappears.

693. The medullary sheath immediately surrounds the pith. It is a thin, delicate tissue consisting of spiral vessels. It communicates with every bud, and sends off detachments of its vessels to the petioles and veins of every leaf. Its tubes secrete oxygen from carbonic acid or water and convey it to the leaves.

694. The wood consists of pleurenchyma and ducts $(\S 666)$ arranged more or less distinctly in concentric zones or layers. The first or inner layer, together with the medullary sheath and pith, is the product of the first year. One new layer is formed each successive year, during the life of the plant.

695. ANNUal circles. The ducts are usually first formed and lie in the inner part of the strata next the center, while the wood-fibers are produced toward the end of the season, and deposited in the outer part. The former are distinguished by the large size of their open ends, while the fibers are minute and compact. This circumstance renders the limits of each layer distinctly perceptible in a cross section, and their number, if counted at the base, will correctly indicate the age of the tree.

696. ExCEPTIONS. There are doubtless some exceptions to this rule. In tropical countries, where there is no distinction of seasons, there may bo several zones deposited annually, or on the other hand, several or all the annual layers may bo so blended by the uniform mixture of the ducts with the wood-tissue as to be undistinguishable. The layers of the beet-root are certainly not annual. They seem to correspond with the number of leaf cycles (§ 228).

697. The alburnum and DURamen-the sap-wood and heart-wood, are well-known distinctions in the wood. The former, named from albus, white, is usually of a light color and softer structure. It is the living part of the wood through whose ressels mainly the sap ascends.

698. How FORMED. The interior layers of the alburnum gradually harden by the deposition of solid matter in their vessels, and the thickening of the cell-walls, until fluids can no longer pass through them. 
Thus the duramen (durus, hard) is formed of a firm and durable texture, the only part valued as timber. Its varying colors in cherry, walnut, rose-wood, are well-known.
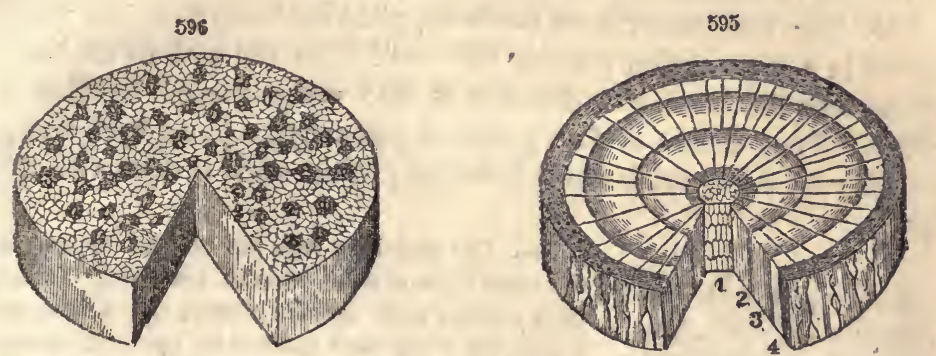

595, Cross-sections of an exogenous stem (Elm), of 2 years' growth; 1, pith, 2, 3, annual layers of woed, next the eambium, 4, bark; 596, and endogenous stem (Sorghum or Millet), where there is no distiaction of layers.

699. THE DUBAMEX IS OF No ACCOUNT IN VEGETATION, and is in this respect dead. Hence it often decays, leaving the trunk hollow, and the tree at the same time as flourishing as ever.

700. The BARK succeeds and replaces the epidermis, covering and protecting the wood. It is readily distinguished into three parts, viz. :

The inner, white bark (liber),

The middle, green bark (cellular),

The outer, brown bark (cortical).

The substance of all these is parenchyma and arranged, like the wood, in layers.

701. THE LIBER or white bark contains scattered bundles of pleurenchyma and cienchyma with its cellular tissue. Its wood-cells are very long ( $\$ 666)$, called bast-cells, and are strengthened with secondary deposits until quite filled up. Hence the strength and toughness of flax and hemp. The strong material of "Russian matting" is from the liber of the linden-tree, and the "lace" of the South Seas from the lace-bark tree. . The liber of other trees is not remarkable for strength.

702. The crLlular or GreEN Bark succeeds to the liber. Its tissue resembles that of the leaf, being filled with sap and chlorophylle. It grows laterally to accommodate itself to the enlarging circumference of the tree, but does not increase in thickness after the first few years.

703. The cortical or brown bark. Its color is not always brown, being rarely white (canoe birch), or straw-color (yellow birch), or greenish (striped maple), or grayish (beech, magnolia). Its substance is always cellular tissue, but differing widely in consistency in different species. Its new layers come from within, formed from the green bark, while its older are sooner or later cast off. 
704. THE CORTICAL LAYERS sometimes accumulate to a considerable thickness (maple, hickory, oak), but are finally rent and furrowed by the expanding wood. In the cork oak (Quercus suber) they attain an excessive growth, furnishing that useful substance, cork. In birch (Betula papyracea) these layers resemble paper, long abiding by their elasticity the expansion of the trunk.

705. The medullary rays (medulla, pith) are those fine lines which appear in a cross-section passing like radii from the pith to the bark, intersecting the wood and dividing it into wedge-shaped bundles or sectors. They consist of firm plates of parenchyma (muriform tissuc, the cell resembling brick-work) belonging to the same system with the pith.

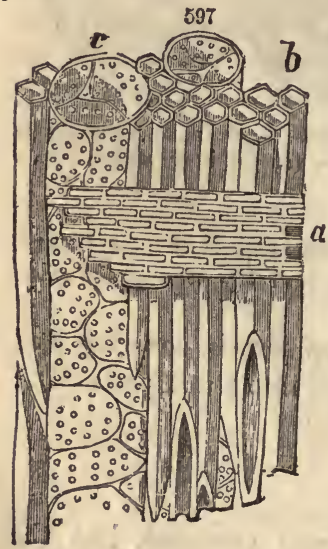

597 , Wood of Oak; section longitudinal, showing, $a$, medullary rays; $b$, wood-cells; $c$, porous ducts.

buds, a mucilaginous, half-organized layer of matter. Its presence loosens the bark and renders it easily peeled from the wood. The cambium is a sap solution of the starchy deposits of the preceding year, now rapidly being organized into cells.

710. THIS IS THE GENerative LAYER whence spring all the growths of the lig. neous system. From this, during each growing season, two layers are developed, one of liber and one of wood, both at first a cellular mass, but the cells with wonderful precision transforming, some into the slender bast-cells of the liber, some into the dotted ducts and fusiform cells of tho wood, some into the muriform tissue of the
706. The medullary rays are no less frequent in the outer layer of wood than in the inner. Hence their number must increase yearly, and a new set commence with each successive layer, extending with those already formed through the subsequent ayers to the bark, as shown in the diagram. (595.)

707. THE SILVER GRAIN. In a radial section $(597,598)$ the medullary rays are more conspicuous as shining plates of a satin-like texture, called tho silver-grain, quite showy in oak, maple. A tangential section shows their ends in the form of thin

708. THEY SERVE AS BONDS to combine into one firm body the successive wood layers, and as channels of communication to and from the bark and heart-wood. They also generate, at their outer exmities, the adventitious buds.

709. The cambium layer. Between the liber and the wood there is formed in the spring, at the time of the opening of the 598

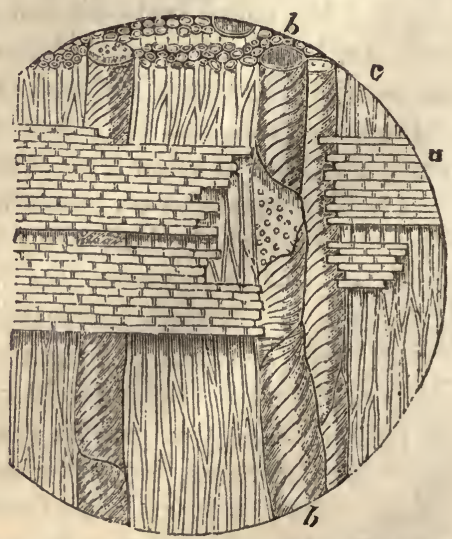

598, Wood of Maple; $a$ modullary rays ; $b$, duots; $c$, wood-colls. 
medullary rays. Through these latter the quickening influence of the cambium pervades both wood and bark.

711. UNLIMTED GRowth is therefore a characteristic of the exogenous stem : for the yearly increments are added to the outside of the wood, and the bark is capable of expansion by lateral growth to any extent.

712. The PECUlfar SECretions of THE PLANT are generally more abundantly deposited in the bark than in the other parts. Hence the bark is more generally sought for its medicinal and chemical properties.

713. The endogenous structure. In the cross-section of a monocotyledonous stem (corn, palm) there is no visible distinction of bark, wood, pith, or of annual layers of any kind.

714. IT Is COMPOSED of tissues quite similar to those of the exogenous stem, but very differently arranged. The body of the monocotyledonous stem consists of parenchyma, within which tissue numerous thread-like bundles of woody matter are imbedded.

715. These bundles CONSIST EACH of one or more dotted ducts accompanied by spiral vessels, pleurenchyma, and often cienchyma also, variously arranged in different species.

716. THE FORMation of theSE BUNDLES is dependent upon the leaves from which they may severally be traced downwards, first tending toward the interior of the stem. Further on they recurve outward again, and finally terminate near the surface, there interlacing and combining with their fellows and forming an excessively hard but inseparable rind (false bark).

717. Cleavage difficult. From this entanglement of the fibers the cleavage of endogenous stems is difficult or impossible. In jointed stems (culms) this entanglement occurs only at the nodes (cane, grasses).

718. The GROWTH of monocotyledonous stems thus takes place by the addition of the new wood bundles to the interior of the stem, and hence such plants are called Inside-growers or Endogens.

719. Peculrar forms of the caudex. The rind of endogenous trees is capablo of only a limited expansion. This limit is soonest attained at the base of the stem long before the upper parts cease to enlarge. Consequently such trunks are often seen of equal or greater diameter at the summit than at the base: so the palmetto, corn, bamboo.

720. The acrogenous structure is found in mosses, ferns, and the other higher tribes of the Cryptogamia. The stems advance, beneath or above the ground, full-formed, growing only at the end, hence called Acrogens.

721. A CROSS-SECTION of a fern stem shows a body of parenchyma strengthened by an outer zone of fibro-vascular bundles, the whole invested with a sort of bark. The bundles are precisely similar to those found in the petioles, showing that the otem is the aggregate of the unaltered leaf-bases. (600.) 


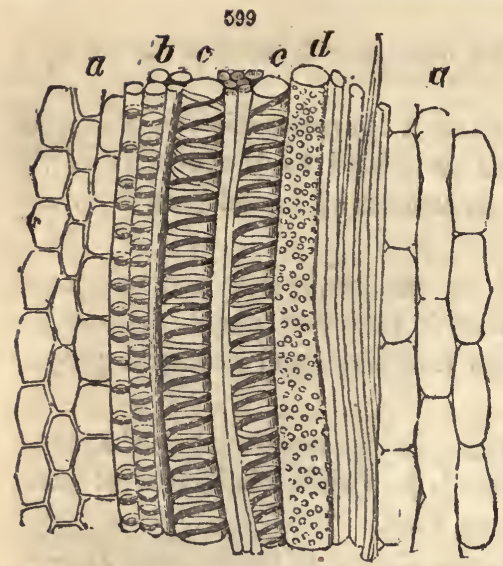

599, Various kinds of vessels in a woodfiber of Bamboo or Rattan. $\alpha$, Celis of parenchyma; $b$, annular cells; $c$, spiral vessels ; $d$, porous duct; $e$, wood-cells.
600

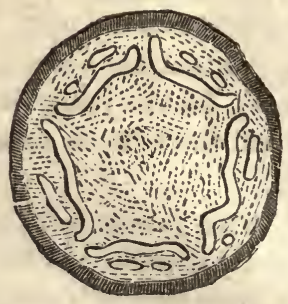

600 , Section of an Acrogenons stem of TreeFern (Cyathea), showing the vascular bundles imbedded near the circumference of the cellular mass.

722. THALLOGENS are the lowest in the scale of rank, having no true axis and no other tissue than parenchyma, which grows in threads or in mass in all directions. The apparent stems (stipes), if any, support the fructification only (sea-weeds, lichens, mushrooms, puffballs, frog-spittle, mildew).

723. THE STRUCTURE OF ROOTs presents few deviations from that of the stems to which they severally belong, being exogenous in Exogens, endogenous in Endogens, etc. In the former class the central pith disappears, its place being occupied mainly by vascular ducts, and the liber, if any, has no bast-cells.
601

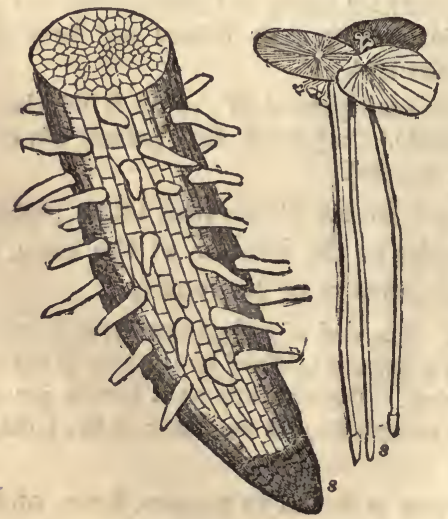

724. THE FIBRLLA and pileorhiza should, however, be mentioned as peculiar in the structure of the root. The former are produced by millions, clothing the delicate epidermis of the young rootlets as with cottony down, especially in light soils. They usually consist of a single cell of the epidermis extended. as seen in figure 601. They are the true absorbents, the mouths of the growing plant.

725. THE PILEORHIZA. The microscope shows that the extreme, advancing point of the delicate, growing fibers is not thrust naked against the opposing soil, but is covered with a cap called pileorhiza (pileus, a cap, rhiza, root), which consists of fobrillæ and $(8)$ pileorhiza. 602, Two plants of older, hardened cells, behind which Lemna minor (Duckmeat). \&, Their pileorhiza. are formed the new cells. In the Duck-meat the pileorhiza is lengthened into a sheath.

726. THE MAANNER OF GROWTH IN THE ROOT is not like that of stems, by the extension of parts already formed, but simply by the addition of new matter at the 
adrancing point. This accounts for the wonderful facility with which it penetrates the soil and finds its way uninjured into the hardest earth.

727. Dictyogens. In those fow Monocotyledons which bear reticulated leaves (Smilax, Dioscorea), the Dictyogens of Dr. Lindley, the roots exhibit a structure resembling that of exogenous stems.

\section{STRUCTURE OF LEAVES.}

728. Nature of the Leaf. The leaf may be regarded as an expansion of the two outer integuments of the bark, or of the green bark and the epidermis, expanded into a broad, thin surface by a woody framework proceeding from the medullary sheath and the liber.

729. The FRAMEwORK of veins is therefore fibro-vascular, abounding in spiral vessels, and strengthened with liber.

730. The parenchyma exists in two strata more or less distinct. In all those leaves which are ordinarily horizontal in position, one surface being upward and the other downward, these two layers are dissimilar; but in leaves with a vertical lamina (iris), and in phyllodia ( $\S 307$ ) the two layers are similar.

731. The LAYERS DESCRIBED. The superficial layer of empty tabular cells, belongs to the epidermis. Next beneath this, in the surface on which the sun shines,

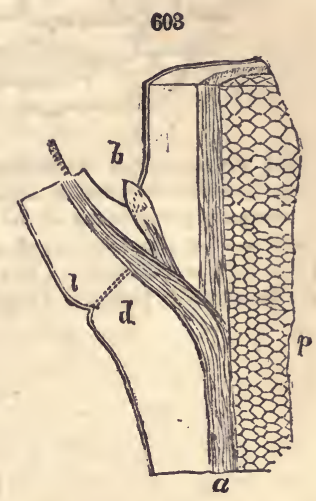

603 , Section of a stem a.t the origin of a leaf; $p$, cellular, or pith; $a$, vascular, the medullary sheath sending off a bundle into the leaf-stalk; $d$, the swelling (pulvinus) just below the articulation of the leaf-stalk $(l) ; b$, the axillary bud. are one or two layers of oblong cells placed perpendicularly to that surface, and more compact than the cells beneath them, which are pervaded by intercellular passages and by the veins.

732. Place of the stomata. The stomata as a rule belong to the shaded side of the leaf, avoiding the sun's direct rays. On the sunny side there are-few comparatively or none. In the submerged leaves of water-plants the epidermal layer is hardly distinguishable, and is wholly destitute of stomata. In such leaves as float upon water (water lilies) stomata are found in the upper surface alone.

733. The chlorophylle. Within all the vesicles of the parenchyma are seen adhering to the walls the green globules, of chlorophylle, which give color to the leaf-dark green above, where it is more compact, paler beneath, where the cells are more-loose and separate.

734. Vessels of cienchyma pervade the under-layer of parenchyma, returning the elaborated juices through the petiole into the cam. bium layer. 


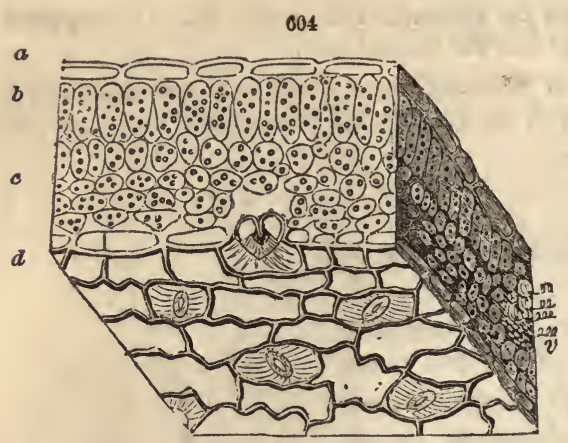

604, Minute portion of a leaf of Viola tricolor, viewed in perspective, showing, $a$, cells of epidermis above; $b$, compact parenchyma of the upper portion of the lear; $c$, loose parenchyma; $d$, epidermal-cells of the lower surface with stomata, one cut and opening into the intercellular passages. (Magnilied 100 diameters.)
735. THE STROCTURE OF BRACTS, sepals, petals, and other organs, which are but modifications of the leaf, hardly requires a separate notice. The same kinds of vessels pervade their parenchyma, but the spiral exist in a larger proportion. In the pistil, the fibrovascular bundles may be traced to the placenta, and thence into the funiculus and raphe of the ovule. In the more delicate organs cblorophylle is wanting, and the peculiar coloring, matter of whatever other tint, is uniformly diffused through the fluid contents of the cells of parenchyma. The depth of the tint depends on the number of cells thus colored.

\section{CHAPTER V.}

\section{VEGETATION, OR THE PHÝSIOLOGY OF PLANT LIFE.}

736. Next inquiries. We have now briefly surveyed the mechanism of the plant, both its outward forms and internal structure. We next inquire into the uses of all this wonderful apparatus; what the specific office which each part performs in the economy of the plant? and how do all parts coöperate in the work of living and growing?

737. THIS IS A SUBJECT OF GREAT EXTENT, and involves many inquiries of deep interest both in science and art,-many inquiries, also, which have never been answered. Our limits confine us to the bare statement of admitted principles, to the exclusion of all speculative discussion.

738. What IS LIFE? This inquiry meets us at the beginning-a problem never solved. The spontaneous action of the plant, the selfdetermined shapes which it assumes, we at once refer to this principle, its vitality; but of the nature of this principle itself we can only say, Is it not a direct emanation from the Supreme Will, the Fountain of all life?

739. Vegetation is Doubtless THE LOWEST FORM OF LIFE. It springs directly from inorganic or mineral matter, and is the first step in the organization of mineral matter. Its material is, therefore, mineral matter rendered organic through the vital force. 
740. The subordination of the vegetable to the animal kingdom is thus manifest in its being fed and nourished on inorganic matter. It is interposed between these two incompatible extremes, and is ordained to transform the innutritious mineral into the proper and indispensable food of the animal kingdom.

741. Parastitc plants do indeed require the ready organized juices of other plants, just as the carnivora among animals live on flesh. Still the general fact remains, that plants alono feed on inorganic matter, and in turn become themselves the food of the animal kingdom.

742. The process of vegetatron consists of imbibing the crude matters of the earth and air, transforming into sap, assimilating to plant juice (latex), and organizing into its own structure according to its own plan. The vital phenomena on which these transformations depend are called absorption, circulation, exhalation, assimilation, secretion, all of which processes take place in the individual cell. Therefore,

743. CeLL-LIFE is an epitome of the life of the whole plant. The cell is never a spontaneous production; it is the offspring of a pre-existing cell. So with the plant; it is always the offspring of a pre-existing embryo or cell. Nothing but a cell can produce or nourish a cell.

744. Two kinds of organic matter make up the cell. The first protoplasm or protein $\left(\mathrm{C}_{40} \mathrm{H}_{31} \mathrm{O}_{12} \mathrm{~N}_{5}\right)$, the material of the primordial utricle (\$645), etc., containing nitrogen.; 2d, cellulose, $\left(\mathrm{C}_{12} \mathrm{H}_{10} \mathrm{O}_{10}\right)$, the material of the outer wall or crust; etc., containing no nitrogen. The former more nearly resembles animal matter, and is the seat of the vital foree and chemical action.

745. What the CELL IMBIBEs. Through the invisible pores of its walls the cell imbibes the fluid in which its food is dissolved, viz., sugar or dextrine, ammonia or some other nitrogenous substance. Such a fluid may

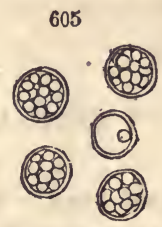

605 , Protococcus viridis, the Green snow-plant.
606

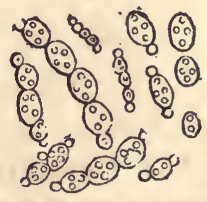

606, Penicillum glaucum, the Yeast-plant. be the flowing sap of the plant or any similar artificial mixture in which the cell is bathed, as (in the case of the yeast plant) a syrup with mucilage.

746. The chemical ciranges. The sugar is thus brought into contact with the protoplasm in the cell, through whose action it is decomposed and its elements transformed into cellulose and water. Thus each atom of (grape) sugar or dextrine becomes

One atom of cellulose, $\mathrm{C}_{12} \mathrm{H}_{10} \mathrm{O}_{10}$ and two atoms of water, $\mathrm{H}_{2} \mathrm{O}_{2}$

$$
\mathrm{C}_{12} \mathrm{H}_{12} \mathrm{O}_{12}=\text { grape sugar. }
$$


The water is exhaled with the rest; the cellulose is retained to incrust a new cell as soon as the primordial utricle shall next divide itself to form one. Or it may be deposited as starch granules for future use.

747. Action of chlorophylle. In the cells of green plants the globules of chlorophylle act an important part. Their formation depends upon the decomposition of carbonic acid $\left(\mathrm{CO}_{2}\right)$, the retention of the carbon, and the exhalation of the oxygen under the stimulus of the. light. If the formation of cellulose continue beyond the present need for cell-formation, the excess is deposited in the form of starch-granules inclosed within the globules of chlorophylle, one in each.

748. Destination of the starch Grandles. When the starch granules are redissolved, they go to incrust the rext new cell or to form a secondary layer in the old cell; or in autumn they go out into the general circulation and are at length stored up in the buds, the cambium, the roots, ready for an early use the following spring,

749. The INCREase of the protoplasm from the decomposition of the ammonia or other nitrogenous compounds present is a more intricate process, but no less evident, and when in excess, this also is deposited in minute globules of gluten, mucus, legumine, chiefly in seeds (wheat, beans, rice), in aid of germination.

750. THE STARCH AND GLUTEN DEPOSTTS of the wheat kernel are about sixtyeight and seventeen per cent. The former is found in the interior cells, the latter in the exterior, adjoining the pericarp or bran. In "flouring" some of the gluten adheres to the bran, and some constitutes the coarser meal, all of which is separated by the "bolt." Extra flour must, therefore, necessarily be deficient in gluten, the only element of the wheat which adapts it to the formation of muscle. A great error.

\section{FERTILIZATION.}

751. Capacity of the cell. Such being the vital energy of the cell, it is easy to admit the possibility of either its solitary existence as a plant (Protococcus, etc.), or of its associated existence, as in the living tissue of most plants.

752. Two modes of CELL-Growtr. Now all plants, without exception, do actually commence existence in the state of a simple cell. But while in the lower plants (Cryptogamia), this simple cell, the plantrudiment is at once discharged, free and independent, to float or grow, in the Phænogamia it is yet a while protected and nourished by other cells, - the cells of the ovule.

753. A Distinction. This primitive cell-plant, after acquiring the requisite means, swells and divides itself into two or more new cells. If these new cells cohere into a tissue assuming a definite form, as in 
the higher plants, the process is called growth; but if they separate, each one still abiding separate, it is reproduction.

754. The embryonic vesicle is the expressive name of the embryonic cell of the Flowering Plants. It has its birth in that large cell of the nucleus of the ovule ( $\$ 539$ ) called the embryo sac, and is in some way developed from the cytoblast ( $\$ 655)$. In appearance it may be like other new cells, but in the impulse or instinct with which it is endowed it is immeasurably different. It looks not to the mere continuation of an old series, but is the projector and pioneer of a new.

755. ITS NEW IMPULSE. Before it can enter upon its course of development so different from the destination of common cells, it must somehow be quickened and energized with an impulse in this new direction. In other words, it must be fertilized, - a process dependent on the pollen grains $(\S 509)$.

756. THE POLLEN TUBE-ITS COURSE. When the pollen falls upon the stigma, it imbibes the saccharine moisture there, expands, and its inner, expansible coat of protoplasm protrudes through the aperture (one or more) of the outer crustaceous coat, in the form of an attenuated tube. This, like a radicle, sinks into the soft tissues of the stigma and style, reaches the ovary, and there meets and enters the micropyle of the ovule.

757. ITS CONTENTS, HOW DISCHARGED. At this juncture the ovule has so turned itself, whether orthotropous, anatropous, etc., as to present the micropyle favorable to this process. The pollen tube makes its way finally to the nucleus and penetrates to the embryo sac. Here its growth ceases; its point is applied externally to the sac, sometimes indents it; but (according to the most accurate observations), does not penetrate it. During this contact the contents of the tube pass by absorption into the sac.

758. GROWTH OF THE FERTILIZED CELLS. Immediately the embryonic globule, thus, somehow endowed with a new instinct, now

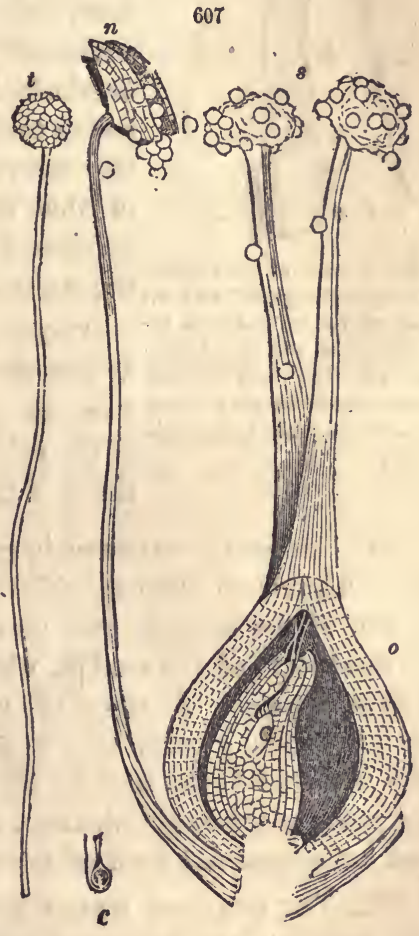

607, Section of the ovary of Polygonnm Pennsylvanicum, in process of fertllization. (Magnified 20 diameters). c, Natural size. $n$, One of the stamens having discharged its polien. $t$, A grain of pollen and its tube. $s$, Styles and stigmas. 0 , Ovary, ovule, em. bryo sac containing the embryonic globale. The extremity of a pollen tube is seen in contact with the embryo sac. 


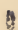

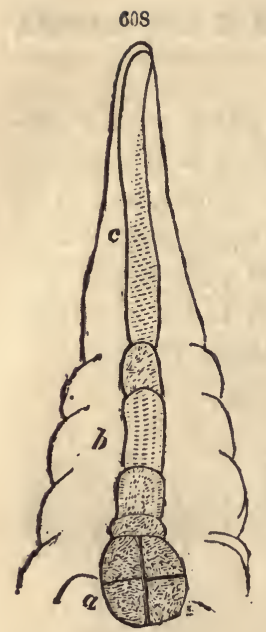

first expands into a proper cell, and is usually attached to the wall of the sac near the micropyle. It then divides itself transversely, becoming two cells; the upper tlongates either with or without subdivision, forming a filament (suspensor); the lower cell enlarges by subdivision, first spherically, and afterwards the little mass begins to take form according to the species, showing cotyledons, plumule, etc., until fully developed into the embryo.

759. Schleiden's view. Owing to the extreme difficulty of observation in this minute field, different views of this process have been advanced. That of Schleiden should not be overlooked. He maintains that the end of the pollen tube actually penetrates the sac and itself becomes the embryonic cell. The pollen grain is in this view the primitive cell, and is itself quickened into development by the contents of the embryo sac.

608 , Growth of the emiry in Hippuris vulgaris. The fertilized cell has divided itselt into several, of which $c, b$, constitute the suspensor attached Where no style or stigma exists, as in the Conito the apex of the sac; $a$, embryo dividing into 2 , then into 4 cells.

760. Fertilization IN the coniferd. feræ, the pollen falls directly into the micropyle of the naked ovule and its tubes settle into the tissue of the nucleus.

761. Chemical changes in germination. The ovule matures with the completion of the embryo, and passes into the fixed state of the seed in which the embryo sleeps. A store of nutritive matter, starch, gluten, etc., is thought. fully provided in the seed for the use of the young plant in germination, until its root has gained fast hold of the soil.

762. The Changes Which oCCUR IN THE SEED at the recommencement of growth, are simply such as are requisite 609 , Ovule of Viola tricolor, showing to reduce its dry, insoluble deposits to a the views of Schleiden. $p$, Pollen; $t$, rube, $r$, raphe; $c$, chnlaza; $b$, primine ; solution which shall contain the proper $a$, secundine; $n$, nucleus; $s$, sac which materials for cell-formation or growth; the tube appears to have penetrated. that is, gluten and other nitrogenous matters, oil, starch, etc., are to be changed to diastase, the same as yeast, and dextrine, the same as gum or grape sugar. 
763. The process. To this end water and oxygen are absorbed, the gluten begins decomposition, forming yeast; fermentation ensues; heat is produced by the slow combustion of the carbon with oxygen forming and evolving carbonic acid, by which process some of the oil and starch is destroyed, while another portion gains water and turns to sugar. All this within the cells of the seed.

\section{RIPENING OF FRUITS.}

764. In the pericarps of most fleshy fruits (grape, pear, apple, peach, strawberry), sugar exists before germination, ready formed in the process of ripening.

765. How THE FRUIT GROWS. In its earliest stages the pericarp consisted of a structure similar to that of green leares, composed of parenchyma, pleurenchyma, vessels, and epidermis with stomata. Its distended growth afterwards results from the accumulation of the flowing sap, which here finds an axis incapable of extension. Thus arrested in its progress, it gorges the pistil and adjacent parts, is condensed by exhalation, assimilated by their green tissues, which still perform the office of leaves. Cell-formation goes on rapidly within, and the excess of cellulose is deposited in the cells as starch. Oxygen is usually absorbed in excess, acidifying the juices.

766. How IT RIPENS. After the fruit has attained its full growth, the process of ripening commences, during which the pulp becomes gradually sweetened and softened chiefly by the change of the starch into more or less of soluble sugar.

767. Honey. In the same way we account for the production of honey in the flower. Copious deposits of starch are provided in the receptacle and dise $(\S 446)$. At the opening of the flower, this is changed to sugar to aid in the rapid development of those delicate organs which have no chlorophylle wherewith to assimilate their own food. The excess of sugar flows over in the form of honey.

768. The Wise economy of the honex is seen in fertilization. For, attracted by it, the insect enters the flower, rudely brushes the pollen from the now open anthers, and inevitably lodges some of its thousand grains upon the stigma!

769. EXPERIMENT HAS PROVED that in all these cases of the formation of sugar from starch oxygen is absorbed and carbonic acid evolved, $-a$ process which wo might expect, since starch $\left(\mathrm{C}_{12} \mathrm{H}_{10} \mathrm{O}_{10}\right)$ contains proportionably more carbon than sugar $\left(\mathrm{C}_{12} \mathrm{H}_{12} \mathrm{O}_{12}\right)$ contains. It is probable that theso two phenomena in regetation are always co-existent. 


\section{CHAPTER VI.}

\section{§1. ABSORPTION.}

770. OFFICE OF THE ROOT. The absorption of liquids, containing in solution the food of the plant, is the peculiar and indispensable office of the root, as may be shown by an

771. Experiment. Take a small growing plant from the earth and immerse it by its roots, which should be nearly or quite entire, in a cup containing a definite quantity of water. Place near it another cup with a like quantity of water to indicate the amount of evaporation. The difference of the diminution in the two cups will be the amount of absorption. A plant of spearmint has thus been found to absorb more than twice its own weight per day. Every one is familiar with the rapid disappearance of water from the roots of potted plants, as Hydrangea, Oleander.

772. The absorbents. An impervious epidermis destitute of stomata everywhere clothes the roots, excepting its fibrillæ and the tender extremities of the rootlets. No part, therefore, is capable of absorption except the latter. But these, by their multiplied numbers, present an adequate absorbing surface to the soil.

773. EXPERIMENT. Let a growing radish be placed in such a position that only the fibrils at the end may be immersed in water; -it will continue to flourish. But if the root be so bent that the fibrils shall remain dry. while the body of the root only is immersed, the plant will soon wither, but will again revive if the fibrils be again immersed.

774. INFERENCE. Hence, in transplanting a tree almost the only danger to its life arises from the difficulty of preserving a sufficient number of these rootlets.

775. The Force with Which plants ABSORB FLuIDs by their roots is surprisingly great, as shown by

776. EXPERIMENT. If the stem of a grape-vine be cut off when the sap is ascending, and a bladder be tied to the end of the standing part, it will in a few days become distended with sap even to bursting. Dr. Hales contrived to fix a mercurial gauge to a vine thus severed, and found the upward pressure of the sap equal to twenty-six inches of mercury, or thirteen pounds to the square inch.

777. But WHAT CAUSES tHis absorption of fluids in a direction contrary to gravitation? In explanation of this phenomenon reference has been made to two well-known principles in physics, viz., to capillary attraction by the tubular vessels and to endosmose by the closed cells, which are far more numerous.

778. EXPERIMENT. Invert the end of several open thermometer tubes in a colored liquid. It will be seen rising in the tubes above its level, to various heights-highest in the smallest calibre.

779. ExP. Suspend a napkin in such fashion that its lowest corner shall dip into a cup of water. In a few hours the water will have ascended into the napkin. These are results of capillary attraction. 
780. Exr. Throw dried prunes, currants, or raisins into water. After a while they will have become swollen and distended with fluid. Now place them in strong syrup; they will again shrink.

781. Exp. Attach a bladder filled with syrup to a long glass tube, and immerse in water. The water flows in and the mixture arises slowly but forcibly in the tube. Reverse the liquids. Pure water from within the bladder will flow into syrup without. The former is a case of endosmose ( $\dot{v} \delta o \nu$, inwards, $\mu \tilde{\omega}$, to seek), the latter of exosmose ( $\dot{\xi} \xi \omega$, outwards).

782. Direction OF THE cURRENTs. The flow will continue until the two fluids are equal in density. In both cases there is also a flowing of syrup into the water, but the greater flow is always from the lighter into the denser fluid.

783. THE FORCE OF ENDOSMOSE is found to depend upon the excess in density of the inner fluid. Syrup, with the density of 1.3, caused a flow of water with an upward pressure of $4 \frac{1}{2}$ atmospheres (Dutrochet). The great force with which the capsule of the squirting cucumber $(\$ 606)$ bursts shows the power of endosmose. But a more probable theory is stated in $\$ 791$.

784. THE USE OF ABSORPTION in the vegetable economy is not merely the introduction of so much water into the plant, but to obtain for its growth the elements of its food held in solution, whether gaseous or earthy. In attaining this object, the roots seem to be endowed with a certain power of selection or choice which we can not explain. Thus, if wheat be grown in the same soil with the pea, the former will select the silica along with the water which it absorbs in preference to the lime; the pea selects the lime in preference to the silica. Buckwheat will take chiefly magnesia, cabbage and beans, potash. This fact shows the importance of the rotation of crops in agriculture.

785. Other means of absorption. The office of absorption is not performed by the root alone. Every green part, but especially the leaf, is capable of absorbing gases and watery vapor.

786. Proofs. Every one knows how greatly plants, when parched and withered by drought, are revived by a shower which sprinkles their leaves without reaching their roots. Air plants or epiphytes ( $\$ 143)$, such as the long-moss and Epidendrum, must rely on this source chiefly for the supply of their food; and when the disserered stems of such plants as the houseleek grow without roots, suspended by a thread in air, it is evident that all their nourishment comes through their leaves.

\section{Circulation.}

787. Tendency of THE FLow. The fluids which are thus taken into the system by absorption can not remain inactive and stagnant. As their inward flow is regular and constant in its season, so must be their upward and outward flow, in a course more or less direct, toward the parts where they find an outlet or a permanent fixture.

788. In those Cryptogams which are composed of cellular tissue alone the circulation of the sap consists only of a uniform diffusion from cell to cell throughout the mass, as through a sponge.

789. IN THE HIGHER PLANTS, the different tissues perform appropriate 
offices in the circulation, some conducting upward, some downward, some conveying the crude sap, some latex, and some air.

790. Air-vessels. Spiral vessels and others of the trachenchyma are generally filled with air, and take no part in the circulation of fluids, except in the spring, when the whole system is gorged with sap. The intercellular passages, also, generally circulate air alone.

791. The moving Force. From the roots the newly absorbed fluid flows upward through the stems and branches, toward the buds, leaves, and flowers, being probably drawn thither into them by the exhalation and consequent exhaustion there going on.

792. Throvgh what tissue. The tissue of the stem and branches through which the ascending sap loves chiefly to travel is the pleurenchyma-those long cells of the wood fiber, whether arranged in broad layers, as in the Exogens, or scattered in slender bundles, as in the Endogens.

793. Throvgh which layers. And when the stem grows old, the sap ceases to traverse the inner layers,- the duramen, where its passage becomes obstructed by thickened cell walls, and frequents only the outer newer layers, - the alburnum, next adjoining the liber.

794. The CRUDE SAP. The fluid which thus flows upward seeking the leaves consists largely of water, is colorless, and is called the crude sap. It contains in solution minute quantities of gases and mineral salts, imbibed by the roots, together with dextrine and sugar (no starch) which it dissolved out of the cells on its way. This is the fluid which flows so abundantly from incisions made in trees in early spring.

795. THE OVERFLOW OF THE SAP depends upon the excess of absorption over exhalation. After the decay of the leaves in autumn, and the consequent cessation of exhalation, the rootlets, being deep in the ground, below the influence of frost, continue their action for a time, and an accumulation of sap in the system, even in the air-vessels and spaces, takes place. Also in early spring, before the leaves are developed, this action recommences, and the plant becomes gorged with sap, which will burst forth from incisions, as in the sugar maple, or sometimes spontaneously, as in the grape. As soon as the buds expand into leaves and flowers, the orerflow ceases.

796. The true sap. Throughout its whole course to the leaves the sap gains in density by solution. There arrived, it loses by exhalation a large part of its water, gains additional carbon, and undergoes other important chemical changes (hereafter to be noticed), and becomes the true sap, dense and rich, both in nutritive matter for the immediate growth and in special products for the future nourishment of the plant.

797. Returning, the true sap distributes its treasures in due and exact proportion as needed to every organ. Its course lies in the tissues of the bark, cellular and woody, first distributed over the under surface 
of the leaves, thence by the leaf-stalks into the liber, and so pervading all, down to the extremities of the roots.

798. ON ITS PASSAGE IT MAKES DEPOSITS of food, first in the cells, of the pith at the base of every incipient bud; then in the cambium region a copious store; next in the medullary rays a due portion, some carried outward for the supply of the cortical layer, and some inward for solidifying the wood; and lastly, the residue, often the richest legacy of all, falls to the root, and fills every branch and fiber, however vast its extent. This last deposit is that which is first met and dissolved by the rising tide of fluid in the following spring.

799. GRowth PROGRESSES DownWARD. Since the flowing of the true elaborated sap is downward, it scarce admits of a doubt that the progress of the growth is also downward, from the leaves to the roots. And on no other supposition can we account for the results of the following

800. Experimext. Girdle an exogenous tree by removing an entire ring of its bark. It will flourish still during one growing season, and form a new layer of wood and bark everywhere above the wound, as before, but not at all below. The next season the tree will die. Why? Because the true sap returning can not descend to nourish the roots.

801. EXP. If a ligature be bound firmly around a stem (sc. of silver-leaf poplar) its growth is checked below, while the part just above will exhibit, after a year or two, a circular swelling evidently caused by the interruption of the descending sap.

802. Exp. If a chip be cut from the trunk, the wound heals evidently from the upper side.

803. ExP. Cut off the top of a branch just below a leaf. The upper remaining internode will perish. It has no leaf above it to send down its food.

804. ExP. Girdle carefully the stem of a potato-plant. No tubers will be formed below. And, again, girdle a fruit tree, and the fruit will for once be increased in amount.

805. IN a FeW INStances trees have SURVIVEd the girdling process. In such cases the medullary rays complete the broken currents. The descending sap, on arriving at the ring, flows inwardly by the medullary rays, making a circuit, and appears again in the bark below the interruption.

806. Rotation. Beside this general circulation of fluids rising and falling from extremity to extremity, there is also a special circulation going on pretty constantly in each new cell, called rotation.

807. Rotation is a flowing of the protoplasm in slender and devious currents on the inner surface of the primordial utricle, rendered perceptible by the opaque particles floating in it. The cytoblast also partakes of the movement. It is well observed in the hairs of Tradescantia, leaves of Vallesneria, and especially in the stems of Chara, where the current expands into an entire revolving layer of protoplasm. It is a vital movement. 


\section{TRANSPIRATION.}

808. Transpiration relates to that important office performed by the leaves and other green organs, whereby pure water is separated from the crude sap and given off into the air. It takes place chiefly through the stomata, and is greatest by day and in a warm, dry atmosphere.

809. UPON THE ACTIVITY OF TRANSPIRATION DEPENDS also the amount of absorption. It not only makes room for the fluids from below to enter, but by disturbing their equilibrium, it creates an upward tendency, as the flame of a lamp draws the fluid up the wick. All the mineral and organic constituents of the sap are of course left in the plant.

810. THE QUANTITY OF PURE WATER TRANSPIRED by plants is immense. A forest makes a damp atmosphere for miles around. Dr. Hales, in a series of instructive experiments in transpiration, ascertained that a sunflower three and a half feet high, with a surface of 5,616 square inches, transpired from 20 to $30 \mathrm{oz}$. in twelve hours; a cabbage, 15 to $25 \mathrm{oz}$. in the same time-equal to the transpiration of a dozen laboring men. We may easily

811. Experiment with a single leaf recently plucked, say. of Podophyllum. Insert its petiole in a narrow-mouthed goblet of water, and around it fill the mouth with dry cotton to restrain evaporation. Over the whole place a bell-glass and expose to the sunshine. The vapor transpired will condense on the bell-glass, equaling (save the solid matters) the loss in the goblet.

\section{RESPIRATION.}

812. Respiration in plants refers to their rerations to the atmosphere. So in animals. These relations are in either case vitally important.

813. Experiment. Place a small, healthy potted plant (sc. Geranium, Mimosa) under the receiver of an air-pump, and thoroughly exhaust the air. At once every vital process ceases-no absorption, no assimilation, no irritability, but speedily decay ensues. A vacuum would bo no more fatal to a sparrow. Air is quite as necessary to the one as to the other.

814. Iliustration. So also when only the roots are excluded from the air by being buried deeply in an embankment, the tree suffers injury and perhaps perishes.

815. Respiration in plants, or aeration (as sometimes called) consists of all those operations by which the sap is brought into contact with the air or subjected to its influence. It occurs in the intercellular passages, in the spiral vessels everywhere, but especially in the leaves and all other organs which have chlorophylle and stomata.

816. The vital importance of REspiration is scen in the vast extent of the respiratory apparatus, consisting of millions of leaves and billions of breathing pores (stomata) and tracher (vessels)!

817. THe FACTs connected with respiration, which seem to have been well established by the experiments of Saussure, Garreau, Moué, Draper, etc., are these : 
1. Carbonic acid $\left(\mathrm{C} \mathrm{O}_{2}\right)$ is absorbed by the leaves and all green tissues, under the direct solar light.

2. Oxygen (O) is absorbed by the leaves and all green tissues in the absence of direct solar light, and by the roots, flowers, fruits, and germinating seeds at all times.

3. The oxygen thus absorbed unites with some of the free (or nascent) carbon already in the tissues, and forms carbonic acid.

4. By a process of assimilation $(\$-747)$ carbonic acid within the green tissues, from whatever source derived, is decomposed under the direct sunshine, and its carbon is retained; but

5. Its oxygen is set free and exhaled.

6. Carbonic acid is exhaled by the leaves anc all the green tissues in the absence of the sunshine, and by all other parts (root, flowers, fruit, and germinating seeds) at all times. Hence it appears that there are

818. Two PHASES of aerial action constantly performed and seemingly opposed to each other: One dependent wholly upon the clear sunshine, in which, by the leaves, etc., $\mathrm{C} \mathrm{O}_{2}$ is absorbed, decomposed, and $\mathrm{O}$ returned to the atmosphere; the other, in which $\mathrm{O}$ is absorbed, and $\mathrm{C} \mathrm{O}_{2}$ exhaled, by the leaves in the absence of sunshine, and by all other parts (roots, flowers, etc.) at all times. Both are equally and vitally important.

819. THE FORMIER PROCESS BECOMES VISIBLE to the eye by the rapid development of chlorophylle accompanying it, the latter by its gradual loss. Hence, during a protracted season of cloudy weather vegetation grows sensibly paler, but a few hours of sunshine restores the green to its wonted depth and richness.

820. BLANCHED PLANTS. Hence, also, plants growing in constant darkness and shade, as potatoes in the cellar, are very pale, and manifest their affinity for light by stretching themselves with famishing eagerness towards the slender sunbeam which gains admittance. Analysis shows structures thus grown to be deficient in carbon. We may easily repeat the

821. EXPERIMENT OF SAUSSURE. Place a quantity of freshly gathered leafy stems under a bell-glass full of rain-water, and thus expose them to the sun. Soon bubbles of gas arise and slowly collect above, pure oxygen gas, as long ago proved by Dr. Priestly.

822. REPEAT THE EXPERIMENT with boiled or distilled water, and no oXygen will appear. Rain-water contains $\mathrm{C}_{2}$ in solution, boiled water does not. The $\mathrm{O}$ must therefore have come from the $\mathrm{C}_{2}$ as would appear.

823. EXPERTMENT. Inclose air-tight in a glass globe the end of a leafy branch, without severing it from the tree. Thus it has been found by careful analysis after a day of sunshine that the proportion of $\mathrm{O}$ was increased at the expense of $\mathrm{C}_{2}$ within the globe; and vice versa by night or in the shade.

824. The ReSults of both transpiration and respiration, as concerns the plants, tend to concentrate the diluted sap by the elimination of the 
water, which served merely for its conveyance, and to assimilate it into food capable of being organized into cells and their various contents.

And it is proper in this place also to notice the effects of this vast machinery upon the constitution of the atmosphere and its relation to the animal kingdom.

825. Carbonic acid gas is dissolved in the atmosphere and somewhat uniformly diffused throughout its whole extent in the proportion of about 4 parts in 10,000, or $\frac{1}{2} \frac{1}{25} \overline{0}$. This gas flows, and is ever flowing into the air from decaying animal and vegetable substances, from combustion, and from the breath of all living animals. The quantity thus added to the atmosphere annually is estimated at 100 billions lbs., or nearly one tenth of the whole amount of carbon, and yet it does not accumulate.

826. The demand and supply. Were we able to compute in pounds the annual growth of the entire plant world, and the proportion of solid carbon which enters into that amount, we should doubtless find that the grand total of the demand equals this grand total supply.

A poisonous atmosphere. And further; not only are the necessities of the plant met by this wonderful circulation, but the necessities of animal existence also. Carbonic acid is poisonous, and should it be left to accumulate unchecked, it would gradually corrupt the air, and within a few centuries extinguish all animal life.

828. Animals and plants mutually dependent. Thus are the two kingdoms of the organic world mutually, through the inorganic, dependent upon each other. The plant furnishes the oxygen which the animal corsumes, the animal the carbonic acid which the plant consumes, while each would perish in an atmosphere of its own production. "Great and marvelous are thy works, O Lord of Hosts! in wisdom hast thou made them all."

\section{CHA P T E VII.}

\section{REVIENW OF THE PRINCIPLES OF NUTRITION.}

829. The four organogens. It has already appeared in the preceding chapters that plants consist chiefly of four simple organic clements, viz. : carbon, oxygen, hydrogen, nitrogen. The first exists in a larger proportion, the last in a smaller than either of the others. Unitedly these four elements constitute about 94 per cent. of all vegetable matter. 
830. CARBON (essentially charcoal) enters so largely into the composition of plants that it retains generally the exact form and texture of the wood after tho other elements have been expelled b5 heat. On this element chiefly depends the solidity and strength. Its proportion is from 40 to 60 per cent. Nitrogen, although equally essential, is less abundant in the tissues, and exists largely only in certain vegetable products. as gluten, albumen, casein, theine.

831. OXYGEN AND HYDROGEN exist in plants combined with other elements, and also combined with each other forming water, especially in all fresh green vegetable matter. The water is expelled by drying, and the following table shows, in a few cases, the proportion for each $100 \mathrm{lbs}$.

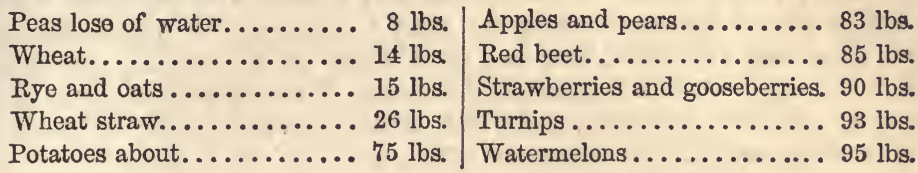

832. Earthy elements. Besides these four universal elements, many other substances, earthy and mineral, are found in quantities greater or less, in different species. Thus forest-trees and most inland plants contain potassa; marine plants, soda, iodine; the grasses, silex, phosphate of lime; rhubarb and sorrel, oxalate of lime; leguminous plants, carbonate of lime; the Cruciferæ, sulphur, etc.

833. THE PROPORTION OF EARTHY MATTER is small and may bo estimated from the ashes. As drying expels the water, so burning expels all other organic elements, and the inorganic earthy, whatever they be, remain in the form of ash. The following table from Bousingault is instructive on this point.

\begin{tabular}{|c|c|c|c|c|c|c|c|c|c|}
\hline & Grain. & $\begin{array}{l}\text { eat } \\
\text { Straw. }\end{array}$ & & $\begin{array}{l}\text { ts } \\
\text { Straw. }\end{array}$ & 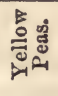 & 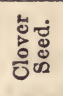 & $\stackrel{\overrightarrow{\mathrm{E}}}{\dot{\mathrm{H}}}$ & 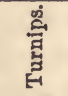 & 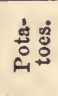 \\
\hline Carbon... & 46.1 & 48.4 & 50.7 & 50.1 & 46.5 & 49.4 & 45.8 & 42.9 & 44.0 \\
\hline Hydrogen. . & 5.8 & 5.3 & 6.4 & 5.4 & 6.1 & 5.8 & 5.0 & 5.6 & 5.8 \\
\hline Oxygen..... & 43.4 & 38.95 & 36.7 & 39.0 & 40.1 & 35.0 & 38.7 & 42.2 & 44.7 \\
\hline Nitrogen. . . . & 2.3 & .35 & 2.2 & .4 & 4.2 & 7.0 & 1.5 & 1.7 & 1.5 \\
\hline \multirow[t]{2}{*}{ Ash....... } & 2.4 & 7. & 4. & 5.1 & 3.1 & 2.8 & 9.0 & 7.6 & 4.0 \\
\hline & 100 & 100 & 100 & 100 & 100 & 100 & 100 & 100 & 100 \\
\hline
\end{tabular}

834. Agricultural Chemistry. Since all theso elements are found in plants, we infer them to be essential ingredients in the food which they require for healthy vegetation; and an inquiry into the sources from which they may be supplied constitutes the chief object of Agricultural Chemistry.

835. The FOOD of PLANTS is air, earth, and water. It is evident that plants do not create a particle of matter, and therefore do not originate in themselves any of the elements which compose them. Consequently they must obtain them from sources without. Carbon is derived from the carbonic acid contained in the atmosphere, and from the decaying vegetable matter of the soil. Oxygen is derived from tho 
water and from the carbonic acld of the atmosphere; hydrogen from water and ammonia, and nitrogen from ammonia and nitric acid, drawn either from the atmosphere or the soil.

836. THE ATMOSPHERE CONTAINS about $\frac{1}{2} \frac{1}{5} \overline{0}$ part of carbonic acid, diffused throughout its whole extent; and as this gas contains 27 per cent. of carbon, it is demonstrable that the whole atmosphere contains more than 600 billions $(600,000,000,000)$ of tons of solid carbon, derived from the sources already mentioned (§ 835), an amount fully adequate to the demands of the regetable kingdom.

837. Sorr consists of two classes of materials, viz. : mineral, and organic. The former, called earths, consists of disintegrated and pulverized rocks, including all the various mineral substances which aro found to enter into the composition of plants, as potassa, soda, silica, lime, etc., all of which are more or less soluble in water. The organic materials consist of the remains of former tribes of plants and animals mingled with the earths; and which, having access to the air, are decomposed, evolving carbonic acid and ammonia both to the air and the water.

838. W $\triangle$ ATER is composed of oxygen and hydrogen $(\mathrm{HO})$ in the proportion of 8 to 1 by weight, or one atom of each to each. Having pervaded the atmosphere in the state of vapor and rain, and percolated through tho soil, it holds in solution carbonic and nitric acids, ammonia, and many of the various minerals abovo mentioned.

839. Arrovia consists of nitrogen and hydrogen combined in the proportion of oue atom of the former to three of the latter $\left(\mathrm{N} \mathrm{H}_{3}\right)$. It arises from decaying animal and vegetable matter, as above stated, and is diffused through the atmosphere in the proportion of about 1 part in 10,000.

840. NITRIC $\triangle C I D$ is also believed to yield nitrogen to plants. It consists of oxe atom of nitrogen to five of oxygen $\left(\mathrm{N} \mathrm{O}_{3}\right)$. During thunder-storms il is generated in the air by lightning and brought down by rain. When combined with the bases, as potassa, soda, etc., it forms nitrates-substances known to be efficient fertilizers in soils.

841. AIR PLANTS. Thus it appears that water, carbonic acid and ammonia (or nitric acid) may yield to plants their four essential organic elements. And since all of them are contained in the atmosphere, some plants are capable of subsisting on air alone (long moss, lichens); but most species are dependent on water, earth, and air, and demand a copious supply.

842. The external circumstances, therefore, first requisite to healthy vegetation are, -1 , free access to an atmosphere which is often agitated by winds; 2 , a proper supply of rain or river water; 3 , a soil possessing the peculiar minerals required by the species to be grown upon it, together with a certain proportion of vegetable mold.

843. The supply. The first of these is everywhere abundantly supplied by nature, and asks no aid from man. The second and third are often deficient, and are to be supplied by the labors of agriculture. By irrigation streams of water are turned from their natural channels to add to the scanty moisture of fields parched with drought; by drainage the inundated bog is converted into a luxuriant lawn.

$\because 844$. THE OBJECT OF TILLAGE is to pulverize and lighten the too compact soil; and thus expose every part to the oxygen of the air in order to hasten its decomposition. Subsoiling, or deep ploughing, is an operation whereby that stratum of earth 
which lies just below the ordinary soil is moved and subjected to atmospheric influence. The sybsoil, with less organic matter, contains often soluble fertilizing earths which may thus be rendered available for the use of plants.

845. THE OBJECT OF MANURING is mainly to increaso tho quantity of organic matter, or to restore to the soil those qualities which have been taken away by the crops. By various amendments (as gypsum, lime, charcoal) ammonia is strongly attracted from the air and yielded again to vegetation. Marl promotes the decomposition of the soil, and ashes add to the potassa-a substance which also exists naturally in soils, being derived from the decomposition of the rocks which contain it, as granite, clay-slate, basalt, etc.

846. BONE MANURE is rich in the phospluates indispensable in the formation of albumine, gluten, and other blood-making qualities of fruits. The mineral phosphate of lime, bone.chalk, etc., are of the samo nature.

847. GuANo is a manure whose great valuo depends upon its abundant nitrates and ammoniacal salts. It is the excrement of sea-fowl which has for ages accumulated in vast deposits on certain coasts and islands of South America and Africa.

848. FALLOW GROUND. Soils are often improved by lying fallow for a season, thus allowing time to form, by decomposition, a fresh supply of that particular ingredient which had been exhausted by previous crops. On the same principle is explained the bencficial effects of a rotation of such crops as require different mineral substances in their composition.

849. Light AND HeAt. After all these materials have been supplied to the plant, still two other agents are requisite, without which the great work of vegetation will not go on. These life-giving principles are light and heat, both of which emanate in floods from the sun. Under their influence the raw material is received into the vessels of the plant and assimilated to its own substance-a process which can be fully comprehended only by Hrm whose power is adequate to carry it on.

850. Digestion. Under the influence of solar light and a temperature above the freezing point, water holding various earths in solution is imbibed by the roots and raised into the tissues of the stem, dissolving as it passes small portions of gum or sugar previously deposited there. In this state it is crude sap. Passing on it enters the leaves, and is there subjected to the action of the chlorophylle ( $\$ 657)$ which chiefly constitutes the apparatus of digestion. Here it is concentrated by transpiration, sending off quantities of pure water. Meanwhile the leaves are imbibing carbonic acid from the air, decomposing it, retaining tho carbon, and returning pure oxygen. Thus elaborated, the sap is now called

851. The Proper JuICE, consisting evidently of carbon and water, with a little nitrogen and minute portions of the mineral substances mentioned above. From this, the vital fluid, are claborated the building material of the vegetable fabric, and all its various products and secretions.

852. Protein, OR PRotoplasM, the substance of the primordial utricle, analogous in composition to the living tissues of animals, and containing nitrogen, is organized, first of all, from this vital fluid. Cellulose (or lignin) next, the peculiar principle of vegetable tissue, whether cellulal, vasoular, or woody, consisting of carbon with the 
exact clements of water, viz., $\mathrm{C}_{12} \mathrm{H}_{10} \mathrm{O}_{10}$. Then, through the action of light, chlorophylle springs into being, clothing the plant in living green. Meanwhilo

853. GUM, STARCH AND SUGAR, nutritive products common to all plants, are also developed from the proper juice-not all to be immediately employed in building up tho tissues, but mostly to be stowed away in reserve for future use. Such deposits are made in the root of the beet, tuber of the potato, and in the fruit generally. These three products, with cellulose, are all composed of carbon and the elements of water, often in identical proportions; thus cane sugar is $\mathrm{C}_{12} \mathrm{H}_{12} \mathrm{O}_{12}$; grape sugar, $\mathrm{C}_{12} \mathrm{H}_{11} \mathrm{O}_{11}$; gum, $\mathrm{C}_{12} \mathrm{H}_{10} \mathrm{O}_{10}$; starch, $\mathrm{C}_{12} \mathrm{~F}_{10} \mathrm{O}_{10}$; cellulose, $\mathrm{C}_{12} \mathrm{H}_{10} \mathrm{O}_{10}$.

854. SugAr Is SOMETIMES PRODUCED DIRECTLY from the proper juico, as in tho root of beet, stalk of maize, and sugar-cano; but oftener, during germination, from the starch deposited in the seed. Its composition, as seen above, differs from that of starch only in containing a larger proportion of the eloments of water or (what is the same) a smaller proportion of carbon. As starch is insoluble, its transformation into soluble gum or sugar is needful to render it available for tho nutrition of the growing embryo.

855. THE FACILITY WITI WHICI THESE FIVE GENERAL PRODUCTS ARE CONVERTED INTO EACII OTHER, both in the growing plant and in the laboratory of tho chemist, is adcounted for by the similarity of their chemical condition. Thus starch, gum and eelluloso may reconvert merely by some change in the arrangement of their constituent atoms, or they may becomo sugar by the addition of ono or two atoms of water.

856. AmoNG TIIE NeMerous SECRETIONS of plants, which our limits forbid us to consider, are tho vegetable acids containing more oxygen proportionately than exists in water; the oily acids, resins and oils, containing less oxygen than exists in water, or none at all. These substances vary in the different species almost to infinity, taking into their constitution, in addition to the four organogens, minuto portions of the mineral substances introduced by rain and river water. Their peculiarities of odor, flavor, color, properties, etc., although so obvious to tho senses, aro occasioned by differences of constitution often so slight as to elude the most delicate tests of the chemist.

857. THE Following TABLE contaINs examples of tho various classes of secretions, arranged in referenco to their relative proportion of oxygen :-

\begin{tabular}{|c|c|c|c|}
\hline CLABS. & NAME AND SOURCE. & FORMULA. & \\
\hline 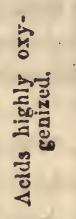 & 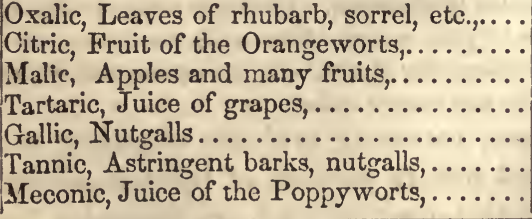 & $\begin{array}{l}\mathrm{C}_{2} \mathrm{H}_{4} \mathrm{O}_{4} \\
\mathrm{C}_{12} \mathrm{H}_{8} \mathrm{O}_{14} \\
\mathrm{C}_{8} \mathrm{H}_{6} \mathrm{O}_{10} \\
\mathrm{C}_{8} \mathrm{H}_{6} \mathrm{O}_{12} \\
\mathrm{C}_{14} \mathrm{H}_{6} \mathrm{O}_{10} \\
\mathrm{C}_{13} \mathrm{H}_{6} \mathrm{O}_{3} ? \\
\mathrm{C}_{14} \mathrm{H}_{4} \mathrm{O}_{14}\end{array}$ & $\begin{array}{l}\text { The propor- } \\
\text { tion of oxy- } \\
\text { gen to hy- } \\
\text { drogen is } \\
\text { greaterthan } \\
\text { in water. }\end{array}$ \\
\hline 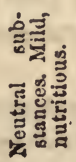 & 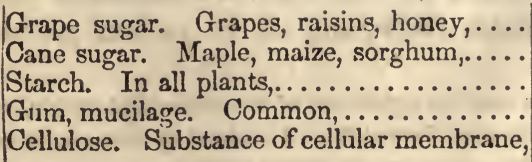 & $\begin{array}{lll}\mathrm{C}_{12} & \mathrm{H}_{12} & \mathrm{O}_{12} \\
\mathrm{C}_{12} & \mathrm{H}_{11} & \mathrm{O}_{11} \\
\mathrm{C}_{12} & \mathrm{H}_{10} & \mathrm{O}_{10} \\
\mathrm{C}_{12} & \mathrm{H}_{10} & \mathrm{O}_{10} \\
\mathrm{C}_{12} & \mathrm{H}_{10} & \mathrm{O}_{10}\end{array}$ & $\begin{array}{l}\text { proportion- } \\
\text { od to by- } \\
\text { drogen } \\
\text { equally, as } \\
\text { in water. }\end{array}$ \\
\hline
\end{tabular}




\begin{tabular}{|c|c|c|c|}
\hline CLABSS. & NAME $\triangle$ ND BOURCE, & FORMULA. & \\
\hline 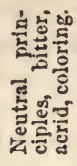 & 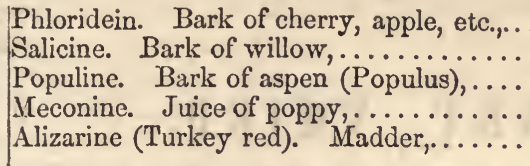 & $\begin{array}{lll}\mathrm{C}_{12} & \mathrm{H}_{7} & \mathrm{O}_{6} \\
\mathrm{C}_{13} & \mathrm{H}_{9} & \mathrm{O}_{7} \\
\mathrm{C}_{20} & \mathrm{H}_{11} & \mathrm{O}_{3} \\
\mathrm{C}_{10} & \mathrm{H}_{5} & \mathrm{O}_{4} \\
\mathrm{C}_{37} & \mathrm{H}_{12} & \mathrm{O}_{10}\end{array}$ & \begin{tabular}{|l|} 
Oxygen in \\
proportion \\
slightly less \\
than water.
\end{tabular} \\
\hline 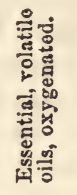 & $\begin{array}{l}\text { Oil of anise. Pimpinella anisum,........ } \\
\text { Oil of cinnamon. Laurus cinnamomum, } \\
\text { Oil of clover. Caryophyllus aromaticus, } \\
\text { Oil of sassafras. Laurus sassafras,...... } \\
\text { Oil of peppermint. Mentha piperita,.... } \\
\text { Oil of valerian. Valeriana officinalis,.... }\end{array}$ & $\begin{array}{lll}\mathrm{C}_{16} & \mathrm{H}_{8} & \mathrm{O}_{4} \\
\mathrm{C}_{18} & \mathrm{H}_{8} & \mathrm{O}_{2} \\
\mathrm{C}_{24} & \mathrm{H}_{15} & \mathrm{O}_{5} \\
\mathrm{C}_{10} & \mathrm{H}_{5} & \mathrm{O}_{2} \\
\mathrm{C}_{24} & \mathrm{H}_{20} & \mathrm{O}_{2} \\
\mathrm{C}_{12} & \mathrm{H}_{10} & \mathrm{O}_{2}\end{array}$ & $\begin{array}{l}\text { Oxygen in } \\
\text { diminished } \\
\text { proportion. }\end{array}$ \\
\hline 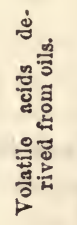 & 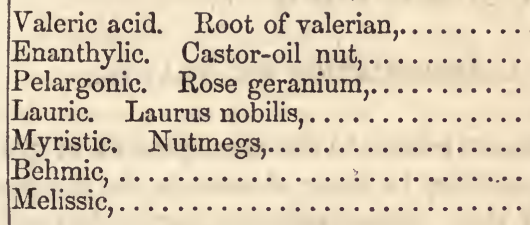 & $\begin{array}{lll}\mathrm{C}_{10} & \mathrm{H}_{10} & \mathrm{O}_{4} \\
\mathrm{C}_{14} & \mathrm{H}_{14} & \mathrm{O}_{4} \\
\mathrm{C}_{18} & \mathrm{H}_{13} & \mathrm{O}_{4} \\
\mathrm{C}_{24} & \mathrm{H}_{24} & \mathrm{O}_{4} \\
\mathrm{C}_{23} & \mathrm{H}_{28} & \mathrm{O}_{4} \\
\mathrm{C}_{44} & \mathrm{H}_{44} & \mathrm{O}_{4} \\
\mathrm{C}_{60} & \mathrm{H}_{60} & \mathrm{O}_{4}\end{array}$ & $\begin{array}{l}\text { In this se- } \\
\text { ries the pro- } \\
\text { portion of } \\
\text { exygen } \\
\text { regularly } \\
\text { diminishes. }\end{array}$ \\
\hline 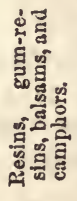 & 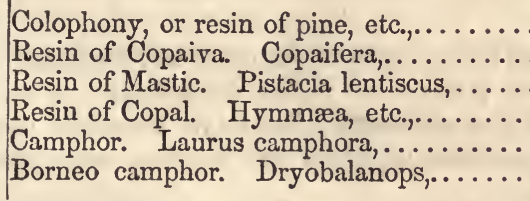 & $\begin{array}{lll}\mathrm{C}_{20} & \mathrm{H}_{14} & \mathrm{O}_{2} \\
\mathrm{C}_{40} & \mathrm{H}_{31} & \mathrm{O}_{4} \\
\mathrm{C}_{40} & \mathrm{H}_{31} & \mathrm{O}_{2} \\
\mathrm{C}_{40} & \mathrm{H}_{31} & \mathrm{O}_{3} \\
\mathrm{C}_{20} & \mathrm{H}_{16} & \mathrm{O}_{2} \\
\mathrm{C}_{20} & \mathrm{H}_{18} & \mathrm{O}_{2}\end{array}$ & $\begin{array}{l}\text { very little } \\
\text { oxygen re- } \\
\text { maining. }\end{array}$ \\
\hline 言离 & 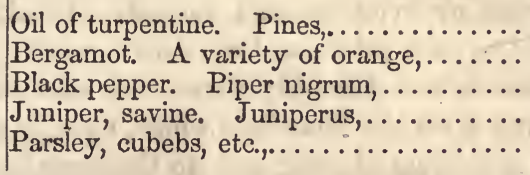 & $\begin{array}{ll}\mathrm{C} 5 & \mathrm{H}_{4} \\
\mathrm{C}_{5} & \mathrm{H}_{4} \\
\mathrm{C}_{5} & \mathrm{H}_{4} \\
\mathrm{C}_{5} & \mathrm{H}_{4} \\
\mathrm{C}_{5} & \mathrm{H}_{4}\end{array}$ & $\begin{array}{l}\text { Carbo-hy- } \\
\text { drogens, } \\
\text { isomeric, } \\
\text { destivute of } \\
\text { oxygen. }\end{array}$ \\
\hline & 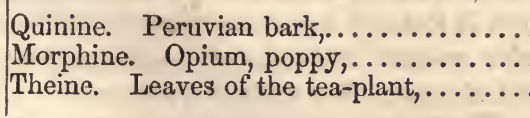 & $\begin{array}{llll}\mathrm{C}_{28} & \mathrm{H}_{22} & \mathrm{O}_{4} & \mathrm{~N}_{2} \\
\mathrm{C}_{34} & \mathrm{H}_{19} & \mathrm{O}_{6} & \mathrm{~N} \\
\mathrm{C}_{66} & \mathrm{H}_{10} & \mathrm{O}_{4} & \mathrm{~N}_{4}\end{array}$ & $\begin{array}{l}\text { Oxygen less } \\
\text { than hydro- } \\
\text { gen. }\end{array}$ \\
\hline & $\begin{array}{l}\text { Nicotine. Tobacco (Nicotiana), } \ldots \ldots \ldots \\
\text { Coneine. Hemlock (Conium), . . . . . }\end{array}$ & $\begin{array}{l}\mathrm{C}_{20} \mathrm{H}_{14} \mathrm{~N}_{2} \\
\mathrm{C}_{16} \mathrm{H}_{15} \mathrm{~N}\end{array}$ & $\begin{array}{l}\text { Oxygen. } \\
\text { none. }\end{array}$ \\
\hline 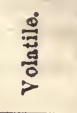 & $\begin{array}{l}\text { Oil of mustard. Sinapis nigra, } \ldots \ldots \ldots \\
\text { Oil of horse-radish. Cochlearia, } \ldots \ldots \ldots \\
\text { Oil of garlic. Allium sativum, } \ldots \ldots \ldots\end{array}$ & $\begin{array}{l}\mathrm{C}_{16} \mathrm{H}_{5} \mathrm{~N} \mathrm{~S}_{2} \\
\mathrm{C}_{16} \mathrm{H}_{5} \mathrm{~N} \mathrm{~S}_{2} \\
\mathrm{C}_{6} \mathrm{H}_{5} \mathrm{~S}\end{array}$ & $\begin{array}{l}\text { Oxygen } \\
\text { none. }\end{array}$ \\
\hline 열. & $\begin{array}{l}\text { Protein. Primordial utricle, } \ldots \ldots \ldots \ldots \\
\text { Gluten. The cereal grains, } \ldots \ldots \ldots \ldots \\
\text { Casein. Leguminous seeds, } \ldots \ldots \ldots \ldots \\
\text { Albumen. Many seeds, } \ldots \ldots \ldots \ldots \ldots\end{array}$ & $\begin{array}{l}\mathrm{C}_{36} \mathrm{H}_{25} \mathrm{O}_{10} \mathrm{~N}_{4} \\
10 \mathrm{Pr}+\mathrm{S} \\
10 \mathrm{Pr}+\mathrm{P}+\mathrm{S} \\
10 \mathrm{Pr}+\mathrm{P}+2 \mathrm{~S}\end{array}$ & \\
\hline
\end{tabular}




\section{P A R T T H I R D.}

\section{SYSTEMATIC BOTANY.}

\section{H A P T E R I.}

\section{OF THE CLASSIFICATION OF PLANTS.}

858. Systematic botany relates to the arrangement of plants into groups and families, according to their characters; for the purpose of facilitating the study of their names, affinities, habits, history, properties and uses.

859. IN THIS DEPARTMENT, the principles of Structural and Physiological Botany are applied and brought into practical use in the discrimination of the different groups, and the limitation of their characters. Besides the immediate uses of Systematic Botany in the determination of species and kinds, as above stated, it accomplishes

860. Another purpose of still higher import. It aids us in studying plants as related to each other, and constituting one great and glorious system. It shows us the Almighty Creator at once employed in tho minutest details and upon the boundless whole, equally attentive to the perfection of the individual in itself, and to the completeness of the grand system, of which it forms a necessary part.

861. The subject of Great Extent. The study of classification introduces the botanist into an extensive field of inquiry. The subjects of his research meet him at every step. They clothe the hill and plain, the mountain and valley. They spring up in the hedges and by the way side. They border the streams and lakes and sprinkle over their surfaces; they stand assembled in vast forests, and cover with verdure even the depths of the ocean. Now, with each individual of this vast kingdom the botanist proposes to acquaint himself, so that he shall bo able readily to recognize its name, and all that is either instructive, interesting, or useful concerning it, whenever and wherever it is presented to his view.

862. The WroNG WAY TO STUDY. Now it is obvious that if tho student should attempt the accomplishment of this labor by studying each and every individual plant in detail, whether with or without the aid of books, the longest life would scarcely suffice him for making a good beginning But such an attempt would be as unnecessary as fruitless. The Author of Naturo has grouped theso myriads of individuals into 
863. Species (\$76). When He called plants into existence, in their specific forms, He endowed each with the power of perpetuating its own kind and no other, so that they have descended to us distinguished by the same characters and properties as at the beginning. When, therefore, the student has formed acquaintance with any individual plant, he is also acquainted with all other individuals belonging to the same species.

864. For EXAMPLE: a single plant of white clover is a truo representative of all the millions of its kind that grow on our hills and in our meadows; and a single description of the white pine will answer in all essèntial points for every individual tree of that noble species, in all lands where it is found.

865. Genera. Although the species are separated from each other by elear and definite distinctions, still they are found to exhibit also constant affinities, whereby they stand associated into larger groups called genera $(\S 80)$. A genus, therefore, is an assemblage of related species, having more marked affinities with each other in general structure and appearance than they have with other species.

866. For example: the white clover and the red (Trifolium repens and T. pratense) are universally recognized as different species, but of the same genus; and a single generic description of one plant of the genus Trifolium will convey intelligence to a certain extent concerning every other plant belonging to its 150 species.

867. Trus are the individual plants of the globe grouped by descent and resemblance, and comprehended under species; and tho species associated into higher groups called genera. "An individual," says Prof. Forbes, "is a positive reality; a species is a relative reality; a genus is an idea-but an idea impressed on nature, and not arbitrarily dependent on man's conceptions An individual is one: a species consists of many resulting from ono; a genus consists of more or fewer of theso manies resulting from one linked together, not by a relationship of descent, but by an affinity dependent on a Divine idea."

868. Orders. But natural affinities do not end here. The genera are yet too numerous for the ready and systematic study of the naturalist. He, therefore, would generalize still further, and reduce the genera to still fewer and broader groups. On comparing the genera with eac'l other, he finds that they also possess in common certain important characters which are of a more general nature than those which distinguish them from each other. By these general characters the genera are associated into orders.

869. FOR EXAMPLE: comparing such genera as the mustard, radish, cabbage, cress, wall-flower, etc., it is seen that, while they differ sufficiently in their generic characters, yet they all have certain marked resemblances, in their didynamous stamens, siliquous fruit, whereby they are obviously associated into the same order - the Cruciferæ. So, also, the pines, the spruces, the cedars, the larches, and the cypress, while as genera they are obviously distinct, yet all bear cones of some form, with naked seeds; hence they are naturally grouped into one Order-the Coniferæ.

870. Classes. In like manner the Orders, by characteristics of resemblance still more general, are associated into a few groups, each of great extent, called Classes, whether natural or artificial. 
871. INTERMEDIATE GROUPS, formed on the same principles, are recognized as Subgenera, Suborders or Tribes, and Subclasses or Cohorts, which will be further noticed and described in another place.

872. Methods of Classification. Two independent and widely different methods of classifying the genera have been generally approved, the Artificial System of Linnæus, and the Natural System of Jussieu. The former is founded solely on characters relating to the organs of fructification, leaving all other natural affinities out of view. The latter, on the contrary, takes for its basis all those natural affinities and resemblances of plants whereby Nature herself has distinguishod them into groups and families.

\section{CHA P TER I I .}

\section{THE ARTIFICIAL SYSTEM.}

873. A SYSTEM OF CLASSIFICATION IS SAID TO BE ARTIFICIAL WHEN, disregarding the real nature of the subjects classified, it rests merely on some obvious external circumstance. As when the books of a library are arranged on shelves according to their size, octavo, duodecimo, etc., or as when the words in a language aro arranged in dictionaries, alphabetically, forming thus class A, class B, ete. In either case the books or the words constituting any group may be quite diverse in charactor, having nothing in common except their octavo size or initial letter. The only use of such an arrangement is convenience of reference.

874. CARL voN Linné (Linnæus) of Sweden, born in 1707, everywhere honorod as the father of systematic and descriptive botany, was the author of that renowned artificial system which bears his namo. For well nigh a century it contınued in almost universal use, and was regarded by his followers with far more respect than by Linnæus himself, who designed it simply as an index or cluo to the regetable kingdom. For ho says (Philosophia Botanica) "Methodi Naturalis fragmenta studiose inquirenda sunt. Primum et ultimum hoc in Botanicis desideratum est."

875. CONSIDERED AS A SYSTEM, the Linnæan arrangement totally fails to exhibit those true relations and affinities of plants which render the knowledge of each kind a guide to that of the others, and combine all into one consistent whole. It can not, therefore, properly be regarded as a system.

876. CONSIDERED AS AN INDEX or key to the vegetable kingdom, it is by no means reliable, for the stamens and styles often vary numerically in the samo plant; and secondly, the species of the same genus often vary in these respects, thus obliging us to violate even specific affinities; and again, when the stamens or pistils are accidentally marred, or lost, or immature, the index must also faii of its purpose. For these reasons this arrangement has fallen into disuse, having been superseded by the Natural Systern, and by other arrangements better adapted to the present advanced state of the science. Yet being intimately connected with the history of botany, and having largely contributed to its early progress, its outlines at least do mand a record in our pages.

877. Tue Linnean System proposes to arrange all the known genera of plants under twenty-four classes, each based on some special character derived from the essential floral organs, as follows: 
§ 1. The FIrst turrteen Classes comprehend all such plants as have their flowers all perfect, their stamens unconnected and and of equal length, or at least neither didynamous nor tetradynamous.

Class I. MoNandria, -one stamen to each flower (Saltwort, etc.).

Class II. Dinndria, - two stamens (Circea, Veronica).

Class III. Triandria, - three stamens (Iris. Nearly all the Grasses!

Class IV. Tetrandria, - four stamens (Galium, Plantago).

Class V. Pentandria, - ive stamens (Vitis, Conium).

Class VI. Hexandria, - six stamens (Lily, Tulip, Luzula).

Class VII. Heptandria, - seven stamens (Trientalis).

Class VIII. Octandria, - -ight stamens (Erica, CEnothera).

Class IX. Enveandria, - nine stamens (Rheum, Sassafras).

Class X. Decandria, - ten stamens (Dianthus, Rhododendron).

Class XI. Dodecandria, - twelve to nineteen stamens (Asarum).

Class XII. I Cos $A$ NDRIA, - twenty or more stamens, perigynous (Rosa).

Class XIII. Polyandria, - twenty or more stamens, hypogynous (Ranunculus, Papaver).

§ 2. The next TWo classes are founded on the relative length of the stamens, the flowers being perfect and stamens generally unconnected.

Class XIV. Didynamia, - four stamens, two long and two short, by pairs, as in Antirninum, Prunella.

Class XV. Tetradynamia, - six stamens, four long and two short, as in the wall-flower and the Cruciferæ generally.

$\S 3$. The NeXT FoUR Classes are determined by the connection or union of the stamens.

Class XVI. MonadelphiA, - stamens united by their filaments into one set, as in Malva, Geranium.

Class XVII. Diadelphia, - - stamens united by their flaments into two sets (Polygala, pea, Lathyrus).

Class XVIII. PolyadelPHIA, - stamens united by their filaments into three or more sets (Hypericum).

Class XIX. SrvgenesiA, stamens united by their anthers, as in the Asters and other Compositic.

$\S 4$. The next class DePends for its character upon the adhesion of the stamens with the pistil.

Class XX. Grinandria, - stamens and styles united, forming a column, as in Orchis, Asclepias.

$\S 5$. The NeXT turee classes include all plants with diclinous flowers, some with pistils, some with stamens only.

Class XXI. Movøera, - staminate and pistillate flowers, both upon the same plant (Pinus, Arum, Hazel).

Class XXII. DIOECIA, - staminate and pistillate flowers on separate plants (Willow, Hemp, Hop, Smilax).

Class XXIII. PoLYGaMis, - staminate, pistillate and perfect flowers either on the same or on different plants, as in Acer, Acacia, Veratrum).

§ 6. The LAST class includes flowerless planis. 
Class XXIV. CrYPTOGAMTA, - plants in which the organs of fructification are concealed (as the name implies) as in ferns, mosses, seaweeds.

878. The LinNeAN ORDERS. Each class is subdivided into orders, and these also are founded on some condition of the essential organs. The orders of the first thirteen classes are determined by the number of styles (or stigmas when the styles are wanting) in each flower.

\begin{tabular}{ll|lr} 
Order 1. Monogynia, & 1 style. & Order 7. Heptagynia, & 7 styles. \\
Order 2. Digynia, & 2 styles. & Order 8. Octogynia, & 8 styles. \\
Order 3. Trigynia, & 3 styles. & Order 9. Enneagynia, & 9 styles. \\
Order 4. Tetragynia, & 4 styles. & Order 10. Decagynia, & 10 styles. \\
Order 5. Pentagynia, & 5 styles. & Order 11. Dodecagynia, & 12 styles. \\
Order 6. Hexagynia, & 6 styles. & Order 12. Polygynia, more than 12.
\end{tabular}

879. THE ORDERS OF cLASS XIV. depend upon their seed vessels.

Order 1. Gymnospermia-Fruit four achenia, as in the Labiatæ.

Order 2. Angiospermia-Fruit inclosing several seeds.

880. THe ORDERS OF CLASS XV. also depend on the fruit.

Order 1. Siliculosa-Fruit a sillicle, as in pepper-grass.

Order 2. Siliquosa-Fruit a silique, as in wall-flower.

881. THE ORDERS OF CLASSES XVI., XVII., XVIII. aro distinguished by the number of stamens and named like the first classes.

Order 1. Triandria-three stamens united by their filaments.

Order 2. Pentandria - five stamens united by their filaments.

882. The orders of cLass XIX. are five, as follows:

Order 1. Equalis-Florets of the head all perfect $(\xi)$.

Order 2. Superflua-Florets of the disk $\Varangle$, of the ray $q$.

Order 3. Frustranəa-Florets of the disk $\Varangle$, ray abortife.

Order 4. Necessaria-Florets of the disk $\hat{\delta}$, of the ray $q$.

Order 5. Segregata-Each floret with a separate involucre.

883. The orders of CLASSES XX., XXI, XXII. distinguished in the same way as the first thirtcen, the XVI., XVII., XVIII. classes; as

Order 1. Monandria-one stamen. Order 2. Diandria-two stamens. Order 3. Triandria-three stamens, etc.

884. The ORDERS OF CLASS XXIII. are founded on the position of the flowers relatively, thus:

Order 1. Monœcia-Flowers $\xi, \hat{\delta}$, $q$ on the samo plant (Acacia).

Order 2. Diœcia-Flowers $\Varangle$ on one plant, $\hat{d},+$, on another (Chamerops).

Order 3. Triocia-Flowers $\Varangle, \hat{\delta}$, and $q$, each on separate plants.

885. THE ORDERS OF CLASS XXIV. are the same as in the Natural Sye tem, and can not be defined by a single character.

Order 1. Felices, ferns.

Order 2. Musci, mosses.

Order 3. Hepaticæ, liverworts
Order 4. Lichens, lichens.

Order 5. Fungi, mushrooms.

Order 6. Algæ, seaweeds. 


\section{CH A P T E R I I I.}

\section{THE NATURAL SY T T M.}

886. The aim of the Natural System is to associate plants into groups and families according to their true natural likenesses and affinities, and thus to make an expression, so far as possible, of the Divine plan in the System of Nature.

887. IT DIFFERS FROM THE ARTIFICIAL arrangement: while that employs only a single character in classification, the natural system regards the total organization, and seizes upon every character wherein plants agree or disagree, and forms her associations only upon the principle of natural affinity. Hence each member of any natural group resembles the others, and a fair description of one will serve, to a greater or less extent, for all the rest.

888. The species and genera are formed on this principle of classification, as above stated, and are truly natural associations. Individuals altogether similar, cast as it were in the same mold, constitute a species. Species agrecing in nearly all respects and differing but in few constitute a genus. Thence the genera, associated by their remaining affinities into groups of few or many, by this same method are organized into Natural Orders and other departments of the vegetable kingdom.

889. Relative value of characters. Although the natural method employs every character, yet it does not regard all of equal value or importance. As a rule, the higher the physiological importance of any organ, the higher will be the value of the characters which it affords.

890. BeCAuse, (1) the less will it be subject to variation, and (2) the more general in respect to other organs will be the resemblance of those plants which agree in respect to that organ. Thus, first in value are those characters drawn from the cellular tissue; second, from the vessels, the stomata, the embryo, and albumen;

- third, from the axis and leaves, the stamens, pistils, and firuit; fourth, from the perianth; fifth, from the inflorescence and bracts.

891. History of THE NATURAL METHOD. Its foundation was first laid 1682, by John Ray, of England. Ho separated the Flowering from the Flowerless plants, and divided the former into Dicotyledons and Monocotyledons. Linnæus, about 50 years later, constructed a fragment of the system, consisting of the names of 67 natural orders, without descriptions. But to Antoine de Jussieu is due the honor of the final establishment of this Method upon the true principles of natural affinity. He arranged the genera then known (A. D. 1780) into 100 natural orders, defining them with so much exactness, that nearly all have withstood the test of time; and have been adopted into our present systems. Robert Brown contributed largely to its completion and introduction into England, by the publication of his Flora of 
New Holland in 1810 ; and finally $\mathrm{D}_{\ominus}$ Candolle, by the publication of his great work "Prodromus Systematis Naturalis Regni Vegetabilis", commenced in 1816, and designed as the universal Flora, brought this system into general use.

892. MaNY systems. But the aim of the natural system as an expression of the Divine Order of Nature is not yet consummated. The lower divisions of the System - species, genera, and orders, - are well defined and settled as truly natural groups. The grand divisions also,-Cryptogamia, Phenogamous Exogens and Endogens (\$ 897), - are fully established. But in the midst, between these extremes, there is a region of uncertainty, respecting the arrangement of the orders into groups subordinate to the grand divisions, viz., into Classes and Subclasses. In this matter, authors have maintained different views, and proposed a variety of systems.

893. The Difficulty lies in this. Wo attempt necessarily a linear arrangement of the orders, placing one after another in succession, thus regarding the affinities $\alpha$ each in two directions only, viz., toward the preceding and the succeeding; whereas each order should be regarded as $n$ center of affinities; being related immediately to all others lying around it, as a province on a geographical map is related equally to all those which touch upon its borders. Hence any linear arraugement of the orders must be in some degreo artificial.

894. One natural system. Although there be but one truly natural system, yet while any portion of it remains imperfectly understood, so far authors may be expected to hold different views, and to attempt by different methods to express that true system. Still the discrepancies observed in the several "Natural Systems," proposed by different writers, are slight compared with the number and importance of the principles now common to them all and universally admitted.

895. The first and Highest division of the Vegetable Kingdom, viz., into the Phænogamia or Flowering Plants, and the Cryptogamia or Flowerless Plants, has already been noticed and defined. These grand divisions, or sub-kingdoms, lie at the foundation of both the systems of Linnæus and of Jussieu, and have in substance been adopted by every subsequent author. It is a division founded in nature, that is, marked by nature herself, for

The Phenogamia ( $\phi a i \nu \omega$, to appear, $\gamma$ '́mos, nuptials),

$a$, Consist of a regular axis of growth with leafy appendages,

$b$, They possess a woody and spiro-vascular structure,

$c$, They develop stamens aud pistils constituting flowers.

$d$, They produce seeds containing an embryo. On the other hand

The Cryptogamia ( $\kappa \rho \dot{\pi} \pi \tau \omega$, to conceal, $\gamma$ ú $\mu o s$ ).

$a$, Are generally destitute of a regular axis and of truo leares,

$b$, They possess mostly a cellular structure only,

$c$, They do not develop true flowers,

$d$, They produce spores having no embryo.

896. Natural Divisions indefinite. The above diagnosis does not mark the absolute limits between the two sub-kingdoms, for the higher Cryptogamia, as the mosses and ferns, give indications of approach to the Phænogamia, both in form and structure, while the lower Phænogamia can scarcely be said to produce flowers. And universally, so gradual is tho transition from group to group, that it is difficult 
or impossible to fix upon characters so definite as to circumscribe completely ang one group, while at the same time they exclude every member of the surrounding allied groups.

897. Skcond Division. The Flowering plants are next resolved into two great provinces, indubitably marked by nature's own hand, and em. ployed in every natural method. The following is their diagnosis.

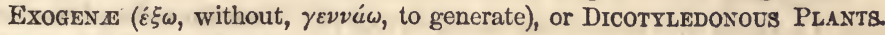

$a$, Growing by layers external to the wood, internal to the bark,

$b$, Leaves net-veined,

c, Flowers 4 or 5-parted, rarely 3-parted,

$d$, Seeds with two or more cotyledons, and

$e$, The radicle producing an axial root.

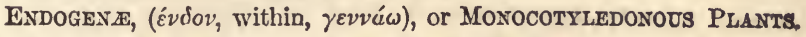

$a$, Growing by scattered internal wood-bundles,

$b$, Leaves parallel-veined,

c, Flowers very generally 3-parted,

$d$, Seeds with one cotyledon, and

$e$, The radicle never producing an axial root.

898. Third division;-Classes. The provinces are next broken into classes-groups of the third rank in extent. Two are constituted of the Exogens, viz. :

$\triangle$ NGIOSPERM $x$ ( $a \gamma \gamma \bar{\varepsilon} \iota n \varsigma$, a vessel, $\sigma \pi \dot{\varepsilon} \rho \mu a$, seed) (oak, rose).

$a$, Flowers more generally perfect or' complete,

$b$, Pistils complete, inclosing the ovules,

c, Seeds inclosed in a pericarp.

d, Embryo with only two cotyledons.

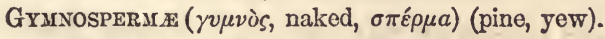

$a$, Flowers imperfect and incomplete,

$b$, Pistils scale-like, without a stigma,

$c$, Seeds truly naked, that is, destitute of a pericarp,

$d$, Embryo mostly with several whorled cotyledons.

Two classes are formed from the Endogens, viz.:

Petalifere ( $\pi \dot{\varepsilon} t a \lambda o v$, petal, $\phi \varepsilon ́ \rho \omega$, to bear).

Plants of the endogenous structure, with flowers constructed on the usual plan; perianth of one or more whorls of petaloid organs, or wanting (lily, Orchis, rush).

GLUMIFER (gluma, husk, fero, to bear).

Plants of the endogenous structure, the flowers invested with an imbricated perianth of glumes, instead of petals and sepals (grasses, grains, sedges).

899. Divisions of the cryptogamia. This sub-kingdom is naturally divided into two provinces, the Acrogens, and Thallogens,terms founded upon their mode of regetation. The former include those tribes which make some approximation towards the Phænogamia, the latter include the lowest tribes in the regetable kingdom.

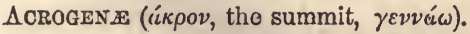

Flowerless plants having a regular stem or axis, which grows by the extension of the apex only, without increasing at all in diameter, generally 
with leaves, and composed of cellular tissue and scalariform ducts (Ferns, mosses, club-mosses, horsetails, etc.)

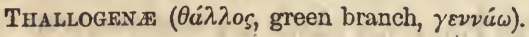

Flowerless plants producing in vegetation a thallus, with no distinction of stem and leaf, or root, and composed of cellular tissue only (Lichens, fungi, etc.)

900. Classes of the flowerless plants. For the sake of analogy and an advantageous comparison with the Phænogams, we may also regard these two provinces of the Cryptogams in the light of Classes founded upon their different modes of fruitbearing. Thus the Acrogens constitute the class

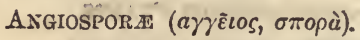

Acrogenous plants, producing their spores in sporangia (vessels) which burst when the spores are mature.

GYMNOSPOR $(\gamma v \mu \nu o ̀ s, \sigma \pi o \rho u)$.

Thallogenous plants reproduced by spores, which aro produced in parent cells, either forming a part of the vegetating thallus, or growing upon the surface of some definite region of the thallus.

901. Fourtu DIvision-conorTs. The six classes, as above constituted, are still each of great extent,-too great for the comprehension of the learner, or practical use. A further division is therefore necessary. To effect this on strictly natural principles botanists have labored hitherto in vain. The truth is, tho members of these several classes are united by affinities so equable as to render it impossible to subdivide, except by distinctions moro or less arbitrary. So adjacent territories, where rivers or other natural boundaries are wanting, must bo separated by artificial lines.

902. The ANGIOSPERMS ARE DIVIDED BY DE CANDOLLe, in his great descriptivo work "Prodromus Systematis Naturalis Regni Vegetabilis" into four sub-classes founded upon the conditions of the floral envelops, viz. :

1. Thalamiflorce, petals distinct, and (with the stamens) hypogynous.

2. Calyciflora, petals (with the stamens) perigynous.

3. Coroliiflora, petals united, hypogynous, stamens epipetalous.

4. Mfonochlamydece, petals wanting.

903. The Plan of Endlicher in his "Genera Plantarum" is more simple and convenient, and has been followed by American writers generally. He separates the Angiospermæ into three "cohorts," thus :

1. Dialypetalce ( $\delta \iota \lambda \nu \omega$, to dissolve). Exogenous plants, having both calyx and corolla, the latter composed of distinct petals (polypetalous), sometimes slightly cohering by the base of the stamens, rarely abortive.

2. Gamopetalce (yauós, union). Exogenous plants, having both calyx and corolla, the latter composed of petals more or less united.

3. Apetalce ( $\alpha$, privative). Exogenous plants with flowers having a calyx only, or neither calyx nor corolla (achlamydeous).

904. The class petalifera may be conveniently separated into two cohorts, as follows.

1. Spadiciflorce. Endogenous plants with flowers having no perianth, or a scaly one, and borne on a thickened spadix, which is often enveloped in a spatks. 
2. Floridece. Endogenous plants with the flowers usually perfect and complete, the perianth double, 3-parted, tho outer often and sometimes both green.

905. The Class GLUMIFEre is equivalent to the cohort Graminoidec, including the sedges, grains, and grasses-a truly natural assemblage.

906. The class angrospore consists of three cohorts defined as follows.

1. Sporogamia. Angiósporous plants, producing spores in which, when germinating, antheridial cells and archegonal, or ovulary bodies, are formed (Lycopodiaceæ, Isoetaceæ, Marsileaceæ).

2. Thallogamia. Angiosporous plants producing spores of one kind in sporanges on the surface of the leaf or stem, the spore germinating into a green prothallus (629) on which are developed antheridia and archegonia, the latter giving origin to a leafy embryo (Equisetaceæ, Filices).

3. Axogamia. Angiosporous plants producing antheridia and archegonia in the axils of the leaves or in buds, the fertilized archegonia giving birth to sporanges filled with spores, all reproducing the plant (Mosses, Hepaticæ, Characeæ).

907. The Class gymnospon $x$ consists of three cohorts, viz. :

1. Aerophyta. Thallogens growing and fructifying in the air, reproduced by spores formed in asci, and by green gonidia formed in the medullary layer of the thallus (Lichens).

2. Hysterophyta. Thallogens growing in or on decaying organic substances and fructifying in the open air, destitute of chlorophylle and starch, reproduced by spores formed in asci, by archegonal spores and by gonidea (Fungi).

3. Hydrophyta. Thallogens with a branching or foliaceous thallus; membranous, gelatinous, or cartilaginous in texture, containing either chlorophylle or a red coloring matter and often starch grains; growing in water, salt or fresh, or in moist substances in damp air (Algæ).

908. The Following Synoptical ARRANGement of the above divisions and subdivisions will exhibit at a glance the relative position and mutual relations of each.

\section{THE VEGETABLE KINGDOM.}

The sub-kingdom, Phanogamia, or Flowering Plants.

Province 1st. Exogence, or Dicotyledons.

Class I. Angiospermx.

Cohort 1. Dialypetalæ, or Polypetalæ.

Cohort 2. Gamopetalæ, or Monopetalæ.

Cohort 3. Apetalæ, or Monochlamydeæ.

Class II. Gymnospermæ.

Cohort 4. Conoideæ.

Province 2. Endogena, or Monocotyledons.

Class III. Petaliferæ, or Algumaceæ.

Cohort 5. Spadicifloræ (Aroideæ, etc.) 
Cohort 6. Florideæ (Liliaceæ, etc.).

Class IV. Glumiferæ, or Glumaceæ.

Cohort 7. Graminoidex (Sedges, grasses).

The sub.kingdom Cryptogamia, or Flowerless Plants.

Province 3. Acrogenoe.

Class V. Angiosporæ.

Cohort 8. Sporogamia (Marsilleacex, Lycopodiaceæ).

Cohort 9. Thallogamia (Filices, etc.).

Cohort 10. Axogamia (Mosses and Hepaticæ).

Province 4. Thallogence.

Class VI. Gymnosporæ.

Cohort 11. Aerophyta (Lichens).

Cohort 12. Hysterophyta (Fungi).

Cohort 13. Hydrophyta (Algæ).

\section{CH A P T R I V.}

\section{§ 1. NOMENCLATURE.-BOTANICAL ANALYSIS.}

909. THE NAMES OF the ORDERS are Latin adjectives (feminino, plural, to agreo with plantee, plants, understood), usually derived from the name of the most prominent, or leading genus, in each, by changing or prolonging the termination into acece, as Rosacea, the rose tribe, Papaveracea, the poppy tribe, from Rosa and $\mathrm{Pa}$ paver. Earlier names, however, derived from some leading character in the order, and with various terminations, are still retained. Thus, Compositce, with compound flowers; Labiata, with labiate flowers.

910. GENERIC NAMES are Latin substantives, arbitrarily formed, often from some medicinal virtue, either supposed or real, or from some obvious character of the genus; sometimes from the native country of the plants, or from tho name of some distinguished botanist, or patron of botany, to whom the genus is thus said to be dedicated. Also the ancient classic names, either Latin or Greek, aro often retained. Examples of all these modes of construction will be hereafter scen.

911. SPECIFIC NAMES are Latin adjectives, singular number, and agreeing in gender with the name of the genus to which they belong. They are mostly founded upon some distinctive character of the species; as Gerardia glauca, glaucousstemmed Gerardia; G. purpurea, purple-flowered Gerardia; G. tenuifolia, slenderleaved Gerardia. Frequently the species is named after somo other genus, which, in somo respect, it resembles; as Gerardia quercifolia, oak-leaved Gerardia. $G$. delphinifolia, larkspur-leaved Gerardia.

912. Commemorative specific names. Species, liko genera, aro also sometimes named in commemoration of distinguished persons. The rules given by Lindley, for the construction of such names, are, 1st. If the person is the discoverer, the specific name is a substantive in tho genitive case, singular number; as, Lobelia Kalmii, Kalm's Lobelia; Pinus Fraseri, Fraser's pine. 2d. If the namo is merely conferred in honor of the person to whom it is dedicated, it is an adjectivo ending 


\section{In nus, na, num; as Erica Linneana, Linnæus' heath; Rosa Lawrenciana, Miss}

Lawrence's rose.

913. RULES FOR THE USE OF CAPITALS. The names of the order, the sub-order or tribe, and of the genus should always commence with a capital letter. The name of the species should never commence with a capital except in the following cases; (1.) when it is derived from the name of a person or of a country, as Phlox Drummondii, Aquilegia Canadensis; (2.) when it is a substantive, as Delphinium Consolida.

914. Synonyus. Very frequently, the same species has been described by different (or even by the same) authors, under different names. In such cases it becomes a question, often of difficult solution, which name is to be adopted. Obviously, the prior name, that is, the original one, if it can be ascertained, is entitled to the most respect; and it is a rule with botanists to adopt this name, unless it had been previously occupied, or be strongly objectionable on some other account. All other names are synonyms.

915. BOTANICAL ANALYSIS. The application of the rules of Systematic Botany to the natural plant, in order to ascertain its affinities, place, name, \&c., is called botanical analysis. This exercise, whether for pleasure or improvement, is the constant pursuit of the practical botanist. A more accurate and useful knowledge of a plant can be acquired in a few minutes, by a careful examination of the living specimen, or even of the dried, than by committing to memory the most elaborate description found in books.

916. During the flowering months, the learner will often in his walks meet with plants in blossom, with which he is jet unacquainted. And he who is duly interested in his pursuit, will by no means fail to seize and analyze each specimen while the short hour of its bloom may last, and to store his memory with the knowledge of its names, habits, and uses. Thus, in a few seasons, or even in one, he will have grown familiar with nearly, or quite, every species of plants in his vicinity.

917. Jet us suppose the pupil in possession of a specimen of an unknown plant in full blossom. In order to study it by the aid of authors, a point immediately requisite is its name. Now, having learned by examination the organic and physiological structure of the flower, leaves, stem, etc., the experienced botanist, who has at his command the characters of all the Natural Orders, will at onco determine to which of them the plant belongs.

918. But this is not to bo expected of the pupil who is supposed to be yet, in a measure, unacquainted with the characters of the orders. He must be guided to the place which his specimen holds in the classification, by a longer course of inquiry and comparison. For the assistance of the learner, therefore, and for the convenience of all, we are happy to be able to add a full series of ANaLYTrcal TABLES, which, with proper use, will seldom fail of conducting them almost immediately to the object of their search.

919. The ANaLYTiCal TABLES which accompany the present edition of our Flora, are in many respects novel in form, and remarkable, at least, for their simplicity. $A$ dichotomal division, that is, of the whole into two parts, is the principle on which they are constructed; and since those divisions are, cach, characterized mainly by a single character, tho tables are technically artificial. But they are also natural to a considerable extent, at least so far as the divisions and sections which they mako are in accordance with the natural method. We subjoin a few examples of the analysis of particular species by the aid of these tables. If the exercise be conducted in the class-room, the successive steps in the process (indicated by the numbers, 1, 2, 3 , \&c., below) may be assigned, in order, to each pupil in the class. 


\section{-}

\section{ANALYSIS OF A POLYPETALOUS HERB.}

920. TO DETERMINe the CoHort. A good specimen of a little yellow-flowered herbaceous plant, common in the grassy fields of cool regions, is supposed to be now in the hands of each pupil of the class. (1.) The first pupil, reading (if necessary) the characteristic of each sub-kingdom, pronounces the plant one of the Phrnogamia, and refers the next pupil to the Provinces, 1 or 2.

(2.) The next reads the characters of those Provinces, and comparing the specimen (which has net-veined leaves and 5-merous flowers), concludes that it is an Exogen. Refer next to the Classes, 1 or 2.

(3.) "Flowers with stigmas, and pistils, \&c.

"Flowers with open scales instcad of pistils (or no pistils at all)," \&c. Our plant has pistils, \&c., and is (moreover, not a pine, spruce or cedar). It is, therefore an Angiosperm. Refer next to Cohort 1, 2, or 3 .

(4.) "Corolla with distinct petals." - This characterizes our plant, and it is pronounced "Polypetalous." Refer then to (A).

921. To Determive the Natural Order, tho (5th) pupil reads the first alterna. tive, or triplet, noted by a star (*), and comparing his plant, finds it to correspond with the first line, for it is an "herb with alternate leaves." Pass now to (11).

(6.) "Flowers regular or nearly so. Fruit never a legume."

"Flowers irregular," \&c. The flower is regular. Pass to (13).

Again a pupil reads :-

(7.) "Stamens 3-10 times as many as the petals."

"Stamens few and definite."-Tho stamens are many. Pass to (15). The next (8) pupil reads, compares, and determines that the stamens are "perigynous on the base of the calyx," and announces the letter (n) as the reference to the next alternative. (9.) Next, the pupil reads and compares his specimen with the triplet (d), and concludes that the sepals are 5. Refer then to the dash (-). (10.) Lastlythe pupil determines that the petals are imbricated in the bud, and consequently belongs to the Nat. Ord. ROSACEA.

922. To DETERMINe the Genus. After a careful comparison of his specimens with the brief diagnosis of the Roseworts (page 325), in order to verify the analysis thus far (11), the learner consults the Table of the Genera, and inquires the character of the carpels, styles, \&c., in order to learn the suborder of the plant. As the carpels are many, and free, he concludes that it is of the Suborder Rosex. Next learn its tribe. (12.) As the "carpels are 1-seeded in an open calyx," we infer that its tribe is Rosidere. Refer to f. (13.) Are the "styles persistent," etc., or "deciduous," etc.? They are deciduous; refer now to the dash (-). (14.) Inquire, "Calyx bractless ?" or "calyx bracteolate?" As the calyx is bracteolate (having five littlo leaves close to the calyx beneath, as if a double calyx), we refer again to the dash (-). (15.) "Receptacle pulpy" or "spongy," or "dry?" The latter is true, carrying us to the next dash (-). (16). Finally, aro the "stamens $\infty$," or " 5 ?" They are numerous, and Potextilla is the genus sought.

923. TO DETERMine THe SPECIES. Having compared the generic description of Potentilla witl our specimens, and assured ourselves of its agreement thereto, (17.) we next inquire, are the "leaves palmately 3-foliolate," "palmately 5-foliolate," or "pinnate?" They aro palmately 3 -foliolate, and our plant is now referable to tho 1st, $2 \mathrm{~d}$, or $3 \mathrm{~d}$ species. (18.) Lastly, the italicized words alone in the description of these species, at once mark our plant as belonging to the first, for it is hirsute, and the sepals exceed the petals. The name is, therefore, P. NorveGica. 


\section{ANALYSIS OF A POLYPETALOUS SHRUB.}

924. Again, suppose the class of pupils in botany to be furnished with specimens of a certain flowering shrub. The cohort of the plant is ascertained, by the process already noticed, to be Dialypetalx, the Polypetalous flowers (A), and we refer to the $(*)$, reading:-

"* Herbs with the leaves alternate or all radical.

" Herbs with the leaves opposite on the stem.

"* Shrubs, trees or undershrubs."-It is decided that our plant is a shrub, and referred to the dash (-). We next read:-

"- Flowers regular or nearly so.

" - Flowers irregular (or the fruit a legume)."-The flowers are quite regular, and referred to (2). We then read:-

"Polyandrous," \&c. "Oligandrous," \&c.-The stamens are numerous, and the plant referred to (3), where we again read :-

"Leaves opposite." "Leares alternate."-They are opposite, and we refer to the letter (s), and read:-

"Stamens on the receptacle, in several sets." "Stamens on the calyx." -The latter is true. Refor to the dash (-). Lastly:-

" - Leaves with a marginal vein." "- Leaves with no marginal vein."-As the latter is true of our specimens, we conclude it to belong to the Order SaxifraGaces, and thither next refer, in order

925. To DETERMne the Gexus. After reading and comparing as before, we read the characters of the tribes; and as our specimens are "shrubs with opposite leaves," we readily conclude that it belongs to the Tribe Hydrangex. We next read:- "Corella valvate in the bud." "Corolla convolute in the bud."-It is the latter. Refer the next reader to the dash (-); "Stamens 20 to 40. Petals 4." "Stamens 10. Petals 5."-In our specimens there are 20 or more stamens with 4 petals, and they must be referred to the Genus Philadelphus. Next turn to that genus and compare characters.

926. The species is next found summarily by the italicized diagnosis in the descriptions, thus :-

"Leaves entire. Sepals scarce longer than the tube.

"Leaves sharply denticulate. Styles united.

"Leaves subdentate. Styles distinct."-Our specimens agrec well with the $2 \mathrm{~d}$, and we conclude that the species for which we have sought is P. grandiflorus, a fine flowering shrub, native of woods in tho Southern States, and also cultivated in shrubberies.

\section{ANALYSIS OF AN APETALOUS HERB.}

927. Specimens of a weed common in cultivated grounds are now supposed to be before us. It has small, homely flowers, not easily discernible except under a lens. As the leaves are net-veined, and the flowers 5-parted, with a calyx only, the learner readily pronounces it a member of the Cohort APETALE, and refers us to (C). The two lines marked with the paragraph (\$i), although placed (for obvious reasons) at some distance apart, are to be read together, thus :-

" " Plants herbaceous, the flowers not in aments."

" IT Plants woody, shrubs or trees."-Our plant is an herb. Refer to the two lines marked with a star (2).

" 2 Flowers with a regular calyx, or a calyx-like involucre. 
" 2 Flowers achlamydeous, - with neither calyx nor corolla."-Our specimens have a regular calyx. Refer to the lines marked (3). .

"Calyx tube adherent to the ovary, limb lobed or toothed.

"Calyx free from the ovary, sometimes enclosing it."-The latter. Refer to the five lines nalked (4). The $3 \mathrm{~d}$ of these lines reads, "Ovary one, 1-3-ovuled, with 2-5 styles or stigmas." Our woed, having a 1-ovuled, 2-styled ovary, well agrees with this description. Refer to (c).

"Fruit 3 seeded, with 3 (often cleft) stigmas."

"Fruit l-seeded."-It is the latter, and refers us, next, to the dish (-).

- Stipules sheathing the stem."

- Stipules none. Calyx scarious-bracteolate."

- Stipules none. Calyx naked. Leaves alternate."

- Stipules none. Calyx naked. Leaves opposite."-In our specimens, the stipules are wanting, bracteoles are wanting, and the leaves are alternate. Hence they belong to Chenopodiacez. We turn and consult that order, as before, to verify our analysis thus far, and to learn the genus.

928. To ascertain the suborder, we must examine the embryo contained in the little shining black seed. By a good lens (or even with good eyes), we learn that the embryo is not coiled, but merely bent into a ring. The leaves also, are thin (not fleshy) and expanded. Hence its suborder is Cyclolobeæ. Refer to the starred (*) lines and determine the tribe. As the inflorescence is normal (that is, of the usual form, or nothing unusual), with perfect flowers and continuous (not jointed) stems, we conclude that it belongs to Tribe Chenopodiex. Refer to (c). As the seed (or the plane of its ring) is horizontal, the pericarp thin and the calyx not bordered we decide that its genus is Cuenopodium.

The species remains now to be determined. We first read:-

"Plant smooth, never glandular, ill-scented. Embryo a complete ring."

"Plant glandular-puberulent, green, aromatic. Embryo half a ring." The latter character applies to our plant. Read the starred (*) lines, respecting the herbage, whether green or glaucous, \&c. It is glaucous in our plant, and covered with mealiness. Refer to species 5-7. Seeing, next, the italicized diagnosis, we finally determine that the species sought is No. 6. C. ALBUM; for the leaves are rhombic-ovate, sinuate-toothed, etc., etc.

\section{ANALYSIS OF AN ENDOGEN.}

929. A grass-like, yellow-flowered piant is now supposed to be found and furnished to the pupils for analysis. Having determined that it is an Endogen (for it has parallel-veined leaves and 3-parted flowers), the pupils next seek

930. TO DETERMINE ITS Class, whether the $3 \mathrm{~d}$ or 4 th. They read the diagnosis of these clases, as follows:-

"CLASS 3d. Flowers with no glumes."

"CLASS 4th. Flowers with greenish, alternate glumes," \&c. The flowers of our plant have no glumes, but a regular perianth. It is, therefore, decided to be one of the Petaliferz, or Class $3 \mathrm{~d}$. Refer to Coliorts 5 and 6 , and the next pupil reads:-

"Cohort 5. Flowers on a spadix, apetalous or incomplete."

"Cohort 6. Flowers complete, with a double perianth." The latter is true of our plant, and it therefore belongs to the cohort of the FLORIDEs. Next refer the pupil to (T), on page 197, in order

931. To Determine the NatUral Order. IIo reads:- 
" Tl Flowers (not on a spadix) in a dense, involucrate head."

"T Flowers (not on a spadix) solitary, racemed, spicate, \&c." The latter is true here. Refer to (3).

"3 Perianth tube adherent to the ovary, wholly or partly."

"3 Perianth free from the ovary." It is adlierent. Refer to (*5). The next pupil rcads:-

"* 5 Flowers diceious or polygamous. Low aquatic herbs."

"* 5 Flowers diœcious, 6-androus. Shrubby climbers."

"* Flowers perfect." The last is true of our specimens. Refer to the dash (-), and read, "- Gynandrous."

"- Monandrous."

"-3-6-androus." It is 6-androus. Refer the next pupil to (6).

"6 Perianth woolly or mealy out-side."

"6 Perianth glabrous out-side." The latter applies to our specimens. Refer to the dash (-). "-

"- Stamens 3, anthers extrorse."

"- Stamens 6." The last is true of our plant. It must, therefore,

belong to the Nat. Ord. Amaryllidacese. Turn to that order, and

932. Determine tae Genus by the table, page 692, thus:

1st. The perianth being "destitute of a crown," refers to **.

$2 d$. The segments being "distinct down to the ovary," etc., refers to $b$.

3d. The "perianth regular," directs to the -

Lastly, The "sepals and petals equal," etc., indicates that our plant belongs to the genus Hypoxis.

\section{ANALYSIS OF A GRASS.}

Having determined that this elegant and common grass is an Endogen (for its leaves are parallel-veined), and that it is a member of the 7th Cohort, the Graminoids, the pupil refers to $G$, and at once perceives, from its hollow culm, split sheaths, \&c., that it is of the 156th Order, Gramineæ. He turns to that Order, and by the several successive steps in the table determines the genus, thus:-

First as to the spikelets, since each one is " $2-\infty$-flowered (as seen in fig. 727 ), with several perfect flowers," he refers to 9.

Second, he determines the inflorescence to be "in panicles," and next refers to 10. Third, as to the awn, he concludes that the "pale is awnless," and refers to na.

Then as to the glumes, he observes that there aro "definitely 2" (as in fig. 7, $a, a$ ), and refers to $\boldsymbol{0}$.

Fifhly, as the pales are "not at all awned," he refers to $\mathbf{s}$.

Next, as to the flowers, he observes that there are several, about 4 or 5 , in each spikelet, and all perfect; therefore, refers to $\boldsymbol{w}$.

Seventh. Of the five lines in this set, he selects the second as best describing his specimen, viz., the "lower pale keeled, 5-veined." Therefore it belongs to tho genus Poa. Then we turn to genus 40 , and determine the species, thus :-

1. As to the "branches of the panicle" they are "about in 5s, half-whorled." Pass to $\mathbf{b}$.

2. The "spikelets" being " 3 to 5 -flowered, subsessile, in rathar dense panicles," we refer to species 13,14 .

Lastly, the "smooth stem," and short, truncate ligules of this specimen prove it to be Poa pratensis, or Spear Grass. 


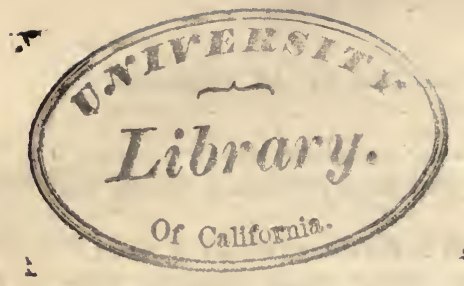

\section{INDEX AND GLOSSARY.}

A (a, privative), prefixed to a Greek word signifies without, as aphyllous, without leaves.

Abbreviations, page, 189.

Abortion, nondevelopment of a part.

Absorption, 770, 775, 791.

Acauléscent, apparently stemless, 169.

Accessory, something superadded.

Accrescnt, growing after flowering.

Accumbent, lying against a thing, 599.

Ácerose, needle-shaped, 277.

Achénium, plural, achenia, 556.

Achlamydoous, without floral envelopes.

Acícular, finely needle-shaped.

Acotylèdonous, without cotyledons. .

Ácrogens, summit-growers, 899.

Acúleate, armed with prickles.

Acuminate, drawn out into a point, 283. Acute, ending in a sharp angle, 283.

Adherent, growing to, 466 .

Adnate, growing fast to, 495 .

Adventitious, growing out of the usual or normal position, as roots, 134.

Aeràtion, same as Respiration, 815. Aeróphyta, includes the Tichens, 907 .

Astivation, 383.

Affinity, resemblance in essential organs. Age of trees, 97.

Aggregate, assembled close together.

Aglumaceous, without glumes, the same as Petaliferæ, 898.

Agricultural Chemistry, 834.

Air bladders, 311.

Air cells or vessels, 790 .

Air plants, 841 .

Ala, wing; Alæ, wings, 474.

Albùmen, 590. Albùminous, 589.

Albúrnum, sap-wood, 697.

Algæ, sea-weeds, 907. Fig. 545-550.

Altérnate, 222.

Altérnate generation, 634 .

Alvèolate, with pits like the honey-comb. Ament, a deciduous spike, 348.

Ammonia, 839.

Amorphous, without definite form.

Amphigástria, 626.

Amphítropous, 539.

Amplexicaul, stem•clasping, 245.

Analysis, Botanical, 915.
Analytical tables explained, 919.

Anastomòsis, union of vessels or veins.

Anátropous, 537.

Ancípital, two-edged.

Androecium, 491.

Andrógenous, stamens and pistils on the same peduncle.

Angiospérmæ, angiosperms, 898.

Angiospores, 900.

Aunual, yearly, 89 .

Annular cells, 652.

Anterior, parts (of a flower) adjacent to the bract.

Anthelmíntic, expelling or killing worms. Anther, 494.

Anthésis, the opening of the flower; flowering.

Antherídia, 629.

Apetalæ, 903. Apetalous, without petals.

Aphyllous, without leaves.

Apóphysis, a swelling: e. $g$ monder tho thecæ of some Mosses.

Apothecia, 631.

Appendícular organs, 433.

Appréssed, closely applied but not adhering to; the same as adpressed.

Ápterous, without wings.

Aquátic, living in water.

Aráchnoid, resembling cobwebs.

Arbòreous, arborescent, tree-like.

Archegònia, 629.

Arcuate, arched or curved like a bow.

Áreolate, having the surface divided into little spaces or areas.

Aril, an extra seed-covering, 586.

Aristate, with an arista or awn (barley).

Armed, bearing prickles, spines, etc.

Articulated, jointed, as the culm of wheat.

Artificial classes, 877.

Artificial orders, 878.

Ascending, arising obliquely; assurgent.

Ascídia, leaves holding water, 308.

Attenuate, becoming slender or thin.

Auriculate, ear-bearing, 267.

Awn, the beard of barley, and tho likc.

Axial root, 122:

Axil (arm-pit), tho angle between the petiole and the branch on the upper side. 
Axillary, growing out of the axils.

Axis, ascending, 146, 148; erect, 148; procumbent, prostrate, trailing, decumbent, 148 ; excurrent, 173 ; solvent, 174; descending, 114.

Baccate, berry-like; covered with pulp. Banner, same as Vexillum, 474.

Banyan tree, 137.

Baòbab tree, 100.

Bark, 700.

Basidia, 631. Fig. 539.

Básilar, basal, attached to the base.

Bast cells, wood-cells of bark, 701.

Beaked, ending in an extended tip.

Bearded, with tufts of long, weak hairs.

Berry, 566.

$\mathrm{Bi}$, Bis, twice (in compound words).

Bícolor, two-colored.

Bicuspidate, with two points or cusps.

Bidentate, with two teeth.

Biénnial, of two years, 90 .

Bifid, cleft into two parts.

Bífoliate, with two leaflets.

Bifúrcate, twice forked, or merely forked.

Bílábiate, two-lipper.

Binate, 288.

Bipinnate, 289.

Bipinnatifid, twice pinnatifid. Fig. 142.

Biternate, twice ternate, 291.

Bívalved, two-valved.

Blade. See Lamina, 239.

Blanched (plants), whitened for the want of light, 820. See Etiolated.

Bloom, a fine, white powder on some plants.

Botany defined, 38.

Botany, elementary, 40.

Botany, physiological, 41, 636.

Botany, systematic, $42,858$.

Bráchiate, with opposite, branches (arms).

Bract, 319, 333.

Bracteate, having bracts.

Bracteoles, or bractlets, 333.

Branches, 107, 152.

Bristles, stiff, sharp hairs.

Bryólogy, the science of Mosses.

Bud, 105. Budding, 215.

Buds axillary, 202; accessory, 206.

Buds, adventitious, 207.

Buds, suppression of, 205.

Bud-scales, 197, 305.

Bulb, 191; tunicated, 193; scaly, 193.

Bulblets, 216.

Caducous, dropping off early.

Calycifilòræ, 902.

Cæspitous, forming tufts or turf.

Calceolate, slipper-shaped.

Cálycine, calyx-like.
Calyculate, having an outer calyx or calyxlike involucre.

Calyptra, the hood of the sporange (cap. sule) of a moss. Fig. 514, 519.

Calyx, the outer floral envelope, 400.

Cambium, 709.

Campanulate, bell-shaped, 477 .

Campylótropous, 533.

Canalículate, channeled.

Canescent, grayish white.

Cápillary, capillaceous, hair-shaped.

Capitate, head-shaped, growing in close clusters, or heads.

Capitulum, a little head, 354.

Cápreolate, bearing tendrils.

Capsule, 576.

Carbon, 830. Carbonic Acid, 825.

Carìna, 474. Carinate, boat-shaped, having a sharp ridge beneath.

Carpel, carpellary, 516.

Cárpophore, 553, 557. Fìg. 432.

Cartiláginous, firm and tough in texture.

Caruncle, 586.

Caryophyllaceous, 472 .

Caryopsis, 560.

Catkin, 348. Seo Ament.

Caudex, 176.

Caulescent, 169. Caulis, 169.

Cauline, relating to the stem.

Cellular tissue, 664. Cell, 639.

Cell-growth, 752; life, 743.

Cellular bark, 702 .

Céllulose, 654, 744.

Centrífugal inflorescence, 343.

Centrípetal inflorescence, 342.

Cephalous, same as Capitate.

Cereal, relating to grains, corn, etc.

Cernuous, nodding (less inclined than pendulous).

spreading Chaff, chaffy. See Paleaceous.

Chalaza, 535.

Chanueled, hollowed out like a gutter.

Characters, relative value of, 899 .

Chartàceous, with the texture of paper.

Chlòrophylle, 657, 733, 747.

Chorisis, 432.

Ciliate, fringed with marginal hairs.

Ciénchyma, 671.

Cion or Scion, 158.

Cinereous, ash gray, ash-color.

Circinate, rolled inward from the top, 213.

Circulation of the sap, 748.

Circumscíssiie, 552.

Cirrhous, furnished with a tendril.

Cirrhous roots, 135 .

Classes, artificial, 877 , etc.

Classes, natural, 898.

Classification, artificial, 873.

Clavate, club-shaped.

Coárctate, contracted, drawn together. 
Coccus, a berry. Also (in the pl. cocci) the 1-seeded carpels of separable fruits. Cóchleate, spiral like the snail-shell.

Cohesion, 438.

Cohorts, 901.

Collateral, placed side by side.

Collum, 118.

Color of flowers, 369.

Colored, of any color except green, which in botany is not a color, while white is.

Column, the combined stamens and styles.

Coma, 585.

Cómmissure, the joined faces of the carpels of the cremocarp.

Common, belonging alike to several.

Complete flower, 412.

Complicate, folded up upon itself.

Compound leaf, 285.

Compound flower, 355.

Compressed, flattened on the sides.

Conceptacle, 631 .

Conduplicate, folded on itself lengthwise.

Cone, 578, 579.

Confluent, uniting, same as Coherent.

Conglomerate, clustered or crowded.

Cónjugate, coupled, joined by pairs.

Connate, 294.

Connéctile, connective, 494, 498.

Connivent, converging, coming together.

Continuous, the reverse of Jointed.

Contorted, twisted, 389.

Convolute, 393.

Cordate, heart-shaped, 267.

Coriaceous, leather-like, 295.

Corm, 189.

Córneous, horn-like in texture.

Corniculate, with a small horn or spur.

Corolla, 401. Corollifloræ, 902.

Córolline, pertaining to the corolla.

Coròna, crown, 435, 407.

Cortical bark, 703 .

Còrymb, corymbous, 350 .

Costate, ribbed, with rib-like ridges.

Cotyledons, 306, 594.

Crassula (a genus of plants), 415 .

Cratériform, of the form of a goblet.

Creeper, creeping stems, 181.

Cremocarp, 557.

Crenate, bordered with rounded teeth.

Crenulate, 279.

Crested or cristate, with an elevated ridge.

Crispate or Crisped, 282.

Crown of the root, 186.

Cruciform (corolla), 470.

Crude sap, 794.

Crustaceous, hard, thin and brittlo.

Cryptogamia, cryptogams, 621, 895.

Cucullate, rolled up into a hood-shape.

Culm, the straw of grasses, 170.

- Cuneate, cuneiform, wedge-shaped, 266.
Cúpule, a little cup (sc. acorn), 562.

Cúspidate, with a sharp, stiff point.

Cuticle, 680.

Cyánic, 370.

Cyáthiform, cup-shaped.

Cycle (in Phyllotaxy), 228.

Cyclòsis, same as Rotation, 807.

Cyme, cymous, 357.

Cymbiform, boat-shaped.

Cypsela, 557.

Cytoblast, 655.

Deca, (in Greek composition), ten.

Deciduous, falling at the end of the season.

Déclinate, bent downwards.

Decompound, much compounded or divided.

Decumbent, 148. Fig. 39.

Decurrent, 244, 286.

Decussate (leaves), 227.

Définite, 503.

Deflexed, bent downward.

Defoliation, the casting off of leaves.

Dehíscence, 496.

Deliquéscent (axis), same as Solvent, 174.

Deltoid, form of the Greek letter $\Delta, 265$.

Dendroid, tree-like in form.

Dendron (in Greek compounds), a tree.

Dentate, 279. Denticulate, 279.

Denuded, become naked.

Depauperate, less developed than usual.

Dependent, hanging down.

Depressed, flattened from above; low.

Dextrine, 762 .

Dextrórse (twining), turning to the right. Fig. 50.

Di (in Greek numerals), two.

Diadelphous, 506.

Diagnósis, a brief statement of the distinctive character of a plant or group.

Dialypetalous, Polypetalous, 903.

Diaphanous, transparent or translucent.

Diandrous, with two stamens, 503.

Díastase, 762.

Dichotomous, forked or two-forked.

Diclinous, 421.

Dicotyledons, Dicotyledonous, 421.

Dictyogens, 727.

Dídymous, double.

Didynamous, Didynamia, 877, § 2 .

Digitate, with several distinct leafets palmately arranged (as in the leaf of the Horse-chestnut).

Diffuse, much divided and spreading.

Dimidiate (anther), halved, 499.

Diœcia, diœcious, 877, §5.

Dipterous, having two wings.

Dischidia, 310.

Disk, 446. Discoid, no rays. Fig. 211.

Dissected, cut into deep lobes.

Dissepiment, 525. 
Distichous, arranged in two rows.

Distinct, separate, not united.

Divaricate, wide-spread, straggling.

Divergent, spreading with a less angle.

Dorsal, on or relating to the back.

Double terms, 301.

Downy, clothed with short, weak hairs.

Drupe, 563. Drupaceous. See Tryma.

Ducts. See Trachenchyma, 668.

Duplicate, in pairs, double.

Duramen, heart-wood, 698.

Dwarfing, 140.

E, ex (in composition), without; as,

Ebracteate, without bracts.

Earthy eiements, 832.

Echinate, prickly with rigid hairs.

Effete, sterile, exhausted.

Elaters, spiral, elastic threads accompanying certain spores. Fig. 506.

Elliptic, elliptical (leaf), 265, a.

Elóngated, lengthened, extended.

Emarginate, 284.

Embryo, 591, 103.

Embryonic vesicle, 754.

Endocarp, 563.

Endochrome, the coloring matter of plants. See Chlorophylle.

Endógenous structure, 713.

Indogens, 70, 897.

Endopleùra, same as Tegmen, 583.

Éndospores, 631.

Linsiform, sword-shaped, 275.

Lntire, even-edged, 278.

Ephemeral, enduring for ono day.

Epi (in Greek composition), upon; as,

Epicarp, 563.

Epidermis, 676.

Epígynous, upon the ovary, 465, 504.

Epipetalous, on the petals, 504.

Epíphytes, plants on other plants, 143.

Episperm, the skin of the seed.

Equitant (astraddle), 214.

Erose, eroded, as if gnawed, 281.

Etærio, 565.

Etiolated, colorless for want of light.

Exalbuminors, without albumen.

Excúrrent, 173.

Exogenæ, Exogens, 69, 897.

Exogenous structure, 691.

Exosmose, flowing out, 781.

Exospores, 631.

Exserted, projecting out of, or beyond.

Extra (in composition), beyond; as,

Extra-axillary, same as supra-axillary.

Exstipulate, without stipules, 240.

Extra Flour (of wlieat), 750.

Extrórse, turned outward, 497.

Falcate, scythe-shaped, curved.

Farinàceous, flour-like in texture.
Fárinous, mealy on the surface.

Fascicle (a bundle), 361.

Fasciculate (leaves), 222.

Feather-veined, 259.

Ferruginous, of $n$ e color of iron rust.

Fertile (flower', seed-producing, 421.

Fertilization, $: 51$, etc.

Fibríllæ, fibrils, 119, 724.

Filament, the stalk of a stamen, 493.

Filiform, slender like a thread.

Fimbriate, fringed, having the edge bordered with slender processes.

Fistular, hollow, as the leaf of onion.

Flabelliform, fan-shaped, 276.

Flagelliform, whip-shaped; long, taper and supple.

Flavescent, yellowish, turning yellow.

Flexuous, zig-zag, or wavy.

Floccous, with hairs in soft fleecy tufts.

Flora, (a) the spontaneous vegetation of a country; (b) a written description of the same.

Floral, relating to flowers.

Floral calendar, 366.

Floral clock, 368.

Floral envelopes, 399

Florets, the flowers of a compound flower. 355.

Flower, 372 , etc. ; origin of, 110.

Flower, the standard of beauty, 372 .

Flowering, 364.

Flower-bud, 195, 374, etc.

Foliaceous, leaf-like in texture or form.

Foliation, the act of leafing.

Follicle, 571.

Food of plants, 835 .

Foràmen, same as Micropyle, 535.

Forms, accommodated, 17.

Forms, arrested, 21.

Forms, graduated, 14.

Forms, typical, 11.

Free, not adherent nor adnate, 462 .

Fringed. See Fimbriate.

Frond, an organ which is both stem and leaf, as in duck-meat, fern, 626.

Frondescent, bursting into leaf.

Fructification, flower and fruit as a whole.

Fruit, 112, 541; growth of, 765.

Fruit, ripening of, 766 .

Frutescent, shrubby, becoming shrubby.

Fulcra (roots), 136.

Fulíginous, smoky brown, blackish.

Fulvous, dull yellowish brown.

Funiculus (a little rope), 535.

Funnel-form. See Irfundibuliform.

Furcate, forked.

Furfuràceous, scurfy.

Furrowed, marked with channels lengthwise.

Fuscous, grayish or blackish brown.

Fusiform, spindle-shaped, 127. 
Galea, galeate, 483.

Gamopetalæ, monopetalæ, 903.

Gamopetalous, with the petals united.

Gamophyllous, of united leaves.

Gamosepalous, with the sepals united.

Geminate, twin, two together.

Gemmation, state of budding (Latin, gemma, bud).

Genículate, bent as the knee (genu).

Genus, 80. Genera, 888.

Germ, the ovary (obsolete).

Germination, 608, 761.

Gibbous, more tumid in a certain place.

Glabrous, smooth or not hairy, 296.

Gladiate, sword-shaped, ensiform.

Gland, glandular, 682.

Glans, 562.

Glaucous, sea-green, bluish, usually with a bloom or whitish powder.

Globous, in form nearly spherical.

Glomerate, collected into close heads.

Glómerule, 362.

Glossólogy, the same as Terminology.

Glumes, 339, 459.

Glumiferæ, 898.

Gluten, 750.

Gonídia, 635.

Granular, composed of grains.

Grafting, 158.

Graminoidex, 905 .

Grand Divisions, 65 .

Growth is downwards, 799.

Gymnos (a Greek prefix), naked; as,

Gymnospermous, with naked seeds.

Gymnospermæ, gymnosperms, 898.

Gymnosporæ, gymnospores, 900 .

Gynandrous, 504.

Gynœcium, 405.

Gynobase, a process of the torus on and around which the carpels are suspended; sc. Geranium, Fig. 428.

Gynophore, a produced torus bearing the ovary on its summit. Fig. 290.

Gyrate, same as Circinate, 213.

Gyrous, strongly bent to and fro.

Habit, the general aspect of a plant.

Habitat, the natural locality, or place of growth of a wild plant.

Hairs, 681. Hairy, liirsute.

Halbert-shaped, hastate. Fig. 155, $l$.

Halved, one haif apparently deficient.

Hastate, with tho base lobes abruptly spreading, as in a halbert. Fig. 155, l.

Hcart-shaped. Fig.155, p. Heart-wood, 697.

Herb, herbaceous, 89, 90.

Herbaceous, grcen and cellular in texture.

Herbarium, 54.

Hesperídium, 567.
Hermaphrodite (flower), with both stamens and pistils.

Heterocéphalous, heads of two sorts in the same plant, some $\hat{\delta}$ and some $q$.

Heterógamous, two sorts of flowers in the same head, some $\hat{\delta}$ and some $q$.

Hexa (Greek numeral), six; as in,

Hexagonal, 6-sided. Hexamerous, 6parted.

Hexandrous, 6-stamened. Hexandria, $877, \S 1$.

Hilum, 537, 588.

Hirsute, hairy with rather long hairs.

Hispid, bristly with stiff hairs, 298 .

Hoary, frost-colored, grayish-white.

Homógamous, head with all the flowers alike, as to the stamens and pistils.

Honey, 767. Honey-bee, 768.

Hooded. See Cucullate.

Horny, of the texture of horn.

Hortus siccus, herbarium, 54.

Humifuse, spreading on the ground.

Hyaline, transparent or nearly so.

Hybrid, a cross-breed between two species.

Hydrogen, 831.

Hydróphyta, 907.

Hyménium, 631.

Hyperborean, inhabiting northern regions. Hypo (in Greek compounds), under; as, Hypocrateriform, salver-form, 480. Fig. 322.

Hypogèan, growing under ground.

Hypogynous, 463, 504.

Hysteróphyta, 907.

Icosandria, 877, Class XII.

Imbricate, imbricated, 390.

Immarginate, having no rim or border.

Immersed. See Submersed.

Inaxial root, 123.

Incised, divided deeply as if cut.

Included, inclosed within, or shorter than; as the stamens in the corolla tube.

Incrassate, thickened.

Incumbent, sc. embryo, 599.

Indehiscent, not opening, 549 .

Indigenous, native of a country.

Induplicate, 388.

Indusium, the shield of the fruit-dot (sorus) of a fern. Fig. 500, 501.

Inferior, lower in position, 465 .

Inflorescence, 320 .

Infundibuliform, funnel-shaped, 479.

Innate (sc. anther), 495.

Innovations, 635.

Inserted, Insertion, refer to the point of junction or apparent origin.

Integument, a coat or covering.

Internode, 161. 
Interruptedly pinnate, 287. Fig. 159. Intrórse (anthers), turned inward, 497. Involùcre, 337.

Involute, rolled inward, 213. Fig. 81. Irregular flowers, 441.

Jointed, having joints, separable pieces.

Jugum, a pair; as, bijugous, with two pairs of leaflets; trijugous, three pairs.

Keel, Keeled. See Carinate.

Kidney-shaped. See Reniform, 271.

Kingdoms of Nature, 31-33.

Labéllum, the odd petal of an orchid, 484.

Labiate, lip-shaped, 483.

Lacerate, torn irregularly by deep incisions.

Laciniate, slashed, with deep incisions.

Lactescent, containing lac, or milk.

Lacunous, with large depressions or pits.

Lacustrine, growing in lakes.

Lamina, the blade of a leaf, 453.

Lanceolate, lance-shaped. Fig. 116.

Lanuginous, woolly, 297.

Latex, the turbid or milky juice of plants.

Laticiferous tissue. Seo Cienchyma, 671.

Latin names of plants, 75.

Layer. See Stolon, 157.

Leaf, 217, etc.; structure of, 729.

Leaf-bud, 195, etc.

Leaflet, the pieces of a compound leaf.

Leaf-stems, 166.

Legume, 572.

Lenticulate, shaped like a double convex lens.

Iiber, the inner bark, 701.

Lichens. Fig. 530-536. Seo Aërophyta, 907.

Ligneous system, 685 .

Ligulate, strap-shaped, 482.

Ligule, the stipules of grasses, 251.

Liliaceous flower, 473.

Limb, the border, 453.

Linear, long and narrow, 275.

Livid, clouded with bluish, brown, and gray.

Lobate, lobed, 270.

Loculicidal, opening into tho cell, 550 .

Locústa, a spikelet of the grasses.

Loment, a jointed legume, 573 .

Lorate, thong-shaped.

Lunate, crescent-shaped.

Lyrate, pinnatifid with the upper lobes mnch larger than the lower.

Macros (in Greek compounds), long or large.

Maculate, spotted or blotched.

Mangrove tree, 138.

Male (flowers), same as Staminate.
Marcescent, withering, but persistent.

Marginal, belonging to the border.

Marginate, having the border different.

Medúlla, pith. Medullary rays, 705.

Médullary sheath, 693.

Membranaceous, membranous, thin and pellucid.

Mericarp, one of the carpels of a cremocarp of an Umbilifer, 557.

Micropyle, 535 ; same as Fdramen.

Microscope, 60.

Midrib, the central vein of a leaf.

Midvein (used in this work), 256.

Mítriform, formed like a conical cap.

Monos (in Greek compounds), one only; as,

Monadelphous, 506.

Monandrous, one-stamened, 503.

Moniliform (roots), 132.

Monocarpic herbs, 91.

Monochlamydeæ, 902.

Monochlamydeous (flowers), 420.

Monocotylè donous, 596, 897.

Monœcious, 877 , 5 .

Monógynous, with one style, 513.

Monopetalæ. See Gamopetalæ, 903.

Monopetalous, 458, 459.

Monophyllous, one-leaved.

Monosepalous, 458, 459 .

Monstrous flowers, 380.

Morphology, 39; of the flower, 372.

Morphology of the leaf, 239.

Mucro, a sharp, small, abrupt point.

Mucronate, 283.

Multi (in composition), many.

Multifid, cut half-way into many segments.

Muricate, bearing short, hard points.

Muriform, like a wall of mason-work.

Muscology, a treatise on mosses.

Muticous, pointless, not pointed.

Mycelium, 628.

Naked seeds, 548.

Napiform (root), 28.

Natant, swimming; under water.

Naturalized, growing spontaneously but not native.

Natural System, 886.

Natural System, history of, 891.

Nectar, honey: Nectary, 433, 456.

Nepenthes, 309.

Nerve, the veins (254) are sometimes so-called.

Netted or net-veined. See Reticulate, 258.

Neutral flower, 422.

Nodding, the summit bent over (sc. snowe drop).

Node, a joint of the stem, 161.

Nodous, knotted; large-jointed.

Nodulous (root), 132 .

Nomenclature, 909. 
Normal, according to rule, regular.

Nuciform, nut-like.

Nucleus, kernel (sc. ovule), 535.

Nut. See Glans, 562.

$\mathrm{Ob}$ (in composition), denotes inversion; as, Obcompressed, flattened back and front.

Obcordate, 284. Oblanceolate, 266.

Oblique, unequal-sided (sc. leaves).

Oblong, 265. Obovate, 266. Obtuse, 283.

Obvolute (in æstivation), 214.

Ochrea, sheathing stipules, 249.

Ochroleùcous, cream-color, pale yellow.

Octo (in Greek composition), eight.

Octandria, 877. Octandrous, 8-stamened.

Octógynous, 8-styled, 878.

Offset, a short lateral shoot, 159.

Oligos (in Greek composition), few; as,

Oligandria, with few stamens.

Olivaceous, olive-green, brownish-green.

Opaque, dull, not shining.

Opercular, with a lid, 496.

Opposite, two at a node, 153, 222.

Orbicular, Orbiculate, circular, 265.

Orchidaceous, 484.

Organogens, 829.

Organography, 39.

Organic world, 30. Organic soil, 837.

Orthótropous (ovule), erect, 536.

Osseous, bony, as the peach-stone.

Oval, 265. Ovate, 265.

Ovary, 515. Ovule, 532.

Oroid, eggr-shaped as in fruits.

Oxygen, 831.

Paleæ or Pales, 339, 489.

Paleaceous, chaffy, having pales.

Palmi-veined, 260. Palmate, 272.

Panduriform, fiddle-shaped.

Panicle, 352. Paniculate, panicled.

Papilionaceous, 474.

Pappus the calyx of Composites, 485.

Parallel-veined, 258.

Paráphyses, jointed threads around the antheridia of mosses. Fig. 522.

Parasites, 144.

Parénchyma, 664, 730.

Parietal, on the wall (paries), 526.

Parted, deeply divided into parts.

Patent, wido open. Patulous, half open.

Pear-shaped, obovoid, larger above.

Pectinate, combed, finely pinnatifid.

Pedate, shaped like a bird's foot, 273.

Pedicel, 328. Peduncle, 327.

Peltate, shield-form, 271.

Pendent, Pendulous, hanging, drooping.

Penícillate, with a tuft of hairs, as if a camel's-hair pencil.

Pente (in Greek composition), five; as,

Pentamerous, 5-parted.

Pentandrous, 503. Pentandria, 877.
Pepo, a fruit like a melon, 568.

Perennial, living several years, 92 .

Perfect flower, with both stamen and pistil.

Perfoliate (through the leaf), 293.

Peri (in Greek composition), around.

Perianth, 402; forms of, 469.

Pericarp, 547.

Perigynium, 488.

Perígynous, 461.

Period of flowering, 365.

Perisperm, same as Albumen, 590.

Peristome, 632.

Persistent, remaining lon $r$ in place.

Personate, 483.

Petals, 401 ; forms of, 455.

Petaliferæ, 898.

Petaloid, with the form or texture of petals.

Petiole, 243. Petiolate, 239.

Petiolule, 246.

Phænogamia, 892, 895.

Phyllodium, plur. Phyllodia, 307.

Phyllotaxy, leaf-arrangement, 220.

Physiology, 41, 736.

Phytology, 43 (Greek, phytos, a plant).

Pileorhiza, cap of a rootlet, 725 .

Pileus, cap of some Fungals. Fig. 537, c. Pilous, with erect, thin hairs, 298.

Pine, size of, 101,-Californian, 101.

Pinnate, 287. Pinnatitid, 268, 269.

Pistil, 405, 511.

Pitchers (leaves). See A scidia, 303.

Pith, 692. Pitted cells, 650, 667.

Pitted, with depressions or excavations.

Placenta, 520 ; free axile, 528.

Pleurénchyma, 666.

Plicate, plaited lengthwise as a fan, 394 .

Flumous, feathery.

Plúmule (a littlo plume), 103, 593.

Pollen, 508. Pollen tube, 756 .

Pollinia, masses of pollen, 510 .

Poly (in Greek compounds), many.

Polyadelphous, 506, - $877, \$ 3$.

Polygamous, Polygamia, 877, \&5.

Polypetalæ. Sec Dialypetalæ, 903.

Polypetalous, Polysepalous, 458.

Pome, a fruit like an apple, 569.

Posterior, next the axis.

Potato, manner of its growth, 188.

Precocious, flowering before the leares.

Præfoliation, vernation, 209.

Premórse, ending abruptly, 185.

Press for drying plants, 57 .

Prickles, 18, 684 .

Prímine, same as Testa, 535.

Primórdial utricle, 645 .

Prismátic, prism-shaped, having several parallel, longitudinal angles.

Procumbent (stem), 148. Fig. 38.

Produced, extended more than usual. 
Proliferous, reproducing, as cymes from the midst of a cyme, flowers from the midst of a flower.

Protein, 744. Protoplasm, 744, 655.

Protothallus, 629.

Pruinous, powdered, as if frosted, 300.

Prùriens, causing an itching sensation.

Pseudo (in Greek composition), spurious.

Pubescent, downy with short, soft hairs.

Pubérulent, minutely downy, 297.

Pumilus, pumilous, dwarfed in sizo.

Punctate, seeming as if perforate, 682, or marked with minute dots.

Pungent, piercing, sharp-pointed.

Putamen, the bony nucleus of a drupe.

Pyramidal, form of a cone or pyramid.

Pyriform, of the form of a pear.

Pyxis, a pericarp with a lid, 570.

Quadri (in composition), four ; as,

Quadrifoliate, four-leaved.

Quadrangular, four-angled.

Quadrijugate, with four pairs of leaflets.

Quadrilateral, four-sided.

Quinque (in composition), five.

Quinate, growing in fives, 292.

Quincuncial, 391. Fig. 248.

Quíntupie, five-fold.

Race (Latin, stirps), a permanent variety, as red-cabbage.

Raceme, 349.

Rachis, axis of the inflorescence, 286, 330.

Radiate, diverging from a common center.

Radiate (in the Composites), the outer row of florets ligulate. Fig. 170.

Radiant, outer flowers enlarged (and often neutral), Fig. 271 ; or (in the Composites), all the florets ligulate.

Radical, from the root, 103.

Radical of the flower, 408.

Radicle, rootlet (of the embryo), 592.

Ramial, of a branch, 221.

Raphe (of the ovule or seed), 537.

Ráphides, 660.

Receptacle, 331, 397, 443, 631 .

Recurved, bent (not rolled) backward.

Reflexed, curved backward excessively.

Refracted, bent suddenly as if broken.

Regma, fruit as of Geranium, 577.

Regular, like parts similar, 412.

Reniform, kidney-shaped, 271.

Repand (margin), 280.

Rèpent, creeping.

Respiration, 812.

Resupinate, reversed, upside down.

Reticulate, netted, 258.

Retrórse, backwards, downwards.

Retùso (apex), 2S4. Fig. 155, c.

Révolute, rolled backwards, 213.

Rhizoma, Rhizome, 183.
Rhombic, Rhomboidal, in the figure of a rhomb, or approaching it.

Ribs, the chief veins of a leaf, ridges.

Ring elastic (of the fern-sporange). Fig. 489.

Ringent (corolla), 483.

Root, 114. Root-stock, 183.

Rosaceous (corolla), 471.

Rostrate, beaked, with a beak.

Rosulate (leaves), arranged around the base of the stem as rose-leaves.

Rotate, wheel-shaped, 475.

Rotation, circulation in the cell, 806.

Rubicund, blushing, rosy red.

Rudiment, the beginning of a thing.

Rugous, wrinkled, 295.

Ruminated (albumen), full of chinks as if composed of numerous folds.

Runcinate, hooded backwards, 269.

Runner, 160.

Sagittate, arrow-shaped, 267.

Salver-shaped. See Hypocrateriform, 480.

Samàra, 561.

Sap, the crude, 794; the true, 796.

Sarcocarp (of the drupe), 563.

Scabrous, rough, 296.

Scaláriform (cells), ladder-shaped, 653.

Scales, 435. Scale-stems, 167.

Scandent, climbing.

Scape, 329. Scarious, 295.

Scattered, sometimes used for alternato.

Scorpoid (inflorescence), 358.

Scrobículate, pitted, with little depressions.

Screw-pine, 136.

Sea-green, light bluish green, glaucescent.

Secúnd, all on one side, or turned ono way.

Secúndine, same as Tegmen, 535.

Seed, 582. Seed coverings, 583.

Seed, longevity of, 602 ; dispersion of, 604.

Semi (in composition), half; as,

Semicordate, half of cordate.

Semilunar, half-moon-shaped.

Semisagittate, and Semiterete.

Sepals, 400. Sepaloid, sepal-likc.

Septum, a partition between two spaces.

Septicidal (dehiscence), 550.

Septifragal (dehiscence), 550.

Seríceous, silky, 297.

Seròtinous, occuring late in the season.

Serrate, Serrulate, 279.

Sessile, sitting, not stalked, 239.

Setæ, 299, 487. Setaceous, bristle-form

Setous, Setigerous, bearing bristles.

Sheath, Sheathing, as the leaves of the grasses.

Shrub, 95.

Silique, 574. Silicle, 575. 
Siliquovs, bearing siliques (as the Crucifers).

Silver-grain (of wood), 707.

Simple, of one piece, not compound.

Sinistrorse, twining from right to left. Fig. 49.

Sinuate, 270. Slips, 158.

Soil, 837.

Solitary, growing alone, or singly.

Sori, patches of fruit in ferns, 632. Fig. 488.

Spadicifloræ, 904. Spadix, 347.

Spathe, Spathaceous, 336.

Spatulate (leaf), 266.

Species, 76, 888. Specific name, 75.

Specimens (of plants), 53, 56.

Spermatozoid, 633. Fig. 497, 553.

Spike, Spicate, 346.

Spikelet, a little spike, as in a grass.

Spine, a woody thorn, 316.

Spindle-shaped (root), 127. Fig. 27.

Spiral arrangement (of leaves), 228.

Spiral cells or vessels, 651 .

Spongelet, Spongiole, 118.

Sporange, 632. Spores, 630.

Sporidia, 630. Sporules, 635

Sporogamia, 906.

Spur, a projecting, slender appendago, 434.

Squarrous, spreading widely, as the involucral scales of some Composites.

Stamens, 404, 491. Staminate flower, 421.

Staminodia, 436, 502.

Starch, 658, 748, 750 .

Stem, or Ascending Axis, 145.

Sterile, not bearing seeds, 421 .

Stigma, Stigmatic, 515.

Stipe, the stalk of the ovary or ovaries; also, the stem of a mushroom.

Stipels, Stipellate, 251 .

Stipules, Stipulate, 240, 247.

Stolon, 157. Stoloniferous, producing stolons.

Stomata, 678, 732. Figs. 582-586.

Strap-shaped, flat, narrow and straight.

Strict, erect and very straight.

Strigous, with sharp, close, rigid hairs.

Strobile (fruit), 578.

Stróphiolate, having an appendage (strophiole or caruncle) about the hilum.

Style, 515. Styloid, style-like.

Sub (in composition), 302 .

Suberous, corky in texture.

Subulate, awl-shaped, 277.

Sreculent, very juicy and cellular.

Sucker, 156.

Suffrutescent, woody at the base only.

Sulcate, furrowed.

Superior, 465, 468 .

Superior calyx, calyx adherent to ovary. Superior ovary, calyx free from ovary.

Supérvolute, 394.
Supra-axillary, situated above the axil Supradecompound, very much divided. Suspénded (ovule), 534. Figs. 414, 419. Suspensor (of the embryo), 758. Fig. 608 . Sútural (dehiscence), 550 .

Sword-shaped, as the vertical leaves of Iris Syconus, fruit, such as the Fig. 580 .

Symmetry (of the flower), 410, 412.

Syn (in Greek compounds), together, union.

Syncarpium, 579.

Syngenesia, Syngenesions, 877, 506.

Synonyms, 914.

Taper-pointed. See Acuminate, 283.

Tap-root, 124, 142.

Tawny, fulvous, dull yellowish brown.

Taxónomy, the science of classification.

Tegmen, the inner seed-coat, $535,583$.

Tendril, 313, 178.

Teratólogy, 380 .

Terete, cylindrical or nearly so.

Term of Plant Life, 83, etc.

Terminal, situated at the end or apex.

Terminology, 44.

Ternate (leaves), in threes, 288.

Tesselated, checkered, as a pavement.

Testa, the outer seed coat, $535,583,4$.

Tetra (in Greek composition), four.

Tetradynamous, 505. Tetradynamia, 877.

Tetrágonal, with four corners.

Tetrágynous, with four pistils.

Thalamiflòræ, 902.

Thallogamia, 906.

Thallogens, 722, 899.

Thallus, 627.

Thecaspores, 630. Theca, Thecæ, 632.

Thorn, 317.

Throat, the orifice of a monopetalous corolla.

Thyrse, 353.

Toméntous, with short, dense, woolly hairs.

Top'shaped, inversely conical.

Torus, same as Receptacle, 331, 397.

Trachénchyma, 668.

Tree, 96.

Tri (in Greek compounds), three.

Triadelphous, the stamens in three sets.

Triandria, Triandrous, 877.

Trígynous, three-styled, 513.

Tricoccous (fruit), with three one-seeded carpels.

Trícolored, with three colors.

Triennial, lasting three years.

Trifid, split half-way into three parts.

Trifoliate, with three leaflets.

Trílobate, having three lobes.

Trímerous, 3-parted, 418.

Tripartiblo, separable into three parts

Triple-veined, 261. Fig. 118. 
Tríquetrous, threo angled.

Tripinnate, thrice pinnate, 289.

Triternate, thrice ternate.

True sap, 796.

Truncate, 284. Fig. 155, $d$.

Trunk (of a tree), 171.

Tryma, fruit as the hickory-nut, 564.

Tube, 459. Tubular corolla, 481.

Tuber, 187.

Iubérculate, covered with warts (tubercles).

Tumid, swollen or inflated.

Tunicate, coated, as the bulb, 193.

Turion, young shoot, as of asparagus.

Typical Flower, 412, 449. Figs. 260, 262.

Typical Forms, 11, 12.

Umbel, 351. Umbellet, a partial umbel. Umbellate, bearing umbels.

Umbilicate, with a sharp depression at end.

Unarmed, with no stings, thorns, etc.

Undershrub, a low shrub, 95.

Undulate, wavy, 280.

Unequally pinnate, 287.

Unguiculate (pctal), having a claw, 453.

Uni (in compounds), one.

Unifoliate, with one leaf or leaflet.

Uniform, of one form.

Unilateral, one-sided.

Unilócular, one-celled.

Unnivalved, with but one valve.

Urceolate, urn-shaped, 478.

Utricle (fruit), 559.

Vaginate, sheathing, the flattened petiole involving the stem.

Valvate, 387.

Valves, Valvular, 550.

Varieties, 78 .

Vascular tissue, 668.
Vaulted, arched.

[736.

Vegetation, or Physiology of Plant Life,

Veins, 253. Veinlets, Veinulets, 257.

Venation (of the leaf), 255.

Véntricous, swelling out on one side.

Vernal, appearing in the Spring time.

Vernation (of the leaf bud), 213.

Ventral, belonging to the front side, $i . e_{\text {, }}$ the side towards the axis.

Vérrucous, covered with warts (verrucæ).

Versatile (anther), 495.

Vertex, the summit, same as Apex.

Vértical, in the direction up and down, or parallel with the axis.

Verticillate, whorled, 222.

Verticilaster, 362 .

Véspertine, appearing in the evening.

Véxillary (æstivation). Fig. 251.

Vexíllum, standard, 474. Fig. 316, 317.

Villous, clothed with long, weak hairs, 297.

Vimíneous, with long flexible shoots, osier. like. [slender.

Vine, 178. Virgate, twiggy, long and

Viscid, Viscous, sticky or glutinous.

Vitta, Vittæe, the minute oil-tubes in the fruit-cont of the Umbeliferæ.

Volva, membrane enclosing the young Fungus. Fig. 537, e.

Wedge-shaped, gradually tapering to the base.

Water, 838.

Whorl, a circle of similar organs.

Witch-grass, 181.

Wood, 694. Wood-cells, 649.

Yeast Plant, 745.

Zoology, 37.

Zoospores, 633.

\section{ABBREVIATIONS AND SIGNS}

\section{OFTEN USED IN DESCRIPTIVE BOTANY.}

ach. achenia.

ast. æstivation.

alter. alternate.

amplex. amplexicaul.

anth. anther.

axill. axillary.

cal. calyx.

caps. capsule.

cor. corolla.

decid. deciduous.

diam. diameter.

ellip. elliptical.

emarg. emarginate.

epig. epigynous.

$f$. or $f t$. feet. fil. filaments.

$f$. flower; fls. flowers.

fr. fruit.

$h d$. head; hds. heads.

hyp. hypogynous.

imbr. imbricate.

inf. inferior.

invol. involucre.

irreg. irregular.

leg. legume.

lf. leaf; lvs. Jeaves.

lfts. leaflets.

lom. loment.

opp. opposite.

ova. ovary. ped. pedunclo.

pet. petals.

perig. perigynous

perig. perigynium.

recep. receptacle.

reg. regular.

rhiz. rhizoma.

$r t$. root.

sds. seeds.

seg. segment.

sep. sepals.

st. stem.

sta. stamens.

stig. stigmas.

sty. styles. 
The names of the months, and of states and countries, are often abbreviated, and always in the same manner as in other works; thus, Apr. April; Jn. June; Mass. Massachusetts; N. Y. New York; Ia. or Ind. Indiana; Car. Carolina; La. Louisiana; etc.

\section{The following Signs are also in general use:-}

(1) An annual plant.

(2) A biennial plant.

If A perennial herb.

$\Varangle$ A perfect flower, or a plant bearing perfect flowers.

8 Moncecious, or a plant with staminate and pistillate flowers.

of Diœcious; staminate and pistillate flowers on separate plants.

$\Varangle$ \& 1 Polygamous; the same species with staminate, pistillate, and perfect tlowers.

5 A plant with a woody stem.

o A staminate flower or plant.

o A pistillate flower or plant.

0 Wanting or none.

$\infty$ Indefinite, or numerous.

$0=$ Cotyledons accumbent.

ol Cotyledons incumbent.

$0 \gg$ Cotyledons conduplicate. $\}$

$\S$ A naturalized plant.

+ A plant cultivated for ornament.

$\neq$ A plant cultivated for use. This, with the two last, are placed at the end of a description. In other situations they have their usual signification as marks of division or reference. In measure of length, or other dimensions, the following signs are adopted in this work:-

$$
\begin{aligned}
& \text { f (without the period) A foot. } \\
& \text { "(a single accent) An inch. }
\end{aligned}
$$

I The note of exclamation, common in botanical works, is used in contrariety to the note of interrogation (?). It denotes, in general, certainty from personal observation. Affixed to a locality, it denotes that the writer has examined specimens either in or from that place. Affixed to the name of an individual, it denotes that the writer lias examined specimens supplied by him. Its use in tho present work is discontinued, except in the case of controverted facts.

AUTHORs' NAMES are usually abbreviated, as follows:-

Adans. Arlanson.

A. DC. Alphonse Do Candolle.

$\Lambda$ it. Aiton.

Arn. Arnott.

Aubl. Aublet.

Bart. Barton.

Benuv. Benuvois.

Benth. Benthain.

Berl. Berlandier.

Bernh. Bernhardi.

Brongn. Brongniart.

Bigl. or Bw. Bigelow.

Buchm. Boehmer.

fiong. Bongard.

Br. Brown.

Cass. Cassini.

Cav. Cavanilles.

Cham. Chamisso.

DC. De Candolle.

Desf. Desfontaines.

Desv. Desvaux.

Dew. Dewey.

Dill. Dillenius.

Duh. Duhamel.

Dumort. Dumortier.

Findl. Endlicher.

Ehrh. Ehrhart.

Eill. Elliot.

Engel. Engelinann.

Freel. Frœilch.

Gart. Gærtner.

Gmel. Gmelin.
Grev. Greville.

Griseb. Grisebach.

Gron. Gronovius.

Hedw. Hedwig.

Hoffm. Hoffinan.

Hook. Hooker.

Huds. IIudson.

Juss. Jussieu.

Lag. Lagasca.

Lam. Lamark.

Lamb. Lambert.

Lehm. Lehmann.

Lindl. Lindley.

L. or Linn. Linnæus.

Lk. Link.

Mart. Martius.

Mentz. Mentzel.

Michx. Michaux.

Michx. f. [filius), Michaux the younger.

Mill. Miller.

Mirb. Mirbel.

Mœnch. Mœnchausen.

Muhl. Muhlenberg.

Nees. Nees von Esenbeck.

Nutt. Nuttall.

Pav. Pavon.

Pers. Persoon.

Pall. Pallas.

Pluk. Plukenet.

Plum. Plumier.
Poir. Poiret.

Ph. Pursh.

R. Br. Robert Brown.

Raf. Rafinesque.

Rich. Richard.

Richn. Richardson.

Rœin. Rœmer.

Salisb. Salisbury.

Schw. Schwenitz.

Schrad. Schrader.

Schult. Schinltes.

Scop. Scopoli.

Ser. Seringe.

Schk. Schkuhr.,

Sm. Smith.

Soland. Solander.

Spr. Sprengel.

Steud. Steudel.

Sw. Swartz.

T. \& G., Torr. \& Gr., Torrey \& Gray.

Torr. Torrey.

Tourn. Tournefort.

Trin. Trinins.

Trant. Trautvetter.

Valll. Vaillant.

Vent. Ventenat.

Wahl. Wahlenberg.

Willd. Willienow.

Walt. Writer.

Wulf. Wulfed. 


\section{ANALYSIS OF THE NATURAL ORDERS,}

FOUNDED UPON THE MOST OBVIOUS OR ARTIFICIAL CHARACTERS, DE SIGNED AS A KEY FOR TIIE READY DETERMINATION OF ANY PLANT, NATIVE, NATURALIZED OR CULTIVATED, GROWING WITHIN THE LIMITS OF THIS FLORA.

\section{PROVINCES, CLASSES AND COHORTS.}

\section{Sub-rinadox I. Phaenogamia or Flowering Plants. (Province.)}

Province 1. Bark, wood and pith distinct, the two former as concentric layers around the latter. Leaves net-veined. Fower, at least, never completely 3-merous, its parts mostly in $4 \mathrm{~s}$ and $5 \mathrm{~s}$. DICOTYLEDONS or EXOGENS. (Cruss.)

Cuass 1. Flowers with stigmas, and pistils enclosing the ovules, becoming seed-ressels enclosing the seeds. ANGIOSPERMS. (Conort.) Соновт 1. Corolla with the petals distinet. POLYPETALOUS. (A) Соновт 2. Corolla with the petals united. GAMOPETALOUS. (B) CoHort 3. Corolla (and often the calyx, also, wanting. APETALOUS. (C)

Cuass 2. Flowers with open scales instead of pistils (or no pistils at all), the ovules naked. (Pine, Cedar, Fir, Yew; Cypress, etc.) GYMNOSPERMS. (ConoRT.) CoHonr 4. The cone-bearing plants (same as Class 2).

Province 2. Bark, wood and pith commingled. Lvs. parallelCONOIDEEE. (D) veined (rarely netted). Fls. 3-merous. MONOCOTYLEDONS or ENDOGENS. Class 3. Fls. with no glumes. PETALIFER As or AGLUMACEOUS. (CoHort.) Cоновт 5. Fls. on a spadix, apetalous or incomplete. SPADICIFLORAE. (E) Conost 6. Flowers complete, with a double periantl. $\quad$ FLORIDE $\mathbb{E}$. (F)

Cuass 4. Flowers invested with green, alternate glumes instead of the perianth which is wanting or minute. GLUMIFER ZE. (Conort). Соновт 7. The Grasses and Sedges (same as Class 4). GRAMINOIDEE. (G) Sob-ringdour II. Cryptogamia, or Flowerless Plants. (Provivce.)

Province 1. With stem and leaves distinguishable, and containing woody tissuo and ressels. ACROGENS or ANGIOSPORE. (II)

Province 2. With a thallus, often stem-like, but containing cellular tissue only. 'IHALLOGENS or GYMNOSPORE. (IK)

\section{A Cohort 1. POLYPETALOUS.}

* Herbs with tho leaves alternate or all radical (11).

* Herbs with the leaves opposite on the stem ( 7 ).

* Shrubs, trees or undershrubs.-Flowers regular or nearly so. (2)

-Flowers irregular (or fruit a legume). (r)

2 Polyandrous, -stamens 3 to 10 times as many as the petals, or more. (3)

2 Oligandrous, - stamens $1-2$ times as many as the petals or fewer. (4)

3 Leaves opposite. (s)

3 Leaves alternate. - Stamens on the torus or the hypogynous corolla. (t) - Stamens and petals on the calyx-tube. (v) 
4 Ovaries simple, distinct or solitary. Vines or erect shrubs. (w)

4 Ovary compound, - wholly adherent to the ealyx. (x)

-free from the calyx or nearly so. (5)

5 Stamens opposite to the petals and of the same number. (y)

5 Stamens alternate with the petals or of a different number. (6)

6 Leaves opposite on the stems. (z)

6 Leaves altcrnate,-compound. (yy)

$$
\text { -simple. (zz) }
$$

7 Polyandrous, - stamens 3 to 10 times as many as the petals, or more. (m)

7 Oligandrous, - stamens 1-2 times as many as the petals, or fewer. (8)

8 Pistils separate and distinct, few or solitary, simple. (n)

8 Pistils united,-ovary compound, free from the calyx. (9)

-ovary compound, adherent to the calyx. (o)

9 stamens opposite to the petals and of the same number. (p)

9 Stamens alternate with the petals or of a greater number. (q)

11 Flowers regular or nearly so. Fruit never a legume. (13)

11 Flowers irregular (rarely regular and the fruit a legume). (12)

12 Stamens numerous, 3 or more times as many as the petals. (k)

12 Stamens fer and definite, $5-12$. (1)

13 Stamens 3 to 10 times as many as the petals. (15)

13 Stamens few and deinite.-Ovary free from the calyx. (14) -Ovary adherent to the calyx. (j)

14 Pistils one, or indefinite (1-15), distinct, simple. (e)

14 Pistils definitely-2 united, the short styles combined into one. (f)

-3 or 4 united, styles or stigmas 3,4 or 6 . (g)

-5 , distinet or united, with 5 distinct styles. (h)

-5 united and the styles combined in one. (i)

15 Stamens hypogynous, - on the receptacle. (16)

15 Stamens perigynous, - on the corolia at base. (c)

-on the calyx at the base. (d)

16 Pistils few or many, distinct (at least as to the styles). (a)

16 Pistils (and styles if any) completely united. (b).

a Petals 5 or more, deciduous. Leares not peltate.

a Petals 3, persistent, withering. Floating leaves peltate.

a Petals numerous, deciduous. Leaves all peltate.

b Sepals 4-6, equal. Petals $\infty$, imbricated in the bud.

b Sepals 5, equal, Petals 5, imbricate. Leaves tuluular.

RANUNCOLACE E. 1

Cabombacéd 7

Nelumbiacex. 8

NХMPH.АCEж. 9

b Sarraceniace. 10

b Sepals 5, unequal. Petals 5, convolute. Flowers or' 2 sorts. Cistacex. 17

b Sepals 2 , with -5 petals imbricated in the bud. Tortulacaces. 22 -4 or 8 petals usually crumpled in the bud. Papaveracex. 11

c Filaments united into a tube. Anther 1-celled.

d. Sepals 2, persistent, capping the pyxis.

d Sepals $3-5$, valvate in the bud. Pod long, 2-carpeled.

d Sepals 3-5.-Petals imbricate in bud. Fruits simple.

-Petals convolute in bud. Fruit compressed.

e Stamens opposite to the imbricated petals. Pistil 1 only.

e Stamens alternate with the petals or more numerous.

f Stamens 6 (tetradynamous). Pods 2-celled.

f Stamens 4, or 8-32. Pod 1-celled.

g Sepals and petals in 3s. Stamens 6. Small herb.

F Sepals and petals in 4s. Stamens 8. Climbing.

Malvacex. 24

P'ORTULACACEA. 22

Trlace $\boldsymbol{x} .26$

ROSACEXX. 47

LOASAOE.X. 53

BERBERIDACE.J. 6

Ranunculace. 1

Crectreras. 13

Capparidacex. 14

IIMNANTHACE. 3.36

SAPINDACE ㅈ. 41

g Sepals, etc., in 5s.-Stam. 5, monadelphous. Climbing. PassmLorace $x .57$

-Stam. 5, distinct. Greenish. Climbing.

-Stam. 5, distinct. Yellow. Erect.

ORDER. 104

-Stam. 5, distinct. Cyanic. Erret.

TURNeraces. 56

-Stam. 3-15.-Fls. $\Varangle$, very many, minute. Crstace $\approx .17$

-Fls. monocious.

ORDER, 113 
h Stamens 5 , alternate with the 5 petals. Seeds $\infty$.

LINACEX. 30

h Stamens 5, opposite to the 5 petals. Seed 1.

ORDER, 80

h Stamens 10, the filaments united at the base.

OXalidaces. 32

h Stamens 6-24 (twice as many as the petals), distinct.

i Ovary one-celled. Leaves radical, irritable.

i Ovary 2-5-celled.-Leaves dotless, mostly radical.

-Leaves dotted. Cauline, pinnate.

j Styles 5 or more. Ovary 1-celled, half-adherent. Sepals 2. Portulacace 2.22

j Style 1, carpels as many as the petals (2-6).

Crassulacese. 60

DroseracẼ 19

ORDRR. 73

Rutaces. 37

j Styles 2, carpels 2, fewer than the (5) petals. Seeds several.

j Styles 2, carpels 2, fewer than the (5) petals. Seeds two.

j Styles $3-5$, ovary $3-5$-celled, 3-5-seeded.

k Ovaries many, or few, rarely 1 , always simple.

Onagraces. 52

k Ovary compound, 3-carpeled, open before ripe.

Saxmragaces. 61

UMBELIFER A. 63

Araliacede. 64

RANUNCELACE. 1

RESEDACE.X. 15

i Sepals 2. Petals 4 (2 pairs). Stam.6. Spurs 1-2, blunt. Fumariaced. 12

1 Sepals 5, very unequal, Petals 3. Stam. 6-8. No spur. Polygalaces. 45

1 Sepals 4, petals 2, all colored alike. Spur slender.

1 Sepals and petals each-4, not very irregular. No spur. CAPPARIDACE 20.14

-5. Stamens 8. Spur slender. Tropeolaces. 35

-5. Stamens 5. Spur blunt or none. Vrolaces. 16

-5. Stam. 10 (or more). Fr. a legume. Lrguminos.e. 46

m Pistils many, entirely distinct, simple.

m Pistils 3-5, united more or less completely.

RANUNOULACE 1

HXPERICACE 2.18

m Pistils 5-10, united, with sessile stigmas and many petals. Mesemriryaces. 23

n Pistil solitary, simple. Petals 6-9. Stamens 12-18.

BERBERIDACE d. 6

n Pistils 3 or more, distinct, simple. Flowers all symmetrical. Crassulaceze. 60

n Pistils 2, consolidated with the 5 stamens. Juice milky.

ORDER. 97

- Carpels as many as the sepals. Anthers open at the top. Merastomaces. 50

- Carpels as many as the sepals. Anthers open laterally.

- Carpels fewer than the sepals,- $\infty$-seeded. Styles 2.

ONAGRACE 52

Saxifragace $\&$. 61 -1-seeded. Styles 2 or $3 . \quad$ Araliacex. 64

p. Style 3 cleft at the summit. -1-seeded. Style 1 (double). Connace 2.65

p Style and stigma 1, undivided.

Portulacacez. 22

ORDER. 78

$\mathbf{q}$ Leaves pinnate, with interpetiolar stipules.

ZYGOPHYLLACEN. 33

q Lvs. simple, toothed or lobed. Flowers cruciform. Stamens 6.

CrucrFras. 13

q Lvs. simple, toothed or lobed. Flowers 5-merous. Stamens 10.

Gerantacese. 31

q Leaves simple, entire. (qq)

qq Petals and stamens on the throat of the calyx.

LYTHRACEA. 51

qq Pet. hypogynous.-Fls. irregular, unsymmetrical.

Polygalace 8 . 45

-Fls. regular-2 (or 3)-parted throughout. ELATINACE 20 -5-parted.-Leaves punctate. HXPERTCace.s. 18 -Lvs. dotless. Caryophyllace.e. 21

r Pistil a simple carpel, becoming a legume. Stamens 10-100.

LeguMinos 46

r Pistil compound,-3-carpeled. Fls. perfect. Lvs. digitate.

-3-carpeled. Fls. moncecious. Cultivated.

-5-carpeled.-Stipules present. Cultivated.

-Stipules none. Native.

SAPINDACE. 41

Begontace. 59

Geraniace. 31

ERICACE d. 73

HYPERICACE. 18

s Stamens on the receptacle, in several sets. Leaves dotted.

s Stamens on calyx.-Ovaries many, free, but enclosed. Calrcanthacks. 48 -Ov. compound, free in the bell-shaped cal. Lrthraces. 51 -Ov. adherent.-Fruit fleshy, baccate. -Fruit dry, capsular.

Mrrtaces. 49

t Petais imbricate or valvate in æstivation. (u)

SAXmrigackx. 61

$t$ Petals convolute.-Anthers 1-celled, turned inwards.

Malvacen. 24

-Anthers 2-celled, turned outwards.

STEBCuLtace 20 
u Ovaries distinct. Petals 6, valvate. Erect shrubs.

Avovace.s. 3

u Ov. distinct. Petals 3-9, imbricate. Trees or erect shrubs. Magnoliacese. 2 u Ov. distinot, few. Petals 6-9, imbricate. Climbing shrubs.Menispenuace.s. 5 u Ov. compound.-Lvs. punctate with pellucid dots. Aurantiaces. 28 -Lvs. opaque.-Sepals valvate. Fls. small. Tillace.s. 26 -Sepals imbricate. Fls. large. Carellaces. 27

v Style 1 with many stigmas. Green, fleshy shrubs. CACTACE 2.54 v Styles several, or 1 with 1 stigma. Woody trees or shrubs. Rosace.s. 47 w Pistils many, spicate on the slender torus. Climbing. Scnuzandracex. 4 iv Pistils 2-6, capitatate on the short torus. Climbing. Menispermaces. 5 or Pistil one only. Flowers 6-parted. Stam. opposite the petals. Berberidace.s. 6 $x$ Flowers 4-parted. Stamens 8. (Flowers red or roseate.) Onagraces. 52 $x$ Fluwers 4-parted. Stamens 4. Flowers whitish. x Flowera 5-parted.-Ovary 5-carpeled, 5 styled.

CORNACE.E. 65 Araliacex. 64 -Ov. 2-carpeled.-Leaves palmate-veined. Grossulacs. $\pi .55$ - Leaves pinnate-veined. Saxurragace de. 61

y Leares opposite, stem climbing with tendrils.

y Leaves alternate. Erect, or vine without tendrils.

z Carpels 3-5, styles short. Leaves simple.

ฯ Carpels 3, styles long, slender. Leaves pinnate, serrate.

z Carpels 2, with 2 slender styles. Samara double.

z Carpels $1-2$, with 1 short style. (Drupe or single samara.)

yy Filaments 10, united into a tube. Leaves bipinnate.

y Fils. 5 , distinct.-Leaves pellucid punctate.

- -Lvs. opaque.-Ov. 3-carpeled, 1-seeded. Anacardiacex. 38

-Ov. of 3 one-seeded carpels. Sapinnacex. 41

zz Petals 4, yellow. Ovary 2-carpeled, 2-seeded.

HAMAMELACER. 62

zz Petals 4-7, eyanic.-Drupe 1-seeded, but with 3 stigmas. Anicardiace.s. 58 -Drupe 4-6-seeded, stigmas 4-6. Aqurroliace. 74 -Capsule $\infty$-seeded. Ericineæ, 73. Prtrosporices. 39 -Cap. 3-seeded (scarlet). Seeds ariled. Celastrace.x. 42 -Capsule 2-3-seeded. Ovules pendulous. § 3, ORD. 73

\section{IB Cohort 2. GAMOPETALOUS.}

S Stamens $(6-\infty)$ more numerous than the lobes of the corolla. (a)

$\$$ Stamens $(2-12)$ fewer than the corolla lobes or of the same number.

*2 Ovary inferior, adherent to the tube of the calyx. (3)

3 Stamens cohering by their anthers. (c)

3 Stamens entirely distinct. (d)

\#2 Ovary superior, free from the tube of the calyx. (6)

6 Flowers regular and the stamens symmetrical. ( $\boldsymbol{\gamma})$

7 Stamens opposite to the lobes of the corolla (and free). (e)

7 Stamens alternate with the corolla lobes (rarely connate). (9)

9 Shrubs, trees, with the carpels or stigmas 3-6. (f)

9 Herbs 1-10-carpelled or shrubs 2-carpeled. (g)

6 Flowers regulat and the stamens reduced to 2. (n)

6 Flowers irregular. Stam. (except in 3 or 4 species) unsymmeirical. (o)

a Filaments 6 , united into 2 equal sets. Herbs.

a Filaments $\infty$, united into 1 tube enclosing the styles.

- ORD. 12

ORD. 24

a Filaments 10, united into a split tube around the 1 style.

ORD. 16

a Filaments $\infty$, united only at the base into 1 or 5 sets. (b)

b Calyx of 5 leafy imbricated sepals. Shrubs, trees.

ORD. 27

b Calyx tubular, 5 toothed or truncate. Shrubs, trees.

a Filam. entirely distinct. -8 or 10 in number. Flowers perfect. ERICAces. 73

-8 and 16 in numb. Fls. polygamous. Emenace a. 76 
c Flowers in a compact head surrounded by an involucre. CoMrosirs. 7C

c Flowers separate, irregular, perfect. Plants erect. LobELIACEE. 71

c Flowers separate, regular, imperfect. Weak vines. Ond. 58

d Leaves alternate. Flowers 5-parted, regular, separate. Campanduacex. 72

d Leaves opposite, with stipules between, or verticiliate. RuBLACE. 67

l Lvs. opp. Stipules none.-Stam. 5-4. Ov. 2-5-celled. Caprifoliacede. 66

-Stam. 2-3. Ov. 1-celled. Valerianacexe. 68

-Stamens 4. Flowers capitate. Dipsace.e. 69

e Herbs. Ovary with 5 styles and but 1 seed.

e Ilerbs. Ovary with 1 style and many seeds.

Plumbagivace. 80

c Trees or shrubs. Ov. 1-styled, 5-celled, 1-sceded.

- f Style none. Drupe 4-6 seeded.

f Style one. Drupe 4-seeded.

f Style one. Capsule $3-5$-celled, $\infty$-seeded.

g Ovary deeply 4-parted, forming 4 achenia.

Primulacede. 78

SAPotace 28. 77

$\triangle$ Quiroliaces. 74

Verbenacede. 88

ERICACEA. 73

g Ovaries 2, distinct (often covered by the stamens). (h)

g Ovary 1, compound, 1-celled (placenta often large). (1k).

g Ovary 1, compound, 2-6-celled. (m).

h Stigmas connate. Flower bud convolutc.

h Stigmas connate. Flower bud valvate?

Aroctnace de. 96

h Stigmas distiuct. Flowers minute, yellow,

Ascleptadacex. 97

k Ovule solitary. Corolla limb entire.

Convolvulace 2 . 93

k Ovules several. Leaves clcft and lobed.

ORD. 101

k Ovules several. Lvs. or lfts. entire.-Fls. not spicate. Gentianace.s. 95

m Leaves all radical. Flowers spiked. -Fls. spioate. Plantaginacezs. 79

m Leaves opposite.-Ovary 2-celled.

Plantaginacede. 79

m Leaves alternate.-Ov. 3-celled. Not twining. $\}$ PoLrmoniacex. 92 -Ov. 2-celled. Twining. Convolvulaces. 93 -Ov. 2-celled, 4-seeded. Erect. Borraginaces. 90 -Ov. 2-celled, $\infty$-seed.-Styles 2. HY Drophy. 91 - Style 1. Solanacex. 94

n Shrubs. Corolla 5-parted, imbricated in bud. JASMrNACEX. 98

n Shrubs. Corolla 4-parted, valvate, or none. Oreace. 99

- Ovary deeply 4-parted, forming 4 (or fewer) achenia. (p)

- Ov. entire, 4-ovuled, 4 or fewer-seeded. Lvs. opposite. Verbenaces. 88 - Ovary entire, $\infty$-ovu'ed, $\infty$ or several-seeded. (s)

p Leaves opposite. Slems square. Stamens $2-4$.

p Leaves alternate Stems round. Stamens 5.

s Trees or climbing shrubs. Seeds winged.

LABIATE. 89

BORRAGINACE. 20

s Trees. Seeds not winged. ScropH. 86. Erect shrubs. Ericaces. 73

s Herbs.-Leafless parasites.

OrobaNCHACE 82

-Lvs. at base. Fruit 1-celled. Fls. spurred.

-Leafy.-Fruit 4-5-celled. Leaves opposite.

-Fruit 2-celled. (t)

t Corolla convolute in bud. Seeds exalbuminous.

t Corolla imbricate in bud. Seeds albuminous. Scropholarhacex. 86

t Corolla plicate in bud. Seeds albuminous.

LENTIBULACE

Pedaliaces. 84

Acanthace. 87

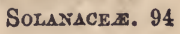

\section{Cohort 3. APETALOUS.}

7. Plants herbaceous, the flowers not in aments (except Humulus, 115). (2)

I Plants woody, - shrubs or trees. (5)

2 Flowers with a regular calyx (or a calyx-like involucre). (3)

2 Flowers achlamydeous, - neither calyx nor corolla, (f)

3 Calyx tube adherent to the ovary, limb lobed, toothed, or entire. (a)

3 Calyx free from the ovary, sometimes enclosing it. (4) 
4 Ovaries several, entirely distinct, each 1-styled, 1-ovuled.

1 Ovary one, 1-ovuled, 1-seeded, style or stigma 1. (b)

4 Ovary one, 1-3-ovuled, with 2-5-styles or stigmas. (c)

4 Ovary 1 , with many ovules and 1 style or stigma. (d)

4 Ovary one, with $4-\infty$ ovules and $2-12$ styles and stigmas. (e)

a Stamens $1-8$, symmetrical with the stigmas.

ORD. 52

a Stamens $8-10$, the stigmas 2. Ovary $\infty$-seeded.

OP.D. 61

a Stamens 6 or 12 , symmetrical with the 6 ovary-cells. Aristozocmaces. 100

a Stamens 5, the style 1. Ovary 2-ovuled, 1-seeded.

Santatacex. 109

b Flowers perfect. Calyx 4-lobed, stamens $1-4$.

OP.D. 47

b Flowers perfect. Calyx entire, funnel-shaped, colored.

b Flowers diclinous. Calyx 4-5-parted, green.

c Fruit 3-seeded, with 3 (often eleft) stigmas.

c Fruit 1-seeded.-Stipules sheathing the stems.

-Stip. 0. Calyx scarious-bracted.

-Stip. 0. Calyx double. Climbing.

Nyctagrnace 2.101

UrTicACEs. 115

Euphorbiaces. 112

Polygorace d. 102

AMARANTACRx. 106

- Stip. 0. Calyx naked. Lss. alternate. Cmenopodice.s. 105

-Stip. 0. Calyx naked. Lvs. opposite.

d Stamens (4) opposite the sepals.

\& 3 , ORD. 21

d Stamens (5) alternate with the sepals.

ORD. 51

e Leaves opposite. Fruit circamscissile (utricle).

ORD. 78

e Leaves opposite. Fruit 4-5-valved (capsule).

ORD. 22

e Leaves alternate.-Fruit 5 -horned, 5-celled (capsule).

ORD. 21

-Fruit a fleshy 4-10-seeded berry. Phytotaccacex. 103

- -Fruit circumscissile (utricle).

f Flowers on a spadix with a spathe. Monocotyledons.

$f$ Flowers in a long naked spike. Stamens 6 or 7 .

Amarantaces. 106

ORD. 131

f Flowers solitary, axillary, minutc. Aquatie plants. (g)

g Stamen 1, styles 2. Leaves opposite.

Satrurace 12.123

g Stamens 2, styles 2. Leaves alternate, dissected.

Caltutricace $x$. 124

5 Flowers not in aments, with the leaves opposite. (h)

5 Flowers not in aments, with the leaves alternate. (k)

5 Flowers (diclinous), the sterile only, in aments. (n)

5 . Flowers (diclinous), both the fertile and sterile in aments. (o)

h Fruit a double samara (2-winged).

ORD. 40

h Fruit a single samara (1-winged), or a drupe. Stamens 2. Orencex. 99

h Fruit not winged,-3-seeded. Stamens 4 .

Eupnorbiaces. 112

-1-seeded: Stamens 4 or 8.

Eleagnace.x. 111

-1-seeded. Stamens 3. Parasites.

LORANTHACE $\boldsymbol{E} .108$

k Style or stigma one. Fruit 1-seeded. (m)

m Calyx free from the ovary.-Anthers opening by valves. Lacraces. 107

m Calyx free from the ovary.-Anthers opening by slits. Thxmelace.s. 110

m Calyx adherent to the ovary.-Ovules 2-4. (Shrubs.) Santanacz. 10 J

-Ovule 1. (Trees.)

k Styles or stigmas 2.-Stamens numerous.

ORD. 65

Ord. 62

-Stamens as many as the calyx lobes.

k Styles or stigmas 3 (rarely 2-4).-Fruit dry, 3-partible. -Fruit a fleshy drupe.

k Styles or stigmas 6-9. Meath-like undershrubs.

k Styles and ovaries 5, searcely united. Leaves pinnate.

n Nut or nuts in a cup or involucre. Leaves simple.

n Nut drupaceous, naked. Leaves pinnate.

ULMaces. 113

Euphorbiacex. 112

ORD. 43

Eupetrace. 116

ORD. 87

Cuptutrers. 119

JUGLANDACE .118

- Fruit fleshy, aggregated (sorosis). Juice (or sap) milky. ArTocarapcz.s. 114

- Frait dry. Plants with a watery juice or sap. (p) 
p Aments globular, racemed. Nutlets 2-celled, woolly.

ORD. 62

p Aments globular, solitary. Nutlets 1-celled, 1 seeded.

Platanacedi. 117

p Aments cylindrical or oblong. (s).

s Ovary 1-celled, 1-seeded. Fruit often fleshy.

Mrricacese. 121

s Ovary 2.ceiled, 2-ovuled, 1-seeded. Fruit often winged. BEtulaces. 120

s Ovary many-ovuled, many-seeded. Seeds comous.

SALICACE 122

\section{Cohort 4. CONOIDEAE.}

Leaves simple. Fertile flowers in cones: Stems branching, woody, jointless.

Confrens. 127

I Leaves simple. Fertile flowers solitary. Stems branching, woody, jointless.

TAXACEX. 128

I Leaves pinnate. Fertile flowers solitary. Stems simple, palm-like. CrCadaces. 128

\section{Conont 5. SPADICIFLOR E.}

Trees or shrubs with palni-cleft leaves all from one terminal bud, and a branching "spadix" from a spathe.

Palmacede. 130

II Herbs with simple, rarely ternate leaves. Spadix simple. (2)

2 Plants frond-like, minute, floating loose on the water.

LEXINACEx. 132

2 Plants with stem and leaves, rooting and fixed. (3)

3 Spadix evident, in a spathe or on a scape.

Aracede. 131

3 Spadix obscure or spilke-like. Stems leafy. (4)

4 Flowers with no perianth, densely spicate or capitate.

4 Flowers with a perianth or not. Plants submersed.

TyPhyce.s. 133

Naladaces. 134

\section{N Cohort 6. FLORIDEA.}

I Fowers (not on a spadix) in a small, densc, involucrate head. (k)

I Flowers (not on a spadix) solitary, racemed, spicate, etc. (3)

3 Periantl tube adherent to the ovary wholly or partly. (a)

3 Perianth free from the ovary. (4)

4 Petals and sepals differently colored (except in Medeola, 147). (c)

4. Petals and sepals similarly colored. (e)

a Flowers diwecious or polygamous. Low, aquatic herbs. Hrdrocharidaoes 186

a Flowers diœeious, 6-androns. Slurubby climbers.

a Flowers perfect,-gynandrous (stamen on the pistil).

Dioscoreaces. 144

- monandrous with half an anther.

$-3-6$-androns. Stamens distinct. (b)

b Perianth woolly or mealy ontside. Ovary half-free.

Orchidacese 138

Marantace.e. 139

b Perianth glabrous outside-Stamens 3 , anthers introrse. - Stamens 3, anthers extrorse. - Stamens 6.

IIEMODORACES. 749

BURMANNIACE. 137

IRIDACE \&. 143

Ayaryllidage

c Carpels many, distinct, acheniate in fruit.

Alisyace. 135

c Carpels 3, united, with the stigmas distinct or not. (d)

d Leaves verticillate in 1 or 2 whorls. Stigmas 3.

Trilliaces. 147

d Leaves alternate.-Stigmas 3. Scurfy epiphytes. -Stigmas united into 1 .

Bromelace. 141

Commelynacew. 152

e Leares net-veined, dilated.-Flowers perfect, 4-parted. Roxвurahucex. 146

c Leaves parallel-veined. (f) -Flowers diceious, 6-parted.

SMILACEX. 145

f Styles, and often the stigmas also united into 1 . (g)

g Flowers colored, regular. Stamens 6 (4 in 1 species). Liliacre. 148

g Flowers colored, irregular or else triandrous. Pontederiaces. 150

g Flowers greenish, glumo-like or scarious.

JuxCACES. $15 i$ 
f Styles and stigmas 3, distinct. (h)

h Leaves rush-like. Ovary of ' 3 one-seeded carpels.

h Leaves linear, lanceolste, etc. Ovary $6-\infty$-seeded. k Petals yellow, small but showy. Plant acaulescent. k Petals white, minute, fringed. Plant acaulescent.

\section{G Cohort 7. GRAMINOIDEÆ.}

I Flower with a single bract (glume). Culm solid, sheaths entire. CrPeraces. 155

I Flower with several bracts (glumes and pales). Culm hollow. Sheaths split on one side.

Grasinex. 156

\section{Province, ACrogens.}

$\S$ Plants with well developed foliage. ( $(1)$

I Leaves few, mostly ample and from subterranean rhizomes. (a)

a Fruit borne on the leaves which are often more or less contracted. Furces. 160

a Fruit borne at the base of the radical, entire or lobed leaves. Marsineaces. 157

I Leaves numerous, small, mostly spirally imbricated on the stem. (b)

b Fruit axillary, sessile, opening by a slit. $\quad$ Lxcopodraces. 158

b Fruit mostly terminal and usually stalked, opening by a lid. Muscr. 162

I Leaves numerous, small, imbricated on the stem in 2 rows. )

$\$$ Plants with the leaves and stem confounded, thallus-like.

$\S$ Plants with verticillate branches instead of leaves. (c)

c Fruit in terminal spikes, and of one kind only.

HEPATIC... 163

c Fruit lateral, scattered on the branches, and of two kinds.

Equisetacede. 159

Characese. 161

\section{IK Province, Thallogens.}

Plants aquatic, with a colored thallus. Fruit immersed in the frond.

Plants on dry rocks, logs, or bark of trees, thalloid or granular.

ALG.5. 164

Plants growing on decaying organisms. Thallus cotton-like, the fruit very different, all without chlorophylle or starch.

Lrchens. 165

Frxต1. 166

Nore.-Six Orders of the Cryptogamia, Nos. 161-166, are necessarily excluded. In the fulfilment of our plan, these ex nsive Orders will constitute a separate and independent volume. 


\section{P A R T F 0 U R TH.}

DESCRIPTIVE BOTANY; OR, PHYTOLOGY.

COMPRISING

\section{THE FLORA OF THE UNITED STATES AND CANADA}

(WITHIN THE LIMITS MENTIONED IN THE PREFACE).

SUb-Kingdom, PH ZENOGÁMIA or FLOWERING PLANTS.-Vegetables having an axial development, leafy appendages and true flowers, their substance composed of cellular, spirovascular, and woody tissue ; their flowers with manifest stamens and pistils, and producing seeds with an embryo. (For sub-kingdom Cryptogámia or Flowerless Plants, see page 810).

Province, EXOGEN OR DICOTYLEDONOUS PLANTS.-Phænógamous plants having a stem composed of a central column of pith enclosed with wood and bark, the latter exterior; growing by the addition of concentric layers external to the wood, internal to the bark. Leaves mostly net-veined. Flowers very generally 5-merous, rarely 3-merous. Embryo with two or more opposite cotyledons. (Province Endogenæ or Monocotyledonous plants, see page 666.)

Cuass I, ANGIOSPERM E-Exogenous plants with netveined leaves. Pistils complete, having stigmas for the reception of the pollen, enclosing the ovules within an ovary which becomes at maturity a seed-vessel enclosing the seeds. Cotyledons only two. (Class II. Gymnospérmæ, with no stigmas, naked seeds, and leaves not netveined, see page 659 .)

CoHont 1, DIALYPETALA or POLYPETALOUS EXOGENS.-Plants having a double perianth, consisting of both calyx and corolla, the latter composed of distinct petals, rarely abortive. (Cohort 2. Gamopetaiæ or Monopetalous Exogens, page 393. Cohort 3. Monochlamydeæ or Apetalous Exogens, page 601.) 


\section{Order I. RANUNCULACEA. CRowfoots.}

Herbs (or woody climbers) with a colorless, acrid juice. Leaves mostly divided, exstipulate, with half-clasping petioles. Calyx.-Sepals 3-15, green or petaloid, distinct, hypogynous. Corolla.-Petals 3-15, distinct, hypogynous, sometimes irregular or none. Stamens $\infty$, distinct, hypogynous, Anthers adnate, opening lengthwise. Ovaries $\infty$ or few, simple, distinct, the cell $1-\infty$-ovuled. Fruit

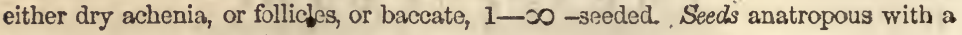
straight, minute embryo in horny albumen.

Illustrated in Figs. 10, 24, 132, 143, 162, 211, 242, 233, 291, 291, 367, 3s6, 415, 45S, 2s6, 285 , \&c.

Genera 48 , species about 1000 , mostly natives of cool, damp climates, thinse of the tropical reglous growing only upon the mountains, and in their proper loeslities abundant.

Properties. Nearly all the genera possess acrid and more or less marcotic properties, somo of them being highly prejudicial to animal life. These qualities are dissipated by a boiling heat or by drying, or heightened by spirits and sugar. The species of IIelleborus anil Aconituin are highly poisonous, but medicinal when rightly used. This order is rich in ornamental cultivated plants.

\section{TRIBES AND GENERA.}

Sepals 4, valvate in the bud. Achenia tailed. (Tribe 1.)

Sepals imbricated in the bud.-Ovaries 1- seeded, acheniate. (2).

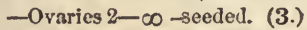

2 Corolla o, or undistlnguishable from the colored calyx. (Tribe II.)

2 Corolla and calyx distinct either in color or form. (Tribe III.)

3 Sepals as perinanent as the stamens. Fruit follicular. (Tribe IV.)

3 Sepals caducous sooner than the stamens. (Tribe V.)

3 Sepals persistent with the follicular fruit. (Tribe VI.)

I. CLEMATIDEÆ. Petals 0, or stamen-like. Leaves all opposite. Cumatrs.

II. ANEMONELE-Sepals deciluous with the stamens. Stem-leaves opposite. ANEMONE,

-Sepals deciduous wlth the stamens. Leaves all radical. Firparica.

-Sepals caducous. Flowers usually imperfect.

Thalictrux.

- Sepals caducous. Flowers perfect.

Trautvetreria. 5

III. RANUNCULEA. - Sepals not appendaged. Flowers scarlet or yellow. $\Lambda$ DONIs.

-Sepals not appendaged. Petals xanthic, a scale at base. RANUNcelus.

-Sepals appendaged. Plant minute. Leaves radical. Mrosurus.

1

2

3

4

5

IV. HELLEBORE As, Perianth regular.

-Petals 0. Sepals white.

-Petals 0. Sepals 6 to 9, yellow.

TSOPYRUL.

Calmul.

-Petals slender, tubular at apex. Roots brigirt yellow. Cortrs.

-Petals minute, tubular at base, 1-lipped.

Trollies.

-Petals small, tubular, 2-lipped. Sepals persistent Hrucisores.

-Pet. suall, concave, 2-lobed. Fls. racemed. roots.yel.Zantuoruza.

-Petals larger than the colored sepals, \&-lobed. NIGELLA.

-Petals larger than the colored sepals, spur-like, equal.AQuiligiA.

IV. IIELLEBORE \&E, Perianth trregular.

-Upper sepal spurred, containing two spurred petals. Dexpurxus.

- Upper scpal hooded, covering the deformed petals. Aconrtux.

จ. CIMICIFUGE

Cinictruga.

- Flowers many, in short racemes. Fruit fleshy. Actea.
- Flower 1 only. Plant 2-leaved. Berry compound. Irdrastis.

VI. P AEONIE E. -Pet. plane, large, showy. Disk sheathing the ovary. P PEovis.

1. CLÉmATIS L. Virgin's Bower. (Gr. $\kappa \lambda \eta \dot{\mu}$ a a vine or tendril.) Calyx of four colored sepals, in restivation valvate-induplicate. Petals none, or if present more like sterile filaments. Stamens $\infty$, shorter than the sepals, the outer or all sometimes sterile. Ovaries $\infty$, in a head. Achenia caudate with the lengthened plumous or pubescent style. 24 Herbs, or vines a little woody, climbing by twining petioles. Leaves opposite. The herbage is acrid and caustic.

\$ Atragexe. Outer stamens petal-like. Lvs. verticillate. Fls. solitary. Vine........No.1 Cr.matis proper. Petals none. Leaves opposite. (*)

- Vines. - Flawers in cymous panicles. .................................. Nos. 2-4 -Fls. solitary. - Sepals panduriform, wavy-eilged................................ 5,6 - Sepals lance-avate with a reflexed point.......................... 7,8

- Erect herbs near $1 \mathrm{f}$. high. Flowers solitary ......................... Nos. 9-11 Exotic, cultivated species......Nos. 12-15 
1 C. verticillàris DC. Stem ascending trees $15 \mathrm{ft}$ by means of its twisting petioles. At each node is a whorl (arising from two buds) of four ternate leaves, and two large purple flowers. Leaflets acute, $1-2^{\prime}$ by $\frac{1}{2}-1$ ', ovate, slightly notched. Sepals lanceolate, acute. 15" by $5^{\prime \prime}$. Filaments aliout 24, outer ones (petals ?) dilated, spatulate, tipped with imperfect anthers.-A handsome climber in highland woods, Vt. (Dr. Phelps) to N. Car. W. to the Rocky Mts. May, Jn. (Atragene Americana Sims).

2 C. Virginiàna I. Lvs. ternate; lfts. smooth, lobed, and cut-dentate.-A common, hardy climber in hedges and thickets, Can. to Ga. and the Miss. Stem 8-15 f. in length, supporting itself on fences and brushwood by means of the long petioles. Leaflets $2-3^{\prime}$ by $1 \frac{1}{4}-2$ ', with mucronate teeth. Sepals 4 , white, oblong-obovate, obtuse. Stamens 28-36. Panicles large, axillary, dichotomous. Fruit furnished with long, plumous tails (caudæ), appearing in large, downy tufts. Aug. $\uparrow$ /

3 C. holoserícea Ph. Lvs. ternate; lfts. pubescent both sides, entire, oblonglanceolate.-In Carolina. Plant climbing; downy or silky in all its parts. Panicles corymbous, trichotomous, few flowered. Flowers dicecious, small, white; the linear petals longer than the stamens. Achenia long-plumed.

4 C. Catesbyàna $\mathrm{Ph}$. Lvs. biternate; lits. ovate, small, mostly 3-lobed, the lobes entire.-In Georgia. Plant climbing, minutely pubescent. Flowers in axillary, divaricately forked cymes, small, mostly $q \hat{b}$. Sepals linear oblong. Filaments in the \& flowers, linear-margined, without anthers. Achenia shortplumed.

5 C. cylíndrica Sims. Lvs. ternate, pinnate, or decompound; lfts. ovate (very variable), acute, smooth, membranous. - Virginia to Ga. and La. Stems climbing, but not extensively, smootl. Leaves exceedingly various. Leaflets $3-15$, glabrous, simple, often lobed or 3-parted, rendering the leaf decompound. Peduncle terminal, bearing a large, nodding, bell-shaped, bluish purple flower. Achonia with short $\left(6-9^{\prime \prime}\right)$ pubescent tails. Apr. May.

B. crispa Lfts. large $\left(2^{\prime}-3^{\prime}\right)$, broadly-ovate, obtuse or subcordate at base. Sepals above much dilated and crisped, spreading or reflexed.-Ga. Varying imperceptibly into $a$. (C. crispa L.)

$\gamma$. Wilteri. Slender thronghout. Leaflets $3-5$, very narrow, acute at each end. Sepals narrow and scarcely wavy. Stamens sometimes sterile.-Ga. Perhaps distinct. (E. Wálteri, Ph.)

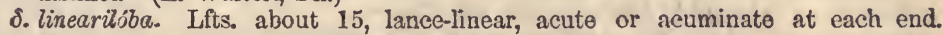
Flower more or less cylindraceous below.-Quincy, Fla., La. (C. linearilóba, DC.)

6 C. reticulàta Walt. Leaves pinnate or ternate. Lfts. obluse at each end, at length rigid and prominently net-veined.-Fla. Ifts. 3-6, stalked as in the other species, oblong, ovate or oval, entire, simple or lobed. Flower terminal, nodding, bell-shaped, pale-purple, much resembling that of No. 5. Sepals $1-1 \frac{1}{4}$ long. Achenia with long silky tails. Apr.

7 C. Viórna L. LeAther-Filower. Lfts. ovate, acute, smooth. Sepals ovate, thick and leathery; ach. with long plumous tails.-Woods, Ohio to Ga. Stems 10-15l in length, striate. Lrs. pinnate, those of the branches (bracts) simple, ovate, subsessile. Lfts. ovate or lance-ovate, simple or 3-lobed. Flower terminal, nodding, dark purp!e. Sepals ovate-lanceolate, 1' long, cuspidate point reflexed. Tails $1 \frac{1^{\prime}}{2}$ long. Jn. Jl

8 C. Pitcheri T\& G. Lfts. rough with prominent veins, coriaceous. Sepals lance-ovate, thick, achenia with short pubescent tails.-Iowa, Ill. to Ark. Leaves pinnate, those of the peduncles simple, subsessile. Leaflets ovate, acute or obtuse, often subcordate at base. Sepals of the nodding flower ovate-lanceolate, dull purple, 8-10" in length, the cuspidate point reflexed. Jn. (Hardly distinct from the preceding.)

9 C. ochroleùca Ait. Lrs. simple, ovate, silliy, pubescent beneath.-Mts. and river banks, N. Y. to Ga. Rare; stem 12-18' high, sericious. Leaves sessile, entire, simple, 2-4' long, $\frac{2}{3}$ as wide, with prominent veins, upper surface at length smooth. Flower terminal, nodding, ovate-campanulate. Sepals silky outside, Fellowish-white within. Plumes of the fruit long, straw-colored. May. 
$10 \mathrm{C}$. ovàta $\mathrm{Ph}$. Leaves broadly ovate, glabrous, glaucous and veiny beneath. -N. Car. to Fla. Stem simple, $1-2 \mathrm{f}$ high, glabrous as well as the whole plant. Leaves entire, simple, on short petioles, the lower subcordate. The stem terminates in a short, nodding, purplo flower, with ovate-acuminate sepals. Achenia with long plumous tails.

11 C. Baldwinii T. \& G. Leaves varying from oblong to lance-linear, the lower 3-lobed or cleft. - Tampa Bay, Fla. (Baldwin.) Slender, 1-2f high. Lvs. acuto at base, about $\frac{1^{\prime}}{2}$ by 2 ', petiolate. Flower cylindrical-campanulate, purplish, on a long terminal peduncle. Plumous tails 2 ' long.

12 C. Flámmula L. Flowers paniculate; lvs. pinnate; lfts. oblong, acute at each end.-S. Europe and N. Africa, often cultivated. Its long, half woody, angular, climbing stems form shady masses, covered with small, white, cymous, extremely fragrant flowers. Lfts. very variable. Fruit tipped with long shaggy tails. Ji., Oct.†

13 C. flórida L. Flowers solitary; sepals acuminate, smooth; Ifts. ovate, acute. -From Japan. Vine $12 \mathrm{f}$ long. Lvs ternate and decompound; lfts. entire. Peduncles longer than the leaves, bearing each a large, white-yellow flower. Jn., Sept.

14 C. Viticella L. Flower solitary; sepals obovate.-From Spain. Vine long and climbing, with ternately decompound leaves. Lfts. entire, ovate or oval. Flower large, purple, the sepals broad, obtuse at end, often double. Jn.-Sept.t

15. C. lasiantha Nutt. Fls. solitary, diœcious, on clustered 2-leaved branchlets; sepals oblong-cuneate, spreading, villous on both sides; lvs. ternate, lfts. broadly ovate, incisely toothed, the terminal 3-lobed or cleft.-Vine delicate, climbing many feet, pubescent or villous. Lfts. about $1_{2}^{\prime \prime}$ by $1^{\prime}$. Peduncles' $3^{\prime}$ long; the pale blue-purple fl. $1 \frac{1}{1}^{\prime}$ broad. $\dagger$ Rocky Mts.

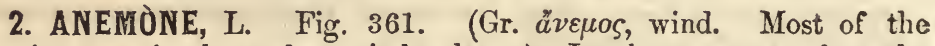
species grow in elevated or windy places.) Involucre remote from the Hower, of 3 divided leaves; calyx regular, of $5-15$ colored sepals; corolla 0 ; stamens $\infty$, much shorter than the sepals; ovaries $\infty$, free, collected into a roundish or oblong head; achenia with a short, rarely lengthened beak; seeds suspended. -2 Lvs. radical, stem lvs. 2 or 3 opposite or whorled, forming the involucre.

\$ Pulsatilia. Carpels many $(50-75)$ with long, plumous tails...................... 1

$\$$ AxEMONe proper. Carpels not produced into tails. (*).

* Pistils many $(50-70)$ in a head, densely woolly in fruit. (a)

a Involucrate leaves sessile, with a single flower.................................. 2 .

a Involuerate leaves petiolate, with $2-3$ flowers........................................ $5-7$

- Pistils fewer $(15-20)$, merely pubescent in fruit....................................... 8,9

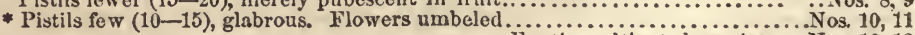

Exotic, eultivated species.... Nos. 12, 13

1 A. Nuttalliàna DC. PASQUE-FLOTER. Plant clothed with silky hairs. St. in flower very short, in fruit 8-12' ligh. Lvs. long-stalked, many-cleft, segments linear or cuneiform, incised. Involucre below the middle of the stem, sessile, subulately dissected, concave or cup-shaped in position. Sep. of the singlo showy flower 5 or $6,1^{\prime}$ long, pale-purple, silky outside, appearing before the leaves, in Apr. Tails of the carpels $1 \frac{1}{4}^{\prime}$ long.-Dry hills, Wisc., IIl., W. to $R$. Mts. (A. patens L. Pulsatilla, Gray.)

2 A. Caroliniàna Walt. Lvs. 3-parted into cuneate-linear, twice trifid segments; invol. similarly cleft half way, hand-shaped; sep. 15-20, obtuse; head of carpels cylindraceous-oblong.-A delicately beautiful plant, Car. to Ark. and Ncbr. Rhizome tuberous, sending up many stalked, multifid leaves and a scape $6-10^{\prime}$ high, bearing the 2 or 3-leaved involucre below the middle, and the single large, fragrant, white or rose-colored flower at top. Scapo pubescent above. Outer sepals dotted with purple, oblong, the inner (or petals) narrower, all nearly persistent. Invol. similar to, or less deeply cleft than the leaves. Apr. (A. tenella, Ph.)

3 A. heterophýlla Nutt. Lvs. of roundish-oval, crenate segments; invol. linear-cleft to the base; sep. acute, 5-13; head of carpels cylindrical. -Ga. (near Macon, Mettauer) to La. (Hale) and Ark. Rhizomo tuberous. Radical lvs. one or 
few, long-stalked (3-5'), ternate, the segments stalked, simple, or incisely 3-lobed or parted. Scape 8-16' high, silky pubescent above. Lvs. of the invol. totally unlike the others, the segments $1-11^{\prime}$ by $1^{\prime \prime}$, placed (in flower) above the middle of the scape. Fl. greenish, scentless: sepals commonly 8, all linear-oblong, $5-6^{\prime \prime}$ long, soon falling. Heads of carpels $1 \frac{1^{\prime}}{2}$ long; ach. Hattened. Mar.-Apr.

4 A. parviflòra Mx. Invol. 2-leaved; sep. 5-6, oval; head of carpels globular.Canada and northward. Stem 2-12' high, pubescent. Lvs. 3-parted, segments cuneiform, 3-cleft, crenate lobed, those of the involucre similar, subsessile. Flowver whitish. ( $\Lambda$. cuneifolia, Ph.)

5 A. multifida DC. RED WIND-FLOWER. Invol. short-petioled; lateral peduncles involucellate: heads of carpels oval.-Rocks, northern Vt. and N. Y., W. to Lake Superior; rare. Plant hairy, about if high. Radical lvs. ternately divided, segm. cuneiform, gashed into 3 linear acute lobes, petioles $2-4^{\prime}$ long. Invol. 2-3-leaved, similar, subtending 2 or 3 peduncles. Involucels 2 -leaved, sessile. Fls. of $5-8$ obtuse sepals, small, purple, varying to white. Jn. (A. Hudsoniana Rich.)

6 A. Virginiàna L. Invol. long-petioled; lateral peduncles involucellato; heads of carpels oblong.-A tall species in dry woods and hilly pastures, Can. to Car. Scape erect, 2-3 f. high, hairy, dividing above into about 3 long parallel 1 -flowered peduncles, middle one naked, lateral ones each with an involucel of two bracts. Lvs. $2-3^{\prime}$ by $3-4^{\prime}, 3$-parted; lfts. ovate-lanceolate, toothed and lobed; petioles $6-10^{\prime}$ long, petioles of the bracts much shorter. Sepals 5 , yellowish green. Fruit woolly, in heads $\frac{3^{\prime}}{4}$ long. July.

ß. ALBA. Fis. larger; sep. white.-Ledges, Vt. (Dr. Robbins.)

7 A. cylínarica Gray. Invol. long-petioled; peduncles all naked; head of carpels cylindrical.-Dry soils, Mass., N. H. to Iowa. Plant silky pubescent, $1-2 \mathrm{f}$ high. LVs. 2-3' wide, 3-parted; segm. cuneate, deeply gash-lobed and cut-toothed, petioles $3-6^{\prime}$ long; ped. 3-6, 1-flowered, 6-10' long, umbellate, sometimes one or two with involucles; sep. 5 , silky, greenish-white, obtuse; heads of fruit $11^{\prime}$ long. May.

8 A. nemoròsa (and quinquefolia) L. Low, smooth, 1-flowered; invol. petiolate.A common and interesting little plant, $6-9^{\prime}$ high, found in old woods, hedges, and in open fields. Radical leaf 1 , ternate, segm. cleft or lobed. Invol. of 3 petiolato leaves, placed in a whorl near the top of the stem, its bracts cut-toothed and lobed, the lateral segments cleft, sometimes quite to the base, so as to render the leaf quinate. At the top of the stem is a single white flower, purplish outside. Apr., May.

9 A. Pennsylvánica L. Hairy: invol. sessile: ped. one, at length 2 or 3 , lateral ones involucellate.- Shores and wet prairies, Can. to Penn. W. to Ind. and Wis. Stem 12 to $20^{\prime}$ high; lvs. large, veiny, those of the root 5-parted, segm. cuneate, 3-lobed, pointed. LVs. of the involucre 3-parted, acuminate-lobed and toothed. First flower on a naked stalk. From its base arise two branches, each 2-leaved (involuceled) and 1-flowered. Sep. 5, obovate, large, white. Jn.-Aug.

10 A. narcissiflòra L. Villous; involucre sessile; achenia flattened.-In Canada and northward. Plant clothed with long silky hairs. Lvs. palmately 3-5-parted, segm. cuneiform, incisely many clcft into linear acuto lohes. Invol. somewhat similar, the sessile leaflets 3-5-cleft. Flowers several, umbelate, white, on leafless stalks.

11 A. thalictroìdes L. Rue ANemone. (Fig. 361.) Glabrous, low; invol. petiolate: ach. grooved.-In woods, Can. to Ga., W. to Iowa, common. A fine little plant of early spring. Root consisting of several oblong tubers; lvs. biternate or triternate, the common petiole $2-4^{\prime}$ long. Lfts. like those of the invol. $6-12^{\prime \prime}$ long, $\frac{2}{3}$ as wide, oval, subcordate, 3-lobed. Invol. of two ternate leaves appearing as a whorl of 6 petiolulate ifts. Flowers several, whito varying to pale purple. Hight 6-S'. Apr., May. (Thalictrum anemonoides $\mathbf{M} \mathbf{x}$.)

$12 \mathrm{~A}$. coronària L. Lvs. ternate, with multifid segments and linear mucronate lobes: sep. 6, oval, close.-From Levant. A hardy, Howering plant, with large single or double variegated flowers. May.†

13 A. horténsis L. Lvs. 3-parted, with crenate, cut-dentatel obes : invol. sessile, of oblong, entire or cut leaflets. Sep. 10-12, oblong.-From Italy. A fino garden species, with doublo and semi-double varietios of red, white, and blue Howers. May.t 
Observation.-Many other foreign species are ornamental, and perbaps rarely cultivated. They all prefer a fresh, loamy soil.

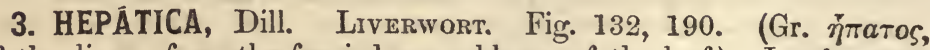
of the liver; from the fancied resemblance of the leaf.) Involucre of 3 entire, ovate, obtuse bracts, resembling a calyx, situated a little belory the flower; calyx of $5-9$ petaloid sepals, disposed in 2 or 3 rows; corolla 0 ; achenia awnless.

E. tríloba Chaix (and acutiloba DC). Lrs. trilobate, the lobes entire; scape 1-flowered, hairy.-Woods, Can. to Ga., and Wisc. This little plant is one of the earliest harbingers of spring, often putting forth its neat and elegant flowers in the neighborhoed of some lingering snow bank. The roat consists of numerous and strong fibers. Irs. all radical, on long, hairy petioles, smooth, evergreen, coriaceous, divided into three lobes, which suggest all its names. Fls. on scapes $3-4^{\prime}$ long, solitary, numerous, generally blue, but frequently in varieties of white and flesh color. In cultivation they become double. In respect to the form of leaves there are two varieties:

a. OBTUSA, lobes obtuse, rounded.-Prefers the south side of hills.

B. ACUTA, lobes acute.-Prefers the north side of hills. (II. acutiloba, D. C.)

4. THalíctrum, Tourn. Meadow RuE. (Said to be from $\theta \dot{\lambda} \lambda \lambda \omega$, to be green.) Calyx colored, of $4-5$ roundish, concave, caducous sepals; corolla 0 ; filaments $\infty$, compressed, dilated upward, longer than the calyx; ovaries numerous $(4-15)$; achenia sessile or stipitate, ribbed or inflated, pointed with the stigma or short style.4 Lvs. ternately compounded, with stalked leaflets. Fls. paniculate, often $q \hat{\delta}$ or $q$ $\succ \hat{f}$.

* Carpels mostly 10 or 12 , beaked with a style............................. Nos. 1, 2

* Carpels few $(1-6)$, with sessile stigmas.................................... Nos. 3,4

1 T. dioìcum $I_{L}+q \hat{\delta}$; stem leaves on a short common petiole; lfts. obtusely 5-7 lobed; ach. about 8, sessile.-Hilly woods, Brit. Am. to Ga and Ala. A slender and delicate plant, glabrous and glaucous, $1-2 \mathrm{f}$ high. Lvs. ternately decompound, the cauline on petioles $1-3^{\prime}$ long, shortening upward. Lfts. roundish, about $\frac{3}{4}$ diameter, with $5-7$ obtuse lobes, paler beneath. Filaments filiform, longer than the 5 obtuse sepals. The slender terminal panicle is often purplish, generally pale green. Fruit strongly ribbed and distinctly pointed. May.

2 T. cornùti I. $\& \hat{\delta}$; stem lvs. all sessile (no common petiole); lfts. roundish obovate, rather acutely "3-lobed; ach. about 12, substipitate, ribbed.-Common in meadows. Stem $3-4 \mathrm{f}$ high, smooth, hollow, jointed, furrowed, Lvs. resembling those of the columbine (Aquilegia), green above, smooth, several times compounded. Lffs. 1-2' long, $\frac{2}{3}$ as wide. Panicles large and diffuse. Jn., $\pi$.

$\beta$. PURPURÁSCENS. Stems purplisl, tall; stem-lvs. sessile or the lower with short stalks; fls. purplish-green, with drooping eapillary fil.; lfts. thickish, the sides revolute. Dry hills, N. H. to Ga. ('T. purpurascens L.)

3 T. clavàtum, D C. Fls. perfect; lvs. cauline: panicle corymbous : ach. stiped.N. Car. (Curtis). Plant very smoooth, $2 \mathrm{f}$ or more in hight. Irs. biternate, on petioles $1^{\prime}$ in length; lfts. roundish, obtusely 3-5-lobed, glaucous beneatl. Panicles loose and capillary. Fruit inflated, obovate, striate, each as long as its slender stipe, acute. Style 0.

4 T. alpìnum L. Lvs. mostly radical: fls. $\Varangle$ in a simple raceme: ach. ovate, sessile.-Can. and northward. Plant about $6^{\prime}$ high, glabrous. Lvs. petiolate, biternate; lfts. roundish, about $4^{\prime}$ diam., crenately toothed. Stems few-leaved, terminating in a cluster of a few nodding flowers on slender pedicels. Filaments filiform. Style 0.

5. TRAUTVETTÈRIA, Fisch. and Meyer. (Named in honor of Trautvetter, a German botanist.) Sepals 4-5, colored, caducous; petals 0 ; stamens $\infty$, petaloid; carpels $15-20$, membranous and in- 
dehiscent, anguiar, 1-seeded, tipped with the short, hooked style.24 Lvs. palmately lobed. Fls. corymbous.

T. palmàta Fisch and Meyer. A coarse plant of the prairies and woods, Va. to Can., W. to Ill. Stem slender, 2-5f high, terete, smooth, terminating in a large branching corymb. Radical lvs. 4-6' wide, by $3-5^{\prime}$ long, rugous and reticulateveined, 5-9 lobed, long-stalked; stem lvs. few, remote, the upper sessile. Fls. many, white. Sepals orbicular, concave, falling as soon as expanding. $\mathrm{I}$, Aug. (Cimicifuga, Hook.)

\section{ADÒNIS, L. Prieasant's-Eye. (Feigned to have sprung from} the blood of Adonis when wounded by the boar.) Sepals 5, appressed; petals 5-15, with a naked (scaleless) claw. Achenia spiked, ovate and pointed with the hardened, persistent style.-Herbs with dissected lvs. and terminal, solitary, red or yellow flowers.

1 A. autumnàlis L. Petals 5-8 (crimson), concave and connivent.-A fine hardy annual, from Europe, naturalized in some parts of the country. Stem thick, branching, If high. Lvs. pinnately parted, with numerous linear segments. Fls. $1 \frac{1}{2}$ diam. Carpels crowned with a very short style, and collected into an ovate or sub-cylindric head. Seeds to be sown in autumn in a light soil.

2 A. vernàlis L. Petals 10-12 (yellow), oblong, spreading.-A handsome perennial, from Europe. Stem branching, If. high. Lvs. sessile, multifid.

7. RANúnCUluS, L. Crowfoot. Buttercups. Fig. 24, 241, $242,294,369,458,386,415$. (Lat. rana, a frog; from the aquatic habitat of some species.) Calyx of 5 ovate sepals ; cololla of 5 roundish, shining petals, each with a nectariferous scale (Fig. 294) or pore at the base inside; filaments $\infty$; achepia $\infty$, flattened, pointed, crowded in a roundish or oblong head.-Herbs, mostly 4 , with alte:nate leaves and yellow flowers.

Seeds (carpels) rough with points or prickles........................... Nos. 1, 2

Seeds (carpels) smooth and even, or merely rugous (a).

a Leaves in fine, numerous, thread-like divisions, under water..................Nos, 3,4

a Leaves all undivided and simple. - Stems creeping................................. 5, 6

-Stems erect.................................. 7 .

a Root-lvs. simply crenate or lobed, stem leaves divided............................. 10, 11

a Leaves all more or less divided, not submersed (b).

b Sepals spreading in flower, shorter than the showy petals............... Nos. 12-14

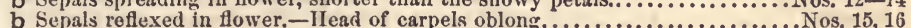

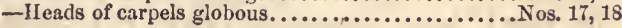

1 R. muricatus L. Glabrous; carpels aculeate, strongly margined, and ending in a stout, ensiform, recurved leals. Va. to La. Stem branched, erect, If high. Lvs. roundish ( $1 \frac{1}{2}^{\prime}$ diam.), cordate, 3-lobed, lobes coarsely crenate-toothed, all similar, and on petioles $1-5^{\prime}$ long. Bracts close to tho flower, simple. Fls. small, few. Pet. obovate, yellow. Carpels large ( $3^{\prime \prime}$ long, including beak). $\$$ Eur.

2 .R. parviflòrus L. Villous; carpels roundish, granulated, tipped with a very short beak.-Va. to La. Stem 6-12' high, slender, branched. Lvs. all petiolate, small, roundish $\left(9-16^{\prime \prime}\right.$ diam.), cordate, 3 -lobed or parted, the segments acutely toothed. Fls. quite small, the yellow petals not exceeding the calyx. Seeds scarcely $1^{\prime \prime}$ in length, in a globular head. $\$$ Eur.

3 R. aquátilis L. $\beta$ CAPILLACEUS. Lvs. all filliformly dissected; pet. white; carpels transversely rugous.-Ponds and sluggish streams, Arctic Am. to S. Car., W. to Rocky Mts. The whole plant is submerged except the flowers, and perhaps a few of the upper leaves. Stem $1-2 \mathrm{f}$ or more in length, slender, weak, round, smooth, jointed. Leaves divided dichotomously into numerous hair-like segments, in outline roundish and $\frac{1}{2}-1^{\prime}$ diam. Ped. thick, $1-1 \frac{1^{\prime}}{2}$ long. Fls. smaller than in R. acris. Petals rather narrow, white, except tho yellow claws. Il., $\Lambda$ ug. 
4 R. multífidus $\mathrm{Ph}$. Floating; st. long; submerged lvs., cleft into numerous eapillary segments, emersed ones reniform, $3-5$ parted, the lobes variously divided; sep. reflexed, $\frac{1}{2}$ as long as the yellow petals; carpels smooth, with a short, straight, ensiform style; hds. globous.-Ponds, sluggish streams, and muddy places, Can., U. S Stem 1-2f or more in length, fistulous. Lvs. pentangular in outline, $\frac{2}{3}-1 \frac{1}{2}^{\prime}$ diam., those below more finely divided; petioles $\frac{1}{2}-2^{\prime}$ in length. Fls. bright yellow, emerging on forked, striate peduncles. May, Jn.

$\beta$. FLUviatilis. Lvs. all capillaceous-multifid; fls. as large as in R. acris. lacustris Beck.)

5 R. Cymbalària $\mathrm{Ph}$. St. filiform, creeping, rooting; lvs. reniform-cordate, crenate-dentate; ped. solitary, mostly 2-flowered; petals spatulate; ach. oblong.In salt marshes on the sea-coast, and at Salina, N. Y. Stem round, sending out runners from the joints. Lvs. radical, $\frac{1}{2}-1^{\prime}$ diam. on long petioles. Scapes $2-6$ ' high, each with 2 small, bright-yellow flowers, and as many obtuso bracts. Nectary naked (not covered by a scale). Jn.

6 R. réptans L. Stem creeping, geniculate, rooting; nodes 1-flowered; lvs. linear, entire, remote.-A slender species, creeping on river banks and other wet places, Can., N. H., W. to Oregon. Stem 6-8' long, round, rooting at tho joints. Lvs. fleshy, 6-12" in length, mostly very narrow and acute at each ond. Fls. small (3-4" wide). Sepals spreading, obtuse. Petals obovate, yellow, fading to white. Nectary covered by a scale. Ach. very smooth. Jl. (R. filiformis Mx.)

$\beta$, ovalis. Lvs. oval and lanceolate; pet. $5-10$.

7 R. Flámmula L. Spen Ŕ̛rort. Stem declinate at base, erect; lvs. all lanceshaped, on sheathing petioles.-An aquatic herb, growing in ditches and swamps, Can. to N. Car., W. to Ill. Root fibrous. Stem 6-18' long, more or less decumbent, succulent. Lvs. $3-6^{\prime}$ in length, entire, or with a fow teeth, thickened at the acuto summit. Fls. solitary, of a golden yellow, on peduneles $\frac{1}{2}$ as long as the leaves. Fruit roundish, twice longer tinan its beak, in a globular head. Jn., Aug. (R. alismæfolius Geyer.)

8 R. pusíllus Poir. Erect; lvs. all petiolate, lower ones ovate, upper ones linearlanceolate; pet. mostly but 3 scarcely longer than the calyx; stam. 8-10; carpels ovate, scarcely pointed.-In wet grounds, N. Y. to Ga. and La. Stems sleader, weak, 6-12' high, dichotomously branched. Lower lvs. subcordate, $\frac{1}{2}-1^{\prime}$ long. $\frac{1}{3}$ as wide, petioles $1-3^{\prime \prime}$ long, upper omes $1-1 \frac{1}{2}$ long, $\frac{1}{4}$ as wide, with minute, remote teeth. Fls. very small, yollow, on long peduncles. May.

9 R. oblongifòlius Ell. Erect or ascending, diffuse, branched; lvs. lance-ovate and lanceolate; fls. minute, stam. about 20.-Car., Ga., and W. Glabrous, or stem puberulent, 12-18' high, dividing above in numerous slender branches and peduncles. Lvs. petiolate, denticulate, upper linear. Fls. numerous, petals yellow, less than $1^{\prime \prime}$ long. Carp. minute, pointless, in round heads. (R. Texensis Engl.)

10 R. abortivus L. Smooth; radicallvs. roundish, cordate, crenate, petiolate; cal. a little longer than petals, reflexed. A rery pretty species in woods, Can. to Ark., remarkable for the dissimilarity of the root and stem leaves. Stem 8-16' high, nearly naked. Root lvs. 8-18" diam., quite regularly margined with crenate divisions, and on petioles $2-5^{\prime}$ long. Lower stem lvs. pedate, with a pentangular outline; upper in 3 deep, linear segments, sessile. Fls. small, yellow. Fruit in globous heads. May, Jn.

$\beta$ micranthus. Hairy, low $\left(3-5^{\prime}\right)$; lower lvs. scarcely cordate, 3 -lobed or 3 cleft. Fls, 1 or 2 . Mass. (Sprague) to Ga.! (R. micranthus, Nutt.)

11 R. rhomboìdeus Goldie. Hirsutely pubescent, much branched; root lvs. rhomboid-cvate, crenate-dentate, on long petioles; sep. spreading, shorter than tho petals; ach. smooth, with very short beaks.-Wis. (Lapham) and Can. W. A low, bushy, hairy species, $6-10^{\prime}$ ligh. Root lvs. about $1^{\prime}$ by $\frac{2}{3}^{\prime}$, often roundish or elliptical, the petioles about $2^{\prime}$ long. Segments of the stem leaves linearoblong, obtuse, oftener entire. Petals yellow, oblong-obovate. Heads of carpels globous. (R. ovalis and brevicaulis, Hcok.)

12 R. fasciculàris Muhl. EARLY CrowFoor. Erect; root fasciculate; radical lvs. appearing pinnate; poduncles terete; carpels scarcely margined.-Rocky woods 
and hills. Root a cluster of fleshy fibres. Root lvs. on petioles $3-8^{\prime}$ long, ternate, with the middle segment long-stalked and again pinnately ternate; lateral segm. mostly sessile, all 3-5 cleft into acute lobes. Stems never creeping. Pubescence silky, appressed. Fls. bright yellow, $1^{\prime}$ broad. Petals spatulatoobovate, with a broad scale. Beak of the carpels slender. Apr., May.

13 R. rèpens I. Root fibrous; radical lvs. ternate with stalked leaflets; peduncles furrowed; carp. broadly margined and pointed.-In moist and shady places. Early flowering stems erect; later branches from the base prostrate, $1-3-4 \mathrm{f}$ long, generally hirsute at the base. Petioles liairy, long. Lvs. hairy on the veins, dark green, ternate, the lits. ovate or broadly crenate, variously lobed and cleft, all (or at least the middle ones) petiolulate. Fls. middle size, bright yellow. Fr. in a round head. May,-Jl. Varies exceedingly in different localities and stages of growth. Some of its more striking forms are:

$\beta$. LINEARILòbUS. St. very long, floriferous, smoothish; lobes of lrs. very narrow. Fruit not strongly margined.

$\gamma$. HíspIDUs. Stem and petioles densely hirsute with soft-spreading hairs; lfts. all distinctly stalked, deeply parted. Fr. short-pointed.

ঠ. Nítidus. Mostly erect, glabrous; fls. large, sep. reflexed; fr. strongly margined. Common South. Probably a distinct species.

14 R. palmatus Ell. Lvs. palmately $3-5$ cleft or divided, with the sinus at base closed, the segm. all sessile and cut-toothed or lobed; carp. few, margined, and straight-beaked. - In wet barrens, Car. to Fla. St. 12-18' high, with a few slender branches, pubescent. Lvs. all petiolate, pentangular in outline, $1-2^{\prime}$ wide, with appressed pubescence. Upper lvs. of 3 linear segments. Fls. few, yellow, small (6-8" diam.) Fr. compressed.

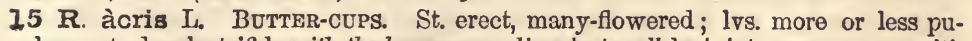
bescent, deeply trifid, with the base segm. divaricate, all laciniate, upper ones with linear segments; ped. terete; cal. hairy, spreading; carp. roundish, smooth, compressed; beak short, recurved.-This is the most common species in N. Eng. and Can., in meadows and pastures, rapidly and extensively spreading. St. $1-2 \mathrm{f}$ high, round, hollow, mostly hairy. Lvs. $1 \frac{1}{2}-3^{\prime}$ diam., upper ones in 3 linear segments. Fls. large ( $1^{\prime}$ diam.), golden yellow. Jn., Sept.

$\beta$. PLìiA. Fls. double, the petals excessively multiplied. Gardens.

16 R. Pennsylvánicus L. Hirsute, with stiff, spreading hairs; lvs. ternate, lfts. sub-petiolate, deeply 3-lobed, incisely serrato; cal. reflexed, rather longer than the roundish petals; carp. tipped with a short, straight style. $-\Lambda$ very hairy species in wet grounds, Can. and U. S. Stem 11-3f high. Lvs. 2-3' diam., lfts. strongly veined and with spreading segments. Fls. numerous, small, bright yellow. Fruit in dense oblong or cylindrical heads.-Jn., Aug. (R. hispidus Ph.)

17 R. sceleràtus $\mathrm{Ph}$. Smooth; lower lvs. 3-parted, segm. 3-lobed, crenately incised, or entire; carp. minute, pointless.-Grows in wet places, Can. to Ga. St. rather thick, hollow, much branched, 1-1 1 1 h high. Lower petioles $3-5^{\circ}$ long, with rather large, palmately $3-5$-parted leaves. Floral lvs. or bracts mostly simple, lanceolate and entire. Fls. small, yellow. Cal. reflexed, as long as the minute petals. Hds. of carpels only $2-3^{\prime \prime}$ long. This is one of the most acrid of the tribe, and will raiso blisters upon tho skin. Jn., Jl.

18 R. recurvàtus L. Hirsute with thin, spreading hairs ; lvs. all similarly 3-parted, segm. oval, unequally incised, the lateral ones 2-lobed; cal. recurved, longer than the lanceolate petals; ach. with a hooked beak.-About if high, in damp woods. Lab. to Fla. Pale green, branching above. Lvs. $1 \frac{1}{2}-2^{\prime}$ long, 2-31' wide, on petioles $3-6^{\prime}$ long. Upper lvs. subsessile and 3-parted quite to the base. Fls. small, with inconspicuous, pale yellow petals. Carp. ovate, tipped with long, hooked beaks. May-Jl.

19 R. bulbòsus L. Hairy; st. erect, bulboris at the base; radical lvs. ternate, lfts. petiolate, incisely dentate, each about 3-cleft; ped. furrowed, cal. reflexed.This is another acrid species, very common in pastures, mow-lands, \&c. Rt. fleshy. St. leafy, furrowed, 6-18' high, hollow, thickened at the base into a sort of bulb, and dividing above into upright peduncles, with golden yellow 
flowers. It is well distinguished from $R$. acris by its reflexed sepals and its furrowed peduneles. The lobes of the root-leaves are also rounded rather than acute at apex. May, Jn. § Eur.

8. MYOSÙRUS, Dill. Mouse-TAIL. Fig. 286, 287. (Gr. $\mu \tilde{v} \varsigma$, $\mu v o ̀ s$, mouse, oủpà, tail; alluding to the long spike of earpels.) Sepals 5 , produced downwards at base below their insertions; petals 5 , with slender, tubular claws: stamens 5-20; achenia very closely spicate on the elongated torus.- (1) Lvs. linear, entire, radical. Scapes 1-flowered.

1 M. mínimus L. Prairies and bottoms, Ill. to La. and Oreg. A diminutive plant, remarkable for its little terete spikelet of fruit, which is often more than an inch long. Lrs. $1-3^{\prime}$ long and $1-2^{\prime \prime}$ wide. Scape a littlo taller, with a single minute, pale yellow flower at top. Carp. very numerous, blunt. Apr.

9. ISOPÝrum, L. False Rue Anemone. Fig: 288. Sepals 5, petaloid, deciduous; petals 5 , small, tubular, sometimes 0 ; stamens $10-40$; ovaries $3-20$; follicles subsessile, acuminate with the style, 2 -several-seeded. - Delicate herbs, with leaves 2-3-ternate, segments 2-3-lobed. Fls. pedunculate, axillary and terminal, white.

1 I. biternàtum Torr. \& Gr. Low, erect, glabrous; pet. none; carp. 3-6, broadly ovate, divaricate, sessile, strongly veined, 2-seedod; sds. ovate, compressed, smooth, and shining.-2 4 Damp shades, Lake Erie to Ark., rare. Rt. fibrous. Stems several, 4-10' high. I IVs. mostly biternate, the radical on long petioles, segm. cuneate-obovate, $4-6^{\prime \prime}$ long, on stalks of equal length. Fls. on slender peduncles $1-2$ ' long. May. Looks like the Rue Anemone.

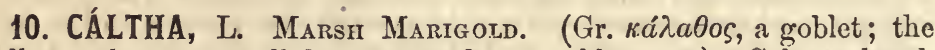
yellow calyx may well be compared to a golden cup.) Calyx colored, of $5-9$ sepals, resembling petals; corolla 0 ; stamens $\infty$, shorter than the sepals; follicles 5-10, oblong, compressed, erect, many seeded.2f Aquatic and very glabrous.

C. palústris L. Lvs. reniform or orbicular, crenate or entire.-Wet meadows, Can. to Car., W. to Oregon. Root large, branching. Stem about If high, sometimes trailing, hollow, round, dichotomous. Lower lvs. 2-4' wide, on long semicylindric petioles, upper ones sessile, all of a dark, shining green, veiny and smooth. Fis. of a golden yellow in all their parts, $1 \frac{1}{2}$ diam., few and pedunculate. Outer row of filaments clavate, twice longer than the inner. The young leaves are in great request in spring for greens. May.

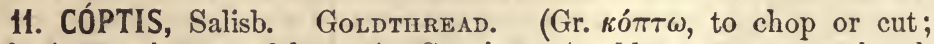
referring to the parted leaves.) Sepals $5-7$, oblong, coneave, colored, deciduous ; petals $5-7$, small, clavate, tubular at apex ; stamens $20-25$; follicles $5-10$, stipitate, rostrate, diverging in a stellate manner, 4-6 seeded.-Low herbs with radical lvs., and a long, slender, perennial, creeping rhizome.

C. trifòlia Salisb. Lvs. 3-foliate; scape 1-flowered; petals mueh smaller than the sepals.-Penn., N. to Arctic Am. St. subterranean, extensively creeping, golden yellow, very bitter and tonic. Lvs. all radical, lfts. sessile, 4-8" long, crenate-mucronate, smooth, coriaceous, common petiole $1-2^{\prime}$ long. Ped. $3-4^{\prime}$ high, with a single minute bract above the middle, bearing a single white, starlike flower. The yellow petals are barely distinguishable by their color among the white stamens. May. Medicinal.

12. TRÓlliUS, L. Globe Flower. (Germ. trol or trollen, globular; alluding to the form of the flowers.) Sepals 5-10-15, roundish 
ovate, colored, deciduous; petals $5-25$, small, linear, tubular at base ; stamens $\infty$, much shorter than the sepals; follicles $\infty$, subcylindric, sessile, many-seeded.- 4 Smooth, with palmately parted leaves.

1 T. laxus Salisb. Sep. 5, oblong, spreading; petals 15-25, shorter than the stamens. - In swamps, Can. to Penn. Not common. About $1 \mathrm{f}$. high. Lvs. deeply cleft into 5 segments, which are lobed and cut-dentate. Fls. $1_{\frac{1}{2}}^{\prime}$ diam., not globular. Sep. yellow, greenish outside. Petals very small, orange-colored. Follicles about 10, crowned with the persistent styles. This is the only American species. Jn. (T. Americanus Muhl.)

2 T. Buropaèus L. Sep. 15, incurved petals 5-10, as long as the stamens.From Europe. St. 2-3f high. Fls. of a rich yellow. A very ornamental plant, of easy culture from seeds or roots. May, Jn. $\dagger$

3 T. Asiàticus L. Sepals 10, spreading; petals 10, longer than the stamens.From Asia. Plant about 2f. high, with ample foliage, and large, deep orangecolored flowers-yellow in some of its varieties. Jn. $\dagger$

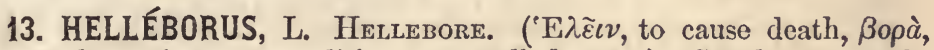
food; the poisonous qualities are well known.) Sepals 5, mostly greenish, persistent; petals .8-10, very short, tubular, 2-lipped; stamens $\infty$; stigmas $3-10$, orbicular; follicles cohering at base, many-seeded.-24 Lvs. coriaceous, palmately or pedately divided. Fls. large, nodding.

H. víridis L. Glabrous; radical lvs. pedately divided, segm. lanceolate, acute, serrate; cauline lvs. few, palmately parted, rearly sessile; peds. often in pairs; sep. roundish ovate, acute, green.-A European plant, § on Long Island. Stem 2-3f high, thick. Apr.

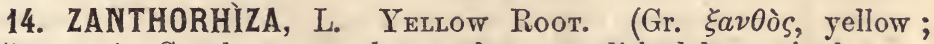
$\dot{\rho} i \zeta a$, root.) Sepals 5 ; petals 5 , of 2 roundish lobes raised on a pedicel ; stamens 5-10; ovaries 5-10, beaked with the styles, 2-3-ovuled; follicles mostly 1 -seeded, seed suspended.-Suffruticous, stem and bark yellow, and bitter. Lrs. pinnately divided. Racemes axillary, compound. Fls. small, dark purple, often $q$ 후 $\hat{\text {. }}$

Z. apifòlia L'Her. River banks N. Y. to Ga. Rt. thick. St. short, woody, leafy above. Lrs. glabrous, about $8^{\prime}$ long, including the long petioles. Lfts. 5 , $2-3^{\prime}$ long, sessile, incisely lobed and dentate. Rac. many-flowered, appearing with the leares. Follicles spreading $\mathbf{1}_{\frac{1}{2}}{ }^{\prime \prime}$ long. March, Apr. (Z. simplicissima $\mathrm{MIx}$.)

15. Nigélla, L. FenNel-Flower. Fig. 143. (Lat. niger, black; the color of the seeds, which are used in cookery.) Calyx of 3 sepals, colored; corolla of 5,3 -cleft petals; styles 5 ; capsules 5 , follicular, convex.-(1) Oriental herbs. Lvs. in many linear and subulate segments.

I N. Damascèna L. Fls. in a leafy involucre; carp. 5, smooth, 2-celled, united as far as the ends into an oroid-globose capsule. A hardy annual of the gardens, to which have been applied the gentle names of "ragged lady," "devil in a bush," \&c. Lvs. twice and thrice pinnatifid, as finely cut as those of the fennel. Fls. terminal, solitary, encompassed and over-topped by a circle of leaves divided liko the rest. They are often double, white or pale blue. Jn.-Sept. $\dagger$

2 N. sativa L. NUTMEG-FLower. St. hairy, ercet; fls. naked; capsules muricate, not united. From Egypt. Rather smaller than the last. Jn.-Sept.f

16. AQUILÉGIA, L. Columbine. (Lat. aquila, the cagle; tho spurred petals resemble the talons of a bird of prey.) Sepals 5, equal, ovate, colored, spreading, caducous; petals 5 , tubular, dilated at the 
mouth, the outer margin erect, the inner attached to the torus, extending behind into a long spurred nectary; stamens $30-40$, the inner ones longer and sterile; styles 5, follicles 5, many-seeded. Lvs. 2-3ternate. Fls. nodding.

1 A. Canadénsis L. Glabrous; spurs straight, longer than the limb; sta. and sty. exserted.-This beautiful plant grows wild in most of the States, in dry soils, generally on the sunny side of rocks. It is cultivated with the greatest ease, and is much more delicate in its foliage and in the hues of its flowers than the common blue columbine. St. branching, a foot high. Lfts. 3-9, cuneate, lobed. Fls. terminal, scarlet without and yellow within, pendulous, much embellished by the numerous descending, yellow stamens and styles. Fruit erect. May.

2 A. vulgàris L. Spurs incurved; lvs. nearly smooth, glaucous, biternate; sty. a little longer than the stamens. - Gardens. St. 1-2f high, with a profusion of handsome, smooth foliage and large purple flowers. Lfts. bifid and trifid, with rounded lobes. In cultivation the flowers become double, by the multiplication of the hollow, spurred petals. They also vary in color through all shades from purple to white. Jn.† \& Eur.

17. DELPhÍniUM, L. Larkspur. Fig. 280. (Gr. $\delta \varepsilon \dot{\lambda} \phi \iota v$, a dolphin, from the fancied resemblance of the flower.) Sepals 5, colored, irregular, the upper one spurred behind; petals 4, very irregular, the two upper ones protracted into a tubular, nectariferous spur, enclosed in the spur of the calyx; styles $1-5$; follicles $1-5$.- Showy herbs. Lvs. palmately divided. Fls. of the cyanic series, never yellow.

$\$$ Leaves many-cleft into linear or subulate divisions............................... 1, 2

\$ Leaves 3-5-parted. the segments lobed. $\left(^{*}\right)$

* Spur as long as the sepals, ascending, straight............................ Nos. 3, 4

* Spur longer tlan the sepals, deflexed at end............................................ 5

I D. Consólida L. Glabrous, with spreading -branches; $f s$. few, loosely racemed, ped. longer than the bracts: sty. solitary, smooth.-The common larkspur of the gardens, sparingly naturalized, fields and roadsides. Lvs. in numerous linear divisions. Jn., J1. It has numerous varieties of double and semidouble flowers of various colors. $+\S$ Eur.

2 D. azúreum Mx. Pubescent or nearly smooth; st. erect; lvs. 3-5-parted, many-cleft, with linear-stalked lobes; petioles some dilated at bas?; rac. strict; petals shorter than sepals, lower one densely bearded, 2-cleft; spur ascending; ovaries 3-5.-24 Native in Wis. and Ark. A very variable species cultivated in gardens. St. 2-4f high. Fls. azure colored. $\dagger$

3 D. exaltàtum L. Petioles not dilated at base; lvs. flat, 3-cleft below the middle, segm. cuneiform, 3-cleft at- the end, acuminate, the lateral ones often 2-lobed; rac. strict, many-flowered; spur slightly longer than the calyx; pods 3 , erect.- 2 Native of the Middle States, rarely of the Northern. St. 3-4f high, straight, erect. Fls. of a brilliant purplish blue. It is deservedly esteemed in the flower garden, and is of the easiest culture. Jl., Aug.t

4 D. tricòrne Mx. Petioles slightly dilated at base; lvs. 5-parted, divisions $3-5$ cleft, lobes linear, acutish; rac. few-flowered, loose; petals shorter than sepals, lower ones 2-cleft, densely bearded inside; spur ascending, straight, as long as the calyx; pods 3, spreading in fruit.-24 Uplands, Penn. to Mo. and Ark. Plant 6-18' high, nearly smooth. Lrs. roundish in outline, on long petioles. Fls. $6-8$, light blue, in a rather loose panicle.

5 D. viréscens Nutt. Pubescent; rac. loose, few-flowered; spur longer than the sepals, ascending, straight, or but slightly deflexed; lower petals deeply 2cleft; fls. greenish white; ovaries 3.-N. Gar. to Ga. W. to Kansas. Plant 8$12^{\prime}$ high. Lvs. 3-5-parted, lobes lanceolate, 2-3-cleft, the middle one mostly entire. Petals much shorter than the sepals, the lower densely bearded.

6 D. elàtum L. BEe LARKsPUR. Lrs. downy, 5-lobed, lobes cuneate at base, trifid, cut-dentate; spur curved downwards.-2f Gardens. St. 5 or 6 f. high. Fls. 
blue, and when viewed at a little distance the stamens and bearded petals ro semble a bee nestling within the calyx. + Siberia.

7 D. grandiflòrum L. Lvs. palmately 5-7-parted, lobes linear, distant; sessile, 3-cleft pedicels longer than bract; petals shorter than calyx.-A superb perennial. Fls. double or single, in racemes, of brilliant dark blue, with a tingo of purple. + Siberia.

Observation. - A few other species may, perhaps, be found in gardens. All aro showy plants, of the easiest culture.

18. ACONITUM, Tourn. Wolfsbane. Fig. 283. (Gr. ákovĩos, without dust; because the plants grow on dry rocks.) Sepals 5, irregular, colored, upper one vaulted; petals 5 , the 3 lower minute, the 2 upper on long claws, concealed beneath the upper sepal, recurved and nectariferous at the apex; styles $3-5$; follicles $3-5 .-2$ Lvs. digitate or palmate. Fls. in terminal spikes.

1 A. uncinàtum L. Stem flexuous; pan. rather loose, with divergent branches; lvs. palmate, 3-5-parted, with rhomboidal-lanceolate, cut-dentate divisions; helmet (upper sepal) exactly conical, short-beaked in front; ova. villous.-A cultivated, poisonous plant, also native, N. Y. to Ga. St. 2f high. Lvs. coriaceous, dark green, $4-5^{\prime}$ wide. Fls. large, purple, 3 or 4 near the summit of each branch. Jl., Aug.

2 A. reclinàtum Gray. St. trailing (3-8f long); lvs. deeply 3-7-cleft, petiolate, divisions crenate, incised or lobed; fls. white, in very loose panicles; helmet soon horizontal, elongated conical, with a straight beak in front.-Alleghany Mts., Va. and Southward. Aug.

3 A. Napéllus L. MoNKsnood. St. straight, erect; lvs. deeply 5-cleft cut into linear segments, furrowed above; upper sep. arched at the back, lateral ones hairy inside; ova. smooth. - A poisonous plant cultivated among flowers. It is a tall, rank perennial, making quite a consequential appearance. St. $4 \mathrm{f}$ high, with a long spicato inflorescence at its termination. Fls. dark blue, surmounted by the vaulted upper sepal, as if hooded in a monk's cowl. Aug. There aro varieties with flowers white, rose-colored, etc.

19. CIMICÍFUGA, L. Bugbane. (Lat. cimex, a bug, fugo, to drive away; alluding to its offensive odor.) Sepals 4 or 5 , caducous; petals stamen-like, $1 \frac{-8}{8}$, small, clawed, 2-horned at apex ; sta. numerous, with slender white filaments; follicles $1-8$, dry, dehiscent.- 4 Lvs. ternatcly decompound. Flowers white, in long, slender racemes.

\$ Macrotrs. Pistil 1, with a broad stigma, and seeds in two rows................... No. 1

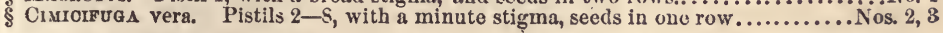

1 C. racemòsa Ell. BLACK SNakeroot. Lfts. ovate-oblong, incisely serrate; rac. very long; caps. follicular, ovoid, sessile.-Plant resembling a tall Actæa, found in upland woods Can. to Ga. St. 4-8f high, with long, panicled racemes of white-sepaled and monogynous flowers. Petals 4-6, small. Sta. about 100 to each Hower, giving the raceme the appearance of a long and slender plume. Fls. very fetid. Jn., Л. (Actæa, L. Macrotys, Raf.)

2 C. Americàna $\mathrm{Mr}$. Glabrous; lvs. triternate, segm. ovate, terminal one euneiform at base, 3-parted or 3-cleft, and incised; petals concave, sessile, 2-lobed, nectariferous at base; ova. $2-5$, stiped, obovate and pod-shaped in fruit; sds. 6-8, flattened vertically. - Mts Penn. to N. Car. and Tenn. St. $3-6 \mathrm{f} \mathrm{high.} \mathrm{Ifts.}$ 2-4' long, with coarse, unequal, mucronate serratures. Fls. smaller than in C. racemosa, in a long panicle of racemes. Aug. (C. podocarpa Eil. Actra podocarpa DC.)

3 C. cordifòlia $\mathrm{Ph}$. Lvs. biternate; lfts. broadly cordate, 3-5-lobed; ova. 1-3; follicles sessite, 8-10-seeded.-Mts. Carolina. St. 3-5f high, terminating in a long glabrous panicle of racemes. Sep. 5, roundish, potals spathulate, bifid, few or wanting. 


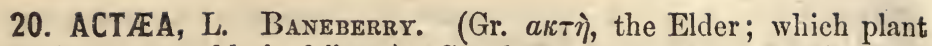
these herbs resemble in foliage.) Sepals 4-5, caducous; petals 4-8, spatulate, long-clawed; filaments about 30 , slender, white; pistil 1 , with a sessile 2 -lobed stigma; berry globous, with a lateral furrow, 1celled; seeds many, smooth, compressed.- 24 with ternately divided leaves. Fls. white, in a short, oblong raceme.

A. spicàta L. $\beta$ RUBRA. RED BANEBERRY. Rac. hemispherical; petals acute; pedicels slender; berries red, ovoid-oblong. - Not uncommon in rocky woods, Can. to Penn. W. to the R. Mts. Plant glabrous, $1 \frac{1}{2}-2 \mathrm{f}$ high, bearing 2 or 3 ample bi or triternate lvs. and a terminal short raceme of white fls. Lfts. ovate, $1-3^{\prime}$ long, half as wide, incisoly lobed and toothed. Petioles 4-7' long, somewhat glaucous. Rac. as broad as long. May. (A. rubra. Bw.)

B. ALBA. MX. Rac. oblong; petals truncate; pedicels of the fruit thicker than the peduncle; berries white.-Common in rocky woods, Can. to Ga. The ample leaves are precisely similar to those of $\boldsymbol{\alpha}$. and the distinetive characters given above are not quite constant. Specimens from Castleton, Vt., have bright red berries on thickened pedicles; from N. Y. (Torr.) have white berries on slender pedicles. The European variety has purplish black berries. May.

21. HYDRÁSTIS, L. Turmeric Root. Fig. 359. (Gr. $\tilde{v} \delta \omega \rho$, water; the plant grows in watery places.) Sepals 3 , petaloid, caducous; petals 0 ; stamens $\infty$, a little shorter than the sepals; ovaries 12 or more, becoming a baccate fruit composed of 1 -seeded acines aggregated into a head.-4 Rhizome thick, knotty, yellow, with long fibrons roots, sending up a single radical leaf and a stem which is 2 . leaved and 1-flowered.

H. Canadénsis I. The only species. It grows in bog meadows. Can. to Car. and $\mathrm{Ky}$. Stem $6-12^{\prime}$ high, becoming purplish, hairy above. St. leaves 2 only, alternate on the upper part of the stem, petiolate, palmate, with 3-5 lobes. Ped. terminal, solitary, 1-flowered. Sep. reddish white, of short duration. Fr. red, juicy, resembling the raspberry. Sds. nearly black. May, Jn.

22. P\&EONIA, L. P\&ONY. Fig. 10-23, 30, 291. (The physician Pceon, according to mythology, first used this plant in medicine, and cured Pluto with it.) Sepals 5, unequal, leafy, persistent ; petals 5 ; stamens $\infty$ (mostly changed to petals by cultivation); ovaries $2-5$, surrounded by an annular disk; stigmas sessile, double, persistent; follicles many seeded.-4 Rt. fasciculate. Lvs. biternate. Fls. large, terminal, solitary.

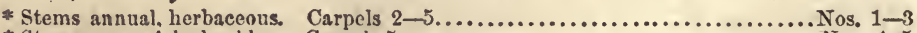

* Stems perennial, shrubby. Carpels 5.......................................... 4,5

1 P. officinàlis L. Common PeONY. Lower lvs. bipinnately divided; Ifts. ovate-lanceolate, variously incised; carp. 2, downy, nearly straight.-The splendid Prony has long been cultivated throughout the civilized world. This species is said to be a native of Switzerland. It is a hardy perennial, requiring very little pains for its cultivation. Among its varieties the double red is most common. The white is truly beautiful. The flesh-colored and the pink are also favorites. May, Jn.t

2 P. albiflòra L. Ifts. elliptic-lanceolate, acute, entire, smooth; follicles 2 or 3 , recurved, smooth. -Native of Tartary. Whole plant dark, shining green and smooth. Fls. smaller than the last, but truly elegant and fragrant. Petals white. Cal. brown, with 3 green, sessile bracts at base. Nine or ten varieties, with flowers single or double, white, rose-colored, \&c., are now mentioned in the catalogues of American gardeners. $t$

3 P. anómala L. Lfts. with many lanceolate segments, smooth; follicles 5 , depressed, smooth; cal. bracteolate. From Siberia. Distinguished by the long narrow segments of the leaflcts. Fls. concave, rose colored. Many varieties.t 
4 P. Moutàn L. Chinese Tree PzonY. St. shrubby; lfts. oblong-ovate. glaucous and somewhat hairy beneath, terminal 1-3-lobed; ova. 5, distinct, sur. rounded by the very large disk.-From China. The woody stem branches into a bush 3-4f high. Lvs. large, on long stalks. Fls. very large, always double in cultivation, fragrant and truly splendid. This plant is remarkable for producing the largest form of disk in the vegetable kingdom.

5 P. papaveràcea L. St. shrubby; lfts. oblong-ovate, glaucous and slightly hairy beneath, terminal one lobed; ova. about 5 , closely united into a globous head.From China. Resembles the last in foliage, but is remarkably distinguished from all the other species by its united carpels. Flowers white, with a purple centre, often single in cultivation. Other species and varieties are cultivated, rarely in this country, amounting to about 150 in all.

\section{Order II. MAGNOLIACEAE. Magnoliads.}

Trees or shrubs with alternate, coriaceous, simple, entire or lobed (never toothed) leaves. Leafbuds sheathed with membranous stipules which soon fall off. Fls. large, polypetalous, polyandrous, polygynous, hypogynous, perfect. Calyx and corolla imbricated in bud, colored alike, in 3 or more 3 -merous circles. Ovaries several or many, compactly covering the elongated torus. Fruit of numerous dry or fleshy carpels, aggregated into a sort of cone. Seeds 1 or 2 in each carpel, with a minute embryo in fleshy albumen. (See Figs. 68, 72, 131.)

An order of 12 genera and 63 species, including some of the most splendid of flowering trees and shrubs. Most of them belong to the Southern States, some to the Western, and a few to Japan, China and India.

Properties. - The bark is aromatic, containing an intensely bitter principle, which is tonio and stimulating. The flowers are fragrant and aromatic in a high degree.

\section{TRIBES AND GENERA.}

Tribe ILLICIEA. Carpels arranged into a single circle................... Ir.tCIUM. Tribe MAGNOLIEA. Carpels imbrieated into a cone-like fruit.*

* Anthers opening inwards. Lvs. folded lengthwise in bud.............Magrour. 2

* Anthers opening outwards. Lrs. folded crosswise in bud........... Lrmodendrox. 3

1. ILLÍ́CiUM, L. Star Anise. Sepals 3-6, colored; petals 6-30; carpels capsular, dry, arranged circuiarly, dehiscent on the upper side, each with one smooth shining seed.-Shrubs with very smooth, evergreen leaves; exhaling, when bruised, the odor of Anise.

1 I. floridànum Ellis. Petals $21-30$, purple; lvs. acuminate.-Swamps, Fla. to La. Shrub 4-8f high. Lvs. on short petioles, oblong-lanceolate, slightly acuminate, entire, smooth, thick, $3-6^{\prime}$ by $1-2^{\prime}$. Fls. about $1 \frac{1}{2}^{\prime}$ broad, on slender, nodding pedicles. Cal. deciduous. Petals purplish crimson, linear obtuse, in 3 whorls. Sta. 30 or more. Ova. about 12 in one regular circle, with short, recurved styles. Seed polished, as large as that of the apple. May.

2 I. parviflòra Mx. Petals 6-12, yellowish; lvs. oblong, obtusish.-River banks, Fla. and Ga. Shrub 6-10f high. Lvs. thick and leathery, entire, on short petioles. Fls. smaller than in the last, nodding, dull yellow. Petals ovate or roundish, concave. May. The bark and leaves of these plants are stronglyaromatic and spicy, in their properties, much resembling Anise. The root of tho latter has the properties of Sassafras.

2. MAGNOLIA, L. (Named for Prof. Magnol, a French botanist of the 17th century.) Sepals 3 ; petals $6-9$; anthers longer than the filaments, opening inwards; carpels 2 -valved, $1-2$-seeded, aggregated into a hard, cone-like fruit; seeds berry-like, and suspended from the opening carpels by a long funiculus.-Trees and shrubs with large, fragrant flowers. Lvs. conduplicate in the bud, embracing and cmbraced by the sheathing stipules. 
* Leares erdate or auriculate at the base. Trees $80-40$ f high.................. Nos, 5, 6

- Leaves acute at tho base, - ferruginous or glaucous beneath, thick................ Nos. 1, 2 -green (not shining) both sides, thin ........................... 3 , 4

Exotic species, cultivated. Nos. 8-10

1 M. grandiflóra L. Big LAUREL. Tree; lvs. rust-downy beneath, evergreen; petals obovate.-In swampy woods, N. Car. to Fla. and Miss. A stately and beautiful tree, attaining the hight of $70-90 \mathrm{f}$, with a diameter of 2 or $3 \mathrm{f}$ at base. Its form in open ground is pyramidal. Bark smooth, gray, resembling that of the beech. Lvs. 6-8' long, thick and firm, oval-oblon;, cntire, dark green and shining above, elothed with a rist-colored tomentum beneath. Fls. pure white, strongly fragrant, 8 or $9^{\prime}$ broad. The seeds after quitting the cells of the ovoid fruit remain several days suspended on a whito thread. May.

2 M. glaùca L. White Bay. Beavar Tree. Shrub or small treo; lvs. oval, obtuse, gaucous-white beneath; petals ovate or roundish, erect.-Native in marshy grounds, Mass. to La., chiefly found near the coast. It is a fine shrub, $5-20 \mathrm{f}$. high, with a grayish bark, crooked, divaricate branches. Lvs. beneath remarkably pale, silky when young, $3-4^{\prime}$ long, $8^{\prime}$ on the young shoots, entire, nearly persistent southward. Fls. 2 ' broad, cup-shaped, with white, concave petals, very fragrant. May (South)-JI.

3 M. acuminàta L. CucuMrer Tree. Lvs. oval, acuminate, pubescent beneath: petals obovate, obtusish.-Groves near the Falls of Niagara, but more abnndant in the Southern States. It is a noble forest tree. Trunk perfectly straight, $4-5 \mathrm{f}$ diam., 60-30f high, bearing an ample and regular summit. Lvs. very acuminate. Fls. 5-6' diam., bluish, sometimes yellowish-white, numerous, and finely contrasted with the rich, dark foliage. Cones of fruit about $3^{\prime}$ long, cylindric, bearing some resemblance to a small cucumber. May.

4 M. umbrélla Lam. UMBrella Tree. Lvs. deciduous, cunsate-lanceolate, silky when young; sep. 3 , reflexed; pet. 9 , narrow-lanceolate, acute. - A small tree $20-30$ f high, common in the southern States, extending north to southern N. Y. and $O$. Branches irregular. Lvs. $16-20^{\prime}$ by $6-8^{\prime}$, appearing whorled at the end of the branches in the form of an umbrella. Fls. terminal, white, $7-8^{\prime}$ diam. Fr. conical, 4-5' long, rose-colored when ripe. May, Jn.

5 M. macrophýlla Mx. Lvs. obovate-spatulate, cordate; pet. rhomb-ovate, white, purple inside at base.-River banks, Chattalıoocheo to Red R. (Dr. Hale), north to the Tenn. (Miss Carpenter), and to the Ky. R. A small tree $30-50 \mathrm{f} \mathrm{high,} 8-10^{\prime}$ diam. Lvs. with a strong midvein, often, on young shoots, $3 f$ in length by if in breadth, glaucous-white beneath. Fls. magnificent, the separate petals measuring $6-S^{\prime}$ in length. Sepals erect, lance-linear. June.

6 M. Fràseri Walt. Lvs. obovate-spatulate, auriculate at the narrowed base, glabrous; pet. pure white. - A slender tree, 25-35f high, Fla. northward to Va. and Ky. Bark smooth, light-gray. Lvs. 6-9' long, 4-6' broad above, much narrowed below, and ending at base in peculiar ear-shaped lobes. Sep. 3, greenish on the back. Pet. 6, lance-ovate, thick, $2 \frac{1}{2}-3^{\prime}$ long, strongly aromatic. Apr. May.

7 M. cordàta Mx. Lvs. broadly ovate, subcordate, acute, whitish and pubescent beneath; pet. 6-9, oblong, yellow.-The yellow flowered species inhabits the upland regions of Ga. and Car. Trunk straight, 40-50f high, covered with a deeply firrowed bark. Lvs. long-petioled, $4-6^{\prime}$ by $3-4^{\prime}$, smootl, and entire. Fls. about $4^{\prime}$ diam., marked within with fine red lines. Fr. cylindrical, $3^{\prime}$ long. May.

8 M. fuscàta. Lvs. evergreen, elliptic or oblong, clothed with fuscous down when young, at length glabrous; branches also fuscous-tomentous; fls. erect.From China. Shrub $3 f$ high. Fls. brownish.

9 M. obovàta L. Lvs. deciduous, obovate, acute, strongly veined, glabrous ; fls. erect; sep. 3 ; petals 6 ; obovate.-From China. Shrub 6 f high, opening its erect, cup-shaped, rose-purple fls. in May.

10 M. conspícua I. YULAN. Lvs. deciduous, obovate, abruptly acuminate, the younger pubescent; sep. none or very small; pet. $6-9$, white or rose color.From China. Shrub or small tree, $10-30 \mathrm{f}$ bigh, with numerous white, fragrant flowers appearing eariy in spring. 


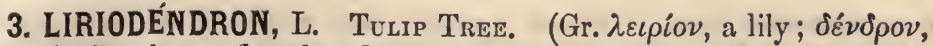
a tree.) Sepals 3 , reflexed, caducous; petals 6 , erect; carpels imbricated in a cone, $1-2$-seeded, indehiscent and attenuated at apex into a lance. olate wing.-Tree, with showy, bell-shaped, upright flowers. Vernation induplicate. Stipules large, oval, caducous. In the bud, each leaf bends inward to an inverted position, infolds all that is within it, and is in itself infolded by its pair of stipules and by the next lower leaf, and so on, as seen in Figs. 68, 72.

I. tulipífera. TUlip Tree. White-Woon. Poplar. A fine tree, one of most remarkable of the American forests, Can. to Lav, especially abundant in the Western States. It is ordinarily about $80 \mathrm{f}$ high, with a diam. of 2 or 3 , but along the Ohio and Miss. rivers it grows much larger. Near Bloomington, Ind., we measured a treo of this species which had been recently felled. Its circumference $4 \mathrm{f}$ from the ground was 23f; $30 \mathrm{f}$ from the ground its diam. was 5 ; ; the whole hight $125 \mathrm{f}$. The trunk is perfectly straight and cylindric. At top it divides abruptly into coarse, crooked, rather unsightly branches. Lrs. dark-green, smooth, truncate at the end, with 2 lateral lobes, $3-5^{\prime}$ in length and breadth, on long petioles. In May and June it puts forth numerous campanulate flowers, greenish yellow, orange within, solitary, broader than the tulip, and erect. The wood is extensively used as a substitute for pine.

\section{Order III. ANONĀCEA. Anonads.}

Trees or shrubs with naked buds, entire, alternate lvs. destitute of stipules. Fls. usually green or brown, axillary, hypogynous, valvate in æstivation. Sepals 3; petals 6 , in two circles, sometimes coherent. Stamens $\infty$, with an enlarged connectile, short filament, and large torus. Ova. several or $\infty$, separate or coherent, fleshy or not, in fruit. Embryo minute in the end of ruminated albumen.

Genera 20 , species 300 , chiefly natives within the tropies of both hemispheres. Four species are found within the limits of the United States, all of the following genus. The Anonads aro generally aromatic in all their parts. Their pulpy fruit, as the custard apples, are sweet and esculent.

ASIMINA Adans. Papaw. Fig. 113. Sepals 3, petals 6, the outer row larger than the inner; stamens densely packed in a spherical mass; pistils several, distinct, ripening but few, which become large, oblong, pulpy fruits with many flat seeds.--Shrubs or small trees, with brownish, axillary, solitary flower's.

* Flowers appearing before the leaves.................................... Nos. 1, 2.

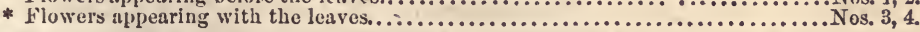

I A. tríloba Dunal. Lvs. obovate-oblong, acuminate; pet. dark purple, exterior orbicular, 3 or 4 times as long as the sep.-A small and beautiful tree, 15-20f high, on banks of streams, Mid., Southern and Western States. Branches and lvs. nearly glabrous, the latter $8-12^{\prime}$ by $3-4^{\prime}$, very smooth and entire, tapering to very short petioles. Fls. $1^{\prime}$ broad, precocious. Fr. about $1^{\prime}$ thick and $3^{\prime}$ long, ovoid-oblong, about 8-seeded, yellowish, fragrant, eatable, ripe in October. Fls. in March, Apr. (Uvaria, Torr. and Gr. Anona, L.).

2 A. parvifiòra Dunal. Lvs. obovate-oval, acuminate; pet. greenish-purple, the outer oval, hardly twice the length of the sep.-Woods near the coast, from Car. to Fla. and La. Shrub 2-3f high, smaller every way than No. 1. Lvs. about half as large, glabrous, obtuse-pointed, tapering to the base. Fls. less than half as large, opening while the branches are naked. Fr. roundish, about $1^{\prime}$ long. May.

3 A. grandiflòra Dunal. Lvs. obovate-oblong, obtuse, grayish-tomentous both sides; outer pet. very large, yellowish white.-Pine woods, Ga., and Fla. Shrub 2 -3f high, its young branches also tomentous. Peduncle and calyx woolly, of about equal length. Outer petals ahout $2^{\prime}$ in length, oval or obovate, obtuse, $6-8$ times longer than the oblong, brownish, inner petals. Apr. 
4 A. pygmæ̇a Dunal. DWARF PAPAW. Lvs. coriaceous, evergreen, linear. lanceolate or linear-oblanceolate, or lin.-oblong or spatulate, etc., glabrous; pet. reddish-brown, obovate-oblong.- Shrub 6-12' high, sandy plains, Ga., and Fla. Lvs. very variable in form, $3-6^{\prime}$ long, usually very narrow, often obovate or elliptical. Pet. about $I^{\prime}$ in length. Carp. ripening about $3,1^{\prime}$ long in fruit, erect. Apr.

\section{Order IV. SCHIZANDRĀCEA.}

Scrambling shrubs with alternate, simple, exstipulate, punctate leaves; with $F l s$. diclinous, axillary, small, hypogynous and polygynous; with Cal. and cor. 3-merous in two or several rows, imbricated; with Stam. few or many, on very short filaments, condensed on a roundish torus. Ova. few or coherent, becoming baccate, $1-2$-seeded in fruit. Seeds suspended; embryo minute, in solid albumen.

Genera 5, species 12, belonging to India, Japan, and the United States.

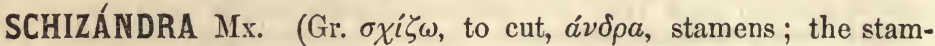
ens are cleft.) 8 Sepals and petals $9-12$, similar, roundish, concave; stamens 5 , anthers connate; earpels at first aggregated in a roundish head, becoming in fruit scattered on the elongating, filiform torus.-A trailing shrub with entire or repandly dentieulate leaves, and small crimson flowers.

S. coccínea $\mathrm{Mx}$. A handsome plant in damp woods, S. Car., Ga., to La. St. 10 or $12 \mathrm{f}$ long. Lvs. alternate, ovate or oval, tapering at each end or somewhat cordate at base. Fls. axillary, solitary, on slender stalks, the upper ones staminato. Carp. and torus red when mature. May, Jn.

\section{Order V. MENispermàCE A. Menispermads.}

Shrubs climbing or twining, with alternate, palmate-veined, exstipulate leaves. Fls. diœcious, rarely $\Varangle$ or $q \Varangle \hat{\delta}$, hypogynous, $3-6$-gynous. Sepals and petalssimilar, in 3 or more circles, imbricated in the bud. Stam. equal in number to the petals and opposite to them, or 3 or 4 times as many. Fruit a 1-seeded drupe with a large or long curved embryo in scanty albumen. (Illust. in Fig. 14i.)

This curious order consists of 44 genera and 302 species, most of them natives of tropical Asia and America, where they become, in the forests, woody climbers of great size.

- Properties. - A few plants of this order contain a bitter minciple in tlieir roots. A foreign species of Menispermum yields the columbo of the shops, which is a valuable tonic; another genus, Anamirta cocculus of India, furnishes the Indian cockle, so intoxicating to fishes.

\section{GENERA.}

\& Stamens $12-20$, sep. 4-8, nut moon-shaped. Lvs, peltate............ Mrisisfrmum. 1

f Stamens 6 ; sepals 6 ; nut moon-shaped. Lvs. sinuate, 3 -lobed............ Cocculus. 2

\& Stamens 6 ; sepais 6 ; nut cup-shaped. Lrs. deeply 5-lobed.............. CalycocarpuM. 8

1. MENISPÉRMUM, L. MooN-SEED. (Gr. $\mu \eta \dot{\eta} \nu \eta$, the moon; $\sigma \pi \varepsilon \dot{\varepsilon} \rho \mu a$, seed; from the crescent form of the seed.) Fls. of ; scpals $4-8$; petals $4-8$, minute, retuse ; $\hat{\delta}$ stamens $12-20$, as long as the sepals, anthers 4-celled; $\&$ ovaries and styles $2-4$; drupes $1-3$-sceded; seeds lunate and compressed.-Fls. white, in axillary clusters.

M. Canadénse I. St. climbing; lrs. roundish, cordate, angular, peitate, the petiole inserted near the base; rac. compound; petals, 6-7, small.-In woods and hedges near streams. Can. to Car. W. to the Miss. Sts. round, striate, 8-12f long. Lrs. 4-5' diam., generally 5-angled, smooth, pale beneath, on petioles $3-5^{\prime}$ long. Fls. in axillary clusters, small, yellow. Drupes about $4^{\prime \prime}$ diam., black, resembling grapes. The root is perennial, and in medicine has the properties of a tonic. Jl.

B. LOBATUM, has the leaves lobed. 
2. cócCULUS, DC. (Diminutive, from Lat. coccum, a berry.) Fls. $\hat{f}$. Sepals, petals and stamens 6 ; anthers 4 -celled; $q$ ovaries 3 to 6 ; drupe globular-compressed, nut curved as in Menispermum. -Fls. in axillary panicles.

C. Caroliniànus DC.-In woods along rivers, S. Ill. to Ga. St. round, slender, trailing. Lvs. pubescent, at length glabrous above, broadly ovate or cordate, mucronate, entire or sinuate-lobed, sometimes hastately 3-lobed, $2^{\prime}$ to $3^{\prime}$ diam., petioles half as long. Fls. very small, greenish. Pet. of the sterile fls. with inflected auricles at the base of each. Drupes red, $1-3$ together, $2^{\prime \prime}$ wide, tho nut curved almost into a circle and finely crenated. Jn., Jl.

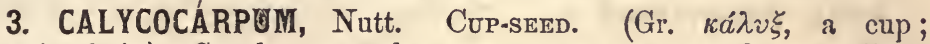

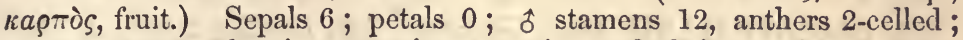
o stamens 6, abortive; ovaries 3 ; stigma fimbriate-radiate; drupe oval with the putamen deeply excavated in front and cup-shaped.-Fls. greenish white, in long axillary panicles.

C. Lyòni Nutt. Ga. (Mettauer) to Ky. A slender vine, very smooth, ascending many feet. Lvs. large, thin, 4-8' diam., the lobes dilated above and acuminate. Petioles long, slender. Rac. slender, 3-12' long. Fls. small, 2" diam., nearly white, about 5 on each ped. Drupe $1^{\prime}$ long, oval. J1. (Menispermum Lyoni Ph.)

\section{Order VI. BERBERIDACEA. BERBERIDS.}

Herbs or shrubs with alternate, usually exstipulate, simplo or compound leares. Flowers perfect, hypogynous, imbricated in æstivation. Culyx of $2-6$ deciduous sepals, in 1 or 2 rows, often with petaloid seales at base. Corolla of as many or twice as many petals as sepals, in one to several rows. Stam. as many as the petals and opposite to them, rarely more numerous. Anthers opening mostly by recurved valves hinged at the top. Pistil one, style short or none. Er. a berry or capsule, seeds several, albuminous. (Figs. 168, 182, 253, 304, 346, 347, 444.)

An order hard to define, including 12 genera and 100 species, some of them of widely different habit and very doubtful affinities. They inhabit the teinperate zones. Some geners, as 1'odophyllum and Jeffersonla, possess catharic properties. Others, as Berberis, contain in their fruits unalle and oxalic acids.

\section{TRIBES AND GENERA.}

Tribr BERBERIDEA.-Shrubs. Embryo long as albunen. Anth. halved......Berreris. 1 Tribe NANDINEA.-Herbs. Embryo short or minute. (*)

* Anthers opening by 2 valves hinged at the top. (a)

a Stamens 6. Fruit 2 drupe-like, soon nakerl seeds.................... CAULOPITLLtTM. 2

a Stamens 6. Fruit a $2-4$ seeded berry........................... Dipiylleria. 3

a Stamens 8. Fruit a capsule opening by a lid...................... JEFFersonia. 4

* Anthers opening by 2 slits lengthwise. Stam. 6-1S.....................PopopuyluUx. 5

1. BÉRBERIS, L. Berberry. (Name from the Arabic.) Calyx of 6 obovate, spreading, colored sepals, with the 3 outer oncs smaller ; corolla of 6 suborbicular petals, with two glands at the base of each; filaments 6 , flattened; anthers 2 separate lobes on opposite edges of the connectile; style 0 ; berry oblong, 1-celled; seeds 2 or 3.-Fine, hardy shrubs.

1 B. vulgàris L. Spines (reduced lvs.) 3-forked; lvs, simple, serratures terminated by, soft bristles; rac. pendulous, many-flowered; pet. entire.-A wellknown bushy, ornamental shrub, in hard gravelly soils. Northern States. Grows 3-8f high. Lvs. $1 \frac{1}{2}-2^{\prime}$ long, half as wide, round-obtuso at apex, tapering 
at base into the petiole, and remarkably distinguished by their bristly serratures. Fls. yellow, a dozen or more in each hanging cluster. Sta irritable, springing violently against the stigma when touched. Berries scarlet, very acid, forming an agreoable jelly when boiled with sugar. The bark of the root dyes yellow. Jn. §? Eur.

$\beta$ Canadensis Willd. Rac. few (6-8)-flowered; berries oval.-Can. (Pursh) to

$\mathrm{Va}$. and $\mathrm{Ga}$., along the Alleghanies. Apparently a reduced form of $a$, with narrower leaves and smaller flowers and clusters. (B. Canadensis $\mathrm{Ph}$. )

2 B. Aquifòlium $\mathrm{Ph}$. Lvs. pinnate, lfts. 3-6 pairs, leathery, with spinulose teeth; fil. with 2 slender teeth.-In woods, Oregon (Rev. G. Atkinson), now often cultivated. A firm bushy shrub, $3-5 \mathrm{f}$ high, with shining: dark green leaflets, resembling the leaves of the holly. Fls. yellow, in short, upright clusters, opening early.t (Mahonia Nutt.)

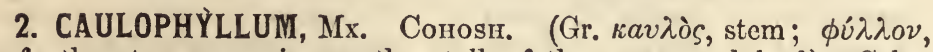
leaf; the stem appearing as the stalk of the compound leaf.) Calyx of 6 green sepals 3-bracted at base; corolla of 6 short, gland-like thickened petals, opposite the sepals ; stamens 6 ; ovary 2-ovuled, becoming a thin pericarp, which soon breaks away after flowering, and the 2 round drupe-iike seeds ripen naked.- 4 Glabrous and glaucous, arising from a knotted rhizome. Lvs. compound.

C. thalictroìdes Mx. Pappoose Root. A curious plant in woods, Can. to Car. and $\mathrm{Ky}$. Plant glaucous, purple when young. St. $1-2 \frac{1}{2} \mathrm{f}$ high, round, dividing above into 2 parts, one of which is a short common petiole of a triternate leaf, the other bears a 2-ternate leaf and a racemous panicle of greenish flowers. Lfts. paler beneath, 2-3' long, lobed like those of the Thalictrum or Aquilegia. Seeds 2 (mostly 1 by abortion), naked after having burst the caducous, thin, pericarp, deep blue, resembling berries on thick stipes. May. (Leontice, L.)

3. Diphylleia, Mx. Umbrella-leaf. (Gr. dis, twice; $\phi \dot{u} \lambda \lambda \otimes v$, Leaf.) Calyx of 5 sepals, caducous; cor. of 6 oval petals larger than the sepals ; stamens 6 ; ovary eccentric ; stigma subsessile; berry fewceeded, seeds attached laterally below the middle.-24 Glabrous, arising from a thick, horizontal root-stock. Lvs. simple, peltate.

D. cymòsa Mx. Along streams or Mits., Va. to Ga., and Tenn. Stems 1-2f high, stout, some of them bearing a single large ( $1-2 \mathrm{f}$ broad) orbicular, cutlobed, centrally peltate leaf; others with two alternate, smaller, roundish reniform leaves, which are peltate near the base, deeply 2-lobed, the lobes cleft, and a terminal cyme of white flowers in June.

4. JEFFERSÒNIA, Bart. Twin-Leaf. (In honor of President Jefferson, a patron of science.) Sepals 4, colored, deciduous; petals 8, spreading, incurved; stamens 8 , with linear anthers; stigma peltate; capsule obovate, stipitate, opening by a circumscissile dehiscence. Rhizome thick, blackish, with a mass of matted fibers. Scape simple, 1-flowered. Lvs. 2-parted or binate. (Figs. 168, 253, 304, 444.)

J. diphýlla Barton. A singular plant 8-14' high, Middle and Western States, S. to Ga. Rhizome horizontal. Each petiole bears at the top a pair of binate, obliquely ovate leaflets, which are placed base to base, and broader than long, ending in an obtuse point, glaucous beneath. Scape as long as the petioles. Fls. large, regular, white. The capsule opens only half round, and has, therefore, a persistent lid. Apr. This plant has, in Ohio, the reputation of a stimulant, and anti-spasmodic, and is there significantly termed rheumatism root.

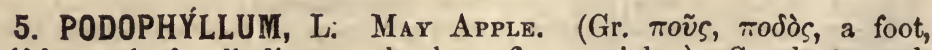
$\psi v \dot{\lambda} \lambda o \nu$, a leaf; alluding to the long, firm petioles.) Sepals 3, oval, 
obtuse, coneave, caducous; petals $6-9$, obovate, concave; stamens $9-18$, with linear anthers; berry large, ovoid, 1-celled, crowned with the solitary stigma. - 4 Low, rather poisonous herbs. Flowering stems, 2-leaved. Fl. solitary.

P. peltàtum L. WiLd MANDrake. In woods and fields, common in the Mid. and Western States, rare in N. Eng. S. to La. Height about If. It is among our more curious and interesting plants. St. round, sheathed at base, dividing into 2 round petioles, between which is the flower. Lrs. broadly cordate, in 5-7 lobes, each lobe $6^{\prime}$ long from the insertion of the petiole, 2-lobed and dentate at apex. Barren stems with one centrally peltate leaf. Fl. pedunculate, drooping, white, about $2^{\prime}$ diam. Fr. ovoid oblong, large, yellowish; with the flavor of the strawberry. The root is cathartic. May.

\section{Order VII. CaBombace}

Herbs aquatic, with the floating lvs. entire, centrally peltate, the submersed ones dissected. Fls. small, erect, one on each peduncle, hypogynous. Petals 3-4, alternate with the 3 or 4 sepals which are colored inside, all persistent. Sla. twice, or 4 or 6 times as many as the petals. Anthers adnate. Ova. 2 or more, distinct. Stig. simple. Fr. indehiscent, tippod with the hardened style. Sds. globular, pendulous. Embryo, minute, 2-lobed, external to an abundant, fleshy albumen.

Genera 2, species 3. American water plants, extending from Cayenne, S America, N. to N. Eng. Properties, slightly astringent.

1. BRASENIIA, Schreb. Water Target. Calyx of $3-4$ sepals, colored within, persistent; corolla of $3-4$ petals ; stamens $12-24$; ovaries $6-18$; carpels oblong, 2 (or by abortion 1)-seeded.- 4 Aquatic. The stems and under surface of the leaves are covered with a viscid jelly. Lvs. all floating, entire.

B. peltàta $\mathrm{Ph}$. It inhabits muddy shores and pools, often in company with the water lily, Can. to Ga. and Ark. Lvs. peltate, elliptical, entire, 2-3' by $1-1 \frac{1^{\prime}}{2}$, with the long, flexible petioles inserted exactly in the center, floating on the surface of the water, smooth and shining above. Fls. arising to the surface, on long, slender, axillary peduncles. Petals purple, about $3^{\prime \prime}$ long. Jl. (Hydropeltis purpurea $\mathrm{Mx}$.)

2. CABÓMBA, Aublet. Sepals 3, petaloid; petals 3 ; stamens 6 ; pistils 3 (rarely 2 or 4 ), nearly the length of stamens, and half as long as the petals and sepals; carpels few-seeded.-Lvs. opposite, mostly submersed and filiformly dissected.

C. Caroliniàna Gray. In stagnant waters, N. Car. to Ga. and La. Stems branched. Floating lvs. small ( $6^{\prime \prime}$ long, $1^{\prime \prime}$ wide) and few, oblong-linear, centrally peltate; submersed lvs. many, reniform in outline, $1-2^{\prime}$ broad, repeatedly di and tri-chotomous into threadlike segments. Ped. $2^{\prime}$ long, 1 -flowered. Fls. white, $5-6^{\prime \prime}$ broad, strictly $\sqrt[3]{ }$, (sometimes $\sqrt{ }$ ), with oval, obtuse petals yellow at base. May.

\section{Order VIII. NELUMBIÀCE无. Water Beans.}

Herbs aquatic, large, with prostrate rootstock and radical, peltate leaves, with flowers large, solitary, on long, upright scapes, 4-5-sepaled; petals numerous, arranged in many rows, as are also the stamens, ovaries separate, each with a simple style and stigma, becoming in fruit 1-seeded nuts half sunk in the hollows of the vory large torus, the seeds with largely developed erabryo, and no albumen. 
This order comprises but a single genus with 2 species, viz., $\mathrm{N}$. speciosum, supposed to be the sacred Egyptian bean of the E. Indies; the other, as follows. The nuts are nutritive, and also at certain seasons, the farinaceous rhizomes.

NELUMBIUM, Juss. Neuumbo. Character's of the genus the same as those of the order.

N. Iúteum L. A magnificent flowering plant, frequent in the stagnant waters of the South and West; in Sodus Bay, N. Y. (Williams); Lyme, Ct. ; near Philadelphia, etc. Rlizome creeping in mud in depths of water from 2 or 3 to $6 \mathrm{f}$. From this arise the simple scapes and petioles to the surface. Lvs. 10-18' diam., orbicular, entire, concave, the petioles inserted at the center. Fls. several times larger than those of Nymphæa odorata, fragrant. Petals concave, obtuse, lightyellow, $3-4^{\prime}$ in length. The nuts imbedded in the torus are about the size of acorns, and remarkable for tho large, leafy embryo. Juno (S.)-Aug.

\section{Order IX. NYMPHAEACEA. Water LiLies.}

Herbs aquatic, with peltate or cordate leaves from a prostrate rhizome. Fls. large, showy, often sweet-scented. Sepals and petals numerous, imbricated, gradually passing into each other. Sep. persistent. Petals inserted upon the disk which surrounds the pistil. Sta. numerous, in several rows upon the disk, often passing into petals. Anthers adnate, introrse. Pistils many, united into a many-celled, manyseeded, compound ovary with a radiate stigma. Sds. embryo inclosed in a sack at the end of a copious albumen next the hilum. (Figs. 453, 232-240.)

Genera 5, species 50, inhabiting the northern hemisphere, Victoria in equatorial America. Their generai aspect is that of an endogen, but they have 2 foliaceous cotyledons. The stems of nymphra contain a powerful astringent principle, which is removed by repeated washing in water, after which they are tasteless, and may bo used for food.

1. NYMPHæA, L. WATER LiLy. (The Greek nymph, or Naiad, of the waters.) Sepals 4 or 5 ; petals $\infty$, inserted on the torus at its base; stamens gradually transformed into petals: stigma surrounded with rays; pericarp many-celled, many-seeded.-2f Aquatic.

I N. odoràta I. Rhizome thick, in mud beneath deep (3-9f.) water, sending its lvs. and fls. to the surface ; lvs. floating, orbicular $\left(5-8^{\prime}\right)$, entire, cleft at base to the centre, where the long petiole is inserted, the lwbes imbricated; fls. white, deliciously fragrant, often with a delicate tinge of purple; filaments yellowish; seeds oblong, half the length of the aril. Jl., Aug. One of the loveliest of flowers.

$2 \mathrm{~N}$. tuberòsa Paine. Rhizome producing oblong $\left(1^{\prime}\right)$ tubers which spontaneously separate; lvs. floating, orbicular-reniform, $\left(6-15^{\prime}\right)$ entire, very veiny, the lobes divaricate; fls. scentless, or nearly so, milk-white (never purplish), pet. very blunt; seeds globular-ovoid. Sodus Bay (Hankenson) to Pa., and westward. Jl.

2. NUPHAR, Smith. Pond Lily. (Neufar is the Arabic name.) Sepals 5 or 6 , oblong, concave, colored within ; corolla of numerous small petals furrowed externally, and inserted with the numerous, truncated, linear stamens on the torus; stigma discoid, with prominent rays; pericarp many-celled, many-seeded.-2f Aquatic. Lrs. oval or oblong, sagittate-cordate.

I N. advèna Ait. Yellow Poxp LiLY. Lrs. floating or erect, with rounded, diverging lobes at base, petioles half-round; sep. 6 ; petals $\infty$; stig. $12-15$-rayed, margin slightly repand. - Very common in sluggish streams and muddy lakes, Can. to Ga., W. to Oregon. A well-looking and very curious plant, but from its filthy habits it has been called, with justice, the frog lily. The rhizomo is large, creeping extensively. Ivs. large, dark green, shining above, and when floating, pale and slimy beneath. Petioles half round. Fls. rather large and 
globular in form, erect, on a thick, rigid stalk. Three outer sepals yellow inside, and the three inner entirely yellow, as well as the petals and stamens Jn.Jl. (Nymphæa Mx.)

2 N. Kalmiàna Ait. Floating lvs. with base lobes approximate, submersed Ivs. membranous, reniform-cordate, the lobes divaricate, margin waved, apex retuse; sep. 5; stig. 8-12-rayed, crenate.-A smaller species, with small yellow fls., growing in similar situations with the last, Northern States. Dr. Robbins, from whose IISS. the above is quoted, thinks it wholly distinct from N. lutea, (Smith) or any other species. Petiole slender, subterete. Upper lvs. $2-3^{\prime}$ long $1 \frac{1}{2}-2 \frac{1}{2}^{\prime}$ wide; lower lvs. $3-4^{\prime}$ diam. Jl. (Nuphar lutea $\beta$ Kalmiàna Torr \& Gr.)

3 N. sagittæefòlia $\mathrm{Ph}$. Lvs. elongated, sagittate-cordate, obtuse; sep. 6 ; pet. 0 ; anth. subsessile.-In slow waters, N. Car. to Ga. (Savannah). Rlizome erect. Ivs. large, 10 to $15^{\prime}$ long. Fls. as large as in No. 2. Outer sep. green; inner, yellow and petaloid.

VICTORIA regia is also a member of this Order, - gigantic Water Lily, native of the rivers of Brazil and Guiana, and successfully eultivated here. Its earliest leaves are linear, then hastate, next sagittate; its late ones become ovate with a deep slit at base. Thence they gradually becomo circular and centrally peltate, exhibiting by a distinct line the union of the base lobes. When full grown they are 4-6f diam. (or 8-12f in their native rivers), with upturned edges and prominent veins beneath. Tho expanded flowers with numerous petals and sepals are $1 f$ in diameter.

\section{Order X. SARRACENiace E. Water Pitchers.}

Herbs aquatic, in bogs, with fibrous roots, perenuial, and with the leaves all radical, urn-shaped, or trumpet-shaped, and large flowers on scapes. Floral envelops 4-10, imbricated, the outer greenish, sepaloid. Stamens $\infty$, hypogynous. Carpels united into a several-celled capsule. (Figs. 174, 175, 176.)

A curious order, chlefly remarkable for the leaves which are of that class called arcidia (\$308). It embraces at present 3 genera and 6 or 8 species; the Heliamphora of Guiana, the Darlingtonia of California and

Sarracènia, Tourn. Pitcher Plant. (Named in honor of $\mathrm{Dr}$. Sarrazen of Quebec.) Calyx of 5 colored sepals, with 3 small bracts at base, persistent; corolla of 5 , incurved, deciduous petals; stigmas 5 , united into a large, peltate, persistent membrane covering the ovary and stamens; capsule 5-celled; seeds very numerous, albuminous.Lvs. holding water, with a wing on the front side and a hood (lamina) at top. Scapes 1-flowered, fl. large, nodding.

Lamina inflected over the throat of the tube................................. 1,2 .

Lamina erect or nearly so, throat open.*

* Leaves ventricous, never spotted with white ................................ 3 .

* Leaves trumpet-shaped, very tall, often mottled and spotted above.................. No. 4 .

1 S. psittacina Mx. Lvs. short, reclined, with a broad semi-ovate wing: Als. deep purple.-Bogs, Ga. Fla. to La. Lvs. $3^{\prime}$ to $5^{\prime}$ long when the plant is in flower, $6-10^{\prime}$ when in fruit, slightly mottled with white on the back. The tube is small and nearly closed by the hooded lamina, which gives to the whole leaf the semblance of a parrot, whence the specific name. Scape if high. Fl. rather smaller than that of S. purpurea. March.

2 S. variolàris $\mathrm{Mx}$. Lvs. elongated, nearly erect, mottled with white on the back, the wing lance-linear; fls. yellow.-Bogs in pine barrens, S. Car., Ga. (Feay and Pond) and Fla. Lvs. 12' to $18^{\prime}$ high, remarkable for their white dia. phanous spots near the top. Tube somewhat ventricous above, nearly enclosed by the strongly inflexed lood; wing $6^{\prime \prime}$ to $12^{\prime \prime}$ wide. Scapes shorter than lvs Flø, about the size of the last. Mar., Apr. 
3 S. purpùrea L. SIDE-SADDLE Flower. Lvs. short, decumbent, inflated most near the middle; lamina broad cordate.-Bogs throughout Can. and U. S. This species is the most common, and on it the genus was founded. Lrs. 6-9' long, rosulate, evergreen, composed of a hollow, pitcher-form petiole, swelling in the middle, with a wing-like appendage extending the whole length inside, from $\frac{1}{2}-1^{\prime}$ wide, and extended on the outside of the mouth into a lamina, covered above with reversed hairs. Their capacity when of ordinary size is about a wine glass, and generally, like the other species, they contain water with drowned insects. Scape $14-20^{\prime}$ high, terete, smooth, supporting a single, large, purple, nodding flower, almost as curious in structure as the leaves. Jn.

3. HETEROPHYLLA Torr. Scape rather shorter; sep. Yellowish green; pet. yellow.-Northampton, Mass. (R. M. Wright). Lvs. scarcely different. (S. heterophylla Eaton.)

4 S. Gronòvii. TROMPET-Leaf. Lvs. tall, straight, erect, tube gradually enlarged to the open throat, wing narrowly linear, lamina sub-erect, roundish, mucronate, contracted at base.-The largest species of the genus, in swampy pine woods, Va. to Fla. and La. Lvs. often $3 \mathrm{f}$ in hight, and the scapes even taller; the lamina as broad as the open throat $\left(2-3^{\prime}\right)$. Fls. very large (when extended $4-5^{\prime}$ diam.) and of exactly the same structure in all the varieties.

a. FLAVA. Fls. yellow; foliage yellowish green, with or without purplish veins (S. flava L. S. Catesbæi Ell.).

B. Alata. Fls. yellow? large; lis. 1-2f high, with the tube somewhat

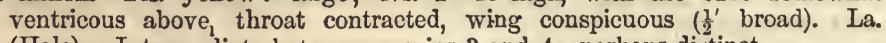
(Hale).- Intermediate between species 3 and 4 ; perhaps distinct.

$\gamma$. RUBRA. Fls. reddish purple, smaller than S. purpurea. Lvs. 1-2f high, with purple veins (S. rubra Walt.).

$\delta$. Drommondir. Fis. purple, very large; lvs, very tall $\left(20-30^{\circ}\right)$, remarkably mottled above with purple veins and white, diaphanous interstices. (S. Drummondii Croom) Fla. (Chapman.)

\section{Order XII. PAPAVERACEA. Poppy-worts.}

Herbs with alternate, exstipulate leaves, and generally a milky or colored juice. Fls. solitary, on long peduncles, never blue, hypogynous, regular, $\sqrt{ }$ or $\sqrt[4]{ }$. Sep. 2, rarely 3, caducous, and petals 4, rarely 6, all imbricated. Sta. indefinite, but some multiple of 4. Anthers 2-celled, innate. Ova. compound. Sty. short or 0. Stig. 2, or if more, stellate upon the flat apex of ovary. Fr. either pod-shaped, with 2 parietal placentæ, or capsular, with several. Sds. $\infty$, minute. Embryo minute, at the base of oily albumen. (Figs. 229-231, 276.)

An order consisting of 15 genera and 130 species, more than two-thirds of which are natives of Europe. The order is characterised by active narcotic properties, principaliy resident in the turbid juice. Opium is tha dried milky juice of Papaver somniferum. The seeds are commonly rich in fired oil. Several of the species are highiy ornamental in cultivation.

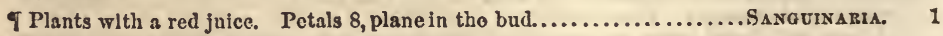

I Plants with a yellow julce. Petals crumpled in the bud. $\left(^{*}\right)$

- Stigmas and placentre 3, 4, or 6. Capsule ovoid. (b)

- Stigmas and placentre 2 only. Capsule long, pod-shaped. (a)

a Pod 1-celled, smooth. Lvs. pinnate......................... Crrewowrux.

a Pod 2-celled, rough. Lrs. palmate............................uUcium.

b Style distinct, but short..................................econorsis.

b Style none, stigma sessile................................ARGrane.

T Plants with a white juice. Petals 4 , crumpled in burl................PAPAvm.

T Plants with a watery juice. Calyx a mitre, falling off whole......... Escrisonourzu.

1. SANGUINÀRIA, L. BLOod-Root. (Latin sanguis, blood; all its parts abound in a red juice.) Sepals 2 , caducous; petals $8-12$, in 2 or 3 rows, the outer longer. Stamens about 24 ; stigma sessile, 1 or 2-lobed; capsule silique-form, oblong, 1-celled, 2-valved, acute at each 
end, many-seeded.- 4 A low, acaulescent plant, with a white flower, and a glaucous, palmate-veined leaf.

S. Canadénsis L. An interesting flower, in woods, Can. and U. S., appearing in early spring. Rhizome fleshy, tuberous, and when broken or bruised exudes an orange-red fluid, as also does every other part of the plant. From each bud of the root-stalk there springs a single large, glaucous leaf, and a scape about $6^{\prime}$ high, with a single flower. Whole plant glabrous. Leaf kidney-shaped, with roundish lobes separated by rounded sinuses. Fl. of a quadrangular outline, white, scentless, and of short duration. The juice is emetic and purgative. Apr., May. (Fig. 557.)

$\beta$. Leaf not lobed, margin undulate. Bainbridge, Ga.

2. CHELIdòniUm, L. Celandine. (Gr. $\chi \varepsilon \lambda \iota \delta \omega \nu$, the swallow; being supposed to flower with the arrival of that bird, and to perish with its departure.) Sepals 2, suborbicular; petals 4, suborbicular, contracted at base; stamens $24-32$, shorter than the petals; stigma 1 , small, sessile, bifid; capsúle silique-form, linear, 2-valved, 1-celled; seeds crested.-24 Fragile, pale green, with saffron ycllow juice.

C. màjus L. Lvs. pinnate; lfts. lobed, segments rounded; fls. in umbels.-By roadsides, fences, etc., arising $1-2 \mathrm{f}$ higl. L Lrs. smooth, glaucous, spreading, consisting of $2-4$ pairs of leaflets with an odd one. Lfts. $1 \frac{1}{2}-2 \frac{1^{\prime}}{2}$ long, $\frac{2}{3}$ as broad, irregularly dentate and lobed, the partial stalks winged at base. Umbels thin, axillary, pédunculate. Petals elliptical, entire, yellow, and very fugacious, like every other part of the flower. The abundant bright yellow juice is used to cure itch and destroy warts. May-Oct. § Eur.

3. GLAÙCIUM, Tourn. Hors Poppy. (Gr. yravkòv, glaucous, the hue of the foliage.) Sepals 2 ; petals 4 ; stamens $\infty$; style none, stigma 2-lobed; ped. 2-celled, linear, very long, rough.-(1) or (2) seagreen herbs, with clasping lvs., yellow juice, and solitary, yellow fls.

G. lùteum Scop. Sparingly naturalized near tho coast, from the Potomac southward. About $2 \mathrm{f}$ high, covered with a glaucous bloom. St. glabrous. Lvs. repandly 5-7-lobed, clasping so as to appear perfoliate. Fls. $2^{\prime}$ broad, of short duration, but many in succession, succeeded by a horn-shaped fruit, which is rough with tubercles, and $6-9^{\prime}$ in length. Jn.-Aug. \$

4. ARgemone, L. Prickly Poppr. (Gr. a $\rho y \varepsilon \mu a$, a disease of the eye, which this plant was supposed to cure.) Sepals 2 or 3 , roundish, acuminate, caducous; petals 4 or 6 , roundish, larger than the sepals; stamens $\infty$, stigma sessile, capitate, 4 or 6 -rayed ; capsule ovoid, prickly, opening at the top by valyes.-(1) Herbs with yetlow juice, spinouspinnatifid lvs., and showy fils.

A. Mexicàna $\mathrm{L}$. Cal prickly; capss. prickly, 6-valred.-A weed-like plant, native at the South and West, $\S$ at the North. St. 2-3f high, braniching, armed with prickly spines. Lvs. 5- $7^{\prime}$ or $8^{\prime}$ long, sessile, spinous on the margin and veins beneath. Fls. axillary and terminal, on short peduncles, $2-3^{\prime}$ diam., yellow. The juice becomes in air a fine gamboge-yellow, and is esteemed for jaundice, cutaneous eruptions, sore eyes, fluxes, etc. July.-Varieties occur with ochroleucous fls. and with largo white fls. (N. Car. Curtis.)

5. MECONÓPSIS, Viguier. Yellow Poppy. (Gr. $\mu \eta \dot{\kappa} \kappa \omega \nu$, a poppy ; ó $\psi$ (s, resemblance.) Sepals 2 , hirsute; petals 4 ; stamens $\infty$; style conspicuous ; stigmas $4-6$, radiating, convex, free; capsule ovoid, 1-celled, opening by four valves. -24 Herbs with a yellow juice, pinnately divided lvs., and yellow fls. 
M. diphylla DC. Lrs. glaucous beneath, segments $5-7$, ovate-oblong, sinuste, cauline 2, opposite, petiolate; ped. aggregated, terminal; caps. 4-valved, echinate-setous. - Woods, Western States. Plant 12-18' high. Lvs. large, 8' by 6', on petioles about the same length, terminal segment somewhat confluent. Ped. about $3^{\prime}$ long. Petals deep yellow, orbicular, $1^{\prime}$ diam. Sty. surpassing tho stam. May. (Stylophorum Nutt.)

6. PAPÀVER, L. Poppy. Fig. 229, 230, 231. (Celtic, papa, pap; a soporific food for children, composed of poppy seeds, etc.) Sepals 2, caducous; petals 4 ; stamens $\infty$; capsule 1 -celled, opening by pores under the broad, persistent stigma.-Exotic herbs, with white juice, abounding in opium. Fl. buds nodding, erect in flower and fruit.

1 P. somníferum L. OPIUs Poppy. Glabrous and glaucous; lvs. clasping, cut-dentate; caps. globous. - (1) with large, brilliantly whito flowers, double in cultivation. St. $1 \frac{1}{2}-3 \mathrm{f}$ high. Lvs. $4-8^{\prime}$ by $2-3^{\prime}$, with rather obtuse dentures. Extensively cultivated in Europe and southern Asia for opium, a drug moro generally applicable and more frequently prescribed than any other article of the materia medica. Jn. Jl. $+\S$

2 P. dùbium L. St. hispid with spreading hairs; lvs. pinnately parted, segm. incised; sop. hairy; caps. club-shaped.-1) Sparingly naturalized in cultivated grounds, Penn. and southward. St. about $2 \mathrm{f}$ high, very slender. Fls. light red or searlet, much smaller than in No. 1, on very long hairy pedicels. Jn. Jl.§

3 P. Rhaèas I. St. many-flowered, hairy; lvs. incisely pinnatifiel; caps. globous.-(1) Distinguished from the last species chiefly by its more finely divided leaves and its globular capsule. About $2 \mathrm{f}$ high. Fls. very large and showy, of a deep scarlet. Varieties are produced with various shades of red and parti-colored flowers, more or less double. Jn. Jl.

4 P. orientale I St. I-flowered, rough; lvs. scabrous, pinnate, serrate; caps. smooth.-4 Native of Levant. St. 3f high. Fls. very large, and of a rich scarlet color, too brilliant to bo looked upon in the sun. Jn. $\dagger$

7. ESCHSCHÓLTZIA, Cham. (Named for Eschscholtz, a German botanist well known for his researches in California.) Sepals 2, eohering by their edge, caducous; petals 4 ; stamens $\infty$, adhering to the claws of the petals; stigmas 4-7, sessile, $2-3$ of them abortive ; cap; sule pod-shaped, cylinḑric, 10-striate, many-seeded.-(1) Lrs. pinnatifid, glaucous. The juice, which is colorless, exhales the odor of hydrochloric acid.

1 E. Douglásii Hook. St. branching, leafy; torus obconic; cal. ovoid, with a very short, abrupt acumination; pet. bright-yellow, with an orange spot at base.-A very showy annual, common in our gardens, native of California, Oregon, etc. The foliage is smooth, abundant and rich, dividing in a twice or thrice pinnatifid manner into linear segments. Fls. $2^{\prime}$ broad. $\dagger$ (Chryseis Californica of Lindl. and Ist edition.)

2 E. Califórnica Hook. St. branching, leafy; torus funnel form, with a much dilated limb; cal. obconic; with a long acumination; fls. orange-yellow.From California. Lrs. and color of flowers as in the preceding, except the latter are more of a reddish, orange hue.t (Chryseis crocea Lindl. and of lst edition.)

\section{Order XII. FUMARIACEA. Fumeworts.}

Herbs smooth and delicate, with brittle stems, and a watery juice. Leaves usually alternate, multifid, often furnished with tendrils. Fls. irregular, purple, white or yellow. Sepals 2, very small. Petals 4, hypogynous, parallel, one or both of the outer saccate; 2 inner cohering at apex. Sta. 6, diadelphous; fil. dilated; anth. adnate, extrorse, 2 outer 1-celled, middle 2-celled. Ova. superior, 1-celled: sty. 
filiform; stig. with one or more points. Fr. either an indehiscent nut 1-2-seeded, or a pod-shaped capsulo many-seeded. Sds. shining, ariled. Albumen fleshy.

Illustrations, $42,43,44,818$.

Genera 15, species 110 ,-some of them beantiful and delicate, inhabiting thickets in the temperate regions of the northern hemisphere. 'They possess no remarkable action upon the animal economy.

Corolla equally 2-spurred or 2-gibbous at base. (a)

Corolla unequal, only one of the petals spurred. (b)

a Petals not united, deciduous. Not climbing..................... Dicentra. 1

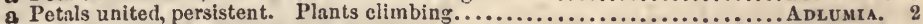

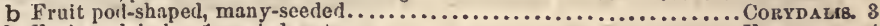

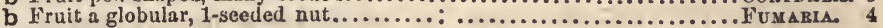

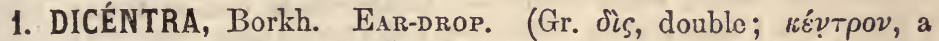
spur; from the character.) Sepals 2, small; petals, 4, the 2 outer equally spurred or gibbous at base, and distinct; stamens united in 2 scts of three each; pod 2-valved, many-seeded.-4 Fls. in racemes on scapes. (Diclytra, DC.)

Low herbs $\left(6^{\prime}\right)$, with white flowers, in simple racemes. ..................... Nos. 1,

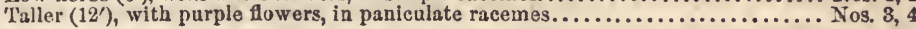

1 D. cucullària DC. Fig. 42, 43, 318. DutChMaN's BREeches. Root bulbiferous; rac. 4-10-flowered, secund; spurs divergent, elongated, acute, straight.Woods, Can. to Ky. A smooth, handsome plant. Rhizome bearing triangular, small, pale red, scale-like tubers, forming a loose bulb under ground. Lrs. radical, multifid, somewhat triternate, smooth, with oblong-linear segments, the petioles rather shorter than the scape. Scape slender 6-10' high. Fls. scentless, nodding, whitish, at summit yellow. Pedicels short, axillary to a bract, and with 2 minute bracteoles near the flower. Spurs about as long as the corolla. Apr., May.

2 D. Canadénsis DC. Fig. 44. SQurret Corv. St. subterranean, tuberiferous, tubers globous, raceme simple, secund, 4-6-flowered; spurs short, rounded, obtuse, slightly incurved.-A smooth, pretty plant, common in rocky woods, Can. to $\mathrm{Ky}$. The rhizome bears a number of roundish tubers about the size of peas, and of a bright yellow color. Lvs. radical, subglaucous, biternate, the lfts. deeply pinnatifid, segments linear-oblong, obtuse, $5-8^{\prime \prime}$ long. Scape $6-8^{\prime}$ high, bearing a few odd-looking flowers. Cor. white, tinged with purple, fragrant, 5" long. Sta. 3 on each lip. May, Jn.

3 D. exímia DC. Rhizome scaly; lvs. numerous; rac. compound, the branches cymous; fls. oblong, spurs very short, obtuse, incurved; stigma 2-horned at apex. -A fine species on rocks, etc., found by Dr. Sartwell in Yates Co., N. Y., S. to N. Car. Lvs. radical, $10-15^{\prime}$ high, somewhat triternate, with incisely pinnatifid, acute segments. Scape $8-12^{\prime}$ high, with several $(4-8)$ eymes, each with 6-10 purplish, nodding flowers. Cor. $8-10^{\prime \prime}$ long, $\frac{1}{4}$ as broad at base. Bracts purplish, at base of pedicels. Jn., Sept.t (Corydalis formosa Ph.)

4 D. formòsa DC. Rhizome many-leaved; rac. slightly compound; fls. ovate, inflated; spurs short, rounded, saccate; stig. entire.-Can. to Or. An elegant and showy species in cultivation, about the size of the last, with foliage less incised and lobes rather obtuse. Rac. secund, the cymes 2 to 4 -flowered. Fls. bright purple, about $10^{\prime \prime}$ long, by $5^{\prime \prime}$ or $6^{\prime \prime}$ wide, the stigma angular, not cleft as in Na 3. May, Jl.

2. ADlumia, Raf. Mountain Fringe. (Named for John Adlum, Washington, D. C., a cultivator of the vine.) Sepals 2, minute; petals 4 , united into a fungous, monopetalous corolla, persistent, bigibbous at base, 4-lobed at apex; stamens united in 2 equal sets; pod 2-valved, many-seeded.-(2) A delicate, climbing vine.

A. cirrhòsa Raf. Rocky hills, Can. to N. Car. Stem striate, many feet in length. Lvs. decompound, divided in a pinnate manner, ultimate divisions 3lobed, smooth, their foot-stalks serving for tendrils. Fls. very numerous, in axillary, pendulous, cymous clusters, pale pink. Cal. minute. Cor. slightly cordate 
at base, of 4 petals united into a spongy mass, cylindric, compressed, tapering upward, 2-lipped. Fine for arbors, Jn., Aug.t

3. CORÝDALIS, DC. (Gr. name of the Fumitory, from which genus this was taken.) Sepals 2, small; petals 4 , one of which is spurred at the base ; stamens 6, diadelphous ; filaments united into two equal sets by their broad bases, which sheath the ovary ; pod 2-valved, compressed, many-seeded.-Lvs. cauline. Pedicels racemous, bractless.

1 C. glaùca $\mathrm{Ph}$. Glaurous, erect; fls. red, yellow at the tip; pods erect; lobes of the lfts. obtuse, bracts minute.--(2) Rocky woods, Can. to N. Car., $1-3$ f. high. Ifts. $I^{\prime}$ long, 3-lobed, Corolla with a short, blunt spur. Racemes panicled. Apr.-Jl.

2 C. aùrea Willd. Low, diffuse, finally ascending $\left(8-12^{\prime}\right)$; lobes of the leaves acute; rac. opp. the lvs. and terminal; fls. secund, bright yellow, spur deflected; pods pendulous. - (2) Rocky shades. Cor. 6". Apr.--Jl.

B. MACRÁNTHA. Fls. $10^{\prime \prime}$; spur nearly as long as the limb. Dakota.

$\gamma$. FLÁvula. Fls. 3-4", pale yellow; spur very short; pet. pointed. Com.

3 C. montàna Engl.? Ascending ; rac. terminal; lf.-lobes obtuse; bracts lanceolate; cor. yellow, spur ascending, nearly as long as the limb; lower pet. at length pendent; pods erect, seeds lenticular. South-West.

4. FUMÀIA, L. Fumitory. (Lat. fumus, smoke; from its disagreeable odor.) Sepals 2, caducous; petals 4, unequal, one of them spurred at the base; filaments in 2 sets, each with 3 anthers; nut ovoid or globous, 1-seeded and indehiscent.-Lrs. cauline, finely dissected.

F. officinàlis $I_{\text {t. }}$ St. suberect, branched and spreading; lvs. bipinnate; rac. loose; sep. ovate-lanceolate, acute, about as long as the globous, retuse nut.A small, handsome, smooth plant, 10-15' high, in sandy fields and about gardens, introduced from Europe. Lfts. cut into segments, dilated upwards. Fls. small, rose-colored, nodding, the pedicels becoming erect in fruit, and twice as long as the bracts. Jl., Aug. \& Eur.

\section{Order XIII. CRUCIFER AE. Crucifers.}
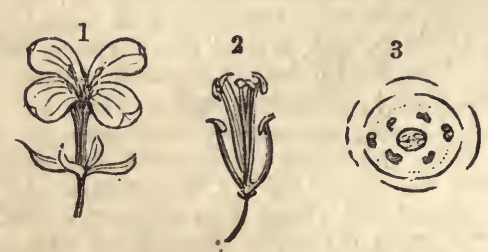

620. A flower of Sinapis nigra. 1. The stannens (4 long and 2 short) and pistll. 2. P'lan of the flower,-stamens in 2 rows, outer row half wanting. 3. A sillque, -4 . partly open, showing the septum with seeds attached. 5. Cross section of a seed, cotyledons conduplicate $(0>>)$. 6. Cross section of a seed of Capsella, the cotyledons incumbent (0II). 7 . Section bo a winged seed of Arabis Canadensis, cotyledons accumbent $(0=)$.

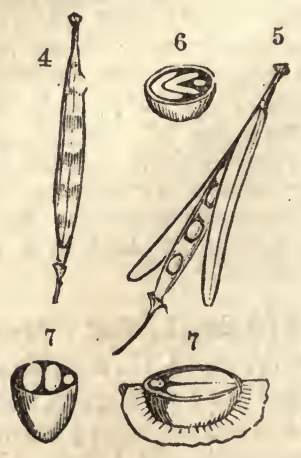

Herbs with a pungent, watery juice, and alternate, exstipulate leaves, with flowers cruciform, tetradynamous, generally in racemes, and bractless. Sepals 4, deciduous; petals 4, hypogynous, with long claws and spreading limbs. Stamens 6 , the 2 outer, opposite ones shorter than the 4 interior. Ovary 2-carpeled, 2-celled 
by a false partition, with parietal placentæ. Fruit a silique, or silicle, usually 2 . celled. Stigmas 2, sessile. Seeds 2-rowed in each cell, but often so intercalated as to form but one row. Embryo with the 2 cotyledons variously folded on the radicle. Albumen 0 .

Illust. $256,812,365,447,443$.

Genera 195 , species 1600 . This is a very natural order, larger than any of the preceding. The greater part of the species are found in the temperate zones. About 100 are peculiar to this continent.

Properties. The Crucifers as a class are of inuch importance to man. They furnish several llimentary articles, which are very nutritious, as the 'Turnip, Cabbage, Cauliflower; several other's are used as condiments, as Mustard, Radish, Cochlearia, etc. They all possess a peeuliar acricl, volatile principle, dispersed through every part, often accompanied by an ethereal oil abounding in sulphur. Tuey are also remarkable for containing more nitrogen than other vegetables, for which reason ammonia is generally evolved in their putrefaction. In medicine they are eminently stimulant and antiseorbutic. None are really poisonous, although very acrid. The root of Isatis tinctoria affords a blue coloring matter.

Obs. The genera of this large order were arranged into sub-orders by De Candolle, according to their various inodes of folding the cotyledon upon the ralicle, which modes are as follows: 1. Cotyledons accumbent, the radicle turned round and applied to the edges of the cotyledons, represented thus $0=2$. Cotyledons incumbent, the radicle applied against the back of one of the cotyleclons, $0 \|$. 3. Cotyledons conduplicate, rallele folded as in the last case, but the cotyledons bent so as partly to enfold it, $0 \gg$, as in the mustarl.

In the analysis of the Crucifers it is Indispensable that the specimens be in fruit as well as flower, and that the student bring to bear all his patience and resolution in the study of the above and other forms of structure in the seed, however minute. In the following synopsis the student may use in analysis either the artificial arrangement of the Genera or tho less obvious but moro natural arrangement of the

\section{TRIBES.}

§ILIQUOS 2 ,-fruit a silique opening by valtes. (Tribes.)

Tribe 1. Arabides. Seeds flattened, often bordered; cotyledons $0=\ldots \ldots . .$. . Cenera $1-10$

Tribe 2. Sistarizex. Seeds oblong, not bordered; cotyledons $0 \| . . . . . . . . . .$. . Gon. 11-14

Tribe 3. Brassicex. Seeds globular, cotyledons $0 \gg$. Flowers yellow............Gen. 15, 16

$\$ \$$ SILICULOS $\mathbb{E}$, - fruit a silicle openlng by valves when more than 2-seeded. (Tribes.)

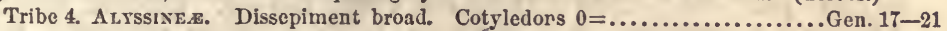

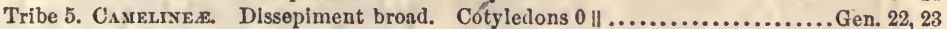
Tribe 6. Trilaspes. Dissepiment narrow. Cotyledons $0=\ldots \ldots \ldots \ldots \ldots \ldots \ldots \ldots$. . . 24

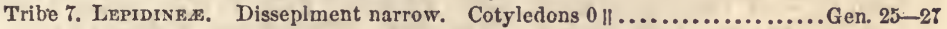
T'ribe.8. Isatides. Dissepiment 0. Sillcle 1-seeded, indehiscent.....................en. 28 §§ LONENTACE $\mathcal{E}$, - fruit a jointed silique, partitioned across. (Tribes.)

Tribe 9. Cakalineds. Cotyledons $0=$, seeds compressed..........................en. 29

Tribe. 10. Raphane.s. Cotyledons $0 \gg$, seeds globous,............................ 30

\section{ARTIFICIAL K.EY TO THE GENERA.}

$\S$ Fruit $a$ silique. Sceds in $a$ double row...................................Genera 1,2 Seeds in a single row. Flowers cyanic (a).

Flowers xanthic $(b)$

a Flowers purple, single. Stigma capitate. Plant native.....................enera 3

a Flowers purple (or white and double). Stigmas horned. Cultivated..................... 14

a Flowers white or roseate. Sillques tlattened, - raised on a filiform stipe......... Gen. 13 -sessile, having no stipe.......Gen. $5,6,7$

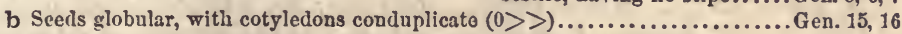

b Seeds oblong or lens-shaped. Siliques terete or flattened, veinless................. 8 . 8 , 9 Siliques squarish, valves $1-3$-reined......Gen. 10, 11, 12

$\$$ Fruit a silicle. Sllicle turgid or flattened, with a broad partitlon (c).

Silicle flattened contrary to the narrow partition (d).

Siliclo with no partition, 1-seeded. Flowers yellow................Gen. 28

c Ornamental exotics, variously colored. Gardens............................. 17, is

c Native plants with-flowers cyanic, white........................ Gen. 19, 20, 23 -flowers yellow. Silicles? oblong........................... 1

Silicles ovoid or globular.............Gen. 21,22

d Seeds sereral in each cell. Silicle triangular.................................... 25

d Seeds only $2,-$ one in each cell. The two outer petals larger.....................en. 24

The petals all equal.........................Gen. 26,27

$\$ \$$ Fruit a loment, jointed and partitioned across.............................. Gon. 29, 30 
1. NASTÚRTIUM, R.Br. WATER CRess. (Lat. nasus tortus; from the effect of these acrimonious plants upon the nose.) Sepals equal at base, spreading; siliques subterete, generally curved upwards, sometimes shortened so as to resemble a silicle; valves veinless; seeds small, lens-shaped, $\infty$, in a double row $(0=)$.-Aquatic plants with pinnate or pinnatifid liss.

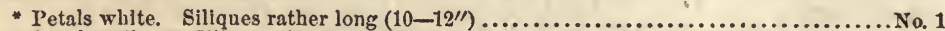

* Petals yellow. Siliques shortened $\left(4-8^{\prime \prime}\right)$, but longer than the pedicels $(a)$.

* Petals yellow. Siliques or silicles $\left(1-6^{\prime \prime}\right)$ 'shorter than the pedicels (b).

a Leaves pinnate or pinnatifid. Diffusely branclied........................... Nos. 2, 8

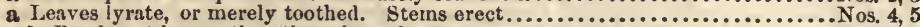

b Petals not longer than the calyx, obscure............................... 6 os. 6

b Petals longer than the calyx, bright yellow...................................... 8,9

1 N. officinàle R. Br. English Water Cress. Irs. pinnate, lfts. ovate, subcordate, repand; petals white, longer than the calyx. $-2 f$ Brooks and springy places, rare. (Yellow Springs, O.) Sts. decumbent, thick, branching, 6-12' long. Lfts. 3-7, broad, mostly rounded at base, obscurely toothed, terminal one largest. Fls. corymbed. Siliques hardly $l^{\prime}$ long. Occasionally cultivated for salad. May, Jn. § .

2 N. tanacetifòlium Hook. TANSEY-Leaved. Upper leaf segm. confluent, lower distinct, oblong or roundish, sinuate-loothed teeth obtuse; pods linear-oblong.-(2) Damp soils, Ga. and Fla., W. and N. W. to the Miss. Sts. smooth, diffusely branched from the base, 4-12' high. Root lvs. 2-4' long, narrow, regularly pinnate with $19-15$ segm. in the larger plants, the 3 upper segm. often confluent. Fls. minute. Pods 4-8" long, slightly curved, on ped. $\frac{1}{3}$ as long, and tipped with a distinct but short style. Mar., May.

$\beta$. овтUsum. Lift. mostly distinct, oval, obtuse; pods shorter ( 3 to $\left.5^{\prime \prime}\right)$, twice longer than pedicel. (N. obtusum, Nutt.)

3 N. Wálteri. Segm. of the lvs. all distinct, narrow, with a few linear, acute lobes or teeth; pods linear, - 4 ? Ga. (Feay and Pond.) and Car. Rt. thick, blackish, with many strong fibres. Lvs. numerous, mostly radical or subcauline, 1-2' long, finely dissected, the terminal segm: 3-lobed. Sts. branched from the base (only?), $3-5^{\prime}$ high, puberulent. Fls. minute. Pods slender, about $5^{\prime \prime}$ long, ped. half as long; style distinct. Mar., Apr. (Sisymbrium Walteri Ell.)

4 N. limòsum Nutt. Ivs. lanceolate, toothed, lower ones pinnatified at base (lyrate), upper entire at base; pods elliptic-oblong $\left(3-4^{\prime \prime}\right)$.-(2) Edges of the Miss., La. (Hale.) Glabrous. Sts. erect, simple, branched only at top, $10-15^{\prime}$ high. Lvs. all cauline and petiolate, the lower irregularly divided at base, where they touch the water. Rac. several. Fls. minute. Pods on very short pedicels, with styles much shorter. Apr., May. Hardly distinct from the next.

5 N. sessiliflòrum Nutt. Lvs. cuneate-obovate, repandly toothed or sub-entire; pods linear-oblong $\left(5-6^{\prime \prime}\right)$, subsessile.-(2) Banks of the Miss. Glabrous. Sts. erect, nearly simple. Lvs. attenuated at base, those of the stem nearly entire. Fls. minute. Rac. elongated in fruit, both pods and stigmas almost sessile. Apr.-Jn.

6 IN. palústre DC. MARSH CRESS. Glabrous; lvs. pinnately lobed, amplexical, lobes confluent, dentate; $\mathrm{rt}$. fusiform; pet. as long as the sepals; silicle spreading, turgid, twice longer than wide.-2 In wet places. St. 1-2f high, erect, branched above. Lvs. $2-3^{\prime}$ long, all more or less pinnatified, with the terminal lobe large, ovate. Fls. numerous, small. Silicle $3^{\prime \prime}$ long, pedicels twice as long, oflen deflexed. Jn.-Aug.

7 N. híspidum DC. Villous; lvs, runcinate-pinnatified, lobes obtusety dentate; silicles tumid, ovoid or globular, the pedicels longer, ascending; pet. scarcely as long as the calyx.-(2) Banks of streams N. H. to Penn. Stem angular, branched, 1 -3f high, with many paniculate racemes above. Lvs. 3-6' long. Fls. minute. Silicles $1^{\prime \prime}$ long, on pedicels $2-3^{\prime \prime}$ long and somewhat spreading. Jn. -Aug.

8 N. sylvéstre R. Br. Woop Cress. Lvs. pinnately divided, segm. serrate or incised; pods linear. style very short. -4 Wet meadows, near Philadelphia (Nutt): 
near Boston (Sprague). Sts. ascending from a prostrate base. Fls. rather large and showy. Pet. $\frac{1}{3}$ longer than calyx. Pods nearly $\frac{1^{\prime}}{2}$ long, the pedicels rather longer, ascending. Jn., Jl. § Eur.

9 N. sinuàtum Nutt. Lvs. pinnatified, segm. lance-oblong, nearly entire; pods oblong, acute, with a slender style.-Banks of the Miss. opposite St. Louis, southward, W. to Oregon. Glabrous and diffusely branched. Lvs. regularly pinnatified, the terminal segm. often confluent. Fls. rather large and showy. Pods about $\frac{1}{3}$ long, slightly curved, the pedicels still longer, spreading or recurved. Jn.

\section{TÚRRITIS, Dillon. Tower Mustard. (Lat. turritis, turreted;} from the pyramidal form of the plant.) Sepals erect, converging; silique long, linear, 2-edged; valves plain, 1-veined; seeds in a double row (margined in one species) $(0=)$. - Fls. white or rose-colored. Stem lvs. inostly sagittate-clasping.

I T. glàbra L. Fls. (cream-volite) erect; siliques long $\left(3^{\prime}\right)$, strictly erect ; stem-lvs. ovate lanceolate. - (1) In rocky fields about New Haven (Eaton) and Can. Glabrous. St. round, simple, $1 \frac{1}{2} \mathrm{f}$ high. Radical-lvs. petiolate, dentate; cauline arrow-shaped and half-clasping at base, smooth, glaucous and entire. Siliques straight and very narrow. May. § Eur.

2 T. strícta Graham. Fls. (rose-white) erect; silique long $\left(3^{\prime}\right)$, erect, finally ascending, stem-lvs. linear-lancoolate - (2) On rocks, N. Y. (rare), W. to Or. Plant glabrous. St. straight, erect, simple, 1-2f high. Root-lvs. spatulate, remotely denticulate; stem-lvs. arrow shaped, clasping, erect, nearly entire. Rac. terminal, elongated in fruit. May.

3 T. brachycárpa Torr \& Gr. Fls. (pale-purple) nodding; siliques shorter $\left(1^{\prime}\right)$, spreading.-Lake shores Mich. Glabrous and glaucous, often purplish. Stem 1-2f high. Root-lvs spatulate, dentate; cauline linear-lanceolate, sagittate and slasping. Fls. rather large.

3. IODÁNThUS, Torr. \& Gray. False Rocret. (Gr. $\iota \omega ́ \delta \eta$ violetcolored, äv0os, flower,) Calyx closed, shorter than the claws of the petals; silique linear, terete, veinless; seeds arranged in a single row in each cell $(0=)$.- Glabrous, with violet-purple flowers in panicled racemes.

I. pinnatífida Torr \& Gr.-4 Penn. to Ill., S. to Ark. St. slender, furrowed 2-3f high. Lvs. thin, sharply dentate, $3-5^{\prime}$ long, $\frac{1}{4}$ as wide, the lower often lyrate-pinuatifid, those of the stem lanceolate, acuminate, scarcely petiolate. Rac. terminal and axillary. Petals long-clawed, with an obovate border. Pods torulous, 15-20" long; sds. oblong, plano-convex. May, Jn.

4. HATTHIOLA, R. Br. Stock. (In honor of P. A. Matthioli, physician to Ferdinand of Austria, and botanic author.) Calyx closed, 2 of the sepals gibbous at base; petals dilated; siliques terete; stigmas connivant, thickened or cornute at the back.-Herbaceous or shrubby, oriental plants, clothed with a hoary, stellate pubescence.

* Perennial or biennial. Stems herbaceons... ............................. Nos. 1, 2.

* Perenuial. Stems slirubby at base................................................. 8,4 .

1 M. ánnuus R. Br. TEN WEeks' sTock. St. erect, branched; lvs. hoarycanescent, lanceolate, obtuse, subdentate; silique swbcylindrical.-(1) A fine garden flower from S. Europe. St. 2 f high, and, with the leaves, covered with a soft, stellate pubescence. Fls. variegated. Jn. $\nmid$

2 M. Græcus R. Br. Grecran STOck. St. erect, branched; lvs. lanceolate, glabrous; siliques somewhat compressed.-(2) From Greece. Plant about If high, distinguished from the remainder of the genus by its smooth foliage. Fls. white, appearing all summer.t

3 M. incànus R. Br. PURPLE JULY Flower. St. erect, branched; Ivs. lanceolate, entire, hoary-canescent; siliques subcylindrical, truncate and compressed 
at apex.-2 Ono of the most popular flowers of the genus, sative of England, etc. St. $2 \mathrm{f}$ high. Fls. purple.-Several varieties are enumerated, as the doublo flowered, Brompton Stock, Brompton Queen. Jn.†

$4 \mathrm{M}$. fenestràlis $\mathrm{R}$. Br. Erect, simple; lvs. crowded, recurved, undulate. downy; siliques downy, broadest at base.-24 From S. Liurope. Plant if high. Fls. numerous, large, purple. Jl., Aug. $\dagger$

5. DENTÀrIA, L. Pepper-root. (Lat. dens, a tooth; from the tooth-like projections of the rhizome.) Sepals converging; silique lance-linear, with flat, veinless valves, often opening elastically; placentre not winged; sds. in a single row, ovate, not bordered ; funiculus broad $(0=)$. - Rhizome 24. Lrs. palmately divided, those of the stem but 2 or 3 , somewhat whorled. Fls. white or purplish, in a terminal raceme.

- Leares of the stem sub-opposite or sub-verticillate...........................

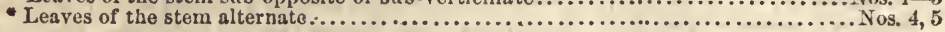

1 D. diphýlla L. St. 2-leaved; lfts. subovate; rhizome continuous, toothed.-In woods and wet meadows, Can. to Car., W. to the Miss. St. about If high, round, smooth, with 2 , nearly opposite, ternate leaves above the middle. Ifts. on very short stalks, the lateral ones oblique, all with rounded, mucronate, unequal teeth. Fls. racemed, large, white; the potals much larger than the calyx. The rootstock is long and large in proportion to the plant, beset with teeth, with a pungent, aromatic taste. May.

2 D. laciniàta Muhl. Cauline lvs. 3, 3-parted, the divisions lanceolate or linearoblong, obtuse, lobed, toothed or entire; rhiz. moniliform.-In woods, Can. and U. S. The rootstock consists of several connected tubers of a pungent taste. Stem If high, smooth, simple. Lrs. usually in a whorl about half way up, the segm. with very irregular, mucronate teeth, rarely subentire, lateral ones sometimes cut nearly to the base, rendering the leaf almost quinate. Root-lvs. generally wanting. Fls. racemed, purplish. Apr., May.

3 D. multífida Muhl. Cauline lvs. mostly 3, and verticillate, rarely 2, multifid with numerous linear lobes; rhiz. tuberous.-In woods, N. Car, to Ala., rare. St. 6-10' high. Lvs. finely dissecte $d$ in a bi- or triternato manner. Fls. white, smaller than in the above species.

4 D. máxima Nutt. Stem about 3-leaved (2 to 7 ); lfts. 3, ovate, toothed or cleft ; rhiz. moniliform, the tubers toothed.-N. Y. and Penn., rare. Tubers of the rootstock thick as the finger, an inch or more in length. St. 1-2f high, bearing a lengthened raceme, with palo purplo flowers which are larger than in No. 1, and several alternate, remote, ternate, petiolate Ivs. Lfts. sharply and coarsely cut-toothed or lobed. May.

5 D. heterophýlla Nutt. St. about 2-leaved (2 or 3), leaflets 3, lanceolate and nearly entire; root-lvs. of 3, ovate-oblong, toothed and cut-lobed lfts. ; rhiz. moniliform, scarcely toothed.-Penn., Va., Ky. A small and delicate species, somo 6' high. Tubers of the root few $(1-3)$, oblong. Radical lf. always present, long-petioled. The alternate stem-lrs. small ( $I^{\prime}$ long), also petiolate. Fls. fow $(6-9)$, palepurple. Jn.

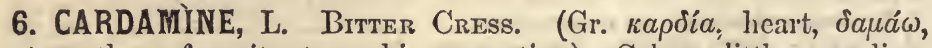
to strengthen; from its stomachic properties.) Calyx a little spreading, silique linear with flat, veinless valves, narrower than the dissepiment, and often opening elastically from the base; stigma entire; seeds not margined, with a slender funiculus $(0=)$. Fls. white or purple.

* Leares pinnate, with many leaflets........................................ 1, 2

* Leaves simple, or partly ternate. Roots mostly perennial. (a)

a Style slender. In low, wet grounds................................... Nos. 3,4

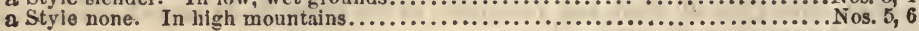

1 C. hirsùta I. St. (hirsute in Europe) glabrous, erect; lvs. pinnately 5-11foliate, terminal in. largest; fls. (white) small; silique erect, linear or filiform; stig. 
minute, sessile.-(2) Common in streams and springy places throughout the country. Aspects various; st. varying from filiform to thick and fleshy. Lifts. few or many, regular or not, lobed, toothed, angled or entire, always obtuse, terminal one generally 3 -lobed. Pods always torulous and straight (except in $\beta$ ) about $1^{\prime}$ long. Mar.-Jn.

B. Virginica Hook. Slender and delicate; lfts. 1 or 2-toothed; pods filiform, incurved.-Grows on rocks and sandy shores.

2 C. praténsis L. Cuckoo Flower. St. ascending, simple; lvs. pinnately 7-15foliate, lfts. petiolate, subentire, lower ones suborbicular, upper linear-lanceolate; sty. distinct. - 4 Swamps, N. Y. to Arc., Am. Whole plant smooth. St. round, striate, $10-16^{\prime}$ high. Lvs. few, $11-2^{\prime}$ long, including the petiole. Lfts. small or minute, regular. Fls. largo $\left(6-S^{\prime \prime}\right.$ broad $)$, few, in a terminal raceme. Pet. white or rose-color. Siliques nearly 1' in length, erect. Apr., May.

3 C. rhomboìdea DC. Sts. sinaple, erect or ascending, tuberiferous at base; siliques linear-lanceolute. - 4 Wet woods and meadows, çommon. Glabrous, $8-14^{\prime}$ high. Tubers 1 to several, roundish, white, bearing ono or several stems. Radical leaves roundish, long-staliked, somewhat cordate, entire; stem lvs. oblong or rhomboidal, angular-subdentats, tho upper lanceolate, sessile. Racemes one or two, with white, showy, flowers. Styles $1^{\prime \prime}$ long; stigmas capitate. Apr.-Ju.

3. purpurea Torr. Slender, erect, few-leaved and purple-flowered.-Cleveland, O., \&c. May.

4 C. rotundifòlia Mx. Sts. decumbent, branching, finally stoloniferous; lvs. all petiolate; siliques linear-subulate; rt. fibrous. - 24 Cool springs and rivulets in Mts., Penn. to Car. (Buckley). Prostrate stems or runners $1-2 \mathrm{f}$ in length. Lrs. roundish, subcordate angular, the lower 3-lobed or ternate, with the terminal lft. much the largest. Fls. smaller than in No. 3, white. May, Jn.

5 C. belliaifòlia I. Lvs. smooth, orbicular-ovate, nearly entire, petiolate; cauline entire or 3 -lobed; siliques erect. - $4 \mathrm{~A}$ minute species, on the summits of the White Mts. (Storrs), \&c.; also, Arc., Am. to Cal. Stem 1 $1 \frac{1}{2}-3^{\prime}$ ligh. Lrs. mostly radical, broadly oval or ovate, $\frac{1^{\prime}}{4}$ long, on petioles as long as the stems. Fascicles corymbous, each of 3 or 4 white flowers. Pet. oval, obtuse, about twice as long as tho calyx. Jl.

6 C. spatulàta MIx. Lvs. hirsute, the radical spatulate, petiolate; cauline sessile, siliques 'spreading.-(1) Mts. of Car. and Ga. Sts. decumbent, slender, $6-8$ ' long. Lvs. about $1^{\prime}$ in length, the lower entire, obtuse; the upper somewhat toothed, narrow. Rac. several, loose, with filiform, spreading, distant pedicels. Fls. white. Pods straight, $I^{\prime}$ long. Apr.

7. ÁRABIS, L. Rock Cress. (Name from Arabia, the native country of some of the species.) Sepals mostly erect; silique linear compressed; valves each with one o: "three longitudinal veins, seeds in a single row in each cell, mostly margined, cotyledons accumbent or. oblique.-Fis. white.

* Leares (all or at least the radical) pinnatifid ................................ 1, 2.

* Leaves all undivided, toother or entire, often clasping. (a)

a Siliques longer $\left(1-2^{\prime}\right)$, straight or curved. Seeds not winged..................... 5. 6.

a siliques long $\left(3^{\prime}\right)$, curved, pendant. Seeds winged.............................. 7,8 .

1 A. Iudoviciàna Meyer. All the lvs. pinnatifid or pinnate, smoothish; st. branched at base; siliques and pedicels ascending; sds. bordered.-(1) N. Car. and $\mathrm{Ky}$. (Curtis) to (Macon) Ga. Sts. 6-10' high, slender. Leaves 1-2' long, at first rosulate, of $6-9$ pairs of oblong, few-toothed leaflets, rachis slightly winged. Pods $7-10^{\prime \prime}$ by $1^{\prime \prime}$, valves veiny. Fls. minute, white. Mar., Apr.

2 A. lyràta L. Upper lvs. smooth, linear, entire; radical lvs. lyrately pinnatifich often pilous: st. branched at base; pedicels spreading; siliques erect, seeds hivt bordered. - (2) Un rocky hills, Can. and Wis. to Va. Sts. declined at base, $6-12^{\prime}$ high. Root-lvs. numerous, rosulate, $1-3^{\prime}$ long, $\frac{1}{4}$ as wide, petiolate, pinnatifid or sinuate-dentate, upper ones sublinear and sưbentire. Fls. middle size ( $3^{\prime \prime}$ long), 
Siliques when mature $1 \frac{1}{2}-2^{\prime}$ long, $1^{\prime \prime}$ wide, tipped with a short style. Cotyledons obliqueiy $0=$ or nearly $0 \|$. Apr., May.

B. A variety (A. PETREA Lam. ?) has very slender, upright stems, smooth, a few small, incised root-lvs., few linear stem-lvs. and cotyledons wholly $0=.-$ Shores of the great lakes (Ohio), Can.

3 A. Thaliàna L. Mouse-enr Cress. Sts. branched at base, erect; lvs. pilous, oblong, nearly entire ; petals twice longer than calyx; pods erect, squarish.-(2) Rocks and sandy fields, Vt. to Iil. and Car. Whole plant pubescent with stellate-hairs. St. several from the same root, erect, simple, slender, $4-12^{\prime}$ high. Root-lvs. rosulate, petiolate, 1-2' long, cauline appressed, an inch long, base somewhat clasping. "Fls. smail, white. Pods $6-8^{\prime \prime}$ long. Cotyledons obliquely $0 \rrbracket$. May. $\S$ Liur. (Sisymbrium, Gay.)

4 A. dentàta Torr. \& Gr. Sts. branched at base, diffuse; lvs. roughish-downy, oblong, sharply toothed; petals hardly longer than calyx; pods sprecuding.-(1) River banks, N. Y. to Mo. Plant scabrous with stellate hairs. Sts. decumbent, a foot high. Root-lvs. 2 ' long by $\frac{3}{4}$; cauline half-clasping with an auriculate base, all very obtuse and irregularly toothed. Fls. small, whitish. Pods very slender, $1^{\prime}$ long. May.

5 A. pàtens Sullivant. Erect, pubescent; cauline lvs. coarsely toothed; sitiques spreading and curved upwards, beaked with a distinct style.-Rocky banks of tho Scioto, 0. (Sullivant), and southward. Sts. $1-2 \mathrm{f}$ high. Root-lvs. rosulate, petiolate; stem-lvs. oblong-ovate or linear, auriculate-clasping. Fls. rather large (5-6" broad), white. Pods nearly 2 ' long. May.

6 A. hirsùta Scop. Erect, hirsute; radical lvs. oblong-ovate, tapering to a petiole, cauline oval or lanceolate, sagittate-clasping; entire or toothed; siliques straight, erect; sty. none.-(2) Found in low, rocky grounds, Can. to Va., W. to Oregon. Sts. 2 or more from the same root, round, hairy at base, near a foot high, slender and parallel. Lvs. scarcely dentate, sessile, with heart-shaped or arrow-shaped bases, the upper acute. Fls. greenish-whito. Siliques $1-2$ ' long. Jn.

7 A. levigàta DC. Tall, glaucous, smooth; stem-lvs. linear-lanceolate, and linear, sagittate-clasping, the upper entire; siliques very long, linear, at length spreading and pendulous.- 4 In rocky woods and low grounds, Can. to Tenn. and westward. St. 2f high, round, simple, or branched above. Root-lvs. often purplish, obovate and oblong, petiolate, $\frac{8}{4}-1 \frac{1}{2}^{\prime}$ long, $\frac{1}{3}$ as wide, with acute teeth. Stem-lvs. $3-5^{\prime}$ long and very narrow. Fls. erect, greenish, the petals hardly longer than the calyx. Siliques $3^{\prime}$ long, scarcely $1^{\prime \prime}$ wide. May.

8 A. Canadénsis L. Sickle PoD. Tall, pubescent; stem lvs. lanceolate, pointed both ways, sessile; silique subfalcate, veined, pendulous.-4 On rocky hills Can. to Ga., W. to Ark. A plant remarkable for its long, drooping pods which resemble a sickle-blade, or rather a scythe. St. 2-3f high, slender, round, smooth. LVs. $3-5^{\prime}$ long, $\frac{1}{4}$ as wide, the lowest early marescent, middle and upper ones sessile or clasping, with narrow bases, remotely denticulate. Fls. small, the narrow, white petals twice longer than the calyx. Pods slender, flattened, $3^{\prime}$ long. May, Jn.

8. CHEIRÁNTHUS, L. Wall Flower. (Arabic kheyry, the name of a certain plant, and Gr. ǎv0os, flower.) Calyx closed, 2 of the sepals gibbous at base; petals dilated; silique terete or compressed; stigma 2-lobed or capitate; seeds flat, in a single series, often margined. $(0=)$. Garden perennials, mostly European. Lvs. undivided.

C. Cheiri L. St. somewhat shrubby and decumbent at base; lrs. entire or slightly dentate, lanceolate, acute, smooth; branches angular; petals obovate; siliques erect, acuminate.-4 From S. Europe. A popular garden flower, admired for its agreeable fragrance, and handsome corymbous clusters of orange or yellow flowers. Plant about $2 \mathrm{f}$ high. Jn.

9. LEAVENWÓRTHIA, Torr. (Named for Dr. Leavenworth, the discoverer.) Calyx rather erect; petals cuneate, retuse or truncate; 
silique flat, linear or oblong, valves indistinctly reined; seeds in a single row, flattened, wing-margined; embryo nearly straight, curving towards an accumbent form.-(2) Low, smooth herbs with lyrate-pinnatifid lvs. Fls. yellowish.

L. Michaùxii Torr. (and L. aurea Torr.). On wet rocks S. E. Ky. to Texas. Plant 2-6' high. Lvs. mostly radical, an inch or two in length, segm. $1-5$, angular. Fls. at first solitary, on slender scapes, finally racemed. Petals twico longer than the sepals, yellow, at least its broad claws. Pods erect, 3-5-seeded. Mar., Apr. (Cardamine uniflora. Mx.)

10. BARbÀreA, R. Br. Wrinter Cress. (In honor of St. Bar. bara who discovered [what are sinee unknown] its medicinal properties.) Sepals ereet; siliques columnar, 2 or 4-angled, valves carinate with a mid-vein; seeds in a single row $(0=)$. - Lvs. lyrate-pinnatifid. Fls. yellow.

1 B. vulgàris $\mathrm{R}$. Br. Upper Ivs. toothed or pinnatifid at base; siliques obscurely 4.angled, pointed with the style.-2) Fields and brooksides, common, N. States. Whole plant glabrous. St. furrowed, $1-2 \mathrm{f}$ high, branching above. Lower lvs. lyrate pinnatifid, with small, oblong pinnæ, and a large, broad-ovate, terminal lobe, dark green, shining, with clasping petioles; upper lvs. sessile, all very obtuse.-Fls. in dense racemes. Pods about $9^{\prime \prime}$ long, usually curved, ascending or erect. May, Jn.

2 B. prècox R. Br. Belle isle Cress. Scurvy Grass. Upper lvs. pinnatifid, with the lobes all linear-oblong; silique 2-edged.-4 Cultivated southward for salad, and sparingly naturalized. St. slender, if high. Lower lvs. with the terminal lobe ovate. Siliques 2 or 3 ' long. Apr., Jn.

11. ERÝSIMUM, L. False WALL Flower. (Gr. épv́w, to cure; from its salutary medicinal properties.) Calyx closed; siliques columnar, 3 -sided, valves with a strong mid-vein ; stigma capitate; seeds in a single series ; cotyledons oblong, 0\|.-Fls. yellow.

1 E. cheiranthoìdes L. Pubescence minute, appressed, branched; lvs. lanceolate, denticulate, or entire; fls. small ; siliques short $\left(8-10^{\prime \prime}\right)$, on slender, spreading pedicels; stig. small, nearly sessile.-1) By streams and in wet grounds, U.S. and Can., not common. St. erect, $1-2 \mathrm{f}$ high, often branched, and, with tho leaves, scabrous. Lvs. acute at each end, $1-2^{\prime}$ long, $\frac{1}{3}$ as wide. Fls. small, yellow, in long racemes. Siliques $\frac{1}{2}$ to near $I^{\prime}$ in length, linear, and somewhat spreading. JJ.

2 E. Arkansànum Nutt. Yellow Phlox. Scabrous, with an appressed pubescence; st. simple; lvs. linear-lanceolate, remotely dentate, sessile, lower ones runcinate-toothed; inflorescence racemous, corymbed at summit; siliques long $\left(3^{\prime}\right)$, erect, on short, erect pedicels; stig. capitate.-2) A fine plant, with large, showy flowers, resembling the wall-flower, on bluffs along rivers, Ohio to Ark. St. $1-3 \mathrm{f}$ high, slender. Lvs. $2-3^{\prime}$ by $3-6^{\prime \prime}$. Sep. straw-colored. Petals large, bright-orange yellow. Siliques $3^{\prime}$ long. Jn., Jl.

12. SISÝMBRIUM, Allioni. (An ancient Greek name.) Calyx halfspreading, equal at base; petals unguiculate, entire: silique subterete, valves concave, marked lengthwise with $1-3$ veins; style very short; seeds in a single series, ovoid, 0\|.-Fls. (yellow) small.

1 S. officinàle Scop. HEDGE MUSTARD. Lvs. runcinate; rac. slender, virgate; siliques subulate, erect, closely appressed to the rachis.- I A common weed, in fields, roadsides, rubbish, etc., Can. and U. S. St. 1-3f high, with spreading branches. Lower lvs. $3-8^{\prime}$ by $1-3^{\prime}$, the lower segments placed at right angles to the midvein, or pointing backwards, the terminal segment largest. Upper lvs. in 3 lanceolate segments at right angles. Fls. small, yellow, terminating the ra- 
ceme, which becomes 1 -2f long, and environed by the appressed sessile pods. Jn., Sept. Medicinal. § Eur.

2 S. Sòphia L. FLIXWEED. Lvs. bipinnatifid, lobes linear-oblong, acute, incised; sepals longer than the petals; silique linear, slender, erect, longer than the spreading pedicel.-Plattsburg, N. Y. (Mrs. Conant), and Can. along the St. Lawrence. Stems erect, 1-2f high. Leaves ovate in outline, finely dissected, almost tripinnatifid. Fls. very small, pale jellow. Siliques $1^{\prime}$ long, very narrow, in long racemes. July.

3 S. canéscens Nutt. TANSEy Mustard. Lrs. bipinnately divided, canescent, lobes oblong or lanceolate, subdentate, obtuse; patals about equalling the calyx; siliques oblong-linear, ascending, shorter (or never longer) than the spreading pedicels.- I: Arctic Sea to Florida. Plant 1-2f high, often nearly smooth. Lrs. about $3^{\prime}$ long, sessile, lance-oblong in outline, segm. $5-7$ pairs, finely divided. Fls. very small. Sillques $3-6^{\prime \prime}$ in length, the seeds somewhat 2-rowed. Variable. Mar., Jn.

13. WÀREA, Nutt. (Named in honor of $M r$. Ware, the discoverer.) Sepals colored, ligulate; petals with very slender elaws, longer than the lamina; silique flattened, long and slender, raised on a slender stipe ; stamens nearly equal, $0 \| .-\mathbb{1}$. Glabrous, entire-leaved plants, with the aspect of Cleome. Fls. white or purple, in short racemes. Siliques curved and declinate.

I W. cuneifòlia Nutt. Lvs. oblong, obtuse, cunoate at base, and sub-sessile.Dry hills, Ga. (Mettauer) and Fla. St. 1-2f high, branched above. Lrs. $\frac{1}{2}-1^{\prime}$ long, rather thick, the upper linear. Fls. in showy clusters at the summits of the branches, white or purplish. Pedicels divergent. Sta. exserted, with the anthers finally circinate. Petals with remarkably slender claws $2^{\prime \prime}$ in length, lamina $1^{\prime \prime}$. Siliques $1 \frac{1}{2}$ or more in length, 4 times longer than the filiform stipe. Jn., Aug.

2 W. amplexifòlia Nutt. Lvs. oblong-ovate, partly clasping.-(1) Fla. In all other respects like No. 1, and in all probability not distinct from it.

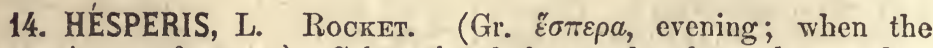
flower is most fragrant.) Calyx closed, furrowed at base, shorter than the claws of the petals; petals bent obliquely, linear or obovate; silique 4-sided, 2-edged or subterete; seeds not margined; stigmas forked, with the apices converging $(0 \|)$.-Fls. cyanic.

I H. matronàlis L. St. simple, erect; lvs. lanceolate-ovate, denticulate; petals emarginate, mucronate; pedicels as long as the calyx.-A fine garden perennial, said to be found native about Lake Huron. St. 3-9f high. Fls. purple, often double, and white in $\beta$ hortensis. Juno-Aug. + Eur.

2 H. áprica I. St. erect, simple, pubescent: lvs. oblong, obtuse, entire, ciliate hispid; pedicels as long as the calyx.-2 From Siberia. Stem a foot high. Fis. purple. May, Jn., $\dagger$.

\section{SINĀPIS, Tourn. Mustard. (The Greek name, oívãti.) Sepals} equal at base, spreading; petals ovate, with straight claws; siliques subterete; valves veined; style short and subulate, or ensiform; seeds in a single series, globular $(0 \gg)$. - Fls. always yellow.

1 s. nigra L. BLACK MUSTARD. Smooth; silique smooth, somewhat 4-angled, appressed to the rachis, and beaked with a slender, 4-sided style. - (1) In cultivated grounds and waste places. St. 3-6f high, round, smooth, striate, branching. Lvs. all petiolate, lower ones variously lyrate and.dentate, upper ones lance-linear, pendulous, entire. Sep. and pet. sulphur-yellow. Pods very numerous, nearly $\mathbf{l}^{\prime}$ long. Sds. numerous, small, globous, nearly black, well known as a condiment. Jn., July. $\ddagger \S$ Eur. 
2 S. arvénsis L. Findd Mustard. St. and leaves hairy; silique smooth, many. angled, torulous, spreading, about 3 times linger than the slinder, ancipital style.-(1) Naturalized in N. Y. (T. and G.) and in Vt. (Robbins). Lower lvs. large, sublyrate-pinnatifid, upper ones oblong-ovate, all repand-toothed. Siliquo somewhat

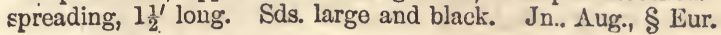

3 s álba L. White MIUstard. LVs. smoothish; siliques hispid, torose, shorter than the ensiform beak sds. large, pale yellow.-1) Native of Luropo. St. 2-5f high, thinly hirsute. Lvs. all lyrately pinnate, dentate, petiolate. Siliques spreading, about 4-seeded. The seeds are used for about the samo purposes as those of S. nigra, esteemod in medicine. Jn., Jl. $\neq$.

16. BRÁSSICA, L. CABBAGE, etc. (Celtic bresic, the cabbage.) Sepals equal at base, (mostly) erect; petals obovate ; filaments without teeth; silique sub-compressed, valves concave, with a central vein; style short, subterete, obtuse; seeds globous, in a single (often double) row $(0 \gg)$. - Fls. yellow.

1 B. campéstris L. CALE. Lrs. somewhat fleshy and glaucous, the lower lyratedentate, subciliate, upper ones cordate-amplexicaul, acuminate.-(1) Cultivated fields and waste places. St. $1 \frac{1}{2}-3$ high, with a few, scattered, reversed hairs below. Lower lvs. $3-7^{\prime}$ long, $\frac{1}{3}$ as wide, upper smaller, entire, with rounded clasping lobes at base, tapering to an obtuse point. Rac. 1-2f long. Sep. erect, spreading. Cor. yellow, $4-5^{\prime \prime}$ diam. Siliques $1_{2}^{\prime \prime}$ long, with the style $\frac{1^{\prime}}{2}$. Sds. small, dark brown. Jn., Jl. § Sweden.

$\beta$ Rutabag. Sw edish Turnip. Rt. tumid, napiform, subglobous, yellowish. -Cultivated like the common turnip: but after a thorough experiment, it is conceded oy farmers to be inferior in value to that root, although it grows to an enormous size. $\ddagger$.

2 B. rápa I. Radical lvs. lyrate, rough, not glaucous, caulino ones incised, upper entire, smooth. $\ddagger$.

$\beta$ DEPRESSA. CoMmon TURNip. Rt. depressed, globous or napiform, contracted below into a slender radicle.- (2) Long cultivated for the table, etc., in gardens and fields. St. $2-4 \mathrm{f}$ high, and with the leaves deep green. Upper lvs. amplexicaul. Pods $1^{\prime}$ long. Sds. small, reddish-brown. Jn. $\ddagger$

3 B. oleràcea I. CABBAGE. Lvs. very srrooth and glaucous, fleshy, repandtoothed or lobed.- (2) Native of Europe, where it grows on rocky shores and cliffs, with no appearance of a head, forming a surprising contrast with the cultivated varieties. The excellence of the cabbage as a pot-herb needs no encomium. $\ddagger$

$\beta$ Bullata. Safoy Cabbage. Lvs. curled, subcapitate when young, finally expanding.

$\gamma$ Botrytis-Cauliflora. Cauliflower. St. low; hds, thick, compact, terminal; fls. abortive, on short, fleshy peduncles. $\ddagger$.

$\delta$ BOTRYTIS ASParagoldes. Broccoli. St. taller; hds. subramous; branches fleshy at the summit, consisting of clusters of abortive flower-buds. $₹$.

$\varepsilon$ Capitata. Head Cabbage. St. short; lrs. concave, packed in a dense head before flowering; rac. paniculate. $\ddagger$.

17. ALÝSSUM, L. MADwort. (Gr. $a$, privative, $\lambda \dot{\sigma} \sigma \sigma a$, ragge; supposed by the ancients to allay anger.) Calyx equal at base; petals entire; some of the stamens with teeth; silicle orbicular or ovat, with valves flat or convex in the centre; seeds $1-4$ in each cell $(0=)$.Showy European herbs.

1 A. saxátile L. Rock Alyssum. Madwort. St. suffruticous at base, subcorymbous; lvs. lanceolate, entire, downy; silicle obovate-orbicular, 2-seeded; sds. margined.-An early-flowering garden perennial, natire of Candia. St. If high, with numerous yellow flowers in close corymbous bunches. Apr., May. $t$. 
2 A. marítimum Lam. SwEET ALYSSUM. St. suffruticous and procumbent at base; lvs. linear-lanceolate, acute, somewhat hoary; pods oval, smooth.2f A sweet-scented garden plant, with fino leaves and small white flowers. St. a foot in length. Fls. from Jn. to Oct.-All the species of Alyssum are of easy culture in common loamy soils. $f$.

18. LUNA'RIA, L. HoNesty. (Lat. luna, the moon; from the broad, round silicles.) Sepals somewhat bisaccate at base; petals nearly entire; stamens without teeth ; silicle pedicellate, clliptical or lanceolate, with flat valves; funiculus adhering to the dissepiment $(0=)$.

1 L. rediviva I. Perendial Satti Flower. St. erect, branching; lvs. ovate, cordate, petiolate, mucronately serrate; silicles lanceolate, narrowed at each end.-24 From Germany. Stem 2-3f high. Fls light purple. Jn.t

2 L. biénnis DC. HONESTY. St. erect; lvs. with obtuse teeth; silicles oval, obtuse at both ends.-(2) These are large, hairy plants, native of Germany. Sts. 3 -4f high. Lvs. cordate. Fls. lilac-colored. The broad, round, silvery silicles are the most remarkable feature of the plants. May, Jn.

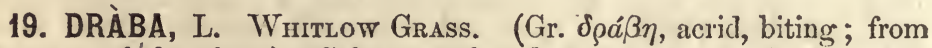
the taste of the plant.) Calyx equal at base; petals equal ; filaments without teeth; silicle oval or oblong, entire, the valves flat or slightly convex, veined; seeds not margined, 2 -rowed in each cell $(0=)$.-Fls. white, rarely yellow. Plants small.

\$ Eropirlu (DC.). Petals 2-parted

\$ Draza proper. Petals entire or unly einarginate. (a)

a Stylo long or short, but distinct. Plants perennial

a Style none Plants annual or biennial. (b)

b Pedicel as long as or longer than tho siliclo................... 4,5

b Pedlcel shorter than the silicle.............................. 6, 7

1 D. (Eróphila) vérna I. WHitzow Grass. Scapo naked; lvs oblong, acute, subserrate, hairy; petals bifid; stig. sessile: silicle oval, flat, shorter than the pedicel.-(1) A little, early-flowering plant in grassy fields, rather rare, Can. to $\mathrm{Va}$. Lvs. all radical, lanceolate, $\frac{1}{2}-1 \frac{1}{4}$ long, $\frac{1}{8}$ as wide, with a few teeth towards the end. Scape a few inches high, with a rac. of $5-15$ small, whito flowers. Cal. spreading. Petals cleft half way down. Silicles about a line wide $3^{\prime \prime}$ long, with deciduous valves. Apr., May.

2 D. arabìsans Mx. St. leafy, erectly branched, pubescent; Ivs. lanceolate, minutely dentate; silicle oblong-lanceolate, smooth, longer than the pedicel; sty. short but distinct.-Lake shores, Willoughby, Vt., N. Y., Mich. 'Sts. several from the same root, $6-8^{\prime}$ high. Radical ivs. about $1^{\prime}$ long, forming rosulate tufts at the top of the short radical shoots; cauline somewhat clasping. Fls. white, in a short raceme. Silicles elongated $\left(4-6^{\prime \prime}\right)$, twisted when ripe so as to appear double. May.

3 D. ramosíssima Desv. Minutely pubesoent; sts. numerous; lvs. linearlanceolate, with remote and slender teeth, upper ones entire; rac. corymbously paniculate; silicle lanceolate, about the length of the pedicel, the style half as long. -On rocks, Harper's Ferry, Va., W. to Ky. Sts. slender, 4-10' long, the barren ones with tufted leaves at top. Lvs. about $l^{\prime}$ long, with one or two teeth on each side. Fls. white. Silicles $3^{\prime \prime}$ in length, ascending. Apr., May.

4 D. nemoràlis Ehrh. St. pubescent, branched; lvs. oval, cauline, lanceolate, toothed; pet. emarginate; silicles oblong-elliptical, half the length of the pedicels; seeds nearly 30.-Mich, Mo. Plant slender, 8-10' high. St. with a few branches. Lvs. mostly radical. Rac. much elongated in fruit, with very long pedicels. Fls. minute, yellowish-white. May.

5 D. brachycárpa Nutt. Minutely pubescent; radical lvs. roundish-ovate, petiolate, cauline oblong or linear, slightly dentate or entire; rac. many-flowered, straigint, elongated in fruit; petals obovate, entire; silicle oval, glabrous, about as long as the pedicels, 10-12-seeded.-24 Grassy places near St. Louis, S. to La 
St. branched and leafj; 2-4' high. Silicles scarcely $2^{\prime \prime}$ in length. Mar, Apr.

$6 \mathrm{D}$. cuneifòlia Nutt. Hirsute, pubescent; st. branching and leafy below, naked above; lvs. cuncate-oblong, sessile, denticulate; rac. elongated in fruit; silicles twice longer than the pedicels, 20-30-seeded.-Fields, Ky. to La. Plant $3-8^{\prime}$ high. Fls. much larger than in the preceding. Petals white, nearly thrice longer than the sepals. Mar., Apr.

7 D. Caroliniàna Walt. Lvs. ovate-roundish, entire, hispid; silicles linear, smooth, longer than the pedicels, corymbous, 30-40-seeded. - Sandy fields, Ct., R. I., S. to Ga. St. 1-3' high, leafy at base, hispid, naked and smooth above. Lvs. clustered on the lower part of the stem, very hairy. Petals white, twice as long as the sepals. Silicle $6^{\prime \prime}$ long, rather obtuse, smooth (or minutely hispid in $\beta$ ?). Apr.-Jn. (D. micrantha Nutt.)

\section{0, ARMORACIA, Rupp. Horse Radish. (Armorica, its native} country, now the province Brittany, France.) Calyx equal at base, spreading; petals entire, much exceeding the calyx; filaments toothless ; silicles ellipsoid or globular, turgid, 1-celled from the incomplete partition; style distinct; seeds few $(0=) .-4$ Lvs. oblong, undivided, or the lower pinnatifid. Fls. white.

1 A. rusticàna Rupp. Radical lvs. oblong, crenate; cauline long, lanceolate, dentate or incised, sessile; silicle roundish, ellipsoid, much longer than the style. -4 A common garden herb, sparingly naturalized in wet grounds. Rt. fleshy, large, white, very acrid. St. 2-3f high, angular, smooth, branching. Radical lvs. near a foot long, $\frac{1}{2}$ as wide, on long channeled petioles. Lower stem-lvs. often cut in a pinnatifid manner, upper toothed or entire. Fls. not large. Silicle much shorter than the spreading pedicels. The root is a well known condiment for roast beef and other viands. Jn. § Eur. (Cochlearia L.)

2 A. Americàna Arn. Aquatic; immerrsed leaves doubly pinnatifid with capillary segments, emersed oblong, pinnatifid, serrate or entire; silicle ovoid, little longer than the style.-Lakes and rivers, Can., N. Y. to Ky. Fls. not large ( $4^{\prime \prime}$ broad). Silicle $2^{\prime \prime}$ long, on long spreading pedicels, much as in No. 1. (Nasturtium lacustre Gray. N. natans $\beta$. Americanum ejusd. Cochlearia aquatica Eaton?)

21. VESICARIA, Lam. Bladder-Pod. (Lat. vesica, a bladder or blister; from the inflated silicles.) Petals entire; silicle globous or ovoid; inflated valves nerveless, hemispherical or convex; seeds several in each cell, sometimes margined $(0=)$. - Fls. yellow.

1 V. Shórtii Torr \& Gr. Lvs. elliptical, sessile, entire; style twice as long as the globous silicle; sds. 2-4, not margined.-(1) Banks of Elkhorn Creek, near Frankfort, Ky. (Short, in North Am. Flora.) St. decumbent, about a span long, slender, stellately pubescent. Lrs. 6-12" long. Pedicels $6^{\prime \prime}$ long, and the silicle as large as the fruit of Coriander.

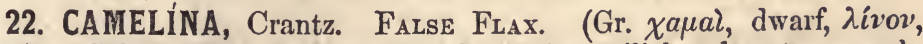
flax.) Calyx equal at base; petals entire; silicle obovate or subglobous, with ventricous valves and many-seeded cells; styles filiform, persistent; sceds obiong, striate, not margined $(0 \|)$.- Fls. small yellow.

C. sativa Crantz. Ivs. lanceolate, sagittate at base, subentire; silicle obovatepyriform, margined, tipped with the pointed style.- I In cultivated fields. St. $\frac{1}{2}-2 \frac{1}{2}$ high, straight, erect, branching. Lvs. roughish, $1-2^{\prime}$ long, clasping the stem with their acute, arrow-shaped lobes. Fls. in paniculated racemes. Silicles $3-4^{\prime \prime}$ long, on pedicels $2-3$ times as long. Said to be cultivated in Germany for the oil which is expressed from the seeds. Jn. § Eur. 
23. SUbULÀRIA, L. AwLwort. (Named in reference to the linear-subulate leaves.) Silicle oval, valves turgid, cells many-seeded; stigma sessile; cotyledons linear, curved and incumbently folded on themselves. - (i) Aquatic acaulescent herbs.

S. aquática L. A small plant, growing on the muddy shores of ponds in Me. and N. H. Lvs. all radica!, entire, subulate, an inch in length. Scape $2-3^{\prime}$ high, racemous, with a few minute white fls. on slender pedicels, only $2^{\prime \prime}$ in length. Jl.

24. IBERIS, L. CANDytuft. (Most of the species are natives of Iberia, now Spain.) The 2 outside petals larger than the 2 inner; silicles compressed, truncate, emarginate, the cells 1 -seeded.-Handsome herbs from the Old World, pretty in cultivation. Fls. white or purple.

1 I. umbellàta L. Herbaceous, smooth; lvs. linear-lanceolate, acuminate, lower ones serrate, upper ones entire; silicles umbellate, acutely 2 -lobed.-This and the following species are very popular garden annuals, very pretty in borders and of very easy culture. I. umbellata is from S. Lurope. St. If high. Fls. purple, terminal in simple umbels, and like the rest of the genus remarkable for having the 2 outer petals longer than the 2 inner ones. Jn., Jl. +

2 I. amàra L. BitTer CANDYTuFT. Herbaceous; lvs. lanceolate, acute, somewhat toothed; fls. corymbed, becoming racemed; silicles obcordate, narrowly emarginate. - (1) Native of England. St. If high. Fls. white. Jn., Jl. †

3 I. pinnàta I. Herbaceous, smooth; lvs. pinnatifid; rac. corymbous, but little elongated after flowering.-1D From S. Europe. Plant if high. Fls. white. Jn.-Aug. +

4 I. sax́tilis L. Shrubby ; lvs. linear, entire, somewhat fleshy, rather acute, smooth or ciliate; fls. in corymbs.-1) From S. Europs. Nearly if high. Fls. white. Apr.-Jn. $\dagger$ (Obs.-Twenty-four species of the Iberis have been described, others of which are less known, but equally ornamental with those above-mentioned.)

25. CAPSÉLLA, Vent. (Derived from capsa, a chest or box; alluding to the fruit.) Calyx equal at base; silicles triangular-cuneiform, obcordate, compressed laterally; valves carinate, not winged on the back; septum sublinear; style short; seeds $\infty$, oblong, small, $0 \| .-$ Fls. white. A common weed.

C. Bursa-pastòris Mænch. Snephend's Punse.-Found everywhere in fields and pastures, roadsides. St. $6-8-12^{\prime}$ high, nearly smooth in the upper part, hirsute below, striate, branching. Root lvs. rosulate, $2-5-8^{\prime}$ long, $\frac{1}{4}$ as wide, cut lobed, on margined petioles, segm. about 13. These leaves aro sometimes wanting (when the weed is crowded), or only dentate. Stem-lvs. much smaller, very narrow, with 2 small, acute auricles at base, half clasping the stem. Fls. snall, in racemes, which are finally $3-12$ ' long. Silicle smooth, triangular, emarginate at the end, and tipped with tho style. Apr.-Sept. § Eur.

26. Lepídium, R. Br. Pepper Grass. (Gr. $\lambda \dot{\varepsilon} \pi \iota \varsigma$, a scale; from the resemblance of the silicle.) Sepals ovate; petals ovate, entire; silicles oval-orbicular, emarginate; septum very narrow, contrary to the greater diameter; valves carinate, dehiscent; cells 1 -seeded. Cotyledons 0\|l (in No. 1, 0=). Fls. white, small, often incomplete.

* Stamens 2 only. Petals 4 , or wanting..................................Nos. 1, 2

* Stamens 6. Silicles winged........................................ Nos. 3,4

1 L. Virgínicum L. Wild Peppergrass. Tongue-Grass. Lvs. linear-lanceolate, incisely serrate, or the upper subentire petals 4; silicles orbicular, emarginate; cotyledons $0 \|$ - (1) In dry fields and roadsides, U. S. St. rigid, round, smooth, if 
high. Lvs. $1-2^{\prime}$ by $1-3^{\prime \prime}$, acute, tapering at base into a petiole, upper ones sessile, lower pinnatifidly cut. Fls. and silicles very numerous, in a panicle of racemes. Fls. very small, mostly diandrous; silicles $1 \frac{1}{3}{ }^{\prime \prime}$ diam., with a notch at

- the end. Taste pungent, like that of the garden peppergrass. Jn.-Oct.

2 I. ruderàle I. Cauline lvs., incised, those of the branches linear, entire; fls. apetalous, and with but two stamens; silicles broadly oval, emarginate, wingless. Dry fields, Mich., Ind., Mo. St. 10-15' high, diffusedly branched. Rac. many. Fls. remarkable for wanting tho petals, which are always present in our other species.

3 L. campéstre R. Br. YELLOW-SEed. Cauline lvs. sagittate, denticulate; silicles ovate, emarginate, scaly, punctato.- (1) In waste places and dry fields, especially among flax. St. strictly erect, round, minutely downy, 6-10' high, branching. Lvs. $1^{\prime}$ long, $\frac{1}{4}$ as wide, with two lobes at base, upper one clasping the stem, all minutely velvety. Fls. small. Silicles $1 \frac{1}{4} "$ long, numerous, in long racemes. Jn., Jl. § Eur.

4 I. satívum L. Peppergrass. Lvs. variously divided and cut; branches without spines; silicles broadly oval, winged.-(1) Native of the East. Sts. 1-3f high, very branching. Silicles 2-3" broad, very numerous. A well known garden salad. Jl. $\ddagger \S$

27. Senebièra, Poir. Carpet Cress. Swine Cress. (In honor of Sericbier, a distinguished vegetable physiologist.) Silicle didymous, with the partition very narrow; valves ventricous, separating but indehiseent, and each 1-seeded, cotyledons ineumbently folded on themselves.-(1) or (2) Prostrate and diffuse, with minute white fls.

1 S. dídyma Pers. Lvs. pinnate, with pinnatifid segments; silicles rugously reticulated, notched at the apex. - Waste places and waysides, soutliern States, common. Sts. spreading circularly like the carpet weed (Molugo), flat on the ground. Lrs. $1-3^{\prime}$ long, oblong in outline, its lobes obtuse, and cleft mostly on the upper margin. Fls. minute. Silicles very small, apparently doubled, rough-wrinkled. Feb.-Jn.

2 S. coronòpus DC. Lvs. pinnate, with the segm. entire, toothed, or pinnatifid; siticles tubercled, not notched at apex.-Waste grounds, Va. and Car. (Pursh), R. Isl. (Robbins). Not common. § Eur.

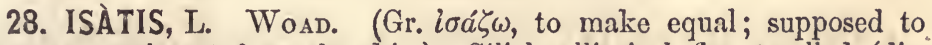
remove roughness from the skin.) Silicle elliptical, flat, 1-celled (dissepiment obliterated), 1-seeded, with carinate, boat-shaped valves, which are scarcely dehiscent $(0 \|)$. None of the species are N. American.

I. tinctòria $\mathrm{L}$. Silicles cuneate, acuminate at base, somewhat spatulate at the end, very obtuse, 3 times as long as broad.-(1) The Woad is native England. It is occasionally cultivated for the sake of its leaves, which yield a dye that may be substituted for Indigo. The plant grows about if high, with large leaves clasping the stem with their broad bases. Fls. yellow, large, in terminal racemes. May-Jl. $\ddagger$

29. CAKÌLE, Tourn. Sea Rocket. (Named from the Arabic.) Silicle 2-jointed, the upper part ovate or ensiform; seed in the upper cell erect, in the lower pendulous, sometimes abortive.-(1) Maritime herbs.

C. maritima Scop. Upper joint of the silicle ensiform or ovate-ensiform.-Native of the seacoast and lake shores, N. States. A smooth, succulent plant, branching and procumbent, 6-12' long. Lvs. sinuate-dentate, oblong-ensiform, caducous. Fls. on short, fleshy peduncles, in terminal spikes or racemes, corymbously arranged. Petals purple, obtuse at end. Silicle smooth, roundish, lower joint clavate-obovate, upper with one elevated line ou each side. Jl., Aug. 


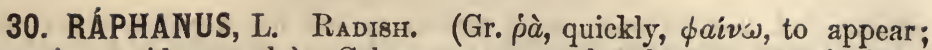
from its rapid growth.) Calyx erect; petals obovate, unguiculate; siliques terete, torulous, not opening by valves, transversely 2 -jointed, joints with one or several cells, seeds large, subglobous, in a single series $(0>>)$.

1 R. Raphanístrum L. WILD RADISIr. Ivs. lyrato; silique moniliform, 3-8-seeded, becoming in maturity 1-celled, longer than the style.-(1) Naturalized in cultivated fields and roadsides, but rare. St. glaucous, branching, 1-2f high, bristly. Lvs. rough, dentate, petiolate or sessile. Cal. bristly. Petals yellow, veiny, blanching as they decay. Jn., Jl. \& Eur.

2 R. sativa L. GARDEN RADISII. Lower lvs. lyrate, petiolate; silique 2-3-seeded, acuminate, scarcely longer than the style.-A well known salad root from China. St. 2-4f high, very branching. Lower lvs. $6-10^{\prime}$ long. Fls. white, or tinged with purple, veiny. Pods 1-2' long, thick and fleshy. The principal varieties are the Turnip Radish, root subglobous; Common Radish, root oblong, terete; Black Spanish Radish, root black outside. Jn.-Aug. $\ddagger$

\section{Order XIV. CAPParIDACE $\Subset$. Capparids.}

Herbs, shrubs, or even trees, destitute of true stipules. Leaves alternate, petiolate, either undivided or palmately compound. Fls. solitary or racemous, cruciform, hypogynous. Sep. 4, Pet. 4, unguiculate. Sta. 6-12, or some multiple of 4, never tetradynamous, on a disk or separated from the corolla by an internode of the torus. Ova. often stipitate, of 2 united carpels. Sty. united into onə. Stig. discoid. Fr. either pod-shaped and dehiscent, or fleshy and indehiscent. Placentoe usually 2. Seeds many, reniform. Albumen 0. Embryo curved. Cotyledon foliaceous. (Illust. in Fig. 290.)

Genera 28 , species 340 -chiefly tropical plants. They are more acrid in their properties than the Crucifers, lut otherwise much resemble them. One species of Polanisia is used as a verinifuge.

Stamens 6 , separated from the petals by an internode............................ 1

Stamens 6 , not separated from the petals...................................... 2

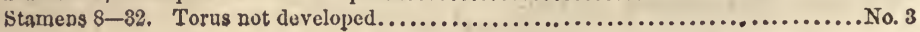

1. GYNANDRÓPSIS, DC. (Gynandria, a Linnæan class, ő $\psi \iota s$ appearance.) Sepals distinct, spreading; stamens 6, separated from the 4 petals by a slender internode of the torus; pod linear-oblong, raised on a long stipe which rises from the top of the torus.-(1) Lvs. digitate. Fls. racemed.

G. pentaphỳlla DC. Middle lrs. petiolate, 5-foliate, floral and lower ones 3-foliate, lfts. obovate, entire or denticulate. - In cultivated grounds, Penn. to $\mathrm{Ga}$. St. simple, 2-3f high. Fls, of a very singular structure. Pedicels about $1^{\prime}$ long, slender. Caly $x$ small. Potals white, $\frac{1}{3}$ as long as their filiform claws. Sta. $1^{\prime}$ long, spreading, apparently arising from the midst of the long styloid torus. Peds. 2' long. § Africa. (Cleome L.)

2. Cleome, L. Spider Flower. Sepals sometimes united at base; petals 4 ; torus not developed between the petals and the stamens, which are $6-4$; pod stipitate more or less.-Herbs or shrubs. Lvs. simple or digitate. Fls. racemed or solitary.

1 C. pungens L. Fig. 290. Glandular pubescent; st. simple, and with the petioles aculeate; lvs. 5-9-foliate, on long petioles, lifts. elliptic-lanceolate, acute at each end, obscurely denticulate; bracts simple; fls. racemed; sep. distinct; pet. on filiform claws; sta. 6 , twice longer than the petals.-2 A tall, showy 
plant, with curious purple flowers, common in gardens, escaped into fields, \&c. South. May-Aug.t § W. Ind.

2 C. speciocíssima Deppe. Pilous; st. branching below, lvs. 5-7-foliate, on long petioles; lfts. lanceolate, acuminate, the upper lvs. simple, bract-like, ovate; petals as long as the pedicels; fruit shorter than its stipe.-(1) Gardens. Plant very showy, 3-4f high. Fls. rose-purple, clustered at the summit of the rising raceme from $\mathrm{Jn}$. to Sept. $\nmid$ Mexico.

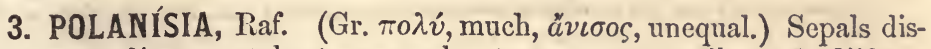
tinct, spreading; petals 4 , unequal ; stamens $8-32$, filaments filiform or dilated at the summit; torus not developed, minute; pods linear.(1) Strong-scented herbs, with glandular, viscid hairs.

P. gravèolens Raf. .Viscid-pubescent; lvs. ternate, lfts. elliptic-oblong; fls. axillary, solitary ; sta. 8-12 ; caps. oblong-lanceolate, attenuate at base.-Gravelly shores, Vt. to Ark. St. If high, branching, striate. Lfts. $1-1 \frac{1}{2}^{\prime}$ long, $\frac{1}{3}$ as wide, nearly entire and sessile; common petiole $1^{\prime}$ long. Fls. in terminal racemes. Petals yellowish-white, narrowed below into long claws. Fil. slender, exserted. Pods $2^{\prime}$ long, glandular-pubescent, siliquose, viscid like every other part of the plant. Jl.

\section{Order XV. RESEDACEZ. Mignonetres.}

Herbs, with alternate, entire, or pinnate leaves. Stipules minute, gland-like. F'ls. in racemes or spikes, small and often fragrant, 4-7-merous. Sepals somewhat united at base, unequal, green. Petals unẹqual, entire or cleft. Sta. 8-20, inserted on the disk. Torus hypogynous, one-sided, glandular. Ova. sessile, 3-lobed, 1-celled, many-seeded. Placentre 2, parietal. Fr. a capsule, 1-celled, opening bo. tween the stigmas before maturity. (Illustrated in Figs. 295, 422.)

Genera 6, species 41, inhabiting the countries aronnd the Mediterranean Sea, having no rery remarkable properties. Reseda luteola contains a yellow coloring matter, and uther species aro very fragrant.

RESEDA, L. (Lat. resedo, to calm; the plants are said to relieve pain.) Sepals $4-7$; petals of an equal number, often cleft; torus large, fleshy, one-sided, bearing the $8-\infty$ stamens.

1 R. Iutèola L. DYeR's WeED. Lvs. lanceolate, with a tooth on each side at base; sepals 4, united below; petals (greenish-yellow) 3-5-cleft.-(1) Nearly naturalized in West. N. Y. St. about $2 \mathrm{f}$ high. The flowers are arranged in a long spike, which, as Linnæus observes, follows the course of the sun, inclining east, south and west, hy day, and north by night.-It affords a useful yellow dye, also, the paint called Dutch pink. § Eur.

2 R. odoràta L. Mignonetre. Fig. 295, 422. Lvs. cuneiform, entiro or 3-lobed; sep. shorter than the 7-13-cleft petals.-A well known and universal favorite of the garden; native of Egypt. The flowers are highly fragrant and no bouquet should be considered complete without them. The variety FruTESCENs is by a peculiar training ( $\$ 87)$ made perennial and raised to the height of $2 \mathrm{f}$, with the form of a tree. The species phyteuma, nativo of Palestine, has a calyx larger than the petals.

\section{Order XVI. VIOLACEA. Violets.}

Herbs with simple (often cleft) alternato leaves with stipules. Fis. irregular, spurred, with the sepals, petals and stamens in $5 \mathrm{~s}$. Sep. persistent, slightly united, elongated at base, the 2 lateral interior. Petals commonly unequal, the inferior usually spurred at base. Sta. 5, usually inserted on the hypogynous disk. Fil. dilated, prolonged beyond the anthers. Ova. of 3 united carpels, with 3 parietal 
placenta. Style 1, declinate. Stig. cucullate. Fr. a 3-valved capsule. Sds. many, with a crustaceous testa and distinct chalaza. (Illustrations in Figs. 101, 305, 348, 402, 604.)

Genera 15, species 300, mostly inhabitants of the Northern temperate zone. The roots of almost all the Violacex possess emetic properties, and soine are valued in medieine. The Ipecac of the shop is partly the product of certain Brazilian species of Ionidium. Several species of the violet are cultivated for the beauty of their flowers.

\$ Sepals unequal, more or less auricled at base......................... Vroua. 1.

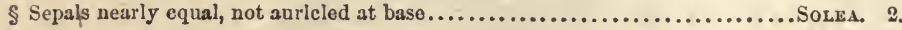

1. Viola, L. Vrolet. Panser. (From the Latin.) Sepals 5, unequal, auricular at base; petals 5 , irregular, the broadest spurred at base, the 2 lateral equal, opposite; stamens approximate, anthers connate, two of them with appendages at the back; capsule 1-celled, 3-valved, seeds attached to the middle of the valves.- 4 Low, herbaccous plants. Ped. angular, solitary, 1-flowered, recurved at the summit so as to bear the flowers in a resupinate position. Joints of the rhizome often bearing apetalous flowers.

* Acaulescent. - Petals yellow................................................. No. 1.

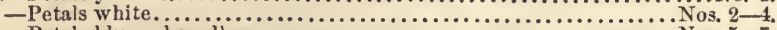

-Petals blue, - beardless...................................... Nos. $5-7$. - bearded.-Lvs. divided..................................... 8, $93,9 \gamma$ -Lvs. undivided.......................... (Exotic No. 21.)

* Caulescent.-Petals yellow. Sts. leafy at the top only....................... Nos. 12-14.

-Petals not quito yellow. - Stipules entire.......................... Nos. 15. -Stipules fringe-toothed.................. Nos. 16-18. - Stipules lyratc-pinnatifid, very large.... Nos. 19, 26.

1 V. rotundifòlia Mx. Fig. 305. Lvs. orbicular-ovate, cordate, slightly serrate, nearly smootl, with the sinus closed; petiole pubescent; cal. obtuse.-A small, early violet, found in woods, N. Eng. to Tenn. Lvs. varying from ovate to reniform, mostly round, with a narrow sinus at base. Veins and petioles pubescent. Ped. as long as the leaves, sub-4-sided, bracted in tho middle. Petals yellow, marked at base with brown lines. Fls. small. Mar., May.

2 V. lanceolàta I. Lvs. smooth, lanceolate, tapering at base into the long petiole obtusish, subcrenate.-Found in wet meadows, Can. and U. S. Rhizome creeping. Ivs. varying from lanceolate to linear, and, with tho stalk $3-5^{\prime}$ long. Petioles half-round. Ped. sub-4-sided. Petals white, greenish at base, upper and lateral ones marked with blue lines, generally beardless. Fls. small, those from the lower nodes of the rhizomo apetalous. Mar. (S)-May.

3 V. primulafòlia L. Lvs. lance-ovate, abruptly contracted at base and decurrent on the petiole; petals nearly equal, beardless.-Found in damp soils, Mass. to Ga. and Tenn. Rhizome creeping. Lrs. sometimes subcordate, rather obtuse, crenate, pubescent or nearly smooth. Pelals obovate, flat, marked with purple lines at base, generally beardless and obtuse. Fls. small, white, on sub-4-sided stalks. May, in N. ling.

3. ACUTA Torr. \& Gr.-Smooth; lvs. ovate; petals acute, lateral ones nearly beardless. Mass. (V. acuta $\mathrm{Br}$.)

4 V. blánda Willd. Lvs. cordate, roundish, slightly pubescent; petiolo pubescent; petals beardless. - Found in meadows, Can. to Penn. Rhizome slender and creeping. Lvs. close to the earth and sometimes with a rounded sinus so as to appear reniform. Petioles half round. Peduncles sub-4-sided, longer than the leaves. Petals white, greenish at base, upper and lateral ones marked with a few blue lines. Fls. small, fragrant. May (V. clandestina Ph. V. amœna Le Conte).

5 V. palústris L. Lvs. reniform-cordate; stip. broadly ovate, acuminate; stig. margined; sep. ovate, obtuse, spur very short; caps. oblong-triangular.-Summits of the White Mts. About $3^{\prime}$ high, pubescent. Lvs. crenate, $I^{\prime}$ by $\frac{8^{\prime}}{4}$. Fls. small, pale blue on peduncles longer than the leaves and bibracteate near the middle. Rhizome creeping, scaly. Jn.

6 T. Selkírkii Goldie. SELKIRK's VIOLET. Lvs. orbicular-cordate, crenately serrate, the sinus deep and nearly closed; spur nearly as long as the petals, thick 
very obtuse.-Grows on woody hills and mountains, Mass., N. Y., Can., rare. A small, stemless violet 2 ' high, with small, pale blue fls. conspicuously spurred. Lvs. rather uumerous and longer than the peduncles. Petals beardless, the upper one striate with deep blue. May.

7 V. pedàta L. Rt. premorse; lvs. pedately 5-9-parted, segments linear-lanceolate, entire; stig. large, obtusely truncate, scarcely beaked; spur short, obtuse.A smooth, beautiful, large-flowered violet, in hilly woods, Can. to Ill. and Fla. Rhizomo fleshy, ending abruptly as if cut or bitten off. Lvs. thick, 2-ternately divided into about 7 obtuse, narrow segments. Petioles with long, ciliate stipules at base. Ped. sub-4-angled, much longer than tho leaves. Petals pale blue, white at base, all of them beardless and entire. Apr., May.

$\beta$. The two upper petals deep violet colored, the others light-blue with much yellow at their bases, as in tho garden pansey. Plants smaller, with large flowers.-In Mt. Hope Cemetery, Macon, Ga.

8 V. delphinifòlia Nutt. Lvs. pedately 7-9-parted, with linear, 2-3-cleft segments all similar; stig. thick, distinctly beaked.-Prairies and bottoms, Ill., Iowa, Mo. Lvs. often finely divided with many dissected segments, pubescent along the edge, prominently veined beneath. Stip. acuminate, subentire. Ped. a little longer than the leaves. Fls. rather smaller than in the last, of a rich blue; lateral petals bearded. Mar., Apr.

9 V. cucullàta Ait. Lvs. reniform-cordate, cucullate at base, acute, crenate; stip. linear; inferior and lateral petals bearded.This is one of the more common kinds of violet, found in low, grassy woods from Arctic Am. to Fla. Lvs. on long petioles, usually rolled at base into a hooded form. Fls. light blue or purple, with scapes somewhat 4-sided, longer than the leaves. Petals twisted, white at the base, marked with lines of deeper blue. Apr., May. This species varies from pubescent to glabrous, from lvs. reniform to ovate, deltoid, or lastate; from fls. deep blue to light-blue or even white, and as is now generally conceded, to the following remarkable forms:-

$\beta$. Palinata. Lvs. (cordate) all or some of them very irregularly liastate-lobed, the middle lobe largest, the earlier lvs. commonly undivided and broadly cor. date. Fls. large. Plant $4-12^{\prime}$ high. (V. palmata L.)-Common at the South.

$\gamma$. SEPtemloba. Lvs. (concave at base) more deeply 5-7-lobed, the middle lobe largest, oblanceolate, all rather succulent and strongly veined beneath; fls. very large. (V. septemloba Lo Conte.)-Low, pine woods, Ga. (Pond). Plant $5-12^{\prime}$ high. A remarkable form truly, but evidently varying into $\beta$. $\Lambda \mathrm{pr}$.

10 V. villòsa Walt. Lvs. roundish-ovate, cordate, obtuse, flat, pubescent, cbscurely crenate, sinus narrow or closed; pet. bearded; stig. beaked.-Sandy woods, middle Ga., common N. to Penn. Plant $2-3^{\prime}$ high. Lvs. spreadiug, scarcely $1^{\prime}$ long, the petioles longer $\left(1-2^{\prime}\right)$. Fls. small, bluish purple, on stalks shorter than the leaves. Mar., Apr.

11 V. sagittàta Ait. Lvs. oblong-lanceolate, sagittate-cordate, subacute, often incisely dentate at base, serrate-crenate, smooth or slightly pubescent; pedicel longer than the leaves; lower and lateral pet. densely bearded. - On dry lills, Can. to Fla., W. to Ark. Lvs. varying from oblong-sagittato to triangular-hastate, on margined petioles. Scapes 3 to $5^{\prime}$ long. Sep. lanceolate, acute. Pet. entire, veiny, purplish blue, white at base. Stig. rostrate, margined. A pr.-Jn.

$\beta$. ovata. Lvs. ovate, abrupt at base and decurrent on tho petioles, pubescent, the upper often incisely dentate at base. (V. ovata Nutt.)-N. J., southward.

12 V. hastàta Mx. Smooth; st. simple, erect, leafy above; lvs. deltoid-lanceolate or hastate, acute, dentato; stip. ovate, minute, ciliate-dentato; lower pet. dilated, obscurely 3-lobed, lateral ones slightly bearded; sep. lanceolate, with a very short spur.-Pine woods, Tenn. to Fla. St. slender, $6-10^{\prime}$ high. Fls. yellow, on stalks shorter than the leaves. Apr., May.

13 V. tripártita Ell. Hairy. St. simple, erect, leafy above; lvs. deepiy 3-parted, lobes lanceolate, dentate; stip. lanceolate.-Upper Ga. Plant about if high, vil- 
lous when young. Lvs. often divided to the base. Fls. yellow, streaked with purple, the stalks longer than the leaves. Mar., Apr.

14 V. pubéscens Ait. Villous-pubescent; st. erect, naked below; lvs. broadr cordate, toothed; stip. ovate, large, subdentate.-A large jellow violet, found in dry stony woods, Can. to Ga. and Mo. St. simple, somewhat triangular and fleshy, bearing a few leaves at the top. Lvs. broad-ovate, cordate or deltoid, obscurely dentate, obtuse, on short stalks. Fl.stalks rather shorter than leaves, with 2 subulate bracts. Lateral petals bearded, and with the upper ono marked with a few brown lines. The plant varies in pubescence, sometimes even glabrous. Height very variable, $5-20^{\prime}$. May-Jn.

B. EIrocarPA Nutt. Capsule densely villous. (V. eriocarpa Schw.)

$\gamma$. scabriescela Torr. \& Gr. St. decumbent, branching from tho root, and with the smaller leaves somewhat scabrous. (V. scabriuscula Schw.)

15 V. Canadénsis L. Smooth; Ivs. cordate, acuminate, serrate; ped. shorter than the leaves; stip. short, entire.-A large species, found in the woods, British Am. to Car., often a foot in hight. Stem subsimple, terete, all the way leafy, with lance-ovate, membranous stipules. Lvs. acuto or obtuse, the lower on very long petioles. Ped. sub-4-sided, with minute bracts. Fls. large, nearly regular. Pet. white or light blue, yellowish at base, the upper ones purplish outsido and marked with bluo lines inside, lateral ones bearded. Flowering all summer.

16 V. striàta Ait. Smooth; st. branching, nearly erect; Ivs. roundish-ovate, cordate, the upper ones somewhat acuminate, crenate-serrate; stip. large, ciliatedentate, oblong-lanccolate; spur one fourth as long as the corolla.-Wet grounds, U. S. and Can. St. $6-12^{\prime}$ high, half round. Ivs. $1-1 \frac{1}{2}^{\prime}$ wide, on petioles 1-2' long. Stip. conspicuous, laciniate. Ped. axillary, often much longer than the leaves. Cor. large, yellowish-white or ochroleucous, lateral petals densely bearded, lower one striate with dark purple. Stig. tubular. Jn.

17 V. Muhlenbérgii Torr. St. weak, assurgent; lvs. reniform-cordate, upper ones rather acuminate; stip. lanceolate, somewhat fimbriate; spur half as long as the corolla, obtuse.-A spreading, slender species, in swamps, \&c., U. S., N. to Lab. Sts. branched below, $6-8^{\prime}$ long, with stipules usually cut into fringe-liko serratures. Lvs. 6-10" diam., younger ones involute at base. Petioles longer than the leaves, and shorter than the axillary peduncles. Bracts subulate, mostly opposite, on the upper part of the stalk. Petals entire, palo purple, the lateral ones bearded. Stig. rostratc. May.

18 V. rostràta I. Smooth; st. terete, diffuse, erect; lvs. cordate, roundish, serrate, upper ones acuto; stip. lanceolate, decply fringed; petals bearded; spur longer than the corolla.-A common violet in moist woods, Can. to $\mathrm{Ky}$., well characterized by its long, straight, linear, obtuso nectary, which renders the largo flowers similar to thoso of tho larkspur. St. 6-8' high, branching below. Petioles much longer than the leaves. Stip. almost pinnatifid. Ped. slender, very long, axillary. Fls. pale bluc. May.

19 V. trícolor L. Pansy, Heartsease. St. angular, diffusely branched; Ivs. oblong-ovate, lower ones ovate-cordate, deeply crenato; stip. as large as the leaves; spur short, thick.-Gảrdens, where its pretty flowers are earliest in spring and latest in autumn. Fls. variablo in size, often $1^{\prime}$ broad, tho 2 upper (lower) petals purple, the two lateral white and with the lower striate, all yellow at base.

$\beta$. ARVENSIS DC. Annual. Moro slender and less branched; upper lvs. ovatospatulate; petals scarcely twice longer than the calyx, yellowish blue, spotted with purple. (V.arvensis Ell.) - This is, doubtless, a mere variety cscaped from gardens, in rocky hills, N. Y. to Ga. Not common. Sts. $3-6-10^{\prime}$ long. May.

20 V. granđiflòra L. St. 3-cornered, simple, procumbent; lvs. ovate-oblong, crenate, shorter than tho peduncles; stip. much smaller than the leaves; fls. large.Native of Switzerland. A beautiful species, with very large flowers (1-2' diam.); all the petals alike are deep purple. Whole plant smooth, $6-12^{\prime}$ long. Stip. $\frac{1}{2}-l^{\prime}$ long. Flowering all seasons but winter. $\dagger$

21 V. odoràta L. SweET, or ENGLish VIOLET. Stolons creeping; lvs. cordate, crenate, nearly smooth; sep. obtuse; lateral petals with a hairy line.-Nativo 
of England. It is well characterized by its long, trailing, leafy runners. The lvs. are truly heart-shaped. Stip. lanceolate, toothed. Ped. longer than the leaves, bracted. Fls. small, fragrant. Several garden varieties are known, and distinguished by the form and color of the flowers; viz:- tho purple, white and blueflowered, the double white, double purplo and double blue-flowered, and the Neapolitan with palo bluo flowers. Apr., May.t

2. SÒleA, Gingins. Green Vrolet. (Dedicated to W. Sole, an English writer on plants.) Sepals nearly equal, not auriculate; petals unequal, the lowest 2 -lobed and gibbous at base, the rest emarginate; stamens cohering, the lowest 2 bearing a gland above the middle; capsule surrounded at base by the concave torus; sceds $6-8$, very large. - If An crect, leafy plant, with inconspicuous axillary flowers.

S. cóncolor Gingins. Green Violet. Woods, Western N. Y. to Mo., and S. to Car. Stem 1-2f high, simple, and, with the leaves, somewhat hairy. Lrs. $4-6^{\prime}$ by $11-21^{\prime}$, lanceolate, acuminate, subentire, tapering to short petioles. Ped. very short, 1 -5-flowered, axillary. Fls. small, greenish, whito. Cal. about as long as the corolla. Lower petal twice larger than the others. Capsulo near $I^{\prime}$ in length. Apr., May.

\section{Order XVII. CISTACE E. Rock Roses.}

Herbs or low shrubs with simple, entire, opposito (at least the lower) leaves, with fls. perfect, regular, hypogynous, in one-sided racemes, very fugacious. Sep. 5, unequal, persistent. Petals 5 (sometimes 3 or wanting) convolute in æstivation. Sta. mostly $\infty$. Caps. 1-celled, 3-5-valved, with as many parietal placentw. Seeds albuminous. Embryo curved or spiral. (Illust. in Fig. 404.)

Genera 7 , species 185, most abundant in S. Europe and N. Africa.

GENERA.

G Petals 8 , linenr-lanceolate, small.............................. 1

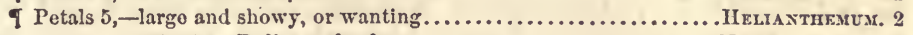

-minute. Delicate shrubs..................... Iiudsoris. 3

1. LECHÈA, L. Prwweed. (In memory of John Lcche, a Swedish botanist.) Sepals, 5 , the 2 outer minute; petals 3 , lanceolate, small; stamens 3 to 12 ; stigmas 3 , scarcely distinct; capsule 3 -celled, 3-ralved; placenta nearly as broad as the valves, roundish, each $1-2$-seeded.2f Often shrubby at base, with numerous very small brownish purple flowers.

1 I. màjor Mx. Hairy; lvs. elliptical, mucronulate; fls. minute, about as long as the pedicels.-In dry woods, U. S. and Can. St. 1-2f high, rigid, brittlo hairy, purple, somewhat corymbously branched. Lvs. of the stem about 4" long, alternate, opposite, or even rerticillate on the prostrate branehes, crowded. Fls. brownish-purple, inconspicuous among the numerous bracts. Caps. roundish, about the size of a small pin-head. Variable. Jl., Aug.

12 L. mìnor Lam. Smoothish; lvs. linear, very acute; fls. small, on pedicel which are mostly twice longer.-Grows in dry, sandy grounds, U. S. and Can. Sts. 8-16' high, slender, red, paniculately branched, often decumbent at base. Stem lvs. $6-10^{\prime \prime}$ by $1^{\prime \prime}$, alternate, revolute at the margin, those of the divergent, filiform branches gradually minute. Fls. twice as largo as in L. major. Petals brownish-purple, cohering at apex. Caps. the size of a large pin-head. Jn.-Sept.

3 I. thymifòlia Ph. Shrubby, hoary with appressed hairs; lvs. linear and linearoblanceolate, rather acute, often verticillate; Hls. small, on pedicels still shorter.Seacoasts, Mass to N. J. Sts. about if high, many from the same caudex, rigid and very bushy. Lvs. 6-1 $0^{\prime \prime}$ long, ereet, erowded. Fls. in terminal, denso cymules, on very short pedicels. Petals brown. Caps. globors. J1.-Sept. 


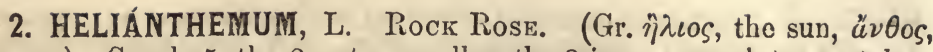
flower.) Sepals 5, the 2 outer, smaller, the 3 inner convolute; petals 5 , or rarely 3 , convolute contrary to the sepals, sometimes abortive; stamens $\infty$; stigmas 3 , searcely distinct ; capsule triangular, 3 -valved, opening at top; seeds angular.-Fls. yellow often of 2 kinds, the later being smaller and apetalous.

1 H. Canadénse Mx. Frost Plant. Hoary pubescent; petaliferous fls. solitary, pedicellate, terminal, apetalous ones axillary, small, clustered, subsessile; cal. acute; Ivs. revolute on the margin, lanceolate, aeute.-In dry fields and woods, Can. to Flor. St. 8-12' high, at length shrubby at baso. Lvs. 8-12" long, $\frac{1}{4}$ as wide, entire, subsessile. Primary fls. with largo bright yellow petals. The axillary fls. later, very small, with very small pet:ls, or apetalous. Sta. declinate. Caps. smooth, shining, those of tho apetalous fls. not larger than a pin's head. Sds. few, brown. May-Sept.

B. оBтUSA. Hoary tomentous; lvs. oblong, obtuse; fls. (all petaliferous?) smaller ( $7^{\prime \prime}$ broad), several, terminal.—Niddlo Flor. St. 3-6' high. Lvs. about $9^{\prime \prime}$ by $2 \%$. Apr. It may provo distinct.

$2 \mathrm{H}$. corymbòsum Mx. Canescently tomentous; fls. in crowded, fastigiate cymcs, the primary ones on elongated, filiform pedicels, and with petals twice longer than the calyx; sep. villous canescent, obtuse; lvs. oblong-lanceolate, margins revolute.Sterile sands, N. J., to Fla. Plant somewhat shrubby, very tomentous when young, at length diffusely branched, about if high. Primary fls. 7 or $8^{\prime \prime}$ diam.; secondary ones apetalous, subsessile. Jn.-Aug. (Heteromeris eymosa Spach.)

3 H. Caroliniànum $\mathrm{N} \mathrm{x}$. Villous, simple, erect; fls. all large, petaliferous and subterminal; sepals acuminate; lvs. oblong-oval, edges denticulate, not revolute.Dry woods, S. Car. to Fla. and La., common. St. rarely branched from the base, brownish, $8-12^{\prime}$ high. Ivs. distinctly petioled, $1-2 \frac{1}{2}$ long, $\frac{1}{8}$ as wide, obtuse or acute, black-dotted beneath. Fls. 1 to 4 , moro than $1^{\prime}$ broad, tho pedicels supra-axillary. Apro, May.

\section{HUDSÒNIA, L. (In honor of William IIudson, author of Flora} $\Lambda$ nglica.) Sepals 3 , united at base, subtended by 2 minute ones outside ; petals 5 ; stamens $9-30$; style filiform, straight ; capsule, 1-celled, 3 -valved, many-seeded.-Low shrubs with very numcrous branches, and minute, cxstipulate leaves.

I H. tomentc̀sa Nutt. Hoary-tomentous; lvs. ovate, appressed-imbricate, acute; fls. subsessile; sep. obtuse. - Shores of the ocean and lakes, Mie. to N. J. and Wis. Plant consisting of numerous slender, ascending stems from the same root, and a multitude of tufted branches, all covered with whitish down. Lvs. less than $1^{\prime \prime}$ in length, closely appressed to the stem. Fls. about $2^{\prime \prime}$ broad, yellow, numerous. May.

2 II. ericoìdes L. Moary-pubescent; lvs. subulate, a littlo spreading; pedicels exserted, as long as the calyx; sep. acutish. $-\mathrm{A}$ very delicate shrub. L. Champlain, Vt., Conway Pond, N. H. to Va., along the coasts. St. $\frac{1}{2} \mathrm{f}$ high, erect, with numerous, short, compound, procumbent branches. Lvs. not more than $\mathbf{l}^{\prime}$ long. Fils. yellow, about $3^{\prime \prime}$ broad. Caps. oblong, pubescent. May.

3 H. montàna Nutt. Minutely pubescent; lvs. fliform-subulate; pedicels longer than the flowers; sep. acuminate, the outer ones longer, subulate.- High Mits. of N. Car. Sts. decumbent, $3-5^{\prime}$ high. Lvs. partly imbricated, $2^{\prime \prime}$ long. Fls. about $5^{\prime \prime}$ broad, the pedicels when in fruit $I^{\prime}$ long. Caps, about 3 -seeded.

\section{Order XVIII. HYPERICACEA. St. JoHn's worts.}

Herbs or shrubs with opposite, entire, dotted, exstipulate leaves, with flowers perfeet, regular, liypogynous, 4 or 5-merous, cymous and mostly yellow; sepals unequal, 
persistent; petals mostly oblique or convolute in the bud; stamens fow or many, polyadelphous; anthers versatile; ovary compound, with styles united or separate, becoming in fruit a 1-celled capsule with parietal placentæ, or 3 to 5-celled when the dissepiments reach the center. Seeds exalbuminous, minute. (Illustrations in Fig. 69, 278, 389, 390.)

Genera 15 , species 276 , very generally distributed, presenting a great rarlety of habit, and flouristing in all kinds of localities. The juice of many species is considered purgative and febrifugal.

GENERA.

Sepals 4. Petals 4, obliqne, yellow.......................................... 1

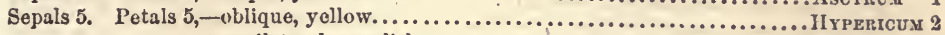
-equilateral, purplisl...................................... 3

1. ASCYRUM, L. St. Peter's Wort. (Etymology uncertain.) Sepals 4 , the two outer usually very large and foliaceous; petals 4 , oblique, convolute; filaments slightly united at base into several parcels; styles 2-4, mostly distinct; capsule 1-celled.-Plants suffruticous. Lvs. punctate with black dots. Fls. pale yellow 1 or 3 terminating cach branch. Pedicels bibracteolate.

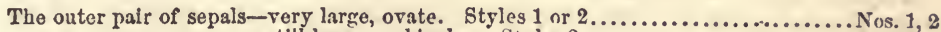

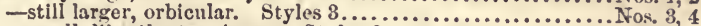

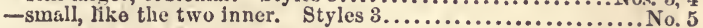

1 A. Cruz-Andreæ L. St. ANDrew's Cross. Branches many, suberect, ancipital above; lvs. linear-oblong, obtuse; outer sep. twice longer than the pedicel; 2 bracteoles a little below the flower. - Sandy woods, N. J. to Ga. and La. Sts. 1 to 2f high, with brown, scaly bark below. Lvs. 6 to $12^{\prime \prime}$ long, minutely dottod, sessile, smaller ones axillary. Cymes leafy. The persistent, ovato sepals closo after flowering. Jn., Jl.

$\beta$ ANGUSTIFòlia Nutt. Lvs. oblong-linear, crowded; outer sepals acute, the two bracteoles close to the flower.-Car. and Ga. (Feay.) Looks very different from $a$, from the smallness of its numerous lvs., which are 3 to $6^{\prime \prime}$ long, $1^{\prime}$ wide.

2 A. púmilum $\mathrm{Mx}$. Low, traiting at base; lvs. oval and obovate, obtuse, sessile; outer sepals shorter than the slender pedicel, inner sepal 0 ; bracteoles 0 .-Ga. and Fla., in dry, piny barrens. Much branched, branches a few inches long. Lrs. about $3^{\prime \prime}$ by 2 , $^{\prime \prime}$ often smaller. Cymes exserted, the pedicels 6 to $10^{\prime \prime}$ long. Pet. rather larger than the sepals.

3 A. stáns $\mathrm{Mx}$. St. crect, ancipital; lvs. oblong, sessile, and half-clasping, obtuso; caps...ovate, acute.-Swamps in pine barreus, N. J. to Fla. and La. Sts. 1 to $3 \mathrm{f}$ high, straight, winged throughout, branched above, usually simplo at baso and shaggy with loose bark. Lvs. 10 to $15^{\prime \prime}$ long, $\frac{1}{3}$ as wide. Outer sepals orbicular, subcordate, $6^{\prime \prime}$ diam., inner lance-linear. Petals uncqual, ovate, acute, a littlo longer than the sepals. Sty. 3, distinct, short. Jn.-Aug.

4 A. amplexicaùle Mx. St. erect, tereto below; lis. broadly ovate, cordate, clasping; caps, oblong.-Ga. and Fla. Sts. 1 to $2 \mathrm{f}$ high, dichotonously branched above, branches somowhat 2 -edged. Lvs. 8 to $12^{\prime \prime}$ long, $\frac{2}{3}$ as broad. Outcr sepals nearly round, $5^{\prime \prime}$ broad, the petals $\frac{1}{3}$ longer.

5 A. microsépalum Torr. and Gr. Bushy; st. scarcely edged; Ivs. oblong and oblong-linear, crowded; sep. oblong-linear, much shorter than the obovate, uriequal petals; sty. 3, long, distinct.-Ga. and Fla. Very different in aspect from the others, with crooked, straggling stems. Lvs. 2 to $4^{\prime \prime}$ long, $1^{\prime \prime}$ wide (in a variety twice as large). Pedicels longer than tho calyx. Fls. $9^{\prime \prime}$ broad. Sty. filiform, as long as the oblong capsule. May.

2. HYPÉRICUM, L. ST. Jons's-wort. (Derivation unknown.) Sepals 5 , connected at base, subequal, leaf-like; petals 5 , oblique; stamens $\infty$ (sometimes few), mostly united at base into $3-5$ parcels, 
with no glands between them; styles $3-5$, distinct or united at base, persistent.-Herbaceous or shrubby plants. Lvs. punctate with pellucid dots, opposite, entire. Fls. solitary, or in cymous panicles, yellow.

Stamens $25-100$, more or less united into sets (a).

Stamens 5-15, not at all united (d).

a Carpels (and styles) 5 or more. Capsule 5 -celled............................. 1, 2

a Carpels 3. Capsule 3-celled (the placentre meeting (b).

a Carpels 8. Capsule 1-celled (the placentre not quite meeting (c).

b Shrubby. Petals not lotted. Leaves lanceolate or oblanceolate..........Nns. 8-5

b Shrubby. Petals not dutted. Leaves linear....................... Nos, 6, 7

b Herbaceous. Petals sprinkled wlth black dots............................. 8 . 10

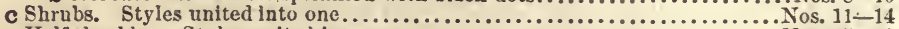

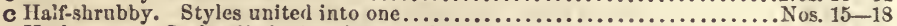

c Herbaccous. Styles distinct, at least at the top............................... 19-22

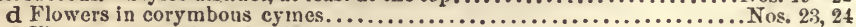

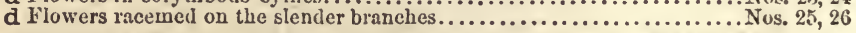

1 H. pyramidàtum Ait. Herbaceous; lvs. sessile, oblong-ovate, acute; sty. 5 ; placentre retroflexed in the cells of the capsule. $-2 f$ Hills and river banks. Ohio and Penn. to Can. St. 3-5f ligh, scarcely angular, smooth, rigid. Branches corymbous, erect, 4-angled. Lvs. of the stem $2 \frac{1}{2}-5^{\prime}$ long, $\frac{1}{3}$ as wide, of tho branches about half these dimensions. Fls. very. large ( $1_{\frac{1}{2}}^{\prime}$ broad) Petals obovate. Sta. capillary, 100 or more. Caps. I' long, ovoid-conical, tipped with the 5 styles. Sds. $\infty$. J1., Aug.

2 H. Kalmiànum L. Shrubby; lvs. linear-lanceolate, very numerous, obtuse; caps. 5-celled, tipped with the 5 styles.-Rocks below Niagara Falls, etc. A handsome species, a foot or more in hight. Lvs. an inch in length, slightly rerolute on the margin, 1-veined, minutely and thickly punctate, sessile. Branches slender and delicate, somewhat 4-angled. Fls. 9" diam. Sta. very many. Aug.

3 H. Buclilèyi Curtis. Low, diffusely branched from tho shrubby base, lvs. wedge-oblong or obovate, subsessile, smooth, very obtuse; fls. terminal, solitary, peduncled; sep. unequal, leafy, obtuse, and with the $\infty$ stam. shorter than tho petals; caps. 3-celled, styles united.-High. Mts. of N. Car. to Ga. Stems 8-12' high. Lvs. 6 or 7 " by 3 or $4^{\prime \prime}$. Resembles Ascyrum Crux-Andreæ.

4 H. prolíficum L. Branching; branches ancipilal, smooth; lvs. oblong-lanceolate, obtuse, narrowed at base, crenulately waved at edge; cymes compound, leafy; sep. unequal, leafy, ovate, cuspidato; petals obovate, a little larger than sepals. - A highly ornamental slirub, $2-4 \mathrm{f}$ high, prairics and ereek shores, Mid. and W. States. Lvs. $2-22^{\prime}$ long, $4-6^{\prime \prime}$ wide. Fls. $9^{\prime \prime}$ diam., orange-yellow in an èlongated inflorescence. Sta. $\infty$. Jl., Ang. $t$.

$\beta$. DEssiflonuM T. and G. Branches very numerous; 1rs. crowded, much smaller (less than $1^{\prime}$ long); fls. very numerous, in compound cymes, and much smaller (about $6^{\prime \prime}$ diam.) -E. Tenn. to Fla. (H. densiflorum Ph.)

5 H. galioìdes Lam. Branches few, terete; lvs. linear-lanceolate, rather obtuso; cymules numerous, axillary and termiral, paniculate; sep. subequal, linear-lanceolate.-S. Car. to Fla. in damp soil. St. 2 to $3 \mathrm{f}$ high, with straight, erect branches and a smooth bark. Ivs. fascicled in the axils as if whorled, 10 to $15^{\prime \prime}$ by 2 to $3^{\prime \prime}$, dotted with large, pellucid glands. Fls. about $7^{\prime \prime}$ diam. Jn., Aug.

6 H. rosmarinifolium Lam. St straight, erect, sparingly branched; lvs. lincar, shorter than the internodes, narrowed at base to a petiole; cymules dense, fewflowered, panicled.-Ky. to Fla. Smooth and handsome, 18 to $30^{\prime}$ ligh, half shrubby. Lvs. $1^{\prime}$ to $1^{\prime}{ }^{\prime}$ long, $1-2^{\prime \prime}$ wide, revolute-cdged, fascicled in the axils as if whorled. Fls. $6^{\prime \prime}$ diam. Sep. subequal, about as long as the obovate petals. Jn., Aug.

7 H. fasciculatum Lam. Shrub much branched, bushy; lvs. linear, very narrow, longer than the internodes, sessile; cymules leaty. - Wet places in pine barrens, Ga., Fla. to La., common. Bush 1 to $2 \mathrm{f}$ high, very leafy. Lvs. nearly $1^{\prime}$ in length, recurved or straight, with smaller ones clustered in the axils. Fls. numerous, 6 " diam. Petals obovate, 1-toothed (like Nos. 4, 5) about the length of the linear sepals. Jl., Sept.

$\beta$. ABBREviATUM. Branches irregular and crooked; 1 ss. very short (2 to $\left.3^{\prime \prime}\right)$, tufted in tho axils; petals 3 times longer than tho sepals.-Car. to Ga. 
8 H. perforàtum L. St. 2-edged, branched; lvs. with pellucid dots; sep. lanceo. late, half as long as the petals. - $4 \mathrm{~A}$ hardy plant, prevailing in dry pastures; Can. and U. S., much to the annoyance of farmers. St. 1 to $2 \mathrm{f}$ high, brachiate, erect, round, with 2 opposite, elevated lines extending between the nodes. Lrs. 6-10" long, $\frac{1}{3}$ as wide, ramial ones much smaller, all obtuse, the dots as well as veins best seen by transmitted light. Fls. numerous, deep yellow, in terminal panicles. Petals and sep. bordered with flno dark-colored glands. Jn., JL. \&ur.

9 H. corymbòsum Muhl. Sts. terete, corymbously branched; lvs. oblong-ovats or oval, obtuse, marked with black (as well as pellucid) dots; sep. ovate, acute (very small) $\frac{1}{3}$ as long as the petals. -24 Woods and plains, Can. to Penn. and Ark. St. 1 to $3 \mathrm{f} \mathrm{high,} \mathrm{with} \mathrm{many} \mathrm{small} \mathrm{fls.} \mathrm{in} \mathrm{a} \mathrm{corymb} \mathrm{of} \mathrm{dense} \mathrm{cymes.} \mathrm{Lvs.} 1$ to $2^{\prime}$ long, nearly $\frac{1}{2}$ as wide, veiny, either clasping or sessile, or (in a variety, E. Tenn.) almost petiolate. Fls. small, petals with oblong black dots. Stig. orange-red, on distinct styles. Jn., Jl.

10 F. maculàtum Walt. St. terete, corymbously branched; lvs. oblong, thickly sprintiled with black dots; sep. lanceolate.-S. Car., Ga. (Feay) Fla. St. at first simple, often becoming diffusely branclied, 1 to $4 \mathrm{f}$ high. Lrs. smaller (about $\mathrm{I}^{\prime}$ by $3^{\prime \prime}$ ). Fls. rather smaller. This species (or variety?) scarcely differs from No. 8 , but in its bluish aspect (from the numerous dots) and smaller lvs. Jl., Aug.

11 H. aùreum Bartram. Branches spreading, ancipital; lvs. thick, lance-ovate, obtuse, sessile; fls. (large) solitary, sessile.-A beautiful shrub, Ga., near Macon. St. 2 to $4 \mathrm{f}$ high. Lvs. 2 to $3^{\prime}$ long, $\frac{1}{3}$ as wide, obtuse or mucronulate, only the strong mid-vein visible, almost petiolate, edge wavy-crisped. Fls. 18" broad. Petals reflexed. Sta. excessively numerous (more than 500), shorter than the 3 . partly united styles. Jn., Aur.

12 H. myrtifollium I. St. terete; lvs. thick, ovate or oblong, cordate-clasping; fls. in a leafy compound fastigiate cyme, the dichotomal sessile.-Ga., Fla. Shrub 1 to $2 \mathrm{f}$ in hight, declined and often divided at base, corymbed above. Lrs. about $1^{\prime}$ long, $\frac{1}{3}$ or $\frac{1}{2}$ as wide, glaucous. Sep. lance-linear, as long as $\left(3-4^{\prime \prime}\right)$ tho petals, at length reflexed. Sta. as long as the sty., which separate at top. May, Jn.

13 H. ambíguum Ell. Branches ancipital; lvs. lance-linear, thin, acute; fls. solitary and in $3 s$ in the axils of the upper leaves.-Banks of the Congaree and Clattahoochee, Ga. Shrub with scaly bark, 2 to $4 \mathrm{f}$ high, with numerous, opposite branches. Lvs. 1 to $2^{\prime}$ long, $3-4^{\prime \prime}$ wide, sessile, mucronate, with a white, callous point. Sep. lance-linear, as long as the 1-toothed petals. Sty. united. May, Jn.

14 H. cistifòlium Lam. St. 2-winged, subsimple; lvs. linear-oblong, obtuso sessile; fls. in a leafless, compound cyme.-Ga. to Fla. and La. Slirub straight and erect, $1 \frac{1}{2}$ to $2 \mathrm{f}$ high. Lvs. $1^{\prime}$ long, $2-3^{\prime \prime}$ wide, opaque, with smaller ones clustered in the axils. Petals twice longer than the oval sepals. Sty. united except at tho top, nearly as long as the capsule. May.

15 H. adpréssum, Bart. St. 2-winged above; lvs. linear-oblong or lanceolate, half erect; cymes few-leaved; sep. lance-linear; caps. almost 3-celled.-Swamps, R. I., Penn. to Ark. Plant about $2 \mathrm{f}$ high. Ivs. $1-2^{\prime}$ by $2-4^{\prime \prime}$, pellucidpunctate, sessile, rather acute. Fls. $6^{\prime \prime}$ diam., $15-20$ in an almost leafless cyme. Sep. unequal, half as long as the oblong-obovate petals. Sty. 1. Aug., Sept.

$16 \mathrm{H}$. nudiflòrum $\mathrm{Mx}$. St. and branches 4-angled and winged; 1rs. ovate-lanceolate or oblong, obtuse, sessile; cyme leafless, peduncled; sep. linear; caps. almost 3-celled.- Wet grounds, Penn. to La. and Ga. Plant woody at base, 1 -2f high, with numerous branches. Lrs. thin, about 2 ' long, with minute, pellucid, reddish dots. Fls. few, small, rather loose in the stalked cyme. Aug., Sept.

17 H. dolabrifórme Vent. St. decumbent at the woody base, scarcely 2-edged above; lvs. linear-lanceolate, spreading, veinless; fls. in a leafy, fastigiate cyme; seps. lance-ovate, about as long as the very oblique (dolabriform) petals.-Ky. and Tenn. Sts. 6-18' long, with scaly bark at base. Lvs. $1^{\prime}$ or more in length, sessile, with smaller ones in the axils with brownish dots. Jl. Aug. 
18 H. sphæerocárpon Mx. St. obscurely 4-sided; lvs. linear-oblong, obtuse, with a minute callous tip, almost veinless; cymo compound, nearly leafless, pedunculate; sep. ovate, mucronate; sty. closely united; caps. globular.-Rocky banks of the Ohio and Ky. rivers. St. somewhat woody at base, 10-15' ligh. Lrs. $1-2$ ' long, $\frac{1}{4}$ as wide, closely sessile, with large, pellucid dots. Fls. at length numerous, $7^{\prime \prime}$ diam. Jl.

$19 \mathrm{H}$. angulósum Mx. Herb smooth; st. acutely 4-cornered; lvs. oblong-lanceolate, acute; cymes leafless; sty. distinct, thrice larger than the ovary.- Swamps in pine barrens, N. J. to Fla. (Bainbridge, Ga., Misses Keen). St. nearly $2 f$ high. Lvs. distinct, opaque, scarcely punctate, $8-12^{\prime \prime}$ long, $1-3^{\prime \prime}$ wide, edges revolute. Fls. often alternate on the uitimate branches. Sepals ovate, striate, acute, 5 times shorter than the orange-colored petals. Jl.

$20 \mathrm{H}$. ellípticum Hook. Herb smooth; st. quadrangular, simple; lvs. elliptical, obtuse, somewhat clasping, pellucid-punctate; cyme pedunculate; sep. unequal; sty. united to near the summit, as long as the ovary.- 4 Low grounds Can. to Penn. St. $8-16^{\prime}$ ligh, slender, colored at base. Lvs. $8-13^{\prime \prime}$ by $2-4^{\prime \prime}$, somewhat erect, about as long as the internodes. Cymes of about a dozen flowers, generally 1 or $2^{\prime}$ above the highest pair of leaves. Central fls. subsessile. Petals acutish, orange-yellow, $2-3^{\prime \prime}$ long; sep. shorter. Stig. minute. Jl.

$21 \mathrm{~F}$. gravèolens Buckley. St. terete, smooth, nearly simple; lvs, oblong-ovate, clasping, punctate beneath; cymes terminal and axillary; sep. and pet. narrow; fil. $\infty$; styles 3.-High Mts., N. Car. (Buckley). Plant with a strong odor. Stem 2-3f high. Lrs. 2' long, half as wide. Fls. largo and numerous. Jl.-Aug.

22 H. pilòsum Walt. Herb rough-downy; st. simple, terete, virgate; lvs. ovatelanceolate, appressed, clasping, acute; cymo few-flowered; sty. distinct, as long as the ovary. - 1) Wet pine barrens, S. Car. to Fla. and La., common. Lrs. $4-8^{\prime \prime}$ long, $\frac{1}{2}$ as wido, very acuts. St. $1-3 \mathrm{f}$ high, quito simple to near tho top, clothed with a rough coat of hairs. Fls. $5-6^{\prime \prime}$ diam., mostly alternato on the branches of the cyme. Jn.-Sept.

23 H. mùtilum L. DWARF ST. JoHn's WORT. St. quadrangular, branched; lvs. obtuse, ovate-oblong, clasping, 5-veined, minutely punctate; cymes leafy; pet. shorter than the sep.; sta. 6-12.-(1) Damp sandy soils, Can. to Ga., W. to Ind. St. $3-6-9$ ' high. Lvs. closely sessile, apparently connate, $4-8^{\prime \prime}$ by $2-5^{\prime \prime}$, outer veins obscurs. Fls. minute, orange-colored. J., Aug.

24 H. Canadénse L. St. quadrangular, branched; lvs. linear, attenuated to the base, with pellucid and also with black dots, rather obtuse; pet. shorter than the lanceolate, acute sep.; sta. 5-10.-(1) Wet sandy suils, Can. to Ga. St. 6-12' high, slightly 4-winged. Lower branches opposite, upper pair forked. Lvs. $8-12^{\prime \prime}$ by $\frac{1}{2}-1$ or 2 ", sometimes linear-lanceolate, radical ones obovate, short. Fls. small, orange-colored. Ova. longer than the styles. Caps. red, very acute, twice as long as the sepals. Jn.-Aug.

25 H. Saròthra Mx. St. and branches filiform, quadrangular; lrs. very minute, subulate; fls. sessile; sta. 5-10.-1) St. 4-8-12' high, branched abovo into numerous, very slender, upright, parallel branches apparently leafless, from the minuteness of the leaves. Fls. very small, yellow, succeeded by a conical brown capsule which is twice the length of the sepals. Jl., Aug.

26 H. Drummóndii Torr. \& Gr. Iranches alternate, square above; lvs. linear, very narrow, acute, longer than the internodes; fls. pedicellate; sta. $10-20$; sep. lanceslate, shorter than the petals, but longer than the ovoid capsulc. (1) Near St. Louis, to Ga. and La. Plant more robust than the last, 10-20' high, very branching. Lvs. $\frac{1}{2}$ long. Fls. about $4^{\prime \prime}$ diam.

3. ELODĖ, Acams. (Gr. $\dot{\varepsilon} \lambda \omega \delta \eta s$, marshy; from the habitat of the plants.) Sepals 5 , equal, somewhat united at base; petals 5 , deciduous, equilateral; stamens 9 (rarely more), triadelphous, the parcels alternating with 3 hypogynous glands; styles 3 , distinct; capsule 3 -celled.4 Herbs with pellucid-punctate lis., the axils leafless. Fls. dull orangepurple. 
1 E. Virgínica Nutt. St. erect, somewhat compressed, branching; lvs. oblong amplexicaul; sta. united below the middle, with 3 in oach set.-Swamps and ditches. U. S. and Can. I Whole plant usually of a purplish hue, 9-20' high Lrs. $1 \frac{1}{2}-2 \frac{1}{2}$ long, $\frac{1}{2}$ as wide, upper ones lanceolate, lower oblong-ovate, all very obtuse, glaucous beneath. Fls. 5" diam., terminal and axillary. Pet.about twico longer than the calyx. Glands ovoid, orange-colored. Caps. ovoid-oblong, acutish. Jl.-Sept.

2 E. petiolàta $\mathrm{Ph}$. Lvs. oblong, narrowed at base into a petiole; fls. mostly i: 3 s, axillary, nearly sessile; filaments united above the middle; caps. oblong, muc! longer than the sepals. - Swamps S. States, N. to N. J. St. about $2 \mathrm{f}$ high. Lvs. $1-3^{\prime}$ long, rounded-obtuse, with a short but distinct petiole. Fls. smaller than in the last. Aug., Sept.

\section{Order XIX. DROSERACE FE. Sundews.}

Herbs growing in bogs, often covered with glandular hairs, with lvs. alternato or all radical, mostly circinate (rolled from top to base) in vernation; fls. regular, nypogynous, 5-merous, the sepals, petals and stamens persistent (withering); ova. compound, one-celled, with the styles and stigmas variously parted, cleft or united seeds $\infty$ in the capsule, albuminous; embryo minute.

Genera, 6, species 90. Curious and interesting plants, scattered orer tho wholo globe wherever marshes are found. The halved stigmas are their most singular characteristic. In the sundew, \&c., each half stigma is distinct, hence apparently doubling their number, but in the suborler, Parnassix, the aljacent halves of different stigmas aro united, and thus stand oppusite to the placentæ.

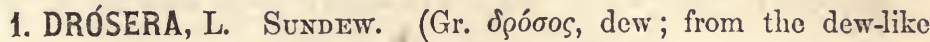
secretion.) Sepals 5 , united at base, persistent; petals 5 ; stamens 5 ; styles $3-5$ each 2 -parted, the halves entire or many-cleft; capsule 3-5-valved, 1-celled, many-seeded.-2 Small aquatic herbs. Lvs. covered with reddish, glandular hairs, secreting a viscid fluid. Vernation circinate.

Scapes $4-6$ times as long as the leaves................................... 1-3

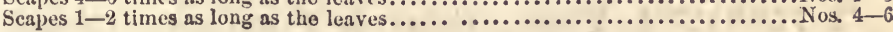

I J. rotundifollia L. Lvs. orbicular, abruptly contracted into the lairy petiole; fls. white. $-A$ curious littlo plant, not uncommon in bogs and muddy shores. Whole plant of a reddish color, like the other Sundews, and beset with glandular hairs which are usually tipped with a small drop of a clammy fluid, glistening like dew in the sun. Lvs. about $5^{\prime \prime}$ broad and with the petioles $1-2^{\prime}$ long. Scapo slender, $5-8^{\prime}$ high, the racemes uncoiling as tho small whito flowers open. Caps. oblong. Jn.-Aug.

2 D. minor. Ivs. obovate, cuneiform at lase, the petioles naked; fls. purple; scapo crect.-More delicato than tho preceding, in marshes, Fla. to Texas. Lvs. forming a rosulate tuft, $8-12^{\prime \prime}$ long, the smooth petiole three times longer than tho lamina, which is $2-3^{\prime \prime}$ wide. Scapes filiform, $3-6^{\prime}$ high, the raceme simplo or forked, $\mathbf{5}$ or 6 -flowered. Petals light purple. Caps. globular. Seeds oblong, tubercled. May. (D. brevifolia $\beta$. major Torr. \& Gr. D. intermedia Chapman.)

$3 \mathrm{D}$. brevifòlia $\mathrm{Ph}$. Ivs. cuneiform-spatulate, forming a small, dense tuft ( $\mathrm{I}^{\prime}$ diam.); petioles very short, hairy; fls. few, rose colored.-In wet, springy places, Car. to Fla. and La. Not half as large as the last. Lvs. 5 or $6^{\prime \prime}$ long, $1-2^{\prime \prime}$ broad, flat on the ground, forming a round, compact rosette. Scapo 2 or $3^{\prime}$ high, bearing one to threo conspicuous flowers. Capsule roundish. Apr.

$4 \mathrm{D}$. Iongifòlia I. Lvs. spatulate. oblong or obovate, ascending, alternate, tapering at base into a long, smooth petiole; scape declined at base; petals white. - Slender and delicate, in similar situations with the last. Lvs. slender, ascending, crenate, beset with numerous hairs tipped with dew-like drops, -length, including the petioles $2-3^{\prime}$. Candex lengthened, deelinate. Scape bearing a simple racem of small, white flowers, arising 4-7'. Jn.-Aug. 
6 D. filifórmis Raf. Lvs. filiform, very long, erect; scapo nearly simple, longer than the leaves, many-flowered; petals obovate, erosely denticulate, longer than the glandular calyx; sty. 2-parted to the base.-Grows in wet, sandy places, along the coast Mass. to Fla., much larger than the preceding species. The lvs. are destitute of a lamina, nearly as long as the scape, beset with glandular hairs, except near tho base. Scape about a foot high, with large purple flowers. Aug., Sept.

5 D. lineàris Goldie. Lvs. linear, obtuse; petioles elongated, naked, erect; scapes few-flowered, about the length of the leaves; cal. glabrous, much shorter than the oval capsule; seeds, oval, shining, smooth.-Borders of lakes, Can., Mich. to the Rocky Mts. (Hooker, Torr. \& Gr.) Scapo 3-6' high, with about 3 small flowers. LVs. about $2^{\prime \prime}$ wide, clothed with glandular hairs, which are wanting on the petiole. Jl., Aug.

2. DION'EA, L. Venus' Fly-trap. (One of the names of Venus.) Sepals spreading; petals 5 , obovate, with pellucid veins; stamens $10-15$; styles united into 1 , the stigmas many-cleft; capsule breaking irregularly in opening, 1-celled; seeds many in the bottom of the cell.- 24 Glabrous herbs. Lvs. all radical, sensitive, closing convulsively when touched. Scape umbeled.

D. muscípula Ell. $\Lambda$ very curious plant, native of sandy bogs in Car., along rivers from the Neuse to the Santee. Sometimes cultivated in a pot of bog earth placed in a pan of water. Lrs. rosulate, lamina roundish, spinulose on the margins and upper surface, instantly closing upon insects and other objects which light upon it. Scape 6-12' high, with an umbel of 8-10 white flowers. Apr., May. $\dagger$

\section{SUBORDER, PARNASSIE.}

Consists of the single genus Parnassia, which differs from the Sundews in having 5 sets of abortivo stamens and the 4 stigmas placed over the parietal placentæ (as if each stigma were compounded of the two adjacent halves of two divided stigmas.-More recently this genus is stationed among the Saxifrages.

3. PARNÁssia, Tourn. Grass of Parnassus. (Named from Mount Parnassus, the abode of the Muses, Graces, \&c.) Sepals 5, united at base, persistent; petals 5 , persistent, nearly perigynous ; stamens in two series, the outer indefinite in number, united in 5 groups, sterile, the inner 5 perfect; capsule 1-celled, 4-valved; seeds very numerous with a winged testa. - 4 Glabrous herbs, with radical lvs. and 1flowered scapes.

1 P. Caroliniàna L. Sterile fil., 3 in each group, distinct to near the base, surmounted with littlo spherical heads; pet. much exceeding the cal., marked with green veins; lvs. radical, or sessile on the scape, broad, oval, with no sinus at the base.-An exceedingly elegant and interesting plant, growing in wet meadows and borders of streams, U. S. to Can. Rt. fibrous. Lvs. 7-veined, broadoval or ovate, smooth, leathery, radical ones long-stalked, the cauline only one, sessile, clasping, a few inches above the root. Scapes $10-15^{\prime}$ high, with a handsome, regular flower about $\mathrm{l}^{\prime}$ diam. Jn.-Aug.

$\beta$. Filments nearly as long as the petals; cauline leaf small or none; rhizome thick and large.-Fla. (Chapman.)

2 P. palústris I. Sterile fil. pellucid, setaceous, 9 to 15 in each set; cauline If., if any, sessile; radical lvs. all cordate.-Bogs and lake shores, Mich. to Lab., and W. to Rocky Dits. Scapes about 6' high, naked or with a single clasping leaf near the base. Fls. white. Sepals oblong-lanceolate. Petals marked with 3-5 green or purple veins.

3 P. asarifòlia Vent. Sterile fil., 3 in each set; petals abruptly clawed; $l v s$, reniform. - IIts., Va. and Car. Lvs. large (I-2' broad), the cauline one sessile, orbicular. Fls. $1 \frac{1_{2}^{\prime}}{2}$ diam. 


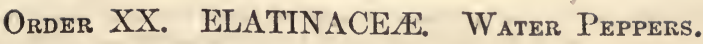

Herbs small, annual, with opposite leaves and membranous stipules. Fls. minute axillary. Sepals $2-5$, distinct or slightly coherent at base, persistent. Petals hypogynous, as many as the sepals. Sta. equal in number to, or twice as many as the petals. Anth introrse. Ova. 2-6-celled. Stigmas 2-5, capitate; placenta in the axis. Fr. capsular. Seeds numerous, exalbuminous.

Genera 6, species 22 , found in every part of the globe, growing in marshes. The following is our only northern genus.

ELATINE, L. (Gr. $\dot{\varepsilon} \lambda a \tau^{\top} \eta$, fir; from the resemblanee of the slender leaves of some species.) Fls. 2-4-merous. Stigmas sessile, minute.

E. Americàna Arn. Mud Purslane. St. diffuse, procumbent, striate, rooting from the joints, with assurgent branches; lvs. lance-oval or obovate, obtuse, entire; sty. 0 ; sep., pet., sta., stig. $2-3$, as well as the cells and valves of tho capsule; stip. very minute.-A little mud plant, on the borders of ponds and rivers, U. S. Fls. axillary, sessile, solitary: Cor, minute, closed. Jl.-Sepi. (Crypta minima Nutt. Peplys Americana Ph.)

\section{Order XXI. CARYOPHYLlaCEA. Pinkworts.}

Herbs with swollen joints, opposite, entire leaves, and regular flowers. Sepals 4 or 5 , persistent, distinct, or cohering into a tube. Petals 4 or 5 , unguiculato or not, bifid or entire, mostly removed from the calyx by a short internode of the torus, sometimes wanting. Stamens distinct, twice as many as the petals, rarely an equal number or fewer. Ovary often stipitate; styles $2-5$, stigmatous the whole length of the inncr surface. Fr. a 1-celled capsule (or imperfectly $2-5$ celled), opening at the top, or loculicidal. Sds. numerous; embryo curved around the albumen. (Seo Figs. 70, 209, 258, 296, 299, 300, 313, 392.)

The Pinkworts as constituted by Endleicher and others, and above characterized, comprehends four Suborders, and in the aggregate SS genera and 1150 species. They are in general destitute of active properties. A few of them aro valued as highly ornamental in cultivation, but tho greater part are insignificant weeds abounding in waste sandy tracts throughout the temperate zones.

§ Leaves furnished with dry, membranous stipules. SUBorder II. (I)

Exstipulate.-Capsulo 1-celled, 3-Co-seeded. Petals rarely absent. Suborder I.(")

-Capsulo 1-celled, 1-seeded. Petals none. Suborder III. (h)

- Capsule completely 8-celled. Petals none. SuBorder IV. (k)

* Sepals united into a tube. Petals long-clawed. Ovary stiped. Tribe 1. (a)

* Sepals distinct or nearly so. Petals subsessile. Ovary sessillo. Tribe 2. (b)

₹ Styles or stig. 3 to 5 . Capsulo 1-celled, $\infty$-seeded. Tribe 3. (e)

f Styles 2 or united into 1. Utriclo 1 -seeded. Tribe 4. (f)

\section{StBorder I. CARYOPHYLLINE.E.}

a 1. SILENE E.-Calyx with scale-like bractlets at base. Styles $2 . . . . . .$. . Duarmes. 1

-Calyx bractless. - Styles 2. Capsulo 4-toothed when open.Saporaria. 2

-Styles 3. Capsule 6-toothed when open.Suzexre 3

-Styles 5. Caps. 10-toothed...A A grostemara, 4..Lrciris. 5

b 2. ALSINE E.-Petals 2-parted (sometimes wanting in No. 7.) (c)

c Styles 5. Capsulo opening at tho top by 10 teeth.....Cerastivar.

c Styles 8. Capsule opening deeply by 6 half-ralves... Struraris. T

-Petals undivided (sometimes wanting in No. 10.) (d)

d Valves of the capsulo 3, each 2-toothed. Styles 3....Arixaria. 8

d Valves, \&c., entire.-Styles 3, always fower than sepals.......Arsix., 9

- Styles 4 or 5, always as many as sepals. . Sagrixa. 10

- Styles 3 \& 5. Disk large, 10-10bed.Ilonkrax 11

SEBORDER II. ILLECEBRINEA.

e 3. SPERguLE E.-Styles 5. Petals white. Lvs. linear, whorled.......... Sr ergers. 13

-Styles 3 and 5. Petals red. Livs. linear, opposite...... Spergularia. 13

-Styles 3 in all tho flowers. -Stipules ovate. Lvs. in 4's.Polrcarpox. 14 -Stip. maltifid. Lrs. opp....Stipulicida. 15 
f 4. PARONYCHIE E-Sepals herbaceous, distinct or nearly so...........PARovrcwa, 16 -Sepals white above, united in a tube below..........Srpiroxrcira. 17

Suborder III. SCLERANTHINEAE.

h Styles 2. Utriclo inclosed in the hardened calyx tube ... Scirleraxtnut. 18

SUborder IV. MOLLUGINEA.

k Styles 3. Stamens hypogynous, 3 or 5. Irerb prostrate. Mollugo.

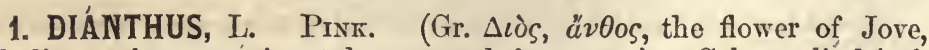
alluding to its preëminent beauty and fragrance.) Calyx cylindrical, tubular, striate, with 2 or more pairs of opposite, imbricated scales or bractlets at base; petals 5, with long claws, limb unequally notched; stamens 10; styles 2, tapering, with long, recurved stigmas; caps. cylindric, 1-celled.-Beautiful Oriental plants, cverywhere cultivated.

$\S$ Flowers in dense corymbs. - Scales as long as the ealyx... ...................... 1, 2 -Seales ovate, awned, short............................................ 7

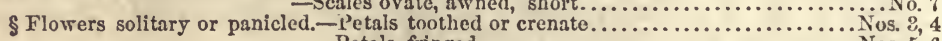
- Petals fringed................................. Nos. 5, 6

1 D. Armèria. WILD PINk. Lvs. linear-subulate, hairy; fls. aggregate, fascicled; scales of the calyx lancealate, subulate, as long as the downy tube.-(1) Our only wild species of the pink, found in fields and pine woods, Mass. to N. J. St. crect, $1-2$ f high, branching. Lvs. erect, $1-2$ ' long, $1-3^{\prime \prime}$ wide at the clasping base, tapering to a subulate point. Fls. inodorous, in dense fascicles of 3 or more. Cal. and its scales $\frac{3^{\prime}}{4}$ long. Petals small, pink-colored, sprinkled with white, crenate. Aug. § Eur.

2 D. barbàtus I. Sweet William or Bunch Pink. Lvs. lanceolate; fls. aggregate, fascicled; scales of the calyx ovate-subulate, as long as the tube.-2f $\Lambda$ ornamental flower, still valued as in the times of old Gerarde, "for its beauty to deck up the bosoms of the beautiful, and garlands and crowus for pleasure." Stems $1 \frac{1}{2} \mathrm{f}$ high, thick. Lvs. 3 to $E^{\prime}$ by $\frac{1}{2}$ to $1^{\prime}$, narrowed to the clasping base. Fls. in fastigiate cymes, red or whitish, often greatly variegated. May-Jl. $\dagger$

3 D. Chinénsis L. Chixa Pixk. St. branched; lvs. lincar-lanceolato; fis. solitary; scales, linear, leafy, spreading, as lony as the tube.-(2) Native of China. An elegant species, well characterized by its leafy, spreading scales, and its large, toothed or crenate, red petals. The foliage, like that of the other species, is evergreen, being as abundant and vivid in winter as in summer.

4. D. caryophýllus I. Carnation, Bizarres, Picotees, Flakes, \&c. Ivs. linear-subulate, channeled, glaucous; fls. solitary; scales very short, ovate; petals very broad, beardless, crenate.-Stem 2-3f high, branched. Fls. white and crimson; petals crenate. This species is supposed to be the parent of all the splendid varieties of the Carnation. Over 400 sorts are now enumerated by florists, distinguished mostly by some peculiarity in color, which is crimson, white, red, purple, scarlet, yellow, and arranged in every possiblo order of stripes, dots, flakes and angles.

5 D. plumàrius L. Pheasant's Exe. Glaucous; st. 2-3-flowered; fls. solitary; calyx teeth obtuse; scales ovate, very acute; lvs. linear, rough at the edgo; petals many-cleft, hairy at the throat.-2 Native of Europe. From this species probably originated those beautiful pinks called Pheasant's-eye, of which there are enumerated in Scotland no less than 300 varieties. Fls. whito and purple. Jn.-Aug. $\dagger$

6 D. supérbus L. Lrs. linear-subulato; fls. fastigiate; scales short, ovatc, mucronate; petals pinnate.-2f A singular, beautiful pink, nativo of Europe. St. $2 \mathrm{f}$ high, branching, with many flowers. Petals white, gashed in a pinnate manner beyond the middle, and hairy at the mouth. Jl.-Sept.

7 D. Carthusianòrum I. The Monthly PINK, common in house cultivation, with bright green, channeled, linear leaves, short, cæspitous stems, pink-red, double flowers, appears to be \& variety of this species.

2. SAPONÀRIA, L. SoAPwort. (Latin sàpo, soap; the mucila. 
ginous juice is said to make soap.) Calyx tubular, 5-toothed, without scales; petals 5, unguiculate ; stamens 10 ; styles 2 ; capsule oblong, 1-celled. Petals often crowned.

1 S. officinàlis L. Bouncrixg Bet. Lrs. lanceolate, inclining to elliptical; fls. in paniculate fascicler; cal. cylindrical; crown of the petals linear. $-24 \mathrm{By}$ roadsides, N. E. to Ga. A shady, smooth, succulent plant, with handsome, pinklike flowers. St. $1-2 \mathrm{f}$ high. Lvs. $2-3^{\prime}$ long, $\frac{1}{3}$ or more as wide, very acute. Fls. many, flesh-colored, often double. The plant has a bitter taste, and makes lather with water. Jl., Aug. \& Eur.

2 S. (Vaccària) vulgàris Mdik. Lvs. ovate, lanceolate, sessile; fls. in panniculate cymes; cal. pyramidal, 5-angled, smooth; bracts membranous, acute.(1) Gardens and cultivated grounds. Whole plant smooth, a foot or more high. Lvs. broadest at base, $1-2^{\prime}$ long, $\frac{1}{4}$ as wide, tapering to an acute apex. Fls. on long stalks, pale-red. Caps. 4-toothed. Sds. globous, black. July, Aug. §t Eur.

3. SILÈNE, L. Campion. (Silenus was a drunken divinity of the Greeks, covered with slaver, as these plants are with a riscid secretion.) Calyx tubular, swelling, without scales at the base, 5 -toothed; petals 5 , unguiculate, often crowned with 'scales at the mouth, 2 or many-cleft, or entire; stamens 10 ; styles 3 ; capsule 3 -celled, opening at top by 6 teeth, many-seeded.

Acanlescent, low, tufted. Perennial........................................

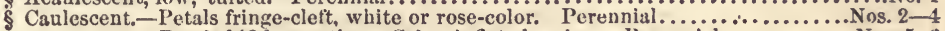
- Petals bifid or entire._Calyx inflated, veiny. Perennial......................... 6 -Calyx close on the pod. (*)

* Flowers spicate, alternate. Annual................................... 7,8

* Flowers not spicate. - Petals pale, closed in sunshine............................... 10 - Petals red, purple, etc.,-bifid..................................... 11, 12

1 s. acaùlis L. Low and densely cæspitous; lrs. linear, ciliate at base; ped. solitary, short, 1-flowered; cal. campanulate, slightly inflated; pet. obcordate, crowned. - 2f A little turfy plant, $1-3^{\prime}$ high, on the White Mits., N. H., and throughout Aretic Am. Sts. scarcely any. Leaves numerous, $\frac{1^{\prime}}{2}$ long. Fls. purple.

2 S. stellàta Ait. Erect, pubescent; lvs. in whorls of $4 s$, oval-lanceolate, acuminate; cal. loose and inflated; petals fimbriate.- 4 An elegant plant, woods and prairies, Can. to Car., W. to 1ll. and Ark. St. 2-3f high, paniculately cymous. Lvs. 2-3' long, $\frac{1}{8}$ as wide, tapering to a long point, sessile. Cal. pale green, with moro deepiy colored veins. Petals white, lacerately fringed, claws webbed at base. Jl.

3 S. ovàta $\mathrm{Ph}$. Erect, puberulent; lvs. opposite, lance-orate, acuminate; cal. ovate, not inflated; pet. many-cleft, crownless.-Virg. to Ga., rare. Sts. stout, 2-4f high, branched from the base. Lvs. 4-5' long, broadest at base. Claws of the white petals exserted from the short calyx, the limb deeply and repeatedly forked, with linear segments. Fil. long, exserted.

4. S. Baldwínii Nutt. Weak hairy; lvs. obnvate-spatulate; calyx not inflated; pet. cuneiform, divaricately fimbriate.-River banks near Quincy, Fla. Sts. decumbent at base, 1 to $2 \mathrm{f}$ high. Lvs. few, much shorter than the internodes, 1 to $2^{\prime}$ long, the upper elliptical, acute. Cyme of 3 to 5 largo ( $2^{\prime}$ broad), palo rosecolored flowers. Apr.

5 S. nívea DC. Minutely puberulent, erect, subsimplo; lvs. oblong-lanceolate, acuminate; fls. few, solitary, leafy; cal. inflated; pet. 2-cleft, with a small bifid crown; caps. shorter than its stipe.-2! In moist places, Penn., Ohio, 1ll., rare. St. slender, leafy, $1 \frac{1}{3}$ to $3 f$ high, generally forked near the top Lvs. 2 to $3^{\prime}$ by 6 to $9^{\prime \prime}$, tapering to a very slender point, floral ones lance-ovate. Fls. 1 to 3 . Cal. reticulated. Petals white.

6 S. inflàta Smith. Bladder CAMPION. Glabrous and glaucons; 1vs ovatelanceolato; fls. in cymous, leafless panicles, drooping; cal oroid-globular, much 
inflated and netted; sty. long-exserted; $m$ ? short-stiped.-2f In pastures, about fences, Charlestown, Mass., etc. St. erect, about $2 \mathrm{f}$ high. Lvs. $1 \frac{1}{2}$ to $3^{\prime}$ long, $\frac{1}{4}$ as wide, rather acuminate. Petals white, cleft half way down. Cal. with pale purple veins. Jl.- The young shoots and leaves may be used as a substitute for Asparagus. § Eur.

7 S. quinquevúlnera $\mathrm{L}$. Branched, villous; 1rs. oblong-spatulate, obtuse, the highest linear; spike somewhat one sided; cal. very villous; petals roundish, en. tire, crowned. - (1) About Charleston, S. C. A foot high. Petals pink or crimson, with the border pale-purple. Jl. § Eur.

8 s. noctúrna I. St. branching, hairy below; lvs. pubescent with long cilir at base, lower ones spatulate, upper lance-linear; fls. appressed to the stem in a dense one sided spike; cal. cylindrical, almost glabrous, reticulated between the veins; pet. narrow, 2-parted.-(1) Near New Haven, Ct. (Robbins) to Penn., Va. Fls. white, greenish beneath. Jl. $+\S$ Eur.

9 S. Antirrhina I. SNAP-DRAGON CATCH-FLY. Nearly smooth, crect, branched above; lvs. lanceolate, acute, the upper linear; fls. few, on slender pedicels or branches; cal. ovoid; pet. emarginate.-(1) Road sides and dry soils, Can. and U. S. St. slender, branching, with opposite leaves, about a foot in height. Lvs. about $2^{\prime}$ long, the upper ones very narrow, all sessile, and scabrous on the margin. A few of the upper internodes aro viscidly pubescent above their middle. Fls. small, red, in loose, erect cymes. Jl.

$\beta$ uinaria. Very slender; lvs. all linear except the lowest, which are linearspatulate; cal. globular. Ga. and Fla.

10 S. noctiflòra L. Viscid-pubescent; st. erect, branching; lower lvs. spatulate, upper linear; cal. cylindrical, ventricous, the alternate veins veinleted, teeth subulate, very long; petals 2-parted.-(1) Cultivated grounds. Fls. rather large, white, expanding only in the evening, and in cloudy weather. $\nmid \S$ Eur.

11 S. Virginica I. Viscid-pubescent; st. procumbent or erect, branching; root-lvs. spatulate, cauline oblong-lanceolate; fls. large, cymous, cal. large, clavate; pet. bifid, broad, crowned.- 24 Gardens and fields, Penn. to Ga. St. 1 to $2 \mathrm{f}$ high, often procumbent at base. Lvs. a little rough at the margin. Cymes dichotomous. Sta. and pistils exserted. Petals large, red. Jn. $\nmid$

12 s. rotundifòlia Nutt. Pubescent, wcak, decumbent, branching; lvs. thin, roundish-oval; fls. soliiary, very. large ; cal. cylindric-campanulate; pet. bifid, crowned.-Rocks, Western States, rare. Lvs. 1 to $3^{\prime}$ by 1 to $2^{\prime}$, the upper suborbicular. Petals deep scarlet. Jn., Aug.

13 S. Pennsylvánica Mx. Viscid-pubescent; sts. numerous; lvs. from the root spatulate or cuneate, of the stem lanceolate; cyme few-flowered; pet. slightly emarginate, subcrenate.-2f Dry, sandy soils, N. Eng. to Ky. and Ga. St. documbent at base, nearly if high, with long, lanceolate leaves, and terminal, upright bunches of flowers. Cal. long, tubular, very glutinous and hairy. Pet. wedge-shaped, red or purplish. Jn.

14 S. règia Sims. SPlendid CATCH-FuY. Scabrous, somewhat viscid; st. rigid, ercet; lvs. ovate-lanceolate; cyme paniculate; pet. oblanceolate, entire, erose at the end; sta. and stig. exserted. $-24 \mathrm{~A}$ large species, beautiful in cultivation, native Ohio to La. Sts. 3 to $4 \mathrm{f} \mathrm{high.} \mathrm{Ivs.} 2$ to $3^{\prime}$ by 8 to $15^{\prime \prime}$. Fls. very large, numerous. Cal. tubular, 10-striate, $1^{\prime}$ long. Petals bright-scarlet, crowned. Jn., Jl. $†$

15 S. Armèria L. GARDEN CATCH-FLy. Very smooth, glaucous; st. branching, glutinous below each node; Ivs. ovate-lanceolate; fls. in corymbous cymes; pet. obcordate, crowned; cal. clavate, 10-striate.-(1) A popular garden flower, sparingly naturalized. St. 1 to $1 \frac{1}{2} \mathrm{f}$ high, many-flowered. Lvs. $1 \frac{1}{2}$ to $2 \frac{1}{2}$ long, $\frac{1}{3}$ as wido; internodes elongated. Cal. $\frac{3}{4}$ ' long, a little enlarged abovo. Petals purple, laminæ half as long as the calyx. Jl., Sept. $+\S$ Eur.

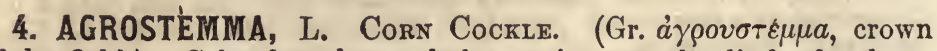
of the field.) Calyx bractless, tubular, coriaceous, the limb of 5 long, leafy, deciduous sepals, exceeding the corolla; petals undivided, crown- 
less; stamens 10 ; styles 5 ; capsule 1-celled, opening at the top by 5 teeth.-(1) and (2). Erect, hairy, dichotomous.

A Gíthago. A well known, handsome weed, growing in fields of wheat or other grains, and of a pale green color. St. 2 to $3 \mathrm{f}$ high, forked above. Lrs. linear, long $\left(3\right.$ to $\left.5^{\prime}\right)$, fringed with long hairs. Fls. fow, large, of a dull purple, on long, naked stalks. Sds. roundish, angular, purplish-black, injurious to tho whiteness of the flour. Jl. § Eur. (Lychnis Githago Lam.)

5. LÝCHNIS, L. (Gr. $\lambda v \chi v o s$, a lamp; some cottony species having been used as lamp-wick.) Calyx bractless, tubular, oblong or ovoid, limb of 5 short lobes, persistent; petals 5 , entire or cleft, mostly crowned; stamens 10 ; styles 5 ; capsule more or less 5 -celled at base, opening by 5 to 10 teeth.-Handsome perennials, cultivated.

$\S$ Fls. perfect,-Petals entire or 2 -parted..................................... -Petals laciniate, or 4 -parted................................................ 8 , 4

$\S$ Flowers dioecious. Petals 2-lobed................................................. 6

1 L. coronària DC. Mullein Pink. Rose Campion. Villous; st. dichotomous; ped. long, 1-flowered; cal. campanulate, veined; pet. broad, entire.Native of Italy. Whole plant covered with dense wool. St. 2f high. Fls. purple, large. Varieties are white-flowered, red double-flowered, etc. $\nmid$.

2 I. Chalcedónica L. Scarlet Lychis or Sweet William. Smoothish; As. fasciculate; cal. cylindric, clavate, ribbed; pet. 2-lobed.-A fine garden flower, native of Russia. St. 1 to $2 \mathrm{f}$ high, with dark green, ovate-lanceolate, acuminate lvs., and large, terminal, convex, dense fascicles of deep-scarlet flowers. It has varieties of white fls. and also with doublc. Jn., Jl. $\nmid$

3 I. Floscùculi L. RAGGEd RoBIN. Smoothish; st. ascending, dichotomous at summit; fls. fascicled; cal. campanulate, 10-ribbed; pet. in 4 deep, linear segments.-Native of Europo. St. 1 to $2 \mathrm{f}$ high, rough angled, viscid above. Lrs. lanceolate, smooth. Fls. pink, very beautiful, with a brown, angular, smooth calyx. Caps. roundish, 1-celled. JI., Sept. $\nmid$

4. I. coronàta L. CHINese LYchnis. Smootl ; fls. terminal and axillary, 1 to 3 ; cal. rounded, clavate, ribbed; pet. laciniate.-Native of China. St. 1 to $2 \mathrm{f}$ high. Petals of lively red, remarkable for their largo size. There are varieties with double red and double white flowers. $f$.

5 I. diúrna I. St. dichotomous-paniculate; fls. $\hat{\delta} \%$; petals half-bifid, lobes narrow, diverging; caps. ovoid-globous.-Nativo of Britain, almost naturalized. Sts. about $2 \mathrm{f}$ high, pubescent. Lvs. 1 to $3^{\prime}$ long, elliptic-ovate, acute. Fls. lightpurple, middle size.

6 L. dioìca L. Diœcious; st' dichotomous-paniculate; petals half-bifid, tho lobes broad, approximating; caps. conical.-Hardy at the South. St. $2 \mathrm{f}$ high, hoary-pubescent. Lvs. lance-ovate, acuminate, 1 to $2^{\prime}$ long. Fls. white, middlosize. Jn.-Aug. † Eur.

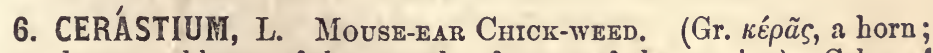
from the resemblance of the capsule of some of the species.) Calyx of 5 , ovate, acute sepals; corolla of 5 , bifid petals; stamens 10 , sometimes 5 or 4 , the alternate ones shorter; styles 5 ; capsules cylindrical or roundish, elongated, opening at the apex by 10 teeth; seeds numerous.-Fls. cymous, white.

Petals about as long as the calyx.

Nos. 1,2

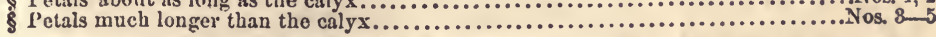

1 C. vulgàtum I. Hairy, pale green, cæspitous; lvs. attenuated at base, ovate or obovate, obtuse; fls. in subcapitate clusters; sep. when young, longer than the pedicels. - (1) Fields and waste grounds, Can. and U. S., flowering all summer. St. 6 to $12^{\prime}$ long, ascending, mostly forked. Lrs. 5 to $8^{\prime \prime}$ by 3 to $5^{\prime \prime}$, mostly very obtuse, lower ones tapering to the base. Fls. in dense, terminal clusters, the terminal (central) one solitary, al ways the oldest. Seps. mostly green, a little shorter than the corolla. Petals white, appearing in 10 segments. 
2 C. viscòsum I. Hairy, viscid, spreading; lvs. oblong lanceolate, rather acute; fl. in loose cymes; sep. scarious and white on the margin and apex, shorter than the pedicels.-4 Fields and waste grounds, U. S. and Can. Plant greener than the last. Sts. many, assurgent, dichotomously cymous. Lrs. 5 to $9^{\prime \prime}$ long, $\frac{1}{4}$ to to as wide, radical ones subspatulate. Fls. white, in diffuse cymes. Pet. hardly as long as the sep., obovate, bifid. Sta. rarely but 5 . Jn.-Aug.

3 C. arvénse L. Pubescent, somewhat cxespitous; lvs. linear-lanccolate, acute, often longer than the internodes; cyme on a long, terminal peduncle, four-flowcred; petals more than twice longer than the calyx; caps. scarcely exceeding the sepals. - 4 Rocky hills. Sts. 4 to $10^{\prime}$ high, decumbent at base. Lvs. 9 to $15^{\prime \prime}$ long, 1 to $2^{\prime \prime}$ wide. Fls. white, rather large. Caps. usually a little longer than the calyx. May-Aug.

4 C. oblongifolium Torr. Villous, viscid above; st. erect or declined; lvs. oblong-lanceolate, mostly obtuse, and shorter than the internodes; fls. numerous, in a spreading cymo; pet. twice as long as the sepals; cops. about twice as long as the calyx.-2 Rocky places. Sts. 6 to $10^{\prime}$ high, thick. Lvs. 9 to $12^{\prime \prime}$ by 3 to $5^{\prime \prime}$, tapering from base to an acute or obtuse apex. Fls. larger than either of the foregoing, white, in two or three-forked cymes. Apr.-Jn.

5 C. nùtans Raf. Viscid and pubescent; st. weak, striate-sulcate, erect; lvs. lanceolate; fls. many, diffusely cymous, on long, filiform, nodding pedicels; pet. nearly twice as long as the cal.; caps. a little curved, nearly thrice as long. - I Low grounds, Vt. to 1ll. and La. Pale green and clammy. Sts. 8 to $15^{\prime}$ high, branched from the base. Lrs. $\frac{1}{2}$ to 2 ' long, $\frac{1}{4}$ as wide. Fls. white. May.Varies greatly at different dates; beginning to flower when small in all its parts.

7. Stelläria, L. Star Chickweed. (Latin, stella, a star-from the stellate or star-like flowers.) Sepals 5, connected at base; petals 5, 2 -parted, rarely 0 ; stamens 10 , rarely fewer; styles 3 , sometimes 4 ; capsule ovoid, 1-celled, valves as many as styles, 2-parted at top; seeds many.-Small herbs in moist, shady places. Fls. in forked cymes or axillary, white.

$\$$ Stems leafy to the top, or with leafy bracts. (a)

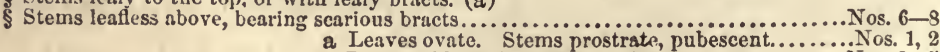

a Leaves oblong, lanceolate or linear..................... $3-5$

1 S. mèdia Smith. CHICKWEEd. Lvs. ovate; st. procumbent, with an alternate, lateral, hairy line; pet. shorter than the sep; sta. 3 to 5 or $10 .-\mathrm{A}$ common weed in almost every situation N. of Mexico, tlowering from the beginning of Spring to the end of Autumn. Sts. branched, becoming cymous, brittle, round, jointed, leafy, and remarkably distinguished by the hairy ridge. Fls. small, white. The seeds are eaten by poultry and birds. § Eur.

2 s. prostràta Baldw. Lrs. ovate, the lower on long petioles, sts. procumbent, hollow, pubescent; fls. on long pedicels; pet. longer than sepals; stam. 7.-1) Ga. and Fla. Sts. 1 to $4 \mathrm{f}$ long, slightly channelled and downy; Jower lvs. subcordate, shorter than the ciliate-petioles. Fls. small. Mar, Apr.

3 S. pìbera Michx. St. ascending, pubescent in one lateral or two opposite lines; lvs. ollong or elliptical, acute, sessile, somewhat ciliate; fls. on filiform, finally recurved pedicels; petals longer than the sepals. -24 In rocky places, Penn. to Ind. and Ga. St. 6 to $12^{\prime}$ high, often diffusely spreading. Lvs. 1 to $21^{\prime}$ by 4 to $10^{\prime \prime}$, with minute, seattered hairs. Fls. $\frac{1}{2}$ diam., axillary and terminal, with 10 stamens and 3 styles. Sep. white-edged. $\mathrm{Apr}$.-Jn.

4. 5. uniflòra Walt. St. glabrous, erect, branched from the base; lvs. linear. subulate, lanceolate, acute; ped. axillary, solitary, 1-fluwered; pet. emarginate, twice as long as the sep.-(1) N. Car., Ga., in swamps. Sts. 10-12' high, slender. Lvs. much shorter than the internodes Ped. filiform, as long (2 to $\left.3^{\prime}\right)$ as the internodes. May.

5 s. boreàlis Bigelow. St. weak, smooth; lvs. veinless, lanceolate. acute; ped. at length axillary, elongated, 1 -flowered; petals 2 -parted (sometimes wanting). 
about equal to the veinless sepals.-(1) Wet places, N. I., N. Y., N. to Arctic Am. $\Lambda$ spreading, flaecid plant. St. 6 to 12 or $15^{\prime}$ long, with diffuso cymes both terminal and axillary. Lvs. 8 to $15^{\prime \prime}$ long, 1-veined. Petals, when present, white, small, at length about as long as the lanceolate, acute sepals. Caps. longer than the calyx. Jn., Jl.

6 s. aquática Pollich. Nearly glabrous; st. slender, decumbent; lvs. lanccoval and oblong, acute, with manifest veinlets; cymes lateral; sep. lanceolate, very acute, 3-veined, rather longer than tho bifid petals; caps. ovoid, about equalling the calyx; sty. 3.- 4 Swampy springs, Penn., Md. (Dr. Robbins); also, Rocky Mts. $\Lambda$ very slender plant, 6 to $12^{\prime}$ long, with inconspicuous flowers Lvs. $6^{\prime \prime}$ by 2 to $3^{\prime \prime}$. May. (Labrea uliginosa Hook.)

7 S. lóngipes Goldie. Smooth and shining; st. more or less decumbent, with ascending branches; lvs. linear-lanceolate, broadest at base, acute; peduncles and pedicels erect, filiform, cymous, with ovate membranous bracts at baso; sep. with membranous margins, obscurely 3 -veined, scarcely shorter than the petals. -24 Lake shores, N. Y. and Mich. Petals white, 2-parted. Fls. in loose cymes. the terminal peduncle or the middle one the longest. Jn.-Aug

8 S. longifòlia Muhl. Lvs. linear; cyme terminal, spreading, with lanceolate, scarious bracts; pediceis spreading; cal. 3-veined about equal to the petals.-U. S. N. to Arc. Circle. The stems are of considerablo length, very slender and brittle, supported on other plants and bushes. Lrs. alternate at base. Fls. in a divaricate, naked cyme, very elegant, white, appearing in 10 segments like the other species. Threo sharp, green veins singularly distinguish tho sepals. Jn.. Jl.

8. ARENÀRIA, L. SANDwort. (Lat. arena, sand; in which most species grow.) Sepals 5, spreading; petals 5, entire; stamens 10, rarely fewer; styles 3 ; ovary 1 -celled ; capsule 3 -valved, valves each 2-parted; seeds $\infty$.-Sty. rarely 2 or 4.

Arevaria. Leares and sepals acute. Seeds not appendaged.................. Nos. 1, 2

Marivgia. Leaves and sepals obtuse. Seerls strophiolate.......................... 3

1 A. serpyllifòlia L. THYMe-Leaved SANDWORT. St. dichotomous, spreading; lvs. ovate, acute, subciliate; cal. acute, striate; petals shorter than tho calyx; caps. ovate, 6-toothed.-(1) By roadsides and in sandy fields, Ms. to Ga. Sts. numerous, downy, with reflexed hairs, a few inches in length. Lrs. but littlo longer than a flaxseed, beautifully ciliate. Fls. on axillary and terminal peduncles. Pet. white, oval, mostly much shorter than the 3 to 5-veined, accuminate, hairy sepals. Jn.

2 A. diffùsa Ell. St. long, decumbent, diffuse; lvs. oblong or ovate-lanceolate, acute at both ends; ped. 1-flowered; sep. acute: pet. oval, entire, much shorter than the calyx, but generally wanting.-Moist woods, N. Car. to Fla. and Ga. Sts. clambering, 2 to $5 \mathrm{f}$ in length, pubescent. Lis. minutely dotted, attenuato at base often to a petiole, 6 to $12^{\prime \prime}$ long. Ped. twice as long, terminal, but soon axillary. Cal. as long $\left(1^{\prime \prime}\right)$ as in No. 1. Apr.-Jn. (Stellaria lanuginosa Torr. \& Gr.)

3 A. lateriflòra L. Upright, slightly pubescent; lrs. oval, obtuso; ped. lateral, 2 to 3 -flowered; sds. (strophiolate) appendaged at the hilum.- 4 Damp, shady. grounds, N. States and Brit. Am. St. 6 to $10^{\prime}$ high, nearly simple, slender. Lrs. elliptical, rounded at each end, 6 to $10^{\prime \prime}$ long, $\frac{1}{2}$ as wide, on very short petioles. Ped. terminal and lateral, 2 to $3^{\prime}$ long, dividing into 2 or more filiform pedicels, one of them with 2 bracteoles in the middle. Fls. 4 " diam.; white petals moro than twice as long as the sepals. Jn. (Mœringia, L.)

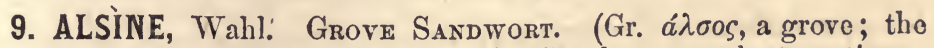
favorite locality of these little plants.) Sepals 5 ; petals 5 , entire or merely notched at apex; stamens 10 ; styles 3 ; ovary 1-celled; capsule deeply 3 -valved, valves entire; seeds $\infty$.- Small, slender herbs, 
with very narrow, minute lvs. and whits fls. (The species were formerly included in the last genus.)

\& Sepals 3 to 5 -rcinerl, acute......................... Nos. $1-3$

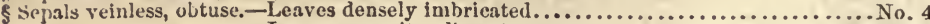
-Leaves opposite, distant.................................... 5 .

1 A. pátula Gray. Diffusely and divaricately branched, glandular-pubescent; Ivs. linear-filiform, obtuse ; petals emarginate.-(1) Rocky cliffs, Va. and Ky. Sts. exceedingly slender, $6-10^{\prime}$ high, many from one root. Lvs. few and minute, 3 to $5^{\prime \prime}$ long, obtuse under a lens. Cyme at length diffuse and many-flowered. Petals twice as long $\left(2^{\prime \prime}\right)$ as the 3 to 5-veined sepals. Jn., Jl. (Arenaria $\mathrm{M}(\mathrm{x}$.)

2 A. Pítcheri. Erect, fastigiately branched, almost glabrous; lvs. linear, obtuse, flat; pel. cntire, twice as long as the 5-veined sepals.-(1) Davison Co., Tenn. (Prof. Calender), and westward. Sts. several from one root, simple, with a fewflowered (3 to 7), pedunculato cymo at top, 3 to $6^{\prime}$ high. Lvs. rather erect, 3 to $6^{\prime \prime}$ by ${ }_{2}^{\prime \prime}$. Pedicels minutely glandular. Petals about $3^{\prime \prime}$ long. (Arenaria, Nutt.)

3 A. strícta. Glabrous, diffuse; st. branched from the baso; lvs. subulate-linear, rigid, so fascicled in the axils as to appear whorled; cymes few-flowercd, with spreading branches.-24 Sterile grounds, Arc. Am. to Car. Sts. 8 to $10^{\prime}$ high. Lvs. 5 to $8^{\prime \prime}$ long, very narrow and acute, rigid, sessile, 1-veined, much fascicled in tho axils. Pet. obovate-oblong, twice as long as the 3-veined, ovatelanceolate sepals. May, Jn. (Arenaria, Mx. Alsine Michauxii Fenzl.)

4. A. squarròsa Fenzl. Cæspitous: st. few-flowered; lower lvs. squarrous-imbricate, crowded, upper ones few, all subulate, channeled, smooth; pet. obovate, 3 times longer than the obtuse, veinless sepals.-4 In sandy barrens, Long Island to Ga. Sts. 6 to $10^{\prime}$ high, pubescent, much divided at base into aimplo branches. Lvs. about $\frac{y^{\prime}}{2}$ long, obtuse, sessile. Fls. white, in small, terminal cymes. Sep. green. Caps. obtuse. Apr.,-Sept. (Arenaria Mx).

5 A. Greenlándica Fenzl. Caespitous; sts. numerous, filiform; lvs. line«r, flat, spreading; ped. l-flowered, elongated, divaricate.-2f Summits of high mountains, N. H., N. Y. to Greenland. It grows in tufted masses consisting of exeeedingly numerous stems about $3^{\prime}$ high, and sprinkled over with large ( $8^{\prime \prime}$ diam.) white fls. with yellow stamens. Lvs. 4 to $6^{\prime \prime}$ by 1 ", numerous. Sepals ovate, veinless. Aug. (Arenaria, Spreng.)

6 A. brevifulia. Erect (not tufted), few-leaved; sts. many, filiform, simple, cymous abovo; lvs. minute, 10 times shorter than the internodes, ovate, subulate; sep. oblong.-Rocks (Stone Mt., \&c.), Ga. Sts. almost capillary, 2-3' high, with about 3 pairs of leaves and 3 to 7 flowers on long pedicels. Fls. not half as large as in the preceding (about $4^{\prime \prime}$ diam.) Lvs. $1^{\prime \prime}$ long. Apr., May. (Arenaria Nutt.)

7 A. glábra. Cæspitous, glabrous; sts. decumbent, filiform; lvs. linear-setaceous, spreading; sep. oval, veinless, half as long as the petals. - $2 \mathrm{M}$ M. Car. to Ga. and Ala. Sts. very numerous, 5 to $8^{\prime \prime}$ high, forming grass-liko tufts, tho branches exceedingly slender, divaricate. Lvs. 5 or $6^{\prime \prime}$ long. It differs from No. 5 , in its bristle-shaped leaves and smaller ( $5^{\prime \prime}$ broad) fls., and from No. 6, in its tufted stems. (Arenaria Mr., nee Ell.)

10. SagínA, L. Pearlwort. (Lat. sagina, food or nourishment; badly applied to these minute plants.) Sepals, styles and petals 4 or 5 , the latter entire, often 0 ; stamens as many or twice as many as the sepals; capsule 4 or 5 -valved, many-seeded.-Diminutive, spreading herbs, with narrow leaves and small, white flowers.

1 S. procùmbens I. Procumbent, glabrous; pet. about half as long as the roundishobtuse sepals; sta. sep. and pet. 4 or $5 .-24$ A small weed, with slender, creeping stems, 3 or 4' long, found in damp places, R. Isl., N. Y. to S. Car. Lvs. very small, linear, mucronate-pointed, connate or opposite. Fls. white and green, axillary, on peduncles longer than the leaves. Jn. 
2 S. erécta I. Ascending, simple, glabrous; pet. as long as the lanceolate, acuie sepals; sep. pet. and sta. 4.- (1) Dry places, Md. Sts. smooth and glaucous, 2 or $3^{\prime}$ high, with only one or two fls. Lvs. linear, acute, 4 to $5^{\prime \prime}$ long. Caps. ovate, as long as the calyx. Apr., May. § Eur. (Monchia quaternella Fenzl.)

3 S. Ellióttii Fenzl. Tufted, decumbent, glabrous; lvs. linear-subulate, very acuto; ped. much longer than tho leaves; fls. $\sqrt[V]{ }$; pet. hardly as long as the sep.; sia. 10.-2) Sandy fields and woods at the South, common. St. 2 to $3^{\prime}$ long. Lvs, 6 to $10^{\prime \prime}$ long, connected at base by a membrane. Fls. much smaller than in No. 1. Petals white, hardly as large as the sepals. Mar., Apr.

4 S. nodòsa Fenzl. Tufted, ascending, glabrous; lvs. subulate, the upper very short and fascicled; fls. $\sqrt[V]{ }$; pet. much longer than the sep.; sta. 10. - 2 Lake shores, Can., Isle of Shoals, N. H. (Robbins). Sts. many from ono root, subsimple, appearing knotted by ths short, dense fascicles of leaves.

5 S. fontinàlis Short. Procambent, glabrous; lvs. linear-spatulate; petals 0 ; sta. 4 to 6.-11 Ky. (Short and Peter.) An herb of larger growth than the other species, on limestono rocks. St3. a foot long. Sep. 4 or 5, obtuse, longer than the depressed capsule. Apr, May.

6 S. apétala I. Erect and pubescent; lrs. linear-subulate; ped. elongated ascending in fruit; sep and sta. 4 ; pet. very minute or 0. - (1) Sandy fields, N. J., Penn. Sts numerous filiform, 2 to $4^{\prime}$ high. Sep acute, shorter than the caps. May, Jn.

\section{HONKÉNYA, Ehrh. Sea Sandwort. (Named in honor of $J$.} G. Honkenya, a German botanist.) Sepals 5, united at base; petals 5, with short claws, entirc; stamens 10 , inserted into the crenate edge of a conspicuous disk; styles 3 to 5 ; capsule 3 to 5 -valred, many-secded.(1) Herbs of the sea coast, with fleshy lis.

II. peploìdes DC. Abundant on the Atlantic coast, N. J. to Lab. Sts creeping with upright branches, If long, forming dense tufts. Lvs. ovate, half clasping, acute, thick, 5 to 7 or $10^{\prime \prime}$ long, more than half as wide, mostly shorter than the internodes. Fls small, axillary, on short peduncles. Sep. veinless, exceeding the white petals. Mây, Jn. (Adenarium, Raf)

12. SPÉRGULA, I. SPURRY. (Lat. spergo, to scatter; from the dispersion of the seeds.) Sepals 5, nearly distinct; petals 5, entire; stamens 5 or 10 ; styles 5 ; capsule ovate, 5 -valved, the valves opposite the sepals; seeds $\infty$; embryo coiled into a ring.-(1) Herbs with fls. in loose cymes. Lvs. verticillate. Stipules scarious.

9. arvénsis L. Lvs. linear-subulate; ped. reflexed in fruit; sds. reniform, angular, rough-A weed in cultivated yrounds, Can. to Ga. Rt. small. St. round, tranched, with swelling joints, boset with copious whorled lvs., somewhat downy and viscid. Two minute stipules under each whort. Cyme forked, the terminal (central) peduncles bending down as the fruit ripens. Petals white, longer than the calyx, capsule twice as long. Sds. many, with a membranous margin. May-Aug. §ु Eur.

13. Spergulània, Pcrs. Red Sandwort. Sepals 5; petals 5, entire; stamen 2 to 10 ; styles and valves of the capsule 3 (rarely 5 , and then alternate with the sepals); seeds $\infty$; embryo curved.-(1) (2) Low, spreading and slender-leaved, with rcd or rose-colored fis. Stip. scarious.

S. rùbra Pers. St. decumbent, mueh branched; Ivs. linear, slightly mucronate; stip. ovate, membranoous cleft ; sep. lanceolate, with scarious margins; eds. compressed, angular, roughish. - Sandy fields, Can. to Flor., near the sea coast. Sts. a few inches in leugth, slender, smooth, spreading on the ground, with small narrow lvs, and drr, sheathing stip. Fls. small, on harry stalks. May-Oct. (Arenaria rubra L.)

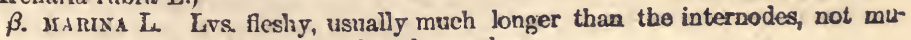
cronate, seeds marginless. - In salt marshes. 


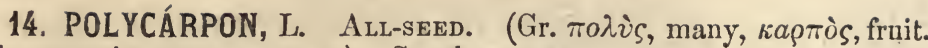
The eapsules are numerous.) Sepals 5, ovate, earinate, scarious-edged; capsule 3-valved, many-seeded.-1) Lrs. opposite and quaternate on the low spreading branches.

P. tetraphýllum L. Lrs. spatulate or oval, tapering to \& petiole, some of them in whorls of 4 ; stam. 3.-Around Charleston, S. Car. A low, much branched plant, sts. 3 to $6^{\prime}$ high. Lvs. 2 to $5^{\prime \prime}$ long. Stip. several at each joint, ovatolanceolate, membraneous. Fls. small, in denso eymes. Pet. much shorter than sep., notched, whitc. May, Jn. § Eur.

15. STIPULÍCIDA, Michx. (Lat. stipula, codo; the stipules being much cleft.) Sepals obłong, with broad, scarious margins; petals 5 , as long as the sepals, entire; stigmas 3, subsessilc; capsule subolobons, 3-valved, few-seeded.-(1) A slender, tufted, dichotomously branched herb, almost leafless, with the small fls. in terminal cymules.

S. setàcea Mx. In dry, sandy soils, Ga. (Feas, Mettauer) and Fla. (Chapman). Sts. many from one root, glabrous, 6 to $10^{\prime}$ high, each several times forked, slender, the branches almost setaceous. Root lvs. roundish-obovate, narrowed to a petiole, $1^{\prime \prime}$ diam. Joints distant, each marked by a fringe of leaves and stipules 1" long. Fls. sessile, 4 to 6 together, green and white, at length reddish. May.

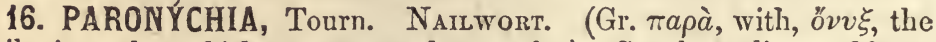
nail; i. c., the whitlow ; supposed cure for.) Sepals 5, lincar-oblong, conuivent, slightly hooded and mucronate or awned near the apex; petals or sterile filaments very narrow and scale-like or none; stam. 2, 3 , or 5 ; stigmas 2 ; with the styles more or less united into 1 ; utricle 1 -seeded, not exceeding the calyx.-Low herbs dichotomously branched, with scarious, silvery stipules, and at least the lower lvs. opposite.

S Paroxycira. Sepals evidently awned at apex. Lrs. linear and subulate......... Nos. 1, 2 \$ A rrcur (Mx. partly). Sep. merely mucronate at apex. Lrs. lanceolate to oral. (*)

* Stems procumbent, diffuse on the ground. Stamens 5........... Nos. 3, 4

* Stems erect, with diffusely ascending branches. Stamens 2 or 3...Nos. 5, 6

1 P. dichotòma Nutt. Glabrous, densely branched; lvs. acerose, mucronate; bracts like the leaves; cymes fastigiate, with no central flower; sep. 3-veined, cuspidate.-24 Rocks (Harper's F'erry), Va., and Car. to Ark., rare. Densely matted and branched, the flowering stems 6 to $12^{\prime}$ high. Lvs. crowded, $1^{\prime}$ by $\frac{1^{\prime \prime}}{2}$. Sty. bifid at top. Minute setæ in place of petals. Jl.-Nor.

2 P. argyrócoma Nutt. Pubescent, tufted, decumbent; lvs. linear, acute; cymes glomerate, terminal; fls. enveloped in dry, silvery bracts: sep. hairy, 1-veined, setacenusly cuspidate.-4 White Nits., N. I., in the gorge behind the Willey house (Chapman) and in the Allegh. and Cumb. Mts. Flowering stens 4 to $10^{\prime}$ high. Lvs. crowded, 6 to $10^{\prime \prime}$ long.-Fls. concealed in tho bracts; the cusp equaling the sepals. Jl.

3 P. herniarioìdes Nutt. Scabrous, diffusely branched; lvs. oval or oblong, mucronate; the raminal alternate. Fls. sessile in the axils of the leaves; sep. 3-veined, merely mucronate.-4 N. Car. (Miss Carpenter) to Ga., in sandy soil. A little depressed plant, spreading on the sand, with minute lvs. and fls. Branches alternate with 1 -sided branchlets. Lvs. $3-2-1^{\prime \prime}$ long, $\frac{1}{2}$ as wide, stip. shorter. Fis. ${ }_{4}^{\prime \prime}$ long.

4 P. Baldwínii Torr. \& Gr. Diffusely branched, procumbent; lvs. linearlanceolate, very acute, all opposite; fls. longer than the setaceous stipules, mostly terminal, stalked; stam. 5.-Fla, (Mettauer), in dry fields. Sts. more openly branched, many from the same root, covering a circular spot $12-20^{\prime}$ diam. Lvs. few, $3-8^{\prime \prime}$ long, $3-2^{\prime \prime}$ wide, sessile.' Fls, a $\frac{7}{3}$ larger than in No. 3. Oct.

5 P. Canadénsis. Stem ercet, slender, pubescent, many times forked, with slender or capillary branches; lrs. lanceolate, varying to oblanceolate; the 
cauline opposite, the raminal alternate; 2 pairs of scarious, subulato stipules at each fork, which are shorter thiun tine flower; style none; utricle equaling the greenish, sepals - Hilly woods, Can. to Ga., W. to Ark. Hight 6-10 or 18', oflen nearly smooth. Lvs. 4-10" long, somewhat stalked. Fils. $\frac{1}{2}$ " long, somewhat pedicellate. Seed globular, rosin colorod. Jn.-Aug. (Queria, L. Anychia capillacea Nutt.)

B. pumila. Dwarf, a few inches $\left(2-4^{\prime}\right)$ high, the lva. reduced in proportion, very pubescent; stems short-jointed, tufted, fls. sessile, glomerate; style as long as the ovary (at least in specimens from Md. sent by Mr. H. Shriver), forked at apex. (A. dichotoma DC.)

17. SIPHONÝCHIA, Torr. and Gr. (Gr. oiф $\omega v$, a tube, that is, Anychia with a tubular calyx.) Sepals linear, petaloid above, coherent into a tube below, unarmed; petals 5 setæa alternate with the stamens; style filiform, minutely bifid; utriele included in the calyx.-(1) Procumbent, diffuse and widely spreading. Fls. in glomerate, terminal cymules.

S. Americàna Torr. and Gr.-S. Car. to Fla. Sts. 1-2f in length. Lrs. oblanceolate, much shorter than the internodes, 12-9-6" long, obtuse. Bracts. like the lvs., very small. Fls. very numerous, $1^{\prime \prime}$ or more in length, with hooked bristles below. Sep. white above. (Herniaria Nutt.)

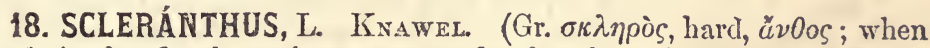
in fruit the floral envelope appears hard and dry.) Sepals 5 , united below into a tube contracted at the orifice; petals 0 ; stamens 10 , rarely 5 or 2 ; styles 2 , distinet; utricle very smooth, inclosed in the hardened calyx tube.-(1) A prostrate, diffuse little weed, exstipulate.

S. ánnuus L. Dry fields and roadsides, N. Eng. and Mid. States. Sts. numerous, branching, decumbent, short $\left(3-6^{\prime}\right)$. Lvs. linear, acute, short, opposite, partially united at their bases. Fls. very small, green, in axillary fascicles. Jl.

19. Móllugo, L. Carpet-weed. Calyx of 5 sepals, inferior, united at base, colored inside; corolla 0 ; stamens 5 , sometimes 3 or 10 ; filaments setaccous, shorter than and opposite to the sepals; anthers simple; capsule 3-celled, 3-valved, many-seeded; seeds reniform.-Lus. at length apparently verticillate, being clustered in the axils.

M. verticillàta L. Lvs. euneiform, acute; st. depressed, branched; pedicels 1-flowered, subumbellate; sta. mostly but 3.-(1) Dry places througliout $\mathrm{N}$. America. Sts. slender, jointed, branched, lying flat upon the ground, forming a roundish patch. At every joint is a cluster of wedge-shaped or spatulate lys. of unequal size, usually 5 in number, and a few flowers, each on a solitary stalk, which is very slender, and shorter than the petioles. Fls. sma!l, white. Jl.-Septo

\section{Order XXII. POrtulacace AE. Purslanes.}

IIerls succulent or fleshy, with entiro leaves, no stipules, and regular flowers. Sepals 2, united at base, rarely 3 or 5. Petals 5, rarely 0 , more or loss imbricated in $x$ stivation. Sta. variablo in number, but opposite the petals when as many. Ova. superior, 1-celled. Sty, several, stigmatous along tho inner surface. Fr. a fyxis, dehiscing by a lid, or a capsule, loculicidal, with as many valves as stigmas. Seeds fow or many, on long funiculi from the base, or on free central placentie.

Genera 27, species 250, inhabiting dry places in every quarter of the world. They possess no remarkable properties.

GENERA.

$\$$ Sepals 5. Petals none. Fruit a pyxis............................. Sesuric. 1

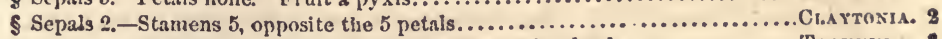

- Stamens 7 to $30,-$ hypogynous, capsule 8-valved...............

-perigynous. Pyxis opening by alid........... Portclaca. 4 
1. SESŨVIUM, L. Sea Purslane. Sepals 5, united below, colored inside; petals 0 ; stamens few or many, always more than the sepals, and inserted on them; capsules (pyxis) few, 3-celled, opening transversely like a lid; seeds $\infty$ minute.--Succulent sea-side herbs, with opposite lvs. and axillary, solitary fls.

S portulacástrum 'T'ourn. Lvs. linear-spatulate; fls. sessile or short-peduncled; stam. $\infty$.-Sea-coast, in sand, N. J. to Fla. St. round, branching, smootl, thick, a foot or more in length. Lvs. obtuse, tapering at base to a petiole, very thick and smooth. Ped. much shorter than the leaves. Sep. ross-white inside, exceeding the rose-colored stamens. Jl., Nov.

2. Claytónia, L. Spring Beauty. Fig. 383, 384. (In memory of John Clayton, one of the earliest botanists of Virginia.) Sepals 2, ovate or roundish, petals 5, emargined or obtuse, stamens 5 , inserted on the claws of the petals; stigmas 3-cleft; capsule 3-valved, 2 to 5 -seeded.-Small, fleshy, early flowering plants, arising from a small tuber. Stem with $1-4$ leaves.

1 C. Caroliniàna $\mathrm{Mx}$. Lvs. ovate-lanceolate; sep. and pet.obtuse.-21 A delicato little plant, common in woods and rocky hills, Can. to N. Car. W. to the Niss. Rt. a compressed, brown tuber, buried at a depth in the ground equal to the hight of the plant. Root lvs. very few if any, spatulate. St. weak, 2 to 3 ' high, with a pair of opposite leaves half way up, which are 1 to $2^{\prime}$ by 4 to $8^{\prime \prime}$, entire, tapering at base into the petiole. Fls. in a terminal cluster, white with a tinge of red, and beautifully penciled with purple lines. Apr., May.

2 C. Virgínica L. Lvs. linear or lance-linear; sep. rather acute, pet. obovate, mostly emarginate or retuse; ped. slender, nodding.-24 In low, moist grounds, Mid. and S. States, W. to Mo., rare in N. Eng. Tuber as large as a hazel nnt, deep in the ground. St. 6 to $10^{\prime}$ long, weak, with a pair of opposite, very narrow lvs. 3 to $5^{\prime}$ long. Fls. 5-10, rose-colored, with deeper colored veins, in a terminal, finally elongated raceme. Apr., May.

3. TALINUM, Adans. Sepals 2, ovate, concave, deciduous; petals 5, sessile; stamens 10 to 20 , inserted with the petals into the torus; style trifid; capsule subglobous, 3-valved, many-seeded.

T. teretifòlium L. St. simple or branched, short and thick; Ivs. linear, crowded at the summit of the stem, on short branches; ped. elongated; fls. in a dichotomous cyme.- 4 An interesting plant on rocks, Penn. to Ga. and westward. Rhizome or perennial stem firm and fleshy, with fibrous roots. Branches 1 to $3^{\prime}$ long. Lvs. 1 to $2^{\prime}$ long, incurved, fleshy. Bracts ovate-lanceolate, minute. Ped. 5 to $8^{\prime}$ high, very straight, slender, and smooth. Fls. $8^{\prime \prime}$ broad, purple, ephemeral. Stam. about 20. Caps. globular, with 35 seeds. Jn., Aug.

4. PORTUláca, Tourn. Purslanes. Sepals 2, the upper portion deciduous; petals 5 (4 to 6 ), equal ; stamens 8 to 20 ; styles 3 to 6 cleft or parted; pyxis subglobous, dehiscing near the middle, manyseeded.-Low, herbaceous, fleshy. Fls. expanding only in sunshine.

1 P. oleràcea I. Lvs. cuneate; fls. sessile.-I) A prostrate, fleshy weed, more common in our gardens than desirable. St. thick and succulent, mueh branched and spreading, smooth. Lrs. fleshy, sessile, rounded at the end. Fls. yellow. The herbage of the plant is of a reddish-green color. Sometimes used as a potherb. Jn., Aug. §.

2 P. granđiflòra Hook. Sts. ascending, much branched, hranches suberect, enlarged upwards; lvs. linear, acute, the axils villous, with long, woolly hairs; fls. terminal, sessile, 1 or few together, surrounded by an irregular circle of leaves 
and dense tufts of wool; pet. obovate; stam. about 15.-4 A very delicato plant, with purple stems and bright purple fls. $1 \frac{1^{\prime}}{2}$ diam.

P. Gillièsii Hook, with short, cylindrical, blunt lvs., somewhat flattened, ascending, branched stems, and large, deep purple fls., is also popular in house cultivation. These species are natives of S. America. $f$

\section{Order XXIII. MEsembry}

Plants neshy, of singular and various form, yet beautiful, with opposite, fleshy leaves. Fils. solitary, axillary and terminal, remarkable for their profusion, brilliant, and of long duration. Sipals definite; petals numerous, colored, in many rows. Sta. indefnite, distinct, arising from the calyx (perigynous). Ova. inferior or nearly superior, many-celled. Stigmas numerous. Caps. many-celled, opening in a stellate manner at the apcx, or one-celled. $S d s$. moro commonly indefinite, attached to the inner angle of the cells, or to a free central placentæ.

Genera 5, species 875, chiefly natives of the arid, sandy plains of the Cape of Good Iope. The speeles are much cultivated for ornament. Lewisia rediviva of Oregon, called Spatlum, is highly valued for its farinaceous, nutritive roots.

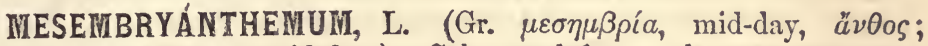
flowers expanding at mid-day.) Calyx 5-cleft; petals very numerous, linear; stamens $\infty$, perigynous; capsule inferior, fleshy, turbinate ; seeds numerous, either axile or parietal.

1 M. crystallìnum L. ICE-PLANT. Biennial, procumbent; lvs. large, ovate, acuite, wavy, frosted, 3-veined beneath.-A popular houss plant, from Greece. It has a creeping; stem, If or more in length, and with the leaves is covered over with frost-like, warty protuberances, giving the plant a very singular aspect. Fls. white, appearing all summer. $f$.

2 M. grandiflòrum L. Perennial, procumbent, spreading; lvs. petiolate, opposite, cordate-ovate; cal. 4-cleft, 2-horned.-4 An interesting plant in house cultivation, from Cape Good Hope. The whole plant fleshy and succulent, liko others of its kind. Fls. pink-colored. Calyx thick, green, tho horns opposite. Caps. translucent, marked at summit with cruciform lines. $f$.

\section{Order XXIV. MaLVacEe. Mallows.}

Herbs or shrubs with alternate, stipulate lvs. and regular flowers, with 5 sepals united at base, valvato in the bud, often subtended by an involucel; 5 petals hypogynous, convolute in the bud, with the stamens $\infty$, monadelphous, hypogynous, and 1-celled, reniform anthers. Pistils several, distinct or united, and stigmas various. Fruit a several-celled capsule, or a collection of 1 -seeded indehiscent carpels. Seeds with little or no albumen, and a curved embryo. (Fig. 252, 352.)

Genera 40 , species 1000 , abundant. in the tropics, frequent in tho temperate zones, entirely wanting in the frigid. Cottm, one of the most important products of the vegetable kingdom, is

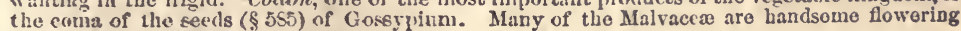
plauts, and are often cuitivated as such.

P'operties.-Generally abounding in mucilage, and destituto of any deleterious qualities.

\section{GENERA.}

\$ Calyx naked, i. e, having no involucel. (b)

$\$$ Caly involucclate.-Carpels (and styles) more than 5. (a) -Carpels 3 to 5 only, -one-seeded. (c)

$-3-\infty$-seeded. (d)

a Involucel of 6 to 9 bractlets. Carpels 1 -seeded..................Auth

a Involncel of 3 distinct bractlets. Carpels 1 -seeded..................... 2

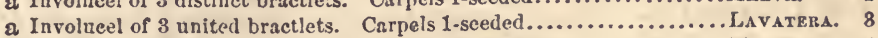

Involucel of 3 distinct bractlets. Carpels 2 -seeded.................. 4 
b Flowers diœcious. Stigmas 10, linear................ NAPAA.

b Flowers perfect. Carpuls 5 or more, 1 -sceded................SIDA. G

b Flowers perfect. Carpels 5 or many, 3 to 9 -seeded.......... A вUтіLox. 7

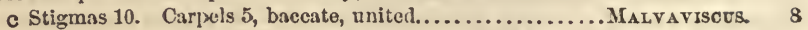

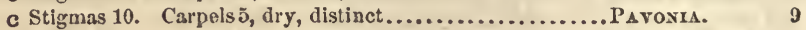

c Stigmas 5. Carpels 5, dry, united into a pod............ Kosteletzkra. 10

d Involucre of many bractlets. Calyx regular............... Hibiscus. 11

d Involucre of many bractlets. Calyx split on one sile........ A Bewascius. 12

d. Involucre of 8 Incisely toothed bractlets................ Gossriviu. 13

1. Althiea, L. Marsh Mallow. (Gr. ä $\lambda 0 \omega$, to cure; the mucilaginous root is highly esteemed in medicine). Calyx surrounded at base by a 6 to 9 -cleft involucel; styles $\infty$, with linear stigmas; carpels $\infty$, 1-seeded, indehiscent, arranged circularly, and at maturity separating from the axis.

I A. officinàlis L. Lvs. soft-downy on both sides, cordate-ovate, dentate, somewhat 3-lobed; ped. much shorter than the leaves, axillary, many-fowered.-4 Me. to N. Y., borders of salt marshes. St. 3f high, erect, firm, covered with thick woolly down, with alternate, velvet-like leaves. Fls. large, axillary and terminal, pale purple. The root as well as the other parts of the plants, abounds in mucilage, and in medicine is often used as an emollient. Sept. $f$ \& Eur.

2 A. ròsea Cav. Hor.LYHock. St. erect, hairy; lvs. cordate, 5 to 7 -angled, rugous; fls. axillary, sessile.-(2) A tall plant, very commonly cultivated in gardens. Numerous varieties have been notieed, with single, double, and semi-doubleflowers, of various shades of color, as white, rose-colored, flesh-colored, dark red, and even a purplish black, purple, rellow, straw-color, etc. $\dagger$ China? (Alcea rosea L.)

3 A. ficifòlia Cav. Fig-LEAVED HoLlYHock. St. erect, hairy; lvs. palmate, 7-lobed beyond the middle, lobes oblong, obtuse, angular-toothed.-(2) St. tall as the above. Fls orange-colored. + Levant. (Alcea ficifolia $L_{\text {.) }}$

2. MÁLVA, L. MALLOW. (Gr. $\mu c \lambda a \chi \eta$, soft; on account of the soft mucilaginous properties.) Calyx 5-cleft, the involucel 3-leared; petals obcordate or truncate; styles $\infty$, with linear stigmas; carpels $\infty$, 1-celled, 1-sceded, indehiscent, arranged circularly, and at maturity soparating from the axis.

\&eaves orbicular, with 5 to 7 angular lobes. Carpels obtuse.................. 1-3

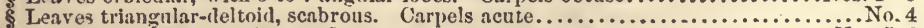

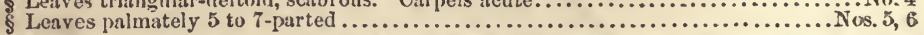

I M. rotundífólia L. Low MaLLow. St. prostrate; lvs. roundish, cordate, obtusely 5-lobed; ped. in fruit reflexed; cor. (pale) twice as long as the calyx.4 Common in cultivated grounds. Sts. numerous, a foot or more long. Lrs. somewhat reniform, crenate, with 5 to 7 shallow lobes, and on long, hairy stalks. Ped. axillary, aggregate. 'Petals pale pink, deeply notched. Fr. depressed-globr ous, composed of the numerous carpels arranged circularly, not wrinkled. The child sportively calls them cheeses. Jn.-Oct. § Eur.

2 M. sylvéstris L. Higri Mallow. St. erect; lvs. 5 to 7-lobed, lobes of tho upper lvs. rather acute; carp. very rugous; pet. (purple) 3 times longer than sep.A popular garden flower of the easiest culture, often springing up spontaneously in fields and road-sides, Mid. and W. States. Height 3f. Fls. reddish-purple, with veins of a darker hue. The whole plant, especially the root, abounds in mucilage. Jn.-Oct. § Eur.

3 M. críspa L. St. erect; lvs. angular-lobed, dentate, crisped, smooth; ffs. (white) axillary, sessile.-1) A tall, straight, simple, erect plant from Syria. Gardens, almost naturalized. St. 5 to $6 \mathrm{f}$ high. Lvs. large, roundish, margins abnndantly crisped and curled. Fls. white, not conspicuous. Jn.-Aug. $\dagger$ \&

4 M. triangulàta Leav. St. erect, hirsute; lvs. strigous, triangular-deltoid, lower ones, cordate, all undivided, coarsely crenate; panicle terminal, diffuse, many-flowered; petals purple; carp. 10 to 15 , slightly beaked.-Prairies and 
bottoms, Wis., Ill. to Ark. A handsome but rather rough species, 2 to $3 f$ high. Root fusiform. Lrs. 2 to $3^{\prime}$ by 1 to $2^{\prime}$, on long, hairy petioles, thick. Fls. nearly as large ( $1 \frac{1}{2}$ diam.) as those of Mr. sylvestris. Beak of the carpels horizontal, a mere angle. Jl, Aug. (Callirrhoe Gray. M. Ilouglitonii, lst ed.)

5 M. papàver Cav. Poppr Mallow. Lrs. palmately 3 to 5-parted, on long potioles, segments oblong or linear, entire or toothed; fls. on very long peduncles. 4 Ga., Fla. to La. A curious species, strongly reminding one of the poppy (Papaver Rheas) in the form and size of the bright red or purple fls., and the very long ( 5 to $8^{\prime}$ ), upright peduncles. Sts. branched from the base, scabrous, ascending 12 to $18^{\prime}$. Lrs. variable, the lobes usually quite narrow and open, 2 to $3^{\prime}$ long. Petals crose-crenulate. Involucel (rarely wanting) shorter than the calyx. NLay-Aur. (Nuttallia, Graham.)

6 M. moschàta L. MUsk MALlow. St. erect; radical lvs. reniform, incised, cauline ones 5-parted; the segments linear-cuneiform, incisely lobed; peduncles shorter than the leaves.-Native of Britain. St. $2 \mathrm{f}$ high, branched. Fils. large and handsome, rose-colored. The whole herb gives out a musk-like odor in favorable weather. Jl. $\nmid$

3. LAVATĖRA, L. (Named in honor of the two Lavaters, physicians of Zurich.) Calyx subtended by an involucel of 3 united bracteoles; stigmas $\infty$, filiform; carpels $\infty$, 1-celled, 1-seeded, indehiscent, arranged circularly as in Malva.

1 L. arbòrea L. TReE MIallow. Lvs. 7-angled, downy, plicato; ped. 1-flowered, clustered in 'he axils, much shorter than the petiole.-(2) A splendid plant for borders or shrubberies, from Europe. Hight about 6f. Fls. purple. Sept., Oct. $\dagger$

2 L. Thuringiaca L. Lvs. somewhat downy; lower ones angular, upper 3-lobed, the middle lobe largest; ped. solitary in each axil. - 4 From Germany. Hight 4f. Fls. light-blue. Sept.

3 L. tríloba Willd. St. and lvs downy; lvs. subcordate, roundish, obscurely 3-lobed above, crenate; ped. solitary, aggregated at top of stem; seps. acuminate, slightly larger than invol.-Gardens. Hight 2-3f. Fls. light purple. $J_{n}$., Jl + Spain.

4. MODİOLA, Mœnch. (Lat. modiolus, a ccrtain measure; from the fancied resemblance of the fruit to a basket.) Calyx 5-cleft, with an involucel of 3 bractlets at base; stigmas $15-20$, capitate; carpels same number, 2-sceded, transversely 2-celled, 2-valved.-(1)(2) Prostrate, with cleft lvs. and small flowers.

M. multífida Mœnch. St. rooting at the joints; lvs. roundish, cordate, $3-5$ cleft, segm. cut-toothed; ped. soon longer than the petioles.-Car., Ga., and Fla. Diffusely spreading $1-2$ f, thinly hirsute. Lvs. about $1^{\prime}$ broad, on petiolcs of similar length. Fls. 5-6" diam., purplish red, opening only in sunshine at midday. Carp. each opening by 2 valves, the valves each tipped with a slender bcak. May-Jl.

5. IJAP六A, Clayt. (Gr. vait $\eta$, a wooded vallcy between mountains, where (layton discovered the plant.) Involucel none; calyx 5-toothed; 1s. diœcious; styles $6-8$, with filiform stigmas; carpels as many, 1 -secded, indehiscent, beakless, circularly arranged.-24 Tall, with large, palmately divided lvs. and small white fls. in leafy panicles.

NV. dioìca $\mathrm{L}$. A rare plant, in rocky valleys and deep shades, Penn., Va., to III. Sts. slender, nearly smooth, 4-6f high, supported by other plants. Lvs. rather rough, 7-11-parted. the segm. linear-lanceolate, coarsely toothed, $3-6^{\prime}$ long, acuminate, upper lvs. 5-parted, much smaller. Fls. $4-5^{\prime \prime}$ diam. Petals twice longer than tho calyx. Aug. (Sida dioica Car.) 
6. SiDA, L. Calyx 5-cleft, without an involucel; fls. perfect; styles 5 or more, with capitate stigmas; ovary 5 to many-celled; capsule of 5 or more 1-seeded carpels; radicle superior.

Leaves palmately parted. Fls, rose-white. Carpels, beaked..................Nos. 1, 2

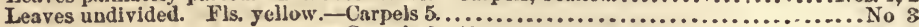

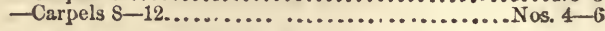

1 S. Napæa Cav. Nearly glabrous; 17s. palmately 5-lobed, lobes oblong, acuminate, coarsely-toothed; ped. many-flowered; carpels 10, acuminate-beaked.2f In rocky woods, Penn. and Va. (rare, more common in gardens). Sts. 2-4f high. Lobes of the lrs. 2-3' long. Fls white, twice larger (7-9" jroad) than in Naprea dioica. Petals obovate, twice longer than tho calyx. Jl. $t$ (Napæa lævis and bermaphrodita L.)

2 S. alcæoides Mx. Strigous-pubescent; lvs. palmately 5-7-parted, the segments laciniate; fls. corymbed, terninal; carp. 10, acute-4 In barren oaklands, Tenn., Ky. Sts. 1-2f high. Corymbs 3-6-flowered. Fls. nearly as large as those of the musk mallow, to which plant this bears a general resemblance. (Callirrhoë alçeoides Gray.)

3 S. spinòsa L. St. rigid, branched, minutely pubescent, Irs. ovate-lanceolate, serrate, with a spinous tubercle at the base of the petiole; stip. setacecus, shorter than the petioles or axillary peduncles; carp. birostrate.-(2) Sandy fields and roadsides, Mid., S. and W. States. Plant bushy, 8-16' high. Lvs. 9-15" long, $\frac{1}{2}$ as wide, mostly obtuse at each end. Petals yellow, obovate, of short duration. Carp. 5. Jl., Aug.

4 S. híspica $\mathrm{Ph}$. Hispid-pubescent; lvs. lanceolate, and rhombic-lanceolato, dentate-serrate; stip. subulate, hispid, longer than the-petioles or axillary, solitary or clustered peduncles; carpels 2-horned, 10-12.-24 Sandy soils, S. Car., Ga. (Feay). Sts. much branched, 12-18' high. Petioles 2-3" long, the peduncles rather longer, jointless. Petals yellow, a little exceeding the calyx. On the young stems the lvs. are rhomboidal. Jl, Aug.

5. S. Ellióttii Torr \& Gr. Lvs. linear-oblong and linear, denticulate, obtuse at base; ped. 1-flowered, a little longer than the very short $\left(2-5^{\prime \prime}\right)$ petioles4 Sandy plains, S. Car. to Fla. St. slender and widely branched, $2-5 \mathrm{f}$ high. Lvs. $1-3^{\prime}$ long, varying from narrowly linear to oblong $\left(1-5^{\prime \prime}\right.$ wide). Fls. $1^{\prime}$ broad, orange-yellow, nearly solitary in the axils. Petals emarginate. Carp about 10. May-Aug.

6 S. rhombifòlia L. Lvs. rhombic-oblong, serrate, cuneate and entire at base; ped. much longer than the petioles, jointed just below the flower; caps. 2-beaked. -Sandy soil, S. Car. to Fla. St. 1 to $2 f$ high, minutely downy. Irs. 1 to $2^{\prime}$ long, rather obtuse at apex. Fls. yellow, 7 to $9^{\prime \prime}$ broad, the stalks 1 to $2^{\prime}$ long: Cal. angular, with broad, cuspidate sepals. Mlay-Jl.

7. ABŨtilon, Dill. Indian Mallow. Calyx 5-cleft, without an involucel, often angular; styles 5 to 20 , with capitate stigmas; carpels as many, arranged circularly, each 1-celled, 3 to 6 -seeded, and opening by 2 valves.

1 A. Avicénnae. Lvs. roundish, cordate, acuminate, dentate, velvety-tomentous; ped. shorter than the petiole, solitary; carp. about 15, 3-seeded, inflated, truncats, 2-beaked. - (1) Native in both Indias and naturalized in most of the States, inhabiting waste places, \&c. St. branched, 3 to 4 f high. Lvs. 4 to $6^{\prime}$ diam., deeply cordate at base, abruptly acuminate at apex, very soft and velvety at surface. Fls. yellow, near I' broad. Jl. §

2 A. striàtum Dick. Shrub, with 5-lobed, long-stalked lvs., the lobes acuminate, dentate; peduncles long, nodding, with a handsome bell-shaped flower, the column exserted.-An elegant green-house shrub, flowering at all seasons. Petals orange-color, with conspicuous purple striæ. † Brazil.

8. MalvaVísCUS, Dill. Glue Mallow. (Lat. malva, mallows, viscus, give.) Calyx 5-cleft, subtended by an involucre of many bractlets; 
petals erect, convolute; styles 10 , with capitate stigmas, the inner longer; carpels 5, baccate, 1-secded, forming a fleshy fruit.-Half slirubby plants, with showy, red flowers.

I M. Drummóndii Torr. \& Gr. Tall, minutely tomentous; lvs. roundish, cordate, angularly-3-lobed, crenate; ped. axillary, solitary, shorter than the petioles; fls. erect; bracteoles 8 , linear-spatulate.-Texas. Naturalized about N. Orleans (Hale). St. round, branched, 3 to $4 \mathrm{f}$ high. Lvs. 3 to $4^{\prime}$ diam., tho petioles half as long. Fls. bell-shaped, scarlet. Column slender, twice longer than the corolla. $t$

2 M. Floridàna, with leaves ovate-cordate, and fls. pendulous, scarlet, grows in S. Fla. and sometimes in tho green-houss.

$3 \mathrm{M}$. arbòrea, with lvs. 3 to 5 -lobed, acuminate, serrate, and scarlet fls., from Jamaica, is cultivated often in the green-houso; and also, M. mollis, velvety, 3-lobed, sub-entire lvs.

9. PAVÒNIA, Cav. (The Latin name of the peacock, suggested by the colors.) Calyx 5-sepaled, surrounded at the base with an involucel of 5-15 bractlets; petals roundish, obtuse ; stigmas 10, linear; carpels 5 , capsular, 2 -valved, 1 -seeded.

P. Lecontii T. \& G. Stem shrubby, much branched; lvs. many, small, sagittateoblong, obtuse, with coarse, obtuse teeth, the lower surface hoary-tomentons, veins prominent; upper surface scabrous; sepals ovate, 3-veined, downy, acumiminate, as long as the 5 oval, acute bractlets; carpels blunt, rugous, scarcely dehiscent.-Liberty Co., Ga. (Mr. W. Jones). Stem 4-5f high. Lvs. $1 \frac{1}{2}-2^{\prime}$ long, the floral much smaller. Fls. $1 \frac{1}{2}{ }^{\prime}$ diam., rose-white, with a deep purplo center. (Malva Lecóntii Buckley?)

10. KOSTELÈTZKYA, Presl. (In honor of Kosteletzky, a German botanist.) Calyx, involucel, styles, etc., as in Hibiscus. Fruit a 5-celled, depressed capsule, with a single seed in each cell.

K. Virgínica Presl. Lvs. acuminate, cordate, ovate, serrate, dentate, upper and lower ones undivided, middle ones 3-lobed; ped. axillary, and in terminal racemes ; fls. nodding, pistils declinate.-2 Marshes near the sea, L. Isl. to Ga. and La. (Hale). The whole plant scabrous, tomentous, about $3 \mathrm{f}$ high. Ivs. 2 to $2 \frac{1}{2}$ by $1 \frac{1^{\prime}}{2}$, long-pointed, some of them somewhat 3-lobed. Fls $2 \frac{1}{2}^{\prime}$ diam., red or rosecolor. Column slender, as long as tho petals. Caps. hispid, acute-angled. Aug. (Hibiscus Virg. L. and Ed. 2d.)

11. HIBÍSCUS, L. Calyx 5-cleft, subtended by an involucel of many bractlets, column long with the stamens lateral and the 5 stigmas capitate ; fr. a 5-celled capsule, loculicidal, the valves bearing the partitions in the middle; seeds 3 or many in each cell.-Herbs or shrubs. Fls. large and showy.

* Calyx, \&c., hispid. Leaves palmately divided............................ Nos. 1, 2

* Caiyx, \&c., tomentous. Lvs. undivided, angularly lobed............................ Nos. 3,4

* Calyx, \&c., glabrous.-Leaves deeply lobed or parted........................... Nos. 5, 6 - Leaves undivided, slightly lobed.................................... 7, 8

1 H. aculeàtus Walt. Retrorsely scabrous; lvs. palmately 3 to 5-lobed, repandtoothed, bractlets of the involucel linear, forked at the end; sep. red-veined, acuminate, very hispid.-Damp soils, S. Car. to Fla. and La. Tall (3-5f) and very rough. Lrs. 2 to $3^{\prime}$ broad, as long as their stalks. Ped. very short (3 to $\left.4^{\prime \prime}\right)$, jointed at base. Cor. $4 \frac{1}{2}$ broad, pale sulphur-yellow, purple in the center. Styles $\frac{1}{3}$ longer than the stamens. Jn.-Sept. (H. scabra $M x$.)

2 H. Triònum L. Flower of AN HOUR Bladder KetMia. Hispid, with scattered hairs; lvs. deeply 3-parted, segm. lanceolate, middle one very long, all sinuate-lobed, lower lvs. angular-lobed; cal. inflated, membranous, veined; brastlets subulate, entire.-(1) A beautiful flower, eseaped from gardens and barely naturalized, branching, 1 to $2 \mathrm{f}$ high. Fls. large, numerous, but soon withering. I'tals of a rich, chlorine yellow, the base of a deep brown. $\dagger$ Italy. 
3 H. Moscheùtos L. Marsi Hrisces. Simple, erect, hoary-tomentous; lvs ovate, obtusely dentate, some of them 3-lobed, nearly smootb above; ped. long axillary, or confluent with the petiole; caps. smooth; sep. abruptly pointed-24 $\Lambda$ tall, showy plant, in brackish marshes by the sea, or near salt springs, and on wet prairies, U. S. and Can. St. round, downy, 4 to $6 f$ high. Lvs. 4 to $6^{\prime}$ by 3 to $4^{\prime}$, often with 2 lateral lobes. Fls. larger than those of the hollyhock, rosecolored, purple in the center. Ped. usually distinct from the petiole, often some of them united with it, and jointed above the middle. Sty. 1' longer than the stamens. Aug.

$\beta$. FLA VESCENS. Fls. larger; pet. (4' long) of a light sulphur yellow, with a purplo base. Marshes, Ind. (H. incanus Wendl.)

4 H. grandiflòrus $\mathrm{Mx}$. IToary-tomentous; lvs. cordate, acuminate, repand-dentate, the lower often 3-lobed, hoary beneath, coriaceous; cor. half-expanding; sep. gradually pointed; caps. densely clothed with woolly hairs. - "Lake shores, N. Orleans" (Hale), to Ga. Stems branched above, 5 to $7 \mathrm{f}$ high. Fls. corymbed, terminal; petals $4 \frac{1}{2}$ ' long, flesh-colored, red at baso, column declined, rather shorter than the petals. Jl.-Oct.

5 H. militàris Car. Glabrous; lvs. hastately 3-lobed, lobes acuminate, serrate; cor. tubular-campanulate; caps. smooth, ovoid-acuminate.-Mid. and W. States. St. 3 to $4 \mathrm{f}$ high. Lrs. cordate at base, 4 to $5^{\prime}$ long, rendered somewhat hastato by a divaricate lobo each sido at base. Petals flesh-color, with a purplish base, 2 to $3^{\prime}$ long. Ped. with the joint above the middle. Jl., Aug.

6 H. coccíneus Walt. Very smooth; lvs. palmate, 5-parted, lobes lanceolate, acuminate, remotely serrate above; cor. expanding; caps. smooth, ovoid.-2t A splendid flower, native of damp soils, in Ga., etc., and is raised from seeds in gardens, northward. Rt. perennial. St. herbaceous, 5 to 9 f high. Segm. of lvs. 6' long, very acuminate. Fls. of a bright carmine red. Petals slender at the base, 4 to 5 ' long. Column still longer, slender and terete. Jl.-Oct. $\uparrow$. (H. specia sus Ait.)

7 H. Caroliniànus Muhl. Herbaceous, glabrous; lvs. cordate, ovate, acuminate, some of them obscurely 3-lobed; ped. distinct fiom the petiole; petals pubescent inside; caps. hairy inside; sds. hispid.-Wilmington Isl. Ga. (Elliott.) A rare species, apparently lost to modern botanists. Petals purple, $4^{\prime}$ long. Caps. globular.

8 H. Syrìacus L. Tree Hibiscus. Arboreous; lvs. ovate, cuneiform at base, 3-lobed, dentate; peduncle scarcely longer than the petiole; involucel about 8-leared.-A beautiful, hardy, free-flowering shrub or small tree, 8 to $15 \mathrm{f}$ high. Fls. purple, large. There are varieties with white, recl, and striped fls., both singlo and double. + Syria.

12. ABELMÓSCHUS, Medik. Okra. (Arabic Ab-el-mosch, grain or seed of musk; the seeds smell of musk.) Calyx large, spathaceous, i.e., splitting to the base on one side; involucel, column and fruit as in Hibiscus.

1 A. Mánihot Medik. Not prickly; lvs. palmately divided into 5 to 7 linear, acuminate, coarsely dentate lobes; ped. and involucel hispid; bracts of the involucel 5 to 7, ovate or lanceolate, acutish, persistent, entire; cal. split on one side; caps. densely hirsute, acuminate.- 4 Western States. A beautiful herb, 4 to $5 \mathrm{f}$ high. Lrs. cordate, lobes 6 to $10^{\prime}$ long, $\frac{1}{2}$ to $11^{\prime}{ }^{\prime}$ wide, separated to near the base, about as long as the petioles. Teeth largest near the summit. The fls. are of an exeedingly rich sulphur yellow, purplo in the center. Petals 3 to $4^{\prime}$ long. Jl., Aug. (Hibiscus, L.)

2 A. esculéntus Medik. OKrA. Lvs. cordate, 5-lobed, obtuse, dentato; petiole longer than the flower; involucel about 5-leaved, caducous. - Native of W. Indies. Plant herbaceous, 2 to $3 \mathrm{f}$ high, nearly glabrous. Petiole with a hairy line on the upper side, nearly if in length. Lamina 8 to $10^{\prime}$ broad. Fls. 1 to $2^{\prime}$ long, on a short peduncle. Petals greenish yellow. The large, mucilaginous pods are used for pickles, or served up with butter. (Hibiscus, L.) 
3 A. Collinsiàna. Lis. pedately 5-parted, segm. linear-oblanceolate, coarsely toothed, acuminats, the lowest obtusely 5-lobed; ped. short, involucel 10 to 12 leaved.-Fla., rare. Plant thinly hirsute or hispid. Lvs. 6 to $8^{\prime}$ broad. Fls. much as in No. 2. (Hibiscus, Nutt.)

13. GOSSÝPIUM, L. Cotton Plant. Fig. 252. (Name said to bo from the Arabic, goz, a silky substance.) Calyx obtusely 5-toothed, surrounded by an involucel of 3 cordate leaves, deeply and incisely toothed; stamens very numerous, lateral ; stigmas 3 , rarely 5 , clavate; seeds $\infty$, involved in cotton.-Fls. yellow.

G. herbàceum L. Cotton Plant. Lvs. 3 to 5-lobed, with a singlo gland below, lobes mucronate; seeds brownish, cotton white.-(1) The species commonly cultivated in the Southern States, and often growing spontaneously. It is an herbaceous plant, about $5 \mathrm{f}$ high, sown in early spring and harvested in autumn. Sts. hirsute above. Upper lvs. often but 2 or 3 -lobed, lobes commonly acuminate, tipped with a mucro. Petioles about as long as tho lvs., peduncles shorter. Fls. handsome, 3 ' broad, light yellow, with a purplo cye, changing to reddish brown. § E. India.

$\beta$ ? Barbadexse. Sea Island Cotton. Glands on the back of the leaf (midvein) 3 ; sds. black, cotton white.-(2) Sown in Sept. and Oct. Cotton long, with a silk-like texture. $\nmid W$. India. Chiefly cultivated near the southern coasts. (G. Barbadense L.)

G. arbòreum is tho Tree Cotton of E. India, with red flowers, and G. Per:1vianum, the Brazil Cotton. The Nankin Cotton is another variety of G. herbaceum. Plants so extensively cultivated as the cotton are liable to much variation. Of the thirteen species described by Do Candolle, oniy the threo abovo named are now regarded as genuine-the others considered as varieties.

The microszope shows the fiber of cotton to ccnsist of a lengthened and generally flattened cell, thus readily distinguished from tho fiber of silk, which is terete and solid, or wool, which is imbricate-scaly.

\section{Order XXV. STERCULiaCEA. Silk Cottons.}

Largo trees or shrubs with simple or compound leaves, with flowers similar to those of the Mallow, except that the anthers are 2-celied and turned outwards. Truit capsular, of 3 , rarely 5 carpels.

Genera 24, species 130, all native of tropical regions. Irere belong the huge Adansonia (BaoLab) of Africa, and the Bombax (silk-cotton trees) of S. America, etc.

STERCULLIA, I. (Stcrculius was the name of a detestable Roman god; alluding to the bad odor of some species.) Calyx 5-lobed, subcoriaceous; stamens monadelphous, united into a short, sessile cup; anth. adnate, 10,15 , or 20 ; carpels 5 , distinct, follicular, 1-celled, $1-\infty$-seeded.-Trees with axillary panicles or racemes.

5. platanifòlia I. Lvs. cordate at base, palmately 3-5-lobed, smooth; calyx rotate, reflexed.-Tree from China and Japan, cultivated at Savannah (Feay). A beautiful tree, with branching, axillary clusters of green fls. and leares resembling thoso of the Sycamore. J1. (Firmiana, Mars.)

\section{Order XXVI. TILIACEA. Lindendlooms.}

Trees or shrubs (rarely herbs) with simple, stipulate, alternate, dentate 1rs., with fls. axillary, hypogynous, usually perfect and polyadelphous; with the sepals 4 or 5 , deciduous, valvate in æstivation, the petals 4 or 5 , imbricated; stamens $\infty$, with 2 celled, versatile anthers. Ovary of 2 to 10 united carpels, a compound style, and 
stigmas as many as carpels. Fr. dry or succulent, many-celled, or 1-celled by abortion. Embryo in the axis of fleshy albumen. (Fig. 185.)

Genera 35 , species 350 , native in all regions, but especially within the tropics. Liko the Mallows, the Lindenbluoms abound in a wholesome mucilaqinous juice, and a tough, stringy bark. of the liber of the European Lindens the celebrated linssi: inatting is manufactured, and in India rarious species of Corchorus yleld a good substitute for hemp, used fur fishing-lines, nets, rice-bags, ete.

1. CóRCHORUS, L. Sepals and petals 4 or 5 ; stamens $\infty$, rarely as few as the petals; style very short, deciduous, stigmas 2 to 5 ; capsule roundish or siliquose, 2 to 5 -celled, many-seeded.-Herbs or shrubs with yellow flowers.

C. siliquòsus L. Branching, minutely hispid; lvs. ovate-lanceolate, acuminate, equally serrate, 4 times longer than the petioles; caps. siliquose, linear, 2-valved. - $A$ bout $N$. Orleans (Hale). St. slender. Lvs. 2 to 3 ' long, $\frac{1}{4}$ as wide, the veinlets running to the points of the serratures. Fls. 4-merous, with 12 or 16 stamens. Pod nearly $2^{\prime}$ long, the numerous seeds in 2 rows.

2. TILIA, L. Linden on Lime Tree. Calyx of 5 , united sepals, colored ; corolla of 5 , oblong, obtuse petals, crenate at apex ; stamens $\infty$, somewhat polyadelphous, each set (in the N. American species) with a petaloid scale (staminodium) attached at base; ovary superior, 5 -celled, 2-ovuled; capsules globous, by abortion 1 -celled, 1 to 2 -seeded. -Trees. Lrs. cordate. Fls. cymous, with the peduncle adnate to the vein of a large leaf-like bract.

\$ Staminorlia 5 , netaloirl, opposite the petals................................ 1, 2

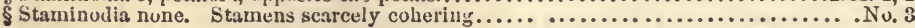

1 T. Americàna I. Bass-woon. Lvs. broad cordate, unequal at base, mucronate-serrate, acuminate, coriaceous, smooth and green on both sides; petals truncate or obtuse at apex; sty. as lony as the petals.-A common forest tree in the Northern and Mid. States. It often grows to the height of 80 f, the trunk straight, and naked moro than half this hight, and 3 to $4 \mathrm{f}$ diam. Lvs. 4 to $5^{\prime}$ by 3 to $4^{\prime}$, those of the young shoots often twice theso dimensions. Bracts yellowish, linearoblong. Petals yellowish white, larger than the staminodia opposite them. Fruit woody, greenish, of the size of peas. Jn.-The inner bark is very strong, and is manufactured into ropes. Tho wood is white, soft, and clear, much used in cabinet work and in the paneling of carriages.

$\beta$ Walteri. Lvs. pubescent (but green) beneath.-A largo trec, Va. to Fla., low country, in woods and along rivers. It takes the place of the smooth varicty (a), which is common northward and alorig the Mits. to Ga. (T. pubcscens $\Lambda$ it. T. laxiflora $\mathrm{Mx}$. T. Americana Walt).

2 T. heterophýlla Vent. Wurve Bass-woon. Lvs. obliquely subcordate, scarcely acuminate, whito and velrety beneath, with darker veins, glabrous, shining, and darlo green above, mucronately serrate; petals obtuse, crenulate; staminodia spatulate; sty. hairy at base, longer than the petals.-Banks of the Olio and Miss. (Pursh.) Not common. Trees 20 to $50 \mathrm{f}$ high. Lvs. very oblique at base, 3 to $5^{\prime}$ diam., well distinguished by tho white surface beneath, contrasted with tho purplo veins. Bract linear-oblong. Cal. hoary, gradually pointed. Fr. globular.

$\beta$ ALB.. Lvs. whitish and minutely tomentous beneath, serratures fino and long-mucronate.-Ky. and southward along the mts. Tree of great size. One specimen (Rock Castle Co.) I judged to be 90f in hight, with wide-spread branches, in open space. Reddish hairs in tho axils of tho veins beneath.

3 T. Européa L. Ime TrEe. Irs. suborbicular, obliquely cordate, abruptly acuminate, serrulate, twice as long as the petioles, glabrous except a woolly-tuft in the axils of the veins beneath.-A highly ornamental tree with very dense foliage, cultivated in parks. Bracts rhombic-oblong. † Eur. (T. mi crophylla, etc.) 


\section{Order XXVII. CaMelliace E: Camellias or Teaworts.}

Trees or shrubs with alternate, simple, feather-veined, exstipulate leaves. Flowers regular, polyandrous, hypogynous, cyanic, with sepals and petals imbricatcd, the former often unequal in size. Stamens moro or less coherent at base into one, three or five sets. Anthers 2-celled. Seeds few, with little or no albumen, cotyledons large.

Genera 33, specics 180. Beautiful flowering plants, 60 or 70 of them natives of $\mathrm{S}$. America, 4 of $\mathrm{N}$. America, the remainder of China and $\mathrm{E}$. Indies. Thelr properties aro stimulating nnu slightly narcotic. The tea, so extensively used as a beverage in the elvilized world is the leaf of 2 or 3 species of Thea. In contains a pecnliar extractive matter ealled theine, and a stimulating, essential otl, whieh becomes narcotle in some hot climates. Thea $B$ ohea and $T$. viridis are the two species which yield all the varieties of chinese teas, according to the various methods of preparing the leaves.

GFNERA.

\$ Calyx of many imbricated sepals. Stamens monalelphous............... CAMmuru. 1

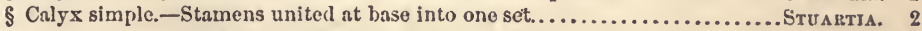
-Stamens in 5 sets, adhering to the base of the petals........ Gordonis. 3

1. CA Púlelia, L. Tea Rose. (In honor of G.J. Kamel, a Jesuit, author of some botanical works.) Sepals many, imbricated, the inner ones larger; petals sometimes adhering at base; filaments $\infty$, shorter than the corolla, united at base ; styles united; stigmas 3 to 5 , acute.Ornamental shrubs, native of China and Japan.

C. Japónica L. JAPAN Rose. Lvs. ovate, acuminate, acutely gerrate, glabrous aud shining on both sides, coriaceous and firm, on short petioles; fls. terminal and mostly solitary ; petals obovate, of a firm texture; sta. about 50 , mostly changcu to petals in cultivation; stig. unequally 5-cleft.-A lofty tree in Japan, its native country, a splendid flowering shrub with us, hardy at the Soutl, but requiring protection at the North. Fls. varying from white to red, resembling the rose, but wanting its fragrance. Over 300 varieties are enumerated.

2. STUÁRTIA, Catesby. (In honor of John Stuart, the Marquis of Butc.) Scpals 5 (or 6), ovate or lanceolate; petals 5 (or 6), cbovate, crenulate; stamens monadelphous at base; capsule 5-celled, 5 ( $\mathbf{r}$ 10-seeded, seeds ascending.-Shrubs with deciduous leaves and lange, showy, fragrant, axillary, nearly sessile flowers.

1 S. Virgínica Cav. Sep. ovate; sta. dark purple; sty. united into ore with a 5-lobed stigma.-Woods, middle country, Fla. to Va. A beautitul shrub, 8 to $12 \mathrm{f}$ high. Lvs. elliptic-ovate, acuminate at both ends, silky-pubescent bencath, sliglttly mueronate-serrulate, $2^{\prime}$ long, $\frac{1}{2}$ as wide. Petals white, nearly $2^{\prime}$ in lergth, slightly pubescent beneath, strongly contrasted with tho short, dark stamens. Nay. (S. Malachodendron L.)

2 s. pentagýna L'Her. Sep. lanceolate; stam. colored like the petals, very numerous; sty. 5, distinct, as long as the stamens.-Woods along streams in highlands, Ky. (Rock Castle and Madison counties) to Ga. $\mathrm{A}$ handsome slirub, 10 to $15 \mathrm{f}$ high. Lvs. thick, glabrous, ovate, acuminate, acute at base, obscurcly mucronate-serrate, 3 to $4^{\prime}$ long, $\frac{1}{2}$ as wide. Petals as large as in No. l, quite silky pubescent beneath, ono of them always much the smallest, whito (scarcely creamcolored). Caps. 5 -angled.

3. GORDÓNIA, Ellis. Loblolly Bay. (In honor of James Gordon, a distinguished nurseryman of London.) Sepals 5, roundisb, strongly imbricated ; petals, 5 ; stamens 5 -adelphous, one set adhering to each petal at base; styles united into one; capsule woody, 5 -celled; seeds 2 or more in each cell, pendulous. Trees with large, white, axillary, pedunculate flowers. 
I G. Iasiánthus L. Lvs. coriaceous, perennial, glabrous, shining on both sides, lance-oblong; peduncles half as long as the lvs.; sty. as long as the stamens. Swamps near the coast, Va. to Fla. The Loblolly Bay is a large tree 50 to $80 \mathrm{C}$ in height, with a rough bark when old, and light, coarse-grained, mahogany-colored w jod. Lrs. 3 to $4^{\prime}$ long, 1 to $2^{\prime}$ wide, acute at each end, fascicled at the ends of tho branches. Sep. very silky outside, small. Petals white, $1 \frac{1}{2}^{\prime}$ long, silky without at base. May-Aug.

2 G. pubéscens L'Her. Lis. thin, serrate, deciduous, oblong-cuneiform, shining above, canescent beneath; fls. on short peduncles; sep. and pet. silky outside.-A tree 30 to $50 \mathrm{f}$ high in Ga. and Fla., or an ornamental shrub in cultivation at tho North, admired for its large white flowers, with yellow stamens and rich fragrance. Lrs. membranous, subsessile, with fine, sharp serratures. May-Aug. (Franklinia Americana Marsh.)

\section{Order XXVIII. AUrantiace AE. Orangeworts.}

Trees or shrubs, glabrous, abounding in littlo transparent receptacles of rolatilo oil, with lvs. alternate, articulated with the petiole which is frequently winged. Fls. regular, 3-5-merous, petals and stamens inserted on a hypogynous disk. Stamens with flat filaments, distinct or cohering in ono or several sets. Ova. compounded of several united carpels. Sty. 1. Fr. a bcrry (orange) many-celled, pulpy, covered with a thick rind. Sds. attached to tho inner angle of each carpel. Albumen, 0. Cotyledon thick. (Figs. 276, 277.)

Genera 20, species 95 , nearly all natives of tropical $\Lambda$ sia, naturnlized throughout all tropical regions, and cultivated in all civilized countries for their beauty and fragrance, both of flowers and fruit.

Properties. These fruits contain free citric and malic acid, and their prulp is grateful to tho taste. The rind contains an aromatic, volatilo oil, which is tonic and stomachic. The rind of the lime yields the oil of Bergamot, and the flower of the orango the oil of Neroli.

CitRUS, L. (Gr. liir $\rho\llcorner o v$, the citron; the fruit of one of the species.) Sepals and petals in $5 \mathrm{~s}$; anthers 20 , or some other and higher multiple of 5 , versatile, the connectile articulated to the filament; filaments dilated at base, polyadelphous; berry $9-18$-celled. $-\Lambda$ noble genus of trees and shrubs, all tropical, combining in its species beauty of form, with shining, evergreen foliage, odoriferous fis., fragrant and delicious fruit. The articulation of the petiole with the lamina is regarded by some botanists as indicating a reduced compound leaf.

1 C. Limònum L. LEMor Tree. Petioles somewhat winged; sta. $35 ; \mathrm{fr}$. oblong-spheroid, with a thin rind and very acid pulp.-A tree about $15 \mathrm{f}$ in hight, which, when laden with its golden fruit suspended among its dark green leaves, makes a most heautiful appearance. It is a native of tropical regions, and is easily cultivated in the temperate climates if protected during winter. $\dagger$

2 C. Aurántium L. Sweet Orange Tree. Petiole winged; leaf slightly oblong, acute, crenulate; sta. 20 ; fr. globous, with a thin rind and sweet pulp.A middle-sized evergreen tree, with a greenish brown bark. When filled with its large, round, golden fruit (sometimes to the number of 20,000 , Lindley), it is one of the most beautiful objects in nature. The cultivation of the orange in. Fla. and S. Ga. has been recently checked by severe frosts. It is easily raised in the green house at the North. $† \S \mathrm{W}$. Indies.

3 C. decumàna L. SHADDOCK TREe. Petioles broadly winged; ottuse, emarginate; fr. very large, with a thick rind.-A tree $15 \mathrm{f}$ in hight. Wings of the petioles as broad as the leaves. Fr. grows to the diam. 'of $7-8^{\prime}$, weighs 14 pounds, and is of a yellowish-green color. $\dagger$

4 C. Limèta L. Lime Tree. Petioles not at all winged; lf. ovate-orbicular, serrate; stam. 30 ; fr. globous, with a sweet pulp, and a protuberance at top. This, like most other species, is native of Asia. Hight above 8f, with a crooked

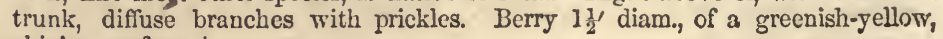
shining surface. $\dagger$ 
5 C. Médica L. Crtron Tree. Petioles not at all winged; lf. oblong, acuto; stam. 40 ; fr. oblong-spheroid, rugous, with an acid pulp.-Commonly about $8 f$ high. Fr. 6 in longth, fragrant. $\nmid$

Obs. In a splendid work entitled "The Natural Ilistory of Oranges," written in French by Risso, of Nice, in 1818, there are described 169 varieties, and 105 of them figured. They are nrranged as sweet oranges, of which there are described 42 varieties; bitter and sour oranges, 32 ; Bergamots, 5 ; Limes, 8 ; Shaddocks, 6 ; Lumes, 12 ; Lemons, 46 ; Citrons, 17. Tho most successful methods of cultivation aro by cuttings.

\section{Order XXIX. MELIACE E.}

Trees or sturubs with exstipulate, often pinnate leaves. Fls. 3-5-merouis, stamens 6 -10, coherent into a long tube with sessile anthers. Disk lyypogynous, sometimes cup-like; style 1. Ovary compound, several-celled, cells 1-2, 4-ovuled. Fruit fleshy or dry, often 1-celled by abortion. Seeds neither winged nor axillato.

Cenera 33, species 150 , natives of the hotter parts of tho globe.

MELIA, I. Pride of India. (Gr. $\mu \dot{\varepsilon} \lambda \iota$, honey; the name was first applied to the Manna Ash.) Sepals small, 5, united; petals spreading; stamen tube 10-cleft at summit with 10 anthers in the throat; ovary 5 -celled, 10 -ovuled; style deciduous; drupe with a 5 -celled, bony nut, cells 1-seeded.-Trees with bipinnate 1vs. and panicles of delicate flowers.

II. Azédarach L. Lvs. deciduous, glabrous, lits. obliquely lance-ovate, acuminate, serrate.-Southern States, common. A large tree $30-40 \mathrm{f} \mathrm{high,} \mathrm{with} \mathrm{light}$ foliage and a profinsion of lilac-colored fls. Drupes as large as cherries, with a poisonous pulp, hanging in clusters through the winter. The bark is esteemed as a vermifuge, but narcotic. Dwarfed specimens are frequent in green houses at the North.

\section{Order xXX. liNacE瓜. Flaxworts.}

Iferbs with entire, simplo leaves and no stipules; with flowers regular, symmetrical, and perfect, 5-(rarely 3 or 4-)merous. Calyx strongly imbricated in the bud, corolla convolute, hypogynous; stamens definite, lyypogynous, alternate with tho petals; styles distinct with capitate stigmas, and each cell of the capsulo more or less divided by a false dissepiment into two 1-seeded compartments. Seeds with littlo or no albumen, attached to axile placentre.

Genera 3, species 90. A very important order in tho arts. The Linum las a rery tenacious nber in its bark, which is wronght into thread and eloth, forming the linen of commerce. Sume species are cathartic, and yield from their secls a fino mucilage. Only one genus need be inentioned here, viz:-

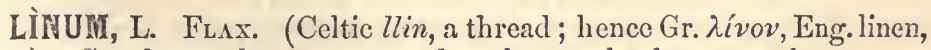
flax.) Sepals, petals, stamens and styles 5 , the latter rarely 3 ; capsules 5-celled; cells nearly divided by a false dissepiment; seeds 10 , suspended, mucilaginous.--Ierbs with a bark of strong fibers, and simple, sessile lis.

* Flowers blne................... (-red, Nn. 7.)......................... 1, 2

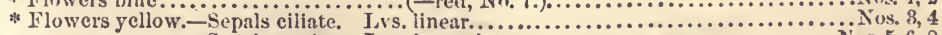

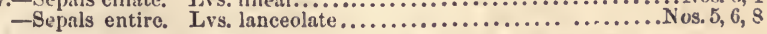

1 L. usitatíssimum L. Comson Flax. St. branching above; lvs. alternate, linear-lanceolate, acute; panicle corymbous; sep. ovate, acute, 3-veined at the base, membranous on the margin; petals crenate- - (1) Introduced and somewhat naturalized in fields. St. 1 to $2 \mathrm{f}$ high, with 3 -veined leaves, and many large, handsome, blue flowers. Jn., Jl. -This important plant has been cultivated from remote antiquity (seo Gen. xli. 42), for the strong fibers of the bark, which are manufactured into linen. The seeds yield linsced oil, so extensively used in mixing paint, printers' ink, etc. They are also medicinal. $§ \uparrow$ 
2 I. perénne I. Perexsial Flax. Glabrous, with virgate branches; lrs. linear, acute, scattered; fls. supra-axillary and terminal; sep. oval, margins membranous, shorter than the globous capsule; petals retuse, blue, 3 or 4 times the length of the sepals. - 4 Native West of the Miss. (perhaps not within the limits of this Flora). Not uncommon in gardens. Also native of Europe and Asia.

$3 \mathrm{~L}$. rígidum $\mathrm{Ph}$. St. angular; lvs. erect, rigid, linear, acute; fls. racemed on the corymbous branches; sep. 3-veined, ovate-lanceolate, acuminato and, with the bracts glandularly fringe-serrate, longer than the globous capsule; styles more or less united at base. - Conn. (Robbins) to Iowa (Cousens), southward and northward; not common. Sts. 10 to $16^{\prime}$ high, erect as well as the branches. Lvs. 4 to $8^{\prime \prime}$ long, scabrous on the margins. Fls. sulphur yellow, $8^{\prime \prime}$ diam. Jn., Jl. (L. Bootii Planch.)-The union of the styles appears variable in degree, in specimens which coincido in all other respects.

4 I. símplez. St. simple, with a small corymb with spreading branches at top; lvs rigid, crect, linear-subulate, alternate; fls. fow; sep. lanceolate, acute, scabrous on the margins, 3-veined, shorter than the globous-ovate capsules; styles distinct.La (Hale). St. slender, 12 to $18^{\prime}$ high. Lrs 4 to $5^{\prime \prime}$ long. Capsules as largo as Coriander.

5 I. Virginiànum $\mathrm{I}$. St. strict, with rather erect, corymbous branches above; leaves lanceolato to linear, acute; fls. showy ( $5^{\prime \prime}$ diam.), all turned to the upper side of the branches; sep. ovate-lanceolate, mucronate, about as long as the depressed capsulo; sty. distinct.-Woods and hills, U. S. and Can. St. near $2 f$ high, terete, glabrous. Lvs. 6 to $8^{\prime \prime}$ by 1 to $2^{\prime \prime}$, with ono distinct vein only. Sep. 1-veined. JL

6 I. diffùsum. St angular, diffusely paniculate; branches and veiny, lanceolate lvs., spreading; flls. alternate, very small (scarcely $2^{\prime \prime}$ broad); sep. ovate, abruptly mueronate, as long as tho depressed capsule; sty. distinct.-Wet prairies, Ind., 0. Very different in aspect from No. 5 , having the stem leaves twico larger ( $l^{\prime}$ by $\left.4^{\prime \prime}\right)$, the branch leaves minute, and the flowers 3 times smaller. Jl.

7 I. grandiflòrum Desf. Fig. 262. Crimsox-COLOREd Flax. Erect, smooth, branched above; leaves elliptic-lanceolate, acute at each end, sessile, the lower and radical lance-obovate, crowded, petals broadly obovate, bright crimson.(1) Gardens (from seeds lately distributed by tho Government). Stem 8-10' bigh. Flowers 1' diam. + N. Africa.

8 I. trígynum Sm. Lvs. elliptical, acute, mucronate, entiro; styles 3 ; caps. 3-celled. Green-houso plant with largo ( $1^{\prime}$ diam.) yellow flowers. $† \mathrm{E}$. Indies.

\section{Order XXXi. geraniaceze. Gerania.}

Herbs or shrubs swollen and separablo at the joints, with stipulate, palmateveined lcaves and symmetrical, hypogynous, 5-merous flowers. Sepals imbricated and petals convolute in xstivation; stamens mostly 10, and monadelphous, the alternate ones often abortive; ovary of 5 sepals, each 2 -ovuled, in fruit 1 -seeded, cohering to an elongated torus (carpophore) from which they separate, curving upwards on the persistent style.

Genera 4, species 500. Geranium and Erodium inhabit chiefly the Northern temperate zones. Pelargonium abounds at the Cape of Good Hope, and occurs in $\Delta$ ustralia; and in cultivation is found every where.

GENERA.

Stamens $10,-$ all perfect. Corolla regular................................. 1 -5 perfect, 5 alternate imperfect. Cor. reg........................ 2 -7 perfect. Corolla irregular...................................... 3

1. GERÁNiUni, L. Crane’s Bill. beaked fruit rescmbles a crane's bill.) Sepals and petals 5 , regular, stamens 10, all perfect, the 5 alternate ones longer, and cach with a nectariferous gland at its base; fruit rostrate, at length separating into 5 long-styled, 1 -seeded carpels; styles smooth inside, at length recurved 
from the base upwards and adhering by the point to the summit of the axis.-Herbaceous, rarely. shrubby at the base. Peduncles 1, 2 or 3 -flowered.

Petals entire, twice as long as the awned sepals.............................. Nos. 1, 2

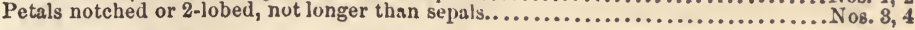

1 G. maculàtum I. Spotted Geraniur. St. erect, angular, dichotomous, rotrorsely pubescent; lvs. palmately $3-5$-lobed, lobes cuneiform and entiro at baso, incisely serrate above, radical ones on long petioles, upper ones opposite, on short petioles; petals entire; sep. mucronate-awned.-2 W Woods, ete., U. S. and Can., but rare in N. Eng. A fino spedes worthy a place among the parlor "geraniums." St. 1 to 2 figh. Lvs. 2 to $3^{\prime}$ diam., cleft $\frac{8}{2}$ way down, 2 at each fork. Fls. mostly in pairs, on unequal pedicels, often somewhat umbeled on tho ends of the long peduncles. Root powerfully astringent. Apr.-Jn.

2 G. Robertiànum L. HERB ROBERT. St. diffuse, hairy; lvs. pinnately 3-parted to the base, the segm. pinnatifid, and the pinne incisely toothed; sep. mucronatoawned, half the length of the entire petals. - (2) Smaller than the preceding, in dry, rocky places. Can to $\mathrm{Va}$. and $\mathrm{Ky}$. It has a reddish stem, with long, diffuse, weak branches. Ivs. on long petioles, somewhat hairy, outlino $1 \frac{1}{2}$ to $3^{\prime}$ diam., with pinnatifid segments. Fls. small, pale-purple. Capsules small, rugous, kecled. Sds. smooth. The plant has a strong disagreeable smell. May-Sept.

3 G. pusíllum I. St. procumbent; lvs. reniform or roundish, deeply 5 to 7-parted, lobes 3-cleft, linear; sep. hairy, awnless, about as long as the emarginato petals. (1) A delicate, spreading species, growing in waste grounds, pastures, etc., L. Isl. and Western N.Y. (Torr). St. weak, If long, branching, covered with short, dcflected hairs. Lvs. opposite, divided almost to the base into 5 or 7 lobes, theso again variously cut. Ped. axillary, forked, bearing 2 purplish-red flowers in $\mathrm{Jn}$. and $\mathrm{Jl}$ \& Eur.

4 G. Caroliniànum L. St. diffusely branched; 1vs. deeply 5-parted, lobes incisely toothed; ped. rather short and clustered on the ends of the branches; sep. mucronate-awned, as long as the emarginate petals. - (1.) Fields and hills, throughout Gan. and U. S. Sts. pubescent, diffuse, 8 to $15^{\prime}$ long, swelling at the joints. Lvs. 9 to $18^{\prime \prime}$ diam., hairy. Fls. small, rose-colored, in pairs, and somewhat fasciculate. Sds. minutely reticulated, reddish-brown, 1 in each hairy, beaked carpel. Jl. (G. dissectum L?).

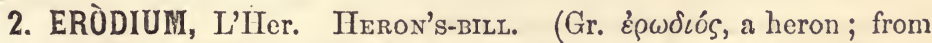
the resemblance of the beaked fruit to the heron's bill.) Calyx 5-leaved; petals 5 ; filaments 10 , the 5 alternate ones abortive; fruit rostrate, of 5 , aggregated eapsules, tipped with the long, spiral style. bearded inside.-Fls. umbellate.

E. cicutàrium Sm. Diffuse, hairy; lvs. pimately divided, segm. sessile, pinnatifid. incised, acute; ped. several-flowered; petals unequal.-Shores of Oneida Lake, N. Y. Sts. mostly prostrate. Lvs. oblong in outline, with many segments. Fls. 2 to $3^{\prime \prime}$ diam. May-Jn. \& Eur. Widely diffused in California.

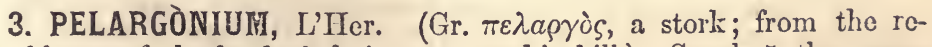
semblance of the beaked fruit to a stork's bill.) Sepals 5, the upper one ending in a nectariferous tube extending down the peduncle with which it is connected; petals 5 , irregular, longer than the sepals ; fila. ments 10,3 of them sterile. - $\Lambda$ large genus of shrubby or herbaceous plants, embracing more than 300 species, and innumerable rarieties, nearly all natives of the Cape of Good Hope. Lower lvs. (in plants raised from the seed) opposite, upper ones alternate.

* Acaulescent (nearly). Rt. tuberons. Lrs. decompound. Pet. yellowish brown...Nos. 1, 2

* Caulescent. - Stems lierbaceous, or somewliat shrubby at base................. Nos. $3-6$

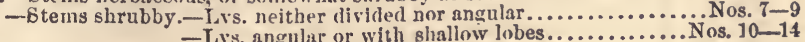

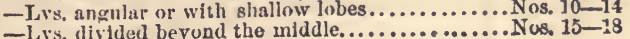


1 P. flàvum Ait. CARRot-I.Is.Ived Geranium. St. very simple; lvs. decompound, laciniate, hairy, segm. linear; umbel many-flowered, fls. brownish-yellow.

2 P. tríste $\Lambda$. Mourninc Geraniusf. Irs. hairy, pinnate; lfts. bipinnatifid, divisions linear, acuto; $f l s$. dark-green, in simple umbels.

3 P. odoratíssimum A. NutMEG-SCEnted Geranium. St. velvety, short, Reshy; lvs. roundish, cordate, very soft; branches herbaceous, long, diffuse.Valued chiefly for tho poiverful, aromatic smell of tho leaves, tho fiowers being small, whitish.

4 P. alchemilloìdes A. Ladies' mantle Geranium. St. villous; lvs. cordate, villous, 5-lobed, palmate; ped. fow-flowered; stig. sessile.-St. 6' high, diffuse, very hairy, with deflexed bristles. Fls. pink-colored.

5 P.trícolor B. Sl. suffruticous, erect; lvs. lanceolate, villous, cut-dentate, trifid; upper pet. glandular at base.-St. $1 \frac{1}{2} \mathrm{f}$ high. This species is distinguished for its beautifully variegated fls. Petals roundish and nearly uniform in shape, but very different in color; the thres lower ones are white, slightly veined, tho 2 upper of a rich purple, almost black at base.

6 P. coriandrifòlium Jac. St. herbaceous, biennial, somewhat downy; lvs. bipinnate, smooth, lobes linear, subpinnatifid.-St. diffuse, 1f high. Distinguished by the finely divided leaves and large fls. The 2 upper petals much ti:e largest, obovate, veined with purple, tho 3 lower, of which the middlo ono is often wanting, are narrow and of pure white.

7 P. glaùcum L'Her. Very smooth and glaucous; lvs. lanceolate, entire, acuminate; ped. 1-2-flowered.-Sts. $3 \mathrm{f}$ ligh, shrubby and branched. The plant is remarkably distinguished by its leaves. Ped. axillary, with 1 or 2 clegant flowers. Petals obovate, of a delicate blush color with red veins.

8 P. betulinum A. Lvs. ovate. unequally serrate, smoothisin; stip. ovatelanceolate; ped. $2-1$-flowered.-St. shrubby, $3 \mathrm{f}$ high. Tho plant is well named for its leaves. Fls. pale-pink, with deep red veins.

9 P. acetòsum A. Lvs. very smooth, obovate, crenate, somewhat fleshy; ped. few-flowered; netals linear.-St. shrubby, $3 f$ high. Named for the acid flavor of the leaves. Fls. pink.

10 P. zonàle L. Horse-shoe Geranium. Lis. cordate-orbicular, obsoletely lobed, toothed, marked with a concentric zone.-St. thick, shrubby, 2-3f high. One of the most popular of all the species. The zone upon the leaf is of various shades. The fls. are of a bright scarlet, umbeled, on long peduncles. It has many varieties, of which the most remarkable is

B. MARGINALE; silver-edged; the leaves of which aro bordered with white.

II P. inquinans A. Lvs. round, reniform, scarcely divided, crenate, viscid; umbels many-flowed; petals obovate, crenate.-Justly admired-for the vivid scarlet of its numerous flowers. The name alludes to the reddish, elammy moisturo which stains the fingers in handling the soft, downy branches.

12 P. peltàtum $\Lambda$. IVY-LEAved Geraniujy. Lvs. 5-lobed, entire, fleshy, smooth, more or less peltate; umbels few-flowercd.-St. climbing, several feet in length. Wholo plant very smooth. $\Lambda$ beautiful species, with umbels of very handsomo purplish flowers.

13 P. tetragònum L'Her. Branches 4-cornered, fleshy; lrs. cordate, bluntly lobed, somewhat toothed; pet. 4, the upper ones pale-pink, with crimson veins, the 2 lower small, white.-Lvs. small, rounded, notehed, with scattered hairs.

14 P. Watsònii Link. Lvs. orbicular, cordate, somewhat lobed, crenatedentate, undulate at the margin; stip. acute, cordate, and somervhat toothed.Fls. largo, purple, variegated, several together.

15 P. grandiffòrum W. Smooth, glaucous; lvs. 5-lobed, palmated, cordato at base, the lobes dentato toward the end; petals 3 times as long as the calyx.Distinguished for the size and beauty of the flowers, which are white, the 2 upper ones elegantly veined, and tinged with red, larger than the rest.

16 P. gravèolens A. Rose-Scented Geranium. Ins. palmately 7-lobed, lobes oblong, bluntly toothed, revolute, and very rough at the edge; umbels many-flowered, capitate.-Nectary about half as long as calyx. Lvs. very fragrant. Fils. purple. 
17 P. rádula A. Lvs. palmate, rough, lobes narrow, pinnatifid, revolute at edge, with linear segments; umbels few-flowered; nectary nearly as Jong as the calyxDistinguished for its large rough leaves deeply divided into linear segments, and and with a mint-like fragrance. Fls. purple.

18 P. quercifòlium A. OAK-LEAVED Geraniom. Lvs. cordate, pinnatifid with rounded recesses, lobes obtusely crenate; branches and petioles hispid.Lrs. rough, often spotted. Fls. purplish.

Ob8. The above are among the more distinguished and popular species of this vast and favorite genus. Innumerable varieties produced from seeds and Iropagated by cnttings aro equally eommon and often of superior beauty. No genns seems to be regarded with so universul favor for greenhouse plants as this. The sjecies and their multitudes of hybrid ereations, produeed by modern ingenuity, are cultivated with assiduous attentlon by nearly every faully which makes the least pretensions to taste throughout the civilized worlil.

\section{Order XXXII. OXALIDACEA. Wood Sorrels.}

Stems low, herbaceous, with an acid juice and alternate compound leaves. Flowers regular, symmetrical, hypogynous, 5-merous. Sepals persistent, imbricated; petals convolute in æestivation. Stamens 10, somewhat monadelphous, those opposite the petals longest. Styles 5, separate; capsule 5-celled, several-seeded; seeds albuminous. (Illust. in Figs. 59. 64, 585.)

Genera 7 , species 328 , inhabiting the hot and the temperate regions. The most notieenble property of the Order is the sonr julce, eontaining oxalic aeid. Several species are cultivated for the beauty of their flowers.

ÓXALIS, L. Wood Sornel. (Gr. ỏzvs, sour.) Sepals 5, distirct or united at base; petals much longer than the calyx; styles 5 , capitate; capsule oblong or sub-globous: carpels 5,1 to sevcral-seeded.Mostly 24, with trifoliate lvs. and inversely beart-shaped leaflets.

1 O. Acetosélla L. Acaulescent; scape longer than the leaves, 1-flowered; lits. broad-obcordate with rounded lobes; sty. as long as tho inner stamens; rt. dentate, scaly. - Woods and shady places, Can. and Northern States. Lrs. palmately 3-foliate, on long, weak stalks, purplish beneath. Ped. longer than the leaves, each with a nodding, scentless flower whose petals are white, yellowish at the base, delicately veined with purple. Tho wholo plant has an agreeable acid taste. Jn.

2 O. violàcea I. Acaulescent, smooth; scape umbeliferous; pedicels, subpubescent; fls. nodding; tips of tho calyx fleshy; sty. shorter than the outer stamens.-An elegant species in rocky woods, etc., throughout the U. S. Bulb scaly. Scape nearly twice longer than the leaves, 5 to $8^{\prime}$ high. Lrs. palmately 3 -foliate, sometimes none; lfts. nearly twico as wido as long, with a very shallow sinus at the very broad apex. Umbels of 3 to 9 drooping flowers. Petals large, violet-colored, striate. Míay.

3 O. strícta L. Caulescent; st. branching; ped. umbeliferous, longer than the petioles; sty. as long as tho inner stamens. - (1) Fields, U. S. and Can., common. It varies in size from 3 to $12^{\prime}$, according to the soil. St. leafy, round, smocth, succulent. Lvs. palmately 3 -foliate, numerous, scattered, on long. stalks. Um.bels on long, axillary stalks, mostly much longer than the petioles. Fls. small, yellow, appearing all summer. Capsules sparingly lirsute, with spreading hairs.When the plant is unsupported, it is more or less decumbent, and is the variety

B. corniculata (O. corniculata L). - Obs. The species (nearly 300 in number) are all pretty, and many from Europe and Africa are becoming rather common in cultivation.

\section{Order XXXIII. Zygopityllace . Bean Capers.}

Herbs, shrubs or trees, with leaves opposite, mostly pinnate (not dotted) and stipulate; flowers 4 or 5 -merous, calyx imbricated and corolla convolute in æestivation. Stamens twice as many as petals, hypogynous, distinct, each often with a scale. Ovary compound; fruit and seeds as in Linacex. 
Genera 9, species 100 , generally diffused. The gum resin guiacum is derived from the genus Guiacum, also that extremely hard and heary wood, lignum-vito.

KALLSTROĖ IIIA, Scop. Sepals 5 , persistent; petals 5 ; stamens 10 , with no scale, the 5 opposite the sepals defective, placed inside 5 hypogynous glands; styles united, stigmas 10-lobed; fruit at length separating into 101 -seeded cocci.-(1) Prostrate and diffuse, with interpetiolar stipules and abruptly pinnate leaves.

K. máxima Torr \& Gr. Lfts. 3 or 4 pairs, oblong or oval, slightly falcate, mucro nate, the terminal pair largest; cocci gibbous at base, tubereled. Wasto places, Savannah. Sts. pubesecnt, 1 to $2 \mathrm{f}$ long. Fls. yellow, axillary, solitary, pedunculate. Jn.-Sept. \& W. Indics. (Tribulus maximus L.)

\section{Order XXXIV. BALSAMiNACEAE. Jewel Weeds.}

Herbs annual, with a succulent stem and watery juice. Lvs. simple, without strpules. Fis. very irregular and unsymmetrical. Sepals 5, deciduous, the 2 upper connate, the lowest spurred or gibbous. Petals 4, hypogynous, united by pairs, or rarely 5, distinct. Slamens 5, hypogynous. Filaments subulate. Anth. 2-celled. Stig. 5 -lobed, sessile. Fr. capsular, 5 -celled, bursting elastically by 5 valves. $S d s$. several in each cell. Embryo straight. (Figures 114, 281, 282.)

Genera 2, species 110 . With regard to its properties and uses, this order is of no importance, but solne of its species aro highly ornamental.

IMPÁTIENS, L. TUUCH-ME-Not. (Impatient with respect to the irritable capsules.) Sepals colored, apparently but 4 (the 2 upper being united), the lowest gibbous and spurred; petals apparently 2, each of the lower being united to the 2 lateral ones; stamens 5 , short, anthers cohering at apex; capsule often 1-eelled by the obliteration of the dissepiments, 5 -valved bursting elastically.-Sts. smooth, succulent, tender, subpellucid, with tumid joints.

1 I. pállida Nutt. Lis. oblong-ovate, coarsely and obtusely serrate, teeth mucronate; ped. 2 to 4-flowered, elongated; lower gibbous sepals dilated-conical, broader than long, with a very short, recurved spur; fls. pale yellow, sparingly dotted.(i) Wet shady places, U. S. and Can. St. 2 to $4 \mathrm{f}$ high, branclied. Lvs. 2 to $5^{\prime}$ long, $\frac{1}{3}$ as wide, with large, obtuse teeth, each tipped with a very short mucro. Fls. large, mostly in pairs. Two outer sepals pale green, callous pointed, the rest palo yellow, the lower produced into a conic nectary, ending in a spur $\frac{1}{4}$ long. Caps. oblong-cylindric $I^{\prime}$ long, bursting at the slightest touch when mature, and scattering the seed. Aug.

2 I. fúlva Nutt. Lvs. rhombic-ovate, obtusish, coarsely and obtusely serrate, teeth mucronate; ped. 2 to 4-flowcred, short; lower gitbous sepal, acutely conical, longer than broad, with an elongated, closely reflexed spur; fls. deep orange, maculate with many brown spots.-(1) In wet, shady grounds, Can. to Ga., more common than the last, somewhat glaucous. St. $1 \frac{1}{2}-3$ f high. Lvs. 1 to $3^{\prime}$ long, $\frac{1}{2}$ as wide, having like tho last a few filiform teeth at the base. Fls. about $\mathrm{l}^{\prime}$ in length: the recurved spur of the lower sepals $\frac{1}{2}$ long. Caps. as in the last. Aug.

3 I. Balsamina L. BAtSAMINE. Lvs. lanceolate, serrate, upper ones alternate: ped. clustered; spur shorter than the flower:- (1) From the I. Indies. It is one of the most beautiful of garden annuals, forming a showy pyramid of finely varicgated, carnation-like flowers. The prevailing colors of the petals are red and white, but the former varies in every possible shade of crimson, scarlet, purple, pink and flesh color. Fls. often double.

\section{ORDER XXXV. TROPAOLACEA. Trophyworts.}

Plants herbaceous, smootl, climbing or twining, with a pungent, watery juice. Lvs. peltate or palmate. Fls. irregrilar, axillary, perfect. Sepals 3 to 5, colored, 
united, the upper ono spurred. Petals $1-5$, the three lower ones stalked, tho 2 upper inserted on tho calyx. Stamens 6 to 10, distinct, unequal, perigynous. Ovary 3 -carpeled; style 1 ; stigmas 3 . Fruit separating into 3 indehiscent, 1-seeded nuts. Sils. large. Albumen 0.

Genera 4, species 40, natives of S. America. They possess the same antiscorbutic properties as tho Cruciferæ. The fruit of the following species is pickled and used as a substitute for capers.

TROP ĖOLUM, L. Indian CRess. (Lat. tropceum, a trophy; the leaf resembles a shield, the flower an empty helmet.) Character essentially the same as of the order.

1 T. màjus L. NASTURTION. Lvs. peltate, roundish, repand on the margin, with the long petiole inserted a little one side of the center; pet. obtuse, the 2 upper distant from the 3 lower, which are fimbriate at base, and contracted into long claws.- (1) Native of Peru. St. at length climbing by means of its long petioles several feet. Lrs. a fino examplo of the peltate form, about $2^{\prime}$ diam. Fls. large and showy, orange-colored, with blotches of deeper shade. They are eaten for salad. Jn.-Oct.

2 T. adúncum Smith. Canary Creeper. Capucinine. St. trailing or climbing; lvs. peltate, palmately 5-lobed, lobes dentate; petals laciniate, the two upper much larger; sep., eutire, acute.-Admired for its grotesque, orange-colored flowers. Climbing by its prehensive petioles liko T. majus. When full grown it will thrive upon air alone. $\nmid$ From Peru.

\section{Order XXXVI. LIMNANTHACEA. Lmananths.}

Herbs annual, with an acrid, watery juice, alternate, pinnatifid, exstipulate leaves. Flowers regular, 3 to 5-merous, perfoct. Sepals united at base, persistent, valvato in æstivation. Petals marescent, hypogynous. Stamens twice as many as petals and inserted with them. Fil. opposito to tho sep. with a small process outside tho base. Ova. of 2 to 5 carpels. Sty. united. Stig. simple. Fr. 2 to 5 achenia, rather fleshy. Sds. solitary.

Genera 2, species 3, mostly natives of the temperate parts of N. America.

FLOÉRKEA, Willd. FaLSe Mermaid. (Named in honor of Floerke, a German botanist.) Sepals 3, longer than the 3 petals ; stamens 6 ; ovaries 3 , tuberculate, style 2-cleft.-(1) Small aquatics, with pinnately divided leaves.

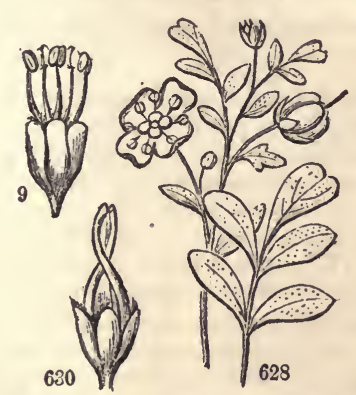

628, Ruta graveolens, leaves, flower, fruit. 9, Xanthoxylum, staminato flower; 630 , pistillate flower.
F. proserpinacoìdes Lindl. Grow's in marshes on rivers and lake shores, $V$ t. to Penn., W. to Mo. Sts. decumbent, less than a foot in length, weak, slender. Lvs. alternate, upper ones or those above the water, pinnately 5-parted, lower or submersed ones mostly 3-parted, all on slender petioles 1 to $3^{\prime}$ in length. Fls. axillary, pedunculate; petals, white, small, about half as long as the sepals. Achenia large, 2 or 1, rouindish.

\section{Ord. XXXVII. RUTACEA. Rueworts.}

Herbs or generally shrubs or trees, with the exstipulate leaves dotted with transparent glands containing aromatic or acrid oil. Flowers regular, 3 to 5-merous, hypogynous, perfect or polygamous. Stamens as many or twice as many as the sepals. 
Pistils 2 to 5, separato or combined into a compound ovary, with as many cells, sessile or raised on a stipe (gynophore); styles mostly cohering. Fruit capsular, or separating into its component 1 or 2 -seeded carpels.

Genera 70, species 500 or more, generally natives of S. Anterien and the temperate climes of other lands, fow in N. America. They are generally possessed of a strongly aromatic, pun' gent tasto or fetid odor, antispasmodic and tonic propertics.

\section{SUBORDERS AND GENERA.}

RUTEE. Flowers perfect. (IIerbs. Stamens 10).

Petals equal, coneave. Capsule 5-lobed.........Reta

Petals unequal, clawed. Capsules separablo.... Dictaunos

XANTIIOXYLEAE. Fluwers $q \forall$ s. (Trees, shrubs.)

Pistils $3-5$, separate below. Stamens 3-3. .XANtroxrLuM 3

Pistils 2, united, Samara 2-seedled.......... Ptelea 4

Pistils 3 to 5, separate. Samara 1-seeded.... Ailantiuus

1. RŨTA, L. Rue. Calyx of 4 to 5 sepals, united at base; petals $4-5$, concave, obovate, distinct, torus surrounded by 10 nectariferous pores; stamens 10 ; capsule lobed.-24 Herbaceous or shrubby, mostly European.

R. gravèolens L. Comson RUE. Suffruticous, nearly glabrous; 1vs. 2 to 3-pinnately divided, segments oblong, obtuse, terminal ones obovate-cuneate, all entire or irregularly cleft; fls. terminal, corymbous; pet. entiro.-Native of S. Europe. St. branched, 3 to $4 \mathrm{f}$ high. Lfts. 6 to $10^{\prime \prime}$ by 2 to $4^{\prime \prime}$, conspicuously dotted. Corolla yellow, 6 " diam. Jn.-Sept. $\ddagger$.

2. DICTÁmNUS, L. Fraxinella. Calyx of 5, deciduous sepals; petals 5 , unguiculate, unequal; filaments 10 , declinate, with glandular dots; capsules 5, slightly united.- 4 Herbs native of Germany.

D. álbus Willd. St. simple; lvs. pinnate, the rachis more or less winged; fls. in a large, terminal, erect panicle.-In gardens. Sts. 1 to $2 \mathrm{f} \mathrm{high.} \mathrm{Fls.} \mathrm{showy,}$ white, varying to rose-color and purple. The whole plant cmits a lemori-scented, aromatic, volatile oil, which is, of course, inflammable, but probably does not, as once affirmed, render the air (about it) inflammable. (D. Fraxinella Link.)

$\beta$ RUBRA. Fls. purple; rachis of the leaves winged.

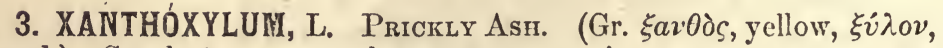
wood.) Sepals 4 or 5 ; petals 4 or 5 , or wanting; stamens as many as the petals in $\hat{\delta}$, rudimentary in $q$; pistils 3 to 5 , distinct below, with coherent styles, in fruit crustaceous; 2-valved, 1 or 2 -seeded.-Shrubs or trees with sharp prickles, pinnate leaves, and small, greenish flowers.

1 X. Americànum Miller. Prickly; lfts. ovate, subentire, sessile, equal at base; umbels axillary; sepals 5 , petaloid, petals wanting (more properly petals 5 , calyx wanting). $-\mathrm{A}$ shrub 10 or $12 \mathrm{f}$ high, found in woods in most parts of the U.S. The branches are armed with strong, conical, brown prickles, with a broad base. Lfts. about 5 pairs, with an odd one, smooth above, downy beneath; common petioles, with or without prickles. Fls. in small, dense umbels, axillary, greenish, appearing before the leaves; seeds large, black. Thie bark is bitter, aromatic, and stimulant, used for rheumatism and to alleviate the toothache. A pr, May.

2 X. Caroliniànum Lam. Prickly; lfts. falcate-lanceolate, very inequilateral, petiolulate; fls. in terminal, umbel-like panicles; sep. minute.-Southern States. Tree attaining considerable size. Some in woods N. of Montgomery, Ala., are nearly 40 f high, with trunk 10 or $12^{\prime}$ diam. Bark light gray, with the prickles protruding through large, corky cones. Lvs. 6 to $15^{\prime}$ long, smooth and shining both sides. Lfts. 7 to 13 , obscurely crenate-serrate, only the odd one equilateral. Fls. numerous, globular, finally expanded, and the 5 stamens exsorted. Bark 
excessively pungent in taste. May.-The cone-like warts on the bark of the larger trees are very curious.

4. PTEleA, I. Shrub Treforl. (Gr. $\pi \tau \varepsilon \lambda \dot{\varepsilon} a$, the clm tree; from the resemblance of the fruits.) $q \not \hat{\delta}$. Sepals 3 to 6 , mostly 4 , much shorter than the spreading petals; $\hat{\delta}$ stamens longer than the petals and alternate with them, very short and imperfect in + ; ovary of 2 united carpels; styles united, short or 0 ; stigmas 2 ; fruit 2-celled, 2 seeded samaræ, with a broad, orbicular margin.-Shrubs with 3 to 5 foliate lis. Fls. cymous.

P. trifoliàta L. Lvs. 3-foliate, lfts. sessile, ovate, short-acuminate, lateral ones inequilateral, terminal ones cuneate at base ; cymes corymbous; stam. mostly 4 ; sty. short. - An ornamental shrub, 6 to $8 \mathrm{f}$ high, West. States, rare in W. N. York. Lfts. 3 to $4 \frac{1^{\prime}}{2}$ by $1 \frac{1}{4}$ to $1^{\frac{3^{\prime}}{4}}$, the ped. rather longer. Fls. white, odorous, nearly $]_{2}^{\prime}$ diam. Samara nearly $1^{\prime}$ diam.

5. Ailánthus, Desf. Chinese "Tree-of-Heaven." (From the Chinese name, Ailanto.) $q$ $\Varangle$ o Sepals 5, more or less united at base; petals 5 ; $\Varangle$ stamens 2 to 3 ; ovaries 3 to 5 ; styles lateral; fruit 1 celled, 1 -seeded samaræ, with oblong margins; $\hat{\delta}$ stamens 10 ; 우 oraries, styles and samaræ as in $\Varangle$.- Oriental trees and shrubs with pinnate lvs. Fls. in panicles. Recently stationed in Order Simarubatera.

A. glandulòsa Desf. Lrs. glabrous, unequally pinnate, lfts. ovate or oblonglanceolate, acuminate, shortly petiolate, with one or two obtuse, glandular teeth each side at base, terminal one long-petiolate. - A tree of large dimensions, and with luxuriant foliago. Trunk straight, with a smooth, brown bark. Lvs. 3 to $5 f$ in length, with 10 to 20 pairs of leaflets, and an odd one. Fls. in terminal panicles, green, very ill-scented, rendering the tree a nuisanee when in bloom (May and June). T'he rapid growth of this tree is its only recommendation as a tenant of our parks.

\section{Order XXXVIII.}

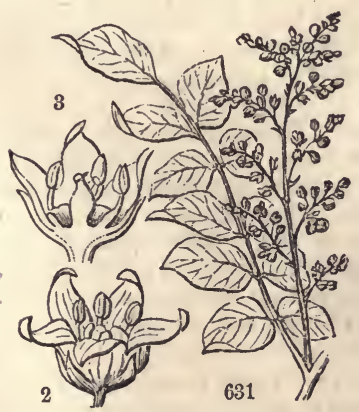

631, Rhus, leaf and panicle. 2. A gtam inate flower. 3. Section of a fertile flower.

\section{ANACARDIACEA. Sumacirs.}

Trees or shrubs, with a resinous, gummy, caustic, or even milky juice. Leaves alternate, simplo or ternate, or unequally pinnate, without pellucid dots. F'ls. terminal or axillary, with bracts, commonly diœcious, small. Sepals 3 to 5 , united at base, persistent. Petals of tho samo numbcr, (sometimes 0), imbricated. Stamens as nuany as petals, alternato with them, distinct or coherent, and perigynous. - Ovary l-celled, frec. Ovu?e one. Styles 3 or 0. Stigmas 3 . Fruit a berry or drupo, usually the latter, and 1-seeded. Albumen 0.

Genera 49, specics 100 , chiefly natives of tropical regions, represented in tho $U$. S. by tho genus lihus only.

Properties.-These plants abound in a resinous juice, which is poisonous, but is used as an incleliblo ink in marking linen, and as an ingredient in varnlsh. Even the exhalations from some of the species are deemed poisonous. The Cashew nut is the.product of a sinall tree of both Indies. When fresh the kernel is full of a milky julee, and has a most delleious taste, but tho coats aro filled with a caustic oll which bllsters the skin and kills warts.

RHUS, L. Sumac. (The ancient name, 'from Celtic, rhudd, red?) Calyx of 5 sepals united at base; petals and stamens 5 ; styles 3 , stigmas capitate; fruit a small, 1 -seeded, subglobous, dry drupe.-Small 
trees or shrubs. Lvs. alternate, mostly compound. Fls. often, by abortion, imperfect.

Leaves simple. Flowers perfect (or all abortive in cultivation)................ Tos. 9, 10 Leaves compound. Flower polygamous. (a)

a Fls. in clustered spikes preceding the trifoliate learcs.................... 8 a Fls. in axillary panicles, with the 3 -13-foliate leaves. Poisonous............. $5-7$ a Fls. in terminal thyrses, with the 9-31-follate leaves. (b)

b Common petiole winged between the lenflets..................... 4

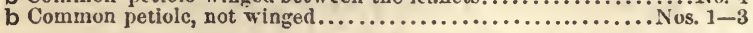

1 R. glàbra L. Lvs. and Uranches glabrous; lfts. 11 to 31, lanceolate, acuminate, acutely serrate, whitish beneath; fr. red with crimson hairs.-Thickets and waste ground, U. S. and Can. Shrub, 6 to $15 \mathrm{f}$ high, consisting of many straggling branches, smooth, except its fruit. Lfts. sessile, except sometimes the terminal odd one. Fls. in terminal, thyrsoid, dense panicles, greenish-red, $+\hat{\delta}$. Fertilo ovaries, clothed with grayish down, which in fruit becomes crimson, and contains malic acid (bi-malate of lime, Prof, Rogers), extemely sour to the taste, Jn., Jl. The bark of this and other species may be used in tanning. The drupes dyo red.

2 R. typhina I. Branches and petioles densely villous; 1fts. 11 to 31 , oblonglanceolate, acuminate, acutely serrate, pubescent beneath; fr. red, with crimson hairs.-A larger slirub than the former, attaining the height of $20 \mathrm{f}$, in rocky or low barren places, Can. and U.S. St. with straggling, thick branches. Lvs. at length 2 to $3 f$ long; lfts. sessile, except the terminal, odd one. Fls. in terminal, thyrsoid, denso panicles, yellowish-green, often $q \hat{f}$ or $q \not \hat{\delta}$. Drupes compressed, compact, the crimson down very acid. Jn. I'ho wood is aromatic, of a sulphur-yellow, and used in dyeing.

B. LACiNiata. Lfts. very irrcgularly coherent and incised; panicles partly transformed into gashed leaves. Hanover, N. II. (Rickard).

3 R. pumila Mx. Procumbent, villous-pubescent; 1fts. 9 to 13, oval or oblong, coarsely tootlied; drupes red, silky-pubescent.-In upper Carolina. Shrub, creeping extensively, with branches 1 to $2 \mathrm{f}$ high, bearing a subsessile, terminal, thyrsoid panicle. Lifts. all sessile, clothed with a velvety pubescence beneath, the threo upper often confluent. This species is very poisorous.

4 R. copallina L. Mountain Sumac. Branches and petioles pubescent; ifts 2. to 21 , oval-lanceolate, mostly entire, unequal at base, common petiole winged; fls. in denso panicles; drupes red, hairy. A smaller shrub, not half the hight of Numb. 2, in dry, rocky places, U.S. and Can. Compound petiole about $6^{\prime}$ long, expasding into a leafy margin, between each pair of leaflets. Lfts. 1 to $3^{\prime}$ long, near $\frac{1}{2}$ as wide, dark-green, and shining on the upper surface. Panicles of fla terminal, sessile, thyrsoid, के $\hat{\sigma}$, greenish. Drupes acid. Jl.

3. Lfts. coarsely and uncqually serrate. N. Y. (Barratt.)

5 R. venenàta DC. Poison Surac. Dog Wood. Very glabrous; lfts. 7 to 13 , oval, abruptly acuminate, very entire; panicles loose, axiliary, pedunculate; drupes greenish-yellow, smooth. A shrub or small treo of fine appearance, 10 to $15 f^{\prime}$ high, in swamps, U. S. and Can. Trunk several inches diam., with spreading branches above. Petioles wingless, red, 6 to $10^{\prime}$ long. Lits. about $3^{\prime}$ long, $\frac{1}{2}$ as wide, sessile, except the odd one. Panicles axillary, $q \hat{\delta}$, those of the barren ones more diffuse. Fls. very small, green. Drupes as large as peas. Jn. The whole plant is very poisonous to the taste or touch, and even taints the air to some distance around with its pernicious effluvium.

6 R. toxicodéndron L. Poison OAK. Poison IVY. Erect, or decumbent; Ivs. pubescent; lfts. 3, broadly oval, acuminate, angular or sinuate-dentate; fls. in recemous, axillary, subsessile panicles; drupes smooth, roundish.-Can. to tho uplands of Ga. $\Lambda$ small, weak shrub, 1 to $3 f$ high, young branches, and lvs. beneath downy. Lfts. 2 to $6^{\prime}$ long, $\frac{2}{3}$ as wide, petiolate, the common petiole 4 to 5 ' long. Fls. small, $q \hat{s}$. Drupes pale-brown. Poisonous, but less so than the last.

7 R. rádicans L. Cursmikg Iry. Stems climbing by means of innumerable radicating tendrils; leaflets ovate, smooth, entire; fls. racemed in axillary panicles. A vigorous, woody climber, ascending trees and other objects 10 to 40 or 50f, common in damp woods, Can. and U. S. Tho stem becomes $1^{\prime}$ to 2 in 
thickness, covered with a grayish, sealy bark, and throws out all along its length myriads of thread-like rootlets, which bind it firmly to its support. Leaflets 8 , of a dark and shining green, the lowest rarely angular. Berries dull white. Fls. greenish. May, Jn.-The juice, like that of the last, is poisonous, and forms an indelible ink. (R. tox. $\beta$. Mx. and Ed. 2d.)

8 R. aromática Ait. Sweet Susic. Lfts. sessile, incisely crenate, pubescent beneath, lateral ones ovate, terminal one rliomboid; fls. in close aments, preceding the leaves; drupo globous, villous.-A small, aromatic slirub, 2 to 6 f high, in hedges and thickets, Can. and U. S. Lfts. 1 to $2^{\prime}$ long, $\frac{1}{2}$ as wide, sessile, the common petiole an inch or two in length. Fls. yellowish with a 5-lobed, glandular disk. Drupes red, acid. May. Not poisonous.

9 R. Cotìnus L. Venetian Sumac. Lvs. obovate, entire; fis. mostly abortive, pedicels finally clongated and clothed with hairs. $-\mathrm{A}$ small shrab $8 \mathrm{f}$ high, native in Ark. according to Nuttall (?), remarkable chiefly for the very singular and ornamental appearance of its long, diffuse, feathery fruit-stalks, showing in the distanco as it the plant were enveloped in a cloud of smoke. Fls. small, in terminal, compound panicles. Lvs. smooth, entire, much rounded at the end. In Italy the plant is used for tanning.

$10 \mathrm{R}$. cotinoides Buckley. A large tree, 40 to $50 \mathrm{f}$ in height, in woods on the high mts. of N. Car. (Buckley). Also in Ark. (Nuttall?). We have seen no specimens, and are unable to give the specific differences between this new species and R. Cotinus, if, indeed, it be distinct, as is probable.

\section{Order XXXIX. PITTOSPORACEA.}

Trees or Sirrubs, with alternate, exstipulate leaves and regular flowers. Calyx and corolla 4 or 5 -merous, imbricated in the bud, deciduous; stamens 5, hypogynous, alternate with the petals. Ovary free, style single, stigmas 2 or more, cells or placento as many. Seeds numerous; embryo in fleshy albumen.

Genera 12 , species 78 , chiefly from Australia.

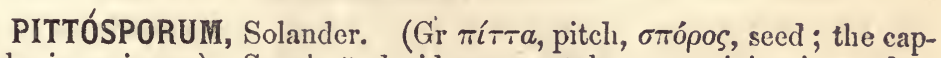
sule is resinous.) Sepals 5 , deciduous; petals 5 , conniving in a tube; capsule 2 to 5 -celled, 2 to 5 -valved; seeds pulpy.-Handsome evergreen shrubs.

P. tobira Leland. Lrs. coriaceous, smooth and polished, obovate, obtuse; caps. 3 -valved.-This plant is hardy in the gardens, south, and common in the greenhouse, north. Lvs. entire, beautifully dark-green and shining. Fls. in terminal clusters, white, very fragrant.

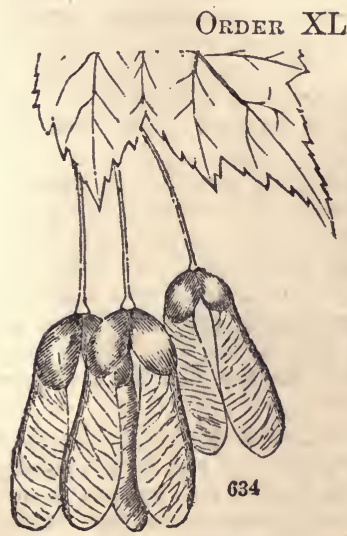

651, Samara of Maplo.

\section{ACERACE无. Maples.}

Tiees or shrubs, with opposite, usually simple and palmate-veined leaves. Stipules 0 . Flowers often polygamous, in axillary corymbs or racemes, hypogynous. Sepals 5, rarely 4 to 9 , more or less united, colored, imbricate in sestivation. Petals 5, rarely 4 to 9 , hypozynous; sometimes 0 . Sta. usually 8 , on a fleshy disk. Ovary 2-lobed, compounded of 2 united carpels. Fr. a double samara with opposite wings, thickened at the lower edges. Albumen 0. (Illust. in Figs. 22, 26, 107, 475, 480.)

Genera $3,8 p e c i e s$. The sap of sereral species of the maple yields sugar by evaporation.

1. ACER, Moench. Maple. (The ancient name, meaning sharp, vigorous.) Flowers ๙ิ $¥$ 우; calyx 5 (4-9)-cleft; corolla 5 
(4-9)-petaled or 0 ; stamens $8(4-12)$; styles 2 ; samaræ 2 -winged, united at base, by abortion 1 -seeded.-Lvs. simple, palmately 5 -lobed.

Flowers in fascicles, preceding the leaves............................... Nos. 1, 2

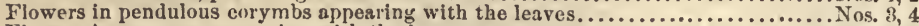

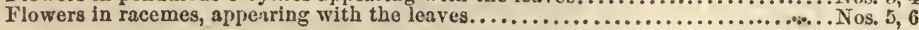

1 A. rùbrum L. Red MAPLE. Swamp MAPLE. Lvs. cordate at base, acutely and incisely toothed, the sinuses acute, glaucous beneatl; pedicels elongated in fruit; petals-linear oblong; ovaries and fruit smooth.-Common in low woods and swamps througbout the country. It is commonly of smaller dimensions than the sugar maple, but sometimes far exceeds it. Specimens at Montezuma, Ind., on the Wabash river, measure about $80 \mathrm{f}$ in height with a trunk $17 \mathrm{f}$ in circumference. Bark rather smooth, becoming dark gray and broken with age. In early spring it puts forth its deep crimson flowers in dense fascicles (about 5 from cach bud). Stamens 4 times as long as the petals. The fruit has its wings $l^{\prime}$ long, at first incurved, finally divergent, mostly red. The leaves vary greatly in form and pubescence, sometimes quite woolly beneath. Curled maple is a variety of tho wood of this species, much prized in cabinet-work.

$\beta$. TRIDENS. Lvs. smaller, 3-lobed, rounded at the base, rather obscurely toothed; fls. and fr. greenish yellow.-N. J. to La. Probably a distinct species. Lvs. whitish and rather smooth beneath, 2 to $3^{\prime}$ broad. Fr. with wings nearly straight, diverging at $90^{\circ}$. (A. rubrum $\beta$ ? T. \& Gr.)

2 A. dasycárpum. Ehrh. White MAPLe. Lvs. truncated at base, unequally and incisely toothed, with rather obtuse sinuses, white and smooth beneath; fls. in crowded, simple umbels, with short pedicels and downy ovaries; petals 0 .- This species much resembles the last, but its leaves aro larger, more pointed, and whiter beneath, and the winged fruit is also larger than that of the red maple or of any of the following species. It is a tall tree, $50 \mathrm{f}$ in height, not uncommon in the N. Eng. forests. The flowers are of a yellowish-green color, as also the fruit. The wood is white, softer and less esteemed than that of other species. The sap yields sugar in smaller proportions than the sugar maple.

3 A. saccharìnum Li. SÜGar MAPLE. Rock MAPLe. Lvs. subcordate at base; acuminate, remotely toothed, with rounded and shallow sinuses, glaucous beneath; fls. pedunculate, pendulous.-This fine tree is found throughout U. S., but most abundant in the primitive soils of N. Eng., constituting the greater part of some of its forests. It is a tree of lofty proportions, $70 \mathrm{f}$ in height, with a trunk $3 \mathrm{f}$ diam. The bark is of a light-gray color, rough and scaly. The branches become numerrous and finely ramified in open situations, and in summer are clothed with a foliage of uncommon luxuriance and beanty, on which account it is more extensively cultivated as a shade tree than any other, not even excepting the majestic and favorite Elm. Maple sugar, perhaps the most delicious of all sweets, is mostly tho product of this species. An ordinary tree will yield 5 to 10 pounds in a season. The wood is very strong and compact, and makes the best of fuel. It is sometimes curled like the red maple, but oftener presents that beautffil arrangement of fibre, called bird's-eye maple, which is highly csteemed in cabinet-work. Tho flowers are exceedingly abundant and suspended on long, thread-like pedicels, and delicately beautiful. Apr.

4 A. nigrum. Mx. Black Maple. Sugar Tret. Lvs. cordate, with the sinus closed, lobes divaricate, sinuate-dentate, paler beneath, with the veins beneath, and the petioles pubescent; fls. on long, slender pedieels; fr. glabrous, turgid at base, the wings diverging.-A large tree, in mountainous situations, Vt. to Ind. Resembles the last, but is probably distinet. Trunk 30 to $70 \mathrm{f} \mathrm{high,} \mathrm{with} \mathrm{a} \mathrm{shaggy}$ bark. Lvs. 3 to $5^{\prime}$ diam, dark green above, the two interior lobes much smaller. Fls. pendulous, on long peduncles, yellowish. Fr. with wings $1^{\prime}$ in length, paleyellow, and moro diverging than A. saccharinum. The sap, like the last mentioned tree, yields sugar abundantly. Apr.

5 A. Pennsylvánicum, L. Striped Maple. Whistle-Tood. Lvs. with 3 acuminate lobes, rounded at base, sharply denticulate, smooth; rac. simple, pendulous. - A small tree or shrub 10 to $15 \mathrm{f}$ high. Can. to Ga. and $\mathrm{Ky}$., but most abundant in our northern woods. The bark is smooth and beautifully striped lengthwise with green and black. Fls. large, yellowish-green, succeeded by long clus- 
ters of fruit, with pale-green wings. The smaller branches are straight and smooth, easily separated frum the bark in spring, and are often manufactured by the boys into certain wind instruments. Hence it is called whistle-wood. In Europe it is prized in ornamental gardening. May. (A. striatum Lam.)

6 A. spicàtum Lam. Moustain MAPLe Busir. Lvs. acute, dentate, pubescent beneath; rac. erect, compound. - A shrub of smaller stature than the last, fuund in mountain or hilly woods tliroughout the country. The bark is a light gray. Lrs. small, rough, divided into 3 or 5 lobes, which are somewhat pointed, with large, sharp teeth, and more or less cordate at base. Fls. greenish, numerous and minute, in cylindric, oblong, closo clusters, becoming pendulous with the winged fruit. Jn.

7 A. Pseudo-Plátanus L. Srcayore. Lrs. cordate, glabrous and glaucous beneath, segm. or lobes acute, unequally dentato; fls. in long, pendulous racemes; samara glabrous. - Native of northern Europe. An ornamental tree, 40 to $50 \mathrm{f}$ high, with very large, dark green leaves. A beautiful variety with striped lcaves is also cultivated, Apr., May. $\nmid$

8 A. macrophyllum $\mathrm{Ph}$., with large, very deeply 5-lobed lvs., nodding racemes, and hispid fruit, from Oregon; is occasionally seen in shubberies and parks. It becomes a large tree, also

9 A. circinàtum $\mathrm{Ph}$., with cordate, 7 tọ 9-lobed lvs., and pedunculato corymbs of flowers, from Oregron. A beautiful tree.

2. NEGUNDO, Mœnch. Box Elder. Asir Maple. Flowers $q$ ơ; corolla 0 ; $q$ flowers racemed, of fascicled; calyx, stamens and fruit as in the last genus. - Lvs. compound, pinnately 3 to 5 -foliate.

N. aceroìdes Mœnch. Lvs. ternate and 5-pinnate; lits. ovate, acuminate, remotely and unequally dentate; $q$ racemes long and pendulous; barren fls. corymbous; fr. oblong, with large wings dilated upwards. - A handsome tree, 20 to $30 \mathrm{f} \mathrm{high,} \mathrm{with} \mathrm{irregular,} \mathrm{spreading} \mathrm{branches,} \mathrm{in} \mathrm{low} \mathrm{grounds,} \mathrm{Can.} \mathrm{to} \mathrm{N.} \mathrm{Car.}$ and Tenn. The trunk is a foot or more in diameter, and when young covered with a smooth, yellowish greon bark. Lfts. serrated above the middle, petiolate, the terminal one largest, all slightly pubescent. Wings of the samara approximate, broadest towards the end. Apr. (Acer Negundo L.)

\section{Order XLI. SAPINDACEA. Indian Soapworts.}

Trees, shrubs, or rarely herbs, with simple or compound, alternate or opposito leaves. Flowers mostly unsymmetrical and irregular, 4 or 5-merous, with the sepals and peta's both imbricated in the bud, with the stamens 5 to 10 , inserted on a hypogynous or perigynous disk; Ovary 2 or 3 -celled and lobed with 2 (rarely morc) ovules in eacli cell. Embryo mostly curred or convoluted, with littlo or no albumen. (Figures 209, 358.)

Genera 73, species 415 , scattered orer all countries, and of various qnalities and uses. The Order is named from the saponaceons principle contained in the seed of Sapinda Saponaria and other species, which makes a lather with water useful in washing. 'The fruits of the I'aullinia aro joisonous, those of Nephelium delicious and wholesome.

TRIEES AND GENERA.

IIPPOCASTANEA. Irs. opposite. Carpels 2-ovuled. Eubryocurved.

Petals unequal. Stamens 7 . Leaves digitate............ BEsculus. 1

SAPINDEA. Leaves alternate. Carpels 1-oviled. Embryo curved.

Trees. Fruit 1 to 3 fleshy, connate, globular carpcls. ................ Sapixdus. 2

Ilerbs, climbing. Fruit an inflated, membranous capsule..... Cardospravum. 3

STAPHYLEA. Lvs. opposite, pinnate. Fruit an inflated capsule........... Stapurba. 4

1. ÉSCULUS, L. Horse Chestrut. Buckeye. Calyx 5-toothed; corolla irregular, 4 or 5 -petaled ; stamens 7 ( 6 to 8$)$, distinct, unequal, inserted on a hypogynous disk; style filiform, ovary 3-celled, with 2 ovules in each cell; fruit coriaceous, 2 to 3 -valved, containing but one 
or very few large, smooth seeds; cotyledons thick, bulky, inseparable.Trees or shrubs with opposite, digitate, 5 to 7 -foliate lvs. Fls. paniculate, terminal.

$\S$ Asculos DC. Fruit covered with prickles, Petals 4 or 5, spreading.............. Nos. 1, 2

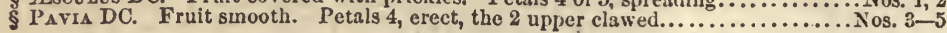

1 Is. Hippocástanum L. HORSE Chestnut. Lvs. of 7 obovate lfts.; pet. 5, spreading; fr. prickly.-A noble tree, justly admired for its majestic proportions, and for the beauty of its foliage and flowers. It is a native of the north of Asia, but is now known throughout Europe and in this country, and is a frequent ornament of courts and avenues. It is of rapid growth, and attains tho height of 40 or 50f. In June it puts forth numerous pyramidal racemes or thyrses of flowers of pink and white, finely contrasting with the dark green of its foliage. The seed is large, mahogany-colored, and eaten only by deer. +

2 IF. glàbra Willd. Omo BuCKEYE. Lfts. 5, oval or oblong, acuminate, serrate or serrulate; fls. in lax thyrsoid panicles; cor. 4-petaled, spreading, with the claws as long as the calyx; stam. nearly twice longer than the corolla; fr. echinate. $-A$ small, ill-scented tree, along the banks of the Ohio and its tributaries. Lfts. 3 to $6^{\prime}$ long, $\frac{1}{3}$ as wide, subsessile, or often contracted at base to short stalks. Fls. yellowish-white, small, slightly irregular. Fr. hardly $1^{\prime}$ diam. May, Jn. (Pavia Ohioënsis Mx.)

3 7f. flàva Ait. Bra Buckeye. SWeEt Buckeye. Lfts. 5 to 7, oblong-ovate or elliptic-ovate, acuminate, serrulate, pubescent beneath; fls. in thyrsoid, pubés. cent panicles, about 6 on each division of the pedunclo; cal. campanulate, not half the length of the corolla; petals very unequal, connivent, longer than the stamens; fr. unarmed.-A large tree, 30 to $70 \mathrm{f}$ high, common in the Southern and Western States. (In Columbia co., Ga., only 4 to $6 \mathrm{f}$ high, Elliott.) Lfts. 4 to $7^{\prime}$ by 1 to $3^{\prime}$. Fls. pale yellow. Fr. globous, uneven on the surface, but not prickly, 2' diam., with 1 or 2 large (1' diam.), mahogany-colored seeds. Apr., May.

4 ZA. Pàvia L. BuCKEYE. Lfts. 5 to 7, oblong-lanceolate, cuneate at base, shortly acuminate, finely serrate; fls. red, very irregular in a lax, thyrsoid raceme; pet. 4 , crect, as long as stamens; cal. tubular, half as long as the 2 shorter petals.A beautiful shrub, 3 to $10 \mathrm{f} \mathrm{high,} \mathrm{common} \mathrm{in} \mathrm{the} \mathrm{Southern} \mathrm{States.} \mathrm{Lvs.} \mathrm{of} \mathrm{a} \mathrm{rich}$ shining green, the veins, petioles and twigs purple. Fls. large ( $l^{\prime}$ long), red, glabrous. Mar.-May. $t$

5 II. parviflòra Walt. Ifts 5 to 7, obovato acuminate, serrate, velvety canescent beneath; petals 4 (white), somewhat similar and spreading, thrice shorter than the capillary stamens. - A beautiful shrub, 2 to $5 \mathrm{f} \mathrm{high,} \mathrm{in} \mathrm{upper} \mathrm{Ga.} \mathrm{and} \mathrm{S.} \mathrm{Car.}$ Fls. very numerous, in a long, slender, raccmous thyrse. The upper petals are rather longer, all on slender, exserted claws. Apr, May. (Ak. macrostachya Mx.)

2. SAPÍNDUS, L. Soap-berry. (That is, by syncope, Sapo Indicus, Indian soap.) Sepals 4 or 5 ; petals as many, or one less by abortion, appondaged inside with a gland, scale or beard; stamens 8 to 10 ; inserted on the upper surface of the fleshy disk; stigmàs 3 ; fruit 3 , connate, globular, fleshy carpels, often by abortion 2 or 1 ; seed large, solitary.-Trees with alternate, pinnate, exstipulate leaves.

S. marginàtus Willd. Common petioles wingless; lits. 9 to 18 , orate-lanceolate, long-pointed, very inequilateral, short-stalked, entire, glabrous, shining above; fls. in dense compound panicles, $\hat{f}+$ or $\hat{\delta} \not \xi q .-G a$. to Ark. Tree 20 to $40 \mathrm{f}$ high, with bright-green foliage and small Als. in large terminal panicles. The barren panicles much more dense and compound than the fertile. Filaments hairy. Berry usually single, rarely triple, reddish-brown, as large as an ounce bullet, its pulp soapy. Seeds loose, rattling.

3. CARDiospérmum, L. Heart-Seed. Balloon-vine. (Gr. кapdía, heart, $\sigma \pi \dot{\varepsilon} \rho \mu a$, seeds; the globous seeds marked with a large cordate hilum.) Sepals 4, the 2 outer smallest; petals 4, each with an emar- 
ginate scale above the base; the 2 lower remote from the stamens, their scales crested; stamens 8, unequal ; style trifid; capsule membranous, inflated.-Climbing herbs with biternate lvs. Lower pair of pedicels clianged to tendrils.

C. Hảliácabum L. Plant nearly glabrous; Ifts. ovate-lanceolate, inciscly lobed and dentate; fr. pyriform-globous, large, bladder-like.-Native on the Missouri and its branches, Torr. \& Gr. Naturalized in the Western States, Mead. A curious vine, 4 to $6 f$ in length, with remarkably, large, inflated, membranous capsules. Jl. $\S$

4. STAPHYLEA, L. BlaDDER-NUT. (A Greek word, meaning a cluster of grapes; from the form of the fructification.) Fls. $\Varangle$; calyx of 5 , colored, persistent sepals; petals and stamens 5 ; styles 3 ; capsules 2 to 3 -celled, thin, and inflated; seeds not ariled. Shrubs with opposite, 3 to 7-foliate lvs. and caducous stipules.

S. trifòlia L. Lvs. ternate; rac. pendulous; pet. ciliate below; fr. ovate.-A handsome shrub, 6 to $8 \mathrm{f} \mathrm{high,} \mathrm{in} \mathrm{moist} \mathrm{woods} \mathrm{and} \mathrm{thickets,} \mathrm{Can.} \mathrm{to} \mathrm{Car.} \mathrm{and} \mathrm{Tenn.}$ Lfts. oval-acuminate, serrate, pale beneath, with scattered hairs. Fls. white, very elegant, in a short, drooping raceme. The most remarkable feature of the plant is its large, inflated capsules, which are 3-sided, 3-parted at top, 3-celled, containing several hard, small nuts or seeds, with a bony, smooth and polished testa. May.

\section{Order Xlit. CElastrace E. Staft Trees.}

Shrubs with simplo leaves alternate or opposite, with flowers small, regular, 4 or 5-merous, perigynous, sepals and petals both imbricated in æestivation, starsens alternate with the petals and inserted on a disk which fills up the bottom of the calyx; carpels 2 to 5, styles united. (Fig. 460.) Fruit freo from tho calyx with 2 to 5 cells. Seeds ariled, few, albuminous.

An order closely related to the last, embracing about 30 genera and 200 species, chiefly inhabiting the temperate zone of each hemisphere. They possess acrid and bitter properties, sometimes emetic and stimulant.

1. CELÁstRUS, L. Staff-tree. Flowers often imperfect; calyx flat, of 5 united sepals; corolla spreading, of 5 sessile petals; capsule subglobous, or 3 -angled, 3 -celled; seeds with an arillus, 1 to 2 in each cell.-Climbing shrubs, with alternate, deciduous lvs. and minute, deciduous stipules.

C. scándens L. Unarmed; st. woody, twining; lvs. oblong, acuminate, serrato; rac. terminal; fls. diocious.-A climbing shrub in woods and thickets, the stems twining about other trees or each other, ascending to a great height. Lvs. alternate, stipulate, petiolate, smooth. Fls. in small racemes, greenish white. Sds. covered with a scarlet aril, and contained in a 3-valved capsule, continuing upon the stem through the winter. $\mathrm{Jn}$.

3. EUÓNYMUS, Tourn. Spindle Tree. (Gr. $\varepsilon v$, good, övo $\mu a$, name.) Flowers perfect; calyx flat, of 5 (sometimes 4 or 6 ) united sepals; corolla flat, inserted on the outer margin of a glandular disk; stamens 5, with short filaments; capsule colored, 5-angled, 5-celled, 5.valved; seeds ariled.-Shrubs erect or trailing, with opposite, serrate lvs.

I E. atropurpùreus Jacq. SPINDLE TreE. BURNing BesH. Branches smooth; Ivs. elliptic-ovate, petiolate, acuminate, finely serrate, puberulent beneath; ped. compressed, many-flowered; fls. usually 4-merous; capsule smooth, lobed. $-A$ smooth shrub, 4 to $10 \mathrm{f} \mathrm{high,} \mathrm{in} \mathrm{shady} \mathrm{woods,} \mathrm{U.} \mathrm{S.,} \mathrm{E.} \mathrm{of} \mathrm{the} \mathrm{Miss.} \mathrm{I.vs.} 2$ to $5^{\prime}$ 
long, $\frac{1}{2}$ as wide, acute or often rounded at base, on petioles $\frac{1}{3}$ to $1^{\prime}$ long. Ped. opposite, slender, 1 to $2 \frac{1^{\prime}}{2}$ long, each with a cyme of 3 to 6 flowers. Cor. dark purple, 4 to $5^{\prime \prime}$ diam. Caps. crimson, smooth. Sds. covered in a bright red aril. Jn.

2 E. Americànus I. BurNing Busi. Branches smooth, 4-angled; lvs. oval and elliptic-lanceolate, subentire below, acuminate, acute or obtuse at apex, smooth, sessile or nearly so; ped. round, about 3-flowered; fls. mostly pentamerous; caps. verrucoss. - Shrub of smaller size than the preceding, with small lvs. in moist woods, U. S. and Can. Lvs. 1 to $2^{\prime}$ long, $\frac{1}{3}$ as wide, coriaceous. Ped. slender, 1, 2 or 4-flowered. Fls. a little larger than in No. 1, yellow and pink, the parts rarcly in 3s. Capsule dark red, warty. Sds. with a bright-red aril. Jn.

$\beta$. овоvatus 'T. \& G. Trailing and rooting; lvs. obovate-oval, rather pointed or obtuse, acute and short-petiolate at base. Ohio, \&c. (E. obovatus Nutt.)

3 E. augustifòlius $\mathrm{Ph}$. Branches 4-sided; lvs. linear-lanceolate, inequilateral and subfalcate, acute at each end, obscurely serrate, almost sessile; pedicels 1 to 3-flowered; fls. 5-merous, pet. distinctly clawed. - Woods near Savannah, Ga. St. decumbent. Branches regularly opposite, so that the plant appears liko a bipinnate leaf. Lvs. 2 to $3^{\prime}$ long, 3 to $5^{\prime \prime}$ wide, sharply acute; fls. as large as in No. 2. Apr., May.

4 E. Europæus L. Lvs. oblong-lanceolate, serrate, glabrous; ped. compressed, 3-flowered; fls. usually tetrandrous. - Native of Europe. A handsome shrub, 4 to $12 \mathrm{f}$ high, sometimes found in shrubberies, although certainly not superior in elogance to No. 1. May-Jl. $\dagger$

\section{Order XLIII. RHAMNACEA. Buckthorns.}

Shrubs or small trees, often spiny, with simple, alternato lvs. with flowers regular, sometimes apetalous or otherwise imperfect; with the stamens perigynous, as many ( 4 or 5 ) as the valvate sepals, alternate with them, and opposite to the petals when they are present. Disk fleshy; capsule or berry with one albuminous seed in each cell.

Genera 42, species 250, distributed throughont all countries except those in the frigid zones. Many aro natives of U.S. Ceanothus is peculiar to N. Ainerica.

Properties. The berries of many species of Rhamnus are violent purgatives. The Zlzyphus Jujuba ylelds the well-known jujube paste of tho shops. The leaves of Ceamothus have becn lised as a substitute for tea.

\section{GENERA.}

Flowers clustered, axillary. Petals as long as sepals or none............. Rirumses 1 Flowers clustered, terminal. Petals on long exserted claws................ Самотичs 2 Flowers panicled, terminal. Petals as long as the sepals................... Broukmid 3 Flowers spjicate, terminal. Petals yery minute......................

1. RHÁmNuS, L. Buckthorn. (The Greek name.) Calyx urceolate, 4 or 5-cleft; petals 4 or 5, notched, lobed or entire, or sometimes wanting; ovary free, not immersed in the thin torus, 2 to 4 -celled; styles 2 to 4 , more or less united; drupe containing 2 to 4 cartilaginous nuts.-Lvs. alternate, rarely opposite. Fls. in axillary clusters.

\$ Flowers tectramerous. Leaves with arcuate veins................................ 1, 2

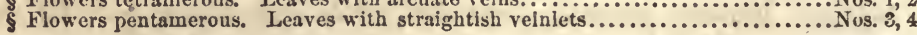

1 R. cathárticus L. Thorny; lvs. ovate; denticulate-serrate; fls. fascicled; polygamo-dicecious, mostly tetrandrous; sty. 4, at apex distinct and recurved; fr. globular, 4-seeded.-Cultivated in hedges, and occasionally found wild in N. Eng. and N. Y. It is a shrub or tree 10 to $15 \mathrm{f} \mathrm{high,} \mathrm{spreading,} \mathrm{with} \mathrm{thorns} \mathrm{termin-}$ nating the short branches. Lvs. somewhat opposite. 1 to $2^{\prime}$ long, 2 as wide, usually with an abrupt acumination, and with 5 to 7 arcuate veins. Pedicels 3 to $4^{\prime \prime}$ long. Fls. greenish. Petals inconspicuous, entire (sometimes 0 ?), narrower than the lanceolate sepals. Berries black, with a green juice, cathartic, and forming with alum the pigment called sap grcen. 
2 R. lanceolàtus $\mathrm{Ph}$. Thornless; lvs. lanceolate or lance-oblong, acute at each end, serrulate, the younger leaves obtuse; fls. 1 to 3 together; petals 2-lobed; styles 2, at apex distinct and diverging; drupes 2-seeded.-Shrub 4 to $8 \mathrm{f} \mathrm{high,} \mathrm{on}$ the rocky banks of rivers, Ind. to Tenn. and Penn. rare. Lvs. about $2^{\prime}$ long, on short, but distinct petioles, often nearly glabrous when old. Fls. yellowish-green, perfect but often fruitless. Berries small, dark red.

3 R. alnifolius L'Her. Shrub erect, with unarmed branches; lvs, oval, acute, serrate, pubescent on tho veins beneath; ped. aggregate, 1-flowered; fls. mostly pentandrous and apetalous; cal. acute; sty. 3 , united, very short; fr. turbinate, black.-A shrub 2 to $4 \mathrm{f}$ high, in sphagnous swamps, Penn. to Can. Lvs. 1 to $3^{\prime}$ lcn $\mathbf{g}, \frac{1}{2}$ as wide, acute at base. Berries about as large as currants, black, 3 -seeded. May, Jn. (R. franguloides $\mathrm{Mx}$.)

4 I. Caroliniànus Walt. Shrub erect, unarmed; Ivs. oblong-oval, obscurely serrulate, acute, paler beneath; fls. perfect, in short, axillary umbels, petals minute; styles united, stigmas 3; fr. globular, 3-seeded.-A handsome shrub or small tree on river banks, Southern States (Feay). Lvs. 3 to $5^{\prime}$ long, $\frac{1}{3}$ as wide, dark green and shining above, the petioles 4 to $5^{\prime \prime}$ long, veins prominent. Fls. small, whitish, 3 to 9 in each umbel which is not longer than the petioles. Berries purple. May, Jn.

2. CEAnÒthuS, L. Jersey Tea. Red-root. Calyx tubular-campanulate, 5-cleft, separating transversely after flowering; petals 5, saccatc-arched, with long claws; stamens mostly exserted; style mostly 3-cleft; capsule obtusely triangular, 3-celled, 3-seeded, surrounded at base by the persistent tube of the calyx.- Shrubby and thornless. Fls. small, aggregated at the end of the branches.

1 C. Americànus L. Lvs. oblong-ovate, or ovate, serrate, 3-veined; flowering branches leafy or leafless, elongated.-A small shrub with a profusion of white blossoms, found in woods and groves U. S. and Can. Very abundant on the barrens at the West. St. 2 to $4 \mathrm{f} \mathrm{high,} \mathrm{slender,} \mathrm{with} \mathrm{reddish,} \mathrm{round,} \mathrm{smooth} \mathrm{branches.}$ Lvs. nearly twice as long as broad, very downy, with soft hairs beneath. Fls. minute, white, in crowded panicles from the axils of the upper leaves. Stamens enclosed in the curiously vaulted corolla. The root, which is large and red, is sometimes used for coloring. The leaves have been used as a substitute for tea. Jn.

$\beta$. GLABRA. Whole plant very nearly glabrous; panicles leafless. Wcburn, Mass. (Dr. Rickard.)

2 C. ovàlis Bw. Lvs. oval-lanceolate or narrowly oblong, with glandular serratures, 3-veined, veins pubescent beneath; thyrse corymbous, abbreviated.-Burlington, Vt. (Robbins), W. to Mich. Shrub 2 to $3 f$ high. Lvs. smooth and shining, 1 to $3^{\prime}$ long, $\frac{1}{4}$ as wide, mostly acute at each end, crenately serrate, the serratures tipped with black, glandular points. Thyrse short, almost hemispherical, $1_{\frac{1}{2}}^{\prime}$ diam., the peduncle 1 to $2^{\prime}$ long. Fls. white, larger than those of the last. May.

3 C. microphýllus $\mathrm{Mx}$ : Diffusely branched, branches very slender; lvs. minute, obovate, rigid, glabrous, strigous beneath, clustered; fls. in a simple, umbellate cluster at the end of each branchlet.-Ga. and Fla. in the pine larrens. Small shrubs with yellowish, striated bark; sts. If or more in length, branching pinnately. Lvs. 1 to $2^{\prime \prime}$ in length, entire or with few teeth. Fls. white in all their parts, 3 to 12 in a cluster.

$\beta$. SERPYLLIFolius. - Sts. more slender, decumbent, branchlets (peduncles, Nutt.) ascending, few-leaved, few-flowered; lvs. rather larger (2 to $\left.3^{\prime \prime}\right)$ oval or obovate, somewhat serrulate.-Savannah (Prof. Pond.). (C. serpyllifolius Nutt.)

3. BERCHÈMIA, Necker. SUPPLE JACK. Calyx 5-parted; petals 5, convolute, enclosing the 5 stamens; ovary half immersed in the disk but free from it, 2-celled; style bifid; drupe oblong, with a bony, 2-celled 
nut.-Unarmed shrubs, erect or climbing. Lvs. pinnate-veined, with many veinlets. Panicles terminal.

I3. volùbilis DC. Climbing, glabrous; lvs. ovate, straiglit-veined, repandly serrate; fls. o $\hat{\delta}$. - Southern States, common in damp, rich soils. St. very supple and tough, climbing 10 to $20 \mathrm{f}$, with smooth, reddish bark and pendant branches. Lvs. about $2^{\prime}$ long, with 10 to 13 pairs of veinlets, smooth and shining. Panicles small, terminating the branchlets. Drupe dark purple, $3^{\prime \prime}$ long, the nut hard and woody. May, Jn.

4. SAGERÈTIA, Brongn. (Named for M. Sageret, a French florist and veg. physiologist.) Calyx 5-cleft; petals 5, convolute; stamens 5; ovary partly immersed in the entire disk; style short and thick, with a 3 -lobed stigma; berry 3 -celled.-Shrubs with the slender branches often spiny, and the lvs. opposite. Fls. in rigid, interrupted spikes.

S. Michàuxii Brongn. Branches at length spiny; lvs. ovate or oblong-ovate, subsessile, shining and subentire; fls. very small, in panieled spikes; petals minute, entire; berry 3 -seeded. - Car. to Fla. along the coast. Shrub much branched. Lvs. $1^{\prime}$ or more long, the veinlets few and obscure, shining above. Oct., Nov.

\section{Order XLIV. VITACEA. Vines.}

Shrubs with a watery juice, tumid nodes, and usually climbing by tendrils; flowers small, regular, racemous, often polygamous or diœecious; calyx minute, truncated, the limb obsolete or 5-toothed; petals hypogynous, valvate in æstivation,

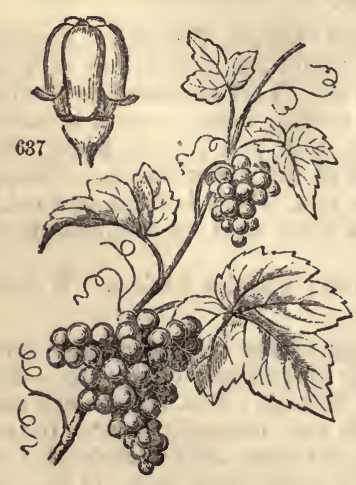
as many as and opposito to the stamens; stamens inserted on the disk which surrounds the 2-celled, 1-styled ovary. Fruit a berry, usually 4-seeded; seeds, bony, albumen hard. (Fig. 449.)

Genera 7, species 260, natives of the warmer parts of both hemispheres. Tne grape fruit is the only important production of this order. The aeid of the grape is tartatic. It contains a sugar which differs from t!le common sugar in containing a snaller quantity of carbon.

637 Flower of V. Labrusca.

1. Vitis, L. Grape Vines. (Celtic gwyd, a tree or shrub.) Petals deciduous, coliering at the top, or distinct and spreading; ovary partly enclosed within the torus, 2celled, cells 2 -ovuled; stigma sessile, capitate; berry 1-celled, 1 to 4 -seeded. Ped. often changed into tendrils.

\$ Petals cohering at top and falling without expaniling.

Leaves hoary or rusty arachnoid-tomentous benenth.................... Nos. 1, 2

Leaves glabrous except the veins and green both sides................... $3,4,7$ $\$$ Petals free at top, finally expanding and falling.

Leaves simple, angular or not.................................. 5

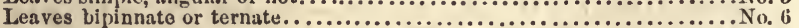

Exotic species....................... 7

1 V. labrúsca I. Lvs. broad-cordate, angular-lobed, hoary-tomentous beneath; berries large.-This vine is native through the U. S., growing in woods and groves. Like most of the $\mathrm{N}$. Am. species, the flowers are polygamous. St. woody, rough-barked, ascending trees often to a great height, and hanging like cables suspended from the branches. Lvs. very large, somewhat 3 lobed, at first white-downy beneath. Fls. small, green, in panicles with a leaf opposite. Fr. large, purple, often green or red. It is valued in cultivation for its deep shade in summer arbors, and for its fruit, which is pleasant in taste. The Isabella and Catawba, and other sorts known in gardens and vineyards are varieties of this species. $\ddagger$

2 V. astivàlis L. Lirs. broadly cordate, 3 to 5-bbed or palmate-sinuate, coarsely 
aentate, with scattered ferruginous hairs beneath; fertile rac. long, panicled, berries small.-Grows in woods, by rivers, \&c. St. very long, slender, climbing, with very large leaves, which are sometimes with deep, rounded sinuses, clothed beneath, when young, with arachnoid, rust-colored pubescence. Tendrils from the peduncles which are dense flowered, and with a leaf opposite. Petals cohering at summit. Berries deep-blue, well flavored, but small, ripo in Sept. Flowers in Jun.

3 V. cordifòlia Mx. Frost Grape. Lvs. cordate, acuminate, somewhat equally toothed, smooth, or pubescent beneath the veins and petioles; rac. loose, manyflowered; berries small-Grows in thickets, by rivers, \&c., ascending shrubs and trees to the height of 10 to $20 \mathrm{f}$ Lvs large, membranous, often 3-lobed, with pubescent veins when young, and with a few acuminate-mucronate teeth. Berries nearly black, rather small, late, acid but well flavored after the frosts of November. Jn. (V. riparia Mx.)

4 V. vulpina L. Fox Grape. Scupperusong. Irs. (small) cordate, slightly 3-angled or lobed, shining on both sides, coarsely toothed, the teeth nnt acuminate; rac composed of many capitate umbels.-River banks Va. to Fla. Sts. many feet in length, straggling or climbing. Lv.s. 2 or $3^{\prime}$ diam., shining most on lower surface, having the sinus at baso acute, and the terminal tooth rather pointed. Fr. large, pleasant, few in a cluster. The variety called "Scuppernong" is quito common in southern gardens.

$5 \mathrm{~V}$. indivisa Willd. Lvs, simple, cordate or truncato at tho base, often angular-lobed; panicles dichotomous; fls. 5-merous; berry 1-celled, 1 or 2 -seeded.Swamps, S. States to St. Louis. St. ascending trees many feet. Lvs. 3 to 5 ' broad, unequally toothed, pubescent on the veins beneath. Panicles with spreading branches, none of them changed to tendrils. Berry small (hardly $2^{\prime \prime}$ diam.), pale-red, mostly 1-seeded. (Cissus Ampelopsis Pers.)

6 V. bipinnàta Torr. \& Gr. Lvs. bipinnaile, lifts incisely serrate, glabrous; fls. 5-merous Southern States along rivers. A species remarkably distinguished by its upright, scarcely twining stem, and its compound leaves. Tho lits. aro rhombic-ovate, about $\mathbf{I}^{\prime}$ in length or less, petiolulate mucronate. Tendrils none. Panicles few-flowered. Berry depressed-globous, tho sizo of a pea, purplishblack. Jn., Jl. (Cissus bipinnata, Ell.)

7 V. vinifera L European Wine Grape. Lvs cordate, sinuately 5-lobed, glabrous; fls all $\Varangle$. -No plant in the vegetable kingdom possesses more interesting attributes, is cultivated with greater care, or has been worse perverted and abused, than the common rine. By cultivation it sports into endless varieties, differing in the form, color, size and flavor of the fruit, and in respect to the hardiness of its constitution.

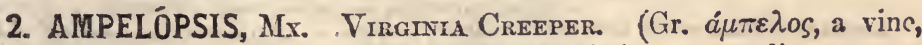
ó $\psi \iota$, appearance.) Calyx entire; petals 5 , distinct, spreading; ovary 2-celled, cells 2-ovuled; style rery short; berry 2-celled, cells 1 to 2 -seeded.-A shrubby vine. The tendrils attach themselves by an adhesive foot-like expansion at the end.

A. quinquefòlia Mx. Lvs. quinate, digitate; Ifts. oblong, acuminate, petiolate, dentate. A vigorous climber, found wild in woods and thickets. It has long been cultivated as a covering for walls, and is best known by the name of woodbine By means of its foot-like, adhesive tendrils, it supports itself firmly upon trees or walls, ascending to the height of fifty feet. The large quinate leaves constitute a luxuriant foliage of dark, glossy green, changing to crimson in autumn. Fls inconspicuous, greenish, in dichotomous clusters. Berries darkblue, smaller than peas, acid. JL

\section{Order XLV. POLYGalaCEA. Mfrkworts.}

Herbs or shrubs, with the leaves mostly simple and without stipules. Fiovers irregular, unsymmetrical, hypogynous, perfect. Sepals 5, very unequal, distinct, 3 exterior, 2 (wings) interior larger, petaloid. Petals 3 , the anterior (keel) larger than the 2 posterior. Stamens 4 to 8 , distinct, or cohering in a tube which is spiit 
on tho upper side. Ovary superior, compound, with suspended ovules, united styles and stigmas. Fruit a 2-celled, 2-seeded pod. Seeds pendulous, furnished with a caruncle.

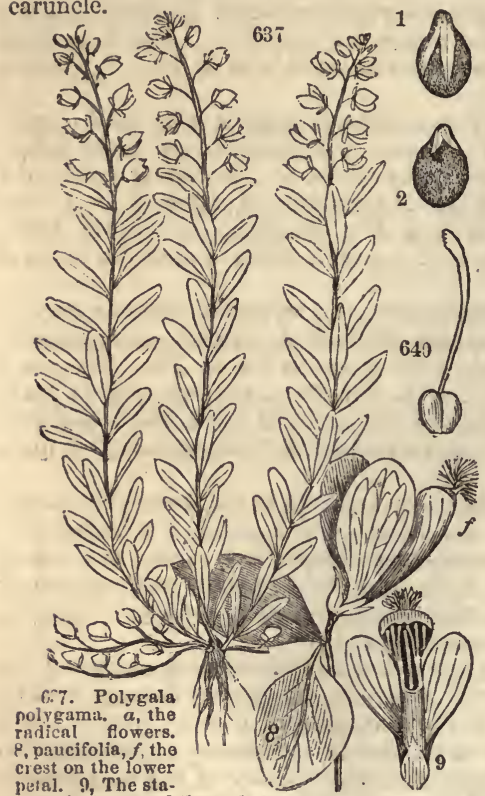

mens in 2 sets and the style seen beneath the hooded mens in 2 sets and the style seen beneath the hooded
luwer petal. 640 , The ovary and the style. 1 . Seed of $P$. Banguinea with its 2 -lobed caruncle. 2 . Seed of $\mathrm{P}$. Nuttallii.

Genera 20, species 500. The genus Polygala is very generally distributed. The other genera are mostly limited each to a particular quarter of the globe. Properties generally bitter, acrid and astringent, with a milky juice in the root. Rlatany-root, the root of Krameria, used in medicine, yields a deep red color and is used to alulterato port wine. The more active species of Polygala, as P. Senega, sanguinea, purpurea, etc., are emetic, purgative and diuretic.

POLÝGALA, Tourn. MrLKwort. (Gr. $\pi 0 \lambda \dot{v} s$, much, $\gamma \dot{ } a^{\prime} \lambda a$, milk ; said to favor the lacteal secretions of animals.) Flowers very irregular. Sepals 5, 2 of them wing-shaped and petaloid; petals 3, cohering by their claws to the filaments, lower one carinate and often crested on the back; stamens 6 or 8 , filaments united into a split tube; anthers 1-celled; capsule obcordate, 2-celled, 2-seeded, loculicidal; seed appendaged with a various caruncle at the hilum.-Bitter herbs in the U. S. and Can. (elsewhere often shrubby), with simple lis. Fls. often of two forms, the subterranean apetalous.

Leaves alternate. -Fls.purple, solitary, 2 to 4. Perennial...................... 1 -Fis. purple, racemed, many. Biennial....................... Nos. 2, 8 -Fls. white. Spike slender. Perennial............................... No. 4 - Fis. purple. Spike capitate.-Caruncle double.................. Nos. 5, 7 - Caruncle appears simple. $\Lambda$ nnual. Nos. \&-10 -Fls.xanthlc.-Spikes solitary, large. Biennial................. Nos. 11, 12 -Spikes numerous, corymbed, small. Biennial..... Nos. 13, 14

Leaves verticillate on tho stem. - Spikes acute, slender................... Nos. 15, 16

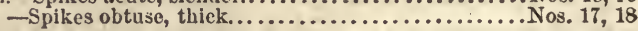

1 P. paucifòlia L. St. simple, erect, naked below; lvs. ovate, acute, smooth; terminal fls. large, crested, radical ones apetalous.-A small, handsome plant, with a few large (10" long) purple flowers. Woods and swamps, Brit. Am. to Ga. St. 3 to $4^{\prime}$ high, with its acuto lrs. mostly near the top, 2 to 4 flowers above them. Cal, of 5 leaves, the upper one gibbous at base. Corolla mostly purple, with a purple crest on its middle lob.o. Tho radical fls. are either close to tho ground or subterraneous, smaller, greenish, wanting the wings of the calyx. May.

2 P. grandiflòra Walt. Ascending, pubescent; Ivs. ovate-lanceolate to lancelinear, acute; fls. distant, pendulous after blooming, wings large, roundish, covering the corolla and fruit, keel as long as the wings $\left(3^{\prime \prime}\right)$, crestless.- (2; Common in dry soils, S. Car., Ga., Fla. to La. A pretty plant, 9 to $12^{\prime}$ high, remarkable for its changeable flowers, rose-colored at first, soon becoming green and drooping, and alone destitute of a crest, having a yellow callosity instead. Lrs. 9 to $15^{\prime \prime}$ long, 2 to $4^{\prime \prime}$ wide, often nearly glabrous. May-Aug.

- 3 P. polỳgama Walt Sts. simple, numerous, glabrous; Ivs. linear oblong, mucronate, obtuse; fls. racemed, short-pediceled, those of the stem winged, those of the root wingless; keel cristate.-Fields and pastures, Can. to Fla. and La. Sts. crowded, many from the same root, angular, smooth. Lvs. smooth, lower 
obovate, apper sessile. Fls. purple, $2^{\prime \prime}$ long, finally drooping. Wings obtuse. Anth. 8. Bracts small, subulate, caducous. Terminal racemes with perfect fls., radical racemes prostrate or subterraneous, wingless and nearly apetalous. Jn., JL. Bitter and tonic. (P. rubella Willd.)

4. P. Sènega I. Seneca SNake-Root. St. erect, smooth, simple, leafy; lvs. alternate, lanceolate, tapering at each end; fls. slightly crested, in a terminal spike-form, slender raceme.-Woods, Western States, rare in Eastern. Root ligneous, branched, contorted, about $\frac{1^{\prime}}{2}$ thick, ash-colored. Sts. 8 to $14^{\prime}$ high, several from the same root. Lvs. 1 to $2^{\prime}$ long, $\frac{1}{3}$ as wide, numerous, scattered. Fls. whitc, in a filiform spike, 1 to 2 ' long. Sep. obtuse, larger than the petals. The root has a sweetish, nauseous taste, soon becoming pungent and hot. Jl. A valuable stimulating expectorant.

ß. LAtifolia T. \& G. Lvs. ovate, acuminate at each end.-St. leafy, more than if high. Lvs. 2 to $3^{\prime}$ long, $I^{\prime}$ or more broad. Ind. (Dr. Plummer.)

5 P. setàcea $\mathrm{M} x$. Sts. filiform, simple, apparently leafless (lvs. minute, deltoidacuminate); spike (small) oblong, acute; wings short-pointed, shorter than the petals; caruncle enclosing the short stipe of the hairy seed.-2f $\mathrm{N}$. Car. to Ga and Fla. Sts. about If high. Lvs. $1^{\prime \prime}$ or less long. Fls. pale roseate, in a spike about half an inch long. Jn., Jl.-Each stem produces several heads during the scason, the next in succession arising from an inferior node after the former has shed its fruit. Hence the naked footstalk often accompanying the single head (Mettauer).

6 P. incarnàta I. Glaucous; st. erect, slender, mostly simple; lvs. ferw, scattered, linear-subulate; spike oblong; wings lanceolate, cuspidate, claws of the petals united into a long, cleft tube; caruncle double, covering the short stipe of the very hairy seed.-(1) Dry soils, N. J., to Fla., W. to Ark. St. 1 to $2 \mathrm{f} \mathrm{high.}$ Lvs. 4 to $6^{\prime \prime}$ long, remote. Spikes 1 to $1 \frac{1^{\prime}}{2}$ long. Fls. pale rose-color or fleshcolor. The slender corolla tube erect, nearly twice as long $\left(4^{\prime \prime}\right)$ as the wings, the keel with a conspicuous crest. Jn., Jl.

7 P. Chapmanì Torr. \& Gr. Very slender, simple, or nearly so; Ivs. linearsubulate; spike loose; roundish oblong, rather acute; wings obovate, slightly clawed; caruncle 2-lobed, covering one side of the thick stipe of the thin-haired seed.-(1) W. Fla. to La. (Hale). Sts. 12 to $18^{\prime}$ high. Lrs, acute, 6 to $8^{\prime \prime}$ long, not $\frac{1}{2}^{\prime \prime}$ wide. Fls. bright rose-color. Heads $5^{\prime \prime}$ thick.

8 P. Nuttállii Torr. \& Gr. St. erect, somewhat fustigiate; lvs. linear; spikee acute, roundish-oblong, dense; wings elliptical, attenuate at base; crest minute; caruncle notched, 'laterul on the thicls seed stipe.-Mass., R. I., to La. St. 6 to 10' high, the branches overtopping the stem. Lvs. 6 to $8^{\prime \prime}$ by $1^{\prime \prime}$, acute. Spikes 5 to 7 "long, 3 to $4^{\prime \prime}$ diam. Wings of tho calyx rose-red. Seeds black, pear-shaped. Aug. (P. sanguinea Nutt.)

9 P. fastigiàta Nutt. Slender and much branched above; lrs. linear; spikes roundish, lonse-flowered; wings ovate-oblong, distinctly clawed; caruncle broad, nearly embracing the small seed-stipe (immature).-N. J. to Fla. in dry soils. St. 8 to $12^{\prime}$ high. Lvs. 8 to $12^{\prime \prime}$ long, $1^{\prime \prime}$ wide, acute. Spikes about $5^{\prime \prime}$ diam., tho fls. distinctly pediceled, and of a brighter rose-color than the foregoing. ( $P$. sanguinea T. \& G.)

I0 P. sanguínea I. St. branching at top; lvs. linear and lance-linear, spikes oblong, obtuse, dense; wings oval or ovate, obtuse, subsessile; caruncle mostly simple, nearly as long as the hairy seed.-An erect plant, 6 to $12^{\prime}$ high, found in meadows and wet grounds, Mass. to La. St. angular, with fastigiate branches, each ending in a smaller spike than that of the main stem, but often overtopping it. Lis $1^{\prime}$ long, 1 to $2^{\prime \prime}$ wide. Heads about $6^{\prime \prime}$ thick. The caruncle is double in a few of the seeds, with divergent segments. Fls purple, caducous. JlOct. (P. purpurea Nutt.)

II P. Iùtea I St. mostly simple; root lvs. spatulate, obtuse, attenuate at base; cauline ones lanceolate, acute; rac. orate-globous, obtuse, dense; fls. pedicillate; wings ovate, mucronate, keel with a minute crest. - Sandy plains, N. J. to Fla. St. 8 to $13^{\prime}$ high, generally many from the same root, seldom with a few spreading branches. Fls. orange-yellow, longer than the bracts, aggregated in one ter minal roundish head which is 8 or $9^{\prime \prime}$ thick. A showy plant. 
12 P. nàna DC. Low, ascending; 1rs. obovato and spatulate, mostly radical; heads ovate, becoming oblong, derso; wings lance-ovate, cuspidate-acuminato twice longer than the slightly crested keel.-S. States, in pine woods, common. Sts. 3 to $5^{\prime}$ high. Lvs. 1 to $2^{\prime}$ long, rosulate. Head often near $1^{\prime}$ thick, dispro. portionately large, the fls. citron-yellow, changing to green. Apr., May.

13 P. ramòsa Ell. Erect, corymbously branched above; spikes loose, oblong, numerous, forming one or more dense, level-topped cymes; radical lvs. few (small), spatulate, cauline oblong-linear; seed oval, caruncled.-Swamps, Del. to Fla. and La. This and the next are species of singular aspect. St. If high. Lvs. about $6^{\prime \prime}$ long, few at the root. Spikes about $4^{\prime \prime}$ diam., the fls. greenish yellow, becoming finally dark green. Fls. pedicelled. Jn.-Aug. (P. corymbosa Nutt.)

14 P. cymòsa Walt. Sts. tall, simple, corymbously branched at top; lvs. mostly radical, linear, pointed, crowded; stem lvs. very few, linear-subulate; racemes spike-like, numerous, forming a dense, fastigiate cymo; seed globular, naked. Swamps, in the pine woods, N. Car. to Fla. Sts. often many from-the same root, 2 to 4 or $5 \mathrm{f}$ high. Lvs. grass-like, 2 to $3^{\prime}$ long, forming a dense tuft at base. Fls. pedicelled, greenish yellow, becoming finally greenish-brown. Jn.-Aug. (P. attenuata Ell. graminifolia Poir. acutifolia T. \& G.)

15 P. verticillàta $\mathrm{L}$. St. branched above, erect; lvs. linear, verticillate both on the stem and opposite branches; spikes slender, stalked; fls. alternate, crested; calycine wings roundish; seed oblong, smooth, caruncle hardly half as long.Found on dry hills, U. S. and Can. St. very slender, square, 6 to $8^{\prime}$ high. Lvs. in whorls of 5 or 6,4 to $10^{\prime \prime}$ long, $1^{\prime \prime}$ wide. Fls. small, greenish-white, in racemes 3 to $10^{\prime \prime}$ long, which are higher upon the branches than upon the main stom. J1.-Oct.

ß. AMBigua. Branches filiform, alternato; lower lvs. verticillate, upper alternate; spikes elongated, with the fls. scattered; seed exactly as in $a .-$ Dry fields and woods, Mass. to Tenn.

16 P. Boylkinii Torr. \& Gr. Sts. erect from an ascending base, simple; lvs. obovate and lanceolate; whorled, a few of the upper linear and alternate; spike slender, pointed, dense; wings, roundish, concave; caruncle $\frac{2}{3}$ the length of the very hairy seed.-Ga. and Fla. Sts. slender, several from the same root, 12 to $18^{\prime}$ high. Lvs. 6 to $12^{\prime \prime}$ long, in $3 \mathrm{~s}, 4 \mathrm{~s}$, and $5 \mathrm{~s}$. Fls. whitish, the wings green, with white borders. Jn., Aug.

17 P. cruciàta L. St. erect, somewhat fastigiate, winged at tho angles; Irs. verticillate in $4 \mathrm{~s}$, linear-oblong, punctate, spikes ovate, dense, obtuse, sessile or nearly so; seed ovate, smooth, caruncle fully as long; wings deltoid-ovate, cuspidate. -In sphagnous swamps and other low grounds, Mass. to Fla. and La. St. 3 to 12' high, very slender, smooth, slightly winged at the 4 angles. Lrs. 2 to $10^{\prime \prime}$ or more long, 1 to $2^{\prime \prime}$ wide (upper ones largest), obtuse, tapering to the base, with small, resinous dots. Spikes capitate, $5^{\prime \prime}$ thick. Wings greenish-purple, much dilated at base. Jl., Aug.

$\beta$. cuspidata. Lvs. linear; heads larger, oblong, squarrous with tho elongated cusps of the wings. This is the more common southern form. (P. cuspidata Hook.)

18 P. brevifòlia Nutt. Slender, branched above; lvs. linear, short, remote, in $4 \mathrm{~s}$, or on the branches scattered; spike oblong, dense, obtuse, on long peduncles; wings ovate-lanceolate, acute; seed just as in No. 17.-N. Y. to Fla. About if high. Heads $4^{\prime \prime}$ thick, 1 to $2^{\prime}$ long (as appears from the squarrous rachis). Lvs. 6 to $9^{\prime \prime}$ long. Fls. roseate. Aug., Sept.

P. BALDwini Nutt. of S. E. Georgia is unknown to the author, unless it be a variety of P. ramosa, differing in its more dense heads of greenish-white flowers.

\section{Order XlVi. LegUminos E. Leguminots Plants.}

Herbs, shrubs, or trees. Leaves alternate, usually compound, margins entire. Stipules 2, at the tumid base of the petiole. Stipels commonly 2, Sepals 5, more or less united, often unequal, the odd one always anterior. Petals 5, either papilionaceous or regular, perigynous, the odd one (when present) posterior. Stamens 
diadelphous, monadelphous or distinct. Anthers versatile. Ova superior, single and simple. Styie and stigma simple. Fr. a legume, either continuous (1-celled), or (3 loment), joined into 1-seeded cells. Sds. solitary or several, destitute of albumen.

Illust. in figs. $99,155,163,151,161,165,177,193,191,191,396,316,317,363,445,416,466$.

The genera and species of thls vast order were estlmated by Mr. Bentham in 1845, as follows:

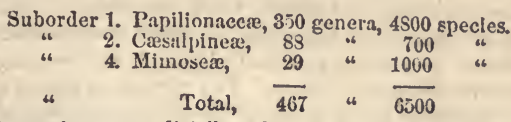

Geography. - The Leguminosa are distributed throughout all lands, with the exception of a few unimportant islands, from the equator to the frigld zones. Of its 6500 specles now known, about 350 are natives of the United states and 'Territories.

Properties. - No family of the vegetable kingdom possesses a higher claim to the attention of the naturalist than the Leguninosx, whether we regard them as oljects of ormament or ntility. Of the former, we night mention the splendid varieties of Cercis, with their purple flowers, tho Acacias, with their airy foliage and silken stamens, tho Pride of India, Colutea and Caesalpina, with a host of others, which, like the Sweet Pea, are redoleut with perfume. Of the latter, the beans, peas, lentils, clover and lucerne, are too well known to require recommendation. Among timber trees, tho Rosewood (a Brazilian species of Minosa), the Laburnnin, whose wood is durable and of an olive-green color, and the Lucnst. of our own country are preëminent.

The following are a few of the important officinal products of this order. In mediclne; liquorice is the prodnct of the ruot of Glyeyrrbiza glabra of S. Europe. The purgative senni consists of leaves of Cassia Senna, C. acutifolia, C. Athiopica, and other species of Egypt and A rabia. C. Marilandica is also a cathartic, but more inild than tho former. The sweet pulp tumarind, is the prodnct of a large and beautifnl tree (Tamarindns Indica) of the $\mathbf{E}$. and W. Indies. Resins and Balsans: Gum Senegal is yielded by Acacia Verek of the River Senegal ; Gum Arabic, by several species of Acacia of Central Africa; Gum Tragacanth, by Astragalus verus, \&c., Persia Bulsam Copriva is the product of several species of Copaifera. natives of Brazil and W. Indies; Bulsam Tolu of Myospermum toluifernum of Peru, and Balsam Peru of M. peruiferum of the same country. Dyes, \&c.: Indigo, the most valuable of all (but a viulent poison), is the product of several sonthern species of Indigofera, as I. anil of the W. Indies, and I. argentea of Egypt. Brazil-roood from Caesalpina Braziliensis. Log-wood from Hranatoxylon Campeashianum, of Campeachy, and Red Sandal-roood from Pterocarpus santalinus of Egypt, \&c., \&.e.

SUBORDERS, TRIBES AND GENERA.

$\S$ Corolla ralvate in æstivation, regular. Flowers in dense heads or spikes.

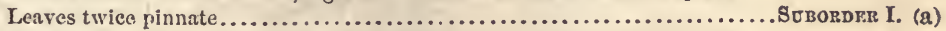

$\$$ Corolla imbricate in restivation, the upper or odd petal interior or the

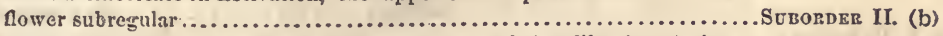

$\$$ Corolla imbrieato in astivation, tho upper petal (vexillum) exterior

Flowers papilionacenus..................................... Suborder III. (*)

* Stamens 10, all distinct. Trine 1. (c)

* Stamens 10, all or 9 united (2)

2 Leaves cirrhous, the rachis ending with a tendril. Tribf 2. (d)

2 Leaves not cirrhous. (3)

3 Pod a loment (\$ij73), of trausverse, 1-seeded joints. Turme 3. (e)

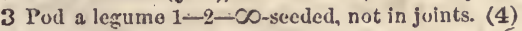

4 Erect (or, if prostrate, with palınately 3 -foliate leáves). Cotyledons thin, becoming leafy in germinatiou. Tribe 4. (f)

4 Trailing or twining vines with pinnately compound leaves. Cotyledons thick, not becoming leaves in germination. Tuाв 5 . (छ)

\section{SUBORDER I. MIMOSEAE.}

a Pods flat, composed of one or more 1-seeded joints........................Mros. 1

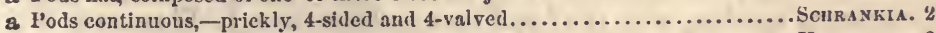
- smootl, - -turgid, filled with pulp................... VAcheLLA. 3 -compressed, dry,-Fls. all perfect........... Dessantius. 4

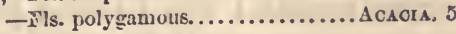

\section{SUbORDER II. CASAIPINEA.}

b Fls. dicecous, greenish, stamens 10. A tree nnarmed............. Gyxiochanus. 6 b Fls. polygamous, green, stamens 5 . Trees tho:ny ............................... 7

b Fls. perfect,-yellow.-Leaves equally pinnate............................ 8 -purple, papilionaceous. Leaves simple........................... 9

\section{SUBORDER III. PAPILIONACE.Z.}

- 1 Podaxyrexe.-Legume flat ani thin, short-stipcd. Lvs. pinnite......... Cr.anastris. 10

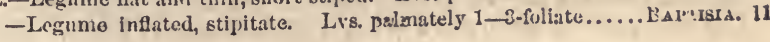


d 2. Vicies. -Erect. Tendrils obsolete. Seeds with the linear hilum at end.........FAnA. 12 _Climbing.-Leaflets serrate. Pods 2 -seedel................................. 13 -Leaflets entire.-Style grooved outside, hairy inside.......PIscm. 14 -Style flattened, hairy most inside....LA Turrets. 15

e 3. HeDYSARER. -Style filiform, hairy most outside......... Vicrs. 16

-Fls. yellow,-Leares palmately 4-foliate. Stam. monadelph...............Zornis. 17 -Leaves jinnate, 7 to 49 -foliate. Stam. diadelphous... . Aesciryvosrns. 19 -Leaves pinnately 3 -fuliate. Pod slender at base........ Strulosantrues. 19 -Leaves pinnately 4-foliate. Pod gibbous at base.............. Aracuis. 20 -Fls. cyanic.-Lvs. pinnate, 5 to 21 -foliate.-Umbels pedunculate............ Coronilia. 21 -Racemes pedunculate........ IIED rsaruar. 22

f 4. Lotex. -Lvs. pinnately 3 -foliate, -stipellate. Pod 3 to 7 -jointed.....D Essodiur. 23 -exstipellate. Pod 1-jointed.......Lespeveza. 24

-Leaves simple, with yellow flowers. - Keel oblong, straight................Grista. 25 - Keel falcate, acuminato.......... Crotalarta. 26

-Leaves palmately 5 to 15 -foliate (rarely simple). (Genus 32 , or)............Lupinus. 27 -Leaves palmately 3 -foliate.-Tree with yellow flowers................... LA Burvun. 28 -Herbs with straight, small pods............Trifolrux. 23 -Ilerbs with carred or spiral pods.............Medicago. 32 -Lvs. pinnately 3-fol.-Pod few-seeded. Fls. (searlet, Gen. 49) wh. or yel.Mennotus. 81 -Pod 1-seeded.-Fis. yellow.-Lvs. resinous-lotted......(Gen. 4i) -Fls. cyanic.-Lvs. dark-dotted......Psoralea. 32 -Lrs. not dotted......... (in Gen. 24)

-Lvs. pinnate, with no odd leaflet, 15 to 25 pairs.-Pod 1-2-seeded....... G Loribius. 83 -Pod co-seeded.......... Sesbania. 84 -Lvs. odd-pinnate, - dotted with dark glands-Shrub. Fls. spicate............ Axorpus. 35 “ 66 -Herb 10-androas............. Dalea. 36 - Herb 5-androus........Petalostemon. 37 -dotless.-Legume 2-celled length wise, turgid........ Astrag a I.ts. 33 -Legume half 2 -celled lengthwise.............. Pric. 39 -Leg. 1-celled.-Herbs. Style halry outside.Tepurosss. 40 - Ilerbs. Style glabrous..... Indigofrara. 41 -Slirubs or trees. Cyanic..... Romrina. 42 -Trees with fls. yellow......... Colvtre. 48

g. 5. Phaseoles.

-Lvs. pinnate, 5 to 15 -foliate. - Vine shrubby. Keel falcate..............W wst.mis. 44 -Herbs. Keel (straight, Gen. 49) spiral.......... pros. 45 -Lvs. pinnately 3 (rarely 1)-foliate.-Fls. yellow. Legumes 5-seeded.......... VIG -Fls. yellow. Legumes 1 to 2-seeded.RHyncosia. 4T -Fls. eyanic. $\left(^{*}\right)$

* Keel with stamens and style spirally tivisted.....................Prraszolus. $4 \mathrm{~S}$

* Keel straightish.-Fis. scarlet. Ereet herbs or trees................. Eryturina. 49 -Fls. purplish.-Calyx ebracteolate.............A AiruICA RP EA. 50 $\rightarrow$ Calyx bibracteolate, -4 -cleft.........GazActia. 51 -4-toothed...... Doricuos. 52 -5 -cleft, long.....Curtoria. 53 -5-cleft, short.Cextroseva. 54

1. Mimo'SA, L. Sensitive Plant. (Gr. $\mu$ ímos, a buffoon; the leaves seem sporting with the hand that touches them.) Flowers $q \ngtr i$. $\Varangle$ Calyx valvate, 5 -toothed; corolla 0 , or 5 -toothed, stamens 4 to 15 ; legume separated into 1 -seeded joints; $\delta$ like the perfect, but without ovaries or fruit.- 4 Herbs and shrubs, natives of tropical America, \&c.

1 M. strigillòsa Torr \& Gr. Nearly unarmed, prostrate, diffuse, strigous; stip. ovale; petioles and peduncles very long; lys. bipinnate, pinnæ 4 to 6 pairs; lfts. 10 to 15 pairs, oblong-linear; heads oblong; leg. broad, 1 to 3-jointed.-Banks of the Miss. (Hale) to K. Fla. Sts. several feet in length, reddish and in appearance smooth. Lfts. 3 to $4^{\prime \prime}$ by $1^{\prime \prime}$, crowded. Ped. and lvs. 6 to $8^{\prime}$ long. Hds. rosecolor, with innumerable spreading stamens. Pods crowded, very hispid. Jl., Aug.

2 M. pùdica L. St. prickly, more or less hispid; lvs. digitate-pinnate, pinnæo 4, of many (20 or more) pairs of linear lfts.-Native of Brazil. St. shrubby, about 
a foot high. Lfts. about $3^{\prime \prime}$ long, very numerous. Fls. small, capitate. It is occasionally cultivated for the curiosity of its spontaneous motions; - the leaves bending, folding, and apparently shrinking away from the touch of the hand.

2. SCHRAN'KIA, Willd. Sexsitive Brier. (In honor of Francis de Paula Schrank, a German botanist.) Flowers $\Varangle \hat{\delta}$; calyx minute, 5 -toothed; petals united into a funnel-shaped, 5-cleft corolla; stamens 8 to 10 , distinct or monadelphous; legume long and narrow, cchinate, dry, 1-celled, 4-valved, many-sceded. - 4 Prickly herbs. St. procumbent. Lrs. sensitive, bipinnate. Fls. in spherical heads, purplish.

S. uncinàta Willd. St. angled, grooved; pinnæ 6 to 8 pairs; lfts. numerous, minute, elliptic-oblong or linear; hds. axillary, 1 to 2 together, on peduncles shorter than the lvs.; leg. long and slender, very prickly.-Dry soils, Clark Co., Mo. (Mead), and Southern States. St. 2 to $4 \mathrm{flong}$, and with the petioles and peduncles armed with short, sharp prickles turned downwards. Lfts. about 2 " by $\frac{1}{2}$ ". Ped. 2 to $3^{\prime}$ long, hds. $\frac{1}{4}$ to $\frac{1^{\prime}}{2}$ diam. Pods 2 to $4^{\prime}$ long. May-Jl. (S. angustata 'T. \& G.)

3. VACHel'LiA, W. and Arn. Sponge Tree. Stamens very numerous, distinct; legume cylindrical, turgid, scarcely dehiscent; seeds in a double row, imbedded in pulp. Otherwise as in Acacia.-Tree armed with straight, stipular spines. Lvs. bipinnate, with a gland. Fls. in globular heads, yellow.

V. Farnesiàna W. \& Arn. Pinnæ 4 to 8 pairs; lits. 15 to 20 pairs, veiny, oblong, crowded; ped. 2 or 3 together.-Grows about N. Orleans (Hale) and along the Gulf to St. Marks, Fla. Lfts. about $2^{\prime \prime}$ long. Pods 2 to $3^{\prime \prime}$ long, blackish when ripe. Said to yield gum.

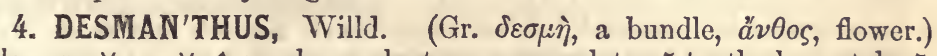
Flowers $\Varangle$ or $\Varangle \hat{o}$; calyx valvate, campanulate, 5-toothed; petals 5 , distinct; stamens 5 or 10 , distinct; legume dry, flat, 2 -valved, 4 to 6 -seeded, smooth.-Herbs with bipinnate lvs. and white fls. in axillary, pedunculate heads. Stip. setaceous. Petioles with one or more glands.

D. brachýlobus Benth. Erect, smoothish; pinnæ 6 to 13 pairs, lits. minute, 20 to 30 pairs; fls. all perfect, pentandrous; pods short ( $1^{\prime}$ long), oblong, somewhat curved, 2 to 4-seeded, and crowded.-4A Along the Miss. from Ill. to La. St.. striate, 1 to $3 f$ high. Jn.-Aug. (Darlingtonia brachyloba and glandulosa DC.)

5. ACA'CIA, Necker. (Gr. áká $\omega \omega$, to sharpen; alluding to the spines.) Flowers polygamous; calyx valvate, 4 to 5 -toothed; petals 4 or 5 , united below, rarely, distinct; stamens 8 to 200 ; legume continuous, not jointed, dry, 2-valved, many-seeded.-Trees, shrubs or lierbs, spincless, or with stipular spines. Lvs. (in the N. Am. species) bipinnate. Fls. in heads or spiked. (This is a large and ornamental genus of chicfy tropical plants, much cultivated in the -greenhouse. In many of them the leaflets disappear and phyllodia (\$307) take their places.)

1 A. lùtea Leav. Prostrate, herbaceous, minutely strigous; stip. lance-subulate; pinnce 3 to 5 pairs, lfts. 12 to 20 pairs, very small ( $2^{\prime \prime}$ long); hds. oblong-cylindric, the peduncles longer than the leaves; fls. yellow, decandrous; pods broad and flat, obtuse, about 6-seeded, and raised on a slender stipe.-Prairies Fla., La. and Ala. Its herbage much resembles Mimosa strigillosa, except the stipules. Pods 1 to $2^{\prime}$ long, $8^{\prime \prime}$ wide, the stipe about $6^{\prime \prime}$. Lvs. ciliate, sensitive, with no glands.

2 A. Julibrássin Willd. Tree glabrous, unarmed; pinna 8 to 12 pairs, lfts. 20 to 30 , halved, acute, inequilateral : gland depressed at the base of the petiole; hds. pedunculate, forming a terminal panicle ; stam. numerous,' long, exserted. - A very ornamental tree cultivated and sparingly naturalized in the Gulf States. Corollas white, with purplish stamens. Pods large, pointed at both ends, contracted between the seeds. 
6. GYMNOC'LADUS, Lam. Coffee Tree. (Gr. yuuvòs, naked, $k \lambda a ́ \delta o s$, a shoot; for its coarse, naked shoots in winter.) Flowers $q \hat{\delta}$. $\hat{\delta}$ Calyx tubular, 5-cleft, equal; petals 5 , inserted into the summit of the tube; stamens 10 , distinct. + Calyx and corolla as above; style 1; legumes 1-celled, oblong, very large, pulpy within.-A slender, unarmed tree, with unequally bipinnate lis. Lfts. ovate, acuminate.

G. Canadénsis Lam. Grows in Western N. Y., Ohio, Ind. S. to Tenn., on the borders of lakes and rivers. Height 50 , with a trunk $15^{\prime}$ diam., straight and simple to the height of 25f, corered with a rough, scaly bark, and supporting a rather small but regular head. The compound lvs. aro 2 to $3 \mathrm{f}$ long, and 15 to $20^{\prime}$ wide, being doubly compounded of a great number of dull green leaflets. Single leaflets often occupy the place of some of the pinnæ. Fls. greenish-white, in long racemes, succeeded by very large curved pods containing each several round, depressed, brown, polished, and very hard seeds. May-JI.

7. GLEDITS'CHIA, L. Honey Loclist. (For John G: Gleditsch, a botanical writer, Leipzig.) Flowers $q \Varangle t$. Sepals equal, 3 to 5 , united at base; petals 3 to 5 ; stamens 3 to 5 , distinct, opposite the sepals, sometimes by abortion fewer or 0 ; style short, often abortive; legume continuous, compressed, often intercepted between the secds by a quantity of sweet pulp. - Trees, with supra-axillary, branched spines. Lvs. abruptly pinnate and bipinnate, often in the same specimen. Fls. small, green, racemous.

1 G. triacánthus L. Branches armed with stout, triple spines; lfts. alternate, oblong-lanceolate, obtuse; leg. linear-oblong, compressed, many-seeded, intervals filed with sweet pulp. - Penn. to Mo. and La. In favorable circumstances it attains the height of 70f, undivided half its length, with a diameter of 3 to 4f. The thorns are 2 to 12 ' long, ligneous, numerously branched, forming horrid masses along the trunk. Foliage light and elegant. Lfts. about 18,1 to $1 \frac{1}{2}$ long, $\frac{1}{3}$ as wide, 1,2 or 3 of them frequently transformed, either partly or wholly, into smaller leaflets ( $\$ 290$ ). Fls. succeeded by flat, twisted, hanging pods 12 to $18^{\prime}$ long, of a dull red. Sds. flat, hard, brown, imbedded in a fleshy substance, at first sweet, but becoming sour. Jn.-The wood is very heavy.

2 G. monospérma Walt. Water Locust. Armed with few, slender, mostly simple spines; lits. ovate-oblong; leg. broadly oval, without pulp, one-seeded.Swamps, S. Car. to Fla. and La., not common. A tree of smaller dimensions than the former, with a smoother bark. Pods about $2^{\prime}$ long with the stipe, $1^{\prime}$ wide. Fls. greenish, in ament-like racemes like the other. $\mathrm{Jn}$.

8. CAS'SIA, L. Senna.' (Hebrew, Katzioth.) Sepals 5, scarcely united at base, nearly equal; petals 5 , unequal, but not papilionaceous; stamens distinct, 10 , or by abortion fewer, anthers opening by terminal pores, the three upper often sterile; legume many-seeded, 1-celled or many-called transversely.-Trees, shrubs or herbs. Lvs. simply, abruptly pinnate.

$\S$ Stam. 5 or 10 , all perfect. Sepals acute. Lfts. small.......................Nos. 1, 2 Stam. 10, the 3 upper abortive. Sep. obtuse. Lits. large. (a)

a Gland on the petiole at or near the base...............Nos. 3,4 a Gland on the rachis between the two lowest leaflets...... Nos. 5,6

1 C. Chamæcrísta.I. Sensitive Pea. Lfts. 8 to 12 pairs, oblong-linear, obtuse, mucronate; fls. large, pedicillate, 2 or 4 in each fascicle; anth. 10, unequal, all fertile.-(1) An elegant plant in dry soils, Mass., Mid., W. and S. States. St. $\frac{1}{2}$ to $2 \mathrm{f}$ ligh, round, pubescent. Lfts. crowded, 4 to $8^{\prime \prime}$ by 1 to $2 \frac{1}{2}$, smooth, subsessile. Fls. 15 to $18^{\prime \prime}$ broad. Bracts lance-subulate, as are also the stipules, persistent. Petals bright yellow, the 2 upper ones with a purple spot. Aug.-The leaves possess considerable irritability.

2 C. níctitans L. Wild Sensitive Prant. Lfts. 6 to 15 pairs, oblong-linear, obtuse, mucronate, sessile; fls. small, 2 or 3 in each subsessile fascicle; sta. 5, sub- 
equal.-In dry, sandy soils, Mass. to La. St. about If long, slender, branching. Lfts. crowded, 4 to $6^{\prime \prime}$ by 1 to $2^{\prime \prime}$. The petiolar gland, as in No. 1 , placed 2 or $3^{\prime \prime}$ below the lowest pair of leaflets. Fls. very small ( $5^{\prime \prime}$ broad), pale yellow, on short pedicels. Jl.-The leaves are quito sensitive, closing by night and when touched.

3 C. Marilándica L. American Senna. Perennial, smootl; lfts. 6 to 9 pairs, oblong-lanceolate, mucronate, an obovoid gland near the base of the common petiole; fls. in axillary racemes and terminal panicles; leg. curved, 12 to 20-seeded.-This handsome plant is frequently met with in alluvial soils (U. S.) growing in closo masses, 3 to $5 \mathrm{f}$ high. St. round, striate, often with scattered hairs. Petioles channeled above, and distinguished by the pedicellod gland near tho base. Ifts. 1 to $2^{\prime}$ by 4 to $9^{\prime \prime}$. Racemes in the upper axils, forming a leafy paniclo. Petals bright yellow, 3 erect and 2 declined. In medicine it is a mild cathartic. Aug.

4 C. occidentàlis L. Annual, smooth; lfts. 3 to 6 pairs, ovate or lance-ovate, sharply acuminate; an obtuse, sessile gland at the base of the petiole; fls. in axillary, short racemes, and panicled above; leg. nearly straight, 25 to 40 -seeded.Waste grounds, Va. to Ga. (Feay), and La. Stem stout, sulcate, 4 to 6 f high. Lvs. 7 to $8^{\prime}$ long, lifts. 2 to $3^{\prime}$. Stip. deciduous. Fls. large, yellow. Pods strongly margined, rigid, torulous. July. § Cuba.

5 C. obtusifòlia L. Annual, smoothish; lfts. about 6, obovate, obtuso; stip. linear-subulate; leg. very long and narrow, recurved, 20 to 40 -seeded; seeds longitudinal.-Dry soils, S. Car. to Fla. and La. Plant 1 to 3 to $4 \mathrm{f} \mathrm{high.} \mathrm{St.}$ round, striate. Lvs. 1 to $2^{\prime}$ long, half as wide. Pods about $6^{\prime}$ long, hardly $2^{\prime \prime}$ wide, the seeds longest, the same way with the pod, not transversely as in No. 4. Fls. large, on slender pedicels. J1.-Oct.

6 C. melanocárpa Vegel. Shrubby; lfts. 2 or 3 pairs, narrowly lanceolate, rather acute at each end, coriaceous; gland pedicellate; rac. pedunculate, in tho upper axils, as long as the leaves.-Ga. Escaped from gardens (Feay). Lits. 12 to $18^{\prime \prime}$ by 4 to $5^{\prime \prime}$. Fls. as large as in C Marilandica. §

9. CER'CIS, L. Judas Tree. Red-Bud. (Gr. keৎkis, a weaver's shuttle; sc. the legumes.) Calyx broadly campanulate, 5-toothed; petals scarcely papilionaceous, all distinct; wings longer than the vexjllum and smaller than the keel petals; stamens 10, distinet; legume compressed, with the seed-bearing suture winged; seeds obovate.Trees with simple, cordate lvs. and rose-colored tls.

C. Canadénsis L. Lvs. broadly ovate-cordate, acuminate, villous on the veins beneath.-A handsome tree, 20 to $30 \mathrm{f} \mathrm{high,} \mathrm{Mid.} \mathrm{and} \mathrm{W.} \mathrm{States.} \mathrm{The} \mathrm{wood} \mathrm{is}$ finely veined with black and green, and receives a fine polish. Lvs. 3 to $4^{\prime}$ by 4 to $5^{\prime}$, entire, smooth, 7 -veined, on petioles 1 to $2^{\prime}$ long. The flowers appear in advance of the leaves, in small, lateral clksters, clothing the whole tree in purple, in early Spring. 'The young twigs will dye wool a nankeen color. The old author Gerarde in compliance with the popular notion of his time, says "This is the tree whereon Judas did hang himself, and not on the elder tree, as it is said."

10. CLADASTRIS, Raf. Yellow-wood. Calyx 5-toothed, tecth short, obtuse; petals of nearly equal length, those of the keel distinet and straight like the wings; vex. large, roundish, reflexed; stam. 10, distinct; filaments glabrous, incurved, legume flat and thin, short-stiped, 5 or 6 -seeded.-A tree with yellow wood, pinnate lrs., and pendulons clusters of white fls.

C. tinctòria Raf. "Hills, in rich" soils. W. Ky. and W. Tenn. Treo 20 to $40 \mathrm{f}$ high, with a smooth greenish bark. Lfts. 7 to 11 , stalked, oval, acuminate, 3 t: $4^{\prime}$ long. Rac. 6 to $10^{\prime}$ long, compound, thyrse-like, showy, resembling thoso of the common locust. Leg. as long as the leaflets, very narrow. $\Lambda$ pr., diay.

11. BAPTIS'IA, Vent. Wild Indigo. (Gr. $\beta a ́ \pi \tau \omega$, to dye; a use to which some species are applied.) Calyx 4 to 5-cleft half way, per- 
sistent; petals of about equal length, those of the keel nearly distinct and straight; vexillum orbicular, emarginate; stamens 10, distinct, deciduous; legume inflated, stipitate, many (or by abortion few)seeded. - 2f Lrs. palmately 3 -foliate, or simple.

S Leaves simple. Flowers yellow..................................... Nos. 1-3

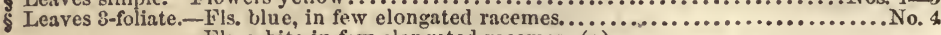
- Fls. white in few elongated racemes. (a)

- Fls. yellow, solitary or in short racemes. (b)

a Stipnles leaf-like, longer than the petioles........................ 5,6 a Stipules much shorter, or not longer than the petioles............................. 7 b Pedicels not longer than the calyx. Drying dark...... Nos. 9, 10) b Pedicels much longer than the calyx. Drying bright. Nos. 11-13

1 B. perfoliàta $\mathrm{P} . \mathrm{Br}$. Glabrous and glaucous, lvs. oval, orbicular, perfoliate; fls. solitary, axillary.-S. Car. and Ga. (Savannah, Fcay) in the pine woods. St. branching, 1 to $2 \mathrm{f}$ high. Lvs. large ( $2 \frac{1}{2}$ by $2^{\prime}$ ), all turned one way, and completely closed at base around the stem or branch. Corolla $6^{\prime \prime}$ long, on a pedicel half as long. Pod largo, inflated. $\Lambda$ remarkable species. May-Jl.

2 B. microphýlla Nutt. "Lvs. simple, sessile, roundish, cuneiform; tho upper somewhat clasping, stipules roundish ; fls. axillary ; legumes short, subglobous." W. Fla. to Ala. St. much branched. Lrs. small (7 to $10^{\prime \prime}$ in length), the upper partially coalescing with the stipules. Described by Mr. Nuttall from lato fruiting specimens. Not since found?

3 B. simplicifòlia Croom. Glabrous; lvs. broadly ovate, obtusc, sessile; stip. none; racemes terminal, elongated, many-flowered; bracts ovate, as long as tho pedicels.-Quincy. Fla. St. furrowed, branching, 2 to $3 \mathrm{f}$ high. Lvs. large (2 to $4^{\prime}$ by $1 \frac{1}{2}$ to $3^{\prime}$ ), rather firm, shining abovo. Fls. $8^{\prime \prime}$ long, tho pedicels shorter. Leg. ovate, about $6^{\prime \prime}$ long. Jn.-Sept.

4 B. austràlis R. Br. Glabrous; petioles short; lfts. obovate or somewhat oblong, obtuse; stip. lanceolate, rather longer than the petioles, distinct at baso; rac. long, erect; leg. oblong-oval, stipe long as the calyx.-Alluvial soils, Ohio River to Ga. and La. St. 2 to $3 \mathrm{f}$ high, branched. Petioles 1 to $6^{\prime \prime}$ long. Lfts. $1 \frac{3}{4}$ to $3^{\prime}$ by $\frac{3}{4}$ to $1^{\prime}$, sometimes acute. Stip. $\frac{1}{2}$ to $1^{\prime}$ long. Fls. indigo blue, large, very showy. Pod about 2 ' long. Jn,-Aug.

5 B. leucophæa Nutt. Villous; petioles almost 0 ; lifts. oblanceolate, varying: to obovate; stip. and bracts large, triangular-ovate, persistent; rac. nodding, the many flowers turned to the upper side on their long pedicels; leg. ovoid or roundish, inflated.-Common in wild prairies, W. States and southward. St. 2 to $3 \mathrm{f} \mathrm{high,}$ smoothish when old. Lfts. 2 to $3^{\prime}$ by $\frac{1}{2}$ to $I^{\prime}$, stipules more than half as largc. Rac. 20 to 50 -flowered, inclined horizortally. Pedicels 1 to $2^{\prime}$ long. Corollas very large, ochroloucous. Apr.

6 B. villòsa Ell. Villous-pubescent; petioles almost 0 ; lits. lance-oblong, $\mathrm{cr}$ oblanceolate; stip. lance-linear, persistent; rac. long (erect?); bracts minute, dsciduous; ped. not secund; leg. oblong. - N. Car. to Ga., rare. Plant of coarso aspect, as well as No. 5, 2 to 3 f high. Lfts. 2 to 3 ' long, obtuse, tapering at basc, becoming smocthish when old. Fls. dirty white, nearly I' long. Jn., Jl.

7 B. leucántha Torr \& Gr. Glabrous and glaucous; lvs. petiolato; lfts. cuneiform-obovate, obtuso; stip. lance-linear about as long as petioles, often caducous; rac. elongated, erect; bracts çaducous; leg. inflated, stipitate.-Conspicuous in rich soils, prairies, etc., W. States to Ga. and Fla. St. thick, 2 to $4 \mathrm{f}$ ligh, branched above. Rac. 6 to $24^{\prime}$ long, with large whito fls. Lfts. 1 to $2^{\prime}$ long. The whole plant turns bluish-black in drying. May-Jl.

8 B. alba R. Br. Glabrous, fastigiate-branched above; petioles slender; ifts. elliptic-oblanceolate, acute at base; stip. and bracts minute, caducous; rac. ercet or nodding, on a long pedunclo; pedicels rather longer than calyx. In rich soils, Va. to Fla. Plant 2 to $3 f$ high. Lfts. about $l^{\prime}$ long, a third as wide, the petiole about half as long. Fls. puro white. Plant does not blacken in drying. Mar. Apr.

9 B. lanteolàta Ell. Much branched, bushy; lvs. subsessile; lfts. narrowly elliptic, varying to oblanceolate, tapering to a petiolule, obtuse; stip. almost none; fls. axillary, subsolitary, short-pedicelled; leg. ovate-globous. Pine woods, S. Car, to Fla. and La. About $2 \mathrm{f}$ high. Foliage yellowish-grcen; lvs. 2 to $3^{\prime \prime}$ 
long, coriaceous. Fls. large, dull yellow. Apr., Jn.-Each plant forms a globular mass which when dry, breaks away and rolls about with the wind frightening horses; hence called horse-devils.

$\beta$. Taller, branches less flexuous; lits. obovate, very obtuse; fls. solitary and somewhat racemed at tho ends of the branches.-Fla., La.

10 B. tinctòria R. Br. Glabrous, branching; lvs. subsessilo; lfts. small, roundish. obovate, acute at base, very obtuse at apex; stip. setaceous, caducous; rac. loose, terminal; leg. subglobous.-A plant with bluish-green foliage, frequent in dry soils, Can. and U. S. St. very bushy, about $2 \mathrm{f}$ high. Lfts. about $7^{\prime \prime}$ by 4 to $6^{\prime \prime}$, cmarginate; petiole 1 to $2^{\prime \prime}$ long. Fls. 6 to 12 or more in each raceme. Petals $6^{\prime \prime}$ long, yellow. Leg. about as large as a pea, on a long stipe, mostly 1-seeded. Jl.-Sept.

11 B. Lecóntii Torr. \& Gr. Somewhat pubescent; lvs. short-petioled; lfts. obovate-oblong; pedicels longer than the fls., with two bractlets; bracts persistent; leg. short-stiped; branches, stipules and racemes as in No. 10.-Fla. and S. Ga. Does not turn black in drying. May.

12 B. megacárpa Chapman. Glabrous, slender; lvs. petioled; lfts. oval; rac. short and short-stalked; stip. and bracts minute, caducous; fls. nodding, on pedicels shorter than the corolla; leg. large, globular, and much inflated.-Near Quincy, Fla. Fls. and lvs. nearly as large as in No. 9. Mature pods $1 \frac{1}{2}^{\prime}$ diam. Does not blacken in drying. May.

13 B. móllis Mx. Minutely-hoary-pubescent, sparingly branched; petioles half as long as the cuneiform-oblanceolate lfts. ; stip. lanceolate, as long as the petioles; pedicels as long as the fls., in terminal racemes. - In mountain woods, $\mathrm{N}$. Car. and Tenn. (Lookout Mt., Chattanooga.) A fine, bright-flowered species, $1 \frac{1}{2} f$ high. Dries bright. May. (Thermopsis mollis Curt.)

12. FA'BA, Mœnch. Horse Bran. Coffee Bean. Flowers as in Vicia, but the seeds oblong, with a long scar (hilum) on the narrower end, and leathery, tumid legumes.-Lvs. equally pinnate, with the tendril obsolete (in the following species). Peduncle shorter than the flowers.

F. vulgáris Mœnch. St. rigidly erect, with very short axillary racemes; lits. 2 to 4 , oval, entire, mucronate or acute; (tendrils obsolete by cultivation;) stip. semisagittate, dentate at base.-Native of Egypt. Frequently found in gardens, but not so much admired for the table as formerly. Fls. white, with a large black spot on each of the alæ. Leg. torulous. Sds. very large, with a large hilum at one end. (Vicia Faba L.)

13. CI'CER arieti'num, the CHICK $\mathrm{PEA}_{\mathrm{E}}$, rarely cultivated may be readily known by its serrated leaflets, a character quite strange in this Order.

14. PI'SUM, L. PeA. (Celtic pis, Lat. pisum, Eng. pea, Fr. pois.) Calyx segments leafy, the upper two shortest; vexillum large, reflexed; stamens 10 , diadelphous ( 9 and 1$)$; style grooved on the back, villous and stigmatic on the inner side; legume oblong, tumid, many-seeded; seeds globous, with an orbicular hilum.-Herbaceous, climbing. Lrs. abruptly pinnate, ending with branching tendrils.

P. satìvum L. Lfts. ovate, entire, usually 4 ; stip. ovate, semi-cordate at base, crenate; ped. several-flowered.-(1) One of the most valuable of leguminous plants, smooth and glaucous. St. 2 to $5 \mathrm{f} \mathrm{long,} \mathrm{nearly} \mathrm{simple,} \mathrm{climbing} \mathrm{by} \mathrm{tendrils.} \mathrm{Lfts.}$ 2 to $3^{\prime}$ long, 2 as wide, obtuse, mucronate, stip. rather larger than the leaflets. Fls. two or more, on axillary peduncles, large, white. This plant has been cultivated from time immemorial, so that its native country is unknown. There are many varieties.

15. LATH'YRUS, L. Calyx campanulate, the two upper sepals shortest; stamens 10 , diadelphous ( 9 and 1$)$; style flat, dilated above, ascending, 
bent at a right angle with the ovary, pubescent or villous along the inside next the free stamen; legume oblong, several-sceded.-Herbaceous, mostly climbing. Lrs. abruptly pinnate, of 1 to several pairs of leaflets. Petioles produced iuto tendrils. Pods axillary.

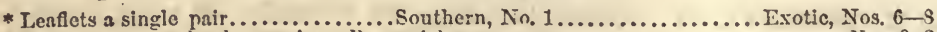

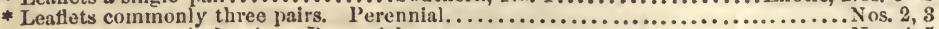

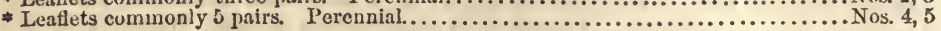

1 I. pusíllus Ell. St. winged; lfts. 2, linear-laneeolate, acuto at cach end; stip. conspicuous, lance-falcate, lialf-sagittato; ped. long, 1 to 3 -flowered.-S. Car. to La. A weak, scrambling vine. Lfts. $1 \frac{1}{2}$ to $2^{\prime}$ long, 4 to $6^{\prime \prime}$ wide; stip. about a third as long. Tendrils branching. Fls. purple. Leg. linear-oblong, 15 to 20 seeded. Apr., May.

2 I. ochroleùcus Hook. St. slender; 1 ts. about 3 pairs, broadly orato; stip. semi-eordate, large; ped. 7 to 10-flowered, shorter than the leaves. - A small, delicato species, rare, in sliady places and on river banks, N. J. to Wisc., N. to Arc. circle. St. 2 to $3 \mathrm{f} \mathrm{long}$, leaning or climbing on otber plant.s. Lfts. 1 to $I_{\frac{1}{2}}^{\prime}$ long, $\frac{3}{4}$ as wide, twice larger than the stipules. Corclla yellowish-whito (ochroleucous). Jn., Jl. (L. glaucifolius. Beck.)

3 I. palústris L. St. winged; stip. semi-sagittate, ovate, mueronate; 1 fts. 2 or 3 pairs, oblong-ovate, mueronato; ped. 3 to 5-flowered, longer than the leaves.A slender climber, found in wet meadows and thickets, N. Eng. to Or. St. slender, square, broadly winged at the angles, supported by the tendrils. Lrs. pinnate-cirrhous; lfts. broad, or narrow-ovate. Fls. drooping, rather large, varicgated with blue and purple. Jn., Jl.

ß. MYRTIFolius Gray. St. square, often slightly winged, weak; lfts. oblonglanceolate, rather obtuse.-Can. to $\mathrm{Md}$. and Ind. Fls. palo purple. (L. myrtifolius Muhl.)

4 I. venòsus Muhl. St. 4-angled; stip. semi-sagittate, lanceolate, very small; ped. 8 to 16-flowered, shorter than the leaves; lfts. 4 to 7 pairs, somewhat alternate, obtusish, mucronate.-In shady grounds, Can. and U. S. St. erect, 2 to 3 f high, mostly smootl. Ped. axillary, 3 to $5^{\prime}$ long. Lfts. ovate, $1 \frac{1}{2}$ to $2^{\prime}$ by $1^{\prime}$, the veins conspicuous. Fls. rather largo and showy, purple. Leg. flat and narrow. Jn., Jl.

5 I. marítimus Bw. BEACH PEA. St. 4-angled, compressed; petioles flat above; stip. cordate-hastate, nearly as large as the 8 to 12 ovate leaflets; ped. manyflowered. - A pale green creeping plant; resembling the common pea, found on sandy shores, N. Y. to Lab., W. to Oreg. St. rigid, 1 to $2 \mathrm{f}$ in length. Stip. connate. Lvs. ending in a branching tendril, the lower pairs of leaflets largest. Fls. large, blue. May-Jl. (Pisum maritimum Pls.)

6 I. latifòlius L. Eremlastixg Pes. Ped. many-flowered; ljis. 2, lanceolate; joints membranous, winged. $-24 \mathrm{~A}$ very showy plant for gardens and arbors, native of England. St. 6f long, climbing, winged between tho joints. Fls. large, pink, clustered on a pedunclo 6 to $10^{\prime}$ in length. Jl., Aug.

7 I. odoràtus L. SwEET PE. Ped. 2-flowered; lfts. 2, ovate-oblong; leg. hirsute. - (1) A well known garden flower, native of Sicily. The flowers appear in June, aro large, variegated with red and white. Very fragrant.

8 I. sativus L. CuIcK PEA. Ped. 1-flowered; 1fts. 2 to 4; leg. ovate; compressed, with two winged margins at tho back. (1) Native of. S. Europe, where it Las been sometimes cultivated for food; but it proves to be a slow poison, both to man and beast, producing ultimately entiro helplessness, by rendering tho limbs rigid, but without pain.

16. VIC'IA, L. Vetcir. (Celtic gwig, whence, Gr. Bıкiov, Lat. vicia, Fr. vesce, and Eng. vetch.) Calyx tubular, with the 3 inferior segments straight, and longer than the 2 above; vexillum emarginate; stamens 10 , diadelphous (9 and 1); style filiform, bent at right angles with the ovary, villous beneath the stigma on the outside (next the lieel); legume oblong, several-seeded.-Herbaccous, mostly climbing. Lrs. abruptly 
pinnate, with several pairs of leaflets, and a branching tendril. Peduncles axillary.

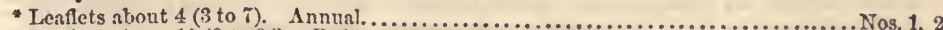

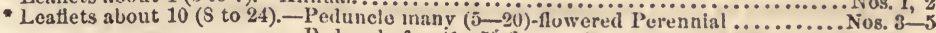
-Peduncle few $(1-5)$-llowered.............................. 6,7

$1 \nabla$. tetraspèrma Loisel. Ped. 1 to 2-flowered, in fl. shorter (in fr. longer) than the lvs.; leg. smooth, 4-seeded; Ifts. 4 to 6, small, linear, obtuso; stip. lanceolato, semi-sagittate.-Slender and delicato plants, banks of streams, \&d., Can. to Penn. Sts. almost filiform, 1 to $2 \mathrm{f}$ long. Lfts. 5 to $10^{\prime \prime}$ by $1^{\prime \prime}$, acute or obtuso. Fls. very small, bluish-white, on filiform peduncles. Leg. 4 to $6^{\prime \prime}$ long, 4 - somotimes 5-seeded. Jl. (V. pusilla Muhl. Ervum, L.)

2 V. acutifòlia Ell. Lfts. 3 to 6, linear, acute; stip. lance-linear; tendrils mostly simple; rac. 3 to 9-flowered, loiger than the leaves.-Ta. and Fla. Very slender, glabrous. St. 3 to 6 f long, climbing. Lfts. 6 to $12^{\prime \prime}$ long, $1^{\prime \prime}$ wide. Fls. small $\left(3^{\prime \prime}\right.$ long), bluish whito. Calyx teeth shorter than tube. Pods $I^{\prime}$ long, about 8 -seeded (4 to 10$)$.

3 V. Americàna Muhl. Ped. 4 to 8-flowered, shorter than the lvs.; stip. semisagittate, deeply dentate; lfts. 10 to 14, elliptic-lanceolate, obtuse, mucronate, veined, somewhat alternate; leg. oblong-linear, compressed, reticulated.-N. Y. W. to tho R. Mts. Sts. slender, 1 to $3 \mathrm{f}$ long. Lfts. $1^{\prime}$ by $5^{\prime \prime}$, subsessile. Fls. blue or purple. Lower calyx teeth broad-lanceolate, much longer than the 2 upper. Style very hairy at the summit. May.

4. V. Caroliniàna Walt. Ped. 6 to 10 or 12-flowered, rather shorter than tho leaves; fls. loose; teeth of the calyx shorter than the tube, the two upper very short; sty. hairy at the summit; stip. lance-linear, entire; lfts. 8 to 12 , linear-oblong or linear, smoothish; leg. not reticulated, oblong.-Woods and river banks. $\Lambda$ slender climber, 4 to 6 f long. Lfts. 6 to $12^{\prime \prime}$ by 1 to $3^{\prime \prime}$, mostly alternate. Fls. $3^{\prime \prime}$ long, pale blue, the banner tipped with deep purple. May.

5 V. Crácca L. Tufted Vetcir. Fls. imbricated, 12 to 20 or more in the raceme; lfts. 12 to 24, oblong, puberulent; stip. semi-sagittate, linear-subulate, entire.$\Lambda$ slender climber, 2 to $3 \mathrm{f}$ long, about fences, hedges, thickets, \&c., lat. $39^{\circ}$ to Can. St. square, downy. Lvs. of many pairs of downy, mucronate lifts., with a branched tendril at the end of the principal stalk. Lfts. 6 to $8^{\prime \prime}$ by 2 to $3^{\prime \prime}$, petiolulate. Fls. blue and purple, in a long, dense, one-sided raceme. Jl.

6 V. sativa I. VetcII. TARES. Fls. solitary, or in pairs, subsessile; lfts. 10 to 12 , oblong-obovate, often linear, retuse, mucronate; stip. semisagittate, subdentate, dotted; leg. erect, roundish, reticulated, smooth.-1) A slender climbing plant, found in cultivated fields, introduced from Europe. St. decumbent or climbing, 2 to $3 \mathrm{f}$ long. Lfts. 8 to $12^{\prime \prime}$ by 1 to $4^{\prime \prime}$, lower ones near the base of the petiole. Fls. pale purple, half as long as the leaves. Leg. 1 to $2^{\prime}$ long. Jn. $\S$

7 V. hirsùta Koch. Lfts. linear, truncate, mucronate; stip. semisagittate, narrow; ped. 3 to 6-flowered, shorter than leaves; leg. hirsute, 2-seeded.-A creeping weed in cultivated fields, N. Y. to S. Car. St. very slender, 1 to $3 f$ long. Lits. 8 to 20,4 to $8^{\prime \prime}$ long, hardly $1^{\prime \prime}$ wide, broadest abovo. Ped. axillary, 3 to 6 flowcred. Cal. segm., rather shorter than the bluish white corolla. Leg. short, with roundish, compressed brown seeds. Jn. $\S \uparrow$ (Ervum, L.)

$\checkmark$. micrantha Nutt, with the fls. minute and solitary on the peduncle, and $\checkmark$. Ludoviciana Nutt. (V. Leavenworthii T. \& G., is the same plant with a more slender habit) sent from W. La. (Hale) have not yet, to my knowledge, been found East of the Miss. River.

17. ZOR'NIA, Gmel. (For John Zorne, M.D., of Bavaria.) Calyx bilabiate, upper lip obtuse, cmarginate, lower 3-cleft; corolla perigynous, vexillum orbicular, with the sides revolute; stamens monadelphous, the alternate anthers different; legume compressed, of 2 to 5 roundish joints.-Herbs with palmately 2 to 4 -foliate lvs. and sagittate stip., which are cnlarged above and supply the place of bracts. (Fig. 184.)

Z. tetraphylla Mx. Lfts. 4 ; stip. or bracts oval, acute; leg. aculeate, about 3-jointed.-A plant of many singular marks, N. Car. to Fla. and Tex. Sts. pros. 
trate, slendir, 1 to $2 \mathrm{f}$ long. Lrs. on long petioles; lits. elliptic-oblong, acute at each end, the lower often obovate. Stip. as such very small ( $1^{\prime \prime}$ long) but as bracts they are as broad as the leaflets but much shorter. Fls. deep yellow. Leg. small, adhesive by their retrorsely rough spines. Jn.-Aug.

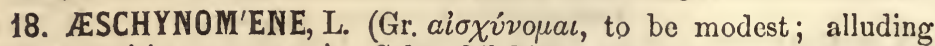
to its sensitive property.) Calyx bilabiate, bibracteolate; upper lip bifid, lower trifid; vexillum roundish; keel petals boat-shaped, distinct at base; stamens diadelphous, 5 in each set; legume exserted, composed of several truncated, separable, 1-seeded joints.-Lvs. odd-pinnate. Stip. semi-sagittate. Rac. axillary.

1 It. híspida Willd. St. erect, somewhat scabrous, as well as the petioles, peduncles and legumes; lfts. very smooth, 27 to 37 (49, Nutt.), oblong-linear, obtuse; stip. ovate, acuminato; rac. 3 to 5-flowered; loment compressed, 6 to 9-jointed.-(1) Marshes, Penn. to Fla. and La. (Hale). St. 2 to $3 f$ high. Ifts. about $\underline{g}^{\prime}$ long. Rac. usually bearing a leaf. Fls. yellow, reddish outside. Leg. $2^{\prime}$ long, sinuate on one side, some of them deeply parted. Aug.

2 IE. viscídula Mx. Slender, procumbent, viscidly pubescent; ifts. 7 to 11, obovate; stip. and bracts veiny; ped. filiform, 1 to 2-fowered; cal. slightly bilabiate, 3 lower teeth nearly equal; pod. 2 or 3-jointed, deeply lobed.-(1) Sandy fields, S. Car. (Ell.) to E. Fla. St difiuse, 1 to $2 \mathrm{f}$ long. Ifts. $6^{\prime \prime}$ long. Fls. small, yellow.

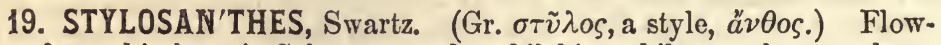
ers of two kinds. $\hat{\delta}$ Calyx somewhat bilabiate, bibracteolate at base, the tube very long and slender, with the corolla inserted on its throat; vexillum very broad; stamens 10 , monadelphous; ovary always sterile, with a very long style. \& Calyx and corolla 0 ; ovary between 2 bracteoles; legume 1 to 2-jointed, uncinate with the short, persistent style.-Lvs. pinnately trifoliate.

S. elàtior Swartz. Pencir Flower. St. pubescent on one side; lits. lanceolate, smooth, acute at each end; bracts lanceolate, ciliato; spikes 3 to 4 -flowered; loment 1-seeded (lower joint abortive). - 4 Dry, gravelly woods, Long Isl. to Fla. and Ark. St. mostly erect, branched, if in hight, remarkable for being densely pubescent on that side only which is opposite the insertion of each leaf, while the other side is smooth. Ivs. on short stalks; lits. $\mathrm{l}^{\prime}$ or more in length. Bracts fringed with yellow bristles. Fls. yellow. J., Aug.

20 AR'ACHIS, Willd. PeA Nut. (Lat. aracos, used by Pliny to designate some subterranean plant.) Calyx bilabiate; corolla resupinate, stamens monadelphous, legume gibbous at base, coriaceous, veiny, turgid, and indehiscent, the joints not separating.-A S. American genus with equally pinnate lvs. and yellow tls.

A. hypogæea Willd. Nearly glabrous; lfts. 2 pairs, oval or roundish, cuneate at base ; stip. entire, lance-subulate, as long as the lfts; fruit subterranean.Cultivated in N. Car. and S. and W. as easily as the sweet potato, and is very prolific. The specific name ( $i \pi 0, \gamma \eta$, under ground) alludes to the curious habit of forcing its ovaries, after flowering, into the soil and there ripening them.

21. CORONIL'LA, L. (Lat. corona, a crown; from the inflorescence.) Calyx bilabiate, petals unguiculate; loment somewhat terete, jointed ; seeds mostly cylindrical.-Mostly shrubs. Lvs. unequally pinnate. Fls. in simple, pedunculate umbels.

1 C. Emerus L. SCORPION SENNa. St. woody, angular; ped. about 3-fowered; claws of the petals about thrice longer than the calyx. $-A$ beautiful, free flowering shrub from France. St. about $3 \mathrm{f}$ high, square, with opposite branches. Ifts. about 7 , broadly obcordate. Fls. rose-colored, collected in little tufts on the ends of the subaxillary peduncles. $\triangle \mathrm{pr} ., \mathrm{Jn} . \dagger$ 
2 C. vària I. St. herỏaceous, erect, smooth, branching:; lrs. sessile, smooth; lfts. 11 to 19, all subsessile, oblong, obtuse; umbels long-pedunculate, 10 to 15 flowered; fls. palo purple.-An elegant European species, 2 to $4 \mathrm{f}$ high, erowned with many hemispherical umbels $l^{\prime}$ diam. Jl.-Sept. $\downarrow$

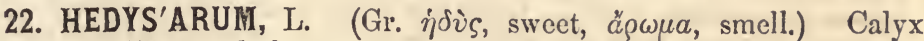
cleft into 5 linear-subulate, subequal segments; keel obliquely truncate, longer than the wings; stamens diadelphous (9 and 1), and with the style abruptly bent near the summit; legume (loment) of several 1-seeded joints connected by their middle.-2f Mostly herbaceous. Lvs. unequally pinnate.

H. boreàle Nutt. Sts. erect; lvs. subsessile, of 6 to 10 pairs of oblong, smoothish lfts.; stip. united, sheathing, with subulate points; rac. spicate, on long peduncles; fls. numerous, deflexed; cal. teeth short, the lower longest; keel longer than the banner or wings ; joints of the legume 1 to 4 , flat, suborbicular, rugosereticulate.-On the precipitous sides of Willoughby Mt., Westmore, Vt. $500 \mathrm{f}$ abovo the lake below, N. to Hudson's Bay. St. rigid, 1 to $2 f$ high, very leafy. Lfts. 5 to $8^{\prime \prime}$ by 2 to $4^{\prime \prime}$, obtuse-mucronulato. Rac. 2 to $4^{\prime}$ long, on rigid peduncles 3 to $5^{\prime}$. Fls. large and handsome, violet-purple. Jn,-Jl.

23. DESMO'DIUM, DC. (Hedysarum L.) Bush Treforl. (Gr. $\delta \varepsilon \sigma \mu \mathrm{o} s, \mathrm{a}$ bond; in reference to the slightly connected joints of the loment.) Calyx 5-cleft, bilabiate, sometimes bibracteolate at base; vexillum roundish; kcel obtuse ; stamens diadelphous (9 and 1), sometimes monadelphous; legume (loment) compressed, jointed, constricted most on the lower (dorsal) suture, the joints 1-seeded, separable, mostly aculeate and adhesive.-4 Herbaceous or suffruticous. Lvs. pinnately trifoliate. Fls. in racemes or panicles, purplish.

$\S$ Legumes distinetly stiped, the stipes about as long as the joints (a).

a Stems prostrate, creeping. Lfts. round or oval....................... 1, 2

a Stems erect. Lfts. ovate, broadly or (in No. 6) narrowly. (b).

b Calyx teeth shorter than the tube............................ $3-5$

b Calyx teeth longer than the tube,-upper one notched...... Nos. 6 -8 - upper one entire.......................... No. 9

$\S$ Legumes subsessile, the stipes, if any, not exeeding the caly $\mathrm{x}$ (c).

c Brnets large, covering the flower buds, calucous (d).

c Bracts inconspicuons, sinaller than the flower buds (e).

d Stipules large ( 6 to 9 "long), ovate-lanceolate...............Nos. 10, 11

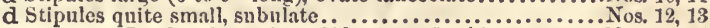

e Leaflets large $\left(2\right.$ to $3^{\prime}$ by 1 to $2^{\prime}$ ), oblung-ovate.. Nos. 14,15

e Leaflets small, orbieular or oval..................... 16-19

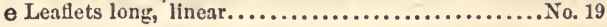

1 D. rotundifòlium DC. St. prostrate, hairy; lfts. suborbicular, hairy on both sides; bracts and stipules broadly ovate. acuminate; rac. few-flowered; loment constricted on both margins nearly alike.-A hairy, prostrate plant, 2 to $3 \mathrm{f}$ in length, found in rocky woods throughout the U. S. Lvs. of 3 roundish lfts., pale beneath, 1 to $2^{\prime}$ diam., on hairy stalks. Stip. cordate, reflexed, hairy. Fls. purple, in axillary and terminal racemes. Pods about 6-jointed. Aug.

2 D. humifùsum Beck. St. procumbent, striate, nearly smooth; lfts. oval, subpubescent; stip. lance-ovate; rac. axillary and torminal; loment slightly constricted on the upper margin, of 2 to 1 , obtusely 4 -angled joints.-Woods, Waltham, Mass. (Bigelow), Penn. (Muhl). A species much resembling the last, but the whole plant is much smoother, with smaller and narrower bracts. St. 2 to $3 f$ long. Lfts. oval or ovate, subacute. Aug.

3 D. nudiflòrum DC. Lfts. roundish ovate. Uluntly acuminate, slightly glaucous beneath; scape radical, panicled, smooth; joints of the loment obtusely triangular.-Common in woods, U. S. and Can. It is remarkably distinguished by having its leaves and fls. on separate stalks often distant from each other. St. 8 to $10^{\prime}$ high, with several ternate, long-stalked, smoothish, terminal lvs. Scape 2 to $3 f$ long, slender, smooth, leafless, panicled, with many small, purplo flowers Aug. 
4 D. acuminàtum DC. Plant erect, simple, pubescent, leafy only at top; lfts. ovate, long-acuminate, the odd one round-rhomboidal; pan. terminal, on a very long peduncle.-Common in woods, U. S. and Can. St. 8 to $12^{\prime}$ ligh, ending in a slender panicle 1 or $2 \mathrm{f}$ long. Lvs. at the top of the stem and below the panicle; terminal Ift. roundish, $3^{\prime}$ diam.; lateral lfts. smaller, all of them covered with scattered, appressed hairs, and conspicuously pointed. Fls. small, flesh-colored. Pods of about 3 triangular joints. Jl., Aug.

6 D. pauciflòrum DC. St. assurgent, leafy all the way, retrorsely hairy; lfts. membranous, pale beneath, scabrous-pubescent above, terminal one rhomboidal, lateral ones inequilateral-ovate, all rather acute or subacuminate; rac. terminal, few-flowered; fls. in pairs; petals a.l distinct, spreading.-Woods, Penn. to Ill. and La. Rt. crceping, tubercular. Sts. often clustered, If higin. Petioles 2 to $3^{\prime}$ long. Lfts. 1 to $3^{\prime}$ long, $\frac{2}{3}$ to $\frac{3}{4}$ as wide. F'ls. 2 to 6 , white or purplish. Leg. of 2 to 3 obtusely triangular joints. Jl., Aug.

S D. paniculàtum DC. Erect, slender, nearly glabrous; lfts. oblong-lanceolate, obtuse; stip. subulate, deciduous; fls. on long ( 4 to $\left.5^{\prime \prime}\right)$ and slender pedicels in paricled racemes; loment of about 3 triangular joints.-A handsome species, near $3 \mathrm{f}$ in hight, found in woods, U. S. and Can. St. striate, 2 to $3 \mathrm{f}$ high. Lvs. of 3 smocth, narrow-ovate. lfts., broadest at tho base, ending with an obtuso point, 1 to $3^{\prime}$ in length. Pods about 3 to 5-jointed, large. Fls. purple, numerous. Jl., Aug.

7 D. viridiflòrum Beck. St. erect, densely pubescent and scabrous above; lfts. ovate, mostly obtuse, scabrous above, softly villous beneath; stip. ovate-lanceolate, acuminate, caducous; panicles rery long; leafless; lower tooth of the hairy calyx thrice longer than the upper; leg. of 3 to 4 triangular joints. - Alluvial soils, N. Y. to Fla. and La. St. 3 to $4 \mathrm{f}$ high, rigid, branched. Lfts. 2 to $3^{\prime}$ long. Corolla violet, turning green in withering. Leg. 1 to $2^{\prime}$ long.

8 D. leevigàtum DC. Glabrous or nearly so; st. simple, erect; lvs. on long petioles, lfts. ovate, rather obtuse; pan. terminal, nearly simple; fls. in pairs, on elongated pedicels; bracts ovate, very small; lower calyx tooth twice longer than the upper.-Woods, N. J., Harper's Ferry, and southward. The smoothest of our Desmodia, 2 to $3 f$ high. Lift. rather coriaceous, 1 to $3^{\prime}$ long, $\frac{2}{3}$ as wide. Pedicels 5 to $8^{\prime \prime}$ long. Fls purple. Joints of the loment 2 to 4 , half rhombic. Sept.

$\beta$. MoNopirylum. Dwarf; smaller in all its parts; very smooth; lower lvs. unifoliate; rac. simple.-Uxbridge, Mass. (Ricard.)

9 D. glabéllum DC. St. erect, smoothish; lfts. ovate, small, scabrous-pubescent botli sides; stip. subulate; lower tooth of the calyx twice longer than the upper cntire one; loment nearly straight on the back, with about 4 half rhombic joints. -In shades, Car. (Ell. Curtis). Aug., Sept.

10 D. cuspidàtum Torr. \& Gr. Erect, smooth; lfts. oblong-oval, or ovate, sharply acuminate; stip. lanceolato-subulate; rac. paniculate, terminal, large, with scattered fls.; bracts deciduous, ovate, acuminate, striate, smooth ; joints of the loment suboval. - A larger species than either of the preceding, found in woods, U.S. and Can. St. branching, erect, 4 to $5 \mathrm{f} \mathrm{high.} \mathrm{Lfts.} 3^{\prime}$ long, widest at base, smooth, entire. Stip. and bracts 8 or $9^{\prime \prime}$ long. Stipels subulate. Fls. large ( $8^{\prime \prime}$ long), purple. Pods in about 6 joints, long, pendulous, rough. Aug. (D. bracteosum DC.)

11 D. canéscens DC. St. striate, scabrous; lfts. ovate, rather obtuse, scabrous on the upper surface, soft-villous beneath; stip. large, oblique, acuminate; pan. terminal, very long, densely canescent, naked; joints of the loment obliquely oval; upper lip of the calyx nearly entire.-Woods, N. Eng. to Fla. and La. An upright, branching plant, with very long panicles of flowers, greenish externally, purple within. St. 3f high, pubescent. Pods about 4-jointed, most constricted on the lower side. Jl., Aug. (D. Aikinianum Beck.)

12 D. Canadénse DC. St. pubescent; lfts. oblong-lanceolate; obtuse, nearly smooth; stip. filiform; bracts ovate, long-acuminate; fls. racemed; joints of tho loment obtusely triangular, hispid.- Rather common in woods, Can., Penn. and Ind. A handsome plant 3 in height. St. upright striate. Lfts. 2 to $3^{\prime}$ long, $1^{\prime}$ wide, with 6 pairs of straightish veins. Fls. purple, about as large as in No. 10, 
in axillary and terminal racemes. Bracts conspicuous before flowering. Pods about 5-jointed.

13 D. sessilifòlium Torr. \& Gr. St. erect, tomentous-pubescent; lvs. sessile, lfts. linear or linear-oblong, obtuse at each end, scabrous above, softly tomentous beneath; stip. subulate; pan. of spicate racemes, very long; bracts. minute; leg. small, hispid, of 2 to 3 semi-orbicular joints.-Woods, the W. States and Tex. St. 2 to 3 f high. Lfts. about $2^{\prime}$ by $\frac{x^{\prime}}{3}$. Fls. small, numerous and crowded. Aug.

14 D. Dillénii Darl. Plant erect, branching, hairy ; lits. oblong, villous beneath ; stip. subulate; rac. panicled; joints of the loment 3 , rhomboidal, reticulate, a littie hairy, connected by a narrow neck.-Moist soils, N. and W. States. St. sulcate, scabrous, 2 to 3 f high. Lfts. 2 to $3^{\prime}$ by 1 to 2 ', smooth above. Panicle large, terminal, naked. Fls. purple. Jl. (D. Marilandicum DC.)

15 D. rígiđum DC. Erect, branching, scabrous, pubescent; lfts. ovate-oblong, obtuse, terminal one the longest; petioles short, hairy; stip. ovate-acuminate, ciliate, caducous, rac. paniculate, very long; leg. with 2 to 3 obliquely oval or semiobovate joints.-Hills and woods, Mass. to La. St. 2 to $3 \mathrm{f} \mathrm{high,} \mathrm{often} \mathrm{with} \mathrm{numer-}$ ous long, erect, rigid branches. Lfts. 1 to $3^{\prime}$ long, $\frac{1}{2}$ as wide, rather coriaceous, reticulate-veined. Fls. violet-purple. Aug.

16 D. ciliàre DC. Erect, slender, scabrous-pubescent; lvs. crowded, on short hairy petioles; lfts. small, orate, short-stalked, pubescent beneath, ciliate on the margin ; stip. filiform, caducous; pan. terminal, lower branches much longer; joints of the short stiped loment 2 or 3 , obliquely roundish, hispid, reticulate.Woods, N. Eng. to La. Hight 2f. Fls. purple. Aug.

17 D. Marilándicum Boott. Erect, branching, hairy; lfts. ovate, obtuse, subcordate at base, the lateral ones as long as tho petioles; stip. subulate; pan. terminal; loment stipe as long as calyx, joints 1 or 2 , obliquely obovate.-Woods, $\mathrm{N}$. States to Fla. St. 2 to 3 high. Lfts. 6 to $12^{\prime \prime}$ by 4 to $8^{\prime \prime}$. Fls. violet-purple, small. Aug. (D. obtusum DC.)

18 D. lineàtum DC. Slender, assurgent; st. finely striate with colored lines; lits. small, roundish oval, smoothish, green both sides; rac. terminal and lateral, very long and loose; loment quite sessile in the calyx, joints about 2, roundish oval.-Dry woods, Can. to Fla. and La. Sts. 2 or 3 f long. Lvs. on short stalks; lfts. 6 to $12^{\prime \prime}$ diam., quite obtusc. Fls. and leg. small.

19 D. stríctum DC. Erect, slender, nearly glabrous; lvs. petiolate; lfts. linear, elongated, coriaceous and reticulately veined, mucronate; stip. subulate; pan. slender, few-flowered; leg. hispid, incurved, of 1 to 3 lunately triangular joints, with a filiform isthmus, the stipe shorter than, or about as long as the calyx.Pine barrens, N. J. to Fla. and La. St. about 3 f higlì. Lfts. 2 to $3^{\prime}$ by 2 to $3^{\prime \prime}$, longer than tho petioles. Fls. small, purple, on slender pedicels. Aug. (D. tenuifolium T. \& G.)

24. LESPEDE'ZA, Mx. (In honor of Lespedez, Governor of Florida, who protected Michaux in his travels there.) Calyx 5-parted, bibracteolate, segments nearly equal; keel of the corolla very obtuse, on slender claws; legume (loment) lenticular, compressed, small, unarmed, indehiscent, 1-seeded.-Genus taken from Hedysarum. 4 Lvs. palmately trifoliate, reticulately veined.

\$ Flowers all complete. Calyx villous, long. Cor. whitish with a purple spot....... Nos. 1, 2 Fls. partly apetalous. Calyx short. Corolla violet. - Stems upright................ Nos. 3,4

1 I. capitàta Mx. Busm Clover. Ifts. elliptical, silky beneath; stip. subulate; fascicles of fls. ovate, subcapitate, shorter than the leaves, axillary; loments hairy, shorter than the villous calyx:-An erect, hairy, half shrubby plant, in dry soi!s, Can. to Car. St. nearly simple, villous, 2 to $4 \mathrm{f}$ high. Lvs. numerous, on sbort petioles, consisting of 3 coriaceous lfts. Lfts. 1 to $1 \frac{1^{\prime}}{2}$ by 3 to $6^{\prime \prime}$, nearly smooth above, covered with silky pubescence beneath. Aug., Sept. (L. frutescens Ell.)

B. ANGustrfolia Ph. Lfts. linear, smooth above. (L. angustifolia Ell.)

2 I. hirta Ell. St. villous; lfts. roundish oval, pubescent beneath; rac. capitate, axillary, oblong, longer than the leaves; cor. and loment about as long as tho 
calyx.-Plant 2 to $4 \mathrm{f}$ high, found in dry woods, Can. and U. S., erect, branching and very hairy. Lrs. less numerous than in the last, on very short stalks consisting of 3, oval leaflets hairy beneath. Ped. hairy, becoming longer than the raceme. Fls. reddish-white, crowded. Aug., Sept.

3 I. Steùvi Nutt. Branched and bushy, tomentous or pubescent; lfts. oval-obovate or roundish, longer than the petiole; rac. axillary, capitate or loose, equaling or exceeding the leaves; leg. villous-pubescent, ovate-acuminate; apetalous fls. few.-Dry soils, Mass. to Ga. and Tex. Sts. assurgent, 2 to $3 \mathrm{f}$ high. Lvs. always hairy beneath, generally so above. Aug. to Sept.-Quite variable, approaching the next species.

4 I. violàcea Pers. Frect or diffuse, sparingly pubescent; lfts. oval, varying to oblong and linear, obtuse, mucronate, as long as, or a little longer than the petioles; rac. axillary, few-flowered, the apetalous ones generally below and subsessile; leg. roundish-ovate, being much longer than the calyx.-Dry woods, Can and U. S. Sts. 1 to $2 \mathrm{f}$ high. Cor. 3 to $4^{\prime \prime}$ long. Pods about $2^{\prime \prime}$ long. Jl., Aug.Varies gradually into the following diverse extremes.

a. Lfts. large (9 to $12^{\prime \prime}$ by 6 to $\left.8^{\prime \prime}\right)$, not longer than the petioles; fls. few, mostly complete, and near the upper part of the branches; rt. strong, creeping; sts. clustered, slender, diffuse or erect.

$\beta$. SESSILIFLORA T. \& G. Lfts. small ( 3 to 6 to $8^{\prime \prime}$ by 1 to $2^{\prime \prime}$ ), oblong to linear, longer than the petioles; fls. mostly apetalous, numerous, in axillary glomerules; st. erect branched. (I. sessiliflora $\mathrm{Ph}$.)

$\gamma$. RETICULATA. Lfts. all linear ( 10 to $18^{\prime \prime}$ by 2 to $3^{\prime \prime}$, rigid, on short, erect petioles; fls. fascicled, on short stalks.-Erect, slender; branches short or none. (L. reticulata Pers.)

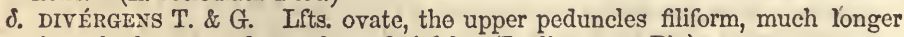
than the leaves and mostly unfruitful. (L. divergens $\mathrm{Ph}$.)

5 工. repens Torr. \& Gr. St. prostrate, diffuse, sparingly pubescent; lfts. oral or obovate-elliptical, smooth above, on very short petioles; ped. axillary, filiform simple, few-flowered, lower ones bearing apetalous flowers; leg. suborbicular, subpubescent.-Dry soils, Can. and U. S. Sts. very slender, numerous. Lfts. 5 to $9^{\prime \prime}$ by 3 to $5^{\prime \prime}$, obtuse. Ped. 2 to $5^{\prime}$ long. Aug., Sept. (H. repens L.)

$\beta$. PRoccmbens. Tomentous-pubescent, varying to pubescent, but the lvs. always smooth above. (L. procumbens $\mathrm{Mx}$.)

$\gamma$. FEAYANA. Smoothish; sts. decumbent and assurgent; lfts. obovate, twico longer than the petioles; upper ped. elongated and bearing apetalous fls.Savannah. (Feay.) Appears intermediate between Nos. 3 and 5.

25. GeNIS'TA, L. Dyer's Broom. Woad-Waxen. (Celtic, gen, Fr., genet; a small shrub.) Calyx with the upper lip 2-parted and the lower 3-toothed; vexillum oblong; keel oblong, scarcely including the stamens and style; stigma involute; stamens monadelphous.-Shrubby plants, with simple lvs. and yellow fls.

G. tinctòria L. Branches round, striate, unarmed, erect; lvs. lanceolate, smooth; leg. smooth. - 2' A naturalized species, in dry, hilly grounds, Mass. Sts. or branches numerous, ascending or erect, if high, from long, woody, creeping roots. Ivs. sessile, alternate. Fls. bright-yellow, axillary, sessile or nearly so, solitary. The whole plant dyes yellow, and, with Woad, green. Aug. § Lur.

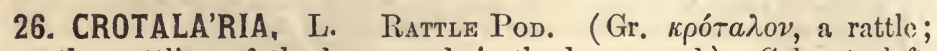
from the rattling of the loose seeds in the horny pod.) Calyx 5-cleft, somewhat bilabiate; rexillum cordate, large; keel acuminate; stamens 10, monadelphous; filamentous sheath cleft on the upper side; legume pedicellate, turgid.-Herbs or shrubs. Lvs. simple or palmately compound. Fls. yellow.

1 C. sagittàlis L. Annual, erect, branching, hairy; lvs. simple, lance-oval to lancelinear; stp.opposite, acuminate, decurrent; rac. 3-flowered, opposite to the lrs.; cor. shorter than the cal.-About a foot high, with a hairy aspect, in woods and sandy fields, N. H. to Ark. St. herbaceous, rigid. Lvs. alternate, en:ire, nearly 
sessile, rounded at the base. Its most remarkable feature is tho opposite, united decurrent stipules, so situated that each pair appears inversely sagittate. Sep. long, hairy. Cor. small, yellow. Sds. fow, rattling in the turgid pod. Jl.

2 C. ovàlis $\mathrm{Ph}$. Perennial, hairy, diffuse; lvs. simple, oval and elliptic, on very short petioles; stip. few, small or minute, partly decurrent; pedicels long, 3 to 6flowered; cor. longer than the cal.-In sandy woods, N. Car. to Fla. and La. Rt. strong, fusiform. Sts. annual, 4 to 10 to $12^{\prime} \mathrm{long}$, prostrate or assurgent; lvs. about $1^{\prime}$ long. Fls. rather showy and remote, with minute, lanceolate bracts. Pods 1' long, rattling. Ap.-Jn.

3 C. Púrshii DC. Perennial; slender, assurgent, nearly smooth; lvs. simple, oblong-linear or linear, subsessile; stip. narrowly decurrent through the whole internode; pedicels long, 5 to 7-flowered; cor. as long as the cal.-In damp shades, $\mathrm{S}$. Car. to Fla. and La. Sts. 12 to $18^{\prime}$ high. Lvs. 2 to $3^{\prime}$ long. Pods much inflated, black, horny, and rattling like the other species when fully ripe. Apr. Jl.

27. LUPI'NUS, Tourn. Lupine. (Lat. lupus, a wolf; because it overruns the field and devours its fertility?) Calyx deeply bilabiate; upper lip 2-cleft, lower entire or 3-toothed; wings united at the summit; keel falcate, acuminate; stamens monadelphous, the filamentous sheath entire; anthers alternately oblong and globous; legume coriaceous, compressed.-Herbs, rarely shrubby. Lvs. palmately 5 to 15 foliate, rarely unifoliate.

1 I. villòsus Willd. Unifoliate, densely silky-tomentous; sts. decumbent-assurgent; lvs. large, elliptic-oblong, long-petioled; rac. terminal, long, dense-flowered. -A very showy plant in the pine barrens, etc., N. C. to Fla. Plant 1 to $2 \mathrm{f} \mathrm{high,}$ remarkably clothed in silky wool, the lvs. 3 to $5^{\prime}$ long, mostly at the base, and the numerous (50 to 100), large, violet, and roseate flowers above them. Pods covered with shaggy wool, oblong, 4 or 5-seeded. Apr., Jn.

$\beta$ DIFrisus T. \& G. Somewhat branched at base, and diffuse; lrs. shorter (2 to $\left.3^{\prime}\right)$, oval-oblong, obtuse, soft-silky, but hardly tomentous; pods very silky.-Near Savannah, etc. (Feay and Pond.) (L. diffusus Nutt.)

2 I. perénnis L. Minutely pubescent, 5 to 7 -foliate; lfts. oblanceolate, mucronate; fls. alternate; caly $\mathbf{x}$ without appendages, upper lip emarginate, lower entire.-2 In sandy woods and hills, Can. to Fla. It is a beautiful plant, cultivated in gardens. It is often called sun-dial, from the circumstance of its lvs. turning to face the sun from morning till night. St. erect, soft, smoothish, a foot high. Ivs. soft-downy, on long stalks; 1 fts. $1 \frac{1}{2}$ to $2^{\prime}$ by 4 to $6^{\prime \prime}$, lanceolate, broadest above the middle. Fls. blue, varying to white in a terminal spike or raceme. May, Jn.

3 L. polyphýllus Lindl. Tall, 11 to 15-foliate; lfts. lanceolate, sericeous beneath; fls. alternate, in a very long raceme; pedicels longer than the lanceolate, deciduous bracts; cal. ebracteolate, both lips subentire; leg. densely hairy.24 A splendid ornament of the garden from Oreg. St. 3 to $5 \mathrm{f} \mathrm{high.} \mathrm{Rac.} \mathrm{a} \mathrm{foot}$ or more long. Fls. scattered (subverticillato in $\beta$. grandifolius, Lindl.), white, purple, or yellow, in different varieties. †

4 I. Nootkaténsis Donn. Nootka Sound LuPINE. St. villous, with long, spreading hairs, 5 to 9 -foliate; lfts. oblong-lanceolate, mucronate, attenuato at base, sericeous beneath; cal. very hairy, both lips nearly entire; bracts linear, hairy, longer than the calyx.-A handsome species from the N. West Coast, 2 to $3 \mathrm{f}$ high, in gardens. Fls. purple. $\dagger$

5 I. arbòreus L. TREe Lupine. Shrubby; fls. yellow, in whorls; cal. appendaged, lip acute, entire.-A handsome exotic shrub, 6f high, with large, yellow fis. $t$

Obs.- Several annual species are occasionally sown in gardens, as $L_{0}$ ALBes, with white fls.; L. PILosus, with rose-colored fls.; L. LUTEUs, with yellow fls.; and L. unsurus, with blue tls. and an appendaged calyx.

28. LABUR'NUM, Benth. Calyx campanulate, bilabiate, upper lip 2 , lower 3 -toothed; vexillum ovate, erect, as long as the straight wings; filaments diadelphous $(9 \& 1)$; legume continuous, tapering to tho 
base, several-seeded.-Oriental, thornless shrubs or trees. Lvs. palmately trifoliate. Fls. mostly yellow.

1 I. vulgàre L. GOLDEN Crrain. Arborescent; lfts. oblong-ovate, acuie at base, acuminate; rac. simple, elongated, pendulous; leg. hirsute.-A small, ornamental tree, $15 \mathrm{f}$ high, from Switzerland. Fls. numerous, large, in rac. If long. † (Cytisus Laburnum L.)

2 L. alpìnum L. Arborescent; lfts. oblong-ovate, rounded at base; rac. long, simple, pendulous; leg. glabrous. - A beautiful tree, 30f high, native of various Alpine regions of Europe. Like the former it develops numerous brilliant, yellow fls, in long, drooping clusters. There aro varieties with ochroleucous, white, and even purple fls.

29. TRIFO'LIUM, Tourn. Clover. (Gr. $\tau \rho \iota \phi \grave{\nu} \lambda \lambda o v$, (three-leaved); Lat. trifolium; Fr. trefle; Eng. trefoil.) Calyx tubular or campanulate, 5-toothed, persistent; petals more or less united at the base, withcring; vexillum reflexed; alro oblong, shorter than the vexillum; carina shorter than the alæ; stamens 10, diadelphous (9 and 1); legume short, membranous, mostly indehiscent, covered by and scarcely longer than the calyx, 2 to 4 -seeded; seeds roundish.-Herbs. Lrs. palmately trifoliate; lits. with straight, scarcely reticulated veins. Fls. in dense heads or spikes.

$\S$ Flowers yellow, in small, dense, ronndish heads......................... Nos. 1, 2 \$lowers cyanic,-pedicellate, finally deflexed. (a) - subsessile, never defiexed. (b)

a Ilearls small, on stalks some ten times longer..................... 3 , 4 a Heads large, on stalks two or three times longer................................. 6 b Calyx teeth plumose, longer than the whitish corolia......... No. 7

b Calyx teeth shorter than the purplo or roseate corolla... Nos. 8-10

1 T. procúmbens L. YELLOW ClOVER. St. procumbent or ascending; lfts. obtuse or retuse, denticulate, terminal one petiolulate; stip. ovate-lanceolate acuminate, much shorter than the petioles; hds. small, subglobous; cor. yellow; sty. 3 or 4 times shorter than the 1-seeded leg.-(1). In dry soils, N. H. to Va. Sts. many from the same root, slender, more or less pubescent, striate, 3 to $10^{\prime}$ long, often suberect. Lfts. 4 to $8^{\prime \prime}$ long, $\frac{1}{2}$ to equally as wide, lateral ones placed 1 to $2^{\prime \prime}$ below the terminal one. Hds. 2 to $3^{\prime \prime}$ diam., on slender peduncles $I^{\prime}$ long. Fls. at length reflexed. Jn., Jl. § Eur.

2 T. agràrium L. St. ascending or erect; lfts. often emarginate, denticulate, all subsessile; stip. linear-lanceolate, cohering with and longer than the petiole; hds. ovoid-elliptic; sty. about equaling the 1-seeded leg.-(1) Sandy fields, N. Eng. Sts. 6 to $15^{\prime}$ high, branched, minutely pubescent. Lits. 5 to $10^{\prime \prime}$ by 1 to $3^{\prime \prime}$. Common petioles 3 to $10^{\prime \prime}$ long, the upper ones shorter than their stip. Hds. of fls. twice larger than in the last, on peduncles about $\mathrm{I}^{\prime}$ long. Fls. at length reflexed. Jl., Aug. \& Eur.

3 T. Caroliniànum $\mathrm{Mr}$. Slender, diffuse; lfts, cuncate-obovate, the middle one obcordate; stip. ovate-acuminate, foliaceous; hds. long-stalked; cal. teeth thrice longer than its tube; leg. 4-seeded.-(1) Fields, S. Car. to Fla. and Tex., almost forming a turf and poor pasturage. Sts. 6 to $12^{\prime}$ long, many from one root. Fls. white or purplish. Ped. 4 to $G^{\prime}$ long. Mar.-May.

4 T. repens L. WiIte Clover. Shamrock. St. creeping, diffuse; lifts. obcordate, denticulate; stip. narrow, scarious; hds. subumbellate, on very long, axillary peduncles; leg. about 4-seeded; cal. teeth shorter than the tube.-24 In all soils, mountainous, meadow or rocky, throughout N. Am. Sts. several from the same root, extending 6 to 12 , rooting at the joints. Ped. angular, much longer than the lvs. Fls. white. May-Sept. Highly valued for pasturage.

5 T. refléxum L. BUfFalo Clover. Pubescent; ascending or procumbent; lfts. obovate or oblong-obovate, serrulate, somo of them emarginate; stip. leafy, semicordate; hds. umbel-like; cal. teeth nearly as long as the cor.; leg. about 4-seeded.-2) Prairies and meadows, W. and S. States. St. 8 to $16^{\prime}$ high. Lfts. subsessile, 7 to $8^{\prime \prime}$ by 4 to $5^{\prime \prime}$; petioles 1 to $2^{\prime}$ long. Hds. large and handsome Ped. 1 to $3^{\prime}$ long. Fls. rose-red, turning brownish when deflected. Apr.-Jn. 
6 T. stolohíferum Muhi. Glatrous, creeping; branches axillary, ascending short; ifts. broadly obcordate, denticulate; stip. leafy, ovate-lanceolate, acuminate; fls. loose, umbellate-capitate; cal. teeth not half the length of the cor.; leg. about 2-seeded.-Fields and woods, W. States. Sts. 6 to $12^{\prime}$ long, several together. Branches 3 to $4^{\prime}$ high, generally with one head which is $1^{\prime}$ diam. Ifts. 6 to $10^{\prime \prime}$ by 5 to $9^{\prime}$. Fls. white, erect. but in fruit all reflexed. May, Jn.

7 I. arvénse $\mathrm{L}$. Hds. cylindrical, very hairy; cal. teeth setaceous, longer than than the cor.; lifts. narrow-obovate.-1) A low plant in dry, sandy fields, Me. to Fla. Sts. much branched, round, hairy; 6 to $12^{\prime}$ high. Lvs. hairy, on short petioles, of 3 narrow lfts., $\frac{1}{2}$ to $1^{\prime}$ long. Hds. of whito or palo red fls., $1^{\prime}$ long, very soft and downy, the slender, equal calyx teeth being densely fringed will fine silky, reddish hairs, and projecting far beyond the corolla. Jl.-Aug. § Eur.

8 T. praténse L. RED Clover. Ascending, thinly hirsute; lfts. spotted, oval, entirs; stip. ovate, cuspidate-acuminate; heads sessile; lower tooth of the cal. longer than the four others which are equal.- 2 This is the common red clover so extensively cultivated in grass lands, with herds' grass (Phleum pratense)-and other grasses, and often alone. Sts. several from the same root, hairy. Lvs. ternate, the lfts. ovate, lighter colored in the center, entire and nearly smooth. Fls. red, rarely white, sweet-scented. All Summer. § Eur.

9 T. mèdium I. ZIG-ZAG CLover. St. suberect, branching, flexuous, nearly glabrous; lfts. not spotted, oblong or elliptical, subentire; stip. lanceolate, acuminat3; hds. ovoid-globous, pedunculate; cal. teeth setaceous, hairy.-24 In meadows, Danvers, Mass. (Oakes). Hds. of fls. larger than in T. pratense. Cor. deep purplo. Lvs. of a uniform green. § Eur.

10 T. incarnàtum L. St. erect, flexuous; lfts. ovate-orbicular, obtuso or obcordate, sessile, crenate villous; spike dense, oblong, obtuse, pedunculate; cal. teeth setaceous, villous. - (1) A fine species from Italy, occasionally cultivated as a border flower, and has been proposed (Dr. Dewey Rep. Herb. Pl. Mass.) for cu!tivation as a valuable plant for hay.

30. MEDICA'GO, L. MedrcK. (Gr. $\mu \varepsilon \delta \iota \iota \eta$, lucerne; from Media, its native country?) Calyx 5-cleft; corolla deciduous, vexillum free and remote from the keel; legume variously curved, or spirally coiled or twisted.-Herbs or shrubs with pinnately 3 -foliate lvs.

* Pods smooth...............Nos. 1, 2, 3.

** Pods spiny................Nos. 4, 5, 6 .

1 M. Iupulína I. NoNe-sucr. Procumbent, pubescent; lfts. obovate, obtuse, cuneate at base; ped. much longer than the leaves, with an oblong spike of small yellow flowers; pods reniform, 1-seeded.-(1) Fields and wasto grounds, Can. to Fla. Sts. 6 to $20^{\prime}$ long. Pods black when ripe, as large as a pin-head. May-Oct. $\S$ Eur.

2 M. satìva L. LucerNe. Erect, glabrous; lfts. oblong-oblanceolate, toothed abore, mucronate; stip. lance-linear; ped. longer than the lvs., with an oblong rac. of large violet fls.; pods spirally twisted, reticulated. - 4 Sts. 2 to 3 f ligls, from a strong, deep root. Highly valued in Europo as a forago plant, with us sparingly cultivated. § Jn., Jl.

3 M. scutellàta L. SxAILS. Lfts. elliptical, denticulate, the lower obovate; stip. ovate, dentate; ped. 1 to 3-flowered, shorter than the leaf; pods, snail-shaped, convex below, flat above, with about 6 concentric-spiral turns. - (1) Gardens, among flowers, cultivated for its curious pods résembling snail shells. JL $+\S$ Eur.

4 M. denticulàta Willd. Procumbent, glabrous; lits. obovate, denticulate, and often emarginate above; stip. laciniate, setose; ped. I to 3 -flowered, shorter than the leaves; pods loosely spiral, with 2 or 3 turns, flattened, strongly reticulated, the border echinate with a double row of hooked spines.-(1) Waste grounds, hero and there. Sts. 1 to $2 \mathrm{f}$ long. Fls, small (yellow in h. s.), purplish. Jn. \& Eur.

5 M. intertéxta L. HEDGeHOG Lfts. rhomboidal, toothed; stip. laciniate; ped. about 2-flowered; leg. oval, 5 or 6 -fold, spirally coiled, echinate, the margins bordered with setaceous, reflexed, appressed prickles.-Gardens, and occasionally spontaneous. Cultivated like No. 3 , for its curious pods. 
6 IM. maculàta Willd, with Jvs. marked with a purple spot, and pods compactly spiral, and echinate somewhat like No. 4, said to be naturalized South; wo havo not met with it, unless an imperfect specimen from Potsdam, N. Y., be this plant. Other species of this curious genus are occasionally found in gardens.

31. MELILO'TUS, Tourn. Melilot. (Lat. mel, honey, and lotus; in drying it exhales a sweet odor.) Calyx tubular, 5-toothed, persistcnt; corolla deciduous, keel petals completely united, shorter than the alo or vexillum; stamens diadelphous (9\& 1) ; legume rugous, longer than the calyx, 1 to few-sceded.-Genus taken from Trifolium. Lvs. pinnately trifoliate, veins of the Ifts. simple or forked. Fls. in racemes.

1 M. officinàlis Willd. St. erect, with spreading branches; lfts. obovate-oblong, obtuse, dentate; rac. spicate, axillary, paniculate, loose; cal. half as long as the yellow corolla; leg. 2-seeded, ovoid.-Alluvial meadow's. St. sulcate, about $3 \mathrm{f}$ high. Lfts. smooth, with remote, mucronate teeth. Fls. in long, 1-sided, slender racemes; petals of nearly equal length. The whole plant is sweet-scented. Jn. $\S$ Eur.

2 M. álba Iam. Sweet-scented Clover. White Melilot. St. erect, branched, lits. ovate-oblong, truncate and mucronate at tho apex, remotely serrate; stip. setaceous; cal. less than half as long as tho whito cor.; leg. 2-seeded, ovoid. (2) Alluvial soils. St. robust, very branching, sulcate, 4 to $6 \mathrm{f}$ high. Lfts. 1 to $2^{\prime}$ long, more obtuse at the apex than at base, mucronately serrate. Fls. numerous, the racemes more looso and longer than in the last. Petals unequal; banner longer than wings or keel. Very fragrant when dried. Jl., Aug. \& \& Eur.

32. PSORA'LEA. (Gr. $\psi \omega \rho \tilde{\lambda} \lambda \tilde{e} o s$, leprous or scaly; alluding to the glandular dots.) Calyx 5 -cleft, campanulate ; segments acuminate, lower one longest; stamens diadelphous, rarely somewhat monadelphous; lecrumes as long as the calyx, 1-seeded, indehiscent. -24 or 5 . Often glandular-dotted; stip. cohering with the base of the petiole. Fls. cranic.

* Leaves palmately 1 and 3 (rarcly 5 )-foliate................................ 1, 2

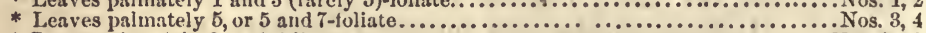

* Leaves pinnately 8 or 1 -foliate........................................................ 5 - 8

* Leaves pinnate, 19 to 21 -foliate...................................................... 9

1 P. canéscens $\mathrm{Mr}$. Very branching, canescently pubescent, lower lvs. 3-foliate, upper 1-foliate, lfts. roundish-obovate, obtuse, tapering at base into a petiolule, dot. ted.-Sandy woods, N. Car. to Fla. Plant $2 \mathrm{f}$ high, excessively branched, forming a globular bush. Fls. in small clusters at the end of the branchlets; small, "blue at first, changing to dull yellow" (Mettauer). Cal. gibbous, almost spurred at base. $\mathrm{Nay}-\mathrm{Jl}$.

2 P. floribúnda Nutt. Canescent, much branched; lfts. 3, rarely 5, dotted, oblong-obovate, varying to linear; stip. setaceous; rac. slender, many-flowered, twico longer than the leaves; pedicels as long as the flowers, and longer than the small, ovate-acuminate bracts; vex. roundish; leg. smooth.-Alluvial soils, Ill. (Mead), Ark. W. to the R. Mts. St. 2 to $4 \mathrm{f}$ high, branches spreading. Ifts. 1 to $2^{\prime}$ by 2 to $4^{\prime \prime}$. Common petiole $\frac{1}{2}$ to $1^{\prime}$ long. Fls. bluish purple, $3^{\prime \prime}$ long, 15 to 30 in the very canescent racemes. Jn.

3 P. subacaùlis Torr. \& Gray. Nearly acaulescent, hirsute; lvs. 7-foliate on very long petioles; lfts. obovate-oblong; fls. in dense, egg-shaped racemes; cal. much shorter than the cor.-Tenn., near Nashville (Dr. Loam in N. Arn. Flora). Lvs. and flower-stalks almost radical, 6 to $10^{\prime}$ long; ifts. about $1^{\prime}$ long.

4 P. Lupinellus $\mathrm{Mx}$. St. slender, glabrous; lvs. 5 to 7 -foliate; lifts. linear-filiform; rac. longer than the lvs., many-flowered; pod incurved at base, recurved at apex, so as to simulato the letter S.-Pine barrens, S. Car. to Fla. Sts. about 2f high. Lfts. 2 to $3^{\prime}$ long. Fls. as large as in P. Aloribunda. May, Ju.

5 P. virgáta Nutt. Virgate, smoothish; lvs. 1-foliate, remote; lits. linear (the lower rarely 3 -foliate and oblong); ped. shorter than the lvs.; spikes rather denseflowered.-Near St. Mary's, Ga. St. about $2 \mathrm{f}$ high. Lifs. 2 to $4^{\prime}$ by 2 to $4^{\prime \prime}$. Fls. palo violet. 
6 P. stipulàta Torr \& Gr. Nearly glabrous and glandless, ascending; 1rs. pinnately 3 -foliate, lfts. elliptic-ovate, obtuse, mucronato; stip. (large) ovate; ped. as long as the lvs.; spikes capitate.-Falls of the Ohio (Jones in N. Am. Flora). Sts. branched from the base. 'The large stipules aro remarkable, resembling those of the red clover.

7 P. Melilotoìdes Mx. Virgate, minutely pubescent; lvs. 3-foliato, 1fts. oblonglanceolate, rather obtuse, on very short petioles, more or less glandular; stip. lanceolate; spike oblong, at length elongated, on virgate peduncles; pods orbicular, transversely wrinkled.-Dry soils, S. and W. Sts. Slender, branched, erect, $2 \mathrm{f}$ high. Lfts. 2 to $2 \frac{1^{\prime}}{2}$ long, $\frac{1}{4}$ as wide. Ped. 6 to $10^{\prime}$ long. May-Jl. (P'. eglandulosa Eill.)

6 P. Onobrychis Nutt. Pubescent; lfts. ovate-acuminate; rac. elongated; cal. much shorter than cor., teeth small, obtuse, equal; leg. ovate, transversely wrinkled.--Low grounds and thickets, W. States. St. rigidly erect, nearly simple, 3 to $5 \mathrm{f}$ high. Lfts. 2 to $4^{\prime}$ long, nearly $\frac{1}{2}$ as wide. Fls. small, pedicellate, blue. Pods exceeding the calyx, rostrate. Jn., Jl.

9 P. multijuga Ell. Ifts. numerous, oblong-lanceolate, obtuse; spikes oblong; cal. villous, teeth very long; bracts small.-In the upper country, Ga. (Elliott), S. Car. (Darby). St. stout, furrowed 1 to $2 \mathrm{f}$ ligh, nearly smooth. Fls. violet. Ifts. 9 or 10 pairs. May, Jn.

33. GLOTTID'IUM, Desv. (Gr. $\gamma \lambda \tilde{\omega} \tau \tau a$, tongue; alluding to the singular structure of the pods.) Calyx campanulate, truncated, minutely 5 -toothed; vexillum reniform, broader than long; legume elliptic-oblong, eompressed, pointed at each end; valves double, the inner membranous, inclosing the seeds after the outer have fallen away; seeds 1 or 2.-(1) Glabrous. Lvs. abruptly pinnate. Fls. small, yellow.

G. Floridànum DC. In waste and damp soils, S. Car. to Fla. and Tex. St. tall and rank (4 to $10 \mathrm{f})$. Ifts. 30 to 50 , linear-oblong, obtuse, mucronate, 6 to $18^{\prime \prime}$ long. Fls. about a third as large as in Sesbania, in slender rac. Pods $18^{\prime \prime}$ by $6^{\prime \prime}$, appearing after the opening of the outer valve, as tongue and lips. Seeds beanshaped. (Sesbania platycarpa Pers.)

34. SESBA'NIA, Pers. Calyx campanulate, subequally 5-toothed; vaxillum longer than the obtuse keel, the claw appended; legume very long and slender, linear, closed between the seeds.--Shrubs or herbs, with abruptly pinnate lvs., caducous stip. and bracteoles, and yellowish flowers.

S. macrocàrpa Muhl. Herb annual, glabrous; lfts. 30 to 50 , oblong-linear, obtuse, mucronate; rac. about 2-flowered, shorter, but the legumes twice longer than the lvs.-Damp grounds, S. Car. to Fla. and La. St. tall (2 to 8f). Lvs. 6 to $10^{\prime}$ long, the lfts. 6 to $9^{\prime \prime}$, glaucous beneath. The extremely slender leg. nearly a foot long, with a bordered margin are very singular. Aug.-Oct.

35. AMOR'PHA, L. Lead Plant. (Gr. $a$, privative, $\mu \rho \rho \phi \eta$, form; alluding to the deficiencies of the corolla.) Calyx subcampanulate, 5 cleft; vexillum concave, unguiculate, erect; wings and keel none; stamens exserted; legume oblong, somewhat curved at the point, scabrous with glandular points, 1 to 2 -seeded.-Shrubs or half shrubby American plants. Lvs. unequally pinnate, punctate. Fls. bluish white, in virgate racemes.

- Leaves stalked (i.e., the lowest lfts. remote from stem) ........................ 1

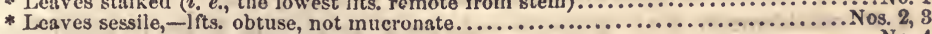

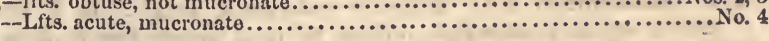

1 A. fruticòsa $I$. Nearly glabrons or somewhat pubescent, shrubby or arborescent; lfts. 9 to 19 , oval, petiolulate, very obtuse, the lower pair remote from the stem; cal. teeth obtuse, short, lower one acuminate and rather the longest; leg. 2-seeded. - A shrub or small tree, 6 to $16 f$ high, Wis. to.La. and Fla., W. to R. 
Mts. Lvs. 3 to $5^{\prime}$ long; lfts. about 1 by $\frac{1^{\prime}}{2}$, rather remote from each other and from the stem. Petiolules scarcely 2 " long. Spicate rac. terminal, solitary or fascicled, 3 to $4^{\prime}$ long. Vexillum purple, emarginate. May, Jn.

2 A. glàbra Desf. Nearly glabrous, shrubby; lfts. oblong or elliptical, dotted, petiolulate, the lowest pair close to the stem; fls. subsessile; cal. teeth short, the 2 upper obtuse, the 3 lower longer, or nearly equal, villous; sty. hairy towards the base.-Near Wilmington and Newbern, N. Car. Plant 4 to $5 \mathrm{f}$ high. Fls. dark blue. Jl. (v. s. in herb. Curtis.) (A. Caroliniana Croom).

3 A. herbàcea Walt. Pubescent and somewhat hoary, shrubby; lfts. 20 to 25 pairs, oblong, obtuse, dotted, the lowest pair close to the stem; fls. subsessile; teeth of the cal. nearly equal, short; cor, whitish.-Pino woods, N. Car. to Fla. Plant 2 to $4 \mathrm{f}$ high, grayish. Lvs. 5 to $7^{\prime}$ long; 1 fts. 6 to $8^{\prime \prime}$ by $3^{\prime \prime}$. Petiolules $I^{\prime \prime}$ long. Spikes many, clustered at top, very downy, 6 to $8^{\prime}$ long. Jn., Jl.

4. A. canéscens Nutt. Suffruticous, and canescently villous, lfts. small, numerous, crowded, ovate-elliptical, subsessile, mucronate; spikes aggregate; fls. subsessile; calyx teeth equal, oval acuto; vex. bright blue; leg. 1-seeded.-A beautiful species, 2 to $4 \mathrm{f} \mathrm{high,} \mathrm{in} \mathrm{dry,} \mathrm{sandy} \mathrm{soils,} \mathrm{Wis.} \mathrm{to} \mathrm{La.} \mathrm{and} \mathrm{R.} \mathrm{Mts.,} \mathrm{and} \mathrm{is} \mathrm{supposed}$ to prefer localities of lead ore. Lws. 2 to $3^{\prime}$ long; líts. coriaceous, 16 to 24 pairs, obtuse at.base, 4 to $6^{\prime \prime}$ by 1 to $2^{\prime \prime}$. Spikes 2 to $3^{\prime}$ long. Jl., Aug.

36. DA'LEA, L. (In honor of Thomas Dale, an English botanist.) Calyx subequally cleft or toothed; petals unguiculate, claws of the wings and keel adnate to the staminate tube half way up; vexillum free, the limb cordate; stamens 10 , united into a cleft tube; ovary 2-ovuled; legume inclosed in the calyx, indehiscent, 1-seeded.-Mostly herbaceous and glandular-punctate. Lvs. odd-pinnate. Stipels 0, stip. minute, setaccous. Spikes mostly dense.

D. alopecuroìdes Willd. Glabrous and much branched; lfts. 8 to 14 pairs, linear-oval, obtuse or retuse, punctate beneath; spike pedunculate, oblong-cylindric, terminal, silky-villous; bracts about equaling the acuminate segments of tho cal.- (1) Prairies and bottoms; IIl., Mo., Car. Plant about 2f high, bushy and leafy and pale green. Ifts. not more than $4^{\prime \prime}$, by $1^{\prime \prime}$, sessile, and nearly in mutual contact. Spikes 1 to $2^{\prime}$ long. Vexillum white, wings and keel palo violet. (D. Linnæi Mx. Petalostemon $\mathrm{Ph}$.)

37. PETALOSTE'MON, Mx. (Alluding to the union of the petals and stamens.) Calyx 5 -toothed, nearly equal; petals 5 , on filiform claws, 4 of them nearly equal, alternate with the stamens and united with the staminate tube; stamens 5 , monadelphous, tube cleft; legume 1 -seeded, indehiscent, included in the calyx.-Mostly 24. Lvs. unequally pinnate, exstipellate. Fls. in dense, pedunculate, terminal spikes or heads.

5 Pexalostemon proper. Calyx teeth short. Ileads not involucrate. Bracts small (a).

a liracts aristate-pointed, longer than the caly x........ Nos. 1, 2

a Bracts obtuse or acute, not aristate, short............... Nos. 3,4

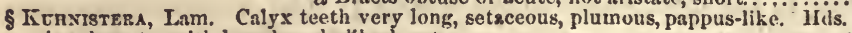

involucrate, with broad, scalc-like bracts...................................... 5

1 P. cándidum Mx. Glabrous, erect; lfts. 7 to 9, all sessile, linear-lanceolate, mucronate, glandular beneath; spikes on long peduncles; bracts setaceous, longer than the white petals; vex. broadly cordate, the other pets. ovate.-A finelooking plant in dry prairies, S. and. W. States. St. 2 to $4 \mathrm{f}$ ligh, eparingly branched, slender. Lfts. 9 to $18^{\prime \prime}$ by 3 to $5^{\prime \prime}$, terminal one largest. Fls. small, white, crowded in denso spikes which are 1 to $3^{\prime}$ long. Jl.

2 P. violàceum $M x$. Minutely pubescent, erest; lits. 5, linear, glandular beneath; spikes pedunculate, oblong or oval, bracts sherter than the violet petals; vex. cordate, the other petals oblong, obtuse at base. $-\Lambda$ beautiful plant, of similar liabits with the last. St. slender, striate, subsimpie, $1 \frac{1}{2}$ to $2 \mathrm{f}$ high. I.fts. about $1^{\prime}$ by $1^{\prime \prime}$, all sessile. Spikes 1 .to 8 , very dense, $\frac{1}{2}$ to $1_{\frac{1}{2}}^{\prime}$ long. Pctals of a bright violet-purple. Jl., Aug. 
3 P. cárneum Mx. Glabrous, erect; lfts. 5 to 7, lance-linear ; spilies oblong, pedunculate; bracts obovate, somewhat exceeding the short teeth of the glabrous calyx; pet. oblong, narrowed at base in the long claws.-Ga and Fla. Slender, branching, 1 to $2 \mathrm{f} \mathrm{high;} \mathrm{lvs.} \mathrm{fascicled} \mathrm{in} \mathrm{the} \mathrm{axils.} \mathrm{Lfts.} \mathrm{acute,} 5$ to $8^{\prime \prime}$ long. Spikes 1' long. Fls. roseate or white. Aug.

4 P. grácile Nutt. Glabrous, decumbent at baso; 1fts. 7, lance-linear; spikes oblong or cylindrical, somewhat sessile; bracts acute, about equaling tho short, blunt calyx teeth; petals ovate; vex. broadly cordate. - 1 W. Fla. and Ala. nearly simple, 1 to $2 \mathrm{f}$ long, leafy to near tho top. Lfts. 3 to $6^{\prime \prime}$ long. Spikes 6 to $12^{\prime \prime}$ long. Fls. white.

5 P. corymbòsum Mx. St. corymbously branched; spikes capitate, sessilo; bracts broad, colored, the outer leaf-bearing and flowerless; lfts. linear, 5 to 7 . A singularly elegant plant of the pine barrens, N. Car. to Fla. Sts. 1 to $2 \mathrm{f} \mathrm{high,}$ many from ons root, each with a corymb at summit. Heads resemblo the Compositæ, with red scales and white laneo-oblong petals. Sept., Oct.

38. AStRAG'ALUS, L. Milk Vetcir. Calyx 5-toothed; keel of the corolla obtuse; stamens diadelphous ( 9 and 1 ); legumes 2 -celled by the introflexion of the lower suture.-Herbaceous or suffruticous, with unequally pinnate lis., and the fls. in spikes or racemes.

\& Legumes straight, cylindric. Flowers ochrolencons........................... 1

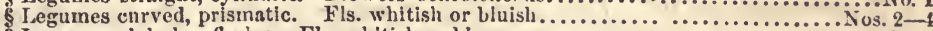

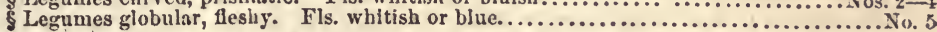

1 A. Canadénsis I. Canescent, erect, diffuse; stip. broad-lanceolate, acuminate; lfts. about 10 pairs, elliptical, obtuse at both ends; the lowest ovate, obtuse; ped. about as long as the lvs., when in fruit shorter; bracts subulate, as long as the cal.; fls. somewhat roflexed; leg. ovate-oblong, terete, suberect, smooth, many-seeded, abrupt at the end and tipped with the permanent style.\& River banks, etc., Can. and U. S. St. bushy, about $3 \mathrm{f}$ high, very leafy. Fls. greenish-yellow, in denso spikes. Pods $\frac{x^{\prime}}{2}$ in length, leathery. Jl. Aug.

2 A. glàber Mx. Nearly glabrous, erect; stip. minuto or 0 ; lfts. 8 to 11 pairs, oblong-lanceolato or linear, obtuso or emarginats; spilies loose, much longer thin the lvs.; bracts subulate, scarcely longer than the pedicels; ler. flattened, reticulated. - 4 Pino barrens, N. Car. to Fla. St. 1 to $2 \mathrm{f}$ high. Fls. greenish whitc. Pods distant, $1 \frac{1}{2}$ long, spreading, incurved, acuto at each end. Apr.

3 A. obcordàtus Ell. Nearly glabrous, decumbent or assurgent; stip. lanceolate; lfts. 7 to 12 pairs, obcordate or obovate, ped. about as long as the lvs., fewflowered, fls. pedicellate; cal. teeth subulate, about as long as the tube; leg. curved, pointed, strongly reticulated.-River banks, N. Car. to Fla. Plant low and leafy, ascending 4 to $8^{\prime}$. Fls. blue and white. Pod $1^{\prime}$ in length. Lfts. 3 to $4^{\prime \prime}$ long.

4 A. distórtus Torr. \& Gr. St. and ped. as in No. 3 ; stip. ovate; lvs. longpetioled, lfts. oblong-obovate, mostly emarginate, 7 to 12 pairs; spikes short; cal. teeth triangular-acuminate, half as long as the tube; leg. smooth, declinate, curved.Prairies, W. Ill. (Mead) to Ark. Branches ascending 4 to $6^{\prime}$. Lfts. 3 to $5^{\prime \prime}$ by 1 to $2^{\prime \prime}$. Fls. blue, $6^{\prime \prime}$ long. Pods $1^{\prime}$ long, beaked with the coiled style. Probably a variety of the last.

5 A .Mexicànus A. DC. Low, branclies decumbent, glabrous; lvs. pedunculate, lfts. 7 to 10 pairs, obovate, emarginato; ped. rather longer than the lvs.; spikes short, 10 to 15-flowered; leg. globular, obtuse, succulent, sweet-tasted.-Prairies, IIl., Mo. to Ark. Plant 3 to $5^{\prime}$ high. Ifts. 2 to $3^{\prime \prime}$ by 1 to $2^{\prime \prime}$. Fls. about $9^{\prime \prime}$ long (yellowish whito in h. s.), bluish? Fr. as large as the plum, and "eaten unripo by travelers, raw or cooked."

39. PHA'CA, L. (Gr. ל́ák $\eta$, lentil, from $\phi a ́ \gamma \omega$, to eat.) Calyx 5 -toothed, kcel obtuse; stamens diadelphous (9 and 1); legume continuous, turgid, 1-celled; placentre tumid, several-secded. 24 Lvs. unequally pinnate. Fls. in axillary, pedunculate raceme. (Differs from Astragalus only in its fruit.)

- Plant densely villous. Flowers greenish rellow.................................. 1

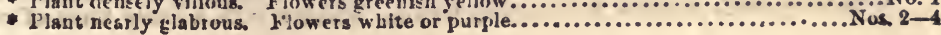


1 P. villòsus Nutt. Low, villous-hirsute, decumbent; lvs. petiolate, lfts. distant, 9 to 15, oval or oblong, the odd one obovate; ped. rather longer than the lvs.; spikes short, somewhat loose; cal. teeth longer than the tube; leg. clothed with long woolly hairs.-Dry sandy fields and woods, S. Car. to Fla. Sts. spreading on the sand, 2 to $3^{\prime}$ long. Ifts. 3 to $4^{\prime \prime}$ by 1 to $2^{\prime \prime}$. Fls. 10 to 15 in a liead, 4 to $5^{\prime \prime}$ long. Mar., Apr.

2 P. neglécta Torr. \& Gr. Erect; 1fts. elliptical, 7 to 13 pairs; stip. minute; rac. many-flowered, rather looso and some longer than the lvs.; leg. not stiped, smooth, roundish ovate, much inflated, with a deep groove at the ventral suture.-By streams and lakes, W. N. Y. to Wis. Plant resembling Astragalus Canadensis, but of fairer and finer look. St. 1 to $2 \mathrm{f}$ high, terete. Lfts. 9 to $15^{\prime \prime}$ by 3 to $5^{\prime \prime}$, minutely puberulent beneath. Fls. white, 10 to 20 in a raceme. Pods about $\frac{B^{\prime}}{2}$ long, with many small sds. Jn., Jl.

3 P. Robbínsil Oakes. Erect; lfts. 5 to 11, elliptical, terminal one largest, stip. triangular-ovate; ped. twico longer than lvs.; rac. short, ovate; cor. horizontal, twice as long as the cal.; leg. stiped, oblong, leeled at the ventral suture, tipped with the recurved, persistent style.-Ledges by rivers and lakes, northern Vt., rare. Plant nearly smooth. St. slender, 8 to $14^{\prime}$ high. Lvs. remote, 2 to $4^{\prime}$ long. Ifts. 4 to $8^{\prime \prime}$ by $1 \frac{1}{2}$ to $3^{\prime \prime}$, petiolulate. Rac. surpassing the stem, on ped. 5 to $10^{\prime}$ long, 12 to 18-flowered. Cor. white, about $5^{\prime \prime}$ long. Pods $1^{\prime}$ long, 4 to 8-seeded. 'May, Jn.

4 P. astragalìna DC. Low, ascending or nearly stemless; lfts. 15 to 21, oval; stip. ovate; ped. at length longer than the lvs.; rac. dense, with 8 or 10 violetcolored fls.; cal. toeth shorter than tube; leg. pendulous, stiped.-Can. along the St. Lawrence and northward. 'St3. 1 to $6^{\prime}$ high.

40. TEPHRO'SiA, L. Gont's Rue. Cat-gut. (Gr. teфò̀s, ashcolored; from the color of the foliagre.) Calyx with 5, nearly equal, subulate tecth; bracteoles 0 ; vexillum large, orbicular; keel obtuse, cohering with the wings; stamens diadelphous (in the following specics) or monadelphous; legume linear, much compressed, many-seeded. - Ilerbs and shrubs, with unequally pinnate lvs.

$\$$ Flowers large $\left(9\right.$ to $10^{\prime \prime}$ long), in a leafy, terminal cluster.......................... 1

Flowers small (5 to $6^{\prime \prime}$ long), spicate on long, leafless peduncles...........................

I I. Virginiàna Pers. Erect, villous; lfts. numerous, oblong, mucronate; rac. terminal, subsessile among the lvs.; leg. falcate, villous.-24 Plant 1 to $2 \mathrm{f}$ high, in dry, sandy soils, Can., Ind., Ill., S. to Fla. St. simple, very leafy. Lfts. 15 to 27,10 to $13^{\prime \prime}$ by 2 to $3^{\prime \prime}$, straight-veined, odd one oblong-obcordate, petiolules $I^{\prime \prime}$ long. Stip. subulate, deciduous. Fls. as large as those of the locust, in a short, crowded cluster. Cal. very villous. Banner white, keel rose-colored, wings red. Jl.

2 T. spicàta Torr \& Gr. Villous with rusty hairs; st. subsimple; 1fts. 9 to 17, oblong-oval or elliptic, mucronate, obtuso or retuse; ped. very long, few-flowered; cal. segm. subulate, longer than the tube.-Common in dry soils, S. States. An unsightly plant. Sts. ascending, 1 to 3 f long, flexuous, scarcely branched, tough. Lvs. few, distant; lfts. $\mathrm{l}^{\prime}$ long. Ped. 6 to 12 to $18^{\prime}$ long. Fls. purplish red. Jn., Aug.

3 T. hispídula $\mathrm{Ph}$. Minutely hispid or pubescent; sts. dichotomous, slender, de. cumbent; lfts. 9 to 19, elliptic-oblong, acute; ped. several, few-flowered; cal. segm. not longer than the tube; pods falcate.-Dry soils, S. States. Sts. 1 to $2 \mathrm{f}$ long. Lrs. remoto; lfts. 10 to $15^{\prime \prime}$ long, mucronate, sometimes nearly linear. Ped. 3 to $6^{\prime}$ long. Fls. reddish purple. May, Aug.

6. ELEGANS T. \& G. Very slender, nearly glabrous; lits. 11 to 17 , narrowly elliptical, acute; ped. fliform; pods nearly straight. - Savannah (Pond). (T. elegans Nutt.)

4 T. chrysophýlla Ph. Soft-pubescent, prostrate, dichotomous; lfts. 5 to 9, oval or obovate, coriaceous, glabrous above, silky pubescent beneath; ped. longer than the lvs.; cal. segm. shorter than the tube.-Ga. (Savannah, Pond) and Fla. St. If or moro long, clothed with a rusty down. Foliago with a lively tinge of yel- 
low. Ifts. about $9^{\prime \prime}$ by $7^{\prime \prime}$, beautifully striate, and wavy at edge. Pods straight (always?) May, Jl.

$\beta$. GRACILIOR. Nearly glabrous, slender; lits. few, oblong $\left(9^{\prime \prime}\right.$ by $3^{\prime \prime}$.) Plant 3 to $9^{\prime}$ long. Pod small (15" long.) Fls. reddish purple as above.-Covington, La. (Hale.)

41. INDIGO'FERA, L. Indigo-PLANT. (Lat. Indigo, fero, to bear.) Calyx with 5 acute segments; vexillum roundish, emarginate; keel spurred each side, at length reflexed; legume 2 -valved, 1 to $\infty$-seeded. - IIerbs or shrubs. Stip. small, distinct from the petiole. Fls. cyanic.

1 I. Caroliniàna Walt. Herb crect, branched; lvs. uncqually pinnate; lfts. 11 to 15 , oblong-ovate, petiolulate; rac. slender, longer than tho lvs.; leg. pendulous, oblong, rugose, veiny, 2-seeded. - If Sandy woods, N. Car. (Dr. Porcher) to Fla. St. 3 to $7 \mathrm{f} \mathrm{high.} \mathrm{Lfts.} 9$ to $12^{\prime \prime}$ long, obtuso or retuse. Rac. 3 to $6^{\prime}$ long; fls. pedicellate, yellowish-brown. Calyx pubescent, small, with 5 short, subulato teeth. Jl., Sept.

2 I. leptosépala Nutt. Herbs decumbent, strigous, with ashy hairs; 1rs. un. equally pinnate, ifts. 7 to 9 , obovate-oblong, subsessile, nearly glabrous above; rac. longer than the lvs., fls. nearly sessile; leg. linear, reflexed, 6 to 9 -seeded.Ga. to Ark. St. 2 to 3 f long. Fls. pale scarlet. Pods $1 \frac{1}{2}{ }^{\prime}$ long, pointed.

42. ROBIN'IA, L. Locust. (In memory of John Robin, herbalist to Louis XIV.) Calyx short, campanulate, 5-cleft, the 2 upper segments more or less eoherent; vexillum large; alæ obtuse; stamens diadelphous ( $9 \& 1)$; style bearded inside; legume compressed, clongated, many-seeded.-Trees and shrubs with stipular spines. Lrs. unequally pinnate. Fls. showy, in axillary rac.

1 R. Pseudacácia I. Comron Locust. Branches armed with stipular prickles; lfts. ovate and oblong-ovate; rac. pendulous, smooth, as well as the Iigumes.-Native in Penn. and the more Southern and Western States, and abundantly naturalized in N. Eng. Hight 30 to $80 f$, with a diam. of 1 to 3 or 4 f. The pinnato lvs. have a beautiful symmetry of form, each coinposed of 8 to.12 pairs of lfts., with one at the end. These are oval, thin, nearly sessile, and very smooth, closing as if in sleep by night. Fls. in rumerous, pendulous clusters, diffusing an agreeable fragrance. Pod narrow, flat, with 5 or 6 small, brown seeds. When young the tree is armed with thorns, which disappear in its maturity. Apr., May.-The wood is very hard and durable.

2 R. viscòsa Vent. CLasmy Locust. Stipular spines very short; branchlets, petioles, and leg. glandular-viscid; lfts. ovate; rac. crowded, erect.-This beautiul tree is native of the Mts. of N. Car. to Ga., where it attains the hight of 40 . The fls. numerous, rose-colored, in erect, axillary clusters, with the thick, dark green foliage, render this tree one of the most brilliant ornaments of the park or the garden. Apr., Jn.

3 R. híspida L. Rose ACACIA. Stipular spines almost wanting, shrub mosthy hispid; rac. loose, suberect.-A beautiful shrub, native of the Southern States, much cultivated in gardens for the sake of its numerous, large, deep rose-colored and very showy fis. Hight 3 to 5 or 8 f. Lfts. 5 or 6 pairs, broadly oval. Fls. inodorous, twice larger than those of the common locust.

43. ColU'tea, L. Bladder Senna. Calyx 5-toothed; vexillum with 2 callosities, expanded, larger than the obtuse carina; stigma lateral, under the hooked summit of the style, which is longitudinally bearded on the back side; legume inflated, scarious. Shrubs with unequally pinnate lvs.

C. arboréscens L. Lfts. elliptical, retuse; rex. shortiy gibbous behind. $-\Lambda$ hardy, free-flowering shrub, native of Italy, \&c., growing almost alone on the summits of Mt. Vesuvius. Sts. 8 to $12 \mathrm{f}$ high. Lfts, soout 3. Fls. large, yellow, 
with a broadly expanded banner. In medicine the leaves aro used instead of senna. Jn.-Aug. $t$

44. WISTA'RIA, Nutt. (In memory of Caspar Wistar, M.D., President of Am. Phil. Soc.) Calyx bilabiate, upper lip emarginate, the lower one 3 subequal teeth; vexillum with 2 callosities ascending the claw and separating above; wings and keel falcate, the former adhering at top; legume torulous; secds many, reniform.-Twining, shrubby plants, with pinnate lvs. Rac. large, with large, colored bracts. Fls. lilac-colored.

$1 \mathrm{~W}$. frutéscens DC. Sts. pubescent when young, at length glabrous; ifts. 9 to 13 , ovate or elliptic-lanceolate, acute, subpubescent; wings with 2 auricles at base; ova. glabrous.-An ornamental, vigorous vine, in rich alluvion, S. \& IV. States. Sts. several yards long, climbing over bushes, etc. Lfts. 1 to $2^{\prime}$ by $\frac{1}{2}$ to ' 1 . Fls. nearly as large as those of the sweet pea, numerous, in rac. 3 to 6 or $8^{\prime}$ long, sheathed in very conspicuous bracts. Sds. spotted. Apr., May. + (Glycino frutescens L. Thyosanthus Ell.)

$2 \mathrm{~W}$. consequàna Benth. Lfts. 9 to 13 , ovate-lanceolate, silky-pubescent; rac. terminal, nodding, loosely many-flowered.-A splendid flowering vine from China. St. of rapid growth, $12 \mathrm{f}$ or more in length. Fls. in long, pendulous clusters. May, Jn. $\uparrow$

45. A'PIOS, L. Ground Nut. ('A $\pi \iota$, the pear; from the form of its tubers.) Calyx campanulate, obscurely bilabiate, the upper lip of 2 very short, rounded teeth, the 2 lateral teeth nearly obsolete, the lower one acute and elongated; keel falcate, pushing back the broad, plicate vexillum at top; ovary sheathed at base.-2f Twining, smooth. Root bearing edible tubcrs. Lvs. pinnately 5 to 7 -foliate.

A. tuberòsa $\mathrm{Ph}$. St. twining; lvs. pinnate, of 7 ovate-lanceolate lfts.; rac. shorter than the lvs. - Thickets and shady woods, Can. and U. S., twining about other plants. St. round, 2 to $4 \mathrm{f}$ in length. Lvs. rather numerous, each consisting of 3 (rarely 2) pairs of leaflets and an odd terminal one. These are ovate, narrow, more or less pointed, smooth, on short pedicels. Rac. axillary, solitary, 1 to $3^{\prime}$ long, crowded. Fls. dark purple. To the root are appended oval, fleshy tubers, which are very nutritious, and would perhaps be cultivated had we not the potato. Jl., Aug. (Glycine Apios L.)

46. VIG'NA, Savi. (In memory of Dominic Vigna, Commentator on Theophrastus.) Calyx of 4 lobes, the upper twice broader, the lower longer; vexillum broad with 2 callosities near the base of the limb; keel not twisted; stigma lateral; legume terete ; seeds not compressed.-Twining herbs. Lvs. pinnately trifoliate.

v. hirsùta Feay. Plant hirsute, the stem retrorsely so; cal. with 1 bractlet at base, segm. all acute, the lower acuminate; lfts. ovate-lanceolate, pointed.-Rice field dams, Savannah (Feay), swamps, N. Orleans (Hale). Sts. scrambling over bushes, many feet long, slender. Lits. 2 to $3^{\prime}$ by $\frac{1}{2}$ to $1^{\prime}$, with scattered, appressed hairs both sides, and minute stipels. Ped. 8 to $12^{\prime}$ long, 3 to 5 -flowered at the top. Fls. pale yellow, the banner $6^{\prime \prime}$ long and $9^{\prime \prime}$ broad. Pods $2^{\prime}$ long, with 4 to 6 large, black, polyhedral seeds. Oct., Nov. (V. glabra Savi? Dolichos luteolus Eill.)

47. RHYNCHO'SIA, DC. (Gr. píyXos, a beak; in reference to the projecting keel.) . Calyx somewhat bilabiate, or 4-parted, with the upper segm. 2 cleft; vexillum without callosities; keel falcate; style glabrous; legume oblique, short, compressed, 1 to 2 -seeded; seeds carunculate. - 4 Erect, or twining. Lvs, resinous-dotted beneath, pinnately 3 -foliate, sometimes reduced to a single leaflet. Fls. yellow. 
\$ RHYwcrosia proper. Calyx segments subulate, the lower much the longest, shorter than the corolla. Fls. in slender racemes.................................. 1

§ Arcyphylud, Ell. Calyx persistent, leafy, segments nearly equal, as long is the corolla. Lvs, coriaceous, rugose. Fls. fascicled or racemed................... Nos, 2-4

\$ Piтcueria, Nutt. Caly x segments lance-subulate, the upper rather the longer, shorter

than the corolla. Fls. axillary, subsolitary,................................ 5

1 R. mínima DC. Scrambling, puberulent; lfts. membranous, rhomboidal, acute with a large angle; rac. much longer than the lvs., about 12-flowered; fls. small, remote, reflexed.-Along rivers, S. Car. to Fla. and La. A delicate vine, sereral feet in length. Ifts. not rugose, 6 to $9^{\prime \prime}$ square, petiolo hardly $1^{\prime}$ long. Rac. axillary, about 6 ' long. Pods $\frac{1^{\prime}}{2}$ long, mucronate.

2 R. volùbilis. Twining, pubescent; lvs 3 -foliate, lfts. broadly oval or orbicular, somewhat rhomboidal, obtuse or acute; rac. few (3 to 10)-flowered, pedunculate; cal. segm. ovate-lanceolate, cuspidate.-Dry woods, Ga. (Miss Keen), to La, (Hale). Sts. 2 to 4 f long, square, especially downy on tho angles. Lower lvs. sometimes? monophyllus; lfts. smaller than in No. 3. Sep. becoming quite large in fruit. (R. difiormis DC. and R. latifolia Nutt.)

3 R. simplicifòlia. Dwarfish, pubescent, erect; lvs. reduced to a single leaflet orbicular or reniform, obtuse--Dry sandy woods, S. Car. to Fla. and La. St. angular, 1 to $3^{\prime}$ high. Lvs. 1 to $2^{\prime}$ broad, very veiny and rugous. Fls. small, in one or more dense tufts. Pods ovate-oblong, $7^{\prime \prime}$ in length. Apr., May. (R. tomentosa, a. T. \& G.)

4 R. erécta DC. Tall, erect, velvety-pubescent; lvs. 3-foliate, lfts. elliptic or oval, acute, terminal one sometimes roundish; fls. fascicled or racemed, axillary and terminal; cal. segm. parted almost to the base, lance-ovate to lance-linear.Dry soils, Md. to Fla. Sts. about 6-angled, 2-5f high. The lowest leaf or lvs. sometimes monophyllous. Lfts. about as large as in No. 3. Rac. 1 to $3^{\prime}$ long. ( 3 to $7^{\prime}$ Ell. in Glycine mollissima.)-The leaflets are sometimes strikingly variegated with lines of black dots along the veins above. (R. tomentosa, rar. Tor. \& Gr. G. tomentosa, var. Mx.

5 R. galactoìdes. Erect, rigid, with many simple, angular, pubescent branches; lvs. trifoliate, lfts. (small) coriaceous, elliptic or oval, margins reflexed, under surface with numerous resinous atoms; pedicels about equaling the petioles, balf as long as the fls.-Ala. and W. Fla. Sts. 2 to $3 \mathrm{f} \mathrm{high.} \mathrm{Lfts.} 6$ to $9^{\prime \prime}$ by 3 to $6^{\prime \prime}$, those of the virgate branches much smaller. Fls. yellow.

48. PHASEOLUS, L. Kidney Bean. (Lat. phaselus, a little boat; from the form of the pods.) Calyx subbilabiate, upper lip 2-toothed, lower 3-toothed; keel with the stamens and style spirally twisted; legume compressed and falcate, or cylindric, many-seeded; seeds compressed, reniform.- Herbaceous, twining or trailing. Lvs. pinnately trifoliate ; lfts. stipellate.

Native species-Fls. racemed. Pods falcate................................... 1

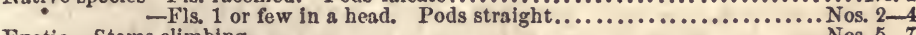

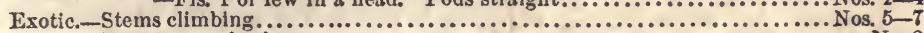

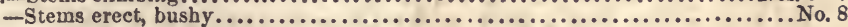

1 P. perénnis Walt. WILd Bean VINE. Twining; pubescent; rac. paniculate, mostly in pairs, axillary; lfts. ovate, acuminate, 3-veined; leg. pendulous, falcate, broad-mucronate. - $4 \mathrm{~A}$ slender, twining vine, in dry woods, Can. and U. S., common. St. 4 to $7 \mathrm{f}$ long, somewhat branching. Lifts. $1 \frac{1}{2}$ to $3 \frac{1^{\prime}}{2}$ long, $\frac{3}{4}$ to equal width; terminal one often subcordate, lateral ones unequally enlarged at base outside, under surface scabrous. Rac. 1 to 3 together, 6 to $12^{\prime}$ long, loose, often unfruitful. Cor. purple and violet. Leg. about $2^{\prime}$ long, $\frac{1}{3}$ ' wide, with compressed, reniform, dark purple seeds. Jl, Aug.

2 P. diversifòlius Pers St. prostrate, diffuse, scabrous with recurved hairs; lfts. angular, 2 to 3-lobed or entire; ped. longer than the leaf, few-flowered, lower tooth of the calyx longer than the tube; leg. pubescent, broadly-linear, cylindric.-(2) A creeping or climbing plant, 3 to $5 \mathrm{f}$ long, on sandy shores and prairies, Can. and U. S. Lfts. 1 to $2^{\prime}$ long, $\frac{3}{4}$ as wide, with scattered hairs beneath, often variously and very obtusely lobed. Ped. 2 to 8 -flowered, 3 to $6^{\prime}$ long. Cor. purplish. Leg. becomes black when ripe, 5 to 7 -seeded. Aug.-Oct. 
3 P. I_éivolus L. St. slender, twining; lfts. between oblong-ovate and lance-ovate, not lobed; ped. slender, several times longer than the lvs., few-flowered; leg. straight, cylindric, 8 to 10 -seeded.-2 Sandy fields, N. Y. to Fla. and La. St. 3 to 5 f long. Lfts. 1 to $2^{\prime}$ by $\frac{1}{4}$ to $1^{\prime}$. Ped. 4 to $8^{\prime}$ long, 4 to 7 -flowered. Cal. with 2 bracts at base. Cor. purplish, vexillum large, roundish. Leg. 2 to $3^{\prime}$ long, very narrow, subfalcate. Aug., Sept. (Strophostylis peduncularis Ell.)

4 P. pauciflòrus Benth. St. slender, retrorsely hirsute; lfts. linear-oblong, not lobed, as long as the petiole, hirsuto and reticulated on both surfaces; stip. subulate; ped. much longer than the lvs.; hds. few-flowered; leg. hirsute, 5 to 8-seeded. - Prairies, Ill. (Mead). Also Ark. and La. St. 2 to 4 f long, prostrate. Lfts. 1 to $2^{\prime}$ by 3 to $5^{\prime \prime}$. Pods 1 to $1_{2}^{\prime \prime}$ long, straight and slender. Jl., Aug. (P. leiospermus T. \& G.)

5 P. valgàris L. St. twining; lits. ovate-acuminate; rac. solitary, shorter than the lvs.; pedicels in pairs ; cal. as short as its two bracts at base; leg. pendulous, long-mucronate; seed reniform, variously, often brightly colored. - (1) Native of IS. Indies. Universally cultivated in gardens, not only for the maturo fruit but for the young pods which constitute that favorite dish, string beans. St. 3 to 8 f long, twining against the sun. Fls. mostly white. Jl.

6 P. multiflòrus $\mathrm{L}$. Scarlet Pole Beax. St. twining; lfts. ovato-acute; rac. solitary, as long as the lvs.; pedicels opposite; cal. longer than the 2 appressed bracts at base; leg. pendulous; seeds reniform.-(1) Native of S. America. St. 6 to $10 \mathrm{flong}$, twining against the sun. Fls. scarlet, numerous, and very brilliant. Fr. not so generally admired as the last. Jl.

7 P. Iunàtus I. Lima Bean. St. twining; lits. ovate, deltoid, acute; rac. shorter than the lvs.; ped. in pairs; cal. longer than its 2 bracts at base; leg. scimetar-shaped, or somewhat lunate; sds. large, much compressed, purplishwhite.-Native of E. Indies. St. 6 to $8 \mathrm{f}$ long. Fls. small, whitish. Much valued and cultivated. Sl.

8 P. nànus L. BusH BEAN. St. smooth, very branching, erect; lfts. broadovate, acute; cal. shorter than its 2 bracts at base; leg. pendulous, compressed, rugous.-(1) Native of India. St. If high. Fls. whitc. Seeds white, small, but there are many varieties. Much cultivated. Jn.

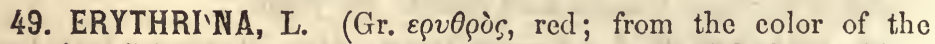
flower.) Calyx campanulate, tubular, truncate or lobed; vexillum long, lanceolate, with no callosities; wings and keel much smaller; stamens straight, nearly as long as the vexillum; style glabrous; legुume torulous.-Trees, shrubs, or herbs, often prickly. Lvs. pinnately trifoliate. Fls. racemed.

1 E. herbàcea L. Glabrous; lfts. rhombic-liastate, with 3 rounded, shallow lobes, petioles, with here and there a small hooked prickle; rac. terminal; cal. truncate; leg. dehiscent.-In rich soils, S. Car. to Fla. and La. A plant of splendid hues, arising from a thick subterranean rhizome, 3 to $4 \mathrm{f} \mathrm{high.} \mathrm{Sts.} \mathrm{simple,}$ purplo. Lfts. 2 to $3^{\prime}$ long, $\frac{2}{3}$ ss wide, the petiole twice as long. Fls. numerous, slender, the banner $2^{\prime}$ long, deep scarlet, the keel and wings very small. Sds. scarlet, the size of a small bean. Apr., Jn.

2 E. Crista-gálli L. Cocks-comB. St. arboreous, unarmed; lfts. ovato or clliptical, coriaceous, the petiole and midvein armed with strong, hooked prickles; cal. short, campanulate, vex. strongly curved.-A handsome flowering slirub or tree, planted at the South. Rac. of many large scarlet flowers, terminal on the branches. Apr., Jn. From Brazil.

50. AMPHICARPE'A, Ell. PeA Vine. (Gr. ä $\mu \phi \iota$, Lat. ambo,

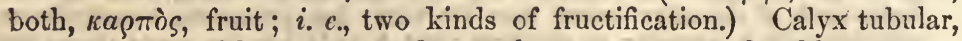
campanulate, with 4 or 5 nearly equal segments; petals oblong; vexillum with the sides appressed; stigma capitate; ovary on a sheathed stipe ; legume flat, 2 to 4 -seeded.-(1) Slender, twining. Lrs. pinnately 
trifoliate. The upper fls. complete, but usually barren, the lower apetalous and fruitful.

1 A. monoìca Nutt. St. retrorsely pubescent; lfts. ovate, thin; cauline rac. simple, pendulous; cal. segm. very short, triángular-acuminate; bracts minute.A very slender vine in woods and thickets, Can. and U. S. St. twining, rough backwards, 4 to $8 \mathrm{f}$ in length. Lifs. very thin, 1 to $3^{\prime}$ long, $\frac{3}{4}$ as wide, lateral ones oblique at base. Rac. axillary, few-flowered. Fls. pale purple. Caulino leg. smoothish, with 3 to 4 dark purple seeds. Radical leg. often subterraneous, with one large, compressed, brown seed. Jl., Sept.

2 A. Pítcheri Torr \& Gr. St. villous, with ferruginous, spreading hairs; lfts. rhombic-ovate; rac. erect, often branched; cal. segm. lance-subulate, a third of the length of the tube: bracts broad, conspicuous.-Alluvion about N. Orleans and W. La. (Hale). Lifts. rather thick, 2 to $3^{\prime}$ by $1 \frac{1}{2}$ to $2^{\prime}$, hirsute both sides. Fls. a little smaller ( $6^{\prime \prime}$ long); fr. a little larger (16 to $18^{\prime \prime}$ long) than in No. 1. Sds. 3 , compressed, purplishi-black.

51. GALAC'TIA, L. (Gr. yáða, milk; some species have a milky juice.) Calyx bibracteolate, 4-cleft, the segments of nearly equal length, upper one broadest, entire; pet. oblong; vexillum broadest and incumbent; keel petals slightly cohering at top; legume many-seeded. - Herbs prostrate or twining, sometimes shrubby. Lvs. pinnately compound. Rac. axillary. Fls. cyanic.

$\$$ Leares pinnate, 7 to 9 -foliate. Stems prostrate, twining........................

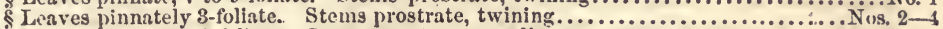

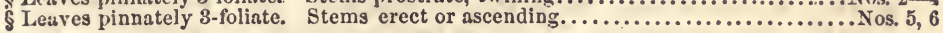

1 G. Ellióttii Nutt. Lfts. 7 to 9, coriaceous, elliptic-oblong, obtuse at each end; ped. longer than the lvs., few-flowered at the top; upper sep. (double) broad, ovate, subulate-mucronate.-Ga. (Feay and Pond). Sts. running or climbing many feet. Ifts. $I^{\prime}$ or more long, minutely pubescent beneath. Pods villous, $2^{\prime}$ long, 4 to 6-seeded. Corolla white or rose color, $7^{\prime \prime}$ long. May-Jl.

2 G. glabélla Mx. St. nearly glabrous; lfts. 3, elliptic-oblong, emarginate at cach end, sub-coriaceous, shining above, a little hairy beneath; rac. pedunculate, about the length of the lvs., fls. pedicellate.-In arid soils, N. J. to Fla. Sts. 2 to $4 \mathrm{f}$ long. Lfts. 10 to $20^{\prime \prime}$ by 5 to $10^{\prime \prime}$, varying in form from elliptic through oblong to orate. Fls. rather large ( 7 to $8^{\prime \prime}$ long), reddish-purple, greenish externally. Pods $1 \frac{1}{2}^{\prime}$ long (immature), erect, falcate. Aug.-Sept.

3 G. móllis Mx. St. softly pubescent; lfts. oval, obtuse, nearly smooth above, softly villous and whitish beneath; rac. longer than the lvs., pedunculate, fasciculate; fls. on very short pedicels; leg. villous.-Dry soils, Md. to Ga. St. several feet long. Ifts. about $\mathbf{I}^{\prime}$ long, $8^{\prime \prime}$ wide. Fls. about half as large as in the last. Aug.-Sept.

4 G. pilòsa Nutt. St. retrorsely hirsute; lfts. 3, oval-oblong, retuse at apex, finely hirsute on both surfaces, paler beneath; rac. twice or thrice longer than the lvs., with scattered, distant fls.-N. Car. to Fla. and La. Sts. several feet in length. Lfts. 1 to $2^{\prime}$ long, half as wide, petioles 1 to $1^{\prime}{ }^{\prime}$ long. Fls. a fourth smaller than in No. 2, pale roseate, pedicellate. Pods villous. Jn.-Sept.

5 G. brachýpoda Torr. \& Gr. St. flexuous, somewhat erect; lfts. 3, oblong or linear-oblong, odd one petiolulate, petioles longer than the lfts. or the few-flowered, stalked rac.-Pine barrens, W. Fla. Sts. leaning, 2 or more f high. Ifts. 12 to $18^{\prime \prime}$ by 4 to $6^{\prime \prime}$. Fls. purplish, about balf as large as in No. 2.

6 G. sessiliflòra Torr. \& Gr. St. flexuous, erect; lfts. oblong-linear or linear, odd one subsessile; petioles longer than the lifs.; rac. very short, sessile.-Ala. and W. Fla. Sts. two or more together, 1 to $2 \mathrm{f}$ bigh. Ifts. 12 to $20^{\prime \prime}$ by 3 to $7^{\prime \prime}$, obtuse or emarginate. Fascicles 3 to 6 -flowered. Fls. purple. Pods erect, 6 to 8-seeded.

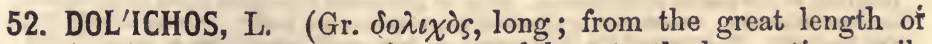
these vines.) Calyx 4-lobed, the upper lobe 2 -toothed or entire, vexil- 
Jum, with 2 or 4 eallosities near the base of the limb; stigma terminal, legume compressed, with few oval, compressed seeds.-Twining herbs with pinnately trifoliate lvs.

D. multiflòrus Torr. \& Gr. Lfts. large, round-ovate, with a short acumination; rac. about as long as the petioles, dense, many-flowered; upper segm. of the cal. entire, lower longest, lanceolate; leg. broad, 3 to 5 -seeded.-River banks, Ga. to La. and Ark. Sts. very long, retrorsely pubescent. Lfts. 2 to $4^{\prime}$ diam., smooth when old. Pods $2^{\prime}$ long, $8^{\prime \prime}$ wide, with an abrupt, incurved beak. Sds. brown, much flattened. Jn., Jl.

B. HALEI. St. minutely pubescent; lvs. glabrous; petioles 3 times longer than the few (5 to 8)-flowered rac.-Near N. Orleans (Hale.)

D. sesquipedàlis W. a vine with very long pods, native of the W. Indies, and D. Cat-iang W., with two erect pods at top of the peduncle, native of $\mathrm{E}$. Indies, are occasionally seen in cultivation at the South (Feay).

53. CLITORIA, L. Calyx bibractcolate, tubular, 5-toothed, segments acuminate; vexillum large, spreading, roundish, emarginate, not spurred; keel smaller than the wings, acute, on long claws; legume linear oblong, torulous, several-seeded.-24 Mostly twining. Lvs. pinnately 3 to 5 -foliate. Fls. very large, solitary or several together.

C. Mariàna L. Glabrous; st. suberect or twining, suffruticous; lfts. 3, oblong. ovate or lanceolate, obtuse, lateral ones petiolulate; ped. short, 1 to 3 -flowered; bracteoles and bracts very short; leg. torulous, 3 to 4-seeded.-Dry soils, N. J. to Fla. St. 1 to $3 \mathrm{f}$ long, round, slender, branched. Lfts. rather remote, about $1^{\prime}$ by $6^{\prime \prime}$. Cor. pale purple, 2 to $2 \frac{1^{\prime}}{2}$ in length, calyx ${ }^{\frac{p^{\prime}}{2}}$, bracteoles $2^{\prime \prime}$. Jl., Aug.

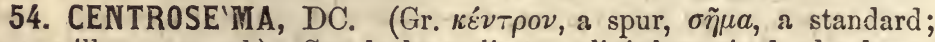
the vexillum spurred.) Sepals lance-linear, slightly united, the lower longest, and with 2 broad bracteoles; vex. very large, with a short spur on the back near the base; keel and stamens much shorter, incurved; legume long, linear, marginèd and long pointed.-4 Twining. Lvs. pinnately 3 -foliate. Fls. very large. Bracts, bractlets, and calyx striated.

C. Virginiàna Benth. St. very slender; lits. oblong-ovate to oblong-linear, firm, very veiny, the veins incurved; ped. 1 to 4 -flowered bracteoles larger (not longer) than the eal.; pod. veined along the margin.-Dry soils, S. States. Whole plant of firm texture, glabrous and very slender, several feet in length. Banner orbicular, $11^{3}$ ' broad, violet blue. Pod 4 to $6^{\prime}$ long, 2 to $3^{\prime \prime}$ wide. Jl., Aug.

\section{Order XlVII. ROSACEAE. Roseworts.}

Herbs, shrubs or trees with alternate, stipulato lvs. and regular flowers. Sepals 5, rarely fewer, united, often reënforced by as many bractlets. Petals 5 , rarely 0 , distinct, inșerted on the disk which lines the calyx tube. Stamens $\infty$, rarely few, distinct, inserted with the petals (perigynous). Ovaries 1,2, 5 or $\infty$, distinct, or often cuherent with each other, or immersed in an excavated receptacle (\$ 444). Fruit a drupe, or achenia, or a dry or juicy etærio (\$565), or pome. Seeds 1 or few in each carpel, anatropous, exalbuminous; embryo straight. (Illustr. in figs. 33, 41, $65,66,79,91,100,106,179,166,167,159,293,307,355,289,380,381,414,439$, $440,441,443,452,461,462$.)

This order, as here constituted, includes five suborders, and together 87 genera and 1000 species. A large proportion of these are natives of temperate climates north of the equator.

Properties. - A highly important order, whether we regard its delicions fruit, its medtcinal products, or the beanty of its tiowers. None of its species (excepting those of the almond tribe) are unwholesome. An astringent principle characterizes the family, residing chiefly in the bark and the roots. The roots of the blackberry have been used in medicine as an astringent; those of the Gillenia, as an emetic; Agrimonia, as a vermifuge. The petals of Rosa damascena yield the well known fragrant oil called attar of rose. The almond, peach, \&c., abound in prussic acid, 
a deadly poison, residing chiefly in tho kernels.-Of the Rosacex, as ornamental flowering shrube, it is scarcely necessary to speak, neither of its many delicious fruits, as the Apple, Pear, Quince, Apricot, Peach, Plum, Cherry, Strawberry, Blackberry and Raspberry.

\section{SUBORDERS, TRIBES AND GENERA.}

\$ Süorder I. SANGUISORBE.A. Carpels 1 (rarely 2-4). Petals 0. Ilerbs. (a)

a Stamens 1 to 4 , style lateral. Flowers scattered.................. A LCImMLLA

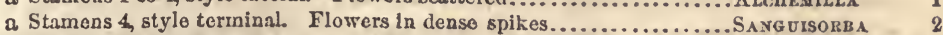

a Stamens $\infty$, stylo terminal, stigma fringed. Fls. spicate............ Porvery 8

\$ Suвorder II. CHRYSOBALANEA. Carpel 1, style lateral. Petals 5.

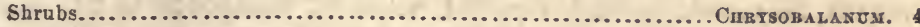

§ Suborder III. AMYGDALEE. Carpel 1, style terminal. Pet. 5. Trees, \&c. (b)

b Stone smooth, globular. Fruit smooth but not glaucous............. Crassus.

b Stone smooth, flattened. Frult glancous with bloom, or downy....... Prexus

b Stono roughened with pits and furrows. - Fruit pulpy ............... Persicd.

$$
\text { -Fruit dry.................... AMYGDALrs }
$$

5 Subordra IV. POME 2 . Carpels 2 to 5 , consolidated with the ealyx. Fr. a pomo. (c)

c Ovary half-superior, 2-carpeled. Leaves very thick, lueid............. Pиотімı.

c Ovary inferior,-Petals bearded. Radicle retracted................Eryonotra

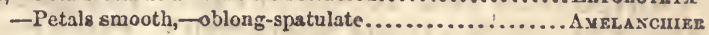

-roundish.-Carpels 1-seeded.......... Crat.EGUs

- Carpels 2-seeded...........Prets

-Carpels co-sceded........ C'rdonzd

\$ StBoRder 7. ROSEE. Carpels 2 to 50 , frec, in an open or elosed calys. (*)

* Tribe 1. Rosides. Carp. 1-seeded aclienia inclosed in the calyx tube. (d)

* Tribe 2. Fragaridex. Carp. 1-seeded. Achenia dry or pulpy in an open calyx. (e)

* Tribe 8. Spiribex. Carpels several-secded follicles in an open calyx. (f)

d Carpels many, in the fleshy calyx. Fls. often double.............. Ros .

d Carpels 2 only, in the dry, fluted, echinate calyx................. Agrisonia.

e Styles persistent on the dry achenia. Petals 8 or $9 . \ldots \ldots \ldots \ldots \ldots \ldots . . \ldots$ Drras. $\quad 17$

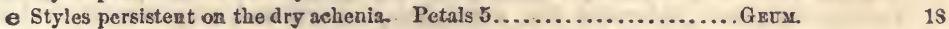

e Styles deciduous, -Calyx bractless. Fr. a heap of pulpy achenla....... Runus. 19

-Calyx bractless. Ach dryish. Sepals unequal..... Daminarda. 20

-Calyx bractless or minutely bracteoled. Sep. equal.. WALdsrernia, 21

-Calyx bracteolate, - Receptacle pulpy, globular, red.Fua ra

-Recept. spongy,glob.Fis. purple.Coxaru.r. 28

-Receptaclo dry.-Stamens $\infty$.. Potrutrila. 24

-Stamens 5... Sibrazdi. 25

Follicles 2 to 10 -seeded, Petals obovate, cyanic................. SPIr.sa. 26

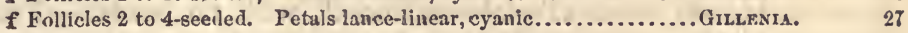

f Follicles 1-seeded. Petals multiplied, orange-yellow.............Ktrkm. 29

1. ALCHEmil'LA, L. Ladies' Mantle. (The plant is called in Arabic âlkêmelyek.) Calyx 4-toothed, with 4 external bracteoles; pctals 0 ; stamens 1 to 4 , carpels ( 1 to 4 ) mostly solitary, with the style lateral, stigma capitate; seed suspended.-Herbs with palmate-lobed or incised lvs. and small green fls.

1 A. arvénsis Scop. PARsLet PIERT. Lrs. incisely 3-lobed or parted, the segments 2 or 3 -cleft, pubescent, cuneate at base; fls. axillary, clustered.-(1) Wasto grounds, E. Va. A worthless weed, so small as to be easily overlooked.

2 A. alpìnus L. Lvs. radical, silky beneath, digitately 5 to 7-foliate, segm. oblanceolate, cuneiform at base, incisely serrate at apex; fls. corymbous. - "On tho peaks of high mts., Vt. and N. H." (Pursh). But the plant has never been rediscovered there. It is an elegant plant, sometimes cultivated. Common in Eur.

2. SANGUISOR'BA, L. Burnet. SAxifrage. (Lat. sanguis, sorbere, to absorb blood; the plant is esteemed a vulnerary.) Calyx tube 4-sided, 2 or 3-bracted at base; limb 4-parted; petals 0 ; stamens 4, opposite the calyx segments; filaments dilated upward; style 1, filiform; achenium dry, included in the calyx.-Herbs with uncqually pinnate ivs. Fls. in dense spikes. 
S. Canadénsis I. Glabrous; lfts. oblong, cordate, obtuse, serrate; spikes cylin. dric, very long; stam. much longer than the cal.-2f In węt meadows, Brit. Am. to Ga. along the mts., and cultivated in gardens. St. 2 to $3 \mathrm{f} \mathrm{high,} \mathrm{smooth,} \mathrm{striate,}$ sparingly branched. Stip. leafy, serrate. Lfts. 2 to $4^{\prime}$ long, $\frac{1}{3}$ to $\frac{1}{2}$ as wide, petiolate, mostly stipellate. Spikes 3 to $6^{\prime}$ long, terminating tho long, naked branches. Bracteoles 3 . Calyx greenish-white, resembling a corolla. Aug.

3. POTE'RIUM, L. Bunnet. (Literally [in Lat.] a drinking vessel, and hence a beveragc.) Flowers 8 . Calyx tube contracted at the mouth, 3-bracteolate, limb 4-parted, petals 0 ; stamens 20 to 30 ; ovaries 2 ; stigrna penicillate; achenia dry, included in the calyx. Herbs with unequally pinnate lis. Fls. spicate.

- P. Sanguisórba I. Herbaceous; st. unarmed, angular, and with the lvs., smooth; Ifts. 7 to 11, ovate or roundish, deeply serrate; spikes or heads subglobous, tho lower fls. staminate. -24 Occasionally cultivated as a salad, but is now less valued in medicine than formerly. It is said by Hooker to be native about Lake Huron.

4. ChRYSOBAla'NUS, L. Cocoa Plum. (Gr. xpvoòs, gold, $\beta a ́ \lambda a$ vos, acorn; in reference to the yellow fruit.) Calyx 5-cleft; petals 5 ; stamens about 20 , in a single series, ovary solitary, sessile, the style arising from the base; ovules 2, collateral ; drupe 1-seeded, with thin pulp. -Shrubs unarmed, with entire, veiny lvs., minute stipnles, and terminal panicles.

C. oblongifòlius Mfx. Lvs. oblong, varying to oblanceolate, subsessile, pedicels and calyx tomentous-hoary; filaments and ovary glabrous; petals sessile; nuclous of the fruit not grooved.-Pine barrens, Ga., Ala. and Fla. A shrub with a slender, prostrate stem or woody rhizome, sending up short branches (8 to $\left.12^{\prime}\right)$, with smooth, coriaceous, subentire lvs., very glossy above, and very strongly veined, acute or obtuse. Fls quito small, whito. Fruit oblong, as largo as a plum. May, Jn.

5. CER'ASUS, Juss. Cherry. (Prunus L.) (Name from Cerasus, a town in Pontus, whence originated the garden cherry.) Calyx 5cleft, regular, deciduous; petals much spreading; stamens 15-20; ovary 2-ovuled; drupe globous, succulent, very smooth, destitute of a glaucous bloom; stone subglobous, smooth, with no border.-Trees or shrisbs. Lvs. conduplicate (folded) in vernation.

$\$$ Lenves cvergreen. Racemes nxillary, bractless.......................... No. 1

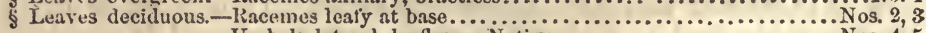

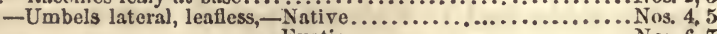

1 C. Caroliniàna Mx. Cherry Laurez. Lvs. oblong-oblanceolate, acuminate, on short petioles, entire, coriaceous; fls. small, in numerous, dense racemes shorter than the lvs.; drupes persistent.-Along rivers, S. Car. to Fla. and La., and much eultivated. A small, beautiful evergreen tree, 30 to 50f high. Lrs. about $2 \frac{1^{\prime}}{2}$ by $1^{\prime}$, glabrous, shining abovo. Drupes black, juiceless, $4^{\prime \prime}$ long. They are considered poisonous as well as tho leaves. In gardens this tree is trimmed into the semblance of walls, domes, arbors, and all manner of fantastic forms.

2 C. serotìna DC. BLACK or WILD CherRy. Lrs. firm, oval-oblong or elliptic, acuminate, smooth, shining above, unequally glandular-serrate; petioles with 2 to 4 glands; rac. spreading, elongated. $-A$ large forest tree throughout the U. S. Trunk 50 to $80 f$ high, of uniform size and undivided to tho height of 20 to $30 \mathrm{f}, 2$ to $4 \mathrm{f}$ diam. Bark black and rough. Lvs. 3 to $5^{\prime}$ long, $\frac{1}{2}$ as wide. In Mray and June it puts forth numerous cylindric clusters of white fls. Fruit nearly black when mature, bitterish, yet pleasant to the taste, and is greedily devoured by birds. The wood, extensively used in cabinet work, is compact, fine-grained, and receives a high polish. The bark is tonic, with a strong, bitter taste.

3 C. Virginiàna DC. CHoKe CHerRY. Lvs. smooth, oval or obovate, shortpointed, thin, not shining, with sharp, subulate serratures, veins bearded on each 
side toward the baso; petiole with 2 glands; rac. lax, short, spreadiug; petals orbicular.-A small tree or shrub, 5 to $20 \mathrm{f} \mathrm{high,} \mathrm{in} \mathrm{woods} \mathrm{and} \mathrm{liedges.} \mathrm{Bark}$ grayish. Lvs. 2 to $3^{\prime}$ long, 1 to $2^{\prime}$ wide, with a short, abrupt acumination. Fls. appearing in May. Fruit (cherries) abundant, of a dark-red color, very astringent to the taste, yet on the whole agreeable.

4 C. púmila Mx. SAND CherRy. Lvs. oblanceolate or obovate, acute, subserrate, smooth, paler beneath; umbels few-flowered, sessile, drupe ovoid. A small trailing shrub, in gravelly soils. Can. and U.S. Branches ascending, 1 to $2 \mathrm{f}$. high. Lvs. 2 to $3^{\prime}$ long, $\frac{1}{4}$ as wide, very acuto at each end. Fls. white, 3,4 or 5 in each umbel, the pedicels smooth, $l^{\prime}$ in length. Fruit small, dark red, acid but agreeable to the taste. May. (Prunus depressa Ph.)

5 C. Pennsylvánica Ait. Wrud Red Cherry. Lvs. oblong-ovate, acuminate, finely serrate, membranous, smooth; umbels corymbous, with elongated pedicels; drupe small, ovoid-subglobous. - A small tree, common in woods and thickets in the Northern States. The trunk rarely exceeds $25 \mathrm{f}$ in height, with a diam. of 6 to $8^{\prime}$. Bark smooth, reddish brown. Lvs. 2 to 5 ' long, $\frac{1}{2}$ as wide, the fine teeth mostly glandular, apex tapering to a long acumination. Fls white, on long $\left(2 \frac{1}{2}^{\prime}\right)$ slender pedicels collected into a sort of umbel. Fruit red, very acid-This tree is of rapid growth, and quickly succeeds a forest clearing, if neglected. May. (Prunus borealis Ph.)

6 C. A'vium Mcench. Duke, Cherry. Ox-heart. Exglisi Cherry. BIGAREAU, \&c. Branches erect or ascending; lvs. oblong-obovate, acuminate, hairy beneath; umbels sessile, with rather long pedicels; drupe ovoid globous, subcordate at base.-Cultivated in gardens, fields, \&c., common. Trunk 20 to $50 \mathrm{f}$ in leight, with an oblong or pyramidal liead. Lvs. 3 to $6^{\prime}$ long, $\frac{1}{2}$ as wide, on petioles 1 to $2^{\prime}$ long, often with 2 glands. Fls. expanding with the leaves, white. Drupes various shades of red, firm but juicy. May.-About 75 varieties are published in American catalogues. $\ddagger$

7 C. vulgàris Mill. Sour Cherry. Large Red. Morello, \&c. Branches spreading; lvs. ovate-lanceolate, acute at apex, narrowed at base, nearly smooth; umbels subsessile, with short pedicels; drupes globous. - A smaller tree than the preceding, much cultivated. Trunk is to $20 \mathrm{f}$ high, with a roundish, compact head. Branches slender. Lvs. 2 to $3^{\prime}$ long, $\frac{2}{3}$ as wide, unequally serrate, on petioles $\frac{1}{4}$ as long, with 2 glands. Fls. white, expanding sooner than the leaves, 2 or 3 from each bud, on pedicels $\frac{2}{3}$ long. Fr. large, various shades of red, acid or subacid. Apr.-Moro than 50 varieties are enumerated. $\ddagger$ (Prunus Cerasus L.)

6. PRU'NUS, Tourn. Plum, Apricot. Calyx 5-cleft, regular, deciduous; petals much spreading; stamens 15 to 30 ; ovary 2-ovuled; drupe ovate, fleshy, gencrally clothed with a glaucous bloom or with a soft pubescence; nucleus compressed, smooth.--Small trees or shrubs. Lis. convolute in vernation. Fls. white, in simple umbels from lateral buds, mostly preceding the lvs.

\$ Drupe downy; stone furrowed nt edges. Lvs, acuminate....................Nos. \&, 9 $\$$ Drupe glabruus-umbels 1 or 2 -flowered. Lvs. ncute............................... $5-7$

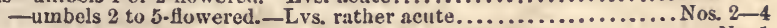
-Lvs, acuminate.............................. 1

1 P. Americàna Marsh. Red Plưs. Yellow Plus. Somewhat thorny ; lvs. oblong-oval and obovate, abruptly and strongly acuminate, doubly serrate; drupes roundish oval, reddish orange, with a thick, coriaceous skin - Hedges and low woods, U. S. and Can., often cultivated for its sweet and pleasant fruit, which is about the size of the Damson. Shrub 10 to $15 \mathrm{f} \mathrm{high.} \mathrm{Lvs.} 2$ to 3 ' long, $\frac{2}{3}$ as wide, petioles $\frac{1}{4}$ to $\frac{1}{2}$ long, mostly with 2 glands at the summit. Fls. preceding the lvs., 3 to 4 in each of the numerous umbels, white. Drupes nearly destitute of bloom, ripe in Aug. Flowers in May. $¥$ (Cerasus nigra Loisel.)

2 P. marítima Wang. BEACH PLUM. Lvs. oval or obovate, slightly acuminate, sharply serrate; petioles with 2 glands; umbels few-flowered; pedicels short, pubescent; fr. nearly round. - A small shrub abundant on the sea-beach, particularly on Plum Island, at the mouth of Merrimac River. Very branching. Lvs 1 to 3 ' long, downy-canescent beneath when young, becoming at length nearly 
smooth. Fls. white, 2 to 5 in each of the numerous umbels. Fr. globular, eatable, red or purple, little inferior in size to the common garden plum. Ripe in Aug., Sept. Fl. in May. (P. littoralis Bw.)

3 P. umbellàta Ell. Lvs. lanceolate or lance-oval, acute or barely scuminate, obscurely serrulate; petioles glandless; umbels 3 to 5-flowered; fr. oval, small, glaucous, red.-Dry soils, in copses, etc., Savannah (Feay, Pond) to Bainbridge, Ga. and Fla. A small, bushy tree, scarcely thorny. The flowers bloom and decay before the lvs. appear. Lvs. small (about $18^{\prime \prime}$ by $9^{\prime \prime}$ ), downy all over or often glabrous, with 1 or 2 glands, if any, on the margin near the base. Drupes pleasantly acid and much used, ripe in Jl. and Aug. Fl. in Mar.

4 P. Chícasa Mx. Chickasaw Plum. Branches spinous; Ivs. oblong-lanceolato or oblanceolate, glandular serrulate, with the glands pellucid, not at all acuminate, nearly smooth; umbels 2 to 3-flowered, pedicels short, smooth; drupo globous.-A fine fruit shrub, nativo of Ark., \&c., often cultivated. Height 8 to 12f, with a bushy head. Lvs. 1 to 2 ', petioles about $\frac{1}{2}$, long. Fls. small, white, expanding with the lvs., in Apr. Fr. red or yellowish-red, tender and succulent, ripe in J!. There are several varieties. $\ddagger$ (Cerasus, DC.)

5 P. spinòsa I. BuACK ThorN. Sloz. Branches thorny; fls. solitary; cal. campanulate, lobes obtuse, longer than the tube; lvs. pubescent beneath, obovateelliptical, varying to ovate, sharply and doubly dentate; drupe globous.-Hedgo rows and cultivated grounds, Penn. (Pursh.). A thorny shrub 12 to $15 \mathrm{f} \mathrm{high,}$ native of Europe. §-Some botanists regard the next two numbers as varieties of this, altered by cultivation.

6 P. insitítia L. WILd BuLlaAce. PLUM. Lrs. ovate-lanceolate or oblanceolate, tapering to the petiole, acute, serrate, pubescent-villous beneath; branches somewhat spiny ; fls. generally in pairs; cal. segm. entire, obtuse; pet. obovate; fr. globular. - Treo 15 to $20 \mathrm{f}$ high, sparingly naturalized. Lrs. 1 to $1 \frac{1^{\prime}}{2}$ long, with short petioles. Petals white. Fr. black, covered with a yellowish bloom. §.

7 P. doméstica L. Common Garden Plum. Damson Plum. Brunches unarmed; lvs. oval or ovate-lanceolate, acuto; pedicels nearly solitary; drupo globous, oval, ovoid and obovoid. - This long cultivated tree or shrub is said to be a native of Italy. It rarely exceeds $15 \mathrm{f}$ in height. Lvs. quite variable in form, 1 to $3^{\prime}$ long, $\frac{2}{3}$ as wide, sometimes obtuse, on petioles about $I^{\prime}$ in length. Fls. white, generally but ono from a bud, expanding whilo the lvs. aro but half grown, in Apr. and May. Fr. black, varying through many colors to white, covered with a rich glaucous bloom, ripe in Aug. Alout 150 varieties aro published in the catalogues of American gardeners. $\neq$.

8 P. Armeniàca Willd. Apricot. Lrs. broadly ovate, acuminate, subcordate at base, denticulate; stip. palmate; fls. sessile, subsolitary, preceding tho lvs.; drupo somowhat eompressed, subglobous, large.-Occasionally cultivated in gardens, \&c. Treo 10-15f high. Lvs. 2 to $3^{\prime}$ long, $\frac{8}{4}$ as wide, smooth, petioles nearly 2 ' long, with several glands. Fls. white. Apr. Fr. purplish-yellow, \&c., 1 to 2 ' diam.; ripe Jl. Aug. There are about 20 varieties. $f$

9 P. dasycárpa Ehrh. BцAсK APRicot. Lrs. ovate, acuminate, doubly serrate; petioles with I or 2 glands; fls. pedicellate; drupo subglobous.-This species is from Siberia.-The tree or shrub is about the size of the last, hardy and thrifty. Lrs. smooth above, pubescent on the veins beneath, 2 to $3^{\prime}$ long, $\frac{2}{3}$ as wide, on petioles near $\mathrm{I}^{\prime}$ long. Fls. white, nreceding the lvs., distinctly pedicellate. Fr. dark purple when mature, in July. Fls. Apr. $\ddagger$ Neither species is yet common.

7. PER'SiCA, Tourn. Peach. Nectarine. (Named from Persia, its native country.) Calyx 5-cleft, tubular-campanulate, deciduous; petals 5 ; drupe fleshy, tomenious or smooth; nucleus somewhat compressed, ovate, acute, rugosely furrowed and perforated on the surface. -Small trees. Lis. conduplicate in vernation.

P. vulgàris Mill. PEACr. Lvs. lanceolate, serrate, with all tho serratures acute; fls. solitary, subsessile, preceding the Ivs.; drupe tomentous.-Tree or shrub, 8 to $15 \mathrm{f} \mathrm{high.} \mathrm{Lvs.} 3$ to $5^{\prime}$ long, $\frac{1}{3}$ as wide, smooth, petioles short, with 
1 or 2 glands. Fls. rose-color, with the odor of prussic acid. Fr. large, 1 to $2 \frac{1}{2}$ diam., yellowish, tinged with purple, densely tomentous.-About 200 varieties of this delicious fruit are named and described in the catalogues of American nurserymen. The double-flowered peach is a highly ornamental variety, blossoming in Apr. and May, but fruitless.

B. Levis. Nectarine. Drupe glabrous.-Closely resembles tho peach in form, foliage, and fls. 'The fr. is 1 to $3^{\prime}$ diam., smooth, yellow, purple, red, \&c. Of its numerous (about 25) subvarieties about a fourth aro cling-stonesflesh adhering to the stone, and the remainder free-stones or clear-stonesflesh free or separating from the stone. $f$

8. AMYG'DALUS, Willd. Alurond. Calyx 5-cleft, campanulate, deciduous ; petals 5 : drupes not fleshy, compressed : nucleus perforate and furrowed, ovate, compressed, one edge acute, the other broad, obtuse.-Trees or shrubs. Lvs. conduplicate in vernation.

1 A. commùnis Willd. Lvs. lanceolate, serrate, with tho lower serratures. glandular; fls sessile, in pairs, appearing before the lvs.-From Barbary. Scarcely cultivated in this country for the fruit, which wo receive mostly from S. Europe. A double-flowered variety is highly ornamental in shrubberies. $f$

2 A. nàna Ait. DWARF SINGLE-FLOWERING ALMOND. Lvs. ovate, attenuato at base, simply and finely serrate; fls. subsessile, appearing before tho lvs.-A very ornamental shrub from Russia. Height about 3 , branching. Lvs. 3 to $6^{\circ}$ long, $\frac{1}{4}$ as wide, smooth, acuminate at each end. Fls. numerous. Petals oblong, obtuse, roseate, often double. May, Jn. $\dagger$

3 A. púmila Ait. DWARf DOUBLE-FLOWERING ALMOND. Lvs. lanceolate, doubly serrate; fls. pedicellate. - Native of China. A low shrub, highly ornamental, common in cultivation. Sts. 2 to $3 \mathrm{f}$ high, branching. Lvs. 3 to $5^{\prime}$ by $\frac{1}{3}$ to $1^{\prime}$, acute at each end, smooth. Fls. very numerous, clothing the whole shrub in their roseato hue, while the lvs. are yet small. May, $\mathrm{Jn}_{\mathrm{n}}+$

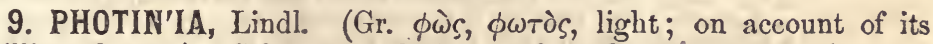
brilliant leaves.) Calyx 5-toothed; petals reflexed; ovary villous, 2 carpeled, half-superior styles glabrous; fruit included in the fleshy calyx; testa cartilaginous.-Elegant shrubs or trees, with coriaceous, persistent lrs. Panicles terminal.

I P. arbutifòlia Lindl. Lvs. oblong-lanceolate, acute, distinctly serrate; pedicels shorter than the cal. - California. Height 10 to 20f. Lvs. dark, shining green, very rigid, revolute at edge. Fls. small, numerous, white.

2 P. serrulâta Lindl. Lvs. oblong, acute, serrulate; pedicels longer than calyx.-China. Lrs. very smooth and shining. Fls. small, white. Both are hardy at the South.

10. ERIOBO'TRYA, Lindl. Loquat. (Gr. "̈pıov, wool, ßótprs, a cluster of grapes; alluding to its villous flowers.) Calyx woolly, of 5 obtuse teeth; petals bearded; stamens erect, as long as the sepals ; styles 5 , filiform, included, hairy; pome 3 to 5 -celled, closed; chalaza none; radicle retracted within the cotyledons.-Shrubs or trees, with persistent lvs.

E. Japónica Linłl. Lvs. lanceclate, wavy, and serrate; fls. in terminal, woolly racemes, with very short pedicels; fr. oval or roundish.-Cultivated and hardy at the South. Fls. small ( $3^{\prime \prime}$ diam.), white. Fr. about the size of the gooseeerry, bright yellow, and agreeable in taste, ripe early. $\nmid$ Japan.

11. AMElan'ChIER, Medic. Shad-Flower. Wild Service. (Fr. Amelancier, the popular name of A.vulgaris.) Calyx 5-cleft, petals 5 , oblong-obovate or oblanceolate; stamens short; styles 5, somewhat united at base; pome 3 to 5 -celled, cells partially divided, 2 -seeded.Small trees or shrubs. Lrs. simple, serrate. Fls. racemous, white.

A. Canadénsis Torr. \& Gr. Lrs. oval or oblong-ovate often cordate at base, 
acuminate or cuspidate or mucronate, sharply serrate, smooth; rac. loose, elongated; segm. of the cal. triangular-lanceolate, nearly as long as the tube; petals linear-oblong or oblanceolate; fr. purplish, globous.-A small tree or shınb, found in woods, U. S. and Brit. Am., rarely exceeding $35 f$ in lieight. Lrs. 2 to $3^{\prime}$ long, downy-tomentous when young, at length very smooth on both sides, very acute and finely serrate. Fls. large, white, in terminal racemes, appearing in early spring, rendering the tree quite conspicuous in the yet naked forest. Fruit pleasant to the taste, ripening in June. (Pyrus Botryapium L. f.)

$\beta$. obloxarròlia T. \&. G. Shrubby; lvs. oblong-oval, mucronate, and with small, sharp serratures; rac. and flowers smaller; pet. oblong-obovate, thrice longer than the calyx. (A. ovalis Hook.)

$\gamma$. Rotundifòlia T. \&. G. Lvs. broad-oval; petals linear-oblong. Shrub 10 to $20 \mathrm{f} \mathrm{high.} \mathrm{(Pyrus} \mathrm{ovalis} \mathrm{Willd.)}$

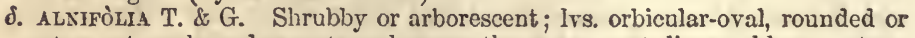
retuso at each end, serrate only near the apex; pet. linear-oblong; stam. very short. (Aronia alnifolia Nutt.)

ع. OLIGOCARPA T. \& G. Shrubby; lvs. mostly glabrous from the first, ellipticoblong, cuspidate; rac. 2 to 4 -flowered, pet. obovate-oblong.-Mountain swamps, N. H., N. Y. and northward.

12. CRATE'GUS, L. ThorN. Hawthorr. (Gr. кра́тоs, strength; on account of the firmness of the wood.) Calyx urceolate, limb 5-cleft; petals 5 ; stamens $\infty$; ovaries 1 to 5 , with as many styles; pome fleshy, containing 1 to 5 bony, 1-seeded carpels, and crowned at the summit by the persistent calyx and disk.-Trees or shrubs, armed with thorns. Lvs. simple, often lobed. Bracts subulate, deciduous, mostly glandular. Fls. corymbous.

\$ Corymbs 6 to 30 -flowered, appearing with the leaves. (a)

a Villous or pubescent. Lrs. plicate or suleate along the veins.......... Nos. 1, 2

a Pubescent. Lvs. plain, not at all plicate, cleft or not................. Nos. 3,4

a Glabrous througliout.-Lvs. abrupt at base, lober, petioled...............Nos. $5-7$

-Lrs. attenuate at base, seldom lobed.............. Nos. 8,9

$\$$ Corymbs 1 to 6 -flowered, -appearing before the downy leaves...................... 8 . 10 -appearing with tho leaves, - pubescent........................ 11

-glabrous....................... Nos. 12, 18

1 C. tomentòsa L. BLACK Thors. Lvs. Uroad-ovate or oval, abrupt at lase, tho margin doubly and sharply serrate or cut into many small lobes, villous or pubescent when young as well as the petioles and compound corymbs of large tls.; veins prominent beneath, sulcate above; fruit rather largo (8 to $9^{\prime \prime}$ diam.) oval or globular, 5-carpeled, 2 to 5-seeded, crimson, tinged yellowish.-Can. to $\mathrm{Ky}$. and Car. Nts. A large shrub or tree 15 to $25 \mathrm{f}$ high. Lvs. half grown with the handsome white fls., finally 2 to $3^{\prime}$ by 1 to $2^{\prime}$. Fl. A pr., May. Fr. Jl. Aug.

B. PLicÀtA. Ivs. smaller, nearly glabrous and strongly plicate. Vt. (T. \& G.), N. H. and N. Y.

$\gamma$. PYRIFòli Ait. Lvs. ovate-elliptic or oval, acute at base, and with the slender petioles and corymbs thinly pubescent, plicate, sharply toothed and slightly cut-lobed. Styles mostly 3.-Mich. to Iowa.

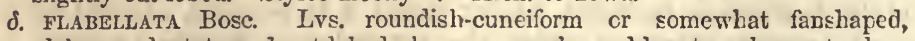
glabrous, dentate and cut-lobed abovo; corymbs and bracts pubescent, glandular.-Ill., Jowa.

$\varepsilon$. MóLLIs Gray. Lrs. large, softly villous, subcordate, with the margin quite conspicuously, many (9 to 13)-lobed; corymbs canescently villous; fruit downy when young.-Ohio to Jowa.

2 C. punctàta Jacq. Lvs. cuneiform-oborate, doubly and often incisely serrate, entire at base, and narrowed to a short, winged petiole, veins straight and prominent, pubescent beneath; corymbs and cal. villous-pubescent; sty. 3 ( 1 or 2$)$; fr. globous, punctate.-Borders of woods, U. S. and Can. Tree 12 to $25 \mathrm{f}$ high. Branches wide-spreading, crooked, covered with cinerous bark. Thorns stout, sharp, 1 to $2^{\prime}$ long, sometimes wanting. Lvs. $1 \frac{1}{2}$ to $2 \frac{1}{2}$ long, $\frac{1}{2}$ as wide, acute or short acuminate; petioles $\frac{1}{2}$ to $1^{\prime}$ long. Fls. white, in somewhat leafy, compound corymbs of 8 to 15 . Fr. 5 to $8^{\prime}$ diam., red or yellowish, eatable in Sept. Fls. Apr.-Jn. 
3 C. arboréscens Ell. Unarmed; lvs. lanceolate, acute at each end, deeply serrate, glabrous above, pubescent in the axles of the veins beneath; cal. hairy, sagm. subulate, obtuse, entire; sty. 5.-Fort Argyle, on the Ogeechee R. (Elliott). A tree 20 to $30 \mathrm{f} \mathrm{high,} \mathrm{with} \mathrm{spreading} \mathrm{branches.} \mathrm{Petioles} \mathrm{short,} \mathrm{with} \mathrm{shorter,}$ linear-lanceolate caducous stipules. Segm. of the cal. reflected. Fr. small, red, 3" diam. Mar., Apr.

4 C. apiifòlia Mx. Pubescent, thorny; lvs. deltoid, truncate at base, deeply 5 to 7 cut-lobed, lobes incisely toothed at end, petiole slender, often longer than the blade; sep. lanceolate; sty. 2 or 3 ; fr. small, red.-In woods, Va. to Fla. and La. A handsome shrub, 8 to $12 \mathrm{f}$ high, with rather short, stout thorns, and large, whito or roseate fls. Lvs. small, broader ( 10 to $\left.18^{\prime \prime}\right)$ than long, fascicled, numerous. Corymbs 10 to 12 -flowered. Fr. oval, about $3^{\prime \prime}$ long. Mar., Apr.

5 C. Oxycántha I. HAwrions. Exglisir Tirors. Lvs. obnvate, obtuse, 3 to 5-lobed, serrate, smoothish, shining above, wedge-shaped at base; corymbs glabrous; sty. 1 to 3 ; fr. ovoid, small.-Hedges, \&c., sparingly naturalized. Shrub very branching, 8 to $18 \mathrm{f} \mathrm{high.} \mathrm{Thorns} \mathrm{slender,} \mathrm{very} \mathrm{sharp,} \mathrm{axillary.} \mathrm{Lvs.}$ $1 \frac{1}{2}$ to $2^{\prime}$ long, nearly as wide, deeply lobed; petioles $\frac{1}{2}$ to $1^{r}$ long. Fls. white, varying to roseate. Fr. 2 to $3^{\prime \prime}$ diam., usually 1-seeded, purple. Used for hedges (extensively in Europe). There aro several varieties. \$ $t$

6 C. coccínea L. White Trons. Lvs. broadly ovate, acutely serrate, 7 to 9 lobed (lobes shallow), thin and smooth, abrupt at base; petioles long, slender, and (with the calyx) smooth and subglandular; sty. 3 to 5.-A thorny shrub or small tree, 10 to $20 \mathrm{f} \mathrm{high,} \mathrm{in} \mathrm{thickets} \mathrm{by} \mathrm{streams,} \mathrm{\& c.,} \mathrm{Can.} \mathrm{and} \mathrm{U.} \mathrm{S.} \mathrm{Branches}$ crooked and spreading, branchlets and thorns whitish. Thorns stout, rigid, sharp, a little recurved, about $1^{1^{\prime}}$ long. Lvs. $1 \frac{1}{2}$ to $2 \frac{1}{2}^{\prime}$ long, $\frac{3}{4}$ as wide, lobed, or (rather) coarsely, doubly acuminate-serrate. Petioles very slender, $\frac{1}{2}$ as long as the lamina. Fls. white, in paniculate, lateral corymbs of about 12 . Fr. 5 " diam., bright purple, eatable in Sept. Fls. May.

7 C. cordàta Ait. WASHington TironN. Thorny, glabrous and glandless; Ivs. cordate-ovate, somewhat deltoid, incisely and often deeply 3 to 5 -lobed, serrate, with long and slender petioles; sep. short; sty. 5 ; fr. small, globous-depressed.Banks and streams, Va. to Ga., cultivated in the Middle States for hedgerows. Shrub 15 to $20 \mathrm{f}$ high, the branches with very sharp and slender thorns 2 to $3^{\prime}$ long. Lvs. abont 2 by $11^{\prime}{ }^{\prime}$, the upper rather cuneate at base, the others truncato or heart-shaped. Pomes $\frac{1^{\prime}}{4}$ diam., numerous, red. Jn. $\S \ddagger$

8 C. Crus-gálli I. Cock-spun TuonN. Glabrous; lvs. obovate-cuneiform, or oblanceolate, tapering to a short petiole, serrate, coriaceous, shining above; spines very long; corymbs glabrous; sep. lanceolate, subserrate; sty. 1 (2 or 3).Hedges and thickets, Can. and U. S. Shrub 10 to $20 \mathrm{f} \mathrm{high,} \mathrm{much} \mathrm{branched.}$ Thorns 2 to $3^{\prime}$ long, straight, sharp and rather slender. Lvs. 1 to $2 \frac{1^{\prime}}{2}$ long, a third as wide, tapering and entire at base, mostly obtuse at apex; petioles 1 to $5^{\prime \prime}$ long. Fls. white, fragrant, in corymbs of about 15, on very short, lateral branchlets. Fr. pyriform, dull red, 2 to $3^{\prime \prime}$ diam., persistent during winter, unless eaten by birds. Jn.-Varies with the lvs. somewhat oblong or oval.

9 C. spathulàta $\mathrm{Mx}$. Glabrous and glandless; lvs. small, coriaceous, shining, oblong-spatulate, attenuated to the subsessile base, crenate above, sometimes lobed; corymbs numerous, lateral, 20 to 25 -flowered; sepals very short; fr. very small, scarlet.-Va. to Fla. and Tex. A handsome shrub 10 to $15 \mathrm{f}$ high, profusely flowering. Lvs. mostly $1^{\prime}$ in length, much inclined to vary, those on the barren shoots much larger, becoming rhomboidal and lobed. Fr. 2 to $3^{\prime \prime}$ diam. Spines few and small. Fls. small, white. Apr., May.

10 C. zestivàlis Torr. \& Gr. APPLE HAw. Fls. just before the elliptical, repand, short-petioled lvs., which, when young, are glandular at edge, and clothed with a rusty tomentum, at length glabrous above; corymbs glabrous, 2 to 5 -flowered; cal. segm. short, triangular, glandless; fr. quite largo (S to $\left.9^{\prime \prime}\right)$, globular, red.In the edges of ponds and rivers, S. Car. to Fla. and La. (Hale). Treo mucls branched, 20 to $30 \mathrm{f}$ high. Fr. ripe in May, juicy, pleasant flavored, and much used. Fls. in Feb., Mar. (Mespilus restivalis Walt.)

11 C. parviflòra Ait. Thorns straight and slender; iss. coriacsous, pubescent, cuneate-obovate, subsessile, crenate-serrate; fls. subsolitary; cai. witi the pedrceis 
and branchlets villous-tomentous; sep. incised, leafy, as long as the pet.; sty. 5 ; fr. large, roundish-obovoid, with 5 bony, 1-seeded nuts.-Sandy woods, N. J. and Southern States. A much branched shrub, 4 to $7 f$ high. Lvs. 1 to $2^{\prime}$ by $\frac{1}{3}$ to $a_{3}^{2}$, the upper surface shining and nearly glabrous when old. Fr. greenish-yellow, near $\frac{1}{2}$ diam., eatable when ripe. A pr., May.

$\beta$. PUíéscens. Shrubs somewhat larger, with larger, roundish, less downy lvs.; petals rather longer than tho calyx. Spines very slender.-Ga. (C. elliptica Ait.)

12. C. flàva Ait. Sommer Haw. Glabrous; thorns straight or arcuate; lvs. membranous, rhombic-obovate, attenuate into a glandular petiole, incised, glandulartoothed and slightly lobed above; corymbs 1 (often 2 or 3)-flowered, glabrous; fls. large; sty. 4 or 5 ; fr. large, pear-shaped, yellowish.-In dry, shady places, Va. to Fla. Tree 15 to $25 \mathrm{f}$ high. Lvs. when mature, 2 to $3^{\prime}$ long; Fr. $9^{\prime \prime}$ long, not well-flavored. Bracts and sepals as well as the petioles glandular. Apr., May.

13 C. víridis I. Glabrous; thorns fow and short; Ivs. thin, roundish or oval, acute at each end, sharply and doubly toothed above; petioles glandless (always?); corymbs 3 to 6-flowered; fls. rather large, the bracts very glandular; sep. subulate; sty. 2 or 3 (rarely 5 ?); fr. large, globular, red, tinged with yellow.-Iowa (Cousens) to Fla. Shrubs 12 to $18 \mathrm{f}$ high. Lrs. 1 to $2^{\prime}$ long, varying from elliptic-ovate to deltoid-ovate (C. populifolia Ell.) or even cordate, sometimes slightly lobed, the petioles slender, often as long as the leaf. Fr. 4" diam, purplish, eatable. Apr., May. (C. coccinea $\beta$. Torr. \& Gr.)

14 C. berberifòlia Torr. \& Gr., with coriaceous, oblong-cuneiform lvs. and (in Sept.) large (6" diam.), deep blue pomes sent from Louisburg, La. by Dr. Hale, is a doubtful member of this difficult genus.

13. PY'RUS, L. Pear, Apple, etc. (Celtic peren; Anglo-Saxon pere; Fr. poire; Lat. pyrus; Eng. pear.) Calyx urceolate, limb 5 -cleft; petals 5, roundish; styles 5 ( 2 or 3 ), often united at base; pome closed, 2 to 5 -carpeled, fleshy or baccate; carpels cartilaginous, 2 -seeded.-Trees or shrubs. Lvs. simple or pinnate. Fls. white or rose-colored, in cymous corymbs.

\$ Prrus. Lrs. simple, glandless; styles distinct; pome pyriform.................... 1 \$aLus. Lrs. simple, glandless; styles united below; fr. globous...................... 2-4 Arovis. Lvs. simple, glandular on the midvein; styles united, etc................... 5 Sorists. Lvs. pinnate; styles 2 to 5 , distinct..................................... 6

I P. communis I. PEAR Tree. Ivs, ovate-lanceolate, obscurely crenate, glabrous and polished above, acute or acuminate; corymbs racemous; cal. and pedicels pubescent; sty. 5 , distinct and villous at base.-Tree usually taller than the apple, 20 to $35 \mathrm{f}$ ligh. Branches ascending. Lvs. 2 to $3 \frac{1^{\prime}}{2}$ long, $\frac{2}{3}$ as wide; petioles 1 to $2^{\prime}$ long. Fls. white. Native in Europe, where in its wild state the fruit is small and unpalatable. The Romans cultivated 36 varieties (Pliny) but, like the apple, varieties without end are now raised from the seed of this delicious fruit. $\ddagger$

2 P. Màlus I. Common Apple Tree. Lvs. ovate or oblong-orate, serrate, not lobed, downy, the veins all incurved; corymbs subumbellate; pedicels and calyx villous-tomentous; pet. with short claws; sty. 5 , united and villous at base; porne globous.-Native in Europe, and almost naturalized here. Tree 20 to $25 f$ high (in thickets 50 to 60 ). Branclies rigid, crooked, spreading. Lvs. 2 to $3^{\prime}$ long, $\frac{2}{3}$ as wide, petioles $\frac{1}{2}$ to $1^{\prime}$ long. Fls. expanding with the lvs., fragrant, large, clothing the tree in their light roseate lue, making ample amends for its roughness and deformity.-The Romans had 22 varieties (Pliny) but the number is now greatly increased. Probably nearly 1000 varieties are cultivated in the U. S. $\ddagger$

3 P. coronària I. SWEET-SCENTED CrAB-TrEe. Lvs. ovate, rounded at base, incisely serrate, often sublobate, straight-veined, pubescent when young, at lengtl smoothish, on slender petioles; pet. clawed; pedicels glabrous; sep. subulate; sty. united and woolly at the base; fr. as well as fls. very fragrant, corymbous.-Borders of woods, Mid., West. and South. States. A small tree 10 to $20 \mathrm{f}$ high, with spreading branches. Lrs. 2 to. $3^{\prime}$ long, half as wide, petioles $\frac{1}{2}$ to $l^{\prime}$ 
long. Fls. very large, rose-colored, in loose corymbs of 5 to 10 . Fr. as large ( 1 to $1 \frac{1^{\prime}}{2}$ diam.) as a sroall apple, yellowish, hard and sour but esteemed for proserves. May. $\neq$

$\beta$. Ioḱssis. Lvs. (when young), pedicels and calyx densely tomentous. Lvs. ovate and oblong, distinctly lobed; (fr. not seen). - Sent from Iowa by. Dr. Cousens.

4 P. angustifòlia Ait. Lvs. lanceolate, acute, or obtuse at base, glabrous, scarcely veiny, crenate-serrate or almost entire, on short petioles; corymbs racemous, few (4 to 7)-flowered; pedicels and calyx outside glabrous; sep. ovate, villous within; sty. distinct, villous at base.-Penn. to Ga. and La. Tree 20 to $30 \mathrm{f}$ high (in woods near Ogeecheo causeway). Lrs. about 4 times longer than wide. Fls. similar to No. 3, rose-purple, large, fine and fragrant. Mar.-T. \& G. describe \& variety with the styles glabrous.

5 P. arbutifòlia L. f. CHOKe BerRy. Lvs. oblong-obovate or oval-lanceolate, obtuse or acute, crenate serrulate, smooth above, tomentous beneath when young, attenuate at base into a short petiole; ped. and cal., when young, tomentous; fr. pyriform or subglobous, dark red.-Low, moist woodlands, U.S. and Can. A shrub 5 to $8 \mathrm{f}$ high. Lvs. 1 to $2^{\prime}$ long, $\frac{1}{2}$ as wide, often subacuminate, subcoriaceous, serratures small, with a glandular, incurved point; petioles 2 to $4^{\prime \prime}$ long. Fls. white, in compound, terminal corymbs of 12 or more. Fr. astringent, as large as a currant. May, Jn. $\dagger$

ß. MELANOCARPA Hook. Lvs., cal. and ped. glabrous or nearly so; fr. blackishpurple.-Swamps. Height 2 to $4 \mathrm{f}$ (P. melanocarpa Willd.)

6 P. Americàna DC. Mountain AsH. Lfts. oblong-lanceolate, acuminate, mucronately serrate, smooth, subsessile; cymes compound, with numerous fls.; pome small, globous; sty. 3 to 5.-A small tree in mountain woods, N. Eng. and Mid. States. Trunk 15 to $20 \mathrm{f}$ high, covered with a reddish brown bark. Livs. 8 to $12^{\prime}$ long, composed of 9 to 15 leaflets; lfts. 2 to $31^{\prime}$ by $\frac{1}{2}$ to $1^{\prime}$, subopposite, often acute, on petioles $1^{\prime \prime}$ in length. Fls. small, white, in terminal cymes of 50 to 100 or more. Fr. scarlet, 2 to $3^{\prime \prime}$ diam., beautiful. May. $\dagger$

B. MICROCARPA T. \& G. Fr. smaller. (P. microcarpa DC.)

7 P. Aucupària L. Enguisi MLountain Ash. Lfts. as in P. Americana, except that they are always smooth on both sides, and, with the serratures, less acute at apex; fls. corymbous; fr. globous.-Native of Europe. A tree 20 to $40 \mathrm{f} \mathrm{high,} \mathrm{often} \mathrm{cultivated} \mathrm{as} \mathrm{well} \mathrm{as} \mathrm{the} \mathrm{last} \mathrm{species,} \mathrm{for} \mathrm{its} \mathrm{ornamental} \mathrm{clusters}$ of scarlet berries. It is a tree of larger size and rougher bark than the last, but is hardly to be distinguished by the foliage, flowers or fruit. $\dagger$

14. CYDO'NIA, Tourn. Qurnce. (Named from Cydonia, a town in Crete, from whence it was brought.) Calyx urceolate, limb 5-cleft; petals 5 ; styles 5 ; pome 5 -carpeled, carpels cartilaginous, many-seeded, seeds covered with mucilaginous pulp.-Trees and shrubs. Lrs. simple. Fls. mostly solitary.

1 C. vulgàris Pers. Lvs. oblong-ovate, obtuse at base, acuie at apex, very entire, smooth above, tomentous beneath; ped. solitary, and, with the cal. woolly; pome tomentous, obovoid. - Shrub 8 to $12 \mathrm{f}$ (rarely 20f) high, with crooked, straggling branches. Lvs. about as large as those of tho pear tree. Fls. white, with a tinge of purple, large, terminal. Fr. large, lengthened at base, clothed with a soft down, yellow when ripe, highly esteemed for jellies and preserves. The plant is reared from layers. $\ddagger$ Eur.

2 C. Japónica Pers. JAPAN QurNce. Irs. glabrous, shining, coriaceous, ovate-lanceolate, acute at each end, serrulate; stip. reniform; spine short, straight; fls. axillary, subsessile.- From Japan. A low shrub, beautiful or even brilliant when in bloom. Fls. about as large as in No. 1, varying in color from the richest scarlet to a delicate blush or white. It is hardy and easily reared. Apr. (Pyrus Japonica L.)

15. RO'SA, Tourn. Rose. (Celtic rhos, red; Gr. pódov; Lat. rosa; Eng. rose.) Calyx tube urceolate, fleshy, contracted at the orifice, limb 5-cleft, the segments somewhat imbricated in restivation, and mostly 
with a leafy appendare; petals 5 (greatly multiplied by culture); achenia $\infty$, bony, hispid, included in and attached to the inside of tho fleshy tube of the calyx.-Shrubby and prickly. Lrs. unequally pinnate. Stip. mostly adnate to the petiolc.

0.38. Our innumerable varieties of garden Roses have mostly originated with the few species mentioned below. To define these varieties in order to their reengnition wonld generally be impossible, for their forms are as evanescent as their names are arbitrary. All that the author hero jroposes is to aid the botanist in tracing back each form to the species whence it sprung. This will be easily done in all cases except with the hybrids.

Styles cohering in an exserted column. Climbers (a).

Styles not cohering. - Stipules nearly free and carlucous (b).

- Stipules adnate to the petiole.-Prickles recurved (c). -Irickles struight $(\mathrm{d})$.

a Leaflets 8 to 5 , mostly 3 . Native and cultivated.............................. 1

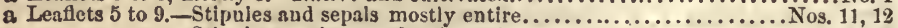
- Stipules pectinate. Sepals entire......................... 3

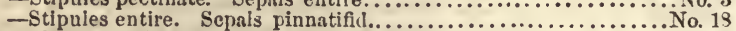

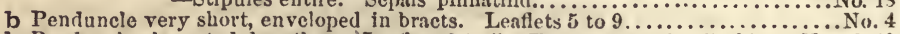
b Penduncle elongated, bractless. Leatlets 3 to 5.-Thorny, mostly climbing... No. 2,19 - Thornless, erect.............. No. 24 c Leaflets not at all glandular. Shrubs erect, -wild...................... 8 -cultivated................Nos, 13, 14 c Leafiets glandular and fragrant beneatb. - Flowers single.................. 9,10 - Flowers double..................... $15-17$ d Wild, native Roses, $1-3 \mathrm{f}$ erect........................................... $5, \tau$ d Cultivated exotics, climbing (No. 20) or erect........................ 21-23

1 R. setígera Mx. Michigar or PraIrIe Rose. Branehes elongated, ascend, glabrous; spines few, strong, stipular; lfts. large, 3 to 5 , ovato; stip. narrow, adherent, acuminate; fls. corymbous; cal. glandular, segm. subentire ; sty. united; fr. globous.-This splendid species is a native of Mich. and other States W. and $\mathrm{S}$. About 20 varieties are enumerated in cultivation, among which is tho Baltimore Belle. They are hardy, of rapid growth, and eapable of being trained 12 to 201. Fls. in very large clusters, changeable in hue, nearly scentless, and of short duration.

2 R. levigàta Mx. CHerokere Rose. Glabrous and polished; branches long, trailing, armed with very strong, curved prickles; lits. 3 , rarely 5 , coriaceous, evergreen, shining, elliptical, sharply serrate; stip. free, setaceous, deciduous; fls. solitary; cal. bristly, sep. entire.-In hedges, etc., Fla. (Tallahassee), N. to Tenn., etc. Sts. very long, numerous, and with their broad, hooked pricks, mako the most impervious of all hedges. Fls. often $3^{\prime}$ diam., white. Apr.-Common also in gardens. $\S$ China.

3 R. multiflòra Seringe. MANY-FLOWERED, or JAPAN Rose. Branches, ped. and eal. tomentous; shoots very long; prickles slender, scattered; lfts. 5 to 7 , ovate-lanceolate, soft and slightly rugous; stip. pectinate, fimbriate; fls. corymious, often numerous; flower-bud ovoid-globous; sep. short; sty. exserted, scarcely cohering in an elongated pilous column; pet. white, varying through roseate to purple.-Grows in hedges with No. 2, about Tallahasseo (Plank road to Bellair). Shrub with luxuriant shoots, easily trained to tho height of 15 to $20 \mathrm{f}$. - Among its varieties are tho Seven Sisters, Boursault's, ete. § Japan.

4 R. bracteàta Linn. MAACARTAey Rose. Branches ereet, tomentous; prickles recurved, often double; lfts. 5 to 9 , obovate, subserrate, eoriaceous, smooth, and shining; stip. fimbriate-setaceous; fls. solitary, terminal, with large bracts subtending the calyx; ped. and cal. tomentous; fr. globous, large, orange.-Naturalized in hedges near $\mathrm{N}$. Orleans (Riddell in T. and G.) Fls. large, white. \& China. Varieties with cream-colored to scarlet fls.

5 R. lùcida Ehrh. Sminixg, or Wird Rose. St. low; prickles scattered, setaceous, the stipular largest, straight; lfts. 5 to 9 , elliptical, simply serrate, smooth and shining abovo; petioles glabrous or subhispid; fls. generally in pairs ( 1 to 3); fr. depressed, globous, and with tho peduncles, glandular-hispid.-Shrub 1 to 3 f high, in dry woods or thickets throughout the U. S., slender, with greenish branches. Lfts. aeute or obtuse, odd one petiolate, the others sessile. Sepals often appendiculate, as long as the large, obcordate, pale-red petals. Fr. small, red. Jn. Jl. (R. Carolina Mx., nec Bw.) 
B. PARVIFLORA. Lfts. oval, mostly vèry obtuse, paler beneath; petioles smooth or pubescent. (R. parviflora Ehrh.)

6 R. nítida Willd. Wrud Rose. St. low, densely armed with straight, slender, reddish prickles; lfts. 5 to 9, narrow-lanceolate, smooth and shining, sharply serrate; 'stip. narrow, often reaching to the lower lfts.; fls. solitary; cal. hispid; fr. globous.-In swamps, N. Eng. (Lexington, Mass.) Sts. 1 to $2 \mathrm{f}$ high, reddish from its dense armor of prickles. Lfts. 1 to $1 \frac{1}{2}^{\prime} \mathrm{long}$, subsessile, odd one petiolulate. Stip. 5 to $8^{\prime \prime}$ long, adnato to the petiole, each side. Fls. with red, obcordate petals. Fr. scarlet. Jn.

7 R. blánda Ait. BuANd Rose. Taller; st. armed with few, scattered, straight, deciduous prickles; lfts. 5 to 7, oblong, obtuse, serrate, smooth, but not shining above, paler and pubescent on the veins beneath; petiole unarmed; stip. dilated; fls. mostly in pairs ( 1 to 3$)$; ped. short, and with the cal. smooth and glaucous; fr. globous.-Shrub, found on dry, sunny hills, N. and M. States. Sts. 2 to $3 f$ bigh, with reddish bark. Fls. rather large. Sep. entire, shorter than the reddish, emarginato petals. Bracts large, downy. Jn.

8 R. Carolina L. Carourna Rose. Swamp Rose. St. tall, glabrous, with strong, recurved, stipular prickles; lfts. 5 to 9, elliptical, acute, sharply and doubly serrate, glaucous beneath, not shining above, petioles hairy or subaculeate; fls. corymbous; fr. depressed-globous, and with tho peduncles hispid.-Swamps and damp woods, forming thickets, Can. and U. S. Sts. 4 to $8 \mathrm{f}$ high, bushy, with reddish branches. Prickles mostly 2 at the base of the stipules. Ifts. 1 to $2^{\prime}$ long, $\frac{1}{2}$ as wide, rather variable in form. Fls. in a leafy corymb of 3 to 7 . Petals obcordate, large, varying between red and white. Fr. dark red. Jn., JL.

9 R. rubiginòsa L. Eglaxtine. Sweer Brier. St. glabrous, armed witi very strong, recurved prickles, with many weaker ones; lfts. 5 to 7, broad-oval, with feruginous glands beneath; fls. mostly solitary; sep. permanent; fr. obovoid, and ped. glandular-hispid.-A stout, prickly shrub, 4 to $8 \mathrm{f} \mathrm{high,} \mathrm{in} \mathrm{fields} \mathrm{and}$ roadsides throughout the U.S. Tho older stems are bushy, much branched, $1^{\prime}$ diam., the younger shoots nearly simple, declined at top. Lfts. small, serrate (tho glands beneath not always present), when rubbed very fragrant. Fls. light-red, fragrant. Fr. orange red. Jn. There aro about 25 cultivated varieties, singlo and double. § Eur. (R. suaveolens $\mathrm{Ph}$.)

10 R. micrántha Smith. SMall-Flowered Sweet Brier. St. glabrous, armed with few, equal, strong, recurved prickles; lfts. 5 to 7 , ovate, rusty-glandular beneath, fls. solitary, small; sep. deciduous from the ovate or oblong fruit; ped. somewliat hispid.-Roadsides and pastures, N. Eng. A large shrub, 6 to $8 \mathrm{f}$ higl, much resembling the last. Fls. usually white, much smaller $\left(15^{\prime \prime}\right.$ diam.) than in that species. Jn. § Eur.

II R. sempervìrens Ser. EVERGREen ROSE. St. climbing; prickles subequal; lfts. persistent, 5 to 7 , coriaceous ; fls. subsolitary or corymbous; sep. subentire, elongated; sty. coherent into an elongated column; fr. ovoid or subglobous, yellow, and with tho ped. glandular-hispid.-Allied to the following, but its leaves are coriaceous and evergreen, persistent until January.-Among the varieties of this (or the next ?) species is the Virginia Lass, with blush whito fls.

12 R. arvénsis L. A Yrshire Rose. Shoots very long and flexile; prickles unequal, falcate; lfts. 5 to 7 , smooth, or with scattered hairs, and glaucous bcneath, deciduous; fls. solitary or corymbous; sep. subentire, short: sty. cohering in a long, glabrous column; fr. ovoid-globous, smoothish.-England. The shoots grow 15 to $20 \mathrm{f}$ in a season, and are very hardy. Fls. white to blush, crimson and purple.-Here belong the varieties known as tho Adam Tea, Afrs. Pierce's, etc.

13 R. cinnamòmea I. CrNsasros Rose. St. tall, with ascending branches; prickles of the younger stems numerous, scattered, of. the branches few, larger, stipular, curved; lfts. 5 to 7 , oval:oblong, simply serrate, grayish-pubescent beneath; stip. dilated and acuminate above, more or less involute, wavy; ped. short and cal. glabrous; sep. entire, as long as the petals; fr. smooth, globous, crowned with the connivent calyx lobes.-Native of Eur. Sts. 5 to $12 \mathrm{f}$ hign, with reddish bark. Fls. mostly double, pink, purple, or red. 
14 R. canina $\mathrm{L}$. DOG Rose. Prickles remote, strong, compressed, falcate; lfts. 5 to 9, with acute, incurved, and often double serratures; stip. rather broad, serrulate; ped. and cal. smooth or hispid; sep. after flowering deflexed and deciduous; fr. ovoid, red.-Native of Europe. Shrub 4 to $8 \mathrm{f}$ high.

$\beta$. Burboniana Ser. Lfts. ovate, subcordate, simply dentate; fls. purple, double and semidouble; pet. concave; sep. entire. $-A$ splendid class of roses, of which more than 100 varieties are cultivated. They are hardy, with amplo and glossy foliage. 18 other varieties are described by Seringe in $\mathrm{DC}$.

15 R. centifòlia I. Hundred-Leaved or Provens Rose. Prickles nearly straight, scarcely dilated at base; lfts. 5 to 7 , ovate, glandular-ciliato on the margin, subpilous beneath; flower-bud short-ovoid; sep. spreading (not deflexed) in flower; fr. ovoid; cal. and ped. glandular-hispid, viscid and fragrant.-From S. Europe. Shrub 2 to $4 \mathrm{f}$ high, very prickly. Fls. usually of a pink color, but varying in hue, form, size, etc., through a hundred known varieties, among which are the incomparable moss rose, the cabbage, etc.

16 R. damascèna Ait. DAMASK ROSE. St. branching and bushy, armed with unequal spines, mostly stipular, cauline ones broad, falcate or hooked; lfts. large, broadly elliptical, downy-canescent; sep. reflexed; fr. ovoid, elongated.Native of the Levant. Shrub 3 to $4 \mathrm{f} \mathrm{high.} \mathrm{Fls.} \mathrm{rather} \mathrm{numerous,} \mathrm{of} \mathrm{a} \mathrm{delicate,}$ pale, roseate hue, usually with very numerous petals, and a delicious fragrance. Among its numerous varieties is the common Mfonthly, low, blooming at al seasons.

17 R. alba L. WHITE GARDEN ROse. Erect, tall, slightly glaucous: prickles slender, recurved, sometimes wanting; lfts. roundish-ovate, shortly acuminate; petioles and veins subtomentous, glandular; sep. pinnatifld; pet. spreading; fr. ovoid, nearly smooth.-From Germany. Shrub 5 to $8 \mathrm{f}$ high. Fls. large, corymbous, sweet-scented, generally pure white, but often in its numerous varieties, tinged with the most delicate blush.

18 R. moschàta L. - MUUSK Rose. Shoots ascending and climbing; prickles cauline, slender, recurved; lfts. 5 to 7, lanceolate, acuminate, smoothish, discolored; stip. very narrow, acute; fls. often very numerous; ped. and cal. subhispid; sep. subpinnatifid, elongated and appendiculate; fr. ovoid, red. Native of - Sts. trailing or climbing 10 to $12 \mathrm{f}$. Fls. peculiarly fragrant, rather large, white, produced in panicles.

19 R. Indica L. Chinese Monthly or Bengal Rose. Erect or climbing, purplish, prickles strong, remote; lfts. 3 to 5, ovate, acuminate, coriaceous, shining, smooth, serrulate, discolored; stip. very narrow; fls. solitary or paniculate; ped. often thickened, and, with tho cal. smooth, or glandular-hispid; sep. mostly entire; stam. inflexed; fr. turbinate?-Splendid varieties, blooming from Apr. to Nov. Fls. of every hue from pure white to crimson, as the Noisette, Sanguinea (foliago as well as fls. blood-red), Youland of Aragon, Giant of battles, Cloth-of-gold (sulphur yellow), and the favorite Tea Roses.

B. LAwrenciana. Miss Lawrence's Rose. St. and branches aculeate, bristly and subglabrous; lfts. ovate, purplish beneath; ped. obovate-acuminate.-A class of varieties with very small flowers, pink to deep purple, (R. Lawrenciana Lindl. R. Indica acuminata Ser.)

20 R. alpina Ser. Alpine on Boursault Rose. Younger shoots echinate with numerous weak prickles, older ones smooth, rarely armed with strong prickles; lfts. 5 to 11 , ovate or obovate, sharply and often doubly serrate; stip. narrow, apex diverging; ped. deflexed after flowering, and with the cal. hispid or smooth; sep. entire, spreading; fr. ovoid, pendulous, crowned with the connivent calyx.-Hardy, vigorous, climbing, with pink, red or crimson flowers.

21 R. eglantèria Ser. Yellow Rose. Austrian Eglantive. St. with a cinerous bark, branches red, both armed with straight, slender, scattered prickles; lvs. 5 to 7 , small, broad-oval or obovate, smooth, shining abore, sharply serrate; cal. nearly naked and entiro; pet. large, broad-obcordate.-From Germany. Shrub about $3 f$ high, bushy. Fls. numerous of a golden yellow, very fugacious, of less agreeable fragrance than the leaves. There are many varieties, both single and double, variegated with red. Jn. (R. lutea Mill.) 
22 R. Gállica L. Common Frencir Rose. St. and petioles armed with numerous, fine, scattered prickles; lfts. mostly 5, elliptical or oval, thick; fls. erect; petals, large, spreading; sep. ovate; fr. ovoid and with the peduncles hispid.-The common red rose of gardens, from which have originated not less than 300 varieties, known in cultivation, and registered in catalogues, as the Velvet, Carmine, Carnation, \&c. Many of them are beautifully variegated, as tho Tricolor, York and Lancaster, Nosegay, Picotée, \&c. The dried petals are used in medicine, and from them are extracted tinctures for cooking. Jn., Jl.

23 R. pimpinellifòlia Scr. Scotcr, or Burnet Rose. St. densely armed with straight, aceroso prickles; lfts. 5 to 9 , roundislı-obtuse, smooth, simply serrate; fls. small, usually roseate, but changing in tho numerous varieties to whits, red or yellow. - Native of Scotland and other parts of Europe. Theso shrubs are but 2 to $3 \mathrm{f}$ high, with small, delicate leaflets. Fls. numerous, globular, very fine, of all colors, even yellow. May, Jn. (R. spinosissima L.)

24 R. Bánksia L. BuNks' Rose. Smooth; 1fts. lanceolate, crowded, 3 to 5, scarcely serrate; stip. deciduous; fls. umbellate; fr. globular, nearly black.From China. Thornless shrubs, with small, cup-shaped lls. Not hardy.

16. AGRIMO'NIA, L. Agrimony. (Gr. aypòs, a field, póvos, alone, a name of dignity for its medicinal qualities.) Calyx tube turbinate; contracted at the throat, armed with hooked bristles above, limb 5cleft, connivent in fruit; petals 5 ; stamens 12 to 15 ; ovaries 2 ; styles terminal; achenia included in tho indurated tubo of the calyx.- 4 Lvs. pinnately divided. Fls. yellow, in long, slender racemes.

1 A. Eupatòria L. Hirsute; lvs. interruptedly pinnate, upper ones 3-foliate, lfts. 5 to 7 , lance-oval or obovate, with small ones interposed, coarsely dentate; stip. large, dentate; petals twice longer than the reflexed calyx.-Roadsides, borders of fields, Can. and U. S., common. St. 1 to $3 \mathrm{f}$ high, hranching, leafy. Lfts. nearly smooth beneath, $1 \frac{1}{2}$ to $3^{\prime}$ long, $\frac{1}{3}$ as wide, sessile, terminal one with a petiolule 1 to $3^{\prime \prime}$ long. Rac. 6 to $12^{\prime}$ long, spicate. Fls. yellow, about $4^{\prime \prime}$ diam. on very short pedicels. Calyx tubo curiously fluted with $10 \mathrm{ribs}$, and surmounted with reddish, hooked bristles. Jl.

$\beta$. HIRSUTA Torr. Smaller and more hairy.

$\gamma$. PARVIFLòrA Hook. Less hairy; fls. smaller, on longer pedicels. (A. parviflora DC.)

2 A. parviflòra Ait. St. and petioles hirsute; lvs. interruptedly pinnate; lfls. numerous (9 to 17), crowded, pubescent beneath, linear-lanceolate, equally and incisely serrate, with small ones interposed; stip. acutely incised; rac. spicatevirgate; fls. small; petals longer than the erect calyx; fr. hispid.-Woods and dry meadows, Penn. to S. Car. W. to Iowa and Tenn. Sts. 3 to $4 \mathrm{f}$ high, tho hairs spreading, brownish and glandular. Lifs. 2 to $3^{\prime}$ by $\frac{1}{4}$ to $\frac{1}{2}^{\prime}$, with smaller ones intermixed. Petals yellow. The plant has an agreeable balsamic odor. Aug. (A. suaveolens Ph.)

3 A incisa Torr. \& Gr. Pubescent and hirsute; lvs. interruptedly pinnate; Ifts. 7 to 11 , with smaller ones interposed, oblong, incisely pinnatifid, canescent beneath; stip. deeply cleft; fls. small, remote, nearly sessile in the slender racemes. -N. Car. to Fla. (at Macon, Ga.) Fls, rather larger than in No. 2. Cal. segm. very short. Jl., Aug.

17. DRY'AS, integrifolia Vahl.-On the White Hills of N. H. Prof. Peck (Pursh),-but never since seen within our limits.

18. GE'UH, L. Avens. (Gr. $\gamma \varepsilon v i \omega$, to taste well; in allusion to the taste of the roots.) Calyx 5 -cleft, with 5 alternate segments or bractlets smaller and exterior; petals 5 ; stamens $\infty$; achenia $\infty$, aggregated on a dry receptacle, and eaudate with the persistent, mostly jointed, geniculate and bearded style. $-24 \mathrm{Lvs}$. pinnately divided. 
Stylo straight, jointless, all of it persistent. Srrversin......................... 1,8 Stylo bent and jointed in the iniddle, hooked or ylumuse. (a)

a Ilead of frults raised on a stipe. Fls. yellow or purple........... Nos. 4-n a Ilead of fruits sessile (no stipe). - Fls. yellow......................... 6,7

- Fluwers white................ Nos. 8,9

1 G. triflòrum Pursh. Villous; st. erect, about 3-flowered; lvs. mostly radical, interruptedly pinnate, of numerous cuneate, incisely dentate, subequal lfts.; bractlets linear, longer than the sepals; sty. plumous, very long in fruit.-Brit. Am. and N. W. States, rare in the Northern. Sts. scarcely a foot high, with a pair of opposite, laciniate lvs. near the middle, and several bracts at the base of tho long, slender petioles. Radical lvs. 5 to $6^{\prime}$ long, the terminal lft. not cnlarged. Fls. rather large, purplish white. Sty. 2' long in fruit. May, Jn.

2 G. Péckii Pursh. Nearly glabrous; st. erect, several-flowered, nearly naked; radical lvs. lyrate-pinnate; the terminal lft. very large, truncate at base, the lateral ones minute; pet. obovate, much longer than the cal.-White Mits. Scape 9 to $15^{\prime}$ high, with several small, incised bracts. Petioles 3 to $5^{\prime}$ long, bearing 4 or 5 dentate, lateral lfts. 1 to $4^{\prime \prime}$ long, and ending in a half round lft. 2 to $4^{\prime}$ wide, lobed and dentate. Fls. $8^{\prime \prime}$ diam., yellow, terminal on the elongated branches. Jl., Aug. Perhaps a variety of the next.

3 G. radiàtum $\mathrm{Mx}$. Very hairy, hispid; st. leafy, 5 to 10-flowered; rt. Ivs. lyrate-pinnate, the terminal lft. very large, broadly reniform-cordate, incised, the lateral ones very small; st. lvs. sessile, cleft and toothed; petals obcordate; sty. persistent, much longer than cal. in fruit.-Roan Mt. N. Car. (Curtis). Sts. 1 to if high, bearing a spreading panicle of large, yellow fls.

4 G. vérnum Torr. \& Gr. Slender and slightly pubescent; st. ascending at base ; radical lvs. pinnately 5 to 9 -foliate, with incised lfts. or often simple and cordate, incisely lobed and dentate; cauline lvs. 3 to 5 -foliate or lobed; stip. large and incised; fls. yellow, erect, very small; sep. reflexed; head of carpels globous, raised on a slender stipe.- Shades and thickets, Ohio to Ill. and Tex. St. 8 to $20^{\prime}$ high, striate, di- or trichomotous at top, few-leaved and few-flowered. Petals yellow and with the sepals hardly more than $1^{\prime \prime}$ in length. Stipe of the head of carpels $\frac{1}{4}$ long. Apr.-Jn. (Stylipus vernus Raf.)

5 G rivàle. L. Pubescent; st. subsimple; radical lvs. lyrato; stip. ovate, acute; fls. nodding, purple; pet. as long as the erect cal. segm.; upper joint of the persistent style plumous.-A fine plant, conspicuous among the grass in wet meadows N. and Mr. States. Rhizomo woody, creeping. St. 1 to $2 \mathrm{f}$ high, paniculate at top. Root lvs. interruptedly pinnate, inclining to lyrate, 4 to $6^{\prime}$ long, terminal lft. large, roundish, lobed and crenate-dentate. St. lvs. 1 to 3, 3-foliate or lobed, subsessile. Fls. subglobous. Cal. purplish-brown. Petals broad-obcordate, clawed, purplish-yellow, veined. Jn.-The root is aromatic and astringent.

6 G. stríctum Ait. Hirsute; radical lvs. interruptedly pinnate; cauline 3 to 5foliate; lfts. obovate and ovate, lobed and toothed; stip. large and erect; bractlets linear, shorter than the sep.; pet. roundish, longer than the cal.; sty. smooth, upper joint hairy.-Fields, moist or dry, N. States and Brit. Am. St. hispid at base, 2 to $3 f$ high, dichotomous, and with spreading hairs at summit. Rt. lvs. 5 to $8^{\prime}$ long, inclining to Iyrate, the terminal lift. largest, obovate and lobed. Fls. numerous, rather largo, yellow. Receptacle densely pubescent. JI, Aus.

7 G. macrophýllum Willd. Hispid; radical lvs. interruptedly lyrate-pinnate, the terminal lft. much the largest, roundish-cordate, cauline with minute lateral litts., and a laige, roundish, terminal one, all unequally dentate; petals longer than the calyx; recept. nearly smooth.-White Mts. and Brit. Am. St. 1 to $2 \mathrm{f} \mathrm{high,}$ stout, very hispid and leafy. Terminal lft. 3 to $5^{\prime}$ diam. Fls. yellow. Jn., Jl.

8 G. album Gmel. Smoothish or pubescent; root-lvs. ternate or the very lowest simple; upper lvs. simple; lfts. ovate, lobed and toothed, the lower mostly obtuse, upper lauceolate; petals as long as calyx; torus clothed with white bristles. Thickets, com. 2-3f. Jl. (G. Virginianum T. \& G.)

9 G. Virginiánum L. Hirsute with spreading hairs, stout; lvs. pinnate below, then ternate, the upper simple; lfts. incisely lobed, lobes wedge-lanceolate, very acute, cut-dentate, upper lanceolate: petals shorter than the calyx; torus nearly naked. Wet thickets. 2-3f. July. 
19. RU'BUS, L. Bramble. (Celtic rub, red; the color of the fruit of some spccies.) Calyx spreading, 5-parted; petals 5, deciduous; stamens $\infty$, inserted into the border of the disk; ovaries many, with 2 ovules, one of them abortive; achenia pulpy, drupaceous, aggregated into a compound berry; radicle superior.- 24 Half shrubby plants. Sts. usually (2; and armed with prickles. Inflorescence imperfectly centrifugal. Fr. esculent.

§ Fruit inseparable from the juicy, deciduous receptacle. Brackifarif.s (a)

n Stems (mostly) creet, stout, armed with stout, recurverl prickles........ Nos. 1, 2

a Stems procumbent, trailing, mostly with slender, minute prickles........... Nos. 3 to 5 $\S \S$ Fruit separating from the dry, persistent receptacle. Rasp BERIIes (b)

b Ienves simple, lobed. Not prickly................................ 6 to 8

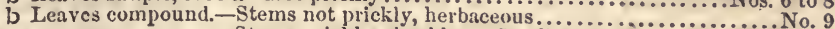
-Stems prickly, shrubby._Corollits single....................... 10-12

-Corollas double.................. 13

1 R. villòsus $\Lambda$ it. HiGH Blackberry. Pubescent, viscid and prickly; st. angular; lfts. 3 to 5 , ovate, acuminate, serrate, hairy both sides; petioles prickly; cal. acrminate, shorter than the petals; rac. leafless, about 20 -flowered. $-\mathrm{A}$ well known, thorny shrub, Can. and U.S. Sts. tall and slender, branobing, recurved at top, 3 to $6 f$ highl. Lfts. $2 \frac{1}{2}$ to $4^{\prime}$ by $1 \frac{1}{2}$ to $2 \frac{1}{2}^{\prime}$, terminal one on a long petiolule, the others on short ones or none. Pedicels slender, $1^{\prime}$ long. Petals white, obovate or oblong, obtuse. Fr. consisting of about 20 roundish, shining, black, fleshy carpels, closely connected into an ovato or oblong head, subacid, well-flavored, ripe in Aug. and Sept.

$\beta$. Frondòsus Torr. Lfts. incisely serrate; rac. with a few simple lvs. or leafy bracts at base; fls. about 10 in each cluster, tho terminal ono opening first, as in all the species, the lowest next, and the highest but ono last. Fr. more acid and with fewer carpels. (R. frondosus Bw.)

$\gamma$. IIUsIrusus T. \& G. St. procumbent or trailing; lrs. smaller; ped. fewllowered.-Often occurs southward with tho ereet forms, and with R. trivialis, from which it is sometimes hard to be distinguished.

2 R. cuneifòlius $\mathrm{Ph}$. SAND ElackberRy. St. erect, shrubby, armed with recurved prickles; lvs. 3-foliate, and with the young branches and pet. pubescent beneath; lfts. cuneatc-obovate, entire at base, dentate above, subplicate, tomentous beneath; rac. loose, few-flowered.-A low shrub, 2 to 3 f high, in sandy woods, L. I. to Fla. Petioles often prickly. Lfts. rarcly 5,1 to $2^{\prime}$ long, $\frac{1}{2}$ as wide, obtuse, or with a short acumination. Petals whito or roseate, 3 times as long as the cal. Fr. black, juicy, well-flavored, ripo in Jl., Aug. Fls. May, Jn.

3 R. híspidus L. St. slender, reclining or prostrate, hispid with retrorse tristles; lvs. 3-foliate, rarely quinate, smooth and green both sides; lfts. coarsely serrate, obovate, mostly obtuse, thickish, persistent; ped. corymbous, many flowered, with filiform pedicels and short bracts; fls. and fr. small. - In damp woods, Can. to Car. Sts. slender, trailing several feet, with suberect branches 8 to $12^{\prime}$ high. Lfts. 1 to $2^{\prime}$ long, $\frac{1}{2}$ as wide, nearly sessile, persistent through tho winter. Fls. white. Fr. dusky-purple, sour. May, Jil. (R. sempervirens Bw.)

$\beta$. setòsus T. \& G. Lfts. oblanceolate, rather narrow, $1 \frac{1}{2}$ to $2 \frac{1}{2}$ long, tapering, and (liko variety $a$ ) entiro at base, sharply serrato above. Fr. red. (R. setosus Bw.)

4 R. Canadénsis L. Northern Dewberry. St. proeumbent or trailing, a little prickly; lvs. 3-foliate, rarely quinate, lfts. elliptical or rhomboid-oval acule or acuminate, thin, unequally cut-serrate; pedicels solitary, elongated, somewhat corymbed; fr. large, black.-Common in dry, stony fields, Can. to Va., trailing several yards upon the ground. Lfts. light green and membranous, nearly sessile, 1 to $1 \frac{1}{2}^{\prime}$ long, $\frac{1}{2}$ as wide. Fls. large, on slender pedicels. Petals obovate, white, twice as long as the calyx. Fr. $\frac{1}{2}$ to $I^{\prime}$ diam, very sweet and juicy in $\mathrm{JL}$ and Aug. Fls. May. (R. trivialis $\mathrm{Pb}$.)

5 R. triviàlis Mx. SOUTHeRN DEwBERry. Procumbent, trailing. with rooting runners, shrubby, armed with bristles and recurved prickles; lvs. 3 -foliate and quinate, persistent, ifts. coriaceous, ovate-oblong or oval, acute or obtuse, sharply serrato; ped. 1 to 3-flowered; fls. large, pet. roundish-obovate; sep. otlong, obtuse, 
reflexed; fr. large, black.-Md. to Fla., common. Sts. long, slender, terete, some of the prickles at length recurved. Lits. small (about $12^{\prime \prime}$ by $8^{\prime \prime}$ ), minutely pubescent. Petioles slender, much shorter tinan tho slender peduncles. Petals white. Fr. well-flavored, ripo in May.

6 R. odoràtus L. MULberRY. St. erect or reclining, unarmed, glandular-pilous; lvs. palmately 3 to 5-lobed, middle lobe longest, unequally serrate; fls. large, in terminal corymbs; pet. orbicular, purple.-A fine flowering shrub, 3 to $5 \mathrm{f}$ high, in upland woods, U. S. and Brit. Am., common. Lvs. 4 to $8^{\prime}$ long, nearly as wide, cordate at base, lobes acuminate, petioles 2 to $3^{\prime}$ long, and, with the branches, calyx and peduncles clothed with viscid hairs. Fls. nearly $2^{\prime}$ diam., not very unlike a rose, save tho (100 to 200) stamens aro whitish. Fr. broad and thin, bright red, sweet, ripe in Aug. Fls. Jn., Jl. t

7 R. Nutlsànus Mocino. St. slirubby, somewhat pilous, with glandular hairs above; lvs. broad 5-lobed, lobes nearly equal, unequally and coarsely serrate; ped. fow-flowered; sep. long-acuminate, shorter than the very large, round-oval, white petals.-A fine species, Mich., Wis. to Oreg., \&c., with very large, showy, white fls. It has received some notice in cultivation as a flowering plant.

8 R. Chamæemòrus I. Choudberry. Herbaceous, diceious; st. decumbent at base, erect, unarmed, 1-flowered; lvs. mostly but 2 , cordate reniform, rugous, with 5 -rounded lobes, serrate; sep. obtuse; pet. obovate, white. $-\Lambda \mathrm{n}$ alpine species with us, found by Dr. Robbins (also by the author, 1855) on the White Mts., and by Mr. Oakes in Me.; N. to the Arc. Sea. Fr. large, yellow or amber color, sweet and juicy, ripo in Sept. Fls. in May, Jn.-This plant may easily be mistaken for Hydrastis.

9 R. triflòrus Rich. St. shrubby, unarmed, declined; branches herbaceous, grcen; lvs. 3 or 5-foliate, lits. nearly smooth, thin, rhombic-ovate, acute, unequally cut-dentate, odd one petiolulate; stip. ovate, entire; ped. terminal, 1 to 3 -flowcred; pet. erect, oblong-obovate.-Moist woods and shady hills, Penn. to Brit. $\mathrm{Am}$. Sts. flexuous, smooth, reddish. Petioles very slender, 1 to $2^{\prime}$ long. Lfts 1 to $2^{\prime}$ by $\frac{1}{2}$ to $1^{\prime}$, lateral ones sessile, oblique or unequally 2-lobed. Pet. white, rather longer than the triangular-lanceolate, reflexed sepals. Fr. consisting of a fow large, dark red grains, acid, ripe in Aug. Fls. May. (R. saxatilis Bw.)

10 R. Idzeus L. GARDEN RASPBERRY. Hispid or armed with recurved prickles; lvs pinnately 3 or 5-foliato; lfts. broad-ovato or rhomboidal, acuminate, unequally and incisely serrate, hoary-tomentous beneath, sessile, odd one petiolulate; fls. in paniculate corymbs; pet. entire, shorter than the hoary-tomentous acuminate cal.-Many varieties of this plant aro cultivated for the delicious fruit. Sts. shrubby, 3 to $5 \mathrm{f}$ high. Lfts. smoothish above, 2 to $4^{\prime}$ long, $\frac{2}{3}$ as wide. Fls. white, in lax, terminal elusters. Fr. red, amber color, or white.-Plants essentially agreeing with tho above described wero found at Cambridge, Vt., in woods, also at Colebrook, Ct., by Dr. Robbins.

11 R. strigòsus Mx. WILD RED RASPBERRY. St. strongly hispid; lvs. pinnately 3 or 5 -foliate, lfts. oblong-ovato or oval, obtuse at base, coarsely and unequally serrate, canescent-tomentous beneath, odd one often subcordate at base, lateral ones sessilo; cor. cup shaped, about the length of the cal.-In hedges and neglected fields, Can. and N. States, very abundant. St. without prickles, covcred witl strong bristles instead. Lfts. $1 \frac{1}{2}$ to $2 \frac{1^{\prime}}{2}$ long, $\frac{1}{3}$ to $\frac{2}{3}$ as wide, terminal one distinctly petiolulate. Fls. white. Fr. hemispherical, light red, and of a peculiar rich flavor, in Jn.-Aug. Fls. May.

12 R. occidentàlis I. Black RAspberry. Thimble Berry. S't. glaucous with bloom, armed witl recurved prickles; lvs. pinnately 3-foliate, lfts. ovate, acuminate, sublobato or doubly serrate, hoary-tomentous beneath, lateral ones sessile; fls. axillary and terminal; fr. black. $-\Lambda$ tall, slender bramble, 4 to $8 \mathrm{f}$ high, in thickets, rocky fields, \&c. Can. and U.S. St. recurved, often rooting at the end. Ifts. 2 to $3^{\prime}$ long, $\frac{1}{2}$ to $\frac{2}{3}$ as wide; common petiole terete, long. Fls. white, lower ones solitary, upper corymbous. Fr. roundish, glaucous, of a lively, agreeable taste, ripe in Jl. Fls. May. †

13 R. rosæéòlius I. Bridat Rose. Erect, branching, armed with nearly straight prickles; lvs. pinnately 3 to 7 -foliate, lits. ovate-lanceolate, subplicate, doubly serrate, smooth beneath, velvety abovo; stip. minute, subulate; sep. spread- 
ing, long-acuminate, shorter than the narrow-obovate, emarginate petals; sty. $\infty$.A delicate house plant, with snow white double fls. Native of Mauritius.

20. Dalibar'DA, L. False Violet. (Named by Linnæus, in honor of Dalibard, a French botanist.) Calyx inferior, deeply 5 to 6 -parted, spreading, 3 of the segments larger; petals 5 ; stamens numerous ; styles 5 to 8 , long, deciduous; fruit achenia, dry or somewhat drupaceous. - 4 Low herbs. St. creeping. Lvs. undivided. Scapes 1 to 2 -flowered.

D. rèpens L. Diffuse, pubescent, bearing creeping shoots; lvs. simple, roundish-cordate, crenate; stip. linear-setaceous; ; cal, spreading in flotwer, erect in fruit.In low woods, Penn. to Can. Creeping stems 1 or $2^{\prime}$ to 10 or $12^{\prime}$ in length. Lvs. 1 to $2^{\prime}$ diam., rounded at apex, cordate at base, villous-pubescent on petioles 1 , 2 or $3^{\prime}$ long. Scapes 1-flowered, about as long as the petioles. Petals white, obovate, longer than the sepals. Jn.

21. WALDSTEI NIA, Willd. Dry Strawberry. (In honor of Franz de Waldstein, a German botanist.) Calyx 5-cleft, with 5 alterate, sometimes minute and deciduous bractlets; petals 5 or more, sessile, decidnous; stamens numerous, inserted into the calyx; styles 2 to 6 ; achenia few, dry, on a dry receptacle.-24 Acaulescent herbs, with lobed or divided radical lis., and yellow fls.

$1 \mathrm{~W}$. fragarioìdes Traut. Lvs. trifoliate; lfts. broad-cuneiform, incisely dentate-crenate, ciliate; scapes bracteate, many-flowered; cal. tube obconic. $-\Lambda$ handsome plant, in hilly woods, Can. to Ga., bearing some resemblance to the strawberry. Rhizome thick, scaly, blackish. Petioles 3 to $6^{\prime}$ long, slightly pubescent. Lfts. 1 to $2^{\prime}$ diam., nearly sessile, dark, shining green above, apex rounded and cut into lobes and teeth. Scape about as high as the lvs., divided at top, bearing 2 to 6 flowers $\frac{1^{\prime}}{2}$ diam. Petals varying from 5 to 10 . Jn.

2 W. lobàta Torr. \& Gr. Lvs. simple, roundish, cordate, 3 to 5 -lobed, incisely crenate: scapes filiform, bracted, 3 to 7 -flowered; cal. tube narrow.-Hills, Ga. (Bainbridge, Columbus). Plant hairy, about $6^{\prime}$ high, from a slender rhizome. Achenia about 2. Petals scarcely as long as the sepals. Apr.-Ju. (Dalibarda lobata Baldw.)

22. FRAGA'RIA, L. Strawberry. (Lat. fragrans, fragrant.) Calyx concave, decply 5-cleft, with an equal number of alternate, exterior segments or bractlets; petals 5 , obcordate, stamens $\infty$; styles $\infty$; lateral, achenia smooth, affixed to a large, pulpy, deciduous receptacle.-24 Sts. stoloniferous. Lvs. trifoliate. Fr. red.

$\S$ Bractlets entire; petals white. Stemless, stoloniferous........................... 1, 2

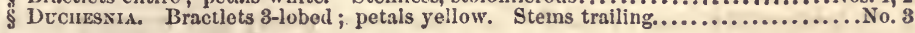

1 F. Virginiàna Ehrh. Pubescent; cal. of the fr. erect, spreading; $a c h$. imbedded in pits in the globous receptacle; ped. commonly shorter than the lvs.Fields and woods, U. S. and Brit. Am. Stolons slender, terete, reddish, often li or more long, rooting at the ends. Petioles radical, 2 to $6^{\prime}$ long, with spreading hairs. Lfts. 3, oval, obtuse, coarsely dentate, subsessile, lateral ones oblique. Scape less hairy than the petioles, cymous at top. Flowers Mar.-May. I'r. May-Jl., highly fragrant and delicious when ripened in the sun.

2 F. vésca Linn. AlpiNe, Wood, or Englisir Strawberry. Pubescent; cal. of the fr. much spreading or reflexed; ach. superficial on the conical or hemispherical receptacle which is without pits, ped. usually longer than the leaves. - Fields and woods, N. States, etc. Stolons often creeping several feet. Lvs. pubescent, and fls. as in F. Virginiana.-Numerous varieties are cultivated in gardens, where the fruit is sometimes an ounce or more in weight.-Fl. Apr., May. Fr. Jn., Jl.

3 F. Indica Ait. Pubescent, trailing, rooting at the joints; lfts. ovate; obtuse, incisely crenate-serrate; stipules lanceolate, free; pedicels axillary, solitary I-flowered; bractlets about equaling the petals, enlarging and leafy in fruit.- 
Escaped from cultivation, now common everywhere from Charleston. S. C. to Tallahassee, etc. The large crimson, oval fruit is quite ornamental but insipid. Ripe in May and Jn. $\S$ India. (Duchesnia Indica Smith. Potentilla Durandi T. \& G.)

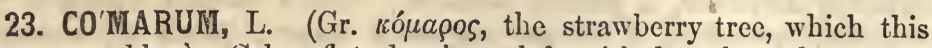
plant resembles.) Calyx flat, deeply 5 -cleft, with bractlets alternating with the seginents; petals 5 , much smaller than the sepals; stamens numerous, inserted into the disk; achenia smooth, crowded upon the enlarged, ovate, spongy, persistent receptacle.-4 Lvs. pinnate. Fls. purple.

C. palústre L. In sphagnous swamps, N. States, Wisc. to the Arc. Circ. Sts. creeping at base, 1 to $2 \mathrm{f}$ high, nearly smooth, branching. Lits. 3,5 and 7 , crowded, $1 \frac{1}{2}$ to $2 \frac{1}{2}^{\prime}$ long, $\frac{1}{3}$ as wide, oblong-lanceolate, hoary beneath, obtuse, sharply serrate, subsessile; petiole longer than the scarious, woolly, adnate stipules at base. Fls. large. Ual. segm. several times larger than the petals. Petals about $3^{\prime \prime}$ long, orate-lanceolate, and, with the stamens, styles, and upper surface of the sepals, dark purple. Fr. permanent. Jn.

24. POTENTIL'LA, L. Cineueforl. (Lat. potentia, power; in allusion to its supposed potency in medicine.) Calyx concave, deeply 4 to 5 -cleft; with an equal number of alternate, exterior segments or bractlets; petals 4 to 5 , roundish ; stamens $\infty$; filaments slender; ovaries collected into a head on a small, dry receptacle; styles terminal and lateral, deciduous; achenia $\infty$.- Herbaceous or shrubby. Lvs. pinnately or palmately compound. Fls. solitary or cymous, mostly yellow.

* Leaves palmately 3 -foliate.................................................. 1-3

* Leaves palmately 5 -foliate......................................................... $4-6$

* Lęaves pinnate. -Shrubs witl axillary pedieels............................................ 7 -IIorbs with axillary pedicels...................................... 8.9 - Herbs with terminal cymes................................. Nos. 10,11

I P. Norvègica I. Hirsute; st. erect, dichotomous above; lfts. 3, elliptical of obovate, dentate-serrate, petiolulate; cymes leafy; cal. exceeding the emarginate petals.-Old fields and thickets, Arc. Am. to Car. Sts. I to $4 \mathrm{f} \mathrm{high,} \mathrm{covered} \mathrm{with}$ silky hairs, terete, at length forked near the top. Caulino petioles shorter than the lvs., lits. $\frac{1}{2}$ to $1_{\frac{1}{2}}^{\prime}$ by $\frac{1}{4}$ to $\frac{1^{\prime}}{2}$ (lower and radical ones very small), often incised. Stip. large, ovate, subentiro. Fls. many, crowded, with palo yellow petals, shorter than the lanceolate, acute bairy sepals. Jl.-Sept.

$\beta$. HIRSUTA T. \& G. Hairs loose, silky; st. slender, erect, subsimple, lower and middle lrs. equal, long-petiolate, lits. roundish-obovate, sessile, incisely dentate; fls. fow; petals rather conspicuous, nearly as long as the calyx.Iry fields. ( $\mathrm{P}$. hirsuta $\mathrm{Mx}$.)

2 P. tridentàta Ait. Smonth; st. ascending, woody and creeping at base; lfts. 3 , obovate-cuneate, evergreen, entire, with 3 large teeth at the apex; cymes nearly naked; petals white, obovate.-On the White Mts. and other Alpine summits in the N. States. Flowering sts. 6 to $12^{\prime}$ high, round, often with minute, appressed hairs. Petioles mostly longer than the leaves. Ifts. sessile, 9 to $18^{\prime \prime}$ by 4 to $6^{\prime \prime}$, coriaceous, smooth. Petals twico longer than the cal. Carp. and ach. with scattered hairs. Jn., Jl. .

3 P. mínima Haller. St. pubescent, ascending, mostly 1-flowered; lvs. trifoliate, lfts. obovate, obtuse, incisely serrate, with 5 to 9 teeth above; petals yellow, longer than the sep.-Alpine regions of the White Mts. Sts. numerous and leafy, 1 to $3^{\prime}$ ligh. Lfts. with the margins and veins beneath hairy. Fls. small. Petals obeordate. Bractlets oval-obtuse, narrow at the base. Jn.-Jl.

4 P. Canadénsis L. 'Villous-pubescent; st. sarmentous, procumbent and ascending; lfts. 5, obovate, silky beneath, cut-dentate towards the apex, entire and attenuate below; stip. hairy, often cleft; ped. axillary, solitary; bractlets longer than the sepals, and nearly as long as the petals.-Common in fields and thickets, U. S. and Can. Sts. more or less procumbent at base, from a fow inales 
to a foot or more in length. Fls. yellow, on long pedicels. Cal. segm. lanceolato or linear. Apr.-Aug.

3. PUMila T. \& G. Very small and delicate, flowering in Apr. and Mar, everywhere; sts. a few inches long. (P. pumila $\mathrm{Ph}$.)

$\gamma$ SIMPLEx T. \& G. Plant less hirsute; st. simple, erect or ascending at base 1fts. oval-cuneiform. Flowering Jn. to Aug. in richer soils. Sts. 8 to $14^{\prime}$ high. Lfts. about $\mathrm{I}^{\prime}$ long, $\frac{2}{3}$ as wide. (P. simplex $\mathrm{Mx}$.)

5 P. argéntea L. St. ascending, tomentous, branched above; lfts. oblong-cuneiform, with a few, large, incised teeth, smooth above, silvery canescent beneath, sessile; fls. in a cymous corymb; petals longer than the obtusish sep.-A pretty plant, on dry or rocky hills, Can. and N. States, remarkable for the silvery whiteness of the lower surface of the lvs. Sts. 6 to $10^{\prime}$, long, at length with slender branches. Lfts. 5 to $9^{\prime \prime}$ by 1 to $2^{\prime \prime}$, with 2 or 3 slender, spreading teeth each side; upper ones linear, entiro. Fls. small; cal. canescent; petals yellow. Jn. Sept.

6 P. récta Willd. Erect, simple, pubescent; lits. 5 to 7, oblong or oblanceolate, coarsely serrate, with large, cleft stipules; fls. in a terminal, expanding cymo; petals obcordate, longer than the ovate, acute sep.-Cultivated and sparingly naturalized, N. Eng. to Ohio. St. 1 to $2 \mathrm{f}$ high. Fls. light yellow.

7 P. fruticòsa L. St. fruticous, very branching, hirsute, erect; 1fts. 5 to 7 , linear-oblong, all sessile, margin entire and rovolute; petals large, much longer than the calyx. - A low, bushy shrub, N. States (Niagara Falls, Willoughby Lake, Vt. etc.) and Brit. Am. Sts. 1 to $2 \mathrm{f}$ high, with a readish bark. Petioles shorter than the leaves. Leaf about $I^{\prime}$ by $2^{\prime \prime}$, acute, crowded, pubescent. Stip. nearly as long as the petioles. Fls. $I^{\prime}$ diam., yellow, in terminal clusters. Jn., Aug. (P. floribunda, Ph.)

8 P. anserìna L. Silver WeEd. Goose Grass. St. slender, creeping, prostrate, rooting; lvs. interruptedly pinnate, lfts. many pairs, oblong, doeply serrate, canescent beneath; ped. solitary, 1-flowered, very long.-A fine species, on wet shores and meadows, N. Ling. to Arc. Am. Sts. subterraneous, sending out reddish stolons 1 to $2 \mathrm{f}$ long. Petioles mostly radical, 6 to $10^{\prime}$ long. Ifts. 1 to $1 \frac{1^{\prime}}{2}$ by 3 to $6^{\prime \prime}$, sessile, with several minute pairs interposed. Ped. as long as the lvs. Fls. yellow, $I^{\prime}$ diam. Jn.-Sept.

9 P. paradóxa Nutt. Decumbent at base, pubescent; lvs. pinnate, lfts. 7 to 9 , obovate-oblong, incised, the upper ones confluent; stip. ovate; ped. solitary, recurved in fruit; petals obovate, about equaling tho sep.; ach. 2-lobed, tho lower portion a thick, starchy appendage.-River banks, Ohio to Oreg., Isl. opposito St. Louis. St. 8 to $12^{\prime}$ long. Lfts. $6^{\prime}$ long, scarcely larger than the entire stipules. Jn., Jl. (P. supina Mx.)

10 P. Pennsylvánica I. Erect, canescently tomentous or soft-villous; lfts. 5 to 9 , oblong, obtuse, pinnatifid or pectinate, upper ones crowded or confluent, larger; cyme fastigiate, at length expanding; petals emarginate, scarcely longer than the acute sepals.-N. Eng. (Pursh.), Can. N. W. to Siberia. (P. pectinata Fisch.)

11 P. argùta $\mathrm{Ph}$. Erect, grayish, pubescent and villous; radical lvs. on long petioles, 7 to 9 -foliate, caulino few, 3 to 7 -foliate, lfts. broadly ovate, cut-serrate, crowded; fls. in dense terminal cymes.-Along streams, etc., Can. and N. States, W. to the Rocky Mts. - St. 2 to $3 f$ ligh, stout, terete, striate, and with nearly the whole plant very hairy. Radical Ivs. one foot or more long; lfts. I to $2^{\prime}$ by 8 to $16^{\prime \prime}$, sessile, odd one petiolulate. Fls. about $8^{\prime \prime}$ diam.; pet. roundish, yellowish white, longer than the sepals; disk glandular, 5-lobed; anth. blackish, with a whito border. May, Jn. (P. confertillora Hitchcock. Boottia sylvestris Bw.)

25. SIBBAL'DIA procumbens, L. "Mountains of Can. and Vt." (Pursh); but not since found within our limits.

26. SPIRE'A, L. (Gr. oreipa, a cord or wreath; the flowers are or may be used in garlands.) Calyx 5-cleft, persistent; petals 5 , roundish; stamens 10 to 50 , exserted; carpels distinct, 3 to 12 , follicular, 


\section{1-celled, 1 to 2 -valved, 1 to 10 -seeded; styles terminal.- - 4 Unarmed} shrubs or herbs. Branches and lvs. alternate. Fls. white or rose-. color, never yellow.

8 Shrubs with lobed or pinnate, stipulate leaves................................ 1, 2

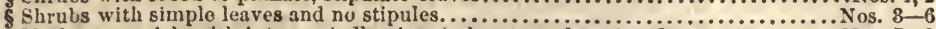

IIerbs perennial, with interruptedly pinnate leaves and perfect fls..................... 7 -9

\$l Herbs perennial, with twice and thrice pinnate-leaves and dioeious fils.................... 10

1 S. opulifòlia L. Nivebark. Nearly glabrous; lvs. roundish, 3-lobed, petiolate, doubly serrate; corymbs pedunculate; carp. 3 to 5 , inflated, and exceeding the cal. in fruit.-A beautiful shrub, 3 to $5 \mathrm{f}$ high, on the banks of streams, Can., Ind., Mo., S. to Ga., rare. Bark loose, outer layers deciduous. Lvs. 1 to $2 \frac{1}{2}$ long, nearly as wide, sometimes cordate at base, with 3 obtuse lobes above; petioles 6 to $9^{\prime \prime}$ long. Corymbs resembling simple umbels, hemispherical, $2 \frac{1}{2}^{\prime}$ diam. Fls. white, often tinged with purple. Follicles diverging, smooth, shining, purple, 2-seeded. Jn. $\nmid$

$\beta$. FERRUGINEA Nutt. Lvs. and branches brownish tomentous.-Ga., Fla.

2 S. sorbifòlia L. Shrub stout, with straggling branches and rough bark; lvs. unequally pinnate, lfts. oblong-lanceolate, the terminal often larger, irregularly lobed, all acuminate, sessile and doubly serrato; fls. in thyrsoid panicles, large, numerous, whito.-In shrubberies. Height 4 to $6 f$. May. + Siberia.

3 S. tomentòsa I. HARDHACK. Ferruginous-tomentous; lvs. simple, ovatelanceolate, smoothish above, unequally serrate; rac. short, dense, aggregated in a dense, slender, terminal panicle; carp. 5.-A small slurub, common in pastures and low grounds, Can. and U. S., particularly eastward. St. very hard, brittle, consequently troublesome to the scythe of tho haymaker. Lvs. dark green above, rusty-white, with a dense tomentum beneath, crowded, and on short petioles. Fls. small, very numerous, with conspicuous stamens, light purple, forming a slender, pyramidal eluster of some beauty. The persistent fruit in winter furnishes food for the snow-bird. Jl. Aug.

4 S. salicifolia L. Nearly glabrous; lrs. oblong, obovate or lanceolate, sharply serrate; rac. forming a more or less dense, terminal panicle; carp. 5.-A small shrub, in meadows, thickets, U. S. and Brit. Am. St. 3 to $4 \mathrm{f}$ high, slender, purplish, brittle. Lvs. smooth, $1 \frac{1}{2}$ to $3^{\prime}$ long, $\frac{1}{3}$ to $\frac{1}{2}$ as wide, acute at each end, petiolate, often with small leaves in the axils. Fls. white, often tinged with red, small, numerous, with conspicuous stamens, in a morə or less spreading panicle. J. Aug. + (S. alba Bw.)

5 S. cory mbòsa Raf. Lvs. ovate or oblong-oval, incisely and unequally serrate near the apex, whitish, with minute tomentum beneath; corymbs large, terminal, pedunculate, fastigiate, compound, dense, often leafy; sty. and carp. 3 to 5.-Mountains, Penn., Fauquier Co., Va. (Robbins), to Ky., S. to Fla. St. slightly pubescent, reddish, 1 to $2 \mathrm{f}$ high. Lvs. nearly smooth above, entire towards the base, 2 to $3^{\prime}$ by $\frac{8}{4}$ to $1 \frac{8}{4}^{\prime}$. Fls. innumerable, white or rose-colored, in a corymb 4 to $6^{\prime}$ broad. May, Jn. † (S. Chamædrifolia Ph.)

6 S. hypericifòlia L. Italian MaY. St. Peter's Wreater. Lvs. obovate-oblong, obtuse, tapering at base to a petiole, entire or slightly dentate, hearly smooth; fls. in lateral, pedunculate corymbs, or sessile umbels; pedicels smooth or pubescent; segm. of tho cal. ascending.-Cultivated in gardens and shrubberies. Shrub 3 to $5 \mathrm{f}$ high, nearly smooth in all its parts. Fls. white, in numerous umbels, terminating tho short, lateral branches. Pedicels as long as the lvs. May. +

7 S. ulmària L. Double Meadow SweEt. Lvs. 3 to 7 -foliate, with minuto lfts. interposed, lateral lfls. ovate-lanceolate, terminal one much larger, palmately 5 to 7-lobed, all doubly serrate, and whitish tomentous beneath; stip. reniform, serrate; pan. corymbous, long-pedunculate.-In gardens, where the numerous white fls. are mostly double. Jl. $\dagger$

8 S. lobàta I. QUEen of tIIE PraIrIe. Lvs. pinnately 3 to 7-foliate, often with smaller lfts. interposed, lateral lfts. of 3 lanceolate lobes, cuneate at base, terminal one large, pedately 7 to 9-parted, lobes all doubly serrate; stip. reniform; pan. large, cymously branched; fls. deep rose-color; carp. 6 to 8. - An herb of 
exquisite beauty in meadows and prairies, Mich., Iowa, to Car. St. 4 to $8 \mathrm{f}$ high. Fls. numerous, and exceedingly delicate. Jn., Jl.

9 L. filipéndula L. Pride of the MEADOW. Herbaceous, smooth, lfts. pinnatifidly serrate, 9 to 21 , with many minute ones interposed; stip. large, semicordate, serrate; corymb on a long, terminal peduncle.-A very delicate herb, often cultivated. Sts. 1 to $3 \mathrm{f}$ high. Lvs. 3 to $6^{\prime}$ long; lfts. 1 or $2^{\prime}$ long, linear, the serratures tipped with short bristles. Fls. white, 4 or $5^{\prime \prime}$ diam., petals oblongobovate. Jn.

Other species of this beautiful genus are sometimes cultivated.

10 s. Arúncus L. GoAt's-Beard. Lvs. membranous, tripinnate, lfts. oblonglanceolate, acuminate, straight-veined, doubly serrate, subcordate, the odd ones ovate-lanceolato; fls. very numerous, small, whitish, in numerous slender racemes, forming a large compound panicle; carp. distinct, glabrous, 3 to 5.-Chiefly along the mountains, Catskill, N. Y. to Ky. and Ga. Sts. slender, 3 to $5 f$ high. Carp. $\mathrm{I}^{\prime \prime}$ long. Jn., Jl. $f$ Plant more delicate than Astilbe, which see, page 371.

27. GILlE'NIA, Mœnch. Indran Physic. (Gr. $\gamma \varepsilon \dot{\lambda} a \dot{\omega}$, to laugh ; on account of its exhilarating qualities.) Calyx tubular-campanulate, contracted at the orifice, 5 -cleft ; petals 5 , linear-lanceolate, very long, unequal; stamens 10 to 15 , very short; carpels 5 , connate at base; styles terminal; follicles 2 -valved, 2 to 4 -seeded.-2 Herbs with trifoliate, doubly scrrate lvs.

1 G. trifoliàta Mœench. Lfts. ovate-oblong, acuminate; stip. linear-setaceous, entire; fls. on long pedicels, in pedunculate, corymbous panicles.-In woods, W. $\mathrm{N}$. York to $\mathrm{Ga}$ A handsome herb 2 to $3 \mathrm{f}$ high, slender and nearly smooth. Lower lvs. petiolate; Ifts. 2 to $4^{\prime}$ long, $\frac{1}{3}$ as wide, pubescent beneath, subsessile. Fls. axillary and terminal. Petals rose color or nearly white, $8^{\prime \prime}$ by $2^{\prime \prime}$. Sds. brown, bitter. Jn., J1. Roots said to be emetic, cathartic, or tonic, according to the dose.

2 G. stipulàcea Nutt. Bowmax's Roor. Lfts. lanceolate, deeply incised ; radical lvs. pinnatifid; stip. leafy, ovate, doubly incised, clasping; fls. large, in looso panicles.-Western N. Y. to Ala. Readily distinguished from the former by the large clasping stipules. Fls. fewer, rose colored. Jn. Properties of the root like the former.

28. KER'RIA, DC. (In honor of Wm. Kerr, a botanical collector, who sent plants from China.) Calyx of 5, acuminate, nearly distinct sepals; corolla of 5 orbicular petals; ovaries 5 to 8 , smooth, globous, ovules solitary; styles filiform; achenia globous.-A slender shrub, native of Japan. Lvs. simple, ovate, acuminate, doubly serrate with stipules. Fls. terminal on the branches, solitary or few together, orange yellow.

K. Japònica DC. JApAN Globe Flower. Common in gardens, etc. Sts. numerous, 5 to $8 \mathrm{f} \mathrm{high,} \mathrm{with} \mathrm{a} \mathrm{smooth} \mathrm{bark.} \mathrm{Iivs.} \mathrm{minutely} \mathrm{pubescent,} 2$ to $3^{\prime}$ by 1 to $1 \frac{1}{2}$, with a very sharp, slender point; petioles 3 to $5^{\prime \prime}$ long. Fls. double in cultivation, abortive, globous, near $1^{\prime}$ diam. $\dagger$

\section{Order XlVIII. CalYCANTHACEA. Calycantus.}

Shrubs with opposite, simple, entire, exstipulate leaves. Flowers solitary, axillary, with the numerous sepals and petals confounded, in several rows, all united below into a fleshy tube or cup. Slamens indefinite, perigynous, with adnate, extrorse anthers. Seeds with convolute cotyledons, otherwise as in the tribe Rosidæ

The order consists of but 2 genera, Calycanthus, American, and Chimonanthus of Japan. The species aro probably but 3 . The flowers aro highiy aromatic, and the same quality resides in the bark.

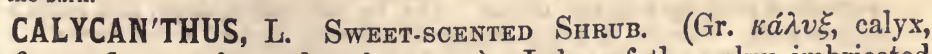
a้v0os, a flower; from the character.) Lobes of the calyx imbricated 
in many rows, lanceolate, somewhat coriaceous and fleshy, colored; stamens unequal, about 12, outer ones fertile; anthers extrorse; pistils few or many, inclosed in the calyx tube, fruit many times larger than that of the rose, loosely enclosing the large achenia.-The bark and lvs. exhale the odor of camphor. Fls. of a lurid purple.

C. flòridus L. Lvs. oval, mostly acute or acuminate, tomentous beneath; branches spreading; fls. nearly sessile.-Fertile soils, along streams, Va. and all the S. States. Not uncommon in gardens farther north, and valued for its exquisite, strawberry-like fragrance. Shrub 3 to $7 f$ high. Lvs. 3 to 5 to $7^{\prime}$ long. Fls. on short branches. Fr. rare, of the size and form of a fig, acute at base, truncate and involute at top, longitudinally veined. (Sent by Prof. Pond.)

$\beta$. LEVIGÀTUS 'T. \& G. Lvs. oblong or ovate-lanceolate. acuminate or gradually acute, glabrous or somewhat scabrous above; branches ercet. $\nmid$ (C. lævigatus Willd.)

$\gamma$. GLAUCES T. \& G. Irs. oblong or ovate-lanceolate, much acuminate, large, glaucous and glabrous or minutely downy beneath; branches spreading. $f$ (C. glaucus WVilld.)

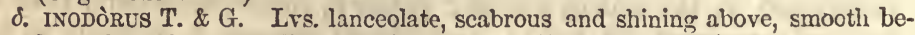
low; branches spreading; fls. inodorous. (C. inodorus Ell.)

\section{Order Xlix. MYrTACEA. Myrtleblooms.}

Trees and shrubs, without stipules. Lvs. opposite, entirc, punctate, usually with a vein running close to the margin. Cal. adherent below to the compound ovary, the limb 4 or 5-cleft, valvate. Petals as many as the segments of the calyx. Stamens indefinite. Anthers introrse. Style and stigma simple. Fruit with many seeds. Albumen none.

A fine order of 45 gener $a$ and 1300 species, native of warm and torrid countries, especially of S. America, and the E. Indies.

Properties. - A fragrant or pungent volatile oil, residing chiefly in the pellncid dotting of the leaves, pervades the odor. The Caryophyllus aromaticus, native of Arabia, a tree about $20 \mathrm{f}$ in height, ylelds the clove (clou, Fr. a nail), which is the drierl flower. Cajeput oil is distilled from the leaves of the Melaleuca Cajeputl, native of the E. Indies. A kind of gum kino is obtained from Eucalyptus resinifera, also a native of Indlia. The root of the Pomegranate yields an extract which is an excellent vermifuge. All the genera are exotic with us. Many of them are highly ornamental in culture.

1. MYR'TUS, Tourn. Mrrtee. (Gr. $\mu \dot{p} \rho o v$, perfume.) Calyx 5cleft ; petals 5 ; berry 2 or 3 -celled ; radicle and cotyledons distinct.Shrubs with evergreen lvs. marked by a marginal vein.

M. commùnis L. Lrs. oblong-ovate; fls. solitary; involucre 2-leaved.This popular shrub is a native of $\mathrm{S}$. Europe. In this country it is reared only in houses and conservatories. Leaves about 1 by 6'. Flowers white. Among tho ancients it was a great favorite for its elegance of form, and its fragrant, evergreen leaves. It was sacred to Venus. The brows of bloodless victors were adorned with myrtlo wreaths, and at Athens it was an emblem of civic authority.

2. PU'NICA, L. Pomegranate. (Lat. punica; Carthaginian or of Carthage, where it first grew.) Calyx 5 -cleft; petals. 5 ; berry many-celled, many-seeded, seeds baccate; placenta parietal.-Deciduous trees and shrubs.

I P. Granàtum L. Arborescent; lvs. lanceolate, with no marginal vein. -A thorny bush when wild, from S. Europe, where it is sometimes used for hedges like the hawthorn. In Fli.e, \&c., it is a tree 15 to $20 \mathrm{f} \mathrm{high.} \mathrm{Lvs.} \mathrm{entire,}$ smooth, 2 to $3^{\prime}$ by 1 to $10^{\prime \prime}$, obtuse. The fls. are scarlet, large, and make a fino appearance. The fr. is large, highly ornamental, and of a fine flavor. Much care is requisite for its cultivation. It requires a rich loam, a sunny situa- 
tion, protected northward by glass. In this way double flowers of great beeuty may be produced. $t$

2 P. nàna L. Shrubby; lvs. linear-lanceolate, acute.-Native of the W. Indies, where it is used as a hedge plant. Shrub 4 to $6 \mathrm{f} \mathrm{high,} \mathrm{with} \mathrm{smaller}$ purple fls., often double. $\dagger$

\section{Order L. Melastomace.e. Melastomes.}

Trees, shrubs or herbs with squaro branches, and usually exstipulate. Lvs. opposite; entire and undivided, without dots and with several veins. Cal. persistent, the tube urceolate, cohering with only the angles of the ovary. Petals as many as the segments of the calyx ( 4 to 6 ), twisted in restivation. Stamens twice as many as petals, sometimes the samo number, inflexed in restivation. Anthers beforo flowering contained in the cavity between the caly $\mathrm{x}$ and tho sides of ovary. Fruit capsular or baccato.

Genera 118, species 1200 . The order is represented in the U. S. by a single genus, tho remainler being natives ehiefly of India and tropical America. No plant of this order is poisonous. All are slightly astringent.

RHEX'IA, L. DeEr-Grass. species are good vulneraries.)

(Gr. $\dot{\rho} \varepsilon \zeta \iota s$, a rupture; some of the Calyx 4-cleft, swelling at the base; petals 4 ; stamens 8 , 1-celled; style declined; capsule 4-celled, nearly free from the investing calyx tube; placento prominent; seeds numerous. - 4 Lrs. opposite, exstipulate, 3-veined.

$\S$ Anthers curved, saccate at base, with a bristly appendago at the insertion of the fliament. - Stem square, winged..................................... 1,

-Sten terete or teretish............................................. $3-5$

\& Anthers straight, terminal.-Stems simple, with purple flowers............................. 7

-Stems brachiate, with yellow flowers.................... 8

1 R. Virgínica L. MEADOW Beauty. St. square, the angles narrowly winged; lvs. sessile, oval-lanceolate, ciliate-serrulate, and with the stem clothed with scattered hairs; cal. hispid.-Grows in wet grounds, Mass. to Ill. and La. St. If or moro high, often 3 -forked above. Lvs. with 3 (rarely 5 or 7 ) prominent veins, 1 to $3^{\prime}$ long, about $\frac{1}{2}$ as wide, acute. Fls. large, in corymbous cymes. Petals bright purple, obovate, hispid beneath, caducous. Anth. long and prominent, crooked, golden ycllow above, with a purple line beneath. Sty. somerwhat longer than the stamens, a little declined. Jl., Aug.

2 R. strícta $\mathrm{Ph}$. St. tall, with 4 strongly winged angles, glabrous; lvs. oratelanceolate, acuminate, setaceously serrate, glabrous, or slightly hispid above; cal. glabrous, the tube very short.-Bogs around pine barrens, S. Car. to Ala. and Fla. St. 3 to $4 \mathrm{f}$ high, slightly bearded at the joints. Lvs. 2 to $3^{\prime}$ long. Fls. purple, largo and fine. Jn., Jl.

3 R. Mariàna L. St. nearly terete, covered with bristly hairs; lvs. lanceolate, acute, attenuato at baso into a very short petiole, and, with the caly $\mathrm{x}$ clothed with scattered hairs. - In sandy bogs, N. J. to Flor. The whole plant is hispid, even the petals externally. St. 1 to $2 \mathrm{f}$ high, slender, and generally with fow branches. Lrs. often narrowly oblong, 4 to 6 times longer than wide, serrate-ciliate. Petals large, obovate, purple. Jn.-Sept.

4 R. lanceolàta Walt. St. much branched, hirsute, terotish; lvs. linear and lance-linear, attenuato to a short petiole, slightly hispid and ciliate; fls. very pale, in fastigiate cymes; cal. glabrous.-Damp soils, N. Car. to Fla. and La. Sts. 1 to $2 \mathrm{f}$ ligh, very leafy, growing in dense patches, with numerous white or palo purple fls. Lvs. 7 or 8 times longer than wide. Jn.-Aug.

5 R. Glabélla Ph. Glabrous and somewhat glaucous; st. simple, teretish; lrs. lanceolate; calyx glandular-hispid.-Damp woods, N. Car. to Fla. and La. St. 2 to $3 \mathrm{f}$ high, dividing at top into a fow peduncles. Lrs. mostly longer than tho internodes ( 1 to $\left.2^{\prime}\right)$, obscurely serrulate, acute, sessile. Cal. rather funnel form above the ovary. Petals pale purple, large, expanding near $2^{\prime}$. Jn.-Aug. 
$6 \mathrm{R}$. ciliòsa $\mathrm{Mx}$. St. tall ( 1 to $2 \mathrm{f}$ high), squarish, glabrous; lvs. broad-ovate, glabrous beneath, sparsely hispid above, the margin serrate-ciliate, with -long, spreading bristles; fls. nearly sessile between the upper pair of lvs; cal. glabrous, the lobes acute.-Damp pine woods, N. Car. to Fla. Lvs. nearly $1^{\prime}$ long, $\frac{2}{3}$ as wide, acute, on short petioles (scarcely $1^{\prime \prime}$ ). Fls. terminal, 1 to 3 together, large, the petals roundish, $9^{\prime \prime}$ long, purple. Jn.-Aug.

7 R. serrulàta Nutt. St. low $\left(6\right.$ to $\left.8^{\prime}\right)$ square, glabrous; lvs. small, roundishoval, glabrous both sides, the margin serrulate, ciliate; fls. subsessile, 1 to 3 between the upper pair of lvs.; cal. glandular-hispid, the lobes short, obtuse.-Open swamps, Ga., Fla. Mfuch liko the last, but smaller in all its parts. Lvs. 3 to $6^{\prime \prime}$ long. Fls. large, purple. Jn., Jl.

8 R. lùtea Walt. Sparsely hispid; st. square, brachiately branched; lvs. lancelinear and oblong-lincar; cal. much constricted above the ovary, the upper portion campanulate, with cuspidate teeth.-Damp pine woods, N. Car. to Fla. St. about $18^{\prime}$ high. The soft, scattered bristles on all its parts are quite characteristic, as well as its showy, yellow, paniculate fls. Jn.-Aug.

\section{Order LI. LYTHRACEA. Loosestrifes.}

Herbs, rarely shrubs, with mostly opposite, entire, exstipulate leaves. Calyx tubular, the limb 4 to 7-lobed, sometimes with as many intermediate teeth. Petals inserted into the calyx between the lobes, very deciduous or 0 . Stamens equal in number to the petals, or 2 to 4 times as many, inserted into the calyx. Ovary free, inclosed in the calyx tube, 2 to 4 -celled. Styles united into one. Fruit, capsulo membranous, enveloped in the calyx, usually by abortion 1-celled. Seeds small, $\infty$, attached to a central placenta. Albumen 0.

Genera 35 , species 300 . Some of the species are found in temperate climes, but most of them are tropical. Lythrum salicaria, native of Europe, N. Ilolland, and U. S., is used for tanning where it abounds. All the species are astringent.

\section{GENERA.}

$\S$ Shrubs with numerous stamens and clawed petals...................AGERstrokru. 1 § Herbs-1.ls. irregular. Calyx inflated, gibbous at basc................. Curnks. -Fls. regular.-Caly x eylindrical, striate, with 5 minute horns...... Lxтruus. $\quad 3$ -Calyx campanulate, -5 teeth with 5 long horns... Nrses. -4 tecth with 4 short horns.. A MMANisia. -4 teeth. Horns 0 , petals 0 .. Нхгов ricira.

1. LAGERStRE'Mila, L. Crape Myrtee. (In honor of Magnus Lagerstroem, a Swedish traveler.) Calyx broadly campanulate, 6-cleft, with 2 bracts below; petals 6 , on claws inserted into the calyx tube; stamens $\infty$; capsule 3 to 6 -celled; seeds many, winged.-East Indian shrubs.

I. In'dica I. Petals crisped, on slender claws; lvs. alternate, roundish ovate, coriaceous, subpetiolate, glabrous; branches winged; fls. in terminal panicles.A common and beautiful exotic, with large, delicately crisped, bluish purple fls. §

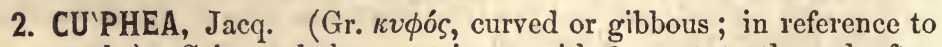
the capsulc.) Calyx tubular, ventricous, with 6 erect teeth, and often as many intermediate processes; petals 6 or 7 , unequal; stamens 11 to 14 , rarely 6 or 7 , unequal; style filiform; capsule membranous, 1 to 2 celled, few-seeded.-Herbaceous or suffruticous. Lvs. opposite, entire. Fls. axillary and terminal.

C. viscosíssima Jacq. Herbaceous, viscid-pubescent; lv8. ovate-lanceolate, petiolate, scabrous; fis on short peduncles; cal. gibbous at base on the upper side, 12-veined, 6-toothed, very viscid.-(1) Wet grounds, Pittsfield, Mass. (Hitchcock), Cambridge, N. Y. (Stevenson) to Ga. and Ark. St. 9 to $18^{\prime}$ high, with alternate branches. Lvs. somewhat repand, 1 to $2^{\prime}$ long. Fls. solitary, one in each axil 
Calyx often purplish. Petals violet, obovate; stamens included. Capsule bursting lengthwise before the seeds are ripe. Aug. (Lythrum petiolatum L.)

3. LY'THRUM, L. Loosestrife. (Gr. $\lambda v ́ \vartheta \rho o \nu$, black blood; referring to the color of the flower.) Calyx cylindrical, striate, limb 4 to 6 toothed, with as many intermediate, minute processes; petals 4 to 6 , equal; stamens as many or twice as many as the petals, inserted in the calyx; style filiform; capsule 2-celled, many-seeded.-Mostly 24 , with entire lvs.

\$ Stamens as many as the petals. Fls. axillary, solitary ......................... 1-3

Stamens twice as many as the petals. Fls. spicate or raceined.............................. 4,5

1 I. hyssopifòlia I. Grass-POLY. Glabrous, erect, branching; lvs, alternate or opposite, linear or oblong-lanceolate, obtuse; fis. solitary, axillary, subsessilo; pet. and stam. 5 or $6 .-A$ slender, weed-like plant, found in low grounds, dry beds of ponds, \&c., Mass. and N. Y., near the coast, rare. Plant 6 to $10^{\prime}$ high, with spreading, square branches. Lrs. sessile, acute at base, pale green, each with a single small flower, sessile in its axil. Petals pale purple. Calyx obscurely striate, with short lobes. $\mathrm{Jl}$.

2 I. alàtum $\mathrm{Ph}$. Glabrous, erect, branched; st. winged below; lvs. lance-ovatc, acute, sessile, broadest at base, alternate and opposite; fls. axillary, solitary.Damp grounds S. and W. States, common. St. 1 to $2 \mathrm{f}$ high, striate, the wings narrow. Lvs. 1 to $2^{\prime}$ long, $\frac{1}{4}$ as wide. Calyx tube 12-striate, 12-toothed, alternate teeth cornute. Corolla purple, wavy, 6-petaled. Stam. 6, included. Jn., JL

3 L. lineàre I. St. slender, somewhat 4-angled, branched above; lvs. linear, mostly opposite and obtuse; fls. nearly sessile; petals and stamens 6.-Swamps near the coast, N. J. to Fla. St. 2 to $4 \mathrm{f}$ high, the angles sometimes slightly winged. Lvs. 1 to $2^{\prime}$ by 2 to $4^{\prime \prime}$, rather fleshy. Fls. small, nearly white.

4 I. Salicària I. More or less pubescent; lvs. lanceolate, cordate at base; fls. nearly sessile, in a long, somewhat verticellate, interrupted spike; petals 6 or 7 ; stam. twice as many as pet.-An ornamental plant, native in wet meadows, Can. and N. Eng., rare. St. 2 to $5 f$ high, branching. Lvs. 3 to $6^{\prime}$ long, $\frac{1}{4}$ as wide, gradually acuminate, eutire, on a short petiole, opposite or in verticels of 3 , upper ones reduced to sessile bracts. Fls. large, numerous and showy; petals purple. Jl., Aug. +

5 I. virgàtum L. St. erect, branched, virgate; lvs. lanceolate, acute each end, floral ones small; fls. about 3 in each axil of the virgate raceme; stam. 12.-A fine species for the garden, native of Austria. St. 3 to $4 \mathrm{f}$ high. Fls. purple. Jn.-Sept. +

4. NESE'A, Juss. Calyx short, broadly campanulate, with 5 erect teeth, and 5 elongated, spreading, hornlike processes; stamens 10, alternate ones very long; style filiform; capsule globous, included, manyseeded.-24 Lvs. opposite or verticillate, entire. Fls. axillary, purple.

N. verticillàta Kunth. Swamps, throughout the U. S. and Can. St. woody at base, often prostrate, and rooting at the summit, 3 to $8 \mathrm{f}$ in length, or erect, and 2 to $3 \mathrm{f}$ high, 4 to 6-angled. Lvs. opposite, or in whorls of 3 , lanceolate, on short petioles, acute at base, 3 to 5 ' long, gradually acuminate and acute at apex. Fls. in axillary, subsessile umbels of 3 or more, apparently whorled, constituting a long, leafy, terminal and showy panicle. Petals 5 or 6 , large, and of a fine purple.

J., Aug. (Decodon verticillatum Ell.)

a. PUBESCens. St. and lvs. beneath pubescent.-R. Island (rare) to La.

B. LAEvigatum. Glabrous and bright green.-More common. N. Eng. to Ill.

5. AMMAN'MIA, L. (To John Amman, of Siberia, professor of botany at St. Petersburg.) Calyx campanulate, 4 to 5 -toothed or lobed, generally with as many horn-like processes, alternating with the lobes; petals 4 or 5 ; stamens as many, rarely twice as many as the calyx lobes; 
capsule globular, 2 to 4-celled, many-seeded.-(1) In wet places. Sts. square and lis. opposite, entire. Fls. axillary.

$1 \mathrm{~A}$. húmilis $\mathrm{Mx}$. St. branched from the base, ascending; lvs. linear-oblong, or lanceolate, obtuse, tapering at base into a short petiole; fls. solitary, closely sessile, all the parts in $4 \mathrm{~s}$; sty. very short.-An obscure and humble plant in wet places, Conn. to Ga., W. to Oreg. Sts. square, procumbent at base, 6 to $10^{\prime}$ high. Fls. minute, with 4 purplish, caducous petals.-A variety has the leaves somewhat dilated at base, approaching tho next species. Aug., Sept. (Ammannia ramosior $L_{\text {. }}$ )

2 A. latifollia L. St. erect, branching; lvs. linear-lanceolate, acute, dilated and auriculated at the sessile base; fls. crowded, and apparently verticillate, upper subsolitary and pedunculate; cal. 4-angled, 4-horned; sep., pet., stam. and cells of capsule 4. -Wet prairies, W. States to La. St. 1 to $2 \mathrm{f}$ high. 'Lvs. 2 to $3^{\prime}$ by 2 to $5^{\prime \prime}$. Fis. purple. Jl.-Sept. (A. ramosior L.)

6. HYPOBRICH'IA, Curtis. Calyx 4-lobed, without accessory teeth; petals 6 ; stamens 2 to 4 ; ovary 2-celled; stigma 2-lobed, subsessile; capsule globous, bursting irregularly, many-seeded.-A submersed, aquatic herb. Lrs. opposite, crowded, linear. Fls. axillary, sessile, minute. (Didiplis Raf.)

F. Nuttállii Curt. A little inhabitant of ponds and sluggish streams, III. (Mead, Buckley) to N. Car. and La. Its habit is similar to a Callitriche. St. mostly submersed, 10 to $2 \theta^{\prime}$ long. Lrs. 10 to $15^{\prime \prime}$ by 1 to $2^{\prime \prime}$, very numerous. Jn.-Aug. (Peplis diandra Nutt.)

\section{Order lit. ONAGRACEA. Onagrads.}

Herbs rarely shrubs, with the flowers 4 (sometimes 2 or 3 )-merous, with the calyx tube adhering to the 2 to 4 -celled ovary, and teeth valvate in the bud; the petals convolute in the bud, sometimes obsolete as well as the calyx teeth. Stamens as many or twice as many as the petals or calyx teeth; ovary 1 to 2 to 4 -celled, styles united, and stigmas capitate or 4-lobed; fruit capsular or baccate, 2 to 4-celled, seeds with little or no albumen. Illust. in Figs. 116, 311, 403, 417.

Two Suborders are comprehended under tbis Order, viz:-the Onagraceæ proper or Epilobieæ, nnd Haloragea. The latter are aquatic herbs of low grade,-reduced Epilobes, the flowers being imperfect or reduced to solitary organs. Both together contain 38 generaand 520 species, particularly abundant throughout America, more rare in the Old World.

They possess no remarkable properties. Many of them are ornamenta!, as the genus Fuchsia, Clarkia, etc.

SUBORDERS AND GENERA.

I. EPILOBIE E. Flowers perfect and complete (sometimes apetalons in Ludwigia) 2-parted or 4-parted. Pollen connected by cobwebs. (*)

II. IIALORAGE. F. Flowers incomplete and often imperfect, small and greenish, 1, 3, and 4-parted. Plants aquatic, often submersed. (c)

* Stamens 8 (or twice as many as the petals). (a)

* Stamens 4 or $2,-$ as many as the petals or sepals. (b)

a Calyx tube not prolonged beyond the ovary.-Seeds eomous..EPtroniuM. 1 -Seeds glabrous..Jussisa. 2

a Calyx tube prolonged, the free summit-slender. Seeds $\infty$... ENoturra. 3 $\rightarrow$ slender. Seeds 1 to 4.Gaura. 4 -short. Petals clawed.Clarkia. 5 -long and enlarged....Fucusia.: 6

b Flowers 4-parted, perfect, sometimes apetalous..Lubwigra. " 7

b Flowers 2-parted, perfect and complete.......... Circ.EA. 8

c Flowers 3-parted, perfect, a petalous............................... 9

c Flowers 4-parted, msnœcious, petals 4 or 0 . Submersed...... MYriophyLLUM. 10

c Flowers 1-parted, perfect, apetalous............................... 11

1. epilo'biUm, L. Willow Herb. Rose Bay. (Gr. émí, upon,

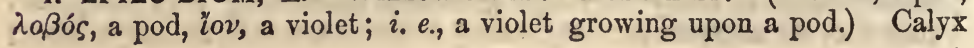


tube not prolonged beyond the ovary, limb deeply 4-cleft, deciduous; petals 4 ; stamens 8 , anthers fixed near the middle ; stigma often with 4 spreading lobes; ovary and capsule linear, 4-cornered, 4-celled, 4 -valved; seeds $\infty$, comous, with a tuft of long silky hairs.-4 Fls. violet purple or white.

§ Leaves alternate. Fls. showy, expanding. Stamens and sty. declined..............No. 1

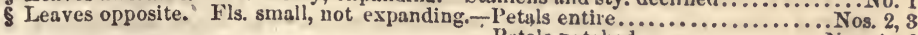

1 E. angustifòlium L. St. simple, erect; lvs. scattered, lanceolate, subentire with a marginal vein; rac. long, terminal, spicate; petals unguiculate; stam. and sty. declined; stig. with 4 linear, revolute lobes.-In newly cleared lands, low waste grounds, Penn. to Arc. Am. St. 4 to 6 f high, often branched above. Lrs. sessile, smooth, 2 to $5^{\prime}$ long, $\frac{1}{4}$ as wide, acuminate, with pellucid veins. Fls. numerous and showy, all the parts colored; petals deep lilac-purple; ora. and sep. (5 to $6^{\prime}$ long) pale glaucous purple. Jl., Aug.

$\beta$. CANÉSCENS. Fls. of a pure white in all their parts; ovaries silvery canescent. Danville, Vt. (Miss Towle.)

2 E. alpinum L. St. creeping at base, usually with 2 pubescent lines, few-flowered; lvs. glabrous, opposite, oblong-ovate, subentire, obtuse, sessile or subpetiolate, smooth; stig. undivided; caps. mostly pedicellate--Mountains, N. States to Arc. Am. St. 6 to $12^{\prime}$ high. Lrs. often slightly petiolate and denticulate, lower obtuse, middle acute, and upper acuminate. Fls. smaller than in E. molle, reddish white.

$\beta$. NUTANS Hornem. St. large, nodding at the summit; lvs. oblong, denticulate.

3 E. palústre L. Minutely tomentous; st. terete, branching; lvs. sessile, lanceolate, subdenticulate, smooth, attenuate at base, rather acute, lower ones opposite; petals small, erect (acute?), twice longer than the calyx; sty. included; stig. clavate; caps. pubescent.-In swamps and marshes, Penn. to Arc. Am. W. to Oreg. Sts. 1 to $2 \mathrm{f}$ high, very branching. Lvs. mostly alternate, 1 to $3^{\prime}$ long, 2 to $6^{\prime \prime}$ wide, entire, or with a few minute teeth. Fls. numerous, rose color. Caps. 2 or $3^{\prime}$ long, on short pedicels. Aug.

3. ALBIFLòrum Lehm. St. slender, at first simple, branched at top; lvs. linear, entire, margin revolute; caps. canescent.-In mud about ponds, $N$. H. and Can. St. 2 to $3 f$ high. (E. lineare Muhl.)

4 E. mólle Torr. Plant velvety-pubescent; st. terete, straight, erect, branching above; lvs. opposite (alternate above), crowded, sessile, mostly entire, oblonglinear, obtusish; petals deeply emarginate, twice longer than the calyx; stig. large, turbinate; caps. elongated, subsessile.-(1) Swamps, Mass. to N. J., rare. St. 1 to $2 \mathrm{f}$ high. Lrs. numerous, 8 to $15^{\prime \prime}$ by 1 to $4^{\prime \prime}$. Fls. rose color. Caps. $3^{\prime}$ long. Sept.

5 E. coloràtum Muhl. St. subterete, puberulent, erect, very branching; lus. mostly opposite, lanceolate, dent-serrulate, acute, sulpetiolate, smooth, often with reddish veins; pet. small, 2-cleft at apex; cal. campanulate: sty. included; stig. clavate; ovules in a single row.-Ditehes and wet, shady grounds, British Am. to Ga., W. to Oreg. St. 1 to $3 \mathrm{f}$ high, becoming very much branclied. Lvs. 2 to $4^{\prime}$ long, $\frac{1}{4}$ as wide, with minute white dots, upper ones alternate and sessile, lower on short petioles. Fls. numerous axillary. Pedicels 1 to $2^{\prime \prime}$ in length, ovaries 4 to $6^{\prime \prime}$, caps. $20^{\prime \prime}$, very slender. Petals roso color, twice longer than tho sepals. Jl.-Sept. - Scarcely distinct from the next.

6 E. tetràgonum L. St. 4-angled, erect, branched and nearly glabrous; lvs. oblong-lanceolate, glandular-serrulate, more or less decurrent, the lower subpetiolate, petals emarginate.-Mts. of N. Car., N. Y. and Can. St. 1 to $2 \mathrm{f} \mathrm{high,} \mathrm{appar-}$ ently winged along the middle by the decurrent lvs. Petals rose red. Stig. clubshaped, pods pedicellate, puberulent.

2. JUSSIE'A, I. (Dedicated to Bernard de Jussieu, founder of the Nat. System.) Calyx tube long, but not produced beyond the ovary; the lobes 4 to 6 , leafy, persistent; petals 4 to 6 , spreading; stamens 8 to 12 ; capsule 4 to 6 -celled, commonly lengthened, opening between the ribs; seeds very numerous. Herbs with alternate lvs. and yellow fis. 
1 J. decúrrens DC. Glabrous; fls. 4-merous; sts. erect, with slender branches, and winged by the decurrent lvs.; 1vs. lanceolate, sessile; caps. clavate, 4-angled, thrice longer than the pedicel, crowned with the lance-ovate, acuminate calyx lobes.- 4 In swamps, Va. to Fla. and La., common. Sts. 6 to 12 to $20^{\prime} \mathrm{high}$. Lrs. 2 to $3^{\prime}$ long. Fls. showy, expanding about $9^{\prime \prime}$. Jl.-Sept.

$2 \mathrm{~J}$. grandiflòra $\mathrm{Mx}$. Hirsute; fls. 5-merous; st. creeping at base, erect; lvs. elliptical, the lower spatulate, acutish, short-petioled; fls, large; ova. slender, shorter than the pedicels; sep. lanceolate, acute.-24 Bogs and ditches, S. Car. Ga. (Savannah, Feay and Pond). Creeping stems several feet long, branches 1 to 2f high. Ova. with 2 tubercles at base. Fls. expanding nearly $2^{\prime}$. May-Aug.

3 J. leptocárpa Nutt. Hirsute; fls. mostly 6-merous, small; st. erect; lvs. lanceolate, subsessile; caps. linear, much longer than the pedicel, crowned with tho lanceolate, acuminate sep. - 1 Fla. and La. to Mo. St. nearly simple, 1 to $2 \mathrm{f}$ high. Caps. nearly 2' long, terete, at length nearly smooth.

4 J. rèpens L. Nearly glabrous; fls. 5-merous, large; st. creeping, ascending; lvs. lance-oval, mostly obtuse, tapering to a slender petiole; caps. cylindrical, much shorter than the long pedicel, with 2 bracteoles at base.- 24 Ponds, La., Ark. Sts. long creeping and floating. Petioles and pedicels about $2^{\prime}$ long. Jn.-Aug.

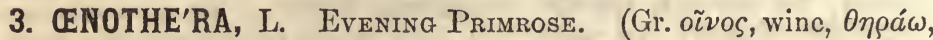
to hunt; the root is said to cause a thirst for wine.) Calyx tube prolonged beyond the ovary, deciduous, segments 4, reflexed; petals 4, equal, obcordate or obovate, inserted into the top of the calyx tube; stamens 8; capsule 4-celled, 4-valved; stigma 4-lobed; seeds many, without a coma.- Herbs with alternate lvs. Fls. yellow.

$\$$ Fls. nocturnal (open by night only). Ovary sessile, oblong................ Nos. 1-3

$\$$ Fls. diurnal. - Caly $x$ tube not longer than tho ovary .................................... 4,5 -Calyx tube about twice longer than the ovary................................. 6 -s -Calyx tubo 3 or 4 times longer than tho ovary........................... 9,10

1 ๔. biénnis I. St. erect, hirsute; lvs. ovate-lanceolate, repand-denticulate; fls. sessile, in a terminal, leafy spike; cal. tube 2 to 3 times longer than the ovary; stam. shorter than the obcordate or obtuse petals; caps. oblong, obtusely 4-angled.(1) and (2) Common in fields and waste places, U. S. and Brit. Am. St. mostly simple, 2 to $5 \mathrm{f}$ high. Lvs. 3 to $6^{\prime}$ long, roughly pubescent, slightly toothed, sessile on the stem, radical ones tapering into a petiole. Fls. numerous, large, opening by night and withering tho next day. Jn.-Aug.

j. MURICita. St. muricato or strigosely hirsute, red; petals scarcely longer than the stamens. St. 1 to $2 \mathrm{f}$ high. (E. muricata Ph.)

$\gamma$. Grandiflòrs. Petals much longer than the stam, rather deeply obcordate. St. branched. + (E. grandiflora Ait.)

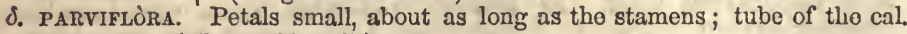
clongated. (E. parviflora L.)

ש. CRUCIÀta. Petals linear-oblong, shorter than the stamens. (GE. cruciata Nutt.)

ל. CANÉSCENS Torr. \& Gr. Petals enlarged; wholo plant canescently hairy.Iowa, etc.

2 ⿷. rhombipétala Nutt. Tall, erect; lvs. lance-linear, sessile, acute, spreading, lower ones petiolate, becoming somewhat pinnatifid; spike strict, fls. large, longer than the leafy bracts; cal. tube very slender, 3 or 4 times longer than tho sessile ovary; petals rhombic-elliptical, acute or acuminate; caps. small.-Wis. (Dr. Parry) to Ark. (Prof. Robertson.) A fine species, with a profusion of strawJellow fls Jn.

3 ⿷. sinuàta L. St. pubescent, diffusely branched or subsimple, decumbent and assurgent; lvs. pubescent, oblong-oval, simuate-dentate, or incised; fls. axillary, solitary, sessilo; cal. villous, the tube twice longer than the ovary; caps. prismatic.-(1) Fields, N. J. to Ga. and La. St. 3 to $8^{\prime}$ long. Lrs. often pinnatifid. Fls. about $6^{\prime \prime}$ diam., pale yellow, turning roseate in withering.

$\beta$. misima Nutt. Low, simple, 1-flowered; lvs. nearly entire,-Pine barrens, N. J. to Gaw (E. minima, Pl.) 
4 Ф. púmila L. Low, pubescent; st. ascending; lvs. lanceolate, entire, obtuse, attenuate at base; spike loose, leafy, naked below; cal. tube shorter than the sub. sessite, oblong.clavate, angular ovary.-2) A small, half-erect plant, common in grass lands, Can. to S. Car. St. 6 to 10' long, round, slender, simple. Lvs. 1 to $1^{\frac{1}{2}}$ by 2 to $3^{\prime \prime}$, radical ones spatulate, petiolate. Fls. yellow, $6^{\prime \prime}$ diam., opening in succession, 1 or 2 at a time. Jn., Aug. (E. pusilla? Mx.)

5 ⿷. chrysántha Mx. St. ascending, slender; fls. small, crowded, spicate; cal. tube equaling in length the ovary, longer than the segm.; petals broadly abovate, emarginate, longer than the stamens; caps. smooth, pedicellate, clavate, the alternato angles slightly winged.-2; Western N. Y. to Mich. St. 12 to $18^{\prime}$ long, purple. Lis. lanceolate, obtuse, attenuate at base, denticulate, radical onos spatulate. Fls. $5^{\prime \prime}$ diam., orange-yellow. Jn., Jl.

6 E. fruticòsa L. St. pubescent or hirsute; lvs. oblong-lanceolate, repand-denticulate; rac. leafy or naked below, corymbed; caps. oblong-clavate, 4-winged, with intermediate ribs, pedicellate.-2 4 In sterilo soils, Mass., Conn., N. Y. to Fla. and W. States. St. hard, rigid (not shrubby), 1 to $3 f$ high. Lvs. variablo in pubescence, form and size, 1 to $3^{\prime}$ by 3 to $8^{\prime \prime}$, sessile, minutely punctate. Fls. fow or rnany, $11^{\prime}$ diam., in a terminal, bracteate, mostly pedunculate raceme. Cal. tube longer than the ovary. Petals broad-obcordate, yellow. Jn., Aug.

3. AMBIGUA. Lvs. membranous; petals longer than broad.

? C. ripària Nutt. Ncarly glabrous; stem ercet, with slender branches, usually purple and polished; lvs. linear-lanceolate, acutish at both ends, petiolate, repanddenticulate, coriaceous; fls. large, loosely corymbed, at length racemed; cal. tube nearly twice longer than the pedicelled ovary; caps. clavate, scarcely winged.(2) Along rivers, N. J. to Fla. and Ala. St. 1 to $2 \mathrm{f}$ high. Lvs. 2 to $4^{\prime}$ long. Fls. as large as in No. 6. A handsome species. May, Jn.

8 ๘. lineàris $\mathrm{Mx}$. Hoary puberulent; st. slender, erect, simplo or fewbranched; lvs. linear, subentire, obtuse, the lowest linear-spatulate; fls. large, corymbed at tho summit of the branches, tube of the caly $\mathrm{x}$ somewhat longer than tho pedicellate ovary; fr. obovate, scarcely winged. - 24 Montauk Point to N. Car. (Miss Carpenter), and Ala. St. 12 to $18^{\prime}$ high. Lvs. 1 to $2^{\prime}$ long. Fls. much as in No. 7. May, Jl.

9 ⿷. glaùca $\mathrm{Mx}$. Glabrous and glaucous; st. erect, with fow, slender branches above; lvs. ovate, sessile, acute or acuminate, obscurely denticulate; fls. large, clustered at the ends of the branches; calyx tube 3 or 4 times the length of the short, pedicellato ovary; caps. oval, 4-winged above--Rock Castle Co. Ky. to Va. and N. Car. St. stout, 2 to $3 f$ high, purplish. Lrs. 2 to $3^{\prime}$ long, often lanceolate. Caps. 4 to $5^{\prime \prime}$ by 2 to $3^{\prime \prime}$. May-Jl.

10 ⿷. Missouriénsis Sims. Simple, decumbent; lvs. coriaceous; lanceslate, acute, or short-acuminate, petiolate, subentire, downy canescent when young; fls. very large, axillary; cal. tube 3 or 4 times longer than the downy-canescent ovary; caps. very large, oval, depressed, with 4 broad-winged margins.-Dry hills, Mo. Remarkable for the magnitude of its fls. and fruit. Petals yellow, crpanding 4 inches. Cal. tube 4 to $7^{\prime}$ long. Caps. $2^{\prime}$ long. Sds. large, crested, in one row in each cell. Jl.-Oct. $\dagger$

C. speciòsa of Ark. and Tex. is a splendid species, with white or roseate fls., fine in cultivation.

GAU'RA, L. (Gr. yaṽpos, superb.) Calyx tube much prolonged above the ovary, cylindric, limb 4-cleft; petals 4, unguiculate, somewhat unequal, inserted into the tube; stamens 8 , declinate, alternate ones a little shorter; ovary oblong, 4-celled, one only proving fruitful, nut usually by abortion, 1 -celled, 1 to 4 -seeded.-Herbaceous or shrubby. Lvs. alternate. Fls. white and red, rarely trimerous.

1 G. biénnis L. St. branched, pubescent; lvs. lanceolate, oblong, remotely dentate; spike crowded; cal. tube as long as the segm.; petals rather declinate, and shorter than the sepals; fr. subsessile, slightly acuminate, 8-ribbed, alternate ribs minute.- A beautiful biennial, on the dry banks of streams, Can. to Ga., rare. St. 3 to $5 \mathrm{f}$ high. Lvs sessile, palo green, acute at each end. Fls. numerous, 
sessile. Cal, reddish ; cor. at first rose-color, changing to deep red; stig. 4-lobed. Fr. rarely maturing more than one seed. Aug.

2 G. fílipes Spach. Paniculate and naked above; lvs. linear-oblong, repanddentate, lower ones almost pinnatifid; branches of the panicle very slender, naked, with tufted lvs. at their base; cal. segm. canescent, longer than the tube or the petals; fr. obovate-clawate, on a filiform pedicel.-Dry ground, S. and W. States. St. rigid, 3 to $5 \mathrm{f}$ high; leafy just below the paniclo. Lvs. 1 to $3^{\prime}$ leng; 2 to $\mathrm{G}^{\prime \prime}$ wide, tapering at each end. Petals oblong-spatulate, rose-color or white. Jl., Aug.

3 G. angustifòlia Mx. Herbaceous, pubescent; lvs. linear, repand-denticulate, rery acute; cal. lobes much longer than the tube or the petals; fr. sessile, ovate, with 4 sharp, almost winged angles, and rather obtuse at each end, 1 or 2-seeded. -S. Car., Ga. (Mettauer), Fla. (Chapman.) Plant strict and slender, fewbranched. Fls. small, white, in paniculate spikes. Jl., Aug.

5. CLAR'KIA, Ph. (In honor of Gen. Clark, the companion of Lewis across the Rocky Mts.) Calyx tube slightly prolonged beyond the ovary, limb 4-parted, deciduous; petals 4, unguiculate, 3-lobed or entire, claws with 2 minute teeth ; stamens 8 ; style 1, filiform ; stigma 4-lobed; capsule largest at base, 4-celled; 4-valved, many-seeded.(1) Herbs (from Oreg. and Cal.) with showy, axillary tls.

1 C. pulchélla $\mathrm{Ph}$. Lrs. linear-lanceolate; petals large, broadly cuneiform, tapering into a slender claw, with 2 reflexed teetl, limb with 3 spreading lobes; alternate stam. abortive; caps. pedicellate.-Gardens. A handsomo annual, with lilac-purple or white fls., of easy culture. $\dagger$

2 C. élegans Inndl. Lvs. ovate-lanceolate, denticulate, on short petioles; petals undirided, rhombic or triangular ovate, with a toothless claw; stam. all fertile, with a hairy scale at the baso of each; stig. hairy ; caps. subsessila, hairy. -Gardens. Fls. smaller than in the last. Petals and stig. purple. Hairs at base of stamens red. $\dagger$

6. FUCH'SIA, L. Ladies' Eardrop. (To Leonard Fuchs; an early German botanist of the fifteenth century.) Calyx tubular-infundibuliform, colored, deciduous, limb 4-lobed; petals 4, in the throat of the calyx, alternate with its segments; disk glandular, 8-furrowed; baccate capsule oblong, obtuse, 4-sided.-Mostly shrubby. South American plants of great beauty.

1 F. coccínea Ait. LAdIES' EARDRoP. Branches smooth; lvs. opposite, and in verticils of $3 \mathrm{~s}$, ovate, acute, denticulate, on short petioles; fls. axillary, nodding; sep. oblong, acute; petals convolute, half as long as calyx.-Native of Chili. $\Lambda$ very delicate and beautiful greenhouse shrub, 1 to $6 \mathrm{f} \mathrm{high.} \mathrm{Fls.} \mathrm{on}$ long, filiform pedicels. Cal. scarlet, much longer than the included, violet-purpio petals. Stam. crimson, much exserted. Berry purple. There are many varioties. (F. Magellanica Lam.)

2 F. grácilis Linàl. St. suffruticous, often simple; lvs. opposite, ovate, petiolate, slightly acuminate, glandular-dentato; fls. opposito, solitary, pendulous, long $r$ than the lvs., petals nearly as long as the sepals and much broader.Chili. A beautiful parlor plant, quite common. St. 2 to $3 f$ high, thick. Fls. larger, but less elegant than in the former, with a red calyx and crimson corolla. $\dagger$ Many varieties.

3 F. fúlgens DC. Lrs. opposite, petiolate, cordate-ovate, acute, denticulate; pedicels axillary, shorter than the flowers, upper ones racemed; cal. tube long, trumpet-shaped, lobes ovate-lanceolate, scarcely exceeding the petals.-From Mexico. Fls. bright-red.

7. LUDWIG'IA, L. Bastard Loosestrife.

(To C. D. Ludwig, Prof. of Botany at Leipzic, 1750.) Calyx tube not prolonged beyond the ovary, limb 4-lobed, mostly persistent; petals 4, equal, obcordate, 
often minute or none; stamens 4, opposite the sepals; style short; capsule short, often perforated at top, 4-celled, 4-valved, many-seeded, and crowned with the persistent calyx lobes.- 24 Herbs in wet grounds. Lvs. entire.

§ Leaves alternate, sessile. (a)

a Petals large, yellow. Fruit pedicellate, short.................... Nos. 1 -

a Petals small, yellowish. Fruit sessile, elongated, sinooth..................... Nos. 4,5

a Pet. 0 or minute. -Fruit elongated, hairy or smooth...................... Nos. 6 , -Fruit short, smooth.-Stem winged.................. -Stem teretish.-Fis. axillary. Nos. 9-11 -Fls. capitate...... No. 12

(Leaves opposite, petiolate.-Fls. sessile, mostly apetalous........................... 13-15

-Fls. pedicellate, with showy petals............................. 16

1 I. alternifòlia L. SEED-Box. Erect, branched, glabrous; lvs. lanceolate, acute, sessile, palo beneath; ped. axillary, solitary, 1-flowered, 2-bracted above the middlo; petals scarcely as large as the spreading, acuminate sepals; caps. large, with 4, winged angles, crowned with the colored calyx.-Shady swamps. St. 1 to $3 f$ high, round, with a strong bark, and several branches. Lvs. with marginal veins, 2 to $3^{\prime}$ long, $\frac{1}{2}$ to $1^{\prime}$ wide. Caps. convex at apex, the angles conspicuously winged. Sep. large, purplish. Petals large, yellow, showy. Jl., Aug.

2 工. hirtélla Raf. Hairy, erect, sparingly branched; lvs. ovate-oblong, sessile, obtuse; fls. axillary, solitary, pedicellate, with 2 bractlets below it; sep. nearly as long as tho pet. ; caps. subglobous, 4-angled and winged.-Moist soils, N. J. to Fla. St. 1 to $3 f$ high. Lvs. numerous, hairy on both sides, $\frac{1}{2}$ to $1 \frac{3^{\prime}}{4}$ by 2 to $8^{\prime \prime}$. Fls. yellow, about $\frac{3^{\prime}}{4}$ diam. Cal. spreading, and, with caps. villous. Jn.Sept. (L. hirsuta $\mathrm{Ph}$.)

3 I. virgàta $\mathrm{Ph}$. Nearly glabrous, erect, virgato; lvs. oblong, closely sessile, obtuse, the upper linear; fls. large, on a slender pedicel; petals longer than the leafy calyx lobes; caps. roundish-cubical, with winged angles, and finally as long as the reflexed cal. lobes.-In dry soils, S. States. Sts. 2 to $3 f$ high. Lvs. 1 to $2^{\prime}$ long. Fls. spreading $1^{\prime}$, on pedicels $6^{\prime \prime}$ long. May-Sept.

4 L. lineàris Walt. Glabrous, slender, with angular, erect branches; lvs. lancelinear, acute at each end; fls. axillary, solitary, sessile; pet. obovate-oblong, slightly longer than the triangular-ovate sep. which are much shorter than the elongated, obovoid-clavate, 4-sided capsules.-Swamps, N. J. and S. States. Plant $I$ to $2 \mathrm{f}$ high, with the habit of Lythrum alatum, often sending out runners at the base, with obovate leaves. Fls. sometimes apetalous. Jl.- Sept. (Isnardia DC.)

5 L. linifòlia Poir. Glabrous, mostly simple, creeping at base, then erect; lvs. spreading, linear, rather acute, tapering to a slender baso; fls. closely sessile; cal.-lobes ovate, acuminate, about the length of the petals and of the oblong, 4sided capsules. - Muddy places, N. Car. to Fla. Plant If laigh, with much the habit of Proserpinaca palustris. Lvs. I' long.

6 I. cylíndrica Ell. Glabrous, erect, much branched; lvs. lanceolate, acute; fls. minute, 1 to 3 together, apetalous; cal. lobes much shorter than the rather slender, cylindrical, abrupt capsule.-S. Car. to Fla. and Tex. St. 3 f high. Lvs. veiny and somewhat denticulate. Capsules 2 to $4^{\prime \prime}$ in length, $1^{\prime \prime}$ wide. Jl.Sept. (Isnardia DC.)

7 I. pilòsa Walt. Villous-pubescent, erect, much branched; lvs. lanceolate, acute; fis. axillary and spiked above; cal. lobes ovate-acuminate, about as long as tho oblong, 4-sided, villous capsule.-Swamp, S. Car. to Fla. and La. Plant 2 to $3 i$ high. Lvs. 2 to $3^{\prime}$ long, those of the branches much diminished, of the stolons spatulate. Caps. about $4^{\prime \prime}$ by 2 or $3^{\prime \prime}$. Jl.-Sept. (Isnardia DC.)

8 I. alàta Ell. Glabrous, few-branched, erect; st. winged by the decurrent bases of the lanceolato lvs.; fls. solitary, apetalous; cal. lobes broadly ovate, nearly as long as the small, 4-sided, obconic capsule.-Swamps, S. States. Plant about $2 f$ high. Lvs. 1 to $3^{\prime}$ long, the lower broad-oval. J1.-Sept. (Isnardia DC.)

9 I. sphærocárpa Ell. Erect, smooth, or nearly so; lvs. lanceolate, acute, attenuato at base; fls. axillary, subsolitary, on very short pedicels ; pet. minute or wanting, as well as the bractlets; sep. as long as the small subglobous caps.-In 
watcr, S. to Ga., partly submerged, or in very wet grounds, near Boston, Mass. St. 2 to $3 \mathrm{f}$ high, brauching, angular. Margin of the lvs. rough, sometimes remotely and obscurely denticulate. Fls. greenish, inconspicnous. Jl.-Sept. (Isnardia DC.)

10 I. polycárpa Short \& Peter. Glabrous, erect, much branched, and often stoloniforous; lvs. lance-linear, gradually acute at each end; fls. apetalous, axillary, solitary, with 2 subulate bractlets at base; caps. 4-angled, truncated above, tapering below, crowned with the 4-lobed stylopodium, - Swamps, W. States. St. 1 to 3 high. Lvs. 2 to $3^{\prime}$ by 2 to $4^{\prime \prime}$, ten times longer than the flowers. Aug.-Oct.

11 I. microcárpa Mx. Glabrous; st. creeping at base, then ascending; lvs. spatulate-obovate, minutely denticulate; cal. lobes roundish, acuminate, larger than the very small, obovate capsule; stig. sessile.-Wet grounds, S. Car. to Fla. St. mostly simple, If high, often with stolons at base. Jl.-Sept. (Isnardia lanceolata DC.)

12 L. capitàta Mx. Glabrous, erect, slender; Irs. lance-linear or lance-oblong, obtuse at the sessile base, obtuse or very acute at the apex; fls. sessile, crowded in a terminal bracted head or spike; cal. lobes shorter than the 4-angled capsule. -5. Car. to Fla. Sts. 2 to $3 f$ high, simple, or with few virgate branches. Lvs. 1 to 3 ' long, the upper linear and taper-pointed. Aug.-Oct. (Isnardia DC.)

13 L. palústris Ell. WATER Purslane. Prostrate and creeping, smooth, and slightly succulent; lvs. opposite, ovate-spatulate, acute, tapering at base into a petiole; fls. sessile, solitary ; pet. 0 , or very small, flesh color; caps. oblong, abrupt at both ends, with 4 green angles; bractlets 0 .- In U. S. and Can., creeping in muddy places or floating in water. St. round, reddish, 10 to $18^{\prime}$ long. Cal. lobes and sty. very short. Caps. $2^{\prime \prime}$ long. Jn.-Sept. (Isnardia L.)

14 I. nàtans Ell. Crecping or floating, smooth and slightly succulent; lvs. oblong, tapering to a petiole, or the lower subsessile; fls. sessile; cal. lobes triangular-ovate, acute, as long as the yellow petals; ova. with 2 conspicuous bracteoles; fr. 4-angled, tapering to the base.-Swamps, S. States. Caps. about $4^{\prime \prime}$ long, at first top-shaped. Jl.-Oct.

15 L. spatulàta Torr. \& Gr. Branched, ascending, downy and not succulent; Irs. oval, tapering to a petiole; fls. very small, apetalous, sessile; caps. pubescent, ovate, somowhat 4-zided, small. - 4 Middle Fla. Plant near if high, diffusely branched from tho base. Lvs. and margined petiole about 2' long.

16 I. arcuàta Walt. Nearly smooth, creeping; lvs. oblanceolate, tapering to the sessile base; fls. solitary, on a slender axillary peduncle, which is twice longer than the lvs.; petals bright yellow, longer than the lance-linear, spreading sepals; caps. clavate, finally arcuate, as long as the persistent calyx lobes.-Swamps, Va. to Fla., along the coast. Sts. 3 to $10^{\prime}$ long. Lvs. $10^{\prime \prime}$ long. Fls. $10^{\prime \prime}$ broad. May-J. (Isnardia pedunculosa DC.)

8. CiRCE'A, L. Enchanter's Nigirshade. (Circe was supposed to have used these plants in her enchantments.) Calyx slightly produced above the ovary, deciduous, limb 2-parted; petals 2, obcordate ; stamens 2, opposite the sepals; capsule obovoid, uncinate-hispid or pubescent, 2-celled, 2-seeded; styles united.-24 Lis. opposite.

1 C. Iutetiàna I. St. erect, pubescent above; lvs. ovate, subcordate, acuminate, slightly repand-dentate, opaque, longer than the petioles; bracts none; fr. roflexed, hispid-uncinate.-Damp shades and thickets, Can. to Car. W. to Ill. St. 1 to 2 f high, sparingly branched, tumid at the nodes. Irs. dark green, smooth or slightly pubescent, 2 to $4^{\prime}$ long, $\frac{1}{2}$ as wide; petiole 8 to $15^{\prime \prime}$ long. Fls. small, rose color, in long, terminal, axillary racemes. Fr. obcordate, with conspicuous hooks. Jn., Jl.

2 C. alpina L. Smooth; st. ascending at base, weak; lvs. broad-cordate, membranous, dentate, as long as the petioles; bracts setaceous; caps. pubescent.A small, delicate plant, common in wet, rocky woodlands, in mountainous districts, N. Eng. Brit. Am., W. to Or. St. diaphanous, juicy, 5 to $10^{\prime}$ high. Lvs 
I to 2 ' long, $\frac{2}{3}$ as wide, acute or acuminate, with small, remote teetl, pale green and shining. Fls. white, rarely reddish, minute, in terminal racemes. $\mathrm{Jl}$.

9. PROSERPINACA, L. Mermaid Weed. (Lat. Proserpina, a Roman goddess; from some fancied resemblance.) Calyx tube adherent to the ovary, 3-sided, limb 3-parted; petals none; stamens 3 ; stigmas 3 ; fruit 3-angled, 3 -celled, bony, crowned with the permanent calyx. - 4 Aquatic. Lvs. alternate.

1 P. palústris L. Lvs. linear-lanceolate, sharply serrate above the water, those below (if any) pinnatifid.-Ditches, swamps and ponds, often partly submerged, N. Eng., Fla. and La. Rt. creeping. Sts. ascending at base, 6 to $20^{\prime}$ high, striate, roundish. Lvs. 10 to $15^{\prime \prime}$ by 2 to $3^{\prime \prime}$, acute at each end, lower ones on short petioles and, if growing in water pinnatifid with linear segments. Fls. greenish, sessile, 1 to $\mathbf{3}$ together, in the axils of the upper leaves, succeeded by a very hard, triangular nut. $\mathrm{Jn}$., $\mathrm{Jl}$.

2 P. pectinàcea Lam. Los. all pectinate, with linear-subulate segm.; fr. obtusely 3-angled.-Sandy swamps, in Mass. (rare) S. to Fla. St. 5 to $10^{\prime}$ high, ascending at base from long, creeping roots Lvs. all finely and regularly divided into very narrow segments. Sty. 0; stig. attenuate above. Fr. rather smaller (less than $I^{\prime \prime}$ diam.) than in P. palustris, rugous when mature. J., Aug.

10. MYRIOPHYL'LUM, Vaill. Water Mrlforl. (Gr. $\mu v p i o s$, innumerable, $\phi \dot{\lambda} \lambda \lambda a$, leaves.) Flowers 8 , or frequently $\Varangle$; calyx 4 -toothed in the $\Varangle$ and $q$ flowers, 4-parted in the $\hat{o}$; petals 4 , often inconspicuous or none; stamens 4 to 8 ; stigmas 4 , pubescent, sessile; fruit of 4 , nut-like carpels, cohering by their inner anyles. - 4 submersed, aquatic herbs. Submersed lvs. parted into capillary segments. Upper fls. usually $\hat{\delta}$, middle ones $\Varangle$, lower $q$.

\$ Stamens 8. Carpels smooth and even. Leares whorled in 3 s...................... 1, 2

$\$$ stamens 4.-Carpels ridged on the baek. Lrs. whorled in 4 s and 5 s...................... 8,4

- Carpels sueoth and even. Lvs. alternate or wanting..................... 5, 6

I M. spicàtum L. Lvs. in verticils of $3 \mathrm{~s}$, all pinnately parted into capillary segments; fls. in terminal, nearly naked spikes; floral lvs. or bracts, ovate, entire, shorter than the fls., lowest ones subserrate and larger; petals broadly ovate; stam. 8 ; carp. smooth.-N. Eng. to Ark., in deep water, the fls. only rising above the surface. St. slender, branched, very long. Lvs. composed of innumerable, hair-like segments, always submerged. Fls greenish, sessile. Jl, Aug. .

2 M. verticillàtum $\mathrm{L}_{\text {. }} \mathrm{Lrs}$. in verticils of $3 \mathrm{~s}$, lower ones pinnately parted into opposite, capillary or setaceous segments; fls. in terminal, leafy spikies; floral lis. pectinate-pinnatifid, much longer than the fls.; petals oblong-obovate; stam. 8; carp. smooth. In stugnant water, Can. to Fla., W. to Or. St. long, less slender than in the last, only tho upper part emerging. Fls. small, green, axillary, with conspicuous floral Irs. Sep. acutc. Anth. oblong. Jl., Aug.

$3 \mathrm{M}$. heterophýllum $\mathrm{Mx}$. Lrs in rerticils of $5 \mathrm{~s}$, the lower ones pinnately parted into capillary lobes; spikes terminal, nearly naked; floral lvs, ovate-lanceolate, serrate, longer than the fls., crowded; petals oblong; stam. 4 to 6 ; carp. scabrous, with 2 slight ridges on the back.-In sluggish water, Can. to Fla. and Tex., rare. St. thick, branching. Lvs. very various, lowest floral ones pectinately divided. Petals somewhat persistent. Sepals minute. Bractlets serrulate. Jn.-Sept.

4 M. scabràtum Mx. Lvs. pinnatifid in whorls of $4 \mathrm{~s}$ and $5 \mathrm{~s}$; fis. verticillate, axillary, upper fls. $\hat{\delta}$, with 4 stam., lower ones 9 ; floral lvs. linear, pectinately toothed; fr. 8-angled, the ridges tuberculate.-Plymouth, Mass. (Oakes), Block Island (Robbins), S. and W. States. St. 6 to $12^{\prime}$ high. Segm. of the lrs linearcapillary.

$5 \mathrm{M}$. tenéllum Bw. Erect and almost leafless; floral lvs. or bracts alternate, minute, entire, obtuse; fls. $\overline{8}$; petals linear; stam. 4 ; carp. smootl, not ridgedAbout the edges of ponds and rivers, Providence, R. I. (Olney), northern part of 
N. Y. to Newfoundland. Rhizome prostrate, creeping, sending up several stems or scapes which are simple and 4 to $12^{\prime}$ high. Fls. small, purplish white, sessile, alternate, a little shorter than the braets, the upper ones $\hat{\delta}$. Jl.

6 M. ambiguum Nutt. Lvs. many, submersed ones pinnate, with capillary segments, niddle ones pectinate, upper linear, petiolate, toothed or entire; fls. mostly ६ ; petals oblong, somewhat persistent; stam. 4; carpels smooth, not ridged on the back.-In ponds and ditches, Penn. to Mass. Sts. floating, upper end emerged, with minute fls. and linear floral lvs. (M. natans DC.) In other situations it raries as follows.

$\beta$. LIMòsus Nutt. St. procumbent and rooting; lvs. all linear, rigid, often entire.-Muddy places, where it is a small, creeping and branching plant. (M. procumbens Bw.)

$\gamma$. CAPILLídeus Torr. Lrs. all immersed and capillary.-Ponds.

11. HIPPU'RIS, L. Mare's Tail. (Gr. ¿trtos, a horse, oípá, a tail.) Calyx with a minute, entire limb crowning the ovary; corolla none; stamen 1 , inserted on the margin of the calyx; anther 2-lobed, compressed; style 1 , longer than the stamen, stigmatic the whole length in a groove of the anther; sced 1.- 4 Aquatic herbs. St. simple. Lvs. verticillate, entire. Fls. axillary, minute.

H. vulgàris L. Lvs. in verticils of 8 to 12, linear, acute, smooth, entire; fls. solitary, often $q \not \xi \hat{\delta}$.- In the borders of ponds and lakes, Penn. to Arc. Am., very rare. Rhizome with long, verticillate fibers. St. erect, jointed, 1 to $2 \mathrm{f}$ high. The flowers are the simplest in structure of all that are called perfect, consisting merely of 1 stamen, 1 pistil, 1 seed in a 1-celled ovary, with neither calyx lobes nor corolla. May, Jn.

\section{Order LIII. LOASACEA. Loasads.}

Herbs often hispid with stinging hairs, with leaves opposito or alternate and no stipules. Filowers axillary, solitary. Culyx adherent to the ovary, 4 or 5-parted, lobes persistent, equal. Petals 5 or 10, in 2 circles, often cucullate, inserted on the calyx. Stamens indefinite, inserted with the petals, free or cohering in several sets. Ovary 1-celled, with several parietal placentse, or ono central. Sty'e 1. Ovrules pendulous. Embryo in the axis of fleshy albumen.

Gegnera 1S, species 70 , natives of America.

MENTZE'LIA, L. (In honor of C. Mentzel, physician to the Elector of Brandenburg.) Calyx tubular, limb 5-parted; petals 5 to 10 , flat, spreading; stamens $\infty, 30$ to 200 ; ovary inferior; styles 3 , filiform, connate, and often spirally twisted; stigmas simple, minute; capsule 1 celled, many-seeded.-Branching herbs. Lvs. alternate.

1 M. oligospérma Nutt. Very rough, with barbed hairs; st. dichotomous; lvs. ovate-lanceolate, tapering to very short petioles, lobed or incisely dentate; petals entire, cuspidate, expanding in sunshine; stam. 20 or more, shorter than the petals; caps. 3 to 5-seeded. - 4 Dry or rocky places, Pike Co., IIl. (Mead), and Mo. to Tex. Rt. tuberous. St. If high, divaricately branched. Lvs. 10 to $15^{\prime \prime}$ by 6 to $8^{\prime \prime}$, upper ones orate. Fls. solitary, of a deep, golden yellow, 8 to $10^{\prime \prime}$ diam, very fugacious. Caps. cylindric, very small. May-Jl.

2 M. Líndleyi Torr. \& Gr. Golden BalzToNid. Hispid; lvs. ovate-lanceolate, pinnatifid, lobes often dentate; fls. solitary or nearly so, terminal; petals broadly obovate, very abruptly acuminate; filaments filiform, and with the seeds numerous.-(1) Gardens. St. decumbent, branching, 1 to $3 \mathrm{f}$ in length, with golden yellow fls. 2 to $3^{\prime}$ diam., the beauty of which is greatly heiglitened by innumerable, thread-like, yellow stamens. (Bartonia aurea Lindl.) † California 


\section{Order LIV. CACTACEA. Indian Figs.}

Stems suceulent and shrubby, usually angular or 2-edged or jointed. Leaves almost always wanting; prickles numèrous and formidable. Flowers solitary, usnally showy and of short duration. Sepals and petals often indefinite and confounded with each other, the sepals from the surface, and the petals from the summit of the ovary. Stam. $\infty$; filaments long and filiform; anth. ovate, versatile. Ovaries inferior, 1-celled, fleshy, with parietal placentre. Style single, filiform, with several stigmas in a star-like cluster. Fr. succulent. Seeds numerous, parietal or in tho pulp, exalbuminous. (Illust. in fig. $47, b$.)

Gexera 18 , species about 800 , all peculiarly A nerican, no one having ever been found in any other quarter of the globe. They abound in the deserts of New Mexico and southward. The prickly pear (Opuntia vulgaris) is the only species found native as far north as $\mathrm{N}$. York. Their aspect is peculiar, usually distinguishable ut sight.

Stignmas $\infty$. Calyx tube not prolonged. Berry tubercular, umbilicate...... Opurtid i

Stigmas $\infty$. Calyx tube prolonged abovo the ovary. Berry areolate, \&c.... Curets 2

Stigmas 5 to 7 -Calyx tubo prolonged. Berry smooth. Axis grooved.......MrLocactus 3

- Calyx tube short. Berry smooth. Axis mammiferous........Man.uzliaria 4

1. OPUn'TIA, Tourn. Prickly Pear. (Opuntianá was a country near Phocis, where this was said to be naturalized.) Sepals and petals numerous, adnate to the ovary, not produced into a tube above it; stamens $\infty$, shorter than the petals; style with numerous, thick, erect stigmas; berry umbilicate at apex, tuberculate, cotyledons semiterete. - Shrubby plants, with articulated branches, the joints usually broad and flattened, with fascicles of prickles, regularly arranged upon the surface.

O. vulgàris Mill. Prostrate, creeping; joints ovate; prickles numerous in each fascicle, often with several subulate spines; lvs. minute, subulate from a broad base; fls. yellow.-A curious, fleshy plant, native in rocky and sandy places, Mass. to Fla. W. to Iowa. The singular form resembles a series of thick, fleshy leaves, 4 to $6^{\prime}$ long, $\frac{2}{3}$ as wide, growing from the tip or sides of each other, and armed with orange-colored spines from the edge of the joints, large, bright-yellow, and succeeded by a smooth, crimson, eatable fruit- + (Cactus opuntia L.)

2. CE'REUS, DC. Sepals very numerous, imbricated, adnate to the base of the ovary and united into a long tube above it, the outer shorter, the inner petaloid; stamens indefinite, coherent with the tube, style filiform, with many stigmas; berry scaly with the remains of the sepals; cotyledons none?-Fleshy shrubs, with woody, prismatic axcs, armed with clusters of spines. Fls. from the clusters of spines.

$\$$ Stock and branches compressed, somewhat leaf-like............................ 1-3

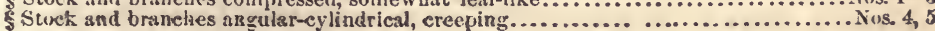

1 C. phyllánthus DC. SPLEENworT. Brauches ensiform, Compressed, scrrate; fls. with the terete, slender tube much longer than the limb of the petals.-From S. Am. The articulations of the stem are $2 f$ or more long, $2^{\prime}$ wide, weak, bordered with large, obtuso serratures, and traversed lengthwise by a central, cylindrical, woody axis. Fls. white, 9 to $12^{\prime}$ long, expanding by night, fragrant. $\dagger$

2 C. phyllanthoides DC. Branches ensiform, compressed, obovate, with spreading, rounded teeth; fls arising from the lateral crenatures of tho branches; tube shorter than the limb of the petals. - From Mexico. A splendid flosver, with leaf-like, fleshy joints, each 6 to $10^{\prime}$ long, 1 to $2^{\prime}$ wide. Fls. rose-colored, $4^{\prime}$ in length, expanding by day.

3 C. truncàtus I. Branching; joints short-compressed, serrate, truncato at the summit; fls. arising from the summit of the joints; sty. longer than tho stam. or reflexed pet.-From Brazil. A very distinet species, a foot or more high. Joints 2 to $3^{\prime}$ long, 1 to $1 \frac{1}{2}$ wide, leaf-like. Fls. 2 to $3^{\prime}$ long, pink-colored. + (Cactus L.) 
4 C. grandiflòrus DC. Creeping, rooting; st. with about 5 angles; fis. terminal and lateral, very large, nucturnal; petals spreading, shorter than the linear-lanceolato sepals.-Mexico. West Indies. Sts. cylindric or prismatic, branching, the angles not very prominent. Fls. expanding by night, and enduring but a fow hours, 8 to 12 ' diam. Sepals brown without, jellow within. Petals white. A magnificent flower, of difticult culture. $\dagger$

5 C. flagellifórmis DC. Sxake CActus. St. creeping, with about 10 angles, hispid; fls. lateral, diurnal; tube slender, longer than the limb of the petals.-From S. Am. St. abont tho sizo of the little finger, cylindric, indistinctly articulated, 2 to $5 \mathrm{f}$ long. Fls. of a lively pink color, smaller than those of the last, and continuing in bloom several days. $\dagger$

3. MelocaC'TUS, Bauh. Melon Thistle. Turk's Cap. (Compounded of melon and cactus, from its form.) Calyx tube adherent to the ovary, lobes 5 to 6 , petaloid; petals as many as sepals, united with them into a long, cylindric tube; stamens and style filiform; stigma 5rayed; berry smooth, crowned with the withered calyx and corolla.Suffruticous, fleshy, leafless. Spadix simple, crowning the globular, decply-furrowed axis. Fls. terminal.

M. communis Link. Axis ovate-subglobous, dark green, 12 to 18-angled; ribs straight; spines fasciculate, subequal-Native of the Caribbean Islands. This remarkable plant appears like a large, green melon, with deep furrows and prominent ribs, and is full of juice. It is surmounted with a spadix, which is cylindric, tuberculate, densely tomentous, bearing the red flowers at the summit. $\dagger$

4. MAMMILA'RIA, Hawarth. (Lat mamma, the breasts; alluding to the tubercles.) Flowers and fruit similar to the preceding genus.Stock roundish or cylindrical, covered with conical or mammæform tubercles, spirally arranged and tipped with a cluster of spines in wool. Fls. sessile among the tubercles.

M. macrómeris Engelm. Bright green, with large, pear-shaped tubercles, each surmounted by a cluster of straight, slender spines, and large (near $3^{\prime}$ diam.) carmine-roseate flowers. † From Now MIexico. - Other species are cultivated in the green-house.

\section{Order li. Grossulace . Currants.}

Low shrubs, often prickly with alternate, palmately lobed leaves. CALYx 5-lobed, adherent to tho 1-cellod ovary, bearing at top the corolla of 5 petals alternating with the 5 short stamens. Anth. introrso. Fruit a 1-celled, inferior berry with 2 parietal placentie. Styles 2 . Seeds $\infty$, emlryo minute, in abundant horny albumen. (Figs. 67, 309.)

Genera 1, species 95 . The gooseberries and enrrants are natives of the $\mathbb{N}$. temperate zone of both continents, but unknown in the tropics or $\mathrm{S}$. hemisphere, except $\mathrm{S}$. America.

Properties. The berries contain a sweet, mneilaginons pulp, tugether with malic or citric acid. They are always wholesome, and usually esculent.

1. RI'BES, L. Currants. (Named from the Arabic.) Character the same as that of the Order.

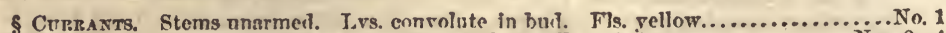

S Curravis. Stems unarmed. Lvs. plicate in bud. - Fruit hairy .......................... 2-4

-Fruit smonth................. Nos. $5-7$

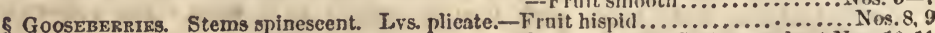
-Fruit sinuoth.-Pei. very short.Nos.10, 11 - Ped. long....... Nos. 12-14

1 R. aùreum Ph. Missouri, or Golden Currant. Plant smooth; ivs. 3-lobed, lobes divaricate, entire or with a few large teeth; petioles longer than the leaves; bracts linear, as long as the pedicels; rac. lax, with many bright yellow fls.; cal. tubular, longer than the pedicels, segm. oblong, obtuse; petals 
linear; fr. smooth, oblong or globous, yellow, finally brown.-Mo., W. to Or. $\Lambda$ beautiful shrub 6 to $10 \mathrm{f}^{\circ}$ high, common in cultivation. Fls. numerous, very fragrant. Apr., May. $\nmid$

2 R. sanguíneum Ph. Lvs. canescent-tomentous beneath; glabrous abore, cordate, 3 to 5-lobed, doubly serrate; rac. long and looso; bracts red, spatulate, rather longer than the pedicels; fls. rose-red; cal. tubular-campanulate, segm. spreading, obovate, as long as the spatulate petals; sty. united into 1; stig. 2-lobed; fr. dryish, with sparso glandular hairs.-Oregon (Rev. G. Atkinson). $\Lambda$ beautiful shrub with largo showy racemes. $\dagger$

$3 \mathbf{R}$. resinòsum Ph. Plant clothed throughout with resinous-glandular hairs; lvs. 3 to 5-lobed, roundish; rac. erect; cal. segm. spreading; petals obtusely rhomboidal; bracts linear, longer than the pedicels; fr. hairy.-Mts. of N. Car. (Parker. Seo N. Am. Fl. p. 55c). We have seen no specimens of this obscuro species.

4 R. prostràtum L'Her. Modxtarn Curraxt. St. reclined; lvs. smooth, deeply cordate, 5 to 7 -lobed, doubly serrate, reticulate-rugous; rac. erect, lax, many-flowered; cal rotate ; berries globous, glandular-hispid, red.-A small sbrub, on mountains and rocky hills, Penn. to Can., ill-scented and with ill-flavored berriessometimes called Sliunk Currant. Prostrate stems, with erect, straight branches. Lrs. about as large as in No. 1, lobes acute. Petioles elongated. Rac. about 8 -flowered, becoming erect in fruit. Bracts very short. Fls. marked with purple. Berries rather large. May. (R. rigens $\mathrm{Mx}$.)

5 R. rùbrum L. CommoN Red Currant. Lvs. obtusely 3 to 5-lobed, smooth above, pubescent beneath, subcordate at base, margin mucronately serrate; rac. nearly smooth, pendulous; cal. short, rotate; bracts much shorter than the pedicels; fr. globous, glabrous, red.-Woods, St. Johnsbury, Vt. (Carey), Wis. (Lapham), N. to the Arc. Ocean. Cultivated universally in gardens.

$\beta$. (WHITE CURRANT). Fr. light amber-colored, larger and sweeter.

6 R. flòridum I'Her. WILD BLACK CuRraxt. Lvs. subcordate, 3 to 5-lobed, sprinkled on both sides with yellowish, resinous dots; rac. many-flowered, pendu. lous, pubescent; cal. cylindrical; bracts linear, longer than the pedicels; fr. obovoid, smooth, black.-A handsome shrub in woods and hedges, Can. to Ky., common, 3 to 4 f high. Lvs. 1 to $2^{\prime}$ long, the width something more, lobes acute, spreading, 3, sometimes with 2 small additional ones; dots just visible to the naked eye. Petioles 1 to $2^{\prime}$ long. Fls. rather bell-shaped, greenish yellow. Fr. insipid. May, Jn.

7 R. nìgrum I. BLACK CURRANT. Lvs. 3 to 5-lobed, punctate with yellonish dots beneath, dentate-serrate, longer than their petioles; rac. lax, hairy, somewhat nodding; cal. campanulato; bracts nearly equaling the pedicels; fr. roundishovoid, nearly black.-Native of Europe, etc. Cultivated and esteemed for its medicinal jelly. Fls. yellowish.-This species much resembles R. floridum.

8 R. Cynósbati L. Prickiy Gooseberry. St. prickly or not; subaxillary spines about in pairs; lvs. cordate, 3 to 5 -lobed, pubescent, lobes incisely dentate; rac. nodding, 2, to 3-flowered; cal. tube ovate-cylindric, longer than tho segm.; pet. obovate, shorter than the cal. segm.; sty. united to the top; berries prickly. -N. and W. States, about $4 \mathrm{f}$ high, in hedges and thickets, mostly without prickles, but armed with 1 to 3 sharp spines just balow the axil of each leaf. Petioles downy. Fls. greenish whitc. Fr. mostly covered with long prickles, brownish-purple, eatable. May, Jn.

9 R. lacústre Poir. Swamp GooseberRy. St. covered with prickles; subaxillary spines several; lvs. deeply 3 to 5 -lobed, cordate at base, lobes deeply incised; rac. 5 to 8 -flowered, pilous; cal. rotate, sty. 2-cleft; berries small, hispid.-In swamps, N. States, and Brit. Am. Shrub 3 to 4 f high. Sts. reddish from tho numerous prickles, which differ from the spines only in size. Lvs. shining above, $1 \frac{1}{2}$ to $2 \frac{1}{2}^{\prime}$ diam. Petioles ciliate, hispid, longer than tho lvs. Fls. green. Fr. covered with long prickles, dark purple, disagreeable. May.-The older stems are unarmed save with a few spines.

10 R. hirtéllum Mx. St. unarmed, rarely prickly; subaxillary spines short, solitary, or nearly so; lvs. roundish, cordate, 3 to 5 -lobed, toothed, pubescent beneath; ped. short, 1. to 2 -Howered; cal. tube smooth, campanulate, segrm. twico 
longer than the petals ; stam. longer than either; sty. hairy, 2-cleft ; fr. smooth.In rocky woods, N. H. and Mass. to Wisc. N. to Hudson's Bay. Lvs. 9 to $18^{\prime \prime}$ diam., generally cleft half way to the middle. Fls. nodding, greenish. Fr. purple. May, Jn. (R. triflorum Bw. R. saxasum Hook.)

11 R. oxycanthoides L. St. clothed with bristly prickles; subaxillary spines 3 , often fower, united at base; lvs. 5-lobed, roundish, subcordate, cat-dentate; ped. about 2-flowered, very short; cal. tube cylindric; sty. cleft half way; fr. smooth. Can., in rocky woods. Readily distinguished from No. 10 by its numerous prickles, but somo of its forms are nearly destitute of them. Fr. bluish purple.

12 R. rotundifòlium Mx. Subaxillary spines mostly solitary, short; lvs. roundish, smooth, 3 to 5 -lobed. incisely crenate-dentate; ped. smooth, 1 to 3 -flowered; cal. cylindrical, smooth, segm. linear, finally reflexed; pet. spatulate, unguiculate; stam. and 2-parted sty. slender, much exserted, smooth; berries smooth.-In woods, N. H. to N. Car. and Mo. Shrub 3 to $4 \mathrm{f}$ high. Sts. with a whitish bark, the younger often prickly. (R. Missouriense Nutt.) Lvs. 1 to $2^{\prime}$ diam, $_{7}$ mostly truncate at base, shining above. Petioles ciliate, 1 to $3^{\prime}$ long. Petals yellowish-white. Fr. purple, delicious, resembling the garden gooseberry. May.

I3 R. grácile Mx. Pubescent; st. scarcely prickly; subaxillary spines 1 to 3 , short, very slender; lvs. roundish, 3 -lobed; ped. 1 to 2 -flowered, long and slender; cal, tube much shorter than the linear, recurved segm.; pet. very small; fi. smooth. Arts. of Tenn. and Ala. Apr.-Probably another variety of No. 12.

14 R. Uva-críspa L. ENGLisH, or GARDEN GooseberRY. St. prickly; Ivs. roundish, 3 to 5 -lobed, hairy beneath, on short, hairy petioles; ped. hair'y, 1-flowered; cal. campanulate; sty. and ova. hairy; fr. smooth or hairy, globous.Gardens. Long eultivated, until there are several hundred varieties, with red, white, green, and amber fruit, often weighing an ounce or more each. Apr. $\ddagger$ Eur.

\section{Order LVI. TURNERACEA.}

Herbs with simple, alternate, exstipulate leaves, with tho solitary Flowers 5-merous, the petals and stamens inserted on the throat of the calyx. Ovary free, 1-celled, with 3 parietal placentæ; styles 3, distinct. Fruit a 3-valved capsule; seeds albuminous, strophiolate.

Genera 2, species 60, confined (with one exception) to tropica. America Prapertics, tonic and aromatic.

TUREERA, Plum. (In memory of Wm. Turner, M.D., author of "A New Herball," London, 1551.) Calyx funnel-form; petals convolute in restivation, longer than the imbricated sepals; styles 3 ; stigmas flabellate, many-cleft; capsule dehiscing to the middle.-Fls. showy, yellow.

T. cistoìdes L. Plant hirsute, erect; fls. in the upper axils and terminal; ped. bractless, but jointed near the middle; lvs. lanceolate, obtusely serrate or entire, subsessile, obtuse, the lower oblong-oval. - 2f Ga. from Savannah, along the railroad, westward (Feay, Pond), and Fla. Sts. 12 to $18^{\prime}$ high, simple or branched from the base. Lvs. 1 to $2^{\prime}$ long. Fls. in a leafy, terminal rac. Ped. $9^{\prime \prime}$ long. Fls. dimorphous (some with the stam. longer, others with the pistils longer). Cor. $1^{\prime}$ diam., deep yellow. Caps. globular, downy. Sds. obovate, sculptured, the membranous caruncle lateral. Jn. - Sept.

\section{Order LVII. PASSIFLORACE.E. Passionworts.}

Piants herbaceous or shrubby, usually climbing, with alternato lvs. and foliaceous stipules. Fls. axillary or terminal, perfect. often with a 3-leaved involucre. Sepais 4 to 5 , united below into a tube, the sides and throat of which are crowned with circles of filamentous processes, which appear to be metamorphosed petals. Petals 5, arising from the throat of the calyx, outside the crown. Stamens 5, monodel- 
phous, surrounding the stipe of the ovary. Ovary superior, on a long stipe, 1-celled; styles 3 . Fruit many-seeded. (Illust. in figs. $48,148,371,372$. )

Genera 12, species 210, chiefly natives of tropical A merica, but cultivated in many otler coun. tries as ornamental tlowers. The fruit of the Granadilla (Passiflora multiformis) is eaten in tho WV. Indies, and highly valued as a dessert, but the root is poisonous.

PASSIFLO'RA, L. Passion Flower. (Lat. flos passionis; the several parts of the flower were compared to the instruments of the Saviour's passion, viz., the cross, the nails, and the crown of thorns.) Calyx colored, deeply 5-parted, the throat with a complex, filamentous crown; petals 5 ; sometimes 0 ; stamens 5 , connate with the stipe of the ovary; anthers large; stigmas 3 , large, clavate, capitate; fruit a pulpy berry.-Climbing herbs or shrubs. Fls. large, of a singular and wonderful structure. (Fig. 372.)

1 P. cœrùlea L. Shrubby; lvs. palmately and deeply 5-parted; segm. linearoblong, entire, lateral ones often 2-lobed; pet. glandular, with a 3-bracteolate involucro near the flower; bractlets entire; fil. of the crown shorter than the cor. -Native of Brazil, where it grows to the thickness of a man's arm and to the height of 30f. Fls. large and beautiful, blue externally, white and purple within, continuing but one day. Fr. ovoid, yellow. $\nmid$

2 P. incarnàta L. Lvs. deeply 3-lobed, lobes oblong, acute, serrate, petioles with 2 glands near the summit; bractlets of the involucre 3, obovate-glandular; crown triple.-Va. to Fla. Sts. climbing 20 to 30f. Fls. large and showy. Petals white. Two outer rows of filaments, long, purple, with a whitish band, the inner row of short rays, flesh-colored. Berry palo yellow, of the size of an apple, eatable. May-JL.

3 P. Iùtea L. Lvs. glabrous, cordate, 3-lobed, obtuse; petioles without glands; ped. mostly in pairs ; pet. narrower and much longer than the sep.-A slender climber, 5 to 10 long, in woods and thickets, Ohio and S. States. Lvs. yellowish green, nearly as broad as long. Fls. small and greenish yellow. Corona in 3 rows, the inner row a membranous disk with a fringed border. Fr. dark purple. May-Jl.

\section{Order LVIII. CUCURBITACE A. Cucurbits.}

IJerbs succulent, creeping or climbing by tendrils, with alternate leaves. Flowers monœecious or polygamous, never bluc. Calyx 5-toothed, adherent. Petals 5, united, inserted on the calyx, tho lobes alternating. Stamens 5, distinct, generally cohering in 3 sets. Anthers very long and wavy or twisted. Ovary inferior, 1-celled, with 3 parietal placentro often filling the cells. Fruit a pepo or membranous. Seeds flat, with no albumen, often ariled. (Fig. 442.)

Genera 60 , species 300 , natives of tropical regions, only a few heing found in the temperato zones of Europe and America. A highly important order of plants, affording some of the most delicious and nutritive fruit. A bitter laxative principlo pervades the group, which is so concen- trated in a few as to render them actively medicinal. The officinal colocynth is prepared froun the pulp of Cucumis Colocynthis, a powerful drastic poison.

$\S$ Corolla white, -6 -cleft. Stigmas 2 . Fruit echinate................... Ecruxocrstı. 1

-5-petalled. Pepo smooth, many-seeded........................... 2

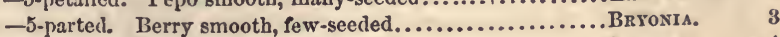

-5 -lobed. Fruit prickly, 1-seeded..................... Sicros. 4

$\$$ Corolla yellow, -5 -lobed. Berry small, smooth, $\infty$-seedel....................... 5

-5-lobed. Pepo large. Seerls thick at edge............... Cucurbita. 6

-5-cleft. Pepo large.-Seeds colorerl, thick-edged.......... Crrnuluus. $\quad 7$

-Seeds white, acute-edged............. Cucumrs. 8

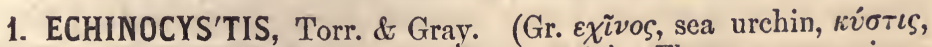
bladder; alluding to the spiny, inflated fruit.) Flowers monœcious. Sterile fi.-Calyx of 6 filiform-subulate segments, shorter than the corolla; petals 6 , united at base into a rotate campanulate corolla; sta- 
mens 3, diadelphors. Fertile fls.-Cal. and cor. as above; abortive fil. 3 , distinct, minute; style very short; stigmas 2 , large ; fruit roundish, inflated, echinate, 4-seeded.-(1) A climbing herb with branched tendrils.

5. lobàta Torr. \& Gr. A smootlish, running rine in rich river soils, Can. to Penn. and Mo. St. deeply furrowed, with long, 3-parted tendrils placed nearly opposito the long petioles. Lvs. membranous, palmately 5 -lobed, cordate at base, lokes acuminate, denticulate. Fls. small, white, the barren ones very numerous, in axillary racernes often If lorz; fertilo ones solitary or several; situated at the base of the raceme. Fr. 1 to $2^{\prime}$ in length, setose-echinate, at length dry and membranous, with 4 large seeds. J1.-Sept. (Sicyos Mx. Momordica echinata Muhl.)

2. LAGENA'RIA, Sez. Gound. (Gr. $\lambda a ́ \gamma \eta v o s$, a flagon or bottle; from the form of the fruit.) Flowers 8 . Calyx campanulate, 5 -toothed; petals 5, obovate. $\delta$ Stamens 5, triadelphous; anthers very long, contorted. I Stigmas 3, thick, 2-lobed, subsessile ; pepo ligneous, 1-celled; seeds ariled, obccrdate, compressed, margin tumid.-Nostly climbing by tendrils.

L. vulgèris Ser. CaLABaSH. BotTLe GouRd. Softly pubescent; st. climbing by brenching tendrils; lvs. roundish-cordate, abruptly acuminate, denticulate, with 2 glands beneath at base; fls. axillary, solitary, pedunculate; fr. clavate, ventrico'is, at length smooth.-(1) Gardens. The hard, woody rind of the fruit is used as ladles, bottles, \&c. Fls. white. Jl, Aug. $\ddagger$ Tropical.

3. SRYO'NIA, L. Bryony. (Gr. $\beta \rho v ́ \omega$, to grow rapidly.) Flowers 8 or $\delta$ ㅇ. Calyx 5 -toothed, teeth short; corolla 5 -cleft or parted; $\hat{\delta}$ stamens 5 , triadelphous, with flexuous anthers; $q$ style trifid; berry small, globular, few-seeded.-Fls. greenish white.

B. Boylzínii Torr. \& Gr. Scabrous pubescent; lvs. deeply 3 to 5 -lobed, cordate, denticulate, acuminate-cuspidate; fls. (small) clustered in the axils, both kinds together, on short pedicels; berries oval, 3-seeded.-In wet grounds, along streams, Ga. to La. (Hale). Sts. 10 to $20 \mathrm{f}$ long, climbing over bushes by simple or forked tendrils. Fr. as large as a small plum, bright crimson, changing to yellow. The seeds with 2 lateral teeth. Jn., Jl.

4. SIC'YOS, L. Single-seed Cucumber. (Gr. oikvos, the ancient name of the cucumber.) Flowers 8 . $\hat{\delta}$ Calyx 5 -toothed; corolla rotate, 5 -petaled ; stamens 5 , monadelphons, or at length triadelphous, anthers contorted. \& Calyx 5-toothed, campanulate; petals 5 , united at base into a campanulate corolla ; styles 3 , united at base ; fruit ovate, membranous, hispid or echinate, with one large, compressed seed.-(1) Climbing herbs, with compound tendrils. Sterile and fertile fls. in the same axils.

S. angulàtus L. St. branching, hairy; lvs. roundish, cordate, with an obtuse sinus, 5-angled or 5-lobed, lobes acuminate, denticulato; of much smaller than $\hat{\delta}$. Can. and U.S. A weak climbing vine, with long, spiral, branching tendrils. Lrs. 3 to $4^{\prime}$ broad, alternate, on long stalks. Fls. whitish, marked with green lines, the barren in long pedunculate rac. Fr. $6^{\prime \prime}$ long, ovate, spinous, 8 to 10 together in a crowded cluster, each with one large seed. J. Sept.

5. MELO'THRIA, L. (Gr. $\mu \tilde{\eta} \lambda \partial \nu$, a melon, $\theta$ piov, a certain food.) Flowers $q . \not \hat{\delta}$ or 8 . Calyx infundibuliform-campanulate, limb in 5 subulate segments; petals 5 , united into a campanulate corolla. $\hat{s}$ Stamens 5, triadelphous. $q$ Stigmas 3 ; fruit a berry, ovoid, small, many-seeded.-Tendrils simple, filiform. 
M. péndula L. Lrs. roundish, cordate, 5-lobed or angled, pointed, slightly hispid; fis. axillary, the sterile in small racemes, the fertilo solitary, on long peduncles. N. Y. to Ga. and La. A delicately slender vine, climbing over other plants. Lrs. small (1 to $2^{\prime}$ diam.) Fls. small, yellowish. Sty. short, surrounded by a cup-shaped disk. Fr. small, oval. Jl.

6. CUCUR'BITA, L. Seuasi. (A Latin word, signifying a vessel; from the form of the fruit.) Fls. 8 . Corolla campanulate; petals united and colerent with the calyx. of Calyx 5-toothed; stamens 5s" triadelphous, anthers syngenecious, straight, parallel. \& Calyx 5toothed, upper part deciduous after flowering ; stigmas 3, thick, 2-lobed; pepo fleshy or ligneous, 3 to 5-celled; seeds thickened at margin, obovate, compressed, smooth.-Fls. mostly yellow.

1 C. pèpo L. PUMPKIN. Hispid and scabrous; st. procumbent; tendrils branched; Ivs. (very large) cordate, palmately 5-lobed or angled, denticulate; fls. axillary, $\hat{o}$ long-pedunculate; $f r$. very large, roundish or oblong, smooth, furrowed and torulous.-1) Fields. Long cultivated as a useful kitchen vegetable or for cattle. Fls. large, yellow. Fr. sometimes $3 \mathrm{f}$ diam., yellow when mature, yielding sugar abundantly. Jl. $\ddagger$ Levant.

2 C. Melopèpo I. FLAT SQUASI. Hairy; st. procumbent, with branched tendrils; lvs. cordate, palmately somewhat 5-lobed, denticulate; fls. pedunculate; fr. depressed-orbicular, the margin mostly torulous or tumid, smooth or warty.Gardens. Cultivated for its fruit, a well known kitchen vegetable. There are many varieties in respect to the fruit. $\ddagger$ Nativity ?

3 c. verrucòsa L. Warted Squash. Crook-Neck SQUash, \&c. Hairy, procumbent, lvs. cordate, palmately and deeply 5-lobed, denticulate, terminal lobe narrowed at base; fls. pedunculate, large; fr. roundish elliptic or clavate, often elongated and incurved at base.-(1) Mentioned by Nuttall as long cultivated by the Indians W. of the Mississippi. Common in our gardens, with numerous well known varieties of the fruit. Jl. $\ddagger$

7. CITRUL'LUS, Neck. Watermelon. (Lat. citrus, an orange.) Calyx deeply 5-cleft, segments linear-laneeolate; petals 5, united at base and adnate to the bottom of the calyx; stamens 5 , triadelphous; style trifid ; stigmas convex, reniform-cordate ; fruit subglobous, fleshy, the succulent placentæ filling the cell; seeds colored, numerous, truncate at base and obtuse on the margin.

C. vulgàris Schrad. Hirsute; st. prostrate, slender; 1vs. somewhat 5-lobed, the lobes obtusely sinuate-pinnatifid, glaucous beneath; fls. solitary, pedunculate, with a single bract; fr. globous or oval, smooth, stellate-maculate.-Extensively cultivated for its well-known delicious, cooling fruit. Fl. Jn.-Aug. Fr. Aug., Sept.-A variety is the citron, a smaller fruit with thicker and firmer rind $\ddagger$ India. Afr.

8. CU'CUMis, L. Cucumber. (Celtic cuce, a hollow vessel ?) Flowers 8 or $\measuredangle$. Calyx tubular-campanulate, with subulate segments; . corolla deeply 5-parted. of Stamens 5, triadelphous. \& Style short; stigmas 3, thick, 2-lobed; pepo fleshy, indehiscent; seeds ovate, flat, acute, and not margined at the edge.-Creeping or climbing by tendrils. Fls. axillary, solitary, yellow.

1 C. sativus L. CUCUMBER. St. prostrate, rough; tendrils simple; Irs. subcordate, broad as long, palmately 5-angled or lobed, lobes subentire, acute, terminal one longest; fr. oblong, obtusely prismatic, prickly, on a short peduncle. - (1) First brought to England in 1573. It is now universally cultivated for the table, either fresh or pickled. Gathered and eaten before maturity. Jn.-Sept. Many varieties.

2 C. Mèlo I. Musk MELoN. St. prostrate, rough, tendrils simple; IVs. subcordate, roundish, obtuse, palmately 5 -angled, lobes rounded, obtuse, obscurely 
denticulate; fls. $q \not \xi \hat{\delta}$, the $\not{q}$ on short peduncles; fr. oval or subglobous, smooth, longitudinally torulous. - (1) Native of Asia, whence it was first brought to England in 1570. Generally cultivated for the juicy, yellowish, delicately flavored flesh of the mature fruit. Jn., Jl. Varieties numerous.

3 C. Angùria I. Prickly Cucumber. St. prostrate, slender, hispid; tendrils simple; lvs. palmately and deeply sinuate-lobed, cordato at base; fr. ovalovoid, or subglobous, echinate. - (1) Cultivated for the green fruit, which is about the size of a hen's egg, and used for pickles. Jl, Aug. $\ddagger$ Jamaica.

4 C. Colocýnthis I. Colocystr. St. prostrate, subhispid; lvs. cordateovate, cleft into many obtuse lobes, hairy-canescent beneath; tendrils short; fls. axillary, pedunculate; $q$ with a globous, hispid cal. tube and campanulate limb, with small petals; $f r$. globous, yellow when ripe, about as large as an orange, and intolerably bitter.-The extract is the colocynth of the shops, poisonous, but medicinal. † From Turkey.

5 C. angùinus L. Serpent Cucusrer. Sts. climbing; 1rs. 3 to 5-lobed, repand-dentate; tendrils forked; $f r$. very long, smooth, cylindrical, coiled.-Cultivated for the curiosity of the long, snake-like fruit. $\dagger \mathrm{E}$. Ind.

\section{Order LIX. BEGONIACEAE. Begoniads.}

Herbs or succulent undershrubs with an acrid juice. Leaves alternate, obliquo at the base, with large, scarious stipules. Flowers diclinous, pink-colored, cymous. Calyx adherent, colored. Sepals of the $f 2$ pairs, decussating; of the $\& 5$, imbricated, or 8. Stamens $\infty$, distinct or coherent in a column. Anthers clustered. Qvary inferior, 3-celled, with 3 large placentr meeting in the axis. Seeds minute, without albumen. Fruit capsular. (Fig. 270.)

Genera 4, species 160, mostly natives of the Indies and S. America-none N. American. They are frequently cultivated as curious and ornamental. Properties astringont and bitter.

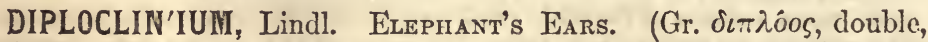
$\kappa \lambda i v \eta$, couch; alluding to the double placentæ.) Fls. 8.- $\hat{8}$ Sepals orbicular, colored like the petals, but larger; petals oblong, acute; stamens combined in a column; anthers in a globous head. o Sepals 3 , lanceolate, larger than the 2 petals; stigma lobes distinct, spiral, erect; capsu!e wings unequal ; placentæ double, or 2 in each cell.Evergreen, succulent undershrubs.

D. Evansiànum Lindl. Glabrous; st. branched, tumid and colored at the joints, succulent; lvs. large, slightly angular, mucronate-serrate, cordate-ovate, very unequal at base, petiolate, with weak, scattered prickles, and straight, red reins, tho under surface deeply reddened; fls. pink-colored in all their parts, except the golden yellow anthers and stigmas; $q$ larger than the $\hat{f}$, and on peduncles twice as long. From China. (Begonia discolor Willd.)-Many other species are found in conservatories-too many for our limits.

\section{Order LX. CrassUlaCEA. House-Leeks.}

Plants herbaceous or shrubby, succulent. Lvs. entire or pinnatifid. Stip. 0. Flowers sessile, usually in cymes and perfectly symmetrical. Sepals 3 to 20 , more or less united at base, persistent. Petals as many as the sepals, distinct, rarely cohering. Stamens as many as tho petals, and alternating with them, or twice as many. Ovary as many as the petals and opposite them. Fil. distinct. Anth. 2-celled, bursting lengthwise. Fruit, follicles as many as the ovaries, each opening by the ventral suture, many-seeded. (Figs. 260, 261.)

Genera 22, species 450 , chiefly natives of the warmer regions of the globe, particularly the Cape of Gool lifope. About 20 are found in N. America. They grow in the thinnest and driest soil, on nakeil rocks, sandy deserts, etc. They have no peculiar property except a slight acridi:8. Many are highly ornamental. 
Trase 1. Crassoxfa. Carpels distinct, forming a clrcle of follicles. (a)

a Flowers all 4-parted. Stamens $4 \ldots \ldots \ldots \ldots \ldots \ldots \ldots \ldots \ldots \ldots$ TruzA.

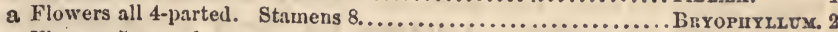

a Flowers 5-parted, or 4 and 5-parted. Petals distinct, spreading.Sedur.

a Flowers 5 -parted. Petals united below, erect, connivent ........ Ecrievreria. 4

a Flowers 6 to 20-parted. Iy pogynous scales laciniatc............. Semprirviver. 5

Tribe 2. Diamorpies. Carpels united Into a many-celled capsule. (b)

b Flowers 4-parted. Stamens 8 ......... Diamorpra. 6

b Flowers 5-parted. Stamens $10 \ldots . . .$. Pestronum. $\quad$.

1. TILle'A, Mx. Pigmy-weed. (To Michael Angelo Tilli, an Italian botanist; died 1740.) Calyx of 3 or 4 sepals united at base; petals 3 or 4 , equal; stamens 3 or 4 ; capsules 3 or 4 , distinct, follicular, opening by the inner surface, 2 or many-seeded.-(1) Very minute, aquatic herbs. Lvs. opposite.

T. símplex Nutt. St. ascending or erect, rooting at the lower joints; lrs. connate at base, linear-oblong, fleshy; fls. axillary, solitary, subsessile, their parts in 4s; pet. oval or oblong; carpels 8 to 10-seeded.-Near East Rock, Now Haven, Ct. (Dr. Robbin s), and Philadelphia, on muddy banks, rare. St. 1 to $3^{\prime}$ high. Livs. 2 to $3^{\prime \prime}$ long. Fls. as large as a pin's head. Petals oval, flat, acute, twice as long as the oval, minute calyx, longer than the stamens and fruit, and of a greenish whito color. Jl. Sept.

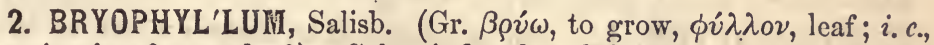
germinating from a leaf.) Calyx inflated, 4-cleft scarcely to the middle; corolla monopetalous, the tube long and cylindrical, 4 -sided and obtuse at base; limb in 4 triangular, acute lobes; seeds many.-An evergreen, fleshy, suffruticous plant, native of E. Indies. Lvs. opposite, unequally pinnate, part of them sometimes simple. Fls. greenish purple.

B. calycìnum Salisb. Not uncommon in house cultivation, requiring but little water, in a well-drained pot of rich loam. St. thick, green, about $2 f$ high. Lvs. 3 to 5 -foliate, with thick, oval, crenate lfts. Fls. in a loose, terminal panicle, pendulous, remarkable for the large, inflated calyx, and the long, tubular, exser ted corollas.-This plant is distinguished in vegetable physiology (see § 532), producing buds and new plants from the margin of its leaves.

3. SE'DUM, L. Stone Crop. (Lat. sedere, to sit; the plants, growing on bare rocks, look as if sitting there.) Sepals 4 or 5 , united at base; petals 4 or 5 , distinct, spreading; stamens 8 to 10 ; carpels 4 to 5 , distinct, many-seeded, with an entire scale at the base of each.Mostly herbaceous. Inflorescenee cymous. Fls. mostly pentamerous.

$\S$ Flower of the branches 4 -merous, central fl. 5 -merous............................ 1, 2

$\S$ Flowers all pentamerous. Spikes not umbellate.................................... 3

1 S. ternàtum $\mathrm{Mx}$. Lvs. ternately verticillate, obovate, flat, smooth, entire, tho upper ones seattered, sessile, lanceolate; cyme in about 3 spikes; fis. secund, tho central one with 10 stamens, the rest with only $8 .-24$ Damp woods, Can. West, Penn., the Southern and Western States. Sts. 3 to $8^{\prime}$ long, branching and documbent at base, assurgent above. Cyme with the 3 branches spreading and recurved, the whito fls. loosely arrranged on their upper side. Jl., Aug. $f$

2 S. pulchéllum Mx. Sts. branching at base, ascending; lvs. alternate, linear, obtuse, sessilo with an auriculate base; spikes umbellate, spreading, finally erect, the crowded flowers unilateral, octandrous, the central fl. usually decandrous.$\mathrm{On}$ rocks and mts., Va. to Ga. and Tex. Sts. 4 to $12^{\prime}$ high, very leafy. Fls. closely sessile, small; petals rose-color, acute. May, Jn.

3 S. telephioìdes Mx. Lvs. broadly lanceolate, attenuate at base, subdentate, smooth; cymes dense, corymbous; sta. 10, the pet, sep. and carp. in 5s.-Found on rocks, lake and river shores, N. Y., N. J., Harper's Ferry, Va., etc. St. a foot high. Lrs. 1 to $2^{\prime}$ long, $\frac{2}{3}$ as wide. Fls. numerous, purple, in a terminal, branching cyme. Jn.-Aug.-Like the other species, very tenacious of life, and will grow when pressed and apparently dried in the herbarium. 
4 S. Telèphium L. Common Orpine. Lrve-forever. Rt. tuberous, leshy, whito; st. erect, very leafy; lvs. flattish, ovate, obtuse, serrate, scattered; cymo corymbous, leafy. - 2 Cultivated and nearly naturalized. Sts. simple, round, smooth, purplish. Lvs. sessile, fleshy. Fls. white and purple, in dense, terminal, leafy tufts. Aug. † Eur.

5 S. àcre L. Exglisir Moss. Wall Pepper. Procumbent, spreading, branching fiom the base; lvs. very small, somewhat ovate, fleshy, crowded, alternate, closely sessile, obtuse, nearly erect; cymo few-flowered, trifid, leafy.-In cultivation it spreads rapidly on walls, borders of flower-beds, etc., densely covering the surface. Fls. yellow. The whole plant abounds in an acrid, biting juice. + Eur.

4. ECHEVE'RIA, DC. (To Echeveri, a botanical draughtsman.) Sepals 5, unequal ; petals 5, coherent below, erect, connivent, carinate; stam. 10 , shorter than the petals ; carpels 5 , tapering into a short, subur late style, with 5 short, obtuse, hypogynous scales.-Handsome, herbaceous or shrubby, fleshy plants, from California and Mexico. Fls. scarlet or yellow.

ஐ. grandiflòra Haw. Glaucous with bloom, crect; lvs. fleshy, spatulate, or obovate, acute, narrowed into a thick petiole; fls. paniculate, erect.-Greenhouse. St. about $2 \mathrm{f}$ high. Lowest lvs. large, rosulate; cauline gradually smaller. Sep. thick. Cor. urn-shaped, orange-purple. + Mex.

5. SEMPERVI'VUII, L. HousE-LEEK. (Lat. semper vivere, to live forever; for their tenacity of life.) Sepals 6 to 20 , slightly cohering at base; petals as many as sepals, acuminate; stamens twice as many as petals; hypogynous scales lacerated ; carpels as many as the petals. -24 IIerbaceous plants or shrubs, propagated by axillary offsets. Lvs. thick, fleshy.

1 S. Tectòrum $\mathrm{L}$. Lrs. fringed; offsets spreading. $-A$ well-known plant of the gardens, with thick, fleshy, mucilaginous lvs. It sends out runners witk offsets, rarely flowering. It is so succulent and hardy that it will grow on dry walls, and on the roofs of houses (tectorum). It is sometimes placed in the borders of flower beds.

2 S. arbòreum. St. arborescent, smooth, branched; lvs. cuneiform, smoothish, bordered with soft, spreading ciliæ.-A curious and ornamental evergreen, from the Levant. St. very thick and fleshy, branching into a tree-like form, 8 to . $10 \mathrm{f}$ high ( 1 to $3 \mathrm{f}$ in pots). Fls. yellow, rarely appearing.

6. DIAMOR'PHA, Nutt. (A Greek word signifying deformed; alluding to its singular dehiscence.) Sepals 4, minute, coherent at base; pet. 4, oval, concave; stamens 8 , with purple anthers; carpels 4 , united below the middle, each with a minute obcordate, hypogynous scale, and dehiscent by an irregular dorsal valve; seeds 4 to 8.-A very small, fleshy, branching herb, with corymbs of white or pink-colored flowers and purplish herbage.

D. pusílla Nutt.-2) On rocks in dry, sunny places, Ga. (Stone Mtt. 16m. E. of Atlanta), N. and S. Car. (Shields). Sts. I to $3^{\prime}$ high, cæespitous, forming patches. Lvs. oval, sessile, $I^{\prime \prime}$ long, alternate. Fls. numerous. Mar., Apr.-A curious litthe plant.

7. PENTHO'RUM, L. Virginia Stone-crop. (Gr. $\pi \varepsilon \dot{v} \tau \varepsilon$, five; on account of the 5-parted, angular capsulc.) Calyx of 5 sepals united at base; petals 5 or 0 ; stamens 10 ; capsules of 5 united carpels, 5 -angled, 5 -celled, 5 -beaked, dehiscent by an obliquely terminal valve; sceds $\infty$, minute.-4 Erect (not succulent) herbs. Lrs. alternate. Fls, yellowish, cymous.

P. sedoìdes I. St. branched and angular above; lvs. nearly sessile, lanceolate, 
acute at each end, unequally serrate; fls. in unilateral crmous racemes.-A hardy plant of little beauty, in moist situations, Can. and U. S. St. 10 to $16^{\prime}$ high, with a few short branches. Lvs. 2 to $3^{\prime}$ by $\frac{1}{2}$ to $1^{\prime}$, membranous, smooth, sharply and unequally serrate. Rac. several, recurved at first, at length spreading, with the flowers arranged on their upper side, constituting a corymbous, scentless, pale, yellowish green cyme. Petals generally wanting. Jl.-Sept.

\section{Order LXI. SAXIFRAGACEA. Saxifrages.}

Herbs or s7rubs. Lvs. alternate or opposite, sometimes stipulate. Sepals 4 or 5, cohering more or less, and partly or wholly adherent. Petals as many as the sepals, inserted between the lobes of the calyx. Stamens as many as the petals and alternate with them, or 2 to 10 times as many. Ovary inferior, usually of 2 carpels, cohering at base, distinct and divergent above. Fruit generally capsular, 1 to 2 celled. Seeds small, many, albuminous. (Figs. 270, 298, 310, 393.)

Genera 42, species 640 , subdivided into four groups as given below. They are distributed in both hemispheres as follows. The Saxitragea belong to the northern and alpine,regions. The Escalloniere to the alpine regions of $\mathrm{S}$. Ameriea. The Philadelphea to the north Temperate Zone, and the Cunoniere to the E. Indies, Australia and S. Amerlea. Many are cultivated for their great beauty. 'Their properties are generally astringent.

\section{SUBORDERS AND GENERA.}

I. SAXIFRAGEA. Merbs. Stipules nono or adnate. Petals imbricate, rarely convolute in the bud. Calyx free or partly adherent. (a)

a Petals wanting. Ovary adherent, 1-eelled. Stamens $10 \ldots . . . . .$. Cnrysosplexiem. 1

a Petals pinnatifid. Ovary half adherent, 1 -celled. Stamens 5 or $10 \ldots \ldots \ldots$...... MrteluA. 2

a Petals entire.-Stamens 10.-0vary 1-celled, nearly free................. Trarelda. 3 -Ovary 2-celled. Fls. perfect. Lvs. simple...Saxifraga. 4 -Ovary 2-celled. Fls. polygamous. Lvs. comp... $\Lambda$ stiLbr. 5 -Stamens 5.-Ovary 2-celled, adherent. Seed rough...........Borkisia. 6 -Ovary 2-celled, free. Seed wing-margined.. Sullivastia. 7 -Ovary 1-celled.-Styles and carpels 2 ...........IIEuchera. 8

-Styles and carpels 3....Lepuropktalon. 9

II. ESCALLONIEA. Shrubs with alternate lvs., no stipules and a valvate corolla bud. (b)

b Calyx free from the 2-celled ovary. Stamens 5. Capsule $\infty$-seeded............ Itra. 10

b Calyx adherent to the ovary. Stam. 5. Ber. $\infty$-seeded. (From S. Ain.)..Escallonia. 11 III. IIYDRANGE As. Shrubs with opposite, simple leares and no stipules. (c)

c Corolla valvate in the bud.-Cymes radiate. Shrub erect...............Hydrangea. 12 -Cymes naked. Shrub climbing............. Decuararia. 13

c Corolla convolute in the bud.-Stamens 20 to 40 . Petals 4.......... Prilladelpues. 14 - Stamens 10. Petals 5. (Asiatic)........... Devtzia. 15

1. Chrysosple'NiUm, Tourn. Water Carpet. (Gr. $x p v \sigma o ̀ s$, gold, $\sigma \pi \lambda \dot{\eta} \nu$, the spleen; on account of the medicinal qualities.) Calyx adnate to the ovary, 4 to 5 -lobed, more or less colored inside; corolla 0 ; stamens 8 to 10 , superior, short; styles 2 ; capsule obcordate, compressed, 1-celled, 2-valved, many-seeded.-Small aquatic herbs.

C. Americànum Schw. Lrs. opposite, roundish, slightly crenate, tapering to the petiole.-A small plant, in springs and streams, spreading upon the muddy surface. St. square, 3 to $6^{\prime}$ long, divided in a dichotomous manner at top. Lvs. opposite, $\frac{1^{\prime}}{2}$ in length, smooth. Calyx 4-cleft, greenish-yellow, with purple lines. Corolla 0 , stamens 8 , very short, with orange-colored anthers, which are the only conspicuous part of the flower. The terminal flower is sometimes decandrous. Apr:, May.

2. MITEL'LA, Tourn. Mitre-wort. (A Lat. diminutive from mitra, a mitre. See Tiarella.) Calyx 5-cleft, campanulate, adherent to the base of the ovary; petals 5 , pectinately pinnatifid, inserted on the throat of the calyx; stamens 5 or 10 , included ; styles 2 , short; capsule 2 -beaked, 1-celled, with two equal valves. - 4 Fls. small, in a slender raceme or spike. 
1 M. diphýlla L. Lvs. cordate, acute, sublobate, serrate-dentate, radical ones on long petioles, the cauline 2, opposite, subsessile.-Very common in the woods of N. Eng. to Car. and Ky. St. a foot or more high, bearing the pair of leaves near the midst. Lvs. 1 to $3^{\prime}$ long, nearly as wide, hairy, on the hispid petioles 2 to $6^{\prime}$ long. Fls. on short pedicels, arranged in a long, thin spike or raceme, and most beautifully distinguished by tho finely divided whito petals. Seeds black and shining. May-Jn. Fig. 298.

2 M. nùda L. Lvs. orbicular-reniform, doubly crenate, with scattered hairs above; scape filiform, fow-flowered, naked or with a single leaf; pet. pinnatifid with filiform segments.-A very delicate species, growing in damp, rich, shady woodlands, Wayne Co., N. Y. to northern N. Eng. LVs. and sts. light green, pellucid. Scape 4 to $6^{\prime}$ high, terminating in a thin raceme of white fls. with finely pinnatifid petals. They are erect or prostrate and send out creeping stolons from the base. Lvs. $\frac{3}{4}$ long and of nearly the same width. Jn.

3. TIAREL'LA, L. Bishop's CAP. (Lat. tiara, a mitre or some other head dress; from the resemblance of the capsule.) Calyx 5parted, the lobes obtuse; petals 5 , entire, the claws inserted on the calyx; stamens 10 , exserted, inserted into the calyx; styles 2 ; capsule 1 -celled, 2 -valved, one valve much larger. -24 Fls. white.

T. cordifòlia L. Lvs. cordate, acutely lobed, mucronate-dentate, pilous; scapo racemous; stolons creoping.--Rocky woods, Can. to Macon, Ga. and Eufala, Ala. Common in N. Eng. and generally associated with Mitella diphylla, which plant, in its general aspect, it much resembles. The scape arises from a creeping rootstock 10 to $20^{\prime}$ high, often bearing a bract. Lrs. 2 to $3^{\prime}$ long, $\frac{4}{5}$ as wide, hairy, and on hairy petioles 4 to $6^{\prime}$ long. Rac. 1 to $2 \frac{1^{\prime}}{2}$ long; fls. wholly white, with minute bractlets. May, Jn.

4. SAXIF'RAGA, I. SAXIFRAGE. (Lat. saxum, a rock, frangere, to break; often growing in the clefts of rocks.) Sepals 5, more or less united, often adnate to the base of the ovary; petals 5 , entire, inserted on the tube of the calyx; stamens 10; anthers 2-celled, with longitudinal dehiscence; capsule of 2 connate carpels, opening between the 2 diverging, acuminate beaks (styles); seeds $\infty .-24$

\& Leaves opposite (small) on the prostrate stem. Fls. pnrplish........................ 1 $\S$ Leaves alternato on tho ascending stem. Fls. yellow or white...................... $2,3,4$ Leaves rusulate at the base of the mostly leafless scape. (a)

a Calyx entirely free from tho ovary (inferior)......................... 5,6 , $\tau$

a Calyx adherent to the base of the ovary (half superior)........................ $8,9,10$

1 S. oppositifòlia L. Lvs. opposite, rather crowded, obovate, carinate, ciliate, obtuse, punctate, persistent; fls. solitary ; cal. free from the ova. ; pet. large, obovate, 5-veined, longer than the stam.- In the same locality as the next species. Sts. purplish, very branching, diffuse. Lrs. bluish-green, 1 to $2^{\prime \prime}$ long. Fls. light purple, large and showy. May, Jn.?

2 S. aizoìdes L. Cæspitous, leafy; lvs. linear-oblong, more or less ciliate, thick, flat, mostly persistent; flowering sts. annual; fls. paniculate, sometimes solitary; sep. ovate, slightly coherent with the ova; pet. oblong, longer than the sep.; stig. depressed; caps rather thick, as long as the styles.-In the clefts of rocks, at Willoughby Lake, Vt. (500 feet above the water), N. to the Arc. Sea. Barren stems short, with densely crowded lvs.; flowering stems ascending, 2 to $4^{\prime}$. long, with scattered lis. Lrs. 4 to $6^{\prime \prime}$ long, about $2^{\prime \prime}$ wide. Pedicels bracteato. Fls. yellow, dotted.

3 S. rivulàris $\mathrm{L}$. St. weak, ascending, 3 to 5 -flowered; radical lvs. petiolate, reniform, crenately lobed, cauline, lanceolate, subentire; cal. lobes broad-ovate, nearly as long as the ovate petals, but much shorter than the short-beaked capsule.-White Mts. N. H. (Oakes), N. to Arc. Am. A very small species, with white, bracteate fls. Sts. about 2 ' high, annual, with alternate lvs.

4 .5. tricuspidàta Retz. St. thick, erect; lower lis. crowded, oblong, 3-cuspidate; fls. fer, large, somowhat corymbed; scp. thick, ovate, shorter than tho oblong- 
obovate, yellow, dotted pet.; caps. ovate, tipped with tho diverging styles.-Lako shores, Can. and northward.

5 S. leucanthemifólia Mx. Viscid-pubescent; lvs. radical, spatulate, cut-den. tate, tapering to a petiole; scape diffusely paniculate, with capillary pedicels; caly.x free, reflexed; pet. unequal.-IIts. of Car. and Ga. Scapes 1 to $2 \mathrm{f} \mathrm{ligh,}$ bearing numerous small fls. Lvs. cut into several largo teeth. Petals white or pink, the three larger spotted with yellow. Jn.--Sept.

6 S. eròsa $\mathrm{Ph}$. Viscid-pubescent; lvs. radical, thin, oblong-lanceolate, acuto, with erose teeth; paniclo oblong, loose, with leafy bracts and divaricato branches; cal. free, with reflexed, obtuse sepals as long as tho equal, obtuse petals.-Mts. Penn. to Car. Scape 12 to $18^{\prime}$ high. Fls. scattered, on slender pedicels. Petals small, white, yellow at base. Jn., Jl.

7 S. Careyàna Gray. Lvs. radical, long-petioled, thin, glabrous, round-ovate, coarsely crenate-dentate, base truncate or subcordate; scapo slender, diffusely cymous-paniculate; pedicels filiform; petals lance-oblong, sessile, twice longer than the recurved sepals; carpels distinct, turgid, free.-Mits. N. Car., on wet, shady rocks. A low herb with small, whito flowers.

$\mathbf{B}$ S. aizooin Jacq. Lvs. mostly radical, rosulate, spatulate, obtuse, bordered with white cartilaginous teeth and a marginal row of impressed dots; fls. corymbous paniculate; cal. (and ped. glandular viscid) tube hemispherical, as long as the 5-toothed limb; pet. obovate; sty. divergent, longer than the calyx.-Southern shores of Lake Superior, to Nova Scotia and northward, on shady, moist rocks. Sts. 5 to $10^{\prime}$ high. Fls. white. Jl.

9 S. Virginiénsis Mx. EARLY SAXIFraGe. Lrs. mostly radical, spatulate-obovate, crenately toothed, pubescent, shorter than the broad petiole; scape nearly leafless, paniculately branched above; fls. many, cymous; cal. adinerent to the base of the ovary; pet. white, oblong, much exceeding the calyx.-An early and interesting plant, on rocks and dry hills, Can. and U. S. Scapo 4 to $12^{\prime}$ high, pubescent, annual. Lvs. rather fleshy, 9 to $13^{\prime \prime}$ by 6 to $12^{\prime \prime}$. Fls. in rather dense clusters, white, or tinged with purple, in early spring. Fig. 310.

10 s. Pennsylvánica L. Lvs. radical, oblong-lanceolate, rather acute, tapering at base, denticulato; scape nearly leafless; branches alternate, with closo cymes forming a diffuse panicle, fls. pedicellate; pet. greenish, linear-lanceolate, but little longer than the cal. - Larger than the foregoing, common in wet meadows, Me. to Ohio. Lvs. fleshy, palo green, 5 to $8^{\prime}$ by 1 to $2^{\prime}$, on a broad petiole. Scape 2 to $3 \mathrm{f}$ high, gross, hollow, hairy and riscid, branched into a large, oblong panicle of yellowish green fls. of no beauty. May.

5. ASTIL'BE, Don. (Gr. $\alpha$, privative $\sigma \tau i \lambda \beta \eta$, brightness; the leaves are not shining.) Polygamous; calyx adherent to the base of the ovary, obconic, with 4 or 5 erect segments; petals 4 or 5 , spatulate; stamens 8 or 10, exserted ; ovary 2-celled ; carpels of the fruit separating and dehiscing lengthwise inside; sceds 1 to 4 in each cell, covered with a loose, membranous testa. - 4 Coarse and weed-like plants. Lrs. compound, 2 or 3 -ternate. Fls. small, yellowish-white, in spicate rac. forming a compound panicle.

A. decándra Don. St. tall, angular; lfts. subcordate, incisely lobed, mucronateserrate; sterile fls. mostly apetalous; sta. 10.-Mts. of S. W. Va., E. Tenn., N. - Car. to Ga. Abundant in its localities. St. 4 to $6 \mathrm{f} \mathrm{high,} \mathrm{with} \mathrm{very} \mathrm{large} \mathrm{pani-}$ cles. Its resemblance to Spirea Aruncus is very striking, but its irregularly cleft Iits. and its twico larger ( $2^{\prime \prime}$ long), 2-carpeled fr. are positivo marks of difference. Jn.-Aug.

6. BOYKIN'IA, Nutt. (Dedicated to Dr. Boykin, of Georgia, a pioneer botanist.) Calyx turbinate adherent, 5 -cleft ; petals 5 , deciduous; stamens 5 ; ovary 2-celled, 2-beaked; capsule invested with the permanent, urceolate calyx tube, dehiscent between the beaks. - 4 Lvs. alternate, petiolate, palmate. Fls. cymous, white. 
B. aconitifòlia Nutt. St. viscid-glandular; lvs. smoothish, deeply 5 to 7 -lobed (like those of Aconitum); cyme fastigiate, the Hs. secund.-Mts. S. W. Va. and N. Car. (Curtis). St. 1 to $2 \mathrm{f}^{\circ}$ higl. Fls. small, numerous. Jl.

7. SULLIVAN'TIA, Torr. \& Gray. (To Wm. S. Sullivant, the distinguished muscologist.) Calyx campanulate, coherent with the base of the ovary, segments ovate, acute; petals oval-spatulate, unguiculate, inserted on the summit of the calyx tube, and twice as long as its lobes; stamens 5 , inserted with the petals, shorter than the calyx ; capsule 2 beaked, 2-celled; seeds $\infty$, ascending; testa wing-margined.-24 Lvs. mostly radical, palmate-veined. Fls. in a loose panicle, small, white.

S. Ohiònis Torr. \& Gr. $\AA$ diffuse, weak-stemmed plant, first discovered in Highland Co., Ohio, by him whose name it bears. St. annual, very slender, 8 to 16 ' long, ascending, glandular. Radical lvs. roundish, cordate, lobed and toothed, 1 to $2^{\prime}$ diam., on long petioles Cauline leaves mostly very small, bract-like, cuneate at base, 3 to 5 -toothed at summit. May, Jn.

8. HEU'CHERA, L. Alum Root. (To Prof. Heucher, botanic author, Wittemberg, Germany.) Calyx 5-cleft, coherent with the ovary below, segments obtuse; corolla of 5 small, entire petals, inserted with the 5 stamens on the throat of the calyx ; capsule 1-celled, 2-beaked, dehiscent between the beaks; seeds many, with a rough, close testa.$4 \mathrm{Lrs}$. radical, long-petioled, petioles with adnate stipules at base.

$\$ \mathrm{Fls}$. small (1 to $2^{\prime \prime}$ long), regular; stam. and sty. much exserted................ Nos. 1-3

Fls. larger ( 3 to 5 "l long), rather oblique; stam. and sty. short............................ 4,5

1 II. Americàna Willd. Viscid-pubescent; lvs. roundish, cordate, somewhat 7 lobed, lobes short and roundish, crenate-dentate, teeth mucronate; panicle elongated, loose; pedicels divaricato; cal. obtuse, short; pet. spatulate, about as long as the calyx; stam. much exserted.-A neat plant, rare in the southern parts of N. Eng. and N. Y., frequent at the W. and S. LVs. 2 to $32^{\prime}$ diam. Scape 2 to 4f high, paniculate, nearly $\frac{1}{3}$ this length. Ped. 2 to 3 -flowered. Cal. more showy than the purplish-white petals. Nfay, Jn.-Root astringent, hence the common name, Alum Root.

2 H. villòsa $\mathrm{Mx}$. Villous, with rusty, spreading hairs; radical lvs. round-cordate, thin, glabrous above, 7 to 9 -lobed, lobes short, crenate-mucronate, ciliate: panicle loose, with filiform branches and pedicels; fls. very small; pet. white, about as long and as narrow as the filaments. - Mts. Md. to N. Car. and Ky. Scape 1 to $3 \mathrm{f} \mathrm{high.} \mathrm{Lvs.} 2$ to $6^{\prime}$ diam., petioles sometimes densely villous.-The plant varies mucl in size. Scapo often with one or more lrs. Jn., Jl.

3 H. cauléscens Ph. Nearly glabrous; lvs. acutely 5 to 7-lobed, cordate, lobes acutely toothed, ciliate; panicle loose, slender; petals white, linear-spatulate, 2 or 3 times longer than the sepals.-High Mts. Car., Ky., Tenn. Scape often bearing a leaf or two below, and with the petioles sornewhat hairy below. May, Jn.

$\beta$. Quite glabrous; radical lvs. slightly lobed; cauline 2, collateral; branches of the panicle racemous, elongated, divaricate.-Buncomb Co., N. Car. (H. Curtisii Gray.)

4 H. pubéscens $\mathrm{Ph}$. Scape naked, minutely pubescent above, and with tho long petiole glabrous below; lvs. glabrous, orbicular-cordate, 7 to 9 -lobed, lobes rounded, and with rounded, mucronate, ciliate teeth; ped. cymous, dichotomous, joints flexuous, almost geniculate; fls. large; pet. longer than the included stam.; sty. exserted.-Mts. Penn., Md., Va. Scapo 1 to 2 f high. Lrs. 3 to 5 ' diam., the veins beneath with a fow scattered hairs. Fls. 5 to $6^{\prime \prime}$ long, purple. May, Jn. (H. grandiflora Raf.)

5 H. híspida $\mathrm{Ph}$. Hispid and scabrous on the upper surface and margin of the obtusely 5 to 7-lobed lvs., the lobes broadly mucronate-toothed, teeth very short, almost retuse; branches of the panicle few-flowered; pet. spatulate, as long as the calyx, shorter than the somewhat exserted stamens.-Mts. of $\mathrm{Va}$. and $\mathrm{N}$. Car., and prairies of Ind. to Mo. The petals purple. The prairie form is less liairy, almost smooth. (H. Richardsoni R. Br.) 


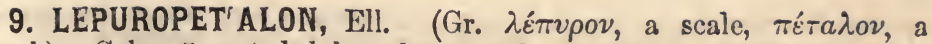
petal.) Calyx 5-parted, lobes obtuse, tube turbinate, adherent to the base of the 3-carpeled ovary; petals 5 , minute, spatulate, persistent; stamens 5, short; capsule globous, 1-celled, 3-valved, many-sceded.A minute, succulent herb, growing in tufts. Lvs. entire, dotted. Fls. terminal.

L. spatulàtum Ell. (1) Grows in hard soils, S. Car. (Charleston), Ga. to Tex. The plant is less than $I^{\prime}$ high, branched from the base, forming little convex tufts. Lvs. spatulate, veinless. Fls. large in proportion, white. Mar, Apr.

10. I'TEA, L. (Gr. name for the willow; for the resemblance of the foliage.) Calyx small, with 5 subulate segments; petals 5 , lancelinear, inflexed at the apex, inserted on the calyx; stamens 5 , inserted into the calyx; styles united; capsule 2-celled, 2-furrowed, 8 to 12 seeded.-A shrub with alternate, simple lvs., and a simple, spicate, terminal raceme of white fls.

I. Virginica IL Margins of swamps and sluggish streams, N. J., Penn. to Fla. Shrub about $6 \mathrm{f}$ high. Lvs. $1 \frac{1}{2}$ to $3^{\prime}$ long, oval-acuminate, serrulate, on short petioles. Rac. oblong-cylindric, 2 to $3^{\prime}$ long. Caps. oblong, acuminate with the style, its 2 carpels separating in maturity. May, Jn.

11. ESCALLO'NIA rubra and E. glandulosa are handsome shrubs, with evergreen leaves and searlet flowers, prized in greenhouse cultivation.

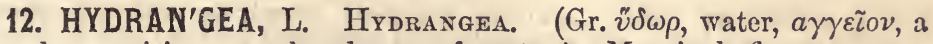
vessel ; requiring an abundance of water.) Marginal flowers, commonly sterile, with a broad, rotate, 4 to 5 -cleft, colored calyx, and with neither petals, stamens, nor styles. Fertile fls. Calyx tube hemispherical, adherent to the ovary, limb 4 to 5 -toothed, persistent; petals ovate, sessile; stamens twice as many as the petals; capsule 2-beaked, opening by a foramen betwcen the beaks; seeds numerous.-Shrubs with opposite lvs. Fls. cymous, generally radiant.

1 H. arboréscens L. Lvs. ovate, obtuse, or corclate at base, acuminate, serratedentate, paler beneath, nearly smooth; fls. in fastigiate cymes.-An elegant shrub, native in the Mid. and West. States, cultivated in the Northern, attaining the height of 5 or $6 \mathrm{f}$ on its native, shady banks. Fertile fls., small, white, becoming roseate, very numerous. The sterilo fls. are often reduced or wanting. The cultivated varieties have either the marginal flowers radiate, or all sterile and radiate. (H. vulgaris $M \mathrm{x}$.)

2 H. quercifòlia Bartram. Lvs. deeply sinuate-lobed, dentate, tomentous bcneatl, and on the petioles and veins above; cymes paniculate, radiant, the storile fls. very large and numerous.-A superb species, native of Fla. and S. Ga., in wet, springy places, also often cultivated. Shrub 4 to $8 \mathrm{f}$ high. Lrs. nearly all as broad as long ( 5 to $\left.10^{\prime}\right)$, green above, hoary beneath ; panicles dense, thyrsoid, large, pyramidal, the sterile fls. $18^{\prime \prime}$ broad, with orbicular, white or roseate sepals. Often cultivated. May, Jn. (H. vulgaris Mx.) (Fig. 271.)

3 H. radiàta Walt. Less. ovate, abrupt or cordato at base, acuminate, serrato, silvery-tomentous beneath; cymes fastigiate, radiate.-Upper country of Ga., Car. and Tenn. Shrubs 6 to $8 \mathrm{f}$ high. Sterile fls., white, smaller than in No. 2, often reduced to 3,2 or 1 sepal. The silver white of the under leaf-surface is a striking character. + May, Jn.

4 H. horténsis I. Changeable Hydrangea. Ivs. elliptical, narrowed at each end, dentate-serrate, strongly veined, smooth; cymes radiant; fls. mostly sterile.-Probably native of China, where it has long been cultivated. Sts. 1 to $3 \mathrm{f}$ high. Lvs. large. Barren fls., very numerous and showy, at first green, passing successively through straw-color, sulphur yellow, white, purple, and pink. The 
perfect fis. aro central and much smaller. It thrives in largo pots of peat mixed with loam, abundantly watered. The flowers enduro several months. $f$

13. DECUMA'RIA, L. (Lat. decem, ten ; from the 10-parted flowers.) Fls. all fertile; calyx 7 to 10 -toothed, tube adherent to the 5 to 10 celled ovary; petals as many as calyx teeth, oblong-spatulate, valvate in the bud; stamens 3 times as many as the petals, in one row, epigynous; stigma as many as petals, radiate, capsule urn-shaped, many-ribbed, crowned with the style, $\infty$-seeded.-A shrub creeping or climbing by rootlets, with opposite lvs. and cymes of white, fragrant fls.

D. bárbara L. $\Lambda$ beautiful climber, in damp woods, N. Car. to Fla. and La., ascending trees 15 to $30 \mathrm{f}$. Lvs. ovate or oval, entire or obscurely serrate, acute or acuminate, very smooth, - those of the young creepers elliptical, irregularly toothed. Cymes terminal on the divergent branches, with numerous fls. Caps. persistent, exhibiting in winter their curious structure. May, Jn.

14. PHILAdEL'PHUS, L. False Syrivga. (To Philadelphus, ling of Egypt.) Calyx 4 to 5-parted, half superior, persistent; corolla 4 to 5-petaled; style 4-cleft; stamens 20 to 40 , shorter than the petals; capsule 4-celled, 4-valved, with loculicidal dehiscence; seeds many, arilled.-Handsome flowering shrubs. Lvs. opposite, exstipulate.

I P. inc̀dorus L. Glabrous; lvs. ovate, acuto or somewhat acuminate, triplereined, entire, or with few obscure teeth; sep. acute, scarcely longer than the tube; sty. united.-Va. to Ala. in the upper country (Buckley). Fls. small, several at the end of each branchlet, inodorous. May, Jn.

2 P. grandiflòrus Willd. Lvs. ovate, acuminate, sharply denticulate, 3-veined, axils of the veins hairy; sep. acuminate, much longer than the tube; stig. 4, linear; sty. united.-A very showy shrub, of high, native at the South, cultivated in shrubberies. Branches smooth, long and slender. Fls. large, in a terminal umbel of 2 or 3 , white, nearly inodorous. Jn.-The upper lvs. are often entire and quite narrow. $\dagger$

3 P. coronàrius L. Mock Orange. Lvs. ovate, subdentate, smooth; sty. distinct.-Native of S. Europe. $\Lambda$ handsome shrub, often cultivated in our shrubberies. The fls. are numerous, cream-colored, showy, resembling those of the orange bcth in form and fragrance, but are more powerful in the latter respect. It grows 5 to 8 high, with opposite, smootl, ovate, stalked lvs. and opposite, reddish twigs bearing leafy clusters of flowers. +

15. DEUT'ZIA gracilis and D. scabra, are two handsome shrubs occasionally cultivated in parks. The genus is readily recognized by the filaments, which are 3 -cuspidate at the top, bearing the anther on the middle cusp.

D. scabra Thunberg, has ovate, acute, sharply serrate, pilous leaves, with terminal, downy racemes of handsome, bell-shaped, white flowers, each usually with 3 pistils. † Eastern Asia.

\section{Order LXII. HAMAMELACEAE. WitchHazelworts.}

Shrubs or trees with alternate, simple leaves and deciduous stipules. F'lowers in heads or spikes, often polygamous or monœcious. Calyx adherent. Petals linear, valvate or convolute in bud or wanting. Stamens twice as many as petals (the opposite sterile and scale-like) or $\infty$. Ovary of 2-carpels, 2-celled and 2-styled, ovules 1 or $\infty$ in each cell. Fruit a woody capsule, 2-beaked, 2-celled and 2-seeded.

Genera 14; species 20, widely diffused. Various species of Liquidambar yleld the pungent resin called storax. Otherwise the products of this order are unimportant. 
2. Foturatrues. Plowers monochlamydeons. Ovary solitary in each cell.

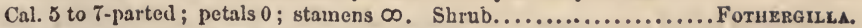

3. Batsaniflud. Flowers mostly achlamydeous. Ovules several in each cell. Calyx none; 1ls. monœcious, in glubous aments..............Lrecida MBAR. 8

1. HAMAME'LIS, L. WrTch HAzeL. (Gr. ä $\mu a$, with, $\mu \tilde{\eta} \lambda o \nu$, fruit; i. e., flowers and fruit together on the tree.) Calyx 4-leaved or cleft, with an involucel of 2 to 3 bracts at base; petals 4, very long, linear; sterile stamens scale-like, opposite the petals, alternating with the 4 fertile ones; capsule nut-like, 2-celled, 2-beaked.-Shrubs or small trees. Petals yellow.

F. Virginiàna L. Lvs. oval or obovate, acuminate, crenate-dentate, obliquely cordate at base, on short petioles; fls. sessile, 3 to 4 together in an involucrate, axillary, subsessile glomerule.-U. S. and Can. A large shrub, consisting of several crooked, branching trunks from the same root, as large as tiie arm, and 10 to $12 \mathrm{f}$ high. Lvs. nearly smooth, 3 to $5^{\prime}$ long, $\frac{2}{3}$ as wide. Petioles $\frac{1^{\prime}}{2}$ long. Cal. downy. Pet. curled or twisted, $9^{\prime \prime}$ long. Cap. woody, containing 2 nuts. This curious shrub is not unfrequent in our forests, and amidst tho reigning desolations of winter puts forth its yellow blossoms. The small branches have been superstitiously used for "divining rods," to indicate the presence of the precious metals and of deep springs of water.

2. FOTHERGIL'LA, L. filius. (Dedicated by the younger Linnæus to Dr. Fothergill.) Calyx campanulate, truncate and obscurely 5 to 7 toothed at the margin, bearing the 20 to 28 clavate filaments in a marginal row; petals none; styles 2, distinct; capsule adherent at base, 2lobed, 2-celled, cells 2-valved, 1 -seeded.-A shrub resembling an alder in its leaves and a witch-hazel in its fruit. Fls. white, appearing before the leaves, in a terminal dense spike or ament.

F. alnifolia L. $f$. Shady margins of swamps, Va. to Fla. Shrub 2 to $4 \mathrm{f} \mathrm{high,}$ with virgate blossoms and stolons. Lvs. oval or obovate, somewhat crenate, pubescent beneath. Cal. white, fringed with the long white or pink stamens. Sty. long, fliform, recurved. Mar., Apr.

3. Liquidam'BAR, L. Sweet Gum Tree. (Lat. liquidam, fluid, ambar, from its ambar-colored gum.) Involucre 4-parted, deciduous; ô ament conical; flowers naked, polyandrous; + aments globous; calyx a scale if any; styles 2, clongated; fruit aggregate (sorosis § 581), globular, consisting of the hardened scales and woody, 2-celled capsules which open between the beaks; ovules many, but only 1 or 2 maturing into a seed.-Trees with fragrant lvs. and exuding a balsamic resin.

I. styraciflua L. Lvs. palmate, with acuminate, serrate lobes; veins villous at their bases. - A large and handsome tree, abundant in the swamps and higher grounds of the South, extending N. to Conn. and Ill. With a diameter of $5 \mathrm{f}$ it arises to the height of 60 . Trunk covered with a deeply furrowed bark. Young twigs yellowish, putting forth leaves of a rich green, which are deeply divided into 5 lobes more star-like than those of the Rock Maple. Fruit a globular, compact ball, suspended by a slender pedicel, consisting of numerous capsules, each containing 1 or 2 seeds. May.

\section{Order LXIII. UMBELLIFER $Æ$ UMBELWORTS.}

Herbs with hollow, striate stems, sheathing petioles and flowers in umbels. Calyx adherent to the ovary, limb entire or 5-toothed. Petals 5, usually infected at the point, imbricate in æstivation. Stamens 5, alternate with the petals, and inserted with them on the disk. Ovaries 2-carpeled, surmounted by the fleshy disk which bears the petals and stamens. Styles 2, distinct or united at their 
thickened bases. Stigmas simple. Fruit a cremocarp (\$ $55 \%$ ), consisting of 2 coherent achenia called mericarps which separate along the middlo space, which is called the commissure.

Carpophore, the slender, simple or forked axis attached to and supporting the mericarps at top, inclosed between them at the commissure.

Ribs -5 ridges traversing each mericarp lengthwise, and often 4 intermediato or secondary ones, some, all, or none of them winged.

Vittce-little tubular receptacles of colored volatile oil imbedded in the substance of the pericarp, just beneath the intervals of the ribs, and also sometimes in the face of the commissure.

Embryo in the base of abundant, horny albumen. (Illust. in figs. 25, 27, 102, 134, 135, 163, 207, 297, 433.)

Genera 270 , species 1500 or more. A largo and well defined natural order, native of damp places, waysides, groves, \&c., In the cool parts of the world. Very few are found in tropical countries, except upon the mountains.

Properties, aromatic, stimulant and carminative, depending npon a volatlle oil residing in the vittre of the fruit, in the roots, \&c. The herbage is frequently pervaled by an acrid, narcotio principle, rendering it very poisonous. Of this nature is the Conlum maculatum (Hemlock), Cicnta virosa, Athusa Cynapinm (Fool's Parsley), besides many others which have at least a suspicious character. But the fruit is never poisonous, and is usually stimulant and aromatic, as Caraway, Anise, Dill, Coriander, \&c. Even the roots and herbage of other species are wholesome and nutritive, as the Carrot, Parsnip, Sweet Cicely, Celery, and Archangelica. The gum resin assafoetida exudes from incisions on the Ferula of Persia. The Gum Galbanum is tho product of Galbanum officinale, an Indian species. The genera of the Umbelliferæ are often best defined by characters foundel npon the number and development of the ribs, the presence or absence of the vittæ, and the furm of the albumen, particularly at the commissure. These parts, therefore, minute as they are, will require the especial attention of the student.

De Candolle subdiviled the Umbelworts into sections, depending upon the form of the albumen and seed, whether (1.) that on the inner face, or (2.) convolute at the sides, or (3.) involute at the ends. This arrangement is often impracticable as a step in the

\section{ANALYSIS OF THE GENERA.}

$\S$ Flowers in simple umbels, sometimes spicate. Leares simplc. (a)

$\S$ Flowers in capitate umbels, $i$. e., sessile, forming dense hearls. (b)

$\S$ Flowers in regularly compound umbels, not sessile in heads. (I)

I Fruit flattened on the back, the margins only singly winged. (c)

l. Fruit flattened on the back, the margin only doubly winged. (d)

1 Fruit terete or flattened on the sides.- Ribs bristly echinate. (e)

- Ribs smooth. Flowers xanthic. (f)

- Ribs smooth. Flowers cyanic. (2)

2 Plants exotic, growing in gardens, \&c. (1)

2 Plants native or naturalized, growing wild. (3)

3 Fruit slender, thrice longer than wide, often beaked. (g)

3 Fruit short, once to twice as long as wide.-Pibs (6 to 10)-winged. (h

- Ribs not winged. (4)

4 Seed furrowed or excavated on the inner face. (i)

4 Seed flat on the inner face.-Involucre none or almost none. (j)

-Involucre of 2 to 8 bracts. (k)

a Fruit flat, orbicular. Leaves ronnd or roundish................. II rDrocotrue. 1

a Fruit globular. Leaves linear, fleshy phyllodia................................. 2

b Flowers partly sterile. Fruit densely muricate, few.............. SANicula. 3

b Flowers all fertile. Fruit scaly, many in the head... ............... ERrNGium. 4

c Flowers yellow. Fruit with a thick, corky margin.............. Polyt denia. 5

c Flowers yellow. Fruit with a thin margin.................. Pastixaca. 6

c Flowers white, $\rightarrow$ of two sorts, - the marginal radiant........... IIErAcLecs. 7 -all alike.-Lfts. 3 to 9 , mostly entire............ RcuemorA. 8

-Lfts. 0 , phyllodla linear............Tiedenassia. 9

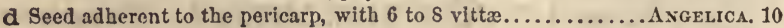

d Seed not adherent, \&c., all covered with vittæ...............HANGELICA. 11

e Involucre of several pinnatifld bracts................... DAcces. 12

f Involucels of ovate, ontire bracts. Leaves simple............ Büpurux. 13

f Involucels none. Carpels with 5 obtuse ribs.................. A xerruv. 14

f Involucels subulate.-Ribs sliarp or winged. Leaflets toothed....Traspiur. 15 - Ribs not at all winged. Leaflets entire.........Zizi.. 10 
g Beak slender, longer than the frnit, Fittre none....................... ScAvorx. 17

g Beak short or none.-Fruit upwardiy hispld..................... Os.rorurzA. 19

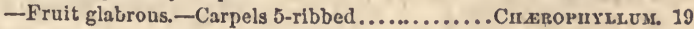

-Carpeis 9-ribbed..............Trepocarpus. 83

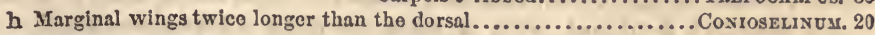

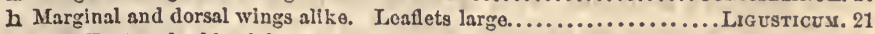

i Fruit a doublo globe. Plant low, early flowering............... Erigenis. 29

i Fruit ovate, - with obscure, straight ribs. Tall...............Ecopres. 29

-with distinct, crinckled ribs. Largo.............. Covicม. 24

j Fruit roundish-oblate (broader than long). With involucels............................. 25

j Fruit roundish-oblong. Involucels nono or almost none............ II Exosciadius. 20

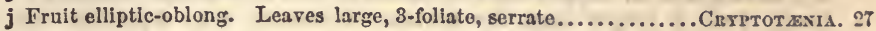

j Fruit ovate, - smooth, strong-ribbed. Involucels drooping................ Erru

-clothed with scales. Involucels spreading............. Leptocaturs. 29

k Calyx teeth obsolete. Leares pinnate, with serrato lfts............... Sre $\mathbf{Y}_{0} 32$

k Calyx teeth persistent.-Leaflets capillaceous. Vittæ 4........ Drscorleura. 80

-Leaflets linear, entire.-Vittx 16. . Neuropirluvs. 81

-Vittæ 6....Crxoscradrußs. 39

1 Flowers of 2 sorts, the outer radiant. Fruit globous.............. Corrasdrex. 83

1 Flowers all aliko.-Fruit terete (not compressed), ovate............. Prmpix ELLA. 34 -Fruit compressed laterally.-Vitta nono........... Egorodium. 35

-Vittæ 8 to $12 \ldots \ldots \ldots$....... A APIU. 86

\{ Carum. 87

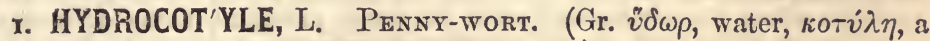
vessel; the concave leaf often holds water.) Calyx obsolete; petals equal, ovate, spreading, entire, the point not inflected; style shorter than stamens; fruit laterally flattened, the commissure narrow; carpels 5-ribbed, without vittæ.-Herbaceous, creeping, usually aquatic plants. Umbels simple. Invol. few-leaved.

* I,eaves reniform or cordate, the base lobes not united........................... 1-3

* Leaves peltate, orbicular, the base lobes united................................. 5

1 H. Americàna $\mathrm{L}$. Smooth and shining; st. filiform, procumbent; lvs. reniformorbicular, slightly lobed, crenate; umbels sessile, 3 to 5 -flowered; fr. orbicular.$4 \mathrm{~A}$ small, delicate plant, growing close to the moist earth beneath the shado of other vegetables, Can. to S. Car. Sts. branching, 2 to $6^{\prime}$ long. Lrs. thin, 1 to $2^{\prime}$ diam., on petioles 2 to $3^{\prime}$ long. Fls. greenish whitc, small, nearly sessile, in simple, capitate, sessile, axillary umbels. Jn.-Aug.

2 H. ranunculoìdes L. f. Lvs. reniform-orbicular, deeply 3-lobed, middle lobes smallest, all crenate; ped. much shorter than the petioles, branched; umbel 5 to 9-flowered, capitate. - 4 Waters, Va. to Ga. and La. (Hale). Sts. rooting at tho joints, or floating. Petioles thick, 4 to $8^{\prime}$ long, ped. 1 to $2^{\prime}$. Lrs. veiny. Sty. spreading and incurved. Jl., Aug.

3 H. repánda Pers. Lvs. broad-ovate, cordate, very obtuse, margin repanddentate; ped. simple, much shorter than the petioles, umbels capitate, 3 or 4flowered.-2f Muddy shores, S. Car. to Fla. and La. (Hale). St. creeping. Ped. radical, slender, 2 to $3^{\prime}$ high, tho petioles 3 to $8^{\prime}$. Fr. large, broader than long. Involucre 2 ovate bracts. Jn.-Aug.

4 H. interrúpta Mruhl. Lvs. peltate, orbicular, crenate: umbels capitate, proliferous, about 5-flowered; fr. acute at base. - 4 In wet places, New Bedford, Mass. to Ga. (Mettauer, Feay). Rt. and stem creeping. Lrs. almost centrally peltate, thin, 8 to $13^{\prime \prime}$ diam. Petioles 2 to $6^{\prime}$ long. Ped. longer than the petioles. Fls. subsessile, in close umbels which become whorls in interrupted spikes by other umbels being successively produced on the extending peduncle. Jn.

5 F. umbellàta L. Lvs. pellate, orbicular, crenate, emarginate at base, on long petioles; scapes about as long as the petioles; umbels simple (rarcly proliferous) fls. 20 to 30, pedicellate. - 2f In ponds and bogs, Mass. to La., rare. Sts. creeping, often submersed, several inches long. Lrs. 8 to $12^{\prime \prime}$ diam., notched at base so as to appear reniform. Petioles a little eccentric, and with the scapes, slender, floating or erect, and 4 to $6^{\prime}$ long. May-Jl. 
2. CRANT'ZIA, Nutt. ('To Prof. Crantz, author of a monograph of the Umbelliferæ.) Calyx tube subglobous, margin obsolete ; petals obtuse; fruit subglobous, the commissure excavated, with 2 vittæ; carpels unequal, 5-ribbed, with a vitta in each interval.-Small, creeping herbs, with linear or filiform, entire lvs. Umbels simple, involucrate.

C. lineàta Nutt. Lrs. cuneate-linear, sessile, obtuse at apex, and with transverse veins, shorter than the peduncles. - 4 Muddy banks of rivers, Mass. to La. Sts. several inches long, creeping and rooting in the mud. Lvs. 1 to $2^{\prime}$ by 1 to $2^{\prime \prime}$, often linear and appearing like petioles without laminæ. Umbels 4 to 8 -flowcred. Ped. $\frac{1}{3}$ longer than the leaves. Involucre 4 to 6 -leaved. Fr. with red vittæ. May-Jl. (Hydrocotyle Mx.)

3. SANIC'UlA, Tourn. Sanicle. (Lat. sanare, to cure; for its reputed virtues as a vulnerary.) Flowers $q \Varangle \hat{\delta}$; calyx tube echinate, segments acute, leafy; petals obovate, crect, with a long, inflected point; fruit subglobous, armed with hooked prickles; carpels without ribs; vittæ numerous. - 2f Umbel nearly simple. Rays few, with many-flowered, capitate umbellets. Involucre of few, often cleft leaflets, involucel of several entirc.

I S. Marilándica L. Lvs. 5 to 7-parted, digitate, mostly radical ; lfts. or segments oblong, incisely serrate; sterile fs. many, pedicellate, fertile ones sessile; cal. segm. entire; sty. slender, conspicuous. recurved.-Thickets, U. S. and Can., common. St. 1 to $2 \mathrm{f}$ high, dichotomously branched above, smooth, furrowed. Radical lvs. on petioles 6 to $12^{\prime}$ long, 3-parted to the base, with the lateral segm. deeply 2-parted; segm. 2 to $4^{\prime}$ long. Caulin $\Theta$ lvs. few, nearly sessile. Involucres G-leaved, serrate. Umbels often proliferous.

2 క. Canadénsis I. Lower lvs. 5-parted, upper 3-parted, segm. orate, mucronate-serrate; sterile fls. few, much shorter than the fertile; sty. shorter than the prickles.-Woods, thickets, $\mathrm{N}$. States to $\mathrm{O}$. and Can., common. About the size of the preceding, or taller. Umbels more numerous and smaller. Lfts. thin, I to $3^{\prime}$ long. Jn.-Aug.

4. ERYN'GIUH, Tourn. (Gr. é $\rho v \gamma \varepsilon \tilde{\imath} v$, to belch; a supposed remedy for flatulence.) Fls. sessile, collected in dense heads; cal. lobes somewhat leafy; petals connivent, oblong, emarginate with a long, inflexed point; styles filiform ; fruit scaly or tuberculate, obovate, terete, without vittæ or ribs. - Herbaceous or suffruticous. Fls. blue or white, bracteate; lower bracts involucrate, the others smaller and paleaceous.

$\$$ Scales or chaff of the heads entire..................................... Nos. 1-3

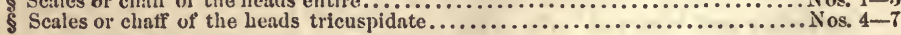

1 घ. yuccæfólium Mx. Erect; lvs. broadly linear, parallel-veined, ciliate with remote soft spines; bracts tipped with spines, those of the involucels entire, shorter than the ovate-globous heads. - 24 Prairies and Pine barrens, W. and S. A remarkable plant appearing like one of the Endogenæ. Very glaucous. St. simple. 1 to $5 \mathrm{f}$ high. Lvs. often 1 to $2 \mathrm{f}$ long, $\frac{1}{2}$ to $1^{1^{\prime}}$ wide. Heads pedunculate, $\frac{1}{2}$ to $1^{\prime}$ diam. Fls. white, inconspicuous. Jlo, Aug. (This name, if allowable as Dr. Gray suggests, is more appropriate than E. aquaticum I. in part.)

2 Æ. prostràtum Baldw? Sts. filiform, prostrate, rooting at the joints; lvs. (small) of two forms in the samo cluster, some ovate, dentate, petiolate, others 3-cleft with lanceolate segments, middle segm. largest; heads on slender peduncles, axillary, small, ovate; involucre bracts 4 to 6 , linear, rather longer than the head; scales entire, shorter than the fls.-2f In wet places, Ga. and Fla. (Mettauer). St. 6 to $12^{\prime}$ long, many from one root. Lvs. 4 to $7^{\prime \prime}$ long. Hds. $3^{\prime \prime}$ long, white, the fls. blue. Jn.-Oct. (E. gracile Ell.)

$\beta$. Fouròsur. Lvs. larger, all 3-cleft, irregularly toothed; bracts of the invol. leafy, twice longer than the oblong heads.-La. (Hale). (E. prostratum Nutt.)

3 ヨ. Baldwínii Spreng. Sts. filiform, prostrate, clustered; lowest lvs, oblong, 
cuneate, petiolate, angular-toothed, lower stem lvs. 3-cleft, with lance-linear, cuttoothed segm., upper all linear or fillorm, clustered, obtuse, entire; ped. longer than the lvs.; hds. very small, globular; invol. not distinguishable from the entire scales. - 4 Tallahassee (Mettauer) to Apalachicola (Chapman). St. 10 to 20' long. Hds. 2" diam. (E. gracile Baldw.)

4 E. aromáticum Baldw. Lvs. pinnate segm. cuspidate, entire, cartilaginous along the margin, the 3 upper more distant and conspicuous; Ifts. of the invol. about 5, 3-cleft; hds. globous, long-pedunculato; scales tricuspidate.-2 In dry pine barrens, Fla. Sts. 9 to $18^{\prime}$ long, assurgent, beset with the short (1') bristly, pinnate lvs. Hds. many, 6 to $8^{\prime \prime}$ diam. Aug.-Nov.

5 E. virgàtum Lam. Lvs. oval or oblong, thin, abruptly petiolate, dentate-serrate, the upper cauline, subsessile; invol. of 6 to 8 linear lvs., longer than the dcpressed, globous hds.; scales tricuspidate.-4 Wet pine barrens, S. Car. to Fla. and La. St. 2 to $4 \mathrm{f} \mathrm{high,} \mathrm{simplo} \mathrm{or} \mathrm{cymously} \mathrm{branched} \mathrm{with} \mathrm{slender,} \mathrm{virgato}$ branches. Hds. $5^{\prime \prime}$ diam. Fls. pale blue or whito. Jl. -Sept. (E. ovalifolium Mx.)

6 E. Virginiànum Lam. Lvs. linear-lanceolate, uncinately serrate, tapering to both ends; invol. of 7 to 8 linear lfts., longer than the hds., 3-cleft or spinous-dentate; scales tricuspidate.-4 Marshes, N. J. (Rev. J. Holton) to Ohio and La. St. hollow, 3 to $4 \mathrm{f}$ high, branched above. Lrs. 6 to $10^{\prime \prime}$ by 5 to $10^{\prime \prime}$, upper ones much smaller. Hds. numerous, less than $I^{\prime}$ in length. Fls. palo blue, or nearly white. Jl., Aug. (E. aquaticum Mx.)

7 E. Mettaùeri. Tall, simple, erect; lvs. linear, few, distinctly dent-serrate, consisting chiefly of the fistular, inflated, membranous midvein, jointed by transverse partitions within and narrowly winged by the lamina; bracts of the invol. 8 to 10 , silvery above, longer than the head, with long, cuspidate teeth; scales tricuspidate.-4 In wet places, Newport, Fla. (Mettauer.) The tallest of our species, often of high. Its characteristic, hollow-jointed lvs. are 12 to $20^{\prime}$ long.Allied to E. Virginianum Lam.

5. POLYTAE'NIA, DC. (Gr. $\pi 0 \lambda \dot{v} s$, many, raıvía, vittæ.) Calyx limb 5-toothed; petals with a long inflexed point; fruit oval, glabrous, lenticularly compressed on the back, with a thickened, corky margin; ribs obscure or obsolete; commissure with 4 to 6 vittæ; seeds planoconvex.-A smooth herb, with bipinnately divided lvs. Invol. 0. Involucel of setaceous bracts.

P. Nuttállii DC. Prairies and barrens, W. States, etc. St. furrowed, scabrous or nearly smooth. Lower lvs. on long petioles, segm. incisely toothed, upper ones 3-cleft, lobes entire or with lateral teeth. Umbels terminal and opposite the lvs., about $2^{\prime}$ broad. Fruit large ( $3^{\prime \prime}$ long) tumid and smooth, with a thick, corky pericarp, and the flavor of turpentine. May.

6. PASTINA'CA, Tourn. Parsmip. (Lat. pastus, food or repast; from the nutritive properties of the root.) Calyx limb 5-toothed; petals broad-lanceolate, with a long inflexed point; fruit much compressed, oval, with a broad margin; carpels with 5 nearly obsoleto ribs; intervals with single vittæ; carpophore 2-parted; seeds flat.(2) Rt. fusiform. Invol. mostly 0 ; involucels 0 or few-leaved. Fls. yellow. (Includes our genera 8, 9, and 31, according to Benth. \& Hook.)

P. sativa I. Lrs. pinnate, downy beneath, lfts. oblong, incisely toothed, the upper one 3-lobed.-Grows wild abundantly in fields, by fences, etc. The root is fusiform, large, sweet flavored, esculent, as every one knows, in its cultivated state, but in its wild state becomes hard, acrid and poisonous, and much dwindled in size. St. 3f high, erect, furrowed, smooth, branching. Umbels large, terminal. Fls. yellow, small. Fr, large, flat. JL §

7. HeRAC'LEUM, L. Cow PARsirip. (Named after the hero Hercules; it being a rank, robust plant.) Calyx limb of 5 small, acute teeth; petals obcordate, with the point inflexed, often radiant in the 
exterior flowers, and apparently deeply 2-cleft; fruit compressed, flat, with a broad, flat margin, and 3 obtuse, dorsal ribs to each carpel; intervals with single vittæ; seeds flat.-Stout herbs with large umbels. Invol. deciduous. Involucels many-leaved.

H. lanàtum L. Lrs. ternate, petiolate, tomentous beneath, lfts. petioled, roundcordate, lobed; fr. orbicular.-Penn. to Lab., W. to Oregon. A large, coarselooking plant, in moist cultivated grounds. Sts. about $4 \mathrm{f} \mathrm{high,} \mathrm{thick,} \mathrm{furrowed,}$ branching, with spreading hairs. Lrs. very large, on channeled stalks. Lfts. irregularly cut-lobed and serrated. Its huge umbels are often a foot broad. Involucre of lanceolate, deciduous leaflets. Petals deeply heart-shaped, white, those of the outer fls. unequally enlarged (radiate). Jn.

8. ARCHEMO'RA, DC. (A fanciful name from Archemorus, who, according to mythology, died from swallowing a bee.) Calyx limb 5 -toothed; petals obcordate with an inflexed point ; fruit oval, lenticular, compressed on the back ; carpels with 5 ribs, marginal ones broadly winged; intervals with single large vittæ, commissure with 4 or 6 ; seeds flat.-24 Invol. 0 or few-leaved. Involucels many-leaved.

I A. rígida DC. Water Dropwort. Cowbane: St. rigid, striate, smooth; lvs. pinnately divided, smooth, lfts. 3 to 11 , oblong-lanceolate or ovate, entire or remotely toothed, sessile; umbels spreading, smooth.-Swamps, Mich. to Fla. and La. St. 2 to $4 \mathrm{f}$ high, slender, terete. Lits. 2 to $4^{\prime}$ by 3 to $9^{\prime \prime}$, varying in outline in the same plant. Umbels 2 to 3 , of many slender rays. Petals white. Fr. with subequal, greenish ribs, and large purple vittæ filling the intervals. Commissure white. Sept.-Said to be poisonous. (Enanthe Nutt.)

B. AsrBigua. Lfts. long-linear, mostly entire. (EEnanthe ambigua Nutt.)

2 A. ternàta Nutt. Lvs. ternately divided, with very long petioles; segm. linear--Margins of swamps in the pine forests, N. to S. Car. Near Newbern (Nuttall). St. 2 to $3 \mathrm{f} \mathrm{high,} \mathrm{slender.} \mathrm{Lvs.} \mathrm{and} \mathrm{petioles} 2 \mathrm{f}$ long; segm. $3^{\prime \prime}$ wide: Fruit as large as that of the parsnip.

9. TIEDEMAN'NIA, DC. (To Prof. Tiedemann, of Hiedelburg.) Calyx limb 5-toothed; petals roundish ovate; fruit flattened dorsally, obovate; carpels with 5 equal, filiform ribs, the lateral coalescing with the broad, marginal wings ; intervals with single large vittæ, commissure with 2 ; seed flat.- 2 ! Smooth, tall, slender. Lis. reduced to fistular-jointed phyllodia. Involucra subulate, 5 to 6 -lvd. Fls. white.

T. teretifollia DC. -Va. to La. and Fla. St. 3 to $6 \mathrm{f} \mathrm{high,} \mathrm{hollow,} \mathrm{round,} \mathrm{striatc.}$ Phyllodia 6 to $16^{\prime}$ long, tapering, the joints $1^{\prime}$ apart. Fr. as large as in parsnip, disk dark brown, not wider than the yellowish wings. Aug., Sept.

10. ANGEL'ICA, L. (Named for its excellencies.) Calyx teeth obsolete ; petals lanceolate, acuminate; fruit dorsally compressed ; carpels 5 -ribbed, the 3 dorsal ribs filiform, the 2 marginal winged, intervals with single vittx; carpophore 2-parted; seed semiterete-Lus. bi. or triternate, sessile, umbels terminal. Invol. 0 or few-leaved. Involucels many-leaved.

A. Curtísii Buckley. Lvs. biternate or with 3 quinate divisions; lfts. thin, ovate or lance-ovate, acuminate, sharply and incisely toothed; bracts of the involucel small, subulate; wings of the fruit broad. $-24 \mathrm{Mts}$. of Ashe Co., N. Car. (Curtis.) Cheat Mt., Va. (Buckley.) Aug.

11. ARCHANGEL'ICA, Hoffm. Angelica. (Named for its preeminence in size and virtues.) Calyx teeth short; petals elliptical, entire, lanceolate, acuminate, with the point inflexed ; fiuit dorsally com. pressed, with 3 carinate, thick ribs upon each carpel, and 2 marginal ones dilated into membranous wings; seed loose in the ripe carpel, 
covered with vittæ. - 2f Petioles usually large, inflated and 3-parted. Umbels perfect. Involucels many-leaved.

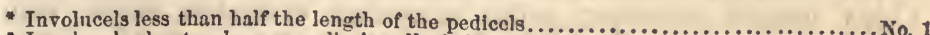

- Involucels about as long as pedicels. - Fruit broadly winged..................................

- Fruit scarcely winged.............................. 5

1 A. atropurpùrea Hoffm. St. dark purple, furrowed; petioles 3.parted, the divisions quinate, lfts. incisely toothed, odd leaflet of the terminal divisions rhomboidal, sessile, the others decurrent; involucels of short, setaceous bracts.-Among the largest of the Umbelliferæ, well known for its aromatic properties, common in fields and meadows, N. and W. States. St. 4 to $6 \mathrm{f} \mathrm{high,} 1$ to $2 \frac{1}{2}^{\prime}$ in thickness, smooth, hollow, glaucous. Petioles large, inflated, channeled on the upper side, with inflated sheaths at base. Terminal lft. sometimes 3-lobed. Umbels spherical, 6 to $8^{\prime}$ diam., mostly puberulent. Fr. $3^{\prime \prime}$ long, winged. Jn. Fls. greenish white. (Angelica triquinata Mx.)

2 A. hirsùta Torr. \& Gr. St. striate, the summit with the umbels tomentous-hirsute; lvs. bipinnately divided, the divisions quinate; segm. oblong, acutish, tho upper pair connate, but not decurrent at base.-Dry woods, N. York to Car. St. simple, erect, straight, 3 to $5 \mathrm{f} \mathrm{high}$. Lvs. on petioles from 6 to $10^{\prime}$ long; ifts. 1 to $2 \frac{1}{2}^{\prime}$ long, $\frac{1}{4}$ as wide, mostly ovate-oblong, often tapering at base. Umbels 3 or 4 , on long, velvety peduncles, 2 to $4^{\prime}$ broad; rays unequal, spreading, densely tomentous. Invol. 0. Involucels of 4 to 6 bracts, about as long as the rays. Jl., Aug. (Angelica Mx.)

3 A. officinàlis Hoffm. GARDEN ANGELICA. St. smooth, round, striate; lvs. pinnately divided into lobate, subcordate, ac!ntely serrate segments, the terminal one 3-lobed; sheaths large and saccate. - Said to be native in Labracior. Cultivated in gardens occasionally for the sake of the stalks, which are to Le blanched and eaten as celery. $\ddagger$ (Angelica Linn.)

4 A. dentàta Chapman. Very slender, finely striate, with slender petioles; lower lvs. first ternate, then ternate or quinate, with lance-ovate, coarsely and remotely toothed, veiny segm., more or less confluent; umbels few-rayed, with scarcely any involucro; involucel 4 to 6-leaved, about cqualing the pedicels; fr. broadoval, broadly winged.-Bainbridge, Ga. (Misses Keen), Quincy, Fla. (Chapman.) Plant 2 to $3 \mathrm{f} \mathrm{high.} \mathrm{Fr.} 1 \frac{1}{2}{ }^{\prime \prime}$ long. Jl., Aug.

5 A. peregrìna Nutt. St. striate, pubescent at summit; 1rs. ternately divided, the divisions quinate, segm. incisely serrate: umbel with many slender rays; invol. 0 ; involucels of many lfts., as long as the umbellets; fr. with obtuse, subequal, scarcely winged ribs. - Sea coast, Me. and Mass. (Pickering.)

12. DAU'CUS, Tourn. CArrot. ( of the carrot.) Calyx limb 5-toothed; petals emarginate, with an inflected point, the 2 outer often largest and decply 2-cleft; fruit oblong; carpels with 5 primary, bristly ribs, and 4 secondary, the latter more prominent, winged, and divided each into a single row of prickles, and having single vittæ beneath; carpophore entire, free.-(2) Invol. pinnatifid. Involucels of entire or 3-cleft bracts. Central fl. abortive.

1 D. Caròta I. St. hispid; petioles veined beneath; lvs. tripinnate or tripinnatifid, the segm. linear, cuspidate-pointed; umbels dense, concave.-The word kar in Celtic signifies red, hence carrot. Naturalized in fields and by roadsides, abundant in the Mid. States. Rt. fusiform. St. 2 to $3 \mathrm{f} \mathrm{high,} \mathrm{branching.} \mathrm{Lvs.}$ numerous, divided in a thrico pinnatifid manner, pale green. Umbels large and very compact, with white fls. blooming all the summer. Cultivation has produced several varieties. Jl.-Sept. $\$ \ddagger$

2 D. pusíllus Mx. St. slender, retrorsely scabrous-hispid: Ifts. pubescent, bipinnatifid, divisions deeply lobed with linear-oblong, merely acute segm. ; invol. bivinnatifid; fr. muricate with barbed prickles.-Dry soils, Savannali (Pond) to S. Car. and La. Sts. 6 to $18^{\prime}$ high. Umbels small, an inch or two broad, enveloped in the many-cleft involucre. Sds. smaller than in the Carrot. 
13. BUPleU'RUM, Tourn. Modesty. Thorough-wax. (Gr. $\beta$ oṽs, an ox, $\pi \lambda \varepsilon v \rho o ̀ \nu$, a rib; from the veined leaves of some of the species.) Calyx margin obsolete; petals somewhat orbicular, entire, with a broad, closely inflexed point; fruit laterally compressed; carpels 5ribbed, lateral ones marginal; seed teretely convex; flattish on the face.-Herbaceous or shrubby. Lrs. mostly reduced to entire phyllodia. Invol. various. Fls. yellow.

B. rotundifòlium L. Lvs. (phyllodia) roundish-ovate, entire, perfoliato; invol. 0 ; involucels of 5 , ovate, mucronate bracts; fr. with very slender ribs, intervals smooth, mostly without vittæ.- (1) In cultivated grounds and fields, N. Y., Penn., and Ind., rare. St. If or more high, branching. Lvs. 1 to $3^{\prime}$ long; $\frac{3}{4}$ as wide, rounded at base, acute at apex, very smooth. Umbels 5 to 9-rayed. Involucels longer than the umbellets. Fr. crowned with the wax-like, shining base of the styles (stylopodium.) Jl, Aug.

14. ANE'THUM, Tourn. Dill. Fensel. (Gr. al0 0 , to burn; the plant (its seeds) is very stimulating.) Calyx margin obsolete; petals involute, with a broad, retuse apex ; fruit ovate or oblong, laterally subcompressed; carpels with 5 obtuse ribs, the lateral ones marginal; intervals with single vittx, commissure with 2.-Umbels perfect, with no invol. or involucels. Fls. yellow.

1 A. gravèolens L. DrLL. Fr. elliptical, compressed, surrmunded by a flat, dilated margin; lvs. tripinnate, segm. capillary; umbels on long stalks.-Nativo of S. Europe. Tho oval, flat, brown seeds are aromatic, pungent, and medicinal. $\ddagger$

2 A. Fœnículum L. Fenvel. Lvs. biternately dissected, segm. linear-subulate, elongated; rays of the umbel numerous, unequal, spreading; carp. turgid, ovate-oblong. - Native of England, \&c. Cultivated in gardens. St. 3 to $5 \mathrm{f} \mathrm{high,}$ terete, branched. Lvs. large and smooth, finely cleft into numerous, very narrow segments. Jl. -The seeds are warmly aromatic. $\ddagger$ (Fœniculum vulgare Gært.)

15. THAS'PIUM, Nutt. Golden Alexanders. (From the Isle of Thaspia, which gave name to the ancient allied genus Thapsia.) Calyx margin 5 -toothed; petals elliptic, with an inflexed point; fruit elliptical, compressed laterally and didymous; carpels convex, with 5 prominent or winged ribs, the lateral margined; intervals with single vitte. - 2f Umbels without an invol. Involucels 3-leaved, lateral. Fils. yellow or dark purple.

$\S$ Leaves 1 or 2 -ternate, the radical often simple............................. 1, $s$ $\$$ Leaves thrice teruate; stem often pubescent at the nodes............................. 8, 4

1 T. aùreum Nutt. Lvs. mostly biternate, lfts. thin, oval-lanceolate; sharply serrate; umbellets with short rays; fr. oblong-oval, 10-winged.-Hills and meadows, U. S. and Can. Sts. 1 to $2 \mathrm{f}$ high, branching above, rather slender, erect, hollow, angular-furrowed, smooth. Lower lvs. on long petioles, the lfts. with coarse serratures, and sometimes quinate, the very lowest one sometimes simple. Umbels about $2^{\prime}$ broad, of 10 to 15 rays, the umbellets dense. Fils. numerous, orangeyellow. Fr. oval, brown. Rt. black, tufted. Jn.

B. APTERUM Gray. Fr. with sharp and prominent ribs, not winged. (Smyrnium aureum $\mathrm{L}$. Zizia aureum Koch.)

2 T. cordàtum Nutt. Radical lvs. simple, cordate, crenate, cauline ones ternate, stalked, segm. acute, serrate; umbels terminal; fr. roundish oval, 6-winged.Shady hills and barrens, U. S. and Can., rare in N. Eng. St. erect, slightly branched, smooth, 2 to 3 f high. Rt. lvs. on long stalks, roundish, heart-shaped, the rest ternate, becoming only 3-parted above, all light green. Umbels dense, with yellow fls. Fr. black, oval, with 3 prominent, paler, winged ridges on each side. May, Jn. (Smyrnium cordatum Mx. Zizia cordatum DC.) 
3. ATROPURPUREUM. Fls. dark purple.-N. Y. to Tenn. (Thapsia trifoliata $\mathrm{L}_{\text {. }}$ )

$\gamma$. APTERUM Gray. Fr. with prominent sharp ribs, scarcely winged (Zizia cordata Koch).

3 T. barbinòde Nutt. St. pubescent at the nodes; lower lvs. triternate, upper biternate, segm. cuneate-ovate, acute or acuminate, unequally and incisely serrate, entire towards the base; umbels terminal and opposite the leaves; fr. elliptical, large ( $3^{\prime \prime}$ long), 6-winged.-River banks, Can. and U. S. St. 2 to $3 f$ high, angular and grooved, branching above. Lvs. smooth, upper ones sub-opposite; segm. 1 to $2^{\prime}$ by $\frac{1}{2}$ to $1 \frac{1}{4}^{\prime}$. Rays about $2^{\prime}$ long, each about 20 flowered. Petals deep yellow. Jn.

4 T. pinnatífidum Gray. St. rough puberulent above; lvs. thrice ternate, tho upper biternate and ternate, lfts. pinnatifid with linear or oblong segm.; fr. oblong, narrowly 8-winged, small (2' long).-Barrens, Ky. to E. Tenn. and W. Car. (Zizia pinnatifida Buckley).

16. ZIZ'IA, Koch. Golden Alexanders. (Dedicated to I. B. $Z_{i z}$, a Rhenish botanist.) Calyx margin obsolete; petals carinatc, apex acuminate, inflexed; fr. oval, contracted at the commissure and didymous; carpels with 5 slightly prominent ribs; intervals with 3 vittre, commissure with 4 ; carpophore 2 -parted; seeds terete or 5 -angled.2f Smooth, erect, glaucous. Lvs. bi or tri-ternate, lfts. entire. Umbels perfect, with no involucre or involucels. Fls. yellow.

Z integérrima DC. Rocky woods, etc. Mich., N. Y., to Ga. Plant 1 to $2 \mathrm{f}$ or more high, readily recognized by its entire leaflets, which aro oblong and ovate, $I^{\prime}$ or : more in length, petiolate. Rays of the umbel very slender, 2 to 3 ' long, about 13 in number, with minute involucels or none. May- $\Omega$

17. SCAN'DIX, L. Venus' Сомв. (Gr. $\sigma \kappa \varepsilon ́ \omega$, to prick; on account of its sharp seeds:) Calyx limb obsolete; petals obovate and oblong, undivided, more or less unequal; fruit laterally compressed or nearly terete, attenuated into a beak which is longer than the seed; carpels with 5 obtusc, equal ribs, vittæ 0 , or scarcely any.-(1) or (2) Lws. finely dissected. Invol. 0 . Involucel 5 to 7 -leaved. Fls. whitc.

S. apiculàta Willd. Slender, with slender branches and long petioles on inflated sheaths; the pinnæ 3 or 4 remote pairs dichotomously deconpound; ultimate segm. acute; umbels about 3-rayed; bracts of the involucel lance-ovate, 2 or 3cuspidato; pet. oblong; fr. beak long, slender, forked at apex with the sty.-A curious plant found near Savannah (Feay), much resembling the S. pecten of Europe. Sts. 12 to $18^{\prime}$ high. Fr. $9^{\prime \prime}$ long.

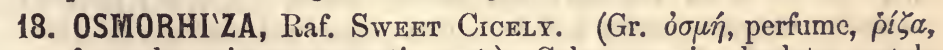
root; from the anisate, aromatic root.) Calyx margin obsolete; petals oblong, nearly entire, the cuspidate point inflexed; styles conical at base; fruit linear, very long, clavate, attenuate at base; carpels with 5 equal, acute, bristly ribs; intervals without vittæ; commissure with a deep, bristly channel.- 4 Lvs. biternately divided, with the umbels opposite. Invol. few-leaved; inrolucels 4 to 7-leaved. Fls. white.

1 O. longístylis DC. Sty. filiform, nearly as long as the ovary; fr. clavate.Woods, Can. to Va., 1 to $3 \mathrm{f}$ high, with inconspicuous umbels of white flowers. Rt. branching, fleshy, of an agreeable, spicy flavor. St. erect, branching above, nearly smooth. Lvs. many, decompound, the ultimate divisions often pinnato; lfts. irregularly divided, the lobes broadly ovate, slightly pubescent. Involucres of linear bracts longer than the rays. Fr. blackish, an inch in length, crowned with the slender persistent styles. May, Jn. (Fig. 207.)

20 . brevistylis DC. Sty. conical, scarcely as long as the breadth of the ovary; fr. somewhat tapering at the summit.-Common in woods, Can. to Penn. W. to Or. A spect similar to that of the preceding, but the root is destitute of the aniselike flavor of that species, being disagreeable to the taste. The plant is moro 
hairy, and with more deeply cleft divisions in the leaves. Invol. deciduous. Umbels with long, diverging rays, of which but few prove fertile. Fr. crowned with short, convergent (not spreading) styles. May, Jn.

19. CHEROPHYL'LUM, L. Calyx limb obsolete; petals obovate, emarginate, point inflexed; fruit laterally compressed, contracted above but scarcely beaked; carpels with 5 obtuse, equal ribs; intervals with 2 vittre, commissure deeply sulcate.-Lvs. 2 to 3-pinnately divided, segm. incisely cleft or toothed. Invol. 0 , or few-leaved; involucel many-leaved. Fls. mostly white.

1 C. procumbens Lam. Decumbent or assurgent, nearly glabrous; segm. of the lvs. pinnatifid, with oblong, obtuse lobes; umbels diffuse, few-flowered, often simple, sessile or pedunculate; invol. 0 ; involucels of 3 or 4 very small oval lfts; fr. linear-oblong, acute; ribs narrower than the intervals.-(1) or (2) Moist woods, Ohio, (Clark) Ky. (Short) to S. Ca. Sts. 1 to 2 f long, pubescent when joung, diffuse, slender. Segm. of the lvs. rather open, about $4^{\prime \prime}$ by $1^{\prime \prime}$. Rays 1 to 4, 1 to 4-flowered, about $2^{\prime}$ long. Apr. May. (Scandix procumbens L.)

2 C. Tainturìeri Hook and Arn. Decumbent or erect; lvs. tripinnate, segm. crowded, again pinnatifid or bipinnatifid, ultijizate segm. very small, oblong, acute; fr. attenuated to a short beak; ribs terete, much broader than the intervals.- E. Ga. (Feay, Pond) to Ala. and La. (Hale). Plant 10 to 20' high, smooth when old. Lvs. very finely dissected, ultimate segm. only $1^{\prime \prime}$ long. Fr. nearly $4^{\prime \prime}$ long, brown and smooth when ripe.

20. CONIOSELINUM, Fisch. (Name compounded of Conium and Selinum.) Calyx teeth obsolete; petals obovate, with an inflected point ; fruit compressed on the back ; carpels with 5 -winged ribs, lateral ones marginal and much the broadest; intervals with 1 to 3 vittæ, commissure with 4 to 8.-(2) Smooth. St. hollow. Lvs. on very large, inflated petioles. Invol. various; involucels 5 to 7 -leaved.

C. Canadénse Torr. and Gr. Lvs. ternately divided, divisions bipinnate, with oblong-linear lobes; invol. 0, or 2 to 3-leaved; fr. oblong-oval; vittæ solitary in the dorsal intervals, -2 to 3 in the lateral.-In wet woods, Me. to Wis., but not common. St. 3 to $5 \mathrm{f}$ high. Lvs. much compounded, the ultimate segments pinnatifid with linear-oblong lobes. Umbels compound. Pet. white, spreading. Sty. slender, diverging. Fr. about 2" long. Aug. Sept.

21. LIGUS'TICUM, L. Lovage. (One species was said to be native of Liguria.) Calyx teeth minute or obsolete; petals obovate, emarginate, with an inflexed point; fruit nearly terete, or slightly compressed laterally; carpels sharply 5 -ribbed, with numerous vittæ. $-2 f$ Lrs. ternately divided. Invol. many-leaved. Fls. white.

1 I. Scotticum I. SEA Lovage. Glabrous; st. lvs. biternate, the upper ones ternate; lateral ifts. oblique, cut-dentate, the terminal one rhomboid; bracts of the invol. numerous, linear.-Fr. narrowly oblong.-Sea coast. Rt. thick, tapering. St. a foot high, nearly simple, striate, smooth. Lvs. petiolate. Lfts. 1 to $2 \frac{1^{\prime}}{2}$ long, dark green, smooth and shining, entire at base, serrate above. Fr. 4 to $5^{\prime \prime}$ long. J1. §. Eur.

2 I. actæfollium Mx. AvGeLico. Glabrous; lvs. triternate, with ovate, dentserrate lfts. ; umbels numerous, forming a whorled panicle or a triply compound umbel; invol. and involucels of about 3 short, ovate-subulate lvs.-Topsfield and Scituate, Mass. (Oakes Russel), on Lookout Mt., Chattanooga, Tenn. Plant 3 to 6 figh. Lfts. 2 to $3^{\prime}$ long, distinct, abrupt at base, rounded or acuto at apex, veiny. Umbels on long, verticillate peds, terminal one abortive. Fr. short, with the ribs distinctly winged. May-Jl.

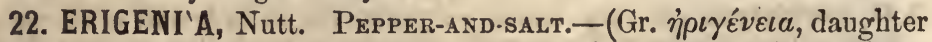
of the early spring; for its early flowering.) Calyx limb obsolete; petals flat, entire; fruit contracted at the commissure; carpels 3-ribbed, 
ovato-reniform.-2f Rt. tuberous. Radical lf. triternately decompound. Involucrate lvs. solitary, biternately compound. Involucels of 3 to 6 entire, linear-spatulate bracts.

E. bulbòsa Nutt. A small, early-flowering herb, shady banks, Western N. Y. to Ohio and Mo. Plant 4 to $6^{\prime}$ high, from a round tuber deep in the ground, with 2 to 4 lvs., the lower one radical, numerously divided, the divisions incisely cleft into narrow segments; the upper ones bract-like, similarly divided, each subtending a 3-raved umbel of white fls, with dark purple or brownish anthers (hence the odd popular name). March, Apr.

23. EU'LOPHUS, Nutt. (Gr. $\varepsilon \dot{v}$, true, $\lambda$ ó parent.) Calyx limb 5-toothed, deciduous; petals olovate, emarginate, with a long inflexed point; fruit contracted laterally, somewhat double; carpels surrounded with large vittæ, 4 in the commissure, ribs obsolete; seed channelled on the inner face. $-2 f$ Tall, slender, smooth, with dis. sected lvs. Invol. nearly 0. Involucel setaccous.-Fls. white.

E. Americàna Nutt. Near Columbus, Ohio (Sullivant), to Tenn. St. round, striate, 3 to $4 \mathrm{f}$ ligh. Ivs. biternately divided, the segm. lance-linear, $\mathrm{I}^{\prime}$ long, acute; upper lvs. of 3 long, enti i segrn. Umbels long-stalked, 8 or 10-rayed. Fr. as large as caraway. Jl.

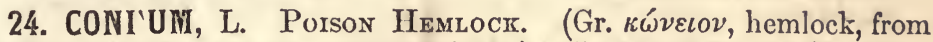
$\kappa \tilde{\omega} \nu 05$, a top; because it causes dizziness.) Calyx margin obsolete ; petals obcordate, with an acute, inflected point ; fruit ovate, laterally compressed; carpels with 5 , acute, equal, undulate-crenulate ribs, lateral ones marginal; intervals without vittæ; seeds with a deep, narrow groove on the face.-(2) Poisonous herbs. Lvs. decompound. Invol. and involucels 3 to 5 -leaved, the latter unilateral. Fls. white.

C. maculàtum L. St. spotted; lvs. tripinnate; lfts. lanceolate, pinnatifid; fr. smooth.-Grows in waste grounds, way-sides. A well known poisonous plant. St. much branched, about $4 \mathrm{f}$ high, very smooth, round, hollow, with purplish spots. The lower lvs. are very large, several times pinnate, bright green, on long, sheathing footstalks. Umbels terminal, the invol. of $\epsilon$ to 8 lanceolate bracts, tho involucels with the inner half wanting. Fls. small, white. Fr. with undulate or wrinkled ribs. A powerful nareotic, exhaling a disagreeablo odor when bruised. Used in medicine. Jl., Aug. § Eur.

25. CiCU'TA, L. Water Hemlock. (A Latin name used by Virgil (Ecl. 2 d and 5 th), but of unknown application.) Calyx margin of 5 broad segments; petals obcordate, the points inflected; fruit subglobous, didymous; carpels with 5 flattish, equal ribs, 2 of them marginal; intervals filled with single vittæ, commissure with 2 vittæ; carpophore 2-parted; seeds terete. - 2f Aquatic poisonous herbs. Leaves compound. Stems hollow. Umbels perfect. Invol. few leaved or 0. Involucels many leaved. Flowers white.

1 C. maculàta I. St. streaked with purple; lower lrs. triternate and quinate; upper biternate; segments lanceolate, mucronately serrate; umbels terminal and axillary.-Common in wet meadows, U. S. and Can. St. 3-6f high, smootl, striate, jointed, hollow, glaucous, branched above. Lfts. or segm. 1-3' long, t$n^{\prime}$ ' wide, finely serrate, the veins mostly running to the notches, rarely to tho points; umbels rather numerous, naked, $2-4^{\prime}$ broad. Involucels of $5-6$ short narrow, acute bracts. Fr. $1 \frac{1}{2}$ diam., 10-ribbed, crowned with the permanent calyx and styles. Jl., Aug.-The thick, fleshy root is a dangerous poison, but sometimes used in medicine.

2 C. bulbiffera L. Axils of the branches bulbiferous; Ivs. biternately divided; Ifts. linear, with remote, divergent teeth; umbels terminal and axillary.-In wet meadows, Penn. to Can. Stem 3-4f high, roond, striate, hollow, green, branching. 
Leares various, those of the stem generally biternate, of the branches ternate Leatlets or segments $2-4^{\prime}$ long, $1-4^{\prime \prime}$ wide, linear or lance-linear, smooth, with slender teeth. Bulblets often numerous, opposite, and within the axils of the bracteate petioles. Umbels terminal. Invol. 0. Umbellets of close, small, white, fls., and slight involucels. Aug.

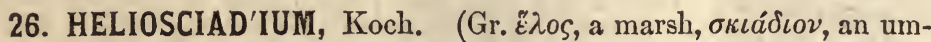
brella or umbel.) Calyx limb obscurely 5 -toothed; petals ovate, entire; styles short; fruit laterally compressed, oval, not scaly; carpels with 5 filiform ribs, the lateral ribs marginal; intervals with single vittx; carpophore free, undivided; seed plano-convex.-Lvs. various. Invol. mostly none. Umbels opposite the lvs., mostly sessile. Fls. white.

1 H. nodiflòrum Koch. Procumbent, striate; lvs. pinnate, lfts. oblong, equally serrate; umbels sessile or on short peduncles; invol. 0 , or of 1,2 or 3 bracts, involucel 6 to 8-leaved, reflexed.-(1) Sts. diffuse, 1 to $2 \mathrm{f}$ long, in wet places about Charleston, S. C. Apr. § Eur. (Sium L.)

2 H. leptophýllum DC. Erect or diffusely branched; lvs. ternately or somewhat pinnately divided, with linear segm.; umbellets pedunculate; invol. and involucels none; fr. roundish.- (I) Savannalh (Feay. Pond) to La. (Hale). Sts. $6^{\prime}$ to $2 \mathrm{f} \mathrm{high.}$ Umbels many, sessile, often one, pedunculate. Fr. smaller than a mustard seed. Jn., Jl.

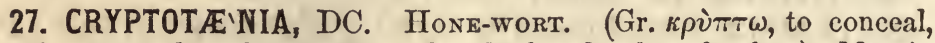
raivia, a wreath or border, from the obselete border of calyx.) Margin of the calyx obsolete; petals with an inflexed point; fruit linear-oblong or ovate-oblong, with slender styles; carpels with 5 obtuse ribs; carpophore free, 2-parted; vittæ very narrow, twice as many as the ribs.2f Lis. 3-parted, lobed and toothed. Umbels compound, with very unequal rays. Invol. 0. Involucels few-leaved. Fls. white.

C. Canadénsis DC. Lvs. smooth; lfts. or segm. rhomboid-ovate, distinct, ontire or 2 to 3-lobed, doubly serrate, lateral ones oblique at base; umbels numerous, irregular, axillary and terminal.-Common in moist woods. St. erect, 1 to $2 \mathrm{f}$ high. Lower petioles 2 to $6^{\prime}$ long, clasping. Lfts. 3,2 to $3^{\prime}$ long, 1 to $2^{\prime}$ wide, petiolulate. Umbels paniculate, of 3 to 5 very unequal rays. Umbellets of 4 to 6 unequal pedicels and minute involucels. Fls. small, white. Fr. near $3^{\prime \prime}$ long, crowned with the straight styles $\frac{1}{2}$ as long. (Sison, L.)

28. EeTHU'SA, L. Fool's Parsley. (Gr. alow, to burn; on account of its poisonous acridity.) Calyx margin obsolete; petals obcordatc, with an inflexed point ; fruit globous-ovate ; carpels with 5 acutely carinated ribs, lateral ones marginal, broader ; intervals acutely angled, with single vittre, cornmissure with 2.-(1) Poisonous herbs. Invol. 0. Involucels one-sided. Fls. white.

丑. cynàpium L. Lrs. bi- or tri-pinnately divided, segm. cuneate, obtuse; involucel:s 3 -leaved, pondulous, louger than the partial umbels.-In waste grounds, N. Eng., not common. St. about 2 f high, green, striate. Lvs. with numerous, narrow, wedge-shaped segm., uniform, dark green, flat. Lfts. of the involucels linear, long, deflected, and situated on the outside. Jl., Aug.-The plant somewhat resembles parsley, but is distinctly marked by the involucels, and by its disagreeable odor. It is said to be poisonous. § Eur.

29. LEPTOCAU'LIS, Nutt. (Gr. $\lambda \varepsilon \pi \tau o ́ s$, slender, $\kappa a v \lambda o ̄ s$, stem.) Calyx limb obsolete; petals ovate, entirc; fruit (often scaly) laterally compressed, ovate, crowned with the short styles; carpels 5-ribbed, lateral ribs marginal; intervals with single vittx, commissure with 2 ; carpophore 2-cleft at the tip; seed plano-convex.-(1) Herbs slender, smooth, 
erect. Lvs. finely divided. Umbels pedunculate, few-rayed. Invol. 0 ; involucel few-leaved. Fls. minute, white.

L. divaricàtus DC. Umbels (very small) 3 to 5-rayed, lateral and terminal; involucel lvs. divided, shorter than the very short pedicels; fr. muricated with short, whitish, erect scales.-Dry sandy soils, S. Car., Ga. Sts. 2 to $8^{\prime}$ high. An insig* nificant weed. Mar., Apr.

30. DISCOPLEURA, DC. Brshop-weed. (Gr. Sírios, the disk, $\pi \lambda \varepsilon v \rho a$, a rib; that is, the disk and ribs (of the fruit) united.) Caly $x$ tceth subulate, persistent; petals ovate, entire, with a minute, inflexed point; fruit ovate, often didymous; carpels 5 -ribbed, the 3 dorsal ribs filiform, subacute, prominent, the 2 lateral united, with a thick, accessory margin; intervals with single vittæ; sceds subterete.-(1) Lvs. capillaceous-dissected. Umbels compound. Bracts of the invol. cleft. Fls. white.

1 D. capillàcea DC. Erect or procumbent; umbels 3 to 10-rayed; Ifts. of the invol. 3 to 5, mostly 3-cleft; fi: ovate.-In swamps near the coast, Mass. to Ga. St. much branched, 1 to $2 \mathrm{f}$ high. Lvs. very smooth, ternately dissected, with filiform, spreading segm. Umbels axillary and terminal, pedunculate, spreading. Invol. lits. about 3 , with setaceous segm. Involucels filiform, longer than the umbellets. Jn. -Sept. (Ammi, Spreng.)

2 D. costàta. Branshed, erect; umbels 7 to 15-rayed; bracts of the invol. 10 to 12, 2 to 5-parted; lf.-segm. filiform, numerous, apparently verticillate; fr. with ribs and vittce strongly contrasted.-Swamps, Ogeechee R. to the Miss., more common than $\mathbb{N}_{0}$. 1, which prevails northward. St. stouter, 1 to $2 \mathrm{f} \mathrm{high.} \mathrm{The} \mathrm{corky} \mathrm{ribs}$ and persistent sepals conspicuous on tho ovate fruit. Oct., Nov. (Ammi costatum Ell.)

3 D. Nuttállii DC. Erect, tall; umbels 15 to 20-rayed; invol. few-bracted, bracts entire; fr. as broad as long.-Wet prairies, Ky. to Fla. and La. Sts. 2 to 6f high, branched above. Lvs. few, but with numerous capillaceous segm. Invol. not half as long as the rays; involucels minute. Umbels near $2^{\prime}$ broad.

31. NEUROPHYL'LUH, Torr. \& Gray. (Gr. veṽpov, a nerve (vein), $\phi \dot{v} \lambda \lambda o v$, leaf; leaves prominently veined.) Calyx limb of 5 lanceolate, persistent teeth; petals obovate, joint inflexed; stylopodium conical; fruit laterally compressed, ovate; ribs filiform, slight; intervals with 3 vittx, commissure with 4 ; seed teretely plano-convex.-2f Tall, slender, smooth. Lvs. ternate, segm. very long, linear, entire, 3-veined. Umbels perfect. Invol. 0 to 3-leaved; involucel 4 to 6-leaved. Fls. white. (The same as Archemora ternata Nutt. ?)

N. Iongifòlium Torr. \& Gr. Swamps, N. Car. to Fla (Chapman). St. 3 to $4 f$ high, branched above, very slender. Rt. lvs. 12 to $18^{\prime}$ long, the segm. much shorter than the petioles. Umbel 5 to 7 -rayed, rays very slender. Bracts of invol. and involucel subulate, very short. Sept.

32. SIUM, L. Water Parswip. (Celtic siw, water; that is, a genus of aquatic plants.) Calyx margin 5-toothed or obsolete; petals obcordate, with an inflexed point; fruit nearly oral; carpcls with 5 obtusish ribs, and several vitta in each interval ; carpophore 2-parted.2f Aquatic. Lvs. pinnately divided. Umbels perfect, with partial and general many-leaved involucra. Fls. white.

I S. latifòlium L. St. angular, sulcate; lfts. oblong-lanceolate, acutely and coarsely serrate, acute; cal. teeth elongated. -A tall plant in swamps and ditches, N. J.? to Ind. and Can. St. 3 to $4 \mathrm{f} \mathrm{high,} \mathrm{smooth,} \mathrm{hollow,} \mathrm{with} \mathrm{deep-furrowed}$ and prominent angles. Lfts. or segm. 4 to $6^{\prime}$ long, 1 to $2^{\prime}$ broad, in 3 to 5 pairs, with a sessile odd one, each with about 10 large, sharp teeth. Umbels very 
large, 20 to 30 -rayed. Cal. segm. acute, exceeding tho broad 5-lobed stylopodium. Ribs of fr not prominent. Jl., Aug.

2 S. lineàre Mx. St. angular, sulcate; lfts. 9 to 11, linear and lanse-linear, finely serrate, acute; cal. teeth obsolete; $f r$. ribs winged.-More common than the last, in swamps, N. J. to Ind. and Can. St. 2 to $4 \mathrm{f}$ high, smooth, with 7 prominent angles. Lfts. 2 to $4^{\prime}$ long, 2 to $4^{\prime \prime}$ wide, the odd and lower ones petiolulate, middle pairs sessile. Umbels $1 \frac{1}{2}$ to $2 \frac{1}{2}^{\prime}$ broad. Invol. of 5 or 6 linear bracts, $\frac{1}{4}$ as long as the 15 to 21 rays. Umbellets with numerous, small, white fls. Fr. roundish, crowned with the broad, yellowish stylopodium. Jl., Aug.

33. CORIAN'DRUM, L. CoRIANDER. (Gr. kógls, a bug; on account of the smell of the leaves.) Calyx with 5 conspicuous teeth; pelals obcordate, inflexed at the point, outer ones radiate, bifid; fruit globous ; carpels cohering, with the five depressed, primary ribs, and 4 secondary more prominent ones, seeds concave on the face.-(1) Smooth. Invol. 0 or 1-leaved. Involucels 3-leaved, unilateral.

C. sativum $I$. Lvs. bipinnate, lower ones with broad-cuneate lfts., upper with linear ones; carp. hemispherical.-Native of Eur., etc. This well-known plant is cultivated chiefly for the seeds which aro used as a spice, as a nucleus for sugar-plums, etc. St. $2 \mathrm{f}$ high. Lvs. numerously divided, strong-scented. Unbels with only the partial involucra. Fls. white. Jl. $\ddagger$

34. PIMPINEL'LA, L. Anise. Calyx limb obsolete; petals obcordate, a little unequal; disk 0 ; flowers perfect or diclinous ; styles capillary, as long as fruit ; fruit ovate, ribbed, with convex intervals.-European herbs, mostly 2 , with pinnately, many-parted lvs., and white fls. Umbels compound. Invol. 0 .

P. Anisum L. Radical lvs. incisely trifid; caulino ones multifid, with narrow. linear segments, all glabrous and shining; umbels large, many-rayed.-Native of Egypt. The aromatic and carminative properties of the fruit are well known. $\ddagger$

35. ÆEGOPO'DIUM, L. Goutweed. Goats-Foot. (Gr. aľ (alyós),

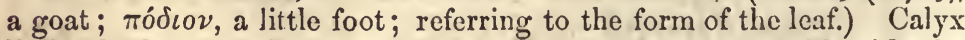
limb obsoletc; fruit compressed laterally, oblong, crowned with the conical bases of the deflexed styles; carpels with 5 filiform ridges, without vittx. - 2f Lvs. 1 to 2 -ternate. Involucra none. Fls. white.

As. podagrària L. St. deeply furrowed, glabrous; lfts. ovato or lanceolate, acuminate, unequally toothed, upper merely 3-cleft.-Gardens. Sts. 12 to $18^{\prime}$ high, from strong, tenacious, creeping roots hard to eradicate. Umbels manyrayed. $\dagger$

36. A'PIUM, L. Celery. (Celtic apon, water; the plants grow in watery situations.) Calyx margin obsolete; petals roundish, with a small inflexed point; fruit laterally compressed nearly double; carpels 5-ribbed, the lateral ribs marginal ; intervals with singlo rittw.-European herbs. Umbels perfect. Invol. 0, or few-leaved. Fls. white.

1 A. gravèolens L. Lower lvs. pinnately dissected, on very long petioles. segm. broad-cuneate, incised; upper lvs. 3-parted, segm. cuneate, lobed, and incisely dentate at apex; invol 0 ; fr. roundish.-(2) Gardens. St. 2 to $3 \mathrm{f} \mathrm{high,}$ branching, furrowed. Radical petioles thick, juicy, If in length. * Umbels with unequal, spreading rays.-The stems when blanched by being buried, are sweet, crisp, and spicy in flavor, and used as salad 'Jn.-Aug. ‡Eur.

2 A. petroselinum Willd. PARSLEY. Lrs. decompound, segments of the lower ones cuneate-ovate, terminal ones trifi, all incised, cauline segm. lancelinear, subentire; involucels of 3 to 5 subulate brats; fr. ovate.-(2) Gardens. St. 2 to $4 \mathrm{f}$ high, branched. Lvs. smooth and shining, with numerous, narrow segm. $\mathrm{Jn}$. - Cultivation has produced several varieties. Esteemed as a potherb, for soup, etc. (Petroselinum sativum Hoffm.) $\ddagger$ Sardinia Greece. 
37. CA'RUM, L. Caraway; (From Caria, the native country of the plant, according to Pliny.) Calyx margin obsolete; petals obovate, emarginate, the point inflexed; styles dilated at base, spreading; fruit oval, compressed laterally ; carpels 5 -ribbed, lateral ribs marginal; intervals with single vittæ, commissure, with 2.-Herbs with dissected lis. Umbels perfect. Involucra various. Fls. white.

C. Cárvi L. Lves. somewhat bipinnatifid, with numerous linear segm. invol. 1-leaved or 0 ; involucels 0 . - St. about $2 \mathrm{f} \mathrm{high,} \mathrm{branched,} \mathrm{smooth,} \mathrm{striate.}$ Lower lvs. large, on long petioles, with tumid, elasping sheaths. Umbels on long pedunclos; involucrate bracts when present linear-lanceolate. Jn.-Cultivated for its fine aromatic fruit, so well known in domestic economy. ‡ Eur.

38. TREPOCARPUS IEthusa Nutt. Western La. (Hale).

39. CYNOSCIADIUM digitatum DC.-Western La. (Hale).

Obs. These plants, of which we have beautiful sjecimens from Dr. Hale, may perhaps bo found E. of the Mississippl.

\section{Order lXIV. araliace A. Araliads.}

Trees, shrubs or herbs closely allied to the Umbellifers in the leares, inflorescence and flowers, but the styles and cells of the OrARY are usually more than 2 (3 to 5), cells 1-ovuled; fruit baccate or dry, 3 to 5-celled, with 1 albuminous seed in each cell.

Genera 22, species 160. They are natives of northern temperate climes of both hemispheres.Several species are well known in medicine, etc., as Ginseng, Spikenard, Sarsaparilla, etc. Tho Latter is sometimes substituted for the Sarsaparilla of the shops.

1. Ara'lia, L. Wird Sarsaparilla, etc. Calyx tube adherent to the ovary, limb short, 5 -toothed or entire; petals 5 , spreading, apex not inflexed; stamens 5 , epigynous; styles and carpels 5 ; berry crowned with the remains of the calyx and styles, mostly 5 -celled and 5 -seeded.Lrs. compound. Fls. in simple, solitary, or racemous umbels.

\$ Plants wholly herbaceous and marmed.................................. 1,2 \$ Plants shrubby at base or wholly sbrubby, prickly.......................................... 8,4 I A. nudicaùlis L. Nearly stemless; If. solitary, decompound; scape naked shorter than the lf., bearing the few umbels. - If A well-known plant, found in woods, most abundant in rich and rocky soil, Can. to Car. and Tenn. It lras a large, fleshy root, from which arise a leaf-stalk and a scape, but no proper stem. The former is long, supporting a single, large, compound leaf, which is either 3 -ternate or 3-quinate. Lfts. oval and obovate, acuminate, finely serrate. Tho scape is about a foot high, bearing 3 simple umbels of greenish als. Jn., Jl.

2 A. racemòsa I. Petryaornet. Spikevand. St. herbaceous, smooth; Irs. decompound; umbels numerous, small, arranged in a decompound panicle-4 In rocky woods, Can. to the S. States. St. 3 to $4 \mathrm{f}$ high, dark green or reddish, arising from a thick, aromatic root. The lf.-stalks divide into 3 partitions, each of which bears 3 or 5 large, ovate, serrate lits. Umbels numerous, arranged in branching racemes from the axils of the lvs. or branches. The root is pleasant to the taste, and highly esteemed as an ingredient in small beer, etc. Jl.

3 A. hispida L. WILD ErDer. Bristly ARALLA. St. shrubby at base hispich, with prickles, herbaceous above; Ivs. bipinnate, lfts. ovate, cut-serrate; umbels on long ped., forming a terminal corymb. $-2 f$ Common in fields about stumps and stoneheaps, N. Eng. to Va. St. I to 2 f high, the lower part wondy and thickly beset with sharp, stiff bristles, the upper part branching, herbaceous. Lits. many, ending in a long point, smooth. Umbels many, simple, globous, forming bunches of dark-colored, nauseous berries. Plant ill scented. Jl., Aug.

4 A. spinòsa L. Angelica Tree. Arborescent; st. and petioles prickly; Ivs. bi- and tripinnate, lfts. ovate, acuminate, sessile, glaucous beneath; unbels numerous, forming a very large panicle; invol. small, few-leaved.-Damp woods, Penn. and Ohio, to Fla and La. Shrub 8 to $12 \mathrm{f} \mathrm{high,} \mathrm{with} \mathrm{tho} 1 \mathrm{ks}$. all crowded 
near the summit. In the South it attains the height of 20 to $30 \mathrm{f}$, usually with. out a branch, imitating the form of the palm (as Elliott remarks) more nearly than any other tree. Its leaves are there 4 to $6 \mathrm{f}$ in length. Fls. white. Aug.Properties emetic and cathartic.

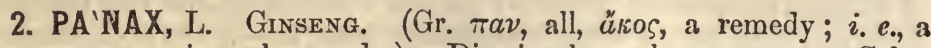
panacea, or universal remedy.) Diœciously polygamous. $\Varangle$ Calyx adnate to the ovary, limb short, obsoletely 5 -toothed; petals 5 ; stamens 5 , alternate with the petals; styles and carpels 2 to 3 ; fruit baccate, 2 to 3 -celled; cells 1 -seeded. $\hat{\delta}$ Calyx limb nearly entire; petals and stamens 5.-Herbs or shrubs. Lvs. 3 (in the herbaceous species), palmately compound. Fls. in a solitary, simple umbel.

I P. trifòlium I. GRoUND-NUT. DWARF GINSENG. Rt. globous, tuberous; lvs. 3 , verticillate, 3 to 5 -foliate, lifs. wedge-lanceolate, serrate subsessile; sty. 3 ; berries 3-seeded.-Common in low woods. Can. to S. States. The globular root is deep in the ground, nearly $\frac{1^{\prime}}{2}$ diam., connected with the stem by a short, screwlike ligament. The st. arises 3 to $6^{\prime}$ above tho surface, smooth, slender and simple. At the summit is a whorl of 3 compound lvs. with a central ped. terminating in a little umbel of pure white fls. Lfts. generally 3, nearly or quite smooth. Barren and fertile fls. on different plants, the latter without stamens, succeeded by green berries, tho former with a single abortive style. May.

2 P. quinquefòlium L. Rt. fusiform; lvs. 3, verticillate, 5-foliate; lfts. oral, acuminate, serrate, petiolate; ped. of tho umbel rather shorter than the common. petiole.-Not uncommon in rocky or mountainous woods. Can. to S. States. Rt. whitish, thick and fleshy. St. round, smooth, If high, with a terminal whorl of 3 compound lvs. and a contral ped. bearing a simple umbel. Fls. small, yellowish, on short pedicels, the barren ones borne on separate plants have larger petals and an entire calyx. Berries bright scarlet. Jn.-Aug. The root is in some estimation as a drug.

3. HED'ERA, L. European Ivy. (Celtic hedra, a cord; from the vine-like habit.) Calyx 5 -toothed; petals 5 , dilated at the base; berry 5 -seeded, surrounded by the permanent calyx. - European shrutby plants, climbing or erect, with simple, evergreen lvs. and green ts.

F. IIeliz L. St. and branches long and floxiblo, attached to the carth or trees or wall by numerous radicating fibres; lvs. dark green, smooth, with white veins, petiolate, lower ones 5-lobed, upper ovate; fls. in numerous umbels, forming a corymb; berry black, with a mealy pulp. - Native of Britain. There are several varieties in gardens. +

\section{Order LXV. CORNACE尼. Cornels.}

Trees and shrubs, seldom herbs, without stipules. Leaves opposite (alternate in one species), simple, with pinnate veinlets. Flowers 4-merous. Sepals adberent to the ovary, the limb minute, 4-toothed or lobed. Petals 4, disti ct, alternate with the calyx teeth, valvato in the bud. Stamens same number as petals, inserted on the margin of tho epigynous disk. Ovary 1 or 2-celled. Fruit a baccate drupe crowned with the calyx.

Genera 9, species 40 . They are natives thronghont the temperate zone of both continents Tho Order is distinguished for its bitter and astring'nt bark. That of Cornus florida is an ex. cellent tonic similar in its aetion to the Peruvian bark. Many aro beautiful sbrubs in cul. tivation.

1. COR'NUS, L. Dogwood. (Lat. cornu, a horn; from the hardness of the wood of some species.) Calyx limb of 4 minute segments; petals 4, oblong, sessile; stamens 4; style somewhat clubshaped; drupe baccate, with a 2 or 3-celled nut.-Trees, shrubs, or perennial 
herbs. Lvs. (mostly opposite) entire. Fls. in cymes, often involucrate. Floral envelops valvate in æstivation. Bark bitter, tonic.

8 Cymes subtended by a 4-leaved, white involucre................................ 1, 2

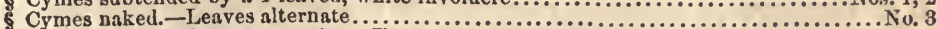
-Leaves opposito.-Twigs and cymes pubescent........................... 4 -Twigs, \&c., glabrous._Drupes white.................... 5,6 -Drupes blue............... Nos. 7,8

1 C. Canadénsis. L. Low Connel or DoG-Wood. Herbaceous, low; upper lvs. whorled, veiny, on short petioles; st. simple.-A small, pretty plaut, in woods, nearly throughout N. Am., N. of lat. $39^{\circ}$. Rhizome creeping, woody. Tho flowering stems erect 4 to $8^{\prime}$ high, bearing 2 small bracts in the middle, and a whorl of 6 leaves at the top, two of which are larger, placed a little lower and opposite. An umbellate cyme of flowers arises from the center of the whorl, and with its large, showy involucre of 4 white leaves, might easily be taken for a single flower. A bunch of red berries succeeds. The barren st. supports a whorl of 4 equal leaves. May, Jn.

2 C. flórida L. Flowering Dogwood. Arboreous; lvs opposite, ovate, acuminate, entire; fls. small, in a close, cymous umbel or head, surrounded by a very large, 4 leaved, obcordato involucre. $-\Lambda$ tree from 20 to $30 \mathrm{f}$ in height, very ornamental when in flower. Woods, U. S. and Can. Wood hard and compact, covered with a rough, cxtremely bitter bark, used in medicine as a tonic. Lrs. (partially expanded at flowering) nearly smooth, veiny, pale beneath. The true fls. are inconspicuous, greenish yellow, but the involucre is very large and showy, of veiny, white obovate lvs. ending in a callous point, which is turned up or down so abruptly as to appear emarginate. Drupes red. May.

3 C. alternifòlia L. Lvs. alternate, oval, acute, hoary beneath; branches alternate, verrucous; drupes purple, globous.-A small tree, N. and W. States and Can., about twice the height of the last, in moist woods. The branches are smooth, even, spreading from the upper part of the stem, and forming a depressed summit. Bark greenish, marked with warty streaks. Lvs. irregularly scattered along the branches, oval-lanceolate, acute, entire veiued, whitish underneath, on rather long stalks. Fls. palo buff color, in a looso cyme. Jn.

4 C. sericea L. Branches spreading, purplish, branchlets woolly; lvs. ovate, rounded at base, acuminate, sillky-pubescent beneath; cymes depressed, woolly; drupes bright blue.-U. S. and Can. $\Lambda$ variety has lvs. tapering at base. A shrub about $8 \mathrm{f}$ high, with opposite, dusky purple branches, and dark red shoots. Lvs. 2 to $4^{\prime}$ long, $\frac{1}{2}$ as wide, varying from ovate and oval to lanceolate, nearly smooth above, with rather prominent veins; petioles $\frac{1}{2}$ to $1^{\prime}$ long. Fls. yellowish white, appearing in June.

5 C. paniculàta L'Her. Branches erect, grayish, smooth; lvs. ovate-lanceolate, acuminate, roughish above, hoary beneath; cymes paniculate; drupes white.-A handsome shrub $10 \mathrm{f}$ high, profusely flowering, common in low woodlands and thickets, N. and W. States and Can. It has numerous and very branching sts. covered with grayish bark, the shoots chestnut-colored. Lrs. 1 to $3^{\prime}$ long. Fls. small, white in all their parts, in many small, conical cymes, succeeded by drupes as large as peas. May, Jn.

6 C. stolonifera $\mathrm{Mx}$. RED OsIFR. St. often stoloniferous; branches smooth; shoots virgate, reddish purple; lvs. broad-ovate, acute, pubescent, hoary beneath ; cymes naked, flat; berries white.-A small tree, N. and W. States, and Can., 8 to $10 \mathrm{f}$ in height, with smooth, slender, spreading branches, which are commonly red, especially in winter. It often sends out from its base prostrate and rooting stems, with erect shoots. Fls. in terminal cymes, white, followed by bluishwhito drupes. May, Jn.

7 C. strícta Lam. Branches erect, brown, glabrous; l's. elliptical or lanco-ovate, nearly glabrous and green both sides; acute at base, long-acuminate at apex; petioles very short; cymes loose, umbel-like, fastigiate, glabrous; cal. teeth subulate, half as long as ovary; pet. ovate-lanceolate, rather acute; anthers and drupes pale blue.-Swamps, Va. to Fla. Shrub 8 to $12 \mathrm{f}$ high, readily known by its slender-pointed, short-stalked Ivs. Apr. 
3. Asperifòli Feay. Lvs. scabrous-pubescent above, downy beneath, rather inclined to elliptical; cymes scabrous.-S. and W. States. (C. asperifolia $\mathrm{Mx}$.)

8 C. circinàta L. Branches verrucous; lvs. orbicular or very broadly oval, white tomentous beneath; cymes spreading, depressed; drupes light blue.-A shrub some $6 f$ high, Can. to Md., W. to Ind. St. grayish, upright, with opposite, cylindrical, green, spotted or warty branches. Lrs. large, about as broad as long, opposite, acuminate, crowned with a white, thick down on the under side. Fls. white. Berries hollowed at base, soft, crowned with the remains of the style. Jn.

2. NYSSA, L. (The name of a nymph or naiad, says Linnæus.) Tulepo, Gum-tree. Fls. diœcious or polygamous. ô Calyx tube very short, limb truncate; petals 5 , oblong; stam. 5-12, mostly 10 , inserted outside a glandular disk in the bottom of the calyx ; ovary 0. o Calyxtube oblong, adherent to the 1-celled ovary, limb truncate, a mere rim as in $\hat{o} ;$; petals $2-5$, oblong, often 0 or soon deciduous; stam. mostly abortive; style large, stigmatic on one side; drupe oval, 1 -seeded.Trees with small green, fls. clustered on axillary peduncles, the sterile more numerous.

I N. multiflòra Wang. Lrs. oblong-obovate, acutish or obtuse at each end, entire; the petiole, midvein and margin villous; fertile peduncles $3(2-5)$-flowered; style revolute; nut short, obovate, striate, obtuse.-Woodlands dry or damp. U. S. A large tree, 30 to $70 \mathrm{f}$ in hight, trunk $1-3 \mathrm{f}$ diam. with a light gray hexagonally broken bark. Lvs. of a firm texture, $2-5^{\prime}$ long, half as wide. $t$ Peduncles 5-9-flowered, fil. at length slender. Drupe often solitary, blackish blue, 5-6" long. Wood soft, but hard to split. Apr.-Jn. (N. aquatica and biflora, auth.)

2 I. uniflòra Walt. SWAMP TulePo. Lvs. green, oblong-ovate or ovate, longpetiolate, entire or denticulate, pubescent or smoothish beneath; fertile flowers solitary, 3-bractcd; on slender peduncles; style nearly straight; sterile fls. 5-10; drupe large, oblong.-Swamps, S. States, common. A tree of large size, $50-$ $80 \mathrm{f}$ high. Leaves when young thin, mostly acute at each end, when full grown large, abrupt or cordate at base, thickish, 3-9' long, the petioles $1-2^{\prime}$. Fruit blue, as large as a plum. Wood soft and white. Apr. May. (N. denticulata, tomentosa, angulizans $\mathrm{Mx}$., etc.)

3 N. capitàta Walt. OGEecheE LIME. Lvs. oral or oblong, short-petiolate, entire, whitened beneath, midvein subvillous, obtuse at apex, acute at base; fertile fls. solitary, on short peduncles, downy, 3-4-bracted, with 5 petals and 10 stamens; sterile fls. 20-30 in each dense globular head; fruit large, oblong.-On river banks (especially the Ogeechee!) S. States. Tree 20-30f high. Ivs. ample, 5-9' long, $2-3^{\prime}$ broad, usually mucronate; petiole $2-6$ " long. Fruit "dark red" as Jarge as a small plum, acid. Mfay, Jn. (N. candicans $\mathrm{Ph}$.)
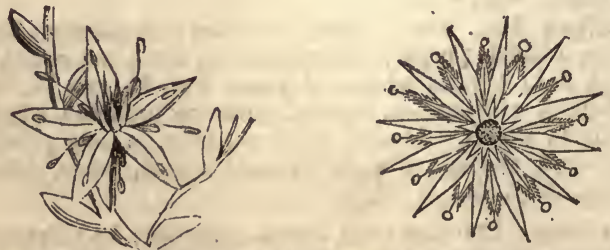

648. Symmetrical flower of Sedum aere. 4, of Sempervirum. 


\section{CoHoRt 2, GAMOPETAL}

Or Monopetalous Exogens.-Plants having a double perianth, consisting of both calyx and corolla, the latter composed of petals partially or wholly united.

\section{Order LXVI. CAPRIFOLIACE E. Honeysuckles.}

Shrubs, rarely herbs, often twining with opposite leaves, no stipules; flowers clus. tered and often fragrant, 5-parted and often irregular ; corolla monopetalous, tubular or rotate; stamens inserted on corolla tube, rarely one less than the lobes; ovary adherent to the calyx; style 1 , stigmas 3 to 5 ; fruit a berry, drupe or capsule. Embryo small, in fleshy albumen.

Genera 16, species 220 , chiefly natives of the northern temperate reglons, and occasionally found in the alpine parts of the tropical zone.

Properties. The fever-root (Triosteum perfoliatum) is a mild cathartic, and in large doses emetic; the iried and roasted berries are sometimes substituted for coffee. The leaves and bark of the Elder are both emetic and cathartic; the flowers are sudorific, and the berries laxative. The beauty and fragrance of the Honeysuckle in cultivation is well known.

\section{TRIBES AND GENERA.}

1. LONICERE A. Corolla tubular, with a filiform style (a).

a IIerbs.-Corolla 5-lubed, the stamens but 4....................LinN $8 \mathrm{~A}$.

-Corolla 5-lobed, the stamens $5 . \ldots \ldots \ldots \ldots \ldots \ldots \ldots \ldots \ldots$. Triostedr. 2

a Shrubs.-Corolla bell-shaped, regular. Berry 4-celled, 2-seeded..... SYMpnoricarpos. 3

-Corolla tubular, lobes unequal. Berry 2 to 8-celled......... Lorrcrra. 4

-Corolla funnel-form. Capsule 2-celled, $\infty$-seeded..........Drervilia.

2. SAMBCCE E. Corolla rotate, deeply'5-lobed. Stigmas sessile (b).

b Shrubs with pinnate leaves. Berry 3 -seeded.... Sa sureos. 6

b Shrubs with simple leaves. Drupe 1-seeded..... Vibursum. 7

1. LINNE'A, Gron. Twin-flower. (Dedicated to Carl Von Linne, the most renowned of naturalists.) Calyx tube ovate, limb 5parted, deciduous; bractlets at base 2 ; corolla campanulate, limb subequal, 5-lobed; stamens 4, 2 longer than the other; berry dry, 3celled, indehiscent, 1-seeded (2 cells abortive). - $4 \mathrm{~A}$ trailing, evergreen herb, widely disseminated throughout the northern temperate zone. Ped. 2 -flowered.

- L. boreàlis Gron. The only species, native of moist, shady, rocky soils, generally in evergreen woods, from lat. $39^{\circ}$ to the Arc. Sea. It has long, creeping, filiform, brownish sts., rooting and branching their whole length, and covering the ground in large patches. Lvs. small, opposite, petiolate, roundish, with obtuse lobes or teeth, and scattered hairs. Ped. filitorm, slightly hairy, about $3^{\prime}$ high (the only erect part of the plant), the lower part leafy, the upper furnished with a pair of minute, linear, opposite bracts, and terminating with 2 pedicellate, nodding flowers. The corolla is rose-colored and very fragrant. Jn.

2. TRIOS'TEUHY, L. FEVER-worT. (Gr. $\tau \rho \varepsilon \iota \varsigma$, three, ò $\sigma \tau \dot{\varepsilon} o v$, a pone; from the three bony secds.) Calyx tube ovoid, limb 5-parted, segments linear, nearly as long as the corolla ; corolla tubular, gibbous at base, limb 5 -lobed, subequal ; stamens 5 , included; stigma capitate, lobed ; fruit drupaceous, crowned with the calyx, 3-celled, 3-sceded; 
seeds ribbed, bony. -24 Herbs coarse, hairy. Lvs. large, connate. Fls. axillary.

1 T. perfoliàtum L. Hirsute; lvs. oval, acuminate; fls. verticillate or clustered, sessile, brownish-purple.-Rocky woods, N. Eng. to Wisc. S. along the Mts. St. stout, 3 to $4 \mathrm{f}$ high, covered with soft, clammy hairs. Lvs. $6^{\prime}$ by $3^{\prime}$, entire, abruptly contracted at base, pubescent beneath. Fls. in clusters of 5 or 6 . Cor. limb in 5 rounded lobes. Fr. a rather dry drupe, crowned with the long, leafy, spreading calyx segm., orange-colored when mature. Jn.-Root large, fleshy, in much repute, having many of the properties of Ipecacuanha.

2 T. angustifòlium I. Hispid; lvs. lanceolate, acuminate, scarcely connate: fls. mostly solitary, short-stalked, yellowish or straw-colored.-S. States to IIl. and Glen Cove, L. I. (Mr. J. Coles). Plant 2 to $3 \mathrm{f}$ high, more slender and rougher than the other. Lvs. about 4 or $5^{\prime}$ by $1^{\prime}$, contracted to a narrow base, roughest on the upper surface. May.

3. SYMPHORICAR'PUS, Dill. SNow-BERRY. (Gr. $\sigma v \nu$, together,

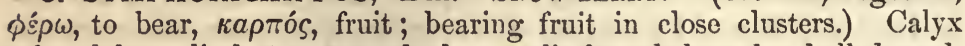
tube globous, limb 4 to 5 -toothed; corolla funnel-shaped or bell-shaped, the limb in 4 to 5 subequal lobes; stamens inserted on the corolla, and as many as its lobes; stigma capitate; berry globous, 4 -celled, 2 -seeded ( 2 opposite cells abortive).--Small shrubs, with entire, oval lvs., and small, rose-colored fls.

1 S. racemòsus Mx. Flls. in terminal, loose, interrupted, often leafy rac.; cor. campanulate, densely bearded within; sty. and sta. included; berries snow-white. -A smooth, handsome shrub, 2 to $3 \mathrm{f}$ high, common in cultivation, and native in W. N. York, Can., \&c. Lvs. oval or oblong, the margin often wavy, nearly or quite smooth, paler beneath, on short petioles. Cor. rose-color, the throat filled with hairs. Berries large, round or ovoid, and very ornamental when mature. Jl, Aug.

2 S. occidentàlis R. Br. WoLF-BERrY. Lrs. ovate, obtusish; spikes dense, axillary and terminal, nodding; cor. somewhat funnel-form, densely bearded inside; sta. and bearded style exserted; berries white.-Woods, Mich. to Wis. and Can. Shrub 2 to $4 \mathrm{f} \mathrm{high.} \mathrm{Lvs.} 1$ to $3^{\prime}$ by $\frac{2}{3}$ to $2^{\prime}$; pubescent or nearly glabrous, paler beneath. Cor. rather larger and more expanded than in the last, purplish white. Jl.

$3 \mathbf{S}$. vulgàris Mrx. Lvs. roundish-oval; spikes axillary, subsessite, capitate and crowded; cor. campanulate, lobes nearly glabrous; sta. and bearded style included; berries dark red. - River banks, Penn. to Iowa (Cousens), and S. States. Shrub 2 to 3 f high. Branches purplish and often pubescent. Lvs. 1 to $2^{\prime}$ by $\frac{8}{4}$ to $1_{2}^{\prime}$, somewhat pubescent. Cor. greenish-red. Jl. (Lonicera Symphoricarpus L.)

4. LONICE'RA, L. HoNeYsuckile. Woodbine. (In honor of Adam Lonicer, a physician of Frankfort, in the sixteenth century.) Calyx 5-toothed, tube subglobous ; corolla infundibuliform or campanulate, limb 5-cleft, often labiate; stamens 5 , exserted; ovaries 2 to 3 celled; berry few-secded; stigma capitate.-A beautiful genus of climbing or erect shrubs, with opposite and often connate lvs.

$\S$ XYLOSTEON. Shrubs erect. Leaves never connate. Flowers in pairs (a).

a Corolla gibbous at base, lobes somewhat irregular...................... Nos. 1-;

a Corolla not gibbous, lobes spreading, equal, roseate............................ 4

§ CAPRIFOLIUM. Shrubs climbing. Fls. sessile, mostly whorled (b).

b Leaves all distinct. Corolla ringent. Cultivated cxotics..................

b Leaves (the upper pair) connate-perfoliate (c).

c Corolla subequal, both tube and limb scarlet.......................... 7

c Corolla limb ringent, - tube equal (not gibbous) at base............... Nos. 8-10

-tubo gibbous at the basc..................... Nos. 11, 12 
1 L. ciliàta Muhl. Fly Honeysuckue. Lvs. ovate, subcordate, ciliate; cor. limb with short and subequal lobes; tube saccate at base; sty. exserted; berries distinct, red.-A branching, erect shrub, 3 to $4 \mathrm{f} \mathrm{high,} \mathrm{found} \mathrm{in} \mathrm{woods,} \mathrm{Me.} \mathrm{to}$ Ohio and Can. Lvs. thin, oblong-ovate, often cordate at the base, somewhat ciliate on the margin, and villous beneath when young. Fls. pale straw-yellow, in pairs at the top of the peduncle, with an obtuse spur turned outwards at the base. Berries ovoid, red, in pairs, but not connate, 3 to 5-seeded. May, Jn.

2 I. oblongifolia Hook. Lvs. oblong or oval, velvety-pubescent beneath, cor. limb deeply bilabiate; tube gibbous at base; ped. long, filiform, erect; berries connate or united into one, globous, purple, bi-umbilicate.-A shrub, 3 to $4 \mathrm{f} \mathrm{high,}$ in swamps, Can. and N. Y. Lvs. almost sessile, 1 to $2^{\prime}$ long, ped. of equal length. Cor. hairy, greenish-yellow outside, purplish inside, the lower lip nearly entire, the upper one 4-lobed, erect. Berries marked with the remains of the two calyces. Jn.

3 I. ccerùlea I. Lvs. oval-oblong, ciliate, obtuse, villous both sides, at length smoothish; ped. short, reflexed in fruit; bracts longer than the ovaries; cor. gibbous at base, lobes short, subequal; berries connate or united into one, deep blue.A low shrub in rocky woods, Mass. and N. Y. north to Hudson's Bay. St. 2f high, with small lvs. and pairs of small, yellow fls., which are longer than their peduncles. Lvs. ovate, oval, obovate and oblong, ending abruptly. May, Jn.

4 I. Tartárica I. TARTarian Honeysuckle. Sts. erect, much branched; Ivs. ovate, cordate, obtuse, smooth, shining, and dark green above, paler beneath, entire, on short petioles; ped. axillary, solitary, 2-flowered; segm. of the cor. oblong, obtuse, equal.-An elegant and much admired shrub, from Russia. Grows from 4 to $10 \mathrm{f}$ high. Livs. 1 to $2^{\prime}$ by $\frac{3}{4}$ to $1^{\prime} \frac{1}{2}$, coriaceous. Fls. small, pale purple, varying to pure white, fragrant. Apr.-Jn. $\downarrow$

5 I. Japónica L. Chinese Honeysuckle. Sts. soft-pubescent; lrs. ovate and oblong, minutely pointed, all distinct, petiolate; ped. axillary, 2-bracted and 2 -flowered; cor. limb ringent, tube equal at base, slender, downy; stam. and sty. exserted.-From China. Sts. flexuous, climbing $15 \mathrm{f} \mathrm{high,} \mathrm{bearing} \mathrm{a} \mathrm{profusion}$ of orange-colored fls. + South.

6 I. Periclýmenum Tourn. Woonbine. Ivs, deciduous, all distinct, clliptical, rather acute, on short petioles; fls. in dense, imbricato, terminal heads: cor. ringent.-A woody climber, native of Europe, cultivated and nearly naturalized. Fls. yellow and red, fragrant, succeeded by red berries. Variety quercifolium has sinuate lvs: May-Jl. $\dagger$

7 I. sempervirens Ait. Trumper Honeysdckle. Lrs. oblong, evergreen, tho upper ones connate-perfoliate; fls. in nearly naked spikes of distant whorls; cor. trumpet-shaped, nearly regular, ventricous above.-In moist groves and borders of swamps, N. Y. (near the city), to Fla. and Ia. St. woody, twining with the sun. The distinct lvs. in the wild plant are elliptical or almost linear; tho connate, but 1 or 2 pairs. Cor. nearly $2^{\prime}$ long, of a lino scarlet without and yellow within. Mar, Apr. (S.)-May-Jl. (N.) †.

8 I. flàva Sim. YELLOW HONEYSUCKLE. Lvs. ovate, glaucous both sides, upper pair connate-perfoliate; spikes terminal, of about 2 close whorls; cor. smooth,

- tube slender, not gibbous at base, limb somewhat ringent; stam. exserted, smooth.-Shrub scarcely twining, N. Y. to Ga., W. to Wisc. Lvs. deciduous, abruptly contracted at base, except the upper perfoliate pair. Fls. in heads of about 10, fragrant. Cor. an inch or more in length, the tube much longer than the lips, bright yellow; upper lip much broader than the lower, in 4 segm. May, Jl. $\dagger$

9 I. gràta Ait. Evergreen HoNeystchle. Lvs. evergreen, obovate, smooth, glaucous beneath, the upper pair connate-perfoliate; fils. in sessile, terminal and axillary whorls; cor. ringent, tube long, slender, not gibbous at base.-Damp woodlands, N. Y., Penn., and W. States. St. climabing many feet. Irs. opposite or in $3 \mathrm{~s}$, margin revolute. Fls. large and very fragrant, 5 or 6 in each whorl. Cor. whitish, becoming yellowish within, reddish without. Sta. exserted. Berries red. Jn. $\dagger$

10 I. Caprifòlium L. Common on Italian Honeysdckle. Lvs. deciduous, the upper pair perfoliate-cunnate: fls. in a single terminal verticil; cor. rin- 
gent, lips a third the length of the tube, strongly revolute.-Native of Europe. Greatly admired in cultivation for its beauty and fragrance. Fls. of various hues, red, yellow and white. Jn.-Aug. $\dagger$

11 I. parviflòra Lam. Lvs. smooth, shining above, glaucous beneatl, oblong, all sessile or connate, the upper pair perfoliate; fls. in hds. of 1 or more approximato whorls; cor. ringent, tube glabrous, short, gibbous at base; fil. bearded.A small, smooth, shrubby climber, in rocky woods, Can. and U. S. St. 8 to $10 \mathrm{f}$ long. Lvs. wavy and revolute on the margin, very glaucous on the underside. Fls. rather small. Cor. $I^{\prime}$ in length, yellow, tinged with dull red, gibbous at base, the short limb in curved segments. Sta. and sty. exserted. Berries orange-colored. May, Jn.

$\beta$. Irs. large, pubescent beneath, all except the upper pair distinct, the lower petiolate; fls. pubescent.-Ohio (Sullivant) and westward. (L. Douglasii, DC.)

12. I. hirsùta Eaton. Lvs. hairy above, soft-villous beneath, veiny, broad-oval, abruptly acuminate, the upper pair connate-perfoliate; fls. in verticillate spikes; cor. ringent; fil. bearded. - A climber of coarser aspect, in woods N. Eng. to Mich. and Can., twining about trees to the height of 15 to 20 . The whole plant is more or less hairy. Lvs. pale green, not shining, the edges and the upper side ciliate with scattered hairs, fls. large, numerous, greenish jellow, in whorled, axillary and terminal clusters. Limb of cor. spreading. Sty. and sta. exserted, Jn. (C. pubescens Goldie.)

5. DIERVIL'LA, Tourn. Bush Honeysuckie. (In honor of Dierville, a French surgeon, discoverer of the original species.) Calyx tube oblong, limb 5-cleft; corolla twice as long, funnel-shaped, limb 5-cleft and nearly regular; stamens 5; capsular fruit 2-celled (apparently 4-celled from the projecting placentæ), many-seeded.-Shrubs, with opposite, serrate, deciduous lvs.

I D. trífida Mœnch. Lvs. ovate, acuminate, on short petioles; ped. axillary and terminal, 1 to 3 -flowered; caps. attenuate above.-A low shrub not uncommon in hedges and thickets, Can. to Car. St. about $2 \mathrm{f} \mathrm{high,} \mathrm{branching.} \mathrm{Lvs.} 2$ to $4^{\prime}$ by 1 to $11^{\prime}$, finely serrate, ending in a long, narrow point. Ova. slender, 4 to $5^{\prime \prime}$ long, about half the length of the greenish yellow corolla. Sta. and sty. much exserted. Stig. capitate. Jn.

2 D. sessilifòlia Buckley. Lvs. glabrous, oblong-ovate or lanceolate, acuminate, sessile or subamplexicaul; peduncles 3 to 5-flowered, crowded in the axils above; caps. cylindric-oblong, short-beaked, crowned with the subulate-setaceous calyx teeth.-High mountains of $N$. Car. (Buckley). Shrub 2 to $4 \mathrm{f}$ high. Leaves 2 to $4^{\prime}$ long. Flowers sessile or pedicillate. Jn., Jl.

6. SAM'BUCUS, L. Elder. (Lat. sambuca, musical instrument, said to have been made of the elder.) Calyx small, 5-parted ; corolla 5-cleft, segments obtuse; stamens 5 ; stigma obtuse, small, sessile ; berry globous, pulpy, 3-seeded.-Shrubs or perennial herbs, with odd-pinnate or bipinnate lvs. Fls. in cymes.

1 S. Canadénsis L. St. shrubby; cymes fastigiate, 5-rayed; Ifts. 3 to 5 pairs with an odd one, oblong-oval, acuminate, smooth.- $\mathrm{A}$ common shrub 6 to $10 \mathrm{f}$ high, in thickets and waste grounds, U. S. and Can. St. filled with a light and porous pith, especially when young. Lfts. serrate, the lower ones often binate or trifoliate. Petioles smooth. Fls. numerous, in very large (2f broad in Ind.) leveltopped cymes, white, with a heavy odor. Berries dark purple. May-Jl.

2 S. pùbens $\mathrm{Mx}$. St. shrubby; cymes paniculate and pyramidal; lfts. ovallanceolate, acuminate, in 2 or 3 pairs, with an odd one, and with the petiole pubescent beneath. - A common shrub, in hilly pastures and woods, Hudson's Bay to Car., growing $6 \mathrm{f}$ high, more or less. Lrs. simply and unequally pinnate; lfts. sharply serrate, very pubescent when young. Fls. in a close, ovoid thyrsus or panicle. Cor. white. Berries scarlet, small. May, Jn.

$\beta$. Leucocìrpa 'T. \& G. Berries white. Catskill Moantains. (Mr. J. Hogg, fide T. \& G.) 
7. VIBUR'NUM, L. (Lat. vierc, to tie; for the pliancy of the twigs?) Calyx small, 5-toothed, persistent; corolla rotate, limb 5-lobed, segments obtuse; stamens 5 , equal, longer than the corolla; stigmas sessile; ovary 1 to 3 -celled, 1 -ovuled; drupe, 1 -seeded.-Shrubs or small trees, with simple, petiolate lvs., white fls. in cymes which are sometimes radiant.

a Cymes radiant, - the outer flowers sterile and showy.......................... 1, 2.

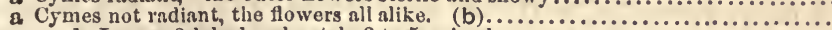

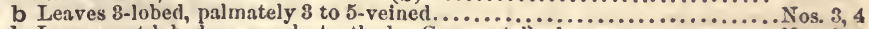

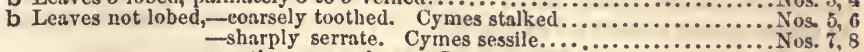
-entiro or nearly so.-Species native............................ 9 , 1i - Species exotic............................... 11, 12

1 V. lantanoìdes I. HовBLE-BUSH. Lvs. orbicular, cordate, abruptly acuminate, unequally serrate; petioles and veins covered with a ferruginous down; cyme sessile; fr. ovate. - A shrub very ornamental when in flower, common in tho rocky woods of N. Eng., N. Y. and Can. Height about 5f. Branches long and crooked, often trailing and rooting. Lrs. very large, covered with a rusty pubescence when young, at length becoming green, the dust and down remaining only upon the stalk and veins. The radiant sterilo fls. of the cyme aro near $\mathbf{1}^{\prime}$ diam., from a greenish color becoming white, flat, with 5-rounded lobes. Inner fls. much smaller, fertile. May.

2 V. Ópulus L. Hign Cranberre. Smooth; lvs. 3-lobed, 3-veined, broader than long, rounded at base, lobes divaricate, acuminate, erenately toothed; petioles glandular; cymes pedunculate. $-\mathrm{A}$ handsome shrub, 8 to $12 \mathrm{f}$ high, in woods and borders of fields, N. States and Brit. Am. Sts. several from the same root, branched above. Lvs. with large, remoto blunt teeth, the stalks with 2 or more glands at base, channeled above. Cymes radiate like the preceding species. Fr. resembles the common cranberry in flavor, and is sometimes substituted for it. It is red, very acid, ripens late, remaining upon the bush after the leaves have fallen. Jn. (V. Oxycoccus $\mathrm{Ph}$.)

$\beta$. RòseUM. GUELDER ROSE. SxOW-BalL. Lvs. rather acuto at base, longer than broad, lobes acuminate, with acuminate teeth; petioles glandular; fls. all neutral, in globous cymes.-This variety is the popular shrub so generally admired and cultivated as a companion of tho Lilac, Snowberry, Philadelphus, \&c. Its dense spherical cymes are wholly made up of barren flowers.

3 V. acerifòlium L. DocksackIE. Lvs. subcordate, acuminate, 3-veined, 3-lobed, acutely dentate; petioles without glands, cymes on long peduncles; stam. exserted. - A shrub 4 to $6 \mathrm{f}$ high, with yellowish green bark, growing in woods, Can. and U. S. LVs. broad, rounded and sometimes cordato at base, divided into 3 acuminate lobes, with a form not very unlike that of the maple leaf, the under surface as well as the younger branches a little downy. Branches straight, slender, very flexible, ending with a pair of lvs. and a long stemmed, cymous umbel of white fls. Fr. oval, compressed. Jn.

4 V. pauciflòrum Pylaie. Nearly smooth in all its parts; lvs. roundish, with 3 short lobes at summit, serrate, mostly 5-veined from the base; cymes small and pedunculate, terminating the very short lateral branches; stam. much shorter than the cor.-A small shrub with white fls., Mansfield, Mtt., Vt., (Macræ), White Mts., N. H. (Robbins), N. to Newfoundland.

5 V. dentàtum L. ARRow-WOod. Nearly smooth; lvs. roundish-ovate, coarsely dentate-serrate, petiolate, straight-veined; cymes pedunculate.-A shrub 8 to $12 f$ high, not uncommon in damp woods and thickets, Can. to Ga. It is called arrowwood from the long, straight, slender branches or young shoots. Lrs. roundish, 2 to $3^{\prime}$ diam., the upper pair oval, the veins beneath prominent, parallel and pubescent in their axils. Fls. white, succeeded by small, roundish, dark blue berries. Jn. - Hardly distinct from the next.

$6 \mathrm{~V}$. pubéscens $\mathrm{Ph}$. Lvs. ovate, acuminate, coarsely dentate-serrate, straight veined, villous beneath and somewhat hairy above, on short stalks; stip. 2, subulate; cymes podunculate, smoothish; fr. oblong.-In dry, rocky woods and thickets, Can. to Ga. A shrub about $6 f$ high. IVs. each with a pair of short, hairy, sub- 
ulate appendages (stipular?) at the base of the very short petiole. Cymes small, few-flowered. Fls. rather larger than those of the foregoing species, white. lir. nearly black. Jn.

3. MOLLE. POISON HAw. Soft, rusty, tomentous throughout the stalks, lvs, and cymes; lvs. rather acule; fls. large.-Tenn. to Ga. (Misses Keen) and La. (Hale). (V. molle Mx.)

7 V. Ientàgo L. SWEET Viburnur. Lvs. ovate and oval, long-acuminate, acutely and finely uncinate-serrate; petiole with undulate margins.-A common tree-like shrub, in rocky woods, Can. to Ga. and $\mathrm{Ky}$. Height 10 to 15f. Livs. smooth, conspicuously acuminate, about $3^{\prime}$ long and $\frac{1}{2}$ as wide, their petioles with a curled or wavy dilated border on each side. Fls. white, in broad, spreading cymes, succeeded by well-flavored, sweetish berries of a glaucous black. Jn.

8 V. prunifòlium L. BLACK Hatr. SLOE. Lvs. smooth, shining above, roundish obovate or ovate, rather obtuse, acutely serrulate, with uncinate teeth; petioles slightly and evenly margined; cymes mostly sessile.-In woods and thickets, $\mathrm{N}$. Y. to Ga. A shrub or small tree, 10 to 20 f high, with handsome, glossy lvs. and large cymes. Lvs. 2 to $3^{\prime}$ long, $\frac{1}{2}$ to $\frac{2}{3}$ as wide, on short petioles, slightly margined. Cymes terminal. Fls. white, succeeded by oval, blackish berries which are sweet and eatable. Jn.

B. FERRUGINeUr. T. \& G. Veins and petiolo beneath covered with reddish brown wool; lvs. narrower.-S. W. Ga. and Mid. Fla. Called possum haw, the black drupes being insipid.

9 V. nùdum L. Smooth; lvs. oval-oblong, or lance-oval, subrevolute at edge, entiro or subcrenulate, not shining, veiny and dotted beneath; petioles not winged; cymes on short stalks.- Shrub or small tree, 10 to $20 \mathrm{f} \mathrm{high,} \mathrm{U.S.} \mathrm{Lvs.} \mathrm{thick,} \mathrm{and} \mathrm{when}$ fully grown 3 to $4^{\prime}$ long, mostly acuto or even short acuminate. Cymes large, on peduncles 1 to $2^{\prime}$ in length, naked after losing their caducous bracts. Fls. white, berries dark blue, covered with bloom, sweetish. Apr.-Jn.-Very variable.

$\beta$. ANgustifolium. T. \& G. Lvs. oblong.lanceolate, acute or acuminate at cach end, margin obscurely repand-denticulate.-South (Pond, \&c.)

$\gamma$. CASSINOIDES T. \& G. Irs: oval, obovate or oblong, obtuse, acute or shortacuminate, margin nearly entire, veins not prominent.-North and South $(V$. cassinoides L.). - Another variety ( $\delta$. ovale) has smaller, oval, obtuse, very cntire Irs. (South), \&c.

10 V. obovàtum Walt. Lvs. small, obovate, obtuse, entire or nearly so, subsessile, dotted beneath; cymes small, numerous, sessile.- Shrub 8 to $15 \mathrm{f}$ high, swampy river banks, Va. to Ga. Branches straggling, some virgate ones, all covered with a profusion of white cymes about $1 \frac{1}{2}$ ' diam. Lvs. at flowering time 6 to $8^{\prime \prime}$ long, finally 10 to $18^{\prime \prime}$. Fr. black, shining, sweet. Apr., May.

11 V. Tínus I. Laurestine. Lvs, coriaceous, lance-ovate, entire, thcir veins with hairy tufts beneath. - $A$ fine evergreen shrub, from Europe. Height 4 to $5 \mathrm{f}$. Lrs. acute, thick but veiny, dark, shining green above, paler beneath. Fls. white, tinged with red, very showy. Degrees of pubescence variable.

12 V. odoratíssimum Ker. Smooth; lvs. coriaceous, evergreen, ellipticoblong, remotely repand-dentate; fls. in paniculate cymes, white, very fragrant.† From China.

\section{Order lXViI. RUBIACE e. Madderworts.}

Trees, shrubs and herbs. Lvs. opposite, somewhat verticillate, entire. Stipules between the petioles, sometimes resembling the leaves. Calyx tube more or less adherent to the ovary; limb 4 to 5-cleft. Corolla regular, inserted upon the calyx tube, and of the same number of divisions. Slamens inserted upon the tube of the corolla, cqual in number and alternate with its segments. Ovaries 2 (rarely more)celled. Style single or partly divided. Fr. various. Seeds one, few, or many in each cell. (Fig. 183.)

Genera 330, species 2800 . It is generally divided into two suborders, viz.. Stellateso and Cinchoner, to which a third, Loganiex (which has fow representatives at tho North) is appended by 
Torrey and Gray. The species of the first suborder, Stellater, are common in the northern parts of both continents; the other suborder prevails chiefly in warm or torrid regions.

Properties.-A very important family, furnishing many useful products. The madder, one of the most important of dyes, is furnished by the root of liubia tinctoria. A simllar coloring matter is possessed by several species of Galium. Peruvian bark, a powerful febrifuge, is tho product of several species of Cinchona, viz., C. micranthia, C. condaminea, C. lanceolata, $\mathbf{C}$. mag nifolia, \&c., all natives of Peru. Their febrifugal properties depend upon tho presence of two alkalies, Cinchonia and Quinia, both combined with Kinic acid. Ipecacuanha, the prince of emetics, is the product of the root of Cephrlis Ipecacuanha, a little shrubby plant with creeping roots, in the dainp forests of Brazil. Several other species of Cinchonem afford substitutes for the true Ipecac.

Coffee is the hard albumen of the seeds of Coffer Arabica, a tree of moderate size, with a light hrown trunk, and a conical shaped head. Leaves shlning, light green. Flowers white, fragrant. The berries are black when ripe. Coffee is sald to have been used in Ethlopia from time immevorial. In Paris and London it seems not to have been in general use earlier than the year 1700 .

\section{SUBORDERS AND GENERA.}

1. STELLATE A. Leavos (and leaf-like stipules ?) whorled. Ovary entirely adherent. (a)

a Flowers 4-parted. Fruit twin. Slender herbs with square stems..... GaLICM.

a Flowers 5-parted. Fruit twin, fleshy and baccate. Stems square..... ReriA.

2. CINCHONEA. Leaves opposite, with stipules between the petioles. Ovary adherent, at least the lower half. (b)

b Tree. Flowers 5-parted, in involucrate cymes.................. PIxkNEYA.

b Shrub. Flowers 4-parted, in globular heads................... CepuaLaxtues. 4

b Herbs. Flowers habitually 4-parted (5-parted in 0 . Halel). (c)

c Flowers twin (2 corollas on one (double) ovary)................... Mitcriel.

c Flowers not twin.-Carpels 2, 1-seeded, both indehiscent.......... DiodiA.

-Carpels 2,1-seeded, one indehiscent............SPErmacocr.

-Carpels 2, few-seeded. Corolla much exserted.Houstonia.

-Carpels 2, $\infty$-seeded. Corolla scarcely exserted.............................. OLdENLANDIA

1. Gallium, L. Cleavers. Bedstraw. (Gr. yáda, milk; the flowers of $G$. verum are used in coagulating milk.) Calyx limb minutely 4-toothed; corolla rotate, 4-cleft; stamens 4, short; styles 2 ; carpels 2, united, separating into 2, 1-seeded, indehiscent nutlets.-Herbs with slender, 4 angled sts. Verticels of 4, 6 or 8 lvs., rarely of 5 .

a Flowers yellow. Leaves in whorls of about 8 . Fruit smooth...................... 1 a Flowers dull purple. Leaves (large) in whorls of 4 . Fruit hispid or not............... 2-4 a Flowers white.-Leaves in 4 s only. Fruit dry. Panicle terminal.................... 5 -Lcaves in $4 s$ only. Frnit smooth, purple berries..................... 6, 7 -Leaves in $4 \mathrm{~s}$ and 6 s. - Fruit hispid with hooked hairs.................. 8 -Fruit smooth or nearly so, dry................... 9-11 -Leaves in 8 , long and narrow. Fruit hispid...................... 12

1 G. vèrum L. Yellow Bedstraw. Erect; lvs. in 8s, grooved, entire, rough, linear; fls. densely paniculate.-2f Found in dry, open grounds, in the vicinity of Boston, probably introduced (Bigelow). Root long, fibrous. St. slender, erect, 1 to $2 \mathrm{f}$ high, with short, opposite, leafy, unequal branches. Lvs. deflexed, linear, with rolled edges. Fls. numerous, small yellow, in small, dense, terminal panicles. Jn.-The roots dye red. The flowers aro used in England to curdle milk. $\S$ Eur.

2 G. pilòsum Ait. St. ascending, hirsute on the angles; lvs. in 4s, oval, indistinctly veined, hirsute both sides and punctato with pellucid dots; ped. several times forked, each division 2 to 3 -flowered; fls. pedicellate, densely hispid.-A tall species found in dry woods and sterile soils, Mass. to Ind., S. to the Gulf. St. I to 2 f high, acutely 4-angled, mostly with few, short, spreading branches, sometimes much branched. Lvs. 9 to $12^{\prime \prime}$ by 4 to $8^{\prime \prime}$, obtusish, very hairy as well as the stem and fruit. Fls. purplish. Jn. (G. puncticulosum Mx.)

3 G. circz'zans Mfx. St. erect or ascending, smooth; lvs. in $4 \mathrm{~s}$, oval or ovatelanceolate, obtuse, 3-veined, smoothish, ciliate on the margins and veins; ped. divaricate, few-flowered; fr. subsessile, nodding, hispid.-Grows in woods, U. S. and Can. St. about If in height; with a few short branches near the top, or simple. Lvs. 1 to $2^{\prime}$ by 4 to $8^{\prime \prime}$. Fls. on very short, reflexed pedicels, scattered along the (usaally 2) branches of the dichotomous peduncle. Fr. covered with

- little hooks as in Circeea. Jl.-The leaves have a sweet taste like liquorice. 
B. LANCEOLATUM Torr. Very smooth; lvs. lanceolate; $f r$. sessile.-A fino variety with larger leaves ( $2^{\prime}$ or more in length). Fls. purple. (G. Torreyi Bw.)

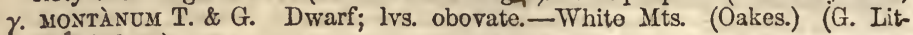
telfi Oakes.)

4 G. latifòlium Mx. St. erect, smooth; lvs. in 4s, lanceolate, 3-veined, very acute; ped. axillary (leafy) and terminal, about twico trichotomous; purplo fls. and smooth fruit on filiform pedicels.-Mts. E. Tenn. and Va. to Ga. An elegant species. St. about $2 \mathrm{f}$ high. Lrs. 1 to $2^{\prime}$ long. Fls. very small, pedicels 2 to $6^{\prime \prime}$ long, divaricate. $\mathrm{Jl}$.

5 G. boreàle L. St. erect, smooth; lvs. in 4s, linear-lanceolate, rather acute, 3-voined, smooth; fls. in a terminal pyramidal panicle.-Grows in rocky, shady places, N. States and Brit. Am. Sts. If or more high, several together, branched above. Lvs. 12 to $20^{\prime \prime}$ by 2 to $9^{\prime \prime}$, tapcring to an obtusish point. Fls. numerous, small, white, in a thyrse-like panicle at top of the stem. Fr. small. Jl. (G. septentrionale Bw.)

6 G. hispídulum $\mathrm{Mx}$. Diffuse, minutely hispid; lvs. in 4s, oval, thickish, mostly acute or mucronate; ped. axillary, 1 to 3-flowered; fr. fleshy and berry-like, large, bluish-purple.-S. Car to Fla. and La. Sts. sharply 4-angled. Lrs. 5 to $7^{\prime \prime}$ by 2 to $3^{\prime \prime}$, margin somewhat revolute. Pedicels of the fr. about $6^{\prime \prime}$ long. Nay-Oct.

7 G. uniflòrum $\mathrm{Mx}$. Glabrous; sts. coespitous, slender, many, ascending; lvs. in 4 s. linear, acute; ped. axillary, solitary, bearing 2 to 4 bracts, mostly 1 -flowered; fr. oblong, fleshy, smooth, purple.-Damp woods, S. Car. to Fla. and La. St. straight, nearly simple, about if high, tho lvs. about $1^{\prime}$ by $1^{\prime \prime}$, and 1 -veined. Fr. smaller than in No. 6. May.

8 G. triflòrum $\mathrm{Mx}$. St. weak, often procumbent, smoothish, shining; lvs. in 53 and $6 \mathrm{~s}$, clliptic and lanceolato, acuminate-cuspidate, 1-veined, scarcely ciliate on the margin; ped. elongated, axillary, 3 (rarely 2)-flowered at tho extremity, often twice di- or trichotomous ; fls. pedicellate; fr. hispid with hooked hairs.-Moist woods, Can. and U. S. St. 1 to 3 f long, slightly branched. Lvs. 1 to 2 ' long, $\frac{1}{4}$ as broad, often obovate. Fl. greenish white, small. Fr. whitish, with its uncinato clothing. Jl.

9 G. aspréllum MLx. Rovgr Cleavers or Curvers. St. diffuse, very branching, rough backwards; lvs. in $6 \mathrm{~s}, 5 \mathrm{~s}$, or $4 \mathrm{~s}$, lanceolate, acuminate or cuspidate, margin and midvein retrorsely aculeate; ped. short, in $2 \mathrm{~s}$ or $3 \mathrm{~s}$.-Common in thickets and low grounds, Can. and N. States. St. weak, 2 to $5 \mathrm{f}$ long, leaning on other plants, and closely adhering to them by its minute, retrorso prickles. Lvs. 5 to $8^{\prime \prime}$ by 2 to $3^{\prime}$. Fls. white, small and numerous. Fr. minute, smooth, often slightly hispid when young. Jl.

10 G. tríficum L. DYer's Cleavers. Goose-Grass. St. decumbent, very branching, roughish with retrorse prickles; lvs. in $5 \mathrm{~s}$ and $4 \mathrm{~s}$, linear-oblong or oflanceolate, obtuse, rough-edged; parts of the fls. mostly in $3 \mathrm{~s} .-2 f$ In low, wet grounds, Can. and U. S. It is ono of tho smallest of the species. Lvs. 3 to $6^{\prime \prime}$ by 1 to $2^{\prime \prime}$, often cuneato at baso. Ped. mostly in $3 \mathrm{~s}$, and axillary. Fls. small, white. Jl.

$\beta$. Tinctòrium Torr. St. nearly smooth; lrs. of the st. in $6 \mathrm{~s}$, of the branches in $4 \mathrm{~s}$; ped. 2 or 3 -flowered; parts of the fl. in $4 \mathrm{~s}$. $-\mathrm{A}$ somewhat less slender variety than the first. Tho root is said to dyo a permanent red. (G. tinctorium L.)

\%. LATIFònIUM Torr. Lvs. in 4s, oblanceolate, obtuse; ped. 3-flowered; parts of the $\mathrm{fl}$. in $4 \mathrm{~s}$.

11 G. concínnum Torr. \& Gr. St. decumbent, diffusely branched, retrorsely scabrous on the angles; lvs. in 6s. linear, glabrous, 1-veined, scabrous upwards on the margins; ped. filiform, twice or thrice trichotomous, with short pedicels; lobes of the corolla acute.-Dry woods and hills, Mich., $\mathrm{Ky}$., Ind. Sts. very slender, 10 to $15^{\prime}$ high. Lvs in numerous whorls, 5 to $8^{\prime \prime}$ by $1^{\prime \prime}$, slightly broader in the middle. Fls. minute and numerous, white. Jn.

12 G. Aparìne L. St. weak, procumbent, retrorsely prickly; lvs. in $8 s, 7 s$, or $6 s$, linear-oblanceolate, mucronate, rough on tho midvein and margin; ped. axillary, 1 to 2-flowered. - (1) In wet thickets, Can. and N. States to Ind. (Plummer.) Sts. several feet long, leaning on other plants and closely adhering by their hooked 
prickles to crery thing in their way. Lrs. 12 to $20^{\prime \prime}$ by 2 to $3^{\prime \prime}$. Fls. numerous, small, white. Fr. rather large, armed with hooked prickles. Jn.-The root will dye red. Tho herbage is valued as a domestic remedy. $\S$ ?

2. RU'BIA, Tourn. MADDER. (Lat. rubra, red; from the coloring matter of its roots.) Calyx tube oroid, limb 5-toothed or obsolete; corolla rotate, 5 -parted; stamens short; styles 2 , united at base; fruit twin, roundish, baccate, smooth.-Herbaccous or shrubby. St. 4-angled, diffuse.

R. tinctòrum L. St. weak, its angles retrorsely aculeate; lvs. in whorls of 6 , lanceolate, the margins and midveins aculeate; ped. axillary and terminal, 3-forked; cor. 5-parted, brownish yellow, with a callous point.-From Europo. Cultivated for its roots which yield that valuablo coloring matter, madder. Jl.

3. PINCKNE'YA, Mx. (Dedicated to Gen. C. C. Pinckney, of S. Carolina.) Calyx tube campanulate, limb 5-parted, one segment of scveral of the flowers dilated into a large rose-colored bract; corolla tube cylindrical, limb 5-lobed, somewhat imbricated in the bud; stamens 5 , from the base of the corolla, exserted; style slender; stigma 2-lobed ; capsule roundish, thinly coriaceous, 2 -valved, many-seeded.A small tree (or large shrub). Stip. caducous, leaving a strong ridge between the petioles.

P. pùbens Mrx. Swamps and along creeks, S. Car. to Fla., common. It is a singularly beautiful tree, 15 to.25f high in its native woods, with a straight and slender trunk. In cultivation it has more the character of a shrub, branching from the baso and flowering when but $10 \mathrm{f}$ high. Lvs. large, ovate, acute or subacuminate at each end. Young branches and cymes downy. Cor. purple within, canescent without. Cymes splendidly radiant by the largely expanded marginal calyxes. Capsules as large as an ounce bullet. May, Jn.-Properties similar to the Perurian bark. (Fig. 183.)

4. Cephalan'thus, L. Button Bush. (Gr. $\kappa \varepsilon \phi a \lambda \eta$, a head, äv0os, a flower; flowers in heads.) Calyx limb 4-toothed; corolla tubular, slender, 4-cleft; stamens 4 ; style much exserted.-Shrubs with opposite lvs. and short stip. Fls. in globous hcads, without an involucre.

C. occidentàlis L. Lrs. opposite and in $3 \mathrm{~s}$, oval, acuminate, entire, smooth; hids. pedunculate. $-\mathrm{A}$ handsome shrub, frequenting the margins of rivers, ponds and brooks, U. S. and Can. It is readily distinguished by its spherical heads of flowers, which are near $1^{\prime}$ diam., resembling the globular inflorescence of the Sycamore. Height about 6 f. Lvs. spreading, entire, 3 to $5^{\prime}$ by 2 to $3^{\prime}$. The fls. are tubular, with long, projecting styles, and are inserted on all sides of the round receptacle. JL.

5. Mitchel'la, L. Partridge Berry. (In honor of Dr. John Mitchell, an English resident in Virginia.) Flowers 2 on each double ovary ; calyx 4-parted; corolla funnel-shaped, hairy within ; stamens 4, short, inserted on the corolla; stigmas 4 ; berry composed of the 2 united ovaries.-Evergreen herbs smooth and crecping, with opposite lvs.

M. répens L. St. creeping; lvs. roundish-ovate, petiolate. - A little prostrate plant found in woods, throughout the U. S. and Can. St. furnished with flat, coriaceous, dark green lvs., and producing small, bright red berries, remarkably distinguished by their double structure, and remaining on the plant through the winter. The corollas are white or tinged with red, very fragrant, sometimes 5 or even 6-parted (Mr. Shriver). Fr. well-flavored but dry and full of stony seods. June. 
6. DIO'DIA L. (Gr. $\delta \varsigma$, twice, oovov, tooth, alluding to the two calyx teeth crowning the ovary.) Calyx, corolia, stamens, style and fruit as in the next genus (Spermacoee) except that the (2 or 3 ) 1-seeded, separable carpels are in both indehiseent ; seeds oval, peltate.-American, chiefly tropical herbs. Stip. fringed with bristles. Fls. small, white, axillary, sessile, solitary or few.

1 D. Virginiàna L. Procumbent, nearly glabrous or hirsute; sts. squarish ; lvs. lanceolate, sessile, entire; bristles of the stip. longer than the sheaths; fls. solitary, opposite; cor. salver form, tube very slender, thrice larger than the cal.; stam. exserted; style deeply 2-cleft, lobes filiform.-2f Damp places, Ill. to Ga and La. St. 1 to $2 \mathrm{f}$ long, somewhat 4 -sided. Lrs. 1 to $2^{\prime}$ by 3 to $5^{\prime \prime}, 1$-veined, often with smaller ones fascicled in the axils. Cor. $6^{\prime \prime}$ long, hairy inside. MaySeptember.

3. has ovate-lanceolate lrs. (D. tetragona Walt.)

$\gamma$. has lance-linear, hairy lvs.; cor. $6^{\prime \prime}$ long. May-Sept. (D. hirsuta Ph.)

2 D. tères Walt. Erect or ascending, hairy or scabrous; lvs. linear-lanceolate, sessile, rough-edged, acute, much longer than the sheaths or fruit; fls. solitary, or several in each axil; cor. funnel-form, with a wide tube, twice longer than the cal.; fl. somewhat hairy and 4-sided.-Sandy fields, N. J. to Ill. (Mead) and S. States. Sts. rather rigid, simple, or branched, 5 to $18^{\prime}$ long, brownish. Lrs. about $1^{\prime}$ by $2^{\prime \prime}$. Cor. reddish white, shorter than the reddish brown bristles. Aug., Sept. (Spermacoce diodina Mx.)

7. SPERMACO'CE, L. (Gr. $\sigma \pi \dot{\varepsilon} \rho \mu a$, seed, à $\kappa \omega \kappa \dot{\eta}$, a point; alluding to the pointed seeds.) Calyx tube ovoid, limb 2 to 4-parted; corolla tubular, limb spreading, 4-lobed; stamens 4 ; stigma 2-cleft ; fruit dry, 2 -celled, crowned with the calyx, separating into 1 open and 1 indehiscent carpel; seeds 2, peltate, furrowed on the face.-Mostly herbaceous and tropical. Fls. small, in dense, axillary, sessile whorls, or clusters.

1 S. glàbra Mx. Glabrous, procumbent at base; lvs. lanceolate, entire; whorls many-flowered; cal. 4-toothed (rarely 5); cor. funnel-form, short, hairy in the throat; anth. included in the tube; stig. subsessile. 24 River banks, W. States St. 1 to 2 f long, terete, with 4 prominent lines, branched. Lvs. 2 to $3^{\prime}$ by $\frac{1}{4}$ to $1^{\prime}$, tapering to each end. Fls. white, 9 to 20 in a whorl, subtended by the subulate bracts of the stipules. Jl., Aug.-Resembles some of the Labiatæ.

2 S. Chapmánil Torr. \& Gr. Nearly glabrous; st. slightly 4-angled; lvs. oblong-lanceolate, attenuate to a petiole ; whorls dense-flowered ; cor. funnel-form, thriee longer than the cal.; stam. and slender sty. exserted.-River banks, Mid. Fla. (Chapman.)

8. HOUSTO'NIA, L. Bluets. (Dedicated to Dr. Wm. Houston, the friend and correspondent of Miller.) Calyx tube ovoid-globous, limb 4-toothed or eleft, persistent; corolla tubular, much exceeding the calyx ; limb 4-lobed, spreading; filaments 4 , inserted on the corolla; style 1 ; anthers and stigmas dimorphous, that is, in some plants, the former exserted and the latter included, in others the style exserted and anthers included; capsule 2-lobed, the upper half free, cells few (8 to 20)-seeded.-Herbs. Stip. connate with the petiole, entire. Fls. solitary or in cymes, white, purplish, or bluish.

$\S$ Corolla salver-form, glabrous. Peluncles 1 -floweretl-terminal................ Nos. 1, 2

$\$$ Corolla salver-form, glabrous. Peduncles 1 floweret - terminary......................

$\S$ Corolla funnel-form. Peduncles $\infty$-flowered, cymous.-Leaves liance-ovate............No. 5

1 F. cœrùlea L. DWARF PINK. Ixvocence. Cæspitous; radical lvs. ovatespatulate, petiolate; sts. erect, numerous, dichotomous; ped. filiform, 1 to 2 -flowcred.-(2) An elegant little plant found in moist grounds, fields, and road-sides, Canada and U.S., often in patches. Cauline lirs. very small, opposite, lance- 
ovate. Sts. very slender, forked, 3 to $5^{\prime}$ high, each branch bearing a flower. Cor. pale blue, yellowish at the center, about $5^{\prime \prime}$ wide. May-Aug. (Hedyotis Hook. Oldenlandia, Gray.)

B. MINOR Mx. Branches and ped. spreading with a wide angle; fls. smaller

- (3 to $4^{\prime \prime}$ wide). - The more common form in the S. States. Mar., April. (H patens Ell.)

2 H. serpyllifòlia $\mathrm{Mx}$. Cæspitous; sts. filiform, procumbent; lvs. roundishovate, abrupt or subcordate at base, petiolate, ciliolate; ped. terminal, very long; cor. lobes broad-oval. 24 ? Springy places among the mts. of Car. and Tenn. Sts. very slender, weak, 6 to $12^{\prime}$ long. Lvs. no larger than in No. 1 (of which this may bo but another variety). May-Jl.

3 H. mínima Beck. Glabrous, simple or dichotomously branching; lvs. linearspatulate, much attenuated to the base; ped. at first nearly radical, at length axillary, often not longer than the leaves; sds. 10 to 15 in each cell, oval, smooth, concave on the face.- (1) Prairies, etc. Mo., Tenn. to La. Very small and delicate, 1 to $3^{\prime}$ high. Lvs about $5^{\prime \prime}$ by $1^{\prime \prime}$. Fls. roso color, nearly as large as in No. 1, a. Mar.-May. (Hedyotis T. \& G.)

4 H. rotundifòlia $\mathrm{Mx}$. Procumbent, creeping, leafy; lvs. roundish-oval, abrupt at base, petiolate; fls. axillary, solitary, ped. mostly longer than the lvs.; caps. emarginate, few-seeded.-24 Sandy, damp places, S. Car. to Fla. and La. Forms small patches. Sts. much branched, 2 to 5 ' long. Lvs. generally longer than the internodes, 3 to $4^{\prime \prime}$ diam. Fls. white, about as large as in No. 1. Mar.-Dec.

5 H. purpùrea L. St. ascending, clustered, branching, 4-angled; lvs. ovatelanceolate, 3 to 5 -reined, closely sessile; cymes 3 to 7-flowered, often clustered; cal. segm. lance-linear, longer than the capsule.-Mid. and W. States S. to Ala. (Eufala), in woods and on river banks. A very delicate flower, about if high. Lvs. 1 to 2 ' long, $\frac{1}{3}$ as wide. Cor. white, often tinged with purple. May-Jl. (Hedyotis Hook.)

6 H. longifòlia Gaert. Radical lvs. oval-elliptic, narrowed to each end; cauline linear or lance-linear, 1-veined; fls. in small, paniculate cymes.-2 Dry hills, Can. to Ga. and Ark. Much more slender than the last. Sts. erect, 5 to $12^{\prime}$ high, 4-angled, smooth or ciliolate on the angles. Lrs. 9 to $15^{\prime \prime}$ by 2 to $3^{\prime \prime}$, cauline sessile, rather acuto at each end, all smooth. Fls. 2 or 3 together on very short pedicels, pale-purple, with deeper colored striæ in the throat. Jn., Jl. (Hedyotis Hook.)

$\beta$. TENuifòlia. St. very branching; lvs. very narrow; ped. filiform; fls. smaller. (H. tenuifolia Nutt.)

$\gamma$ ciliolati. Lvs. oblong-linear, rather obtuse, often ciliate; branches mostly erect.-Banks of rivers and lakes, N. Y. to Ohio and Ky. Varies imperceptibly into a. (H. ciliolata Torr.)

7 H. angustifòlia $\mathrm{Mx}$. Slender, tall, strictly erect; lvs. narrowly linear, 1veined; fls. very numerous, short-pedicelled, in compact, terminal cymules; cal. lobes subulate; caps. obovoid or top-shaped.-2 Prairies and bottoms, IIl. to La. Sts. slightly 4-angled, nearly terete, $10^{\prime}$ to $2 \mathrm{f}$ high, branching. Lvs. 12 to $18^{\prime \prime}$ long, acute, attenuate at base, $1^{\prime \prime}$ wide. Cor. white, hairy inside, $2^{\prime \prime}$ long. Jn., J. (Hedyotis stenophylla T. \& G.)

9. OLDENLAN'DIA, L. In memory of Oldenland, a German physician and botanist, who died at the Cape of Good Hope.) Calyx 4 or 5-lobed, persistent; corolla funnel-form, with a short tube, little longer than the calyx, 4 to 5 -lobed; stamens 4 to 5 ; style short or 0 , stigmas 2 ; capsule wholly adherent to and inclosed in the calyx tube; seeds very numerous and minute (40 to 60 in each cell.)-Herbs erect or prostrate. Stip. with 2 to 4 subulate points each side. Fls. small, axillary, white.

1 O. glomeràta Mx. CREeping GreEn-HeAd. St. assurgent, branching; lvs ovate-lanceolate, pubescent, narrowed at the base into a short petiole, or sessile; fls. glomerate in the axils and terminal, cor. shorter than the deafy cal. teeth. - $A$ 
plant varying in size from 1 to $2^{\prime}$ to as many feet, found in swamps, \&c., N. Y. to La. Lvs. ${ }^{\prime}$. in length, apparently connate from the stipules adhering to each side of the petiole. Stip. 2-cleft into narrow, subulate divisions. Cal. in 4 deep, leafy divisions, which are much longer than the white, rotate corolla. Stam. nearly exserted. Sty. very short. Caps. opening crosswise. Jn.-Sept. (Hedyotis Ell.)

2 O. Bóscii. St. erect, diffusely branched; lvs. lance-linear, acute, attenuated to a petiole, 1-veined; stip. 2-pointed each side; fls. axillary, sessile, 1 to 3 together; cor. shorter than the triangular-subulate caly $x$ teeth, which are shorter than the roundish capsule. - 4 Borders of ponds, \&c., Car. to La. Sts. 6 to 10' high. Lvs. 1' by 1 to $2^{\prime \prime}$. Cor. purplish. Jl--Sept. (Hedyotis DC.)

3 O. Hàlæi, with pentamerous fls., a prostrate, succulent perennial, found by Dr. Hale on the Red River, La., may yet be found $\mathbf{E}$. of the Miss.

\section{Order LXVIII.-VALERIANACE E. Valerians.}

Herbs with opposite leaves and no stipules. Calyx adherent, the limb either membranous or resembling a pappus. Corolla tubular or funnel-form, 4 to 5-lobed, sometimes spurred at base. Stamens distinct, inserted into the corolla tube, alternate with, and generally fewer than its lobes. Ovary inferior, with one perfect cell and two abortive ones. Seeds solitary, pendulous, in a dry, indehiscent pericarp.

Genera 12, species 1S5, widely diffused in temperate cllmates. The true valerian of tho shops, used in hysteria, epilepsy, sc., is a product of Valeriana officinalls. The roots of several other species possess a heavy odor, and are tonic, antispasmodic, febrifugal, \&z. The spikenard (John xil. 3, \&c). of old, valued as a perfume and a stimulant, is from the root of Nardostachys Jatamansi.

1. VAleria'NA, L. Valerian. (To King Valerius, a patron and friend of botanists.) Calyx limb at first very small, involute, at length crolving a plumous pappus; corolla funnel-form, regular, 5 -cleft ; stamcns 3 ; fruit 1-celled, 1-seeded.-2f Lvs. opposite, mostly pinnately divided. Fls. in close cymes.

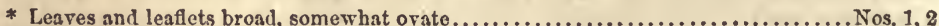

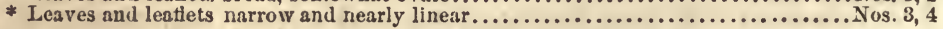

1 V. pauciflòra $\mathrm{Mx}$. Glabrous, erect or decumbent, often stoloniferous at base, radical lvs. ovate, cordate, slightly acuminate, on long petioles, crenate-serrate, cauline, 3 to 7-parted; lifs. ovate, terminal one much the largest; cymules fewflowered, corymbous; corolla tube long (7 to $\left.8^{\prime \prime}\right)$, and slender.-Ohio to Va. and Tenn. St. mostly simple, 1 to $2 f$ high. Lvs. of the succors mostly undivided, 1 to $1_{\frac{1}{4}}^{\prime}$ by $\frac{8}{4}$ to $1_{\frac{1}{2}}^{\prime}$, petioles 1 to $4^{\prime}$ long. Flls. pale purple or white. Jn., Jl.

$2 \mathrm{~V}$. sylvatica $\mathrm{L}$. St. erect, striate, simple; radical lvs. ovate or subspatulate (never cordate), undivided; cauline one pinnately divided; segm. ovate-lanceolate, entire or subserrate, the terminal one often dentate ; cor. short ( 3 to $\left.4^{\prime \prime}\right)$; fr. ovate, compressed, smooth.-St. 1 to $2 \mathrm{f}$ high. Swamps, Vt. to Mich., very rare. Lrs. ciliate with scattered lairs, those of the root petioled, sometimes aurieulate at base, those of the stem with 4 to 8 lateral segm. and a large terminal one. Fls. numerous, rose-colored, appearing in July.

3 V. édulis Nutt. Simple, smooth, and somewhat fleshy; rt. lvs. linear, spatulate, entire, the cauline pinnately cleft into 3 to 7 lance-linear, acute segm., margins densely and minutely ciliate, mostly attenuated to the base, panicle compound; cor. short (2 to $\left.3^{\prime \prime}\right)$; fr. compressed, 4-ribbed, crowned with the late cal. limb of 10 or 12 plumous setæ.-Low grounds, Can., Wis., Ohio. Rt. Jellowish, fusiform. St. 1 to 3 h high. Rt. lvs. many, 3 to $8^{\prime}$ long, segm. 2 to $4^{\prime \prime}$ wide. Fls. white, in a dense panicle which is greatly expanded in fruit. Jn.-The fleshy root is said to be cooked and eaten by the Indians. (V. ciliata T. \& G.)

$4 \mathrm{~V}$. officinàlis L. VALERIaN. Lvs. all pinnate; lfts. lance-linear or lancoolate, the latergl and terminal similar, nearly cntire; cor. small, short (2" $2^{\prime \prime}$, in a crowded, compound cyme.-From Europe. It yields the valerian of the shops. 
2. VALERIANEL'LA, Mœnch. DC. (Lat. diminutive of Valeriana.) Calyx limb obsolete; corolla tube short, not sperred, limb 5-lobed, regular; stamens 3 ; stigmas 3-cleft or entire; fruit 3-celled, 2 of them empty and more or less inflated, the other with one seed.-(1) Stems forked above. Lvs. opposite, oblong or linear, entire or toothed, sessile. Fls. in dense, terminal cymelets. The specific characters are afforded mainly by the fruit.

* Fruit ovate in outline, glabrous or pubeseent. Flowers white....................

* Fruit orbicular, glabrous, -compressed dorsally. Flowers white......................... -compressed laterally. Flowers blue......................... 5

1 V. Fagopỳrum. Lvs. oblong-spatulate, subentire; fr. smooth, ovoid-triangular, the empty cells converging to the obtuse angle, with no groove between them; fis. large ( $1 \frac{1}{2}{ }^{\prime \prime}$ broad).-West N. Y. to Ohio. St. 8 to $18^{\prime}$ in height. Bracts lanceolate, acute. Fr. resembling that of Buckwheat (Polygonum Fagopyrum, in form, containing one large seed and two empty cells. Fls. thrice larger than in the next. Fr. $1 \frac{1}{2}{ }^{\prime \prime}$ long. Jn. (Fedia, T. \& G.)

2 V. radiàta Dufr. Lvs. mostly toothed towards the base, linear-oblong; obtuse; fr. pubescent, ovoid, somewhat 4-angled, 1-toothed at apex; empty cells not convergent, but with a groove between them; futile cell flattish, broader than the other 2 ; fls. small ( $\left(\frac{1}{2} "\right.$ "wide).-Low grounds, Mich., Ohio, to Ala. St. 6 to $12^{\prime}$ high, dichotomous like the other species, smooth. Lvs, oblong, more or less tapering to the base, 1 to $2^{\prime}$ by 2 to $4^{\prime \prime}$. Fr. less than $1^{\prime \prime}$ long, at length nearly smooth. (Fedia, Mx.)

3 V. umbilicàta (Sull.) Lrs. oblong-lanceolate, toothed or incised at the base; fr. subglobous, inflated, apex 1-toothed, the anterior face deeply umbilicate and perforated into the sterile cells which are much larger than the fertile one.-Moist grounds, Columbus, Ohio, (Sullivant). Plant smooth, 1 to $2 f$ high, many times dichotomous. Fls. in numerous cymules, corymbously arranged. Fr. nearly $1^{\prime \prime}$ diam., with 1 rib at the back produced into a tooth at apex. (Fedia, Sull.)

4 V. patellària (Sull.) Lvs. toothed at base; fr. obicular, much flattened, concave, notched at both ends, the sterile cells widely divergent, at length forming a winged margin to the fertile cells.-Wet grounds near Columbus, Ohio, (Sullivant). Resembles the last except in its fruit. (Fedia, Sull.)

5 V. olitòria Mœnch. Lamb LetTuce. Lvs. spatulate-obtuse, radical one petiolate; fr. compressed laterally as to the seed, oblique, at length broader than long, not toothed at apex; fertile cell longer than both the others, with a corky back; empty cells united, but with a groove (in the circumference) between; fls. pale blue.-Naturalized in some portions of the U.S. St. smooth, 8 to $12^{\prime}$ ligh, dichotomous. Lrs. mostly entire. Fls. in dense cymules. Fr. l' diam. Jn. † $\S$ Eur.

\section{Order lXIX. DIPSACE瓜. Teaselworts.}

Herbs with whorled or opposite leaves and no stipules. Ftowers in dense heads surrounded by an involucre as in Compositæ. Calyx adherent, pappus-like, surrounded by a special scarious involucel, corolla tubular, somewhat irregular, the limb 4 to 5-parted. Stamens 4, alternate with the lobes of corolla, often unequal. $A n$ thers distinct. Ovary inferior, one-celled, one-ovuled. Style one, simple. Fruit dry, indehiscent, with a single suspended seed. (Fig. 206.)

Genera 6, species 150. The order is nearly allied to the Compositx. The species are all na tives of the temperate regions of the eastern continent, none of them A merican. Their properties are unimportant. One of the species below is useful in dressing cloth.

1. DIP'SACUS, L. TEAsel. (Gr. $\delta i \psi a ́ \omega$, to thirst; water is held in the axils of the leaves.) Flowers in heads; involucre many-leaved; involucel 4 -sided, closely investing the calyx and fruit; calyx superior; corolla tubular, 4-cleft, lobes erect; fruit 1-seeded, crowned with the 
calyx.-(2) Plants stout, prickly. Lvs. opposite, connate (sometimes distinct) at base. Heads oblong, the middle zone of florets first expanding. (Fig. 206.)

I D. sylvéstris Mill. Wild Teaser. Lvs. connate, sinuate or jagged; hds cylindrical; bracts of the involucre longer than the heads of fls., slender and pungent, bent inwards; chaff of the receptacle pungent, not hooked.-A tall, thistle-like plant, growing in hedges and by roadsides, Mass. to Ind. St. about $4 f$ high, angled and pricky, with the opposite, lance-shaped lvs. united around it. Fls. bluish, in a large oval, or cylindrical head whose bracts are not hooked, as in the next species, but straight. JI. \& Eur.

2 D. Fullònum L. Fuller's Teased. Ivs. connate, entire or serrate; hd. cylindrical; bracts hooked; invol. spreading.-Gardeus. Rt. fleshy, tapering. St. erect, furrowed, prickly, hollow, about $5 \mathrm{f}$ high. Lvs. 2 at each node, united at their bases around the stem in such a way as to hold a quantity of water. Fls. whitish, in large oval or ovoid heads. Cultivated for the use of the clothiers (fullonum) who employ the heads with their hard, hooked scales to raise the nap upon woolen cloths. Jl. $\ddagger$ Eur.

2. SCABIO'SA, L. Scabish. (Lat. scabies, leprosy; plants said to cure cutaneous diseases.) Flowers in heads; involucre many-leaved; involucel nearly cylindrical, with 8 little excavations; calyx limb consisting of 5 setæ, sometimes partially abortive. - 2f Large, mostly European herbs with opposite lvs.

I S. succìsa L. Devils'-BIT. Rt. premorse; st. IVS. remotely toothed, hds. of fls. nearly globous; cor. in 4 equal segments.-In gardens, though rarely eultivated. The stem is about if ligh. Corolla violet. + - Eur.

$2 \mathrm{~S}$. atropurpùrea L. Mournisg BRIDE. Lrs. pinnatifid and incised, hds. of fls. radiant; receptacle cylindric; outer crown of the seed short, lobed and crenate.-A beautiful species, 2 to $4 \mathrm{f} \mathrm{high,} \mathrm{with} \mathrm{dense} \mathrm{heads} \mathrm{of} \mathrm{purple} \mathrm{fls.}+$ Native country unknown.

\section{Order LXX. COMPOSITE. Asterworts.}

Plants herbaceous or shrubby, with compound flowers (of the old botanists) i.c., the flowers in dense heads (capitula) surrounded by an involucre of many bracts (scales), with 5 united anthers and the fruit an achenium (cypsela). Leaves alternate or opposite, exstipulate, simple, yet often much divided. Fls. (florets) $\infty$, crowded, sessile, on the receptacle with or without pales (chaff). Cal. adherent, the limb wanting or divided into bristles, hairs, etc. (pappus). Cor. tubular, of 5 lobes with a marginal vein, often ligulate or bilabiate. Stam. 5, alternate with the lobes of the corolla, anthers cohering into a tube. Ov. 1-celled, with 1 erect ovule; style single with 2 stigmas at summit. $F r$. a cypsela ( $(557)$, dry, indehiscent, l-seeded, often crowned with a pappus.

Illnstrated in flgs. $55.118,141.142,145,146,170,192,193,211,212,213,214,215,324,328,329$, $330,331,332,333,361,379,416,434$.

Genera 1000 or more, species 9000 ? the most extensive and the most natural of all tho Phingamous Orders, always distingnislied at sight by the capitate flowers and the united anthers. It comprehends nearly one-ninth of all the species, of flowering plants. The general inflorescence is centrifugal, that is, the central or terminal heads are first developed, while the inflorescence of the heads is centripetal, the outer flowers first expanding. In color the flowers aro various; sometimes those of the disk and ray aro of different colors, again they are a!l of tho the same, but In the former case the disk florets are almost always yellow.

This immense order is diffused throughout all countries of the globe, but in very different proportions. According to Humboit, they constituto about one-seventh of the Phanogamous Flora of Germany, one-eighth, of France, one-fifteentb, of Lapland, one-sixth, of North Ameriea (north of Mexico), and one-half, of Tropleal America. In New Holland they are in the proportion of abont one-sixteenth, according to Brown, while in the island of Sicily they are one-half. The Liguliflura are said to be most abundant in cold regions, and the Tubulifiorse in hot regions. The Labiatiflore are almost exelnsfvely confined to Sonth America. In the northern parts of the world the Compositæ are universally herbaceous, bnt towarls the tropies they gradnally become frutescent and even trees. In Chill they are generally shrubs, and on the island of St. Helena they are trees.

Properties, dec.-The Compositæ furnish comparatirely few nsefnl products. A bitter principle pervades the wholc, which, when combined with resin and astringent inuclage, becomes 
tonic and febrifugal, as in the chamomile, colt's-foot, thoroughwort golden rol, etc. Some are anthelmintics from the prevaleneo of the resinous principle, as tansey, Arternisia, Vernonia. Others are aromatic and extremely bitter, as wormwood and all the species of Artemisia. Other species are very acrid, as may weel. The Jurusalem artichoke (Ilelianthus tuberosus) the vegetable oyster (Tragopogon), the true artichoke (Cynara), lettuce, danielion and a few others, arn the only species useful for food. The order abounds in orname'ntal plants.

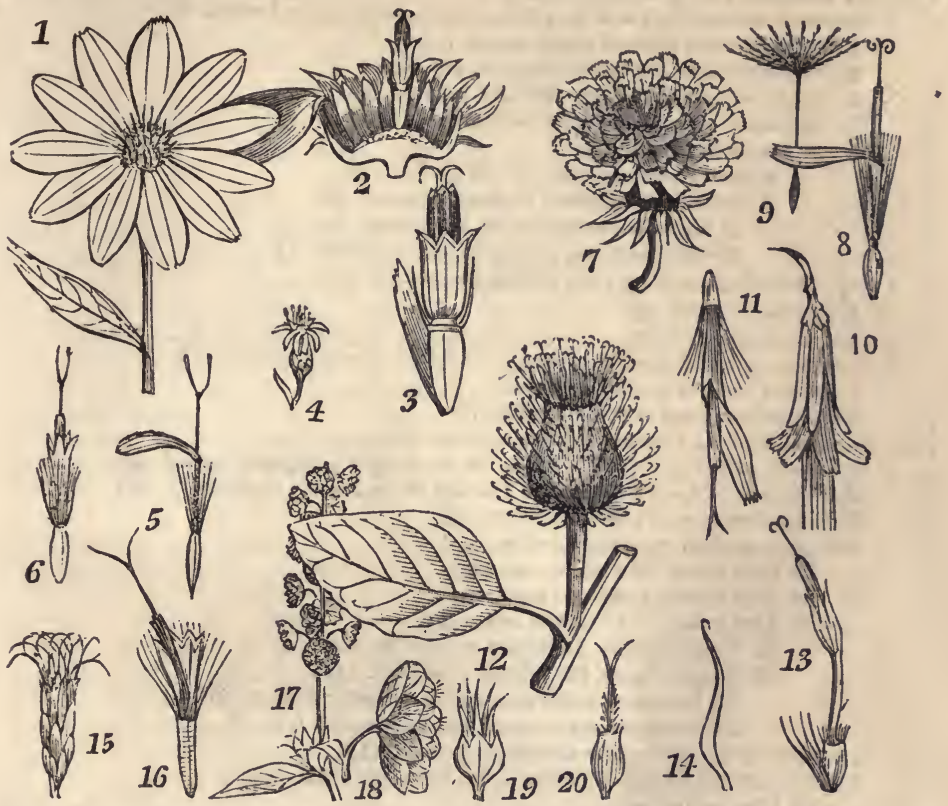

641, bis. 1. Helianthus head radiate. 2. Vertical section of the head showing the scales of the involucro and a single disk-flower remaining upon the convex receptacle. 3. A perfect disk-flower showing every part. 4. Head (radiate) of Solidago. 5. A pistillate, ligulate flower of the ray. 6. A perfect disk $\mathrm{H}$. 7. A (radiant) head of Taraxacum. 8 . A perfect, ligulate fi. 9. Achenium, with its long beak and plnmous pappus. 10. A (radiant) head of Nabnlus altissimus. 11. A flower. 12. Lappa major, head discold. 13. A flower. 14. One of the hooked scales. 15. A (discoid) head of Eupatorium purpureum. 16. A flower. 17. Ambrosia (Pigweed). 13. Staminate head enlarged. 19. Pistillate involucre enlarged. 20. The fertile flower.

The following (not conveniently used in Analysis) are De Candolle's

\section{SUBORDERS AND TRIBES.}

I. TUBULIFLOR A.-Corolla of the perfect fis. tubular, 5-lobed. (A)

Triba 1, Vernoniacese. Branches of the style long, slender, terete, and hispid all over. Heads discold; flowers all alike perfect............................ 1-8

Trime 2, Eupatoriacese. Branches of the style elavate, obtuse, flattened, minutely pubescent. IIds. discoid. Fls. all allke, perfect.....................Nos. 4-15

Tribe 3, Asteroidex. Branches of the style flat, linear, downy above and opposite the distinct, stigmatic lines, appendaged at top. Ileads discold

- or radiate...................................................... 16-85

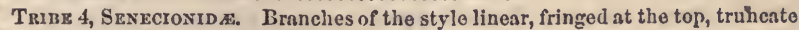
or extended into a conical, hispid appendage......................... Nos. $36-87$

Trinr 5, CyNarex. Stylo thickened or node-like at top; branches not appendager, the stigmatic lines not prominent, reaching the apex..................... $83-97$

II. LIGULIFLOR A.-Corollas all lignlate (rallant), the flowers all perfect. (B)

Tribe 6, Crciroracex. Branches of the style long, obtuse, pubescent all over; stigmatic lines commencing below their midllle. Juice milky................. Nos.98-114

III. LABIATIFLOR AE.-Corolla of the perfect flowers bilabiate. (C)

Tribi 7, Mulisiack.s. Style nearly as in Cynarew, the branches obtuse, very convex outside, minutely downy the top. 


\section{ARTIFICIAL ANALYSIS OF THE GENERA.}

\section{A. SUBORDER, TUBULIFLORA.}

$\$$ Heads discoid, that is, without rays. (1)

I Receptacle naked, $i . e$., with no pales or bristles among the Aowers. (2)

2 Pappus a circle of $5-20$ chaffy scales. (a)

2 Pappus none, or a short, tonthed margin. (b)

2 Pappus composed of many capillary bristles. (3)

3 Leaves upposite. (II eads homogamous.) (d)

3 Leaves alternate. (4)

4 Heads homogamous,-fls, all perfect. (c)

4 II eads heterogamous, fls. not all perfect. (5)

5 Scales herbaceous, often deciduous. (e)

5 Scales scarlous, persistent, often colored. (f)

1 Receptacle chaffy bearing pales among the flowers. (6)

6 Leaves alternate. $(\mathrm{g})$

6 Leaves opposite. (h)

1 Receptacle bearing bristles, or deeply alveolate (honey-combed). (7)

7 Pappus none, or consisting of scales. (i)

7 Pappus composed of many bristles. (j)

5 Heads radiate, 1.0. , the outer flowers ligulate. (8)

8 Receptacie naked (not chaffy), or (in No. 67) deeply honeycomb-celled. (9)

9 Pappus of 5-i2 seales which are 1-awned or (in No. 61) cleft-bristly. (k)

9 Paipus none, or of a few short awns. (1)

9 Pappus of many capillary bristles. (10)

10 Rays cyanic, in a singlo row. (m)

10 Rays cyanic, in several rows. (n)

10 Rays yellow, in about one row. (11)

II Pappus double, or of very unequal bristles. (o)

11 Pappus simple, the bristles all similar. (12)

12 Involucre scalés imbricated, the outer shorter. (p)

12 Involucre seales equal, not imbricated. (r)

8 Receptacle chaffy, with pales among the flowers. (13)

13 Disk and ray flowers both fertile, the latter pistillate. (14)

14 Rays yellow (s)

14 Rays cyanic. $(t)$

13 Disk flowers sterile, ray flowers fertile. (u)

13 Disk flowers fertile, ray flowers sterile. (15)

15 Achenia obcompressed, often beaked. ( $\nabla$ )

15 Achenla compressed laterally, or not at all. (x)

a Corolla lobes one-sicled. IIead large, many-flowered.....................STokrsis. 2

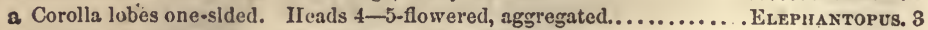

a Corolla lobes equal-Leaves opposite. Pappus awned...................Ageratum. 4 -Leaves twhorled. Pappus obtuse.................. ScLERoleris. 5 -Leaves alternate.-Pappus scales $8-10 . . . \ldots \ldots . . .$. Potypteris. 63 - Pappus scales 12-20.......... IIYMENOPAPPUs. 64

b Leares opposite. Flowers diœcious, obscure.......................... AMBrosts. 45

b Leaves alternate. -Flowers yellow. Disk conical I....................MATRICARIA. 73

-Flowers yellow. Disk convex................... TANACETUX. 75

-Flowers whitish.-Erect, leafless above...........ADEvocauLon. 15

-Erect, leafy.......................ARTEMisia. 76

- Low and depressed.................... Soliva. 76

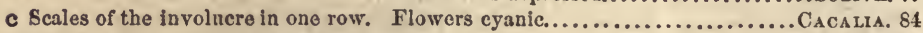

c Seales of the involucre in one row. Flowers yellow...................... SENECro. 80

c Scales imbricated.-Flowers yellow..............................BGELoviA. 27

-Flowers whitish. Evpatorium 10 , and ................. Kunsia. $s$

-Flowers purple.-Pappus simple..................... Liatris. 7

-Pappus double....................... Vkrvonra. 1

d Achenia 10-striate. Flowers purple............................... B̈mckei.la. 9

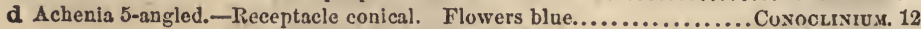

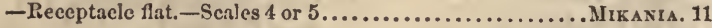

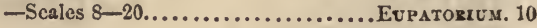


- Shrubs. Flower dløcious, the $q$ and $s$ in different heads............... BAccranis. 85

- Herbs. - Stem winged. Heads spicate............................ Pterocaulon. 36 -Stem wingless. - Ileads corymbous, purplish................... Puvcura. 84 -Ileads panlculate.-Pappus reddlsh............... Conчza. 82 -Pappus white............... ERecritites. 83

f Receptacle chaffy except in the center.............................. FILAGo. 80

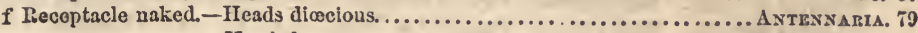

-Heads heterogamous. - Involucre erect............ GNapialicu. Ts -Involucre radiate...........IIELicurrsux. 82

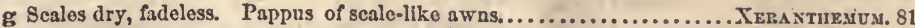
g Scales herbaceons. -Flowers diœclous. Frult a burr................. X -Fls. all perfect.-Pappus of 5 or 6 scales.................. -Papp. of many bristles........... Carpinepiorus. 6

h Flowers yellow. Pappus 2 inversely hispid awns................................. 59

h Flowers yellow. Pappus 2 erectly hispid awns.................... Corkorsis. 57

h Flowers whitish, -diœcious. Anthers yellowish.............................. 45

-monœcious. Antliers yellow............................ 44

-all perfect. Anthers black............................................ 47

i Outer scales of the invol. Jeafy. Pappus none.................... Carthamus, 93

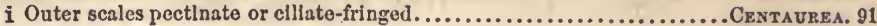

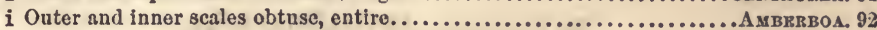

j Pappus plumons. Achenia obovate.......................................... S

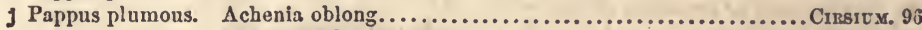

j P'appus scabruus, - triple, each row by 10 s.................................. 94

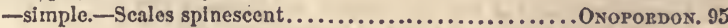

-Scales hooked........................................ 97

k Leares opposite. Papp. scales deeply cleft into bristles.................. Drsopra. 61

k Leaves alternate.-Rays fertile............................................ 65

-Rays sterile.-Receptacle naked or fimbriate..........GAIL.LARDIA. 62 - Receptacle areolate,...................LETOPODA. $60^{\circ}$ -Receptaclo deeply-celled...............BALWINIA. 67

1 Leaves opposito.' Involucre donble, outer 8 united..................... DAmLI. 28

1 Leaves opposite. Involucro single; scales nnited...................... TAGETEs. 89

1 Leaves alternate. - Pappus of a few short awns or bristles.................... Boltonia. 24

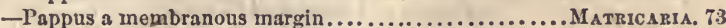

-Pappus 0.-Rays fertile, disk sterile..................endula. 90

-Fls. all fert.-Invol. scales equal............... Bes.tis. 22 -Invol. broad, flat......... Levca NTIIEMU. 72 -Invol. hemispherical..... Cirnrsantuexum. 74

m Rays neutral sterile, $3-12$; Pappus simple..................................... 16 m Rays plstillate, fertile, -about 5. Achenia very silky.............. Suricocarpus. 17 -S-12. Pappus double................... DipLopapts. 19 $-5-75$. Pappus simple............................... 18

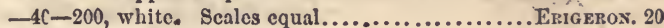

n Flowers diœcions, purplish. Leaves all radical ...................... NARDosmi, 14, n Fls, all fertile.-Onter pappus 0 or very short bristles.................... Erigeron. 20 -Outer pappus a crown of short, pointed scales.......... CALLISTEPHits. 21

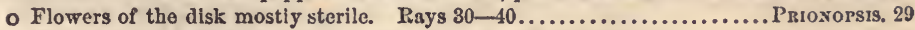

- Fls. all fertile.-Pappus double in the disk, none in the ray........... IIEterotuec. 30 - Pappus double in both disk and ray................. Снвтsopsis. 31

p Heads large, about 20-rayed. Pappus in one row....................... Inula. 83

p Heads very small, 1-15-rayed.-Pappus 1 row, shorter than nchenia... DracuYcista. 25 - Pappus 1 row, tawny, longer than achenia.. Isopappus. 29 -Pappus irregularly 2-rowed, white........ Solid AGo. 26

r IIead solitary, on a scape with alternato bracts..................... Tessilako. 13

r Heads corymbed, \&e.-Leaves alternate............................. SExEcio. 86

-Leaves opposite........................................ 87

s Shrubby: Pappus 4-toothed, obscure.............................Borkicilis. 37

8 Herbaceous. - Scales (the 4 outer) united into $a$ cup............... Tkma gonothecA, 50 - Scales distinct.-Achenia 4-angled. Pappus 0............. IIrLIo Psis. 49

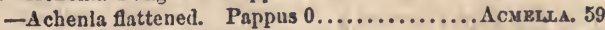
-Ach. flat, with a 2-awned pappus........... VerBesixa. 60 
t Leaves alternate. Pappus none. Achenia terete..................... Avturmis. 69

t Leaves alternate. Pappus none. Achenia obcompressed....................

t Leaves opposite.-Pappus none...................................... 38

-Pappus of fringed scales Hds. sm. Rays 5, sm. white. $\S$ Eur. Galinsoga.

-Papp. of the disk a siugle awn of the ray $0 . \ldots \ldots \ldots \ldots \ldots$. Z Invis. 48

u Leaves opposite. Rays yellow. Pappus none........................PoLxunra. 89

u Leaves opposite. Puys yellow. Papp. a 2 or 3 -toothed crown........ Crinrsogonum. 40

u Leaves alternate.-Rays whitish, very short, 5 only.............. Partireniu. 49 -Rays yellow. -Achenia winged................................ 41 -Achenia wingless.................BERL $\Lambda$ NdERA. 42

$\checkmark$ Achenia with erectly lispid awns, or awnless; never rostrate......... Corropsis. 57

$\checkmark$ Achenia with retrorsely hispid awns, often attenuated above............. BrneNs. 58

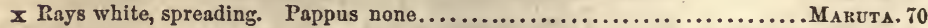
× Rays purple, pendant. Pales sharp, elongated................................... 51 x Rays yellow.-Pappus none. Achenia quadrangular................ RUdBeck1A. $\$ 2$ -Pappus none. Achenia compressed.................... Lepachis. 53 -Pappus of 2 deciduous awns. Ach. wingless............. HelixNtuus. 54 - Pappus of 2 persistent teeth. Ach. winged........... Heilintiella. 55 -Papp. of 2 persistent awns. Ach. broad-winged.......... Actinomeris. 56

\section{B. SUboRder, LIGULIFLORA.}

$\$ \S$ Pappus none, or consisting of little scales. (a)

$\S \S$ Pappus double (of scales and bristles), or simple and plumous. (b)

$\$ \S$ Pappus composed of capillary bristles, not plumous. (*)

* Achenia terete or angular, not flattened. (c)

* Achenia evidently flattened. (d)

a Flowers yellow. Pappus none. Heads paniculate.....................Lampsana. 98

a Flowers yellow. Pappus none. Heads solitary or umbellate.............. A Pogox. 99

a Flowers blue.-Pappus of many little scales. Recept. naked..................cuorium. 100

-Pappus of 5 scales. Receptacle chaffy............... Cataxanche. 106

b Flowers purple. Feathery pappus on a long filiform beak.............Tragopogon. 104

b Flowers white. Feathery pappus on a short beak or sessile.............LENTodon. 103

b Flowers yellow.-Pappns of many bristles with the scales................ Crntura. 102

-Pappus of 5 bristles and 5 scales....................... KigIA. 101

c Flowers whitish or purplish, mostly nodding. Stem leafy................ NABALEs. 107

c Flowers rose-purple, erect. (Stem almost leafless.)................. Lygodesmia. 111

c Flowers yellow.-Achenia long-beaked. Pappus white..............TARAxAcum. 109 -Achenia long-beaked. Pappus reddish............ Prrkopappus. 110 -Achenia not beaked.-Pappus dull white or tawny...... Hieracius. 105 -Pappus bright white............. Troximon. 108

d Achenia contracted into a slender benk. Fls. mostly yellow........................ 112

d Achenia scarcely beaked.-Flowers mostly blue...................... MugEdur. 113 -Flowers yellow. Papp. silky................ Soncruvs. 114

\section{SÜBORDER, LABIATIFLOR E⿺.}

$\$ \$$ Ifead radiate, solitary, nodding in bud. Pappus capillary................. Cuaptaliı, 115

\section{Suborder I. TUBULIFL O R AE.}

\section{TrIBE 1. VERNONIACEA.}

\section{VERNO'NIA, Schreb. Iron WeEd. (Named for William Vernon,} an English botanist who traveled in America in search of plants.) Flowers all tubular, perfect; involucre of ovate, imbricated scales, the inner longest; receptacle naked; pappus double, the exterior chaffy, the interior capillary. 2f Herbs or shrubs. Lvs. alternate. Fls. purple (in our species.)

$\$$ Scales of the involucre all obtuse and closely appressed 
1 V. fasciculatta Mx. St. tall, striate or grooved, tomentous ; lvs. narrow-lanceolate, tapering to each end, serrulate, lower ones petiolate; hds. numerous, in a somewhat fastigiate cyme, invol. ovoid-campanulate; scales appressed, mucronate or obtuse.-Woods and prairies, W. States, very common. A coarse, pur. plish.green weed 3 to $10 \mathrm{f}$ high. Lvs. 4 to $8^{\prime}$ by 1 to $2^{\prime}$, smooth above. Cymes compact or loose. Heads large or small. Cor. showy, dark purple, twice longer than the involucre. Jl.-Aug. Variable.

2 V. Noveboracénsis Willd. Lvs. numerous, lanceolate, serrulate, rough, cymo fastigiate; scales of invol. filiform at the ends. - A tall, showy plant with numer. ous large, dark purple flowers, found in meadows and other moist situations, U.S. St. branching at top, reddish, 3 to $6 \mathrm{f}$ high. Lvs. crowded, paler beneath, radical otses often lobed. Cymes terminal, flat-topped, compound. Scales and corolla deep purple, the former ending in long, threadlike appendages, or in one variety (V. prealta Less.) partly cuspidate. In another variety (V. tomentosa Ell.) the plant beeomes tomentous in the corymbs and under surface of the leaves. Sept.

3 V. scabérrima Nutt. St. simple, corymbed abovo; lvs. crowded below, sessile, lanceolate and lance-linear, scabrous above, margins revolute, subentire; hds. 20 to 30 -flowered; scales lanceolate, ciliate, protracted into long, flexuous points; pappus whitish, exserted but shorter than the appendaged scales.-In pine barrons. Height 2 to 3 f. Invol. usually green ; cor. purple. Jn.-Aug.

$4 \mathrm{~V}$. angustifòlia Mx. Slender, many-leaved; lvs. linear or lance-linear, the lowest serrulate, upper entire with revolute margins; cymes corymbous, with very slender peduncles; hds. 10 to 15 flowered; scales acute or mucronate, the lower spreading and more or less filiform-pointed; pappus purplish, twice longer than the invol.-N. Car. to Fla. and La., in the pine barrens. About $2 f$ high. Sept., Oct.

5 V. ovalifòlia Torr. \& Gr. Lvs. lance-oval or lance-oblong, acute, sessile, sharply serrate, veiny; cymo loose, fastigiate; hds. rather large, scales appressed, acute or mucronate, much shorter than the pappus.-Mid. Fla. (Chapman). St. 3 to $4 \mathrm{f}$ high. Hds. about 20 -flowered, with a purplish pappus.

6 V. oligophýlla Mx. St. nearly beafless, slender; lvs. mostly radical, oblongobovate, dentate-serrate, the 2 or 3 cauline lvs. bract-like, lanceolate, serrulate; cyme loose, somewhat dichotomous, with few heads; scales with spreading, acuminate tips.-Swampy pine woods, N. Car. to Fla. Sts. about $2 \mathrm{f}$ high. Jn., Jl.

2. STOKE'SIA, L'Her. (In honor of Jonathan Stokes, M. D., an English botanist.) Flowers all tubular, the marginal larger, ray-like, irregular; scales of the involucre imbricated, in several rows, the outer spinulous and leaf-like; receptacle naked; fruit 4-angled; pappus of 4 or 5 awn-like, rigid, deciduous scales. -4 Erect, with a downy stem, alternate livs., and terminal, large heads of showy blue fls.

S. cyama L'Her. A rare and ornamental plant, found in S. Car., Ga., and La, rarely in gardens. It resembles a Centaurea. Height about $2 \mathrm{f}$. Lrs. sessile, ertire, glabrous, tho bracts spinulous at base, gradually passing into the scales. Outer corollas with the innercleft deeper, limb spreading, palmate, imitating rays.

3. ELEPHAN'TOPUS, L. Elephant's-Foot. (Gr. éż́фas, elephant, rov́s, foot; alluding to the form of the leaves in some species.) Heads 3 to 5 -flowered, glomerate into a compound head with leafy bracts; flowers all equal ; involucre compressed, the scales about 8, oblong, dry, in 2 scries; corolla 5-cleft, one of the clefts deeper than the others, segments acuminate; achenia ribbed, hairy ; pappus chaffy-setaceous. $-2 f$ Erect, with alternate subsessile lvs. Cor. violet purple.

1 E. Caroliniànus Willd. St. much branched, leafy, hairy; lvs. scabrous and somewhat hairy, ovate or oval-oblong, obtuse, crenate-serrate, lower ones on petioles, upper one subsessile; hds. terminal and subterminal.-Dry soils, Penn., 
Ohio to Fla. and La. St. 20 to $30^{\prime}$ high, flexuous, the branches divaricate. Lower stem lvs. 5 to $7^{\prime}$ by 3 to 5 , upper about $2^{\prime}$ by $1 t^{\prime}$, the highest oblong, smaller, subtending the glomerules in the form of an invol. Scales $3^{\prime \prime}$ long. JI.-Sept.

2 E. tomentòsus L. St. hirsute, nearly leafless, simple or dichotomous above; radical lvs. large, hirsute-tomentous, oblong-spatulate or obovate, crenate, narrowed to a winged petiole, cauline small and bract-like at the forks, or none; bracts thick, broad-ovate, scales rigid.-S. Car., Ga., Fla., to La., common in the pine woods. St. I to $2 \mathrm{f}$, often quite simple, with a single, large glomerule at top. The stiff, acute scales are $5^{\prime \prime}$ long. Jl.-Sept.-Varies with more branches and leaves, towards No. 1.

\section{TRIBE 2. EUPATORIACE $A$.}

4. AGERA'TUM L. (Gr. $a$ (privative) and $\gamma \tilde{\eta} \rho a \varsigma$, old age ; $i . c$. fadeless; misapplicd in this case.) Heads $\infty$-flowered, $\Varangle$, discoid ; scales linear, imbricated, pointed; receptacle naked; corollas all tubular; fruit (cypsela) 5 -angled, narrowed at base; pappus 5 to 10 chaffy, awned scales.-(1) (2) Mostly tropical, with opposite, petioled liss. and corymbed heads.

A. conyzoìdes L. Branching; lrs. ovate, tooth-crenate, acute or cordate at base, somewhat rugous; pappus of 5 subulate, denticulate scales as long as the cor. but much shorter than the conspicuous branches of the style. Near Savannah (Pond). Sts. 12 to $18^{\prime}$ high, downy. Lower petioles half as long as tho leaves. Fls. blue or white. Apr., Jn. \& The cultivated variety called $\Lambda$. Mexicana has nearly all its leaves cordate, and flowers always ? blue.

5. SCLEROL'EPIS, Cass. (Gr. $\sigma \kappa \lambda \eta \rho o ́ s, ~ h a r d, \lambda \varepsilon \pi i \varsigma$, scale.) Head $\infty$-flowered, $\Varangle$, discoid; scales equal, linear, in 2 series; receptacle naked; corolla 5-toothed, enlarged at the throat; branches of the style much exerted; achenia 5-angled, crowned with a cup-shaped pappus of 5 obtusc, horny scales. $-2 f$ Aquatic, glabrous, simple, with 1 to 3 terminal hds. Lvs. verticillate; fls. purple.

S. verticillàta Cass. In shallow water, N. J. to Fla. St. decumbent at base, I to $2 \mathrm{f}$ high. Lvs. in numerous whorls of about $\sigma^{\prime}$ linear-setaceous, entire, $1^{\prime}$ in length. Head commonly solitary at the top of the stem. J1.-Sept. (Sparganophorus $\mathrm{Mx}$.)

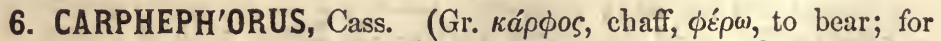
its chaffy receptacle.) Heads (about 20-flowered), involucre, flowers and fruit as in Liatris; receptacle chaffy ; pales narrow, 3-veined, rigid, shorter than the flowers.-2f Sts. simple, leafy, corymbous at top, with middle sized heads of purple flowers. (Liatris, Mx. Ell.)

* Scales of the involucre acute, downy-tomentous............................. 1, 2

* Seales of the involucre rounded-obtuse, nearly glabrous....................... Nos. 8,4

1 C. pseudo-liatris Cass. Slender, erect, tomentous-pubescent; lvs. rearly glabrous, linear-subulate, rigid, the cauline gradually shorter, closely appressed to and covering the stem; hds. few in a racemous cyme; scales rigid, ovate-lanceolate, appressed.-Gadsden Co., Fla. to Ala. and La. Plant strictly erect, $2 \mathrm{f}$ high, its tomentum grayish. Hds. 15 to 20 -flowered. (L. squamosa Nutt.)

2 C. tomentòsus Torr. \& Gr. Erect, downy and corymbous above; rt. lvs. lanceolate, petiolate; cauline lance-ovate, sessile, erect, the upper pubescent; scales lance. ovate, acute, mostly appressed, glandular tomentius.-Swamps, Va. to Ga. St. 2f high, bearing a loose, spreading corymb. Pales linear, pappus purplish Sept., Oct. (L. Walteri, Ell.)

3 C. bellidifòlius Torr. \& Gr. Low, nearly glabrous, tufted; root-lvs. spatulate, petiolate, obtuse, 3-veined, cauline mostly linear; branches with 1 to 5 heads; 
scales herbaceous, glabrous, oblong and obtuse.--Sand hills about Wilmington, N. Car. Sts. numerous and much branched, 8 to $12^{\prime}$ high. Scales leafy, green, pappus rather plumous than barbellate. Sept. (L. bellidifolia Mx.)

4 C. corymbòsus Torr. \& Gr. St. single, stout, erect, hairy; lvs. nearly smooth, oblanceolate, obtuse, tapering to the base, the upper small, oblong, sessile; hds. about 20, 20-flowered, in a dense corymbous cymo; scales smooth, oblong-oval, very obtuse, with a broad, scarious margin.-Swamp margins, N. Car. to Fla. St. about 3 high. Fls. pale purple. Sept., Oct. (L. corymbosa Nutt.)

7. LIA'TRIS, L. (Gr. $\lambda \iota$, an emphatic prefix, ar $\rho \omega s$, invulnerable; used as a vulnerary.) Heads few to many ( 5 to 60 )-flowered; flowers all $\Varangle$, tubular; involucre oblong, imbricate ; receptacle naked; pappus of $\infty$ capillary bristles, mostly plumous; achenia tapering to the slender base, 10-striate; styles much exserted.-2f Iferbs with simple, erect stems, alternate, entirc lvs., and handsome rose-purple fls. in spicate, racemed, or paniculate hds., blooming from Aug. to Nov.

\$ Ileads in a corymb or thyrse-liko panicle. Root fibrous......................... 1, 2

\$ Ireads in a spike or a simple raceme. Root a roundish tuber (a).

a Scales of the involucre colored and petaluid at their lengthened ends................ 3

a Scales not petaloid, green or slightly tingerl at the end (b).

b Pappus evidently plumous. Corollas $(13$ to 60 ) hairy within..............Nos, 4,5

b Pappus evidently plumous. Corollas ( 3 to 5 ) smooth within...................

b Pappus only barbellate (smooth to the naked eye) (c).

c Heads 3 to 7 -flowered, -in one-sided spikes or racemes...............Nos. 8,9

-in a regular spike, raceme (or panicle).............

c IIeads 20 to 40 -flowered, roundlish, with rounded scales....................... 13

c Heads 7 to 15 -flowered.-Scales all similar, obtuse.................. Nos. 13,1 , - Scales all, or the inner only acute............. Nos. 15, 16

1 工. odoratíssima Willd. VAnilla-Plant. Deer's-Tongue. Glabrous; rt.Ivs. obovate-spatulate, obtuse, 5 to 7 -veined, tapering to the base, cauline oblong, clasping; hds. about 8-flowered, in many cymes, constituting a large, loose corymb; scales all obtuse; fr. smoothish.-Pine barrens (Va. ?) to Fla. and La., abundant. Sts. 1 to $3 \mathrm{f}$ high. Corymbs leafless. Fls. bright purple. Sept., Oct. -The fleshy leaves exhale a rich fragranco (compared to Vanilla) even for years after they are dry, and are therefore by the southern planters largely mixed with their cured tobacco, to impart its fragrance to that nauseous weed.

2 I. paniculàta Willd. St. simple, virgate, viscid-tomentous; rt.-lvs. spatnlatelanceolate, acute, tapering to a petiole, cauline small, appressed, lanceolate-acuminate; hds. about 5 -flowered, in an oblong, dense, thyrsoid panicle.-Damp pino barrens, Ga., Fla. St. 2 to 3 f high. Scales fow, all obtuse. Fls. pale purple or white. Sept., Oct.

3 I. élegans Willd. Villous-canescent above; Ivs. glabrous, the radical oblanceolate, 3 to 5-veined, cauline linear, the upper bract-like, spreading; spike or racemo dense; hds. oblong-cylindrical, 4 to 5-flowered; scales lance-linear, prolonged into a colored, petaloid appendage longer than the flowers; pappus evidently plumous.-A remarkablo species, in pino barrens, Va. to Fla. and Tex. St. 3 or $4 \mathrm{f} \mathrm{high,} \mathrm{ending} \mathrm{in} \mathrm{a} \mathrm{spike} 6$ to $16^{\prime}$ long. The purple appendaged scales more showy tlian the florets. Aug., Sept.

4 I. squarròsa Willd. Blazisg STAR. Smooth or scabrous-pubescent; Ivs. linear, lower ones attenuated at base; rac. flexuous, leafy; hds. few, 20 to 40 flowered, sessile or nearly so; invol. ovate-cylindric; scales large, squarrousspreading, outer larger, leafy, inner mucronate-acuminate, scarcely colored; fls. numerous; pappus plumous. - $\mathrm{A}$ splendid plant, native N. Y. (Eaton) Penn. to Fla. and W. States. Sts. 2 to 3 f high, thickly beset with long, linear leaves. IIds. 5 to 20 , with large, brilliant purple florets. Aug. $\dagger$ It varies with the heads only 12 to 15 -flowered (Georgia, Feay), smooth or hairy, \&c.

5 L. cylindràcea $\mathrm{Mx}$. St. low, slender, and very leafy, smooth and somewhat hirsute, lvs. rigid, linear, mostly 1-veined; hds. fow, sessile or pedicellate, cylindrical, 15 to 20-flowered; scales short, ciliate, close, rounded or obtuse, and abruptly mucronate at apex; pappus plumous.- Prairies and barrens, Mich. to Iowa (Cousens) and No. St. 6 to $18^{\prime}$ high. Lvs. 2 to $5^{\prime}$ by 2 to $4^{\prime \prime}$. Heads $1^{\prime}$ long, 
rarely solitary, sometimes 10 or 12 , mostly about 5. Fls. bright-purple. ЛSept.

6 I. Boylrínii Torr. and Gr. Slender, erect; lvs. linear, punctate, elongated, the upper short and setaceous; hds. 3 to 5-flowered, sessile, or with short appressed ped. in a close virgate spike; scales few, the outer subulate, short, the inner lance-linear, margins scarious, tips acuminate, spreading, as long as the plumous pappus.-W. Ga. Plant nearly smooth, 1 to $2 \mathrm{f}$ high, with pale purple forets. Aug., Sept.

$\eta$ 工. tenuifòlia Nutt. Smooth, slender, simple; lvs. narrowly linear or filiform, the lower crowded, very long, diminishing upwards to setaceous bracts; hds. 5 . flowered, crowded, on scaly, filiform ped. forming a long raceme; scales oblong, obtuse, mucronulate, outer very short; pappus plumous, scarcely longer than the villous fruit.-Pine barrens, N. Car. to Fla. Very elegant, 2 to $4 \mathrm{f}$ high. Rt. lvs. resembling those of the long-leaved pinc, in a crowded tuft. Rac. of purple fls. 1 to $2 f$, ped. I'. Aug.-Oct.

8 I. secúnda Ell. Slender, ascending and recurved; lvs. linear, short; the radical linear-lanceolate; rac. recurved, long, slender, with the heads all turned to the upper side (secund); invol. about 10-scaled and 5-flowered; pappus plumous (under a lens).-Dry sand hills, Mid. Car. and Ga. Sts. 1 to 3 f high. Beautifully distinguished by its long (6 to 12') secund racemes. Aug., Sept.

9 L. pauciflòra $\mathrm{Ph}$. St. simple, glabrous; lvs. linear; pan. (composed of simplo racemes?) virgate, leafy, branches short, with few hds.; hds. subsessile, secund, 3 to 5 -flowered; scales erect, lanceolate, acute, glabrous.-Ga. (Bartram, Pursh.) A species at present unknown. Probably a var. of the last.

10 工. grácilis $\mathrm{Ph}$. Pubescent, slender, simple; lvs. linear, 1-veined, short, the lower lanceolate, obtuse, all glabrous, ciliate at base; hds. 3 to 5 to 7 -flowered, on divaricate, slender, hairy pedicels, in a long virgate raceme, larely paniculate; scales few, appressed, oblong, obtuse, shorter than the purple barbellate pappus. Dry pine barrens, Ga., Fla., Ala. Plant grayish, 2 to $3 f$ high. Hds. small. Fr. villous. Sept., Oct.

11 I. pycnostáchya Mx. Simple, more or less hirsute, rery leafy; lvs. rigid, ascending, straight, lower ones long, lanceolate, veined, obtuse, upper short, narrow-linear; spike dense and thick, long and bracted below; hds. numerous, cylindrical, sessile, 5-flowered; scales appressed, with acute, scarious and colored squarrous tips.-Prairies, Ill. to Tex. A stout species, distinguished from L. spicata, chiefly by its acute, squarrous scales, and few-flowered heads. St. 3 to $5 \mathrm{f}$ high. Spikes cylindrical, 10 to $20^{\prime}$ long. Aug. Varies with stem and invol. nearly glabrous (L. brachystachya Nutt.)

12 L. scariòsa L. GaY Feather. Scabrous-pubescent; lis. lanceolate, lower on long petioles, upper linear and much smaller; hds. remotely racemed, 20 to 40 flowered, globous hemispherical; scales obovate, very obtuse, purplish; fis. rumerous; pappus scabrous. - A beautiful plant, 4 to $5 \mathrm{f} \mathrm{high,} \mathrm{in} \mathrm{woods} \mathrm{and} \mathrm{sandy} \mathrm{fields,}$ Can., Mass. (Ricard) to Ga. and La. St. rather stout, whitish above. Lrs. numerous, entire, lower 3 to $9^{\prime}$ long, upper 1 to $3^{\prime}$ by 1 to $3^{\prime \prime}$, rongh-edged. HIds. 5 to $20,1^{\prime}$ diam., in a long raceme, each 20 to 40 -flowered. Cor. purple. Aug. $\dagger$

13 I. spicàta Willd. Lvs. lance-linear, smoothish, punctate, ciliate, lower ones narrowed at base; hds. in a long, terminal spike, sessile; scales of the invol. oblong, obtuse; fls. about 8; pappus scabrous-plumous.-Native from N. J. and Mich. to Fla. and La. Abundant in prairies. A beautiful species, often cultivated. St. 2 to $5 f$ high. Hds. numerous, with bright purplo fls. Aug. +- Varies with smaller, 5 to 7 -flowered heads. (L. resinosa Nutt.)

14 I. graminifòlia Willd. Glabrous or with scattered hairs; st. slender and simple; lvs. linear, l-veined; hds. 7 to 12 -flowered, mostly pedicellate, spikes or racemes sometimes paniculate below; invol. acute at base; scales many (12 to 18), obovate-spatulate, very obtuse, appressed, outer row shorter; ach. hairy.-N. $\mathrm{J}$. to Ga. and Ala. St. 2 to $3 \mathrm{f}$ high. The lower lvs. are lance-linear, 3 to $4^{\prime \prime}$ wide, upper subulate. Hds. generally pedicellate, pedicels 4 to $12^{\prime \prime}$ long. Fr. hairy, shorter than the scabrous pappus. Sept., Oct.

$\beta$. DUBIA. Inflorescence sometimes compound below, or partly paniculate 
hds. on short pedicels, 7 to 10 -flowered; scales somewhat narrower, ciliate. -Pine barrens, N. J. to Ga. (Miss Keen.) Approaches L. spicata. (IL dubia Bart.)

15 L. pilòsa Willd. St. simple, pubescent; lvs. linear, pilous-ciliato; hds. loosely racemed; scales linear-oblong, rather obtuse; peduncles bracteolate.-In pine barrens and sandy fields, N. J. to Car. (Pursh.) Seven-mile Mt., Va. (Read.) Very rare and obscure.

16 I. heterophýlla $\mathrm{R}$. Br. St. simple, glabrous; lvs. lanceolate, smooth and glabrous; upper linear-lanceolate, many times smaller; hds. spicate, very shortpedunculate; invol. subsquarrous, scales lanceolate, acute, naked (not ciliate).-S. Car. and Ga. (Bartram.) A doubtful species, variety of L. scariosa?

8. KUH'NIA, L. (To Dr. Adam Kuhn, of Pennsylvania, a pupil of Linnæus.) Heads 10 to 25 -flowered, $\not$; scales of the involucre lanceolate, loosely imbricated ; receptacle naked ; corolla slender, 5-toothed; pappus in a single series, plumous ; achenia cylindrical, striate, pubescent. - 4 Herb with alternate, resinous-dotted lvs., and corymbed hds. of pale yellow florets.

K. eupatoroìdes L. Lrs. lanceolate and lance-ovate, varying to lance-linear, usually serrate, petiolate, sprinkled with resinous dots, especially beneath; corymb few or many-flowered.-Shady soils, N. J., Penn. and Iowa (Cousens), to Fla. and La. Sts. 2 to 3 f high. Lvs. thin, 1 to $4^{\prime}$ long, often coarsely and unevenly toothed, lower 3-veined, upper 1-veined, and very small. Hds. few, terminal. Pappus very plumous, white or tawny. $\Lambda$ ug., Sept.

$\beta$. Lvs. lance-linear, mostly entire, sessile; pan. spreading, many-flowered; fis. and fr. unchanged.-With the other varieties (K. Critonia Willd.)

9. BRICKEL'LIA, Ell. (To Dr. Brickell, of Savannah.) Heads many-flowered, ф̧; scales imbricated, lanceolate or linear,-striate; rcceptacle naked, flat; corolla tube slightly expanded above, 5 -toothed; branches of the style clavate; fi. 10-striate, contracted above; pappus setaceous, in one series. - 2f Herbs with tripli-veined leaves and large heads of purple florets in corymbs.

B. cordifòlia Ell. Pubescent; lvs. all opposite, triangular, truncate or cordate at base, crenate, petiolate; corymbs dense, few-flowered; hds. 30 to 40 -flowered; scales obtuse, conspiciously striate, the inner as long as the purple pappus and corollas. - W. Ga. (Pond) and Fla. A plant of fine appearance, 2 to $4 \mathrm{f}$ high. Lvs. large, sprinkled with shining dots beneath, 3-veined, the lateral veins marginal just at the base. Sds. brown, longer than the purple pappus. Aug, Sept.

10. EUPATO'RIUM, Tourn. Boneset. (To Eupator, King of Pontus, who first used the plant in medicine.) Flowers all tubular, $\Varangle$; involucre imbricate, oblong; style much exserted, deeply cleft; anthers included; receptacle naked, flat; pappus capillary, simple, scabrous ; achenia 5-angled.-2f Herbs, generally with opposite, simple lvs. and corymbous hds. Fls. of the cyanic series, that is white, blue, red, etc., never yellow.

5eaves mostly alternate, pinnately dissected. Heads paniculate................. Nos, 1, 2

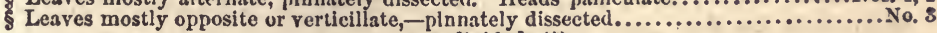
-undivided. (*)

* Scales imbricated in several rows, the onter gradually shorter. (a)

a Flowers bluish. Leaves opposite. Scales strongly striate...................... 4

a Flowers purplish. Lvs. whorled. Scales streaked and tlesh colored............ $5-7$

a Flowers white, -5 only in each head. Leaves subsessile. (b)

b Leaves acute at base. Scales with acuto white points............. Nos. 8, 9

b Leaves acute at base. Scales obtuse, short, downy......................... 10-13

b Leaves obtuse, roundish or truncate at the base........................... 14-16

a Flowers white, 7 to 15 in each heal. Jeaves various...................... 17 . 20

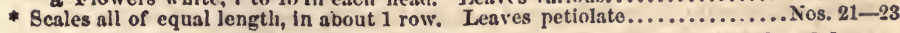

1 E. fœniculàceum Willd. DOG FENNEL. Very branching, nearly glabrous; ivs. all alternate, the lower compoundly pinnate with linear filiform segments, the 
upper setaceous, simple, fascicled; hds. small, very numerous, 3 to 5 -flowered, on short pedicels; scales 8 to 10 , mucronate.-A common weed, in fields and damp soils, Va. to Fla. St. 3 to $10 \mathrm{f}$ high, bearing innumerable fine cut lvs. and a compound pyramidal panicle of innumerable hds. Fls. yellowish-white, littlo moro than $1^{\prime \prime}$ long. Lvs. often channeled on the upper side. Sept., Oct.

2 F. coronopifòlium Willd. Much branched, pubescent; lvs. mostly alternato (the lower opposite), the lower twice pinnatifid with lance-linear lobes and segments; upper lvs. linear, fascicled; hds. small, very numerous, 5-flowered; scales 10, with scarious margins and cuspidate points.-In dry, thin soils, N. Car., Ga. to Fla., common. St. 3 to $5 \mathrm{f} \mathrm{high.} \mathrm{Lrs.} \mathrm{and} \mathrm{fls.} \mathrm{immensely} \mathrm{numerous,} \mathrm{as} \mathrm{in} \mathrm{No.} 1$. Fls. white, about $2^{\prime \prime}$ long. Panicle often 2f long. Sept., Oct.-Distinct from No. 1 ?

3 ஐ. pinnatífidum Ell. Pubescent; lvs. laciniate-pinnatifid, segm. linear, toothed or entire, the lower whorled in $4 \mathrm{~s}$, middlo opposite, upper alternato; hds. small, numerous, 5 to 9 -flowered, in a fastigiato corymb; scales oblong, mucronate.Pine barrens, Car. to Fla. Height 3 to 4 f. Hds. about the size of No. 2, to which this species is evidently related.

4 E. ivæefclium L. St. terete, branched; Ivs. opposite, lanceolate, tapering to each end, subsessile, subserrate, 3-veined; hds. pedicellate, 15 to 20 -flowered; scales 20, imbricated, the outer gradually shorter, all erect, obtuse, with 3 to 5 distinct strice. - TWoods, near N. Orleans. Herb 3 to $5 \mathrm{f}$ high. Lrs. 2 to $3^{\prime}$ long. Florets light blue, in a few large, corymbed hds. Aur., Sept.

5 E. purpùreum L. (not of Willd., Ph., nor DC.) St. solid, green, or sometimes purplish, with a purple band at the joints about $\mathrm{I}^{\prime}$ wide; lvs. feather-veined, in whorls of $3 \mathrm{~s}, 4 \mathrm{~s}$ and $5 \mathrm{~s}$ (rarely in $2 \mathrm{~s}$ ), ovate, smooth above, downy on the veins beneath, coarsely serrate.-Dry woods and meadows, common. St. 3 to 6f high. Lvs. large, thin, 8 to $10^{\prime}$ by 4 to $5^{\prime}$. Corymb lax, palo purple, varying to whitish. Aug., Sept. (E. trifoliatum Darl.)

$\beta$. TERnifolium. St. solid, slender, green, with a purple blush; lvs. in $3 \mathrm{~s}$, very thin, lanceolate.-Mountain woods, etc. Height about 3 f.

G E. maculàtum I. PURPLE Boneset. St. solid, striate, hispid or pubescent, greenish and purple, with numerous glands and purple lines, the glands on the stems and leaves give out an acrid effluvium in flowering time; lvs. tripli-veined, 3 to 5 in a whorl, ovate.-Low grounds, U. S. and Can. Herb 4 to $6 f$ high. Ivs. petiolate, 6 to $7^{\prime}$ by 3 to $4^{\prime}$, usually pcinted, strongly serrate. Fls. purple. Jl., Sept. (E. purpureum $\beta$. Darl.)

$\beta$. URTICIFoliom Barratt. Slender; 1rs. thin, much elongated,-height 4 to 5 f.

7 E. fistulòsum Barratt. Trumper WEeD. St. fistulous, glabrous, glaucouspurple, striato or fluted; lvs. oblong-lanceolate, in whorls of $5 \mathrm{~s}$ or $6 \mathrm{~s}$, largest in tho middle of the stem, rather finely glandular serrate, midvein and veinlets lividpurple; corymb globous, with whorled peduncles.-A majestic herb, thickets, U. S. and Can. Height 6 to 10f, hollow its wholo length. Lvs. including the $1^{\prime}$ petioles, $8^{\prime}$ by $2^{\prime}$. Corymb often if diam. It does not appear to posses tho acrid properties of E. maculatum. J1.-Sept. (E. purpureum Willd. in part. B. angustifolium T. \& Gr.)-Intermediato forms occur, rendering the distinctions of this species and the two preceding numbers a gravo question.

8 E. álbum L. Scabrous-pubescent; lvs. oblong-lanceolate, strongly serrate, sessile, rather acute, obscurely 3-veined; corymb fastigiate; hds. clustered, oblong, 5-flowered; scales 8 to 14, lance-linear, tipped with a white, scarious acumination, longer than the fls.; cyps. glandular.-Sandy soils, Penn. to La. St. about $2 \mathrm{f}$ high, corymbously divided above. Lvs. 2 to $3^{\prime}$ by $\frac{1}{2}$ to $1^{\prime}$, upper ones entiro and alternate. Invol. concealing the fls., and with them copiously sprinkled with resinous dots, whitish. Aug.-Oct. (E. glandulosum $\mathrm{Mx}$.) - $\Lambda$ variety has the leaves rather obtuse and crenate. (Tenn.)

9 E. leúcólepis Torr. \& Gr. Nearly glabrous; st. simple; lvs. linear-lanceolate, obtuse, closely sessile, serrate, lower ones obscurely tripli-veined; corymb fastigiate, canescent; hds. 5 -flowered; scales 8 to 10 , scarious and white at the summit, as long as the fls. - Sandy fields, N. J. to La. St. 2 to $3 \mathrm{f}$ high. Lvs. $1 \frac{1}{2}$ to to $2 \frac{1^{\prime}}{2}$ by $\frac{1}{4}$ to $\frac{3^{\prime}}{4}$, glaucous-green both sides, divaricate with the stems, apper ones 
linear and entire. Cor. dilated at mouth, with short, obtuse lobes, white. Aug.Ocl. (E. glaucescens $\beta$. leucolepis DC.)

10 E. hyssopifòlium L. Lvs. opposite, often verticillate, linear-lanceolate, ob. scurely tripli-veined, punctate, lower ones subserrate, upper ones entire; scales short, oval, grayish pubescent, very obtuse.-A more delicate species, smooth, or minutely pubescent, in dry tields, Mass. to Iowa and La. St. about $2 \mathrm{f}$ high, branching into a spreading corymb. Hds. 5 -flowered, very small, in dense clusters, and $3^{\prime \prime}$ long, scales half as long. . Aug., Sept. $\beta$. linearifolium is more pubescent, with
the lower lvs. serrate.-South.

11 E. cuneifòlium Willd. Pubescent; lvs. small, glaucous both sides, broadly oblanceolate or oblong, obtuse at apex, acute at the subsessile base, slightly serrate abore the middle; hds. small, in a loose corymb, 5-flowered; scales (2" long) soft-villous, obtuse, much shorter than the fls.-Rich shady soils, S. Car., Ga. to Ala. St. 1 to $2 \mathrm{f}$ high. Lvs. 8 to $18^{\prime \prime}$ long. Fls. white. Aug., Sept.

12 3. parviflòrum Ell. Soft-puberulent, diffusely branched; lvs. mostly opposite (in $3 s$ below), lanceolate, acute, acutely serrate above the middle, entire bo low, and tapering to the sessile base, 3-veined; hds. small and crowded; scales pubescent, glandular (like the 3 preceding), outer very short, inner linear, obtuse.Low grounds, Va. to Fla. and La. Height 1 to 3f. Pan. compound, loose. Lvs. 1 to $3^{\prime}$ long, the upper scattered. Hds. about $2^{\prime \prime}$ long, scales $1 \frac{1}{2}$ ". Aug.-Oct.

13 E. altíssimum L. St. pubescent tomentous, tall, corymbous at the summit; lvs. lanceolate, remotely and acutely serrate above the middle, pubescent, tapering to each end, subsessile, conspicuously 3-veined; hds. 5-flowered; scales 8 to 12 , elliptical, obtuse, pubescent.-Woods and sandy soils, Penn. and W. States (Plummer). St. round, striate, 3 to $7 \mathrm{f}$ high. Lvs. 3 to $4^{\prime}$ long, much resembling those of Solidago Canadensis; small ones often fascicled in the axils. Corymb compound. Cor. whitish, nearly twice as long $\left(5^{\prime \prime}\right)$ as the scales. Sept., Oct. (Kuhnia glutinosa DC.)

14 E. teucrifolium Willd. Lvs. opposite, sessile, ovate, rough, veiny, the lower ones doubly serrate, upper ones subserrate or entire; st. paniculate, pubescent, with fastigiate, corymbous branches above; scales elliptical, faintly striate, rather acute.-Mass. to La. Plant hairy, 2 to $3 \mathrm{f}$ high, with a somewhat panicled corymb of white flowers. The upper ivs. are often entire. Invol. 5-flowered, with twice as many scales in 2 rows. Closely allied to the following, but is much more rough. Aug. (E. verbenæfolium Mx. E. pubescens Pers.)

15 E. scssilifòlium L. Lvs. opposite, amplexicaul, ovate-lanceolate, rounded at the base, very smooth, serrate; st. smooth; inner scales oblong-obovate, obluse.Plant 2 to $4 \mathrm{f} \mathrm{high,} \mathrm{in} \mathrm{rocky} \mathrm{woods,} \mathrm{Mass.} \mathrm{to} \mathrm{Ind.} \mathrm{and} \mathrm{Ga.-St.} \mathrm{slender,} \mathrm{erect,}$ branching at top into a corymb with white fls. Lvs. large, tapering regularly from the somewhat truncate base to a long point, with small serratures, paler beneath. Flower-stalks downy. Hds. 5-flowered, with twice as many scales in 2 rows. Sept.

16 E. rotundifòlium Willd. HOARHOUND. Lvs. opposite, sessile, roundishovate, subcordate at base, 3-veined and veinleted, coarsely serrate, scabrous above, pubescent beneath; hds. about 5 -flowered; inner scales acuminate, as long as the flowers. - A bushy, compact species, in dry fields, N. J. and S. States. St. 2 to $3 \mathrm{f}$ high, roughish. Lvs. 1 to $2^{\prime}$ by 9 to $20^{\prime \prime}$, obtuse or broadly acute. Hds. fastigiate-corymbous. Invol. very pubescent, concealing the white florets. Pappus longer than cor. Sty. much exserted. Aug. Sept.

17 E. pubéscens Muhl. St. hirsute; lvs. opposite, sessile, distinct, ovate, acute, obtusely dentate, rough-pubescent; corymb fastigiate; invol. about 8-flowered; scales lanceolate, acute, rather shorter than the flowers.-A large, rough plant, 3 to If high, growing on dry grounds, N. H. to Penn. Distinguished from No. 16 by its larger lvs. ( 2 to $3^{\prime}$ by $1_{2}^{1}$ to $\left.2^{\prime}\right)$, hds., and proportionately shorter scales, which are about 12, the outer much the shortest. Aug. (E. ovatum Bw.)

18 E. perfoliàtum L. THOROUGH-WORT. BONESET. Lvs. connate-perfoliate, very pubescent.-A common, well-known plant, on low grounds, meadows, U. S. and Can., abundant. St. 1 to $5 \mathrm{f}$ high, round, rough, and hairy. Each pair of lvs. are so united at the base as to constitute a single lamina, centrally perforated by the stem, and placed at right angles to it; they are rough, rugose, serrate, 
tapering to a long point, and both combined, are 8 to $14^{\prime}$ in length. Hds. about 12 -flowered, clustered in large, terminal corymbs. Cor. white. Aug.-The plant is bitter, and is used in medicine as a tonic.

19 E. resinòsum Torr. St. minutely tomentous; lvs. linear-lanceolate, closely sessile, distinct, tapering to a long acumination, divaricate with the stem, slightly viscidly resinous-glandular both sides; corymb fastigiate, compound: hds. 10 to 15-flowered; scales obtuse, hoary-tomentous.-Wet, sandy soils, N. J., Penn. St. 2 to $3 \mathrm{f} \mathrm{high,} \mathrm{growing} \mathrm{in} \mathrm{tufts.} \mathrm{Lvs.} 3$ to $6^{\prime}$ by 3 to $6^{\prime \prime}$. Aug., Sept.-This singular species appears to be nearly confined to the pine barrens of N. J., where it was first found by Dr. Torrey.

20 E. seròtinum $\mathrm{Mx}$. St. soft-puberulent, diffusely branched; lvs. petiolate, lance-ovate, acute or acuminate, sharply serrate, triple-veined, nearly glabrous; corymbs compound; hds. 12 to 15 -flowered; scales 9 to 11 , nearly alike, scariousedged, very pubescent.-Ind. to Iowa (Cousens), and Ga. (Miss Keen). St. 4 to $6 \mathrm{f}$ high, somewhat paniculato above. Lvs. 4 to $6^{\prime}$ by $\frac{3}{4}$ to $1 \frac{1^{\prime}}{2}$, upper ones nearly entire, scattered; lower ones opposito, with largo irregular serratures. Sept., Oct.

21 E. ageratoìdes L. St. smooth, branched; lvs. on Iong petioles, subcordate, ovate, acuminate, dentate, 3-veined, nearly smooth; corymbs compound; invol. simple, smootl. - Rocky hills and woods, Can. and U. S. St. round, 2 to $4 \mathrm{f} \mathrm{high,}$ and with the whole plant nearly smooth. Lvs. large, 3 to $6^{\prime}$ long, 2 to $4^{\prime}$ broad at base, coarsely toothed, petioles 1 to $2^{\prime}$ long. Hds. numerous, in small clusters, constituting a compound corymb. Invol. scales mostly in a row, containing 12 or more flowers of a pure white. Aug., Sept.

22 E. aromáticum I. St. rough, pubescent, corymbous at summit; lvs. petiolate, opposite, subcordate, lance-ovate, acute, 3-veined, obtusely serrate, smoothish; invol. simple, of about 12 lance-linear pubescent scales.-A handsome species, in low woods, Mass. to La. Whole plant slightly pubescent, about $2 \mathrm{f} \mathrm{high.} \mathrm{Lrs.} 2$ to $4^{\prime}$ long, $\frac{1}{2}$ as wide, on petioles less than an inch long. Hds. of the fls. large, 10 to 15 -Howered, whito and aromatic, in small corymbs. Scales about equal. Aug., Sept.

23 E. incarnàtum Walt. Minutely scabrous, diffusely branched; lvs. deltoidovate, long-petioled, pointed, coarsely crenate-toothed, truncate or cordate; hds. on slender ped., about 20-flowered; scales 12 to 15 , linear-acuminate, faintly 2 striate, glabrous; cor. lobes pale-purple-Damp soils, N. Car. (Shriver) to Fla. (Chapman) and Tex. Height 2 to 3 . Corymbs very loose, paniculate. Sept., Nov. Approaches Conoclinium, but readily distinguished by its short, blunt styles.

11. MIKA'NIA, Willd. Climbing Boneset. (In honor of Prof. Mikan, of Prague.) Flowers all tubular, ६̧; involucre 4-leared, 4-1lowered; receptacle naked; pappus capillary, simple, scabrous; anthers partly exserted; achcnia angled.-Mostly climbing herbs. Lis. opposite.

M. scándens Willd. St. smooth; Irs. cordate, repand-toothed, acuminate, tho lobes divaricate, rather unequal ; hds. in pedunculate, axillary corymbs. - A beautiful climber of wet thickets, Mass. to Ga. (Miss Keen) and La., rather rare. Every part smooth. Lvs. 2 to $3^{\prime}$ by 1 to 2 , on petioles 1 to $2^{\prime} l o n g$, apex tapcring to a long point. Branches short, nearly naked, each bearing a snall corymb of white or pink colored fls., almost always 4 in a head. Aug., Sept.

12. CONOCLIN'IUM, DC. (Gr. kĩvos, a cone, $\kappa \lambda i ́ v \eta$, bed or receptacle.) Heads many-flowered; receptacle conical, character otherwise as in Eupatorium. -24 Herbaceous or suffruticous. Lvs. opposite, petiolate, serrate. Fls. blue or purple, in crowded corymbs.

C. cœlestinum DC. Herbaceous, nearly glabrous, much-branched, lvs. deltoidovate, truncate or subcordate at base, tapering to an obtusish apex, crenate-serrate, 3-veined, petiole slender, about half as long as the lamina; corymbs numerous, subumbellate; scales numerous, linear.-Hedges, thickets, roadsides, \&c. Penn., Southern and W. States. St. 1 to $2 \frac{1}{2} \mathrm{f}$ high, terete, with opposite branches 
Lvs. 1 to $2 \frac{1}{2}$ ' long, $\frac{2}{3}$ as wide. Fls. 20 to 50 in a head, of a beautiful sky blue, roddish in fading. Aug., Sept.

13. TUSSILA'G0, Tourn. Colt's-Foot. (Altered from the Lat. tussis, cough; considered a good expectorant.) Head radiate, manyflowered; flowers of the ray $q$, those of the disk of; involucre simple; receptacle naked; pappus capillary. $-2 f$ Lvs. radical. Fls. yellow, with very narrow rays.

T. fárfara L. A low plant in wet places, brooksides, N. and M. States, and is a certain indication of a clayey soil. Scapo scaly, about $5^{\prime}$ high, simple, appearing with its single, terminal, many-rayed, yellow head in March and Apr., long beforo a loaf is to be seen. Lvs. arising after tho flower is withered, 5 to $8^{\prime}$ by 3 to $6^{\prime}$, cordate, angular, dentate, dark green above, covered with a cotton-like down boneath, and on downy petioles. §?

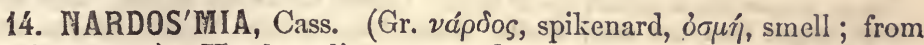
the fragrance.) Heads radiate, many-flowered, somewhat of of; flowers of the ray $q$, of the disk $\Varangle$, but abortive in the sterile plant; involucre simple; receptacle flat, naked ; pappus capillary. - 2f Lvs. radical. Fls. cyanic. The ray flowers of the sterile heads are in a single row; of the fertile heads in several, but very narrow.

N. palmàta Hook. Scapo with a fastigiate thyrse or corymb; lvs. roundish-cordate, 5-7-lobed, tomentous beneath, the lobes coarsely dentate.-In swamps, Fairhaven, Vt. (Robbins), Sunderland, Mass. (Hitcheock) W. to R. Mts. Very rare. A coarse, acaulescent plant, with large, deeply and palmately-lobed leaves, and a stout scape covered with leaf-scales and 1-2f high. The heads are fragrant, numerous, with obscure rays, those of the barren plants almost inconspicuous. May.

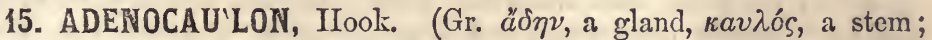
i. e., glands stipitate.) Heads discoid, few-flowered; corollas all similar, tubular; flowers of the margin of, of the disk $\delta$; scales of the involucre equal, in one series; receptacle naked; cypsela clavate, bearing stalked glands above; pappus none.-2f Nearly acaulescent, with alternate lvs. and small, paniculate hds., also gland bearing.

A. bìcolor Hook. St. leafy below, nearly naked above; lvs. deltoid, cordate, angular-toothed, decurrent on the petioles, glabrous above, arachnoid-pubescent beneath. - Shores of L. Superior (Dr. Pitcher, fido T. \& G.), to Oreg. (Hook). Sts. 1 to $2 \mathrm{f}$ high, slender. Fls. white.

\section{TrIBE 3. ASTEROIDEA.}

16. GALATEL'LA, Cass. (Lat. diminutive of Galatea, from which genus this was taken.) Heads many-flowered; rays few (3 to 12) sterile, ligulate; disk-flowers $\Varangle$, tubular; scales closely imbricated, without green tips; receptacle alveolate, toothed; corollas of the disk deeply 5 cleft; achenia silky-villous; pappus simple, copious, capillary, that of the ray similar. $-2 f$ Herbs corymbed, with alternate lis. Rays cyanic. G. hyssopifòlia Nees. Glabrous, erect, 1vs. lance-linear, acute, 3-veined, entire; invol. ovoid, half as long as tho disk; interior scales obtuse, membranous, outer acute, fleshy; rays 3 to 9, longer than the disk.- "Md. Car. and Ga. common." (Darby.) Height 1 to 2 f. Rays, palo purple. Aug.-Oct.

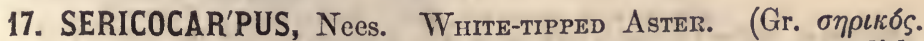
silken, карто́, fruit.) Heads few-flowered ; ray flowers 4 to $6, ?$; disk-

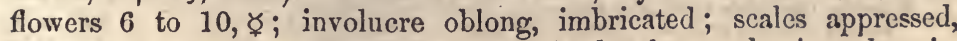
white, with green spreading tips; receptacle alveolate; achenium obconic, 
very silky; pappus simple. -2 Herbs with alternate lvs. and close corymbs. Rays white.

- S. solidagíneus Nees. Smooth; lvs. linear-oblanceolate, obtuse, entire, sessile, obsoletely 3-veined, rough on the margin; corymb fastigiate; hds. aggregate, subsessile, 5-rayed; scales obtuse, white, with green tips; pappus white.-In woods, Can to La. Very elegant. Sts. clustered, slender, simple, about $2 \mathrm{f} \mathrm{high.}$ Lvs. smooth, 1 to $2^{\prime}$ by 3 to $5^{\prime \prime}$. Hds. small ( $3^{\prime \prime}$ long). Invol, oblong. Scales with conspicuous green tips. Rays long, white. Jl., Aug. (Aster solidaginoides Mx.)

2 I. conyzoìdes Nees. St. somewhat pubescent, simple, corymbus at top; lvs. oval-lanceolate, smooth beneath, slightly 3-veined, narrowed at base, acute, the upper ones sessile, nearly entire, the lower narrowed into the petiole, serrate; invol. cylindrical, the scales oval, obtuse, appressed, slightly reflexed at summit; rays 5, short, pappus rusty.-Common in woods and thickets, Mass to Flor. Stems somewhat 5-angled, 1-2f high. Leaves somewhat fleshy. Ray short, but longer than the disk, white. July, Aug. (Aster Willd. Conyza asteroides L.)

3 s. tortifòlius Nees. Grayish-pubescent, roughish, corymbous above; lvs. short, oblong-obovate, sessile, twisted to a vertical position, and both sides alike minutely scabrous; scales regularly imbricated in many rows, the green tips slightly spreading; pappus white.-Dry woods and barrens, Va. to Fla. and La. Height about 2 f, often branched below. Lvs. 8 to $12^{\prime \prime}$ long, obtuse or acute. Hds. larger than in the others, about $5^{\prime \prime}$ long. Sept., Oct.

18. AS'TER, L. (Gr. $\alpha \sigma \tau \eta \dot{\rho}$, a star; from the radiated flowers.) IIds. radiate; involucre oblong, imbricate; seales loose, often with green tips, the outer spreading; disk flowers tubular, $\Varangle ;$ ray flowers + , in one row, generally few $(6-100)$, ligulate, oblong, 3 -toothed at apex, finally revolute; receptacle flat, alveolate; pappus simple, capillary, scabrous ; achenium usually compressed.-A large genus of $2 f$ herbs, very abundant in the U. S., flowering in late summer and autumn. Lvs. alternate. Disk fls. yellow, changing to purple, ray flowers blue, purple or white, never yellow.

§ BготrA, DC. Scales closely imbricated, slightly tippei with green. IIds. corymbous, rays 6 to 15 , white or roseate. Lvs. cordate. petioiate, serrate, large................... 1, 2

$\S$ Calliastrum, T. \& G. Scales lonscly imbricated, with green spreading $t_{i j .}$. Heads corymbous or few, large, rays 12 to 30 , violet. Leaves never cordate, rigid; pappus unequal, rigid, the inner slightly club-shaped. - Leaves all or the lower serrate..... Nos. 8-5 -Leaves cintire............................ 6,7

\$ Astrer proper. Scales (variously) imbrleated, with green tips or wholly green. paniculate or racemous. Pappus soft, equal (none club-sliaped). (a)

a Leaves elasping with a cordate or auriculate base. (b)

a Leaves sessile or petiolate, none of them cordate or auriculate. (c)

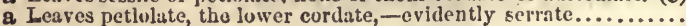

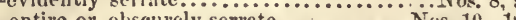

Leaves entire, - very small ( 1 to $3^{\prime \prime}$ long), erect or reflexed. - middle sizo (1 to $3^{\prime}$ lons), - A chenir silky.............. Nos. 13, 14 -Achenir smooth..................... 20,85

b Leaves serrate (moro or less). -Seales spreading, equal, in 2 rows. . . . . . . . . No. 1s -Scales Imbricated, in 3 to 5 rows................. 19-21 c Leaves silky on both sldes alike. Pappns tawny............................ 22, 23 c Leaves not silky.-Involuere closely inbricated. (d)

-Involnere squarrons, the seales spreading. (e)

d Leaves all entire. - Scales of the involucre obtuse........................ 24, 25

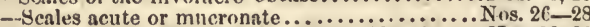

d Leaves (lower) sharply serrate. - IIcards larger $\left(4\right.$ to $6^{\prime \prime}$ long)........ Nos. 29, 80 -IIcads small ( 2 to $3^{\prime \prime}$ long)........ Nos. 31,82

- Seales obtuse, in sereral rows, in nequal. Leaves also obtuse...Nos. 33, 34

๑ Scales acute, in several rows, unequal. - Pappus tawny ....... Nos. $35-37$ - Pappus bright .......... Nos. $38-40$

- Scales acute, in nne row, equal. Leares linear. Ieads solitary... No. 41

8 Scariosx. Scales (variously) imbricated, with scarious margins and destitute of

green tips. (f)

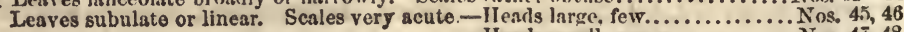




\section{§ 1. BIOTIA, DC. CORYMred Asters.}

1 A. corymbòsus Ait. St. corymbous-fastigiate, nearly smooth, branches pubescent; lvs. thin, ovate-acuminate, serrate, with sharp spreading teeth, the lower cordate, petiolate, the petioles wingless; invol oblong, 6 to 9-rayed, imbricato with close-pressed, acute scales.-Common in dry woods, N. and Mid. States. St. $2 f$ high, often reddish, more or less flexuous. Ivs. large, mostly smooth, the

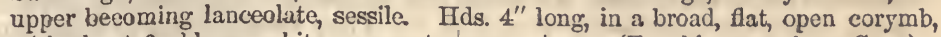
with about 6 oblong, white or roseato rays. Aug. (Eurybia corymbosa Cass.)

2 A. macrophýllus Willd. St. rough-pubescent, widely branched; lvs. ovate, petiolate, serrate with short, depressed teeth, rough, the upper ovate-lanceolate, sessile, lower cordate, petiolate, petioles somewhat winged; invol. cylindric, closely imbricate with oblong, acute scales; rays 8 to 15.-Woods N. States and Can. St. furrowed, 1 to $2 f^{\prime \prime}$ high. Lvs. often very large $\left(6\right.$ to $10^{\prime}$ by 3 to $\left.6^{\prime}\right)$. Pays white or palo blue. Hds. 6" long. Sept (Eurybia corymbosa Cass)

\section{§2. CAIIIASTRUM, Torr. \& Gr. Violet-Flowered Asters.}

3 A. mirabilis Torr. \& Gr. Scabrous, simple below; lvs. ovate, serrate, the lowest petiolate tho others sessile, those of the branches roundish, small; iuvol. hemispherical, shorter than the disk, scales imbricated, in 4 or 5 series suecessively shorter, with obtuse, green, recurved tips; rays about 20.-Columbia, S. Car. (Prof: Gibbs in N. Am Flora II, 165). Wo have not met with this species.

4 A. ráäula Ait. Erect, simple below, angular; lvs. lanceolate, acuminate, narrowed to the sessilo base, sharply serrate, rugous and rough; invol. imbricate, squarrous with the skort spreading green tips of the scales.-Moist groves and hedges, Me. to Penn. Height 1 to 3 f, remarkable for its straight, smooth stem, stiff, sharply serrate lvs. Branches nearly leafless, simple, caeli bearing a singlo large head, rarely more, with 20 pale violet rays spreading 121'. Aug., Sept.

5 A. spectábilis Ait. Erect, rough-puberulent abovo; lvs. roughish, oblonglanceolate, sessile, entire, the lower obscunely serrato; branches corymbed; invol. hemispherical, with sqmarrous, spreading, ciliate scales.-A low, handsomo Aster, of pine barrens, Mass. to N. J. and Ky. St. 1 to $2 \mathrm{fligh}$, branching above into a nearly simplo corymb of 10-15 largo and showy leads, cach with about 20 long violet bluo rays. Sept.-Nov.

6 A. surculòsus $\mathrm{Mx}$. Sts arising from a knotted creeping rhizome, low, slender, simple or corymlsous at top; lvs. linear-lancedate, entiro or subserrate, upper linear, clasping; hds. 1 to 5 ; scales linear-oblong, ciliate, inner obtuse, outer with green spreading tips; rays about 20.-Wet pine barrens, N. J. to N. Car. and Tenn. Sts. smoothish, 12 to $18^{\prime}$ lirh. Rt.-lvs. spatulate, 4 to $C^{\prime}$ long. IIds. large, olreonic, with violet-purple rays. Sept.

B. GRAcris Gray. Hds. smaller and moro numerous (8 to 12), with the involucre moro close, and the rays about 12 (A. gracilis Nutt).

7 A paluảòsus L. Slcnder, glabrous; lvs. long, linear, rigid, margins scarcely rough, clasping at base; hds. I to 6 , hemispherical; seales green, lance-linear, somewhat spreading; rays about 30 , longer than the $\left(6^{\prime \prime}\right)$ involuere.-Swamps in pine barrens, N. Car. to Fla. and La. Sts 2 to 3 f high. Hds. very large, with violet-blue rays spreading $1 \frac{1}{2}$ to $2^{\prime}$. Pappus tawny. Aug.-Oet.

\section{§3. ASTER proper. PANicled Asters.}

8 A. cordifòlius I. St. paniculate, smoothish; lower Ivs cordate, hairy beneath, sliarply serrate, aeuminate, petiolats; petioles winged; invol closely imbricate, the scales with short, green tips.-Common in rocky woods, N. and W. States. Stem with a handsome panicle of racemes at top of numerous, rather small flowers. Rays 10-15, palo blue varying to white. Lower leaves large. Petioles more or less winged, hairy. Above, the leaves aro gradually reduced to small or minute bracts. Sept.

9 A. sagittifòlius Willd. ARROW-LEAVED ASTER. St. with racemous branches above, smooth; lis. oblong-lanceolate, acuminate, sessile, serrate in the middle, radical ones ovate, oblong, cordate-sagittate, serrate, petiolato; invcl loosely imbricate, scales linear-subulate. - Low woods, N. ard IV. States and Can. Stem 
2-4f high, dividing into many ascending, rigid branches, with numerous and crowded heads, forming a compound panicle of leafy racemes. Heads small, each with about 12 rays, which are white or with various shades of blue. Leaves becoming smaller above, lanceolate and even linear. Sept.

10 A. undulàtus L. St. paniculate, puberulent; branches bracted, 1 (or few)flowered; lvs. oblong-cordate, amplexicaul, entire, hairy, somewhat undulate or crenate-serrate, lower ones ovate, cordate, subserrate, with winged petioles; invol. closely imbricate.-Dry woods, U. S. Plant rough, about $2 \mathrm{f}$ high, with slender branches. Lewer lvs. on winged petioles, cordate, acuminate, upper one.s becoming narrow-ovate and clasping. Fls. pale blue, solitary or somewhat clustered, forming a loose, racemous panicle. Aug., Sopt.

B. Diversifòtus. Very slender; lvs. shorter in proportion, ovate and oblong; branches slender, 1-flowered.-South (Pond.) (A diversifolius, $\mathrm{Mx}$.)

11 A. azùreus Lindl. Scabrous; st. and racemous-paniculate branches slender but rigid; lvs. lance-ovate, cordate, slightly serrate, on slender petioles, middle and upper ones lanceolate and linear, acute at each end, sessile, entire, highest subulate; hds. broadly obconic; scales oblong-linear, acute, appressed.-Woods and prairies, W. States. St. about $2 \mathrm{f}$ high. Lvs. of several forms between the lowest corlato to the small, subulate, numerous, floral ones of the slender branches. Rac. panicled, with middle sized heads, sometimes reduced to a single raceme or head

$11 \frac{1}{2}$ A. anómalus Eng. Lvs. as in No.11. Invol. with loose recurved scales.Limestone cliffs. Ill. (J. Wolf), Iowa (Dr. Cousins), and Mo. Hds. large, handsome.

12 A. Shortii Hook. Slender and nearly glabrous, simplo or somewhat branched above; lvs. lance-ovate, deeply cordate, petiolate, long-acuminate, entire, upper ones sessilo and obtuse at base; hds. middle-size, racemous or racemous-paniculate, rather numerous; invol. broad-campanulato; scales scarious, close, greentipped, shorter thun the disk flowers.-A distinct and beautiful species, on rocky banks of streams, Ohio to $A$ rk. Stem a littlo flexuous, $2-4 \mathrm{f}$ high. Lower leaves about $5^{\prime}$ by $1^{\prime} \frac{1^{\prime}}{2}$, tho others successively diminished upwards to the flowers whero they are minuto. Rays violet blue.

13 A. squarròsus Wait. Very slender, scabrous, with long, simple branches; lvs. very small, triangular, cordate-amplexicaul, reflexed-squarrous; hds. terminal; invol. obconic, scales imbricated with ovate, green, squarrous points; achenia pubescent. $\rightarrow$ N. Car. to Fla. in cry soil. A very singular Aster, $2 \mathrm{f}$ or more high, rigid, shrubby at base. Lower lvs. remoto, $1^{\prime}$ long, middle and uppor crowded, stiff, mucronate, 1 to $2^{\prime \prime}$ long. Hds. middle size, with ncar 20 showy bluo rays. Pappus rather tawny. Sept.-Nov.

14 A. adnàtus Nutt. Scabrous; stems and branches ascending, very slender; lvs. oblong-ovate or lanccolate, approximate, erect, and adherent to the stem by the midoin, the summit being frec.-A still more curious species, found in Fla. to La. Sts. shrubby at base, 1 to $4 \mathrm{f}$ high. Lrs. as sma!l as in the last, hds and fls. also similar. Sept.-Nov.

15 A. patens $\mathrm{L}$. St. simple, paniculate above, pubescent; lvs. ovate-oblong, acute, cordate-clasping, scabrous on tho margin pubescent; pan. loose; hds. terminal on the branchlets; scales imbricate, lanceolate, lax, only the points herbaceous. - Grows in moist grounds, Mass., N. Y., to Ga. (Feay, Pond.) St. 2 to 31 ligh, slender, branching above into a loose spreading paniele. Lrs. 1 to $3^{\prime}$ long, $\frac{1}{3}$ to $\frac{1}{2}$ as wide. Hds. large, with 20 to 30 violet-colored rays. Pappus tawny. Aug.-Nov.-Variable. ( $\Lambda$. amplexcaulis Willd.)

B. PHLOGIFouius. Simple or racemous-paniculate; lrs. lanco-ovate, cordateauriculate, very acute, edges ciliato; hds. large, spreading $16^{\prime \prime}$. Pappus deeply tawny. -N. Y. to Ohio.

16 A. INova Anglies L. IIds. terminal, crowded, comewhat fastigiate; st. hispid, paniculate; lvs. linear-lineeolate, amplexicaul, auriculate at base; scales equal lax, linear-lanceolate, rather longer than tho disk, green their whole length. $-\Lambda$ large and beautiful Aster, in fields, meadows and shades, more common in the $\mathbf{M}$. and W. States than in N. Eng. St. 4 to $6 f$ high, straight, erect, viscidly hairy, colored. Lvs. very numerous, entire, with 2 auricular appendages at base. Fls. large, in a kind of loose, paniculate corymb. Ray-fls. deep purple, numerous (75 to 100). Pappus deeply tawny. Ach. hairy. Sept. $\nmid$ 
17 A. amethýstinus Nutt.? Clothed with a minuto hoary tomentum; st. racemous-paniculate; lvs. linear-lanceolate, entire, rough, acute, with somewhat auriculate appendages at the clasping base; invol. broad-bell-shaped; scales hispid-pubescent, imbricated, erect, with acute squarrous, green tips; ach. silky Moist soils, Ms. (Dr. Robbins, etc.) to Ill. (Mr. J. Wolf.) Hds. with showy blue rays, expending $1^{\prime}$. Differs from Nuttall's descr. in its scales which are not of equal length. Sept.

18 A. paníceus I. St. hispid, paniculate; Ivs. amplexicaul and more or less auriculate at base, appressed serrate, roughish above; invol. loose, longer than the disk, the scales linear-lanceolate, long and revolute, nearly equal and 2-rowed.-A large, handsome aster, common in swamps and ditches, sometimes in dry soils, N. States and Can. St. 4 to $6 f$ high, generally red (at least on the South side), furrowed, hispid. Lvs. rough-edged and rough beneath, acuminate, and some narrowed at base. Rays 30-60, long $\left(5^{\prime \prime}\right)$ narrow, pale-purple, showy. Aug.-Sept.

$\beta$. vimíseus. Tall, slender, smoothish ; hds. few, very large; lvs. narrow.

$\gamma$. FIRMros. Low $(2-3$ f.) scabrous, stout; lvs. thick, subentire. Hds. many.

S. GLABER. Low (2f.) simple, smouthish; lvs. narrow, erect, entire; sc. loose but not recurved; rays large, $20-30$, pale. Swampy thickets, III. (J. Wolf.)

ع. CANDidus. The common form (a) with white rays. N. Y. (Mr. Hankenson.)

19 A. prenanthoìdes Muhl. St. hairy or pubescent above, corymbous-paniculate; lvs. oval-lanceolato, serrate, acuminate, attenrate at base into a long winged petiole which is auriculate at the insertion; invol. imbricated with several rows of linear. green-tipped, spreading scales.-Grows in low woods, N. Y. to Ky. Stem 2-3f high, with a terminal, corymbous paniclo of largo heads on short peduncles Rays showy, palo blue. Leaves with the petiolo 5 to $10^{\prime}$ long. Branch leaves smaller, nearly entire. Sept.-Nov.

20 A. lævis L. Very smooth; st. angular; branches simpl, 1-flowered; Ivs. half-elasping, oblong, entire, shining, radical subserrate, lanceolate, upper auricled at base; invol. closely imbricate, the scales broadly linear, rigid, thickened and herbaceous at the apex; ach. glabrous. - A very smooth and beautiful species, 2 to $3 \mathrm{f}$ high, growing in low grounds. St. polished, green, often somewhat glaucous; lvs. rather fleshy, the lowest tapering to a winged petiole. Fls. large and showy, with numcrous rays of a fino blus becoming purple. Sept.-Nov. (A. mutabilis L. A. amplexicaulis Muhl.)

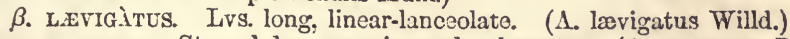

$\gamma$. CY.LNEUS. St and lvs. conspicuously glaucous. (1. cyanous PlL) Beantiful varieties, especially the lattcr.

21 A concínnus Willd. not of Necs. St. simple, paniculate or racemous, pubescent; IVs. lanceolate and lance-linear, narrowed and clasping at the base, remotely serrate, upper ones entire. Invol. closely imbricate, scales green at the tip.Woods, N. States. A slender species 1 to $2 \mathrm{f}$ ligh. Branches of the paniclo rather short and romoto. Livs. 3 to $5^{\prime}$ long, acuminate, varying from $\frac{1}{2}$ to $1^{\prime}$, in width, smooth except tho midvein beneath, branch lvs. fow and much smaller. Hds. middile size, with 10 to 15 bluish-purple rays. Sept-Nov.

22 A. seríceus Vent. Sts. slender, clustered, glabrous below, silky, pubescent, branched above; lvs. clothed on both sides with a dense, appressed, silky-canescent tomentum, lance-oblong, cntire, acute aud mucronate, sessile; hds. large, mostly solitary, terminal on the short, leafy branchlets; scales lanceolate, silky. canescent like the lvs., spreading at tip; ach. smooth. - A singularly elegant Aster, with shining, silvery foliage, prairies and river banks, Wisc. and Iowa to Miss. St. 1 to $2 \mathrm{f}$ high. Lower lvs. 2 to $3^{\prime}$ by 9 to $16^{\prime \prime}$, the upper much smaller. Rays deep violet-blue. Pappus fulvous. Aug.-Oct. $f$ (A. argenteus Mx.)

23 A. cóncolor I. St. subsimple, erect, pubescent; lvs lance-oblong, entire, mucronate, grayish, with a minute, silky pubescence both sides, upper ones cuspidate-acuminate; rac. terminal, virgate, simple or somewhat compound, elongated; scales lanceolate, silky, acute, appressed; ach. villous.-Pine barrens, $\mathbf{N}$. J. to Fla. A slender and virgato plant, I to $3 f$ high, sometimes branehed below. Rt. often tuberous. Lvs. $1_{2}^{\prime \prime}$ by $\frac{1}{2}^{\prime}$, reduced in size upwards. Hds. in a long rac, with purple rays and a rust-colored pappus. Aug.-Nov.-Resombles a Liatris. 
24 A. turbinéllus Lindl. Smooth or slightly scabrous; branches and branchlets very slender; lvs. lanceolate, tapering to each end, acute, slightly clasping, entire; invol. clavate-turbinate, acute at base, as long as the disk fls. $\left(6^{\prime \prime}\right)$; scales imbricated in many rows, linear, obtuse, with short green tips.-Woods and river bottoms, Ill. (Mead.), Mo., ete., to La. Sts. 2f high, somewhat corymbous. Lower lvs. 3 to $5^{\prime}$ by $\frac{3}{4}$ to $1_{\frac{1}{2}}^{\prime}$, the others gradually reduced upwards to tho scales. Hds. middl 3 size, with blue rays and brownish pappus. Sept.

25 A. dumòsus $\mathrm{L}$. Smooth or pubcrulent; branclies racemous-panicled, $l_{v}$. numerous, smooth, linear, sessile, entire or tho lowest subserrate, those of tho branches very short; invol. obtuse at base, clcsely imbricato; scales obtusr. About 2 f ligh, in dry shades and borders of woods, U. S. St. much branched, very leafy, the lower lvs. 2 to $3^{\prime}$ long, tho upper smaller and becoming very minute. H Is. small, with about 24 purplish-white rays. Quito variable in respect to tho extent of its branching inflorescence, tho acuteness and size of its lvs., the obtuseness of its scales, etc. Rt. lvs. 1 to $3^{\prime}$ long, st. and branch lvs. 2 to $12^{\prime}$ long. Sept.

$\beta$. CORIDIFOLIUS is a starved, attenuato form, very slender every way.

26 A. cárneus $\mathrm{I}$. Smooth; st. dividing into many straight, paniculate, leafy branches; lvs. uniform, linear-lanceolato, acuminate, entire, the lower ones tapering to a sessile base, the upper amplexicaul; scales rather acute, close, much shorter than the disk.-Moist fields, E. and W. 'St. 2-3f., often purple. Lrs. 5' to 5". Hds. many, middle size. Rays 20-30, purple to rose-colored. Sept.Oct.

26! A. mutábilis Willd. St. smooth, paniculatc-branched from base, denseflowered; lvs. linear-lanceolate, serrulate, thickish, all clasping, upper lanceoblong, entire; hds. medium; scales loose, lanceolate, much shorter than the disk; rays pale. Wet soils. Ill. 2-3f. Varies, with liss. serrate, hds. few, ctc.

27 A. ericoides I. Smoothish; branches virgate, branchlets seeand, 1-heaced; lvs. spatulate, and linear, and subulate; hds. small; sc. as long as the disk, with subulate, mucronate, spreading tips.-Rocky fields. Stem 1-3f. bigh.

23 A. racemòsus Ell. Rough-pribescent, with many erect branches; lvs. linear and linear-subulate, very acute, margins very scabrous; hds. spicate-racemed and crowded on the upper part of the branches; scales very acute, as long as tho disk, somewhat spreading, rays very short. $\rightarrow$ S. Car. to Fla. on the islands and coast. St. 2 to $3 f$ high. Tho very small heads (2" long) aro almost rayloss. Sept., Oct.

29 A. simplex Willd. Glabrous; st. corymjous-panicu'ate nboro; lvs. lanceoiate, acuminate, entire, the margins scabrous, lower ones sorrate; scales loosely imbricated, linear-subulate.-Another variable species in low grounds, U. S. and Can. St. 1 to 5 f high, somewhat corymbous. Lvs. 2 to 4 by 5 to $10^{\prime \prime}$, very smooth both sides, tapering to a slender point; those of the branches and branchlets proportionately smaller. Hds. rather few, middle sizo ( 4 to $5^{\prime \prime}$. long), on the short branchlets. Sept. Sometimes low with smaller hds., again tall with larger.

$\beta$. DIVERGECS. Branches diffise, loosely racemous, pubescent in lines; 4-6f.

$29 \frac{1}{2}$ A. subasper Lindl.? Pubescent above, racemous branched, branches short, dense-flowered; lvs. lanceolate, acuminate, altenuate to a short petiole, rough, appressed-serrate, the upper reduced, entire, sessile; invol. closely imbricated ; rays purple.-Dry, poor soils, Ill., scaree, (Mr. J. Wolf.) 2--3f. high, strict. Lvs. 6'-6". Differs from Lindley's in its broader leaves. Sept.

30 A. tenuifòlius I. St. smooth, erect, paniculate-branching, with 1-flowered branchlets; lus. linear and linear-lanceolate, tapering at each end, long-acuminate, entire, with roughish margins, the lower ones often serrate in the middle; invol. scales very slender, erect, acute, stightly longer than the disk.-Grows in moist fields, E. and W. 2-6f. Lvs. $5^{\prime}-1^{\prime}$. Rays 20-30, long, pale purple. Sept.

$\beta$. BELLIDIFLòrus. Lvs. scabrous, subclasping; scales rather loose. Western.

$\gamma$. Distichus, Lvs. and striet brauches in 2 rows. Lvs. serrulate. IJl. (Mr.J. Wolf.)

31 A. Tradescánti I. Smooth or smoothish; branches virgate, paniculate; lvs. lance-linear, tho lower remotely serrate, sessile; invol. closely imbricate; scales linear-filiform, scarcely equaling the disk.-A fine species, with numerous 
Ivs., growing in fields, Mass. to La St. rigid, brownish, 2 to $3 \mathrm{f} \mathrm{high,} \mathrm{terete,}$ with numerous small hds. densely racemed and somewhat 1 -sided on the erectspreading, slender branches. Lower st. lvs. $4^{\prime}$ long, gradually reduced in size upwards. Rays pale purple. Aug.-Oct.

B. FRAGiLis. Caulino IVs. serrulate or entire, short; hds. much scattered on tho branches. (1. fragilis Willd.)

32 A. miser Ait. T. \& G. STARvEd Aster. St. racemous-paniculate, hairy or pubescent; lvs. sessile, lanceolate, sharply serrate in the middlc; invol. imbricated with lance-linear, acutish scales; rays short. $-\Lambda$ very variablo species, common in old fields, hedges, U. S. and Can. In height it varies from 6 to $30^{\prime}$, and in luxuriance proportionately to the moisturo or fertility of the soil. The st. is very branching or nearly simple, bearing a large, compound, racemous paniclo, or a few simplo racemes. Lrs. narrow-lanceolate, or broad-lanceolate, always serrate, 1 to $5^{\prime}$ in length. IIds. usually numerous, small, with small, whito or pur-

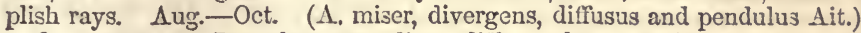

$\beta$. DIFFuses. Branches spreading, diffuss; lvs. clliptic-lanceolate, moro or less narrowly so, midvein hairy beneath; hds often sessile, forming short, crowded spikes, or long, virgate ones.

$\gamma$. IIRSUTICAUlis. St. hirsuto; lvs. long and narrow, midvein hirsuto; hds. racemous or spicate, upper ones in short, denso branches; scales linear. ( $\Lambda$. hirsuticaulis Lindl.)

33 A. multiflòrus L. Grayish, pubescent; st. diffusely branched; lvs. linear, entire, sessile, obtusc-mucronate, margins subciliate; hlds. small ; invol. imbricate, squarrous, linear or spatulate, with oblong, obtuse, ciliate scales.-A very bushy Aster, If, with very numerous, small fls. crowded on the racemous branclies, - each with about 12 white rays spreading 5 to $6^{\prime \prime}$. Lvs. 1 to $2^{\prime}$ long, obtuse, very narrow, diminishing upwards to tho scales. Rocks and dry fields, U. S. Variable. Sept.

34 A. grandiflòrus L. Rough with stiff hairs; st. rigid, branched, branches somewhat corymbed and I-flowered; lvs. linear-spatulate or linear-oblong, small, obtuse, rigid, subclasping; hds. very large; invol. squarrous, of numerous, obtuse, reflexed seales, tho outer leafy.-Dry, rocky places, Va. to Ga. About $2 \mathrm{f}$ high. Lvs. below 1 to $2^{\prime}$ long, diminishing upwards Rays showy, spreading 18 to $20^{\prime \prime}$, blue-purplo. Sept.-Nov.

35 A. Caroliniànus Walt. Rough-pubescent, divaricately branched; lrs. lance-ovate or oblong, acute, entire, clasping, the baso abruptly produced into small, auriculate lobes; hds. very large, scattered; scales imbricate, with squar-

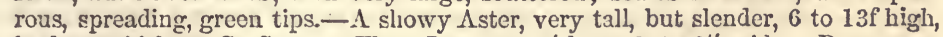
in damp thickets, S. Car. to Fla. Lvs. 1 to $3^{\prime}$ long, 3 to $9^{\prime \prime}$ wide. Rays rosepurple, numerous, spreading $15^{\prime \prime}$. Sept., Oct.

36 A. oblongifòlius Nutt. St. rigid, diffusely branched, hairy; branches spreading, witl looso and irregular branchlets; lvs. oblong-lanceolate, acute, mucronate, partly clasping, entire, rough-edged, or the branches and branchlets gradually passing into the leafy, lanceolate, subequal, spreading scales. - Prairies, \&c., IV. States. Plant 1 to $2 \mathrm{f} \mathrm{high,} \mathrm{often} \mathrm{glandular-viscid.} \mathrm{Caulino} \mathrm{lrs.} 12$ to $20^{\prime \prime}$ by 3 to $5^{\prime \prime}$; those of tho branches $6^{\prime \prime}$ by $2^{\prime \prime}$, of the branchlets $3^{\prime \prime}$ by $\frac{I^{\prime \prime}}{2}$, indistinguishable from tho scales. Rays purple. Pappus brownish. Sept., Oct. ( 1 oblongifolius and A. graveolens Nutt.)

37 A. Elliòttii Torr. \& Gr. Glabrous, stout; st. angular; lvs. ampls, lanceolate, subclasping (not auricled), serrate, with remote, small, appressed teeth; hds. middlo size, corymbous-paniculatc; ped. naked; scales somewhat equal, linear-attznuate, with spreading or recurved greenish tips.-River-swamps, N. Car. to Ga. A very stout Aster, 2 to $4 \mathrm{f}$ high. Lower lvs. $6^{\prime}$ to $8^{\prime}$ long, narrowed to a winged petiole. Rays narrow, bright purple. Pappus tawny-white. Oct., Nov.

38 A. virgàtus Ell. Glabrous; st. and branches virgate, strict, racemed; lvs. linear-lanceolate, entire, half-clasping, margins ciliolate-serrulate, the upper reduced, becoming subulate, erect, numerous on the branches and peduncles; scales lance-acuminate, the outer loose-spreading, graduating into the bracts; ach. glabrous.-Ga. to La. Sts. 2 to 3 f high. Lvs. below, 3 to $6^{\prime}$ by 3 to $6^{\prime \prime}$, firm and shining. Sept., Oct.-Probably passes into the next.

39 A. Novi Bélgii L. New York Aster. St. terete, stout, often glaucous, 
the branches pubescent in lines; lvs. subclasping, lanceolate and lance-linear, taperpointed or very acute, coriaceous, rough-edged, the lower subserrate; hds. large, racemed or subcorymbed; scales about 3 rows, subequal, acute, erect, shorter than the disk; ach. pubescent. -N. Eng. to Va. (Pursh), more common westward to Wis. and Iowa. Comprehends many smooth and elegant varieties, which we vainly try to separate. St. 2 to 4 f high. Lower lvs. 3 to $5^{\prime}$ long. Rays blue, expanding 9 to $12^{\prime \prime}$. Aug.-Oct. (1. laxifolius Nees. A. æstivus Ait.)

ß3. LETIFLòrus. Slender; branches divergent; lvs. rigid, long and narrow, scabrous; rac. loose, tho ped. nearly leafless-Ohio, Wis. Beautiful, with long, pale purple rays. (A. salicifolius Willd.)

$\gamma$. PREALTUS. Strict, with orect branches, bearing the leafy clusters near the summit; lvs. very narrow, elongated, cilio-serrulate on the margin.-N. H. to Wis. Height 3 to 4 f. IIds. somewhat smaller. (A. præaltus Poir.)

40 A. longifòlius Lam. Glabrous; st. very branching, branches spreading, many-flowered; lvs. subamplexicaul, linear-lanceolate, entire (the lowest rarely subserrate), very smooth; scales lanceolato, nearly equaling the disk, the outer loosely squarrous-spreading; ach. smooth.-Fields and thickets, Mass., N. Y., to Car. St. 3 f high. Lrs. pale below, shining above, smooth both sides, the lower ones 4 to 6 ' long. Hds. numerous, showy, with 25 to 30 , light-blue rays. Ach. twice longer than in the last. Oct., Nov.- Some specimens are minutely pubescent at the tops of the branches. Others have the outer scales quite leaf-like. (A. lrvigatus $\mathrm{Ph}$. A. laxus Willd. A. clodes T. \& G.)

41 A. graminifòlius $\mathrm{Ph}$. Subpubescent; st. slender, branches filiform, erect; lower lvs. very numerous, narrow-linear; ped. slender, 1-flowered ; scales linearsubulate, loose, in one or two rows, equal, finally reflexed.-N. H. (Eddy.) High cliffs, Willoughby Lake, Vt.; also on an island in Wait's River, Bradford, Vt., 1860. Branches simple, leafy, naked at the end, 1-flowered, somewhat corymbous. Rays 15 to 25 , much longer than the disk, purple or rose-colored. Jn., Jl. -Rare and interesting, very different in aspect from any of the foregoing.

\section{§ 4. SCARIOSI. WHITE-SCALED ASTERS.}

42 A. acuminàtus $\mathrm{Mx}$. St. simple, flexuous, angular, branching into a corymbous panicle above; lvs. broad-lanceolate, narrowed and entire at the base, serrate and acuminate; invol. scales lax, linear.-Mts. woods, Can., N. Eng., N. Y. Stem a foot high, rough, downy. Leaves large, unequally and remotely serrate above, and ending in a long, acuminate point. Panicle corymbous, terminal, fewflowered, nearly or quite naked. The leaves are mostly situated just below the corymb, sometimes scattered. Heads rather large, with about 15 long, white rays. Aug.

43 A. nemoràlis Ait. Branches corymbed or 0 ; ped. 1-flowered, nearly naked, filiform; lvs. narrowly lanceolate, acute at each end, veinless, subentive; scales very acute, loose, shorter than the disk; rays long, about 20.-A handsome plant, in swampy woods, N. H., Mass. to N. J. Rather rare. Stem slender, $10-20^{\prime}$ high. Leaves numerous, $10-18^{\prime \prime}$ by $2-4^{\prime \prime}$, rarely subdentate. Heads large, fow, often but one, terminating the simple axis or branches. Rays large, white or pale purple. Sept., Oct.

44 A. ptarmicoìdes T. \& G. St. corymbous-fastigiate above; lvs. linear-lanceolate, acute, rough-margined, entire, lower ones dentate, attenuated into a short petiole; rays short.-A very distinct Aster, low and leafy, found in rocky soils, by streams and lakes, Vt. (Robbins) to Mo. Rare. Stems clustered, simple, each bearing a spreading panicle of heads, which are below the middle size, and furnished with snow-white rays. July-Sept. (Heliastrum, DC.)

45 A. flexuòsus Nutt. St. branching, slender, flexuous, very smooth; lvs. long and succulent, the lower ones sublanceolate-linear, upper ones subulate; branches leafy, 1-flowered; invol. scales lanceolate, acuminate, appressed; rays numerous, shorter than the involucre; ach. subpubescent.-Grows in salt marshes, Mass. to Flor. The whole plant very smooth, If high, with large, purple flowers; disk yellow. Aug.-Oct.

46 A. Chapmanii Torr. \& Gr. Glabrous; st. strict, slender, corymbous at summit; branches filiform, 1-flowered; lvs. linear-subulate, appressed, numerous ; 
scales in 5 or 6 series, closely imbricated; rays longer than the invol.; ach. glab. rous. - Swamps, Fla. (Chapman.) A curious $\Lambda$ ster, very slender, with large lids., 20 to 30 -rayed, spreading 2 ', purple.

47 A. linifòlius L. SEA ASTER. St. paniculate, much branched from tho baso; lvs. long, linear, very acute, the uppermost subulate; invol. cylindric, with subu. late scales in about 3 rows; rays minute, in two series, scarcely exserted.- $-\Lambda n$ annual species, found in salt marshes, Mass. to Car. St. 12 to $18^{\prime}$ high, very smooth, thick, reddish. Lvs. smooth, sessile. The plant is very branching, with numerous small hds., almost discoid from the shortness of the rays. Aug.

48 A. subulàtus $\mathrm{Mx}$. Annual; slender, much branched, glabrous; branches corymbed, slender; lvs. linear-subulate, scabrous, long-linear below; scales lancelinear, acute, in 2 or 3 series; rays numerous, narrow, longer than the dish, in one row.--Damp grounds, S. Car. to Fla. Sts. 1 to 3 f high. Hds. small, with about 20 blue rays longer than the disk. Sept., Oct. (A. divaricatus Nutt.)

3. Exmis. Taller, with fewer branches, corymbed; hds. racemed or solitary. Rays pale purple.-Columbus, Ga. (A. exilis Ell.) Height 2 to 4 f.

19. Diplopap'Pus, Cass. Double-bristled Aster. (Gr. $\delta \iota \pi \lambda o ́ o s$. double, $\pi a ́ \pi \pi \circ \varsigma$, pappus.) Heads many-flowered; ray-flowers about 12, $\%$; disk-flowers $\Varangle$; involucre imbricate, scales narrow, destitute of green tips; receptacle flat, subalveolate; pappus double, the exterior very short (about $\frac{1}{2}$ "long), interior copious, capillary; achenia compressed. - 2f Lvs. entire, alternate. Rays cyanic. Disk yellow.

\$ Rays riolet. Achenia silky. Brlstles of tho inner pappus alike.................... 1

\& Rilys whitish. Some of the longer bristles clavellate. - Ach. smoothish........... Nos, 2, 8 - $A$ ch. villous................... 0.4

1 D. linariifòlius Hook. St. straight, roughish; branches 1-flowered, fastigiate; scales imbricate, carinate, as long as the disk; lvs. linear, entire, l-veined, mucronate, carinate, rough, rigid, those of the branches recurved.-A handsome species, in dry woods, along streams, U. S. and Can. Stems subsimple, purplish, about a foot high. Leaves numerons, obtuse, with a small, mucronate point, shining above. Branchlets near the top, leafy, each with one rather large and showy, violet-colored head. Aug., Sept. (Aster, L.)

2 D. umbellàtus Hook. St. smooth, straight, simple; hols. numerous, in a level corymb ; lvs. long, lanceolate, smooth, acuminate at each end, rough on the margin; invol. scales obtusely lanceolate; ach. pubescent in lines.-Low grounds, river banks, fields, N. Eng. to La. St. 3 to $4 \mathrm{f}$ high (in dry fields but 1 to $2 \mathrm{f}$ ) purplish, channeled, branching at top into a large, level-topped, compound corymb. Lvs. narrow, entire, 4 to $6^{\prime}$ in length, those of the branchlets smaller. Rays about 12, white. Disk yellow. Aug., Sept. ( $\Lambda$. amygdalinus Mx. $\Lambda$. umbellatus Ait.)

$\beta$. AMYGDALINUS. St. roughish above, green; branches of the corymb divaricate; lvs. broader.-Lower and less elegant than variety $a$. Common.

3 D. cornifolius Less. St. smooth below, scabrous and slightly paniculate above, few-flowered; lvs. elliptical, thin, long-acuminate at both ends, entire, with scattered hairs, rough-edged, invol. scales imbricate, shorter than the disk, obtuse; ach. glabrous.-Grows in woods N. and M. States. Whole plant nearly smooth, erect, 1 to $2 \mathrm{f}$ high. Lvs. paler beneath, on very short stalks or sessile. Fls. fow, large; outer scales very short. Rays about 10, white. Jl., Aug. (Aster, Muhl.)

4 D. obovàtus Torr. \& Gr. Cinereous-pubescent, corymbous above; lvs. oblongobovate or elliptical, acute, sessile or the lower or short petioles, tomentous beneath; scales loose, linear-subulate, acute, in about 3 rows, downy, rusty yellow; ach. silky-villous. - Damp shades, S. Car. to Fla. Height 2 to 3f. Lvs. longer than the internodes $\left(2\right.$ to $\left.3^{\prime}\right)$, rarely with a few teetl. Invol. broadly obconic. Rays narrow, white, spreading $\mathbf{1}^{\prime}{ }^{\prime}$. Pappus rusty white. Sept., Oct. (Aster, Ell.)

20. ERIG'ERON, L. Flea-Bane. White-weed. (Gr. $\eta \rho$, the spring, yé $\omega \nu$, old man; because it is soon hoary.) Heads many-flowered, subhemispherical ; ray-flowers 9 , very numerous ( 40 to 200 ), narrow, linear; flowers of the disk $\Varangle$; receptacle flat, naked ; seales of tho inro- 
lucre nearly in one row and equal; pappus generally simple.-Herbs with alternate lvs. Rays cyanic. Disk yellow.

S Rays minute, shorter than the cylindrical involucre. Pappus simple............. Nos, 1,2 Rays lung, showy, 30 to 4). Pappus simple. Leaves all rullical..................... 8 § Rays lons, showy, 50 to 200.-Pappus simple. Leaves clasping................... 4-6 -Pappus double. Leaves sessile, \&c...................... 7 -9

1 E. Canadénse L. Inrol. oblong; rays numerous $(40-50)$, crowded, minute; pappus simple; st. hairy, paniculate; lvs. lanceolate, lower ones subserrate.-A very common annual plant of no beauty, growing by roadsides and in fields, throughout N. Am: Stem $\frac{1}{2}-9$ fl high, branching, hairy and furrowed. Leaves very narrow, with rough edges. Flowers white, very numerous, small, of mean appearance, irregularly racemous upon the branches, and constituting a large, oblong panicle. The plant varies greatly in size, according to the soil. $-\Lambda$ starred form is E. pusillum Nutt.

$2 \mathrm{E}$. divaricàtum $\mathrm{Mx}$. Decumbent and diffusely branched, hirsute; Ivs. linear and subulate; hds very small, loosely corymbous; rays minute.-Dry soil, W. States S. to La. Plant of a greyish or bluish aspect, $3-G^{\prime}$ high, but at length spreading 1-2f. Leaves 4-12" by $\frac{1}{2}-1$ ". Rays purplish. Juno-Aug.

3 E. nudicaùle Mx. Glabrous; lvs. oborate or spatulate, radical, rosulate, entire; one or two sessile, bract-like on the simple stem or scape; hds. few, corymbous; invol. hemispherical; rays narrow, 30 or more, conspicuous.-Pine barrens, Va. to Fla. and La. Lvs. about $2^{\prime}$ long. Scapo $18^{\prime}$ high, very slender. Rays white. May, Jn.

4 E. bellidifòlium Muhlenb. Robins'Plantats. Hirsute; radical lis. obovate, obtuse, subserrate; st.lvs. remote, mostly entire, lance-oblong, acute, clasping ; hds. $3-7$, in a close, terminal corymb; rays 50 to 60 , nearly twico longer than tho involucre, linear-spatulate.-Dry fields and thickets, U. S. and Can. Stem erect, simple, sometimes stoloniferous, $1-2 f$ high. Leaves $2-3^{\prime}$ by $6-9^{\prime \prime}$, mastly broadest above the middle. Rays bluish (rarely reddish)-purple. This is our earliest species, flowering in May and June. Resembles tho following. ·(E. pulchel$\operatorname{lum} \mathrm{Mx}$ )

5 E. Philadélphicum I. Pubescent or hirsute; lvs. thin, lower spatulate, crenate-dentate, upper oblong-oblanceolate, narrowed to the clasping (sometimes cordate-auriculate) base, subserrate; hds. few, on long; slender ped.; rays 150 to 200 , filiform, more than twice longer than the invol.-Woods and pastures throughout $N$. Am. St. slender, 1 to $3 f$ high. Livs. 2 to $4^{\prime}$ by 6 to $9^{\prime \prime}$, lower much attenuated at base, upper acute. Rays reddish-purple or flesh-colored, nearly as slender as hairs. Jn.-Aug.

B. RICARDI. Cauline lvg. cordate-ovate. MIeriden, N. H. (Ricard).

$\gamma$. St. stout, with coarsely serrate lvs., approaching the next.

6 ヨ. quercifolium Lam. Pubescent; $r t$. lvs. oblong-abovate, lyrate-pinnatifid, or deeply sinuate-toothed, the cauline sharply serrate, clasping; upper entire; hds. small, numerous, corymbous, with innumerable filiform rays, twice longer than the invol.-S. Car. to Fla. and La. Differs from the preceding in its smaller and more numerous hds. as well as its lvs. Rays pale purple, Mar. Jn.

7 I. ánnuum Pers. Common Freabane. White-weed. Hirsute, with scattered hairs, branching; lvs. coarsely serrate, the lowest ovate, contracted at base into a winged petiole, stem leares ovate-lanceolate, sessile, acute, the highest lanceolate; rays very numerous and narrow; pappus double.-A common weed, in fields and waste grounds, Can. to Penn. and Ky. Stem thick, 2-4f high, striate, terminating in a large, diffuse, corymbous panicle of large heads. Rays white or purplish, 100 or more, short. Jn.-Aug. (E. heteropliyllum Muhl.)

8 E. strigòsum L. Plant, rough, with short, appressed hairs, or nearly smooth; lvs. lanceolate, tapering to each end, entire, or with a few large teeth in the middle, lower ones 3 -veined and petiolate; pan. corymbous; pappus double.-A rough weed, in grassy fields, Can. and U. S. St. about $2 \mathrm{f}$ high, slender, furrowed, with close, short, stiff hairs, and bearing a large, loose corymb. Lrs. also with closepressed bristles, sessile. Rays very narrow, white. Jn.-Oct.

3. St. simple, smooth; lvs. entire, pubescent; fls. corymbed; rays 100 to 150. (E. integrifolium Bw.) 
9 E. glabéllum Nutt. Lvs. smooth, entive, spatulate, long-tapering at base, upper lanceolate and lance-linear, sessile, acuminate; hds. 4 to 6, corymbed; invol. hemispherical, pubescent as well as the peduncles; rays very numerous, palo blue.-Wis. to Nebr. 12 to $18^{\prime}$ high. Lvs. long and narrow. Rays 100 or more. Jl., Aug.

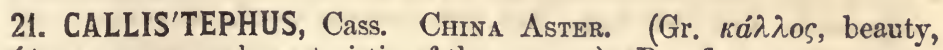
$\sigma \tau \dot{\phi} \phi o \varsigma$, a crown ; characteristic of the pappus.) Ray-flowers + , numerous; disk-flowers $\Varangle ;$ involucre hemispherical; receptacle subconvex; pappus double, each in 1 series, outer series short, chaffy-setaceous, with the setre united into a crown; inner series of long, fliform, scabrous, deciduous bristles. - I Exotics. Lvs. alternate.

C. Chinénsis Ness. St. hispid; branches divergent, 1-flowered; 1rs. orate, coarsely dentate, petiolate, cauline ones sessile, cuneate at base.-Said to be originally from China. Stem about $18^{\prime}$ high, with long branches, each terminated by a single, large head. Rays dark purple. Disk yellow. July-Sept.-Cultivation has produced many beautiful and even splendid varieties, double and semidouble, with white, blue, red, flaked and mottled rays. $\dagger$ (Aster Chinensis L.)

22. BEL'LIS, L. Garden Daisy. (Lat. bellus, pretty; a term quite appropriate to the genus.) Heads many-flowered; rays o ; disk $\Varangle$; involucre hemispherical, of equal scales; receptacle subalveolate, conical ; pappus none.-Low herbs, either (1) and caulescent or $2 f$ and acaulescent. Hds. solitary.

1 B. integrifòlia Mx. Annual, diffusely branched; lvs. entire, spatulate-obovate, upper oblong-lanceolate, sessile; scales lance-ovate, setaceous-acuminate, with scarious margins.-Wet prairies, Ky. to Tex. Sts. 6 to 12'. Rays violet-purple, in hds. similar to the next. Mar.-May.

2 B. perénnis I. Perennial; root creeping; scape naked, single-flowered; lvs. obovate, crenate. - 2f Native of England and other parts of Europe, nearly naturalized in some parts of N. England in cultivated grounds. Scape 3 or $4^{\prime}$ high, with a single white head which is single, doublo or quilled in the different varieties. Blossoms in the spring and summer months.

23. DAH'LIA, L. (In honor of Andrew Dahl, a Swedish botanist, pupil of Linnæus.) Heads many-flowered, rays $\$$, disk $\Varangle$; involucre double, the outer series of many distinct scales, the inner of 8 scales united at base; receptacle chaffy; pappus none. $-2 f$ Splendid Mexican herbs. Lvs. pinnate, opposite.

I D. variábilis Desf. St. green; rachis of the lvs. winged; lfts. ovate, acuminate, serrate, puberulent or nearly smooth; outer invol. reflexed; ray fls. $\&$, sterilo or fertile.-These superb and fashionable plants are natives of sandy meadows in Mexico. They have coarse and roughish lvs. resembling those of the common elder, but the flowers are largo and beautiful, sporting into innumerable varieties, single and double, of every conceivable shade of scarlet, crimson, purple, red, rarely yellow, blooming from July until arrested by frost.

2 D. coccínea Cav. St. frosty, or hoary, hollow; lvs. with the rachis naked; lfts. roughish beneath; outer invol. spreading; rays neuter. - Stems about $4 \mathrm{f} \mathrm{high.}$ Foliage rather glaucous. Rays scarlet, saffron-color or yellow, never purple or white.-The Dahlias are generally cultivated by the divisions of the tuberous roots, which, as soon as the frost blackens the tops, are to be taken up and preserved through the winter in a dry place, free from frost.

24. BOLTO'NIA, L'Her. (To J. B. Bolton, author of "Ferns of Great Britain," \&c., 1788.) Hds. many-flowered; ray-flowers $\%$, in a single series, those of the disk tubular, $\Varangle ;$ scales in 2 series, appressed, with membranous margins; receptacle conic, punctate; achenia flat, 2 or 3 -winged; pappus of minute setæ, 2 (to 4 ) of them usually length- 
ened into awns. - 2f Glabrous, branching herbs. Lvs. lanceolate, entire, sessile. Hds. loosely corymbous. Rays purplish-white.

1 B. glastifolia L'Her. Lvs. linear-lanceolate, narrowed to the base, the lowest serrate; hds. in a loose paniculate corymb; fr. obovate, with 2 awns, and several minute setæ between.-Prairies, \&c. West and South. Very slender, 3-7f. high, strict. Lrs. $3-5^{\prime}$ long. Rays pale, spreading $7-9^{\prime \prime}$. Jl.-Aug.

2 B. decùrrens. Lvs. oblong, margins decurrent on the winged stout stem; hds. corymbous, globular in fruit; ach. as in No. 1; rays purple. Bottoms W.

3 B. diffùsa Ell. Lvs. linear-lanceolato and linear-subulate, all entire; hds. small, in a diffuse panicle with very numerous and slender branchlets; ach. obovate, narrowly winged, with 2 awns less than half its length, and several very minute setæ between.-Ga. to La., common. A very slender and diffusely branched plant, 3 to $7 \mathrm{f} \mathrm{high.} \mathrm{Rays} \mathrm{spreading} \mathrm{about} 5^{\prime \prime}$. Aug.-Oet.

4 B. asteroìdes L'Her. Lvs. lanceolate, all entire; hds. in a somewhat condensed corymb, on long peduncles; branches leafy; ach. broadly oval, smooth, with 4 to 5 minute setæ, none of them produced into awns.-Margins of swamps, Penn. to Ga. Plant 1 to $3 \mathrm{f}$ high. Rays 13 to 20, spreading 6 to $7^{\prime \prime}$. Aug., Sept.

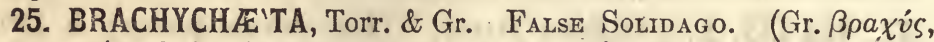
short, $\chi$ aí $\eta$, hair ; in referenee to the pappus.) Heads few-flowered; rays 4 or 5 ,, , ligulate; disk-flowers 4 or $5, \Varangle$, tubular; involucre cylindric, imbricate; receptacle naked; pappus a single row of scalelike bristles shorter than the obconic achenium. - 2f Habit that of a Solidago. The golden yellow heads arranged in little clusters, forming one or several unilateral, recurved racemes.

B. cordàta Torr. \& Gr., Woods, E. Ky. (near Cumberland Gap) to Ga., along tho mts. St. 2 to $4 \mathrm{f}$ high, simple or with several branches above, pubescent. Lvs. alternate, cordate, ovate, acute or acuminate, the lower petiolate, more or less cordate, serrate, the upper entire, sessile. Heads small ( $3^{\prime \prime}$ long), in 1 (or more) long, recurved, nearly leafless, interrupted rac. Aug.-Oct.

26. SOLIDA 'GO, L. Goldenrod. (Lat. solidari, to unite; from the vulnerary qualities of the plants.) Flowers of the ray about 5 , + , remote; of the disk $\Varangle$; involucre oblong, imbricate, with appressed scalcs ; receptacle punctate, narrow; pappus simple, capillary, scabrous.-2f Herbs, very abundant in the U. S. St. erect, branching near the top. Lvs. alternate. Hds. small, with 1 to 15 (very rarely 0 ) small rays. Fls. yellow (one species whitish), expanding in the autumnal months.

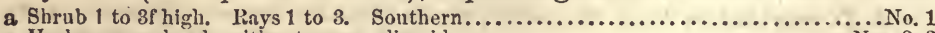

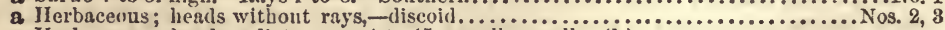

a Herbaccous; heads radiate, rays, 1 to 15 , usmally small. (b)

b Seales of the involucre with recurved, herbaceous tips....
b Seales inbricated, ereet, scarious, seldom herbaceous. (c)

c Rays white or cream-colored. Clusters axillary and terminal................. 6 c lays golden yellow. (d)

d Inflorescence nxillary (ehlefly), in elusters or short racemes. (e)

e Sterns pubescent................................................ $8, \gamma$

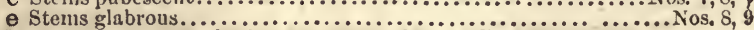

d Inflorescence terminal, virgate or panieulate. (f)

f Clusters or rne. ereet, not seeund. Lvs, feather-veined. (g)

g Heads large, with loose seales. Alpine plants............... Nos. 10-12

g Heals not large. Plants glabrous. Rays 4 to $7 \ldots \ldots \ldots \ldots$........... 13-15

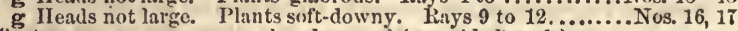

$f$ Clinsters or raeemes recurved and seeund (one-sided). (h)

h Leaves 3 (or 1 )-veined. Very snooth, salt-marsh herbs......Nos. 19, 19

h Laaves evidently 3-velned. Herbs inland, \&c. (k)

k Leaves entire or very nearly so........................ 20, 21

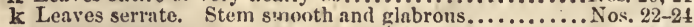
$\mathbf{k}$ Leaves serrate. Stem ronghish-pnbescent..................... 25, 26

h Leaves not veiny, thick, subentire. Herbs inland................ 27-29

h Leaves evidently feather-veined, mostly serrate. (m) $\mathrm{m}$ Stein halry or downy. Leaves rough or not......... Nos. $30-32$ $m$ Stem glabrous. Leaves glabrous or not. Rays 2 to 5 Nos. $33-35$ $m$ Stem glabrous. Lvs. glabrous or not. Rays 6 to 12. (n) 
n Racemes distant, loosely if at all panicled...........Nos. 86, 37

n Racemes close, furming compact panicles............. Nos. $38-40$ d Inflorescence terminal, in a fastlgiato cory mb. (o)

- Leaves lanceolate, auple. Stem smooth, glabrous.................... 41, 42

- Leaves lanceolate, ample. Stem rough, pubescent ....................... 43-46

- Leaves linear. Heuls small, scales close-pressed..................... 47, 48

I s. pauciflosculòsa Mx. Shrub, much branched, glabrous, glaucous and somewhat viscid; lvs. somewhat lanceolate and linear, obscurely 3 -veined, obtuse, sessile, entire; panicle compound, of erect racemes; hds. 5 to 7 -flowered, with 1 to 3 large rays. -S. Car. to Fla., barrens near the coast. A low bush, about $2 \mathrm{f}$ high, remarkably distinguished among our Solidagos as a shrub. Lvs. 1 to 2' long, leathery. Ray, usually solitary. Aug.-Oct.

2 S. discoìdea (Ell.) Villous-pubescent, hoary; lvs. ovate, petiolate, coarsely serrate, the upper ovate-lanceolate; rac. erect, in a virgate or thyrsoid pan.; hids. discoid, about 12-flowered; scales downy-canescent, the acute herbaceous tips squarrous-spreading.-Ga. and Fla. (uplands), to La. Plant 3 to $4 \mathrm{f}$ high, remarkable for its rayless fls. and squarrous aster-like involucre. Lower lvs. 3 to $4^{\prime}$ long, gradually reduced upwards. Sept., Oct.

3 s. brachyphýlla Chapm. Rough-pubescent; lvs. numerous, appressed-serrate, spatulate, oval and ovate, glabrous; rac. secund, in virgate panicles; scales erect (not spreading), obtuse, smooth; hds. discoid; disk-flowers 5 to 6. Mid. Fla., uplands (Chapman). Tall (4 to 6f), with erect leafy branches. St. lvs. I' long, diminishing upwards. (Allied to S. altissima.)

4 S. squarròsa Muhl. St. stout, simple, densely pubescent above; lvs. smooth, lower very broad, oval-spatulate, serrate, acute, upper lanceolate-elliptic, highest, entire; rac. glomerate, rigid and pubescent; scales rigid, oblong, squarrous with spreading green tips; hds. many flowered; rays 10-12, elongated.-A handsome species, found on rocky hills, Can. to Penn. Stem $2-5 \mathrm{f}$ high. Heads very large, forming a large terminal spike of short, dense, axillary fascicles or racemes. Sept.

5 S. squarrulòsa (T. \& G.) Pubescent, striate; lvs. rough, numerous, oval or lanceolate, the upper cntire, tho lower serrate, all abruptly contracted at base but scarcely petiolate; hds. large (20 to 25 -flowered), in a terminal, virgate racerne; rays 6 to 10 ; scales linear or lance-subulate, with loose herbaceous tips, tho outer spreading, bract-like.-Uplands, N. Car. to Fla. and La. St. 2 to 31 high, often branched above. Lvs. 1 to $2^{\prime}$ long. Aug., Sept. (S. squarrosa Nutt. S. petiolaris Ait.?)

6 S. bicolor L. Hairy; st. simple; Irs. elliptical entire, acute at each end, lowrer serratc, short-stalked; rac. short, dense, axillary, paniculate-virgate above; invol. scales obtuse; rays about 8 , whitish.-Woods and dry hills, Can., N. Mid., \& W. States. Remarkably distinguished among the solidagos by having white or cream-colored rays. St. 2 f high, a little hairy. Lvs. hairy on both sides, mostly entire, gradually reduced in size upwards. Axillary clusters approximating above into a terminal, interrupted spike. Rays short and obscure, Л., Aug. (Aster bicola Nees.)

$\beta$. HIRSUTA. Fls. all yellow.-Penn. (S. hirsuta, Nutt.)

7. S. Búcllleyi Torr. \& Gr. Villous-pubescent; lvs. oblong, serrate, acute at each end, subsessile; clusters axillary, loose, much shorter than tho lrs.; ped. villous; scales glabrous, acutish, rays 4 to 6 , disk-flowers 9 to 12 ; ach. compressed, glabrous.-Interior of Ala. (Buckley). St. 2 to $3 \mathrm{f}$ high? Lvs. as large as in No. 8 , the hds. larger. Oct.

8 S. latifòlia Muhl. St. somewhat flexuous, angular, smooth below, pubescent above; - lvs. broadly ovate, acuminate at each end, deeply serrate, pubescent beneath; petioles margined; rac. axillary and terminal ; ach. silky pubescent.-A. singular and well-marked species common in dry woods and by rocky streams, U. S. and Can. St. slender, simple, about 2 figh. Lvs. 3 to $5^{\prime}$ by 2 to $4^{\prime}$, with acute, often long-acuminate serratures. Clusters very short, axillary, the stem ending with a long terminal one. Hds. few. Sept.-Variable. The clusters are often long and loose, and exceeding tho lvs. (S. ambigua Ait. S. macrophylla Bw.)

$\beta$. PUbens. Pubescent, becoming densaly so above, especially the scales MIts. of N. Car. (Curtis)-(S. pubens Curtis.) 
9 s. cæsia $\Lambda$ it. St. erect, round, smooth and glaucous, often flexuous; ivs. smooth, linear-lanceolate, lower ones serrate; rac. axillary, erect, ach. minutely pubescent. - A very elegant species, in thickets and dry woods, Can. and U. S. Stem 2 to $4 \mathrm{f}$ high, of a bluish-purple color, terete and slender, somewhat flexuous, simple or branched. Leaves 2-5' long, ending in a long point, sessile, glaucous beneath. Racemes axillary, numerous, short. Flowers of a deep, rich yellow. Rays 3-5, once and a half the length of the involucre. Aug. (S. axillaris, $\mathrm{Ph}$.)

$\beta$. FLEXICAULIS. St. flexuous, angular; lvs. ovate-lanceolate, longer than the subcapitate racemes.-Leaves about $2^{\prime}$ by $\frac{1^{\prime}}{2}$. Rays pale yellow. (S. flexicaulis, $\mathrm{Ph}$. not of $\mathrm{L}_{\text {. }}$ )

$\gamma$. Curtisir. St. tall, strict, striate-angular.-Mts. N. Car. Height 3 to 5 f. (S. Curtisii, T. \& G.)

$10 \mathrm{~S}$. thyrsoìdea Meyer. St. simple, flexuous, very smooth, pubescent abovo; lvs. smooth, ovate, coarsely and sharply serrate, acute, the lower on long petioles, the upper subsessile, lanceolate; rac. mostly simple, short; hds. large, with conspicuous rays. - A coarse showy golden rod, in woods, White Mits., N. H., Willoughby and Green Mts., Vt. It is remarkable for the long slender stalks of tho lower ovate leaves, and for the large hds. which exeeed in size most other species. St. 1 to $3 f$ high, racemes axillary and terminal, usually in a thyrse-like panicle. Aug. (S. virgaurca, Bw.)

11 S. Virgaùrea L. $\quad \beta$. AlpiNa (Bw.) St. flexuous, furrowed, pubescent at top; st. Irs. lanceolate, serrate, lower ones oval; contracted to a petiole, rac. erect, ray elongated; hds. large, about 30-flowered; scales very thin, acute. This is tho only species common to the two continents. Ono of its numerous varicties is seen scattered here and there on the lower summits of the White Mts., N. II., Essex Mts., N. Y., L. Superior, C. W., also ? Mits. of N. Car. The hds. are few, sometimes one only, but larger than those of most other species, and of a rich, golden yellow: St. often purple, 2 to $3^{\prime}$ high, simple, with axillary and terminal flowers. Aug.-(S. glomerata MIx. whoso description answers well to tho larger specimens of $\mathrm{S}$. virgaurea.)

12 s. húmilis $\mathrm{Ph}$. Glabrous; st. simple, erect; radical lvs. oblanceolate, petiolate, obtuso and crenate-serrate at apex; the cauline oblanceolate; and lanceolate, acute; rac. simple or panculate; hds. middle size, about 12-flowcred; scales oblong, obtuse; rays short.-Rocks along mountain streams, Vt., N. H., to Newfoundland. St. 6 to $12^{\prime}$ high, somewhat glutinous. Rac. slender, strict. Lvs. of the stem about $2^{\prime}$ by 3 to $4^{\prime \prime}$, serrulate. Hds. 6 to 8 rayed. Aug., Sept.

$\beta$. Taller; hds. more numerous, in short, glomerate clusters, forming a dense, slender, interrupted rac.-Near tho Willey House, White Mts.

$13 \mathrm{~S}$. virgàta $\mathrm{Mx}$. Glabrous, strict, virgate, tall, simply racemous at top; lvs. entire, thickish, oblong-lanceolate, and oblanceolate, rough edged, the lowest subserrate, petiolate; hds. about 15 -flowered; rays 5 to 7 ; ach. pubescent.Damp pine barrens, N. J. to Fla. St. 3 to 5 f high. Lower lvs. 3 to $4^{\prime}$ long, gradually reduced above to the bracts of the peduncles 3 or $4^{\prime \prime}$ in length. Rac. $6^{\prime}$ to 1 f long, composed of small clusters. Sept., Oct.

I4 S. strícta Ait. Smooth; st. strict, erect, simplo; cauline lvs. lanceolate, very entire, rough-edged, ralical lvs. serrate, very long; rac. paniculate, erect; ped. smooth; hds. about 10-flowered.-In wet woods, N. States. St. (and every other part) very smooth, about $2 \mathrm{f}$ high. Lvs. 2 to 4 to $8^{\prime}$ by $\frac{1}{4}$ to $\frac{1}{2}$ to $1^{\prime}$, lower attenuated at base into a long, winged petiole. Pan. terminal, close, composed of short, dense, appressed racemes. Aug.

15 S. speciòsa Nutt. St. smooth, simple; lvs. lanceolate, entire, and scabrous, on the margin, thick, the radical and lower lvs., subserrate, very broad; rac. erect, numerous, forming a terminal, thyrsoid panicle; pedicels shorter than the invol., pubescent; rays largə, 6 to 8.-Woods, Mass. to Ohio and Ga. A noble species, 2 to $6 \mathrm{f} \mathrm{high.} \mathrm{St.} \mathrm{stout,} \mathrm{often} \mathrm{purple,} \mathrm{furrowed.} \mathrm{Lvs.} \mathrm{ample,} \mathrm{some} \mathrm{of} \mathrm{them} 6$ ' by 3'. Hds. exceedingly numerous, about 15 -flowered, with conspicuous rays of a rich yellow, in a large, showy, pyramidal panicle. Aug.-Oct.

$\beta$. ERECTA. Panicle slender, spicate. - With tho other; merely a reduced form. (S. erecta DC.) 
16 s. verna Curtis. Hoary pubescent; st. few-leaved, branched nearly naked, loosely panicled; lower lvs. finely serrate, ovate, veiny, on margined petioles, the upper lance-ovate or oblong, entire; scales lance-linear, smoothish; rays 10 to 12 , disk fls. 16 to 20 ; ach. pubescent.-An early fiowering Solidago, in pino barrens, N. Car. to Fla., rare. St. 2 to $3 f$ high, erect or sometimes inclined and the racemes a little recurved. Lowest lvs. $3^{\prime}$ by $2^{\prime}, 5$-veined, the others partly 3-veined. Mas, Jn.

17 S. pubérula Nutt. Dusty puberulent, simple strict; lvs. lanceolate, entire, attenuate at base, the lower oblanceolate, subserrate; pan. spicate, erect, dense but compound; ped. pubescent; scales linear-lanceolate, acute; rays about 10, elongated; disk fls. about 13.-Woods, Me. to Ga. St. straight, purplish, 2 to 3f high, terminating in a long, thyrsoid spiko of dense, appressed racemes. Lvs. very minutely pubescent both sides, the lorrest on close, winged stalks. Hds. rather large, bright yellow. Aug.-Oct. (Also S. pulverulenta Nutt.)

18 S. sempervìrens L. St. smooth; lvs. lanceolate, somewhat succulent, smooth, entire, and scabrous on the margin, subamplexicaul, obscurely 3-veined; rac. secund, paniculate; pedicels scabrous-pubescent; rays elongated 8 to 10, diskfls. 15 to 20.-Marshes along the coast, and river banks, within the influenco of the brackish water. St. 3 to $6 f$ high, purplish, somewhat glaucous, with numerous long and narrow leaves. Hds. large. Rays showy. Sopt. (S. lævigata Ait.)

19 S. angustifòlia Ell. St. smooth, strict, branched or simplo; lvs. lance-linear: thick, smooth, entire, sessile, short and erect, 1-veined, the lower lanceolate, tapering at base; pan. dense, crect, virgate; pedicels glabrous, slender; hds. small, 15 to 20 -flowered; rays about 7.--Brickish swamps, S. Car. to Fla. and Tex. Sts. 2 to $4 \mathrm{f} \mathrm{high.} \mathrm{Ivs.} \mathrm{diminishing} \mathrm{upwards,} \mathrm{the} \mathrm{highest} \mathrm{subulate.} \mathrm{Hds} \mathrm{very} \mathrm{nu-}$ merous, partly inclined to one side. Scales acute. Sept., Oct.

20 S. nemoràlis Ait. Dusty-subtomentous; lvs. roughish, acute, obscurely 3veined, attenuate at base, sub-entire the lower petiolate; rac. secund, paniculato; hds. small; rays 5 to 6 , disk-fls. 5 to 7.-Dry fields and roadsides, Can. and U. S. A common, starved-looking species, with a grayish, dusty aspect. Height 1 to $2 \mathrm{f}$. Lvs. often fascicled in the axils. Hds. with conspicuous rays. Pan. dense, composed of many short racemes, inclining to one side, or often of a single, terminal recurved one. Again, the stem divides into branches, each bearing a panicle. Sept.

$\beta$. Very slender, minutely puberulent, terminated by a slender spicato (recurved) panicle.-In woods. Lvs, as long as in S. cæsia.

21 5. rupéstris Raf. Smooth, slender; lvs. linear-lanceolate, attenuate at both ends, plainly 3-veined, entire, or the lower subserrulate; hds. small, about 15flowered, in a simple, slender panicle; rays very short.-Ind., Ky., on river banks. St. 2 to $3 f$ high, often branched. Lrs. 2 to $3^{\prime}$ long, veins whitish beneath. $\Lambda$ ug., Sept. Too near the next.

22 S. Missouriénsis -Nutt. Glabrous, low, simple, slender; lvs. lance-linear, tapering to each end, plainly 3-veined, very acute and rough-edged, lower ones with acute, slender serratures, radical, oblanceolate, petiolato; rac. small, in a dense, pyramidal, or somewhat corymbous pan.; ped. glabrous; scales with greenish tips; hds. small, 12 to 15 -flowered.-A delicato species, 1 to $2 \mathrm{f}$ high, in dry prairies, Ill. and Mo. Ixs. smooth and shining, lower 3 to $4^{\prime}$ by 3 to $5^{\prime \prime}$, the others gradually reduced upwards to minute bracts. Rays about 8. Jl., Aug.

23 s. seròtina Willd. St. round, striate, smooth; lvs. linear-lanceolate, acuminate, slightly serrate, obscurely 3-veined, veins beneath pubescent; rac. secund, recurved, paniculate; ped. pubescent; hds. small, 15 to 20-flowered.-A smooth species in meadows and thickets, U. S. and Can. St. 3 to 6 f high, very smooth, often glaucous or purple. Lvs. 3 to 5 to $7^{\prime}$ long, smooth; margin scabrous, upper entire. Fls. numerous, forming a moro or less compact panicle, inclined at summit. Rays less than $\mathbf{l}^{\prime \prime}$ long. Sept.-Variablo and scarcely distinct from the next.

24 S. gigántea Ait. St. smooth, striate; lvs. lanceolate, serrate with sharp, spreading teeth, margins rough-ciliate, strongly 3-veined; rac. axillary and loosely panicled; branches pubescent; ped. and pedicels hairy; hds. 15 to 20 flowerod.- 
A large, showy species, in low, open grounds, U. S. and Can. St. green, sometimes purplish, 4 to $7 \mathrm{f}$ high, often much branched above. Lvs. 2 to 4 to $7^{\prime}$ long, acuminate at each end, often with divergent teeth. Pan. often diffuse, on spreading, leafy branches. Aug.-Oct.-Rays twice longer than the last.

25 S. Canadénsis L. St. downy; lvs. lanceolate, serrate, 3-veined, acuminate, rough; rac. paniculate, secund, recurved; rays short, about 8 , disk-fls. about 7 ; scales linear.-(Fig. 118.) Fields, hedges, U.S. and Brit. Am., common. From $18^{\prime}$ to 5 f high. Stem furrowed, terminated by a copious panicle which inclines to one side. Lrs. sessile, $3^{\prime}$ long, sometimes nearly entire, and perhaps a little downy. Heads almost innumerable, very small, with very obscure, yellow rays. Aug.-Oct.

$\beta$. PRòcera. St. villous; lvs. rough, villous beneath; hds. larger, and with larger rays. - In low grounds, 4-7f high. Leaves distinctly 3-veined. (S. procera Ait.)

26 S. Shórtii Torr. \& Gr. St. minutely rough-downy; lvs. oblong-lanceolate, sharply serrate, strongly 3 -veined, acute, very smooth; rac. secund, dense; pan. contracted, elongated; scales linear-oblong, with greenish tips; rays 5 to 7, disk-fls. 5 to 7.-Banks of the Ohio River, Ind. and Ky. Sts. 1 to $2 \mathrm{f}$ high. Readily distinguished from the last. Jl., Aug.

27 S. pilòsa Walt. Hirsute, tall, stout; lvs. lance-oblong, remotely serrulate, rough, thick, obsoletely veined, midvein liairy beneath, upper lance-ovate, sessile, entire; pan. pyramidal; rays 7 to 10 , minute, disk-fls. 5 or $6 .-$ Pine barrens, N. J. to Fla., in damp places. St. 4 to $7 f$ high. Lrs. 2 to $4^{\prime}$ long below, reduced upivards, very numerous, yellowish-green. Pedicels with subulate bracts, similar to the outer scales. Sept., Oct.

28 S. odòra Ait. St. round, pubescent in lines, slender; lvs. linear lanceolate, acute, abrupt and sessile at base, very entire, smooth, punctate, with pellucid dots, roughedged; rac. paniculate; rays 2 to 4 , disk-fls. 3 or 4.-In dry, fertile woodlands and sunny hills, U. S. and Can. Stem 2-3f high, yellowish-green. Leaves $1 \frac{1}{2}-3^{\prime}$ by $3-5^{\prime \prime}$, with a strong, yellowish midveir, but no veinlets. Panicle inclined. Racemes $2-3^{\prime}$ long, spreading, each generally with a leaf at base, and a simple row of small heads on the upper side. J1.-Sept.-The only species of Solidago which has properties generally considered either agreeable or useful. The leaves are aromatic and yield by distillation a fragrant volatilo oil.

$\beta$. RETRORSA. LVs. linear below, subulate above, often twisted; rays 1,2 or 3 ; st. pubescent all over. S. W. Ga. (Miss Keon). Punctato lvs. acute. Scales, \&c., as in $a$. (S. retrorsa $\mathrm{Mx}$.)

29 S. tortifòlia Ell. St. rough, pubescent; lvs. numerous, linear, subentire, often twisted at the base, small, scabrous above, not punctate; rac. recurved, in a pyramidal panicle; scales obtuse; ray and disk-fis. each 3 to 5.-N. Car. to Fla. and Tex., in dry fields. St. 2 to $3 \mathrm{f} \mathrm{high,} \mathrm{often} \mathrm{much} \mathrm{branched.} \mathrm{Lower} \mathrm{lvs.} 2$ to $3^{\prime}$ long, reduced upwards to subulate bracts. (Elliott.) Aug.-Oct.-Is this tho same as our $\beta$. No. 28?

30 s. altíssima L. St. hairy, tall ; lvs. lanceolate, very veiny, lower ones deeply serrate, rough and wrinkled. Scales acute; rays 6 to $8 .-\mathrm{A}$ variable species, tho tall, rough varieties of which are common about the borders of fields, in hedges, U. S. and Brit. Am. Stem rough with hairs, erect, 3-5f high, much branched at top. Leaves variously toothed or serrate, numerous both upon the stem and branches. Branches widely spreading, each terminating in a recurved paniclo with the flowers turning upwards. Scarcely two of the plants look alike. The branches aro very widely spread, or but little diverging, with few and scattered heads, or with numerous heads; tho leaves aro equally or unequally serrate, hairy or woolly. Aug.-Oct. (S. rugosa Willd.)

31 S. Drummóndii Torr. \& Gr. St. velvety; lvs. ovate or broadly oval, acuto at each end, sharply serrate, smoorh above, velvety beneath, veiny ; scales oblong, obtuse; rays 4 or 5.-Ill. near St. Louis. (Drummond in N. Am. Fl.) St. 1 to $2 \mathrm{f}$ high.

32 S. Rádula Nutt. St. rough-downy, simplo; lvs. oblong-spatulate, tapering to the sessile base, serrate above, very rough, rigid, the lowest petiolate; pan. contracted; disk-fis. 3 to 6, rays 5, very short.-Ill. near St. Louis (Engelman), to La. Plant slender. 1 to $2 \mathrm{f}$ high. IIds. small, crowded, in short, secund racemes Sept. 
33 S. ulmifolia Muhl. Sl. glabrous, with heiry branches; lvs. thin, elliptic-ovate, serrate, acuminate, sessile, tapering to the base, smooth above, villous beneath; rac. paniculate, recurved-spreading; ped. "villous; hds. small; scales acute; rays 3 or 4 , disk-fls. 3 or 4 .- In woods and low grounds, N. and W. States. $\Lambda$ species, of striking form, like Brachychrta, with the slender, arched branches of the Elm. St. striate, about 3f high, rarely with scattered liairs. Radical lrs. tapering to winged petioles, and hairy both sides, with coarse and unequal serratures, upper ones entire, middle ones about $3^{\prime}$ by $11^{\prime}$. Rays de ap yellow. Aug., Sept.

34 S. Boottii Hook. St. glabrous, with hairy branches; lvs. orate or lance-ovate, serrate, lower contracted to marginal petioles, upper sessile, acuminate at both ends; rac. long, recurved, loosely panicleil; $h d s$. middle size; scales oblong, ob. tuse; rays 2 to 5 , disk-fls. 8 to 12.-Sandy soils, N. Car. to Fla. and Tex. Plant 2 to $5 \mathrm{f}$ high, variable, with tho stem smooth, or more or less rough-downy. Aug. -Oet.

35 S. linoìdes Solander. Smooth throughout; st. slender, simple; Ivs. lanceolate, finely serrate and scabrous on the margin, radical ones petiolate, upper entire; hds. small, in short, secund, at length spreading racemes; scales oblong-linear, obtuse, approssed; rays 1 to 4, short, disk-fls. 4 to 5 , short.-A small species, near Boston (Greene in N. Am. F'lo.) to N. J. St. 12 to $20^{\prime}$ high. Lvs. 1 to $5^{\prime}$ by 3 to $6^{\prime \prime}$. Pan. small, usually turned to one side. Sept., Oct.

36 S. Muhlenbèrgii Torr. \& Gr. St. furrowed, glabrous; lvs. smooth both sides, strongly and sharply serrate, the radical ovate, petiolate, cauline, elliptical-lanceolate, acuminato at each end; rac. secund, short, remote, axillary, spreading; pedicels pubescent; hds. 15-20-flowered; scales linear, obtuse.-In damp woods and thickets, N. H. to Penn. Stem 2-3f high, generally simple, bearing a long, open panicle. Leaves large, notched with very acute or acuminato teeth, featherveined. Heads middlo size, with 6-3 rather largo rays. Aug.-Oct. (S. arguta Muhl.)

37 S. pátula. Muhl. St. smooth, angular-striate; lvs. elliptic, acute, serrate, very scabrous above, smooth beneath, lower ones oblong-spatulate; rac. paniculate, loosely spreading; pedicels pubescent; hds. about 12 to 15-flowered; scales much imbricated, oblong, very obtuse.-In wet places, Can., N. and W. States, not common. St. 2 to $4 \mathrm{f} \mathrm{high,} \mathrm{virgate,} \mathrm{often} \mathrm{purple,} \mathrm{strongly} \mathrm{angled,} \mathrm{with} \mathrm{leafy} \mathrm{branches}$ at the top. St. lvs. 1 to $2^{\prime}$ long, $\frac{1}{3}$ as wide, radical ones 2 or 3 times larger. Rac. short, on the ends of the spreading branches. Sept.

38 s. ellíptica Ait. Erect, glabrous throughout, leafy; lvs. elliptical, acuto at each end, obscurely serrate, uppor ones sessile, entire; rac. short, recurved, in a dense pyramidal panicls; hds. middle sizo; rays 5 to 8, very short, disk-fls. 6 or 7 ; scales linear-oblon 2 , obtuss.-_Salt marshes, R. Isl. (Olney), near N. Y. (T. \& G.), to Ga. St. 3 to $5 \mathrm{f}$ high, bearing a close, somewhat leafy pyramidal panicle. Lvs. 2 to $4^{\prime}$ by $\frac{1}{2}$ to $11^{\prime}$, rough-edged, the serratures appressed and rather remote. Rays oblong, rather large, pale yellow. Oct.
$\beta$. Elló́triI. Pan. moro widely spreading.-South. (S. Elliottii T. \& G.)

39 S. argùta Ait. St. strict, smooth; lvs. smooth, acutely and unequally serrate, with diverging teeth, cauline, elliptical, sessile, highest entire and small, radical oblong-ovate, attenuate at baso into winged petioles; rac. secund, dense, in a spreading, corymbous panicle; hds. middle sizo; rays about 10, disk-fls. 9 or 10 ; ach. smooth.- In meadows and woods, U. S. (from lat. $33^{\circ}$ ), N. to the Arc. circle. A smooth, shining plant 3 f ligh, with a large, dense, corymbous panicle. Rac. recurved, a finger's length, the compound pedicels roughish, bracted. Aug., Sept.

B. JUNCEA. Lvs. lanceolate, subserrate, upper entiro; st. brownish, striate; rays twico as long as the invol.; pan. less dense.-Open fields. (S. juncea Ait. S. ciliaris Muhl.)

40 S. neglecta Torr. \& Gr. St. smooth, striato; lvs. smooth, acute, serrate, with divergent teeth, cauline linear-lanceolate, subentire highest linear, sessile, lowest lanceolate (large), tapering to a long petiole; rac. secund, erect, at length recurved, in an abrupt or oblique panicle; hds. middle size; rays 6 to 10 , disk-fls. 7 to 12 ; ach. smooth.- Swamps Hanover, N. H. (Ricard, \&c.) to Ind. and southward. St. 3 to 4 f high, terete. Rt. lvs. 6 to $12^{\prime}$ long, feather-veined; upper obscurely 3 -veined. $\Lambda$ ug., Sept. $-\Lambda$ handsome Solidago, best known by its peculiar panicle. 
41 S. Ohiénsis Riddell. Glabrous throughout; lower lvs. lanceolate, obtuse, entire or serrulate above, tapering to long petioles, upper oblong-lanceolate, $a b$ ruptly acute, sessile, entire; hds. numerous, 15-20-flowered, rather large, in a dense, fastigiate corymb.-Meadows and prairies, western $\mathrm{N}$. Y. to Ind. A perfectly smooth Solidago, 2-3f high. Stem simple, reddish, leafy. Leaves of a firm texture, the radical $6-8^{\prime}$ by $1-1 \frac{1^{\prime}}{2}$, on petioles of equal length, middle cauline, about $2^{\prime}$ by $5^{\prime \prime}$. Heads about 6-rayed. Sept., Oct.

42 S. Riddéllii Frank. Stout and nearly glabrous, corymbously branched; radical lvs. very long, lance-linear, long-pointed entire, on long, margined, carinate petioles, cauline lvs. clasping at base, arcuate, carinate, narrow, acute, cntire ; branches leafy; hds. $20-24$-flowered, densely clustered in a compound, fastigiate corymb. -Wet prairies Ohio, Wis. to Mo. A well marked species, 15-30' high. Radical leaves $12-18^{\prime}$ long, almost grass-like, cauline $3-6^{\prime}$ by $\frac{1^{\prime}}{2}$, with a strong midvein, and generally much recurved. Rays small, 6-9. Sept. (S. Mexicana B. Hook.)

43 S. corymbòsa Ell. Stout, glabrous; with the corymbous branches hirsute; lvs. sessile, oblong-lanceolate, thick, rigid, smooth, the lower and radical subdentate, upper entire, rough-ciliate; hds. large, in loose racemes, the outer secund, forming a fastigiato corymb; scales pubescent, oblong, obtuse; rays about 10 , disk-fls. about 20 ; ach. glabrous. - Middle Ga. Plant 4 to $6 \mathrm{f} \mathrm{high,} \mathrm{differing} \mathrm{from}$ S. rigida in its smooth stem and leaves, smaller hds., \&c. Sept., Oct.

44 S. Houghtonii Torr. \& Gr. Like S. Ohiensis, but smaller, with a few very large hds., - found in Northern Mich. in the State Survey. Aug.

45 S. rígida L. Stout, rough-hairy; lvs. rigid, ovate-oblong, rough with minute hairs, the upper very entire, the lower serrate; branches corymbous-paniculate, with close, sliort racemes, the lower somewhat secund; hds. very large; scales obtuse; rays large, 7 to 10 , disk-fls. 25 or more; ach. glabrous.-A rough plant in dry fields and rocky woods, Ct. to Mo. and Tex. Abundant in western prairies. St. 3 to $5 \mathrm{f}$ ligh, round, striate, with rigid lvs., of which the radical ones are sometimes near a foot long. Hds. 4 to $5^{\prime \prime}$ long and wide. Rays about $3^{\prime \prime}$ by $1^{\prime \prime}$, deep-yellow. Aug., Sept.

46 S. spithamæa Curt. Villous; lvs. lance-oval or oblong; thin, smoothish, sharply serrate, margin ciliate; hds. middle size, corymbous; scales lanceolate, acute; rays 6 to 8 , disk-fls, 15 to 20 ; ach. pubescent.-High Mts. of N. Car. (Curtis). A low plant, growing in tufts, with hairy stems, branches and corymbs, and inconspicnous rays. Aug., Sept.

47 S. lanceolàta Ait. St. angular, hairy, much branched; lvs. linear-lanceolate, entire, 3-veined, rough-margined, slightly hispid on the veins beneath; corymbs terminal, fastigiate; rays minute, about 17, disk-fls. 10.-In woods and meadows, Canl. and U. S. St. 2 to $4 \mathrm{f} \mathrm{high,} \mathrm{with} \mathrm{numerous,} \mathrm{very} \mathrm{long} \mathrm{and} \mathrm{narrow} \mathrm{lvs.} \mathrm{which}$ are distinctly 3-veined and acutely pointed, smaller ones often fascicled in the axils. Fls. in terminal, crowded, corymbed clusters. Invol. ovate. The whole plant is fragrant. Sept.

48 S. tenuifòlia Ph. St. angular, smooth, with many fastigiate branches; lvs. narrowly linear, spreading, mostly 1 -veined, scabrous on the margin, the axils leafy; corymb terminal, consisting of clustered hds. ; rays about 10, scarcely as long as the disk.-Meadows near the sea-coast, Mass. to La. Also Wis. (Lapham.) A very slender species, distinguished from $\mathrm{S}$. lanceolata by the extrem? narrowness of the leaves and the thinner, moro open corymb, which is often reduced to a fer hds. Aug.-Oct.

27. BIGELO'VIA, DC. (In honor of Dr. Jacob Bigelow, the we!lknown author of "Florula Bostoniensis," \&c.) Heads discoid, 3 to 4flowered, the flowers all tubular, $\Varangle ;$ involuere cylindrical, as long as the flowers; scales rigid, linear, closely imbricated; receptacle pointed by a scalc-like cusp; achenia obconic, hirsute; pappus bristles in one series. - 2f Glabrous, slender. Lrs. alternate, entire. Hds. fastigiately corymbous, with yellow fls. and colored scales. 
B. virgàta DC. Smooth in all its parts; st. virgately branched from near the base; branches corymbous-fastigiate above; lvs. narrowly linear, 1-veined, the cauline linear-spatulate; scales glutinous.-Swamps, N. J. to Fla. and Tex. A plant resembling Solidago tenuifolia in aspect, 1 to $2 \mathrm{f} \mathrm{high.} \mathrm{Lvs.} 2$ to $3^{\prime}$ by 1 to $2^{\prime \prime}$, rather firm and somewhat remote. Fls. bright yellow, the scales also yellowish. Aug.-Oct.

28. ISOPAP'PUS, Torr. \& Gr. (Gr. ‘̌os, equal ; $\pi a ́ \pi \pi \circ \varsigma$, pappus.) Heads radiate; ray fls. 5 to 12 , $q$, disk-fls. 10 to $20 \%$; scales of the involucre lanceolate-subulate, closely imbricated; receptacle alveolate, achenia terete, silky-villous; pappus a single row of equal capillary bristles.-(2) Rough-hairy, branching, with alternate lvs. and loose panicles.

I. divaricàutus T. \& Gr. Scabrous, with thin, hispid hairs; lrs. linear-lanceolate, taper-pointed at each end, sessile, nearly entire; lids. on slender, naked pedicels ; rays about 7 , longer than the invol, disk-fls. about 12 ; scales slender-pointed, shorter than the tawny pappus.-Dry sandy soils, Ga. (Feay) to Fla. and Tex. Plant $6^{\prime}$ to $3 \mathrm{f}$ high. Hds. in a diffuse panicle, invol. $2^{\prime \prime}$ long, rays $3^{\prime \prime}$, bright yel: low. Aug.-Oct.

29. PRIONOP'SIS, Nutt. (Gr. $\pi \rho i \omega \nu$, a saw, o้ $\psi \iota$, resemblance; alluding to the serrate leaf.) Heads depressed, radiate, many-flowered; rays in one series,, , disk fls. $\Varangle$; scales imbricate, squarrous ; receptacle alveolate, flat; ach. glabrous, turgid ; pappus deciduous, of rigid, scabrous, very unequal bristles, the inner row longer than the corolla.Leaves alternate. Fls. showy, yellow.

P. Chapmanii Torr. \& Gr. Hairy or downy, strict, erect; lvs. crect, smooth, lance-linear, serrate, with remote setaceous teeth; hds. few; scales cuspidate.24 Swamps in pine barrens, Mid. Fla. (Chapman). Jn., Jl.

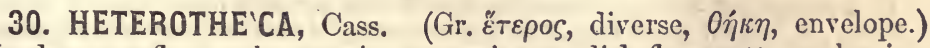
Heads many-flowered; rays in one series, $q$, disk-flowers $\Varangle ;$ scales imbricated, appressed; receptacle alveolate, fringed; achenia minutely canescent, of the ray without pappus (naked), of the disk with a double pappus, the outer very short, scale-like, the inner of capillary bristles. if Herbs hairy, corymbously branched, with alternate lvs. and yellow flowers.

H. scàbra DC. St. erect, flexuous, striate; lvs. oblong-ovate, petiolate, dentate, scabrous ; petioles abruptly winged as if stipulate at base; hds. large, in a loose, paniculate corymb; rays 15 to 20 ; pappus tawny-red, the outer white.-A showy plant, in dry soils near the coast, S. Car. to Fla. and Tex. Plant 2 to $3 f$ high. Lrs. 2 to $3^{\prime}$ long, diminishing upwards, where they are lance-oblong and sessile. The ray achenia are glabrous, with a minute crown, those of the disk silky. Rays of a rich yellow, expanding $9^{\prime \prime}$. Sept., Oct.

31. CHRYSOP'SIS, Nutt. (Gr. Xpvoós, gold, ơ $\psi \varsigma s$, appearance.) Heads many-flowered; ray-flowers $q$, disk-flowers $\Varangle$; involucre imbricate; receptacle subalveolate, flat; pappus of the ray and disk similar, double, the exterior short, interior copious, capillary; achenium hairy, compressed.-2f Hairy herbs, with alternate and entire leaves and yellow flowers.

\$ Leaves linear, grass-liko; achenia linear.................................. Nos. 1-4 $\S$ Leares lance-oblong; achenia obovate, compressed (a).

a Outer pappus serlo-ilike......................... Nos, 5,6

a Outer pappus bristle-form................................... 7,8

1 C. graminifòlia Nutt. Canescent with long silky hairs; lvs. linear, erect, entire, grass-like, tapering to both ends, the upper numerous and reduced to subu- 
late bracts; hds. corymbous; ach. sillyy-pubescent.-Del. to Fla., common in the pine woods. Sts. 1 to $2 \mathrm{f}$ high. Branches usually 1 -flowered. Hds. 5 to $6^{\prime \prime}$ long and wide. Pappus tawny-white. Jl.-Oct. (C. argentea Nutt.)

2 C. oligantha Chap. Canescent with long silky hairs; lvs. lance-linear and linear, erect, entire, tapering to both ends; st. above, nearly naked; hds. fow, large; pappus white; ach. silky-villous.-S. W. Ga. and Fla., in damp pine woods. Height 1 to $2 \mathrm{f}$. Hds. 1 to 6 , a third larger than in No.1. Rays spreading 14 to $17^{\prime \prime}$, appearing in Apr. and May.

3 C. pinifòlia Ell. Glabrous, rigid; lvs. narrowly linear, rigid, erect, crowded, the upper setaceous; hds. solitary, terminal, corymbous; ach. villous; pappus reddish-brown, the outer scale-like, whitish. - Sandy hills, middle Ga. St. 1 to $2 \mathrm{f}$ ligh. Hds. nearly as large as in No. 2. Lower lvs. 3 to 5 ' long. Sept., Oct.

4 C. falcàta Ell. Woolly and villous; lvs. sessile, linear, very acute, subfalcate, spreading. veins pilous on both sides; hds. small, in axiliary corymbs; invol. pilous.-A low, leafy plant, in dry, sandy soils, near the sea, Mass. to N. J. St. thick, leafy, about $8^{\prime}$ high. Hds. small, bright yellow, in crowded, paniculate corymbs. Rays 3-toothed at the apex. Sept., Oct. (Inula falcata Ph.)

5 C. Mariàna Nutt. Silky-arachnoid; lrs. oblong-lanceolate, subentire, smooth when old; the upper sessile, acute, the lower spatulate and generally obtuse; corymb simple; scales acute, viscidly-pubescent; rays 15 to 20.-Sandy barrens, N. J., Md. to Fla., common. St. and lvs. clothed with scattered, long, silky, deciduous hairs. Plant about 2 f high. Lrs. 1 to 2 ' long. Corymbs somewhat umbeled; hds. few, large, 16 to 20-rayed, yellow, on viscid-glandular peduncles. Aug.-Oct. (Inula Mariana I.)

6 C. villòsa Nutt. Erect, leafy, villous-pubescent, and strigous; lvs. entire, sessile, ciliate towards the base, lower ones oblong-spatulate, upper oblong-linear or lanceolate; hds. large, solitary, and terminal, somewhat fastigiately corymbous; scales linear-subulate, strigous; rays 20 to 30.-Prairies, Ill. to Or. St. 1 to $2 \mathrm{f}$ high. Lvs. 1 to $2^{\prime}$ by 3 to $5^{\prime \prime}$, whitish and rough. Rays oblong-linear, entire, golden-yellow. Jl.-Sept. (Ámellus. Ph. Diplopappus Hook.)

7 C. gossýpina Nutt. Clothed throughout, with a cottony tomentum; lvs. oblong, obtuse, entire, the lower spatulate, upper sessile; hds. solitary, corymbous; scales woolly; pappus tawny, the outer bristle-form, white.-Va. to Fla., in the barrens. St. 1 to $2 \mathrm{f}$ high. Lvs. 1 to $2^{\prime}$ long. Hds. larger than in No. 5, with about 25 rays. Aug.-Oct.

8 C. trichophýlla Nutt. Clothed with long, weak hairs below, nearly glabrous above; lvs. narrowly ob'ong, obtuse. Otherwise as in No. 7.-N. Car. to Fla. and La., in dry soils. Aug.-Oct.

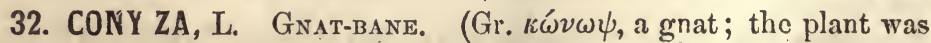
supposed to expel gnats and fleas.) Hds. discoid ; flowers all tubular, those of the margin $q$; of the centre $\hat{o}$ or $\not{q}$; scales in several rows ; receptacle flat or convex ; achenia compressed ; pappus one row of capillary bristles.-Illerbs chiefly tropical. Fls. yellow.

C. sinuàta Ell. Hairy and cinerous-pubescent; lower lvs. sinuate-lobed, acute, middle repand-dentate, upper linear, entire; hds. paniculate; fls. white, all fertile; ach. oblong, almost glabrous.-Charleston, S. C. and Savannah, Ga. (Pond), common - "appearance of an Erigeron," (Elliott.) St. a foot or more high. Lvs. narrow, 12 to $18^{\prime}$ long. Florets very numerous (100 or more) in each head. Pappus pale cinnamon color. Apr.-Jl.

33. IN'UlA, L. Elecampane. (Ancient Lat. name.) Heads many-flowered; involucre imbricate; ray-flowers numerous, + , diskflowers $\Varangle ;$ receptacle naked ; pappus simple, scabrous; anthers with 2 bristles at base. $-2 f$ Coarse European herbs, with alternate leaves and yellow flowers.

Eelènium L. Lvs. amplexicaul, ovate, rugous, downy beneath; invol. scales ovate.-Herb coarse-looking, in pastures and̆ road̃sidies, N. Eng. to Ill. Stem 4- 
$6 f$ high, furrowed, branching, and downy above. Radical lvs. very large ( 1 to $3 \mathrm{f}$ by 6 to 12 ), serrate those of the stem clasping. Hds. large, solitary, terminal. Rays linear, with 2 or 3 teeth at the end. Esteemed as a tonic and expectorant. Jl., Aug. $\S$

34. PlU'CheA, DC. Marsh Flea-bane. Heads many-flowered, those of the margin + , of the center $\not$, but sterile; involucre imbricated; receptacle flat, naked; style undivided; pappus capillary, simple.-Strong-scented herbs, with alternate lvs. and corymbs of purple fls., and copious, reddish pappus.

1 P. camphoràta DC. Lvs. ovate-lanceolate, somewhat pubescent, acuto, sessile or short-petioled, serrate, serratures mucronate: Als. in crowded corymbs. -24 A fleshy, strong-scented plant, native of salt marshes, Mass. to Flor. Stem a foot high, thick, downy, with alternate lvs. and axillary branches. Fls. light purple. Aug. (Conyza camphorata Muhl. C. Marilandica Mx.)

2 P. foétida DC. Erect, nearly glabrous, very leafy; lvs. broadly lanceolate, acute or acuminate at each end, petiolate, feather-veined, obtusely subserrate; $h d s$. numerous, in paniculate corymbs; scales ovate-lanceolate, acute.-A strong-scenter. plant, in open, hilly grounds, Western States. St. 1-2f high, subsimple. Lrs. $4-7^{\prime}$ by $1 \frac{1}{2}-3^{\prime}$, sprinkled with minute dots; petioles $\frac{1}{2}-1^{\prime}$ long. Hds. numerous. Aug.-Oct. (Baccharis, L. Conyza camphorata $\mathrm{Ph}$.)

3 P. bifrons DC. Pubescent, leafy; lvs. oval-oblong, acute, finely serrate, cordate-amplexicaul, veiny; hds. in compound, corymbous clusters.-Moist, low lands, S. Car. to Fla. and La. Sts. 1 to 3 f high, strict. Lrs. 2 to $3^{\prime}$ long, $1^{\prime}$ wide. Fls. very numerous, as in the other species, dull purple. Jl.-Sept.

35. BAC'CHARIS, L. Groundsel Tree. (From Bacchus, wine; its fragrance resembling that of wine.) Heads discoid, many-flowered, diœcious; involucre imbricate, cylindric, or ovate, with subcoriaceous, ovate scales; sterile flowers with the stamens exserted; receptacle naked; pappus capillary.-Shrubby plants, with alternate lvs. and white fls.

1 B. halimifòlia I. Glabrous, vhitish-scurfy; lvs. 03ovate, incisely dentate above, the highest lanceolate, panicle compound, leafy; fascicles pedunculato, terminal, in a dense panicle.-Ct.; N. Y. to Ga. An elegant shrub, 6 to $12 \mathrm{f}$ high, growing on sea-coast and river alluvion. Every part is covered with white dust. Tho fertilo hds. growing upon separate plants are in large, loose, terminal panicles, and furnished with very long, slender pappus. Cor. white, 20 in each head. Sept.-Marits cultivation.

2 B. angustifòlia Mx. Glabrous, diffusely branched; lvs. linear, sessite, entirs; hds. small, 15 to 20 -flowered, cylindrical, axillary, loosely paniculate. - S. Car., Fla., and La., in the edge of salt marshes. A fine shrub, 6 to $10 \mathrm{f} \mathrm{high,} \mathrm{with}$ slender, tough branches. Lvs. 2 to $3^{\prime}$ long, 1 to $3^{\prime \prime}$ wide, acute. Hds. less than $2^{\prime \prime}$ long, in a diffuse, leafy panicle. Sept., Oct.

3 B. glomeruliflòra Pers. Glabrous, minutely scurfy; lvs. all obovate tapering to a short petiole, very obtuse, repand-few-toothed; $h d s$. in sessile glomerules, in the axils of the upper lvs.-Va. to Fla. and La., along the coasi. St. 3 to $5 f$ hight, palo green as well as the whole plant. Lrs. 1 to $2^{\prime}$ long, $\frac{2}{3}$ as wide. Hds. thrico larger ( $3^{\prime \prime}$ long and wide) than in No. 1. Sept.-Nov.

\section{TRIBE 4. SENECIONID \&.}

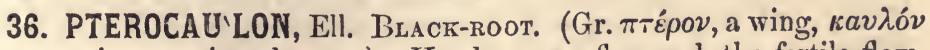
a stem; i. e., a winged stem.) Heads many flowered, the fertilo flowers $q$ in several rows, the sterile flowers central (!), mostly $\nsucceq$; seales imbricated, caducous with the fruit, $q$ corollas 3 -toothed, $\Varangle 5$-cleft; achenia angular, hispid ; pappus of equal capillary bristles longer than 
the involucre.-2f Rhizome tuberous. Lvs. alternate, very densely tomentous beneath, decurrent into the wings of the stem. Hds. sessile, densely crowded into a woolly terminal spike. (Conyza, Mx.)

P. pycnostáchyum Ell. St. simple; lvs. lanceolate, finely serrulate, smooth above; spike continuous. - Sandy soils, S. Car. to Fla. A curious piant, 2 to $3 \mathrm{f}$ high. Lrs. a finger's length, dark green above, creamy-white beneath, as are also the wings of the stem. Spike 2 to $3^{\prime}$ long. May-Aug.

37. BORRICH'IA, Adans. SeA Ox-Eye. (Dedicated to Olof Borrich, a Danish botanist.) Heads radiate, many-flowered; rays $o$, fertile; scales imbricated, the outer leafy; receptacle flat, chaffy, the chaff rigid, persistent; achenia 4-angular, crowned with a 4-toothed pappus. -Shrubby maritime plants with opposite lvs. and solitary, yellow hds. (Buphthalmum, L.)

B. frutéscens DC. Minutely canescent downy; lvs. lanceolate and oblanceolato obscurely repand-toothed, slightly connate at base, chaff of the recept. cuspidate with a rigid point. - Va. to Fla. St. 1 to $3 \mathrm{f}$ high. Lvs. 2 to $3^{\prime}$ long, rounded at the end (with a cuspidate point), varying to linear, the upper alternate. Jn.Oct.

38. ECLIP'TA, L. Head many-flowered; ray fls. $q$ numerous narrow; disk $\Varangle$ tubular, mostly 4-toothed; scales $10-12$, in 2 rows, leafy, lance-ovate; receptacle flat; chaff bristly; achenia somewhat angular or 2.edged; pappus 0 .-(1) Herbs strigose with rigid hairs, erect or procumbent. Lvs. opposite. Heads axillary and terminal, solitary. Fls. white. (Fig. 328.)

E. erécta L. St. often decumbent; lvs. lanceolato or lance-oblong, tapering to each end, subserrate; ped. longer than the lieads; scales or leaves of the involucre acuminate.-Damp soils, Md., Ohio, and Ill., S. to Flor. Stem often rooting at the lower joints, $1-3 \mathrm{f}$ long, with an elastic, thread-like fiber. Leaves 1 to $2^{\prime}$ long, rough, obscurely tripli-veined. Heads small, with minute flowers and short rays. The juice turns black, and is said to dye wool black. Jn.-Sept. (E. procumbens and brachipoda, Mx.)

39. POLYMINIA, L. LEAF-CUP. (The name of one of the ancient Muses; why applied to this plant is not obvious.) Heads radiate. Involucre double, outer of 4 or 5 large, leafy scales, inner of about 10 leaflets, concave ; ray-flowers pistillate, few ; disk sterile ; receptaclo chaffy; pappus none.-2f Clammy herbs. Lvs. opposite. Fls. yellow.

1 P. Canadénsis L. Viscid-villous; lvs. denticulate, petiolate, acuminate, lower pinnatifid, upper 3-lobed or entire, rays shorter than the invol.-A coarse, broadleaved, hairy-viscid plant, $3-5 \mathrm{f}$ high, Can., N. Y. to Iil, and the mts. of Car. Stem with opposite leaves and spreading branches. Flowers light-yellow, the rays short, surrounded by the concave leaflets of the double calyx in such a man. ner as to form a sort of cup, hence called Leaf-cup. Leaves feather-veined, $3-8^{\prime}$ Iong, and nearly as wide, lobes deeply divided and acuminate. Heads $\frac{1^{\prime}}{2}$ diam. June.

- 2 P. uvedàlia L. Hairy and rough, stout; lvs. 3-lobed, acute, decurrent into the petiole, lobes sinuate-angled; rays 7 to 12 , much longer than the involucre.-. In highland woods. Stem 3-6f high. Lower leaves very large. Flowers large, yellow, the rays oblong, obtuse. Jl.-Neither of these plants has been found in N. Eng., and they are rare in N. Y., but not uncommon in the W. and S. W. States.

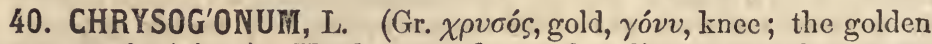
flowers at the joints.) Heads many-flowered, radiate; rays about $5,+$, fertile, disk $\Varangle$ but sterile; scales in 2 rows of about 5 each, the outer 
leafy, the inner chaffy; receptacle flat, chaffy; achenia of the ray obcompressed, obovate, each embraced by a chaff-scale; achenia of the disk abortive; pappus a small, 2 to 3 -toothed crown.-2f A little prostrate herb, with opposite lvs. and solitary, pedunculate, bright yellow verual fls.

C. Virginiànum L.-In rich shady soils, Mrd. to Ill., common southward to the Gulf. One of the earliest flowers of spring. Plant flat on the grouud, hirsute, at first acaulescent, at length caulescent and ascending. Lvs. ovate, tapering to a petiole, crenate. Rays expanding 7 to $9^{\prime \prime}$. Feb.-May.

41. SIL'PHIUM, L. Rosin-WEed. (The ancient name of some resinous plant.) Heads many-flowered; ray-flowers numerous, in 2 or 3 rows, fertile, outer row ligulate; disk-flowers sterile ; involucre campanulate, scales in several series, leafy and spreading at summit; receptacle small, flat, chaffy; achenia broad, flat, obcompressed, crowned with a 2-toothed pappus. - 2f Stout, coarse, resinous herbs. Hds. large. Fls. yellow.

* Stem nearly leafless, scape-like. Lvs. very large, alternate, mostly radical...... Nos. 1-8

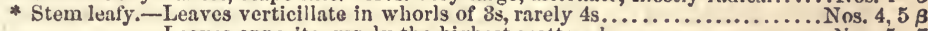
-Leaves opposite, rarely the highest scattered............................. $5-7$ -Leaves alternate (the lowest opposite or verticillate or alternate)......... No. 9

-Leaves connate-perfoliate....................................... 9

1 S. laciniàtum L. Polar Plant. Very rough, with white, hispid hairs; lvs. alternate, pinnately parted, lower petiolate, segments sinuate-lobed or entire; hds. spicate, distant; scales ovate, appendaged and squarrous at apex.-Western States to Tex., producing columns of smoke in the burning prairies by its copious resin. Stem 3-10f high. Lower lvs. 1-2f long, much divided, resembling those of some thistles. Heads $4-8$, very large, with large, yellow rays. J1.-Sept.

2 S. terebinthinàceum L. PRAIRIE BuRDOCK. St. and ped. glabrous; lvs. mostly radical, ovate and ovate-oblong, cordate, dentate-serrate, obtuse, scabrous, on long petioles; hds. few, paniculate; scales roundish and oval, glabrous, rays about 20.-Prairies, W estern and Soutliern States. Plant oxuding resin. Stem 4-8f high, nearly naked and simple. Leaves $1-2 \mathrm{f}$ long, $7-16^{\prime}$ wide. Inrolucre globous. Hds. $1^{\prime}$ diam., rays $1^{\prime}$ long. Achenia narrowly 2 -winged. Jl- Sept.

$\beta$. PINNa Tifidum. Lvs. more or less deeply lobed or pinnatifid.-Prairies, etc., with the other form. (S. pinnatifidum Ell.)

3 s. compósitum Mx. Glabrous throughout; st. slender, almost naked, glaucous; lvs. radical, on long petioles, deeply sinuate-pinnatifid, the segments sinuatelobed or toothed; hds. corymbed, on long peduncles; scales oval, obtuse; ach. roundish-obovate; rays about 10.-Barrens, N. Car. to Fla. (Feay). St. 3 to 6 f high. Hds. $7^{\prime \prime}$ diam., about 10-rayed, rays about as long $\left(4^{\prime \prime}\right)$ as the involucre. June.-Aug.

$\beta$. RENIFORME. LVs. roundish or reniform, cordate, slightly sinuate-lobed or toothed.-Upper districts of Ga. and Car.

4 S. trifoliàtum I. St. glabrous and often glaucous, terete or 6-sided; caulinet lvs. lanceolate, acute, scabrous above, smooth below, remotely dentate, on very short petioles, verticillate in $3 s$ or $4 s$; upper ones opposite; hds. loosely cymose, on rather long peduncles; scales broadly ovate, rather obtuse, smooth; ach. oval, with 2 short teeth.-Dry woods and prairies, Ohio and Southern States. Stem 4-6f high.-Leaves $4-6^{\prime}$ by $1-2^{\prime \prime}$. Rays 12-16, expanding about $2 \frac{2^{\prime}}{2}$. Ach. 3 to $4^{\prime \prime}$ long, 2 to $3^{\prime \prime}$ wide. Aug., Sept.

5 S. integrifòlium Mx. Scabrous; st. quadrangular, striate, simple; lvs. opposite, sessile, ovate-lanceolate, entire or slightly dentate; hds. in a elose corymb; scales 'squarrous; ach. roundish, broadly.winged, with 2 long teeth.-Western States $\mathrm{S}$. to Ga. Stem very rigid, 3-7f high. Leaves rigid, broad and clasping at base. Heads middle-size. Rays 12-20. ' $1^{\prime}$ in length. Ach. 4 to 5" long, 4" wide. Jl., Aug. 
ß. TERNÀTus. St. 6-sided; lvs. ternately verticillate.-Prairies, with the common form; apparently connecting this with S. trifoliatum, from which it is nevertineless distinct.

6 S. scabérrimum Ell. St. hispid; lvs. opposite, rigid, oval somewhat pointed, serrate, very roughly nispid on both sides, the lower petiolate, upper subsessile, entire; scales ciliate-serrulate, squarrous; ach. large, roundish, broadly winged, with convergent teeth.-W. Ga. to La. St. 3-4f high. IIds. nearly $\mathrm{I}^{\prime}$ diam., rays 20 or more, spreading 2'. Ach. $6^{\prime \prime}$ long. Aug., Sept.

7 S. levigàtum Ell. Smooth and glabrous; lvs. opposite, thick, lance-oblong, subserrate, somewhat pointed, the lower petiolate, upper sessile, with an abrupt base, highest cordate, entire; scales ovate, obtuse, ciliate-squarrous; ach. oval, narrowly winged, the teeth short, divergent.-W. Ga. and Ala. St. 2 to $3 \mathrm{f} \mathrm{high,}$ somewhat 4-angled. Hds. small, corymbed, rays spreading $1 \frac{1}{2}$. Achenia $4^{\prime \prime}$ long. Aug., Sept.

8 S. Asteríscus L. Hispid, often hairy; st. terete, striate; lvs. mostly alternate, lanceolate, crenate-serrate, obtusish, the lower tapering to a petiole, opposite or alternate, upper sessile; scales squarrous, leafy; ach. roundish-obovate, with short divergent teeth.-Dry soils, Va. to Fla. and La., common. St. 2 to $4 \mathrm{f}$ high, generally purple. Lower lvs. (rarely whorled) 4 to $7^{\prime}$ long. Hds. few, $1^{\prime}$ broad, with 12 to 15 rays, $1^{\prime}$ in length. Ach. 3 to $4^{\prime \prime}$ long. Jn.-Aug.-Variable, being sometimes nearly smooth, the lower lvs. sometimes sinuate-toothed, etc.

$\beta$. PUMmum. Downy or tomentous, low; lvs. elliptical, obtuse, subserrate, upper entire; hds. smaller; ach. with very short teeth or almost truncate. Ga. (Feay), (S. pumilum $\mathrm{Ph}$.). The teeth of the ach. aro not invariable in this genus.

9 S. perfoliàtum L. Cup-plant. St. square; lvs. large, thin, opposite, connateperfoliate, ovate, coarsely toothed, narrowed towards the base; hds. in a trichotomous cyme, on a long ped.; scales ovate, obtuse, squarrous; ach. broadly obovate, winged, emarginate.-Along streams, etc., Mich. to Tenn., plant coarso and forbidding, 4 to $7 \mathrm{f}$ high. Lvs. 8 to $14^{\prime}$ by 4 to $7^{\prime}$, the upper pairs forming a cup with their connate bases. Hds. large, with 12 to 20 rays. Ach. $6^{\prime \prime}$ long. Л., Aug. (Also, S. connatum L.)

42. BERLANDI'ERA, DC. (Named for Berlandier, a botanical collector.) Heads radiate; ray-flowers $q$, fertile, in one series; disk $\Varangle$ but sterile; scales in 3 scries, leafy, subequal; receptacle chaffy; pales obtuse; achenia all marginal, in one row, obcompressed, wingless, obovate, more or less adherent to the inner scales of the involucre; pappus minute.-24 Herbs velvety-canescent, with alternate, cordate, petiolate lvs. and hds. juith yellow rays.

1 B. tomentòsa Torr. \& Gr. Caulescent, whitened with a close, soft tomentum; st. simple; lvs. oblong, obtuse, crenate, petiolate, somewhat smooth and green above; hds. in small, dense corymbs.-Barrens, Ga., Fla. and La. St. 1 to $2 f$ high. Lrs. 2 to $3^{\prime}$ by $1^{\prime}$, the upper and-lower surfaces strongly contrasted in color. Rays 7 to 10, spreading 2'. Apr.-Aug. (Silphium Ph.)

2 B. subacaùlis Nutt. Acaulescent, at length somewhat caulescent, roughish canescent; lvs. radical, lyrate or sinuate-pinnatifid, the lobes crenate-toothed; scapes eiongated, bearing a single head.-Ga. and Fla. May, Jn.

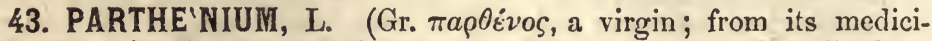
nal efficacy.) Heads many-flowered; ray-flowers 5 , somewhat ligulate, fertile; disk flowers tubular, sterile; involucre hemispherical, scales in 2 series, outer ovate, inner orbicular; receptacle conical, chaffy; achenia 5 , compressed, cohering with 2 contiguous pales.-American horbs with alternate lvs.

1 P. integrifòlium L. St. pubescent, striate, erect; lvs. hispid-scabrous, lanceovate, coarsely dentate-crenate, coriaceous, lower petiolate, upper sessile, hds. many, tomentous, corymbed.-2f Dry soils, Mid. and W. States. St. rigid, 3 to 
5f high. Radical petioles If long. Lrs. 4 to $12^{\prime}$ long, $\frac{1}{2}$ as wide. Hds white with 5 very short cucullato rays. Jl.-Sept.

2 P. Hysteróphorus L. Annual, puberulent, decumbent, lower lvs. bipinnatifid, upper linear; hds. numerous, very small, in a diffuse panicle.-River banks, Fla. to La.

44.' I'VA, L. Marsh Elder. Highwater Shrub. Heads discoid, monœcious, involucre of 3 to 9 scales, distinct or partly united; marginal flowers 1 to 5 , fertile, the others sterile; receptacle cliaffy; achenia obconic, obtuse; pappus none.-Herbs or shrubs. Lower lvs. opposite.

1 I. frutéscens L. Shrubby; lvs. fleshy, lanceolate, coarsely serrate; upper lance-linear, entire; hds. axillary; scales 5, distinct, rounded; ach. 5.-Borders of salt marshes, Mass. to Fla., common. St. 3 to $8 f$ high, with numerous opposite branches and lvs. Hds. small, green, drooping on short stalks, in leafy, paniculate racemes. Jl.-Sept.

2 I. ciliàta Willd. Annual, hairy; lvs. ovate, acuminate, petiolate, coarsely toothed, upper lance-ovate; hds. spicate; scales 3 , distinct, roundish, ciliate; ach. 3.-Wet grounds, Ill. to La. A coarse plant of no beauty, 3 to $7 \mathrm{f}$ high. Lvs. 3 to $4^{\prime}$ long. Spikes dense, 3 to $5^{\prime}$ long, numerous, panicled, green, liko an Ambrosia. Aug.-Oct.

3 I. imbricària Walt. Herbaceous, terete, glabrous; lvs. fleshy, linear-lanccolate, 3-nerved, tapering to the sessile base; hds. axillary; invol. of 6 to 9, fleshy, obtuse, rounded scales in 2 rows, their margins scarious, lacerated; ach. 2 to 4.\& Sea coast, N. Car. to Fla. Plant 1 to $2 \mathrm{f}$ high. Lvs. 1 to $2^{\prime}$ long. Hds. drooping, on short pedicels, in leafy clusters or racemes. J1-Oct.

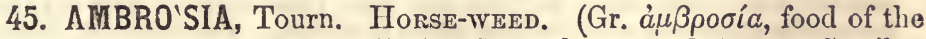
gods; a term strangely applied). Hds. heterocephalous. Sterile: involucre of several scales united into a depressed, hemispherical cup, many-flowered: anthers approximate, but distinct; receptacle naked. Fertile; involucre 1-leaved, entire or 5-toothed, 1-flowered; corolla 0 ; styles 2 ; stamens 0. - Herbaccous plants with mostly opposite lvs. and unsightly flowers.

$\S$ Sterilo heads sessilc, densely spicnte, chaffy. Leaves alternate...................... 4 $\S$ Sterile heads pedicellate, racemed, not chaffy. -Leaves opposite......................

-Leaves alternate.............................. 2,3

1 A. trífida I. Hairy, rough ; lvs. 3-lobed, serrate, the lobes oval-lanceolate, acuminate; $f r$. with 6 ribs ending below the conical summit.-1) A very tall, herbaceous plant, along streams, \&c. Can. and U. high, erect, branching, furrowed. Ieaves opposite, in 3 large, deep lobes, with long points and close serratures. Flowers mean and obscure, in slender, leafless, terminal racemes, the fertilo in axillary glomerules. $\Lambda \mathrm{ug}$. - It is greedily eaten by horses.

B. INTEGRIFOLIA. Lvs. ovate, acuminate, serrate, bristly on botl sides, ciliato at base, often some of them 3-lobed. (A. integrifolia Muhl.)

2 A. artemisizfòlia L. HIOG-WEED. Lvs. twice-pinnatifid, nearly smooth; petioles ciliate; rac. terminal, panicled; st. virgate.-1) A. common and troublesomo weed of the gardens, fields, \&c. (Can. to Ga.) far moro worthy of its English than its Latin namo. Stem 2-3f high, branching, pubescent when young. Leaves with segments acuto and parallel. Earren flowers small, green, in terminal racemes, the fertile ones sessile about the axils of the upper leaves. Aug., Sept. (A. elatior $\mathrm{Ph}$.)

3 A. psylostachya DC. Whitish with appressed woolly hairs, branched; lvs crowded, rigid, the lower opposite, bipinnatifid, upper lanceolate, sessile, pinnatifid; sterile hds. in spicate racemes, fertile clustered at the base of the sterile spikes, in the axils of the upper leaves; fr. hairy.-(1) Prairies, Wis. to Tex Stem 1-5f high, at length very branching and leafy. Aug., Sept. 
4. A. bidentàta $\mathrm{Mx}$. Very hirsute; st. branching; branches simple; lvs. crowded, mostly alternate, closely sessile or partly clasping, undivided, oblong, with a single tooth or short lobe on each side near the base; sterile hds. densely spicate, fertile axillary; fr. 4-angled, acutely pointed, the 4 ribs produced in 4 short spines. -1) Prairies, Ill. to Lav Stem 1-3f high, with numerous leaves and very dense, terminal spikes. Jl.-Sept.

46. XAN'THIUM, Tourn. Clot-weed. Heads heterocephalous. Sterile, in globous heads ; scales distinct, in one row; anthers approximate, but distinct; receptacle chaffy. Fertile: involucre 2-leaved, clothed with hooked prickles, 1 or 2 -beaked, enclosing 2 flowers; stamens 0.-(1) Coarse weeds with alternate lis.

I X. Strumarium L. Rough, unarmed, branching; lvs. cordate, lobed, 3-veined, unequally serrate; fr. elliptical, armed with uncinate, stiff thorns, and ending with 2, spreading; straight horns. - A coarss, rough plant, in old fields, \&c., $\mathrm{N}$. Eng. and Mid. States. Stem branched, bristly, spotted, 2-3f high. Leaves large, on long stalks, rigid. $\hat{\delta}$ Fls. fow together, terminal, globular, green; 우 in sessile, axillary tufts. Fruit a hard, 2-celled burr, near an inch long, covered with stiff, hooked prickles, which, like those of the common burdock, serve to disperse the seeds. Aug. - Variable; fruit more than $1^{\prime}$, or less than $1^{\prime}$ in length; thorns very close or somewhat scattered; horns spreading or incurved. (X. echinatum Murray.)

2 X. spinòsum L. Whitish-downy, armed with triple, slender, subaxillary spines, spines at base of the leaves triple, slender; lvs. ovate-lanceolate, cuneate at base, petiolate, 3-lobed or dentate or entire, under surfaco and veins above whitish, twice longer than the spines; invol. oblong, with slender, uncinate thorns.Roadsides and fields, Mass. to Penn. and Ga. Plant about if high, very conspicuously armed with straw-colored spines $\frac{3}{4}-1^{\prime}$ long. Heads sessile, sterile in the upper, fertilo in the lower axils. Sept.-Nov.

47. MELAN'THERA, Cass. (Gr. $\mu \varepsilon \dot{\lambda} \alpha$ s, black, Lat. anthera, anther.) Heads discoid; flowers all tubular; $\not ;$ scales in 2 subequal scries; receptacle chaffy, the pales partly investing the flowers; achenia short, truncate, angular; pappus a few minute caducous awns or bristles. - 2f IIerbs rough, with square stems, opposite, petioled, 3veined lvs. and long peduncled hds. Cor. whitc. Anth. black, tipped with a white appendage.

M. hastàta Mx. Lvs. hastately 3-lobed, acuminate, dentate, on slender petioles; scales ovate-lanceolate, acuminate, pales rigid, eusp-pointed.-Dry soils, S. Car to Fla and La. Sts. 3 to of high, beautifully variegated with purple, the branches slender, erect, ferw-flowered. Lvs. deep green, very rough, 4 to $6^{\prime}$ long, the upper smaller. Hds. near $6^{\prime \prime}$ broad, of stiff scales and singularly contrasted, colors.-J1.-Sept.

48. ZIN'NIA, L. (To John Godfrey Zinn, a German botanist, 1557.) Heads radiate; rays $q$, disk tubular, $\not{\gamma}$; scales of the involucre oval, margined, imbricate; receptacle chafty, conical; pappus of the disk of 1 or 2 erect, flat awns.-(1) American herbs, with apposite, entire lis. and solitary terminal hds. Rays bright colored, showy.

Z. multiflòra L. Lvs. ovate-lanceolate, abrupt at base, scarcely petioled; hds. on peduncles as long as the lvs.; pales obtuse, entire; ach. of the disk with one awn.-Fields and waysides, Ga., Fla., to Tex. Sts. $6^{\prime}$ to $2 f$ high, simple or nearly so. Lvs. 1 to $2^{\prime}$ long, rather obtuse. Ped. enlarged upwards, hollow. Rays about 12, oval, scarlet within, yellowish without. May, Jn. §

2 Z. élegans L. Lvs. ovate, cordate, sessile-amplexicaul; hds. on ped. longer than the lvs.; pales serrated; ach. of the disk with 2 awns. -Gardens; Plant tall, elegant and showy, with brilliant fls. of varying colors, as orange, scarlet, crimsou, purple, violet and white. Jl., Aug. † Mexico. 
3 Z. pauciflorum, with bright yellow flowers is sometimes cultivated.

49. HELIOP'SIS, Pers. OX-EYe, (Gr. $\eta \lambda \iota s$, the sun, $\delta \psi \iota s$, appearance; flowers radiant like the sun.) Hds. radiate; involucre imbricate, with ovate, subequal scales; rays linear, large, $ᄋ$; disk $\not{q}$; receptacle chaffy, conical, the pales lanceolate; achenia 4 -sided; pappus $0 .-24$ Lvs. opposite. Hds. large. Fls. yellow. (Helianthus, L.)

H. lèvis Pers. St. smooth; lvs. ovate-oblong, coarsely serrate, petiolate, 3veined, smooth beneath, upper ones usually lanceolate, lower ones more or less truncate at base.-A large, symmetrical plant, in hedges and thickets, U. S. St. angular, striate, di- or trichotomously branched above, 3 to $5 \mathrm{f}$ high. Lvs. 2 to $6^{\prime}$ by 1 to $4^{\prime}$, acute, distinctly 3 -veined. Branches thickened at the summit, each terminating with a large, solitary, yellow head. Rays lanceolate, broad at base and obtuse at summit. $\mathrm{Jn}$., Jl.

$\beta$. GR.́cilis. Small and slender; lrs. scabrous, ovate-lanceolate, acute at base. - 2f high. (H. gracilis, Nutt.)

$\gamma$. SCÀBRA. St. and lrs. scabrous and yellowish-green; lvs, somewhat deltoid, distinctly truncate at base.-6f ligh. Common in Ind. (H. scabra, Hook.)

50. TETRAGONOTHE'CA, Dill. (Gr. $\tau \varepsilon \tau \rho a$, four; yó $v v$, angle; $0 \dot{\eta} \kappa \eta$, envelope.) Heads radiate; involucre double, the outer of 4 leafy bracts united at base, the inner of 8 small scales similar to the chaff of the conical receptacle; achenia smooth, truncate, destitute of pappus. $-2 f$ Herb clothed with viscid hairs, opposite lvs., with yellow-Howered, large hds.

T. helianthoìdes L. Sandy soils, Va. to Fla. and Ala. A stout, coarse, unsightly herb, $2 \mathrm{f}$ high. Lvs. ovate, sessile, repand-toothed, 3 to $5^{\prime}$ long. IIds. 1 or few, on long peduncles, the rays spreading nearly $3^{\prime}$. Cor. strongly veined. Apr.-Jn.

51. eChina CeA, Mœnch. Purple Cone-flower. the hedgehog; from the character of the pales.) Heads radiate; involucre, scales in 2 rows; ray flowers neutral ; disk flowers $\Varangle ;$ receptacle conic, with rigid, mucronate pales; achenia 4-angled; pappus $0 .-24$ Lvs. alternate. Rays purple, pendulous. (Rudbeckia, L., Nutt.)

1 E. purpùrea Moench. Very rough; lower lvs. broad-ovate, 5-veined, atten wato at base, remotely toothed; cauline lanceolate-ovate, acuminate, nearly entire; rays 12 to 15, very long, defloxed, bind.-Thickets and barrens, W. and S. States. Plant slowy, 4 f high, branched. Lrs. 4 to $8^{\prime}$ long, rough with short, stiff bristles, 3-reined. Hds. large, solitary, on long ped. Disk thickly beset with the stiff, pointed, brown chaff.' Rays 2 to $3^{\prime}$ long, pendulous, rarely varying to white. $\dagger$ Jl. -Sept.

2 E. angustifòlia DC. St. hispid, subsimple, slender, naked above; lvs. entire, hispidly pubescent, 3-veined, lower lanceolate, petiolate, upper lance-linear, sessilo; seales in about 2 rows, short; rays 12 to 15 , slender, drooping.-Prairies and marshes, Ill., Mo. to Tes. Plant of a moro slender habit than the last, 2 to $3 f$ high. Hds. on long, naked ped. Rays 1 to $2^{\prime}$ long, purple, varving to white. Disk brown. May-Jl.

52. RUDBECKI'A, L. (To the celebrated Olaus Rudbeck, Professor of Botany, at Upsal, Sweden.) Heads radiate ; involucre scales nearly cqual, leafy, in a double row, 6 in each ; ray-flowers neutral ; disk perfect; receptacle conic or columnar, with unarmed pales or chaff; achenia 4-angled; pappus none, or a lacerate or toothed margin. $-2 f$ Lvs. alternate. Hds. large. Rays yellow.

§ Rays large, drooping. Disk columnar, at least in frnit...................... 1, 2

\$ Rays spreading. Disk dark purple, conical or rounded. $\left(^{*}\right)$

* Leaves deeply lobed ar parted, the upper undivided........................ 3,4

* Leaves undivided. - Pales of tho disk whitish-dewny............................. 5,6

- Pales dark purblo as well as tho diowers.................. Nos. $7-9$ 
1 R. nitida Nutt. Glabrous, shining, subsimple, lvs. thick, lanceolate, acute, the lower subserrulate, petiolate, upper sessile or clasping; hds. few or solitary, with long, drooping rays; pappus coroniform, lacerate at summit.-Ga., Fla., to La. $\mathbf{\Lambda}$ handsome herb, 3 to $5 \mathrm{f}^{\circ}$ high, in swampy thickets. Lvs. with prominent veins and veinlets. Hds. on long naked peduncles. Rays 9 to 12 , nearly $2^{\prime}$ long. Disk dark purple, oblong-ovate or spicate in fruit. Jn., Jl.

2 R. laciniàta L. Glabrous; lower lvs. pinnate, segments 3-lobed, upper ones ovate; pappus crenate.-In the edges of swamps and ditches, Can. and U.S. A tall, showy plant, resembling Helianthus, from which, however, it is readily distinguished by its conical, at length ovate disk. St. round, branching, 6 to $8 \mathrm{f}$ high. Lrs. alternate, ample, rough, upper ones generally ovate, the rest variously divided, toothed or cut, petiolate. Fls. large, terminal. Rays $1 \frac{1}{2}$ to 2 long, oblanceolate, bright yellow, spreading or drooping. Aug. (R. lævigata $\mathrm{Ph}$.)

3 R. subtomentòsa $\mathrm{Ph}$. St. branching, tomentous-pubescent; Ivs. petiolate, hispid-scabrous above, softy subtomentous beneath, serrate, the lower deeply 3lobed or 3-parted, upper undivided, ovate, acuminato; hds. corymbous; scales numerous, spreading; rays 10 to 15 , spreading; disk at length globous; pales bearded, shorter than the corollas. - Prairies, \&c., Western and S. W. States. St. 3 to $5 \mathrm{f}$ high, angular, marked with brown lines. Lvs. 3 to $5^{\prime}$ long, on petioles 1 to $24^{\prime \prime}$ long. Rays orange yellow, about $1^{\prime}$ long. Jl., Aug.

4 R. tríloba I. Hirsute; branches panicled spreading; lower cauline lvs. mostly 3-lobed, coarsely serrate, acuminate; upper ovate lanceolate somewhat clasping, serrate or entire; radical ones ovate or oval, obtuse, crenate-dentate or incisely lobed, petiolate; hds. rather small, disk dark purple; at length oroid; rays 8 , broad-oval, rather longer than the linear, reflexed scales.-Fields, Mid. and W. States. A handsome species, 2 to $4 \mathrm{f}$ ligh, very branching. Lvs. 2 to $4^{\prime}$ long, 3-veined. Rays deep yellow, 6 to $10^{\prime \prime}$ long, $\frac{2}{3}$ as wide. Chaff cuspidate-awned at the summit. Aug., Sept.

5 R. móllis Ell. Soft-woolly or tomentous all over; lvs. oblong, sessile or clasping; scales linear lanceolate, reflexed; rays 15 to 20 , elongated; disk dark purple except the canescent pales. W. Ga. An interesting species, confined as yet to a narrow limit. Plant whitened with down, 2 to $3 f$ high. Irs. small. Hds. large; rays an inch long. Pappus almost none. Aug.-Oct.

6 R. Heliópsidis Torr. \& Gr. Slightly downy; lvs. ovate or oval, 5-veined, mostly obtuse, petiolate; scales obtuse, squarrous; rays 10 to 12 ; disk conical, dark purple except the downy canescent pales.-Barrens, W. Ga. and Ala. Plant 1 to $2 \mathrm{f}$ high. Lrs. 2 to $3^{\prime}$ long, the lower on long petioles. Pappus scarcely any. Aug., Sept.

7 R. hirta L. Very hirsute or hispid; st. simple or somewhat branched; ped. naked; lvs. ovate-spatulate, 3-veined, petiolate, mostly entire, tho upper ones sessilc, ovate-lanceolate; invol. scales numerous, narrow, imbricated in 3-rows; rays spreading, oval; pales bearded.-A showy plant in dry soils, Can. W. to Fla., rarely in N. Eng. Sts. subsimple or branching from the base, each branch leafless towards the summit, and bearing a large head with 12 to 15 bright yellow rays. These are an inch long, and surround a broadly conical disk of dark brown chaff and flowers. + Jl., Sept.

8 R. fúlgida Ait. St. hirsuto with rigid hairs; branches slender, naked above: lvs. strigous-pubescent, remotely dentate, radical petiolate, ovate, 5-veined, cauline lance-oblong, tapering to the sessile, subclasping base; scales oblong, spreading, as long as the spreading rays; pales glabrous, linear-oblong, obtuse.-Mountains, Penn. to Ohio and $\mathrm{Ga}$. St. 1 to $3 \mathrm{f}$ high. Rays 12 to 14, scarcely longer than the leafy involucre, deep orango-yellow. Jl.-Oct. $f$ (R. chrysomela Mfx. R. spatulata $\mathrm{Ph}$.)

9 R. speciòsa Wender. St. hispidly hirsute; branches slender, clongated, naked above; lvs. scabrous-pubescent, strongly dentate acuminate, radical ovate, 5-reined, on long petioles, cauline ovate and lanceolate, 3-veined, upper sessile; scales lance-linear, much shorter than the spreading rays; pales linear-oblong, acute.Borders of woods, IIl. (Jenney), Ohio to Penn. A large and very showy species, 2 to 4 high. Lvs. rather thin, radical, 4 to $5^{\prime}$ by 3 to $4^{\prime}$, the teeth mucronulato; 
petioles 6 to $10^{\prime}$ long. Rays about 18, oblong, linear, bright yellow. Aug.Oct. $\dagger$

53. LEP'ACHYS, Raf. Heads radiate; involucre in one series of linear scales; ray flowers few, neutral, disk perfect; receptacle columnar, chatfy; chaff obtuse, and bearded at apex; pappus 0 ; fertile achenia compressed, 1 to 2 -winged.- 4 Lvs. alternate, pinnately divided. Hds. of fls. yellow, with long, drooping rays.

I. pinnàta Torr. \& Gr. Scabrous; lvs. all pinnate, the divisions 3 to 7, some of the lower ones 2-parted, the rest undivided; rays elongated.-In dry soils, Western N. Y., W. and S. States. St. 2 to $4 \mathrm{f}$ high, slender, furrowed and hispid. Hds. very showy. Rays yellow, about $2^{\prime}$ in length, pendulous, the disk ovate, purple. Jn.-Sept. (Rudbeckia Mx. Obeliscaria Cass.)

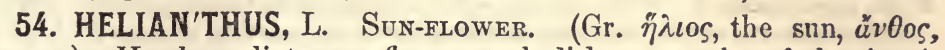
flower.) Heads radiate, ray-fls. neutral, disk $\Varangle ;$ scales of the involucre imbricated in several series; receptable flat or convex, the chaff persistent, embracing the achenia ; pappus of 2 chaffy awns, deciduous ; achenia compressed or 4-sided, not margined.-Herbs mostly 24 , rough. Lvs. opposite, the upper often alternate, mostly tripli-veined. Rays yellow, disk yellow or purple.

$\S$ Disk (its corollas and pales) dark purple, mostly conrex. (a)

a Herbs annual. Leaves chiefly alternate....

Nos. 1,2

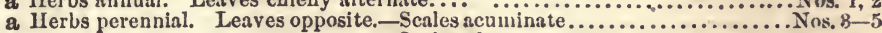

$\S$ Disk (its corollas and pales) yellow. (b)

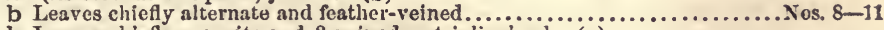

b Leaves chiefly opposite and 3-veined or tripliveined. (c)

c Scales erect, closely imbricated.-Plants green, rough................ Nos. 12,18

- Plants whitish, downy................... Nos. 14, 15

c Scales loosely spreading. Heads large, 9 to 15 -rayed. (d)

d Scales lance-linear, longer than disk. Leaves thin................ Nos. 16, 17

a Scales lance-ovate, as long as the disk. Leaves thick............... Nos. 18-21

c Scales loosely spreading. Heads small, 5 to s-rayed........................... $22-25$

1 H. ánnuus I. Erect, stout; lvs. all cordate, 3-veined, only the lowest opposite; ped. thick; hds. large, nodding; ach. glabrous.-This stately annual is from S. America. It grows in any soil, but its magnitude is in proportion, varying from $2 \mathrm{f}$ to 10 , or even $15 \mathrm{f}$. The cnormous size of the flowers with their broad rays of brilliant yellow aro too well known to require description. A variety occurs with tho flowers all radiate. Jl., Aug.-An edible oil has been expressed from tho seeds.

2 H. débilis Nutt. Decumbent, slender; lvs. ovate, serrulate, petiolate, mostly alternate; hds. small, solitary, pedunculato; scales narrow, slender-pointed; ach. pubescent.-(1) Fla., La. (Not within our limits?). Sts. 1 to $2 \mathrm{f}$ long. Hds. half an inch diam. Rays about 12.

3 H. Rádula Torr. \& Gr. Erect, hirsute, simple, bearing a singlo head; lvs. sessile or ncarly so, roundish obovate or ovate, obtuse, opposite, crowded below; scales and pales lanceolate, acuminate, erect, dark purple; rays 7 to 10 , rarely none. - 2 Barrens, Ga., Ala., Fla. Sts. often clustered, 1 to $3 f$ high. Lvs. very rough on the upper surface. Hds. near $1^{\prime}$ diam., disk dark purplo. Aug., Sept. $f$ (Rudbeckia, Ph.)

4 H. heterophýllus Nutt. Slightly hispid, slender, bcaring a single head; lvs. opposite, entire, subsessile, the lower oval, upper linear-lanceolate, scales acuminate, erect, ciliate; pales acute; rays 12 to $18 .-2 f \mathrm{~N}$. Car. to Fla. and La. ${ }^{-S t} 1$ to $2 f$ high. Hds. $6^{\prime \prime}$ diam., rays expanding $2 \frac{1^{\prime}}{2}$. Aug., Sept.

5 H. angustifòlius $\mathrm{I}$. Erect, slender, scabrous or hispidly lirsute; lvs. scssile, lance-linear, tapering to a long point, 1-veined, rigid, opposite, the upper often alternate, subdenticulate, often revoluto; hds. pedunculate, few; scales lancelinear, the long point spreading; pales linear, 3-tonthed.-Sandy or rocky places, N. J., Ky., and S. States, comrnon. St. 2 to $3 f$ high, subsimple. Lvs. 2 to $E^{\prime}$ by 3 to $6^{\prime \prime}$, broadest at the abrupt baso. Rays 12 to 18 , expanding about 2'. Disk lowers brown at the summit. Aug.-Oct. 
6 H. rígidus Desf. St. rigid, simple or with few branches, scabrous or smocthish, nearly naked above; lvs. lanceolate, tapering to each end, petiolate, mostly opposite, tripli-veined, serrulate or entire, rigid, scabrous both sides; hds. few; scales in many rows ovate, acute, regularly imbricate, shorter than the disl; pales obtusish.-Prairies, \&c., Wis. (Lapham), to Mo., La., \&c. Plant 2 to $4 f$ high. Lis. 3 to $6^{\prime}$ by $\frac{1}{2}$ to $I^{\prime}$, very rough with papillous hairs, but less so than $H$. diraricatus. Rays 12 to 20, expanding 2 to $3^{\prime \prime}$, light yellow. (H. scaberrimus Ell.)

7 E. atrorùbens L. St. with few long, naked peduncles above, hirsute below; lvs. ovate, or oval, obtusish, abruptly contracted into winged petioles, subserrate, rough or hispid, 3-veined; scales obovate or oblong, obtuse, 3-veined, about equaling the disk; pales obtusish.-Dry soils, Va. to Fla. and Ark. St. 2 to 4 f high. Lvs. mostly near the base, large. Hds. small, few, with 12 to 15 rays, 9 to $10^{\prime \prime}$ long. Aug.-Oct.

8 E. gigánteus L. St. rough, hairy lvs., alternate (the lowest opposite), lanceolate, acuminate, serrate, scabrous, obscurely 3-veined, tapering at baso into short, ciliate, winged petioles; scales lanceolate-linear, ciliate; pappus of 2 short, slightly fringed scales.-Can. to Car. and $\mathrm{Ky}$., in low grounds and thickets. Stern $4-8 \mathrm{f}$ high, purplish, branching above into a corymbous panicle of large, yellow flowers. Leaves $2-5^{\prime}$ by $\frac{1}{2}-1^{\prime}$, opposite or alternate in various degrees. Rays $12-20$. Variable.

" $\beta$. A (T. \& G.)

9 I. tomentòsus Mx. St. stout, pubescent, branched above; lvs. mostly alternate, acuminate, nearly entire, scabrous above, tomentous or nearly glabrous beneath, lower ones ovate, petiolate, upper long-lanceolate, subsessile; hds. long-pedunculato; scales lance-linear, long-acuminate, villous, squarrous; chaff 3 -toothed, lirsute at summit.-Dry soils, Ill. to Ga. Plant 4 to $8 f^{\prime}$ high, with ample lvs. and fls. Lvs. 6 to $12^{\prime}$ by 2 to $6^{\prime}$, some of them tripli-veined. Rays elliptical lanceolate, about $15^{\prime \prime}$ long. Aug.-Oct. $\dagger$

3. Lvs. oval, mostly opposite.-Ga. (H. spatulatus Ell.)

20 H. grosse-serràtus Martens. St. smooth and glaucous; lvs. mostly alternate, lanceolate, or lance-ovate, long-acuminate, sharply serrate, scabrous above, hoary and softly pubescent beneath, abruptly contracted into naked petioles; scales lance-subulate, loosely imbricated, sparingly ciliate, as long as the disk.-Ohio, Ind., Ill., to La. Allied to H. giganteus. St. 4 to $6 f$ high. Lvs. 6 to $9^{\prime}$ by 1 to 2', broadest near the base, lower ones rather coarsely serrate. Rays 15 to 20 , cipanding near 3'. Aug., Sept.

11 H. tuberòsus L. Jerusalex ARTichoKE. Root bearing oblong tubers; lvs. 3-veined, rough, lower ones opposite, cordate-ovate, upper ovate, acuminato, alternate; petioles ciliate at base. - 2f Native of Brazil. The plant has been cultivated for the sake of its tuberous roots, which are used for pickles. It is naturalized in borders of fields, hedges, \&c. Sept. $\S \ddagger$

12 H. lætiflòrus Pers. St. rough and branched above; lvs.oval-lanceolate, acuminate, serrate, tripli-veined, ver $\bar{y}$ rough on both sides, on short petioles, upper ones often alternate; scales ovate-lanceolate, ciliate, appressed, a little shorier than the disk; chaff entiro or 3-toothed; rays 12 to 20.-Barrens, \&c., Ind., Ohio (Torr. \& Gr.) A rough, but showy plant, 3 to 4 f high. Lvs. thick, 5 to $8^{\prime}$ by $1 \frac{1}{2}$ to $2 z^{\prime}$. Rays nearly $2^{\prime}$ in length. Disk yellow. Aug.-Oct. $\nmid$

13 H. occidentàlis Riddell. St. slender, simple, nearly naked above; lvs opposite, oval, scabrous, obscurely serrate, contracted at base into long, hairy petioles, upper ones small and few, entire; hds. pedunculate; scales lance-oval, appressed. Sand prairies, W. States. St. 3 to $5 \mathrm{f}$ high, scape-like, slender. Lvs. 3 to 5 ' by 1 to 2 , upper ones 1 to $2^{\prime}$ long. Hds. few, middle size. Rays 12 to 15 , light yellow. JL-Sept. $\uparrow$

14 H. móllis Lam. St. villous; lvs. ovate, acuminato, sessile, cordate and clasping, entire or subserrate, tomentous canescent, opposite, upper ones sometimes alternato; scales lanceolate, villous canescent; pales entire, acute and canescent above. Prairies and barrens, Ohio, Ind., Mo., common. A hoary and villous speeies, 2 to 4f high, nearly simple. Lrs. 3 to $5^{\prime}$ long, $\frac{1}{2}$ to $\frac{3}{4}$ as wide. Rays 15 to $25, \frac{1}{2}$ to $\mathbf{1}^{\prime}$ by $1^{\prime}$. Jl.-Sept. (H. canescens Mx.) 
15 H. cinèreous. $\beta$. Sullivantir Torr. \& Gr. Rough, cinereous-pubescent; st. virgate, somewhat naked and branched above; lvs. opposite (the upper often alternate), ovate-oblong, narrowed to the sessile base, the lower to a winged petiole; scales lanceolate, canescent, pales pointed, with 2 lateral teeth.-Ohio (Suliirant). St. 2 to $3 \mathrm{f}$ high. Hds. as large as in No. 14.

16 H. decapétalus L. Lvs. opposite, ovate, acuminate, irregularly toothed, thin, 3-veined, scabrous above, smooth or nearly so beneath, on winged petioles; scales lanceolate-linear, subciliate spreading, nearly equal; rays 9 to 12, palo yellow.Copses, along streams, Can., N. Eng. and Middle States. St. 3 to 4 f high, purplish. Invol. varying in all degrees of leafiness between the present form and the variety following. Aug. $\dagger$

$\beta$. FRONDOsus. Outer scales larger and leaf-like. (H. frondosus L.)

17 E. tracheliifolius Willd. Lvs. opposite, those of the branches mostly alternate, thin, scabrous both sides, tripli-veined, appressed-serrate, acuminate, petiolate, lower ones ovate, middle lance-ovate, upper lance-linear; scales lance-linear, attenuate-acuminate, longer than the disk, loosely spreading, ciliate; chaff slightly 3 toothed; rays 12 to 15. - Tall, handsome, in thickets, \&c., Ohio to Ill. and Tenn. St. purplish, 3 to $8 \mathrm{f}$ high. Lvs. 3 to $6^{\prime}$ long. Hds. middle size, at top of the slender, suberect branches. Rays expanding 2 to $3^{\prime}$.

18 H. doronicoìdes Lam. St. branched, rough or hirsute above; lvs. opposite, petiolate, t7te upper alternate and subsessile, ovate and ovate-lanceolate, acuminate, tripli-veined, serrate, very scabrous above, smooth and pubescent beneath; scales lance-linear, ciliate, longer than the disk; rays 12 to $15 .-\mathrm{W}$. and S. States. Also at Ponghkeepsie, N.Y. (W. R. Gerard.) St. $4-7$ f. Lvs. 3 to $10^{\prime}$ by 1 to $3^{\prime}$; petioles $\frac{1}{4}$ to $1^{\prime}$ long. Rays very showy, 15 to $20^{\prime \prime}$ by 4 to $6^{\prime \prime}$. . Jl.-Sept.

$\beta$. PLENA-FLORA, Fls. all radiate.-Gardens. A handsome flower, somowhat like a yellow Dahlia. $\ddagger$

19 H. strumòsus L. St. smooth below, scabrous above; lvs. ovate-lanceolate short petioled, all similar, acuminate, finely serrate, scabrous above, smooth os tomentous-canescent beneath; hds. fow, about 10-rayed; scales ciliate, equaling the disk, squarrous-spreading at tip.-2f Grows in swamps, \&c., Can. and U. S. St. 3 to $5 \mathrm{f}$ high, erect, branching above, Lvs. petiolate, with an acute point and close serratures, the lower surface varying in the degree of pubesconce. Rays bright yellow, an inch or more in length. Scales hairy. Jl.

20 H. hirsùtus Raf. St. simple or dichotomous above, scabrous, hirsute; lvs. opposite, petiolate, subserrate, 3-veined, ovate-lanceolate, obtuse at base, acuminate, very scabrous above, hirsute beneath; scales ovate-lanceolate, acuminate, hirsute, as long as the disk; rays 11-15.-Dry soils, Western and Southern States. Stem 4-7f high, with irregular, alternate branches. Leaves $3-10^{\prime}$ by $1-3^{\prime}$, petioles $\frac{1}{2}-1^{\prime}$ long. Rays very showy, $15-18^{\prime \prime}$ by $4-6^{\prime \prime}$. Jl.-Sept. (H. diversifolius Ell.)

B. PUBESCENS. Lrs. tomentous beneath, subsessile. (H. pubescens Hook.)

21 H. divaricàtus I. St. smooth, branching or simple; lvs. nearly opposite, sessile, ovate-lanceolate, 3-veined, scabrous above, smooth beneath; panicle trichotomous, slender, fow-flowered.-Rocky woods, brook-sides, U. S. and Brit. Am. Stem $5 f$ high, glaucous. Leaves rather abrupt at base, tapering to a long, acute point, with obtuse serratures. Flowers large, although small for the genus, few, yellow and showy. The panicle is either 2 or 3-forked. Aug., Sept.

3. SCABERRIMUS. St. subsimple; lvs. thick, exceedingly rough and rigid; opposite or ternately verticillate.-Barrens, West.

22 H. microcéphalus Torr. \& Gr. St. glabrous; lvs. opposite, thin, oblong-lanceolate, acuminate at each end, petiolate, roughish above, downy beneath; hds. very small; scales with slender, spreading points; rays 5 to 7.-Thickets, W. Can., W. States, to La. St. 3 to $6 \mathrm{f}$ high, fork-branched, or sometimes irregularly. Lrs. 4 to $5^{\prime}$ long. Hds. 3 to $4^{\prime \prime}$ diam., rays spreading $1 \frac{1^{\prime}}{2}$. Jl.-Sept.

23 H. Schweinitzii Torr. \& Gr. St. pubescent, with appressed, bristly hairs; lvs: rough above, densely tomentous-canescent beneath, otherwise as in No. 22.-N. Car. in the upland counties (Curtis). Similar to H. microcephalus, except in its rough and downy clothing:

24 E. lævigàtus Torr. \& Gr. "Smooth throughout; st. slender, nearly simple; 
hds. small, but larger than in No. 22. Charaoter otherwise as in that species. Alleghanies of $\mathrm{Va}$ and Car.

25 H. longifòlius $\mathrm{Ph}$. Very smooth, often clustered; lvs. chiefly opposite, long. lance-linear, acute, entire, obscurely 3-veined, sessile, the radical somewhat serrate and petioled; scales ovate, acute, the outer with spreading tips; rays 8 to i0, short.-Western Ga. St. 4 to $7 \mathrm{f}$ high, smooth and dark purple. Hd. not larger than in No. 22. $-\mathrm{A}$ rare species.

55. HELIANTHEL'LA, Torr. \& Gr. (Lat. diminutive of Helianthus.) Involuere, flowers and pales as in Helianthus; achenia compressed, 4angled, one or more of its angles slightly winged and produced into a persistent, awn-like or chaffy appendage.-2f Lrs. scattered.

H. tenuifòlia Torr. \& G:. Rough, slender; lvs. narrowly linear; scales lancesubulate, spreading, hairy; rays 10 to 12 ; pales 3-lobed; ach. 2-toothed at the summit. Sand bills, Gadsden Co., Fla. (Chapman).

56. ACTINOM'ERIS, Nutt. (Gr. ảıтív, a ray, $\mu \varepsilon ́ \rho \circ \varsigma$, a part; partially radiate.) Heads many-flowered, ray flowers 4 to 14 , rarely 0 ; involucre scales foliaceous, subequal, in 1 to 3 series; receptacle conical or convex, chaffy ; achenia compressed, flat, obovate, mostly winged, $z$ awned. $-2 f$ Plants tall, with 3 veined, serrate lvs. Hds. corymbous. Rays when present yellow

* Stem winged with the decurrent, alternato leaves.........................Nos. 1-3

* Stem not at all winged, with mostly opposite leaves............................... No. 4

1 A. helianthoides Nutt. St. hirsute, winged except near the base; lvs. alternate, ovate-lanceolate, decurrent, acuminate, serrate, hirsute and scabrous; corymb contracted; rays 6-14, long, irregular; scales erect.-In barrens and prairies, Western States. It is a rough plant, with the aspect of a Helianthus. Stem 2-4f high. Leaves $2-4^{\prime}$ by $6-14^{\prime \prime}$, grayish. Rays $1^{\prime}$ long. Fls. all yellow. Jn., Jl. (Verbesina Mx.)

2 A. squarròsa Nutt. St. tall, winged, branching above, somewhat pubescent; lvs. alternate, often opposite, oblong-lanceolate, elongated, tapering to each acute or acuminate end, scabrous, decurrent; hds. small; scales spreading or reflexed; rays $4-8$; regular, short; receptacle very small.-Dry, alluvial soils, W. N. Y. and W. States, common. An unsightly weed, 5-10f high. Leaves 6-14' by $1-3^{\prime}$, sharply serrate, especially the lower. Rays $\frac{1^{\prime}}{2}$ long. Fls. all yellow. Aug. -Oct. (Coreopsis alternifolia L.)

3 A. alba Torr. \& Gr. St. narrowly winged, rarely wingless; lvs. glabrous but rough, narrowly lanceolate, acute at each end, finely serrate; scales lance-linear, few, in about 2 rows; rays none; ach. broadly winged, with 2 spreading awns; cor. white.-S. Car., Ga. to La., common in moist, rich soils. St. 4 to $6 \mathrm{f}$ high. Lvs. 5 to $8^{\prime}$ long. Hds. in small corymbs, globular. Aug.-Oct. (A. squarrosa, B. Nutt.)

4 A. nudicaùlis Nutt. Rough, hairy; st. wingless, naked and branched above; lvs. ollong, unequally serrate, acute, closely sessile, the upper bract-like; hds. paniculatc, corymbed; scales pubescent, in 2 or 3 rows; rays 7 to 12, linear; ach. ibroad-obovate, narrowly winged.-Ga. (Feay, Pond), Fla., Ala., in sandy soil. St. 2 to 3 f high. Lvs. 2 to $3^{\prime}$ long. Ach. $1^{\prime \prime}$ long. Awns crect. Fls. all yellow. Rays 1 to $1 \frac{1}{2}$ long. Sept., Oct.

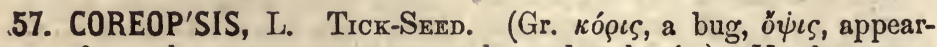
ance; from the concavo-convex, 2-horned achenia.) Heads manyflowered, radiate, rays about 8 , rarely 0 ; involucre double, each 6 to 12-leaved; receptacle chaffy ; achenia obcompressed, emarginate, each commonly with a 2-toothed, upwardly hispid pappus, sometimes with none.-Lvs. mostly opposite. Rays usually yellow; disk fls. yellow or dark purple. 
Corollas of the disk dark parple. (a)

a Ray flowers yellow with a purple base. Achenia incurved........Nos. 1, 2

a Ray flowers wholly yellow, Achenla not incurved, $2-a$ wned...... Nos. 3-5

Corollas of the disk yellow. Rays rose-colored. Leaves simple.................... Nos. 6, 7

Corollas of the disk and ray all yellow (disk brownish in No. 9). (b)

b Leaves sessile, divided often so as to appear verticillate..............Nos. $S-11$

b Leaves petiolate, never serrate,-plnnate with lance-linear segments. Nos. 12, 13 - simple, or rarely auricled below... Nos. 14-15

b Leaves petiolate, serrated. - simple; achenia awns obsolete......... Nos. 16-17

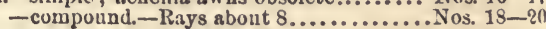

-Rays wanting...................... 21

1 C. Drummóndii Torr. \& Gr. Pubescent; lvs. pinnately divided, sometimes simple, segments (or leaves) oval, entiro; scales lanceolate-acuminate; rays unequally 5-toothed, twice longer than the invol.; ach. obovate, incurved, scarcely toothed.-1) From Texas. St. 10 to $20^{\prime}$ high. Rays large, yellow, with a purple spot at base. + (Calliopsis, Don.)

$\beta$. Atros.nguinea. A garden variety with dark orango fls. $\dagger$

2 C. tinctoria Nutt. Glabrous; lvs. alternate, radical ones subbipinnate, lfts. oblong-linear, entire, smooth, cauline subpinnate, lfts. linear; rays 3-lobed at the apex, ach. wingless, toothless.-A handsome border annual, native of the upper Missouri. St. 1 to $3 f$ high, with light, smooth foliage. Hds. with yellow rays, beautifully colored with purple at their base. Flowering all summer. $\dagger$ (Calliopsis $\mathrm{DC}$.

3 C. gladiàta Walt. Glabrous; st. terete, lvs. thickish, alternate, some of them ternately divided, tho lower lanco-oblong, long-tapering to a clasping petiole, upper lance-linear, acute; outer scales lance-ovate; ach. fringed with 2 slender awns.Moist soils in barrens, N. Car. to Fla. St. 2 to 3 f high, slender. IIds. several, corymbed; rays 3-toothed at the dilated apex, yellow; disk purple. Aug., Sept.

4 C. angustifolia Ait. Glabrous; st. square; lvs. opposite, sometimes the lower alternate, undivided, the lower spatulate, long-petiolate, upper linear, spatulate, $o b$ tuse; outer scales ovate, obtuse; ach. wing-fringed, the 2 awns very short.-Moist soils, in barrens, N. Car. to Fla. and La. Sts. slender, 2f high. Hds. several, corymbed, with the rsys 3-lobed at the dilated summit. Jn.-Sept.

5 C. CEmleri Ell. Glabrous; st. angular above; lís. opposite, or tho lower alternate, lance-ovate, narrowed to a clasping petiole, upper lanceolate; outer scales oblong, obtuse; ach. margined, ciliate, the 2 awns very short.-W. Ga. and Fla., near the Chattahoochee. Sts. $2 f$ high. Lvs. rather thick, entire, the upper always opposite. Jl., Aug.

G C. nudàta Nutt. Glabrous, rory slender; lvs. fow, terete, rush-like, alternate, the lower very long; hds. few; outer scales very short, obtuse, inner ovate, acutish; rays wedge-obovate, unequally crenato-lobed.-2f $\mathrm{A}$ curious species, in shady swamps, Ga. and Fla., near Savannah to St. Mary's and $\Lambda$ palachicola. Sts. 2 to 3 f high. Lvs. 1 to $10^{\prime}$ long. Rays somewhat fan-shaped, rose-purple, spreading $20^{\prime \prime}$. Apr.-Jn.

7 C. ròsea Nutt. St. branched; lvs. opposite, 1-veined, linear, entire, ped. short; outer scales very short; rays oblong, obscurely tridentate. - if A very delicate species in wet grounds, Mass. (Dr. Robbins), to N. J. St. slender, erect, 8 to $16^{\prime}$ high. Lvs. 1 to $2^{\prime}$ long, scarcely $1^{\prime \prime}$ wide, clothing the stem. Hds. few, small. Rays rose-color, varying to white. Disk light yellow. Jl., Aug.

8 C. senifòlia Mx. Mfinutely downy or glabrous; lvs. opposite, ternate, sessile, appearing in whorls of 6 ; lfts. ovate-lanceolate, sessile, acute, thick; scales downy, obtuso; rays oval-oblong, entire.-Sandy soils, Va., Ky. to Ga., common. St. 1 to $2 \mathrm{f} \mathrm{high,} \mathrm{angular,} \mathrm{strict,} \mathrm{slender.} \mathrm{Rays} \mathrm{bright} \mathrm{yellow,} \mathrm{l}^{\prime}$ long. Corollas of the disk yellow. Jl., Aug.

$\beta$. Stellata. Lfts. lance-linear, and even linear, mostly glabrous.-Ky. and

Tenn. Lvs. 2 to $3^{\prime}$ long. (C. stellata Nutt.)

9 C. delphinifòlia Lam. Glabrous; lvs. opposite, sessile, divided into lfts. which are each again 2 to 5-parted, segm. linear, entire, acute; disk corollas brown at summit; outer scales linear, inner ovate, all obtuse; rays acute.-Barrens, Va. to Fla. and Ala. St. 1 to $2 \mathrm{f}$ high. Lfts. 1 to $2^{\prime}$ long, 1 to $3^{\prime \prime}$ broad. Hds. small. Aug.

10 C. verticillàta L. Glabrous branched Ivs. 3-divided, closely sessile, divisions 
pinnately or bipinnately parted, segments filiform, linear, obtuse; rays acute or (in cultivation) obtuse and 2 or 3-toothed; ach. obovate, slightly 2-toothed.-2f Moist places, Md. and Western States. Stem I-3f high. Leaflets apparently verticillate in $6 \mathrm{~s}$. Heads with bright yellow rays, near $1^{\prime}$ long. Outer scales oblong-linear, obtuse, united at base. June-Aug.

11 C. palmàta Nutt. Nearly smooth; st. branched, angled and striate, very leafy to the summit; lvs. sessile, deeply 3-cleft (to below the middle), rigid, lobes linear, acutish, entire or again cleft; rays obovate-oblong; ach. linear-elliptic, incurved.-Dry prairies, W. States. Stem 1-2f high, sometimes much branched. Leaves $1-2 \frac{1}{2}^{\prime}$ long, somo of them undivided, lobes $2-4^{\prime \prime}$ wide. Heads 1 or several, with yellow rays. Outer scales linear oblong, obtuse. Jn., J. (Calliopsis, Spreng.)

12 C. trípteris L. Glabrous; st. simple, tall, corymbous at summit; Ivs. coriaceous, opposite, petiolate, 3-5-divided, divisions linear-lanceolate, entire, acute; ldds. small, on short peduncles, rays obtuse. - A tall, smooth, elegant species, in dry soils, Southern and Western States, common. Stem 4-8f high; slender, terete. Divisions of the leaves $3-5^{\prime}$ by $\frac{3}{4}-1 \frac{1}{2}^{\prime}$. Rays spreading $\frac{1}{2}^{\prime}$ long. Outer scales linear, obtuse, spreading, much smaller than tho inner. Jl.-Oct. (Chrysostemma, Less.)

13 C. grandiflòra Nutt. Glabrous; st. low, simple or branched; lvs. petiolate, lanceolate, mostly pinnately or ternately divided, segments lance-linear or linear; hds. solitary, on long peduncles, large; rays 4 to 5 -cleft at apex.-Mo. to Ala. and Tex. Plant if high. Hds. much like No. 14. J1.-Sept.

14 C. lanceolàta L. St. ascending, often branched below; lower lvs. oblanceolate, petiolate, the upper lanceolate, sessile, all entire, with scabrous margins; hds. solitary, on very long, naked peduncles; rays 4-5-toothed at apex; ach. suborbicular, with 2 small teeth. $-2 f$ Native of the Southern States. Heads showy. Rays about $8,1^{\prime}$ by $\frac{1^{\prime}}{3}$. Jn.-Aug. $\nmid$

15 C. auriculàta L. Pubescent; lower lvs, roundish-ovate, petiolate, some of them with 2 small, lateral segments at baso (auriculate), the upper oblong, nearly or quite sessile; hds. few, on long peduncles; outer scales oblong-linear.-Dry soils, Va., Ky. to Ga. and La. Plant 1 to $3 f$ high, variable. At first (May, Jn.) it has divided lvs. and very long peduncles. Later (Jl., Aug.), it is tall, the lvs. all entire, the lower having perished. Hds. similar to No. 14. May-Aug.

16 C. latifòlia Mx. Very glabrous, tall; lvs. thin, opposite, ovate, acuminate, unequally toothed, petiolate, tho upper ovate-oblong; hds. small; rays 5 to 6 , entive; outer scales 4 to 5, linear, spreading.-Mts., N. Car. to Ga. Plant with amplo lvs. and few large, yellow rays. Aug.

17 C. argùta $\mathrm{Ph}$. Smooth or nearly so; sts. strict, striate-angled; lvs. of tho stem simple, petiolate, ovate and ovate-lanceolate, acuminate, mucronate-serrate; lids. ferw, large, on slender, naked peduncles; outer scales about.8, as long as tho. inner; rays 9 to 12, 3-cleft; ach. oblong, awns obsolete.-Car. (Pursh), WV. Ga., in the upland districts. Differs much from C. aurea. St. 2 to $5 \mathrm{f}$ high. Irs. 1 to $3^{\prime}$ long. Rays spreading $1 \frac{1^{\prime}}{2}$. (Root lvs. not seen). May-Jn.

18 C. aùrea Ait. Nearly glabrous; lower lvs. pinnately divided, upper ternately, or simple; divisions ovate, lanceolate and lance-linear, acuminatc, sharply serrate; outer scales about 8 ; linear as long as the inner; rays about 8 , obtuso; ach. teeth very short. - (2) Ditches, etc., N. Car. to Fla. and La. An untidy weed, 2 to $4 \mathrm{f}$ high. Hds. small, corymbed. Ach. $2^{\prime \prime}$ long. Aug., Oct.

19 C. aristòsa Mx. Sparingly pubescent; lvs. pinnately 5 to 9-parted, segments lance-linear, incisely serrate or pinnatifid; hds. small, with conspicuous rays; outer invol. of 10 to 12 linear, green scales longer than the inner, villous at base; awns slender, spreading, about as long as the achenium.-2). Low woods, W. States. St. obtusely 4 -angled, 2 to $3 \mathrm{f}$ high. Lvs. thin, 4 to $6^{\prime}$ long, petioles $\frac{1}{2}$ to $1^{\prime}$. Rays 8, orange-yellow, expanding $1 \frac{1^{\prime}}{2}$. (C. involucrata Nutt.)

20 C. trichospérma Mx. St. glabrous, square, dichotomous; lvs. pinnately 5 to 7-parted, briefly petiolate, segm. lanceolate, inoised or serrate; scales of the outer invol. ciliate, linear, long as the inner; rays entire, large; ach. narrow-cuneate, with 2 short, stout awns.-(1) In wet grounds, N. Y., Mass. to Car. A smooth, 
branching plant, I to $2 \mathrm{f}$ high, with a panicle of large, showy, yellow heads. Lrs. mostly opposite, thin, the upper 3-cleft, subsessile. Ach. $\frac{1}{2}$ long, awns half as long. J., Aug.

21 C. discoìdea Torr. \& Gr. Glabrous, much branched, erect; lvs. ternate, longpetiolate; lfts. ovate-lanceolate, strongly dentate, hds. discoid on slender peduncles; outer involucre 3-5 linear-spatulate, leaf-like bracts; ach. linear-oblong, twice longer than the 2 erect awns which are hispid upwards. - I Ohio to La. Stem and branches purplish. Terminal leaflets $3-5$ by $\frac{1}{2}-1 \frac{1}{2}$, lateral much smaller. Heads small (3" diam.), about 30-flowered. Jl.-Sept.

58. BI'DENS, L. Burr-MARIGold, (Lat. bidens, two-toothed; the achenia have two (or more) barbed teeth.) Involucre double; scales somewhat similar, or the outer foliaceous; rays 4 to 8 (sometimes none), neutral; disk-flowers perfect; receptacle chaffy, flat; pappus of 2 to 4 awns rough backwards; achenia obcompressed, obscurely quadrangular.-Lvs. opposite, incised. Fls. yellow.

\$ Achenia linear, somewhat 4-angled, 3 to 4 -awned. Rays fow or none................... I \$chenia flattened, breadest at top, -Rays none or very few............................ 2 4 - Rays about 8 , showy, reguiar....................... Nos, 5,6

1 B. bipinnàta I. SpaNtsH Needles. Smooth, lvs. bipinnate, Ifts lanceolate, pinnatifid, rays very short or none; outer invol. the length of the inner; ach slender, elongated. - (1) Grows in waste places Conn., N. Y., west to Ill. St. 2 to 4 f high, branching, smooth. Lvs bipinnately dissected, nearly smooth. Hds. of flowers on long peduncles; each with 3 or 4 (or none) obscure, obovate, jellow rays. Jl.-Sept.

2 B. frondòsa I. Hds. discoid; outer inrol 6 times as long as the flower, is leaflets ciliate at base; lower lvs. pinnate, upper ones ternate, lanceolate, serrate; ach. 2-awned.-(1) A common weed, in moist, cultivated fields throughout Can. and U. S., often called Beggar-ticks from the 2-horned achenia which adhero to every passer-by. St. $2 \mathrm{f}$ ligh, diffusely branched. Lower 1vs. in $2 \mathrm{~s}$ or $5 \mathrm{~s}$. Ils. in clusters at the end of the branches, without rays, yellow, leafy. Aug., Sept.

3 B. connàta Willd. Hds discoid, smooth; lvs. lanceolate, serrate, stightly connate at base, lower ones mostly trifid; outer scales longer than the head, leafy; ach. with 3 awns. - (1) In swamps and ditches, Can. N. Eng., to Mo. St. I to $3 f$ high, smooth and 4-furrowed, with opposito branches. Lvs. thin, taper-pointed, often all undivided. Hds. scarcely ever with a ray. Aug. (B. tripartita, Bw.)

4 B. cérnua L. Hds. subradiate, cernwous; outer invol. as long as the flower; lvs. all simple, lanceolate, subconnate, dentate-In swamps and ditches, $\mathrm{Can}$. to $\mathrm{Pa}$. and Wisc. St. 1 to $2 \mathrm{f} \mathrm{high,} \mathrm{purplish,} \mathrm{branched,} \mathrm{round} \mathrm{at} \mathrm{base,} \mathrm{striate} \mathrm{above.}$ Branches opposite. Ivs. opposite, somewhat connate at base. Fls. yellowish green, finally drooping, generally with small jellow rays about 8 in number. Aug., Oct:

5 B. chrysanthemoides L. Rays 3 times as long as the nearly equal invol.; lvs. oblong, attenuate at each end, connate at base, dentate.-1) A low plant, with large, yellow-rayed flowers, in muddy places, Can. and U. S. Stem 6-20' high, round and smooth. Leaves smooth, with few remoto teeth, narrow, opposite, with narrow, connate bases. Flowers commonly erect, rays about 8 , large, spreading. Scarcely distinct from B. cernua. Sept., Oct.

6 B. Bécliii Torr. St. subsimple; submersed lvs. capillaceous-multifid; emersed ones lanceolate, connate, acutely serrato or lanciniate; fls. radiato; rays longer than the involucre.-24 In water, N. Y. (Sartwell), \&c. Vt. (Chandler), N. to Can. Stem 2-3f long, simple or with minute, slender branches above. Lower leaves dissected as in Ranunculus aquatilis; upper $1-2^{\prime}$ long, $\frac{1}{2}$ as wide, deeply serrate. Head solitary, terminal, yellow. July, Aug.

59. ACMEL'LA' L. (Gr. à $\mu \dot{\eta}$, a point; from the sharp taste of the foliage?) Heads radiate; involucre shorter than the disk, double, appressed, pubescent; receptacle, conical, chaffy; pales embracing the Dowers; rays about 12 , + , disk $\Varangle ;$ achenia compressed, those of the 
ray angular, mostly awnless.-(1) Herbs with an acrid taste, opposite Ivs., solitary, yellow heads. Tropical.

A rèpens Pers. St. decumbent, rooting at the lower joints, diffuse; lvs. lanceolate or oblong-lanceolate, acute at each end, petiolate, more or less serrate; hds. solitary, on axillary and terminal peduncles; scales lance-ovate; rays 10 to 12.Wet places, S. Car. to Fla. Sept, Oct. (Spilanthes Nuttallii, T. \& G.)

60. VERBESI'NA, L. CROwn-BEARD. Heads few or many-flowered; rays + , few or none, disk $\Varangle$; scales in 2 or more serics, imbricated, erect; chaff concave, or embracing the flowers; achenia compressed, 2-awned.- 4 American plants, sometimes shrubby. Lvs. often decurrent, serrate or lobed. Hds. solitary or corymbous.

1 V. siegisbéclkia Mx. St. 4-winged; lvs. opposite, ovate or lance-ovate, serrate, acuminate, triple-veined, tapering to a winged petiole, hds. radiate, in trichotomous cymes; rays 1 to 5 ; ach. wingless; fls. yellow.-Roadsides and dry fields, W. and S. States, common. St. 4 to $6 f^{\prime}$ high. Lvs. 5 to $8^{\prime}$ by 3 to $4^{\prime}$, thin. IIds. about 25 -flowered, with yellow corollas, and yellow, lanceolate rays, the latter about $9^{\prime \prime}$ long. Aug., Sept. (Coreopsis alata Ph. Actinomeris alata Nutt.)

2 V.•Virginica L. St. narrowly-winged, pubescent above; lvs. alternate, lanceolate or lance-ovate, subserrate, scabrous, acute or acuminate, tapering to the sessilo base; lower ones decurrent; corymbs compound, dense; rays (oval) and disk-fls. white; ach. winged.-Dry woods, Penn. to La. Stem 3-5f high, and leaves beneath often more or less tomentous. Heads about 20 -1lowered, the 3 or 4 rays scarcely $\frac{1}{2}$ long. Aug. Sept.

3 V. sinuàta Ell. St. wingless, striate-angled, pubescent; lvs. alternate, ovate, acumirate, contracted to a long, slender base, irregularly repand-toothed and some of them sinuate-lobed or pinnatifid; hds. corymbous; rays 3 to 5 , oval, and with the disk white; ach. broadly winged.-Sandy soil, S. Car., Ga. (Feay), Fla. St. 2 to 4 high, with ample, coarse lvs. Hds, similar to the last, about 12 -flowered. Lvs. feather-veined. Sept.-Nov.

61. DYSO'DIA, Cav. False Dog-Fennel. Heads many-flowered; rays $\uparrow$; disk $\hat{o}$; involucre of a single series of partially united scales, usually calyculate; achenir elongated, 4-angled, compressed; pappus scales chaffy, in one series, fimbriately and palmatoly cleft into bristles. -1) Herbs with large, pellucid glands. Lrs. mostly opposite and pinnately parted or toothed. Hds. paniculate or corymbous. Fls. yellow.

D. chrysanthemoìdes Lagasca. St. glabrous, much-branched; lvs. pinnately parted, lobes linear, toothed; hds. terminal on tho short branchlets; scales united at base, scarious, obtuse, with large, oblong glands; outer scales 7 to 9 , linear; pappus bristles slender, as long as the involucre.-Prairies and roadsides, III, Mo., to La. An ill-scented plant, about $1 \mathrm{f}$ high, with finely divided lvs. Aug.Oct. (Tagetes papposa Vent.)

62. GAILLAR'DIA, Fougeroux. Heads radiate; rays neutral; scales in 2 or 3 series, acute, leafy, spreading, outer largest; receptacle convex, fimbrillate (naked in the following species); rays cuneiform, 3cleft; achenium villous with long hairs from its base; pappus of 6 to 10 long awns, which are membranous at base.-Lvs. alternate, entire, often dotted. Hds. on long, naked peduncles.

1 G. lanceolàta Mx. Pubescent; lvs.. lanceolate or linear, sessile, the lower petiolate; scales as long as the disk; disk-fls. with long, subulate, pubescent teeth; receptacle smooth, (not fimbrillatel). - (2) Barrens, S. Car. to Fla. and Tex. St. 1 to $2 \mathrm{f}$ high, slender, ending in long, naked flower-stalks. Lvs. 1 to $3^{\prime}$ long, rather oblong. Scales and disk purple. Rays yellow. May-Aug.

2 G. pulchella Fouger. Pubescent; lvs. lanceolate, the lower short-petioled. 
toothed or incised, upper subclasping; scales very hairy, longer than the disk; disk corollas with subulate teeth; receptacle fimbrillate, with slender awns.-(1) La., Tex, and in gardens. St. branching. Hds. 1 to $1 \frac{1^{\prime}}{2}$ diam. Rays 10 to 12 , violet-purple, with yellow teeth.

63. POLYP'TERIS, Nutt. (Gr. $\pi 0 \lambda v ́ \varsigma$, many, $\pi \tau \varepsilon \dot{e} \rho o v$, a wing ; from the feather-like pappus.) Heads discoid; flowers all perfect, tubular and similar; scales flat, scarious, in 2 or 3 series, appressed ; receptacle naked; achenia 4-angled, slender at base; pappus of 6 to $12 \mathrm{mem}$ branous, pinnately striate scales.-Lvs. scattered, lanceolate. Fls. cyanic. (Palafoxia, T. \& G.)

P. integrifòlia Nutt. Rough; st. corymbous above; lvs. linear-lanceolate, entire; outer scales loose, acuta, inner obtuse; pappus of 8 to 10 acuminate squamio with fringed or plumed edges-Barrens, S. W. Ga. and Mid. Fla. Sts. 3 to $5 f$ high, bearing the large, purplish heads in a level-topped corymb. Aug.-Oct.

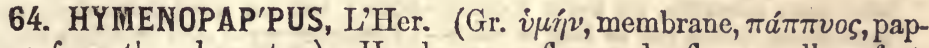
pus; from the character.) Heads many-flowered; flowers all perfect, tubular; scales 6 to 12 , in 2 series, oval, obtuse, membranaceous, colored; receptacle small, naked; anthers exserted; achenia broad at the summit, attenuate to the base; pappus of many short, obtuse, membranous scales in onc scries.-(2) or 4 North American, villous herbs. St. grooved and angled. Lrs. alternate, pinnately divided.

H. scabiosæeus L'Her. Hoary-villns, or nearly glabrous; lvs pinnately or bi pinnately parted, segments linear or oblong, entire or sparingly toothed; hds. in simple corymbs; scales obovate, 7-11, white, greenish at base, undulate on the margin, longer-than the disk; cor. deeply lobed; ach. pubescent.-Ill. to Fla. Stem 1-2f high, whitish with soft cotton when young, at length purplish and glabrous. Segments $1-1 \frac{1}{2}$ by $1-2^{\prime \prime}$, rather acute. Hds. whitish, about 21-flowered. Apr., May. (South.)-Aug.

65. HelE'NIUM, L. American Sneezewort. (Named for the celcbrated Helen, who is said to have availed herself of its cosmetic properties.) Involucre double, the outer of leafy, narrow scales, the inner chaffy ; ray pistillate; pappus of five, one-awned, chaffy leaves ; receptacle globous, naked in the disk, and chaffy in the ray only: ray flowers half 3 -cleft; seed villous.-Lrs. alternate, decurrent. Rays yellow.

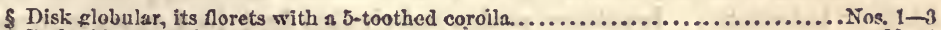

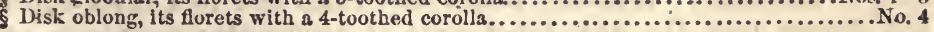

1 F. autumnàle L. Lvs. lanceolate, serrate, smooth or slightly pubescent, de. current; fls. loosely corymbous. - 2f In damp places. St. 2 to $3 \mathrm{f} \mathrm{high,} \mathrm{branching}$ strongly, winged by the decurrent lvs. Lvs. tapering to each end, or ellipticlanceolate, more or less deeply serrate. Fls. large, numerous, terminal, with drooping rays, each ending in 3 obtuse teeth, and longer than the large, globous disk. The plant is very bitter. Aug.

ß. canaliculàtum. Rays concave, canaliculate or 3-furrowed. (H. canaliculatum Lam.)

2 H. parviflòrum Nutt. Lvs. lanceolate, subentire, smooth, scarcely decurrent; hds. solitary, or in small, scattered clusters.-Ga. (Nuttall.) Heads about half as large as in No. 1. Disk globous, longer than the filiform scales. Rays flat. Pappus scales awned, half as long as the corolla. Ach. smooth.

3 K. tenuifolium Nutt. Smoothish; branches numerous, fastigiate, very leafy; lvs. linear or filiform, entire, fascicled; scales subulate; disk globous.-Fields waysides, Ga. (Feay, Pond) to La. St. 1 to $2 f$ high, naked and woody below; 
branches upright. Ivs. 1 to $2^{\prime}$ long. Hds. 4 or 5 " diam. Rays about 12, spreading 9 or $10^{\prime \prime}$. Apr.-Nov.

4 H. quadridentàtum Labill. Smoothish, much branched; 1vs. oblong, sparingly lobed or toothed, the highest lanceolate, entire; disk oblong, longer than the rays; pappus scales obtuse.-Swamps, Miss., La to Ark. St. 1 to $3 \mathrm{f}$ high, with solitary, terminal, small hds. Lvs. about 4-toothed or lobed. Disk fls. 4toothed. Jn.-Aug.

66. LEPTOP'ODA, Nutt. (Gr. $\lambda \varepsilon \pi \tau o ́ s$, slender, $\pi$ ov́s, foot; alluding to the elongated peduncles.) Heads many-flowered; rays neutral, cuneate, $3-4$-cleft ; disk $\Varangle$; scales spreading, numerous, attenuate ; receptacle conical ; chaff 0 ; pappus of 6 -10-fringed squamæ. $-2 f$ North American herbs, with the liabit of Helenium.

$\$$ IIeris corymbed, on short peduncles. Pappus cuspidate-awned...................... 1 Head solitary, on a long peduncle. Pappus awnless.-Achenia glabrous...................... 2, 3

I I. brachýpoda Torr. \& Gr. St. leafy, corymbous at summit; lvs. decurrent, lanceolate, subentire, the lower toothed, obtuse; $h d s$. on short peduncles; scales lance-linear, about half as long as the 8-12 drooping rays; disk brownish-purple. - Separated from Helenium only on account of its sterile rays. In damp soil, from Southern Ill. to Tex. and S. States. Stem about $2 \mathrm{f}$ high. Heads several or numerous. Rays broadest at summit, rather deeply and irregularly toothed, $7-9^{\prime \prime}$ by $4-5^{\prime \prime}$. (Helenium quadridentatum Hook.)

2 I. Helénium Nutt. Smooth; lvs. lanceolate or lance-linear, entire or remotely denticulate, mostly slightly decurrent, the lowest tapering to a petiole: pappus awnless, lacerated; ach. glabrous; rays 20 or more in one row.-Moist soils, S. Car. to Fla. and La. About $2 \mathrm{f} \mathrm{high,} \mathrm{leafy} \mathrm{below,} \mathrm{ending} \mathrm{in} \mathrm{a} \mathrm{long,} \mathrm{naked}$ stalk, bearing ono hd. Lvs. 3 to $6^{\prime}$ long. Disk 5 to $8^{\prime \prime}$ broad. Mar., Apr.

3 I. incìsa Torr. \& Gr. Glabrous ; lvs. lanceolate, sessile, not decurrent, sinuatepinnatifid or incised; pappus awnless, lacerated; rays about 40, in 2 or 3 rows; ach. glabrous.-Ga. (Le Conte).

4 I. pubérula Macbr. St. clustered, tomentous or dorwny; lvs. lance-linear, occasionally toothed or incised, not decurrent; ach. hairy; pappus scales obtuse.N. Car. to Fla. Sts. 1 to $2 \mathrm{f} \mathrm{high,} \mathrm{usually} \mathrm{many} \mathrm{from} \mathrm{one} \mathrm{root.} \mathrm{Lvs.} 2$ to $4^{\prime}$ long, half-clasping. Rays 20 to 30 , broadly wedge-shaped, spreading $1 \frac{1}{2}$ to 2 '. 'Apr., May. (H. pinuatifida Nutt.)

5 I. brevifòlia Nutt. Nearly glabrous; lvs. all entire or nearly so, the cauline decurrent, the lower oblong-spatulate, obtuse, highest lanceolate, acute; ach. hairy.-N. Car. to Ala. St. 1 to $3 f$ high, occasionally branched, and with more than 1 head. Hd, about as largo as in No. 4. May, Jn.

67. BALDWIN'IA, Nutt. (To Dr. William Baldwin, one of our pioneer botanists.) Involucre scales imbricated in 2 to 4 rows, appressed, shorter than the disk, inner acute or acuminate; receptacle convex, deeply alveolate with horny walls; rays 8 to 20 , neutral, in one row, narrow-cuneiform, 3-toothed; disk flowers $\Varangle$, tube horny below ; achenia immersed in the cells, silky-villous, crowned with a pappus of 9 to 12 oblong scales. - 2f Herbs simple or corymbed, naked above, with alternate, linear, punctate lvs. and yellow fls.

1 B. uniflòra Nutt. Puberulent, simple, 1-flowered; hd. about 20-rayed; pappus 9-leaved.-Open swamps, Va. to Fla. and La., near the coast. Plant 1 to $2 \mathrm{f} \mathrm{high,}$ striate-angled. Lrs. thick, linear-spatulate below, linear and bract-like above. Disk 7 to $8^{\prime \prime}$ wide, rays narrow, spreading nearly $2^{\prime}$. Cells of the receptaclo just like a honey-comb, 2 to $3^{\prime \prime}$ deep. Jl.-Sept.

2 B. multiflòra Nutt. Glabrous, much branched, with a corymb of fls.; lvs. very numerous, narrowly linear; rays about 10 ; pappus 12-leaved; ach. marked with 12 rays on its flat summit.- Sand hills, Ga., Fla. Plant 1 to $3 \mathrm{f}$ high, slender, 
the Ivs almost filiform. Hds. about $1_{2}^{\prime \prime}$ broad, including the rays. Invol. squarrous. Aug., Sept. (Actinospermum angustifolium T. \& G.)

68. mARSHAL'LIA, Schreb. False Scabisir. (To Humphrey Marshall of Penn., one of our earliest botanical authors.) Involucre scales lance-linear, subequal, erect, in one or two rows; receptacle convex, with linear, rigid pales; flowers all tubular, $\Varangle$; corolla lobes slender spreading; achenia 5-angled; pappus of 5 or 6 membranous, awned scales. - 2f Ornamental herbs, simple or branched, with alternate, entire, 3-veinicd lvs., and solitary long-stalked hds. of purplish fls. resembling a Scabish.

1 M. latifolia $\mathrm{Ph}$. St. simple, leafy; lvs. ovate-lanceolate, acuminate, sessile; scales rigid, acute; pales narrowly linear; pappus triangular-acuminate.-Dry soils, Va. to Ala. (Shields) along the mountains. A smooth, handsome plant if high, with a slender, purple stem. Lvs. about $2^{\prime}$ long, conspicuously 3 -veined. Cor. 6 to $7^{\prime \prime}$ long, with slender tubes, scales half as long. May, Jn.

2 M. angustifòlia $\mathrm{Ph}$. St. mostly branched, leafy; lvs. below narrowly lanceolate, above narrowly linear, all acute; scales acute, pales setaceous; pappus ovateacuminate.-Swamps, \&c., N. Car., Tenn. to Fla. A beautiful plant. Sts. often clustered at base, if high. Lvs. 3 to $6^{\prime}$ long, the lower petiolate, upper shorter, diminished to bristie form bracts. Jn.-Aug.

$3 \mathrm{M}$. lanceolàta $\mathrm{Ph}$. Simple, leafy below, naked above; lvs. lanceolate or oblanceolate, mostly obtuse, tapering to a petiole, the upper sessile: scales oblong, linear, obtuse ; pales spatulate; ach. pubescent.-Upper districts N. Car. to Ga. and Ala. Sts. 1 to $2 \mathrm{f} \mathrm{high.} \mathrm{Apr.-Jn.}$

69. AN'THEMIS, L. Chamomile. Involucre hemispherical, with nearly equal scales; rays numerous, pistillate; receptacle chaffy, convex or conic; achenia crowned with a slight border.-European herbs with much divided lvs.

1 A. arvénsis L. St. erect, hairy; Ivs. bipinnatifid, hairy and canescent, segments linear-lanceolate; ach. crowned with a narrow margin ; pales lanceolate, cuspidate, longer than the flowers.-(2) Grows in dry, cultivated fields. A pilous, inodorous plant, somewhat resembling the Mayweed. Stems diffusely branching, 8-15' high. Heads large, solitary on the leafless, downy summits of the branches. Disk yellow, rays white. July. § Eur.

2 A. nóbilis IL St. prostrate, branching from the base, woolly; lvs. decompound. pinnatifid, segments linear, subulate; pales scarious, lanceolate, scarcely as long as the flowers.-24 Grows wild occasionally in fields, and is cultivated in gardens. The strong and agreeable scent of the ChamomiLe is well known, also its tonic and anodyne qualities, which chiefly reside in the flowers. July-Sept. § Eur.

70. MARU'TA, Less. MAY-WEED. Involucre hemispherical, imbricated; rays neutral; disk perfect; receptacle conical, chaffy (at least at the summit) ; pappus 0 ; achenia smooth.-European herbs, with alternate, much divided leaves. Rays white.

M. cotula DC. St. erect, nearly smooth; lvs. bipinnatifid, segments linear-subulate; pales bristly, shorter than the flowers.-(1) Waste places, in hard, dry soils, especially by roadsides, in patches of great extent. Stem branching, diffuse, if high, with alternate leaves divided and subdivided into a multitude of segments. Flowers solitary, on terminal, striated stalks. The plant is ill-scented. Linnæus says it is grateful to toads, drives away fleas, and is annoying to flies. Jn.Sept. § Eur. (Anthemis L.)

71. ACHille'A, L. Millforl. Yarrow. (Named after.Achilles, a disciple of Chiron, who first used the plant.) Involucre ovoid, of unequal imbricated scales; rays 5 to 10 , short, pistillate; receptacle flat, 
chaffy ; achenia without a pappus. $-2 f$ European herbs with much di. vided, alternate lvs. Hds. radiate.

1 A. Millefollium L. Lvs. bipinnatifid, with linear, dentato, mueronate seg. ments ; st. furrowed, corymbed at top; scales oblong; rays 4 to 5 , short.-Fields, pastures, \&c., N. Eng. to Or. and Arctic Americr. St. a foot high, branching at top into a dense, flat-topped corymb of white or rose-colored fls. It has an agreoable, pungent taste and smell. Jn.-Sept.-The variety with rose-purple flowers is very pretty in gardens.

2 A. ptármica L. SNeEzewort. Lvs. linear, acuminate, equally and sharply serrate, smooth.-Found in moist grounds and shady places, Can. and N. Y. (Pursh), Mass. (Nichols). Plant about $15^{\prime}$ high, branching at top into a diffuse corymb of white fls. The lvs. are remarkably distinct from the yarrow. The dried powder of the leaves, used as snuff, provokes sneezing. A variety with double flowers occurs which is quite ornamental in pots. Aug. $f \S$ Eur.

72. LEUCAN'THEMUM, Tourn. WhITE-WEEd. (Gr. $\lambda \varepsilon v \kappa o ́ s$, white, ü 0 os, flower; the heads have large, conspicuous rays.) Involucre broad, depressed, imbricated ; rays pistillate, numerous ; receptacle flat, naked; achenia striate ; pappus none.-Herbs with alternate lvs. Hds. radiate.

I. vulgare Lam. St. erect, simple or few-branched, with solitary heads; lvs. clasping lanceolate and oblong, toothed above, cut-pinnatifid at the base; scales edged with brown.-2f A great annoyance to the farmer, in fields and pastures, U. S. to Arc. Am. St. about 2f. high. Lvs. comparatively few and small. Heads large (13-16" broad). Rays many, ligulate, white. Jl.-Sept. $\S$ Eur. (Chrysanthemum Leucanthemum, L.)

$\beta$. TUBULIFlòrum (Tenney). Rays tubular, elongated, white, deeply cleft into 5 or 3 lobes.-Poughkeepsie, N. Y. (Mr. W. R. Gerard.)

73. MATRICA'RIA, Tourn. Fever Few. Involucre scales imbricate, many-flowered, with membranous margins; reeptacle conical or convex, naked; pappus a membranous margin crowning the achenia, or none.- Herbs chiefly perennial, with alternate lvs. Hds. with or withont rays. (Pyrethrum, Smith.)

IM. parthènium L. Hds. radiate; lvs. petiolate, flat, tripinnate, tho segm. ovate, cut; ped. branching, corymbous; st. erect; invol. bemispherical, pubescent.Fields, rare. Several varieties of the Fever-few are cultivated, and are in great favor with many florists, on aecount of their fine pyramidal form, surmounted with a corymb of pure white, double flowers which retain their beauty for several weeks. + Eur.

2 M. discoìdea DC. Hds. discoid; lvs. sessile, 2 to 3-pinnately parted, lobes small, linear-oblong, acute; hds. on simple peduncles; scales equal, oval, obtuse, with white, scarious margins much shorter than the conical disk.-(1) Ill. opposite St. Louis, also in Oregon. Sts. 3 to $8^{\prime}$ high. Disk 2 to $3^{\prime \prime}$ broad and high. Pappus obsolete.

3 M. Balsámita Willd. Evglisn Mrnt. Pubescent; hds. discoid; st. erect; lvs. ovate, oblong, serrate, the lower potiolate, upper sessile, auriculate at base; hds. corymbed; pappus none.-Gardens. St. 1 to $2 \mathrm{f}$ high. The plant is yellowish green, clothed with loose, minute tomentum, with the fragrance of spearmint.

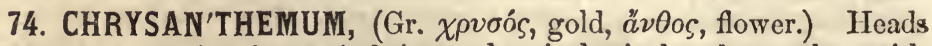
heterogamous; involucre imbricate, hemispherical; the scales with membranous margins; receptacle naked; pappus none.-Ornamental plants from China and other eastern countries. Lvs. alternate, lobed. IIds. radiate.

1. C. coronàrium I. Annual; st. branched; lvs. bipinnatifid broader at the summit, acute.-Native of S. Europe and N. Africa The variety with double 
flowers is frequently cultivated as a hardy annual. St. about $3 \mathrm{f}$ high, striato, smooth, erect, with alternate, clasping lvs, Fls. large, terminal, solitary, yellow. Aug.

2 C. carinàtum Wiild. Annual; lvs. bipinnate, fleshy, smooth; inrol. scales carinate.-Native of Barbary. Hds. large and beautiful; disk purple, rays white, with a yellow base. A variety has rays entirely yellow. JL-Oct. (C. tricolor Andr.)

3 C. Sinénse Sabine. Perennial; lvs. coriaceous, stalked, sinuate-pinnatiful, dentate, glaucous; rays very long.-A native of China, where it hiss long been cultivated and highly esteemed for its beauty. $\Lambda$ great number of vurieties liave been produced with double, semidouble, and quilled flowers of every possible shade of color. It is of very easy culture in any common soil. The plants are propagated by divisions, by suckers, and by cuttings. (Pyrethrum Sinense DC.)

75. TANACE'TUM, L. TANSY. (Said to be a corruption of atavaria, deathless; for the durable flowers.) Involucre hemispherical, imbricate, the scales all minute; receptacle convex, naked; pappus a slight, membranous border; achenia with a large, epigynous disk.-Lvs. alternate, much dissected. Fls. yellow, discoid.

T. vulgàre I. Lvs. pinnately divided, segments oblong-lanceolate, pinnatifid and incisely serrate; hds. fastigiate-corymbous, ray fls. terete, tubular, 3-toothed.-2f in old fields and roadsides. Stems clustered, 2 - $3 \mathrm{f} \mathrm{high,} \mathrm{branched} \mathrm{above} \mathrm{into} \mathrm{a}$ handsome corymb of yellow flowers. Aug.-The whole plant has a strong and aromatic smell and bitter taste. The seeds are anthelmintic. A variety called double tansey occurs, with dense and crisped leaves. § Eur.

2 T. Huronénse Nutt. Lvs. bipinnately divided, lobes oblong, often again pinnatifid; hds. large, corymbd; ray fls. flattened, unequally 3 to 5-cleft.-Shores of Lake Huron and Mackinaw Strait, to Hudson's Bay. Plant 1 to $3 \mathrm{f}$ high, somewhat tomentous. Hds. larger than in No. 1, eitron-yellow.

76. ARTEMIS'IA, L. Wormwood, \&c. (Probably from Artemis, one of the names of the goddess Diana.) Involucre ovoid, imbricate, with dry, eonnivent scales; receptacle without pales; disk-flowers numerous, $\Varangle$, tubular, ray flowers few, often without stamens and with a subulate corolla or none; achenia with a small disk; pappus 0.Bitter herbs. Lvs. alternate. Cor. yellow or purplish, discoid.

$\S$ Receptacle vlllous or hairy. Flowers all fertile................................ 1, 2 8. Recptacle naked._Flowers all fertile. Laves or segments lanceulate............. Nos. 3, 4 -Flowers all fertile. Leaves or segments linear................. 5 , 6 -Flowers of the disk sterile. Leaves or segments linear................. 7-9

1 A. frígida Willd. Lvs. pinnately parted, silky canescent, lfts. linear and 3-5cleft; heads nodding, globuos, in panicled racemes; scales of the invol. canescent, roundish, the inner oblong; corollas glabrous.-Rocky hills, Minnesota, Dakota, and westivard. Plant branched from base, $6-12$. July-Aug.

2 A. Absínthium L. Cosmon WorMwood. Lvs. multifid, clothed with short, silky pubescence, both sides; segments lanceolate; hds. hemisperical, drooping; receptacle hairy.-24 Growing among rubbish, rocks, and by roadsides, N. Eng., Can. Stems angular, branched, with erect racemes of nodding, yellow flowers The whole plant is proverbially bitter, and of powerful medicinal qualities as a tonic, stomachic, \&c. \& Eur.

3 A. Ludoviciàna Nutt. Canescently tomentous all over; lvs. lanceolate, lower incisely and remotely serrate or subpinnatifid, upper entire; $h d s$. ovoid, subsessile, arranged in a simple, slender, leafy panicle. -24 Lake and river shores, Mich. to Mo. W. to Oreg. Stem $2-5 \mathrm{f}$ high, simple or branched. Leaves quite variable in size and also in pubescence, sometimes nearly smooth. Heads small and crowded.

4 A. vulgàris L. MбGWORT. Lvs. canescent-tomentous beneath, cauline ones pinnatifid, segm. lanceolate, acute, subdentate, floral ones entire, linear-lanzeolate; 
hds. erect, ovoid, subsessile; invol. tomentous.-4 Fields, roadsides, banks of streams, \&c., Vt., N. H. 'St. 2 to 3 f high, branching into a paniclo of spicato racemes. Lrs. very variable, but never attenuated to linear, now obtuse, now acute, from the same locality (Hanover, N. H. Ricard.) Hds. few-flowered, purplish.

5 A biénnis Willd. Plant erect, smooth; lrs. bipinnately parted, upper ones pinnatifid, all with linear, acute, and mostly incised lobes; hds. sessile, arranged in a close, narrow, leafy panicle of short spikes.-2) Western States and northward. Also eastward to the Hudson R. (Mr. C. B. Gerard.)

6 A. Abrótanum L. Southerswood. St. erect; lower lvs. bipinnate; upper ones capillary, pinnate; invol downy, hemispherical. $-24 \mathrm{~A}$ well known shrubby plant in gardens, about $3 \mathrm{f}$ high. Leaves alternate, much divided into very narrow, linear segments. Flowers numerous, nodding, yellow. Native of S. Europe. $\ddagger$

7 A. boreàlis Pallas. Cuespitous, silky-villous or smoothish; st. simplo; lower lvs. petiolate, linear-lanceolate, entire towards the base, ternately, pinnately, or bipinnately parted above, with linear lobes, upper linear, 3 to 5 -cleft or entire; ldds. hemispherical, spicate or racemous-paniculate.-4 Keweena $\mathrm{Pt}$, Lake Superior (Houghton, in N. Am. Fl.) St. 6 to $10^{\prime}$ high.

8 A. Canadénsis Mx. SeA Worarwood. St. erect or decumbent; lvs. pinnatifid with linear segments; fls. subglobous, sessile, in a panicle of racemes. $-2 f$ Rivers and lake shores, N. Eng. and Can. Shores of the great lakes. St. 2 to $4 \mathrm{f}$ high, much branched, sulcate, brownish, mostly erect. Hds. 2" diam., numerous, forming a large paniclo of racemes. Scales with a membranous margin. Aug.

9 A caudàta Mx. Glabrous, simple, densely paniculate; lvs. bipinnately divided, upper pinnate, segm. filiform or setaceaus, alternate; hds. ovoid-globous, pedicellate, crect.-(2) On the sea-coast, N. H. to Ga. St. 3 to $5 \mathrm{f} \mathrm{high,} \mathrm{strict.}$ Lvs. in many thread-like and somewhat fleshy segm.; hds. $11_{2}^{\prime \prime}$ diam., in a strict, dense panicle. Outer scales ovate, inner scarious, elliptical. Aug., Sept.

77. SOLIVA Ruiz. \& Pav. (To Salvator Soliva, a Spanish botanist and physician.) Involucre of 5 to 10 to 15 scales in one row; receptacle flat, naked; fertile flowers in several rows, apetalous; $q$ fls. few, interior, with a 3 to 5 -toothed corolla; achenia obcompressed, tipped with the persistent style and no pappus.-Little depressed herbs with pinnately divided lvs. and sessile hds.

S. nasturtiifòlia DC. Plant very small, minutely pubescent; lvs. pinnately 5 to 9-parted, lobes oblong, obtuse; scales 10 to 15; ach. obconic, rugous, crowned with a dense tuft of wool instead of pappus -S. Car., Ga., near the coast, banks of the Ogeechee, growing with Sencbiera. Plant flat on the ground, forming a dense mat. Lvs. 6 to $10^{\prime \prime}$ long, lobes $1^{\prime \prime}$. Hds. disproportionately large $\left(2\right.$ to $3^{\prime \prime}$ broad), axillary, depressed. Ach. wrinkled transversely. Mar., Apr.

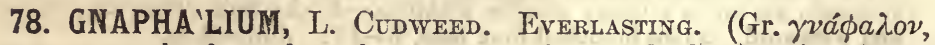
cotton or wool; from the soft, cottony surface of the herbage.) Heads discoid, heterogamous; involucre imbricate with scarious, colored scales; marginal flowers subulate, pistillate, mostly in several rows; central flowers $\not{\gamma}$; receptacle flat, naked; pappus a single row of scabrous, hair-like bristles.-Herbs generally clothed with whitish wool. Lvs. alternate, entire.

* Heads in terminal corymbons clusters........................................... 1-3

* Ileads in axillary, somewhat spicate cluster.............................................. 4,5

1 G. decúrrens Ives. Lvs. decurrent, linear-lanceolate, very acute, naked above, white and woolly beneath; fls. in dense, roundish, terminal clusters.-2f A stout species, covered with a dense, hoary pubescence. It grows in hilly pastures, \&c., N. H. Vt. to N. J. Stem $2 \mathrm{f} \mathrm{high,} \mathrm{with} \mathrm{scattered} \mathrm{leaves} \mathrm{and} \mathrm{spreading} \mathrm{branches.}$ 
- Leaves on the upper side green, scabrous and viscid. Scales whitish, with yel low corollas. Aug.

2 G. polycéphalum $\mathrm{Mx}$. Erect; lvs. sessite, linear-lanceolate, acute, scabrous above, whitish tomentous beneath, as well as the paniculate stem; hds. capitate, corymbous; scales ovate-lanceolate, acute.-(1) Common in fields, \&c., Can. and U. $\mathrm{S}$. It is distinguishable by its strong, agreeable odor, and its brownish color. Stem I-2f high, whitish, with a cottony down, much branched. Hds. much larger than in the next. Involucre with whitish scales and yellow flowers. Aug.

3 G. uliginòsum L. CuDweed. St. diffusely branched, woolly; lvs. sessile, linear-lanceolato; hds. small ( $1^{\prime \prime}$ wide) in terminal, crowded, leafy clusters ; scales obtuse, yellowish or brownish; ach. smooth.- I A small, spreading plant, clothed with whitish down, common in sandy places where water occasionally stands, $\mathrm{N}$., Mid. and W. States. Stem $4-6^{\prime}$ high. Leaves numerous, acute, narrowed at the base. Scales of the involucre oblong, obtuse, yellowish. Aug.

4 G. purpùreum L. St. erect, simple or branched from the base, tomentous; lvs. linear-spatulate or obovate-spatulate, downy-canescent beneath, green above; $h d s$. sessile, crowded, terminal and axillary; scales acuminate.-1) Grows in sandy fields and pastures, N. H. to Ind. and La. Stem 8-12' high, sending out shoots at the base. Heads with tawny, purplish scales and yellow corollas. June.

5 G. supinum Villars. Cospitous, woolly; lvs. linear; hds. few, oblong, in a spicate raceme or solitary; scales acute, brown; pistillate fls. in but one row.White Mts., N. H. (Nuttall.) Sts. 2 to $4^{\prime \prime}$ high.

79. ANTENNA'RIA, Br. Everlasting. (Name in allusion to the bristles of the pappus, which resemble antennæ.) Heads diœcious; involucre of imbricate, colored scales; pistillate corollas filiform ; receptacle subconvex, alveolate; pappus a single row of bristles. - 2f Tomentous. Lvs. alternate, entire. Hds. corymbous, with white or brownish, never yellow scales. (Gnaphalium L.)

1 A. margaritàcea $\mathrm{Br}$. St. erect, simple, corymbously branched above; lvs. linearlanceolate, acute, 3-veined, sessile, woolly beneath, stem woolly; corymbs fastigiate; scales elliptic, obtuse, opaque, white.-2f Fields and pastures, U. S. and Brit. Am. St. 1 to $2 f$ high, and with its numerous, scattered lvs. clothed with white and cotton-like down. Hds. numerous, hemispherical, fadeless. Fls. yellow. Jl.-Named for its dry, imperishable, pearl-white scales.

'A. plantaginifòlia Br. Mouse-Ear. Everlastivg. Stolons procumbent; st. simple; radical lvs. oval, obovate or spatulate, mucronate, 3-veined, silky-canescent, st. lvs. small, lanceolate; scales ovate, obtuse.-2f Borders of woods, \&c., U. S. and Brit. Am., flowering in early spring. Whole plant whitish with down. St. 5 to $8^{\prime}$ high, often with stolon's at base. Rt. lrs. much larger than those of the stem. St. lvs. few, bract-like. Hds. in a terminal, dense cluster, purplish white. Feb.-May. (A. dioica Br.)

80. Fila'go, Tourn. Cotton Rose. Cunweed. (Apparently from the Latin flum, a thread; on account of the cottony bairs.) Heads heterogamous; involucro of a few villous scales; marginal flowers + ; receptacle columnar, naked at the apex, chaffy at base; achenia terete, central ones with a hairy pappus.-Downy-canescent berbs. Lvs. alternate, entire.

F Germánica I. St. dichotomous or proliferously branched abovo; Ivs. linearlanceolate, acute, crowded, erect; hds. few-flowered, in dense, capitate clusters, terminal and lateral; scales cuspidate, passing insensibly into the pales of the receptacle, each with a pistillate flower in the axil.- (1) Fields and roadsides, Mass., N. Y. to Va. St. 6 to $10^{\prime}$ high. Scales straw-0olor, with a green line outside. Jl.-Oct. \& Eur. 


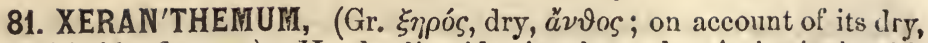
imperishable flowers.) Heads discoid; involucre hemispherical, with radiant, colored, opaque, scarious scales; receptaclo paleaceous ; pappus paleo-setaceous. - (1) Native of S. Europe.

X. annuum Willd. Eternal Flower. St. erect, branched; lvs. oblonglanceolate, obtusish, alternate, entire; hds. large, terminal, solitary; scales of the involucre obtuse, scarious, inner ones of the ray spreading, lanceolate, obtuse. -A singular plant, half hardy, of easy culture. Stem 2-3f high. The radiant involucro scales are of a rich purple, but there are varieties with red, white, blue and yellow scales. The flowers retain their beauty for years.

82. HELICHRY'SUM. (Gr. golden sun) is another genus of fadeless flowers, of which several species are occasionally cultivated. Tho spreading scales are of various colors. II. bracteosum is the finest species, having yellow scales, heads on long stalks and lanceolate leaves.

83. ERECH'TITES, Raf. FIRE-WEED. (Gr. égé $\chi \vartheta \omega$, to trouble; the species are troublesome weeds.) Flowers all tubular, those of the margin pistillate, of the disk perfect; involucre cylindrical, simple, slightly calyculate; receptacle naked; pappus of numerous, fine, capillary bristles. - (1) Lvs. simple, alternate. Fls. corymbous, whitish.

E. hieracifòlius Raf. St. paniculate, virgate; lvs. oblong, amplexicaul, acute, unequally and deeply toothed with acute indentures; invol. smootl ; ach. hairy. -A rank weed, growing in fields (Can. and U. S.), particularly in such as havo been newly cleared and burnt over. St. thick and fleshy, branching, 3f ligh, roughish. Lvs. of a light green, large, irregularly cut into many deep and acuto teeth. Fls. terminal, crowded, destitute of rays, white. Invol. large and tumid at base. Aug., Sept. (Senicio hieracifolius L.)

84. Cacallia, L. Wild Caraway. Tassel Flower. (An ancient Gr. name of an uncertain plant.) Flowers all tubular, $\Varangle$; involucre cylindric, oblong, often calyculate with small scales at the base; receptacle not chaffy; pappus capillary, scabrous.-Mostly 2 . Smooth. Lvs. alternate. Hds. of fls. corymbed, mostly cyanic.

$\$$ Scales of the involucro united, about 12 . Flowers 60 to 80, scarlet.................. 8

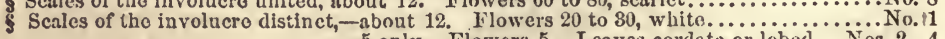
-5 only. Flowers 5. - Leaves cordato or lobed... Nos. 2-4

1 C. suavèolens I. Glabrous; st. striate-angular; lvs. petiolate, hastate-sagittate, serrate, smooth, green on both sides; fls. corymbed, erect; invol. manyflowered.-2f Western N. Y. to Conn. (Robbins), to Ga. and Ill. Stems 4-5f high, striate, leafy. Radical leaves on long stalks, pointed; cauline ones on winged stalks. Flowers whitish, in a terminal, compound corymb. Scales and peduncles smooth, with setaceous bracts beneath the involucre, and beneath the divisions of the peduncles. Aug.

2 C. renifórmis Muhl. St. sulcate-angled; lvs. palmately veined, nearly smooth, green both sides, petiolate, lower ones reniform, upper flabelliform; corymb ccmpound, fastigiate; hds. 5-flowered.-Woods, Ind., Ill., Penn., S. to Car. St. 3 to 6 high, nearly simple, glabrous. Lvs. 3 to $12^{\prime}$ by 5 to $18^{\prime}$, repand-dentate, lower: petioles very long. Scales of involucro 5, obtuso, whitish. Jl.

3 C. atriplicifòlia L. St. terete; lvs. petiolate, smooth, glaucous beneath, palmate-veined, angularly lobed and dentate, tho lower subcordate; fls. corymbed, crect; invol. 5-flowered. -N. Y. to Ga. and Ill. St. 3 to $5 f$ high, leafy. Lvs. alternate, the lower ones as large as the hand, with large, unequal teeth or lobes. Hds. small, ovoid-cylindric, whitish, loosely corymbous at the top of the branches. J.-Sept. 
4 C. diversifòlia Torr. \& Gr. Plant not glaucous; st. striate-angled; lower lvs. ovate, obtuse, repand-toothed, upper 3 to 5-lobed, somewhat hastate; hds., corymbs and Hs. as in the preceding (of which it seems to be a variety). - Swamps along the Chattahoochee, Fla. Plant 2 to $3 f$ high. May.

5 C. tuberòsa Nutt. St. angular-sulcate; lvs. oval or ovate, strongly 5 to 7 . veined, obtuse or subacute, entire or repand-denticulate, not glacous, lower ones tapering into long petioles, upper ones on short petioles; hds. in compound corymbs.-Marshes, W. States. St. 2 to $5 \mathrm{f}$ high, branched above. Lvs. rather thick, 3 to ' 7 ' long, $\frac{2}{3}$ as wide, veins converging to the apex. Hds. oblong, 5 -leaved and 5-Howered, white. May:-Jl.

6 C. ovàta Ell. St. terete; lvs. glaucous beneath, 3 to 5-veined, ovate and oval, entire or undulate-margined, contracted at base into petioles; corymb fastigiate.Macon, Ga. (Mettauer), Ala., Fla., in moist woods. St. smooth, glaucous, 3 to $4 \mathrm{f}$ high. Lower lvs. on long petioles, rather obtuse; upper ones nearly sessile, rather acute. Scales broad-linear, acute. J1.-Aug.

7 C. lanceolàta Nutt. St. terete; lvs. glaucous beneath, 3-veined, lanceolate and lance-linear, entire or with few sharp teeth, lower tapering to petioles, upper sessile; corymb simple.-Wet grounds, Ga. Fla. St. 4 to $6 f^{\circ}$ high. Lvs. below 4 to 6 ' long, diminishing upwards. Scales linear, acute. Aug., Sept.

8 C. coccinea Curt. TASSEL Flower. Radical lvs. ovate-spatulate, cauline amplexicaul crenate; invol. ovate-cylindric, scales linear, at length reflexed; ach. ciliate; pappus in several rows. - A pretty garden flower, native of the E. Ind., \&c. St. If or more high. Fls. bright scarlet. Jn.-Sept. A bed or patch sown thickly makes a fine appearance. (Emilia sagittata, DC.)

85. CINERARIA, Less. (Lat. cinereus, ash-colored; for its soft, white down.)-Hds. radiate; rays pistillate; invol. scales in one row, scarious on the margin; recept. naked, flat; ach. beakless, obcompressed; papp. capillary.-Greenhouse shrubs with mostly alternate leaves.

1 C. amelloìdes Willd. Leaves opposite, ovate, smooth; peduncles each bearing a single head with blue rays. - Shrubby, 2 to $3 f$ high. $+\mathrm{S}$. Africa.

2 C. speciosa Schrad. Lvs. alternate, reniform, denticulate, on inflated petioles; hds. in a simple raceme terminating the simple stem, with yellow rays. -Shrub 4 to $6 \mathrm{f}$ high. + Siberia.

3 dìscolor Willd. Lvs. alternate, oblong-lanceolate, acuminate, denticulate, smooth, white beneath; hds. corymbous, with yellow rays.-Shrub 3 to $4 \mathrm{f} \mathrm{high}$. t Jamaica.

4 C. lanata Willd. Lvs, roundish, 7-angled, cordate, woolly beneath; hds. solitary on each peduncle; rays white within, of a vivid purple outside.- $+\mathrm{Ca}$. naries. Very beautiful.

5 C. populifolia H. K. Lvs. somewhat angular, cordate, downy beneath, the petioles appendaged; $h d s$. corymbous; rays red.-The florists have produced many hybrids of superior beauty; as the Rosy Morn, Jenny Lind, Vicar of Wakefield, \&c.

86. SENE'CIO, L. Groundsel. (Latt. senex, an old man; the word is synonymous with Erigeron.) Involucre of many equal scales or invested with a few shorter ones at base; flowers all tubular, $\Varangle$, or usually radiate and rays $\%$; receptacle not chaffy ; pappus simple, capillary and copious.-A vast genus embracing 600 species of herbs and shrubs. Lvs. alternate. Fls. mostly yellow, exceeding the invol.

$\$$ Heals discoid. Root annual............................................ No. 1

\& Heads radiate. - Radical leaves undivided. A Achenia glabrous............................ 2, s - Radical leaves undivided. A chenia pubescent.................... Nos. 4,5 - Radical leaves divided, as well as the cauline...................... Nos. $6-8$

1 S. vulgàris L. St. paniculate, erect, angular; lvs. sinuate-pinnatifid, dentate, amplexicaul.- (1) A weed growing about houses, in waste grounds, rubbish, \&c. N. States. St. $18^{\prime}$ high, leafy, branching, generally smooth. Lvs. alternate, thin, 
bright green, the radical ones stalked. Fls. without rays, terminal, scattered, yellow, appearing all summer. § Eur.

2 S. aùreus L. Radical lvs. ovate, cordate, crenate-serrate, petiolate, cauline ones lyrate-pinnatifid, dentate, terminal segments lanceolate; ped. subumbellate, thick; rays 8 to 12 ; ach. glabrous. - 24 Plant with varying forms, in meadows, woods, (U. S. and Brit. Am.), with golden yellow fls. St. smoothish, striate, erect, 1 to $2 \mathrm{f}$ high, simple, or branched above, terminating in a kind of umbellate, simple or compound corymb. Lower stem lvs. lyrate, upper ones few and slender. Ped. more or less thickened upwards. Scales linear, acute, purplish at apex. Rays spreading about $1^{\prime}$. May-Aug.

$\beta$ BALSÁMTT E. St. villous at base; lvs. few, small and distant, pubescent, radical ones oblong-lanceolate; ped. villous at base.-Rocky hills and pastures. (S. Balsamitæ, Muhl.)

$\gamma$ GRícILIS. Radical lvs. orbicular, on long petioles, cauline few, linear-oblong, incisely dentate; ped. short, pilous, with small, few-rayed heads.-A slender state of the species, on rocky shores. (S. gracilis, $\mathrm{Ph}$.)

$\delta$ oвovìtus. Radical lvs. obovate to oblong-spatulate; ped. elongated.Meadows, \&c. (S. obovatus, Willd.)

$\varepsilon$ LANCeolititus. Radical lvs. lanceolate, acute, cauline lanceolate, pinnatifid at base.-Shady swamps, \&c.

3 S. obovàtus Ell. Tomentous when young, at length glabrous; root lvs. obovate or roundish, crenate, with an attenuated sessile base, cauline few, small, culpinnate; corymb small; rays 10 to 12 ; ach. glabrous.-Va. to Fla. St. a foot high, nearly leafless. Lvs. mostly radical, near $3^{\prime}$ broad and long, often slightly petioled; the upper lvs rapidly diminished. Rays spreading about 1'. May.

4 S. tomentòsus Mx. Clothed with soft, cotton-like, nearly persistent tomentum; root lvs. oblong or oblanceolatio or ovate, obtuse, tapering to a long, slender petiole, crenate, the upper sessile; hds. fastigiate, rays 12 to 15 ; ach. pubescent.-2f Va. to Fla. and La. St. 1 to $2 \mathrm{f} \mathrm{high,} \mathrm{often} \mathrm{nearly} \mathrm{leafless} \mathrm{above.} \mathrm{Corymb} \mathrm{simple,}$ subumbellate. Root lvs. with their petioles 6 to $9^{\prime}$ long, 1 to $3^{\prime}$ wide. Rays spreading $16^{\prime \prime}$. Apr.-Jn.-The leaves aro exceedingly variable. A variety (on Stone Mt., Ga.) is low, densely tomentous, with the lvs. all radical.

5 S. anónymus. Plant clothed with a white, partly deciduous tomentum; root lvs. small, oblong, obtuse, crenate-serrate, some of them slightly lobed, tapering to a petiole, cauline lvs. long and narrow, remotely sinuate-pinnatifid, the segm. cut-dentate; hds. subumbellate, small, ach. pubescent.-2f ? Montgomery, Ala. St. 16 to $24^{\prime}$ high. Root lvs. $\frac{1}{2}^{\prime}$ wide and with their petioles 2 to $3^{\prime}$ long. 'St. lvs. $6^{\prime}$ long, the upper $1^{\prime}$, almost bipinnatifid. Rays 8 to 10 , spreading about $7^{\prime \prime}$. May., Jn.

6 s. Canadénsis I. Lvs. glabrous, bipinnate with linear, lobed, obtuse segm., the upper fow pinnately divided; corymbs compound, fastigiate; rays 9 to 12 .if Canada (Kalm, in Willd. Spec., \&c.) Upper districts of the S. States. Hds. rather small. Jn.-Possibly our S. anonymus is a variety of this. (S. millefolium T. \& G.

7 S. lobàtus Pers. ButTer-IWEed. Glabrous or slightly floccous at base; lvs. all lyrate-pinnatifid (or the upper pinnatifid), the lobes crenate, distant, odd ono roundish; corymbs somewhat compoundly umbeled; invol. slightly calyculate; rays 10 to 12 ; ach. minutely hispid.-(1) Low, wet grounds, N. Car. to Fla. and La., common. St. siriate, 2 to 3 f high. Lvs. 4 to $6^{\prime}$ long, terminal lobe $1^{\prime}$ diam. Rays spreading about $11^{\prime \prime}$. Mar.-Jl.

8 s. pseudo-elegans DC. PURPLE JACOBळA. Lrs, equal, pinnatifid pilous-viscid, spreading; ped. somewhat scaly; invol. calyculate with leafy scales; scales mostly withered at the tips.-(1) Native of the Cape of Good Hope. A beautiful plant in cultivation. Fls. of the disk yellow, of the rays brilliant purple. A variety has double fls. with colors equally fine. Another variety has white fls. Jn.-Aug. $\dagger$ (S. elegans L.)

87. AR'NICA, L. Involucre of equal, lanceolate scales, 1 or 2-rowed; ray flowers 7 , disk $\Varangle$; receptacle flat, with scattered hairs; pappus single, rigid and serrulate. -2 St. simple. Lvs. opposite. Fls. yellow. I A. mollis Hook. Pubescent; st. leafy; Ivs. becoming nearly glabrous, thin, 
veiny, dentate, ovate-lanceolale and oblong, radical ones stalled, cauline sessile; hds. few ; invol. hairy, with acuminate scales; ach. hairy.-Ravines, White Mts., N. H., Essex Mts., N. Y. Also Rocky Mts. St. 1 to $2 \mathrm{f}^{\circ}$ high. Lvs. 2 to $5^{\prime}$ in length, the upper one broad at the base, the lower tapering to a winged petiole, often acute, but not acuminate. Jl.

2 A. nuaicaùlis Ell. Hirsute; los. all sessile, subentire, oval or ovate, 3 to 5 veined, the veins converging to the apex, cauline small, 1 or 2 pairs; hds. few, large, terminal; rays about 12, 3-toothed at end; ach. glabrous. - Wet, sandy soils Va. to Fla. St. If high, scape-like. Lvs. mostly radical, resembling those of the plantains (Plantago), but smaller ( 2 to $3^{\prime}$ long.) Rays spreading fully $2^{\prime}$

Apl., May.

\section{Tribe 5. CYNAREAE.}

88. CYN'ARA, L. (Gr. $\kappa \dot{v} \omega \nu$, a dog; the stiff, hard spines of the invol. resemble a dog's teeth.) Heads discoid, homogamous; involucre dilated, imbricate, scales fleshy, emarginate, pointed; receptacle setaceous ; pappus plumous ; achenia not beaked.-Natives of the Old World.

1 C. Scólymus L. GARDEN ARTichoKe. Lys. subspinose, pinnate and undivided; invol. scales ovate. - 2f Gardens and cultivated grounds. A well known garden esculent. The parts used are the receptacle, the lower part of the involucre and the upper portion of the stalk. It is cultivated from suckers placed in rows, 3 feet apart. Aug., Sept. $\ddagger \S$ Eur.

2 C. cardunculus L. CARDOoN. Lvs. spiny, all pinnatifid; invol. scales ovate. -2f Flowers purple. This plant is blanched or etiolated, by heaping earth around it, whence its petioles become crisp, tender, and are used like celery. $\ddagger \S$ Eur.

89. TAGE'TES, L. Marigold. (For Tages, a Tuscan divinity, son of Genius and grandson of Jupiter.) Heads heterogamous; involucre simple, tubular, of 5 to 10 united scales ; ray flowers 5 , persistent; receptacle naked; pappus of 5 erect awns.-(1) Herbs of tropical Amer ica. Lvs. pinnately divided.

1 T. pátula L. FRENCH MARIGoLd. St. erect, with widely spreading branches; segm. of the leaves linear-lanceolate; ped. elongated, subcylindric, one-Howered; invol. smooth.-Plant about $2 \mathrm{f}$ high. Rays orange yellow; variegated with dark purple. $\dagger$

2 T. erécta L: AFRICan MARigold. St. stout, erect; segm. of the lvs. lanceolate, ciliate-serrate; ped. 1-flowered, ventricous and thickened at the summit; invol. angular.-The hds. are twice larger than in T. patula, and on shorter peduncles. - These are well known and popular garden flowers with several varieties. $\dagger$

90. Calen'Dula, L. Pot Marigold. (Lat. calenda, the first day of the month; some species blossom monthly.) Heads radiate; involucre of many equal leaves, in about 2 series; rays $q$, fertile, disk $\hat{\delta}$, sterile; receptacle naked; achenia of the disk membranaceous; pappus 0.-An oriental genus of annual herbs. Lvs. alternate.

C. officinàlis L. Viscid-pubescent; st. branched; lvs. oblong, acute, mucronate, sessile, subdentate and scabrous-ciliate on the margin; hds. terminal, solitary; ach. carinate, muricate, incurved.-A common and handsome garden plant, from S. Eurone. It has double, lemon-colored, and other varieties. Flowers large and brilliant, generally orange-colored. Jn.-Sept. †

91. Centau'REa, L. Knap-weed. Bachelor's-button. (The centaur, Chiron, it is said, cured with these, his foot wounded by Her- 
culcs.) Heads diseoid ; involucre imbricate; ray flowers longer than the rest, sterile, often wanting; receptacle bristly; pappus of filiform, scabrous bristles in several series.-A genus of oriental herbs with alternate lvs.

* Scales of the involucre with a fringed or pectinate appendage...................Nos. 1, 2

* Scales of the involucre merely ciliate, or tipped with a spine............................... 4

1 C. nígra L. St. erect, branched, pubescent above; lower lvs. angular-lyrate, upper lanceolate, dentate, scales ovate, with an erect, capillary, fringed appendage; ray and disk-fls. alike. $-24 \mathrm{~A}$ troublesome weed, in meadows and pastures, Mass. St. about $2 \mathrm{f} \mathrm{high,} \mathrm{simple,} \mathrm{or} \mathrm{oftener} \mathrm{divided} \mathrm{into} \mathrm{elongated} \mathrm{branches.} \mathrm{Hds.} \mathrm{few,}$ large, terminal, solitary. Fringed appendage of the scales dark brown. Fls. purple. Jl., Aug. § Eur.

2 C. Americàna Nutt. St. erect, sulcate, sparingly branched; lower lvs. oblongovate, repand-dentate, upper ones lanceolate, acute, all sessile and glabrous; hds. few or solitary, very large; ped. thickened at summit; ray fls. twice longer than the disk; scales with a pectinate-pinnate, reflexed appendage.-1) Ark. and La., naturalized in Ill. (Mead.) Cultivated in gardens. St. 2 to $4 \mathrm{f}$ high, with large, showy, pale-purple hds. Appendages straw-color. $f$

3 C. Cỳanus L. BACHelor's-ButTon. St. erect, branching, downy; lvs. linear, entire, downy, the lowest subdentate; scales ciliate-serrate; ray flowers much enlarged.-(1) Cultivated and sparingly naturalized in old fields. It is a liardy annual, justly popular for its handsome flowers which aro very variable in color. Hds. ovoid, solitary on the ends of the branches. Jl.-Sept. § Eur.

4 C. Calcítrapa L. Star Thistle. St. diffusely branched, bairy; lvs. sessile, pinnately lobed, lobes linear, toothed, upper mostly entire; hds. sessile; middle scales tipped with a strong, spreading spine with 1 or 2 minuto spines each side; pappus 0.-1) (2) Va. Fls. purple. § Eur.

92. AMBER'BOA, DC. Sweet Sultan. Heads discoid; involucre imbricated; ray-flowers wanting or larger than the rest, sterie; pappus of oblong or obovate pales, attenuated to the base, all similar, rarely small or 0.-Eastern herbs with alternate lvs.

1 A. moschàta Willd. Lrs. lyrate-dentate; invol. subglobous, smooth; scales ovate; ray-flowers scarcely enlarged, not exceeding the disk; pappus 0.A handsome border annual from Persia. Flowers purple. A variety has white Howers. July-Oct. (Centaurea L.) †

2 A. odoràta, a. amboracea. DC. Yellow Sweet Sultan. Lower Ivs. broadly subspatulate, dentate, upper lyrate at base; hds. globous; ray-fls. enlarged upwards, longer than the disk; pappus chaffy, a little shorter than the fruit.-From Levant. Leaves scarcely pinnatifid. Flowers yellow. $\dagger$ (Centaurea suaveolens Willd.)

$\beta$. GLAUCA. Lrs. often deeply pinnatifid; flowers purple. $\nmid$ (Centaurea glauca Willd.)

93. CAR'THAMUS, L. SAFFRON. (Arabic, qorthom, to paint; from its coloring property.) Heads discoid; involucre imbricated, outer bracts foliaceous; flowers all tubular and $\varnothing$, filaments smooth; pappus 0 ; receptacle with setaceous pales; achenia 4-angled.-Oriental herbs.

C. tinctorius I. St. smooth ; lvs. ovate-lanceolate, sessile, spinous-denticulate.-(1) Native of Egypt, but long cultivated in other lands on account of its orange-colored flowers. Stem branching, striate, 1-2f high. Leaves subamplexicaul, smooth and shining. Heads large, terminal, with numerous long and slender flowers. The latter aro useful in coloring, and as a nursery medicine. July. $t$

94. CNICUS, Vaill. Bressed Tuistre. (Gr. เvi applied to these herbs.) Heads discoid ; involucre rentricous, imbricate with doubly spinous scales; ray-flowers sterile; receptacle very 
hairy; pappus in 3 series, the outer 10-toothel, the 2 inner each 10-bristled.-Oriental herbs.

C. benedictus L. Lvs. somewhat decurrent; dentate and spiny; invol. doubly spinous, woolly, bracteate.-(1) Native of Persia, Tauria and Greece. About $2 f$ ligh, with yellow flowers. Sparingly naturalized. June.-It was formerly in great estimation in medicine, but is now considered worthless. $\ddagger \S$

95. ONOPOR'DON, Vaill. CotTon Thistle. . Heads discoid, homogamous; involucre ventricous, imbricate with spreading, spinous scales; receptacle deeply alveolate ; pappus copious, capillary, scabrous; achenia 4-angled.-Large, branching herbs, with decurrent leaves.

O. acanthium I. Invol. scales spreading, subulate; lvs. ovate-oblong, decurrent, sinuate, spinous, woolly on both sides.-(2) This fino looking thistle occurs naturalized in waste grounds, and is about $3 f$ in height. The whole plant has a white, cottony appearance. Stem winged by the decurrent leaves. which are unusually large. Involucre round, cottony, spinous. Flowers purple. July, Aug. $\S$ Eur.

96. CIR'SIUH, Tourn. (Cnicus L.'Muhl.) Thistle. (Gr. kípбos, a swelling of a vein, which this plant was supposed to heal.) Heads discoid, homogamous; involucre subglobous, of many rows of spinous-pointed, imbricated scales; receptacle bristly; style scarcely divided; pappus copious, plumous ; achenia compressed, smooth.Herbs with alternate lvs., generally armed with spinous prickles. Fls. cyanic.

* Leaves decerrent on the stem moro or less. Seales tipped with spines..............Nos. 1, 2

* Leares not dccurrent.-Heads involucrate with a whurl of 12 to 20 splny bracts........ No. 3 -Heads naked.-Flowers ochroleucous. Scales prickly.............. 4 -Fls. purple. - Lvs. white-tomentous beneatli...Nos. 5-7 -Lvs. green.-Stem low, simple.. Nos. 8,9 -Stem tall, branched. "10-12

1 C. lanceolàtum Scop. Common Tmsrue. Lvs. decurrent, pinnatifid, hispid, the segments divaricate and spinous; $h d s$ several, ovoid, villous; scales lanceolate, tipped with a spine, spreading.-(2) Common in borders of fields, roadsides, N. Eng. and Mid. States, always distinguished by the decurrent leaves. St. 3 to $4 \mathrm{f}$ high, winged by the decurrent leaves which are white and woolly beneath, armed with formidable spines at all points. Fls. numerous, large, purple. Invol. scales, webbed, each ending in a spine. Jl.-Sept.

2 C. Lecóntii Torr. \& Gr: Slender, simple, with one head; lvs. linear-lanceolate, more or less decurrent, with a few spinous teeth, glabrous above, white-floccous beneath, invol. ovoid, arachnoid when young; scales not spinous, merely mucronate or acuminate-pointed.-Ga. to La. St. about $2 \mathrm{f}$ ligh. Hd. large, ( $\mathrm{l}^{\prime}$ or more diam.) terminal.

3 C. horrídulum Mx. Lvs. sessile, pinnatifid, acutely cut, spinous; hds. invested with an external invol. of about 12 to 20 very spinous bracts; scales sharp-pointed, but unarmed.-(2) Found in meadows and hills, N. Eng. to Fla. St. 1 to $3 \mathrm{f} \mathrm{high,}$ invested with wool. Lrs. somewhat clasping, woolly and hairy, armed with stiff spines. Hds. large ( $\mathrm{I}^{\prime}$ diam.), with yellowish white corollas, tho scales webbed. Aug.

$\beta$. Elciorrir. Corollas purple, 2 ' long. Bracts about 12.-South (Elliott). Flan, near Quincy.

4 C. Pítcheri, Torr. \& Gr. White-tomentous; lvs. rigid, pinnately parted, margins revolute, segm. long, linear, toothed or entire, spinous; hds. axillary; scales arachncid, acuminate, tipped with a weak, spreading prickle.-Sandy lake shores, Mich. and Can. West. Cor. ochroleucous. Jn., Jl.

5 C. díscolor Spreng. Lvs. sessile, pinnatifid, rough-haired, downy beneath, segm. 2-lobed, divaricate, spinous; invol. globous, the scales ovate, appressed, with spreading spines at the tip.- (2) A slender thistlo 3 to $5 \mathrm{f}$ high, much branched and leafy at the summit, found in thickets, N. Eng. to Ill. Hds. terminating the branches, 1' diam., with reddish purple corollas. Jl. Aug. 
6 C. altíssimum Spreng. Tall, branched, villous-pubescent, leafy to the top ; lvs. whitish beneath, spinous-ciliate, sessile, lanceolate oblong, often sinuate-dentate, lower undivided or pinnatifid petiolate, lobes or teeth spinescent. Hds. large, scales ovate-lanceolate, outer one with a spreading spine at apex. - Fields and barrens, Penn. and W. States, common. St. 3 to $8 \mathrm{f}^{\prime}$ high. Lvs. 6 to $8^{\prime}$, by 1 to $6^{\prime}$. Hds. about $1^{\prime}$ diam., with linear-lanceolate bracts at base. Fl. purple or purplish white. Aug.

7 C. Virginiànum Michx. Slender, mostly simple, and naked above; lvs. sessile, lanceolate, margin revolute, entire or repand-dentate, teeth spinescent, or sometimes remotely sinuate-lobed or pinnatifid, upper surface glabrous, under surface tomentous-canescent; hds. small; invol. subglobous; scales tipped with a short, spreading prickle.-Woods, Ohio, and S. States. Plant about the size of the Canada thistle, clothed with an arachnoid pubescence, with few or many heads (sometimes but one) which aro about $\frac{1^{\prime}}{2}$ diam. Flowers purple. Apr.-Sept. (Carduus, L. Cnicus, $\mathrm{Ph}$.)

8 C. repándum Mx. Arachnoid when young; lvs. crowded to the top, at length green both sides, clasping oblong-linear, undulate, spinous-ciliate; hds. 1 or 2 ; scales, outer ovate-lanceolate, inner subulate-acuminate.-Barrens, N. Car. to Ga.

9 C. púmilum Spreng. Hairy; lvs. few above, green on both sides, clasping, oblong-lanceolate, pinnatifid, the segm. irregularly lobed, ciliate, spinous; hds. few, very large, subtended by 1 to 5 bracts; invol. round-ovate, spinous.- (2) A common, low, turgid thistle, in roadsides, pastures, N. Eng. and Ifid. States. St. 1 to $2 \mathrm{f}$ high, stout, striate, with 1 to 3 very large heads of fragrant, purple fls. Aug. (Cnicus odoratus Muhl.)

10 C. mùticum Mx. Lrs. pinnatifid with divaricate segments; hds. on naked peduncles without bracts; invol. ovoid with unarmed, villous-arachnoid, glutinous scales.- (2) A fine looking thistle found in damp soils. Can. and U.S. St. branching, 3 to if high. Lvs. armed with spines at each angle. Hds. I' diam., with deep purple corollas, the scales webbed and glutinous on the back. Aug., Sept.

11 C. glaber Nutt. Tall, slender, nearly glabrous; lvs. lance-linear, rigid, with spinescent, divaricate segments, the lower slightly decurrent; hds. naked, on leafless stalks; scales setaceously mucronate, strongly keeled, almost glabrous, the inner attenuate-acuminate. -N. Jer. to Ga. St. very smooth, angled, 3 to $5 \mathrm{f} \mathrm{high.} \mathrm{Lvs.}$ minutely arachnoid beneath. Hds. $6^{\prime \prime}$ diam., truncate at base. Fls. purple. Jl. Sept.

12 C. arvénse Scop. Canada Thistre, Cunsed Thistre. Lvs. sessile, sinuatepinnatifid, wavy, spinous; st. panicled; hds. numerous, small, invol. round or ovate, with minute spines, scales close-pressed, ovate-lanceolate. $-2 f$ Common in fields, roadsides and waste places, N. Eng. to W. States, rery troublesome to the farmer. Root creeping, long and tenacious of life. St. $3 \mathrm{f}$ high, with a branching panicle at top. Hds. small ( 4 to $5^{\prime \prime}$ diam.) purple, the involucre nearly thornless, and is the only part of the plant that can be safely handled. Jl. § Eur.

97. LAP'PA, Tourn. BuRDock. (Lat. lappa, a burr, from Gr. $\lambda a \beta \varepsilon \tau \nu$, to lay hold of; a characteristic term.) Heads discoid, homogamous; involucre globous, the scales imbricated and hooked at the extremity ; rcceptacle bristly; pappus bristly, scabrous, caducous.-(2) Coarse, European herbs. Lvs. alternate, large.

I. màjor Gaert. Ivs. cordate, unarmed, petioled.-Common in waste and culti. vated grounds, fields. N. Eng., Mid. and W. States. Each plant is a large, conical, ill-scented and coarse-looking mass of vegetation, surmounted by a branching, irregular panicle of ovoid heads with tubular corollas of an exceedingly delicate pink color. The leaves are very large, with wavy edges. It has a wonderful design for the dispersion of its seeds. The scales of the involucre all end in a minute, firm hook, which seizes hold of everything that passes by. Jl., Aug. § Eur. (Arctium Lappa L.)

B. Leaves pinnatifid.-Penn. (Darlington). 


\section{SUBORDER II. LIGULIFLOR A.}

98. LAMPSA'NA, Tourn. Nipple-wort. (Gr. $\lambda a \dot{\pi} \tau \omega$, to purge; "Lapsana greatly relaxes the body," says Pliny.) Heads radiant, 8 to 12-flowered; involucre cylindrical, angular, scales 8 , erect, in one row, with 2 or 3 minute bractlets at base; receptacle naked; achenia glabrous; pappus 0.-Slender, oriental herbs, with small, yellow hds. in paniculate corymbs.

I. commùnis I. St. branched, panioled, leafy; lvs. ovate, petiolate, dentate; ped. cylindrical; invol. angular in fruit.-(1) Waysides, Can. East (Hook). Near Boston (Oakes). §

99. APO'GON, Ell. (Gr. a, privative, $\pi \omega \gamma(\omega \nu$, beard; as destitute of pappus.) Heads radiant; involucre scales ovate, acuminate, about 8 , in 2 rows ; receptacle naked; achenia glabrous, oval, longitudinally $12-$ striate; pappus 0.-(1) Herbs glabrous and glaucous, branched from the base. Lvs. alternate, lanceolate. Hds. small, yellow.

A. húmilis Ell. S. Car. to Fla. and La. A small, slender, smooth plant, common in sandy soils. Sts. 3 to $12^{\prime}$ high, trichotomously branched above. Ivs. varying from lance-linear to linear, and from entire to lyrate-lobed, the radical tapering to a petiole. Hds. few, small, the fls. spreading about $3^{\prime \prime}$. Mar.- Jn. (A. lyratum Nutt. A. gracilis DC.)

100. CICHO'RIUM, Tourn. Succory. (The Egyptian name chikouryeh, whence Gr. $\kappa \iota \chi \omega \rho \eta$, and Eng. succory.) Involucre double, the outer of 5 leafy scales, the inner of about 8 linear ones; receptacle chaffy; pappus scaly; achenia not rostrate, obscurely 5 -sided.-Oriental herbs with bright blue fls., about 20 in a head.

1 C. intybus L. Fls. in pairs, axillary, sessile; lower lvs. runcinate. - 2f Plant 2 - $3 \mathrm{f}$ high, with large, showy, sky-blue tlowers, in grass fields, by roadsides, common in many localities. Stem round, with few long branches, rough. The upper leaves become cordate acuminate, sessile, inconspicuous, only the radical ones runcinate. The flowers are $1-2^{\prime}$ diam., and placed rather remote on the long, nakedish branches. Corollas flat, 5-toothed. The root is used in France as a substitute for coffec. July-Sept. § Eur.

2 C. Endivia I. Ennive. Ped. axillary, in pairs, one of them elongated and 1-headed, the other very short, about 4-headed; hds. capitate.-A hardy annual, esteemed and cultivated for salad. Also a remedy for jaundice. $† \mathrm{E}$. Indies.

101. KRIG'IA, Schreb. Dwarf Dandelion. (To Dr. Daniel Krieg, a German botanist who traveled in this country.) Involucre manyleaved, nearly simple, equal ; receptacle naked; achenia turbinate, striate, 5 -angled; pappus double, consisting of 5 broad, membranous scales alternating with as many slender, scabrous bristles.-(1) Acaulescent herbs. Hds. solitary, with 20 to 30 yellow fls.

1 K. Virgínica Willd. Early radical, Ivs. round-spatulate, subentire, the later lvs. lance-oblong, angular-toothed, or lyrate-pinniatifid; heads solitary, on scapes finally longer than the leaves, glabrous.-Dry, sandy soils, Can. to Ga. Leaves all radical. Scapes $2-10^{\prime}$ high, bearing each a small head of deep yellow flowers. Late flowering specimens show many scapes branched from the base. (K. dichotoma Nutt.) May-Aug.

2 K. Caroliniàna Nutt. Lvs. lyrate-pinnatifid, with irregular, oval or angutar segments, the terminal one roundish and largest, primary lvs. linear-lanceolate, fewtoothed or entire, scapes always simple, solitary at first, finally several 1-flowered. -Dry, sandy soils, S. Car. to Fla, and Tex. Scapes 1 to $4^{\prime}$ high. Lrs. 1 to $2^{\prime}$ long, rosulate. Fls. spreading 4 to $6^{\prime \prime}$. Feb.-May. 
102. CYN'THIA, Don. (One of the names of Diana; fancifully applied to this genus.) Involucre nearly simple, of equal, narrow scales; receptacle flat, alveolate; pappus double, the outer minute, scaly, inner copious, capillary ; achenia short. $-2 f$ Lvs. alternate or all radical. Hds. with 15 to 20 yellow flowers.

1 C. Virgínica Don. St. few-leaved, branched above; lvs. oral and lance-oval, entire or remotely toothed, rarely sinuate-pinnatifid, the radical on winged petioles, cauline amplexicaul, entire.-In barrens and dry soils, Western N. Y. to Ill. smooth and glaucous. St. 1 to $2 \mathrm{f}$ high, often dichotomously divided, with 1 to 2 clasping leaves at the forks. Radical lvs. 3 to $5^{\prime}$ long. Hds. terminal on tho bracteate and subumbellate peduncles, with deep yellow flowers. Scales united at oase in a somewhat double series. May-J1. (Krigia, Nutt.)

2 C. Dandèlion DC. Acaulescent; scapes leafless, simple, 1-flowered; lvs. elongated, lance-linear, entire or remotely toothed, rarely pinnatifid, the primary lvs. oblong-spatulate.-Low grounds, Md. to Ga. and Tex. Scapes 6 to $18^{\prime}$ high, several from the same root. Lrs. some of them nearly as long as the scapes, moro generally entire; when pinnatifid, the lobes are 2 or 3 on each side, triangular. A variety in the mountainous districts produces at length a short, decumbent stem. (Hyosiris montana Mx. C. lyrata Nutt.)

103. LEON'TOdON, L. Autumnal Hawnвit. (Gr. $\lambda \varepsilon \dot{\varepsilon} \omega \nu$, a lion, ódov́s, a tooth; in reference to the toothed leaves.) Involucre imbricate, the outer scales very short; receptacle naked; pappus plumous, persistent on the somewhat rostrate achenia.-Acaulescent herbs with yellow fls., -many in a head. (Apargia, Willd.)

I. autumnàlis I. Scape branching; ped. scaly, lvs. lanceolate, dentate-pinnatifid, smoothish.-Common in the eastern parts of N. Eng., grass lands and roadsides. Fls. simulating the dandelion. Rt. large, abrupt, scape round, striate, hollow, decumbent at base, 6 to $18^{\prime}$ high, with a few branches and scattered scales. Lvs. spreading, $6^{\prime}$ long, with deep, round sinuses, and covered with remote hairs. IHds. 1' diam. Ji.-Nov. § Eur.

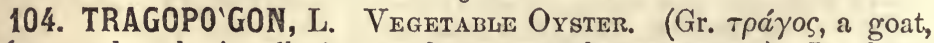
$\pi \omega \gamma \omega \nu$, a beard; in allusion to the tawny, showy pappus.) Involucre simple, of many leaves; receptacle naked; pappus plumous, achenia longitudinally striate, contracted into a long, fliform beak.- (2) European herbs, with long, linear, grass-like lvs.

T. porrifòlius L. Involucre much longer than the corolla; lvs. long, linear, undivided, straight; ped. thickened upwards. St. 3 to $4 \mathrm{f}$ high. Fls. terminal, solitary, large, bluish purple. Cultivated in gardens for the root, which is long, tapering and nutritious. When properly prepared it has a mild, sweetish taste, which has been compared to that of the oyster. $\ddagger \S$ in W. N. Y.

105. HIERA'CIUM, Tourn. HAw KweEd. (Gr. lépa , a hawk; supposed to strengthen the vision of birds of prey.) Involucre more or less imbricated, ovoid, many-flowered; scales very unequal; achenia not rostrate ; pappus a single row of copious, tawny, fragile bristles.2f Lvs. alternate, entire or toothed.

* Ireads 40 to 50 -flowered. Involucre more or less imbricated............... Nos 1,3

* Heads 12 to 30 -flowered. Involucro simple.-Achenia contracted at the top................. 8 , 1 - Achenia not contracted upwards.... Nos. 5,6

1 H. Canadense Mx. St. erect, subvillous, leafy, many-flowered; lvs. sessile, lanceolate or oblong-ovate, acute, divaricately and acutely dentate, the upper ones somewhat amplexicaul, with an obtuse base; pauicles axillary and terminal, corymbous, downy; invol. strongly imbricated.-In open dry or rocky woods, N. Eng. to Wis. and Can. Stem stout, $1-2 f$ high, more or less pubescent, the poduncles downy but not glandular. Leaves somewhat pubescent or hairy. Heads large and showy, yellow Involucre sometimes with a few glandular hairs. Aug. (H. Kalmii Spreng.) 
2 F. scabrum Mx. St. leafy, scabrous and hispid; lvs. elliptic-obovate, scabrous and hirsute, entire or the lower slightly dentaie; ped. thick, and with the invol. densely glandular-hispid; hds. 40-50-flowered.-Dry hills, borders of woods, Can. to Car. and $\mathrm{Ky}$. Stem 1-3f high, round, striate, rather stout. Lower leaves petiolate, upper sessile, subacute, often purplish as well as the stem. Heads large, with yellow flowers. Achenia obtuse at apex, bright red. Aug.

3 H. Iongipilum Torr. Plant densely pilous with long, straight, ascending, bristly hairs; st. strict, simple, smoothish and nearly leafless above; lrs. crowded on the lower part of the stem, oblong-lanceolate, attenuated at the base, entire; hds. glandular-tomentous or hispid, 20-30-flowered, in a small, terminal panicle.Barrens and prairies, W. States. Plant $1-2 f$ high, remarkable for the long ( $\left.6^{\prime \prime}\right)$ brownish hairs with which the lower part is thickly clothed. July-Sept.

4. H. Gronovii L. St. leafy, hirsute, paniculate; invol. and pedicels glandularpilous; radical lvs. obovate or oblanceolate, entire, or denticulate, strigous, the midvein beneath very villous; upper ones oblong, closely sessile, ach. 20 to 30 , contracted above.-Dry hills, Can. and U. S. Stem 1 to 3 f, furnished with a few leaves below, naked abovo and bearing a narrow, elongated panicle. Lower leaves tapering into a long stalk. Flowers yellow, on glandular, slender pedicels. Achenia tapering upwards from tho middle, but not rostrate. Aug., Sept.

$5 \mathrm{H}$. venòsum L. Scape or st. naked or with a single leaf, smooth, paniculate; lvs. obovate, somewhat acute, entire, a little hairy above, nearly glabrous beneath, ciliate on the margin, veins colored; invol. glabrous, about 20 -flowered; ach. linear.-In woods, \&c., N. Eng. to W. States. Stem 1-2f high, dark brown, slender. Paniole diffuse, several times dichotomous, corymbous. Heads rather large, on slender pedicels, with bright yellow flowers. Jl., Aug.

6 H. paniculàtum I. St. slender, leafy, diffusely paniculate, whitish pubescent below; lvs. lanceolate, glabrous, membranaceous, acute, with remote spreading teeth, or entire; paniclo diffuso; ped. very slender; hds. 10-20-flowered.-A smooth, slender plant, in damp woods, Can. to Ga. Stem 1-3f high, several times dichotomous. Leaves thin, $2-4^{\prime}$ long. Heads small, numerous, with yellow flowers. Pedicels long and filiform, forming a very diffuse panicle. Aug.It is not easy to determino the oxact limits of the last three species. A thorough revision of tho genus will probably reduce them to one, viz.; $H$. Gronovii.

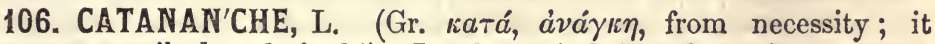
must necessarily be admired ?) Involucre imbricated, scarious; receptacle paleaccous; pappus paleaceous, 5-leaved; pales awned.-(D) Oriental herbs, with alternatc, lanceolate lvs.

C. ccrùlea L. Lvs. linear lanceolate, villous, somewhat bipinnatifid at base; lower scales of the involucre ovate, mucronate.-From S. Europe. A handsome annual, 2 to $3 f$ high. Hds. solitary, on long peduncles, with blue spreading, ligulato corollas toothed at apex. J1-Sept. $\dagger$

107. NAB'ALUS, Cass. Drop Flower. (A barbarous name.) Involucre cylindric, of many linear scales in one row, calyculate with a few short, appressed scales at base ; receptacle naked; pappus copious, capillary, brownish, 2-rowed, persistent; achenia not beaked, smooth, striate.-Erect herbs with a thick, tuberous, bitter root. Hds. 5 to 18 , flowcred, not yellow, although often straw-colored. (Prenanthes L.)

$\S$ IIeads pendulous, giabrons. Leaves variously lobed or shaped. (a)

a Dwarf species $\left(6\right.$ to $10^{\prime}$ high) native of high mountains..................... 1, 2

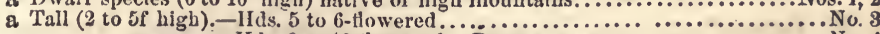
-IIds. 8 to 12-Howered.-Pappus tawny....................... 4 - Pappus straw colored............. Nos, 5,6

§ IIeals nording or erect, hairy. Leaves mostly undivided. (b)

b IIeads about 12 -flowered. Pappus straw-color...................... Nos. 7, 8

b Heads about 25 -flowered. Pappus tawny or dusky $\ldots \ldots \ldots \ldots \ldots \ldots \ldots \ldots \ldots \ldots \ldots$ No. 9

1 N. Boottii DC. St. simple, dwarf; lower lvs. subcordate or hastate-cordate, obtuse, the middle oblong, the upper lanceolate, mostly entire; hds. nodding, racemed; invol. 10 to 18-flowered, of 10 to 15 obtuse, proper scales calyculate at the base with lax linear scales half thoir le!gth; pappus straw-color.-White Mts., N. H., and 
Essex Mt., N. Y. St. 5 to $8^{\prime}$ high, bearing tho hds. in a subsimple raceme. Fls. whitish and odorous. Jl., Aug.

2 N. nànus DC. St. simple, low, smooth; lvs. on slender petioles, the lowest variously lobed or parted, the others successively deltoid-hastate, ovate and lanceolate; hds. in small, axillary and terminal clusters, forming a short, racemous panicle; invol. greenish-purple, of about 8 scales and 10-12 flowers; pappus dingy white.-White Mts., N. H., with No. 1, where we find it with the same sportive character of foliage as appears in other species. Stem 5-10' high. Feads with whitish flowers. Aug. (P. alba. $\beta$. nana Bw.)

3 N. altíssimus Hook. St. smooth, slender, straight, paniculate above; lvs. more or less deeply 3-5-cleft, all petiolate, angular, denticulate and rough-edged, tho lobes acuminate; hds. pendulous; invol. of 5 scales and about 5-flowered.Tall, with cylindric, yellowish, nodding flowers, in woods, Newfoundland to N. Eng. and $\mathrm{Ky}$. Stem $3-5 \mathrm{f}$ ligh, bearing a narrow and elongated panicle. Heads in short, axillary and terminal racemes. Aug.

$\beta$. ovatus. Cauline lvs. nearly all ovate, on slender petioles.

$\gamma$. condatus. Lrs. cordate, on slender petioles. (Prenanthes cordata Willd.)

$\delta$. DELToideA. Lvs. deltoid, acuminate, acutely denticulate. (P. deltoidea Ell.)

$\varepsilon$. DISSECTUS. Lvs. mostly 3-parted or divided, segments entire or deeply cleft into 2 or 3 narrow lobes.

4 N. albus Hook. LioN's-FOot. White Letruce. St. smooth and somewhat glaucous, corymbous-paniculate above; radical lvs. angular-hastate, often more or less deeply lobed; stem lvs. roundish-ovate, dentate, petioled, the lobes or leaves obtuse; hds. pendulous; invol. of 8 scales, 9-12-flowered; pappus brown. -Moist woods and shades, N. Eng. to Iowa, and Can. to Car. Stem stout, $2-4 \mathrm{f}$ high, purplish, often deeply so in spots. Leaves very variable, all irregularly toothed. Scales purplish. Fls. a dingy white. Aug.

$\beta$. SERPEntaria. Radical lvs. palmate-sinuate, those of the stem on long petioles, with the middle segment 3-parted; upper lvs. lanceolate.-Has the reputation of curing the rattlesnake's bite. (Prenanthes serpentaria $\mathrm{Ph}$.)

5 N. Fràseri DC. St. smooth, corymbously paniculate above; lvs. subscabrous, hastate or deltoid, often pinnately lobed, on winged petioles, the upper ones lanceolate, subsessile; invol. of about 8 scales, 8-12-flowered; pappus straw-colored.2f In dry, hard soils, Conn. and Mid. States (rare) to Fla., common. Stem 2-4f high. Leaves as variable as in other species, sometimes all being lanceolate, with only irregular indentures instead of lobes. Heads drooping, with purplish scales and cream-colored corollas. It is readily distinguished from $\mathrm{N}$. albus by the moro lively color of the pappus. Aug. ( $\mathrm{P}$. rubicaulis $\mathrm{Ph}$.)

6 IN. virgàtus DC. Glabrous and glaucous, slender and simple; lower lvs. sinuatepinnatifid, petiolate, middle ones toothed, sessile, upper entire partly clasping, gradually reduced to the minute, subulate bracts; hds. clustered, in a long compound, virgate, somewhat secund raceme; invol. with about 8 scales and 10 flowers; pappus-straw-colored.-A remarkably slender, wand-like species, in sandy soils, N. J. to Fla. St. 2 to $4 \mathrm{f}$ high, racemous half its length. Lrs. gradually simplified from the base upward, as in most of the species. Sept., Oct.

7 N. racemòsus Hook. Glabrous, simple, slẹnder; lvs. all undivided, lower oval-lanceolate, sharply denticulate, petiolate, upper ovate-lanceolate, subclasping, entire; $h d s$. in nodding fascicles, arranged in a long, interruptedly spicate panicle; invol. of 8 to 9 scales, with 9 to 12 fls.; pappus straw-color.-N. J., N. W. States and Can. St. 2 to $4 \mathrm{f}$ high. Fls. pale red-purple.

$\beta$. Lvs. deeply and irregularly pinnatifid,

8 N. ásper Torr. \& Gr. St. strict, simple, scabrous; lvs. simple, scabrous-pubescent, dentate, lower ones oblong-oval, on margined petioles, upper lance-oblong and lance-linear, subentire, sessile; $h d s$. erect, in small fascicles, in a slender, elongated, compound raceme; invol. strongly hirsute, of 7 to 10 scales and with 11 to 14 fls.; pappus straw-color.-Dry prairies and barrens, W. States (Dr. Skinner), common. St. 2 to $4 \mathrm{f}$ high, nearly smooth. Lvs. 3 to $5^{\prime}$ long, pubescent or glabrous. Rac. 1 to $2 f$ long. Fls. ochroleucous. Sept. (N. Illinoensis DC.)

9 N. crepidineus DC. Nearly glabrous; st. tall, stout, corymbously paniculate; 
Ivs. large, irregularly toothed, petioles winged, lower ones oblong-ovate, somewhat hastate or deltoid, upper oblong-lanceolate; hds. nodding, in small, pedunculate and panicled clusters; invol. hairy, of 11 to 14 scales, with 25 to 35 fls.; pappus tawny.-Fields and thickets, W. States. One of the largest species. St. 5 to $8 \mathrm{f}$ high. Lvs. 4 to $12^{\prime}$ by $2 \frac{1}{2}$ to $7^{\prime}$, obtuse or acute. Hds. large but not numerous, with brown scales and yellowish fls. Aug.-Oct.

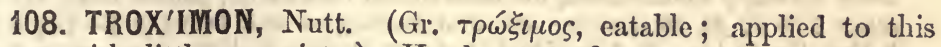
genus with little propriety.) Heads many-flowered; involucre campanulate, scales loosely imbricate, lance-ovate, membranous, in 2 to 3 rows ; achenia oblong-linear, compressed, glabrous, not rostrate ; pappus setaceous, copious, white.- 4 Lvs. all radical. Scape bearing a single, large, showy hd. with yellow fls.

T. cuspidàtum $\mathrm{Ph}$. Rt. fusiform; lvs. linear-lanceolate, acuminate, margins tomentous, often undulate; scales acuminate-cuspidate, erect, smooth, in 2 series, the outer nearly equal to the inner. Prairies, Wisc. (Lapham), Ill. (Mead.), W. to the Rocky Mts. (Nuttall). Apr.-Jn. (T. marginatum Nutt.)

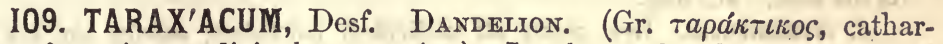
tic; from its medicinal properties.) Involucre double, the outer of small scales much shorter than the inner, appressed row; receptacle naked; achenia produced into a long beak crowned with the copious, white, capillary pappus.-Acaulescent herbs, with runcinate lvs.

T. Dens-leònis Less. Outer scales of the involucre reflexed; lrs. runcinate, smooth, dentate. -2 In all open situation, blossoming at all seasons except winter. Lrs. all radical, the teeth or lobes bent backwards. After the flower is closed and decayed, the hollow scape rises higher and bears a head of fruit full fledged, the airy, globular form of which is very conspicuous in the tall grass. The leaves in Spring furnish an excellent pot herb. Apr.-Nov. §Eur. (Leontodon Taraxacum L.) (Fig. 324.)

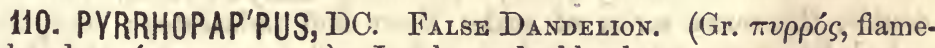
colored ; $\pi a ́ \pi \pi o s$, pappus.) Involuere double, the outer row numerous, loose and spreading; receptacle naked; achenia 5-grooved, at length long-beaked, bearing a copious, soft capillary, reddish-pappus.-(1) and if Hds. solitary on long peduncles, large, with numerous deep yellow fls. (Borkhausia, Nutt.)

P. Caroliniànus DC. St. simple or branched, scape-likc; lvs. mostly radical, lanceolate, acute, sinuate-toothed, lobed, or pinnatifid, some or all of them often entire.-Fields and pastures, very common. Sts. with 1 to 3 small lvs., 6 to $20^{\prime}$ high. Outer scales subulate-filiform, inner linear. $A \mathrm{ch}$. oblong, beak filiform, longer $\left(7^{\prime \prime}\right)$ than the showy pappus. Hds. in flower $18^{\prime \prime}$ to $2^{\prime}$ broad, turning to the morning sun. Mar.-Jl.

111. LYGODES'MIA, Don. (Gr. $\lambda \dot{v} \gamma o s$, a wand, $\delta \varepsilon \sigma \mu o ́ s, ~ a ~ b o n d$; alluding to its slender habit.) Involucre, flowers, \&c., as in Nabalus, except that the pappus is very copious, soft, smooth, whitish, and the corollas rose-colored. - In habit remarkably different from Nabalus, with linear-subulate lvs. and erect hds. on long, naked peduucles. (Prenanthes, Nutt.)

I. aphýlla DC. St. scape-like, erect, slender, striate, once or twice forked above; lvs. nearly all radical, short, linear-filiform.-Pine woods, Ga., Fla. (Mettauer.) St. $2 \mathrm{f} \mathrm{high.} \mathrm{Hds.} \mathrm{few,} \mathrm{cylindrical,} \mathrm{the} \mathrm{invol.} \mathrm{10"} \mathrm{long;} \mathrm{cor.} \mathrm{showy,} \mathrm{exserted}$ about the same length. Root lvs. 6 to $10^{\prime}$ long. May.

112. LACTU'CA, Tourn. Letruce. (Lat.lac, milk; from the milky, abundant juice.) Involucre few-flowered, scales imbricated in 2 or more unequal rows; achenia obcompressed (flattened same way as the 
scales), glabrous, abruptly narrowed to a long, filiform beak; pappus copious, soft, capillary, white, fugacious.-Herbs with leafy stems and paniculate hds. of various colors. (Fig. 333.)

1 I. graminifòlia Mx. St. terete, simple, strict; lvs. long, linear, entire, or the lower sparingly sinuate-lobed, the lobes turned backwards; panicle loose, naked; scales 6 to 9 ; fls. 20 or more; ach. oval, as long as their beaks $\left(2^{\prime \prime}\right)$.- - Dry solls, S. Car., Ga. to La. St. 2 to $4 \mathrm{f} \mathrm{high,} \mathrm{not} \mathrm{very} \mathrm{slender,} \mathrm{hollow.} \mathrm{Lvs.} \mathrm{partly} \mathrm{elasp-}$ ing, 3 to 6 to $8^{\prime}$ long, 3 to $4^{\prime \prime}$ wide. Cor. purple, varying to white, rarely yellow. $\Lambda$ pr.-Sept.

2 L. elongàta I. TRUMPET MILKWEed. Lvs. smooth and pale beneath, amplexicaul, runcinate-pinnatifid, upper lanceolate, entire, sessile; hds. racemouspaniculate; scales few; fls. 12 or more.-A common rank plant, growing in hedges, thickets, where the soil is rich and damp. St. hollow, stout, 3 to $6 f$ high, often purple, bearing a leafless, spreading panicle of numerous hds. of fls. Lvs. very variable, the lower 6 to $12^{\prime}$ long, commonly deeply runcinate. Corollas yellow, varying to purplish. Achenia oblong, compressed, about the length of the beak. Jl., Aug.

$\beta$. INTEGRIFolIA. Lvs. nearly all undivided, lanceulate, sessile, the lowest often sagittate at baso. (L. integrifolia Bw. L. sagittifolia Ell.)

$\gamma$. SANGUINEA. Leaves runcinate, amplexicaul, mostly pubescent, glaucous beneath; fls. purple. St. 2 to $3 \mathrm{f}$ high, often purple. (L. sanguinarea Bw.)

3 L. sativa L. GARDEN LeTTUCE. St. corymbous; lvs. suborbicular, the cauline ones cordate.-(1) Cultivated for salad. Plant with very smooth, yellowish green foliage, which in one variety (capitata) is so abundant as to form heads like the cabbage. Fls. numerous, small, with yellowish corollas. The milky juico contains opium, hence the unpleasant narcotic effects when eaten too freely. $\ddagger$

113. MULGE'DIUM, Cass. Wrud Letruce. (Lat. mulgeo, to milk; in allusion to the milky juice.) Involucre many-flowered, somewhat double, the outer scries of scales short and imbricated; receptacle naked, faveolate; pappus copious, soft, capillary, crowning the short. beaked achenia, which are compressed contrary to the scales.-Lvs. mostly spinulous. Hds. with many yellow or cyanic fls. (Sonchus, IVilld. Agathyrsus, Don.) (Fig. 332.)

\$ Corollas blue. Pappus bright white...................................... Nos. 1, 2 $\$$ Corollas cream-colored, turning jurplish. Pajpus tawny......................................... 3

1 M. acuminàtum DC. Lvs. ovate, acuminate, petiolate, dentate, undivided, or the radical slightly runcináte; hds. loosely paniculate, on somewhat bracteolate peduncles; ach. slightly beaked.-In hedges aud thickets, N. Y. to Ind. and S. States. A smooth plant, 3 to $6 f$ high, with the stem often purplish. Lvs. 3 to $6^{\prime}$ long, the lower ones often deltoid-hastate or truncale at base, sinuate-denticulate, narrowed at base into a winged petiole. Hds. small. Scales dark purple, with blue corollas. Pappus white on the short-beaked, ovate-acuminate achenia. Aug., Sept.

2 M. Floridànum DC. Lvs. runcinately pinnate-parted; segm. few; serratodentate, upper ones triangular, acute or acuminate; panicle loose, crect, compound; ach. short-beaked.-W. and S. States, hedges and waste grounds. Plant with a torminal panicle of blue flowers. St. 3 to $6 \mathrm{f} \mathrm{high.} \mathrm{Lvs.} 4$ to $8^{\prime}$ long, variable in form. Hds. small. Rays expanding 9". Jl.-Sept.

3 M. leucophæum DC. Lrs. numerous, lyrate-runcinate, coarsely dentate; hds. paniculate, on squamous-bracteate peduncles; pappus tawny ; cor. yellowish.Moist thickets, N. and W. States. A tall, leafy plant, nearly smooth. St. 4 to 10f high. Lvs. 5 to $12^{\prime}$ long, irregularly divided, the segm. repand-toothed, the radical on long stalks, the upper ones sessile, often undivided. Hds. small, in a long, slender panicle. Aug., Sept.

114. SON'CHUS, L. Sow-Thistre. (The ancient name.) Involucre many-flowered imbricate, of numerous unequal scales, at length 
tumid at base; receptacle naked; pappus of simple, copious, whitesilky hairs, in many series: achenia compressed, not rostrate.-Lrs. mostly spinulous. Hds. with many yellow fls.

\$ Flowers bright yellow, in showy heads. Achenla angular. Perennial..............No. 1 $\$$ Flowers pale yellow, in large heads. Achenia tlat. Annual................................ 3

1 S. arvénsis L. Root creeping; stem glabrous, erect; lvs. runcinate-pinnatifid, spinulous-dentate, cordate, clasping at base, with short and obtuse auricles; panicles umbellate-corymbous; ped. and invol. hispid; ach. somewhat 4-angled, ribs transversely rugulous.-Waste grounds, naturalized, E. Mass. and S. N. York, rare. St. angular, about $2 \mathrm{f}$ high. Hds. large, with deep yellow Hls. $\S$ Eur.

2 S. asper Vill. Ivs. cordate-amplexicaul, oblong-lanceolate, undulate, spinulousdentate; ped. subumbellato; ach. oval-obovate, 3-ribbed on each side.-Found in similar situations with the next, but less common, U. S. St. 1 to $2 \mathrm{f}$ high, smooth except at the summit of the branches where it is often hispid-glandular. Lvs. with numerous, short, spiny teeth, wavy or slightly runcinate, the upper ones clasping so as to appear perfoliate. Scales with fow seattered hairs. Aug., Sept. (S. spinulosus Bw. S. Carolinianus Walt.)

3 S. oleràceus L. Lvs. sagittate-amplexicaul, runcinate-pinnatifid, subspinulous, dentate; ped. downy; invol. at length smooth; ach. many-striate.-A sordid looking plant, in waste ground, among rubbish, \&c. Plant of a glaucous hue. St. angular, hollow, fragile, 2 to $3 f$ in height. Lrs. apparently clasping, with large, retreating lobes at base, wavy and serrated in a runeinate manner, the teeth ending in weak spines. Invol. dilated at base, with yellow corollas. Sept. § Eur.

\section{SUBORDER III. LABIATIFLORA.}

115. CHAPTA'LIA, Vent. (Dedicated by Ventenat to the celebrated French chemist $M$. Chaptal.) Heads radiate; involucre campanulate; scales in few series, linear, acute; receptacle naked; ray flowers $q$, ligulate, disk-flowers $\Varangle$, but sterile, bilabiate, lips equal, outer 3 -, inner 2-parted ; achenia glabrous ; pappus capillary. $-2 f \Lambda$ caulescent herbs. Lvs. all radical. Hd. solitary, cyanic.

C. tomentòsa Vent. Lvs. oblong-ovate or lanee-oval, on a short petiole, retrorsely denticulate, clothed with a dense, white tomentum beneath; seape loosely tomentous; hd. nodding until in flower, thence crect on tho slender, simple scape.-Moist pine barrens, N. Car. to Fla. and La. An interesting plant, alone representing the suborder Labiatæfloræ. Lvs 2 to $4^{\prime}$ long, 6 to $15^{\prime \prime}$ wide, often subsessile, the upper surface at first arachnoid, at length smooth. Scapo 6 to $12^{\prime}$ high. Rays about 20, rose-red or white. Disk florets pale yellow. Mar., Apr.

\section{Order LXXI. LOBELIACE瓜. LobeLtads.}

Herbs or shrubs with a milky juice, alternate, exstipulate lvs. and scattered fls. Calyx 5-lobed or entire. Cor. monopetalous, irregular, split down to the base on one side. Stamens 5, free from the cor., united into a tube at least by their anthers. Ovary adherent to tho calyx tube. Style 1. Stigma surrounded by a fringe. Fruit a capsule 2-3-(rarely 1-) celled. Seeds numerous, albuminous.

Genera 29, species 375 , most abundant in countries near the troples, as W. Indies, Brazil, Bandwich lslands, but common also throughout the temperate zones.

Properties. The speeies of Lobelia are more or less poisonous. The milky juice is acrid and narcotic, producing effeets similar to those of Tobncen. L. inflata has long been considered a rernedy for spasmodie asthma, but more recently is adopted in the regular practice of the "Botanic School" of Medicine as an emetie, expectorant and sudorific, applicable in numerous diseases. Liko Aconite and other medicinal poisons, it is, of course, to be userl with caution. 
1. LOBE'LIA, L. (In honor of Matthias de Lobel, physician and botanist to James I.) Corolla tubular, irregular, cleft nearly to the base on the upper side, upper lip of 2 separate lobes, lower 3-lobed; stamens with the anthers united above into a curved tube; stigma 2-lobed; capsule opening at the summit; seeds minute.-Herbaceous plants, with the fls. axillary and solitary, or in terminal, bracted racemes.

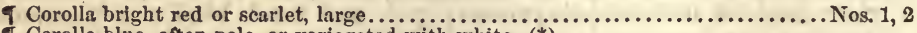

\& Corolla blue, often pale, or variegated with white. $(*)$

* Calyx lobes auriculate at base and often denticulate. (a)

a Leaves acute or somewhat acuminate........... Nos. $3-5$

* Calyx lobes not auricled, entire. (b)

a Leaves obtuse or scarcely acure.................... Nos. 6,7

b Leaves cauline,-denticulate. Stem simple.......Nos. 8,9 -denticulate. Stem branching. Nos. 10, 11 -entire. Stem very slender..... Nos. 12, 13

b Leaves radical or nearly so. Stem naked....... Nos. 14, 15

1 I. cardinàlis L. CARDINAL Flower. St. simple, glabrous; lvs. oblong-lanceolate, slightly toothed, acute at each end, sessile; fls. in a terminal, bracted, secund raceme; stam. longer than the corolla.-A tall species frequent in meadows and along streams, Can. to Car.W. to Ill. St. 2 to $4 \mathrm{f} \mathrm{high,} \mathrm{often} \mathrm{quite} \mathrm{glab-}$ rous as well as the whole plant. Lvs. 2 to $4^{\prime}$ by 8 to $15^{\prime \prime}$, usually denticulate. Fls. on short pedicels, few or numerous, in a superb, nodding raceme. Bracts linear-subulate, much shorter than the flowers. Cor. deep scarlet, near $2^{\prime}$ in length. Jl., Aug. †-A variety from Potsdam, N. Y., has the leaves all entire. Another var. from Mass. has white corollas with more narrow segments.

2 L. fúlgens Willd. Mexican Cardinal Flower. St. erect, simple, pubescent; lvs. pubescent, narrow-lanceolate, acuminate, subentire and revolute at edge; raceme many-flowered; stam. the length of the corolla.-Cultivated. Even superior in size and splendor to No. 1. Stems 3 to $5 \mathrm{f}$ high, racemes 2 to $3 \mathrm{f} \mathrm{long.}$ † Mexico. (Banks of the Mississippi, Pursh. Probably an error.)

3 I. syphilítica L. Blue Cardinal Flower. St. erect, simple; lvs. oblonglanceolate, acute or acuminate, unequally serrate, somewhat hirsute; rac. leafy; cal. hispidly ciliate, with the sinuses reflexed.-2f A showy plant, in wet meadows and along streams, U. S. and Can., more common in the W. States. Stem erect, 2-4f. high, simple, angular. Lvs. acute at each end, hairy. Fls. $1^{\prime}$ long, light blue, showy, each solitary in the axil of a lance-ovate bract. July.

$\beta$. CANDIDUS. Corollas pure white. A singular variety found at Poughkeepsie, N. Y., by G. M. Wibbur ; also, Wayne Co., by E. L. Hankenson.

4 I. glanđulòsa Walt. Pubescent or nearly glabrous, simple; lvs. linear-lanceolate, rather acute, sessile, glandular-denticulate ; fls. few, rather large ; cal. tube short, hispid or pubescent, lobes lanceolate, cordate or somewhat auriculate at base, mostly denticulate, half as long as the stamens, which are but half the length of the corolla. - 2f In damp barrens, Va. to Fla. and La. Sts. $18^{\prime}$ to $2 \mathrm{f} \mathrm{high.} \mathrm{Lvs.}$ 1 to $3^{\prime}$ long. Fls. $9^{\prime \prime}$ long, bluc. Pedicels 2 to $3^{\prime \prime}$. Varies much in pubescence. Sept., Oct.

5 I. Iudoviciàna. Hispidly pubescent, strict, erect, simple; lvs. small, crowded, oblong-linear, sessile, strongly denticulate; fls. subsessile; cal. truncate at base, densely hispid, segm. ovate-acuminate, half the length of the corolla, densely fimbriate-toothed.-La. (Hale). A plant widely different from the foregoing. Height 1 to 2 f. Lvs. less than $l^{\prime}$ long, 1 to $2^{\prime \prime}$ wide, all similar (radical not seen). Cor. blue, 8 to $9^{\prime \prime}$ long, hispid.

6 L. leptóstachys A. DC. Glabrous; st. erect, virgate, simple; lvs. oblonglanceolate, minutely-denticulate, sessile; fls. subsessile, small, not secund, in a long, slender spike, cal. segm. lanceolate-acuminate, longer than the tube of the corolla; bracts lance-linear, denticulate, longer than the pedicels.-Prairies, W. States to Ia. St. 1 to $2 \mathrm{f}$ high. Lrs. 1 to $2^{\prime}$ by 4 to $8^{\prime \prime}$. Rac. 6 to $12^{\prime \prime}$ in length, the bracts and sepals rather conspicuous. Fls. light-blue, about $4^{\prime \prime}$ long. Much resembles L. spicata. Jl.

7 I. pubérula Mx. Soft puberulent; st. erect, simple; lv's. ovate-oblong or clliptical, obtuse, sessile, repand-denticulate; rac. spicate, secund; fls. large; cal. ciliate, the segments shorter than the tube of the corolla - 2f Wet grounds, Ohio, 
Penn. to Ga. and La. St. 12-30' high, scarcely furrowed. Lrs. covered with a short, downy or silky pubescence, 1 to 2 ' in length and half as wide. Fls. twice larger than in No. 7, on very short pedicels, each solitary in the axil of an ovate-lanceolate bract, forming a one-sided raceme, leafy below. Cal. Lairy at base. Cor. of a bright purplish blue. Jl.

8 I. amcena Mx. Erect, simple, glabrous (rarely a little pubescent); lvs. lanceolate, altenuated at each end, the lower petiolate, repand-denticulate; fis. large, secund; calyx-tube abrupt at base, very short, lobes subulate nearly as long as the corolla.-Ditches and damp soils, Va. to Ga. Sts. 1 to $3 f$ high, with numerous fls. of a bright blue. Lvs. 2 to $3^{\prime}$ ( 4 to $6^{\prime}$, Nutt.) long. Corolla about $10^{\prime \prime}$ long. Differs from No. 7 in its pointed, smooth lvs., sepals without auricles, \&c. Pedicels very short. Sept., Oct.

9 L. spicàta Lam. Puberulent; st. erect, simple; lvs. oblong, sessile, mostly obtuse, obscurely denticulate, radical ones spatulate; fls. (small) usually crowded, in a long, slender raceme; pedicels as long as the flowers, or entire, subulate bracts; sep. subulate, as long as the tube of the corolla. $-2 f$ Fields and prairies, Can. and U.S. St. $1 \frac{1}{2}$ to $2 \mathrm{f}$ high, somewhat grooved, few-leaved, ending in a spike-like raceme 6 to $10^{\prime}$ long. Cor. palo blue, 3 to $4^{\prime \prime}$ long, the palate bidentate. Jl.Sept.-Differs from No. 6 in its slender pedicels, absence of auricles, \&c. (L. Claytonia $\mathrm{Mx}$.) With a loose fewer-flowered raceme, it is the same as $\mathrm{L}$. pallida Muhl.

10 L. inflàta L. Indiax ToBacco. St. hairy, branched, erect; lvs. ovate-lanceolate, sessile, serrate, pilous; caps. inflated.-1) In fields and woods, Can. and U. S. Root fibrous. Stem erect, very rough, angular, simple, becoming branched in proportion to the luxuriance of the growth, 10-15' high. Leaves elliptical, sessile, hairy and veiny. Flowers in leafy spikes, axillary, peduncled. Corolla small, pale blue, leaving an oval, turgid capsule in the calyx. J.-Sept.-This plant is much renowned in Pharmacy. See remarks under the order.

11 L. Boykínii Torr. \& Gr. St. glabrous, branched, branches erect, virgate; lis: linear, erect, glandular-denticulate; fls. on slender, flattened pedicels in long, loose racemes; cal, turbinate, with lance-linear, acuminate segm. - Wet soils, Ga. and Flo. We merely saw this species in the herbarium of Dr. Curtis.

12 I. Nuttallii DC. Glabrous; st. erect, very slender, almost filiform, subsimple; lvs. few and remote, subentire, radical linear-spatulate, cauline, rather acute; fls. few, remote; pedicels as long as the corolla; calyx-tube almost nont.-An exceedingly slender plant, around sandy swamps, L. Isl. to Car., 1 to $2 \mathrm{f}$ high, often branched. Lvs. 6 to $12^{\prime \prime}$ by 1 to $1 \frac{1}{2}^{\prime \prime}$. Pedicels. 3 to $10^{\prime \prime}$ long, blue as well as the flowers. Jl., Aug.

13 L. Kalmii L. Glabrous; st. slender, erect; radical lvs. spatulate, stem Irs. linear-lanceolate, obtuse. rac. lax, few-flowered, leafy; pedicels longer than the flower, minutely. bracteolate; cal. tube obovate.-A small and delicate species, insphagnous or rocky banks of streams, Me. (Miss Towle), to Niagara and Wis. St. 6 to $12^{\prime}$ high, commonly simple. Lrs. sessile, $1^{\prime}$ long and 1 to $2^{\prime \prime}$ wide, upper ones entire, lower with remote, minute teeth. Fls. remote, axillary to bracts. Cor. pale blue, the 3 lower segments obovate. Aug.

14 I. paludòsa Nutt. Lvs. linear-spatulate, thickish, obtuse, petiolate; scape with a few small, linear bracts, simple; fls. loosely racemed, pedicels about as long as the calyx segments.-In bogs Del. to Fla. and La. Scapes 2 to $3 f$. Lrs. few, near the base, 5 to $10^{\prime}$ long, 5 or $6^{\prime \prime}$ wide, slightly glandular-crenate. Fls. pale blue, rather larger than No. 13 (6" long). Apr.-Jn.

15 I. Dortmánna L. Lvs. submerged, tufted, linear, entire, hollow with 2 lonigitudinal cells, short, obtuse; scape simple, nearly naked; fls. in a terminal ráceme, remote, pedicellate, nodding. - 2 A curious aquatic, growing in ponds, N. States to Ga., the flowers only rising above the water. St. erect, hollow, long, bearing above the surface a raceme of 3 or 4 remote, pedicillate flowers. Lvs. radical, erect, recurved at the top, $2^{\prime}$ long. Fls. pale blus. Caps. half free, lipped with tho style. $\mathrm{JI}$. 
16 I. Erynus L. Glabrous, slender, diffuse; lvs. toothed, the lower elliptical, petiolate, the upper lance-linear; fls. scattered, small; cor. blue with a white palate; sepals linear.-O S. Africa. Pretty in pots. $\dagger$

17 L. Douglassii. Glabrous, sparingly branched; st. slender, angular; lvs. sessile, ovate, 3-veined; ova. sessile, long-acuminate, triangular, contorted, much longer than the leaves; cor. blue, with a white spot in the middle of the lower lip.-Native of the Rocky Mts., \&c. A beautiful annual, with bright-blue flowers. $t$ (Clintonia, Doug.)

\section{Order lXXiI. CAMPANUlaCEA. Bellworts.}

Herbs with a milky juice, alternate leaves, and without stipules. Flowers mostly blue: showy. Calyx superior, generally 5-cleft, persistent. Corolla regular, campanulate, generally 5-cleft, withering, valvate in æstivation. Stamens 5, free from the corolla; anthers distinct, 2-celled; pollen spherical. Ovary adherent to the calyx, 2 or more celled. Slyle covered with collecting hairs. Capsule crowned with the remains of the calyx, loculicidal. Seeds many.

Illnst. in fig. $31 \mathrm{~s}, 319$.

Genera 23, species 500, cliefly abounding in tho northern temperato zono and in South Africa. Of its 500 species, accurding to Alphonse Do Candolle, only 19 inhabit the torrid zone. The Campanulacea are interesting chiefly for their beauty, being destitute of any important known properties.

1. CAMPAN'ULA, Tourn. (Lat. campanula, a little bell; from the form of the flowers.) Calyx mostly 5-cleft; corolla campanulate, or subrotate, 5 -lobed, closed at base by the broad, valve-like bases of the 5 stamens; stigma 3 to 5 -cleft; capsule 3 to 5-celled, opening by lateral pores.-Mostly 2 . Fls. generally in racemes, sometimes spicate, or few and axillary.

$\$$ Corolla rotate, flat, deeply 5 -lobed, arranged in leafy spikes............... Nos. 1, 2

$\S$ Corolla campanulate, broadly or narrowly (a).

a Flowers on slender pediceis, solitary or panicled (b).

b Root leaves unlike the stem leaves. Corolla large ( 6 to 12 " broad)........ Nos. 3,4

b Root leaves and stem leaves similar. Corolla small ( 2 to $5^{\prime \prime}$ broad).......... Nos. 5, 6

a Flowers sessile or nearly so. Stem erect. Gardens......................... 7 -9

1 C. Americàna L. St. erect; lvs. ovate-lanceolate, acuminate, uncinately serrate, contracted to a winged petiole, veins often ciliate; fls. axillary, sessile; style exserted, decurved.-A tall, erect, ornamental species in copses, woods, \&c. Western N. Y. and Penn. to Ill., common. Also cultivated in gardens. St. 2 to 3 figh, nearly smooth. Lvs. ending in a long point, smooth, with fino teeth. Fls. blue, flat, on short stalks, or sessile, numerous, solitary, or several in each upper axil, forming a terminal, leafy raceme. Corolla spreading. Aug. † (C. acuminata Mx.) C. Illinoensis Frosen (in DC.) is a branching state of the samo plant.

2 C. planiflòra DC. Very glabrous; st. simple; lvs. sessile, coriaceous, shining, radical, crowded, ovate or obovate, obtuse, crenulate, cauline linear-lanceolate, acute, subentire; fls. in a spicate raceme; cal. lobes ovate, acute, $\frac{1}{3}$ as long as the campanulate-rotato eorolla. - Native about Hudson's Bay (Pursh.) $\Lambda$ species with numerous blue fls. Stem about a span high. $f$ (C. nitida Ait.)

3 C. rotundifòlia I. HARE BELL. St. weak, slender; radical lvs. ovate or reniform-cordate; cauline, linear, entire; fls. few, nodding.-Fine and delicate, with blıe, bell-shaped fls. On damp rocks, rocky streams, N. States and Brit. Am. St. a foot or more high, smooth. The root lvs. generally decay on the opening of the flowers, so that a specimen with these $\left(7\right.$ to $10^{\prime \prime}$ by 4 to $\left.7^{\prime \prime}\right)$ is rather rare. Caulino lvś. smooth, linear, $2^{\prime}$ long and scarcely a lino in width. Els. trminal, in a loose panicle, drooping. Root creeping, perennial. Jn., Jl.

4 C. persicifòlia L. St. angular, erect; lvs. rigid, obscurely crenate-serrate, radical oblong-obovate, cauline lance-linear; fls. large, broadly campanulate. - A beantiful species, native of Europe, with very large, bluo (varying to white) flowers. Corolla about $I^{\prime}$ broad. $\dagger$ 
5 C. aparinoides $\mathrm{Ph}$. St. flaccid, slender, branching above, triangular, the angles inversely aculeate; lvs. lance-linear, subentire; fls. terminal-A slender annual, found in wet meadows, Can. and Wis. to Ga. St. 12 to $18^{\prime}$ high, its 3 angles rough backwards, by means of which it supports itself upright among tho grass. Lvs. smooth on the upper surface, 1 to $2^{\prime}$ in length. Fls. broad, bell. shaped, $4^{\prime \prime}$ wide, white, on thread-like, flexuous peduncles at the top of the stem. Jn.-Aug.

$\beta$. ERINOIDES. Lrs. elliptical, less than $1^{\prime}$ in length; fls. smaller. (C. erinoi$\operatorname{des} \mathrm{Mx}$.)

6 C. divaricàta Mx. Glabrous, erect, with slender, divaricate, paniculate branches; lvs. narrow-lanceolate, pointed at each end, sharply dentaie; fls. campanulate, pendulous on the slender branchlets.-Rocky woods, along the Mts., $\mathrm{Ky}$., Va. to Ga. Plant about $2 \mathrm{f}$ in height. Lvs. 2 to $3^{\prime}$ by 2 to $5^{\prime \prime}$. Corolla exactly bell-shaped, 4 to $5^{\prime \prime}$ broad, its segments revolute. Jl., Aug.

7 C. glomeràta L. St. angular, simple, smooth; lvs. scabrous, oblong-lanceolate, cordate-sessile, lower petiolate; fls. crowded in a dense head; cal. lobes acuminate, half as long as the funnel-shaped corolla.-A European species, cultivated in gardens, naturalized at Danvers, Vt. (Oakes.) It is a handsome plant, about 2f high, with numerous bell-shaped flowers of an intense violet-blue, varying to pale purple. In cultivation it has many varieties. $\S \dagger$

8 C. Mèdium L. CANterbury Bells. St. simple, erect, hispid; lus. lanceolate, obtusely serrate, sessile, 3-veined at base; fls. erect, bell-shaped, with an obtuse base.- (2) An ornamental border flower, from Germany, and of tho easiest culture. Root biennial. Stem several feet in height, undivided, rough with bristly hairs. Flowers very large, the base broad, limb reflexed, of a deep blue. Several varieties occur with double or single flowers, of blue, red, purple and white corollas. June-Sept. $f$

9 C. lanuginòsa, with ovate, crenate, rugous and somewhat woolly lvs. and rather large flowers, acuto at base, is sometimes cult., and also a few other species.

2. SPECULA'RIA, Heist. (Lat. speculum, a mirror; alluding to the flower of S. speculum.) Calyx 5-lobed, tube elongated; corolla rotate, 5 -lobed; stamens 5 , distinct, half as long as the corolla, filaments hairy, shorter than the anthers; style included, hairy; stigmas 3 ; capsule prismatic, 3 -celled, dehiscing in the upper part.-(1) Fls. axillary and terminal, sessile, erect.

1 S. perfoliàta Lam. St. simple, rarely branched, erect; lvs. cordute, crenate, amplexicaul; fls. sessile, aggregate, axillary. - Plant somewhat hairy, a foot high, found in fields and roadsides. The strict, upright stem, is furnished with distant, short, alternate, heart-reniform, veiny, stem-clasping leaves, containing $1-4$ crowded flowers in the concavity of their upper surface. Flowers axillary and terminal, the upper clusters larger. Corolla blue or purple, with spreading segments, calyx seg. acute, lanceolate. Jn., Jl. (Campanula amplexicaulis Mx.)

2 S. Ludoviciàna Torr. St. at length producing numerous slender branches; lvs. broad-ovate, acute, subentire, sessile or slightly amplexicaul; fls. axillary and terminal on the slender branches.-La. (Hale) and S. Car. (Curtis.) Plant similar in size and appearance to No. 1, but its flowers are rather smaller, with quite slender ovaries.

3 S. spéculum L. VENos' LookING-GLASS. St. diffuse, very branching; lus. oblong-crenate; fls. solitary; scales at the base of the corolla sometimes wanting.-A pretty border flower, named from the form of the blue corolla, which resembles a little, round, concave mirror (speculum). Aug. $f$

\section{Order. LXXIII. ERICACEA. Heathworts.}

Plants shrubby or suffruticous, sometimes herbaceous with Lvs. simple, alternato or opposite, mostly evergreen, without stipules. Corolla regular or somewhat i- 
regular, 4 to 5-cleft, the petals rarely distinct. Stamens as many or twice as many as the petals, free, hypogynous. Anthers 2-celled, generally open by pores, often appendaged. Pollen (except in Monotropere) compounded of 4 united grains. Em. bryo straight, lying in the axis of, or in the end of tleshy albumen. Illust. in figs. $38,45,110,203,320,345,350,355$.

Genera 66, species 10S6, dispersed throughont all countries, but comparatively rare in the torrid zone. The true Ericacere (Heaths), are chiefly natives of the Cape of Good Ilope, there being none in Asia, New Ilolland, and but one or two in Anerica. 'I'he Tribo Vaccineæ ure chiefly natives of $\mathrm{N}$. $\Lambda$ merica.

Properties. -The Ileath worts are, in general, astringent and diuretic. Some of tlem yield a stimulating and aromatic resinous matter. The Bearlierry, (Aretostaphylus Uva-ursi) is a well known remedy in nephritic complaints. $\Lambda \mathrm{n}$ infusion of the leaves is astringent, demulcent and diuretic. Similar properties are also possessed by the Pipsisslwa (Chimaphlia umbellata). The speeies of Rhododendron and Kalmia are pervadel by a narcotic principle, rendering them (particularly their leaves) often actively poisonous. The honey collected from their flowers by the bees appears so have been so to some of the soldiers in the retreat of the immortal ten thoulsand (Xenophon's Anabasis). The berries of the Vaceinex (Whortleberries, Blueberries and Cranberries,) and of Gaultheria procumbens (spicy Wintergreen) are esculent and wholesome.

The true position of our suborders Cyrillex and Galacina is not known. We follow De Candolle in appending them to Ericacex rather from convenience, as their babit certainly points to this order.

\section{SUBORDERS AND GENERA.}

I. VACCINEA. Shrubs. Calyx adherent. Fruit a berry crowned by the calyx teeth. (*)

* Erect shrubs with 5-parted flowers and 10-seeded fruit................Garlussacia. 1

* Erect shrubs with 5-parted flowers and $\infty$-seeded fruit. No resinous dots.. VAccisium. 2

* Trailing shrubs. Corolla deeply 4-eleft, - reflexed. Fruit red.............. Oxrcoccts. 3 -spreading. Fruit white........... CHogenes. 4

II. ERICINE As. Shirut or trees. Calyx free. Corolla and stamens hypogynous. Sds. $\infty$. (a) a Flowers 4-parted, stamens 8. Capsule 4-celled,-loculicidal...................ERica. 5 -septicidal. (b). (No. 13.)

a Flowers 5-parted, petals distinct or very nearly polypetalous. (f)

a Flowers 5-parted, petals united, $\rightarrow$-monopetalous. (b)

b Corolla saucer-form, holding the anthers in 10 pits................... KaLMLA, 6

b Corolla salver-form, very fragrant. . Trailing shrublet...................EIG EA. 7

b Corolla funnel- or bell-form, with spreading lobes. (e)

b Corolla urceolate (ovoid, cylindric or globular), lobes small. (c)

c Fruit fleshy, the matured ovary 5 -seeded................... Arctostapiry 0.8

c Fruit fleshy, the matured calyx $\infty$-seeled ................... Gaultheria. 9

c Fruit dry, capsular, opening into the cells (loculieidal). (d)

d Shrublet moss-like, with linear leaves. Valves 2-cleft.........CAssiope. 10

d Shrubs with ample leaves. Valves entire.................. Andromed. 11

d Tree with ample leaves and slender racomes............. Ox YDENDRUM. 12

c Fruit dry, capsular, opening between the cells.................. Mesziesis. 13 e Stamens 5 , included. Plant and leaves very small .................Lorseleguria. 14

e Stamens 5 (rarely more), long-exserted. Corolla funnel-form............Azalea. 15

e Stamens 10 (rarely fewer), exserted. Corolla bell-form............hHododrandon. 16 f Corolla very irregular, open before the leaves appear.....................Rnodora. 17 f Corolla regular, -7 -petaled. Stamens $14 \ldots \ldots \ldots \ldots \ldots \ldots \ldots \ldots \ldots \ldots \ldots \ldots \ldots \ldots \ldots$ Befaria. 13 -5-pétaled.-Capsulo 5-celled.........................LeduM. 19 -Capsule 3-celled.-Fls. umbeled ...........Leiopirluum. 20 -Fls. racemed................Clethra. 21

III. CXRILLEAE. Sirubs. Cal. free. Pet. and stam. hypogynous. Cells of caps I-seeded. (g) g Flowers 4-parted, with 8 stamens and a 2-celled capsule....................LiotriI. 22 g Flowers 5-parted, -with 5 stamens and a 2-celled capsule................ Crriura. 23 -with 10 stamens. Capsule 3-cellel, 2-winged........ Mr cocariun. 24

IV. PXROLE स. Merbs evergreen, woody. Cal. free. Pet. 5, distinct. Testa of sd. loose. (h) h Flowers racemed, many. Herbs nearly acauleseent..................... Priol... 25

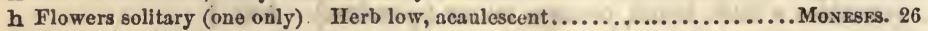
h Flowers umbeled, few. Stems ascending. Style very short............. CinmapinLa. 27

V? GALACINEAE. IJerb evergreen, aucaulescent. Filaments 10, monadelphous, alternately sterile; anthers 5, one-celled. Capsule 3-celled, $\infty$-seeded.......GaLAx. 28

VI. MONOTROPE E. Iferbs leafless, verdureless, with scale-like bracts. (k) k Corolla polypetalous. Plant white, reddish or ta wny..................Monotropa. 29 k Corolla monopetalous, - campanulate, in a short spike................. ScHweivitziA. 30 -ovoid, in a looso raceme......................Ptrzospora. 31 


\section{Suborder I. Vaccine}

1. GAYLUSSA'CIA, II. B. K. Huckleberry. (In honor of the distinguished chemist, Gay-Lussae.) Calyx adherent, 5-toothed; corolla urceolate or campanulate, 5-cleft or toothed; stamens 10, anthers awnless, the cells produced upwards into tubular beaks opening at the apex; berry drupe-like, globular, 10-celled, 10-seeded.-Shrubs resembling tho Vaceinia. Lrs. often resinous-dotted beneath. Fls. in lateral, bracted racemes, white or reddish, small. Fr. black or dark blue, sweet. (Vaccinium L.)

* Racemes nxillary. Lenves evergreen, dotless, very smooth ..................... No. 1

* Racemes lateral. Leaves dutted beneatl, - mucronate, thlck............................. 2

$\rightarrow$ not mucronate, thin........................ Nos. 3,4

1 G. buxifòlia. Box HuckleberRy. Very smooth; lvs. oval and ovate, finely crenate-dentate, thick and firm; rac. dense, axillary and terminal subsessile, tho pedicels very short; cor. short-ovoid; filaments glandular; berries light blue!Rocky hills, New Bloomfield, Perry Co., Penn. (Rev. D. H. Focht), W. Va. (Curtis) and E. Tenn. A handsome littlo evergreen, if high, with leaves (7-9' by $\left.4-5^{\prime \prime}\right)$ like those of the Box, and white Ils. delicately tinged with red. May. (V. buxifolium Salisb. V. brachycerum $\mathrm{Mx}$.)

2 G. dumòsa Torr. \& Gr. Branchlets, lvs. and pedicels sprinkled with minuto bristles and resinous dots; lvs. obovate-oblong, subsessile subcoriaceous, obtuse, mucronate, entire or ciliate-serrulate; rac. with persistent bracts; pedicels bracteolate in tho middle; cor. cylindric-campanulate, including the stamens and style.Swamps and thickets, Uxbridge, Mass. (Robbins), S. to Fla. A small shrub, if ligh, with leafy racemes. Lvs. about $16^{\prime \prime}$ by $7^{\prime \prime}$. Fls. white or purplish, each from the axil of an oval bract. Berries black, insipid, large. Jn. (V. dumosum Andr.)

$\beta$. HiRTElla. Plant more or less hairy.

3 G. resinòsa Torr. \& Gr. Black Huckleberny. Branohes cinereous-brown, villous when young; lvs. oblong-ovate or oblong-lanceolate, rather obtuse, entire, petiolate; rac. lateral, secund; pedicels short, subbracteolate; cor. ovoid-conic, at length, subcampanulate, 5 -angled; berries black.-This common shrub of woods and pastures (Can. to Va. and Tenn.) is about $2 \mathrm{f}$ high, very branching. Lvs. 1 to $2^{\prime}$ long, rarely acute, shining beneath, with resinous patches and spots. Petiole $1^{\prime \prime}$ in length. Fls. small, drooping. Corollas contracted at the mouth, greenish or yellowish purple, longer than the stamens but shorter than the style. Berries globous, sweet and catable, ripe in August. May. (V. resinosum Ait.)

$\beta$. BREvifolia. Corolla very short, when open as broad as long.-Quincy, Fla.

4 G. frondòsa Torr. \& Gr. Blue Dangles. High Blueberry. Lrs. oblongobovate, obtuse, entire, glaucous beneath; rac. loose, bracteate; pedicels filiform, bracteate near the middle; cor. ovoid-campanulate, including the stamens; berries blue.-Grows in open woods, N. Eng. to Fla. and La. A shrub 3 to $5 \mathrm{f} \mathrm{high,} \mathrm{with}$ round, smooth and slender branches. Lvs. twice as long as wide, the margin slightly revolute. Rac. lateral (not axillary), the bracts deciduous. Pedicels 5 to $10^{\prime \prime}$ in length. Fls. reddish-white, succeeded by large, globous, blue and sweet berries covered with a glaucous bloom when mature. May, Jn. (V. frondosum Willd.)

2. VACCIN'IUM, L. BuUEberry. Calyx adherent, 5-toothed; corolla urceolate, campanulate or cylindric, $\operatorname{limb} 4$ to 5 -cleft, reflexed; stamens twice as many as the lobes of the corolla, generally included; anthers with 2 awns on the back, or awnless, the 2 cells prolonged into a tube opening at apex; berry invested with the calyx 4 or 5 (falsely 8 to 10)-celled, cells many-seeded.-Shrubs or undershrubs with scattered lvs. Fls. solitary or racemous, white or reddish, small, Fr. generally eatable. A false partition often divides the cells, each partly into 2. (Fig. 350.) 
\$ Anthers 2-awned back of the 2 horns. Lenres deciduons. (a)

a Filaments smooth. Fr. 4 to 5 -celled. Low alpine undershrubs............. Nos. 1, 2

a Filaments hairy. Fruit partly 10 -celled. Talier $(2$ to $20 \mathrm{f}$ high.)............. Nos. 3,4 \$ Inthers 2-horned, withont the awns. Filaments 10 , hairv. (b)

b Leaves evergreen. Flowers 4-parted. Fruit 4-celled....................... 5

b Leaves evergreen. Flowers 5-parted. Fruit partly 10 -celled.................... 6, 7

b Leaves deciduous. Fruit partly 10-celled. Fls. in short, close racemes. (c)

c Corolla beli-shaped. Leaves hairy both sides, entiro...................... s

c Corolla cylindrical. Leaves smooth or nearly so........................ $9-11$

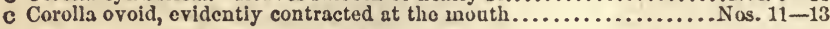

1 v. uliginòsum L. BILBERRY. Procumbent; IVs. obovate, very obtuse, entire, smooth, not shining, glaucous and veiny beneath; fls. mostly solitary, axillary; cor. ovoid-globous, 4-clefl; anth. 8, with 2 slender awns.-A low, alpino shrub, White-Mts. Sts. with numerous rigid branches. Lrs. $4^{\prime \prime}$ by $3^{\prime \prime}$, scarcely petiolate, crowded near the ends of the branches, and of a bluish-green. Fls. half as long as the leaves, subsessile, sometimes 2 together. Berries oblong, dcep blue, crowned with the style. Jn., Jl.

$2 \mathrm{~V}$. cæespitòsum Mx. BILBERRY. Dwarf, cæespitous; lvs. obovate, attenuato at the base, thin, serrate, reticulate with veins, shining; ped. subsolitary, 1-flowcred; cal. very short; cor. oblong, suburceolate, 5-toothed; stam. 10.-White Mts. (Oakes), N. to Hudson's Bay. St. a few inches high. Fls. numerous, nodding, on short pedicels. Anth. with 2 long awns at the back. Berries large, globous, blue, eatable.

3 V. stamíneum L. DEERBERRY. Lvs. oval-lanceolate, acute, dull, glaucous beneath; pedicels solitary, axillary, nodding; cor. campanulate-spreading, segm. acute, oblong; anth. 10, with the long tubes exserted and 2 awns at their base.Dry woods, Can. to Fla. and La. Shrub 2 to $3 \mathrm{f}$ high, very branching. Lrs. I to '2' long, mostly rounded at base, and on very short petioles, those on the slender flowering branches very much smaller. Cor. white. Stam. conspicuously exserted, but shorter than the style. Berries large, greenish white, bitter. May, Jn. (V. elevatum Banks.) - Varies with tho leaves beneath nearly white to green, smooth to pubescent, and with smaller flowers.

$4 \mathrm{~V}$. arbòreum $\mathrm{Mx}$. Lvs. obovate, acuto and short-petioled at base, mucronate and glandular-serrulato or entire, veiny, shining above, pale green and subpubescent beneath; pedicels axillary to bracts, secund, in leafy racemes; cor. cylindric-bell-shaped; anth. 10, included, 2-awned.-Woods, N. Car. to Fla. Shrub or small tree, 8 to $20 \mathrm{f}$ high. Lvs. usually small, rather thick, $1^{\prime}$ to $18^{\prime \prime}$ long. Fls. numerous, elegant, rose-white, half as long as their pedicels. Berries black, dryish, ripening but fuw seeds. May, Jn. $\rightarrow$ V. myrtilloides? Ell. with the bracts onlarged to lvs. in fruit.)

5 V. Vitis-Idæa L. Decumbent, much branched, smooth, evergreen; Ivs. oval, thick, murgin revolute, obtuse, small, dark green above, pale beneath; fls. solitary or in short clusters, 4-parted; cor. campanulate. - Summits of the Whito Mts. N. I., also rocky hills, E. Mass. and Me. Sts. 3 to $6^{\prime}$ long. Lvs. crowded, 4 to $7^{\prime \prime}$ long, channeled along the midvein above. Fr. small, mealy, sour. Jn., Jl.

6 V. Myrsinítes Mx. Erect, much branched; lvs. small, elliptical, acuto at each cnd, glabrous, serrulate; fls. in small, lateral clusters of 2 to 5 ; cor. ovoid, urceolate; sty. slightly exserted.-A beautiful little shrub 1 to $2 \mathrm{f}$ high, common in woods, $\mathbf{N}$. Car. to Fla. Branches greenish. Lvs. 3 to $\mathbf{5}^{\prime \prime}$ long, varying from ellip ${ }_{i c}$ to obovate or roundish, perennial, often purplish. Cal. purple, cor. rosecolored. Fr. rather large, bluish black, sweet, pulpy, many-seeded. Mar., Apr.

7 V. myrtifòlium Mx. St. simple, decumbent at base, from long, creeping roots; bark green, puberulent above; lvs. cuneate-obovate, or oral, palo and with scattered glandular hairs beneath; fls. in dense, sessile, lateral clusters of 6 to 12 ; cor. oulong-cylindric; anth. unawned.-S. Car. to Fla. Sts. If high. Lvs. scattered, 1 to $2^{\prime}$ long, obtuse or acute, tapering to a short petiole. Berries small, pedicellate, globous, black. Mar., Apr.

8 V. Cánadénse Rich. Branches reddish-green, pubescent, leafy; lvs. subsessile, elliptic-lanceolate or oblong, acute at each end, villous beneath, tomentous on the veins above, entire; rac. fasciculate, sessile, subterminal; cor. campanulate; cal. lobes acute. - $A$ shrub 8 to $12^{\prime}$ high, not uncommon in rocky fields and thickets, Can., Mo., N. H. to Wis. and tho R. Mits. Lvs. 8 to $12^{\prime \prime}$ by 3 to $5^{\prime \prime}$. Fls, about 
3" long. Sty. and stam. included. Berries bluo and sweet, similar to those of No. 9. May.

9 V. Pennsylvánicum Lam. Common Low Blueberry.-Branches green, with 2 pubescent lines; lvs. subsessile, crowded, elliptic-oblong, acute at each end, minutely serrulate, thin, glabrous, and shining, with the reins beneath puberulent; fls. in short, bracteate, dense, subterminal racemes; cor. ovoid-cylindrical. -Thickets and pastures in hard soils, Can. to Penn., common in N. Eng. A low under-shrub, 6-12' high, growing in dense patches. Leaves $8-12^{\prime \prime}$ by $4-6$ ". Flowers reddish-white, $3^{\prime \prime}$ long. Bracts mostly colored. Berries large, blue, sweet and nutritious. May. (V. tenellum Ph.)

$\beta$. NIGRUM. Lrs. dark green; berries black and shining, destitute of bloom.-

With variety $a$. (V. ligustrinum $\mathrm{Ph}$. ?)

$\gamma$. Alpivum. Dwarf, decumbent; Irs. very small (3 to $4^{\prime \prime}$ long), narrow-oblanceolate.-Summits of tho White MIts. with No. 5 (V. angustifolium Ait.)

10 V. vacíllans Poland. Low, bushy; lvs. oval, elliptical or ovate, acute or mucronate, pale green, dull, glaucous beneath, at length glabrous, minutely serrulate; rac. dense-flowered, preceding the full-grown lvs.; fls. a little longer than the pedicels; cor. ovoid-cylindric, slightly contracted at the mouth.-Hilly woodlands, N. Eng., N. Y., Penn. to Clinch Mt., Tenn. Shrub 1 to $2 \frac{1}{2} \mathrm{f}$ high, with greenish branches. Lvs. $I^{\prime}$ to $18^{\prime \prime}$ long, corolla 4", reddish white. Berries bluish black, sweet. May, Jn.

11 V. corymbòsum I. Common Higr BLueserRy. Tall; flowering branches nearly leafless; lvs. oblong-oval or elliptical-lanceolate, acute or acuminate at each end, entire, pubescent when young, often glaucous beneath; rac. short, sessile; cor. ovoid-cylindrical.-A tall shrub, 5 to $10 \mathrm{f} \mathrm{high,} \mathrm{growing} \mathrm{in} \mathrm{shady} \mathrm{swamps,} \mathrm{copses,}$ hedges, \&c. Can. to Fla. Branches green or purplish. Lvs. 1 to $2^{\prime}$ long, usually with a slight pubescence on tho veins beneath. Fls. numerous, nodding, generally appearing in advance of the leaves. Corolla large for the genus ( $5^{\prime \prime}$ long) purplish white. Stam. included, sty. often exserted. Berries large, black, often with a tinge of purple, subacid. Mar.-Jn.-Varies exceedingly. Some of its more striking varieties are

$\beta$. Vingìtum. Branches short, entirely nalked when in flower; rac. numerous, cor. oblong-ovoid, angular, bright rose-color.-Common southward. Sts. 4 to $6 \mathrm{f}$ high (V. virgatum $\mathrm{Ph}$. ?)

$\gamma$. AMCENUM. Lvs. oblong; cor. cylindrical, large, reddish wlite; style included.-Shrub 6 to $10 \mathrm{f}$ high. Berries black.

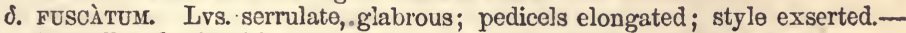
A smaller shrub with corollas red and white, striped. Calyx brown.

$\varepsilon$. GLÀBRUM. Plant glabrous throughout.-Not common.

$12 \mathrm{~V}$. galezans $\mathrm{Mx}$. Flowering branches leafy; lvs. sessile, cuneate-lanceolate, subserrate, veiny, glabrous when old; fls. in small, sessile fascicles; cor. ovoid, much contracted at the mouth; style exserted. - Swampy woods, Va. (Pursh) to Ga. and La. Sts. If to $18^{\prime}$ high, green with a reddish or yellowish tinge. Young lvs. also reddish. Cor. small, yellowish white. Berries small, black. A few lrs. are sometimes persistent. Apr., May.

13 V. hirsùtum Buckley. Whole plant, with fls. and fruit, densely hirsute; rac. small, axillary and terminal; lvs. deciduous, ovate, entire, mucronate, subsessile, cor. oblong, nearly closed at throat, with 5 short teeth; anth. awnless, included; fil. and style hairy; berry globous, $\infty$-seeded.-Mts. N. Car. (Buckley). Bush much branched, if high.

3. OXYCOC'CUS, Pers. Cranberry. (Gr. ogús; acid, кókкos, berry.) Calyx adherent to the ovary, 4-cleft; corolla 4-parted, with narrow, reflexed segments; stam. 8, convergent; anthers tubular, 2parted, opening by oblique pores; berry globous, 4-celled, many-seeded. -Shrubs, with alternate lvs. and red and purple berries.

* Stem erect, with membranous, decidous leaves, Berries swectish .......................No. 1

* Stem prostrate, slender; leaves evergreen, small. Berries acid,......................... 2, 8

1 O. erythrocárpus Ell. Lvs. oval, acuminate, thin, ciliate-serrulate; fls. axillary, solitary, the long segments at length reflexed.-Mts. of $\mathrm{Va}$. and Car. Sts. 
with divaricate branches, 1 to $3 f$ high. Lrs. much larger than in the other spo cies, veins beneath pubescent. Berries globular, scarlet, translucent. Jn.

20 . palústris Pers. St. filiform, prostrate; lvs. ovate, entire, revolute on the margin; pedicels terminal, 1-flowered; segments of the corolla ovate.-A prostrate under-shrub, found in Alpine bogs, Brit. Am. and N. States. Stems creeping extensively, smooth, purple, with erect branches. Lvs. very small (2 to $3^{\prime \prime}$ long), exactly ovate. Fls. several together on the summits of the branches. Pedicels an inch in length, with 2 nearly opposite bracts in the middle. Cor. light pink. Stamens purple. Fruit smaller than in the next species, crimson, ripe in Oct. Fls. in June.

3 O. macrocárpus Pers. St. creeping, filiform; lvs. oblong, obtuse at each end, edges revolute, glaucous beneath; pedicels axillary, elongated, l-flowered; segments of the corolla linear-lanceolate.-Sphagnous swamps Va. to the Arc. Ocean. Stems $8-15^{\prime}$ in length, brown, with ascending branches. Lvs. numerous, $4-6$ " by $2-3^{\prime \prime}$, rounded at each end, on very short petioles, smooth both sides. Fls. flesh-colored, pedicels 5-15" long, solitary in the axils of the upper leaves. Berry large, bright scarlet, ripe in Oct. Fls. in June.

4. CHIOG'ENES, Salisb. (Gr. $\chi \iota \omega \nu$, snow, $\gamma \varepsilon v o \varsigma$, offspring; in allusion to its evergreen habit.) Calyx 4-cleft, persistent; cor. broadly campanulate, limb deeply 4-cleft; stam. 8, included, filaments very broad and short, anther cells distinct, awnless on the back, bicuspidate at apex, opening longitudinally; ovary adherent, except at the summit, 4-celled; fruit white, 4-celled, many-seeded.-A prostrate, evergreen undershrub, with alternate leaves. Fls. solitary, axillary. (Fig. 38.)

C. hispídula Torr. \& Gr. A delicate woody creeper, in old shady woods, mountains, N. Eng. to Newfoundland, W. to the R. Mts. Stems ligneous, slender, creeping extensively, with numerous branches, and clothed with short, appressed, reddish hairs. Leaves numerous, alternate, and roundish-oval, $4-6^{\prime \prime}$ by $3-4^{\prime \prime}$, abruptly acute, dark evergreen above, paler beneath. Cor. white, its parts in $4 \mathrm{~s}$. The leaves and white berries have an agreeable spicy flavor like those of Gaultheria procumbens. (Vaccinium L.) May, Jn.

\section{Suborder II. ERICINE A. The Heath Tribe.}

5. ERI'CA, L. Heatr. Heather. (Gr. $\varepsilon \rho \varepsilon i ́ k \omega$, to break; in allusion to the brittleness of the branches and stems.) Calyx 4-cleft; cor. tubular, globous, ovoid, urceolate, campanulate or hypocrateriform, limb short, 4-lobed; stam. 8; style filiform; caps. 4, rarely 8-celled, 4 -valved, loculicidal; seeds $2-\infty$ in cach cell, affixed to the axillary placentr, usually conformed to the smoothish or shining testa.-European, or chiefly South African shrubs, branching, mostly brittle. Lrs. linear, acerous, margin revolute, verticillate, rarely alternate. Fls. axillary, solitary, verticillate, or terminal, corymbous or capitate, mostly nodding. Cor. of the cyanic series, from purple through red to white, very rarely orange or yellow.

Obs. Of this vast and beautifnl genus, 429 species are described by Mr. Bentham in the Prodromus of DC., Part vii., pp. 613-693. All these species have been cultivated in Europe, and many in this country, but their successful culture is attender with more care than that of most other plants, and they have never as yet received general nttention. To describe so few species as the jimits of this work would permit, where so thany are rarely and none generally met with, would be of little satisfaction to the student.

6. KAL'MIA, L. American Laurel. (Named by Linnæus in honor of Peter Kalm, Prof. at Abo, Finland.) Calyx 5-parted, corolla with 10 prominences beneath and 10 corresponding cavities within, including the 10 anthers; border 5-lobed; filam. elastic; capsule 5-celled, 
many-seeded.-Beautiful shrubs, natives of N. America. Lrs. entire, evergreen, coriaceous. Fls. in racemous corymbs, white and red.

* Flowers in terminal corymbs. Lvs thick, mostly acute...................... Nos. 1, 3

* Flowers in lateral corymbs. Leaves obtuse.............................................. 4

* Flowers solitary, axillary. Calyx elongated, deciduous................................. 5

1 Ir. latifòlia L. CALICo Busn. Spoon-wOod. Lvs, alternate and ternate, ovallanceolate, acute at each end, smooth and green on both sides; corymbs terminal, viscidly pubescent.-A profusely flowering shrub, sometimes attaining the height of a small tree. It is found in all the Atlantic States from Maine to Fla., and W. to Ohio and $\mathrm{Ky}$. in woods. Wood crooked, fine-grained and compact. Leaves 2-3' long, smooth and shining, acute at each end and entire. Flowers in splezdid corymbs, white or variously tinged with red, abundant. Corolla with a spreading limb 9-10" diam. and a 5-lobed margin. The leaves aro narcotic and poisonous to some animals. May, Jn.

2 K. glauca Ait. SwAMr LAUREL. Branches ancipitous; lvs. opposite, subsessile, lanceolate, polished, glaucous beneath, revolute at the margin; corymbs terminal, the peduncles and bracts smooth - A delicate shrub, $2 \mathrm{f} \mathrm{high,} \mathrm{found} \mathrm{in} \mathrm{swamps,} \mathrm{etc.,}$ Penn., Ky., N. Eng., N. to Arc. Am. Stem slender, the branches distinctly 2-edged by an elevated ridge extending from the base of each opposite leaf to the next node below. Lvs. smooth and shining, white underneath, and $\mathbf{l}^{\prime}$ in length. Fls. 8-10 in each corymb. Corolla about $\frac{1^{\prime}}{2}$ diam., pale purple. June.

$\beta$. rosMarinifolia. Leaves linear, more revolute, green beneath.

3 IK angustifòlia L. SHEEP-POLSON. Lvs. ternate and opposite, elliptical-lanceolate, petiolate, obtuse at each end, smooth; corymbs lateral; bracts linear-lanceolate. - Shrub 2-4f in height, in marshes and by ponds, Can. to Car. W. to Ky. Leaves with rounded ends entire, smooth, 1-2' long, and $\frac{1}{2}$ as wide, on short petioles. Flowers deep purple, in small, axillary fascicles apparently whorled, about half as large in No. 1. Bracts minute, about 3 at the base of each pedicel. Jn-Said to be poisonous to cattle.

4 I. cuneàta Mx. Lvs. scaitered, sessile, cuneate-oblong, obtuse, mucronate, glandular-pubescent beneath; fls., in sessile, lateral clusters of 4 to 6.-Mts. of N. Car. (Michaux), in swamps, S. Car., near Georgetown (Elliot), near Camden (Nuttall). Shrubs about as large as No. 3 . Lvs. about $1^{\prime}$ long. Pedicels $l^{\prime}$ long, filiform, with minute bractlets. Cor. white, red in the center. $\mathrm{Jn}$., $\mathrm{Jl}$.

5 K. hirsùta Walt. Very slender, branched, hairy; lvs. scattered, sometimes opposite, ovate, lanceolate, or linear-oblong, acute, sessile; pedicels as long as the leaves; cal. segm. lance-linear, nearly equaling the corolla limb.-Barrens, -5 . Car. to Fla., abundant in wet places. Sts. terete, about if high. Lvs. small (4 to $6^{\prime \prime}$ long), edges mostly revolute. Fls rose-colored, about $7^{\prime \prime}$ broad. May-Jn.

7. EPIGE'A, L. Training Arbutus. May Flower. (Gr. exí, upon, $\gamma \tilde{\eta}$, the earth; from its prostrate habit.) Calyx large, 5-parted, with 3 bracts at base; corolla hypocrateriform, tube villous within, limb 5-parted, spreading; stamens 10; anthers dehiscent by 2 longi. tudinal openings; capsule 5-celled, 5-valved.-Suffruticous trailing. Lvs. evergreen, cordate, ovate, entire, alternate.

I. repéns I. Lvs. cordate-ovate, entire; cor. tubo cylindrical.-2f Woods, Newfoundland to $\mathrm{Ky}$. and Penn. This little shrubby plant grows flat upon the ground, $10-15^{\prime}$ in length, covered with a bairy pubescence in all its parts. Lvs. $2-2 \frac{1}{2}$ ' by $1 \frac{1}{2}$, , roundish at the end and abruptly tipped with a very short point. Fls. very fragrant, white or tinged with various shades of red, in small axillary clusters Calyx green. The tube of the corolla hairy within, longer than the calyx, the border in 5, rounded, spreading segments. Apr., May.

8. ARCTOSTAPH'YLOS, Adans. BEAR-BERRY. (Gr. ă $\rho$ אToS, a bear, $\sigma \tau a \phi v \hat{\lambda} \dot{\eta}$, a cluster of grapes; that is Bear-berry.) Calyx 5-parted, persistent; corolla ovoid, diaphanous at the base, limb with 5 small, recurved segments; anthers 10, with 2 long, reflexed awns, opening by 
pores; drupe with a 5-celled putamen, the cells 1-seeded.-Trailing shrubs, with alternate lvs. (Arbutus L.)

I. A. Uva-ursi Spreng. Procumbent; lvs. entire, obovate, smooth, on short petioles, evergreen, coriaceous, shining above, paler beneath; fls. in short, terminal, drooping clusters; drupe globular, about as large as a currant, deep red, nearly insipid, the nucleus consists of 5 bony seeds firmly united-together.-Rocky hills, N. States and British America. Stem prostrate except the younger branches, which arise $3-8^{\prime}$. Lvs. about $1^{\prime}$ in length, $2-3^{\prime \prime}$ wide, often spatulate in form: medicinally they are astringent, and much valued in nephritic complaints. May.

2 A. alpina Spreng. Procumbent; lvs. thin, deciduous, obovate, acute, serrate, ciliate when young; fls. in short, terminal racemes; bracteoles ovate, broad, ciliate, about equaling the pedicel.-High Mts., in Me. and Can., alpine regions of the White Mts. (Robbins). Flowers white. Berries black.

9. GAUlthe'ria, Kalm. Boxberry. Checkerberry. WinterGREEN. (To one Gaulthier (or Gaultier), a French physician at Quebec.) Calyx 5 -cleft, with 2 bracts at the base; corolla ovoid-tubular, limb with 5 small, revolute lobes; filaments 10, hirsute; capsule 5-celled, invested by the calyx which becomes a berry.-S Suffruticous, mostly American plants. Lvs. alternate, evergreen. Pedicels bibracteolate.

G. procúmbens $\mathrm{L}$. St. with the procumbent branches erect or ascending; lvs. obovate, mucronate, denticulate, crowded at the top of stem; fls. few, drooping, terminal.-A little shrubby plant well-known for its spicy leaves, and its well-flavored, scarlet berries; common in woods and pastures, Can. to Penn. and $\mathrm{Ky}$. The branches ascend $3^{\prime}$ from the prostrate stem or rhizome which is usually concealed. Lvs. thick, shining, acute at each end. Cor. white, contracted at the mouth. Fr. consisting of the capsulo surrounded by the enlarged calyx which becomes of a bright scarlet color. Jn.-Sept.

10. CASSIO'PE, Don. Moss-Plant. (In Grecian mythology Cassiope was the mother of Andromeda.) Sepals bractless, imbrieated, ovate; corolla globular-campanulate, 4 or 5 -lobed ; anthers 8 or 10 pendulous cells opening by a terminal pore, with a long reflexed awn behind; capsule 4 or 5-celled, valves 4 or 5, 2-parted; placenta pendulors, many-seeded.-Small, alpine, moss-like or heath-like shrubs. Fls. solitary, pedicellate.

C. hypnoides Don. St. filiform, spreading; lvs. evergreen, subulate, smooth, crowded; ped. solitary, terminal ; fls. 5-parted. One of the smallest and most delicate of shrubs, summits of the White Mts., N. H. and Mts. of N. Y. and Me. Sts. woody, much branched at base, 2 to $3^{\prime}$ high. Lrs. minute, evergreen, imbricated, concealing the stems. Fls. large in proportion ( $\mathrm{l}_{\frac{1}{2}}^{\prime \prime}$ long) nodding; ped. $1^{\prime}$ long in fruit. Cal. purple. Cor. light-red, twice as long as the calyx, lobes erect. Stam. included. Jn. (Andromeda, L.)

11. ANDROME'DA, L. (Andromeda of ancient fable, was chained to a rock near the sea; the original species, No. 1, grows near water.) Calyx 5-parted, persistent, not becoming fleshy in fruit; corolla urceolate, the mouth more or less contracted, 5 -toothed; anthers 10, cells 2 , opening by a terminal pore; capsule 5-celled, 5-valved, often reinforced with 5 external valvelets; seeds numerous, from lateral or suspended placentæ.-Shrubs or small trees, with deciduous or evergreen, entire, or serrulate, alternate lvs.

\& Flowers in a terminal, nodding umbel. Anthers $2-a$ wned at apex.................. 1 Flowers in racemes or axillary. (*)

* Calyx calyculate, with 2 bractlets at its base. (a)

a Anthers awnless. Racemes leafy. Pericarp double. (CAssandra)......Nos. 2, 3

a Anthers awned. Racemes leafless. (Lvs, evergreen, No. 7 ) Lrs. deciduous. Nos. 4,5

- Calyx naked at base; bracts at the base of the pedicels. (b) 
b Anther cells each 2-awned at apex. Cor. bell-shaped. Panicle terminal......No. 6

b Anthers with 2 reflexed long awns on the back. Evergreen........... Nos. 7,8

b Anthers with 2 deflex-spreading bristles at the back. Capsule with 5 narrow valvelets applled to the sutures. (Preris)........................ 9, 10

b Anthers awnless, cells often minutely 2-toothed at apex. (c)

c Corolla cylindric. liacemes sessile. Valvelets 0. (Lxucotroe)..Nos. 1I-19

c Corolla globular. Valvelets of cupsule 5, couspicuous (LroNiA). Nos. 14-16

1 A. polifòlia. WIL Rosemary. Erect; lvs. entire, linear-lanceolate, coriaceous, revolute on the margins, glaucous beneath; fls. subglobous, in a dense, terminal corymb. - A low, smooth, evergreen shrub, 1 to $2 \mathrm{f}$ high, growing by the side of ponds and in swamps, N. Eng. to Wis., N. to Arc. Am. Lvs. very smooth. 2 to $3^{\prime}$ long, on very short petioles, dark green and smooth above, bluish whito beneath. Clusters of flowers drooping. Cal. white, tipped with rod. Cor. rosecolored. Jn.

2 A. calyculàta L. Leather-LEAF. Erect; lvs. oval-oblong, obtuse, obsoletely servulate, flat, ferruginous beneath; rac. terminal, leafy, subsecund; fls. short-pedicelled, solitary, axillary, forming leafy racemes; cor. oblong-cylindrical. - An evergreen shrub, 2 to $4 \mathrm{f} \mathrm{higl,} \mathrm{flowering} \mathrm{early} \mathrm{in} \mathrm{wet} \mathrm{situations,} \mathrm{Can.} \mathrm{and} \mathrm{most} \mathrm{of} \mathrm{the}$ U. S. The lvs. are coriaceous, shining, dotted, about an inch long and half as wide, those of the raceme not half as large. Fls. 20 to 30 in each raceme, white. Cal. double, the outer of 2 bracts, the inner of 5 acute sepals. Apr., May.

3 A. angustifòlia $\mathrm{Ph}$. Lvs. linear-lanceolate, acute, margins revolute, somewhat ferruginous beneath; rac. terminal, leafy, secund; pedicels short, solitary, axillary; cal. acuminate; bractlets minute, acute; cor. oblong-oval.-Open swamps, Car., Ga. Evergreen. Nearly allied to the preceding. Apr., May. (Cassandra, G. Don.)

4 A. racemòsa I. (Fig. 203.) Lvs. oval-lanceolate, acute or slightly acuminate, glabrous, serrulate ; rac. terminal, secund, elongated, one-sided, strict, ascending; cal. ovate-acuminate, cor. cylindric; anth. cells each 2-awned at apex; seeds wingless. - Shrub 4 to $6 f$ high, wet woods, Can. to Fla. W. to Ky. It is remarkablo for its naked racemes 2 to $4^{\prime}$ in length, each with its 12 to 30 white fls. all turned downwards. Lvs. 1 to $2^{\prime}$ in length, deciduous. Pedicels short, with 2 ovateacuminate bracts at the base of the colored calyx. Jn., Jl. (Zenobia, G. Don.)

5 A. recúrva Buckley. Branches and rac recurved-spreading; lvs. ovate or lanceolate, acuminate; cal. segm. ovate; anth. cells each 1-awned; caps. conspicuously lobed; seeds flat, winged_-Mts. and hills, Va., N. Car. A straggling, deciduous-leaved shrub; much resembling the last. Apr., May.

6 A. speciósa Mx. Lvs. oval, obtuse, mucronate, serrate, reticulate-veiny; flowering branches racemo-litie, aggregated, leafless; cor. campanulate; anth. cells each 2-awned.-Swamps Va. to Fla. An ornamental shrub 3 to $4 \mathrm{f}$ high. Lve glabrous, deciduous. Fls. several from each bud, large (4" long), shorter than their pedicels, white. Jn.

$\beta$. PULverulextA. Ivs. roundish-ovate, crenate, and with the branches whitish pulverulent-Grows with the other form.

7 A floribúnda Lyon, (Ph.) Lvs. glabrous, thick, evergreen, oblong-ovate, acute or acuminate, petiolate, serrulate, often ciliate; rac. dense-flowered, paniculate; pedicels bracted, secund; cal. bractlets minute. - Va. to Ga. along the Mts. Shrub 2 to $10 \mathrm{f} \mathrm{high,} \mathrm{very} \mathrm{handsome,} \mathrm{with} \mathrm{a} \mathrm{terminal} \mathrm{panicle} \mathrm{of} \mathrm{numerous} \mathrm{white} \mathrm{fls.}$ Anth. each with 2 long, reflexed, white awns. Apr.

8 A. Croomia Torr. Lvs. oval and oblong, obtuse, coriaceous, veiny, serrate towards the apex, petiolate; rac. short, in the axils of the upper lvs.; pedicels bractless; cal. naked, sep. triangular-lanceolate, $\frac{2}{3}$ as long as the ovoid corolla; anth. each with 2 long, black, reflexed awns at tho back.-Damp woods, Quincy, Fla. A slender shrub, 1 to 3 high.

9 A. nitida Bartram. Fetter-Bush. Ivs. thick, evergreen, elliptical, slightly acuminate at each end, perfectly smooth, with a vein running close to each revolute margin; fis. in pendulous clusters of 6 to 10 , in the axils of divaricate lvs.; cor. ovoid-oblong; valvelets linear.-By streams and in sandy swamps, N. Car. to Fla 1 singularly elegant shrub, 3 to $6 \mathrm{f}$ high. Branches sharp-angled. Fls. numerous. Cal. green, tipped with purple, much smaller than the rose-colored corolla. Mar., Apr. 
ק. RHombirolia. Lvs. roundish-oval, obtuse or abruptly pointed; cal. half as long as the turgid-ovate corolla. (A. rhombifolia Pers.?)

10 A. Mariàna L. Staggerbush. Glabrous; lvs deciduous, oval, subacuto at each end, flat, entire, subcoriaceous, paler beneath; flowering branches leafless; pedicels fasciculate; cal. lobes linear, foliaceous: cor. ovate-cylindric; stam. 10, fil. villous.-Woods and dry, sandy soils, N. J., Penn. to Fla., common. An ornamental shrub, 2 to $3 \mathrm{f}$ high, with very smooth, deciduous foliage, and largo (5" long), whito or pale red fls. Caps. urn-shaped, the valvelets narrow-linear. Seeds angular. Jn., Jl.-After flowering the caly $x$ and corolla sometimes becomo very large and erect, as if diseased. (Leucothoë, G. Don.)

11 A. axillàris Lam. Lvs. oblong or elliptic-lanceolate, acute, or slightly pointed, petiolate, spinulous-serrulate, glabrous, or minutely strigous beneath; fls. in axillary, denso racemes, not dronping, much shorter than the lvs.; sep. broad-ovate, obtusish; cor. ovoid-cylindrical.- - Banks of streams, Va. to Fla. in the low country, common. Shrub 2 to $3 f$ high. Lvs. large ( 3 to $5^{\prime}$ long). Rac. spike-like, interrupted. Feb., Mar.; again in Sept.

12 A. Catesbæ̀i Walt. Lvs. ovate-lanceolate, conspicuously acuminate, rounded at base, petiolate, serrulate, with appressed, spinulous teeth, thick, strigous beneath; fls. in spicate, drooping racemes as long as the blade of the leaves; sep. ovate-oblong, acute.-Banks of streams, Penn. (Miss Carpenter, Blue Ridge), to Ga. in the mountainous district. Rac. 2 to $3^{\prime}$ in length, on the long, recurved branches. May. (Leucothoë, Don.)

13 A. acuminàta I. PIPE-WOOD. Lvs. very smooth, rigid, ovato and lanceolate, gradually acuminate, entire, on short petioles; rac. few-flowered; cor. cylindrical; sep. broad-ovate, acuto; caps. globular, strongly lobed.-Shady swamps, S. Car. to Fla. Sts. 3 to 10 high, straight and hollow. Ivs. 2 to $4^{\prime}$ long, $1^{\prime}$ wide. Fls. white, abundant and handsome. Apr.-The stems are used by smokers in pipe-making.

14 A. ligustrina Muhl. Pubescent; lvs. deciduous, obovate-lanceolate, acuminate-cuspidate, finely serrulate; fls. somewhat paniculate, in terminal, leafless racemes; caps. 5 -angled by the linear valvelets. - Shrub, 4 to $8 \mathrm{f} \mathrm{high,} \mathrm{in} \mathrm{swamps,}$ \&cc., Mid. and S. States. Ivs. abruptly acuminate, paler beneath, 2 to $3^{\prime}$ long and nearly half as wide, on short petioles. Fls. small ( $1^{\prime \prime}$ long), nearly globous, white, in dense panicles. ( $\mathrm{Jn} .-\mathrm{Jl})$.

$\beta$ : FrondosA. Panicle with small lrs. scattered among tho fls. (A. fiondosa Muhl.)

15 A. ferrugínea Walt. Shrubby; lvs. evergreen, distant (not crowded), oblanceolate or obovate, obtuse, tapering to very short petioles, thick, revolute-edged, rust-scaly beneath; fls. in axillary umbels; valvelets of the capsules nearly as large as the valves. - Pine woods, Ga. and Fla. Shrub 3 to $5 \mathrm{f}$ high. Lvs. 1 to $2^{\prime}$ long. Fruit appearing when open as if 10 -valved. Jn.

16 A. rígida $\mathrm{Ph}$. Arborescent; branches rigid, erect; lvs. rigid, coriaceous, crowded, obovate, acute, strongly revolute edged, rust-scaly beneath; fls. numerous, in axillary umbels, blossoming in April; fruit as in the last.-Sandy pino barrens, S. Car. to Fla. A small tree, 10 to $20 \mathrm{f} \mathrm{high,} \mathrm{remarkably} \mathrm{rigid} \mathrm{and} \mathrm{leafy.}$ Lrs. 1' long; pale or yellowish-green.

17 A. montàna Buckley. Lrs. evergreen, ovate-lanceolate, minutely serrate or entire, ciliate; fls. in large, terminal and axillary panicles; pedicels 3-bracted, bracts subulate, the 2 upper opposite; ped. pubescent.-High Mts. of N. Car. Shrub 5 to $6 \mathrm{f}$ high. Lvs. $2^{\prime}$ by $1^{\prime}$, the petiole $6^{\prime \prime}$ long. Stem above sprinkled with mucronate glands.

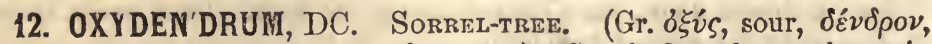
a tree; the herbage is sour to the taste.) Sepals bractless, valvate in the early bud; corolla urceolate, ovoid, 5-toothed; stamens 10, anthers linear, erect, awnless, cells opening lengthwise; capsule oblong, truncate, 5-celled, 5-valved, placentæ below, seeds many, ascending.-A tree, with deciduous, petiolate, oblong-lanceolate, acuminate, serrulate Ivs. and terminal panicles of slender, spicate racemes. 
O. arboreum DC. Ohio, Penn., along the Alleghany Mts. to Flor. A fine tree, $40-50$ f high, trunk $10-15^{\prime}$ diam. Bark thick and deeply furrowed. Leaves 4 $-5^{\prime}$ by $1 \frac{1}{2}-2^{\prime}$, villous when young, at length smooth, with a distinctly acid tasto. Flowers white, 3 " long. Capsulo pyramidal, 5-sided. June, July. $\nmid$

13. IIENZIESIA, Smith. (To Menzies, the discoverer of the original species (M. ferruginea) in Oregon.) Calyx deeply 4 or 5 -cleft; corolla irecolate or campanulate, 4 or 5 -lobed ; stamens 8 to 10, anthers opening by terminal pores; capsule 4 to 5 -celled, the dissepiments made by the introflexed margins of the valves; seeds many.-Low, shrubby plants, of various habits. Fls. in terminal clusters.

§ Prýr.opock, Salisb. Leaves evergreen, leath-like. Flowers 5-parted............... No. 1 $\$$ Mexzizs proper. Leaves deciduvus. Flowers 4 -parted............................. No. 2

1 M. taxifòlia Robbins. Mountain Heath. St. prostrate at base; lvs. linear, obtuse, with minute, cartilaginous teeth; ped. terminal, aggregate, 1-flowered; fls. campanulate, decandrous; cal. acute.-Shores of the "lake" on the White Mts. N. H., on Mit. Katahdin, Me. It resembles a heath in its flowers; and some of the fir tribes in its leaves and stems. St. decumbent at base, 6 to $10^{\prime}$ long, with crowded lvs above which are 5 to $7^{\prime \prime}$ in length. Fls. drooping, purple, at the top of the highest branch, the colored ped. $18^{\prime \prime}$ in length. Fr. erect. Jn.

2 M. ferruginea Smith. $\beta$. GLobularis Sims. Branches and pedicels with scattered hairs; IVS. oval-lanceolate, ciliate above and on the veins beneath; apex tipped with a gland; fls. in terminal panicles, nodding on the slender pedicels. -Mts. Penn to Car. abundant near Winchester, Va. (Pursh). Shrub 4 f high. Fls. greenish purple, small, one on each pedicel which is glandular pubescent, $18^{\prime \prime}$ long. Cor. short-urceolate. Jn.

14. LOISEleU'RIA, Desv. Alpine Azalea. (To Loiseleur Delongchamps, a French botanist.) Calyx 5-parted, lobes equal; corolla subcampanulate, 5-parted, regular; stamens 5, equal, erect, shorter than the corolla, anthers dehiscing laterally from the apex; ovary roundish; style straight, included; capsule 2 to 3 -celled, 2 to 3 -valved, manyseeded.-A little, branching, procumbent shrub, with opposite, petiolate, evergreen, entire lvs. Pedicels terminal, solitary, 1-flowered. Cor. rose color, (Azalea, L.)

I. procúmbens Desv. Summit of the Whito Mts., N. H. Sts. 3 to $6^{\prime}$ long. very branching and leafy. Lvs. elliptical, thick, shining, not more than $3^{\prime \prime}$ by $1^{\prime \prime}$, margins strongly revolute. Fls. glabrous, on very short, purple pedicels, in the midst of the lvs. Jn., JL.

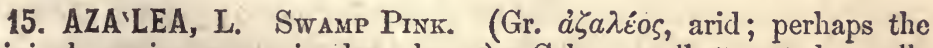
original species grows in dry places.) Calyx small, 5-parted, corolla funnel-form, somewhat irregular, with 5 spreading lobes; stamens 5 , filaments and style long, exserted, declined, anthers opening by pores; - capsule 5-celled, 5-valved, $\infty$-seeded.-Erect shrubs. Lrs. alternate, deciduous, oblong or obovate, entire. Fls. in umbeled clusters, terminal, large and showy, (Rhododendron, Don.)

$\$$ Calyx lobes all (or rarely one excepted) very short or minute. ..................Nos. 1, 8

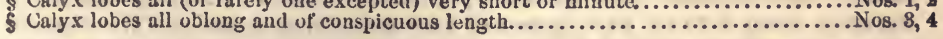

1 A. viscòsa L. Branchlets hispid; lvs. obovate, oblong or lanceolate, the edges, midvein and petiole bristly; fls. appearing with the adult lvs. very viscid, the tubc much longer than the segments; stam. exserted; style much longer.-Moist woods. $\mathrm{Can}$. to $\mathrm{Ga}$. and $\mathrm{Ky}$. Shrub 4 to $7 \mathrm{f} \mathrm{high,} \mathrm{with} \mathrm{spreading} \mathrm{branches.} \mathrm{Lvs.} 1$ to $2^{\prime}$ long, often glaucous. Fls. fragrant, white or rose color, with full grown lvs. Cal. very small. Tube about 1' long, downy and clammy, slender. May-Jl. (A. glauca Ph.)

$\beta$. NítidA. Ivs. shining above, smooth both sides, green, oblanceolate. - $\mathbf{A}$ low shrub in mountain swamps. Cal. segm. obsolete. 
\%. níspiDA. Branchlets and lvs. above very hispid; lvs. lanceolate, glaucous, glabrous beneath; tube shorter.-Mts., N. Y., Penn. (Pursh.)

2 A. nudiflòra L. Pinxter-Bloom. Young branchlets hairy; lvs. oblanceolato and obovate, downy beneath; clusters naked, appearing with or before the young leaves; cal. very small; cor. slightly viscid, tube downy, scarcely longer than the segments; stam. (5 to 7) much exserted.-Frequent in forests throughout the country, especially southward. St. crooked, much branched, the branchlets often in irregular whorls. Pedicels short. Tubo nearly $l^{\prime}$ long, segm. spreading $1 \frac{1}{2}^{\prime}$. Stam. twice as long as the tube, style thrice. Its varieties in color are numerous and splendid, e. g., pink-colored, slightly fragrant; deep purple; white variegated with purple and yellow; white with a buff-colored center, fragrant; buff-colored all over, very fragrant. Ap.-Jn.

$\beta$. CALYCOSA. Cal. with one of its segm. subulate, 3 or 4 times longer than the others (not constantly so even in the same umbel.)-Ga. (Miss Wyman). (A: bicolor $\mathrm{Ph}$. ?)

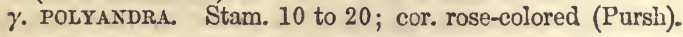

3 A. calendulacea Mx. Flamixg Pinxter. Young branchlets pubescent; Irs. oblong; attenuated to the base, mucronate, smoothish or pubescent; corymbs nearly or quite leafless; cal. lobes oblong; tube of the cor. hirsute, not viscid, shorter than the ample lobes.-A splendid flowering shrub, in mountains and woods, Penn. to Ohio and Ga. Fls. very numerous, limb expanding 18 to $20^{\prime \prime}$, usually yellow and bright crimson, showing at distance like flame.-Its varieties are numerous, e. g., flame-colored; brick-red (very rich); saffron-yellow. Cultivation has produced many more. May, Jn.

4 A. arboréscens Ph. TREe AzaleA. Branches smooth; lvs. obovate, both sides glabrous, glaucous beneath, margins ciliate, veins nearly glabrous; corymbs leafy with full grown leaves; cal. lobes oblong, acute; cor. tube not viscid, longer than the lobes; stam. and sty. exsert.-Rivulets near the Blue Mts., Penn. to (Macon) Ga. Shrubs 10 to $20 \mathrm{f}$ high. Fls. rose color, scales of the flower buds large, yellowish-brown, with a fringed whito border. Sepals fully $2^{\prime \prime}$ long. $\Lambda$ very distinct species. May-J1.

5 A. Póntica L. Lvs. ovate and oblong, pilous-ciliated on the margin, acute or acuminate; fls. with full grown lvs. viscid; tube funnel form, about as long as the segments; stam. very long-exserted.-Cultivated. This splendid shrub comes from Asia Minor, but is in no wise superior in beauty to our own A. calendulacer (which it much resembles). Varieties of every hue. (R. flavum Don.)

16. RHODODEN'DRON, L. Rose Bar. (Gr. póoov, a rose, $\delta \varepsilon ́ v \delta \rho o v$, a tree.) Calyx (small) deeply 5-parted, persistent; corolla campanulate, slightly unequal or regular, 5-lobed; stam. 10 (rarely fewer), mostly declinate, anth. opening by 2 terminal pores; capsule 5 -celled, 5-valved, many-seeded.-Shrubs with alternate, entire, evergreen lvs. Fls. in dense, terminal umbels from large, scaly buds. (Fig. 355.)

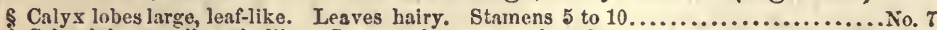
\$ Calyx lohes small, scale-like._Leaves obtuse at each end........................ 1, 2 -Leaves acute, rusty or silvery beneath................ Nos. 8,6 -Leaves acute, glabrous beneath................................ 4

1 R. I Lappónicum Wahl. LAPLAND ROSE BAY. Dwarf; lvs. elliptical, obtuse, very small, roughened with concave rusty scales both sides; fls. in terminal, leafy clusters, campanulate, limb spreading, 5-lobed; stam. 5 to 7 to 10 , exserted.An erect shrub, 8 to $10^{\prime}$ high, native of high mts., N. Eng. and N. Y. Branches numerous, with a rough bark. Lvs. about $5^{\prime \prime}$ by $2 \frac{1}{2}$ ", revolute, ferruginous beneath, crowded. Cor. 7 to $8^{\prime \prime}$ diam., deep purple, regular. Jn., Jl.

2 R. Catawbiénsis Mx. CAtawba Rose BaY. Lvs, oval, rounded-obtuse at each end, paler beneath, smooth; cal. lobes oblong, elongated; cor. broad-campanulate; stam. 10.-On the highest summits of the Alleghanies, Va. and Car. Shrub 3 to $5 f$ high. Fls bluish purple, without spots, much larger than in No. 1. Jn.

3 R. punctàtum L. Ivs. oval-lanceolate, acute at each end, ferruginous and sprinkled with resinous dots beneath; cal. teeth very short; cor. narrow, campanu- 
late or funnel-form, segm. wavy.-A handsome shrub 4 to $6 \mathrm{f}$ high, on the highlands of Car. and Ga. Fls. smaller than in No. 4, pink-red. Jn., Jl.

4 R. máximum L. Lvs. obovate-oblong, acute, smosth, coriaceous, discolored beneath, subrevolute on the margin, cal. lobes oval-obtuse ; cor. somewhat campanulate, unequal, pet. roundish.-A splendid Howering shrub, streams and lakes, N. Eng. to the mits. of Car. Stems crooked, 6 to $20 \mathrm{f}$ in height. Lvs. very smooth and 4 to 7 ' long, entire, thick and leathery. Corymbs 15 to 20 -flowered, in the midst of the evergreen lvs. Scales of the flower-bud near an inch long, abruptly acuminate. Cor. pink or rose-colored, varying to white with purple dots, sometimes dotted with yellow, $1 \frac{1}{2}$ to 2 ' diam. Jl., Aug.

5 R. Pónticum. I, Lvs. oblong-lanceolate, attenuated to each ond, smooth and scarcely paler beneath; corymbs short, terminal; cor. campanulate-rotate; cal. lobes subacute, rery short.-From Asia Minor. Fls. large, often $2^{\prime}$ diam., purple, but in cultivation very variable. $\dagger$

6 R. arbòreum Smith. St. arborescent; lvs. lanceolate, glabrous, with silvery spots beneath; fls. densely corymbed; cor. lobes with crenulate, curled margins; ped. and cal. pubescent. - A most beautiful tree or shrub from Himmaleh Mts. Fls. purple, red, white, cinnamon color, \&c. †

7 R. Indicum Sweet. Branchlets, petioles, veins and sepals strigous but not glandular; Ivs. cuneate-lanceolate, ciliate, acuminato at each end; fls. terminal, 1 to 3 together, on short pedicels.-From Java. Sep. lance-ovate, 5 to $8^{\prime \prime}$ long. Fls. scarlet, purple, crimson, flame-color, \&c. In cultivation very bril liant. $t$ (Azalea Indica L.)

17. RHODO'RA, Dunham. (Gr. $\rho$ ódov, a rose; from the color of the fis.) Calyx 5-toothed, persistent; cor. adnate to the calyx, deeply divided into 3 segments, upper one much the broadest, $2-3$ lobed at the apex, in æstivation enfolding the 2 lower entire segments; sta. 10 , declinate; fil. unequal; anth. opening by 2 pores; caps. 5 -celled, 5 valved; cells many-seeded.-Shrub with deciduous, alternate leaves, and pale purple flowers.

R. Canadénsis L. A handsome, flowering shrub, in bogs, mountain or plain, Can. to Penn., frequent. Sterns 2-3f high, clothed with a smooth, brown bark, each dividing at top into several erect, flowering branches. Each branch, while yet naked of foliage, bears a terminal cluster of $3-5$ sessile flowers. Corolla $1^{\prime}$ long, about equaling the deflected stamens and style. Leaves obovate-oblong, downy-canescent beneath. Apr., May.

18. BEFA'RIA, Mut. (So named by Mutis, in honor of Bejar, a Spanish botanist.) Flowers heptamerous; calyx 7-toothed, campanulate; corolla of 7 distinct petals; stamens 14 ; capsule 7-celled, 7valved, many-seeded.-Small shrubs, often viscid-hairy, with alternate, entire lvs. and flowers in dense, racemous panicles. (Bejaria, A. Juss.)

B. racemòsa Vent. Branches hispid and glutinous; Ivs. ovate-lanceolate, glabrous; fls. in a terminal, paniculate raceme.-Sandy margins of swamps and ponds, E. Ga. and Fla., and the adjacent Islands. A handsome evergreen shrub, 3 to $4 \mathrm{f} \mathrm{high.} \mathrm{Lvs.} \mathrm{very} \mathrm{entire,} \mathrm{erect,} 1$ to $2^{\prime}$ long. Fls. on slender pedicels, white, tinged with red, petals oblong-obovate, spreading near 2'. Jn., Jl.

19. LE'DUM, L. Labrador Tea. (The Gr. name of the Cistus.) Calyx minute, 4-toothed; corolla 5-petaled, spreading; stamens 5-10, exserted; anthers opening by 2 terminal pores; capsule 5 -celled, 5 valved; opening at the base.-Shrubs. Lvs. alternate, evergreen, entire, ferruginous-tomentous beneath, coriaccous. Fls. in terminal corymbs, white.

I. palústre (and I. latifolium Ait.) Lrs. elliptio-oblong or oblong-linear; sta. 5-10, more or less exserted.-Mountain bogs, Penn. to Lab. and Greenland, 
Whito Mts. I Not uncommon. A shrub 2-3f high, readily known by its leaves which are smooth above, clothed beneath with a dense, ferruginous down, and strongly revolute or replicate at the margin. Petioles and younger twigs also downy. Leaves 1-2' long, nearly $\frac{1}{3}$ as wide. Corymbs terminal, of about a dozen white fls. July.

3. ANGLSTIFòlum. Lvs, narrower, almost linear; sta. mostly 10.

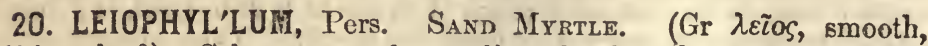
$\phi v i \lambda \lambda o \nu$, leaf.) Calyx 5-parted, equaling the length of the capsule; pet. 5 , ovate oblong, spreading; sts. 10, exserted; fil. subulate; cells of anthers dehiscing by a lateral eleft; ovary globous; sty. filiform; eaps. 3-celled, 3-valved, many-seeded.-Small, smooth shrubs, with erect branches. Lvs. alternate, entire, oval, coriaceous. Corymbs terminal. Fls. white.

I. buzifolium Ell-Pine barrens, N. J. to Car. Shrub 8-12' high, much branched. Leaves $4-5^{\prime \prime}$ by $2-3^{\prime \prime}$, very smooth and shining, margin strongly revolute. Flowers numerous and small. May, June.

21. CLE'THRA, Gaert. Sweet Pepper-Bush. (Gr. name of the Alder, which these plants somewhat resemble.). Calyx 5-parted, persistent; petals 5 , distinct, obovate ; stamens 10, exserted, anthers suspended in the bud, at length erect; style persistent, stigma 3-cleft; capsule 3celled, 3-valved, $\infty$-seeded, enclosed by the calyx.-Shrubs and trees. Lvs. alternate, petiolate. Fls. white, in downy-canescent racemes. Bracts deciduous.

1 C. alnifòlia I. Ivs. cuneiform-obovate, acute, acuminately serrate, green on both sides, smooth or slightly pubescent beneath; fls. in terminal, elongated, simple or branched racemes; bracts subulate.-A deciduous shrub 3 to $8 \mathrm{f} \mathrm{high,}$ in swamps. E. Can. to Ga. Lvs. 2 to $3^{\prime}$ long, $\frac{1}{2}$ as broad above, with a long, wedge-shaped base, tapering into a short petiole. Rac. 3 to $5^{\prime}$ long. Ped. and cal. hoary-pubescent, the former $2^{\prime \prime}$ in length, and in the axil of a bract about as long. Cor. white, spreading, sweet-scented. Jl, Aug.

$\beta$. ToMentòsa. Lvs. downy or tomentous beneath; rac. slender, often somewhat paniculate; fls. smaller.-Common in the South. Apr.-In. (C. tomentosa Lam.)

$\gamma$. Scגibra. Lvs. coarsely serrate, scabrous both sides.-Near Bainbridge, Ga. Rac. and fls. as in $\beta$. Petals about $2^{\prime \prime}$ long. (C. scabra Pers.)

$\delta ?$ PANiculàta. Lvs. cuneate-lanceolate; rac. collected into a paniclo.-S. Car. (Bartram). We have not seen this plant. (C. paniculata Willd.)

2 C. acuminàta $\mathrm{Mx}$. Arborescent; lvs. glabrous, glaucous, beneath, ovate, acuminate, abruptly acute at base, finely serrate, on slender petioles; rac. terminal, solitary; bracts longer than the fls., caducous.-Mts. along streams, Ky., Va., to S. Car. Shrub or tree, 10 to $18 \mathrm{f}$ high. Lvs. largo ( 4 to 6 "long), half as wide, thin, Fls. often secund (turned upwards). Anth. dark purple, much exserted. J. Aug.

\section{Stborder III. CYRILle $A$. Tite Cyrillads.}

22. ELLIOT'TIA, Muhl. (To Stephen Elliott, Esq, of Charleston, S. C., the well known botanical author.) Calyx small, 4-toothed; corolla of 4 petals slightly cohering at base ; stamens 8 , anthers sagittate; style slender, with a capitate, undivided stigma ; capsule 3 -celled, 3 -seeded.-A shrub with virgate branched alternate, deciduous, lanceolate, entire lvs. and terminal racemes of white fls.

E. racemòsa Mubl.-Dry, rich soils, S. Ga. Shrub 4 to $8 \mathrm{f}$ high. Lrs. pubescent and slightly glaucous on the under surface, on short petioles. Flowers in Jn.-Unfortunately, this plant has not fallen under our observation. 
23. CYRIL'LA, L. (In honor of Dominico Cyrilli, physician and botanical author, Naples.) Calyx 5-parted, minute, petals 5, distinct, pointed, spreading; stamens 5 , hypogynous anthers opening lengthwise; style short, with 2 stigmas; capsule 2-celled, 2-seeded, indehiscent; seeds suspended.-A large shrub with the branches irregularly whorled, with entire, elliptic-oblong, perennial lvs. and the white fls. in slender clustered racemes.

C. racemiflòra Walt.-Margins of swamps and streams, in pine barrens, N. Car. to Fla. Shrub 12 to $18 \mathrm{f}$ high, with spreading branches and a light gray bark. Lvs. varying from oval to narrow-oblong, mostly acute, very smooth, tapering to a short petiole. Fls. very small, in racemes 4 to $6^{\prime}$ long. The racemes and new branches simultaneously spring from the apex of the preceding years' growth. $\mathrm{Jn}$.

24. MYLOCA'RIUM, Willd. Buckwheat Tree. (Gr. $\mu \dot{v} \lambda \eta$, a mill, $\kappa a ́ \rho v o v$, a kernel, a fanciful name.) Calyx 5-toothed, minute; petals 5, obovate, obtuse ; stamens 10, very short ; pistil with winged angles ; capsule corky, 2 or 3 -winged, 3-celled, with 3 subulate seeds.-An evergreen shrub, with branches irregularly whorled, elliptical lvs., and terminal rac. of white, fragrant fls.

M. ligustrìnum Willd.-Borders of swamps, Ga. and Fla. A perfectly smooth, elegant shrub, 4 to $8 \mathrm{f}$ high. Lrs. thick, rather acute, entire, flat, veinless, sessile, $1^{\prime}$ to $18^{\prime \prime}$ long. Fruit drupe-like, pendulous, 2, rarely 3 of the angles produced into corky wings, suggesting the idea of buckwheat. Apr., May.

\section{Suborder IV. PYrolede. The Wintergreen Tribe.}

25. PYR'OLA, Salisb. Wintergreen. (Lat. diminutive of Pyrus, as the leaves (of P. elliptica) resemble those of the pear tree.) Calyx 5 -parted; petals 5 , equal; stamens 10 , anthers large, pendulous, fixed by the apex, 2-horned at base, opening by 2 pores at top; style thick as if sheathed; stigmas 5 , appearing as rays or tubercles; capsule 5celled, 5-valved, opening at the angles, many-seeded.-Low, scarcely suffiruticous, evergreen herbs. Lvs. radical or nearly so, entire. Scapes mostly racemous, from a decumbent stem or rhizome. (Fig. 345.)

\$ Stamens and style straight. Stigmas peltate, 5 -rayed............................ 1, 2 \$ Stamens and style straight. Stigmas peltate, 5 -rayed.................. (a)

a Leaves dull (not shining). - Petals greenish-white.......................... Nos. 8,4

a Leaves thick and shining. Flowers white or rose-colored........................... 5,0

1 P. secúnda L. Lvs. broadly ovate, acute, subserrate, longer than the petiole; rac. secund; cor. oblong. - In dry woods, Can. and Nor. States. Plant 5 to $8^{\prime}$ high, bearing one or two fascicles of leaves near the base. Lvs. acute at each end, with appressed-pointed serratures, appearing crenate. Ped. scape-like, bearing a 1-sided cluster of 10 to 15 greenish-white fls. Petals oblung, shorter than the style. Jn., Jl.

2 P. minor L. Lvs. roundish-ovate, coriaceous, repand-crenulate; petioles dilated at base, shorter than the laminæ; rac. subspicate; bract equaling or exceeding the very short pedicels; cal. lobes short, subacute; sty. included in the globular corolla.-In woods, White Mts., N. H., and Brit. Am. Scapo angular, 6 to $9^{\prime}$ high. Lvs. mucronulate at apex. Cor. white, slightly tinged with purple. Jl.

3 P. chlorántha Swartz. Lvs, orbicular, crenulate, half as long as the narrow petiole; rac. few-flowered; segm. of the cal. very short, obtuse; pet. oblong; pores of the anth. conspicuously tubular; stig. projecting beyond the sheath.-In woods, Can. and N. States, common. Lrs. smaller than in either of the following, often perfectly orbicular, but more frequently inclining to ovate, $\frac{1}{2}$ to $I^{\prime}$ diam. smooth, shining, coriaceous, petioles 1 to $2^{\prime}$ long. Scapes erect, angular, 8 to $12^{\prime}$ high, bearing a long open raceme. Fls. nodding, large, petals greenish white Jn., Jl. 
4 P. ellíptica Nutt. Lvs. elliptical, membranous, obscurely dentate, longer than the petioles; scape mostly naked; cal. small, with ovate, obtuse segments, pores of the anth. scarcely tubular.-In woods, Can. and N. States to Wis. Lrs. 1 to $2^{\prime}$ long, more than half as wide, mostly acute, subentire, thin, smooth and light green. Scape 5 to $9^{\prime}$ high, slender, seldom bracteate, bearing short racemes. Fls. nodding, very fragrant; pedicels longer than the bracts, but only half as long as the declinate, recurved style. Pet. white. JL.

5 P. rotundifòlia I. Lvs. orbicular-ovate, entire or vrenulate, shorter than the dilated petiole; scape 3-angled; segm. of cal. ovate, pores of anth. distinctly tubular; sty. clavate, the 5 stigmas projecting and often distinct.-Common in woods, Can. to Car., W. to Wis. Lrs. all radical, round or inclining to ovate, nearly $2^{\prime}$ diam., smooth and shining, with conspicuous, reticulate veins, petioles margined, as long as, and sometimes longer than the blade. Scape 6 to 12 ' high, bracteate at base and in the middle. Fls. drooping, large, fragrant, white, in an oblong, terminal raceme. Jn., Jl.

$\beta$. ULiginosa. Liss. rather dull, petioles much longer than the blade; fls. smaller.-Swamps, Galen, N. Y. (Sartwell), \&c. (P. uliginosa Torr. \& Gr.)

$6 \mathrm{P}$. asarifòlia $\mathrm{Mx}$. Lvs. reniform-orbicular, coriaceous, entire or crenulate, shorter than the dilated petiole; scape angular, furrowed; rac. lax, many-flowered; segm. of cal. triangular-lanceolato; anth. not produced into tubes; sty. produced beyond the sheath. - In old woods, Can. and N. States. Lvs. all radical, $1_{4}^{1}$ to $1 \frac{3}{4}^{\prime}$ diam., smooth and shining, conspicuously cordate at base, longer than, but not twice as long as the margined petioles. Scape 5 to $10^{\prime}$ high, purplish, bracteate at base and near the middle, racemous one half its length. Hls. nodding, remote, large, deeply tinged with purple in all their parts. Sty. about the same length and curvature as the pedicels. Jn.

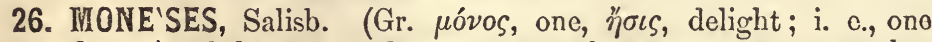
pretty flower.) Calyx 5-parted; cor. 5-parted, rotate; sta. 10, regular, 2 -spurred at base, opening by 2 tubular pores at apex; sty. rigid ; stig. peltate, radiately 5-cleft or lobed; caps. 5-valved, 5-celled, many-sceded. - 2f Low, simple, smooth. Lvs, at top of the stem roundish, crenulate, petiolate, veiny. Peduncle terminal, one-flowered, longer than the stamens. Fls. white.

M. grandiflòra Salisb. Woods, among mosses, Bradford, Vt., Keene, N. H. (Bigelow), Dexter, Jeff. Co., N. Y. (Vasey), Brit. Am. Root creeping. Stem ascending, very short. Leaves $7-9^{\prime \prime}$ diam. Scape or peduncle about $3^{\prime}$ high, slender, with a bract near the middle. Flower 9" diam. June. (Prrola uniflora L.)

27. CHIMAPH'ILA, Ph. Pipsissiwi. (Gr. $\chi \varepsilon \tilde{\imath} \mu \alpha$, winter, $\phi \iota \lambda \dot{\varepsilon} \omega$, to love; equivalent to the English name Wintergreen.) Calyx 5-parted; petals 5 , spreading; stamens 10 ; filaments dilated in the middle; anth. cells produced into tubes, opening by a 2 -lipped pore at apex; style very short, thick; capsule 5-celled, opening from the summit; seeds $\infty$. - Small, suffruticous, evergreen plants, with the habit of Pyrola. Lvs. cauline, serrate, evergreen, opposite or irregularly verticillate. Fls. terminal. (Fig. 45.)

1 C. umbellàta Nutt. Prince's PINe. Lvs. cuneate-lanceolate, serrate, in $4 \mathrm{~s}-$ $6 \mathrm{~s}$; umbel 4 to 7 -flowered; bracts linear-subulate; sty. immersed in the ovary.\& In dry woods, flowering in July. A common, little evergreen, Can. and $\mathrm{N}$. States. Leaves in 2 or more irregular whorls, $2-3^{\prime}$ long, $\frac{1}{4}$ as wide, remotely and distinctly serrate, on short petioles, coriaceous, shining, of a uniform dark green color. Peduncle terminal, erect, $3-4$ ' long, bearing $4-7$ light purplo flowers on nodding pedicels $8^{\prime \prime}$ long. Jl.-Both this and the following species are tonic and diuretic (Bw.)

2 C. maculàta Pursh. Lvs. lanceolate, acuminate, rounded at base, remotely serrate, discolored, opposito or in $3 \mathrm{~s}$; ped. 2-3-flowered; fil. woolly.-Can. to Car. 
and Tenn., in sandy woods. Habit much like the last, but it is readily distinguished by its variegated leaves. Stem $3-4^{\prime}$ high. Leaves $1-2^{\prime}$ long, $\frac{1}{8}$ as wide, marked with a whitish streak along the midvein and veinlets. Flowers purplish-white, on nodding pedicels. Jn., Jl.

\section{Suborder V. GA LA CIN E A .}

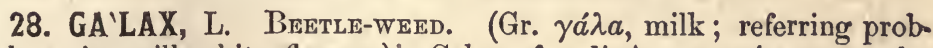
ably to its milk-white flowers.) ${ }^{\circ}$ Calyx of 5 distinct, persistent sepals; corolla of 5, oblong-obovate, distinct petals ; stamens hypogynous, filaments 10 , united into a tube with as many teeth, those opposite the petals sterile, anthers 5, 1-celled opening across the top ; capsule 3-celled; seeds $\infty$, inclosed in a loose, cellular testa. - 2f Roots tufted, creeping, deep red, sending up roundish-cordate, long-stalked, glabrous lvs, and a scape bearing. a dense raceme of white fls.

C. aphylla L. Damp, mountain woods, Md. (Mr. Shriver) to Tenn. (at Cumberland Gap), and S. Car. Lvs. large (2 to $3^{\prime}$ diam.), crenate-dentate, often reniform. Scape 1 to $2 \mathrm{f}$ high, naked except a mass of red scales at the base. Spike several inches long, milk-white. Jl., Aug.

\section{Suborder VI. MONOTROPEA.}

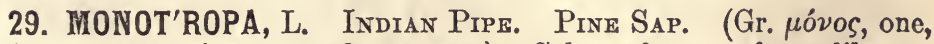
$\tau \rho \varepsilon ́ \pi \omega$, to turn; i. e., turned one way.) Calyx of 1 to 5 bract-like sepals; petals 4 to 5 , connivent in a bell-shaped corolla, gibbous at base ; stamens 8 to 10 ; anthers opening transversely at apex; stigma discoid, 5 -rayed; capsule 4 to 5 -celled, 4 to 5 -valved; seeds numerous, minute. - Low, parasitic herbs, of a white or tawny color, furnished with scalelike bracts instead of leaves.

§ Sepals (or bracts) 1 to 3: Flower solitary, scentless. Style very short...............No. 1

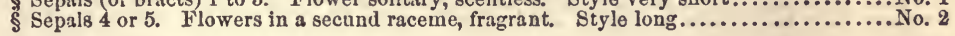

I M. uniflora L. INDIAN PIPE. BIRD's Nest. St. short; scales approximate ; fl. nodding; fr. erect.-Common in woods, Can. and U. S. A small, succulent plant, about $6^{\prime}$ high, of a dirty white in all its parts. St. furnished with sessile, lanceolate, semi-transparent lvs. or bracts, and bearing a large, terminal flower, sessile and nodding on the reflexed top. Common in woods, near the base of trees on whose roots it is doubtless parasitic. Jn.-Sept.-In the southern plant the flower is more or less pedunculate.

2 IM. Hypópytis L. PINe SAp. Bird's NeST. More or less downy; pedicels as long as the flower; caps subglobous.-Woods, N. Y., Can. to Car. W. to Wisc. The whole plant is of a tawny white or reddish color. Root a tangled ball of fibers. Scape $6-10^{\prime}$ high, with many concave scales, covered with down. Fls. $7-12$, in a terminal raceme, drooping at first, becoming erect. Pedicels $1-2^{\prime \prime}$ long, bracts and flowers 3 times as long. Only the terminal flower is generally decandrous; the lateral ones have 8 stamens and 4 petals. Aug.

30. SCHWEINIT'ZIA, Ell. Carolina BeEch-Drops. (To Rev. Lewis de Schweinitz, of N. C., a pioneer botanist.) Calyx persistent, of 5 erect, ovate-acuminate sepals; corolla persistent, campanulate, limb 5 -lobed; stamens 10, anthers awnless, opening by pores at apex; style thick, stigma large, 5 -angled, capsule 5 -celled, 5 -valved; seeds numerous, minute.-Plant leafless, brównish. Fls. subsessile, capitate, reddish. white, with the odor of the violet.

S. odoràta Ell. Rich, shady soils, Md. to N. Car. (Curtis). Plant 3 to $4^{\prime}$ high, with the habit of Monotropa. Feb.. Mar. 


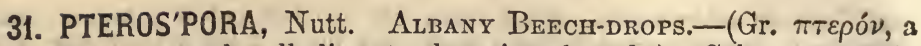
wing, $\sigma \pi o \rho a$, a seed; alluding to the winged seeds.) Calyx 5-parted; corolla urceolate, roundish-ovoid, the limb 5 -toothed and reflexed; stamens 10, anthers peltate, 2-celled, 2-awned, opening lengthwise; capsule 5-celled, 5 -valved; seeds very numerous, minute, winged at the apex. - 2f Plant leafless, brownish-red. Fls. racemed, white, resembling those of Andromeda.

P. andromèdea Nutt. In various parts of $\mathrm{N}$. $\mathrm{Y}$. and Vt., rare. First discovered by Dr. D. S. C. H. Smith, near Niagara Falls, 1816. Scape 12 to $30^{r}$ high, dark purple, clothed with short, viscid wool. Rac. 6 to $12^{\prime}$ long, with 50 or moro nodding fls. Pedicels irregularly scattered, 6 to $8^{\prime \prime}$ long, axillary to long, linear bracts. Cor. shorter than the pedicels, somerwhat campanulate, open at the throat. J. (Monotropa procera Ea.)

\section{Order LXXIV. AQUTFOLIACEA. Hollyworts.}

Shrubs or trees, with evergreen, alternato or opposito, simple, coriaceous, exstipulate leaves. Flowers small, axillary, sometimes diœcious. Sepals 4 to 6 , imbricato in bud, very minute. Cor. regular, 4-6-cleft or parted, hypogynous, imbricate in restivation. Sta. inserted into the very short tube of the corolla and alternate with its segments. Anth. adnate. Ova. free from the calyx, 2-6-celled, with a solitary, suspended ovule in each cell. Fr. drupaceous, with $2-6$ stones or nucules. Albumen large, fleshy.

Genera 11, species 110, natives of Amerien and S. Africa, only one, Ilex the IIolly. Ilex aquifolium, which gives name to the Order, being found in Euroje.

Properties. - Tho bark and leaves of Prinos verticillatus (black alder) are eminently astringent and tonic, as well as those of the llolly. The berries are emetic and purgative. 'The leaves of Priuos glaber, and Ilex Paraguensis aro used for tea, the latter well known as the Mato or Paraguay Tea.

The lilea of uniting the two genera Ilex and Prinos was alranced by Dr. Wm. Baldwin, in 1816 ("Reliquix," p. 341) in consequence of discovering some of the deciduons species of liex which he at first inistook for Prinos. The suggestion has sinco been repented by several authors, and at lengtlı Prof. Gray (Manual, p. 263) includes both under one name (Ilex). The two gromps, however, seem to us quite as distinct as Gaylussacia and Vaccinium; and morcover, Nemopanthes is internedicite.

\section{GENERA.}

$\$$ IIabitually tetramerous. Drupo with 4 , bony, sulcate nutlets.................. ILEx. 1

\$ Habitually tetramerous. Drupo with 4, horny, smooth nutlets............ Nesopaxtirs. 2

\$ IIabitually hexamerous. Berry with $6(7, \S)$ sinooth, cartilaginous sceds...........Privos. 3

1. ILEX, L. Holly. (The ancient name of the Holm Oak, the derivation uncertain.) Fls. 4 (rarely 5 )-parted, mostly perfect but many abortive; calyx 4-toothed, persistent; corolla of 4 obtuse petals distinct or scarcely united at base; stamens 4 ; stigmas 4 , or united into one; drupe red, with 4 bony nutlets, ribbed and furrowed on the convex back.-Lvs. alternatc. Fls. small, white, lateral, single or clustered.

Trees evergreen - the leaves armed with splnous teeth........................... Shrubs evergreen - the leaves unarmed, serrate or entire................................ Shrubs deciduous, the leaves thin, serrate or entire.......................................

1 I. opàca L. AMERican Holit. Arboreseent; lrs. oval, acute, with strong, spinous teeth, coriaceots smooth, and shining, fascicles lax, peduncles compound; cal, teeth acuto; drupe ovate, nutlets 5-ribbed on the back.-A tree of middle size, quite generally diffused throughout the U. S., from Mass. to Ga. and La. It is chiefly interesting for its foliage, which is of an exceedingly rich, shining, perennial green. Fls. in scattered clusters at the base of the new branchlets, and the fertilo ones are succeeded by red berries, which remain until late in Autumn. Jn.

$\beta$. Lrs. mostly entire, a few of them with a single spinous tooth towards the apex.-Macon, Ga., \&c. Lvs. exactly oval, very different from I. Dahcon. 
2. I. Dahoon Wa!t. D.Imooy HoLly. Lvs. oblong-lanceolatc, coriaceous, smooth shining, ovate or somewhat pointed at each end, beneath pubescent, at least on the midrein, as well as the petioles and pedicels, margin entire or sometimes serrate, clusters of fls. pedunculate; fls. 4-parted.-A fine shrub, 5 to $12 \mathrm{f} \mathrm{high,} \mathrm{in}$ swamps, Va. to Fla. Lvs. 2 to $3^{\prime}$ long, a third as wide, pale beneath. Drupes red, the 4 bony nutlets rugous-ribbed, on the convex back. May.

$\beta$. Lvs. larger, oblong-elliptic, obtuso, on very short petioles.-Ga. (Dr. Feay).

$\gamma$. Lvs. linear-lanceolate, cuneate at base, mostly entire, acute.-Ga. (I. ligustrina Ell.)

3 I. Cassèna Walt. CASSEna Tea. Lvs. oval, obtuse, crenate, glabrous, shining when old; clusters about 3-flowered, scarcely peduncled; fls. 4-parted; nutlets about 3-ribbed on the convex back.-A shining, evergreen, bushy shrub, common in S. States, near the coast, 6 to $15 \mathrm{f}$ high. Lrs. littlo moro than $1^{\prime}$ long. Fertile fls. nearly sassile, sterilo pedicels 2 to $3^{\prime \prime}$ long. Drupe scarlet, with 4 bony nutlets. Mar., Apr.-Used by the Creek Indians as a tea.

4 I. myrtifòlia Walt. Lvs. linear-oblong, small, glabrous, acute or submucronate, nearly entire, shining above, branchlets glandular-puberulent; ped. slender, bracteolate, corymbously 3 to 9 -flowered, or the fertile 1-flowered; drupes red.-A large shrub 12 to $20 \mathrm{f} \mathrm{high,} \mathrm{in} \mathrm{the} \mathrm{borders} \mathrm{of} \mathrm{ponds} \mathrm{in} \mathrm{pine} \mathrm{barrens,} \mathrm{Md.} \mathrm{(Shriver)}$ to Fla. Branches crooked, divaricate, with light gray bark. Lvs. less than $1^{\prime}$ in length, shining, rigid, often with a few acute serratures. May.-Varies with the branchlets smooth; lvs. obtuse, more or less serrate, \&c.

5. I. decídua Walt. Lvs. lanceolate, acute or slightly acuminate at both ends, glabrous, slightly appressed-serrato; ped. 1-flowered, short ( $3^{\prime \prime}$ long), the sterilo glomcrate, the fertile solitary; fls. 4 to 5-parted; cal. ciliate; nutlets large, obtusely ridged. - Shrub 6 to $9 \mathrm{f}$ high, with slender branches, in sandy woods, Car. to Fla., common. Lvs. thin, at flowering time $1 \frac{1}{2}$ to $2^{\prime}$ long, tapering to slender petioles. Ped. 2 to $3^{\prime \prime}$ long. Apr. (I. prinoides L.)

$\beta$. URBANA. Ivs. (2 to $3^{7}$ long) cuneate-oval, obtuse, crenately appressed-serrate, dark green, attenuate at base.-Ill. opposite St. Louis, \&c.

6 I. montícola Gray. Lvs. ovate, obtuse, or subcordate at base, acuminate, glabrous, serrate, thin; fls. on short pedicels, 4-parted; cal. ciliate; nutlets strongly ridged.-Mountain woods, Catskill, N. Y. to Car. Shrub about $6 f$ high. Lvs. large, deciduous, 2 to $4^{\prime}$ by 1 to $2^{\prime}$, at base acute, obtuse or subcordate. Pedicels 3 or more in a cluster, 1 to $2^{\prime \prime}$ long. (I. ambigua Torr. N. Y. Fl.)

2. NEMOPAN'THES, Raf. (Gr. $\nu \tilde{\eta} \mu a$, a thread, $\pi$ oús, a foot; äv0os, a flower; alluding to the slender pedicels.) Calyx 4 to 5 -lobed; petals 4 to 5 , distinct, linear or oblong; stamens 4 to 5 ; ovary hemispherical ; stigmas 4 to 5 , sessile ; fruit a subglobous drupe, with 4 to 5 smooth, horny nutlets. - Shrubs with alternate, entire, deciduous lvs. Fls. on slender pedicels, usually diœecio-polygamous by abortion. Berries red.-A genus intermediate between Ilex and Prinos.

1 IN. Canadénsis Raf. Canadux Holly. Lvs. deciduous, oval, very entiro, smooth, mucronate-pointed; ped. nearly solitary, long; fr. somewhat angular. A shrub, 4-6f high, with smooth branches, growing in damp or rocky woods, Can., N. Eng. to Mich. Leaves oval or ovate-oblong, about $2^{\prime}$ long, on petioles $\frac{1}{3}$ as long. Flowers small, greenish-white; ped. 7 to $12^{\prime \prime}$ long. Segments of the corolla acute, long as the stamens. Ovary of the barren flowers pointed, of tho fertile with a 4-lobed stigma. Berries dry, red. May, Jn. (Ilex, Mx.)

2 N. ambigua. Lvs. oval, entire, mucronate, petiolate, glabrous both sides, ciliate on the margin when young; sterile fls. 4-parted, on slender, aggregated pe, duncles; fertile solitary, on very long peduncles.-Slopes near Flint R., Ga. Shrub 4 to $8 \mathrm{f}$ high. Lvs. small, 1 to $2^{\prime}$ by $6^{\prime \prime}$ to $1^{\prime}$. Sterile pedicels less than $1^{\prime}$ in length, fertilo more than $1^{\prime}$ when in fruit. Berry 4 to 5 -seeded, red. Mar., Apr. (Prinos ambiguus $\mathrm{Mx}$.)

3. PRI'NOS, L. WINTER-BERRy. (Gr. $\pi \rho i \omega$, to saw ; alluding to the serrated leaves.). Flowers small, habitually 6-parted and perfect, 
but often abortive; calyx 6 -cleft; corolla monapetalous, subrotate, 6 parted; stamens 6 (in the sterile flowers rarely fewer, in the fertile rarely more) ; berry 6 -seeded, seeds with a smooth, cartilaginous testa. - Shrubs with alternate lvs., small white fls., and red or black berries.

s Leaves declduons, thin. Berries red...................................... 1,

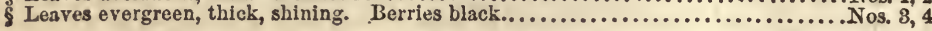

1 P. verticillàtus L. BLACK ALDER. Lvs. lance-oval, serrate, acuminate, pubescent beneath; fls. axillary, the fertile ones aggregate, the barren subumbellate.-This shrub is found in moist woods or swamps, Can. and most of the States, usually growing about $8 \mathrm{f}$ hight. Leares narrowed at base into a short petiole, uncinately serrate, with prominent, pubescent veins beneath. Flowers white, diœcious, small, the pedicels scarce more than $1^{\prime \prime}$ in length. Berries scarlet, in little bunches (apparently verticillate), roundish, 6-celled and 6-seeded, permanent. Jl. (P. Gronovii Mx.)

2 P. lævigàtus $\mathrm{Ph}$. Ins. lanceolate, appressed-serrulate, glabrous on both sides, shining above, minutely pubescent on the veins beneath; fls. hexamerous, the fertile axillary, subsessile, ô glomerate, on slender peduncles. - Swamps and marshes, N. and Mid. States. Shrub 6 to $9 \mathrm{f}$ high, with grayish and warty branches. Lvs. 2 to $3^{\prime}$ by 8 to $12^{\prime \prime}$, pointed at each end ; petioles 6 to $10^{\prime \prime}$ long. Fls. mostly solitary, the sterile on pedicels $6^{\prime \prime}$ long, the fertile pedicels scarcely 2". Berries large, red. Jn.

$\beta$. LANCEolatus. "Sterile fis. triandrous." Pursh.-Dr. Hale sent specimens from La. labelled P. lanceolatus. The lvs. and berries accord well with our specimens of No. 3, and also with Pursh's I. lanceolatus. The fruit is 6seeded.

3 P. glaber I. INK BERRY. Lvs. coriaceous, cuneate-lanceolate, glabrous, shining, serrate at the end.-A beautiful shrub, 3 to $4 \mathrm{f}$ high, found in swamps, Mass., R. I. to N. Y. and Car. Lvs. very smooth, leathery, shining, 1 to $1 \frac{1{ }^{\prime}}{2}$ by 5 to $7^{\prime \prime}$, broadest above the middle. Pedicels subsolitary, 1 to 3 -flowered. Fls. white, mostly 6-parted. Berries roundish, black and shining. Jn., Jl.

$4 \mathrm{P}$. coriaceus $\mathrm{Ph}$. Ivs. obovate, acute at base, short-acuminate, sharply serrate near the apex, very thick, shining above, minutely black-dotted beneath; fls. 6 to 8-parted, sterile aggregated, fertile solitary; berry black, with 6 to. 8 smooth seeds. - A shrub 4 to $6 \mathrm{f} \mathrm{high,} \mathrm{in} \mathrm{wet} \mathrm{woods,} \mathrm{Savannah} \mathrm{(Pond)} \mathrm{to} \mathrm{Bainbridge,} \mathrm{Ga.}$ and Fla. Lvs. remarkably thick and leathery, about $2^{\prime}$ long and $1^{\prime}$ wide, with 2 to 4 mucronate, appressed teeth. Berries large, astringent; seeds lens-shaped. May. (P. atomarius Nutt.)

\section{Order LXXV. STYRACACEA.}

Trees or shrubs with alternate, simple leaves, destitute of stipules. Fls. or racemes solitary, axillary, bracteate. Cal. 5-rarely 4-lobed, imbricated in æstivation. Cor. 5-rarely 4 or 6-lobed, imbricated in æstivation. Sta. definite or $\infty$, unequal in longth, usually cohering. Anth. innate, 2-celled. Ova. adherent, 2-5-celled, the partitions sometimes hardly reaching the center. Fr. drupaceous, generally with but one fertile cell. Sds. 5-1.

Genera 6, species 115, sparingly distributed throngh the tropical and subtropical regions of both continents, only a few in colder latitudes. Storax and Benzoin, two fragrant gum resins, regarded as stimulant and expectorant, are the products of two species of Sty rax, viz. of $\mathbf{S}$. officinale, a Syrlan tree, and $\mathrm{S}$. benzoin, native of Malay and the adjacent islands.

\section{TRIRES AND GENERA.}

I. SYMPLOCINEA. Anthers numerous, innate, globular. Calyx 5-cleft.

Flowers yellow................SYMpLocos

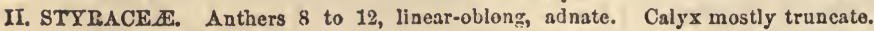
Flowers white (a).

a Flowers pentamerous, Fruit wingless, 1 -seeded............. Stroax. 2

a Flowers tetramerous. Fruit winged, \& to 8 -seeded.......... HaLrsia. 8 
1. SYM'PLOCOS, Jacq. (Gr. $\sigma \dot{\mu} \mu \pi \lambda$ okos, connected; referring to the stamens.) Calyx 5-cleft; corolla 5-parted, spreading, imbricated in bud; stamens $\infty$, in 5 clusters, one attached to the base of each petal, filaments slender, anthers globular; ovary 3 -celled, the lower half adherent; drupe dry, with a 3-celled, mostly 1-seeded nut.-Shrubs or trees, with axillary clusters or racemes of small yellow fls.

S. tinctòria L'Her. Lvs. oval or elliptical, acuminate, acute at base, thick, obscurely denticulate, puberulent beneath; fls. sessile, in axillary, dense clusters of 6 to 12 ; cal. lobes ovate, obtuse.-Va. to Fla. and La. A small tree 10 to $20 \mathrm{f}$ high. Lvs. mostly evergreen, crowded near the ends of the branches, 3 to $5^{\prime}$ long, sweet to the taste, turning yellowish in drying, and affording a useful yellow dye. Fr. oblong-ovoid (5 to $6^{\prime \prime}$ long), crowned with the calyx teetl. Mar., Apr.

2. STY'RAX, Tourn. Calyx campanulate, truncate or 5-toothed; corolla deeply 5-parted, much longer than the calyx; stamens 10, joined to the base of the corolla, filaments united into a short tube at base; anthers linear, erect; ovary adherent at base; fruit coriaceous, 1-celled, mostly 1-seeded. Shrubs with alternate lvs. and axillary racemes of white, drooping, showy fls.

1 S. pulverulénta $\mathrm{Mx}$. Branchlets, pedicels, and calyx pulverulent-downy; lvs. broadly oval, obtuse, glandular-serrulate, rust-downy beneath; fls. axillary and 2 or 3 together at the end of the branchlets-Va. to Fla. Shrub 2 to $3 \mathrm{f} \mathrm{high,}$ growing in clumps, wet places. Branches virgate. Lvs. small, about $1^{\prime}$ by 8 to $9^{\prime \prime}$, nearly sessile. Ped. 2 to $3^{\prime \prime}$ long. Cal. hoary, with minute, sharp teeth. Pet. 6" long. Mar., Apr.

2 S. Americàna Lam. Plant glabrous; lvs. oblong or elliptical acute at each end, wavy or remotely denticulate at edge; rac. leafy, few-flowered; pedicels shorter than or about as long as the flower; cal. turbinate, short.-Shrub with slender, straggling branches, 4 to $8 \mathrm{f} \mathrm{high,} \mathrm{in} \mathrm{swamps,} \mathrm{Va.} \mathrm{to} \mathrm{Fla.} \mathrm{and} \mathrm{La.} \mathrm{Lvs.} 1$ to $3^{\prime}$ long. Rac. 3 to 5 -flowered. Fls. 6 to $7^{\prime \prime}$ long, axillary, and partly naked. Cal. $\mathrm{I}^{\prime \prime}$ long. Apr. (S. glabrum Mx.)

$\beta$. LEVE. Lvs. thicker; pedicels shorter than the flower; corolla downy.Car. to La. The lvs. are often ovate. (S. leve Walt.)

3 S. grandifòlia Aiț. Lvs. ample, broadly. obovate, acute at base, short-acumb nate or acute, entire or dentate, hoary-tomentous beneath; rac. tomentous, naked, longer than the lvs., $\infty$-flowered.-Va. to Fla., common. Shrub 6 to $12 \mathrm{f}$ high. Lvs. 3 to $6^{\prime}$ by 2 to $5^{\prime}$, the petioles only 3 to $4^{\prime \prime}$. Rac. often branched, 5 to $8^{\prime}$; cor. imbricated in bud, wide bell-shaped, longer than the pedicels. Apr., May.

$\beta$. GRANDIDENTÀTA (Feay). Lvs. strongly centate, smaller ( 2 to $3^{\prime}$ by 1 to $2^{\prime}$ ), pet. nearly as broad as long. -Ga.

3. HALE'SIA, Ellis. SNowdrop Tree. (To the learned and venerable Stephen Hales, D.D., F.R.S., 1730.) Calyx obconic, briefly 4-lobed; corolla inserted into the calyx, campanulate, with a narrow base, 4-cleft or 4-parted; stamens 8 to 12, connate into a tube below; style filiform, pubescent; fruit dry, 4-winged, wings equal or alternately smaller; seeds 1 to $3 .-\mathrm{N}$. Am. shrubs or trees. Lvs. alternate, abruptly acuminate, finely denticulate or entire. Fls. in advance of the lvs. pendulous, in lateral clusters of 3 to 5 , white, showy.

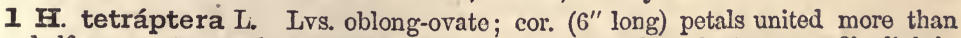
half way; sty. much exserted, twice longer than the 12 stamens; fil. slightly united; fr. equally 4-winged.-Va. to Ky. to Fla. Shrub or small tree 10 to $20 \mathrm{f}$ high. Lrs. downy beneath, at length ample ( 2 to $5^{\prime}$ by 1 to $\left.3^{\prime}\right)$. Fls. in clusters of about 3, shorter than the pedicels. Apr., May.

2 H. díptera L. Lvs. oblong-obovate; cor. ( $1^{\prime}$ long $)$, petals slightly united at base, oblong-obovate, style not exsert. as long as the 8 stamens; fil. united half way up; fr. 2-winged.-Woods, Car. to Fla, W. to Ark. Small or large tree, usually 
15 to $20 \mathrm{f}$ high. Prof. Pond describes one on the Ogeechee R., $45 \mathrm{f}$ high, trunk $18^{\prime}$ diam. Mr. Buckley one in N. Car., whose trunk measured $17 \mathrm{f}$ in circumference. Lvs. quite large ( 4 to 6 or $7^{\prime}$ by 2 to $3^{\prime}$ ). Fls. in clusters of 3 to 5 , on ped. 1 to $2^{\prime}$ long. The 2 -winged pods are near $2^{\prime}$ long. It begins to bloom sereral weeks later than No. 1. Apr. (H. parviflora Mix. ?)

\section{Order LXXVI. EBENACEA. Énonads.}

Trees or shrubs without milky juice and with a heary wood. Leaves alternate, exstipulate, coriaceous, entire. Inflorescence axillary. Flowers by abortion diœcious seldom perfect. Cal. free, 3 to 6-cleft, divisions nearly equal, persistent. Corolla regular 3 to 6-cleft, often pubescent, imbricate in æstivation. Stamens twice or 4 times as many as the lobes of the corolla. Fr. a fleshy, oval or globous berry. Seeds large, suspended, albuminous.

Genera 10 , species 160 , mostly native of the Indies and the tropics, one only being found as far North as N. Y.

Properties.-Diospyros is remarkable for the bardness and dark color of the woor. Ebony is the wood of D. Ebenus, Kbenaster, and other species, natives of Africa. The fruit of the species below is eatable when fully ripe, although extremely bitter and astringent before maturity. The bark is cminently febrifugal and astringent.

DIOSPY'ROS, Dalesch. Persimmon. Fls. of of. Cal. 4-6-lobed; cor. tubular or campanulate, 4-6-cleft, convolute in rstivation. $\delta$ Sta. $8-50$, mostly 16 ; fil. shorter than the anthers; ova. abortive; sty. 0 . + Sta. mostly 8 , without anthers; sty. 2-4-cleft; berry ovoid or globous, 4-12- mostly 8-celled, cells 1-seeded.-A large genus of shrubs or trees, mostly tropical.

D. Virginiàna L. Lvs. elliptic, abruptly acuminate, entire, smooth, petioles, veins and margins puberulent; rac. axillary, 3 to 1 -flowered, pedicels shorter than the flowers; cal. 4-parted; stam. 8.-In woods, lat. $42^{\circ}$, to Fla. and La., frequent. A shrub or small tree at the North, a tree of large dimensions South and West. Leaves $3-5^{\prime}$ long, entire, glaucous beneath. Flowers obscure, pale greenishyellow, the fertile ones succeeded by a round, orange-red fruit as large as the garden plum, and containing $6-8$ stony seeds. They are rendered sweet and palatam ble by the frost. Bark tonic and astringent. $\mathrm{Jn}$.

\section{Order LXXVII. SAPOTACEA. Soapworts.}

Trees or shrubs, mostly with a milky juice, and simple, entire leaves. Flowers small, regular, perfect, mostly in axillary clusters. Calyx free, persistent. Corolla hypogynous, short, stamens usually as many as its lobes and opposite to them, inserted into its tube along with one or more rows of appendages. Anthers extrorse. Ovary 4 to 12-celled, with a single anatropous ovule in each cell. Seeds large, usually albuminous.

Genera 21, species 212 , chicfly tropical.

Valuable for their sueculent fruit, as the marmalade, star-§pple, etc., for their febrifugal bark, some species of Achras being used as a substitute for Cinchona, and their gum resins, as tho Gutta-Percha obtained from the tree Isonandra Gutta.

BUME'LIA, Swarts. (The Greek name of the Ash.) Calyx 5-parted corolla 5-cleft, with a row of 10 narrow appendages on the edges of the lobes; stamens 5 , opposite the lobes, alternate with 5 petaloid, sterile stamens; ovary 5-celled; style filiform; drupe ellipsoid, 1-sceded. - Shrubs and trees, with a very hard, firm wood. Branchlets often changed to spines. Lvs. entire, of a firm texture. Fls. aggregated with the lvs. from buds of the preceding year, white or greenish. Our species are all more or less spiny.

* Leaves bairy beneath............Nos. 1, 2. ** Leaves giabrous both sides...... Nos. 3,4 
1 B. tenax Willd. Clusters and lvs. beneath silky-ferruginous; lvs. Wedge-oblong or obovate, obtuse, attenuated to the slender petiole; clusters 20 to 35 -flowered, pedicels 3 to 5 times longer than the flowers, longer than the petioles; cor. and appendages exceeding the calyx; drupe oval.-Dry sandy soils, S. Car. to Fla. and La. Tree 20 to $30 \mathrm{f}$ high, with tough twigs (as all the rest have). Spines stout, 6 to $12^{\prime}$ long. Lvs. 2 to $3^{\prime}$ long, 5 to $8^{\prime \prime}$ wide, shining, rusty or tawny but glistening beneath. Drupe beautifully corrugated when dry. Jn., Jl.

2 B. lanuginòsa Pers. Lvs. oval-lanceolate varying to oborate, membranous woolly ferruginous beneath, obtuse or rather acute; fascicles few (6 to 12)-flow. ered, pedicels short, but as long as, or longer than the petioles, both wcolly; drupe globular.-Wet soils, S. Ill. to Car. and La. Shrub 8 to $12 \mathrm{f} \mathrm{high,} \mathrm{with} \mathrm{spreading,}$ spiny branches. Lvs. $18^{\prime \prime}$ to $3^{\prime}$ long, woolly, not silky beneath. Pedicels 2 to 4' long. Jn., Jl.-Variable. (B. tomentosa DC., B. oblongifolia Nutt.)

3 B. Iycioìdes Gaert. Glabrous, or nearly so; lvs. wedge-elliptical, rather acute, attenuated to the slender petiole; clusters densely (20 to 30 )-flowered; pedicels twice longer than the fls. but rather shorter than the petioles; cor. near twice longer than the cal.-Damp soils, Ky., N. Car. to La. A small tree with the branches nearly straight. Spines on the older branches short, stout. Lvs. including the petiolo 2 to $3^{\prime}$ long, pedicels $3^{\prime \prime}$, fl. $1^{\prime \prime}$, greenish-white. May, Jn.

4 B. reclinàta Vent. Glabrous; branches divaricate; lvs. obovate, obtuse, small, narrowed to a short petiole; clusters 15 to 20 -flowered; pedicels slender, half as long as the leaf; cor. twice as long as the calyx.-Rivers banks, Car. to Fla. A straggling shrub. Lvs. scarcely $1^{\prime}$ long. Jn., Jl.

\section{Order LXXVIII. PRIMULACEA. Primworms.}

Herbs low, with the leaves mostly radical or mostly opposite, with the flowers 5(rarely 4 to 6)-parted, regular and monopetalous, the stamens 5 , inserted on tho corolla tube and opposite to its lobes, the ovary one-celled, with a free central placenta, stylo 1, stigma 1, the capsule 1-celled, co-seeded; seeds with fleshy albumen.

Genera 30 , species 216 , common in the northern temperate regions, growing in swamps, groves by rivulets, and often among the snow of "cloud-capped mountains." Many are beautiful and highly prized in culture. Properties unimportant.

\section{TRIBES AND GENERA.}

I. Hotronies. Ovary superior. Capsule opening by valves. Leaves pectinate. Hotrowia.. 1 II. Primuledi. Ovary superior. Capsule opening by valves. Leaves undivided. (*)

* Acaulescent._Corolla lobes spreading, tube eylindrical................ Purmula. 2

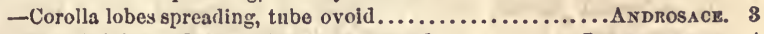
-Corolla lobes reflexed.-Stamens exerted.............. Dodecatuens. 4 -Stamens included................ CrcLaMrav. 5

* Caulescent.-Corolla wanting. Leaves opposito........................ 6 -Corolla 7 -parted. Leaves in one whorl............... Terentalis. $\tau$ -Corolla 6-parted. Leaves opposite................................... 8 -Corolla 5-parted. Leaves opposite or whorled............ Lrsimacira. 9

III. Avagalimex. Ovary superior. Pyxis opening by a lid.-Flowers 5-parted....Anagallis. 10 -Flowers 4-parted. Centenculus. 11

IV. Samolex. Ovary half inferior. Leaves alternate. Flowers 5-parted...........SAmolus. 12

1. HOTTO'NIA, L. Water-Feather. (To Peter Hotton, professor in the University of Leyden. Died 1709.) Calyx 5-parted; corolla salver-fgrm, with a short tube, and a flat, 5-lobed limb; stamens inserted in the tube of the corolla, included; stigma globous; capsule globous-acuminate.-2f Fleshy, aquatic herbs, with pectinate-pinnatifid, submersed, radical lvs.

H. inflàta Ell. WATER-FEATHER. Scape articulate, the internodes and lower parts inflated; fls. verticillate, pedunculate. $-A$ curious aquatic plant in swamps and stagnant waters, Mass., R. I. and Ct., N. Y. to Fla. and La. Stem immersed, round, thick, spongy, with a whorl of finely pectinate leaves (1 to $2^{\prime}$ long) at or near the surface of the water. Peduncles or scapes several together arising in a 
sort of umbel from the top of the stem, 8-10' long, inflated between the joints, Flowers small, white, in numerous verticils, generally 4 in each, subtended by a lance-linear bract. Apr., (Fla.), Jn. (Mass.) (H. palustris Ph., nec L.)

2. Prim'Ula, L. Primrose. Auricula. (Lat. primus, first; because its blossoms appear earliest in spring.) Calyx angular, 5-cleft; corolla salver-shaped or often rather funnel-shaped, with 5 entire or notched or bifid lobes; stamens included, filaments very short; cap. sule ovoid, 5-valved, valves often bifid, opening at the top, $\infty$-seeded.Herbs (mostly European) with the lvs. all radical and fls. in an involucrate umbel, often showy.

* Plants native, wild. Corolla salver-form, abruptly spreading.................Nos. 1, 2

* Plants exotic, cultivated. (a)

a Corolla salver-form. -The lobes abruptly spreading....................Nos. 3,4

a Corolla funnel-form.-Leaves rugons, hairy, toothed............................. 5, 6 -Leaves plain, smooth, often entire.................... Nos. 7,8

I P. Mistassínica $\mathrm{Mx}$. Lvs. spatulate, dentate or crenate, obtuse or acute, attenuate at base, green both sides; invol. $1-8$-flowered; bracts 3 times shorter than the pedicels, linear-subulate; cal. much shorter than the tube of the corolla; cor. salver-form, lobes obcordate.-Shores of Seneca Lake, N. Y. (Dr. Sartwell), Lake Willoughby, Vt. and throughout Brit. Am. A very delicate plant, 3 to $7^{\prime}$ high. Leaves about $5,5-8^{\prime \prime}$ by $3-4^{\prime \prime}$, almost petiolate. Flowers $5^{\prime \prime}$ diam., white. Pedicels 7 " in length.

2 P. farinòsa L. $\beta$. Ajrericana, Torr. Bird's-erye Primrose. Lvs. narrow, veiny, elliptic-lanceolate, obtuse, denticulate at apex, attenuate at base, under surface covered with a yellowish-white, farinaceous dust; invol. farinaceous, $3-20$ flowered, shorter than the pedicels; bracts long-acuminate; cal. segments lanceolate, acute; cor. salver-form, lobes obcordate, bifid, obtuso.- Shores of Lakes Huron and Superior (Nutt., Houghton), N. to lat. $66^{\circ}$. Scape 6-12' high. Flowers pale purple, yellow in the center.

3 P. grandiflòra Lam. Common Prrmose.-Lvs. obovate, oblong, rugous, villous beneath, toothed; umbel radical; fl. stalks as long as the leaves; cor. flat, - 2 Native of Europe. An interesting garden plant, esteemed for its early flowering, and for its being prolific in variation. In its wild state its flowers are yellow and single, but by cultivation they becomo double, and in the numerous varieties, red, pink, white, orange, purple, \&c., and the umbels, in numerous instances, are on a scape. Apr. $\nmid$ (P. vulgaris Huds.)

4 P. purpurea Royl. Lvs. lanceolate, obtuse, very smooth, covered beneath with yellowish farina, margin undulate, revolute; scape thick, glabrous, longer than the leaves; invol. Co-flowered, as long as tho pedicels, farinaceous beneath; cor. segments obovate, obtuse, not emarginate.-Nativo of the mountains of $\mathrm{Na}$ paul, Asia. Flowers dark purple. $\dagger$

5 P. officinàlis Jacq. Cowslip Primrose. Lvs. toothed, rugous, hairy boneath; umbels many-flowered, flowers all nodding; cal. angular; cor. concave. - 4 Native of Britain. Flowers yellow. Plant smells strongly of anise. Leaves are used as a potherb, and aro recommended for feeding silk-worms. Its varieties may be increased by raising from the seed. Jn. + (P. veris Cam.)

6 P. elàtior Jacq. Ox-LIP PRIMROSE.-Lvs. toothed, rugous, hairy on each side; umbel many-flowered, with the outer flowers nodding; cor. flat. - 4 Nativo of Britain. Flowers yellow, scentless, in a simple umbel elevated upon a scapo a foot high. Apr., May. +

7 P. aurícula L. Auricula. Ins. obovate, entire or serrate, fleshy; scapo many-flowered, central, as long as the leaves; invol. of short leaves; cal. powdery. -2 Native of tho Alps. $\Lambda$ well known favorite of the florist. The cultivated varieties aro isnumerable, and many of them of exquisite beauty and fragrance. May. $\dagger$

8 P. calycina Duby. Lvs. lanceolaie, thin, smooth, entire, acute, surrounded with a white margin; invol. 3-5-flowered, as long as the pedicels; cal. tube ventricous; cor. lobes obcordate, emarginate.-Native of Mts. in Lustria Flowers purple, very beautiful. $\nmid$ 


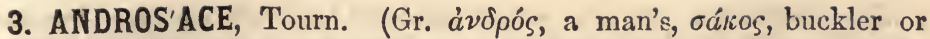
shield; from the form of the leaf.) Calyx 5-cleft or toothed; corolla funnel-form or salver-form, the 5 lobes entire, tube constricted at the throat, ovate, shorter than the calyx; filaments and style very short; capsule globous.-Minute cxspitous herbs with radical, rosulate lvs.

A occidentàlis $\mathrm{Ph}$. Lrs. oblong-spatulate and ovate, entire, glabrous; scape solitary, or few, puberulent; bracts oval, pedicels slender; cal, angular, segm. acute; cor. lobes long, obtuse.-(1) Gravelly shores of the Miss., Ill. (Gray), and Mo. (Nutt.) Scapes 1 to $3^{\prime}$ high.

4. Dodecath'eon, L. American Cowslip. Pride of Ohro. (Gr. $\delta \omega \delta \varepsilon \kappa a$, twelve, $\theta \varepsilon o i$, gods ; alluding to its curious flowers which are about 12.) Calyx 5-parted, reflexed; cor. tube, very short, limb rotate, 5-partd, segm. reflexed; sta. 5 , inserted into the throat of the corolla ; fil. very short; anth. large, acute, connivent at apex; style exserted; caps. oblong-ovoid, 5-valved, many-seeded.-2f Root fibrous, with radical, oblong lvs., an erect, simple scape, and a terminal umbel of nodding white flowers and erect fruit.

1 D. Meàdia L. Lrs. oval or oblong, obtuse, attenuate at base into a marginal petiole, glabrous, entire or repandly dentate; scape 9-20 flowered; bracts of the invol. ovate, inner ones lanceolate; sep. lanceolate, acute, entire; fil. united into a tube much shorter than the subulate anthers.-A singularly elegant herb, on prairies, dry or rocky soils, Penn. to Ind., Ill., Wisc. and throughout the Western States. Whole plant very smooth. Leaves all radical, 7-10' long, often quite entire. Scapes 1 to $2 \mathrm{f}$ high. The nodding flowers with their winglike, reflexed petals and beak-like anthers, exhibit a very unique appearance. May, Jn. (Fig. 297, 394.)

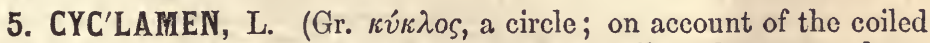
fruit stalks.) Calyx bell-shaped, 5-parted; corolla tube ovate, short, limb 5-parted, reflexed; anthers 5 , included, sessile; capsule globous, 5 -valved.-Oriental herbs. Rt. a large tuber. Lvs. all radical, ovate or roundish, cordate. Scapes naked, erect, with one nodding flower, but in fruit coiling up, and hiding the capsule in the ground.

1 C. Europæ̀um L. Lvs. roundish-reniform, crenate; pet. lance-ovate, obtuse. - Ivs. purple beneath. Fils. roseate, fragrant. † Eur.

2 C. Còum Mill. Lvs. reniform-orbicular, entire; pet. ovate-orbicular, obtuse.Lvs. purple beneath. Fls. inodorous, purple. † Asia Minor.

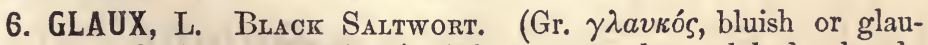
cous ; from the hue of the plant.) Calyx campanulate, 5 -lobed, colored; corolla none; stamens 5 ; capsule roundish, surrounded by the calyx, 5 -valved, 5-seeded.-2f Maritime, branching, glabrous, with opposite lvs. and small axillary, solitary fls.

G. marítima L. A small, fleshy plant, found occasionally on the salt marshes on the sea coast, Can. to N. J. Stem more or less procumbent at.base, 4 to $6^{\prime}$ high, smooth, branching and very leafy. Lrs. s. $^{\prime}$ in length, roundish-ovate, obtuse, entire, nearly or quite sessile, smooth, fleshy and darkly glaucous. Cal. white, tinged with red. $\mathrm{Jl}$.

7. TRIENTA'LIS, L. Chickweed Wintergreen. (Lat. triens, the third part of a foot $\left(4^{\prime}\right)$; alluding to the height of the plant.) Calyx and corolla 7 (6 to 8)-parted, spreading; stamens 7 (6 to 8); fruit capsular, somewhat fleshy, $\infty$-seeded.-St. low, simple. Lvs. subverticillate. Pedicel 1-flowcred. 
T. Americàna Ph. St. erect, simple, leafless at base; lvs. glemerate, few, narrow-lanceolate, serrulate, acuminate; sep. linear, acuminate.-This little plant is common in the rocky woods of Can., N. States, southward to Atalanta, Ga. St. 3 to $6^{\prime}$ high, with an irregular whorl of 4 to 8 , lanceolate, smooth and shining Ivs. at the top. In the midst of these are 1 to 4 wlite, star-like fls., borne on simple, filiform pedicels. The lvs. are mostly $3^{\prime}$ long and $1^{\prime}$ wide. Segm. of cor. longer than tho acute cal. lvs. May, Jn.

8. NAUMBUR'GIA, Mœnch. (Dedicated to one Naumburg, an early German botanist.) Calyx and corolla deeply 5 to 6-parted; petals linear-lanceolate, spreading, separated by minute intervening teeth; stamens 5 to 6 , inserted into the base of the corolla, exserted, anthers cordate ; capsule globous, 5 -valved; seeds few, on a globous placenta, $-2 f$ with opposite lvs. Fls. small, in dense, thyrsoid racemes. (Lysimachia L.)

IN. thyrsiflòra Mœnch.-An crect, smooth herb, about $2 \mathrm{f}$ high, Mass., Vt., N. Y., W. to Ohio, N. to Arc. Am. IVs. many pairs, sessile, lanceolate acute, entire, punctate, somewhat canescent beneath, 2 to $3^{\prime}$ by $\frac{1}{2}$ to $1^{\prime}$. Rac. somewhat capitate, on filiform, axillary ped. Fls. yellow. Stam. much exserted, united into a tube at base. Jn.

9. LYSIMACH'IA, L. Loose-strife. (To Lysimachus, King of Sicily, who first used it. Pliny.) Calyx 5-parted, rotate or campanulate, tube very short; stamens 5 , inserted into the corolla at base; filaments often somewhat counate or with intervening, sterile ones; capsule globous, 5 to 10 -valved, opening at the apex; seeds few or many. - Herbs 2f, with opposite or verticillate entire lvs. (Fls. yellow.)

\$ Sterilo filaments 0. Perfect stamens 5, unequal. Leaves and often the flowers dotted. (a) a Flowers verticillate, in a terminal, bracted raceme........... Nos. 1, 2 a Flowers opposite or verticillate, axillary or panicled.......... Nos. 8,4 \$ Stcrile filaments 5 short teeth interposed between the perfect stamens. Dutless. (b)

b Stem erect. Leaves opposite, acute and tapering at base........ Nos. 5, 6

b Stem erect. Leaves opposite, obtuse or suberdate at base.......... No. 7

b stem decumbent and trailing, Leaves oppusite.................. Nos. 8,9

1 I. stricta Ait. Simple or branched, erect; lvs. opposite (rarely) ternate, lanceolate or lance-linear, glabrous, punctate, acute, sessile; fls. verticillate, in a long, lax, terminal raceme; pet. lanceolate spreading. - 2 In low, wet grounds, Can., N. Eng. to Va. and Ohio. Plant smooth, 1-2f high, raceme 6-8' long. Ped. $I^{\prime}$ long, spreading, each with a subulate bract at base. Stamens 2 long and 3 short, united at base. Fls. yellow, streaked with purple. After flowering it throws out bulblets from the axils of the leaves, which will produce new plants the following spring. Jl.

$2 \mathrm{~L}$. Herbemónti Ell. Glabrous, simple; lvs. whorled in $4 s$ or $5 s$, sessile, lanceovate or ovate, obscurely 3-veined, acuminate, glaucous beneath; margin revolute, entire; fls. verticillate, in a terminal, bracted racemo.-A handsomo species, near Columbus, S. Car. (Herbemont). Plant 2 f high. Lvs. becoming more narrow above, passing into the linear bracts, and with tho brignt yellow fls., sprinkled with dots. Stem unequal. Jn., Jl.

$3 \mathrm{I}$. quadrifòlia I. Simple, erect; lvs. verticillate, in $4 s$, rarely in $5 \mathrm{~s}$ or $3 \mathrm{~s}$, sessile, lanceolate, acuminate, punctate; ped. axillary, 1-flowered, in $4 \mathrm{~s}$ (3s or $5 \mathrm{~s}$ ); pet. oval, obtuse.-2f In low grounds, river banks, Can. to Car. and Ky. Stem $18^{\prime}$ ligh, somewhat hairy, simple, with many whorls of $4-5$ leaves, each bearing a flower-stalk in its axil. Corolla yellow, with purple lines. Stamens unequal, united at base into a short tube. Anth. purple. Jn.

4 I. Fràseri Duby. Glandular-pubescent and branched above; lvs. opposite, petiolate, ovate, often cordate, acuminate, glabrous; fls. in a compound, terminal, bracted panicle.-In. S. Car. (Frazer in DC.) Fls. numerous. Cal. segm. acuminate, the margins thickened, brownish, ciliated. Stam. unequal, 2 of them shorter than the other 3 , sterile fil. none. 
5 L. longifòlia Ph. Prairie Monerwort. St. slender, 4-angled, flexuous, branched above; lvs. linear-shining, rigid, sessile, margin revolute; fls. opposite or mostly quaternate and terminal on the stem and branches; sep. lance-linear, acuminate; pet. longer than the calyx, roundish-ovate, erose-dentate, abruptly acuminate. - Common in low prairies, W. States. The large yellow flowers aro very conspicuous among the grasses. Stems $12-20^{\prime}$ high, purple. Leaves 2$3^{\prime}$ by $2-3^{\prime \prime}$, coriaceous, deep green. Flowers numerous, $9^{\prime \prime}$ diam., of a brilliant yellow. Anth. large. J. (L. revoluta Nutt.)

6 I. hýbrida Mx. Smooth and erect; lvs. flat, veiny, oblong-lanceolate or lanco. linear, acute at each end (the lower often shortened and obtuse), petioles ciliatc, short; fls. nodding; ped. axillary; stam. united in a very short tube at base, with intermediate processes.-2f Moist meadows and prairies, Can. and U.S. The fls. resemble those of tho L. ciliata. St. If to $18^{\prime}$ high, simple or branched. Lvs. 1 to $3^{\prime}$ by 3 to $8^{\prime \prime}$, the two upper pairs usually approximate, forming a whorl of 4 , with 4 axillary fls. Jl. (L. angustifolia Lam. L. heterophylla Mx.)

7 I. ciliàta I Subsimple, orect; lvs. opposito, rarely quaternate, ovate, subcordate or ovate-lanceolate, petioles ciliate upper side; fls. nodding mostly opposite; sta. distinct, with 5 abortive filaments. - 2f In gravely soils and near streams, U. S. and Can. Root creeping. Stem somewhat 4 -sided, $2-3 \mathrm{f}$ high, simple or with' a few opposite branches. Leaves large, pointed, somewhat cordate at base, on petioles fringed with cilex, the upper ones apparently quaternate. Flowers large, yellow, axillary. Stamens inserted iuto a ring. Jl.

B. TóxSA. Petioles ontirely destitute of cileæ; lvs. smaller,-Mts. E. Tenn., near the Cumberland Gap. Plants 6 to $18^{\prime}$ high.

3 I. rádicans Hook. St. erect at base, glabrous, then decumbent, long, trailing, branching and rooting at the joints; lvs. lance-ovate, gradually acute, the long petioles more or less ciliate; fls. small, loosely paniculate on the slender branches. -Wet places, Va. (Aikin) to La. (Hale). Sts. 2 to $4 \mathrm{f}$ long. Petioles half as long (1') as the leaves. Fls. half as large as in No. 4.

9 I. nummulàría I MoNexworT. St. weak, trailing; lvs. roundish, subcordate, obtuse, on very short petioles; fls. opposite, axillary, large, sep. ovate, subcordate, acuminate. - Found at Middlebury, Vt. (Prof. Lathrop), and shores of $\mathrm{L}$. Mich. (Nutt.). Eur.

\section{Anagal'́lis, L. Scarlet Pimpernel. Poor Man's Weather-}

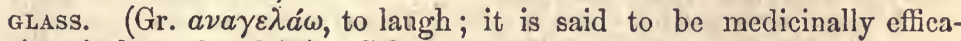
cious in hypochondria.) Calyx 5-parted; cor. rotate, deeply 5-parted, longer than the calyx, tube 0 ; sta. 5 , hirsuto; anth. introrse; caps. globous, membranaceous, circumscissile. Herbs with square stems and (mostly) opposite lvs. Ped. axillary, solitary. (Fig. 39.)

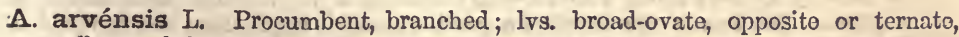
sessile; ped. longer than the leaves; sep. linear-lanceolate, about equaling tho petals; pet. crenato-glandular.-(1) A trailing plant, in fields, road-sides, \&c., U. $\mathrm{S}$. (except the colder parts of N. Eng.), and in almost all other countries. Stem $6-20^{\prime}$ long, with elongated branches, or simple. Leaves $6-8^{\prime \prime}$ by $4-6^{\prime \prime}$. Fls. small but pretty, with scarlet petals, opening at 8 o'clock, A. Mr., and closing at 2 P. Mr, in damp weather not open at all. Jn.-Aug.-Dr. Buel. of Killington, Ct., sent us specimens with blue flowers !

11. Centun'Culus, L. False Pimpennel. Calyx 4-parted; cor. urceolate-rotate, 4-cleft, shorter than the calyx; sta. 4, beardless, united at base; caps. globous, circumscissile; seeds very minute.-(1) Verv diminutive, with alternate lvs. Fls. axillary, solitary, subsessile.

C. mínimus L. Erect or ascending, branched; lvs. subsessile, ovato or lanceovate, obtusish, entire, alternate, lower opposite; sep. linear-subulate, equaling the capsule.-Wet places, Ill. (Mead), and Southern States. Plant 1 to $2^{\prime}$ high in IIl., but 3 to $C^{\prime}$ long in La. Leaves about $2^{\prime \prime}$ by $1^{\prime \prime}$. Flowers reddish ? Jl. 
12. SAM'OlUS, L. Water Pimpernel. (Celtic san, salutary, mos, a pig; a specific for the diseases of swine, says Pliny.) Calyx partly ad. herent, 5-cleft; cor. hypocrateriform, 5 -cleft; sta. 5 , alternating with 5 scales (sterile filaments); caps. dehiscent at top by 5 valves, many-seeded. -Herbs with alternate lvs. Fls. corymbous or racemous. (Fig. 272.)

S. valerándi I. $\beta$. A MrERICANus (Gray). St. simple or branched; lvs. obtuso, ovate or obovate, the radical petiolate; fls. in a raceme or panicle of racemes, pedicels with a minute bract near the middle; pet. longer than the sep.-In wet, gravelly places, frequent throughout the country. Sts. $6^{\prime}$ to If high, simple when first flowering, becoming often much branched. Lvs. thin, about $1^{\prime}$ long. Ped. less than $1^{\prime}$, with small (near 2" diam.) milk white fls. $\Lambda$ white spot in the axils of the branches. Jl,-Sept. (North), Apr.-JI. (South). (S. floribunda of authors.)

\section{Order LXXIX. PLANTAGINACEE. Ribworts.}

Herbs rarely shrubby, with radical leaves and the flowers in a spike on a scape. Flowers regular, tetramerous. Stamens 4, alternate with the lobes of the corolla and inserted on its tube. Anthers versatile, filaments usually slender and exserted. Fruit a membranous pyxis, with 1, 2, or many albuminous seeds.

Genera 3 , species 200 , most abundant in temperate climates, scattered throughout all countries of the globe. Properties unimportant.

Planta'G0, L. Plantain. Ribwort. Sepals 4, membranous, persistent; corolla monopetalous; border 4-toothed, spreading, persistent and withering on the fruit; stamens 4 (rarely 2), the long, slender filaments exserted, or in some of the fls. included; ovary $2(-4)$. celled; pyxis membranous, opening below the middle by a lid, when the loose dissepiment falls out with the seeds.-(Herbs acaulescent.) Fls. small, whitish, in a slender spike raised on a scape.

$\S$ Stamens uniformly exserted. Corolla lobes sprending. Flowers reniform. (a)

a Seeds 7 to 16. Leaves broadly ovate, 7 -veined. Spike dense..................... 1

a Seeds 4 only. Leaves oblong or cordate, 3 to 7 -veined............................. 2,8

a Seeds 2 only. Leaves lanceolate. Scape tall................................... 4,5

a Seeds 2 or 4 . Leaves linear, fleshy.............................................6. 7

\$ Stamens mostly included, with short anthers. Flowers dimorphous? (b)

b Seeds 2 only. Corolla lobes roundish, reflexed. Leaves linear................... 8

b Seeds 2 , rarely 8 or 4 . Corolla lobes, erect. Leaves lanceolate...................... 9

b sceds 4 to 20 . Leaves linear. Plants very small................................ 10, 11

I P. major I. Common Plantain or Ribwort. Lvs. ovate, smoothish, somewhat toothed, palmately 7-veined, with long, channeled footstalks; scape round; fls. densely spiked; seeds 7 to 16. - 2f Common always at the door and by the wayside. The leaves are reputed a good external application for wounds, \&c. The seeds are eaten by sparrows and other small birds. Lrs. broad, flat, with about 7 veins, each containing a strong fibre which may be pulled out. Scape 1 to $3 f$ high, with a very long (5 to $\left.20^{\prime}\right)$, cylindric spike. Fls. white, inconspicuous, appearing in succession all summer. § Eur., \&c.

2 P. Rugelii Dcne. Lvs. oblong or oblong-elliptical, obtuse, 3 to 5-reined, attenuated to a petiole; ped. slender, terete; spike cylindrical, more or less loose-flowered; bracts acutish, shorter than the smooth sepals.-Ala. (Decaisne in Prod. DC. XIII, p. 700). Allied to P. major, perhaps too nearly.

3 P. cordàta Lam. Lvs. cordate-ovate, broad, smooth, subpinnately 5 to 7 -veined, obscurely toothed; fls. loosely spicate, lower ones scattered, with ovate, obtuse, bracts; pyxis 4-seeded. - 2f Can. to Tenn. and Ga., along streams. Our largest native species, nearly as large as $P$. major. Spikes 6 to $8^{\prime}$ long, on scapes twice as high. Lrs. 3 to $6^{\prime}$ long, more or less cordate at base. Cor. white, with obovate segments. Pyxis a third longer than the calyx, with 2 margined seeds in each cell. Jn., Jl.

4 P. lanceolata I. Lrs. lanceolate, tapering at each end, petiolo channeled; spike ovate or cylindric, dense; scape angular; bracts and cor. Wbes acuminate. - 
If Can. to Ga. Common in pastures and grass lands. Easily known oy its longer lvs. tapering at the base into a broad stalk, and with from 3 to 5 strong ribs; by its shorter spike (1 to $2^{\prime}$ long), with dark colored corollas, and whitish, projecting stamens, and its slender, upright stalk ( 8 to $15^{\prime}$ long) with prominent angles. Flowering from May to Oct. It is freely eaten by cattle.

5 P. sparsiflòra $\mathrm{Mx}$. Lvs. lanceolate or oblong, tapering at each end, petiole flat; ped. slender, terete, much longer than the lvs.; spike long, remotely-flowered, or interrupted; bracts, sepals and brown petals obtuse.-Moist pine barrens, S. Car. and $\mathrm{Ga}$. (Curtis). Plant usually smooth often pubescent below. Flowers all summer. (P. interrupta Lam.)

6 P. marítima L. Ivs. linear, channeled, nearly entire, woolly at base; spikes cylindrical, dense; scape round; posterior sep. concave and crested on the back. Grows in salt marshes, along the coast, Me. to $\mathrm{N}$. J. It has a large perennial root sending up a scape varying in height from $3^{\prime}$ to $1 f$, and numerous, very fleshy, dark green, linear leaves, deeply grooved on the inside and 6 to $10^{\prime}$ long. Spike slender, of numerous, subimbricate, whitish fls. Aug.

P. juncoìdes. Lrs. erect, entire, linear, fleshy, attenuated to the subacute apex, bearded at base; scapes terete, scarcely longer than the lvs.; spikes oblong, nostly loose-flowered; bracts orbicular-ciliato; sep. not crested. - Salt marshes, N. J. Plant more slender than the preceding. Jl. (P. maritima $\beta$. Poir.)

$8 \mathrm{P}$. aristàta $\mathrm{Mx}$. Lvs. linear, erect, villous; ped. terete, longer than the leares; spikes cylindrical, dense-flowered, villous when young; bracts attenuated to long, setaceous, rigid awns; cor. lobes round-cordate, uniformly colored, conspicuous; seeds large, finely punctate in lines.-Prairies in Ill., abundant at Odin's Station. Lvs. 3 to $4^{\prime}$ long. Ped. with spike about $9^{\prime}$ high, the latter beset with awns 3 to 6 to 8 "long. Jn., Jl. (P. Patagonica Gray.)

9 P. Virginica L. Lesser Plantain. Lvs. obovate-lanceolate, hoary pubescent, subdenticulate; scape angular; spikes cylindric, pubescent, dense-flowered above, often loose-flowered below; seeds rarely more than 2 ; bracts shorter than the ciliate sep.-A biennial species on sandy or stony hills in the southern part of N. Eng. and N. Y. to Ga. and La. Much smaller than P. major. The wholo plant is covered with soft, gray pubescence. Scapo 4 to $8^{\prime}$ high, hairy. Lvs. 2 to $3^{\prime}$ long, narrowed at base into petioles, obtuse at tho end. Cor. yellowish, with very acute segments, erect when including the stamens.. Л. (P. purpuruscens Nutt ?)

IQ P. heterophýlla Nutt. Lvs. linear, entire, and with a few slender teeth or lobes, attenuate at each end; ped. many, slender, as long as the lvs; spikes looseflowered; cor. closed upon the conical fruit, the short lobes crowning it as a crest; pyxis 10 to 20-seeded.- (1) (2) Wet grounds. Md. to La. Small and slender. Scape almost threadlike, 4 to $7^{\prime}$ high, lvs. about $3^{\prime}$. (P. pusilla Dene. P. Ludoviciana Riddell.)

11 P. pusilla Nutt. Lvs. linear, entire, thin, pubescent; scapes longer than the lvs., very slender, with scattered or approximate fls.; fr. scarcely longer than the calyx, crowned with the cor. lobes, 4-seeded.- (1) The smallest species of the genus, 1 to $6^{\prime}$ high, in dry soils, N. Y. to Ga. and W. States. (P. perpusilla Dene.)

\section{Order lXXX. PlUMBaGiNACEA. Leadwonts.}

Herbs or undershrubs with the leaves alternate or all clustered at the root. Flow: ers regular. Calyx tubular, 5-toothed, plaited, persistent. Corolla hypocrateriform, of 5 petals united at base, or sometimes almost distinct. Sta. 5, hypogynous and opposite the petals or inserted on their claws. Ova. 1-celled, free from the calyx. Styles 5 (seldom 3 or 4). Fr. a utricle, or dehiscent by valves, containing 1 anatropous seed.

Genera 10 , species 230 , mostly senside or salt marsh plants, found in all latitudes.

Properties. - The ront of Statice Limonium is one of the best and most powerfui of all astringents. The species of Plumbago are acrid and escharotic, so inuch so, that the rnots of P. Europæus are said by Lindley to be employed in Europo by beggars, to ralse blisters on the face, in order to excite compassion. 


\section{TRIBES AND GENERA.}

I. STATICE E. Styles distinct, at least above. Utricle not valvate. (a)

a Stigmas capitate. Style connated at base. Lvs. acerous. Scape terete...Acantholoxon. $\delta$ a Stigmas capitate. Styles distinct at base. Leaves flat. Scape 3-angled....Gonrolouon. 4 a Stigmas filiform.-Styles glabrous. Scape branching...................... Statice. 1 -Styles plumous. Scape capitate............................. 2

II. PLUMBAGEA. Styles united to the apex. Pericaip subvalvate. (b)

b Corolla hypocrateriform. Calyx not enlarged ln fruit.................. Plumago. 8

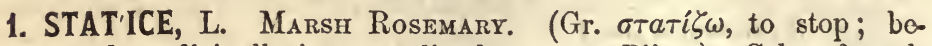
cause used medicinally it stops diarrhœa, says Pliny.) Calyx funnelform, limb scarious, 5-nerved, 5-parted; petals scarcely united at base ; filaments 5 , adnate to the very base of the corolla; ovary crowned with the 5 glabrous, filiform styles, utricle regularly or irregularly circumscissile. - 4 Herbs with the scape branching the flowers 3-bracted, sessile on the 3-bracted branchlet.

S. Limònium L. Very smooth; lvs. oblong-elliptical or oblanceolate, acute, tipped with a bristle, tapering to a long petiole; scapes terete, fistulous, bracted, paniculate; spikelets 1-flowered (rarely 2), involucrate with 3 bractlets, remotely secund on the branchlets; cal. lobes very acute.-Salt marshes along the coast, from Newfoundland to S. Car. Seape 6 to $12^{\prime}$ high. Lrs. $1^{\prime}$ to $18^{\prime \prime}$ long, the petioles rather longer. The root is large, ligneous, strongly astringent, much valued in medicine. J.-Oct. (S. Carolinianum Walt.)-Differs from the European varieties which have mostly 2 to 3 -flowered spikelets, more close on the branchlets, cal. lobes scarcely acute, \&c.

2. ARME'RIA, Willd. Thrift. Flowers collected in a dense head; involucre 3 to many-leaved; calyx tubular-campanulate, 5 -angled, with 5 shallow lobes, scarious and plaited; petals, stamens, \&c., as in Statice.4 Lvs. radical, mostly linear. Scape simple, appendaged above.

A. vulgàris Willd. Scape terete, smooth; lvs. linear, flat, obtuse; outer bracts of the invol. ovate-acute, shorter than the sheathing appendage at their base.-A neat and elegant plant, native near the sea-coast, Brit. Am. (Hook.) Often cultivated. Lvs. 3 to $4^{\prime}$ by 2 to $3^{\prime \prime}$, numerous, crowded. Scape about if high, bearing a singular sheath at top, formed according to Lindley by the adherent bases of involucral lvs. Fls. rose-colored. Jn.-Aug.

2 A. latifòlia Willd. Scapo solitary, tall; lvs. very broad, oblong, 5 to 7veined; fls. (rose-red) in a large head from a long sheath; bracts scarious, the outer oblong-lanceolate, acuminate-cuspidate.- + Portugal.

3. PLUMBA'G0, Tourn. Leadwort. (Lat. plumbum (lead), a disease of the eyes, which it was reputed to cure. Pliny.) Calyx herbaceous, glandular, 5-lobed, not enlarged after flowering; corolla salverform, tube longer than calyx, limb twisted in æstivation; anthers 5 , linear ; style 1, stigmas 5 , filiform ; utricle membranous, mucronate with the persistent style.-Herbs or shrubs. Fls. cyanic, numerous through the season.

1 P. Capénsis Thunb. St shrubbr, scarcely climbing; lvs. oblong entire, glaucous-tubercular beneath, petiolate; fils. in short, derse, terminal spikes, palo blue. - † Caps of Good Hope. Very pretty. Southward it is hardy.

2 P. cœrùlia Kunth. St. herbaceous, erect; Ivs. ovate-oblong, acuminate, petiole winged and auriculate at base; fls. in terminal, loose spikes, blue.-2f $\dagger$ Peru and Chili.

4 GONIOLÒMON speciòsum Boiss. (Statice speciosa L.), with white fls., 3 or 4 in each spikelet.

G. Tartáricum Boiss (S. Tartarica L.), with pink As., 1 or 2 in a spikelet, both from Russia, are occasionally cultivated. Also 
5 ACANTHOLÒMON' caryophyllàceum Boiss. (S. Echinus L.), turfy, with stiff, linear, 3-cornered, needle-shaped, recurved lvs. and scape, twico as high, bearing a single spike.- + From Asia.

\section{Order LXXXI. LENTIBULACEA. Butterworts.}

Herbs small, growing in water or wet places, with showy, bilabiate fls. on scapes. Calyx inferior, of 2 or 3 sepals. Corolla irregular, bilabiate, personate, spurred. Stamens 2, included within the corolla and inserted on its upper lip. Anth. 1celled. Ovary 1-celled, with a free, central placenta. Style 1. Stigma cleft. Fruit. Capsulo many-seeded. Seeds minute. Embryo straight, with no albumen.

Genera 4, species 175, natives of swamps, pools, and rivulets, diffused throughout nearly all countries. Propertles unimportant.

1. PINGUIC'ULA, L. Butrerwort. (Lat. pinguis, fat, from the greasy appearance of the leaves.) Calyx 5-parted, somewhat bilabiate; cor. bilabiate or rarely subregular, upper lip bifid or 2-parted, lower trifid or 3-parted, spurred at base beneath ; sta. 2, very short; stig. sessile, 2 -lobed; caps. erect; seeds $\infty$. - 2f In wet places. Lvs. radical, rosulate, entire. Scapes 1-flowered, nodding.

* Flowers bluc.......Nos. 1, 2, 3.

** Flowers yellow......No. 4

1 P vulgàris L. Lvs. ovate or elliptic, obtuse, unctuous-puberulent above, scape and calyx subpubescent; cor. lips very unequal, lobes obtuse, entire; spur cylin. drical, shorter than the corolla.-Wet rocks and thin, damp soils, N. Y. (near Rochester, Dewey, Beck.) N. to Arctic Am. (Hooker.) Scape 6-8' high, with solitary, nodding fls. Leaves all springing from the root, fleshy, spatulate or ovate, with a tapering base, fleshy and unctuous to the touch. Corolla with a purplo tube, lined with soft hairs. Flowering early in Apr. and May.

2 P. elàtior Mx. Lvs. ovate-spatulate, scape villous at base; cal. glandularpuberulent; cor. tube ventricous, bairy within, lobes subequal, emarginate, ; spur compressed, obtuse, about half as long as the tube.-Wet grounds, S. Car. to Fla., more common in the middle districts. The lvs. are very small proportionately (scarcely $1^{\prime}$ long in our. specimens), while the slender and bractless scape is 8 to $14^{\prime}$ high. Sep. oblong, obtuse, the 2 lower approximating. Cor. $1^{\prime}$ to $15^{\prime \prime}$ long, greenish blue? with purple lines. Mar., Apr.

3 P. púmila Mx. Dwarf Butrerwort. Lvs. roundish-ovate, glabrous; cor. tube oblong, lobes emarginate, spur nearly as long as the tube, nearly acute; caps. globous.-Ga. and Fla. to La., common in springy places. Lrs. 3 to $4^{\prime \prime}$ diam., thin. Scapes filiform, 2 to $4^{\prime}$ high. Fls. vary in size with the plant, from $3^{\prime \prime}$ to $7^{\prime \prime}$ long, pale blue. Apr.

4 P. lùtea Walt. Lrs. obovate, elliptic; cor. bell-shaped, palato hairy, lobes subequal, sinuate-dentate; spur slender, a third as long as the cor.-Car. to Fla., common in the low country in wet grounds. Lvs. 1' long, nearly as wide, soft, yellowish green, curled, the scape about $6^{\prime}$ high. Fls. muci smaller than in No. 2, bright yellow. Spur 2 to $3^{\prime \prime}$ long. Mar., Apr.

2. UTRICULA'RIA, L. BLADDERWORT. (Lat. utricula, a little bottle; alluding to the air vessels appended to the roots.) Calyx 2parted, lips subequal ; corolla irregularly bilabiate, personate, spurred; stamens 2 ; stigma bilabiate ; capsule globular, 1-celled.-Herbs aquatic, loosely floating. or fixed in the mud.-Lvs. radical, multifid or linear and entire, mostly furnished with little inflated vescicles as buoys. Scape erect.

8loating. Scape involucrate, with $a$ whorl of large, inflated petioles. .................. 1

Floating. Scape naked. Branches proflucing bulblets and bladders (a).

a Flowers purple. Branches whurled, subinersexl................................ 2 
a Flowers yellow. I.eaves (2-ranked) and bladders on separate branches........... No. 3

a Flowers yellow. Leaves (eapillaceous) bearing the bladders (b).

b Spur acute or notched, about as lung as the lips.......................... 4 to 6

b Spur obtuse, short. Flowers of 2 kinds, the lipless duwn on the stems........ No. 7

b spur obtuse, short. Pedicels all on the scape, -erect in fruit................. 8,9 -recurved in fruit.......... Nos. 10,11

U. inflàta Walt. Upper lvs. in a whorl of 5 or 6 at the surface of the water; petiole and midvein inflated, lower lvs. capillaoeous, dissected, suomerged; scape 4 to 5 -flowered. $-2 f$ In ponds, Me. to Fla. W. to Ohio. The proper stem (rhizome) is very long, branching, suspended in the water by innumerable minute air bladders, and the 5 or 6 involucrate, hollow lvs., which are many-cleft at the end. Fls. 4 or 5 together upon a scape 8 ' in length, pedunculated, with sheathing bracts. Spur nearly as long as the corolla, appressed to the lower lip, striate, emarginate. Cor. yellow, the upper lip broad-ovate, entire, lower 3-lobed. Aug.

2 U. purpùrea Walt. St. long, floating, branched; lvs. submersed, fibrillous, verticillate, pinnately dissected, segments capillary, utriculato; scape assurgent, 2-3-flowered upper lip roundish-truncate, lower lip larger, its lateral lobes cuculJate, smaller than the central; spur conical, flattened, appressed to and shorter than the upper lip.-(1) Pools, Me. to Fla. W. to Wis. Readily known by the large, bright, purple fls. Stem $1-3 f$ long. Leaves about $1 \frac{1{ }^{\prime}}{2}$ long. Utricles small. Scape $3-5^{\prime}$ high. Corolla $8^{\prime \prime}$ broad, the spur $3^{\prime \prime}$, greenish. Aug.

3 U. intermèdia Hayne. Lvs. all submersed, in 2 rows, alternate, dichotomously many-parted, segm. rigid, linear-subulate, ciliate-denticulate; leafless branches bearing all tho bladders and terminal bulblets; scapes 2 to 3 -flowered, upper lip entire, twice as long as the palate; spur conical, acute; ped. of the fruit erect.-Swamps, Can. and N. States to Wis. Scapo 4 to $8^{\prime}$ high. Leafy stems 3 to $6^{\prime}$ long, and tho leaves about $3^{\prime \prime}$ (in our specimens). Jn., Jl.

$\beta$ ? Robbinsir. Leaf-segments linear-setaceous, flaccid, entire, 8 to $12^{\prime \prime}$ long; scape tall ( 7 to 12 ), 3 to 7 -flowered; spur fusiform, acute, nearly as long as the lower lip.-Swaraps, Uxbridge, Northbridge, Mass. (Robbins).-Quite unlike the preceding in its leaves and spur.

4 U. striàta Le Conto. Lvs. numerously subdivided, submerged, capillary, bearing the bladders, or vesicles; scape 2-6-flowered, with a few scales; flowers large, upper lip broad, divided into 3 lobes, the middle lobe striate with red, lower lip crenate, sides reflexed, having dark spots upon the palate; spur slender, $o b$ tuse, with a notch at the end, pressed against the lower lip of the corolla and nearly as long.-(1) Swamps, L. Isl. to Fla. Root submerged, slightly attached to the mud. Leaves (radicles ?) few, capillary, appendaged with few air vessels. Scape a foot high, generally with 2 flowers. June.

5 U. longiróstris Ell. Lvs. submersed, dichotomously divided, segm. setaceous, bearing the vescicles; scapes 1 to 2 -flowered; upper lip slightly 3-lobed, lower entire; spur linear.subulate, ascending, emarginate at apex, longer than the lower lip.- Stagnant pools, S. Car. to Fla. Scape 3 to $5^{\prime}$ high. Fls. yellow, middle size. Jn.

6 U. biflóra Lam. Irregularly whorled, capillaceously divided, root-like, bladderbearing; scape slender, 2 to 3 -flowered, pedicels many times longer than the bract or calyx; spur straight, oblong, acute, appressed to the corolla, and of cqual length; fr. erect.-Ditches, S. Car. and Ga. Scape 3 to $4^{\prime}$ high, pedicels 3 to $4^{\prime \prime}$. May, Jn.

7 U. clandéstina Nutt. Lvs. all submersed, capillaccous, multifid, bladderbearing; fls. 2 or 3 on the slender scape, also solitary on slender, axillary pedicels among the lvs. on the stem, the latter apetalous, fertile; spur very obtuse, shorter than the 3-lobed lower lip.-Ponds, Mass. (Robbius) to N. J. Sts. almost capillary, $6^{\prime}$ to $2 \mathrm{f}$ long, with many bladders. Scape 3 to $4^{\prime}$ high (seldom seen), with corollas expanding about $3^{\prime \prime}$. Cauline pedicels 6 to $7^{\prime \prime}$ long, the cor. tubular, never opening. JL.

8 U. gíbba L. (and Le Conte). Minute, floating, with hair-like lvs. and few utricles; scape 1 to 2 -flowered, naked; segm. of the yellow cor. roundish, upper lip emarginate, lower subtrilobate, middle lobe crenate, subrevolute; spur gibbous (that is) very short and obtuse.- 4 In pools, R. I. (Olney), Mass., N. Y. to 
Car. Submersed stems dichotomous, short and filiform. Scapes 2 to $3^{\prime}$ bigh, often with but 1 small, yellow flower The lvs. appear rather like fine radicles. J.

9 U. bipártita Ell. Lvs. fibrillous-multifid, bearing the bladders; scape 1 to 3 flowered; lower lip of the calyx bifid or 2-parted; cor. lips entire, the lower twice as long as the obtuse spur.-(1) Ditches, Ga., Fla., in soft, muddy places (Elliott), floating (Le Conte). Scape 2 to 3 ' high. Oct.

10 U. mìnor I. Lvs. submersed, several times forked, segm. linear-setaceous, short, utriculate; scape 3 to 6-flowered; cor. ringent, upper lip ovate, emarginate, as long as the palate, lower obovate, flat, much longer than the obtuse, deflexed spur.-Pools, Can. and N. States to Wis. Plant about half the size of No. 11. Cor. gaping, pale, yellowish. Fruit nodding. Jl.

11 U. vulgàris I. Lvs. capillaceous, multifid, fibrillous; vesicles numerous, small; st. or rhizoma very long, floating; scape simple, 5-11-flowered! spur conical, obtuse, shorter than the closed cor. lips. - 2f In stagnant pools, U. S. and Can. Floating stems several feet long, very branching. Leaves very numerous, $1^{\prime}$ in length. Utricles furnished with a fringed, valvate aperture, usually inflated. Scape 5-10' high, stout, arising out of the water. Flowers alternate, showy, yellow, $5-6^{\prime \prime}$ long, lower lip larger, with a projecting palate, striped with brown. Jn, Jl. (U. macrorhiza Lo Conte.)

12 U. resupinàta Green. Sts. creeping, fibrillous, rooting; lrs. linear-capillary, erect, undivided and entire; scapes numerous, simple, l-flowered, with a minute clasping bract near the top; spur obtuse, cylindric, ascending, shorter than the elongated tube of the purplo cor.-Muddy shores of ponds, Tewksbury (Green), Plymouth and Uxbridge, Mass. (Robbins). Leaves generally numerous, 6-15' high, the bract $1^{\prime}$ below the flower. Corolla light purple, $4^{\prime \prime}$ long, lips roundish, entire, remoto from the spur. Jl.

13 U. subulàta L. Minute; st. fibrillous, rooting, crecping, urticulate; lvs. few and minute, among the fibrillous roots, entire, linear, petiolate, glandular-obtuse, sometimes 0 ? scapes few, fliform, 1 to 5 -flowered; bracts ovate, clasping; pedi. cels 4 to 5 times longer than the ovate, obtuse, veined sepals; cor. upper lip ovate, entire, lower 3-lobed; spur acute appressed to and nearly equaling tho lower lip. -A minuto species in springy places, Can. to Fla. and La. Scapo 2 to $4^{\prime}$ high. Lvs. 2 to $3^{\prime \prime}$ by $1^{\prime \prime}$. Fls. yellow, 3 to $4^{\prime \prime}$ broad. Jn.

14 U. cornùta $\mathrm{Mx}$. Scape rooting, tall, erect, scaly, with 2 to 5 subsessile fls.; lvs. fugacious or 0 ; lower lip very broad, 3 -lobed, its center (palate) very prominent, sides reflexed, upper lobe much smaller, emarginate; spur subulate, acute, de curved away from the cor., and of equal length.-Can. to Fla. and La., in shallow waters or mud. St. or scape 9 to $12^{\prime}$ high. Pedicels scarcely $2^{\prime \prime}$ long in flower, 3 to $6^{\prime \prime}$ in fruit. Spur 4 to $4^{\prime \prime}$ long. Fls. large, yellow. Jn.-Aug. (U. perconata Lo Conte.)

\section{Order lXXXII. OrOBANCHACE F. Broomrapes.}

Herbs fleshy, leafless, growing parasitically upon the roots of other plants. Calyx 4 to 5 -toothed, inferior, persistent. Corolla irregular, persistent, imbricate in estivation. Stamens 4, didynamous. Anthers 2-celled, cells distinct, parallel, often bearded, at base. Ovary 1-celled, free from tho calyx, with 2 or 4 parietal placentæ. Capsule enclosed within the withered corolla, 1-celled, 2-valved. Seeds very numerous and minute, with albumen.

Genera 12, species 116, mostly natives of the northern temperate zonc. Properties astringent and bitter.

\section{GENERA.}

- Flowers polysamous, on spicate branches ; sterilo abore, fertile below........EpIrnzgts. 1

- Flowers perfect,-in a dense, thick spike. Calyx 2-bracted............... Conoprours. 2 -on naked, terminai peduncles. Calyx bractless.............ApHrLon. \&

1. EPIPHE'GUS, Nutt. BeEChDrops. (Gr. $\dot{\varepsilon} \pi i$, upon, $\phi \eta \gamma$ ós, the beech; being parasitic on the roots of that tree.) Monociously polyg- 
amous, the upper flowers complete but sterile, the lower imperfect, fertile ; Calyx 5-toothed; ô corolla tubular, compressed, curved, upper lip emarginate; stamens barely included; of corolla 4-toothed, short, deciduous, without expanding ; stamens imperfect ; capsule, 2-valved, opening on the upper side.-Parasite on the roots of the beech. Branches simple, spicate, floriferous their whole length.

ஐ. Virginiàna Bart.-In Beech woods, Can. to $\mathrm{Ga}$ and $\mathrm{Ky}$. Root a ball of rigid, short, brittle radicles. Plant if high, leafless, of a dull, red color, glabrous, branching and flower-bearing its whole length. Fls. alternate, subsessile, brownish white, the sterile, 4 to $5^{\prime \prime}$ long. Aug., Sept.

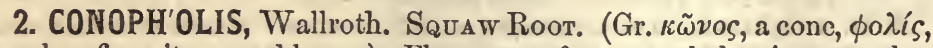
a scale; from its resemblance.) Flowers perfect, crowded, spicate; calyx with 2 bractlets at the base, unequally 5 -cleft; corolla ringent, 2 -lipped, tube curved, upper lip 2-lobed, lower 3-parted; anthers sagittate 2-celled, cells acute at base; capsule with 2 placentre on each valve.-Stem short, thick, simple, covered with ovate-lanceolate, acute, imbricated scales, the upper with the fls. subsessile in their axils.

1 C. Americana Wallr. Very smooth; stem very thick; scales oval-lanceolato; calyx more deeply cleft on the lower side; cor. ventricous; stam. exserted.-Old woods, Can. to Ga. and La. Stem 4-7' high, and near $1^{\prime}$ thick, of a brownish yellow, covered with pale, polished scales regularly imbricated as in a Pine cone. July. (Orobanche, L.)

2 C. Iudoviciàna. Glandular pubescent; stem rather thick, very short; scales ovate; cal. subequally and deeply cleft; cor. tubular, much longer than the bracts; stam. included.-Alluvial soil, Ill. (Hall, fide Gray), to Nebraska. St. 3 to $4^{\prime}$ high. Fls. very numerous and crowded. Cal. segm. linear, acute. Cor. purple. Oct. (Orobanche, Nutt. Philipæa, Don.)

3. APHYL'LON, Mitchell. (Orobanche, L.) Naked Broomrape. (Gr. á, privative, $\phi \dot{v} \lambda \lambda \circ \nu$, a leaf ; alluding to its leafless character.) Flowers perfect, solitary, on long bractless peduncles or scapes; calyx regularly 5-cleft, campanulate ; corolla tube elongated, curved, border spreading, subequally 5 -lobed ; anthers included, cells distinct, mucronate ; capsule with 4 , equidistant placentæ. Plants glandular, pubescent. St. very short, producing at the summit, 1, 2, or many flower stalks, and few if any scales.

I A. uniflòra Torr. \& Gr. Ped. in pairs or simple, naked, each 1-flowered.-A small, leafless plant, with the general aspect of a Monotropa, found in woods and thickets. Can. and U.S. St. not exceeding $\frac{1}{2}$ in length. This divides at its top generally into 2, scape like, erect, round, simple, naked peduncles 4 to $5^{\prime}$ high, downy, purplish white, with a nodding flower at the top, of the same hue. Jn., Jl.

2 A. fasciculàta Torr. \& Gr. Ped. many, nearly terminal, about the length of the stem; scales few, ovate; cor. lobes short, rounded.-Islands in Lake Huron (Engelman, fide Gray), W. to Nebraska. Stem arising 2 to $3^{\prime}$ out of the ground. Ped. 6 or more, same length. Fls. pale purple. May.

\section{Order LXXXIII. BIGNONIACEA. Trumpet Flowers.}

Trees, shrubs, or rarely herbs, often climbing or twining, with opposite, exstipulate leaves. Flowers monopetalous, irregular, 5-merous, showy. Stamens 5, 1 or 3 sterile, didynamous, or diandrous. Anthers 2-celled. Ovary 2-celled, seated in a fleshy disk. Style 1. Stigma of 2 plates. Capsule coriaceous, 1 to 2-celled, 2-valved, many-seeded. Seeds generally winged, destitute of albumen. 
Genera 44, species 450, mostly South Ameriean. Others are diffused in all conntries, particularly within the tropics. Several of the Brazilian species of Bignonia afford a valuable tim. ber. But this order ts best known for the beauty of its Howers. (Figs. 210, 284, 285, 279.)

* Leares compound. Valves of the pod parallel with the partition........... Bignoxia. 1

* Leaves compound. Valves of the pod contrary to the partition ............ Trсомa. 2

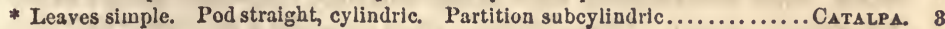

1. BIGNO'NIA, Tourn. (Named for the Abbe Bignon, Librarian to Louis XIV.) Calyx margin 5-toothed or entire; corolla somewhat bilabiate, 5 -cleft, fumnel-shaped ; stamens didynamous, 4 fertile, 1 a sterile filament; eapsule long and narrow; valves flat or scarcely convex, parallel with the partition.-Trees, shrubs, or woody climbers, often with tendrils.

B. capreolàta I. Cross-vine. Climbing, glabrous; lvs. binate, cirrhous, leaflets 2, lance-ovate, cordate, acuminate, entire, a branched tendril between; ped. 1-flowered, 2 to 3 together, axillary; calyx nearly entire.-Woods, Va. and Tenn. (Miss Dana), to Fla. and La. A vine with smooth, reddish brown bark, 30 to 50f long, very slender, over shrubs, up tall trees. Fls. large, red, orange within. Pods 7 or $8^{\prime}$ long, ${ }^{\prime}{ }^{\prime}$ wide, curved, flat, with many broad-winged seeds both sides of the broad partition. Mar.-May.

2. TECO'MA, Juss. (Bignonia L.) Trumpet Flower. Calyx campanulate, 5-toothed; corolla tube short, throat dilated, limb 5-lobed, subbilabiate or equal; stamens 4 , didynamous, with the rudiments of a fifth, anther-cells 2, diverging; capsule 2-celled, 2-valved, the valves contrary to the partition; seeds winged.-Trees or shrubs, often climbing. Lrs. opposite, digitate, or unequally pinnate.

1 T. rádicans Juss. Climbing by radicating tendrils; lvs. unequally pinnate, lfts. 4 or 5 pairs, ovate, acuminate, dentate-serrate, puberulent beneath along the veins; corymbs terminals; cor. tube thrice longer than the cal.; stam. included.A splendid climber in woods and thickets, along rivers, Penn. to Fla., W. to Ill. St. 20 to $80 \mathrm{f}$ in length, ascending trees. Lrs. 10 to $15^{\prime}$ long, lfts. 2 to $3^{\prime}$ by 1 to

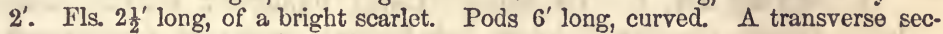
tion showing a cross. Seeds very numerous. Jn.-Aug. $\dagger$

2 T. Capénsis Lindl. Glabrous; lrs. unequally pinnate, lits. 3 to 4 pairs, roundish-ovate, acuminate, serrate, bearded in the axils of the veins beneath; racemes pedunculate, dense-flowered; cor. long, tubular, incurved; stam. and sty. exserted.-Cultivated. Cor. 2' long, yellow scarlet. The style far projecting. $\dagger$ Cape of Good Hope.

3 T. grandiflòra Delaun. Chinese Trumpet Flower. Climbing, glabrous; lvs. unequally pinnate, lfts. 3 to 5 pairs, ovate-acuminate, dentate-serrate; panicle terminal ; pedicels nodding, biglandular; cor. tube scarcely longer than the 5-cleft calyx.-Fls. of a rich scarlet, shorter and broader than in T. radicans. $t$ China and Japan.

3. CATAl'PA, Scop. Catalpa. (The Indian name.) Calyx 2-parted; corolla eampanulate, 4 or 5 -cleft, the tube inflated; stamens 2 fertile, 2 or 3 sterile; stigma 2-lipped; capsule 2-celled, long, cylindric.-Trees. Lvs. opposite or ternate-verticillate, simple, petiolate. Fls. in large, showy, terminal panieles.

C. bignonioìdes Walt. Lrs. membranous, ovate-cordate, pubescent beneath, acuminate, subentire ; branches of the panicle di-trichotomous; cal. lips mucronate.-A fine, wide spreading tree, native in the Southern States, but cultivated at the North for ornament and shade. In favorable circumstances it attains the height of 50f, with a diam. of nearly $2 \mathrm{f}$. IVs. beautifully heart-shaped, with a silky luster, often a foot in length. It blossoms in great profusion. Cor. campanulate, white, with yellow and violet spots. Caps. cylindric near a foot in length; seed winged. May-J. (Seo Figs. 210; 284, 5; 463.) 


\section{Order LXXXIV. PEDaliace.e. Pedaliads.}

Herbs mostly strong-scented and glandular-hirsute. Stipules 0. F'lowers axillary, solitary, large, monopetalous, didynamous, 5 -merous, irregular. Ovary 1 to 2-celled, of 2 carpels. Style 1. Stigma divided. Fruit becoming 4 or 6 -celled by the diverging lobes of the 2 placentæ. Seeds few or many, large, wingless.

Genera 14, species 25, natives of tropical America, etc. Some of them have been introdneed into the United States.

\section{TRIBES AND GENERA.}

I. PEDALINEA. Fruit drupe-like, fleshy withont, produced into a beak......MARTrNIA. 1 II. BESAME E. Fruit capsular, dry, dehiscent, never beaked...............Snsмus. 2 1. MaRtyn'ia, L. Unicorn Plant. (In honor of John Martyn, botanical author and professor, Cambridge, Eng., 1760.) Calyx 5-cleft, 2 to 3 -bracteolate at base ; cor. campanulate, tube gibbous at base, limb 5 -lobed, unequal; sta. 5 , one rudimentary and sterile, 4 didynamous; caps. coriaceous, ligneous, 4 -celled, 2 -valved, each valve terminating in a long, hooked beak.-(1) Chicfly southern, branching, viscid-pilous. Lvs. opposite, petiolate, subcordate, roundish.

1 M. proboscídea Glox. Branches mostly decumbent; lvs. cordate, entire, suborbicular, villous, upper ones alternate; fls. on long, axillary peduncles; beaks much longer than the capsule.-A coarse, strong-scented plant, along rivers, fields, etc., S. and W. States. Stem 1-2f long. Leaves paler beneath. Corolla pale, dull yellow, very large, the limb nearly as broad as the leaves, spotted with brownish-purple. Sta. bright yellow, exserted. The curious pods are furnished with an incurved horn ( 2 when the valves separate) abruptly bent at the end into a very sharp grappling hook.

2 M. lùtea Lindl. With yellow fls. and horns longer than the pod, is sometimes cultivated, also M. diandra, with pink fls. spotted with purple, and horns shorter than the pod.

2. SES'AMUH, L. OrL-SEed. Calyx 5-parted; corolla campanulate, 3-cleft, the lower lobes the longest; stamens 4, didynamous; stigma lanceolate; capsule 2-celled, the cells divided by the inflexed edges of the valves.-(1) Of India. Lrs. petiolate, the lower opposite, upper alternate.

S. Indicum DC. Lrs. lanceolate-ovate, lower ones 3-lobed, upper ones undivided serrate. - Native of $\mathrm{E}$. India. Stem erect, about $18^{\prime}$ high. Leaves alternate, entire. Flowers axillary, subsessile. Corolla pale purple. The seeds yield an excellent oil which will keep several years without injury. It is used in cookery for all the purposes of sweet oil. Five pounds of the seeds yield about one pound of oil. The leaves are emollient.

\section{Order LXXXY. LOGANIACEÆ.}

Herbs or shrubs with opposite leares, with stipules between the petioles, sometimes reduced to an elevated line or ridgo. Flowers 4 or 5-parted, monopetalous, -regular, æstivation various. Ovaxy superior, style simple, stigmas as many as the cells of the ovary. Fruit capsular or baccate, 2-celled, many-seeded, or a 1 to 2seeded drupe. Seeds albuminous, mostly winged or peltato. (Fig. 221, 302.)

Genera 25, species 200, chiefly tropical.

Properties.-Generally poisonous, often possessed of the highest degree of renom. The pervading poisonous prineiple is strychnia, especially abundant and fatal in the seeds of Stryehnos Nux-vornica, an East Indian tree, with small, greenish flowers. S. toxifera, of Guiana furnishes the terrible Woorali, poison for arrows, likewise 8. cogens of Central America, \$. Tieute of Java, yields the celebrated Upas. The species of Spigelia, under the name of Pink-root, are used as a vermifuge, but are dangerous.

Obs. - This order has been appended to Rublacex, but its freo ovary is a decisivo mark of dis. tinction, although otherwise nearly related. 


\section{GENERA.}

I Corolla tubular, lobes 5, valvate in bud. Seeds wingless. (a)

a Styles wholly united into one: Corolia tube long............ Spigeria. 1

a Styles distinct, with the stigmas united. Cor. tube short.....Mrtreola. 2

₹ Corolla campanuiate, lobes 4 or 5 , imbricate in bud. (b)

b Flowers 4-parted. Diffuse herbs................. PolypeEsurs. 8

b Flowers 5-parted. Twining shrubs................. Gessemivar. 4

1. SPIGE'LIA. L. Pink-root. (To Adrian Spigelius, Professor of Anat. and Surg. at Padua, 1578-1625.) Calyx 5-parted, segments linear-subulate; corolla narrowly funnel-form, limb 5-cleft, equal; stamens 5 ; anthers convergent; capsule didymous, 2-celled, few-seeded. - Herbaccous or suffrutescent. Lvs. opposite. Stip. small, interpetiolar. Fls. sessile, in terminal spikes.

S. Marilándica I. Erect, simple, nearly glabrous; st. square; lvs. sessile, ovatc-lanceolate, acute, or acuminate, margin and veins scabrous-pilous; spikes 3 to 8-flowered; cor. tube 4 times longer than the cal.; anth. exserted; lobes of tho cor. lanceolate; caps.. glabrous, shorter than the cal.-24 In woods, Penn. to Ill., S. to Fla. An elegant dark green herb, a foot high. Lrs. 3 to $4^{\prime}$ by $1 \frac{1}{3}$ to $2 \frac{1{ }^{\prime}}{2}$, entire, often ovate-acuminate, the stipules scarcely perceptible. Fls. $1 \frac{1}{2}$ to $2^{\prime}$ long, somewhat club-shaped, scarlet without, yellow within. Sty. exserted. Jn.A celebrated anthelmintic.

2. MITRE'OLA, L. (Lat. mitreola, a little mitre; from the form of the capsule.) Calyx 5-parted; corolla tubular, short, 5-cleft, hairy in the throat, lobes valvate in bud; stamens 5 , on the corolla tube, included; ovary 2-celled, styles 2 , united at the top with one stigma, separate below, as well as the 2 horns of the $\infty$-seeded capsule.-(1) Glabrous herbs. Stipules minute. Fls. small, white, in scorpoid racemes, forming a terminal, stalked cyme.

1 M. petiolàta Torr. \& Gr. Erect, branched; lvs. lanceolate or oblóng-ovate, acute, tapering at the base into a petiole; fls. somewhat distant in the racemes.-A plant of singular aspect, in damp shades, Va. to Fla. and La. St. 1 to $2 f$ high, Lrs. thin, about $2^{\prime}$ long, including the short petiole. Cymes about twice trichotomous, the small fls. all on the upper side of the racemes. Capsules mitre-form. Jn.-Sept. (Ophiorhiza Mitreola, L.)

2 M. sessilifòlia Torr. \& Gr. Erect, nearly simple; lvs. broad-oval; or ovate, sessile, acute, much shorter than the internodes; fls. contiguous in the racemes. Damp soil, S. Car. to Fla. and La. More slender than the other, 10 to $18^{\prime}$ high. Lrs. thickish, not veiny, 6 to $8^{\prime \prime}$ by 4 to $6^{\prime \prime}$. Cymes small, compact. Fls. about half as large as in No. 1. Jn.-Aug. (Anonymus, Walt.) $\beta$. angustifolia, Torr. \& Gr. has lance-elliptical leaves; at Quincy, Fla.

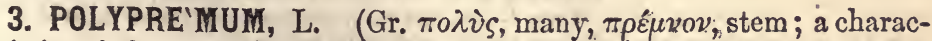
teristic of the plant.) Calyx 4-parted, segm. subulate, membranousmargined at base ; cor. broadly campanulate, 4-parted, lobes slighly unequal, obtuse; throat bearded; stam. 4, adherent to the corolla tube, included, anth. globular; stig. entire, subsessile ; caps. oroid, 2-celled, 2-ovuled, loculicidal, $\infty$-seeded-(1) "Zlerb glabrous, diffusely much branched from the base, with opposite, linear-subulate lvs. connected at base by a slight stipu'ar membranc. Fls. sessile, cymous, small, white.

P. procúmbens $\mathrm{L}$. Dry fields, $\mathrm{Va}$, to $\mathrm{Fla}_{\mathrm{a}}$ and $\mathrm{La}$. Plant forming roundish patches, with somewhat the aspect of Scleranthus, its numerous stems procumbent or ascending; 6 to $12^{\prime}$ long. Lvs. hardly $l^{\prime}$ long, rigid. Cal. persistent, its pointed sepals exceeding the eapsule. May-Sept.-Bentham refers this, genus. to Serophulariaceæ. Torr. \& Gr., hither.

4. GELSE MIUM, Juss. Yelzow Jessaminr. (Ital. gelsemio, the 
common name of the Jessamine.) Calyx 5-parted, lobes oblong ; corolla funnel-form, with 5 , short, rounded lobes, quincunncial in bud; tilaments 5 , on the corolla; ovary smooth, short-stiped ; style filiform; stigmas 2, each 2-parted, and with the anthers dimorphous, i. e., in some plants the stamens exceed the stigmas, in others the stigmas exceed the stamens, as in Houstonia; capsule twin, compressed, with a very narrow dissepiment (or 0 ?), valves each 2 -cleft at top, cells few (4 to 6 )seeded, seeds winged.-Shrub slender, smooth, climbing, with cvergreen lvs. and large, showy yellow fls. Stip. reduced to a raised rim.

G. sempervìrens Ait. Woods and banks of streams, Va. to Ala. and Fla., very abundant. A slender vine, twining and overrunning bushes and low trees, and profusely flowering. Ivs. coriaceous, shining, revolute at edge, lanceolate, acute at each end, short-petioled. Cor. tube $1^{\prime}$ long, of a rich golden yellow. In one variety the stamens equal the corolla and the style but half as long; in the other vice versa (a fact first pointed out to the author by Professor Pond, March, 1857). Fls. in Mar.-May.

\section{Order LXXXVI. SCROPHULARIACE.E. Figworts.}

Herbs chiefly, without fragrance, the leaves and inflorescence various. Flowers irregular, 5-merous, didynamous or diandrous (rarely pentandrous). Calyx free from the ovary, persistent. Corolla monopetalous, imbricated in bud. Stamens inserted in the tube of the corolla, 1 or $\mathbf{3}$ of them usually rudimentary. Ovary free, 2-celled, with 1 style, a 2-lobed stigma, and becomin" in fruit a 2-celled, many-seeded capsule, with axilo placentx. Seeds albuminous. (Fig. 204, 326, 362, 399, 427, 463.)

Generce 1S0, species 1800 , abundant in every part of the world, from the equator to the regions of perpetual frost. They constitute about 1-36 of the Phænogamia of N. America.

Properties.-Generally ncrid, bitter and deleterlous plants. The most remarkable ofticinal species of the tribe is the Foxglove (Digitalis), which exercises a wonderful control over tho action of the beart, in regulating its pulsations. It is also employed in cases of dropsy, liemorrhage, dc. Taken in excess it speedily caises death. The Veronica Virginica (Culver's Physic) and Linaria vulgaris ('Toad-flax) are purgative and einctic. Numerous species are cultivated for ornament. Many aro parasitic and turn black in drying.

\section{SUBORDERS, TRIBES AND GENERA.}

I Leares alternato (In ono garden plant mostly opposite, No. 6.) (*)

* Infloresconco compound, centrifugal, (Showy garden exotics.) (Tribe 1.)

* Inflor. simple, centripetal.-Stamens 5. Corolla rotate. (Tribo 3.)

-Stam. 4. Corolla spurred or saccate at base. (Tribe 4, a)

-Stam. 4. Climbing vines, in gardens. (Tribe 4, b)

-Stam. 4 or 2. Ilerbs small, creeping, leaves linear. (Tribe 7)

-Stain. 4 or 2. Herbs erect. Cor. not galeate, (Tribo 8)

-Stam. 4. Cor. upper lip galeate, vaulted. (Tribe 12, n)

$\checkmark$ Leaves opposite (or in one southern specles, scattered No. 29). (2)

2 Stamens 2, included. Corolla 2-lobed, the lower inflated. (Tribo 2)

2 Stamens 2, included. Corolla tubular, labiate. (Tribe 6, f)

2 Stimens 2, exserted. Corolla rotato or salver-form. (Tribe 9)

2 Stamens 4, perfect, tho fifth rudiment about as large, consplcuous. (Tribe 5, c)

2 Stamens 4, perfect, the fifth rudiment minute or none. (3)

3 Inflorescence compound, in panlcles or verticillasters. (Tribe 5, d)

3 Inflorescence simple.-Corolla labiate, not galeate. (Tribe 6, e)

-Corolls lablate, and galeato. (Tribe 12,0)

-Corolla salver-form. Anthers 1-celled. (Tribe 10)

-Corolla bell or funnel-form, \&c. Anthers 2-celled. (Trlbe 11)

1. SALPIGLOSSIDELE. (Corolla in bud plicato at the clefts. Inflorescence centrifugal.)

Trire 1. Salpiglossex. -Stamens 2. Corolla deeply cleft................Schizantuus. 1

-Stamens 4. Corolla salver-form, tube long......... Browallia. 2

II. ANTIRRAINIDEA. (Corolla in bud imbricate, npper lip covering the lower).

Tribr 2. Calceolariede. Inflorescence compound. Calyx 4 -cleft....... Calceolaria. 3

Tribe 3. Vrrbasceze. Inflorescenco simple, centripctal. Cor. rotate..... Vrrbabcira. 4 


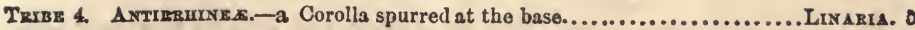

-a Corolla saccate at the base, large............ Antrinuinum. 6

-b Corolla gibbous at base, large..............Maurandra. 7

-b Corolla equal at base, large............ Lopuosperuuar. 8

Tribe 5. Cheronez.-C Sterile filament a scale. Fls. small, lurld...... Soropirularia. 9

-c Sterile fil. shorter than the rest. Seeds winged..... Crumorz. 10

-c Sterile fil. equaling the rest. Sds, wingless........ PexrstrexoN. 11

- d Corolla bilabiate. Ilerbs.................. Colurnsia. 12

-d Corolla tubular, bell-form. Tree.............PAwrovia, 13

Trane 6. Gratrolex.- Calyx prismatic, 5-anglod. Corolla long.............Mimulus. 14

- Calyx 5-parted, equal. (Lvs. many-cleft)........... Сохов вA. 15

-O Calyx 5-parted, unequal. (Leaves entlre)......... Irmpristis. 16 -f Calyx 5-parted. Sterile fil. short or 0........Grarioza. 17 -f Calyx 5-parted. Sterilo fil. exserted.......... Ilysaxtiut8. 19 -f Calyx 4-lobed. Sterile fil. 0. Fls. minnte...... Mrcrantu 19

III. RIINANTHIDEAE. (Corolls in bud imbricate, the lower or lateral lobes exterlor.)

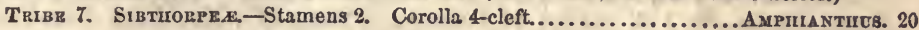

-Stamens 4. Corolla 5-cleft......................LixoseluA, 21

Trime S. Digrtazme.-Stamens 2. Calyx 4-parted. Flowers small........... Sinturris, 22

-Stamens 4. Calyx 5-parted. Flowers large......... Drgrtalis. 23

Tribe 9. Vhronioks.-Stamens divergent. Upper ivs. often alternate..... VrronicA. 24:

Tribe 10. Buchingex.-Stam. approximate by pairs. Upper Ivs, alternate..Bucirnera. 25

Tarar 11. Gerardies.-Stamens long-exserled. Corolla tubular...... Macranturra, 26

-Stam. short.-Cor. yellow, tube short as limb ....... Srrmera. 27 -Cor. yellow, tube clongated......... D Asrstoma. $2 S$

-Cor. purple. Lv8. very slender.......GERARDi. 29

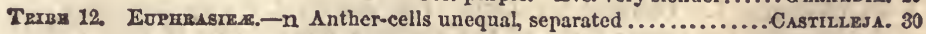

-n Anther-cells equal.-Calyx 10-ribbed......... ScrwalbEA. 31 -Calyx not ribbed....... Propicularis. 32

- Cal. inflated. Sds. many, winged......... Rurvanturs. 33

-o Cal. not infl.-Sds. many, wingless..........Eupnrasia. 84 -Sds. 1 to 4 , oblong.........MELAMPYRUM. 35

1. SCHIZAN'THUS, Raiz \& Pavon. (Gr. $\sigma \chi i \zeta \omega$, to 'cut, äv0os; the cor. is much divided.) Corolla irregular, the upper lip 5-cleft, external in æstivation, lower much smaller, 3-parted; filaments 4, 2 of them sterile; capsule 2-celled.-(1) from Chili. Lrs. pinnatifid, alternate. Cymes supra axillary.

S. pinnàtus Ruiz \& Pavon. IVs 1-2-pinnately cleft; cor. tube shorter than the calyx, middle segment of the posterior lip, 2-lobed, cucullate, lateral segment falcate-spatulate, middle segment of the anterior lip emarginate, lateral 4-lobed; sta. exserted.-Plant $1-2 \mathrm{f}$ high, with delicate and beautiful flowers in clusters opposite the leares. Cal and ped. viscid-pubescent. Cor. purplo and yellow, with a dark spot in the midst. $f$

2. BROWAL'LIA, L. (Named for Bishop Browallius, a friend of Linnæus, and defender of his system.) Corolla salver-form, with a long tube, and oblique, 5 -lobed limb; anthers of the two posterior stamens halved, sub-1-celled; lobes of the stigma broad, divaricate; capsule membranous, valves bifid.-South American herbs, with alternate, entire lvs. and cyanic fls.

I B. đimíssa L. Lvs. petiolate, ovate; lower fls. axillary, upper in a racomo ; calyx hairy. - St. 1 to $2 \mathrm{f}$ bigh, with spreading branches. Cor. tube slender, 6 " long, limb blue or violet. + Brazil, \&c. (B. elata I. is the same.)

2 B. grandiflòra Grah. Upper lvs. sessile, subcordato; fls. loosely racemed; cal teeth nearly as long as the tube-Cor. limb broader than in the other, pale blue. + Peru.

3. CALCEOLA'RIA, L. (Lat. calceolus, a slipper; alluding to the shape of the corolla.) Calyx 4-parted, valvate in the bud; corolla slightly adhering to the calyx, the tube very short, limb 2-lobed, lobes 
entire, concave or spur-like, the lower inflated, and in the bud slightly covered by the smaller upper lobe; stam. 2, lateral, with no rudiments, capsules ovoid-conical, valves bifid, seeds striate.-Herbs rarely shrubby, from S. America and N. Zcaland. Lrs. opposite or verticillate. Fls. of all colors, endlessly variegated in cultivation, very curious.

1 C. Corymbòsa Ruiz \& Pav. Somewhat shrubby, erect; root lvs. ovate, crenate-dentate, cauline few, opposite, ovate or oblong, sessile; corymb loose; cor. upper lip shorter than calyx, lower broadly ovate, obtuse, contracted at base, open beyond tho middle.-Yellow. + Chili.

a C. angustifòlia Ruiz \& Pav. Half-shrubby, very branehing; lvs. often whorled in 3s, lance-ovate, acute, sharply serrate, pubeseent; panicle oblong; cor. upper lip very short, lower ovate, acutish, incurved-spreading, with a long, contracted, narrow base, open beyond the middle.-Yellow. + S. Am.-Mrr. Bentham enumerates 114 species of Calceolaria, many of which have found their way into our greenhouses. We must omit further notice of them.

4. VERBASCUM, L. Mullein. (Lat. barba, beard; a name significant of the beard with which the plant is covered.) Corolla rotate, 5 -lobed, unequal ; stamens 5 , declinate, all perfect; capsule ovoid-globous, 2 -valved.-(1) rarely $2 f$ or suffruticous. Lvs. alternate. Fls. in spikes or paniculate racemes.

1 V. thápsus L. Common MuLLenv. Lvs. decurrent, densely tomentous on both sides; rac. spiked, dense; three of the stamens downy, two of them smooth.The tall, dense, club-shaped spikes of the common mullein are very conspicuous in every slovenly field and by all roadsides, U. S. and Can. Stem erect, 3-5f bigh, woolly, its angles winged by the decurrent base of the leaves, generally simple, occasionally with one or two branches above. Flowers rotate, of a golden yellow, nearly sussile. Jn.-Aug. § Eur.

2 V. Blattària L. Motr MulueIs. Lvs. clasping, oblong, smooth, serrate; ped. 1-flowered, solitary, racemous.-1) Grows in waste grounds, roadsides, N. Eing. to Ind. and S. States. Stem $3 \mathrm{f}$ high, branching above, bearing a terminal, leafy raceme $2-4^{\prime}$ long. Lower leaves oblong, obovate; upper ones cordate-ovate, all coarsely and doubly serrate. Flowers on pedicels near an inch in length. Corolla yellow or white, marked with brown at tho back. Stamens unequal, purplish, the filaments all hairy. Jn., Л. \& Eur.

3 V. Lýchnitis I. White Moluein. Whitish subtomentous; st. and paniculate branches angular; lvs. green above, crenate, lower petioled, narrowed to the base, upper ones sessile; panicle pyramidal, fascicles loosely many-flowered; cal. small, with lance-subulate segments; fil. with white wool.-Sandy fields near Oneida Lake, S. to $\mathrm{Ga}$, raro. Leaves very canescent beneath. Flowers pale yellow. \& Eur.

5. LINA'RIA, Juss. ToAD-FLAX. (Lat. linum, flax; from the reresemblance of the leaves of some of the species.) Calyx 5-parted; corolla personate, upper lip bifid, reflexed, lower 3-cleft; throat closed by the prominent palate; tube inflated, with a spur behind; capsule 2celled, bursting at the summit.-Herbs. Lower lis. generally opposite, upper alternate. Fls. solitary, axillary, often forming terminal, leafy racemes.

$\S$ Prostrate, with hastate leares, nd capsule opening by 2 lids....................No. 1

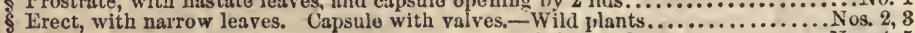

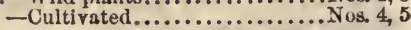

I I. Elátine L. Procumbent, hairy; lvs. alternate, hastate, entire; ped. solitary, very long.-(1) Fields, Can. to Car. A small, creeping species. St. 1 to $2 f$ in length. Irs. 6 to $8^{\prime \prime}$ by 3 to $4^{\prime \prime}$, with a conspicuous auricle each side at base. Cor. yellow, the upper lip bright purple beneath, on long stalks. Cal. hairy, as well as the whole plant. Jn.-Sept. 
2 I. Canadénsis Dumont. Ivs. scattered, erect, linear, obtuse; fls. racemed; st. simple; scions procumbent; fls. blue.-1) A small species in road-sides, fields, Can. and U. S. St. very slender, nearly simple, 6 to $12^{\prime}$ high, smooth, furnished with small, remote lvs. A few leafy, prostrate or ascending shoots are given off from the base of the stem, having roundish, opposite or whorled lvs. Fls. small, in a loose raceme. Throat closed by the light blue palate. Spur filiform, as long the corolla, but in the very slender Southern variety much shorter or 0 . JnSept.

3 I. vulgàris Mill. Common TOAD-FLAx. Lvs. linear-lanceolate, crowded; spikes terminal, fls. dense, imbricate; cal. smooth, shorter than the spur.- 4 A very showy plant, common by roadsides, N. Eng. to Ky. and Ga. St. erect, smoothish, 1 to 2 f. high, very leafy, and with numerous short, leafy branches. Cor. yellow, with a long spur, mouth closed with a prominent orange-colored palate. J1-Aug. § Eur.

$\beta$. Pelòria. Cor. regular or nearly so, ventricous, with 5 spurs and 5 stamens, or with 3 spurs. Poughkeepsie (W.S. Gerard), Chester Co., Pa. (Darlington.)

4. I. triornithóphorum Willd. Trines-BIRDS. Erect, spreading, smooth and glaucous; lvs. all verticillate in $3 \mathrm{~s}$ or $4 \mathrm{~s}$, broad-lanceolate, acute; fls. interruptedly racemous, generally verticillate, on long pedicels. - 2f A showy plant, 2 to $4 \mathrm{f} \mathrm{high}$, remarkable for the form and hue of the corolla, which resembles three littlo birds seated in the spur. † Eur.

5 I. 'bipártita Willd. Glabrous, erect; lvs. linear, alternate; pedicels much longer than the cal.; sep. lance-linear, acute, membranous at the margin; cor. upper lip deeply 2-parted; spur slender, arcuate. -1 beautiful annual. Cor. 8 to $10^{\prime \prime}$ long, violet-blue, palate orange. $†$ Barbary.

6. ANTIRRHINUM, L. SNap-Dragon. (Gr. avti, like, $\dot{\rho} i v$, a nose; from a fancied resemblance.) Calyx 5-scpaled; corolla gibbous (not spurred) at base, the upper lip bifid, reflexed, lower trifid, closed by the prominent palate; caps. valveless, dehiscent by 3 pores.-European Lerbs with the lower lvs. opposite, the upper alternate. Inflorescence as in Linaria.

1 A. Màjus L. Lrs. lanceolate, opposito; fls. racemed; sep. glandular-hairy, lanceolate, obtuse, short. - 2f An elegant and popular garden flower, 1 or $2 f$ high. Flowers large, pink-colored, the lower lip white and the mouth yellow, with a gibbous prominence at base beneath. There are varieties with scarlet, scarlet and white, and double flowers. $\uparrow$

2 A. Oróntium, $\beta$. Grandiflorum Chav.-Glabrous or hairy above, spreading; lvs. oblong-lanceolate; fls. remote, subsessile, upper ones subracemous; cal. segments equaling the corolla, and oroid and very oblique capsule.-(2, A showy garden plant, 1-2f high. Cor. $6^{\prime \prime}$ long, rose-color or white, with purple spots and veins. $\nmid$

7. MAURAN'DIA, Ort. (Named for the lady of Dr. Maurandy of Carthagena.) Calyx 5-parted; corolla tubular, gibbous at base ; palate prominent or with 2 folds; capsule ovoid-globous, base oblique, cells opening by many valve-like teeth.-2f Mexican herbs, with long, flexuous branches, climbing or twining.

I II. sempervirens Ort. Glabrous; lvs. cordate-hastate, angular; ped. axillary, 1-flowered; cal. segm. lanceolate, glabrous. - An evergreen climber with large, pale, violet-purple fls. Cor. $1 \frac{1}{2}$ long, the throat open. $\dagger$

2 M. Barklayàna Lindl. Glabrous except the cal.; lrs. broadly triangular-cordate, or hastate; cal. segm. linear-lanceolate, clothed with long, glandular hairs. $-\Lambda$ beantiful climber. Corolla purple, oblique, rather larger than in No. 1.

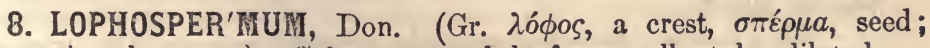
from the character.) Calyx 5-parted, leafy; corolla tube dilated upwards, throat open, between 2 hairy lines; capsule globular, subequal, 
opening irregularly by a rift below the apex.-2f Mexican, climbing by their petioles. Lrs. mostly alternate. Ped. long, flexuous, axillary.

1 L. erubéscens Zucc. Lvs. triangular-cordate, coarsely dentate or angularlobed, pubescent; cal. segm. ovate, hirsute; cor. pubescent, limb at length widegpread.-A hairy climber, with soft, rugous lvs. 2 to $4^{\prime}$ broad. Cor. of a rich red, $2 \frac{1}{2}$ to $3^{\prime}$ long, with an ample border.

2 I. scandens Don. Lvs. cordate-ovate, acuminate, coarsely dentate, minutely puberulent; cal. segm. ovate-lanceolato; cor. glabrous, Jimb erect-spreading.-Less hairy and with smaller flowers. Fls. scarlet.

9. SCROPHULA'RIA, L. Frgwort. (So named from the resemblance of the roots to scrofulous tumors.) Calyx in 5 acute segments; corolla subglobous, limb contracted, sub-bilabiate, lip with an internal, intermediate scale (sterile filament); capsule 2-celled; valves with 2 inflated margins.- Herbs or suffruticous, often fœtid. Lvs. opposite. Cymes in simple or compound terminal, thyrsoid panicles.

S. nodòsa L. Glabrous; st. angled; lvs. ovate, ovate-oblong, or the upper lan. ceolate, acute, serrate or subincised, base broadly cordate or rounded or acutish; thyrse oblong, leafless or scarcely leafy at base; cymes pedunculate, loosely manyflowered; cal. segments broadly ovate, obtuse, slightly margined; sterilo anth. a roundish, green scale on the corolla. - 2 In woods and hedges, Can., and U.S. Rare in N. Eng. Stem 4-6f high, with paniculate, opposite branches aboro. Leaves 3-7' long, smooth, thin, often long-acuminate. Fls. ovoid, 3-4" long. Limb very small, of a dull olive color. July-Oct. (S. Marilandica L, and lanceolata $\mathrm{Ph}$.

10. CHELO'NE, L. Turtle-head. SNake-head. (Gr. $\chi \varepsilon \lambda \omega ́ v \eta, a$ tortoise; from the appearance of the flower.) Calyx deeply 5-parted, with 3 bracts at base; corolla inflated, bilabiate, the fifth filament abortive, smooth above, shorter than the rest; anthers woolly; caps. valves entire; seeds broadly membranaceous, winged.-24 with opposite lvs., distinguished from Pentstemon chiefly by the seeds.

1 C. glàbra L. Smooth; lvs. subsessile, oblong-lanceolate, acuminate, serrate; fls. densely spiked.-A plant of brooks and wet places (Can. and U. S.), with flowers shaped much like the head of a snake, the mouth open and tongue extended. Stem mostly simple, $2 \mathrm{f}$ high, erect. Lvs. of a dark and shining green above, with irregular serratures, sessile or nearly so. Fls. large, in a short, terminal, dense spike. Cor. white, often tinged with red, inflated, contracted at the mouth, with short, gaping lips. Aug., Sept.

$\beta$. PURPURE.. Lvs. distinctly petiolate, acuminate; cor. rose-purple.-This variety prevails in the Western States. It is larger in its leaves and flowers. Petioles $\frac{1}{2}-l^{\prime}$ long. Flowers very fine. (C. purpurea Mill. ?)

2 C. Iyòni $\mathrm{Ph}$. Smooth; 'lvs. ovate, acuminate, petiolate, serrate, the lower cordate; fls. in a denso spike. -N. Car. to Ga., along the Mts. Stem $1-2 \mathrm{f}$ high. Ieaves $3-6^{\prime}$ long, $2-4^{\prime}$ wide, veins very prominent beneath. Fls. purple, $1^{\prime}$ in longth, similar to No. 1. Tho spike as in that species, often branches, becoming somewhat capitate. Jl.-Sept.

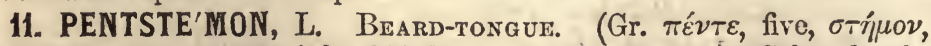
a stamen; on account of the fifth large abortive stamen.) Calyx decply 5-cleft; corolla elongated, often ventricous, lower lip 3-lobed, spreading; the fifth filament sterile, bearded, longer than the rest or about as long; anthers smooth ; seeds $\infty$, angular, not margined.-2f rarely $\xi$, of $\mathbf{N}$. America, branching, paniculate. Lvs. opposite. Fls. showy, red, violet, blue or white.

* Leares dissected. Sterlle filament, bearded at the apex.......................... 1

- Leares undivided. - Sterile filament glabrous or nearly so .............................. 8 , 9 -Sterile filament bearded.-Lower lip bearded inside................ 3, 7 
1 P. disséctus Ell. Minutely puberulent; lvs. pinnately parted, segm. linear, entire or few-lobed; panicle loose, with long, few-flowered peduncles; cor. sume. what bell-shaped, sterile filament bearded at tho apex.-In Middle Ga. St. near $2 \mathrm{f} \mathrm{high.} \mathrm{Leaf-segm.} \mathrm{distant,} \mathrm{rather} \mathrm{obtuse,} \mathrm{margins} \mathrm{revolute.} \mathrm{Cor} 9$ to $10^{\prime \prime}$ long, purple, resembling that of Gerardia, but curved. Jn., Jl--Blackens in drying.

2 P. grandiflòrus Fraser. Erect, glabrous and glaucous; radical lvs. petiolate, obovate-oblong, cauline broadly ovate or orbicular, sessile or clasping, all entire; panicle long, slender and racemous, interrupted; cor. broadly campanulate; sterile fil. dilated and puberulent at apex.-Ill., near Prairie du Chien (Riddell) and westward. St. $3 \mathrm{f}$ high. Fls. I to 3 together in the upper axils. Cor. $15^{\prime \prime}$ long, variously shaded with blue and purple.

3 P. pubéscens Soland. More or less pubescent; radical Irs. ovato or oblong, petiolate, cauline lanceolate-oblong or lance-ovate, serrulate, sessile; paniclo loose; cor. tube gradually dilated, lower lip plaited and bearded inside, upper lip shorter; sterile stam. longitudinally bearded.-River banks, bluffs, hills and barrens, Can. to Fla. (rare in N. Eng.). A handsome plant, 1 to $2 \mathrm{f}$ high. St. round, smooth below, supporting a loose, oppositely branched paniclo of bluish-purplo fls. Cor. $\mathbf{1}^{\prime}$ in length; the barren fil. broadest at end. Jn.

$\beta$. LAvigatus. Nearly or quite glabrous; lvs. clasping; sterile fil. shorter.

4 P. grácilis Nutt. Glabrous; radical lvs petiolate, elliptic-oblong or lanco. oblong, cauline linear lanceolate, amplexical, entire or remotely serrulate; paniclo pubescent, slender; ped. erect; cal. segm. ovate-lanceolate, acuminate; cor. tube long and narrow, scarcely dilated upwards, smooth inside; sterile stam. longitudinally bearded.-River bottoms, near Chicago, Ill. (Mead), also Mo. and Can. W. Plant simple, glaucous, $2 \mathrm{f}$ high. Ped. 3 to 7 -flowered. Fls. nodding, 9 to $10^{\prime \prime}$ long, pale blue. Jn.

5 P. digitàlis Nutt. Glabrous; radical lvs. petiolate, oval-elliptic or oblong, cauline lauceolate, amplexicaul, serrate, or rarely entire; panicle loose; ped. erect, spreading; cor. tube abruptly campanulate-dilated, beardless, upper lip shorter than the lower; sterile sta. longitudinally bearded. Rich soils, Ohio, Ind. to Ga. and La. St. about $3 \mathrm{f}$ high. Lvs. 4 to $6^{\prime}$ long, often dilated at base. Fls. numerous. Cor. 12 to $15^{\prime \prime}$ long, bluish-purple, varying to white. Jn, Jl.

6 P. campanulàtus Willd. Glabrous; lvs. acutely serrate, lance-linear or lance-ovate, long-acuminate, often dilated at base; panicle long, loose and secund; cor. tube ventricous above, lobes subequal; sterile fil. bearded.-A very variable species, 2 to 3 f high, with large fowers, varying from light purple to dark red or purple. + Mexico.

7 P. barbàtus Nutt. Scarlet Pent. Glabrous and glaucous; lvs. entire, lower oblong, upper lance-linear; panicle long and loose; cor. tube long, scarcely dilated upwards; lower lip and sterilo til. densely bearded.-Height 2 to 4 . Cor. scarlet, $13^{\prime \prime}$ long. † Mexico.

8 P. speciòsus Doug. Erect, glabrous, glaucous; radical Irs. petiolate, oblong-spatulate, cauline sessile, lanceolate; panicle elongated, slender, virgate, socund; cal. segm. ovate-oblong, acuminate, margin membranous; cor. tube enlarged upwards; sterile fil. filiform, glabrous. - Height 3 to $4 \mathrm{f}$. Fls. $1 \frac{1}{2}{ }^{\prime}$ long,

- blue. + Oregon.

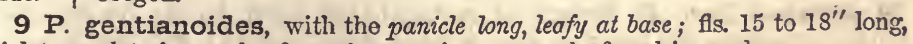
violet, scarlet, \&c., and a few other species are rarely found in gardens.

-12. COLLIN'SIA, Nutt. Innocence. (In honor of Z. Collins, Esq., of Philadelphia.) Calyx 5-cleft ; corolla bilabiate, orifice closed, upper lip bifid, lower trifid, with the middle segment carinately saccate and closed over the declinate style and stamens; capsule ovoid or globous, with 2 membranous, bifid valves; seeds large, concaro-convex.-(1) With verticillate or opposite lvs., axillary and terminal inflorescence.

1 C. vérna Nutt. (Fig. 362.) Minutely puberulent; lowest Irs. ovate or oblong, petiolate, middle and upper sessile, ovate-lanceolate, cordate-amplexicaul, dentate, floral ones lance-linear, entire; verticillasters 2 to 6 -flowered; cor. 2 or 3 times shorter than the pedicels, twice longer than the calyx.-Banks of streams, shaded or 
open, N. Y. near Utica (Gray) to Ill. A tender herb 8 to $18^{\prime}$ high, branched from the base. Lvs. 1 to $2^{\prime}$ by $\frac{1}{2}$ to $1^{\prime}$, dilated at base. Pedicels 1 to $1 \frac{1}{2}$ long. Cor. 5" long, variegated with blue and white, singular and pretty. May, Jn.

2 C. parviflora Dougl. Lower lvs. ovate, petiolate, upper oblong or lanceolate, few-toothed, the floral lanceolate, entire; verticillasters 2 to 6 -flowered; cor. little shorter than the pedicels, scarcely longer than the calyx. - Shores of Lako Superior to Or. (Pitcher). A smaller plant, with smaller, blue fls.

3 C. bícolor Benth. Lower lvs. ovate, petiolate, upper ovate-lanceolate, sessile, crenate, the floral entire, lanceolato; verticillasters 6 to 10-flowered; pedicels shorter than the hairy calyx.-Taller than $C$. verna, $2 \mathrm{f}$ high, with larger, showy fls. Cor. 8 to $10^{\prime \prime}$ long, rose-violet, upper lip white. + California.

13. PAULOW'NIA, Siebold. Calyx deeply 5-cleft, fleshy; corolla tube long, declinate, enlarged above, limb oblique, with rounded segments; stamens 4, arched downwards, with no rudiment of a fifth ; capsule ligneous, acuminate, valves septiferous in the middle; seeds $\infty$, winged: -Tree, native of Japan.

P. imperiàlis Sieb.-A splendid tree, in parks, with the habit of Catalpa. Branches crooked, nearly horizontal. Lvs. 7 to $12^{\prime}$ by 4 to $9^{\prime}$, opposite, petiolate, broad-cordate, above entire or somewhat trilobate, villous-canescent both sides, smoothish above when full grown. Panicles very large, terminal, many-flowered. Cor. $1 \frac{1}{2}$ to $2^{\prime}$ long, between violet and rose-color, striped and spotted within. $\dagger$

14. MIM'UluS, L. Monkey Flower. (Gr. $\mu \iota \mu \omega$, an ape; from the resemblance of the ringent or grinning corolla.) Calyx tubular, 5angled, 5-toothed; corolla ringent, the upper lip reflected at the sides, palate of the lower lip prominent; capsule 2 -celled, many-seeded ; stigma thick, bifid.-Herbs prostrate or erect, with square stems and opposite lvs. Ped. axillary, solitary, 1-flowered.

$\$$ Leaves pinnate-reined. Flowers blue (wild) or yellow (cultivated)..............Nos. 1, 2, 6

$\$$ Leaves palmate-velned. Flowers yellow or scarlet..................................... $3,4,5$

1 M. ríngens L. Lvs. sessite, smooth, lanceolate, acuminate; ped. axillary, longer than the flowers. - $2 f$ A common inhabitant of ditches and mud soils, Can. and U. S., with large, blue, ringent flowers. Stem erect, square, smooth, about $2 \mathrm{f}$ high. Leaves sessile, opposite, serrate, acute, lanceolate. Peduncles about as long as the leaves, square, curved upwards, axillary and opposite. Caiyx tubular, 5-angled and 5-toothed. Corolla palo blue, jellow within. Jl., Aug.

2 M. alàtus. Lvs. petiolate, smooth, ovate, acuminate; ped. axillary, shorter than the flowers; st. winged at the 4 corners. - 4 In N. Y. to Ind. (Plummer), and S. States. This, like the last species, inhabits ditches and other wet places, and grows to nearly the same height. The square stem, erect, smooth, and winged at the 4 angles, affords an adequato distinction. Leaves stalked, ovate. Flowers ringent, on short stalks, light purplo. Calyx teeth rounded, mucronate. Aug.

3 M. Jamèsii Torr. St. decumbent, rooting at the lower joints; lvs. subentire, roundish-reniform, the lower on long petioles, 5 to 7-veined; ped. about as long as the leaf; cal. ovate, upper tooth largest; cor. tube scarcely exserted.-Shores of L. Superior, Min., Nebr. Fls. small, yellow.

4 M. lùteus L. Ascending or erect; Ivs. orbicular-ovate or oblong, lower long-petiolate, sublyrate, apper sessile or clasping, many-veined; ped. longer than the lvs.; cal. tube ovoid, upper tooth largest; cor, tube broad, twice longer than the calyx.-2 Fls. yellow, often spotted with rose or purple, large and very showy. + California.-Varies greatly.

5 M. Cardinàlis Dougl. Erect, branched, villous; lvs. ovate, erose-dentate, narrowed and amplexicaul at base, many-veined; ped. longer than the lvs.; cal. tube large, inflated; cor. lobes reflexed.- 4 St. loosely branched, 2 to $3 \mathrm{f} \mathrm{high.}$ Cor. scarlet, the tube hardly longer than the calyx, limb large and brilliaut. + California. 
6 IM. moschàtus Doug. MUSK Plant. Decumbent, hairy and viscid, Irs. ovate, acute, dentate, feather-veined; ped. about as long as the leaf; cal. teeth lanceolate, acuminate, unequal. -4 Herb rooting at the joints, a foot long. Cor. tube exceeding tho calyx, yellow. The plant exhales the odor of musk. t Oregon.

15. CONO'BEA, Aublet. Calyx' 5-parted, equal; upper lip of the corolla 2-lobed, lower lip 3-parted; fertile sta. 4; anth. approximating by pairs, cells parallel; caps. globous, oroid, valves breaking. away from the placentiferous dissepiment; seeds $\infty$, ovoid.-American branching herbs, with opposite lvs. Ped. axillary, solitary or in pairs, 1-flowered, 2 bracteoles near apex.

C. multífida Benth. Low, diffusely branched, puberulent; lvs. petiolate, pinnately dissected; segments linear or cuneate, lobed or entire, obtuse; cor. lobes entire; caps. ovoid, valves at length 2-parted-1) Sandy banks of rivers, common, Ohio to La. A plant 4-6' high, with finely divided leaves, and of a grayish aspect. Leaves $1^{\prime}$ long, in 5 or 7 segments, the petiole as long as the flowers. Corolla greenish, hardly exceeding the calyx. Capsule $1 \frac{1}{2}$ long. Jl. (Capraria, $\mathrm{Mx}$.)

16. HERPES'TIS, Gært. (Gr. غं $\rho \pi \eta \sigma \tau \dot{\eta} \zeta$, a creeper.) Calyx 5-parted, unequal; cor. subbilabiate, upper lip emarginate or 2-lobed, lower 3lobed; sta. 4, didynamous, parallel ; caps. 2 -furrowed, 2-celled, valves parallel with the dissepiment, the margins inflexed; seeds $\infty$, small.Obscure weeds with opposite lvs. Ped. 1-flowered, axillary, or subracemous, often with 2 bracteoles near the calyx.

\$ Flowers yellow, corolla 4-cleft, upper segment (lip) entiro. Plant erect.............. No. 1 \$ Flowers blue._-Corolla 4-cleft, upper segment (lip) emarginate........................... 3 -Corolla 5-cleft, lobes nearly equal. Leaves crenate........................ 4

1 H. nigrescens Benth. Tall; lvs. oblong, crenate-serrate, cuneate at base, obtuse or acute; ped. bractless, equaling or exceeding the leaves the posterior lobe of the calyx oblong-obtusish.- 4 Car. to Fla. and La. Wet. Plant 1 to $2 f$ ligh, often branched. Lvs. 1 to $2^{\prime}$ long, thick, obscurely feather-veined, the upper shorter than the (1 $)$ pedicels. Cor. yellow, rather longer $\left(5^{\prime \prime}\right)$ than the calyx $\left(4^{\prime \prime}\right)$. Aug., Sept. . (Gratiola acuminata Walt.)-Blackens in drying.

2 H. rotunđifòlia $\mathrm{Ph}$. St. mostly glabrous, creeping; lvs. orbicular-obovate, entire, glabrous, many-veined; pedicels ebracteate, 1-3-together, 2 or 3 times longer than the calyx; lower cal. seg. ovate; cor. $\frac{1}{3}$ longer than tho calyx. $-2 f$ A prostrate mud plant, in ponds, Ill. (Mead) to La. (Hale.) Stem if in length. Leaves 6$12^{\prime \prime}$ diam., about 9-veined, sessile. Peduncles thick, half as long as the leaves. Calyx $2-3^{\prime \prime}$ in length. Flowers blue. Aug.

3 H. amplexicaulis $\mathrm{Ph}$. St. floating, woolly; lvs. amplexicaul, ovate, obtuse, entire, many-veined, glabrous above; ped. solitary, shorter. than the calyx; cal. lower segm. cordate; cor. $\frac{1}{8}$ longer than the calyx; hypogynous disk long, 10 toothed at apex.- Swamps and ditches, N. J. to La. (Hale.) A few inches in length, with leaves 6 to $8^{\prime \prime}$ long. Fls. nearly $5^{\prime \prime}$ long. Sty. dilated at the end. Aug.

4 H. Monnièra Humboldt. Glabrous, fleshy, prostrate; lvs. cuneate-obovate, obscurely crenate or entire, 1 to 3 -reined; ped. as long as the lvs.; cal. subtended by 2 linear bractlets, its 3 outer segm. ovate.- 4 An obscure weed, on inundated banks, Penn. to Ga. and La. Lvs. 6 to $8^{\prime \prime}$ long, obscurely veined, sessile, or the lower contracted to a short petiole. Fls. few, cor. spreading 3 to $4^{\prime \prime}$, pale blue, on ped. 6 to $12^{\prime \prime}$ long. Aug. (H. cuneifolia Ph.)

17. GRATI'OLA, HEDGE Hrssop. (Lat. gratia, favor; alluding to its medicinal virtues.) Calyx 5-parted, subequal; cor. upper lip entiro or slightly bifid, lower trifid, the palate not prominent; sta. 2 , fertile, mostly with 3 sterile filaments; caps. 2-celled, 4-valved, valves inflexed 
at margin.-Herbs with opposite lvs. Ped. axillary, 1-flowered, usually bibracteolate near the calyx.

Flowers sessile. Cells of anthers vertical. Plants rigid, bristly-hairy............Nos. 7,8

Flowers pedunculate. Anther cells transverse. Plants smooth or viscid (a).

a Sterile filaments none, or very minute aud pointed ........................ $1-3$

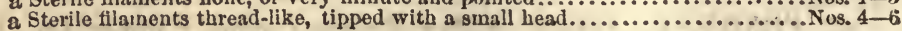

1 G. Virginiàna L. St. ascending, branched; lvs. lanceolate, sparingly toothed; ped. as long or longer than the leaves; cor. twice longer than the calyx; sterile fil. none. - 2f U. S. and Can. Stem 4-8' high, more or less pubescent, round, declining, and branching at base. Leaves $1-2^{\prime}$ long, and $\frac{1}{3}$ as wide, smooth, lanceolate, sessile, dentate or nearly entire near the ends, subconnate or amplexicaul. Cor. white or pale-yellow, twice longer than the calyx or the 2 bracts. Jl.

2 G. Floridàna Nutt. St. ereet, branched; lvs. lanceolate, few-toothed; ped. longer than the leaves; cor. 4 times longer than the calyx; sterile fil. none?-2) Dry soils, fields, \&c., Ala. and Fla. Plant 6 to $9^{\prime}$ high, with the appearance of $G$. Virginiana, but smaller lvs. and larger fls. Ivs. hardly $1^{\prime}$ long. Ped $l^{\prime}$ to $18^{\prime \prime}$ long. Bractlets scarcely as long as sepals. Cor. 7 "long, tube yellow within, limb rose color.

3 G. sphærocárpa Ell. Glabrous, ascending, branched; lvs. lanceolate-ovate, attenuato to the base, sparingly toothed; ped. scarcely longer than the calyx.-Low grounds, Western States to Ga. Plant a few inches ligh, differing from the last chiefly in the short peduncles, round capsules, broader leaves, \&c. Flowers whitish, $5-6^{\prime \prime}$ long. Jn. (G. Caroliniensis Lo Conte.)

4 G. aùrea Muhl. Smooth; lvs. oblong-lanceolate, subentire, clasping; ped. as long as, or longer than tho leaves; cor. yellow; sterile fil. 2, short.-A small, perennial herb, 6 to $8^{\prime}$ high, in muddy places, Mass. to Fla. St. declining and rooting at the base, quadrangular, simple or branching. Lrs. sessile, a littlo clasping, smooth, punctate, acute or nearly so, oftep with a few teeth near the end. Fls. golden yellow, axillary, alternate, on slender stalks. Fil. 4, adhering to the corolla, 2 of them minute, sterile. Aug.

5 G. Viscòsa Schwein. Viscid-pubescent, ascending; lvs. lance-ovate or oblong, clasping, acute, 3-veined, acutely serrate; ped. longer than the leaves; bractlets (2) and sepals (5) twice shorter than the (white) corolla tube, twice longer than capsule. - 4 Wet places, N. Car., Ky., to Fla. and Ia. St. simple, obtusely angled, 9 to $12^{\prime}$ long. Lrs. 6 to $9^{\prime \prime}$ long, teeth slender. Ped. 1'. Cor. white, tube yellow within. (G. Drummondii Benth.)

$\beta$. DRommondi. Sepals and bractlets subulate, thrico longer than the capsule. -La. (Hale.)

6 G. ramòsa Walt. Glabrous or viscid-puberulent; st. ascending from a prostrate base, terete; ivs. linear-acute, with few teeth near the summit; bractlets minute or none; sopals linear; sterile fil. filiform. - 2l Muddy shores, S. Car. to Fla. Sts. simple or branched from the creeping base. Lvs. 6 to $9^{\prime \prime}$ long, 1 to $2^{\prime \prime}$ wide, with 2 or 4 teeth. Ped. nearly equaling the leaves. Cor. white, yellow within. May-Jl. (G. quadridentata Mx.)

7 G. pilòsa Mx. Erect, hispid; lvs. ovate, few-toothed, clasping, rugous; cortube scarcely longer than the calyx.-4 Car. to Fla. and La, in wet places. Plant If high, rough with stiff, white hairs. Lvs. 6 to $8^{\prime \prime}$ long, 3 to $5^{\prime \prime}$ broad, irregularly 3-veined. Fls. sessile, shorter than the leaves, white. Jl.-Sept.

8 G. subulàta Baldw. Erect, hispid; lvs. linear or lance-linear, margins revolute, entire; cor. tube slender, thrice longer than the calyx. - 4 Damp sandy places, Ga. (Feay, Pond), Fla. (Mettauer, Chapman, \&c.) Plant generally much branched, 5 to $8^{\prime}$ ligh. Lvs. 5 to $8^{\prime \prime}$ long, rigid, distant, or often densely imbricated. Cor. tube 4' long, persistent and recurved after flowering. Sept., Oct.

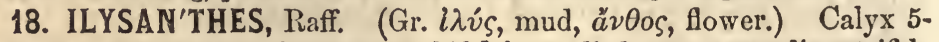
parted ; cor, upper lip short, erect, bifid, lower liplarger, spreading, trifid; sta. 2 fertile; 2 sterile fil. forked, one of the divisions glandular, obtuse, the other acute, or rarely with half an anther; caps. orate or oblong, about equaling the calyx.-With opposite lvs., and axillary, 1-flowered ped., resembling Gratiola in habit. (Lindernia, L.) 
1 I. gratioloìdes Benth. Glabrous, ascending, much branched; lvs. ovate or oblong, obtusish, subdentate, lower attenuated to a petiole; cor. erect, twice longer than the calyx, on bractless peduncles; sterile fil. bearing the glabrous, acute lobe below the middle.-1) Can. and U. S. in wet places. A low, inconspicuous plant, $3-6$ or $8^{\prime}$ high. Leaves $5-8^{\prime \prime}$ long, sometimes mostly sessile, commonly the lower distinctly petiolate. Corolla bluish-white, much exserted, $5^{\prime \prime}$ long. Jl., Aug.-( $\mathrm{I}_{\text {. dilatata and attenuata Muhl.) }}$

2 I. refrácta Benth. Slender, smooth, erect; mostly subradical, oval-oblong and spatulate, cauline few, small and remote, lance-linear; ped. filiform, subterminal, few, deflected after flowering; cor. tube 4 times longer than the linear sepals. - if Damp pine-woods, N. Car. to Ga. (Mettauer, near Macon). St. 6 to $10^{\prime}$ high, sparingly branched. Lower lvs. 7 to $9^{\prime \prime}$ long, cauline 1 to $5^{\prime \prime}$. Fls. $5^{\prime \prime}$ long, light blue. Jn.

3 I. grandiflòra Benth. Smooth, creeping, diffuse; lvs. thick, orbicular, entire, subclasping, veinless; ped. very hairy; sterile fil. 2 ; partly exserted, lobe-bearing in the middle, thickened at the end.- $2 f$ Ga. (between Savannah and Augusta, Nutt.) in sandy swamps. Lrs. 3 to $4^{\prime \prime}$ diam. Ped. $1^{\prime}$ long, cor. 6", violet blue.

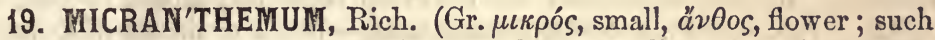
is its character.) Calyx 4-toothed or cleft; corolla upper lip shorter, cntire, lower trifid; stamens 2 fertile, a glandular scale at the base of each, sterile filament none; style short, apex clavate or spatulate, entire ; capsule 2-valved.-(1) Slender, glabrous, creeping, with opposite lvs. and minute flowers.

$\$$ Calyx deeply cleft, segments longer than the unequal corolla lips.................. No. 1

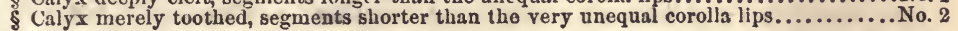

$1 \mathrm{M}$ orbiculàtum $\mathrm{Mx}$. Lvs. orbicular or roundish-obovate, obscurely 3-veined, entire, contracted to a very short petiole; fls. solitary, axillary, much shorter than the leaves and on pedicels shorter than the calyx. - N. Car. to Fla. and La., common, in mud or shallow water. Sts. diffuse, filorm. Lvs. often crowded, 2 to $4^{\prime \prime}$ long, 2 to $3^{\prime \prime}$ wide. Fls. globular, less than $1^{\prime \prime}$ long, white. All summer. (M. omarginatum Ell.)

2 M. micrántha. Lvs, roundish, ovate, crowded, sessile, obscurely 3-veined; fls. sessile, axillary, very minute.-Inundated banks of rivers, Delaware to the Ogeechee, probably not common. Plant a few inches long, branched. Fls. white, the middle segm. of the lower lip largest and spreading. Sept., Oct. (Herpestis micrantha Ell. Hemianthus micranthemoides Nutt.)

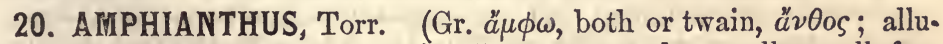
ding to its two-fold inflorescence.) Calyx 5-parted; corolla small, funnel form, limb 4-lobed, lower lobe larger, stamens 2, included; anthers 2-celled; style lightly bifid, lobes acute ; capsule obcordate, compressed, valves septiferous in the middle; seeds numerous.-(1) Acaulescent, minute, with fls. both sessile and on scapes.

A. pusillus Torr. On wet rocks, Newton Co., Ga. (Leavenworth). A minute herb, with the lvs. nearly radical, linear, obtuse, entire, 1 to $2^{\prime \prime}$ long. Fls. white, hardly $1^{\prime \prime}$ long, some sessile among the leaves, others on simple, filiform pedun. cles $1^{\prime}$ long. Mar., Apr.

21. LIMOSEL'LA, L. Mudwort. (Lat. limus, mud; its locality.) Calyx 5-cleft; corolla shortly campanulate, 5-cleft, equal ; stamens approximating in pairs; capsule partly 2 -celled, 2 -valved, many-seeded. Minute aquatic herbs. Scape 1-flowered.

น. tenuifòlia Nutt. Acaulescent; lvs. linear, scarcely distinct from the petiole; scape as long as the leaves; cor. segments oval-oblong, shorter than the calyx.(1) R. I., Mass., N. Y., Penn. A minute plant, an inch in height, growing on
the muddy banks of rivers. Leaves and flower-stalks radical. Flowers very small, blue and whito. Aug. 
22. SYNTHY'RIS, Benth. (Gr. oúv, together, Ovpis, a door; sc. valves closed.) Calyx 4-parted; corolla subcampanulate, segments 4, erect-speading or 0 ; stamens 2 , inserted into the tube of the corolla, exserted; anther cells parallel, distinct; capsule compressed, obtuse or emarginate, loculicidal, seeds plano-convex.-2f N. American, with a thick root. Radical lvs. petiolate, cauline bract-like, on the scape-like stem, alternate. Fls. racemed or spicate.

S. Houghtoniàna Benth. Hirsute, radical lvs. ovate, subcordate at base, crenulate, obtuse; scape erect, clothed with foliaceous bracts, dense-flowered abovo; cor. as long as the calyx, upper segment longer than the other very short ones.Dry hills, Wis. (Lapham). Lvs. 2 to $3^{\prime}$ by $1 \frac{1}{3}$ to $2^{\prime}$, on petioles about an inch long, some of the leaves often suborbicular. Bracts much smaller, ovate and ovate-lanceolate, clasping. Scapo 9 to 12 ' high. Spiko elongated in fruit.

23. DIGITA'LIS, L. Fox-glove. (Lat. digitabulum, a thimble.) Calyx 5-parted; corolla campanulate, ventricous, upper lip reflexed, spreading, middle segment of the lower lip broadest; capsule ovate, 2celled, 2-valved, with a double dissepiment.-Herbs or shrubs of Europe and Asia. Lower lvs. crowded, petiolate, upper alternate. Fls. in showy racemes. Poisonous and medicinal.

$\S$ Corolla tube subglobons, scarcely longer than the lower lip.............. Nos. 1, 2, 7

\$ Corolla tube campanukte, I wiee longer than the lower lip...................... $3,4,6$

\$ Corolla tube subcylindric, twice longer than the lower lip.........................

$I \mathrm{D}$. orientàlis Lam. St. and lance-linear lvs. glabrous; spike interrupted, glandular-villous; pedicels very short; cal. segments ovate-lanceolate, acute; cor. pubescent, lower segments oblong, obtuse.-2f Bythinia. Height 3f. Corolla purplish, spotted.

2 D. ferruginea. Lrs, oblong-lanceolate, very smooth; rac. many-flowered; cal. segments orel-elliptical, obtuse; cor. limb subglobous, woolly, lower segment ovate. -4 in Greece, Armenia and Circassia. Corolla rust-colored, $16^{\prime \prime}$ long, lower lip longest, densely bearded. $\dagger$

3 D. purpurea I. Lvs. oblong, rugous, petiolate, crenate; cal. segm. ovate oblong; cor. obtuse, upper lip entire; ped. as long as the calyx.-(1) Plant 2 to $3 f$ high, with large, rough, downy lvs. Fls. numerous, in a long, simple spike, large, crimson, often white, with eyc-like spots within. Jl. $\ddagger \dagger$ Eur.

4. D. grandiflòra Allioni. Lrs. ovate or oblong-lanceolate, veiny, serrulate, amplexicaul; rac. tomentous, lax ; cal. segments lanceolate, acute; cor. ventricouscampanulate, segments broader than long, lowest twice broader than the lateral. $2 f$ in Europe. Plant 2-3f high. Flowers $1 \frac{1}{2}^{\prime}$ long, yellow, varying to brownish or orange. $\dagger$

5 D. lutea L. Very smooth; lvs. oblong or lanceolate, denticulate; rac. Eeculd, many-flowered; cal. segments lanceolate, acute; cor. glabrous, tube subventricous, lower segment half as long again as the rest.-2 Europe. Stem $3 f$ high. Flowers $8-10^{\prime \prime}$ long, yellow, varying to white. $\dagger$

6 D. Thápsi, with mullein-like lvs. all radical and flat on the ground.

7 D. leucophæea, with very large, dense, leafy racemes of dusky white fls., and a few other species may bo found in gardens. There are also many hylorids, difficult of course, to determine.

24. VERON'ICA, L. SPeEdwell. (Perhaps namea for St. Veronica.) Calyx 4-parted; corolla subrotate, deeply 4-cleft, lower segments mostly narrow; stamens 2 , inserted into the tube, exserted; sterile fil. 0 ; capsule compresśed, 2-sulcate, often obcorđate, 2-celled, few-secded.Herbs or shrubs (the following species herbs). Lvs. opposite. Fls. solitary, axillary or in raçemes, blue, flesh-colored or white.

Tall, erect (1S' to 4f). Fls. In dense, terminal spikes. Corolla tube elongated.....Nos. 1, 13

Low, weak (3 to $12^{\prime}$ ). Leaves opposite (at base). Corolla tube very short. (a) 
a Racemos opposite, axillary. Capsule roundish, emarglnate............... Nos. 2, 3

a Racemes alternate, axillary. Capsule not rounded, very flat.......................... 5

a Racemes terminal, or the flowers axillary and not racemed. (b)

b Floral leaves like the rest, not longer than the recurved peduncles........ Nos. 6-S

b Floral leaves bractlike, longer than the erect peduncles. (c)

c Perennial. Peduncles equaling or exceeding tho calyx.............Nos.9, 10, 14

c Annual. Ieduneles shorter than tho calyx or nono........................ 11, 12

1. V. Virgìnica L. CuLver's PIrsic. Erect, tall, glabrous; lvs. verticillate in $4 s$, $5 s$, or $6 s$, lance-ovate to lance-linear; spikes mostly several, paniculate.- $2 f$ Woods, thickets and barrens, Can. to Ga., W. to Iowa. A conspicuous plant. arising 2-5f. Stem simple, straight, smooth, with whorls of acuminate, finely serrate leaves which are subpetiolate and glaucous beneath. Flowers numerous, nearly sessile, in spikes 3 to $10^{\prime}$ long. Corolla white, tubular, pubescent inside. Stamens and style twice as long as the corolla. Л. (Leptandra Virginica Nutt.)

2 V. Anagallis L. Glabrous erect; lvs. sessile, clasping and subcordate, lanceolate, acutish, entire or serrulate ; rac. in opposite axils ; caps. orbicular, slightly notched. - 2f A smooth, fleshy plant, frequenting the borders of brooks and pools, Can. and U. S. Stem about if high. Leares $2-3^{\prime}$ by $5-7^{\prime \prime}$. Racemes (sometimes but 1 at a node) longer than the leaves, loose, pedicels $\left(2-3^{\prime \prime}\right)$ scarcely. longer than the bracts. Flowers bluish-purple, small. Jn., Jl.

3 V. Americana Schwenitz. Brooknme. Glabrous, decumbent at base, erect, above; lvs. ovate or ovate-oblong, acute or obtusish; serrate, petiolate, abrupt at base; rac. opposite, loose; caps. roundish, turgid, emarginate. $-2 f$ In brooks and clear waters, Can. and U. S. Plant rather fleshy, very smooth, 12-18' long, more or less decumbent and rooting at base. Leaves $1-2^{\prime}$ long, petioles margined. Racemes longer than the leares. Pedicels $\left(3-5^{\prime \prime}\right)$ twice longer than tho bracts. Flowers blue or bluish-purple. Jn., Jl.-(V. Beccabunga Am. authors.)

4 V. scutellària I. SKULL-CAP. SPEEDwell. Glabrous, ascending, weak; lvs. linear or lance-linear, sessile, acute, remotely denticulato; rac. in alternate axils very loose; pedicels divaricate; capsule flat, broader than long, cordate at both ends. - 2f Slender and weak, in swamps and marshes, N. Eng. and W. States, and Brit. $A \mathrm{~m}$., common. St. 10 to $16^{\prime}$ high. Lrs. ( 2 to $3^{\prime}$ by 2 to $3^{\prime \prime}$ ) much longer than the internodes. Ped. and pedicels filiform, the latter $\left(6\right.$ to $\left.9^{\prime \prime}\right)$ six times longer than the bracts. Fls, rathor large, flesh-color, with purple lines. In.Aug.

5 V. officinàlis L. OFficinal Speedweld. Roughish-pubescent; St. prostrate, branched; lvs. briefly petiolate, and subsessile, obovate-elliptic or oblong, obtuse, serrate, mostly narrowed to the base; rac. dense, many-flowered; pedicels shorter than the calyx; caps. puberulent, obovate-triangular, slightly emarginate.- $2 f$ In dry woods and open fields, Can. to Ga., rare. Plant trailing, 6 to $12^{\prime}$ long, with ascending branches. Lvs. $I^{\prime}$ to $18^{\prime \prime}$ by 6 to $9^{\prime \prime}$. Fls. pale blue, forming rather long, axillary, erect, pedunculate spikes. May-Jl. § Eur.

6 V. Buxbaúmii Tenore. Prostrate, hairy; lvs. roundish-ovate, coarsely cro nate-serrate, the floral similar, all on short petioles; ped. longer than the lvs. ; caps. triangular-obcordate, broader than long.-Rare in waste grounds, E. States. Plant 7 to $12^{\prime}$ long, lvs. nearly $1^{\prime}$ long. Cal. spreading $\&$ to $6^{\prime \prime}$. Cor. larger than tho calyx, blue. Caps. co-seeded.

7 V. agréstis L. NECKIVEED. St. procumbent, diffusely branching; lvs. cordateovate, deeply crenate-serrate, floral similar, all petiolate; ped. as long as the leaves; caps. roundish, acutely notched, $\infty$-seeded.-(1) In cultivated fields, Can. and Atlantic States, not common. A small, pilous plant, 2 to $8^{\prime}$ long, branching mostly at base. The lvs. are roundish-ovate, the lower shorter than their petioles, tho upper alternate. Fls. small, light blue, veined, their stalks recurved in fruit. Segm. of tho cal. fringed, ovate, equal. May-Sept. § Eur.

8 V. hederæfòlia L. Prostrate, pilous; Ivs. petiolate, cordate, roundish, coarsely 3 to 5-toothed or lobed; ped. scarcely longer than the lvs.; sep. triangular, subcordate, acute, closed in fruit; caps. turgid, 4-seeded.-Dry or rocky soils, I. Isl. to Dol, rare. St. diffusely branched. Lvs. rather fleshy, 6 to $12^{\prime \prime}$ diam., tho upper larger and alternate. Cal, segm, ciliate. Cor, smaller than the calyx, blue. Mar., May. § Eur. 
9 V. serpyllifòlia L. Subglabrous, much branched below; sts. ascending; lv8. oval, subcrenate, obtuse, lower roundish and petiolate, upper sessile, passing abruptly into oblong, entire, alternate bracts; ped. longer than the ovate sepals; caps. obcordate, broader than long. - 2 M Meadows and mountain valleys, in grass, ctc., U. S. and Can. Plant varying in height from $3^{\prime}$ to $12^{\prime}$. Leaves rather fleshy, 3-veined, 4-12" long, petioles $0-2^{\prime \prime}$. Racemes bracted, rather close in flower, elongating in fruit to $2-5^{\prime}$. Corolla scarcely exceeding the caly $x$, blue and white, penciled with purple lines. Maj-Aug.

10 V. alpina L. Branched at base, ascending; lvs. roundish-oval, subentire, very obtuse, short-petioled, upper elliptical and much smaller; rac. hairy, fewflowered, usually dense; ped about as long as the calyx; stam. shorter than the corolla; caps. obovate, emarginata - White Mits., N. H. and Rocky Mts. Plant 1 to $5^{\prime}$ long. Lrs. about $4^{\prime \prime}$ by $5^{\prime \prime}$. Fls. small, blue.-Scarcely distinguishable from dwarf specimens of No. 9 .

11 V. peregrìna L. Ascending, subglabrous; lvs. petiolate, oblong, few-toothed, obtuse, upper sessile, oblong, obtuse, serrate or entire, floral oblong-linear, entire, longer than the subsessile flowers; caps. suborbicular, slightly notched, the lobes rounded. - (1) Throughout N. Am., in fields or clayey soils. Plant often branched from the base, 4 to $10^{\prime}$ high. Lvs. rather fleshy, the upper cauline, 6 to $11^{\prime \prime}$ long, floral much smaller. Sepals oblong, longer than the pale blue or white corolla. Caps. hardly broader than long. May, Jn. (V. Marilandica Willd.)

12 V. arvénsis L. CoRN Speedwelc. Puberulent-pilous, simple or branched, erect or assurgent; lvs. ovate or roundish, subcordate, incisely crenate, lower ones petiolate, upper and floral alternate, lanceolate, crenate, sessile; ped. shorter than the calyx. - Frequent in dry fields, N. H. to Ga. and La. A small, pubescent, pale-green plant, 2 to $6^{\prime}$ high. St. nearly erect, branching from the base, the leares assurgent. Cor. shorter than the cal., pale blue, penciled with purple lines. May, Jn. $\S$

$\beta$. RENIFonMIS. LVs. sessile, reniform, entire. (V. reniformis Raf.)

13 V. spicàta L. SPIKed SPEedwell. Erect, tall; lvs. petiolate, ovateoblong or lanceolate, lower ones obtuse, crenate, upper acute, crenate-serrate, entire at apex; rac. mostly solitary; pedicels much shorter than the sepals ; cal. mostly hoary-pubescent.-2f Europe and Asia. A beautiful garden species with numerous varieties. Flowers blue, roseate, etc. $\dagger$

$14 \mathrm{~V}$. gentianoìdes Vahl. St. cxespitous; flowering branches erect, simple; lvs. thick, entire, or sparingly crenate; lowest crowded, obovate or oblong, the rest remote, oblong or lanceolate, the floral bract-like; rac. loosely many-flowered, pubescent; ped. many times longer than the calyx.-Fls. rather large, blue. $\dagger$ Asia.

25. BUChNE'RA, L. Blue-mentrs. (In honor of $J$. G. Buchner, a German botanist, 1743.) Calyx 5-toothed; corolla salver form, tube slender, limb flat, in 5 , obovate-oblong, subequal lobes ; stamens 4 , included, anthers halved, i.e., with but one cell ; capsule 2-valved.-Herbs, with the lower lvs. opposite, the upper alternate. Fls. in a terminal spike.

B. Americàna L. Tall, slender, hispid, very rough; lvs. oblong-lanceolate, fewtoothed, obtuse, 3-veined, the lowest oblong-obovate; highest linear ; spike longpeduncled; fls. dense, becoming remoto in fruit; cor. tube slender, pubescent, twice as long as the hispid, tubular calyx, or the deep blue cor. lobes. $-N$. Y. to Ga. and La. Sts. 2 to $3 f$ high, simple or few-branched, the upper half naked or with bracts only. Lvs. 1 to $2^{\prime}$ long. Fls. 6 to 12 in the spike, 6 to $7^{\prime \prime}$ long. Jn. -Aug. (B. elongata Sw.? (Darby) is the same plant). Blackens in drying.

26. MACRAN'THERA, Torr. (Gr. Makpós, great, Lat. anthera, anthers; a mongrel word.) Calyx tube campanulate, lobes 5 , long and narrow; corolla tubular, limb oblique, segments short, entire, stamens 4, long, exserted, subequal; style long, filiform; capsule ovate, acumi- 
nate.-2f Herbs tall, with opposite, pinnatifid lrs., long, decurved peduncles, and cylindraceous, ycllow fls.

$1 \mathrm{M}$. fuchsioides Torr. Cal. segm. but little shorter than the corolla.-Ala., La. Plant 2 to $3 \mathrm{f} \mathrm{high.} \mathrm{Lrs.} \mathrm{lanceolate,} 2^{\prime}$ long, with lanceolate segments. Rac. long, loose, secund. Cor $1^{\prime}$ long.

2 M. Lecóntii Torr. Cal. segm. entire, linear-lancoolate, scarcely one-third the length of the corolla.-Dry pine woods, Ga., Fla. Lvs. ctc., as in the other.

27. SEYME'RIA, Ph. (In memory of Henry Scymer, Esq., an English naturalist.). Calyx deeply 5-cleft; cor. tube short, dilated, 5 -lobed, lobes ovate or oblong, entire, equaling or longer than the tube; sta. 4, subequal; valves of the capsule loculicidal, entire; seeds $\infty$. Herbs erect, branching. Cauline lvs. mostly opposite and incised. Fls. yellow.

$\S$ Tube of the corolla broadly campanulate, incurved, as long as the limb..............No. 1

$\$$ Tube of the corolla much shorter than the subrotate limb............................. 2,3

1 s. macrophýlla Nutt. Erect, tall, sparingly pubescent; lvs. large, the lower deeply pinnatifid, segments lance-oblong, incised, terminal one the largest, upper lanceolate, serrate or entire; cor. tube incurved, scarcely longer than the limb; sty. short, dilated and slightly bifid at apex; caps. ovate-acuminate.-2f In woods, White River Valley, Ind., Ohio (Clark) to Ark. Height 4-6f, with the habit of Dasystoma. Lower leaves $\left(5-7^{\prime}\right.$ by $\left.2-3^{\prime}\right)$ lance-ovate in outline, floral $\left(2-3^{\prime}\right)$ mostly opposite. Corolla $\frac{1^{\prime}}{2}$ long, very woolly within. July.

2 S. pectinàta $\mathrm{Ph}$. Viscid-pubescent, profusely branched; lvs. oblong, half-pinnatifid or cleft half way to the midvein, segm. few, entire, short, linear, obtuse, upper lvs. merely toothed; caps. pubescent, acute with the style, at length obtuse. -N. Car. to Fla. and Tex., in the upper districts. Plant 2 to $4 \mathrm{f}$ high, the numerous branches opposite. Lvs. small, an inch (or less) long, the rachis oblanceolate. Sep. oblong-linear, longer than the pedicel. Cor. subrotate, 5 to $6^{\prime \prime}$ broad. Aug.-Oct.

$3 \mathrm{~S}$. tenuifòlia $\mathrm{Ph}$. Minutely puberulent, much branched; lvs. setaceously bipinnatifid, rachis and segments all equally attenuated; caps. globular, rostrate.Wet pine barrens, N. Car. to Fla. and La. Plant 2 to $3 \mathrm{f}$ high, quite slender and nearly smooth. Lvs. $6^{\prime \prime}$ and less long, only the lower segments dissected, upper entire. Cor. lobes oblong, spreading about $4^{\prime \prime}$. Ped. twice longer than the calyx. Aug., Sept.

28. DASYS'TOMA, Raf. (Gerardia, L.) Yellow Foxglove. (Gr. $\delta a \sigma \nu ̀ s$, hairy, $\sigma \tau o ́ \mu a$, mouth ; alluding to the corolla.) Calyx campanulate, half 5-cleft, imbricate in æstivation; corolla tube dilated, longer than the 5 entire lobes, woolly within; stamens didynamous, scarcely included, woolly; anthers all equal, awned at base; capsule ovate, acute, 2 valves bearing a septum in the middle; seeds many. $-2 f$ Herbs tall, erect. Lower lvs. opposite, upper generally alternate. Cor. large, yellow. All blacken in drying.

* Segments of the calyx entire. Plants pubescent..........No. 1) or glubrous.......Nos. 2, 3

* Segments of the calyx toothed or pinnatifd. Plants pubescent........................... 5

1 D. flàva. Plant pubescent, subsimple; lvs. nearly sessile, oblong-lanceolate, entire or toathed, the lower pinnatifid or incised; cal. lobes oblong, obtuse, rather shorter than its tube; ped. very short. - A showy plant, 2 to $4 \mathrm{f}$ high, in woods throughout the U.S. LVS. 2 to $4^{\prime}$ long, tapering to the subsessile base or petiole, the upper mostly entire. Cor. about 18" long. Aug., Sept. (D. pubescens Benth. G. flava L.)

2 D. integrifòlia. Plant glabrous, subsimplo; lvs. lanceolate, acute, entire, or the lowest somewhat toothed; ped. shorter than the calyx.-Woods, S. E. Ohio to III. and Tenn. Sts. often much branched, 1 to $2 \mathrm{f}$ high. Lvs. 1 to $3^{\prime}$ long, petiolate. Fls smaller, the cor. about $1^{\prime}$ long. Not at all glaucous like the next. Aug. (D. quercifolia $\beta$. ? Benth. G. integrifolia Gray.) 
3 D. cquercifòlia Benth. Plant glabrous and glaucous, paniculate-branched; Irs. paler beneath, petiolate, lower ample, bipinnatitid, upper oblong lanceolate, pinnatifid or entire; ped. as long as the calyx; segm. of the cal. larce-acuminate, longer than its tube.-Woods and thickets, N. Eng. to Ga. and Mich., common. St. tall, purplish, covered with a glaucous bloom, 3 to 5 f high. Lvs. 4 to $8^{\prime}$ long, sinuate or incised. Fls. large, and of a brilliant yellow, opposite and axillary, ncar the top of the stem, forming a loose spike. Cor. trumpet-shaped, near $2^{\prime}$ long. Aug. (G. quercifolia $\mathrm{Ph}$. G. glauca Eddy.)

4 D. pediculària Benth. Pubescent or nearly glabrous, branched; lvs. ovate lanceolate, pinnatifid, with toothed or incised segments; pedicels longer than the hairy calyx, segm. tooth or incised, equaling the top-shaped calyx tubc.-Dry hilly woods, Can. to $\mathrm{Ga}$. and $\mathrm{Ky}$., common. St. bushy, very leafy, 2 to $3 \mathrm{f}$ high, sprinkled with a woolly pubescence. Lvs. 2 to $3^{\prime}$ long, divided like those of the Louse-wort. Cor. rather bell-shaped, $15^{\prime \prime}$ long, the cal. $5^{\prime \prime}$. Aug. (G. pedicularia L.)

5 D. pectinàta Benth. Tery hirsute; lvs. lanceolate, pectinate-pinnatifid, segm. subdentate or incised; ped. shorler than the hairy calyx, segm. toothed, longer than the cal. tube.-Pine woods, Car. and Ga. Fls. as large as in the last. Jl, Aug. (G. pectinata Torr.)

29. GERAR'DIA, L. (In honor of John Gerard, an English botanist of the 16th century.) Calyx campanulate, briefly or narrowly 5 -toothed; cor. tubular, ventricous or subcampanulate, tube longer than the 5 broad, entire unequal lobes; sta. didynamous, in pairs, shorter than the corolla, length unequal; caps. obtuse, or briefly acuminate; seeds $\infty$.-American herbs, rarely suffruticous. Lvs. opposite. Fls. axillary, solitary, purple or rose-color.

1. OtopirLis, Calyx segments longer than its tube, 2 anthers much smaller..........No. 1

2. Grrardia proper. Calyx segments short, equal. Anthers all equal. (\$)

\& Corolla bilabiate, upper lip very short, ereet. Peduncles longer than corolla......... No. 2

\& Corolla lobes subequal, all spreading, throat usually hairy. (a)

a Leaves almost none, opposite scales instead. Flowers large...................... 3

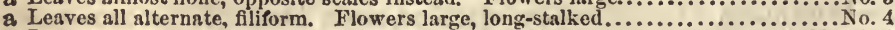

a Leaves opposite.-Peduncles not longer than the calyx..................... os. 5,6 - Peduncles wuch longer.-Flowers large (about 9 " long.)..... Nos. 7, 8 -Flowers small (about $6^{\prime \prime}$ long).... Nos. 9, 10

1 G. auriculàta Mx. Scabrous, hirsute, subsimple; lvs. ovate-lanceolate, mostly cntire, upper auriculate at baso; fls. nearly sessile.- (1) Penn. to Iowa and La., in low grounds. A rough, rigid .plant, 12 to $18^{\prime}$ high. Lvs. $1^{\prime}$ to $18^{\prime \prime}$ long, sessile, the floral with an oblong lobe on each side at base. Cor. dilated and spreading at mouth; lobes entire, rounded, purple, rarely white. Short stamens similar, but twice smaller. Aug., Sept.

2 G. Mettaùeri. Glabrous, slender, diffusely branched; lvs. linear-filiform, scarcely rough-edged; ped. filiform many times longer than the calyx which has short, triangular tecth; cor. distinctly bilabiate, upper lip very short, emarginate, straight, vaulted, fringe-ciliate, lower lip of 3 broad, spreading lohes.-- (1) Wet sandy places, Middle Fla. (Dr. Mettauer). Sts. 1 to $2 \mathrm{f}$ high. Lvs. 5 to $12^{\prime \prime}$ long. Ped. 6 to $12^{\prime \prime}$ long. Fils. purple, with 2 yellow stripes in the spotted tube.

$\beta$ ? CLAUSA. Cor. tube dorsally compressed, throat closed by the inflexed upper lip.-With the others. Fls. light purple.

$\gamma$ ? NUDA. IVS. (except a fow at tho base) reduced to minute bracta scarcely $1^{\prime \prime}$ long; fls. all terminal, rather smaller ( 5 "long, light purple.

3 G. aphylla Nutt. Erect, with slender branches, leafless, with fow, remote, scarious scales or short bristle-like lvs; ped. bracteolato; cul, truncate, with minute, gland-like teeth; caps, globular, exceeding tho calyx.- (1) N. Car. to Fla and La. in wet places, coastward. Plant 2 to $3 f$ ligh, often simple, with few flowers, or diffusely few-branched with many tlowers, Fls. deep purple, nidalo size, lobes subequal, pedicels short, i. e., the bractlets aro near the llowers, Jn., Jt.

4 G. filifòlia Nutt. St. terete, diffusely branched; lvs. filiform, terete, allernats and much fascicled; ped. alternate, much longer than the lvs.; cal, teeth short, setaceously acute; cor, ample, smooth.- (1) St. Afary's, Ga, to Apalachicola, Fla 
Plant rigid, 2 to $3 f$ high. Lrs. never an inch long, always scattered. Ped. 1 to 2 ' long. Fls. numerous, large. Aug.-Oct.

5 G. maritima Raf. St. angular; lvs. linear, fleshy, short, rather obtuse; fls. small; ped. scarcely as long as the truncate calyx; lobes of tho cor. spreading, 2 upper fringed.- (2) Salt marshes, along the Atlantic coast. Plant branched, 4 to $10^{\prime}$ high. Lvs 6 to $8^{\prime \prime}$ long, subterete and quite fleshy. Fls. about $6^{\prime}$ long, inclined to be terminal. Caps. globular. Jl.-Sept.

6 G. purpùrea L. St. angular, branched; lvs. linear, acute, scabrous on the margin; ped. shorter than the caly $x$ which has a truncato tube with short setaceously acute teeth. Cor. ample, smooth or pubescent. - (1) Wet grounds, N. Eng. to Fla. and La. Plant of varying form according to situation, 1 to $2 \mathrm{f}$ ligh (2 to If South). Lvs. 1 to $2^{\prime}$ long, often with smaller ones fascicled in the axils. Fls. large, ( $\mathbf{I}^{\prime}$ long), purple, the ped. $\mathbf{1}^{\prime \prime}$, rarely $2^{\prime \prime}$ long. Aug. (G. Plukenetii Ell ?)

$\beta$. Fasciculata. Tall, with fascicles of smaller lvs. in the axils; cor. pubescent, lobes ciliate.-S. States, common (G. fasciculata Ell.).

7 G. áspera Doug. Sparingly branched; lvs. scabrous, long and narrowly linear, the floral exceeding the calyx; ped. twice longer than the calyx; cal. teeth lanceolate, acute, nearly as long as its tube; cor. ample, smooth. (1) Ill. to Iowa (Cousens), \&c. Closely allied to G. purpurea. Sts. 1 to $2 \mathrm{f} \mathrm{high.} \mathrm{Lvs.} 18^{\prime \prime}$ to $2^{\prime}$ long, rigid, rough. Cor. deep purple, about 1' long, not always smooth. Ped. 3 to $5^{\prime \prime}$. Aug.

8 G. linifolia Nutt. St. terete, virgate, inclined, subsimple, screral from the same base; lvs. opposite, smooth, thick, long, lance-linear, and linear, erect, the upper reduced to bracts; ped. many times longer than the calyx which is truncate, with scarcely any teeth.-N. Car. to Fla., in wet pine barrens. Sts. 2 to $3 f$ high, terete. Ivs. 2 to $3^{\prime}$ by 2 to $3^{\prime \prime}$. Cor. large, pubescent, its lower lip spotted. Aug.-Sept.

9 G. tenuifòlia Vahl. Paniculate, much-branched; sts. angular; lvs. linear; ped. axillary, longer than the flowers, about equaling the lvs.; caps. globular.(I) A slender and delicate species, usually very branching, in fields and woods, $U$. S. and Can. St. 6 to $12^{\prime}$ high. Lvs. about an inch long, very narrow $\left(1^{\prime \prime}\right.$ in width) entire, rough-edged, often coiled. Fls. opposite, axillary, on slender stalks, an inch or less in length. Cor. purple, spotted within, border much spreading, smooth and nearly equal. Cal. teeth short and acute. Aug.-Sept.

10 G. setàcea Walt. St. erect, sparingly branched, slender, 4-angles margined; Ivs. remote, linear or setaceous, acute at each end, the floral ones 2 or 3 times shorter than tho very long peduncles; cal. teeth very short, acute; cor. lobes short, spreading; caps. roundish ovoid, scarcely exceeding the calyx. - (1) S. and W. States, dry grounds. Plant 12 to $18^{\prime}$ high, the stem and few branches quite slender and rough on the slightly winged angles. Lrs. 5 to $10^{\prime \prime}$ long, few and far between. Ped. 1 to $11_{2}^{\prime}$ long. Cor. $\left(5\right.$ to $\left.6^{\prime \prime}\right)$ glabrous, light purple or rosecolor. Jl., Aug. (G. Skinneriana, 2d edit.)-Scarcely blackens in drying.

30. CASTILLEJJA, L. (Euchroma, Nutt.) Pannted Cup. (Named for one Castillejo, a Spanish botanist.) Calyx tubular, 2-4-cleft; cor. galea (upper lip) linear, very long, carinate-concave, lower short, 3-lobed; sta. beneath the galea, didynamous; anth. oblong-linear, with unequal lobes, cohering in the form of an oblong disk, the exterior fixed by the middle, interior pendulous.-Herbaceous or suffruticous. Lvs. alternate, the floral often colored at the apex. Fls. subsessile, in terminal, leafy bracts.

1 C. coccínea Spreng. Lvs. sessile, pinnatifid, with linear and divaricate segments; bracts about 3-cleft and colored at the summit, longer than the corolla; cal. 2-cleft, nearly equaling the corolla, segments retuse and emarginate.- $2 f$ Wet meadows, Can. and U. S., rare in N. Eng., remarkable for its large, bright, scarlet (or bright yellow!) bracts. Stem angular, simple, 8-12' high. Leaves with about 2 , long, linear segments on each side. Bracts crowded near the summit of the stem, each with a dull yellow flower in its axil, less showy than itself. Miay, Jn. 
2 C. sessiliflòra $\mathrm{Ph}$. Pilose-pubescent; lvs. sessile, clasping, oblong-linear, mostly trifid with the lobes divaricate; cal. sessile, elongated; spikes dense; cor. long, exserted, arched, segments of the lower lip acuminate.-2f Prairies, Wis. (Lapham) and westward. Stem 8-14' high, several from the same root, simple, leafy. Leaves grayish, $2-2 \frac{1^{\prime}}{2}$ long. Flowers crowded. Corolla tubo slender, $2-3^{\prime}$ in length, greenish-white, with a slight tinge of purple. Style and stamens enfolded by the upper lip, and a little exserted. May. (E. grandiflora Nutt.)

3 C. septentrionalis Lindl. Lvs. linear, undivided, the upper lanceolate, tho floral subovate, subdentate at the end, all 3-veined; cal. with acute teeth, shorter than the corolla. - 2f A hardy inhabitant of Alpine and high northern regions, White Mts., N. H. to Hudson's Bay. St. a foot high, simple. Lvs. sessile, smoothish, becoming lanceolate towards the upper part of the stem, and near $2^{\prime}$ long. Tuft of fls. at top of the stem. Bracts broader and shorter than the leaves, 5 to 7-reined, of a pale straw color tipped with purple. Fls. straw-colored, nearly concealed by the bracts. Aug. (Bartsia pallida Ph.)

31. SCHWAL'BEA, L. ChAFF-SEED. (In honor of Schwalbe, a German botanist.) Calyx tube 10-ribbed, inflated, obliquely 4-cleft, upper division small, lower large, emarginate or 2-toothed; corolla ringent, upper lip entire, arched, lower 3-lobed ; eapsule oblong; seeds many, chaffy.if With alternate leaves and flowers in a terminal spike.

5. Americana I. In sandy barrens and marshes, N. Y. to Fla. and La. Stem 12f high, pubescent, stout, simple. Leaves sessile, ovate-lanceolate or oblong, 3-veined, $1^{\prime}$ to $20^{\prime \prime}$ long, with a ciliate margin. Bracts ovate, acuminate, diminishing upwards. Flowers on simple, alternate, very short pedicels, in a long spike. Corolla dull purple or brownish-yellow, twice as long $\left(1-1_{4}^{1 \prime}\right)$ as the permanent, strongly-ribbed calyx. Jn.

32. PEDICULA'RIS, L. Lousewort. (Lat. pediculus, a louse; probably from its efficacy in destroying that insect.) Calyx ventricous, 2 to 5 -cleft, the segments leafy, or sometimes obliquely truncate; corolla vaulted, upper lip compressed, emarginate ; lower lip spreading, '3-lobed; capsule 2-celled, oblique, mucronate; seeds angular.-Herbs. Lvs. alternate, rarely subopposite, often pinnatifid. Fls. spicate.

1 P. Canadénsis L. Hirsute; st. simple; lvs. alternate, petiolate, lance-oblong, pinnatifid, lobes oblong-ovate, crenate-dentate; spike short, dense, leafy; cal. truneate downwards; cor. galea abruptly incurved, with 2 setaceous teeth; caps. 'ending in a prolonged ensiform bea's.- 24 Pastures and low grounds, U. S. and Can. St. erect, if high. Lvs. 3 to $6^{\prime}$ by 1 to $2^{\prime}$, chiefly radical. Spike short, hairy, with a few small leaves at the base. Cor. yellowish and purple, the upper lip long, erect, forming a galea or helmet, cut square off at the end, with a bristlelike tooth at each corner. Beak of the capsule often near $l^{\prime}$ in length. MayЛ. (P. gladiata Mx.)

2 P. lanceolàta Mx. Nearly glabrous; st. branched; lvs. subopposite, briefly petiolate or sessile, oblong-lanceolate, doubly incised crenate; spike rather dense; cal. 2-lobed; cor. galea as long as the lip, incurved over it and closing the throat; caps. short, ovoid. - 2f In alluvial woods, N. Y. to Wis. (Lapham), S. to Va. St. I to $2 \mathrm{f} \mathrm{high,} \mathrm{smooth,} \mathrm{with} \mathrm{pubescent} \mathrm{lines,} \mathrm{nearly} \mathrm{opposite} \mathrm{lvs.,} \mathrm{and} \mathrm{\&} \mathrm{few} \mathrm{axillary}$ branches. Lvs. 3 to $5^{\prime}$ by 1 to $1 \frac{1^{\prime}}{2}$. Spike 1 to $3^{\prime}$ in length, with ovate-lanceolato bracts. Cal. and cor. smooth, the latter greenish yellow, $1^{\prime}$ long. Style a littlo exserted. Sept. (P. pallida Ph.)

33. RHINANTHUS, L. Yellow Rattle. (Gr. $\dot{\rho} \iota \nu$, nose, äv0os; alluding to the singular appearance of the compressed galea.) Calyx 4-toothed, ventricous; corolla tube cylindrical, as long as the calyx, limb ringent, galea appendaged, compressed, lip broader, deeply divided into 3 obtuse segments; capsule 2 -valved, compressed, obtuse.-D Erect, with opposite lvs. 
R. Crista-gálli L. Mostly glabrous; lvs. oblong or lanceolats; cor. scarcely a third longer than the calyx; appendages of the galea transversely ovate, broader than long.-Meadows, Plymouth, Mass. to Arc. Am. St. a foot high, smooth, branching. Lvs. opposite, nearly sessile, cordate-lanceolate, acutely serrate, rough. Fls. axillary, crowded into a leafy spike. Cal. inflated, contracted at the mouth, with 4 nearly equal teeth, and much shorter than the yellow, ringent corolla, but becoming very large and inflated in fruit, rattling with the ripo seeds. J1. § Eur.

34. EUPHRASIA, L. Exebright. (Named for Euphrosine, one of the Graces, meaning cheerfulness.) Calyx 4-cleft; upper lip of the corolla galeate, concave, apex 2-lobed, the lobes broad and spreading, lower lip spreading, trifid, palate not folded; stamens didynamous, ascending beneath the galea; capsule oblong, compressed, $\infty$-seeded.-Herbs with opposite lvs. and the fls. in spikes.

E. officinalis L. Lvs. ovate or oblong, the cauline obtuse, crenate, floral (or bracts) acute, cut-serrate with cuspidate teeth; cal. lobes subequal; lower lip of cor. with its lobes deeply emarginate.-(1) A diminutive tenant of the White Mts. and Can., rare (common in Europe). Plant branched, slender, 2 to $6^{\prime}$ high. Lrs. 1 to $3^{\prime \prime}$ long. Fls. bluish white, $3^{\prime \prime}$ long.

35. MELAMPY'RUM, L. Cow Wheat. (Gr. $\mu \dot{z} \lambda a \varsigma$, black, $\pi v \rho o ́ \varsigma$, wheat; the seeds blacken the flour of wheat if ground with it.) Calyx 4-cleft; upper lip of the corolla compressed; the margin folded back; lower lip grooved, trifid; capsule 2-celled, oblique, opening laterally; seeds 1 to 4, cylindric-oblong, smooth.-Herbs with opposite lvs. Fls. solitary in the upper axils.

M. praténse I. Lvs. linear and lanceolate, petiolate, glabrous, tho upper gencrally broader and toothed at base; fls. axillary, distinct; cal. teeth slender, half as long as the corolla.- (1) Inhabits woods, Can. to Ga. W. to Ky. St. with opposite branches, 8 to $10^{\prime}$ high, round, erect. Lvs. opposite, 1 to $1_{\frac{1}{2}}^{\prime}$ by 3 to $5^{\prime \prime}$, tho floral ones broader, with (or without) setaceous teeth at baso and tapering to an obtuse point. Fls. in the axils of the upper leaves, yellowish, slender, the corolla twice the length of the calyx. Jl. (M. Americanum $M$ x. differing from the European variety in its more slender corolla.)

\section{Order LXXXVII. ACANTHACEA. Acantrads.}

Herbs or shrubs with opposite, simplo leaves and regular, bracted flowers. Calyxo pentamerous, equal or unequal, imbricated in the bud. Corolla 5-merous, tubular below, limb more or less bilabiate, convoluto in bud. Stamens didynamous or diandrous, inserted on the tube of the corolla. Fruit a 2-celled, 4 to 12-seeded capsule. Seeds supported by hooks or cup-shaped processes of the placentæ, exalbuminous.

Genera 155, species 1450, chiefly tropical, fo few only, extending Into the United States. They are mostly destitute of active properties, and in aspect mero weeds. Tet among them are many remarkable for their beauty. Acanthus mollis is celebrated as having, by its leaves, suggested the style of the Corinthian capital in ar chitecture.

I. ANECMATACANTHE E. Seeds destitute of hooked supports. (a)

a Corolla regular. Seerls few, ndnate to a cup instead of a hook........... Tnurmergra. 1

a Corolla bilabiate. Seeds many, with papilla instead of hooks............... Euxraria. 2

II. ECIIMATACANTHEA. Secds subtended by hooked processes. (b)

b Corolla funnel-form, subregular stamens didynamous. (Ruklliks.) (c)

c Anthers 2-spurred at base. Capsule 4-seeded in the middle............ Calopinasns. 3

c Anthers not spurred. Capsule 2 to 16 -seeded from the middle...... Dipteracastuus. 4

c Anthers not sparred. Capsule 12 to 16 -seeded from the base........ Cripuracantuus. 5

b Corolla bilabiate, ringent. Stainens 4. Capsule $\infty$-seeded from the base.Hrgropuru. 6

b Corolla bilabiate. Stamens 2.-Corolla resupinate, upper lip 3-toothed.... Diclipter. $\tau$ -Corolla straight, lower lip 3-toothed. Wild.RuYTigLossA. 8 -Corulla straight, lower lip 3-parted. Cult.Crktantukra. 9 
1. THUNBER'GIA, L. (In honor of C.P. Thunberg, Prof. of Bot. at Upsal). Calyx short, truncate or many-toothed, subtended by 2 bract. lets ; corolla funnel-bell-form, throat inflated, limb 5-cleft, subregular; stamens 4, didynamous; anthers cells parallel, ciliate, one of them awned at base ; capsule globular, 3 to 4 -seeded.-Shrubs or climbing herbs of the Old World.

I T. grandiflòra Roxb. Climbing; lvs. cordate, angled, acuminate, hispid; cal. limb truncate, entire.-In cultivation, a hardy perennial climber, clothed all over with fine reversed hairs, with large blue flowers $1 \frac{1^{\prime}}{2}$ deep and $3^{\prime}$ broad. $+\mathrm{E}$. Ind. Variable.

2 T. alàta Bojer. Twining, silky-villous; lvs. cordate-sagittate, acute, on winged petioles; cal. 12-cleft, bracteoles repand.-In cultivation, perennial, the whole plant soft-villous. Lvs. repand, and 5-veined. Fls. large, yellow, with a purple base, $11_{2}^{\prime}$ deep, campanulate with a curved tube. + E. Africa. Variable.

2. ELYTRA'RIA, Vahl. (Gr. Ě $\lambda v \tau p o v$, an envelope or bract; from the bracted inflorescence.) Calyx 5 or 4-parted, segments unequal; corolla bilabiate lower lip or 3 bifid segments; stamens 2 fertile, 2 sterile, included; anther cells parallel; capsule 8-seeded from the base, without hooks.-Herbs acaulescent, with radical lvs. Scape covered with appressed leaf-like, clasping scales. Fls. small, one beneath each bract of the terminal spike.

1 E. virgàta Mx. Scapes several, slender, terete, glabrous, erect, covered with ovate, clasping, cuspidate, alternate scales; lvs. radical, narrow-oblong, tapering long to the petiole, repand or wavy; fls. in a dense, imbricated spike, each flower covered by a broadly ovate, coriaceous, cuspidate, ciliate scale; cal. with 2 linear bractlets which are villous-ciliate as well as the segments; cor. white, with its 5 segm. nearly equal.- Wet plains S. Car. to Fla. (Mettaucr). Scapes If high. Lvs. 3 to $6^{\prime}$ long, 5 to $8^{\prime \prime}$ wide. Fls. $4^{\prime \prime}$ broad. Summer. (Anonymus Carolinensis Walt.)

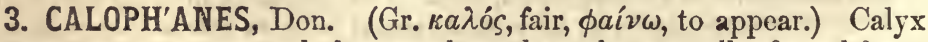
segments setaceous, much longer than the tube; corolla funnel-form, limb subregular, 5 -lobed; stamens 4 ; anther cells spurred or mucronate at base, parallel; capsule lanceolate, empty below, 4-seeded in the middle; flowers axillary, opposite, mostly solitary, with narrow bracts and bractlets.-Low, pubescent herbs with blue corollas spotted in the throat.

1 C. oblongifolius Don. Densely pubescent, ascending from a procumbent or creeping base; lvs. obovate, obtuse, obscurely denticulate, narrowed to the subsessile"base; fls. solitary, subsessile, opposite, with oblong bractlets equaling the deeply parted calyx and the corolla tube.- 4 Pine barrens and gravelly plains, Ga. and Fla. common. Herb 6 to 12 ', branched at base, simple above. Lvs $I^{\prime}$ long, rarely rather acute. Cor. showy, a littlo exceeding the lvs., purplish blue, with deeper purple spots. Apr. (Ruellia oblongifolia $\mathbf{M x}$. Ph.)

2 C. humistratus Shutt. Smooth, prostrate, diffuse; lvg. oblong, oral, rather obtuse, entire, narrowed to a petiole; fls. axillary, subsessile, solitary or 2 or 3 together; bracts oblong-spatulate, shorter than the strict, setaceous calyx segm.I S. Car. to Fla., in rich soils. Lrs. distinctly petiolate. Cal. segm. very slender, scabrous, membranous edged below, $5^{\prime \prime}$ long, equaling the 4-seeded capsule. (Ruellia humistrata, Mx.)

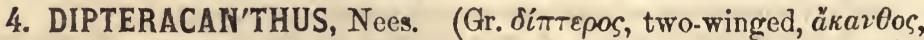
Acanthus.) Calyx deeply 5-cleft ; corolla funnel-form, limb subequally 5-lobed; stamens 4, included; anther cells parallel, not awned ; capsule compressed and empty at base, 2 to 12 -seeded above ; seeds orbicular, compressed, with hooked, abrupt processes.-Mostly herbs with 
opposite, solitary or fascicled flowers. Bracts leafy, often stalked. Fls. large, showy, blue or purple.

3. D. strèpens Nees: Herb erect: lvs. ovate or obovate-oblong, somewhat repand, cuneate at base and petiolate, smootnssh or thinly downy; ped. axillary, very short, about.3 (1 to 4)-flowered; bractlets lance-oval, equaling or exceeding the calyx; sep. lance-linear, ciliate, a little shorter than the tube of the loug-funnel-form corolla. Dry soils, Mid. W. and S. States, common. Plant variable, 9 to $16^{\prime}$ high, often branched, nearly smooth. Lvs. large, 2 to $3^{\prime}$ long, the fls. half or two-thirds as long. Caps. oblanceolate, 6-seeded or by abortion fewer. Hooks grooved. Jn.Sept. (Ruellia strepens L.)

2 D. ciliòsus Nees. Herb erect, hoary-hirsute; lvs. ovate, the lower obovate, . upper oblong, all obtusish at apex and abrupt at base, subsessile; fls. subsessile, with oblong or lanceolate bracts not longer than calyx; sep. setaceous, hairy, not half as long as the long tube of the corolla.-Rich soils W. and S. States. Plant if or more high. Lvs. 18 to $30^{\prime \prime}$ long, the fls. nearly as long. A variety has smaller leaves almost dentate. (Ruellia ciliosa $\mathrm{Ph}$.)

B. HYBRIDUS. Low, decumbent, very hirsute.-Near Savannah (Feay). Stems 2 to $4^{\prime}$ long, with short internodes. Fls. sometimes shortened.

3 D. noctiflorus Nees.-Cal. segm. linear-banceolate, thrice shorter than the very long corolla tube. Otherwise as in D. ciliosus,-Ga. (near Savannah, Lo Conte) and Fla. (Ruellia tubiflora Le Conte.)

5. CRYPHIACAN'THUS, Nees. (Gr. кpv́фıos, clandestine, äkav0os.) Calyx deeply 5-parted, spreading in fruit; corolla bell-funnel-form, limb equal ; stamens 4, included; anthers sagittate; stigma simple; capsule oblong, terete, 12 to 16 -seeded from the base; seeds roundish, cordate, compressed, silky, subtended with hooks.-Herbs villous, with corm-like base and fasciculate roots. Ped. 3 -flowered.

C. Barbadénse Nees. Caulescent; lvs. ovate, cuneate at base and petiolate, entire or undulate-dentate, smocthish or hairy; ped. somewhat cymous, longer than the petiole or even than the leaves; cal. segm. subulate-acuminate, glandular, hirsute; cor. tube shorter than the limb. $-4 \mathrm{~A}$ low, leafy plant, Va. to Fla., Tex. Mex. \&c. (Nees). (Ruellia tuberosa and clandestina L.)

6. HYGROPH'ILA, R. Br. (Gr. $\dot{v} \gamma \rho \dot{\eta}$, waters, $\phi \iota \lambda \dot{\varepsilon} \omega$, to love.) Calyx tubular, about half 5-cleft, with narrow, equal segments; corolla bilabiate, ringent, lower lip convex and rugulous in the midst, trifid; stamens 4 , didynamous, not exserted; anther cells divergent-sagittate, violet-colored; stigma simple, subulate; capsule 6 -striate, $\infty$-seeded from the base; seeds small.-Herbs in swamps, \&c., stoloniferous, 4-angled. Fls. clustered in the axils.

H. Lacústris Nees. Erect, subsimple, minutely pubescent; lvs. lanceolate, narrowed to both ends, sessile, subentire; verticils many-flowered; cal. smoothish.-Borders of lakes near N. Orleans. (Hale). Stems 1 to $2 \mathrm{f}$ high above the water, very straight and simple. Fls, white. (Ruellia justiciæflora Hook.)

7. DICLIP'TERA, Juss. (Gr. $\delta \iota \varsigma$, double, $\kappa \lambda \varepsilon i \omega$, to shut; referring (to the 2-valved capsule.) Calyx 5-parted, equal, sessile, in a bracted head; corolla resupinate, bilabiate, upper lip 3-toothed; stamens 2 ; anther cells straight, placed one above the other; capsule 4-seeded; dissepiment and walls separating from the back of the valves and curving upwards; seeds discoid, on hooks.-Herbs with the small flowers in axillary, involucrate, finally terminal heads.

D. brachiàta Spr. St. 6-angled, brachiate-branched, glabrous; lvs. orate-oblong, subentire, obtusely acuminate, contracted at base to a long petiole; hds. fewflowered, sessile or the lower on a leafy peduncle, the upper at length spicate; involucrate lvs. very unequal; oapsule oval the valves first curving backwards 
then each splitting from the dorsal rib and curving upwards fiom the base.Roanoke R., N. Car. (Pursh) to Ga. (Pond) and La. (Hale). Plant 2 to $3 f$ high, lvs. 2 to $3^{\prime}$ long, on stalks half as long. Fls. purple, 5 or $6^{\prime \prime}$ long.

8. RHYTIGLOS'SA, Nees. (Gr. $\dot{\rho} v \tau i s$, a wrinkle, $\gamma \lambda \tilde{\omega} \sigma \sigma a$, tongue; referring to the wrinkled palate.) Calyx 4 or 5-parted; corolla bilabiate, upper lip narrow, lower 3 -lobed, with a rugous, veiny palate; stamens 2 ; anther cells more or less distinct, subtransverse, placed one above the other; capsule compressed, 4-seeded from the middle upwards; seeds tuberculate, with hooks.-Herbs, loose-leaved, with axillary or spicate, bracted flower's.

1 R. pedunculòsa Nees. Erect, angular, very smooth; lvs. long-lanceolate, scarely oblique or ensiform, obscurely crenato or wavy, subpetiolate; spikes axillary, subcapitate, on very long peduncles opposite or alteruate; bracts and sepals lanceolate, subequal, half as long $\left(3^{\prime \prime}\right)$ as the ringent corolla; lower half of the capsule empty, valves recurved when ripe.-River banks, Niagara to Tex. and Ga. Plant 2 to 3 f, Irs. 2 to $4^{\prime}$ by 6 to $12^{\prime \prime}$. Corollas $6^{\prime \prime}$ long, violet-purple. Caps. same length. Jn. Jl. (Dianthera Americana L. Justicia pedunculosa Mx.)

2 R. ensifórmis. Decumbent at base, then erect, very slender, 4-angled, smooth; lvs. linear, oblique or ensiform, very encire, thick, sessile; peduncles subterminal, very long; spikes at length loose-flowered; bracts half as long as the linear subulate sepals which are a third as long as the showy corollas.-E. Ga. to Apalachicola, Fla. St. 1 to $2 \mathrm{f} \mathrm{high,} \mathrm{in} \mathrm{bogs.} \mathrm{Lrs.} 3$ to $6^{\prime}$ by 2 to $3^{\prime \prime}$. Ped. twice as long. Cor. purple, $1^{\prime}$ or more long, resembling those of Arethusa. Confounded with the preceding hitherto, but very different. (Justicia ensiformis Walt.?)

3 R. húmilis Nees. Glabrous, ascending, 4-angled; lvs. oblong or lanceolate, or the lower oval, obtusish, subcrenate, attenuate at base to a short petiole; spikes simple, axillary, pedunculate; fls. loose, mostly secund; bractlets much shorter than the subulate calyx lobes, which equal the tube of the small corolla; caps. acuminate, the lower half empty and stalk-like.-S. Car. to Fla. and La. Flant 1 to if high, often much lower. Lvs. 2 or $3^{\prime}$ long, the spikes at length exceeding them, 5 to 10 -flowered. Cor. 5 "long, light purple? (Justicia humilis Mx.)

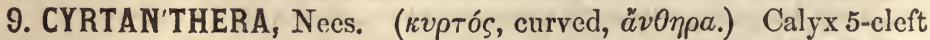
or parted, equal; corolla ringent, upper lip falcate, lower in 3 narrow segments; stamens 2 , recurved at apex, anthers short, nodding, capsule 4-seeded ?-Herbs from tropical America, with showy clusters of flowers.

C. carnea. Stem stout, tall, half-shrubby; lvs. ample, ovate, subdeltoid or ovaloblong, long-cuneate at base, petiolate; bracts and bractlets' lanceolate, acuminate, ciliate, larger than the caly $x$; fis. in a dense, thyrse-like, terminal head, light purple or flesh-colored, large, many in bloom at once.-In the greenhouse. $f$ (Justicia carnea Hook. C. magnifica Nees.)

\section{Order LXXXVIII. VERBENACEA. Vervains.}

IIerbs (or generally shrubs and trees) with opposite, exstipulate leaves. Flowers with a bilabiate or more or less irregular monapetalous corolla. Stamens 4, didynamous, rarely equal, sometimes only 2. Style 1. Fruit dry or drupaceous, 2 to 4-celled (1-celled in Phryma) forming as many 1-seeded nutlets. Seeds erect or pendulous, with little or no albumen.

Genera 56, species 700, the herbs chiefly natives of temperate regions, the shrubs and trees of warm and tropical regions, where in some instances they are very large. The Teak-tree (Tectoria grandis) of India, justly styled the "Oak of the East" is a timber tree of great size, often 100 feet in height. The wood is greatly durąble, and contains silex. Medicinal properties unimportant. The order affords anany fine ornaments for the garden.

\section{GENERA.}

\$ Ilerbs. Fruit dry, -of 41 -seeded carpels. Corolla 5-parted.......... Vermexa. 1 -of 2 one-seeled carpels. Corolla 4-parted...........Lippia.

-of 1 one-sceded nutlet. Corolla bilabiate........... Pнrтм. 
5 Shrubs. Fruit fleshy.-Flowers 4-parted, axillary. Drupe 4-seeded..... Caluricarpa. 4 -Flowers 4-parted, axillary. Drupe 2-seeded......Lantana. 6 -Flowers 4-parted, terminal. Drupe 2-seeded.... A Alorsia. 6 -Flowers 5-parted.-Seeds 4. Leaves simple...... Crerodendorum. 7 -Seed 1. Leaves compound...Vrirx.

1. VERBE'NA, L. Vervann. (Celtic fer-foen, to expel stone; hence Eng. vervain, Lat. verbena.) Calyx 5-toothed, with one of the teeth often shorter; corolla funnel-form, limb somewhat unequally 5-lobed; stamens 4 , included, the upper pair sometimes abortive; drupe splitting into 4, 1-seeded, indehiscent carpels.-Herbs or undershrubs. Lrs. opposite. Fls. sessile, mostly in spikes or bds.

* Spicate ; the open corollas lateral in slender spikes. (a)

a Stem simple (mostly) bearing a single spike. Leaves oblong................... 1, 8

a stem branched, with many spikes. -Leaves mostly simple............................ -Leaves much divided........................ Nos. $6=8$

* Corymbed; the open corollas forming a terminal (spike) corymb...................... Nos. 9-11

1 V. angustifòlia Mx. Erect, mostly simple; lvs. oblong-linear, tapering to the base, remotely serrate, with furrowed veins; spikes filiform, solitary, axillary and terminal ; cor. blue; bracts as long as calyx. A small, hairy species found on rocky hills and other dry soils, N. Y. to Va., W. to the Miss. St. not more than a fcot high, with narrow ( 2 to $3^{\prime}$ by 3 to $\left.5^{\prime \prime}\right)$, rough lvs. and slender spikes of deep blue fls. Jl. (V. rugosa Willd.)

2 V. Caroliniàna L. Assurgent subsimple; scabrous-puberulent; lvs. oblongobovate, obtuse or bluntly acute, crenate-dentate, sessile; fls. in a lcose terminal spike; cor. large, rose-colored; bracts minute, half as long as the calyx; carp. 4, not separating. - 2f Dry soils, S. States, common. St. 1 to $2 \mathrm{f}$ high. $\mathrm{Lrs}_{8} 18^{\prime \prime}$ to $3^{\prime}$, varying to oval, and in some specimens decidedly hastate! often acute. Spike 6 to $12^{\prime}$ long. Fls. showy, $6^{\prime \prime}$ long, cal. 2". May-Jl.

3 V. hastàta I. COMMON VERVAIN. Erect; lvs. lanceolate, acuminate, incisely serrate, petiolate, the lower ones lobed or hastate; spikes erect, dense, slender, panicled; fls. imbricated.-24 Frequently by roadsides and in low grounds, mostly throughout the U.S. and Can. St. 3 to $6 f$ high, with paniculate, opposite branches above. Lvs rough and rugous, 2 to $4^{\prime}$ long, variously toothed. Fls. small, blue, arranged in long, close, imbricated spikes which are erect and parallel. Jl.-Sept. §Eur. (V. paniculata Lam.)-Varies with the Ivs. incised or pinnatifid, and spikes loose-flowered;- - evidently hybrids. (Engelm.)

4 V. urticæfòlia I. Erect, subpubescent; lvs. ovate and ovate-lanceolate, serrate, acute, petiolate; spikes axillary and terminal, loose filiform; fls. separate; bracts shorter than the calyx. $-2 f \Lambda$ bout roadsides and rubbish. $\Lambda$ weed of uninviting appearance, 2 to $3 \mathrm{f}$ high, with lvs. resembling those of the nettle. It has long, slender, weak, green divergent spikes remotely filled with small, white, distinct llowers. Seeds 4. J., Aug. §Eur."

5 V. stricta Vंent. MulleIN-LEAVEd Vervain. Hirsute and hoary; st. thick rigidly erect, branched abovo; lvs. oval or obovate, unequally dentate, sessile, acute, rugous; spikes erect, strict, imbricate and dense-flowered.-2f An erect, rigid, and rather handsome species, in dry fields, W. States, common. Very hirsute, 1 to $3 \mathrm{f}$ high. Lrs. 2 to $3^{\prime}$ by 1 to $2^{\prime}$, numerous, veiny and whitish bereath. Cor. blue, thrice larger (4" broad) than in V. bastata. Jl.

$6 \mathrm{~V}$. bractiòsa $\mathrm{Mx}$. Decumbent, branched, divaricate, very hairy; lvs. laciniate, rugous; spikes terminal, thick, many-flowered; bracts lance-linear, longer than the fls., thrice longer than the calyx. - 2f Dry fields and roadsides, Mid. W. and S. States. Whole plant hairy and hoary, 8 to $16^{\prime}$ long, remarkablo for its squarrous, bracted spikes. Lvs. 1 to $2^{\prime}$ long. Fls. small, blue. Jn.-Sept. (Zapania, Lam.)

7 V. spùria I. Assurgent, divaricately branching, hairy; lvs. ovate-lanceolate, 3-cleft, laciniately lobed and toothed; spikes slender, loose; bracts a little longer than the calyx. - 2f Conn., Md. to Ga. An unsightly plant, with a square stem, 1 to $2 \mathrm{f}$ high, half ercet, di- and trichotomous above. Lrs. attenuate and subpetiolate at base. Spikes 3 to $6^{\prime}$ long, dense before flowering, loose after. CRl. $1^{\prime \prime}$ long, cor. $2^{\prime \prime}$, blue. Aug., Sept.-Differs from V. officinalis of Europo in its petiolate lvs and longer bracts. 
8 v. strigòsa Hook. Erect, rigid, strigous-pubescent, hoary, branched; lvs. ob. long, 3-parted to the base, incisely lobed and toothed, sessile; fls. in loose, strict spikes; cor. large; bracts as long as the calyx; carp. 4, not separating. $-\mathrm{N}$. Orleans (Hale). St. hollow, 2 to $3 \mathrm{f}$ high, acutely 4 -angled. Lf. lobes all acute, very veiny. Cor. purple? 4 to $5^{\prime \prime}$ long.

9 V. Aubletia I. Weak, assurgent, rather hairy; lvs. ovate-oblong, 3-parled, pinnatifid or incisely lobed and toothed, acute at base and petiolate; spikes solitary, pedunculate; bracts half as long as the cylindrical calyx; corollas showy, corymbed, segm. emarginate.-(1) Va. to Ill. (Lapham), La. and Fla. in dry soils, also in gardens where its beautiful flowers present every variety of color. Apr., Nay.

10 V. chamædrifòlia Smith. Ascending, hispid; lvs. oblong, acute, serrate, lower somewhat lobed, upper subentire; spike long-peduncled; bracts a third as long as the long-cylindric calyx; cor. showy, corymbed; segm. emarginate.- if Many of the pretty garden Verbenas aro varieties of this species from Buenos Ayres.

11 V. sororia Don? Prostrate, somewhat hairy; lvs. multifid, with narrow, ciliate segments; spikes pedunculate, short; bracts half as long as the slender calyx; cor. small, lobes emarginate.-Garden Verbenas, with much smaller flowers, usually pure white. † Asia.

2. LIP'PIA, L. Fog-Fruir. (To Augustus Lippi, a French physician.) Calyx 2-parted, compressed, erect, membranous, shorter than the tube of the corolla; corolla funnel-shaped, limb sublabiate, upper lip entire or emarg. lower 3-lobed; stam. didynamous, included; drupe dry, thin, enclosed in the calyx, 2-seeded.- Shrubs or prostrate herbs, with opposite lvs. IIds. of fls. on axillary peduncles. (Zapania, Juss.)

I. nodiflòra Mx. Glabrous, procumbent; st. 4-angled, geniculate, simple, lvs. lanceolate, varying to oblanceolate, obtuse or acute, cuneate at base, petiolate, shorter than the peduncles. - 2f On river banks, Penn. to Ind., Ill. and La. Sts. If or more long. Lvs. with conspicuous veins, 1 to $2^{\prime}$ long, $\frac{1}{3}$ to $\frac{1}{2}$ as wide, potioles 3 to $6^{\prime \prime}$. Ped. 2 to $3^{\prime}$. Hds. ovoid or roundish, at length cylindric-oblong. Fls. small, purplish white. Л., Aug. (Z. nodiflora and lanceolata Ph. \&c.)

3. PHRY'MA, L. Lop-seed. Calyx cylindric, bilabiate, upper lip longer, 3-cleft, lower lip 2-toothed; corolla bilabiate, upper lip cmarginate, much smaller than the 3.lobed lower one; stamens included; fruit dry, oblong, striate, 1-celled, 1-seeded.-2f Inerbs with opposite lvs. Fls. opposite, spicate, deflexed in fruit.

P. Ieptostáchya I. Rocky woods, Can. and U. S. Stem 2-3f high. Leaves large $\left(3-6^{\prime}\right.$ long), thin and coarsely toothed, on short stalks. Fls. small, opposite, light purple, in very long and slender spikes, of which one is terminal, the rest opposite and axillary, each often with a pair of bracts below. After flowering the calyx closes upon the fruit and becomes reflexed baekwards close to the stem. Jl.

4. Callicar'Pa, L. French Mulberry. (Gr. ká $\lambda \lambda o s$, beautiful, картós, fruit; for its abundant purple berries.) Calyx 4-toothed, bellshaped; corolla short-bell-shaped, limb of 4 obtuse segments; stamens 4, unequal, exserted; stigma capitate, 2-lobed; drupe juicy, enclosing 4 nutlets.-Shrubs with opposite lis. and axillary, subumbellate fls.

C. Americána $\mathrm{I}_{\text {. }}$ Branches and Irs. beneath downy; Ivs. ovate, acuminate at each end, crenate-dentate, smooth above; clusters cymous compound, shorter than the petioles; fruit forming dense verticils. - Light soils. S. States common. Shrub much branched, 3 to 5 f high. Lvs. 3 to $5^{\prime}$ by 2 to $3^{\prime}$ discolored beneath. Fis. small, purple. Berries abundant, as large as in Elder, sweetish. May-Jl.

5. LANTA'NA, L. (An ancient name for the Viburnum; from tho resemblance.) Calyx membranous, minute, obsoletely 4-toothed; cor. 
funnel-form, the tube long-exserted; limb oblique, sublabiate, upper lip bifid or entire, lower trifid; stam. didynamous, included, inserted in the cor. tube; drupe fleshy, double, the parts separable, 1-seeded.-Tropieal shrubs with square stems, opposite leaves, and capitate, showy flowers.

1 L. Cámara L. Branches and ped. scabrous-pubescent, often aculeate; lrs. ovate and ovate-oblong, or subcordate, short-petiolate, serrate; reticulate-rugous, scabrous; ped. many, dense-flowered, subumbellate, as long as the leaves; bracts lance-linear, half as long as the corolla.-S. Ga., Fla. to La., and S. to Brazil. Shrub 2 to $6 \mathrm{f}$ high. Fls. at first golden yellow, soon becoming orange and finally red. Drupes small, blue. Jn. - Aug. (L. Bartramii Baldw.) $\dagger$

2 I. míxta L. Plant pilous-hirsute, with wide-spread branches, mostly armed with reversed prickles; lvs. shaped as in No. 1; ped. longer than the leaves; bracts linear-lanceolate, hairy, the outer as long as the corolla.-Greenhouse shrub 3 to $4 \mathrm{f}$ high. Fls. at first whitish, then yellow, next orange, lastly red. $\dagger$

6. ALOYS'IA, Ortega \& Palan. (To Mary Louisa, queen of Spain, mother of Ferdinand.) Calyx deeply 4-eleft; corolla tubular, limb 4lobed, oblique; stam. didynamous, included; capsule double, parts 1 seeded; stig. emarginate.-Shrubs with the small fls. in a panicle of spikes or racemes. From S. Am. (Lippia, Sehauer.)

A. citriodòra Kunth. LeMroN-SCENTEd ALOYSIA. Smooth or the branches roughish; lvs. verticil. in $3 \mathrm{~s}$ and $4 \mathrm{~s}$, linear-lanceolate, short-petioled, acute at each end, mostly entire, glandular-punctate beneath, coriaceous, with divaricate, straight veinlets; panicle terminal, naked or leafy below.-Gardens, cult. for its delightful fragrance which is exhaled by the numerous small fls. as well as the bruised leaves. + Paraguay.

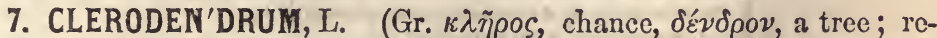
ferring to its doubtful medicinal effects.) Cal. bell-shaped, 5-toothed; cor. salver-form, tube often elongated, limb subequally 5 -cleft; drupe baccate, 4-carpeled, carpels, 1-seeded.-Tropical shrubs or trees, with opposite leaves and fls. in cymes.

1 C. paniculàtum L. Lrs. long-petioled, cordate-hastate, 5 to 7-lobed, lobes acute; panicle of cymes terminal, large, pyramidal; cor. tube slender, 4 times longer than the calyx.-Shrub with ample leaves and scarlet ( $6^{\prime \prime}$ long) corollas. + Asia.

2 C. squamàtum Vahl. Lvs. roundish, deeply reniform-cordate, lobes acuminate, repand-dentate; pyramidal panicle terminal, loose, wholly colored.-Shrub 8 to 10 figh. Fls. scarlet. Stam. long-exserted. Cor. limb rovolute. † Japan. -Other species are rarely cult.

8. VITEX, L. Chaste-tree. Calyx 5-toothed; cor. cup-shaped, limb 5-lobed; bilabiate; stem. didynamous, ascending, exserted; drupe entire, 4-celled, 4-seeded.-Shrubs with opposite, mostly digittatc leaves, and paniculate cymes.

I v. Negúndo. Leaves long-petiolate, digitately ternate or quinate, lits. oblong, acuminate, serrate; panicle compound.-Shrub if high. Cor. purple, pulverulent. Stam. little exserted. + Mauritius.

2 V Agnus-cástus L. Lvs. long-petioled, 5-7-foliate; lfts. lanceolate, acuminate, entire; panicles terminal and axillary, interrupted; cymes subsessile.-Shrub 6 f high. Cor. pale, lilac. Stam. long exserted. † S. Eur.

\section{Order lixxix. Labiate. Labiate Plants.}

Herbs with square stems and opposite, aromatic, exstipulato leares. Flowers axillary, in verticillasters, sometimes as if spiked or in heads. Corolla labiate 
(rarely regular), upper lip 2-cleft or entire, arched or almost wanting, overlapping in bud the lower 3-cleft, usually larger lip. Stamens 4, didynamous, or only 2. Anthers 2-celled, cells often separated. Ovary free, deeply 4-lobed, the single style arising from the base of the lobes. Fruit composed of 4 , or by abortion fewer, separable, 1-seeded nuts or achenia.

Illustrations in Figs. 75, 86, 117, 325, 273, 351.

Genera 125 , species 2350 , chiefly natives of temperate reglons, being most abundant between Latitudes $40^{\circ}$ and $50^{\circ}$ of the northern hemisphere.

Properties - This well known family is universally pervaded by an aromatic, volntile oil, and a bitter principle; the former rendering them eminently tonic, cordial, and stomachie; the latter, where it prevails, febrifugal. The Pennyroyal, Lavender, Suge, Hoarhound, Thyme, Spearmint, Peppermint, Horsemint, Rosemary, \&c., dec., plants whose qualities are too well known to require particular mention here, are all members of this useful family. Not one spo cies is poisonous or even suspicious.

\section{TRIBES AND GENERA.}

\$ Stamens 2, perfect, -ascending beneath the galea ; anthers 1-celled. (Tribe IV.) - exserted, dlstant; anthers 2-celled (d).

5 Stamens 4, perfect, -all declined towards tho lower lip. (Tribe I.) -erect, or ascending towards the upper lip (2).

2 Stamens of equal length, corolla almost regular, 4 to 5-lobed $\left({ }^{*} e\right)$.

2 Stamens, the upper pair longer than the lower (outer) and calyx 18 to 15-veined. (Tribe V.)

2 Stamens, the lower pair longer than the upper (Interior) pair (3).

3 Stamens divergent, apart, mostly straight and exserted (e).

3 Staniens parallel, ascending and long-exserted from the upper side (b).

3 Stamens parallel, ascending in pairs beneath the upper lip (4).

4 Calyx 13-veined, 5-toothed, and somewhat 2-lipped (f).

4 Calyx 5 to 10-veined, or irregularly netted (5).

5 Calyx strongly 2-lipped, npper lip truncate, closed in frult (h).

5 Calyx not 2-lipped, 3 or 4-lobed, open in fruit (k).

5 Calyx subequally 5 -toothed, teeth not spinescent $(m)$.

5 Calyx subequally 5 -tcothed, teeth spinescent $(n)$.

5 Calyx unequally $s$ to 10 -toothed $(0)$.

I. OCIMOIDE.E.-Corolla upper lip 4-lobed, lower entire, flattish............... Ocruru. 1

-Corolla upper lip 4-lobed, lower saccate, deflexed............... Ir ripris. 2

-Corolla upper lip 2-lobed, lower 3 -lobed.................Lavanduca. 3

II. $\triangle J U G O I D E A .-b$ Stamens exserted through a fissure in the tube..........TEUCRIUM. 4 b Stamens very long, involute, arching the corolla.... Tricuostemsa. 5 *c Corolla limb equally 5 -lobed. Stamens short............ Isaxturs. 6

III. SATUREJEAE-(Stamens direrging or ascending, 2-celled. Cor. lobes flattish, spreading.)

${ }^{*} c$ Corolla limb 4-lobed, upper lobe broadest................Mentha. 7

d Corolla nearly regular, 4 -lobed. Calyx naked in the throat................ Lrcopus. 8

d. Corolla bilabiate, -cyanic, throat naked. Stamens straight.............CuniLA. 9

-cyanic, throat naked. Stamens ascending............ HEDEOMA. 10 -yellow, throat with a hairy ring inside........... Colninsonin. 11

- Calyx 15-reined. Stamens exserted, divergent......................... Hrssopus. 12 e Calyx 10-veined, the veins obscured by hairs. Cor. yellow, fringed..... Colussonia. 11 - Calyx 10 to 13-veined,-throat naked.-Stamens straight, divergent.. Prcsantuenux. 13 -Stamens ascending, anth. spurless..S ATUREJA. 14 -Stamensaseending, anth. spurred.DieeraNDra. 15 -throat hairy-Bracts roundish, large............. OrıGanum. 16 -Bracts narrow, minute................TuYsurs. 17

$f$ Tube of the corolla straight. Leaves small, subcrenate or entire.............. CALAMINTIA. 18 f Tube of the corolla curved upwards. Leaves large, coarse-erenate...........Menissa. 19

IV. MONARDE E.-Connectile long, transverse, distaneing the anther cells........SALVIA. 20 -Conneetile continuous with fil. thothed at the juncture.... Rosma rixus. 21 -Connectile inconspicuous.-Calyx subequally toother.........Monanda. 22 -Calyx bilabiate, aristate...... Buepurulia. 23

V. NEPETE AE.-Stamens distant, exserted. Flowers in terminal spikes........ Lopisantulus 24 -Stamens all ascending.-Anther cells divergent, much........... NePETA. 25 -Anther cells divergent, little... Dracocepilal.cm. 26 -Anther cells parallel. Fls. large...Cedrosella. 27

VI. STACHYDE RE-(Stamens parallel, ascending. Cor. upper lip galeate. Cal. 5 to 10-veined.) h Calyx lips toothed, upper 3 teeth minute, lower 2 large................. PruNsLla. 28 
h Calyx lips entire, upper with an appendage on the back............. ScrtelLaria. 29

k Calyx 3-lobed. Anthers all distinct. Flowers purpie streaked........MAcBridra. 80

k Calyx 4-lobed. Anthers, the highest palr connate................. SYNANDRA. 31 $m$ Corolla tube Inflated in the midst, whitish. Lips smail............... Puysosteg IA. 32 $m$ Corolla tube inflated at the throat, purple. Lower lip long................. LAMrux. 33 m Corolla infiated in the broad, concave upper lip, purple or yellow........... PuLoxis. $3 t$ $m$ Corolla not inflated, short.-Calyx salver-form, 10-ribbed.............. BA.LLota. 35

-Calyx broad-bell-form, netted............ Moluuckula 36

n Anthers opening transversely, ciliate fringed. Lvs. notched.......... GALEOPsis. 37

n Anthers opening lengthwise. -Achenia rounded at the top............. SтАсн Ys. 38 -Achenla truncate, 3 -angled at top........ LEovurus. 39

o Corolla white, upper lip flattish. Style equally bifid............. Marrubium. 40

- Corolla white, upper lip concave. Style unequally bifd............ LeUCAs. 41

- Corolla scarlet, exserted. Calyx upper tooth longest................ LEonotr., 42

1. O'CIMUM, L. Sweet Basil. (Gr. ő $\zeta \omega$, to smell; the plants arc strongly aromatic.) Upper lip of calyx orbicular, lower 4-fid ; corolla resupinate, one lip 4-cleft, the other undivided; stamens 4, declined, the lower pair longer, the upper often with a process at their base.Verticels 6-flowered, in terminal, interrupted racemes.

O. basilicum L. Lvs. smooth, ovate oblong, subdentate, petiolate; cal. ciliate.-(1) Plant 6 to $12^{\prime}$ high, with peculiarly smooth and soft leaves, variously colored, exhaling a delightful odor. St. retrorsely pubescent above, branched. Stam. exserted. Fls. white or bluish. Jl., Aug. $\ddagger$ E. India. Cultivated as a culinary herb.

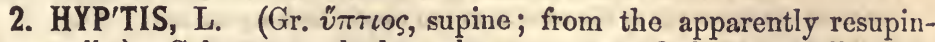
ate corolla.) Calyx 5-toothed, teeth acute or subulate; corolla tube cylindric, limb 5-lobed, the lower abruptly deflexed, contracted at its base, the 4 others flat, erect or spreading; stamens 4, declinatc; achenia ovoid or oblong.- In our species the flowers are capitate.

1 H. radiàta Willd. Herbaceous; lvs. glabrous, lance-ovate, unequally crenateserrate, narrowed to a petiole; hds. globular, long-pedunculate; bracts lanceoblong, obtuse, forming an involucre, longer than the calyx, as if radiate; cal. teeth acutely subulate, rigid. - 2f In damp fields, Car. to Fla. and La., common. St. $18^{\prime}$ to $3 \mathrm{f}$ high, square and hollow. Lrs. with their stalks 3 to $5^{\prime}$ long. Hds. hemispherical in flower, in fruit globular. Invol. about 12-leaved. Jl.-Sept.

2 H. spicàta Poit. Branches aculeate-scabrous on the angles; lvs. ovate, unequally serrate, acute, petiolate, whitish puberulent beneath; hds. loosely racemed, semi-oval, scarcely as long as their peduncles; racemes panicled; bracts ovate, much shorter than the calyx. - If In Fla. Plant 1 to $2 \mathrm{f} \mathrm{high.} \mathrm{Hds.} 4$ to 7 -flowercd. Cal. inflated at base, truncate, with short, setaceous teeth. Cor. violet-blue.

3. LAVAN'DULA, L. Lavender. (Lat. lavare, to wash. Used in perfumery.) Calyx ovoid-cylindric, with 5 short teeth, the upper one often largest; corolla upper lip 2-lobed, lower 3-lobed, lobes all nearly equal; tube exserted; stamens included.- 4 .

I. spica I. Lvs. linear-oblanceolate, tapering to the base, sessile, revoluto at the edge, the upper ones linear-lanceolate, the highest shorter than the calyx; spike interrupted; bracts subulate.-Plant $12-18^{\prime}$ high, suffruticous, branching from the base. Leaves crowded at the base of the branches, clothed with a whitish down. Calyx villous. Cor. much exserted, lilac-colored. Jl. ‡-The plant is delightfully fragrant, and by distillation yields the well known oil of lavender.

4. TEU'CRIUM, L. Germander. (Teucer, the founder of Troy, is said by Pliny to have first employed it medicinally.) Calyx subcam. panulate and subregular, in 5 acute segments; corolla with the 4 upper lobes nearly equal, the lowest largest, roundish; stamens 4, exserted from the deep cleft in the upper side of the tube. 
T. Canadénse L. Plant erect, hoary-pubescent; lvs. lanceolate, acute, serrate, petiolate; bracts linear-lanceolate, about as long as the calyx; spike long, of many crowded verticils of flowers; upper teeth of calyx broader.- 4 Can. and U. S., fields and road-sides. St. about $2 \mathrm{f}$ high, usually simple, square, with concave sides. Irs. 3 times as long as wide, somewhat rounded at base, green above, more or less hoary beneath. Fls. disposed in a terminal spike. Cor. purplish, apparently without the upper lip, instead of which is a fissure through which the stamens are exserted. Jl.

$\beta$. VirginicuM. Lvs. ovate-oblong, crowded, large, subsessile. (T. Virginicum $\mathrm{L}$. ) - A well marked variety.

5. TRICHOSTEM'MA, L. Blue Curls. (Gr. $\theta \rho i \xi$, hair, $\sigma \tau \tilde{\eta} \mu a$, stamen; for its long, hair-like filaments.) Calyx very oblique, veiny, unequally 5-toothed, lower lip of 2 short teeth, upper twice as long, of 3 teeth, all acute; corolla tube slender, short, limb obliquely 5 -lobed; stamens 4, filaments very long, exserted and curved; anther cells divaricate.-(1) Cymes loose, the central, that is, terminal fls. incurved, or resupinate by the continued growth of the stem. Cor. blue.

1 T. dichótoma I. Lvs. oblong-lanceolate, attenuate at base, obtuse, entire pubescent, as well as the stem and branches.-Dry or rocky soils, Mass, to Ga., La., Ill. An interesting plant a foot high. St. obtusely 4-angled, hairy, bushy. Branches opposite and dichotomous. Ivs. slightly petiolate, ' 1 ' to $18^{\prime \prime}$ long, 4 to $\eta^{\prime \prime}$ wide. Fls. axillary and terminal, becoming inverted by the bending of the pedicel. Cor. purple. Stam. slender, of a delicate, purplish hue, gracefully bending from the lower lip of the corolla to the upper, forming an arch. Aug.

2 T. lineàre Nutt. Lvs. linear, nearly smooth; st. and branches puberulent.Dry soils, N. Y. (at Salem) to Ga. and La. Very slender, a foot high, branched above, or often its whole length. Lvs. $1^{\prime}$ to $18^{\prime \prime}$ long, $2^{\prime \prime}$ rarely $3^{\prime \prime}$ wide. Cal. very veiny, the short triangular teeth setaceously acuminate. Fls. as in the other, about 4" long. Jl., Aug.

6. ISAN'ThuS, Mx. False Pennyroyal. (Gr. loos, equal, à $\theta 0 c$, the flowers being regular; a character very rare among the Labiatæ.) Calyx subcampanulate, equally 5 -toothed, throat naked; corolla 5-parted, tube straight and narrow, segments of the border ovate and equal; stamens subequal, incurved, ascending, longer than the corolla.- 24 Herb riscid pubescent, with lance-elliptic, entire lis. acute at cach end. Fls. axillary.

I ccruleus Mx.-Branching, leafy, in dry fields, N. and W. States, with the aspect of Pennyroyal. St. rounded, slender, 12-18' high, with branches and lvs. opposite. Lvs. an inch or less in length, and a fourth as wide, distinctly tripliveined. Fls. numerous, 1 or 2 in each axil, blue. Calyx leaves lanceolate, longer than the tube. $\mathrm{\Omega}$.

7. MENTHA, L. Mint. (Mintha, the daughter of Cocytus, is fabled to have been changed into one of these plants.) Calyx equally 5-toothed; corolla nearly regular, tube scarcely exserted, border 4-cleft, the broadest segment emarginate; stamens 4, straight, distant; anther cells parallel ; filaments naked.-2f Strong scented herbs. Fls. in dense verticils.

\$erticils approximating, forming a terminal, leafless spike................... Tos. 1, 2

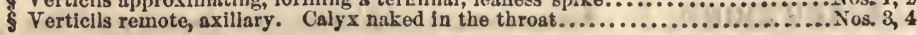

I M. víridis I. Spearmint. Lrs. subsessile, oblong-lanceolate, acute, incisely serrate; bracts setaceous, and, with the teeth of the calyx, somewhat bairy; spikes slender, interrupted, attenuate above.-24 Can. and U. S. Plant highly esteemed for its agreeable, aromatic properties. In wet soils, rapidly spreading by its creep. ing roots, with erect, branching, 4-angled stalks, 1-2f high. Spikes composed of 
distinct, axillary cymes, apparently whorled, a little remote from each other. Peduncles smooth, round, shining. Corollas pale purple. Jl, Aug. § Eur.

2 M. piperita Smith. PEPPERMINT. Lvs. smooth, ovate, and lanceolate, serrate, petiolate; bracts lanceolate; cal. quito smooth at base, punctate; spikes oblong or cylindric, obtuse.-Wet places, and cultivated in gardens. It has a more penetrating taste and stronger smell than the other species, pungent to the tongue, followed by a sensation of coldness. The plant has a purplish stem, 2 to $3 \mathrm{f} \mathrm{high,}$ with scattered, deflexed hairs. Lvs. sharply serrate, dark-green. Spikes seldom more than $1^{\prime}$ in length. Cor. purplish. Jl. § Eur.

3 M. arvensis L. Corn Mint. Field Mint. St. ascending, much branched, retrorsely hirsute; lvs. ovate, serrate, petiolate, acute, rounded or abrupt at base; verticils axillary; pedicels smooth; cal. hirsute.-Penn., Ohio, rare. St. stout, often erect, about if in height. Lvs. varying to oblong or ovate-lanceolate, sometimes nearly smooth, about twice longer ( 1 to $\left.2^{\prime}\right)$ than wide, sereral times longer than the petioles. Fls. small, numerous, pale purple. The plant smells like decayed cheese. Jl. $\S$ Eur.

4 M. Canađénsis L. Horsemrst. Ascending, soft-pubescent with spreađing hairs; lvs. petiolate, lanceolate, serrate, acute at each end; fls. in axillary cymes; stam. generally exserted.-Can. to Ky. and Penn. An herbaceous, grayish plant, 1 to $2 \mathrm{f}$ high, growing in muddy situations. St. square, usually branched and beset with spreading hairs. Lrs. serrate, on opposite, downy footstalks. Fls. apparently in whorls, pale purple. Calyx hairy. Aromatic like Pennyroyal but less so. Jn., Jl.

$\beta$. BOREALIS. Plant nearly smooth. (M. borealis Mx.)

8. LYC'OPUS, L. WATER Hoarhound. (Gr. $\lambda u ́ k o s, a$ wolf, toús, a foot; a fanciful name.) Calyx tubular, 4-5-cleft; cor. subregular, 4cleft, the tube as long as the calyx, upper segment broadest, emarginate; sta. 2 distant, diverging, simple; 3ty. straight, as long as tho stamens; ach. 4, obliquely truncate at apex.-2f Bog herbs, with the very small fis. in axillary, dense clusters.

1 I. Virgínicus I. BugLe WEED. Irs. broad-lanceolate, serrate, tapering and entire at both ends; cal. teeth 4, obtuse, spineless, shorter than the achenia.-Can. and U. S., in wet soils. St. smooth, obtusely 4-angled, with the sides concave, 12 to $18^{\prime}$ high, usually simple, bearing small whorls of minute purplish fls. Lvs. with remote, teeth-like serratures, petiolate or very slender at base. The whole plant often changes to purple. It often sends out long slender runners from tho base. Jl., Aug.

2 L. Europaèus I. Lvs. oblong-lanceolate or lance ovate, petiolate, acute, sinuate-toothed or lobed, the lower incised; calyx teeth 5, acuminate-spinescent, longer than the smooth achenia.-A plant in wet places, widely diffused and exceedingly variable, scarcely two specimens similar. St. 1 to $2 \mathrm{f}$ high, sharply angled rarely stoloniferous. Lrs. 1 to 2 to $4^{\prime}$ long, the segments quite unequal. Clusters very small. Aug. (L. sinuatus Ell., Benth., \&c.)-It dyes a permanent black.

$\beta$. Exaltatus. Lower lvs. pinnatifid, with the segments subserrate; st. usually tall.-With the others, V. to Fla. (L. exaltatus Ph.)

$\gamma$. ANGustifòlius. Lvs. only serrate, narrowly lanceolate or oblong, tapering to both ends. Sometimes nearly entire I Fls. exactly as in the other varieties. S. W. States. (T. angustifolius Nutt.)

9. CUNI'LA, L. Dittany. (The ancient Roman name for Pennyroyal.) Calyx 10-ribbed, equally 5 -toothed, throat densely villous; upper lip of corolla flat, cmarginate; stamens 2, erect, cxserted, distant,

C. Mariàna L. Lvs. ovate, serrate, subsessilo; cymes pedunculate, corymbous, axillary and terminal. - $2 f$ Grows on rocks and in dry woods, N. Y. to Ga. and Ark. Stem 4-angled, mostly purple, branching, smoothish, 1-2f high. Leaves small, nearly smooth, roundish or subcordate at base, tapering to a point and punctate with pellucid dots. Flowers with subulate bracts at the baso of tho 3-forked pedicels. Calyx punctato. Corolla nearly twico as long as the culyx, 
pubescent, palo red. Stamens and style much exserted, of the same hue as the corolla. The herb is delightfully fragrant, and used in febrifugal infusions. Jl, Aug.

10. Hedeo'ma, Pers. American Pennyroyal.

(Gr. $\dot{\eta} \delta \dot{v} s$, sweet, o $\mu_{\dot{\eta}}$, smell.) Calyx 13-striate, gibbous at base, bilabiate, throat hairy, upper lip 3-toothed, lower 2-cleft; corolla bilabiate, upper lip erect, flat, emarginate, lower spreading, 3-lobed; stamens 2 fertile, ascending.Low, fragrant herbs.

I H. pulegioìdes Pers. Lvs. oblong, few-toothed, petiolate, narrowed to each end; verticils axillary, 6-flowered; cor. equaling the calyx.-(1) A small, strong-scented herb, held in high repute in the domestic materia medica. Stem erect, branching, $6^{\prime}$ high. Leaves opposite, with $1-2$ teeth each side, on very short petioles, smooth on the upper surface, roughish beneath. Calyx ciliate, 2 lower divisions spined. Abundant in dry pastures, Can. and U. S. Flowering all summer.

2 H. híspida Ph. Lvs. linear, entire, sessile, obtuse; verticils about 6-flowered; cor. searcely as long as the calyx.-(1) Borders of the Mississippi and Missouri, to Ark. Herb a few inches high, branching, very leafy and somewhat hairy. Lvs. $6^{\prime \prime}$ long. Cal. teeth awned. Jl.

3 ? H. bractiolata Nutt. Pubescent, simple, slender; lvs. linear lanceolate, acute at each end, entire; pedicels setaceously bracteolate, 3 to 5 -flowered; cal. oblong, equal; cor. minute?-Car. (Nuttall). (Micromeria? Benth.)

11. COLlinso'NIA, L. Horse Balar. (To John Collinson, an English botanist.) Calyx ovoid, 10-striate, upper lip truncate, 3toothed, lower 2-cleft ; corolla exserted, campanulate-ringent, upper lip in 4 subequal lobes, lower lip longer, declined, fimbriate; stamens 2 (rarely 4), much exserted, divergent.-24 Herbs strong scented, with large, ovate, serrate, petiolate lvs. and yellowish fls., in a terminal, leaf. less panicle or raceme.

* Stamens 2 perfect-the upper pair of flaments minute points.................... Nos. 1, 2 - the upper pair of flaments eapitate. Southern........................ 3

* Stamens 4 perfect, long exserted. Leaves very large. Southern........................ 4,5

1 C. Canadénsis L. Glabrous or sparsely pubescent; lvs. acuminate, coarsely serrate, abrupt or subcordate at base; panicle loose, elongated ; cal. teeth subulate, not longer than its tube; stam. 2, exserted.-A coarse herb, in woods and fields, Can. to Ky. and Car. St. 4-sided, 3 to $4 \mathrm{f}$ high (smooth or a little pubescent). Lvs. thin, 6 to $8^{\prime}$ long and 3 to $4^{\prime}$ wide. Fls. in a large compound raceme, with opposite branches and pedicels. Cor. 5 to $6^{\prime \prime}$ long, greenish-yellow, the lower lip elongated and fringed. Style and stamens very long. Flowering in summer.

B. TUBERòsa. Lvs. somewhat rhombic-oval, acute at both ends; fls. smaller. - Car to La. (i Iale). (C. tuberosa Mx.)

2 C. scabriúscula Ait. Nearly glabrous; lvs. small (18" to $3^{\prime}$ long), acute, rather abrupt at base, scabrous on the upper surface; panicle very loose, leafy at base; fls. small; cal. teeth subulate, scarcely longer than its tubo; stam. 2, sterile fil. minute. -S. Car to Fla., near Savannah. Plant 2 to of high. Petioles half as long as the leaves. Fls. opposite. Cor. thrice as long $\left(4\right.$ to $\left.5^{\prime \prime}\right)$ as calyx. Sept.-Nov.

3 C. punctàta Ell. Pubescent, lvs. large (5 to $\eta^{\prime}$ long), acuminate, rather acuto at base, conspicuously resinous-punctate beneath; rac. paniculate, the lower axillary; fls. small; cal. teeth subulate-awned, longer than its tube; stam. 2, exserted, sterile fil. capitate. - Rich soils, S. Car. and Ga. (Feay). Plant 2 to $6 f$ high. Petioles a third as long as the leaves. Cor. twice longer ( 4 to $\left.5^{\prime \prime}\right)$ than calyx teeth. Sept, Oct.

4 C. verticillàta Baldw. Viscid-pubescent above; lvs. broad-oval, acute or acuminate, abrupt at base, coarsely dentate, falsely verticillate by the proximity of pairs; rac. simple, elongated, with thefls. verticillate; cal. teeth setaceous-pointed; 
stam. 4.-On Lookout Mt. Tenn. 1 to Middle Ga. Plant 1 to $2 \mathrm{f}$ high, simple. Lvs. large (6 to $8^{\prime}$ long), petioles about $2^{\prime}$. Rac. 5 to $10^{\prime}$. Fls. twice larger (7 to $9^{\prime \prime}$ long) than in Nos. 2 and 3. Stam. and sty. very long, spreading. Lower lip strongly fringed. May, Jn.

5 C. anisàta $\mathrm{Ph}$. Viscid-pubescent; lvs. broad-ovale, acute, subserrate, at base cordate or truncate, scabrous above, the floral similar, very small, sessile; panicle dense-flowered; fls. opposite; cal. teeth ovate, obtuse, with a short mucro, the 3 upper longer; stam. 4.-Middlo Ga. (Feay), Ala., Fla. ? Plant 1 to $2 \mathrm{f}$ high. LvS. 5 to $7^{\prime}$ by 3 to $5^{\prime}$, very rugous, often short acuminate, petioles $1^{\prime}$ to $15^{\prime \prime}$. Fls. about as large as in No. 1. Jl.-Sept.

12. HYSSO'PUS, L. Hyssop. (Hebrew ezeb; Arabic uzzof; English hyssop.) Calyx tubular, 15-striate, equally 5-toothed, upper lip of the corolla erect, flat, emarginate, lower lip 3-parted, the middle segment largest, tube about as long as the calyx ; stamens 5, exserted, diverging.

H. officinàlis L. Lvs. linear-lanceolate, acute, entire, sessile; cal. teeth erect;

fls. in racemous, secund verticils; middle division of the corolla 2 -lobed, entire. - 2f Cultivated for its reputed medicinal properties. A handsome plant, growing in tufts $2 \mathrm{f}$ high, with delicate foliage and bright blue flowers. Jl. $\ddagger \mathrm{S}$. Eur.

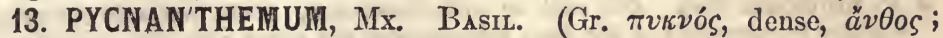
alluding to the dense, capitate inflorescence.) Calyx tubular, 10 to 13striate, 5-toothed, teeth equal or subbilabiate, throat naked within; upper lip of corolla nearly entire, lower lip trifid, middle lobe longest, all ovate, obtuse, stamens 4 , distant, subequal, anthers with parallel cells. if Erect, rigid herbs, all N. American. Verticils dense, many-flowered.

\$ Calyx subbilabiate, in flattish, often loose cymes. Leares petiolate. (a)

Calyx subequally cleft, in roundish, dense heads. (b)

a Teeth of the calyx ovate, acute, awnless................................. 1

a Teeth of the calyx produced into bearded awns, shorter than corolia.................... 2-4 b Calyx teeth and bracts with naked awns equaling the corolla............... Nos. 5, 6 b Calyx shorter than tho corolla.-Heads panicled. Leaves subpetiolate... Nos. $7-9$ - Heads corymbed. Leaves sessile .... Nos. 10-12 -Head solitary, large..................... No. 13

1 P. albéscens Torr. \& Gr. Lvs. ovato or lance-ovate, subserrate, acuto at each end, subglabrous, whitened beneath, the upper whitened both sides, all petiolate; fls. separate, at length in little secund racemes; cal. teeth much shorter than its tube. - Ala. to La. St. 2 to $3 \mathrm{f}$ high, much branched. Lrs. $18^{\prime \prime}$ to $3^{\prime}$ long, often puberulent beneath. Cymes many, in fruit $1^{\prime}$ to $18^{\prime \prime}$ broad. Fls. as in all the species, small, reddish.

2 P. Túllia Benth. Lvs. ovato or oblong, acuto or acuminate, subserrate, and with the stem villous-pubescent, the floral whitened, fls. separate, at length in little secund simple racemes; cal. toeth ending in subulate, bearded awns, about equaling the tube.-Mts. of E. Tenn., N. Car. to Ga. Lvs. as in No. 1, varying from ovate to lanceolate. Lower lip of calyx somewhat shorter.

3 P. incànum Mx. WILD BAșiL. Lvs. oblong-ovate, acute, subserrate, rounded at the base, petiolate, hoary-tomentous beneath, the floral whitened both sides; cymes dilated, not in racemes; cal. teeth subequal, subulate, aristate, bearded at apex.-Rocky woods and barrens, Can., N. Mid., W. States. St. 2 to 4 f high, covered with soft, whitish down like the rest of the plant. Cymes all canescent, $\mathbf{1}^{\prime}$ or less broad. Cor. pale red, dotted with purple. Aug. (P. Loomisii, Nutt.)

4 P. clinopodioides Torr. \& Gr. Lvs. oblong-lanceolite, acute at each end, subserrate, smoothed above, pubescent beneath; sts. and branches villouspubescent; cymes contracted and almost capitate, terminal and sessile at the upper nodes; bracts ciliate; cal. teeth subulate, often tufted with hairs at apex.-Dry soils, N. Y., N. J., to Ind. Plant corymbously branched, 2 to $3 f$ high, scarcely canescent, never whitened. Lrs. 2 to $3^{\prime}$ long. Cymes less than $6^{\prime \prime}$ broad. Aug.r Sept.

5 P. aristàtum Mx. Lvs. ovate-oblong, acute, subserrate, rounded at base, on short petioles, and with tho stem glabrous or minutely canescent-downy; bracts rigid, 
pointed with beardless awns like the calyx teeth, as long as the corolla.-Pino barrens, N. J. to Fla. St. 1 to $2 \mathrm{f}$ high. Lvs. $18^{\prime \prime}$ to $2^{\prime}$ long, the floral sometimes whitened. Heads few, rather larger (6 to $9^{\prime \prime}$ diam.).

G P. hyssopifòlium Benth. Lvs. linear-oblong, obtuse, subentire, subsessile, and with the stem glabrous or minutely canescent-downy; hds. few, large (nearly $1^{\prime}$ diam.). Barrens, Va. to Fla. and La. St. 1 to $2 \mathrm{f}$ high. Lrs. $1^{\prime}$ to $18^{\prime \prime}$ long, less rigid than in No. 5 .

7 P. Torrèyi Benth. Lvs. linear-lanceolate, acute, thin, nearly entire, tapering at base to a very short petiole, and with the stem slightly pubescent; bracts and subulate calyx teeth white-pubescent.-Dry soils, near N. Y. city, and in N. J. Perhaps too near P. lanceolatum, but the tapering, petiolate base of the long, narrow, thin leaves are usually well defined. Cymes scarcely capitate. Aug., Sept.

8 P. pilòsum Nutt.' Ivs. lanceolate, subentire, acute at each end, subsessile, and with the stem and branches more or less clothed with soft, spreading hairs; cal. tecth ovate-lanceolate, acute, and with the bracts canescent-villous.-Prairies, \&c., W. States to Tenn. and Ga. Plant about $2 f$ high, paniculately branched (but the lower branches longer, ascending), hoary with a pubescence, never whitened. Lvs. 2 to $3^{\prime}$ long. Cymes somewhat dilated, hardly capitate, 6 to $9^{\prime \prime}$ broad. Aug.

9 P. mùticum Pers. Lvs. ovate or ovate-lanceolate, acute, remotely subserrate, rounded or subcordate at the base, subpetiolate, the upper with the corymbously paniculate branches minutely pubescent and whitened; cal. teeth triangular-ovate, equal, short, the bracts scarcely longer.-Dry woods, Me. to La. Plant 2 to $3 \mathrm{f}$ high. Lvs. of a firm texture, 1 to $2 \frac{1}{2}^{\prime}$ long, usually half as wide. Heads small, compact, roundish, 4 to $6^{\prime \prime}$ diam. Cor. purplish white, dotted. Aug.

$10 \mathrm{P}$. lanceolàtum $\mathrm{Ph}$. Lvs. linear-lanceolate, entire, acute, rigid, rounded at base, sessile, nearly glabrous, tho corymbous branches pubescent on the angles; cal. teeth short, triangular-ovate, hairy.-Common in dry woods, Mass. to Ill., Tenn. and N. Car. Handsome and fragrant, 1 to $3 f$ high. Lvs $18^{\prime \prime}$ to $2^{\prime}$ long, 2 to $5^{\prime \prime}$ wide. Hds. dense, all raised to near the same level, 4 to $6^{\prime \prime}$ broad. Cor. purplish, spotted. Aug.

$11 \mathrm{P}$. linifolium $\mathrm{Ph}$. Glabrous, corymbed; Irs. linear, attenuated to each end, sessilo, entire, rigid; hds. compact; bracts ciliate and cal. teeth pungently awnpointed.-Dry woods and prairies, Mass. to Iowa, Ky. and Ga. Plant very smooth, littlo fragrant, 1 to $2 \mathrm{f}$ high. Ivs. $1^{\prime}$ to $18^{\prime \prime}$ long, 1 to $3^{\prime \prime}$ wide. Hds. small, numerous, dense. Fls. whitish. Aug.

12 P. nùdum Nutt. Glabrous, palo green, subsimple; lvs. small, few ovate-oblong, obtuse at each end, entire, sessile; fls. in loose heads, terminal, corymbed, inner bracts subulate, very short.-Mts. N. Car. to Ga. St. strict, 1 to $2 \mathrm{f}$ high. Lvs. erect, $1^{\prime}$ long or less. Hds. few-flowered. Cor. pubescent. Jl., Aug.

13 P. montànum Mx. Lvs. lanceolate, serrate, acute, the lower rounded at base, glabrous as well as tho stem; hds. globous, subtended by many bracts, terminal or sessile at the upper nodes; bracts villous-ciliate, very acute, outer ovate, inner linear; cal. teeth short, acute.-Mts. Va. and Car. Plant resembling a Monarda, 1 to $2 \mathrm{f}$ high, fragrant. Jl. (Monardella, Mx.)

14. SATURE'JA, L. SUmmer Savory. (Arabic satur, the general name for labiate plants.) Calyx tubular, 10-ribbed, throat not hairy; segments of the bilabiate corolla not equal ; stamens diverging, scarcely exserted.-Herbs with small lvs. and purplish fls.

S. horténsis L. St. branching; lvs. linear oblong, entire, acute at the end; ped. axillary, cymous. - $2 f$ River banks, W. States, rare. St. branching and bushy, $1 \frac{1}{2} \mathrm{f}$ high, woody at base, frequently changing to purple. Lvs. numerous, small and narrow, with axillary cymes of pink-colored fls. Cal. about as long as the cor. Jl. Aug. $\ddagger$ Italy. A culinary, aromatic herb.

15. DICERAN'DRA, Benth. (Gr. $\delta \iota \varsigma$, twice, $\kappa \varepsilon \rho a \varsigma$, a horn, av $\rho a$, anthers.) (Elliott's name had been preoccupied.) Calyx 13-striate, tubular, upper lip subentire, lower bifid, throat hairy; corolla tube ex- 
serted, straight, strongly bilabiate, upper lip erect, emarginate, lower 3 . lobed, spreading; stamens 4, the lower pair larger exserted, distant, anther cells distinct, divaricate, horned at apex.-(1) Southern. (Ceranthera Ell. nec Beauv.)

1 D. linearifòlia Benth. St. and branches virgate; lvs. linear; cymes axillary, pedunculate, 1 to 3 to 5 -flowered, with minute bracts; cor. twice longer than calyx.-Dry woods S. Car. to Fla. (Misses Keen). Fragrant, smoothish plants, about If high. Irs. $I^{\prime}$ long, or the lower nearly $2^{\prime}$. Fls. showy pink-colored, forming slender, raceme-like panicles. Sept., Oct. (C. linearifolia Eill.)

2 D. densiflòra Benth. St. diffusely branched; lvs. oblong-lanceolate, the upper linear; cymes axillary, subsessile, 5 to 10 -flowered.-E. Fla. 1 variety ?

16. ORIG'ANUM, L. Marjoram. (Gr. ópos, a mountain, and yávos, joy.) Calyx tube 10-striate, 5 -toothed, hairy in the throat; corolla tube scarcely exserted, upper lip erect, flat, emarginate, lower lip with 3 noarly equal segments ; stamens 4, ascending, distant.-2f Lvs. subentire. Fls. in dense oblong spikes, with imbricated, colored bracts.

1 O. valgàre L. Lvs. ovate, entire, hirsute, petiolate; spikes in a paniculate corymb; bracts ovate, longer than the calyx; cal. teeth equal.-In fields and thickets. St. 12 to $18^{\prime}$, purple, leafy, branching above. Lvs. a very little serrate, opposite, hairy, sprinkled with resinous dots, paler beneath. Petioles hairy, $\frac{1}{4}$ as lcng as tho leaves. Bracts tinged with purple. Fls. purplish white. The plant has a highly aromatic taste. Jl., Aug. $\ddagger \S$ Eur.

2 O. Majoràna L. Lvs. oval, or obovate, obtuse, entire, petiolate, hoarypubescent; spikes roundish, compact, pedunculate, clustered at the end of the branches; bracts roundish; cal. upper lip roundish, tube cleft below.-It has a pleasant aromatic flavor, and is employed in various ways as a seasoning. Plant soft downy, a foot high. Fls. pink-colored. Jl., Aug. $\ddagger$ Portugal.

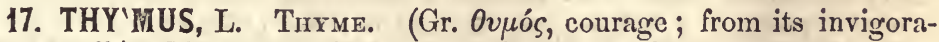
ting smell.) Flowers capitate or verticillate; calyx ovoid, 10 to 13nerved, bilabiate, hairy in the throat, upper lip 2 -fid, lower 3-fid, stamens 4 exserted, diverging, anther cells parallel.-2f. With small entire strongly-veined lvs., minute bracts, and purple or white fls.

1 T. Serpyllum L. Wind Thyme. Mother of Thyme. St. decumbent; lvs. flat, elliptical, obtuse, ciliate at base; fls. capitate. - 2f Mass., N. Y. and Penn. An aromatic plant, similar to the following, but milder and rather more pleasantly flavored. Stems suffruticous, wiry, slender, and wavy, with leafy, downy, and ascending branches, each terminating in a small, dense, oblong head of purplo flowers, much frequented by bees. Leares entire, petiolate, punctate, smoothish, ciliate. Corolla purple, spotted. June. $\ddagger \S$ Eur.

2 T. vulgàris L. St. erect or decumbent at base; lvs. revolute at the sides, oblong-ovate and lanceolate; verticils in terminal, leafy spikes.-Sts. suffruticous, numerous, branched, 6 to $10^{\prime}$ high. It is highly aromatic, as well as the other species, and is peculiarly attractive to bees. Jn., Jl. ‡ Eur. A culinary vegetable.

18. Calamin'THA, Mœnch. Calamintr. (Gr. kádos, beautiful,

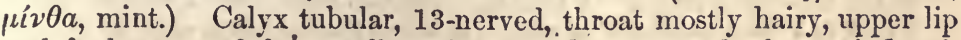
3-cleft, lower 2-cleft; corolla tube straight, exserted, throat inflated, limb bilabiate, upper lip erect, entire or emarginate, lower spreading, its middle lobe largest; stamens 4, the lower pair longer, usually ascending. $-2 f$

\$ Herbs hairy. Cymes dense, capitate, bracted. Calyx tube curred, 2-lipped.............No: 1 Herbs hairy. Cymes loose, pedunculate, axillary. Calyx tube straight, 2-lipped....... No. 2

Herbs smooth. Cymes loose, sessile, bracted. Calyx straight, teeth snbregular........ No. 3

Shrubs low, slender, nearly smooth. Cymes few-flowered. Flowers large........ Nos. 4 ta 6 
1 C. Clinopòdium Benth. WILd BASIL. Villous; lvs. ovate, subserrate; verticils dense, sessile, many-flowered, hairy ; bracts numerous, subulate. - 2f Low woods, N. and W. States. Plant 1 to $2 \mathrm{f} \mathrm{high.} \mathrm{St.} \mathrm{square,} \mathrm{simple} \mathrm{or} \mathrm{sparingly}$ branched, and as well as the whole plant, clothed with whitish hairs. Lvs. petiolate, tapering to an obtuse point, pale. Fls. purplish, in heads mostly terminal, near $1^{\prime}$ wide, involucrate with bracts.

2 C. Népeta Link. Villous with soft, whitish hairs, much branched below; Ivs. small, broad-ovate, obtuse, subserrate, petiolate; cymes few-flowered in the upper axils, becoming somewhat racemed; cal. teeth subulate, the 2 lower longer; cor. upper lip emarginate, the lower in 3 equal lobes.-Dry hills, roadsides, \&c., throughout Tenn. and $\mathrm{Va}$. Plant about $2 \mathrm{f}$ high, strongly aromatic. Lvs. about half an inch long. Cor. white, thrice longer ( 3 to $\left.4^{\prime \prime}\right)$, than the calyx. Jl., Aug. $\S$ Eur.

3 C. glabélla Benth. Glabrous, decumbent at base, diffusely branched; lvs. narrowly oblong, subpetiolate, few-toothed or entire, tapering to the base; verticils 6 to 10 -flowered; cal. teeth subulate-acuminate; bracts as long as the pedicels -On limestone rocks, Ohio to Ark. Sts. 1 to $2 \mathrm{f}$ long. Lvs. $I^{\prime}$ to $18^{\prime \prime}$ long. Cor. moderately bilabiate, near twice longer $\left(4\right.$ to $\left.5^{\prime \prime}\right)$ than the calyx, pale violet. Jn.

$\beta$. DIVERSIFoliA. Flowering stems nearly erect, the barren prostrate, like runners, bearing small, ovate, entire lvs.; plant generally smaller, with the floral lvs. narrow, and mostly entire.-Limestone rocks, Niagara Falls, to the Falls of St. Anthony, and to Ark. Fragrant like pennyroyal. Upright sts. 6 to $12^{\prime}$ high. Lvs. 1'. Lvs. of the runners 3 to $4^{\prime \prime}$ long. (C. Nuttallii Benth.)-These two very diverse forms are connected by specimens found in Ohio (Sullivant apud Torrey), having the characteristics of both.

4 C. canéscens Torr. \& Gr. Minutely canescent-downy, shrubby; lvs. linear, obtuse, entire, revolute-edged, much fascicled; verticils of 2 opposite fls.; cor. thrico longer than the strongly 2-lipped calyx. - Sandy seaboards, Fla. Shrub scarce a foot high, with numerous lvs., 7 to $8^{\prime \prime}$ by $1^{\prime \prime}$, and ferw rose-red pretty fls., as largo as in No. 2. May.

5 C. coccínea Benth. Lvs. narrowly obovate-oblong, obtuse, entire, short-petioled; verticils of 2 to 6 fis.; cal. upper lip very short, tube 3 or 4 times shorter than the ample corolla.-E. Fla. Shrub with virgate branches. Lvs. 6 to $8^{\prime \prime}$ long. Cor. a fine scarlet, glandular-pubescent, 15 to $18^{\prime \prime}$ long. (Cunila coccinea Nutt.)

6 C. Caroliniàna Swartz. Sts. glabrous and simple; lvs. very smooth, ovate, obtuse, crenate-serrate, tapering to a petiole; cymes few-flowered, on short peduncles; cal. strongly 2-lipped, nearly naked in the throat; cor. ample, tubo enlarged upwards.-Dry woods, N. Car. to Fla. and La. A pretty flowerer, somewhat shrubby, If high or more. Cymes in the upper axils 3 to 5-flowered. Lvs. 1 or less long. Bracts as long as the calyx, the corolla thrice longer ( 7 to $\left.8^{\prime \prime}\right)$, rosepurple, spotted. Jn.-Aug. (C. grandiflora Ph.)

19. MELIS'SA, Tourn. BaLm. (Gr. name of the bee, from $\mu \varepsilon \lambda$, honey; which bees seek in these flowers.) Calyx 13-ribbed, the upper lip 3-toothed, flattened and dilated, lower bifid; corolla tube recurvedascending, upper lip erect, flattish, low spreading, 3-lobed, the middle lobe mostly broadest; stamens ascending.

M. officinàlis $\mathrm{L}$. Pubescent ; st. erect, branching; fls. in loose, axillary cymes, subscssile; lvs. orate, acute, coarsely crenate-serrate, on slender petioles; bracts few, ovate-lanceolate, petiolate.- $2 f \mathrm{~N}$. Eng. to Ind. and Tenn., in waste grounds and in the deepest forests. A well known garden plant. St. 1 to 2 to $3 \mathrm{f} \mathrm{high.}$ Lrs. 2 to $3^{\prime}$ long, petioles $I^{\prime}$ or more. Bracts of the same form, diminished. Cor. twice longer $\left(7^{\prime \prime}\right)$ than tho calyx, yellowish white. Jl., Aug. $\ddagger \S$ Eur. Fra grant of lemons. Balm tea is a popular remedy.

20. SAL'VIA, L. SAGE. (Lat. salveo, to be in health; probably from its salutary qualities.) Calyx striate, bilabiate, upper lip 3-toothed or entire, lower bifid, throat naked; corolla ringent, tube equal, upper lip straight or falcate, lower spreading or pendent, 3-lobed; stamens 2, connectile transversely articulated to the filament; supporting at each 
end a cell of the dimidiate (halved) anther; achenia 4.-A large genus of 400 species, usually with showy fls. The transverse connectile constitutes the essential character. (Fig. 75, 351.)

$\$$ Herbs native.-Calyx slightly 2-lipped, sub-3-tootherl, equal. . . . . . . . . . . . . . ... Nos. 1-3 -Caly $\mathrm{x}$ deeply 2 -lipped, 5 -toothed, lower lip longer............................ 4 . \$ Herbs or shrubby, in gardens. Flowers bluo. Calyx teeth bristle-pointed.................. 7, 8 $\$$ Shrubby, in garden and greenhouse. Hlowers large, scarlet......................... 9,10

1. S. azurea Lam. Frect, puberulent above, branching; lvs. linear-ollong and linear, remotely toothed, or tho upper ontire, all attenuate at base; rac. slender, many-flowered, verticils about 6-flowered; cal of 3 broad, acute, subequal teeth, half as long as the pubescent corolla; sty. bearded.-S. Car. to Fla. and La. Plant of varying aspect, according to soil, \&c, usually slender and subsimple, 1 to 2 or 3 high, with lvs. narrow, subentire, 2 to $3^{\prime}$ long, 2 to $4^{\prime \prime}$ wide. Fls. $7^{\prime \prime}$ long, of a fine azure blue. Summer.

2 S. urticifòlia I. Erect; lvs. cauline, rhombic-ovate, acute, crenate-serrate, truncate-cuneate at base to a short or winged petiole; verticils 4 to 10 -flowered, distant, in a terminal, interrupted raceme; cor. $s$ moot $h$, tube but a little longer than the calyx, the lower lip thrice longer.- 2 In hilly woods, Va. to Fla. and Aia. St. simple, 12 to $18^{\prime}$ lighl. Lrs. thin, 2 to $4^{\prime}$ long, the upper larger. Cor. blue, 5 " to $6^{\prime \prime}$ long. May.

3. LONGIFoliA. Tall ( 3 to $6 \mathrm{f}$ ), with panicled racemes; Ivs all serrate, the lower lance-oblong; fls. larger ( $3-9^{\prime \prime}$ long).-Ga. to Ark. (S. longif. Nutt.)

3 S. coccínea I. Erect, hoary-pubescent; lvs. ovate, cordate, acute, finely crenate, petiolate, whitish-tomentous beneath; verticils 6 to 10 -flowered, in a simple raceme; cal teeth acute; cor. red, smooth, twice longer, tube dilated upwards, upper lip erect, much the shorter.-4 Gan Fla. to La. St. 1 to $2 \mathrm{f}$ high, often branched. Lrs $6^{\prime \prime}$ to 1 to $2^{\prime}$ long, the middle largest. Cor. bright red or scan let, $8^{\prime \prime}$ long. Upper lip of the calyx often purple. Summer.

4 S. Iyràta L. Erect; lvs. radical, rosulate, lyrate, crose-dentate, the cauline about one pair above, bract-like, linear-spatulato; fls. in whorls of 6 , racemed at top of the square scape; cal. upper lip shorter, teeth subspinous; cor. thrico longer than the calyx, its lower lip much the longer.-2f. Woods, W. Can. to Fla., rare in N. Eng. Scape 6 to $15^{\prime}$ high. Lvs oblong-oval in outline, $18^{\prime \prime}$ to $3^{\prime}$ long, petioles half (or more) as long. Fls. showy, near $1^{\prime}$ long, violet-purple. The whole plant is usually purplish. Apr.-Jn.

5 S. obovàta Ell. Erect; lvs. broadly obovate, entire, sinuate, narrowed to a long tapering base, the floral orate, shorter than the calyx; verticils 6 -flowered; remote, in a simple raceme; cal. upper lip truncate, with 3 minute teeth; cor. thrice longer, with the galeate upper lip thrice shorter than the lower.- if Middle Ga. to La. St. 1 to $2 \mathrm{f}$ higl. Lrs larger abowe and clustered 4 to $7^{\prime}$ by 2 to $5^{\prime}$. Fls. blue $\mathrm{Jn}, \mathrm{Jl}$

6 5. Claytòni Ell. Lrect; lis. cordate-ovate, or lance-ovate, sinuate-pinnatifid, the segm. toothed, rugous, more or less pubescent beneath; verticils 6-flowered; floral Ivs ovate-acuminate, smaller; cal teeth of the upper lip connivent, of the lower longer, acuminate - 2f Sandy pastures, Beaufort, S. Car. (Bachman). Sts. If high. Fls. small. Summer.

7 S. Sclàrea IL CLARRY. Irs. ample, rugous, broad-ovate, cordate, doubly crenate; bracts colored, concave, longer than the calyx; upper lip of the cor. high-arched, much longer than the lower.- (2) A strong-scented exotic, 1 to $3 f$ ligh, with viscid lvs. as large as the hand. The fls. and bracts are variegated with pale-purple and yellowish-white, in whorled spikes. Cal. with spinous teeth. Native in Italy. $\ddagger$

8 S. officinàlis I. Cоммом SAGf. Shrubby, lvs. oblong-lanceolate, crenulate, rugous; whorls few-flowered; cal. mucronate; upper lip of the cor. as long as the lower and somewhat vaulted.-A well-known garden plant, with a shrubby stem, rugous leaves of a dull green color and an uromatic fragrance. Flowers in whorls forming a spike. Corolla ringent, blue, with a lengthened tube and viscid calyx, somewhat brown. July. $\ddagger$ S. Lur. - Very useful in domestic economy and medicine. 
9 S. fúlgens Cav. St. branching at base, weak, ascending, pubescent; lvs. long-petiolate, ovate-lanceolate, subcordate, crenate-dentate, smootli above, pubescent beneath; fls. opposite, in terminal racemes; bracts deciduous; cal. slightly colored, upper lip truncate, subentire; cor. fimbriate-ciliate, $3-4$ times longer than the calyx; sty. exserted. $-2 f \mathrm{~A}$ beautiful greenhouse plant. Flowers bright crimson or scarlet, near 2 ' long. There are several varieties. $f$ Mexico.

10 s. spléndens Sellow. St. erect, glaiorous; lvs. broad-ovate and ovate, petiolate, rounded or acute at base, glabrous both sides, dent-serrate, acuminato; fls. opposite, racemous; bracts deciduous; cal. scarlet, and, with the corolla, pubescent, upper lip entire, acuminate, lower lip 2-toothed.-2f Gardens. Plant 2-4f high, branched. Flowers 2 ' long, scarlet. After flowering the calyces onlar re, and become as brilliant as the corollas. $f$ Mexico.

21. ROSMARI'NUS, L. Rosemary. (An ancient Latin name, compounded of ros, dew, and marinus, of the sea.) Calyx bilabiate, upper lip entire, lower bifid; corolla bilabiate, upper lip 2-parted, lower lip reilexed, in 3 divisions of which the middle is the largest; fil. 2 fertile, elongated, ascending towards the upper lip, having a tooth on the side.Shrub, with sessile, linear lis.

R. officinàlis L. An erect, evergreen shrub, 4f high, much branched. J.eaves opposite, obtuse, linear-oblong, entire, smooth, dark green and shining above, downy and sometimes whitish beneath. Flowers axillary and terminal, of a kright blue color, having, like the leaves, a strong aromatic fragrance Jiko camphor: It yields by distillation a large proportion of fragrant oil. $\ddagger$ S. Eur.

22. MONAR'DA, L. Mountain Mrnt. (Name in honor of Monard$u 3$, a Spanish botanist of the 16th century.) Calyx elongated, cylinc'ric, striate, subequally 5-toothed; cor. ringent, tubular, upper lip lincar, lower lip reflexed, 3-lobed, the middle lobe narrowest; sta. 2, fertile, ascending beneath the upper lip, and mostly exserted; anth. cells divaricate at base, connate at apex.-2f Verticils few, dense, manyflowered, bracted.

* Calyx densely hairy in the throat. Corolla purplo or whitish................. Nos. 1, 2

* Calyx naked in the throat. Corolla scarlet or yeliow............................. Nus. 3,4

I M. fistulòsa L. HorsEMint. WILD Bergasor. Irs. orate-lnneeolate and lariceolate, obtuse at base, acute or acuminate, petiolate, more or less pubescent; hds. of fls. terminal, few, but many-flowered, bracts sessile; cal. slightly curved, with the throat hirsute.-Hedges, thickets, rocky banks, W. Vt. and Can. to Ga. Common westward. Exceedingly variable. St. 2 to $4 \mathrm{f} \mathrm{high,} \mathrm{acutely} \mathrm{4-angled,}$ often lollow, frequently purple, simple, or with a few opposite branches. Lvs. mostly acuminate, acutely serrate, nearly smooth, 2 to $4^{\prime}$ long and on petioles $\frac{1}{5}$ their length. Outer bracts leafy, often partially whitened. Cor. much exserted, $1^{\prime}$ in length, rarying from greenish-white and pale purple to blue. J., Aug. (M. allophylla, oblongata, clinopodia and twenty other synonyms are cnumerated in Bonth.)

2 M. Bradburiàna Nutt. St. simple, glabrous; $l v s$, ovate or oblong-lanceolate, subsessile, rounded at base, hirsute pubescent both sides, margin subdentate, apex acute; cal. pilous, curved, densely bearded at throat, segm. subulate spinous; hds. large, terminal ; outer bracts broad-lanceolate, ciliate, colored.-Prairies and bottoms, Ohio to Ill. St. slender, about 3 f high. Lvs. sometimes slightly petiolate, 2 to $3^{\prime}$ long, 5 to $8^{\prime \prime}$ wide, with long, bristly hairs beneath. Bracts purple. Cor. purple. JI.

3 M. punctàta L. HorsemiNT. Minutely pubescent; st. obtusely angled; lvs. oblong-lanceolate, tapering to a petiole, remotely and obscurely serrate, the upper and bracts sessile; bracts colored, longer than the verticils; cal. teeth unequal, rigid, throat naked; cor. glabrous, strongly punctate.-Barrens, N. J., common, to Fla. (Miss Keen) and W. States. St. 2 to 3 high, branched. Lvs. $18^{\prime \prime}$ to $2^{\prime}$. Cor. pale yellow, with brown spots, upper lip villous at the apex. Bracts large yellow and red. Sept._Medicinal. 
4 M. dídyma I. St. branched, acutely 4 -angled; lvs. broadly ovate, acuminate, somewhat rough, on short petioles, veins and veinlets hairy beneath; fls. (crim. son) in terminal, often axillary heads; bracts colored; cal. throat naked. - Swamps, Can. to the Mts. of Ga. . Plant 2 to $3 f$. Lvs. 2 to $5^{\prime}$ long, very broad at base, often cordate, serrate. Heads often proliferous, with large, ovate-lanceolato bracts tinged with the same color as the fls. Cor. $15^{\prime \prime}$ long. 1 bortive fil. 2, short, the perfect exserted. Jl. Handsome and fragrant. $f$

23. BLEPHIL'IA, Raf. (Gr. $\beta \lambda \varepsilon \phi a \rho i s$, the eyelash; probably referring to the ciliate bracts.) Calyx 13-ribbed, bilabiate, upper lip 3-toothed, lower lip shorter, 2-toothed, the teeth setaccous; corolla bilabiate, upper lip short, erect, oblong, obtuse, entire, lower lip of 3 uncqual, spreading lobes, the lateral ones orbicular; stamens 2, fertile, ascending, exserted.-2f Verticils dense, terminal and subterminal.

I B. hirsùta Benth. Whole plant hirsuto; lvs. ovate-lanceolate, acuminate, serrate, petiolate; fls in axillary verticillasters and terminal heads; bracts colored, shorter than the flowers, oblong, acuminate - In damp woods, rare N. Eng., common in TV. States. St. 1 to $2 \mathrm{f}$ high, diffusely branching, roughly pubescent. Petiole 3 to $6^{\prime \prime}$ long, lvs. 3 to 4 times as long, somewhat rounded at base. Fls. small, forming several dense whorls near the end of each branch. Cor. $5^{\prime \prime}$ long, pale purple, with spots of a deeper hue. Jn, JL

2 B. ciliàta Raf. St. hirsute, simple, acutcly 4-angled; lvs. fow oblong-lanceolate, acute at the base, subsessile, serrate, minutely pubescent; fls. in dense, approximatc, involucrate, terminal and subterminal verticils, bracts ovate, veiny, glabrous, ciliatc, as long as the calyx-Fields, barrens, Penn. to Miss., very abundant in the W. States. Plant 2 to $4 \mathrm{f}$ high, generally simple, rarely with 1 or 2 branches. Lvs. $18^{\prime \prime}$ to $30^{\prime \prime}$ long, a fourth as wide. Hds. larger than in No. 1, an inch in diam. Jn.-Aug. (Monarda ciliata L. nec Mx.)

24. LOPHAN'THUS, Benth. (IIyssopus L.) HedGe Hyssop. (Gr. $\lambda o ́ \phi o s, a$ crest, äv0os; flowers in dense, terminal spikes.) Calyx 15-ribbed, oblique, 5-cleft, upper segments longer; corolla bilabiate, upper lip bifidly emarginate, lower lip 3 -lobed, the middle lobe broader and crenate; stamens diverging. - 2 Tall, erect. Verticils spicate.

1 I. nepetoìdes Benth. St. smooth, quadrangular, with the angles acute and slightly winged; lvs. ovate and ovate-lanceolate, acutely serrate; petioles smoothish, calyx teeth ovate, green, obtusish. - If Middle and Western States, common about fences and dry hedyes. Stem 3-6f high, the sides somewhat concavo and the angles prominent. Lvs. acuminate, about $4^{\prime}$ by $2^{\prime}$. Flowers in crowded axillary verticils, forming a terminal, green spike, which is nearly continuous above. Corolla greenish-yellow. July, Aug.

2 I. scrophularifollius Benth. St. pubescent, quadrangular, with the angles obtuse; lvs. cordate-ovate, crenate-serrate; petioles ciliate-pubescent, cal. teeth lanceolate, colored, acute.-With the general aspect of the former species, and found in similar situations. The herbage is often changed to dark purple. Stem 2-4f high, purple. Leaves about $5^{\prime}$ by $3^{\prime}$, coarsely serrate, acuminate. Flowers in crowded, axillary verticils, forming a long, dense, terminal spikc. Corolla palo purple, more conspicuous than in the first. Jl, Aug.

25. IEP'ETA, L. Catnep. Ground Ivy. (Said to be from Nepet, a town in Tuscany.) Calyx tubular, 5-toothed; corolla tube slender below, dilated and naked in the throat, upper lip cmarginate, lower 3-lobed, the middle lobe largest and crenate, margin of the orifice reflected; stamens approximate, ascending; anther cells divergent. (Fig. 117.)

\$ Tall. Verticils in a terminal-raceme. Calyx nearly regular........................ 1 \$ GLEcroxa. Low, diffuse. Flowers axillary. Calyx curved, oulique.................. 2

1 N. catària I CATMINT. "Erect, hoary-tomentous; lvs. petiolate, cordate, 
coarsely crenate-serrate; fls. spiked, the whorls slightly pedunculated.- 24 About old buildings and fences. St. square, pubescent, branching 2 to $3 f$ high. Lvs. very evenly bordered by tooth-like or crenate serratures, and as well as the whole plant covered with a soft, hoary down, paler beneath. Fls. many, white or purplish, the lower lip dotted with crimson. J1. \& S. E. Europe. - Eaten greedily by cats.

2 N. Glechòma Benth. Grut-over-THE-Ground. Lrs. reniform, crenate; cor. about 3 times as long as the calyx. - 2f A creeping plant, about walls, hedges, etc. Sts. radicating at base, square, varying in length from a few inches to 1 to 2f. Lvs. petiolate, downy, glaucous, $1^{\prime}$ or less broad. Fls. axillary, about 3 together. Cor. bluish purple, with a variegated throat. Usually the anthers aro so collated as to form 2 littlo crosses. May. \&Eur. and Asia.

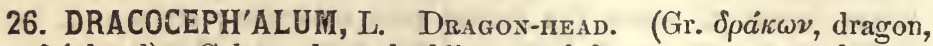
$\kappa \varepsilon \phi a \lambda \eta \dot{\eta}$, head). Calyx subequal, oblique, 5 -cleft, upper segments larger; cor. bilabiate, upper lip vaulted, emarginate, throat inflated, lower lip spreading, 3-cleft, middle lobe much larger, rounded or subdivided; sta. distinct, ascending, the upper pair longer than the lower.

D. parviflòrum Nutt. Subpubescent; lvs. lanceolate, deeply serrate, petiolate; bracts leafy, ovate, ciliate, mucronate-serrate; cal. upper segment much the largest; fls. small, verticillate, subcapitate, cor. scarcely exceeding the calyx.(2) Borders of the great lakes, Northern N. Y. to L. of the Woods, very rare. Fls. bluish, small, the verticils almost spicate. Cal, dry and membranous. Upper lip of the corolla arched, emarginate, central lobe of lower lip crenate. J.

27. CEDRONEL'LA, Mœnch. (Gr. $\kappa \varepsilon \dot{\delta} \rho o v$, oil of cedar; from the fragrance.) Calyx subcampanulate, 5-toothed; corolla tube exserted, throat dilated, upper lip straight, flattish, emarginate or cleft, lower 3fid, middle lobe largest; stamens 4, ascending, the upper Ionger, anthercells parallel.-Fls. spicate, bracted.

C. cordàtum Nutt. Stoloniferous; st. and elongated petioles pubescent; Ivs. cordate, obtusely crenate, sparingly hirsute above; spike unilateral ; bracts broadovate, entire, nearly as long as the ealyx; ped. bibracteolate, mostly 1 -flowered : cal. segments acute, almost pungent.- 4 Rocky streams and Mts. Ohio and Va. Stem about if high, quadrangular. Leaves 3 or 4 pairs, almost as broad as long, petiole about as long as the lamina $\left(1^{\prime}\right)$, upper pairs subsessile. Cor. pale blue, about $l^{\prime}$ long, orifice much dilated. $\mathrm{Jn}$.

28. BRUNel'LA, Tourn. Self-Heal. Blưe-curls. (German Brune, a disease of the throat for which it was a reputed remedy.) Calyx about 10-ribbed, upper lip dilated, truncate, with 3 short teeth, lower lip with 2 lanceolate teeth; filaments forked, one point of the fork bearing the anther.-2/ (Prunella, L.)

B. vulgàris L. St. ascending, simplo; lvs. oblong-ovate, toothed, petiolate; verticils close, spicate; upper lip of cal. truneate, with 3 awns.-A very common plant, in meadows and low grounds. N: Am;, lat. $33^{\circ}$ to the Arc. Sea. St. varying from $8^{\prime}$ to $2 f$ high, obtusely 4-angled, hairy, simple or slightly branched. Leaves fow, opposite, slightly toothed, the stalks gradually becoming shorter from the lower to the upper pair which are sessile. Flowers blue, in a large, oblongovate spike of dense verticils. Bracts imbricated, reniform, 2 beneath each verticil. Flowering all summer. A var. with white fls. occurs in N. Y. (G.M. Wilbur.)

29. SCUTELLA'RIA, L. SkUll-CAp. (Lat. scutella, a small vessel; from the resemblance of the calyx.) Calyx campanulate, bilabiate, lips entire, upper one appendaged on the back and closed after flowering; cor. bilabiate, upper lip vaulted, lower dilated, convex, tube much exserted, ascending, throat dilated; sta. ascending beneath the upper lip; anth. approximate in pairs; ach. tubercular. 
\$ Flowers large ( 7 to $13^{\prime \prime}$ long), racemed at top of the stem, with bracts. (a) a Bracts ovate, abrupt at base. Lips of the corolla short.......................... 1, 2 a Braets lance-oblong, aeute at base. Leaves notehed, petiolate. (b)

b Galea of thu corolla longer than the lower p......................... Nos. 3, 4

b Galea of the corolla not longer than the lip..................................... 0 a Iraets leaf-like, longer than the calyx. Leaves entire, subsessile................... 7 \$ Flowers large or small, opposite, solitary, in the axils of the leaves....................... 8-10 \$lowers small ( $3^{\prime \prime}$ long), in slender, axillary, one-sided racemes.......................... 11

I 5. versícolor Nutt. Erect, branching, glandular-hirsute; lvs. petiolate, broadly ovate, crenate, cordate, pubescent, veiny, the floral sessile, broad-ovate, not cordate, entire, as long as the calyx; rac. simple or branched, long, many-flowered; fls. opposite; cal. hirsuto; cor. lower lip scarcely longer than the upper.-Prairies and open woods, Ohio to Mro. and. La. St. $18^{\prime}$ to 3 to $4 \mathrm{f}$ high. Lvs. very veiny, thin, 2 to $4^{\prime}$ by $18^{\prime \prime}$ to $3^{\prime}$, petioles nearly as long. Rac. 3 to $6^{\prime}$ long. Ped. shorter than calyx. Cor. 6 to 7 "long, blue above, lateral lobes little shorter than the lips. Jl. (S. cordifolia Muhl.)

2 S. saxátilis Riddell. Weak; branched, ascending, pubescent; 1rs. petiolate, cordate-ovate, coarsely crenate, upper oval, obtuse, floral ovate, short-petiolate, entire; rac. loose, elongated; cor. lower lip twice longer than the upper.-Rocky banks, S. Ohio to Va. and Tenn., along the Mits. Plant 1 to $2 \mathrm{flong}$, rac. 5 to 8 '. Ivs. usually thin and rugous, $1^{\prime}$ to $18^{\prime \prime}$ long, scarcely longer than the petioles. Cor. $8^{\prime \prime}$ long, blue, tubo pale. Jl. Aug. (S. rugòsa, 2d Ed.)

$\beta$. CRassifòlia. Lvs. mostly ovate, of firmer texture.-New Orleans (Hale). Cal. more enlarged in fruit.

3 S. canéscens Nutt. St. erect, tall, pubescent; lvs. petiolate, oblong-ovate or ovate, rounded or attenuate at base, minutely pubescent both sides, paler beneath, margin crenate, apex acute, the lower cordate; rac. terminal and axillary, pedunculate, paniculate, bracts lance-linear; fls. canescent; upper lip the longer, tube gradwally enlarged.-Dry grounds, Mid. and W. States, abundant. St. usually purple, 1 to $3 f$ high. Lrs. 2 to $3^{\prime}$ long, 1 to $2^{\prime}$ wide, often with a purple margin and purpiish spots. Cor. $10^{\prime \prime}$ long, tube white, lips blue, lateral lobes very short. Jn., Jl.

4 S. villòsa Ell.? St. villous-pubescent, slender, branching; lvs. lanceolate or lance-ovate, acuto at each end, sparingly hispid above, the petioles and veins beneath villous, deeply serrate; rac. paniculate, loose; cal. hispid; cor. tube slender, expanding only at the throat, galea large, inflated, strongly incurved, many times longer than the lip.-Ga. (Feay). Apparently 2 to $3 f$ high. Lvs. 1 to $2^{\prime}$ long. We have but a single specimen.

5 S. serràta Andr. Erect, subsimple, nearly glabrous; lvs. petiolate, ovate, acuminate, crenate-serrate, cuneate at base, the floral lance-oblong; rac. subsimple, fls. large, pubescent (not hoary) lips of equal length.-Woods, Ill. and S. States. St. 2 to 3 f high. Lvs. green both sides, or often purplish. Rac. few-flowered. Cor. more than $\mathrm{l}^{\prime}$ in length, the lip as long or a little longer than the galea. Jl

6 5. pilòsa $\mathrm{Mx}$. St. erect, mostly simple, hirsute-pubescent; lvs. pubescent, rhomboid-ovate or oval, obtuse, crenate-serrate, petiolate, in remote pairs; rac. terminal, rather short, bracts elliptic-ovate; lips of the cor. large, the lower a little longer.-Open woodlands, Penn. to Ga. St. 1 to $2 \mathrm{f} \mathrm{high,} \mathrm{purplish.} \mathrm{Lvs.} \mathrm{few,} 1$ to $2 \frac{1}{2}^{\prime}$ by 8 to $18^{\prime \prime}$, more or less acute at baso and obtuse at apex; narrowed to

- the petiole. Rac. generally simple and few-flowered, with opposite, elliptical bracts. Pedicels and cal. hairy. Cor. tube nearly white below, blue at the summit, $9^{\prime \prime}$ long, the later fls. shorter. Jn.-Aug. (S. ovalifolia Bart.)

7 S. integrifollia L. Erect, negarly simple, densely pubescent; lvs. ovate-lanceolate, and linear-lanceolate, tapering to the base, subacute, entire, subsessile, the lower ovate; rac. loose, leafy; bracts lanceolate, fls. large. $-2 f$ Mid. and S. States, dry soils. St. $9^{\prime}$ to $2 \mathrm{f}$ high, with large blue fls. in terminal racemes. The lvs. (1 to $2^{\prime}$ long), vary in breadth and margin, the lowest being sometimes ovate and crenate. Cor. blue and white, slender at base, enlarged above, 8 to $9^{\prime \prime}$ long. Jn., Jl. (S. hyssopifolia Pers. S. Caroliniana Ph.) - The plant is intensely bitter.

8 s. nervòsa $\mathrm{Ph}$. Slender, erect, subsimple, stoloniferous; lvs. broad-ovate, subcordate, crenate-serrate, sessile, glabrous, 3-5-veined, lower roundish-ovate, upper ovate and lance-orate, slightly petioled; fls. axillary, solitary.-Rocky shades, along streams, Penn. to Ill. and La. Roots creeping, often sending out long, filiform stolons. Stem $8-15^{\prime}$ high, weak. Leaves. $2-15^{\prime \prime}$ by $5-12^{\prime \prime}$, the 
middle pairs largest, acute or obtusish. Floral leaves entire, small. Flowers few, pale blue, $4^{\prime \prime}$ long. May-Л.

9 S. párvula Mx. St. simple or branching at base, square, puberulent; lvs. ob. long-ovate, obtuse, entire, sessile; fls. small ( $\left.3^{\prime \prime}\right)$ axillary, opposite.-Pastures, Mid. and W. States. Plant 3 to $6^{\prime}$ high. Root generally with tuberous internodes, and fibrous at each joint. Lvs. 3 to $6^{\prime \prime}$ long, $\frac{1}{2}$ as wide, lower $3^{\prime \prime}$ diam. Fls. rather numerous, longer $\left(4^{\prime \prime}\right)$ than the leaves, blue. Jn.

10 S. galericulata L. Common Scull-CAP. St. erect, simple, or branched; lvs. lanceolate-cordate, remotely crenate-serrate; fls. axillary, solitary, large ( $1^{\prime}$ long).2f Meadows and ditches, Can. to Penn. Abundant. The wbole plant glabrous. Stem square, 12-18' high. Leaves truncate-cordate at base and acutish at apex, scarcely petiolate, $1^{\prime} \frac{1^{\prime}}{2}$ by $\frac{1^{\prime}}{2}$. Flowers much larger than the preceding, rarely more than 1 from the same axil, with a vizor-like calyx like that of the other species. Cor. an inch in length, blue. Aug.

11 s. lateriflòra L. MAD-DOG SKuLu-CAP. St. branching, nearly glabrous; lvs. ovate-lanceolate, acuminate, serrate, petiolate; rac. lateral, axillary, leafy.Meadows and ditches, lat $38^{\circ}$ to Arc. Am. St. square, 1 to $2 \mathrm{f} \mathrm{high,} \mathrm{very} \mathrm{branch-}$ ing. Lvs. opposite, rounded at base, acuminate or acute, coarsely. serrate, on petioles an inch in length. Rac. opposite, axillary, somewhat 1-sided; on long: stalks, with small blue fls. and small lvs. Jl., Aug.-The English namo is due to the singular form of the calyx, which after flowering, closes upon the seeds like a cap or vizor.

30. MACBRI'DEA, EIl. (Dedicated by Elliott to $D r$. Wm. Macbride, of Charleston.) Calyx campanulate, 3-lobed, upper lobe oblong, narrow, lower, rounded; corolla tube long-exserted, throat inflated, upper lip erect, entire, lower short, spreading, the middle lobe rounded, broadest; stamens ascending under the upper lip, anthers approximate by pairs.-2f Glabrous. Verticils 6 -flowered, subterminal, bractless.

M. púlchra Ell.-Swamps, middle districts, N. Car. to Ga. St. obtusely 4-angled, 1 to $2 \mathrm{f}$ high. Lvs. oblong-elliptical, petiolate, obscurely serrate or sinuate, tho floral short, sessile, ovate-entire. Verticils 1 or 2. Cal. green, thin, veiny, $6^{\prime \prime}$ long, cor. 18", streaked with bright purple and white. Aug., Sept.

31. SYNAN'DRA, Nutt. (Fig. 86, 325.) (Gr. $\sigma v v$, together, àv $\rho \varepsilon s$; in allusion to the coherence of the anthers.) Calyx 4-cleft, segments unequal, subulate, converging to one side; upper lip of corolla entire, vaulted, the lower obtusely and unequally 3 -lobed; throat inflated; stamens ascending beneath the galea, upper pair of anthers cohering; having the contiguous cells empty.-(2) Fls. solitary, axillary, somewhat spicate above.

S. grandiflòra Nutt. St. subsimple, nearly smooth, subterete; lvs. cordate-ovate, acuminate, obtusely dentate, often dilated at base, petiolate, the floral sessile; fls. solitary, sessile; cal. segm. ovate, setaceously acuminate, two upper langer than the two lower; cor. tube somewhat funnel-form, mouth much inflated.-Woods, Cleveland, Ohio, to Tenn. St. 6 to $18^{\prime}$ high. Lvs. 1-to $2^{\prime}$ long, nearly as wide, petioles 1 to $3^{\prime}$. Cor. $1^{\prime}$ long, upper lip very large, rounded, white, lower lip striated with purple lines. Jn.

32. PHYSOSTE'GIA, Benth. Lion's-heart. (Gr. $\phi \dot{\sigma} \sigma x$, a bladder, and $\sigma \tau \dot{\varepsilon} \gamma \eta$, a covering; from the inflated corollas.) Calyx campanulate, subequally 5 -toothed; corolla tube much exserted, throat inflated, upper lip concave, middle division of lower lip largest, roundish, emarginate; stamens 4 , unconnected, ascending beneath the upper lip, the two lower rather longer.-4 Fls. opposite, in a terminal, bracteate, 4 -sided spike. P. Virginiàna Benth. Cal, in fruit ovate, inflated; cor. gaping, upper lip concave.-A beautiful plant, native in Penn.. S. and W. States, often. in gardens. It varies much in stature, is very smooth, dark-green. St. square, thick, rigid, 1 
to $4 \mathrm{f}$ high. Lrs. opposite, closely sessile, 3 to $6^{\prime}$ by $3^{\prime \prime}$ to $3^{\prime}$ (the lower often very large), with remote and shallow teeth. Fls. numerous, dense, or often subremote. Bracts subulate. Cor. pale purple, about an inch long, spotted inside. Aug., Sept. (D. Virginiana, denticulatum, variegatum and obovatum of authors.)

33. LA MIUM, L. Hensit. (Lat. lamia, the name of a sea monster, to which the grotesque flowers may be likened.) Calyx 5-veined, with 5 subequal, subulate teeth; corolla dilated at throat, upper lip vaulted, galeate, nearly entire, lower lip broad, emarginate, lateral lobes truncate, often toothed on each side near the margin of the dilated throat; stamens 4 , ascending.

1 I. amplexicaùlis L. LVs. roundish, incisely crenate, floral broadly cordate, obtuse, sessile, amplexicaul, lower one petiolate; anth. hairy.-1) Waste grounds Mid., S. and W. States. Sts. ascending, several from the same root, 6 to $10^{\prime}$ high, with opposite, broad, short, hairy lvs., lower ones on stalks 1 to $2^{\prime}$ in length. Fls. in dense verticils, in the axils of the upper leaves. Cor. purple, downy, the tube much exserted, the lower lip spotted with white. May-Nov. § Eur.

2 L. purpùreum L. Lower lvs. roundish, the floral ovate, all crenate, petiolate, the petioles longer than the calyzes; cor. tube straight; anth. hairy.-(1) Waste grounds, Penn., rare. § Eur. †. Varies with the lvs. white-striped.

34. PHLO'MIS, L. Jerusalem Sage. (Gr. $\phi \lambda$ óg, a flame; the dried, woolly leaves of $P$. lychnitis were used in ancient lamps.) Calyx 5 to 10 -veined, limb equal, truncate or 5 -toothed; corolla upper lip galeate, carinate, broad, entire or emarginate, incurved, the lower spreading, trifid; stamens ascending beneath the galea; upper filaments adnate, often with a subulate appendage at base; anther cells divaricate, confluent ; achenia 3 -angled.-Fls. often showy, in axillary, bracted verticils. Lvs. rugous.

1 P. tuberòsa L. Tall, smoothish; lvs. ample, ovate, obtuse, crenate, deeply cordate, floral lance-oblong; bracts subulate and with the calyx somewhat ciliate; cal. limb truncated, with 5 rigid points; cor. galea very hairy inside. - 4 Shores of L. Ontario, near Rochester (Dewey) and Can. Plant 3 to $5 \mathrm{f} \mathrm{high,} \mathrm{with} \mathrm{lvs.}$ near a foot long. Verticils remote, with 30 to 40 purple fls. \& E. Eur.

2 P. fruticòsa L. Branches and oblong-ovate lvs. beneath cottony-tomentous; verticils dense-flowered, very woolly. Shrubby, $3 \mathrm{f} \mathrm{high.} \mathrm{Curious} \mathrm{in} \mathrm{cultivation}$ with its grotesque yellow fls. S. Lur.

35. Ballo'TA, L. Black Hoariound. (Gr. $\beta a ́ \lambda \lambda \omega$, to reject; on account of its offensive odor.) Calyx funnel-form, 10-veined, 5toothed ; corolla bilabiate, tube cylindrical, as long as the calyx, upper lip concave, crenate, lower lip 3-cleft, middle segment largest, emarginate ; stamens 4, ascending, exserted; ach. ovoid-triangular.-2f.

"B. nìgra L. Lvs. ovate, subcordate, undivided, serrate; bracts linear-subulate; cal. somewhat truncate, throat dilated, teeth spreading, acuminate.-Is frequer.t about hedges, \&c.., Mass and Conn. Stem 2-3f high, pubescent, as well as the opposite, broad leaves. Flowers purple or white, in axillary verticils. Jl. Has the general appearance of Hoarhound (Marrubium), but not its fragrance. § Eur.

36. MOlucCel'LA, L. Molucca Balm. Shell Flower. (Brought from the Molucca Islands, \&c.) Calyx campanulate, very large, the margin expanding, often repand-spinous; cor. tube included, limb bilabiate; stamens 4 , ascending.- I.

M. læ̇vis L. St. ascending; subsimple, glabrous; lvs. petiolate, roundishovate, incisely crenate; fls. in a terminal, leafy raceme; cal. campanulate, equally 5-toothed, nearly twice longer than the corolla, teeth awnless. A curious plant in gardens, smooth in all its parts and of a glaucous green, $1-2 \mathrm{f} \mathrm{high.} \mathrm{It} \mathrm{is}$ 
chiefly remarkable for its ample, bell-shaped calyx, in the battom of which is seated the yellowish-green flower. + Syria.

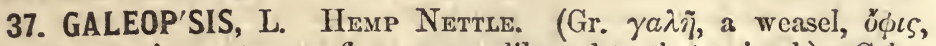
appearance; its grotesque flowers are likened to that animal.) Calyx 5-cleft, spinescent; upper lip of the corolla vaulted, subcrenate, lower lip with 3 unequal lobes, having 2 teeth on its upper side, middle lobe largest, cleft and crenate ; stamens exserted beyond the tube; anther cells opposite, transverse.-Verticils distant, many-flowered.

I G. tetràhit L. St. hispid, the internodes thickened upwards; lvs. ovate, hispid, serrate; cor. twice as long as the calyx, the upper lip nearly straight, concave.A common weed, in waste and cultivated grounds, N. States. St. 1 to 2 to $3 f$ high, obtusely 4-angled, remarkably tumid below the joint, and covered with prickly, deflexed bristles. Leaves hairy on both sides, ovate, acute, serrate. Fls. in dense verticils. Calyx with 5 acute, bristly teeth. Corolla variegated with white and purple, upper lip concave, purple, longer than the lower. June, July. $\S$ Eur.

2 G. ládanum L. St. glabrous or pubescent, internodes equal; Ivs. lanceolate, subserrate, pubescent; upper lip of the cor. slightly crenate.-A smaller species, growing among rubbish in gravelly soils, \&c., N. Eng., rare. Stem about a foot high, not swollen below the joints, with opposite branches. Flowers in dense, remote whorls. Corollas usually rose-colored, often white or variegated, spotted with crimson. Aug., Sept. \& Eur.

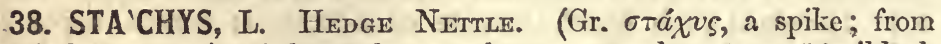
the inflorescence.) Calyx tube angular, campanulate, 5 or 10 -ribbed, 5-toothed, upper teeth often larger; corolla bilabiate, upper lip erect, spreading or somewhat vaulted, lower lip spreading, 3-lobed, middle lobe largest; stamens ascending, lower ones longer; anthers approximate in pairs.- Verticils 2 to 10 -flowered, approximate in terminal racemes.

* Plants glabrous, or nearly so. Calyx teeth divaricately spreading...............Nos. 1, 2

* Plarits hispid. . Calyx teeth suberect.-Leaves subsessile, petioles 0 to $\%$ loni..... Nos. 3,4 -Leaves all petiolate, petioles 6 to $12^{\prime \prime}$ lung. Nos. 5, 6

1 S. hyssopifòlia Mx. St. ascending or erect, glabrous or sparsely hairy; lvs. sessile, lance-linear, finely serrulate, acute, small, margin and baso hispid; verticils 4-flowered, distant; cal. and very slort bracts ciliate, teeth subulate, spreading, twice shorter than the corolla.-2 4 Wet soils, in barrens, Mass. to Mo. and S. States. Plant slender, 6 to $12^{\prime}$ high. Lvs. $1^{\prime}$ in length, rarely longer, 2 to $4^{\prime \prime}$ wide. Fls. sessile, 7 "long. Teeth of calyx shorter than its tube. JI.

2 S. glàbra Riddell. St. glabrous or slightly hispid downward, erect, often branched; lvs. glabrous, oblong-ovate, rounded or truncate at base, all petiolate, acute or subacuminate, serrato; cal. glabrous, teeth lance-subulate, spinulous, divaricate, as long as the tube of the corolla-2f Woods, streams, N. Y. to Mich. and S. States. Plant slender or rather stout, $15^{\prime}$ to $3 \mathrm{f}$ high. Lrs. 2 to $4^{\prime}$ long, the petioles 6 to $12^{\prime \prime}$. Spikes at length 3 to $7^{\prime}$ long. Fls. slender, pale red and purple. Jl., Aug.

$\beta$. DEBILIS. Weak, much branched, from a decumbent base.-Ga., La.)

3 s. palústris L. St. stout, erect, hispid, with retrorse bristles; lvs. many, hispid, hoary beneath, on short petioles, oblong-lanceolate, subacuminate, narrowed towards the obtuse base, crenate-serrate; cal. hispid, teeth acuminate-spinulous, erect-spreading; cor. twice longer than the calyx. - 2f By streams and in moist shades, Can. and Wis. to Car. Herb rough and coarse, 1 to $4 \mathrm{f}$ high. Lvs. 3 to $6^{\prime}$ long, petioles a few lines.' Bracts longer than the calyx. Fls. widely gaping, 7 to $8^{\prime \prime}$ long, pale red spotted with purple. Jn.-Aug. (S. hispida Ph.)

4 S. áspera Mx. St. slender, erect or flexuous, retrorsely hispid; lvs. sparsely 7ispid, subsessile, ovate-lanceolate, acuto or acuminate, sharply serrate, obtuse at base; cal. glabrous, but ciliate on the angles, and the lanceolate, spinulous, suberect teeth.- 4 Can. and U. S., in damp places, common. Plant much moro 
slender and smooth in aspect than tho preceding, yet technically scarcely different. It is green rather than hoary, about $2 \mathrm{f}$ high, simple. Lvs. 2 to $3^{\prime}$ by 6 to $9^{\prime \prime}$. Cal. smoothish, the teeth usually purple, equaling the tube of the purple spotted corolla. Jl., Aug.

5 S. Nuttalliàna Shuttlew. St. stout, erect, often branched, hispid with bristly, spreading hairs; lvs. elliptical-ovate, acuminate, crenate-serrate, sparsely hispid, narrowed to a cordate base, petiolate; cal. pubescent, teeth triangular, very acute, shorter than the tube of the corolla or calyx.-2 Ohio to Tenn., along shaded banks. Plant light green, 3 to $5 \mathrm{f}$ high, with large leaves. St. with grooved sides and hispid angles. Lvs. 4 to $9^{\prime}$ by $18^{\prime \prime}$ to $40^{\prime \prime}$. Verticils remote. Cor. light red, with purple stripes and dots, the tube much exserted. Jl., Aug. (S. sylvatica Nutt.)

$6 \mathrm{~S}$. arvénsis L. Annual; st. decumbent, hairy; lvs. ovate, cordate, petiolate, obtuse, crenate, the highest shorter than the lanceolate, acute teeth of the hispid calyx; cor. tube included, lips short.-In waste grounds near Boston, \&c. Plant slender, $3^{\prime}$ to If long, with long, spreading hairs. Lvs. 1' or less. Cor. pubescent. $\S$ Eur.

39. LEONU'RUS, L. Mother-wort. (Gr. $\lambda \dot{\varepsilon} \omega \nu$, a lion, ov́pá, tail; from the appearance of the spikes of flowers.) Calyx 5 to 10 -striate, 5 toothed, teeth subspinescent ; upper lip of the corolla entire, hairy, concave, erect, lower lip 3-lobed, the middle lobe obeordate; stamens 4, ascending beneath the upper lip. Mostly 24.

1 L. Cardiaca I. Lvs. palmate-lobed, uppermost lanceolate, often trifid, all of them toothed, cuneiform at base; cor. longer than the calyx, the tube with a hairy ring within.-Tartary, whence it was first introduced into Europe and thenco to America, ever following the footsteps of civilized man. Common in wasto places. Stem 3-5f high, downy, square, large, purplish, bearing its opposite, stalked, rough leaves arranged in 4 vertical rows. Fls. in many whorls. Calyx rigid and bristly. Cor. purplish, hairy without, variegated within. July.-It has reputation as an ingredient in herb drinks for colds, coughs, \&c. \$

2 I. marrubiástrum L. Lvs. oblong-ovate, incisely and coarsely serrate, the floral lanceolate, tapering at each end, incisely dentate; cor. shorter than the calyx. teeth, tube naked within, upper lip somewhat vaulted, pubescent.-Penn., Ind., rare. A plant of vigorous growth, 2-4f high, with opposite, ascending branches. Leaves $2-3^{\prime}$ in length, the lowest on long petioles. Verticils many-flowered, remote but numerous, forming an interrupted, leafy spike. Corolla reddish white. July, Aug. § Eur.

40. MARRU'BIUM, L. Hoarhound. Calyx tubular, 5-10 striate, with 5 or 10 subequal teeth; cor. bilabiate, upper lip erect, flattish or concave, entire or bifid, lower lip spreading, 3-lobed, middle lobe broadest, emarginate, tube included; sta. included in the tube.-2f.

M. vulgàre L. St. ascending, hoary pubescent; lvs. roundish, ovate, crenatedentate, downy canescent beneath; cal. of 10 setaceous, uncinate teeth.-Fields and roadsides. St. 1 to $2 \mathrm{f}$ high, branching at base, or several from the same root. Lvs. petiolate, 1 to $2^{\prime}$ diam., whitish and rough veined above, very woolly beneath, rounded and toothed. Fls. white, in sessile, axillary, dense, hairy verticils. Cal. woolly, tho teeth spreading and alternately shorter. Jl., Aug. § Eur. Well known as an ingredient in cough candy.

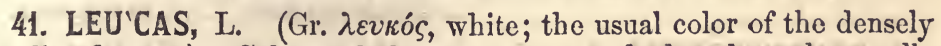
woolly flowers.) Calyx tubular, 8 to 10 -toothed, subequal; corolla. tube included, upper lip concave, erect, entire, very hairy without, the lower longer, spreading, trifid, middle lobe the largest; stamens beneath the galea; filaments not appendaged, achenia 3 -angled.-Fls. in axillary verticils. 
L. Martimcénsis Br. Erect, pubescent; lvs. petiolate, ovate, crenate, rugous, the floral lanceolate; verticils distant, large, globular, many-flowered; cal. incurved, oblique, upper tooth longest. - (1) Herbs 1 to $2 \mathrm{f}$ high, with small white flowers. Escaped from gardens, Ga. $\S$ W. Ind.

42. LEONO'TIS, Br. LION's-EARs. (Gr. $\lambda \dot{\varepsilon} \omega \nu$, a lion, $\dot{\omega} \dot{\imath}$, ears ; a fanciful name alluding to the corollas.) Calyx 10-veined, apex incurved, throat oblique, sub-10-toothed, upper tooth largest; corolla tube exserted, limb bilabiate, upper lip concave, erect, entire, lower short, spreading, trifid; stamens 4, ascending under the galea; anthers in pairs.-Verticils dense, with numerous, linear-subulate bracts. Fls. scarlet-yellow.

I. nepetæeòlia $\mathrm{Br}$. Herb stout, erect; lvs. thin, ovate, crouate; cal. teeth 8 , the upper much the largest, all spinescent; cor. scarlet, about twice longer than the calyx.- (1) Waste and cultivated grounds, S. Car. and Ga., common. Plant large and very showy, 4 to $7 \mathrm{f}$.high. St. deeply 2 -grooved on the 4 sides, angles rounded. Lvs. comparatively. small, $18^{\prime \prime}$ to $30^{\prime \prime}$ by 12 to $20^{\prime \prime}$, on long petioles. Clusters terminal and subterminal, near $2^{\prime}$ diam., beset with the calyx spines and the brilliant, downy corollas $10^{\prime \prime}$ in length. \& Africa.

\section{Order xC. BorragiNaCEA. Borrageworts.}

Herbs (shrubs or trees), with round stems and branches, not aromatic. Leaves alternate, generally rough, with stiff hairs. Stipules none. Flowers seldom yellow, generally in a coiled (scorpoid) inflorescence. Sepals 5. Petals 5, united below, regular, very rarely irregular. Stamens 5, inserted in the tube. Ovary deeply 4-lobed, forming in fruit 4 separate, 1-seeded achenia in the bottom of the persistent calyx. Style 1, gynobasic, seed separable from the pericarp, exalbuminous. Illust. in figs. $220,372$.

Genera 54, 8pecies 6S3, mostly natives of temperate climates in the Northern hemisphere.

Properties.-Mucilaginous and emollient plants, never poisonous. The important red dye, alkanet, is the product of Anchusa tinctoria, \&c. Many are esteemed for their beauty in cultivation.

\section{TRIBES AND GENERA.}

I. EHRETIE E. Ovary entire, 4-celled. Sty. terminal. Fr. baccate. Shrubs.Tournerorta. 1

II. IIELIOTROPEA. Ovary entlre. Style terminal. Frult dry separating into parts. (a)

a Corolla tube cylindrical, throat open. Fruit separating into 4 parts......IIrelotropium. 2

a Corolla tube conical, throat constricted. Fruit separating into 2 parts... II ELorirtus. 3

III. BORRAGEA. Ovary deeply 4-lobed. Style basllar. Fruit 4, achenla. (b)

b Corolla irregularly 5 -tobed, throat open, naked. Blue............................ 4

b Corolla regularly 5-lobed. (c)

c Achenia unarmed, fixed by their excavated base, throat closed. (d)

d Corolla wheel-form. Anthers exserted. Bluo.................. Borrago. 5

d Corolla tubular-bell-form. Style exserted. White..............Sympiytum. 6

d Corolla salver-form, with the slender tube bent. Blue.............. Lycopsis. 7

c Achenia unarmed, fixed by their small, flat base. Thront open or closed. (e)

e Corolla tubular, with the lubes erect and acute. White.......... ONosmoprum. 8

- Corolla lobes rounded, imbricated in bud. White or yellow.... Litiospermum. 9

- Corolla lobes rounded, imbrlcate in bud. Purple, blue, large...... Mertensia. 10

o Corolla lobes rounded, convolute in bud. Bluc or white, small......Mrosotis. 11

c Achenla armed with barbed prickles.-Corolla salver-forın....... Ecmnospermum. 12 -Corolla funnel-form........... Crnoglossum. 13

1. TOURNEFOR'TIA, L. Summer Heliotrope. (Dedicated to Joseph Pitton de Tournefort, the founder of Systematic Botany.) Calyx 5-parted, corolla salver-form, throat naked; stamens 5, included; style short; fruit 2-carpeled, 4-celled and 4-seeded.-Shrubs. with entire lvs. and secund spikes. 
T heliotropoides Hook. Shrubby at base, with herbaceous, hairy branches, erect; lvs. oval, pubescent, obtuse, undulate on the margin; ped. terminal, 2 or 3 times dichotomous; cor. tube included, lobes obtuse, fruit globular.-The fls. are numerous, small, pale lilac, and inodorous. + Buenos Ayres.

2. HELIOTRO PIUM, Tournef. Heliotrope. (Gr. $\ddot{\eta} \lambda \iota s$, the sun, $\tau \rho \varepsilon ́ \pi \omega$, to turn ; the flowers were said to turn with the sun.) Calyx 5parted, corolla salver-form, lobes shorter than the tube, the sinuses plicate and prominent in the bud; anthers sessile; style short, stigma conical, the achenia cohering at base, at length separable.-Herbs or shrubs. Fls. white or purple, in unilateral, scorpoid spikes.

1 H. Europæuum L. Herb erect, pubescent; lvs. oval, obtuse at each end, petiolate, wavy; spikes lateral and terminal, single or forked; cal. lobes hirsute, obtuse, equaling the cor. tube, and also as long as the fruit.-(1) Rocky banks, at Harper's Ferry, \&c. A delicate annual 8 to $12^{\prime}$ high. Lvs. 1 to $2^{\prime}$ long, two-thirds as wide. Fls. small, white, in spikes sereral inches in length. Aug. $+\S$ Eur.

2 H. curassávicum L. Herb glabrous, procumbent at base; lvs. linear-lanceolate, obtuse, entire, glaucous; spikes usually forked; sep. obtuse, much shorter than the fruit. - (1) Sandy shores, St. Louis to N. Orleans. A foot high. Lrs. 1 to $2^{\prime}$ by 2 to $3^{\prime \prime}$. Fls. very small, bluish. § W. Ind.

3 H. Peruviànum L. Shrubby, erect, pubescent, somewhat hoary; lvs. short-petiolate, lance-ovate, rugous; spikes numerous, aggregated, corymbous; cor: tubetwice longer than the calyx.-A pretty green-house shrub, 1 to $2 \mathrm{f}$ high. Lvs. serrulate, twice as long as wide. Fls. very fragrant, white or tinged with purple. + Peru.

3. HELIOPH'YTUM, DC. (Gr. $\ddot{\eta} \lambda \iota s$, the sun, $\phi v \tau o ́ v$, a plant; from its relation to Heliotropium.) Calyx 5 -parted; corolla salver-form, throat constricted, 5-rayed; anthers included; style very short; nuts 2, each 2-celled (sometimes with 2 additional empty cells).--Herbs with habit of Heliotrope.

H. Indicum DC. Herbs erect, branching, hairy; lvs. ovate, erose-serrulate, acute, base abruptly contracted into a petiole; often subcordate, rugous, very veiny; spike terminal, solitary; simple (rarely forked !) ; cor. much exserted, pubescent; fr. miter-form, the two nuts divaricate, showing the 4 empty cells between.Waste grounds, pastures, Ill., Ind. to Ga. St. furrowed, 1 to $2 \mathrm{f} \mathrm{high.} \mathrm{Lvs.} 2$ to $3^{\prime}$ long, or more. Spikes 2 to $6^{\prime}$ long. Cor. blue or purple. Carpels bifid at apex. $\S \mathrm{S} . \mathrm{Am}$. E. Ind.

4. ECH'IUM, Tourn. VIPER's Bugloss. (Gr. 'ع̋ $\chi \varsigma$, a viper ; from the spotted stem of some species.) Calyx 5-parted; segments subulate, erect; corolla campanulate, obliquely and unequally lobed, with a short tube and naked orifice; stigma cleft; achenia tuberculate, base flat, imperforate.-Herbs or shrubs. Fls. irregular, in spicate, panicled racemes.

E. vulgàre L. St. herbaceous, rough with bristles and tubercles; cauline lvs. lanceolate, and rough with bristles; spikes lateral, hairy, deflected.-(1) A rough plant, with large, handsome, violet-colored flowers, found in fields and wasto grounds, N. States. Stem $18-20^{\prime}$ high, round, with entire, dull green leaves, which are $2-6^{\prime}$ long, and $\frac{1}{5}$ as wide, lower ones petiolate, upper ones amplexicaul. Flowers in numerous, crowded, axillary, recurved spikes, appearing in June and July, § Eur.

5. BORRA G0, Tourn. Borrage. Calyx 5-parted; corolla rotate, with acute segments; orifice crowned; flaments converging; achenia ovoid, muricate, excavated at base, inserted lengthwise into an excavated receptacle.-European herbs. 
1 B. officinàlis $\mathrm{L}$. Lvs. ovate, alternate, the lower ones petiolate; cal. spreading; ped. terminal, many-flowered; filaments included.- (1) A common inhabitant of the garden. The whole plant is rough with short, bristly hairs, erect, $2 \mathrm{f}$ high, with terminal clusters of handsome, sky-blue flowers during summer. It was formerly in high repute as a cordial. Tho young leaves form a good salad and pot-herb. $\ddagger$ Eur.

2 B. orientàlis. Ivs. cordate, petiolate; ped. many-flowered; fil. exserted, vil lous. - (1) An ornamental garden plant, E. Eur. Stem and leaves hairy. Flowers blue, appearing in the spring months. $\neq$ (Psilostemon, DC.)

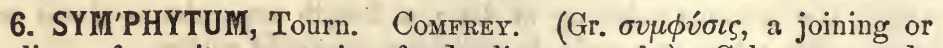
healing; from its reputation for healing wounds.) Calyx 5-parted; corolla tubular-campanulate, orifice closed with 5 , subulate scales, converging into a cone ; achenia smooth, ovoid fixed by an excavated base. - 4 Oriental herbs.

S. officinàle I. Hairy, branching above; lvs. extensively decurrent, the lower and radical petiolate, ovate-lanceolate, upper and floral lanceolate; sep. lanceolate, acuminate; cor. limb with 5-recurved teeth.-A large, coarse-looking mucilaginous plant, in gardens and low grounds, Mid. States. Whole plant rough with dense hairs. Stem $3-4 \mathrm{f}$ high, winged by the decurrent leaves, bearing terminal, revolute racemes. Corollas white, pink and red, appearing all summer. $\ddagger \S$

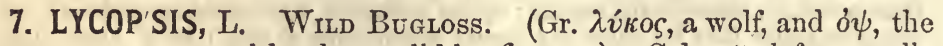
eye ; name suggested by the small blue flowers.). Calyx 5-cleft ; corolla funnel-form, tube incurved, orifice closed with ovate, converging scales; achenia perforated at base, ovcid, angular.-(1) Distinguished mainly by the curved corolla tube.

I. arvénsis I. Plant hispid; lvs. lanceolate, repand-denticulate; rac. leafy; fls. sessile; cal. shorter than the curved tube of the corolla.-A very hispid, almost bristly plant, in fields and roadsides, N. States, probably introduced. Stem erect, branching, roundish, about a foot high. Leaves 5 or 6 times as long as wide, the margin irregularly and slightly toothed. Fls. small. Calyx erect. Corolla skyblue with white scales within. June, July. § S. Eur.

8. ONOSFO'DIUN, Mx. (From Onosma, another genus of this order, and $\varepsilon \tilde{\imath} \delta o s$, appearance.) Calyx deeply 5-parted, with linear segments; corolla cylindrical, having a ventricous, half 5 -cleft limb, with the segments converging and the orifice open; anthers sessile, sagittate, included ; style much exserted ; achenia imperforate, whitish, shining:4 North American. Rac. terminal, subspicate, one-sided. Fls. white.

1 o. Virgínicum Alph. DC. Clothed with appressed, stiff bristles from a tubercular base; lvs. oblong, sessile, entire, acute or rather obtuse, 5-veined, cal. very bristly, lobes lance-linear; cor. hispid or nearly smooth, a third longer than the calyx, the segm. tance-subulate; anth. strongly sagittate.-Dry soils, N. Eng. to Fla. and $\mathrm{La}$. Plant mostly erect, 15 to $30^{\prime}$ high, branching, very rough. Lvs. variable, 15 to $30^{\prime \prime}$ by 5 to $9^{\prime \prime}$. Floral lvs. bractlike. Cor. 4 to $5^{\prime \prime}$ long. Jn.-Aug. (O. hispidum Mx.)

2 O. Caroliniànum DC. Tall, clothed with long spreading, rusty-white, bristly hairs tubercled at base; lvs. lance-oblong, sessile, entire, 7-veined, acute, gradually diminished upwards; fls. shaggy, bristly; cal. lobes lance-oblong; cor. near twice longer, limb dilated, segm. ovate, obtusish; anth. linear-oblong, cells scarcely diverging at base.-By streams, W. N. Y. to Wis., La. and Ga. St. hollow, 2 to $4 \mathrm{f} \mathrm{high,} \mathrm{branched.} \mathrm{Lvs.} 2$ to $3^{\prime}$ or more long, nẹar $1^{\prime}$ wide. Cor. 5 to $6^{\prime \prime}$. Ach. large, white. May-Jl. Varies in leaves and hairiness.

$\beta$. soLLE. Bristles short, appressed, and on the lower surface of the oblong-ovate lvs. soft downy, except the 7 prominent, bristly veins.-Plant smaller. Lvs. approaching to ovate, acute or obtuse. $(0$. molle Mx.) - Chicfly S. Western. 
9. LITHOSPER'MUM, L. Grammell or Gromwell. (Gr. $\lambda l \vartheta o \varsigma$, a stone, and $\sigma \pi \varepsilon \dot{\rho} \mu a$, seed; the seeds being hard and shining like little pebbles.) Calyx 5-parted, persistent; corolla funnel-form or salverform; limb 5 -lobed, orifice open, or with 5 gibbous appendages, alternating with the stamens; anthers included; stigma obtuse, bifid; achenia bony, rugous or smooth, imperforate at base.-Herbaceous or suffruticous, generally with a thick, reddish root. Fls. spiked or racemed, bracted, white or yellow.

$\S$ Achenia rugous-tubereled. Corolla throat open, not appendaged....................No. 1

$\$$ chenia sinooth and white. Corolla throat appendaged. - Flowers white................... $2-4$

-Flowers yellow.............. 5 - 7

1 I. arvénse L. WheAt-THIEF. Lvs. linear-lanceolate, obtuse, hairy; cal. nearly equal to the corolla, with spreading segments; ach. rugous.- (1) A rough, troublesome weed, in fields and waste grounds. Stem branching, erect, 12-15' high, from a fusiform root with reddish bark. Lvs. bright green, rough, sessile, 1-2' in length, with only the central vein; the lower ones obtuse and narrowed to the base; upper ones subacute. Fls. small, white, subsessile, solitary, in the axils of the upper leaves. May, Jn. § Eur.

2 工. officinàle L. Erect, very branching above; lvs. lanceolate, acute, veiny; cal. nearly equal to the tube of the corolla; ach. smooth. - 2f A rough, grayish plant, in dry, gravelly soils, N. and Mid. States. Sts. much branched, clustered, arising 1 to 2 f from a white, fusiform root. Lvs. grayish green, rough on the upper side, hairy beneath, rather acute, entire, 2 to $3^{\prime}$ by 6 to $9^{\prime \prime}$. Fls. small, white, axillary; solitary, pedicellate, in recurved, leafy spikes. Achenia ovate, polished, stony, usually but 1 or 2 perfected. JI. § Eur.

3 I. latifòlium Mx. Erect, subsimple, scabrous; lvs. ovate, sharply acuminate, tapering to the sessile base, veined, scabrous ; rac. leafy, few-flowered; sep. lancelinear, longer than the corolla, and spreading in fruit; ach. punctate with minute impressions, shining white, ovoid-turgid.-Woods and thickets, N. Y. to Ill. and $\mathrm{Va}$. Sts. many from the same root, strict, $2 \mathrm{f}$ high. Ivs. 2 to $4^{\prime}$ by 1 to $2^{\prime}$, strongly veined. Nuts generally but. 2, half as long as the calyx. Fls. small, white.

$4 \mathrm{~L}$. angustifòlium $\mathrm{Mx}$. Procumbent at base, much branched, roughish and somewhat hoary with an appressed pubescence; lvs. linear, rigid, edges slightly revolute; fls. scattered, lateral; ach. roundish-ovoid, shining, but punctate with minuto impressions.-Sand prairies, along rivers, Wis. (Lapham) to Ark. and westward. Plant 6 to $15^{\prime}$ high. Lvs. 1' long. Fls. small, cor. white, scarcely longer than the calyx.

5 工. canéscens Lehmann. Prccoon. Erect, subsimple, softly villous; lvs. oblong or linear-oblong, obtuse, silky-canescent above, villous beneath; fls. axillary; tube of the cor. thrice as long as the very short calyx.-2! Prairies, fields, and dry hills, Can. N. Y. to Ill. and S. States. St. 8 to $12^{\prime}$ high, erect, simple, rarely a little branched above. Lvs. sessile, 2 to $3^{\prime \prime}$ wide and 4 times as long, 1-veined. Fls. crowded near the summit of the stem. Cal. segm. lanceolate, acute, $2^{\prime \prime}$ long. Cor. bright orange-yellow, 6" long. Jn., Jl. The root dyes red. (Batschia, Mx.)

6 I. hírtum Lehm. Erect, simple, rough-hairy; lvs. sessile, linear-lanceolate, obtuse, ciliate-hirsute both sides, floral ovate-lanceolate; cal. lobes linear, hirsute, half as long as the corolla; cor. segm. spreading, obovate, entire, tube hispid inside at base; ach. ovoid, shining. - 2f W. and S. States, in dry soils. Sts. 8 to $15^{\prime}$ high, clustered. Fls. crowded. Cor. orange-yellow, 7 to $8^{\prime \prime}$ long. Cal. segm. enlarged in fruit. Apr.-Jn. (Batschia Carolinensis Gmel.)

7 I. longiflòrus Spreng. Erect, strigous with a cinerous pubescence; lower lvs. lance-linear, attenuated to the base, upper ones linear, acutish; rac. leafy, terminal; cal. segm. linear, much longer than the pedicel; cor. tube 4 times longer than the calyx, lobes crenulate, wavy. -4 Wis. to Natchitoches, La. (Hale.) St. 10 to $15^{\prime}$ high, slender, branched near the top. Lrs. 2 to $3^{\prime}$ long, 2 to $4^{\prime \prime}$ wide, the floral scarcely as long as the flowers. Cor. yellow, the tube 9 to $12^{\prime \prime}$ long. Fr. much shorter than the calyx, smooth, white. Jl. (Pentalophus, DC.) 
10. MERTENSIA, Roth. (Pulmonaria, Tourn.) Sмooth Luvawort. (Named for Prof. F. C. Mertens, of Bremen, Germany.) Calyx short, 5-cleft; cor. tube cylindric, twice longer than the calyx, limb subcampanulate, 5 -cleft, throat naked, or oftener with 5 folds or ridges between the insertion of the stamens; sta. inserted at top of the tube; anth. subsagittate; ach. smooth or reticulated. $-2 f$ St. and leaves usually glabrous and pellucid-punctate, the radical many-veined, cauline sessile. Rac. terminal.

1 M. Virgínica DC. Erect or ascending, very smooth; radical lvs. large, petiolate, oval, ovate or obovate, cauline sessile, lance-ovate or oblong, all entire, obtuse; cor. tube 3 times longer than the calyx, twice longer than the limb.-Dry, rich soils, N. Y. to S. Car. and Iowa. A plant of rare beauty, 12 to $18^{\prime}$ high. Lrs. 2 to $6^{\prime}$ long, the cauline feather-veined. Fls. numerous, nodding, somewhat trumpet-shaped, $10^{\prime \prime}$ long, varying through every shade of bluo and lilac even on the same plant. May. (Lithospermum pulchrum Lehm.)

2 IM. marítima Don. Glabrous, procumbent or ascending; lvs. ovate, obtuse, fleshy, glaucous, the radical petiolate, cauline sessile; rac. leafy; cal. deeply cleft, scarcely half as long as the glabrous, 5-cleft corolla.-Sea shore, N. Eng., rare, Can. and northward. St. diffusely branched. Fls. purplish blue, limb longer than the tube, which exhibits 5 folds at its summit. $\mathrm{Jl}$.

3 M. paniculàta Don. Scabrous with minute hairs, erect; radical lvs. petiolate, ovate, cordate, cauline ovate-oblong, sessile, all acuminate and veined; cal. hispid, thrice shorter than the subcampanulate corolla.-Shores of the great Lakes, from Superior to Bear I., also in gardens. An elegant plant, with fls. varying from bright blue to white, paniculate, nodding.

11. MYOSO'TIS, Dill. Forget-ME-Not. (Gr. $\mu \tilde{v} s$, a mouse, and (oṽs) $\tilde{\omega} \tau o s$, an ear; from the form of the leaves.) Calyx 5-cleft; corolla salver-form or funnel-form, tube about equaling the calyx, the 5 lobes convolute in bud, orifice closed with short, concave scales; achinia ovate, smooth, with a small cavity at base.-Herbs, slightly villous. Rac. at length elongated, bractless, or with a few, small lvs. at the base. Fls. never axillary.

\$ Racemes one-sided. Calyx clothed with minute, appressed hairs, if any................ 1 Lacemes two-sided. Calyx beset with spreading, minutely-hooked bristles................... 3

I M. palústris Roth. B. LAXA (Fig. 220). Minutely strigous or smoothish, somewhat branched, erect; lvs. linear-oblong, obtuse, with short, scattered hairs; rac. without bracts; pedicels divaricate in fruit, twice as long as the short, spreading, smoothish, equal calyx.-4 Ditehes and marshes, Can. and U. S., very slender, about a foot high. Lvs. scattered, sessile, about $1^{\prime}$ by 2 or $3^{\prime \prime}$. Rac. terminal, or often ono of them supra-axillary, one-sided. Fls. 2 to $3^{\prime \prime}$ broad, blue, with a yellow center. Ped. 3 to $6^{\prime \prime}$ long. May-Aug. (M. cxspitosa Schultz.)

$2 \mathrm{M}$. arvénsis $\mathrm{L}$. Hirsute with tubercular hairs, branching; lvs. oblong-lanceolate, acute; pedicels spreading in fruit, twice as long as the open, equal calyx, in loose racemes, which are not at all leafy among tho flowers at their base.-(2) Fields, \&c. Sts. 6 to $15^{\prime}$ high. Lvs. $1^{\prime}$ and less in length. Fls. 2 to $3^{\prime \prime}$ broad, wnite? Jl., Aug. We describo from English specimens, having seen none native. (M. intermedia, Link.)

3 M. stricta Link. Roughly hirsute with spreading, mostly tubercled hairs; lvs. oblong, or the lower spatulate-oblong, obtuse or acute, pedicels ascending, as long as the closed, uncinate-bristly, unequal calyx, in racemes which are leafy at base. (2) Dry fields and hills, Conn., N. Y., to Wis, La. and Ala. Plant varying greatly in aspect at different stages of growth, yet always recognized by its calyx, which is decidedly bilabiate, the lower lip of 2 longer teeth. Plant 6 to $16^{\prime}$ high, grayish. Lvs. $1^{\prime}$ long, or in larger specinens $2^{\prime}$. Fls. very small ( $1^{\prime \prime}$ broad), white. May-J. (M. verna Nutt. M. arvensis Torr.) 
12. ECHINOSPER'MUM, Swartz: BurR-SEEd. (Gr. $\dot{\varepsilon} \chi$ ivoc, the seaurchin, $\sigma \pi \varepsilon \dot{\rho} \rho \mu$, seed; from the character.) Calyx 5-parted; corolla hypocrateriform, orifice closed with concave scales; achenia 4, erect, bearing 1 to 3 rows of echinate prickles, smooth between, compressed or angular, fixed to a central column.-Herbs with bracted rac. and small, blue fls.

E. Láppula Lehm. St. branched above; lvs. lanceolate or linear-lanceolate, hairy; cor. longer than the calyx, the border erect-spreading; ach. each with. 2 rows of hooked prickles on the margin.-(1) An erect herb, in dry soils, roadsides, N. States to Arc. Am. Stem having a dry, grayish aspect, from its dense hairs, about a foot high, undivided except at the top, where it branches into a kind of panicle. Leaves $1^{\prime}$ by $1-2^{\prime \prime}$, sessile. Flowers very small, blue. Jl. (Rochelia Rœe. Cynoglossum Scop.)

13. CYNOGLOS'SUM, Tourn. Hound's Tongue. (Gr. $\kappa v ́ \omega v$, a dog, $\gamma \lambda \tilde{\omega} \sigma \sigma a$, tongue ; from the form of the long, soft leaves.) Calyx 5parted ; corolla short, infundibuliform, vaulted ; orifice closed by 5 converging, convex scales; achenia covered with echinate prickles, dcpressed, forming a broad, pyramidal fruit, and each fixed laterally to the style.-Cor. blue, purple or white.

\$ Racemes without bracts or nearly so.......................................... 1, 2

$\$$ Racemes bracted at base, but the pedicels always extra-axiliary............................. 3

1 C. officinàlis L. Comanon Hound's Tongue. Silky-pubescent, leafy to the top; root-lvs. lance-oblong, attenuate at base to a petiole, upper sessile or amplexicaul; rac. bractless, paniculate, not stalked; nuts margined in front.- 2 . Waste grounds, pastures, common. Plant of a dull green color, emitting a disagreeable smell. St. erect, hairy, 1 to $2 \mathrm{f} \mathrm{high}$. Lvs. with soft down on both sides, entire, 6 to $10^{\prime}$ by 1 to $2^{\prime}$, tapering into a long, attenuated base, the upper much smaller. Clusters terminal, panicled, recurved at the end. Fls. with a downy calyx and a dull red corolla. Cal. leaf-like in fruit. Sds. rough with hooked prickles. JI. $\S$ Eur.

2 C. Virgínicum L. Hirsute-pilous; lvs. oblong-oval, acute, upper ones clasping, cordate, all on the lower half of the stem; corymb terminal, leafless, on a long, naked peduncle. - 2f Inhabiting woods and thickets, Vt. to Va. and Ill., rare in N. Eng. A hairy plant, 2f high, simple, bearing at the top of its leafless summit a small, panicled corymb of pale purple flowers. Radical lvs. 5 to $6^{\prime}$ long and half as wide. Cal. and pedicels very hairy. Jn. (C. amplexicaule Mx.)

3 C. Morrisòni DC. BegGar-Ticks. St. widely branched; lvs. oblong-lanceolate, acuminate, scabrous above, pubescent beneath; rac. divaricate, dichotomous; fr. densely covered with prickles, doubly barbed at tho point.-(1) In rocky grounds and rubbish, Can. to Fla. St. furrowed, 2 to $3 \mathrm{f}$ high, with many slender, remote, wide-spread branches, each terminating in a centrifugal, racemous inflorescence. Lvs. entire, remote, large ( 4 to $8^{\prime}$ long), tapering to each end, the lower ones petioled. Fls. very small, white, the pedicels nodding in fruit. JL (Echinospermum Virginicum Lehm.)

\section{OrDER XCI. HYDROPHYLLACEA. HYDrophyLL.}

Herbs mostly, with alternate lobed leaves and regular bluish flowers. Calyx 5cleft, usually with appendages at the clefts, persistent, free. Corolla 5-lobed, often with 10 honey scales or furrows near the base. Stamens 5, inserted into the corolla, with a deeply bifid style. Ovary entire, ovoid, free, 1-celled, with 2 parietal, several-seeded placentæ. Fruit 2-valved, filled by the placenta. Seeds reticulated, albuminous.

Genera 18 , species 77 , chiefly American. Properties unimportant. 


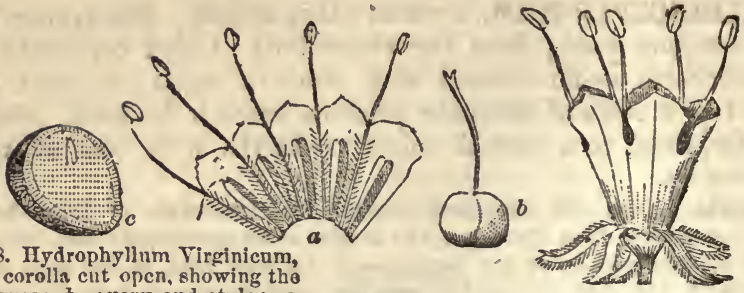

FIG. 678. Hydrophyllum Virginicum, hower: $a$, coros; $b$, ovary and style; $c$, section of seel.

GENERA.

\$ Placentre central, large, many-seeded. Cymes not scorpoid....................Hrdrolra. 6

$\$$ Placentæ parietal (at least in the middle), bearing few (1 to 4, rarely many) seeds.

b Lobes of the corolla convolute in astivation. (c)

b Lobes of the corolla imbricate (quincuncial) in the bud. (d)

c Stamens exserted. Flawers in forked, scorpoid racemes..........HYpropmyLuU. 1

c Stamens included. Flowers solitary, opposite the leaves.............. Nemopura. 2

d Flowers solitary. Calyx much enlarged in fruit... ......................... 8

d Flowers racemed.-Lobes of the corolla entire (seeds 4.)........... PHackLra. 4

-Lobes of the corolla entire (seeds $\infty$ ).............Eutoca. 5

-Lobes of the corolla fringed................. Cosmanthus. 6

1. HYDROPHYL'LUM, Tourn. Water-leaf Burr-Flower. (Gr.

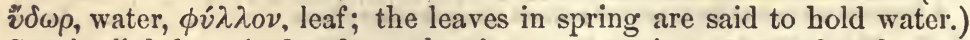
Sepals slightly united at base, the sinuses sometimes appendaged; corolla campanulate, convolute in bud, with 5 longitudinal, margined nectariferous grooves inside; stamens exserted; capsule globous, 1-celled, 2 -valved, 4 -seeded, 3 of the seeds mostly abortive; placentæ 2, fleshy, free except at the base and apex.-2f Radical lvs. on long petioles, pinnately or palmately veined, cauline alternate. Cymes scorpoid, bractless.

\$ Calyx appendaged between the sepals at base. Stamens as long as the corolla........ No. 1

$\$$ Calyx not appendaged. Filaments much exserted............................... $2-4$

1 H. appendiculàtum Mx. Lvs. subpalmately 5-lobed, the lower almost pinnatifid, the lobes dentate, diverging, and with the long petioles, ped. and cal. hirsute; sep. lance-subulate, the appendages at the base ovate, acute, 4 times shorter; cor. glabrous except the minute appendages inside; stam. included.N. Y, near Rochester, to Wis. and Va., in woods. Sts. 12 to $18^{\prime}$ high, branched. Petioles 1 to $4^{\prime}$ long. Lvs. roundish in outline, the broad, acute lobes pointed and diverging in a stellate manner. Cal. 4 to $5^{\prime \prime}$ long, appendages deflexed, $1^{\prime \prime}$ long. Cor. blue. May.

2 H. Virgínicum L. Plant nearly smooth; lvs. pinnatifid and pinnate, the segments oval-lanceolate, incisely serrate; fascicles conglomerate; ped. longer than the petioles.-An inhabitant of moist woods, Can to Car. and Western States. Stem a foot high, bearing large, roundish tufts of flowers, stamens and style very conspicuous, twice the length of the bell-shaped corollas. Leaves few, on long, clasping petioles, with about 5 distinct leaflets, the upper 3 more or less confluent at base, all irregularly toothed. Corollas varying fiom white to sky-blue. Jn.

3 H. Canadénse L. Lvs. smoothish, palmate, roundish, with 5-7 shallow lobes, unequally dentate, teeth obtuse-mucronate; fls. in crowded fascicles; ped. shorter than the forked petioles.-Quite different in aspect from the last. Found in alpine woods, Can. to Car. W. to Ind. Stem 12-18' high, with large, roughish leaves, divided into 5-7 lobes. Fascicles of fls. dense, terminal, but shorter than the petiole which seems to continue the stem. Cor. white or variously tinged with purple, much longer than the pedicels. Jn., Jl.

4 H. macrophýllum Nutt. Whole plant reversely hispid with white hairs; los. ollong-oval, in outline, pinnatifid, lower segments distinct, upper confluent, all incised into rounded, mucronate teeth, cauline solitary or few, much smaller; cymes terminal, long-pedunculate, dense-flowered; cor. glabrous except the grooves inside. 
-Ohio, to the Alleghany Mts. of Va. Stem a foot high, almost leafless, with a terminal globous cyme of white flowers. Radical leaves 6 to $10^{\prime}$ long, the segments ovate-oblong. Corolla $6^{\prime \prime}$ long, stam. 10". Jn.

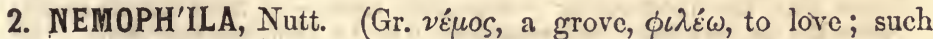
is their usual locality.) Calyx 5-parted, the sinuses with reflexed appendages ; corolla rotate-campanulate, the 5-lobes convolute in bud, obtuse, the tube inside bearing 10 minute folds or scales; stamens included; ovary globous, 1-celled, 2-valved, with 2 placentr, free except at the ends, each 2 to 12-ovuled.- I Herbs fragile, diffuse, with opposite or alternate, pinnately parted lvs., one-flowered, ped. and cyanic fls.

I N. microcàlyx Fisch. \& Meyer. Glabrous, decumbent, branched; lvs. triangular in outline, 3-cleft, or the lower 5-parted, segm. with rounded mucronato lobes; ped. slender, opposite to and nearly equaling tho petioles; cor. small, about twice longer than the calyx; seeds 1 to 2--Damp woods, Macon, Ga., Ala.; to Ark. and La. Sts. many, 6 to $12^{\prime}$ long, or often but 3 to $6^{\prime}$, very tender. Lvs. all alternate, less than $1^{\prime}$ long, the petioles often longer. Fls. white, 1 to $2^{\prime \prime}$ broad. Lvs. ovoid, pitted. Apr. (N. evanescens Darby. Ellisia, Nutt.)

$2 \mathrm{~N}$. insígnis Benth. Lrs. oblong, pinnately 7 to 9 -lobed, lobes ovate, acute, ped. longer than tho leaves; cor. twice as long as the calyx, rotate-campanulate; seeds 10 to 12. Plant procumbent, in gardens, somewhat hairy, 1vs. 1 to $2^{\prime}$ long. Fis. $l^{\prime}$ or more broad, white with a bluo border. + California.

3 N. maculàta Benth. Procumbent, with lvs. similarly lobed with the last, and with the fls. white, with 5 large violet-colored spots on the border. + California.

3. ELLIS'IA, L. (In honor of Joseph Ellis, F.R.S., an English naturalist, correspondent of Linnæus.) Calyx 5-parted, equaling the tubular-campanulate, caducous corolla, sinus naked; cor. tube with 5 -pairs of minute appendages within, limb 5-lobed; sta. included; nectary annular, 5-toothed; sty. bifid, with linear lobes; caps. ovoid-globous, 2 valved; seeds 4 or fewer ripening.-(1) Herbs, with pinnatifid lrs. Cor. white.

E. Nyctelæ̀ea L. Ascending, branching, with fow, scattered hairs; lvs. petiolate, upper ones alternate, segments 9 to 11 , linear-oblong, nearly distinct, sparingly dentate; ped. 1-flowered, opposite the leaves, about as long as the sepals; cal. seg. triangular-acuminate, broad at base, longer than the tube of the corolla.-(1) Woods and river banks, Md. to Iowa and Ala. Stem 4-10' long. Leaves 1-2' long. Calyx at length remarkably large for the size of the plant, nearly an inch in diam. Corolla lobes obtuse, emarginate, with purple spots at base inside. May-Jl.

4. PHACE'LIA, L. (Gr. $\phi a ́ \kappa \varepsilon \lambda o s$, a bundle or fascicle; alluding to the fasciculate racemes.) Calyx 5-parted, not appendaged; corolla tubular campanulate, caducous, 5 -lobed, lobes entire, imbricate in bud, tube within furnished with 5 margined grooves; stamens 5 , mostly exserted; ovary 1-celled, hispid; style bifid; capsule ovoid, 2-valved, valves bearing the placento in the middle; seeds 4 to 10 .-Herbs hispid, with alternate lvs. and loose or dense, one-sided racemes.

* Racemes forked or corymbed.....Nos. 1,4. * Racemes simple....Nos. 2, 8.

I P. bipinnatífida Mx. Hairy, suberect; lvs. incisely pinnatifid, long-petiolate, lateral segm. 2 to 4, incisely lobed and toothed, terminal trifid; rac. elongated, forked subpaniculate; cor. lobes entire, twice longer than the calyx, shorter than (sometimes as long as) the stamens. 2f or (2) Woods and lill sides, Penn. to Ind. (Plummer), Mo. and N. Car. Plant sometimes nearly smooth, 1 to $2 \mathrm{f}$ high, bearing several leafless racemes at top. Lvs. 3 to $6^{\prime}$ long, including the petiole. Cor. $6^{\prime \prime}$ broad, bluc, the grooves bordered with narrow, pubescent margins. May, Jn. 
2 P. hirsuta Nutt? Erect, branching, sparingly hirsute; lvs. pinnatifid, 5 to 7. lobed, the lower petiolate, almost pinnate, upper sessile, lobes oblong, acutish, thoso of the radical lvs. rounded; rac. simple, terminal, 9 to 15 -flowered, pedicels twico longer than the linear-oblong bristly-ciliate sepals.-A more delicate species, on Stone Mt. Ga. and Ark. Sts. smoothish, 6 to $12^{\prime}$ high, sparingly leafy. Cor. $7^{\prime \prime}$ broad, violet blue, 10-spotted around the yellowish throat. Grooves obscurely bordered. Stam. not longer than cor. May, Jn.

3 P. parviflòra $\mathrm{Ph}$. 'Sts. weak, smoothish, procumbent, subsimple; lvs. all petiolate, the lowest elongated, with roundish, remote, stalked leaflets, tho upper with distant oblong-lanceolate, entire, acuto segm.; rac. simple, loose, terminal, 6 to 12 flowered; pedicels at length twice longer than the oblong-spatulate, smoothish sepals; fls. small.-(2) Shaded banks, Penn. to Ga. Plant diffuse, ascending, 6 to $10^{\prime}$ long. Lvs. with their petioles 1 to $3^{\prime}$ long, lobes distant, small. Fls. palo blue, $4^{\prime \prime}$ wide. Apr., May.

4 P. congésta Hook. Downy-canescent; lvs. pinnate, lfts. alternate, very unequal, some sessile, others petioled, all incisely lobed, the terminal confluent; rac. corymbous; sep. lance-linear; cor. campanulate, twice longer than the calyx; stam. exserted. - (1) Herb a foot high, in gardens, with numerous bright bluo fls. + Texas.

5. EUTO'CA, R. Br. Calyx 5-parted; cor. deciduous, 5-lobed, imbricate in bud; nectary-grooves 0 ; filam. exserted, with minute scales at

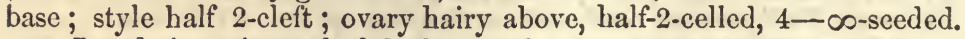
-I Lvs. hairy, pinnately lobed or entire.

1 E. víscida Benth. - Glandular-pilous, viscid, branched, suberect; lvs. petiolate, ovate, coarsely, and unequally dentate or lobed; racemes scorpoid, at length elongated; sep. linear, a third as long as the tubular-campanulate, deep bluo corolla; seeds $\infty$.-Gardens. If high. Fls. near l' long. † California.

2 E. Franklínii Br. Pubescent, simple, erect; root-lvs. crowded, cauline alternate, all pinnatifid, lobes $5-7$; rac. short, spike-like, cor. blue, spreading-campanulate, a third longer than the calyx; seeds $\infty .-$ Gardens. Fls. numerous. California.

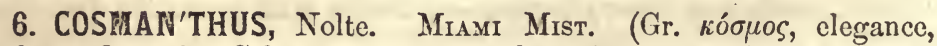

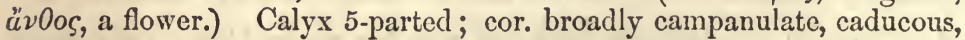
5-cleft, tube without appendages; sta. 5, about equaling the (fringed) corolla ; nectary minute; ova. hairy except at base, 1-celled; sty. bifid; caps. 2 -valved, valves septiferous in the middle; seeds 4 , rugulous.-(1) Delicate herbs, with alternate lvs. Rac. long, bractless. Fls. small, white or pale blue.

1 C. Púrshii. Nearly glabrous; lower lvs. petiolate, pinnatifid, segments few, cntire, ovate, terminal one largest, upper lvs. sessile, pectinately pinnatifid, with $\mathbf{5}$ to 7 oblong, acute, lobes; rac. terminal, simple, 9 to 15 -flowered; pedicels longer than the lance-linear sepals.-Fields and river bottoms, Penn. to Ga., W. to Ia. and $\mathrm{Ky}$. Plant $8-12$ ' high, with slender branches. Radical leaves with obtuso lobes, mostly sliorter than the petiole. Cor. delicately fringed, light blue, 5 to $6^{\prime \prime}$ broad, spreading. May, Jn. (C. fimbriatus Nolte. Phacelia fimbriata Ph. not Mx. P. Purshii Buckley.)

2. C. fimbriàtus $\mathrm{Mx}$. Much branched from the base, pubescent; sts. slender, assurgent; lower lvs. petiolate, pinnate, with roundish segments, upper sessile, cleft into 5 to 7 oblong, obtuse lobes; rac. terminal, simple, 5 to 12 -flowered; pedicels about as long as the oblong-spatulate, obtuse sepals.-Mts. Va., Tenn. (Miss Dana), to Ga. Sts. 4 to $8^{\prime}$ long. Fls. white, delicately fringed, 4 to $5^{\prime \prime}$ diam. May.

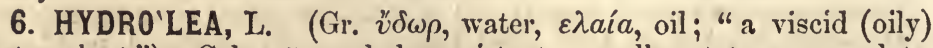
water plant.") Calyx 5 -sepaled, persistent; corolla rotate-campanulate, 5 -lobed ; stamens 5 , adherent to the corolla tube; styles 2 , stigmas capitate-depressed; capsule 2-celled, 2-valved, the large, fungous pla- 
centæ axial, borne on each surface of the free, false dissepiment, seeds many.-Herbs with alternate, undivided lis., and axillary or terminal cymes of blue fls.

1 H. corymbòsa Macbride. Unarmed, sparingiy birsute above; lvs. sessile, lance-ovato; branchlets corymbed, each bearing a terminal flower; sep. lanceolate. acute, hispid; cor. thrice longer than the calyx; caps. roundish-ovoid, glabrous. $-2 f$ Ponds in pine barrens, Ga. and S. Car. (Bachman). Sts. 1 to $2 \mathrm{f} \mathrm{ligh.} \mathrm{Lrs,}$ $1^{\prime}$ to $18^{\prime \prime}$ long, with downy veins and margins. Fls. showy, nearly bell-shaped, 1 ' broad, "azure with yellowish veins and 5 white spots near the base," (Elliott.) Jn.-Aug.

2 H. quadriválva Walt. Spiny, more or less hispid; lvs. lanceolate, petiolate, very acute at both ends, entire; cymes 4 to 6-flowered, axillary, upper sessile, lower pedunculate ; sepals ovate, acuminate, a little shorter than the corolla. $-2 f$ In stagnant waters, S. Car., Ga. to La. St. 2f high. Spines straight, slender, axillary, 3 to $5^{\prime \prime}$ loug. Lvs. 2 to $3^{\prime}$ long. Cor. azure blue, 5 to $6^{\prime \prime}$ broad. Caps. as large as a pea, with numerous minute seeds. Jl.-Sept.

3 H. ovàta Nutt. With ovate-acuminate lvs. and terminal clusters is found in W. La. and Ark., probably not nativo within our limits. Rarely seen in gardens.

\section{Order XCII. POLEMONIACEA. Pirloxworts.}

Herbs with alternate or opposite leaves and 5-parted, regular, showy flowers. Corolla monopetalous, the lobes convolute, rarely imbricate in æstivation. Stamens 5, adherent to the corolla tube, and alternate with its lobes. Ovary 3-celled, stigma 3-cleft; capsule 3-celled, 3-valved, loculicidal. Seeds few or many, albuminous, attached to a permanent columella. (Illustr. in Fig. 301.)

Genera 17, species 104, chiefly N. American. They are valued and cultirated only as ornamental plants.

\section{TRIBES AND GENERA.}

I. POLEMONIEAE. Sepals united at base. Lobes of the corolla convolute in bud. (a)

a Corolla salver-form. Filaments unequal. Leaves entire................ PuLox.

a Corolla bell-form. Filaments equal. Leaves pinnate................... PoLEMonicy. 2

a Corolla funnel-form. Filaments equal. (Leaves pinnately dlssected).....Grisi. 3

II. DIAPENSIE E. Sepals distinet, oval. Lobes of corolla imbricated......... DiAPENSIA. 4

\section{PHLOX, L. Phlox. Lychnidia. (Gr. $\phi \lambda \hat{z} \xi$, a flower; from} the color and profusion of the flowers.) Calyx prismatic, deeply 5-cleft ; corolla salver-form, the tube more or less eurved; stamens very unequally inserted in the tube of the corolla above the middle; capsule 3-celled, cells each 1-seeded.-A highly ornamental, North American genus. Lvs. mostly opposite, sessile, simple, entire. Fls. in terminal, cymes, corymbed or panicled. (Fig. 301.)

* Lobes of the corolla rouncled and entire at the end. (1)

1 Panicle of cymes oblong or pyramidal, many-flowered...................... 1, 2

1 Panicle of cymes corymbed, level-topped, flowers fewer. (2):

2 Plants glabrous. Calyx teeth shorter than its tubes...................Nos. 3, 4

2 Plants hairy. Calyx teeth attenuated, longer than the tube. (3)

3 Leaves narrow, linear or nearly so.............................. Nos. 5,6

3 Leaves broad, ovate or lanceolate, etc............................ Nos. $7,8, \beta ., 9$

* Lobes of corolla notched or bifid at the end.-Leaves distant.................... Nos. 8 , 10 -Leaves imbricnted........................ 11

1. P. paniculàta I. Glabrous, erect; lvs. oblong or ovate-lanceolate, acuminate at each end, or the upper abrupt at base, rough-edged, flat; corymbs paniculate, subpyramidal, many-flowered; cal. teeth setaceous-acuminate, nearly as long as the tube; pet. roundish-obovate, entire. $-2 f$ This favorite is found native in woods and river banks, $\mathrm{W}$. States to Penn. and Car. St. 2 to $3 \mathrm{f}$ high, ending in a large, oblong-pyramidal panicle of innumerable pink-colored, scentless flowers. Lvs. 3 to $5^{\prime}$ by 9 to $16^{\prime \prime}$, lower ones distinctly petioled. Cor. tube a little curved, 12 to 15" long. J.-Sept. $t$ 
B. ACCMINita. Lrs. ovate-acuminate, pubescent beneath as well as the stem; panicle with fewer flowers.-In rich alluvion. (P. acuminàta $\mathrm{Ph}$.)

2 P. maculàta L. St. erect, scabrous or nearly smooth, purple-spotted; lower lvs. lanceolate, the highest ovate, cordate at base, all subcoriaceous, roughish or smooth; panicle obloug or subpyramidal; cal. teeth lanceolate, acute, about half as long as its tube; pet. orbicular.-2f Moist fields, Penn. to Car. and Western States. Stem 2-3f high, mostly punctate, with purple spots. Lower branches of the panicle shorter than the leaves, or often elongated. Corolla tube more or less curved, smooth. Petals obtuse or retuse, purple, varying in gardens from white to crimson. Jn. $f$ (P. pyramidalis Sm.)

3. GRAcíLIOR. Tall, slender, scabrous; lvs. linear and lance-linear. Ga. (Feay).

$\gamma$. suaviolens. Smooth; fls. white, sweet-scented.-Gardens. (P. suaveo. leus Ait.)

3 P. Carolina L. Glabrous; st. declinate at base, ascending, often branched; lvs. lanceolate from an ovate (rarely cordate) base, acuminate or gradually acute; paniclo corymbous, of denso, few-flowered cymes; cal. teeth lanceolate, acuminate. Woods, prairies, Mich. to Ga. St. often procumbent at base, thickish, smooth, $9^{\prime}$ to $2 \mathrm{f} \mathrm{high.} \mathrm{Lvs.} 2$ to $4^{\prime}$ long, variable in form. Corymb simple or often compound and ratber diffuse. Sep. united two-thirds their length, the points soft, spreading. Cor. tube $1^{\prime}$, lobes rose purple, roundish, spreading $1^{\prime}$. May-Jl. +

B. ovìtA. St. roughish or puberulent; lvs. broad $\left(1^{\prime}\right)$; corymb loose.-South. (P. ovata $\mathrm{Ph}$.

$\gamma$. NíridA. Lvs. lance-oblong, dark green, shining.-S. W. (P. nitida Ph. ?)

4 P. glabérrima $\Upsilon_{\text {. }}$ Glabrous; sts. slender, clustered, subsimple, erect; lvs. lancelinear or oblong-linear, gradually acute or acuminate, rounded or acute at base, thickish, often with revolute margins ; corymb subsimple, few-flowered; cal. teeth lanceolate, sharply acuminate.-Prairies and barrens, Wis. to Ga. and Tenn. Sts. 1 to $3 f$ high, with light green foliage. Lvs. 2 to 3 to $4^{\prime}$ long, 3 to $5^{\prime \prime}$ wide, very smooth except the rough edges. Sep. united two-thirds their length. Cor. tube 9 to $12^{\prime \prime}$ long, slightly eurved, lobes pale pink. Jn., Jl.

5 P. pilòsa L. Smooth or puberulent below, glandular pilous above; st. declinato at base, slender, assurgent, subsimple; lvs. linear and lance-linear, margin subrevolute, base half-clasping, attenuate to an acute apex; panicle corymbous, fewflowered, loose; cal. segm. subulate-aristate, much longer than the tube.-Prairies and copses, Wis. to N. J., Ga., Fla. and La. A common, slender Phlox, 1 to 21 high. Lvs. 1 to $3^{\prime}$ long, rigid. Cor. small, palo red or bluish, tube 7 to $8^{\prime \prime}$ long, lobes spreading 7 to $8^{\prime \prime}$. May, Jn. (P. aristata Mx.) Varies to glabrous (La. Hale) when it still differs from No. 4 by its long setaceous calyx teeth.

$\beta$. Floridìna. Smoothish below; lvs. oblong-lanceolate; sep. lanceolatesetaceous.-Fla. (at Quincy!) and elsewhere. Approaches the next. (P. Floridana Benth.)

6 P. involucràta. Hoary-pubescent; sts decumbent and branching at base, thin, simple and erect; lrs. linear-oblong, rather obtuse at each end, half-clasping, suberect, flat, the floral similar and closely subteriding the dense corymbs as if involucrate; cal. teeth longer than its tube, linear or subulate-spatulate; cor. lobes roundish-obovate, angled at apex.-Very elegant, common in dry soils, throughout the S. States. Sts. 6 to $12^{\prime}$ high. Lvs. about $1^{\prime}$ long. Cor. deep purple varying to carmine-red. May, Jn. (P. pilosa Walt., Mx., Benth., etc., not L. ß.? Walteri, Gray.)

7 P. réptans $\mathrm{Mx}$. Stolons creeping; sts. assurgent; Ivs. ovate, obovate or oblong, obtuse; corymbs few-flowered; cal. puberulent, segments linear-subulate; pet. obovate, entire. - If Hillsides and mountains, Ind. (Plummer) to S. Car. Flowering-stems $6^{\prime}$ high (Southern specimens 6 to $12^{\prime}$ ), with small $\left(4-9^{\prime \prime}\right.$ by $2-4^{\prime \prime}$ ) aud remote leaves. Stolons with leaves $2-3$ times larger, somewhat crowded at the end. Flowers 3-8. Corolla bluish-purple, tube scarcely twice longer than the calyx. June.

8 P. divaricàta L. I.ow, diffuse, pubescent; Ivs lanceolate, ovate or oblong, acutish; panicle corymbous, loose ; cal. roughish-puberulent, segm. linear-subulate; cor. lobes emarginate at the end.-2f Can., Wis., N. Y. to Ga. and Ala. (banks of the Chattahoochee!). Sts. loosely branched, a foot or more long, flaccid. Lvs. 
1 to $2^{\prime}$ long, acute, the lower tapering to the base, the upper broad and clasping at base, the floral linear setaceous. Yedicels diverging, as long as the caly $\mathrm{x}$ which is half as long as the corolla tube. Cor. of a peculiar light but brilliant grayish blue. Apr., May.

$\beta$. LaPhaMII. Lvs. ovate, pet. obtuse, entire.-Wis. (Lapham) Western Roserve (Cowles) and southward, not uncommon.

9 P. Drummóndii Hook. Drummond's Lyounidra. Erect, dichotomously branched, glandular-pilous ; lvs. mostly alternate, oblong or lanceolate, scabrous; corymb dense-flowered; cal. hairy, segm. lanceolate, setaceous, elongated, revolute ; cor. tube pilous, segm. obovate, entire.-1) Banks of Flint R., S. E. Ga.! and Tex. One of the handsomest species of the genus, common in cultivation. Whole plant glabular-scabrous, 8 to $12^{\prime}$ high. Fls. very showy, all shades from white to dark purple, and exquisitely penciled with a star. May, Jn.

10 P. bifida Beck. Low, assurgent, diffusely branched, puberulent; lvs. amplexicaul, subrevolute on the margin, acutish, lower lance-ovate, upper lancelinear; corymbs very loose, 2-5-flowered; cal. segments linear, acute; cor. tube curved, segments deeply bifid.-A very distinct species, and very rare, in Mo. (Beck), Cass Co.. Ill. (Mead). Stem brownish-purple, slender, 6' high. Leaves 12-15" by 1-2", lower much shorter. Pedicels 1 ' long. Cor. purple, tubo much curved. Apr.

11 P. subulàta (and P. setacea L.) Moss PrNk. Procumbent, cæspitous, much branched, pubescent; lvs. rigid, subulate or linear-subulate, ciliate, fascicled in the axils; cal. teeth linear-subulate, very acute ; cor. lobes cuneate, emarginate. Rocky hills, Penn. to Ga. and Ky., abundant in its localities, in dense, turfy masses, spangled over in May with rose-colored flowers. Corymb, 3-6-flowered. Cor. white or pink, deeper purple in the center. May. $\nmid$

2. Polemo'niUm, L. Greek Valerian. (Gr. $\pi 0 ́ \lambda \varepsilon \mu o s$, war; Pliny relates that two kings fought for the merit of its discovery.) Calyx campanulate, 5-cleft; corolla rotate-campanulate, limb 5 -lobed, erect, tube short; stamens declined, equally inserted at the throat, filaments with hairy appendages at base; capsule 3-celled, 3-valved, cells many-seeded.-Herbs with alternate, pinnately divided lvs. Fls. terminal.

1 P. réptans L. St. smooth, branching, diffuse; lvs. pinnately 7-11-foliate, leaflets oval-lanceolate, acute; fls. terminal, nodding; cells of caps. 2-3-seeded. 2f Woods and damp grounds, Wis. to N. Y. and mts. of S. Car. Stem 12-18' high, weak, fleshy. Leaflets mostly 7, subopposite, smooth, entire, sessile, an inch long and half as wide. Segments of the calyx lanceolate-acute, persistent, much shorter than the tube of the corolla. Corolla blue, lobcs short, rounded at the ends. Anthers introrse. Root creeping. May. $\dagger$

2 P. ccrùleum L. St. smooth, simple, erect; lvs. pinnately 11 to 7 -foliate, segm. acuminate; fls. erect; cal. equaling the tube of the corolla; cells of caps. 6 to 10-seeded.-(2) A handsome plant, in gardens. Sts. clustered, about $2 \mathrm{f}$ ligh, hollow, stout, each dividing at top into a corymbous panicle. Lvs. mostly radical, on long, grooved petioles; lfts. all sessile, ovate-lanceolate, subopposite, oblique, odd one lanceolate. Fis. terminal, suberect. Cor. blue, $6^{\prime \prime}$ diam. † Eur.

3. GIL'IA, Ruiz \& Pavon. (Named for P. S. Gilio, a Spanish botanist.) Calyx 5-cleft, segments acute; corolla tube long or short, limb regularly 5-lobed; stamens 5 , equally inserted at top of the tube ; disk cup-form; capsule oblong or ovoid, few or many-seeded.-Herbs with alternate, pinnatifid lvs. Fls. paniculate, capitate or scattered, elegant and showy, lilac purple to white.

1. IpoMopsis. Corolla funnel-form, the tube mnch exserted......................... No. 1 12. Gris proper. Cor. lobes subrevolute, tube included in calyx..................... No. 2

I G. coronopifòlia Pers. Standing CrPRESG. St. strictly erect, tall, hairy; lvs. crowded, pinnatifid with subulate divisions; thyrse elongated, with very short 
branches; cor. tube thrice longer than calyx, segm. oval-oblong, erect-spreading; stam. barely exserted.- (2) Along rivers, S. Car., Ga., Ala. A splendid herb, 2 to $4 \mathrm{f} \mathrm{high,} \mathrm{its} \mathrm{plume-like} \mathrm{form} \mathrm{closely} \mathrm{beset} \mathrm{with} \mathrm{delicate} \mathrm{fringe-like} \mathrm{leaves} \mathrm{and}$ bearing at top a long (1f) thyrse of scarlet red flowers. Cor. 15" long. Jl. (I pomopsis, Mx. Cantua, Juss.).- A more slender form found in Fla. is G. Floridana Don.

2 G. trícolor Benth. Tricolored Gilia. St. erect, nearly smooth; Ivs. tivice or thrice pinnatifid, with narrow, linear segments; cymes paniculate, 3 to 6 -flowered; cor. tricolored, 2 or 3 times ionger than the calyx, tube very short.-(1) An elegant little garden plant, from California, if high. Fls. numerous, limb pale lilac-blue, throat purple and tube yellow. $\ddagger$

4. DIAPEN'SIA, L. Calyx of 5 oval imbricated sepals, closely subtended by imbricated bracts; corolla campanulate, imbricated in the bud ; filaments 5 , flat, arising from the sinuses of the corolla; anthercells diverging at base and the dehiscence transverse; capsule papery, enveloped in the persistent calyx, 3-celled, many-seeded.-Prostrate undershrubs with densely imbricated, linear lvs, and solitary terminal fls.

\$1. Diapensia proper. Anthers without awns. Flowers pedicellate..................... 1

\$2. Pyxidanturra. Anthers with the lower valve awned. Flowers sessile................. 2

1 D. Lappónica L. Cæspitous; lvs. dense, spatulate, fleshy, evergreen, obtuse and entire; fls. pedunculated. - if A little, leafy plant, $2-3^{\prime}$ high, growing on the summits of the White Mts. in N. Hampshire, forming dense tufts among the rocks. Leaves crowded, pale beneath, fleshy, $5-\$^{\prime \prime}$ by $l^{\prime \prime}$ with a revolute margin, clasping base, and broadly obtuse point. Fls. on slender ( $l^{\prime}$ long) terminal, solitary peduncles. Calyx of 5 , obtuse leaves, langer than the leafy bracts at its base. Corolla white, with 5 , flat segments. July.

2 D. barbulàta Ell. Branches short, ascending; lvs. lance-cuneiform, acute, pubescent at base; fls. terminal, sessile; lower valve of the anther beaked or awned at base. - $\Lambda$ prostrate, creeping plant, abundant in pine barrens, N. J. to Car., forming dense beds. Stems $3-6^{\prime}$ long, subhispid. Leaves $1-2^{\prime \prime}$ by $\frac{1}{2}-1^{\prime \prime}$. Flowers white, $3^{\prime \prime}$ diam. Sepals denticulate, as long as the corolla tube. May, Jn.-The beak of the anther is variable, sometimes reduced to an acute point. (Pyxidanthera barbulata $\mathrm{Mx}$. D. cuneifolia $\mathrm{Ph}$.)

\section{Order XCIII. CONVOLVUlaCEAE. Bindweeds.}

Chiefly twining or trailing herbs, sometimes parisitic, sometimes shrubby. Leaves (or scales when leafless) alternate. Flowers regular, pentamerous and 5 -androus. Sepals imbricated. Corolla monopetalous, 5-plaited or lobed, convolute in bud. Ovary free, 2 (rarely 3)-celled or falsely 4-celled, or of 2 distinct, 1-ovuled pistils. Capsule to 6-seeded. Embryo large, coiled in mucilaginous albumen. (Illustr. in fig. $49,56,303,321,338,455,456$.)

Genera 50, species 700, abundant in tropical climates, rare in cold.

Propertie8. - The roots of many spccies abound in an acrid, milky juice which is strongly purgative. Jalap of the shops is the product of the root of Exogoninu purga, of Mexico, and of otlier species; scammony, of Convolvulus scainmonla, native of Levant. The drastic qualities of both depend upon the presence of a peculiar resin. Other species have large farinaceous tubers. The Sweet Potato, a valuable article of food, is the product of C. Batatas, native at the Soutb.

\section{TRIBES AND GENERA.}

III. CUSCUTINE.2. Lenfless, parasitic, twining. Embryo without cotyledons...Cuscuta. 10

II. DICHONDRE E. Leafy. Ora. 2, distinct, with 2 distinct styles. South...Dicnosdra. 9

I CONvolvule s. Leafy. Ovary 1. Capsule dehiscent. Cotyledons leafy. (a)

a Ovary 2-celled. Styles 2. Peduncle longer than the leaves................ StYursaA. \&

a Ovary 2-celled. Styles united into one. (b)

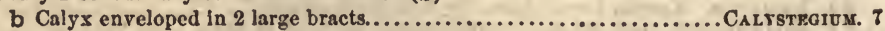

b Calyx naked.-Stamens exserted. Tube of the corolla slender...... CALrNYCTion. 6 -Stamens included.-Stigmas 2, linear...............Covvolvules. 5 


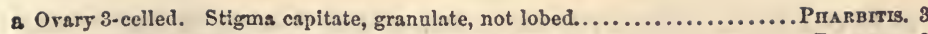

a Ovary 4-celled.-Stamens included. Corollas, larga................................. 2

-Stamens exserted. Corollas rather small...............QuAMocLIr. 1

1. QUA'MOCLIT, Tourn. CrPress-vine. Sepals 5 , mostly mucronate; corolla tubular-cylindric, with a salver-form border; stamens exserted; style 1, stigma capitate, 2 -lobed; ovary 4-celled, cells 1 -seeded. -Twining herbs, mostly American. (Fig. 303.)

1 Q. vulgàris Choisy. CrPress-viNe. Lvs. pinnatifid to the midvein, serments linear, parallel, acute; ped. 1-flowered; sep. ovate-lanceolate.- (1) An exceedingly delicate vine, Penn. (Eaton) and S. States generally cultivated. Stems glabrous, very slender, twining and climbing to the height of 5-10f. Fls. much smaller than those of the common morning glory, scarlet, varying to crimson and rose-color. Trained upon twine it forms an exquisite awning. July, Aug. $\nmid \S$ E. Ind.

2 Q. coccínea Moench. Lvs. cordate, acuminate, entiro or angular at base; ped. elongated, about 5-flowered; cal. awned.- (1) S. States, rare in the Western, along rivers, frequent in gardens. Fls. very delicate, $1^{\prime}$ long, limb spreading $9^{\prime \prime}$, light scarlet, nearly entire. Jn.-Aug. (Ipomæa L.)

2. BATATAS, Rumph. Sweet Potato. (The original Indian namo of the common potato, transferred.) Calyx of 5 sepals; corolla campanulate, with a spreading limb; stamens 5, included; style simple; stigma capitate, 2 -lobed; capsule 4-celled, 4-valved, with 4 erect seeds. -Herbs, or shrubby, chicfly American. Juice milky.

I B. littoralis Chois. Creeping, sending out runners; lvs. smooth, petiolate, thick, sinnate, with 3 to 5 rounded lobes, or somewhat panduriform, emarginate, cordate; ped. 1-flowered, as long as the leaf; sepals ovate, abruptly acuminate; seeds tomentous. - 2f Sand hills near the coast, S. Car. to Fla. Fls. large. Stam. much shorter than the tnbe of the yellowish white corolla. Sty. with 2 capitate stigrnas. Aug.-Oct. (Convolvulus L. C. obtusilobus Mx.)

2 B. macrorhìza. Creeping or twining; lvs. cordate, entire, sinuate or lobed, tomentous-pubescent beneath; ped. 1 to 5-flowered, longer than the petioles but shorter than the leaves; sep. ovate, obtuse; seeds villous with long hairs.-2f Sandy soil, islands of S. Car. and Ga. (Elliott). Rt. fusiform, attaining a largo size. Sts. several feet in length. pubescent. Ped. 2 to 3 ' long. Cor. large, purplish, white. Stam. barely included. Stig. 2, capitatc. Jn.-Oct. (B. Jalapa (?) Chois. Convolvulus Ell.)

3 B. édulis Chois. Sweet Potato. Creeping, or twining; lvs. variously 3 to 5-palmate or pedate-lobed or angled, lobes acute, base cordate with a broad sinus, 5-veined, smoothish; ped. 3 to 5-flowered, as long or longer than the petioles. - If Root bearing oblong, tereto tubers which taper to both ends. Sts. 4 to' $8 \mathrm{f}$ long. Lrs. 2 to $5^{\prime}$ long, on petioles 2 to $6^{\prime}$. Fls. showy, rose-purple. $\ddagger$ E. India. (Convolvulus Batatas L.)-Extensively cultivated West and Soutli for its rici, nu. tritious tubers. (Fig. 56.)

3. PHAR'BITIS, Chois. Monnivg Glony. (German farbe, color; in reference to the brilliant flowers.) Calyx 5-sepaled; corolla campanulate or inclining to funnel-form; style single; stigma capitate, granulate; ovary 3 (rarely 4)-celled, cells 2-seeded.-Beautiful climbing and twining herbs, everywhere cultivated for ornament.

I P. purpùrea. St. climbing and twining, retrorsely pilous; lvs. cordate, entire; fl. nodding; ped. 2-5-flowered; pedicels thick; cal. hispid. - (1) In fields, Mid. and W. States. Stems climbing many feet. Leaves roundish, heart-shaped. Flowers large, beautiful, generally of a dark purple, sometimes blue, flesh-colored, striped, \&ic. A well known and favorite climber and free flower, of the easiest culture. Jn. $\S+$ (Fig. 49, 338.) (P. hispida Chois. Convolvulus L.) 
2 P. Nil Chois. Mornivg Glory. Lvs. cordate, 3-lobed; fls. half 5-cleft; ped. shorter than the petioles, 1-3-flowered; sep. ovate, long-pointed, densely hairy below.-A very beautiful twining plant, found wild, Penn. to Flor., in fields, but best known as a garden annual. Stem and leaves somewhat hairy. Flowers large, the tube white and the border of a clear blue color (whence its specific name, Anil or Nil, indigo), drying light scarlet. It is of the easiest culture, and raised from the seed. July-Sept. $\dagger$

4. IPOME'A, L. FALSE BIND-WEED. (Gr. $\iota \psi, \iota \pi T o s$, bind-weed (or

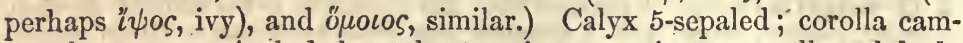
panulate; stam. included; style 1; stigma capitate, rsually 2-lobed; ovary and capsule 2-celled, cells 2 -seeded.-A large genus of herbs, shrubs or trees, chiefly tropical. Our species are herbs, creeping or climbing.

* Flowers capitate, involucrate, small, blue. Sepals hairy.........................1

* Flowers separate.- Sepals bristly eiliate, capsules somewhat hairy...................... 2,8 - Sepals glabrous._-Flowers purple. Maritime...................... 4, 5

-Flowers white, rarely yellow......................... 6

1 I. tamnifòlia I. St. terete, hirsute; lvs. hirsute ovate, cordate, acuminate; ped. as long as the leaves; fls. (small, blue) in involucrate heads, bracts unequal, lanceolate or linear, acute; sep. very hairy, linear-subulate.-1) Middle Ga. to La. Vine trailing and climbing, clothed all over with tawny hairs. Lvs. large, on long petioles. Ped. 2 to $3^{\prime}$ long. Fls. erowded, $9^{\prime \prime}$ long, blue.

2 I. commutàta R. \& S. St. slightly pubescent; lvs. cordate, entire or 3-lobed, smoothish, hairy at the insertion of the long petiole, auricles obtuse below, middlo lobe dilated at base or ovate; ped. about equaling the petioles, 2 to 5-flowered; sepals lanceolate, acuminate, ciliate-hirsute, 4 times shorter than the corolla; caps. hairy.- (1) In dry fields, S. Car. to La. Sts. twining and climbing. Petioles 1 to 2 ' long. Fls. usually $\mathbf{3}$ on each peduncle, purple, varying to pink, bell-shaped, $18^{\prime \prime}$ long. Jl.-Oct. (I. trichocarpa Ell.)

3 I. lacunósa L. Minutely pubescent; st.twining; lvs. cordate, acuminate, angular-lobed or entire, on long petioles; ped. 1 to 3-flowered, half as long as the petioles; sep. bristly ciliate, oblong-lanceolate, acute, half as long as the corolla; caps. pilous.-(1) Penn., Md. to Fla., La. and Ill. A small, prostrate species, 2 to cf long, in dry fields and hills. Lrs. $2^{\prime}$ by $1 \frac{1}{2}^{\prime}$, deeply cordate, often deeply 3lobed, petioles 1 to $3^{\prime}$ long. Fls. about $1^{\prime}$ long, white with a purplish rim. Aug., Sept. (C. micranthus Riddell.)

4 I. Pes-càpræ Sw. St. prostrate, slightly scabrous; lvs. roundish, emarginate or 2-lobed, rather thick, petiolate, strongly veined; ped. 1 to 5 (generally 3)-flowered, as long as the petioles; sep. ovate-lanceolate; cor. ample, with a short tube.Coast and Isl. of Ga. Lvs. 2 to $3^{\prime}$ long and wide, as long as the petioles and peduncles. Pedicels bracted, 1 to $2^{\prime}$ long. Cor. near 3' long, purple. Jn.Sept.

5 I. sagittàta Desf. Glabrous; lvs. cordate-sagittate, veiny, gradually acute and mucronate, auricles acute or rounded, petioles elongated; ped. as long as the petiole, but much shorter than the solitary, ample flower; sep. ovate, obtuse, short. $-2 f$ Borders of salt marshes, S. Car., Ga. to La. St. long and twining. Lvs. 2 to $3^{\prime}$ long, the sides nearly straight. Ped. very thick. Cor. $3^{\prime}$ long, the border spreading $2^{\prime}$ or more, purple. Jn.-Aug.

6 I. sinuàta Ort. St. hirsute; lvs. glabrous, or the veins beneath hirsute, palmately 7-cleft, the segm. pinnatifid, with obtuse teeth; ped. 1 to 2 -flowered, as long as the petioles; sepals lance-ovate, nearly as long as the tubo of the campanulate corolla. - $2 f \mathrm{Ga}$., Fla, in calcareous soils (Michaux). Lvs. varying to sinuate-lobed. A twining vine. Fls. white, $1^{\prime}$ long. (I. dissecta Ph.)

7 I. ciliolàta Pers. St. smooth; lvs. cordate, acuminate, smooth, the margir sparingly ciliate, petioles elongated; ped. 1-flowered, 2-bracted above, as long as the petioles; sep. broadly ovate, obtuse or mucronulate; cor. tubular, companulate. - 24 N. Car. and Tenn.- Vine twining and climbing, with lvs. elegantly heartshaped, and large yellow corollas. Sep: large 7 to $9^{\prime \prime}$ long. (I. ciliosa Ph.) 
8 I. panduràtus Meyer. Wind Potato. (Fig. 321.) MaN-of-THE-EarTH. St. twining; lvs. broad-cordate or panduriform; ped. 1 to 5 -flowered, longer than the petioles; cal. smooth, ovate, 3 to 4 times shorter than the ample corolla.- 4 In sandy fields, N. Y. to IH. and Ga. Sts. several from the samo root, 4 to 8 flong, slender, smooth. Lrs. 2 to $3^{\prime}$ long, and about the same width, acute or obtuse, with rounded lobes at the base, sometimes lobed and hollowed on the sides and becoming fiddle-shaped. Ped. bearing several largo flowers. Cor. near $3^{\prime}$ long, white, with a purple center. Jl., Aug.

5. CONVOL'VULUS, L. BIND-WEED. (Lat. convolvere, to entwine; from the habit of most of the species.) Sepals 5, corolla campanulate; style 1 ; stigmas 2, linear-cylindrical, often revolute; ovary 2-celled, 4ovuled; capsule 2-celled, 4-sceded, or by abortion fewer.-Herbs or shrubby plants, twining or erect. None native.

1 C. arvénsis I. Striate, angular, gencrally prostrate; lvs. sagittate, somewhat auriculate; ped. mostly 1-flowered, bibracteate near the apex; scp. roundishovate; caps. smooth. - $2 f$ Fields and pastures, Maine to Car., not common. Stems several feet long, climbing or prostrate, a little hairy. Leaves 1-2' long, the lower ones obtuse. Flowers small. white, often with a tinge of red. The small, acute bracts are near the middle of the peduncle. Jn.

2 C. tricolor I. St. ascending, villose; lvs. lance-obovate, subspatulate, sessile, ciliate at base; ped. 1-flowered, bracteate, longer than the leaves; sep. oratelanceolate, acute; cor. tricolored; caps. villous. - I St. weak, 1 to $3 \mathrm{f} \mathrm{long.} \mathrm{Cor.}$ yellowish in the center, white in the middle zone, and of a fine sky blue on the outer part of the border. Jl. + Eur.

6. CALYNYC'TION speciosa, native of W. Ind., rarely seen in cultivation, may possibly be found wild in Fla.

7. CALYSTE'GIA, Br. (Gr. $\kappa a \lambda v \xi$, calyx, $\sigma \tau \varepsilon \dot{y} \eta$, a covering ; alluding to the conspicuous calycino bracts.) Calyx 5-parted, included in 2 large, foliaceous bracts; cor. campanulate, 5-plicate; sta. subequal, shorter than the limb; ova. half bilocular; 4-ovuled; sty. simple; stig. 2, obtuse ; caps. 1-celled, 4-seeded.-Herbs twining or prostrate. Ped. 1-flowered, solitary.

1 C. spithamæus Br. St. erect or assurgent; Irs. oblong-lanceolate, subcordate, hoary-pubescent ; ped. 1-flowered, about as long as the leaves.-24 An crect, downy species, 8-10' (a span) high, found in fields and hilly pastures, Can. to Penn. W. to Ill. Stem branching, leafy, bearing one, often two or more large, white flowers, on peduncles 2-4' long, issuing from near the root. Leaves $2-3^{\prime}$ long, $\frac{1}{2}$ as wide, oval, with an abrupt, cordate baso, and on petioles $\frac{1}{4}$ as long. Bracts concealing the calyx. June.

2 C. Sèpium Br. Rutland Beautx. Glabrous; stem twining; Ivs. cordatesagittate, the lobes truncate and apex generally acute; ped. quadrangular, 1flowered; bracts cordate, much longer than the calyx. - 2f A vigorous climber, in hedges and low ground, Can. to Car. W. to Iowa. Sts. 5 to $8 f$ in length. Lvs. 2 to $4^{\prime}$ long, half as wide. Fls. numerous, large, white with a reddish tinge. Bracts close to the corolla, concealing the calyx. Jn., Jl. $f$ (Convolvulus L.) The wild plant (Convolvulus repens $\mathrm{L}_{\text {. }}$ ) is often more or less pubescent.

3 C. Catesbeiànus $\mathrm{Ph}$. Tomentous; st. twining; lvs. oblong-ovate, cordate or sagittate, acute or rather obtuse, petiolate, auricles obtuse; ped. 1-flowered longer than the petiole but shorter than the leaves; bracts lance-oblong, acute ! (obtuse, Pursh, subacuminate, Choisy), cordate, twice longer than the calyx, half as long as the purple corolla. - Sandy soils, Car. and Ga. Sts. a few feet long. Lvs. small, 1 to $2^{\prime}$ long. Cor. showy, $18^{\prime \prime}$ long. Apr., May.

4 C. paradózzus $\mathrm{Ph}$. Differs from the foregoing in its bracts, which are "linear and remote from the flower.-Va. to Car." (Pursh). Probably a mero variety; wo venture to suggest that both may bo only states of C. Sepium. 
8. STYLIS'MA, Raf. (The name has reference to the plurality of the styles.) Sepals 5, equal; cor. campanulate; ovary 2-celled; styles 2, rarely 3 , stigmas capitate; stamens included. $-2 f$ Slender, creeping, soft-pubescent.

I S. evolvuloìdes Chois. Lrs. oval or obloug or linear, entire, obtuse or rarely retuse at both ends, on short petioles; ped. longer than the leaves, 1 to 3-flowered; bracts subulate, shorter than the pedicels; sep. ovate, acuminate, thrice shorter than the corolla; sty. distinct to near the base.-2f Dry, sandy or rocky soils, S. E. Ohio to Va., Ga. and La. St. trailing several feet, subsimple. Lvs. $1^{\prime}$ to $18^{\prime \prime}$ long, 1 to $9^{\prime \prime}$ wide. Ped. 2 to $3^{\prime}$. Cor. 8 to $10^{\prime \prime}$ long, white. Jn.-Sept. (Convolvulus aquaticus Walt. C. trichosanthus Mx., C. tenellus Lam.)

2 s. Piclzeríngii Gray. Lrs. narrowly linear; bracts resembling the leaves, equaling the flower; sty. united to near the top; stem pubescence and peduncles as in No. 1.-2f Pine barrens, N. J. and N. Car. (Convolvulus Pickeringii Torr.)

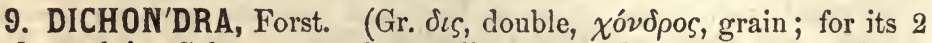
seed-vessels.) Calyx 5-parted ; corolla campanulate, 5-cleft; ovaries 2, styles 2, stigmas thick; capsules utricular, 1-seeded.-2f Prostrate, with roundish-cordate or reniform lvs. and inconspicuous fls.

D. rèpens Forst. Lvs. much shorter than their petioles, pubescent or silky beneath, entire; ped. much shorter than the petioles, sep. oblong-spatulate, obtuse, villous, a little larger than the oval cor. segm. -Wet grounds, S. States. A little turfy creeper, rooting at every joint, 3 to $12^{\prime}$ long. Lvs. varying from $3^{\prime \prime}$ diam. to $9^{\prime \prime}$; petioles 1 to $3^{\prime}$. Cor. greenish white, 1 to $2^{\prime \prime}$ broad. Mar.-May.

10. CUSCUTA, Tourn** Dodder. (Fig. 456.) Calyx 5 (rarely 4)cleft or sepaled; corolla globular-campanulate, 5 (rarely 4)-cleft; stamens 5 (rarely 4), appendaged with scales or fringes at base; ovary 2 -celled, 4-ovuled; styles 2 ; capsules mostly 4-seeded; embryo spirally coiled, without cotyledons.- (1) Herbs without verdure, germinating in the soil, at length withering at the root, and deriving their nourishment from other plants about which they twine from right to left. Stem yellowish or reddish. Lvs. none, or minute scales instcad. Fls. variously aggregated.

\$ Stigmas filiform, as well as the styles. Capsules regularly circumscissile............. No.1

Stigmas capltate. Capsule indehiscent, or never bursting at base. (*)

* Sepals united. Ovary and capsule globular-depressed. (1)

1 Flowers in subglobous cymes. Corolla withering at base of capsule.......Nos. 2-4

1 Flowers in paniculate cymes. Corolla withering at top of capsule................5

* Sepals united. Ovary and capsule more or less conical (2)

2 Corolla lobes acute, inflexed at the apex................................ 6, 7

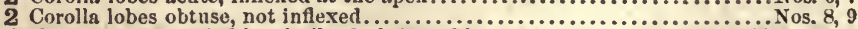

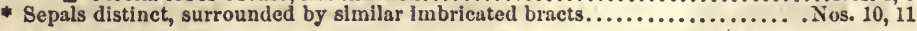

I C. epilinum Weih. FuAx DodDer. Fls. sessile, in small, dense, remoto heads; cal. 5-parted, segm. broad; cor. globous-cylindric, scarcely longer than the calyx, with acutish lobes, withering around the depressed-globous capsule; scales small, crenate-dentate; sty. short.-Middle States, growing on flax. Sts. reddish orange. Fls. yellowish white. Cal. thickish. Stam. included. Stig. acute. Caps. opening around the base. Jn. \& Eur. (C. Europæa, Darl. and others, not of $\mathrm{L}_{\text {. }}$ )

2 C. obtusiflòra (H. B. K.) $\beta$. GLANDULòsA Engelm. Sts. low, bright orango colored; fls. pedicellate, in loosely globular clusters, and dotted with red, shining glands; sep. rounded-obtuse, as well as the soon-reflexed cor. lobes; sty. thick. subulate, stig. capitate; ova-large, depressed, soon outgrowing the withered corolla, leaving it at its base; scales large, often exceeding the tube, deeply fringed. -Ga. (Pond), Fla to La. Parasticic mostly on Polygonum. Fls. 1 to $11^{\prime \prime} \circ$ long. Caps. $1 \frac{1}{2}$ to $1 \frac{3^{\prime \prime}}{4}$ diam. 
3 C. chlorocárpa Engelm. Low, branching orange-colored; fls. usually 4-parted, short-pediceled, in scattered, globular clusters; cor. tube campanulate, nearly the length of the acute lobes and acute cal. segm.; scales small, 2-lobed, or oftener of small, lateral teeth; sty. thick, as long as the large ovary; caps. depressed, thin.Wis. to Ark., also in Del. on Polygonum, \&c. Fls. about $1^{\prime \prime}$ long. Fr. greenish yellow.

4 C. arvéngis (Beyrich) $\beta$. PENTAGONa Eng. Low; fls. small, 5-parted, pedicoled, in compound or branching clusters; cal. angular, lobes suborbicular, obtuse, thin and shining, as long as, or longer than the shallow tube of the cor.; lobes of the corolla acute or acuminate, longer than the tube, reflexed, with the point inflexed; anth. round, oval; scales large, deeply fringed; sty. slender; caps. globular. Ill., Va., to Fla, on many plants. Sts. scarce if high. "Fls. less than $1^{\prime \prime}$ long. Caps. yellowish.

5 C. tenuiflòra Engelm. Pale, much branched; fls. mostly 4-parted, short.pediceled, slender, cymous-paniculate, at length conglomerate; cal. turbinate; cor. tube slender, longer than the calyx, or its own short, ovate obtuse lobes; sty. capillary, as long as the depressed ovary; caps. globous, bearing the dead corolla at top, often but 1 to 2-seeded.-Ill. and Westward, in wet places, on Cephalanthus, Aster, \&c. Cor. $1^{\prime \prime}$ or less in length. Caps. 1 to $1_{4}^{1 \prime}$ diam.

6 C. décora (Chois. Engelm.) $\beta$. PUlCherrma Engel. Fls. pedicellate, 5-parted, large, broad-campanulate, loosely paniculate; cal. lobes acute, length of the corolla, crenulate on the margin; lobes of the fleshy cor. acute, erect or spreading, point inflexed; sty. as long as, or longer than the ovary; caps. enveloped by the dead corolla; sds. beaked, rough.-S. Ill. to Fla. and Tex., growing on Leguminosæ, Compositæ, \&c. Fls. larger than in any of the preceding species, $1 \frac{1}{2}$ to 1:" long, fleshy, white. Anth. and stig. yellow or purple. (C. indecora Chois. in DC.)

7 C. infléxa Engelm. Fls. pediceled, mostly 4-parted, in loose, paniculate cymes, at length glomerate; cor. fleshy, subcylindric, lobes erect, with the acute points inflexed and margins crenulate; scales minute, reduced to lateral teeth; sty. divaricate on the thickish brown capsule which bears the dead corolla at its top.III. to Va. and Ga., on Hazel, Rhus, Salix, Helianthus, and other herbs and shrubs, in open woods and prairies. Fls. $1^{\prime \prime}$ long.

8 C. Gronòvii Willd. St. filiform, thick, often high-climbing; fls. mostly 5-parted, at first loosely paniculate, finally dense; cor. tube deeply campanulate, longer than the cal. lobes, obtuse, flat, spreading, not reflexed; soales large, oval, deeply fringed; ova. oval, slightly conic, invested at base with the dead corolla.-Can. and U. S., on coarse herbs and shrubs. The most common of all our species, in low, damp or shady places, the only one in N. Eng. Sts. light orange. Fls. $1 \frac{1}{4}$ to $1 \frac{1}{2}{ }^{\prime \prime}$ long.

$\beta$. LAtiflòra (Engelm.) Cal. thin; cor. tube shallow, as long as the lobes; seales narrow.-Mass. to Car. and Ill. (C. Saururi Eng.)

9 C. rostràta Shutt. Fls. large (2 to $3^{\prime \prime}$ long), pedicellate, in loose, paniculate cymes; cor. deeply campanulate, lobes obtuse; scales small, deeply incisely fringed; ova. elongated, bottle-shaped; caps, wiih an elongated, 2-pointed beak 2 to $3^{\prime \prime}$ long; sds. 1 to 4 , bluntly rostrate.-Alleghanies, Md. to S. Car., in shady woods, on tall, coarse herbs. Nearly allied to the last.

10 C. glomeràta Choisy. St. filiform; fls. in compact masses, surrounding the stem, sessile ; sep. 5 ( $1^{\prime \prime}$ long), surrounded by many squarrous bracts; cor. tubularcampanulate, 5-lobed, longer than the calyx, withering on top of capsule, lobes lanceolate, acute, spreading or reflexed; scales fimbriate.-Abundant in Mo., Ill. and Iowa, chiefly on the Compositæ. Fls. about $2^{\prime \prime}$ long, forming compact, cylindrical masses, while the stems decay, appearing as if springing from the stems of other plants... Cor. white and scarious. Anth. partly exserted. Jl.

11 C. compácta. Juss. St. thick; fls. sessile, lateral, in dense masses; sep. and bracts minute $\left(\frac{1}{4}{ }^{\prime \prime}\right)$, orbicular; cor. tube slender, with 5 oblong lobes, withering on the summit of the acutish capsule, like a calyptra; sds. mostly but 1 or 2.-Banks of the St. Lawrence R., N. Y. to Ill. and the Mts. of Ga., on shrubs, as Hazel, Alder, Andromeda. The twined clusters in fruit are often 9 to $18^{\prime \prime}$ diam. 
B. ADPRÉSSA Engelm. Cor. broader; caps. less pointed; sds. 2 to $4 .-711$. to Va. and La., on Rhus, Smilax, \&c.

\section{Order XCIV. SOLANACEF. Nightshades.}

Plants herbaccous, rarely shrubby, with a colorless juice and alternate leaves. Flowers mostly regular, often extra-axillary, 5-parted, on bractless pedicels. Corolla valvate or plicate in the bud and often convolute. Calyx persistent. Stamens 5, adherent to the corolla tube, alternate with its lobes; anthers 2-celled. Fruit a 2-celled capsule or berry. Seeds $\infty$, with a curved embryo in fleshy albumen.

Illust. in Figs. 54, 322.

Genera 64, species 1000 or more (1675, Dunal.), generally diffused, but most abundant in the tropics.

Properties highly important. A largo portion of the genera are pervaded by a narcotic principle, rendering the herbage and fruit dangerously poisonuus, yet furnishing some of the most active medicines, as the Henbane (Hyoscyamus), Belladonna (Atropa), Stramonium (Datura), Tobacco (Nicotiana), \&c. At the same time several species of Solanuin afford wholesome and nutritious food, not because they are free from the narcotlc principle, but because it is expelled in the process of cooking or ripening in the sun. Such are the tubers of the invaluable Potato, the fruit of the Tomato and Egg plant. The genus Capsicum is entirely freo from narcotine, and produces the well-known stimulant fruit Cayenne Pepper.

\section{GENERA.}

\& Corolla wheel-shaped, the tube very short. Anthers convergent (a).

$\$$ Corolla bell-shaped, the broad tube including the erect anthers (b).

\$ Corolla funnel-form, tube long, and-the limb somewhat irregular (c). -the limb quite regular (d).

a Stamens connate, opening by slits inside. Berry torous.............. Lrcopersicuk. 1

a Stamens connivent, opening by terminal pores. Berry round............ Solanux. 2

a Stamens connivent, opening by sllts. Berry dryish, angular.................... 8

b Corolla bluish. Berry dry, inclosed in the enlarged calyx........... Nicandra. 4

b Corolla yellowish. Berry juicy, inclosed in the enlarged calyx......... Phrsalis. 5

b Corolla purplish. Berry black, sitting on the open calyx.............. c Stamens exserted, declining. Capsule opening by a lid......... Hroscramus. 7 c Stamens included, unequal. Capsule opening by valves............ Pertenia. 8 d Stamens exserted, growing to the summit of the tube................ Neirexbergia. 9 d Stamens exserted, growing to the bottom of the tube............................. 10 d Stamens included.-Calyx 5-angled. Capsule spiny or smooth............ Datura. 11 -Calyx terete. Stigma capitate................................ 12 -Calyx teretish. Stigma 2-lobed. Flowers small........ Famiana. 13

1. LYCOPER'SICUM, Tourn. ToMato. (Gr. $\lambda \dot{v} \kappa o s$, a wolf, $\pi \varepsilon \rho \sigma \iota k o ́ v$, a peach; a fanciful name.) Calyx 5 to 6 to $\infty$-parted; corolla rotate, with a short tube and a plicate-valvate limb; stamens 5 to 6 to $\infty$, exserted; anthers connate at apex, longitudinally dehiscent on the inner face; berry fleshy, 2 to 3 to $\infty$-celled.-Lis. pinnately compound. Ped. extra-axillary, $\infty$-flowered.

I. esculéntum Mill. Hairy; st. herbaceous, weak; lvs. unequally pinnatifid, segments cut, glaucous beneath; cor. many-lobed; $f r$. torulous, furrowed, smooth.-1) This plant resembles the potato in its general aspect. It grows 3 - If high, with jagged leaves, greenish-yellow flowers, and an unpleasant odor. The fruit is large and abundant, with acute furrows, at first green, becoming when ripe of a beautiful red. This plant has come into high repute, and its cultivation is almost universal, for its agreeable and wholesome fruit, which presents numerous varieties of form, size and color.

2. SOLA'NUM, L. Potato. (Solum, the ground or soil.) Calyx 5parted, persistent; corolla rotate, subcampanulate, tube very short, limb plicate, '5-cleft, lobed or angular ; anthers erect, connivent, distinct, opening at the top by 2 pores; berry 2-celled, subglobous or depressed; seeds $\infty$.-An immense genus of herbs or shrubs, unarmed or 
prickly. Lvs. sometimes twin, pinnatifid or undivided. Ped. solitary or several, 1 to $c$-flowered, terminal, but becoming lateral by the extension of the axis.

§ Lnarmed, Anthers ovate-elliptic, pores terminal-introrse (a).

a Ilerbaceous, with pinnatifid leaves. Raceme exceeding the leaves..............No. 1

a Herbaceous, with undivided leaves. Racemo shorter than tho leaves....... Nos. 2-4

a Shrubby, climbing or erect. Berries red.............................

§ Armed with sharp spines. Anthers linear-oblong, pores terminal-extrorse (b).

b Peduncles cxceeding the leaves, many-flowered.................... Nos, 8,9

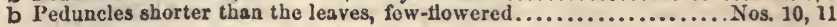

I S. tuberòsum L. CoмmoN Potato. St. herbaceous; subterranean branches bearing tubers; lvs. pinnatifid, segm. unequal, the alternate ones minute; cor. 5-angled; pedicels jointed.-(2) This valuable plant is a native of the Cordilleras of S. America, where it still grows wild. Although it now constitutes so large a portion of the food of civilized man, it was scarcely known until the 17 th century, and was not extensively cultivated before the middle of the 18th. The varieties of the potato are very numerous, differing in their timo of ripening, quality, color, form, size, almost endlessly.

2 s. nigrum L. BlAcK NightSiAde. St. herbaceous, angular, smoothish; lvs. ovate, toothed and waved; umbels lateral, drooping.-(2) A weed-like plant, without beauty and of suspicious aspect, about rubbish, in old fields, N. and ,W. States. Stem erect, branching, angular, a foot high. Leares almost always with the lamina perforated and the margin erose as if gnawed by insects. Ped. generally midway between the leaves. Fls. white, anthers yellow. Berries globous, black. Reputed poisonous, but is used medicinally. Flowers in summer $\S$ Eur.

3 S. nodiflòrum Jacq. St. herbaceous or half-shrubby, branched; branches terote, herbaceous, glabrous; lvs. ovate, entire, or subrepand, acute, glabrous; fis. subumbellate, minute; stalks and cal. puberulent.-2f S. Car. to Fla. and La. Stem 2 to $3 \mathrm{f}$ high, with a ridge descending from each petiole. Lvs. 2 to $4^{\prime}$ long, half as wide, petioles near $1^{\prime}$. Ped. filiform, 6 to $12^{\prime \prime}$ long, growing from thickened nodes a little below the next leaf, bearing several ( 3 to 8 ) white fls. Cor. cup-form, 2" broad. Fr. not seen.

4 S. pycnánthum Dunal. St. herbaceous, slender, angular-furrowed, hispid; lvs. ovate-oblong, acuminate, attenuate to a petiole, subrepand, puberulent, pale beneath; ped. short, filiform, hirsute, 1 to 3 -flowered, subopposite to the leaves.Ga. about Savannah (Dunal, apud DC. Sed dubito.) Plant green. Lvs. 1 to 2' by 3 to $8^{\prime \prime}$, petioles 2 to $5^{\prime \prime}$. Fls. nodding, 2 to $3^{\prime \prime}$ broad, white? Anthers yellow. Berry globular.

5 S. Dulcamàra L. BItTersweEt. WoOdr Nigrishide. St. shrubby, flexuous; lvs: ovate-cordate, upper ones hastate or laciniate; clusters cymous, subopposite and terminal-A well-known shrubby climber, with blue flowers and red berries, N. Eng. to Ark. Stem branching, several feet in length, climbing about hedges and thickets in low grounds. Lower leaves entire; the upper ones becoming auriculate or hastate. Flowers drooping, on branching peduncles from the side of the stem. Corolla of 5 reflexed segments, purple, with 2 green spots at the base of each segment. Berries bright red, said to be poisonous. Jl. $\S$ Eur.

6 S. Pseudo-Cápsicum I. Jerusalem Cherry. St. shrubby; lvs, oblonglanceolate, subrepand; ped. 1-flowered, opposite the leaves.- 5 A small, ornamental shrub, cultivated. Stem 2-4f high, branching into a symmetrical summit. Leaves dark evergreen, smooth and shining, about $2^{\prime}$ long. Flowers white, with orange anthers, drooping, succeeded by a few scarlet, globous berries of the size of small cherries to Mauritius, \&c.

7 S. sempervìrens Dun. Shrubby, twining and alimbing; branches herbaceous; lvs. entire, lance-ovate or elliptic, obliquely cordate, obtuse, with a blunt cusp, very smooth and shining; panicles terminal, divaricate, roughish and hairy.Shrubberies, arbors \&c., hardy South. An elegant climier. Branches cinnamoncolored, glandular. Lrs. thick, of a bright, shining green. Cor. plicate, 5 or 6 times larger than tho calyx. † Guiana. 
8 s. Carolinénge L. Horse Nertuz. St. and petioles aculeate; lvs. oblongovate, petiolate, strigous, angular-lobate, acute, midvein beneath with a few spines; rac. raked, loose, supra-axillary; berries globous. - 2f Roadsides, \&c., N. Y. to 1il. and Ga. A rough weed, 1-2f high, armed with straw-colored, scattered prickles. Leaves $4-6^{\prime}$ by $2-3^{\prime}$, usually in unequal pairs, with a few large, repand lobes or teeth. Flowers white, lateral and terminal. Corolla white, 1215" diam. Berries yellow. Jn.

9 S. Virginiànum L. St. erect, prickly ; lvs. long-petioled, deeply pinnatifid, lobes angular-sinuate, acute or obtuse, pubescent; petiole and midvein prickly, margins ciliate; rac. leafy, prickly. - Va. to Car. (Pursh.), Ga. (Feay, Pond.) Plant much branched, 18' to $3 f$ high, bright green, roughish with minute tomentum. Sts. slightly angular. Lvs. 7 to 9-lobed. Cor. $15^{\prime \prime}$ broad, pale violet. Anth. 4", linear. Prickles straight, $5^{\prime \prime}$ and less, whitish. Jl.

10 s. mammòsum L. APPLE OF SODOM. St. herbaceous, villous, with scattered spines; lvs. roundish-ovate, subcordate, lobed, both sides aculeate and very villous; berries inversely pear-shaped (mammosa.)-(1) Waste places, roadsides, Car. (Pursh), Ga., Ala. (Montgomery), to La. A woolly, spiny weed, 1 to $3 f$ high. Lvs. about as broad as long, 3 to 7 -lobed, paler beneath, armed on the veins witl straight spines 3 to $8^{\prime \prime}$ long. Cor. violet colored, 5-parted, 12 to $15^{\prime \prime}$ diam., soft villous outside. Fr. yellow, at first globular. May, Jn. (S. pumilum Dun., same as S. hirsutum Nutt., is probably a starved form of this species.)

11 S. esculéntum Dunal. EGG Plant. St. prickly; lvs. ovate, subsinuate, downy, prickly; fls. 6 to 9-parted.-(1) An herbaceous, branching plant, about $2 \mathrm{f}$ high. The fruit, with which it is heavily laden, consists of egg-shaped berries, from the size of an egg to that of an ordinary water melon, smooth, and of a glossy purple. It is considered wholesome and delicious. Like the tomato, it is cultivated from the seed sown early in warm, dry, and mellow soil. $\nmid$

$\beta$. Fr. smaller, white.-Cultivated for the curiosity of the fruit, which when ripe can scarcely be distinguished by its appearance from a hen's egg.

3. CAP'SICUM, Tourn. Pepper. (Gr. $\kappa a ́ \pi \tau \omega$, to bite.) Calyx erect, 5-cleft, persistent; cor. rotate, tube very short, limb plaited, 5lobed; anthers connivent; fruit capsular, dry, inflated, 2 to 3-celled; seeds flat, very acrid.-A large genus of herbaceous or shrubby plants, pervaded by a heating, acrid principle. Lvs. often in pairs. Ped. axillary, solitary.

C. ánnuum L. Red Pepper. Cayenxe Pepper. St. herbaceous, angular, branching above; lrs. ovate, acuminate, entire, petiolate, glabrous ; ped. smooth ; cal. angular, with short, acute lobes; cor. lobes spreading, longer than the stamens; berry oblong or subglobous, red.-D India. Cultivated for its fruit, whose stimulant properties are well known.-There are in gardens several varieties in respect to the fruit.

4. NICAN'DRA, Adans. Apple of Peru. (In honor of Nicander, a Greek physician, B. c. 50.) Calyx 5-cleft, 5-angled, the angles compressed, sepals sagittate; corolla campanulate; stamens 5 , incurved; berry 3 to 5 -celled, enveloped in the persistent calyx.-(1) Peruvian herbs.

N. physaloìdes Adans. St. herbaceous; lvs. glabrous, ample, ovate-oblong, sinuate, angular; fls. solitary, axillary, on short peduncles; cal. closed, with the angles very acute.-Cultivated in gardens, whence it has strayed into the neighboring fields. It is a large, coarse herb, 2 to $5 f$ hight very branching. Lvs. 4 to $7^{\prime}$ long, 2 to $4^{\prime}$ wide, decurrent. Cor. slightly lobed, white, with blue spots in the center. J1.-Sept. § Peru.

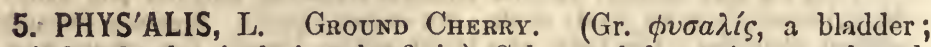
the inflated calyx inclosing the fruit.) Calyx 5 -cleft, persistent, at length ventricous; corolla campanulate-rotate, tube very short, limb obscurely 
5-lobed; stamens 5 , connivent; berry globous, inclosea within the inflated, 5-angled, colored calyx.-Herbs (rarely shrubs). Lvs. alternate or unequally twin. Fls. solitary, nodding, extra-axillary. Pubescence of flattened hairs.

Anthers yellow. Root (always ?) perennial.................................. 1-8 Anthers blue or violet-colored. Root annual. (a)

a Peduncles elongated. Fruit not filling the closed ealyx.............. Nos. 4-6

a Peduncles very short. Fruit flling the open calyx.......................... 7

$1 \mathbf{P}$. viscòsa $\mathrm{L}_{\text {. }}$ Pubescent, erect or decumbent; branches somewhat dichotomous and angular; lvs. solitary or in pairs, ovate, more or less cordate, repandtoothed or entire; fls. spotted or dark purple in the throat; anth. yellow, 1 or 2 often longer.-Dry fields and road-sides, Can. and U.S. Plant if high, often viscid. Lvs. variable, twice as long $\left(1-4^{\prime}\right)$ as the petioles; when in pairs, one of them is much smaller. Cor. twice as long as the calyx, greenish-yellow, the 5 spots often confluent. Fruit yellow or orange-colored, pleasant to the taste. Jn., Jl. (P. Pennsylvanica I. P. tomentosa Walt. P. heterophylla Nees)

$\beta$. nyctaginea. Calyx hirsute; corolla not spotted. (P. nyctaginea Dun.)

2 P. lanceolàta Mx. (nec Dunal.) Decumbent, branching, hirsute or pubescent (at first erect); lvs. in pairs, unequal, elliptic-lanceolate, tapering and acute at each end, petiolate, entire or repand-denticulate; ped. filiform, scarcely as long as the slender petiole; cor. spotted; stam. yellow, equal ; cal. in fr. rounded and umbilicate at base.- 4 Dry soils, Car., Tenn., Ga. to La. Sts. 6 to $15^{\prime}$ long, often diffuse. Lvs green, and with their petioles about $3^{\prime}$ long, all twins except the lowest. Fls. 6" long, yellow. Jn.-Aug.

3 P. Alkekéngi L. Strawberry Tomato. St. subsimple, pubescent; lvs. deltoid-ovate, acuminate, repand; cor. not spotted; cal. in fr. ovoid-globous, colored; stam. yellow. - 4 Gardens. Plant less branched than other species, 1 to $2 \mathrm{f} \mathrm{high}$. Irs. 3 to 4 ' long, including the petiole, attenuated at base: Cor. yellow. Berry greenish yellow or orange, inclosed in the reddened calyx. Fr. eaten raw or cooked.

4 P. pubéscens L. Much branched, pubescent or tomentous, viscid, at length decumbent; lvs. ovate or cordate, unequal at base, acute or subacuminate, dentate or nearly entire; ped. shorter than the petioles; cor. spotted with dark brown in the throat; anth. blue.-In damp places and shades, S. and W. States. Plant 9 to $18^{\prime}$ high. Sts. angled and furrowed. Lvs. 2 to $3^{\prime}$ long, petioles $1^{\prime}$, single on the stem, twin on the flowering branches. Cor. 6 to $8^{\prime \prime}$ long: (P. hirsuta Dun.)Among our specimens are somo nearly smootl.

5 P. angulàta L. Erect, often diffusely branched, glabrous; lvs. ovate or oblong, unequally dentate-serrate; cor. spotless; stam. blue; cal. segm. triangular, subulate, as long as the tube, in fruit truncate at base and sharply 5-angled.- (1) Sandy soils, Va. to Fla. (Savannah, Pond), and westward. Lvs. on long, slender petioles. Cor. less than 6 ". long. Cal. in fruit longer than broad, or ovoid.conical.

6 P. Iinkiàna Nees. Diffusely branched, glabrous; lvs. ovate-oblong, acuminate, often long-pointed, sinuate-dentate, with subulate-pointed teeth, base attenuate to the petiole; cor. slightly spotted; anth. violet; cal. in fruits roundish-ovate, pointed: -1) S. Car. and Ga. (Feay). A striking species, 2f or more in height. Sts. strongly angled. Livs. 3 to $6^{\prime}$ long, including tho (1 to $\left.2^{\prime}\right)$ petiole. Fr. cal. $1^{\prime}$ diam.

7 P. Philadélphica Lam. Nearly glabrous, erect, branching, branches forked, strict; lvs. obliquely ovate, acuminate, angular-repand; ped. much shorter than the petioles; cor. with spots and stripes in throat; cal. filled with the fruit and open when mature; anth. violet.-(1) Dry banks of streams, Middle and W. States. Lvs. acute at base, twice longer than the petioles. Ped. 2 to $3^{\prime \prime}$ long, pubescent.

6. AT'ROPA, L. Deadly Niahtshade. (Name of one of the Three. Fates in Grecian mythology, whose office it was to cut the thread of human life.) Calyx 5-parted; corolla campanulate, limb. 5-cleft, valvate-plicate in bud; stamens 5 , distant, included; style subexserted: 
berry globous, 2-celled, sitting on the enlarged calyx.-Herbs of lurid colors. Lvs, often twin.

A. Belladónna L. St. trichotomous; lvs, ovate, entire; berries black.This poisonous herb is far less repulsive in its appearance than most others of its order. The lurid, pale purple of the flower, indeed, looks suspicious, but not its smell-nor the berries, which are larger than cherries, round, green, at length of a fine, glossy black, full of a purple juice. Stem $5 \mathrm{f}$ high, branching below, and with the large leaves, inclines more or less to a purplish hue. $\ddagger \S$ Eur.

7. HYOSCYAMUS, Tourn. Henbane. (Gr. is, iós, a pig, and

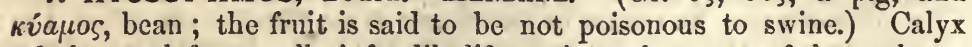
tubular, 5-cleft; corolla infundibuliform, irregular; one of the 5 obtuse lobes larger; stamens 5 , declinate ; stigma capitate ; capsule ovoid, 2 celled, opening with a lid near the summit.-Coarse, weed-like herbs, native in Eastern countries.

H. niger L. Branching, erect, very leafy ; lvs. sinuate, clasping; fls. sessile.-(2) A tall, well known, foetid weed, growing about the rubbish of old houses, roadsides, \&G. Tho whole plant is hairy, viscid, and of a sea-green hue, emitting a foetid odor. Stem $2 \mathrm{f}$ high, round. Leaves large, oblong, cut into acute, sinliate lobes. Flowers in terminal, one-sided spikes; the corolla straw-color, finely reticulated with dark purple veins. The whole plant is reputed poisonous, but has long been regarded as an excellent medicine in nervous diseases, coughs, convulsions, \&c. Ji. § Eur.

8. PETUNIA, Juss. (The Brazilian name is petun, latinized Petunia.) Calyx tubular, 10-veined, 5-parted, segments oblong-spatulate; corolla funnel or salver-form, tube cylindric, limb spreading, usually 5 lobed; stamens 5 , inserted in the middle of the tube, unequal, included, anthers cordate; stigma capitate; capsule 2-celled; seeds minnte.South American herbs. Lvs. alternate, entire, the floral twin. Ped.1flowered.

1 P. Nyctaginiflòra Juss. Diffuse, glandular-villous; st. erect, branched; lvs. solitary, ovate-oblong, obtusish, subsessile, floral sessile, cordate-ovate, subopposite; ped. axillary, solitary, exceeding the leaves; cor. tube slightly enlarged above, thrice longer than the calyx, with a widc-spreading limb. - if Gardens. Fls. large, white, numerous.

2 P. violàcea Lindl. Glandular hairy; st. prostrate at base, then erect, sparingly branched; lvs. ovate, short-petiolate, acute, the upper ovate-lanceolate; ped. solitary, equaling the leaves; cor. tubo inflated; limb cleft into rounded, acute lobes. - 2f Sts. numerous, 6 to $16^{\prime}$ long. Cor. large, violet-purple. Both species are great favorites in gardens, and by mixture sport into endless varieties, among which is

$\beta$. Atkinstìna. Lvs. ovate, whitish; cal. segm. ligulate; cor. tube twice or more longer than the calyx.

9. NIEREMBER'GIA, Ruiz et Pav. (Named for Nieremberg, aSpanish Jesuit.) Calyx persistent, tubular or subcampanulate, 10-veined, curved, 5-cleft; corolla funnel-form, tube long and slender, limb ample, spreading, plicate, slightly unequal ; stamens 5 , inserted in the throat, unequal, connivent; anthers hid beneath the stigma; capsule 2-celled, seeds many, minute, 3 -angled.-South American, chicfly herbs, creeping, with elegant, solitary, extra-axillary fls.

1 N. aristàta Sweet. Puberulent, pale-green; sts. filiform, very branching: lvs. narrowly linear, acute; fls. pedunculate, opposite the leaves, solitary; cal. campanulate, seg. linear-subulate, acute, twice shorter than the slender, glandular cor. tube.-St. 3 to $9^{\prime}$ long. Lvs. 1 to $2^{\prime}$ long, $1^{\prime \prime}$ wide. Cor. large, white, tinged with purple, 3 striæ on each lobe. 
2 N. filicaùlis Lindl. Glabrous, ascending, diffuse; sts. filiform, lus. very narrow, sessile, linear-lanceolate, acute or obtuse, opposite the peduncles; cal. obconic bell-shaped, segm. linear-lanceolate, acute; cor. tubo glandular, little longer than the calyx, limb undulate, obtusely 5-lobed.-Sts. a foot high. Lvs. 6 to $10^{\prime \prime}$ long. Cor. lilac or white, with a 5-rayed star of violet lines. + Both species from Buenos Ayres.

10. LYCIUM, L. Matrimony Vine. (Named from Lycia, the native country of the original species.) Calyx $2-5$-cleft, short; corolla tubular, limb mostly 5 -lobed, spreading, orifice closed by the beard of the filaments; stamens $4-5$, exserted; berry 2 -celled; seeds sereral, reniform.-Shrubs, the branches ending in a spinous point, and often having axillary spines. Fls. axillary, solitary, or in pairs.

I. bárbarum L. St. angular; branches long, pendulous, somerhat spiny; IVs. often fasciculate, lanceolate; cal. mostly 3-cleft.-Native of Barbary, cultivated and nearly naturalized. It is a shrub, with long, slender, trailing or hanging branches which oversperead walls, \&c., with a thick, tangled mass. Leaves smooth, 3 times as long as wide, often broadest above, acute or obtuse, tapering into a petiole. Flowers greenish-purple. Berries orange-red. † Barbary.

11. DATURA, L. Thorn Apple. Jimson (i.e., Jamestown)-werd. (An alteration of the Arabic name Totorah.) Calyx large, tubular, ventricous, 5-angled, deciduous, with a persistent, orbicular, peltate base; corolla infundibuliform, tube cylindric, long, limb 5-angled and plaited; stamens 5 ; stigma obtuse, bilamellate; capsule 2-celled, 4valsed; cells 2-3-parted.-(1) Herbs, with bluish-white or purple, solitary, axillary flowers.

1 D. stramonium L. St. dichotomous; lvs. ovate, smooth, angular-dentate; caps. spiny, erect.-A well-known poisonous plant, growing among rubbish in waste places. Stem about $3 \mathrm{f}$ high, smooth, hollow. Leaves large, situated at the base of the dichotomous branches, their sides unequal; with large, irregular teeth and sinuses. Flowers solitary, axillary; corolla funnel-shaped, with a long tube and a plaited, 5-toothed border, the color cream-white. Fruit egg-shapect, the size of a small apple, covered with spines. Aug. \& Central America? Poisonous and narcotic, but used for asthma, \&c.

B. TítcLA. St. purple; Als bluish-white.-(D. tatula L.) More common Westward.

2 D. (BRUGMANSIA) sanguínea Ruiz \& Pav. (B. bicolor Pers.) is a coarse looking, large-leaved shrub with huge, trumpet-bell-shaped fls. distinguished by the cuspidate angles of the red or white corolla, is now often seen in greenliouses. The yellow capsules are unarmed.

12. NiCOTIA'NA, Tourn. Tobacco. (In honor of John Nicot, of Languedoc, who seems to have introduced it into Europe.) Calyx urceolate, 5-cleft; corolla infundibuliform, regular, limb 5-lobed; stamens 5; stigmas emarginate; capsule 2-celled, 2 to 4-valved.-(1) Coarse, narcotic herbs, with simple lvs. and terminal fls. Cor. white, tinged with green or purple.

1 IV. rústica IL Cormon Toracco. Viscid-pubeseent; lvs. petioled, ovate, entire; tube of the cor. cylindric, longer than the calyx, segments sound, obtuse.For the purposes of tobacco this plant is considered inferior to the Virginian. Stem 12-18' high. Flowers greenish-yellow, in a terminal panicle or raceme. In Western N. Y., \&c., said to have been introduced by the Indians. Aug. $\S$

2 N. Tabacum IL Vrrginis ToBACco. Viscid-pubescent; lvs. lanceolate, sessile, decurrent; cor. tube inflated at the throat, lobes acute. - Native of Central America, particularly the island of Tobago, and the Province of Tabasco in Mex. ico, whence it was first exported to Europe, 1586. It is extensively cultivated in the Middle and Western States, and is exported in vast quantities. Stem 4-6f 
high, paniculate above. Ieaves $1-2$ f by $\frac{1}{2}-$ if entire. Flowers rose-color, not inelegant. Jl.-The use of this nauseous and poisonous weed has become almost universal, and illustrates tlie despotic power of habit. Sir Walter Raleigh has the honor of first introducing the practice of smoking into England, more than 200 years ago, and in his house at Islington, is still to be seen a shield bearing his arms, with a tobacco-plant at the top. (Loudon.)

3 N. longiflòra Cav. With long, spreading branches; lvs. acuminate, radical ovate-lanceolate, short-petioled, cordate-lanceolate, sessile; fls. lateral, solitary, pedicellate, arranged in a simple terminal raceme; cor. tube filiform, very pubescent, 5 times longer than the calyx, segments lance-orate, acute.-Gardens South. Cor. white, variegated with purple and yellow.

13. FABIANA imbricàta Ruiz. \& Pav. is a fine little shrub resembling a 'l'amarix, with small ( 6 " long) ovate lrs. eovering the numerous branches and small violet-white fls. + Chili.

\section{Order XCV. GENTIANACEA. Gentianworts.}

Herbs smooth, with a colorless, bitter juice, with entire, exstipulate leaves. Flowers regular, mostly centrifugal in inflorescence and convolute in the bud. Calyx perristent; corolla withering, its lobes alternate with the stamens. Ovary free, 1-celled

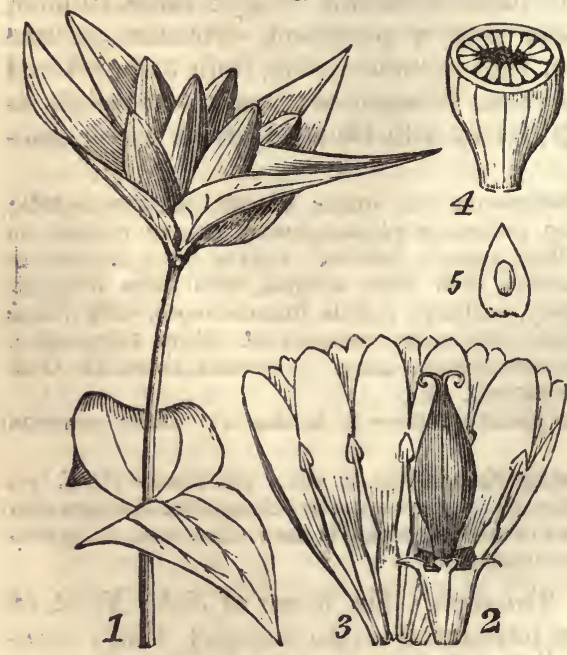
with 2 , more or less projecting parietal placentæ. Fruit a 2-valved, septicidal, $\infty$-seeded capsule, rarely baccate. Seeds with a minute, straight embryo in the axis of fleshy albumen.

Genera 60 , species 450 , found in every part of the world.

Properties.-An intensely bitter principle called gentianine pervades the whole order without exception, residing in every part, rendering them tonic and febrifugal. The gentian of the shops is most commonly the prorluet of Gentlana lutea, but most other species, and species of other genera, as Limnanthenum, Sabbatia, Frasera, \&c., are valued in medicine for the same propertles, and may be used in its stead. Many are cultivated for ornament.

Fig. 664. 1, Gentiana Andrewsii. 2, The calyx and capsule. 3, The corolla laid open, showing the folds (2lobed) between the proper petals, and the stamens attached at base. 4, Capsule cut aeross. 5, Seed magnified, with its large, loose testa.

\section{Tribes AND GeNera.}

II. Menxarture. -Cor. valvate-Induplicate in the bud. Leaves alternate or radieal. (a)

a Petals beardless or nearly so. Lenves simple, floating................Linnastuemurs. 9

a Petals bearded inside. Leaves trifoliate, erect..........................errantues。 8

1. Gentuane a.-Corolla convolute (in No. 7, imbricate) in the bud. Leaves opposite. (b)

b Sepals only 2 . Corolla 4 -parted, tubular campanulate.................. OBоLARIA. $T$

b Sepals as many as the petals, more or less united. (c)

c Corolla lobes furnished each with a spur in the midst................. Halenia. 6

c Corolla lobes furnished each with $a$ large central gland................. Frasera. 5 c Corolla lobes plain, withont spurs or glands. (d)

d Leaves reduced to seales. Corolla decply 4-parted..... BA rtoria. 4

d Leafy.-Corolla tubular, blue or white............... Gentiana. 3

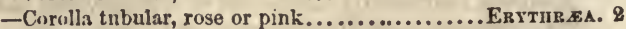

- Corolla rotate, rose or pink................... SAвbatra. 1 
1. SabBa'tia, Adams. American Centaury. (In honor of Sabbati, a distinguished Italian botanical author.) Calyx 5 to 12-parted; corolla rotate, limb 5 to 12 -parted; stamens 5 to 12 ; anthers erect, at length recurved, 2-celled, opening by chinks ; style 2-parted, slender, decidious; capsule 1-celled, the valves a little introflexed.-(2) Slender herbs, very beautiful, with pedicellate, mostly roseate fls. All N. American.

5. Corolla mostly 9 (rarely 7 to 12 )-parted, rose-red. Lapithea MGriseb............ Nos. 1, 2

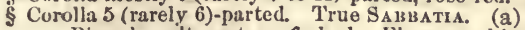

a Branches alternate or forked.-Flowers white or nearly so.............. Nus. 3,4

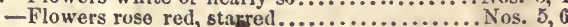

a Branches opposite. - Flowers white, cory mbed............................... 7 , 8 -Flowers rose-red, janiculate.............................. 9, 10

1 S. gentianoides Ell. St. strict, terete, subsimple; lvs. longer than the internol:s, linear, rigid, erect, floral reflexed; fls. 8 to 10-parted, in small, terminal and axillary capitate cymes; cal. segm. subulate, shorter than the obovate-spatulate, obtuse petals.-Ponds in pine barrens, Ga. to La. and Tex. Plant 1 to $2 \mathrm{f}$. high. Lvs. 2 to 3 ' long. Fls. very handsome, deep rose-color, $16^{\prime \prime}$ diam. $\Lambda$ ug. (Lapithea, Griseb.)

2 S. chloroides $\mathrm{Ph}$. St. slender, weak, subterete; lvs. lanceolate, erect; branches few, alternate, 1-flowered; fls. 7 to 12-parted; sep. linear, shorter than the corolla. -Wet grounds, Mass., R. I. to Ga. and Fla. St. 2 to 3 f high, somewhiat angular. Lvs. 1 to $1 \frac{1}{2}$ long, closely sessile, acute, veinless. Fls. solitary, terminal. Cor. nearly $2^{\prime}$ diam., much larger than the calyx, bright purple with a yellow base. $\mathrm{Jn}$.

3 S. calycòsa $\mathrm{Pl}_{\text {. }}$ St. erect, terete, fork-branched, rather rigid; lvs. oblong, 3veined, obtuse; fls. solitary, 5 to 6-parted; cal. leafy lance-oblong, equaling or exceeding the corolla; pet. oblanceolate.-Fields and meadows, Va. to Ga. and Ia. St. a foot high, subangular, with spreading branches. Lvs. 1 to $2^{\prime}$ long, sessile, mostly obtuse, oval, thin. Fls. on long, rigid peduncles, about $I^{\prime}$ diam., pink colored. Sep. acute. Fruit as large as a pea. Jn.-Sept.

4 S. paniculàta Ell. St. terete, or slightly angled at base; internodes much exceeding the leaves; branches alternato; lvs. linear, the lower oval and rarely roundish; panicle diffuse but its branches strict; cal. segm. linear-setaceous, 2 or 3 times longer than its tube, twice shorter than the corolla; cor. segm. 5, obtuse.Damp pine barrens, South, common. Much branched, 1 to $2 \mathrm{f}$ high. Lvs. 4 to $10^{\prime \prime}$ long. Fls: white, $\mathbf{I}^{\prime}$ diam. Jl.-Oct.

5 S. grácilis Salisb. St. slightly angular, internodes twice longer than the leaves; branches flaccid, 1-llowered, alternate, spreading; lvs. linear and lance-linear, the lowest lance-ovate; panicle diffuse, few-flowered; cal. segments linear-setaceous, about equaling the corolla; cor. 5-parted, lobes elliptic-oblong, obtuse.-Marshes and meadows, Penn. to Fla. and Li. Very slender, 1 to $2 \mathrm{f}$ high, with long, almost filifurm branches. Fls. terminal, subsolitary, 14" broad, on long peduncles. Ji., Aug.

G S. stellàris $\mathrm{Ph}$. St. somewhat angular, sparingly fork-branched, with long, 1-Howered branches; lvs. lanceolate and obovate-lancsolate, acute; cal. segm. linear, varying in length but much shorter than the 5-parted corolla, the tube top-shaped, very short.-Marshes, Can. to Car. St. 3 to $15^{\prime}$ high, often diffusely branched. Lvs. about $1^{\prime}$ long, the upper almost linear. Fls. of a bright rose-color, with is yellow star bordered with deep red. Jl.-Sept. S. gracilis (Ell.), which it closely resembles.

7 S. corymbosa Baldwin. St. slightly 4-angled, internodes twice longer than the leaves; branches opposite; lvs. ovate-lanceolate, 3-veined, aeutish, upper ones lanceolate; cyme fastigiate, terminal; cal. segm. linear, 3 times longer than its tube, twice shorter than the corolla; cor. 5 to 6-parted, white, lobes obovate-olong, obtuse.-Pine barrens, N. J. to Ga. St. a foot high, branching near the summit. Lvs, an inch in length, closely sessile. Fls. few, generally 6-merous, white. Jn., Jl. (Chironia lanceolata Wait.)

3 S. macrophýlla Hoak. St. terete, glaucous; internodes twico longer than 
the leaves; branches opposite; Irs. ovate, acuminate-cuspidate; 5-veined, clasping and subconnate at base, the upper lanceolate; panicle fastigiate; cal. segm. setaceous, shorter than its short tube; cor. segm. 5, elliptic.-In La. (Hale, near Covington). St. 2 f high. Lvs. 2' long. Fls. smaller than any here noticed, about 7 " broad, white.

9 s. angulàris $\mathrm{Ph}$. St. quadrangular, with winged angles; lvs. ovate, amplexicauh 5-veined; panicle corymbous; ped. elongated; sep. lance-linear, half as long as the corolla, distinct almost to the base; cor. segments obovate, obtuse.-Wet meadows and prairies, Can. to Car. and Ark. Stem 10-18' high, much branched, branches opposite. Icaves closely embracing the stem, $1-2^{\prime}$ by $\frac{1}{2}-1 \frac{1}{2}^{\prime}$, as long as the internodes or often shorter. Flowers numerous, $1 \frac{1}{4}-11^{\prime}$ diam., deep roseco!or, the star in the center greenish. Л., Aug. (Chirònia, L.)

10 S. brachiàta Ell. St. slender, subquadrangular, internodes 2-4 times longer than the leaves; branches opposite, suberect; lvs. linear and lance-linear, lower ones ovate, all acutish, sessile; panicle oblong; cal. segments linear, twice longer than the tube, twice shorter than the corolla; cor. 5-parted, segments oblongobovate, obtuse, light purple.-Dry, grassy, prairies, Ia. abundant, also Tenn. and Car. Stem a foot high, few or many-flowered. Leaves $9-12^{\prime \prime}$ by $1-3^{\prime \prime}$. Flowers $15^{\prime \prime}$ diam., of a delicate blush-purple, the star in the center yellow, bordered with green. Jl., Aug. (S. concinna, 2d Edit.)

2. ERYTHRE'A, Renealm. (Gr. é $\rho v \theta \rho o ́ s$, red.) Calyx 5, rarely 4parted, angular; corolla funnel-form, twisted and withering above the capsule, tube cylindric, limb 5-4-parted; sta. 5-4, inserted near the top of the tube; anth. exserted, spirally twisted ; sty. 1; stig. bilamellate or capitate; caps. 2-valved, 1 or partly 2-celled.-1) St. subangular. Lvis. connate at base. Fls. cymous, roseate, white or yellow.

1 ... Muhlenbérgii Griseb. St. simplo below, dichotomously branched above; lvs. ovate-long, obtusish; cymes loose, dichotomous; fls. pedicellate; cor. tube a litlle longer than the calyx, segments oblong-lanceolate, acutish.-N. Y., Penn. Very rare. St. 3 to $8^{\prime}$ high, 1 to 3 times forked. Lvs. 4 to $7^{\prime \prime}$ by 1 to $3^{\prime \prime}$, closely sessile. Fls. lateral and terminal-central, the pedicels in the forks near $\frac{1}{2}$ long, the others shorter. Cor. bright purple, tube yellowish green, slender. Jl.-Sept. (E. pulchella Hook. Exacum puichella $\mathrm{Ph}$.?)

2 F. spicàta Pers. St. dichotomously branched, crect; Ivs. ciasping and slightly decurrent, lower ones oval, obtuse, upper lanceolate, acute; fls. sessile, mostly lateral on the long branches; sep. linear, acute, erect ; cor. tube slender, contracted at the neck, lobes spreading, obtuse; anth. linear-oblong, finally twisting outwards.- (1) Coast of Maryland (Pickering). Sandy margins of the seashore, Nantucket (Oakes). Whole plant very smooth and intensely bitter, 6 to $12^{\prime}$ high. Lvs. $1^{\prime}$ long, fleshy, pale green. Cor. $8^{\prime \prime}$ long, rose or nearly white. (E. Pickeringii Oakes.) \& Eur.

3 E. Centaurium Pers. Erect, branched above; lvs. oblong, acutish at each end ; fls. subsessile in the loosely corymbed cymes; cor. tube twice longer than the calyx, lobes short, oval, obtuse, erect-spreading.-Fields, Oswego, N. Y. and Can. St. 5 to $10^{\prime}$ high. Lvs. $1^{\prime}$ and less in length, half as wide, 3-veined. Fls. $6^{\prime \prime}$ long; rose-color, its yellow anthers exserted, and soon twisted. Aug. § Eur.

3. GENTIA'NA Tourn. (To Gentius, king of Illyria, who discovered the tonic virtues of this genus.) Calyx 5 to 4-parted or cleft; corolla marescent, tubular at base, limb 4 to 5-parted, segments either spreading, erect or convergent, often furnished with intermediate, plicate appendages; stamens 5 to 4 , inserted in the corolla tube; stigmas 2 , revolute or erect; styles short or 0 ; capsule 2 -valved, 1-celled, manyseeded.-Herbs of various habit. Lvs. opposite. Fls. terminal or cymous.

$\$$ Corolla destitnte of folded appendages - and the segments entire................ Xos. 10, 1

Corolla with folded, often toothed appendages between tho lobes. (a) 
a Flowers solitary, terminal, blue or white................................ 4

a Flowers clustered, -yellowish or cream-white........................... 5 , 6

- blue,--never opening; the folds as long as segments............... 7 -opening; the folds shorter than segments............. Nos. 8,9

1 G. quinqueslòra L. St. 4-angled, branching; lvs. ovate-lanceolate, acute, 3-veined; fls. terminal and axillary, about in $5 \mathrm{~s}$, pedicellate; cor. tubular-campanulate, with 5 lanceolate, setaceously acuminate segments; cal. very short, segm. subulate-linear. (2) Woods and pastures Can. and U. S. Stem a foot high, smooth, generally branched. Leaves 3-5-veined, half-clasping, acute, smooth. Fls small, on pedicels half an inch in length. Corolla pale blue, 4 times as long as the sepals. Sept., Oct.

$\beta$. PARviflora. Cal. enlarged, lobes foliaceous, lance-linear, half as long as the smallish corolla.-This variety prevails in the W. States.

2 G. crinita Frœlich. Blug Fringed Gentuan. St. terete, erect; lvs. lanceolate, acute; fls. tetramerous; cor. segm. conspicuously fringe-ciliate.-Not uncommon in cool, low grounds, Can. to Car. Stem If high, round and smooth. Branches long, with a slight curve at base, becoming erect and straight, each bearing a single, large, erect flower at the leafless top. Leaves broadest at base, tapering to the apex, $1-2^{\prime}$ long and $\frac{1}{5}$ as wide. Calyx square, segm. acuminate, equaling the tube of the corolla. Cor. of a bright bluish-purple, the segments obovate, finely fringed at the margin. Aug.- $\Lambda$ beautiful and interesting plant.

3 G. detònsa I. St. nearly strict, simple or branched; lvs. linear and lance-linear, the lowest rosulate, spatulate; ped. 1-flowered, very long, subsolitary; cal. $4(-5)$ cleft, lobes ovate and lanceolate, nearly equaling the corolla; cor. lobes roundishobtuse, ciliate at the sides, crenate at top, erect-spreading; stig. distinct. $-\mathrm{N}$. Y., Wis. (Lapham) N. to Hudson's Bay. A fine species, with large blue flowers. Stem a foot high. Leaves $1-2 \frac{1}{2}^{\prime}$ by $1-3^{\prime \prime}$, tapering to an acute point. Peduncles 4-7' long, each with a single large, erect, showy flower. Cor. 15-20" long, obconic or bell-shaped, blue.

4 G. angustifòlia Mx. St. erect, slender, 1-flowered; fls. pedunculate; lvs. linear obtuse, smooth, the lower ones subcuneate; cor. funnel-form, narrow, open, 5-cleft, twice as long as the calyx, lobes ovate-oblong, obtuse, twice as long as the lacerate folds. - 2f N. J. to Fla. in sandy fields. Stem a foot high. Lvs. $1^{\prime}$ long. Flower large, sky-blue, $20^{\prime \prime}$ long. Calyx deeply cleft, with linear segm. Sept., Oct.-A variety at the South (Quincy, Fla., Dr. Danalson) has white fls. $13^{\prime \prime}$ long.

5 G. ochroleùca Froel. Sts. nearly or quite smooth, simple, terete; fls. sessile, clustered at summit, rarely in one or two of the upper axils; lvs. oval-lanceolate, the highest lanceolate, lowest obovate-lanceolate, all narrowed to the sessile base, obscurely 3-nerved, rather acute; cal. segm. lance-linear, a third longer than the tube, nearly as long as the greenish-white, open corolla.-Va. to Fla. frequent. Sts. about if high. Lvs. much longer than the internodes. Cor. $2^{\prime}$ long, with green veins and purple stripes, lobes ovate, folds very short. Sept., Oct.

6 G. álba Muhl. (Gray). .Very smooth; st. stout, erect; fls. densely clustered at the summit, solitary in one or two axils; lvs. ovate-lanceolate, or. lanceolate,

- half clasping at the broad base, graduaily acuminate, 3-veined; cal. segm. ovate, much shorter than its bell-shaped tube, 4 times shorter than the cream-white corolla. Woods and prairies, Middle, W. and S. States. St. 1 to $2 \mathrm{f} \mathrm{high.} \mathrm{Lvs.} 3$ to $4^{\prime}$ by $\mathrm{I}^{\prime}$ to $18^{\prime \prime}$. Cor. $30^{\prime \prime}$ long, the ovate lobes much longer than the jagged appendages or folds; open but connivent. Jl.-Sept. (G. ochroleuca Griseb. \&c.)

7 G. Andrewsii Griseb. Closed Blug Gentian. Lvs. oval-lanceolate, 3-veined, acute; fls. in whorled heads, sessile cor. ventricous, clavate-campanulate, closed at top, 10-cleft, the inner segments plicate and fringed, equaling the exterior; cal. segm. ovate-oblong, many times shorter than the deep blue corolla. $-4 \mathrm{Brit}$. Am. to Car. A landsome plant, conspicuous in meadows and by brook-sides. Stem 12-to $18^{\prime}$ high, simple, erect, smooth, with opposite, smooth leaves, scabrous on the margin, resembling those of the common Soapwort. Flowers erect, 18" long, subsessile, inflated, so nearly closed at the top as to be easily mistaken for buds; and the young botanist waits in vain to see them expand. Sept., Oct. (G. Ssp onaria, 2d. edit., \&c.) 
8 G. Saponària L. St. ascending or erect, smooth; fls. clustered at the summit and often in the axils; lvs. ovate-lanceolate to lance-obovate, acutish, roughmargined, narrowed to the subclasping base; cal. segm. lance-linear or spatulate, about equaling the tube, half as long as the corolla; cor. bright blue, lobes connivent, ovate, open, twice (more or less) longer than the cleft folds.-Va. to Ga, and La. St. 8 to $18^{\prime}$ high, slender or rather stout. Lvs. 1 to 2 to $3^{\prime}$ long. Cor. $18^{\prime \prime}$ to $2^{\prime}$ long. Cal. segm. varying from lance-linear to lance-obovate! Aug., Sept.

$\beta$. LINEÀRIS. St. slender, ascending; lvs. linear and lance-linear, rigid; cal. segm. mostly linear; cor. folds very short. - Can. to Car. and Ky. A common form, so peculiar that we might as well perhaps regard it as a species. (G. Pneumonantho Mx.)

9 G. pubérula $\mathrm{Mx}$. St. erect or ascending, slender, rough, scarcely puberulent; fls. clustered, rarely solitary; Ivs. ovate and ovate-lanceolate, half-clasping, very rough-edged, acute, short but longer than the internodes; cal. segm. lanceolate, about as long as its tube, half as long as the subcampanulate, bright blue corolla; cor. subfunnel-form, lobes acute, thrice longer than the cleft folds. -W. and S. States. Plant 10 to $18^{\prime}$ high, very leafy and scabrous. Lvs. $9^{\prime \prime}$ to $20^{\prime \prime}$ long. Fls. 15" long. It varies with leaves linear-lanceolato and less rough. (G. Catesbæi Eil.)

4. BARTO'NIA, Muhl. (Centaurella Mx.)-Screwstem. (Dedicated in 1801 , by Dr. Muhlenburg, to Benj. F. Barton, Prof. of Botany, Philadelphia.) Flowers 4-merous; sepals appressed; corolla subcampanulate; petals slightly united, nearly erect; stigma thick, glandulous, somewhat bifid; eapsule 1-celled, 2-valved, invested by the permanent calyx and corolla; seeds very numerous and minute. $-2 \mathrm{~N}$. American, slender, erect herbs, with scale-like lvs. and small white fls.

1 B. vérna Muhl. St. short, simple; ped. 1-flowered, the lower much longer, often alternate; cor. segm. spatulate, obtuse, thrice longer than the calyx; ova. conical, tipped with the distinct style. Bogs, Va. to Ga. Sts. 3 to $5^{\prime}$ high, clustered. Scales $1^{\prime \prime}$ long, as in the other, the fls. white, $3^{\prime \prime}$ long. March.

2 B. tenélla Muhl. St. branching above, branches subdivided; lvs. subulate, minute; pan. erect, many-flowered; pedicels subequal; sep. distinct, a third shorter than the corolla; ova. ovate, sty. almost $0 .-\mathrm{A}$ slender and nearly naked plant, 5 to $8^{\prime}$ high, of a yellowish-green. color, in wet grounds, Mass. to Ga. St. squaro, often twisted, with very minute, bract-like leaves, which aro mostly opposite. Ped. simple or branched. Pedicels bracteate at base, 2 to $3^{\prime \prime}$ to $5^{\prime \prime}$ in length. Cal. segm. linear-lanceolate, acute. Cor. white, small, $1_{\frac{1}{2}}^{\prime \prime}$ long. Aug.

$\beta$. вrAchiata. Branches and pedicels elongated, decurved, $i$. e., outwards and upwards, and often alternate; cor. more open, lobes very acute, twice longer than the calyx.-Southward (B. Moseri Steud.).

5. FRA'SERA, Walt. Columbo. (In honor of John Fraser, an American eultivator of exotics.) Flowers mostly tetramerous; petals united at-base, oval, spreading, deciduous, each with 1 or 2 bearded, orbicular glands in the middle; style 1 ; stigmas 2 , distinct; capsule compressed, 1-celled; seeds few, imbricate, large, elliptic, margined. -2f Showy and tall, with opposite or verticillate leaves.

F. Carolinénsis Walt. St. tall, erect, glabrous; branched above; rs. oblong; lanceolato, acutish, sessile, feather-veined, entire or wavy; panicle compound, pyramidal, leafy, verticillate; cal. segments acute, shorter than the oblong, obtusish petals; gland solitary, oval-orbicular.-Moist woods, Western N. Y., Wis. and S. Car. Stem dark purple, 4-7-9f! high, perfectly straight, 1-2' thick at base. Leaves smooth, subcarnous, $3-12^{\prime}$ by $1-3^{\prime}$, in whorls of $4-6$, rarcly opposite. Petals greenish, with blue dots and a large purple gland near the base. June, July.-Highly valued as a tonic.

6. HALE'NIA, Borkh. FeLwort. (Derivation unknown.) Flowers tetramerous; corolla short-campanulate, petals spurred at base, with 
glands at the base of the spur within; stigmas 2, terminating the acuminate ovary; capsule 1-celled; seeds indefinite, obtuse, fixed to the sutures of the valres.-Erect, branching.

H. deflézza Griseb. St. erect, leafy; lvs 3 to 5-veined, radical ones oblong-spatu. late, tapering into a petiole, cauline ones oblong-lanceolate, acute, sessile; spurs cylindric, outuse, deflexed, half as long as the corolla.-2) Swamps, Can., Ban'gor, Maine (Miss Towle), N. Y., and Wis., rare. Stem about 18' high, obtusely 4-angled, smooth, with few branches above. Leaves $1 \frac{1}{2}-2^{\prime}$ long, $\frac{1}{2}$ as wide Flowers greenish-yellow, in terminal fascicles. Corolla persistent, with 4 spreading horns or spurs descending between the sepals. Aug. (Swertia Mx.)

7. OBOLA'RIA, L. Pennywort. (Gr. óßòós, a small coin; from the form of the leaves.) Calyx of 2 cuneate-oblong sepals or bracts; corolla tubular-campanulate, marescent, 4-cleft, lobes entire or crenulate; stamens inserted on the corolla at the clefts; stigma subcapitate, bifid; capsule 1-celled, 2-valved; seeds $\infty$, very minute.-2f Lvs. opposite. Fls. axillary and terminal, sessile, with leaf-like sepals.

O. Virgínica L. Penn. to Car., W. to Ky., in woods. Stem 4-8' ligh, often in clusters, subsimple or with a few opposite branches above. Leaves cuneate-obovate or roundish-rhomboidal, sessile and decurrent at base, fleshy, obtuse or truncate at apex, lower ones small and remote, upper crowded, glaucous-purple, sepals or bracts similar. Corolla pale purple or whitish, longer than the stamens. Capsule ovoid, obtuse, surrounded by the withered corolla. Apr., May.

8. MENYAN'THES, Tourn. Buck BeAN. (Gr. $\mu \eta \dot{\nu}$, a month, ä $v 0$ os; reputed an emmenagogue.) Calyx 5-parted; corolla rotate or funnelform, limb spreading, 5 -lobed, villous within, without glands at the base; stamens 5 ; style 1 ; stigma bifid; capsule 1-celled.-Bitter herbs, actively medicinal. Lvs. trifoliate.

M. trifoliàta L. Grows in swamps, margins of ponds, etc., N. Am. N. of latitude $38^{\circ}$. This fine plant arises from large, black roots descending deep into the boggy carth. Stem 8-12' high, round. Leaves on long, round footstalks stipuled at base. Leaflets obovate. Peduncle long, naked, terminal, bearing a pyramidal raceme of flesh-colored flowers. Pedicels thick, bracteate at base. Sepals obtuse, about a third as long as the corolla. Petals acute, about as long as the stamens, remarkably and beautifully distinguished by the soft, fringo-liko hairs at the base and in the throat of the tube. May.

9. Liminan'themum, Gmel. Flonting Heart. (Gr. $\lambda i \mu \nu \eta$, a

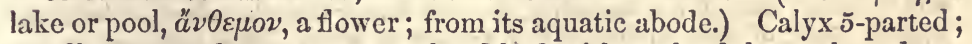
corolla 5-parted, rotate, segm. furnished with a glandular scale at base, often bristly; stamens 5; style short or none; stigma 2-lobed; capsule many-seeded, 1-celled, opening by decay.- 2f Curious aquatics, generally in stagnant water. Petioles long, bearing the flowers in an umbellate cyme below the roundish leaf, and oblong or cylindric tubers capable of producing new plants. (Villarsia Vent.)

1 L. lacunòsum Griseb. Lvs. small (1 to 2' diam.), orbicular, cordate, entiro smooth above, pitted and rugous beneath; cor. segm. twice as long as calyx, broadobovate, smooth, gland at base, subsessile, hairy; caps. ovoid, little longer than the calyx; seeds not muricate, shining.-In shallow waters, Me., Mass., N. Y. to Car. Petioles 1 to $3 \mathrm{f}$ long. Leaf 1 to. $2^{\prime}$ diam., lobes diverging and somewhat angled, upper surface green, lower purplish. Umbel half an inch below the blade, sub. mersed pendulous, the fls. one by one rising above the water as they expand. Cor. 7 to $8^{\prime \prime}$ broad, white, tube and glands yellow. Jl. (V. cordata Ell. V. lacunosa Vent.)

2 L. trachyspérmum Gray. Lvs. veniform, oval or orbicular, somewhat peltate, coriaceous, obscurely crenate, smooth abovo, spongy and pitted bencatli ; cor. 
segm. oblong, thrice as long as calyx, gland at base hairy, stipitate; caps. ovoid, twice longer than the calyx; sty. very short; seeds lens-shaped, shining, border muricate with sharp tubercles.-Ponds, S. States, Savannah (Feay), N. Orleans (Hale). Petioles 2 to $8 \mathrm{f}$ long, according to the depth of the water. Lvs. $2 \frac{1}{2}$ to $4^{\prime}$ by 3 to $5^{\prime}$, purplish, variegated beneath. Fls. white, with yellow center, $10^{\prime \prime}$ broad. Seeds straw-color. Jn. (Menyanthes trachyspermum Mx.)

\section{Order XCVI. APOCYNACEA. Dog-Banes.}

Plant with an acrid, milky juice, entire, exstipulate, mostly opposito leaves. Fowers 5-parted, regular, the calyx persistent, the corolla twisted in æestivation. Stamens 5, with distinct filaments, anthers filled with granular pollen. Ovaries 2, distinct, but their stigmas blended into a head-shaped mass Fruit 1 to 2 follicles, or capsular or baccate, with albuminous seeds.

Genera 90, species 700 , chiefly tropical.

Propertie8 - These plants possess netive and often suspicious qualities residing in the white julce with which the order is pervaded, and in the seeds which are often deadly poisons. The alkaloid strychnine or strychnia, one of the most violent poisons is the active principle of the seeds of the Strychnos Nux-vonica of India. It is sometimes administered as a medicino, but wlth doubtful snecess. S. Tiente of Java is ono kind of Upas. Cerbera Tanghin, a tree of Madagascar, is powerfnlly poisonous, a single seed being sufficient to destroy twenty persons. The $A$ pocznex are emetic, and becoming highly valued in hydrocephalus, etc. The juice contains cavutchouc in small quantities, but in Sumatra this is obtained largely from the juice of Urceola elastica.

\section{GENERA.}

a Herbs erect, with bell-shnped, whitish corollas and silky seeds.............Apocrveru. 1

a Herbs erect, with funnel-form, blue corella and naked seeds............... A msonis. 2

a Herbs twining, with funnel-form, yellow corolla and silky seeds.......... Forstrenoxis. 3 b Shrubs (cultivated) with the corolla throat 5-angled, crownless........ Vines. b Shrubs (cultivated) with the corolla throat crowned with 5 ligules.....Neriux. 5

1. APOC'YNURi, Tourn. DoG's-BaNe. (Gr. àmó, away, $\kappa \dot{v} \omega v$, dog ; Pliny says this plant is fatal to dogs.) Calyx very small ; corolla cam ${ }^{-}$ panulate, lobes short; stamens included; filaments short, arising from the base of the corolla, and alternate with 5 glandular teeth; anthers sagittate, connivent, cohering to the stigma by the middle; ova. 2; stigmas cunnate; follicles long, sublinear, distinct.-Herbs, suffrutescent, erect, with opposite, entire, mucronate lvs. Cymes terminal and axillary. Pedicels not longer than the pale flowers.

1 A. androszemifolium I. DOG'S-BANE. Smooth; Ivs. ovate; cymes lateral and terminal; limb of cor. spreading, the tube longer than the calyx.-A smooth, elegant plant, $3 \mathrm{f} \mathrm{high,} \mathrm{in} \mathrm{hedges} \mathrm{and} \mathrm{borders} \mathrm{of} \mathrm{fields.} \mathrm{Stem} \mathrm{reddened} \mathrm{by} \mathrm{the}$ sun, erect, branching above. Leaves dark green above, paler beneath, opposite, rounded at base and acute at apex, $2-3^{\prime}$ long and $\frac{2}{3}$ as wide, on petioles $\frac{1}{4}$ long. Cymes paniculate, at the top of the branches and in the axils of the upper leares. Pedicels $\frac{1^{\prime}}{3}$ long. Cal. much shorter than tho corolla. Cor. as long as the pedicels, bell-shaped, white, striped with red, with 5, acute, spreading segments Follicles 3 to $4^{\prime}$ long. Jn., Jl.-Medicinal.

$\beta$. INCÀNUM. Lvs. hoary-pubescent beneath.

A. cannabinum L. Smooth; lvs. oblong, varying from oval to lance-oblong, mucronate, short petiolate; cal. lobes lanceolate, about equaling the corolla tube; cor. lobes erect. - In shady soils, Can. to Ga. and Ark. Plant widely branched, 2 to $4 \mathrm{f}$ high. Lvs. smaller and thicker than in No. 1, 2 to $4^{\prime}$ long, 6 to $16^{\prime \prime}$ wide, usually rounded at base and acute at apex, often obtuse or acute at both ends, the petioles 1 to $3^{\prime \prime}$ long. Fls. in dense, upright cymes, and not as large as in No. 1. Cor. white, with erect segments, lardly $2^{\prime \prime}$ long. Follicles $3^{\prime}$ long. Jn.-Aug.

3. PUBEScens. Lvs. beneath and cymes pubescent. (A. pubescens R. Br.)

$\gamma$. IIYPERICIFOLIUMr. Lvs. narrowly oblong, subsessile, smooth; ova. inclining to ovate-oblong; cymes generally longer than tho leaves. (A. hypericifolia Ait.) 
2. AMSONIA, Walt. (To Charles Amson, of S. Carolina?) Calyx 5-cleft, segments acuminate; cor. 5-cleft, tube narrowly funnel-form, bearded inside, hispid at throat, segments linear convolute in bud; stamens 5 ; style 1 ; ovaries 2 , connate at base; follicles 2 , erect, slender, fusiform; seeds in one row, cylindric truncate at each end, naked. -Lvs. alternate, entire, subsessile. Cymes terminal, corymbous. Fls. blue.

1 A. Tabernæmontàna Walt. Lvs. ovate-lanceolate, acuminate, acute at base, briefly petiolate, puberulent beneath; margin slightly revolute; sep. glabrous, lanceolate, acuminate; cor. woolly outside near the top of the tube.-A plant of singular appearance, in prairies and damp grounds, W. and S. States. Stem terete, smoothish, $2 \mathrm{f}$ high, branched above. Leaves numerous, $3-4^{\prime}$ by $1-1 \frac{1}{2}$, conspicuously veined beneath. Flowers palo or livid blue, in several terminal, cymous clusters. Corolla $8^{\prime \prime}$ diam., very hairy at top of tubo. Follicles in pairs, $2-3^{\prime}$ long, about 6-seeded. May, June. (A. Latifolia $\mathbf{M x}$.)

2 A. salicifòlia $\mathrm{Pb}$. Very glabrous and lance-elliptic, acuminate at each end, conspicuously petiolate; cal. segm. triangular acute; cor. tube glabrous outside or more or less woolly. - In damp soils, Tenn., Car. to S. Ga. and borders of Fla. Plant 12 to $18^{\prime}$ high. Lvs. but half as large as in No. 1,2 to $3^{\prime}$ by 6 to $9^{\prime \prime}$. Cymes terminal, short-stalked. Cor. blue, formed as in the other species. May, $\mathrm{Jn}$.-Varies with the leaves more or less pubescent when young, and the cor, tubo woolly. Always more delicate than No. 1.

3 A. ciliàta Walt. Lvs. approximate or crowded, lance-linear and linear, often very narrow, margins ciliate; st. pubescent, leafless above; clusters corymbous, at length paniculately branched; cor. glabrous outside.-Sandy soils, dry and moist, Car. and Ga., common. Sts. 1 to 2 f high. Lvs. $18^{\prime \prime}$ to $2^{\prime}$ long, 1 to $3^{\prime \prime}$. wide, sometimes much narrower than $1^{\prime \prime}$, almost filiform. Fls. light blue, as in the other species, $6^{\prime \prime}$ long. $\beta$. FILIFolis, growing on sandy hills, has tho long pedunculate inflorescence paniculate. $\Lambda$ pr., May. ( $\Lambda$. angustifolia Mx.)

3. FORSTERO'NIA, Meyer. (Dedicated to $T$. $F$. Forster, an English botanist.) Calyx segments 5 , ovate; corolla funnel-form, not appendaged, deeply 5-cleft, lobes convolute (to the left) in bud; anthers sagittate, adherent to the stigma, the membranous tip inflexed; stigma 2-lobed at apex, 5-angled in the middle; follicles 2, distinct, spreading, glabrous; seeds many, comous.- Twining shrubs, with opposite, petiolate lvs. and cymes of small fls.

F. diffórmis DC. Branches smooth; lvs. oval and lance-oval; abruptly acuminate, acute at base, thin, glabrous above, puberulent beneath when young; cymes podunculate, axillary and terminal, as long as the leaves; cal. segm. long acuminate from an ovate base.-Damp or swampy grounds, Va. to Fla., climbing over shrubs. Lvs. varying from elliptical to nearly orbicular, 1 to $2^{\prime}$ broad. Cor. 3 to $4^{\prime \prime}$ long, palo yellow. Stam. included. May-Aug.

4. VIN'CA, L. Periwinkle. (Lat. vinculum, a band; from the long, twining branches.) Calyx 5-parted, segments acuminate; corolla funnel or salver-form, convolute, border 5-cleft, with the lobes oblique, orifice 5 -angled; 2 glands at the base of the ovary; follicles 2, erect, fusiform; seeds oblong.-Trailing shrubs. Lvs. opposite, evergreen. Juice slightly milky.

1 V. minor I. Sts. procumbent; lvs. elliptic-lanceolate, smooth at the margins; Als. pedunculate; seps. lanceolate. $-\mathrm{A}$ handsome evergreen, flowering in May. Sts. several feet in length, round, smooth and leafy. Leaves opposite, smooth and shining, about an inch long. Flowers solitary, axillary, alternate, violet, varying to purple or even white, inodorous + Eur.

2 V. .major L. Sts. nearly erect; lvs. ovate, ciliate; fls. pedunculate; sep. 
setaceous, clongated.-Shrub with numerous, slender, straggling branches, very leafy, forming light masses of evergreen foliage, flourishing best beneath the shado of other plants. Leaves 2 to $3^{\prime}$ in length, slining, rounded or somewhat cordate at base. Flowers blue, appearing in May and June. † Eur.

5. NE'RIUM, L. O Oleander. (Gr. vipòs, damp; referring to the locality of the plants.) Calyx with 5 teeth at the base outside of the corolla; corolla hypocrateriform, segments contorted, orifice with a corona consisting of 5 , laciniate leaflets ; filaments inserted into the middle of the tube; anthers sagittate, adhering to the stigma by the middle.-Oriental shrubs. Lvs. evergreen, opposite or ternate.

N. Oleánder I. Lvs. lanceolate, acute at each end; corona segm. of 3 to 4 lance-acuminate teeth. - In the greenhouse and shrubberies. St. regularly branched. Lrs. commonly 3 together, on short stalks, smooth, very entire, coriaceous, with prominent, transverse veins beneath. Fls. terminal, corymbcus, large and beautiful rose-colored. One variety has white flowers, another variegated, and a third double. This splendid shrub is common in Palestine (Rev. S. Hebard), growing by rivulets, \&c. It is supposed to be the plant to which the Psalmist alludes, Ps. i. 3, and xxxvii. 35.

\section{Order XCVII. ASCLEPIADACEA. Asclepiads.}

Plants (chiefly herbs in the United States) with a milky juice, often twining.

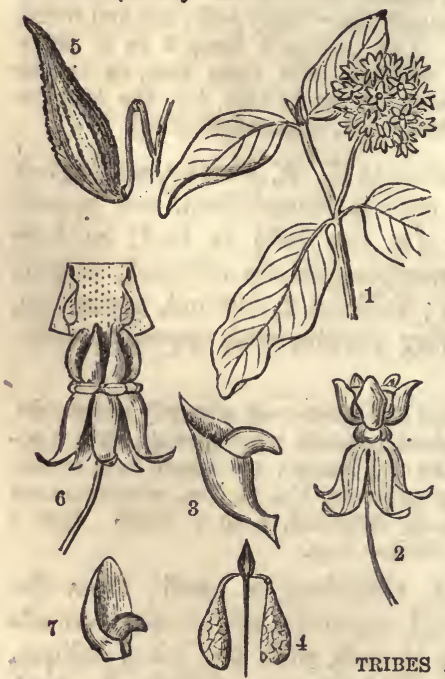

Leaves opposite (rarely whorled or scattered), without stipules, entire. Flowers generally umbellate, 5-parted, regular, the sepals and also the petals united at base, both valvato in æstivation. Stamens united, adherent to and covering the fleshy mass of the two united stigmas. Pollen colering in masses. Ovaries 2, forming follicles in fruit.

Genera 141, species 910 , chicfly natives of tropical regions, and especially abundant in $\mathrm{S}$. $\Delta$ frica, S. India and New Ilolland, but are not uncommon in teinperato regions.

Properties.-Similar to those of the Apocynacex but far less active. The juice is acrid and generally to be, at least, suspected. $\Lambda \mathrm{few}$ of tho species are medicinal, but none of much conscquence.

FIG. 670.-1. Asclepias cornuti. 2. A flower, the petals and sepals reflexed, and the corona erect. 3. One of the segments of the corona with the horn bent inwardly. 4. A pair of pollen masses suspended from tho glands. 5 . A mature follicle. 6. Vertical section of $P$. phytolacoides showing the 2 ovaries. 7. Lobe and horn of the corona.

1 PERIPLOCE.A. Filaments distinet. Pollinia single (not in pairs), granular. (*)

* Anthers bearded on the back. Pollinia 5. Sten twining...............Prriploca. 1

11. ASCLEPIADEA. Filaments connate. Pollinia 10 , in pairs, pendulous, vertical. (a)

a IIoods cach sheathing a little horn. Petals reflexed.................... AscLepras. 2

a Iloods of the crown destitute of a horn. (b)

b Petals reflexed. IIoods erect, adnate to tho anthers............................ 3

b Petals expanding. Iloods ascending, free from anthers.....................

b Petals erect.-Plant erect. Anther heal pedicellate.............. Ponostig.r.. 5 -Plants twining. Crown fleshy retuse....................snvere. 6 -Plant twining. Crown thin, 2-awned.............. Exsleisia, 7 
III. GONOLOBE E. Filaments connate. Pollinia 10, in pairs, horizontal. (c)

c Corolla wheel-shaped. Plants twining, with cordate leaves..............Gorozorus, s

IV. ST APELIEAE. Filaments connate. Pollinia 10, ascending or erect. (d)

d Crown simple, of 5 fleshy segments. Twining. Cnltivated................. HorA. 9

d Crown double, an outer and an inner. Not twining. Cultivated........... Stapexta. 10

1. PERIP'LOCA, L. (Gr. $\pi \varepsilon \rho \iota$, around, $\pi \lambda$ ó $\kappa^{\prime}$, a binding or twining; from the habit of the plant.) Calyx minute; corolla rotate, flat, 5 -parted, orifice surrounded by a 5 -cleft, urceolate corona, terminating in 5 filiform awns; filaments distinct, anthers cohering, begarded on the back; pollinia solitary, 4-lobed; follicles 2, smooth, divaricate; seeds comous.-Twining shrubs. Fls. in umbels or cymes.

P. Græca I. Lrs. ovate, acuminate; corymbs axillary; cor. villous within-A climbing shrub, 10-15f long, sparingly naturalized in Western N. Y., also cultivated in gardens. Leaves opposite, $3-4^{\prime}$ long, $\frac{1}{3}$ as wide, and on petioles $\frac{1}{3}^{\prime}$ long. Flowers in long, branching, axillary peduncles. Sepals minute, lanceolate, acuto. Petals very hairy within, linear, obtuse, dark purple. Follieles about $2^{\prime}$ long. Aug. \& S. Eur.

2. ASCLE'PIAS, L. MrLk weed. (From Esculapius, the fabulous god of medicine and physicians.) Calyx deeply 5-parted; corolla deeply 5 -parted, valvate in restivation, finally reflexed; staminal corona 5 leaved, leaflets cucullate, with an averted horn-like process from the base curved towards the stigma ; antheridium (connate mass of anthers) 5 -angled, truncate, opening by 5 longitudinal fissures; pollinia (masses of pollen) 5 distinct pairs fixed by the attenuated apex to a cleft gland, pendulous ; follicles 2, ventricous; seeds comous.-2f Mostly N. American, with opposite, verticillate, rarely alternate lvs. Umbels between the petioles.

\$ Leaves linear, long and narrow (lance-lincar in the cultivated No. 19). (*)

* Leaves all opposite, or rarely the highest alternate...................... Nos. 17-19

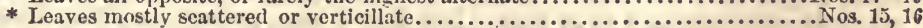

\$eaves broader, ovate, lanceolate, \&e. Plants all native. (2)

2 Stems dividing above into branches, corymbed or panicled..................... 13, 14

2 Stems simple,-Leaves sessile, cordate-clasping at base........................... 11, 12

2 Stems simple.-Leaves petiolate, the petioles often quite short. (3)

3 Flowers (small) with a white crown and purplish-white corolla........... Nos. $8-10$

3 Flowers with a white crown and greenish-white corolla................... $5-7$

3 Flowers (large) with both crown and cerolla purple-tinged. (4)

4 Follieles sinnothish (as are all the foregoing).... Nos. 3, 4

4 Follicles sprinkled with soft warty spines.......... Nos. 1, 2

1 A. cornùti Decaisne. Simple, stout; lvs. oblong-ovate, short-acuminate, shortpetiolate, downy beneath; pedicels shorter than the leaves, densely many-flowcred; cor. lobes ovate reflexed, 4 times shorter than the pedicils; hoods of the crown ovate, obtuse, not longer than the uncinate horn.-A common, very milky herb, 3 to $4 \mathrm{f} \mathrm{high,} \mathrm{in} \mathrm{hedges} \mathrm{and} \mathrm{road-sides.} \mathrm{Ivs.} 5$ to $8^{\prime}$ by 2 to $3^{\prime}$; veinlets, as in most species, nearly at right angles to the midvein. Pcd. stout, between the petioles, bearing a globular umbel of a hundred greenish purplo flowers, few of which prove fruitful. Pods full of seeds with their long silk. Jl.

2 A. Sullivantii Engel. Tall, very smooth; lvs. ovate-oblong, erect, cordate, on very short petioles; hoods of the crown obovate, obtuse and entire at apex, obtusely auriculate without on each side at base; horns slender but obtuso; follicles with scattered, warty spines.-Near Columbus, Ohio ("Sullivant." Mr. A. H. Watson). Said to resemblo A. cornuti in foliago and fruit, but remarkably different in its crown. Petals 4 to $5^{\prime \prime}$ long, greenish purple. Hoods twice as long as the ar. thers. Jl.

3 A. purpuráscens I. St. simple, erect, puberulent; lvs. elliptical, ovate-elliptical or ovate, mueronate, narrowed at base into a short petiole, smooth above, tomentous-pubescent and paler beneath; ped. terminal, shorter than the leaves; loods oblong or lance-ovate, obtuse, horns falcate, acute, abruptly bent to horizontal.-In hedges and thickets, N. II., Mass, to Wis, and Ky. St. $3 f$ or more 
high, simplo or slightly branched at top. Ivs. with tho midvein purple. Cal. small, green. Cor. dark purple, with reflexed segments. Crown purple, twico as long as the antheridium, the points of its horns lying close upon it. JL.

4 A. rubra L. St. simple, erect; lvs. ovate-acuminate, very acute, subcordate or rounded at base, on very short petioles, glabrous; umbels on long, mostly terminal peduncles; few-flowered; hoods of the crown acute, rather longer than the suberect horn.-A small and elegant species in Penn., N. J., and Car., not common. St. 1 to $2 \mathrm{f} \mathrm{high,} \mathrm{with} \mathrm{a} \mathrm{pubescen't} \mathrm{line} \mathrm{on} \mathrm{one} \mathrm{side.} \mathrm{Lvs.} 3$ to $5^{\prime}$ by 1 to $2^{\prime}$, in remoto pairs, the upper sometimes alternate. Ped. 1 to 5,2 to $3^{\prime}$ long, pedicels about $1^{\prime}$. Fls. purple, tho crown red. Follicles ventricous-acuminate, smoothish. Jl., Aug. (A. lancifolia $\mathrm{Mx}$. A. acuminàta $\mathrm{Ph}$.)

5 A. phytolaccoides $\mathrm{Ph}$. PoKe-leaved Srikiweed. St. simple, erect, puberulent; lvs. broadly ovate, attenuated ai base and apex, acute, smoothish both sides, glaucous; ped. whitish puberulent, many-flowered; pedicels slender, loose, about as long as tho peduncle; antheridium stipitate; hoods truncate, with 4 unequal teeth; horns subulate, exserted, suberect.-Tall and handsome, in low, shady grounds, Can. to Ga. and Ark. St. 4 to 5 f high. Lvs. 6 to $9^{\prime}$ by 2 to $4^{\prime}$. Umbels near the top on lateral peduncles 4 to $6^{\prime}$ long, with about 20 large flowers on nodding pedicels near $2^{\prime}$ long. Petals greenish, crown white, tinged with pink. June.

6. A. variegàta I. St. simple, erect, smoothish; lvs. ovate or oval, abrupt at each end, mucronate, glabrous, glaucous beneath; ped. lateral or terminal, oncthird as long as the leaves, umbellate, many-flowered; cor. segm. ovate; hoods orbicular; horns broad-falcate, with the apex horizontal or suberect; follicles oblong, with a long, slender point, minutely puberulent.-Woods, N. J. to Fla. (at Tallahassee) and Wis. St. 2 to $4 \mathrm{f}$ high. Lvs. with a slight acumination, at length slightly undulate. Umbels about 2, 20 to 30-flowered. Cor. white.

7 A. nívea L. St. terete, pubescent; lvs. lanceolate or oblong-lanceolate, acute, attenuated at base into a long petiole, minutely puberulent, scarcely paler beneath; ped. shorter than tho leaves, mostly terminal, often compound; umbels small, few (10 to 17)-flowered; petals ovate, reflexed, half as long as the pedicels; hoods ovate, longer than the falcato horns.-S. W. Ga. (Miss Keen) to La. A pretty, white-flowered species 1 to $2 \mathrm{f}$ high. Lvs. 3 to $4^{\prime}$ long, petioles near 1'. Flower buds 2 " long. Jn.-Aug.

8 A. Vàseyi Torr. \& Gr. St. low, pubescent; lvs. ovate or oblong-lanceolate, acute, abruptly contracted to short petioles, pubescent beneath; umbels nearly sessile, few (10 to 15-flowered; petals oval; hoods ollong-obtuse, yellowish white, longer than the horns. - Prairies and barrens, Wisa (Lapham), Ill., Min. Sts. If (more or less) high. Lvs. 2 to $3^{\prime}$ long. Cor. buds tinged with purple, about $2^{\prime \prime}$. Jn.

9 A. parviflòra $\mathrm{Ph}$. Half-shrubby and branched at base; sts. ascending, smooth; lvs. lanceolate, attenuate at base and apex, on long petioles, smooth, thin; ped. much shorter than the leaves, few (12 to 18)-flowered; umbels small, pubescent, with small flowers; petals ovate, thin, thrice shorter than the pedicels; hoods ovate, shorter than the filiform horns. - Woods along rivers, Ind. (Green Co.) to Ga. and La. Sts. clustered, $18^{\prime}$ to $3 \mathrm{f}$ high, vcry leafy. Ivs. 4 to $6^{\prime}$ (including tho $1^{\prime}$ petiole) by $1^{\prime}$ to $18^{\prime \prime}$. Umbels several, $1^{\prime}$ diam. Cor. purplish white, bud $1^{\prime \prime}$ long. Jl., Aug.

10 A. quadrifolia $\mathrm{Ph}$. St. ercet, simple, smooth; lvs. smooth, thin, short-petiolate, ovate, acuminate, some of. them in whorls of 4 ; umbels few, lax, on long terminal or axillary peduncles; hoods, elliptic-ovate, with short, included horns.-An elegant species in dry woods. Can. and U. S. St. about $2 \mathrm{f}$ high, slender, often with 1 or 2 hairy lines. Ivs. opposite, tho upper or middle pairs near together so as to appear in $4 \mathrm{~s}, 2$ to $3^{\prime}$ long, $\frac{1}{2}$ as wide, acuto or acuminate, on petioles 2 to $4^{\prime \prime}$ long. Fls. small, tho petals pale pink, 2 to $3^{\prime \prime}$ long, crown near 2", whito on filiform stalks with a pubescent line. Jl.

$\beta$. LANCEOLÀta. Ivs. lanceolate, acuminate at both ends, the upper whorled; fls. smaller (petals less than $2^{\prime \prime}$-long).-Mass. (Ricard). Ind. (Plummer).

11 A. obtusifòlia $\mathrm{Mx}$. St. simple, erect; lvs. oblong or oblong-ovate, obtuse, mucronate, sessile, cordate and subamplexicaul, undulate, very smooth both sides; umbels terminal, many-flowered, glabrous, long-pedunculato; hoods abrupt, 
almost truncate at apex, horns arcuate, falcate, inflexed.-In shady grounds, prairies, Mid., W. and S. States. St. 2 to 3 f high, bearing a single (rarely 2) terminal umbel of 30 to 40 large, reddish green or greenish flowers. Lvs. 4 to $5^{\prime}$ long, a third as wide, with a broad, rounded, mucronate apex. Petals 4 " long. Corona nearly white, its segments large, slightly 2-toothed. Л. (A Meadii Torr. ex. descr.)

12 A. amplexicaulis Mx. St. simple, flexuous, often tortuous above, smooth; lvs. ovate, obtuise, not mucronate, cordate, closely sessile, glabrous and glaucous; ped. lateral and terminal, many-flowered; petals ovate, reflexed, twice shorter than the slender pedicels; hoods ovate, including the acute, recurved horns.Fields, copses, S. Car. to Fla. and Ala. St. clothed with largo lvs., 1 to $2 \mathrm{f}$ high. Lvs. $2 \frac{1}{2}$ to $5^{\prime}$ long, two-thirds as wide, beautifully netted with pellucid veins, base lobes large, rounded. Petals $3^{\prime \prime}$ long, of a light dull purple. Apr.-Jn.

13 A. incarnàta $\mathrm{L}$. St. tall, branching abovo; lvs. opposite, lanceolate on short petioles, slightly tomentous; umbels numerous, erect, mostly terminal, often in opposite pairs; hoods ovate-oblong, with subfalcate, ascending horns.- A handsoms species found in wet places, Can. and U. S. St. 3 to $4 \mathrm{f}$ high, with 2 hairy lines. Livs. 4 to $7^{\prime}$ by 6 to $18^{\prime \prime}$, rather abrupt at base, tapering to a very acuto point, on petioles $6^{\prime \prime}$ long. Umbels close, 2 to 6 together at the top of the stem or branches, each an inch or more in diam., 10 to 20 -flowered. Cor. deep' purple, corona paler. $\mathrm{Jl}$. $\dagger$

$\beta$. PUlchra. St. and lvs. densely tomentous, the latter elliptic-lanceolate.St. 4 to $5 \mathrm{f} \mathrm{high}$. $\dagger$

14 A. tuberòsa L. ButTerfly WEed. St. ascending, hairy, with spreading branches at top; lvs. alternate, oblong-lanceolate, sessile; umbels numerous, forming a large, terminal corymb; hoods bright orange, oblong, narrow, with slender, subfalcate, suberect horns.-Dry fields, Can. and U. S. Root large, fleshy, sending up numerous stems $2 \mathrm{f}$ high, leafy. Lvs. scattered, only the upper ones quite sessile, acute or acuminate, obtuse at base, 2 to $4^{\prime}$ by $6^{\prime \prime}$ to $1^{\prime}$. Corymb of numerous, bright orange-colored flowers. Petâls and crown of equal length (3 to $\left.4^{\prime \prime}\right)$. Pods or follicles lanceolate-pointed, and like the other species containing long, silky down. Aug.-Medicinal.

15 A. Michàuxii Decaisne. Ascending, sleuder, puberulent; lvs. scattered (the lowest opposite), long-linear, sessile, mucronate; umbels terminal, solitary or somewhat panicled; petals ovate, greenish white; hoods short, ovate, yellowish, including the short horns. - Wet pine barrens, S. Car. to Apalachicola, Fla., and to La. St. 12 to $18^{\prime}$ high. Lvs. 3 to $4^{\prime}$ long, 1 to $3^{\prime \prime}$ wide, rather numerous. Flower buds greenish, scarce $2^{\prime \prime}$ long, sweet-scented. May, Jn. (A. longifolia Mx. in part. A. angustifolia Ell.)

16 A. verticillàta Ell. St. erect, simple, marked with pubescent lines; lvs. generally verticillate, very narrowly linear, revolute; hoods short, 2-loothed, horn falcate, exserted.-A slender and delicate species, $2 \mathrm{f}$ high, in swamps or moist meadows, Can. and U.S. Lvs. in 'whorls of 4 to 6,3 to $5^{\prime}$ long, a line in width. Fls. small, greenish white, in small, lateral umbels. Ped. half as long as the leaves. Jl.

17 A. paupércula Mx. St. virgate, erect, glabrous; lvs. linear and linear-oblong, margins narrowly revolute, both sides glabrous, tapering into a short petiole; ped. 1 or 2 at top of the stem, umbel puberulent, few (6 to 10)-flowered; fls. large; petals oblong, half as long as the pedicels; hoods ovate, dilated above, horns short, included. -N. J. to Ga. and La., in wet woods. St. 3 to $4 \mathrm{f} \mathrm{high,} \mathrm{very} \mathrm{smooth.}$ Lvs. green on both sides, rough on the edges, mostly very narrow. Petals purple, 4" long. Crown stipitate, yellow. J1., Aug. (A. lanceolata Walt.)

18 A. cínera Walt. Erect, virgate, smooth; lvs. opposite, narrowly linear or filiform, acute, edges revolute; ped. alternate at summit of the naked stem, very few (3 to 6)-flowered, bracteolate; petals ovate-oblong, thrice shorter than the pedicels; hoods shorter than the stamens, including the horns.-Damp barrens, S. Car. to Fla. Sts. very slender, 2 to 3 high. Lvs. 1 to $3^{\prime}$ long. Petals 2 to $3^{\prime \prime}$ long, of an ashy and glaucous purple. Jn., Jl.

19 A. curassávica $\mathrm{L}$. Half-shrubby and branched at base, puberulent; st. terete; lvs. linear-lanceolate and lanceolate, acuminate, petiolate; umbels solitary, 
lateral, shorter than tho Ivs. with few large flowers; petals ovate, acute, refloxed, half as long as pedicels; hoods ovate, longer than the recurved horns.-Gardens. Tall and elegant. Fls. scarlet, varying to white. $† W$. Ind.

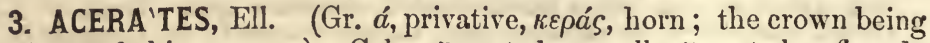
destitute of this process.) Calyx 5-parted; corolla 5-parted, reflexed; crown segments 5 , erect, adnat to the anthers and destitute of either horns or scales; pollinia 5 pairs, suspended by a thread-like beak; otherwise as in Asclepias. - 2f Lrs. opposite or alternate. Umbels lateral.

1 A. viridiflòra Ell. Branched at base, stout, ascending, pubescent-hoary; lvs. opposite, oval, obtuse, mucronate, petiolate, thick, varying to oblong-ovate or even lanceolate, with close veinlets combined at edge into a marginal vein; umbels nearly sessile, small, dense-flowered; petals ovate, reflexed, nearly as long as the pedicels; crown segm. oblong, erect, adnate to the anthers.-In gravelly soils, Can. to Ga. and Ark. Sts. about $2 \mathrm{f}$ high. Lvs. exceedingly variable, 2 sto 4 to $6^{\prime}$ long, wide in all proportions. Fls. small, green, inelegant, in 2 to 5 umbels. Ped. I to $3^{\prime \prime}$ long. JI. (Asclepias lanceolata Ives.)-Prof. Pond sends specimens from W. Ga. with the leaves all nearly orbicular! (A. obovata Ell ?)

2 A. monocéphala Lapham. Low, stout, hairy; lvs. lanceolate, subsessile; umbel solitary, terminal on the naked summit of tho stem, with numerous greenish flowers; crown sessile, the obtuse concave hoods erect-spreading, as long as the antheridium.-Prairies, Wisc. (Mr. A. 1L. Watson). Plant near If high. (Asclepias lanuginosa Nutt. ?)

3 A. longifòlia Ell. Scabrous-puberulent; st. ascending, simplo; lvs. alternate, numerous, linear and lance-linear, subsessile, acute; umbels half as long as the lcaves, numerous, many-flowered, pubescent, axillary, pedunculate; crown-hoods stipitate, shorter than the antheridium.-Mich. to Ia., and Miss., in meadows and prairies. Stem stout, $2-3 \mathrm{f}$ high. Leaves $3-5^{\prime}$ (including the $1-3^{\prime \prime}$ petiole) by $3-5$. Flowers very numerous in each umbel, green, peduncle and pedicels about 1' long. July, $\Lambda$ ug.

4. ANAN'THERIX, Nutt. (Gr. a privative, $a \nu 0 \dot{\varepsilon} \rho \iota \xi$, a beard; of similar import with Acerates.) Calyx short, 5-parted ; corolla 5-parted, petals broadly ovate, imbricated, reflexed-spreading; crown of 5 hollow, closed, horn-like, segments incurved, free from the anthers, doublemargined and furnished with a crest-like scale along the interior surface; pollinia 5 pairs, suspended by a thread-like beak. Otherwise as in Asclepias.-24 Herbs erect, with oblong, narrow, opposite lvs. and terminal paniculate umbels. Petals leaf-like, green.

1 A. connivens Feay. St. half-shrubby, firm, terete, strict, puberulent; lvs. oval or rather oblong, erect, subsessile, acute or obtuse; ped. 1 to 4, somewhat panicled along the nakedish summit, 7 to 12 -flowered; petals oval, with a short cusp; crown segm. thrice longer than the anthers, incurved from a spreading base or areuate, connivent over the anthers.-E. Ga. in pino barrens, (Feay, Pond). Sts. about $2 \mathrm{f}$ high. Lvs. 18 to $30^{\prime \prime}$ long, 4 to $9^{\prime \prime}$ wide. Petals $5^{\prime \prime}$ long. Jn. (A. viridis Nutt. Asclepias connivens Baldw.)

2 A. paniculàtus Nutt. St. stout, angular, contort d, assurgent, hirsute; lrs. narrowly oblong $\varphi$ obtuse, mucronate, on short petioles, pubescent; ped. 3 to 5 , paniculate at the leafy summit, 5 to 9 -flowered; petals ovate, erect-spreading; crown segm. spreading, not longer than the anthers, 3 times shorter than the leaflike petals.-Ga. (Feay, Pond) to Ark. Sts. 12 to $18^{\prime}$ lighl, very leafy. Lvs. 2 to $3^{\prime}$ long. Petals 6 to $8^{\prime \prime}$ long. (Accrates paniculata Decaisne. Asclepias viridis Walt.)

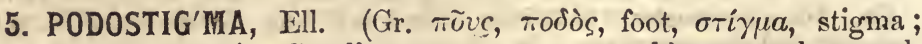
from the character.) Corolla segmerts 5, crect, oblong, much exceeding the calyx; crown pedice!late, segments 5 , without hores, short, 
concave, split on the inner side, apex reflexed; pollinia suspended by the attenuated apcx, compressed ; stigma depressed, 5-angled; follicles 2, long, slender, sinooth. - 2f St. low, simple. Lrs. opposite. Umbels extra-axillary, few-flowered.

P. pubéscens Fnl. In wet or moist grounds, S. Car., Ga., Fla. (Macon, Prof. Loomis), Tallahasseo (Mettauer) and A palachicola! Plant of singular appearance, 8 to $14^{\prime}$ high, slender, pubescent. Lvs. linear-oblong, rarely linear-ovate, obtusish, sessile, erect, 1 to $18^{\prime \prime}$ long. Umbels 3 to 5 , alternate, 3 to 5 -flowered, rather shorter than the leaves. Fls. cylindric bell-shaped, yellowish green, $4^{\prime \prime}$ long, crect, the crown conspicuously pediceled. May, Jn.

6. SENTE'RA, Reich. Calyx of 5 lanceolate, acute sepals; corolla subrotate, 5-parted, acute, glabrous ; crown segm. 5 , erect, flattish, retuse, adnate to the base of the sessile anthers; pollinia ovoid, fixed by the apex, pendulous; stigma bifid; follicles 2 , smooth ; seeds comous. -2f Slender, twining, with linear, fleshy lvs., few-flowered umbels. (Lyonia, Ell. nec Nutt.)

S. marítima Deen. In salt marshes, S. Car. to Fla., twining around tho rushes, \&c. Wholo plant very smooth. Lvs. opposite, sessile, channeled, $1^{\prime}$ long. Umbels between the leaves, 7 to 10 -flowered. Sep. ciliolate, erect. Petals acute, greenish, twico longer than the white crown. Follicles very slender. Jn.-Oct. (S. maritima Ell.)

7. ENSLE'NIA, Nutt. (In memory of Mr. Aloysius Enslen, who collected many plants in the Southern States.) Calyx small, 5-parted; cor. 5-parted, segments erect; corona 5-leaved, leaflets membranaceous, free, truncate, each terminated by 2 filiform, flexuous lobes; pollinia oblong, obtuse at base and apex, pendulous; stig. 5-angled, conical; follicles cylindraceous, smooth.- $2 f$ A twining herb, with opposite, cordate-ovate, acuminate lvs. Ped. racemous-umbellate, many-flowered. Fls. white.

E. álbida Nutt.-W. and S. States, common. Sts. slender, with an alternate, pubescent line. Lrs. thin, glabrous, with rounded, auriculate lobes at base, 2 to $3^{\prime}$ Iong and wide, ending in a slender point, margins entire. Ped. axillary, as long as the petioles. Fls. ochroleucous, sweet-scented, $2^{\prime \prime}$ long. Jl, Aug.

8. GONOL'OBUS, Mx. (Gr. $\gamma \tilde{\omega} \nu \rho \varsigma$, angle, $\lambda \circ \beta o s$, pod; the fruit of some species is angular.) Calyx 5 -parted, spreading; corolla subrotate, 5-parted, convolute in bud; crown a small, fleshy, undulate-lobed ring, attached to the throat of the corolla; anthers opening transversely beneath the stigma; pollinia 5 pairs, horizontal; follicles turgid, seeds comous. - 2f More or less shrubby, twining or prostrate. Lvs. cordate, hairy, opposite. Umbels extra-axillary.

I G. macrophýllus Mx. St. tomentous-pubescent and with soft, scattered hairs; Ivs. broad, ovato or oval, cordate, acuminate, pubescent beneath, at length glabrous above; ped. shorter than the petioles, 2 to 5 -flowered, with linear bracts at summit; petals linear or linear-oblong obtuse, $\left(6^{\prime \prime}\right.$ long), smooth above, minutely puberulent beneath; follicles costate-angled. -Thickets along streams, Penn. to Ky. and Ga. Vine trailing or climbing 3 to 5 f. Lvs. thin, 3 to $6^{\prime}$ by 2 to $4^{\prime}$, the lobes at base rounded and often nearly or quite closed, with a short acumination at apex. Fls. dark purple. Petals 5 to $7^{\prime \prime}$ by $1^{\prime \prime}$. Jn., Jl. (G. discolor, B. M.)

B. LEVIS. Plant nearly smooth, cor. segm. smooth both sides.-South. (G. levis $\mathrm{M} x$.)

2 G. hirsùtus Mr. St. hirsute-pubescent; lrs. broad-ovate, acuminate, cordate, minutely pubescent both sides; ped. shorter than the petioles, few-flowered, with 
setaceous bractlets at top; petals ( $3^{\prime \prime}$ long) oblong, obtuse or acute, minutely puberulent outside; follicles muricate.-Woods, Can. to Fla. and Ala. Lvs. as in the last, from which this species technically differs only in its broader (dark purple) petals and prickly fruit. Lvs. seldom exceeding $4^{\prime}$ by $3^{\prime}$. Petals about $3^{\prime \prime}$ 'by $1 \frac{1}{2}$ ". May-Aug.

3 G. prostràtus Ell. Branched at base, hirsute-pubescent; branches herbaceous, prostrate; lvs. small, broadly ovate-reniform, acute, sinus broad, auricles rounded, inflexed; umbels sessile, 3 to 5 -flowered; sep. lanceolate, hairy; cor. segm. ovate, obtuse, ( $1^{\prime \prime}$ long), very hirsute inside; crown 5-lobed, very short.-E. Ga. in sands (Feay). Sts. 6 to $12^{\prime}$ long. Lrs. $1^{\prime}$ or less long, nearly as wide, the upper somewhat acuminate. Fls. dark purple, $3^{\prime \prime}$ broad. (Chthlamia pubiflora Decn.)

9. HOYA, R. Br. Wax Plant. (Named for Thomas Hoy, an English florist.) Calyx small, 5 -sepaled ; corolla rotate, flat, valvate in bud; staminate crown of 5 depressed, spreading segments; anthers membranous at tip; pollinia fixed by the base, oblong, connivent; follicles smooth, seeds comous.-Shrubs twining, with fleshy lvs. and fls. in extra-axillary umbels.

H. carnòsa R. Br. Branchlets puberulent; lvs. thick, glabrous, ovaloblong, short-pointed; ped. shorter than pubescent pedicels; cor. fleshy, papillous inside, segm. triangular, reflexed at the apex; corona segm. oval, acute, edges revolute.-Garden and greenhouse. Fls. pink-colored, in dense umbels, very fine. $t$ E. Ind.

10. STAPELIA, L. (Named for Bodoeus à Stapel, a physician of Amsterdam.) Calyx 5-parted; corolla rotate, 5-cleft, fleshy; crown double, the exterior of leaves entire or parted, the interior of horn-like segments ; pollinia erect, 5 pairs, turgid; follicles smooth, erect; seeds comous.-Plants of S. Africa, fleshy, branching, leafless; branches angular, angles toothed, bearing large, fleshy, dark red, rugous flowers, of a most disgusting odor. Some are cultivated in our greenhouses, as A. birsuta, A. bufonia, \&c.

\section{Order XCVIII.-JASMINACEA. Jasminworts.}

Shrubs often twining, with opposite or alternate, mostly compound leaves. Calys and corolla 5 to 8-parted, the latter imbricated in æstivation. Stamens 2 , in the tube of the corolla Ovary free, 2-celled, 2 to 8-ovuled. Fruit a berry or capsule. Seeds erect, with little or no albumen. Fig. 78.

Genera 6, species 100. Ornamental shrubs abounding in tropical India. The essential oil which pervades the order, residing chiefly in the Howers, is exquisitely fragrant. On this account, as well as for their beauty, theso plants are cultivated.

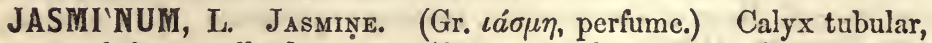
5 to 10-cleft; corolla hypocrateriform, tube long, limb flat, 5 to 10 cleft ; berry double ; seeds 2 , solitary, ariled.-Shrubs bushy or climbing. Lrs. opposite, rarely alternate, compound. Petioles articulated. Fls. paniculate.

1 J. frùticans L. Yeliow JASMrNe. Smooth, erect; branches angular; lvs. alternate, trifoliate, rarely simple, ifts. curved; fis. few, subterminal; cal. segm. subulate; cor. tube twice longer than the calyx, limb of 5 obtuse lobes.St. $3 \mathrm{f}$ high. Fls. yellow, inodorous, tube about $6^{\prime \prime}$ long. Propagated by layers. $+\mathrm{S}$. Iur.

2 J. officinàle L. WhITE JASMrNe. Smooth, scarcely climòing; branches subangulate; lvs. opposite, compound, lfts. 3 to 7, lanceolate, acuminato ; panicles terminal, few-flowered, corymbous; cor. tube twice longer than the calyx. Stem several feet in lengtl. Flowers white. Both species aro beautiful and 
much cultivated. The deliciously fragrant oil of Jasmino of the shops is extracted from this plant. + Asia.

\section{Order XCIX. OLEACEA. Olives.}

Trees and shrubs with opposite, simple, sometimes pinnate-leaves, with flowers 4 parted, regular, rarely apetalous, the corolla valvato in the bud. Stamens 2 to 4 , mostly 2, and fewer than the corolla lobes. Ovary 2-celled, with 2 suspended ovules in each cell, and fruit fleshy or capsular, seeds 4 (or fower by abortion), with abundant albumen. Fig. 265.

Genera 24, species 130, natives of temperate climates. The ash is very abundant in $\mathrm{N}$. Amerlea. The Phillyreas and the Syringas are all Oriental.

Properties.-Olive oil is expressed from the pericarp of the Olive (Olea Europæa). The bark of this tree, and also of the ash, is bitter, astringent, and febrifugal. Mranna, a sweet, gentlo purgative, is the ennerete discharge of several species of tho Fraxinus, particularly of the European F. Ornus. The specles of tho ash aro well known for their useful timber.

\section{TRIBES AND GENERA.}

I. FRAXINEA.-Fruit a dry, wlnged samara. Leaves pinnate............... Fraxrvus. 1 II. SYRINGEAs.-Fruit a dry, 2-celled eapsule. Leaves mostly simplo (a).

a Calyx persistent; corolla salver-form cyanic....................Srrivg . 2

a Calyx decidaous; corolla subeampanulate, yellow ............... Forsyrur. 3

III. OLEINEA.-Fruit a fleshy drupo or berry. Corolla present. Leaves simple (b).

b Corolla lobes long, linear, pendulous, stamens included............. Cnrovasrics. 4

b Corolla lobes short. Stamens included. Fruit a berry..............ueustrom. 5

b Corolls lobes short. Stamens exserted (c).

c Stylo 2-parted. Leaves serrate.................................. 6

c Stylo slmple.-Drupo shell bony. (Panicles axillary)............ Or.s. 7

-Drupe shell papery. Panicles terminal......... Visiaxia. 8

IV. FORESTIERE E.-Fruit a fleshy drupo. Corolla none. Leaves simple... Forestiera. 9

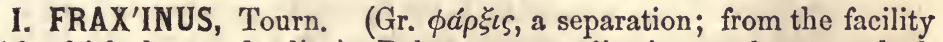
with which the wood splits.) Polygamous or diœcious; calyx 4-toothed, rarely obsolete; petals 2 or 4, coherent at base, oblong or linear, or altogether wanting; stamens 2 ; stigma bifid ; samara 2-celled, flattened, winged at apex, cells 2 -ovuled, but 1 -seeded; seeds pendulous, compressed._-Trees or shrubs, with opposite, odd-pinnate lvs. and fls. racemed or panicled. American species are all dicecious and apetalous trees.

5 Flowers with a corolla of 4 or 2 white, linear-oblong petals. Cultivated............... No. 8 Flowers spetalous, polygamous. Ieaflets 11 to 13 . Cultivated......................... Flowers apetalous, diocious. Fruit always winged at apex (*).

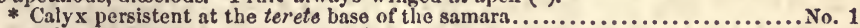

* Calyx persistent at the narrov, flattened base of the samara.................... 2-4

* Caly $x$ none, the samara naked at the broad base............................. 5os. 6

1 F. Americàna L. White AsIr. Ifts. 7 to 9, petiolulate, ovate or lance-oblong, acuminate, entire or obscurely subserrate, shining above, glaucous beneath; petioles and branchlets terete, smooth; buds yellowish-velvety; panicles compound, axillary, loose; samara linear-oblong, obtuse, narrower and terete at tho calyculate base, seed portion half as long as wing.-Woods, Can. to Ga. and La. A forest tree, 40 to $80 \mathrm{f} \mathrm{high;} \mathrm{trunk} 2$ to $3 \mathrm{f}$ diam. Ivs. If long, usually of 7 smooth lfts., which are 3 to $4^{\prime}$ by $18^{\prime \prime}$ to $2^{\prime}$. Fruit 13 to $15^{\prime \prime}$ by 2 to $21^{\prime \prime}$. Apr., May. (F. acuminata Lam. F. epiptera Mx.)-Timber light; tough and strong, much used by carriage-makers, \&c.

2 F. pubéscens Walt. RED Asir. Lfts. 7 to 9, petiolulate, ovate-lanceolate or elliptic-lanceolate, acuminate, subserrate, veins bencath, petioles and young branches velvety-pubescent; samara narrow-lanceolate, obtuse, the calyculate base acute, flattish, slightly margined by the decurrent wing.-Swampy or low grounds, Can. and U. S., more common in Penn. and Va. A smaller tree than No. 1, 30 to 60 high, but nearly allied to it. Bark deep brown. Lfts. often reddish 
beneath, 2 to 3 ' by $18^{\prime \prime}$ to $2^{\prime}$. Timber less valuable. Apr., May. (F.tomentosa $\mathrm{Mx}$.)

3 F. viridis Mx. f. Grees Asir. Lfts. 7 to 9, petiolulate, ovate or ovate-lance. late, acuminate, serrate, green and glabrous both sides, beneath slightly glaucous and pubescent in the axils of the veins; petioles and branchlets glabrous; samara, calyculate, spatulate, obtuse, the seed portion as long as the wing.-A small treo 15 to $25 \mathrm{f}$ high in wet woods U.S., especially the Western, Wis. to Tenn. and Car. Lfts $2 \frac{1}{2}$ to $4^{\prime}$ long, with a long, slender point. Fruit 12 to $15^{\prime \prime}$ long. May. (F. concolor Muhl. F. juglandifolia DC.)

4. F. platycárpa Mx. Lfts. 5 to 7, short-petioled, subserrate, elliptic, acuto at both ends, or slightly acuminate, petioles and veins boneath pubescent; samara elliptic-oblanceolate, attenuato at base, broad above, obtuse, calyculate, and often with a third wing! - Wet woods, Va. to Fla. and La. Lfes. distant, 3 to $5^{\prime}$ long, a third as wide. Samara 18 to $20^{\prime \prime}$ long, $6^{\prime \prime}$ or more wide abovo the middle, tapering to the narrow, margined base.

$\beta$. TRIPTER. Lfts. oblanceolate and oblong, samara more frequently 3 -winged. -S. Car. to La. (F. triptera Nutt.)

5 F. quadrangulàta $\mathrm{Mx}$. BLUE Asr. Lfts. 7 to 9, short-petioled, ovate-lanceolato or oblong, acuminate, sharply serrate, obtutish at base, glabrous, veins beneath at base downy; branchlets glabrous, square, with 4 linear or slightly membanous angles, at length tereto; buds velvety; samara oblong, obtuse at each end, naked (no caly $\mathrm{x}$ !) at base. $-\Lambda$ tall tree in rich woods, Ohio to Tenn. and Iowa. Trunk 60 to $80 \mathrm{f} \mathrm{ligh.} \mathrm{Lfts.} 3$ to $4^{\prime}$ long, distinctly petiolulate; petiolules 2 to $5^{\prime \prime}$ long. Anth. of the fertile fls. oval, narrowed towards the base. Timber strong and clastic, like that of No. 1. May.

6 F. sambucifòlia Lam. BLACK AsH. WAter AsH. Lfts. 7 to 11, lance-ovate, sessile serrulate, acuminate, smooth above, tawny villous at their insertion and in the axils of the veins beneath; fr.' oblong, with similar ends, obtuse or emarginate, naked (no calyx) at basc.-Common in swamps or moist woods, Northern U. S. and Can. Height 40 to $70 \mathrm{f}$, with a trunk $2 \mathrm{f}$ diam. Bark brown. Buds blue. Lfts. 3 to $4^{\prime}$ long. Samara 16 to $20^{\prime \prime}$ by 3 to $4^{\prime \prime}$, entirely naked at baso! May.-Wood purplish, tough, elastic, excellent for the cooper and basketmaker.

7. F. ezcélsior L. Europeax Asr. Lfts. 11 to 13, subsessile, lance-oblong, glabrous, with slender serratures; racemes short, dense, samara linear-oblong, obtuse, obliquely emarginate.-Parks. A tall tree, in many varieties, among which $\beta$. pendula, Weeping Ash, is the most interesting. † Eur.

8 F. Ornus L. Flowering Asi. Lfts. 7 to 9, subpetiolulate, lanceolate, serrate above, entire at base, bearded on the veins beneath; buds downy; panicles dense; petals 2 or 4 (white), linear-oblong, much longer than the calyx; samara lance-linear, obtuse, attenuate at each end.-Parks. † From Eur.

2. SYRIN'GA, L. Lilac. (Gr. $\sigma \tilde{v} \rho \iota \gamma \xi$, a shepherd's pipe; from the use once made of its branches.) Calyx small, 4-toothed, persistent; corolla salver-form, tube several times longer than the calyx, limb cleft into deep, obtuse, spreading valvate segments; stamens short, included within the tube. Capsule 2-celled, 2-valved.-Oriental, flowering shrubs,

with simple, entire leaves.

1 s. vulgaris L. Comrox Limac.-Lvs. cordate-ovate, entire, glabrous, green both sides; inflorescence thyrsoid; limb of cor. subeoncave.-There are many varieties in this beautiful shrub. $\alpha$. Corolla lilac-purple, in a dense thyrse. $\beta$. CCERULEA. Fls. purplish-blue. $\gamma$ ALBA. Cor. white, thryse subcompound. Apr., Jn.-One of tho most popular shrubs, beautiful in foliage and fls. † Hungary.

2 s. Pérsica L. Persian Lilac. Lvs. lanceolate, acute, smooth, both sides green, sometines pinnatifid; limb of the cor. flattish.-A smaller shrub than tho first, with smaller thyrses of white or lilac-blue flowers. The leaves vary from entire to pinnatifid, small at flowering time. Apr., May. $\dagger$ Persia.

3 S. villosa Vall. $\beta$. Chinensis. Lvs. elliptic, acute at each end, hairy beneath. $-\dagger \mathrm{N}$. China. 
3. FORSY'THIA, Vahl. Calyx very short, companulate, 4-parted, deciduous ; corolla somewhat bell-shaped, lobes twisted in the bud; stamens 2, inserted in the bottom of the tube, included; ovary 2-celled, cells $\infty$-ovuled; capsule ovoid, 2-celled; seeds many, pendulous, narrowly ivinged.-Shrub with opposite branches and scaly buds.

F. suspénsa Vahl.-Shrubberies, comn, Lvs. often in whorls of 3s or 4s, petiolate, simple or pinnately divided, serrate. Fls. preceding the leaves, one from a bud, pedicelled, yellow, with long lobes. $f$ China. (Syringa, Thunb.)

4. Chionan'ThUS, L. Virginia Fringe Tree. (Gr. $\chi \iota \omega v$, snow, a้ $\nu$ Oos ; fls. snow-white.) Calyx 4-parted, short; cor. tube very short, limb 4-parted, lobes linear, elongated; sta. 2, inserted into the cor. tube, included ; sty. very short; drupe fleshy ; putamen bony, 1-celled, 1-seeded.-Trees with opposite leaves. Branchlets compressed. Racemes terminal and axillary.

C. Virgínica L. Lvs. oval and oblong-lanceolate; pedicels long, 1-flowered; cal. glabrous; cor. segm. linear, acute, flaccid.-A shrub or small tree, highly ornamental, in roods, S. Penn. to Fla., Ky., Tenn. Lvs. coriaceous, smooth, of various forms, oval, or ovate, rhombic, lanceolate, etc., on the same tree, 3 to $6^{\prime}$ long. Fls. in rather dense, pendulous panicles. Petals snow-white, 8 to $10^{\prime \prime}$ in length. Drupes oval, purple. Apr.-Jn.-Far South it is called Old-man's-beard.

5. Ligus'trum, L. Privet. Prim. (Lat. ligo, to bind, from the use made of its shoots.) Calyx minutely toothed; cor. tube short, limb with spreading, ovate lobes; sta. 2 ; sty. very short; berry 2celled, 2-4-seeded; seeds convex on one side, angular on the other.Shrubs with simple lvs. Fls. in terminal panicles, tetramerous.

L. vulgàre L. Lvs. lanceolate and obovate, acute or obtuse, on short petioles ; panicle dense, terminal. - A smooth shrub, 5-6f high, in woods and thickets, N. Y. to Va., W. to the Miss. Branches wand-like with opposite, entire, smooth, dark green leaves which are $1-2^{\prime}$ long, $\frac{1}{2}$ as wide, varying from obovate to elliptical, with a rounded, obtuse or acute point. Flowers small, numerous, white. Anthers large, exserted. Berries black, in conical bunches, bitter. It is said to lave been introduced from England where it is used for hedges. May, June.

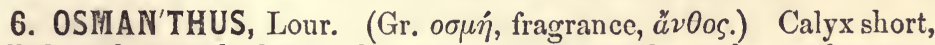
bell-shaped, 4-toothed ; corolla subrotate, 4-parted; anthers adnate to the inner side of the filaments; style 2-parted, lobes thick, acute.Habit of Olea. (Olea Thunb.)

O. fràgrans Lour. Lvs. elliptic-lanceolate, serrate, glabrous; corymbs or panicles short, axillary, pedicels rather long; style 2-parted.-Shrub with small, white, very oaborous flowers which are said to be used by the Chinese to adulterate and flavor tea. The fls. vary to red. $t$ China and Japan.

7. O'LEA, Tourn. Olive. (Gr. Edaía, Lat. olea, the Olive tree, oliva, the fruit, oleum, the juice.) Calyx short, bell-shaped, 4-toothed; Icorolla tube short, limb 4-parted, flat, spreading; stamens 2 , inserted in the bottom of the tube, opposite, exserted; ovary 2-celled, 2 pendulous ovules in each cell ; drupe fleshy, oily, shell bony, 2 or 1-seeded by abortion.-Trees or shrubs, with opposite, entire, coriaccous krs. and white, often fragrant fls.

O. Americàna L. Lvs. lanceolate-elliptic, entire, smooth and shining, acute, attenuated to a petiole; rac. compound, as long as or longer than the petiole; bracts connate, persistent; fis. diœcious; fruit globular.-In the low country, Va. to Fla. The American Olive is a tree 15 to $20 \mathrm{f}$ high. Wood fine-grained, hard, and when dry difficult to split. Lrs. 4 or $5^{\prime}$ long, petioles $1^{\prime}$. Fls. small, fra- 
grant, the fertile and barren on separate trees. Drupes larger than peas, violetpurple, dryish. Apr., May.

8. VISIA'NIA, DC. (Dedicated to Visiani, Professor of botany at Patavia.) Calyx, corolla and stamens as in Olea; fruit obovate or oblong, with a very thin pulp, and thin, papery shell.-Trees with opposite, entire lvs. and loose, terminal, many-flowered panicles. (Olea, Wall.)

V. paniculàta DC. Lvs. orate, acute, entire, glabrous; paniclo glabrous; bracts deciduous; style club-shaped; fruit obliquely ovate.-Fls. small, white, numerous, in large naked panicles. Irs. coriaceous, $3^{\prime}$ long, petioles $9^{\prime \prime}+{ }^{\prime}$ China.

9. FORESTIE'RA, Poir. (Dedicated to M. Forestier, a French physician.) Diœcious, apetalous ; flower buds in the axils of the last year's leaves, scaly with roundish, thin scales, and many-flowered; $\delta$ flowers sessile, crowded, each of the 2 stamens surrounded by a caducous calyx of 4 oblong, minute sepals $; ~ \&$ flowers pedicellate, umbellate; calyx obselete; ovary tipped with a slender style and a capitate stigma, 2celled, cells 2-ovuled; drupe with 1 suspended seed.--Shrubs or small trees, with opposite, simple lvs. and minute fls. (Adelia Mx. Borya Ph.)

I F. acuminàta Poir. Lvs. glabrous, green both sides, lance-elliptic, acuminate at each end, serrulate above, on slender petioles ; fruit an oblong-cylindric, pointed, fleshy, glaucous-purple drupe.-In sluggish streams, 11l. (opposite St. Louis!) to Ga. (Macon, Mettauer I). Shrub 10 to $18 \mathrm{f}$ high. Lvs. thin, 2 to $3^{\prime}$ long, petiole $I^{\prime}$. Mar., Apr. ( $\Lambda$. acuminata Mx. F. ligustrina Gr.)

2 F. ligustrina Poir. Lvs. ovate and oblong, attenuate to the petiole, obtuse, coriaceous, serrulate, margins slightly revolute, glabrous above, midvein sparsely puvescent beneath; staminate flowers in small, lateral, globular clusters (fertile plant not seen). - Near Savannah (Feay). Shrub 10-15f? high, with slender branches and branchlets. Lrs. with the petioles 1 to $2^{\prime}$ by 6 to $10^{\prime \prime}$, reticulate, not dotted, beneath.

3 F. porulòsa Poir. Leaves oblong-lanceolate, obtuse, sessile, coriaceous, margins revolute, lower surface dotted (porulous) and ferruginous.-On the sea-coast, Geergia and Florida (Pursh.) Leaves all opposite. (A. poralosa Mx.) 


\section{CoHort 3. APETAL无,}

Or Monochlamydeous Exogens. Dicotyledons with no corolla, the calyx or perianth green or colored, consisting of a single series of similar organs, or often wholly wanting.

\section{Order C. ARISTOLOCHACE. E. Birthworts.}

Low herbs or climbing shrubs, with alternate leaves and perfect flowers. Perianth tube adherent to the ovary, brown or dull, valvate in the bud. Stamens 6 to 12, epigynous and adherent to the base of the styles. Ovary 6-celled, becoming a 6celled, many-seeded capsule or berry. Seed albuminous, embryo minute. Fig. 133.

Genera 9, species 130, most abundant in the tropical countries of S. America, thinly diffused throughout the northern hemisphere. Properties tonic and stimulant. Both tho following gerr cra are successfally employed in medicine.

1. ASA'RUM, Tourn. Wild Ginger. (Gr. $a$, not, $\sigma \varepsilon \iota \rho a ́$, a band, because rejected in wreathing garlands.) Calyx campanulate, regular, 3-cleft; stamens 12, placed upon the ovary, anthers adnate to the middle or summit of the filaments; style very short; stigma 6-rayed; fruit fleshy, 6-celled, crowned with the calyx.-2f Herbs with creeping rhizomes and 1 or 2 lvs. on each branch. Fls. solitary.

\$ Leaves in palrs. Calyx lobes pointed, reflexed. Ovary wholly adherent............... 1 Leaves solitary. Calyx lobes obtuse, suberect. Ovary partly free....................... 2, 8

1 A. Canadénse I. Irs. 2, broad-reniform, on long, opposite petioles with the flower between; calyx woolly, deeply 3 -cleft, the segm. reflected.-In rich, shady soil, Can. to Ga. and W. States. Ivs. radical, large, 2 to $4^{\prime}$ by 3 to 5 ', with a deep sinus at base, and a soft, velvet-like surface. Fl. solitary, on a nodding peduncle, and close to the ground, sometimes even buried just beneath the surface. Cal. purplish, of 3 broad, long-pointed divisions abruptly spreading. Fil. longer than the anthers, their tips (connectile) produced beyond them. May-Jl. -The rhizome is a popular medicine, used in measles and whooping cough.

2 A. Virgínicum L. Lvs. solitary, orbicular-ovate, glabrous, coriaceous, deeply cordate, entire, obtuse; fl. subsessile; cal. short, subcampanulate, glabrous externally.-Grows in light soils among rocks, and Mts., Va., Ky. to Ga. A low, stemless plant, very similar in habit to the preceding. Each branch of the rhizome bears a terminal leaf and a flower. Leaf 2 to $3^{\prime}$ diam., very smooth, clouded with spots, the petiole twice longer, lobes at base rounded and nearly closed. Flower many times shorter than tho petiole. Calyx segments obtuse, of a dusky purple, greenish outside. Apr.

3 A. arifolium Mx. Lvs. solitary, broadly hastate, puberulent on the veins, thin, with a deep sinus at base, the lobes obtusely angled and turned slightly outward; cal. inflated-urceolate, contracted above, with 3 very short, obtuse lobes at summit. Rich soils, Va. to Fla. and La. Rhizomes slender, white. Petioles 2 to $3^{\prime}$ long. Lvs. 2 to $3^{\prime}$ by 1 to $2^{\prime}$, margins wavy. Fls. $9^{\prime \prime}$ long, roughish, purplish-brown as lang as their stalks. Mar.-May.

2. ARISTOLO'CHIA, Tourn. Birtnwort. (Gr. äpıбтos, excellent, doxeia, child-birth; alluding to the medicinal properties.) Calyx tubular, tube variously bent and inflated above the ovary, border un- 
equal; anthers 6 , subsessile upon the style; stigma 6-lobed; capsule 6. celled, septicidal, many-seeded.-St. erect or twining.

\& Stem erect. Caly $x$ tube sigmoid $(i$. e., twice bent like the letter $S)$.................. 0 . 1, 2 $\$$ Stem climbing. Calyx tube recurved, once bent upwards .......................... 3 , 4

1 A. serpentària L. Virginia Svake-root. St. erect, flexuous; lvs. petiolate, oblong or ovate, thin, cordate, acuminate; ped. radical, many bracted; cal. tube smoothish, contracted in the midst, -limb obscurely 2-lipped.-A curious vegetable in hedges and thickets. Penn. to Ill. and La. St. 8 to $13^{\prime}$ high, subsimple, jointed, herbaceous. Lvs. variable in width, 2 to $4^{\prime}$ by $9^{\prime \prime}$ to $2^{\prime}$ rarely larger. "Fls. few. Cal. dull purple, of a leathery texture, tubular, 7 to 9 "long, twice bent almost double, enlarged at each end, the limb with 3 short, obtuse lobes. Caps. obovate, 6-angled, 6 to $9^{\prime \prime}$ long. Jn., Jl.

$\beta$. ? IIASTìta. Lrs. lance-oblong, or oblong linéar, auriculate at base, on potioles as short as the auricles.-S. Car, to La. St. very slender and usually simple. Fls. not seen. Lvs. 2 to $3^{\prime}$ by 3 to $5^{\prime \prime}$. (A. hastata Nutt.)

2 A. reticulàta Nutt. St. erect, very flexuous, hirsute, simple; lvs. oval, sessile, cordate-clasping with decussating lobes, apex obtuse or bluntly acute; veinlets and veinulets finely reticulated, all prominent and hairy beneath; ped. below the lvs., simple or branched, hirsute, bracted; cal. small, densely woolly.-La. (Hale.) About If high. Fls. $5^{\prime \prime}$ long, about half the size of No. 1. Lvs. rather thick, 3 to $4^{\prime}$ by 2 to $3^{\prime}$.

3 A. Sìpho L'Her. Dutchman's PIPE. St.twining, shrubby; lvs. glabrous, ample, roundish, cordate, entire, petiolate; ped. 1-flowered, furnished with a single, ovate clasping bract; cal. tube bent, ascending, limb 3 -cleft, equal. -A vigorous climber in mountainous woods, Western Penn. to Ky. and S. States. St. woody, twining, and ascending trees 30 to $40 \mathrm{f}$. Leaves $6-12^{\prime}$ diam., alternate, sprinkled with soft hairs. Flowers solitary, the tube long $\left(16^{\prime \prime}\right)$ bent at nearly a riglit angle, in the form of a (siphon or) tobacco pipe, and of a dull brown color. May, Jn. $\uparrow$ Highly ornamental for arbors.

4 A. tomentòsa Sims. Twining, shrubby; lvs. downy or hairy beneath, roundish, cordate, entire, petiolate, very veiny; ped. solitary, 1-flowered, bractless; cal. cowny, bent upwards, greenish-yellow, limb dark-purple, nearly equal, rugous, reflexed, 3-cleft, thrcat oblong and oblique, nearly closed.-Woods along rivers, $\mathrm{S}$. III. to La. and Ga. St. climbing tall trees 30 to $40 \mathrm{f}$. Lvs. 4 to $6^{\prime}$ long, 3 to $4^{\prime}$ wide. Ped. as long as the petioles. Cal tube $\left(20^{\prime \prime} \mathrm{long}\right)$ contracted above the ovary and strongly recurved. Stig. 3-lobed. May. Jn.

\section{Order CI. NYCTAGINACEA. Marvelworts.}

Herbs (slirubs or trees) with tumid joints, entire and opposite leaves. Fiowers surrounded with an involucre (calyx-like when the flower is solitary). Calyx a delicate, colored, funnel-form or tubular perianth, deciduous above the 1-celled, 1-seeded ovary, leaving its persistent base to harden and envelop the fruit (achenium) as a kind of pericap. Stamen 1 to several, definite, slender, hypogynous, exserted, unequal. Embryo coiled around the copious white albumen. Fig. $373,460$.

Genera 16, species 110, chiefly tropical, south of the equator.

Properties.-The roots are purgative, especially those of the beautiful cultivated genusFour-o'clock.

\section{GENERA.}

* Involucre calyx-like, involving but a single, large flower...................mabiur.

* Involucre involving several ( 3 to 5 ) small flowers..................... Oxrbapucs. 2

* Involucre none, the minute flowers with deciduous bracts.............. BoeriraAvia. 3

1. mirab'ilis, L. Marvel of Peru. Four-o'clock. (Lat mirabilis, wonderful, admirable; a name well applied.). Involucre calyx-like, 5-lobed, 1-flowered, lobes acuminate; perianth (calyx) tubular-funnel- 
form, limb spreading; stamens 5 , scarcely with the style exserted; achenium enveloped in the persistent base of the calyx. $-2 f$ Herbs mostly Mexican and Peruvian, everywhere cultivated.

1 M. Jalàpa L. Erect; lvs. ovate, acuminate, base obtuse or subcordate, petiolate, glabrous; fls. 3 to 6 in each terminal fascicle, short-stalked; perianth open in the evening and night.-This is the true Four-o'clock, opening its multitudinous brilliant flowers at about that hour P. M., for a long succession of summer days. Their variety in color is infinite. $\dagger$ Peru.

2 M. dichótoma L. Erect, glabrous; lvs. ovate, subacuminate, base obtuse or narrowed to the petiole; fls. sessile or nearly so; lobes of invol. ovate-acute; perianth strict, with a small scarcely dilated limb.-Gardens, less frequent. Fls. smaller, yellow, red and white. + Mexico.

3 M. longiflòra $\mathrm{L}$. Weak, diffuse, viscid-pubescent; lvs. cordate-acuminate, upper sessile, lower long-petioled; fls. sessile, clustered at apex; invol. lobes linear; tube of the perianth very long, pubescent.-Gardens. Fls. white. + Mexico.

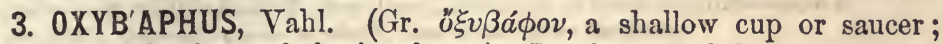
alluding to the form of the involucre.) Involucre 5-cleft, containing 3 to 5 flowers (in one species), persistent and spreading in fruit; perianth with a very short tube, and a plicate, bell-shaped, deciduous limb; stamens 3 ; style simple, stigma capitate; fruit ovoid, ribbed, 1 -seeded. $-2 f$ Herbs with tuberous roots, opposite lvs. and small fls. (Calymenia, Allioni.)

1 O. nyctagíneus Sweet. Nearly smooth, erect, with alternate or forked branches; lvs. broadly ovate or oblong, subcordate, acute; peduncles solitary, axillary and terminal; invol. pubescent, 3 to 5-flowered. - 2f Alluvial soils, Wis. to Tenn., rare; common in Nebraska. (Nuttall.)

2 O. angustifòlius Sweet. St. terete, puberulent above, with alternate branches; lvs. narrowly lanceolate, thick but veiny, entire or serrulate, acute, narrowed to tho subsessile base; ped. several times shorter than the leaves, axillary and terminal; invol. 3-flowered, half-5-cleft, lobes broad, obtuse; ovary hispid.-Dry soils S. Car., Ga. to La. St. 2 to 3 f high. Lvs. 2 to $3^{\prime}$ by 5 to $9^{\prime \prime}$, or in some specimens (A. linearis Ph.) much narrower. Ped. 2 to $5^{\prime \prime}$ long. Cal. purplish. Jn.

3 O. álbidus Sweet. St. angular, and pubescent in lines, simple; lvs. narrow, lance-oblong, acute at each end, petiolate; ped. solitary, axillary, half as long as the lvs.; invol. 2 to 3-flowered, deeply 5-cleft, segm. ovate, acute, ribs of fruit hispid. -1) Dry soils, S. Car., Ga. (Mettauer.) Sts. 12 to $18^{\prime}$ high. Lvs. $2^{\prime}$ to $30^{\prime \prime}$ long, 4 to $6^{\prime \prime}$ wide. Ped. $1^{\prime}$ long, alternate, each with a whitish involucre $10^{\prime \prime}$. broad and 2 to 3 small fls. May. (A. alb. Pl.)

3. BOERHAA'VIA, L. (Dedicated to Borhaave, of Holland, a friend and patron of Linnæus.) Involucre 0 ; bractlets deciduous ; perianth funnel or bell-form, colored, 5-lobed, upper half deciduous, lower persistent; stamens 1 to 4 ; fruit 5 -ribbed, truncato at apex, 1 -seeded.-Lrs. opposite, mostly petioled.

B. erécta L. Glabrous; lvs. ovate, wavy, pale beneath; fls. in a strict, much branched panicle.-1) Sandy soils, S. Car. to Fla. and La. 'St. 3 to $4 \mathrm{f} \mathrm{high,} \mathrm{nu-}$ merously dividing above into filiform, erect branchlets. Lvs. all below, $2^{\prime}$ long, roundish at base, on petioles nearly as long. Fls. minute. Jn.-Sept.

\section{Order CII. POLYGONACEE. Sorrelworts.}

Herbs, rarely shrubs, with aiternate leaves and mostly sheathing stipules (ochrea) surrounding the stem above each tumid joint. Flowers mostly perfect. Perianth or ealyx 3 to 6-cleft, mostly colored, imbricated in bud and persistent. Stamens 4 to 15 , perigynous or free. Ovary 1-celled, free, with a single, erect orule. Styles or stigmas 2 or 3 . Fruit a 3-angled achenium enclosed in tho calyx. Seed erect, 
albuminous, with a straight or curved inverted embryo. Illust. in Figs. 80, 375, 407, 408, 409, 413, 607, 103, 112.

Genera 33, species 690 (Meisner) widely diffused in all lands, but most abundant in the temperate zones.

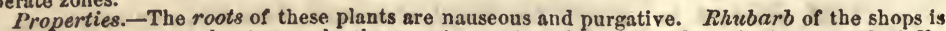
the root of Rheum palniatum and other species, native of Tartary. But the leaves and stalk: of Sorrel, the petioles of Garden Rhubarb, etc., are ngreeably tart, and contain oxalic acid; the petioles of the latter, together with the farinaceous seeds of the Buck-wheat, are well-known articlos of food.

\section{TRIBES AND GEXERA.}

I. ERIOGONE \&. Flowers in dense, involucrate umbels, Ochrex 0.......... Eriogonux. 1

II. POLYGONEA. Flowers not involucrate. Oehreæ present. (a)

a Calyx 4-parted, regnlar. Stamens 6. Styles 2. Achenia winged............ Oxrrus. 2

a Calyx 6-parted. Stamens 9. Sepals all similar, short.................... Ruruv. 3

a Calyx 6-parted. Stamens 6. Sepals 3, inner Increasing, tuberculate............ TuMEx. 4

a Calyx 5-parted (irregularly 4-parted in one species). (b)

b Sepals, the 3 inner fimbriate-pectinate. Pedicels solitary.............Trrsanelua. 5

b Sepals entire, -3 , closed on the achenia, or all open. Pedicels solitary. Polxgonfrla. 6 -all closed on the achenium. Pedicels usually fascicled..Pourgonur. 7

-all open. Nectarles 8. Pedicels fascicled in the bract... FAGOpYross. 8

1. ERIOG'ONUM, Mx. (Gr. Ě $\rho \iota v$, wool, yóvv, knee; being woolly at the joints, etc.) Flowers many in each common 5 -toothed involucre ; calyx deeply 5 -cleft; stamens 9 ; styles 3 ; achenia 3 -angled or 3 -lobed; cmbryo in or near the axis of scanty albumen.-Herbs clothed with dense cottony wool. Lvs. alternate, exstipulate, mostly at the base of the stem, the upper bract-like, often whorled at the forks of the umbellate inflorescence. Invol. solitary or capitate. Pedicels within the invol. 1-flowered.

I E. tomentòsum $\mathrm{Mx}$. Lower lvs. crowded, spatulate, obovate or oblong, petiolate, beneath rusty white, tomentous, veins tawny red; flowering branches several times forked; invol. solitary, campanulate, sessile, 5-toothed, loose-flowered; cal. colored, funnel-form. 2 \& Sandy hills, S. Car. to Fla., frequent. St. 1 to $3 \mathrm{f}$ high. Lvs. 2 to $3^{\prime}$ long, those of the stem much smaller. Fls. 3 to $4^{\prime \prime}$ long, cream-white, with wool of the same color outside. Jn. Aug.

2 E. longifòlium Nutt. Lower lvs. crowded, oblong-linear, with a long, attenuated base, beneath white-tomentous, upper lvs. scattered; panicle ample, several times forked; bracts minute; invol. solitary, campanulate, pedunculate manyllowered; cal. green, woolly.-Fla. to Ark. St. 2 to $4 \mathrm{f} \mathrm{high.}$

2. OXYR'IA, R. Br. Mountain Sorrel. (Gr. o $\xi \dot{v} s$, acid; in allusion to the qualities of its leaves.) Calyx herbaceous, 4-sepaled, the 2 inner sepals erect, larger, the 2 outer reflexed; achenium lens-shaped, thin, girt with a broad, membranous wing; stamens 6 , equal ; stigmas 2, sessile, penicillate. - 2f Low, nearly acaulescent, alpine plants.

O. renifórmis Hook. Radical lvs. reniform, on long petioles; outer sepals oblong, half as long as the inner, valvular sepals; fruit orbicular.-Found on the summits of the White Mts., in moist ravines; and N. to the Arc. Sea. The plant is acid to the taste, like Rumex acetosus. Stem $3-4^{\prime}$ in height, nearly leatless racemed or subpaniculate. Jn. (Rumex digynus L.)

3. RHE'UM, L. Rhubard. (Rha, the river Volga, on whose banks the plants are said to be native.) Calyx colored, 6-sepaled, persistent; stamens 9 ; styles 3 , very short, spreading; stigmas multifid, reflexed ; achenia 3-angled, the angles margined.-2f Fls. fasciculate in racemous panicles.

R. Rhapónticum L. Garden RHubarb or Pie-plaxt. Lvs. ample, smocth, cordate-ovate, obtuse; petioles channeled above, rounded at the edges.Gardens. Stem stout and fleshy, 3-4f high, hollow, with large, sheathing stipules at tho joints. Loaves very large, $1-2 \mathrm{f}$ long, $\frac{2}{3}$ as wide, on petioles of 
nearly the same length. Panicle terminal, at first enclosed in a white, membran ous bract which at length bursts, disclosing innumerable greenish-white flowers. May. $\ddagger$ Siberia. - The large juicy petioles are well-known to the pastry cook. Their agreeable acidity is due to the presence of oxalate of lime.

4. RU'MEX, L. Dock. Sorrex. Calyx of 6 sepals nearly distinct, the 3 inner (valves) larger, petaloid, connivent over the achenium, 1 or more of them usually bearing a tubercle or grain on the back, the 3 outer herbaceous, reflexed in fruit ; stamens 6 ; styles 3 , short ; stigmas penicillate-fringed; achenium and seed 3 -angled, embryo lateral._Weed-like herbs with small, greenish fls. in racemes or pavicles.

\$ LAPATIIUM. Flowers all or mostiy perfect. Valves bearing grains on the back. (*)

* Valves entire or merely angular. (a)

a Pedicels in fruit 2 to 5 times lunger than the $8 u b$-cordate valves.............Nos. 1,3

a Pedicels in frult twice longer than rounded or truncate valves................. Nos. 3,4

a Pedicels in fruit shorter or not longer than the valves. (b)

b Leaves flat, all tapering to both ends........................... Nos. 5,6

b Leaves wavy, the lower cordate or subcordatc................................ Nos. 7 , 9

* Valves conspicuously toothed on each side near the base.............................. $9-11$

$\$ \triangle$ CETOSA. Flowers diœeious. Valves grainless. Leaves acid (hastate)............ Nus.12, 13

1 R. crispus L. YELLow DocK. Irvs. lanceolate, waved, acute, the lower oblong, subcordate; pedicels twice longer than caly $\mathrm{x}$; valves broad-ovate, cordate, each bearing a grain. - 2f Can. and U. S. A weed too common in cultivated grounds, about rubbish, etc., much to tho annoyance of the farmer. Stem $2-3 \mathrm{f} \mathrm{high,}$ smooth, channeled, from a yellow, fusiform root. Flowers numerous, in a large panicle, consisting of many racemes of half-whorls, interspersed with leaves. Pedicels 3 to $4^{\prime \prime}$ long. Calyx-valves each with a grain on the back. Jn. § Eur. -The root is used in medicine for cutaneous diseases.

2 R. verticillàtus I. WATER Dock. Lvs. oblong-lanceclate, acute at each end; valves entire, broad-ovate, each bearing a grain; rac. leafless, with flowers in close whorls; pedicels elongated, thickened, upwards. - If An aquatic species of muddy situations. Can. and U. S. St. $2 \mathrm{f}$ high, with long, tubular sheaths and fow branches. Lvs. long, narrow, acute, flat. Whorls 10 to 30 -flowered. Pedicels 7 to $10^{\prime \prime}$ long, deflexed. Jn. (R. Brittanicus L. ? fide Gray.)

3 R. Hydrolapàthum Hudson. $\beta$. Americana Gray. Great Water Dock. Lvs. lanceolate, acuminate, lower lance-oblong, very long, upper minutely undulate-crenulate, all acute or attenuate at base, petiolate; panicle compound, at length naked; verticils at first distinct; valves roundish-ovate, obtuse, all grain-bearing. 4 Northern U. S. Ponds and ditches. St. 3 to 5 f high. Lvs. somewhat glaucous, lower very large, 1 to $2 f$ long, 2 to $5^{\prime}$ wide, with a stout midvein. Pedicels in fruit 5 to $6^{\prime \prime}$ long, twice longer than the calyx; (R. aquaticus Smith.)

4 R. Floridànus Meisn. Lvs. long-lanceolate, acuto and unequally narrowed at both ends, flat; panicle, leafless above, racemes at length denso; pedicels twico longer than the fruiting calyx; valves broadly ovate-deltoid, bluntly acuminate, all grain-bearing.-Fla. (Rugel apud Meisner.) Pedicels 3 to $5^{\prime \prime}$ long.

5 R. altíssimus. PeACH-LEAved Dock. Glabrous, tall, erect; lvs. flat, thich, linear-elliptic, entire, petiolate, tapering to cach end; rac. slender, paniculate, somewhat secund, leafless or the lowest verticil axillary; fls. all $\Varangle ;$ valves larger, broad-cordate, one graniferous, one abortively so, and the third naked. - 2f Marshy prairies and borders of streams, Mid. and W. States. $\Lambda$ very showy Rumex, $3-6 \mathrm{f}$ high, slightly branched abovo. Leaves $3-5^{\prime}$ by $\frac{1}{2}-1^{\prime}$, somowhat acuminate, broadest in the middlc. Verticils approximate, pedicels reflexed, not longer than the valves. Jn.

6 R. salicifòlius Weinm. $\beta$. BIGELòvir. PALE Dock. Lvs. thin, wavy at edge, attenuate-acuto at each end, linear-lanceolate, petiolate; paniclo simple, leafy at base, racemes spicate, looso and interrupted below ; pedicels much shorter than the fruiting calyx; valves all grain-bearing, ovate-oblong, scarcely longer than the grains.-Sea coast, Mass. and Can. Sts. terete, slightly furrowed, 2 to $3 f$ high. Lvs. 4 to $7^{\prime}$ long. Grains unequal, large, whitc. Jn. (R. pallidus Bw.)

7 R. conglomeràtus Murr. Lrs. orate or oblong, base rounded or cordate, the upper lanceolate, attenuate-acuto at cacb cnd, margins crispato; panicle somewhat 
spreading, leafy, with remote axillary verticils, the highest leafless; pedicels shorter than the small fruit calyx; valves ovate-oblong, blunt, all grain-bearing. $-2 f$ Ditches and wet places, N. States, Can. St. 2 to 3 f high. Lower lvs. on long petioles. Grains large, red. May. § Eur. (R. acutus Sm.)

8 R. sanguíneus I. RED-VEINĖD DOCK. Lvs. lance-oblong wavy, acuminate, obtuse at base, or the lower cordate, mostly with red veins; pan. leafless excepit at base, whorls distant; pedicels shorter than fruit calyx; valves small, obovateoblong, obtuse, 1 or 2 of them grain-bearing.-Wasto places, N. States and Can. St. reddish, 2 to $3 f$ high. Jl. \& Eur.-In 3. viRIDIs the veins are green.

9 R. obtusifòlius L. Lower lvs. ovate obtuse, cordate, wavy on the margin, upper lance-oblong, acute or acuminate at each end, all petiolate; panicle leafy, whorls distant; pedicels as long as the fruit caly $\mathrm{x}$; valves hastate-ovate, with 3 or 4 spreading, subulate teeth on each side, one valve chiefly grain-bearing.-N. Eng., Mid. and W. States. A weed as unwelcome as the first, in fields, door-yards, \&c. St. 2 to $3 f$ high. Lvs. large (6 to $12^{\prime}$ by 3 to $8^{\prime}$ ), sometimes red-veined. J. $\S$ Eur.

10 R. maritimus L. GoLden Dock. Lvs. long-lanceolate, the lower abrupt at base, the upper attenuate-acute at each end; whorls dense-flowered, the lower subdistinct, with lirrear bracts, upper confluent; pedicels filiform, longer than fruit calyx; valves rhombic-ovate, bearing 2 long, bristly teeth each side, with an acuminate point, all grain-bearing.-(2) Borders of brackish waters, Mass. to S. Car. Low (1f) and much branched. Calyx in fruit yellowish green, densely clustered. Jl. (R. persicarioides Hook.)

11 R. púlcher L. Lower li's. oblong, cordate, often fiddle-shaped, upper lanceolate, acute, obtuse at base; panicle leafy, whorls distant; pedicels shorter than fruit calyx, thickened; valves ovate-oblong, unequally grain-bearing, each with several straight, strong lateral teeth. - 2f About Charleston, S. C. (Elliott). Jn. Jl. § Eur.

12 R. Acetosélla L. Field Sorreu. Sheep Sorrel. Lvs. oblanceolate-hastate, about as long as the petioles, the auricles divaricate, oblong, a third as long as the blade, in the upper lvs. smaller or wanting; fls. diœcious, valves not increasing in fruit, nor grain bearing.- 2 A common weed in pastures and waste grounds throughout the U. S., preferring dry, hard soils. St. $\sigma^{\prime}$ to If high, leafy. Lrs. very acid, but pleasant to the taste. Fls. small, red or reddish, collected in panicled racemes, the valves destituto of granules. Stamens and styles on separate plants. Jn.-Aug.

13 R. Engelmànni Ledeb. Lrs. lanceolate or linear, hastate, the lower 2 or 3 times shorter than the long petioles, the auricles very small, acutish, many times shorter than the blade; panicles entirely leafless; fls. diœcious; valves increasing in fruit, orbicular-cordate, grainless.- $2 f$ Ga., Fla. to Tex., also Mo. Sts. 1 to $2 f$ high, much furrowed. Lrs. palo beneath. Fls. purple. (R. hastatulus Baldw. nec Campd.)

5. THYSANEL'LA, Gray. Calyx colored, 5-parted, lobes all crect, the two outer cordate-sagittate at base, the 3 inner smaller, pectinatefimbriate; stamens 8 ; styles 3 ; achenia 3 -angled, acuminate.-A smooth, erect herb, with the habit of Polygonella. (Polygonum, Ell.) T. fimbriàta Gray.-Pine barrens, Ga. and Fla. St. 2 to $3 f$ high, terete, branched. Sheaths truncate, cylindric, entire, striate, fringed with long, soft, whito bristles, bearing the leaf at top. Lrs. linear, parallel-veined, acute, 1 to $2^{\prime}$ long. Fls. in crowded, panicled spikes. Bracts (sheaths) obliquely truncate, tipped with a long awn, 1-flowered. Cal. white, tinged with roso color. Jl.-Oct.

6. POLYGONEL'LA, Mx. (Lat. diminutive, implying a little of dwarf Polygonum.) Calyx 5-sepaled, colored, persistent and withering, erect-spreading, or at length the 3 inner sepals increasing and connivent; stamens 8 , included; styles 3 or almost wanting; achenia 3 -cornered, naked or inclosed in the 3 inner sepals become scarious valves; embryo straight, axile or lateral in a groove at the angle of the albu- 
men - Herbs or shrubs with very narrow, deciduous lvs., and the small fls. solitary in each ochrea. (Polygonum, Nutt., \&c.)

\$lowers subsessile. Filaments all filifornı. Leaves broader above, spatulate........ Nos. 1, 2 $\$$ Flowers on capillary pedicels 2 "long. 3 iuner flaments dilated at base. Lvs. liliear. Nus. 3,4

1 P. parvifòlia Mx. Somewhat shrubby; branches strict, leafless abovo; lvs. linear-cuncate, obtuse; paniclo compound, spreading; rac. numerous, sessile, filiform, short, with imbricated bracts; fls. subsessilo; inner sep. oval, soon equaling the acute achenium, 2 outer reflexed.-Pine barrens, N. Car. to Fla., Ala. and Ark. A delicate, much branched shrub, 1 to $2 \mathrm{f}$ high. Sts. brittle, brownish. Lvs. 1 ' long, 1 to $3^{\prime \prime}$ wido above, tortuously spreading. Fls. minute, white.

2. Prácile Nutt. Annual, glaucous; branches filiform, paniculate; "Ivs. spatulate, obtuse, 3 to 5 -veined; rac. almost capillary, bracts approximated; pedicels very short, reflexed; sep. reflexed-spreading, at length the 3 inner exceeding the acuminate fruit. - Dry, sandy places, Car. to Fla. and La. Sts. strict, furrowed, 2 to $3 \mathrm{f}$ high. Branching issuing from between tho joints. Lvs. few, $1^{\prime}$ to $18^{\prime \prime}$ long. Fls. nodding, $1^{\prime \prime}$ long, longer than tho peduncle, white or flesh-colored.

3 P. Meisneriàna Shutt. Shrubby, very leafy; lvs. linear-filiform, obtuse, nearly perennial, glaucous; achrex subimbricated, grcen with a conspicuous white, membranous border; rac. many-flowered; achre:e 1-flowered, with setaceously acuminate bracts; 2 outer sepals reflexed.-Near Macon, Ga. (Mettauer) and Ala., rare. A delicate, bushy shrub, 1 to $2 \mathrm{f} \mathrm{high.} \mathrm{Lvs.} 6$ to $10^{\prime \prime}$ long, somewhat tereto and fleshy. Fls. roseate or white, on jointed, solitary pedicels $2^{\prime \prime}$ long.

4 P. articulàtum Meisn. St. erect, with erect branches, soon nearly natied; ivs. linear, caducous from tho top of the tubular, truncato sheaths; spikes panicled. filiform; fls. solitary, pedunculated, with imbricated, truncated bracts; sep. erectspreading.- (1) N. Y. to Mich., in dry grounds. St. slender, strict, 1 to $2 \mathrm{f}$ ligh. Lvs. $6^{\prime \prime}$ to $1^{\prime}$ by $1^{\prime \prime}$, obtuse. Fls. flesh-colored, showy, $\dot{1}^{\prime \prime}$ long, on nodding, hairlike peduncles. Ach. not inclosed, triangular, acuminate. Aug.- 1 true Polygonella in' habit and character, as the genus is defined by Meisner.

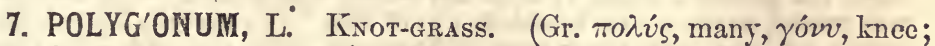
i.e., plant with many joints.) Calyx of 5 sepals, rarely fewer, colored or greenish, similar, imbricated in bud, at length all connivent, persistent; stamens 8 , rarely fewer; styles 2 or 3 , mostly 3 , short filiform ; achenia 3-cornered or lens-shaped, inclosed in the dry, withered calyx; embryo curved, lateral, lying in a groove at one angle of the albumen.- $A$ vast genus of herbs with ochreate-jointed stems and small, white, red, or greenish fls.

§ Stems armed with retrorse prickles. Lcaves cordate sagittate. Ecnurocaulor.... Nos. 20, 21

$\S$ Stems unarmed, twining. Leaves cordate-hastate. Triarin...................... 17-19 $\S$ Stems crect or decumbent, unarmed. Leaves hardly ever cordate. (*)

* Calyx unequally 4-cleft. Styles 2, long deflexed. Tovaria....................... 16

* Calyx equally 5-parted. Styles erect. (a)

a Sheaths salver-form. Stamens 7. Stylo 2-parted. Tall. Amblrocomux.No. 15 a Sheat hs subcylindrical. Stamens $5,6,8$. Styles 2 or 3 . (b)

b Flowers in leafless, terminal, spike-liko raccmes. Persicaria. (c)

c Raceme one, dense. Stum at base or rhizome decumbent Nos. 13, 11

c Racomes several. Sheatlis naked, not fringed............ Nos. 11, 12

c Racemes several. Sheaths bristly fringe-ciliate. (d)

d Style 2 (or 3)-clefi. Achenia tlat or lexs-sliaperl......Nos. S-10

d Style 3-cleft. Achenia sharply 3 -cornered............ Nos. 5-7

b Flowers axillary or scldom forming a leafy raceme. (e)

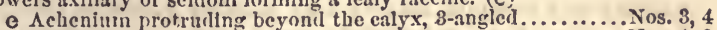

e Achenium included in tho calyx, 3-angled........................ 1, 2

1 P. aviculàre I. BIRD's Kхот-GRAss. St.procumbent; lvs. elliptical-lanceolate, rough-edged, acutish at each end; fls. subsessilo; ach. striate, dull, inclosed; stam. 5 to 8.- (1) A common weed in fields, highways and door-yards, U. S. and Brit. Am. Sts. slender, $\frac{1}{2}$ to $1 \frac{1}{\mathrm{f}} \mathrm{long}$, striate, smooth, branching, with short, white, torn, remotely reined stipules at the joints. Lvs. smooth, except tho edges, $1^{\prime}$ by $3^{\prime \prime}$, more or less. Fls. reddish, small, 2 or 3 together in tho axils of the leaves, appearing all summer. (P. littoralo Mcisn.) 
$\gamma$. ERECTUM. Stems ascending or erect; lvs. larger, elliptic or oval, petiolate; fls. pedicellate; stam. mostly 5. - In richer or shady soils, more common westward. (P. erectum L.)

2 P. ténue Mx. St. slender, rigid, erect, with long, simple branches, acute-angled; lvs. linear-lanceolate and linear, erect, acute; sheaths (stipules) bristly-fringed at top; fls. alternate, subsolitary; ach. included.-A small, slender plant, on rocky soils, N. Eng. to the Mts. of Ga. and Wis. St. 6' to If high. Lvs. 1 to $11^{\prime}$ long, 1 to $2^{\prime \prime}$ wide, 3-veined, sessile. Fls. white. Jl, Aug.

3 P. marítimum L. Prostrate, diffusely branched, glaucons; st. striate, with very short internodes; sheaths gibbous at base, byaline, torn; lvs. fleshy, oval or linear-oblong, nearly veinless; fls. sessile; ach. sharply angled, a littlo exserted, smooth and shining. - 2f Sandy shores, R. I. to S. Car. Sts. 6 to 12' long. Lvs. few and small, 2 to $4^{\prime \prime}$ long. Fls. often crowded in leafy racemes, rose-purple, green at base, $1^{\prime \prime}$ long. (P. aviculare, $\beta$. glaucum, $2 d$ edit.)

4 P. ramosíssimum $\mathrm{Mx}$. St. tall, erect or ascending, much branched, striate; sheaths 6-veined, at length torn ; lvs. lance-oblong or linear, petiolate; fls. subsolitary, pedicellate, greenish; ach. exserted, smooth but dull.-(1) Sandy shores of streams and lakes, Mich. to Ill. Much like P. aviculare, but rigidly erect, 2 to $3 f$, with larger, petiolate lvs. $2^{\prime}$ long, and larger sepals, $1 \frac{1}{2}{ }^{\prime \prime}$ long in fruit, green, with narrow white borders.

5 P. hirsùtum Walt. HAIRY KNOT-GRASS. Hirsute, with long, spreading, tawny hairs; sheaths ciliate; lvs. Ianceolate, obtuse at base, gradually narrowed to the point; spikes 2 or 3 , very slender; bract equaling its 2 or 3 pedicels; stamens 7 to 8 ; style 3-cleft; ach. shining.-(2) Swamps, N. Car. to Fla. St. slender, rooting at base, ascending 2 to 4 f. LVs. 2 to $3^{\prime}$ by 4 to $10^{\prime \prime}$, mostly smooth above, sometimes dense-hairy like the stem. Fls. white. May-Aug.

6 P. hydropiperoides Mx. MILD WATER-PEPPER. St. smooth; sheaths hairy, bristly-ciliate, long and narrow; lvs. linear-lanceolate, tapering to each end, stightly appressed-hairy (not acrid); spikes 2 or more, slender, loose-flowered at base; cal. glandless; stam. 8; style half-3-cleft; ach. shining.-4 Ditches and wet ground, common. St. branched, 1 to $3 \mathrm{f}$ high. Irs. narrowed into a short petiole, not acrid. Fls. rather large, white-roseate, rather close, 4 or 5 from each bract. Aug., Sept. (P. mite Pers.)

$\beta$. SETÁceUM. Ivs. lanceolato; stip. conspicuously fringed with long bristles. - - In clayey soils, southward. (P. setaceum Baldw.)

7 P. acre H. B. K. St. ascending, slender, glabrous; sheath smoothish, fringed with bristles, bearing the leaf near the base; lvs. acrid, lanceolate, acuminate, filiform, interrupted at base; bracts truncate, 1 to 3 -flowered; ped. scarcely exserted; stam. 8; stylo 3-parted; ach. 3-cornered.-Wet places, ditches, common S. and W. Cal. greenish at base, flesh-colored, brown-dotted like the lrs. Ach. shining. J.-Sept. (P. punctatum Ell. P. hydropiperoides Ph.)

8 P. Hydropìper L. WATER-PEPPER. Glabrous; sheaths bristly-ciliate; lvs. lanceolate, tapering to both ends, minutely, pellucid-punctate (very acrid); spikes loose-flowered, slender, short (2 to $\left.5^{\prime}\right)$ nodding; ped. exserted; cal. glandularpunctate; stam. mostly 6 ; sty. 2 or 3-cleft; ach. flattish (rarely obtusely triangular), dull, minutely roughiened. - I Damp waste grounds, ditches, \&c., 1 to $2 \mathrm{f} \mathrm{high.}$ Lvs. not more than $6^{\prime \prime}$ wide. Fls. green and rose-colored. Ach. black. Jl.Sept. \& Eur.

9 P. Càreyi Olney. St. erect, hirsute, miuch Uranched; lvs. lanceolate, with scattered and appressed hairs; stip. scarious, tubular, truncate, hairy-ciliate; spikes axillary and terminal, on very long, nodding peduncles thickly beset with glandular hairs; stam. 6 to 8 included; sty. 2 ; ach. orbicular-ovate, mucronate, tumid, shining.-(1) Swamps, N. Eng. and N. Y.? Plant 3 to $5 f$ high. Lvs. 3 to 6 ' by $6^{\prime \prime}$ to $i^{\prime}$, midvein and margins hairy. Cal. greenish-purple, tinged with white, minutely dotted.

10 P. Persicària L. St. erect; lvs. lanceolate, the upper surface usually marked with a brownish spot; stip. fringed; spikes dense, oblong, erect; ped. smooth; stam. 6 ; sty. 2, half united; ach. shining, flattened.-1) A common species about buildings, fences, wet grounds, \&c. St. smooth, branched, leafy, I to $2 \mathrm{f}$ high, 
often colored. Lvs. 2 to $4^{\prime}$ long, a fourth as wide, entire, short-stalked, acuminate. Fls. rose-colored, in many spikcs, 1 to $2^{\prime}$ long, 5 or $6^{\prime \prime}$ thick. Jn.Aug. \& Eur.

11 P. Pennsylvánicum I. (Fig. 103, 607.) St. smooth, tumid at the joints; lvs. lanceolate, petiolate; stip. glabrous, not ciliate; spikes oblong, crowded; ped. and often the branches above glandular-hispid; stam. 8; sty. 2-cleft; ach-lenticular, with flat sides.-(1) Margirss of ponds and ditches, common. St. geniculate branched above, 2 to 4 f high. Lvs. 3 to 5 ' long, $\frac{1}{3}$ as wide, slightly scabrous with appressed hairs. Spikes short and dense, large, and somewhat nodding. Fls. large, rose-colored, pedicellate. Jl.

12 P. incarnàtum Ell. St. geniculate smooth below; sheaths smoothish; Ivs, lanceolate, smooth except the roughish midvein and margins, or minutely pubescent abovo; branches and peduncles glandular-dotted; spikes linear, nodding, at length elongated; cal. minutely glandular; stam. 6; sty. 2-cleft; ach. lenticular with concave sides. - I In ditches and pools, W. and S. States. Sts. 2 to $3 \mathrm{f} \mathrm{high.}$ Lvs. 5 to $9^{\prime}$ by 1 to $3^{\prime}$. Fls. flesh-color or white, in spikes 1 to $3^{\prime}$ long. JLSept. (P. lapathifolium, 2d Edit.)

13 P. amphíbium L. St. assurgent, prostrate or tecumbent at base, rooting at the lower joints; lvs. oblong-lanceolate and oblong, acute, or rounded or cordate at base, petiolate, smooth, acute or acuminate at apex; spike terminal, ovoid or oblong, dense; sta. 5, sty. 2-cleft.-Marshes, ponds, Can. and U. S., more common North. A very variable species, with large leaves and a terminal, dense spike of bright red flowers. Stip. large. Lvs. 5 to $7^{\prime}$ by 1 to $2^{\prime}$, often shining. Spikes 1

to 2 ' long, the shorter mostly thicker. ( $\Lambda$ ug. P. coccinum Muhl.)

3. AQUÁTICUM. Floating, smooth; lvs. ovate-lanceolate or oblong-ovate, shining, thick; spikes more usually short and thick. (P. fluitans Eaton.)

$\gamma$. TERRÉSTRE. Ascending or crect, more or less hirsute; lvs. lance-oblong, acute or acuminate; sheath lirsute; spikes moro commonly elongated.Varies into the other. (Mr. S. H. Wright.)

24 P. vivíparum L. Alpine Bistont. St. low, erect from a creeping rhizome, simple; lvs. linear-lanceolate, revolute at the margin; spike linear, solitary.-24 White Mts., N. H. to Arc. Am. A dwarf alpine species $6^{\prime}$ high, bearing a single spike of white flowers which aro often transformed into bulblets while on the stem. Lvs. 1 to $1 \frac{1}{2}^{\prime}$ by 2 to $3^{\prime \prime}$, with entire, obtuse, smooth stipules. Jl.

25 P. orientàle I. Prince's Feather. St. ercet, paniculately branched; lvs large, with hairy, salver-form stipules; sta. 7; sty. 2.-1 Native of the East, naturalized in fields and roadsides, throughout tho U. S. A tall, showy plant, often cultivated for ornament. Stem 5-8f. Lvs. 6-8' long, ovate, acuminate. Spikes numerous, large, red, plume-like, terminal. Aug. $†$ Eur.

26 P. Virginiànum L. St. simple, minutely appressed-hairy above; lvs. ovate and lanceolate, acuminate, short-petiolate; sheath bristly; rac. wand-like, terminal; fls. remote, solitary in each sheath; cal. 4-parted; stam. 5, included; sty. 2, bent downwards, hooked at apex, as long as the shining, tumid-lenticular achenium. - 2f Shades, Can. and U. S. St. 3 to $4 \mathrm{f}$ high, the raceme half its length. Lvs. large, 3 to $6^{\prime}$ long; half as wide. Fls. greenish-white. Jl., Aug.

17 P. convólvulus L. KNот-BINDweEd. St. prostrato or climbing, twining, roughish; sheaths naked; lvs. hastate, acuminate; fls. in axiilary fasicles or interrupted racemes; cal. obtusely keeled; ach. purplish-black, dull, exserted.-1) Fields and waste grounds, Can. to Car. Sts. angular, 2 to $3 \mathrm{f}$ long. Lrs. 1 to $2^{\prime}$ by 7 to $15^{\prime \prime}$, petioles half as long. Cal. whitish, twice longer than the pedicels. Jl., Aug. \$ Eur.

18 P. cilinòde Mx. Minutely pubescent, twining; sheaths girt at base with a ciliate hairy ring; lrs. deeply cordate, ovate, acuminate, lobes scarcely hastate; rac. paniculate, loose-flowered, axillary and terminal; ach. shining.-Fields and hedges, Can. to Wis. and Ga. St. slender, often reddish-purple, 3 to 6 to $8 \mathrm{f}$ long. Lvs. $l^{\prime}$ to $18^{\prime \prime}$ by 9 to $15^{\prime \prime}$, petioles about half as long. Panicles simple, $5^{\prime}$ long or loss. Cal. wingless, scarcely keeled, not quite covering the brown achcnium. J1.-Sept.

19. P. dumetòrum I. IIEDG IINDWEaD. St. smooth, twining and climbing; 
joints naked; lvs. cordate-hastate, acuminate, auricles acute; fls. in loose, pedunculate racemes which are naked or leafy; cal. with the 3 outer sep. acutely keeled and winged on the back, closely covering the smooth, black achenium.-(1) Thickets, Can. and U. S. St. 3 to 8 to 12 f long, climbing over bushes, \&c. Lvs. 2 to $3^{\prime}$ by 1 to $2^{\prime}$, petioles nearly as long. Wings of the calyx narrower than the fruit, produced often at the apex. J.-Sept.

20 P. sagittàtum L. SCratch Grass. St. prostrate, rough-angled; lvs. lanceolate-sagitate; fls. capitate; sta. 8 ; sty. $3 .-1$. Wet grounds, Can. and U. S. A rough, climbing species, 2 to $5 f$ in length. St. square, the angles very rough with prickles pointing downwards. Lvs. acute, 2 to $3^{i}$ long, a third as wide, with straight auricles and smooth stipules. Fls. in small, terminal heads, whitish. Jn.

21 P. arifolium L. St. aculeate with reversed prickles; lvs. hastate, acuminate, with divaricate, acuminate auricles; spikes few-flowered; fls. distinct; stam. 6; sty. 2.-(1) Wet grounds, Can. to Ga. and W. States. Distinguished from the last by its larger, halbert-shaped leaves which are 2 to $4^{\prime}$ long and $\frac{1}{2}$ as wide. Petioles to $\mathbf{l}^{\prime}$ long. Clusters racemous, slender, loose, few-flowered, at the ends of the branches. Jn., Jl.

8. FAGOPY'RUM, Tourn. Buckweat. (Gr. фáyos, German Budie, Eng. the beech, $\pi v \rho o$ s, wheat; - beech-nut-wheat.) Calyx colored, equally 5.parted, spreading, withering, not enlarged in fruit; stamens 8 , with 8 nectariferous glands between ; styles 3 ; stigmas obtuse; achenia 3 -angled, much exceeding the calyx.-(1) Herbs with cordate-hastate lvs., oblique sheaths and panicled rac. of white-roseate fls.

F. esculéntum Monch. Erect, smoothish; lvs. cordate with obtuse lobes; ach. angles wingless, entire, the sides ovate-triangular.-Old fields, sparingly naturalized, cultivated. St. 2 to 4 f high. Lrs. 2 to $4^{\prime \prime}$ long, half as wide. Fls. numerous, very grateful to bees. Fruit black, a valuable grain. $+\S$ Asia.

\section{Order CiII. PHYTOLACCACEE. Pokeworts.}

Herbs with alternate, entire leaves and perfect, 5-parted, hypogynous flowers. Calyx free. Slamens 5 to 30 , alternate with the sepals when of the same number. Ovary usually compound, of several carpels, each 1-ovuled cohering in a crrcle. Styles and stigmas as many as carpels. Fruit baccate or samara-like. Seeds erect, with the embryo coiled around the farinaceous albumen.

Genera 20, species S0, seattered in all parts of the world. Their properties are purgative or emetic, yet bitherto little used or understood.

1. PhytolaC'CA, Tourn. Poкe. Gargot-weed. (Gr. фútov, a plant, Lat. lacca, lac or lake ; from the juice of the berries.) Calyx 5parted, resembling a corolla; stamens 5 to 25 ; styles and carpels 5 to 12 ; berry superior, depressed, globular, with as many seeds as styles. -Herbaceous. Rac. terminal, soon becoming opposite the leaves.

P. decándra L. Lrs. ovate, acute at both ends; fls. with 10 stamens and 10 styles. - 2f Roadsides, U. S. and Can., common. Root very large and branching. St. with a diam. of 1 to $2^{\prime}, 5$ to $8 \mathrm{f}$ high, round, smonth, branching, and when mature of a fine, deep purple. Lrs. $5^{\prime}$ by 2 to $3^{\prime}$, smooth, of a rich green color, entire and petioled. Rac. cylindric, long, at first terminal, becoming finally opposite the leaves. Fls. greenish-white. Fruit a dark purple berry, with juice staining a beautiful purple color. Jl.-Sept.

2. RIVI'NA, Plum. (Tu memory of $A$. Q. Rivinus, Prof. of Botany at Leipzic.) Calyx 4-parted, 3-bracteolate; sepals equal, suberect in fruit; stamens 4 or 8 ; ovary 1-celled, 1-styled, 1-ovuled, berry at 
length, dry, globular, with 1 vertical seed; embryo annular.-2f Half shrubby, with alternate, petiolate, pinnate-veined lvs. and fls. in simple terminal, soon lateral racemes.

R. lèvis L. Erect, branched, glabrous and bright green; lvs. ovate, acuminate, subcordate or obtuse at base, subcrenulate; rac. longer than the leaves; fls. rosewhite, green in fruit; stam. 4; sep. oval, obtuse.-Fla. to Tex. Plant 6 to $\mathrm{kt}$ high, much resembling in aspect Phytolacea. St. furrowed. Lvs. 2 to $4^{\prime}$ by 1 to $2^{\prime}$, petioles $1^{\prime}$ to $18^{\prime \prime}$. Sep. enlarged in fruit, then $2^{\prime \prime}$ long.

\section{Order CIV. BASELlaCE $Æ$.}

Herbs glabrous, often twining and climbing, with alternate leaves. Flowers perfect, regular, with a double, imbricated calyx often colored. Stamens perigynous. Otherwise as in Chenopodiaceæ. Fig. 363.

$\Lambda$ small order, containing 6 genera and 21 species, chiefly tropical.

BoUSSingaul'Tia, Kunth. Mexicin Vine. (Dedicated to the celebrated chemist Boussingault.) Fls. membranous, calyx open, the exterior shorter; tube very short; stigmas 3 , subclavate; pericarp membranous; embryo annular with the albumen central.-Vines twining to the right. Lrs. thick, petiolate. Fls. in spicate rac.

B. baselloìdes Kunth. Lvs. rather fleshy, broadly cordate-ovate, acuminato or the larger ones obtuse, short-petioled; racemes loose, simple or branched; fil, dilated below; stig. sessile. - Cultivated for shades and arbors. A vine of rapid growth, arising many feet. Lvs. $1-3^{\prime}$ long. Racemes numerous, greenish. † S. Am.

\section{Order CV. ChenopodiacE E. Chenopods or Goose-foots.}

Herbs chiefly weed-like and homely, more or less fleshy, with alternate, exstipulate leaves. Bracts not scarious. Flowers minute, greenish, regular. Calyx imbricated in bud. Stamens perigynous, as many as, and opposite to the calyx lobes, or fewer. Ovary 2-styled, 1-celled, becoming a 1-seeded, thin utricle or caryopsis. Embryo coiled into a ring around the albumen or spiral without albumen. Fig. 435.

Genera 72 , species 510 , often maritime plants, moro generally weeds, abounding in the temporate zones, in neglected and waste fields.

Properties.-Generally bland and innocent. Some are useful for food, as the Beet, Mangelwurtzel, Orache, Spinach, \&c. Others contain an essential oil, which renders them tonic, antlspasmodic and anthelmintic; as Chenopodium botrys, C. ambrosioides, C. anthelminticum; tho latter yields the officinal worm-seed oil. Salsoli, Salicornia and other sea-side species yield soda from thelr ashes in great abundance.
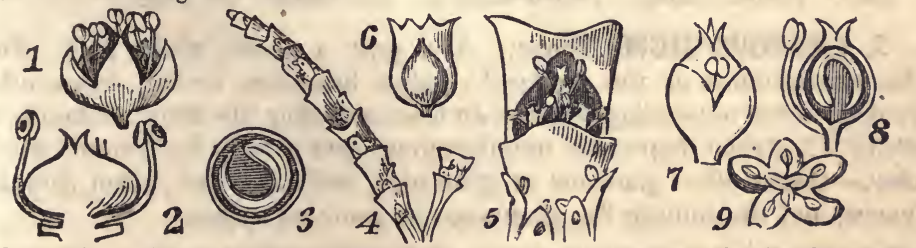

FIG. 678.-1. Fluwer of Chenopodium album. 2. Calyx, \&c., removed, showing the ovary and two (hypocynous) stamens. 3. Cross section of the seed, showing the colled embryo. 4. Branch of Salicornia herbacea. 5. Two joints magnified. 6. Ovary of a flower. 7. Flower of Blitum capitatum, with the fleshy calyx. 8. Vertical section of the ovary. 9. Flower of Beta vulgaris.

\section{SUBORDERS, TRIBES AND GENERA.}

§ SPIROLOBE \&. Embryo a spiral coil. Lenves linear, fleshy. Stems continuons. (*)

* Tribe Saisole e. Emb. a cunic spir.-Cal. winged on the back. (Lvs. splny)...Salsoza. 11

* Tribe Sudenez. Emb. a flat spiral.-Cal. not append. Lvs. acutisb....... Cuenopodina. 10

8 CYCLOLOBE 2 . Embryo annular,-a ring. Leaves membranous, flat, or none. (*) 
* Tr. Salicors. Inflor, anomalous. Fls. imbedded. St. jointed, (leafless)....SAzicorria, 9

* Tribe Spinacied. Inflor, norual. Fls. of two sorts. St. continuous. Lvs. brosd. (a)

a Fruit enclosed in a hardened calyx without bracts. Cultivated.......... SprNacra. 8

a Fruit naked (no ealy $x$ ) between two united bracts. Leaves oval......... OBIovk. 7

a Fruit naked (no calyx) between two subdistinct bracts, Lvs. triangular. Armiplex. 6

- Tribe Cnenopodike. Inflor. normal. Fls. perfect and alike. St. contin. Lvs. broau. (c) c Seed vertical. Pericarp thin, smooth, mostly in a fleshy calyx......... Burtux. 5 c Seed vertical. Pericarp thin, glandular, in a wrinkled caly......... Rou BIEvA. 4 c Seed horizontal. Pericarp thin, in a plain, unbordered calyx...... Criexopodium. 3 c Seed horizontal. Pericarp thin, in a calyx bordered all around....... Crclocosa. 2

c Seed horizontal. Pericarp thick and hard, calyx ribbed............... BEx . 1

1. BE'TA, Tourn. BEET. (Celtic bett, red, the usual color of the Beet-root.) Calyx urceolate, 5 -cleft, persistent, finally indurated at base; stamens 5, with no staminodia ; ovary depressed, half inferior; stigmas 2 ; utricle with a thickish, hardened, depressed pericarp enclosed in the calyx; seed horizontal.-Herbs with fleshy roots, furrowed stems, alternate lvs. and greenish, spicate fls.

B. vulgàris L. Lvs. acute, glabrous, undulate or entire, green or purplish, the lower ovate-oblong, attenuate at base into a long petiole, upper subsessile, oblong; fls. greenish-white, in sessile glomerules of 2 to 4 forming slender spikes which are arranged in large, somewhat leafy panicles.-2) Fields and gardens, every where cultivated. Rt. mostly deep red. S. Eur.-This useful culinary, by long culture has run into many varieties, distinguished chiefly by the color and quality of the nutritious root.

$\beta$. CICLA. SCARCITY. Root eylindraceous, rather slender, whitish; lvs. somewhat rough or hispid, with very thick veins; fls. 3 together.

$\gamma$. RAPA. TURNIP BEET. Root short and thick, sweet and juicy, white or red. d. MANGEL-WURTzEL. Root very large, mostly white. Cultivated for stock.

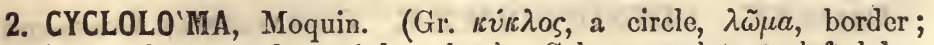
referring to the appendage of the calyx.) Calyx urceolate, 5-cleft, lobes strongly keeled, persistent, finally appendaged outside with a circular, membranous, horizontal border or crown; stamens 5 ; styles 3 ; utricle depressed, enclosed in the transversely winged calyx.- (1) Herbs with furrowed stems, alternate, petiolate, lobed lvs., and a spreading panicle of small sessile fls.

C. platyphýllum Moq. Sandy banks of the Miss.. III. (opposite St. Louis) and westward. St. wide-branched, ascending 1 to $2 \mathrm{f}$ from a prostrate base, whitedowny above. Lrs. 2' long more or less, oblong-lanceolate, petiolate, sinuatetoothed or lobed, lobes sharply mucronate. Fls. less than $1^{\prime \prime}$ long, 1 to 3 -glowerate. Panicle leafless. Crown scarious. Seed black. Jl., Aug.

3. CHENOPO'DIUH, Tourn. (Gr. $\chi \dot{\eta} \nu$, a goose, $\pi$ oṽs, foot; from the resemblance of the leaves.) Calyx bractless, 5-cleft, lobes often keeled, never appendaged, more or less enclosing the fruit; stamens 5 ; styles '2; utricle depressed, membranous, sced mostly horizontal, lenticular.- Herbs often glaucous or glandular, with alternate, often rhombic leaves, and the minute fls. glomerate in panicled spikes.

5 Mants smooth, never glandular, ill-scented. Embryo a completo ring (*).

* Hurbage green, rarely purplish, not glaucous or mealy (a).

a Leaves entire, ovate-oblong, in slender petioles.......................... 1

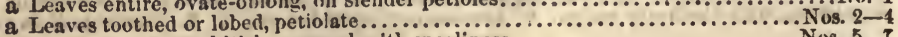

* Herbage glaucous or whitish, covered with mealiness............................ 5

5 Plants glandular-puberulent, green, aromatc. Embryo a haifring (b).

b Flowers glomerate, axillary, in spike-like racemes..................... Nos.8, 9

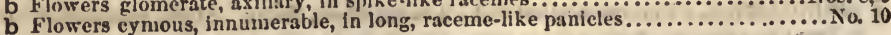

1 C. polyspérmum L. Procumbent or suberect, branched from the base; Ivs. petiolate, divaricate, ovato or oblong, obtuse or acute, thin, entire, glabrous, 
bright-green; rac. strict, spike-like, leafless; seed shining, margin acute; fruit partly inclosed.-(1) Gardens, waste grounds, rare. (C. acutifolium Sm.) Plant smooth, pale green or purplish, if or more high. Calyx minute, lobes obtuse, at length spreading and the fruit naked. \$ Eur.

2 C. hỳbridum L. Erect, much branched; lvs. petiolate (ample), broad, subcordate, acuminate, deeply sinuate-angled, thin, glabrous, bright green, the terminal lobe longest, all acuminate, upper deltoid; rac. diffusely panicled, loose, leafless; seed regous, dull; fr. partly inclosed.-(I) A strong-scented, rigid herb, 2 to $4 \mathrm{f}$ high, in waste grounds, N. Eng. to Ky., common. St. furrowed. Lvs. partly palmate-veined, 3 to $5^{\prime}$ by 2 to $4^{\prime}$, petiolo 1 to $2^{\prime}$. Fls. sessile, greenish. JL. $\$$ Eur.

3 C. muràle IL Ascending, sulcate-angled, branched; lvs petiolate, ascending, ovate-rhombic, acute at base, unequally and acutely toothed, thin, shining, bright green; rac. divaricate, subcorymbous, rather loose and leafless; seed dull, rugous, acute-edged, very flat; fr. almost inclosed.- (1) Fields, gardens, north and south, rare. St. 12 to $18^{\prime \prime}$ high. Lvs. 2 to $3^{\prime}$ by $1^{\prime}$ to $18^{\prime \prime}$, subtripliveined, petiolo $1^{\prime}$. Fls. mealy. Stam. exserted: Aug. § Eur.

4 C. úrbicum I. $\beta$. RHомвіFolium. Erect, angled, branched; lvs. petiolate, ascending or erect, rhombic-triangular, acute, sinuate-toothed, with long, acute teeth, thin, green, the lighest iance-linear, subentire; rac. long, erect-panicled, rather densc-flowered, nearly lealless; seed shining, obtuise-edged; fr. partly inclosed.-(1) St. 2 to 3 f high, marked with green lines; branches suberect. Lvs. 2 to $3^{\prime}$. long. Rac very strict Cal. lobes obtuse, green. Stam. exserted. (C. rhombifolium Mruhl.)

5 C. Bosciànum Moq. Irect, branched; lvs. small, petiolate, divaricate, lancelinear, very acute, thin, ertire, glaucous-green above, canescent beneath; spikes loose, leafy; seed shining, acute-margined; fr. wholly inclosed.- I Car. to Tex. St. $18^{\prime}$ to $2 \mathrm{f}$ ligh, slender, green-striate, branches ascending. Lvs. $5^{\prime \prime}$ to $1^{\prime}$ long, 1 to $2^{\prime \prime}$ wide. Fls. minute, mealy, sessile.

6 C. album L PIGWEed. Érect, sulcate-striate, thinly branched; lvs. petiolate, ascending, rhombic-ovate, cuneate at base, sinuate-toothed or subentire, thin, pulverulent, pale green or whitish, upper oblong or lance-linear, entire; rac. dense or loose, subpaniculate, nearly leafless; seed smooth and shining, acute-edged, wholly inclosed. - (1) The most common of weeds in fields and gardens. St. 2 to 4 to if high, beautifully striate with green and purple. Branclies subsimple, ascending. Lrs. 18 to $30^{\prime \prime}$ long, petiole a third as long. Fls. mealy. J1.-Sept. (C. viride $L_{n}$ a greener, narrow-leaved var.)

7 C. glaùcum. IL Prostrale or ascending, sulcate-striate, branched; $2 v s$. petiolate, ollong or ovate-ablong, obluse, sinuate-angled or remotely dentate, thin, pale green above, mealy and white-giaucous beneath; rac. simple, leafless, rather dense-flowered; seed shining, acute-edged, partly incio sed. - (1) Mass, Penn., rare. Plant somewhat tleshy, if long, smootl. Lvs. 1 to $2^{\prime}$ long. Calyx sometimes abortively 2 or 3-lobch, anc then the seed is erect. (Koch.)

8 C. ambrosioides I. MexicAN Tra. Erect, sulcate, branched; lvs. short petioled, ascending, oblong, the upper attenuate at each end, acutish, remotely sinuate-dentate or subentire, thin, puberulent, glandular beneath, light green, the upper lance-linear, very entire; rac. spike-like, dense-flowered, leafy; seed smooth and shining, obtuse-edged; fruit wholly inclosed.-(1) Waysides, waste places. Plant yellowish green, pleasantly aromatic, 1 to $2 f$ high. JL, Aug. \$ Mex. \&c.

9 C. anthelmínticum L. WORM-SEED. "Erect, angular, subsimple; lvs. ovateoblong. petiolate, acute, attenuate at base, deeply sinwate-serrate, the lower almost pinmatifid, thin, smoothish, glandular beneath, bright green; rac. spike-like, axillary, subsi:nple, dense-flowered, leafless, paniculate above; sty. mostly 3 ; seed smooth, shining, obtuse-margined; fruit wholly inclosed. - 2r In light soils, pastures, and waste grounds, common south and west. Plant strongly aromatic, 1 to $3 f$ high, with small branches (or none), forming a leafy paniclo of leafless spikes. Jn.-Aug.

20 C. Bòtrys L. OAK of Jerusalem. Erect, suleate-angled, much branched; Ivs. long-petioled, ascending, oblong, obtuse, sinuate-subpinnatifid with obtuso 
lobes, glandular-pubescent, glaucous green, the floral bract-like ; fls. cymous-pan; culate, in long ascending, raceme-like panicles; seed smooth, nearly globular. (1) Plant 1 to $2 \mathrm{f}$ ligh, branched from the base. Lvs. few, 1 to $2^{\prime}$ long, petioles half as long. Fls. innumerable, minute, clammy, covering nearly the whole plant. Jn.-Aug. Strongly fragrant of turpentine.

4. ROUBIE'VA, Moq. (Named for G.J.Roubieu, a French botanist.) Calyx oblong-urceolate, 5 -toothed, in fruit rugous and inclosing the utricle like a capsulo; stamens 5 ; styles and stigmas 3 ; seed lenticular, vertical, embryo a complete ring. $-2 f \mathrm{~A}$ diffusely branched, pibescent herb, with alternate, multifid lvs. and small green fls. (Chenopodium, L.)

R. multífica Moq.- Wasto grounds, waysides about the city of N. Y. (HoIton). A strongly-scented, prostrate herb, 1 to $2 \mathrm{f}$ long. Lvs. small, $1^{\prime}$ less or more long, pinnatifid with oblong lobes. Fls. numerous, glomerate, axillary, sessile, in bracted, panicled racemes. Fruit nearly ' $1^{\prime \prime}$ long. § S. America.

5. BLI'TUM, Tourn. Burte. Calyx 3 to 5 -parted, finally unehanged or becoming juicy and berry-like in fruit; stamens 1 to 5 , with filiform filaments; styles 2 , utricle compressed, inclosed in the calyx; seed vertical, embryo a complete ring.-(1) Lvs. alternate, petiolate. Fils. glomerate.

§ Ifeals (glomerules) axillary, subspicato above. Cal. thickened in fruit. Stig. united. Nos. 1, 2 Heads furming a dense, terminal spike. Calyx dry. Stigmas distinct................. No.3

1 B. capitàtum L. STrA Wberry BLITE. Lvs. triangular-hastate, toothed; hds. in terminal, interrupted, leafless spilies; stam. 1 to 5 ; fr. consisting of the reddened flowers, appearing like strawberries, full of a purple juice, taste insipid; seed dull.-Va. to Arc. Circle. A weed-like plant growing in fields, and sometimes cultivated in gardens as a flower, or a culinary. Sts. purplish-striped, branching, 1 to $2 \mathrm{f}$ high. Heads of fls. sessile, near together, on the branches and summit of the stem. Jn. $t$

2 B. marítimum Nutt. Much branched, angular; lvs. lanceolate, attenuaie at each extremity, incisely dentate; hds. axillary, sessile, spicate; cal. somewhat fleshy; stam. 1; seed shining.-A coarse, unsightly plant, in silt marshes, N. Y. to N. J. St. 1 to $2 \mathrm{f}$ ligh, very branching. Lvs. fleshy, with $\mathbf{2}$ or more largo teeth each side. Fls. very numerous and minute, becoming thickish in fruit. Seed much flattened. Aug.

3 B. Bonus-Hénricus Reichenb. Good KING HeNRY. Plant mealy, ascending, subsimple; lvs. triangular-hastate, entire or sinuate, green; glomerules forming a terminal, leafless spike, not fleshy in fruit; stam. 5.-Waysides, Can. N. Eng., rare. $\$$ Eur.

6. AT'RIPLEX, Gaert. Flowers monœcious or diœcious. \& Bract. less; calyx 3 to 5 -scpaled; stamens 3 to 5 , hypogynous; pistil rudimentary; $q$ ovary 2 -styled, with no stamens, inclosed between 2 leaf-like bracts, or in some species partly furnished with a 5 -sepaled calyx without bracts; fruit compressed, inclosed; seed vertical (horizontal when the calyx is present), embryo annular.-Herbs or shrubs, usually clothed with scurf or mealiness, with alternate, petiolate lvs. and densely glomerate-spiked green fls.

1 A. hastàta L. Ascending, diffusely branched; lvs. alternate or subopposite, triangular hastate, sinuately toothed or nearly entire, the upper lanceolate, entire; fruit bracts triangular:deltoid, slightly muricate, margin denticulate or entire.(1) Marshes and waste grounds, N.Y. to Ga. Sts. 1-2f. long, striate with green. Lrs. including the petiole $1-3^{\prime}$ long, thin and green (mealy in marshes): Fls. in glomerate axillary and terminal racemes, $f$ and of mixed. Aug.-Sept.

$\beta . ?$ oBLovgrfóLia. Lvs. all oblong-lanceolate, scurfy-dotted; bracts very large in fruit; stem rigid, erect, if. or more. Lake shores, N. Y. (Haikensun.) 
2 A. horténsis L. GARDEN ORACHe. Erect, branched; lvs. alternate, triangu. lar-hastate or oblong, subcordate acute, entire or with a few coarse teeth at base, bright green both sides; upper lanceolate or lance-linear, fruit-bracts ovate, entire. -1) Scarce in cultivation or spontaneous. A potherb used as spinage. Jl. § Asia.

7. OBIONE, Gaert. Fls. monœcious or diœcious. of Bractless; calyx 4 to 5 -sepaled; stamens 4 to 5 , hypogynous; o bibracteate, bracts more or less united, at length inflated, hardened and connivent; caly $\mathbf{x}$ none; styles 2 ; fruit compressed, included in the capsular bracts; seeds vertical, beaked; embryo annular.-Herbs pale or whitish, scurfy or mealy; lvs. alternate or opposite. Fls. densely glomerate, greenish. (Atriplex, Tournef.)

O. arenària Moq. SAND ORACHE. Mealy-canescent, ascending, branched, unarmed; lvs. short-petioled, alternate, oval or oblong, obtuse, entire, the upper " acuminate-mucronate; fr. bracts subsessile, broad-cuneate, united, truncate, denticulate at apex.-(1) Sandy seabeach, Mass. to Fla. (A palachicola). St. 6 to $12^{\prime}$ long or high, reddish. Lvs. I' more or less long, attenuate at base. Staminate fls. mostly in the terminal clusters, fertile in the axillary. Jl.-Sept.

8. SPINA CIA, Tourn. SpInage. (Lat. spina, a spine or prickle; on account of the prickly fruit.) Flowers diœecious, bractless, $\hat{o}$ calyx 3 to 5 -sepaled; stamens 4 or 5, cxserted; $q$ calyx tubular, inflated, 2 to 4-toothed, hardening at length into a false capsule; styles 4 , slender; achenium compressed, inclosed in the capsular, spiny, or unarmed calyx; seed vertical.- (1) Herbs with alternate, petiolate lvs. and axillary green fls.

S. oleràcea Mill. Lvs. hastate-lanceolate or sagitate; fruit-calyx solitary, 3-angled, armed with 2 to 4 slender prickles, or unarmed.-1) Gardens. St. 1 to 2 f high. Lrs. 2 to $3^{\prime}$ long, nearly half as wide, often toothed at base, thick, soft, glabrous, bright green. Fr. near $2^{\prime \prime}$ long, sessile, our variety usually unarmed. Jn., Jl. $\ddagger$

9. SALICOR'NIA, Tourn. Saltwort. Samphire. (Lat. sal, salt, cornu, horn; in allusion both to its locality and appearance.) Flowers immersed in the excavations of the jointed stem 2 or 3 together; calyx bladder-like, denticulate at apex, at length spongy, membranous-margined, inclosing the compressed utricle; stamens 1, 2; styles 2 ; seed rertical ; embryo annular, conduplicate.-Seaside herbs, jointed, succulent, glabrous and slmost lcalless, with opposite branches. Fls. minute, sessile, spicate.

1 S. herbàcea L. Annual, erect or assurgent, the joints somewhat thickened at the summit, ending in 2 obtuse teeth; spikes elongated, tapering and rather obtuse at the summit-Salt marshes, N. Eng. to Ga., also at Salina, N. Y. St. dividing into simple branches, 8 to $12^{\prime}$ high, obscurely 1 -sided, with very short internodes. Lvs. 0. Fls. minute, placed in little hollows at the base of the upper joints, tho lateral sometimes sterile. Aug.

2 S. mucronàta Lag.? DWARF SALTwort. Annual, erect; the joints somewhat 4-angled below, with 2 ovate, acute, mucronate teeth at the summit; spikes very thick, obtuse. -Salt marshes, N. Eng. to L. Isl. St. 4 to $\mathbf{3}^{\prime}$ high, thick, little. branched. Spikes oblong-cylindric, $1^{\prime}$ or more long, near a fourth of an inch thick, at length reddened. Sept.

3 S. ambígua Mx. Perennial, procumbent, branching, branches ascending, fiexwous; joints truncate, flattened, enlarged above, with 2 depressed, obtuse teeth.-Sandy sea-beaches, R. I. to Fla. Sts. woody at base, prostrate from long, creeping root. stocks. Aug., Scpt. 
10. CHENOPODINA, Moq. Glasswort. Flowers $q$, bracteolate: calyx urceolate, 5 -parted, fleshy, in fruit subbaccate ; stamens 5 ; stigmas 2 or 3 , sessile; utricle depressed, inclosed in the calyx ; seed lenticular, horizontal; albumen 0 , or scanty and divided into two portions above and below the flat spiral embryo.-Smooth, maritime plants, with alternate, sessile, fleshy lvs. and axillary fls. (Chenopodium, L.)

C. marítima Moq. Branches diffuse, prostrate or erect; lvs. long, linear, semtterete, upper shorter; fls. in sessile axillary glomerules, 2 or 3 together; fruit cal. inflated; seed shining.-(1) Salt marshes, Can. to Fla. Sts. 1 to $2 t^{\prime}$ long or high, becoming woody at base, southward. Lvs. 6 to $15^{\prime}$ long, $1^{\prime \prime}$ thick, acute. Fls. very small, green, with roundish calyx lobes. Utricle thin, semitransparent, containing a black, shining seed. Aug. (C. maritima L. also Salsola linearis Ell.)

11. SAL'SOLA, Gaert. SALTwORT. (Lat. sal, salt; the plants contain much alkaline salt.) Flowers, $\not$, with 2 bractlets; sepals 5, at length winged horizontally on the back, forming a broad, scarious border; stamens 5 ; styles 2 , united at base; utricle depressed, inclosed in the base of the stellately 5-winged calyx; seed horizontal, globous; embryo spiral (cochleate) with no albumen.-Maritime, fleshy plants with terete lvs. and axillary, scssile fls.

S. Kzàli L. Herbaceous, decumbent; lvs. alternate, subulate, channeled, spinous, smooth; fls. solitary; fruit-calyx wings larger than the sepals, orbicular, spreading. (1) A rigid, prickly and very branching plant, of the sea-shore, Can. to Ga. St. 1 to $2 \mathrm{f}$ high, diffuse. Lvs. about an inch long, sessile, ending with a spine. Fis. green, succulent, sessile, bracteate, the wings in fruit pale roseate, $1 \frac{1}{2}$ "longSeed with a thin testa and a green embryo coiled like a little snail shell.

3. Carolimina. Suberect, glabrous, often purplish; lvs. dilated at base; fruit-calyx wings rose-purple.-Soutbward. (S. Caroliniana Walt.)

\section{Order CVI. AMARANTACEA. Amarantiss.}

Herbs weed-like with opposite or alternato leaves, and a bracteate, spiked or capitate inflorescence. Flowers generally with an imbricated involucre of 3 dry, scarious bracts. Sepals 3 to 5 (rarely but 1), persistent and often colored, unchanged in fruit. Stamens 3 to 5 fertile, hypogynous. Ovary compressed, l-celled, 1 to $\infty$ ovuled. Style 1. Fruit a utricle, caryopsis or berry. Seed vertrical, albuminous Embryo annular.

IIlustrated in figs. 1SS, 406.

Gener 46 , species $4 \mathrm{SU}$, most sbundant within the tropics. Their properties aro not important. A few are cultivated for their richly-colored imperishable flowers; others are mere weeds.

\section{TRIBES AND GENERA.}

1. CELOSIE AG. Anthers 2-celled. Ovary many-avuled. (Cultivated)............erosra. I

II. ACHYRANTHE.E. Anthers 2-celled. Ovary one-ovuled. Leaves alternate. (*)

* Flowers nnonøecious or polygamous-Utricle circumscissile................Asaranters. 2 -Utricle indehiscent.................... Evxouts. 3

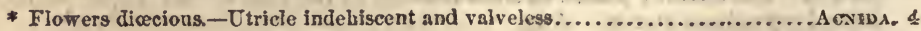
-Ctricle dehiscent, eircunscissile....................... Mosteusa. 5

III. GOMPHRENE Xs. Anthers one-celled. Ovary one-uvuled. Leaves opposite. (a)

a Sterile stamens none. - (Flowers white, paniculate)..................... Iresixz. 6 a Sterile stamens none.-(Flowers crimson, dc. Capitate. Cultivated)..... Gosspurena. 7 a Sterile stamens 5 , the 5 fertile in a tube.-Heads nxiliary............... Treanture. S -Spikes terminal and axillary..... FBakuiCmA, 9

1. CELO'SIA, I. Соскsсомв. (Gr. $\kappa \eta \dot{\lambda} \varepsilon$ sos, shining; characteristic of thr brilliant colors of some species.) Flowers perfect, 3 -bracted; calyx of 5 , erect-spreading sepals; stamens 5 ; anthers 2 -celled; stigmas 2 , 
3 , recurved ; utricle circumscissile, many-seeded, more or less inclosed in the ealyx.-Herbs or shrubs smooth, erect, with alteruate lvs. and brilliant, scarious fls.

C. cristàta L. Lvs. ovate-lanceolate, petiolate; spikes subsessile, ovatepyramidal, or (in cultivation) compressed, dilated and truncate at the apex, or excessively branched; fls. subsessile, 2-styled; sep. mucronate, longer than the bracts.-(1) Gardens. This curious and popular annual is said to be native of $\mathrm{E}$. Ind. Its broad spikes are of fantastic shapes and of the richest erimson, varying to white.

2. AMARAN'TUS, Tourn. (Gr. $a$, not, $\mu a \rho a i v \omega$, to fade, äv0oc, flower; sc. unfading flowers.) Amarantu. Flowers polygamous, 3bracted; calyx 5 to 3 -sepaled, equal, erect; stamens 5 to 3 , with no rudiments; style 0 ; stigmas 2 to 3 ; utricle ovate, 2 to 3 -beaked, partly inclosed, circumscissile; seed 1.-(1) Herbs with alternate leaves tapering to a petiole, and minute green or purplish fls. in axillary or terminal clusters.

$\$$ Flowers in long axillary and terminal, paniculate spikes, and 5-parted. (*)

* Herbage and flowers more or less tinged with crimson.................... Nos. 1, 2

* Herbage and flowers green, never tinged with crimson.............................. $8-5$

$\S$ Flowers in remotish, axillary, dense glomerules, and 3 -parted.......................... 6, 7

1 A. hypochondriacus L. PRIncE's FeATHER. Erect, furrowed, smoothish, and somewhat reddened; lvs. long-petioled, oblong-lanceolate, pointed at each end, roughish beneatl; panicle branched; spiles erect, very obtuse, the terminal one much the longest and largest, lateral short and crowded; fls. deep purple; cal. shorter than the long-awned bracts.-Fields and gardens, spontaneous and often cultivated. Very tall ( 3 to 4 to $6 f$ ) and showy. Lvs. 4 to $\delta^{\prime}$ long, petioles nearly same length. $+\S$ Mex.

2 A. paniculatus Moq. Prince's Feather. Erect, subterete, pubescent, palo green; lvs. oval or ovate-lanceolate, taper pointed at each end, purplish on tho margin; panicle very branching, spikes erect or spreading, cylindric, acutish, crowoded, all nearly equal; fls. reddish green or (in variety SANGUINEUS) blood-red; bracts short-awned, a little longer than the calyx. - Fields and gardens. St. 3 to $5 f$ high, with purple lines. Lvs. 4 to $8^{\prime}$ by 2 to $3^{\prime}$, petiole 2 to $3^{\prime}$. Spikes slender. $+\S \mathrm{Mex}$.

3 A retroflézus L. Erect, subterete, pubescent, glaucous green; lvs. longpetioled, ovate or subrhombic, acuminate, obtuse at apex, undulate; panicle pyramidal, spikes oblong-ovate, thick, crowded, in a dense panicle, the terminal hardly longer; fls. dense, pale green; bracts awned, twice longer than the calyx; utricle included,-A common weed in cultivated and waste grounds. St. 2 to $4 \mathrm{f}$ high. Lvs. 3 to $5^{\prime}$ by 18 to $30^{\prime \prime}$ with prominent veins, petiole 2 to $3^{\prime}$. Spikes 6 to $9^{\prime \prime}$ thick and rather short. Jl.-Sept.

4 A. chloróstachys Willd. Ivs. ovate, obtuse, intense green, as well as the flowers; panicle raceme-like, with acute spikes, terminal spike longest and flexuous; bracts a third longer than the calyx; utricle exserted; otherwise as in No. 3.-Cultivated and waste grounds. St. 3 to $4 \mathrm{f}$ high. Lrs. 2 to $3^{\prime}$ by 1 to $2^{\prime}$, petiole 2 to $3^{\prime}$. Fls. smaller than in that species. Jl-Sept. \& Asia.

5 A. hýbridus L. Erect, angular, glabrous, green; lvs. ovate-oblong or ovate acute, bright green; panicle loosely branched; spikes erect cylindric obtuse, terminal one long, rigid, lateral short, close; fls. loose, green, cal. shorter than the awned bracts, as long as the utricle. - Cultivated and waste grounds, common. St. 2 to $4 \mathrm{f}$ high. Lvs. 2 to $4^{\prime}$ by 9 to $18^{\prime \prime}$, petioles longer. Panicle long, sometimes tinged with red. Jl-Sept. $\S$ Mex.

6 A. álbus L. WHITE PIGWEed. Erect, subterete, whitish, with spreading branches ; lvs. long-petioled, ovate, rhomb-ovate or obovate, very obtuse, glabrous, light green; glomerules remote, in pairs, much shorter than the petioles; fls. dense, green; cal. much shorter than the rigid, subulate, pungent bracts, twice shorter than the utricle.-A common weed, roadsides, waste grounds. Sts. 1 to 
2f high, at length diffuse. Lvs. 1 to $2^{\prime}$ by 3 to $7^{\prime \prime}$, petiole 1 to $2^{\prime}$; branch-lvs much smaller. Clusters 4 to 5 -flowered.

7 A. melanchólicus I. LovE-LIES-BLEEDING. Erect, glabrous, usually dark purple; lvs. long-petioled, lance-ovate or lance-oblong, obtuse, eniarginate; glomerules geminate, subpedunculate, shorter than the petioles; fis. dense, dark purple; bracts, calyx and utricle subequal. Gardens. St. 1 to $2 \mathrm{f}$ high, simple. Lvs. 2 to $5^{\prime}$ long, petiole 2 to 3 . Clusters amplexicaul. $†$ Asia.-Varies much in color.

B. TRícolOR. Ivs. oblong-lanceolate, tho young red with a yellow apex, the adult bright red at base, violet in the middle, green at apex, the old green with a violet base. $t$.

3. EUX'OLUS, Raf. (A name intended to signify well-closed; referring to the valveless utricle.) Flowers monœcious, 3 -bracted; calyx 3 (2 to 5)-sepaled, sepals equal, erect, glabrous; stamens 3 ( 2 to 5$)$; stigmas 3 ; utricle ovate, 1 -seeded, valveless and indehiscent, or tearing open ; seed vertical, embryo annular.-(1) Herbs with the habit of Amarantus (Amarantus, L.)

$\$$ Spines 2 in each axil. Bracts not longer than the 5 sepals........................ 1

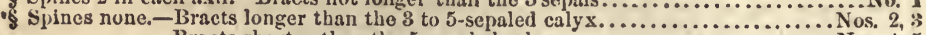
-Bracts shorter than the 5 -sepaled caly $x$................................. 4,5

1 E. spinòsus Feay. Smooth, striate, purplish, much branched; lvs. longpetioled, rhomb-ovate, or lance-ovate, obtuse, dull green, with 2 axillary spines; panicle sparingly branched, spikes erect, acute, the terminal longest ; fls. crowded, 5-parted; bracts, sepals and rugous utricle about equal in length.-Cultivated and waste grounds, Penn. to IIl. and S. States. St. and branches flexuous, 1 to $3 \mathrm{f}$ high. Lvs. 2 to $3^{\prime}$ long, petioles nearly as long, spines sharp, 3 to $8^{\prime \prime}$ long, Utricle certainly valveless (as first noticed by Dr. Feay), and falling without opening. Seed dark brown, polished. Jn.-Oct.

2 ت. lívidus Moq. Erect, branched, smooth, livid-purplish; Irs. long-petioled, elliptic or ovate, obtuse, emarginate, upper acutish; axillary spikes shorter than the petiole, the terminal long, slender, rigid, acute, somewhat interrupted; fls. crowded; sep. 3 , thrice longer the bracts; fr. rogous, acute.-Cultivated and wasto lands, Va. to Fla. and La. St. stout, hollow, striate, 2 to $3 \mathrm{f} \mathrm{high.} \mathrm{Lvs.} 3$ to $6^{\prime}$ by 2 to $3^{\prime}$, petiole $2^{\prime}$ to $30, "$, purple. Terminal spike 2 to $4^{\prime}$ long. Fls. 3 -parted. Utricle slightly exserted. 'Jn.-Sept.

3 Ð. defléxus Raf. Ascending, diffusely branched, ashy green, puberulent, branches deflexed: lvs. petiolate, rhomb-lanceolate, obtuse; spilies thickish, abtuse, somewhat nodding, axillary and terminal; fls. crowded, short-pedicelled; sep. $\mathbf{3}$ to $\mathbf{5}$. longer than the bracts; $f r$. smooth.-Waste and cultivated grounds, Mid. States. Sts. branched from base, slender, if long. Lrs. wavy, prominently veined beneath, 6 to $15^{\prime \prime}$ long. Stigmas 2 or 3, very short, white. Utriclo exserted. Aug., Sept. § Eur.

4 A. víridis Moq. Erect, smooth, livid, purple; lvs. long-petioled, ovate, obtuse; spities axillary and terminal, paniculate, rather long, loose, acutish; sepals 3 , twice longer than the bracts; utricle roundish-ovate, rigulous.-Cultivated and wasto grounds, Ala. and La. St. sulcate, 1 to $2 \mathrm{f}$ high. 'Terminal spikes 2 to 3 ' long. Readily recognized by the baldness of the minute fls.

5 E. púmilus Raf. Low, very smooth, diffusely branched, lvs. sulsessile, ovato, obtuse, smooth, fleshy, clustered at the ends of the branches; fls. in small, axillary glomerules, sessile; cal. 5-parted, purplish; fr. smooth, ovate, twice longer than than the calyx.-Sandy sea coast, N. Y. to Ga. Aug.-Oct. (A. pumilus Ell.)

4. ACNI'DA, L. WAter Hemp. (Gr. $a$, not, кví $\eta$, the nettle; a nettle-like plant which does not sting.) Flowers diœcious, 3-bracted. t Calyx of 5 equal, erect sepals; stamens 5 , anthers oblong, 2-celled; $\%$ calyx 0 ; ovary 1 -celled, 1 -ovuled, with 3 to 5 stigmas; fruit a fleshy, valveless utricle; seed vertical.-(1) A marsh herb, with alternate, petio- 
late, entire, smooth lvs. and small, green, subpedicillate fls. in slender, axillary and terminal spikes.

A cannabina L.-Salt marshes, brackish swamps, Can. to Ga. and La. St. tall, 3 to 6 to 8 , thick, subterete. Lvs. ovate-lanceolate, 2 to 5 to $8^{\prime}$ long, acuminate, wavy, cuneate at base, petiole 1 to 2 ' long. Fruit paniclo loose. Bracts $\delta$ lanceovate, shorter than the calyx, of linear-subulate, very unequal. Fr. near $2^{\prime \prime}$ long. J1.-Oct.

5. MONTELIA, Moq. Flowers, bracts, stamens, inflorescence, nearly as in Acnida. Stigmas 3, very long, bristle-shaped, feathery; fruit a thin utricle, with a tortuous circumscissile dehiscence.-(1) Herb glab rous, with long-petioled lvs. and small, greenish, spicate fls.

II. tamariscina Gray.-Damp sandy soils or shores, W. States, rare in N. Eng. St. flowering at all heights from 1 to $5 \mathrm{f}$, angular, branched, lvs. lance oval, 1 to $5^{\prime}$ by 6 to $15^{\prime \prime}$, petiole as long. Spikes interrupted and leafy at base, continuous above. Bracts of acute, shorter than the calyx, of rigid, subulate, longer than the ovary which in fruit opens by a tortuous line. Seed dark brown, polished. Jl. - Sept. (A. ruscocarpa and altissima Mx. A. Miamensis Ridd.)-Varies with the clusters all axillary, hardly forming spikes.

5. IRESI NE, Brown. (Gr. $\varepsilon \iota \rho \varepsilon \sigma \iota \omega ́ v \eta$, an olive-branch bound with tufts of wool borne by supplicants.) Flowers dinecious or $\Varangle, 3$-bracted; calyx of 5 erect sepals; stamens 5 , anthers 1 -celled; stigmas 2,3 ; utricle roundish ovate, valveless, 1 -seeded, included in the calyx; seed vertical.-Herbs with opposite, petiolate lvs. and minute, densely spicate or capitate, often woolly fls. suggesting the name.

I. celosioides L. St. erect, furrowed, paniculate above; lvs. scabrous, punctate, lower oblong, acuminate, upper ovate-lanceolate; panicle compound, large, rather dense. - A tall handsome annual, 3 to $4 \mathrm{f}$ high, on river banks, Ohio near Cincinnati, to Ill. and La. Lvs. tapering to the base into a winged petiole, 3 to $6^{\prime}$ by 2 to $4^{\prime}$. Panicle of delicate, whitish fls. large, with opposite branches, branchlets and pedicels, nearly or quite leafless. Sept., Oct.

7. GOMPHRE'NA, I. Globe Amaranth. Flowers perfect or polygamous, 3-bracted ; calyx 5-scpaled or 5-cleft, sepals erect; stamens 5 , filaments dilated and 3-cleft at apex, middle tooth bearing the 1-celled anther; stigma capitate; utricle valveless, 1-seeded, included in the calyx. Herbs or shrubs of S. America. Lvs. opposite. Fls. usually capitate.

G. globòsa I. Erect, trichotomously much brançed, pubescent; lvs. shortpetiolate, oblong, acute, mucronate, entire; fls. bright purple, in globular, 2-bracted, pedunculate, terminal heads; bracts glabrous, longer than the woolly calyx. Gardens. Stem 1 to $2 \mathrm{f}$ high. Branches suberect. Hds. near $\mathrm{I}^{\prime}$ diam, fadeless. + E. Indies.

8. TELAN'THERA Brown. (Gr. $\tau \varepsilon ́ \lambda \varepsilon \iota \iota s$, full, complete, Lat. antherce; alluding to the perfect flowers.) Fls. perfect, 3-bracted; calyx of 5 sepals ; stamens 5 , with 5 intervening, elongated, sterile filaments ; 'anthers 1-celled; style short, stigma capitate; utricle valveless, 1-seeded, included in the calyx.-Herbs or shrubs with opposite lvs., axillary and terminal hds. of fls.

T. polygonoìdes Moq. $\quad \beta$. REPENS. Procumbent, diffusely branched, hairy; lvs. oval, obtuse, attenuate to a winged petiole; hds. sessile, 1 to 2 together, oval, obtuse; fls. whitish silvery; bracts shorter than the ovate-acuminate, mucronate, unequal sepals, inner sep. hairy. - 2 Cultivated grounds, roadsides, in the vicinity of the coast, S. States. Sts. slender, 1 to $2 \mathrm{f}$ long. Lrs. including the petiole 6 to $15^{\prime \prime}$ by 4 to $7^{\prime \prime}$. Hds. 3 to $4^{\prime \prime}$ long. Feb. - Oct. 
9. FRELLICH'IA, Mœnch. (Named for J. A. Frolich, a German botanist.) Flowers perfect, 3-bracted; calyx tubular, 5-cleft at apex; stamens 5 , connate into a tube, appendaged with as many sterile filaments; anthers 1-celled; stigma capitate or tufted; utricle valveless, 1 -seeded, enclosed in the hardened calyx which bears 2 or 5 longitudinal crests. - (1) Herbs with jointed, villous stems, opposite lvs. and spicate fls.

F. Floridàna Moq. Nearly simplo, strictly erect, arachnoid pubescent; lvs. linear, tapering to the base, obtusish at apex; fls. imbricated, in short, dense, clustered, cottony spikes.-On sandy river banks, Ill., also Fla., Ga. to La. Plant 1 to $3 f$ high, with a terminal, virgate panicle 6 to $10^{\prime}$ long. Lrs. 1 to $2^{\prime}$ by 3 to $5^{\prime \prime}$. Spikes 6 to $12^{\prime \prime}$ long. Calyx white-scarious, persistent, contracted above, enclosing the utricle. Jl, Aur.

\section{Order CVII. LAURACEA. Laurels.}

Trees and shrubs aromatic, mostly with alternate, simple, punctato leaves. Fiowers with a colored perianth of 4 to 6 slightly united, strongly imbricated sepals. Anthers 2 or 4-celled, opening upwards by as many recurved, lid-like valves. Ovary 1-celled, 1-ovuled, free, in fruit a berry or a drupe. Seed without albumen.

Genera 50 , species 450 , chiefly natives of the Tropies.

Properties. - The species of this highly important order are thronghout pervaded by a warm and stimulant aromatic oil. Cinnamon is the dried bark of Cinnanomum Zeylanicum, of Ceylon, sc. Camphor is obtained from many trees of this order, but chlefly from Camphora oficinarum, of Japan, China, \&c. Cassia Bark, Proun Cinnamomum aromaticum, of China. lersen gratissima, is tree of the W. Indies, yields a delicious fruit called the Aroendo pear. Some of the following species are slso moderately modicinal. The elassic Laurel is Laurens nobilis of S. Europe.

\section{GENERA.}

\$ Flowers perfect, the calys persistent. Ieaves evergreen. . . . . . . . . . . . . . . . PErsia. 1

5 Flowers declinous. Calyx deciduous. Leaves decilluous. (*)

* Involuere none. Anthers 4-eelled, 4-valved. Lvs. lobed..................SAssafras. 2

* Involuere 4-leared. Anthers 2-celled, 2-valved. Leaves entire............... Brxzorx. 3

* Involucre 4-leaved. Anthers 4-celled, 4-valved. Leaves entirc......... Trmantuska. 4

1. PER'SEA, Gaert. Red Bay. Bay Galls. Flowers perfect, umbellate, with no involucre; calyx of 6 sepals persistent in fruit; stamens 12 , the 3 inner sterile, reduced to mere glands, anthers 4-celled ( 2 cells above and 2 below); drupe oval, seated on the persistent calyx, containing 1 large seed.-Trees evergreen, the fls. in axillary, pedicellate umbels.

P. Caroliniénsis Mx. Lrs. oblong-lanceolate or oblanceolate, acute or pointed at each end, coriaceous, entire, glaucous beneath; umbels simple or compound, on long peduncles; sep. coriaceous, velvety, the 3 outer smaller; drupe oval, blue. Va. to Fla. in swamps. A tree 30 or 40 f high, with a deeply furrowed bark and coarso branches; but more commonly in poor soils a stinted shrub filling the sandy swamps. Lvs, evergreen, about $6^{\prime}$ by $18^{\prime \prime}$, attenuated to a short petiole. Drupo $5^{\prime \prime}$ by $4^{\prime \prime}$. Apr., May. - Wood of a fine rose-color, once used in cabinet-work.

2. SAS'SAFRAS, Nees. SAsSafras. (Spanish, salsafras, saxifrage; from the supposed resemblance of properties.) Diœcious; involucre 0; calyx 6-parted, equal, deciduous; of stamens 9 , in 3 rows, the inner with a pair of stipitate glands at the base of each; anther 4-celled; o stamens 6 , imperfect; ovary ovoid, acuminate; style short, stigma capitate; drupe ovoid, on a fleshy pedicel.-Trees deciduous, with tho fls. yellow in terminal clusters appearing before the leaves. (Laurus, L.)

5. officinàle Nees. Lvs. of two forms, ovate and entire, or 3-lobed and cuneato at base; fls. in terminal and axillary, corgmbous racemes, with linear bracts.-U. 
S. and Can. An interesting shrub or small tree, 10 to $20 \mathrm{f} \mathrm{high.} \mathrm{Leaves} \mathrm{alter-}$ nate, petioled, those of the young shoots ovate-lanceolate, others with 3 large lobes. Fls. greenish-yellow, in clustered racemes at the end of the last year's twigs; drupe blue. A pr.-Jn. Every part of the tree has a pleasant fragrance, and a sweetish, aromatic taste, which is strongest in the bark of the root.

3. BENZOIN, Nees. Spice Wood. (Named for its fragrance, which is compared to that of the resinous substance, benzoin.) Flowers diœcious with 4 involucrate scales; calyx 5 to 6 -parted; of stamens 9 , in 3 rows, the inner lobed and gland-bearing at base; anthers 2 -celled; of stamens 15 to 18 , sterile, filiform; drupe obovoid, on a pedicel not thickened.-Trees or shrubs with entire, deciduous lvs. and small, lateral clusters of yellow fls. preceding the lvs.

1 B. odoriferum Nees. Lvs. obovate-lanceolate, veinless, entire, deciduous; fls. in clustered umbels; buds and pedicels smooth.-A shrub 6 to $12 \mathrm{f} \mathrm{high,} \mathrm{in} \mathrm{moist}$ woods, U. S. and Can. Lvs. cuneiform and acute at base, 2 to $4^{\prime}$ long, half as wide, paler beneath. Fls. pedicellate, in small, sessile umbels, 4 or 5 from each bud. Drupes red. May. (Laurus Benzoin, L.)

2 B. mellissæefòlium Nees. Lvs. oblong-lanceolate, abrupt or cordate at base, veiny, pubescent beneath; fls. in clustered umbels; buds and pedicels villous.Borders of shallow ponds or exsiccated swamps, S. States. Shrub 2 to $3 f$ high, with running roots and virgate shoots. Lvs. with prominent veins. Fls. about 3 from each bud. Drupes red. Feb., March. (Laurus mellissæfolia Walt.)

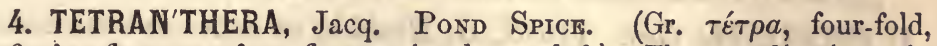
à 0हpòs, flowery; four flowers in the umbel.) Flowers diœcious, in little stalked umbels, with a 4 or 5 -leaved deciduous involucre; calyx 4 or 6 -parted, deciduous; $\hat{\delta}$ stamens 9 , in 3 rows; anthers unequally 4-celled ( 2 cells above and 2 below); $q$ stamens 12 to 15 rudiments; stigma dilated, 2-lobed, smooth; drupe naked.-Lrs. deciduous. Fls. yellow, appearing before the lis.

T. genículàta Nees. Branches divaricate and geniculate; lvs. small, oblong and oval, nearly smooth, cuneate at base, mostly obtuse at apex; umbellets terminal, glabrous, on distinct pedicels.-In sandy swamps, borders of lagoons, Va. to Fla. Shrub 8 to $15 \mathrm{f} \mathrm{high,} \mathrm{with} \mathrm{branches} \mathrm{and} \mathrm{branchlets} \mathrm{remarkably} \mathrm{crooked} \mathrm{and} \mathrm{strag-}$ gling forming an angle of $90^{\circ}$ at every fork. Lvs. $1^{\prime}$ to $18^{\prime \prime}$ long, 5 to $8^{\prime \prime}$ wide. Drupes red. Feb., Mar. (Laurus geniculata Walt.)

\section{Order CVIII. LORANTHACEA. Loranths.}

Shrubby plants parasitic on trees, with thick, opposite, exstipulate leaves. Flowers mostly declinous, an adherent calyx of 4 to 8 lobes, with stamens of the samo number, opposite tho calyx lobes. Ovary 1-celled, becoming a fleshy fruit with one albuminous seed. Fig. 37, D.

Genera 25, species 400, mostly tropical in America and Asia, a few flourishing northward as far as our latitude. They pussess the remarkable property of planting themselves on trees and subsisting on their julces. They are slightly astringent. Bird-lime is formed in part from the viscid pulp of the fruit of the Mistletoc.

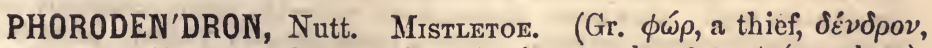
a tree; they live on stolen food.) Diœcious; calyx 2 to 4 (mostly 3)lobed, lobes erect; $\hat{\delta}$ anther sessile on the base of each lobe, 2-celled, the cells divergent; + calyx adherent to the ovary; stigmas sessile; stamens 0 ; fiuit a pulpy berry.-Herbage fleshy, yellowish green. Sts. jointed, brittle, woody, firmly engrafted on the limbs of trees, especially Oaks, Elms, Apples, \&c. Fls. imbedded in the jointed rachis. 
P. flavéscens Nutt. Branches opposite, sometimes verticillate, terete; Ivs. cur. neate-obovate, 3-veined, obtuse; spikes axillary, solitary, about as long as the leaves; berries white, semi-transparent.-N. J. to Ill. (Lapliam), and the S.

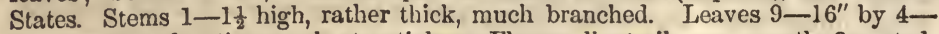
9", smooth and entire, on short petioles. Fls. small, sterile ones mostly 3-parted. Berry with a viscous pulp adhering to the limb it touches until it strikes ropto April.

\section{Order CIX. SANTALACEA. Sandalworts.}

Trees shrubs and herbs, with alternate, undivided leaves, with the calyx tube adherent to the ovary, limb 4 to 5 -cleft, valvate in rstivation, the stamens as many as the sepals, inserted at their base and opposite to them, an ovary 1-celled, with a free central placenta bearing at top 2 to 4 suspended ovules, but in fruit drupaceous, 1-seeded, crowned with the persistent calyx.

Genera 20, species 200, natives of Europe, America, Australasla, \&c. The fragrant sandalwood is the product of Santalum album, \&c., of India.

\section{TRIEES AND GENERA.}

I. BUCKLEYEA. Fls. diœcious, tho pistillate dichlamydeons, with no stamens.

\& Calyx lobes 4 ; petals 4 , caducous. fstamens 4. Shrubs............... Buckuera. 1

II. SANTALEA. Flowers perfecl or polygamous, always monochlamydeous. (a)

a Flowers in spikes or racemes. Drupe pyriform. Shrubs............. Proclakia. 2

a Flowers in cymous umbels. Nut ovoid. Half shrubby............... Comandra. 3

1. BUCKLE'YA, Torr. (To S. B. Buckley, an active and successful botanist.) Flowers $\hat{o} q$, the $q$ dichlamydrous; outer (ealyx) lobes 4 , lanceolate ; inner (corolla) lobes 4, ovate, acute, 1-veined, caducous; stamens 0 ; style included, 4-lobed; $\hat{\delta}$ monochlamydeous; lobes 4, ovate, acute, valvate in bud, opposite the 4 stamens inserted at their base; disk concave, lobes 4 , alternate with the sepals; fruit oblong, drupe-like, 10-furrowed, 1-secded.-A shrub or small tree, with subsessile, entire lvs., the sterile fls. clustered, pedicellate, the fertile solitary, all terminal, small.

B. distychophylla Torr.-Mts. of E. Tenn. Shrub with the slender twigs velvety-puberulent, as well as the veins and flower-stalks. Lvs. ovate, acuninate, 9 to $18^{\prime \prime}$ long, thin, ciliate on the margin, obtuse at base, on very short petioles. if fls. $1 \frac{1}{2}$ " broad, in the midst of caducous bractlets. $\&$ Fl. subtended by 4 bractlets. Fr. 8 to 9 "long, narrowed at base into tho short stipe. (Borya distychophylla Nutt.)

2. PYRULA'RIA, MIx. Orl-nut. (Diminutive of Pyrus; its fruit resembling a little pear.) Flowers diœcious; calyx 5-cleft, subeampanulate; disk 5-toothed, glandular, half-adherent to the ovary ; style 1 ; stigmas 2 or 3 , sublenticular; drupe pyriform, 1-seeded, inclosed in the adhering base of the calyx.-Shrubs with the habit of Celastrus. Lvs. alternate, entire. Rac. terminal.

P. pùbera Mx. Shrub unarmed; lvs. oval-oblong, acute, puberulent, pellucidpunctate; rac. spike-like, terminal._Margins of mountain streams, Fenn. to Ga. Shrub 4-6P high. Root fetid. Leaves $2-3^{\prime}$ by $1-1 \frac{1}{2}^{\prime}$, entire, acuminate, petjolate, veins prominent beneath. Flowers small, greenish yellow. Calyx tubo short, nearly filled with the glandular disk in the $\delta$ flowers, the segments reflexed in the $\%$. Stamens alternate with the glands of the disk, opposite to those of the calyx Drupe 7 to $9^{\prime \prime}$ long, 5 to $7^{\prime \prime}$ thick. May. (Hamiltonia oleifera Muhl.)

3. COMAN'DRA, Nutt. Bastard Toad Flax. (Gr. kw $\mu \eta$, hair, a้ $\nu \delta \rho \varepsilon$, , stamens; stamens connected to the petals by a tuft of hairs.) 
Calyx somewhat urceolate, tube adherent, $\operatorname{limb} 4$ to 5 -parted; stamens 4 to 5 , opposite the sepals, and connected to them by a tuft of hairs; filaments inserted into the top of the perigynous, 5-lobed disk, between its lobes; fruit drupaceous, 1-seeded, crowned with the limb of the calyx.-Very smooth, suffruticous plants. Ped. axillary and terminal. Fls. small, umbellate.

6 1. Eucosandra. Flowers perfect. Leaves all alternate......................... 1

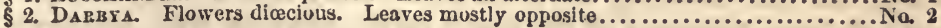

1 C. umbellàta Nutt. Erect; lvs. oval-lanceolate; fis. subcorymbed, terminal ; connecting hairs yellow. - 24 Plant about a foot high, in rocky woods, U. S. and Brit. Am. Stem slender, striate, generally branching at top. Leaves entire, alternate, acutish, $1-1 \frac{1}{2}^{\prime}$ long, and $\frac{1}{3}$ as wide, tapering to a very short petiole. Flowers small, white, in little umbels of about 3. Each umbel is furnished with a deciduous involucre of about 4 small leaflets, the whole constituting a kind of corymb. June.

2 C. Dárbya A. DC. Lrs. elliptical; cymes lateral, about 5-flowered; calyx lobes spreading-reflexed, connecting hairs white.-Ga. near Macon (Darby), N. Car. near Lincolnton (Curtis). A small shrub with terete, blackish branches, the branchlets herbaceous, sliort, leafy. Lvs. thin and pale, 12 to $18^{\prime \prime}$ by 5 to $8^{\prime \prime}$, short-petioled, apex obtuse or submucronate. Cymes shorter than the leaves, on slender peduncles. Pedicels 1 or $2^{\prime \prime}$ long. Bracts deciduous. Calyx lobes ovate, acute. Fruit unknown. (Darbya umbellulata Gray.)

\section{Order CX. THYMELACE E. Dapinads.}

Shrubs with a very tough, acrid bark, entiro leaves and perfect flowers, with tho calx tubular, colored, the limb 4 (4 or 5)-parted, regular, the tube bearing the stamens as many or usually twice as many as its lobes, and free from the ovary, which is 1-celled, 1-ovuled, the suspended seed with little or no albumen.

Genera 40, species 375, very abundant in Australia and S. Africa, sparingly disseminated in Europe and Asia. The only N. American genus is the following.

Propertie.3.-The bark is acrid and caustic, raising blisters upon the skin. It is composed of interlaced fibers, which are extremely tough, but easily separable. The lace-bark treo (Lagetta) of Jamaica is particularly remarkable for this property.

DIR'CA, L. Leather-wood. (Gr. dipra, a fountain; the shrub grows near mountain streams or rivulets.) Calyx colored, tubular, with a truncate or obscurely 4-toothed limb; stamens 8, unequal, longer than and inserted into the tube; style 1; berry 1-seeded.-Lvs. alternate, simple. Fls. expanding before the oblong-obovate lvs., 3 from each bud.

D. palústris $\mathrm{L}$ - $-\mathrm{A}$ shrub $5 \mathrm{f}$ in height when full grown, U. S. and Can. The fls. appear in April and May, much earlier than the leaves. They are small, yellow, funnel-shaped, about 3 together, with a bud-like involucre. Isrs. from the samo buds, entire, on short petioles, pale underneath. Stam. much longer than tho calyx, alternately a long and a short one. Berry oval, small, red. Every part of this shrub is very tough. The twigs furnish "rods for the fool's back," the bark is used for ropes, baskets, \&c.

DAPHNE is a genus differing from Direa by its spreading calyx limb and included stamens.

D. Mezéreum, with deciduous lvs. and D. Laureola with evergreen lvs. aro occasionally cultivated.

\section{Order cXi. elateagnace}

Shrubs or trees usually with the leaves covered with a silvery scurf, entire; flowers mostly dicecious, the calyx free, entire, persistent, becoming in fruit pulpy 
and berry-like, inclosing the 1-celled, 1-seeded achenium. Seed ascending, embryo straight, albumen scanty.

Genera 4, species 30 , thinly dispersed throughout the Northern hemisphere.

1. SHEPHER'DIA, Nutt. (In honor of John Shepherd, curator of the botanic garden of Liverpoel.) Flowers of $\hat{o} .-\hat{o}$ Calyx 4-cleft; sta. 8, alternating with 8 glands. + Calyx tube closely investing the ovary, but not adhering to it, limb 4-lobed; sty. 1; stig. oblique; berry globous, composed of the fleshy calyx.-Shrubs with spinescent branches, and opposite, deciduous leaves. Fls. aggregated.

I ธ. Canadénsis Nutt. Ivs. elliptic-ovate, nearly smooth above, clothed beneath . with stellate hairs and ferruginous, deciduous scales.-A shrub $6-8 \mathrm{f}$ high, found in Vt., N. Y. and W. to Wis. (Lapham), and Can., by streams and on river banks. Leaves obtuse at each end, the upper surface green, with few, scattered, stellate hairs, lower surface white, with rust-colored spots; densely tomentous, margin entire; petioles $2-4^{\prime \prime}$ long, lamina $1-2^{\prime}$. by $\frac{1}{2}-1^{\prime}$. Fls. minute, in small, lateral, nearly sessile clusters. Berries oval, scaly, consisting of the fleshy calyx inclosing the achenia in its tube, sweetish to the taste. J1.-A curious and ornamental shrub.

2 S. argéntea Nutt. Lvs. oblong-ovate, obtuse, both surfaces smooth and equally covered with silvery scales.-A small tree, $12-18 \mathrm{f}$ high, with thorny branches. Leaves $1-2^{\prime}$ by $4-9^{\prime \prime}$. Petioles $\frac{y^{\prime}}{2}$ long, margin entire, the surface of a light, silvery hue, sprinkled with rust-colored spots. Fruit the size of a currant, scarlet, well-flavored. † Mo.

2. EleaG'NUS, L. Oleaster. (Gr. Eiaía, the olive; the trees having a resemblance to the olive.) Flowers perfect. Calyx 4-cleft, campanulate, colored on the inner side; sta. 4, alternate with the calyx lobes; anth. subsessile; sty. short; fruit baccate, consisting of the achenium inclosed in the dry, farinaccous calyx tube, marked with 8 furrows.- Trees or shrubs, cultivated for the silvery foliagc. Leaves alternate.

1 E. argéntea $\mathrm{Ph}$. Lvs. broad-ovate or oval, wavy, acutish at each end, both surfaces, particularly the lower, silvery and shining, with ferruginous scales. $-A$. beautiful shrub, with reddish branches and small, roundish-ovate, cartilaginous drupes. $\dagger$ Mo.

2 E. angustifòlia L. Lvs. narrow-lanceolate, acute at each end, entire, alternate, smooth, canescent; fls. axillary, aggregate. $-\mathrm{A}$ tree of middlo size, cultivated for its beautiful foliage and pleasant date-like fruit. + Eur.

3 E. latifòlia L. Lvs. ovate, evergreen. † E. Ind.

3 HIPPOPH 1 rhamnoìdes, with linear-lanceolate lvs, silvery white boneath, tetrandrous, dicecious flowers, and a crowd of yellow, acid drupes, is a European shrub, occasionally seen in shrubberies.

\section{Order CXII. EUPHORBIACEA. SpUrgeworts.}

Iterbs, shrubs or trees, usually with a milky, acrid juice. Flowers diclinous, somotimes enclosed in a cup-shaped involucre. Calyx inferior, sometimes wanting. Corolla scale-like or colored, often wanting. Ovary frec, sessilo or stipitate, 2, 3 (or more)-carpeled; styles distinct or united. Fruit of 2, 3 (or more), 1 to 2-seeded carpels (rarely of 1 carpel) united to a common aris, at length separating. Embryo in fleshy albumen. Fig. 371.

Genera 200, species 2500 (Lindley), chicfly natives of S. America, not more than 60 species being found in $\mathrm{N}$. A merica, north of Mexico.

Properties. - In acrid, stimulant and poisonous principle, residing chicfly in the milky juice, pervades the whole order. This principle varies in activity from mild stimulants to the most active poisons; but it is volatile and easily expelled by heat. Tapioca is a starch-like accumulation formed in the roots of the Jatropha Maniliot. When fresh, shis root is a violent polson, 
but loses its deleterions propertieg by washing and exposure to heat. Castor-oil is expressed frou the seeds of lileinus communis. Croton-oil from the seeds of Croton 'liglium. Caoutehoue is yielded in abuudance by several S. American species.

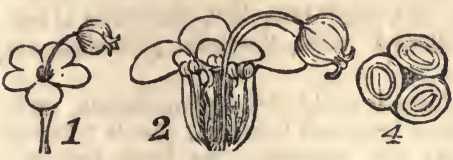

FIG. 687.-1. Ilearl or capitulum of Euphorbla curollata; with the corolla-like involncre, anil pedicellate pistlllate flower. 2. The involucre tubo cut open, showing the inonanilrous, staminate flowers surronnding the pistillate. 8 . One of tho s llowers, with a tootheil bract at base. 4. Cross section of the ovary, showing the 8 one-seedorl cells or carpels.

O58. Our specimens of the Enphorbiacere rere submitted to the inspection of Dr. Engelmann, of St. Louis, and are here deseribed nearly in accordance with his nomenelature.

GENERA.

8 Cells of the ovary onc-oruled; frult 3 (rarely 2 or 1)-seeded. (*)

- Flowers in a cup-shaped Involucre, the of many, each inerely a stamen, with ono \& flower, an ovary exserted on a pelicel...................... Euprorion 1

* Flowers not in an involucre 8 , all apetalous, having a calyx only. (a)

a Flowers diandrous, in a terminal spike. Plants glabrous............. Struxrara. 2

a Flower 2 to 3 -androus, in racemes. Plants hairy or downy............TrAGiA. 8

a Flowers 8 to 12 -androus, in small spikes with large bracts.............. ACALYPIA. 4

a Flowers 10 to 15 -androus, in cymes, with white sepals. Stinging..... Cxidoscouts, 5

a Flowers polyandrous, in panicles; fruit echinate. Plant glabrous......... Ricrevs. 6

* Flowers not in an involuere 8 , the sterile and often the fertile, also with petals. (b)

b Ova. 3 (rarely 2)-celled and seeded. Fis. clustered. Woolly, downy or scurfy.Crotox. 7

b Ova. 1-celled, 1-sceded, indehiscent. Fls. axillary, small. Sllvery scurfy.Crorovopsis, 8

Cells of the ovary 2-ovuled; fruit 6 (or abortively fewer)-seeded. (c)

c Calyx 6-parted; stamens 3 , united. Flowers axillary, small............. Puru.untuos. 9 c Calyx 4-parted; stamens 4, distinct, large. Flowers in bracted spikes.... PAcirsa vor. 10 c Calyx 4-parted; stamens 4, distinct. Flowers axillary. Shrub. Leaves opposite..Buxus. 11

1. EUPHOR'BIA, L. (Named for Euphorbus, physician to Juba, ling of Mauritania.) Spurge. Flowers 8 , several in an involucrate cluster; involucre calyx-like, eup-shaped, with 4 or 5 petaloid segments alternate with as many large glands; flowers achlamydeous, the $f 12$ or more each consisting of a single stamen on a pedicel which is axillary to a little bract; $\$$ flower solitary, central, a 3-carpeled, 3 -styled and 3 -sceded ovary raised on a slender pedicel; capsule 3 -lobed, separating into 3 bivalved nutlets.-Herbs or shrubs with a milky juice. Lvs. generally opposite or verticillate, often alternate, sometimes none. Involucres flower-like, axillary or umbellate.

$\$$ Stenis spiny, thick, ereet.-Dtipules none. Floral leaves scarlet........................

Stems unarmerl, crect. Leaves destitute of stipnles, alternate or opposite. (*)

* Involucre with 4 or 5 glands which are 2 -horned or crescent-shnperl. (a)

a Uinbel of many rays. Stem-leaves narrow, alternate. Seeds smooth. $2 f \ldots$... Nos. 2, 3

a Umbel of 3 rays, and forkel. - Stem leaves alternate, thin ................ Nos. 4, 5

a Umbel of 3 or 4 rays, and forked. - Stem leaves opposite, thick.................. 6

* Involucre with 5 white, petal-like glands or appendages. (b)

b Ileals nearly sessile. Leaves with broad, white margins..................... 7

b Heals perlunculate, solitary or subpaniculate. Leaves broal oval................ 8,9

b Ileads pedunculate, umbellate. Leaves oblong, inostly narrow............... 10, 11

- Involucre with 1 to 5 glands neitlier jetal-like nor horned. (c)

c Inflorescence in compound cymes, with long peduncles.................... No. 12

c Inflorescence in compound umbels, with short peduncles. (d)

d Seeds reticulated or wrinkled. Leaves serrulate..................... 13, 14

d Seeds smonth and evell, in a rough, warty fruit............................... 15, 16

c Inflorescence solitary, axillary. Leaves all opposite....................... 17

c Intlorescence a simple, terminal cluster. Leaves alternate or opposite.... Nos. 19,19

5 Stems unarmed, chiefly prostrate, diffuse. Leares all opposite, small. with small, entire or cleft stipules. Involucres axillary or clustered. May to Nov. (1) (e)

e Leaves serrulate or serrate. Seeds roughened with winkles or pits. (f)

f Stem ascending or erect, smooth or smoothish. Seeds black or amber color. Nns. 20, 21

f Stem prostrate, hairy or puberulent as well as tho leaves and fruit...... Nos, 22, 23, 24

- Leaves entire. Seeds smooth und even. Plants glabrous...................... 25, 26, 27

1 E. spléndens Bojaris. St. suffruticous, fleshy, armed with rigid, sharp thorns; lvs. ovate, tapering to the base, glabrous, entire, acute, mucronate; ped. axillary, 2 or 3 times dichotomous; floral lvs. in pairs, broader than long, cuspidate, scarlet. $-\Lambda$ singular and showy garden plant. + Madagascar. 
2 E. Cyparissias I. Crpress Spurge. Lvs. linear-setaceous, crowded on the stem, with a spiral arrangement; floral lvs. broadly cordate, all sessile; umbel of many simple rays, with several scaltered branches below it; glands crescent-shaped; fr. granulated.-Gardens and fields, rare. Sts. much branched, ascending If high, with numerous leaves 6 to $10^{\prime \prime}$ long, less than $1^{\prime \prime}$ wide, the floral yellowish, very different. §Eur.

3 E. Ésula L. Lvs. lanceolate-linear, the floral broadly cordate, mucronate, umbel of many rays, the rays forked, with scattered branches below it; glands 2-horned; fruit nearly smooth.-Fields, Mass. (Oakes), not common. Sts. much branched, If high. Lvs. 1' or more long, the floral yellowish. Glands brown. § Eur.

4 E. Péplus L. Lvs. membranous, roundish, tapering into the pctiole, very obtuse, entire, smooth, the upper floral ovate; umbel of 3 , rarely 5 rays, then forked; glands lunate, with 2 long horns; ovaries with a double-winged keel at the back, rugous and scabrous; seed dull grayish white, with 2 longitudinal furrows and 4 rows of dots.-Waste places, N. Eng., rare. St. 7 to $12^{\prime}$ bigh. § Eur.

5 E. commutàta Engelm. Decumbent and branched at base, smooth; sts. crect; lower lvs. oval, petiolato; floral lvs. numerous, thin, broader than long, all sessile, very obtuse; ovaries obtusely angled, not winged, seeds dotted all over. $-2 f$ Along streams, W. Va. to Ohio, Ill. frequent, and S. to Fla. Sts. a foot high, once or twice trichotomous, tho floral lvs. so applied at baso as to appear orbicular and perfoliate, 6 to $9^{\prime \prime}$ diam. Horned glands usually but 4 .- Has been confounded with E. Peplus. Jn.

6 E. Lathỳris L. MOLE-Tree. CAPER SpUrge. St. erect, stout, smooth; Irs. lance-linear, rather acute, entire, glabrous, sessilo; umbel mostly 4-rayed, rays dichotomous; glands of the invol. lunate, 2-horned, the horns dilated and obtuse. -2. Cultivated grounds and gardens. Stem $2-3 \mathrm{f}$ high. Leaves $2-4^{\prime}$ by $3-9^{\prime \prime}$, numerous and arranged in 4 rows on the stem. Umbel of 4 verticillate branches with a central subsessile head. J1-Sept. \$ Eur.-Supposed efficacious in expelling moles from the ground.

7 E. marginàta Pursh. Lvs. oblong-lanceolate, subcordate, sessile, acute, mucronate, entire on the margin, glabrous; umbel 3-rayed, onco or twice dichotomous; involucrato lvs. oblong, cordate, colored and membranaceous at the margin; inner segments of the floral involucre roundish; caps. hoary-pubescent.-(1) $A$ handsomo species, remarkable for the variegated leaves of the involucre. $f$ Shores of the Ky. River at Paris, abundant. Doubtless escaped from the gardens. § Nativo in Nebraska.

8 E. mercurialìna $\mathrm{Mx}$. Sts. slender, weak, simply trichotomous; lvs. opposite or ternately whorled, nearly sessile, oval, entire; ped. terminal, solitary, bearing a single involucre.-2f Near Knoxville, Tenn. Jl., Aug., (Michaux). - A very obscuro and long-lost species. We gathered a singlo specimen 10 miles S. of Tallahassee, Fla., in 1857, differing from the description of Michaux only in its lower lvs. being scattered. It is about $9^{\prime}$ high, smooth. Lvs. I' long, entire, obtuse, villous-ciliate on their lower margins and very short petioles. Invol. lobes minutely edged with white.

9 E. paniculàta Ell. Erect from a decumbent base, slender, striate-angled, thinly pubescent; lvs. oval or elliptical, subrepand, revolute on the margins, glaucous beneath, short-petioled, the cauline alternate, ample, the floral small and bract-like, opposite; inflorescence irregularly forked, or paniculate; invol. small ( $1^{\prime \prime}$ diam.), glands slightly expanded, greenish white.-Ga. and Fla. Sts. 8 to $18^{\prime}$ high. Lvs. about $18^{\prime \prime}$ by $10^{\prime \prime}$. Invol. thrice smaller than in No. 10, of which it is considered a variety by Dr. Engelmann.

10 E. corollàta I. Flowerivg Spurge. Erect; caulino and floral lvs. oblong, narrow, obtuse; glands of the invol. obovate; petaloid; umbel 5-rayed, rays 2 or 3 times di- or trichotomous. - $2 f$ In dry fields, etc., Can. and U. S. Stem slender, erect, $1-2 \mathrm{f}$ high, generally simple and smooth. Leaves $1-2^{\prime}$ long, often quite linear, very entire, scattered on the stem, verticillate and opposite in the umbel. The umbel is generally quite regularly subdivided. Corolla-like involucre large, white, showy. July, Aug. - The central head is 2 or 3 weeks earliest.

B. ANGUSTIFòniA. Lvs. oblong-linear; umbel often becoming irregular or more or less paniculate.-Chiefly Southward. 
11 E. Curtísii Engelm. Smooth, very slender, branched from the base; division then cymously branched; lvs. all similar, opposite, narrowly linear, 1ather acute; invol. broadly obconic, the glands (inner segments) narrowly bordered with a whito membrane.-A very slender species, allied to E. corollata, about $10^{\prime}$ high. Lvs. 5 to $10^{\prime \prime}$ long, less than $1^{\prime \prime}$ wide. The narrow whito border of invol, consp:cuous. Ga. (Feay, Pond,) to N. Car. (Curtis.)

12 E. grácilis Ell. Very smooth and slender, st. 2 or 3 -forked below, the branches then repeatedly forked; lvs. all similar, oblong and oblong-linear, obtuse, entire, subpetiolate, mostly opposite; invol. on long peduncles, dark purple with oval glands; fr. strongly 3-lobed, smooth, seeds smoothish, dull.-Sandy pine barrens, S. Car. to Fla. Plant 5 to $10^{\prime}$ high, wholly purple when young. Lvs. 8 to $12^{\prime \prime}$ long, very variable in width. Mar., Apr.

$\beta$. ROTUNDIFòlis. Lvs. roundish or quito orbicular, entire, edged with purple. -With the other, $6^{\prime}$ high. A singular variety.

13 E. helioscòpia L. Sun Spurge. Erect; floral lvs. obovate, cauline wedgeform, sharply serrate, smooth; umbel 5-rayed, then 3-rayed and forked; fruit smooth and even; sds. reticulated. - (1) A milky weed in cultivated grounds, N. H. to Niagara, S. to Car., remarkable for tho symmetry of its vegetation. Stem smooth, erect, $8-16^{\prime}$ high. Leaves scattered, $\frac{2}{3}-1 \frac{1}{2}$ long, $\frac{2}{3}$ as broad at tho rounded or retuse apex, tapering to tho base. Umbels subtended by a large involucre of 5 obovato leaves. Each of the 5 rays is pilous with scattered hairs and subdivided into an umbellet of 3 rays with a 3-leaved involucel, and theso finally into 2 or moro pedicellato fascicles. June, July. § Eur.

14 E. Arkansàna Engelm. \& Gr. Slender; floral lvs. roundish-ovate, subcordate, obtuse, caulino oblong-spatulato or obovate, all serrulate and glabrous; umbel once or twice trichotomous, then simply forked; glands entirc, subsessile; fruit warty, seeds reticulated.-Lexington, Ky. (Short, in Gray's Manual) to Ark. and La. (E. tetrapora Engelm., found in W. La. (Hale), differs from this in having 2-horned glands of the involucro and seeds nearly smooth and even. The foliage is almost indentical (fide spec. labeled by Dr. Engelmann).)

15 E. obtusàta Ph. WARted SpURGe. Lvs. all sessile, obtuse, finely serrulate, tapering to the base, sparsely hairy beneath, the cauline oblanceolate, floral roundish cordate, clasping, mucronate; umbel 3 to 5 -rayed, rays 2 or 3 times forked; fr. muricate, with wart-like points; styles 2-cleft; sds. compressed, smooth and even.-Waste grounds, Can. to Va. and W. States. A smooth, erect plant, if ligh. Irs. 1' or moro long, the floral much shorter. Invol. subsessile, with small, hairy lobes, and large, oval glands. Sds. brown when ripe.-Closely resembles Ii. platyphylla $\mathrm{L}$.

16 E. Darlingtònii Gray. Lvs. entire, oblong-lanceolato and oblanceolate, acute, narrowed to the base, subsessile, pilous beneath, the floral ovate; umbel 5 to 8-rayed, rays once or twice divided; segm. of the invol. colored, entire, subreniform; fr. slightly warty; sds. smooth.-2f Moist woods, Penn. to N. Car. (Curtis). St. 2 to $3 \mathrm{f}$ high, smooth, rarely branched below the umbel. Lrs. 3 to $4^{\prime}$ by $1^{\prime}$, entire or slightly serrulate above, those of the stem alternate, of the branches opposite, and nearly as broad as long. Floral invol. purplish brown within. Caps. at length nearly smooth. May, Jn. (E. memoralis Darl., nec Kit.)

17 I. Ipecacuánhæe L. IPECAC SPURGE. Procumbent or suberect, smooth, with numerous, diffuse, forking stems; lvs. opposite, obovate and oblanceolate, cntire, obtuse, subsessile; ped. clongated, axillary, 1-flowered; seeds white, dotted, flattened.-4 Sandy soil, near the coast, Conn. (Robbins) to Ga. Rt. perennial, very long. St. rather thick and succulent, 3 to $8^{\prime}$ long. Lvs. $1 \frac{1}{2}$ to $2^{\prime}$ by 3 to $6^{\prime \prime}$, varying from obovato to linear. Hds. solitary. Ped. as long as the leaves. Jn.

18 E. heterophýlla Mx. (Engelm.) St. thick, green, glabrous, much branched, tall; lvs. ovate, or sinuate-toothed, or panduriform, tho highest often lance-linear, all on slender petioles and scattered; invol. all clustered and terminal, each with 5 ovate lobes; fr. large, smooth, seeds ovoid, tubercled.-W. Ill. to Iowa (Cousens), S. to Ga. (Pond). Plant of singular aspect, 1 to $3 \mathrm{f} \mathrm{high.} \mathrm{Lvs.} 18^{\prime \prime}$ to $2^{\prime}$ long, on stalks half as long, usually narrowed in the middle to a fiddle-shape, the 
upper stained deep red on the edges, \&c., more or less. Invol. reddish, with a sessile gland. Jn., J. (E. cyathiflora Jacq.)

19 E. dentàta Mx. St. low, slender, hairy, brachiately branched; lvs. opposite, petiolate, ovate-lanceolate, obtuse, coarsely dentate, paler and hairy beneath; invol. subsessile, in a terminal cluster, each with 5 ovate, laciniate lobes; fr. minutely velvety; seeda globular, tubercled. - In shady places, Penn. to Iowa and La. Plant 6 to $12^{\prime}$ high; lvs. 1 to $2^{\prime}$, mostly lanceolate, but varying to linear. Invol. with one or more stalked glands. Seeds grayish. Jn.-Aug.

20 E. hypericifolia L. St. smooth, branching, nearly erect, branches divaricato spreading; lvs. oval-oblong, very oblique, serrate all around; corymbs terminal; seeds rugous, black. - (1) A slender and branching plant, found in dry and rich soils, U. S. and Can. Stem 10-20' high, usually purple, very smooth, the branches often pubescent. Leaves tripli-veined, marked with oblong dots and blotches, ciliate, $6-12^{\prime \prime}$ long, and $\frac{1}{4}$ as wide, oblique, on very short petioles. Corymbs of small, white heads, terminal and axillary. July, Aug.

21 E. glyptospérma Engelm. Decumbent at base, much branched, slender, glabrous; lvs. oblong, oblique, obtuse, serrulate towards the end; stipules cleft and fringed; invol. subsessile, appendages crenulate, white; sds. angular, sculptured, amber color.-Madison, Wis. (Lapham), and southwestward. A delicate species. Lvs. $6^{\prime \prime}$ by $2^{\prime \prime}$, and smaller, strongly arcuate. Stipules whitish, cleft into hair-like processes.

22 E. maculàta L. Procumbent; branches spreading; lvs. serrate, oblong, hairy; fls in crowded, axillary clusters; seeds brownish, 4-angled, wrinkled.(1) Plant spreading flat upon the ground, in sandy fields, Can. and U. S. Stem $6-12^{\prime}$ in length, much branched, hairy. Leaves opposite, $3-6^{\prime \prime}$ long and $\frac{1}{2}$ as wide, oblong, obtuse, serrulate, smooth above, often spotted with dark purple, the margin ciliate, pale and hairy beneatb, on short stalks. Heads of flowers small, crowded near tho summit, involucre minute, white. J1.-Sept. This and Nos. 23 and 24 are too closely allied.

23 E. humistràta Engelm. Procumbent, roughly and minutely villous, diffuse; Ivs. obliquely clliptical, obtuso at both ends, denticulate near the apex, sparsely hairy beneath; ped. crowded in lateral clusters, shorter than the very short petiobs; invol slit on the back, appendages subentire; sds. ovate, 4-angled, minutely roughened (not wrinkled), ash-colored.-Banks of tho Mississippi, St. Louis (Engelman) and southwestward. Lvs. 4 to $7^{\prime \prime}$ by 2 to $4^{\prime \prime}$, sometimes nearly smooth, sometimes spotted above. Fr. puberulent, acutely angled. Seed $\frac{2}{5}$ long.

24 E. prostràta Ait. Prostrate, very diffuse, villous-pulverulent; lvs. roundishoval, very obtuse at both ends, minutely serrulate towards the apex, villous beneath; ped. clustered, longer than the very short petioles; invol. appendages obtuse, entire; fr. woolly; sds. 4-angled, transversely rugous.-River banks, S. W. States (Hale). Spreading in large patches, with rather dense foliage, clothed all over with a fine dusty wool. Lrs. of two sizes, the cauline 3 to $5^{\prime \prime}$ by 2 to $3^{\prime \prime}$, the ramial scarce half as large. Seeds light brown.

25 E. polygonifòlia I. KNot-Grass Spurge. Procumbent; lvs. entire, lanceolate and oblong, obtuse at base; invol. subsessile, in the axils of tho branches, solitary; seeds large (I" long) smootl, ovoid.- (I) Sea shores, R. I. to Fla. A very smooth, succulent, prostrate plant, with milky juice. Stems 6-10' long, dichotomous, procumbent. Leaves oblong and linear-lanceolate, rarely cordate at base, $3-5^{\prime \prime}$ by $1^{\prime \prime}$, petioles about $1^{\prime \prime}$. Stipulcs subulate and simple. Heads small, in the forks of the purple stem. June, July.

26 E. cordifòlia Ell. Prostrate, spreading, glabrous; lvs. obliquely cordate at the base, oval, obtuse, entire, distinctly petiolate; stipules laciniate; ped. nearly as long as the leaves, loosely clustered, subterminal; invol. appendages oval, white, conspicuous; fr. angular; seed obtuse-angled, smooth.- (1) In cultivated lands, Car. to Fla. and La. Spreading in large patches, with alternate branches and open foliage. Lvs. 3 to $5^{\prime \prime}$, rarely $6^{\prime \prime}$, slightly variegated. Sds. brownish white.

27 E. sérpens H. B. K. (Engelman). Prostrate, spreading, glabrous; lvs. very small, roundish-oval, obtuse at both ends, cntiro; ped. much longer than the petioles, solitary or several in the axil; invol, appendages scarcely any; sds. smooth, obtusely angled.-Banks of the Miss., St. Louis (Engelm.) to N. Orleans (Hale), 
Our most delicate species. Lvs. 1 to $2 \frac{1}{2}$ "long and less, elegantly variegated. Seeds minute, light brown. (E. herniarioides Nutt.)

2. STILLIN'GIA, Gard. (Named for Dr. Benjamin Stillingfleet.) Flowers 8 , in a terminal, dense spike, apetalous; $\hat{o}$ calyx cup-form, lobed and crenulate; stamens 2, filaments exserted, with short, 2-lobed anthers; + calyx 3 -lobed; style trifid, with 3 diverging, simple stigmas; capsule 3-lobed, 3-celled, 3 -seeded.-Plants smooth, erect, with alternate lvs. Fertile fls. at the base of the sterile spike.

1 S. sylvática I. St. herbaceous or shrubby at base; lvs. oval-lanceolate, cuneate at the subsessile base, obtuse at apex, serrulate; spike solitary, simple, with large, cup-shaped glands among the yellowish flowers. - 2f Sandy soils, Va. to Fla. and La. St. mostly simple, $18^{\prime}$ to 3 f high. Lvs. 2 to 3 to $4^{\prime}$ long, thick, smooth. Spike 2 to $3^{\prime}$ long. Mlay, Jn.

2 s. ligustrina Mx. Shrubby, branching; lvs. lanceolate, tapering to both ends; very entire, petiolate; staminate fls. short-pedicelled, 1 to each bract, with 2 glands.-In Ga. and Car., margins of streams. Plant 6 to 12f high.-Description compiled from Michaux, Pursh and Nuttall. We have not seen the plant.

3 s. sebifera L. TALLOW TREe. Arborescent, with very smooth branches, lvs. long-petioled, rhomboidal, acuminate, entire; sterile fls. very small, many from each involucre; fruit stalked, large (6" diam.) for the genus.-Seacoast, S. Car., Ga. to La. Tree 20 to $40 \mathrm{f}$ high. Lvs. as broad as long $\left(2\right.$ to $\left.4^{\prime}\right)$, conspicuously pointed. Petioles of equal length. § China.

3. TRA'GIA, Plum. (From Tragus, an early German botanist.) Flowers 8 ; coroila none; $\hat{o}$ calyx 3 -parted; stamens 2 or 3 , distinct; $\$$ calyx 5 to 6 to 8 -parted, persistent; style 3 -cleft, stigmas 3 ; fruit 3 lobed, 3 -celled, separating into 3 bivalve, 1 -seeded nutlets. $-2 f$ Herbs (or tropical shrubs). often climbing. Lvs. mostly alternate, pubescent, stipulate. Fls. snall, racemed.

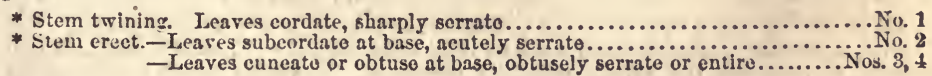

1 T. macrocárpa Willd. Reclining, much branched, its slender summits twining, sparsely lirsute; lvs. long-petiolate, cordate-ovate, acuminate, sharply serrato; rac. much clongated; fr. large.-Hedges, copses, $\mathrm{Ky}$. (Michaux) to La. (Hale). Sts. 2 to 4 f lorg. Lvs. large (1 to $3^{\prime}$ long), exactly heart-shaped. . Fr. nearly half an inch diam. (T. cordata Mx.)

2 T. urticæfòlia Mx. Erect, hirsute, sparingly branched; lvs. ovate-lanceolate, unequally and sharply serrate, subcordate or truncate at base, on short petioles; rac. axillary, elongated; fr. very hairy; sds. globular, very smooth, hollow. - S. States, common. Plant 1 to $2 \mathrm{f}$ high. Lvs. 2 to $3^{\prime}$ long, half to a fourth as wide. Fruit 3 " diam. May-Aug. (T. angustifolia Nutt.)

3 T. ùrens I. Erect, branched, villous-pubescent; lvs. obovate-oblong, varying to lance-linear, cuneate at base, subsessile, coarsely few-toothed above, or entire; rac. axillary, bracted, few or many-flowered; fr. downy.-Dry grounds, Va. to Fla and Ala. A homely weed, 10 to $15^{\prime}$ high, half shrubby, soft downy, and not (as Linnæus supposed) stinging. Branches mostly simple. Lvs. $1^{\prime}$ or more long. Fr. downy, about $4^{\prime \prime}$ diam.

$\beta$. LINEÀris. Lvs. elongated, linear nearly or quite eutirc.-Ga. to Fla. Seeds usually hollow as in all tho varieties. (T. linearifolia Ell.)

4 T. betoniczefòlia Nutt. Much branched from a decumbent base, hairy; lvs. oval, obtuse at both ends, coarsely crenate-dentate, short-petioled; stip. oval, consp:cuous; fls. mostly solitary, opposito to the leaves, pedunculate.-Near $\mathbf{N}$. Orleans (Hale). Plant if high. Lrs. $1^{\prime}$ or more long.

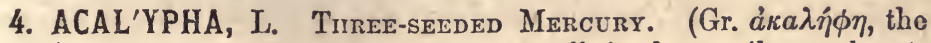
sottle.) Flowers \&; corolla 0 ; $\delta$ very small, in short spikes; calyx 4- 
parted; stamens 8 to 12 , filaments very short. united at base, with halved anthers; + calyx 3 -parted; styles 3 , elongated, 2 or 3 -cleft or fringed; fruit scparating into 3 bivalve, 1 -seeded nutlets, rarely simple. - (1) Herbs (or tropical shrubs) rescmbling nettles. Lvs. alternate, petiolate. Fls. axillary, the fertile in short clusters at the base of the little staminate spikes, surrounded by a large cut-toothed bract.

1 A. Virgínica L. Hairy or downy, branched; lvs. oblong-lanceolate, obscurely serrate; involucrate bracts broadly ovate, deeply cut-toothed, veiny ; sterile spikes slender, peduncled, usually exceeding the involucre; seeds oval, ash-colored, smoothish.-Dry fields, Can. and U. S. A rough weed, 10 to $20^{\prime}$ high, often decumbate at base. Lvs. 12 to $30^{\prime \prime}$ long, varying from ovate to lanceolate or lancelinear, obtusely pointed, tho petioles about as long. The little green spikes 4 to $10^{\prime \prime}$; fertile clusters in the same axils, sometimes alone. - Jn.-Aug. (Also A. gracilens $\mathrm{Gr}$.)

$\beta$. srovococca (Engelm.) Very slender, with lance-linear, subentire lvs. and a simple, 1-celled, 1-seeded fruit.-W. III.

2 A. Caroliniàna Walt. Minutely downy, branched; lvs. ovate, cordate, closely and strongly serrate, acute; sterile spikes short, fertile fls., also spicate, terminal; invol. bracts deeply palmate with linear segments; sds. roundish ovoid, light ashcolored, roughened with hard, black points.-Ind. to N. J., Ga. and La. Plant slender, 1 to $2 \mathrm{f} \mathrm{high,} \mathrm{nearly} \mathrm{smooth.} \mathrm{Lvs.} 1$ to $2^{\prime}$ by 9 to $16^{\prime \prime}$, on slender petioles. Seeds larger $\left(1^{\prime \prime}\right)$ than in No. 1.

5. CNidos'Colus, Pohl. Spurge Nettle. (Gr. kvi $\delta$, a nettle, $\sigma \kappa \tilde{\omega} \lambda$ os, a prickle.) Flowers 8, showy; calyx colored, convolute, coralline; corolla 0 ; hypogynous glands 5 , of stamens 10 , united at base, alternately short; o calyx 5-parted; styles 3 , each 2 or morecleft; capsule 3-carpeled, 3-sceded.-Herbs often beset with stings.

C. stimulòsa Gray. Hispid, with bristly stings; lrs. palmately 3 to 5-lobed, cordate at base, ciliate, lobes acute or acuminate, with few mucronate teeth, lateral lobes 2-parted; fls. terminal at length opposite the leaves, cymous; sep. white, oval, spreading; styles many-cleft at top; caps. hispid.- $24 \mathrm{~A}$ low herb, in sandy soils, throughout the South, painfully common. It varies much in the width of its leaf-segments. Stings white, often half an inch long. Mar.-Jl. (Jatropha stimulosa $\mathrm{M} \mathrm{x}$.)

6. RIC'INUS, Tourn. Castor Orl Plant. (Lat. ricinus, a bug; from the resemblance of the seeds.) Flowers 8 , apctalous; calyx 3 to 5 -parted, valvate in the bud; of stamens $\infty$, with irregularly united filaments; + style short, stigmas 3, 2-parted, plumous, colored ; capsule echinate, 3-lobed, 3-celled, 3-seeded.-IItrbs or shrubs.

R. commùnis L. St. frosted or glaucous, white, herbaceous; lvs. peltate, palmate, lobes lanceolate, serrate; caps. prickly. - Nativo of the E. Indies, where it becomes a tree, although an herbaceous annual in the N. States. In Ga. La. and Fla. it is a stout shrub! St. tall, smooth, of a light bluish green color. Lvs. 4 to $12^{\prime \prime}$ diam., on long petioles. From its seeds is expressed the well known castor oil of the shops. For this purpose it is extensively cultivated in the S. and W. States.-The purgativo property resides in the embryo, not in the albumen.

7. CRO'TON, L. (Name in Greek of the same import as Ricinus.) Flowers 8 ; $\hat{8}$ calyx 4 or 5 -parted, cylindric-valvate in bud; corolla of 4 or 5 petals, often small ; stamens 5 to 20 ; 9 calyx 5 , rarely 8-cleft; corolla often minute or none; styles 3 , once or repeatedly forked ; capsule 3-lobed, 3-celled, 3-carpeled, carpels 1 -seeded.-Plants clothed with scurf, down or wool, usually glandular and aromatic. Hairs stellate. Lrs. alternate. 
Plants downy. Fertile calyx 5-parted, with 2 styles, pondulous......................1 Plants hairy or scaly. Fertile calyx 5-partod, with 3 styles, each 2 or 3 -cleft......... Nos. 2-4 $\$$ Plants densely woolly. Fertile calyx 8-parted. Styles 3 , each twice 2-cleft............Nos. 5, 6

1 C. monanthógynum Mx. Stellately pubescent, tri- and dichotomously branched, slender; lvs. on slender petioles, ovate and ovate-oblong, broad and sometimes subcordate at base, mucronulate, entire, silvery beneath; fls. in the forks, the sterilo 2 or 3 in a little erect, stalked head; the fertile mostly solitary in the samo axil, recurved; fr. 2-seeded.-1) Prairies, Pike Co., Ill. (Holton) and south-westward. Herb near If high, lvs. I' long. Fls. very small. Jn.Sept.

2 C. glandulòsum L. ITispid, glandular, tri- (or 4)-chotomously branched; lvs. clustered at the forks, petiolate, lance-oblong or linear-oblong, serrate, bearing 2 cup-shaped glands at base; fls. in small clusters, sessile in the forks and terminal, the fertile at the base, 5-parted, the sterile 4-parted, octandrous.-(1) In fields and waste grounds, Ill. to Va., Ga. and La. A straggling herb 1 to $3 f$ high. Lvs. 1 to 2 ' long. Sd. light ash-colored. Jn.-Sept.

3 C. argyránthemum Mx. Clothed with glandular scales, branched at baso; lvs. oval or oblong, tapering to a petiole, obtuse, entire, silvery beneath; fls. in a capitate, terminal spike, silvery whitish all over, fertile at base, 5-parted, with 3 styles, cach 3-cleft at top; sterile 5-parted, octandrous.- 4 Sandy soils, Ga. (Wayno Co., Dr. Town) and Fla. (Tallahasseo!). Sts. 9 to $18^{\prime}$ high, simple, often clustered. Lvs. $1^{\prime}$ to $18^{\prime \prime}$ long, half to a third as wide. Scales stcllate, with a central gland. Fls. short-pediceled. Apr.-Jn.

4 C. marítimum Walt. Half shrubby, diffusely and trichotomously branched, branches elothed with a steilular tomentum; lvs. broadly oval, obtuse, entire, subcordate, palo above, silvery beneath, petiolato; fls. in dense spikes, terminal and in the forks, the sterile many, the fertilo commonly 2 at the base; caps. tomentous. - 4 Drifting sands along the seacoast, S. Car. to Fla. and Tex. (Engelman). Sts. straggling and spreading 2 to 3 f. Lvs. shining with a silvery scurf, not hairy beneath, nearly as broad as long.

5 C. capitàtum $\mathrm{Mx}$. Annual, woolly or tomentous, hoary, branched; lvs. longpetioled, oval-oblong; obtuse, entire, rounded at base; fls. in terminal, capitato clusters, the fertilo at tho base, with a large ( $8^{\prime \prime}$ diam.) 8-cleft calyx; stamens 10 to 12.-Dry barrens of Ill. to La. Also in N. J. (Kniskern in Gray's Manual). Herb 1 to $2 \mathrm{f} \mathrm{high.} \mathrm{Lvs.} 18^{\prime \prime}$ to $2^{\prime}$ long, often rather lanceolate and acutish, searcely longer than their petioles. Seeds polished, cinerous-brown, mottled. Jn. - Sept.

6 C. Lindheìmeri Eng. \& Gray. Shrubby, erect, trichotomously branched, clothed with a dense, hoary tomentum, lvs. oblong-lanceolate, rounded or subcordate at base, acute, entire, lower petioles elongated; spikes terminal and in tho forks, mixed or separate, sterile fls. many, sessile, fertile larger, 2 or 3 at the baso or alone; cal. very woolly, +7 or 8 -parted; styles 3 , twice or thrico forked, red; ova. very villous. - Sands, near the coast, La., Tex. Shrub 2 to $4 \mathrm{f}$ high, lvs. 2 to $3^{\prime}$ long. + Fls. a mass of rusty wool, $5^{\prime \prime}$ broad.

8. CROTOIVOP'SIS, Mx. (Named for its resemblance (ü $\psi \iota \varsigma$ ) to the genus Croton.) Flowers 8 , minute, in terminal and axillary spikes; $\hat{o}$ calyx 5-parted; corolla of 5 petals; stamens 5 , distinct; 9 calyx 5 parted; corolla none; stamens 5 rudimentary scales; stigmas 3 , each bifid; ovary simple ; capsule 1-celled, 1-seeded, indehiscent.-(1) Herb slender, branching, silvery-scurfy, with small, alternate lvs. Upper fls. sterilc.

C. linè̀ris Mx.-Sandy swamps, N. J. to Fla., La. and III. (Lapham). Sts. as slender as the flax, at length repeatedly forked, 1 to $2 f$ high, clothed with rusty glands in shining scales, as well as the small ( 6 to $10^{\prime \prime}$ long), linear-oblong, acuto lvs. Fr. oval, acute, muricato glandular. Jn.-Sept.

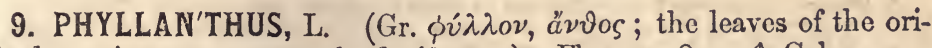
ginal species are apparently floriferous.) Flowers 8 - $\hat{\delta}$ Calyx per- 
sistent, with 6 spreading, colored segments; stamens 3 , rery short, filaments united at base, anthers didymous. $q$ Calyx as in the $\hat{f}$; styles 3 , bifid; capsule 3 -celled; cells 2-valved, 1-2-seeded.-Herbs or shrubs with alternate, stipulate leaves and minute, axillary flowers.

P. Carolinénsis Walt. (P. obovatus Willd.) St. erect, herbaceous, with alternate branches; lvs. simple, entire, glabrous, oval and obovate, obtuse, slightly petioled; fls. few, subsolitary, axillary.-(1) A small-leaved, delicate plant, Penn. to Ill. and South. Stem 6-10' high, slender, the branches filiform. Leaves of the stem $6-8^{\prime \prime}$ by $4-5^{\prime \prime}$, of the branches twice, and of the branchlets four times smaller. Flowers 1-3 in each axil, the of with the of nearly $1^{\prime \prime}$ diam., whitish. July, Aug.

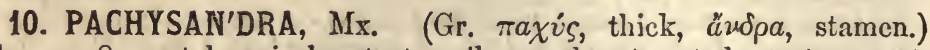
Flowers 8 , apetalous, in bracteate spikes; calyx 4-parted; 3 stamens 4, filaments distinct, large, subclavate; ovary a rudiment; $q$ styles 3 , recurved; capsule 3-horned, 3-celled, cells 2-valved, 2 -secded. - 24 Herbs procumbent, from long, creeping, rhizomes. Lrs. ncarly glabrous, alternate, exstipulate. Spikes situated below the lvs.

P. procumbens $\mathrm{Mx}$. Sts. simple; lvs. few, oval, coarsely crenate-toothed, narrowed into a slender petiole; spikes from near the base of the stem, $\infty$-flowered, the fertile below the sterilo each subtended by 2 or 3 narrow bracts.-Mts. of Va. and E. Tenn. to Ga. Sts. 6 to $9^{\prime}$ long. Lvs. 1 to $2^{\prime}$, all of them above the few spikes which are about the same length. Mar.-May.

11. BUX'US, L. Box-wood. (The Greek name of this plant was

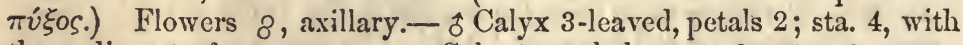
the rudiment of an ovary. 9 Cal. 4-sepaled; pet. 3 ; sty. 3 ; caps. with 3 beaks and 3 cells; seeds 6 .-Shrubs and trees. Lvs. cvergreen, opposite.

B. sempérvirens I. Irs. ovate: petioles hairy at edgo; anth. ovate, sagittate.-Var. ANGUSTIFolid has narrow, lanceolate leaves. Var. sUFfruticosa, the dwarf box has obovate leaves and a stem scarcely woody, highly esteemed for edgings in gardens. - The box with its varieties is native of Europe, and furnishes the well-known box-wood so extensively used by engravers, mathematical instrument makers, \&c.

\section{Order CXIII. UlmaCEA. Elmworts.}

Trees with a colorless juice, alternate, deciduous leaves and stipules, with the flowers perfect, or abortively polygamous, in loose clusters, never in aments. Calyx subcampanulate, bearing the stamens opposite to its lobes, filaments straight, ovary free, 1 or 2 -celled, with two stigmas, forming in fruit a samara or a drupe. Seed suspended, with no albumen and leafy cotyledons. Fig. 46. E. 115, 437.

Gonera 9, species 60, native of the northern temperate zone.

Properties.-A stringent, mucilaginous, innoxlous. The mucilaginous bark of tho Slippery Elm (Ulmus fulva) is the only important medicinal product. Most of the Elms afford excellent timber.

I. UL'MUS, L. Elm. (The Latin name, from elm, Teutonic.) Flowers ६. Calyx campanulate, 4 to 8 -cleft; stamens 4 to 8 ; styles 2 ; ovary compressed forming a flattened samara with a broad membranous border.-Trees, rarely shrubs. Lrs. scabrous, often abrupt at base. Fls. fasciculate or racemed, appearing before the lvs.

$\$$ Samara ciliate-fringed with hairs, and on slender pedicels. (a) a Flowers and frult corymbous-umbellate. Branches not corky................. 1 a Flowers and fruit manifestly racemed. Branches corky ................................ 3 S Samara destitute of a fringe, subscssile or short pedlceled........................... $4-6$ 
1 U. Americàna L. White Fus. (Fig. 437.) Lvs. ovate, acuminate, serrate, often doubly so, unequal at base; fls. pediceled in loose clusters; fr. oval, smooth except the densely ciliate margin, its 2 beaks with points incurved and meeting.-U. S. and Can. A majestic tree, usually distinguished by its long pendulous branches. The trunk attains a diameter of 3 to $5 f$, loosing itself suddenly at top in 2 or more primary branches. These ascend, gradually spreading, and repeatedly dividing in broad, graceful curves, and affording a good example of the solvent axis (\$174). It is a great favorite as a shade tree, and is frequently seen rearing its stately form and casting its deep shade over tho "sweet homes" of $\mathrm{N}$. Eng. A pril.

2 U. racemòsa Thomas. CoRK Eußr. Branchlets downy, often with thick, corliy ridges; lvs. ovate, acuminate, auriculate on one side ; fls. in racemes ; pedicels in distinct fascicles, united at their base, fruit ovate, elliptic, ciliate. $-A$ tree found in low grounds, Meriden, N. II. to N. Y., and westward. The twigs and branches are remarkably distinguished by their numerous, corky, wing-liko excrescences. Leaves ' $3-4$ ' long, $\frac{2}{3}$ as wide, produced into a rounded auricle on one side, doubly serrate, smooth above, veins and under surfaco minutely pubescent. Flowers pedicellate, $2-4$ in ench of the fascicles which are arranged in racemes. Calyx 7-8-cleft. Stamens 7-10. Stigmas recurved. Samara pubescent, the margin' doubly fringed. Apr.-Much like No. 1, except its inflorescence and bark.

3 U. alàta Mx. WINGed Eux. WhaHoo. Branches smooth, here and thero winged with 2 corky ridges; lvs. oblong-lanceolate, small, acute, doubly serrate, all slightly unequal at base; fls. in racemes; cal. lobes obovate, obtuso; fruit downy all over, ciliate-fringed on the margin, beaks slender.-Common in the S. States. Treo with its branches more regularly cork-winged than in No. 2, its leaves much smaller (18 to $30^{\prime \prime}$ long) and subequal at base, the petioles only $1^{\prime \prime}$ long. (Fruit misrepresented in Michaux.)

4 U. fúlva I. SuIPpery Eus. Red ElM. Branches rough; lvs. oblong-ovate, acuminate, nearly equal at base, unequally serrate, pubescent both sides, very rough; buds covered with fulvous down; fls. sessile; fr. nearly orbicular, scarcely ciliate.-Woods and low grounds, N. Eng. to Car. The Slippery Elm is much sought on account of the mucilago in tho inner bark. Its diameter is 1 to $2 f$ and height 20 to 40 . The lvs. are larger, thicker and rougher than those of tho White Elm, and exhale a pleasant odor. Fls. collected at the ends of the young shoots. Cal. downy, sessile. Stam. short, reddish, 7 in number. Apr.

5 U. campéstris L. ExGuish ELM. Lvs. (small) ovate, doubly serrate, unequal at base ; fls. subsessile, densely clustered; sta. 5-8; cal. segments rounded, ebtuse; samara suborbicular, the border destitute of a fringe of hairs.-From Europe. Introduced and naturalized in the Eastern States to a small extent. It is a majestic tree, 50-70f high. The main trunk is usually excurrent (\$173). Branches rigid and thrown off at a large angle, foliage dense. In form it favorg the Oak more than our native Elms. Many trees of this kind, in the vicinity of Boston, are particularly remarked in Emerson's Report, pp. 301, 302.

6 .U. montàna I. Scotcr Elsr. Wych Ely. Lvs. (large), obovate, cuspidate, doubly and coarsely serrate, cuneato and unequal at base, very scabrous above, evenly downy beneath; fr. subumbellate, rhombic-oblong; scarcely cloven, not ciliate.-Another European Elm often planted in our parks. It is a large tree, rather resembling our Slippery Elm than the White Elm.

7 U. crassifòlia Nutt. With very small (1'long), thick, oval, obtuse lrs. grows in W. La., probably not E. of the Miss. It flowers in Sept. only. (Hale.)

2. PLA'NERA, Gmel. (In honor of John J. Planer, a German botanist.) Flowers monœcious-polygamous; calyx campanulate, 4 to 5 cleft; stamens 4 to 5 ; stigmas 2, oblong, diverging; fruit 1-celled, 1-seeded, wingless, dry, nut-like, indehiscent.-Trees with the habit of Ulmus.

P. aquática Gmel. Lrs. small, smooth, ovate, acute, serrate, equal at baso; fis axillary, in clusters of 2 to 5 ; sig. plumous; nut roughened witl scale-like points -River swamps, N. Car. to Ga. A tree 30 to 40 f high. Feb., Mar. 
3. Cel'tis, Tourn. Netrle Tree. Segar-berry. (Celtis was the ancient name for the Lotus.) Flowers monecio-polygamous. $\hat{\delta}$ Calyx 6-parted; stamens $6 ; \Varangle$ calyx 5-parted; stamens 5 ; style 2 ; stigmas subulate, elongated, spreading; drupe globular, 1-seeded, seed with little albumen.-Trees or large shrubs. Lvs. mostly oblique at base. Fls. subsolitary, axillary.

1 C. occidentàlis L. Trees; lvs. ovate, subcordate or truncate, acuminate, entire and unequal at base, serrate, rougl above, and rough-hairy beneath; peduncle longer than the petiole; sep. triangular-ovate, erect; fr. solitary.-Tree some $30 \mathrm{f} \mathrm{high} \mathrm{in} \mathrm{N.} \mathrm{Eng.} \mathrm{where} \mathrm{it} \mathrm{is} \mathrm{rarely} \mathrm{found,} \mathrm{much} \mathrm{larger} \mathrm{(} 3$ to $5 \mathrm{f} \mathrm{diam}$., 50 to $70 \mathrm{f}$ high) and more abundant South and West. The trunk has a rough but unbroken bark, with numerous slender, horizontal branches, forming a wide-spread and dense top. Lvs. with a long acumination, and remarkably unequal at the broad base. Fls. axillary, solitary, small and white, succeeded by a small, round drupe.

$\beta$. CRASSIFòtia. Lvs. thick, rough, serrate, cordate, dark green and mottled above. Also a largo tree, tall in woods, wide-spread in open lands. Both are often mistaken for Elms.

$\gamma$. INTEGRIFòLIA. Lrs. entire, thin, smooth; bark smooth and unbroken.Banks of the Miss., St. Louis, to N. Orleans. We have specimens with mast of the lvs. perfectly entire, some on the same branch witl 1 or 2 notches, others notcled a fourth of the circuit, \&c. (C. Mississippiensis Bosc.)

2 C. pùmila Ph. Shrub; lrs. broadly ovate, acute or slightly acuminate, partly serrate, smooth on both sides, pubescent only when young; fls. solitary; sep. mostly 6, oblong-linear, as long as the styles, horizontally spreading.-A straggling shrub, 3 to $10 \mathrm{f} \mathrm{high,} \mathrm{in} \mathrm{hilly} \mathrm{districts,} \mathrm{Va.} \mathrm{to} \mathrm{Fla.} \mathrm{(Chattahoochee).} \mathrm{Flowering} \mathrm{at}$ the height of (2f Nutt) $6 f$. The peculiarity of the flower may perhaps entitle this shrub to the rank of a species. Sep. near 2 " long. Drupes glaucous black, sweet. Mar.-May.

\section{Order CXIV. ARTOCARPACEA. Artocarps.}

Trecs or shrubs with a milky acrid or noxious juice, with large deciduous stipules. F.owers $\delta$ or 8 , collected into dense heads or aments, naked or with a lobed calyx. Ovary free, 1 (rarely 2)-celled, 1-ovuled, forming fleshy, aggregated fruit (sorosis or syconus, §580). Achenium with an erect or pendulous, albuminous seed. Figs. 36, $149,450,451$.

Genera 31 , species 240 ? generally natives of the tropies or at least of warm climates. They are closely allied to the Nettleworts, diffuring chiefly in fruit, juice and habit.

Properties. - The juice is almost always deleterious, sometimes in $\mathrm{n}$ high degree. It contains caoutchouc. The celibiated Bohon Upas, the most deally of all poisons, is tie concrete juice of Antiaris toxicaria of the Indian Archipelago. Its poisonous property is said to be lue to the presence of strychnia. Mennwhlle the famous cono tree of S. A merica vields milk which is rich and wholesome. Gum lite is obtained abundantly from Ficas Indica. "The renowned Banyan tree is Fleus religiosa. In this order are also found many excellent fruits. Figs are the fruit of Ficus Carice se. Brerd fruit is the componnd fruit of Artocarpus; mulberies of Morus nigra. Fustic, a yellow dye, is the wood of $\mathrm{N}$. tinctoria of S. America.

\$ Flowers inside the excarated receptacle, both kinds together.................. Ficus, 4

Flowers external, the 2 kinds separate, in two kinds of aments. (*)

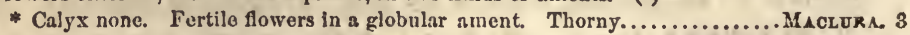

* Calyx 4-parted. Fertile ament globular. Style 1................. Dnovssoxeria. 2

* Calyx 4-parted, lobes spreading. Fertileaments oblong. Styles 2............... 1

1. MO'RUS, Tourn. MUlberry. (Celtic mor, black; the color of the fruit.) Flowers moncecious or diœecious, the $\hat{\delta}$ in loose catkins; the $q$ in dense spikc-like catkins; calyx 4-parted; stamens 4 ; styles 2 ; achenium compressed, enclosed within the baccate calyx, the whole spike thus constituting a compound berry (sorosis.)-Trees with alternate, gencrally lobed lrs. Fls. inconspicuous. 
1 M. rùbra L. RED MULBeRRY. Lvs. scabrous, pubescent beneath, rounded or subcordate at base, equally serrate, acuminate, ovate or (in the young trees) palmately and oddly lobed; fertile spikes cylindric; fr. dark red.-In N. Eng. a rare shrub 15 to $20 \mathrm{f}$ high. In the Mid. S. and W. States it attains the elevation of $40-60 \mathrm{f}$, with a diameter of 1 to $2 \mathrm{f}$. Roots yellow. Trunk covered with a grayish bark, much broken and furrowed. Wood fine-grained, stong and durable. Leaves $4-6$ ' long, $\frac{2}{3}$ as widc, entire or divided into lobes, thick, dark green. Flowers small. Fruit of a deep red color, with the aspect of a blackberry, composed of the entire catkin, made pulpy and sweet. Apr., May.

2 M. álba L. WHite Mulberry. Ivs. glabrous, cordate and oblique at basc, unequally serrate, either undivided or lobed; fr. whitish.-Cultivated for the sake of its leaves as the food of silk worms. A tree of humble growth. Leaves $2-4^{\prime}$ long, $\frac{2}{3}$ as wide, acute, petiolate. Flowers green, in small, roundish spikes or heads. Fruit of a yellowish-white, insipid. $\dagger$ China.

$\beta$. Multicaulis. (Chinese Mulberry.) Lus. largo (4- $7^{\prime}$ long, $\frac{7}{3}$ as broad.)

-Shrub.

3 M. nìgra L. BLACK Mulberry. Lvs. scabrous, cordate, ovate or lobed, obtuse, unequally serrate; fertile spikes oval.-Cultivated for ornament and shade, in this as well as in many other countries. Fruit dark red or blackish, of an aromatic, acid flavor. † Persia.

2. Broussone'tia, L'Her. Paper Mulberry. (In honor of $P$. N. V. Broussonet, a distinguished French naturalist.) Flowers diœceous; ô ament cylindric; calyx 4-parted; + ament globous; receptacle cylindric-clavate, compound; calyx 3 to 4-toothed, tubular; ovaries becoming fleshy, clavate, prominent; style lateral ; seed 1, covered by the calyx.-Trees from Japan.

B. papyrifera Vent. Lvs. of the younger treo roundish-ovate, acuminate, mostly undivided, of the adult tree 3-lobed; fr. hispid. - A fine hardy tree, occasionally cultivated. It is a low, bushy-headed tree, of rapid growth, with large, light green, downy leaves, and dark red fruit a littlo larger than peas, with long, purple hairs. The divided lvs. resemble those of the white mulberry.

3. MaClU'RA, Nutt. Osage Orange. (To William Maclure, Esq., of the U. S., a distinguished geologist.) Flowers ô $q$, in aments. Calyx 0 ; ova. numerous, coalescing into a compound, globous fruit, of 1 sceded, compressed, angular, cuneiform carpels ; sty. 1, filiform, villous. -A lactescent tree, with deciduous, alternate, entire, exstipulatc leaves and stout, axillary spines.

M. aurantiaca Nutt. $-\mathrm{A}$ beautiful tree, nativo on tho banks of the Arkansas, \&c. Leaves $4-5^{\prime}$ by $1 \frac{1}{2}-2 \frac{1}{2}^{\prime}$, glabrous and shining above, strongly veined and paler beneath, on short petioles, ovate or ovate-oblong, margin obscurely denticulate, apex subacuminate, rather coriaceous. The fruit is about the size of an orange, golden yellow when ripe, suspended by an axillary peduncle amid the deep green, polished foliage. Extensively cultivated for hedges.

4. FI'CUS, Tourn, Fig. Banyan. (Gr. ovkĩ. Lat. ficus. Celtic figueren. Teutonic fiege. Anglo-Saxon Fic. Englișh Fig.) Flowers monœcious, minute, fixed upon the inside of a fleshy, turbinate, closed receptacle; ô calyx 3-parted ; stamens 3 ; $q$ calyx 5 -parted ; ovary 1 ; seed 1 ; fruit (syconus) composed of the enlarged, fleshy receptacles inclosing the numerous, dry, imbedded achenia.

F. Cárica Willd: Commox Fia. Lvs. cordate, 3-5-lobed, rcpand-dentato; lobes obtuse, scabrous above, pubescent beneath. - Supposed to be a native of Caria, Asia, although cultivated for its fruit in all tropical climes. With us it is reared only in sheltered locations as a curiosity. The delicious fruit is well known. Leaves very variable in form. 


\section{Order CXV. URTiCACE $A$. Netrleworts.}

Herbs (and some tropical shrubs) with a watery juice, a tough, fibrous bark. Leaves stipulate, often opposite, flowers small, monœcious or diœcious, in panicles, racemes, or dense clusters, furnished with a regular calyx. Stamens opposite to the calyx lobes. Ovary 1-celled, ovule erect, orthotropous. Fruit a simple achenium. Figs. 50, 459.

Genera 25 , species 700 ? generally diffused in all climes. We retain under this order the Cannabinea, dismissing the Artocarpea, thus constituting a group which is at least practically natural.

Properties. - The Nettleworts are remarkable for the caustic secretion of their glandular, stinging hairs, which, bad enough in our common nettle, attains a terrible virulence in certain E. Indian species. The juice of the Ifempworts is bitter and narcotic. Savage natlons procure an intoxicating liquor from the Hemp, and the more civilized a strong stimulant from the IIop. The fibrous bark of Ilemp and other species is highly valuable in the arts.

\section{SUBORDERS AND GENERA.}

I. URTICE \&.-Filaments crenulate, expanding elastically. Fortile calyx 3 to 5 -sepaled or toothed. Seed albuminous, with a straight embryo (*).

* Ilerbs with stinging hairs. -Stamens 4. Leaves opposite................ Urtica. 1 -Stamens 5. Leaves alternate...............LAPORTeA. 2

* Lerbs stingless.-Stamens 8. Fertile calyx 3-sepaled. Leaves opposite.....Prles. 3 -Stamens 4.-Fls. in slender spikes. Lvs. opp. or alt.... Bøunkria. 4 -Fls. in involucrate cymes. Lvs. altern..PArietaria. 5

II. CANNABINE.E.-Filaments straiglit, or not elastic. Fertile calyx of 1 sepal, lateral, embracing the ovary. Seed exalbuminous, with a curved or spiral embryo (*).

* Fruit a valveless achenium, in a strobile-like ament. Twining........... Huxulus. 6

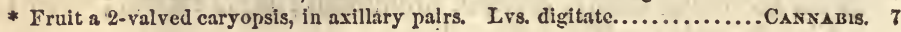

1. UR'TICA, Tourn. NeTtLe. (Lat. uro, to burn; in reference to the stinging species.) Flowers 8 , sometimes $\hat{o}$; ; $\hat{o}$ calyx 4 -sepaled, with a cup-shaped, central rudiment of an ovary; stamens 4 ; $q$ calyx persistent, 4-sepaled, the outer pair minute, the inner at length surrounding the shining, compressed achenium; stigma 1, sessile.-Herbs with stinging hairs. Lvs. opposite. Fls. green, in axillary or subterminal clusters or racemes.

$\$$ Clusters eompound, Jonger than the petioles............................. 1, 2

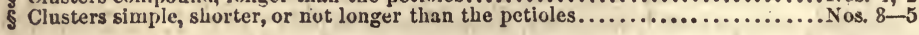

1 U. pròcera Willd. St. tall, simple, 4-sided, slightly hispid with few stings; lvs. lanceolate, acute or obtuse at base, rough, hispid, prominently 5-veined, acutely serrate; panicles axillary, very branchiug, numerous, interruptedly spicate, lower ones sterile, upper fertile.-Borders of fields, waste places, N. Eng. and Can. St. 3 to $5 \mathrm{f} \mathrm{high,} \mathrm{with} \mathrm{a} \mathrm{tough} \mathrm{bark.} \mathrm{Lvs.} \mathrm{with} \mathrm{the} \mathrm{serratures} \mathrm{incurved,} \mathrm{acute} \mathrm{or}$ somewhat acuminate at apex, 3 times longer than the petioles. Fls. in glomerate panicles on the upper part of the stem. Jl. (U. gracilis Ait.)

2 U. dioìca I. Stinging Netrue. Very hispid and stinging; lvs. cordate, lanceovate, conspicuously acuminate, coarsely and acutely serrate, the point entire, petioles thrice shorter; fls. 8 or $\hat{o} . q$, in branching, clustered, axillary, interrupted spikes longer than the petioles. - 2f Waste places, common. Stem 2-4f high, branching, obtusely 4-angled, with opposite, short-stalked leaves which are 3-4' long, and about $\frac{1}{2}$ as wide. Flowers small, green, in axillary clusters, of mean aspect, corresponding with the insidious character of the plant. Jl., Aug. $\S$ Eur.-Its power of stinging resides in minute, tubular hairs or prickles, which transmit a venomous fluid when pressed.

3 U. ùrens I. DWARF NetruE. Lvs. broadly elliptic, or ovate, petiolate, 3reined, deeply and acutely serrate; clusters in spike-like, loose, simple pairs.-1) Weed, in cultivated grouuds. Stem $12-20^{\prime}$ high, hispid with venomous stings, branching. Leaves $I^{\prime}$ or more long, half as broad, on short petioles and with large serratures. Stipules small, lanceolate, reflexed. Flowers in drooping, pedunculate clusters about as long as the petioles, both the sterilo and fertile in the 
samo axil. Raro northward, frequent South. Feb., Mar. (South). Apr.-Jn. (North). § Eur.

4 U. purpuráscens Nutt. Assurgent, beset with spreading stings; lvs. broadly ovate, cordate, 3-veined, coarsely crenate-serrate; glomerules capitate, much shorter than the petioles, dense, axillary, spicate at top.-Ky. to La. Sts. purplish, 13 to $18^{\prime}$ high, clustered. Ivs. variegated, $1^{\prime}$ long and wide, petiole 6 to $9^{\prime \prime}$. Mar. -May.

5 U. chamædroides $\mathrm{Ph}$. St. bristly with stings; lis. subsessite, ovate, serrate, strigous beneath; glomerules axillary, sessile, subglobous, reflexed.-On the islands of Ga. (Pursh.) Lvs. small. Stings whito and very conspicuous. May.-Is this a variety of $U$. urens?

2. LAPOR'TEA, Gaudich. Wood NetTle. Flowers 8 or $\hat{\delta} q ; \beta$ calyx 5 -parted ; stamens 5 ; ovary rudimentary, hemispherical ; $q$ calyx 4-sepaled, the 2 outer minute, the 2 inner foliaceous in fruit; stigma subulate, elongated ; achenia compressed-lenticular, very oblique, finally reflexed on the winged pedicel.- 2f Hairs stinging. Liss. ample, alternate, ovate. Fls. in axillary panicles, the lower sterile, upper fertile.

I. Canadénsis Gaud. Hispid and stinging; lvs. on long petioles, broad-ovate, rounded or subcordate at base, serrate, acuminate; panicles axillary, solitary or in pairs, divaricate, mostly shorter than the petioles, the fertile nearly terminal, clongated in fruit.-Damp woods, U. S. and Can. St. 2 to $6 \mathrm{f} \mathrm{high,} \mathrm{mostly} \mathrm{simple,}$ flexuous at top. Irvs. 3 to $5^{\prime}$ by 2 to $3^{\prime}$, more or less hispid both sides, sometimes nearly smooth. Lower petioles $3^{\prime}$ long. Fls. minute, in panicles 1 to $4^{\prime}$ in length, the fertile panicle about 2', erect, enlarged in fruit. Aug. (Urtica Canadensis and divaricata $L$.)

3. PILEA, Lindley. Rrch-weed. (Lat. pileus, a cap; from the resemblance of one of the sepals of P. muscosa.) Flowers 8 or $\delta q$. $\hat{\delta}$ Calyx of 3 or 4 equal sepals ; stamens 3 or 4 . क Calyx of 3 oblong, unequal sepals; stamens rudiments 3 , cucullate opposite the sepals; achenium roughened, opaque, ovate, erect, nearly naked.-(1) Smooth, stingless, with opposite lvs., united stipules and dense, axillary clusters, both kinds mixed.

P. púmila Gr. Ascending, Treak, succulent; lvs. on long petioles, rhombicovate, crenate-serrate, membranous and glabrous, 3-veined; fls. in short clusters; o sepals slightly unequal.- (1) In waste places, about buildings and in woods, $\mathrm{U}$. S. and Can. St. fleshy, semi-transparent when growing in shades, smooth and shining, 3 to $18^{\prime}$ long, simple or branched. Lvs. pale green, 1 to $2^{\prime}$ by 8 to $16^{\prime \prime}$, petioles of about the same length. Sep. much shorter than the greenish, mottlcd achenium, one of them a little longer than the other two. Jl--Sept. (Urtica, I. Adice, Raf.)

4. BEHME'RIA, Jacq. False Netrle. (Named for G. F. Bchmer, a German botanist.) Flowers 8 or $\hat{f}$ o . o. Calyx 4-parted, with lanceolate, acute segments ; stamens 4 ; $q$ calyx tubular, truncate or 4 toothed, persistent and closely investing the ovate, pointed achenium. - Herbs or shrubs, stingless. Lvs. opposite or alternate. Fls. clustered.

I B. cylínärica Willd. Herbaceous, diøcious, smoothish; lvs. opposite, ovate, acuminate, dentate, on long petioles; sterile spikes interrupted, fertile cylindric.$\Lambda$ coarse, nettle-liko plant, in swamps and bottoms, Mid. and W. States. St. slender, obtusely 4-angled, channeled on each side, 2 to $3 \mathrm{f} \mathrm{high.} \mathrm{Ivs.} \mathrm{3-veined,}$ 3 to $5^{\prime}$ long, lali as wide, petioles 2 to $3^{\prime}$; the upper sometimes not quito opposite. Fls. minute, the fertile spikes 1 to $2^{\prime}$ in length, tho barren spikes longer and more slender. Jl., Aug. (Urtica capitata I ?)

2 B. Laterifòra Muhl. 'Tholo plant rough-pubéscent, monøecious'; liss, all alternate, ovate-lanceolate, long-acuminate, centate, rounided and subpeltate at base, on 
short petioles ; upper spikes long and sterile, lower short, dense, fertile.-Borders of ponds, S. W. States. St. strict, 2 to $3 f^{\prime}$ high, very rough. Lvs. 3 to $5^{\prime}$ long, a fourth as wide, thick, on petioles 4 to $7^{\prime \prime}$ long. Fertile spikes as long as the petioles, sterile nearly as long as the leaves.

5. PARIETA'RIA, Tourn. Pellitory. (Lat. paries, a wall; some of the species prefer to grow on old walls.) Flowers monœcio-polygamous, in clusters, surrounded by a many-bracted involucre. ô Calyx 4-sepaled; stamens 4, at first incurved, elastically expanding. क Calyx tubular-campanulate, 4-lobed, inclosing the ovary ; stigma tufted ; achenium polished, inclosed within the persistent calyx.-Herbs weed-like, with usually alternate lvs. Clusters of green fls., axillary.

1 P. Pennsylvánica Muhl. Lvs. oblong-lanceolate, veiny, tapering to an obtuse point, entire, punctate with opaque dots; invol. longer than the flowers. - (1) A rough, pubescent herb, found in damp, rocky places, Vt. to Wis. and Ga. Stem erect, simple or sparingly branched, $6-12^{\prime}$ high. Leaves alternate, entire, hairy and rough, about $\frac{1}{2}^{\prime}$ wide and 3 or 4 times as long, petiolate, and ending with an obtuse acumination. Segments of the involucre about 3, lance-linear. Flowers dense, greenish and reddish white. May, Junc.

2 P. Floridàna Nutt. Lvs. roundish-ovate, obtuse, as long as the petiole, opaquely punctate; fls. as long as the involucre.-(1) Damp, sandy soils, Ga. and Fla. St. decumbent at base, branches erect, 10 to $12^{\prime}$ high. Lvs. small, $1^{\prime}$ long, including the filiform petiole, 3 to $5^{\prime \prime}$ wide. Bracts linear. May-Oct.

6. HU'MULUS, L. Hop. (Lat. humus, moist earth; the hop grows only in rich soils.) Flowers $\hat{o} q .-\hat{o}$ Calyx 5-sepaled; stamens 5 ; anthers with 2 pores at the summit. $q$ Bracts imbricate, large, entire, concave, persistent, 1-flowered, forming an oblong ament; calyx of 1 sepal; membranous, entire, persistent; styles 2 ; achenium invested by the thin calyx ; embryo coiled.- 4 Twining with the sun. Lvs. opposite. Fls. in axillary panicles and strobile-like aments.

H. Iùpulus $\mathrm{I}$. The hop-vine is found wild in hedges, \&c., throughout this country, and is, as every one knows, extensively cultivated for the sake of its ament-like fruit. It has a long, annual stem of rapid growth, always twining with the sun, rough backwards with reflexed prickles. Leaves very rough, generally 3-lobed, cleeply cordate at base, on long stalks. Flowers of the barren plants innumerable, panicled, greenish; those of the fertile, in aments with large scales. Cal. and scales in fruit covered with reddish, resinous atoms (lupulin) in which the virtue resides. $\mathrm{Jl}$.

7. CAN'NABIS, Tourn. Hemp. Flowers of $q$. - $f$ Calyx 5-parted; stamens 5. क Calyx entire, oblong-acuminate, opening longitudinally at the side; styles 2 ; caryopsis 2-valved, inclosed within the persistent calyx ; cmbryo curved. (1) Lvs. opposite, digitate. Fls. axillary, of in cymous panicles, $q$ in sessile spikes.

C. sativa I. Irs. palmately 5 to 7 -foliate. - The hemp springs up spontaneously in our hedges and waste grounds. It is a tall, erect plant, with handsome petiolate leaves. Lfts. lanceolate, serrate, 3 to $5^{\prime}$ long, $\frac{1}{5}$ as wide, the middle ono largest. Fls. small, green, solitary and axillary in the barren plants, spiked in the fertile ones. It is cultivated in Ky., Tenn., \&c., as one of the staples. Jn. § India.

\section{Order CXVi. empetraceAe. Crowberries.}

Shrubs low, evergreen, heathlike, with crowded, narrcw leaves and small, diclinous flowers. Calyx of 4 to 6, hypogynous, persistent, imbricated scales, the inner often colored. Stamens 2 or 3 , pallen grains quaternate. Ovary free, 2 to 9 -celled, 
2 to 9-ovuled. Fruit fleshy, with as many 1-seeded nuts. Seed ascending, albuminous, radicle inferior.

Genera 3, species 4, natives of N. Europe, N. America and the Straits of Magellan. Properties, acidulous. The berries are nutritious.

\section{GENERA.}

* Stamens 8. Stigmas 6 to 9-rayed. Berry 6 to 9-secded.................. Empetrum. 1

* Stamons 3. Stigmas 8 or 4, style slender. Drupe 8 or 4 -seeded......................... 2

* Stamens 2. Stigmas 4. Berry 2-seeded. Shrub ercet................................ 8

1. EM'PETRUM, Tourn. Crowberry. (Gr. $\dot{\varepsilon} v$, upon, $\pi \dot{\varepsilon} \tau \rho o s$, a stone; from the places of its natural growth.) Flowers $\hat{\delta}+{ }^{\circ}$. Perianth consisting of 2 series of scales, the 3 inner petaloid; $\delta$ Starnens 3 , anthers pendulous on long filaments. $\&$ Stigma subsessile, 6 to 9-rayed; drupe globular, with 6 to 9 seedlike nutlets.-Alpine undershrubs.

E. nígrum L. Procumbent branches smooth; lvs. imbricated, linear-oblong, obtuse at each end, nearly smooth, with a revolute margin.-A small, prostrate shrub, found on the granite rocks of the White Mts. of N. H., and the calcareous mountains of Vt. The stem is 1 to 3 or $4 \mathrm{f}$ long, much branched and closely covered all around with evergreen leaves, which are 2 or $3^{\prime \prime}$ long, half a line wide. Flowers very small, reddish, crowded in the axils of the upper lvs. Berries black, not ill-flavored. May, Jn.

2. CORE'HA, Don. (Oakesia, Tuckerman.) (Gr. «óp $\eta \mu \alpha$, a broom; from the resemblance.) Flowers $t$ o or $\hat{\delta} \Varangle q$. Perianth of 5 or 6 bractlets, the 3 inner sepaloid. $\hat{\delta}$ Stamens 3 , sometimes 4 , with exserted filaments. $\quad$ O Ovary 3 or 4-celled; style filiform, 3 or 4-cleft, with narrow stigmas; drupe globular, minute, with 3 or 4 nutlets.diffuse undershrubs. Lvs. linear.

C. Conrádii Torr. Diffuse, very slender, glabrous; lvs. linear, revolute on tho margin, coriaceous; fruit dry.-Sandy and rocky plains, here and there, from Can. ? Me. to N. J. Sts. If high, with a reddish-ash-colored bark, with short, verticillate branches. Lvs. evergreen, numerous, spiral or imperfectly verticillate, $3^{\prime \prime}$ long, linear, revolute. Fls. in terminal clusters of 10 to 15 , with brownish seales and purplo stamens and styles.-Plants with $\Varangle$ aro less common than those with $\delta$ or $q$. Mar., Apr.

3. CERAti'Ola, Mx. Sand-hill Rosemary. (A Latin diminutive, from $\kappa \varepsilon$ pas, a horn; referring to the stigmas.) Flowers 8 . Perianth of 6 to 8 imbricated, concave, fimbriate scales, the two or 4 inner membranous. $\delta$ Stamens 2, exserted, anthers 2-celled, roundish. $q$ Ovary 2-celled; style short; stigmas 4 or 6 , spreading, toothed; fruit a drupe with 2 -seed-like nuts. - $\mathrm{A}$ shrub with verticillate branches, crowded, acerous lvs. and axillary, sessile fls.

C. ericoìdes Mrx-Hills or plains sandy or gravelly, Augusta, Ga. to A palachicola, Fla. Shrub evergrecn, 3 to $6 \mathrm{f}$ high. Young branchlets downy. Lvs. in close whorls of $3 \mathrm{~s}$ and $4 \mathrm{~s}$, about $6^{\prime \prime}$ long, rigid, acute. Fls. lateral, stigmas purple. Fr. yellowish, small, astringent. Aug., Sept.

\section{Order CXVII. PlataNACEA. Stcamores.}

Trces with a watery juice, alternate palmate leaves and sheathing, scarious stipules. Flowers moncecious, in globular aments, destitute of both calyx and corolla. Sterile.-Stamens single, with only small scales intermixed. Anthers 2-celled, linear. Fertile.-Ovary terminated by a thick stylo with one side stigmatic. Nut clavate, tipped with the persistent, recurved stylo. Seed solitary, albuminous. Fig. 82. 
Genus 1, species 5? Trees of the largest dimensions, natives of Barbary Lerant and $\mathbb{N}$. America.

Plat'anus, L. Plane Tree. Button Wood. Sycamore. (Gr. $\pi \lambda a \tau v ́ s$, broad; in reference to the ample foliage.) Character of the genus the same as that of the order.

P. occidentalis L. Lvs. angularly lobed and toothed; stipules obliquely ovate; branches whitish; fertile heads solitary. - The largest (though not the loftiest) tree of the American forest. Along the Western rivers trees are found whose trunks measure from $40-50 \mathrm{f}$ in circumference, or more than $13 \mathrm{f}$ in diameter I It flourishes in any soil, but is most frequently met with on the stony borders and beds of streams. Leaves very large, tomentous beneath when young. The petiole covers the axillary bud in its concave base. Fls. in globular aments or balls, which hang upon the tree on long pedicels most of the winter. The bark is yearly detached from the trunk in large scales leaving a white surface beneath. May.

\section{Order CXVIII. JUGLANDACEA. Walnut.}

Trees with alternate, pinnate, exstipulato leaves and monœcious flowers. Sterite flowers in aments, with an irregular perianth. Fertile, solitary or clustered. \& Calyx regular, 3 to 5-lobed, tube adherent to the partly 2 to 4-celled ovary. Fruit a tryma (\$564), with a fibrous epicarp (shuck) and a bony endocarp (shell). Seed large, orthotropous, exalbuminous, with lobed, often sinuous, oily cotyledons.

Genera 4, species 27, mostly North American.

Properties.-The well-known fruit of the Butternnt, walnut, pecan nut is sweet and wholesome, sbounding in a rich drying vil. The epicarp is very astringent. The timber is highly valuable.

1. JUG'LANS, L. Walnet. (Lat. Jovis glans; $i$. e., the nut of Jove ; a name given it by way of eminence.) $\hat{o}$ - Flowers in an imbribricated, simple ament; calyx scale 5 -6-parted, somewhat bracteate at base ; stamens about 20. $\Varangle$ Calyx 4-cleft, superior; corolla 4-parted ; stigmas 2 ; fruit drupaceous, epicarp spongy, indehiscent, endocarp rugous and irregularly furrowed.-Trees of large size. Leaflets numerous. Sterile aments axillary. Fertile flowers terminal. Pith separating into thin, transverse disks.

1. J. cinèrea L. White WALNUT. Butternvt. Ifts. numerous $(15-17)$, lanceolate, serrate, rounded at tho base, soft-pubescent beneath; petioles villous; fr. oblong-ovate, with a terminal obtuse point, viscid, hairy; shell oblong, acuminate, deeply and irregularly furrowed.-A common tree, Can. to Ga. and W. States. It is 40-50f high, with a large, but short trunk. Branches horizontal, and unusually wide-spreading, forming a very largo head. Leaves $12-20^{\prime}$ long, consisting of 7 or 8 pairs of leaflets, with an odd one. Barren flowers in long aments; fertile in short spikes. The kernel is rich in oil, and pleasant-flavored. The wood is of a reddish hue, light, used in panneling and ornamental work, Bark cathartic. April, May.

2 J. nigra L. BLACK WALNET. Lfts. numerous (15 to 21), ovate-lanceolate, serrate, subcordate, tapering above; petioles and under side of the leaves subpubes. cent; fr. globular, glabrous, uneven with scabrous punctures. $-A$ common and stately forest tree in the Mid. S. and W. States, sparingly found in the Northern. It arises $60-90 \mathrm{fl}$ high with a diameter of $3-6 \mathrm{f}$. In open lands it spreads widely into a spacious head. The duramen of the wood is compact and heary, of a deep violet color, with a white alburnum. It is used extensively west of the Alleghanies, for building and fencing, every where for cabinet work. Apr., May.

2. CA'RYA, Nutt. Hrokorix. Shagbarks. (Gr. kapúa, the walnut, from $\kappa a \rho a$, the head; in allusion to the shape of the nut?) $\hat{o}$ Aments imbricated, slender and mostly 3 -parted or trichotomous; scales 
3-parted; stamens 4-6; anthers hairy. \% Calyx 4-cleft, superior; corolla 0 ; style 0 ; stigma divided, 2-lobed, the lobes bifid; epicarp 4-valved; nucleus subquadrangular, even.-Large trees, with hard and strong timber. Lfts. few. Both kinds of fls., and the lvs. from the same bud, the of terminal. Pith continuous.

5 Leaflets 13 , to 15 , seythe-shaped. Not oblong, thin-shelled, rery sweet............No. 1

Lecflets 7 to 11 . Nut with a tender shell and very bitter kernel...................... 2, 3

\$ Leaflets 5 to 9.-Nut roundish, hard-shelled, sweet and eatable. (*)

* Valves of the epicarp distinct to the base. Bark with looso plates...........Nos, 4,5

- Valves of the epicarp united below. Bark continuous, firm.............. Nos.6-8

1 C. olivaefórmis Nutt. PECAN-NUT (PE-CÀws). Lf. with a slender petiolo and 13 or 15 lanceolate-falcate lfts., all acuminate, sharply serrato and short petiolulate, fr. oblong, 4-angled, valves distinct; nut (olive-shaped) oblong, with a thin shell and delicious kernel.-Low, inundated river banks, Ind. (Wabash), Ill. to La. At Terre Haute are specimens 80 to $90 \mathrm{f} \mathrm{high,} \mathrm{with} \mathrm{a} \mathrm{rough,} \mathrm{shaggy} \mathrm{bark,}$ the smaller with bark slightly broken. Lfts. seldom less than 13 , often 15,5 or $6^{\prime}$ long, by 1 to $2^{\prime}$, decidedly falcate, nearly smooth. The kernel fills the shell, and not being divided by bony partitions, is easily extracted. Its rich flavor is well known. Mar.-May.

2 C. amàra Nutt. BitTenxut. Lfts. about 9, ovate-oblong, acuminate, sharply serrate, smooth both sides except the pubescent veins and midvein, odd one subscssile, the rest sessile; $f r$. subglobous, with the sutures prominent above, valves half united; nut white, very thin-shelled, smooth, subglobous; kernel bitter.Grows in most of the U. S., but attains its greatest size in Penn. and along tho Ohio valley. Winter bud orange yellow. The nut may be broken by the fingers and contains a kernel so bitter that animals will scarcely touch it. May.

3 C. aquàtica Nutt: WATER BitTernut. Lfts. about 11, lanceolate, oblique, acuminate, subentire, sessile, tho odd ono petiolulate, fruit pedunculate, ovate, sutures prominent; nut small, angular, compressed, with a very tender, reddish shell and bitter kernel. - Southern States, in swamps and rice-field ditches. Tree 30 to $40 \mathrm{f}$ high. Ifts. slightly inequilateral, of a shining rich green both sides, resembling the peach leaf. Fruit wholly unpalatable, and timber of little value. Apr.

4 C. álba Nutt. ShaGBark. Lf. long-petioled, of $5 \mathrm{lfts}$, the 3 upper oblanceolate, the 2 lower much smaller, oblong-lanceolate, the terminal petiolulate, lateral sessile, all subacuminate, sharply serrulate, downy beneath; fr. depressed-globular; valves distinct; nut roundish, compressed, subquadrangular, with a thin shell and large, sweet kernel.-Native from Me. to Wis., S. to Ga. In forests it is very tall, straight and slender, with a rough, shaggy bark consisting externally of long broad plates loosely hanging. Lfts. uniformly 5 , the 2 lower deflexed, odd ono tapering to a stalk 5 to $8^{\prime \prime}$ long. Aments 3 on each stalk, long, slender, pendulous. Fertile fls. 2 or 3 together, sessile, terminal. Wood straight-grained, very fertile, heavy, elastic, excellent as timber or fuel, while the fruit is of the richest flavor. Apr., May.

5 C. sulcàta Nutt. THick-SHellbark. Lfts. 7 or 9 , oblanceolate, acuminate, sharply serrate, the odd one subsessile, atteruate to the base; fr. large, oval, subquadrangular, 4-furrowed, valves opening to the base; nut longer than broad, pointed at each end, with a very thick shell and rich-flavored kernel.-Penn. to Ga., rarc, but common, W. of the Alleghanies. Tree 40 to $80 \mathrm{f}$ high, with a shaggy bark in loose narrow plates. Ifts. often 9 , the lower pair smaller, odd one generally sessile,-a good mark of distinction. Nut usually twice larger than in C. alba, and scarcely less delicious. Mar.-May.

6 C. tomentòsa Nutt. Mockernut. Leaf of 7 or 9 lfts., odd lft. petiolulate, the lateral sessile, all oblong-lanceolate, obscurely serrate or entire, rough-downy beneath as well as the thick pitiole; aments very slender, hairy; fr. globular or suboval, valves united at base; nut subhexagonal, with a very thick shell and well-flavored kernel. - Native throughout the country but more abundant West and South. A large tree 40 to $60 \mathrm{f} \mathrm{high} \mathrm{in} \mathrm{woods.} \mathrm{Bark} \mathrm{thick} \mathrm{and} \mathrm{rugged,} \mathrm{but}$ not scaly. Winter bud large, hard, grayish white. Lvs. strongly resinous-scented. Fruit varying in size from $1^{\prime}$ to $2^{\prime}$ diam., with a very thick husk, rounded shell, 
and a comparatively small kernel difficult of extraction. Taste inferior to the shellbark. Wood with a small duramen, excellent for fuel. Apr., May.

7 C. glàbra Torr. PIGNuT. Lfts. 5 or 7 , ovate-lanceolate, subacuminate, serrate, nearly glabrous both sides; fruit roundish-obovate ur pyriform, half 4-valved; nut smooth and even or slightly angular, hard, thin-shelled, with a bitterish but eatable kernel.-Forests U. S. and Can., growing to the height of $60-100$ f. Trunk 1 to $2 \frac{1}{2} \mathrm{f}$ diam., covered with a moderately even bark. Lfts. mostly 7 , often 5 , sometimes 9 , the odd one tapering to a short stalk. The fruit is considerably variabie in form and quality, often pear-shaped, then obovate or roundish, always somewhat bitter. Wood exceedingly tough and hard, and excellent for fuel. Mar., May. (Juglans, Muhl. C. porcina Nutt.)

8 C. microcárpa Nutt. Lfts. 5 or 7, oblong-lanceolate, glabrous, glandular beneath, serrate, conspicuously acuminate; aments glabrous; fr. roundish-ovoid, valves thin, united below; nut thin-shelled, small, slightly quadrangular. - A large tree 60 to $80 \mathrm{f} \mathrm{high,} \mathrm{in} \mathrm{moist} \mathrm{woodlands,} \mathrm{Penn.} \mathrm{to} \mathrm{Ky.} \mathrm{and} \mathrm{Tenn.?} \mathrm{Trunk} 1 \frac{1}{2}$ to $2 \mathrm{f}$ diam. with an even bark. Ifts. mostly 5 , often 7,4 to $8^{\prime}$ by 2 to $3^{\prime}$, the under surface tufted in the axils of the veinlets, and sprinkled with dark glandular dots. Fruit about the size of a nutmeg. Nut with a thin shell, not mucronate, eatable. May.

\section{Order CXIX. CUPUlifer A. Mastworts.}

Trees or shrubs. Leaves alternate, simple, straight-veined, with deciduous stipules. Flowers monœcious, the sterile in aments which are racemed or capitate. of Calyx scale-like or regular, with 5 to 20 stamens inserted at its base. $q$ Calyx tube adherent to the ovary, the toothed limb crowning its summit. Ovary 2 to 3 to 6 celled, with sessile stigrnas and 1 or 2 ovules in each cell. Fruit a 1-celled, 1-seeded nut, solitary or several together invested by an involucre which forms a scaly or echinate cupule. Seed destitute of albumen, filled by the embryo with its large cotyledons. Lilust. in figs. $6,7,8,9,71,138,139,140,202,418,438,471,472,473$, 474. 46. B.

Genern 8, species 265, constituting a large portion of the forests of the northern temperate regions, and of mountainous tracts within the tropics.

Properties. - The bark of the oak and other genera is well known for its astringent quallties. The edible fruit of the hazel-nut, chestnut, beech, Sc., are toowell known to require description. Cork is the bark of Quercus Suber. Nutt galls are prodnced from the petioles of $Q$. infectoria of Asia Minor, being caused by wounds made by insects. But the timber is of the highest quality and value.

GENERA.

Sterile flowers in aments, fertile, solitary, or few together. (*)

* Involucre of many scales, valveless, cup-like, jartly enclosing tho 1 nut....Qurects. 1

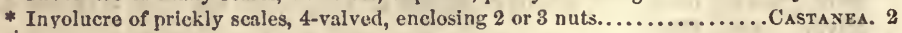

* Involucre of soft, prickly scales, 4-valved, enclosing 2 nuts............... FAGus. 3

* Involucre of 2 or 3 large, lacerated, united seales, valveless, with $1-2$ nuts..Corrucs. 4

$\$$ Sterile flowers and fertile, both kinds in pendulous aments. (*)

* Involucre scales in pairs, with their elges united, inflated................ Ostr. $\mathbf{A}$.

* Involucre scales in pairs, distinct, 8-lobed, becoming leaf-like............ Carpints. 6

1. QUER'CUS, L. OAк. (Celtic quer, fire, cuez, tree. The Celtic name is drys, hence druid.) of Fls. in loose aments ; calyx mostly 5cleft; stamens 5-10. \& Cupule cup-shaped, scaly; ovary 3-celled, 6-ovuled (Fig. 418), 2 of the cells and 5 of the ovules abortive; stigmas 3 ; nut (acorn) coriaceous, 1-celled, 1-sceded, surrounded at the base by the enlarged, cup-shaped, scaly cupulc.-A noble genus of trees, rarely shrubs. Aments axillary, pendulous, filiform, with the flowers separate, in one section, not maturing fruit until the second year (fruit biennial). Timber invaluable. Fig. 420 . 
\$ Leaves mostiy entire, the ends subequal, the petioles very short. Frult (2). (*)

* Peduncle longer than the oblong acorn. Leaves evergreen...................... 1

* Peduncle shorter than the acorn.-Leaves downy beneath.................. Nos. 2, 3

-Leaves smooth both sides........................ 4, 5

5 Leaves 8 -lobed and dilated above, short-petioled, awnless when mature. Fr. (2)... Nos. 6, 7

\$ Leaves 8 to 9-lobed or pinnatifid, broad, lobes setaceously anoned. Frult (2). (*)

* Leaves at base cuneate, sliort-petioled, 8 or 5-lobed. Shrubs or small trees.... Nos. 8-10

* Leaves at base abrupt or truncate, mostly long-petioled, 7 to 9 -lobed. (a)

a Nut one-thirl immersed in the saucer-shaped, fine-sealed cup.............. Nos. 11, 12

a Nut near half immersed, in the hemispherical, coarse-scaled cup. (b)

b Leaves cinerons-downy beneath, acorn also downy ........................ 13

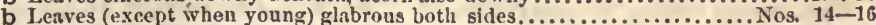

\$ Leaves 5 to 9-lobed, divisions obtuse, never bristle-awned. Fruit (1), sessile.... Nos. 17-19 Leaves 13 to 25 -tocthed, downy beneath, teeth awnless. Acorn sweet, eatable. (c)

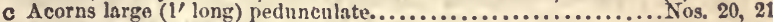

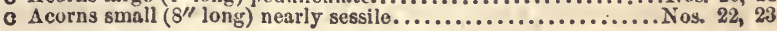

1 Q. vìrens Ait. LIve OAK. Lvs. coriaceous, elliptic-oblong, obtuse, downy and paler beneath; cup turbinate; nut oblong-obovoid, on a slender peduncle. In the maritime or low districts of the S. States. Tree 40 to 50 , rarely 70 f high, of slow growth. Branches widely spreading. Bark blackish and thick. Wood very heavy, close-grained, yellowish. Lvs. $18^{\prime \prime}$ to $3^{\prime}$ long, short petioled, the old ones cinerous-green, revolute-edged. Peduncle about $1^{\prime}$ long, acorn $9^{\prime \prime}$ by $6^{\prime \prime}$, maturing the second year. May.-Tho timber is in great demand for ship building and is fast disappearing.

2 Q. cínera Ph. UPLAND WILLOW OAK. Lvs. coriaceous, tardily deciduous, lanceolate-oblong, entire, apex acutish, mucronate, margin revolute, white-downy beneath, attenuate at base; cup subsessile, saucer-shaped, nut subglobous.-Sandy or pine barrens, Va. to Fla. A shrub or small tree, 4 to $20 \mathrm{f} \mathrm{high,} \mathrm{trunk} \mathrm{not} \mathrm{exceed-}$ ing 4 to $6^{\prime}$ diam. Lvs. partly persistent, $1^{\prime}$ to $30^{\prime \prime}$ long, resembling those of the live oak, but mucronate, and on the shrubby stocks often toothed. May.

$\beta$. SERICEA. Dwarf; lvs. silky; tomentous beneath, 1 to $3^{\prime}$ long, deciduous.South, in pine barrens. (Q. sericea Ait. Q. pumila $\mathrm{Mx}$.)

3 Q. imbricària Mx. Laurel $\mathrm{O} A \mathrm{~K}$. Shingle $\mathrm{OAK}$. (Fig. 138.) Lvs. deciduous, lance-oblong, acuto at each end, briefly petiolate, very entire, shining-glabrous above, subpubescent beneath (but not hoary), mucronate at apex; acorn subglobous, in a shallow cup; scales of the cup broad-ovate.- $-\Lambda$ beautiful tree, very abundant in the W. States, also common along rivers, Penn. to Ga. Trunk 40$50 \mathrm{f}$ high, 1-2f diam., with a smooth unbroken bark, and a large head of coarse, irregular branches. The leaves are dark green, thick and firm in texture, $3-5^{\prime}$ by $1-1 \frac{1}{2}$, forming a dense, heavy foliage. June.-The timber makes miserable shingles. In Indiana it is called Jack-Oak.

Q. Phéllos L. Willow OAK. Lvs. deciduous, linear-lanceolate, tapering to each end, very entire, glabrous, mucronate at apex; acorn subglobous, in a shallow cup. - A tree 30 to $60 \mathrm{f}$ high, borders of swamps, N. J. to Fla. and W. States. Trunk straight, 10 to $20^{\prime}$ diam., covered with a smooth, thick bark. The leaves which bear considerable resemblance to those of the willow, are of a light green color, dentate when young, 3 to $5^{\prime}$ in length. Acorns $6^{\prime \prime}$ diam. May.-Tho tumber is of little value.

$\beta$. maRitima. Low, shrubby; Ivs. evergreen.-Sea coast, Va. to Fla. A fow feet high.

5 Q. laurifòlia Mx. SwAMp LAUREL OAK. Lvs. oblanccolate or lance-obovate, acute, mucronate, entire, or some of them with 2 lateral teeth above, glabrous botl sides, base abruptly ending in a very short petiole; cup saucer-shaped, nut depressed-ovoid.-Damp woods, and often planted for shade, S. Car. to Fla. A tree with handsome, dense foliage, partly evergreen, 30 to $50 \mathrm{f} \mathrm{high.} \mathrm{Bark} \mathrm{blackish,}$ rough. Lvs. 2 to $3^{\prime}$ long, coriaceous, green both sides, shining above, often appearing tricuspidate. Ped. $1 \frac{1}{2}$ "long. Acorn as broad as long, cup 6" across. May.

$\beta$. oвTUSA. Lrs. obtuse, not mucronate, sessile.-Ga. (Pond). Fruit the same.

6 Q. aquática Mx. WATER OAK. Lvs. wedge-obovate, entire, or mostly dilated and obscurely 3-lobed above, not mucronate, glabrous both sides, gradually attenuated to a very short petiole; cup subsessile, very shallow, nut globular.-Swamps, Md. to Fla., also planted for shade. It is a handsome, round-headed tree, with 
very dense foliage of a bright, shining green. 'Lvs. 2 to $3^{\prime}$ long, 1 to 2 ' wide above, coriaceous, but mostly deciduous, very variable, but always cuneate. Cup (" across, $1^{\prime \prime}$ deep. Apr., May.

7 Q. nigra L. Barren OAK. BLACK Jack. Iron OAK. Lvs. coriaceous, cuneiform, obtuse or subcordate at base, mostly 3-lobed at apex, lobes subequal, entire or toothed, setaceous-mucronate when young, smooth and shining above, rustdowny beneath; villous in the axils of the veins; cup turbinate, half covering the globular nut; scales of the cup obtuse, scarious.-A small, gnarled tree, with dark, massy foliage, in sandy soils, N. J. to Ill. and S. States. Trunk 20 to $30 \mathrm{f}$ high, with a thick, black, broken bark. The leaves are very firm in texture, 3 to 7 to $8^{\prime}$ by 2 to 5 ', broadest above, the middle lobe narrowest. Petioles 3 to $6^{\prime \prime}$ long. May.-The wood is very valuable for fuel. (Q. ferruginea Mx.)

8 Q. tríloba Mx. DowNY BLAcK OAK. Lvs. oblong-cuneiform, acute at the base, on very short petioles, 3-lobed at the end, rusty-tomentous beneath, lobes mucronate with setaceous awns, middle one longer; fruit with a flat cup and a depressed-globous acorn. - A tree of rapid growth, 25 to $40 \mathrm{f} \mathrm{high,} \mathrm{in} \mathrm{tho} \mathrm{pine} \mathrm{bar-}$ reus of N. J. to Fla. Lvs. very large, those of the young shoots 8 to $12^{\prime}$ long and often 5-lobed, approaching, perhaps, too closely the next. May.-It has been recommended for hedges.

9. Q. Catesbài Mx. Barren Scrub OAK. Lvs. short-petiolate, cuneato at base, deeply siuuate-lobed, glabrous on both sides, lobes 3 to 5 , divaricate, acuto and setaceous-pointed, simple or toothed with setaceous-pointed teeth; cup large, turbinate, half covering the ovoid nut, scales obtuse, the upper inflexed.-Pine barrens, Car. to Ga. A tree 20 to $25 f$ high, with large and very irregular leaves, 6 to $10^{\prime}$ long and nearly as wide, smooth, at length coriaceous, deciduous. Cup about $8^{\prime \prime}$ broad, nut covered with an ashy meal. May.

10 Q. ilicifollia Willd. SHRUB or Scrub OAK. Bear OAK. Lvs. petiolate, obovate-cuneate, with 3 or 5 angular lobes, entire on the margin, whitish downy beneath; cup subturbinate; acorn ovoid. - A shrub, common throughout the U. S., growing only on gravelly hills and barrens, which it occupies exelusively in largo tracts. St. 3 to $4 \mathrm{f}$ high, divided into numerous straggling branches. Lrs. 3 to $4^{\prime}$ long, petioles 6 to $12^{\prime \prime}$. Acorns $6^{\prime \prime}$ loag, abundant, and said to bo greedily eaten by bears, deer, and swine. May. (Q. Bannísteri Mx.)

$\beta$. ? Georgiaxa. Lvs. glabrous, except a tuft in the axils of tho veins; cup flat, covering only one-fourth of the ovoid nut.-On stone Mt., Ga.!. (Q. Georgiana Ravanel.)

11 Q. rùbra L. RED OAK. Lrs. on long petioles, smooth, obtusely sinuate, lobes rather acute, shallow, incisely dentate; acorn large; cup shallow and flat, smoothish; nut turgid-ovoid.-The red oak is the most common species in tho Northern States and in Canada. It is a lofty, wide-spreading tree, $70 \mathrm{f}$ in height, with a diameter of 3 or 4 . Leaves $6-10^{\prime}$ long, smooth on both sides, with deep and rounded sinuses between the narrow, mucronate lobes. The flowers appear in May, succeeded by large acorns $\left(9^{\prime \prime}\right.$ long) contained in cups so shallow as rather to resemble saucers. The wood is reddish, coarse-grained, of little value as timber, but excelleut fuel.

12 Q. palústris Mx. PIN OAK. Tater OAK. (Figs. 6-9.) Lvs. on long petioles, ob!ong, deeply lwbed with broad, rounded sinuses, smooth, axils of the veins tufted-villous beneath, lobes divaricate, vather narrow, dentate, acute; cup flat, smooth; acorn small, nearly spherical.-The pin oak is most luxuriant in the W. States, and the adjacent distriets of other States, rare in N. Eng., growing in swamps and cold, clay soils. Height 60 to $80 \mathrm{f}$, with a diameter of 2 to 4 , and light, open foliage. Bark blackish. Leaf lobes narrower than the spaces between. Wood coarse-grained, little esteemed as timber. Acorns $7^{\prime \prime}$ long, round, in shallow cups. May.

13 Q. falcàta L. Spanish OAK. Lvs. long-petiolate, elongated, obtuse or rounded at base, ashy-tomentous beneath, deeply sinuate lobed, lobes 5 to 7 , rarely 3 , narrow, bristle-pointed, simple or toothed, more or less falcate; acorn small, roughened, globular, cup shallow, subsessile, its margin incurved.-Va. to Fla., in the lower distriets. A tree of large dimensions, 60 to $70 \mathrm{f} \mathrm{high,} \mathrm{most}$ fourishing in Mid. Fla. Lvs. 5 to $6^{\prime}$ long, on vigorous shoots much larger, peti- 
vles about $2^{\prime}$ long. Cup $6^{\prime \prime}$ across, $1 \frac{1}{2}{ }^{\prime \prime}$ deep. Nut fuscous, with a brown, astringent seed. Timber reddish, coarse-grained. Apr., May.

3. TRINACRIS. Lvs. 3 and 5-lobed, the terminal lobe long and narrow-lanceo. late, narrowed to its base; petioles $3^{\prime}$ long.-Large trees at Tallahassee.

14 Q. tinctòria Bartram. BLACK OAK. YELLOW-BARK OAK. Lvs. obovateoblong, sinuate-lobed or pinnatifid, pubescent beneath, finally glabrous, lobes oblong, obtuse, mucronate; cup thick, shallow; acorn depressed globous.-Found throughout the U.S. It is one of the loftiest trees of the forest, 80 to $90 \mathrm{f}$ in height, and 4 to $5 f$ diam. Bark deeply furrowed, black or deep brown, yellow within. Lvs. 6 to $8^{\prime}$ long, broadest toward the end; quite variable, yellowish after frost. Acorns brown, $7^{\prime \prime}$ diam., about half covered with the subsessile, scaly cup, which is $9^{\prime \prime}$ diam. Bark used in tanning, also yields quercitron, a useful dye.

15 Q. coccínea Wang. Scarlet OAr. Lvs. on long petioles, oblong in outline, deeply sinwate-pinnatifid, smooth and shining both sides, nearly truncate at base, lobes divaricate, dentate, acute; cup turbinate, scaly; acorn short, ovate.-Most abundant in the Niddle and Southern States, but is often met with in the more southern parts of $\mathrm{N}$. Eng. to $\mathrm{Ill}$. It is a large tree, $80 \mathrm{f}$ in height, with a diameter of 3 or 4. Leaves of a bright, shining green, with 3 or 4 deep sinuses each side, remarkably rounded and broad at the base. By the frosts of autumn they are changed to scarlet, unlike those of the red oak, which become dull red or brown. Acorns large, similarly rounded at both ends, half immersed in the cup. Bark very thick, used in tanning.

16. Q. heterophýlla Mx. BARTraM's OAK. Lvs. on long petioles, coriaceous, oblong or oblong-ovate, round or subcordate at base, margin with a few shallow, tooth-lite lobes, or often only wavy, lobes setaceous-acuminate; acorn subglobous, in a hemispherical cup; scales of the cup oblong-ovate, obtuse.-Ohio to Ill, rare. Lvs. exceedingly variable, 4 to $6^{\prime}$ by $1 \frac{1}{2}$ to $2^{\prime}$, smooth and shining above, tomentous along the veins beneath, generally broad and abrupt at base. Fruit $9^{\prime \prime}$ diam. (Q. Leana Nutt.? Clark.) Our specimens well agree to Michaux's figure and character.

17 Q. álba L. Whiтr OAK. (Fig. 139.) Lvs. short-petioled, cuneate at base, oblong in outline, at length coriaceous and smooth, sinuate-pinnatifid, lobes subequal, obtuse; acorn sessile; nut ovoid or oblong, only a third immersed in the subliem:spherical, tubercular cup.-U. S. and Can. A tree preeminent among the sons of the forest for grandeur, strength, and usefulness. With a diameter of 4 to $6 f$, it attains the height of 70 to $80 \mathrm{f}$, but its magnitude varies greatly with the soil. Lvs. 3 to 5 ' long, downy beneath when young. Acorn 8 to $9^{\prime \prime}$ long. Bark whit. ish. Timber useful for innumerable purposes, and the bark for tanning and in medicine. May, Jn.

18 Q. macrocárpa Mx. (Fig. 140, 194.) Lvs. deeply and lyrately sinuate-lobed (most deeply in the middle), lobes obtuse and repand, upper dilated; acorn very large, cup very deep, composed of distinctly imbricated and hard-pointed scales, the upper filiform-pointcd, forming a fringe; nut globular ovoid, more than half inclosed.-N. Eng. (rare) to IIl. and S. States. Tree 60 to $70 \mathrm{f} \mathrm{high,} \mathrm{with} \mathrm{rich,}$ green foliage. Lvs downy beneath, at length nearly smooth, 6 to 10 to $15^{\prime}$ long, stalks not $1^{\prime}$. Acorns 12 to $15^{\prime \prime}$ long, sometimes nearly fringeless or nearly corcred. May. (Q. lyrata Mx.) A beautiful tree, with valuable timber. (Also Q olivieformis $\mathrm{Mx}$.)

19 Q. obtusíloba Mx. Iron OAK. Lvs. deeply sinuate, cuneiform at the base, pubescent beneath, lobes very obtuse, the 3 upper ones dilated, each 2-lobed; cup hemispherical; acorn oval-The iron oak, called also post oak, box white oak, tur- liey oak, is common in the Mid., W. and S. States, rare in N. Eng. It is a tree of moderate size, with widely spreading and very crooked branches. The bark is grayish-white. Lvs. thick, strongly tomentous beneath, in 4 or 5 lobes, which are sometimes arranged so as to appear cuneiform or stellate. Acorns very sweet. Timber is fine graiued, strong, and durable. May. (Q. stellata Willd.)

20 Q. Prìnus Willd. Swamp Chestivet OAK. Lvs: on long petioles, obovate, acute, pubescent beneatl, with large, somewhat equal, obtuse or rounded teeth; acorn short-peduncled, large; cup tubercular, about half inclosing the ovoid nut -This oak is seldom met with in N. Eng., but abounds in the rest of the country. 
It is a lofty tree, arising to the height of $50 \mathrm{f}$, with its undivided, straight and uniform trunk, and thence with its expansive top to the height of 80 to $90 \mathrm{f}$. Acorns large and sweet. Ped. 3 to $6^{\prime \prime}$ long, acorn 12 to $15^{\prime \prime}$. The timber valuable. (Q. prinus palustris $\mathrm{Mx}$.)

$\beta$. yonticola. Rock Chestrut OAK. Lrs. glaucous beneath; nut oblongovate, about a third covered by the cup.-In mountain woods.

21 Q. bícolor Willd. Swaurp White OAK. Lvs. oblong-ovate, downy, white underneath, with large, irregular teeth above, somewhat sinuate-lobed in the middle, subentire below, on very short petioles; acorns on long peduncles, in pairs, cup hemispherical, with pointed scales, nut oblong-ovoid.-In low, swampy woods, U. S. It is a beautiful tree, attaining, in farorable situations, the height of $70 \mathrm{f}$. Foliage rich and luxuriant; lvs. smooth and green above, white-downy beneath, 5 to $7^{\prime}$ by $2 \frac{1}{2}$ to $4^{\prime}$. Ped. 1 to $2^{\prime}$ long. The trunk bark grayish-white, dividing into large, flat scales. It affords excellent fuel and timber. (Q. prinus discolor Mx.)

22 Q. castànea Muhl. Chestnut OAK. Lvs. long-petioled, lance-oval or lanceobovate, acuminate downy and glaucous-hoary beneath, with coarse, subequal, acute and submucronate teeth; acorn nearly sessile, cup hemispherical, covering about a third of the roundish-oroid, light brown nut.-Mid., S. and W. States, in rocky or sandy soils. A large tree, 40 to $60 \mathrm{f} \mathrm{high,} \mathrm{with} \mathrm{a} \mathrm{whitish,} \mathrm{furrowed}$ bark. Lvs. 4 to $6^{\prime}$ long, more nearly resembling the chestnut leaf than any other oak. Acorns about $9^{\prime \prime}$ long, sweet-flavored. Used for rails and shingles.

23 Q. prinoides Willd. DWARF Chestrut OAK. Shrub with lvs. on short petioles, obovate, acute at the base, glaucous beneath, with large, subequal, sinuate terth, callous at the tip; cup hemispherical, acorn ovate. - This is one of the most diminutive of all the oaks, never exceeding 3 to $4 \mathrm{f}$ in height. It is a native of the N. and Mid. States, in barren woods, but not common. The flowers appear in May, followed by acorns of middle size, very sweet and very abundant.

2. CASTA'NEA, Tourn. Chestnut. (Castanea was a city in Thessaly, famed for the growth of chestnuts.) of Flowers clustered in long, slender, cylindric aments; calyx 5 to 6-parted; stamens 5 to 15 . + . Flowers in $3 \mathrm{~s}$, inclosed in a 4 -lobed involucre, which in fruit becomes coriaccous and beset with prickles; calyx 5 to 6 -lobed, tube adherent to the 3 to 6 -celled, 3 to 6 -ovuled ovary; stamens 5 to 12 , abortive; stigmas as many, as the cells; fruit a 4 -valved involucre enclosing 1 to 3 one-seeded nuts.-Trees and shrubs. Lrs. mostly deciduous, alternate, acuminate, expanding before the flowers.

1 C. vésca L. Lvs. oblong-lanceolate, acuminate, mucronately serrate, smooth both sides; nuts mostly 2 or 3 logether.-Abundant in particular districts throughout the U. S. It is a lofty tree in woods, with a large, straight trunk. Lvs. 6 to $9^{\prime}$ long, $\frac{1}{4}$ as wide; teeth mucronate, with the prolonged, straight veins. Aments as long as the leaves, and so numerous as to impart their yellowish hue to tho whole tree when in blossom. Nuts of a peculiar brown, villous above, enclosed in the enlarged cupule or burr which is beset on all sides with strong, compound, acute spines. Timber coarse-grained, strong, elastic, light and very durable. July, fruit in Oct.-The nuts are smaller but sweeter than those of tho European variety (the Spanish Chestnut).

2 C. púmila Michx. Chinquapin. Lvs. oblong, ovate or obovate, mucronate-serrate, hoary-tomentous beneath; nut solitary. - Sterile places, N. J., Penn. to Ga. and T'enn. Slirub 6-12f ligh, much branched. Leaves $3-5$ ' by $1 \frac{1}{4}-2$ ', smooth above, generally obtuse at base, acute at apex, margins mucronate, with the projecting, straight veinlets; petioles $6^{\prime}$ long; under surfaco nearly white. Aments axillary, the lower staminate, $6-10^{\prime \prime}$.long, upper fertile, with remote, pistillato flowers. Involucre of fruit bristly and prickly, 4-lobed. Nut (by abortion) solitary, small, ovoid, sweet. Fl. Jn. Fr. Oct.

3. FA'GUS, Tourn. BEEcr. (Gr. $\phi \eta \gamma o ́ s$, the beech; it also signifies something eatable.) $\delta$ Flowers in a capitate ament suspended by a 
slender peduncle; calyx 6-cleft, campanulate; stamens 5 to 12 . $\&$ Flowers 2, within a 4-lobed, prickly involucre composed of united linear scales; calyx with 5 to 6 minute lobes; ovary 3 -celled, 6 -ovuled; styles 3 ; nut 1 -seeded, acutely 3 -angled, enclosed within the enlarged, spiny involucre or capsule.-Lofty trees, with smooth ash colored bark. Lvs. alternate, plicate in vernation. Buds slender, pointed.

F. sylvática L. (Figs. 438, 471-4. 46, B.) Lvs. broadly ovate-lanceolate, briefly petiolate, obtuse at base, ciliate, with soft white hairs when young, at length nearly glabrous, with small, remote teeth, apex acuminate; buds lanceolate-cylindric, imbricated with brown scales, developing both leaves and flowers; nuts ovoid triangular, obtuse-mucronate. $-\Lambda$ common forest tree, abundant in the U. S. and Can. The trunk is tall and straight in forests, 50-80f high, but lower and with an expansive head in open situations, always known by the light gray, unbroken bark. Leaves with very regular and straight veinlets, $4-6^{\prime}$ long, $\frac{1}{2}$ as wide, often persistent through the winter. $\delta$ Aments pubescent, peduncles $2^{\prime}$ long. Nut small, 2 together in the 4-lobed burr, oily, sweet and nutritious. Timber compact, fine-grained. May. (F. ferruginea Ait.) THE RED BEECH is now regarded only as a variety, with the wood softer, and of more easy cleavage, and perhaps a slight difference in foliage. There are several beautiful varieties in cultivation, with purple foliage, silver foliage, \&c. See garden catalogues.

4. COR'ÝLUS, Toưrn. HAZEL-NuT. (Gr. kópvs, a bonnet; to which the cupule enwrapping the nut may well be compared.) of Flowers in a cylindric ament; calyx of 2 scales united at base to the bract; sta mens 8 ; anther 1-celled. 9 Involucre of 2 to 3 seales, 1 to 2 -flowered; calyx adherent to the 2-celled, 2 -ovuled ovary; stigmas 2 ; nut ovoid, surrounded with the enlarged, coriaceous, lacerated involucre.-Shrubs. Iments and capitate fertile clusters subterminal, expanding before the lis.

1 C. Americàna Walt. Lvs. roundish, cordate, acuminate; invol. roundish, campanulate, much larger than the roundish nut, its border dilated and coarseiy serrate.-Shirub 5 to $6 f^{\prime}$ high, growing in thickets and borders of fields, U. S. Lvs. 3 to $G^{\prime}$ long, $\frac{2}{3}$ as wide. From the ends of the branches hang the long, pendulous aments of barren flowers in April. The nuts are remarkably distinguished by the large, bell-shaped invol. in which each one is enveloped. They are a wellflavored fruit, though somewhat inferior to the European hazel or fibert.

2 C. rostràta Ait. Lvs. ollong-ovate, acuminate; stip. linear-lanceolate; invol. campanulate-tubular, longer than the nut, 2-parted, with dentate segments.-This species is found in the same localities as tho former, is a rather smaller shrub, and chiefly differs from it in the involucre which is covered with short, stiff hairs, and contracted at the top into a long $\left(1\right.$ to $\left.1 \frac{1}{2}^{\prime}\right)$, narrow neck, like a bottle. Nuts as in C. Americana. May.

3 C. Avellàna L. FILrert. Lrs. roundish, cordate, acuminate; stip. ovate-oblorg, obtuso; invol scarcely exceeding the fruit. - Shrub 3 to 10 f high, in gardens, \&c. Lvs. nearly sessile, doubly serrate, 3 to $5^{\prime}$ long. Sterile aments $3^{\prime}$. long, the fertile clusters at their base. Nut larger than the native species. + Asia.

5. OS'TRYA, Michel. Hop Hornbeam. Iron-wood. Lever Woón. (Gr. öбтpeov, a scale; in allusion to the conspicuous sacs (not scales) of the fertile aments.) of Flowers in a cylindric ament; calyx scale roundish-ovate, ciliate, 1-flowered; anthers 8 or more, conspicuonsly bearded at the summit. \& Flowers geminate, in a loose, imbricated ament; flowers cnclosed each in an inflated, membranous sac which at length. enlarged, contains the matured nut. - Small trees, flowering before leafing.

O. Virgínica Willd. Lvs. ovate, acuminate, serrate; fertile ament oblong, per- 
dulous; buds rather acute.-A small tree disseminated throughout the U. S., 25-30f in height. Its bark is remarkable for its fine, narrow, longitudinal divisions. Leaves about twice as long as wide. The fruit is similar in appearance to bops, suspended from the ends of the branches, consisting of membranous, imbricated sacs (cups?) containing each a flower. The wood is very white, hard and strong, much used for levers, \&c. Apr., May.

6. CARPI'NUS, L. Hornbeam. (Celtic car, wood, and pino, the head; alluding to its use in making yokes for cattle.) $\hat{o}$ Flowers in a long, cylindric ament; cal. scale roundish, clliate; sta. 8-14, slightly bearded at summit. $\%$ Flowers in a loose ament; scale large, oblong, 3lobel, 1-3-flowered; cal. 6-toothed; stig. 2 ; nut long, ovoid, furrowed, 1-seeded.-Small trees. Scales of the $q$ aments persistent and becoming foliaccous.

C. Americàna I. Lvs. oblong-ovate, acuminate, unequally serrate; scales of tho fertile ament 3-parted, the middle segment much the largest, oblique, with a lateral tooth.-A small tree (12-20f high), common in woods throughout the $U$. S. The wood is very fine-grained, compact and white, covered with a light gray or ash-colored bark. Leaves $2-4^{\prime}$ long, $\frac{1}{2}$ as wide, petiolate. From the ends of the branches hang the long, loose, pale green, leafy aments, consisting of alternate pairs of enlarged scales, with a dark-colored nut at the base of each. Apr., May.

\section{Order CXX. BETUlace . Birchworts.}

Trees or shrubs with deciduous stipules. Bark separating into thin layers. Leaves alternate, simple, with the veinlets running straight to the margin. Flowers moncecious, amentaceous, mostly naked, 3 in the axil of a 3-lobed bract. of Siamens definite, distinct. Anthers 2-celled. \& Ovary 2-celled, 2-oruled, becoming in fruit 1-celled and 1-seeded (by abortion) membranous and indehiscent. Seed pendulous, without albumen. Figs. 77, 90, 106, 111, 419, 420.

Genera 2, species 65, chiefly natives of the cool parts of the northern hemisphere. Properties generally astringent. The birches are often fine timber trees.

1. BE'TULA, Tourn. Bircir. (Betu is the Celtic name for the birch.) $\delta$ Flowers in a cylindric ament; bracts deeply 3 -parted, peltate; calyx a scale; stamens 4. o Ament oblong-ovoid, scales trilobate; calyx 0 ; ovaries 3 under each seale; stigmas 2, filiform; nut compressed, with a membranous margin.-Trees and shrubs, with the outer bark laminated and horizontally fibrous, the inner aromatic. Branchlets dotted. Lvs. ovate, serrate. Figs. 419, 420.

* Trees with a yellowish bark, smoothish leares, and short, erect, o aments............No. 1

- Trees with a reddish-l)rown bark and ovate-oblong, suberect, $q$ aments............ Nos. 2, 3

- Trees with a white bark, long-stalked leaves and drooping $q$ aments.............. Nos. 4, 5

* Shrubs with brownish bark, roundish leaves and short, ercet, $q$ aments............... Nos, 6, 7

1 B. excélsa Ait. Yellow Bırcir. Lrs. orate-elliptic, subacuminate; subcordate, coarsely, sharply, and doubly serrate, smooth when old, on short, downy petioles; fertilo aments erect, ovoid-oblong; lobes of the bracts subequal, acute, diverging.-A common forest tree, N. Eng. to Mich. and Can., arising in woods to the height of 60 to 80 , with a trunk 2 to $3 \mathrm{f}$ in diam., invested with a thin, yellowish, silvery outer bark stripping off in transverse shreds. Barren aments 2 to $4^{\prime}$ long, cylindric, clustered, and pendulous at the ends of the branches; fertile $1^{\prime}$ long, $6^{\prime \prime}$ diam. Apr., May.

2 B. lénta L. Black Bircir. Sweet Bircir. Mahogany Birch. (Fig. 202.) Lvs. cordate-ovate, acuminate, acutely, finely, and doubly serrate, veins beneath and petioles hairy; fertile aments erect, oval-oblong, thick, obtuse, pedunculate; cales hairy, the lobes obtuse, subequal, diverging.-This noble species is common in the Eastern and Middlo States, often exceeding $60 \mathrm{f}$ in height, with a 
diameter of 2 to $3 \mathrm{f}$. Tho trunk is invested with a dark brown or reddish bark, which becomes rough in old trees, and is remarkable for its agreeably aromatic fragrance and flavor. Leaves $3-4^{\prime}$ long, about $\frac{1}{2}$ as wide. Sterile aments $2-3^{\prime}$ long, fertile much shorter and thicker. In spring the cambium affords the boys a delicious morsel. Wood reddish, strong, compact. Apr., May.

3 B. nigra Ait. RED BIRCH. Lvs. rhombic-ovate, acute at each end, doubly serrate, or obscurely 9 to 13-lobed, glaucous beneath; fertile ament sessile, erect, ovoid, scales villous, the segments linear, equal.-A tree 30 to $50 \mathrm{f} \mathrm{high,} \mathrm{growing} \mathrm{on}$ banks of streams and in river swamps, Mass., Ill. and Fla. (!) Trunk covered with a reddish or chocolate-colored bark which at length becomes very loose and torn, hanging in shreds, and finally rough like that of the black cherry. Branches arched and slender; branchlets almost filiform, often clothing the trunk to the baso. Lvs dark green above, about $3^{\prime}$ by $2^{\prime}$ often smaller, petioles 6 to $8^{\prime \prime}$ long, pubescent. May. (B. rubra M̀́.)

4. B. populifòlia Ait. Poplar-leaved Birch. White Brrch. (Fig. 106.) Lvs. delloid, long-acuminate, unequally serrate or obscurely many-lobed, very smooth, on smooth petioles; fertile aments pedunculato; scales with roundish, lateral lobes. -Like the next, distinguished for the white cuticlo with which the trunk is invested. It is common in the rocky and mountainous woods of N. Eng., where it seldom exceeds 30 to $40 \mathrm{f}$ in height. The branches are covered with a reddishbrown bark, very slender, and throw out in May, long, pendulous aments.

5 B. papyràcea Ait. PAPER Brreh. CAxOE Birch. Lvs. ovate, acuminate, doubly serrate, the veins hairy beneath; fertilo aments nodding, pedunculate; lateral lobes of the calyx short, roundish. - This birch is abundant in the hillsido woods of N. Eng. to Wis. and Can. It sometimes attains the height of $60-70 \mathrm{f}$, but is generally smaller. Trunk 1-2f diam., covered with a tough cuticle consisting of numerous laminx, the outer of which is snow white. Of this the Indians construct their light canoes. Branches dark brown. Leaves $2-3^{\prime}$ long, $\frac{1}{2}$ as wide. Sterile aments $1-2$ ' long. The wood is of a fine, compact texture, casily wrought. May, Jn.

$\beta$. Mivor. Lvs. smaller, ovate, glabrous, acute, somo of them roundish-obtuse. -Whito Mts. Shrubs 6-9f high.

6 B. púmila L. DWARF BIRch. Shrub erect, its ascending branches glandularpunctate, glabrous; lvs. obovate, entire at base, obtusely serrate, glabrous; fertile ament cylindrical, about as long as the leaves; scales half 3-cleft, lobes ovateoblong, middle one rather longest; nut orbicular, conspicuously margined,-A beautiful shrub inhabiting the mountainous districts of $N$. and N. W. States, N. to Hudson's Bay. Height 2 to 6 . Lvs. about $9^{\prime \prime}$ by 6 or $7^{\prime \prime}$, very regularly toothed. Aments of both kinds 7 to $9^{\prime \prime}$. (B. glandulosa Mx.)

7. B nana I. Truy Bincr. Shrub, low trailing, smooth; lvs. orbicular, crenate, reticulated beneath; scales of the of ament deeply 3-parted; seeds orbicular, nearly wingless. - This miniaturo tree is found on the summits of Mit. Clinton, Mt. Franklin, \&c., of the White Mts. It is scarcely more than a foot in height, often but a few inches, the branches few and straggling, the lvs. $\frac{1}{3}$ to $\frac{21}{3}$ diam., smooth both sides pale and distinctly reticulate beneath, and on petioles 1 to $2^{\prime \prime}$ long. (B. Litteliana Tuckerman.)

3. AL'IJUS, Tourn. Alder. (The ancient Latin name from Celtic al, near, lan, the river bank.) of Aments cylindric, drooping, the bracts with 5 bractioles beneath; calyx 4-parted; stamens 4, anthers 2-celled. $\quad$ Aments ovoid, bracts cuneate, truncate, fleshy, 2 -flowered; calyx of 4 scales adnate below to the bracts, all persistent and woody in fruit; fruit compressed, wingless or winged. Shrubs arising from large and strong roots. Buds pedunculate. Lvs. plicate in vernation, \& Aments panicled. (Fig. 111.)

§ Fruit wingless, Nos. 1,2. \$§ Fruit broadly winged. (AlN 1 STER, Spach.) No. 8.

1 A. incàna Willd. Speckled $\Lambda$ Lder. Black Alder. Lvs. submembranous, oblong, acutish, obtuse at base cr cordate, margin somewhat lobed, sharply serrate, glaucous-pubescent beneath; veins hirsute, their axi's naked; stip. oblong- 
lanceolate; fertile aments oval.-Not uncommon along streams, N. Eng. to Wis. and Can. A tall shrub or small tree, readily distinguishable by the forma and pubescence of the leaves. (A. glauca Mx.)

2 A. serrulàta Willd. Swooth ALDER. Lvs obovate, acuminate, doubly serrulate, smooth beneath, except the veins and their axils; stip. elliptical, obtuse.-A well known shrub growing in clumps, and forming thickets on the borders of ponds and rivers, and in swamps. Stems numerous, rather straight, 10-15f in height. Leaves $2-4^{\prime}$ long and $\frac{3}{3}$ as wide, strongly veined; petioles $\frac{1}{3}-\frac{1}{2}$ long. A ments 2-3' long, slender, pendulous, fascicled at the ends of the branches; fertile ones short, thick, dark brown, persistent, several together a little below the sterile one. Mar., Apr. (A. rubra Tuckerman.)

3 A. víridis DC. Mountaix AzDER. Lvs. oval, acute, obtusish at base, doubly serrate, clothed with a soft viscid pubescence, or subglabrous, villous on the veins and axils beneath; stip. broadly ovate; fertile aments on long peduncles, oval.High mountain streams, N. Eng. N. Y. and Can. An elegant shrub, 3-4f high. Leaves varying to broad-ovate, rarely cordate, nearly smooth in the alpine state, otherwise softly pubescent and sprinkled with resinous particles. Apr. (A. crispa $\mathrm{Mx}$.)

\section{Order CXXI. MYricaCEA. Galeworts.}

Shrubs with alternate, resinous-dotted, often fragrant leaves, with tho flowers monœcious or diœcious, achlamydeous, both kinds in scaly aments. $f$ Stamens 2 to 8. \& Ovary 1-celled, with 1 erect ovule; stigmas 2, filiform. Fruit dry or drupaceous, indehiscent. Seed with no albumen.

Genera 3, species 20, fonnd in the temperate parts of N. America, in India and S. Africa, and one species in Europe. Sweet Fern is highly aromatic and astringent. The fruit of the Baylerry bush yields wax abundantly.

1. MYRI'CA, L. Candleberry Myrtle. (Gr. $\mu v p i \zeta \omega$, to perfume, The name anciently designated the Tamarind tree.) Flowers $\hat{o} q$. Aments $\hat{\delta}$ cylindrical, $q$ small, ovoid-capitate. $\hat{o}$ Stamens 4 to 6 , short, erect, anthers large; 4-valved. 우 Ovary 1 to each bract, with 3 scales at its base, superior; styles 2 , spreading; stigmas 2 , acute ; drupe 1-celled, 1-seeded, covered with wax or resinous dots.' Stip. very fugacious or 0 .

1 M. Gàle L. Sweet Gale. Dutcr Mrrtle. Lvs. clustered, cuneate-zanceolate, obtuse and serrate above, margin very entire and slightly revolute below, tapering to a very short petiole; sterile aments clustered, of ovate, cordate, acuminate, ciliato scales; fr. dotted in au oblong, dense, amentaceous head.-A branching shrub, $3-4 \mathrm{f} \mathrm{high,} \mathrm{on} \mathrm{the} \mathrm{inundated} \mathrm{borders} \mathrm{of} \mathrm{ponds} \mathrm{and} \mathrm{mountain} \mathrm{lakes,} \mathrm{Can.} \mathrm{to} \mathrm{Car.}$ Leaves dark green, paler beneath with a strong midvein, $9-18^{\prime \prime}$ by $4-6^{\prime \prime}$, entiro $\frac{1}{8}$ the length. $\quad f$ and $q$ aments on separate plants, the former terminal, about $1^{\prime}$ in length, the latter axillary and much shorter. Fruit and leaves when crushed, with a pungent, spicy odor. May.

2 M. cerifera L. BAyBERRY. WAX MYrtle. Lvs. glabrous, cuneate-oblong, rather acuto or obtuse, distinctly petiolate, margin entire or remotely undulatedentato above; aments cotemporary with the leaves, scattered, naked, the of larger, with lax, roundish scales; $f r$. spherical, distinct, clustered, covered with wax. - This interesting and useful shrub is found in dry woods or in open fields, Nova Scotia to Flor., W. to Lake Erie. Height 2-8f, covered with a grayish bark. Very branching with uumerous dry looking leaves, 18 to $30^{\prime \prime}$ by 6 to $9^{\prime \prime}$. Aments 6 to $9^{\prime \prime}$ long. Drupe $1 \frac{1}{2} "$ long, covered with white wax, - the bayberry tallow of commerce. Mlay.

3 M. Carolinénsis I. Lvs. larger, evergreen, coríaccous, cuneate-elliptical, acute, with about 4 acute teeth near the apex, petiolato; of aments solitary or several in the axils of the old leaves; $q$ naked, with rounded, acuminate scales.-Swamps, S. Car. to Fla. Shrub 4 to 8 f high. Lrs. 3 to $5^{\prime}$ by 1 to 2 ', petiolo $1^{\prime}$ or less. 
f Aments as long as the petioles, $q$ much shorter. Fruit, large, globular. (Pursh. Our specimens in flower.) Mar., A pr.

2. COMPTONIA, Soland. SweEt Ferv. (In honor of Henry Compton, Loid Bishop of London.) Flowers 8, \& Ament cylindric; bract reniform-cordate, acuminate; calyx-scale 2-parted; stamens 3 , forked, each bearing 2 half anthers. $q$ Ament ovate; calyx-scales 6 , longer than the bract; styles 2 ; nut ovioid, 1-celled.-Low shrubs. Lvs. long and narrow, pinnatifid-lobed, with small stipules, strongly aromatic.

C. asplenifòlia Ait. Lvs. long, linear-lanceolate, alternately sinuate-pinnatifid. -A shrub $2 f$ high, common in dry woods and hills, Can. to Md. (Shriver) and TVis. (Lapham). The main stem is covered with a rusty brown bark which becomes reddish in the branches, and white downy in the young shoots. Lvs. numerous, on short peduncles, 3 to $4^{\prime}$ by $6^{\prime \prime}$, divided riearly to the midvein into numerous rounded lobes so as to resemble those of the Spleenwort. Stip. in pairs, acuminate. Barren flowers in erect, cylindric catkins, terminal and lateral. Fertile fls. in a dense, rounded burr or head, situated below the barren one. Fr. a small, ovate, brown, 1-celled nut. May.

\section{Order CXXII.-SALICACE E. Willoworts.}

Trees or shrubs with alternate, simple leaves and deciduous or persistent stipules. Flowers $f \circ$, both kinds in aments, one under each bract of the ament. Calyx none or cup-form and entire. Ovary 1 to 2 celled, with 2 short styles. Fruit a capsule, 2-valved, co-seeded. Seeds with a coma, and no albumen. Illust. in figs. 47, a ; 81, 93, 266, 267, 268, 269, 465.

Genera 2, species 220 , chiefly natives of the northern temperate and frigid zones, one specles, Salix arctica, extending farther north than any other known woody plant.

Properties.-The bark is astringent and tonic, possessing the febrifugal properties of the sulphate of quinia. The wood is employed for various economical purposes. Several of the Willows and Poplars aro much admired as shade trees.

1. SA'LIX, Tourn. Willow. Osier. (Celtic sal, near, and lis, water; alluding to their usual locality.) Aments cylindric, bracts imbricated, entire, 1-flowered, each with a nectariferous gland at base. $\hat{o}$ Calyx 0 ; sta. 2-7. $q$ Calyx 0 ; ova. ovoid-lanceolate, acuminate; stig. 2, mostly bifid; caps. 1 -celled, 2 valved, valves acuminate, finally revolute at summit; seeds numcrous, minute, comous.-Trees, shrubs and undershrubs. Lrs. usually narrow and elongated, usually with conspicuous stipules. Aments terminal and lateral.

$\S$ Aments sessile, expanding before the leaves in early spring. Stamens 2. Ovaries clothed with wool, silk or down. Shrubs or suall trees. (*)

* Ovaries pedicellate. Leaves subentire, grayish-downy, rugous, margins subrevolute. Upland grayish shrubs. Aments sinall ................... I

* Ovaries pedicellate. Leaves serrulate, smooth and shining above, glaucous be. neath. Aments large, very Lairy. Shrubs 8 to 15 f..................... 4-6

* Ovaries pedicellate. Leaves sermate, grayish-silky beneath, drying black. Aments with 2 or 3 bracts at base..................................... 7,8

* Ovarles sessile. Leaves subentire, not drying black................................. 10

$\$$ Aments more or less pedunculate, expanding with the leaves in late spring. Ovaries mostly glabrous. (*).

* Ovaries clothed with silk or down and pedicellate. Stamens 2. (a)

a Leaves downy both sides. Ovary long-beaked. Shrub erect............. No. 11

a Leaves glabrous when mature. Shrubs low, mostlyalpine, spreading... Nus. 12-14

* Ovaries glabrous. Shrubs alpine, low, creeping or ascending............. Nos. 15-17

* Ovaries glabrous. Shrubs erect, or trees, 3 to 60 of high. (a)

a Ovaries pedicellate. Scales greenish-yellow, deciduous. (b)

b Stamens mostly 2 , sometimes 3 . Leaves glanerus beneath...........Nos. 18,19

b Staniens mostly 5 (4 to 6$)$. Leaves green on both sides................

a Oraries pedicellate. Scales dark or black, persistent. (b)

b Leaves corlate or at least truncate at the base, 4 to $15 \mathrm{f} \mathrm{high........Nos.} \mathrm{22,} 23$

b Ieaves acute or tapering at base. Shrubs 6 to 10 f high................

a Orarles sessile. Stamens 2. Trees of the largest sizo................. Nus. 26, 27 
1 S. trístis Ait. SAGE WILLOW. Lvs. linear-lanceolate or oblanceolate, cuneato at base, entire or remotely undulate-toothed, margin subrevolute, apex acute or obtusish; stip. minute, narrow-lanceolate, caducous; aments very small ; scales orbicular-oblong, hairy at the margin; ova. with grayish, silky pubescence; sty. short.-Sandy or dry tields, borders of woods, pastures, N. Eng. to Wis. and Car. A small, downy shrub, with a profusion of naked aments. Leaves at length numerous, often crowded and rosulate at the ends of the branches, 1-2' long, tapering from above the middlo to a very short petiole, the margin often revolute, under surface glaucous, often pubescent. Varies with the twigs and the diminished lvs. grayish whito.

2 S. Muhlenberghiàna Barratt. Lvs. oblanceolate, remotely serrate, glabrous above, pubescent and not rugous beneath; young branches smooth; stip. lunate, subdentate; aments precocious, diandrous; scales lanceolate, obtuse, villous; ova. pedicellate, lanceolate, silky; sty. long, bifid; stig. 2-lobed.-A shrub in dry soils, N., Mid. and W. States, 4-8f high, with brown twigs. On the ends of these, cone-like excrescences aro often produced by the punctures of insects Aments, covered with very hairy scales, appearing beforo tho leaves in April. (S. humilis Marshall? S. conifera Mulıl.)

3 S. cándida Willd. White Willow. Lvs. lanceolato or linear-lanceolate, very long, obscurely serrulato at the summit, pubescent above, hoary-tomentous beneath, revolute on the margin; stip. Tanceolate, as long as the petioles; aments cylindric; scales obovate, obtuse, very long, hairy; stig. 2 -lobed.-A boautiful species in shady woods, Mid. and W. States. Stems 4-6f high. Leaves 8-12' by $1-2$. Catkins dense, white with denso wool. Styles and stigmas dark red, $\frac{1^{\prime}}{2}$ in length. Apr., May.

4 S. díscolor Muhl. Branches pubescent when Joung, brownish or greenish; lvs. oblong or obovate-oblong, acuto or rather acuminate, remótely serrulatetoothed, pubescent when young, glaucous beneath; stip. lunate, entire, or with obtuse teeth; aments oblong-cylindric, sillky, erect; scales very hairy, oblanceolate, acute; ovaries on short pedicels, densely silky. - Shrub or small tree, 7 to $15 f$ high, in wet places, N. Eng. to Ill. and Car. Lrs. 2 to $5^{\prime}$ long, finally glabrous, the stipules usually conspicuously toothed at baso. Aments $1^{\prime}$ to $18^{\prime \prime}$ in flower, the fertiie at length $2^{\prime}$ or more. Sterilo dense, silky white.

5 S. eriocéphala Mx. WoOLLY-HEADED STAMP WILLOW. Branchlets very pubescent, brown or purplish; lvs. lanceolate-elliptic or oblong, cuneate at base, entire or remotely serrulate above, under surface glaucous or ferruginous, both surfaces pubescent when young, at length the upper surface green and nearly smooth; stip. semicordate, with sharp serratures, aments oval-oblong, densely villous; scales obovate, obtuse. $-\Lambda$ small tree, putting forth its largo and exceedingly woolly catkins in Apr. Grows in swamps, N. Eng.

6 S. sensitiva Barratt. Frost or TeNder Wrllow. Lvs. ovate-lanceolate, acuminate, cuneate and entire at base, finely serrate at the apex, and more distantly and strongly serrate towards the base, glabrous and rather thin; stip. subfalcate, serrate; ô aments rather lax; scales rather lax, lightly clothed with grayish black hairs. - A small tree about 15 f high, found in various parts of $\mathrm{N}$. Eng., \&c. The aments and twigs are frequently destroyed by frost at flowering time, being thinly protected with hairs. Lvs. smooth, 3 to $5^{\prime}$ by $1 \frac{1}{2}$ to $2^{\prime}$. Aments $1 \frac{1^{\prime}}{}$ long.

7 S. serícea Marsh. Gray Wrilow. Lvs. lanceolate, serrulate, acuminate, smooth above, silky beneath; stip. ovate-oblong, denticulate, deflected, deciduous; scales oblong, hairy, black at the tip, rather longer than the pedicel of the oblong, silky ovary; stig. sessile, obtuse. $-\mathrm{A}$ shrub 6 to $8 \mathrm{f}$ high, in inundated meadows, N. Ling. to Wis. and Va. Branches purplish, long and slender, very tough, except at the base, where they are very brittle. Lvs. 2 to $4^{\prime}$ by $\frac{1}{2}$ to $1^{\prime}$. $\%$ Aments very abundant, $\frac{1}{2}$ long. (S. grisea Willd.)

8 S. petiolàris Smith. LoNG-STALKED Green OsIer. Lvs. lanceolate, serrate, acuminate, smooth, glaucous beneath, silky at base, mostly inequilateral: stip. lunate, dentate; aments appearing before the leaves; scales lax, obovate, obtuse, hairy, black, shorter than the pedicel of the ovoid-acuminate, silky ovary; stigma 2-lobed, short-styled.-Low grounds, banks of streams, Conn. to Ill. and S. Car. 
Shrub or small tree, 1 to $15 \mathrm{f}$ high, with long, slender, smooth, purple or yellowish green twigs, tough and elastic, used in basket making. (S rosmarinifòlia $\mathrm{Ph}$.)

B. FUSCita. Lrs. obovate-lanceolate, acuto; aments of a leaden hue from tho thinner hairs.

9 S. viminàlis L. BASKET OSIER. Lvs. linear-lanceolate, very long, acuminate, subentire, silky-canescent beneath; stip. minute; branches virgate; aments precocious; scales roundish, very hairy; filaments distinct; ova. sessile, ovoid; sty. filiform; stig. undivided, acute.-Wet meadows and margins of rivers. Sts. 10 to 12f high, with long, straight, slender, and flexible branches. Lvs. often a foot in length, narrow, covered with a snow-white pubescence beneath. Aments very hairy. May. \& Eur.

3.0 S. purpùrea L. PURPle WrLlow. Lvs. partly opposite, obovate-lanceolate, serrulate above, very smooth, narrowed at the base, aments cylindrical, with leafy bracts at base; scales orbicular, black; filaments united into 1, with 2 anthers; ovary sessile, ovate-elliptic; sty. very short; stig. emarginate.-Low grounds, river banks, and cultivated like the last for basket-making. Shrub 6 to $10 \mathrm{f}$ high. Twigs very long, slender and tough, covered with a smooth, olive-colored bark.

11 S. rostràta Richardson. Branches erect, straight, pubescent, at length smooth; lvs. broadly or obovate-lanceolate, acute, subentire, at length coriaceous, smooth above, glaucous-pubescent beneath; stip. semicordate, dentato; aments short, cylindric, dense, the fertile ones becoming very long and loose; scales oblong, membranous, hairy at the apex; ova. narrow-lanceolate, silky, long-acuminate, on very long pedicels; sty. very short; stig. lobed, the lobes bifid or entire. -Shrub or small treo 8-10f high. Bark of tho trunk dark-colored, of tho branches yellow.

12 s. longifòlia Muhl. LoNG-Leaved WrLLow. Lvs. linear, acuminate at each end, elongated, remotely toothed, smooth, nearly of the same color on both sides; stip. lanceolate, dentate; arrents tomentous, pedunculate; sta. 2 ; scales flat, rCtuse; ovary short-stalked; fil. bearded at base, twice longer than the scales.River banks from the Conn. and Ohio to Oregon and Brit. Am. It possesses a remarkable power of rooting, extending itself and binding the loose sands together. Stems about $2 \mathrm{f}$ high, with brown branches and white branchlets.

13 s. phylicifòlia L. MouxtaIN Willow. Lvs. ovate or lanceolate, remotely repand-serrate, glabrous, glaucous beneath; stip. semicordate, oblique at apex; aments bracteate, ô sessile; caps. pedicellate, conical-elongated, somewhat silky; sty. long.-White Mts. A handsome, low shrub, spreading, with broad-elliptical, very smooth leaves, the margins repand-serrate.

14 S. rèpens L. Creeping Willow. Low, creeping; lvs. obovate or lance-obovate, acutish or bluntly acuminate, obscurely crenate-toothed, glabrous and shining abovc, silky-pubescent, at length glabrous and glaucous beneath, reticulate both sides; stip. oblong, very caducous; aments short, few-flowered, very silky; stam. 2 ; ovary silky, pedicellate.-Alpine summits White $\mathrm{Mts}$. and northward. Sts. a fow inches above ground. Lvs. 8 to $12^{\prime \prime}$ by 4 to $6^{\prime \prime}$, petioles 3 to $4^{\prime \prime}$, clothed with silky pubescence when young, very smooth when old.

15 S. pedicillàris $\mathrm{Ph}$. Lvs. elliptic-oblanceolate, acute or cbtuse, rather obtuso at base, entire, both sides glabrous, beneath slightly glaucous and reticulateveined; aments pedunculate; caps. ovate-conic, glabrous, long-pedicellate; scales short, obtuse, a little hairy ; sty. very short; lobes of the stigma cleft.-Mountain swamps, N. Eng. and N. Y. A low and elegant shrub, with rather a virgato habit, remarkable for its entire smoothness. On mountains it is more straggling. Lvs. light, yellowish green, 1 to $2^{\prime}$ long, very entire. (S. myrtilloides Tucker.)

16. S. Uva-úrsi $\mathrm{Ph}$. Lvs. elliptical or obovate, obtuse at each end, glandulardenticulate, smooth above, glaucous-smoothish beneath, silky-villous when young; aments pedunculate, cylindric, dense; caps. ovate-conic, briefly pedicellate, glabrous; scales obovate, black, silky; stam. one; stig. bifid, lobes at length cleft.-Whito Mts. N. H. A low or prostrate surub. Lvs. 3 to $5^{\prime \prime}$ by 2 to $3^{\prime \prime}$. Aments 6".

17 S. herbàcea L. Hern Willow. Arctic Willow. Dwarf; lvs. orbicular, cordate, serrate, glabrous, veiny; aments fuw-llowered, sessilo; scaies small, glab- 
rous; ovaries sessile, lanceolate, glabrous; style short; stig. lobes bifid.-On the alpine regions of the White Mountains, N. to Lab. and the Arc. Islands. An interesting little shrub, the smallest of its tribe. Stem ascending, 1-2' high. Leaves about $3^{\prime}$ diameter, smooth and shining on both sides. Stipules wanting. Roots long, creeping, branching. Jn., Jl.

18 S. fragílis L. Crack Willow. BEdFord Willow. Lvs. ovate-lanceolate, glabrous, whole margin serrate, acuminate, petioles glandular; stip. semicordate, pointed, dentate; ova. on short pedicels, oblong-ovoid, glabrous ; stig. bifid, longer than the styles; scales oblong, about equaling the ovaries, pubescent, ciliate; of with an abortive ovary.-A tall tree, 60 or $80 \mathrm{f}$ high, native in Great Britain. It has a bushy head, with numerous oblique, irregular branches. The twigs break off at base by a slight touch. The wood is of a salmon-color. (S. Russelliana Sm.) § Eur.

19 s. decipiens Hoffm. Branches smooth, highly polished; lvs. lanceolate, glabrous, serrate, acuminate, floral ones often obovate and recurved, petioles somewhat glandular; stip. small, semi-ovate, acute, dentate, often 0 ; ova. pedicellate, glabrous, acuminato; sty. longer than the 2-cleft stigma.-A small, elegant tree, remarkable for the polished, light, reddish-brown twigs, appearing as if varnished. The young twigs stained with crimson. It is often set in rows for ornament and shade. \& Eur.

20 S. nigra Marshall. BLACK WILLow. Lvs. lanceolate and lance-linear, attenuate at each end, serrulate, smooth and green on both sides, petiolo and midvei above tomentous; stip. dentate, caducous; aments erect, cylindric, villous; scalcs oblong, very villous; fil. 3 to 6 (generally 5), bearded at base; ova. pedicellate, ovoid, smooth; sty. very short; stig. bifid.-A large shrub or small tree, 10 to 15 to $20 \mathrm{f} \mathrm{high,} \mathrm{on} \mathrm{the} \mathrm{banks} \mathrm{of} \mathrm{streams,} \mathrm{Can.} \mathrm{to} \mathrm{Fla.} \mathrm{and} \mathrm{Ark.} \mathrm{Branches} \mathrm{very} \mathrm{brittlo}$ at base, pale yellow. The trunk has a blackish bark. Lvs. narrow, 4 to 8 ' long. Sterile aments $3^{\prime}$ long.

B. Falcita. Lvs. long and moro or less falcate. (S. Purshiana Spr. S. falcata $\mathrm{Ph}$.)

21 S. Iùcida Muhl. SHINixg WrLow. Lvs. ovate-lanceolate long-pointed, rounded at base, smooth and shining; stip. oblong, serrate; stam. 3 to 5 , mostly 5 ; scales lanceolate, obtuse, serrate and smooth at the tip, hairy at the base; ovaries lanceolate-subulate, smooth; style bifid; stigmas obtuse.-A small and beautiful tree, common in N. Eng., Middle States, Mich. and British Am. Trunk 12-15f high, 3-4' diam. Branches smooth, dark, shiniug green. Leaves broad and glossy, dark green above, tapering to a long point. May.

22 S. cordàta Muhl. Lvs. oblong-lanceolate, acuminate, cordate at base, smooth; stip. large, roundish-ovate, finely serrate; stam. sometimes 3 ; scales lanccolate, woolly, black, twice shorter than tho pedicel of the lanceolate, smooth ovary; sty. very short; stig. bifid.-An elegant shrub, 6 to $8 \mathrm{f}$ high, in swamps throughout the Mid. States. Branches green and smooth, with light-green lvs. an inch wide and $3^{\prime}$ long. Aments an inch long, accompanying tho leaves in $\Lambda$ pr. and May. (S. Torreyana Barratt.)

23 S. rígida Muhl. StifF-Leaved Willow. Lvs. oblong-lanceolate, acuminate, subcordate, rigid, smooth, coarsely serrate, the lowest serratures elongated, petioles villous; stip. very large, reniform-ovate, obtuse, glandular-serrate; aments triandrous; scales lanceolate, woolly, black, a third shorter than the pedicel of the lanceolate, smooth ovary; sty. very short; stig. 2-parted.-A small tree, 10 to $15 \mathrm{f}$ ligh, growing in swamps. Branches green, red towards the end, the younger ones pubescent. Much used in basket-making. Apr., May.

24. S. myricoides Muhl. Gale-Leaved Willow. Lvs. oblong-lanceolate. acute, with 2 glands at base, obtusely serrate, smooth, glaucous beneath, stip. ovate, acute, glandular-sorrato; aments villous, black; ova. on long pedicels, glabrous ; sty. bitid; stig. bifid.-Swamps, N. Eng. to Va. A small shrub, with green branches, the branchlets purple, smooth. Lvs. at length thick and coriaceous, the serratures each tipped with a gland. Apr.

$25 \mathrm{~S}$. angustàta $\mathrm{Ph}$. Lvs. lanceolate, acute, very long, gradually attenuated as base, very glabrous, serrulate, nearly the same color both sides; stip. semi-cordate; aments erect, somewhat glabrous; ova. pedicellate, ovoid, glabrous sty. bifid; stig. 
2-lobed.-Banks of streams from the Conn. to the Miss. An excellent osier, with very long and slender twigs, long and narrow leaves.

26 S. vitellina L. Yellow Willow. Golden OsIer. Lvs. lanceolate, acuminate, with thickened serratures, smooth above, paler and somewhat silky beneath; stip. 0 ; aments cylindric; scales orate-lanceolate, pubescent outside; ova sessile, ovate-lanceolate, smooth; stig. subsessile, 2-lobed.-This willow was probably introduced, but is now very common by roadsides, \&c. It is a tree of moderate height, with shining yellow branches. May.

$\beta$. CERULEA. Lrs. with a bluish hue, nearly or quite smooth beneath. - On river banks.

27 S. Babylónica I. Weeping Winlow. (Fig. 47, a). Branches pendulous; lvs. linear-lanceolate, acuminate, smooth, glaucous beneath; stip. roundish, oblique, acuminate; ova. sessile, ovate, smooth. - A large tree of rapid growth and of a most graceful and elegant form, cultivated until nearly naturalized. Only the o plant has yet been recognized in the U. S. § Eur.- $\beta$. ANNularis, the curled willow, with the leaves regularly recurved into rings or coils, is a cultivated variety.-The long, slender branchlets very naturally indicate the English namo of the tree and give it a place in the church-yard to "weep" over the remains of the departed. The Latin namo was happily suggested to Linnæus by the 137 th Psaim:

"By the rivers of Babylon there we sat down;

Yea, wo wept, when wo remembered Zion.

Wo hanged our harps upon the villons in the midst thereof."

2. POP'UlUS, Tourn. Poplar. Aspen. (Lat. populus, the people; being often planted along the public ways.) Aments cylincric; bracts lacerately fringed; calyx an oblique, disk-like cup, its margin entire; of Stamens 8 to 30 . O Ova. superior; style very short, bifid; stigma large, 2-lobed; capsule 2-valved, 2-celled.-Trees of large dimensions. Wood soft and light. Buds varnished with a fragrant resin. Lvs. broad, petioles long, often compressed vertically, and glandular. Aments latcral, expanding before the lvs.

* Branchlets winzed or angular. Leaves orate-cordate, acuminato.................Nos. 1, 2

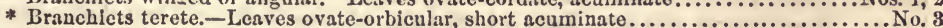
-Leaves ovate-orbicular, obtuse or aente........................ - Leaves ovate, aeuminate. Stamens 20 to 50 ?..................... Nos. $6, \tau$ -Leaves deltold, ncuminate, smooth.......................... Nos. 8, 9

-Leaves lobed, white-tomentous beneath.............................. No. 10

1 P. angulàta Ait. Water Poplar, Westery Cotron Tree. Branches acutely angular or winged; lvs. ovate-deltoid, subcordate, uncinate-serrate, acuminate, glabrous, younger ones broadly cordate.-A treo of noble dimensions, growing along tho rivers of the S. and VV. States. Trunk 40 to $80 \mathrm{f}$ high, 1 to $3 f$ diam., bearing a broad summit, with coarse branches and branchlets. Lvs. on adult trees 2 to $3^{\prime}$ long, about tho same width, truncato at base, on younger shoots they are 2 or 3 times larger, with a cordate base. Petioles longer than tho lvs. Branchlets remarkably thick, greenish, spotted with white, striate. Buds shortovoid, green, not coated with resin. Timber not valuable. Mar., Apr.

2 P. monilífera Ait. NECK-LACE POPLA1. COTTON-WOOD. Branchlets angular, becoming terete; lvs. broadly deltoid-ovate, acuminate, serrate-dentate, smooth, teeth incurved, ciliate, base nearly entire and subcordate; scales of the ament lacerate-fringed, not hairy; stigmas 3 or 4, very large.-A large tree, 60 to $80 \mathrm{f}$ high, in woods along rivers and lakes, Western Vt. to Ill. and La. Trunk cylindric, straight, 1 to $3 \mathrm{f}$ diam. Lvs. 2 to $4^{\prime}$ long, conspicuously acuminate, nearly as wide as long, on petioles of nearly equal length. Fertile aments recurved or pendulous, at length 4 to $8^{\prime}$ long and the capsules remote. Buds varnished as in the other species. Apr. (P. lævigata Willd.)

3 P. tremuloìdes Mx. AMERICAN Aspen. Irs. orbicular-cordate, abruptly acuminate, dentate-serrate, pubescent at the margin; bracts of the ament 3 or 4cleft, margin silky-fringed.-Abundant in N. Eng. and in the Mid. States, growing in woods and open lands. St. 25 to $40 \mathrm{f}$ in height, with a diam. of 8 to $12^{\prime}$. Bark greenish, smooth, except on the trunks of tho oldest trees. Lvs. small ( 2 to $21^{\prime}$ 
long and of equal or greater width), dark green, petioles 2 to $3^{\prime}$ long and laterally compressed, so that they can scarcely remain at rest in any position, and aro thrown into excessive agitation by the slightest breeze. The trembling of the "aspen leaf" is proverbial. Aments plumed with silken hairs, about 2' long, pendulous. Apr.

4 P. grandidentàta MX. LARGE POPLAR. Lvs. roundish-ovate, acute, with large, unequal, sinuate teeth, smooth, villous when young; bracts fan-shaped, 5-cleft and silky-fringed.-Woods and groves, Can. and Nor. U. S. not uncommon. St. $40 \mathrm{f} \mathrm{high,} \mathrm{with} \mathrm{a} \mathrm{diam.} \mathrm{of} 1 \mathrm{f}$, straight, covered with a smooth, greenish bark. Branches distant, coarse and crooked, clothed with leaves only at their extremities, with terete twigs. Lvs. 3 to $5^{\prime}$ long and nearly as wide, clothed with thick white down in spring, but becomirig perfectly smooth. Aments 3 to $4^{\prime}$ long, all the parts hairy, the sterilo longer than the fertile. Stam. about 12, as in the preceding species. May.

5 P. heterophýlla L. Cotron Tree. Branches terete; lvs. roundish-ovate, obtuse, uncinately serrate, cordate at base, the small auriculate lobes over-closed, white-tomentous when young, at length nearly smooth; ovaries with a long pedicel and conspicuous style.-Swamps, N. Eng. (rare) to Ill. and La. $\Lambda$ tree 40 to $60 \mathrm{f}$ high, trunk 1 to $2 \mathrm{f}$ diam. Lvs. 3 to $6^{\prime}$ long, with small teeth, blunt or never acuminate at apex, and the base lobes often so overlapping as to conceal the insertion of the petiole. Apr., May.

5 P. balsamífera I. Balsam Poplar. Tídamernac. Branches tereto; lvs. ovate, acuminate, with close-pressed serratures, whito and reticulato-veiny beneath, glabrous both sides; bracts of the ament dilated, laciniate-fringed, slightly hairy; stam. 40 to 50.-Swamps and river banks, Me. to Penn., N. Y., Can. and the N. W. coast. A large tree, 40 to 80 f high, trunk 1 to $2 \mathrm{f}$ diam. Lvs. 2 to $4^{\prime}$ long. Sterile aments 2 to $3^{\prime}$ long, fertile at length 4 to $6^{\prime}$. Stam. purple. Buds in spring covered with an aromatic resin which may be separated in boiling water.

7 P. cándicans Ait. BALM of Gruead. (Fig. 268, 269). Branches terete, lis. ovate, cordate, acuminate, closely and unequally serrate, whitish and reticulateveined beneath, petiole hirsute; bracts of the ament oval, laciniate-fringed; stam. about 20.-A fine tree of strong and peculiar fragrance, often cultivated, rarely growing wild, Can. and the Northern U. S. Height 30 to 50f, with a pyramidal head of dense ample foliage. Lvs. 4 to $6^{\prime}$ long; at length smooth and dark green above. Sterile aments 2 to $3^{\prime}$ long, fertile 4 to 6 . Buds filled throughout with fragrant resin.

8 P. nigra $\mathrm{L}$. $\beta$. BETUlifòlia Torr. BLACK Poplar. Young branches pubescent; lvs. deltoid-rhombic, conspicuously acuminate, finely crenate-serrate, smooth both sides; aments without hairs.-Trees 30 to $40 \mathrm{f}$ high, planted at Hoboken, N. J. and perhaps in Penn. † isur. (P. betulifolia Ph. P.. Ifudsonica Mx.)

9 P. dilatàta Ait. Lombardy Poplar. Lvs. smooth, acuminate, deltoid, serrate, the breadth equaling or exceeding the length; trunk lobed and sulcate.Early brought to this country, and has been planted about many a dwelling and in village streets. Its rapid growth is tho only commendable quality it possesses, while the lugge worms by which it is often infested render it a nuisance. † Italy.

10 P. álba I. ABele. Silver-léaf Poplar. Lvs. cordate, broad-ovate, lobed and toothed, acuminate, dark green and smooth above, very white-downy beneath; fertile aments ovate; stig. 4.-A highly ornamental, cultivated tree. Nothing can be more striking than the contrast between the upper and lower surface of tho leaves. + Eur.

\section{Order CXXIII. SAURURACEA. Saururads.}

Merbs with jointed stems, alternate, entire leaves furnished with stipules. Flowers in spikes, perfect, naked, having neither corolla nor calyx. Stamens definite. Ovaries 3 to 5, more or less united. Seeds ascending. Embryo enclosed in a sac (amnios), outside of hard, mealy albumen. Fig. 264. 
Genera 4, spectes 7. natives of China and North America, growing in marshes and pools. Properties Unimportant.

SAURU'RUS, L. LIZARD-TAIL. (Gr. oav́pa, a lizard, ov́ $\rho a ́$, a tail ; alluding to the form of the inflorescence.) Inflorescence an ament or spike of 1 -flowered scales; stamens $6,7,8$ or more; anthers adnate to the filaments; ovaries 4 ; berries 4, 1-seeded.-2f St. angular. Lvs. cordate, acuminate, petiolate.

S. cérnuus Willd.-Common in marshes, U. S. and Can. St. $1 \frac{1}{2}$ to $2 \mathrm{f}$ ligh, weak, furrowed. Lrs. 4 to $6^{\prime}$ long and half as wide, smooth and glaucous, with prominent veins beneath and on petioles 1 to $2^{\prime}$ long. Spikes slender, drooping at summit, longer than the leaf. Scales tubular, cleft above, white. Fls. very small and numerous, sessile, consisting only of the long stamens, and the ovaries with their recurved stigmas. Jl, Aug.

\section{Order CXXIV. CALLITRICHACEA. Starwort.}

Herbs aquatic, small, with opposite, simple, entire leaves. Flowers axillary, solitary, very minute, polygamous, achlamydeous, with 2 colored bracts. Stamen 1 , rarely 2 ; filament slender; anthers 1-celled, 2-valved, reniform. Ovary 4-celled, 4-lobed; ovules solitary. Styles 2; stigmas simple points. Fruit 1-celled, 4-seeded, indehiscent. Seeds peltate, albuminous.

Genus 1, species 6, growing in stagnant waters, both of Europo and America.

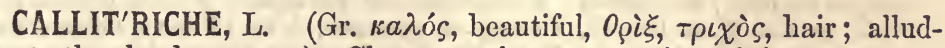
ing to the slender stems.) Character the same as that of the order.-(1)

1 C. vérna L. Floating; lvs. obovate-spatulate, 3-nerved, the lower more narrow or linear; fls. subsessile; bracts 2, longer than the ovary; fr. obtusely margined, obcordate.-A little aquatic, common in pools and ditches. Sts. numerous, slender, consisting of 2 tubes, 8 to 12 to $20^{\prime}$ long, according to the depth of the water. Lvs. 4 to $6^{\prime \prime}$ long, with the tapering base, $\frac{1}{2}$ to $2^{\prime \prime}$ wide, the floating broadest. The fls. solitary, rarely 2 in the axil, the outer a stamen only. Bracts white. Stamen posterior, yellow, styles 2, filiform, anterior. Caps. $\frac{1}{2}$ " long, suboval. Apr. -Jl. (C. intermedia Willd. C. heterophylla $\mathrm{Ph}$. C. aquatica Bw.)

2 C. autumnàlis L. Floating; lvs. all linear, I-nerved, or the highest linearspatulate; fls. subsessile; bracts shorter than the ovary or none; fr. oval, acutely margined.- In similar situations with the first, S. States, less common. Sts. 1 to 2f long. Lvs. 5 to $7^{\prime \prime}$ long, often bifid, a few of the lighest 3 -veined. MaySept. (C. linearis Ph.)

3 C. terréstris Raf. Sts. short, diffuse, prostrate; lvs. very small, oblong, all similar, fls. sessile, 2-bracted; fruit broader than long, deeply obcordate, 2-winged on the margins. - A much smaller species, on the muddy borders of ponds, covering the surface. Sts. 1 to $2^{\prime}$ long. Lvs. 1 to $2^{\prime \prime}$ long. Fr. $\frac{1^{\prime \prime}}{4}$ long. Jn.-Aug. (C. brevifolia $\mathrm{Ph}$. C. platycarpa Kutz.)

\section{Order CXXV. PODOSTEMTACEA. Threadfoots.}

Merbs aquatic with the habit of seaweeds, with alternate; dissected leaves, with flowers minute, perfect, naked or with 3 sepals, stamens 1 or many, hypogynous. Ovary compound, 2 to 3-celled, with as many stigmas, and numerous ovules. Fruit a many-seeded capsulc, ribbed and somewhat pedicelled. Albumen none.

Genera 20, species 100 , frequent in S. America and E. India, 1 only in N. America. They all grow in running water, attached to stones like the following species.

POdOSTE'MUM, L. C. Rich. Threadfoot. River Weed. (Gr. $\pi 0 \tilde{v} \varsigma, \pi o \delta \grave{s}$, a foot, $\sigma \tau \dot{\eta} \mu \omega \nu$; the stamens being apparently on a common foot-stalk,) Stamens 2, with the filaments united below; ovary 
oblong-ovoid; stigmas 2, sessile recurved; capsule 2-celled; seeds minute.-Small, submersed herbs, adhering to stones and pebbles.

P. ceratophýllum Mr. Lrs. dichotomously dissected; fls. solitary, axillary.Mid. W. and S. States, in shallow streams. St. a few inches long, usually destitute of roots and attached to stones by lateral, fleshy processes. Lrs. numerous, olive-green, alternate, coriaceous, divided into many long, linear-setaceous segments. Fls. on short, thick peduncles, the 2 stamens and styles at length bursting through the lacerated calyx. JI. (Lacis ceratophylla Bougard.)

\section{Order CXXVI. CERATOPHYLLACEA. Hornworts.}

Herbs aquatic, with verticillate, dichotomously dissected leaves. Flowers mo. nocious, sessile, axillary, minute, with neither corolla nor calyx. Involucre 8 to 12 cleft. of Anthers (12 to 24) sessile. o A simple, 1-celled ovary. Seed suspended, orthotropous, embryo with 2 pairs of cotyledons.

Genus 1 only, with $6 ?$ species, in the streams and pools of the northern hemisphere.

Properties-Unimportant.

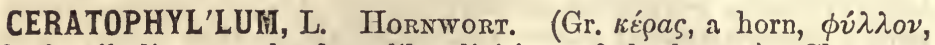
a leaf; alluding to the horn-like divisions of the leaves.) Character the same as that of the Order.

C. demérsum L. Lrs. 6 to 8 in a whorl, doubly dichotomous, dentate-spines. cent on the back; fls. axillary; fr. 3-spined.- 4 An aquatic weed in ditches, etc., N. Y. to Va., W. to Ill. St. floating or prostrate, 8 to $16^{\prime}$ long, filiform, with numerous whorls of leaves. These are dichotomously divided into 2 or more narrow, stiff segments. Fls. minute, axillary, sessile, with sessile anthers. Fr. an oblong, beaked capsule, with 1 seed. J.-Sept.

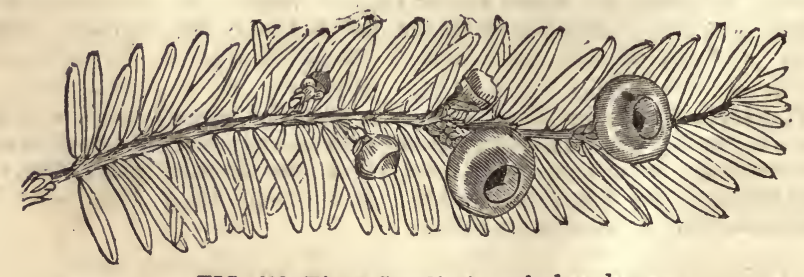

FIG. C92. Táxus Canadensis-naked seeds. 


\section{CLASS II. GYMNOSPERMAE.}

Exogenous plants with chiefly parallel-veined leaves, always diclinous, with the flowers very incomplete. Pistils none, or represented by open scales. Ovules axillary or naked, fertilized by the direct application of the pollen, becoming at maturity naked seeds, destitute of a true pericarp. Cotyledons often more than 2. This Class constitutes the

\section{CoHort 4. CONOIDEAE.}

\section{Order CXXVII. CONIFERA. Conifers.}

Trees or shrubs mostly evergreen, abounding with a resinous juice. Leaves scattered or fascicled, acerous, linear or lanceolate, parallel-veined. Flowers monœcious or diœcious, achlamycleous, in aments or cones. \& Stamens 1, or several united. q Ovary, style and stigma wanting. Ovules 1 or several at tho base of the carpellary scale. Fruit a strobile (cone), woody with the scales distinct, or baccate with the scales fleshy and coherent. Illust. in Figs. 46, S. 87, 152, 153, 367, 449, $468,579$.

Genera 20, species 110, natives of all climates, but most abundant in the temperate zones, those of the sonthern, however, very different from the pines, spruces, larches and cedars of the northern.

Properties.-Few orders can be named, which are of more importance to mankind, whether in reference to their invaluable timber or their resinous secretions. Turpentine, tar, pitch and resin, are the product of the pines. Burgundy pitch is yielded by Pinus sylvestris of Europe; Venetian turpentine, by the Larix; oil of Savin by Juniperus Sabina of Lurope, etc. In stature the Conifera are the loftlest of all trees. Pinus strobus, arises often 200f. Araucaria imbricata of Chill 250f, and Sequoya gigantea of California 400 .

\section{SUBORDERS AND GENERA.}

I. ABIETINEAs. \& Scales many, each subtended by a bract, with 2 inverted ornles (their micropyle turned downwards) at the base inside. Seeds winged. (*)

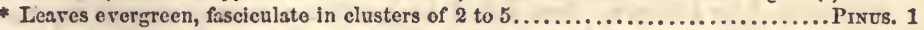

* Leaves evergreen, separate, scattcred...................................... 2

* Leaves deciduous, many in the fascicles on short lateral branchlets...............Aarx. 3

II. CUPRESSINEA. \& Scales few, bractless, each with 2 to $S$ erect ovules. (*)

* Flowers moncecious. Fruit a woody cone opening at maturity. (a)

a Leaves evergreen, scale-like. Cone-scales oblong, loose, flattish, 2-ovuled.....TnuJA. 4

a Leaves evergreen, scale-like or subulate. Cone-scales peltate, angular.... Curressus. 5

a Leaves deciduous, linear, 2-rowed. Cune-scales peltate, angular......... Taxodium. 6

* Flowers diccious. Fruit a fleshy cone, the scales consolidated, verry-like..JunIPEaUs. $\tau$

1. PI'NUS, L. Prne. (Celtic pin or pen, a rock or crag; from the locality of many species.) Flowers monœeious. $\hat{f}$ Aments clustercd, terminal; stamens $\infty$, with 2 cells and a scale-like connective; pollen grains triple. $f$ Aments conical or cylindric, the carpellary scales bracted, each bearing on its base within 2 inverted ovules; strobile composed of the imbricated hardened scales which are often thickened or awned at the tip ; sceds nut-like, winged; cotyledons 3 to 12 , linear.Trees with evergreen, acerous lvs. in fascicles of 2 to 5 , each fascicle subtended and invested by a membranous scale or leaf. (Fig. 152.) 
5 Leares fascicled in 5 s. Cone scales not thickened at the end, unarmed............... No. Leaves in 3 s. Cone scales at the end thickened and prickly or spiny..................... Leaves in $2 \mathrm{~s}$ (rarely $3 \mathrm{~s}$ ). - Scales at the end thickened and spiny................. Nos, $5-7$ - Scales at the end thickened, but unarmed............................. 9

1 P. stròbus L. White Pine. Weymoutif Pine. Lvs. in 5s, slender, with very short sheaths; cones solitary, cylindric, loose, pendant longer than the lvs.A most majestic and useful forest tree. Can., N. Eng. to Penn. and Wis. The trunk is perfectly straight, covered with a comparatively smooth bark, and, in some instances, 5-7f in diameter, and 80 to $100 \mathrm{f}$ in height without a limb; then, sending out a few branches, it forms a tufted head far above the surrounding forest. Branches whorled only in the young trees. Leaves about $4^{\prime}$ long, numerous, slender, of a bluish green, forming an extremely soft and delicate foliage. Wood soft, fine-grained, easily wrought, very durable, used in immense quantities in architecture. The large trunks are in particular sought for the masts of ships. May.

2 P. palústris Lamb. Loxg-Leaved or Broom Pres. Lvs. in 3s, very long, crowded at the ends of the branches, with elongated, ragged, half-persistent sheaths; cone subcylindrical, nearly as long as the leaves; scales tipped with small, recurved spines.- $\mathbf{N}$. Car. to Fla., very abundant and valuable. The trunk is 15 to $20^{\prime}$ diam., arising with a slight diminution 40 or 50 f to the branches, thence 20 to $40 \mathrm{f}$ to the summit. Bark slightly furrowed. Lvs. dark green, 10 to $15^{\prime}$ in length. Buds very long, whitish. Sterilo aments violet colored, $2^{\prime}$ long. Cono 8 to $10^{\prime}$ long. Sds. with a thin whito testa. Timber strong, compact, resinous and durable, used at the south in vast quantities. The young trees look like brooms. The old are festooned with the long moss. They yield nearly all the turpentine and resin of commerce. As fuel it burns with fragrance, splendor and heat.

3 P. Taèda I. Loblolly Pive. Old-Field Pine. Lvs. in $3 \mathrm{~s}$, long, light green, with long, subentire sheaths; cones oblong-ovoid, deflexed, half as long as the leaves, the scales tipped with a short inflexed spine.-Abundant in pine woods and sandy fields as a second growth, Va. to Fla. A tall tree, 50 to 80 or even $100 \mathrm{f} \mathrm{high,}$ with a wide-spreading summit. Bark thick and very rugged. Lvs. 6 to 10' long, rigid, sheaths blackish, $6^{\prime \prime}$ long. Sterile aments $I^{\prime}$ long, densely clustered, lightreddish. Cones 3 to $5^{\prime}$ long.-Less valuable for turpentine or timber than $P$. palustris, but equally excellent as fuel and light.

$\beta$. seròtina. POND PINe. Cone ovoid, thick (as large as a goose egg), polished and shining, nearly unarmed. Tree smaller.

4 P. rígida Miller. PItch Prve. Lvs. in 3s, rigid, with short sheaths; cones pyramidal-ovoid, clustered; scales with short, thick, reflexed spines.-Common in barren, sandy plains, which it often exclusively occupies. It is of moderate height at the north ( 25 to $30 \mathrm{f})$, but attains a great height ( 40 to $70 \mathrm{f})$ in the S. States. The trunk, which is seldom straight, is covered with a very thick and rough bark cleft with deep furrows. Lvs. 4 to $6^{\prime}$ long. Cones usually several together, 2 to $3^{\prime}$ long. The wood is heavy with resin, is used in arehitecture for flooring, and in ship-building, and is excellent as fuel for steam engines.

5 P. mitis Mx. Yellow Pine. Sprece Pine. Lvs. in pairs (sometimes in $3 \mathrm{~s})$, slender, channeled, with elongated sheaths, scattered all over the branchlets; cones not generally clustered, oblong-ovoid, half the length of the shortish lvs.; scales with a short, weak, slightly incurved prickle.-Widely diffused throughout the country. A tree of slow growth, 30 to 50 to $80 \mathrm{f}$ high. Bark rough, broken into broad plates. Lvs. 3 to $5^{\prime}$ long, bluish green, in $3 \mathrm{~s}$ on young trees or the more vigorous shoots. Cones 18 to $30^{\prime \prime}$ long, rugged with the projecting point of the scales. Timber close-grained, moderately resinous, used in immense quantities for all kinds of architecture.

$\beta . ?$ PAUPERA. Bark smoother than the pines in general, the branches resembling those of the beech; lvs. short, (3 to $\left.4^{\prime}\right)$ and thinly scattered; cones smaller than a hen's egg, with minute, straightish spines; barren aments $6^{\prime \prime}$ long. - Ga. Tree 40 to $50 \mathrm{f} \mathrm{high.} \mathrm{(P.} \mathrm{glaber} \mathrm{Walt.} \mathrm{?)}$

6 P. púngens Mx. Southern Modntain Pine. Lvs. in pairs, short, rigid, acute, somewhat channeled, rough-edged; sheaths very short; cones ovoid, longer than the leaves; scales tipped with a long, recurved and hooked spine.-Lookout Mt. I Tenn. and Table Mt., Grandfather Mt. \&c., N. Car. and Va. Trco with rough 
and scaly bark, gnarled spreading branches, 20 to $30 \mathrm{f} \mathrm{high.} \mathrm{Ivs.} 18$ to $30^{\prime \prime}$ long, cones finally 2 to $3^{\prime}$ long, the spines fully $3^{\prime \prime}$ long, the points hooked. In the young cones the spines are projecting, with the points hooked. Branchlets bluish red. Resembles the next.

7 P. ínops Ait. Jersey or Scrub Pine. Lvs, in pairs, rather short, obtuse, rigid, channeled above, terete beneath, margins obscurely serrulate; cones recurved, ovoid-oblong, as long as the leaves ; scales compact, obtuse at base, with a straight, subulate priclile. - A tree 15-25f high, on barrens in the Middle States. Branches straggling, and, with the trunk, covered with a rough, blackish bark. Branchlets glaucous. Leaves $1-2$ ' long. The wood abounds in resin. May.

8 P. resinòsa Ait. Norway Pine. Red Pine. Lvs. in pairs, channeled elongated, with elongated sheaths; cones ovoid-conic, rounded at the base, subsolitary, about half as long as the lvs.; scales without spines, dilated in the middle.-It abounds in the northern parts of the U. S. and in Canada, attaining the height of 80 , with a trunk of $2 \mathrm{f}$ in diameter, very straight and uniform. Bark smoother, and of a clearer red than other pines. Leaves chiefly collected towards the ends of the branches, always in pairs, $5-8^{\prime}$ in length, the sheaths 6 to $12^{\prime \prime}$. Timber fine-grained, resinous, strong and durable. May. (P. rubra, MIx.)

9 P. Banksiàna Lambert. Scrub PiNe. Lvs. in pairs, rigid, curved, short, acute, terete upon the back and channeled above, margins somewhat seabrous; cones ovate-acuminate, recurved, tortuous, longer than the lvs., scales without spines, obtuse, smooth.-A small tree, with long, spreading, flexible branches, abounding in barrens, in Me. to Wis. and British America. Leaves about an inch in length. Cones nearly twice as long as the leaves, usually in pairs. Apr., May. (P. ruprestris $\mathrm{Mx}$.)

2. A'BIES, Tourn. Spruce Fir. of Aments axillary, clustered towards the ends of the branches; 9 scales of the cone thin, flat, not thickened nor spine-pointed at the end; seeds with a persistent wing; cotyledons 3 to 9 . - Trees with evergreen, solitary, scattered lvs. never sheathed at base. (Fig. 46, S.)

$\S$ Cones erect, bracts conspicuous with the scales. Leares flat, whitened bencath....Nos. 1, 2 Cones pendant, bracts inconspiouous. - Scales rounded and entire at tip................. 3 , 4 - Scales eroded or dentate at tip.................... 5os. 6

1 A. balsàmea Marshall. Fir BalsaM. Lvs. linear, flat, obtuse, glaucous-silvery beneath; cones cylindric, large (3 to $4^{\prime}$ long); scales broad, compact; bracts obovate, mucronate, slightly projecting.-A beautiful evergreen, common in humid forests of the northern U. S. and Can. Branches nearly horizontal, gradually becoming shorter upwards, forming a regularly pyramidal head. The lvs. are little longer than those of tho hemlock ( 8 to $10^{\prime \prime}$ long) spirally arranged, bright green above, silvery whito beneath. Cones $1^{\prime}$ thick, bluish purplo when growing. Bark smooth, abounding in reservoirs filled with a resin or, balsam which is considered a valuablo medicine. May. (Pinus, L. Picea Mx.)

2 A. Fràseri Ph. Double Fir Balsam. Lrs. flat, glaucous beneath, linear, often emarginate, subsecund, erect above; cone ovoid-oblong, erect, very small; bracts elongated, reflexed, oblong-cuneate, emarginate, briefly mucronate, incisely toothed. - Smaller tree than the last, much resembling it in habit, in Mts. N. Eng. to Car. Lvs. $3^{\prime \prime}$ long, and much crowded. Cones 1 to 2' long when mature, singularly distinguished by tho long-pointed, violet-colored, reflexed bracts. Sterilo aments terminal. May.-A highly ornamented shacie tree.

3 A. Cánađénsis Mx. HЕмцоск. Lvs. linear, flat, obscurely denticulate, glaucous beneath, in 2 rows; cones ovoid, terminal, scarcely longer than the leaves; scales rounded, entire.-A well known evergreen inhabitant of rocky, mountainous woods Brit. Am. to Car. and Wis., commonly attaining the height of $70-80 \mathrm{f}$. The trunk is large in proportion, straight, covered with a rough bark. Branches brittlo and nearly horizontal, with pubescent twigs. Leaves $6-8^{\prime \prime}$ in length, less than $1^{\prime \prime}$ wide, arranged in 2 opposite rows. Cones very small. Wood soft, elastic, cf a coarse, loose texture, not much valued for timber. The bark is extensively used in tanning. May. (Pinus, I.)

4. A. álba Mx. White or Single Spruce. Ivs. 4-sided, incurved; cones lax, 
pendulous, subcylindric, with entire, broadly obovate, somewhat 2-lobed scales.Very abundant in humid and rocky woods, Can. to Car. and Wis. Height 50f. Trunk 1 to $2 \mathrm{f}$ diam. at the base, regularly diminishing upwards. Lower branches longest, the others becoming gradually shorter upwards. Lvs. $\frac{1}{2}$ to $\frac{3^{\prime}}{4}$ long, placed on all sides of the branches. Cones small. The timber is useful in the frames of buildings, \&c. May. (Pinus, Ait.)

5 A. nigra Mrx. Black or Double SprdCE. Lvs. 4-cornered, seattered, straight erect; cones ovoid, pendulous; scales elliptical-obovate, erosely dentate at the edge, erect. -Abounds in the the northern U. S. and Can., where dark, mountain forests, are often wholly composed of it. It is a large tree, 70-80 high, with a straight trunk and a lofty pyramidal head. The leaves thickly cover the branches, dark green, Jittle more than $\frac{1}{2}^{\prime}$ in length. Cones $1-2^{\prime}$ long. Timber light, strong, elastic, much used in architecturo. That salutary beverage, spruco beer, is mado from the young branches. May. (Pinus L.)

6 A. excélsa DC. Norway Spruce. Branches pendulous; lvs. elongateä, somewhat 2-ranked; cones long, cylindrical, pendulous; scales broad, with a slightly projecting and 2-toothed apex.-Parks and shrubberies. A tall stately evergreen with dense and dark green foliage. Lrs. about 1' long, crowded. Cones very showy, and elegant, 5 to $8^{\prime}$ long, more than $1^{\prime}$ diam.-It grows luxuriantly, and is a finer tree than any of our native species. $f \mathrm{~N}$. Eur.

3. LA'RIX, Tourn. Larcir. Tamarack. Aments scattered all over the branches, bud-like; $\hat{o}$ anthers 2 -celled, cells opening lengthwise, with simple pollen grains; $q$ cones erect, oval or roundish, scales colored, persistent; seeds with a proper wing.-Lrs. deciduous, acerous, soft, scattered, and in axillary, many-leaved fascicles.

1 L. Americàna $\mathrm{Mx}$. Lvs. filiform, very slender; cones ovoid, inclining upwards even when the branches are pendulous; scales few, thin and inflexed on the margin; bracts elliptical, often hollowed at the sides, abruptly acuminate with a slender point.-A beautiful tree, often seen in shrubberies, and thinly interspersed in forests, Can. to Penn. and Wis. It is remarkably distinguished from the pines by its deciduous leaves, the branches being bare nearly half the year. The treo arises $80-100$ f, with a straight and slender trunk and horizontal branches. Leaves $1-2$ ' long, collected in bunches of $12-20$ on the sides of the branches. Cones deep purple, 6 to $10^{\prime \prime}$ long. Wood most valuable being very heavy, strong and durable. Apr., May.

$\beta$. PENDULA. Branches slender and drooping.-A beautiful variety. (P. pendula Ait.)

2 I. Europæea DC. WHite LARCr. Lvs. flattish, filiform-linear ; cones oblong, scales siightly reflexed on the margin.-Rarely cultivated. Treo much resembling No. 1, of moro rapid growth, 60 to 80 figh. Lvs. 1 to $2^{\prime}$ long, cones about 1 . + Eur.

4. THU'JA, Tourn. Arbor Vits. (Gr. Oúw, to sacrifice; the wood is fragrant in burning and was used in sacrifice.) Flowers 8.$\hat{o}$ In an imbricated ament; anther cells 4 on each scale-like connectile; of flowers in a cone, scales few, each bearing 2 erect ovules at the base inside; seed winged; integument membranous; cotyledons 2.-Trees or shrubs. Lrs. evergreen, scale-like, imbricate and appressed to the ancipital branchlets.

1 T. occidentàlis L. Branchlets spreading; lvs. imbricate in 4 rows, rhomboid-ovate, tuberculate on the back; cones oblong, the inner scales truncated and gibbous below the Iip.-This tree is often called white cedar, and from its resemblance might easily be mistaken for the Cupressus thyoides. It abounds in the northern U. S. and Can. on the rocky borders of streams and lakes, and in swamps. It has a crooked trunk, rapidly diminishing in size upwards, throwing out branches from base to summit. The evergreen foliage consists of branchlets much more flat and broad than those of the White Cedar. Cones terminal, consisting of a few long, loose scales. Wood very light, soft and durable. Maj. 
2 T. orientàlis L. Branches erect; lvs. slightly furrowed in the middle, cones erect, roundish or obovoid; scales acute, recurved or spreading at the points.Cultivated shrubs or small trees much branched. The 'lattened, fan-shaped ramifications vertical, not horizontal as in the other. + China.

\section{CUPRES'SUS, Tourn. Cypress. (From the Isle of Cyprus,} where the Cypress is very abundant.) Flowers $8 .-\hat{o}$ in an ovoid ament; anthers 4, sessile at the base of the peltate scales; 9 in a strobile (cone); scales peltate, bearing 4 to 8 , erect (orthotropous) ovulus at base inside; seed angular, compressed; integuments membranous; cotyledons 2 or 3.-Trees with evergreen, flat, squamous, imbricated lvs. Fertile aments becoming indurated cones.

C thyoìdes $\mathrm{Mx}$. WIIITE Cedar. Branchlets compressed; lvs. imbricate in 4 rows, ovate, tuberculate at base; cones spherical. $-N$. Eng. (from Winchendon Mass.) to Ga. W. to O. It usually occurs in swamps, which it densely and exclusively occupies. Height $40-60 \mathrm{f}$. The leaves consist of short, minute, evergreen scales, covering the finely divided branchlets, in 4 imbricated rows, and each one furnished with a minute gland or tubercle on the back. The wood is white, fine-grained, and wonderfully light, soft, and durable. Used in the manufacture of shingles, pails, fences, \&c. Posts made of this cedar it is said will last 50 years. May.

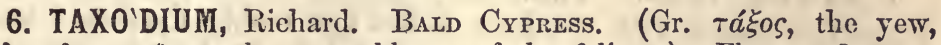

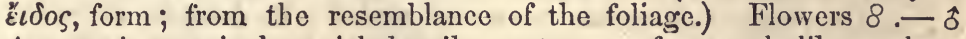
Aments in terminal, panicled spikes; stamens few, scale-like, peltate, bearing 2 to 5 anther cells. क Cones sessile in pairs, roundish, placed below the sterile; scales numerous, bearing 2 ovules at the base, becoming thick, angular, peltate 2 -seeded in fruit; cotylendos 6 to 9.-Trees with deciduous, linear lvs. arranged in 2 rows.

T. distychum Rich. Lrs. distychous; flat, deciduous with the slender branchlets. -One of the largest trees of the forest, native of N. J. to Mex. It grows in wet soils, forming what is called the cypress or cedar swamps of the S. States. The trunk arises to the height of $125 \mathrm{f}$, with a circumference of 25 to $40 \mathrm{f}$, above the conical base, usually of smaller dimensions. The enormous roots produce large, conical excrescences covered with bark but leafless, 1 to $3 \mathrm{f}$ high. The head is wide-spread and often depressed. Foliage light green and open. Cones $\mathbf{I}^{\prime}$ diam., composed of the indurated, combined scales. Timber light, fine-grained and durable. $\dagger$

7. JUNIP'ERUS, L. JUNIPER. (Celtic, juneprus, rough or rude.) Flowers $\hat{o}$ \&, rarely $8 .-\hat{o}$ Ament ovate; scales verticillate, peltate, each with 4 to 7 anther cells at base. $q$ Ament globous; scales few, united at base, concave; ovules 1 , rarely more, at the base of each scale; berry formed of the enlarged, fleshy scales containing $2-3$ bony seeds ; cotyledons 2.-Trees or shrubs. Lvs, cvergreen, mostly acerous, opposite or in whorls of 3.

1 J. commùnis L. Common Juntper. (Fig. 153.) Lvs. ternate, spreading, subulate, mucronate, longer than the berry.-Can. to N. J. and Wis. A shrub, with numerous, prostrate branches, growing in dry woods and hills, often arising iry a slender pyramid, 6-8f high (rarely arboreous Robbins). Leaves arranged in whorls of $3,5-8^{\prime \prime}$ long, acerosc-lanceolate, ending in a sharp, bristly point, channeled and glaucous on the midvein above, keeled and green below. Barren flowers in small, axillary aments or cones; fertile ones on a distinct shrub, small, axillary, sessile. Berries roundish, oblong, dark blue, ripening the second year from the flowor. They are then sweetish, with a tase of turpentine. In medicine they are diuretic and cordial. May.

2 J. Virginiàna. RED CERAR. Upper lvs. imbricate in 4-rows, ovate-lanceolate, pungertly acute, appressed, older ones acerous, cuspidate, spreading; trunk arbore- 
ous.-Found throughout the U. S., but chiefly in the maritime parts, growing in dry, rocky places. It is a tree of middle size, sending out numerous, horizontal branches. Leaves dark green, the younger ones small, ovate acute, scale-like, overlying each other in 4 rows, upon the subdivided branchlets; the older ones 6" long. Flowers inconspicuous, the staminate in oblong, terminal aments, $3^{\prime \prime}$ long; the fertilo on separate trees, producing small, bluish berries covered with a white powder. Wood reddish, very light, durable, used in making drawing pencils, etc. Apr., May.

3. PROSTRÀt. Lvs. ovate, submucronate, glandular in the middle, appressed; berries tubercular; st. prostrate, creeping.-A shrub, on gravelly shores, witb. creeping branches $4-8 \mathrm{f}$ long.

\section{Order CXXVIII. TAXACEA. Yews.}

Trees or shrubs, with narrow, parallel-veined or broad fork-veined leaves, and the flowers diclinous, achlamydeous, surrounded with imbricated bracts. of Flowers several together, each consisting of one or several coherent anthers. \& Flowers solitary or clustered, each consisting of a single naked ovule, terminal or axillary. Fruit a solitary seed usually surrounded at base by a fleshy cupule. Fig. 421 .

Genera 9 , species 50 , generally natives of the temperato regions.

1. TAX'US, Tourn. YEw. (Gr. Táłov, an arrow; arrows were formerly poisoned with the juice of the $\mathrm{Yew}$ tree.) Flowers $f$ of or $\mathcal{E}$, axillary, surrounded with numerous scales. of Aments globular, composed of 8 to 10 stamens; anthers peltate, 6 to 8 -celled, cells dehiscent bencath. $\quad$ Flowers solitary, consisting of a single ovule, becoming in fruit a seed nearly enclosed in a pulpy cupule.-Trees or shrubs, with evergreen, linear, alternate lvs.

1. T. Canadénsis L. Dwarf Yew. Ground Hemlock. (Fig. 42i.) Shrub low or prostrate; lvs. linear, mucronate, 2-ranked, revolute on the margin; sterilo ament globous; drupes depressed-globous, open at top.-A small evergreen shrub with the general aspect of a dwarf hemlock spruce (Pinus Canadensis). It grows on thin rocky soils in shady places, 2 to $3 f$ high, Can. to Penn. and Ky. Lvs. nearly an inch long, arranged in 2 opposite rows on the sides of the branchlets. Staminate flowers in small, roundish, axillary heads. Drupes coralline-red, concave or open at the summit, displaying the top of the black seed. May.

2 T. baccàta L. Enguish YEW. Tree of low stature, attaining a great sizo; lvs. linear and spatulate-linear, imbricated all around the young branchlets, finally spreading and distichous; fr. oblong-oval or somewhat bell-shaped, open at tho top.-Trees attaining great age in Engdand, with short, huge trunks and widespread branches. $\dagger$

2. TORRE'YA, Arnott. (Dedicated to Prof. John Torrey, of New York.) - Flowers 8.- of Aments oblong, many-flowered, bracts at base imbricated in 4 rows; stamen a pedicellate scale, bearing several anther cells at base. $\quad$ Ament ovoid, 1-flowered, consisting of a solitary ovule surrounded with bracts; fruit oblong-ovate, a nut-like seed enclosed in a thick, fibro-fleshy testa.-Small evergreen trees, with spreading branches and 2-ranked, linear lrs.

T. taxifòlia Arn.-Along the Chattahoochee, Mid. Fla., and cultivated at Quincy (by Judgo Dupont). Tree 15 to $30 \mathrm{f} \mathrm{high.} \mathrm{Branches} \mathrm{ramifying} \mathrm{distichousiy} \mathrm{and}$ horizontally. - Lvs. dark green, shining, very acute, mucronate-pungent, margins revolute, $18^{\prime \prime}$ long. Drupo near $1^{\prime}$ long, with a brittle epicarp.

3. SALISBURIA adiantifolia Smith, is occasionally seen in gardens and shrubberies, called Jingko, in Japan. It is remarkably distinguished by its broad, fan-shaped, fork-veined petiolate lis. It bo comes a tree 40 to $80 \mathrm{f}$ in height. † Japan. 


\section{Order CXXIX. CYCADACEA. Cycades.}

Trees of low stature, simple trunks with the internodes undereloped and the surface scarred with the fallen leaves which were pinnate, parallel-veined, circinate. Flowers diœcious, in cones, $\hat{\delta}$ anther covering the under surface of the connective. $\uparrow$ Scales peltate, scale-like or leaf-like, bearing naked ovules dorsal or marginal.

Genera 7 , species 46 , chiefly tropical. The Cycades form the connecting link between the Exogens and the Cryptogamia.

CY'CAS revoluta, a palm-like plant, representing this order endures the winters of the far South, and is frequent in the greenhouses of the North. Its long, pinnate leaves are all clustered at the summit of the short, abrupt trunk which is tesselated all over with leaf-scars.

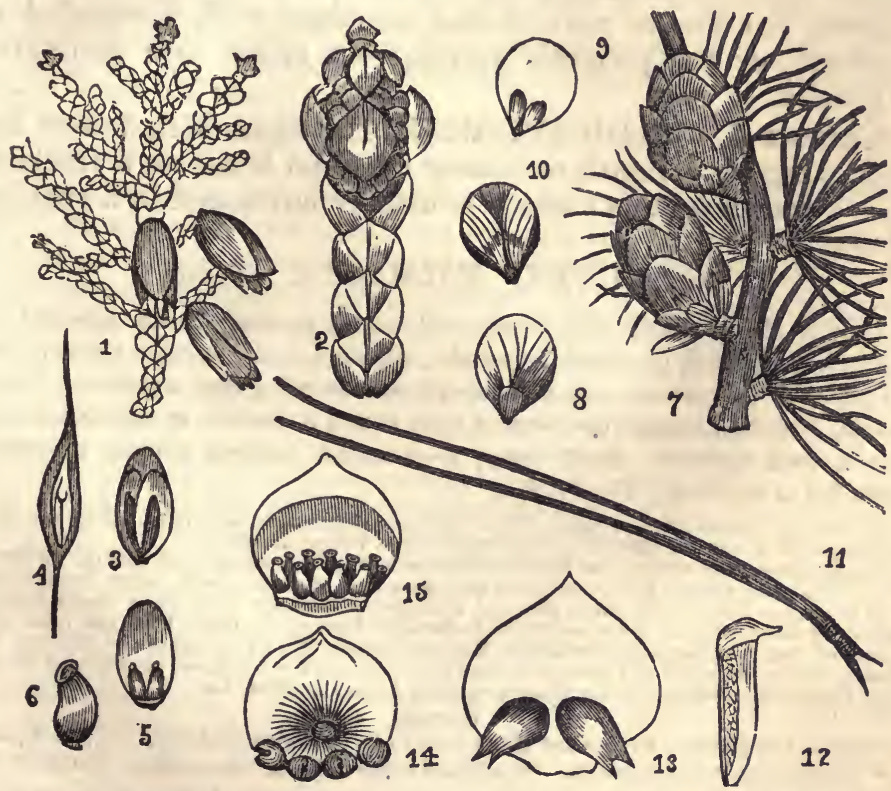

FIG. 693.-1. Branch of Thuja occidentalis, with strobiles. 2. A magnified branchlet with a zone of staminate flowers. 3. A carpellary scale with the two winged seeds. 4. $\Lambda$ vertical tranverse section of one of the seeds, showing the embryo, \&c. 5. The inmature, erect orules. 6. One of the ovules enlarged, showing the micropyle at top. 7. Branch of Abies Americana. 8. Scale, with the bract. 9. Scale with immature ovnles. 10. Scale with ripe seeds. 11. A pair of leaves of Pinus resinosa. 12. Anther of Pinus sylvestris. 13. Scale of the cone, with the ovnles turned downward. 14. Staminate scale of Cupressus, with pollen. 15. Fertile scale, with many erect ovules 


\section{Province, EN D O G E N S,}

OR Monocotruedons. Phænogamous Plants having a stem without the distinction of bark, wood and pith, composed of thread-like bundles of trachenchyma imbedded irregularly in the general cellular mass, the newest interior, not forming layers in growth. Leaves mostly parallel-veined. Flowers very generally 3-merous. Embryo with one cotyledon, rarely with 2 alternate and unequal.

Class III. PETALIFER 无. Plants of the endogenous structure, the flowers normal and complete with a whorled perianth, or the perianth wanting-in either case destitute of glumes.

CoHoRT 5, SPADICIFLORAE. Endogens with flowers having no perianth or a scaly one, and borne on a thickened rachis (spadix) which is usually enveloped in a spathe.

\section{Order CXXX. Palmace e. Palms.}

Trees or shrubs chiefly with unbranched trunks growing by the terminal bud. Leaves large, plaited, on sheathing petioles, collected in one terminal cluster. Flowers perfect or polygamous, on a branching spadix bursting from a spathe. Perianth double, 3-merous, hexandrous, ovaries (and styles) 3, distinct or commonly united into 1, each 1-ovuled. Fruit fleshy, 1-3-secded, embryo minute, superficially imbedded in albumen. Fig. 47, d, e.

Genera 73 , species 500 ? of noble aspect and most interesting attributes. They are chiefly tropical, a few advancing into the wamer parts of the Temperate Zone.

The properties anil uses of the Palms are of the highest infiortance and variety. From the drupes of several African Palms, and from the Cocon Nut, vil is ubtained. Other species secrete wax from their leaves. Starch is obtained abundantly from the Sago Palm (Sagus Rumphii) and many other species. Even sugar, and alcoholic liquors, are male frou the juice of the unopened spathe of Saguerus saccharifer, Manritia vinifer, \&c. The bud of the Cabbage Palm (Areea oleracea) is boiled and eaten as a vegetable. Among the fruits, are enumerated the date, from Phœnix dactylifera, und the cocoa-nut, from Attalea funifera. \&c.

\section{GENERA.}

* Flowers all perfect. Ovaries and styles united into 1. Berry single.............. SA вA.. 1

* Hlowers perfuct and staminate. Ovaries and styles distinct. Drupes 3...... Can mжrops. 2

1. SA'BAL, Adanson. Palmetro. Fls. perfect, sessile, outer perianth (calyx) cup-like, 3-cleft or 3 -toothed, inner of 3 subdistinct, oblong sepals; stam. 6 ; fil. subulate, thcir broad bases contiguous or connate, anth. ovate-cordate; ovaries 3 , soon united into 1 ; style 3 angled; fruit a single globular or 3-lobed, 3 (rarely 1 or 2)-sceded dryish berry.-Caudex procumbent or erect, covered by the persistent bases of the leaves. Leaves palmately many-cleft, segm. implicate, 2 cleft at apex, spadix branching, sheathed with many spathe-like bracts. Fls. small, white or greenish.

1 S. Palmetto Loddig. PALmietro. Caudex erect, arborescent; Ivs. coriaceous, glaucous-green, lamina fan-shaped, segments numerous, implicate, united to near the ensiform summits; petioles broad, compressed, nearly the length of the lamina; spadix flexuous, glabrous, much shorter than the leaves; spathe double; style 
thick, obtuso; berry globular.-Woods along the coast, Ga. and Fla. (scarce N. to the Cape Fear R.). One specimen in the street, front of the P. O., Charleston. Caudex 20 to $50 \mathrm{f}$ high, usually enlarged upwards, and rugged above with the split bases of the old leaf-stalks. The majestic leaves are all terminal, from 1 bud, and 6 to $10 \mathrm{f}$ long. Spadix from the same bud, which in early spring is tender and nutritious like the cabbage. The use of the leaves in hat-work, \&c., is well known. Jn., Jl. (Chamærops, Mx.)

2 S. Adángoni Guernsent. DWARF Palmetto. Caudex prostrate; lvs. rigid, glaucous; petioles shorter, naked; spadix strict, glabrous, branchlets remote-flowered; style thick, obtuse, scarcely shorter than the petals; berry depressed-globous. - In low, sandy swamps, along the coast, Neuse river to the Apalachicola, \&c., often in wide patches. Spadix slender, about as high (3 to $4 \mathrm{f}$ ) as the leaves. A compound branch issues from each alternate sheath. Fls. numerous, $1 \frac{1}{2}$ " long, calyx half as long. Berry bluish black, $3^{\prime \prime}$ diam. Jn.-Aug. (S. pumila Walt.)

3 S. serrulàta R. \& S. Caudex creeping; petioles aculeate-serrate; lamina flabeliform, 10-12-cleft; spadix thick, flexuous, branchlets densely greyish pubescent; style very slender, subulate; berry oblong-ovoid.-Flat pino barrens, S. Car. to Fla., common. The prostrate rhizomes attain a diam. of 4 to $6^{\prime}$, creeping many feet. Leaves 2 or $3 \mathrm{f}$, in dense masses, affording nice shelter for rattlesnakes! Sheaths of the spadix long $\left(2-3^{\prime}\right)$, loose. Fls. rather close on the branchlets, $2 t^{\prime \prime}$ long, caly $\times \frac{1}{3}$ as long, stylo single, tapering to a setaceous point. Berry dark blue, 5" diam. Jl., Aug.

3. Minima. Every way smaller; lvs. about 7-cleft.-E. Fla. (S. min. Nutt.)

2. CHAM E'ROPS, L. Bloe Palmetro. (Gr. $\chi a \mu a i$, on the ground, $\dot{\rho} \omega \psi \psi$, a bush.) Fls. polygamo-diccious, sessile or short pedicellate; calyx 3 -parted, cor. (inner perianth) 3-petaled, valvate in bud; stam. 6 or 9 ; fil. connate at base, anth. oblong or linear-oblong, cordate; ovaries 3 , distinct, stigmas 3 , sessile, subulate, berries 3 , or by abortion fewer, 1-seeded.-Palms acaulescent. Lvs. palmately many-cleft, segm. split at apex with no intervening threads. Petioles aculeate at base and edge. Spadix dense-flowered, fls. yellowish.

C. Hýstrix Fraser. Caudex low, making offsets at baso; pctioles spiny in the axils; spadix very short; drupes ovoid, apex oblique, ratlier large, hirsute.In clayey soils around Savannah, to Fla. Caudex creeping, becoming several inches in diam. In the axils of the sheathing leaf-stalk is a thick, matted, brown, canvas-like stipule, and rigid, sharp, needle-shaped spines 3 to $6^{\prime}$ long. Spadix enclosed in the radical sheaths, bearing a dense mass of hairy, brown drupes $6^{\prime \prime}$ in length. Jn.-Aug.

\section{Order CXXXI. ARACEA. Arotds.}

Herbs with a creeping rhizome or corm, and an acrid or pungent juice, with the leaves simple or compound, often veiny, and the flowers mostly diclinous and naked. Inflorescence a spadix, dense-flowered, naked. or mostly surrounded with a large spathe. Perianth none, or of 4 to 6 scales. Stamens hypogynous, with ovate-extrorse anthers. Ovary free, stigma sessile. Fruit baceate or dry, seeds albuminous, embryo axial. Fig. 91, 201.

Genera 46 , species 240 , nbundant in tropical regions, more rare in temperate, one only, Calla palustris, extending to the northern frigid zone.

Properties. An acril, volatile principle pervades the order, which is, in some instances, so concentrated as to become poisonous. The corms and rhizomas abound also in starch, which in some cases when the volatile acridity is expelled in drying or cooking, is edible and nutricious, as in Colocasia \&c.

Fig. 709. Calla palustris, its spathe spadix and flowers. $\delta$, One of the flowers, consisting of an nvary surrounded by six stamens. c, Cross section of the ovary.

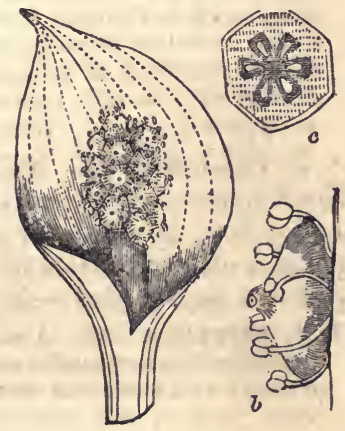




\section{GENERA.}

5 Spadix enveloped in a spathe. (*)

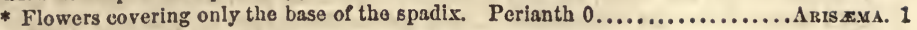

* Flowers covering the whole spadix, and (a)

a Monoclous. Perianth 0. Berry 1-seedel. Spathe convolute......... Premandra. 2 a Monocious. Per. 0. Berry 3 to 6-seeded. Spathe large, revolute, white. Richardia. 3 a Perfect.-Perianth 0. Spathe open, white........................ CAlLA. 4 -Perianth regular. Spathe shell-form, purplish......... Symplocarpes. 5 \$ Spadix naked, having no spathe, - terminal, yellow....................... Orovтium. 6 -lateral; scape leaf-like......................Aconus. 7

1. ARIS E' IIIA, Martins. Dragon-root. Indian Turnip. (äpov, arum, $\sigma i \mu a$, a sign.) Spathe convolute at base, limb arched or somewhat plain; spadix covered with flowers below, naked and elongated above; flowers diclinous, achlamydeous; $\hat{o}$ above the fertile, each flower consisting of 4 or more stamens with anthers opening at top; $q$ ovary 1-celled; stigmas depressed; ovules 2 to 6 , orthotropous, erect from the base of the cell; berry red, 1 or few-seeded.-2f Scape arising from a a corm or tuberous rhizome, sheathed with petioles of the radical, veiny lvs. (Arum, L.)

I A. triphyllum I. JACK-IN-THE-PULPtr. Acaulescent; lvs. trifoliate, mostly in pairs, leaflets oval, acuminate; spadix clavate, obtuse; spathe ovate, acuminate, flat and inflected above.-A curious and well known inhabitant of wet woodlands, Can. to Ga. W. to the Miss. The stem is a rugous, fleshy, subterraneous corm giving off radicles in a circle from the edge. Scape 8-12' high, erect, round, embraced at the base by the long sheaths of the petioles. Leaflets, $2-7^{\prime}$ long, $\frac{1}{2}$ as wide. Spathe green without, usually variegated within with stripes of dark purple alternating with pale green. Spadix much shorter than the spathe, varying from green to dark purple. Fruit a bunch of bright scarlet berries. The corm loses its fiercely acrid principle by drying, and is then valued as a carminative, \&c. Apr., Jn. (Arum, atrorubens Ait.)

2 A. quinàtum. Acaulescent; lvs. with very long sheaths, in pairs one or both quinate; lfts. oval-lanceolate, acuminate, narrowed at base to a short petiole or sessile; spadix long and slender, nearly inclosed in the ovate-lanceolate spathe, which is briefly inflected at the pointed apex; berry 1 to 2 -seeded.-Ga. and $S$. Car. (Curtis.) Scape 1 to $2 \mathrm{f}$ high. Lvs. with long petioles and still longer sheaths. Lfts. 5 to $10^{\prime}$ long, spathe 3 to $5^{\prime}$ (Arum quinatum Nutt.)-Perhaps identical with A. pentaphyllum (Schott.) of India.

$\beta$. OBTÚSO-QUINATUM. Lfts. rounded-obtuse, mucronate, abruptly narrowed to a long petiolule.-Georgia (Feay, Pond).

3 A. Dracóntium Schott. Green Dragon. Acaulescent; lf. mostly solitary, pedate; lfts. 7 to 11 , oblong-lanceolate; spadix subulate, longer than the convolute, oblong spathe.-Less common in N. Eng. than the former species, found in wet places, banks of streams, U. S. Stem a fleshy, subterraneous corm. Scape slender, $10^{\prime}$ to $2 \mathrm{f} \mathrm{high.} \mathrm{Leaf} \mathrm{on} \mathrm{an} \mathrm{erect,} \mathrm{sheathing} \mathrm{petiole,} \mathrm{which} \mathrm{is} \mathrm{dichotomous}$ above, each half bearing 2-4 leaflets with an odd one at the fork. Leaflets 5 to $8^{\prime}$ long, one-third as wide. Spathe green, $1-2^{\prime}$ long, rolled into a tube at base. Spadix slender, with its long, tapering point much exserted. Fruit a bunch of red berries. Jn., Jl. (Arum Dracontium L.)

2. PELT'ANDRA, Raf. (Gr. $\pi \dot{\varepsilon} \lambda \tau \eta$, a shicld or target, å $\nu \delta \rho \varepsilon \varsigma_{\text {.) }}$ Spathe convolute; spadix covered with flowers, staminate above, pistillate below; perianth 0 ; anthers 8 to 12 , attached to the margin of a peltate, oblong, connectile, and opening by a terminal pore; berry 1 celled, 1 to 3 -seeded.-2f Rt. fibrous. Lvs. sagittate.

I P. Virgínica Raf. Acaulescent; lvs. oblong, hastate-sagittate, acute at apex, the lobes obtuse; spathe elongated, incurved, green, wavy on the margin; spadix covered with staminate flowers the greater part of its length.-A smooth, dark green plant, in wet grounds, N. Y. and Ms. to Car. Leaves radieal, numerous, 
8-12' long, $\frac{1}{2}$ as wide, on petioles as long as the scapes. Scapes many from the same root, $8-15^{\prime}$ long. Spathe closely involving the spadix, green, 3 to $5^{\prime}$ long, lanceolate, wavy on the margin. Spadix slender, acuminate, shorter than the spathe, its compact stamens 6-sided. Fr. a cluster of green berries inclosed in the base of the spathe after the upper part of both spathe and spadix has decayed. Jn. . (Arum, L. Calla, Bw. Lecontia, Cooper, Rensselieria, Beck, Caladium, Lindl.)

2 P. glaùca Feay (M S.). Acaulescent; lvs. ovato-hastate, acute or short-acuminate, lobes broad and obtuse at end; scape as long as tho leaves; spathe involute, entire, gradually evolved and widened above, acuminate, white, spadix much shorter; berries red, 1-seeded.-Maritime parts of S. Car. and Ga. (Feay, Pond.) A smooth, glaucous plant with 1 to 3 radical lvs., and one or more slender scapes 12 to $20^{\prime}$ high. Lvs. 5 to $7^{\prime}$ long, with large base lobes, and a vein running close to the margin. Spathe about $3^{\prime}$ long, spadix about $2^{\prime}$. Fruit smaller than in No. 1. Seeds without albumen, as in that species. May, Jn. (Caladium glaucum Ell.)

3. RICHAR'DIA, Kth. Egyptian Calla. Spathe involute at base, spreading, marescent; spadix covered with flowers, fertile below, staminate above; anthers $\infty$, free, sessile, 2 -celled, on a broad connectile; ovaries incompletely 3 -celled, intermixed with sterile filaments; berry few-seeded, seeds suspended.- $2 f$ Herb with a thick rhizome, tall, erect, radical leaf-stalks, and scapes with a large, white spathe.

R. Ithiópica. A fine, showy plant of the green-house and parlors. Lvs. 2 to $4 \mathrm{f}$ high, hastate-cordate, thick, smooth, on sheathing petioles. Scape rather taller, bearing a eylindric spadix within the large, involved, milk-white spathe. † Cape Good Hope.

4. CAL'LA, L. (Probably altered from kajós, beautiful.) Spathe ovate, spreading, persistent, colored; spadix covered with flowers with no perianth; filaments slender, with 2-celled anthers, encircling each ovary; ovary 1-celled, 5 or 6-ovuled, the upper often abortive; berry red, depressed, few-seeded.- 2 . An aquatic herb with a prostrate, creeping rhizome, cordate lvs. and a broad white, open spathe.

C. palústris L.-An interesting plant in shallow waters, Penn. to N. Eng., Wis. and Brit. Am. Lvs. 2 to $3^{\prime}$ long, nearly as wide, cuspidate, long-petioled, smooth and entire. Scape thick, 4 to $6^{\prime}$ high. Spathe clasping at the base, recurved, with a twisted cusp, much longer than the oblong, cylindric spadix. Jl.-The rhizome is acrid, but Linuæus tells us that the Laplanders extract a wholesome breadstuff from it.

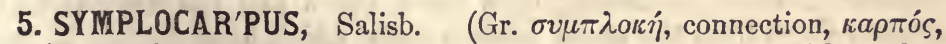
fruit.) Spathe shell-form, ventricous; spadix oval, covered with perfect flowers; perianth deeply 4-parted, segments cucullate, cuneate, truncate, persistent, becoming thick and spongy ; berries globous, 1-seeded, imbedded in the spadix, and with the fleshy perianth forming a kind of sorosis ; seed without albumen.-2f Aquatic, acaulescent herbs.

S. foètidus Nutt. SKunk CABbage. Lvs. cordate-oval, acute; spadix subglobous, preceding the leaves.-A common plant, Can., N. Eng., Mid. and W. States, growing in swamps, meadows and ditches, renowned for its odor, which is scarcely less offensive than that of the animal whose name it bears. Early in spring, the swelling spathe is seen emerging first from the ground or water, more or less covered with purplish spots, its edges partly infolded, and its point incurved. It incloses the spadix, which is oval, covered with flowers of a dull purple. The leaves, which arise after the flowers, are of a bright green, numerous, becoming very largo (often $20^{\prime}$ by $12^{\prime}$ ). (Pothos fotida $\mathrm{MIx}$. Iciodes, Bw.) 
6. ORON'TiUm, L. Golden Cluz. (Name of doubtful origin.) Spathe none; spadix cylindric, eovered with perfect flowers; perianth 4 to 6 -sepaled; stamens 4 to 6 ; ovary few ; stigma sessile; fruit a dry berry or utricle, seed without albumen. $-2 f$ Acaulescent, aquatic. Fls. yellow at the summit of the scape, which thickens upwards into the spadix.

o. aquáticum.-This interesting plant is a native of inundated banks and pools, U. S. Lvs. lanceolate, 6 to $9^{\prime}$ by 2 to $3^{\prime}$, smooth, of a deep green, velvet-like surface above, paler beneath, on long, radical petioles. Scape thick and terete, about a foot in length, closely invested by a short sheath at base, and ending in a spadix of a rich yellow color, covered with small, perfect, yellow fls. of an offensive odor-the upper ones often tetramerous. May.

7. ACO'RUS, L. Sweet Flag. (Gr. $a$, privative, and kóp $\eta$, the pupil of the eyc ; supposed to cure maladies of the eye.) Spadix cylindric, covered with flowers, and issuing from the side of a leaf-like scape; perianth 6 -sepaled; stamens 6 , linear ; ovary free ; stigma sessile, minute ; fruit dry, 3-celled, many-seeded.-2f Herbs with a fleshy, aromatic rhizome. Lvs. radical, ensiform, as well as the scape.

A. cálamus L. Summit of the scape above the spadix very long and leaf-like.Grows in wet soils throughout the U. States. The thick, prostrate, creeping rhizome is highly valued for its aromatic flavor, its warm and pungent taste. The long, sword-shaped leaves are readily distinguished by the ridge running their whole length. The cylindrical spadix is about $3^{\prime}$ long and $3^{\prime \prime}$ diam., covered with small, green flowers. Jn., Jl.

\section{Order CXXXII. LEMNACEA. Duckmeats.}

Herbs minute, stemless, floating free upon the water, and consisting of a leaf-like frond, or a tuft of leaves, with one or more fibrous roots. Flowers bursting from the substance of the frond, or axillary, inclosed in a spathe, the sterile consisting of 1 or 2 stamens, the fertile of a 1-celled ovary. Fruit a utricle, with 1 or more seeds. Embryo straight, in fleshy albumen. Fig. 602.

Genera 4, species 20, little aquaties, widely diffused. They are regarded as reduced aroids, and among the simplest of Phenogamous piants.

1. LEM'NA, L. Duck-Meat. (Perhaps altered from $\lambda \varepsilon \dot{\varepsilon} \mu a$, a scale.) Sterile and fertile flowers in the same spathe, the former 2 collateral stamens, the latter a simple, carinate ovary, with a style and stigma. - (1) Herbs, consisting of a frond (stem and leaf confounded), sending down from the under surface roots which hang loosely in the water, and producing from the margins the spathaceous flowers. (The following sections are regarded as genera by Schleiden.)

\$ LEMNA, Schleiden. Fils. filiform. Ovule solitary. Frond with a single root....Nos. $1-3$ \$ TELMATOPHACE, Schl. Fils, dilated in the middle. Ovs. 2 to 7 . Fronds 1-rooted..No. 4 \$ SPIRODELA, Schl. Fils, narrowed below. Ovules 2. Frond many-rooted...........No. 5

I I. trisulca I. IVY-LEAVED DUCK-MEAT. Fronds elliptic-lanceolate, thin, serrate at one extremity and caudate at the other; roots solitary.-Floating in ponds and pools of clear water. Fronds nearly $\frac{z_{2}^{\prime}}{2}$ in length, diaphanous, with a tail-like appendage at base, obtuse at apex, the new ones issuing in a cruciate manner from lateral fissures in the margin of the old. Root a solitary fiber, ending in a sheath. Flowers very minute. Utricle sitting on the upper surface of the frond. June-Sept.

2. I. minor L. Fronds thickish, roundish or obovate, several conjoined; root solitary.-This little floating plant occurs in dense patches on the surface of stagnant waters. The leaves, properly fronds, adhere $2-3$ together, $2^{\prime \prime}$ in length, rather 
thick, and convex below. Root undivided, sheathed at the end. Flowers minute from a cleft in the margin of the fronds, near the base. Jn.-Sept.

3 I. perpusílla Torr. SMrallest Duck-Meat. Fronds obovate, thin; rt. solitary; seed erect.-Ponds on Staten Island. Fronds $\mathbf{1}^{\prime \prime}$ or more long, grouped or single, bright green. Stamens with fliform filaments, maturing in succession. Ovary obliquely acuminate, with a short style. Sd. striate, erect in the ovary. Aug. (Torrey).

4 I. gibba L. Fronds obovate, hemispherical beneath, nearly plain above; root solitary.-Floating on the surface of stagnant waters, N. York. Fronds about a line in length, pellucid and reticulated beneath. Filaments recurved as in the other species. Fruit roundish, indehiscent, 1 to 7 -seeded. Jn., Jl.

5 I. polyrhìa L. Fronds broad-ovate, a little convex beneath, rts. numerous. -Floating in stagnant waters. Fronds resembling flax-seed, but larger (2 to $4^{\prime \prime}$ long), scattered on the surface of the water, of a firm, but succulent texture, becoming purplish. Rts. in thick bundles of 8 to 10 black fibers from the under surface of the fronds. All these species are caten by ducks and other aquatic birds. Jn.-Sept.

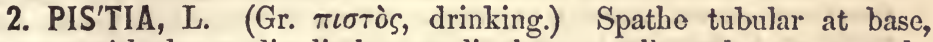
connate with the spadix, limb open, ligulate, cucullate above; $\hat{o}$ anthers 3 to 8, adnate to the thick summit of the spadix, subglobous, opening transversely; o ovary 1 , at the base of the spadix, 1-celled, $\infty$ ovuled, becoming a berry in fruit.-Floating herbs, consisting of rosulate tufts of little, veined, entire lvs., sending out filiform stolons. Spadix axillary, on a short scape.

P. Stratiòtes I. Ivs. roundish-obcordate, margin undulate, veins lamelliform, confluent into a truncate area at base. In the var. SPATHulata (P. spathulata $\mathrm{Mx}$.) the leaves are rather obovate than obcordate, and abruptly contracted into a short petiole.-(1) S. Car. to Fla. and La. (Curtis), in stagnant waters. Spathe white. May.

\section{Order CXXXIII. TYPHACE曆. Trphads.}

Herbs growing in marshes and ditches, with rigid, ensiform, sessile leaves. Flowers moncecious, arranged on a spadix or in heads, with no spathe. Perianth of a few scales, or a tuft of hairs, or 0 . Stamens 1 to 4 , with long, slender filaments. Ovary with 1 pendulous ovule. Seed albuminous, with an axial embryo. Fig. 457.

Genera 2 , species 13 , widely distributed throughout the world.

I. TY'PHA. L. (Gr. Tvфos, a marsh; where all the species grow.) Spadix of flowers long, cylindric, dense; is stamens about 3 together, united into a common filament; of flowers below the sterile; ovary pedicellate, surrounded at base by a hair-like pappus.-Root 2f. Spadix terminal, the upper staminate, the lower pistillate. Fls. very numerous.

T. latifòlia (and angustífolia Linn.) Cat-TaIL. REed Mace. Lrs. ensiform, concave within near the base; sterile and fertile spikes close together, or a little remote. $\mathrm{A}$ common, smooth, tall inhabitant of the water, in muddy pools and ditches, U. S., Can. Stem 3 to $5 \mathrm{f}$, round and smooth, leafy below. Spikes terminal, 6 to $10^{\prime}$, brown, composed of slender, downy fowers, packed solid. The upper portion is slender, composed of the sterilo flowers. Leaves somewhat swordshaped, erect, $2-4 \mathrm{f}$ and nearly $1^{\prime}$ wide. They are called flags, and useful for weaving the seats of chairs, \&c. July.

$\beta$. ANGeStífolis. Sterile and fertile spikes a little remote $\left(\begin{array}{l}1 \\ 4\end{array}-2\right.$ '). - Found in the same situations with the former. $\Lambda$ well marked variety, but differing only in the more slender habit, and less complete development of its parts. 


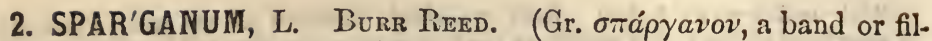
let; in reference to the long, ribbon-like leaves.) Spadices many, globous, the lower fertile, the upper consisting of numerous stamens with scales intermixed; filaments slender; anthers oblong-linear, 2-celled; o pistils numerous, sessile, each surrounded by 3 or 6 scales, which represent a perianth ; stigma ligulate, unilateral, fruit nut-like, sessile, 1-seeded.- 4 Aquatic herbs. St. leafy, simple or branched. Lvs. long, linear, sheathing at base.

\$ Stigmas mostly 2. Stems of the inflorescence branching. Erect...................... 1

Stigmas always single. Stem simple.-Erect. Heads large (half inch diam.)................ No. -Floating or erect. Heads small..................... 3,4

1 s. ramòsum Huds. Lvs. triangular at base, their sides concave; common flower-stalks branched; stig. 2, linear.-Grows in pools and ditches, where it is conspicuous among other reedy plants for its globular burrs of flowers. Stem 1-2f high, flexuous, round, with a few branches above. Leaves $\frac{1}{2}-2 \mathrm{f}$ long, 4-8" wide, lincar, arising above the stem, triangular towards the base, and sword-form upwards, tapering, but obtuse. Heads of flowers light green; fertile ones $2-5,6^{\prime \prime}$ diam., the lowest generally raised on a short, axillary stalk; sterilo ones above, more numerous, smaller, sessile. Aug.

2 S. simplex Smith. Lower lvs. equal with, or exceeding the stem, which is nearly simple, floral ones concave at base and erect; stig. always simple, ovateoblong, oblique, scarcely more than half the length of the style.-Ponds and lakes. Stem 1-2f high, simple or divided at base. Leaves mostly radical, $1-2 \frac{1}{2} \mathrm{f}$ by $3^{\prime \prime}$, carinate at base. Fertile heads sessile, generally 3,6 to $8^{\prime \prime}$ diam., below the several barren ones, with the simple styles conspicuous. Aug. (S. Americanum Nutt.)

3 S. natans L. Lvs. floating, flat; common flower-stall simple; stig. ovate, very short; head of sterile fls. subsolitary; fruit beaked and stipitate.-Lakes and pools, U. S. and Brit. Am. Stem long and slender, and, with the leaves, floating upon the surface of the water. Leaves thin and pellucid. Heads of fertile flowers axillary, generally 2, small, mostly sessile. Sterile cluster terminal. Aug.

4 S. angustifòlium Mx. Slender, weak, simple, erect or floating; lvs. narrowly linear, shorter than the stem when erect, elongated when floating; heads very small, axillary, the lower pedunculate; stigma single, short; fr. scarcely beaked, sessile. -N. Eng., N. Y., Can., pools and streams. Sts. 1 to $2 \mathrm{flong}$, lvs. 1 to 3 to $9^{\prime}$ or more, obtuse. Hds. scarce a fourth of an inch diam.

\section{Order CXXXIV. NAIADACEA. NaIAds.}

Water plants with jointed stems, and sheathing stipules, or sheathing petioles. Flowers perfect or diclinous, naked or with a 2 to 4-parted periantl. Stamens definite. Ovaries free, sessile, 1-ovuled. Stigma simple, often sessile. Fruit indehiscent. Seed without albumen, with a straight or curved embryo.

Genera 9 , species 60 , in waters and marshes, salt or fresh in all countries.

\section{GENERA.}

- Flowers axillary, sessile, the staminate reduced to a single stamen (a).

a Fertile flowers reduced to a single pistil, with 2 or 3 stigmas. Lvs. opposite..NAJAs. 1

a Fertile flowers with about 4 pistils in a cup, with as many stigmas...... ZasionzLlir. 2

- Flowers spadaceous, or 2 to 20, sessile on a spadix or spike (b).

b Flowers monœecious, seated in 2 rows on the side of a linear, flat spadix.....Zostrra. 3

b Flowers perfect, naked, 2 to 5, 4-merous ; fruit raised on slender stipes....... Puppis. 4

b Flowers perfect; perianth 4-sepaled; stam. 4. Pistils and achenia 4.. РотамоGrton. 5

1. NA'JAS. L. WATER NyMPH. (Gr. váw, to flow; hence Naïs, or Naides, Nymph of the waters; from the habitat.) Flowers axillary, sessile, solitary, the of reduced to a single stamen; filament slender, 
often elongated, anther 4-valved, valves spreading; $q$ perianth 0 ; style short, stigmas 2 or 3 , subulate; fruit a little 1-seeded, drupe-like nut.-Herbs entirely submersed, with opposite lvs. Fls. minute.

N. fléxilis Rostk. St. filiform, cæspitous, dichotomously branching; lvs. opposito or fasciculate in $3 \mathrm{~s}, 4 \mathrm{~s}$ or $6 \mathrm{~s}$, at the nodes, linear, obscurely denticulate, spreading, 1-veined.-A slender plant, Can. to N. J. and W. States, consisting of tufts of thread-like knotted stems 6 to $12^{\prime}$ long. Lvs. $\frac{1}{2}$ to $1^{\prime}$ long, $\frac{1}{2}{ }^{\prime \prime}$ wide, sessile and sheathing at base. Flowers solitary, sessile, axillary, very small, the fertile ones consisting of an oblong ovary tipped with a filiform style, with 2 to 3 stigmas at summit. Aug. (N. Canadensis Mx. Fluviatilis, Pers.)

$\beta$. FRÁGILIS. St. and lvs. rather rigid, the latter mostly opposite and recurved. (Caulinia fragilis Willd.)

2. ZANniCheL'LIA, Micheli. Horn Pondweed. (In honor of Zannichelli an eminent botanist of Venice.) Flowers axillary, usually both kinds together; $\hat{o}$ stamen 1 ; filament elongated; $q$ calyx monophyllous; corolla 0 ; ovaries 4 or more, each with a single style and stigma, and becoming in fruit an oblong, incurved, subsessile achenium.-(1) Submersed, slender, branched, with entire, linear, scattered leaves.

Z. palústris L. St. fliform, floating; lvs. opposite, linear; anth. 4-celled; stig. entire; acl. toothed on the back.-In pools and ditches, N. States. St. round, smooth, 1 to $2 \mathrm{f}$ long, branching, leafy. Lvs. grass-like, 2 to $3^{\prime}$ long, sessile. Flowers issuing from axillary bracts, small, 2 together, a sterile and a fertile, the former consisting of a single, naked, ereet, yellowish-brown stamen, the latter of 4 to 6 ovaries which are free from the inflated, 1-sided, 2 to 3 -toothed calyx. Jl, Aug.

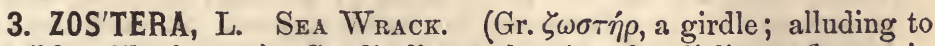
its ribbon-like leaves.) Spadix linear, bearing the diclinous flowers in 2 rows on one side; perianth $0 ; \hat{o}$ anther ovoid, sessile, opening lengthwise with conferroid pollen; pistils alternating with the stamens : style bifid; utricle 1-seeded.-24 Maritime herbs. Stip. united into a sheath.

z. marina I. St. trailing, throwing out tufts of fibrous roots at the joints; branches floating, simple; lvs. alternate, linear, entire, sheathing at base, 1 several feet in length; receptacle or spadix linear, flat, pale green, 2 ' long, issuing from a cleft in the base of the leaf, covered in front with a double series of naked flowers - 2f Aquatic, growing in the sea on sandy banks and shallows (Maine to $\mathrm{Ga}$.), and is thence. washed upon the shore by the waves. Like other sea-weeds, it is gathered for manure. Aug.

4. RUP'PIA, L. Ditch-GRAss. (In honor of Ruppi, a German botanist.) Flowers $\Varangle, 2$ together on a spadix or spike arising from the sheathing base of the leaves; perianth 0 ; stamens 4 , each a 1-celled, sessile anther; ovaries 4 , pedicellate, becoming in fruit 4 dry drupes or achenia. - 4 Herb slender, branching, submersed except the flowers.

R. marítima L. A grass-like plant, salt water bays and ditches along the coast. Stems several feet long, filiform, branched, floating. Leaves $1-2 \mathrm{f}$ long, linear and setaceous, with inflated sheaths at base, all immersed. The common peduncle is contorted and spiral, and by winding and unwinding bears the spadix of naked, green flowers on the surface of the water as it rises or falls. July.

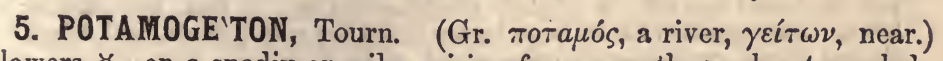
Flowers $\Varangle$, on a spadix or spike arising from a spathe; calyx 4-sepaled; anthers 4 , alternate with the sepals; ovaries 4 ; achenia 4 , sessile flatted on one or two sides; seeds curved or coiled.-Mostly $2 f$, aquatio 
and submersed, only the flowers arising above the surface of the water. Spadix (or spike) pedunculate, 3-10-flowered. Lvs. stipulate, parallel-veined, lower alternate, the upper mostly opposite. Fls. small, greenish.

5 Leaves of two kinds ; the floating, oval-elliptieal, coriaceous petiolate, stipules free

from the petlole, connate; submersed leaves thin, $\left({ }^{*}\right)$

* Floating leaves broader than the subinersed ones. (a)

a Leaves all conspicuously stipulate.................................... 1, 2

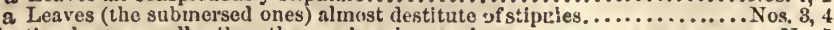

- Floating leaves smaller than the ample submersed ones.......................

$\$$ Leaves of one kind only, all growing beneath the water's surtace. ( $)$

- Stipules entirely free from the petiole or leaf. (a)

a Leaves lanceolate, petiolate or merely sessile......................

a Leaves oval or oblong, broad and clasping ar base................................. 8,9

a Leaves linear, - Stems evidently compressed more or less.................. 10,11

-Stems terete, very slender.......................

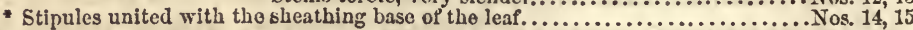

I P. natans I. BROAD-LEAVED POND-WEeD. Floating lvs. coriaceous, oblong, or elliptic-ovate, acute or obtuse or cordato at base, on long petioles, submersed ones linear-lanceolate, membranous, elongated, attenuated to petioles at base, lowest reduced to mero petioles; stipules connate, distinct from the petiole, elongated; spikes rather dense, shorter than the peduneles; fruit somewhat semi-globous, roughish, more or less carinate at the back.- $\Lambda$ very common species, in slow waters or ponds, N. Eng. to Wis. St. slender, 1 to $3 \mathrm{f}$ long, according to the depth of the water, branched. Upper lvs. 2 to $4^{\prime}$ long, about half as wide; petioles 2 to $8^{\prime}$, submersed. Spike 1 to $2^{\prime}$ long. Jl., Aug.

2 P. heterophýllus Schreb. Floating lvs. lanceolate or oblong, 5 to 7-reined. tapering to the petioles, scarcely coriaceous, submersed lvs. long, narrowly linear, membranous, aeute, l-veined, slightly tapering to the sessilo base; stip. nearly distinct, resembling tho lvs.; spikes dense, on thickened peduncles; fr. compressed, suborbieulir.-Ponds and slow waters, frequent. St. round, slender or filiform, often branched. Lower lvs. 3 to $6^{\prime}$ by $1 \frac{1{ }^{\prime \prime}}{}{ }^{\prime \prime}$, remote, upper about 2 to $3^{\prime}$ by $\frac{1^{\prime}}{2}$. Spikes $1^{\prime}$. long, peduncles 2 to $4^{\prime}$. (P. Claytonia Tuckerman.)

3 P. diversifollius Bart. St. filiform, branching; upper lvs. oval or lanee-aval, 5-veined, on short petioles, lower ones submerged, sessile, filiform, alternate, often densely fascicled, not at all reticulated, obtuse.-Common in pools and ditches. A very slender and delieate species, only the upper lvs. arising to the surface. These are 6. to $10^{\prime \prime}$ by 2 to $4^{\prime \prime}$, acute at each ond, on hair-like petioles 3 to $6^{\prime \prime}$ long. Spadices dense, short, 5 to 6-flowcred. Jl. (P. setaceum Pl..)-Varies with tho leaves nearly a!l of either kind.

4 P. hỳbridus Mx. Floating lvs. elliptic-oblong, coriaceous, searcely veined, longer than their petioles; submersed lvs. long-linear, thin, sessile; stipules abovo equaling the petioles, those of the submersed lvs. very short or wanting; spikes cylindrie, dense, on short, thickened ped. ; fruit keeled on the back, seed coiled into a ring.-Pools and slow waters, S. ? and W. States. Sts. mostly simple, very slender, 1 to 3 f long. Lower lvs. 3 to $5^{\prime}$ long, alternate, upper opposite, $I^{\prime}$ to $18^{\prime \prime}$. Spike about $1^{\prime}$. A liandsome species.

5 P. flùitans Roth. Floating lvs. opposite, oval-laneeolate, coriaccous, acute at each end, shorter than the petioles; submersed lvs. larger than tho floating, lanceol:te, sessile, short-acuminate, strongly reined, wavy, thin, not shining, faintly reticulated; stip. large, conuate; ped. thickened, cylindric.-In clear, deep waters, N. New Eng. and Can. Sts. simple or branched, several feet long. Submersed lvs. 5 to $7^{\prime}$ long, a third as wide, the floating 2 to $3^{\prime}$ long. Stip. 2 to $3^{\prime}$ long. Spikes 2' long, rather dense-flowered. Aug.

6 P. lúcens L. Lvs. shining, oblong-lanceolate, acuminate, flat, large, the short petioles continuing in a thick midvein; spikes long, cylindric, many-flowered; ped. thickened upward; fr. slightly keeled. - 2f Can., N. Eng., \&c. Rivers and lakes. Distinguished for its large leaves which are very pellucid, and, when dry, slining above, conspicuously cross-veined, 3 to $5^{\prime}$ long, an inch or more wide, each with a lanceolate, double stipule above its base. Spadix $2^{\prime}$ long, of numorous green flowers, on a peduncle 2 or 3 times as long, thick and enlarged upwards. Jn. 
7 P. obrùtus. Lvs. linear-lanceolate, sessile, rather acute, only the midvein conspicuous, alternate, approximate, the lower stip. wanting; spikes long, pedunculate; ped. not enlarged upwards; ach. inflated, margined on the back, beak in. curved, both sides conspicuously umbilicate.-A remarkable species, first found at Lyndon, Vt., since seen southward to $\mathrm{Ga}$.; in slow waters. St.round, slender, simple. Lvs. uniform, 3 to $4^{\prime}$ by 4 to $6^{\prime \prime}$, taporing to tho slightly clasping base, tho two upper opposite. Spike dense, $1 \frac{1}{2}$ long, ped $3^{\prime}$. Seed coiled into a ring as shown by the pits of the fruit.

8 P. pralongus Wolfg. Lrs. oblong or ovate, obtuse, many-veined, with threo stronger veins, all reticulately connected, baso amplexicaul; ped. very long; spike cylindrical, many-flowered; fr. ventricous, lunate, acutely carinate on the back.Ponds and rivers, Northern States and Can. The plant is wholly submersed, sending up its spike to the surface on a very long stalk. We have gathered it in Niagara river, growing in depths of 6 or 8f. July, Aug.

9 P. perfoliàtus L. Lvs. cordate, clasping tho stem, uniform, all immersed; spikes terminal; fls. alternate; fruit not keeled.-A common species growing in ponds and slow waters, wholly below the surface except the purplish flowers. Stem dichotomous, very leafy, 6-10' long. Leaves alternate, apparently perfoliate near the base, $1 \frac{1}{2}$ long, $\frac{1}{3}$ as wide, obtuse, pellucid. Spadix on a short peduncle $\left(1-2^{\prime}\right)$, few-flowered. Jl.

10 P. pauciflòrus Pursh. St. dichotomous, slightly compressed, filiform; 1rs. linear, alternate, sessile; fls. few in the spike, prd. short; fruit distinctly crested on tho back.-A delicate species, in rivers, \&c. Leaves numerous, obtuse, tapering to the stipulate base, $2-3^{\prime}$ long, a line wide, 3 -veined, of a bright green color. Peduncle an inch long, terminal, bearing $3-5$ greenish fls. above the water, but ripening the seeds below. (P. gramineum Mx.)

11 P. compressus L. St. compressed, ancipital, flexuous; Ivs. broad-linear, obtuse; spike short, pedunclo elongated.-A very distinct species in ponds and rivers. Stem 1-2f long, branching, weak, flattened, green, with sheathing stipules above the nodes. Leaves $3-4^{\prime}$ in length, $2^{\prime \prime}$ wide, closely sessile, remote, the margins perfectly parallel, ending in an abrupt point. Spadix terminal, $\frac{1}{2}-1^{\prime}$ long, on a pedunclo $1-2^{\prime}$ long, and bearing $5-25$ flowers. Jl. (P. zosterifolium Schum.)

12 P. pusillus L. St. filiform, flexuous, branched; lvs. linear-subulate, membranaceous, very acute, sessile, not narrower than tho stipules; spikes capitate, few-flowered; fr. ovoid-compressed, umbilicate each side.-Shallow waters, N. Eng. to Ohio and Can. A very delicato species, wholly submersed. Leaves 1 $-2^{\prime}$ by $\frac{I^{\prime \prime}}{2}$, a little longer than the internodes. Spikes $3-5$-flowered, the peduncles $\frac{1}{4}$ long. Fruit with sharp pits, as in P. obrutus, and rather inflated.

13 P. Tuclzermàni Robbins? St filiform, with capillary branches; lvs. few, all capillary and confervoid, with minute, membranous stipules; spikes fow (6 to 9)flowered, oblong, on a long, filiform peduncle, which is slightly thicker than the stem ; (fruit immature).-In clear water, Uxbridge, Mass. (Ricard) (White Mts., Alleghany Mts. Tuckerman? in Gray's Manual.) An exceedingly delicate species. The leaves taper to the fineness of cobwebs. Spike $4^{\prime \prime}$ long, the ped. about $5^{\prime}$ long.

14 P. pectinatus (and P. marinus L.) St. slender, branched, striate, flexuous; lvs. numerous and fascicled in the axils, long, narrowly linear, acuminate, on sheathing stipules; spikes cylindrical, the lower fls. remote; ped. filiform, long. - Plant submersed in deep water, bushy and very leafy, N. Eng. ? Middle States I W. to Wis. (Lapham ?) Leaves $4-7^{\prime}$ by (less than) $1^{\prime \prime}$, thin, the midvein scarcely perceptible. Fruit large, purplish, rough, a little compressed, neither carinate, nor umbilicate. Jn.

15 P. Robbínsii Oakes. Lvs. lance-linear, approximate, sheathing the stem with the adnate stipules, lamina auriculate at base, margin minutely ciliate-serrulate; spikes oblong, small and ferv-flowered; ped. shorter than the leaves.First discovered by Dr. Robbins in Pondicherry Pond, Jefferson, N. H. Since found in many other ponds in N. H., Mass. W. to Ohio. St long, branched, almost wholly enclosed in the sheaths. 'Lrs. 2 to $4^{\prime}$ by 2 to $3^{\prime \prime}$, very acute, somowhat crowded. 


\section{CoHoRT 6, FLORIDE}

Endogenous plants with the Flowers usually perfect and complete, the perianth double, 3-parted, the outer often, and sometimes both, green.

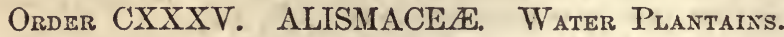

Marsh herbs, with parallel-veined, petiolate leaves and branching peduncles. Flowers perfect or monœcious, with a regular double perianth. Sepals 3, green; petals 3, colored or green; stamens hypogynous. Ovaries 3 or more, separating into as many 1-seeded achenia.

Genera 9, species 70, listributed in all parts of tho world, moro common in temperato elimates. One species of Sagittaria is cultivated for food in China (S. Sinensis). (Our specimens wero revised by Dr. Engelman.)

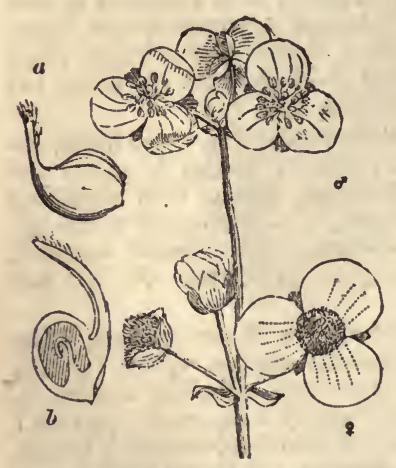

SUBORDERS AND GENERA.

I. ALISMEA. Petals white, with a green calyx. Embryo curved. Leaves rush-like, with no lamina. (a) $\quad$ Stam 6. Alisma. 1.

a Fls. all perfect. $\{$ Stain. 9.-24. Ecurv. 2.

a Fls. diclinous. Stam. $\infty$... SAgitraria.

II. JUNCAGINE s. Petals greenish, like the sepals. Embryo straight. Leaves mostly expanded to a lamina. (b)

b Anthers oval. Lrs. radical... Triglocmis. 4

b Anth. linear. Lvs. canline.Scuevcrizeria. 5

FIG. 712. Inflorescence of a Sagittaria, leaf and flowers. $a$, One of the pistils enlarged. $b$, The pistil of Alisma cut open, showing the seed and curved cmbryo.

1. Alis'ila, L. Water Plantaix. (Celtic alis, water?) Flowers $\Varangle ;$ sepals 3 , persistent; petals 3, æstivation involute; stamens 6 ; ovarics and styles numerous, arranged in a circle, forming as many flattened achenia. - 2f Acaulescent, marsh herbs, with mostly expanded leaves, and with panicled flowers.

A. plantàgo L. Lvs. all radical, ovate or oval, subcordate, abruptly acuminate; scape many-flowered; fls. verticillate in the panicle; carpels 15 to 20 , ribbed on the back, forming an obtusely triangular whorl. $-\mathrm{A}$ common, smooth, handsomo inhabitant of pools and ditches. Lvs. resembling those of the common plantain, with about 5 veins running from end to end, connected by cross veinlets. Petioles $8-12$ ' long. Panicle a scape, $1-2 \mathrm{f}$ high, with numerous, small, rose-white flowers. Jl., Aug. (A. trivialis and parviflora $\mathrm{Ph}$.)

2. ECHINODO'RUS, Richard, Engelm. (Gr. Exivos, the sea-urchin,

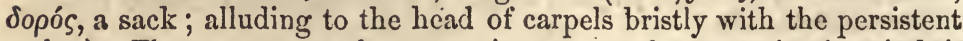
styles.) -Flowers $\Varangle$; sepals 3 , persistent; petals 3, xstivation imbricate; stam. $6-\infty$; ovaries and styles $\infty$, imbricated in a head, forming as many flattened, beaked achenia.-Scape crecping or crect, flowcrs verticillate.

1 E. radicans Engelm. Leaves ample, ovate, obtuse, cordate, about 7-veined, on long petioles; scape prostrate, running and rooting at tho proliferous joints; fls. 
clustered at the nodes, on long pedicels; stam. 18-24; heads of carpels ovoid, achenia short-beaked, very numerous (100-200). - 2f Swamps, W. Ill. (Engelmann in Gray's Manual) S. to Ga. (Mettauer) and La. (Hale). Lvs. 5-12' by 3-7', strougly heart-shaped. Scapes several, 2-4f long, producing roots and small leaves as well as flowers at the upper joints. Flowers white, much resembling those of Sagittaria. Jn., Jl. (Alisma, Nutt.)

2 E. rostratus Engelm. Leaves ovate, rather acute, cordate, about 5-veined, the later ones oblong, all long-petioled; scapes erect, much exceeding the leaves, sharply angled; stam. 12; heads of carpels globular; ach. numerous (100), strongly ribbed and bealed. - (1) River swamps, Ill. near St. Louis (Engelm.) S. to Ark. Much smaller than the preceding. Lrs. $1-3^{\prime}$ long, petioles $2-4^{\prime}$. Scapes $1-36$. Elowers about half as large as in Sagittaria. (Alisma, Nutt.)

3 E. parvula Engelm. Dwarf; leaves elliptic-lanceolate, very acute, tapering to a petiole of equal length; scapes erect, 3-6-flowered; pedicels reflexed in fruit; stam. 9 ; heads of carpels depressed-globular; ach. about 20, beakless. - (1) Muddy shores, Ill, Mo. to Mich. (Engelm.). Plant a few inches (1-3 or $\left.4^{\prime}\right)$ high, often stoloniferous. Leaves, excluding petiole, less than $I^{\prime}$ long. Fls. about $3^{\prime \prime}$ diameter.

\section{SAGITTARIA, L. Arrow-hend. (Lat. sagitta, an arrow; from} the peculiar form of the leaf.) -Flowers 8 , rarely + of ; sepals 3 ; petals larger, colored, xestivation imbricate; stam. $\infty$; ovaries very numerous, crowded into a head, forming in fruit as many flat, margined, bcaked achenia.-Acaulescent marsh herbs, with a milky juice. Lvs. commonly arrow-shaped, often lanceolate, linear, or even reduced to mere petioles. Scapes with fls. in whorls of $3 \mathrm{~s}$, the lower perfect. Petals white.

\$ Lower (fertile) pedicels mnch shorter than the uppe: (sterile) ones............. Nos, 1, 2

\$ Fertile perlicels as long as the sterile. (a)

a Filaments longer than the anthers. Lrs. not sagittate....................... 3

a Filaznents very short.-Leaves lanceolate and linear, mostly................... - Leaves oval-obtuse, sagittate at base....................... 8

1. S. variábilis Engelm. Lvs. generally sagittate; scape 12-angled, upper fls. sterile, on pedicels but twice longer than those of the lower fertile fis.; fil. glabrous, longer than the anthers; ach. obovate, with a conspicuous, averted beak.-A curious aquatic, conspieuous among the Rushes and Sedges of sluggish waters, Can. and U. S. Lvs. 3 to $10^{\prime}$, the lobes about as long as the lamina, petioles much longer. Scape $10^{\prime}$ to $2 f$, simple or branched, 3 of the angles prominent. Fls. mostly in $3 \mathrm{~s}$, with ovate, slender-pointed bracts, often dicecious. Petals roundish, showy,

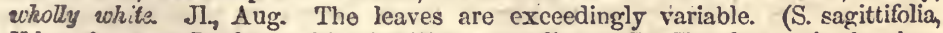
Ed. 1, \&c. nec. L , from which it differs, according to Dr. Engelmann, in the characters emphasized above.)

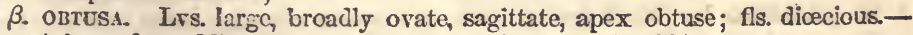
A large form, Mid., W. and S. States. (S. obtusa Willd.)

$\gamma$. LATIFOLIA. Lvs. large, broad-ovate, acute, with ovate, acuminato lobes.

S. GRAciuss. Lvs. linear, with linear, long, acute, spreading lobes.

ع. PUBESCLNS. Plant pubescent in all its parts; lvs. and their lobes ovate.

$2 \mathrm{~S}$. heterophýlla $\mathrm{Pb}$. Lvs. smooth, linear-lanceolate, rarely some of them elliptical and sagittate; scape simple, weak; bracts roundish, obtuse; upper fls. sterile, on long pedicels, the lovest whorl fertile, almost sessile; fil. very. short; ach. narrowly obovate, long-beaked.-Muddy shores, common S. and W. Leaves almost as variable as in No. .1, but the other marks are very distinctive. Stalks if to se cral, according to the depth of water. Blades 5 to $10^{\prime}$ in length. Fls. large, 12 to $16^{\prime \prime}$ diam.; white. July.

$\beta$. EIGID. Plant rather rigid in habit, erect; lvs. narrowly lanceolate; acuto at apex, acute or obtusish at base.-Lake shores. (S. rigida I'h.)

$\gamma$. Avgestifolia. Lrs. nearly linear, delicate, often floating as well as the weak, e!ongated scape.

3 s. lancifòlia I., MIx. Lvs. lance-cblong, acutish, feather-veined, long-tapering at base to a very long petiole; scape tall, branched; Als. in $3 \mathrm{~s}$, all long-pedi- 
cellate; bracts broad-ovate, short-pointed; fil. hairy, longer than the anthers ; ach. obovate-falcate.-River swamps, Conn. ? Va. to Fla. and La. (Hale). Stalks stout, $3 f$ or more, according to the depth of water. Leaves thick and leathery, 8 to $14^{\prime}$, the veins diverging from the midvein, crossed by the veiulets. Fls. white, showy. (S. falcata $\mathrm{Ph}$.)

B.? Very slender, erect, with mearly linear leaves; bracts and sep. scabrous.La. to Tex.

4 S. gramínea $\mathrm{Mx}$. Lvs. ovate-lanceolate, varying to linear, rarely sagittate; scape erect, slender, longer than the leaves; lower whorls fertile; all the pedicels slender, equal; filaments short as the anthers; ach. beakless.-In shallow water or mud, common. Lvs. commonly very narrow, attenuate-pointed, 4 to $12^{\prime}$ or more. Scape 5 to $20^{\prime}$ in height, the pedicels $1^{\prime}$ or less. Flowers small, 8 or $9^{\prime \prime}$ diam., white; stam. few. The forms with lance-ovate leaves constitute a well marked variety. (S. simplex, Ed. 2.)

5 S. pusílla Nutt. Petioles (leaves?) short, linear, obtuse, summits only foliaceous; scapo simple, shorter than tho leaves; fs. few, fertile one solitary, deflexed; stam. mostly 7.-A diminutive species on muddy banks, N. Y. to Ga. Leaves rarely subulate, an inch or two long, less than a line wide. Scapo $2-4^{\prime}$ high. Flowers $4-7$, the lowest one only fertilo. Aug.

6 S. nàtans $\mathrm{Mx}$. Irs. floating, oval-lanceolate, obtuse, 3-veined, tapering to the base, lower ones subcordate; scape simple, fow-flowered; lower ped. elongated. In water, Penn. (Muhlenberg) to Car. Scape mostly erect, $3-6^{\prime}$ long. Leaves 1-2' long. Flowers few, small, the upper sterile (Elliot).

7 s. uliginòsa Engelm. Lrs. oval-sagittate, rounded-obtuse, lobes triangular; scapes several, as tall $\left(6-10^{\prime}\right)$ as the lvs; fls. in pairs, the lower pair (fertile) on thick pedicels, longer than the upper; bracts obtuse; ach. broad-obovate, longpointed.-St. Louis, perhaps not within our limits.

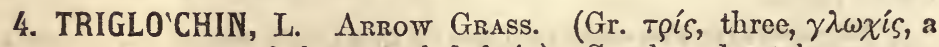
corner; on account of the 3 -angled fruit.) Sepals and petals concave, deciduous, the former inserted a little below the latter; stamens 6 , very short; anthers large, extrorse; ovaries 1 -ovuled; stigmas adnate; fruit clavate, composed of $3-6$ united, indehiscent, 1-seeded carpels. $-2 f$ Lvs. grass-like, all radical.

I. T. marítimum L. Fruit ovate-oblong, grooved, of 6 united carpels; scapo longer than the leaves. - A rush-like plant in salt marshes and ditches on the sea-coast, and at Salina, N.Y., also lake shores, N.Y., Wis. IVs. linear, semi-cylindric, smooth, thick, 6-12' long, less than a line wide. Scape obtusely angled, simple, 9-18' long, bearing a long raceme of $30-40$ green flowers on pedicels $1-2$ " long. Fruit separating into 6 linear carpels, each containing a linear seed. The plant has a sweetish taste, and cattle are fond of it. July. (T. elatum. Nutt.)

2 T. palústre L. Fruit nearly linear, of 3 united carpels; scapo scarcely longer than the leaves.- In marshes, Salina, N. Y. N. to Arc. Am. Leaves very numerous, fleshy, smooth, very narrow. Soapo $6-12^{\prime}$ high, ending in a racems with rather remote, very small, green flowers on podicels $2-3^{\prime \prime}$ long. The siender fruit is attenuated at base, obtuso at apex, grooved and margined, cunsisting of 3 very slender carpels. July.

5. SCHEUCHZE'RIA, L. (To the Scheuchers, two brothers, distinguished botanists.) Sepals and petals oblong, acute, persistent; sta. 6, with linear anthers; stigmas sessile, lateral ; ovaries 1 -2-ovuled; capsules inflated, compressed, 2-valved, 1-2-seeded.-2f Lvs. cauline, linear, sheathing at base.

S. palústris L. A rush-liko plant, in swamps, Vt., Penn., to Ill. Root-stock horizontal, fleshy. Stem about a foot high, simple, angular. Leaves semi-cylindric, $4-6^{\prime}$ long, in the barren shoots much longer, sheathing at base. Raceme terminal, 5-8-flowered. Flowers yellowish-green, on sinat pedicels, each axillary to a bract. Stamens large, exserted, erect. June, July. 


\section{Order CXXXVI. HYDROCHARIDACE Æ. Frogbits.}

Aquatic herbs with parallel-veined leaves and diclinous fls. on a slender-stalked spadix. Perianth regular, 3 to 6-parted, the inner segments petaloid. Stamens 3 to 12. Ovary adherent to the perianth, 1 to 9-celled, with 3.6 or 9 large stigmas. Fruit dry or succulent, many-seeded, indehisent. Seeds without albumen.

Genera 12, species 20, native of fresh water in Europe, N. America, E. Indies and N. IIolland. They appear to possess no active properties.

1. LIMINO'BIUM, Richard. Frogs-iit. (Gr. $\lambda i ́ \mu \nu \eta$, a lake, Bios, dife.) Flowers monœcious, arising from subsessile spathes; $\hat{\delta}$ spathe. 1-leaved, about 3-flowered, calyx 3-sepaled, corolla 3-petaled, petals oblong-linear; stamens 6 to 12 , monadelphous; o spathe 2-leaved, 1 . flowered; calyx and corolla as in the $\hat{\delta}$; stamens 6 , subulate rudiments ; ovary 6 or 9 -celled, becoming a $\infty$-seeded berry. $-2 f$ Herb acaulescent, in stagnant waters, multiplying by stolons, and with floating lvs. Fls. showy, white, the $\hat{f}$ on long stalks.

I. Spongia Rich.-In Braddock's Bay, L. Ontario (Sartwell); scarce at the north, common in the south, E. Ky. 1 to Ga. (Feay) and La. (Hale). Lrs on long petioles, roundisí, obtuse or broadly acute, often cordate, $1^{\prime}$ to $18^{\prime \prime}$ diam. Ped. of the sterile fls. slender, about 3 ' long, of the fertile, thick, about 1' long, both kinds eitlser together on the same stalk or on different stalks which are connected by the stolons (Dr. Feay). The leaves beneath are purplish and spongy with largo cells. J!, Aug. (Hydrocharis, Bosc. H. cordifolia Nutt.)

2. ANACH'ARIS, Richard. Dirch Moss. (Gr. $a \dot{a} v$, an indefinite particle, ä $\chi \alpha \rho \iota$, uncomely.) Flowers polygamous, solitary, from a tubular, bifid, axillary spathe; perianth 6-parted, colored; of minute, with 9 oval, nea:ly sessile anthers; $q$ perianth excessively produced into a filiform tube above the ovary, $\lim 36$-parted, stamens 3 to 6 , often abortive; style capillary; adherent to the tube of the perianth; stigmas 3 , large; fruit few-seeded. If Small aquatic herbs, with submersed pellucid opposite or verticillate lis.

A. Canadénsis Planchon. Lvs. verticillate in $3 \mathrm{~s}$ and $4 \mathrm{~s}$, lanceolate, oblong or linear surrulate; stig. 2-lobed.--Resembling a coarse moss, in still waters and bogs. St. filiform, diffusely dichotomous, very leafy. Lvs. 3 to $6^{\prime \prime}$ by (less than) $\mathrm{I}^{\prime \prime}$, thin and diaphanous, sessile, obtuse. Fls. minute, of a dingy white, the slender, hair-like tube 2 to $10^{\prime}$ long, according to the depth of the waters. Stigmas recurved letwecn the segments, crested with glandular hairs Aug. (Udora, Nutt.)

3. VALLISTE'RIA, Michcli. Eel-Grass. (In honor of Anthony Vallisncr, a French botanist.) Flowers $\hat{3}$ o ; spathe ovate, 2 to 4 parted. of Spadix corered with minute flowers, enclosed in a 3-parted spathe; corolla $0 . \quad$ \& Spathe bifid, l-flowered; perianth elongated; scpals lincar ; stigmas 3 , ovate, bifid; fruit elongated, cylindrical, manyseeded.-2f Submersed. Lvs. all radical, grass-like. Scape spiral, very long.

V. spiriñlis L. Lrs. linear, obtuse, serrulate at the end, tapering at the base, floating.-A curiocs plant, in slow moving or stagnant waters, U. S. Leaves linest, $1-2 f$ long, about $\frac{1^{\prime}}{2}$ wide, the edges thinner than the middle. Scapes several, of the sterile plants short, of the fertile plants very tortuous, 2-4f long when exfended, thread-like, thickened at the top, bearing each a single, white lower at or near the surface. Sepals and petals crowning the $\left(1^{\prime}\right)$ long, narrow, incurred ovary, which, is half concealed in the spatho. Jl, Aug. (V. Americana $\mathrm{N} x$.) 


\section{Order CXXXVII. BURMANNIACE A.}

Small annual herbs wilh slender, scaly or naked stems and scale-like, tufted leares. Flowers perfect, with a tubular, 6-toothed perianth adherent to the ovary. Stamens 3 , opposite the smaller teeth (petals), introrse, or 6 and extrorse. Capsule 1 or 3 . celled, seeds numerous, minute, loose in a membranous testa.

Genera $\boldsymbol{\tau}$, species 30 , in wet, grassy places in the warm parts of $\Delta$ sia, Africa and $\Delta$ merica They are said to be bitter and astringent.

1. APTE'RIA, Nutt. (Gr. $a$, privative, $\pi \tau \varepsilon \rho o ́ v$, a wing.) Perianth bell-tubular, tube longer than the slender teeth, marescent ; teeth alternately narrower; capsule globular, wingless, 1-celled, valves opening first at base; placentæe parietal ; seeds innumerable, oblong, very minute.-(1) Herbs apparently leafless.

A. setàcea Nutt. Erect, very slender, with remote, subulate scales, and dividing above into 2 racemes; fls. distant, pedicellate.-Moist, shady woods, Fla. and La. (Hale). St. 4 to $6 \mathrm{f}$ high. Raceme often simple. Coralla 3 to $4^{\prime \prime}$ long, purplish.

2. BURMAN'NIA, L. (Dedicated to one Burmann, a German botanist.) Perianth tube scarcely produced above the ovary, often 3-winged below, limb with 3 inner teeth much shorter; capsule prismatic, often 3 -winged, cells 3 , with a thick placentæ in the axis; seeds numerous.(1) Leatless.

1 B. biflòra L. St. capillary, simple, with scarcely perceptible bracts, and 1 or 2 , rarely more, small light blue flowers at top, the angles of the tube conspicuously= winged.-Grassy swamps in the lower districts, Va. to Fla. and La. St. 2 to $3^{\prime}$ high. Fls. 2 to $3^{\prime \prime}$ long. Oct., Nov.

2 B. capitàta L. St. setaceous, furnished with a few subulate bracts, simple, erect, bearing at top a dense cluster of white fls.; ovary and fruit scarcely winged.Upper districts of S. Car. and Ga. (Bachman), less common and with smaller fls than in the last. St. 6 to $8^{\prime}$ high. Sept.

\section{Order CXXXVIII. ORCHIDACE E. OrChIDs.}

Herbs perennial, with fleshy roots, simple, entire, parallel veined leaves. Flowers very irregular, with an adherent, ringent perianth of 6 parts. Sepals 3, usually colored, odd one uppermost by the twisting of the ovary. Petals 3 , usually colored, odd one lowest by the twisting of the ovary. Lip (labellum, the odd petal) diverse in form, often lobed, frequently spurred at base. Stamens 3, gynandrous (consolidated with the style), 2 of them or more, rarely 1 of them, abortive or obsolete, the pollen powdery, or coherent in waxy masses. Ovary inferior, 1-celled, with 3 parietal placentæ and innumerable ovules. Fruit capsular, 3-valved. Seeds numerous and very minute. Illust. in Figs. 29, 37, b, 57, 85, 200, 327, 366.

Genera 394, species 8000 ? They are among the most interesting and curious plants, nimost always remarkable for the grotesque form of their tortuous roots and stems, and the fragrance, brilliancy and orld structure of the flowers.

The Orcbids are natives of nearly every part of the world. In the tropics multitudes of them are epiphytes, growing on living trees or decaying timber.

This order is remarkable for those qualities only which please the eye. They not only excel in beauty and delicacy, but often elosely imitnte oljects of the animal kingiom, as bees, flies, spiders, loves, swans, pelicans, \&c., especiaily those of the tropical regions. Many of its species are cultivated for ornament, but few of them possess either active or useful properties. Tho salep of commerce is a nutritive, mucilaginous substance afforded by the roots of snme Asiatic Orchis. The aromatic vanilla, used to flower chocolate, \&c., is tho fruit of the West Indian

Vanilla claviculata. 
TRIBES AND GENERA.

5. CYPRIPEDIE A6 Anthers 2, fertile, the 8rd a petal-liko appendage over the stigma. Lip a large, fuflated spurless sack........ Cripkipenru 1

\$ OPHRYDE E, \&c. Anther only 1, terminal or dorsal on the stigma. (*)

* Lip produced belind into a spur which is free from the avary. (a)

a Anther erect, terminal; pollinia 2, granular, pedicellate and attached to as many glands on the stirma, which glands are (b)

b concealed in a pouch (Flowers large, rose-colored, lip entire) in.......... Orcnis. 2

b naked and close together (Flowers small, lip entiro or toothed) in...GrMNADENIA. 3

b naked and widely separated (Lip entire or lobed, or cleft or fringed.) Pratantiera. 4

a Anther bent over the end of the stigma like a lid. Pollinia 4............. Tirularia. 5

* Lip not proluced into a spur behind, or the spur is adnate to the ovary. (c)

c Lip a large, inflated sack with 2 spur-like points below the apex........ CaLYPso. 6

c Lip not saceate. Plants brown, leafless, or with radical leaf. (d)

d Lip hooded, i. e. its margins involute. Pollinia 8. Fls. expanding.....BletrA. T

d Lip concare, sessile, often with an adnate spur. Pollinia 4... Corallormzra. 8

d. Lip concave, raised on a claw. Pollinia 4. Plant with 1 late lenf... Aplectruy. 9

c Lip not saccate. Plants green and with leaves. (e)

o Lip flat. Flowers obscure, in racemes nearly bractless. (f)

f Lip entire, dilated ; Column minute. (Leaf 1.).............Mrcrostruis. 10

f Lip sagittate or cordate. Column lengthened. Leaves $2 . . .$. ... Lipparts. 11

f Lip 2-lobed or cleft at apex. Lrs. 2, cauline opposite............. Lister. 13

e Lip channeled, recurved. Fls. whitish, in bracted spikes. (g)

g Sepals reflexed. Lip arched and recurved, 3-lobed............ Cranicnis. 13

g Sepals erect.-Lip ascending, embracing the column.......... SpIrantries. 14

-Lip gibbous beneath, pointed at apex........... Goodyera. Is

e Lip bearded or 3-lobed. Stamen lid-like. Flowers showy. (h)

h Flowers several, purple, with a bearded lip posterior.......... CALOPOGoN. 10

h Flowers with the lip anterior (as in the order generally). (k)

k Column free from the lip, clavate. Fls. purplish............ Pogonra. 17

k Column adherent to the tip below. Fls. purple........... Aretiusa. 18

k Column adherent to the lip. Fls. yellow. On trees...... Epidendrux. 19

1. CYPRIPE'DIUM, L. Lady's Slipper. (Gr. Kvitpls, Venus, $\pi o \delta \_$, a slipper; from the slipper-like form of the lip.) The 2 lower sepals united into 1 segment, or rarely distinct; petals spreading; lip inflated, saccate, obtuse ; column terminated by a petaloid lobe (barren stamen) and bearing a 2-celled anther under each wing.-Fls. large, very showy, distinguished for the large, inflated lower petal or lip ; lvs. large, plaited, veined.

\$ Sepals 2, the lower compound of 2 united either wholly or near the tip. (*)

* Stem leafy.-Flowers 1 to 3 , mostly but 1 , yellow............................... 1, 2

-Flowers solitary or several, white or rose-colored.................... Nos. 8, 4

* Stem a leafless scape, 2-leaved at base. Flower rose-colored....................... No.5

$\$$ Sepals 8 , the 2 lower entirely distinet.............................................. 6

1 C. pubescens Swartz. Large Yellow Ladies Slipper. St. leafy, Ivs. broad-lanceolate, acuminate; sepals lanceolate; lip shorter than the linear, twisted petals, compressed laterally, convex both above and below; sterile stamen triangular, acute; plant pubescent. - Woods and meadows, Can. to Wis., S. to Ga. Sts. usually several from the same root, If or more high. Lvs. 3 to $6^{\prime}$ by 2 to 3 , manyveined, clasping at base. Flower mostly solitary. Segm. 4, greenish with purple stripes and spots, the lower bifid, composed of 2 united sepals, the lateral 2 to $3^{\prime}$ by $3^{\prime \prime}$, wavy and twisted. Lip moccasin-shaped, bright-yellow, spotted inside, with a roundish aperture. May, Jn.

2 C. parviflòrum Salish. Syaller Yellow Ladies' Slipper. St. leafy; Irs. lanceolate-acuminate; sep. ovate or lance-ovate; lip shorter than the petals, compressed from above and beneath; sterile stamen triangular, acute; plant pubescent.-In low woods and prairies, Can. to Wis. and Ga. (Miss Wyman). More common westward. Plant 8 to $12^{\prime}$ high, rarely taller, very leafy. Flower a third smaller than in No. 1. Petals 1 to $18^{\prime \prime}$, twisted or not. Upper sep. broadest. Lip evidently flattened on tho upper side, convex laterally, dull yellow. May, Ju. 
3 C. cánđiđum Willd. St. leafy; lvs. oblong-lanceolate, acuto; $\mathrm{f}$. terminal, soli tary; sep. elliptic-lanceolate, acuminate, lower scarcely bifid at apex; petal lance-linear, longer than the laterally compressed white lip; sterile stamens lanceolate, obtuse.-Border of woods, prairies, Penn. to Ind. (P!ummer), Wis. and Can. St. about if high, simple. Ivs. 3 to $6^{\prime}$ by $1 \frac{1}{2}^{\prime}$, sheathing the stem. Ovary pedicellate. Lip $\mathrm{l}^{\prime}$ in length. Petals and sepals nearly $2^{\prime}$. May.-Well distinguished by its sterile stamens as by its color.

4 C. spectábile Sw. St. leafy; lis. ovate-lanceolate, acuminate; lobe of tho column elliptic-cordate, obtuso; sep. broad-ovate, obtuse; lip longer than the petals, cleft before.-A tall, superb species, found in swamps, Can. to KJ. and Car. Stem thick, 2 feet or more liigh, hairy. Leaves $6-10^{\prime}$ by $2-4^{\prime}$, veined, plaited, hairy. Flowers $2-3$ on each plant, very large. Lip white, striped with purple, $2^{\prime}$ long, $1_{\frac{1}{2}}$ broad; upper segment largest, lower one smaller, composed of 2 sepals completely united. Jl.

5 C. acaùle Ait. Scapə leafless, 1-flowered; lvs. 2, radical, elliptic-oblong, rather acute; lobe of the column roundish-rhomboidal, acuminate, deflexed; pet. lanceolate; lip longer than the petals, eleft before.-A beautiful plant, in dark woods, Car. to Arc. Am. Leaves largo, plaited and downy. Scape 10-14' high, with a singlo lanccolate bract at the base of the large, solitary flower. Sepals $\frac{1^{\prime}}{2}$ long, the two lower completely united into a broad lanceolate one beneath the lip. Petals lateral, wavy. Lip $2^{\prime}$ by $1^{\prime}$, purple, forming the most showy part of tho flower. May, Jn. (C. humile Sw.?)

6 C. arietinum Ait. RAM's HesD. St. leafy; Ivs. elliptical, striate-veined; sep. 3, distinct (the 2 lower not united), linear-lanceolate, the upper oblong-ovate, acuminate; 2 lateral pet. linear; lip as long as the petal, saccate, obconic.-In damp woods, Can., Me., Vt. (Dr. Phelps) to N. Y. and Wis.? Stems usually clustered, flexuous, 8-12' high, lower part sheathed. Leaves $3-5,2-3^{\prime}$ by $\frac{1}{2}-1^{\prime}$, sessile, amplexicaul. Flower mostly solitary, with a leafy bract at base. Segments about equal in length, the upper one as broad as the other 4 together. The singular form of the lip readily suggests the namo of this curious plant. May.

2. OR'CHIS, L. (Gr. óp $p \iota s$, the ancient name.) Flower ringent, sepals and petals similar, some of them ascending and arching over the column; lip turned clownwards, produced at base beneath into a spur which is distinct from the twisted ovary; stamen 1, anther 2-celled; pollinia 2 , one in each cell, composed of numerous waxy grains implicated in a cobweb tissue; pedicellate and attached to 2 glands of the stigma which are contained in one common little pouch. Fls. several, large, bright-colored, in a spike or raceme.

O. spectábilis L. Lvs. 2, nearly as long as the scape; lip obovate, undivided, crenate, retuse; segments of tho perianth straight, the lateral ones longer; spur clavate, shorter than the ovary, bracts longer than the flower:-This pretty littlo plant is found in shady woods and thickets, among rocks, etc., U. S. and Can. Root fasciculate. Leares few, radical, ovate, $3-6^{\prime}$ long, $\frac{1}{3}$ to $\frac{1}{2}$ as widc. Scape 4-6 high, acutely angled, with a lanceolate, acute bract and $3-5$ large, showy flowers. Segments of tho perianth purple, ovate-lanceolate. Lip and spur white or whitish, each about $8^{\prime \prime}$ long. May, Jn.

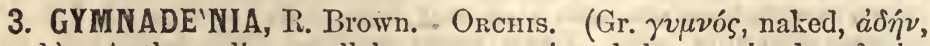
gland.) Anther-cells parallel or converging below; glands of the stigma to which the pollinia are attached naked. Otherwise as in Orchis.

1 G. nívea. St. very slender, lowest leaf long, linear, acute, the others (6 to 12) very much smaller, subulate, bract-like; fls. 20 to 30 , small, in an oblong-cylindric spiko; lip (white) oblong, crenulate or wavy, longer than the petals, produced belind into a filiform spur which is nearly twice longer than the ovary; column very short; pollinia at length naked.-Ga. (Pond) to Fla. and La: (Hale). Root fibrous, producing tuberous corms. St. 1 to $2 \mathrm{f}$ high, leaf 6 to $8^{\prime}$ long, 3 to $4^{\prime \prime}$ widc. Fils. white, very delicate, rather smaller than in Nos. 2 and 3. (Orchis nivea Baldw.) 
2 G. EffCerstita Lindl. St. slender; lowest leaf linear-oblong or oblanceolate, obtuse, the others 3 or 4 , rery small and bract-like; fls. 7 to 12 , sessile, in a short, opon spike; sep. obtuse, erect-spreading; lip a little longer, truncate and 3-toothed at the apex, produced behind into a slender, often clavellato spur which is longer than the ovary. - In damp woods, Can. and U. S. Root a few thick fibers. St. 12 to $18^{\prime}$ high, leaf about $6^{\prime}$, bracts $1^{\prime}$ and less. Spike often as wide as long, with small, greenish-white fls. Spur 4 or 5 " long, usually curved. Jn., Jl. (O. tridentata Willd.)

$\beta$. Clavellat ta has the fls. more diverging and the spur conspicuously clubshaped.-South.

3 G. flàva Lindl. St. flexuous, leafy; lower lvs. narrow-lanceolate, acute, upper gradually smaller; spike densely many-flowered; lip (yellow) ovate, crenulate or somewhat wavy, longer than the broad-ovate, obtuse sepals, shorter than the subulate spur.-Swamps, in pine barrens, N. J. to Ga. and La. Rt. of thickened fibres. St. 12 to $15^{\prime}$ high, with lvs. nearly as long as the internodes. Spiko globular or oblong, with 30 to 50 small, orange-colored fls. Sep. about $1^{\prime \prime}$ long, spur nearly $3^{\prime \prime}$, lip 2". Jn., Jl. (O. flava and nigra Nutt.)

4. PLATAN'ThERA, Richard. Orchis. (Gr. $\pi \lambda a \tau v \dot{s}$, broad, ả $0 \eta \rho a ́$, anther.) Anther cells diverging below, and the two glands to which the pedicellate pollinia are attached widely separated. Otherwise as in Orchis. (Platanthera and Gymnadenia are separated from Orchis by characters purely artificial, and should be reunited with it.)

* Ienf only one. Flowers greenish-white. Lip entire or 3 -lobed..................... 1, 2

* Leaves only two, roundish, large. Flowers greenish. Lip entire......................... 3 4

* Leaves several, clothing the stem more or less. (a)

a Lip unlivilerl and entire, neither fringed, lubed, nor toothed, whitish ..........Nos. 5,6

a Lip undivided, - but 3 -toothed, not fringed. Flowers yellowish.................... 7,8 -bnt fringed. Flowers bright yellow or white.............. Nos. 9-11

a Lip 3 -parted, - segments fringed. Flowers white or greenish................. 12, 13 - se mments fringed. Flowers purple............................ 14, 15 -segments merely toothed, terminal ono 2 -lobed. Fls. purple....... No. 16 -segments entire, long, linear-setaceous. Whitish.................. 17, 18

1 P. obtusàta Lindl. Lf. solitary, oblong-obovate, obtuse; st. bearing the leaf near its base; spike loose; upper sep. broadest; pet. subtriangular; lip linear, entire, with 2 tubercles at base, as long as the arcuate, acute spur.-Found in muddy ponds and ditches, N. II. "(Storrs), N. to Lab. Stem slender, angular, 6-8' high, terminating in a thin spike of about a dozen small, greenish-white flowers. Leaf tapering at base, usually obtuse at the summit, $2-3^{\prime}$ in length, and 1 in breadth, issuing with tho stem from $2-3$ radical, sheathing bracts. July.

2 P. rotundifòlia Lindl. If. solitary, roundish-ovate; scape naked; spike fewflowered; bracts obtuse, shorter than the ovary; sep. and pet. obtuso; lip 3-lobed, lateral lobes subfalcate, middle one obcordate; spur as long as the lip.-Ct., Penn. (Eaton), Can. Seapo near a foot high, slender, without a bract. Leaf $2-4^{\prime}$ long, $\frac{3}{4}$ as wide, spotted, sheathing at base. Flowers about a dozen, of a greenishwhite, remsrkablo for their broad, 3 (almost 4)-lobed, pendent lip. (0. rotund. $\mathrm{Ph}$.)

. 3 P. orbiculàta Lindl. Lvs. 2, radical, suborbicular, rather fleshy; scape bracteate; upper sep. orbicular, lateral ones ovate; lip linear-subspatulate, nearly twice as long as the sepals; spur arcuate, compressed, clavate, twice as long as the ovary. - A remarkable plant, not uncommon in old woods and in thickets, Penn. to Can. and IV. States. Leaves lying flat upon the ground, $3-6^{\prime}$ diam., rather inclining to oval or ovate with the apex acute. Scape $1-2 \mathrm{f}$ high, sheathed with a few bracts, bearing a raceme of numerous, greenish-white flowers. Lip 9 to $12^{\prime \prime}$ by $1^{\prime \prime}$ or narrower. Spur $1 \frac{1}{2}-2^{\prime}$ long. Jl. (O. orbiculata $\mathrm{Ph}$.)

4 P. Hćolseri Lindl. Lvs. 2, radical, suborbicular or suboval, fleshy; scape naked; bracts lanceolate, nearly as long as the flowers; upper sepal ovate, erech, lateral ones deflexed and meeting behind; pet. acute, lip lanceolate, projecting, acuminate, a little longer than the sepals; spur subulate, arcuate, about twice longer than the ovary.-Woods, Can., N. Eng. to Wis. (Lapham), rare. Resembles 0 . orbiculata, but is very distinct. Scape 8-12' high, without a bract bolow the flowers. Leaves $4-5^{\prime}$ long, nearly or quite as wide. Flowers 12-18, 
in a straight raceme, yellowish-green, the spur $9-12^{\prime \prime}$ in length. ' $\mathrm{Jn}$, $\mathrm{Jl} . \quad(\mathrm{Q}$ Hookeriana, 2d Edit.)

5 P. hyperbòrea Lindl. St. leafy; lvs. very crect, acute, lanceolate; spike elongated, many-flowered; bracts linear-lanceolate, acute, longer than the flower; sep. deflexed; petals and lip linear, obtuse, subequal, the latter somewhat lanceolate, and about as long as the pendulous, obtuse spur.-A tall, leafy, variable species, in mountainous woods and open meadows, N. Y. to Micl. and Can. Stems thick, 1 to 3 or even $4 \mathrm{f}$ high. Lvs. lanceolate, 4 to $7^{\prime}$ by 1 to $1 \frac{1}{2}^{\prime}$. Flowers greenish in shades, nearly white in open situations, forming a long, more or less dense spike. Jl.-A coarser plant than the next, which it often approaches in the more slender variety Huronensis.

6 P. dilatàta Lindl. St. slender; lvs. lance-linear and linear, acute; spike manyflowered, virgate; bracts lance-linear, about as long as the flowers; upper sepal ovate, obtuse, the lateral narrower and spreading; lip linear, entire, obtuse, dilated and rhomboid at base, about equaling the petals, and a little shorter tban the obtuse, incurved spur, which is longer than the ovary.-Swamps, N. States (rare) and Can. More slender and delicate than the last, $10^{\prime}$ to $2 \mathrm{f}$. high. Lrs. often narrow and grass-like 6 to $10^{\prime}$ long. Fls. 10 to 50, pure white, varying to greenish. Spur about $4^{\prime \prime}$ long. Jl. (O. dilatata Ph.)

7 P. bracteàta Torr. St. leafy; lvs. oblong, obtuse, upper ones acuto; spike lax; bracts 2 to 3 times as long as the flowers; sep. connivent, ovate; petals linear, erect; lip linear-cuneate, fruncate, 3-toothed at the end, the middle tooth small or obsolete; spur short, inflated, obtuse.-A small, green-flowered orchis, in shades. St. 6 to $9^{\prime}$ high. Lvs. about 3,18 to $30^{\prime \prime}$ by 6 to $12^{\prime \prime}$, upper bracts as short as the flower. Spikes 2 to $3^{\prime}$ long. Fls. yellowish-green. . Lip as long as the ovary, 3 times as long as the sack-like spur. Can. to Va., W. to Ill. Jl., Aug. (Peristylus Lindl.)

8 P. flàva Gray. St. leafy, lower lvs. oblong, acute, upper lanceolate, acuminate; spike rather dense, cylindric; bracts longer than the fls.; lip oblong, obluse, with a tooth each side at base; palate with one tuberculate tooth; spur filiform, rather shorter than the sessile ovary.-In alluvial soils, North and South. St. flexuous, 12 to $18^{\prime}$. high. Lvs. about 3 , with long sheaths, 3 to 6 or $7^{\prime}$ by $\frac{3}{4}$ to $2^{\prime}$, tapering to an acute summit. Fls. in a long, thin spike. Sep. short, ovate, green. Petals yellowish, drying brownish. Upper bracts about as long as tho flowers, lower one 2 or 3 times as long. The tubercle of the lip is a remarkable character. Jn. (O. flava L. O. herbiole and fuscescens $\mathrm{Ph}$. O. biclentata Ell.)

9 P. cristata Lindl. Crested Orchis. Slender, lower lvs. lance-linear, very acute, the sepal gradually reduced, linear, acuminate; spike oblong, densely C-flowered; sep. and pet. roundish (1 to $2^{\prime \prime}$ long), the latter crenate; lip oblong, pinnately fimbriate, nearly as long as the spur which is half as long as the slenderbeaked ovary. - Swamps, N. J. to Ga. and La. A delicate, yellow Orchis, 18' to $2 \mathrm{f}$ high. Lvs. 6 to $10^{\prime}$ long. Fls. quite small, the sep. and pet. scarcely more than $1^{\prime \prime}$ long, spur 2 to $3^{\prime \prime}$. Jn., Jl.

10 P. ciliàris Lindl. YelLow FrINGED OrCmIS. Lower IVs. lanceolate; spike oblong, dense, with numerous large fls.; bracts shorter than the ovary; lip. oblong-lanceolate, deeply fringe-ciliate, twice longer than the linear, notched petals; spur longer than the slender-beaked ovary.-Delicately beautiful, with bright orangocolored fls., in swamps, Can. and U. S., not common. St. about $2 \mathrm{f}$ high. Lvs. sheathing at base; lower ones 3 to 5 ' long, rapidly diminishing upwards. Sep. roundish, obtuse, concave. Petals linear, very small, incised at the summit; the lip narrow, lanceolate, conspicuously fringed, $4^{\prime \prime}$ long. Spur $1^{\prime}$ in length. J., Aug.

II P. Blephariglòttis Lindl. Write Frivged OrCHIs. Lower lvs. lanceolate, channeled; spike oblong, dense; bracts linear, acuminate, shorter than the white flowers; petals spatulate, dentate at apex; lip lanceolate, ciliate, as long as the upper sepal, spur much longer than the long-beaked ovary-In swamps, N. Y. to Car., resembing the last species, but distinguished, at least, by the color of its fls. which are of a pure white. St. 1 to $2 \mathrm{f}$ high. Flowers fewer than in the lașt. Sepals roundish-oblong, lateral reflexed. Lip fringed in the middle, $2^{\prime \prime}$ long. Jn., Jl. 
12 P. lácera Gray. RAGGed Orchis. Lower lvs oblong, obtuse, upper one narrow, acuminate; bracts longer than the flowers; sep. retuse; pet. emarginate; lip 3-parted, segments cuneate, capillaceous-multifid; spur filiform, cluvate, as long as the ovary. - Swamps and meadows, Can. to Car. Stem $1-2 \mathrm{f}$ high, smooth, sleuder. Leaves fer, $3-6^{\prime}$ by $\frac{1}{2}$ to $]^{\prime}$, mostly acute. Flower numerous, in a long, loose spike, of a greenish-white, not showy. Sepals ovate. Petals oblonglinear, entire, lip reflexed, very deeply laciniate. Readily distingiushed from tho following by its more slender habit, greenish flowers, and the entire (not fringed) petals. July.

13 P. leucophèa N. White-FLowered Prairie Orchis. St. leafy; Ivs. lancoolate, tapering to. a narrow, obtuso point, channeled; bracts shorter than the ovaries; rac. oblong. sep. roundish-oblong, acutish; lateral petals obovote, denticulate; lip 3-parted, flabelliform, segments deeply fimbriate; spur subulate-clavate, curved, twice as long as the ovary. - Wet prairies, W. States. Stem 1-3f high. Leaves 2-6' long. Raceme about 12-flowered. Sepals and spur yellowish, petals white. Ovary curved, $1^{\prime}$ long.

14 P. Psycòdes Gray. Purple Fringed Orchis. Lower lvs, lanceolato, diminishing upwards; lip 3-parted, scarcely longer than the petals, the segments cuneiform, ciliate-fimbriate; lateral pet. ovate, erose-crenulate or slightly fringed, spur filiform, elavate, longer than the ovary, common in meadows, Can. to Ga., W. to Wis. Stem 1 $\frac{1}{2}-2 \frac{1}{2} \mathrm{f}$ high, smooth, slender. Leaves $3-6^{\prime}$ long. Flowers showy, numerous, in a terminal, cylindric spike, light purple. Lip somewhat longer than the petals, its 3 spreading segments very veiny and sparingly bristle-cleft. Spur an inch in length. J1. (O. fimbriata Ph. Bw. O. incisa \& fissa Muhl.)

15 P. Bigelòvii. LARge Fringed Orchis. Lower lvs. oblong, oval, obtuse, upper ones very narrow; bracts shorter than the orary; rac. oblong; lip dependent, twice as long as the petals, 3-parted, the segments fan-shaped and fimbriate, the middle one largest, with connivent fimbriæ; lateral pet. fimbriate; spur ascending, clavate, longer than the ovary. $-A$ superb plant, considered the most beautiful of the genus, in wet meadows, Can. to Penn. Stem 2-3f high, thick, hollow, with several sheathing bracts at base. Leaves 2 or 3 principal ones, $4-7^{\prime}$ by $1-2$, upper ones linear, an inch or two long. Flowers purple, in a terminal raceme, $3-6^{\prime}$ long. Middle segm. of the lip nearly semicircular, twice as long as the lateral ones. June. (P. fimbriata Lindl. O. grandiflora Bw.)

16 P. peramœna Gray. St. tall, leafy; lvs. lanceolate and lance-linear; bracts nearly equaling the ovary; sep. roundish-ovate; lateral petals denticulate; lip 3parted, divisions cunciform, dentate, middle one 2-lobed; spur filiform, clavate at eud, curved, longer than the ovary.-A large and showy species in marshy grounds, Penn. to Ind. and southward. Stem slightly winged. Leaves $4-6^{\prime}$ long. Fls. violet-purple, large, $20-50$, in a terminal spike. Ovary $1^{\prime}$, and spur $1^{\prime} 1^{\prime}$ long. June, July. (P. fissa Lindl.)

17 P. Michàuxii. St. very leafy; lower lvs. elliptic-oval, acute, upper much reduced, lanceolate: spike few-flowered, loose; lip 3-parted into long linear setaceous segments; petals 2-parted, lower division linear-setaceous; spur near twice longer than the ovary.- Pine barrens, S. Car. to Fla. (Chapman) and La. (Hale). Plant 12 to $16^{\prime}$ high. Lrs. about $3^{\prime}$ by $1^{\prime}$. Spur filiform, clavellate at end, near $2^{\prime}$ long. Fls. rather distant, white. Aug.-Oct.

18 P. rèpens. St. very leafy, from a creeping rhizome; lvs. all linear-lanceolate, elongated, lower bracts longer than the flowers; spike closely many-flowered; lip 3parted into setaccous segments; petals 2-parted, lower segment setaceous; spur recurved, scarcely longer than the ovary.-Borders of ponds in pine barrens, $\mathrm{S}$. Car., Ga. to La. (Hale.) Strikingly similar to the last, yet strikingly distinct, $12^{\prime}$ to $18^{\prime}$ high. Flowers greenish yellow, about half as large, spur about half an inch long, filiform. Lvs. 5 to $8^{\prime}$ long, tapering to a very acute point. Aug., Sept.

19 ? P. quercícola. Root epiphytic, creeping; Ivs. all cauline, lance-ovate, acute, rounded at base; petioles sheathing the stem; spike dense, few or many-flowered; fis. small, ringent, sep. and pet. ovate, obtuse; lip spatulate, free from the column, slightly recurved; spur saccate, scarcely as long as the lip, half as long as the ovary.-Chielly growing in tho rough bark of oaks, Fla. (Chapman) to La. (Hale). 
- Plant 3 to $10^{\prime}$ high, with 2 to 20 flowers. Lrs. 6 to $18^{\prime \prime}$ long, thin, the sheath half scarious. Sep. about $I_{\frac{1}{2}}^{\prime \prime}$ long.-Habit quite unlike any of the foregoing species.

5. TIPULA'RIA, Nutt. (Tipuls, the crane-fly; from the fancied resemblance of the flowers.) Sepals spatulate, spreading; petals lancelinear, lip sessile, 3-lobed, middle lobe linear, much the longest; spur filiform, very long; column wingless, free; anther operculate, persistent; pollinia 4, parallel.-Corms several; connected by a thick fiber. Lf. solitary. Fls. without bracts.

1 T. díscolor Nutt. A slender, green-flowered plant, resembling a Corallorhiza, growing in pine woods, Vt., Mid. States to Ga. Rare northward. Lf. petiolatc, ovate, plaited, smooth, and longitudinally veined 2 to $3^{\prime}$ long. Scape 10 to $15^{\prime}$ high, bearing a raceme of many small, greenisl, nodding fls. Spur nearly twice as long as tho ovary. Manner of growth similar to that of Aplectrum. Jl.

6. CALYP'SO, Salisb. (Named for the goddess Calypso, from $\kappa a \lambda v i \pi \tau \omega$, to conceal.) Sepals and petals subequal, ascending, secund; lip inflated, large, 2-pointed or spurred beneath near the end; column petaloid ; pollinia 4.-Scape 1-1lowered, 1-leafed, arising from a corm.

C. boreàlis Salisb. $\Lambda$ beautiful and interesting plant, in cold mossy bogs, Vt., $\mathbf{A}$. N. Y., Can., but very rare. Scape 6 to $8^{\prime}$ higl, bearing a single large flower at top and sheathed with several bracts. Lf. broad-ovate, smooth veined, 1 to $2^{\prime}$ long. Fl. near the size of Cypripedium, variegated with purple and yellow, tho lip its most conspicuous part, bearing 2 projecting points beneath tho apex. May.

7. BLE'TIA, Ruiz ct Pav. (Named for Luis Blet, a Spanish botanist.) Petals and sepals distinct, nearly equal ; lip sessile, cucullata by its induplicate side-lobes, spurless (in our species); column free; pollinia 8 , in pairs, waxy, each pair pedicellate.-Sts. or scapes simple, arising fiom globular corms and bearing a raceme or head of showy fls.

1 B. aphýlla Nutt. Leafless; scape tall, terete, bearing 3 to 5 short, sheathing remote bracts; raceme long, loose, with ovate, acute, spreading bractlets; fls. many, much longer than their pedicels; lip divaricately veined; spur none.-Car. to $\mathrm{Ky}$., Fla. and La. A singular plant, in the borders of swamps, 15 to $30^{\prime}$ high, the thick stem tapering above. Sheaths about half an inch long. Sep. (brownish purple) and pet. (yeilowish brown) 8" long. Lip 3-lobed, with 5 broad plaits or folds. Aug., Sept.

2 B. verecúnda H. K. Lvs. all radical, broadly lanceolate, plaited and prominently veined; scapo; scape tall, bearing a many-flowered raceme; petals connivent; lip with divaricate veins and folds, the side-lobes narrowed towards the apex; the middlo crispate, emarginate, broader than long; spur none.-Ga. and Fla. (Pursh.). Common in the W. Indies. Scape 2 to $3 f$ high. Fls. purple, large and showy. Jn., Jl.

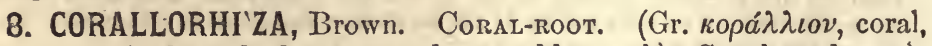
pí̧ $a$, root; its branched roots much resemble coral.) Sepals and petals nearly equal, converging; lip produced behind; spur short and adnate to the ovary, or none; column free; pollinia 4, oblique (not parallel), free.-Plants leafless, simple, of a brown color, arising from coralline roots, sheathed with bracts and bearing a raceme.

* Spur conspicuously prominent, but ainate. Lip 3 -lobed ......................... 1

* Spur wholly obliterated $\rightarrow$ Lip crenulate, wavy, not at all lobed..............................

-Lip entire, slightly toothed near the base...................... 3,4

1 C. multifòra Nutt. Scape many-flowered; lip cuneate-oval, spotted; 3-parted, the middle lobe recurved, lateral ones short and ear-like; spur conspicuous, adnate; caps. elliptic-obovoid, pendulous.- In woods, growing on the roots of trees, N. Eng. and Mid. States, Root coralline. Scape 10 to $15^{\prime}$ high, leafless, brownish- 
purple, sheathed with a few bracts. Fls. larger than in tho other species, 15 to 20 , erect, spreading, in a long raceme. Lip showy, 3 to $4^{\prime \prime}$ long, white, sprinkled with purplo spots. Spur yellowish, conspicuous, but short and adnate to tho ovary: Jl.

2 C. cdontorhìza Nutt. Lip undivided, oval, obtuse, crenulate, spotted; spur none; capsule oblong or subglobous. - A singular plant, with no leaves or green lierbage, iuhabiting old woods, Can. to Car: and $\mathrm{Ky}$. The root is a collection of small, fleshy tubers, articulated and branched much like coral. Scape 9-14' high, rather fleshy, striate, smooth, invested with a few long, purplish-brown sheaths. Flowers 10-20, in a long spike, of a brownish-green. Lip white, generally with purple spots. Capsules large, reflexed, strongly ribbed. Jl., Aug.

3 C. innàta R. Brown. Scape few-flowered; lip oblong, angularly 2-toothed towards the base, spotless, deflexed above; spur none or obsolete; caps. elliptic-obovoid, reflexed.-Riel damp woods, N. States and Can., rare. Scape not bulbous at base, 5 to $8^{\prime}$ high. Fls. 5 to 10 , dull purple, with a white lip. May, Jn.

4 C. Macráei Gray. Scape many-flowered; fls. large, on very slort pedicels; lip oval, obtuse, 3-nerved, entire above, obscurely auricled at base ; spur none.- "Canada, along the great Lakes." Also ? Northern N. H. Plant 10 to $16^{\prime}$ high. Sep. and and pet. $6^{\prime \prime}$ long. Caps. reflexed, oval, $6^{\prime \prime}$ long.-Our speeimens from Nor. N. H. are $18^{\prime}$ high, 20 -flowered, agreeing with Dr. Gray's description as far as we can judge by the fruit.

\section{APLEC'TRUm, Nutt. Adam and Eve. Putty-root. (Gr. $a$,} $\pi \lambda \tilde{\eta} \kappa \tau \rho o \nu$, a spur; the lip being without a spur.) Sepals and petals distinct, nearly equal, converging; lip unguiculate, 3-lobed, obtuse, middle lobe crenulate, palate ridged; spur none; column free, anther a little below the apex; pollinia 4, oblique, lenticular!-Scape and raceme as in Corallorhiza, but arising from a globous corm after the single, large, coriaceous, biennial leaf.

A. hyemale Nutt. A fino plant in woods, Can. to Fla., rare. Rather frequent westward. The corms are near $1^{\prime}$ thick, composed of strongly glutinous matter, and connected by a thick fiber. A new corm is produced annually, in advance of the old, which dries up the second or third year. Leaf elliptic or ovate, 3 to $5^{\circ}$ long, many-veined, twice longer than the petiole, arising late in the season from the new corm, remaining through the winter, until the scape (12 to $18^{\prime}$ high) arises by its sidc. Sheaths brownish, 2 or 3 . Perianth brownish, 6 " long. Caps. pendulous, $I^{\prime}$ long. May.

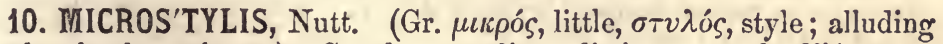
to the slender column.) Sepals spreading, distinct; petals filiform or linear, spreading; lip sessile, concave, spreading, hastate or bidentate at base, not tubereled; column minute, with 2 teeth or lobes at the summit; pollinia 4, loose, cohering by pairs in each cell.-Erect from tuberous bulbs, with 1 or 2 lvs. and small, racemed fls.

I M. ophioglossoìdes Nutt. If. solitary, ovate, amplexicaul; st. 5-angled; rac. short, obtuse; pedicels much longer than the flowers. - A small plant, in woods, \&c. Can. and N. States. Stem 5-9' high, with a single leaf a little below the middle. Tho leaf is rather acute, smooth, ovate or oval, about $2^{\prime}$ in length, 1 in width. At the base of the stem is an abrupt sheath. Fls. whitish, minute, numerous, in a terminal raceme an inch or more in length, dense at top, often abortive. Pedicels about 4 " long. Jn. (Malaxis, Mx.)

2 M. monophýllus Lindl. Lf. solitary, ovate, sheathing at base; rac. elongated, many-flowered, pedicels about as long as the flowers; bracts minute; sep. acute, spreading; lateral petals reflexed, linear; lip triangular-hastate, cucullate, acuminate with a recurved point.-In shady swamps, N. Y., rare (Hadley, Gray.) Stem 2 to $6^{\prime}$ high, 3-angled, with a subspicate raceme of 20 to 40 small, greenish fls. Jl. (Malaxis, Willd. Ophrys, L.) 


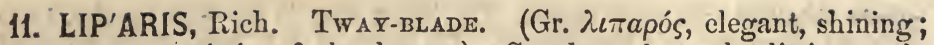
a term characteristic of the leaves.) Sepals and petals distinct, sublinear, spreading or deflexed ; lip spreading, flat, ascending, often exteterior; column winged; pollinia 4, parallel with each other, without pedicels or glands. -Erect from tuberous bulbs, with about 2 lvs. and a raceme.

1 I. lilifòlia Rich. IVs. 2, ovate-lanceolate; scape triangular; petals filiform, reflexed; lip large, wedge-obovate, abruptly cuspidate at the broad end.-Damp woods, Can. to Car. W. to Wis. Lrs. radical, 3 to $4^{\prime}$ long, rather acute, tapering into a sheathing base. Scape about $6^{\prime}$ high. Fls. 10 to 20 , in a terminal, rather showy raceme. Pedicels near an inch in length. The 3 sepals greenish-white, linear, 2 upper petals capillars, yeliowish-white. Lip $6^{\prime \prime}$ long, $4^{\prime \prime}$ wide, purplotranslucent. Jn. (Malaxis lilifolia. Sw.)

2 L. Lcesèlii Rich. Lrs. 2, ovate-oblong, obtuse, keeled, shorter than the fewflowered racemes; scape angular; lip oblong, mucronate incurved, wavy; sep. and pet. linear, subequal. - About half as large as the preceding, in moist meadows and fields, Can. N. Eng. to Penn. and Wis. Lvs. 2 to $3^{\prime}$ long, about $l^{\prime}$ wide, obtuse or acute, sheathing at base. Scape 3 to $5^{\prime}$ high. Fls. about 6 , appressed to the rachis, in a thin raceme. Pedicels about $2^{\prime \prime}$ in length. Lip 2" long. Sepals and pet. greenish-white. Ovaries clavate, as long as the pedicels. Jn. (Malaxis Correana Bart.)

12. LIS'TERA, R. Brown. Tway-blade. (Named for Dr. Martin Lister, an English naturalist.) Sepals and petals somewhat equal, spreading or reflexed; lip usually pendulous, 2-lobed, or 2-cleft; column wingless, the beak rounded; anther dorsal, ovate; pollen powdery.St. 2-leaved above the middle, with a raceme. Lrs. opposite.

1 L. cordàta R. Brown. Lrs. roundish, subcordate, acuto; rac. few-flowered; pedicels tho length of the ovary; lip linear, 2-toothed at base, deeply bifid, with divaricate, linear segments; column very short.-Root fibrous. St. 4 to $8^{\prime}$ high, furrowed. Irs. 8 to $10^{\prime \prime}$ diam., sessile, about half way up the stem. Fls. minute, greenish-purple, 10 to 15 , in a short raceme. A delicate little plant, in woods and sphagnous swamps, among mountains, \&c., N. States, and Brit. Am. Jl., Aug.

2 L. convallarioìdes Hook. Lvs. roundish-ovate; rac. few-flowered, loose, pubescent; sep. ovate-lanceolate; lip. cuneate-spatulate, twice as long as tho sepals, 2 -toothed at base, with 2 roundish lobes and an intermediate minute ono at tho apex; column elongated.-Car, to Arc. Am. Root fibrous. St. very slender, 5 to $10^{\prime}$ high, sheathed with a few bracts, bearing the 2 lvs. above the middle. Lrs. $I^{\prime}$ or more long, nearly as wide. Fls. small, tho broad, obcordato lip about $4^{\prime \prime}$ long, purplish. May.

3 L. pubéscens Nutt. St. pubescent, leafless; lvs. all radical, ovate, acute; fls. in a racemo; lip 2-lobed, the other segments connivent, about as long as the lip; caps, clavate.-Pine barrens, Car. and Ga. Fls. greenish-white. Jn., Jl. -We have seen no specimen. Is it a Cranichis?

4 L. austràlis Lindl. Lvs. ovate; fls. minute, puberulent, on pedicels twice longer than the ovary, in a loose, slender raceme; lip linear, cleft into 2 linearsetaceous segments, 3 or 4 times longer than the sepals. - Swamps, N. Jer. to Ga. Ifay, Jn.

13. CRAN'ICHIS, Swartz. (Gr. kpávos, a helmet?)-Sepals spreading or reflexed; lip narrow, entire, arched; column straight, bearing the anther on the back, parallel with the style; pollen farinaceous.Lvs. nearly radical. St. bracted, bearing a slender spike. Fls. obliquely cernuous.

C. multiflòra Ell. St. slender, with a few shenthing bracts, pubescent abovo; lvs. ovate-lanceolate, acute, on short, sheathing petioles near the base; spike manydlowered, rather loose; sep. pubescent, lanceolate, mostly reflexed; petals linear, 
connivent and curved upwards, lip recurved almost to a half circle, channeled, its base embracing the column.- Sandy soils, S. Ga. Fla. to La. (Described from an imperfect specimen resembling a Spiranthes.) St. 10 to $20^{\prime}$ high. Lvs. 1 to $2^{\prime}$ long. Perianth scarce $5^{\prime \prime}$ long, greenish-white. Sept., Oct.

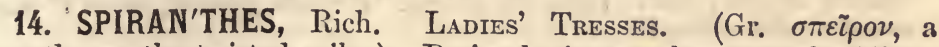
wreath; sc. the twisted spike.) Perianth ringent; lower sepals oblique and including the base of the lip; upper sepal connivent with the petals; lip oblong, channeled, parallel with the column, and with callous processes at base; column curved, stigma ovate, rostrate, becoming bidentate at apex; anther dorsal ; pollinia 2, each 2-lobed, powdery.St. scape-like, bearing many white fls. in an oblique, spiral row.

* Spike with the rachis twisted, and the flowers in one moderately twisted row......Nos. 1, 2

* Spike with the rachis straight but the flowers in a dense spiral all around............Nos. 8, 4

1 工. gràcilis Bigelow. Slender Ladies' Tresses. Lvs, all radical, ovate or ob. lanceolate, fugacious; scape with remote sleaths; fls. in a single row, which is moderately spiral; lip oblong-spatulate, crenulate-wavy at the recurved tip, tho callosities distinct; plant nearly glabrous.-A very delicate plant, not uncommon in old woods, Can. and U. S. Scape very slender, 8 to $12^{\prime}$ high. Lvs. close on the ground, 1 to $2^{\prime}$ long, contracted to a petiole, usually withering before the flowers appear. Fls. white, fragrant. Rachis twisted more than the row of flowers, but in the opposite direction. Jl., Aug.

$2 \mathrm{I}$. tórtilis $\mathrm{Ph}$. Tall, slender; lvs. mostly at base; long and linear; tho caulino distant and sheathing; bract-like; fls. in a single row, moderately iwisted, on a twisted rachis; perianth elongated $\left(5^{\prime \prime}\right)$; lip oblong, acute, pinnately lobed, lobes crenulate; plant more or less pubescent above.-Grassy plains, Car. to Ala. and Fla. St. 2 to ' 3 high, stouter than in S. gracilis. Lvis. 6 to $10^{\prime}$ long, 2 to 5 " wide. Spike 3 to 5' long. Jn. Jl.

$3 \mathbf{S}$. cérnua Rich. Lvs. linear-lanceolate, the lower elongated, the cauline gradually smaller; spike dense-flowered, thick, oblong, the flowers oblique and cernuous; lip oblong, obtuse, wavy and crenulate, recurved, longer than the petals; plant pubescent above.-Can. and U. S., common in meadows, \&c. St. 9 to $18^{\prime}$ or more, somewhat leafy. Lvs. 3 to 6 to $10^{\prime}$ long, 3 to $6^{\prime \prime}$ wide. Spike 1 to $3^{\prime}$ long. Fls. large for the genus, fragrant. Perianth 4 to $5^{\prime \prime}$ long, cream-white. Aug.-Oct.

4 S. latifolia Torr. Lvs. nearly radical, oblong or linear-lanceolate, 3 to 5-veined; st. with 2 or 3 sheathing bracts; fls. (small 3 to $4^{\prime \prime}$ ) in an oblong, denso spiko which is somewhat twisted; lip oblong, obtuse, crenulate-crisped on the margin. about 5-veined, callositios adnate; plant quite glabrous.-In moist grounds, Cis... to Penn. A low plant, often concealed in the grass, 4 to $8^{\prime}$ high. Lrs. 3 or more, 2 to $4^{\prime}$ long, often obtusish. Fls. rather larger than in No. 1, white, the lip yellowish, with green lines. Jn., Jl.

15. GoOdye'RA, R. Br. Rattlesnake Plantain. (Named for John Goodyer, an obscure English botanist.) Perianth ringent; calyx inflated, upper sepals with the petals vaulted, the two lower sepals placed beneath and including the saccate, entire lip, which is without callosities and abruptly acuminate and reflexed at apex; anther on the back of the free column; pollinia 2, composed of angular grains.Bracted scapes arising from creeping rhizomes, with radical, ovate lvs. and a downy spike of small white fls.

1 G. repéns R. Br. Lvs. orate-lanceolate, obscurely reticulated with white, lip ovate, with an oblong, obtuse acumination; column acutely 2-horned at the summit; spike secund or slightly twisted, minutely pubescent. Rocky mountain woods, Can. to Car. St. slender, 5 to 8 ' high, bearing a spike 2 to 3 'ilong. Lvs. 9 to 12 " in length, curiously netted with white lines, but less so than the next (which is scarcely distinct from this). Jl., Aug.

2 G. pubéscens $\mathrm{R}$. Br. Lrs. ovate, and conspicuously reticulate with whito; 
lip roundish-orate, with a narrow, abrupt, recurved point; column rounded and obscurely 2-toothed at apex; spike dense, with the fls. spirally arranged, pubescent. - Woods, Can. and U. S., with its several lvs. radical and singularly mottled with white and dark green. St. 6 to $12^{\prime}$ high. Lrs. 1 to $2^{\prime}$ long, contracted into a short, winged petiole. Spike 2 to $4^{\prime}$ long. Perianth greenish, about $2^{\prime \prime}$ long, nearly as wide.-Jn., Jl.

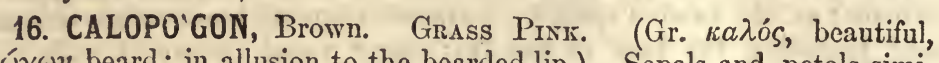
$\pi \omega \gamma \omega \nu$, beard; in allusion to the bearded lip.) Sepals and petals similar, distinct; lip on the upper side of the flowers (the ovary not twisted as in other Orchids), unguiculate bearded; column free, winged at the summit; pollen angular.-Corm bearing a grass-like lf., a naked scape with several showy fls.

C. pulchéllus $\mathrm{Br}$. Lf. radical, linear-ensiform, veined; scape few-flowered; lip crect, narrowed at base, with an expanded border and a concave, crested disk. A beautiful plant, in swamps and damp meadows, U. S. and Can. Scape slender, 10 to $20^{\prime}$ high, with a long leaf ( 8 to $12^{\prime}$ by $\left.\frac{1^{\prime}}{2}\right)$ sheathing its base. Fls. 3 to 8 , large, purple, remarkable for their apparently inverted position; lip expanded at apex, spatulate, crested with white, orange and purple clavate hairs, and on tho upper side of tho flower, while tho column is below! Jn., Jl. (Cymbidium Willd.)

17. POGO'NIA, Juss. (Gr. $\pi \omega \gamma \omega \nu$, beard; in allusion to the bearded lip.) Perianth irregular, sepals and petals distinct; lip sessile or unguiculate, cucullate, bearded inside; column wingless, elongated, free ; pollinia 2, farinaceous.-Habit various. Lvs. 1 or more. Fls. purple.

Sepals abont equal, and similar to tho petals, light purple. Lip scarcely lobed........ Nos. 1, 2 Sepals much longer than, and unlike the petals, dark brown. Lip 3-lubed.............. Nos. 3, 4

1 P. ophioglossoides Br. Rt. fibrous; St. furnished with an oval-lanceolate leaf and a foliaceous bract near tho single flower; sep. and pet. about equal; lip. fimbriate.-An interesting plant, much taller than the bulbous Arethusa, found in swamps and muddy shores, Can., N. Eng. to Car. and Ky. The stem is very slender $9-16^{\prime}$ high, with 2 remoto leaves, tho one placed about midway, $2-3^{\prime}$ long, lanceolate, acute, sheathing at the base; the other (a bract) much smaller, situated near tho flower. Flower large, nodding, pale purple. Lip long as petals and sepals $\left(\frac{3^{\prime}}{4}\right)$ June. (Arethusa L.)

2 P. verticillàta Nutt. Lvs. 5, lance-oval verticillate; fl. solitary, tho 3 outer petals very long, linear, inner ones nearly thrice shorter, lanceolate, obtuse; lip 3lobed, the middle lobes undulate.-Swamps, Can. to Ga. (Mr. Wm. Jones), common. Stem 8-12' high, with a whorl of leaves near the top and a flower $1-2^{\prime}$ above it. Leaves $1 \frac{1}{2}$ ' long, $\frac{1}{2}$ as wide, abruptly acuminate. 'The flower is remarkable for its sepals being abovo $2^{\prime}$ long, very narrow, and of a greenish-brown color. Lip crested in the middle. July. (Arethusa Willd.)

3 P. pendula lindl. THREE-BIRDS. Rt. tuberous; st. leafy, about 4-flowered at the top; lvs. clasping, ovate, alteruato; fls. axillary nodding; lip. entire, scabrous, not bearded; fr. pendulous.-A small, delicato plant, in swamps, Mid. and W. and S. States. St. scarcely $6^{\prime}$ ligh, slightly angled, with about 3 fls. which with the ovary are $1^{\prime}$ long. The fruit often resembles 3 little birds. Lvs. 3 to 6,4 to $8^{\prime \prime}$ long, purplish. Fls. light purple, the segments of the perianth equal, converging, and rather longer than the lip. Aug. (Triphora Nutt.)

4 P. divaricata $\mathrm{R}$. Br. Ivs. 2, one of them in the middle of the stem, lancoolatelinear, subfalcate, the other terminal, bract-like, at the base of the single, large, flower; sep. narrow, wide-spread, recurved at apex, one third longer thian the lanceolate, acuminate petals; lip spatulate, 3-lobed, middlo lobo rounded, cuspidate; lateral lobes somewhat involute.- 1 fine, showy plant, near $2 \mathrm{f}$ high, in grassy swamps, Va. to Fla. and La. If. 2 to $4^{\prime}$ by 3 to $5^{\prime \prime}$, rather oblong than lanco shaped, the bract scarce half as large. Potals $l^{\prime}$ long, pink, sop. 18", brownishpurplo. Lip green, with purplo veins. Apr., May.

18. ARETHU'SA, Gronov. (Arethusa, a nymph of Diana, trans 
formed to a fountain.) Perianth somewhat ringent; sepals and petals cohering at the base; lip spurless, adnate to the column at base, deflected at the end, and bearded inside; pollinia 4, angular.-St. low, sheathed, 1-flowered, arising from a corm or bulb imbedded in moss.

A. bulbòsa $L$. This beautiful and interesting plant is found in wet meadows and swamps, Can. to Va. W. to Wis. Stem 6-12' high, invested with about 3 long, loose sheatls, with lanceolate points, the upper ones rarely at length produced into a short linear-spatulate leaf. At the top is a single, large, fragrant flower of a rich purple color. At the base of the flower is a small spatho of 2 unequal bracts. Junc.

19. EPIDEN'DRUh, Swartz. Tree Orchis. (Gr. $\varepsilon \pi \iota$, upon, $\delta \varepsilon v$ $\delta \rho o v$, a tree.) Sepals and petals spreading; lip united with the column and forming a tube which is sometimes decurrent on the ovary; anther terminal, opercular; pollinia 4, separated by complete, persistent partitions, and each narrowed at base into a reflexed, elastic pedicel. -Epiphytic plants, vegetating in air and the scanty soil lodged in the bark of trees. Sts. few-leaved at base, naked and many-llowered above.

E. conópseum II. K. 'Sts. tufted, 2-leaved simplo; lvs. coriaceous, oblong-lanceolate, acute or mucronate, sessile; fls. 3 to 7, spicate, erect, yellow; lip 3-lobed, middle lobe obcordate, spreading as well as the narrow-linear, obtuse petals.Cliiefly on the Magnolia grandiflora, in damp woods, low country, S. Car. to Fla. and farther West. Root an entangled mass of thick fibers. Sts. in clusters, 5 to $8^{\prime}$ high. Lrs. $I^{\prime}$ to $18^{\prime \prime}$ long. Fls. expanding 5 or $0^{\prime \prime}$, tinged with purple. Aug., Sept.

\section{Order CXXXIX. MARANTACEA. $\Lambda$ rroworts.}

Herbs with a creeping rhizome, sheathing petioles, and amplo leares, with parallel veins diverging from the midveiu. Fis. with spathaceous bracts. Perianth adherent, irregular, of 3 circles, each of 3 parts, tho inner often abortive. Stamens 3 , petaloid, 2 sterile, the $3 \mathrm{~d}$ fertile, lateral, with only half an anther. Ovary inferior, 1 to 3-celled. Seeds albuminous, embryo not in a sac (vitcllus).

Genera 6, species 166 , chiefly found in the tropics. They are remarkable, as an order, for the abnndance of pure starch contained in the rhizomes of nany species, constituting the genuine arrow root of commerce. This is chiefly obtained from Muranti arundinacea and nobilis: E. Indies, and $\boldsymbol{M}$. ramosissima, W. Indies. Some are cultivated for ornament.

1. THA'LIA, L. (Named for John Thalius, a German physician and author.) Flowers contained in a 2-leaved, glume-like spathe; calyx 3sepaled, small, concave, lance-ovate; corolla 6 -parted, the 3 outer segments equal, 3 inner very unequal; stamen 2-parted, the outer segment petaloid, inner slender, bearing the 1-celled, ovate (half) anther; style short, twisted, with a large, lip-shaped stigma; fruit capsular, thin, with 1 or 2 large seeds; embryo recurved. $-2 f$ Lvs. with long sheaths. Scape paniculate.

T. deälbàta Roscoe. Lvs. ovate-lanceolate, acuto and revolute at apex, rounded at base, petiole distinct, much shorter than its sheath; scape and panicle powdered; spathe of 2 very unequal lvs., 2-flowered, but usually 1-fruited, pilous; pericarp membranous, inclosing 1 large, farinaceous seed, in which the slender embryo lies distinct, bent double. - A tall, elegant plant, in marshes, S. Car. (Curtis) to Fla. Abundant in the Chattahoochee R. near A palachicola. Scape slender, 3 to 5 to $7 \mathrm{f}$ ! ligh, bearing a large, forking panicle, with several lance-linear, deciduous bracts. Lrs. 9 to $14^{\prime}$ by 4 to $8^{\prime}$, often subcordate. Fls. purple, half concealed in the bracts.

2. CANNA, L. Indian Srot. (Derivation doubtful.) Calyx of 3 sepals, persistent on the fruit; corolla 6-parted, with unequal segments, 
the outer often reflexed; stamen petaloid, 2-lobed, the upper lobe bearing the 1-celled (half) anther on its margin ; style petaloid, fleshy, stigma obtuse; capsule muricate, 3-celled; seeds globular.-2f Handsome, evergreen herbs, with large lvs. and showy panicles, or spikes.

$\S$ CORYTHIUM.* (Gr. (кópvs) корv0ós, with a helmet.) Tubo of the corolla prolonged above the ovary, with the outer segment spirally attached, and reflexed, inner segment and the stamen dilated and coroniform; anther wholly adnate.

1 C. fláccida Roscoe. Glabrous; lvs. lanceolate, acuminate, tapering to a long, sheathing base; fls. spicate, 2-bracted; sep. erect, lance-linear; cor. tube more than twice as long as the sepals; limb of the inner petals spreading, flaccid, wavy, yellow, the outer lance-linear, reflexed; stigma obliquely dilated above, terminating the corolla tube. - $\mathrm{A}$ fine plant, around ponds, S. Car., Ga. and Fla. Stem 3 high. Lvs. near $2 f$ long (including the narrow base), 2 to 4 ' wide. Fls. about $4^{\prime}$ long. Caps. oval, 12 to $16^{\prime \prime}$ long.-This plant, with its congeners, might perhaps constitute a new genus.

$\S C A N N A$ proper. Corolla tube short or none, segments erect or spreading above, the inner not coroniform; anther free above.

2 C. Indica Rosc. Glabrous; Ivs. ovate, acuminate, abrupt at base; cor. tube scarcely longer than the sepals; segm. strap-shaped or spatulate, subequal, inner erect.-Often cultivated. Lvs. large, smooth and glossy, the lamina more than If long. Fls. near 2 ' long, red and yellow. $+W$. Indies.

\section{Order CXL. aMaryllidaCE E. Amaryllids.}

Herbs perennial, chiefly bulbous, with linear leaves not scurfy nor woolly. Flowers showy, mostly regular and on scapes, with an adherent, 6-parted perianth. Stamens 6, anthers introrse. Ovary 3-celled, with styles united into 1. Fruit a 3-celled capsule or berry. Seeds 1 to $\infty$, with fleshy albumen. Figs. 315, 342, 395, 396.

Generi 68, species 400, chiefly tropical plants, most abundant in Brazil and S. Africa. Very few are found in our climate.

Properties. A few of the Amaryllids possess poisonous properties, which is very rare among the Endogens. The Hottentots are said to poison their arrows by dipping them in the viseid juice of the bulbs of Hæmanthus toxiearius. The bulbs of Nareissus poeticns, and of other species, are emetic. The fermented juice of the Agave forms the intoxicating pulque of the Mexicals, Alany are highly ornamental in cultivation.

\section{GENERA.}

Perianth bearing a crown on the summit of its tube. (")

* Crown a thin membrane conneeting the stamens................... Pavcratiuar.

- Crown a firm cup containing the stamens......................Narclssus.

5 Perianth destitute of a crown. (**)

** Segments united into a tube abore the ovary. Stamens perigynous. (a)

a Flowers solitary, tube of the perianth straight. erect............ZEPHYraNTrus. 3

a Flowers many, tube of the perianth straight................AAvE.

a Flowers many, tube of the periantli curved................ Pouranturs.

** Segments distinct down to the ovary. Flowers nodding. (b)

b Perianth irregular. Stamens declined and curved............. Sprekelis. 6

b Perianth regular. - Sepals (all white) !arger than petals..........GALANTius. 7 -Sepals (green-tipped) as large as petals.....LEucosur. 8 -Sepals and petals equal, yollow............. Irypoxis. 9

1. PANCRA'TIUM, L. (Gr. $\pi a ́ v$, all, rpatús, powerful; the name was first applied to the medicinal squill.) Tube of the perianth produced above the ovary, long and slender, dilated in the throat, limb regular, 6-parted; stamens 6 , inseried on the throat, their bases connected by an ample membrane forming a broad, funnel-shaped corona; anthers linear, versatile; capsule 3 -valved, $\infty$-seeded.-Bulbs tunicated, bearing long lis. and a scape with a bracted umbel of showy fls. 
1 P. rotàtum L. Scapes 2-6-flowered; lvs. long, strap-shaped, obtuse; ovary ovate-triangular; sep. and pet. linear, as long as the tube; crown lroad-funnelshaped or top-shaped, the margin 12-toothed, alternate teeth stameniferous stamens and declined style nearly as long as the sepals; anthers yellow.-Marshes and low grounds, along streams, throughout the S. States. Bulb white, an inch or more in diam. Scape $18^{\prime}$ to $2 \mathrm{f}$ bigh. Fls. usually but 2, white. Perianth and tube about $3^{\prime}$ long, the crown about $18^{\prime \prime}$ broad, very thin and often torn. A pr. May. (P. Mexicanum L. Hymenocallis Herbt.)

2 P. coronàrium Lo Conte. Scape many-flowered; lvs. linear-lanceolate, obtuse; petals linear, thrice longer than the crown, which is large, funnel-shaped, 18-angled, or having 2 angular teeth between the stamens, and ofien a jagged sinus between the teeth; stam. much shorter than the petals, with long (6 to $\left.8^{\prime \prime}\right)$, linear, yellow anthers.-River swamps, along the coast, Car., Ga. (Pursh) to La. (Mr. R. Green). Scapes and Ivs. 2 or $3 f$ long. Fls. white. Style much longer than the stamens.

3 P. marítimum I. Scapo many-flowered; 1vs. linear, strap-shaped, glaucous, longer than the scapo; perianth funnel-shaped, segm. lance-linear, spreading above, longer than the crown; crown funnel-shaped, its base adherent to the segments, its margin with 6 pairs (12) of prominent teeth, alternating with the stamens, which are borne in the sinuses. River swamps, S. Car., Ga. (Walter, Catesby) and westward (Le Conte). Not lately seen? Scape $18^{\prime}$ to $2 \mathrm{f}$ high. Fls. very fragrant; evanescent. (P. occidentalis Lo Conte?) Eur.

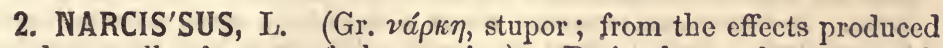
by the smell of some of the species.) Perianth regular, 6-parted, bearing on its throat a cup or bell-form crown (consisting of a whorl of united sterile stamens); fertile stamens 6 , inserted within the tube and concealed within the crown.-A genus of well known, much cultivated flowers, many of them very fragrant and beautiful. They have bulbous roots, ensiform leaves, and usually yellow fls., with a long, compressed spathe, opening on one side and deciduous.

$\$$ Crown longer than the tubo of the perianth................................ 1

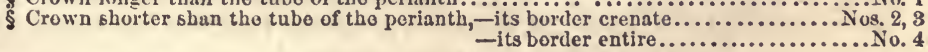

1 IN. Pseudo-Narcíssus I. DAFfodiL. Scape 2-edged, straight, striated; segments sulphur color; corona with a serrate-crenate orifice, and as long as the petals. -Gardens. Root bulbous. Leaves linear, a foot long, striate, veined. Scapo a foot high, bearing at the top a single, very large flower, with a very long cup or corona. April, May. † Eur. (Ajax, Haworth.)

2 IV. Jonquílla L. JoxquiLs. Scapo 1-3-flowered; segments reflexed, spatulate; cup (corona) much shorter than the segments, saucer-shaped, spreading, crenate.-Gardens. Scape a foot high, round, slender, bearing at the summit a few flowers of a rich yellow, and very fragrant. May, Jn. † Spain. (Queltia Herbert.)

3 N. poéticus I. PoeT's Narcissus. Scapo 1-flowered; segments imbricato at base, reflexed; corona expanded, flat, rotate, crenulato; 3 anth. shorter than tho tube.-Gardens. Scapo about a foot high, leaves of the same length. It bears a single flower, which is mostly white, but having the crown singularly adorned with circles of crimson, white and yellow. Jn. † S. Europe.

4 IN. Tazétta I. Spathe many-flowered; corona campanulate, truncate, shorter than tho petals; lvs. flat.-Gardens. Root a large bulb. Leaves smooth, swordshaped. Scape naked, striate, a foot high, with 10-12 flowers. Corolla whitc, cup a strong yellow, not fragrant. $\Delta$ pril, May. † Spain. (Hermiono Herbert.)

3. ZEPHYRAN'THUS, Herbert. Amaryllis. Atamasco Lily.

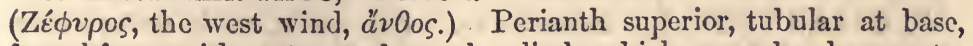
funnel-form, with a 6-parted, regular limb, which spreads above; stamens 6 , inserted in the throat, or one of them lower down, filaments slender; anther versatile; style filiform, somewhat declined; stigma 
3 -fid; seeds $\infty, 2$ rows in each sell, black.-Bulb tunicated, sending up a scape with linear lvs. Spathe 1-leaved. Fls. erect, showy and beautiful. Fig. 315.

Z. Atamásco Herbt. Spathe 2-cleft, acute; flowers solitary, pediceled; cor. campanulate, suberect, with the segm. equally spreading above; filaments much excesding the tube, but shorter than the segments.- An attractive flower, in wet clay soils, Va. to Fla. Lvs. linear, a foot long. Scape round, 6 to $12^{\prime}$ high. Spathe a little colored, bifid at the summit. Flower large, white and pink. Sepals lanceolate, 3 to $3 \frac{y^{\prime}}{2}$ long (including tho $1^{\prime}$ tube). March (S.), May (N.) (Amaryllis L.).

4. AGA 'VE, L. (Gr. ayavós, admirable.) Perianth tubular-funnelform, adherent to the ovary, 6-parted; stamens 6, exserted; anthers linear, soon versatile; capsule coriaceous, obtusely triangular, 3-celled, many-seeded.-A splendid American genus. Root sometimes ligneous. Stem herbaccous. Lvs. mostly radical, thick and rigid, channcled, often spiny. Scape many-flowered.

1 A. Virgínica L. FALSE ALOE. Acaulescent, herbaceous; lvs. linear-lanceolate, fleshy, glabrous, with cartilaginous serratures on the margin; scape simple, glabrous, with leaf-like scales and sessile, tubular flowers.-Rocky banks, Penn. to Ga. Root premorse, tuberous. Scape 4 to of higl, terete, glabrous, loosely spicate above. Radical leaves long, acute. Flowers $I^{\prime}$ long, greenish-yellow, very fragrant, tubo longer than the subulate segments. Anth. long exserted. Capsulo roundisl, obscurely 3 -angled, 3 -furrowed. Sept. $\uparrow$

2 A. Americàna L. American Aloe. Century Plant. Acaulescent; lvs. spinous-dentate, lanceolate, coriaceous and fleshy; scape branched, lofty and arborescent; cor. tube contracted in the middle; pedicel as long as tho corolla.The largest of all herbaceous plants, native of tropical America, often cultivated. It is a popular notion that it flowers but once in a hundred years, but it is known to flower much oftener, according to the culture it rcceives. Leaves radical, thick, $3-6$ or $8 f$ long, $4-12^{\prime}$ wide. The scape arises from the center of tho leaves to tho height of 15 to 25 f, bearing a pyramidal panicle of innumerable yellow flowers. There is a variety with striped leaves. $\uparrow$

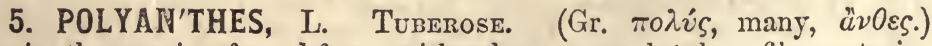
Perianth superior, funnel-form, with a long, curved tube; filaments inserted into the throat, included; ovary at the bottom of the tube, the summit free.-Rt. an upright rhizome, thick, producing tubers above. St. terete, solid, simple, $\infty$-flowered.

P. tuberc̀sa I. Lvs. linear-lanceolate; petals oblong.-A green-houso plant. Sts. bulbous at base with tuberous branches. Scape scaly, 2 to $3 \mathrm{f} \mathrm{high,} \mathrm{with} \mathrm{al-}$ ternate, large, white, regular fls. of a delicious fragrance, which is most powerful at evening. Aug., Sept. † Ceylon.

6. SPREKE'LIA, EndI. JACOBEA LiLy. Perianth adherent 6-leaved, subbilabiate and spreading above; inner segm. narrower; stam. 6, inserted on the ovary, unequal, and with the style declined, but bending up at apex.-Bulbous. Scape fistulous, 1-flowered. Lrs. linear.

S. formosíssima Herbt. Lvs. radical ; fls. nodding, rery ringent, tube fringed; sta. included in the involute lower segments.-A splendid flower, grown in light, loamy so:l. - Leaves thick, oblong, narrow. Scapo a foot high. Spathe red, disclosing a singlo large flower of a fine dark red color. Jn. $-\Lambda$ ug.

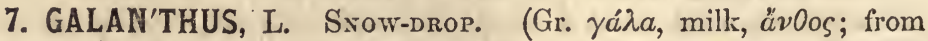
the color.) Perianth superior, segments distinct, the 3 inner shorter, notched or lobed; stamens 6 , inserted on the top of the ovary, erect, included; style straight, longer than the stamens; stigma entire; cap- 
sule 3-celled, loculicidal, $\infty$-seeded.-Bulb tunicated, acrid. Scapo 2edged, solid. Spathe 1-leaved. Fls. white, pendulous. Caps. maturing under ground.

G. nivàlis. SNow-DROP. Lvs. linear, radical, keeled, acute; scape 1-flowered. -Native of the Alps, well known in gardens, flowering early in spring. It is a small plant, half a foot high, arising from a perennial bulb, bearing a single, large, nodding flower, white as snow. Stem usually furnished with 2 long, narrow leaves towards the top.

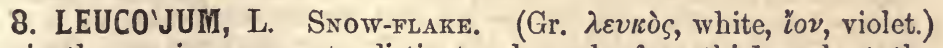
Perianth superior, segments distinct, subequal, often thickened at tho apex; stamens 6 , inserted on the tip of the orary, included; style erect, thickened upwards ; stigma entire, obtuse; capsule fleshy, 3valved, loculicidal, $\infty$-seeded.-Bulb tunicated. Scape 2-edged, fistulous. Lvs. few. Spathe 1-leaved. Fls. pendulous.

1 L. æstivum L. Lvs. linear, a little shorter than the scape; spathe many (4 to 8)-flowered; caps. pyriform, with numerous black seeds in each cell.-Gardens, very pretty. Lrs. 6 or more, of a rich green, long, channeled, sheathing. Scape 6 to $10^{\prime}$ high, sharply 2-angled, bearing at top an umbel of pedicellate nodding fls. issuing from a spathe. Sep. puro white, 6 to $8^{\prime \prime}$ long, tipped with a green thickened point. May, Jn. † Eur.

2 I. vérnum L. Lvs. linear or strap-shaped, sheathing at baso; scape 1 or 2 -flowered; perianth segm. with divergent veins, white, marked with a green or yellow tip; seeds 7 in each cell, straw-colored.-Gardens, less frequent than tho other. Mar., Apr. † Eur. (L. rinosma, Herbert.)

9. HYPOX'IS, L. Star-grass. (Gr. i $\pi o ́$, under, o $\xi \dot{v} \varsigma$, sharp; on account of the pointed base of the fruit.) Spathe 2-leaved; perianth 6-parted, regular, persistent; stamens 6 ; capsule elongated, narrowed at the base, indehiscent ; seeds numerous, roundish, with a black, crustaceous integument.-Small, bulbous, grass-like plants, with yellow fls. Lvs. radical, linear.

$1 \mathrm{H}$. erécta I. Pilous; scape about 4-flowered, shorter than tho linear-lanceolate lvs, - In woods and meadows, Can. and U. S. Lrs. all radical, 6 to $12^{\prime}$ by 3 to $5^{\prime \prime}$, very acute. The slender, hairy scapes, several from the samo root, arise 6 to $8^{\prime}$, divided at top into a sort of umbel with 3 to 5 peduncles, having each a minnte, subulate spathe at the base. Perianth hairy and greenish without, yellow within; segm. oval, rather obtuse. $\mathrm{Jn}$.

2 H. filifollia Ell. Sparingly pilous; scupe 2-flowered, shorter than the filiform lvs.-In dry, sandy soils, Ga. and Fla. Samo height as the other species. Lrs. 8 to $12^{\prime}$ long, thread-shaped, but channeled, not half a lino wide. Fls. rather largo (9 to $11^{\prime \prime}$ diam.).

\section{Order CXLI. BROMELIACEA. Bromeliads.}

Herbs, chiefly epiphytic, with persistent, often scurfy leaves, channeled and sheathing. Calyx 3-parted or 3-toothed, often green. Corolla 3-petaled, distinct, imbricated, colored. Slamens 6 , perigynous. Slyle single; ovary 3-celled, with numerous ovules. Seeds numerous, embryo at the base of meaiy albumen, radicle next the hilum. Fig. 37, c.

Genera 23, species 170, nearly nll natives of tropical America. Among them is Ananassa sativa, the pine apple, very abundant in the Bahamas, which delicions fruit consists of the entire spike of flowers, with bracts and stem blended into one tleshy mass-a sorosis. Another useful plant is our own Tillandsia usneoides-the Spanish moss uf commerce.

TILLAND'SIA, L. Lovg Moss. of Abo, author of Flora Aboc̈nsis.) (Named for Prof. E. Tillands, Perianth double, 3 sepals mem- 
branous, convolute into a tube, 3 petals colored, spreading above; stamens scarcely cohering with the base of the sepals; ovary free; capsule clongated, the 3 valves splitting each into 2 layers, of which the outer is membranous, the inner cartilaginous; seeds club-shaped, raised on comous stipes.-Plants grayish with scurf, growing on trees.

1 T. usneoìdes L. Buack Moss. Spantsh Moss. St. filiform, branching, long, flexuous, pendulous; lvs. recurved, filiform (1 to 2' long); peduncle 1-flowered, short.-Very common in the low country, from the Dismal Swamp, Va. to Fla. and La., hauging in long dark gray tufts and festoons from every tree. It is collected, dried and beaten until the bark falls off, when the black, elastic, tough, thread-like stem is used as hair in upholstery, \&c. Flowers May-Aug.-Very different in habit from the next.

2 T. Bartramii Ell. Stems clustered, erect, simple, enveloped in bract-like sheaths; lvs. mostly radical, channeled, linear-subulate, from a dilated, half clasping base, which is brown and polished, much longer than the stem; fls. 2 to 4 , in a bracted, terminal spike.-Swamps, Liberty County, Ga. (Pond). Root a dense mass of crowns with fibers, "on the bark of old trees" (Elliott). Sts. about 6" high, and with the lvs. $\left(6\right.$ to $\left.12^{\prime}\right)$ forming dense tufts. Fls. ....... Capsule $9^{\prime \prime}$ long, sessile, enveloped in imbricated bracts. Inner valves dark brown Seed stipo clothed with a long, silky coma. Jn.

3 T. recurva L. Lvs. subulate, recurved; scape setaceous, erect, longer than the lvs., bearing about 2 flowers at the summit.-On old trees, Ga. and Fla., forming tufts covered with grayish scales. (Pursh.) We saw specimens of this species in the herbarium of Rev. Dr. Bachman, but took no description.

\section{Order CXLII. It EMODORACEA. Bloodworts.}

IIerbs perennial, with fibrous roots, equitant or rosulate leaves, and perfect flowers. Perianth regular, 6-parted, scurfy or woolly outside, more or less adherent. Stamens 6, or 3 and opposite the petals, anthers introrse. Ovary 3-celled, 1-styled. Capsule covered with tho withered porianth. Seeds with cartilaginous albumen.

Genera 13, species 50, sparingly occurring in N. America, S. Africa, New Holland, \&c. The root of Lacnanthes tinctoria abounds in a red culoring inatter. One of the most intense bitters known is Aletris farinosa.

\section{GENERA.}

\$ Ovary wholly adherent. Stamens 8, exserted. Perianth woolly outside.....LAcraxrmas. 1 § Ovary half free. Stamens 6, included.-Corymbed perianths woolly all over....LopirouA. 2 -Racemed perianths rugous-scurfy......... Aletris. 8

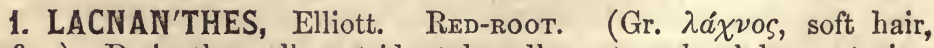
a้v0os.) Perianth woolly outside, tube adherent; calyx lobes exterior, of 3 linear sepals, as long as the 3 lance-oblong petals; stamens 3 , equaling the petals and opposite to them; filaments and filiform, declined style exserted; capsule 3-celled, truncated, many-seeded.An herb with red roots, equitant, ensiform lvs., and a dense, woolly corymb.

L. tinctòria Ell. Swamps and borders of ponds, R. I. (Olney) to Fla. An interesting plant, with rush-like lvs. St. erect, strict, 18 to $24^{\prime}$ high, clothed with white wool above. Lrs. mostly radical, fleshy, 3 to $4^{\prime \prime}$ wide and nearly as high as the stem. Cauline lvs. remote and bract-like. Corymb terminal, compactly many-flowered. Fls. densely clothed with white wool outside, glabrous and yellow within. Anthers bright yellow, at length revolute. J1., Aug. (Dilatris, Pursh.)-Tho root is said to be employed in dyeing.

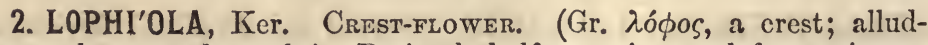
ing to the crested petals.) Perianth half superior, 6 -cleft, persistent, 
woolly outside and inside; petals narrower than the sepals, somewhat interior; stamens 6, filaments naked, anthers erect; style conical, 3partible; stigma simple; capsule opening at the summit, 3-celled, 3-valved, many-seeded.-An herb with a creeping root, flexuous stem, woolly above, and a loose cormyb, densely clothed with soft, white wool.

I. Americàna. 'Sandy swamps, pine barrens, N. J. St. 1 to $2 \mathrm{f}$ high, erect, hoary-tomentous when young. Lvs. glaucous, narrowly linear, equitant, glabrous, the lower and radical long, cauline 2 or 3 , shorter. Corymb finally much expanded, many flowered. - Corolla woolly and yellow within, segments reflexed, about as long as the stamens. Capsule ovate, dissepiments arising from the center of each valve. Seeds white. Jl., Aug. (L. aurea Ker. Conostylis, $\mathrm{Ph}$. )

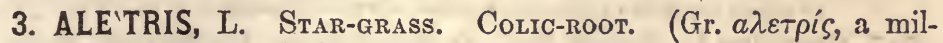
ler's wife; because of the mealy-looking flowers.) Perianth 6-cleft, tubular, rugous as if scurfy or mealy, persistent; stamens issuing at the top of the tube, style 3-sided, 3-partible; ovary adherent at base only; capsule opening at top, many-seeded.-Smooth herbs, very bitter, lvs. radical, rosulate, and scape many-flowered.

1 A. farinòsa L. Lvs. broad-lanceolate; fls. white, oblong-tubular, pediceled; perianth in fruit rugous or mealy in appearance.-Grows in low grounds, in most of the States. Root premorse. Scape 20-30' high, with remote seales or bracts, and surrounded at base with a circle of lanceolate, sessile leaves. These are 3-4' long, $\frac{1}{4}$ as wide, and lie flat. upon the ground. Flowers in a long, thin raceme. Perianth white, $\frac{1}{3}^{\prime}$ long, on very short pedicels, rugous without, when old. Medicinal. July.

2 A. aùrea Walt. Lrs. lanceolate; fls. yellow, subsessile; perianth short, tubularcampanulate, finally rugous and very scabrous.-In the pine barrens of $\mathrm{N}$. J. to Fla., abundant. Scarcely different from the preceding except in color. Scapo 2-3f high, with rather distant yellow flowers in the spicato raceme. Irs. all radical, 2 to $3^{\prime}$ by $3-4^{\prime \prime}$. Jl., Aug.

\section{Order CXLIII. IRIDACEA. IrIDs.}

Herbs with corms, bulbs or rhizomes, equitant, 2-ranked leaves and spathaceous bracts. Perianth tube adherent to the ovary, segments in 2 sets, often unequal and convolute in bud. Stamens 3, alternate with the petals, anthers extrorse. Style 1, stigmas 3, often petaloid. Capsule 3-valved, 3-celled, loculicidal. Seeds many, witl hard, fleshy albumen. Figs. 76, 151, 425.

Genera 52, species 550, chiefly natives of the Cape of Good Hope, or of the middle of Europe or N. Americn.

Properties.-More remarkable for beanty than utility. Some of them are cathartic, as Iris tuberosa. The aromatic orris root is the dried rhizome of Iris florentina of $\mathbf{S}$. Europe. Saffion consists of the dried orange-colored stigmas of Crocus sativus.

\section{GENERA.}

\$ Flowers irregular, somewhat bilabiate, nodding................................ $\boldsymbol{T}$

$\S$ Flowers regular and equilateral, mostly erect. (*)

* Sepals similar to tho petals in form, size and position. (a)

a Stamens distinct. Tube very long, partly under ground.............. Crocus. 6

a Stamens distinct. Tube short or none above the ovary................. IxIA. 5

a Staniens monadelphous. Flowers small, blue. Plant grass-like...Sisxarucurux. 4

* Sepals larger than the petals and otherwise dissimilar. (b)

b Stamens monadelphous. Petals spreading, panduriform............ TigridiA. 8

b Stamens distinct, - stigmas slender, on a slender style............. NeMastyus. 2 -stigmas petaloid, on a very short style................. Iris, 1

1. IRIS, L. Flower-De-LuCE. (Name from the Greek, signifying rainbow; on account of the varied color of the flowers.) Sepals 3, 
reflexed, larger than the 3 erect petals; stamens distinct; style short or 0 ; stigmas petaloid, covering the stamens.-Herbs from tuberous, horizontal rhizomes, with ensiform lvs., and large showy fls.

S Stems leafy, tall ( 1 to $3 \mathrm{f})$, mostly bearing several flowers. (")

* Sepals and petals beardless. Wild plants seldom cultivated. (a)

a Leaves linear, grass-like. Ovary and pod 2 -grooved on the sides.............. 1

a Leaves sword-shaped. Flowers blue. Sepals much larger than petals... Nos. $2-4$

a Leaves sword-shaped. Flowers tawny or copper-colored, Petals reflexed.... No. 5

* Sepals or perianth bearded. Cultivated exotics. (b)

b Steu many-flowered. Flowers blue or whitish. Sepals and petals notched..No. 6

b Stem many-flowered. Flowers deep blue. Spatbes also colored..I. Germanica. +

b Stem 1-flowered, flower striped. l'etals reflexed.................. SusianA. t

$\$$ Stem or scape low ( 2 to 6 ) and nearly leafless, mostly 1.flowered. (**)

** Sepals beardless, but with 3 longitudlnal fulrls (crested)............... Nos. 7,8

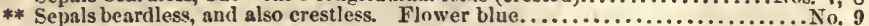

* Sepals bearded in a longitudinal line. Flowers bright blue.................. 10

1 I. Virgínica I. Boston IRIs. St. round, slender, few-flowered; lvs. linear, long; fls. beardless; ova. triangular, the side doubly groaved.-In similar situa. tions with the next, readily distinguished by its very slender habit. Mass. to $\mathrm{N}$. J. Rhizoma fleshy. Stem smooth, 1-2" in diam., 1-2f high, branching at top and bearing $2-6$ flowers. Bracts at the base of the branches withering. Leaves few, alternate, grass-like, 6-10' long, amplexicaul. Sepals narrow, yellow, edged with purple. Petals linear-lanceolate. Jn. (I. prismatica Ph.)

2 I. versícolor L. Common Blue Frag. St. terete, flexuous; 1rs. ensiform; fls. bcardless; petals as long as the stigmas; ova. triangular, with concave sides and roundish angles.-Wet grounds, U. S. and Can. Rhizoma large, horizontal, acrid. Stem 2-3f high, acute on one side, often branched, bearing several large, showy flowers. Leaves a foot long, $\frac{1}{2}-1^{\prime}$ wide, erect, sheathing at base. Sepals spatulate, purple, the claw variegated with green, yellow and white, with purple lines. Petals erect, paler, a little shorter than the stigmas. Style short, bearing 3-petaloid stigmas which are bifid at the end, purple or violet, concealing tho stamens beneath. Anther oblong; seeds flat. Jn.

3 I. hexágona Wait. Six-ANGLed InIs. Lvs. sword-shaped, longer than the terete, flexuous stem; spathe I-flowered; sep. spatulate, rounded at end, crenulate, reflexed, much larger than the oblong-spatulato petals, with a longitudinal, glandular-yellow lino; filam. dilated, linear; stig, deeply 2-cleft; ova. with 3 deeply furrowed angles, caps. 6-angled.-Swamps and pools, N. Car. to Fla. and Ala., frequent. St. $2 \mathrm{f}$ high. Fls bright blue, the sepals variegated with purple, yellow and white. Apr.-Jn.

4 I. tripétala Walt. TineE-PETALEd IRIS. Lvs. linear-ensiform, shorter than the terete, slender stem; spathe lanceolate, 1-flowered; sep. longer than tube, beardless and nearly crestless, many times longer than the rudimentary, 3-toothed petals; stig. 2-toothed near the base; caps. obscurely 3-angled, acuminate.-Ponds S. Car. and Ga. (Bachman). Rare. St. about $2 \mathrm{f}$ high, from a creeping rlizome. Fls. purple. Tho petals mero rudiments, much shorter than the stigmas. Apr. May.

5 I. cùprea $\mathrm{Ph}$. St. tall, flexuous, angled on one side; lvs. broad-ensiform, as long as the stem; spathe often 2-flowered; sep. obovate, emarginate, larger than the petals, all reflexed; stig. linear, dilated at base, half as long as the petals; caps. sharply 6-angled, ventricous.-In river swamps, Ga. to La. (Hale). Sts. 3f high, 4 to 10-flowered. Perianth tawny (Elliott), of a beautiful copper color veined with purple-(Pursh), limb spreading 3'. Apr., May. (Ell.), Jl. (Ph.)

6 I. sambucina L. Flower-DE-Luce. Fr. Fleur-DE-LIS. St. many-flowered, longer than the leaves; segm. of the perianth emarginate, outer ones flat; lvs. bent inwards at the point; spathe membranaceous at the apex; fls, bearded, lower ones pedunculate; stig. with acute, serrate divisions.-Nativo of the south of Europe. Common in gardens. The prevailing color of the flower is light blue, often fading to white. May. $\nmid$

7 I. cristàta Ait. Crested IrIs. Ivs. lanceolate-ensiform, as long as the low, compressed scape; tube of the perianth very slender (2' long), exceeding the spathe or the segments; sep. oblong, obtuse, entire, each with a triple, wavy, longitudinal crest or fold justead of a beard, and equaling tho narrower petals; ova. acutely 3 - 
angled.-Pine barrens, Mid. Ga. and S. Car. (Bachman). St. and lvs. 3 to 5', high. Fls. blue, the sepals in the middle yellow. Feb., Mar.

8 I. lacustris Nutt. Northern LAKE IRIS. Lvs. ensiform, longer than the low, oompressed, 1-flowered scape; seg. of the perianth nearly equal, obtuse, cmarginate, the sepals scarcely crested, as long as the slender tube; caps. turbinate, 3 -sided, margined.-Islands of Lake Huron, near Mackinaw, Nuttall. Roots extensively creeping. Leaves $2-5^{\prime}$ by $3-4^{\prime \prime}$, those of the scape bract-like. Scapo 1 to $2^{\prime}$ high. Fls. pale bluo, the sepals rather broader. Jn.

9 I. vernata L. Vernal IRIS. Lvs. linear-ensiform, rigid, rather longer than the luw, 1-flowered scape; tube of the perianth filiform ( $2^{\prime}$ long), about equaling tho length of the segm.; sep. and petals nearly equal, oblong-obovate, obtuse, neither crested nor bearded, stig. deeply bifid.-Hilly woods of the interior S. States. St. or scape 3 to $5^{\prime}$ high, sheathed with colored bracts. Fls. palo bluc, the sepals with an oblong, or orange yellow, spottod stripe. Mar., Apr.

10 I. pumila L. Dwarf Iris. Scape very short (3 to 6'), 1-flowered; spathe shorter than the tube; sep. reflexed, narrower than the erect petals. $-\Lambda$ small species from Hungary, cultivated in tho edgings of walks. Lvs. numerous, broad ensiform, suberect. Fls. large, deep purple, appearing in early spring. $†$

2. NEMAS'TYLIS, Nutt. (Gr. $\nu \eta \dot{\eta} \mu$, thread, $\sigma \tau \tilde{v} \lambda o s$, stylc.) Spathe 2-leaved; perianth segments distinct down to the top of the ovary, the sepals spreading, larger than the ascending, concave petals; stamens 3 , filaments shorter than the anthers; style slender, enlarged and 3-cleft above ; capsule oblong-cylindric.-Stem very slender, with linear-ensiform lvs. from a bulb. Spathe 2-flowered.

N. gemmiflòra Nutt. Swamps along rivers, La. (Hale.) A pretty flower 15 to $20^{\prime}$ high, lvs. same length, 3 to $5^{\prime \prime}$ wide, tapering at each end. Fls. on pedicels shorter than the spathe, the sepals $I^{\prime}$ long, obovate-spatulate, bluish-purple, tho azuro petals about half as large.

3. TIGRID'IA, L. TIGER-FLower. (Lat. tigridis, of the tiger; sc. in colors.) Spathe 2-leaved; perianth regular, the 3 scpals larger than the 3 petals; stam. monadelphous, fil. united into a long tubc.-Bulbous.

T. pavònia L. St. simple, flexuous; lvs. ensiform, veined; segm. flat; petals panduriform.-A superb plant of tho gardens. St. $2 \mathrm{f}$ high, crect, terete, leafy, branching. Lvs. erect, a foot long. Flowers inodorous, 5 to $6^{\prime}$ broad, yellow, variegated with scarlet, crimson and purple. It is very cvanescent, lasts but a few hours, but a new one appears daily for several weeks. † Mexico.

4. SISYRINCHIUM, L. Blue-eyed Grass. (Gr. oṽ $s$, a hog, and

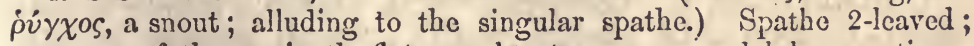
segments of the perianth flat, equal; stamens monadelphous; stigma 3-cleft. - 2f Grass-like plants, with compressed, winged or ancipital scapes, from fibrous roots.

1 S. Bermudianum L. Scape simple, winged; valves of the spatho unequal, the longer scarcely equaling the flowers; petals mucronate.-A delicato little plant, with blue flowers, common in low grass lands, Can. and U. S. St. or scapo 10 to $12^{\prime}$ high, so winged as to resemblo the leaves, smooth and mostly simple. Lrs. linear, about as long as the scape, sheathing at base. Spatho 2 to 5 -flowered, tho longer valve acuminate. Fls. purplo or blue, on filiform pedicels. Sepals a littlo broader than the petals, spreading. Cap. globous. Jn., Jl. (S. anceps. Cav.) $\beta$. АLBA. Flowers white. - Wet prairies, \&c.

2 S. mucronàtum $\mathrm{Mx}$. Scapo simple, filiform, barely 2.edged; spathe colored, outer valve longer than the fls., ending in a long, mucronate point.- - vid. States, W. to Iowa, common in wet prairies, whero the grass is not luxuriant. Lrs. rad. ical, a line wide. Scape 6 to $10^{\prime}$ high, narrowly winged, setaceously slender. Spathe 3 to 4-flowered, tinged with purple. Fls. smaller than in the preceding, of a fine blue color. Jn.-Appears very distinct from the other. 


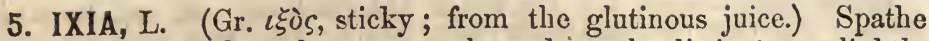
of 2 or 3 ovate, short bracts; petals and sepals distinct or slightly united, similar, regular, spreading, tube straight, adherent; stamens 3 ; filaments and style filiform, straight, often connate; ovary 3-celled.-A large genus, chiefly from S. Africa. Lvs. ensiform.

1 I. celestina Bartram. Lvs. linear-subulate, many times shorter than the 1flowered scape (Linn. Ell.). - Borders of swamps, Ga. and Fla. (Bartram); rare.We have a single flower without stem, lvs. or fruit, gathered in E. Fla. by Prof. Loomis, and sent us by Dr. Feay. It is of a bright purplish blue, spreading $2 \frac{1}{2}^{\prime}$. Segm. about equal, oval, obtnse, united into a tube $4^{\prime \prime}$ in length. Stamens and style apparently distinct, $6^{\prime \prime}$ long.

2 I. (PARDANTHUS) Chinensis L. Lvs. ensiform, vertical, sheathing shorter than the tall, terete, flexuous stem; panicle somewhat dichotomous and corymbous; perianth broad-campanulate, segm. 'distinct down to the top of the ovary, oblong, twisting after flowering; capsule ovoid, the valves deciduous, seeds black, roundish, shining, attached to the central column, and resembling a large blackberry.-Plentifully naturalized on the bluffs at Merom, Ind. St. 3f high. Fls. orange, spotted. Jn. $\uparrow \S$

6. CRO'CUS, L. (Named from the youth Crocus, who according to Grecian mythology, was changed into this flower.) Perianth funnelform, the segments united at base into a long and slender tube; stigma 3 -cleft, convolute, crested. - Spathe radical, 1-2-leaved, thin, transparent. The long tube of the flower nearly or quite sessile upon the bulb. After flowering, the ovary arises from the ground by the growth of the scape, to ripen its seeds in the sun.

1 C. sativus L. SAFrron. FALL Crocus. Lrs. linear, revolute at the margins; stig. 3-parted, as long as the corolla, reflexed. Leaves radical, with a longitudinal, white furrow above. Flower with a long, white tube, and purple, elliptical segments. Stigmas long, emarginate, exsert, of a deep orange-color. Its virtues, both medicinal and coloring, reside chiefly in the large stigmas. Sept.$\Lambda$ variety, perhaps the most common, has yellow perianths. $\ddagger$ Asia.

2 C. vernus L. Spring Crocus. Stig. included within the flower, with 3 short, wedge-shaped segments.-Scape an inch or two high, 3-sided. Flowers vary in color, generally purple, often yellow or white; tube very long, slender, gradually enlarged upwards, closed at the mouth with a circle of hairs, limb campanulate, much shorter than the tube. Antl. Jellow, sagittate. Mar., Apr. † Eur.

7. GLADIOLUS, L. Corn-FLAG. (Lat. gladius, a sword; in reference to the form of the leaves.) Spathe 2-leaved; perianth irregular, 6-parted, somewhat 2-lipped ; stamens 3, distinet, ascending ; stigmas 3 , broader above; seeds winged.-A large genus of bulbous plants, none native. Fls. showy.

G. communis L. Spike unilateral; upper petal the (upper lip) covered by the lateral sepals, the lower sepals largest; tube longer than the ovary.-A fine showy flowerer in gardens. St. 2 to $3 \mathrm{f}$ high, with the large, rosy purple fls. arranged in a long, somewhat spiral row upon it. The 3 lower segments aro marked by $a$ white stripe. Color variable. $+\mathrm{S}$. Europe.

\section{Order CXLIV. DIOSCOREACEA. Yam Roots.}

Plants shrubby, twining, arising from the tuberous rhizomes, with broad net-veined leaves. Flowers diœcious, regular, hexandrous, tube adherent, limb 6-parted. Ovary 3-celled, 3 to 6-ovuled, 3-styled. of Stamens 6, perigynous. Fruit a capsule 3 or (by a'ortion) 1-celled, or a berry. Seeds compressed, albuminous. 
Genera 7, species 150.-The only remarkable or useful product of this order is $Y a m s$, an important article of fond in all tropical countries. They are the large, mucilaginous, sweetish tubers of Dioscorea sativa, dic.

8. DIOSCO'REA, L. Yam Root. (In honor of Pedacius Dioscorides, a Greek physician and florist of about the reign of Nero.) Flowers $\hat{o}$ q; styles of the fertile flowers 3 ; cells of the capsule 2-sceded; seeds membranaceously margined.-Slender, shrubby climbers, twining with the sun. Lvs. simple and palmately veined or palmately divided. Fls. green, inconspicuous, in axillary spikes or panicles.

I D. villòsa I. WILD YAMr. Lrs. broad-ovate, cordate, acuminate, 9-11-veined, the margin entire or wavy, lower surface downy or glabrous, never villous; upper surface glabrous; petioles elongated, the lowest somewhat verticillate in $4 \mathrm{~s}$, the next subopposite, the middle and upper alternate; $\hat{o}$ plant with the spikes paniculate, $q$ with the spikes simple. - A delicate twining vine, in thickets and hedges, U. S. and Can., rare in N. Eng. Stem woolly, reddish-brown, 1-2" diam., 5-10-15f long, running over bushes and fences. Leaves 2-4' long, $\frac{3}{4}$ as wide, distinctly cordate and acuminate. Petioles $2-4^{\prime}$ long. Peduncles axillary. Ovaries at first elliptic, finally almost as broad as long. June, July. (D. quarternata $\mathrm{Ph}$. )

2 D. satìva L. YAsr. Lrs. alternate, roundish-ovate, long-cuspidate, sinuate-cordate, glabrous, 9 to 13 -nerved, outer nerves bifid, transverse reins simplo; st. terete, smooth ; $\hat{o}$ spikes densely paniculate; $f$ spikes aggregate. Var. ACULEATA, stems aculeate.-Native of E. India. This species, with its varieties, is understood to be that which is known as the Sweet Yam, cultivated in Ga. and Fla., and all tropical countries, on account of its sweet and nutritious tubers. $\ddagger$

\section{Order CXLV. SMILACEA. Sarsaparillas.}

Herbs or shrubs, often climbing. Leaves reticulate-reined. Flowers diccious cr monœcious. Perianth free from the ovary, 6-parted, regular. Stamens 6, inserted into the base of the segments. Anth. 1-celled (2-lameilate). Ovary 3-celled; cells 1 or many-seeded. Style 1 or none. Stigmas 3. Berry roundish, few or many-seeded. Seeds orthotropous albuminous. Fig. 586.

Genera 2, species 120 , thinly disseminated through most countries. The dinretio and emulcent sarsaparillas are the roots of several, chiefly S. American species of smilax.

SMI'LAX, L. Green Brier. Sarsaparilla. (Gr. $\sigma \mu i \lambda \eta$, a grater; from its prickly stems.). Flowers of $q$, perianth deciduous, of 6 similar, spreading, sepaloid segments; of stamens 6 , on the base of the segments and shorter than they; anthers adnate; $q$ stamen 0 , or sterile filaments; stigmas 3, sessile; berry globular, 1 to 3 -celled, 1 to 6 seeded.-24 Herbs or shrubs, mostly climbing by stipular tendrils, often prickly. Lvs. entire, petiolate, palmately veined. Fls. green or yellowish, in axillary, stalked umbels. (In the elaboration of this genus we have been greatly aided by the accurate observations of Dr. Feay, of Savannah.)

§ Coprosmantuus. Herbaceous (unarmed). Leaves long-petioled. Flowers fatid. (*)

* Leaves glabrous on both sides. Stems climbing...................... Nos. 14, 15

* Leaves downy or hispid on the veins beneath. Erect or elimbing.................... 12, 13

5 Smilax proper. Shrubby, armed or not. Leaves short-petioled, Seeds 1 to 3 . (*)

* Pubescent, prostrate, unarmed. Leaves cordate, evergreen. South.................. 11

* Glabrous, climbing. Leaves acute at base. Peduncle sliorter than petiole....... Nos. 9, I0

* Glabrnus, climbing. Leaves abrupt or cordate at base. (a)

a Leaves panduriform or somewhat contracted in the middle............. Nos, 7,8

a Leaves ovate or oblong, deciduous. (b)

b Plants unarmed........................................... 5,6

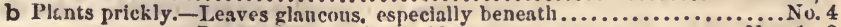
- Leaves green on both sides................................. 1-3

1 s. rotundifòlia L. CommoN GREen Brier. St. tereto or sub-4-sided, flexuous, aculeate, ligneous, climbing; lvs. short-petiolate, roundish-ovate, 5 to 7 -veined, 
glabrous, round or subcordate at base ; acuminate-cuspidate at apex; ped. many. flowered, little longer than the petioles; berries black, glaucous.-A strong, thorny vine, extending 10 to $40 \mathrm{f}$ in hedges and thickets, U. S. and Can. St. woody, smooth, except the scattered thorns which proceed from tho wood. Branches 4-angled. Lvs. 2 to $3^{\prime}$ by $1 \frac{1}{2}$ to $3^{\prime}$, cordate or tapering at base. Tendrils strong, from the wings of the petioles. Fls. small, greenish, in small, axillary umbels. Berries round, mostly 1-seeded. Mar.-Jn.

. CADUCA. Smaller, with ovate, thin lvs. (S. caduca I.)

$\gamma$. QUADRANGuLìis. Branches 4-angled. (S. quadrangularis Muhl.)

2 s. híspida Muhl. St. terete, climbing, hispid below with weak, slender prickles, nearly unarmed above; branchlets quadrangular; lvs. glabrous, green both sides, ovate, subcordate, cuspidate, rough-edged, 5-veined, thin, deciduous; ped. twice as long as the petioles; berries black, 1 to 3-seeded.-Thickets, N. Y. to Mich. and Can. Climbing 8 to 12 f. Lvs. 2 to $3^{\prime}$ long, rather broadly ovate. Ped. $1^{\prime}$ or more in length. Umbels 4 to 6-flowered. Jn.

$3 \mathbf{S}$. Wálteri $\mathrm{Ph}$. St. armed or unarmed, with angular branches; lvs. cordateovate, 3-veined (or 5-veined, tho 2 outer inconspicuous), glabrous; ped. about as long as the petioles; berries of two forms, globular, and oblong-acuminate, red, 1 to 3 -seeded. - Woods, in the low districts, Va. to Fla. Straggling stems climbing in thickets. Lvs. deciduous, large (3 to $5^{\prime}$ long), more or less cordate. Fls. fragrant. Apr.-Jn. (S. China Walt.)

4 S. glaùca Walt. False Sarsaparilla. St. slightly 4-angled and aculeato above; lvs. ovate, cuspidate, 5-veined, edges smooth and entire, glaucous, especially beneath; ped. twice or more longer than the petiole; berries black, with a bloom, 1-3-seeded.-Thickets, L. Isl. to Ga., W. to Ky. Root long, slender. St. stout, somewhat flexuous, armed with a few scattered, hooked prickles. Lvs. finally nearly orbicular, 2 to $3^{\prime}$ diam., abruptly contracted at each end, with 3 strong veins and 2 lateral smaller ones. Petioles short, margined with 2 tendrils. Fls. in small, thin umbels, yellowish-white. Mar.-Jn. (S. Sarsaparilla Ph., etc., nec L. S. spinulosa Torr.)

5 S. Pseudo-China L. St. terete, unarmed; cauline lvs. ovate, cordate, ramial ovate-oblong, all 5.veined, on short petioles; ped. flat, nearly as long as the leaves; berries black. ?-Sandy woods, N. J. to Car., W. to Ohio. Root large, tuberous. St. purplish-brown, very smooth, branching and climbing by tendrils which ariso from the base of the petioles. Lvs. 2 to $4^{\prime}$ by 1 to $2^{\prime}$, slightly hispid on the reins beneath. Ped. 2 to $3^{\prime}$ long. May, Jn.

6 S. sarsaparílla L.? St. and quadrangular branchlets unarmed; lvs. oblongovate, thin, both sides green, 5-veined, cuspidate, rounded or subcordate at base; ped. flat, a little longer than the petioles; berries large, globular, mostly 1-seeded, bright pink-red when fully ripe.-River banks, N. J.? to Ky. and La. (Mr. R. Green). Rt. with long, creeping rhizomes. Vines with tendrils. Lrs. large, 3 to $6^{\prime}$ long, half as wide, deciduous. Ripe fruit persistent until Spring. Ped. 1 to $2^{\prime}$ long. Apr.-Jl.-This is regarded in La. as the true medicinal Sarsaparilla.

7 S. tamnoides I. St. terete, branches and branchlets 4-angular, flexuous, aculeate; lvs. glabrous, ovate with the sides more or less concave, varying to hastate or panduriform, acuminate, spinulous-scabrous on the margin, truncate or subcordate at base, 5 to 9-veined; ped. 2 to 3 times longer than petiole; berries spherical, black, 1-seeded.-Sandy woods, N. J. to Ill. and the S. States, common, climbing 8 to $20 \mathrm{f}$. Lvs. of various forms on different stems of the same root, shining-green both sides, tardily deciduous, or sometimes, in sheltered situations, persistent all winter. Mar., Apr.-Jn. (S. panduratus, hastata, Bonanox. Ph. et auct.)

8 S. marítima Feay. St. armed; branches angular, flexuous, unarmed; lvs. lanceolate, auriculate-hastate, coriaceous, 5-nerved at base, 3-nerved above, cuspidate, glabrous, edges smooth and even; ped. twice longer than the petiole, or shorter; berries large, 2 or 3-seeded, red before maturity, finally black.-Sandy bluffs of the salt-water rivers near the coast, Savannah and southward.' Lvs. rarely somewhat ovate. Fls. very fragrant. Jn. (S. Beyrichii Kunth? S. ovata Ph. Tho latter name, although the earliest, is utterly inappropriate.)

9 S. laurifòlia L St. aculeate, terete, branches flexuous, unarmed; lvs. coria 
ceous, oval-lanceolate or oblong, varying to linear, 3 to 5-veined (the lateral veins marginal), cuspidate, acute at base, evergreen; petioles and ped. short, the latter sometimes panicled; berries black, ]-seeded.-N. J. to Ga. A vigorous, evergreen ciimber, ascending trees to a great height. St. with a few scattered prickles. Lvs. numerous, very thick and smooth, 2 to $4^{\prime}$ long, often more abrupt at apex than base. Jn.-Aug.

10 S. lanceolàta I. St. aculeate below, terete, branches and unarmed branchlets subangular, lvs. membranous, lanceolate and lance-orate, varying to ovate (in the of plants), 5-veined, acuminate-cuspidate, narrowed at base to a short petiolo which is twice longer than the very short peduncle; berries 1 to 3 -seeded, red until ripe when they are also perfectly black.-Damp woods coastward, Va. to Fla. $\Lambda$ stout vine, often $1^{\prime}$ diam. and $40 \mathrm{f}$ high on trees. Lrs. 2 to $4^{\prime}$ long, a third to two-thirds as wide, ped. 1 to $5^{\prime \prime}$ long, 10 to 20 -flowered. Jn., Jl. (S. alba Ph). Closely related to No.' 9 .

11 S. púmila Walt. Unarmed, low; branchlets terete, pubescent; Ivs. ovate, cordate, acutish, 3 to 5 -veined, slining above, soft pubescent beneath; ped. as long as the petiole; berries red, 1 to 3 -seeded.-Shady rich soils, S. Car. to Fla. and La. Quite different in habit from our other species. St. 1 to $3 \mathrm{f}$ long, running along on the ground. Lvs. perennial, becoming firm, 2 or $3^{\prime}$ long, varying from oblong-ovate to roundish-ovate, always cordate. Ped. 6 to $8^{\prime \prime}$ long, with small, white flowers and berries red when ripj. Oct. (S. pubera Mx.)

12 S. herbàcea I. CARRION FLOwEr. St. herbaceous, terete, erect, simple, glabrous; lvs. pubescent beneath, crowded toward the summit, ovate, 5 to 7 -veined, cuspidate, rounded or subcordate at base, on petioles a third as long; ped. not twice longer than the petioles; berries red, becoming bluish-black when fully ripe, 2 to 3 -seeded.-Thickets and low grounds, Can. and U. S. St. 2 to 3 f high, without tendrils. Lvs. 3 to $5^{\prime}$ long, two-thirds as wide, more or less downy beneath. Ped. 2 to $3^{\prime}$ long, with an umbel of 8 to 16 yellowish-green flowers of a sickening odor. $\Lambda \mathrm{pr}$.-Jn.

13 S. lasioneùron Hook. St. terete, climbing, subsimple, unarmed; lvs. oblong; broadly-ovate, cordate, rounded and mucronate at apex, 7 -veined, glaucous and hispid-pubescent on the veinlets beneath, glabrous and green above; ped. a littlo longer than the petiole, many-flowered; tendrils from the base of tho petioles. Thickets, Ind., Ill., Wis. and Can. Sts. slender, several fect long. Ped. much shorter than the leaves, which are often $5^{\prime}$ by 3 ', beautifully fringed on, the veins beneath.

14 5. pedunculàris Muhl. TALL Carrion Flower. St. herbaceous, angular, tall, striate, inclining or leaning, branched; leaves 7 to 9-veined, orate, acuminate, glabrous, glaucous, especially beneath, rounded or subcordate at base, the lower subtriangular, petioles a third as long, bearing 2 filiform tendrils at base; ped. much longer than the leaves, $\infty$-flowered; berries red, at last bluo 6-seeded.Damp thickets and meadows, Can. and U.S. St. 3 to 6 to $E$ f long, its slender summit nodding or climbing. Lrs. 2 to $4^{\prime}$ long. Ped. 5 to $6^{\prime}$ long, 30 to 50 flowered, greenish, with a disgusting odor. May, Jn.

15 S. tamnifòlia Mx. St. herbaceous, terete, climbing; lvs. long-petioled, 5Yeined, glabrous, subtriangular-hastate, cordate, tapering to tho obtuso apex, baso lobes rounded, upper lvs. lanceolate; ped. longer than the petioles; (berries bluishblack, Dr. Gray).-N. J. to Car. (Michaux.) (S. tamnoides Ph.)

\section{Order CXLVI. ROXBURGHLACEF.}

Shrubby plants with twining or creeping stems and many-veined, netted leaves. Flowers perfect with a 4-parted, petaloid, persistent perianth. Stamens 4, on the lowest base of tho segments. Ovary free, obliquc, 1-celled. Pericarp follicular ? at length 2-valved. Seeds several, costate, fimbriatc-arillate.

$\Lambda$ small Order, of 2 genera (now that Croomia is added) and 5 species, Roxburghia grows in the hotter parts of E. India.

CROOM'IA, Torr. (In honor of the late II. B. Croom of Florida.)- 
Perianth of 4 oral segments, imbricated in 2 rows (2 interior); stam. 4 , opposite the segments, slightly perigynous, anth. introrse, innate, cells distinct; ovary 1-celled, with 4-6 suspended ovules; stigma sessile; fruit ovate, "seeds $1-3$, copiously fringed along the raphe and funiculus as if arillate, and ribbed lengthwise; embryo monocotyledonous." - 2 Rhizome slender, creeping, sending up annual stems with about 6 petiolate, lance-ovate, cordate leaves, and a few small whitish, axillary flowers.

C. pauciflora Torr.-S. Ga. (Feay, Pond) and Fla. (near Quincey !) Stems glabrous, If high, bearing at top 6 leaves pedately arranged. Lvs. 3-4' long, short acuminate, thin, 7-9-veined, pet. $I^{\prime}$ long. Peduncles capillary, $1^{\prime}$ long. Fls. few, near 2" wide when open. Apr.-The true character of this plant as monocotyledonous was first demonstrated by Dr. Gray.

\section{Order CXlviI. TrilliacEA. Trilliads.}

Herbs with simple stems, tuberous roots and verticillate, net-veined leaves. Flowers terminal, 1 or few, perfect, mostly 3-parted. Calyx lierbaceous, corolla more or less colored. Slamens 6 to 10 . Ovary free, 3 to 5 -celled, bearing in fruit a juicy, $\infty$-seeded pod. Figs. 356, 53, 88.

Genera 4, species 30, in woodlands, temperato parts of Europo, Asia and N. America. The roots of some species are emetic.

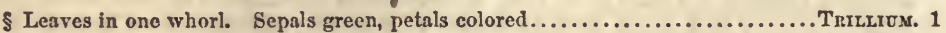

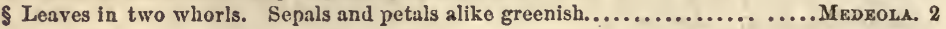

1. TRIL'LIUM, Miller. WaKe-RoBin. (Lat. trilix, triple; every part being in $3 \mathrm{~s}$.$) Perianth deeply 6$-parted, in 2 distinct series, outer of 3 sepals, inner of 3 colored petals; stamens 6 , nearly equal, anthers longer than the filaments; stigmas sessile, distinct or approximate; berry 3celled, cells many-seeded.-2f St. simple. Lrs. 3, whorled at the top of the stem, reticulate-palmate veined. Fls. solitary, terminal. Fr. purple

Flowers sessile, petals dark purple, ereet...................................... 1, 2

$\$$ Flowers on a peduncle raised above the leaves. $(*)$

* Leaves petiolate, ovate, rounded at the base. Petals thin, delicate..............Nos. 3, 4

* Leaves sessile, rhomboidal, nearly as broad is long. Petals thickish.................... 6

$\$$ Flowers on a peduncle deflexed beneath the leaves. - Style scarcely any................... 7 , 8

-Style 1, as long as stigmas.............. 9

1 T. séssile I. Lvs. rhombic-ovate, or suborbicular, acute, sessile, spotted; $\mathrm{fl}$. closely sessile, erect; sep. erect, ovate-lanceolate or lanceolate, acute; pet. linearlanceolate, purple, a third longer than the sepals; anth. long, erect.-A small species, in fertile soils, Middle, Western and Southern States. Rhizoma horizontal, thick. Stem 6-12' high, slender. Leaves rather thick, $1 \frac{1}{2}-3^{\prime}$ by $1-2$ ', smooth and entire, blotched with dark purple. Sep. 8 to $12^{\prime \prime}$ long, the petals narrower and mnch longer, dark purplo. Apr. May. (T. discolor Wray.)

2 T. recurvàtum Beck. Lvs, ovate or obovate, attenuated to a petiole, acute; $\mathrm{fl}$. closely sessile; pet. lanceolate-ovate, very acute, attenuate at base, erect, as long as the recurved sepals. - A small Trillium quite distinct, although allied to the last, in shady woods, Wis. to La. Stem $8-10^{\prime}$ high, rather thick. Leaves $2-2 \frac{1^{\prime}}{2}$ by $1 \frac{1}{2}-2$ ', with distinct, short petioles, not usually spotted. Petals purple, and with the green, reflexed sepals about $1^{\prime}$ long. May.

3 T. nivàle Riddell. SNowy TriLlium. St. low; lvs. ovate or oval, rather obtuse, distinctly and abruptly petiolate; fl. short, pedunculate, erect; pet. spatulate. obovate, obtuse, white, one third longer than the calyx.-The smallest species here described, in stony or dry fields, Ohio to Wis. Stem 2-4' high, from a thick. 
tuberous root. Leaves $8-18^{\prime \prime}$ by $5-12^{\prime \prime}$, petioles $2-4^{\prime \prime}$, about equaling the peduncle. Sepals green, much narrower than the snowy petals which are about $8^{\prime \prime}$ by $4^{\prime \prime}$. Mar., Apr.

4 T. erythrocarpum Mx. SMImING WAKE-RoBIN. Lvs. ovate, acuminate, rounded at base, abruptly petioled; ped. erect; pet. lanceolate-ovate, recurved, twice as long as the sepals-Can. to Ga. A beautiful flower, adorning our woods in Mray and June. Stem 8-12' ligh, with a whorl of 3 broad-ovate leaves at top. These are 3-veined, rounded at base, long acuminate, $3-4^{\prime}$ long, $\frac{2}{3}$ as wide, petiole $2-3$ " long. Flower nearly erect. Petals wavy at the edges, white, finely radiated with purple lines at base. The root is considered medicinal. (T. pictum $\mathrm{Ph}$.)

B. CLEvELAindicum. Sepals leaf-like, larger than the petals which are partly or chiefly green.-Brunswick, Me. (Ricard). A metamorphosis.

5 T. grandifòlium Salisb. Lvs. broadly rhomboid-ovate, subsessile, abruptly acuminate; ped. inclined; $\mathrm{f}$. suberect; petals mvch longer than the calyx, spatulate-obovate, connivent at base.-Damp, rocky woods, Mid., S. and W. States, abundant. St. 8 to $12^{\prime}$ high. Lvs. 3 to $5^{\prime}$ diam. Fls. larger than in any of the preceding species. Petals $1 \frac{1}{2}$ to $2^{\prime}$ in length, broadest near the apex, with a short, abrupt acumination, white, varying to rose-colored. May.

6 T. erectum L. BATI FrowER. St. thick; lvs. rhomboidal, acuminate, sessile; ped. inclining; $f$. nodding; petals ovate, acute, scarcely longer, but much broader than the sepals.-A conspicuous plant in woods, of fine appearance, but offensive odor. At the top of the stem, which is a foot high, is a whorl of 3 leaves which are 3-veined, $3-5^{\prime}$ long, of equal width, and a single, nodding flower, on a nearly erect peduncle. Petals broad-ovate, an inch long, twice as wide as the sepals and of a dusky purple, greenish outside. May. (T. atropurpureum Curt.)

$\beta$. ALBA. Petals white or cream-color.-More common West and South.

7 T. pénduium Muhl. St. slender; lvs. subsessile, roundish-rhomboidal, acumi. nate; ped. long, horizontal or deflexed, flower pendulous; petals lance-ovate, shortacuminate, flat, not recurved, nearly as small as the calyx; stig. as long as the anthers, revolute at end.-Woods, Mid., W. and S. States. A large species, with a smallish flower. St. 10 to $15^{\prime}$ high. Lvs. 3 to $5^{\prime}$ diam., similarly pointed at each end. Ped. nearly twice the length of the flower, half the length of the leaves. Petals white. Apr.-Jn. (T. cernuum Torr. N. Y. Flo.)-Perhaps runs into T. erectum, but is very distinct from the next.

8 T. cérnuum I. Droopixg Triliuum. St. tall, slender; lvs. thin, ovate or elliptic-ovate, acuminate, petiolate; ped. decurved beneath the leaves, as long as the flower; petals lanceolate, channeled, undulate, recurved, longer and much wider than the recurved sepals; stam. recurved, much longer than the stigmas.-Damp woods, N. Eng. ? N. Y. to Ky. and the up country of Ga. St. 1 to $2 \mathrm{f}$ high. Lvs. 3 to $6^{\prime}$ by 2 to $4^{\prime}$, distinctly petioled. Ped. a third as long as the leaves. Petals near $2^{\prime}$ long, delicate, white or roseate. Apr.-Jn.

9 T. stylosum. St. slender; lvs. elliptic-ovate, pointed at both ends, short-petiolate; ped. shorter than the flower, nodding and deflexed; petals lance-obovate, obtuse or short pointed, undulate, flat, spreading, much exceeding the oblong, acute sepals; ova. produced into a style which is as long as the stigmas; stam. clongated.-Woods, in the up country of N. Car. (Miss Carpenter) to Ga. (Mr. Jones). A small plant with a large flower. St. 8 to $10^{\prime}$ high. Lvs. 2 to $3^{\prime}$ by 20 to $30^{\prime \prime}$. Petals roseate, 15 to $18^{\prime \prime}$ long. Apr.-Jn. (T. Catesbæi Ell.)

\section{MEDE'OLA, Gronov. Indian Cucumber-root. (Named after} the fabulous sorceress, Medea, for its supposed medicinal virtues.) Perianth deeply parted into 6 petaloid, revoluto segments; stamens 6 , with slender filaments; stigmas 3 , divaricate, united at base; berry 3celled; cells 3 to 6 -seeded. Stem simple, arising from a white, tuberous rhizome (which is thought to resemble the cucumber in flavor) bearing 2 whorls of lvs. and 1 to 3 terminal fls.

M. Virgínica L. None can but admire the symmetry of its form. St. erect, 1 to if high, invested with loose, cottony wool. Lower whorl near the middle of the 
stem, consisting of 6 to 8 wedge-lanceolato lvs. ( 3 to $4^{\prime}$ by 9 to $\left.12^{\prime \prime}\right)$; the other at the lop, of about 3 ovate, shorter leaves. FIs. in the upper whorl, 1, 2 or 3 , pendulous, with greenish, revolute segments. The stigmas are very long, reflexed, dark red. Jl.

\section{Order CXLViII. LILIACEA. Lilyworts.}

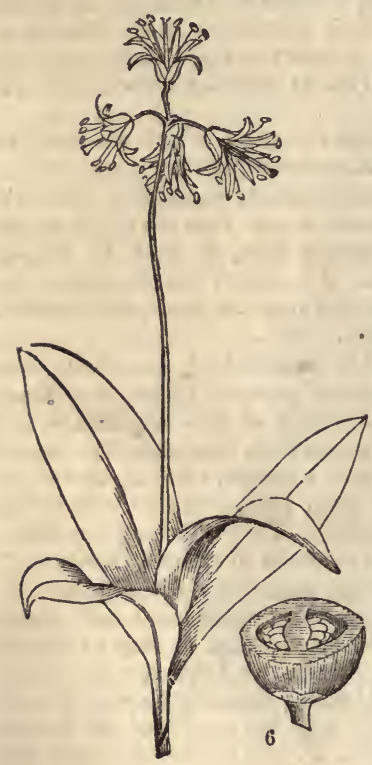

Ilerbs with bulbous or tuberous stems, parallelveined, sessile leaves, flowers perfect, regular, generally large and richly colored, perianth 6 (rarely 4)-parted, uniformly colored, free from tho ovary, stamens 6 (rarely 4), perigynous; anthers introrse (extrorso in Uvularia), styles wholly or partly united, ovary superior, 2 or 3-celled. Fruit a capsule, loculicidal, or a pulpy berry. Seeds free or many, with fleshy albumen. Illustr. in figs. 58, 60, 63, 108, 171, 254, 259, 400, 454.

Genera 147 , species 1200 , chlefly natives of temperate regions. The flowers of most are beautiful, of many brilliant, and of some truly splendid.

Properties.-The order abounds in a bitter, stimulant principle and slso in mucilage. Some of the bulbous species yjeld a nutritious diet, as the Asparagus, Onion, Garlic. The well known active medicine, squills, is the bulb of Scilla maritima, of S. Europe. The varions kinds of officinal aloes, are the product of several species of Aloe. The powerful astringent, Dragon's l, lood, is tho concentrated juice of Dracrena Draco of the Canary Isles. (The Tribe Uvularia is intermediate between Liliacero and Melanthaces, approaching the latter by its mostly extrose anthers, but best according with the former in its united styles, fruit, and in habit.)

FIG. 715. Smilacina boreallis. 6. $\Lambda$ berry cut open, showing tho 2 cells, \&c.

\section{TRIBES AXD GENERA.}

5 Plants bulbons at the base, or with a thiek, woody caudex. (*)

* Perianth segments unitecl, forming a tubular flower. (d)

* Perianth segments separate, not forming a tube. ( $\dagger$ )

+ Stem (or caudex) leafy, at least below, few or many-flowered. (b)

+ Stem (scape) sheathed at base, bearing a solitary flower. (a)

t Stem (seape) sheathed at base, leafless, many-flowered. (c)

$\delta$ Plant with a rlizome, creeper, or fibrous roots. (**)

** Stamens deelinate and curved-ascending. Flowers showy. (e)

** Stamens straight and equal in position. $(H)$

tt Perianth segments united to near tho summit. (f)

tt Perianth segments separate, not forining a tube. ( $\ddagger)$

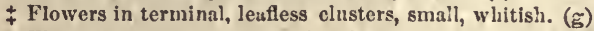

$\ddagger$ Flowers axillary, or terminal and subsolitary.-Leaves filiform, \&c. (h)

-Leaves ovate, \&c. (k)

(Tribe TULIPEA. Perianth 6-leaved. Fruit a capsule. Seed-coat soft and pale.)

a Flowers nodding.......................................... ERYTuroniUs. 1

a Flowers erect................................................ TULAP. ${ }_{2}^{2}$

b Nectary a linear groove at the base of each segment................... Liliva 3

b Nectary a roundish cavity at the base of each segment............... Fritrildaria. 4

b Nectary nonc. Flowers panicled,-large. Seeds many............... Y Ecca. 5

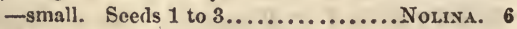

(Tribs ASPHODELE As. Frnit a capsule. Sced-coat crustaceous, black.)

c Flowers in racemes, blue or purple............................... Scrus. 7

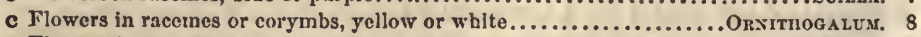

c Flowers in umbels, - white or roseate. Stamens straight...................uru. 9

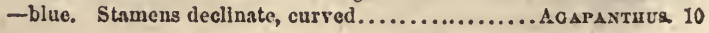


d Perianth limb revolute, as long as the tubo..................... Hracrerruts. 11

d Perianth limb spreading, much shorter than tube.................... Musoari. 12

e Perlanth segments distinet. Base of the stamens valve-like.... Aspioderus. 13

e Perlanth segments half-united.-Stamens perigy nous.......... Hrmzrocallir. 14

-Stamens hypogynous.............. Funkia. 15

(Triba CONVAllaRINEd. Rhizome. Fruit a berry. Seed-coat thin, pale.)

f Perianth tubular-oblong, greenish. Peduncles nxillary............. Polygoratur. 16

f Perianth broad-campanulate, white. Raceme leafless.................. Convallaria. 17

g Seape leafless, bearing an umbel. Berry 2-celled................... Chintonis. 18

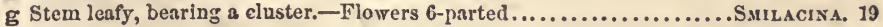

- Flowers 4-parted.................MAJantuesum. 20

h Stems branehing. Flowers small, axillary. Berry red...........Asparages. 21

(Tribe UVULARIEA. Root fbrous. Anthers mostly innate and opening outwards.)

k Filaments flat, as long as the sagittate anthers. Berry many-seeded...STrerpopirs. 22

k Filaments filiform, much longer than the anthers. Berry 3 to 6 -seeded...Prosartrs. 23

k Filaments shorter than the long, linear anthers. Capsule 6 to $\infty$-seeded..Uvuraria. 24

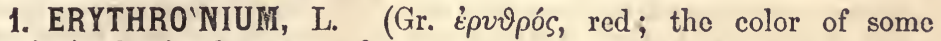
species.) Perianth campanulate, segments recurved, the 3 inner ones (petals) usually with a callous tooth attached to each side at base, and a groove in the middle; style long; capsule somewhat stipulate, seeds ovate.-2f Leaves 2, subradical. Scape 1-flowered. Fls. nodding, liliaceous.

1 E. Americànum Smith. Yellow Erythroniur. Scape naked; lvs. spotted, lanceolate and involute at the point; segments yellow, oblong-lanceolate, obtuse, inner ones bidentate near the base; sty. clavate; stig. undivided. $-\Lambda$ beautiful littlo plant, among the earliest of our vernal flowers, found in rich, open grounds, or in thin woods, U. S. and Can. The bulb is deep in the ground. Scape slender, 3$4^{\prime}$ high. The 2 leaves are of equal length $\left(5^{\prime}\right)$, ono of them nearly twice as wido as the other, both clouded with brown spots. Flower drooping, yellow, revolute in the sunshine. May. (E. Dens-canis Mx.)

2 E. álbidum Nutt. White Erytirronium. 'Scape naked; lvs. elliptic-lanceolate; segments of white, linear-lanceolate, rather obtuse, inner ones without dentures at base, subunguiculate; stig. 3-cleft, lobes reflexed.-About the size of the last, in wet meadows, near Albany, N. Y.(Storrs) to Wis. (Lapham). Leaves without an acumination, tapering to the base, of equal length including the petiole $\left(4-5^{\prime}\right)$, one of them twice as wide as the other. Scape a little longer than the leaves, bearing a single, white, nodding flower. Segments $11^{\prime}$ long. April, May.

3 E. bracteàtum BW. Scape bracted; lvs. lanceolate, very unequal; segm. greenish-yellow.-An alpine species, found in Vt., Boott. It is a smaller plant, distinguishable by the inequality of the leaves, one of which is 3 or 4 times as large as the other. Scape shorter than the leaves, with a narrow, lanceolate bract, $11^{\prime}$ long, a little below the flower. Flower greenish-yellow. Segments about $9^{\prime 4}$ long, gibbous at base. Jn.

2. TULIPA, Tourn. Tulip. (Persian thouliban, a turban; alluding to the form of these magnificent flowers.) Perianth campanulate ; stamens short, subulate; anthers broad-linear, deeply emarginate at base; style very short; stigma thick; capsule oblong, triangular.- $2 f$ Herbs acaulescent, with coated bulbs, sessile lvs., and a simple scape bearing a solitary, crect flower.

T. Gesneriàna L. Scape 1-flowered, smooth; lis. ovate-lanceolate; fls. erect, segments obtuse, smooth.-Named for Gesner, a Zurich botanist. Its varieties are endless, and may be produced by first planting the seed in a rich soil, then transplanting the bulbs into a poorer soil. Thus at length the flowers become broken or variegated with colors in that exquisite manner so much admired. More than 700 varieties are described in florists' catalogues. A pr., May, Jn. t From Persia.

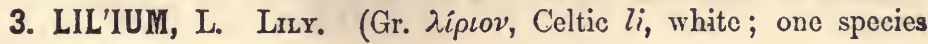


is the emblem of purity.) Perianth campanulate, segments spreading above or recurved, each with a longitudinal honey groove within, from the middle to the base; stamens shorter than the style, anthers versatile; capsule subtriangular, the valves connected with latticed hairs; seeds 2-rowed in each cell.-2 Herbs with bulbous and leafy stems. Lvs. sessile, alternate or verticillate. Fls. terminal, large and showy.

Flowers white, nolding. Plants cultivated............................. $8 . \ldots$, 9

Flowers orange-colored or red, spotted. $\left(^{*}\right)$

* Leaf-axles bearing bulblets. Leaves scattered.............................. 6, 7

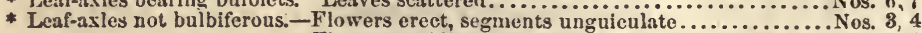
- Flowers nodding.-Lvs, 1-veined, oblanceolate........... No. 5 -Lvs. 3 to 5-veined, lanceolate.......... 1, 2

1 L. Canađénse L. Yellow LiLY. Lvs. 3-veined, mostly verticillate, lanceolate, the veins hairy beneath; ped. terminal, elongated, usually by $3 \mathrm{~s}$; $f$. nodding, the segments spreading, never revolute.-Can. and U.S. A plant of much beauty, frequently adorning our meadows in summer. Bulb scaly. Stem round, 2-4f high, surrounded by several remote whorls, each consisting of $4-6$ leaves, and often a few scattered ones at baso. These are $2-3^{\prime}$ by $\frac{1}{2}-1^{\prime}$. Flowers $1-3$, sometimes $7-20$, pendulous, yellow, or orange-colored, spotted with dark purplo inside. July.

2 I. supérbum L. StPerb Lilu. Turk's CAP. Lvs. linear-lanceolate, acuminate, 3-veined, glabrous, lower ones verticillate, upper ones scattered; fls. often in a pyramidal raceme, nodding, segments revolute-Can., Mid. and W. States. Few cultivated plants are more ornamental than this inhabitant of prairies and meadows. Root bearing a white, squamous bulb. (Fig. 60.) St. erect, round, straight, 4 to $6 \mathrm{f} \mathrm{high.} \mathrm{Lvs.} 2$ to $3^{\prime}$ by 4 to $9^{\prime \prime}$. Fls. 3 to 20 or more, of a bright orange color with purple spots. Sep. and pet. linear-lanceolate, beautifully and fully revolute. Very distinet, at least in appearance from the foregoing. Jl.

3 L. Philadélphicum L. Philadelpiria Lily. Lvs. linear-lanceolate, acute, 1-veined, upper verticillate, lower generally scattered; fls. subsolitary, campanulate, terminal, erect; pet. and sep. lance-ovate, obtuso or barely aeute, erectspreading, unguiculate.-Dry pastures, fields and barrens, U. S. and Can. An elegant and showy plant, 15 to $20^{\prime}$ high. St. terete, smooth, simple. Lvs. 2 to $3^{\prime}$ by 3 to $5^{\prime \prime}$, sessile, smooth, collected into 1,2 or 3 , or more whorls of $3 \mathrm{~s}$ to $5 \mathrm{~s}$, with the lower scattered. Fls. usually solitary, rarely 2 to 4 , and umbellate. Sep. and pet. deep orango color, spotted at base, $2 \frac{1}{2}^{\prime}$ long, standing apart on claws about $6^{\prime \prime}$ long. Jn.

4 L. Catesbài Walt. Cateser's Lily. Lvs. linear-lanceolato and linear-acuminate, all scattered, sep. and pet. undulate, long-unguiculate, ovate-lanceolate, tapering to a long, thickened acumination, which is reflexed above.-Damp pine barrens, Md. to Ky. and all the S. States. St. 18 to $30^{\prime}$ high, smooth and polished, often purple. Lrs. 1 to $2^{\prime}$ (the lower $3^{\prime}$ ), by 1 to $4^{\prime \prime}$, subereet, spreading. Sep. and pet. 3 to $4^{\prime}$ long, tho claws $I^{\prime}$ or more, yellow, tho lamina scarlet, spotted with red and purple. Jl., Aug.

5 I. Caroliniànum Mx. Lvs. 1-veined, oblanceolate, or spatulate, acuminate, tapering to a slender, sessile base, in whorls of about 5 , the lower scattered; flower inostly solitary, nodling; segm. lance-linear, recurved, tapering to a slender acuniination, midvein winged; stylo curved upwards.-A moro delicate species than tho last, $18^{\prime}$ to $3 \mathrm{f} \mathrm{high,} \mathrm{rarely} 3$-flowered. Lvs. $18^{\prime \prime}$ to $3^{\prime}$ by 9 to $16^{\prime \prime}$, membranous. Fls. deep yellow, spotted with purple, the segm. sirongly recurved, but not revolute. Jl., Aug.

6 L. bulbíferum L. ORANGe LILY. Lrs. scattered, 3-veined; fls. campanulate, erect, rough within, segm. sessile.-Gardens. St. thick, round, $4 \mathrm{f}$ high, bearing small, roundish, dark-colored bulbs in the axils of the leaves. Fls. large, orange-colored, resembling in form those of $L$. candidum, but are scabrous within. Jl. I Italy.

7 L. tigrìnum Gawl. TIGer-SPOTtEd Lilu. Lrs. scattered, sessile, 5veined, the upper cordate-ovate; perianth revolute, papillous inside.-Gardens, common in cultivation. St. $6 f$ high, with a pyramid of dark, orange-colored, spotted fls. Axils of lvs. bulbiforous. Aug. † China. 
8 I. cándidum L. WHite LiLy. Lrs. scattered, graded, lanceolate, narrowed at the base; fls. several, campanulate, smooth inside.-Gardens. It has a thick stem, if high, supporting a raceme of very large, snowy-white fls., which have long been regarded as the very perfection of whiteness and purity. Jl. t.Levant. Fig. 3.

9 I. Japónicum Thunb. Lvs. scattered, lanceolate; flower solitary, campanulate, nodding.-Greenhouse. A noble species, requiring careful management. Its flower is large, nodding, terminal, white, on a stem $2 f$ high. + China.

4. Fritilla'RIA, Tourn. Chequered Lily. (Lat. fritillus, a chess-board; alluding to the chequered petals.) Perianth campanulate, with a broad base and nectariferous cavity above the claw of each segment; stamens as long as the petals ; stigma trifid; capsule coriaceous, 3-celled, septifragal.-Herbs with coated bulbs, simple, leafy stems, bearing 1 or more nodding fls.

1 F. imperiális L. Crown Imperiat. Rac. comous, naked below; lvs. entire-Native of Persia. A fine, showy flower, of easy culture. Stem thick, striate, $3 f$ high, the lower part invested with the long, narrow, entire leaves; the upper part is naked, bearing at the top a racemo of several large, red or yellow, nodding flowers, beneath a crown formed by the pairs of small, narrow leaves, at the base of each pedicel May. + (Petilium, Kunth.)

2. F. maleàgris L. Lvs. alternate, linear, channeled; st. 1-flowered.Native of Britain. Stem a foot high, with alternate, long, very narrow leaves. The flower, which is usually solitary, is large, nodding, and beautifully chequered with purple and pale red or yellow. May. $†$

5. YUC'CA, L. Bear's-grass. Spanish Daggers. (The Indian name.) Perianth of 6 petaloid segments, withering-persistent, the inner broader; stamens 6 , shorter than the petals, inserted into their base; ovary free; stigmas 3 , sessile ; capsule oblong, obtusely hexagonal, 3-ralved at apex, 3-celled, cells more or less divided by a false dissepiment; seeds numerous and 2-rowed in each cell.-Wts. subterranean, or arising in a leafy or naked caudex, with rigid, linear, or swordshaped, perennial lvs., and a terminal panicle of showy, white, pedicellate fls.

$\$$ Caudex searcely arising above the grouni. Leaf margin bearing threads................. 1

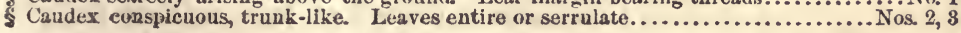

1 Y. filamentòsa I. Bear's-Thread. Acaulescent or nearly so; 1rs. linearlanceolate, rigidly acute, coriaceous, the margin filamentous, that is, bearing long, thread-like fibers; segm. lance-ovate, acuminate, erect-spreading.-In light soils, S. States, and often cultivated. The lrs. are nearly erect, 1 to $2 \mathrm{f}$ long, $\mathrm{I}^{\prime}$ to $18^{\prime \prime}$ wide, all densely clustered at the top of the short caudex, which is at the surface of the ground, or a few inches above it. Scape 5 to $8 f$ high, bearing a large pyramidal panicle of simple racemes. Fls. cup-shaped, segm. $15^{\prime \prime}$ long. Aug.

$\beta$. RECURViròlia. Somewhat cauleseent; lvs. lance-linear or linear, recurved, rarely somewhat filamentous. (Y. recurvifòlia Salisb. ?)

2 Y. gloriòsa I. Caulescent, caudex some $3 f$ high; lvs. erect, lanceolate, rigid, thick, subplicate, very acute, the margins very entire; perianth ovoid-campanulate, segm. lanceolate. - Sandy sea-coasts, Car. to Fla. Caudex balf-shrubby, thick, simple, fleshy, strongly scarred below with the old leaf-stalks. Lvs. 12 to $18^{\prime}$ long, 2 to $3^{\prime}$ wide, clustered above. Panicle of racemes 2 to $3 f$ long, erect from the summit of the caudex, with numerous cup-shaped, white, nodding flowers. Jn., Jl. $\dagger$

3 Y. aloëfòlia Walt. Spanish DagGers. Cuulescent; caudex some $10 \mathrm{f} \mathrm{high,}$ often branched, naked and marked with leaf-scars below; lvs. densely clustered above, very rigid, thick, strict, deflexed when old, lanceolate, apex spinescent, 
margin rough-serrulate; segm. oblong, acutish.-Thickets, near the sea-coast, S. Car. to Fla. A shrubby, palm-like plant, of singular and forbidding aspect when not in flower. Leaves a foot or more long, sliarp and rigid like daggers. Fls. white, with a violet base and violet spots. Jn.-Aug. (Y. Draconis L.)

6. NOLI'NA, L. C. Rich. (For P. C. Nolin, an American botanist.) Diœcio-polygamous ; perianth (small) of 6 , ovate, spreading, subequal segments ; stamens 6 , shorter than the perianth; ovary free, 3 cornered, 3-celled; stigmas 3 , recurved, with a very short style; capsule 3-winged, 3 (or by abortion 2 or 1 )-seeded.-Root bearing a coated bulb. St. scape-like, branched into several long, simple, nearly bractless racemes of very small, white fls.

N. Georgiàna Mx. Dry sand hills, S. Car. and Ga. (Mettauer). Bulb very large (Elliott). Scape 2 to 3 high, with a few short lvs. at its base, which diminish to scales upwards. Root lvs. linear, 1 to $2 f$ long, numerous, reeurved, their bases much dilated and imbricated. Panicle large. Rrc. loose, if or more long. Pedicels 5 to $6^{\prime \prime}$ long. Perianth spreading $3^{\prime \prime}$.

7. SCIL'LA, L. Seuill. Perianth 6-parted, petals and sepals similar, spreading (blue or purple) ; filaments 6 , subulate or filiform, smooth, hypogynous; style filiform-clavellate ; capsule free, 3-celled, 3-valved, obtusely 3-angled ; cells with 1 or several roundish, black seeds.-Bulb coated, bearing several linear lvs. and a scape with a raceme.

I S. esculénta Ker. QUaßrasir. Lrs. linear, carinate, flaccid and recurred, tapering to both ends, shorter than the scape; bracts solitary, subulate, scarious, longer than the pedicels, which are about the length of the flowers; fil. filiform; stig. 3-toothed.-Grassy, wet prairies, along the rivers, Wis. to Ohio, the uplands of Ga., and westward. Bulb nutritious, about $\mathbf{z}^{\prime}$ diam., resembling a small onion. Scapo 1 to $2 \mathrm{f}$ high. Lvs. nearly as loug, grass-like. Rac. 2 to $3^{\prime}$ Iong. Pet. and sep. linear-lanceolate, 4 to $6^{\prime \prime}$ long. Anth. oblong, yellow. May. (Phalangium, Nutt. Camassia, Lindl. C. Fraseri Torr.)-Improves by cultivation as to the size both of the bulbs and flowers.

2 S præbracteàta Haw. SQunu. Lvs. broad-linear, longer than tho scape; bracts as long as tho pedicels; flowers in a large conical paniclo; perianth spreading, persistent.-Bulb large, white. Fls. blue. † S. Eur.

8. ORNITHOG'ALUM, L. Star-of-Bethlehem. (Gr. ópvi0os, of a bird, $\gamma a ́ \lambda a$, milk; why so-called is not obvious.) Perianth deeply 6 parted, regular, persistent, segments many (3 to 7)-veined, spreading, (white, green or yellow) ; filaments 6 , dilated at base, scarcely perigynous, ovary free; style erect, tapering or subtrilobate; capsule 3-lobed, 3-celled, 3-valved above; seeds few or many in each cell, shining, black.-Bulbous plants, scarcely differing from Scilla except in the color of the fls.

1 O. cròceum Ell. Yeliow Star-OF-BethleneMr. Lrs. narrowly linear, radiical, longer than the slender scape which bears an oblong raceme of saffron-yellow flowers at top; bracts scarious at apex, obtuse, sheathing, many times shorter than the slender pedicel; segm. lance-ovate, obtuse, 3-veined, erect after flowering, with a greenish-orange stripe on the back; sty. and stam. subulate, shorter than the segments.-Mid. Ga., rare. (On Stone Mt., $16 \mathrm{~m}$. from Atlanta! Also at Macon, Dr. Mettauer.) Scape 10 to $20^{\prime}$ high, almost filiform. Rac. I0 to 15flowered. Ped. 8 to $12^{\prime \prime}$ long, As. half as long. Apr., May. (Phalangium MIx., Nutt.)

2 O. umbellàtum L. Whte StaR-of-Bethuenes. Lvs. linear, channeled, as long as the scape, emarginate; scape bearing a few white, green-striped fls. in a loose corymb; pedicels longer than the bracts; filaments lanceolate-subulate.Gardens, and naturalized in many localities. Scape near If ligh. Segm. of the star-like perianth beautifully marked with a longitudinal stripe on the outside. May. 
9. AL'LIUM, L. Garlic. Onron. (Celtic all, hot or burning.) Flowers in a dense umbel, with a membranous, 2-leaved spathe; perianth deeply 6-parted, segments mostly spreading, ovate, the 3 inner somewhat smaller; ovary angular; stigma acute; capsule 3 -lobed.Strong-scented, bulbous plants. Lvs. mostly radical. Umbel on a scape.

\$ Leaves flat, lanecolate, perỉshing before flowering. Capsule 3-seeded. Native.......No. 1

$\$$ Leaves flat, linear. Filaments simple. Ovary crested with a crown of 6 lvs. Native. (*)

* Stamens conspletiously longer than the serals. Umbel nodding..................... 2

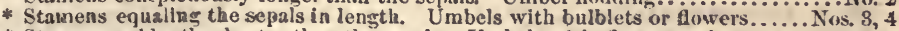

* Stamens evidently shorter than the sepals. Umbels with tlowers only........ Nos, 5, 6 \$ Leaves flat, lanceulate or lance-linear. Filaments trienspidate. Cultivated................ 7 , 8 Leaves terete and hollow. - Stem leafy half way up. Filaments tricuspidate........... No.9 -Scape naked. Filaments not tricuspidate................. 10-12

1 A. tricóccum Ait. Lance-Leaved Garlic. Scapo terete; lvs. lanceolate. ololong, flat, smooth; umbel globous; ovule and seed solitary in each cell of the 3-celled capsule.- - if A strong-scented plant, common in damp woods, N. H. to Va. and Wis. Bulb oblong, acuminate. Lvs. 5 to $8^{\prime}$ long, an inch or moro wide, acute, tapering into a petiole, all withering and disappearing before the opening of the flowers. Scape a foot or more high, bearing a thin, 2-leaved, deciduous spathe at top, with an umbel of 10 to 12 white fls. Jn., JL.

2 A. cérmuum Roth. Nodning Garlic. Scape angular; lvs. Jinear, flat, very long; umbel cernuous; stam. simple, much longer than the perianth.-Mid. S. and IV. States. This is our handsomest species. Bulb 6 to $8^{\prime \prime}$ diam. Scape mostly 4 -angled, smooth, slender, 15 to $24^{\prime}$ high, mostly recurved at top. Umbel 12 to 20-flowered. Pedicels 7 to $8^{\prime \prime}$ long. Fls. rose-colored. Ova. 6-toothed, becoming a roundish, 3 -seeded capsule. Jl.

3 A. stellàtum Nutt. Lvs. radical, linear, about equaling the nearly tereto scape; umbel many-flowered, erect (when in flower, nodding before); petals oblong-ovate, acute, equaling the stamens; filam. subulate, simplo; ova. 3-lobed, each lobe bearing 2 -teeth, or 2-crested above; caps. 3-angled, 3-celled, 6-seeded. -Mo., Ill. to Can. W. A low species, in gravelly soils. Scapo and lvs. 10 to $15^{\prime}$ high. Fls. roseate. Bulb oblong-ovate, eatable.

4 A. Canadénse Kalm. Scape terete; lvs. linear; umbel capitate, bulbiferous; filam. simple, dilated at base-2f In woods. Lvs radical, $\frac{2}{3}$ as long as the scape, smooth, nearly flat above. Scapo 12 to $18^{\prime}$ high, round, smooth, bearing a spathe of 2 ovate, acute bracts at top, with a head of bulbs and flowers. The bulbs are sessile, each furnished with a bract beneath, and among them are a few whitish flowers on slender pedicels. Jn.

5 A. mutábile $\mathrm{Mrx}$. Lvs. linear-setaceous, thin, sheathing at base, shorter than the terete scape; umbel many-flowered, crect; spathe 3-leaved, purplish; segm. ovate-lanceolate, longer than tho stamens; filam. simple; ova. crested; caps. 3-lobed, 3-seeded.-Damp woods, Ga., Fla. and Ala. Common at Montgomery. Bulb small, an inch or two in the ground, clothed with a thick net-work of fibers. Scape 12 to $20^{\prime}$ high, strict. Fls. 20 to 40 , white or roseate. Perianth $2^{\prime \prime}$ long. Filam. purple, anth. white. Tastes strong of garlic. Mar.-May.

6 A. striàtum Jacq. Scape slender, 3-angled, longer than the linear, striate leaves which are sheathing at base; spathe of 2 ovate bracts; umbel few (3 to 7)-fiow. ered; segm. ovate-lanceolate, witl midvein greenish purple, near twice longer than the stamens; filam. dilated at base; caps. downy, perfecting, 2 or 3 seeds in each cell.-Woods and prairies, IIl. (Hall, Lapham), and S. States. Scape 8 to 12' high. Lvs. 1 to $3^{\prime \prime}$ wide. Pedicels 1 to $2-3^{\prime}$ long, seldom more than 5 in number. Fls. larger than in our other wild species, spreading about 10", white. Mar-May.

7 A. sativum L. Common Garlic. Buib compound; st. leafy to the middle; lvs linear-lanceolate; spathe 1-leaved, long-acuminate; umbel bulbiferous: stam. tricuspidate.-Gardens. The bulb is composed of several smaller ones surrounded by a common membrane, acrid and very strong-scented. St. 2f high. Fls. small, white. Used in seasoning and sometimes in medicipe. Jl. $\ddagger$ Sicily.

3 A. perrum L. LeEk. St. compressed, leafy; Ivs. sleathing at base 
channeled and keeled; umbel of fls. globous; stam. tricuspidate, a little longer than the rough-keeled sepals. - Gardens. Rt. bearing a scaly, cylindrical bulb. Stem $2 \mathrm{f}$ high, bearing long, linear, alternate, sheathing lvs., and at the top a large umbel, of small white fls. Jl. Switzcrland.

9 A. vineàle L. Crow Garulc. St. slender, with a few leaves; cauline lvs. terete, fistulous; umbel bulbiferous; sta. exsert; fil alternately tricuspidate, the middle point bearing the anther. $-2 f$ Meadows, Mid. and W. States. Leaves 6-12' long. Scape 1-2f high, bearing a spathe of 2 small bracts at top, and an umbel of flowers with which bulbs are sometimes intermixed. Perianth purple. June, July. §

10 A. schcenopràsum I. Crves. Scape somewhat leafy at base, equaling the terete, filiform, fistulous lis.; spathe of 2 bracts, nearly as long as the capitate umbel; segm. lanceolate, acuminate, longer than the filam. which are toothless and dilated at base.-Lake shores, Can. Common in gardens, growing in tufts. Bulbs small. Scape less than if high. Umbel l' diam. Fls purple. Jl.

11 A. fistulòsum I. Welsh ONION. Scape leafy at base, inflated in the midst; lvs. fistulous throughout, terete, about the length of the scape; umbel dense, globular, fruitful; sep. acuminate, with a green keel; stam. exserted, with simple filaments; ova. 3-lobed, green.-Gardens. Scape and lvs forming dense tufts, $18^{\prime}$ high. + Asia.

12 A. Cepa L. Common Onion. Scape fistulous, swelling towards the base much longer than the terete, fistulous lvs.-(2) Gardens. Bulb compressed, or round, or oblong in figure. The scape, which appears the second year, is 3 to $4 f$ ligh, straight, smooth, stout, bearing at top a large, round umbel of grcenishwhite fls. Universally cultivated for the kitchen.

$\beta$. PROLIFERUM. TOP ONION. Umbels bulbiferous and proliferous, i.e., producing secondary bulbs and plants at top, with fow flowers or none.

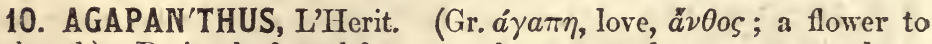
be loved.) Perianth funnel-form, regular, 6-parted; stamens 6 , adnate to the base of the tube, curved upwards; ovary free; style filiform, curved at the end; stigma entire; capsule 3-lobed, 3-celled, manyseeded.-Rit. tuberous. Lvs. radical, thick, linear. Ścape thick, bearing an umbel with a 2-leaved involucre.

A. umbellàtus L'Her. Lvs. linear; umbel many-flowered; pedicels as long as the perianth.-A fine, showy plant for the parlor or greenhouse, easily reared in pots. Scape $2 \mathrm{f}$ or more high, with an umbel of numerous fls. of a rich blue. $+\mathrm{S}$. Africa.

11. HYACINTHUS, L. IIYAcintri. (Hyacinthus of Grecian fable, was killed by Zephyrus, and transformed into this flower.) Perianth tubular campanulate, regular, 6-cleft, segments spreading-recurved; stamens 6 , adherent to the tube, free at apex ; ovary free; cells of the capsule about 2 -seeded.-Herbs acaulescent, from a coated bulb. Fls. racemed.

H. orientàlis L. Perianth funnel-form, half 6-cleft, ventricous at the base.if A well-known flower, long prized and cultivated. Lvs. thick, linear-lanceolate, 3 to $5^{\prime}$ long. Scape twice as long as the leaves, thick, bearing a racemo of numerous blue flowers which are often double. The tube is enlarged at base by the roundish ovary within it. Stam. adherent a third the length of the tube, deeply included. Segments oblong, obtuse, recurved, rather shorter than the tube. Mar., Apr. $\nmid$ Levant.-Varies with fls. white, pink, red, etc.

12. MUSCA'RI, Tourn. Grape Hyacinth. Perianth tube ventricous, ovoid or campanulate, throat constricted, limb of 6 very short, obtuse, spreading segments, sometimes with a crown. Otherwise as in Hyacinthus.

1 M. racemòsum L. Fls. fragrant, roundish-ovoid, nodding; Ivs. linear, channeled, arcuate-recurved, flaccid.-Gardens. Scape terete, 4 to 6 ' high, shorter 
than the leaves. Fls. about 2" long, fragrant. Tube deep blue, limb white, much smaller. † Eur.-Varies to white. (Botryanthus K.)

$\beta$. plumátilis. Rac. changed (by cult.) to a diffuse, feathery, sterile panicle.

2 M. botryoìdes L. Fls. inodorous, subglobous, nodding; lvs. linear-lan. ceolate, narrowed below, channeled, erect.-Flowers nearly a month later than the other. † Eur. - Varies with fls. azure, pale, white, roseate. (Botryanthus K.)

3 M. moschàtum Willd. Fls. fragrant (musk-like), ovoid, subinflated, throat constricted just below the short, spreading, 6-lobed limb, and bearing a small 6 lobed crown; tube persistent, bluish green or greenish violet, the limb yellowish; lvs. fleshy, linear; rac. dense.-Gardens. † Asia

13. ASPHOD'ELUS, L. Asphodel. (Gr. $\alpha$, privative, $\sigma \phi a \lambda \lambda \omega$, to surpass; a flower not surpassed in beauty.) Perianth 6 -parted, spreading; stamens 6, declinate and upcurved, their bases dilated into as many valves covering the free ovary; capsule globular, 3-celled, cells 2-seeded.-2f Rt. fasciculate. Lrs. radical, subulate. St. scape-like, erect.

1 A. lùteus I. Yellow AsphodeL. St. simple, leafy; lvs. 3-cornered.-A plant of easy culture and rapid increase. St. 3 high, thickly invested with 3-cornered, hollow leaves. Fls. yellow, in a long spike, reaching from the top almost to the base of the stem. Jn. + Sicily.

2 A. ramòsus I. WHITE ASPHODEL St. naked, branched; ped. alternate, longer than bract; lvs. ensiform, carinate, smooth.-Gardens. Not so tall as the preceding, but with larger, white fls. Jn. † S. Eur.

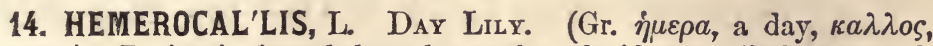
beauty.) Perianth funnel-shaped, regular, deciduous; limb 6-parted, veined, spreading; stamens 6 , inserted in the throat, curved upwards; ovary free; style slender, curved like the stamens and longer, stigma entire; capsule with 3 few-seeded cells. $-2 f$ Root fasciculate. St. leafy, crect. Lvs. linear, striate, keeled. Fls. large, xanthic, solitary or racemed.

1 H. fulva L. Lvs. linear-lanceolate, carinate; pet. obtuse, wavy; veins of sep. branched.-Naturalized in some parts of this country. A well-known, showy, border flower. Leaves very numerous, mostly radical, an inch wide and a foot or more long. Scape round, thick, naked, smooth, branching, 3f high. Flowers very large, liliaceous, of a tawny red. Style striate. July. + Levant.

2 H. flava I. Lrs. broad-linear, carinate; segments flat, acute; veins of the sepals undivided.-A foot high. Flowers a bright yellow, much smallor than those of $\mathrm{H}$. fulva. Scape branching. JL. † Siberia.

15. FUN'KIA, Spreng. White Day Lily. (For Henry Funk, a German cryptogamist.) Perianth funnel-shaped, deciduous; stamens 6, hypogynous, and with the style declinate-curved; capsule 3-celled, elongated, 3-angled; seeds many, 2-rowed, winged at end.-2f Root fasciculate. Lvs. all radical, ovate or oblong, petiolate. Seape racemed above. Fls. large, cyanic.

1 F. ovàta Spr. Lvs. broad-ovate, subcordate, acuminate; rac. many-flowered; fls. funnel-form, soon nodding; bracts ovate, acuminate, twice longer than the pedicel. - Gardens. Lvs. large, very smooth, veined, on long petioles. Scape If high. Fls. white. Jn. † Japan. (Hemerocallis Japonica Thunb.)-Varies with violet-colored flowers.

2 F. subcordàta Spr. Lrs. ovate-cordate, acuminate; rac. few-flowered; fls. nodding, with a very long tube; bracts much longer than the pedicel.-Gardens. Fls. white, very fragrant. † Japan.

3 F. albo-marginàta Hook. Ivs. ovate-lanceolate, elegantly margined with white; rac. short, with remote, declinate fls.; bracts ovate, all equal, twice longer 
than the pedicels.-Gardens, rare. Fls. lilac, variegated with white and purple lines. † Japan.

16. POLYGona'TUh, Tourn. True Solomon's Seal. (Gr. $\pi 0 \lambda v \zeta$, many, yóvv, knee; from the many-jointed rhizome.) Perianth tubular, limb short, 6-lobed, ercet; stamens 6, inserted near and above the middle of the tube, included; ovary free, 3 -celled, cells 2 to 6-ovuled; style slender, included; berry globular, 3 to 6 -seeded.-2f Rhizome horizontal, thick. St. erect or curving, leafy above. Fls. axillary, pendent, greenish white.

P. multiflòrum Desf. St. recurved, smooth; lvs. distichous, lanceolate, amplexicaul, smooth above; peduncles axillary, 1 to 4 -flowered.- 4 In woods, free States and Can. Stem 1 to $3 \mathrm{f}$ high, most recurved in the tallest plants. Leaves more or less clasping at base, or only sessile in the smallest plants, $2 \frac{1}{2}$ to $6^{\prime}$ by 1 to $2 \frac{1^{\prime}}{2}$, veined, smooth and glossy above, paler and generally pubescent beneath. Peduncles filiform, branching, scarcely a fifth as long as the leaves. Flowers 5-8" long, pendulous, greenish, sub-cylindric. Berries dark blue or blackish when ripe. Apr.-Jn.

a. Lvs. very amplexicaul, smooth both sides, distinetly reined; peduncles clongated, the lower 4 -flowered; fil. puberulent.-In rich damp soils. This var. is common to Europe! and America! (P. angustifolium Ph. P. biflorum Ell.)

B. PUBÉSCENS. Lvs. pubescent beneath, glaucous, slightly clasping; st. I to $2 \mathrm{f}$ high; fls. as short as the peduncles.-Common in N. England.

$\gamma$. GIGANTEUM. Tall, green and glabrous throughout; lvs. partly clasping; ped. 2 to 6-flowered.-In rich alluvion. St. 3 to $7 f$ high. (P. caniculatum $\mathrm{Pb}$.)

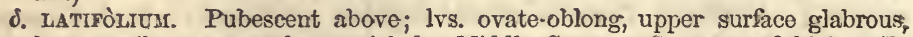
base sessile or somewhat petioled.-Middlo States. St. 2 to if high. (P. latifolium Muhl. P. hirtum. Ph.)

17. CONVALlA'RIA, L. Lily of the Vallex. (Lat. convallis, a valley; the locality of some species.) Perianth campanulate, of 6 united segments, lobes of the limb recurved; stamens 6 , included, perigynous; ovary 3-celled, 1-styled, cells' 4 to 6 -ovuled; barry ferw-seeded.- $2 f$ Rhizome creeping, slender. Lvs. radical, and scape very smooth, low, bearing a secund raceme of white, drooping fls.

C. majàlis I. An elegant, sweet-scented plant, native of mountain woods, Va. to Ga., also of Europe, and is, or deserves to be, a frequent inhabitant of our gardens. Irs. 2, seldom 3, ovate-elliptical. Scape $6^{\prime}$ high, with the small, elegant flowers depending from its upper half in a single rank. May.

18. CLINTO'NIA, Raf. (In hanor of Gov. DeWitt Clinton, of N. Y.) Perianth campanulate, of 6 equal, distinct segments; stamens 6, hypogynous, anthers linear-oblong; ovary oblong, 2 (rarely 3 )-celled; style clongated; berry (blue) 2-celled, cells 2 to 10-seeded.-2f Rhizome creeping. Lvs. all radical, few (2 to 5), broad. Scape naked, bearing an umbel.

1 C. boreàlis Raf. Norturern Cirntonia. Lrs. broad-oval-lanceolate; fls. 2 to 5 in the bractless umbel, cernuous; berry-cells many-seeded. - Mountainous or hilly wood, Can., N. Eng. to Car., W. to the Miss. Rhizome creeping to some extent. Lvs. 4 to $7^{\prime}$ long, $\frac{1}{3}$ as wide, petiolate, radical or nearly so, smoath and glossy, fringed with scattered hairs. Scape erect, round, 8 to $13^{\prime}$ high, bearing at top a beautiful umbel of 3 to 6 , yellowish-green, nodding fls. Perianth liliaceous, of 6 oblanceolate, erect-spreading segm. Berries of a rich amethystine blue. (Convallaria Poir.)

2 C. multiflòra Beck. Lvs. oblong-lanceolate, pubescent beneath; umbel many (12 to 30)-flowered, bracted; fls. erect or spreading; berry cells 2-seeded.-Woods, 
Chatauque Co., N. Y. (Torrey) to Car. along the Alleghanies. Lrs. 6 to $9^{\prime}$ by $\mathbf{1}$ to $2^{\prime}$, scarcely acuminate, striate. Scape 8 to $10^{\prime}$ high, pubescent. Umbel corym. bous, with the fls. small ( 4 to $5^{\prime \prime}$ long), white, spotted with purple inside, odorous. Jn. (Convallaria umbellata Poir.)

19. SMILACI'NA, Desf. Solomon's Sear. (Lat. diminutive of smilax, but with no good reason.) Perianth of 6 equal, spreading segments united at the base; stamens 6 , slender, perigynous, anthers short; ovary globous, 3 -celled (rarely 2-celled), with 2 ovules in each cell; style short, thick; berry globous, pulpy, 1 to 3 -seeded.- -24 Rhizome creeping, thick or slender. St. leafy, bearing a terminal cluster of white fls.

\$ Racome compound. Stamens longer than the perianth. Ovules collateral.............No. 1 Raceme simple. Stameus shorter than the perianth, Ovules one above the other.... Nos. 2, 3

1 S. racemòsa Desf. Clustered Solomov's SEAL. St. recurved; Ivs. oval, acuminate, subsessile; rac. compound.-Copses, common, Car. and U. S. Rhizome thick, sweetish to the taste. Stem 18' - 2f high, downy, always gracefully recurved at top. Lvs. 4 to $6^{\prime}$ long, a third as wide, veined, sharply acuminate, minutely downy. Petioles 0 to $2^{\prime \prime}$ long. Fls. very many, small, white in all their parts, in an oval panicle of racemes. Berries red, dotted, subpellucid, as large as peas. Apr.-Jn. (Convallaria, L.)

2 S. stellàta Desf. St. erect; lvs. many, lanceolate, acute, amplexicaul; fls. few, in a simple raceme.-Along rivers, Can. and Northern States, W. to the Miss. St. 10 to $20^{\prime}$ high, round and smooth. Lvs. 8 to 10 , glabrous, glaucous beneath, 4 to $6^{\prime}$ by 9 to $12^{\prime \prime}$, tapering gradually to the apex. Fls. white, about $8,4^{\prime \prime}$ diam. Segm. lance-oblong, obtuse, twice longer than the stamens. Berrics nearly black. May, Jn. (Asteranthemum Kunth.)

3 S. trifoliàta Desf. Erect; lvs. 3 or 4, oval-lanceolate, tapering to both ends, amplexicaul; rac. terminal, simple.-A delicate little species in mountain-swamps, Can., N. Eng. (rare), W: to Wis. St. 3 to $5^{\prime}$ high, pubescent, angular. Lvs. 2 to $3 \frac{y^{\prime}}{2}$ long, a fifth to a third as wide, somewhat acuminate. Fls. 4 to 10 , on pedicels 2 to 7 "long, white. Segm. obtuse, finally reflexed, a third longer than the stamens. Ovary often but 2-celled, with 2 stigmas. Berry 2 or 3-seeded, dark red. May. (Convallaria, I. Asteranthemum Kunth.)

20. Majan'THEMUM, Mœnch. 'Two-leaved Solomon's Seal.

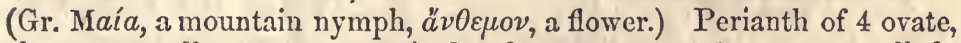
obtuse, spreading segments united at base; stamens 4 ; ovary 2-celled; otherwise as in Smilacina.-Rhizome creeping. St. bearing 2 or 3 lvs. Fls. in a simple terminal raceme.

M. bifòlium DC. A small plant frequent upon the edges of woodlands, Can., N. Lng., W. to Wis. St. angular, about $6^{\prime}$ high. Lrs. 2 , rarely 3 , about $2^{\prime}$ long, $\frac{1}{2}$ as wide, ovate, distinctly cordate, sessile, or the lowest on a petiole. Rac. erect, an inch long, consisting of 12 to 20 white fls. Bcrry small, round, aud when mature pale red, speckled with deep purple. May.

21. ASPAR'AGUS, L. (The ancient Greek namc.) Perianth 6parted, segments erect, slight spreading above ; stamens 6 , perigynous ; style very short; stigmás 3 ; berry 3 -celled, cells 2 -seeded.-2f Rts. fibrous, matted. Sts. with very narrow lvs. and small fls.

A. officinàlis L. St. herbaceous, unarmed, very branching, erect; lvs. setaccous, flexible, fasciculate.-Escaped from gardens and naturalized on rocky shores. St. 2 to $4 \mathrm{f}$ high. Lvs. filiform, $\frac{1}{2}$ to $1 \frac{1}{2}^{\prime}$ long, pale pea-green. Fls. axillary, solitary or in pairs. Berries globous, red. It is one of the oldest and most delicate culinary vegetables, was no less praised in ancient Rome, by Pliny, Cato and other writers, than at the present day. Diuretic. Jl. § Eur.

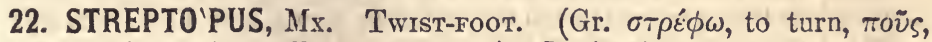
foot; a twisted footstalk or peduncle.) Perianth 6-parted, campanu- 
late; segments with a nectariferous pore at the base of each; anthers longer than the filaments ; stigma very short; berry roundish, 3-celled; seeds few, hilum with a very slender raphe.-2f St. branched. Fls. axillary, solitary, generally with the peduncle distorted, or abruptly bent near the midule.

I S. ròseus $\mathrm{Mrx}$. Smooth; lvs. oblong-orate, clasping, margin serrulate-ciliate; under surface green like the upper; pedicels short, generally distorted in the middle; segments spreading at apex; anth. short, 2-horned; stig. trifid.-Can. to Car. and Tenn. A common species, native of woods. Stem a foot or more high, round, dichotomously branching. Leaves $2-1^{\prime}$ long, $\frac{1}{2}$ as wide, ending in a slender point, smooth, but conspicuously edged with minute, rough hairs. Flowers reddish, spotted, suspended beneath the branches, one under each leaf. Jn.

2 S. amplexifolius DC. Smooth; lvs. oblong-ovate, clasping, smooth and entire on the margin, glaucous beneath; pedicels solitary, geniculate and distorted in the middle; sep. long-acuminate, reflexed ; anth. sagittate, acute-pointed, entire; stig. truncate.-Can. and Mid. States. Native of woods. Stem round, dichotomous, $2 \mathrm{f}$ high. Leaves 2 to $3^{\prime}$ long, $\frac{1}{2}$ as wide, very smooth. Peduncles opposite the leaf, twisted and bent downwards each with a bell-form, drooping flower gibbous at base, of a pale straw-color. Fruit oblong, red, many-seeded. Jn. (S. distortus Mx. Uvularia L.)

23. PROSAR'TES, Don. (Gr. $\pi \rho \circ \sigma a \rho \tau a ́ \omega$, to suspend; alluding to the pendulous flowers.) Perianth as in Uvularia ; stamens 6 , perigynous, included, with long, filiform filaments; ovary 3-celled, with 2 suspended ovules in each cell; style elongated, trifid ; berry roundish oblong, 3 to 6 -seeded.-2f St. erect, with divergent branches, scattered, sessile, ovate, thin, pubescent lvs. and drooping, terminal, greenishpurple fls.

P. lanuginòsa Don. Lrs. ovate-oblong, acuminate, cordate or rounded at the clasping base, pubescent beneath; pedicels in pairs; perianth segm. linearlanceolate; style smooth.-Mts. N. Y. to Car., W. to Or. St. 12 to $18^{\prime}$ high, 2 or 3 times forked above. Lvs. 2 to $3^{\prime}$ long, veined. Pedicels 6 to $8^{\prime \prime}$ long, downy. Fls. spreading-bellishaped, segm. near $6^{\prime \prime}$ long. Berry red. May.

24. UVULA'RIA, L. BeLL-wort. (Lat. uvula, the palate; the flower depends like that organ.) Perianth connivent-campanulate, deciduous, deeply 6-parted; segments linear-oblong, acute, erect, with a nectariferous cavity at the base of cach ; filaments very short, scarcely perigynous; anthers linear, half as long as the petals; style trifid; capsule 3 -celled; seeds few, with a very tumid raphe.-Lvs. alternate. Fls. solitary, terminal, becoming axillary, nodding.

\$ Leaves perfoliate near the base. Capsule obovoid-triangular, truncate............Nos. 1, 2

$\$$ Leaves sessile or half-clasping. Capsule ovoid or oval-triangular............................ 3,4

$i$ U. perfoliàta L. MEALY BEILworT. Lvs. perfoliate, elliptical, subacute; perianth subcampanulate, tuberculate-scabrous within, segm. acute; anths. cuspidate; caps. truncate. -2 Can. and U. S. A handsome, smooth plant, in woods. Stem 10-14' high, passing through the perfoliate leaves near their bases, and dividing into 2 branches at top. Leares $2-3^{\prime}$ by $\frac{2}{3}-1^{\prime}$, rounded at the base, acute at apex. Flower palo yellow, pendulous. Segments linear-lanceolate, $11^{\prime}$ long, twisted, covered within with shining grains. Anthers $\frac{3^{\prime}}{4}$ long. May. (U. flava Smith.)

2 U. grandiflòra Smith. Lvs. perfoliate, elliptic-oblong, acute ; fl. terminal, solitary, pendulous; segments acuminate, smooth within and without; anth. obtuse.$2 f$ Can. and U. S. Larger than either of the foregoing. In woods. Stem 1215 inches high, passing through the perfoliate leaves near their bases, dividing into 2 branches at top, one of which bears the largc, yellow, pendulous flowe: 
Leaves almost acuminate, rounded at base. Anthers $\frac{3}{4}$ long. May.-Readily distinguished by tho smooth petals.

s U. sessilifòlia L. WiLd OATs. Lvs. sessile, lance-oval, glaucous beneath; caps. stiped, oval-triangular.- $2 f$ Can. and U.S. A common species, found in woods and in grass lands. Stem smooth, slender, 6-10' high, dividing at the top into 2 branches, ono bearing leaves only, the other, leaves and a flower. Leaves smooth and delicate, dark green above, paler beneath, 1-11' long. The flower is cylindric, near an inch lorg, yellowish-white, of 6, long, linear petals. May.

4 U. pubérula Mx. Lvs. amplexicaul and rounded at base, oval, of the same shining green both sides, puberulent along the margins, as well as the stem; perianth segm. acute, smooth both sides; capsule sessile (no stipe), ovoid.-Mts. Va. to Car. St. 8 to $12^{\prime}$ high. Fls. yellowish-white, larger than in U. sessilifolia.

\section{Order CXliX. Melanthacea. Melanths.}

Herbs perennial, sometimes bulbous, often poisonous, with parallel-veined leaves, perianth double, regular, persistent, of 6 consimilar, green or colored segments, stamens 6 , with extrorse anthers, 3 distinct styles and a free, 3-celled ovary, capsule 3-celled, 3-partible or septicidal, and seeds few or many with a thin seed coat. Figs. 61, 62, 464 .

Genera 30 , species 130 , rather generally diffused in northern countries.

Properties.-The order is generally pervaded by drastic, narentic and poisonous qualities, most powerful in Veratrum and Colchicum. The corms and seeds of the latter are the most impor tant inedicinal products of the order. Their virtuo is due to an alkaline principlo called veratria, which is found in this genus, as well as in most of the others.

GENERA.

$\S$ Anthers 1-eelled, extrorse, cordate, becoming peltate by opening. $\left(^{*}\right)$

* Inflorescence paniculate, or a raceme somewhat branched at base. (a)

a Sepals glandular at base inside, clawed. Stamens perigynons.........Mranturtu. 1

a Sepals glandular at base inside, clawed. Stamens hypogynous.........ZIGadErts. 2

a Sepals not gland bearing. Stamens perigynons.................... Veratrux. 3

* Inflorescence racemous, with white flowers. Stamens perigynous........ A Mintunum. 4

* Inflorescence spicate, with green flowers. Stamens hypogynous...... Sch evocaulox. 5

\& Anthers 2-celled, extrorse. Capsule loculicidal. Flowers racemons. (b)

b Flowers perfect. Filaments dilated at base. Ovary cells 2 -ovuled..... Xrropurulom. 6

b Flowers perfect. Filaments fliform. Ovary cells $\infty$-ovuled............. Inronias. T

b Flowers diœcious, white. Stem leafy......................... Crimanlirium. 8

\& Anthers 2-celled, introrse. Capsule septicidal. Flowers racemous. (c)

c Stamens 6. Flowers greenish or yellowish, 9 to $40 \ldots \ldots \ldots \ldots \ldots \ldots$.............. Torifdia. 9

c Stamens 9 to 12 . Flowers deep yellow, 6 to 9 , mostly $6 \ldots \ldots \ldots \ldots . . . . . . . .$. Preza. 10

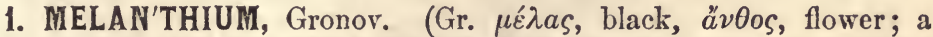
false name if applied to the yellowish flowers.) Flowers monœciously polygamous; perianth rotate, 6-parted, segments oblong, acutish, cordate or auricled, and with 1 or 2 glandular, brownish spots at base; the claws bearing the stamens; ovary often abortive, capsule exserted, subovoid, trifid at the summit and tipped with 3 persistent styles; seeds broadly winged.-St. erect, thickened at base, bearing an open pyramidal panicle of simple racemes. Lvs. lanceolate, varying to linear.

M. Virgínicum L. Wet meadows and margins of swamps, Wis. to N. Y. and Fla. St. 3 to $4 f$ high, leafy. Lvs. about a foot long, $6^{\prime \prime}$ to $2^{\prime}$ wide, sessile, on a contracted and subclasping base. Fls. about $8^{\prime \prime}$ broad, on short pedicels, arranged in simple, alternate racemes, and together constituting a pyramidal panicle 10 to $15^{\prime}$ in length. Lower fls. generally sterile. Jl., Aug.

$\beta$. HYBRIDUM. Lower lvs. lanceolate and lance-oval-A larger growth. hybridum R. \& S.)

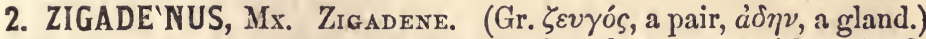
Perianth decply 6-parted, spreading, colored, each segment with 2 glands 
above its contracted base ; stamens inserted in contact with the ovary ; capsule membranous, 3-celled, many-seeded, septicidal; seeds scarcely winged.-24 St. simple, paniculate above, smooth and glaucous, as well as the linear lvs. Fls. greenish.

1 z. glaberrimus $\mathrm{Mx}$. Rhizome creeping; lvs. linear, channeled, recurved; pan. icle pyramidal ; bracts ovate, acuminate; segm. of the perianth acuminate, glands 2 on the claw of each.-S. States. St. 2 to $3 \mathrm{f}^{\prime}$ high. Lower lvs. about $10^{\prime}$ long, upper ones gradually diminishing, all concave and tapering to a point. Panicle terminal, loose, consisting of many greenish-white fls. Sep. ovate-lanceolate, free from the stamens, the 2 glands orbicular, distinct and conspicuous. Jn.

2 Z. glaùcus Nutt. St. bulbous, nearly naled; lvs. shorter than the stem, linear, rather obtuso; panicle simple; bracts lanceolate, shorter than the pedicels; segments oval or obovate, obtuse, each with an obcordate gland.-Sandy shores, Can. to N. Y. and Wis. Stem $10-15^{\prime}$ high. Leaves glaucous, upper gradually reduced to bracts. Raceme subsimple, sometimes a little compound at basc. Flowers few (10-20), greenish-white, on pedicels $1^{\prime}$ long, tho segments with the 2 glands united. Capsule oblong-ovoid, carpels divergent at apex, 6-8-seeded. Jl., Aug.

3 Z. leimanthoìdes Gray. Rt. fibrous; lvs. linear, flat; pan. simple, the terminal raceme elongated; segments obovate, with a glandular spot at base, and longer than the linear styles; sds. winged at the apex, lanceolate, compressed.-N. J. to Lr. Stem roundish, $2-4 \mathrm{f}$ high, the lower leaves about half as long, pale green, acute. Flowers white, on filiform pedicels, finally recurved. Segments of the perianth obtuse, a little shorter than the capillary filaments. July.

\section{VERA'TRUM, Tourn. False Hellebore. (Lat. vere, atrum,} truly black ; alluding to the dark color of the flowers or root.) Flowers by abortion $\hat{o} \not q+$; segments of the perianth united at base, petaloid, spreading, sessile and without glands ; stamens 6 , shorter than the perianth, and inserted on its base; ovaries 3 , united at base, often abortive ; styles short; capsule 3-lobed, 3-partible, $\infty$-seeded.-Rt. lvs. alternate. Fls. paniculate.

\$ Stem stout and very leafy thronghout. Sepals lanceolate, acuminate................ 1

$\$$ Stem slender, nearly naked.-Sepals obtusish. Leaves oval and lanceolate.............. 2, 3 -Sepals acuminate. Leaves linear...................... 4

1 V. víricle Ait. Lrs. lance-oval, acuminate; st. stout and very leafy; paniclo compound, racemous; bracts oblong-lanceolate, bracteoles longer than the downy pedicels.-Can. to Ga. A large-leaved, coarse-looking plant, of our meadows and swamps. Root large, fleshy, with numerous long fikers. Stem $2-4 \mathrm{f}$ high, striate and pubescent. Leaves strongly veined and plaited, the lower near a foot long and half as wide, sheathing at tho base. Flowers numerous, green, in many axillary (or bracted) racemes, which togetlier form a very large, pyramidal, terminal panicle. July. Root emetic and stimulant, but poisonous. (V. album Mx.)

2 V. Woodii Robbins. Indiana Veratrum. Lrs. mostly radical, lanceolato and linear-lanceolate, glabrous, veined and plicate, acute tapering to a long, winged, sheathing petiole; st. or scape terete, tall, erect, with remotc, lancelinear bracts; panicle simple, slender, pyramidal, many-flowered; fls. ô $\Varangle$, subsessile; segments oblanceolate, sessile (the stamens nearly free and of equal length) dark brownish-purple within.-Woods, Green Co., Ia., III. (Mead) and Iowa (Cousens). Root fasciculate. Leaves $10-16^{\prime}$ long (including the $4-8^{\prime}$ petiole), $2-4^{\prime}$ ! wide. Bracts $1-3^{\prime}$ long. Scape 3-6f high, paniculate $\frac{1}{3}$ its lengich. Flowers 9" diam., almost black, with red stamens, upper and lower sterile. Ovary oblong, crowned with 3 spreading styles half its length. Seeds compressed, winged with the broad, loose, membranous testa. July.- Very different from the next.

3 V. parviflòrum Mx. Ivs. mostly radical, oval and lance-oval, glabrous, scarcely plicate, contracted at base into winged petioles; stem scape-like, terete, bracted - panicle elongated, very loose, with filiform branches; fls. dingy green, on filiform pedicels, segm. lance-spatulate, unguiculate, the claws bearing the stamens, which are scarcely half as long.-Bluo Ridge, Va. (Miss Carpenter) to the Mts. of 
Ga. Lvs. shorter and broader than in No. 2. St. 2 to $5 f$ high. Fls. very open, $5^{\prime \prime}$ diam., sometimes all sterile. Jl. (Melanthium monoicum Walt.)

$4 \mathrm{~V}$. angustifòlium $\mathrm{Ph}$. Grass-Leaved Veratrum. Lvs. narrowly linear, flat, very long, lowest obtuse, upper ones diminishing to subulate bracts; fls. in a slender panicle of racemes, those of the terminal raceme (except a few of tho highest) perfect and fertile, those of the lateral racemes mostly sterile; segments narrowly lanceolate, subulate, acuminate.-A very slender, grass-like species, in woods, W. States to the Mts. of Car. Stem. 3f high, with greenish-white flowers. Leaves $1-2 \mathrm{f}$ by $2-3^{\prime \prime}$, half-clasping. Panicle $1 \frac{1}{2} \mathrm{f}$ long, pedicels shorter than the flowers, each with a very minute bract. June, July. (Stenanthium, Gray.)

4. AMIAN'THIUM, Gray. FLY-PoIson. (Gr. áuíavtos, pure, immac-

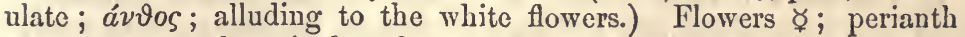
segments scarcely united at base, petaloid, spreading, sessile and without glands; stam. 6, hypogynous, as long as the segments; anthers reniform ; ovaries 3 , more or less united ; caps. 3 -lobed, 3 -partible ; carpels follicular, 1-4-seeded; testa of the seeds loose, at length fleshy.Herbs with scapiform stems, grass-like leaves, and a raceme of numerous, white, long-pediceled fls, turning green with age.

1 A. muscæetoxicum Gray. St. bulbous; lvs. flat, lower broad-linear, obtuse, upper reduced to bracts; rac. simple; segments oblong, obtuse, shorter than the stamens; pedicels filiform; carpels distinct above; sty. divergent; seeds ovoid, red. -Shady swamps, N. J., Penn. and Southern States. Stem 1-2f high. Leaves mostly radical, about if long. Raceme 2 to 4', rarely longer, dense-flowered, pedicels 6-9" long. Perianth and stamens white, the latter rather tho longest. Carpels united only at base, the summits horn-like and diverging. Seeds rather large, scarlet-red when ripe. Apr.-Jn. (Helonias erythrosperma Mx.)

2 A. angustifòlium Gray. St. slender, scarcely bulbous; lvs. narrowly linear, tapering to a long, acute point; rac. simple; sep. oval, acutish, scarcely longer than the stamens; sty. filiform, contiguous; seeds linear.-Damp pine woods, Car. to (Bainbridge, Ga., and) Fla. St. 2 to $3 \mathrm{f} \mathrm{high.} \mathrm{Lvs.} 9$ to $18^{\prime}$ long, 2 to $3^{\prime \prime}$ wide, somewhat keeled. Rac. 3 to $5^{\prime}$ long, $l^{\prime}$ diam. Ped. ascending. Anth. yellow, twice smaller than in No. 1. Plant of a deep green. A pr.-Jn.

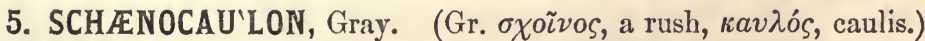
Perianth herbaceous; of 6 linear-oblong, suberect, persistent sepals ; stamens 6, hypogynous, much exserted, with large, reniform, 1-celled anthers; ovaries 3, slightly conjoined; stigmas 3.-Herb bulbous, acaulescent, glabrous, with the lvs. all radical, very long and narrow, sedge-like, and a very slender scape. Fls, in a slender spike.

S. grácile Gray. Sandy soils, Ga. and Fla. Scapes 2 to $3 \mathrm{f} \mathrm{high,} \mathrm{lrs.} \mathrm{half} \mathrm{as}$ long. Spike 2 to $4^{\prime}$, with pale green fls. Fr. yet unknown. A pr., May.

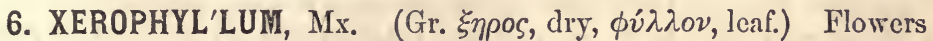
$\Varangle ;$ leaflets of the perianth oval, spreading, petaloid, sessile, and without glands ; stamens 6 , filaments dilated and contiguous at base ; ovary subglobous; styles 3 , linear, revolute; capsule subglobous, 3-lobed, 3celled, cells 2 -seeded.-Herbs with numerous dry, setaceous leaves, the lower longer, rosulately reclined, the upper gradually reduced. Rac. simple, with white, showy fls.

X. asphodeloìdes Nutt. Sandy plains, N. J. to Car. St. 3 to $5 \mathrm{f}$ high, very leafy. Radical lvs. If long, very narrow, crowded and cæspitous. Fls. in a long, dense, showy raceme. Segm. spreading $5^{\prime \prime}$, obtuse. Pedicels $1^{\prime \prime}$ or moro long, bractless at base, but with 2 bractlets above the base. Jn.

7. HELO'NIAS, L. (Gr. $\dot{\varepsilon} \lambda o s$, a marsh ; where some species grow.) Flowers $\Varangle$; perianth 6-parted, spreading; petaloid, the segments sessile, 
persistent, without glands; stamens 6, hypogynous, at length longer than the perianth, anther's short, oval; styles 3, distinct; capsule 3celled, 3-horned; cells loculicidal, many-seeded.-Lvs. mostly radical, narrow, often gramineous, sheathing at base. Fls. in a terminal, simple raceme.

H. bullàta L. N. J., Penn. to Va. Scape 10 to $18^{\prime}$ high, rather thick and fleshy, hollow, nearly naked. Lrs. lance-spatulate, about as long as the scape, 1 to $1 \frac{1}{2}$ ' wide. Rac. short. Pedicels as long as the flowers, colored. Fis. purple, segm. obtuse, with blue anthers. May. (H. latifolia Ph.)

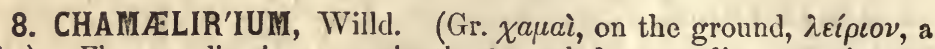
lily.) Flowers dinecious; perianth 6 -sepaled, spreading, persistent; sepals narrow; filaments 6 , perigynous, filiform, longer than the sepals (short in the $\Varangle$ ); ovary free, with 3 distinct styles; capsule oblong, loculicidal ; seeds many, linear-oblong, winged at each end.-Rt. tuberous, premorse. St. leafy, strict, slender. Lvs. lanceolate, the radical oblanceolate and obovate-obtuse. Rac. spike-like, nodding, denseflowered, yellowish-white.

C. lùteum Gray. Brazing Star. Low grounds, Can. and U. S. St. 12 to $30^{\prime}$ high, furrowed. Radical lvs. 3 to $5^{\prime}$ by 6 to $12^{\prime \prime}$, in a sort of whorl. Fls. small, very numerous, in long, terminal, spicate racemes, which are more slender on the barren plants. Ovaries as long as the linear petals, subtriangular. Caps 3-furrowed, oblong, tapering to the base, opening at the top. The fertile plants are taller, more erect, but with fewer flowers. Apr.-Jn. (Helonias dioica Ph.)

9. TOFIELD'IA, Iudson. (To Mr. Tofield, a Scotch gentleman, residing near Doncaster.) Flowers $\Varangle$, calyculate, with 3 remotish, united bracts; lfts. of the perianth petaloid, spreading, sessile, and without bracts; sta. 6 ; anth. roundish-cordate, introrse; ovaries 3 , united; styles distinct, short; ova. 3-lobed, 3-partible; capsule $\infty$-seeded.Lis. equitant, subradical. Scape not bulbous. Fls. spicate or racemous.

$\S$ Pedicels clustered in 3 s. Stems scabrous-glandular........................... Nos. 1, 2

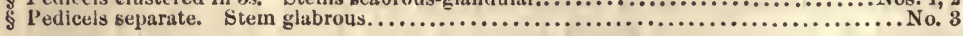

1. T. glutinòsa Nutt. St. leafy below, glandular-scabrous, simple; lvs. a fourth the length of the stem, linear-ensiform, glabrous, obtuse; rac. oblung, few-flowered, close, composed of 3-flowered, alternate fascicles; caps. longer than the perianth. -Woods, Ohio to Wisc., N. to Arc. Am. Stem slender, scape-like, 1-1 $\frac{1}{2} \mathrm{f}$, dot. ted with dark-colored glands. Leaves $3-6^{\prime}$ by $3-6^{\prime \prime}$, carinate. Spicate raceme 1-1 $\frac{1}{2}^{\prime}$ long, 9-18-flowered. Involucre truncate, 3-toothed, a little below the perianth. Petals and sepals oblanceolate, less than "2" long, carpels 4 ".

2. T. pùbens Dryand. St. leafy at base, rough-puberulent; lvs. nearly half thi length of the stem, linear-ensiform, strongly striate, acute, glabrous; rac. linear. elongated, composed of many remotish, alternate fascicles; pedicels 2 to 3 together, as long as the flowers; fls. 3-bracted at base; capsule scarcely exceeding the perianth.-Pine barrens, Del. to Fla. St. 2 to $3 \mathrm{f}$ high, slender. Lvs. more than twice longer than in No. 1. Rac. 6 to $8^{\prime}$ long, 30 to 40 -flowered. Fls. small, greenish-white. Jl.-Sept.

3 T. glàbra Nutt. St. leafy below, glabrous; lvs. nearly as in No. 2; rac. elongated, dense, with the pedicels separate (not clustered), scarcely longer than their bracts ; carpels distinct to near the base; stig. sessile.-Car. to Ark., in wet grounds. St. 1 to $3 \mathrm{f}$ high. Rac. 2 to 5 ' long, 20 to 30 -flowered. Seeds linearoblong, not caudate.

10. PLEE'A, L. C. Rich. (Gr. $\pi \lambda \varepsilon \iota \grave{s} s$, the Pleiades; its flowers.) Perianth colored, persistent, 6-sepaled, stellately spreading; stamens 9 
to 12 , hypogynous, longer than the sepals ; anthers introrse; styles 3 ; capsule 3-partible, $\infty$-seeded. - 2f Herb glabrous, with a slender, rushlike stem, dry, rush-like lvs., and a raceme of 6 to 9 yellow fls.

P. tenuifölia Rich. Bogs, N. Car. (Curtis), S. Car. (Michx.), St. 1 to $2 \mathrm{f}$ high, from red, fibrous roots. Lvs. perennial-green, very narrow, sheathing at base, nearly if long. Caps. brown.

\section{Order Cl. PONTEDERIACEA. Pontedertads.}

Plants aquatic, with tho leaves parallel-veined, mostly dilated at base. Fls. spatkaceous. Perianth tubular, colored, 6-parted, often irregular and circinate after flowering. Stamens 3 or 6, unequal, perigynous. Ovary free, 3-celled. Style 1. Stigma simple. Capsule 3 (sometimes 1)-celled, 3-valved, with loculicidal dehiscence. Seeds numerous (sometimes solitary), attached to a central axis. Albumen farinaceous.

Genera 6, species 30 , found exclusively in $\Delta$ merica, E. Indies, and tropical $\Delta$ frica. They are of no known use.

\section{GENERA.}

Flowers irregular, blue. Stamens 6. Utricle 1 -seeded................... Pontederta. 1 Flowers regular. - Anthers 3 , of 2 forms. Leaves reniform............... IIETERANthera. 2 -Anthers 3, of one form. Leaves linear................. Scrrollera, 8

1. PONTEde'RIA, L. Pickerel Weed. (In honor of Julius Pontedera, a botanic author and professor, of Padua, about 1720.) Perianth bilabiate, tubular at base, under side of the tube split with 3 longitudinal clefts (the 2 lower sepals free), circinate after flowering and persistent; stamens unequally inserted, 3 near the base and 3 at the summit of the tube; utricle 1 -seeded (2 cells abortive).-Lvs. radical, longpetioled. St. 1-leaved, bearing a spike of blue fls.

1 P. cordàta L. Lvs. cordate-oblong, obtuse; petiole shorter than the peduncle; spike cylindrical, pubescent.-24 Can. and U. S. A fine, conspicuous plant, native of the borders of muddy lakes, \&c., growing in patches extending from the shores to deep water. Stem thick, round, erect, arising 1-2f above the water, bearing a single leaf. Leaves $4-7^{\prime}$ by $1 \frac{1}{2}-3^{\prime}$, very smooth and glossy, almost sagittate, with veins beautifully arranged to conform to the margin. Flowers in a spike, arising above the spathe, very irregular. Perianth 2-lipped, each lip 3cleft, always blue, appearing in July.

B. ANGUSTIFoliA Torr. Lvs. narrow, truncate and subcordato at base.

2 P. lancifòlia Muhl. Lvs. lance-oblong or lance-linear, rather acute at each end; petiole shorter than the peduncle; spike cylindrical, pubescent.-Pools and ditches, Ga. (Feay) and S. Car. More slender every way than the other, 15 to $30^{\prime}$ high. We can detect no difference in its flowers, but the permanent difference of the leaves is worthy of consideration. Apr., May.

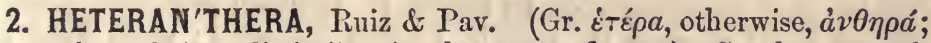
the anthers being dissimilar in the same flower.) Spathe severalflowered; tube of the perianth long and slender, limb 6-parted, equal ; stamens 3 ; anthers of 2 forms, the lower oblong-sagittate, on a longer filament; capsule 3-celled, many-seeded. Lvs. mostly reniform, longpetioled.

H. renifórmis R. \& P. St. prostrate or floating; lvs. suborbicular, reniform or auriculate at base; spathe acuminate, few-flowered.-On muddy or inundated banks, Mid. and W. States. Stem 4' to a foot or more in length. Leaves $\mathbf{1}^{\prime}$ by $\frac{3^{\prime}}{4}$, on petioles $1-2^{\prime}$ long, with a broad sinus at base, and a short, abrupt acumination. Spathe closely enveloping the 2 or 3 very evanescent, white flowers. Tube of the perianth $\frac{1}{2}^{\prime}$ long, limb in 6 oblong segments. Filaments inserted at 
the orifice, 2 of the anthers small, round, yellow, the other oblong, greenish. $\Pi_{\text {., }}$ Aug. (Leptanthus, Mx.)

3. SCHOL'LERA, Schreber. (Dedicated to one Scholler, a German botanist.) Spathe several-flowered; tube of the perianth very long and slender, limb 6-parted, equal ; stamens 3 , with similar anthers ; capsule 1-celled, many-seeded.-Lvs. alternate, sheathing at base, grass-like, submersed. St. floating, rooting at the lower joints.

S. gramínea Willd. A grass-like aquatic, in flowing water, N. States. St. slender, dichotomous, 1 to $2 \mathrm{f}$ long. Lvs. 3 to $6^{\prime}$ long, 1 to $2^{\prime \prime}$ wide, obtuse at apex, slightly sheathing at base. Flower solitary, issuing from a short ( $1^{\prime}$ spathe), tube $1^{\prime}{ }^{\prime}$ long, limb in 6 linear-lanceolate sagments, yellow. Stam. 3 (4, anthers); filaments broad, one of them abortive, the other 2 with linear anthers longer than the thick style. Jl., Aug. (Leptanthus, Mx.)

\section{Order CLI. JUNCACEA. Rushes.}

Plants herbaceous, generally grass-like, often leafless, with small, dry, green flowers. Perianth more or less glume-like, regular, 6-leaved, in 2 series (sepals and petals.) Stamens 6, arely 3, hypogynous. Anthers 2-celled, introrse. Style 1. Ovary 3-carpeled, 3 (or by the dissepiment not reaching the center 1)-celled. Capsule 3-valved, with the dissepiments from the middle of the valves. Seeds few or many, with a fleshy albumen. Fig. 377 .

Genera 15, species 200, chiefly natives of the cool parts of the earth. Properties unimportant.

\section{GENERA.}

Perianth yellow (greenish outside). Stigma 1. Capsule $\infty$-seeded............ NArtuecrum. 1 Perianth green or brownish. Stigmas 3.-Capsule 3 -seeded...................LuzuLA. 2 -Capsule $\infty$-seeded..................... Juncus, 3

1. NARTHE'CIUM, Mœhr. (Gr. vá $\vartheta \vartheta \eta \xi$, a rod or wand; in allusion to the slender inflorescence.) Perianth 6-parted, colored, spreading, persistent ; stam. 6 ; filaments hairy ; caps. prismatie, 3-celled; seeds $\infty$, ovatc-oblong, appendaged at each extremity. $-2 f$ Root fibrous. Lvs. ensiform. Scape nearly naked. Fls. yellowish.

N. Americànum Ker. Lvs. radical, striate, narrow-ensiform; rac. lax, interrupted; pedicels with a bract at base, and a setaceous bracteole near the flower. -An interesting little plant, in pine barrens and sandy swamps of N. J. Also in Can. Scapes 8 to $12^{\prime}$ high, terete, with 2 or 3 subulate bracts. Leaves numerous, much shorter than the scape. Pedicels $3-7^{\prime \prime}$ long. Perianth greenish externally, yellow within, about half as long as the yellowish, mature capsule. Aug.

2. LU'ZULA, DC. Wood Rush. (Italian lucciola, a glow-worm; from the dew glistening upon its flowers.) Perianth persistent, bibracteate at base; stamens 6 ; capsule 1-celled, 3 -seeded; seeds fixed to the bottom.-Stem jointed, leafy. Lvs. grass-like, on entire sheaths. Fls. terminal, green or brownish.

$\$$ Flowers separate, pedicellate, in umbels or panlenlate cymes...................... 1, 2 $\$$ Flowers aggregate, - in pedunculate heads forming an umbel or cyme.......................... 4 -in sessile heads forming a nodding black spike................... 5

1. I. pilòsa Willd. Lvs. pilous; umbel cymous, spreading, consisting of subequal 1-flowered, simple pedicels; caps. obtuse, shorter than the sepals.-Common in woods and groves, N. S. and Can. St, 4 to $16^{\prime}$ high. Radical lvs. numerous, 2 to $4^{\prime}$ long, linear-lanceolate, veined, fringed with long white hairs. Umbels 8 to 12-flowered, with a leafy bract. Pedicels 5 to $10^{\prime \prime}$ long, finally deflexed. Perianth brown, with 2 green bractlets. May. 
2 I. parviflòra Dest. St. elongated; lvs. lance-linear, glabrous; corymb decompound; ped. elongated, the branches with 3 to 5 pedicellate fls.; sep. ovate, acuminate, longer than the oval-triangular, obtuse-mucronate capsule.-White Hills, N. H. (Prof: Bosworth), Graylock Mt., Mass. (Chadbourne), etc. Stem 12 to $18^{\prime}$ high. Radical lvs. 8 to $10^{\prime}$ by 3 to $5^{\prime \prime}$, those of the stem much shorter, all very smooth. Panicle large, nodding, many-flowered. Capsule black. Jn. (L. melanocarpa Desv.)

3 I. campéstris Willd. Fueld Rusir. Lvs. hairy; spikes g'obular or ovate some on long peduncles, some nearly sessile; sep. lanceolate, acuminate-awned, longer than the obtuse capsule; seeds with a conical appendage at base. - In meadows, U. S. and Can. St. simple, straight, 3 to $12^{\prime}$ high. Lvs. grass-like, 2 to $6^{\prime}$ long, with tufts of cotton-like hairs. Heads in a sort of umbel, with an involucre of 2 or 3 short, unequal lvs. Perianth rust-colored, capsule at length brown. May.

$\beta$. BULbòsA. Bulbous; lvs. narrowly linear; sep. shorter than the globular, dark brown capsules.-Lookout Mit., Tenn. St. $6^{\prime}$ high. With the other, but flowers earlier.

4 L. arcuàta E. Meyer. Lvs. linear, channeled, glabrous; heads few, 3 to 5-flowered, on unequal, filiform, often recurved pedicels; bracts ciliate; sepals acute, reddish-brown, about equaling the roundish-elliptical capsulo; seeds not appendaged.-White Mits., N. H. (not common) and Arc. Am.

5 T. spicàta IC. Lvs. linear, hairy at the base; spike cernuous, composed of several sessile globular heads; sep. acuminate-arvned, about equal in length to the subglobous short-pointed, black capsule. Whito Hills, N. H. (Prof. Bosworth). St. 8 to $10^{\prime}$ high, slender, simple. Lvs. 2 to $3^{\prime}$ long, a line wide, smooth except at tho base. Spike an inch long, appearing greyish black when mature. Seeds oval, with a small, oblique appendage. Jl.

3. JUN'CUS, L. Russr. (Lat. jungo, to join; because ropes were anciently made of these plants.) Perianth 6-sepaled, glume-like, persistent; stamens 6 , rarely 3 ; capsule mostly 3 -celled; seeds numerous, attached to the inner edge of the dissepiments.-St. simple, leafy or leafless, with terete, flat or channeled lvs., entire sheaths and small, bibracteate, greenish fls.

\$ Cyme or paniele lateral, bursting from the side of the scape above the middle. (a)

a Leaves none. Flowers separate, mostly hexandrous, greenish............... Nos.1-3

a Leaves few, radical, jointless. Flowers eapitate, 6 -androus, brownish................. 4,5

$\$$ Cyme or panicle terminal on the stem or scape. Leaves present. (b)

b Flowers capitate, few or many in each head (c)

c Leaves jointed (nodous) with internal, transverso partitions. (d)

d Stainens 3. - Heads green or pale straw-colored...................... 6-8

-IIeads brown or ehestnut colored............................... 9,10

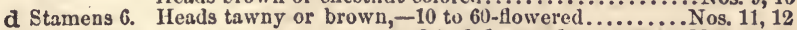

-2 to 9 -flowered...................... 13,14

c Leares not jointed.-Heads many, brown. Sepals obtuse. Stamens 3 ....No. 15

- Heads fow or many, green. Sepals awned............... 16

-IIeads mostly but one. Sepals ncute. Stamens 6. Nos. 17, 18

b Flowers separate, not in heads, mostly secund. Stamens 6 . (e)

e Stems leafy, panicle diffuse, many-flowered.......................... 19, 20

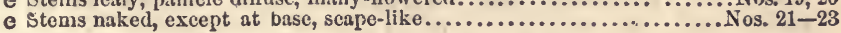

1 J. Bálticus Willd. Baltic Rusr. Rhizome creeping, prostrate, rooting; scapes numerous, sheathed at base, opaquo terete, rigid, slender, pungently acute; panicle near the summit, small; fls. separate, brown; sep. subequal, ovate-lanceolate, very acute, equaling the elliptical, mucronate capsule.-Sandy shores, Me. to Wis. and Can. Scapo leafless, 1 to $3 f$ high, hard, tough, closely arranged along the scaly rootstock, the slieaths $3^{\prime \prime}$ to $3^{\prime}$ long. Panicle 2 to $5^{\prime}$ below the apex of tho scape, 1' long. Fls. 20 to 40 , reddish brown.

2 J. effùsus I. SOFT RusH. Bult-Rusir. Scape straight, not rigid; panicle lateral, loose, decompound, sometimes dense; fls. separate; sep. green, taperpointed, as long as the obovate, obtuse capsules.-Very common in ditches and moist lands, forming tufts, Can. and U.S. Scape solid, with a spongy pith, soft, striate, 2 to $3 f$ high, bearing a loose, spreading panicle which protrudes from a 
fissure opening in the side of the stem about half way up. Fls. small, green, numerous, with 3 white anthers and yellowish seeds. Jn., Jl.

3 J. filifórmis L. (not Mx.) Rhizome creeping, leafless, scape slender, filiform minutely striate, flaccid; panicle subsimple, lateral, near the middle of the scape; fls. separate; sep. pale, nearly equal, lanceolate, a little longer than the pale, shining, obovate, mucronate capsule. Borders of lakes, N. States and Can. Scape 1 to $2 \mathrm{f} \mathrm{high,} \mathrm{with} \mathrm{a} \mathrm{few} \mathrm{brown} \mathrm{sheaths} \mathrm{at} \mathrm{base.} \mathrm{Fls.,} \mathrm{some} \mathrm{pedicellate,}$ somo sessile. Ji.

4 J. setàceus Rostkow. Scape filiform, striate; umbel lateral, subsimple, feroflowered; ped. compressed, several flowered; perianth segments very acute.Swamps, Penn. to Fla., growing in tufts, about $2 \mathrm{f}$ high. Scapes weak and slender (not setaceous), sheathed at base with the shorter leaves. Panicle small, 20 to 30 -flowered, bursting from the side of the scapo some distance below the summit. Fls. in small heads, scarcely brownish. Jn., Jl.

5 J. marítimus Lam. BıACK RUSII. Scapes numerous, tall, rigid, terete, sheathed at base; panicle decompound, far below tho summit; fls, aggregated in roundish lieads; sep. lanceolate, acuminate, longer than the roundish-obovate, mucronato capsule.-In brackish marshes, Va. to Fla. Seapes 2 to $5 f$ high, forming dense tufts. Paniclo 2 to $3^{\prime}$ long, with numerous heads, and subtended by a shorter bract. Fls. dark brown. Jl. (J. acutus Ell, etc.)

6 J. scirpoides Lam. St. leafy, terete, stout; lvs. terete, slender, with frequent joints; panicle cymous, branches few, suberect, heads 5 to 20 , green, about 20 flowered; scp. rigid, lance-acuminate, sharp; stam. 3, nearly as long; style much exserted; caps. taper-pointed, as long as the sepals; seeds oblong, merely acute at cach end.-Can. and U. S., especially coastward, in wet places. St. 1 to $2 \mathrm{f} \mathrm{high,}$ about 3-leaved below. Lvs. shorter than the stem. Heads 3 to $4^{\prime \prime}$ diam., finally straw-colored. May-Jl. (J. echinatus Ell.)

$7 \mathrm{~J}$. polycéphalus $\mathrm{Mx}$. St. few-leaved, terete, strict; lvs. terete-compressed, slender, strict, many-jointed; panicle decompound, loose; heads 5 to 15 , globous, many-flowered; sep. sububate, acuminate, bristle-pointed, the 3 outer longer and wider, greenish, stam. 3, nearly as long; caps. oblong-triangular, abruptly acuminate, longer than the sepals, at length brownish; seeds oblong, with a white tail at each end.-Wet places, Can. and U. S. Sts. 12 to $30^{\prime}$ high, rigid, but slender, the lvs. shorter. Heads 8 to 20 -flowered, $4^{\prime \prime}$ diam. May-JL. (J. paradoxus Gray.)

8 J. débilis Gray. Sts. weak and slender, flattened; lvs. flattened, obscurely jointed; panicle de- or suprade-compound, loosely spreading; hds. few-flowered, straw-color; sep. lanceolate, acute, shorter than the oblong capsule; seeds oblong, acute at each end.-Common in wet places, Can. and U. S. Sts. 9 to $24^{\prime}$ long, from fibrous roots. Heads about 5-flowered (in spec. from Wis., 1 to 3flowered), fls. $2^{\prime \prime}$ long. Lvs. nearly filiform in the smaller plants. (J. subverticillatus Muhl. nec Wulf.)

$9 \mathrm{~J}$. acuminàtus $\mathrm{Mx}$. St. slender, strict, terete; lvs. terete, many-jointed; panicle decompound, branches suberect; heads numerous, 3 to 5-flowered, chestnut brown, fls. erect; sep. strongly veined, lanceolate, acute and mucronate, much shorter than the oblong-triangular, abruptly pointed capsule; seeds tailed at both ends.-Very common in bogs, etc., Can. and U. S. Sts. 9 to $30^{\prime}$ high, slender or rather stout, the slender lvs. much shorter, many-jointed. Capsules becoming deep brown or (in the Southern spec.) almost black.

10 J. Póndii. St. rather stout, terete; lvs. terete-compressed, jointed; panicle spreading, diffuse, decompound; heads numerous, globular, 5 to 12-flowered, chestnut colored; sep. equal, lance-acuminate, bristle-pointed, as long as the triangularovate, abruptly pointed capsule; stam. 3 ; seeds oval, merely acute at each end.Wet places, Car. to Ga. (Feay, Pond,) and Ky. Sts. 1 to $2 \mathrm{f}$ high, with 1 or 2 short leaves. Heads 20 to 40,3 to $4^{\prime \prime}$ diam., in a wide panicle. Mar.-Jn. (J. acuminatus Ell, nec Mx.)

11 J. megacéphalus. St. stout, ascending at base; lvs. distinctly nodous, elongated, the upper usually exceeding the inflorescence; heads few, glomerate, or some pedunculate, rarely paniculate, large, 30 to 60-flowered, tawny; sep. subulate, bristle-pointed, scarcely shorter than the acuminate capsule; stam. 6 ; seeds 
acute.-Borders of streams and lakes, N. Y. to Wis., S. to Fla. St. $16^{\prime}$ to $3 ?$ high. Heads 5 to $6^{\prime \prime}$ diam., globular, 1 to 5 to 12 , clustered or panicled. Sepals with tawny awns, greenish at base. (J. nodosus, $\beta$. megacephalus Torr.)

12 J. nodòsus L. St. erect, slender ; lvs. slender or often filiform, distinctly nodous, the upper often exceeding the inflorescence; $h d s$. few ( 1 to 5 to 9 ), in a simple cluster, tawny or brown, 5 to 20-flowered; sep. ovate-lanceolate, acuminateawned, 3-veined, shorter than the rostrate capsule; stam. 6 ; seeds oval, acute.Sandy swamps and shores, Can. to Car. Sts. 12 to $18^{\prime}$ high. Heads 3 to $5^{\prime \prime}$ diam.-Appears very different from the last. (J. Rostkovii L. Meyer.)

13 J. articulàtus L. $\beta$. PELOCARPUS Gray. Stem erect, compressed, 1 to 3 leaved; lvs. terete-compressed, setaceous, obscurely nodous; panicle spreading; heads 2 to 6-flowered; oblong-lanceolate, the outer acute, the inner obtuse, scarcely as long as the triangular-oblong, bluntly mucronate capsule; stam. 6 ; seeds slightly apiculate.-N. Eng. to Mich. and Can., in wet places, not common. Sts. 9 to $18^{\prime}$ high. Hds. chestnut colored. Anth. Jellow. (J. pelacarpus E. Meyer.)

14 J. militàris Bigl. BAyoner Rusir. St. stout, terete, sbeathed at base, bearing below the middle a single terete, nodous, erect leaf which much exceeds the inflorescence; panicle erect, compound; hds. many, brown, 4 to 9-flowered; sep. lanceolate, acute, as long as the acuminate capsule.-Bogs coastward, Mass. to Ga. St. 2 to $3 \mathrm{f}$ high. Leaf 15 to $30^{\prime}$, overtopping tho stem by six inches cr more. Heads small. Stamens mostly 6 .

15 J. marginàtus Rostkow. St. compressed; lvs. flat, smootl, gramineous; panicle, corymbous, simple, proliferous; hds. 2 to 9 -flowered, tawny or chestnutcolored; bracteoles awned; sep. obtuse, soft, about as long as the obtuse cap. sule; stam. 3.-In low grounds, N. E. to Ga., W. to Ill. Sts. 1 to $3 f$ high. Radical lvs. numerous, sheathing, cauline 1 or 2. Panicle consisting of several globous, 3 to 6 -flowered heads, both pedunculate and sessile, longer than tho crect bracts at base. Sep. edged with dark purple, with a grcen keel. Jn.Aug.

$\beta$. BIfLònus. Stouter (2f high); hds. very numerous, mostly 2 or 3 -flowered, nearly black.-South, common.

16 J. repens $\mathrm{Mx}$. Low, tufted with creeping stolons; lvs. subulate-linear; fascicled at the lower joints; cyme simple; hds. few, 3 to 8 -flowered; sep. subulate, awn-pointed, the 3 inner much longer; caps. slender, trisulcate, mucb shorter than the perianth.- Wet places, Ga. and Fla. Sts' many, 2 to $6^{\prime}$ high. Fls. 3 to $4^{\prime \prime}$ long.

17 J. Stýgus L. St. filiform, erect, rigid, leafy; Ivs. setaceous, slightly channeled, obscurely nodous; hds. few (1 or 3 ), terminal, about 3 -flowered; sep. oblong, acute; stam. 6 ; caps. triangular-elliptic, acute, longer than the perianth; seeds oblong, the loose testa produced into an appendage at both ends.-Perch Lake, Jefferson Co., N. Y. (Gray) and Newfoundland. Fls. unusually large, straw-color.

18 J. trifidus L. St. sheathed at base; leaf solitary, linear setaceous, near the top; sheath ciliate; bracts foliaceous, long, grooved; hd. solitary, sessile botween 2 long bracts, about 3 -flowered, terminal; capsule blackish, giobular, beaked.White Hills, N. H., and Mt. Marcy, N. Y. Sts. crowded, threadlike, 6' high. Radical Irs. 1 to 2, very short, cauline leaf resembles tho 2 bracts, apparently forming with them a foliaceous, 3-bracted invol. $\mathrm{J}$.

19 J. Cónradi Tuckm. St. low, erect, slender, leafy; lvs. few, subfiliform, obscurely nodous; fls. separate, scattered, central and unilateral on the slender branches of the di-trichotomous panicle; sep. lanceolate, margins scarious, rather shorter than the acuminate caps.-Wet places, Can. and U. S., chiefly coastward. Sts. 6 to $9^{\prime}$ high, wiry, turfy. Stam. 6 . Fls. often changed to littlo tufts of leaves.

20 J. bufònius L. TOAD RUSH. Low, slender, tufted; sts. forking; branches floriferous their whole length; fls. separate, greenish, remote; sep. lance-subulate, awn-pointed, the 3 outer longer; caps. triangular oblong, obtuse, mucronulate, much shorter than the perianth; seeds oval, obtuse.-(1) Damp, waste places, in all 
countries. Sts. many, 3 to $8^{\prime}$ long. Lvs. fow, 1 to $2^{\prime}$ long. Fls. many, secund. Jn.-Aug.

21 J. Greenii Oakes \& Tuckm. Scapo tall, subtereto, striato; lvs. filiform-setaceo'ss, subterete, scarcely channeled, shorter than the scape, with sheathing base; panicle dense, branches suberect; bracts setaceous, one of them much longer than the panicle; fls. single, approximate; sep. ovate, acute, twice shorter than the triangular-acute, shining caps.-Wet grounds, R. I., Mass. (Ricard). A handsome rush, 1 to $2 f$ high, rigid, strict. Lvs. all radical. Panicle 2 to $3^{\prime}$ long, one of the bracts twice longer, the other twice shorter. Caps. 2" long, reddish brown.

22 J. ténuis Willd. St. scape-like, slender, erect; lvs. subradical, linear-setaceous, shorter than the stem; bracts $2-3$, much longer than the panicle; fls. single, approximate, green; sep. acuminate, longer than the subglobous-triangular capsule.- A very common rush, about foot-paths and roadsides, and in fields and meadows, U. S. and Can. Stems wiry, 6-24' high. Leaves very narrow, 3-8' long. Panicle subfasciculate, 5-10-flowered, varying to subumbellate and 2030 -flowered, the rays very unequal. Jn., Jl.

B. Dichótourus. Panicle regularly forked onco or twice, branches erect, incurved, with the contiguous fls. regularly distychous; sep. scarcely longer than the capsule.-Waysides, Somerville, Mass., also South. (J. dichotomus Ell.)

23 J. bulbòsus L. $\beta$. GenÁRDI. St. very slender, compressed; lvs. mostly radical, linear-setaceous, shorter than tho stem; panicle small, few-flowered, subtrichotomous, longer than the bracts; fls. separate, approximate by pairs or $3 \mathrm{~s}$, dark-colored: sep. equal, acute, incurved, rather shorter than the subglobous, obtuse, caps.-A common rush, in salt marshes, N. J. to the Arc. Sea, usually with dark green foliage and brown capsules. Sts. not bulbous, tufted, erect, or decumbent and stoloniferous, 1 to $2 \mathrm{f} \mathrm{high,} \mathrm{tough} \mathrm{and} \mathrm{wiry.} \mathrm{Lvs.} 3$ to $8^{\prime}$ long, bracts 6 to $12^{\prime \prime}$. Fls. 12 or more, at length brown or blackish. Jl, Aug.-It makes good hay.

\section{Order CLII. COMMELYNACEAE. Spiderworts.}

Herbs with flat, narrow leaves which aro usually sheathing at base. Perianth of 2 series, the outer of 3 herbaceous sepals, the inner of 3 colored petals. Stamens 6, somo of them usually deformed or abortive, hypogynous. Ovary 2 to 3-celled, cells few-ovuled. Style and stigma united into one. Capsule 2 to 3-celled, 2 to 3valved; cells often but 2 -sceded, with loculicidal dehiscenco. Seeds few, with dense, fleshy albumen. Embryo opposito tho hilum. Figs. 584, 592.

Genera 16, species 260, chlefly natives of the Indies, Australia and Africa, a few N. America. They are of little importance to man. The anomalous genus, Mayaca, constitutes an order by itsclf in Kunth.

\section{GENERA.}

$\S$ Flowers irregular, elustered in a spathe-like, cordate, floral leaf............ CoMmzLrNA. 1 $\S$ Flowers regular, clustered; floral leaves like the rest. Stamens $6 . . . \ldots$.... Tradescaytia. \& \$ Flowers regular, solitary, axillary stamens 3. Moss-liko herbs..................

1. COMMELYNA, Dill. (In honor of the brothers Commelyn, German botanists.) Fls. irregular; sepals herbaceous, petals colored; stamens 6,3 of them sterile and furnished with cruciform glands for anthers; capsule 3 -celled, 3-valved, one of the ralves abortive,-Lrs. lance-linear with sheaths at basc. Fls, enfolded in a conduplicate, persistent, spathaceous, cordate bract, erect in flower, recurved before and after. Petals blue, open but a few hours.

* Prostrate spathe opposite the leaves, complicate, base-lobes free.............. Nos. 1, 2

* Erect or ascending. Spathe subterminal, - complicate, subpeltate.................. 3 -cucullate-peltate........................... 4, 5

1 C. commùnis I. Procumbent, much branched; branchlets marked with a hairy line; lvs. sessile, ovate-lanceolate, acuminate, rounded at base, margin finely serru- 
late; slieath open, ciliate; spathe opposite the leaves, roundish-cordate, complicate; ped. in pairs, 1 to 3 -flowered; petals unequal (blue), the odd one reniform; sep. (pale) the 2 lateral larger, connate below.-In wet grounds, Car. and Ga. Prostrate and spreading 1 to 3 f. Lvs. 3 to $5^{\prime}$ long. Jn.-Nov. (Elliott.)

2 C. agrària Kunth. St. procumbent, glabrous, branched; lvs. oblong or oblongovate, obtuse, the upper short-petioled; sheaths ciliate; spathe opposite the leaves, cordate-ovate, acuminate, complicate, 3 to 4 -flowered; odd petal (blue) roundishovate.-River banks, S. Ill. to La. Sts. If or more in length. Lvs. small (15 to $30^{\prime \prime}$ long). Fls. often polygamous. Sep. pale. Two of the (blue) petals clawed. (C. Cajennensis Rich.)

3 C. Virgínica L. St. assurgent, branching, subgeniculate; lvs. lanceolate, subpetiolate, sheaths split to the base; spathe broad-cordate, distinct and open at base (except a short cohesion), enfolding 2 peduncles and several flowers; pedicels contorted; pet. unequal, the lower one much smaller, unguiculate.-Dry soils Middle! Southern and Western States! Plant nearly smooth, 12-18 high, glabrous. Leaves $3-5^{\prime}$ by $8-14^{\prime \prime}$, varying from lance-linear to lance-ovate. Spathe veiny, 3-5-flowered. Jl., Aug. (C. angustifolia Mx.)

4 C. hirtélla Vahl. Strictly erect, tall, and conspicuously pubescent; lvs. longlanceolate, sheaths densely rusty-bearded at the throat; spathe subsessile, small, clustered at the summit of the stem; petals subequal. - In shady woods, Va. to S. Car. St. 2 to $3 \mathrm{f}$ ligh, rather thick and firm. Lvs. 5 to $8^{\prime}$ long, both sides hairy. Spathe subreniform when open, $5^{\prime \prime}$ long, glabrous, colored, base lobes cucullate, slightly united.-Hardly distinct from No. 1.

5 C. erécta L. St. erect, branched at base, ciliate-pubescent; lvs. lanceolate, subpetiolate, sheaths entire, elongated, ciliate-pilous; spatho deltoid-falcate, united and entire at base as if peltate, about 2-flowered; pet. nearly equal.-Rocky woods, thickets, Penn. (Muhl.) Harper's Ferry to Ga. St. simplo or branched at base, upright, $1-2 \mathrm{f}$ high. Leaves $3-5^{\prime}$ by $6-12^{\prime \prime}$, usually lanceolate, pilousscabrous, the sheaths 9 to $11^{\prime \prime}$ long. Spatho broadly funnel-shaped. Jl, Aug: (C. Virginica $\mathrm{Ph}$.)

3. ANGUSTIFòlis. Of very slender habit, with lance-linear lvs. and the spathe conspicuously arcuate (hawk-bill-shape). - Southern.

2. TRADESCAN'TIA, L. SPIDERwort. (Named in honor of John Tradescant, gardener to Charles I.) Flowers regular; sepals persistent; petals large, suborbicular, spreading; filaments clothed with jointed hairs ; anthers reniform.-2f Fls. in terminal, close umbels, subtended by 2 or 3 long, leafy bracts.

* Umbels sessile, terminal and axillary, with leaf-liko bracts................... Nos. 1, 2

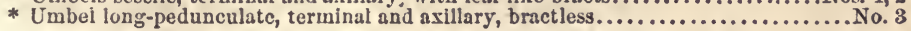

1 T. Virgínica L. St. erect, simple or branched; lvs. lance-linear, or linear channeled above, sessile, ciliate or glabrous; fls. in a terminal, subumbellate cluster, pedicels finally elongated and reflexed; cal. pubescent.-Moist meadows, prairies, \&c., Mid., W. and S. States common. Stem thick, round, jointed, $2-3 \mathrm{f}$ high. Leaves numerous, $12-18^{\prime}$ by $6-12^{\prime \prime}$, the bracts similar. Petals large, suborbicular, of a deep, rich blue, soon fading. May-Aug.-The juice of tho plant is viscid and spins into thread; hence the common name.

2 T. pilòsa Lehm. St. erect, smoothish, bractlets hairy; lvs. lanceolate with a narrow base, long-acuminate, complicate, on a loose sheath, and pilous both sides, the floral like the rest; umbels both terminal and axillary, many-flowered, dense; pedicels and sepals glandular-hairy.-Shady river banks, Ill. to Ohio and La. St. 2f ligh. Lvs. 4 to $7^{\prime}$ by 6 to $12^{\prime \prime}$, sheaths entire, 8 to $10^{\prime \prime}$ long. Fis. in the upper axils, small, bluish purple.

3 T. ròsea Mx. St. erect, simple; lvs. linear, glabrous, channeled, amplexicaul ; ped. elongated; cal. glabrous.-Penn. to Ga., in moist woods. Stem 8-12' highLeaves $6-8^{\prime}$ by $2-3^{\prime}$. Umbel terminal, subtended by 2 or 3 subulate bracts. Pedicels nearly $1^{\prime}$ long. Flowers much smaller than in the preceding species. Petals rose-colored, twice longer than the smooth calyx. MIay. 
3. MAYA'CA Aublet. Flowers regular; sepals 3, green, lanceolate; petals 3 , obovate, colored; stamens 3 , opposite the sepals, persistent; ovary 1-celled, style filiform, stigma simple; capsule 3-valved, seeds several, attached to the middle of the valves.-Moss-like aquatics, glabrous, creeping, branched, densely clothed with narrowly linear lvs. Ped. axillary, solitary, 1-flowered.

M. Michaùxii Schott. \& Endl. Ped. longer than the lvs., reflexed in fruit; caps. 9 to 12 -seeded; petals white.-In shallow waters, Va. to Ga. (Feay, Pond) and Fla. (Mettauer). Sts. several inches long, somewhat resembling Sphagnum. Lrs. numerous and minute, bifid, 2 to $3^{\prime \prime}$ long, ped. thrice longer. Sep. near $3^{\prime \prime}$ long. Seeds globular, white. J. (Syena fluviatilis $\mathrm{Ph}$.)

\section{Order CLIII. XYRIDACEAE. XYrids.}

Herbs sedge-like, with equitant leaves and a scape bearing a head of flowers. $P e$ rianth 6-parted, in 2 series, sepals 3 , glumaceous, petals 3 , unguiculate. Stamens 3 , with extrorse anthers, and inserted on the claw of the petals. Capsule 3-valved, 1-celled, with parietal placentæ, or 3-celled. Seeds numerous, albuminous, orthotropous, embryo at the apex.

Genera 5, species 70, natives of tropical Asla, Africa and America, a fow species of Xyris extending into the Únited States. Of no important use.

XY'RIS, L. Yellow-Eyed Grass. (Gr. Evpós, acute-pointed; in allusion to the form of the leaves.) Heads of flowers ovoid-cylindric ; sepals unequal, the 2 lateral glume-like, keeled, persistent, the odd one membranous, involving the corolla in bud and deciduous; petals equal ovate, crenate, with narrow claws as long as the sepals; capsule 1celled, with parietal placentr.-Lvs. linear, rigid, radical, sheathing the base of the scape. Fls. in a terminal, dense head, with cartilaginous bracts (scales); petals yellow.

* Leaves very short ( $\$$ to $\left.30^{\prime \prime}\right)$. Sepals fringeless, tuftless. Small and delicate. South.... No. 1

* Leaves elongated one-third to three-fourths the length of the seape. (a)

a Sepals with a wingless, fringeless keel, rarely erested. Plant bulbous at base........No. 2

a Sepals with a winged, fringed keel and erested apex, - short as the seale................. 3,4 -twico longer than the scale.... No. 5

1 X. brevifòlia Mx. (nec Ell.) Irs. linear, subulate, falcate, acute, distychously imbricated, 3 to 5 times shorter than the filiform, angular scape; head oval, few-flowered, bracts rounded at apex; sep. acute, lanceolate, the keel not winged, merely scabrous.-Springy places, Car. to Fla. Our smallest species. Scape 4 to $8^{\prime}$ high. Lvs. 8 to $30^{\prime \prime}$ long, about $1^{\prime \prime}$ wide. Head not larger than a peppercorn. Apr., May.

$2 \mathrm{X}$. bulbòsa Kunth. Bulbous; lvs. narrow-linear, obtusish, half as long as the angular, sulcate stem, both twisted; head globular ovoid, bracts roundishovate, very obtuse; sep. oblong-lanceolate, minutely bearded on the sharp keel and tufted at apex, a little shorter than the bract.-Bogs, N. Eng. to Ga., W. to Ind. Scape slender, 9 to $30^{\prime}$. high, lvs. 5 to $15^{\prime}$. Head about $5^{\prime \prime}$ long, bracts closely imbricate, concave. Jn.-Sept. (X. Jupicai Mx. X. Indica Ph. X. torta Sm.)

3. Mixor. Dwarfish (3 to $8^{\prime}$ high), slender; lvs. thrice shorter, scarcely twisted; sep. with an evident tuft at apex.-S. E. Ga. (Miss Keen.)

3 X. Caroliniàna Walt. Lvs, rigid, narrowly linear, a third or more shorter than the flexuous, rigid, slightly 2-edged scape; head elliptical, yellowish brown; sep. narrow, scarcely longer than the oval scales, conspicuously fringed on the keel above the middle and crested at the obtuse apex.-Sandy swamps, N. Y. to Fla. Sts. 1 to $2 \mathrm{f}$ high, more or less twisted. Lvs. 6 to $18^{\prime}$ long, 1 to $2^{\prime \prime}$ or the outer $3^{\prime \prime}$ wide. Head 6 to $7^{\prime \prime}$ long. Petals rather large. Jl., Aug. (X. flexuosa Ell. nec Muhl.)

$4 \mathrm{X}$. ambígua Kunth? Ivs. gladiate-linear, plain, 2 to 3 times shorter than scapes; scapes (often clustered) distinctly 2-edged, tall; head elliptic-oroid, large, 
scales rounded-obovate; sep. shorter than the scales, fringed along the winged keel. -Wet pine barrens, Ga. (Feay). Scapes strict, I to $3 \mathrm{f}$ high. Lvs. strict, 6 to 9, by 2 to $4^{\prime \prime}$, gradually acute. Heads 7 to $9^{\prime \prime}$ long. Aug., Sept. (X. brevifolia Ell.)-The leaves in our specimens are not all rough-edged as in Kunth's.

5 X. fimbriàta Ell. FeATHered XYRIS. Lvs. linear-gladiate, erect, nearly as long as the scape which is strict, striate, and enlarged at the summit; head oval or oblong, scales rounded, loosely imbricated; sep. twice(l) longer than the bracts, conspicuously fringed on the keel above.-Sandy swamps, R. I. (Olney), N. J., (Rev. I. T. Holton) to Fla. Scape 2 to 3 f high. Lvs. 20 to $30^{\prime}$ long, about $3^{\prime \prime}$ wide, sheathing below. Head 6 to $8^{\prime \prime}$ long. Bracts tawny-edged. Seeds innumerable, elliptical, minute. Jl., Aug.

\section{Order CliV. ERIOCAULONACEA. Pipeworts.}

Herbs perennial, aquatic, with linear, spongy, cellular leaves, sheathing at base. Flowers monœcious or diœcious, in a dense head. Perianth 2 to 6-parted or wanting. Stamens 6, some of them generally abortive. Anthers mostly 1-celled, introrse. Ovary 2 or 3 -celled, cells 1 -seeded. Seeds pendulous.

Genera 9, species 200, chlefly tropical. They are of no known use.

\section{GENERA.}

- Stamens ( 4 or 6 ) twice as many as the petals. (Scape 7 to 12 -ribbed)..........Erocaulor. 1

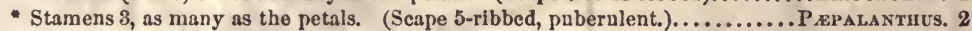

- Stamens 3, and no petals. Scapo 5-ribbed, short, hairy................................... 3

1. ERIOCAU'LON, L. Pipewort. (Gr. ěpıov, wool, kavdós, stem.) Flowers 8 , collected into an imbricated head; involuere of many bracts; $\hat{\delta}$ in the disk (rarely mixed); perianth double; sepals 3 , subregular; petals united to near the summit; stamens twice as many as the petals; o in the margin; perianth double; sepals 3 , petals 2 or 3 , distinct; stamens 0 ; ovary sessile or stipitate; style 1 , stigmas 2 or 3 ; capsule 2 or 3 -seeded.-2f Acaulescent. Lvs. grass-like, Hat, tufted at the base of the slender, simple, one-headed, fluted scape. (Fls. 4-parted in one specics.)

1 E. decangulàre L. Scape tall, slender, marked with 10 ribs and furrows; lvs. linear-ensiform, suberect, half as long as the scape; bracts of the depressed involucre acute; chaff acuminate and tipped with a white fringe as well as the perianth. -Ponds, in pine barrens, S. States, common. Scape 1 to $3 \mathrm{f}$ high, very strict, clustered. Lvs. 6 to $16^{\prime}$ high, 3 to $4^{\prime \prime}$ wide. Head $5^{\prime \prime}$ broad, very white, with the fringes, the corollas tipped with black. Jl., Aug.

2 E. gnaphaloìdes $\mathrm{Mx}$. Scape tall, slender, marked with 10 rits and furrows; lvs. ensiform, subulate, many times shorter than the scape, spreading; invol. depressed; bracts obtusish; chaff acute, white fringed as well as the perianth.Swampy pine barrens, N. J. to Fla., common. Scape mostly single, if to $30^{\prime}$ high. Lvs. 2 to $4^{\prime}$ long, 3 to $5^{\prime \prime}$ wide, gradually tapering to an acute or setaceous point. Head similar to No. 1. Jn.-Aug.

3 E. septangulàre Withering. Scape slender, 7-furrowed, short or tall, and weak according to the depth of the water; lvs. linear-setaceous, pellucid, 5-veined, very short; head small, globular; bracts of the invol. obtuse.-In shallow water, Can. to N. J. and Mich. Sts. clustered, $3^{\prime}$ to 3 f, filiform, reaching the surface of the water. Lvs. in a small tuft, submersed. Head 2 to $3^{\prime \prime}$ diam., white with the fringes of the compact flowers. Jl., Aug.

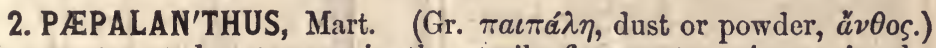
Flowers 3-parted; stamens in the sterile flowers 3 ; stigmas in the fertile flowers 3 ; capsule 3 -seeded.-Otherwise nearly as in Eriocaulon. from which the genus was separated. 
P. flavidulus Kunth. Acaulescent, turfy; scapes numerous, filiform, 5-ribbed and furrowed, finely puberulent; lvs. linear-setaceous, many times shorter than the scapes; head globular; bracts of the involucre oblong; obtuse, straw-colored, dry; fls. not fringed.-Wet, sandy barrens, Va. to Fla. Sts. 6 to $9^{\prime}$ high, lvs. 1 to $2^{\prime}$. Heads $3^{\prime \prime}$ diam. with a straw-colored invol. and silvery white perianths. Apr.-Jn. (Eriocaulon Mx.)

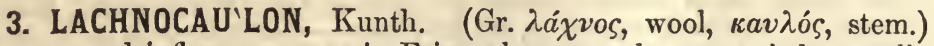
Flowers and inflorescence as in Eriocaulon; 8 calyx 3 -sepaled; corolla 0 ; stamens 3 ; anthers 1-celled, filament united below; $q$ calyx $3-$ sepaled; corolla reduced to a tuft of hairs surrounding the 3 -seeded ovary.-Habit of Eriocaulon.

I. Michaùxii Kunth. Wet, sandy plains, Va. to Fla. Scapes 1 to $5^{\prime}$ high, numerous, 5-ribbed, filiform, clothed with thin, spreading, woolly hairs. Lvs. linear-subulate, about $I^{\prime}$ long, tufted. Head very small ( $1^{\prime \prime}$ diam.), globular, greenish-white. Apr., May. (Eriocaulon villosum Mx.)

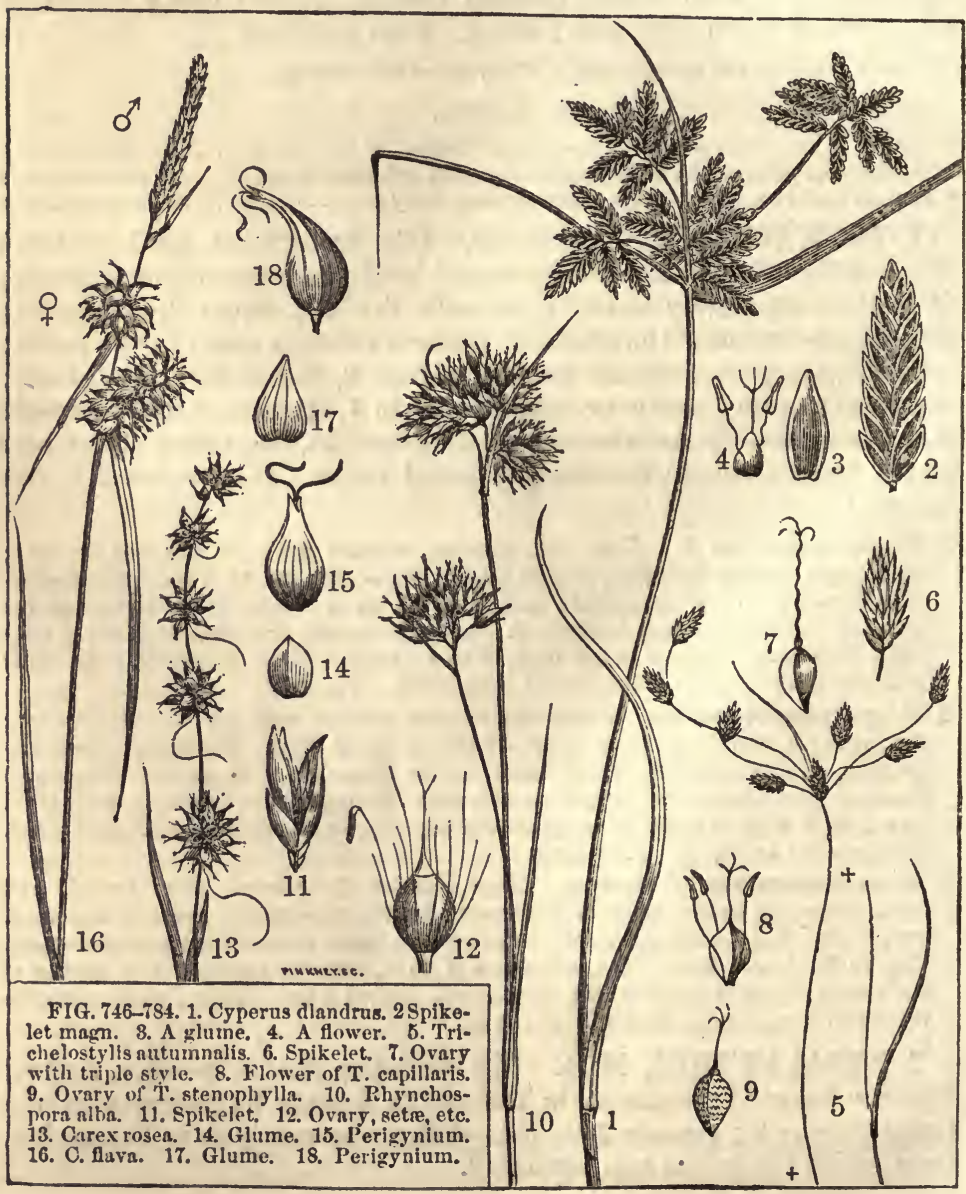




\section{Class IV. G L U M I F E R AE.}

Plants of the endogenous structure, having the flowers invested with an imbricated perianth of alternate glumes instead of sepals and petals, and collected into spikelets, spikes or heads. The Class is equivalent to the CoHorT 7. GRAMINOIDEÆ.

\section{Order ClV. CyPerace A. The Sedaes.}

Herbs grass-like or rush-like, with fibrous roots and solid culms. Leaves mostly linear, channeled, arising from entire or tubular sheaths. Flowers spiked, perfect or diclinous, one in the axil of each glume. Perianth none, or represented by a few hypogynous bristles (setoe), or a cup-shaped or a sac-shaped perigynium. Stamens definite (1 to 12), mostly 3. Anth. fixed by their base, 2-celled. Ovary 1-celled, with an anatropous, erect ovule, forming in fruit a utricle. Embryo enclosed in the base of the albumen.

Genera 120, species 2000. The Sedges abound in almost all climes of the globe, and in all localities, but are more common in the mealows, marshes and swamps of the temperate zones. $\Delta$ bout 40 genera and 400 species are known in North America.

Properties.-They are in general little used for food or in the arts. Their coarse herbage is often eaten by cattle, but they are nearly destitute of the sweet and nutritious properties of the grasses. The leaves of some of the larger species are used in Italy to bind flasks, and in weaving the bottoms of chairs. Yet, although of so little apparent value, their vast numbers authorize the belief that they subserve many highly important ends in the economy of nature.

\section{TRIBES AND GENERA.}

§ Tring 1. CYPEREA. Glumes distichous (2-rowed). Flowers perfect. (*)

* Inflorescence axillary. Perigynium or perianth of 6 to 10 setæ.......... Dusicmum. 1

* Inflorescence terminal. Perigynium none.-Spikes 2 to $\infty$-flowered......... Crperus. 2 -Spikes 1-flowered, capitate..... Krulingra. 3

§ Tribr 2. SCIRPE A. Glumes imbricated in several rows, each (except sometimes the lowest) flower bearing. Inflorescence wholly terminal or wholly latcral (never both). Flowers perfect. (*)

* Perianth of 3 ovate petals and (often) of 3 setæ......................... Furrexa. 4

* Perianth of 3 to $\infty$ hypogynous setæ. (a)

a Achenium crowned with a tubercle. Spiko solitary, terminal..............erociraris. 5

a Achenium not tuberc.-Setæ 3 to 6 , short, or else tawny. Spikes 1 to $\infty$...Scirpus. 6 - Setre $\infty$ (rarely 6), long, white, cottony........ Eriopnorcar. 7

* Perianth 0.-Stylo 2-eleft, smooth.-Spikes 2 to 3, lateral...............IIEMICArPIIA. S -Spikes $\infty$, in a terminal head.........Lipocarpira. 9

-Style 2-cleft, ciliolate. Spikes 5 to 10 , terminal...............mbristruis. 9 -Style 3-cleft, smooth. Achenium 3-angled............. Tricnenostruis. 10

\$ TRIBE 3. RHYNCHOSPOREA. Glumes imbricated in several rows, many of the lowest empty. Inflorescence both terminal and axillary (except in No. 12). Flowers perfeet or diclinous. (c)

o Achenia crowned with the persistent style or its bulbous base. (d)

d Perianth none (no setre).-Spikes diffusely cymous...................PsrLocarYA. 11 -Spikes capitate. Bracts colored.......... Dichromena. 12

d Perianth of setre.-Achen. tuberculate with the base of the style.... Ruyscrospora. 13 -Acheninm horned with the entire long style... Crratoscuarus. 14

- Achenla not tubercnlate,-brown like the scales. Setæe none.................... 15 -white or whitish, crustaceous, Setw none.........ScLEer. 16 
5 Tribe 4. CARICEA. Glumes imbricated or alternate. Setwo 0 . Perianth (perigynium) of united scales, sac-like, enclosing the acheninm. Style 2 or 8 cleft. Flowers diclinous......................................... CAREx. 17

1. DULICH'IUM, Rich. (Gr. $\delta v \omega$ two, $\lambda \varepsilon \iota \chi \circ \nu$, scale; the glumes are in two rows.) Spikes linear-lanceolate, subcompressed; glumes sheathing, closely imbricated in 2 rows; style long, bifid, the persistent base crowning the compressed achenium; ovary invested with 6 to 9 barbed setæ. - 2f St. leafy. Spikes sessile, alternately arranged in 2rowed, axillary racemes.

D. spathàceum Pers. Marshes, borders of streams, U. S. and Can. St. round, leafy, and somewhat 3-sided above, thick, sheathed below. Lvs, alternate, pointing 3 ways, 2 to $4^{\prime}$ by $3^{\prime \prime}$. Sheaths tubular, shorter than the internodes. Clusters axillary from within the sheaths, and terminal, each consisting of 8 to 10 linear-lanceolate, alternate spikes in 2 rows. Spikes 5 to 7 -flowered, nearly an inch in length. Glumes linear-lanceolate. Aug.

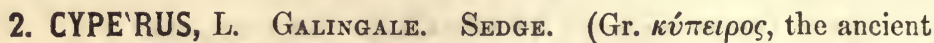
name.) Spikes compressed, distinct, many-flowered; glumes imbricated in 2 opposite rows, nearly all with a flower enclosed; flowers without setæ; stamens 3 , rarely fewer; style 3 -fid (rarely 2 -fid), deciduous.-Mostly $2 f$. St. simple, leafy at base, mostly triangular, bearing an involucrate, simple or compound head or umbel at top.

5 Prcreus. Style 2-cleft. Achenium lens-shaped. Spikes flat, 10 to 30 -flowered.-

- Stamens 2 (partly 8 in No.1)......................................... 1-3

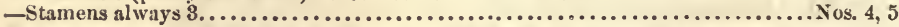

$\$$ Crprous. Style 3-cleft. A chenlum 3-angled. Spikes flattened or teretish, 5 to 40 flowered, the one lowest glume empty. (*)

* Culm with many jounts, teretisli, and with leafless sheaths at base.................... 6

* Culm jointless, triquetrous, and with leaves below. (a)

a Pair of scales within each glume free, persistent. Ileads dense................ 7 a Pair of scales adnate to the rachis, or wanting. (b)

b Spikes racemously arranged along the rachis. Stamens 3 . (c)

c Spikes 10 to 20 -flowered, the clusters 2 -rowed............................ 8,9

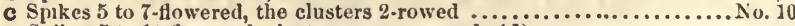

c Spikes 5 to 10 -flowered, clusters inany-rowed. (d)

d Spikes terete or tetragonal............................... 11, 12

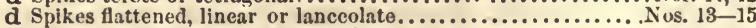

b Spikes capltate on the summit of the rachis. (e)

e Glumes with recurved points. Stamen 1 only.................... 16, 17

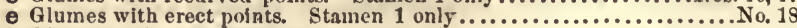

e Glumes with erect points. Stamens 3. (f)

f Umbel simple.-Spikes terete, few-flowered...................... 19 -Spikes flattish, 6 to 10 -flowered............ Nos. 20, 21 -Splkes flat, 12 to 40 -flowered......................... 22 I Umbel compound. Spikes 6 to 30 -flowered...................... 23-25

S Mariscts. Style 3-cleft. Achenium 8-angled. Splkes teretish, 1 to 4 -flowered, in dense heads, the 2 lowest glumes empty..................................... 26, 27

1 C. diándrus Torr. Culms slender, reclining, 4 to $10^{\prime}$ high; umbel contracted, of 2 to 5 short, unequal rays; spikes flat, ovate or oblong, 12 to 24-flowered, obtusish, fascicled at the top of the rachis; glumes obtusish, l-veined, membranous, green on the keel, the sides rust-colored in various shades; stam. mostly 2 ; sty. 2-cleft, exserted; ach. obovate, dull.-Marshy grounds, N. E. to W. States, common. A handsome Sedge. Scales 5 to $8^{\prime \prime}$ long, near $2^{\prime \prime}$ wide. Aug.

$\beta$. castaxeus. Scales of a dark chestnut color, shining, coriaceous, closely imbricated; styles scarcely exserted.

$\gamma$. PAUCIFloikUs. Spikes very short, 5 to 9-flowered; glumes chestnut brown, with yellowish margins; lvs. linear-setaceous. $-\mathrm{N}$. Ohio.

2 C. INuttállii Torr. Culms triquetrous, tufted, 4 to $12^{\prime}$ high; rays few and short, loøse; spikes (2 to $6^{\prime \prime}$ long) linear-lanceolate, flattened, very acute, 10 to 20flowered; scales acute, loosely imbricated, yellowish-brown; stam. 2 ; ach. oblongobovate, obtuse, with a half 2-cleft style.-Brackish meadows, Mass. to La. Lrs. mostly shorter than the culms. Invol. of 4 leaves, 2 of them very long. Spikes 6 to $12^{\prime \prime}$ long, in loose, irregular umbels. Aug. 
B. Mrnmus. Invol. of 1 or 2 lvs. Spikes 1 or 2,10 to 12 -flotwered; glumes loosely imbricated, acute; stam. 1.-Culm and lvs. setaceous. N. J. (Torr.)

3 C. Gatèsii Torr. Culm 8 to 12 ' high, slender, obtusely 3-angled, umbel of 6 to 8 distinct, very unequal rays; spikes alternate, rather remote, linear-lanceolate, 10 to 12 -flowered, the lowest compound; scales acute, loose, pale straw-yellow; stam. 2 ; sty. deeply 2-cleft; ach. obovate, obtuse, dull, dark gray.-Near Mobile, Ala. (Gates, in Torr. Cyp.). Plant pale green. Invol, about 3-leaved.

4 C. flavéscens I. Culm 4 to $10^{\prime}$ high, leafy below; umbel of 2 to 4 short rays; spikes linear, obtusish, 15 to 20 or 30 -flowered; glumes obtuse, straw-color, broadovate, 1-veined; stam. 3 ; sty. deeply 2-cleft; ach. suborbicular, dark brown, shining.--Marshy grounds, U. S., common in Penn. (Jackson). Lvs. about as high as the culms. Spikes 5 to $9^{\prime \prime}$ long, $11^{\prime \prime}$ wide, in crowded fascicles of 3 to 6 on each short rachis. Aug.

5 C. flavicòmus $\mathrm{Mx}$. Culm 1 to $3 \mathrm{f}$ high, 3-angled; invol. 3 to 5-leaved, very long; umbel somewhat compound, of many ( 4 to 7 ) spreading rays; spikes numerous, lance-linear, divaricate, loosely 12 to 30 -flowered; glumes very obtuse, brownish yellow, green and 3-veined on the keel, with a broad, white-scarious margin; stam. 3 ; sty. short, 2-cleft; ach. obovate, blackish.-Bogs, also in dry soils, Va. to Fla. Spikelets 7 to $10^{\prime \prime}$ long. Glumes somewhat truncate and emarginate. May-Sept.

6 C. articulàtus L. JorNted SEDGE. Culm 2 to $6 f$ high, with internal joints, and several leafless sheaths towards the base; lvs. none or sheath-like; umbel compound, loose, with about 5 rays; invol. 2 or 3 -leaved, short, spikes linearsubulate, alternate, 14 to 20 -flowered; glumes lanceolate, obtusish, with a groen kecl, membranous sides, white, with red dots ; stam. 3 ; sty. 3-cleft; ach. acutely 3-angled.-River swamps, S. States. Rt. jointed, creeping. Jn.-Aug.

7 C. erythrorhizos Muhl. Culm 2-3f high, obtusely triquetrous, longer than the leaves; umbel compound; rays $5-9,3-4$ ' long, each with $3-4$ sessile clusters; sheaths entirc; spikelets very numerous, $6^{\prime \prime}$ long, crowded and spreading in tho oblong subsessile (heads) clusters, a little flattened, about 13-flowered; outcr glumes mucronate, closely imbricated, chestnut-brown, veinless and shining, the inner ones entirely free from tho rachis; sta. 3 ; ach. smooth and shining, much shorter than the glume.- Wet grounds Penn. and Southern States.

8 C. Fỳdra Mx. Nut Grass. Culm 6 to $12^{\prime}$ to $2 \mathrm{f}$ high, 3-angled; lvs. shorter than the culm; umbel simple, 3 or 4-rayed, rays nearly as long as the involucre; spikes linear, alternate and 2-rowed on the rachis, 14 to 24-flowered; glumes ovate, veinless, acute, separate at tho tips, of a fine purple brown; stam. 3 ; sty. 3-cleft, much exserted; ach. 3-angled.-Sandy ficlds, Va. to Fla. and La. Very troublesome in eotton fields. Rhizomes creeping and branching cxtensively, bearing tubers. Spikes 6 to $12^{\prime \prime}$ long. Apr.-Jl.

9 C. phymatòdes Mulıl. Culm 1-2f high, 3-angled, striate; lvs. subradical, as long as the stem; umbel 4-6-rayed; rass often branched, bearing $12-20$ linear, obtuse spikelets somewhat in 2 rows; sheaths obliquely truncate, involucels 0 ; spikelets $12-20$-flowered, $6-8$ " long, the lowest generally fasciculato; glumes veiny, yellowish.-24 Moist fields, N. Y. to Wis. and S. States. Rhizomes creeping, bearing small, round tubers at tho ends. May-Aug.

10 C. dissitiflòrus Torr. Culms slender, tumid at the base, 1 to $2 \mathrm{f}$ high; lvs. narrow, nearly radical; umbel 3 to 5 -rayed, suberect, half as long as tho involucre; spikes remotely alternate, subdistychous on the slender rays, teretish, slender, 5 to 7 -flowered, $6^{\prime \prime}$ to $1^{\prime}$ long; glumes lance-oblong, acuto; ach. brown, 3-anglod. -E. Tenn. ? to La. Plant slender, erect. Rays of tho umbel 1 to $3^{\prime}$ long. Spikes divaricato and reflexed. Aug.

11 C. Michauxiànus Schultes. Culm acutely triangular; umbel compound, with short rays; spikelets 6-9-flowered, the lower ones compound; rachis very broad, easily separating at the joints; ova. ovoid-triangular, enfolded by the interior, adnate scales.-(1) Brackish swamps, generally near the sea, Middlo and Southerm States. Stem $12-15^{\prime}$ high, reddened at the base, longer than tho leaves. Spikolets $9^{\prime \prime}$ long, 7-9-flowered.

12 C. tetrágonus Ell. Culm 2 to 3 f high; lrs. shorter, channeled, serrulate on the margins and keel; umbel many-raycd, involucels rone; clusters oblong-cylin- 
dric; spilies.3 to 5-flowered, with a broad rachis and distinclly 4-angied; glumes slightly mucronate; ach. oblong, 3-angled.-Marshes, S. Car. to F'la. (Elliott. Baldwin.)

13 C. strigòsus L. Culm triquetrous, leafy only at base; lvs. broad-linear, roughmargined, about as long as the stem; umbel some compound, with elongated rays and oblong, loose clusters, their sheaths 3-bristled; involucels 0 or setaceous; spikelets numerous, linear-subulate, spreading horizontally, 8-10-flowered, 7-9" long; invol. of about 6 leaves, the 2 outer ones very long.-Wet grounds, U. S., frequent. Stem $1-2 \mathrm{f}$ high, bulbous at base. Umbel yellowish. Sept.

$\beta$. SPECIòsUs. Umbel compound, the partial umbels with leaf-like involucels. (C. speciosus Vahl.)

14 C. stenólepis Torr. Culm 2 to $3 \mathrm{f} \mathrm{high,} \mathrm{slender,} 3$-angled; umbel simple, of 3 or 4 elongated rays; invol. 3 or 4-leaved; ochrea (sheaths) truncate, pointless; spikes crowded, spreading or reflexed, linear, flattened, 5 to 8-flowered, in ovoid clusters; glumes distant, lance-linear, veined; ach. linear-oblong.-N. Car. to Ga. and Tenn. Spikes 6 to $8^{\prime \prime}$ long, of a dusky yellow.

15 C. Schweinítzii Torr. Culm 8-12' high, triquetrous, rough on the angles; Irs. shorter than tho stem, about a line wide; umbel simple, erect, 4-6-rayed, rays clongated, unequal; sheaths truncate, entire; invol. 3-5-leaved, longer than the leaves, scabrous on the margin; spikelets $6-7$, alternate, approximate, in cylindric clusters, 6-8-flowered, with a small, setaceurs bract at the base of each; scales membranaceous on the margin; sta. 3; sty. 3-cleft, scarcely longer than tho smooth achenia. - Shore of L. Ontario (Sartwell) of Lake Erie (Sullivant) to Ark.

16 C. infléxus Muhl. Culm setaceous, leafy at base, $2-3^{\prime}$ ligh; lvs. equaling the stem; umbel 2-3-rayed, or conglomerate and simple; invol, of 3 long leaves; spilielets oblong, 8-12-flowered, 10-20 together, densely crowded into the ovoid lieads; glumes yellowish, veined, squarrous-uncinato at tip; sta. 1.-Banks of streams. Freo States and British Provinces. Aug., Sept.

17 C. acuminàtus Torr. \& Hook. Culm 3 to $12^{\prime}$ high, slender, obtusely triquetrous; lvs. erect, radical, as long as the stem; umbel 1-6-rayed; invol. 3-4leaved, very long; rays unequal, each with a globous head of $15-40$ spikelets; spikelets 3-11", oblong-linear, obtuse, 15-25-flowered; fls. very regularly imbricated in 2 rows; glumes acute, with the point recurved; sta. 1 ; ach. dull-grayish. -IIl. (Mead.) and westward.

18 C. virens $\mathrm{Mx}$. Culm 2 to $4 \mathrm{f}$ high, stout, 3-angled; lvs. nearly as long, strongly keeled, rough-edged; umbel compound, with 5 to 7 very unequal rays; invol. of 4 or moro leaves, very long, involucels leafy; spikes ovate, in dense, globular lieads, flattened, 10 to 20-flowered; glumes acute, greenish; stam. 1; ach. 3-angled, acute at each end.-Swamps, S. States. Spikes 3 to $5^{\prime \prime}$ long. Nut dull yellow. (C. vegetus Ell. Torr.)

19 C. echinàtus. Culm $10^{\prime}$ to 2 f high, 3 -angled, bulbous at baso; 1 rs. numerous, rather shorter; invol. 6 to 10-leaved, long; umbel simple, 6 to 10-rayed; spikes short, teretish, acute, 3 to 6 -flowered, in dense, globular heads; glumes striate, tawny, appressed; stam. 3; ach. obovate.-Dry fields, S. States. Root with numerous fibres. Plant very leafy. Spikes 2 to $5^{\prime \prime}$ long, with a broad rachis. (C. Baldwinii Torr. Mariseus, Ell.)

20 C. Gràyii Torr. Culm 8-12' high, filiform, obtusely triangular, erect, tubcrous at base; lvs. radical, channeled, about $\frac{1}{2}{ }^{\prime \prime}$ wide; umbel 4-6-raycl capillary, erect, spreading; sheaths truncate; hds. loose, of $6-8$ spikelets; spikelets linear, compressed, 8-7-flowered; scales ovate, veined, obtuse, imbricated, interior ones lanceolate; sta. 3 ; sty. 3-cleft; ach. obovate-triquetrous, $\frac{2}{3}$ the length of the scale, gray, dotted.-Sandy fields, Mass. to N. J. Sept.

21 C. filicúlmis Valıl. Culm slender, almost filiform, tuberous at base, 8-12' long, leafy only at base; lvs. mostly radical, carinate; umbel simple and sessile, or with 1 or 2 rays; spikes linear-lanceolate, 3-8-flowered, flattened when old, collected into globous heads; glumes remote, loose, ovate, yellowish.-Dry, rocky hills, N. Eng. to Fla., W. to Ill. Aug. (C. mariscoides Ell.)

22 C. compréssus $\mathrm{L}$. Culm naked, 3-angled, 3 to $8^{\prime}$ high, tumid at base; umbel sessile or simplo and few-rayed, rays spreading; spikes lanceolate, 2-edged, 
12 to 40-flowered, loosely aggregated in heads; rachis winged; glumes ovate, slightly veined, acuminate, yellowish, very acutely keeled; stam. 3 ; acl. obovate, 3-angled, shining.-Dry fields, S. States. Spikes 6 to $12^{\prime \prime}$ long, sharply serrated by the projecting points of the glumes. Root fibrous.

23 C. dentàtus Torr. Culm about $1 \mathrm{f}$ high, leafy at base, triquetrous; lvs. a little shorter than the stem, strongly keeled; umbel compound, 6-10-rayed; invol. of 3 unequal leaves, one of them longer than the umbel; spikes 3 on each peduncle, $3-7^{\prime \prime}$, lance-ovate, flat, 8 (rarely 5 to 30 ) flowered; glumes acute, spreading at the points, giving the spikes a serrated appearance; sty. 3-cleft; ach. triangular.-2f Swamps, Mass., to N. Y. and Fla. Rhizomo creeping, bearing tubers. Spikes often morbidly cnlarged.

24 C. Lecóntii T'orr. Culm 3-angled I to $2 \mathrm{f}$ high, leafy at baso; Irs. linear, about the same height; invol. 3 to 6 -lvd., longer than the umbel; umbel compound, many-rayed; spikes oblong, obtuse, flat, in small digitato clusters, 20 to 40 flowered; glumes closely imbricated, acute, yellowish, the points obtusish, callous, scarcely separated; stam. 3.-Fla.! to La. An elegant species. Spikes 4 to $7^{\prime \prime}$ by $2^{\prime \prime}$. Rhizome creeping.

25. C. léptos Schultes. Culm weak, 1 to $2 \mathrm{f}$ high, 3 -angled; lvs. radical, shorter ; umbel compound or decompound, of numerous (12 to 15) filiform rays, with a short, 2-leaved involucre; spikes 3 to 5 in each loose head, lance-linear, 12 to 20 -flowcred; glumes ovate-lanceolate, acute, keeled, the keel green, sides yellow with 2 red lines.-Damp soils, N. Car. to Fla. and La. Spikes 3 to $4^{\prime \prime}$ long. Sept., Oct. (C. gracilis Muhl.)

26 C. ovulàris Vahl. Culm acutely 3-angled, nearly naked, 6 to $16^{\prime}$ high; Ivs. shorter, nearly smooth; umbel simple; rays $3^{\prime \prime}$ to $2^{\prime}$ long; $h d s .1$ to 5 , globular, one sessile, tho rest on the spreading rays; spikes linear-subulate, $3^{\prime \prime}$ long, 50 to 100 in each head; fls. 2 to 4, 1 or 2 fertile; invol. 3 or 4-leaved, outer lys. very long; glumes ovate, obtuse, greenish, tho two lowest empty.-Bors and low grounds, M, W. and S. States, common. Aug., Sept. (Mariscus Vahl. Kyllingia $\mathrm{Mx}$.)

27 C. retrofráctus Vahl. Culm obtusely trianguiar, nearly leafless, pubescent, 2 to $3 \mathrm{f}$ high; lvs. pubescent, 3 to $4^{\prime \prime}$ wide, about half as long as tho stem; umbels simple; rays unequal, long, 6 to 8 ; invol. 3 to 5 -leaved; bracts unequal, not longer than the rays; spikes 70 to 100 , subulate, 1-flowered, finally retrorsely im. bricate into obovate heads; 2 lower glumes empty.-Mid., W. and S. States, rare northward. Aug., Sapt.

\section{KYLLIN'GIA, L. (In honor of Peter Kylling, a Danish botanist.)} Spikes compressed; scales about 4, the 2 lowest short and empty, the third only usually with a fertile flower; stamens 1 to 3 ; style long, 2cleft; achenia lenticular.-Sts. triangular. Hds. sessile, solitary or aggregated, involucrate.

$1 \mathrm{~K}$. púmila Mx. Cæspitous; culm 2 to $12^{\prime}$ high, slender; lvs. mostly radical, shorter than the stem, smooth; hds. generally solitary, sometimes triple, closely sessile, oval or oblong; invol. 3-leaved, 1 to $2^{\prime}$ long; spikes 1 -flowered, very numerous, about $2^{\prime \prime}$ long; the lowest glume or glumes very small; sta. always 2 ; ach. lens-shaped, fulvous.-Wet banks, Columbus, Ohio (Sullivant) to Ill. (Lapham) and S. States. Variable. Aug. K. sesquiflora Torr. is a taller form, with triple heads. (Florida, Chapman.)

4. FUIRENA, Rotboll. Chot-Grass. (In honor of George Fuiren, a Dutch botanist.) Glumes imbricated on all sides into a spike, awned below the apex; petaloid scales 3 , cordate, awned, unguiculate, investing the achenium, which is abruptly contracted to a stipe at base.- 4 St. angular, lcafy. Spikes umbeled or capitatc, axillary and terminal.

I F. squarròsa $\mathrm{Mx}$. Culm 1 to $2 \mathrm{f}$ high, obtusely triangular, sulcate; lvs. flat, ciliate, shorter than tho stem; sheaths hispid-pilous; spikes clustered, ovoid, mostly terminal, 7 to 12 ; awns nearly as long as the glumes; petals ovate, cuspi- 
date with a short bristle; ach. twice the length of the stipe.-Bogs and swamps, Mass. to Mich., S. to Fla. and La.

$\beta$. Pumil. Culm a few (3 to 6 ) inches high, spikes 1, 2 or 3 ; glumes ovatelanceolate, with short awns; petaloid scales ovate-lanceolate.

2 F. hispida Ell. Culm triangular, sulcate, hispid above, 2 to $3 \mathrm{f} \mathrm{high} \mathrm{;} \mathrm{lvs.} \mathrm{linear,}$ 5 to $8^{\prime}$ long, flat, hispid-pubescent, with very hispid sheaths; spikes 3 to 12 , in clusters of 3 to 6 , ovoid-oblong, mostly terminal ; awns longer than the glumes, spreading-recurved; petals ovate, mucronate; stam. 3, scarcely longer than the corolla; sty. twice as long as the stamens. - Car. to Fla. and La. Differs from No. 1 chiefly in its hairiness.

3 F. scirpoìdea $\mathrm{Mx}$. Culm slender, 1 to $2 \mathrm{f}$ high, 3-angled, striate, leafless, but with several sheaths; spikes 1 to 6, ovoid, terminal, dingy brown, not squarrous; glumes short awned or cuspidate; petals ovate, shorter than the claws; stam. 3 ; ach. triangular, pointed at both ends.-S. Ga. and Fla. Rhizome creeping. Heads as large as the white bean.

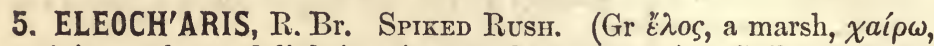
to rejoice; plants delighting in marshy grounds.) Spikes terete; glumes imbricated all around; bristles of the perigynium mostly 6 (3 to 12) rigid, persistent; style 2 to 3 -cleft, articulated to the ovary ; achenium crowned with a tubercle which is the persistent, bulbous base of the style.-Mostly 2 . St. simple, leafless. Spike solitary, terminal.

\$ LIMNOCHLOA. Spiko cylindrical, elongated $(17)$, glumes rounded, pale, splrally arranged. Culms stout, 2 to $4 \mathrm{f}$ high................................................... 2

§ ILEOCHARIS. Spikes ovoid or lanceolate, teretely imbricate (*).

* Spike lance-oblong, length thrice greater than the diameter (a).

a Culms terete ( 1 to $2 \mathrm{f}$ ). Spike rusty brown, 5 to $10^{\prime \prime}$ long................... 3

a Culuns flattened, hair-like or thread-like, narrower than spike................. 4,5

a Culms 8 -angled, stout, as broad as the spike. Lvs. ? floating.................. 6

* Spike ovoid-oblong, length less than thrice the diameter (b).

b Spikes greenislx white, globous-ovoid, 2 to $3^{\prime \prime}$ long. South.............Nos. 7, 8

b Spikes brown, or the glumes brown in the center (c).

c Culms 4 or 5 -angled, 2 to 12 high.................................. 9,10

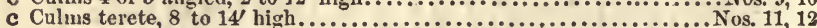

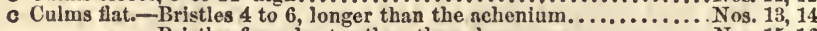

-Bristles few, shorter than the ach. or none....................... 15, 16

8 CH ATOCYPERUS. Spike tlat, glumes imbricated in 2 or 3 rows. Cuims capil-

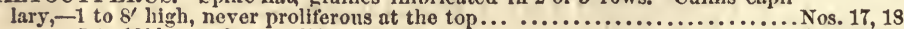

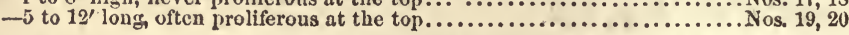

1 E. equisetoìdes Torr. Culm about $2 \mathrm{f}$ high, papillous, terete, $2-3^{\prime \prime}$ diam., with about 20 joints, produced by internal, transverss partitions; sheath radical, obtuse, membranous; spike oblong-cylindrical, about I' $^{\prime}$ in length, acute and slightly contracted at base; glumes roundish-ovate, cartilaginous, obtuse; bristles 6 , as long as the achenium; sty. 3-cleft; ach. brown, shining.-Bogs, Cumberland, R. I. (Olney), Del. to Ga. It strikingly resembles Equisetum hyemale.

2 E. quadrangulàta $\mathrm{R} . \mathrm{Br}$. Culm 2-4f high, acutely and unequally quadrangular, the broadest side convex, the others concave; sheaths radical, purplish; spilie $1^{\prime}$ or more in length; glumes roundish-ovate, obtuse, coriaceous; bristles 6 ; ach. obovate, of a dull white.-Penn., Md. (Robbins); to Ga. and La. In swamps and inundated banks.

3 E. palústris $\mathrm{R}$. Br. Rhizomes creeping; culms subterete (slightly 4-sided below), spongy, $9^{\prime}$ to $2 \mathrm{f}$ high, varying from filiform to $1 \frac{1^{\prime \prime}}{2}$ diam.; spikes oblonglanceolate, rather obtuse, 3 to 6 to $10^{\prime \prime}$ loug, many-flowered; glumes oblongovate, obtuse, rusty or tawny brown, with a broad, locse, scarious margin, the lowest enlarged; ach. obovate, smooth, shining, yellowish.

B. CALVA. Bristles none; culms filiform.-W. N. Y. (E. calva Torr.).

4 E. intermèdia Shultes. Tufted culms sctaceous, diffuse, compressed, furrowed, hard, wiry, 6 to $8^{\prime}$ long; spike lance-ovate, acute, 2 to $3^{\prime \prime}$ long, 7 to 9-flowered; glumes, lance-ovate, acute, reddish-brown, with a green midvein; bristles 6 , white, longer than the achenium; sty. 3-cleft; ach. obovate, attenuated to the base, striate, of a light brown color.-In running water, forming a dense turf, $\mathbb{N}$ H. to Ga., W. to Ohio. $\mathrm{J}$. 
5 E. tricostàta Torr. Culm filiform, flattened, striate, 1 to $2 \mathrm{f}$ high; spike cylindric-oblong, dense-flowered, 6 to $9^{\prime \prime}$ long; glumes ovate, obtuse, rusty brown, with a broad, scarious margin and a green inidvein; bristles 0 ; ach. obovate, with 3 promicent, thick angles, roughish, brown, crowned with a whitish, minute tubercle; style 3-cleft. - Wet places, N. J. to Fla.

6 E. Robbínsii Oakes. Culms clustered, $9-25^{\prime}$ high, rigid, sharply triangular, pale green, several of them fruitless; sheath truncate; spitie $3-12^{\prime \prime}$ long, scarcely thicker than the stem, placed $2-5^{\prime \prime}$ below its apex; glumes $3-9$, linear-lanceolate, acute, finally brownish; bristles 6 , twice longer than the achenium; ach. $1^{\prime \prime}$ long, pale brown; tubercle closely sessile.-Ponds and ditches, N. H. and Mass. (Ricard). Very distinct. In water a part of the stems are floating and as fine as hairs. Jl.

7 E. capitàta Brown. Culm filiform, furrowed, angular, $4^{\prime}$ to $6^{\prime}$, in tufts ; spike globular-ovoid, $2^{\prime \prime}$ long, greenish white; glumes 12 to 15 , oblong, obtuse; bristles 6, some of them a littlo exceeding the ach, which is broadly obovate, lens-shaped, black, shining, crowned with a minute, depressed tuberclo; style 2 cleft.-Wet places, Ga., Fla. to La.

8 E. álbida Torr. Culm filiform, terete, striate, sulcate on one side, 8 to 12'; spike ovoid, acute, 2 to $3^{\prime \prime}$ long; glumes 20 to 30 , whitish, ovate, rather acute; bristles 6 , brown, longer than the chestnut-colored, smooth, broad-ovate ach. ; tubercle small, acute; style 3-cleft.-Wet, sandy places, Ga., Fla. to La. Known at sight by its whitish heads. Sheaths very short.

9 E. olivàcea Torr. Culms coespitous, 2-4' high, slender, subcompressed, sul. cate, soft: spike ovate, acutish, $2-3^{\prime \prime}$ long, 20-30-flowered; glumes ovate, obtuse, reddish-brown, with scarious edges and a green midvein, the lowest largest; bristles 6 ; sty. 2-cleft; ach. broadly obovate, smooth, of a dull, blackish-olivo color when ripe.-Sands, generally partly submersed, Providence, R. I. (Olney) Mass. to Ga.

10 E. ténuis Schultes. Culm almost filiform, quadrangular, the sides sulcate, $8-15^{\prime}$, with a long, purple sheath at base; spike 2 to $3^{\prime \prime}$ long, elliptic-oval, acuto at each end; glumes dark purple, ovate, obuse, the lower ones larger and empty; ova. roundish, tapering below, invested with 2 or 3 or 0 setæ-Common in wet places, Can. and U. S. Jn., Jl.

11 E. obtùsa Schultes. Culm sulcate, subterete, $6-15^{\prime}$ high; spike ovoid, very obtuse, often nearly globous; glumes 60 to 100 , round, dark brown, with whitish margins; ach. obovate, compressed, smooth, brown, invested with 6 setæo as long as the glumes, and crowned with a broad, flat tubercle.-Shallow waters, Can. and U. S., common. Jl.

12 E. tuberculòsa R. Br. Culm columnar, striate, 12' high, leafless, sheathed at base; spike ovate-lanceolate, acutish, glumes very obtuse, loose; ach. somewhat triquetrous, not larger than the sagittate tubercle with which it is crowned; bristles 6, as long as the tubercle.- -Sandy swamps, N. Eng. to Flor. and La. Remarkable for its large tubercle. Jl.

13 E. símplex Torr. Culm acutely 3-angled (terete Torr.), filiform, striate, 12 to $18^{\prime}$; spike ovoid, acutish; scales ovate, obtuse, whitish with a brown center; bristles 6 , rigid, longer than the ach., which is broad-obovate, furrowed lengthwise, olive-green, crowned with a large, distinct, conic-beaked tubercle; stylo 3 cleft.-Wet places, N. Car. to Fla. and La.

14 E. rostellàta Torr. Culm 15-20', clustered, angular and sulcate, slender, almost filiform, rigid; sheaths obliquely truncate, the lowest blackish at summit; spike lance-ovate, acute, $3-4^{\prime \prime}$ long; glumes $12-20$, lance-ovate, smooth, light brown, edge scarious; bristles 4 to 6 , longer than the smooth $a c h$., which is $b i$ convex, olive-brown, with a confluent, acuminate tubercle, shorter than the 6 bristles.-R. I. (Olney), N. Y. (Sartwell), to Mich.

15 E. melanocárpa Torr. Culm compressed, furrowed, slender, almost filiform, wiry, 12-18' high; sheaths truncate; spike lance-oblong, rather acute, $4-6^{\prime \prime}$ in length, 20-40-flowered; glumes ovate, obtuse, brownish, with scarious margins and a prominent, yellowish midvein; bristles 3 , purple; ach. obovate-turbinate, blackish; tubercle broad, flat, pointed in the center.-Providence, R. I. (Olney).

16 E. compréssa Sullivant. Culm 12-18' high, cæspitous, much compressed, 
narrowly linear, striate; sheath close, truncate; spike oblong-ovate, $3-5^{\prime \prime}$ in ling:h, 20-30-flowered; glumes ovate-lanceolate, acute, mostly 2-cleft at apex: dark purple on the back, with a broad, scarious margin; bristles 0 ; ach. obovatepyriform, shining, minutely punctate, of a light, shining yellow, the minute tubercle fuscous. - Wet places N. Y. to Ill.

17 E. aciculàris $\mathrm{R}$. Br. Culm leafless, setaceous, quadrangular, very slender, 3 -6' high; spike compressed, oblong-ovate, acute, 4-8-flowered; glumes obtusish, the lowest one larger and empty; ach. obovoid, triangular, striated lengthwise.-Edges of ponds, often partly submersed, U. S. and Brit. Am. Very delicate. June, July.

18 E. pigmæa Torr. Culm 1-2' high, setaceous, compressed, sulcate; spikes ovate, compressed, 3-6-fld.; gl. mostly empty; bristles 6, longer than tho achenium, slender, scabrous backwards; ach. ovate, acute, triangular, smooth, not striate, whitish and shining; tuberclo minute.-Sea coast, Mass., to Fla. and La.

19 E. microcárpa Torr. Culm capillary, 4-angled, 5 to 8 ' long; spike oblong, compressed, 10 to 20-flowered, about $2^{\prime \prime}$ long, often proliferous; glumes ovate, acutish, keeled, chestnut brown, the lowest much the largest, bristles 3 to 5 , shorter than the achenium which is minute, smooth, whitish, with a very minute tubercle.-Wet places, N. J., also La.

20 E. prolífera Torr. Culms capillary, 4-angled and furrowed, 4 to $12^{\prime}$ long, in dense tufts; spike minute, 1 to $2^{\prime \prime}$ long, compressed, 4 to 6-flowered; glumes ovate, chestnut brown, with scarious margins, often proliferous, that is, producing new culms instead of flowers; bristles 3 or 4 , much shorter than the acherium which is 3-angled and with a broad, depressed tubercle.-Fla.! to La. (Hale). (Chætocyperus Baldwinii Torr.)

6. SCIR'PUS, L. Club-rush. Bullrush. (Celtic cirs, the general name for rushes.) Glumes imbricated on all sides; perigynium of $3-6$ bristles, persistent; sty. 2-3-cleft, not tuberculate at base, deciduous ; achenium biconvex or triangular. $-2 f$ Stems mostly triquetrous, simple, rarely leafless. Spikes solitary, conglomerated or corymbous.

§ ScIRPus. Bristles retrorsely denticulate, about equaling the achenium. (*)

* Spike single, terminal, with a short, erect bract at its base.................... 1-3

* Spikes several or many clusterel on each culin. (a)

a Clusters of spikes lateral - on the terete, jenfless culm ................ Nos. 4, 5 -on the triangular enlm................................. 6 -

a Clusters of spikes terminal, mostly umbellate. (b)

b Glumes lacerately 3 -toothed. Spikes liorge $\left(9\right.$ to $12^{\prime \prime}$ lon" $)$.......... Nos. 9, 10

b Glumes entire.-Spikes small $\left(1^{\prime \prime}\right)$, collected in globular heads........... - Spikes small (2 to $3^{\prime \prime}$ long), separate.................. 18

5 Tricoprorum. Bristles 6, tortuous, tawny, nuch longer than the achenium, and

exserted. Stem (eulus) leafy. Umbel decompound......................... 14, 15

1 S. planifòlius Mfull. Culm cospitous, leafy at baso, acutely and roughly 3angled, 5-10' high; lis. broad-linear, flat, rough on the margin, equaling the stem; spike oblong-lanceolate, compressed, terminal, 4-8-flowered; glumes ovatemucronate, ycllowish; bracts at the base of the spike, cuspidate, outer oncs longer than the spike; ach. reddish-brown, invested with 6 bristles longer than itself.In cold, hard soils, Mass. (Robbins), N. Y. to Del. June.

2 S. E:tbterminàlis Torr. Culm floating, furrowed, inflated, leafy below, 1 to $3 \mathrm{f}$ long; lvs. very narrow, almost capillary, 2 to $4 \mathrm{f}$ long; spike someuhat terminal (the stem being continued above it in the form of a bract), lanceolate; style 2-cleft; bristles 6.-Streams, \&c., Mass. to N. Y., Mich. Aug.

3 S. cæspitòsus L. Culm coespitous, round, sheathed at base with rumerous ru. diments of leaves; spikes compressed, terminal; 2 lower glumes involucre-like, as long as the spike; ach. witl 6 bristles.-Grows in dense tufts, 4-12' high. Spiko 1-5-flowered, reddish-brown. On the alpine summits of Mts., N. States. Jl.

4 S. débilis Pursl. Culm cæspitous, roundisl, deeply striate, 9 to $16^{\prime}$ high, with a few subulate leaves at base; spikelets about 3 , short-ovoid, sessile, crowded, lateral, the culm continuing a fourth of its length above them, glumes ovate, obtuse, carinate, pale green; ach. obovate, mucronate; bristles 4 or 5.-Borders of ponds and rivulets, N. Eng. to Car. Aug. 
5 s. lacústris I. LAKE Bullrusir. Culm smooth, leafless, fllled with a porous pith, 5 to $8 f$ high, cylindric, tapering above the panicle, and abruptly ending in a short cusp; panicle cymous near the top; ped. rough, twice compound; spikelets ovoid, closely imbricate; scales ovate, mucronate, pubescent; bracts shorter than the panicle.-The largest species of bullrush, frequenting the muddy margins of rivers and ponds, U. S. to Aro. Am. July. (S. acutus Muhl.)

6 s. púngens Vahl. Culm nearly naked, 3-angled, corners acute and two of the sides concave, about $3 \mathrm{f}$ high and ending in a sharp point; - lvs. few ard short, from the top of the sheath; spikes lateral, $1-5$, ovate, crowded and sessile, at various distances below the point; glumes round-ovate, mucronate; bristles 6 ; style 2-cleft.-Ponds and marshes, fresh and salt, throughout N. America. (S. triqueter $\mathrm{Mx}$.)

7 S. Olneyi Gray. Culm triquetrous-winged, leafless, 2-7f high; sheath radical, tipped with a short $\left(1-2^{\prime}\right)$ leaf; spikes $6-12$, sessile, aggregated, $2-3^{\prime \prime}$ long, placed $9-12^{\prime \prime}$ below the triangular apex of the stem; glumes roundish-ovate, mucronate; bristles 6-12; ach. obovate, plano-convex, gibbous at apex. - Salt marshes, Sekonk river, R. I. (Olney), Tom river, N. Y., Kneiskeru. Remarkably distinguished by its 3-winged stem. July.

8 s. Tórreyi Olney. Culm $2 \mathrm{f}$ high, 3-angled, with concave sides, rather slender, leafy at the base; lvs. 2 or 3 , if or more long, slender; spikes $2-4$ (rarely 1), sessile, distinct, acute, ovate-oblong; scales ovate, mucronate, smooth ; sty. 3-cleft ; ach. obovate, acuminate, unequally $\mathbf{3}$-sided, shorter than the bristles.-Borders of ponds, N. Eng. to Mich. The stem here as in the last, is prolonged abovo tho spikes, in tho form of an involucral leaf. Jl., Aug. (S. mucronatus Ph.? Torr.)

9 s. marítimus L. SeA Bullrusir. Culm acutely 3-angled; leafy, 2-3f high; lvs. broad-linear, rough-edged, carinate, taller than the stem; spikes conglomorate, 6-10, nearly an inch long, corymbous; invol. of about 3 very long leaves; glumes ovate, 3 -cleft, the middle segment subulato and reflexed; style 3-cleft: bristles 3-4, much shorter than the broad-obovate, lenticular, darl brown, polished achenium.-Salt marshes, N. Eng. to Flor. Aug.

10 s. fluviátilis Gray. Culm triangular-winged, leafy, stout, 3 or $4 \mathrm{f} \mathrm{high;} \mathrm{lvs.}$ broadly linear, very long; invol. lvs 5 to 7 , far exceeding tho umbel; umbel somewhat compound, spikes separate or conglomerate, large (9 to $12^{\prime \prime}$ long), fulvous; glumes 3-cleft, bristles 6, whitish, longer than the sharply 3-angled, oblong, black achenium, which is tipped with a whitish beak.-Borders of lakes and rivers, W. N. Y. and W. States. Jl., $\Lambda$ ug. (S. maritimus, $\beta$. fluv. Torr.)

$11 \mathrm{~S}$. atrovìrens Muhl. Culm obtusely triangular, leafy, $2 \mathrm{f}$ high; cyme compound, proliferous; invol. of 3 leaf-like bracts longer than the cyme; spikes ovate, acute, crowded, 10 to 20 in a globous head; hds. numerous, $4^{\prime \prime}$ diam., dark olive green; glumes ovate, mucronate; bristles 4,' straight, hispid downward, as long as the smooth, white achenium.-Common in meadows, Mid. and W. States. Jn., Jl. Very different from S. sylvaticus L. of Europe.

12 S. polyphyllus Vahl. Culm obtusely triangular, leafy, 2-3f high; cymo decompound, its principal branches about 5, unequal, with truncate sheaths at base; spikelets clustered in heads of $3-6$; glumes obtuse, reddish-brown; ach. smooth, yellowish-white, twice shorter than the 4 or 5 smooth tonvuous bristles.Much resembles the last species. Margins of waters, N. Eng., Ill. and S. States. (S. brunneus Muhl.)

13. S. divaricàtus Ell. Culm obtusely triangular, very leafy, 3 to $4 \mathrm{f}$ high; lvs. flat, broadly linear or lance-linear, 3 to $6^{\prime \prime}$ wide, shorter than tho culm; umbel loose, large, decompound, rays filiform, divaricate, recurved; spikes all separate, pendulous, oblong-ovoid, 2 to $3^{\prime \prime}$ long, rust colored, pendulous; glumes many, acute; bristles tortuous, rather longer than the achenium which is tawny, elliptic3-angled, acute at each end.-Wet barrens, S. Car. to La. (Hale).

14 S. Erióphorum Mx. Culm obtusely triangular, leafy, 3 to $5 \mathrm{f}$ high, lvs. $2 \mathrm{f}$ long, rough-edged; invol. 4 or 5 -leaved, longer than the umbel; umbel terminal, decompound, large and loose; spikes mostly pedicillate, 2 to $3^{\prime \prime}$ long, ovoid, in smaller clusters; bristles 6 , capillary, curled, very conspieuous, being 5 or 6 times as long as the white achenium.-A common, stiff, rank, meadow sedge, which 
cattlo do not eat, U. S. and Can. Aug. (Tricophorum cyperinum Pers.) Variable.

$15 \mathrm{~S}$. lineàtus $\mathrm{Mx}$. Culm triangular, very leafy, 2 to $3 \mathrm{f}$ high; umbels terminal and axillary, decompound, at length nodding; invol. 1 or 2 bracts, shorter than the umbels; spikes ovoid, pedunculate, solitary; glumes lanceolate, ferruginous ; bristles 6, as long as the glumes, hardly exserted.-Swamps in most of the States. Aug. (Tricophorum, Pers.)

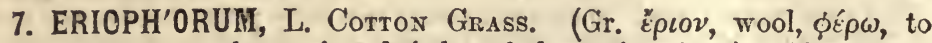
bear ; alluding to the copious bristles of the perigynium.) Glumes imbricated all around into a spike; achenium invested with many, rarely only 6 , very long, dense, woolly or cottony hairs.- Stem generally leafy. Spikelets mostly in umbels, finally clothed with the long, silk hairs.

Bristles of the perigynium 6. Spike single.............................. No. 1

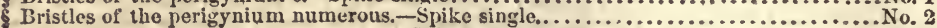
- Syikes several. (*)

* Spikes collected into a subsessile, capitate cluster........................... 3

* Spikes separate, yedunculate, in umbellato clusters.................................... 5

1 E. alpinum L. Culm very slender, acutely 3-angled, naked, somewhat scabrous, $8-16^{\prime}$ high, with $3-4$ radical sheaths; radical 1vs. very short, subulate; spike oblong, terminal, about $2^{\prime \prime}$ in length ; hairs 6 to each flower, woolly, white, crisped, 4 times as long as the spike.-Bog meadows, often alpine, N. H. to N. Y. and Penn. Jl.

2 E. vaginatum I. Sheathed Cotton Grass. Sts. densely cæspitous, obtusely triangular, slender, smooth and rigid, $1-2 \mathrm{f}$ high; uppermost sheaths inflated; spikelet ovate, oblong, $6-8^{\prime \prime}$ long, of a blackish color, with scarious glumes; hairs $30-40$ to each flower, straight, white and glossy, twico as long as the spikelet, conspicuous, as well as in other species, even at a distance among tho meadow grass.-N. Eng. to Mick., N. to Arc. Am. Jn., Jl.

3 E. Virgínicum L. Culm strict, firm, slender, tereteish, 2 to 3 f high; lvs. smooth, narrowly linear, shorter; invol. 2 to 4-leaved, longer than the inflorescence; spikes many, ovoid, acute, $3^{\prime \prime}$ long, glomerate, with very short peduncles, forming a capitate cluster; stam. 1 , tawny, cxserted with 3 tawny styles; achcnium flattened, obovate, keeled on the back, pointed, invested with 70 to 200 pale cinnamon colored setre which aro 4 to $7 "$ long.-Bogs, Can. and U. S. Jl., Aug. In flower tho heads are tawny red.

B. confertissimum. Heads very largo $\left(20^{\prime \prime}\right.$ diam.) and denso with white sotæ. -In Northern N. II. (E. confertissimum Ed. 2d.)

4 E. polystachyon L. Culm somewinat triangular, smooth, $1-2 \mathrm{f}$ high; cauline lvs. 2-3, broad-linear, flattened below, triquetrous at the end; invol. 2-leaved; spikes about 10 , on rough peduncles which aro long and drooping and sometimes branched; setæ $30-40$ to each flower, white, $6-8^{\prime \prime}$ long, ach. obovate, obtuso. -Very conspicuous in meadows and swamps, U. S. and Brit. Am.

5 E. grácile Koch. Culm obtusely 3 -angled, $18^{\prime}$ to $2 \mathrm{f}$ high, roughish above; lvs. triquetrous, channeled on the upper side, scarce $1^{\prime}$ wide; invol. one-leaved, very short; ped. roughish or subpubescent, nodding; spikes 3 to 8 , ovoid, some subsessile, othors on peduncles 1 to $4^{\prime \prime}$ long; glumes striate, brownish; bristles 50 or r:ore in each flower, 8 to $10^{\prime \prime} \mathrm{lng}$, white; ach. lance-obovate, obtuse. Bogs, N. States and Can. Common in N. J. (Jackson) (E. angustifolium Torr.).

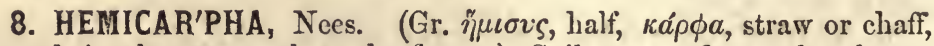
there being but one scale to the flower.) Spike many-flowered; glumes imbricated all around; interior scale 1, embracing the flower and fruit; bristles 0 ; stamens 1 ; style 2 -cleft, not bulbous at base, deciduous; achenium compressed, oblong, subterete.-2f Low, tufted, with setaceous culms and leaves.

H. subsquarrosa Nees. Culm setaceous, compressed, sulcate, recurved, $2-3^{\prime}$ high; lvs. setaceous, shorter than the scape; spikes $2-3$, terminal (appa' rently lateral), subsessile, ovoid, nearly $2^{\prime \prime}$ long; invol. of 2 bracts, ono appear. 
ing like a continuation of the scape, thrice longer than the other; glumes $\infty$, with a short, recurved or squarrous point, finally brown; ach. minute, of a dull, brownish-white.-Sandy banks, N. Eng. to Penn., Ky. and S. States. (Isolepis, Schrad.)

9. LIPOCAR'PHA, Brown. Spikes many-flowered; glumes spatulatc, imbricated all around; interior scales 2 , thin, subequal, involving the flower and the fruit; perianth none; stamens 1 ; style 2 or 3-fid; achenium coated with the scales.-Culms leafy at base. Spikes numerous, collected into an involucrate, terminal head.

I. maculàta Torr. Culms triangular, 3 to $8^{\prime}$ high, longer than the narrowly linear, often involute, smooth leaves; invol of 2 long Ivs. and 1 short one, spikes 3 or 4, ovoid, acute, closely aggregated; glumes very numerous, acute, narrowed to the base, white hyaline, marked with red dots, green along the midvein, longer than the 2 interior seales (spikelet); stamen 1 ; style bifid, longer than the tawny, oblong acherium - Wet grounds, Ga. to Fla. (Kyllingia Mx)

10. FIMBRIS'TYLIS, Vahl. (Lat. jimbris, a fringe, stylus, style; from the ciliate style.) Glumes imbricated on all sides; bristles 0 ; style compressed, 2-cleft, bulbous at basc, deciduons, often ciliate on the margin. - 4 With the habit of Scirpus. Lvs. mostly radical.

$\$$ Spikes in a subsimple umbel, rusty bown, fow, as thick as a pepper-corn..........Nos. 1, 2 \$ Spikes in a clunse head. Invol. very lung. (No. 3.) Spikes 2 only, lateral. (No. 4). Nos. 3, 4

1 F. spadicea Vahl. Culm I to $3 \mathrm{f}$ high, hard and rigid, flattened, channeled; lvs. semi-tercte, filiform, channeled; umbel of few rays, longer than the 2 or 3 subulate lvs. of the invol.; spikes ferv, ovoid-oblong becoming oblong-cylindric, when old, 3 to $6^{\prime \prime}$ long, $2^{\prime \prime}$ thick; glumes broad-ovate, mucronate, rust-colored, finally dark chestnut brown; stam. 2 or 3 ; style fringe-pubescent; ach. whitish, minzutely dalted.-Marshes, N. Y. to Fla. IV. to IIL (Lapham). JL-Sept. (F. castaneus Mx.)

B. FLnetGrneA. Umbel of many rays, somowhat compound. (F. ferrugineus Vahl.)

2 F. laxa VahL. Culm 2 to $12^{\prime}$ high, flattened, striate; lvs. flat, linear, glawcous, rough-edged, shorter than the culm; umbel few-rayed, shorter than one of the leaves of the involucre; spikes ovoid, acute, $3^{\prime \prime}$ long; glumes ovate, brown; stamen 1; sty. dark purple, fringed; ach. whitish, with 6 to 8 prominent ridges lengthwise-Clay soils, Yenn. to III. and S. States Jl.-Sept. (F. Baldwinii Torr.)

3 F. argéntea Vahl Glaucous; culms tufted, 2 to $4^{\prime}$ high, setaceous, compressed; lvs. radical, filiform, as long as the culms; spikes 5 to 8 cylindric-oblong, acute, sessile, straw-oolored, in a dense head; invol. 3 or 4-leaved, many times longer than the head, usually loxyer than the culm; glumes 20 or more, lance-ovate, mucronate; stam 1; sty. 2-cleft, ciliolate; ach whito minute.-Gal to La. (F. congesta Torr.)

4 F. distáchya Chapman? Culms setaceous, leafless, tufted, 3 to 4 ' high; spikes 2, globular-ovoid, lateral, sessile near the top of tho culm, $1^{\prime \prime}$ long, dark brown; glumes very tuumerous; sty. 2-cleft; ach. minute, but as long as tho glume-Wid. Fla (Chapman. It is Hemicarpha subsquarrosa Nees.)

11. TRICHELOS'TYLIS, Listiboudois. (Gr. т $\rho \chi \eta \lambda$, threefold,

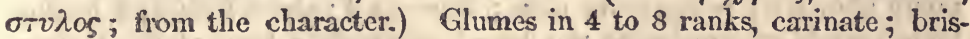
tles none; style 3-cleft, deciduous below the bulb (if any) at the base; achenium triangular. - if Sts. leafy at the base. Spikes in a terminal head or umbel.

Spikes in a compound umbel, oblong, ferruginnns............................ Nos. 1, 2

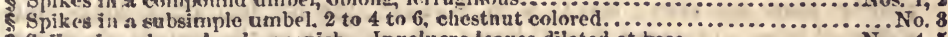

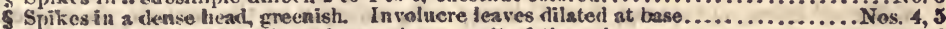
Spike solitary, greenish, lateral near the summit of the culm., .........................

1 T. autumnàlis. Culm compressed, 2-edged, cxespitous, leafy at base, $3-10^{\prime}$ 
high; lvs. flat, linear, shorter than the stem; umbel compound, diffuse; invol 2-leared; spikelets lanceolate, acute, somewhat 4-sided, 2-3 together; glumes brown, mucronate; ach. white.- - Wet places, along rivers, etc., N. Eng.! to Ga., W. to Mo. July. (Fimbristilis, R. \& S.)

2 T. coarctàta. Culm filiform, teretish, 8 to $12^{\prime}$ high; lvs. setaceous, with bearded sheaths; umbel compound, contracted; invol. Ivs. many, short setaceous, one a little longer than the umbel; spikes 15 to 20 , linear-oblong, $3^{\prime \prime}$ long; glumes about 12 , acute, rust-colored; stam. 2 ; sty. deeply 3 -cleft; ach. obovate, 3-angled. -Dry, sandy soils, S. Car. to Fla. (Isolepis Torr. Scirpus Ell.)

3 T. capillàris. Culm cæspitous, nearly naked, 3-angled, capillary, 4-8' high; lvs. subradical, setaceous, shorter than the stem; spikes ovoid, 2-4, in a simple umisel, inner one sessile; glumes oblong, ferruginous, margin pubescent; ach. white.-In sandy fields, Mass. to Fla., W. to $\mathrm{Ky}$. and Ohio. Aug. (Isolepis, R. \& S. I. ciliatifolius, Ell., a taller form ( 7 to $\left.10^{\prime}\right)$ with 4 to 6 spikes.)

4 T. stenophylla. Culms twisted, 2 to $4^{\prime}$ high, setaceous, as long as the setaceous lvs.; spikes 4 to 6 , ovoid, acute, few-flowered, sessile, in a dense head; invol. lvs. 3 or 4 , dilated at base, ciliate, 2 or 3 times longer (3 to 12") than the head; glumes ovate-acuminate, keeled, greenish; sty. 3-cleft; ach. short-triangular, black-pruinous when mature.-Dry soils, Car. to Fla. Jl.-Sept. (Isolepis, Kunth. Scirpus, Ell.)

5 T. Wárei. Culm filiform, terete, furrowed, near If high; lvs. 2 to $3^{\prime}$ long, channelsd; spikes 6 to 12, ovoid, in a dense head; invol. Ivs. 3 or 4, longer than tho head, base dilated and cut-fringed; glumes ovate, obtuse, ciliate; ach. white, rugulous, obovate-triangular.-T. Fla. (Ware, Torr. Oyp.). Very near the precedin. (Isolepis, Torr.)

6 T. carinàta. Culm flattencd, setaceous, 3 to $6^{\prime}$ high, with a short, solitary setaceous leaf near the base; spike single, ovoid, lateral near the top of the culm; glumes green, 5 to 8 , broad-ovate, veined acuminate; sty. 3-cleft; ach. shorttriangu?ar, grayish, half as long as the glume.-Near N. Orleans (Hale) (Isolepis, Hook. \& Arn.).

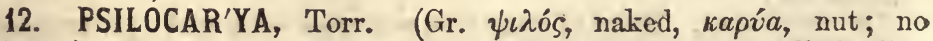
bristles.) Flowers $\Varangle$. Glumes $\infty$, imbricated all round, all fertile; perigynium 0 ; stam. 2 ; filaments long, persistent; style 2-cleft, dilated or tuberculate at base; achenium biconvex, crowned with the persistent style.-Stems leafy. Spikes lateral and terminal, cymous.

I P. scirpoìdes Torr. Culm slender, leafy, smooth, 3-sided, 5-9' high; Ivs linear, smooth, $3-5^{\prime}$ by $1^{\prime \prime}$, cauline about 2 ; cymes terminal, and one from the sheath of each cauline leaf; spikes about $3^{\prime \prime}$ long, oblong-ovate, in small, loose clusters, 20-30-flowered; glumes chestnut-colored, thin ovate, acute; ach. tumid, dark brown, crowned with tho long style, which is much dilated at base.-Borders of ponds, Smithficld, R. I. (Olney), Mass. (Greene), and Ark. (Hale).

2 P.rhynchosporoìdes Torr. Culm 8 to $14^{\prime}$ high, leafy, smooth; Ivs. linear, $2^{\text {"n }}$ broad, overtopping the culm; umbel few-rayed; spikes ovoid, 2 to $3^{\prime \prime}$ long, all pedunculate, 8 to 10-flowered; glumes roundish ovate, obtuse, pale brown; ach. roundish, lenticular, strongly rugous; tubercle short, obtuse,.-Quincy, Fla. (Chapman).

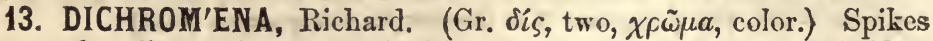
flattened, collected into a terminal head; glumes imbricate on all sides, many abortive; pcrigynium none ; stamens 3 ; styles 2-cleft; achenium lens-shaped, crowned with the broad, tuberculate base of the style. Rhizome creeping. Culms leafy. Lvs. of the invol. usually whitened at the base.

1 D. leucocéphala Mx. Culm triangular, 2 to $3 f$ high; lvs. concave, narrow, shorter than the culm; invol. 6 to 8-leaved, the lvs. lanceolate, long-pointed, whitened below, spreading, 1 to $4^{\prime}$ long; ach. truncate at the summit, transversely rugulous.-Bogs, Md. to Fla. and Ia. Known at a distance by its white involucre. 
2 D. latifòlia Baldw. Culm tereteish, stout, $9^{\prime}$ to $2 \mathrm{f} \mathrm{high;} \mathrm{lvs.} \mathrm{broadly} \mathrm{linear,}$ very long, overtopping the culm; invol. 8 to 10 -leaved, whitish, Jecoming dull red at the base; ach. roundish in outline (except the tubercle), roughened, dull, the tubercle broad, conical at top, base 2-horned, decurrent on the edges of the ach. with its horns.-Ponds in pine barrens, N. Car. to Fla.

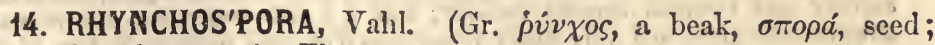
from the character.) Flowers $\Varangle$ or $\delta \not q$, few in each spikelet; glumes loosely imbricated, the lowest small and empty; perigynium of 6 to 12 bristles; stamens 3 to 12 ; style bifid; achenium lens-shaped or subglobous, crowned with a tubercle, the distinct, bulbous base of the style. $2 f$ St. leafy, 3-sided. Inflor. terminal and axillary. Setæ hispid (under a strong magnifier).

\$ Setre densely plumous. Aehenlum subglobous-oroid (terete).................. Tos, 1,2 \$ seta naked, denticislate or hlspid. Achenium miore or less flattened. $(*)$

* Achenium transversely rugous. Setæ upwardly bearded. (a)

a Setæe shorter than the acheniuin................................ Nos. $3-5$

a Setæe equaling or exceeding the achenium...... (b)

b sptkes in drooping panicles. Achenlum oblong.................... 6

b Spikes in erect or spreading panicles. Achenium roundish............ 7 os. 7

b spikes coryinbous or fascieulate.-Acheninu orbicular........ Nos. 10, 11-

-Achenium oval............... Nos. 12, 13

* Acheniun smooth and eren. (c)

c Culm and leaves very slevider, filiform or setaceous. (d)

d Setse 6 to 10, retrersely hispid (under a strong inagnifier).... Nos. 14-16

d Setæ 6, upwardly hispid............................................ 17-19

c Culin wiry, firm. Leaves lincar. (e)

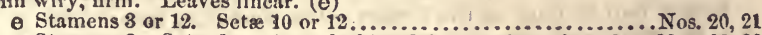

e Stamens 3. Setre 6, -retrorsely hispid, konger than the ach.... Nos. 22, 23 - lpwardly hispid, - - shorter than the ach... Nos. 24, 25 -long as the achenium...... No. 26

I. R. plumòsa Ell. Culm rigid, wiry, $8^{\prime}$ to $2 \mathrm{f}$ high; lvs. rigid, involute, setaceous above, half as long as the culm; spikies lance-ovate, cliestnut red, in a terminal fascicle; rarely a smaller axillary fascicle below on an exserted peduncle; mhimes broad-ovate, acute; bristle (selo) 6, densely plumous, as long as the globuLar-ovoid, rugons achenium; tuberclo short.-Dry pine barrens, N. Car. to Fla.

$\beta$. SEMIPLUMòsA. Setæ feathery lialf way up, naked and denticulate above.-

Near N. Orleans (Ingalls. R. semiplumosa Gray., Monog., Rhyn., p. 213).

2 R. oligántha Gray. Culm filiform, 8 to $12^{\prime}$ high, with one or two filiformsetaceous Ivs. about the same height; spikes 2 to 6 , pedicellate, rarely solitary, lance-ovate, fuscous-red, lateral near the summit of the culm; glumes ovate, mucronate; setæ 6, as long as the ach and short tubercle, plumous below, hispid above. -N. Car. to Fla., in sandy bogs.

3 R. cymòsa Nutt. Culm I to $2 \mathrm{f}$ high, triangular, angles acute; radical lvs. linear, shorter than the stem, cauline rising above the stem; corymbs 3 to 4 , the terminal largest; spikelets ovoid, in close fiscicles of about 5 ; glumes broad-ovate, dark brown; bristles $6, \frac{2}{3}$ as long as the broad ovate, transversely ruguous achenium; tubercle depressed, much shorter than the achenium.-N. J. to La. Jl, Aug.

4 R. Torreyàna Gray. Culm $2 \mathrm{f}$ high, teretish, slender, cæspitous, striate; lvs. staceous, the radical 6 to $10^{\prime \prime}$ long, cauline much shorter; corymbs few-flowered, the lateral, if any, on capillary peduncles; spikes ovoid, pedicellate or sessile; glumes ovate, mucronate, brown; bristles 6 , scarcely half as long as the oblongobovate achenium; tubercle short, nearly as broad at base as the achenium.-N. J. JL, Aug. (Holton.)

5 R. rariflòra Ell. Culms tufted, 6 to $16^{\prime}$ high, filiform, with much shorter, setaceous leaves; spikes lanceolate, fuscous, near $2^{\prime \prime}$ long, pedicellate, few in 2 or 3 loose, simple, corymbous panicles terminal and lateral; bracts capillary; glumes ovate, acute; setæ about 6 , nearly as long as the strongly rugous, roundish obovate achenium; tubercle very short.-S. Car. to Fla. and La., in bogs. Has the aspect of a Trichelostylis.

6 R. inexpánsa Vahl. Culm slender, teretish, rather rigid, $18^{\prime}$ to $3 \mathrm{f}$ high ; lvs. narrowly linear, flat, smooth, half as long as the culm; spikes lanceolate, fusoous, about $3^{\prime \prime}$ long, 3 to 5 -flowered, forming several axillary and terminal, rather long, 
drooping panicles; setce nearly twice longer than the ruguus, oblong, flattish ache nium and short tubercle.-Wet soils, S. Car. to Fla. and La. (Schoenus Mx.)

7 R. miliàcea Gray. Culm slender, triangular, very leafy below, af high, fistulous; lvs. rather rigid, flat, lance-linear, smooth, glaucous, 6 to $8^{\prime}$ long, 3 to $4^{\prime \prime}$ wide; spikes obovate, all pedicellate, 3 to 5 -flowered, forming diffuse, compound, axillary and terminal cymous panicles; setce 6 , a little longer than the roundish obovate achenium and very short tubercle.-Wet pine barrens, N. Car. to Fla and La. (R. sparsa Vahl. Schoenus Lam.)

8 R. cadùca Ell. Culm acutely triangular, 1 to $3 f$ high; lvs. broadly linear, smooth, 2 to $3^{\prime \prime}$ wide; spikes ovate, large ( 4 to $5^{\prime \prime}$ long), pedicellate or sessile, in several rather close, erect, axillary and terminal panicles; glumes caducous, ovate, tho outer broad; setce twice longer than the orbicular-ovate, rngous achenium; tubercle flattened, conical, a third as long as the achenium.-Tet soils, N. Car. to Fla.

9 R. schcenoìdes. Culm triangular, 2 to $3 \mathrm{f}$ high, leafy at base; Irs. linear, $2^{\prime \prime}$ wide, glabrous, not half the length of tho cuim; spikes very numerous, lance-ivate, small ( $2^{\prime \prime}$ long), sessile or nearly so, clustered, forming several axillary and terminal, pedunculate panicles; glumes fuscous, broad-ovate; setro twico as long as the obovate, flat, rugous achenium and small tubercle. Bogs, Ga., Fla. to La. (Scirpus, Ell.)

10 R. pátula Gray. Culm 3-angled, thick and stout at the base, $2 \mathrm{f}$ high; lvg. linear, short; spikes ovate, small $\left(2^{\prime \prime}\right.$ long), forming several spreading, loose-flowered corymbs, of which the terminal one is much the longest; setæ scarcely exceeding the roundish, flattened, strongly rugous achenium and tubercle, the latter nearly half as long as the former.-Ga. and Fla, rare.

11 R. Ellióttii Gray. Culm 3-angled, slender, 1 to $2 \mathrm{f} \mathrm{high;} \mathrm{Ivs.} \mathrm{lincar,} \mathrm{flat,}$ glabrous, serrulato on the margins, the cauline short; spilies ovate, sessile in fascicles forming 3 or 4 few-flowered, subsimple corymbs, borne on exserted peduncles; setæa a little longer than tho roundish-ovate, minutely rugous ackenium; tubercle very short, flattened, conic.-Wet soils, Ga. and Fla. Jn.-Sept.

12 R. microcárpa Baldw. Cuilm slender, teretish, tufted, nearly naked; lvs. narrowly linear, setaceous at end, mostly radical; spikes turgid-ovate, dark brown, 1 to $2^{\prime \prime}$ long, loosely fascicled in several approximate, pedunculate corymbs ; setw very fragile, scarcely equaling the minute, ovate, flat, rugous schenium.-Wet grounds, N. Car. to Fla.

13 R. punctàta Ell. Culm slender, 3-angled, 1 to $2 f$ high; lvs. lance-linear, acute, rough-edged; spikes ovate, chestnut brown, fascicled, in several pedunculate corymbs; seto a little longer than the achenium, which is ovate, compressed, and rugous-netted, with impressed dots in the furrows.-Marshes, Ga. and Fla.

14 R. alba Vahl. Culm triangular above, very slender, leafy, smooth, 10-16' high; lvs. linear-setaceous, clianneled; corymbous fascicles pedunculate, both terminal and from the axils of the sheatis, with setaceous bracts; spikelets lancelate, acute at each end, with crowded, lanceolate, whitish glumes; setve 9 or 10 , as long as the ach. and tubercle.-In wet, shady grounds; common. July-Sept.

15 R. Knieskérnii Carey. Culms in tufts, 6 to $16^{\prime}$ high, slender; Ivs. mostly cauline, setaceous, linear, shorter; spikes small ( $1^{\prime \prime}$ long) in 4 or 5 dense fascicles, distant along the whole length of the culm; setæ 6 , downwardly hispidulous, as long as the minute, obovate achenium.-In bog iron soil, N. J. (Holton), rare. (R. distans? Nutt.)

$16 \mathrm{R}$. capillàcea Torr. Culm 6 to $12^{\prime}$ high, filiform, glabrous, triangalar; Ivs. setaceous, much shorter than the stem; spikes 1 to 3 to 6 (mostly in 1 terminal fascicle), oblong, each with a setaceous bract; glumes chestnut-colored, with scarious edges; bristles 6 , much longer than the oblong, substipitate achenium; tubercle about half the length of the achenium.-Swamps, N. Y. (Sartwell), Pean. to Mich.

17 R. fúsca Roem. \& Schult. Culm 3-angled, about 2f high; lvs. setaceous-carinate; smooth; fascicles alternate, pedunculate; bracts setaceous, longer than the ovoid spikes; glumes brown, ovate; ach. obovate, its pointed tubercle as long, both equaling the hispid setoe. -Wet places, Mass. to N. J, rare. 
18 R. gracilénta Gray. Culms 1 to $2 f$ high, very slender or filiform, smooth; lus. linear-setaceous, much shorter than the stem; corymbs small, fasciculate, the lateral on slender peduncles exserted from the sheaths; spikes ovoid; glumes ovate, acute, dark brown; bristles 6 , a third longer than the roundish-ovoid achenium; tubcrele flat, subulate, as long as the achenium.-Dry grounds, N. Y. to Fla.

19 R. filifòlia Torr. (nec Kunth). Culm filiform, 6 to 12 to $18^{\prime}$ high, lvs. filiform, or almost capillary, many, much shorter; spikes very small (1"long), in 2 or 3 small fascicles, the lateril pedunculate; setoe 6, upwardly scabrous-hispid, as long as the roundish-ovate, lens-shaped, smooth achenium and the hispid-scabyous tubercle.-N. Car. to Fla. Its hispid tubercles distinguishes it from Nos. 17 and 18.

20 R. Baldwínii Gray. Culms slender, acutely 3-angled, 2 to $3 f$ high ; lvs. linear, acute, keeled, $2^{\prime \prime}$ wide, glaucous, not ciliate, spilies ovate, in a crowded, fasciculate, terminal corymb; seta 12, upwardly hispidulous, as long as the smooth, roundishovate achenium; stam. 3.-Pine barrens, Ga.

21 R. dodecánđra Baldw. Culm rigid, 3-angled, 1 to $3 \mathrm{f} \mathrm{high;} \mathrm{lvs.} \mathrm{rigid,} \mathrm{cori-}$ aceous, keeled, rough-edged, broadly linear (2 to $4, "$ wide), all nearly equaling tho culm at first, at length the culm longer; spikes ovate (lance-ovate when young), 4 "long, light chestnut color, pedicellate, in 4 to 6 pedsnculate corymbs; setæ 6 to 12, as long as the large (1 $\frac{1}{2}{ }^{\prime \prime}$ diam.), roundish, smooth achenium; stam. 10 to 12, much longer; tubercle broad, depressed.-Bogs, S. Ga., Fla. (R. megalocarpa and pyncocarpa Gray.)

22 R. glomeràta Vahl. Culm slender, smooth, leafy, a foot or more high; lvs. flat, carinate, rough-edged; corymbed fascicles very remote, in pairs, axillary and terminal; spikelets lanceolate; glumes keeled, mucronate, brown; ach. obovoid or cuneiform, very smooth as long as the tubercle; setæe 6 , rough, backwards.In bogs, Can to Fla. July, Aug.

23 R. cephalántha Gray. St. 2-3f high, triangular, stout; lvs. linear, very narrow, the lower and radical nearly as long as the stem; hds. roundish, axillary and terminal, dense, 5 to $7^{\prime \prime}$ diam., the 2 upper often near; spikelets lance-oblong; glumes ovate-oblong, dark brown; setæe 6, twice longer than the achenium; ach. roundish-ovoid, a little compressed, very obtuse.-N. J. pine barrens.

24 R. fasciculàris Nutt. Culm teretish, 1 to $2 \mathrm{f} \mathrm{high,} \mathrm{veiny;} \mathrm{lvs.} \mathrm{narrowly} \mathrm{linear,}$ much shorter; spikes small ( $1 \frac{1}{2}{ }^{\prime \prime}$ long), fuscous brown, densely fascicled, in several terminal fascicles, and usually several axillary ones; setæ half as long as tho roundish-obovate achenium.-S. Car. to Fla. Inflorescence quite variable, sometimes copiously terminal, again scattered down the culm.

25 R. ciliàta Vahl. Plant light glaucous; culm $8^{\prime}$ to $2 f$ high, ancipital, striate; Ivs. lance-linear, short, obtusish; spikes elliptical, chestnut-colored, all collected into a dense terminal fascicle with several short bracts; setæ very short, at the base of the roundish, lenticular achenium.-N. Car. to Fla.

26 R. distans Nutt. Culm slender, wiry, teretish, 1 to $2 \mathrm{f}$ high; lvs. linear setaceous, shorter, mostly at base; spikes small ( $1^{\prime \prime}$ long), ovate, in a terminal fascicle, usually with 1 or 2 lateral, somewhat distinct fascicles; setæ upwardly hispidulous, about as long as the broad, ovate, smooth achenium which is not half as large as in R. glomerata. $-\mathrm{N}$. Car. to Fla. Name not very appropriate.

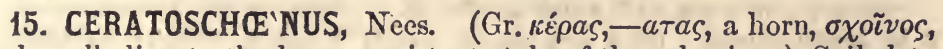
rush ; alluding to the long, persistent style of the achenium.) Spikelets $2-5$-flowered, one flower $\measuredangle$, the rest $\delta$; glumes loosely imbricated, somewhat in 2 rows, lower ones empty; perig. of 5 or 6 rigid, hispid. or scabrous bristles; stam. 3 ; style simple, very long, persistent and crowning the smooth, compressed achenium.- $2 f$ Stems leafy. Corymbs compound.

1 C. longiróstris Torr. Glabrous and glaucous; culm 3-4f high, triangular; lvs. $12-16^{\prime}$ by $4-6^{\prime \prime}$, flat, rough-edged; fls. in very large, terminal and axillary corymbs, terminal one the largest; spikes lanceolate, acuminate, $8^{\prime \prime}$ long, loosely. fascicled in $4 s$ or $5 s$ on the long peduncles; glumes brown, ovate; bristles shorter 
than the achenium, which is $2^{\prime \prime}$ long, and crowned with the $\left(\tau^{\prime \prime}\right)$ long, subulate horny style.-Ohio to Fla Common in wet places. Aug. Rhyncaspora corniculata Gray.)

2 C. macrostàchya Torr. Glabrous; culm 2-3f high, triangular; lvs. 1-2f by $2-4^{\prime \prime}$, rough-edged; axillary carymbs subsimple, terminal ones compound; upper spikelets densely fascicled; ach. ovate, smooth; bristles erectly hispid, twice as long as the achenium; style persistent, nearly 4 times as long as tho achonium.-Mass. (Robbins). (Rhyncospora ejusd.)

16. CLA'DIUM, Browne. Flowers ô $\Varangle q q$; glumes imbricated somewhat in 3 rows, lower ones empty; bristles 0 ; stam. 2 ; style 2 - $3-$ cleft, deciduous; achenium subglobous, the pericarp hard, thickened and corky above. -24 Stem leafy. Corymbs or panicles terminal and axillary.

1 C. mariscoides. Torr. Bog Rusir. 'St. terete, leafy, $20-30^{\prime}$ high, hard and rigid; lvs. narrowly linear, channeled above, rounded beneath, much shorter than the stems; bracts short; umbels $2-3$, erect, the lateral on long, exserted peduncles; rays $3-7$, some of them very short; spikes aggregated in heads of $4-8$, lance-ovate, $3^{\prime \prime}$ long; glumes tawny-brown, about 6 , the upper usually $\Varangle$, the next $\hat{\delta}$, and the rest empty; ach. ovoid, short-beaked with the remains of the 3cleft style.-Bogs; Can. to Penn. July. (Sehœenus, Muhl.)

2 C. effùsum Torr. SAw-Grass. Culm obtusely 3 -angled, 6 to $10 \mathrm{f} \mathrm{high;} \mathrm{Ivs.} 3$ to $10 \mathrm{f} ! \mathrm{long}, 4$ to $10^{\prime \prime}$ wide, tapering to a very long, 3 -angled point, margins sharply serrate-barbed; corymbs numerous, decompound, diffuse, approximated and forming a large, elongated panicle; spikes $2^{\prime \prime}$ long, 3 or 4 together, brown; ach. ovoid, $1^{\prime \prime}$ long.-Ponds and swamps, N. Car. to La. (Hale). 1 coarse and rank sedge.

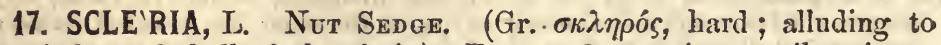
the indurated shell of the fruit.) Fowers 8 , staminate spikes intermixed, fertile spikelets 1-flowered, glumes fasciculate; perigynium cupshaped or 0 ; achenium globous, ovoid or triangular, with a thick, bony pericarp; style 3 -cleft, deciduous. - 4 Stems leafy. Spikes in fascicles or panicles.

\$ SCLERra. Achenium ovoid or globons, base invested with a short perigynium. (*)

* Achenium smooth, ovoid. Perigynium annular, subentire...................Nos. 1, 2

* Achenium rutgons-warty, globular. Perigynium 6 or 3 -lobed...................... Nos. 3 , 4

* Achenium reticulated or hispid-rugous, globular. Perlgynium 3-lobed....... Nos. 5, 6

\$ HYPOPORUM. Achenium ovoid-triangalar, base fluted. Perigynium none. (a)

a Fascicles 4 to 7 , interrnptedly spiked. Ach. smooth or rugous........... Nos. 7, 8

a Fascicles single, terminal. Achenium ribbed or smooth...................Nos. 9, 10

1 s. triglomeràta $\mathrm{Mx}$. WHIP-GRASS. Culm erect, acutely triangular, rough, leafy, 3-4f high; lvs. linear-lanceolate, rough-edged; spikes lateral and terminal, alternate, in about 3 subsessile, triglomerate fascicles, and much shorter than tho leafy bracts; glumes ovate, cuspidate, dark purple; ach. globous, smooth and polished, white, nearly $2^{\prime \prime}$ diam., invested at base with an entire, crustaceous rim. -Swamps, in nearly all the States. Jn., Jl.

2 S. leptocúlmis. Culm very slender, acutely 3 -angled, 2 fhigh; lvs. smooth, flat; sterile spikes elongated (4" long), in 2 fascicles, the lateral one remote from the terminal, on a long, filiform penduncle; glumes dark purple; stam. 3 ; ach. ovoid, obtuse. white, polished minutely corrugated; perig. annular, with about 8 minute tubercles.-Fla. Pairs of spikelets 3 or 4 . (S. oligantha Torr. nec Mx.)

3 S. ciliàta $\mathrm{Mx}$. Culm 1 to $2 \mathrm{f}$ high, acutely 3 -angled, the angles scabrous above; lvs. channeled, pubescent as well as the sheaths; bracts fringed with long, whitish hairs; fascicle subsolitary, terminal ach. subglobous, white, roughened with scattered warts; perig. a narrow border, bearing 3 obtuse tubercles.-Damp soils, S. Car. to Fla.

4 S. pauciflòra Muhl. St. 10 to $16^{\prime}$ high, triangular, slender, smoothish; lvs. narrow, ncarly smooth; sheaths pubescent; fascicles 1 to 3 , fow-flowered, tho 
lateral, if any, pedunculate; bracts foliaceous, ciliate; spikes in pairs; glumes membranous, mucronate, somewhat ciliate; sty. 3-cleft; ach. globous, rough, white and shining; perig. a narrow ring upon which are 6 roundish, minute tubercles. - Wet or dry soils, N. H. to Ohio and Fla. Aug.-There are several well marked rarieties.

$\beta$. Very slender, smoothish; lateral fascicle l-flowered, sessile, or none.-Mass. to Ohio. About If high.

$\gamma$. Very slender, scabrous-hirsuto; lateral fasciclo 1 to 2 -flowered, sessile; lower bracts much exceeding the culm.-Ga. and Fla. (S. Carolina Willd. ?)

J. Stouter, tall (2 to $3 \mathrm{f}$ high), edges denticulate-ciliate; lateral fascicles on short $(1$ to 2 ) peduncles. - S. States.

5 S. reticulàris $M x$. St. 1 -2f high, triangular, rather slender; $1 v s .1^{\prime \prime}$ wide, channeled, radical 6-12' long, cauline few; fascicles $2-5$, lateral and terminal, distant, loose-flowered, subsessile; spikelets somewhat in pairs, the of manyflowered, at the base of the $\Varangle ;$ glume light brown, ovate acuminate; sta. 2 ; perig. 3-lobed; ach. globous, of a dead white, $\frac{3^{\prime \prime}}{4}$ diam., conspicuously reticulated and deeply pitted.-Borders of ponds, R. I. (Olney), to Fla. The achenium is a curious and beautiful object.

6 S. láxa Torr. St. 1-2f high, weak, diffuse, acutely triangular, slender; lvs. flat, $2^{\prime \prime}$ wide, smooth; fascicles about 3 , open one terminal, the others lateral and very remote; ped. 2-6" long, compressed, slender, often recurved; spikelets distant, in pairs, the sterile at the base of the $§ ;$ sta. 2 ; perig. deeply 3 -lobed; ach. about $1^{\prime \prime}$ diam., globous, whitish, marked with brownish, papillous transvezse ridges, and pits. - Near tho sea coast, N. J. to Fla. Sept. (S. reticularis Mnhl.)

7 S. verticillàta Muhl. St. 6-8-12' high, triquetrous, slender, glabrous; lvs. linear, narrow and flat, shorter than the stem; fascicles smooth, purple, 4-6, sessile, few-flowered, appearing as if verticillate; bracts minute, setaceous, about as long as the fascicles, scabrous upward; scales of $q$ ovate, smooth, scabrous and keeled; ach. globous, rugous, a littlo more than $\frac{1}{2}{ }^{\prime \prime}$ diam., abruptly mucronate and somewhat 3 -sided at base.-Very abundant in Junius, N. Y. (Startwell) to Car., IV. to Ohio (Sullivant). (Hypoporum verticillatum Nees.)

8 S. interrúpta $\mathrm{Mx}$. Pale green, sparingly hirsute; culm 3-angled, 12 to $30^{\prime}$ high; lvs. linear, flat, striate, 3-veined, much shorter than the culm; fascicles few-flowered, 5 to 7 , alternate, approximate at the summit forming an interrupted spike 2 to $3^{\prime}$ long; glumes conspicuously cuspidate and bristly-ciliate, rusty brown; ach. $\frac{1}{2}$ "long, smooth, purplish white, 3-sided and fluted at base.-N. Car., Fla. and La.

9 S. grácile. Filiform, smooth, 1 to $2 f$ high; culm 3-angled; lvs. few, shorter; spikes $3^{\prime \prime}$ long, few ( 1 to 5 pairs), in a terminal fasciclo; glumes ovate, mucronate, purplish brown; bract erect as if a continuation of the culm; stam. 3 ; ach. $1^{\prime \prime}$ long, white, ovoid, obscurely 3-angled, longitudinally ribbed.-S. Ga., Fla. to Texas. (Hypoporum Torr.)

10 S. Baldwínii. Culm sharply 3-angled, edges scabrous, jointless, 2 to $3 f$ high; - lvs. radical, long, linear, keeled; spikes 3 to 5 pairs, 5 " long, in a terminal tascicle; bracts 3 , the longest erect, all purple at base; glumes brownish purple, lanceolate, acuminate; stam. 3; ach. large (near 2 " long), ovoid, dull, even, whitish.-Ga. and Fla. (Chapman.)

18. CAREX, L. SEDGE. (The classical name, perhaps from Lat. careo, to lack; referring to the sterile spikelets.) Fls. diclinous; spikes 1 or more, either androgynous (with both staminate and pistillate fls.), or with the two kinds in separate spikes on the same plant (monœcious) or rarely on separate plants (diœeious); glumes single, 1-flowered, lower ones often empty; î stamens 3 ; q stigmas 2 or 3 ; perigynium (of 2 united scales) of various forms, persistent, enclosing the lenticular or triangular achenium. $-2 f$ Culms triangular, growing in tufts. 
The following account of our specles of Carex is from the pen of Prof. C. Dewey (D.D.), rerised by him expressly for the present Edition. The annexed Aualytical Tublo has been prepared by ourselves (with tho ald of copluus and well authenticated specimens, among which is a foll set communiented by Dr. Sartwell), on the basis of the artficial subrlivision of the genus mlopted by Prof. Dewey in the former edition. It is useless to admonish the student that this table is not perfect, and may sometimes lead him astray. Yet, in the maln, Its subdivisions are correct, and cannot fail to leal to correct results, and thus greatly facilitate the study of this tho most extensive and diffienlt genus in our Flora.

N. B.-In the specific descriptions the reader is often referred as follows: (Bontt, illnst.) or (B. t.). These refer by number to the Illustrations of the Genus Carex, in the recent splendid work of Francis Buott, M.D., President of tho Linnæan Soc. of England.

§ I. STIGMAS 2. ACHENIUN DOCBLE-CONVr: (*)

* A. Spike single, -moncelous, staminate nt the top............................ 1 -dicecious, or \& spike wlth stancens at base............................ 2,3

- B. Spikes severul, androgynous (with botl kinds of flowers). (i)

9 1. Stamens varlously situated, above, below, or in the middle, sometimes

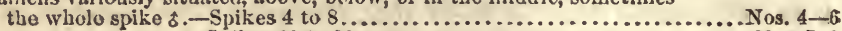

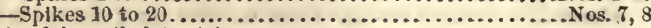

2. Stamens at the summit of the spikelets. (a)

a Spikelets evidently paniculato and perigyuium not rostrate............... Nos. 9, 10 a Spikelets 3 to 6 , approximate into one spike. (b)

b Spike ovate. - Glume equaling the perigyninm........................ 11-13

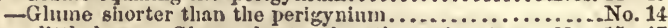

b Spike oblong, a little loose. Glumo shorter than the perigynium.... Nos. 15-17 a Spikelets 3 to $S$, remote. Perigynium radiating,-longer than glume..... Nos. 1S-20

a Spikelets $S$ to $\infty$, approximate in a decompound spike. (c)

c Perigynium rostrate, not longer than the glume................ Nos, 22, 23

c Perigynium rostrate, longer than the glume. (d)

d Spiko cylindrical, ot 8 to 15 spikelets......................... 24, 25

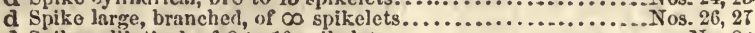

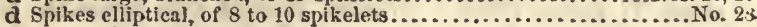

8. Stamens at the base of tho spikelets. (e)

e Perigynia radiating, in remote spikelets-Glumes green.............. Nos. 29-81

- Perigynia suberect, spikelets ovate-lanceolalumes lyyaline, white..........Nos. 32, 8:

e Pericynia suberect, spikelets oval. (f')

i Perigynia not winged, about equaling the hyaline or brown glume...Nos. 37, 33 f l'erlgynia distinctly winged, broadly or narrowly. (g)

g Perigynia short-rostrate, - - shorter than the glume.............Nos, 39,40

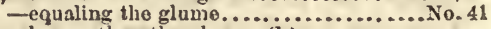
-longer than the glume. (h)

h Perigynia spreading (not radiate)..................... Nos. 42, 43

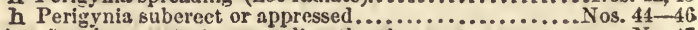

g Perigynium long-rostrate, - equaling the glume.................... 47

-longer than tho glume................ $45-5$ '

* C. Staminate and pistillate flowoers in separate spikes. (I)

I 4. Staminate spiko single. - o Spikes sessile, 1 or 2 only .................... 51

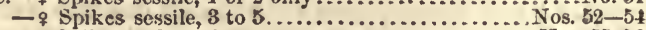
—o Spikes pedunculate...................................... 55,56

I 5. Staminate spikes 1 or more and the o spikas often staminate at sumuit. (k)

is Glumes awnless, mostly obtuse and dark colored. (1)

1 Sterile spikes 1 or 2.-Glumes all obtuse and black................ Nos. 57, 5s

-Glumes, at least the lower, acute, brown.................5. 59 -61

1 Sterile spikes 2 to 4 . Glumes acutish or acate.....................Nos, 62,63 k Glumes of the fertile spikes awned. (m)

$m$ Sterile spikes 1 or 2 . Plants not maritime.......................... 64, 65

$m$ Sterile spikes 2 or 3 . Plants maritlme................................... 66, 67

\$II. STIGMAs 3. Achenium Triquetrous. (*)

* D. Spikes androgynous (with both kinds of flowers). (Т)

I 5. Stamens at the sumsnit of the spike. (n)

n Spikes single.-Leaves 2 , broad, flat, with no midvein ...................... fis

-Lenves several, linear or setaceons...................................... $69-71$

$\mathbf{n}$ Spikes several, some of them on long, radical perluncles. (o)

o Glumes of the fruit not longer than the perigynia...............Nos. 72,73

o Glumes of tho fruit long and leaf-like............................... 74 . 76

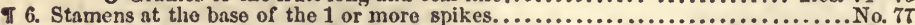

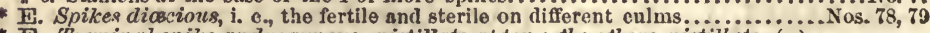

- F. Termincl spike androgynous, pistillate at top; tho others pistillate. (p)

p Perlgynlum hairy (at least, when young) as well as thelvs., and bright-green.Nos. 80-82

p Perlgynium smooth. - Spikes erect or nearly so. Glumes green................... No. 83 -Spikes erect or nearly so. Glumes dark..................... $84-86$ - Spikes drooping. - Glumes acute, dark......................... 87 -Glumes awned or cuspidate............. Nos. 88-90

* G. Strminate spike single, entively staminate. ( $(\mathbf{)})$

I 7. Plstillate spikes sessile or solitary, few, mostly ovoid. (q)

q Pistillate spikes oblong, dark brown, \& Spikes stalked..................... 91

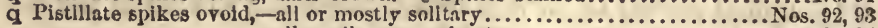

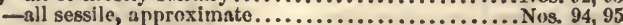

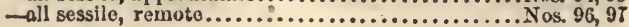


ป \&. Pistillate spikes with enclosed or nearly enclosed peduncles. Perigynia mustly inflated, beakel, angular-striate. Spikes often quite large. (r)

r Perigynium pubescent, brownish, abruptly beaked.................. Nos. 99, 99

I Perigynium sinooth, yellowlsh, with a short, recurved beak................. 100, 101

I l'erigynium smooth, inflated, with a long, straight beak. (s)

s Spikes very short. - Whole plant yellowish green................. Nos. 102-104 -Whole plant dark green or bright green........ Nus. 105,100

s Splkes oblong-cyllndric, -very large, Perig. conlc-rostrate............... -middle size, very abruptly rostrate................ 110

I 9. Pistillate spikes with exserted peduncles. Perigynia 3-angled, scarce inflated, not much beaked, and (as well as the glumes) more or less colored. ( $t$ )

t Leaves lanceolate or lance-linear, 4 to $10^{7}$ wide. (u)

u Perigynium acuminate with $\mathrm{n}$ recurved polnt................... Tos. 111-113

u Perigyn. acute or obtuse.-Lvs. lanceolate, shorter than culms...... Nos. 114, 115 -Lvs. lance-linear, long as culms............ Nos. 116, 117

Leaves linear or setaccous ( 1 to $2^{\prime \prime}$ wide or less). ( $v$ )

v Perigynia sinooth and not rostrate. (w)

w Bracts all exceeding the-oblong, dense spikes.

Nos. 11S, 119 -slender, loose spikes................. Nos. 120, 121

w Bracts shorter than the spikes or culm. ( $x$ ) $x$ Leaves setrceous and all radical. Glumes white...........No. 12 ? $\mathbf{x}$ Leaves linear. - Spikes blackish. White Mts................... 128 -Spikes tawny............................ 124, 125 -Spikes green.-Gi. (mostly) obtuse....Nos. 126, 127 -Glumes mucronate..... Nos. 128, 129

Perigynia smooth (scabrous in No. 135), rostrate. (У)

B Bracts leafy, exceeding the stem and fruit.................... 180-182

Y Bracts not exceeding the stem or fruit. (z)

z Spikes linear, slender, quite loose-flowered.............Nos. 133, 134

z Spikes cylindrical, rather close, 3 in number.................. 185, 136

z Spikes oblong, 6 to $\infty$-fld. - Culm 4 to $6^{\prime}$ high, very delicate.. No. 187 -Culm 1 to $2 f$ high......... Nos. 133-14)

v Perigynia hairy, -sterile spike linear, slender....................... 141, 142

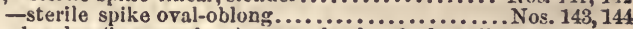

7 10. Pistillate spikes with poduncles (long or short), scarcely sheathed at all. (aa)

aa Spikes all erect.-Perigynia not rostrate or but slightly so............ Nos. 145-147

- Perigynia rostrate, the orifice entire, or nearly so..... Nos. 148, 149

- Perlg. rostrate (few), spindle-shaped, 2-toothed............ No. 153

as Spikes (the pistillate) soon mostly nouding. (bb)

bb Perigynia not rostrate. - Spikes ovoid, thick................... Nos. 151-153

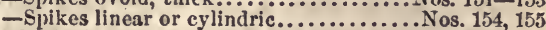

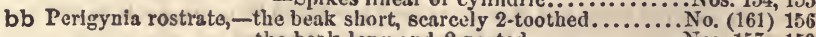
-the beak long and 2-parted...................... 157-159

- H. Staminate spikes usually 2 or more. Perigynice rostrate. (cc)

ce Perigynia elothed with wool, hairs or mealiness. (dd)

dd Perigynia long-beaked, hispid-pubescent, 2-cleft, green...............No. 160

dd Perigynia short-beaked, -mealy glaucous, chocolate-colored.................. 161

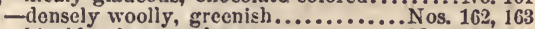
- hispid jubescent, brown.................... 164, 165

ce Perigynla glabrous (or merely scabrons in No. 172). (ee) ee Spikes ( $q$ ) on exserted peduncles. (ff)

ff Glumes dark brownish purple. Bracts shorter than culm........No. 166 ff Glumes greenish or tawny, or yellowish. (gg)

gg Perigynium tapering into very short beaks..........Nos, 167, 168

gg Perigynium long-beaked, horizontal or reflexed.............

gg Perigynium long-beaked, ascending.-Beak conical... Nos. 171, 172

-Beak cylindric.Nos. 173, 174

ee Splkes ( $q$ ) on sheathed, or very short peluncles, or sessile. (hh)

hh Spikes cylindrical, length more than thrice diam. (kk)

kk Perigynium short-beaked or beakless. Lank aquaties.Nos. 175, 176

kk Perigynium decidedly beaked.-Glumes ąwned...... Nos. 177, 178

-Glimes lanceolate. Nos. 179, 180

hh Spikes oblong or oval, turgid, length not thrice the diam. (nn)

nn \& Spikes 2 or 3 in number.-Beak cylindric......... Nos. 181,182

- Beak conical..................... 183

an \& Spikes 1 or $2,-$ pedunculate. Beaks cylindric..... Nos. 184, 1s5

- sessile, small. Beaks cunical............No. 186

\section{Stigmas 2.-Achenium double convex.}

1 C. capitàta I. Spike capitate or nearly globous, of at the summit; fr. (perigynium) roundish-ovate, close compressed, convex-concave, glabrous, acutish, longer than the ovate and rather obtuse glume; lvs. slender.-Heights of tho White Mits. (Robbins).

2 C. gynócrates Wormesk. \& Spiko oblong, rather loose-fowered; perigynium 
suboval or oblong, tapering at base, veined, convex-terete, attenuate above into a terete, shortish, straight or sulrecurved, bidentate beak, nearly horizontal in maturity, longer than the ovate and acute glume; culm slender, 4 to $6^{\prime}$ high, with long slender leaves sheathing at base. Wayno Co., N. Y. (Sartwell), N. to Greenland, (C. Davalliana, $2 \mathrm{~d}$ edit.)

3 C. éxilis Dew. (Boott, Illust., No. 45.) \& Spike terminal, ovate or oblong, close-flowered, staminate below, sometimes a single f spike or a single $q$ 'spike; perig. ovate-lanceolate, convex above and slightly below, serrulate on the margin, minutely veined above, 2-toothed, diverging, somo longer than the ovate-lanceolato glume; culm 12 to $20^{\prime}$ high, stiffly erect, and lvs. setaceous.-Swamps, E. Mass (Oakes), Sandford Lake, N. Y. (Sartwell).

$\beta$. ANDrógrna. One or more short $q$ spikes bolow the terminal.-Manchester, N. Y. (Kneiskern).

4 C. stérilis Willd. (Boott, Illus., No. 135.) Spike compound, ô below, often diœcious; spikelets $4-6$, ovate, subapproximate; perig. ovate, acuminate or subrostrate, bifid, compressed, triquetrous, scabrous on tho margin, equaling the ovate, acutish glume; st. 2 f higl, erect and stiff. Wet places, common. (C. stellulata ß. sterilis Torr., Carey.)

5 C. bromoìdes Schk. Spikelets numerous, alternate, of below, sometimes ail \&; perig. lanceolate, erect, acuminate, scabrous, nerved, bifid, twice longer than the ovate-lanceolate glume.-Common in small bogs, in wet places.

6 C siccàta Dew. (Boott, Illust., No. 50.) Spikelets numerous, ô above, often wholly $\hat{\delta}$, ovate, close or approximate; perig. ovate, lanceolate, acuminate, compressed, nerved, bitid, scabrous on the margin, equaling the ovate, lanceolate glume. -Sandy plains, Westtield, Mass. (Davis); Ipswich, Mass. (Oakes); widely spread over the country, but not abundant, W. to Ill.

7 C. Sartwellii Dew. Spikelets 12-20, ovate, sessile, compact, bracteato, lower ones especially fructiferous; upper often $\hat{o}$ at apex, sometimes wholly $\hat{o} ;$ perig. ovate, lanceolate, convexo-concave, subulate, slightly 2 -toothed, margined and scabrous on the edge, a little longer than the ovate and acute glume; lvs. flat, linear, shorter than the stem.--Junius, Seneca Co., N. Y. (Sartwell).

8. C. dístycha IIuds. Spikelets many, 2-rowed or compressed into a flattened, compound, loose spike; spikelets oblong-ovate, close, alternate, often branched below and the lowest sometimes remote, upper and lower often $q$, and the intermediate wholly $\hat{o}$, or from the middle wholly $\hat{o}$ upwards; perig. ovate, narrowrostrate, margin serrulate, narrow, equaling the ovate, acute glume; culm erect, leafy below.-Wis. (Lapham), IIl. (Vasey), Mich. (Cooley), N. to Arc. Am. (C. intermedia Good.)

9. C. decompósita Muhl. (Boott, Illust., 53.) Spile decompound or paniculate; spikelets very many, ovate, alternate; perig. ovate, convex on both sides, triangular, acutisli or short rostrate, short, brownish, glabrous, larger than the ovate, acuminate, whitish glume; st. 18-30' ligh.-Found in swamps, Michigan, and in Yates Co., N. York (Sartwell).

10 C. prairea Dew. Spiko below branched; spikelets ovate, sessile, 5 to 7 on a branch; perig. ovate-lanceolate, convex both sides, scabrous on the margin, slightly bifid, smaller than the ovate-lanceolate glume; st. $2-3 \mathrm{f}$ high, leafy towards the base.-Abundant in the prairies of Michigan, and sparingly found in N. England and N. Y. Resembles C. paniculata $L$, which has a much broader ovate glume shorter than the perigynium and is far more paniculate, and for which this has been taken. From No. 24 it is far separated by its panicle, and the color and shape of its fruit.

11 C. cephalóphora Willd. Spikelets ovate, densely aggregated into an ovate head $\left(11_{2}^{\prime}\right.$ long), bracteate, about 5 ; perig. ovate, acuminate, compressed, bifid, scabrous on the margin, with a short, ovate, and scabro-cuspidate glume, which equals it; st. 8-16 high.-Borders of ficlds and woods, common, but not abundant.

12 C. Muhlenbérgii Schk. Spikelets alternate, obtuse, approximate into an ovate-oblong head, $\frac{8}{4}^{\prime}$ long, with a long bract at tho lower one; perig. ovate, convex above, very smooth, nerved, bifid, scabrous on the margin, some diverging, a little shorter than the ovate and mucronate glume; st. 12-18' high.-In 
fields, not very common, readily distinguished from the three preceding and following.

13 C. stenophýlla Wahl. Spikes 3 to 5, aggregated into a roundish head; perig. ovate roundish-ventricous, subplano-convex, vined, scabrous or serrulate on the margin, bidentate, about equaling the ovate, acute glume; culm 3 to $6^{\prime}$ high, smooth, with long, narrow leaves.-Ill. to Nebraska and Brit. Am.

14 C. chordorrhìa L. Spikelets $3-5$, aggregated into a head, ovate, sessilo; perig. ovate, acuminate, subrostrate, convex above, equaling the broad, ovate and acute glume; st. branching towards the base and sending out roots at the joints; spikes rarely bearing on!y stamens.-Marshes, N. Y., common (Sartwell), Mich. (Cooley.)

15 C. Leavenwórthil Dew. Spitelets 4 to 6, small, ovate, sessile, bracteate, aggregated into an oblong head, the lower sometimes separated a little; perig. ovate, broad, short, convex above, abruptly short-beaked, slightly bifid, glabrous, scabrous on the edge, scarcely twice longer than the short, ovate, acute glume; culm rarely if high, slender, leafy towards the base; lvs. narrow, flat; wholo plant palo green.-Ky. (Short) to Ala. (Wood), Fla. (Chapman) and La. (Leavenworth.)

16 C. cephaloìdea Dew. Spikelets 4-6, ovate, aggregated closely, sessile and bracteate; perig. ovate, obtusish; bifid, scabrous on the margin, plano-convex, very diverging in maturity, about twico as long as the short, ovate, obtusish glume. -Dry fields, not abundant, but common over Now England and Now York. In hedges it is often four feet long, and subrostrate, leafy towards tho base. (C. sparganoides, $\beta$. Carey.)

17 C. muricàta I. Spikelets about 5 , ovate, sessile, approximate, bracteate, lower ones sometimes remotish; perig. ovate-lanceolate, plano-convex, 2-toothed, horizontal, scabrous on tho margin, sometimes longer than the ovate-lanceolate glume.Fields near Boston (Green, Curtis), and common in Arc. Am.

18 C. sparganioìdes Muhl. Spikelets 7-10, ovate, rather distant, bracteate, sessile; perig. ovate, acute, compressed, diverging, acuminate, 2-toothed, scabrous on the margin, nearly twics the length of the ovate, acute, or mucronate glume; st. about $2 \mathrm{f}$ high, with long, striate leaves.

$\beta$. RAMEA Dew, has ono branch or more at tho base, with several spikelets in the place of the lower spikelet, and is the C. divulsa of Pursh.-About cultivated and moist fields, common.

19 C. rc̀sea Schk. Spikelets 3-5, subremote, sessile, alternate, stellate, even before maturity, lowest long-bracteate; perig. oblong-lanceolate, $5-12$, convex above, scabrous on the margin, 2-toothed, very diverging, or even reflexed, twico as long as the ovate-obtuse glume; st. 8-16' high.

B. RADIATA Dew. Spikelets distant, about 3-flowered, with setaceous bracts; perig. oblong, acuto; st. $4-8^{\prime}$ high, flaccid or lax, setaceous, with very narrow leaves. - Common in pastures and moist woods; tho variety is about woods, or open places in woods.

20 C. retrofléxa Muhl. Spikelets about 4, cvate, alternate, subapproximate, sessile, bracteato and stellate in maturity; perig. ovate, acutish, 2 -toothed, subscabrous or smooth on tho margin, reflexed and spreading, about equal to the ovate and acute glume; st. about a foot high.-Readily distinguished from tho preceding. Woods and pastures, not abundant. (C. rosea, $\beta$. Tourn.)

21 C. dispérma Dew. Spikelets 3 or 4, erect, subapproximate, lowest bracteate; perig. 1 or 2 , rarely 3 , ovate, obtuse, nerved, plano-convex, short-beaked, glabrous, twice longer than the ovate, acute, submucronate glume; st. slender, 5 to $12^{\prime}$ high, flexile, in tufts of several, with narrow and linear leaves.-Wet woods, N. Eng. to Wis. (C. tenella, Carey, Boott., not of Ehrh.).-The species is common in N. Eur., but had never been recognized in this country, when described, 1824.

22 C. vulpinoìdea Mx. Spikelets orate-oblong, obtuse; spitee decompound, bracteate, conglomerate; perig. ovate, acuminate, densely imbricate, bifid, triplinerved, diverging, a little shorter than the ovate-cuspidate glume; st. obtusely triangular, round and leafy towards the base.-Common in fields. (C. multiflora Mubl.) 
B. morosperma Dew. Spikelets closely aggregated, whole spike less compact ; perig. more convex, shorter, less acuminated into a beak, very abundant.-Grows with the other, in dry and moist situations. (C. microsperma Wahl.)

23 C. setàcea Dew. Spikelets ovate, alternate, obtuse, conglomerate, bracteate; perig. ovate-lanceolate, acuminate, compressed, bifid, some diverging, about equal to the ovate-lanceolate, awned glume; st. $2 \mathrm{f}$ high, acutely triangular, scabrous above and striate. - Wet places, not abundant.

24 C. teretiúscula Good. Spikelets ovate, acute, sessile, decompound, brownish, lower one bracteate; perig. ovate, acute, convex and gibbous, scabrous on the edge, spreading, longer than the ovate, acuto glume; fr. brown; st. 18 to $36^{\prime}$ high, leafy towards the root.-Wet places, common, in tufts.

25 C. stipàta Muhl. Spike often decompound; spikelets oblong, aggregated, numerous, bracteate; perig. ovate-lanceolate, round at the base, plano-convex, nerved, bifid, subscabrous on the margin, diverging, twice longer than the ovatelanceolate glume; st. thick, acutcly triquetrous, concave on the sides.-Wet places and marshes, abundant.

26 C. Crus-Corvi Shuttl. (Boott. Illus. No. 64.) Spike decompound, subpaniculate, commonly large, and branching below; spikelets ovate, numerous, aggrogated, sessilo; perig. short-ovate, very long-rostrate, veined, convex-concavo, often horizontal, thrice longer than the ovate, acute glume; culm leafy; lvs. rough-edged; plant light green.--River swamps, Wis. to Ohio and Fla. (C. Halei Dew. C. sicæformis Boott.)

27 C. vulpina L. Spike long, large, decompound, forming densely aggregated heads, often with single but close and oval spikelets, and often less compacted; perig. ovate, broad, tapering into a 2-toothed beak, often diverging in ripening, a littlo longer and narrower than tho ovate, acuto glumo; culm large, strong and rough.-Ohio (Sullivant) to Nebraska (Hayden).

28 C. alopecoìdea Tuckerman. (B. t. p. 67.) Spiko compound, rather loose, spikelets 8 to 10, aggregated into an oblong head, bracteate, sessile; perig. ovato, plano-convex, scarcely nerved, acuminate, serrulate on the edge, bifid, subrostrate, a little longer than the ovate and acuminate glume; st. triquetrous, scabrous on the edges.-Moist woods, Penn. and N. Y. (Sartwell).

29 C. stellulàta Good. Spikelets 4-6, ovate, remotish, sessilo; perig. broadovate, contracted into a short beak, compressed, slightly bifid, scabrous on the edge, diverging and reflexed, a littlo longer than the ovate, obtusish glume; st. erect, stiff, leafy below, 8-24' high.-Common in wet places over tho Northern States.

30 C. scirpoìdes Schk. Spikelets about 4, ovate, approximate, sessile, obtuse, lowest bracteate; perig. ovate, cordate, compressed, lanceolate or rostrate, scabrous on the margin, diverging or horizontal, longer than the ovate-lanceolate, acuto glume; st. 6-16' high, leafy towards the base. - Wet places in the country. The more lanceolate fruit and glume, and more flexible stem, separate it from the preeeding. C. scirpoides has the stamens chiefly below the upper spikelet. (C. stellulata $\beta$. Torr. \&c.)

31 C. Búclzleyi Dew. Spike compounded of about 5 ovate, alternate, approximate spikelets; perig. ovate-lanceolate, 2-lobed at the orifice, concave or flattish bclow, smooth, about twice longer than the ovate-acute glume; culm about if ligh, slender, with lance-linear lvs. towards the base; stam. chiefly at the base of the upper spikelets.-Mrts. of Car. and Ga. (Buckley.) (C. Gibhardi, Buckl. nec. Schk.)

32 C. curta Good. Spikelets 4-7, ovate-oblong, upper subapproximate, lower ofton remote; perig. round-ovate, obtusish, diverging, convexo-coneave, 2-toothed, slightly scabrous, longer than the ovate, white, hyaline glume; st. 1-2f high, usually light green, with silvery or hoary spikelets.-Moist places over the country. (C. Richardi $\mathrm{Mx}$.)

33 C. tenélla Ehrh. nco Schk. Spikelets 3 or 4, ovate, roundish, remote, sessile, few (2 to 6)-fruited; perig. lance-ovate or roundish, rostrate, longer than tho ovato, hyaline, whito glume; culm 1 to $2 \mathrm{f}$ high, slender, flaccid, and with tho lvs. green. 
-N. Eng. and N. Y. Common in wet places. (C. sphærostachya Dew., Ed. 2. C. carescens $\beta$. vitilis, Carey. C. vitilis Fries., \&c.)

34 C. Dewreyàna Schk. (B. t. 69.) Spikelets about 3, sessils, ovate-lanceolate, alternate, subremote, highest bracteate; perig. oblong-lanceolate, rostrate, acuminate, bifurcate, plano-convex, slightly scabrous on the margin, a littlo longer than the ovate-lanceolate, awned, hyaline glume; st. 1-4f long, subprocumbent, with radical leaves; whole plant yellowish-green. Common in open woods or on the borders of woods.

35 C. trispérma Dow. (B. t. 78.) Spikelets about 3, remote, sessile, alternate, highest ebracteate; perig. ovate-oblong, acute or short-rostrate, plano-convex, at the orifice entire, nerved, subscabrous on the edges, somewhat diverging, longer than the oblong, acute, and hyaline glume; st. 10-24' high, prostrate or recurved, filiform, slender, longer than tho leaves.-In tufts, in marshes or wet woods; common in N. Eng. and N. Y.

36 C. argyrántha Tuckm. MS. Spike compounded of spikelets 5 to 8, roundish, obovate, alternate, subaggregated above, rounded below, with squarrous bracts, except the lowest, which has a long; leafy point; perig. ovate, compressed, at length spreading, green, many-reined both sides, and winged by a wide margin, lacerated above, glabrous, acuminate in a short, bifid beak, equaling the membran. ous, white, lanceolate, acute glume.-Amherst and Sunderland, Mass. (Tuckerman.) Culm 1 to $3 \mathrm{f}$ high, weak, obtuse-angled, twico longer than the lance-lincar leaves.

37 C. tenuiflòra Wahl. Spikelets 2-3, ovato, clustered, sessile, alternate, lower one bracteate; perig. ovate-oủlong, acutish, plano-convex, equaling the oblong-ovate, hyalino or white glumo; st. a foot or more high, slender, subprostrate, longer than the flat and narrow leaves. Light green. Spikelets whitish.Burlington and Salem, Vt., in swamps (Robbins), Oriskany and Ogdensburg, $\mathrm{N}$. Y. (Kneiskern), Southampton, Mass. (Chapman).

38 C. Liddòni Boott. (Illus. 51.) Spikelets 5-7, oblong-ovate, closely aggregated; perig. ovate, lanceolate, acuminate, obliquo at the orifice, glabrous, margin serrulate, scarcely longer than the ovate-lanceolate glume, which is acute and hyaline on the edges; perig. and glumes rather chestnut brown; plant yellowishgreen.-Brit. Am. (Boott.) Mich. (Cooley).

39 C. alàta Torr. Spike composed of 4 to 8 spikelets, ovate, large, approximato and sessile; perig. roundish, sometimes obovate, nearly flat and close, abruptly short-beaked, 3-veined on the back, 2-toothed, broadly winged, finally scabrous on the beak, shorter than tho lance-ovate glume; culm smooth, 3 to $4 \mathrm{f} \mathrm{high;} \mathrm{lvs.}$ rough-edged and pale green.-N. Car. to Fla.

40 C. stramínea Wall. Spike compound, erect; spikelets about.6, ovate, shortoblong, alternate, sessile, subapproximato; perig. broad, roundish-ovate, compressed, ciliate-serrate on the margin, acuminate-beaked, 1-veined on the back, 2-toothed, widely winged, commonly shorter than the ovate-lanceolate glume, st. 12-20' high, longer than tho leaves; spikelets whitish or tawny.-Common in woods and fields. (C. festucacea Ell.? nec Schk.)

a. BREvion Dew. Spikelets 3-5, often closely approximate, and moro nearly round; perig. shorter-ovate and shorter-rostrato, scarcely longer than the ovate-lanceolato glume.-This is tho plant originally described by Willdenow.

B. minor Dew. Spikelets small, 5-6, globous or obovate, less approximate; perig. small, ovate, acuminate, less winged, serrulate, about equaling the ovate, acute glume.

41 C. foènea Múl. Spiko compound, 5 to 10 ovate spikelets, aggregated above; perig. ovate-acuminate, winged, scabrous-margined, large and close, 2-toothed, about equal to tho oblong-lanceolate glumo; culm largo and smooth, leafy below; plant glaucous.-Penn. (Mublenberg) and salt marshes, R. I.' (Olney).

42 C. mirábilis Dew. Spikelets 7-11, ovate-globous, alternate, sessile, often closely aggregated into a lance-ovoid head, bracteate below; perig. ovate, sublanceolate, scabrous on tho margin, concavo-convex, rostrate, 2-toothed, subdiverging, scarcely twico longer than the ovate, lanceolate glumo; st. 18-36', orect, 
stiff, rough above, rather slender; plant light green.-Common about fences and hedges, and has a specially rigid appearance. (C. festucacea $\beta$. Torr. Carey.)

43 C. cristàta Schw. Spikelets 6-14, globous, sessile, closely aggregated into an oblong, thick head of a crested form, bracteate; perig. ovate, oblong, compressed, winged, rostrate-acuminate, bifid, concavo-convex, scabrous on the margin, longer than the oblong, lanceolate glume; st. $1-3 \mathrm{f}$, acutely triangular.-Plant yellow: ish-green. Common in fields and meadows on colder soils. (C. lagopodioides $\beta$. Carey.)

44 C. lagopodioìdes Schk. Spikelets 8-20, beakless, green, ovate, rather near, alternate and sessilo; perig. round-lanceolate, tapering at both ends, concavoconvex, nerved, bidentate, scabrous on the margin, nearly twice as long as the ovate-lanceolate glume; st. nearly $2 \mathrm{f}$, leafy; the whole light green.-Common. (C. scoparia, $\beta$. Torr.)

45 C. ténera Dew. Spilie compound, recurved; spikelets about 5 , obovate, remotish, alternate, sessile, attenuated below, the lowest bracteate; fr. tawny, ovate, comprossed, somewhat winged, rostrate, nerved, ciliate-serrate, longer than the oblong-lanceolato scale; st. $15-30^{\prime}$, small and slender, erect, with a nodding spike, longer than the leaves.-Light green. Common. (C. straminea $\beta$. Torr. C. festucacea $\beta$. Carey. The inconsistency of these synonyms favors our own view of this species.)

46 C. festucàcea Schk. Spike erect; spikelets 5-8, obovate and clubform, sess.lo and alternate, approximate, lower ono bracteate; perig. tawny, roundish-ovate, rostrate, winged, striate, 2 -toothed, scabrous on the margin, longer than the ovate, lanceolate glume; st. 15-30', erect and stiff, leafy below.-Plant palo green. Spikelets greenish to brown. Common in fields, but not abundant. Tho clubform spikelets from the decurrent scales of the of flowers, especially mark this species.

47 C. adústa Boott. Spikelets several, 4 to 8 or more, often not approximate, tapering below in maturity; perig. ovate-lanceolate, or ovate, long-rostrate, narrow-winged and serrulate, veined, scarcely bifid, as long and broad as the glume; culm 15 to $24^{\prime}$, leafy towards the base.-R. I. (Olney) to L. Sup. and Brit. Am.

48 C. scopària Schk. Spikelets 5-10, usually 5-7, ovate, sessile, approximate, the lowest with a long, deciduous bract; perig. ovate-lanceolate, nerved, erect, slightly margined, glabrous, longer than the lanceolate, acuminate glume; st. 18-24', leafy towards the root.-Moist places, very common. (C. ovalis Ell.)

$\beta$. AGGREGATA Dew. Spikelets aggregated into a head, somewhat spiral.

49 C. sychnocéphala Carey. Spikelets ovate, closely aggregated into a head (as the name purports), sessile, slender, with long, leafy bracts; perig. ovate, very long, lanceolate, or tapering into a long beak, with scabrous edges, a little longer than the lance-ovate glume; plant short and very pale green.-N. Y., Jefferson Co. (Boott. Ill., 111), at Little Falls (Vasey, Kneiskern). Remarkable for its slender, beaked fruit.

50 C. árida Schw. and Torr. Spikelets oval-oblong, 5-10, somewhat tapering at both ends, large and approximate, close-flowered, dry and chaff-like; perig. lancelinear, compressed, thin, distinctly winged, bidentate, nerved, acuminate, iwice longer than the ovate-lanceolate glume; plant light green in all its parts.-Com. mon in Ohio and Mich., 18-36', and further W. and S. (C. Muskingummensis Schw., scoparia, $\beta$. Torr.)

51 C. miliàris $\mathrm{Mx}$. (B. t. 187.) Culm erect, slender, rough abovo; lvs. flat, very narrow; $q$ spike sessile, sometimes 2 and distant, ovoid, tawny; bract seta. ceous, short; î spike pale, rather long-peduncled; perig. spheroidal, smooth.Marshes, Can., especially at L. Mistassins.

52 C. Floridàna Schw. ô Spike short and sessile; $\$$ spikes 2 to 4, approximate, ovate, sessile, bracteate, the lowest sometimes a little recurved; perig. oblong, tapering below, rather obovate, plano-convex, abruptly rostrate, short-bifid, scabrous above and on the back, about as long as the ovate-oblong, red-edged, scabrous, cruspidate glume; culm 2 to $6^{\prime}$, slender, 3 -sided; lvs. radical, flat, twice to t'arice longer than the culm; plant palo green; ach. oval, lens-shaped.-Fla. to La. 
53 C. dubitàta Dew. of Spike erect, oblong, short, with oblong, obtuse, black, white-edged glumes; $q$ spikes 2 to 4 , ovate, sessile, approximste, the lowest oblong and short-pedunculate, subremote, leafy-bracted, all black; perig. oval, short-apiculate, concavo-convex, orifice entire, equaling or slightly exceeding the oblong-obovate, black, white-edged glume; culm, 8 to $12^{\prime}$, triquetrous, smooth, stiff, with flat, smooth lvs. (C. saxatilis Ed. 1st.)-Probably this is the plant called C. saxatilis L. in the Flor. Dan., in Eng. Bot. and of Schk. But as Dr. Boott proves C. saxatilis (L) and C. pulla (Good.) to be the same, this plant can belong to neither. It is called C. rigida (Good.) by Carey in the Manuel of Gray, but difiers from it in many characters given by Goodenough in his full description.

54 C. lenticulàris Mx. (B. t. 76). Spikes cylindric, obtuse, rather slender, near, sessile except the lowest; fo spike 1, rarely 2, 1' long, or the lower shorter; $q$ spikes 2 to 5 , mostly 4 , leafy-bracted, not dense-flowered, the lowest moro remote and attenuated below; perig. ovate-clliptic, slightly conviex both sides, pale, then yeliowish, short-beaked, longer than the narrow-oblong, obtuse glume; culm 8 to $12^{\prime}$ high, smooth, triquetrous, with flat leaves; bracts not sheathing, the lowest overtopping the stem.-At L. Avalanche, N. Y. (Torr. \& Gray), to Bear L. (Richardson).

3. Albi-montàna. Perig. ovate-oblong, acuminato or tapering above to a point longer and moro convex, and sometimes beginning to curve backwards, with a less obtuse, or short acute glume variable in length.-Ponds, White Mts. (Oakes, Tuckerman.)

$\gamma$. BLAKEI. Intermediate between the two forms preceding; fruit less acute, nearly elliptical, its glume obtuso and always shorter.-Harrison, Me. (Rev. J. Blake).

55 C. aùrea Nutt. ô Spike short, cylindric, pedunculate; $\uparrow$ spikes 3 , oblong, loose-flowered, subpendulous, exsertly pedunculate, subapproximate, bracteate; perig. globous, obovate or pear-form, obtuse, nerved, entiro at the mouth, longer than the ovate, acute or short-mucronate glumo; st. 3-10', slender, often subprocumbent.-Plant glabrous, green. Common in wet grounds, N. Eng. and westward and northward. (C. pyriformis Schw.)

56 C. Mitchelliàna Curtis. of Spike sometimes with $q$ fls. in the middle; $f$ spikes 2 or 3 , cylindric, slender, loose-flowered, remotish, pedunculate, and tho lowest short-sheathed; perig. ovate, acute, short-rostrate, entire at the orifice, about cqualing the ovate, cuspidato glume; culm 15 to $20^{\prime}$ high, acutely triquetrous, subscabrous above, loafy towards the base.-Wet places, N. Car. (Curtis).

57 C. tórta Boott (Ill. 156). Spikes cylindric, slender; q spikes 3 or more, very long, rather loose-flowered, attenuated below, staminate at vertex, upper nearly sessile, lower pedunculato and diverging recurved; perig. ovate, convex, terete upwards, often acuminate, recurved, about equaling the narrow-lanceolate, rather obtuse, black glumo; culm nearly $2 \mathrm{f}$ high, erect, rather slender, triquetrous, but scarcely rough-edged, leafy towards the base; color light green. - Wet places in most of the States. (C. acuta, $\beta$. sparsiflora, Ed. 1st.)

58 C. caespitòsa. ô Spiko single, oblong, cylindric, sometimes 2, with oblong, black scales; \& spike $2-3$, short-cylindric (1'long), erect, obtuse, rather thick, remotish, bracteate, lowest one short-pedunculate; perig. ovate, obtuse, glabrous, entire at the orifice, scarcely rostrate, a little longer than the oblong, obtuse, black glume; st. 6-14', scabrous on the edge, leafy towards the base; lvs. flat.-Wet places, Ipswich, Mass. (Oakes) N. Y. and Michigan. (Cæspitosa Good. nec. L.)

59 C. apérta Boott. ơ Spikes 1 or 2, cylindric, erect; $q$ spikes 2 to 4 , oblongcylindric, approximate above, sessile, stam. at apex, lowest somewhat remote and pedunculate; perig. ovate, roundish, short-rostrate, 2-toothed, short-pedicellate, shorter than the lanceolate acute glume; culm 1 to $18^{\prime}$, rough-edged above.- Wet meadows, N. Eng. and far westward and northward. (C. acuta $\beta$. erecta Dew. Ed. 1st.)

60 C. strictior Dew. ô Spikes $1-2$, with oblong and blackish, acutish glumes ; o spikes $2-3$, cylindric, ô above, and hence acutish, lowest short-pedunculate; perig. ovate, compressed, acute, glabrous, entire at the orifice, early falling off, glabrous, a little longer than the oblong and acute rusty glume; st. a foot and more, triquetrous and rough on the angles, with reticulated filaments connecting the 
leaves towards the base; lvs. erect, close; whole plant glaucous except the spikes -Wet places, common. Nearer C. crespitosa than C. stricta.

61 C. stricta Gooden. of Spikes 1-2, cylindric, lower one sessile, and the scalo rusty brown and obtuse; + spites $2-3$, long-cylindric, upper half $\hat{\delta}$, lower longer, short-pedunculate, loosely-flowered below; perig. ovate-acuminate or eliptic, compressed at the orifice entire or slightly emarginate, and its glume strongly ferruginous, the lower ones acute-lanceolate, the upper linear and obtuse, commoniy longer and narrower than the perigynia; st. 2f with reticulated filaments connecting the leaves (Boott). - Wet places, as bogs, common.

62 C. angustàta Boott. ô Spikes 2 or 3, cylindric, slender; $q$ spikes 1 to 4 , cylindric, sessile, often nodding, the lowest short-pedunculato, the upper stam. at apex and hence tapering above or acuto; perig. oval or ovate, acutish, entire at orifice, or short-beaked, scarcely veined, equaling or shorter than the narrow or oblong, subacute, variable brown glume; culm $2 \mathrm{f}$, acutely triquetrous, scabrous, not robust, longer than tho stiff, narrow, glaucous leaves.-Very common in large bogs over tho country. (C. acuta, ed. 1st. and Am. auth. not of L.)

63 C. aquatilis Wahl. of Spikes 1-4, crect, cylindric, lowest bracteate, tho glume oblong, obtusish; $\%$ spikes often 3 , cylindric, thick above, $1-2^{\prime}$ long, subcrect, short-pedunculate, densely-flowered; perig. elliptic, lenticular, rather small, entire, glabrous, protruded at tho orifice, scarcely equaling the green, ovate, acutish glume; st. 20-30' high, rather obtuse-angled and scarcely scabrous.-In marshes and wet places, common.

64 C. gynándra Schw. (B. t. 48.) ô Spikes one or more, lax, oblong, sometimes with a few $\&$ flowers; $\&$ spilies about 3 , oblong, cylindric, pedicellate, nodding, attenuated below, and more loosely flowered, often ot at summit; perig. ovate, sub-inflated, short-rostrate, entire at the orifice, glabrous, about $\frac{1}{3}$ as long as tho oblong, obtusish, scabrous-awned glumo; st. 12-24' high, rough, triquetrous.Common in wet places.

65 C. crinita Lam. (B. t. 47.) of of Spikes mostly 1, long, slender; spikes about 4, long-cylindric, densely-flowered, recurved, with a long, reclined pedunclo; perig. ovate, suborbicular, obtusish, emarginate at the orifice, convex both sides; glumes terminated by a long, serrato point moro than thrice the length of the perigynia; st. 20-42' high, recurved, rough-edged, palo green. Common in dry grounds. (C. paleacea Wahl. Ed. 1st.)

66 C. marítima Vahl. (Schk. fig. 74.) Spikes long, cylindric, subpendulous or recurved; $q$ spikes 1 to 3 , pedunculate, bracted; perig. suborbicular, short-rostrate or apiculate, emarginate, veined, rather close, much shorter than the longawned, ovate-oblong, or emarginate-awned glume; culm 10 to $18^{\prime}$, erect, with smooth leaves.-Sea coast, Mendon, Mass. and northward (Carey).-This is the real C. paleacea Wahl described by him in almost the same language as his next species, C. maritima.

67 C. salina Wabl. (Schk. fig. 185.) Spikes cylindric, erect; $q$ spikes 2 or 3 , remotish, short-pedunculate, dense-flowered, leafy-bracted; perig. elliptic, shortapiculate, double-convex, entire at the orifice, shorter than the oblong, acute, short awned glume; culm 8 to $16^{\prime}$, leafy below, with long leafy bracts auriculate at their base. - Salt marshes, MIass. to $\Delta \mathrm{rc}$. $\Delta \mathrm{m}$.

\section{Stigmas 3.-Achonium triquetrous.}

68 C. Fràseri Sims. Spike oblong, of glume oblong, acutish; $q$ fls. at the base in an ovoid or globous mass; perig. ovate or oblong, short-beaked, apex entire, longer than the oblong; obtuse glume; culm 8 to $10^{\prime}$, flat, leafless; lvs. 2 radical, flat, wide, veined, with no midvein, pale or glaucous and longer than the culm. - Tyger valley, Penn. (Muhl.), Mits. of N. Car. (Curtis). (C. lagopus Mubl.)-A peculiar and striking plant.

69 C. polytrichoides Muhl. Spike oblong, terminal; perig. 3-8, oblong, alternate, erect, subtriquetrous, glabrous, emarginate, twico longer than the ovato and 
obtuse, and rarely mucronate glume; st. 4-12', very slender, with setaceous and subradical leaves.-Common in wet, cold grounds. (C. microstachya $\mathbf{M} \mathbf{x}$.)

70 C. leucóglochin Ehrl. Spike about 4-flowered, with 1 or 2 if flowers at the apex; perig. lanceolate, subtriquetrous and tapering, much reflexed, twice longer than the oblong-lanceolate glume; culm 3-8', with subradical and linear leaves.-In Ashfield and Hawley, Mass, in a marsh (Porter.) C. pauciflora Lightfoot.)

71 C. obtusàta Lilj. (Sclik. fig. 159.) \& Glumes oblong, obtuse, white; perig. about 4, ovate-globous, or ellipsoid, tapering-rostrate, smooth, scarious at the orifiec, a little longer than the ovate, acute, membranous glume; culm 2 to 6 , erect, leafy below, longer than tho lvs., with the fruit nearly black in maturity, color palo green.-N. States and Brit. Am.

72 C. pedunculàta Muhl. Spikes about 5, 3-sided, distant, on slender, recurved peduncles; perig. obovate, triquetrous, recurved at the apex, commonly glabrous, a little longer than the oblong or obovate, mucronate, finally brown glume; culm 4 -12 , triangular, rather procumbent; sta. sometimes removed a littlo from the o spike.-Common in woods. Flowers early in the spring.

23 C. Baltzéllii Chapm. (B. t. 41.) Spikes cylindric, long, dark-colored, with oblong-obovate, obtuse or emarginate, submucronate glumes; $\delta$ spike tapering below; $\&$ spikes 1 to 4 , tho caulino one peduncled, remote from the staminato, with some $\delta$ fls. at its apex, the others on long, slender and nearly radical peduncles, all lax-flowered; perig. oblong-obovate, obtuse, short-rostrate, pediceled, veined, pubescent, equaling or surpassing the glume; culm 6 to $10^{\prime}$ slender, triquetrous, much shorter than the flat, rather wide radical leaves.-Fla.

74 C. Wildenòwii Schk. (B. t. 95.) Sts. or radical ped. 1-3; spike commonly single, stameniferous above, or the stamens removed a littlo; perig. 5 to 9 , scabrous, alternate, loose, oblong and inflated a little, tapering at the base and conic-rostrate above; $q$ glumes ovate and acute, tho lower ones long and leaflike, much surpassing the stem.-On dry grounds, common throughout the U. S. -One variety has the of spike distinct; another is destitute of the long and leafy scales, and is frequent at the North as well as in Fla.

75 C. Steudèlii Kth. (B. t. 96.) Sts. or radical ped. 1-8' long; spike commonly single, with about 12 sterile fls. above; perig. 2 or 3 , scabrous above; subglobous or ellipsoid and inflated, alternate, stipitate, terete; conic-rostrate, with an oblique orifice; $q$ glumes usually long and leafy; lvs. smooth, soft, narror, longer far than the culms.-Jefferson Co., N. Y., and in Ohio and the Western States.

76 C. Báckii Boott. (t. 97.) Ped. radical, 1-4f high, stiff, thick, or large; spike single, with about 3 sterile fls. above; perig. ovate, globous, smooth throughout, 2 to 4, conic-rostrate, entire at the orifice, when mature pear-shaped, the beals articulated to the fruit; of glumes usually long and leaf-like, inclosiug the fruit; lvs. radical, flat, thick, rough or scabrous and short.-Jefferson Co., N. Y. and Arc. Am.-The two preceding species are closely related, and yet look very different. The first (No. 74) is the slenderest.

77 C. squarròsa $\mathrm{L}$. Spikes 1-4, oblong, cylindric, obtuse, upper one attenuated below at first by the decurrent of flowers, all very densely flowered; perig. ovate, subglobous, long-rostrate, 2 -toothed, horizontal, glabrous and subsquarrous, longer than the lanceolate glume; cm. 1-2f, slender for the large spike or spikes; lower spikes pedunculate.-Largo and fine. It is C. typhina $\mathbf{M x}$, when only one spike is present.-N. Eng. to III. and southward.

$\beta$. (C. TYPHINoIDES Schw.) Spikes 2, the lower on a very long peduncle, and both longer and smaller.

78 C. scirpoidea Mx. Spike oblong, cylindric, acutish; f glumo oblong, obtusish; perig. ovate (oval), subrostrate, pubescent, longer than the ovate, acutish, scarious darli purple giume; st. 4-10', erect; lvs. flat and long.-White Mts., N. H. (Oakes), Willoughby Mt., Vt. (Wood), Drummond's Isle, Micli. and northward (Carey).

79 C. Boottiàna Benth. (B. t. 42.) Spikes oblong-cylindric, attenuato at base, with a scale-like lract; a s spike on one culm and a $q$ spike (or 2) on another, sparse-flowered below; perig. oblong-obovate, hairy, apiculate, entire at orifice, 
pedicellate, veined, smaller than the ollong-obovate, short mucronate, dart purple, white-edged glume; culm 6 to 12' high, longer than the cauline, but shorter than the radical bright-green leaves.-La. (Urummond), Ala. (T. M. Peters). Curious and distinct, allied to C. Baltzellii.

80 C. virescens Muhl. (B. t. 72.) Spikes 2-4, oblong, orect, alternate, the lower subsessile, bracteate; upper spike very rarely wholly ô; perig. ovate, obtuse, costate, pubescent, longer than the ovate, pubescent and mucronate glume, or about equal to it; st. 1-2f, rather slender; lvs. towards the base.-Whole plant pubescent and light green.

$\beta$. Costata Schw. Perig. strongly costate, outer sheaths purplish-brown; lvs. numerous and larger. Both are common in open woods and hedges.

81 C. trìceps $\mathrm{Mx}$. (B. t. 117 in part). Spikes 3, short-ovate, ercct, quite near, the upper short-peduncled, lowest leafy-bracted; perig. obovate, obtuse, roundishtriquetrous, pubescent when in flower, roughish, usually much longer than the ovate acute glume; culm 1 to $2 f$, triquetrous, scabrous above, with shorter, subradical, scabrous lvs. -N. Car. (Curtis) to Fla. and Ala. Differs considerably from the following, although the two are united by Boott.

82 C. hirsùta Willd. (Schk., fig. 172.) Spikes 3, short-oblong, thick, alternate, erect, rather near, upper subsessile, lowest pedunculate, all dense-flowered; perig. ovate-triquetrous, obtusish, entire at the orifice, veined, very pubescent when young, rough and glabrous in maturity, longer than the ovate, acuminate, glabrous glumes; culm 12 to $18^{\prime}$, stout, erect, scabrous above; lvs. and sheaths strongly scabro-pubescent, grayish green.-Moist upland meadows, Can. to Penn., and far West.

$\beta$. Pedunculata (Torr.) Spikes oblong-cylindric, pedunculate; lvs. slightly pubescent; young glumes much longer than the perigynium.

$\gamma$. Cuspidita. (Dew.) Glumes ovate, cuspidate, longer than the perig.; lvs., sheaths, and culm very hirsute.-Ill. (Vasey).

83 C. zstivàlis Curtis. (B. t. 133.) Spikes 3 to 5, cylindric, slender, suberect, loose-flowered, bracteate; ô glumes oblong, rather obtuse at the base of the upper spike, lowest spike pedunculate; perig. elliptic, 3-sided, tapering at both ends, glabrous, entire at orifice, longer than the ovate, obtuse, often mucronate glume; culms in tufts, 16 to 24 , slender, with flat, pubescent lvs., and leafy bracts.-Mts. of N. Car. (Curtis), also on Saddle Mt., Mass. (Dewey). Jl., Aug.

34 C. Shortiàna Dew. Spikes 4 or 5, long-cylindric, crect, dense-flowered, tho highest half-staminate below, the others nearly all fertile, exsert-pedunculate; perig. obovate, obtuse, convex-compressed, tapering at base and subpedicellate, minutely apiculate, scarcely longer than the ovate, acute glume; culm 12 to $30^{\prime}$, with long lvs.; plant strong and fine, bright green.-Marshes, Penn. to Ill. and farther South. A distinct and beautiful species.

85 C. oxýlepis Torr. (B. t. 131.) Spikes 3 to 6, long-cylindric, erect, exsert-peduncled, bracteate, thie lower remotish and loose-flowered at the base; perig. oblong, subtriquetrous, glabrous, tapering at either end, 2-lobed or notched at orifice, a little longer than the ovate-oblong, cuspidate, white edged glume; culm 15', erect, rather slender, leafy, pale green; spikes rather dark.-Fla. (Chapman) to Tex. (Torr.)

86 C. Buxbaumii Wahl. Spikes about 4, short, cylindric, thick, upper ono sometimes wholly $\hat{\delta}$, and sometimes $q$ above and below; pistiliferous oblong, subremote, subsessile, bracteate; perig. ovate-oblong, acutish, or obovate, obtuse, subtriquetrous, entire at the orifice, nerved and glabrous, scarcely equal to the oblong and mucronate glume; st. 10-18' high, leafy towards the base.-Common in wet grounds. It is described as sometimes having 2 stigmas in Europe, but placed by Schk., Wahl, \&c., in the division having 3.

87 C. atràta L. Spikes 3 to 5 , oblong-ovate, somewhat nodding, the upper rather near and sessile, lower pedunculate, scarcely sheathed; perig. roundish-oval, compressed, glabrous, short-beaked, slightly bidentate or notched, a little shorter than the dark, oblong glume; culm about If, with light green foliage and black spikes. White Mts. and Brit. Am.

88 C. gracíllima Schw. (B. t. 134.) Spikes 3-4, long, graceful, sub-looscflowered, distant, long-pedicellate, recurved in maturity, bracteate, upper one 
rarely all $\delta$; perig. oblong, triquetrous, obtuse, oblique at the orifice, slightiy 2lobed, longer than the oblong, obtuse, and short-awned glume; st. often $2 \mathrm{f}$, reddish towards the base, leafy and subprocumbent, palo green.-Common in damp meadows.

89 C. formòsa Dew. (B. t. 130.) Spikes 3-4, oblong, short and thick, distant, 1-sided, on a long and slender peduncle, recurved; perig. oblong, triquetrous, subinflated, acutish at either end, nearly entire or 2.lobed at tho orifice, twice longer than the ovate and acule glume; st. 1-2f, 3-sided, dark brown towards the base, yellowish bright green.-Common in wet meadows.

90 C. Davísii Torr. (B. t. 132.) Spikes 4, oblong, cylindric, subsparsely flotrered, remote, pedicellate, pendulous in maturity; perig. oblong-conic, subinflated, subtriquetrous, nerved, acutish, short-rostrate, 2-lobed at the orifice, glabrous towards maturity, about equaling the oblong, scabrous-awned glume; st. 1-2f, triquetrous, scibrous above, with leaves equaling it; lvs. and sheatbs pubescent, sometimes but very little, light green.-First found on the alluvial meadows of the Housatonic in Mass. (Dewey). Sometimes nearly pubescent.

91 C. pracox Jacq. Â Spiko erect, subclavate; $q$ spikes $1-3$, ovate, bractcate, approximate, lower ono short-pedunculato; perig. $6-12$, ovate and subglobous, triquetrous, pubescent, short-rostrate, equal to the ovate, acute, or mucronate glume ; cm. 2-6', leafy at the base.-On rocky hills, Salem, Mass. (Pickering), Ipswich, Mass. (Oakes).

92 C. nigro-marginàta Schw. f̂ Spike erect, short-cylindric, with oblong, obtuse, dark glumes, white on the edge and green on the keel; + spikes 1, 2, rarely 3 , ovate, 4 to 6 -flowered, the lowest squarrous-bracted, near the $\hat{\delta}$, on one long, scabrous stem or ped. ( 6 to $8^{\prime}$ long), 2 or 3 short ( 2 to $4^{\prime}$ ), and radical ped. all on the samo root; perig. ovato or oblong, tapering below or pediceled, slender-beaked, roughish, about equaling the ovate or lance-oblong, dark glume, which is white on the edge and keel; lvs. radical, scabrous, recurved, bright green, longer than the culm. -Dry hills, Penn. to Fla. and La.

93 C. umbellàta Schk. Dwarf; î spike short, erect; + spities several, each on its low, radical peduncle, ovate, subumbellate, green; perig. ovate or globous, $5-8$, acutish at either end, rostrate, short-bidentate, pubescent, equaling the ovatelanceolate glume; st. $\frac{1}{2}-4^{\prime}$, with very long leaves.

$\beta$. VICINA Dew. 1 or $2 q$ spikes close to the $\hat{\delta}$, sessile; the other $q$ spikes on their own stems or radical peduncles.-In small tufts on dry hills. Both varieties grow on tho same root, but Schk. saw and figured only the first.

94 C. Emmónsii Dew. Â Spike sessile, short ( $\left.3^{\prime \prime}\right)$; 9 spikes 2-3, approximate, sessile, few-flowered, very short, often one long, radical peduncle ; perig. globoustriquetrous, attenuated at the base, rostrate, pubescent, at the orifice oblique, about equal to the ovate glume; culm filiform, decumbent, 6-10', leafy at the base, pale ash-green.-On dry fields and hilis; common. (C. Noveæ-Angleæ, $\beta$. Carey.)

95 C. Pennsylvanica Lam. of Spike erect, pedunculate, long (6 to $\left.8^{\prime \prime}\right)$, subtriquetrous, with an obtuse glume; o spikes $1-3$, ovate, subsessile, subapproximate, few-flowered; perig. ovate-globous, tomentous, short rostrate, slightly 2-toothed, about equal to the ovate-acuminate, or oblong-acuminate, deep reddish glume; st. 4-12', erect, stiff, with short culm-lvs., and often with long, stiff, root-lvs. (when it is C. marginata, as in Schk., fig. 143).-Open woods and hedges, commonmuch resembles tho preceding, but readily distinguished by its different aspect and its deep reddish-brown scales.

96 C. Nova-Angliz Schw. ô Spike short, slender, oblong; $q$ spikes $2-3$, ovate, alternate, sessile, remotish, few-flowered, bracteate; perig. 3-6, oval-triquetrous, rostrate, costate, slightly pubescent, a little longer than the ovate, mucron. ate glume; st. $4-8$ ', slender, subdecumbent, longer than the leaves.-Pale green. Open woods in high grounds. (C. varia $\beta$. minor Boott.)

3 . Collecta Dew. St. 10-16', very slender; erect; क spikes 2-4, lower short-pedunculate; perig. moro tapering into a beak, slightly bidentate.-High lands of Mass.: not abundant.

97 C. varia Muhl. ô Spike erect, short or subelongated; \& spikes 3, ovate, sessile, rather near, bracteate, few-flowered; perig. ovate or sub-globous, subtriquetrous, acuminatc-rostrate, bifid, scabro-pubescent, about equal to the ovate, acuminate 
glume; st. 6-15', erect, slender, purple towards tho base. Pale green.-Dry woods and hedges; common.

$\beta$. PEDICELlatA Dew., has pistillate spikes ovate-oblong, short-pedicellato erect, loose-flowered; perig. more numerous.-Grows in the same situations.

98 C. vestita Willd. (B. t. 120.) if Spike single, rarely 2, cylindric-oblong; of spikes 2 , ovate-oblong, sessile, subapproximate, bracteate, often with stamens above; perig. ovate, suborbicular, subtriquetrous, nerved, short-rostrate, bifid, pubescent, a little longer than tho ovate-oblong, acutish, submucronate glume; st. 18-30', acutely triangular and leafy below.-Common in wet places orer tho country.

99 C. pubéscens Mull. (B.t. 60.) \& Spikes 2-3, oblong, rather loose-flowered, erect, bracteate, the lowest pedunculate; perig. lance-ovate, triquetrous, rostrate, nearly entire at moutl, pubescent, a little longer than the ovate-oblong, carinate, mucronate glume; st. $10-20^{\prime}$ high, and with tho leaves, pubescent.-Moist wonds and meadows; common.

100 C. flàva L. i Spikes 2-4, ovate-oblong, approximate, sometimes androgynous; perig. ovate, closely imbricate, costate, bidentate, reflexed with a long, curved beak, longer than the ovate-lanceolato glume; st. 10-20' rather obtusely angled or triquetrous ; glabrous; yellowish-green.-Wet and cold soils; common in this country as well as in Eur.

$\beta$. LEPIDOCÁRPA. Taller and more slender, with short, round-ovate spikes aggregated, or except the lower, with perig. rostrate and recurved in maturity, about twice as long as tho ovate, obtuse glumes.-With the other. (C. lepidocarpa, Ed. 2.)

101 C. I'deri Ehrb. Spikes sometimes androgynous; $q$ about 4, clustered, nearly sessile, short-oblong, sometimes $\hat{f}$ above or below, bracteate; perig. rather obovate, subinfiated, nerved, bidentate, diverging with a subulate beak, a little longer than tho ovato glumo; st. 2-10', leafy.-Palo yellow. Mass and N. Y., abundant in Pittsfield, Mass., and at Niagara Falls.

102 C. folliculàta I. nec. Schk. \& Spikes 2-4, ovato or capitate, densely flowered, distant, the peduncles sometimes projecting far beyond the sheaths, often $\hat{f}$ at the apex, long bracteate; perig. oblong-conic, much inflated, diverging or horizontal, long-rostrate, twice longer than the oblong-ovate, acute, long-awned glume; st. 2-5f, leafy; Ivs. linear-lanceolate, long and flat.-Palo yellow. In wet or marshy places; common. (C. Xanthophysa Wahl.)

103 C. rostràta $M x$. ô Spike short and small; $q$ spikes $2-3$, sub.globous, or capitate, bracteato; perig. aggregated into a head, small, erect, or subdiverging, oblong-conic, very long-rostrate, slightly inflated at the base, twice longer than the ovate-oblong, acutish glume; st. 8-16', few-leaved, erect, stiff.-Pale yellow. At the base of the Whito Mts., N. H., Oakes; also in Canada, where Mx. found it. Not recognized as the plant of Michaux till 1840, Sil. Jour. XXXIX, p. 52.

104 C. turgéscens Torr. Spike oblong, cylindric, erect; $q$ spikes 2 or 3 , ovate-globous, few (10 to 12)-flowered, highest sessilo and near the $\hat{t}$, lowest often quite remote, exsertly pedunculate, perig. ovate, inflated, diverging, conicrostrate, bidentate, striate, twice longer than tho ovate, acute glume; culm 2 to $3 \mathrm{f}$, slender, longer than the leaves, yellowish or pale green.-Fla. to La. (Chapm. Ingalls.)

105 C. Ellióttii Schw. \& Spike cylindric, 1'long, with oblong, obtuse glumes; o spikes 2 or 3 , ovate, roundish, sessile, upper starninate at apex, lowest sometimes pedunculato; perig. ovate-triquetrous, glabrous, veined, rostrate, 2 -toothed, about twice as long $\left(3^{\prime \prime}\right)$ as the ovate, obtuse glume; culm 1 to $2 \mathrm{f}$, triquetrous, recurved.-N. Car. to Fla. (C. castanea El. nec Wabl. C. Baldwinia Dew. in Sil. Jour.)

106 C. intuméscens Rudge. (B. t. 148.) \& Spike oblong, pedunculate; $q$ spikes $1-3$, few-flowered, approximate, bracteate, erect, nearly sessile, the lower ono sometimes remote and exsertly pedunculate; perig. ovate-conic, large and much inflated, acuminate-rostrate, bidentate, nerved, diverging, very glabrous, thrice longer (5 to $\left.6^{\prime \prime}\right)$ than the ovate-cuspidate glume; st. a foot or more high, erect, stiff; leafy, dark green and very glabrous.-Wet grounds, in open woods or marshes; common. (C. Solliculata Schk.) 
107 C. lupulina Muhl. (B. t. 149.) f Spike erect, slender, subsessile; $q$ spikes $2-4$, ovate-oblong, large, $\left(20^{\prime \prime}\right.$ by $\left.9^{\prime \prime}\right)$ and thick, or oblong-cylindric, short-pedun. culate, erect, densely flowered, approximate, the lowest sometimes long-pedunculate and distant; perig. ovate-conic, ventricous, long, conic-rostrate, bicuspidate, nerved, glabrous, about thrice longer than the ovate-lanceolate, acuminate glume; st. I-3f, triquetrous, leafy; lvs. and bracts long, flat, wide, striate, scabrotus on the edge.-Bright green. Well named from its hop-like spikes. Marshes and about ponds, common. (C. lurida Wahl.)

108 C. lupulifórmis Sartwell. (B. t. 150.) \& Terminal spike long cylindric, pedunculate, sometimes 1 or 2 short sessile ones below it; $q$ spikes 3 to 5 , large (2 to $\left.3^{\prime}\right)$, cylindric, $\left(9^{\prime \prime}\right.$ thick) near, subsessile, the lowest more or less remote on a long, exsert peduncle, all leafy bracted and subloose-flowered; perig. globousovate, inflated, long and large, terete, scabrous-rostrate, 2-horned, more than twico longer than the ovate, cuspidate glume; culm 2 to $3 \mathrm{f}$, erect, large, stiff, surpassed by the leafy bracts as well as by the lanceolate, rough, bright, green leaves.Borders of inarshes, common. (C. lupulina, $\beta$. polystachya Torr.)

109 C. tentaculàta Muhl. \& Spikes 2-4, oblong, cylindric, (24" by 6 or $\left.7^{\prime \prime}\right)$ bracteate, upper one sessile, the rest nearly sessile, densely flowered; perig. ovate, inflated, long-rostrate, bidentate, nerved, diverging, glabrous, twice longer than the ovate and small scabro-mucronate glume; st. 1-2f, often large, triquetrous; Ivs. linear-lauceolate, longer than tho stem. - In clusters in wet or marshy places; common.

110 C. stenólepis Torr. of Spike short and small, rarely wanting; $q$ spikes 3 to 5 , cylindric, obtuse, oblong or rarely short, highest sometimes androgynous, upper aggregated on the zigzag stem, lowest long-pedunculate, all very denseflowered, erect and stiff, with long and leafy bracts; perig. oblong-obovate, inflated, tapering below, abruptly obtuse, long-beaked, bifurcate, a littlo longer than the ovate-linear, awned glume; culm 1 to $2 \mathrm{f}$, erect, strong, smooth, striate, with flat, rather wide, rough-edged, bright green leaves.-Va. to Ill., in marshes, rare, late-flowering.

111 C. plantaginea Lam. nec Muhl. (B. t. 88.) of Spike erect, large, subclavate, with oblong and acute glumes; $q$ spikes 3 to 5 , oblong, erect, remote, sparse-flowered, 2 upper nearly inclosed-pedunculate, the lower ones exserllypedunculate, with subulate bracts; perig. oblong, triquetrous-elliptic or cuneiform, tapering at either end, recurved at the apex, and entire at the orifice, longer than the ovate-cuspidate glume; st. 8-18' high, erect, triquetrous, with dark brown sheaths; lvs. radical, broad, (9 to $\left.10^{\prime \prime}\right)$, ensiform, strongly 3-nerved.-Bright green. Hedges and open woods, common, and one of the first appearing species in the spring. (C. latifolia Wahl.)

112 C. Careyàna Torr. (B. t. 89.) \& Spike erect, oblong, with oblong and obtuse glumes; $q$ spikes 2 or 3 , ovate, loose and few-flowered, distant, upper subsessile, all leafy bracteate; perig. ovate, triquetrous, subinflated, nerved, acuminate, tapering at the base, smooth and glabrous, entire at the orifice, twice longer than the ovate, mucronate glume; st. 1-2f, erect, smooth, leafy towards the base; lvs. linear-lanceolate, 6" wide.-Pale green. Woods, Auburn, N. Y., (Carey) and Ohio (Sullivant). Closely related to C. plantaginea.

113 C. laxiflora Lam. nec. Schk. (B. t. 87.) \& Spikes 2-4, subfiliform, erect, attenuate, sparse-flowered, remote with a 2-edged peduncle, leafy bracteate, upper one subsessile ; perig. oval-triquetrous, tapering at both ends, short-rostrate, attenuate, glabrous, striate, excurved at the apex, a little longer than the oblong-mucronate or ovate-acute glume; st. 6-12', acutely triquetrous; lvs. radical, of medium (3 to $\left.4^{\prime \prime}\right)$ width. - Glaucous or light green. Woods and hedges, common. Variable. (C. anceps Willd, Am. auct.)

$\beta$. PatulifoliA Dew. (C. anceps. Schk., fig. 195.) Lvs. radical, broad, manyveined, narrower at the base; sheaths with long and leafy bracts; perig. longer-rostrate.

$\gamma$. ANGUSTIFolia Dew. (Schk. fig. 128.) St. a foot high; lvs. narrow, striate, long; perig. short-rostrate and much recurved.

114 C. platyphylla Carey. (Boot. t. 90.) \& Spike with oblong, acute glumes; \& spikes 2 or 3 , oblong, slender, few (3 to 6 )-flowered, erect; not compact; perig. ovate, triquetrous, acute, short-beaked, subrocurved, entiro at the orifice, longer 
than the ovate, acute or cuspidate glumo; culm 3 to 8 ; erect, triquetrous, slender, at length nearly prostrate, with sheathing, leafy bracts; lvs. radical, broad ( 7 to $10^{\prime \prime}$ ), 3-veined, pale green.-Shades, N. States. Confounded with No., 111 or $113, \beta$, until described by Carey in Sill. Jour. and Gray's Manual.

115 C. zanthospérma Dew. (B. t. 86.) \& Spike cylindric, short, sessile, with oblong, obtuse glumes; \& spikes 3 to 6 , oblong, cylindric, rather loose-flowered, leafy-bracted, suberect, subremote, tho lowest sometimes recurved; perig. ovate, oblong, obtusish, minutely veined, slightly apiculate, yellow ochre color in maturity, twice or thrice longer than (or the lower equaling) the broadly ovate, acute or mucronate glume; culm 10 to 16', erect, smooth, and with the lanceolate, sheathing lvs. at length yellowish.-N. J. to Fla. and Tex. (C. flaccosperma Ed. 1.)

116 C. blánda Dew. i Spikes 2-4, oblong, cylindric. subsparse-flowered, alternate, approximate, bracteate, highest subsessile, the lowest on a long, 2-edged peduncle; perig. obovate and scarcely attenuate below; subtriq. nerved, recurved at the apex, entire at the orifice, little longer than the ovate, scabro-mucronato glume; st. $8-12$, triquetrous, leafy towards the base; lvs. long as the stem.Pale green or glaucous. Meadows and dry, open woods, common. (C. conoidea Muhl. nec Schk., C. laxiflora $\beta$. Carey, Boott.)

117 C. retrocúrva Dew. \& Spikes 2-4, on long, filiform, recurved peduncles, bracteate, subdense-flowered, short and thick, oblong; perig. ovate, triqu. nerved, obtusish, equaling the ovate, cuspidate glume; st. $6-12^{\prime}$ high, prostrate; lvs. radical and wide.-Glaucous. Open woods, rare. Has been considered C. digitalis, Willd., but is different.

118 C. conoìdea Schk. nec Muhl. (B. t. 81.) fot Spikes 2-3, oblong, or ovateoblong, remote, erect, rather dense-flowered, bracteate; perig. oblong-conic, obtusish, glabrous, nerved, subdiverging, entire at the mouth, a little longer than the ovatesubulate glume; st. 8-12' high; lvs. towards the base, shorter than the stem. Bright green. Moist, upland meadows, common.

119 C. grisea Wahl. (B. t. 85.) fo Spike oblong, slender; \& spikes 2 to 4 oblong, lax-flowered, fow-flowered, erect, remote; perig. ovate, or oblong-ovate, obtusish, glabrous, ventricous, nerved, subtriquetrous, entire at the mouth, a little longer than the ovate, scabro-mucronate glume; st. 10-18" high, triquetrous, lcafy.Bright, to pale green. Woods, hedges and meadows, common, N. and Mid. States. (C. laxiflora Schk. et Muhl. nec Lam.)

120 C. júncea Willd. \& Spike short-cylindric, with oblong, obtus spikes 2, rarely 3, filiform, loose and alternate-flowered, pedunculate, long-setaceous-bracted; perig. lanceolate, slender, subtriquetrous, longer than the ovate, obtuse, white-edged glume; culm If or more, slender, longer than the radical, bristleform leaves; aspect light green, rush-like.-Roan Mts., N. Car. (C. miser Buckles).

121 C. digitàlis Willd. (B. t. 92.) S Spikes about 3, loosely 4-10-flowered, oblong, distant, lax and recurved, leafy-bracted; perig. ovate, triquetrous, alternate, nerved, glabrous, short and obtuse, entire at the orifice, longer than the lance-ovate glume; st. 4-12', shorter than the long, linear, decumbent leaves.Pale green. (C. Caroliniana Buckley.)

B. VAN VheCKII Dew. Smaller; perig. more remote and smaller.-Open, moist woods, common. Has been mistaken for C. oliocarpa, Schk. \& Muhl.

122 C. eburnea Boott. (t. 184). \& Spikes 2-3, erect, 3-6-flowered, ovate, with white, leafless sheaths, and tho upper higher than the s spike; perig. ovateglobous, rostrate, or slightly obovate, glabrous and brown in maturity, twice longer than the white, ovate, hyaline glume; cm. 4-10', erect, with subradical and bristle-form-leaves.-Pale green, ccmmon, limestone grounds. S. W. Vt. to Kay. and southward.

123 C. Washingtòniana Dew. ố Spike erect, slender, with oblong, obtuse, dark brown glumes; $q$ spikes 2 to 4, rarely 6, upper short, sessile, near, lower much longer, loose-cylindric, subremote, stalked, loose-flowered, all brown; perig. ovoid, tapering above, compressed-triquetrous, orifice entire, about equaling or often shorter than the ovate-lanceolate, dark-brown, white-edged glume; culm if or more, triquetrous, smooth, longer than the fat, smooth lvs.; light green.-White Mits. N. H., the most common Carex there, forming a turf with the mosses and 
lichens on the borders of ponds. (C. rigida, $\beta$. Carey; but differs in its fruit, glume, loose spikes, lvs. \&c.)

124 C. granulàris Muhl. (B. t. 84.) \& Spikes 2-4, cylindric, oblong, denseflowered, subercet; perig. roundish-ovate, nerved, very short-beaked and recurved, entire at the orifice, nearly twice as long as the ovate-acuminate glume; st. 8-16', erect or subdecumbent, smooth, leafy.-Glaucous green except the mature, yellow spikes. Moist soils in meadows and hedges, along brooks, abundant.

B. RECTA. Perig. ovate, slightly inflated, short-acute, straight-beaked or acuminate; in some the lower spikes are also long-peduncled.-S. Ill. (Vasey) and La. (Hale).

125 C. panicea I. i Spikes 2-3, loose-flowered, remotish, lowest long-pedunculate; perig. subglobous, obtuse, entire at the mouth, a little greater than the ovate, subacute glume; st. a foot high, triquetrous, leafy at the baso; lvs. shorter than the stem.-Light green. Near Boston (Pickering).

126 C. lívida Vahl. of Spike oblong; \& spikes 2-3, oblong-cylindric, sublooseflowered; perig. ovate-oblong, subtriquetrous, subinflated, obtuse or acutish, entire at the orifice; longer than the obtuse, oblong glume; st. $6-16^{\prime}$ high, erect, triquetrous, striate, with leaves about its own length.-Glaucous green. Sphagnous swamp, near Utica, N. Y. (Gray) cedar swamp, N. J., and more northern regions. (C. Grayana, Ed. 1.)

127 C. tetánica Schk., fig. 207. ㅇ Spikes 2-3, oblong, loose-flowered, remote; perig. obovate, recurved at the apex, entire at the orifice, with an ovate glume, obtusish at the upper and mucronate at the lower part of the spike; st. 6-10' high, triquetrous, longer than tho flat and linear-lanceolate leaves.-Light green. Upland meadows, rare. Its recurved short beak or cramped neck (whence its name) distinguishes it from C. Woodii.

128 C. Woodii Dew. $\&$ Spikes 1 to 3, erect, cylindric, loose-flowered, tho lowest pedunculate, finally recurved; perig. obovate, tapering below, subpediceled, triquetrous, obtuse, orifice mature closed, sometimes short-apiculate, veined, glabrous, longer than the broad, hyaline, green-keeled, rarely mucronate glume; culm 10 to $20^{\prime}$, slender, stiff; lvs. very short; plant with a close, slight pubescence, palo green.-Shores of Perch Lake, \&c. Jeff. Co., N. Y. (Drs. Crawe and Wood). A clear species (Dr. Vasey).

129 C. Meàdii Dew. (B. t. 82.) of Spike ovate-oblong, often long, with glumes oblong, obtuse, tawny-edged; o spikes 2 to 4 , oblong or cylindric, rather laxflowered, upper often staminate at apex, lowest long-stalked, remote, all leafybracted; perig. oval or oblong, tapering some at both ends, veined, with entire orifice, scarce equaling the broad-ovate, acute or obtuse-mucronate, tawny-edged glume; culm 8 to $10^{\prime}$, erect, leafy below, rough above, longer than the leaves; pale green.-A ugusta, IIl. (Mead), Mich. and Ohio. (C. panicea Carey; but clearly distinct.)

130 C. oligocarpa Schk. (B. t. 93.) \& Spilies 2 or 3 erect, 3 or 4-flowered, bracteate; perig. obovate, roundish-triquetrous, short-rostrate, entiro at the mouth, longer than the oblong-mucronato glume; culm 6 to $12^{\prime}$ high; lis. flat and shorter towards the base; plant light green.-Open woods or hedges, rare. Differs frem the following species in its fruit, pubescence, and stouter, coarser aspect.

131 C. Hitchcockiàna Dew. (Boott. t. 94.) ô Spike erect, pedunculate; \& Spikes 2-3, erect, 5 to 10-flowered, lowest distant; perig. oval-triquetrous, tapering at both ends, inflated, alternate, bent at the apex, striate, with a short, truncated and open beak, about equaling or shorter than the oblong or ovate, mu. cronate glume; st. 10-24' high, erect, stiff, scabrous above, with long and leafy bracts; st. lvs. and bracts scabrous and subpubescent.-Borders of woods, $N$. Eng. to IIl. and $\mathrm{Ky}$.

132 C. styloflexa Buckley. ô Spikes cylindric, short, slender, crect, with oblong, obtuse glumes; $\&$ spikes 1 to 4 , oblong, dense, some of them near the staminate and subsessile, the others distant or very remote, on long (2 to $\left.6^{\prime}\right)$, filiform, exsert, drooping peduncles, leafy-bracted ; perig. ellipsoid, tapering below, rostrate, often recurved, once to twice longer than the ovate or lance-linear, nembranous glume; culm 2f, slender, flaccid, triquetrous, longer than the smooth, light green 
leaves.-Mts. N. Car. (Buckley) and Va. to Fla. (C. laxiflora, ק. styloflexa, Boott. t. 87).

133 C. débilis Michx. ô Spike erect, filiform; $q$ spikes $3-4$, not very rarely pistillate above, filiform, loose-flowered, flexuous, nodding, remotish, 1-2' long; perig. oblong-lanceolate, subtriquetrous, alternate, rostrate, bifid, glabrous, nerved, nearly twice longer than the ovate-lanceolate glume; st. 1-2f, triquetrous and scabrous above, leafy towards the base.-Bright green. Noist woods and meadows, common. (C. flexuosa Schk.)

134 C. arctàta Boott. \& Spiles 3-4, long and slender, loose-flowered, nodding and remote; perig. ovate, triquetrous, lanceolate or long-rostrate, subventricous, bifid, glabrous, little surpassing the ovato, membranaceous, mucronato glume; st. $10-20^{\prime}$, scabrous above and leafy below.-Pale green. In the same situations as the preceding, common. (C. Sylvatica Dew. Sill. Jour.)

135 C. Sullivantii Boott. (t. 122). \& Spikes 3, oblong, erect, cylindric, rather loose-flowered, bracted, the lowest long-pedunculate and sparse-flowered below; perig. ovate or oval, apiculate, scarcely veined, scabrous-hairy, short-pediceled; $q$ glume on the lowest spike obovate, obtuse or emarginate, long-cuspidate, the cusp extending above the fruit; on the upper spike the cusp is shortened and the oblong glume scarce equals the fruit; culm 1 to $2 f$, longer than the leares; plant slightly hairy, light green.-Columbus, Ohio (Sullivant).

136 C. Inneisternii Dew. \& Spikes 3, long-cylindric, rather distant, sublaxflowered, with recurved peduncles; perig. ovate, oblong, subtriquetrous, glabrous, terete-conic, rostrate, short-2-toothed, a little longer than the ovate and oblong glume which is obtusish and short-mucronate.-Woods, Oriskany and Rome, N. $\mathrm{Y}$. Closely related to $\mathrm{C}$. Sullivantii, but differs materially when mature, in. the fruit, glume and long triquetrous achenium. Also, by the same marks, from C. arctata Boott. to which Carey improperly (as mentioned by Boott. t., 122) refers it.

137 C. capillàris I. of Spike small; क spikes $2-3$, ovate, oblong, about 6 flowered, loose-flowered, long and recurved pedunculate; perig. oval, short-rostrate, oblong, oblique at the orifice, longer than the oblong, ovate, obtuse glumo; st. $2-7^{\prime}$ high, leafy at the base; lvs. narrow, long.-Grows in tufts, very delicate, 4 to 6', pale green. Alpine regions of the White MIs. (Robbins).

138 C. fúlva Good. \& Spilces 3, oblong, subdense-flowered, erect; perig. ovato, round, short-rostrate, bicuspidate, smooth, binerved, twice longer than the ovate, dark brown, subacute glume; st. a foot high or more, triquetrous, leafy towards the base.-Pale green. Near Boston (Greene). (C. binervis Ed. 1.)

139 C. lrevigàta Smith. \& Spike one and crect, sometimes 2 ; i spikes 2-3, oblong, bracteate, pedunculate, nodding; perig. ovate-lanceolate, triquetrous, nerved, rostrate, bifurcate, subdense-flowered, about equal to the ovate, cuspidate glume; st. 1-2f, scabrous above, leafy towards the base.-Light green. Near Boston (Green). Raro. This and the last probably introduced from Eur. (C. Greeniana Ed. 1.)

140 C. flexilis Rudge. (B. t., 79). \& Spikes 2-4, ovate-oblong, cylindric, rodding; perig. ovate, subconic, rostrate, bidentate, scarcely shorter than the ovate, obtusish, oblong glume; st. 12-18', orect, striate; lvs. short, and shorter below; lvs. and bracts ciliate.-Bright green. Oneida Co., N. Y. (Gray), and far westward. (C. castanea Wahl.)

141 C. venústa Dew. (B. t., 123.) \& Spike long, slender, with oblong, obtưse, tawny glumes; $f$ spikes 2 or 3 , long-cylindric, rather loose-flowered, lowest distant, on a long, exsert stalk, often sparse-flowered, recurved, dark; perig. conic above, tapering below into a pedicel, short-beaked, 2-toothed, veined, rough-pubescent, twice longer than the ovate, obtuse (sometimes mucronate) glumo; culm 1 to $2 \mathrm{f}$, longer than the linear-lanceolate, light green leaves.-S. Car. to Fla.

142 C. tenars Chapm. (Boott. t., 59.) \& Spiko short, cylindric, with oblong, acuto glumes; $\$$ spikes 2 or 3 , ovate or oblong, dense, subsessile, the lower sometimes remote; perig. oval, triquetrous, some tapering below, conic-beaked or shorter and 2-toothed, finely striate, pubescent, twico longer than the narrow-ovate, acuto 
glume; culm 1f, erect; Ivs. short, flat, both glabrous.-Ga, Fla. (C. Chapmanii Sartw.)

143 C. Richardsonil R. Brown. of Spike oblong, erect, stalked, with ovate, obtuse, brown, white-bordered glumes; of spikes I to 3 , smaller, oblong, lax, the upper near, the lowest more remote, all longer than the broad, membranous, white, obtuse bract; perig. ovate-triquetrous, very obtuse, scarcely beaked, orifice entire, below tapering, pubescent, scarcely equal to the brown, ovate, acute, whitecdged glume; culm 4 to 10 , scabrous, longer than the scabrous leaves.-Woods, Greece, N. Y. (Bradley), Ill. (Mead.), and Arc. Am. A fine species with a wide range.

144 C. dasycárpa Mruhl. (B.t., 57.) ô Spike oblong, erect, subsessile, small; o spikes 2 or 3 , short-oblong, alternate, hoary, the lowest remote, bracts longer than the culm; perig. oblong-ovate, triquetrous, short-beaked, veined, dense-villous, emarginate at orifice, longer than the ovate-acuminate glume; culm 8 to $14^{\prime}$, triquetrous, glabrous, longer than the hairy, narrow-lanceolate lvs. ; grayish green. -Dry fields, N. Car. to Fila.

145 C. Michigánsis Dew. Terminal spike staminate, oblong-clavate, erect, short stalked; 9 spikes 1 to 3 , rarely 4, oblong-filiform, lax, some or all three stam. at apex, squarrous-bracted, the upper sessile, lower short-stalked; perig. (too young) oblong-obovate, lance. acute, bifid, some villous, shorter than the oblong, acute, rusty brown $g l_{\text {. ; }}$ culms clustered, 6 to $14^{\prime}$, slender, triq., shorter than the linear, stiff, rough-edged lvs.-Mich. (Wm. Boott, Esq.).

146 C. Tórreyi Tuckm. ô Spike oblong, short ped.; i spikes $2-3$, short, oblong, subsessile, erect; perig. oblong, abovate, very obtuse, glabrous, subtriq. entire at the orifice, subrostrate, twice longer than the acute gl.; st. 12-18' erect, triq., with subradical and pubescent lvs.-Pale green. N. Y. (Tuckerman.)

147 C. Cràwei Dew. $\quad$ S Spikes 3-6, cyl. short and thick, densely flowered, sometimes aggregated, sometimes remote, the lowest often subradical and long-ped.; perig. ovate, terete, scarcely rostrate, diverging, entire at the orifice, twice longe: than the ovate and obtusish gl.; of spike with one or two small ones at its base. -Jeff. Co., N. Y. It commemorates the name of Dr. Crawe, its discoverer, who was soon after drowned, on a botanical excursion, in Griffin's Bay.

148 C. Ignòta Dew. ô Spike cyl., slender, erect, long-stalked, scale-bracted, with oblong, obtusish gls.; \& spikes 2 or 3, oblong, lax, erect, leafy-bracted, the lowest long-ped.; perig. elliptic-triq., tapering below, conic-rostrate, slender, entire at the orifice or slightly 2 -toothed, recurved more or less, a little longer than the ovate, acute, lanc. or cuspidate gl.; culm 18 to 24', pale green.-La. (Hale).

$\beta$. Fugifónuis. A smaller form; perig. more spindle-form, and the glume acute, shorter in proportion. Fla. (C. fusiformis Chapman.)

149 C. scabràta Schw. ô Spilie short-stalked; of spities 3-6, cyl, subrecurved, remotish, long-ped.; perig. ovate-oblong, subinflated, subbifid, rostrate, quite scabrous, longer than the ovate-lanc., acuminate, short-bidentate, ciliate, gl.; culm $1-2 f$, acutely triq., rough. above, longer than the lvs. towards the base.-Bright green. Along brooks and streams, common. N. States, N. Car. (Curtis).

150 C. subulàta $\mathrm{Mx}$. of Spike erect, small, short, with lanc., white gl. ; क spikes 3 to 5 , oblong, 3 to 7 -fruited, distant, sessile above, the highest close to the staminate, the lower exsert-ped., leafy-bracted, sometimes of at apex; perig. subulate or lance-ovate, long, rostrate, slender, veined, glabrous, with 2 curved teeth divaricate or reflexed, more than thrice longer than the white, lanc. gl; culm 6 to 14 to $24^{\prime}$ high, very slender, lax, smooth; lvs. smooth, striate, flat, shorter than the culm ; very light green.-Can. to N. J., along the coast.

151 C. palléscens L. + Spikes 2-3, oblong, short, cyl., distant, yellowish green, nodding towards maturity; perig. oval, obtuse, round, about equal to, or $a$ little shorter than, the ovatc, pale gl. ; st. 6-16', hardly erect; bracts sometimes transversely rugous.-Plant often subpubescent, and of a light green. In dry meadows. Common.-C. undulata Kunze, is admitted by Kunze himself to be only var., differing chiefly in its wavy, lowest bract.

152 C. limòsa $I_{\text {. }}$ q Spikes $1-3$, ovate or oblong, long-ped., subloose-flowered, smoothish, pendulous; perig. elliptic, compressed, very short-rostrate, cntire at 
the orifice, abnut equal to the oblong and obtuse, or ovate, cuspidate, rust-colored gl. ; culm 8-16', ascending, obtusely triq., with subradical flat and narrow lvs. Glaucous green. Marshes, common.

153 C. irrígua Smith. $\quad$ Spikes $2-3$, ovate-oblong, thickish, nodding; perig. roundish-ovate, short-rostrate, subcompressed, shorter than the ovate-lanceolate, chestnut-brown gl.; st. near a foot high, longer than the flat, subeurved lvs.; glaucous. - $f$ Spike rarely $q$ at the summit, or $q$ spikes with stamens at the base. Marsh. Bridgewater, N. Y. (Gray) also in marshes in Mass. and Mich. (Cooley), rare. (C. limosa, $\beta$ irrigua Wahl.)

154 C. rarifiòra Smith. $\quad$ S Spikes about 2 linear, quite loose-flowered, long-ped., nodding; perig. ovate, oblong, triqu., depressed, equaling the ovate, subcircinate, brown gl. ; culm 10'. Glaucous. White Mountains, N. H. (Barratt). (C. limosa B. rariflora Wahl.)

155 C. Barráttii Torr. (B. t. 176.) ô Spiko 1, erect, cyl., long (rarely 2), with ovate, obtuse, dark gls.; $q$ spikes 2 to 6 , often long-cyl., staminate at apex, the lower on slender, recurved pedicels, upper erect, commonly single, sometimes 2 or 4 from the same bract, purple or dark; perig. ovate or lance-ovate, often with a very short beak, obtuse, slightly diverging, roughish, longer than the ovate dark gl. ; culm 1 to $2 \mathrm{f}$, longer than the long, rough leaves; glaucous green.-N. J. to N: Car. (Curtis). (C. flacca Carey. C. recurva Huds.)

156 C. milliàcea Muhl. ô Spike erect, slender; $\&$ spikes $2-3$, long-cyl., slender, loose-flowered below, nodding; perig. ovate, triq., glabrous, subrostrate, entire at the orifice, longer than the oblong, emarginate or obcordate, awned gl.; st. 12-24', slender, seabrous; lvs. linear-lanc.-Yellowish green. Wet meadows, common.

157 C. hystricina Willd. (B. t. 152.) of Spike rarely pistillate at the summit; $q$ spikes $2-4$, oblong, cyl., attenuate, subdistant, long-bracteate, nodding, Farely sheathed; perig. ovate, diverging, inflated, subtriq., nerved, bifid, glabrous, twice longer than the oblong, emarginate, submucronate gl. ; culm 12-24', scabrous above, with long, linear-lance. Ivs.-Yellowish green. Wet places, very common. (See Sill. Journ., 1848, C. Georgiana.)

$\beta$. CoòleYI. f Spikes short small, of spikes often short-ovate, the lowest on a very long (5 to $\left.8^{\prime}\right)$, recurved, filiform pedunele; culm very slender, prostrate, shorter than the long, narrow lvs.-Mich. (Cooley). (C. Cooleyi, Ed. 1.)

158 C. Pseudo-cypèrus L. (Schk. fig. 102.) ô Spike cyl. and elongated; o spikes 3-4, cyl., long-ped., rather remote recurved-pendulous, with long and leafy bracts; perig. ovate, lanc., bidendate, reflexed, and a little shorter than the ovatelanc. or setaceous gl.-Common about ponds and ditches. It is smaller in all its parts than C. comosa (Boott), the fruit of the latter is deeply and widely bifureate, and its glume is hispid or ciliate. The two have been confounded in our country, though long known.

159 C. comòsa I. (B. t. 36.) ô Spike long and slender, rarely pistillate above;

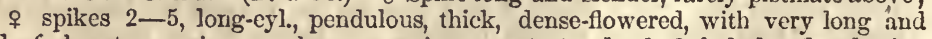
leafy bracts; perig. ovate-lane., acuminate, rostrate, deeply 2-forked, reflexed, triq., glabrous, generally longer than the lanc., mueronate, setaceous gl.; culm 18-30', large, rough, with long and wide, rough leaves and bracts. Plant very glabrous and yellowish-green. Wet places about ponds and ditches, common. (C. furcata Ell.)

160 trichocárça Muhl. $q$ Spikes about 3, erect, rarely 1 , or $q$ above, cyl., lower shorter; $\&$ spikes 2-4, ereet, long-cyl., smoothish, rather loose-flowered; perig. ovate, conic, inflated, nerved, rostrate, bifurcate, densely pulescent, about twice longer than the ovate-lanc. gl.; culm 15-30', scabrous above; and with pubescent leaves and sheaths. - Light green. In wet and marshy places, common.

3. TURBinàta Dew. I spikes ovate or short oblong, thick, remote, denseflowered; perig. subdiverging, ovate and conic, rostrate, longer than the ovate-oblong, mucronate gl. ; st. 2-3f.-Glaucous green. In a pond in Beckman, N. Y., thero abundant.

161 C. verrucòsa Mfuhl. î Spike (rarely 2) cyl., large, obtuse, stalked, with 
oblong, retuso, mucronato gls.; $q 3$ to 6 , soon nodding, cyl., leafy-bracted, $\delta$ above, lowest exsert-ped. ; perig. ovate-compressed, triq., glaucous, short-rostratebifid, scarcely veined, about equal to the ovate-oblong, emarginate, mucronate or awned brown gl.; the awn extending beyond the perig.; culm 2 to $3 f$, erect, stiff, triq., striate; lvs. and bracts stiff, rough, often over-passing the culm; color glaucous green, with dark spikes.-Wet grounds, Penn. to Ga., La. and Ky. Apr., May. (C. glaucescens Ell.)

3. ANDRógYNA Curt. Spikes 4 to 7, large, 3 to $4^{\prime}$ long, upper one staminate at base, the others pistillate and in part staminate at apex.-Wilmington, $\mathbf{N}$. Car. (Curtis). "An autumnal var.," flowers in Oct.

162 C. lanuginòsa Michx. ô Spikes 2, oblong, slender, erect; $q$ spikes 2-3, cyl., erect, dense-flowered, sometimes short-oblong and thick, subrostrate; perig. ovate, short-rostrate, bicuspitate, subtriq., thick, pubescent and woolly, about equaling tho ovate-lanc., awned gl. ; culm 12-24, nearly round below, with flat, linear-lanc. lvs. and bracts.-Glabrous and jellowish-green. Wet places and marshes, common. (C. pellita Muhl.)

163 C. filifórmis L. (B. t. 121.) ô Spikes $2-3$, with oblong glumes; o spikes $2-3$, ovate, oblong, short-cyl., close-flowered, remotish, erect; perig. ovate, villous, short-rostrate, bifurcate, about equaling the ovate, acute gl.; culm $20-30$, erect, slender, stiff, with convolute lvs. and bracts.-Pale green. Marshes, common.

164 C. striàta Mx. (B. t. 141.) \& Spikes I to 4, commonly 2, oblong, cyl., erect, the lower sessile, shorter; $q$ spikes 2 , rarely 1 , long-cylc., ereet, dense, with peds. inclosed, upper often $\hat{\delta}$ at apex; perig. ovate, acuminate, inflated, rough-downy, orifice bifid, scarce rostrate, twice longer than the acute, tawny gl.; culm $14-20^{\prime}$, crect, leafy-bracted, longer than the striate, lanc. Ivs.-Penn., N. J. to Fla. (C. polymorpha, Ed. 1.)

165 C. Houghtónii Torr. (B. t. 49.) \& Spikes 1 to 3, oblong, erect, purple to pale, with oblong, obtuse, mucronate, white-edged gls.; 9 spikes 2 or 3 , thickish, oblong-cyl., leafy-bracted; perig. ovate, inflated, short-rostrate, dirty brown, bifur. cate, veined, hispid-downy, nearly twice longer than the ovate, mucronate, whiteedged $g l$. ; culm about 1f, erect, stiff, triq., rough, about equaling the lvs.-Fla (Chapman!), also Lake La Biche, N. W. Ter. (Houghton).

166 C. polymórpha Muhl. Var. 2. (B. t. 56.) of Spikes 1 to 3, oftener 2, oblong, erect, sessile, with oblong, obtuse glumes; of 2, sometimes 1, oblongcyl., erect, rather loose, upper staminate at apex, lower remote, exsert-ped.; perig. oval-ovate, slightly inflated, subtriq., short-rostrate, orifico oblique, veined, glaucous, a little longer than the ovate, reddish, white-edged gl.; culm 2 to $20^{\prime}$, erect, stiff, triq., longer than the light green lvs., which are reddish at the root.Sandy plains, Mass. to Penn. and W. N. Y. (C. Halseyana, Ed. 1.)

167 C. Cherolkeénsis Schw. (B. t. 78.) f Spikes 2 or 3, cyl., erect, the highest larger, pedunculate, rarely pistillate at base; $q$ spikes 3 to 6 , cyl, distant, ofen staminate at apex, highest sessile, the others exsert-ped., nodding, loose, rarely twin; perig. lance-ovate, glabrous, veined, compressed-triq., subinflated, tapering into a whitish beak, much longer than the ovate, acuminate gl.; culm 10 to $20^{\prime}$ high, leafy below and long as the lvs.; plant flaccid, grayish green.-Ga., Fla., La. and Mo. (C. Christiana Boott.)

168 C. paludòsa Good. (Schk., fig. 103.) fo Spikes 2 or 3, cyl, erect, the lower shorter, smaller, sessile; $q$ spikes 1 to 4, cyl., erect, rather dense, not distant, alternate, lowest often long-stalked, scarcely sheathed, attenuate below, and there loose-flowered, all bracted; perig. ovate, tapering into a short beak, bidentate, distinctly many-veined both sides, nearly equaling the narrow, cuspidate gl.; culm $18^{\prime}$ to $2 \mathrm{f}$, erect, scabrous above, longer than the light green lvs. - Near Boston (Wm. Boott).

169 C. gigántea Rudge. (B. t. 151.) ô Spikes 1 to 3; erect, cyl., slender, near, the lower shorter, sessile, with ovate, acute, or lanc. gls.; \& spikes 2 to 4 , cyl., loose, staminate at apex, remote, the lower on long, exsert stalks, often nodding, with long, leafy bracts; perig. ovate or globous, ventricous, abruptly contracted into a long, slender, cyl, beak, veined, smooth, divaricate, in maturity much longer than the lance-ovate, awned, white-edged gl.; culm 18 to 30 to $36^{\prime}$, stout, longer than the broad, strong lvs.-Marshes, Ky. to S. Car. and La. 
170 C. retrórsa Schw. of Spikes about 3, rarely 1, often with a fow perig. at the base; \& spikes 4-6, oblong, cyl., approx., dense-flowered, with long and leafy bracts, the lowest often remote and long ped.; perig. ovate-inflated, subglobous, rostrate, bifurcate, nerved, reflexed, twice longer than the lanc. gl.; culm $15-30^{\prime}$, scabrous above, large, stiff, and leafy.-Bright green. In clusters, about pools of water, common. The lower spikes sometimes have 1 or 2 smaller spikes attached to them.

171 C. Schweinitzii Dew. ot Spikes 2, rarely 1, upper long and slender, lower with a few perig. at the base; of spikes 2-4, oblong, cyl., subapprox., subrecurved, rather close-flowered, lowest often long-ped. ; perig. ovate-oblong, tapering above, rostrate, inflated, nerved, glabrous, bifurcate, longer than the subulate, subsetaceous gl. ; culm 6-12', scabrous above, very leafy.-Pale yeliowish-green. Wet sandy grounds, N. Y., N. J., and northward.

172 C. miràta Dew. of Spikes 2 or more, long-cyl., near, loose, with long, linear, rough-awned gls.; $\uparrow$ spikes 2, long-cyl., stalked, lax-flowered, suberect, bracted, yellowish, staminate at apex; perig. lance-ovate, slender, long-conic, rostrate, scarcely inflated, scabrous, oblique at the long-cuspidate beak, diverging, long-pediceled, equaling or longer than the narrow, rough-awned gl.; culm $2 f$, erect, very rough, stiff, shorter than the stiff, rough edged lvs.; light-yellowish green.-Greece, N. Y. (Bradley). (C. aristata, Boott, \&c., but very different.)

173 C. Iongirćstris Torr. (B. t. 77.) ô Spikes 3, short; + spikes 2-3, cyl., quite loose-flowered, pendulous, subdistant, with filiform ped.; perig. ovate, globous, inflated, glabrous, long-rostrate, hispid, a little longer than the lance or ovate, cuspidate gl.; st. $15-30^{\prime}$, rather slender, stiff, leafy below.-Bright green. On light soil of hedges in N. England and N. York, common.

174 C. Vàseyi Dew. of Spikes 2 to 4 , slender, the highest long-cylindric, the next shorter; + spikes 2 , often 3 , long-cyl., loose, remote, bracteate, only the lowest long-ped. ; perig. ovate-oblong, inflated, long-terete-rostrate, somo what triq., serrate on the bifurcato beak, glabrous, veined, much longer than the lance-oblong glume; culm about $2 f$ crect, stiff, shorter than the rough lvs. ; bright green.-Wet places, N. Y. to Ill. (Vasey). (C. vesicaria $\beta$. Boott., \&c.)

175 C. lacústris Willd. of Spikes $3-4$, erect, sessilo; + spikes $2-3$, crect, oblong, cylindric, short-pedunculate; perig. ovate-oblong, tapering or lanceolate, bifurcate, glabrous, a little longer than the oblong, mucronate gl.; culm 2-3f, scabrous above, erect and large, with long and large leaves and bracts.-Light green. Marshes. Common. (C. riparia Muhl. nec Gooden.)

176 C. ripària Gooden. \& Spike 3-5, oblong, thick, erect, sessile; o spikes $2-3$, erect, oblong, often long-cylindric; perig. orate-elliptic, contracted into a short, bifurcate beak, glabrous, about equaling or shorter than the ovate, mucronate, or oblong-lanc. gl. ; culm 2-3f, scabrous above, leafy below.-Bright green. Mich. (Cooley) and westward. Distinguished from the preceding by its broader, more inflated fruit, and its oblong-ovate, mucronate glume, which often surpasses the perig.

177 C. aristàta R. Br. (B. t. 58.) \& Spikes 2-4, cylindric, distant, closeflowered, erect; perig. ovate, oblong, nerved, deeply bifid, very glabrous, longrostrate, longer than the oblong, awned, greenish glume; lvs. and sheaths villous on the under side; st. a foot or more high-Bright green. Watertown, N. Y., far west and north. Is not this very closely related to No. 160?

178 C. utriculàta Boott, (t. 37.) f Spikes 3 or 4, slender, cyl., long, often bracteate; \& spikes about 3, long-cyl., large, often stam. above, subremote, the lowest tapering below, loose and stalked, with bracts surpassing the culm; perig. oval-oblong, drawn into a terete, tapering, bifurcate beak, smooth, veined, strawcolored, larger than the lanceolate, purple, rough-awned glume; culm 2 to $3 \mathrm{f}$, shorter than the broad, stiff, nodous, netted, glaucous lvs.-Abundant in marshy places wide over the country: (C. ampullacea, $\beta$. Carey.)

$\beta$. SPARSIFLòra. Spikes all very long $\left(4\right.$ to $\left.6^{\prime}\right)$, slender, the $q$ spikes very loose, and more so below, the lowest long-pedunculate; perig. smaller and glume longer. - Watertown, N. Y. (Crawe).

179 C. ampullacea Good. of Spikes 2 or 3 , cyl., erect; f spikes 2 or 3 , longcyl., erect, quite dense, short-ped., bracteate; perig. ovato-globous, a littlo inflated, 
diverging, veined, glabrous, abruptly contracted to a small, round, bifurcate beak, a little longer than the lanceolate glume; culm 20 to $30^{\prime}$, obtuse-angled, with long lvs. and bracts; light green.-Marshes over the country, not abundant.

180 C. monile Tuckm. (B. t. 71.) \& Spikes 2 to 4, long-cyl., slender, with long-lanceolate gls.; i spikes 2 or 1 , long-cyl, short-ped., rather loose, tapering below sometimes and more loose, remote, erect, bracteate; perig. globous or ellipsoid, inflated, short-rostrate, bidentate, yellowish, many-veined, more than twice longer than the oblong-lanc. gl.; culm 15 to $30^{\prime}$, erect; lvs. and bracts long, bright greel. - Marshes, not abundant, N. Eng. to O. and westward.

181 C. Olneyi Boott (t. 40.) of Spikes about 3, cyl., slender, near; $q$ spikes commonly 2, cyl., thick, dense, yellowish, approx. more or less ped., the lowest tapering below, more lax at the base, often some nodding and bracted; perig. inflated-ovoid, with a short, cyl., scabrous, bifurcate beak, diverging, longer than tho lanc. gl.; culm 15 to 22 ', stout, obtuse-angled, rough above, shorter than tho long, stiff, white-edged lvs.-R. I. (Olney).

182 C. Iuckermàni Boott (t. 38). fo Spikes 2-3, cylindric, lower ones sessilo and short, with an oblong, acutish glume; of spikes $2-3$, oblong, cyl., thick and large, scarcely pedunculate, subloose-flowered; perig. much inflated, ovate, large, conic, costate, bifurcate, all glabrous, nerved, twice longer than the ovate-lanc. gl. ; culm about $2 \mathrm{f}$, erect, scarcely scabrous; bracts and lvs. long, not wide; light green.-Wet places in meadows, common, and has been ranked under C. bullata. Distinguished No. 181, by the short, smooth beak of its membranous, pellucid perig. as well as by its different o spikes.

183 C. vesicària L. ô Spikes about 3, erect, oblong; $q$ spikes $2-3$, cyl., erect, dense-flowered, alternate, long-bracteate; perig. ovate, oblong-conic, tereto, inflated, rostrate, nerved, diverging, glabrous, bicuspidate, nearly twice longer than the oblong-lanc. gl.; culm about $2 \mathrm{f}$, shorter than the lvs.-Bright green. Marshes. Not common.

184 C. bullàta Schk. of Spikes 3, erect, slender, cyl., with oblong-lanceolato glumes; of spikes 2-3, rather oblong, cyl., nearly erect; perig. ovoid-globous, inflated, glabrous, costate, with a long, scabrous beak, bifurcate, longer than tho lanc. gl.; culm $20^{\circ}-30^{\prime}$ high, rather slender, triquetrous, scabrous above, leafy and shorter than the leaves.-Glabrous, light green. In wet meadows. Common. This is C. bullata as described in Sill. Jour., Vol. ix. p. 71, and named by Schk. from its (ball-shaped) globous perigynium, comporting with his fig. 166. Carey and others have adopted another form under that namo, which hero follows, named from the inflation of the fruit.

185 C. physèma Dew. fo Spikes 2 or 3, cyl., slender, contiguous, the lowest bracteate; ; spike 1, rarely 2 , subrotund or ollong-cyl., thick, dense-flowered, remote, Jellowish, the lowest ped., at length nodding, with a bract leafy and surpassing tho culm; perig. turgid-ovate, with a long, cyl., scabrous beak, divaricate, inflated, glabrous, broader and longer than the lanceolate, acute, white-edged $\mathrm{gl}$; culm 12 to $24^{\prime}$, slender, firm, shorter than the narrow, flat, firm, light green lvs. -N. Eng. to Penn., in humid meadows. (C. bullata Boott, t. 39, nec Schk.) .

186 C. oligospérma Michx. of Spities several, sometimes one, erect, slender, long-cyl., with an oblong, obtusish gl. ; $\$$ spikes 1-3, ovate, globular, sessile, distant; perig. few, ovate, inflated, acute, nerved, short-rostrate, entiro at the orifice, glabrous, a little longer than the ovate-lanc. gl.; culm 1-2f, scabrous above, leafy below; lvs. involute and rush-like, light green.-Marshes and lako borders, Can., N. Eng., N. Y., Mich. and Ga.

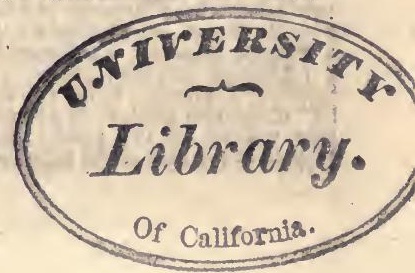




\section{Order CLVI. GRAMiNEAE. Grasses.}

Herbs, rarely woody or arborescent, with (mostly) hollow, jointed culms; with leaves alternate, distychous, on tubular sheatlis split down to the nodes, and a ligule (stipules) of membranous texture where the leaf joins the sheath. Flowers in littlo spikelets of 1 or several, with glumes distychously arranged, and collected into spikes, racemes or panicles. Glumes, the lower pair of scales in the spikelet, alternate, enclosing the fls. Pales (palæ) the outer pair of scales of each particular flower, unequal. Scales (perianth) usually 2 or 3 , minute, hypogynous, distinct or united. Slamens 1-6, commonly 3, anthers rersatile, of 2 distinct cells. Ovary simplo with 1 ascending ovule, 2 styles and 2 feathery stigmas. Fruit a caryopsis. Embryo lateral, at the base of the farinaceous albumen.

Genera 300, species about 3500 , universally diffused thronghont the world, having no other limits than those that bound vegetation in general. But the species and their claracters aro widely different in different climes. In temperate zones the grasses elothe a large portion of the eartlis surface with a compact, soft, green, carpet-like turf; but in tropical regions this beantiful grassy turf disappears and the grasses become larger, more tsolated like other plants, fewer in the number of individuals, with broaler leaves and more showy flowers.

Properties. -This family doubtless contributes more to the sustenance of man and beast than all others combined. Its sweet and nutritlous properties reside both in the farinaceons nlbumen of the seed and in the herbage. No poisonous or even suspicions herb is found among them, with the single exception of Lolium temnlentum. The poisonous and medicinal Ergot or Spurred Rye is only a parasitic fungus, and therefore forms no exception to this remark. The stems of many grasses contain sugar, as the.Maize and Sugar Canb. Silex is also a frequent ingredient. To this Order belong the eommon grains, Maize, Wheat, Rye, Rice, Barley, Oats, etc. The inost important of the cultivated grasses are Phleum or Timothy grass, several kinds of Poa, Agrostis, Alopecurus, Festuca, Aira, Panicum, Cinna, Briza, etc.

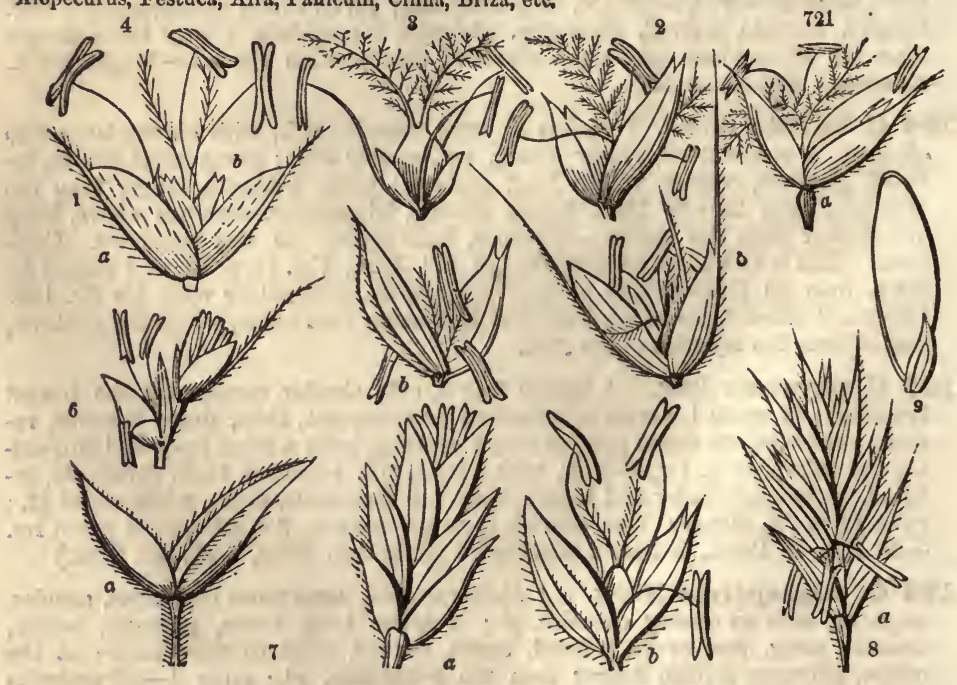

FIG. 721. Agrostis alba; a 1-flowered spikelet; $a$, the two glnmes. 2. A flower, with the two palen, three stamens and two plumows stigmas. 3. Leersia oryzoides; a flower removed from its glumes, showing its 2 bypogynous seales, three stamens and ovary with the two stgmas. 4. Phleum pratense; a 1-flowered spikelet; $a$, glumes; $b$, truncate palea ; etc. 5 . Polypogon; 2. 1-flowered spikelet; glunes and lower palez awnel. 6. Holcus lanatus; a two-tlowered spikelet; $a$, glumes; $b$, the two flowers (upper staminate). 7 . Pua pratensis; $a$ 4-flowered spikelet; $a$, the two glumes; $b, a$ single flower, with two palea, etc. $\delta$. Festirea durluscula; a 5 -flowered spikelet; $a$, two glumes; $b, a$ single flower. 9. The caryopsis of Ilordeum, showing the embry o at the base of the copious albumen. 


\section{TRIBES AND GENERA.}

Spikelet 1-fowered with no apparent rudiment of a second A. (2)

5 Spikelet 2-flowered, ono of the fls. sterile or rudimentary. (7)

$\$$ Spikelet 3-flowered, the 2 lower (lateral) fls. sterile or rudimentary. (i)..............Tribo

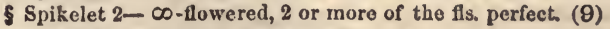

2 Inflorescence paniculate. (3)

2 Infiorescence strictly spicate, spikes equilateral. (5)

2 Inflorescence strictly spicate, spikes unilateral. (6)

3 Glumes none (or minute and the stamens 6 ). (a)...................... Tribe 1

3 Glumes present, at least 1 conspicuous. (4)

4 Pales of the flower thin and soft, often awned. (b)................... Tribe 2

4 Pales of the flower coriaceous, - tipped with awns. (f) $\ldots \ldots \ldots \ldots \ldots \ldots \ldots$.

-awnless. (g)........................ Tribe 5

5 Spikes cylindric, the spikelets condensed all around. (e).................... Tribo 8

5 Spikes prismatic, spikelets sessilo in rows. $(\mathbf{v}) \ldots \ldots \ldots \ldots \ldots \ldots \ldots \ldots \ldots \ldots \ldots$ Tribe 9

6 Spikelets rounded on the back, appressed to the rachis. $(\mathrm{g})$................. Tribe 5

6 spikelets acutely keeled on the back, imbricated on each other. $(x)$ \}

7 Upper fls. of the spikelet abortive,-Fls, in unilateral spikes. $(x) \ldots \ldots . . . . .$. Tribe 10

-Fls. paniculate. (k)..................... Tribo $t$

7 Lower flower of the spikelet abortive. (8)

8 Pales coriaceous, firiner in texure than the gls. Paniculate. $(\mathrm{g}) \ldots \ldots \ldots \ldots$. Tribe 5

8 Pales membranous, thinner than the glumes. Spicate. (bb)...............Tribe 11

9 Flowers in 2 or 4 -rowed, - equilateral spikes. (v)..................... Tribo 9

-unilateral spikes. (x)................... Tribo 10

9 Fls. in panicles more or less diffuse. (10)

10 Pale awned at the tip or awnless. (n) $\ldots \ldots \ldots \ldots \ldots \ldots \ldots \ldots \ldots$ Tribe 8

10 Pale awned on the back or below the tip. (k).................. Tribo 7

Tr. 1. ORYZEA. (Spikelets 1-flowered, panicled. Gls. obsoleto. Stam. 1-6.)

a Flowers perfect, flattened laterally, awnless.-Gl. 0. Stam. 2 or 3 ............ Lernsia. 1

-Gl. minute. Stam. 6........... OryzA. 2

a Flowers monccious, convex on the back, awned. Stamens 6.............Zizania. 8

Tr. 2. AGROSTIDEA. (Spikelets 1-flrd., panicled. Gl. and pales thin. Grain free.)

b Fls. surrounded at base with a tuft of long, silky hairs.............. CalaAMagrostrs. 9

b Fls. naked or thinly bearded at base. (c)

c Glumes both long-awned and longer than the awned pales.............Porypogon. 8

c Glumes both awn-pointed (or minute and the pale awned)... .....MUmLBNBErGia. 7

c Glumes awnless, conspicuous. (d)

d Pale stalked in the glumes, awned on the back, monandrous........... Crives. 6

d Palo sess. in the gls. 3 -androus, -acute, awnless. Gls. shorter..... Sporonolus. 5

-obtuse, often awned on the back.....Agrastrs. 4

Tr. 3. PHLEOIDE 1 . $-\rightarrow$ Gls. nnited at base, awnless. Pale 1, awned...... A Lopecurus. 10 -o Gls. distinct, mueronate. Pales 2, awnless............. Pru.kum. 11

Tr 4. STIPACE AE. -f Awn of the flower simple, straight, deciduous........... Oryzopsis. 14 -f Awn of the flower simple, twisted, very long............. STIPA. 18 -f Awn of the flower triple or 3-parted........................sistida. 12

Tr. 5. PANICIE As. (Spkl. 2-fl., lower fl. abortive. Gls. very unequal. ६ Pale coriaceons.)

g Spkl. apparently 1-flowered, the lower glume wanting and the single abortive pale

supplying its place.-Fls. spicate, unllateral......................PAsPALvM. 15 -Fls. diffusely panicled, all alike.................. Mrus.uux. 16

-Fls. paniculate, 2 sorts, one under ground.... AMPHICARPUM. 17

g Spkl. evidently 2-flowered, both gl. present, abort. fl. neutral or $\delta$. (h)

h Fls. paniculate,-without awns or spines. Gl. very unequal............ Pisters. 18 -with the glumes and pale coarsely awned.......... Oplisureses. 19

h Fls. spike-panicled,-each with an Invol. of awned pedicels............. SrTArIA. 20 -each with a hardened, burr-like invol............ Crscurus. 21

Tr. 6. PHALARIDELE, $-\mathrm{i}$ Sterile fls. 2 minute rudiments. Panicle spicate.....Pralaris. 22

-i Sterilo fls. 2 awned pales. Panicle spicate....AxтиохалтuUd. 28

-i Sterile fls. both 2-valved, ơ. Panicle open....... Hrerochlos. 24

Tr. 7. AVENEx. (Spkl. 2- $\infty$-fird., panicled. Gls. large. Pale awned bolow the tip.)

k Spikelet with 1 perf. flower and 1 awned stam. flower-above............... Hoccus. 25 -below.....\$ ArRHENATHzRUM. 28

K Splkelet with definitely 2 perfect fls. Pale subentire, $a w n$ dorsal..............Aras, 26 is Spikelet with 2 or moro perfect fls. Pale 2-toothed at apex. (m) 
m $\Lambda$ wn between the 2 teeth, twisted; glumes very large............ Daxtnoria. 27 $m \Delta$ wn dorsal below the mildle (except in the cultivated Oat)............Avkn. 28 m Awn dorsal above the mlddle.-Fis. $2-5$. Teeth cuspidate.......... Trisetra. 29

- Fls. $5-\infty$. Teeth acutish............. Broves. 30

Tr. 8. FESTUCACE.E. (Spkl. 2- $\infty$-flrd. panicled, awnless, or the lower pale tipped with a straight bristle or awn. Glumes 2.)

n Glumes definitely 2, all the lower fls. of the spkl. perfect. (0)

n Glumes several, indefinite, the lower fls. abort. and glume-like. (p)

- Lower pale 3-cuspidate at apex, fringe-bearded below. (q)

- Lower pale mueronate or awn-polnted (except in 1 Festuca). (r)

- Lower pale obtuse or acute, not at all awned. (s)

q Upper pale naked, lower with 3 cusps and 2 teeth..................... Tricusprs. 81

q Both pales fringed, lower wlth 1 awn and 2 cuspidate teeth............. Uralepis. 82 r. Glumes and pales keeled,-herbaceous, 5-veined. Fls. glomerate....... Dactruis. 38 -inembranous, 8-veined. Pan. spicate.........Kaleria. 81 r Gls. and pales rounded on the back, - both coriaceons. Graln free.... Diarrirena. 35 - pale papery, gi. alherent..........Frstuca. 36

s Spkl. 2-3-flrd. with some abortive terininal fls. Pale papery, not keeled. (t)

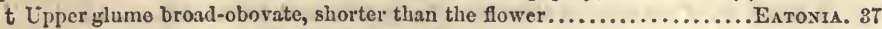

t. Upper glume oblong, $7-9$-veined, longer than tho fls......................... 88

s Spikelets 2-50-flowered, all perfect. Pales usually thin. (u)

u. Lower pale keeled, 3-reined, membranous like the glumes...........Eragrostrs. 89

u Lower palo keeled, 5-veined, usually cobwebbed at base..................... 40

u Lower pale convex-keeled, obscurely 9-veined. Pan. spiked........ Bryzoprrcm. 41

u. Lower pale convex, 7 (-5)-veined, never webbed at base.............. GLYceria. 42

u Lower pale convex-ventricous, cordate, obscurely veined...............BrizA. 43

p IIerbaceous. -Fls. glabrous, awnless, falcate-pointed............. UnıL. 44

-Fls. silky-villous at base. Tall, stout........... Piragmites. 45

p Woody, tall (the flowering branclies low). Fls. short-awned... Arevorvaria. 46

Th. 9. IORDEACE. A. (Spkl. 1-10-fld., sessile, alternate in a spike. Rachis jointed.)

v Spikes several. Spikl. solitary at each joint, 1-flowered.................prurus. 47

v Spike single.-Spikelets 1-flowered, 3 at each joint....................IIordevx. 4S

-Spikelets $2-\infty$-flowered, - several at each joint............ Eurutus. 43 -1 at each joint. (w)

w Glume 1, in front of the spikelet which is edgewise to rachis............ Lourtr. 50 w Glumes 2, opposite.-Spikelet 3 - $\infty$-flowered................. Trimicum. 51

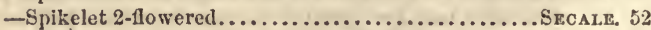

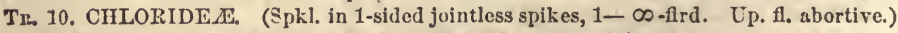

x Spikes very slender, inany, in an equilateral raceme. (y)

J Spikes raceme-like. Spkl. with several perfect fls................LeptocrLoA. 53

y Spikes with sessile, 2-flowered spkl., 1 1. \& rudiment........... Gruxopogos. $5 t$

x Spikes slender, several, digitately arranged above, or, in No. 55, axillary. (z)

z Spikelets.with 1 perfect flower,-awnless, globular, no rudiment.......MAxrsurus. 55

-awnless, oblong, with a rudiment...... Crrodos. 56 -awnerl, glume 3 -lobed..............Eestacir 3 . 5т

z Spikelets with several perfect flowers. - Fls. awnless............... ELEusive. 58 -Fls. awned............. DactrLoctenca. 59

x Spikes thick and dense, $1-\infty$. Spikl. with 1 perfect flower. (aa)

aa Spikes several or many.-Flower with no rudiment.............. SPARtru. 60 aa Spikes 1, few, or many. Flower with a terminal rndiment........... Bovtr.lovA. 61 a. Spiko solitary, recurved. Awns terminal and dorsal............... Ctexidy. 62

Tx. 11. SACCIIARIEAE. (Spkl. in pairs or 3s, 2-flowered, the lower flower abortive.

Fertile pales thinner than the glumes, except in No. 66.)

bb Fis. (the fertile) imbedded in the cavities of glabrous, jointed spikes. (cc)

ce Spikes monccious, $\delta$ abortive, o below, both naked............... Tripsıc cm. 63 cc Spikes monœcious of above panicled, o below enveloped in husks..........ZEA. 64 ce Spikes uniform,-terete. The pedunculate spkl. abortive......... RotтвøLLia. 65 -compressed. Both spikelets fertlle............ Strnotapırum. 66

bb Fls. not imbedded, spicato or panicled, mostly long-bearded. (dd)

dd Goth spikelets of each pair fertile.-Lower 11. awned.............. Er.rastnes. 67 -Flowers awnless.............. SACCHARUM. 68

dd Only one spikl. of each pair fertile.-Fls. and rachis halry ........ Axdropogon. 69 -Fls. and rachis smoothlsh....... Sorgnum. 70

dd The lower spikelet on each spike fertile, in a bony shell................ Corx. 71 
1. LEER'SIA, Soland. Cut Grass. False Rice. (In honor of John Daniel Leers, a German botanist.) -Spikelets 1-flowered, $\Varangle$, flat; glumes none; paleæ boat-shaped, compressed, awnless, bristly-ciliate on the keel, nearly equal in length but the lower much broader, enclosing the free, flat grain (caryopsis). - 2f Swamp grasses, with flat, retrorsely rough-edged leares, and the fls. racemous-paniculate, somewhat secund, jointed to the pedicels.

1 D. oryzoides Swartz Cut Grass. Culm retrorsely scabrous, 3-5f high; ws liuceolate, carinate, the margin very rough backwards; sheaths also very rough with retrorse prickles; panicle much branched, diffuse, sheathed at the base; spikelets spreading; patere full $2^{\prime \prime}$ long, ciliate on the kieel, white, compressed and closed; sta. 3. - If A very rough grass, common in swamps; by streams, etc., U. S. and Can. $\Delta$ ug.

2 L. Virgínica Willd: Whrre Grass. Culm slender, branched, geniculato or decumbent at base, 2-3f long, nodes retrorsely hairy; ivs. lance-linear, roughish ; sheaths roughish backwards, striate; panicle simple, at length much exserted, the lower branches diffuse; fls. pedicellate, in short, appressed, flexuous racemes; lower palea scarcely more than $1^{\prime \prime}$ long, green-veined, mucronate; sta. 1-2.-24 Damp woods, U. S. and Can. Aug.

3 L. lenticulàris Michx. CATCH-FLY Grass. Plant smoothish; culm erect, 2-4f high ; panicle erect; fls. large, roundish-oval, near 3" diam., imbricated; sta. 2 ; pales with the keel and veins ciliate.-2f Wet places, Ct. (Eaton) to III. and S. States. Not common. Said to catch flies by tho sudden closing of ita pales.

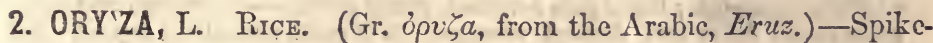
lets 1-flowered, $\Varangle$; glumes 2 , very small, cuspidate; pales 2 , boatshaped, flattened, the lower one broader and mostly tipped with a straight awn; stam. 6; stigmas with branching hairs; grain oblong, free, smooth, enveloped in the pales.-Mostly (1). Fls. in a branching panicle of racemes. Spikes hispid, jointed to the pedicel.

O. sativa I. Culm 2-4f high, striate; lvs. long, rough, lance-linear; ligule long (near $\left.1^{\prime}\right)$, erect, pointed; panicle with erect branches, $6-9^{\prime}$ in length; outer pale strongly 5-veined or keeled, hispid-ciliate and commonly tipped with a short awn.-Extensively cultivated in the S. States, both in upland meadows and in low inundated grounds. The former variety-the upland rice, is usually awnless, the latter is awned. A most important Cereal. + Asia.

3. ZIZA'NIA, Gron. Indian Rice. (Zı ̧aiviov, the Greek name of some similar plant.) - 8 Glumcs 0 ; spikelets 1-flowered; palcæ 2, herbaceous. ô Palew subequal, awnless; stamens 6. क Spikelets subulato; palex unequal, linear, lower one with a straight awn; styles 2 ; caryopsis enveloped in the plicate palex.-Stout, aquatic grasses, with a large panicle of both kinds of flowers.

1 Z. aquática L. Culm $\frac{11}{2}$ in diameter, fistular, smooth, 6f highl ; IVs. lancelinear, 2-3f long, an inch wide, smooth, serrulate ; panicle a foot or more long, pyramidal, the lower branches divaticate and sterile, the upper spicate and fertile; spikelets on clavate pedicels; awns long $\left(18^{\prime \prime}\right)$, hispid ; fr. slender, $\frac{3 \prime}{4}$ long, blackish, very caducous, farinaceous. - 4 Inundated shores of ponds and rivers, U. S. and Can. The fruit, which is very abundant, affords. sustenanco to wild geese, ducks, and other water fowls. Aug.

2 Z. miliàcea Michx. Culm erect, C-10f high; lvs. very long, narrow, glau. cous; paniclo large, diffuse, pyramidal; glumes with short $\left(1-3^{\prime \prime}\right)$ awns; $\hat{c}$ and of fls. intermixed; sty. 1 ; fr. ovate, glabrous. - 2f Growing in water, Ohio to Fla. and La. Lvs. coriaceous, 2-3f long, 6-12' wide. Apr.-Aug.

3 Z.? flùitans Michx. Culm long, slender, branching, floating in tho water; 
Ivs. lance-linear, flat, ciustered, 1-2' long, 2-3" wide; "spike solitary, axillary, setaceous, about 4-flowered; paleæ awnless; stig. 2, very long; fr. reniform." - 2f Water, S. Car. to Fla. and La. (Hale, whose specimens are without fls. or fruit.) (Hydrochloa, Palis. Hydropyrum, Kunth.)

4. AGROS'TIS, L. Bent Grass. (Gr. áypós, a field; growing in fields and pastures.) - Spikes 1-flowered; glumes 2, subcqual, awnless, usually longer than the flower; pales 2, thin, pointless, naked, the lower 3-5-veined, sometimes awned on the back, the upper often minute or wanting; grain frec.-2f mostly, and cæespitous, with slender culms and an open paniclc.

\& A rostis proper. Upper palea to to as long as the lower. Fls, rather denso...... Nos, 1, 2 Tricuodius. Upper palea minute or wanting. Panicle thin. (*)

* Lower palea with a long exserted awn on the back. .Nos. 3,4

* Luwer palew awnless, or bearing a very short awn...Nos. 5,6

1. A. vulgàris With. RED TOP. DEW Grass. Herd's Grass of the S. States. Culm erect, 1-2f high; panicle purple, oblong, with short, spreading or divaricate, rouglish branches; lvs. linear, with very short ligules (sometimes the upper one elongated); lower pale twice as large as the upper, and nearly as long as the lanceolate, acute glumes, mostly awnless.-U. S. and Can. A very valuablo grass spread over hills, vales and meadows, forming a soft, dense turf. Variablo. (A. polymorpha Huds. A. pumila Is A. hispida Willd.)

2 A. álba L. White Bent. English Bent. Bonnet Grass. Florix Grass. Culm decumbent, geniculate, rooting at the lower joints and sending out stolons; lvs. linear, smooth, those of the stolons erect and somewhat subulate; ligules long, membranous; panicle dense, narrow and contracted after flowering, greenish white or slightly purplish; lower pale 5-veined, rarely awned.-A common and valuable grass in old fields and drained swamps. It is quite variable in aspect. $\S$ Eur. (A. stolonifera L. A decumbens Mubl.)

$\beta$. STRícta. Lower pale with an awn from its base twice longer than itself (A. stricta Wilid.)

$\gamma$. DISPAR. Southelx Bent. Larger $(2-3 \mathrm{f}$ high) in all its parts; outer palo obtusely 3-toothed. Much valued in somo parts of the S. States. (A. dispar Mx.? Kunth.)

3 A. canina I. BRown BENT. DOG's BENT. Culm rooting at tho lower nodes, slender, somewhat branched, about $2 \mathrm{f}$ high: lvs. setaceous involute, the upper linear; panicle diffuse, ovoid, at length brownish, branches rough, diverging, dividing beyond their middle; glumes subequal, shorter than the lower pale which bears a long awn a little below the middle of the back; upper pale minute.- Wet meadows, E. States, rare. § Eur.

$\beta$. ALpina. Culms low, in small tufts, with contracted panicles, nearly smooth, purplish ; awn twisted.-Mts., N. States. (A. Pickeringii Tuckm.)

4 A. arachnoides Ell. Culm crect, slender, $5-8^{\prime}$ high; paniculate more than lialf its length; lvs. linear-setaccous, $1-3^{\prime}$ long; panicle narrow, branches capillary, floriferous half their length; glumes green, ovate, acute, $\frac{1}{2}^{\prime \prime}$ long, equal; pale a little shorter, bearing on its back above the middle a contorted awn 5 or 6 times longer than itself, and as fine as a gossamer.-Car. to Ga. (Feay). The awns, from their fineness, can hardly be seen without a lens. Apr.

5 A. scàbra Willd. Rodgr HaIr Grass. THIN Grass. Culms tufted, erect from a decumbent vase, very slender, $1-2 \mathrm{f}$ high; lvs. linear, 3-6' long, rough, the radical involute-setaceous; ligule oblong, obtuse; panicle large, with long, capillary, erect, or divergent, scabrous-hispid whorled branches, trichotomously divided near the end; spikelets in terminal clusters, at length purplish; glumes lance-linear, acuminate, scabrous-hispid on the keel.-Fields and pastures, U. S. and Brit. Am. Remarkable for its thin and airy panicles which are at length driven before the wind. Jn., Jl. (T. laxiflorum Mx. T. montanum Torr.)

$\beta$. oneóphila. Culm 6-12' high, simple, panicle less diffuse; pale, with a short, twisted awn at its back.-Mts. and rocky woods. (A. montana Tuckm.)

$\gamma$. Perḱnnans. Panicle pale green, branches shorter, floriferous more than half their length.-In damp shades. (T. scabrum Muhl. A. scabra, ed. 2d.) 
6. A. elàta Trin. Taller Pirrs Grass. Culm erect, rigid, thin, simpic, rather stout, $2-3 \mathrm{f}$ high, leafy; lvs. broadly $\left(1-2^{\prime \prime}\right)$ linear, scabrous, flat, $6-8^{\prime}$ long, the sheaths scarcely smooth; panicle purple, contracted, with long, whorled, erectspreading branches dense-flowered half their length; glumes lanceolate, 112", tho the upper a little longer than the 5-veined pale.-Swamps, N. Jer. to Ga., Ala. and Ky. (Jackson).-Jl., Aug. (T. elatum Ph. A. altissimum Tuckm.)

5. SPOROB'OLUS Brown. -Drop-seed Grass. (Gr. $\sigma \pi$ Topá, seed, $B a i \lambda \lambda \omega$, to cast.)-Spikelets 1-flowered; glumes 2, unequal, the lower smaller; f1. sessile; palex 2, beardless, awnless, usually exceeding the glumes, the upper 2 -keeled; stam. 2 or 3 ; stig. plumous with simple hairs; caryopsis free, often with a loose pericarp, deciduous.-Tough, wiry grasses with mostly rolled and rigid leaves and the panicles more or less contracted.

\$ Vinfa. Grain (caryopsis) linear-cylindric. Glumes subequal................. Nos. 1, 2

\$ SPono Bolus. Grain oval or globous, some loose in the pericarp. (*)

* Glumes very unequal, one of them as long as the paler. (a)

a Panicle open and stalked, pyramidal........................... Nos. 8,

a Panicle sheathed at the base more or less.............................. Nos. 5,6

* Glumes somewhat equal, both shorter than the palex. (b)

b Panicle contracted and spike-like, sheathed or not............... Nos. 7, 8

b Panicle open and stalked, long and raceme-like.......................

1 S. Virgínicus Beauv. Culms numerous, assurgent, procumbent and hairy at base, branched, about a foot long; lvs. somewhat 2-rowed, involute, rigid, erect, $2-3^{\prime}$ long, with smooth sheaths which are hairy at the throat and swollen with the enclosed panicles; panicles spike-form, terminal and lateral, the lateral ones concealed; glumes nearly equal, nearly as long as the subequal palece.-2f Sandy soils, Middle and S. States.-Sept., Oct. (Agrost. L.)

2 S. vaginzeflòrus Torr. Culms simple, ascending, slender, forming tufts 6-12' high ; lvs. involute-subulate, rather rigid, short $\left(2-4^{\prime}\right)$; panicles contracted, spike form, lateral and terminal, mostly concealed in the sheaths; glumes about equal, and equaling the subequal pales; caryopsis linear, a third shorter than the pales.(1) Dry, gravelly fields, U. S. more common W. and S. ( $\Lambda$ gr. Muil. Crypsis, Nutt.)

3 S. heterólepis. Culm 1-2f high, smooth; lvs. sctaceous, somewhat convolute, scabrous on the margins; lower sheaths pubescent, upper ones smooth; paniclo spreading, pyramidal, few-flowered; glumes purplish, very unlike, outer one subuliform, inner one ovate, cuspidate, membranaceous in texture, 1-veined; pales oblong, obtuse, thin, a little shorter than tho superior glume, tho lower 1-veined, apiculate, the upper 2-veined, shorter; sta. 3; anth. linear, reddish; fr. roundish, smooth.-Conn. to Wisc. not rarc. $\Lambda$ ug., Sept. (Vilfa, Gray.)

4 5. júnceus Mrich. Glaucous; culm crect, 1-2f high, terete, slender; 1vs. erect, $2-6^{\prime \prime}$ by $1^{\prime \prime}$, concave, convolute when dry, margin scabrous; sheaths much shorter than the internodes; st.p. short; pan. oblong-pyramidal, branches verticillate, about in $6 \mathrm{~s} ;$ glumes purple, similar, lanceolate, acute, upper as long as tho palex, the lower twico shorter; palea subequal; anth. and sty. whitish. - 2f Penn. to Flor. and La., in barrens. Aug.-Oct.

5 S. cryptánarus Gray. Culm 2-3f high; lis. broadly ( $\left.2^{\prime \prime}\right)$ linear, fiat; sheaths bearded at the throat; panicle pyramidal, its base cnclosed by the terminal sheath, branches spreading, hairy in the axils; fls. bluish; pales subequal, as long as the upper glume, twice longer than the lower.-Dry, sandy soils, W. and S. States, rare nortbward. Aug. (Agr. \& Vilfa cryptandra Torr.)

6 s. asper Kunth. Rt. white, fibrous; culm stout, glabrous, geniculato at base, 2f high; lvs. rigid, involute, rough-edged, $2-8^{\prime}$ by $1-3^{\prime \prime}$, tapering to a pungens point; branches with short leaves, barren, also ending in a long, pungent point; sheatlis ciliate at edge and bearing dense tufts of long, white hairs at top; panicles terminal and lateral, nearly enclosed in the long sheaths; spikelets blackish-green; lower glumo very short, upper a little longer than the pales; fr. compressed, obovate $\frac{1}{2}^{\prime \prime}$, in length. - 2f Ohio, (Sullivant) to Ill. (Agrost. Mx. Vilfa, Beauv.)

7 S. longifòlius. Culms slender, tufted, $2-3 \mathrm{f}$ high, from long fibrous roots; lis. ail involute, very long $(1-3 \mathrm{f})$, tapering to a long thread-liko poipt; panicle 
slender, $3-6^{\prime}$ long, wholly inclssed in the terminal swelling sheath; glumes unoqual, very white, much shorter than the white, subequal, obtuse pales; grain oval, $\frac{1}{3}$ as long $\left(\frac{2}{3}{ }^{\prime \prime}\right)$ as the pales.-W. N. Y. (Mr. R. S. Brown) and southwestward. After the sheath falls away the mature fls. turn brownish. (Agrost. longif. Torr. ?)

8 S. Ihdicus Brown. Culm erect, terete, glabrous, $2-3 \mathrm{f}$ high; lvs. involute, tapering to filiform; sheath beardless at throat; joints blackish; panicle long (1f), slender, open, composed of short, erect, alternate spike-like racemes; glumes 2, unequal, mucl shorter than the subequal pales; grain dark resin-colored, oblong, $\frac{9}{3}$ as long as pales.-Pastures and waste grounds, S. States. (A. Indica L.) § W. Indies.

9 S. compréssus Torr. Glabrous; culm erect, much compressed, simple, leafy, branched at base, 1-2f high; lvs. narrowly linear, scarcely shorter than tho stem; keel prolonged into the open sheath; stip. very short; panicle purple, subsimple, contracted, the branches few and erect; glumes equal, acute, shorter than the paleæ, the upper emarginate, rarely mucronate; paleæ ovate, obtuse, smooth, sometimes deeply cleft; stig. purple.-Sandy swamps, N. J. Sept.

10 S. seròtinus Torr. Culm 12-18' high, filiform, compressed, growing in patches, smooth, often viviparous at the nodes; 1rs. $2-3^{\prime}$ by $\frac{1}{2}{ }^{\prime \prime}$, keeled, smooth; sheaths open; stip. ovate, short; panicle 3-10' long, capillary, diffuse, branches flexuous, alternate; spikelets elliptical, scarcely $\frac{1}{2}$ " long; glume ovate, 1-veined, unequal, half the length of the paleæ; paleæ smooth, the lower one shorter; sta. 3. -Long Island (Kneiskern) to Me. and Mich. July. (Vilfa, Torr. Poa modesta Tuckm.)

6. CIN'NA, L. Sweet Reed Grass. Spikelets 1-flowered, compressed ; glumes 2, subequal, without awns, upper one 3-veined; palex 2, naked at base, on short stipes, lower one larger, enclosing the upper, with a short awn a little below the tip; stamen 1 ; grain oblong, free. -2f Erect, simple, tall, with a large panicle.

1 C. péndula Trin. Culm smooth, 3-5fhigh; lvs. linear-lanceolate, 12-18' by $3-5^{\prime \prime}$, pale green, rough-e̊dged, with smooth, striate sheaths; stip. long, lacerated; panicle white-green, near a foot in length, rather attenuated above and nodding, with the branches capiliary, drooping, and arranged somewhat in 4s; glumes 2" long, linear-lanceolate; lower palea with a short straight awn a littlo below the tip.- If A beautiful grass, sought by eattle, in rich, shady soils, N. States and Can.

2 C. arundinàcea Willd. Culm and leaves as in No. 1. Plant bright greer; panicle purple and green, erect and with ascending or erect branches which aro floriferous more than half their length; glumes $3^{\prime \prime}$ long, lanceolate, lower palece awnless or the awn scarcely equaling the obtuse point.-U. S., in shady woods, chiefly southward. $\Lambda$ finer looking grass than the preceding! Jl., Aug.

7. MUHLENBER'GIA, Schreber. Drop-Seed Grass. (In honor of Henry Muhlenberg, D.D., an eminent American botanist.) - Spikelets 1-flowered, fl. sessile in the glumes and mostly bearded at the base; glumes 2, unequal, shorter than the pales, acute or awned, sometimes minute, the lower rarely obsolete ; pales 2 , the lower awned or mucronate at apex, upper 2-keeled ; stam. 3-2 ; stig. 2, plumous; caryopsis free.-Culms often branched. Panicles simple, mostly contracted.

\$ Mrerchnergia. Glumes manifest. Panieles slender, terminal and latera]. (*)

* Glumes awned and twice longer than the awnless palex ...................

* Glumes pointed, not longer than-the mueronate paler............................. 2,3

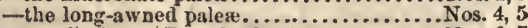

8 Brachyelytruar. Glumes minute, the lower obsolete. Paniele slender......................... 7 Trichocnlos. Glumes small, both present. Paniclo diffuse, capillary..................... 8

1 M. glomeràta Trin. Glaucous; culm compressed, erect, smooth, with appressed branches or subsimple, $1 \frac{1}{2}-4$ f.high; lvs. somewbat 2-rowed, erect, flat, rough, $3-5^{\prime}$ long, with closed sheaths; panicle spicate, dense, conglomerated, in- 
terruptea, 2-3' long, many-flowered; glumes linear, $\frac{1}{2}$ the length of their awns; lower paleæ mucronate. $-2 f$ Bog meadows, also on rocky mountains, N. Eng. to Mo. Aug., Sept. (Polypogon racemosus Nutt.)

2 M. Mexicana Trin. Culm erect or ascending, with swelling nodes, much branched and leafy above, often nearly leafless below, $1 \frac{1}{2}-3 f$ high; Ivs. lanceolate, scabrous, with half-clasping sheaths; panicles numerous, terminal and tateral, spike-clustered, dense-flowered and purple-spotted, lateral ones partly enclosed in the sheath; glumes narrow acuminate, mostly shorter than the subequal, pubescent pales. - 2f Wet shades, N. Eng. to Wisc., common. Aug. (Agrostis L.)

3 M. sobolífera Gray. Culm erect, slender, producing shoots at base, branched, 18-30' high ; branches erect and filiform; nodes not swelling; Ivs. linear-lanceolate, with open sheaths; panicle simple, filiform, with appressed branches, and rather crowded spikelets; palex equal, longer than the acuto glumes-2f Rocky hills, N. Eng. to Ill. and S. States, frequent. Aug. (Agrostis Muhl.)

4 M. sylvática Torr. \& Gr. Culm ascending, 2-3f long, much branched, diffuse, smooth, with swelling nodes; lvs. lanceolate, scabrous, veined, 4-6' long, with smooth, open sheaths; panicles slender, ratber dense; glumes nearly equal, acuminate, a little shorter than the palece; awns several times longer than the spikelet.-2f Rocky shades, N. Y. to Ill., N. J., Penn. Septo (Agrostis Torr.)

5 M. Willdenòwii Trin. Culm erect, subsimple, pubescent at the nodes, with a few appressed brauches; lvs. $6-9^{\prime}$ by $2-3^{\prime \prime}$, lanceolate, veined, scabrous; spreading, with pubescent sheaths; panicle contracted, very slender and long, with remote, filiform branches; glumes subequal, acuminate, half as long as the palece; awn 3-4 times the length of the spikelet.- $2 f$ Rocky woods, Can. and U. S. July, August. (Agr. tenuifora Willd.)

$6 \mathrm{M}$. diffùsa Schreb. Culm decumbent, diffuse, branching, slender, compressed; branches assurgent; lvs. 2-3' by $2^{\prime \prime}$, linear-lanceolate, rough, with smooth, striate, open sheaths; panicles terminal and lateral, with remote, appressed, rough branches; spikelets $2^{\prime \prime}$ long, pedicellate, often purplo; awn about as long as the paleæ; glumes extremely minute. -24 Borders of woods and shady fields N. Eng. to Car. and Ky. Aug.

7 M. aristàta Pers. Culm erect, simple, retrorsely pubescent at the nodes, $2-3 \mathrm{f}$ high; lvs. lanceolate, scabrous, ciliate on the margin, 4-6'long, $3^{\prime \prime}$ or more wide, with somewhat open sheaths; panicle terminal, simple, racemous, contracted; spilielets $6^{\prime \prime}$ (16" including the awn) long, pedicellate; glumes minute, tho lower obsolete; lower palex half as long as its awn, upper paleæ with a short awn (abortive pedicel) at base lodged in the dorsal groove. $-2 f$ Rocky hills, Can. and U. S., frequent. July. (Brachyelytrum Beauv. M. erecta Roth.)

8 M. capillàris Kunth. Cæspitous; culms erect, very slender and smooth, 18$24^{\prime}$ high; lvs crect, becoming filiform towards the end. 1-1 $\frac{1}{2} \mathrm{f}$ long; paniclo diffuse, with the branches $1-4^{\prime}$ long, in pairs, and as fine as hairs; spikelet's purple; lower palex produced into an awn 3 or 4 times its length.- 2 Sandy soils, N. Eng. to $\mathrm{Ga}$. and $\mathrm{Ky}$. An exceedingly delicate grass, with large, purple, glossy and almost gossamer-like panicles, waving in tho brceze. Jn., Jl. (Trichochloa DC.)

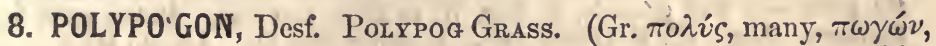
beard.) Spikelets 1-flowered, densely panicled; gls. 2, subequal, thin; carinate, both similarly awned, much longer than the flower; pales thin, the lower usually awned near the tip, upper bicarinate; grain free, oval, smooth.-Leares flat. Panicle spike-like.

P. Monspeliénsis Desf. Culm simple, decumbent below, if or moro high; lvs. lance-linear, much shorter ( 2 to $5^{\prime}$ by 2 to $\left.3^{\prime \prime}\right)$, acute-pointed, minutely downy; panicle much-branched, spicate-lobed, 2 to $3^{\prime}$, the branches very short and densetlowered, pale; gls. hispidulous, $l^{\prime \prime}$ long, the awns a little longer.-Fields, coastward, N. Eng. ? common South. § Eur.

9. CALAMAGROS'TIS, Adans. (Name compounded of Calamus and Agrostis.) Spikelets 1-flowered; glumes 2, subequal, acute or acumi- 
nate; palex 2, mostly shorter than the glumes, surrounded with white, bristly hairs at base, lower one mucronate, mostly awned below the tip, the upper one often with a stipitate pappus (abortive rudiment of a second flower) at base.-2f Rhizomes creeping. Culms simple, tall, with a contracted or open panicle.

Paniclo expanding. Glumes some shorter than tho palex. Rndiment none......... Tos. 1, 2 Panicle contracted. Gl. some longer than palex. Rudiment plumous. (*)

* Glumes $2-8 \prime \prime$ long. Palea short-awned-abore the middle..................... 3

* Glumes 5-7" long. Palea scarcely awned near the tip........................... 4, 6

1 C. brevípilis Torr. Culm terete, slender, 3-1f high; lvs. broad-linear, the sheaths glabrous; ligule hairy; panicle pyramidal, loose, with the diffuse, capillary branches solitary or in pairs; glumes unequal, bearded at base, ovate, acute, 1-veined, shorter than the equal, obtuse, awnless pales; pappus or hairs very short, not half the length of the palece.- 2f In sandy swamps, N. J. (Torrey). (A. Epigeios Muhl.)

2 C. longifolia Hook. Culm 2-4f high, stout; Ivs. rigid, involute-filiform, tapering to a long point; paniclo pyramidal; g'umes unequal, lanceolate, the upper as long as the equal pales; pappus-like hairs copious, more than half the length of the pales.-Sandy shores of the great Lakes, N. Mich. and C. W.

3 C. coarctàta Torr. Glaucous; culm erect, 2-4f high; lvs. linear-lanceolate, scabrous, with the veins and keel white; sheaths striate; stip. oblong, obtuso; panicle condensed and spike-form, the branches rigidly erect, short and aggregated; glumes acuminate, lanceolate, lower 1-veined, upper 3-veined, lower palo 5-veined, bifid at the apex, with a short, straight awn just above the middle of the back.-2f Bogs, Mass. to Minn. and S. States? July, August. (Agrostis glauca Muhl. Arundo stricta Spr.)

4 C. purpuráscens Brown. Paniclo spicate, purplish, 3-6' long, half tho length of the culm; glumes scabrous; palex 2, the lower scabrous, toothed at the apex, awned upon the back below the middle; abortive rudiment plumous, twice longer than the hairs at its base, and twice shorter than the pales.-White Mts., N. H. (Tuckerman), Rocky Mts. (Richardson),-Rare and unimportant. (C. Pickeringii Gr. C. sylvatica Trin.)

5 C. confìnis Nutt. Culm 2-5f high, erect simplo; lrs. 2-3" wide, smooth; panicle 4-8' long, slender, contracted, branches short, appressed, 4 or 5 together; glumes oblong-lanceolate, $2 \frac{1}{2}$ " long, rough on the keel and sides, barely acuto; palece nearly equal, acute, oblong, as long as the glumes, lower one rough, 3-veined, notched at tip, with a short awn inserted below the middle, nearly as long as the flower; hairs $\frac{2}{3}$ the length of the pales.-Penn. and Penn Yan, N. Y. (Sartwell). Aug. (C. inexpansa Gr.)

6 C. Canadénsis Beauv. ReEd Grass. Blue JorNt. CuIm smooth, erect, rigid, 3-5f high; lvs. linear-lanceolate, striate, with smooth, veined sheaths; panielo erect, rather loose, oblong, the branches capillary, aggregated in $4 \mathrm{~s}$ and $5 \mathrm{~s}$; glumes very acute, smoothish, much longer than the palea; lower palece bifid at the apex, with a hair-like awn arising from below the middle of the back; hairs as long as the pales.- 2f Wet grounds, N. Eng. W. to Mich. and Can. Makes good hay, common. Aug. (C. Mexicana Nutt. C. agrostoides Ph. Arundo Mx.)

7 C. arenària Roth. MAT Grass. Saxd REED. Rit. creeping extensively; culm erect, rigid, $2-4 \mathrm{f} \mathrm{high;} \mathrm{lvs.} \mathrm{involute,} \mathrm{if} \mathrm{by} \frac{I^{\prime}}{2}$, smooth and glaucous, pungently acute; sheaths smooth; stip. oblong; panicle dense, with erect, appressed branches, $6-10^{\prime}$ long, and an inch thick; spikelets compressed, greenish-white; lower paleæ longer than the upper.- 4 On sandy lake shores and sea coasts, Can. to N. J. Of great value in confining loose, sandy beaches. Aug. (Ammophila, Host. Psamma, Palis. Arundo, L.)

10. ALOPECU'RUS, L. Fox-Tail Grass. (Gr. ả $\lambda \omega \pi \eta \xi$, fox, ov่ $\rho a ́$, tail.) Spikelets 1-flowered; glumes subequal, connate, distinct, flatcarinate; lower pale flat-carinate, generally equaling the glumes, awned on the back below the middle; upper pale wanting; styles often con- 
nate, stigmas plumous, elongated.-Fanicle contracted into a cylindric, dense spike.

1 A. praténsis L. . Culm erect, smooth, leafy, about $2 \mathrm{f} \mathrm{high,} \mathrm{bearing} \mathrm{an} \mathrm{erect,}$ dense, many-flowered, cylindric, obtuse, compound spike, about 2 ' long; lve. flat, smooth, the upper shorter than its swelling sheath; stipules ovate; glumes ciliate, connate below the middle, as long as the pale; awn twisted, scabrous, nearly thrice the length of the flower:- 4 Fields and pastures, Northern States. An excellent grass. Jn., Jl. §.

2 A. geniculàtus L. BENT FoX-TAIL. Culm ascending, geniculate below, sparingly branched, 1-2f high ; spike cylindrical, about $2^{\prime}$ long; lvs. linear, 3-6' long, the upper equaling or exceeding the smooth, flat, acute, slightly inflated sheath; stipules oblong, entire; glumes slightly connate at base, hairy outside; palece truncale, smooth, half as long as the geniculate awn.-2f Wet meadows, N. Eng., Mid. States and Brit. Am. Jn. §

3 A. aristulàtus Mx. WILD WATER Fox-TAIL. Glaucous; culm decumbent at base, bent at the joints, ascending 1 to $2 \mathrm{f}$; lvs. linear, flat, gradually acute; glumes subequal, pubescent, obtuse, shorter than the obtuse pale, which bears on the middle of its back a short awn scarcely exceeding its apex; anth. oblong, yellow. - 4 Native in Ohio to Minn. (Lapham) and Ill. Jn.-Aug. (A. genicularus, $\beta$. Ed. 2d.)

11. PhleUM, L. Cat-Tail Grass. (Gr. $\phi \lambda \varepsilon$ cos ; used by the ancients probably for a different plant.) Glumes 2, equal, carinate, much longer than the pales, rostrate or mucronate; pales 2 , included in the glumes, truncate, awnless.-Compound spikes cylindric, very dense.

1 P. praténse I. Tniotuy or Herd's Grass. Culm erect, simple, terete, smooth, 2-4f high; lvs. linear-lanceolate, flat, glaucous, roughish; sheaths striate, smooth; stip. obtuse, lacerated; gls. cuspidate, in a dense, long, cylindric, green spike; anth. purple; stig. white.-This is probably the most valuable of all grasses. It is extensively cultivated in N. Eng., Mid. and W. States, but it fails further South. Jn., JL. \& Eur.

2 P. alpinum L. Mountain Herd's Grass. Culm about if high, simple, erect; lvs. shorter than the sheaths, broad and clasping at base, acute at apex, smooth; sheaths inflated; spicate pan., oblong-ovate, very short ( 4 to $5^{\prime \prime}$ long); gls. truncate, mucronate, with a fringed keel; awns as long as the glumes.-2f Alpine regions of the White Mts, N. H. Also native of Arc. Am.

12. ARISti'DA, L. Beard Grass. Poverty Grass. (Latin arista, an awn ; characteristic of the genus.) Panicle contracted or racemous; spikelets 1-flowered, flower stipitate; glumes 2, unequal; pales pedicellate, lower one with 3 awns at the tip, upper one very small, awnless; ovary stipitate; seales 2 , entire; stamens 3 ; stigma plumous.

S Awns twisted-confluent below, and jointed to the pale, very long................... 9 \$ Awns distinct below and not jointed to the pale. ( $\left.{ }^{*}\right)$

* $\Lambda$ wns about equal and divaricate, - thrice as long as the flower................. 7,8 -twice as long as the flower......................... 6 , 7

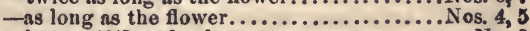

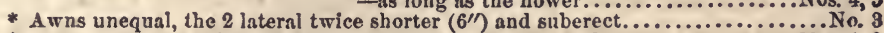

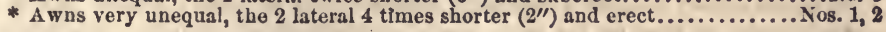

1 A. dichótoma Mx. Cæspitous; culm dichotomously branching above; panicle contracted-racemous; gls. 3 to $4^{\prime \prime}$ long; lateral awns very short, erect, tho intermediate one nearly as long as the pales $\left(3^{\prime \prime}\right)$, spreading, contorted.-(1) A slender grass, in sandy soils, U. S., common. Culms 8-12' high, branching at each joint. Lvs. very narrow, with very short, open sheaths, and a very short stipule. Spikelets slender, on clavate peduncles. Aug.

2 A. ramosíssima Engelm. Culms diffuse, tufted; rac. loose-flowered, simple, sleuder; glumes with short awns, 3 or 5-veined; lower pale about as long as the glumes (7 to $\left.9^{\prime \prime}\right)$, lateral awns short $\left(2^{\prime \prime}\right)$ erect, middle one spreading, $1^{\prime}$ long.-(1) Dry places, IIL. (Engelm.) 
3 A. grácilis Ell. Culm rery slender, a foot or moro high; Ivs. setaceous, scarco $1^{\prime \prime}$ wide, erect, with short sheaths, pilous at the throat; panicle very slender; spikelets somewhat remote, appressed; lateral awns short $\left(6\right.$ to $\left.7^{\prime \prime}\right)$, erect, intermediate one longer (10 to $\left.12^{\prime \prime}\right)$, spreading. - 2f Sandy places, Mlass. to Ga., W. to Ill. 1 grass of little value, as well as the other species of this genus.

4 A. lanàta Poir. Culm erect, 2 to 4 f, hairy and branched below; lvs. linear, flat, If long, 2 to 3 " wide, hairy, especially on the upper surface; sheaths longer than the joints, clothed with a woolly tomentum; branches of the erect, contracted panicle, tomentous at base; glumes unequal, longer than the pales; awns about equal, spreading, as long as the pale $\left(4\right.$ to $\left.6^{\prime \prime}\right)$, the middle rather longest.-24 In poor, sandy soils, S. States. Sept., Oct. (A. lanosa Ell.)

5 A. spicifórmis Ell. Culm 1 to $3 \mathrm{f}$ high, simple; lvs. and sheaths glabrous, tho latter shorter than the joints; panicle dense-flowered, spike-like and cylindrical ; glumes much shorter than the flower, both awned; middle awn of the flower longest, villous at the base, all three about as long as the pale.- - 2f Wet pine barrens,

S. Car. to Fla. Sept., Oct.

6 A. purpuráscens Poir. Culm erect, simple, filiform, 2-3f; lvs. very narrow, flat, erect, a foot in length, with short, open sheatlis; panicle long, loosely spicate; spikelets on short, clavate, appressed pedicels ; gls. 4 to 5 " long, purplish; awns $1^{\prime}$ long, nearly equal, divaricate, twice the length of the glabrous pale.-2f Sandy woods, Northern States. Sept. (A. affinis Kunth. A. racemosa Muhl.)

7 A. strícta Mx. UPRIGHT ARISTIDA. Culm strictly erect, cæspitous, branched, 1-3f; lvs. straight, erect, pubescent, linear, convolute above; panicle long, loosely racemous; spikclets appressed; gls. (3 to $5^{\prime \prime}$ long) unequal, very acute, lower pales hairy at base; awns twice as long as the pales, spreading, the middle one the longest. - 2f Penn. to Fla. (Chapman), W. to Mich.

8 . oligántha Mx. Culms erect, sparingly branched, 12 to $20^{\prime}$ high; pan. ra-

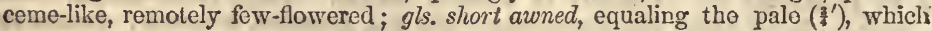
bears 3 divaricate awns thrice its own length, the middle one some longer; lvs. involute setaccous. - 2f Prairies, Ill. to Ark. and Va.

9 A. tuberculòsa Nutt. Culm crect (declinate at base), 8-20', rigid, with small tubercles in the axils of the numerous branches; nodes tumid; lvs. long and narrow-linear; pan. large, loose, simple; spikelets pedicellate; gls. nearly $1^{\prime}$ long; linear, awned; upper paleæ involute, the awns $2^{\prime}$ long, hispid upwards, twisted together to near the middle, thence finally horizontally divaricate. $-2 f$ A very singular species, in dry prairies, Ill., Wis. to Ky., Tenn., also found in N. J.

13. STIPA, L. Weather Grass. (Lat. stipa, a foot-stalk; alluding to the stipitate fruit.) Spikelets 1-flowered, the flower deciduous, with its thick, bearded, pointed stipe; glumes membranous; pales coriaceous, shorter than the glumes, the lower with a long, twisted or bent awn jointed at the apex; caryopsis striate; stamens 3 ; stigma plumous:- $2 f$ Fls. paniculate. Lvs. very narrow. The long awns are delicately hygrometric twisting or untwisting according to the state of the atmosphere.

I S. avenàcea I. BLACK OAT Grass. Culm naked above, 2-3f; Ivs. smootl, striate, setaceous, chiefly radical ; panicle spreading, somewhat 1-sided, 4-6' long, at length diffuse, branches capillary, solitary and in pairs; glumes nearly equal, mucronate, as long as the dark. brown, cylindric fruit; scales 2, lanceolate; awn twisted below, bent above, $2-3^{\prime}$ in length.-U. S. and Can. (S. Virginica Pers.)

2 s. júncea Pursh. Culm 2-3f; lvs. convolute filiform, smooth inside, long; pan. loose; gls. loose, filiformly acuminated to more than twice the length of the fruit; fr. attenuated at base into a stipe, which is a third of its length, stipe acute, pubescent; paleæ obtuse, distinctly articulated to the awn, which is smooth and slender, at length contorted and 4-6' in length. $-2 f$ Prairies, Ill., Mo. When in fruit the pungent stipe adheres to everything that comes in its way. Aug.

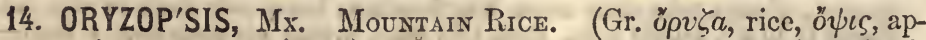
pearance.) Spikelets 1-flowered; glumes membranous-bordered, veined, 
subequal, and about equaling the oblong, terete, deciduous, short-stiped flower; lower pale coriaceous, involute, inclosing the caryopsis and tipped with a simple, jointed awn; scales linear-oblong.-2f Fls. in a slender or spike-like panicle.

$\$$ Sheaths all leaf-bearing. Stipe of tho flower nearly glabrous, very short............No.,1

\$ Sheaths, at least the upper, leafless. Stipo consplcuously bearded...................... 2,3

1 O. melanocárpa Muhl. Culm erect, simple, leafy, 18-24'; panicle simplo, flexuous, few-flowered; spikelets racemous, ovoid-lanceolate; glumes acuminate, mucronate, $5-6^{\prime \prime}$ in length, smooth; pales hairy, nearly black when ripe, tho lower one tipped with all awn an inch in length; fruit black.-Rocky hills, U. S. and Can., frequent. Aug. (Piptatherum nigrum Torr.)

2 O. asperifòlia $\mathrm{Mx}$. Culm nearly naked, purple at base, 10-20'; lvs. subradical, erect, rigid, pungent at the point, nearly as long as the stem, cauline ones few and very short; spikelets in a racemous, simple, flexuous panicle, 2 to $4^{\prime}$ long, $1-2$ upon each branch; glumes abruptly acuminate; pales white, the lower one with a long, bent awn.-Woods, N. States N. to Subaretic Am. Leaves green through the winter. Caryopsis white, about as large as rice, farinaceous. May. (Urachne Trin.)

3 O. Canadénsis Torr. Culms slender, 9 to $18^{\prime}$ high, naked above; lower sheaths bearing rigid, involute-filiform lvs.; pan. 1 to $2^{\prime}$ long, narrow, tho branches mostly in pairs; gls. often purplish, 1 to $2^{\prime \prime}$ long; pales white, bearded with whitish hairs, the awn short and deciduous or vanting.-Rocky woods, N. Eng., to tho shores of L. Superior. May. (Stipa juncea Mx., nec L. S. Canadensis Poir: Urachne Trin. Milium pungens Torr.)

15. PAS'PALUM L. (Gr. $\pi a \sigma \pi a \lambda o s$, millet;'from the resemblance of the seeds.) Spikelets plano-convex, in unilateral spikes; glumes (apparently) 2, membranous, equal, ovate or orbicular, closely pressed to the fertile flower; stigmas plumous, colored; caryopsis coated with the smooth, coriaceous pales. (But theoretically, the lower glume is obsolete and its place supplied by the empty pale of an abortive flower. In Nos. 19 and 20 the lower glume appears, under a lens, as a mere rudiment.) - Spikes linear, the fls. in 2 or 4 rows; rachis not jointed; pedicels articulated.

§ PAspalum. Spikelets suborbiculak̆ obtuse, crowded. Spikes alternate. (*)

* Spikes many $(7$ to 30$)$, with the spikelets mostly 4 -rowed.................... 1, 2

* Spikes few (1 to 3), mostly solitary, slender (1" wide), 2 or 3 -rowed............... 3

* Spikes few (2 to 6) -with the spikelets in 2 rows, near $2^{\prime \prime}$ wide............. Nos. 4,5 -with the spikelets in 3 rows, near 3 " broad. (a)

a Leaves very hairy. Culms decumbent................No. 6

a Leaves only ciliato on the margins..................... 7,8

a Leaves very glabrous, margins scabrous...........Nos. 9, 10.

$\$$ Digrraru. Spikelets ovato or laneeolate, acute. Spikes mostly digitate. (**)

** Rachis leaf-like, broader than the 2 rows of spikelets beneath it.......... Nos. 11, 12

*** Iachls narrow, triquetrous or flat, with the spikelets close-appressed. (b)

b Glumes (glume and pale) abont equal, as long as the flower. (c)

c Spikelets lanceolato. Spikes in pairs or threes................. Nos, 18, 14

c Spikelets ovate. Splkes 2 to 4 oftener in pairs............................... $15-17$

b Glume scarce half as long as the pale. Spikes 5 to 12 , clustered..... Nos. 18, 19

** Rachis flliform with the spikelets loose and subremote................ Nos. 20, 21

1 P. virgàtum L. Culms decumbent at base, glabrous, 18 to $30^{\prime}$; lvs. broadlinear, rough-edged, 12 to $18^{\prime}$ by 5 to $6^{\prime \prime}$; sheaths glabrous, with a hairy throat; spikes numerous (7 to 12); rachis straight (not flexuous), flat, narrower than the 4-rowed, dense, orbicular, obtuse spikelets.- $2 f$ Moist soils, S. States, common in the low country. Ji.-Oct.-A very smooth variety is the P. confertum Lo Conte.

$\beta$. PURpurascens. Culm below, lvs. and sheaths dark purple. (P. purpurascens Ell.)

2 P. undulàtum Poir. "Plant very glabrous; lvs. long and linear, somewhat. carinate; margin scabrous, base ciliate, sheaths glabrous; spikes many; rachis flat, glabrous, margins scabrous, narrower than the 2 to 4-rowed spikelets; lower glume pubescent, upper glume (palea) smooth, transversely plaited near the margins.)" Kunth. Ga. and Fla. $A$ variety of No. 6? (P. plicatum $\mathrm{M}$.. .) 
3 P. setàceum Mx. Culm ascending from a decumbent base, very slender, 1 th $2 f$, with very remote joints; lvs. lance-linear, $3-7^{\prime}$ by $2-3^{\prime \prime}$, ciliate and sof hairy; sheaths pubescent, upper one very long; spike generally solitary, often 2, on a long, very slender peduncle, sometimes with another scarcely exserted from the sheaths; spikelets plano-convex, with the flat side out, $\frac{3^{\prime \prime}}{4}$ diam., 1 or 2 on each very short pedicel, appearing 2-3-rowed in the 1-sided spike.-Dry fields, Mass., to IIl. and S. States. Aug. (P. debile and ciliatifolium Mx.)

$\beta$. LONGIPEDUNCULATUM. Larger, less hairy, and spikelets evidently 3-rowed. -S. States. (P. longip. LeC.)

4 P. læve Mx. Culm erect, rather firm, 18'-3f, glabrous; lrs. generally smooth pilous only at the base, broadly linear; lower sheaths sometimes hairy; spikes 2-6, alternate, spreading, with a few long, white hairs at the base; spikelets in 2 rows; rachis flexuous, flat on the back; pedicels undivided, with one spikelet; spikelets twice as large (1 $\frac{1}{2}{ }^{\prime \prime}$ diam.) as in the preceding; glume orbicular-ovate, 3-veined.-Grassy banks of rivers, Conn. to Ind. and S. States. Aug. Quito variable, including several reputed species.

$\beta$. UxDulosum. Lvs. rather long and broad, with wavy-margins. (P. Lecontianum Schult.)

$\gamma$. Floridanum. Spikelets enlarged (near 2" long), glume 5-reined. (P. macrospermum Flgg.)

8. AltissimuM. Strict and tall ; sheaths much compressed. (P. altissimum LeC.)

5 P. angustifòlium Le Conte. Culm erect, wiry, glabrous, $2 \mathrm{f}$ high; lvs. glabrous, narrowly linear, almost setaceous, compressed carinate, 9 to $18^{\prime}$ long; sheaths long, smooth; spikes 2 or 3 , alternate, divaricate, 1 to $2^{\prime}$ long, with a fow hairs at base; spikelets orbicular, $1^{\prime \prime}$ diam. in 2 rows, with a very narrow rachis. -4 Wet places, Ga., Fla. to La. A distinct species. Seeds blackish.

6 P. dasyphyllum Ell. Culm decumbent at basc, 12 to $30^{\prime}$ high, glabrous; lvs. broadly linear, clothed with copious soft hairs as well as the long sheatlis; spikes 2 to 4, large, spreading, the ped. slightly exserted from tho upper sheath; spikelets oval, obtuse, large, in 3 rows; teeth of the rachis 2 -flowered.-Dry fields, S. States, common. (1)? Jl.-Oct.

7 P. latifòlium Le Conte. . Glabrous; culm erect, stout, tall (2 to $3 f$ ), from a slightly decumbent base; ivs. flat, large, lance-linear, 6 to $12^{\prime}$ by 5 to 10", margins ciliate; sheaths hairy at throat, shorter than the long internodes; spikes 2 to 4, 2 to $4^{\prime}$ long, alternate, suberect, pilous at basc; spikelets largo ( $1 x^{\prime \prime}$ diam.), in 3 rows on the narrow, flexuous rachis. -4 Car. to Fla. and La.

8 P. tenue Kunth. Glabrous; culm erect, very slender; lvs. narrow, very long, ciliate on the margins, sheath ciliate; spikes 4 or 5 , very slender, alternate, spreading, hairy at base; spikelets orbicular, in 3 rows; rachis flexuous, narrow, the teeth 2-flowered. - 2f N. J. to Ga. (Lo Conte). Differs from No. 5, in its ciliato lvs. and 3-nerved spikelets.

9 P. arundinàceum Poir. "Glabrous; lvs. somowhat sword-shaped (compressed-carinate), the margin scabrous; spikes alternate, elongated; spikelets in 3 rows; gls. (gl. and pale) equal, obtuse.-Carolina." Poiret.

10 P. præ̀cox Walt. Glabrous throughout; culm erect; lvs. lance-linear, very long; spikes 3 to 5 , alternate, dense-flowered, with a tuft of long hair at base; rachis linear, straight (not flexuous), narrower than the 3 rows of very smooth, orbicular, compressed spikelets; gls. 3-veined. $-2 f$ Wet places, Car. to Fla. May. -Aug. (P. lentiferum Lam.)

11 P. flùitans Kunth. Culm decumbent and ascending 10 to $20^{\prime}$, generally floating; lvs. scabrous, lance-linear, 2 to $5^{\prime}$ by 4 to $6^{\prime \prime}$; sheaths inflated, open, ciliate at base; spikes 20 to 50,1 to $2 \frac{1^{\prime}}{2}$ long, the lower somewhat verticillate; rachis foliaceous, nearly $I^{\prime \prime}$ broad, covering the 2 rows of ovate, acute spikelets and projecting in a point beyond them.- (1) River swamps, S. IIl to Va. and S. States. Oct. (P. mucronatum Mubl. Ceresia, Ell.)

12 P. Walteriànum Schult. Culm decumbent, branching, ascending; lvs. glabrous, lance-linear, 2 to $4^{\prime}$ by 3 to $5^{\prime \prime}$; sheaths open, all glabrous; spikes 2 or 3 on each branch, 1 to $2^{\prime}$ long; rachis very broad (near $2^{\prime \prime}$ ), covering the 2 rows of oval, acute spikes but not projecting beyond them.- (1) Wet soils, Car. to Fla. and La. Jl-Sept. (P. vaginatum Ell.) 
13 P. Digitària Poir. Mostly glabrous; culm erect from an inclined base, 1 to $2 \frac{1}{2}$ ligh; lvs. lance-linear, flat, 6 to $16^{\prime}$ by 5 to $8^{\prime \prime}$, on long sheaths; spikes a pair, conjugate, slender, 2 to $4^{\prime}$ long, at top of the long naked ped. or upper internode of culm; spikelets lanceolate, in 2 opposito rows on the vertically compressed flexuous rachis. - (I)? Damp pine woods, Va. to Fla. and La. (Millium paspaloides Ell. P. Michauxiana Kth.)

14 P. tristáchyum Le Conte. Glabrous, decumbent below, 12 to $20^{\prime}$ high; culm filiform above; lvs. linear, flat, 3 to $8^{\prime}$ by 2 to $3^{\prime \prime}$, margins sparingly ciliate; sheaths compressed; spikes usually 3 , approximato (the 2 highest paired), very slender; rachis flexuous, triquetrous; spikelets lanceolate, 2-rowed, whitish, $I^{\prime \prime}$ long, close-pressed, gl. and pale scarcely longer than the flowers. - (1) Wet places, Ga. Fla. to La.

15 P. conjugatum Berg. Nearly glabrous and erect, 1 to 2f, slender; lvs. broadly linear, 2 to $4^{\prime}$ by 2 to $4^{\prime \prime}$, on compressed sheaths; upper sheath very long and nearly leafless; spikes 2, a conjugate pair, on the filiform upper internode, very slender, 2 to $3^{\prime}$ long; rachis nearly as wide as the 2 rows of minute ( $\frac{1^{\prime \prime}}{2}$ long), round-ovate, acute, white, ciliate spikelets. - (1) Waste places about N. Orleans (Hale).

16 P. dístichum I. Nearly glabrous; culms some inclining at base, 12 to $18^{\prime}$ bigh; lvs. lance-linear, bearded at the throat, 2 to $3^{\prime}$ by 2 to $3^{\prime \prime}$; spikes 2 , a pair nearly or quite conjugate, dense-flowered, 1 to $2 \frac{1^{\prime}}{2}$ long; rachis narrower than tho 2 rows of ovate, acuminate ( $1 \frac{1}{2} "$ long), glabrous spikelets. - 2f Wet grounds, S. States.

$\beta$. TRístachuMr. Spikes in $3 \mathrm{~s}$, closely approximate.

17 P. ambíguum DC. Glabrous; culms clustered, decumbent, 8 to $15^{\prime}$ high; lvs. lance-linear, shorter than tho sheaths ( 2 to $4^{\prime}$ by 2 to $\left.4^{\prime \prime}\right)$; spikes 2 to 4 , about $2^{\prime}$ long, slender; spikelets crowded, 2-rowed, ovate, $2^{\prime \prime}$ long, gl. and palo about cqual, not longer than the purplish flower, both hairy. - Sandy fields, especially South. Often purplish. Aug., Sept. § Eur. (Panicum glabrum Gaud.)

18 P. seròtinum Fluegge. Decumbent, creeping and rooting, with upright branches; lvs. and sheaths villous with white soft hairs, the former lance-linear, short, about $1^{\prime}$ by $2^{\prime \prime}$; spikes digitate, about in 5 s, slender, 2 to $3^{\prime}$ long; rachis flat, about as wide as the 2 rows of elliptical spikelets $\left(\frac{1}{2}{ }^{\prime \prime}\right)$; spikelets all pedicellate, in $2 \mathrm{~s}$; gl. a fourth as long as the striato pale, and flower. - (1) Sandy fields, Car. to Fla. and La. Forms a dense carpet. Jl.-Oct. (Digitaria villosum Ell.)

19 P. sanguinàle Lam. Purple Finger Grass. Crab Grass. Culms documbent at base, radiating and branching at the lower joints, $1-2 \mathrm{f}$; lvs. linearlanceolate, on long, loose sheaths, softly pilous, the sheaths strigously hairy; spikes $3-5^{\prime}$ long, fascinate at the top of the stem, 5 to 9 together; spikelets in pairs, oblong-lanceolate, closely appressed to tho flexuous rachis, in 2 rows, glume $\frac{1}{2}$ as long as the flower.- (1) Common in cultivated grounds, N. Eng., W. Ind. Aug.Oct. (Panicum, L. Digitaria, Scop.)

20 P. filiforme Swartz. Culm erect, filiform, simple, 12-18'; lvs. short, nearly smooth, narrow-lanceolate; lower sheaths very hairy, upper glabrous; spikes $2-4$, filiform, erect; rachis flexuous; spikelets in $3 s$, all pedicellate; glume solitary, as long as the pale (abortive flower). - (1) Dry, gravelly soils, N. Y. to Ky. Aug. (Panicum, L. Digitaria, Muhl.)

21 P. interrúptum. Culm strictly erect, wiry, tall (2 to 3f); lvs. long, linear, 8 to $15^{\prime}$ by 3 to $4^{\prime \prime}$, clothed with copious soft hairs, as well as the sheaths; spikes 3 or 4, raceme-like, 2 to $6^{\prime}$ long, the spikelets ovate, acutish, in remote pairs distinctly pedicellate, rachis filiform.-Dry soils, La. and Tex. (Hale). (P. racemosum Nutt. nec Jacq.) The inflorescence is almost paniculate.

16. MIL'LIUM, L. Mrluet Grass. (Probably from the Latin mille, a thousand, on account of its fertility.) Spikelets 1-flowered, not articulated with their pedicels; glumes 2, without involucre or awns; pales 2 , shorter than the glumes, awnless, oblong, concave, persistent and cartilaginous, coating the caryopsis. (Comparing Millium with Panicum, it appears that the 2 glumes of the former are, in fact, a glume, and a 
pale of a second (abortive) flower, the upper pale and the lower glumo being obsolete.)-Inflor. an open panicle.

M. effùsum L. Culm upright, simple, smooth, 3 to 6 or $8 f$ higb; lvs. flat, 8 to $12^{\prime}$ by $6^{\prime \prime}$ to $1^{\prime}$, on smooth, striate sheaths; branches of the panicle clustered, spreading, remote; spikelets ovate, few and scattered, acute, about $1^{\prime \prime}$. long.-In woods, Penn. to Can. and Wis. Plant pale green. Summer.

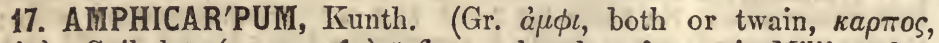
fruit.) Spikelets (apparently) 1-flowered and perfect as in Millium, but of 2 kinds, terminal, deciduous and sterile, the radical fertile; glumes 2 , Janceolate, acute, awnless, as long as the 2 coriaceous pales; stamens 3 ; stigmas 2, plumous, purple.-2f Cæspitous, erect, strict, with erect, lance-linear lvs., the terminal fls. in a strict, contracted, slender panicle, the radical fls. are each solitary, on a slender ped., and subterranean.

A. Púrshii Kunth. Pine barrens, N. Jer. (Long-a-coming, Jackson). Culm 2f high, glabrous. Lrs. 2 to $3^{\prime}$ by 2 to $3^{\prime \prime}$, hairy, as well as the sheaths, the unper sheath long and without a leaf. Fan. on a long, exserted ped. Spikelets $1 \frac{1}{2}$ long, the radical ones $22^{\prime \prime}$, veiny; the glume clasping the longer, neutral, single pale. Aug. (Millium Amphicarpon $\mathrm{Ph}$.)

18. PAN'ICUM, L. Panic Grass. (Lat. panicula, the mode of flowering, or panis, bread, which some species afford.) Glumes 2, unequal, awnless, the lower much smaller; flowers 2, dissimilar, the lower abortive or sterile, with 1 or 2 pales, the upper pale membranous; the upper $\Varangle$, with the pales cartilaginous, polished, equal, concave, awnless, coating the caryopsis; stamens 3 ; stigmas plumous, purple.-Differs from Paspalum in the presence of the lower (true) glume. Panicles simple or compound.

$\S$ Spikelets acute or pointed, very numerous, racemed in large panicles. $\left({ }^{*}\right)$

* Abortive flower neutral, consistinc of a single palea. (a)

a Panicle capillary, with the spikelets solitary ............................. Nos. 1, 2

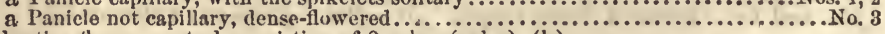

- Abortive Hlower nentral, consisting of 2 paleæ (pales). (b)

b Panicle contracted, cylindric. Upper glume gibbous........................ 4

b Panicle open.-Glume 8-veined. 'The 2 pales equal........................... 5 -Glume 5 to 7 -veined,-longer than abortive flower................... 6,7 - shorter than abortlve flower................ No. 8

* Abortire flower staminate, with 2 pales. Tall, very smooth.......................... 10

§ Spikelets obtuse or barely acute, solitary, pedicellite, not numerous. $(* *)$

** $\Lambda$ bortive flower (nentral) consisting of a single pale...................... Nos. 11-18

** Abortive flower of 2 pales, the upper small and scatious. (c)

c Leaves narrow, obscurcly veined, 1 to $5^{\prime \prime}$ widle. (d)

d Spikelets densely fringed with silky hairs; fertilo flower colored...........No. 14

d Spikelets glabrous or sparsely pilons; fertile flower white. (dd)

dd Spikelets less than 1" long, roundish or oval; glume B-veined...Nos. 15, 16

dd Spikelets 1 to $1 \frac{1}{\prime \prime}$ long, oval; glume 9-veined.................... Nos. 17, 18

c Leaves broad, conspicuonsly veined, 5 to 20 " wide. (e)

e A bortive flower usually staminate with 3 stamens.

o Abortive flower neutral, never with stamens. (f)

f Plant very downy, witl soft, dense, relvety hairs...................... 20

f Plant smonthish or pilous-ciliate, branched or simple................... Nos. 21,22

\$ Spikelets barely aeute, in short $\left(1^{\prime}\right)$, dense, secund, alternate spikes. Southern........ Nos. 23, 24

1 P. capillàre. Culm nearly simple, assurgent and thick at base, 1-2f; lvs. hairy, broad-linear, acuminate, 4-6' long; sheaths covered with bristly hairs; pan. large, pyramidal, capillary, loose, expanding; spikelets small ( $\frac{2}{3}{ }^{\prime \prime}$ long), often purple, oblong-ovate, purple, lanceolate, acuminate, smooth, on long, hispid peduncles; abortive fl. of 1 palea.-(1) Fields and roadsides, U. S. and Can. Aug.-Panicles often if or more long, with a very light, airy appearance. In poor or shady soils it is much reduced.

2 P. autumnàle Bosc. Culm very slender, assurgent, 10 to $20^{\prime}$ high; lvs. glabrous, lance-linear, at length convolute, 2 to $3^{\prime}$ long; sheaths glabrous; pan. diffuse, bearded in the axils, with long, strict, roughish, capillary, 1-flowered branches; 
wikelets oblong-lanceolate, acute, glabrous; glumes veiny, very unequal, tho lower minute.-Sand hill, Mason Co., 1ll. (Mead, in Gray's Manual).

๖ P. prolíferum Lam. Culm assurgent, geniculate at base, very smooth, thick and succulent; lvs. linear-lanceolate, 4 to $6^{\prime \prime}$ wide, 10 to $15^{\prime}$ long, on tumid sheaths, ligules ciliate; pan. large, pyramidal, terminal and axillary, smooth; spikelets oblong, acute, veiny, $1^{\prime \prime}$ long, densely racemed; lower glume $\frac{1}{5}$ as long as the upper; abortive fl., with 1 pale.-1) Marshes, especially brackish and sandy, Mass. to La., also along the Western rivers. Aug., Sept. (P. geniculatum Mubl.) In uplands more slender, not succulent.

4 P. gibbum Ell. Culm terete, assurgent, 2 to 3 f, with black joints; Irs. lance. linear, glabrous, 4 to $8^{\prime}$ by 4 to $8^{\prime \prime}$, on smooth, strongly striate sheaths; pan. densely contracted, often purple, fusiform, about $6^{\prime}$ long; strict; spikelets near $2^{\prime \prime}$ long, obtusish, lewer glumo very small, upper very large, 11-veined, remarkably gibbous at base, upper pale nearly as long as tho lower.-(1) Wet soils, S. States. J..-Sept. (P. Eilliottianum Schl.)

5 P. hìans E!l. Culm very slender, almost filiform, decumbent and rooting at tho lower joints, about $2 \mathrm{f}$ high ; lvs. narrowly lincar, 8 to $16^{\prime}$ long, glabrous; sheaths hairy only at the throat; paniclo pyramidal, spikelets racemed, $\frac{1}{2}{ }^{\prime \prime}$ long; lower glumo half as long as the upper, neutral pales equal, conspicuous (gaping), a littlo longer than the fertile.-Damp pine barrens, S. States, common. Aug.Oct. (P. debilo Poir. P. divaricatum Mx.)

6 P. agrostoìcies Muhl. Culm compressed, glabrous, 11-3f high, often geniculate at baso; lvs. long and numerous, caulino linear-lanceolate, carinate, roughedged, on short, striato sheaths; panicles terminal and lateral, pyramidal, composed of racemed, spreading or deflexed branches; spikelets $1^{\prime \prime}$ long, purple, lancoovate, acute, crowded; upper glume 3-veined, $\frac{1}{3}$ longer than the lower; upper neutral, pale, nearly as long as the lower.-2f Meadows, frequent. July. (P. fuscorubens Nutt.)

7 P. ánceps Mx. Culm compressed, 2 to 3f; lvs. linear, carinate, very long, rough-edged; sheaths ancipital, pilous on the throat and margin; pan. erect, pyramidal, with subremote, subsimple, interruptedly racemous bramches; spikelets $1 \frac{1}{2}$ "long, lanceolate, very acuminate, and when mature, forked; lower glume and upper pale half as long as the lower pale, scarcely shorter than the fertile flower; upper glume 7-veined.-Wet soils, N. J. and S. States. Aug.-Nov.

8 P. vilfifórme. Glabrous throughout; culm decumbent, ascending 2 to $3 f$, branched; lvs. long, linear, scarcely rough-edged; sheaths with a tuft of hairs at throat; pan. simple, with racemed, spreading branches; spikelets $2^{\prime \prime}$ long, lanccolate, acute; lower glume $\frac{1}{4}$ to $\frac{1}{3}$ as long as the upper, 7 -veined glumie which is shorter than the lower pale (while in Nos. 6 and 7 it is longer than tho lower pale !).- Wet meadows, E. Tenn.! Jl.; Aug.

9 P. amàrum Ell. Glabrous, leafy; culm 2 to $3 f$ high, stout; lvs. glaucous, coriaceous, rigid, linear, 10 to $18^{\prime}$ long; margins involute, not scabrous; sheath somo shorter than the joints; pan. large, contracted, its very smooth branches appressed; spikelets thick, $2^{\prime \prime}$ long, ovate, acuminate, lower glume nearly as long as the sterilo pales, which contain 3 orange-colored stamens. - 4 Sandy shores, Conn. to Fla. and La. (Halc). Lvs. excessively bitter (Elliott). Aug.-Oct.

10 P. virgàtum L. Glabrous and often purple; culm 3-5f high; lvs. flat, long, linear-lanceolate, hairy at base; sheaths striato; stip. with long, white cilix; pan. pyramidat, loose, spreading, diffuse, very large; fls. acuminate, the glumes $2 \frac{1}{2}$ "long, very pointed, divaricate, the lower $\frac{2}{3}$ as long as the upper; pales of tho abortive flower nearly equal, enfolding the purple stamens. - if Salt-lick prairies, fields, \&c., N. Y. to Ind., S. to the Gulf. Aug.

11 P. verrucòsum MIuhl. Culm slender, decumbent and geniculate, branching from the base, $1-2 \mathrm{f}$ high; lvs. lance-linear, flat, 4 to $6^{\prime}$ by 2 to $4^{\prime \prime}$, spreáding, smooth; pan. much expanded, few-flowered; spikelets $\frac{1}{2}$ to $\frac{1}{3}$ "long, covered with warty points (verrucous) obovate, bluish; abortivo flower of one palea, and neuter.(1) ?. Swamps and thickets, Mid: and S. States. Panicles terminal and lateral, looso and capillary. Aug. (P. debilis Ell. nec Poir. P. ramulosum Mx.)

12 P. frágile Kunth. Culm geniculato at base, assurgent, branched, very brittle, 
1f; lvs. subulate, scabrous, 2 to $4^{\prime}$ long; sheaths glabrous, longer than the joints; pan. very simple, the few, solitary, sma!l spikelets on very lonj setaceous pedicels; lower glume subulate: sterile pale single, as long as the glume, a little longer than the fertile flower,-Dry, sandy soils, rare, N. Car. to Ga.

13 P. villòsum Ell. Villous throughout with soft white hairs; culm geniculate below, 1 to $2 \mathrm{f}$; lvs. flat, erect, 2 to $3^{\prime}$ by 3 to $4^{\prime \prime}$; sheaths much shorter than tho joints; pan. small (2 to $3^{\prime}$ long), looso; spikelets oval, $1^{\prime \prime}$ long, green; lower glume roundish, $\frac{1}{4}$ as long as the 7 -veined, upper one, which equals the single, sterilo pale and fertile flower.-Evergreen in damp places, S. States (Feay, \&c.). Apr., May.

14 P. ciliatiflòrum. FrInged Grass. Culm erect, strict, 1 to $3 \mathrm{f}$, glabrous; lvs. erect, long, linear, flat, narrow, scarcely distinct from their sheaths; pan. virgate, subsimple, $3^{\prime}$ long; spikelets pedicellate, oval, the glumo and lower abortive pale obtuse, subequal, the 5 veins ciliate-fringed with silky, purplish hairs; upper palo much smaller, oblong; fertilo pales thinly chartaceous, brown or blackish when mature.- Varies with tho leaves more or less hairy, and the curious silk fringe of the spikelets more or less copious. In pine barrens, $\mathrm{S}$. States. Sept. (Phalaris villosa Mx. Aulaxanthus ciliatus and rufa Ell. P. ignoratum Kth., an absurd namo which we venture to discard.)

15 P. dichótomum L. Culm at first subsimple with a single terminal panicle, becoming more or less branched, with lateral, subsimple panicles; lvs. lanceolate, 1 to $4^{\prime}$ by 2 to $4^{\prime \prime}$ or $5^{\prime \prime}$, hairy or smooth, as likewise the sheaths; terminal pan. exserted, often long-pedunculate, small ( 1 to $3^{\prime}$ long), oval in outline, loosely fewflowered; spikelets small (about $\frac{1}{2}$ "long), oval or roundish; lower glume very small, upper equaling the sterilo palo and fertile flower, upper sterile $\frac{1}{3}$ to $\frac{1}{2}$ as long as the lower, scarious, bifid.-2f Common everywhere, in meadows, fields and woods. Jn.-Sept.-The following are the more striking forms of this exceedingly variable species (which includes P. nodiflorum, laxiflorum, nitidum Lam., barbulatum Mx., sphærocarpa Muhl., lanuginosum, ensiforum Ell., \&c.).

$\beta$. NITIDUM. Smooth and shining; spikelets palo purplo; upper pale very short.

$\gamma$. SPHAROCARPUM. Hairy; lrs. suberect; spikelets dark purple; upper palo deeply bifid.

d. BARBuLitum. Taller; nodes with a ring of retrorse hairs; lvs. spreading; spikelets purplish: upper pale entire.

ع. LANUGINòsum. Woolly; lvs. linear-lanceolato; spikelets green; upper palo clongated, very obtuse. Approaches the next species.

16 P. depauperàtum Muhl. Culm cæspitous, erect, 9 to $12^{\prime}$ high, simplo abovo tho baso; lvs. linear, rigidly erect, lower short, upper about $5^{\prime}$ by $2 \frac{1^{\prime \prime}}{}$; pan. simple with ascending branches, the peduncle very short or becoming very long; spikelets green, oval, acute, $\frac{2}{3}$ to $1^{\prime \prime}$ long; outer glume roundish, $\frac{1}{3}$ as long as tho inner, '7-veined one; upper neutral palo (always?) bifid, half as long as tho lower. -Hilly woods, N. States and Can. Jn. (P. rectum R. \& S.)

$\beta$. INvolutus. Lvs. involute; ending in a long, rigid point. (P. involutum, Torr.)

17 P. pauciflòrum Ell. Culm mostly erect, at length, somewhat decumbent and branched; lvs. erect, linear-lanceolate, faintly 9-veined, tapering to near the base; 3 to $5^{\prime}$ by 5 to $7^{\prime \prime}$, sparingly hirsute as well as the close sheaths; pan. exserted, simple, raceme-like, few-flowered; spikelets 10 or more, obovate, obtuse, $1^{\prime \prime}$ long; lower glume broad-ovate, $\frac{1}{2}$ as long as the upper one; upper neutral palo similar to the lower. - Wet or shady places, Mid., W. and S. States. Jn., Jl.

18 P. pubéscens Lam. Culm slender, finally branched, glabrous, 2 to $3 f$ long; lvs. lance-linear, 9-veined, 3 to $6^{\prime}$ by 3 to $5^{\prime \prime}$, clothed with reflexed hairs as well as the open sheaths; pan. small, expanded, fow-flowered, pubescent; spikelets large (1 $\frac{1^{\prime \prime}}{2}$ long), hairy, oval, obtuse, green; outer glume, lanceolate, $\frac{2}{3}$ as long as the inner 9-veined ono; inner neutral palo nearly as long as the outer.-Dry fields, etc., N. Y. to Ohio and S. States. Jn. (P. dichótomum $\beta$. Gray.)

19 P. latifolium L. Culm mostly erect, 1 to $2 \mathrm{f} \mathrm{high;} \mathrm{lvs.} \mathrm{lanceolate,} \mathrm{base} \mathrm{dilated}$ and cordate-clasping, 3 to $5^{\prime}$ by $1^{\prime}, 11$ to 13-veined, smoothish; sheaths hirsuto at throat; pan. exserted, compound, loose, about $3^{\prime}$ long; spikolets oval, obtuso, 
$11_{2}^{\prime \prime}$ long, green; lower glume ovate, not half as long as the upper; abortive pales subequal, usually with 3 stamens.-In moist, shady places, U. S. and Can. Jn., Jl. (P. scoparium and nervosum Lam. P. ciliatum Eil., etc.)

20 P. zanthophỳsum Gray. Culm generally simple, glabrous, 9 to $15^{\prime}$ high ; Ivs. lanceolate, 3 to $6^{\prime}$ by 5 to $7^{\prime \prime}$, not dilated at the ciliate, clasping base, smooth, 9 to 11-veined; pan. long-exserted, simple, raceme-like, few-flowered; spkl. roundish-obovate $1 \frac{1}{2}$ " long; lower glume ovate, 3-veined, acutish, $\frac{1}{2}$ as long as the upper many-veined one; abortive pales oftener with 3 stameus.-Dry soils, N. Eng. to Wis. (Lapham). Rare. Jn.

21 P. viscidum Ell. Hoary, with a dense, short, soft, viscid pubescence; culm decumbent, assurgent 2 to 4f, stout; joints a smooth brown ring; lvs. lancelinear, 3 to $6^{\prime}$ by 6 to $16^{\prime \prime}$; sheaths much shorter than the internodes; pan. rather large (4 to $6^{\prime}$ long); loose; spkl. light green, $1^{\prime \prime}$ long, oval, acutish, lower glumo very small, upper pale very small, truncate. 24 Damp places, N. J. to Ga. (Feay).

22 P. clandestìnum L. Culm with short, axillary, appressed branches, 2 to $3 f$ high, rigid, leafy; lvs. 3 to $6^{\prime}$ by $1^{\prime}$, lanceolate, subcordate at base; sheaths hispid with papillæ in the grooves bearing bristly hairs, and enclosing the short lateral panicles; spkl. elliptical, acutish, $1 \frac{1}{2}$ " long, striate, often purple; upper pale of the neutral fi. obtuse.- 2f Moist woods, Mass. and Mid. States. Jl., Aug.

23 P. microcárpon Muhl., Darl. Culm 18 to $30^{\prime}$ high, erect, simple, glabrous; joints glabrous; lvs. lanceolate, veined, ciliate at base, undulate and scabrous on the margin, scabrous above, smooth beneath, 6 to $10^{\prime \prime}$ wide; sheaths deeply striate, smooth'; stip. 0 ; pan. much branched, nearly smooth; spkl. small, $\left(\frac{1}{2}\right.$ " long), roundish-obovate, purple, numerous, scarcely pubescent; upper sterile palo minute; fr. shining, bluish white.-2f.

24 P. Wálteri Ell. Culm slender, glabrous, erect, 2f; lvs. linear 3 to $6^{\prime}$ by 2 to $3^{\prime \prime}$, glabrous as well as the open sheaths; spikes thick, dense, 1 -sided, alternato (tho 2 lower sometimes opposite), 6 to $12^{\prime \prime}$ long; spkl. imbricated in 3 rows, broad-ovato; glumes minutely hispíd, the lower half as large, upper 3-veined; abortive pales unequal, staminate; fertile fl. roundish.-Damp grounds, Can. to Fla. and La. Jn.-Aug. (Nearly allied to Oplísmenus.)

25 P. Aurelianum Halo (MS.). Culm decumbent, geniculate, slender, branched, glabrous; lvs. lanceolate, glabrous, 1 to $2^{\prime}$ by 3 to $4^{\prime \prime}$, sheaths ciliate; spikes slender, 6 to $12^{\prime \prime}$ long, alternate, 1 -sided; spkl. ovate, acute; lower glume $\frac{1}{2}$ as long as the upper, smooth and 5-veined one; abortive pales equal, staminate; fertile fl. ovate.-Damp soils, about N. Orleans (Hale).

26 P. miliàceum I. MILLET. Lrs. lance-linear and sheaths hairy; eulm 2 to $3 \mathrm{f} \mathrm{high} \mathrm{;} \mathrm{pan.} \mathrm{large,} \mathrm{open,} \mathrm{nodding;} \mathrm{spkl.} \mathrm{solitary,} \mathrm{ovate;} \mathrm{gls.} \mathrm{acuminate-}$ mucronate, subequal; pales obtuse.-Cultivated. † Turkey.

27 P. Jumentòrum Pers. Another cultivated species; from N. Africa. Much valued South. It is tall, stout, smooth. The spikelets are singularly arranged in $2 \mathrm{~s}$ or $3 \mathrm{~s}$, one or two sterile to each fertile. Seeds black.

19. OPLIS'MENUS Beauv. Cock-spUr Grass. (Gr. o $\pi \lambda \iota \sigma \mu a$, armament, $\mu \varepsilon v o s$, courage; alluding to the stout awns.) Spikelets, \&c. as in Panicum, except that the lower abortive pale (and often the glumes) is prolonged more or less into an awn.-Coarse grasses with the fls, in dense paniculate racemes.

1 0. Crus-gálli Kunth. BARN-YARD Grass. Terete, smooth, $3-4 \mathrm{f} \mathrm{high;} \mathrm{lvs.}$ linear-lanceolate, flat, serrulate, with smooth, striate sheaths and no stipule; pan. simple or apparently so, branches spike-form, compound, alternate and in pairs; rachis hairy and rough; glumes scarcely awned, hispid-bristly; lower abortive ' palea ending in a rough awn, 6 " to $18^{\prime \prime}$ long; fertile fl. ovate.-(1) A coarse, weedy grass, introdueed into cultivated grounds, barn-yards, \&c., common. Aug., Sept. $\S$ Variable. (Panicum, L.)

$\beta$. MUticus. A wns very short, or the pale merely subulate-pointec. Common.

$\gamma$. HISPIDUS. Sheaths very bristly; awns very long.

2 O. hirtéllus R. \& S. Culm glabrous, decumbent, branched; lvs. lanceolate, flat, 1 to $2^{\prime}$ by 2 to $4^{\prime \prime}$, with scattercd, appressed hairs on the upper surface; 
sheaths ciliate; pan. of remote, short $\left(6^{\prime \prime}\right)$, dense, alternate spikes, the rachis fiex. uous; glumes nearly equal, both awned; lower pale with a stout awn which is much longer than those of the glumes; upper pale minute; fertile $f$. lanceolate.Dry shades, Car. to $\mathrm{Ga}$. and La. Aug.-Oet. (Panicum, L.)

20. SETA'RIA, Beauv. Bristly Fox-tail Grass. (Lat. seta, a bristle.) Spikelets, \&c. as in Panicum, but each subtended by a cluster of awn-like bristles (abortive pedicels), forming a sort of bristly involucre.-Fls. in dense, cylindric spikes or spike-like panicles.

\$ Bristles of the involucre rough backwards, in pairs, short...................... 1

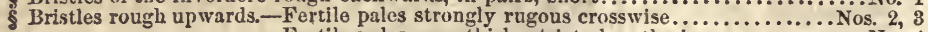
- Fertile pales smoothish, striate lengthwise................. 4 -Fertile pales smoothish, not striate....................... 5,6

1 s. verticillata Beauv. Culm smooth, about $2 \mathrm{f}$ high; Ivs. lance-linear, roughedged; sheaths smooth, hairy on the margin; spicate pan. composed of shorh divided branches in interrupted verticils, $2-3^{\prime}$ long; bristles of the invol. in pairs, rough backwards, as well as the upper part of the culm; paleæ of the $\Varangle$ roughishpunctate.- (1) Sandy fields, N. Eng. to Ohio, more frequent South. July. §

2 s. glauca Beauv. Bотtre Grass. Culm 2-3f; lvs. lance-linear, carinate, rough, hairy at base; sheaths striate, smootlı; ligules setous; spitie cylindric, yellowishgreen, 2-4' long, nearly simple; invol. of 6-10 fascicled, scabrous bristles much longer than the spikelets; fertile pale, transversely rugous.- (1) Fields and roadsides, N. Eng. to Ohio. Jl., Aug.

$\beta$. PURPURAscexs. Sheaths and spikelets pilous, awns purple.

3 S. corrugàta Schul. Culm terete, 2 to 3 f; lvs. linear, 8 to $12^{\prime}$ by 3 to $4^{\prime \prime}$, very scabrous, as well as the sheaths; ligules setous; pan. terete, dense, spikelike, 3 to 6 ' long, compounded of many appressed spikes, each of many spikelets; bristles as many as spkls. (one at the base of each) and 3 or 4 times as long; caryopsis and its pales strongly corrugated (Elliott). - Savannah (Baldwin).

4 s. víridis Beauv. WILd TrмотнY. Culm smooth, 2-3f; lvs. lanceolate, flat, minutely serrulate; sheaths striate, hairy on the margin, and with a setous stipule; spike 1 to $3^{\prime}$ long, cylindric, compound, terminal, green; involucre of $4-10$ fasciculate bristles, much longer than the spikelets; paleæ of the perfect flower longitudinally striate, punctate, and minutely corrugated under a lens.- (1) Common in cultivated grounds, Northern States. July, Aug:-

5 S. Itálica Kunth. Culm somewhat compressed, about 4 to $6 f$ high; lvs. lanceolate, $1-2 \mathrm{f}$ long, an inch wide; sheaths roughish, pilous at the throat; spike compound, interrupted at the base, nodding, 6-8' long sometimes 12 to $18^{\prime}$ long and '1' thick (Feay); spikelets conglomerate; invol. of 2 or more bristles, several times longer than the flower; fertile fl. polished, shining, $\frac{1}{2}$ "long.- (1) Ditches, Mid. and S. States. July.

6 s. Germanica Beauv. Mmlet. Bengat Grass. Culm 2-4f high, simple, leafy; Ivs. lance-linear, flat, acuminate, serrulate on the margin; sheaths striate, close, pubescent; stip. bearded; spike compressed, yellowish, oblong-cylindric; rachis densely hirsute; involucrate bristles $4-8$, as long as, or longer than tho spikelets, yellowish; glumes unequal, ovate; ఫ palece $1^{\prime \prime}$ long, obscurely 3-veined, dull with minute corrugations. - (1) In fields, often cultivated. $\S$ (S. Italica $\beta$. Kunth.)

21. CENCHRUS L. Burr Grass. (Gr. kevXpos, the ancient name of the millet.) Flowers racemous or spicate; involucre burr-form, laciniate, echinate, persistent, and becoming hard in fruit, including $1-3$ spikelets; glumes 2, 2-flowered, outer smaller; flowers dissimlar, the lower sterile, the upper perfect; scales 0 ; branching; spikelets sessile.

1 C. tribuloìdes I. St. 1-2f long, erect or procumbent and geniculate at base; lvs lance-linear, conduplicate, gradually acuminate, $3-5^{\prime}$ by $2-3^{\prime \prime}$; sheaths open, about as long as the colored joints; spike with the burr-like involucres approximate; invol. cartilaginous, beset externally with many sharp, retrorsely 
hispid spines as long as itself and containing $2-3$ spikelets; glumes acuminatomucronate, about $3^{\prime \prime}$ long, producing but 1 caryopsis.- (1) Sandy alluvion, N. J. to Can. and Wis. The adhesive burrs are annoying.

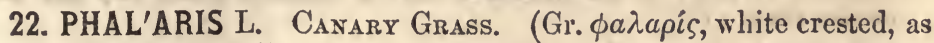
are the flowers.) Spikelets 1 (theoretically 3)-flowered; glumes 2, subequal, carinate; paleæ 2, coriaceous, awnless, shorter than the glumes, coating the caryopsis, each with an external, accessory palea or abortive rudiment at base. Grasses with flat lvs. contracted, often spikelike panicles.

I P. arundinàcea $\mathrm{L}$. Culm erect, sparingly branched or simple, 2-5f high; lvs. spreading, lance-linear, veined, rough-edged, on smooth, striate sheaths; pan. very dense, elliptic-oblong, somerwhat secund, $3-6^{\prime}$ long, glumes 3 -veined, whitish, scabrous; rudiments pilous. - 4 Common in ditches and swamps, Can. to Car. and Ky. A large, showy grass, but not valuable. July, Aug. (P. Americana Torr. nec Ell.)

$\beta$. PICTA is tho well-known striped or ribbon grass, with beautifully variegated leaves longitudinally striped in endless diversity. $f$

2 P. Canariéngis L. Canary Grass. Culm erect, or geniculate at the lower joints, round, striate, leafy; if or moro high; lvs. lance-linear; panicles spicate, ovoid, erect; 1 to 2 ' long; glumes whitish, with green veins; winged on the keel; rudiments smooth.-(1) Fields and pastures, not common. The glumes are curiously marked with white and green. The fruit is the chicf food of Canary birds. Jl. § Isle Fortunatus.

23. ANTHOXAN'THUM, L. Sweet-scented Vernal Grass. (Gr.

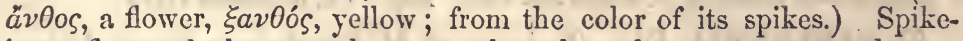
lets 3 -flowered, the central one $\not$, the 2 lateral ones neuter, each consisting of one bearded palea ; glumes 2, unequal, the upper one larger, inclosing the flowers; palex of the $\Varangle 2$, short, awnless; stamens 2.

A. odoràtum L. Slender, erect, 10-18'; lvs. short, striate, pale green; pan. spicate, oblong-ovoid; spikelets pubescent, on short peduncles; pales of the lateral fls. linear-oblong, ciliate on the margin, one of them with a bent awn from near the base, the other with a straight awn from the back near the summit.An early-flowering, deliciously fragrant grass, in most of the States and Can. Jay, Jn. § Eur.

24. HIEROCH'LOA, Gmel. Seneca Grass. (Gr. ¿epos, sacred, $\chi \lambda \dot{0} a$, glass ; from its fragrance.) Spikelets 3-1lowered; glumes 2, scarious; lateral flowers staminate, triandrous ; central flower $\Varangle$, diandrous (rarely triandrous). -Sweet-scented. Inflor. paniculate.

1 H. boreàlis R. \& Sch. Smooth, glossy; culm simple, erect, 15-20'; radical lvs. as long as the stem, cauline $2-4^{\prime}$ long, lanceolate, mucronate; panicle rather 1 -sided and spreading, pyramidal, few-flowered, 2-3' long; branchlets flexuous; spikelets broad, subcordate, colored, unarmed; glumes acuminate; lower pale ciliate.-2 Wet meadows, Virg. to Arc. Am. Very fragrant. May.

2 H. alpìna R. \& S. Smooth; culm erect, stout, 6-8'; lvs. linear-lanceolate, acute; sheaths tumid, longer than the internodes; panicle ovoid, $1 \frac{1}{2}-2^{\prime}$ long, with the branches in pairs; spikelets purple, compressed, large, longer than the branches; glumes lanceolate; lower fl. with an awn about as long as the pales.-24 Summits of the White Mits. (Bigelow). Jn.

25. HOL'CUS, L. Soft Grass. (Gr. ỏ $\lambda$ kós, something which draws; application obscure.) Spikelets 2 -flowered; glumes herbaceous, boatshaped, mucronate ; flowers pedicellate, the lower one perfect and awnless, upper one $\hat{\delta}$ or neuter,. awned on the back, -Fls. in an open panicle.

H. lanàtuss L. Iọary pubescent; culm $1 \frac{1}{2}-2$ high; i lis. lance-linear, 2-5' long; 
sheaths striate; pan. oblong, dense, whitish, with a purplo tinge; fls. shorter than the glumes; sterile one with a recurved, included awn.-2f Common in wet meadows, N. Eng., to the uplands of Ga. A beautiful grass, very soft with whitish down. J!.

26. AI'RA, L. (Gr. aĩ a, a deadly weapon; originally applied to a poisonous grass.) Spikelets 2 -flowered, without abortive rudiments; glumes 2, membranaceous and shining, subequal; one of the flowers pedicellate; palea subequal, pilous at base, the lower one lacerate at apex and awned on the back.-Fls. in panicles of a silvery purplish hue.

5 Glumes much longer than the pales, Awns long................................ 1

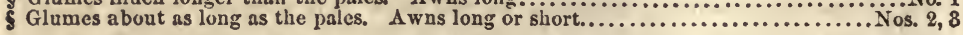

1 A. atropurpùrea Wahl. Cæspitous, a foot high; culms very slender; lvs. flat; pan. thin, with spreading branches; glumes much longer than the flowers; pales hairy at apex.-High Mits. of N. Eng. and N. Y. Aug.

2 A. flezuósa $\mathrm{I}$. Culm smooth, 1-2f high, nearly naked; lvs. setaceous, smooth, with striate sheaths and truncate stipules; pan. loose, sprcading, trichoto. mous, with long, flexuous branches; awns geniculate, twice longer than the pales. - 2f Vales and hills, U. S. and Brit. Am., common. An erect, elegant grass, growing in tufts. Jn.

3 A. cæespitòsa L. Cæspitous, glabrous; st. $18-30^{\prime}$ high; lvs. narrow-linear, scabrous above, smooth beneath, flat; panicle pyramidal, capillary, oblong, finally diffuse; awns straight, about as long as the pales, which are longer than the bluish glumes.-2f Swamps, N. States and Can. May. (A. aristulata Torr.)

27. DANTHO'NIA, DC. (In honor of $M$. Danthoine, a French botanist.) Spikelets 2-7-flowered; glumes 2, subequal, longer than the spikelet of flowers, cuspidate; paleæ hairy at the base, lower one bidentate at the apex, with a twisted awn between the teeth, the upper one obtuse, entire.

D. spicàta Beauv. St. slender, nearly erect, 12-18' high, tower lvs. numerous, 4-6' long, flat, hairy above, cauline lvs. much shorter, subulate, erect, on very short sheaths; panicle simple, spicate, short, erect; spikelets $3-8$ or 10 , about 7 flowered; glumes a little longer than the flowers; lower palea hairy, about half as long as its spirally twisted awn.-Pastures and open woods, common. June -Aug. (Avena, L.)

28. AVE'NA, L. OAt. Spikelet 2 to 5 -flowered; glumes 2 , loose and membranous, awnless, often as long as the pales; pales 2 , herbaceous, at length subcoriaceous, the lower one bifid and usually with a twisted or bent awn at the back.-Fls. paniculate.

5 ARRHENATHERUM. Gls. nnequal, 2-flowered, with a rudiment; lower fi. staminate. No. 1 AIRUPSIS. Gls. subequal, 2-flowered, with no rudiment, fls. both perfect. Dwarf..... No. 2 $\$$ IVENA proper. Gls. equal, longer than the 2 fis., and strongly striate. Cultivated.... No. 3

1 A. elàtior L. Culm $2-4 \mathrm{f}$, geniculate, smooth; lvs. lance-linear, rough on the margin and upper surface; panicle loose, equal, nodding, branches in pairs or ternate; spikelets 2-flowered; awn twice as long as the palea; upper flower $\Varangle$, mostly awnless. - if $\Lambda$ tall grass, introduced and naturalized in cultivated grounds. May, Junc. (Arrhenatherum avenaceum Beauv.)

2 A. præecox Beauv. Cæspitous; culm erect, a fow inches high; lvs. $\frac{1}{2}-1^{\prime}$ long, rough; sheaths deeply striate; panicle dense, racemous; spikelets ovate, 2 flowered, glumes as long as the flowers; lower palea with a bent awn from tho lower part of the back twice its length.-(1) N. Y. to Virg. Jn. (Aira, L.)

3 A. sativa L. Соммол OAT. Culm smooth, 2-4f high; lvs. linear-lanceolate, veined, rough, with loose, striate sheaths; stip. lacerate; panicle loose; spikelets pedunculate, pendulous, 2 -flowered, both flowers perfect, the lower one mostly awned; palece somewhat cartilaginous, closely embracing tho caryopsis.-1) A 
highly important grain, ono of the staple productions of the soil; said to havo been first discovered in the Island of Juan Fernandez.

B. NIGRA. BLACK OATs. Palece dark brown, almost black, awnless.

$\gamma$. SECUNDA. HORSE-MANE OATS. Panicle l-sided; awns short.

29. TRISE'TUM, L. (Lat. tria, three, setum, a bristle; a characteristic term.) Spikelet 2-5-flowered; glumes 2, shorter than tho tlowers; lower palea with 2 bristles at the apex and a soft, flexuous awn from above the middle of the back; scales ovate; fruit coated, furrowed.-Very closely related to Avena.

1 T. palústre Torr. Culm erect, contracted at the nodes, slender, smooth, about 2f high ; lvs. lance-linear, about $3^{\prime}$ long, roughish, on smooth, striate sheaths; panicle oblong; contracted, nodding, yellowish-green; spikelets about $3^{\prime \prime}$ long, 2-3flowered, middle flower abortive, upper one pedicellate, its lower palea ending in 2 setous teeth, and awned below the tip, lower one mostly awnless. - 2f Wet meadows, Mass., N. Y. to Fla. May-July. (Avena, Mx. Aira pallens, Muhl.)

2 T. mólle Kunth. Minuiely and softly puberulent throughout; culm If high; lrs. narrow, 2 to $4^{\prime}$ long; pan. contracted and spike-like, $2^{\prime}$ long; awn at length deflexed, longer than the beardless flowers.-Mts. and rocks, N. H. to Mich. and Can. (Avena, Mx.) Scarcely differs from tho foregoing, which is also sometimes downy.

3 T. purpuráscens Torr. Culm leafy, 2f high; lvs. narrow-linear, keeled, 4-6' long, and with the sheaths smooth ; panicle very simplo, almost a raceme, few-flowered, $4-6^{\prime}$ long; glumes 3 to 5-flowered, very unequal, entire; spikelets 6 to $8^{\prime \prime}$ long, lanceolate, terete, often purple, smooth; lower palea 7-veined, cleft into 2 bristly points at the apex; awn geniculate.-2f Mountain bogs, N. Eng. to Wis. and Can. June.

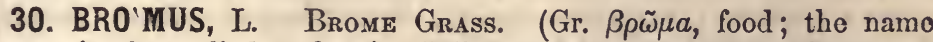
was anciently applied to Oats.) Spikelets 5 to $\infty$-flowered; glumes unequal, membranous, veined; lower pale 5 to 9 -veined, convex or carinate on the back, awned from below the mostly bifid tip; upper palo ciliate on the 2 keels, often bifid; caryopsis linear, adherent to the upper pale.-Coarse grasses with flat lvs. and large, paniculate, nodding spikelets.

5 Glumes narrow, the lower 1-veined, upper 3-veined. Pale keeled..................Nos. 6,5

8 Glumes veiny, the lower 3 to 5 , upper 5 to 7 -veined (a).

a Lower pale compressed-carinate, the awn scarcely any........................ 4

a Lower pale rounded on the back, the awn conspicuous................................. $3-1$

1 B. secalìnus L. Ssrooth Cheat on Chess. Culm smooth, 2 to $4 \mathrm{f} \mathrm{high;} \mathrm{lvs.}$ lance-linear, 6 to $12^{\prime}$ long, rough and some hairy above, on smoothish sheaths; pan. spreading in fruit, branches subsimple, with few nodding spikelets; splil. ovate, turgid, smooth, 7 to 10 -flowered; fls. soon diverging and rather distinct, oblong, longer than the short, flexuous awn.-D A handsome but worthless grass, in fields of wheat and other grains, and in waste grounds. Jn., J. § Eur.

2 B. móllis L. Dowry Chess. Culm slender, some downy, 12 to $18^{\prime}$ to $2 f$; 1vs. flat, hairy both sides, lance-linear, on sheaths clothed with deflexed hairs; pan. erect, contracted in fruit; spikelets ovate, compressed, about 6-flowered, downy all over; fls. oblong, closely imbricated, not longer than their straight awn.-(1) (2) Wheat fields and waste grounds, rare. Lower pale $\frac{1}{6}$ longer than the upper. Jn. § Eur. Varies in pubeseence. (B. racemosus L. $\beta$. arvensis, Ed. 2.)

3 B. Kálmii Gray. Culm slender, $18^{\prime}$ to $3 \mathrm{f}$; lvs. and sheaths more or less hairy, sometimes excessively so ; pan. simple, small, 3 to $4^{\prime}$ long; splil. drooping, closely. 7 to 12-flowered, densely silky all over; lower glume 3-veined, upper 5; lower pale much longer than the upper, 5 to 7-veined, the awn $\frac{1}{3}$ of its length. - 2f Dry hilly woods, U. S. and Can. Jn., J. (B. purgans Torr. nec L. fide Prof. Gray.)

4 B. unioloides Thunb. \& Kth. Rescue Grass. Culm $18^{\prime}$ to 3 f, glabrous; 
Ivs. smoothish, on sheaths more or less hairy or almost smooth; pan. large, 6 to $10^{\prime}$ long, branches subsimple, whorled; spikelets smooth, lance-ovate, much com. pressed, 2-edged, I' long, $\frac{1}{8}$ as wide, 8 to 12 -flowered; lower glume 3 , upper 5veined; lower pale 7 to 9 -veined, much larger than the strongly 2 -keeled upper, with scarcely any awn.-(1) Cultivated at the South (in 1857) from seeds distributed by the government, but proved no better than our Chess. † Peru.

5 B. ciliàtus L. Culm erect, smooth, 2 to $4 \mathrm{f} \mathrm{high;} \mathrm{lvs.} \mathrm{flat,} \mathrm{somo} \mathrm{pubescent,} 6$ to $12^{\prime}$ long, on sheaths moro or less pilous with deflexed hairs; pan. large, erect, 5 to $8^{\prime}$ long, finally nodding, branches in $2 \mathrm{~s}$ and $4 \mathrm{~s}$, compound; spikelets at first lance-fusiform, 7 to 11-flowered, the fls. soon separating; glumo lower 1, upper 3veined; pales compressed-carinate above, silky-haired near the margins, twice longer than the straight awn.-2 Damp woods along rivers, U. S. and Can. Jn., JI. (B. Canadensis Mx. B. pubescens Muhl. B. purgans, Ed. 2.)

B. PURGANS. Pan. more open; spkl. silky-hairy all over.-Mid. and S. States.

6 B. tectòram L. Culm slender, 1 to $3 \mathrm{f}$, pubescent above; lvs. pubescent; sheaths ciliato with few long hairs; pan. compound, at length 1 -sided and nodding; pedicels capillary; spikelets linear-oblong, minutely downy, about 5-flowered; glumes lower 1-, upper 3-veined; lower pale 3-veined, carinate, scarious-edged, lance-subulate, scarcely as long as its awn.-(I) N. York (Sartwell), Penn. (Jackson). (B. sterilis Torr.) $§$

31. TRICUS'PIS, Beauv. (Lat. tres, three, cuspis, a point; referring to the structure of the lower pale.) Spikelets terete or tumid, 3 to 9-flowered, upper flower abortive; glumes 2, unequal, awnless; pales 2 , the lower larger, hairy-fringed along the keel and the 2 lateral veins, and ending in 3 short cusps or mucrones (the projecting veins and midvein) and 2 intermediate teeth, upper pale 2-toothed; stamens 1 to 3 ; stigmas plumous; caryopsis smooth, free, 2-horned.-Erect, simple. Pan. mostly with racemous branches.

1 T. seslerioides Torr. FALSI RED-TOP. Culm hard and firm, glabrous, 4 to $5 \mathrm{f}$ high; lvs. glabrous, linear, involute when dry, sheaths hairy at the throat; pan. open, loose, 8 to $12^{\prime}$ long, the slender branches at length spreading; spikl. teretish, lanceolate, about 5 -flowered, purple, 2 to $3^{\prime \prime}$ long; cusps of the lower palo very short.-2f A splendid grass, in dry fields, N. Eng. to Ill. and S. States. Aug., Sept. (Poa Mx. Windsoria poæformis Nutt. Uralepis cuprea Kunth.)A variety has smaller, 3 to 5 -flowered, palo purple spikelcts and flexuous branches. Another var. has the spikelets white.

2 T. ambigua Kunth. Culm strictly erect, 2 to $4 \mathrm{f} \mathrm{high,} \mathrm{slender} \mathrm{and} \mathrm{firm,}$ glabrous as well as the linear, convolute-filiform lvs., and the sheaths which are scarce half the length of the internodes; pan. contracted, small, 3 to $5^{\prime}$ long; spike'lets few, subsessile, ovate turgid, 5 to 7 -flowered, tho fls. at length divaricate, more or less purplo. - 24 Car. to Ga. and La. Spkl, not longer, but much thicker than in No. 1. Sept. (Poa, Ell.)

3 T. strícta. Glabrous; culm slender, firm, erect, 3 to $6 \mathrm{f} \mathrm{high;} \mathrm{pan.} \mathrm{very} \mathrm{strict,}$ spike-like, dense; spkl. sessile, flat, nearly as broad as long, 7 to 9-flowered; glumes lance-linear, much longer than the pales, about as long as the spikelets.- if Miss. and La. Lrs. very long, flat. Pan. about $6^{\prime}$ long, $6^{\prime \prime}$ wide. A sirgular grass. (Windsoria Nutt.)

32. URAL'EPIS, Nutt. S SANd GRAss. (Gr. òvpá, tail, $\lambda \varepsilon \pi i \varsigma$, a scale ; a characteristic name.) Spikelets 2 to 5 -flowered, fls. distant; glumes 2 , shorter than the flowers, unequal, awnless ; pales 2 , very unequal, both conspicuously fringe-bearded along the 2 or 3 veins, the lower 2 cleft, with the midvein produced into a short, straight awn between the 2 segments; upper 2-keeled.-Culms decumbent, branched. Pan. small, the branches racemed.

1 U. purpùrea Nutt. Cæspitous; culms procumbent at base, bearded at the 
nodes $10-18^{\prime}$; 1rs. subulate, the apper ones shorter than the sheaths, hairy boneatb; pan. simple, racemons, terminal and lateral, concealed in the sheaths of the leaves, the upper one partly exsert; spikelet 3-flowered; awn of the pale about as long as the lateral, obtuse segments.-Sea coast, among the drifting sands, Mass. to Ga. Taste of the plant bitter. Aug. (U. aristulata Nutt.)

2 U. cornùta Ell. Culm $2 \mathrm{f}$ high, and with the narrow $\left(1^{\prime \prime}\right)$ leaves and sheaths hairy; pan. slender, composed of a fow small, few-flowered branches; glumes 2, subequal, very acute, purple as well as the 2 pales; upper pale longer than the glume, the midvein prolonged in an elongated, at length recurved awn bejond tho segments.-S. States. (Triplasis Americana Beauv.)

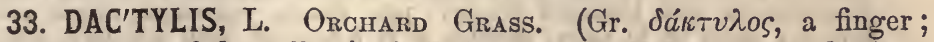
from the form of the spikes.) Spikelets aggregated, compressed, 3-5flowered; glumes unequal, herbaceous, the larger one carinate, shorter than the flowers; paleæ subequal, lanceolate, acuminate, the lower one emarginate, carinate, mucronate, upper bifid at apex; scales dentate.Lvs. carinate. Pan. composed of dense clusters.

D. glomeràta L. Culm roundish, 2-4f; lvs. linear-lanceolate, carinate, a little scabrous, glaucous; sheaths striate; stip. lacerate; pan. remotely branched, rather secund; spikelets about 4-flowered, in dense, glomerate, unilateral, terminal clusters; glumes very unequal; anth. large, yellow. - 2f. A fine, well-known grass, of rapid growth, introduced in shady fields, as orchards, \&c. June. § Eur.

34. KELE'RIA, Pers. (In honor of $M$. Koler, a German botanist.) Spikelets compressed, 2 to 7-flowered; glumes 2, subequal, acute or acuminate, shorter than the flowers; upper flower pedicellate; pales 2, the lower often acuminate-mucronate. $2 \digamma$-Grasses cæspitous, erect, simple, with dense panicles.

K. cristàta Smith. Culm 20-30' high, smooth, leafy to one-half its height, rigidly erect; lrs. flat, erect, pubescent, $2-3^{\prime \prime}$ by $1-2^{\prime \prime}$, shorter than their pubescent sheaths; stip. short, lacerate; panicle spicate, narrow, $3-5^{\prime}$ long, $6-8^{\prime \prime}$ diam., branches very short; spikelets $2^{\prime \prime}$ long, silvery and shining, compressed, about 2-flowered, with an abortive pedicel; glume linear-oblong, acute, serrulato on the keel, upper one longer. - Mid., W. States and Can. $-\Lambda$ variety (K. nitida Nutt.), is smaller and more delicate.

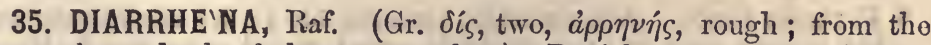
two scabrous keels of the upper palex.) Panicle racemous or simple; glumes 2, very unequal, $2-5$-flowered, rigid, acuminate, mucronate; paleæ cartilaginous, lower cuspidate, upper much smaller, emarginate; caryopsis coated, as long as the upper pale; scales ovate, ciliate.

D. diándra. Culm erect, nearly leafless, slender, rigid, $15-30^{\prime}$; lvs. few, subradical, broadly linear, flat, rough-edged, $10-16^{\prime}$ by $5-7^{\prime \prime}$, nearly glabrous; sheaths close; stip. obsolete; panicle very simple and slender, branches erect, few, spikelets 2-flowered; glumes broad-ovate, upper twice larger, 5-veined; pales much longer than the glumes, the upper with 2 roughish, green keels, and conspicuously mucronate; sta. 2 ?-River banks, Ohio to Ill. (D. Americana Beauv. Festuca Mx.)

36. FESTU'CA, L. FrScUe Grass. (The ancient Latin name.) Spikelets 3 to $\infty$-flowered; glumes 2 , unequal, mostly carinate; pales firm, naked, the lower rounded (not carinate) on the back, obscurely veined, acute, or mucronate, or awned; stamens 3 , rarely 1 or 2 ; stigmas plumous; caryopsis linear-oblong, mostly adherent to the upper pale.--Spikelets in racemes or panicles, the fls. remote, not webbed at base. 
Fls. awned_-Awns conspicuous, about equaling or exceeding the pales.............. Nos. 1, 2 -Awns much shorter than the lanceolate pales.......................... Nos. 8,4

Fls. awnless. - Panicle cuntracted, with short, ascending branches................ Nos. 5, 6

- Panicle very. loose, with spreading or retlexed branches....................... 7,8

1 F. Myùrus I. Culm 6-12' long, erect, geniculate near the base; lvs. 2-3' long, subulate, concave; stip. bifid or retuse; panicle slender, crowded; spikelets 4-6-flowered; glumes minute, equal; fls. subulate, hairy; lower pale with an awn twice its length; sta. 1 ; stig. plumous, white.- D Sandy fields, Car. to Ga. Mar., $\Lambda \mathrm{pr}$.

2 F. tenélla Willd. Slender Fescue. Culm filiform, wiry, often growing in tufts and geniculate at base, $6-12$; lvs. erect, linear-setaceous, $2-3^{\prime}$ long; sheaths subpubescent, with lacerated stipules; pan. simple, contracted, rather secund, branches alone or in pairs; spikelets 6 to 9-flowered, with subulate, subequal glumes, at length brownish; fls. subulate, their awns of about equal length.-1) Sandy fields, N. Eng to Ill. and S. States.

3 F. ovina L. SHEEP's Fescue. Culm erect, asceuding at base, $6-10^{\prime}$; lvs. very narrow, rough, radicai ones very numerous, $2-4^{\prime}$ long, cauline few, short, erect; pan. few-flowered, simple, contracted; spikelets ovate, about 4-flowered; pale lance-ovatc. - 4 A valuable grass for pasturage. Jil. \& Eur.

$\beta$. vivípar.. Glumes and pales changing to leafy tufts.-Mts.

4 F. duriúscula L. HARD Fescue. Culm smooth 12-18'; lvs. linear, very acute, a little scabrous; stipules membranaceous, lacerate; pan. oblong, spreading, inclining to one side, branches in pairs; spitelets nearly terete, 5-7-flowered; lower glume smaller, upper one 3-veined; palex unequal, lower with short awns. -24 Fields and pastures. A fino grass, common, Car. to Can. June, July.

$\beta$. RUBRA. Spikelets 7 to 11-flowered; herbage often tinged with red.-Dry fields, eastward.

5 F. praténsis Huds. Meadow Fescue. Culm smooth, 3-4f high; lrs. lance. linear, smooth, rough-edged, a foot long, on smooth, loose sheatlis; panicle subcrect, branches short, in pairs, ascending; spikelets lance-ovate, acute, 6 to 9-flowered, 6-9" long, racemous on the branches; lower glume shorter; lower palex acuminate or mucronate.-A fine grass, in meadows, U. S. and Can. Jn. $\S$

6 F. elàtior L. Tall Fescue Grass. St. smooth, 2-3f high ; lvs. lance-linear, veined, smooth, rough-edged, about $8^{\prime}$ long; sheaths veined, smooth with obsolete stipules; panicle branched, erect in flower, spreading, somewhat 1-sided, branches subsolitary, spikelets short, alternate somewhat secund, 2 to 5 -flowered, about 3 " long; pales smooth, chartaceous, barely acute.-Ficlds and meadows. Jn., Jl. §

7 F. rígida Kunth. Culm decumbent, ascending 3 to $5^{\prime}$; lvs. much shorter, subulate, involute when dry; pan. subsimple, secund, an inch or two long, the branches alternate, appressed; spikelets lance-linear, 5 to 9-flowered; fls. acutish, terete, purplish.-In dry soils, Car., near the coast. Plant dwarf and rigid. Apr., May.

8 F. nùtans Willd. Nodnivg Fescue. Culm erect, slender, smooth, with black nodes, about $3 f$ high; lvs. narrow-linear, a foot long, veined; panicle sleuder, diffuse, at length nodding, and the slender branches deflexed; spikelets lance-ovate, 3-5flowered; fls. smooth, awnless and nearly veinless. - 2f Open woodlands, in most of the States. June. (F. Shortii Kunth., when the grass is stouter and the spikelets about 5 -flowered.)

37. EATO'NIA, Raf. (Dedieated to Prof. Amos Eaton, the wellknown author of the "Manual of Botany," which bears his name.) Spikelets mostly 2-flowered, numerous, paniculate, silvery ; glumes 2, very dissimilar, the lower linear, 1-veined, upper broadly obovate, obtuse or abruptly pointed, 3 -veined, with broad, scarious margins ; pales obtusish, awnless, chartaceous, glabrous; caryopsis oblong.-4 Smooth and delicate grasses with simple, eæspitous culms.

E. obtusàta Gray. Culm erect, geniculato below, leafy, 1 to $2 f$; nodes pubescent, blackish, contracted; 1rs. 3 to $6^{\prime}$ by $2^{\prime \prime}$, scabrous, acuminate, shorter than the sheaths; stip. lacerato; pan. contracted, 3 to $5^{\prime}$ long, 6 to $12^{\prime \prime}$ diam., dense, branches fascicled, short, appressed; spikelets $1 \frac{1}{2}$ "long, 2-tlowered, tumid; lower 
glume about as long but very much narrower than the obovate, obtuse, puberulent upper one; pales scarious at summit, a little exserted.-Penn. (Jackson) to Wis. (Lapham), and S. States. Jn., Jl. (Aira, Mx. A. truncata Muhl. Kœ. leria Torr., and Ed. 1. R. paniculata Nutt. Reboulea, Kunth. E. purpuras. cens Raf.)

2 F. Pennsylvánica Gray. Erect, tufted, minutely puberulent, usually about 2f high ; lvs. flat, short, 1 to $3^{\prime}$ by $2 \frac{1}{2}^{\prime \prime}$; pan. slender, open, usually with diverg ing branches, and 5 to $10^{\prime}$ long; spikelets rather loose, $1 \frac{1}{2}$ "long; upper glumo abruptly short-pointed; pales acutish, exserted half their length.-Rocky woods and meadows, U. S. and Can., frequent but not abundant. The larger varieties are very elegant. Jn., Jl. (Aira mollis Muhl. Kœleria DC. Reboulea, Kunth., Gray.)

38. MEL'ICA, L. Melic Grass. (Lat. mel, honey.) Glumes 2, unequal, membranous, obtuse, 2 to 5 -flowered ; flowers a little longer than the glumes, the upper incomplete and more or less contorted; pales truncate, veiny, as well as the glumos; caryopsis free, not furrowed.-Lvs. flat. Spikelets pedicellate, in a subsimple panicle.

M. mùtica Walt. Culm $3-4 \mathrm{f}$ high, glabrous; lvs. linear, flat, pubescent beneath; stip. lacerate; paniclo glabrous, loose, few-flowered, erect or a little nodding, branches simple, solitary; spikelets $6-8^{\prime \prime}$ long; lower glume shorter, very smooth; palex veined; upper fl. neuter, pedicellate, consisting of very short, roundish pales often twisted together. $-2 f$ Rich upland soil, Penn. to Wis. and S. States. Varies, with a paniclo reduced to a mero raceme. Jn. (M. glabra MLx. M. speciosa Muhl.)

39. ERAGROS'TIS, Beauv. Spikelets 5 to $\infty$ (rarely fewer)-flowered, compressed ; glumes and fls. membranous; lower pale carinate, 3 -veined, not webbed, upper pale persistent on the flexuous rachis after the free caryopsis has fallen with the lower.-Hairy or roughish grasses with involute lis., sheaths at throat and axil of branches often bristly and fls. in panicles, the branches mostly scattered. (Poa, L.)

\$ Spikclets few-flowered (fis. 2 to 4 , rarely more).............................. 10 , 9, 8 S Spikelets many-flowered (fls. 5 to 30 ). (b)

b Panlcle diffuse, capillary, longer than the rest of the culm.............Nos. 7, 6, 5

b Panicle contracted, rather dense. - Culms decumbent below................... Nos. $4,3,2$

-Culms procumbent, creeping................ No. 1

1 E. reptans Nees. Culm branched, creeping, rooting at the joints, 6-12'; lvs. subulate, flat, $2-3^{\prime}$ long; sheaths open, pilous on the margin and throat; pan. 1-2' long, branches short, simple, in fascicles, few-flowered; spikelets linearlanceolate, with 12-20 acuminate flowers.--(1) On sandy banks of rivers, N. Y. to $\mathrm{Ky}$. and La. Jl, Aug.-The plant is somewhat diœcious.

2 E. pozoìdes Beauv. Culm oblique or decumbent, geniculate, 1-2f long; Ivs. lanceolate, attenuate at end, scabrous on the margin and above; sheaths pilous at the throat; stip. short, bearded; panicle expanding, branches subdivided, flexuous, subpilous in the axils; spikelets ovate-oblong, 12-20-flowered; glumes nearly equal. - (1) A fine-looking grass, fields and waste grounds, common. Jl., Aug. §Eur. It has a strong, peculiar odor. Varies much; the later growths aro in more denso tufts, with smaller spikelets. (E. megastachya Ik. P. Eragrostis L.)

3 E. pilòsa L. Culms in tufts, geniculate, ascending, 6 to $12^{\prime}$; 1vs. narrow-linear, or subulate, short; sheaths slightly bearded at the throat; pan. oblong, some of the middle branches opposite; spikelets linear, bluish, about as long ( 3 to $\left.4^{\prime \prime}\right)$ as the pedicels, 6 to 12-flowered, the rachis at length becoming pectinate or serrulate with the persistent upper pales.-(1) In sandy or gravelly waste places, Conn. to Ga. and W. States. Jl., Aug. § Eur. (E. peotinacea NIx., a more appropriato name, as the plant is scarcely pilous.)

4 E. conférta Trin. Culm rather stout, geniculato below, branched, 2 to $3 f$; lvs broad-lanceolate, rough, llat, and sheaths naked; pan. long ( 5 to $\left.12^{\prime}\right)$, narrow, branches and branchlets very numerous, suberech, each racemous with the small, 
numerous spikelets which are 7 to 11 -1lowered and only $11_{2}^{\prime \prime}$ long; pales hyaline, ovate, pointed, 3-veincd. - (1) Car. to Ga. and La. (Poa conferta Ell.) The 2 pales fall together.

5 E. nitida. Culm erect, glabrous and polished as well as the whole plant, 12 to 20 . Lvs. long, linear, involute when dry, with a few hairs at top of sheath; pan. diffuse, much longer than the culn; spikelets lanceolate, about 8-flowered, hyaline glumes and pales sharply serrulate on the keel.-(1) S. Car. and adjacent islands. Jn. - $\Lambda$ ug. (Poa nitida Ell.)

6 E. hirsùta. Culm subsimple, compressed, crect, 1-2f; lvs. lance-linear, attenuate at end, surpassing the stem, hairy at base; sheaths loose, longei than the internodes, lower ones hairy, upper ones smooth; stip. fringed; panicle very large, capillary, branches spreading, reflexed in fruit, hirsute in the axils; spikelets oblong, 2 to $3^{\prime \prime}$, purplish, 5 to 16 -flowered, long pedicelled; pale ovate, acute, distinctly 3-veined, upper ciliate.-2f Sandy fields, U. S. Jl., Aug. The rachis never (?) becomes pectinate. (Poa hirsuta Mx.) - Varies with the lrs. and sheaths nearly smooth and spikelets larger (P.spectabilis $\mathrm{Ph}$.) Also with the whole panicle, except the spikelets, hirsute like the axils. And thirdly, with the spikelets racemously appressed along the branchlets (P. refracta Ell.)

7 E. Púrshii Schrad. Culm decumbent at base, ascending 6 to 12 or $20^{\prime}$; lvs. subulate, 1 to $3^{\prime}$ long, upper surface rough; sheaths very hairy at throat; pan. long and loose, the lower branches, or all, hairy in their axils; ped. capillary, longer than the spikelets which are lance-oblong; 5 to 12 -flowered; pales merely acute, purplish.-(1) Dry fields, Md. to Ga., common. Jl., Aug. (P. tenella? Ph. Eil.)

8 E. capillàris Nees. Culm branched at base, smooth, 1 to $2 f$; lvs. linear, attenuated above, flat, smooth; sheaths striate, with long hairs about the throat and margin; stip. short: pan. very large (near a foot long) with diffusely spreading, capillary branches, axils not bearded, or the lower slightly; spikelets ovate, acute, about 3-flowered, on rather rigid, long, capillary pedicels; pales scabrous, $3^{3 \prime \prime}$ long, acute, the 2 side veins scarcely visible. -Dry grounds, U. S. Aug.

9 E. trichodes. Culm simple, 12 to $20^{\prime}$, erect; lvs. long (10 to $\left.18^{\prime \prime}\right)$, rough, thinly hairy, as well as the sheaths, throat with long hairs; pan. rather longer than culm, narrow, capillary, only the lower axils bearded; spikelets not colored, 2 to 5 (mostly 3)-flowered; pales and gls. hyaline, distinctly 3-veined, lanceolate, $1_{2}^{1}{ }^{\prime \prime}$ long. - 2f Sandy soils, S. and W. States. (P. trichodes Nutt. P. tenuis Ell.)

10 .. . erythrógona Nees. Culms very branching, in tufts, ascending 3 to $10^{\prime}$; joints a narrow red ring; lvs. narrow, convolute when dry, the upper about equaling the oblong, rather dense panicle; spikelets 2 to 5 (mostly 3 )-flowered, 1 to $11^{\prime \prime}$ long, bluish; gls. lanceolate; pales ovate, all acute and nearly veinless.-1) Wasto and cultivated grounds, Penn. (Jackson) to IIl. and South. Whoie plant bluish.

40. PO'A, L. Spear Grass. Meadow Grass. (Gr. tóa, grass.) Spikelets 2 to 5 (rarely 9 )-flowered, compressed; glumes subequal, pointless, shorter than the contiguous flowers ; pales herbaceous, soft-awnless, the lower compressed-carinate, 5 -veined, usually clothed on the veins below with a cobweb-like, matted wool, the upper pale bicarinate; stigmas simply plumous; caryopsis free.-Smooth grasses with soft flat lrs., the fls. paniculate.

I Branches of the panicle in $2 \mathrm{~s}$, $3 \mathrm{~s}$, or often single. (*)

* Flowers not webbed, merely pubescent on the back. (a)

a Annual. Panicle dense with subsessile spikelets.........................

a Perennial. Panicle loose, spikelets long-pedicellate............................... 1

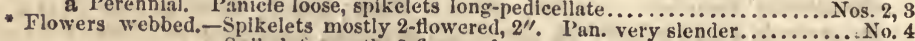
-Spikelets mostly 2-flowered,-many, paniclo diffuse.................. 5,6 -few (4 to $\mathrm{s}$ ). Mountains................ 7

I Branches of the panicle in about $5 \mathrm{~s}$, half-whorled. (b) b Spikelets 2 to 4 -flowered

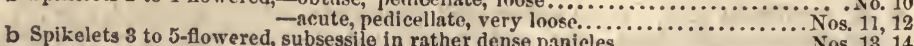

1 P. ánnua I. ANwual Spear Grass. Culms decumbent and rooting at the 
base, compressed, 3 to $8^{\prime}$; lvs. lance-linear, short, smooth, carinate, on loose, glabrous sheaths; stip. oblong, dentate; panicle spreading, the branches generally solitary, at length horizontal ; spikelets ovate-oblong, rather numerous, containing about 5, loose flowers.- (1) A small, abundant, annual grass, Can. and U. S., forming a dense, soft and beautiful turf. May-Sept.

2 P. flexuòsa Mulıl. Culm erect from a tufted base, 12 to $20^{\prime}$; Ivs. 2 to $5^{\prime}$ by $1 \frac{7}{2}$ to $2 \frac{1}{2}^{\prime \prime}$, gradually acute; upper half of the culm naked, bearing a thin, open pan.; branches mostly in pairs, filiform, often flexuous, long (2 to $3^{\prime}$ ), with the few pedicellate spikelets at the end; fls. 3 or 4, lanceolate, scarious-pointed, pubescent but not webbed at base, the gls. about as long $\left(2 \frac{1}{4}{ }^{\prime \prime}\right)$. - - $f$ Woods, Va., $\mathrm{Ky}$. to Ga. Spikelets not purplish. Apr.-Jl. (P. autumnalis Muhl.)

B. SCARtòsa. Fls. of the spikclet 4 to 6 , narrowly lanceolate, remote, nearly glabrous, with conspicuously scarious (blunt) points.-E. Tenn.

3 P. hexántha. Culm weak and slender, 18 to $24^{\prime}$, erect from tho decumbent lower joint; lvs. 3 to $5^{\prime}$ long, very gradually attenuated, the upper reaching the panicle which is very open, the branches in pairs, long $\left(2\right.$ to $\left.4^{\prime}\right)$, bearing the longpediceled spikelets near the end; spikelets oblong $\left(4^{\prime \prime}\right)$, mostly 6 (5 to 7)-flowered, fls. remote, oblong, villous (not webbed) at base, very obtuse and compressed at the scarious apex.- 2f Found at Atlanta, Ga., in meadows, perhaps a foreigner. Spikelets few but large. Jn.

4 P. dinántha. Culms in dense tufts, very slender, $18^{\prime}$ to $2 \mathrm{f}$, from fibrous roots ; lvs. narrowly linear, about $3^{\prime}$ by $1^{\prime \prime}$, soon reflexed, sheaths rather shorter; ligulo short, truncate; pan. very slender and few-flowered, branches erect, very few, solitary or 2 together; spikelets 2 or 3 (mostly 2)-flowered; fls. acute, obscurely veined, smooth, except the copious web at base, the acuto glumes much shorter. -Fields, Montgomery, Ala. May, Jn.

5 P. brevifòlia Muhl. Culm compressed, 1 to 2f; lvs. of the culm about 2, flat, oblong; cúspidate and pungent, lower about $1^{\prime}$ long, upper $6^{\prime \prime}$, root lvs. long and narrow, all erect, keeled and pungent at the point; ligule truncale, lacerato; sheaths nearly as long as the nodes; pan. loose, branches filiform, in pairs ; spikelets ovate, 3 to 4 -flowered; fls. rather obtuse, $21_{4}^{\prime \prime}$ long, slightly webbed. 2f Penn. (Jackson) to Va. and Ill. Spikelets often tinged with purple. Apr., May. (P. pungens Nutt. P. cuspidata Bart.)

6 P. débilis Torr. Culm erect $18^{\prime}$ to $2 \mathrm{f}$; lvs. lance-linear, flat, gradually acute; ligule oblong, acute; pan. loose, few-flowered, somo spreading, branches mostly in pairs, flexuous; spikelets ovate, obtuse; 3 (rarely 2)-flowered; fls. very obtuse, $1 \frac{1}{2}$ "long, faintly 3 -reined, webbed at baso; palea green; glumes ovate, acute. Rocky woods, Conn. to Ill.

7 P. láxa Hœnke. Culm cæspitous, $6-8^{\prime}$; lvs. linear, acute, erect; stip. lanceolate; pan. 1-2' long, contracted, nodding, branches mostly in pairs, smooth, flexuous; spikelets $21_{2}^{\prime \prime}$ long, ovate, 3 -flowered; fls. often purple, acute, hairy, somewhat webbed at base; glumo lance-ovate, slightly scabrous on the keel; lower palea hairy below, upper rough-edged; anth. violet.-2f Mountains N. Eng. and N. Y. to Arc. Am:

8 P. alpina L. Culms erect, $6^{\prime}$, from fibrous roots; lrs. short, broadly linear, obtuse, lower with short, truncate ligules, upper with oblong, acute ones; pan. equal-sided, erect, ovate or oblong, loose, the branches in pairs, spreading, with rather large, ovate, short-pediceled, 5 (4 to 9)-flowered spikelets; fls. ovate.Can. West and high northward. Jn.

9 P. compréssa. BLUE Grass. Culm decumbent and rooting at base, much compressed, 12-18'; lvs. linear, short, bluish green; sheaths rather loose, with a short, obtuse stipule; pan. contracted, $3^{\prime}$ by $1^{\prime}$ or less, somewhat secund, branches very short, in $2 \mathrm{~s}$ and $3 \mathrm{~s}$; spikelets ovite-oblong, flat, 3 to 7 -flowered, subsessile, fls. rather obtuse, webbed. A valuable grass, with sweet and nutritious herbage, propagating itself everywhere (Va., Tenn., northward) in woods, pastures and meadows. May, Jn. (a month later than P. pratensis).

10 P. sylvéstris Gray". Culm erect, compressed, 2 to $3 \mathrm{f}$; Irs. flat, soft, 3 to $6^{\prime}$ long, 1 to $2^{\prime \prime}$ wide, gradually attenuated; ligules blunt; pan. oblong-pÿramidal, thin, branches in $5 \mathrm{~s}$ or more, flexuous, 1 to $2^{\prime}$ long, spikelets ( $\left.2^{\prime \prime}\right)$ pedicellate, broad-ovate, 2 or 3 -flowered; fls. oblong, obtuse, copiously webbed.-Rocky woods. 
Wis. to Ohio, S. to Miss. and Ala. Upper half of culm naked. Pan. 4 to $66^{\prime}$ by 2 to $3^{\prime}$. Apr. (South) to Jn.

11 P. seròtina Ehrh. Meadow Redtop. Four Meadow. Culm erect, weak, 2 to $3 f$; lvs. narrowly-linear, flat, 10 to $15^{\prime}$; ligules elongated $\left(2\right.$ to $\left.3^{\prime \prime}\right)$, lacerate; pan. $\left(6^{\prime}\right.$ to $10^{\prime}$ or $12^{\prime}$ by $2^{\prime}$ to $\left.4^{\prime}\right)$, branches in $5 \mathrm{~s}$, flexuous, capillary; spikelets all pedicellate $\left(1 \frac{1}{2}\right.$ to $\left.2^{\prime \prime}\right), 2,3$, rarely 4 -flowered; fls. webbed, acute, tawny red at apex, or at length colored throughout.-Wet meadows and woods, common in the N. States and Can. Jn.-Aug. Varies with the spikelets all 2-flowered and colored, on the diffuse, capillary branches (in woods and swamps), or all 3 or moreflowered, branches suberect.-Makes excellent hay.

12 P. nemoràlis L. WoOd Spear Grass. Culm slender, 2-3̂f; lvs. narrowlinear, pale green, smooth as well as the sheaths; ligules scarcely any; pan. 6-10' long, slender, nodding when in fruit, branches capillary, flexuous, in $5 \mathrm{~s}(2 \mathrm{~s}$ to $5 \mathrm{~s})$; fis. very acute; spikelets ovate, about 3-flowered, spreading and at length remote, slightly webbed at base.-2f A tall thin grass, in wet, open woods, N. Eng. to Wis, and Can. Jn., Jl.

13 P. triviàlis L. Rougn MEadow Grass. Culm sometimes stoloniferous at base, roughish backwards, 2-3f; lvs. lance-linear, acute, rough-edged, lower ones very long, cauline as long as tho roughish sheaths with long, acuminate ligules; panicle diffuse, expanding, scabrous, branches 4-5 together in half-whorls; spikelets oblong-ovate, $2-3$-flowered.- 4 N. States. June, July.

14 P. praténsis L. Spear Grass. June Grass. Culm terete, smooth, 1-2f; lvs. carinate, linear, abruptly acute, radical ones very long and numerous, cauline shorter than the veined, smooth sheaths; lig. short, truncate; pan. diffuse, branches 3-5 together in half-whorls; spikelets ovate, acute, with about 4, acute flowers; glumes lanceolate, rather acuminate. -24 An excellent grass both for hay and pasturage, very abundant. Apr. (South) May (West) Jn. (North.)

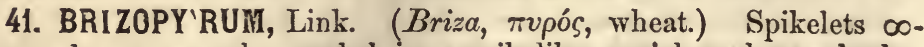
flowered, compressed, crowded in a spikelike panicle; glumes herbaceous, unequal; pales awnless, subcoriaceous, lower compressed, but not carinate, faintly many-veined, acute.-Lvs. mostly involute, smooth and rigid.

1 B. spicàtum Hook. Culm branched at base, erect 1 to $2 \mathrm{f}$; cauline lvs. numerous, 3 to $6^{\prime}$ long; sheaths longer than the joints, close, upper ones hairy at throat; spike-like pan. oval, yellowish, consisting of short, fasciculate branches with sessile spikelets; spkl.oblong, 5 to 9-flowered; fis. triandrous.- Salt marshes, N. Y. to Car. Jl. (Uniola ed. 2. Poa Michauxii Kunth.)

42. GLYCE'RIA, Brown. ManNa Grass. (Gr. $\gamma \lambda v \kappa v ́ s$, sweet, on account of the sweet taste of the grains.) Spikelets many-flowered, teretish or turgid, rachis jointed; glumes subequal, pointless; pales awnless, webless, herbaccous, the lower usually 7-veined, rounded on the back (not carinate); stigmas doubly plumous; ovary smooth, grain free. $-2 f$ Smooth grasses from creeping rhizomes in wet places, with simple panicles. Sheaths mostly fistular (not split).

\$ Salt marsh Grasses. Lower pale 5-veined. Stigmas sessile, simply plumed.......Nos. 9, 10

In fresh swamps, sc. Lower pale 7-veined. Stigmas doubly plumous. (a)

a Spikelets linear-lanceolate, in a very simple panicle............................Nos. 1, 2

a Spikelets linear-oblong, in compound, spreading panicles.......................... 3 , 4

a spikelets ovate, short, turgid, - in slender, appressed panicies................... -in an open, recurved panicle....................... Nos. 7,8

1 G. Huitans Brown. Culm compressed or ancipitous, ascending at base, $3-5 f$; lvs. lance-linear, smooth beneath, about a foot long; sheaths veined, smooth, with a very large stipule; panicle secund, long, slender, slightly branched; spikelets 8 to $10^{\prime \prime}$ long, linear, appressed, 7 to 12-flowered; fls. obtuse; lower pale 7. veined, denticulate.-2 Swales, \&c. Can., N. States to La Jn, JL. (Festuca fluitans, I.)

2 G. acutiflora Torr. Culm somewhat compressed, 1-2f; lrs. narrow, atten. 
uated above, half as long as the stem; panicle simple, long, raceme-like, appressed; spikelets linear, 9 to $12^{\prime \prime}$ long, 4-6-flowered; distant fls. very slender, acute, indistinctly veined. - 4 Inundated meadows, N. Eng., N. Y. June. (Festuca brovifolia Muhl.)

3 G. aquàtica Smith. Culm stout, leafy, 4 to $5 \mathrm{f}$; lvs. broad-linear, flat, thin; pan. erect, diffuse, branches at length spreading, flexuous, 3 to 5 together, in half whorls; spilielets linear-oblong, purple, 2 to $3^{\prime \prime}$ with 6 to 8 ovate-obtuse flowcrs.-2f Wet meadows, N. States and Can. A large and handsome grass, cultivated for hay in Eur. (Poa, L.)

4 G. pállida Trin. Culm weak decumbent, ascending 1 to $2 \frac{1}{2} \mathrm{f}$; lvs. flat, linear, 10 to $16^{\prime}$ long, glaucous beneath; stip. clongated; pan. loose, few-flowered, branches capillary, spreading; spikelets $3^{\prime \prime}$, oblong-linear, 5 to 9 -flowered; lower glume 3-veined; lower palea 5-veined, 5-toothed at the apex when old.-26 Swamps, Can. to Va. and West? June, July. (Poa dentata Torr.)

5 G. nervàta Trin. Culm smooth, 3 to $4 \mathrm{f}$; Ivs. lance-linear, striate, rough above, about a foot long, on striate, roughish sheaths; lig. lacerate; pan. large, loose, diffuse, equal, branches weak, pendulous in fruit, long and capillary, in $2 \mathrm{~s}$ or $3 \mathrm{~s}$; spikelets ovate-oblong, containing about 5 , obtuse, conspicuously 7 -veined flowers. - 2f A valuablo grass in wet meadows, N. Eng. to Ill. Jn. (Poa, Willd.)

6 G. elongàta Trin. Culm round, erect, smooth, 3f; lvs. narrow-linear, smooth, 8 to $15^{\prime}$ long; sheaths striate, smooth; lig. very short; pan. $\left(8\right.$ to $\left.10^{\prime}\right)$ elongated, raceme-like, nodding, branches solitary or in $2 \mathrm{~s}$, appressed; spikelets ovate-obtuse, tumid, containing about 3 obtuse, 5-veined flowers. - 2f Wet meadows, N. Eng. to Penn. and Ill. Jl. (Poa, Torr.)

7 G. obtùsa Trin. Culm smooth, firm, 2 to $3 \mathrm{f}$; lrs. dark green, linear, often surpassing the culm, and with tho sheaths smooth; pan. dense, ovate, many-flowered, 3 to 4'; erect; spikelets ovate, acute, tumid, thick, containing 5 to 7, smooth, ovate, obtuso flowers; lower palo obscurely 7-veined._-2f Swamps, N. Eng. to Penn. Aug., Sept. (Poa, Muhl.)

8 G. canadénsis Torr. Culm round, smooth, erect, 3 to $4 \mathrm{f}$; lvs. broad-linear, rough, glaucous, on smooth sheaths; lig. lacerate, ovate-obtuse; pan. large, 6 to $8^{\prime}$ long, branches flexuous, in half whorls, much spreading or pendulous in fruit; spikelets short, ovate, tumid, 6 to 8-flowered; glumes much shorter than the lower flower; upper pale very obtuse, lower about 7-veined; stam. 2.-2f $\Lambda$ large grass, in shady grounds, N. States, Can. Jl., Aug. (Poa, Torr.)

9 G. marítima Wahl. Culm somewhat geniculate, round, about a foot high; lvs. somewhat glaucous, rough-edged, involuto; pan. erect, dense, branches in pairs, scabrous; spikelets terete, linear, purplish, about 5 -flowered; fls. obtuse, indistinctly 5-veined.-2 Salt marshes, Mass. Jn. (Poa, Huds.)

10 G. distans Wahl. Very smooth; culm firm and leafy, oblique, round, branched at base, 1-2f; lvs. flat, lance-linear; pan. spreading, branches fasciculate, in $3 s$ to $5 s$, crowded, straight; spikelets oblong, somowhat racemed, sessile, crowded, about 3-flowered; glumes minute, unequal.-2f Salt marshes, N. Y. (Poa fasciculata Torr.)

43. BRI'ZA, L. Quaking Grass. (Gr. $\beta \rho i \zeta \omega$, to nod, as in sleep; alluding to the pendulous spikelets.) Spikelets cordate, 6-9-flowered; glumes 2, shorter than the lower flowers; palex ventricous, lower one cordate at base, embracing the upper which is suborbicular and much shorter; caryopsis beaked.-Paniculate spikelets large, drooping on slender pedicels.

I B. media L. Culm naked above, 1-2f; lvs. flat, smooth, lance-linear; stip. short, obtuse; pan. erect, few-flowered, branches wide-spreading, capillary, purplish, bearing the ovate cordate, tumid, pendant and tremulous spikelets at the ends, these are about 7-flowered, greenish-purple; paleæ veinless.-2f Meadows and pastures, coastward, N. Eng. to Penn. May. § Eur.

2 B. máxima L. Pan. nodding at the summit; spikelets oblong, cordate, 23 to 17-flowered. - (1) Gardens, occasionally cultivated as ornamental. + + Eur. 
44. UNIOLA, L. Union Grass. (Diminutive from Lat.unus, one; many flowers in one spikelet.) Spikelets compressed, 2-edged, 3 to 20 -flowered; lower flower or fls. neutral, of one pale; glumes 2, carinate; lower pale flattened and wing-keeled, the upper double wingkeeled, both awnless; stam. 1 or 3 ; caryopsis free. $-2 f$ Smooth, erect, flat-leaved grasses.

5 Spikelets on slender pedicels, large, elliptic. Pales unequal. Stamen $1 . . . . . \ldots$ No. 1 \$ Spikelets subsessile, - large $\left(6\right.$ to $16^{\prime \prime}$ long). Pales about equal....................... 2,3

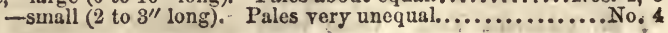

1 U. Iatifolia MIx. Culm 2 to 4f, smooth, subsimple; lvs. 8 to $18^{\prime}$ by 6 to $12^{\prime \prime}$, lance-linear, glabrous, rough-edged; sheaths longer than the internodes; paniclo loose, 8-12' long, nodding; spikelets all on long peduncles, about $10^{\prime \prime}$ long, ovate, flat, about 10 -flowered; glumes unequal, near twice shorter than the fls. Dry woods, middle and Western States. Singularly elegant and showy. Aug.

2 U. paniculàta I. SEA-SIDE OATS. Culm 4 to $8 \mathrm{f}$; 1vs. narrow, convolute, very long; sheaths fringed at the throat; pan. large and spreading; spikelets ovate, short-pediceled, 12 to 20-flowered, several of the lower fls. neutral; pales about equal; the lower 9-veined, obtuse; stam. 3.- Sand hills along the coast, Va. to Fla. A tall rank grass. Jl., Aug.

3 U. nítica Baldw. Culm very slender, wiry, branched below, 2 to $5 \mathrm{f}$; lvs. narrow, 2 to $4^{\prime \prime}$ wide; pan. slender and spike-like or with several spike-like spreading branches; spikelets subsessile, broader than long, about 7-flowered, the 2 or 3 lower and the 1 highest abortive; pales about equal, long-pointed, the upper re-incurved at base; stam. 1. Ga. to La. Whole plant very smooth and shining. Jn., Л.

4 U. grácilis Mx. Culm slender, leafy, 3 to 4f; lvs. broadly-linear, tapering to a slender point, flat, 12 to $18^{\prime}$ long; sheaths shorter than the joints; pan. long racemous, branches solitary, short, remote, erect; spikelets with about 3 fertilo fls.; lower pale spreading, $\frac{1}{3}$ longer than the upper; glumes rigid, acute.-Seacoasts, N. Y. to Ga. and La. Aug.

45. PHRAG'MITES Trin. REED. Spikelets 3 to 6-flowered, tho lowest flower sterile and monandrous; rachis beset with long, silky hairs; glumes 2, acute, keeled, very unequal ; lower pale subulate, silky-villous at base (except in the lowest flower); stam. 3 ; style 2 ; caryopsis frec. $-2 f$ Grasses tall, with broad, flat lvs. and a large, diffuse panicle.

P. commùnis Trin. Culm smooth, stout, erect, 6- $12 \mathrm{f}$ high, often an inch in diameter at base; lvs. lanceolate, $1-2 \mathrm{f}$ by $1-2$ ', rough-edged, smooth and glaucous; panicle large and loosely branched, branches in half whorls, rather erect, slender; spikelets 3-5-flowered, very slender, erect; glumes shorter than the flowers which are of a dark hue, with tufts of white, silky hairs, about as long as the paleæ. - 4 Swamps and about ponds, Mass. to Ill. and Con. July. (Arundo Phragmites $L_{\text {., ed. 2.) }}$

46. ARUNDINA'RIA Rich. CANE. Spikelets compressed, 5 to 12 flowered; flowers imbricated, distant; glumes 2, small, awnless; lower pale ovate, acuminate-mucronate, not carinate; stamens 3 ; stigmas 3 ; plumous; scales 3, entire ; caryopsis free, deciduous. - 2f Grasses shrubby or arborescent, often branched, the branches verticillate-fascicled. Fls. both perfect and staminate.

A. macrospérma $\mathrm{M} x$. Culm woody, from strong, running rhizomes; Irs. linear-lanceolate, smooth, glaucous, all dimensions from $1^{\prime}$ by $3^{\prime \prime}$ to If by $2^{\prime}$; sheaths fringed at throat; flowering branches mostly arising from the rootstocks, 6 to $12^{\prime}$ or $18^{\prime}$ high, with sheaths only, bearing 1 to several large ( 1 to $2 \frac{1}{2}$ ) spikelets; pales herbaceous, $8^{\prime \prime}$ long.-In swampy soils, throughout the S. States. The fertile plants are small and inconspicuous, while the barren arise 15 to $25 \mathrm{f}$ in the 
I.

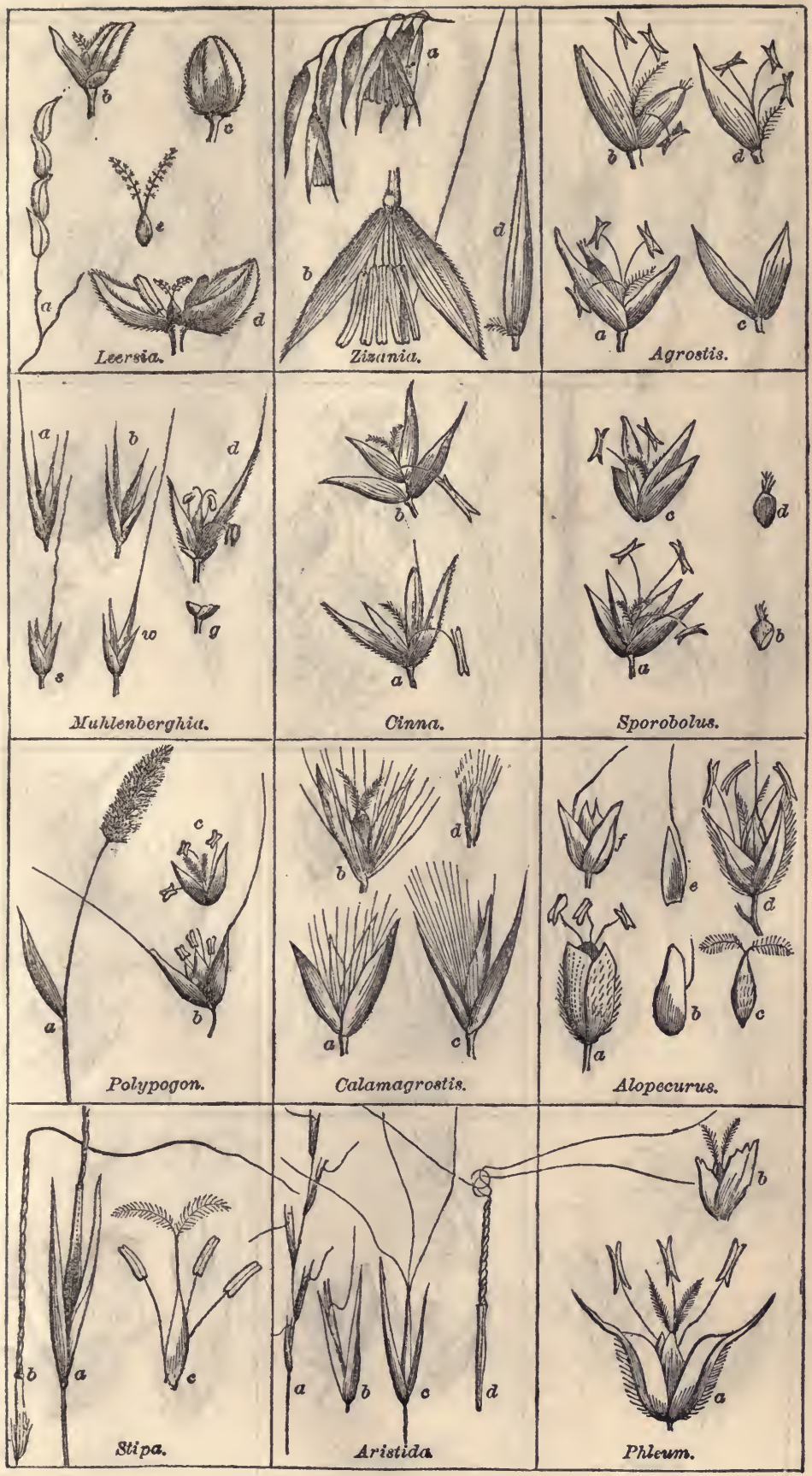


II.

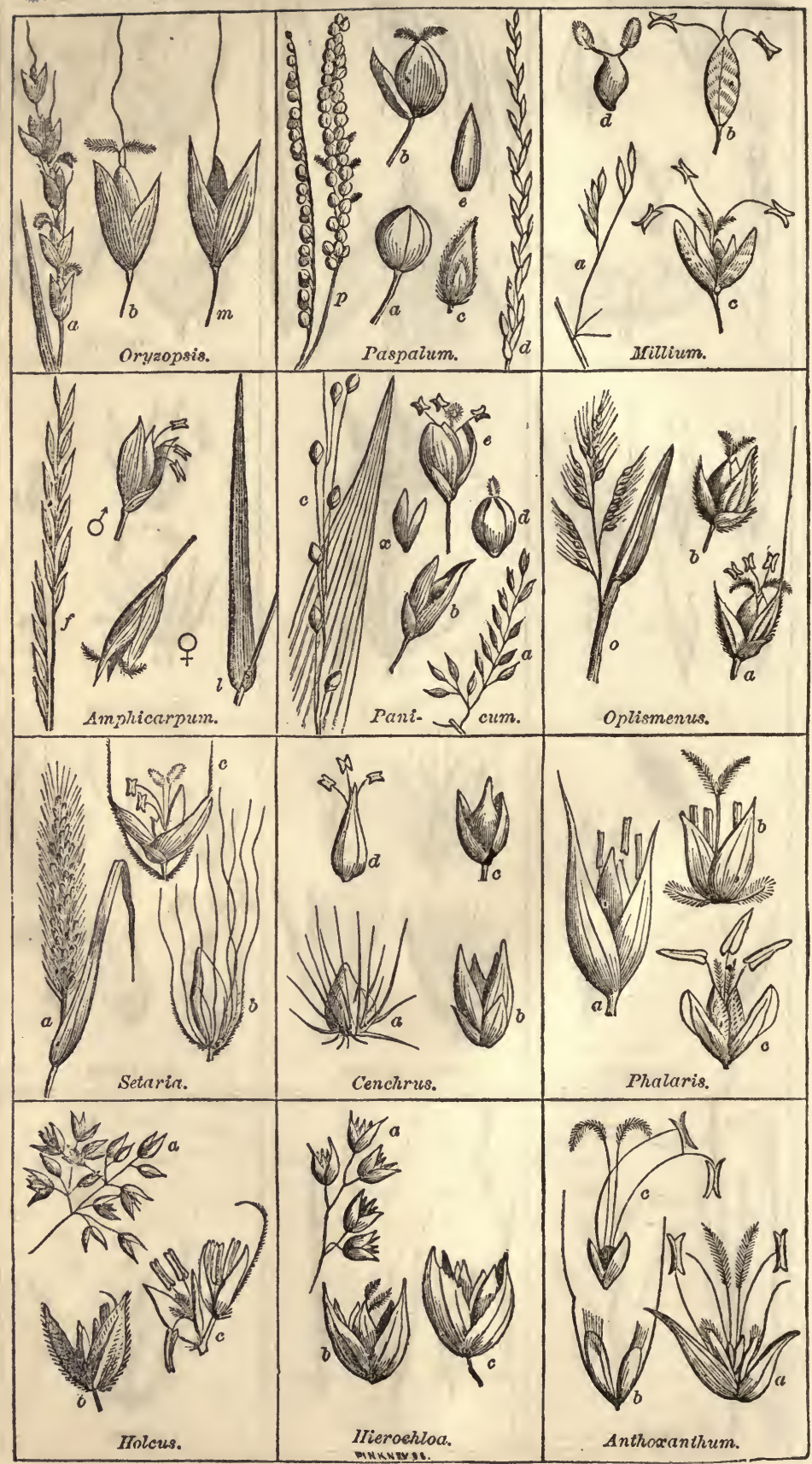


I I I.

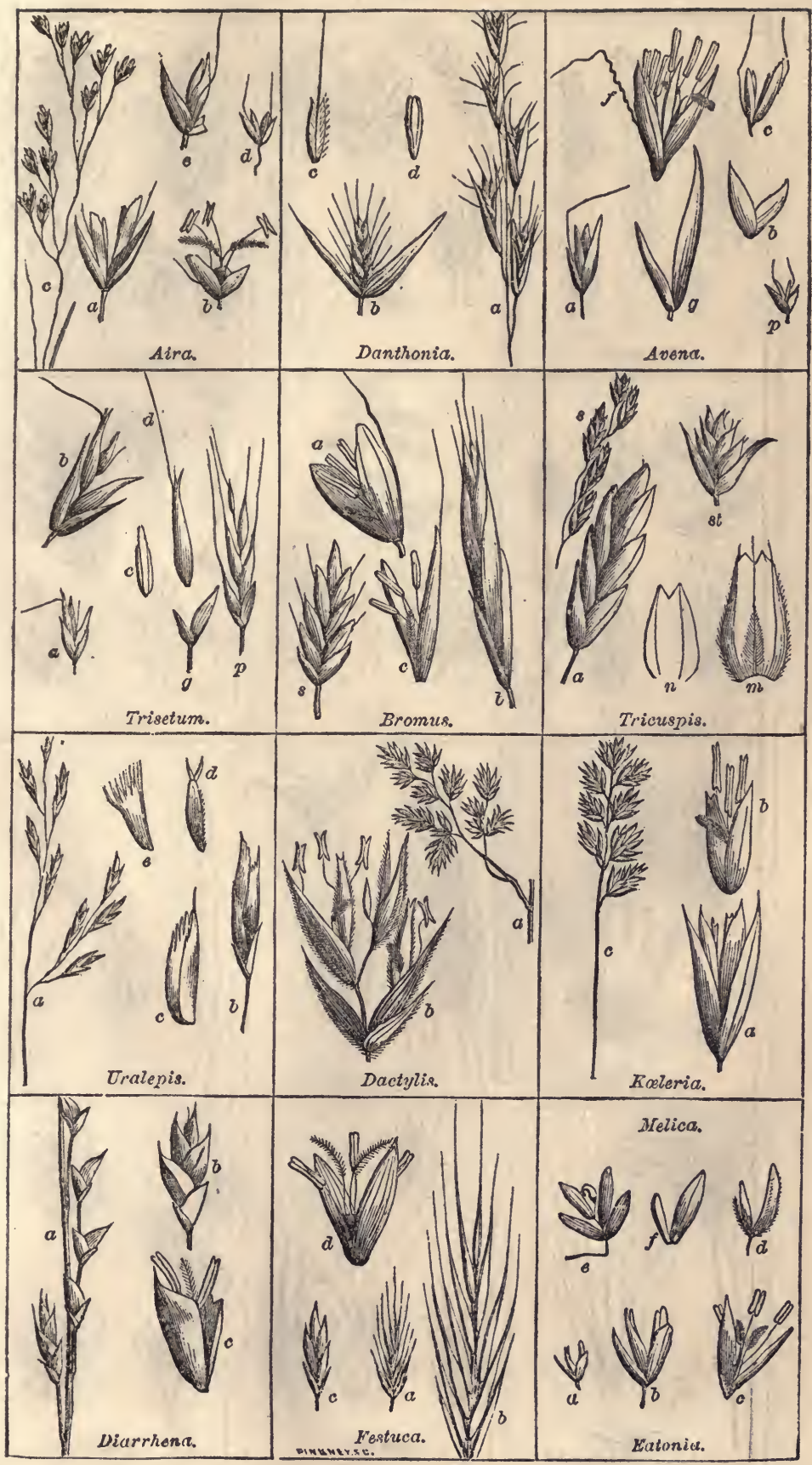


IV.

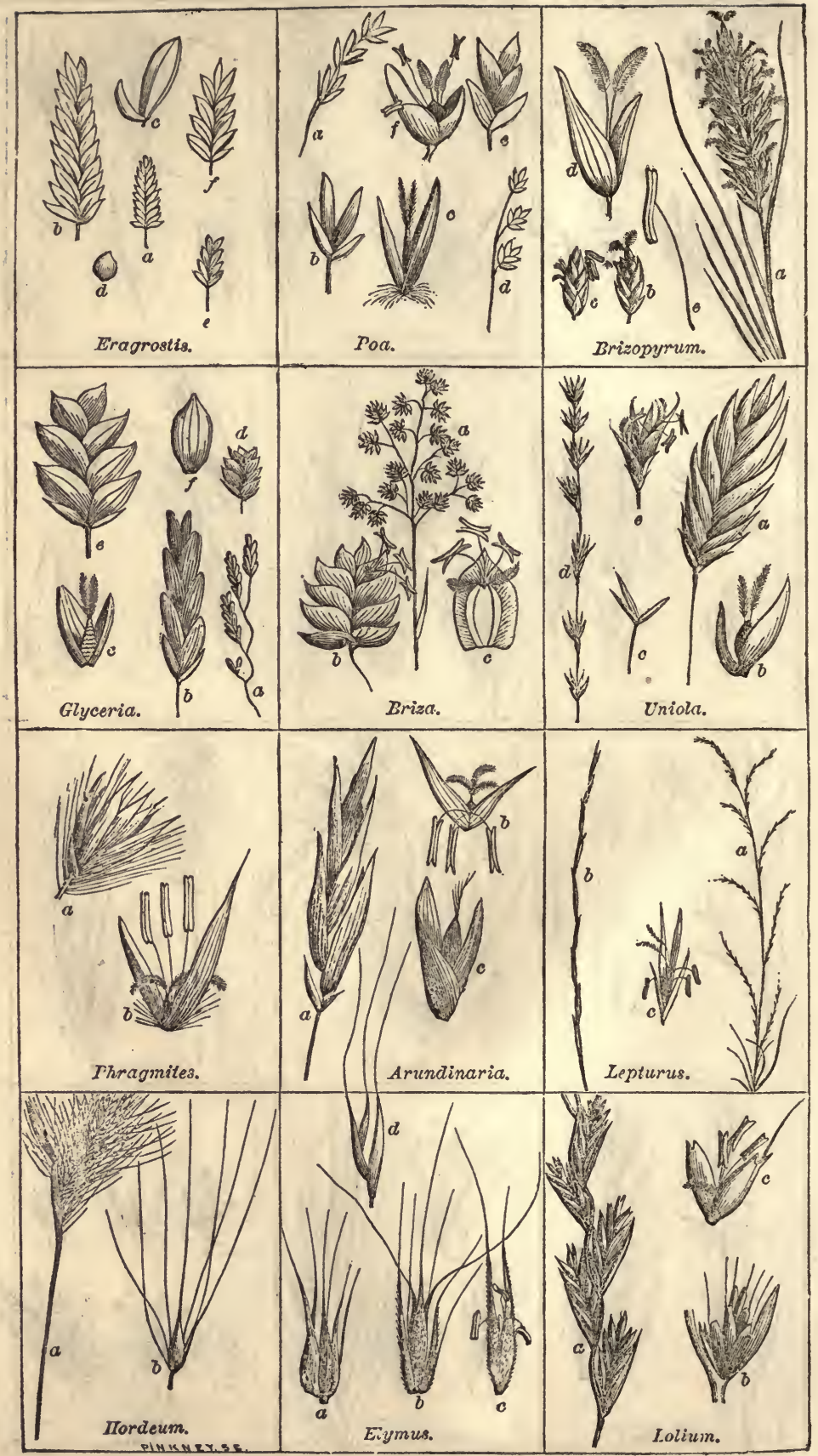




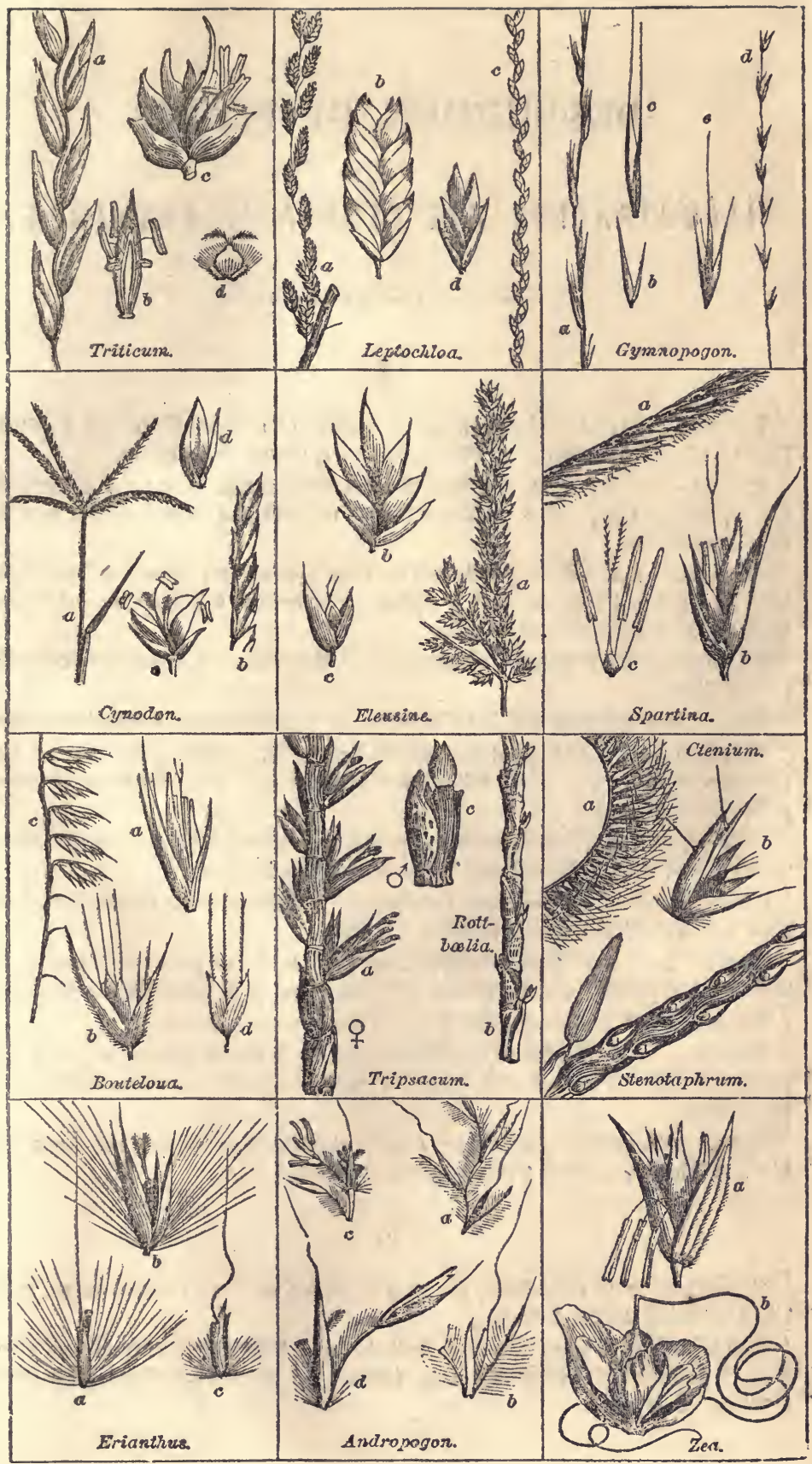




\section{DESCRIPTION OF PLATES}

\section{ILLUSTRATING THE GENERA OF GRAMINEF.}

\section{I.}

LEERSIA, $a$, $\mathrm{L}$. orizoides, a racemc. $b$, spikelet, an open flower. $c$, a spilkelet (flower) of L. lentieularis. $d$, Flower open. e, Ovary and stigmas.

ZizaniA - $a$ Z. aquatiea, staminate flowers, natural size (n. m.). $b$ A staminate flower, enlarged (n). $\quad d$ A pistillate flower, $\mathrm{m}$. with one stigma visible and one long-awned pale.

Agrostrs.- $A$ A. vulgaris, spikelet, $m$. with glumes and pales. $b$ The flower with its 2 pales, 3 stamens and 2 styles. c A. scabra, 2 glumes, $\mathrm{m}$. d Flower with 1 pale, 3 stamens, and 2 styles.

SpововоLus. $a$ S. asper, a spikelet m. $b$ The grain. $\quad c$ S.lpngifolius, spikelet. m. $d$ Graia.

Crnva. $a$ C. pendula, a spikelet m. open. $b$ C. arundinaeea, a spikelet $\mathrm{m}$. open.

Munlevbergia. a M. Mexieana, spikelet m. $b$ M. sobolifera, spilzelet m. $s$ M. sylvatica, spikelet $\mathrm{m}$. w M. Wildenowii, spikelet $\mathrm{m}$. $d$ M. diffusa, spikelet $\mathrm{m}$. $g$ The 2 small glumes

Polypogon. a P. Monspeliensis, paviele, diminished (lim.). b A \&piliclet, with glumes, dic. $c$ Flower with pales, stamens and styles.

Calamagrostis. $a$ C. confinis, spikelet ni. $b$ A flower-the 2 pales, ovary and 2 styles. $c$ C. Canadensis, spikelet $\mathrm{m} . \quad d$ Grain.

Alopecurus. $a$ A. aristulatus, spikelet $m$. $b$ Lower pale. $c$ Ovary and 2 styles. $d$ A. pratensis, spikelet $\mathrm{m}$. e Lower pale. $f$ A. geuiculatus, spikelet $\mathrm{m}$.

Phleur. $\quad a$ P. pratense, spilielet $m$. $b$ The 2 pales and ovary.

Aristids. $a$ A. Uichotoma, spikelets n. m. $b$ A single spiliclet in. $c$ A. purpuraseens, spikeles m. $d$ A. tuberculosa, pale $\mathrm{n}$. $\mathrm{m}$. with its 3 large twisted and bent awus.

Stips. $a^{\prime}$ S. avenacea, spikelet. $b$ pale with the long twisted and bent awn, n. m. c Flower, m. with 3 stamens, ovary, 2 styles.

\section{II.}

Oryzorşıs. a O. asperifolia, n. m. $b$ Spikelet, m. $m$ O. melanocarpa, spikelet $m$. showing the black fruit.

Paspalum. $p$ P. laeve, n. m. a Spikelet, m. $b$ Spikelet, with its true glume open. $\quad d$ Paspalum sanguinale, n. m. a spike. c A spikelet, showing the glume in front. $d$ A palc. 
Milciurr, $a$ M. effusum, n. m. $\quad l$ Spikelet elosed. $c$ Spikelet open. $d$ Ovary and pistils.

Axpricarpum. $f \Lambda$. Purshii, n.m. $l$ Leaf. ô Staminate flower, of the panicle. \& Pistillate flower, of the root.

Pavicux. a P. agrostoides, n. m. $b$ Spikelet. c P. paueiflorum n. e Spikelet. $d$ Fiertile pales. $x$ Neutral palez.

Oplismenus. o O. Crus-galli, dim. $a$ Spikelet m. $b$ Spikelet of $\beta$ muticus.

Seraria, $a$ S. viridis. $b$ Spikelet $m$, with its bristly involuere. $c$ Spikelet of the sane in flower, showing two of the bristles.

Cencurus. $a$ C. tribuloides, the burr-like involuere. $b$ Spikelet. $c$ Pales in fixit. $d$ Pales in flower.

Phalaris. $a$ P. arundinacea $m$. $b$ Flower, and the 2 hairy rudiments at base. c P. Canariensis, spikelet.

Antroxantiusr. $a \Lambda$. odoratum, spikelet $m$. $b$ The 2 awned rudiments. The perfect flower, 2 pales, 2 strmens, 2 styles.

Hrercculos. $a$ H. borealis, n. m. $b$ Spikelet. $c$ Same, with the glumes removed, showing the 3 flowers.

Horcus, $a$ H. lanatus, n. $m$. $\quad b$ Spikelet $m$. $c$ The two flowers separated from the glumes.

\section{III.}

Arra. c A. caespitosa n. m. a Spikelet $b$ Flower. $d$ A. flexuosa, spikelet n. $m$. $e$ Part of the same magnified.

Danthonra, $a$ D. spicata $\mathrm{n} . \mathrm{m} . \quad b$ Spikelet $\mathrm{m} . \quad c$ Lower pale. $d$ Upper pale. Ávens. A A. elatior, spikelet $n . \mathrm{m} . g$ Glumes. $f$ Flowers. $p$ A. praeeox, spikelet $\mathrm{n} . \mathrm{m} . \quad b$ Glumes. $c$ Flowers.

Trisetuar. $a$ T. palustre, spikelet, n. m. $\quad b$ Same m. c Pales of the lowest flower. $p$ T. purpuraseens, spikelet, n. m. $g$ Glumes. $d$ A flower, closed.

Bromus. \& B. seealinus, spikelet, n. m. $a$ A flower. $b$ B. ciliatus, spikelet before flowering, n. m. c A flower open.

Tricuspis. $\delta$ T. seslerioides, n. m. $a$ Spikelet. $m$ Lower pale of flower. $n$ Upper pale. st T. strieta, spikelet enlarged 2 diameters.

Uraleprs. a U. purpu:en, n. m. $b$ Spikelet m. c Lower pale. $d$ Grain. e Upper pale.

Dacryuls. $a$ D. glomerata, n. m. $\quad b$ Spikelet in flower.

Koelerra. $c$ K. eristata, n. m. $a$ Spikelet. $b$ Flower.

Drarriena. $a$ D. diandra, n. m. $b$ Spikelet. $c$ Flower.

Frstuca. $a$ F. tenella, spikelet, n. m. $\quad b$ Same m. $\quad$ F. nutans, spikelet, n. m. $d$ Flower.

Eatonia, $a$ E. obtusata, spikelet n. m. $b$ Same m. $c$ Lower flower. $d$ Upper flinwer, with an empty pedieel.

Melica. e M. mutica, spikelet n. m. $f$ Pales of a flower.

IV.

Erıgrostis. $a$ E. poaeoides, spikelet n. m. $\quad b$ Same m. $\quad$ Pales of a flower. $d$ Grain. $e$ E. hirsuta, spikelet n. m. $f$ Same m. 
PoA. a P. dinantha, n. m. b Spikelet m. c Flower. d P. debilis, n. m. e Spikelet m. $f$ Flower.

Brizopyrum. a B. spicatum, $q$, n. m. b. Spikelet $q$, n. m. e Spikelet $f, n$. m. $d$ Flower $q$ open. $e$ A stamen of $\hat{o}$.

Glyceria. a G. aquatica, n. m. b Spikelet m. c Flower. $d$ G. Canadensis n. m. $e$ Spikelet m. $f$ A pale.

BrizA, a B. media, dim. $b$ Spikelet n. m. c Flower.

Uniola. $a$ U. latifolia, spikelet n. m. b Flower. c Glumes. d U. gracilis, n. m. e Spikelet $\mathrm{m}$.

Prragmites. a P. communis, spikelet $\mathrm{n}, \mathrm{m}$. $\quad b$ A flower open.

Arundivaria. a A. macrosperma, spikelet n. m. $b$ Flower. c Same with fruit.

Lepturus. a L. paniculatus, dim. $\quad b$ Raceme n. $m$. c Spikelet in flower, m. Hordeur. $a$ H. jubatum, half size. $b$ Spikelet $n . m$.

Eursus. $\quad a$ E. Virginicus $\beta$ areuntus, spikelet n. m. $\quad b$ E. Canadensis, spikelet n. m. c Flowers. $d$ E. Hystrix, spikelet $\mathbf{n} . \mathrm{m}$.

Lolium. a L perenne, n. m. 6 L. temulentum, spikelet n. m. c Flowez open, $\mathbf{m}$.

\section{V.}

Tвimcum. a T. repens, n. m. 6 A flower. e T. vulgare, spikelet n. m. $d$ Orary, scales, and styles.

Leptocilos. a I. fascicularis, branch, n. m. b Spikelet. c L. filiformis, n. ma d Spikelet.

Grmnopogov. a G. racemosum, branch, n. m. 6 Glumes. e Pales. $d$ G. filiformis, branch, n. m. e Spikelet m. $d$ Spikelet closed.

Crnodor. a C. Dactylon, dim. c Spikelet in flower. $b$ Portion of spike. d Glumes.

Euedsine. $a$ E. Indica, n. m. $b$ Spikelet m. $c$ Spikelet in fruit.

Spartina. $a \mathrm{~S}$. polystachia, branch, $\mathbf{n}$ m. $b$ Spikelet. e Flower without the pales.

Bouteloof. c B. curtipendula, n. m. a Spikelet. $\delta$ B. hirsuta, spikelet. $d$ The abortive flower.

Tripsacum. $\quad a$ T. dactyloides, n. m., $q$ pistillate flowers. of staminate flowers.

Rotrbenia. b. R. rugosa, n. m. c A joint of the spike with one sessile, fertile spikelet, and one pedicelled, abortive spikelet.

Stenotaphrum. c S. dimidiatum, under side of the spike.

Crenudu. $a$ C. aronaticum, n. m. $b$ Spikelet in fruit.

Erranthos. a E. alopecuroides, a joint of the rachis and spikelet, $\mathbf{n} . \mathbf{m}$. $b$ Spikelet $m_{\text {, }}$ in fruit. $c$ E. brevibarbis, spikelet and joint of rachis, n. $m$.

Andropogor. a A. scoparius, several spikelets, n. m. 6 One spikelet, m. with a joint of rachis. c A. Halei, 2 spikelets, n. m. d Spikelet, m., with a joint of rachis.

ZEA. a Spikelet, staminate, from the tassel. $\quad$ Spikelet, pistillate and fertile, from the ear, with its long style. 
brakes and scarcely erer flower. The firm, jointed, hollow, straight and tall culms are variously useful.

47. LEPTU'RUS, Br. Spikelet 1 on each joint of the filiform rachis, immersed in a cavity, 1 or 2 -flowered; glumes coriaceous, acute, the lower often wanting; pales membranous, awnless, shorter than the glumes; grain free.-Lr's. and spikes very narrow.

I. paniculàtus Nutt. Culm scarcely 1f, compressed; lvs. short, rigid, sheathing the base of the panicle; pan. or naked rachis incurved, acutely triangular, rigid, bearing 6-10 compressed, subulate spikes on one side, each 1-2' long; spikelets remote, on one side the rachis; glumes rigidly fixed, unequal, parallel; paleæ 2 , the outer of the same texture as the glumes, inner membranaceous. - Ill. (Mead), Mio. (Nuttall).

48. HOR'DEUM, E. BARLEY. (The ancient Latin name.) Spikelets 3 at each joint of the rachis, 1 -flowered, the lateral ones sometimes abortive; glumes 2, subulate, nearly equal, awned; palex 2, lower lance-ovate, long-awned, upper obtusely acuminate; caryopsis adhering to the palce.

1 H. vulgàre L. Fơr-RowEd BARLEY. Culm smooth, 2-3f; lvs. lance-lincar, carinate, nearly smooth; sheaths auriculate at the throat; spike thick, about $3^{\prime}$ long; spikelets all fertile, l-flowered, with an awn-like rudiment at the base of the upper palea; glumes collateral, shorter than the flowers; fr. arranged in 4 rows. - 4 Extensively cultivated. May.

2 I. dístichum It Two-lzowed BarLey. Culm 2-3f; lvs. lance-linear, scabrous above; sheaths auriculate at the throat; spike $3-4^{\prime}$ long, linear, compressed; lateral spikelets abortive, awnless; fr. arranged in 2 rows.- 1 Moro common, and is generally preferred for malting to the former species. June.

3 H. jubàtum L. Sevirrel-taIr Grass. Culm slender, round, smooth, simple, about $2 f$; lvs. broad-linear, $4-6^{\prime}$ long, rough-edged, otherwise smooth, as well as the sheaths; spikes $2-3^{\prime}$ long spikelets with the lateral flowers neuter; glumes and paleæ produced into fine, smooth awns, 6 times as long (2') as the flowers; abortive flowers on short pedicels.-(2) Marshes, N. Eng. to Mo., N. to Subarc. Am. June.

4 H. pusillum Nutt. Culm $4-6$, decumbent or geniculate at the base; Ivs. about $1 \frac{11}{2}$ long, rather obtuse, glaucous, striate; upper sheath tumid, embracing the spiko; spike linear, about $1 \frac{1}{2}^{\prime}$ long; glumes by $3 \mathrm{~s}$, collateral, imbricated, lateral; abortive fls. awnless; awn of the central sessile $\not$, as long as those of the involucre, twice the length ( $\left.7^{\prime \prime}\right)$ of the pales, glumes all awned, the inner setaceous from the base.-Ohio to IIl. and Mo.

\section{EL'YMUS L. Lyme Grass. Wird Rye. (Gr. $\varepsilon \lambda \dot{v} \omega$, to en-} velop; as the spike in the sheath.) Spikelets 2 to 4 at each joint of the rachis, 2 to 6-flowered; glumes 2, subequal, subulate, both placed - on the outer side of their spikelet forming an involucre to the group, sometimes minute or obsolete; pales lanceolate, coriaceous, the lower mostly awned.

$\$$ Elruvs proper. Inrolucre present, consisting of the conspicuous glumes . (a) a Spikelets 1 to 5 -flowered, hard, rough, with conspicuous awns. (b)

b Spikelcts glabrous, merely rough, 2 or 3 -flowered.......................... 1, 2

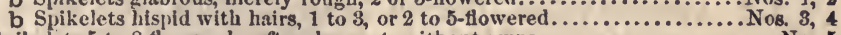

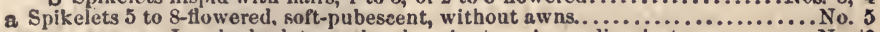

\$ Gyxnostacuvm. Invol, obsolete or the gls, minute. Awns divaricate....................... 6

1 E. Virginicus L. Culm smooth, 3 or 4f, erect; lvs. lance-linear, flat, scabrous, deep green, $4^{\prime \prime}$ broad; sheaths striate; lig. very short; spike erect, thick, 3 to $5^{\prime}$ long; spikelets in pairs, 2 or 3 -fiowered, the collateral glumes in front, thickened and subconnate at base, striate, and with the pales, produced into rather short (6 to $10^{\prime \prime}$ ), scabrous awns. - 2 Banks of streams, U. S. A Southern variety has the glumes very thick and arcuate at base (liko E. Caput-Medusæ L.). Aug. 
2 E. Europzus L. Culm erect, 3 to 5 f, Ivs. lance-linear, scabrous, with somowhat hairy sheaths; spike suberect, 5 to 8 ', very scabrous but nearly glabrous; spikelets ternate, 2-flowered, with long (15 to $\left.25^{\prime \prime}\right)$, stout, straight, diverging awns all of similar length.-Along rivers, S. States. The long parallel awns give it quite a different appearance from No. 3.

3 E. Canadénsis L. Culm erect, 3 to $5 f$; lvs. lance-linear, flat, smooth, dark green, or often glaucous; spike rather looso and spreading, 4 to $8^{\prime}$ long, generally nodding, rachis hairy, spikelets more or less hairy, in $2 \mathrm{~s}$ and $3 \mathrm{~s}, 3$ to 6 -flowered, awns of the fls. usually curved, longer ( 7 to $17^{\prime \prime}$ ) than those of the glumes. - $A$ tall grass, looking like Rye, with long, recurved, waving spikes. River banks. Aug.

4 E. striàtus Willd. St. slender, erect; lvs. and sheaths smooth, the former lance-linear, acuminate, scabrous on the upper surface; spike erect, 2 to $3^{\prime}$ long; invol. 4-leaved, strongly veined; spitielets in pairs, somowhat spreading, hispid, 1 to 3-flowered; awns 3 or 4 times as long as the pale. - 2f Mfass. to Penn., W. to Ohio, rare. A small and slender species. Jnly. (E. villosus Muhl. is some larger, with very hairy glumes.)

5 E. móllis Trin. Culm velvety pubescent above, stout, 2 to 4 f; lvs. involutecompressed, glabrous as well as the striate sheaths; spike thick, crect, 6 to $8^{\prime \prime}$; spikelets in pairs, about 7-flowered, awnless, all clothed with a sof pubescence; glumes shorter than the fls.-Lake shores, MFin. and Can. W.

6 E. Hýstrix I. Culm round, smooth, $2-4 f$; lvs. lance-linear, carinate, scabrous, generally glaucous and with the sheaths striate; spike $4-6^{\prime}$ long, erect; rachis nearly smooth, flexuous; spikelets remote, diverging, almost horizontal, 2-3flowered; glumes 0 , rarely 1 or 2 ; fls. smoothish; lower paleæ terminating in a very long awn. - If An odd-looking grass, in moist woods, N. States, common. Jl.

50. LO LiUM, L. Darnel Grass. Spikelets many-flowered, sessile, remote, with the edge to the rachis; glume to the lower spikelet single, to the terminal one 2 ; palea herbaceous, subequal, lower one shortawned or mucronate, upper bifid-toothed.

1 I. perènne I. RAY DARNel. Smooth ; culm terete, 1-2f; lvs. lanco-linear, shining-green, on striate sheaths with truncate stipules; rachis flexuous, groored, 5-6' long; spikelets awnless, about 16, longer than the glume, 7-9-flowered, alternate, in two opposite rows; lower paleæ 5-veined, upper with 2, prominent, rough keels.-2f Meadows, cultivated grounds, ctc. May, June. §lur.

2 L. temuléntum L. Poisonous Darnex. Culm terete, smooth, 2f; lvs. lancelinoar, rough-edged, and with the sheaths, smooth on the surface; stip. truncate; rachis flexuous, 4-6' long; spikelets much compressed, 5-7-flowered, not longer than the glume; lower pale 5-veined, produced into an awn twice its length.-(1) Remarkably distinguished from all other grasses by its poisonous seeds. N. Eng. to Penn. July. § Eur.

51. TRIT'ICUM; L. WheAT. (Lat. tritum, rubbed or ground; alluding to the manner of its preparation for food.) Spikelets imbricated in 2 rows, sessile on the tecth of the rachis, about 5-flowered, with the upper flowers abortive; glumes 2, equal, opposite, ovate, concave, mucronate; palex 2, lower awned or mucronate; scales 2, collateral.-Fls. arranged in spikes.

\$ Tríticus proper. (1) Glumes oblong, obtuse, ventricous-concave. Spike 4-sided.....No. 1 AGroryon, Kth. 24 Glumes lanceolate, pointed. Spikelets mostly 2-ranked....... Nos. 2, 3

1 T. vulgàre Villars. Common WheAT. Culm terete, smooth, tho internodes somewhat inflated, 3 to $5 f$; lvs. lance-linear, reined, roughish above; stip. truncate; spike parallel, somewhat 4-sided; spikelets orowded, broad-ovate, about 4-flowered; glumes ventricous; awns of the upper paleæ generally longer than the flowers.-(1) and (2) This is without doubt the most valuable plant of the Order. Cultivated from the earliest historic times. Many varieties are known to farmers, classed as Summer Wheat, and WINTER WHEAT; AwNed or AWNLESS.

B. compositum. Egyptian Wneat. Spike compound. Spikelets awned.

2 T. repens I. CođcH-Grass. QuicIr Grass. Culm trailing at tho lower 
joints; from creeping rhizomes, 1 to $2 \mathrm{f}$; lrs. lance-linear, rough above and somewhat hairy; stip. sliort truncate; spike compressed, about $3^{\prime}$ in length; spikelets remote, alternate, lance-oblong, 5-6-flowered; awns short or none; glumes lanceolate, 5 -veined, acuminate.- 4 A vile weed, in tields and gardens, extremely difficult to eradicate. June-Aug. $\S$

$\beta$. DASYSTÁCHIUM. Glaucous, very smooth; spikelets 5 to 9 -flowered, whitish all over with downy hairs.-Lake shores, Wis, Mich., Can.

3 T. canìnum R. \& S. DoG's Couch Grass. St. 2-3f, erect or obliquo; Iv\& flat, smooth; stip. almost wanting; spikelets about 5-flowered; glumes 3-veined, and with the outer palea, terminating in a straight, scabrous bristle, longer than the flowers - Delaware (Muhlenberg) to Micli. $\S$

52. SECA'LE, L. Rye. (Celtic segal, from sega, a sickle.) Spikelets solitary on the teeth of the rachis, $2-3$-flowered, the 2 lower flowers fertile, sessile, opposite, the upper one abortive; glumes subulate, opposite, shorter than the flowers; lower palea with a very long awn, upper often bifid at apex; scales abortive, hairy.

S. Cereàle I. Culm hairy beneath the spike, 4-6f; lvs. lance-linear, roughcdge, and rough above, glaucous; spike about $5^{\prime}$ long, linear, compressed; paleæ smooth, lower ciliate on the keel and margin; awns scabrous-ciliate, long, straight, crect.-(1) or (2) The native country of this highly valuable grain is unknown. It has long been cultivated. Jn., Jl.

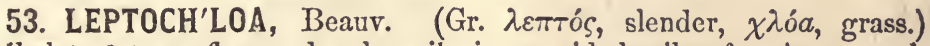
Spikelets 2 to $\infty$-flowered, subsessile, in one-sided spikes forming a panicle raceme; glumes carinate, awnless; pales membranous, lower 3-veined, carinate, awnless or awned; stamens 3 ; stigmas simply plumous.Lrs. flat and soft. Pan. composed of many slender spikes. (Oxydenia Nutt.)

\$ Spikelets sessile, few-1lowerel, lower pale entiro at the acutish apex.............. Nos. 1,2 Spikelets pedicellate, 6 to 9 -fluwered, lower pale notched and mueronate at $\mathrm{cnd}$............. 8

1 工. mucronàta Kunth. Culm geniculate at the lower joints, 2 to $3 \mathrm{f}$, ascending; sheaths hairy, loose; lvs. lance-linear, tapering to a long acumination; pan. a foot or more long, the numerous spikes very slender, 2 to $4^{\prime}$, flowering their whole length; spikelets green, sessile, minute, 2 to 4 -flowered, awnless, shorter than the inucronate-pointed glumes.-(1) Fields, S. States, common. Jl.-Oct.

2 I. filifórmis R. \& S. Culm geniculate below, upright 3 to $4 \mathrm{f}$; sheaths some hairy; lvs. lance-linear, rough-edged, twice larger (1f by $9^{\prime \prime}$ or less) than in tho last; pan. near 2f long, the numerous spikes very slender, straight and suberect, 5 to $8^{\prime}$ long; spikelets purple, sessile, minute, sub-3-flowered, a littlo exceeding the merely acuto giumes; fls. obtuse.-(1)? Fields, S. States. (Oxydenia attenuata Nutt.)

3 I. fasciculàris Gr. Glabrous, stout, ascending from a geniculato base 2 to 4f; lvs. long and broad (1f by $9^{\prime \prime}$, more or less); pan. dense, oblong, 9 to 15', with very many sessile, secund spikes 2 to $3^{\prime}$ long; spikelets short-pediceled, lance-oblong ( 3 to $\left.4^{\prime \prime}\right)$, flat, about 9-flowered; lower pale oblong, ciliate below, mucronate-awned in the notch at the apex.-Marshy soils, N. Y. to La., W. to Ill. (Fcstuca, Lam. F. multiflora Walt. F. polystachia Mx.)

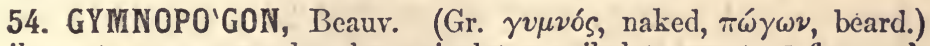
Spikes setaccous, corymbously paniculate ; spikelets remote, 1-flowerea, with a rudiment; glumes 2-keeled, subequal, lance-linear; lower pale with a straight awn from a little below the tip; rudiment aristiform.Low, reed-like. (Anthopogon, Nutt.)

1 G. racemòsum Beauv. Culm ascending 18 to 24', with short internodes; Ivs. ovate-lanceolate, 1 to $2^{\prime}$ by 4 to $8^{\prime \prime}$, glabrous, flat, spreading, in 2 rows; sheaths hairy at the throat; lig. obsolete; pan. large, pyramidal, branches simple, rigid, flowering near their whole length, soon spreading or reflexed, 3 to 5 ' long; 
glumes linear, pungent; awn of the fl. 3 to 4 times its length, that of the rudiment half as long. - 4 Sandy fields, N. J. to Ga. and La.

2 G. brevifòlium Trin. Culm slender, decumbent below, ascending 8 to $16^{\prime}$; internodes short $\left(1^{\prime}\right)$, sheaths about as long, smooth; lvs. linear-lanceolate, 1 to 2', very acute; spikes almost hair-like, somewhat corymbed, flowering only above the middle; glumes subulate; awn of the flower as long as the pale, that of the rudiment wanting. $-24 \mathrm{Md}$. to La. (Hale).

55. MANISU'RUS, L. Lizard-tail Grass. (Gr. $\mu a ̃ v \iota s$, lizard, ovpá, tail.) Spkl. in pairs, 1-flowered, the lower $\measuredangle$, upper abortive ; $\varnothing$ gl. 2, the lower roundish, saccate-concave, coriaceous, larger than the flattish, membranous upper gl.; pales 2, much smaller than the glumes, thinly membranous; stam. 3 ; styles 2 ; abortive spkl. of merely 2 empty, subequal, subcoriaceous glumes.-(1)

M. granulàris Swtz. Culm $2 \mathrm{f}$ or more; erect, branching, with hairy sheaths; leaves flat, 1 to $4^{\prime}$ in length; spikes solitary, on short, lateral branches, partly involved in a spath-form leaf, jointed, unilateral, $\frac{1}{2}$ to $1^{\prime}$ long, colored; $\Varangle$ fls. globular, the gl. warty-tesselated.-About Charleston, S. C. (Bachmau l). $§$ E. Ind.

56. CYN'ODON, Rich. Bermuda Grass. (Gr. $ı v \omega v$, a dog, ödoc, a tooth; alluding to the singular one-sided spikelets.) Spikes digitate or fasciculate; spikes unilateral, in a single row, 1 -flowered, with a rudiment, glumes membranaceous, shorter than the flowers, persistent; $\not$. upper palea bifid-toothed; rudiment minute, pedicellate, in a groove of the upper palca; scales truncate.

C. Dáctylon Pers. Culm ereeping extensively; stolonilerous at base, $6^{\prime}$ to 2f long; lvs. hairy on the margin and towards the base, narrow-linear; sheaths hairy ; spikes $4-5$, digitate, spreading, $2-\mathbf{3}^{\prime}$ long, $1^{\prime \prime}$ wide, serrated with the uneven spikelets; glumes scabrous on the keel, lanceolate, acute; paleæ subequal, the lower broader, enfolding the upper.- 2f A vigorous creeper, in sands and hard soils, Penn. to the Gulf.

57. EU'STACHYS, Desv. Sea-side Finger-grass. (Gr. evं, well, $\sigma \tau a ́ \chi v \varsigma$, a row.) Spikes digitate; spkl. sessile on one side of the rachis, 2-flowered; upper fl. sterile; upper gl. larger, short-awned at the 2 . lobed apex; lower pale thin, keeled, mucronate below the tip. $-2 f$ Culm creeping, compressed. Lvs. flat.

E. petræa Desv. Diffusely branched; rooting at the joints; lvs. linear, obtuse, rough-edged, $2-4^{\prime}$; sheaths compressed, keeled, serrulate on the keel; longer than the joints; spikes strict; erect, fascicled, 4 to 6 ; lower $\Varangle$ pale coriaceous, brown, silky-ciliate on the keel below and margins above, the midvein extended into a short subterminal awn._-Brackish soils, S. Car, Ga. (Bachman). Jn.-Aug. (Chloris, Elli.)

58. ELEUSI'NE. (From Eleusis, where Ceres, the goddess of harvests, was worshipped.) Spikes digitate, unilateral; spikelets $5-7$ flowered; glumes obtuse, unequal, lower one smaller; palex unequal, upper one bifid toothed; scale truncate, fimbriate; caryopsis triangular, ovate, enclosed in a separate membrane or perigynium.

E. Indica I. Culm oblique, compressed, procumbent and branching at base, 12 $16^{\prime}$ long ; lvs. linear, somewhat hairy, on smooth, loose sheaths hairy at the throat; spikes $2-4$, rarely more or less, linear, straight divaricate, $2-4^{\prime}$ long; $2^{\prime \prime}$ wide ; spikelets closely imbricate, smooth; upper glume 5-veined; fr. dark brown.- $\mathfrak{C}$ Common about houses, foot-paths, \&r. Mid. and W. States. Aug.

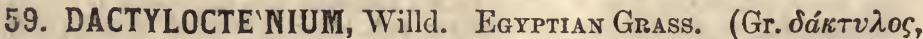

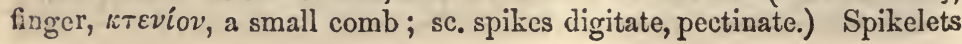


2 to $\infty$-flowered, arranged in several unilateral, digitate spikes; glumes. carinate-compressed, the upper awned; pales membranous, the lower carinate-boat-shaped, acute-mucronate; stamens 3 ; caryopsis frec, glabrous.

D. Egýpticum Willd. Culm geniculate and rooting below, ascending if to $18^{\prime}$; sheaths half as long as the internodes, smoothish; lvs. ciliate at base, $6^{\prime}$ by $3^{\prime \prime}$, more or less; spikes usually 4 (carinate), rachis mucronate at the naked tip; spikelets 3-flowered, the upper sterile.- (1) Fields, common, Va. to Fla.' Jl.-Oct.

60. SPARTINA, Schreb. Marsir Grass. (Gr. otaptiov, a rope; from the resemblance of the creeping rhizomes?) Spikes imbricated in a double row on one side of the rachis, strictly 1 -flowered, no rudidiment; gl. laterally compressed, earinate, coriaceous, pointed or awned, unequal; pales subequal, awnless ; style or styles very long. - 4 Rigid, chietly maritime. Spikes in a raccme.

$\S$ Spikelets with the upper glume deeldedly awned and hispid.................. 1 S. Sikelet unawned, or merely mucronate. - Styles nnited............................ 2 -Styles distinet................... Nos. 3, 4

1 I. cynosuroìdes Willd. Culm slonder, smooth, 3 to 4f; lrs, 2 to $4 \mathrm{f}$ long, sublinear, convolute and filiform at the end; sheaths striate, glabrous; pan. loose, slender, composed of 5 to 12 alternate, one-sided, pedunculate spikes 2 to $3^{\prime}$ long; spkl. subloose-imbricated; gl. acuminate, one of them with an awn about its own length, the other about equaling the white pales.-Marshes, Can. to Fla. and westward, about salt licks! A coarse, sedgy grass, not valuable.

2 S. polystáchya Wiild. Culm stout, thick, 4 to 8 ;, erect, smooth; lvs. smooth, long, broadly linear; spikes numerous (20 to 50$)$, stiff, suberect, subsessile; spikelets coriaceous; upper gl. barely mucronate, little longer than tho enequal pales, twice longer than the subulato lower glume.-Marshes, chiefly southward. The hollow culm is often 8 or $9^{\prime \prime}$ thick.

3 s. júncea Willd. Rt. creeping extensively; culm slender, smooth, 1 to 2 , crect, rigid; Ivs. convolute, setaceous abovo; rigid; sheaths very long; spikes few (3 to 6) $1^{\prime}$ or moro long, dense, subsessile; fls. arvnless; gls. very unequal, the upper littlo exceeding tho pales, thrice longer than the lower glume; the long styles scarcely united.-Marshes along tho coast.

4 S. alternifòlia Loisel. SoFT MARSI Grass. Culm succulent, terete, 3 to 5 f, crect from long creeping roots; lvs. channeled, very smooth, continuous with the open sheaths, often exceeding tho culm; spikes 6 to 12 or more, appressed, sessile, the rachis of each produced beyond the fls. to a subulate point; gls. very. unequal, upper near twice longer, acute; sty. nearly distinct.-Salt marshes. It is greedily eaten by cattle, has a strong, rancid smell and affects the milk mado of it. (Elliott). (S. glabra Muhl.)

61. BOUTELOU'A, Lagasca. Spikelets sessile, in unilateral short spikes; glumes carinate, the upper one larger, shorter than the several' flowers; lower flower perfect, upper ones abortive; lower pale 3-cleft, segments subulate, mucronate, in the $\Varangle \mathrm{fl}$., conspicuously awned in the short-stalked sterile ones; stamens 3. (Atheropogon, Muhl. Eutriana, Trin.)

$\S$ Spikes 20 to 40 , very short, In one long, unilateral raceme...................... 1

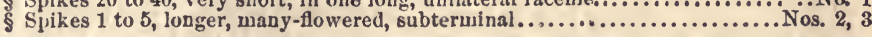

1 B. curtipéndula Gray. Culm 1 to $2 \mathrm{f} \mathrm{high,} \mathrm{genicclate} \mathrm{at} \mathrm{base,} \mathrm{ascending,}$ terete; lvs. linear-lanceolate, हmoothish beneath, pilous above; lig. short, truncate; spikes 4 to $6^{\prime \prime}$ long, 20 to 40 , on short, flat ped., thinly arranged in 2 lateral rows, each with 4 to 8 spikelets; spkl. 2-flowered arranged in 2 rows on the under side of the flat, partial rachis; gls. unequal, the lower awn-like and slightiy adhering to the rachis; anth. 3 , bright red; fr. oblong; abortive fl. with its middle awn conspicuous. - 2f Mid. and W. States. Guilford Conn. (Robbins). (A. apludioides Mubl. Chloris curtipendula Mx.) 
2 B. oligostáchya Torr. Culm filiformly slender, 6 to 12', erect, nearly naked; lvs. glabrous, setaceous; fls. condensed in 2 or 3 (rarely 1 to 5 ) short spikes which are nearly terminal; spikelets numerous, pubescent; midale awn of the villous pale longest, equaling the glume.-Min., Iowa, S. to Miss. (Bachman !)

3 B. hirsùta Lag. Culms crspitous, leafy at the base; lvs. lance-linear, hispid on the margin and midvein; fls. condensed in 2 or 3 (rarely 1 to 4 ) short spikes which are nearly terminal; pale pubescent, its 3 awns subequal, exceeding the glandular bristly lower glume.-Sandy soil, Ill, and Wis.

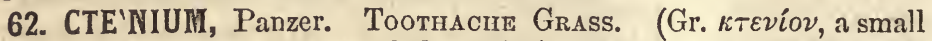
comb; from the resemblance of the spike.) Spikelets 4 or 5 -flowered, closely imbricated on one sicle of a flat rachis; middle flower $\not{q}$, the 2 lower and 1 or 2 upper sterile; upper glume exterior, with an awned tubercle on the back; lower $\Varangle$ pale awned near the apex, silky-fringed below.-Spike solitary, recurved. (Monocera, Ell.)

C. aromáticum. Culm 3 to $5 \mathrm{f}$ ligh, rigidly erect, glabrous; lvs. much shorter, involute-setaceous abovo; spike 4 to $6^{\prime}$ in length, curved backwards, very dense, beset with 3 rows of short, stout awns, the lateral awns obliquely divaricate.-2f Swamps, in pine barrens, S. States. The appearance of the spikes is very curious and striking. Tasto of the fresh herbage pungent (Egilops, Walt. C. Americanum Spr.)

63. TRIP'SACUMI L. Sesame Grass. (Gr. трí $\beta \omega$, to grind; application not obvious.) Spikes staminate above, fertile below; glumes 2, coriaccous; pales 2, membranous; î spikelets 2 -flowered, outer flower staminate, inner neuter; + spikelets 2-flowered, the lower flower abortive; outer glume enclosing the flowers in a cavity of the thick, jointed rachis, with an aperture each side at base, the joints readily separating.

T. dactyloìdes I. St. slightly compressed, smooth, solid with pith, brown at the nodes, 4 to $6 f$; lvs. near an inch broad, long, lance-linear, smooth beneath, roughish above; spikes 5 to $8^{\prime}$ long, usually 2 to 3 together, digitate, terminal, cvidently unilateral.-2f River banks and seashores, Mid., W. and S. States. A large, coarse and very singular grass, of littlo value as food for cattle.

ß. monostachyon. Spike single.

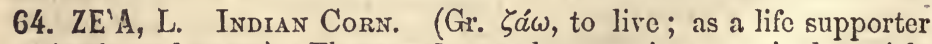
of animals and man.) Flowers $\mathcal{B}$, awnless; $\hat{o}$ in a terminal panicle of racemes, the spikelets 2-flowered; glumes herbaceous, subequal; pales membranous, upper bifid; anthers 3 , linear; $q$ partly imbedded in a thick, continuous axillary spike (spadix) which is enclosed in many spathaceous bracts; lower flower of each spikelet abortive; glume broad, thick, membranous, obtuse; style filiform, very long, exserted and pendulous; abortive flower of 2 pales.-1) Culm solid.

Z. Mays I. Rt. fibrous; culm erect, stout, 5 to $15 \mathrm{f}$, grooved on one side, very smootl and leafy; Ivs. ample, linear-lanceolate, 2 to $3 f$ by 2 to 3 ', channeled. The varieties of this noble plant, produced by climate and culture, are numerous. It is native in S. Am., but low widely cultivated and how important to man wo need not write. Every part is known by familiar names. The panicle of of fls. at the summit is the tassel. The spike of the of fls. is the ear, its rachis the cob, its pistils the silk, and the bracts of its spathe the husks. The kernels are in 8, 10, 12 , etc., rows, always some even number, yellow, white, red or spendidly purple.

65. ROTTBCLl'LiA, Brown. (A personal name.) Rat-tail Grass. Spikelets in pairs at each joint of a terete, jointed spike, one sessile in a cavity of the rachis, 2 -flowered, the other pediceled, abortive; sessile spikl. with the lower flower abortive; glumes 2, subequal, outer con- 
cave, coriaceous, inner thin or hyaline, like the (smaller) pales; stamens 3.-Grass erect, tall.

1 R. campéstris Nutt.? Glabrous; culm simple, slender (2 to $4 \mathrm{f}$ ), with blackish, somewhat geniculate joints; lvs. very narrow, involute-setaceous; spike solitary, 'terminal, little thicker than tho culm, 2 or $3^{\prime}$ long; ped. spikelet obsolete; $;$ gl. ovate, acute, faintly impressed-c̈otted.-La. (Hale.)

2 R. rugòsa. Glabrous; culms rather stout, 3 to $5 f$, erect, branched; lrs. flat, linear; spikes solitary, several, terminal and axillary, 2 to $3^{\prime}$, less thick than the base of the culm; ped. fl. of 2 empty ghumes; $\Varangle$ outer gl. ovate, acute strongly reticulately rugous. - Prairies, La. (Hale.) (Apogonia, Nutt.)

66. STENOTAPHRUM, Trin. Spike compressed; spikelets 2-flowered, in pairs at each joint, imbedded, 1 sessile and 1 pedicellate (or in $4 \mathrm{~s}$ to $6 \mathrm{~s}$ ); glumes membranous, the outer minute, inner large; flowers each of 2 coriaceous pales, similar, but the lower $\delta$; styles 2, slender; stamens 3 ; grain free. -2 Culms decumbent, branched joints of spikes not scparable.

S. dimidiàtum. Glabrous, very leafy; culm 2 to $4 \mathrm{f}$; lvs. flat, broadly linear, on broad, open sheaths; spikes lateral and terminal, solitary, much compressed, 3 ? by 2 to $3^{\prime \prime}$, the rachis flat on the back, spikelets in 2 lateral rows in front, the sessile embraced by the pedicel of the other.-Low grounds, coastward, S. States. Jn.-Sept. (Rottbœllia, Thumb. S. Americanum Schrank.)

67. erian'thus, Rich. Plume Grass. Beard Grass. (Gr.

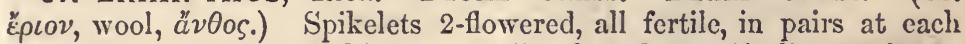
joint of the slender rachis, one sessile, the other pedicellate; glumes membranous, subequal, longer than the flowers; pales hyaline, tho lower flower of 1 neutral, the upper of 2 , perfect, with the lower pale awned; spikelets involucrate at base, with a tuft of bristly hairs. $-2 f$ Stout, crect grasses, remarkable for their large woolly or silky, tawny panicles.

* IIairs of the involucre much longer than the spikelet...................... Nos. 1, 2

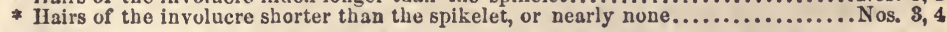

1 E. alopecuroìdes Ell. Culm 5 to 8 or 10f, erect, stout, silky bearded, especially at the joints; lvs. broadly linear; flat, silky pubescent, 2 to $3 \mathrm{f}$ by 1 to $2^{\prime}$; pan. dense, cyliudric-oblong, very large (12' to $20^{\prime}$ long); hairs of the invol. twice longer thau the short (2 to $\left.2 \frac{2^{\prime \prime}}{2}\right)$ spikelets, a third as long as the straightish awn which is terminal on its pale. - Swampy pools in pine barrens, Va. to Fla. and La. The plume-like panicles are magnificent !

2 E. contórtus Ell. Culm 4 to 6f, erect, glabrous; lrs. broadly linear, flat, smooth, except a tuft of silky hairs at base; pan. contracted, oblong, 6 to $10^{\prime}$; hairs of the invol. long, silky, thrice longer than the spikelet (which is $3^{\prime \prime}$ ), $\frac{2}{3}$ the length of the spirally contorted awn which issues from near tho base of its deeply bifid pale.-Wet grounds, about Charleston, S. C. to N. Orleans. Pan. of a lighter hue than the last.

3 E. brevibárbis Mx. Culm stout, 3 to $7 f$, crect, glabrous; lvs. broad-linear, smooth, except at the base; pan. large (1 to 2f), contracted, lance-oblong, the rac. more distinct from the fewer hairs; hairs of the invol. hardly as long as the larger $\left(4^{\prime \prime}\right)$ spikelet, $\frac{1}{4}$ the longth of the awn which is some twisted and its palo bifid.-Low grounds, S. States. Sept., Oct.

4 E. stríctus Baldw. Culm 4 to 7 f, strictly erect and glabrous; lvs. very long; narrower $\left(3\right.$ to $\left.5^{\prime \prime}\right)$ than in the other species, rough-edged; pan. very strict, 1 to $2 \mathrm{f}$ long, branches erect, appressed; invol. of hairs minute; awn straight, terminal on its deciduous pale.-Ga. to $\mathrm{La}$. The whole panicle is reddish brown. Aug., Sept.

68. SACCHARUM, L. Sugar Cane. (Gr. ó́k $\chi a \rho$, Arabic, soukar, Eng. sugar.) Spikelets all fertile, in pairs, one sessile, the other pedi- 
cellate, 2-flowered, lower fl. neuter with a single pale, upper fl. perfect, of 2 pales; gl. subequal, awnless; pales thin and hyaline, awnless; stam. 1 to 3.-2f Gigantic, tropical Grasses with branching panicles. Spikelets cinctured at base with long silky hairs.

S. officinàrum L. Culm solid with pith, closely jointed, 8-20f, erect, with many broad, flat, linear-lanceolate leaves; panicle 1 to $2 \mathrm{f}$ in length, composed of numerous long, filiform loosely erect-spreading racemes, richly clothed with the long white silky involucrate hairs.-Native in S. Asia. Among sugar plants this still holds the preëminence. Its delicious product, now the indispensablo luxury of the world, was unknown to the ancients. It is propagated from cuttings of the rhizome, and seldom permitted to waste its sweetness in flowering.

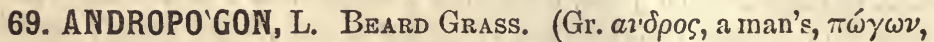
beard.) Spikelets in pairs at each joint of a slender rachis, one on a plumous-bearded pedicel, incompletc, the other sessile, 2-flowered; lower flower of 1 empty pale ; upper $\Varangle ;$ pales thin, hyaline, the lower of the $\Varangle$ tipped with an awn; glumes subeoriaceous; stamens 1 to 3 ; grain frec. - 2f Coarse Grasses. Inflor. various.

5 Inflorescenco in a naked (leafless) panicle. Sterile spikelet $n$ mero pedicel............No. 1 8 Inforescence in distinct sjikes exserted trom the sheaths. (a)

a Sterile spikelets nothing but barren yerlicels. Syikes sheathed at base....Nos. 2, 8 a Sterile slikelets with glnmes on the pedicels. (b)

b Spikes silvery white, in conjurate pairs........................ 4

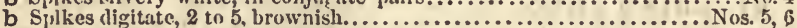

b Spikes single, terminal, one on each branch................................ 7.

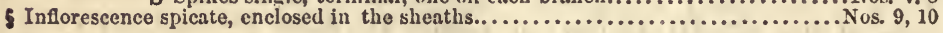

1 A. nùtang L. Indian Grass. Wood Grass. Culm simple, 3 to $6 f$, erect, with smooth sheaths and glaucous lvs.; pan. rather dense, oblong, slender, at length nodding; spikelets in pairs or $3 \mathrm{~s}$, apparently pedicellate, but the fertile is, in fact, sessile as in the other species, all tawny, the sterile reduced to mere pedicels in contact with the $\not$, ciothed with short bristles; $\Varangle$ spikelet bristly-ciliate, with a ring of bristles at base, and tipped (tho lower pale) with a contorted awn. - Sandy fields or woods, Can., N. Y. to Ga. and La. ( $\Lambda$. avenaceus Mx. A. ciliatus Ell. Sorghum, Gray.)

2 A. macrùrus $\mathrm{Mx}$. Culm 2 to $3 \mathrm{f}$ erect, much branched and bushy; lvs. long, linear, upper spathiform, lance-linear; racemes small, very numerous, fascicled at the upper joints forming a large leafy and silky panicle; splk. minute, with a straight bristle-like awn, the neutral only a fine pedicel merely, with white, silky hairs lialf as long $\left(3-4^{\prime \prime}\right)$ as the awn; stam. 1.-Damp soils, S. States. Sept., Oct.

3 A. virginicus L. Culm tall (3 to $6 f$ ) compressed, more or less downy with scattered hairs as well as the long and narrow, carinate lvs.; upper half diffusely paniculate; spikes conjugate, soft, feather-like, hardly as long (8 to $\left.12^{\prime \prime}\right)$ as their bract; abort. fl. a mere capillary pedicel, longer than the $\not$ fl. with thin silky whito hairs half as long as the straight similar awn.-Dry soils, S. States, common. Oct. (A. dissitiflorus Mx.)

$\beta$. VAGINATUS differs only in its fewer, shorter spikes and longer bracts which often much exceed them. (A. vagin. Ell.)

4 A. argénteus Ell. Culm purplish, slender, much branched, glabrous, branches mostly solitary, spikes conjugate, 1 to $1 \frac{1^{\prime}}{2}$ long, exserted beyond the sheath; spkl. appressed to the rachis; abortive fl. a minute, subulate glume on a thick ped. appressed to the $\not$, its fawn-white hairs copious, half the length of the roughish, brown awn.-Dry soils, S. States. The silvery hairs conceal the fls.

5 A. furcàtus Muhl. Forked SpIKE. St. semiterete above, 4-7f high; lvs. lance-linear, rough-edged, radical ones very long; spikes digitate or fasciculate, in $2 \mathrm{~s}-5 \mathrm{~s}, 3-5^{\prime}$ long, purple; spikelets appressed, abortive one on a plumous pedicel, ô with 2 paleæ, awnless, perfect one with 2 unequal glumes; lower palea bifid, awned hetween the divisions. - 26 Meadows and low grounds, Can., N. Y. to Ga. and W. States. Aug. (A. ternarius $\mathrm{Mx}$.)

6 A. tetrástychus Ell. Culm glabrous, 2 to $3 \mathrm{f}$ erect, with long, keeled, very 
hairy lvs. and sheaths; branches solitary, alternate, forming a contracted panicle; spikes usually in $4 \mathrm{~s}$, conjugate, terminal; gls. serrulate, longer than the hairs of the pedicel; perf. spkl. monandrous, and with a straight awn.-Damp pine barrens about Charleston (Elliott).

7 A. scopàrius Michx. Broos Grass. St. slender, paniculate, $3 \mathrm{f}$ high, branched, one side furrowed, branches solitary or 2 or 3 -fascicled, erect; lvs. lance-linear, somewliat hairy and glaucous; spikes simple, lateral and terminal, on long peduncles, 2-3 from each sheath, purple; spikelets remote, abortive one neuten mostly subulate-awned, the hairs of its ped. as long as the ६̧ spikelet.-In dry fields, forming tufts, U. S. and Can.

8 A. Hàlei. Culm rigid, 3 to $5 \mathrm{f}$ high, strict, with long, slender branches above, each with a single terminal short $\left(12\right.$ to $15^{\prime \prime}$,) spike; lrs. long, rigid, rough-edged; sterile splil. of both gls. short-awned, ped. broad above, with stiff hairs shorter than - the fls.; awn of the perfect fl. twisted.-S. W. States. A coarser plant than No. 7.

9 A. clandestina, with the soft, silky, white spikelets always concealed in a fascicle of sheaths, and

10 A. Neèsii Kunth, with very slender glabrous spikelcts almost concealed, aro found in W. La., and possibly E. of the Miss.

70. SOR'GHUM, L. ВRоoм CorN, \&c. Spikelets diffusely paniculate, in $2 \mathrm{~s}$ or $3 \mathrm{~s}$ on the slender, spreading branches; the middle spikelet complete, 2-flowered, the lower flower abortive, lateral spikelets sterile, awnless, the pedicels smooth or merely pubescent; glumes coriaceous; pales membranous; stamens 3.-Stout Grasses, with solid culms.

I S. saccharàtum L. Broom ConN. Culm thick, solid with pith, 6 to 10f; lvs. lanceolate, acuminate, pubescent at base; pan. large diffuse, with long, verticillate, at length nodding branches; gls. of the perfect spikelet hairy, persistent.-(1) The uses of this fine, cultivated plant are well known. $\ddagger$ E. Ind.

2 S. vulgàre I. INDIAN MILLET. Culm erect, round, solid with pith, 6 to 10f; Ivs. carinate, lanceolate; pan. compact, oval, erect until mature; gls. and pales caducous; fr. naked.- (1) Rarely cultivated as a curiosity, or for the seed as food for poultry. $\ddagger \mathrm{E}$. Ind.

The Chinese Sugar Cane, recently in cultivation here, is probably a variety of this species; also the African Millet, Imphee. Neither variety will yield a crystallizable syrup, and cannot, therefore, rival the supremacy of the Southern Cane.

71. CO'IX, L. Joв's Tears. Spikelets 2-flowered, sessile, several in a spike which is involute at the base, the involucre closed around the lower (fertile) spikelet, becoming bony and polished; upper (sterile) spikelets several, remote from the fertile, all awnless; grain roundish, free.-Culm branched; lrs. broad, flat.

C. Lácryma L. Culm half terete; sterile fls. naked; fir. (ossified involucre) ovoid.-(1) Gardens. Plant 1 to $2 f$ high, bushy, with lanceolate lvs. Spikes pedunculate, aggregated at the end of the sheathed branch. The curious fruit is finally very hard, perforated, used by the children for beads. 


\section{Subringdom, CR Y P.TOGA M I A,}

Or Flowerless Plants. Vegetables destitute of true stamens and pistils, gradually descending to a mere cellular structure, with reproductive organs of 1 or 2 kinds, producing, instead of seeds, minute, dust-like bodies (spores) having neither integuments nor embryo.

Province, ACROGENS. Flowerless plants, having a regular stem or axis which grows by the extension of the apex only, without increasing in diameter, generally with leaves, and composed of cellular tissue and scalariform ducts. (Ferns, Mosses, Club-mosses, Horsetails, etc.)

\section{Order ClViI. Marsileace}

Herbs creeping or floating, with the leaves petiolate or sessile, circinate in vernation. Fruit (sporocarps) situated at the base of the leaves or leafstalks, containing the capsular sporanges of one kind with 2 kinds of spores, or of 2 kinds with the different spores separated.

Genera 6, species 20 ? inhabiting ditches and inundated places in nearly all countries, but chiefly in temperate latitudes.

1. MARSIL'EA, L. Sporocarps at the base of the leaf-stalks, of one kind, 2-celled, cells transversely many-celled; spores inserted on each horizontal placenta.-24 Stems creeping, rooting; lvs. petiolate.

1 M. quaärifolia L? Glabrous; prostrate stems slender, wiry, 8 to $16^{\prime}$ long; lvs. palmately 4-foliate, on filitorm petioles 1 to $3^{\prime}$ high, lfts. broadly obovate or fan-shaped, obtuse; fr. (sporocarps) round-oval, borne on short, axillary stalks, and as large as a pepper-corn.-Sent from La. by Dr. Hale. Perhaps the locality is beyond our limits.

2 M. vestita, a very delicate species, with stems and petioles as fine as threads, with the quaternate leaflets and the very small sessile sporocarps clothed with minute, silky, brown hairs, is sent from Iowa, near the Mississippi R. by Dr. Couzens. It probably grows in Ill. Height of liss. 1 to $2^{\prime}$.

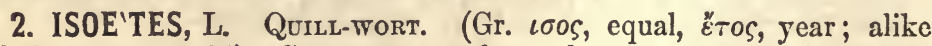
all the year round?) Sporocarps oval, membranous, 1-celled, immersed in the dilated base of the frond; spores subglobous, slightly angular, attached to numerous filiform receptacles, those in the outer fruits larger, angular, triple or in $4 \mathrm{~s}$, apparently of a different nature.

I. lacústris L. Lvs. cæspitous, subulate, semiterete, dilated and imbricated at base.-A curious aquatic, in water at or near the margin of ponds and rivers, $\mathbf{N}$. Eng. and Mid. States, often wholly submersed. Lrs. radical, numerous, tufted, simple, 2 to $10^{\prime}$ long, somewhat spreading, containing numerous cells divided by longitudinal and transverse partitions. Fr. whitish, rather large, in the excavated base of the leaves which dilated portion is ordinarily as long as wide; in var. RIPARIA, broader than long; in var. ENGELMANNI, longer than broad.

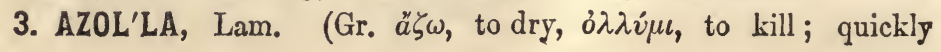


killed by drought.) Fruit sessile on the under side of the branches, of 2 kinds; the sterile smaller, opening all around, containing a thick body bearing 3 angular lobes (antheridia) above; the fertile a thin pericarp bursting irregularly, containing many globular, stalked sporangia each with a few spores.-Minute, floating, resembling a Jungermannia. with filiform stems and lobed fronds.

A. Caroliniàna Willd. Lvs. ovate-oblong, obtuse, imbricated, fleshy, floating, reddish beneath, scarcely more than $\frac{1}{3}$ " in length; sterile fruits in pairs or solitary, at the base of the fertile, many times smaller than it.-Lakes and marshes N. Y. to Ill. and S. States.

4. SALVIN'IA natans $L$, inserted in previous editions on the authority of Pursh, has not been observed since.

\section{Order ClVIII. LYCOPODIACEA. Club Mosses.}

Plants crecping or erect, branching, rarely simple, abounding in ducts, with the leaves small, numerous, crowded, entire, lanceolato or subulate, 1-nerved. Fruits sessile, axillary or crowded into a spike, 2-valved, containing few rather large spores, or numerous minuto ones appearing like powder.

Genera 5 , species 200 ? Like the Equisetacex, these plants appear tu have been rery abunlant in the first ages of the world, and to have attained a gigantic size, althongh at present but a few feet in lengtl. Properties unimportant. Somo are emetic. Tho powder contained in the sporangia is highly inflaminable, and is used in tho manufacture of fireworks.

LYCOPO'DIUM, L. Club Moss. (Gr. $\lambda v ́ \kappa o s$, a wolf, $\pi \circ \tilde{u} \varsigma$, a foot.) Spore cases all of one kind, 1-celled, reniform, open. ing transversely, 2-valved ; spores numerous, minute, sulphur-yellow.-Lrs. in 4,8 or 16 ranls.

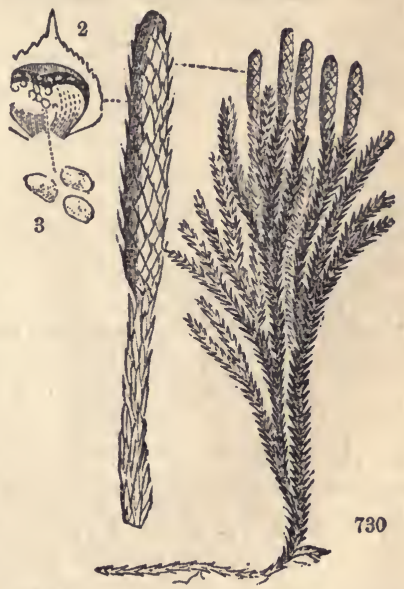

780, Lrenpodlum dendroidem. 781, A sinule spike. 732, A seale with its axillary sporango burstlng. 733, Spores.

$\S$ Fruit in pelunculated spikes (the fertilo branches nearly leafless). (a)

a spilkes several ( 2 to 6 ) on each perluncle............................. 1, 2

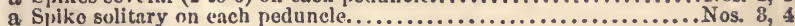

$\$$ Fruit in sessile spikes (the branches leafy throughuut). (b)

b Leaves of the spike bract-like, discolored........................ 5 , 6

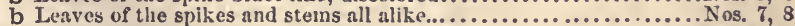

§ Fruit scattered, axillary, forming no distinct spike................... . os. 9, 10

1 I. clavàtum I. Common Club Moss. St. creeping; braiches ascending; lvs. scattered, incurved, capillaceous-acuminate; spikes in pairs, rarely in $3 \mathrm{~s}$, cylindrical, pedunculate; bracts of the spike ovate, acuminate, erosely denticulate.-A well known evergreen, trailing upon the ground in shady pastures and woods, common. Stem and branches clothed with numerous linear-lanceolato leaves which are entire or serrulate, and end in a pellucid, curved bristle. Spikes perfectly straight, parallel, erect, and upon an crect peduncle. July.

2 I. complanàtum I. Festoon Grouxd PINE. St. trailing; branches dichotomous; lvs. 4-ranked, unequal, the marginal ones connate, diverging at apex, tho superficial ones solitary, appressed; ped. elongated, supporting 4-6 cylindric spikes.-A trailing evergreen, common in woods and shady grounds. Stem round, creeping among the moss and leaves, often $10 \mathrm{f}$ in length. Branches rumerously subdivided, eompressed, somewhat resembling the brauchlets of the cedar. Lrs minute, very acute. July. 
3 L. sabinæfòlium Willd. Ground FIr. St. elongated, creeping; branches erect, short, dichotomous, with fastigiato divisions; lvs. imbricated and branches erect, terate-subulate, spikes peduncled by the attenuated and slightly leafy summits of the branches, cylindric, solitary, with cordate, acuminate bracts. - White Mts. and Brit. Am., creeping among rocks, with erect, numerously divided branches, a few of the divisions terminating in spikes an inch in length. July. (L. chamæcyparissus Braun.)

4 I. Caroliniànum L. Southern Ground-Pine. St. and branches creeping; lvs. lanceolate, entire, appearing 2-ranked, the lateral rows spreading with the 2 intermediate rows appressed; peduncle erect, solitary, elongated, bearing a single spike; bracts sublauceolate, entire.-In muddy grounds, N. J. to Ga. Both the stem and its branches are prostrate, with erect, slender peduncles $3-6^{\prime}$ high. July.

5 I. dendroìdeum Michx. Tree Club Moss. Ground Pine. St. erect; branches alternate, crowded, dichotomous, erect; lvs. linear-lanceolate, in 6 equal rows, spreading; spikes several or many, I on each branchlet.-An elegant littlo plant, common in woods, readily distinguished by its upright, tree-like form. Plant about 8 ' ligh, with branches more or less diverging. These are subdivided into numerous, forked branchlets, radiant, so as together to represent a spiral arrangement. Spikes $2-6$, an inch long. July.

$\beta$. oBscunum. (L. obscurum $L$.) Branches spreading; spike one.

6 I. annotinum L. INTERruPted CLUB MOSS. St. creeping; branches twice dichotomous, ascending; lvs. in 5 rows, linear-lanceolate, mucronate, spreading and serrulate near the tip; spike oblong, solitary.-In mountain woods, N. Eng., Can. Branches subdivided near their base, branchlets simple, 4 or more, $6-8^{\prime}$ high. Leaves at length reflexed at end. Spike rather cylindric, an inch in length, distinct from the branch. July.

7 L. alopecuroìdes L. Fox-TAIL Club Moss. St. creeping, subramous; branches simple, long, ascending, bearing a single sessile spike at top; lvs. linearsubulate, ciliate-dentate at base, spreading; spike leafy.-Swamps, N. J. to Fla. and La. Stem extensively creeping. Branches $6-16^{\prime}$ high, rarely subdivided, densely clothed with a fine, soft foliage. Spike $1-2^{\prime}$ long, very leafy. Aug.

8 L. inundàtum L. MARsh Club Moss. St. creeping, often submersed; branches simple, solitary, erect, with a single leafy spike at top; lvs. linear, scattered, acute, entire, curved upwards. - In swamps, Can. to Car. Spikes $\frac{1}{2}-1^{\prime}$ long, at the summit of branches which are $5-7^{\prime}$ long, arising from the base of the stem. Bracts of the spikes leaf-like, dilated at base, spreading at the end, larger than the stem leaves which are 1-2" long. July.

9 I. lucídulum Mx. SHiñng Club Moss. St. ascending, dichotomously divided; lvs. in 8 rows, linear-lanceolate, denticulate, shining, spreading, or a little reflexed; sporanges in the axils of leaves not changed nor crowded into a spike.In wet woods, U.S. and Can. The foliage of this species is dark green and shining, more ample than is common to the genus. Stems $8-16^{\prime}$ long, nearly erect. Leaves $3-5^{\prime \prime}$ long, distinctly serrate. Thecæ hemispherical or reniform, in the axils of the leaves near the top of the stem. Jl.

10 L. Selàgo L. Frr CLUB Moss. St. erect, dichotomously and fastigiately branched; lvs. scattered, imbricate, lance-linear, entire, rigid and pungent, but awnless-A smaller species than the last, found on the summits of the White Mts. Stems 2 to $6^{\prime}$, branches compact, densely clothed with stiff, shining, spreading leaves arranged somewhat in 8 rows, and $2-3^{\prime \prime}$ in length. Sporanges axillary. Aug.

2. SELAgInel'La, Spr. Dwarf Club Moss. Fruits of two kinds, viz., antheridia, which are 1 -celled, opening at apex; and oophoridia containing 1 to 4 (rarely 6 ) globous angular grains.-Habit various. Spikes quadrangular. Bracts in 4 rows. (Lycopodium L.)

Leaves all alike, many ranked, surrounding the stem................... 1, 2

$\$$ Leaves 4 -ranked, those of the lateral rows much larger............................ 3

1 S. rupéstre Spr. Stems in dense, branched tufts, ascending, subdivided; lvs. scattered, imbricate, linear-lanceolate, capillaceous-acuminate, ciliate; spiko soli- 
tary, quadrangular.-A very small species, creeping on rocks, moss-like. Stem a few inches in length, with numerous branches, which are $\frac{1}{2}-1^{\prime}$ long, clothed with grayish-green leaves. Spike $\frac{\lambda^{\prime}}{2}$ long, 4-rowed, seeming a mere continuation of tho branch. Jl. (S. rupestre L.)

2 s. selaginoìdes Gray. St. filiform, creeping; branches nearly erect, the flowering ones simple; lvs. scattered, lanceolate, a little spreading, ciliate-denticulate; spike solitary, leafy.-In moist woods, N. States and Can. Spikes yellowishgreen, about $\frac{g^{\prime \prime}}{4}$ long, the bracts foliaceous and twice larger than the true leaves, which are about a line in length. Branches $3-6^{\prime}$ high, the sterile ones much . divided. Jl. (L. selag. L. S. spinosa Beauv.)

$3 \mathbf{S}$. àpus Spring. St. branching, prostrate and rooting near tho baso; lrs. orbicular-ovate, acute, membranaceous, alternate, amplexicaul, in 2 rows, with minute, acuminate, superficial ones in a third row on the upper side; spikes subsolitary.-A small, creeping, moss-like species, in wet, rocky shades, Can. to Ga., not common. Stem $2-5^{\prime}$ inches long, filiform. Leaves less than a line in lengtl, Spikes leafy, scarcely distinguishable from the branches. July, Aug. (Lo apodum L.)

4 S. ornithopodioìdes Spr. BIRD-CLAW Moss. Irs. semicordate, orate, obtusish, entire, in 4 rows, the lateral spreading, distant below, crowded above, the superficial much smaller, appressed; spikes lateral, axillary, sessile; stems and branches prostrate.-Greenhouse and gardens. $\Lambda$ pretty moss-like creeper, with light green foliage. + Eur.

3. PSILO'TUM, R. Br. (Gr. $\psi \iota \lambda o ́ s$, naked.) Sporangia sessile, 3celled, imperfectly 3 -valved by terminal chinks, filled with farinaceous spores.-Stem fork-branched, with alternate, minute leaves, as if leafless. (Bernhardia, Willd.)

P. triquetrum Swtz. Stem erect, many times forked, and branches three-angled, 8 to $10^{\prime}$ high ; lvs. remote, subulate, less than $1^{\prime \prime}$ long, and the 3-lobed fruit sessile along the branches.-Rocky cliffs, on the sea-coast of L. Fla. (Michx. in herb. Bachman.)

\section{Order ClIX. EQUISETACE无. Horsetails.}

Plants leafless, simplo stems, or with whorled branches. Stems striate-sulcato, jointed, fistular between, and separable at, the joints. Sheaths dentate, crowning each internode. Fructification a dense, oblong-cylindric, terminal and cone-liko spike, composed of 6-sided, peltate-scales arranged spirally, bearing beneath 4 to 7 spore-cases which open laterally. Spores, globular, each with 4 elaters attached, involving them spirally, or open when discharged. (See Figures.)

An Order consisting at present of a single genus, growing in wet grounds, on river banks, and borders of woorls, throughout most countrles. Tho Equisetaceæ abound in tho fossil remains of coal measures with other Cryptogamia, as Lycopodiacer and Filices, indicating that theso plants were onee of gigantic dimensions, and formed a large part of the original flora of our globe. Species about 10.

Properties.-They abound in silex, and hence are used by cabinet-1nakers, combmakers, \&c., in polishing their work.

\section{EQUISE'TUM, L. ScoURING} Rush. (Lat. equus, a horse, seta, hair.) Character the same as that of the order.-The sheaths may be regarded as a whorl of united leaves. The ridges of the stem. are air-tubes, and the grooves alone are pierced with the sto- Section of the spike, enlargecl. $737, \Lambda$ peltato sealo alone are pierced with the sto- with 7 sporanges benenth (or one componnd spo-
range), magnified. 738 , A spore with its elators, mata.

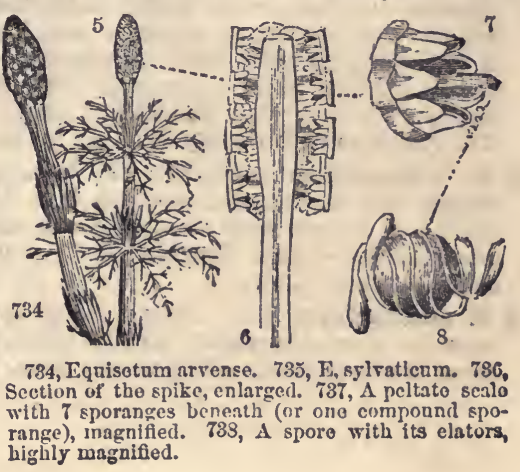




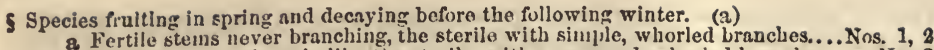

a Fertile stems at length, like the sterile, witl compound, whorled branches...... No. 3 Species fruitius in summer nnd lasting through the following winter.

b Stems with whorls of simple brinches from tho midule joints.................... 4

b Stems mostly simple, Jarge, 20 to 40 -furrowed.......................... 5,6 , 7

b Stems always simple, very slender, 8 to 9 -furrowed..................... 8,9

1 马. arvénse I. Field IIorsetarl. Fertile sts. erect, simple; sterile, 12 to 14 furrowed, with simple, ascending, quadrangular branches, and decumbent at base. -Low grounds, Can. to Va. and Ky. Fertilo stems first appearing, 6-8' high, with $3-5$ joints surmounted by large, inflated sheaths cut into long, dark brown toeth. Spiko oblong, $\frac{1}{2}-2^{\prime}$ long. Sterilo stems rather taller than the fertile, romaining through tho season, after theso havo decayed. At each joint is a whorl of simple, rough branches, issuing from the baso of tho sheaths, their joints also sheathed. $\Lambda$ pril.

2 E. ebúrneum Schreb. Irory Morserarl. Fertile, st. simplo, its sheaths numerous, of $3 \mathrm{lvs}$. with subulate teeth; sterils st. very smooth, ivory-white, about 30-furrowed; branches simple, sheaths 4 or 5 -leaved, with crect, subulato teeth.Shores of the Great Lakes. Barren stems 2 to $5 \mathrm{f}$ high. May.

3 E. sylváticum L. Wood HonsetaIL. Sterilo and fertilo sts. 12 or 13-furrowed, with compound, rough, deflexed, angular branches.-Grows in woods and low grounds, N. States and Brit. Am. Stems $9-16^{\prime}$ ligh; the fertile with $4-5$ whorls of branches from the base of the sheaths which are $2-3^{\prime}$ apart, and cleft into soveral large, tawny red teeth or segments; the sterilo taller and more slender, with moro numerous whorls of branches. Tho branches aro all subdivided and curved downwards. Spike oval-cylindric, pedicellato. May.

4 E. limòsum L. PIPEs. Sts. somewhat branched, erect, striate-sulcato; branches from tho middlo joints, simple, short, 5-sided, smooth; spike oblongovoid; sheaths appressed.-Borders of ponds and swamps, frequent. Stems 2$3 f$ high, slonder, rarely simple, generally with $2-6$ whorls of branches about the middle. Branches very irregular in length and position. Sheaths $3-4^{\prime \prime}$ long, white at the summit, tipped with as many black, subulato teeth as thero are furrows $(15-20)$. This species is greedily devoured by cattle. July.

5 E. læevigatum Braun. Tall, erect, simplo or somewhat branched; sheaths elongated, appressed, green, with a blacl lorder, of about 22 lvs., sheaths of tho branches about 8 -leaved, with subulate, persistent points.-Dry soils, Wis. and South, along tho Miss. River. Stems $18^{\prime}$ to 2 or 3f. Apparently distinct.

6 E. robústum Braun. Very tall and stout, simple or somewhat branched above; sheaths short, appressed, with a llack girdlo above the base, rarely with a black border, consisting of 40 (in the branches 11) leaves, the ovate-subulato points deciduous, leaving an exact truncate margin.- - Panks of the Western rivers, Terro Haute, to St. Louis and South. Forms with fower lvs. in the sheaths seem to connect this with tho next.

7 E. hyémale L. Scourixg Rusir. Sts. all simple, erect, rery rough, each bearing a terminal, ovoid spike; sheathcinereous white, black at the base and summit, sliort, with about 20 subulate, awned and deciduous teeth.-Very noticeablo in wet, sliady grounds, and by brooksides. Stems about $2 \mathrm{f}$ high, often 2 or moro united at base from tho same root. Sheaths $2-3^{\prime \prime}$ long, $1-2 \frac{1}{2}^{\prime}$ apart, the whito ring much broader than the black, at length entire from the falling off of the teeth. The roughness of tho cuticle is owing to the silex in its composition. June.

8 I. variegàtum Schleicher. St. branching only at base, $\mathrm{C}$ to 12 , simple, straight and very slender, roughish, 5 to 9 -furrowed; sheaths very short, brown, teeth 5 to 9 ovate with broad, scarious margins and tipped with deciduous setaceous points. - Banks of streams, N. Eng. to Wisc. and Can, not common. Internodes about $\mathrm{I}^{\prime}$. July.

9 E. scorpoides $\mathrm{Mx}$. Stems growing in tufts, thread-like, 4 to $8^{\prime}$, flexuous and recurved, 3 or 4-furrowed; sheaths black, 3 or 4 -tootbed, teeth ehort-ovate, scarious, bristlc-pointed.-Hilly woods, Penn. to N. Eng., Wisc. and Can." July. 


\section{Order ClX. Filices. Ferns.}

Stem a perennial, creeping, horizontal rhizome, or sometimes erect and arborescent. Fronds (fruit-bearing leaves) rariously divided, rarely entire, with forked veins, and mostly circinate vernation. Fructification cccupying the back or margin of the fronds, arising from the veins. Sporangia (spore-cases) of one kind, scattered or clustered in sori, 1-celled, containing numerous, minuto spores. $A n$ theridia and pistillidia formed after germination, on tho young plant. (Seo figs. 491-501.)

Genera 200, species 2000.- $\Lambda$ largo and interesting order of flowerless plants, distinguished for their elegant, plume-like fuliare. They aro usually a few inches to a few fect high, but some of the tropical species, as tho Cyathex of both Indies, are $15-25$ fect high, vicing with the palms in size and beauty.

Properties. - Generally mucilaginous and mildly astringent, hence considered pectoral. Aspidium and P'teris are anthelnintic. Osmvinda regailis has been suceessfully administered for the rickets.

Observation.-The fructification of the ferns, with its various appencloges, is toc minuto to be well ebservel by the naked eye; but an examination of it with the aid of a good lens cannot fail to bo interesting and satisfactory.

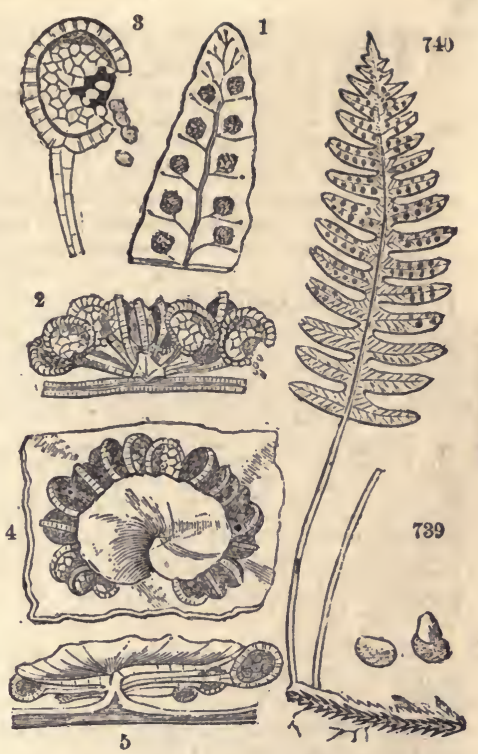

739 Polypodinm rnlgare. 7\$) Frond. 741 Lobo of the frond enlarged, showing the sori. 742 One of the suri enlarged, showing the sporangia. 743 One sporango further magnifiech bursting and discharging the spores. 744 Sorus of Aspidium marginale covered with the indusium. 745 Same, sido vier.

\section{SUBORDERS AND GENERA.}

$\S$ Frond cauline, solitary, straight in rernation. Stem crect. (s)

\$ Fronds cauline, several, palinate (or radical and fliform). (b)

§ Fronds all radical, clustered (never filiform), cireinate in vernation. (¿)

2 Sporangia spiked or panicled, naked (not involved in revoluto fronds). (b)

2 Sporangia on the back of the fronds,-but involved in the revolute segm......Nos. 8, 10 -nct involvel; begments llat. (c)

Stborder I. OPHIOGLOSSE $A$. (Spornngia naked, smooth, cartilaginous, 2-valved; no ring.)

a Fructification spicate. Frond entire, reticulate-reined............ Onmoglossus. 1

a Fruetification panieulate. Frond divided, fork-veined.............. Dotracuiver. 2

StвоRDER II. OSMUNDEA. (Sporangia reticulate-roughened, papery, 2-ralved,

with no ring, spicate or paniculate.)-b Fronds palmate. Climbing............. Lraodicx. 3 -b Fronds nliform. Erect... ..............Scnuzk. 4 -b Fronds 1-2-pinnato.................. Osuess. 5

Suborder III. POLYPODINE valreless, torn open by the elastic ring which encircies it vertically.)

c Sporangia seattered singly all over the surface (not in sori), naked..... Acrostrecar. c Sporangia collected in dots (sori) springing from the veins. (¿)

d Fruit-dots naked, having no induslum (special covering). (e)

- Fronds all nlike, flat. Fruit-dots orbienlar..................... Polypodiev. 7

- Fronds sterile and fertilo very different; the fertile spike-like...... Strutmupreris. 8

d Fruit-dots invested with special coverings (indusia). (g)

g Fruit-dots marginal; indusium a narrow, reflectel edge of frond. (h)

h Indusinm continuous all around the segment......................Preris. 9

$\mathrm{h}$ Indusium from the apex of the segm.-Midvein central........ CuerLastues. 10

h Indusinm a reflected tooth at the sinus between the segments.... Dicksosis, 12 
G Fruit-dots dorsal, oblong or linear, parallel with the midvein...... WoodwARDIA. 13

G Fruit-dots dorsal, oblong or linear, transverse to the midvein. ( $k$ )

k Indusia single, regularly arranged in 2 rows................ Asplexium. 14 Ik Indusia single, scattered irregularly, placed angularly........ Antigra.M. A. 15 is Indusia double, regularly arranged. Frond simple......... Scolopendaruy. 16

G Fruit-dots dorsal, orbicular. (o)

- Indusium cup-shaped, fised beneath all around the sorus......... Woopsis. 17

- Indusium hood-shaped, fixed at the base and 2 sides........... Cistopteris. 19

- Indusium peltate or renif" $m$, -all involved in the berry-like segm. Oxochra. 19 -all superficial on the flat segm...... Aspidiuk. 20

1. OPHIOGLOS'SUH, L. AdDeR's Tongue. (Gr. ơ $\phi \iota \varsigma$, a serpent, y $\lambda \tilde{\omega} \sigma \sigma a$, tonguc.) Sporangia roundish, depressed, opening transversely, arranged in two rows along the margins of the fertile frond which is contracted into a linear spike; indusium none, veins reticulated.

1 o. vulgàtum L. Frond simple, oblong-ovate, obtuse, reticulations elongated; spike cauline, root of thick spreading fibres. - A curious little plant in low grounds. Fronds solitary, 2-3' long, $\frac{2}{3}$ as wide, amplexicaul, entire, smooth, without a midvein, situated upon the stem or stipe a littlo below the middle. Stipe 6-10' high, terminating in a lance-linear, compressed spike, $1-2^{\prime}$ long, with the fruit arranged in 2, close, marginal ranks. Sporangia opening outwards and borizontally, becoming lunate, distinct, straw-colored. Vornation straight, not circinate. June.

2 O. bulbòsum L. Frond simple, ovate or orbiculate, or reniform, subcordate, nearly or quito radical, obtuso; reticulations short, spike cauline; root a subglobous bulb.-Wet pino barrens, N. J. (Pursh) to Ga. and La. Sts. about $3^{\prime}$ high, often 2 from tho samo bulb, spiko short, oblong ( 4 to $\left.8^{\prime \prime}\right)$. Ivs. 2 or 3 , one of them cauline. Bulbs, 3 to $6^{\prime \prime}$ diam.

2. BOTRYCHIUM, Swartz. Moonwort, Grape Fern. (Gr. Botprs, a cluster of grapes; from the resemblance of the fructification.) Sporangia subglobous, 1-celled, 2-valved, distinct, coriaceous, smooth, adnate to the compound rachis of a racemous panicle; valves opening transversely.

$\$$ Frond ternately divided, situated near the base of the stipe or stem............. Nos. 1, \&

$\$$ Frond linnately divided, situated at or above the middle of the sten................... 8,4

1 B. lunarioìdes Swartz. Scapo bearing the frond near the base; frond in 3 bipinnatifid divisions; segments obliquely lanceolate, crenulate; spikes bipinnate. -Native of shady woods and pastures. Frond almost radical, of a triangular outline, $3-5^{\prime}$ long and wide, of a stouter texture than No. 4, distinctly petiolate. Scape thick, 8-12' high, bearing a tawny, compound panicle $2-4^{\prime}$ in length, composed of numerous little 2-ranked spikes. Aug. (B. obliquum Mubl. B. fumarioides Willd.)

$\beta$. DISSECrusr. Frond near the baso of the scape, more numerously dissected, almost tripinnatifid. (B. dissectum Willd.)

2 B. símplex Hitchcock. Frond ternate, borno near half way up the stalk; lfts. cuneate-obovate, subentire or incised, unequal; spiko compound, interrupted, unilateral; capsnles sessile, yellow.-Dry hilly pastures, Vt. and Mass. Stipe or scape 3 to $6^{\prime}$ ligh. Closely resembles B. lunaria of Eur. Frond varies from simply ternato to ternate-pinnatifid. Jn.

3 B. negléctum. MERIDEN MOoswort. Frond simply pinnate, with oblongovate or oval, incised leaflets, and borno near the summit of the scape ; capsules pedicellate, subsolitary, in an oblong panicle--Rocky woods, N. H. (Meriden l) Allied rather to the next than to No. 1. St. 5 to $8^{\prime}$ high. Frond 9 to $20^{\prime \prime}$ long, half as wide. Lfts. 3 or 4 pairs. Pan. often larger than the fronds. Caps. brownish, on very short, thick stipes. July.

4 B. Virginicum I. Rattlessake Fern. Stipe with a single frond in the mid. dle; frond twice and thrice pinnate, the lowest pair of pinnæ springing from the base; ultimate segments obtuse, somewhat 3-toothed; spikes decompound; plant subpilous.-A beautiful fern, the largest of its genus, in low woods. Stipe or scape $1-2 f$. high, bearing the frond about half-way up. This is apparently ternate, the lower pair of divisions arising from the base. It is almost tripinnate, 
the ultimate segments being decurrent and more or less confluent at base, with 3-5 cut serratures. Panicle terminal, 3-6' long, reddish-tawny. June, July.

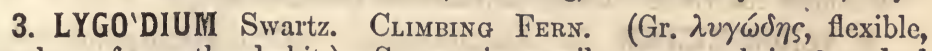
slender; from the habit.) Sporangia sessile, arranged in 2-ranked spikelets issuing from the margin of the contracted frond, opening on the inner side from the base to the summit; indusium a scalc-like veil covering each sporange. (Fig. 109.)

I. palmàtum Sw. Stem flexuous, climbing; fronds conjugate, palmate, 5-lobed, lobes entire, obtuse; spikelets oblong-linear, from tho upper fronds, which aro divided and contracted into a compound spike. - This is one of the fow ferns with climbing stems, and the only one found in the U. S., Mass. to Ky. and S. States, rare. Plant of a slender and delicate structure, smooth. Stem 3-4f long. Stipes alternate on the stem, forked, supporting a pair of fronds which aro palmately divided into 5-9 segments. Fertile fronds terminal, numerously subdivided into linear-oblong segments or spikelets, with the fruit in 2 rows on the back. July.

4. SCHIZE'A Smith. (Gr. $\sigma \chi i \zeta \omega$, to cut, cleave; alluding to the many-cleft spikes.) Sporangia oval, radiate at top, sessile, bursting laterally; indusium continuous, formed of the inflexed margins of the leaflets which are contracted, spike-like, crowded at the summit of the fertile frond.

S. pusilla Pursh. Frond simple, linear, tortuous; spikes few, crowded at the top of a long, slender stipe or scapo.-A very delicate fern, found in the pino barrens, Quaker Bridge, N. J. (This is the only locality clearly known.) Fronds numerous, cæspitous, $2-3^{\prime}$ long, $\frac{1}{2}-1^{\prime \prime}$ wide. Fertile stipes several, $3-6^{\prime}$ high, filiform, with a few short unilateral spikelets at top arranged in 2 rows. Capsules semewhat turbinate, in 2 rows on the inner side of each spikelet. August.

5. OSMUN'DA, L. Flowering Fern. Sporangia globular, half 2 valved, roughened on the surface somewhat in lines, pedicellate and clustered on the lower surface of the frond or a portion of it, which is more or less contracted into the form of a panicle; spores green.-Tall, handsome Ferns. V cins forked, straight.

\& Frond bipinnate with distinct pinne; the upper part contracted and fertilo........... No. 1

Frond pinnate with pinnatifld pinnx, partially or separately fertile................... 2 , 3

1 O. regàlis Mx. Fronds bipinnate, fructiferous at the summit; segments of the leaflets lance-oblong, distinct, serrulate, subsessile; raceme large, terminal, decompound.-A large and beautiful fern, in swamps and meadows. The fronds aro $3-4 f$ high, smooth in all their parts. Leaflets or pinnæ opposite, remote, each with 6-9 pairs of leaves with an odd one. These are an inch or moro long, $\frac{1}{4}$ as wide, obtuse, the petioles $0-\frac{1}{2}$ " long. Above, the frond is crowned with an amplo bipinnate panicle of a deep fulvous hue, with innumerable, small, globular, 2valved spore-cases covering the segments. Jn. (O. spectabilis Willd.)

2 O. cinnamòmea L. Cinnamon Ferv. Sterile frond pinnate, leaflets elongated, pinnatifid, segments ovate-oblong, obtuse, very entire; fertile frond bipinnate, leaflets all contracted, paniculate, subopposite, lanuginous as well as the stipe.-This is among the largest of our ferns, growing in swamps and low grounds. Fronds numerous, growing in clumps, 3-5f high, most of them barren, the stipe and rachis invested with a loose, cinnamon-colored wool. The fertile fronds resemble spikes, $1-2 \mathrm{f}$ long, an inch wide. Leaflets all fertile, erect, with the segments covered with fruit in the form of small, roundish capsules, appearing, under a microscope, half-2-cleft. June.

3 O. Claytoniàna L. InterrdPted Flowering Fern. Frond smooth throughout, pinnate with lance-linear pinnatifid lits.; lobes obtuse, entire, the veinlets all once forked, some (2 to 7$)$ of the intermediate leaflets fertile.-Common in low grounds. Fronds ample, 2 to $3 \mathrm{f}$ high, light green, interrupted near the middle by 2 to 4 pairs of fertile leaflots, which are so mirch metamorphosed as to resemble dense, compound racemes, densely corered with small reddish-brown sporangia. 
Jn. (O. interrupta Mx.) As tho sterilo lfts. unfold latest, early specimens show t'io upper lfts. fertile. Rarely the lowest lfts. aro all fertile.

6. ACROS'TICHUM, L. Golden Fern. (Gr.ảleós, a point, $\sigma$ tixos, a line or row ; from the fruit dots and lines.) Sporanges scattered (not in sori), occupying the under surface of the whole or a part of the frond. -Fronds of various habit.

A. aùreum L. Frond pinnate, pinnæ alternate, oblong-lanceolate, entire, cquilateral, cuneate at base, tho upper bearing the fructitication.-In deep swamps near the sea coast, Fla. (Pursh). Cultivated occasionally in the greenhouse. It is a noble Fern 3 to $5 \mathrm{f}$ high. Common in the W. Indies.

7. POLYPO'DIUM, L. Polypod. (Gr. $\pi 0 \lambda \dot{v} \varsigma$, many, $\pi 0 ́ \delta a$, feet; from the multitude of creeping rootstocks.) Sori roundish, scattered on various parts of the under surface of the frond, with no indusium (cover or involucre).-Ferns of various habit.

\$ Margrisaria (simply piunate) reticulate-reined, clothed with scales............ No. 1

\$ Polrrodrus. Frond with tho veins forked, distinct, - simply pinnate................ 2 -bipinnatifid............. Nos. 3,4 -ternate, bipinnatifil........... 5

1 P. incànum $\mathrm{Ph}$. Fronds deeply pinnatifid; segments alternate, linear, very entire, obtuse, scaly beneath, the upper ones gradually smaller; stipe scaly, bearing the fertile segments near the apex; sori solitary and distinct.-A parasitic fern, $3-6^{\prime}$ high, growing on the inclined, moss-clad trunks of living trees, particularly of the huge Sycamore, and the Magnolias, in the damp forests along rivers, W. States! and also Southern. The scales resemble tho indusia of other Ferns, but have no fruit under them. The veins are invisible.

2 P. vulgàre I. COMMON POLYPOD. Frond deeply pinnatifid, smooth; segm. linear-oblong, obtuse, crenulate, the upper ones gradually smaller; sori large, distinct.-Rather common on shady rocks and in woods, forming tangled patclies with their roots which are clothed with membranous scales. Fronds 6 to 12', clivided into alternate segments nearly to the midvein. Stipe naked and smooth. Segments parallel, a little curved, about $\frac{\lambda^{\prime}}{4}$ wide. Fruit in large, golden dots in a double row, at length brownish. July. (P. Virginianum Villd.)

3 P. Phegópteris I. BEEcir PoLyPoD. Frond bipinnatifid, triangular in outline, veins hairy, the lower pinnæ deflexed but curving forward toward the apex; segments linear-oblong, obtuse, entire, ciliate, the lower adnate and decurrent; stipe retrorsely pubescert, rachis chaffy. - Shady woods, Can. to Wis. and N. States. Frond longer than wide ( 3 to $6^{\prime}$ by $2 \frac{1}{2}$ to $\left.5^{\prime}\right)$. Sori small, about 4 on each segment. July.

4 P. hexagonópterum Mx. Triangular Polypod. Frond bipinnatifid, pinnoe rather distant, tho lowest deflexed; segments lanceolate, obtuse, ciliate, crenate or dentate, glandularly puberulent beneath, the lowest decurrent and forming a conspicuous wing to the rachis; stipe smooth.-Moist open woods, U. S. common South. Frond wido as long (5 to $\left.8^{\prime}\right)$ triangular. Sori many on each segment. JL. (P. Phegopteris $\beta$. cd. 2.)

5 P. Dryópteris I. Tennate Polypod. Frond ternate, bipinnate; branches of the frond spreading, deflexed, segments obtuse, subcrenate; sori marginal; root filiform, creeping.-This beautiful fern grows in shady places and mountainous wooks, common North. Root black and very slender. Stipe slender and delicate, smooth, nearly a foot high, dividing into 3 light green, drooping, compound leaflets of a very delicate texture. JL.

$\beta$. CALC.1REUMr. Branches of the frond erect, rather rigid. (P. calcareum Sm.)

8. STRUTHIOP'TERIS, Willd. Ostricir Fern. (Gr. otpovoós, an ostrich, $\pi \tau \varepsilon p i s$, a fern.) Fertile fronds contracted, the margins rolled backwards and covering the round, confluent sori, which are otherwise without an indusium.-Fronds bipinnatifid, the fertile pinnæ moniliform. linear. 
S. Germánica Willd. A Fern of noble port, in jow woods and swamps, $\mathbf{N}$. States and Can., common. The sterile fronds are often 5 or $6 f$ high, commonly about $3 \mathrm{f}$, numerous, in a circular clump. Stipes smooth, channeled. Pinnæ numerous, crowded, long, linear, each with numerous oblong segments of which the lowest is longer and acute, all more or less connected at base. Fertile fronds few in the midst of the sterile, much smaller, the pinnæe subterete, 1 to $2^{\prime}$ long, crowded. Sori about 5 in each segment, on the raised onds of as many veinlets. Aug.

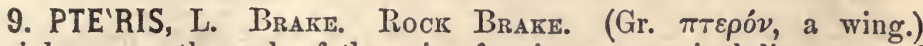
Sori borne on the ends of the veins forming a marginal line, covered with the nembranous, reflected edge of the frond.-Fronds once to thrice pinnate or decompound.

\$ Frond pedate, or terrste and bipinnatifid. Sori in a continnous line.........Nos. 1, 2

$\$$ Frond partly bipinnate. Sori at first distinct but soon continuous.............. Nos, 8,4

1 P. aquilina I. Common Brake. Frond 3-parted; branches bipinnate; ifts. oblong-lanceolate, lower ones pinnatifid, upper ones entire; segments oblong, obtuse.-Abundant in woods, pastares and waste grounds. Fern $2-5 \mathrm{f}$ in height, upon a smooth, dark purple, erect stipe. Frond broad-triangular in outline, consisting of 3 primary divisions, which are again subdivided into obtusely pointed, sessile leaflets. These aro entire above, becoming gradually indented towards the base of each subdivision. Sori covered by the folding back of the very margins of the segments.

$\beta$. CAUDÀt. Segm. of the pinnæ linear oblong, the terminal one much elongated.-The common Southern form.

2 P. pedata Willd. Frond ternately parted, the lateral divisions 2-parted, all pinnatifid; segm. linear-lanceolate, acute, the lowest segment of the terminal division pinnatifd; terminal division long-cuneiform at base, recesses acute.-On rocks, Va. (Pursh). Fern about $6^{\prime}$ high.

$3 \mathbf{P}$. atropurpùrea L. ROCK BRAKE. Frond pinnato; rachis hairy; lower lits. ternate or pinnate, segments lance-oblong, obtuse, obliquely truncate or subcordate at the petiolate base.-Fern $6-10^{\prime}$ high, growing on rocks, Can., Wis., Vt. to Tenn.! and Ala.! Frond twice as long as wide, of a grayish hue, the two lower divisions consisting of $1-3$ pairs of leaflets with a long, termiral segment. All the segments distinct, with margins conspicuously revolute. Some of the larger have 1 or 2 auricles at base. Stipo and rachis dark purple, with dense, paleaceous hairs at base. June-Aug. (Allosorus, Gr. P. Alabamensis Buckley, when the upper segments are generally auricled.)

4 P. gracilis Michx. Frond slender, lanceolate, sterilo ones pinnate, leaflets pinnatifid, segments broad-ovate, obtuse; fertile bipinnate, leaflets linear-oblong, crenate.-A delicato species, growing on rocks. Fern $4-6^{\prime}$ high, smooth and shining throughout. Both this and No. 3 are homogeneous in habit with the others. Their separation to a new genus is an over-refinement. (Allosorus, Presl.)

10. CheIlan'TheS, Swartz. Lip Fern. (Gr. $\chi \varepsilon \tilde{i} \lambda$ os, a lip, åv0os ; from the form of the indusia.) Sori roundish, distinct, situated at the margin or apex of the segments; indusia distinct, formed from the reflected margin and opening inwards.-Segments of the frond with the midvein central.

1 C. vestita Swartz. Stipe and rachis hairy; frond Vipinnate, oblong-ovate in outline, hairy on both sides; leaflets alternato; segments oblong, alternate, sessile, distinct, crenately pinnatifid, the ultimate segment very entiro; sori distinct, their indusia unchanged.-Rocky banks, Penn. to Mo. and South. Stipe slender, rigid, $2-3^{\prime}$ long, dark brown. Fronds $3-6^{\prime}$ by $1-2^{\prime}$. Leaflets lance-orate in outline, 6-12" long. $\Lambda$ small and delicate, hairy Fern. Jl.

2 C. tomentòsa Link. Stipe stout, and with the rachis and frond clothed with a dense ferruginous wool; frond tripinnate, ultimate segments rounded or oblong, obtuse (upper ones confluent), fruit-bearing around the whole margin.- $N$. Car. (Curtis) aud Tenn. Fern If to $18^{\prime}$ high, much larger and more hairy than the preceding. Both species are less hairy on the upper than the under surface. 
11. AdIAN'TUM L. Matden-hair. (Gr. a, privative, diaivw, to moisten; as the rain slides off without wetting it.) Sori oblong or roundish, marginal ; indusia membranaceous, formed from the reflexed margins of distinct portions of the frond and opening inwardly.-Stipe polished. Ultimate segments dimidiate, the midvein on the lower margin.

I A. pedàtum L. Frond pedate; divisions pinnate; segments oblong-rhomboid, incisely lobed on the upper side, obtuse at apex; sori oblong, subulate.-This is, doubtless, the most beautiful of all our ferns, abounding in damp, rocky woods. Stipe 8-14' high, slender, of a deep, glossy purple approaching to a jet-black. At top it divides equally into 2 compound branches, each of which gives off, at regular intervals, $6-8$ simply pinnate leaflets from the outer side, giving the whole frond the form of the crescent. July.

2 A. Curtísii, N. sp. (We saw specimens of a new Adiantum in the herbarium of Rev. M. A. Curtis, from the Mts. of N. Car. But our notes are insufficient at present for its proper diagnosis.)

12. DICKSO'NIA L'Her. (In honor of James Dickson, a distinguished English cryptogamist.) Sori marginal, roundish, distinct, terminating a vein ; indusium double, the proper one cup-shaped, opening outwards, the other formed of a reflected lobule of the margin and opening inwards.

D. pilosiúscula Willd. Fine-hatred Mountain Fern. Frond bipinnate; leaflets lanceolate, sessile; segments pinnatifid, decurrènt, oblong-ovate, ultimate segments toothed; stipe a little hairy.-A large and delicate fern, in pastures, roadsides, among rocks and stones. Fronds $2-3 \mathrm{f}$ high, in tufts, and remarkable for their numerous divisions and subdivisions. Stipe and rachis smooth, with the exception of a few, soft, scattered hairs. Leaflets alternate, approximate; segments deeply divided into 4-toothed, ultimate segments. Sori minute, solitary, on the upper margin of the segments. July. (D. punctilobula, Hook.)

13. WOODWAR'DIA, Sm. (To Thomas $J$. Woodward, an English botanist.) Sori oblong, straight, parallel with, and close to the midvein, on transverse, anastamosing veinlets; indusia arising from the same veinlet on the outer side, free and opening on the inner side towards the midvein.-Fronds pinnate or pinnatifid.

$1 \mathrm{~W}$. onocleoìdes Willd. Fronds of two kinds; the sterile simply pinnatifid pinnæ, lanceolate, repand, slightly serrulate; fertile fronds pinnate, the pinnæ entire, linear, acute.-In swamps, not common. Fern about a foot high, growing in tufts. Barren fronds numerous, of a narrow-lanceolate, acuminate outline. Leaflets with decurrent or confluent bases. Fertile fronds fewer, with linear segments nearly covered on the back with the fruit in oblong, longitudinal sori ${ }_{4}^{\prime}$ in length. Aug. (W. angustifolia $\mathrm{Sm}$.)

2 W. Virgínica Willd. Fronds all similar, pinnate, very smooth, the leaflets pinnatifid, lauceolate, sessile; sori in interrupted lines near the midrein of the leaflets and oblong, obtusish segments. - In low woods and swamps. Frond about $2 \mathrm{f} \mathrm{high,}$ on a smooth stipe, lanceolate in outline, and pale green. Leaflets alternate, deeply pinnatifid, with numerous, spreading, obtuse and slightly crenate lobes. Fruit arranged in lines along each side of the midveins, both of the segments and leaflets. July, Aug. (Doodia, R. Br.)

$3 \mathrm{~W}$ : thelypteroides $\mathrm{Ph}$. Fronds nearly similar, pinnate, the pinnce sessile, villlous at base, linear-lanceolate, pinnatifid; the segments in the sterilo fronds oblong, obtusish, in the fertile short-triangular, acute, all entire; stipe pubescent, angular.-Sandy swamps, near Charleston, S. Car. Resembles the preceding but is not half its size. Jl. (Pursh.)

14. ASPLE'NIUM, L. SPLeEnwort. (Gr. $a$, privative, $\sigma \pi \lambda \eta \dot{v}$, the spleen; from its supposed medicinal virtues.) Sori linear, or linearoblong, separate, oblique to the midvein, arising with its indusium, from 
the upper or forward side of the lateral veins and opening towards the midvein.-Ferns of various habit. Veins forked or pinnate.

\$ ATrYriUм. Induslum oblong, subreniform, opening half around. Frond hijinnate...No. 7 Asplestou proper. Indusium narrow, straightish, opening only on one edge. (a)

a Frond bijinnatifil, with numerous pinne (leaflets), Stalks green................ 6 a Frond bipinnatifid, wlth few divisions. Stalks greenish...................... 4, 5

a Frond simply pinnate, - thin, large, with green stalks......................... 8 -subcoriaceous, with dark purplo stalks....................... 1, 2

1 A. Trichómanes L. Dwarf Spleenwort. Frond pinnate; lfls. roundish, subsessile, small, roundish-obovate, obtusely cuneato and entire at base, crenato above ; stipe black and polished.-A small and delicate fern, forming tufts on shady rocks. Frond $3-6^{\prime}$ high, lance-linear in outline, with 8-12 pairs of roundish, sessile leaflets, $3-4^{\prime \prime}$ long. Fruit in several linear-oblong, finally roundish sori on each leaflet, placed oblique to tho midvein. July. ( $\Lambda$. melanocaulon Mulul.)

2 A. ebéneum Willd. Eronx SpleEnwort. Frond pinnate; lfls. lanceolate, sub. falcate, serrate, auriculate at base on tho upper sido; stipo smooth and polished.A beautiful fern, in dry woods, hills. Fronds 8-14' high, on a slender stipe of a shining brown or black color. Foliage $5-9^{\prime}$ long, $1-1 \frac{1}{2}^{\prime}$ wide, linear-lanceolate in outline. Leaflets near an inch in length, rather acuminato and curved at apex, dilated at base on the upper side, and sometimes on the lower. Fruit arranged in short lines on each side the midrib. July.

3 A. angustifòlium Michx. Frond pinnato; lits. alternate, upper ones subopposite, linear-lanceolate, serrate towards the apex, somewhat repand, the baso truncate on the upper side and rounded on the lower.-In low woods, frequent, Vt. to Ga. Fronds thin, fragile, $1-2 \mathrm{f}$ high, in tufts, tho outer ones barren, inner fertile. Sori large, diverging from tho midrib, parallel with the veins, at length confluent. July.

4 A. Ruta-murària L. Frond bipinnate at base, simply pinnato above; lfts. small, petiolate, cuneate at lase, erose-dentate at the blunt apex.-An extremely small and delicate fern, in dry, rocky places. Frond 2-3' high, $\frac{1}{2}$ as wide, smooth, growing in tufts, somewhat coriaceous. Segments usually 3 on each leaflet, less than $\frac{y^{\prime}}{2}$ long. Stipo flat and smooth. Sori linear-oblong, slightly oblique, of a rusty-brown color, finally confluent. July.

5 A. montànum Willd. (A. Adiantum-nigrum. Michx.) Frond glabrous, bipinnate; lfts. oblong-ovate, parted into a few (j or 6) 2 or 3 -toothed segments; sori linear, finally confluent.-Mountain rocks, Penn. to Car. (Curtis), W. to Ky. Fronds growing in tufts, $4-8^{\prime}$ high, rhombic or oblong-lanceolate in outline, mostly bipinnate, but moro or less divided according to tho size. Segments moro obtuse than in the foreign A. Adiantum-nigrum. July.

6 A. thely pteroides Michx. Silvery SpleENwort. Frond bipinnatifid; ifts. pinnatifid, oblong-lanceolate, acuminato; segments oblong, obtuse, serrate-crenate; sori in parallel, oblique lines.-A fine, large fern, on shady banks of streams. Fronds $1 \frac{1}{2}-3 \mathrm{f}$ high, of an ovate-acuminate outline, on a slightly chaffy, pale stipe. Leaflets distinct and ratlier remote, narrow, $4-6^{\prime}$ long. Segments rounded at the end, near $\frac{1}{2}$ long. Sori arranged in 2 rows on each segment, ono on each side the midvein, convergent below, with shining, silvery indusia when young. July.

7 A. Filix-fœmina Bernh. Frond hipinnate; Ifts. lanceolate, acuminate; seg. oblong-lanceolate, deeply cut-pinnatifid; ultimate seg. 2-3-toothed; sori reniform or lunate, arranged near the veins; stipe smooth.-A delicate, finely-divided fern in moist woods. Fronds $1-2 \mathrm{f}$ high, with subopposite divisions. These are subdivided into distinct, obtuse segments, which are themselves cut into oblong, deep serratures, and lastly, the serratures are mostly with $2-3$ teeth at the summit. Sori large, at first in linear curves, finally confluent, giving the whole frond a dark brown hue. July. (Aspidium, Swtz.)

15. ANTIGRAm'ma, Presl. W WLKing Ferv. (Gr. avti, like,

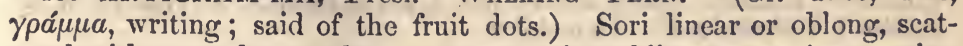
tered withont order on the transverse veins, oblique at various angles, often in pairs and facing each other; indusium simple, linear.-Frond simple, veins reticulated in the midst, forked and free only in the margin. 
1 A. rhizoplýlla J. Smitl. Frond mostly undivided, lanceolate, stipitate, subcrenate, cordate-auriculate at base, the apex attenuated into a long, slender acumination, rooting at the point.-This singular fern grows in rocky woods, not very common. The frond is $4-S^{\prime}$ long; the long, slender, linear point bending over backwards, reaches the earth, and there strikes root, giving rise to a new plant, Thus the plant may wall: by ycarly steps. July. (Asplenium, ed. 2. Camptosorus. Link.)

2 A. pinnatifida. Frond pinnatifid, lanceolate, abrupt at base, the apex attenuated into a long acumination and sometimes striking root; segments or lobes roundish-ovate; sori irregularly scattered, at length large and confluent, covering the lobes, and even the slender summit. Crevices of rocks, on the banks of the Schuylkill (Nuttall), Ky. and Tenn. (Curtis) rare. Fronds tufted and spreading, 4 to $8^{\prime}$ long. (Asplenium, Nutt.)

16. SCOLOPEN'DRIUM, Smith. HART's-Tongue. (Gr. $\sigma \kappa o \lambda o \pi \varepsilon ́ \nu \delta \rho a$, the centipede; suggested by the appearance of the under side of the leaf.) Sori linear, transverse, scattered; indusium double (arising from 2 contiguous parallel veins), occupying both sides of the sorus, along the middle, finally opening length wise.

S. officinàrum Willd. Frond simple, ligulate, acute, entire, cordate at base.Shady rocks, Chittenango, N. Y., (Sartwell.) Stipe rather short (3-5' long), chaffy, bearing the frond suberect, $8-15^{\prime}$ high, $2-3^{\prime}$ wide, bright green, paler beneath. Sori oblique to the midvein, $6-9^{\prime \prime}$ in length. Rhizoma large, creeping. July.This curious fern appears to bo confined to the vicinity above mentioned, where it was first detected by Pursh. It is there abundant. (Asplenium Scolopendrium L.)

17. WOOD'SIA, Brown. Rock PolyPod. (In honor of Joseph Woods, an excellent English botanist.) Sori roundish, scattered; indusium beneath the sorus, early opening above it, with a multifid or fringed margin, including the pedicellate spore cases, like a calyx.-Small, cæspitous, ferns with pinnated fronds.

§ HrPopretes, Torr. Indusium closed over the sorus at first, toothed when open...... No. 1 Woodsia proper. Indusium concealed under the sorus, fringed with long hairs... Nos. 2,3

1 W. ilvénsis Br. Rusty PoLyPoD. Frond pinnate, leaflets pinnatifid, lanceolate; segments ovate-oblong, obtuse; sori near the margin, at length confluent; stipe, rachis and midveins cluaffy.-Growing in tufts, on rocks and in dry woods North and South. Fronds 5 or $6^{\prime}$ high, on brown stipes which are more or less cliaffy. Foliage 3 or $4^{\prime}$ long, $\frac{1}{3}$ as wide, oblong-lanceolate in outline, with rustcolored chaff beneath, with opposite and alternate leaflets hardly an inch in length. The lower leaflets are pinnatifid, upper ones wavy on the margin or entire. (W. rufidula Beck.)

2 W. obtùsa Torr. Frond subbipinnate, or nearly tripinnate, minutely glandular-pilous; lfts. distant; segments of the leaflets pinnatifid; ultimate segments roundish-oblong, obtuse, bidentate; sori round, one at cach cleft between the lobelets, at length crowded; stipe somewhat chaffy.-About a foot high, among and on rocks, N. Y. to Ky. and Tenn. Fronds lance-oblong in outline, 3 times as long as wide. Segments of the leaflets crenate-serrate, the lower ones distinct, upper confluent. Sori orbicular, becoming nearly confluent, each at first inclosed in the silvery indusium which when open is notched into little teeth on the margin. July. (W. Perriniana, ed. 2.)

3 W. glabélla R. Br. Fern smooth and glabrous, pinnate, lance-linear in outline, 2 to 5 ' high; lfts. distant below, subopposite, ovate, very obtuse, a few lines long, the upper with the margins only crenate, the lower deeply cleft into 3 to 7 lobelets; indusium fringed, open.-Rocks, Little Falls, N. Y. (Vasey! in herb. Curtis), Willoughby Mt., Vt. and Can.

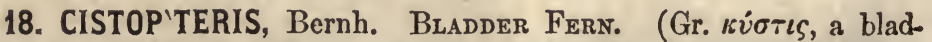
der, $\pi \tau \varepsilon \rho i \varsigma$, fern.) Sori roundish; indusium hood shaped, vaulted, 
closed and subtending the sorus on throe sides, opening on the fourth which looks towards the apex of the segment; veins forked, free.

I C. bulbifera Bernh. Frond bipinnato, mrrowly lanceolate, segments of the lfts. opposite, oblong, serrate, the lower cma pinnatifid; rachis bulbiferous, wingless; sori roundish, placed singly at tho @lefts between the lobelots.-In damp woods, frequent. Frond 12 to $18^{\prime}$ high, nemarkable for the little bulbs produced in the axils of the rachis, which, falling to tho ground, take root. Foliage narrow, tapering to an acute summit. Stipe sys woth. J!. (Aspidium, Swtz).

2 C. frágilis Bernh. Frond bipini.rtr, oblong-lanceolate in outline, delicate in texture; lits. ovate-lanceolate, segm. nhing, obtuse or acute (3 to $\left.5^{\prime \prime}\right)$, incisely lobed or pinnatifid, its lobes subentire; rashis winged by the decurrent lfits.; sori singlo at the baso of each tooth; stim glander, longer than frond.-A delicate Fern on moist rocks, frequent. Fronds 6 to $12^{\prime}$ high, dark green, jts divisions rather remote, and with the subdivisi,ns, considerably variable in form. Sori small, about 1 at tho base of each lolc, soon naked. Jn., Jl. (Aspidium tenuo Swtz.)

19. ONOC'LEA, L. Sexaitive Fern. (Gr. ǒvos, a kind of vessel, $\kappa \lambda \varepsilon i \omega$, to close.) Fronds sterile and fertile; sori clustered, confluent; proper indusium very thin, lateral; common indusium formed of the segments of the frond, whose margins are revolute and contracted into the form of a berry, opening, but not expanding.-Sterile fronds deeply pinnatifid, ample; fertile bipinnate, with recurved and globular, contracted segments.

O. sensíbilis L. Common in low grounds. Fronds about a foot high, the barren ones broad and somewhat triangular in outline, composed of broad, oblong, sinuato divisions, the upper ones smaller, nearly entire, becoming united at base. The fertile frond is very dissimilar in its form to the others, resembling a compourd spike enclosing the fruit in the giobular segments of its short divisions. Color dark brown. Jl.-Very sensitive to frost.

$\beta$. oвtUsilobìta Torr. Fertile frond segments leaf-like, only partially revolute, not concealing the sori._Mass., N. Y., very rare. (O. obtusiloba Scbk.)

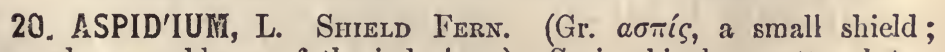
from the resemblance of the indusium.) Sori orbicular, scattered, terminal or lateral on the pinnate veins; indusium orbicular, peltate or reniform with a deep sinus, covering the sorus, opening all around.

\$ Tipper half of the frond fruitful, contracted, unlike the lower sterlle half..........Nos. 1, 2 $\$$ Upper half of tho frond like the lower, not contracted. (a)

a Frond simply jinnate, lfts. ovate, semianriculate....................... 3

a Frond bifinnate, segments semiauriculate, sharj-twothed.............. Nos. 4, 5

a Frond bipinnate, segments equilateral, deeply jinnatifid.................... 6

a Frond pinnate with pinnatifid leaflets. (b)

b Segments subcoriaceous, with the sori near the midrein............Nos. 7 , 8

b Segments subcoriaceous, with the sori at the margin.................... 9

b Segments soft and thin, - smoothish. Sori in 2 rows..................... 10, 11

- bairy. Sori without order..................... 12

1 A. acrostichoides Willd. Leaflets of the frond undivided, subsessile, falcatelanceolate, auriculate on the upper side at base, ciliate-serrulate, only the upper ones fertile; sori at length confluent; stipo chaffy.-Common in rocky shades. Frond 15-18' high, of a narrow-lanceolato outline. Stipe with loose, chaffy scales. Leaflets numerous, slightly curving upwards, $1-2^{\prime}$ in length, (incised in A. Schweinitzii Beck), the terminal ones, which alono are fruitful, are contracted in size, the under sido becoming overspread with tho sori. June-Aug.

2 A. Ludoviciànum Riddell. Frond tall ( 2 to $4 \mathrm{f}$ ), rigidly erect, narrowly oblonglanceolate in outline, pinnate and barren below, bipinnate, fruitful and contracted above; lower lfts. incisely pinnatifid with very obtuse, subentiro lobes, upper with distinct, oblong, obtuse, crenate-serrate segments; indusia peltate, in 2 intramarginal rows.-Swamps, Ga., Fla. to La. The short stipe and long rachis chaffy.

$3 \triangle$. lonchitis Willd. Frond pinnate, linear-lanceolate in outline, rigidly erect 
( 8 to $12^{\prime}$ ); lits. obliquely triangular-ovate, auricled on the upper side at base, largest ( $l^{\prime}$ long) in the middle, gradually reduced above and below to the base, all beset with close, spiny teeth, and covered with fruit beneath. -N. Mich. Br. Am.

4 A. aculeàtum Swtz. Segments of the leaflets ovate, subfalcate, acute, aculeate-serrate, truncate and auricled on the upper side at base, upper leaflets fertile; stipe and rachis cliaffy.-Manstield Mt., Vt., and Mts. in Essex Co., N. Y., (Macræ). Fronds dark grcen, in tufts 1-2f high. Segments of tho leaflets on very short petioles, somewhat dilated at baso on the upper side, deeply serrate, each serrature tipped with a short spinous bristle. Sori in rows, distinct. Aug.

5 A. fràgrans Swtz. Frond coriaceous, pinnate with deeply pinnatifid or pinnate lfts, lance-ovato in outline, glandular and fragrani; lfts. narrow-pointed, with a dozen pairs of small, obtuse, bristiy serrate segments which are unequal at base; indusia large, orbicular, peltate, covering segments.-Rocks, Penokee Iron Range, L. Sup. (Lapham) and northwest. Frond 6 to $12^{\prime}$ high. Stipo and rachis chaffy.

6 A. spinulòsum Willd. Leaflets oblong-lanceolate, distinct; segments distinct, oblong, obtuse, incisely pinnatifid; ultimato segments mucronate-serrate; stipo chaffy; indusium umbilicate.-Woods and shady pastures. Fronds 1-2f high, nearly tripinnate, the foliage about twice as long as wide, acuminate at apex, abrupt at base. Leaflets also acuminate, but the segments rather obtuse, all distinct at base, except those near the summit, serratures with short, soft bristles. Stipe with large, tawny scales. Sori large. Jl. (A. dilatatum Swtz.) Variable.

7 A. Goldiànum Hook. GoldIE's Fer.. Frond ample, oval or ovate, in outline (10 to $16^{\prime}$ long, two-thirds as wide) pinnate, as long as the smooth stipe; lfts. broad-linear, alternate, deeply pinnatifid, crenate-appressed-serrate, acutish, with 2 rows of distinct fruit-dots near the midvein; indusium reniform-peltate. - A large Fern in rocky woods, N. and W. States and Can. Ifts. close together, about 30 pairs, with about 20 pairs of segments. Stipe chaffy at base, scarcely so above.

8 A. cristàtum Swtz. Stipe with a few large, oblong, torn scales, chiefly at baso; frond narrowly lanceolate; leaflets deeply pinnatifid, remote, short-petiolulate, broadest at base, the lower triangular-ovate; sori large, in a single row each side the midvein of each dentate segment; indusium fixed near ono side. - Woods, Can., N. H. (Rickard) to N. Y. and N. J. A beautiful Fern, 20 to $30^{\prime}$ high. Frond dark green, $15-18^{\prime}$ by $5-8^{\prime}$. Leaflets gradually narrowing from basc to apex. Segments nearly distinct, more or less distinctly serrate-dentate, each with $1-25$ dark-brown sori (lower leaflets fruitless). July. (A. Lancastrienso Spr.)

9 A. marginàle Swtz. MARginar Shield-Fern. Segments of tho leaflets oblong, obtuse, decurrent, crenate-sinuate, repand at base, lower ones almost pinnatifid; sori marginal; stipe chaffy.-A large, handsome Fern, in rocky woods, common. Frond 12-18' high, very smooth (rachis a littlo chaffy), its divisions nearly opposite. Segments of the leaflets distinct, near an inch long, $\frac{1}{4}$ as wide, contracted at base, then decurrent, forming a narrow margin along the rachis. Fruit in round dots, in regular rows along the margins of the segments. Indusium large, orbicular, with a lateral sinus. July.

10 A. Thelýptera Swtz. LADY FERN. Frond smoothish, lance-ovate; ifls. slender, distant, deeply pinnatifid, gradually shorter from near the base upwards; segm. acute, margins reflexed in fruit; sori in 2 lines, as near the midvein as the margin.-A delicate Fern, in damp shades, frequent, about if high, half as wide. Lfts. 2 to $3^{\prime}$ long, about 20 pairs, lowest pair as long as any. Segm. 25 pairs. Jl.

11 A. Novaboracénse Willd. NEw.York FER. Frond smoothish, ellipticlanceolate; lfls. slender, near or distant, deeply pinnatifid, gradually shorter boin ways to a point from the middle, the lower reflexed; segm. obtuse, oblong, flat; sori in 2 rows close to the margin, at length confluent.-Fern as thin and delicato as the last, 12 to $18^{\prime}$ high, 3 to $4^{\prime}$ wide, with about the same number of divisions.

12 A. patens Swz. Frond soft and thin, pubescent with rusty hairs all over, lanceolate, pinnate; Ifts. linear, pointed, pinnatifid, lobes short-oblong, very obtuse entire, with simply pinnate veins; indusia round-reniform, small, scattered withont order near the midrein.-Dry woods, Fla. (Chapman). Fern 12 to $18^{\prime}$ high, tire stipes a third of this length. Ifts, about 25 pairs, segm. 18. (A molle Kunze). 


\section{A T I N. I N D E X.}

** The names of the Natural Orders, and of the higher divisions, are in Capitals, Synonyms and Subgenera are in Italics. The numbers inclosed in parentheses refer also to Synonyms.

A belmoschns ........ 270 A bies ............... 6.31 A butilon.............. 268 Acalypha............ 629 ACA NTHACE Acantholomon....... 509 Acer............(287) 285 Acerates ............. 594 Acetosa..............665 A chillea............ 457 Achyrantheo........6 616 Acmella............453 Acnida ............6 618 Aconitum...........2.211 Acorıs ............. 670 Acrostichum ....... 818 Actæa.........211, 212 Actiuomeris ......... 450 Actinospermum...... 457 Adelia..............6.60 Adenarium......... 261 Adenocaulon ........ 419 Adiantum.......... 820 Adice.

Adtumis.

Eyilop. ............. 806

Ayopodium .......... 388 Aischynomene...... 306 Asculus............. 287 Athusa................ 38 Agapanthus......... 712 Agathyrsus .........444 A gave............. 69 foratum.............4 412 Agrostemma ........... 256 Agrostemma........ 256 Ajlanthus.......... 283 Aira....(790, 791, 795) 79 Airopsis............. 790 Ajax...............693 Alcea ................ 266 Aletris ..............697 69 Alisma................ 677) 676 ALIS.M Allium...............71t Allosorus........... 819 Alnus..............643 A lopecurus .......... 778 Aloysia............... 539 A lsine ............. 259 Althea ............. 266

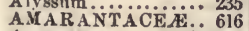
Amarantns......(618) 617 AM A RYLID A CE 692 Amary 7 is ..........6.693 Amberboa ........... 466
Amelanchier......... 329 Amellus............. 438 Amianthium ........ 719 Ammannia........... 349 Ammi................... 387 Ammophila.................. 315 A mpelopsis.......... 293 Amphiauthus ....... 525 Amphicarpar....... 322 Amphicarpum ...... 784 Amsonia ........... 589 Amygdalew.......... 325 Amygdalus. $\because \ldots \ldots \ldots 329$ ANACARDIACE 20. Anacharis .......... 679 Anantherix......... 594 Andromeda.........4 486 Andropogon ......... 808 Androsace ........... 503 Anemone ............ 202 Anethum ........... 382 Angelica............ 380 A NGIOSPERM $A$... 199

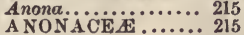
Anonymus......... 534 Antennaria ........4 461 A nthemis ........... 457 Anthopogon .......... 803 Anthoxanthum ...... 789 Antigramma ........8 821 Antirrhinum....... 519 Anychia.........(263) 262 Apargia ............4 470 APETAL A phyllon ........... 512 A pios.................. 320 A pium............... 388 A plectrum........... 687 A POCYN A CE A pocynum .......... 588 Apogon ............. 469 Apogonia ............... 807 Apteria ...............6.680

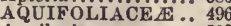
A quilegia........... 209 Arabis .............. 231 A.RACE $\$$........... 667 Arachis.............. 306 Aralia ............ 389 A RALI A CE Arbutus............. 486 Archangelica.......... 380 A rchemora .......... 380 Arctium............4 468 Arctostaphylus ...... 485 Arcyphyllum ......... 321 Arethusa ...........6 690 A rgemone.............222 Arisæma..............66 66
Aristolochia ........ 601 Biotia ........... 421 ARISTOLOCHIACE. BE, Blephilia............... 551 Armeria . 601 Bletia............6. 6r A rmor

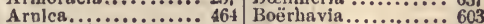

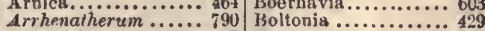

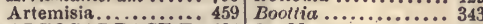
ARTOCARPACË. 634 Borkhausia ........... Arum...........668, 669 BORRAGINA CE $\not 3.559$

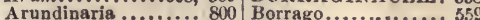
Arundo ..........778, 800 Borrichia............. 440 A sarum.............6.6. 601 Borya............6.60

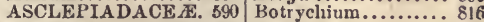

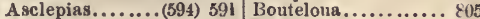
Ascyrum........... 247 Boykinia.................. A simina ............. 215 Brachycha......... 450 Asparagus........... 715 Brachyelytium........ Asphodelus.........713 Brasenia..........219 Aspidium ........... 823 Brnssica.............. 225 Asplenium.......... 820 Brickellia............ 415 Asteranthemum...... 715 Briza ............ 799 Aster.......(420-429) 420 BROHELI A CE. ... 695 ASTEROIDE $A$.... 419 Bromus........... 79 Astilbe..............371 Broussingnultia.....61 Astragalus........................ 317 Bs Atheropogon......... 805 Browallia.......... 517 Atragene...........201 Brugnansia ........ 58 Atriplex.......(615) 614 Brumella...........65\% Atropa.............5 579 Bryonia............ 264 Aulaxanthus........786 13ryophyllin....... 367 AURANTIA CE E... 274 Bryzopyrum ......... 798 Avena.......(790,791) 790 Buclue:a......... $5: 8$ Azalea, (489).Azolla.. 810 Bucklera ...........622 Baccharis.......... 439 Bumelia............ 500 Baldwinia........... 456 Buphthalmum ....... 440 Ballota............. 555 Bupleurum........... 382 Balsamiflua.................. 685 BAISAMINACEA . 240 BUTMANNIACE $\$ 680$ Baptisia........... 301 Buxus............6 632 Barbarea............ 233 Cabomba............. 219

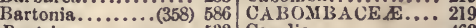
Bartsia........... 532 Cacnlia............ 462

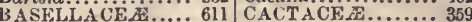
Batatus........... 571 Cartus............. 3:9 Batschia............. 561 Cakile............. 239 Befuria ............. 491 Calamngrostis........ 777 Begonia ........... 366 Calaminha........ 547

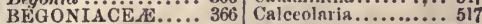
Bejaria........... 491 Calendula.......... 465 Bellis............. 429 ('alla .............6.69 Benzoin...........621 Calliastrum........ 421 BER BERI A D A CE 217 Callicarpa.......... 598 Berberis ..........2 217 ('alliopsis.......451, 452 Berchemia........... 291 Callir, ho $\ldots \ldots \ldots \ldots 267,268$ Berlandiera.........442 Cnllistephus........429 Bernkardia........ 813 CALLITRICIIA CE 42657 Beta............612 Callitriche........6.657

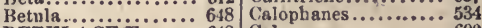
BETULA CE $2 \ldots . .646$ Calopogon...........6.60 Bidens........... 453 Calth .......... 208

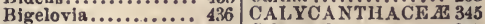

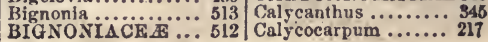




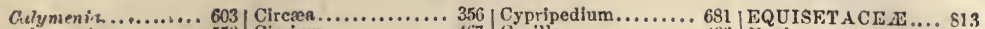

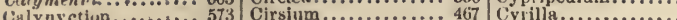

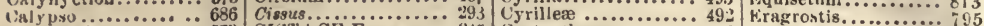

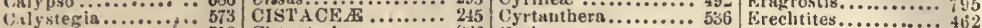

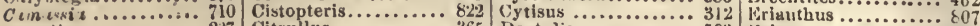

Catuelina .......... 237 Citrullus............ 365 Dactylis ........... 793 Kiriea .............

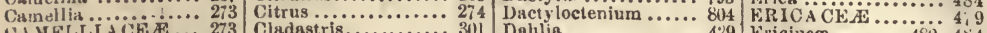

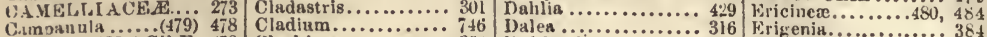

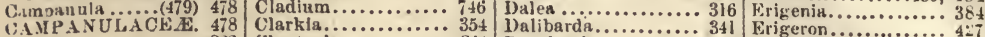

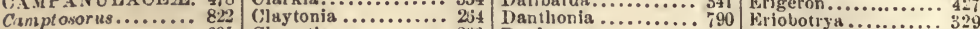

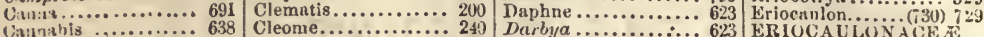

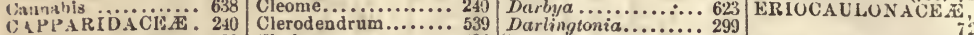

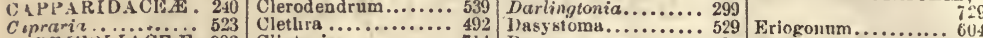

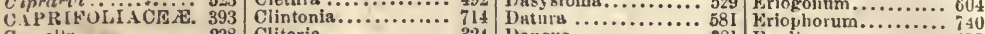

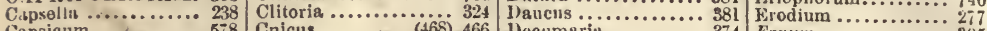

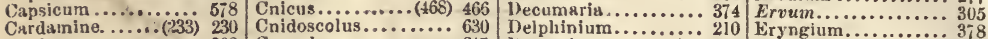

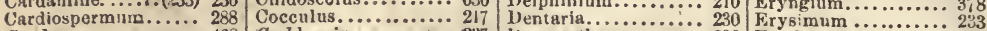

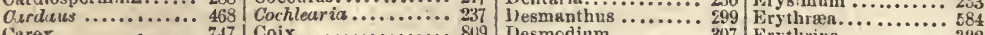

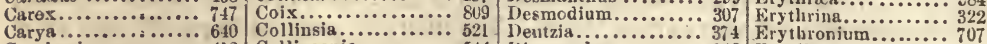

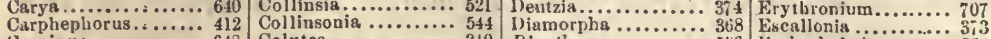

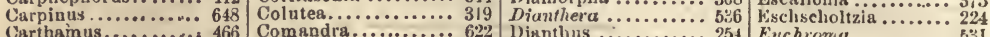

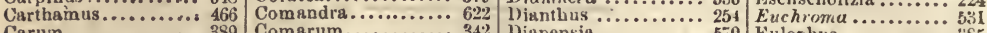

Carum . .

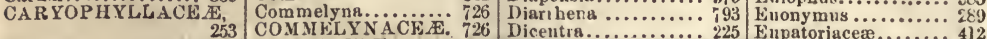

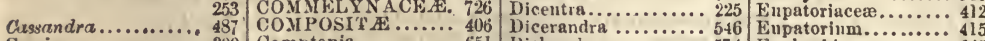

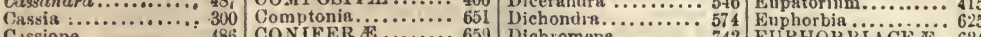

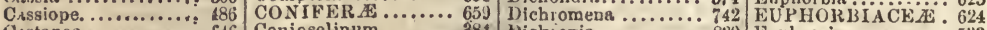

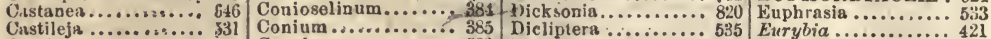

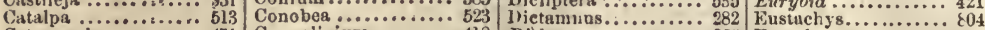

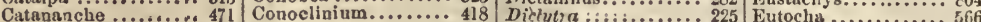

Culinia

Caulophylium.......... 218

Ceanothus ............291

Cedronella $\ldots \ldots \ldots \ldots . .652$

CELASTRAC

Celastrus .............. 289

Celosia...............6.6.6. 634

Celtis ................6.6. 63

Conopholis ........ 512 Diervilia .......... 396 Eutriana........... 84

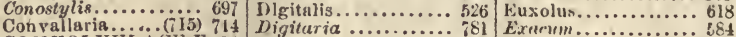

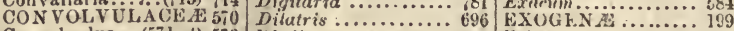

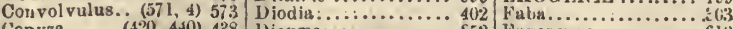

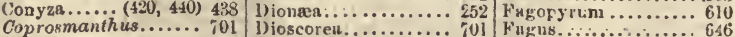

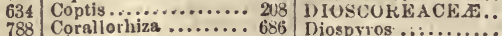

Centaurez.......(466) 465

Centrosema......... .638

Centunculus........... 505

Cephilunthus ........... 40

Ceranthera........... 547

Cerastlum.................... 2

Cerasus................. 328

CER ATOPHŸLï.

CKA

Ceratoschœnus........ 658

Ceratoschwnus. ......7 745

Ceresia.................

Vereus....

Chreropliyli............. 359

Chotocyperua ......... 73

(Yhamælirlum......... 720

Chamerops...........6.667

Cituptalia........... 47

Cheilanthes .......... 819

Cheiranthus . $\ldots . . . . .23$

Chelidonium.......... 223

Clielone.............. 520

Chenooodium..... (6ii) 61 :

CHENOPUDIACEN 61

Chimaphila........... 49

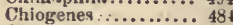

Chionanth is......... 59

Chironia.........583, 584

Chloris............... 805

Chryseis.............. 224

Chrysobalaneæ......... 325

Chrysobalanus ....... 326

Chrysogonum........ 440

Chrysopsis .......... 437

Chrysosplenium....... 369

Chrysastemma........ 45:

Chthlamia ........... 59

Cicer ................ 3

Cichoracere.......... 407

Cichorium ........... 46

Cicuta................

Cinchonem............

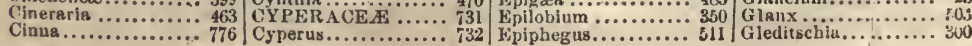

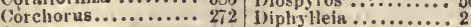

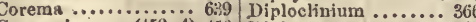

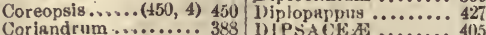

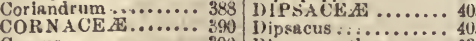

Cornus ........... 390 Dipteracanthis .......

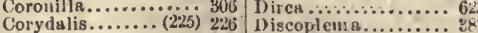

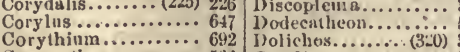

Cosmanthus.......... $560^{\circ}$

Cranichis ...........6.68 1) 688 but.............

Crantzia ............ 378 Drncoceplialuin...... 55

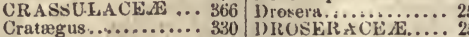

Crocus ........... 700 1)ryas............ 33

Croomia............. 03 Duchesuia......... 342

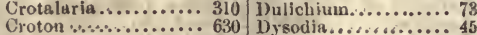

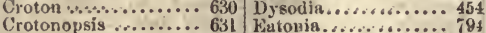

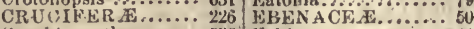

Cryphiacautlus ......5.535 Echinacea.......... 445

Crypsis ............ 775 Fehinocyst is ......... 3

CIYY TOG A.MIA.... 810 lichinospermum...... 56.

Cryptotrenia ......... \&86 80 Echium ........... 559

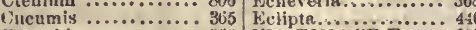

Cneurbita .......... 365 FitA I I A CE..... 253

CUCURBITACE $A . .363$ Elatine $\ldots \ldots \ldots \ldots .2$

Cunila ............ 543 EI.A.

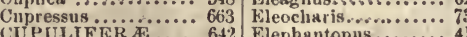

CUPULIFER \& .... 642 Flephantopus ........ 411

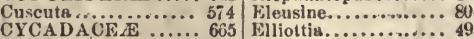

Cycas ............6. 665 Ellisia .............. 56

Cyclamen ........... 503 Elodea ............. 250

Cycloloma ........... 612 Elymus............ 80

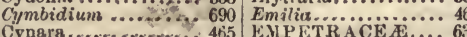

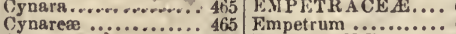

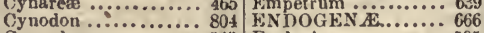

Cynoglossum ........56.3 Enslenia.......... 595

Cynosciadium ........ 389
Cynthir...........

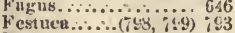

Ficus .............. 6is

Filngo :............. 461

FIl.1C kis............ 815

limbrists lis.......... it

Firnima

Floerkea............

Fodia

Foniculum..............2

Forestiera..........600

Forsteronia .......... 5t9

Fothere

Frugatia ............ 375

Frauklinice............274

Fraseral . . .......... $5<6$

Fraxi1н18........... 597

Fritilhu.jn..........

Frolichin...........6.6. 6

Fuclisia. $2 . \ldots \ldots \ldots \ldots$. is

Finirena............... ?ús

FUMARIACER .... 224

Funkia .

Gaillardia............ 454

Gulucinea........480, 495

Galuctia ............

Gulanıhus .......... 694

Galutelia.......... 419

Galeorsis.............. 55

Galiwm ........... \$!9

GAMUPKTAL,AE.... 393

Gaultheria.........4 486

Guva ............... 353

Gay lussacia......... 481

Gelseminum........ 515

Geuisth............. 310

Gentiana.................. 84

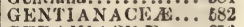

GERA NIACKA .... 2;6

Geranium........... 2/6

Gerardia.........529, 580

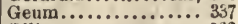

Gilia................ 569

Gillenia............. 345

Gladiolus ........... ; 60

G]asicjum............" 23 


\begin{tabular}{|c|c|c|c|}
\hline & & & \\
\hline ... I31 & ... 496 & Leucot/loe & entzelin \\
\hline$\ldots 798$ & ‥ 253 & Littris....... & Menyanthe: \\
\hline & $\begin{array}{l}\text { Illicium....... } \\
\text { llysanthis ... }\end{array}$ & $\begin{array}{l}\text { Ligusticum ... } \\
\text { Ligustrum ... }\end{array}$ & $\begin{array}{l}\text { Menziesia. } \\
\text { Mertensia. }\end{array}$ \\
\hline .. 619 & Impatiens................ 280 & I.ILIACHAS......... TU & 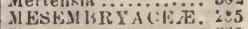 \\
\hline & ndigofera........... 319 & & \\
\hline ... 595 & $\ldots \ldots .438$ & LIMNANTHACEA & Mespilus.... \\
\hline ...689 & $\ldots \ldots .229$ & & \\
\hline$\ldots \ldots 273$ & $\ldots \ldots \ldots(5 ; 1) 572$ & $\ldots 6 i 9$ & Micromerir. . \\
\hline$\ldots \ldots 2_{i} 1$ & sis.......... 5io & chloa ......... & \\
\hline$\cdots \cdots 0$ & & - 525 & \\
\hline & CEA $A \ldots \ldots$ & & $\ldots \ldots$ \\
\hline & & & \\
\hline $\begin{array}{l}2 \ldots \\
\ldots \ldots 60 \\
\ldots\end{array}$ & & 93). Lin & Mirabilis............ \\
\hline & Isnardia......... 355,356 & & \\
\hline & ...... 810 & & \\
\hline & $\ldots \ldots \ldots 741$ & $\ldots \ldots \ldots(539) 5.38$ & \\
\hline & . $\ldots \ldots \ldots \ldots$ & & \\
\hline & & 215 & \\
\hline & , $\ldots \ldots \ldots \ldots \ldots$ & & \\
\hline$\cdots$ & $\ldots \ldots \ldots \ldots \ldots$ & & \\
\hline a.. 3 & $\ddot{m} \cdots \cdots$ & & \\
\hline$\ldots 3$ & EAE..... & & \\
\hline$\ldots \ldots \ldots 622$ & $\cdots \cdots$ & & \\
\hline $\begin{array}{l}\ldots 541 \\
\ldots 390\end{array}$ & & $\begin{array}{r}514 \\
.489\end{array}$ & \\
\hline 403,404 & EA .. 640 & & \\
\hline m........... 347 & Juglans :- & & a..........(496) 495 \\
\hline 156) 455 & .... 722 & 551 & 1.....(495) 480 \\
\hline a......... 4 & 676 & Lo & \\
\hline & ….... 723 & & \\
\hline$\ldots 4$ & $\ldots \ldots 663$ & $6 \geq 1$ & \\
\hline$\ldots 4$ & ............ & 354 & \\
\hline ( & & 236 & Ml \\
\hline$\ldots$ & K & $\cdots \cdots \cdots$ & \\
\hline a....... 385 & 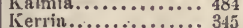 & $\ldots \ldots \ldots$ & \\
\hline $18 \ldots \ldots \ldots \ldots 209$ & Koeleria......... & . $\frac{25 i}{55 i}$ & \\
\hline $18 \ldots \ldots \ldots \ldots \ldots 719$ & kosteletzkya........ 269 & DIACEAE.. OII & \\
\hline ilis & Krigia..........(470) 469 & .. 811 & Mi \\
\hline 525 & $\ldots \ldots \ldots \ldots(41 \%) \quad 415$ & .. $5(0)$ & MI \\
\hline & ria $\ldots \ldots \ldots(74 t) 7$ & 543 & \\
\hline 204 & IA.......... & $5 i 6$ & $M_{y}$ \\
\hline & iatilloræ......... 4,5 & & \\
\hline$\pi$ & & & \\
\hline 63 & & $L_{y}$ & $\cdots$ \\
\hline . $(525) 523$ & lon......... & $14 y$ & \\
\hline & (5) & ESL. & \\
\hline 721 & hes......... & (.... & \\
\hline s..... & ........... & 554 & \\
\hline & $\cdots \ldots \ldots$ & ..... & \\
\hline $3 i 2$ & .......... & $\ldots$ & 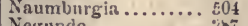 \\
\hline & & & \\
\hline $4 ; 0$ & na........... & IA ... & \\
\hline 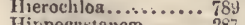 & $\ldots \ldots$ & $\ldots$ & $\ldots .$. \\
\hline$\ldots$ & thum............ & & \\
\hline & that...$\ldots \ldots \ldots$ & 815 & \\
\hline 358 & tea............. & $s, \ldots, \ldots$ & .... \\
\hline$\cdots \cdots$ & $\ldots \ldots \ldots \ldots \ldots$ & $\therefore \cdots$ & $\ldots .$. \\
\hline$\ldots$ & $x \ldots \ldots \ldots \ldots \ldots 6_{303}$ & $\begin{array}{r}265 \\
268\end{array}$ & $\cdots$ \\
\hline$\ldots 501$ & 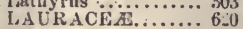 & $\begin{array}{l}268 \\
\text {. } 3600\end{array}$ &.$: 87$ \\
\hline a $\ldots \ldots \ldots \ldots \ldots$ & rues.........620, 6:I & 804 & .......... \\
\hline & 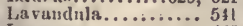 & 691 & $\ldots \ldots \ldots \ldots \ldots$ s \\
\hline & ria............. & $(734,735) 732$ & urgia........ \\
\hline $6: 23$ & enworthie....... 2 & & $\ldots \ldots \ldots$ \\
\hline 712 & ea............? & & \\
\hline & tia.. & & \\
\hline & $\ldots \ldots \ldots \ldots$ & EAS & \\
\hline 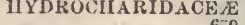 & & 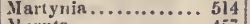 & ACliki.. \\
\hline & As..... & & 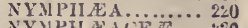 \\
\hline (1) & $\ldots \ldots$ & & UEA \\
\hline &.. & & $\ldots$. \\
\hline & & & \\
\hline & & & $20 \cos$ \\
\hline & & & \\
\hline & $\cdots \cdots \cdots$ & & $i l l .$. \\
\hline & & & \\
\hline & $\ldots(473)$ & & \\
\hline 69 & $\ldots \ldots 4^{4}$ & & \\
\hline us. & Lepidium ... & & $\ldots \ldots \ldots(60 i)$ \\
\hline & Leptandra. & CFA.. 3 & .. 597 \\
\hline & & & $A C B A B$. \\
\hline & aulis & E. . . & \\
\hline & tochloa.. & & \\
\hline & $a$. & & \\
\hline & & & \\
\hline & & & Ophiorhiza \\
\hline & & & \\
\hline is & ithemum .. & TRNAC & \\
\hline & & & \\
\hline
\end{tabular}




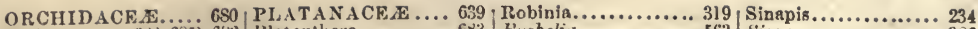

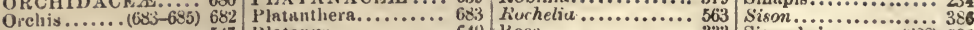

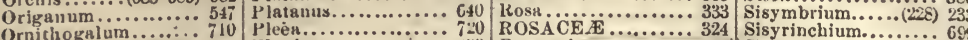
Ornithogaim .̈.

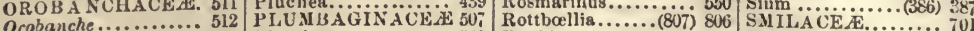

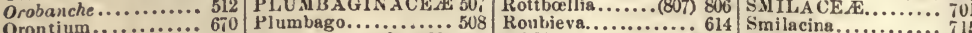

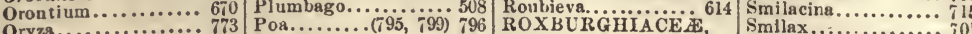

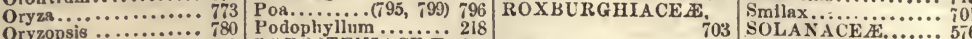

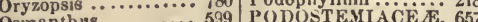

Osinsnthus .............. 5383

Osmorhiza............. 883

Ostry a............6.647 Pogonia............6.690

OXALIDACE E.....

Oxalis 0 ................ 27

Oxycoccus............

Oxydendrum........4 48

Oxydenia ............ 8i3

Oxyria ...........6.60

Puchysandra.........6 632

Pæonia ............... 212

Palafoxia............4 45

PALMACE

Panax ................ 39

Panicum ........(787)

Papaver $\because \ldots \ldots \ldots \ldots . .$.

Pardanthus..........

Parietaria.

Parnassia.

Paronychia ............

Parthenium........... 442

Paspalun............7.781 78

Passiflor:

PASSIFLOR ACEX.

Pastinaca

Paulownia.

Pavia

Paronia.

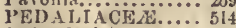

vedleularis

l'elargonium............

Peltandra...

Pentalophus........... 56

P'enthormm........... 368

Peqlis ............... 5: 350

Periploca............ E

Persea..............6.6. 60

Persich................ 328

PETALIFER E......6 666

Petalostemon .......... 316

Petilium.............

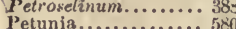

Petunia............... 58

Phacelia............. 565

Phalangium...........

Plinlaris..........(786) 189

Pharbeolus............... 521

Plitadelphus.......... 37

Philipoa ............. 512

Phleum............. 779

Phlomis ............ 555

Phlox............ 567

Pliotinia............... 329

Phragmites ......... 800

Phryma ............ 538

Phyllanthns........6.6.31

Physostegia........... 551

Pliytolacca.........6.610

PHYTOLACCACE 610

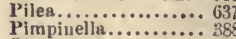

Pinckneya............ 40

Pinguicula ........... 509

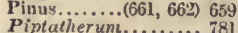

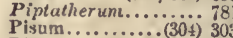

Pistia................... 6il

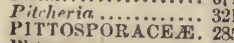

Pltosporum.......... 28

Pltosporum ..........2285

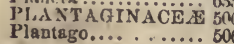

olanisia ........... 24

POLEMONIACEA.. 56

Polemonium ........ 56

Polycarpon ............ 269

Polygala............29.

POI,YGALACEA ... 29
POLYGONACE.. .60

Polygonatum........ 7l

Polygonella..........6 606

Polygonum ...........64 607

Poly ypodium........... 818

Polypogon.............

Polypteris............. 455

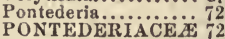

Populus.............. 655

Portulaca $\because \ldots \ldots \ldots$

Potamogeton.........6.6. 673

Potentilla........... 342

Poterium.

Prenanthes..........(47i) 47

Primula $\ldots \ldots \ldots \ldots \ldots . . .50$

Prinos............... 497

Prionopsis............. 437

Proserpinaca.......... 757

Prunella............. 552

Prunus ...........(326) 327

Psiloearya.............. 778

Psiloxtemon............ 560

Psilotum............ 813

Ptelea............... 25:

Pteris ................. 819

Pterospora............4.496

Pulmonaria ......... 562

Pulsatilla........... 2u2

Punica............... 346
Pycnnnthemum.... 545

Pycreus............... 73 .

Pyrethrum........... 459

Pyrrhopappus........ 47

Yyrularia ........... 622

pyxidanthera......... 570

Quamoclit............ 5

Queltin.............. 693

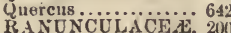

Ranunculus......... 205

Kuphanus...........2 240

Rehoulea............... 795

Reseda.............241

RHAMNACE A ..... 290

Rhaninus ........... 290

Rheum.............6 604

Rhexia.............. 347

lhododendron...(489) 490

Hhodora ............ 491

Rhus............... 283

Rhynchospora...(746) 74

R hynchosporeæ..... 7

Rhytiglossa.......... 536

Ribes ................. 360

Richardia,............6.669

Rivina................
Polytænia.............. 379

Pyrolex............493, 480
Rubia.

RUBIACE

Rubus ............... 339

Ruellia...........534, 535

Rumex..........(604) 605

12 uppia............6 67

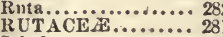

Sabal...................66 66

Sabbatia ............. 58

Saccharum.

Sagina....

Sagittaria.

ALICACE $¥$.

Salicornia.
Salisburia....

Salix.....

Salsola.

Salvia......

Salvinia.

Sambuicis.

Samolus.......

Sanguisorba....

Sanicula.

SANTALACE

SAPINDACE

Sapindus............. 288

Saponaria .......... 25

Sarracenia $\ldots \ldots \ldots \ldots{ }^{22}$

Sassafras.............. 620

Safureja $\ldots \ldots \ldots \ldots . . .54$

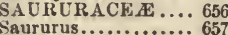

Saxifraga ................ 370

SAXIFRAGACE AE.. 36

Scabiosa.............. 406

Scandix...........(384) 383

Scheuchzcria........ 678

SChIZAnd N

Schizan............. 817

Schizanthus.......... 5!

Schcrius .........744, 74

Schollera.................. 744

Schrankia.............. 299

Schwalbea............ 53

Scilla.................710

Scirpea...........742, 73

Scleranthus..........2 26

Scleria............... 74

Scolopendrium....... 82

Scrophularia $\ldots \ldots \ldots \ldots 52$

Scutelliria.......... 55

Secale.............. 8503

Sedum............... 367

Selnginella............. 812

Sempervivum .................. 368

Senecio................62)

Senecionida...................... 595

Sericocarpus ......... 419

Sesamania............... 514

Sesuvium .............264

Setaria.....

Seymeria

Shepherdia...

Sibbaldis

Sicyos.

30 Silene.....

610 Silphism
Solanum.......... 5it

Solidngo .............. 245

Soliva............... $46^{\circ}$

Sonchus.............. 174

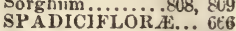
sparganophorus...... 412 Sparganum...........6 672 partina............. 845 pecularia......... 479 Spergula ............. 261 Spergularia.......... 261 Spermacoce .......... 402 Spilanthes.............. 55 Spinacia............... 615 Spiræa .............. 343 Spiranthes ..........6.68 Sporobolus........... 775

Sprekelia........... 694

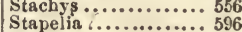

Staphylea........... 289

Statice............. 508

Stellaria..........(259) 258

Stenanthium ......... 719

Stenotaphrum....... 807

STERCULIACF

Stillingia............ 629

Stipa..............(781) 780

Stipaces.............771

Stipulicida.......... 262

Stokesia............4 41

Streptopus
Strophiostylis........... 715
S22

Strophiostylis ........ 322

Struthiopteris......... 818

Stylipus............. 358

Stylisma .............. $5 i$

Stylophorum ..........224

Stylosanthes......... 306

STRACACE $2 . . .449$

Styrax ............... 499

Sullivantia............. 3.

Swertia............. 587

Syena.............. 728

ymphoricarpus ...... 39

Symplocarpus.......... 669

Symplocos........... 499

Synandra........... 854

Syntliyris ......... 526

Syphonichia ........ 263

Syringa ............. 598

Tagetes...............(454) 465

Talinum ............ 264

Tanacetumi.......... 4:9

Taraxacum .......... 47

TAXACHE..........6 664

Taxodium........... 663

Taxus.................66 66

ecoma.............. 513

Telanthera ........6.6 619

Tetragonotbeca....... 445

Tetranthera......... 6:1

Teucrium ........... 541

Thalia ............. 69

Thalictrum......$(203) 204$

Thapsia .............. 383

Thaspium........... 582

Thnja.............6. 66

Thunbergia ........... 534

TH Y MELACE $2 . .6623$

Thymins ............ 547

Thyosanthes.......... 320

Thy rsanella.........., 606

Tiarella.............. 370

4 Tiedmanuia.......... 380

268 Tigridia.............. 699

255 Tilin................. 272

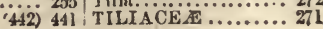


Tillxa ............. 367 Tillandsia............. 695

Tipularia.............6 686

Totieldir............... 720

Torreya..............664

Tradescantia.......... 727

Tragla .............. 629

Trngopogon...........470

Trautretteria.........20.1

Tribulus.

Trichelostylis......... 741

Trichochloa.......... 777

irlebophorum......... 740

Trichostemma ........ 542

Tricuspis. ............. 792

Trientalis ............ 503

Trifolium ............ 312
Triglochin.........678

TRIILIA CE

Trillinm............. 704

Triosteum............ 393

Triphora ...........6.690

Tripsacum............ 806

Trisetum...........791

\begin{tabular}{|c|c|}
\hline Triticum............ 80 & \\
\hline Trollins..... & Vachellia \\
\hline TROP KOL,ACEA... 280 & Valeriuna. \\
\hline Tropacolum ......... 281 & VALERIANACEAE. \\
\hline Troximoll..... & Valeriainella......... \\
\hline Tubulifloræ.. & Vallisneria \\
\hline Tulipa..... & Veratrum.. \\
\hline Turnera........ & Verbascum. \\
\hline TURNERACEA & Verbena... \\
\hline Turritis .......... & VERBENACEA \\
\hline Tussilago... & Verbesina........ \\
\hline Typha..... & Vernonia... \\
\hline TYPH ACEAE & Veronica... \\
\hline Udora........ & Vesicaria. \\
\hline ULMACEA & Vicia..... \\
\hline Ulmus ....... & Victoria. \\
\hline UMBELIFER A & Vigna...... \\
\hline Uniola......... & Vilfa....... \\
\hline Urachne... & Villarsia... \\
\hline Uralepis.... & Vinca...... \\
\hline Urtica.......... & Viola ....... \\
\hline URTICACEA & VIOLACE \\
\hline Utricularia... & Visiania..... \\
\hline Uvaria...... & VITACE AE. \\
\hline Uvularia...... & Vitex...(539). \\
\hline Vaccineæ ..... & Waldsteinia. \\
\hline
\end{tabular}

Warea............. Windsoria........... is

Wistaria................

Woodsia.............. ह22

Woodwardia........... r:

Xanthinm ............ 444

Xanthoxylum....... $8 \varepsilon$

Xerautliemum ....... 462

Xerophyllum ........ 719

Xylosteon .............. s94

XYRIDACEA..... T58

Xyris ..................28

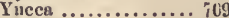

Zannichelia............. 673

Zanthorriza ........... £

Zapania............ E

zea................ \&c6

Zenobia............. 487

Zephyranthus........ 693

Zigadenus............. 717

Zinnia.............. 444

Zizania.............. 773

Zizia ..............(382) 383

Zostera................... 673

ZYGOPHYLLACEA 279

\section{INDEX OF ENGLISH POPULAR NAMES.}

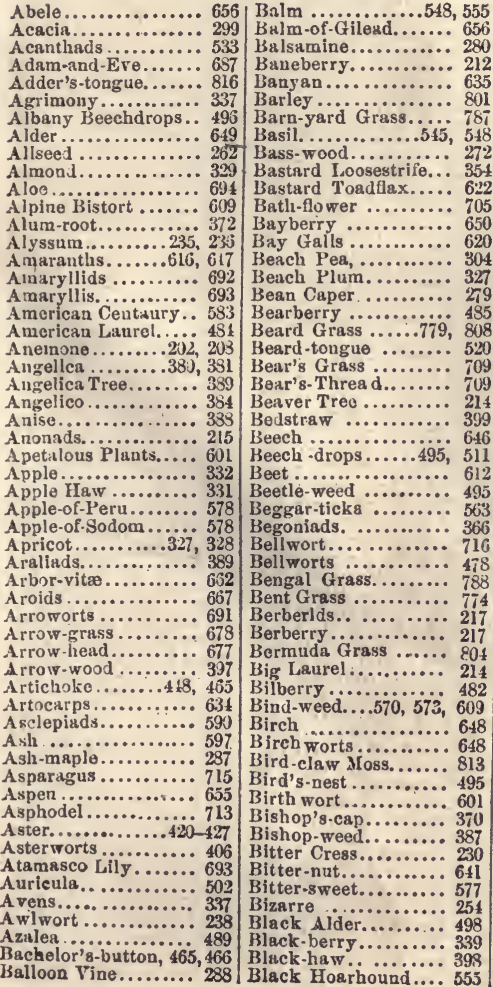

Black Moss

Black Nirht-sho.... $696 \mid$ Bugle-weed......... 843 Black Oat Grass..... 7 70 Bull-rush.........722, 738 Black-root.......... 439 Burr Dock.......... 468 Black Saltwort.......503 Burnet. Black Snake-root.... 211 Burning Bush...2.289, 290 Black Thorn......328, 330 Burr-flower........... 564 Bladder Fern ........ 822 Burr Gras8........... 788 Bladder Ketmia...... 269 Burr Marigold......... 453 Bladder-nut.......... 289 Burr Reed........... 672 Bladder-pod .......... 237 Burr-seed............ 56 ? Bladder Senna....... 319 Bush Clover,............ 309 Bladder wort .........509 Bush Trefoil ...........207 Blazing-star...... 413,720 Button Bush..........401 Blessed Thistle ...... 466 Buttonwood.........640 Blite.. ............6.6. 614 Butteicups......205, 207 Blood-root............ 222 Butterfiy-weed....... 593 Blood worts ..........6. 696 Butternut...........6.640 Blueberry .......481, 483 Bnttermeed...........464 Blue-curls .......542, 552 Kntterwort......... E69 Blue-dangles......... 481 ('abbage............... 295 I3lue-eyed Grass...... 699 Cnctus................. \&60 Blue Flag............ 69: Chlabash............... 964 Blue Grass ......... 79i cale.............. 295 Blue-hearts ......... E28 ("n)aminth.......... 847 Blue-joint Grass...... 778 Calico Bush ......... 465 Blue Palmetto...... 667 California Poppy..... 24 bluets.............. 402 Camellias............ $2 \pi 3$ Bog Rush........... 746 Calypso............ 686 Boneset.........415, 417 Campion.........255, 257 Bonnet Grass......... 774 Cannda Thistle ...... ic 8 Borrage............ 559 Canary ('reeper....... i $\varepsilon 1$ Borragewort8........ 558 Canary Grns........ $i \varepsilon 9$ Bottle-Grass........ 788 Candleberry ........ 650 Bouneing Bet........255 Candytuft ........... 288 Bowman's root....... 345 Gane............... \& E0 Box-berry .......... 486 Cinterbury Bells..... 479 Box Elder........... 887 Caper Spurge ........ 626 Box-wood........... 6:32 Capparids.......... 240 Brake.............. 819 Capuchin .......... $\approx \varepsilon 1$ Bramble............ 239 Caraway $\ldots \ldots \ldots \ldots \ldots$ e........ Bridal Rose.......... 340 Cardinal-flower ...... 4 4 6 Broceoli............ 235 Cardoon ............ 465 Bromeliads .......... 695 Carnation.......... 254 Brooklime............ 527 Carpet Gress.......... 2£9 Broom Corn........... 809 Carpet Weed........ 263 Broom Grass......791, 809 Carrion-fiower....... 703 Broom-rape......... 512 Carrot ............ 381 Bryony.............. 364 Cassena Ten......... 497 Bnck-Bean,......... 587 Castor-oil Plant...... 080 Buekeye..........287, 288 Catalpa............. 513 Buckthorn........... 290 Catch-fly............256 Bnck wheat ........... 610 Catch-fly Grass...... 773 Buck wheat Tree..... 493 Cat-gut............. 318 
Cat-tnil

Cauliflowe

Cauliflower .......... 235

Cedar ..............6.6 60

Celaudine...........223

Celery

Century Plant........694

Chaff-seed........... 532

Chamomile......... 45

Chaste Tree.......... 539

Cheat

Checkerberry.......4.48

Chenopods.........6.61\}

Cherry...........326, 3

Cherry Laurel......... 32

Chestnut..............6.6. 646

Chick Pea........303, 30

Chick-weed......257, 25

Chick Wintergreen...

China A ster........... $4^{2}$

Chinquapin .........6.640

Chokeberry........... 33

Choke-cherry........3

Cinnamon Fern ......8

Cinquefoil............ 34

Citron 'I'ree.......... 27

Clary ..

Clesvers.............. 399 , 40

(jllmbing Boneset.... 418

Climbing Fern...... 817

Clintonia.....

Clot-weed............ 44

Clond-berry............ 3to

Clover

31

Club Mloss ........811, 81

Cock's-comb........322, 616

Cockspur Grass...... 78

Cocos Plum...........

Coffee 13emn.......... 303

Coffee Tree.......... 30t

Cohosh...............21s

Colic-root........... 697

Colocynth.

Colts-foot ........... 419

Columbive........... 209

Columbo............. 586

Cone-flower.

Conilers. ....

(n) 659

Coral-root ...........6.686

Corn-cockle........... 256

Coriander............ 388

Cornels............... 390

Corn Flag..........700

Cornel. G........... 391

Cotton Grass........ 740

Cotton Rose.......... 461

Cotton Thistle....... 467

Cotton Tree.....655, 656

Couch Grass.......802, 80

Cowbane.

Cow-wheat.................. 38

Crab (irass...............

Crab Tree.

Cranberry.

Crane's-bill

Crape Nyrtle.

Cress........2:8, 232, 2

Crocus wer.........6

Cross Vine.......... 700

Crowberry ......6.6.8, 639

Crow foots ........200, 205

Crowmbeard.......... 454

Crown Imperial........709

Crucifers............ 2:6

Cuekoo-flower.......2.231

Cuenmber........361-365

Cucneits .............. 363

Cintweed..........450, $4 t j$

Culver's P'hysic...... 52?

Cupuplant........... $44_{2}$

Cusseed:.............217

Currants ................

Cut tirass.

Cycrues.

C'ypress.

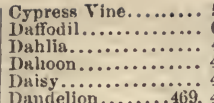

Dandelion........469, 473

Daphnads............

gy lily .......... Flowering Fern

erdly Nightshade .. 579

Fly-poison.

Deer-grass..........37, 774 Fool's Parsley.

Deer's-tongue........4 413 Forget-me-not.

evil's-bit..........4 406 Forked-spike

ewberry........339, 340 Foul-mendow

Dill

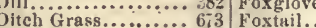

Ditch Moss

Dittany .............5.5. Fraxinell .

The

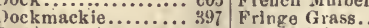

Dodder............. 5i 4 Fringe Tree...

Oogbune............ 558 Frogbits

logivood.... $284,390,391$ Frost Plant.

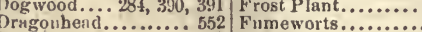

Drugonroot..........6.6.68 Fumitory .

1) ropseed Grnss...775, 776 Gale, Gale

Dry Strawberry..... 341 Garget-weed

) uckmeat............6.6\% Garlic

Dutel Myrtle......6.650 Gay-feather

i) utchmun's-breeches. 2:

Ditelimun's Pipe.....6 60

I) warf Dandelion..... 46

1) yer's-broum ......... 310

Fardrop..........225, 35

Ebonads . ........... 500

Eel Grass..........679

Eglantine...........335, 33

Eryptian Calla ......66

Gyptian Grass ...... 80

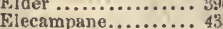

Elephant's-ears ....... 36

Elephint's-foot....... 4l

Elm, Elmworts .. 632, 6

Enehanter's Night-

shade.

Endive.............. 469

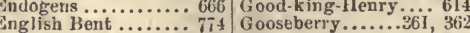

English Mlint.........4.48 Goose-foot....(Gen. 3), 612

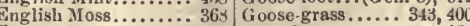

Eternal Flower ...... 46:

Evening Primrose ... 35.2 Gout-......

Everlasting .....440,461 (Grammell.

Everlasting Pea...... 3ut Grape Fern

Eyebright........... 5:33

Fulso Aloe..........69.

Falso Dandelion........ 47

Fulse Iog-femmel...... 45

False Flnx .......... 23

False Mermaid....... 28

False Nettle......... 687

False Pennyroyal ..... 54

Fnlse Redtop........ 792

False Rocket...........229

False Seabish ........ 4.57

False Solidago ....... 430

alse Syringa......... $3 i$

Felwort ............... 58

Fennel .................. 382

Ferns .............. 81

Fescue Grass...... 793, 79

Fetter Jush..........48

Feverfew............. 45

Fig .................6.6.6.6.

Figwort ............. 52

Figrworts............ 516

Finger Grass......7.7. 73, 804

Fireweed........... 46?

Fir, Fir Balsam.....66 66

Grape Hyacinth

Grape Vine

Grasses.

Grass-of Parnassus.

Grass Pink

Greek Voly...

Green Brier.

Green Dragon

Green Violet.

romwell.

Ground Cherr

Ground Fir

Ground IIemlock.........

irround Ivy

nit...... 320, 390

Ground Pine.... 811, 812

Gronndsel Tree....... 439

Guelder Rose.......... 397

Gum Tree........... 39

Gymnosperms ...... 6.5

llardlass..

Hare bell.

Ilart's-tongue

Heviv.

Hawthorn....

Hawkbit.

Ilawkweed

Irazelnut.

Henrtsease
Heath, Heather ...... 48

Heathworts .......... 4 4 79

Hedgelog ........... \$13

Hisuge Hyssop.. .5:3, 651

Heage Mustard .......
Hedge Netule.....

Heliotrope......... iss, \& \&

Hellebore........... 69

H em lock ........... E61

Hemp............ 638

Hem $\mathrm{p}$ Nettle......... 656

Hembane........... 580

Henbit............. 555

Herb-Robert .........277

Ilerd's Grass..... 7 4 , 779

. Her on's-bill ..........

Hibiscus......... $29,2,0$

High Cranberiy..... : 97

High-water Sliub.... 443

Horrhound......417, 557

Hobble Bush........

Holly Holly worts. 496,497

Ilollyhock ......... 266

Honesty ..............236

Honewort............. st 6

Iloney I.ocust........

IIoneysuckle. ...... $94-86$

Jloneysuekles........ 43

4 Hop ................ 6:8

85 Hornbeasn ........... is

2 Horn Pondweed...... ti 3

llorn Popry ........... 2.3

Hornwort ............ CEs

5.2 Lorse bean ...............

Horse Chestnut ..287, is

Horse Ilevils ..........

9 Horsemint ........5.3. 5. 0

3 Horse Nettle........ 5is

Horse-tail......... \&i, 814

Horse-wecd.............. 443

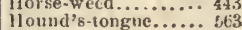

IIouseleek ...........

Houseleeks .......... 66

Huckleberry......... 481

0 IIyaeinth ........... 712

Hy dropliylls .......... 563

Hy ssop ............ 545

I e Plants ..........2 265

Indiana Veratrum ... 718

Indian Corn..........

Indian Cress $\ldots \ldots \ldots$. 2t

Indian $\mathrm{Fi}$.

Indian Grass.......... \& $(1) 8$

16 Indian Mlullow ........ 24:

712 Indian Millett.. . . . . 8u9

3 Indian l'hysic....... 345

70 Indian Pipe.......... 495

2 Indian Rice...........7 7

90 Indian shot........... 91

49 Indian Sonjworts .... 257

9 Indian Tobacco ......4 4i

Indiun Turnip....... 668

Indigo Plant......... 319

Innocence.........4. 402,521

Irids ..............6.697

Ironweed............410

Ironwood ...........6.647

Italian May .......... 344

Ivy..............

Jacober. ... 464

Jacoben Iily .......... 694

Japan Globeflower ... 345

Japan Rose .........273

Jasmine ............ 596

Jasminew orts........ 596

Jersey Tea ........... 291

Jerusalem Artichoke. 448 Jernsalem Cherry .... 5i7

Jerusalem Sage...... 5i5

0 Jessamine ........... $8 \$ 6$

70 Jewel-weed .......... 280

470 Jimsoll-weed........ ! 81

647 Jingko.............. 664

241 Job's-tears........... 809

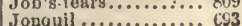




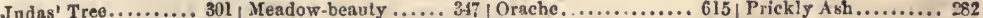

J

June Grass ..........798 Meadow Redtop ..... 798 Ureharil Gruss .......743

Junlper..............6. 663

Kidney Beav...... 32

Knap-weed ...........465

Knawel. B............ 609

Knet-grass..........6 60

I.abrador Tea....... 491

Ladies lirdrop ...... 35

Iaadies' Slipper.681,682,517

I.adies' Tresses ...... 689

Lady Fern .......... 824

I_amb Lettuce....... 405

I.arch ............ 662

Isaurel............. 620

Laurestine............. 393

Lavender........... 5 51

Lead wort ........507, 508

I.eaf-cup............4 440

Leather-flower .......20 20

I.eather-leaf ........ 48

Leek

I,eguminous Plants .. 29

I.emon.

I.ettnce

Leverwood............6 647

Lilac.

Lilly.

707-709

Jily worts ...........7 705

Lime Tree ....... 272,274

Limnanths...........2 281

Linden ............. 272

Lindenblooms........ 27

Lion's-ears ........... 558
Lion's foot ......... 472

Iion's-heart............ 55

Lip Fern ............ 819

Liveforever

Meadow Rue.......204 204 Orchids............. 680

Mediek............3 313 Orpine .............368

Melanths ..........7l6 Usage Orange........635

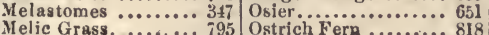

Melic Grass. ....... 795 Ostrich Fern ........ 818

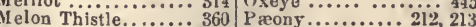

Venispermads ....... 216. Painted cup ......... 531

Mermaid-weed ......... 35i Palmetto..............6. 666

Mexican Tea.......6.613 Palms ............666 666

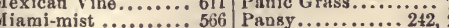

Ylenonette

Milkweeds.

Milk worts

Milk Vetch

Millet.

Millet Grass

Mint

Mistletoe

Mitrewort

Mockernit.

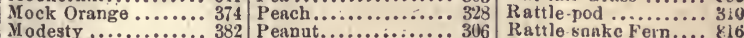

566 Padsy

Prickly Poppy........

Pride of India........ 275

Pride of Ohio .........503

ride of the Meadow . 345

Prim ...............

Primworts .............. sul

Prince's-featlier...609, 617

Prince's Pine ........ 494

Privet............. 599

Pumpkin..............

Pursianes........263, 264

Putty-root........... C 8 r

Quaking Grass......... i $\$ 9$

Quamash............ 70

Queen-of the-Praitio.. 34

Quich Grass.......... Y Y

Quillwort ........... 810

Quinee.

Radish................. 240

Ragged Robin ..... 257

Kan's-head......... 882

Ráspberry ...............

R at-tuil Grass $\ldots \ldots \ldots$ \& $86^{\circ}$

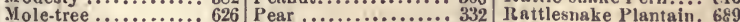

Molucca Balm......555 Pearlwort.......... 260 Red Bay..........6\%

M o neywort .......... 505 Pea Vine............ 322 Red Bud............

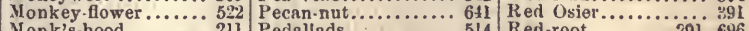

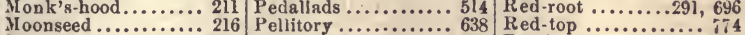

Moonwort .......... 816 Pencil-flower......... 306 Reed ............ 8 0

Horning Glory ...... 571 Pennyroyal ..........544 Reed Grass..........76, 778

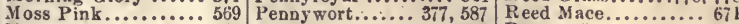

Moss Plant ..........486 Pepper............578 Rescue Gruss ........ 991

M otherwort........557 Pepper-and-Salt......384 Rhubarb ........6.64

Mountain Ash ....... 333 Pepper-grass.....238, 239 Ribworts .......... 566

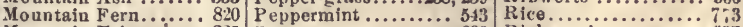

Mountain Fringe..... 225 Pepper-root .......... 230 Richweed........... 637

Mountuin Heath .....489 Pepperworts .......810 River-weed ........657

Mountain Mint.......550 l'eriwinkle......... 589 Robin's Plantain.....428

Lizard-tail .............. 657

Kizardtail Grass....... 804

Loasads ............. 358

Lobeiliads ........... 475

Loblolly Bay ......... 273

Long $\mathbf{M}$ oss................. 695

Inosestrife.......349, 50

I.oquat.

Ioranths.

Lousewort

....... 53

Love-lies-bleeding ... 618

Lucerne............. 313

I.ung wort $\ldots \ldots \ldots \ldots \ldots . \ldots \ldots 6^{2}$

Inpine............. 3ll

Lychnidia...........56

I ychnis ............ 257

Lyme Grass..................... 801

Madder worts.......... 39

Madwort............ 235

Magnolinds ........... 213

Maidenhair ...............266-263

Mallows ............ 265

Mangel-Wurtzel......6 6l.

Manna Grass......... 798

Man-of-the-Earth ..... 573

Mare's-tail........................... 358

Marigold ........... 465

Marjoram

Marsh Eider......... 443

Marsh Fleabane...... 439

Marsh Nallow ....... 266

Marsh Marigold....... 208

Marsh Rosemary...... 508

Marvel-of-Peru......6.602

Marvel

Mastworts.

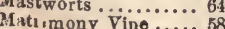

Mat Grass .......... 778

Iay tpple.

May-flower.

May weed.

Mountain Sorrel

Mourning Brido

Mouse-ear

80 Persimmon

Mud Purslane ....... 253 Phloxworts .......... 56

Mudwort............ 525 Pickerel-weed......... 721

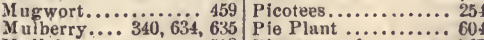

Mullein .............518 P'igmy-weed ......... 567

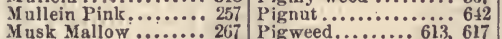

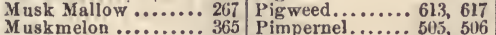

Musk Plant ........5.5. Pine..........6.659-661

Mustard ........ 233-235 Pine-sap ........... 495

Myrtle.........346, 492 Pink ............... 254

Naiads

Pink worts

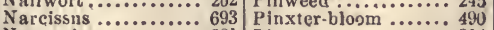

Nasiurtion .......... 281 Pipes .............. 814

N eck weed............ 527

Nectarine

Nelumbo

328 Pipewort.

Roek Cress .............. 25l

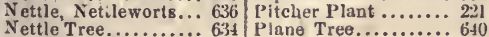

New York Fern..... 8. 82t Plantain ............ . .

Nightshades....5.5,577 Plum.........327, 328

Ninebark............ 344
Nipplewort......... 469 Plume Grass......... 807

Nonesuch ..................... 313 Poison Ilemlock

Nut Grass........... 733 Poison Ivy......... 28

Nutmeg-flower .......209

Nut Sedge ...

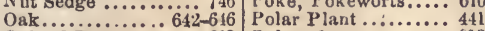

Oak-of:Jerusalem.... 613

Oat ............... 790

Oil-nut.

Oil-seed...

Old

Oleander ............ 590

Oleaster...........623, 624

Ollve .............. 599

Ollves.

485

Onion.

Oplum Poppy

711,712

Pomegranate.

Rock Polypod .......... 8*22

Rock Rose........ 245, 246

Rose ...........333, 337

Rose Acacia.......... 319

Rose Campiou........... 257

Kosemary........550, 639

Rosew orts ........... 324

Rosin-weed .......... 441

Rue ................. E2

Rneworts ............ 28d

Rush ............722-727

Rutland Beanty ...... 5i 3

Saftron.................. 803

Sage ................ 548

Saltwort........615, 616

Samphire ...........6 615

Sandulworts ........6.622

Sand Grass........... 792

Sand Myrtle....... 49:

Sand Reed .......... $7 \%$

Sanicle ...........

Sarsaparilla..389, 701, 702

Sassatras ...........6.6.

Satin-flower.......... 26

Saururads............. 656

Saw Grass ... $3 \ldots \ldots \ldots$ ? 36

Scabish ............. 406

Searcity ................ 612

Scorpion Senna....... 306

Scouring Rush .. 813,814

Scratch Grass ........6.610

Screw-stem ........... 586

Pond-weed ........673-675 Scuppernong......... 293 glass ... 505 Wea Ox-eye .......... 440

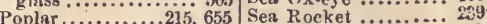

Poppy..........223, 224 Sea Sandwort........ 261

Poppyworts.............. 800

Sea Wormwood ....... 460 


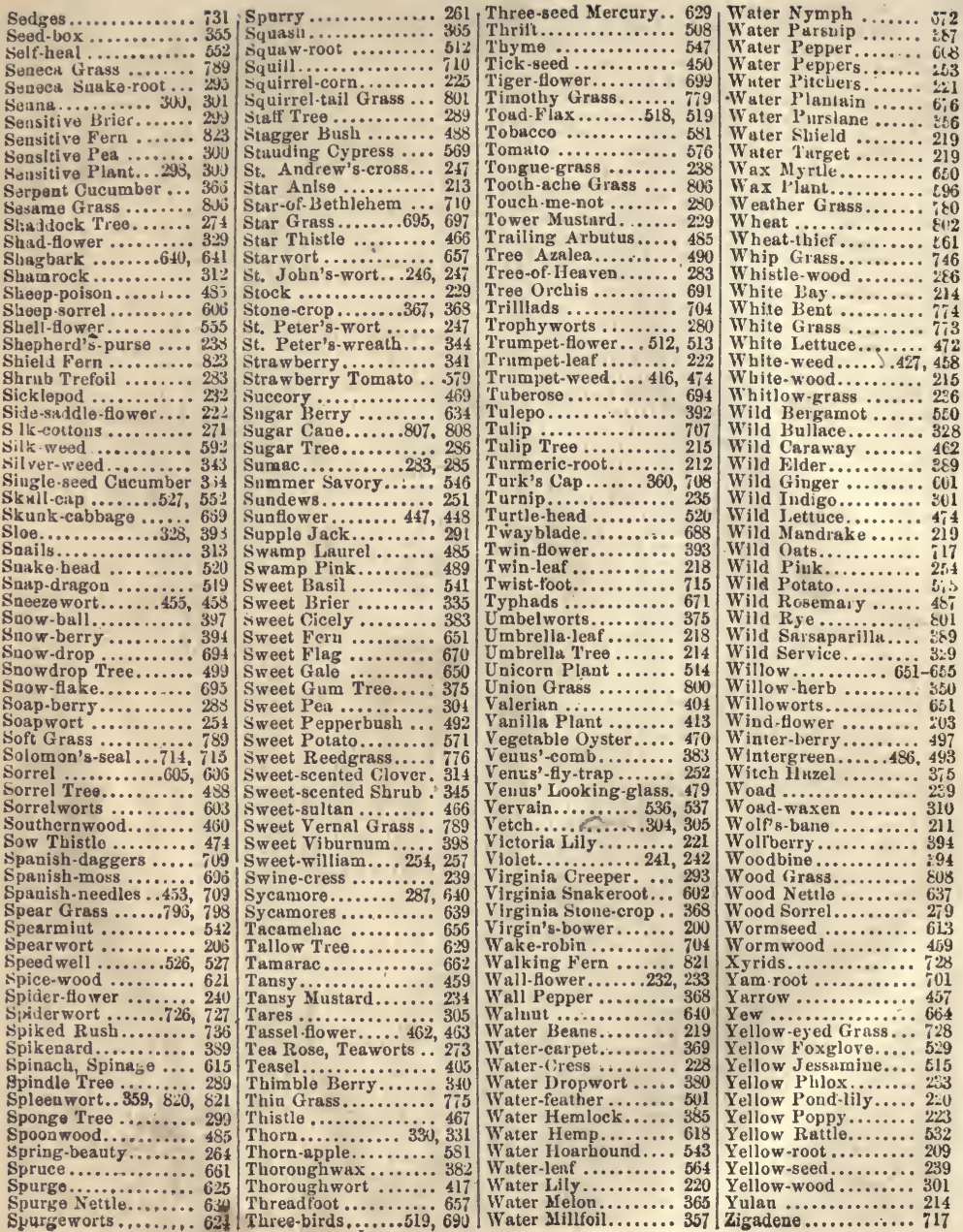





THIS BOOK IS DUE ON THE LAST DATE STAMPED BELOW

AN INITIAL FINE OF 25 CENTS WILL BE ASSESSED FOR FAILURE TO RETURN THIS BOOK ON THE DATE DUE. THE PENALTY WILL INCREASE TO 50 CENTS ON THE FOURTH DAY AND TO \$1.00 ON THE SEVENTH DAY OVERDUE.

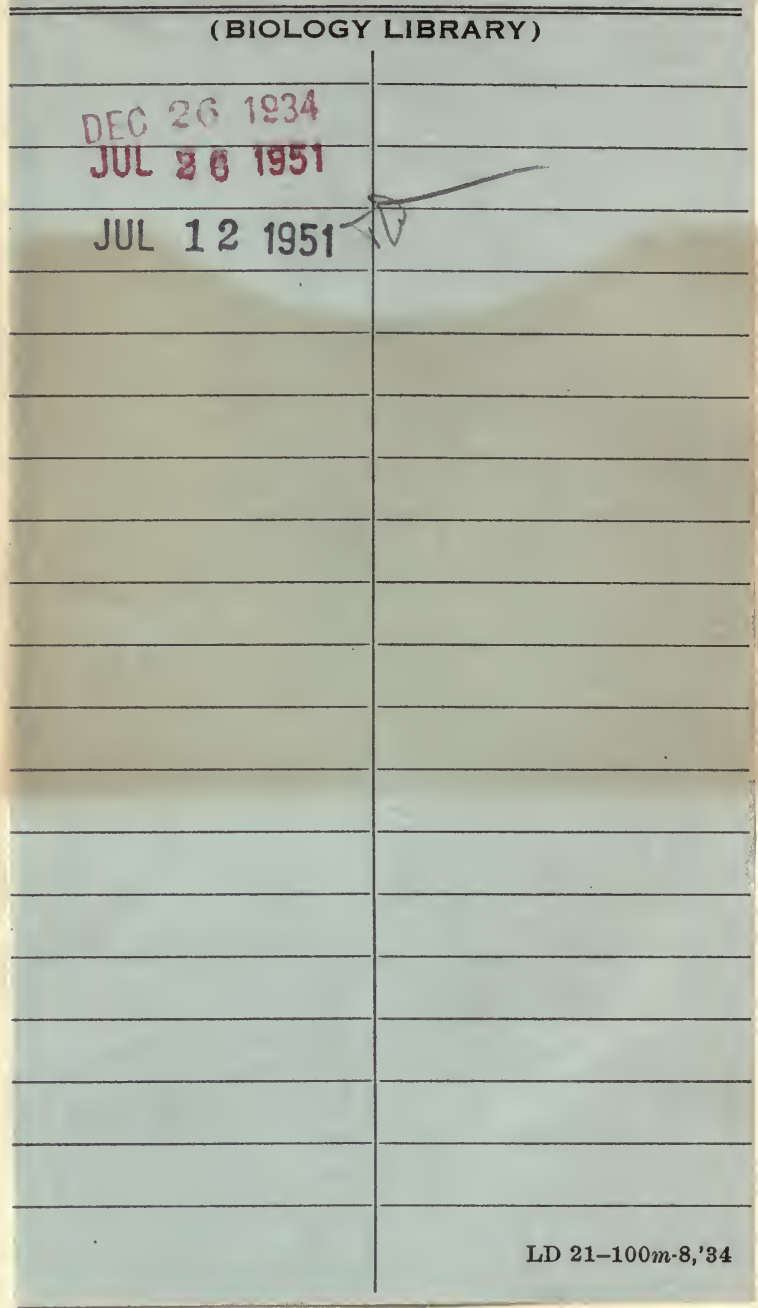



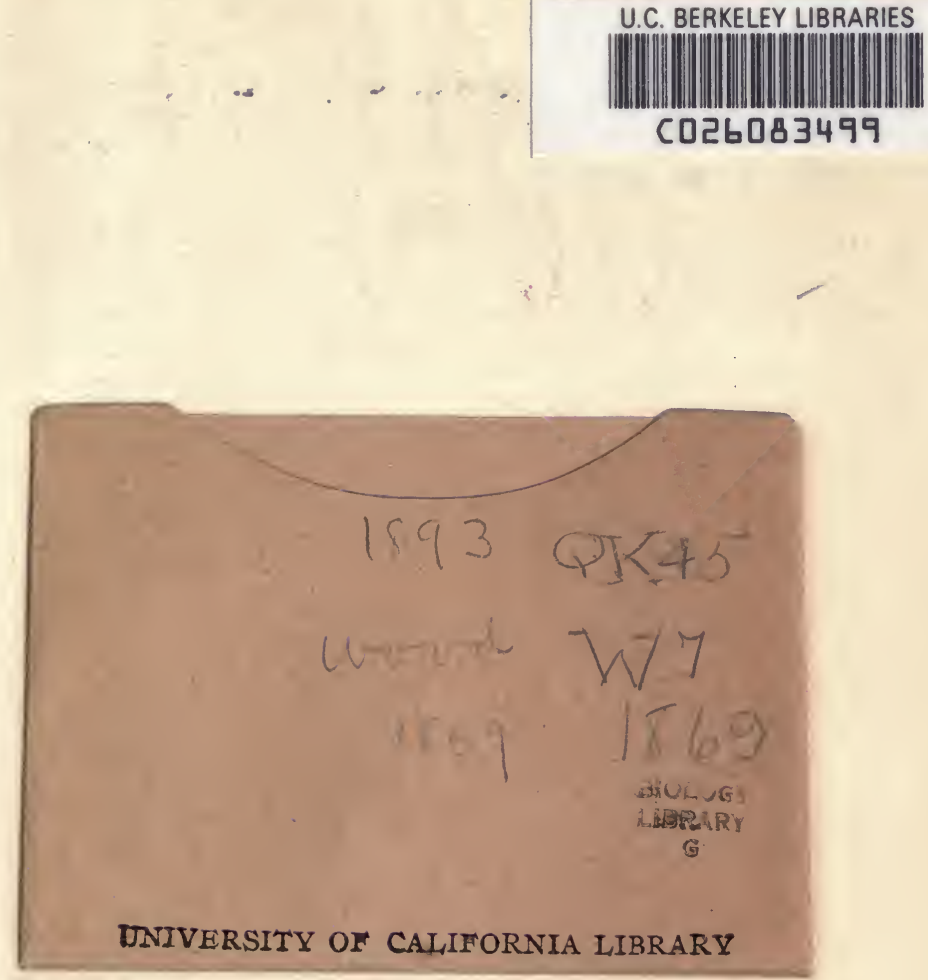


\section{$\sin$}

sis -200

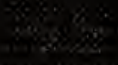

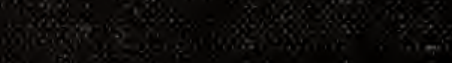
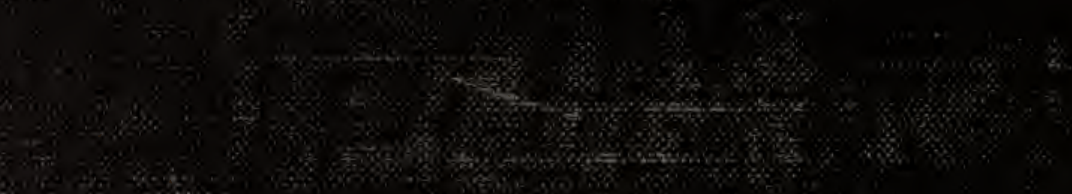

sis 